\title{
INTERNATIONAL GONFERENGE ON EURASIAN ECONOMIES 2017
}




\title{
INTERNATIONAL CONFERENCE ON EURASIAN ECONOMIES \\ 2017
}

\author{
Editors: \\ Selahattin Sarı \\ Alp H. Gencer \\ Batuhan Tufaner
}

\author{
Copyright (C) 2017 \\ Eurasian Economists Association
}

\begin{abstract}
ALL RIGHTS RESERVED.
This book contains material protected under International and Federal Copyright Laws and Treaties. Any unauthorized reprint or use of this material is prohibited. No part of this book may be reproduced or transmitted in any form or by any means, electronic or mechanical, including photocopying, recording, or by any information storage and retrieval system without express written permission from the publisher.
\end{abstract}

Beykent University Publication No: 122

ISBN: 978-975-6319-32-1

Typesetting: Alp H. Gencer \& Hülya Üzümcü

Print: Tekin Ozalit Baskı 


\section{INTERNATIONAL GONFERENGE ON EURASIAN ECONOMIES 2017}

\section{Istanbul - Turkey}

10-12 July 2017 


\section{FOREWORD}

We are proud to have completed the eighth International Conference on Eurasian Economies, held in Istanbul, Turkey with the cooperation of Beykent University, Manas University and Eurasian Economists Association on 10-12 July 2017. The conference was held in Istanbul in conjunction with of $20^{\text {th }}$ year anniversary of Beykent University.

The political climate in Turkey as well as warnings not to visit Turkey in foreign media due to overblown terrorist threats have unfortunately impacted foreign attendance severely. Even though 131 abstracts were submitted to the conference from 10 countries, in the end only 78 accepted papers from 5 countries were presented at the conference. On the other hand, many academicians attended the conference even though they had no papers to present, so the total attendance was around 125 academicians. The fact that the rectors of Beykent University, Manas University and Izmir Democracy University, as well as deans of many faculties, , professors and associate professors, people from the financial sector and executive boards attended the conference show that interest in the conference is high and continual. We would like to extend our deepest appreciation to all participants and sponsors who have trusted and supported the conference's organizing committee.

As in previous years, presented papers are collected into this proceedings book. A considerable amount of time and effort is put into evaluating and formatting the papers for the book. Each paper is evaluated by at least two judges before being accepted. We would like to thank our judges, scientific and organization committee members who contributed their valuable time and support to evaluating every paper. Additionally, we would like to extend our gratitude to Dr. Alp Gencer and Alpin Gencer, who helped to design our web platform with great patience despite all of the difficulties and prepared the book of proceedings for publication.

We would like to extend our greatest appreciation for the continuous support of International Conference on Eurasian Economies by Beykent University's Board of Trustees' Chairman and members, Rector Prof. Dr. Mehmet Emin Karahan, the Secretary General Murat Süslü and Public Relations Department, as well as the administrative staff. As a first, Beykent University presented each attendee a tablet computer with the papers pre-loaded, which was very well received.

Our appreciation is also extended to our partners. The Rector of Turkey-Manas University, Prof.Dr. Sebahattin Balcı honored us by attending the conference and presenting awards. Also thanks to Prof. Dr. Jusuf Primbaev of Manas University and his team for evaluating Russian submissions and disseminating announcements about the conference in Central Asia. Also, we would like to acknowledge the Eurasian Economists Association for funding the "Best Paper Award". The Hiç family deserves a special thanks for presenting the "Doctoral Studies Support Award" in memory of Prof. Dr. Mükerrem Hiç.

Financial support is one of the most important elements in organizing scientific conferences. For this, our gratitude goes out to the Republic of Turkey Prime Ministry - Turkish Cooperation and Coordination Agency's (TIKA's) President and the corresponding head of department Dr. Mehmet Y1lmaz along with his staff for their continued support since the beginning of The International Eurasian Conference.

Finally, our greatest appreciation goes to all of the academicians, researchers and participants whose contributions have made this conference a success. We hope and believe that the International Eurasian Conference 2017 has made important contributions to the Eurasian region and scientific community at large.

We hope to see you in our next conference to be held in Bishkek on 5-7 October 2017.

\section{Prof. Dr. Selahattin Sarı}

Conference Chair 


\section{ÖNSÖZ}

Uluslararas1 Avrasya Ekonomileri Konferansı'nın sekizincisi; Beykent Üniversitesi, Kırgızistan Türkiye Manas Üniversitesi ve Avrasya Ekonomistler Derneği'nin ortak organizasyonuyla 10-12 Temmuz 2017 tarihlerinde İstanbul'da gerçekleştirilmiştir. Konferans, Beykent Üniversitesinin 20nci kuruluş yılı olması nedeniyle İstanbul'da organize edilmiştir.

Son yıllarda Türkiye'de ortaya çıkan siyasal ve teröre yönelik gelişmeler maalesef organizasyona iştirakler konusunda etkili olmuştur. Özellikle batı ülkelerinde ortaya çıkan Türkiye aleyhindeki haberler, sanki ülkede her gün terör yaşanıyormuş görüntüsünün verilmesi ve Türkiye'ye gidilmemesi yönündeki kampanyalar konferansa katılacak bilim adamlarını etkilemiştir. Konferansa özet gönderim aşamasında 10'un üzerinde ülkeden 131 başvuru olmuştur. Ancak; bahsedilen nedenlerden dolayı özellikle Avrupa ülkelerinden katılacak olanlar bildirilerini geri çekmişlerdir. Kabul verilen bildiri sayısı 78'ye, katılımcı ülke sayısı 5'e düşmüştür. Diğer taraftan konferansta bildirisi olmayan çok sayıda öğretim üyesi dileyici olarak iştirak etmiş ve konferans yaklaşık 125 katılımcının iştiraki ile gerçekleşmiştir. Bütün olumsuzluklara rağmen katılımın yüksekliği konferansa olan ilginin büyüklüğ̈̈nü göstermektedir. Konferansa Beykent Üniversitesi, Manas Ü̉niversitesi, İzmir Demokrasi Üniversitesi Rektörlerinin ve çok sayıda dekanın katılması, profesör ve doçentlerin ağırlıklı olması finans sektörü ve üst kurullardan katılımlar konferansın bilim dünyasındaki yerini ve önemini bir kez daha öne çıkarmıştır. Konferans düzenleme komitesine olan güven ve desteklerini konferansa iştirakleriyle şereflendiren tüm katılımcılara öncelikle teşekkürlerimizi arz ediyoruz.

Her sene olduğu gibi bu sene de konferansta sunulan bildiriler kitap haline getirilmiştir. Gerek bildirilerin değerlendirilmesi aşamasında, gerekse kitap haline getirilmesi aşamasında ciddi emek sarf edilmektedir. Her bildiri en az iki hakem tarafından değerlendirilmektedir. Bu değerlendirmelere zaman ayıran ve destek veren hakemlerimize, bilim kurulu üyelerimize, konferans hazırlıklarının başlamasından itibaren çok yoğun mesai harcayan organizasyon komitesindeki arkadaşlarımıza, web sayfası dizaynında her türlü müdahaleye rağmen sabırla işlemleri yerine getiren Dr. Alp Gencer'e ve Alpin Gencer'e teşekkürlerimizi sunarız.

Uluslararası Avrasya Ekonomileri Konferansı'nın gerçekleştirilmesinde her konferans hazırlığında olduğu gibi desteklerini esirgemeyen Beykent Üniversitesi Mütevelli Heyet Başkan ve üyelerine, Üniversite Rektörü Prof. Dr. Mehmet Emin Karahan, Genel Sekreter Murat Süslü ve başta Halkla İlişkiler olmak üzere tüm idari birimlerin personeline sonsuz teşekkürler. Konferansa iştirak edenlere bildiriler yüklenmiş olarak Beykent Üniversitesince tablet verilmesi bu tarz organizasyonlar içinde Uluslararası Avrasya Ekonomileri Konferansı'nın farklılığını ortaya koymuştur. Manas Üniversitesi olarak Rektör ve Dekanlarıyla birlikte konferansı onurlandırmaları nedeniyle Rektör Prof.Dr. Sebahattin Balcı'ya diğer taraftan, Rusça bildirilerin değerlendirilmesi ve Orta Asya'da gerekli duyuruların yapılmasında destek veren Prof. Dr. Jusup Primbaev ve ekibine teşekkürler. "En İyi Bildiri” ödülünü tahsis ederek konferansa destek veren Avrasya Ekonomistler Derneği yetkililerine, yine konferansa "Prof. Dr. Mükerrem Hiç Doktora Teşvik Ödülü”nü tahsis ederek destek veren sayın Hiç ailesine teşekkürlerimizi sunarız.

Konferansların gerçekleştirilmesinde en önemli unsur finansman kaynağıdır. Uluslararası Avrasya Ekonomileri Konferansı'nın en başından itibaren her zaman yanımızda olan ve destek veren T.C. Başbakanlık Türk İşbirliği ve Koordinasyon Ajansının başta başkanı olmak üzere ilgili daire başkanı Dr. Mehmet Yılmaz'a, ilgili uzman ve personeline teşekkürler. Konferansımızı genelde olduğu gibi bu konferans organizasyonunda da destekleyen T.C. Merkez Bankası Başkanının şahsında ilgili tüm birim yetkililerine ve uzmanlarına teşekkürler.

En büyük teşekkürümüz elbette ki konferansın oluşmasını sağlayan akademisyen, araştırmacı ve katılımcılaradır. Uluslararası Avrasya Ekonomileri Konferans1 2017'nin başta Avrasya Ülkeleri olmak üzere bilim dünyasına katkı sağlayacağı inanç ve dileğiyle, 5-7 Ekim 2017 tarihinde KırgızistanBişkek'de düzenlenen 9ncu konferansta buluşmak üzere...

\section{Prof. Dr. Selahattin Sarı}

Organizasyon Kurulu Başkanı 


\section{ADVISORY BOARD}

- Prof. Dr. Mehmet Emin Karahan (Rector, Beykent University, Turkey)

- Prof. Dr. Sebahattin Balc1 (Rector, Kyrgyzstan-Turkey Manas University, Kyrgyzstan)

- Prof. Dr. Turgut Özkan (Dean, Faculty of Economic and Administrative Sciences, Beykent University, Turkey)

- Prof. Dr. Hakan Çetintaş (Dean, Faculty of Economic and Administrative Sciences, Kyrgyzstan-Turkey Manas University, Kyrgyzstan)

\section{ORGANIZING COMMITTEE}

- Prof. Dr. Selahattin Sarı (Beykent University, Turkey)

- Prof. Dr. Jusup Pirimbaev (Kyrgyzstan-Turkey Manas University, Kyrgyzstan)

- Assoc. Prof. Dr. İlyas Sözen (İstanbul Kavram MYO, Turkey)

- Ph.D. Candidate Mustafa Batuhan Tufaner (Beykent University, Turkey)

- Asst. Prof. Dr. Aynura Turdalieva (Kyrgyzstan-Turkey Manas University, Kyrgyzstan)

- Assoc. Prof. Dr. Ayşen Hiç Gencer (Istanbul Aydın University, Turkey)

- Asst. Prof. Dr. Naime İrem Koşan (Beykent University, Turkey)

- Asst. Prof. Dr. Sitk1 Sönmezer (Beykent University, Turkey)

- Assoc. Prof. Dr. Volkan Öngel (Beykent University, Turkey)

- Assoc. Prof. Dr. Özgür Ömer Ersin (Beykent University, Turkey)

- Ph.D. Candidate Bekir Aşık (Beykent University, Turkey)

- Asst. Prof. Dr. Ayfer Ustabaş (Beykent University, Turkey)

\section{WEB \& PRINT DESIGN}

- Dr. Alp Gencer (Germany)

- Mr. Alpin Gencer (Germany)

- Mrs. Hülya Üzümcü (Turkey) 


\section{SCIENTIFIC BOARD}

- Prof. Dr. Ahmet Ay (Selçuk University, Turkey)

- Prof. Dr. Harun Bal (Çukurova University, Turkey)

- Prof. Dr. Mehmet Balcilar (Eastern Mediterranean University, Cyprus)

- Prof. Dr. Viktor Barhatov (Chelyabinsk State University, Russia)

- Prof. Dr. Tansu Barker (Brock University, Canada)

- Prof. Dr. Ersan Bocutoğlu (Avrasya University, Turkey)

- Prof. Dr. Cihan Çobanoğlu (University of South Florida, United States of America)

- Prof. Dr. Mustafa Kemal Değer (Karadeniz Technical University, Turkey)

- Prof. Dr. Ljubomir Drakulevski (Ss. Cyril and Methodius University, Macedonia)

- Prof. Dr. Hüseyin Avni Egeli (Dokuz Eylül University, Turkey)

- Prof. Dr. Ömer Selçuk Emsen (Atatürk University, Turkey)

- Prof. Dr. Cevat Gerni (Doğuş University, Turkey)

- Prof. Dr. Ahmet İncekara (İstanbul University, Turkey)

- Prof. Dr. Danijela Jacimovic (University of Montenegro, Montenegro)

- Prof. Dr. Gani Kaliev (Academy of Agricultural Sciences, Kazakhstan)

- Prof. Dr. S. Ridvan Karluk (Antalya AKEV University, Turkey)

- Prof. Dr. Nuriddin Kayumov (Tajikistan Academy of Sciences, Tajikistan)

- Prof. Dr. Merim Koichueva (Kyrgyz-Russian Slavic University, Kyrgyzstan)

- Assoc. Prof. Dr. Igor Kokh (Kazan Federal University, Russia)

- Prof. Dr. Turar Koychuev (National Academy of Sciences, Kyrgyzstan)

- Prof. Dr. Fevzi Okumuş (University of Central Florida, United States of America)

- Prof. Dr. Jusup Pirimbaev (Kyrgyzstan-Turkey Manas University, Kyrgyzstan)

- Prof. Dr. Tatiana Pyshkina (Academy of Economic Studies of Moldova (ASEM), Moldova)

- Prof. Dr. Orazaly Sabden (Institute of Economics, Kazakhstan)

- Prof. Dr. Mehmet Sarışık (Sakarya University, Turkey)

- Prof. Dr. Euphrasia Susy Suhendra (Gunadarma University, Indonesia)

- Prof. Dr. Ferenec Szavai (Kaposvar University, Hungary)

- Prof. Dr. Muammer Tekeoğlu (Çukurova University, Turkey)

- Prof. Dr. Mustafa Topaloğlu (Özyeğin University, Turkey)

- Prof. Dr. Khodjamakhmad Umarov (Institute of Economics, Tajikistan)

- Prof. Dr. Bahadir Umurzakov (G.V. Plekhanov Russian University of Economics in Tashkent, Uzbekistan) 


\section{Contents}

\section{OPENING SESSION}

Session Chair: Prof. Dr. Selahattin Sarl

\#1947: Sosyo-Ekonomik Dönüşümler ve Tarihsellik 1

- Prof. Dr. Muammer Tekeoğlu (Çukurova University, Turkey) *

SESSION 1A: Growth \& Development

Session Chair: Prof. Dr. Murat Nişancl

\#1955: Economic Growth in the Eurasian Transition Economies: The Roles of Institutional and Structural Factors

- Prof. Dr. Melike Bildirici (Yıldız Technical University, Turkey)

- Assoc. Prof. Dr. Özgür Ömer Ersin (Beykent University, Turkey) *

\#1870: The Effect of Globalization on Economic Growth: Panel Data Analysis for ASEAN Countries . .16

- Asst. Prof. Dr. Mesut Savrul (Çanakkale Onsekiz Mart University, Turkey)*

- Prof. Dr. Ahmet İncekara (İstanbul University, Turkey)

\#1956: The Effects of Inflation, Openness to Trade and Value Added in Production on Economic Growth in Transition Economies

- Assoc. Prof. Dr. Özgür Ömer Ersin (Beykent University, Turkey) *

- Prof. Dr. Melike Bildirici (Yıldız Technical University, Turkey)

\#1888: Effectiveness of Experimental Approaches in Economics: A Case of Ultimatum Games Experiments .33

- Prof. Dr. Yusuf Akan (Atatürk University, Turkey)

- Ph.D. Candidate Aslı Cansın Doker (Erzincan University, Turkey) *

\#1856: The Influence of Political Economy on the "Self-Determination of Peoples" 38

- Asst. Prof. Dr. Yavuz Çilliler (İstanbul Kent Üniversitesi, Turkey) *

SESSION 2A: Finance

Session Chair: Prof. Dr. Turgut Özkan

\#1835: Content Analyses on Mission Statements of the Commercial Banks in Kyrgyzstan . .44

- Asst. Prof. Dr. Seyil Najimudinova (Kyrgyz-Turkish Manas University, Kyrgyzstan)*

\#1829: Monetary Policy Response on Exchange Rate Dynamics: The Case of Indonesia 54

- Dr. Ferry Syarifuddin (Bank Indonesia, Indonesia)*

\#1852: Analysis of Innovation Performances of European Union Member Countries .65

- Asst. Prof. Dr. Miraç Eren (Ondokuz Mayıs University, Turkey) *

- Assoc. Prof. Dr. Selahattin Kaynak (Ondokuz Mayıs University, Turkey)

\#1832: Innovativeness of SMEs in Small Non-Oil Producing Post-Communist Economies .70

- Asst. Prof. Dr. Kamalbek Karymshakov (Kyrgyzstan-Turkey Manas University, Kyrgyzstan)

- Dr. Burulcha Sulaimanova (Kyrgyz-Turkish Manas University, Kyrgyzstan) *

- Dr. Dastan Aseinov (Kyrgyzstan-Turkey Manas University, Kyrgyzstan) 
SESSION 3A: International Economics

Session Chair: Assoc. Prof. Dr. Ayşen Hiç Gencer

\#1866: The Economy-Politics Reflections of Turkey-Russian Relationship During Syria Crisis 78

- Ph.D. Candidate Mehmet Nazım Uygur (Şırnak University, Turkey) *

\#1935: The 36 Strategies of the Chinese: Can It Be a Eurasian Strategic Model in a Global Context?

- Prof. Dr. İsmail Melih Baş (Beykent University, Turkey)*

\#1831: International Migration in Kyrgyzstan: Dynamics and Determinants

- Dr. Burulcha Sulaimanova (Kyrgyz-Turkish Manas University, Kyrgyzstan) *

- Mr. Daniyar Jasoolov (Public Fund AVEP, Kyrgyzstan)

\#1912: The Relationships Between the Female Labor Force Participation Rate and Economic Development: A Correlation Analysis for Turkey

- Asst. Prof. Dr. Ayfer Ustabaş (Beykent University, Turkey) *

- Assoc. Prof. Dr. Tanses Yasemin Gulsoy (Beykent University, Turkey)

SESSION 4A: Hukuk

Session Chair: Prof. Dr. Faruk Andaç

\#1954: Fidic Kuralları Çerçevesinde Yürütülen Tahkim Yargılamalarında Türk ve Yabancı İnşaat Firmaların Karşılaştı̆̆ Sorunlar

- Asst. Prof. Dr. Cahit Ağaoğlu (Beykent University, Turkey) *

\#1824: Ticari Sirların Ceza Hukuku Tarafindan Korunması

- Prof. Dr. Çetin Arslan (Hacettepe University, Turkey)

- Ph.D. Candidate Didar Özdemir (Hacettepe University, Turkey) *

\#1847: Öjenik Bağlamında Batı Ülkeleri'nde ve Türkiye'de Politika Yapımı Üzerine Karşılaştırmalı Analiz .132

- Ph.D. Candidate Ertuğrul Eryücel (Gaziosmanpaşa University, Turkey)*

SESSION 1B: Diş Ticaret I

\section{Session Chair: Prof. Dr. Harun Bal}

\#1953: Bakü-Tiflis-Kars Demiryolunun Türkiye ile Türk Cumhuriyetleri Arasındaki Uluslararası Ticarete Katk1s1

- Asst. Prof. Dr. Hakan Emanet (Beykent University, Turkey)*

\#1930: Havayolu Taşımacılığı Talep Esnekliği Üzerine Ampirik Bir Analiz: Türkiye Örneği

- Prof. Dr. Harun Bal (Çukurova University, Turkey)

- Pınar Gümüş Akar (Gaziantep University, Turkey)*

- Ph.D. Candidate Müge Manga (Çukurova University, Turkey)

\#1900: Seçilmiş İmalat Sanayi Alt Sektörlerinde Sektöründe Türkiye ve Dünya Arasındaki Dikey ve Yatay

Endüstri İçi Ticaret

- Prof. Dr. Cevat Gerni (Doğuş University, Turkey)

- Assoc. Prof. Dr. Sabri Azgün (Atatürk University, Turkey)

- Asst. Prof. Dr. Ziya Çağlar Yurttançıkmaz (Atatürk University, Turkey)

- Prof. Dr. Ömer Selçuk Emsen (Atatürk University, Turkey) * 
\#1854: Uluslararası Ekonomik İşbirliği ve Kalkınma Teşkilatı Üye Ülkeleri için Linder Teorisinin Ampirik Bir Analizi 161

- Prof. Dr. Ebru Çağlayan Akay (Marmara University, Turkey)

- Asst. Prof. Dr. Zamira Oskonbaeva (Kyrgyzstan-Turkey Manas University, Kyrgyzstan) *

\#1864: Dış Ticaret Açıklarında Gelir ve Fiyat Etkisinin Sektörel Bazda Ekonometrik Analizi: Türkiye Örneği .

- Asst. Prof. Dr. Ş. Mustafa Ersungur (Atatürk University, Turkey) .168

- Asst. Prof. Dr. Mehmet Barış Aslan (Muş Alparslan University, Turkey) *

- Asst. Prof. Dr. Ömer Doru (Şırnak University, Turkey)

SESSION 2B: Dış Ticaret II

\section{Session Chair: Prof. Dr. Cevat Gerni}

\#1843: Kırgızistan'da Cari İşlemler Açığının Sürdürülebilirliği 178

- Asst. Prof. Dr. Damira Baigonushova (Kyrgyzstan-Turkey Manas University, Kyrgyzstan) *

- Asst. Prof. Dr. Junus Ganiev (Kyrgyzstan-Turkey Manas University, Kyrgyzstan)

- Asst. Prof. Dr. Nevin Aydın (Kyrgyzstan-Turkey Manas University, Kyrgyzstan)

- Ph.D. Candidate Mairam Baigonusheva (Marmara University, Turkey)

\#1915: Giderek Gelişen Hizmet Ticareti ve Rekabet Gücü: Türkiye Ekonomisinde Gelişmeler (1980-2015) .189

- Asst. Prof. Dr. Ziya Çağlar Yurttançıkmaz (Atatürk University, Turkey)

- Assoc. Prof. Dr. Sabri Azgün (Atatürk University, Turkey)

- Assoc. Prof. Dr. Ayşen Hiç Gencer (Istanbul Aydın University, Turkey)

- Prof. Dr. Ömer Selçuk Emsen (Atatürk University, Turkey)*

\#1879: Dış Ticaretin Ölüm-Kalım Meselesi 198

- Ph.D. Candidate Erhan Pişkin (Akdeniz University, Turkey) *

\#1891: Avrasya ve Türkiye'nin Seçilmiş Ekonomik Göstergeler İtibariyle Özet Bir Değerlendirilmesi 207

- Asst. Prof. Dr. Hakkı Çiftçi (Çukurova University, Turkey) *

\#1841: Türkiye'nin Ekonomik ve Ticari Ortakları İçinde Rusya'nın Yeri

- Ph.D. Candidate Hamdi Aydın (İstanbul Gelişim University, Turkey) *

SESSION 3B: Finans I

Session Chair: Prof. Dr. Müslüme Narin

\#1884: Ağırlıklı Ortalama Fonlama Maliyetinin BIST100, BISTXBANK ve Döviz Kuru Üzerine Etkisinin Analiz Edilmesi

- Asst. Prof. Dr. Serdar Kuzu (Istanbul University, Turkey)

- Ph.D. Candidate H. Muhammet Kekeç (Istanbul University , Turkey) *

\#1836: Kırgızistan'da Döviz Kuru, Resmi Rezervler ve Para Arzı Arasındaki İlişki

- Asst. Prof. Dr. Junus Ganiev (Kyrgyzstan-Turkey Manas University, Kyrgyzstan)*

- Asst. Prof. Dr. Damira Baigonushova (Kyrgyzstan-Turkey Manas University, Kyrgyzstan)

- Asst. Prof. Dr. Nevin Aydın (Kyrgyzstan-Turkey Manas University, Kyrgyzstan)

- Prof. Dr. Müslüme Narin (Gazi University, Turkey)*

- Ph.D. Candidate Alpay Öznazik (Gazi University, Turkey) 
\#1951: Döviz Kurunun Yurtiçi Fiyatlara Yansıması: OECD Ülkelerinden Bulgular

- Prof. Dr. Harun Bal (Çukurova University, Turkey)

- Asst. Prof. Dr. Mehmet Demiral (Ömer Halisdemir University, Turkey)

- Asst. Prof. Dr. Filiz Yetiz (Ömer Halisdemir University, Turkey) *

\#1946: Sahiplik Yapısı ile Sermaye Yapısı ve Kar Payı Dağıtım Kararları Arasındaki İlişkinin Borsa İstanbul 30 Endeksinde Test Edilmesi .254

- Assoc. Prof. Dr. İlhan Ege (Mersin University, Turkey) *

- Tuğba Nur Topaloğlu (Mersin University, Turkey)

SESSION 4B: Finans II

Session Chair: Prof. Dr. Ahmet Ay

\#1842: Kırgızistan'da Devlet Borçları ve Borç Yönetimi .262

- Tolkun Zhumakunova (Kyrgyzstan-Turkey Manas University, Kyrgyzstan) *

- Asst. Prof. Dr. Raziiakhan Abdieva (Kyrgyzstan-Turkey Manas University, Kyrgyzstan)

\#1917: Dışa Açık Büyüme Modeli ve Türkiye'de Dış Borçlar

- Asst. Prof. Dr. İlkay Noyan Yalman (Cumhuriyet University, Turkey)

- Asst. Prof. Dr. Özcan Ișık (Cumhuriyet University, Turkey)

- Ph.D. Candidate Şerife Merve Koşaroğlu (Cumhuriyet University, Turkey) *

\#1911: Elektronik Vergi Uygulamalarının Vergi Denetimi Üzerindeki Etkisi: Türkiye Örneği

- Asst. Prof. Dr. Tuğçe Uzun Kocamış (İstanbul University, Turkey)

- Ph.D. Candidate H. Muhammet Kekeç (Istanbul University, Turkey) *

\#1825: Finansal Oranlar Kullanılarak Risk Yönetimi ve Havayolu Sektörü - Bir Uygulama

- Ph.D. Candidate Burcu Sakız (Istanbul Aydın University, Turkey) *

\#1892: Enerji Fiyatlarındaki Volatilitenin Makroekonomik Performans Üzerine Etkisi

- Assoc. Prof. Dr. Neşe Algan (Çukurova University, Turkey)

- Asst. Prof. Dr. Erhan İşcan (Çukurova University, Turkey)*

- Ph.D. Candidate Duygu Serin (Çukurova University, Turkey)

- Ph.D. Candidate Duygu Kara (Çukurova University, Turkey)

\#1878: Petrol Fiyatları ve BIST Sektör Endeksleri İlişkisi

- Prof. Dr. Reşat Karcıoğlu (Atatürk University, Turkey)

- Ph.D. Candidate Muhammet Özcan (Atatürk University, Turkey)

- Asst. Prof. Dr. Ensar Ağırman (Atatürk University, Turkey) *

\section{SESSION 1C: Makroekonomi}

\section{Session Chair: Prof. Dr. Mustafa Kemal Dĕger}

\#1916: Doğrudan Yabancı Yatırımlar ile Aramalı ve Sermaye Malı İthalatı Arası İlişkiler: Türkiye Ekonomisi Üzerine Toda-Yamamoto Nedensellik Analizleri (2005 M1-2016 M12)

- Prof. Dr. Mustafa Kemal Değer (Karadeniz Technical University, Turkey) *

- Muharrem Akın Doğanay (Karadeniz Technical University, Turkey)

\#1934: Bilgi Ekonomisinin Dönüşümü Üzerine Bir İnceleme

- Asst. Prof. Dr. Emine Firat (Aksaray University, Turkey)

- Prof. Dr. Zeynep Karaçor (Selçuk University, Turkey)

- İnci Mine Özkan (Aksaray University, Turkey)* 
\#1927: Sürdürülebilir Kalkınma Perspektifinde Uygulanan Yenilenebilir Enerji Kaynakları 318

- Prof. Dr. Bedriye Tunçsiper (Balıkesir University, Turkey)

- Asst. Prof. Dr. Emine Firat (Aksaray University, Turkey)

- İnci Mine Özkan (Aksaray University, Turkey)*

\#1914: Ülke Kredi Notlarının Sermaye Piyasalarına Etkisi

- Ph.D. Candidate Mustafa Batuhan Tufaner (Beykent University, Turkey)

- Asst. Prof. Dr. Sitk1 Sönmezer (Beykent University, Turkey) *

- Assoc. Prof. Dr. Ahmet Alkan Çelik (Beykent University, Turkey)

SESSION 2C: Büyüme

Session Chair: Prof. Dr. Süreyya Hiç

\#1869: Teknolojik Gelişme Göstergeleri ile Ekonomik Büyüme Arasındaki Nedensellik İlişkisi: Türkiye Örneği

- Assoc. Prof. Dr. Neşe Algan (Çukurova University, Turkey)*

- Ph.D. Candidate Müge Manga (Çukurova University, Turkey)

- Prof. Dr. Muammer Tekeoğlu (Çukurova University, Turkey)

\#1921: Lewis'in İki Sektörlü Büyüme Modeline Çin Özelinde Bakış: Büyümenin Sınırlarına Gelindi mi? ....339

- Prof. Dr. Murat Nişancı (Erzincan University, Turkey) *

- Prof. Dr. Selahattin Sarı (Beykent University, Turkey)

- Ph.D. Candidate Aslı Cansın Doker (Erzincan University, Turkey)

- Assoc. Prof. Dr. Ahmet Alkan Çelik (Beykent University, Turkey)

- Prof. Dr. Ömer Selçuk Emsen (Atatürk University, Turkey)

\#1839: Sürdürülebilir Ekonomik Büyüme Kavramına Teorik Bakış

- Assoc. Prof. Dr. Oğuz Bal (Kocaeli University, Turkey)*

\#1949: Yeşil Üretim Uygulamaları

- Asst. Prof. Dr. Nevin Aydın (Kyrgyzstan-Turkey Manas University, Kyrgyzstan)*

\#1929: Doğrudan Yabancı Sermaye Yatırımları ve Ekonomik Büyüme Arasındaki İlişki: Azerbaycan Örneği .

- Asst. Prof. Dr. Serap Ürüt Kelleci (Aksaray University, Turkey)

- Asst. Prof. Dr. Emine Firat (Aksaray University, Turkey)*

SESSION 3C: Kalkınma

\section{Session Chair: Prof. Dr. Hakan Çetintaş}

\#1882: Türkiye'de Sürdürülebilir Kırsal Kalkınma İçin Köyden Kente Göçün Önlenmesinde Etkili Unsurların Saptanması ve Bir Araştırma

- Prof. Dr. Lutfiye Özdemir (İnönü University, Turkey) *

- Ph.D. Candidate Orhan Polat (İnönü University, Turkey)

- Gamze Seyitoğlu (Gazi University, Turkey)

- Sevde Çiçekli (Mehmet Akif Ersoy University, Turkey)

\#1845: Tarıma Dayalı Sanayi İşletmelerinin Ar-Ge Potansiyelinin İncelenmesi: Çanakkale İli Örneği 379

- Assoc. Prof. Dr. Sibel Tan (Çanakkale Onsekiz Mart University, Turkey)*

- Cansu Tepeli (Çanakkale Onsekiz Mart University, Turkey)

- Dr. Bengü Everest (Çanakkale Onsekiz Mart University, Turkey) 
\#1846: Organik Tarım Yapan Üreticilerin Mevcut Tarım Politikalarından Faydalanma Düzeyini Etkileyen Faktörlerin Analizi: İzmir İli Seferhisar İlçesi Örneği .385

- Assoc. Prof. Dr. Sibel Tan (Çanakkale Onsekiz Mart University, Turkey)*

- Uğur Şimdi (Çanakkale Onsekiz Mart University, Turkey)

- Dr. Bengü Everest (Çanakkale Onsekiz Mart University, Turkey)

\#1936: Etkin Enerji Kullanımı Bakımından Türkiye Ekonomisinin MINT Ülkelerindeki Yeri: Karşılaştırmalı Bir Ayrıştırma Analizi .... 392

- Prof. Dr. Harun Bal (Çukurova University, Turkey)*

- Asst. Prof. Dr. Banu Tanrïver (Osmaniye Korkut Ata University, Turkey)

- Ph.D. Candidate Müge Manga (Çukurova University, Turkey)

\#1840: Rusya, Kazakistan ve Azerbaycan'ın Devlet Bütçe Giderlerinde Sosyal Harcamaların Karşılaştırmalı

Analizi

- Assoc. Prof. Dr. Elchin Suleymanov (Baku Engineering University, Azerbaijan)*

- Prof. Dr. Farhad Rahmanov (Azerbaijan State Economy University, Azerbaijan)

- Assoc. Prof. Dr. Anar Eminov (Azerbaijan Tourism and Management University, Azerbaijan)

SESSION 4C: Sektörel Analizler

Session Chair: Prof. Dr. Süleyman Karaçor

\#1853: Sağlık Sektöründe Kurumsal Sürdürülebilirlik Yönetimi ve İstanbul Avrupa Yakasında Faaliyette Bulunan Hastanelerde Bir Araştırma

- Asst. Prof. Dr. Kerem Toker (Beykent University, Turkey)

- Asst. Prof. Dr. Fadime Çınar (Beykent University, Turkey) *

\#1834: Estetik ve Güzellik Sektöründe Verilen Tedavi ve Bakım Hizmetlerinin Talebini Etkileyen Demografik ve Sosyo-Psikolojik Özellikler

- Ph.D. Candidate Gülay Bakar Tamer (İstanbul Gelişim University, Turkey) *

\#1913: Hemşirelerin Sosyal Sorumluluk Algılarının İncelenmesi (Sakarya İli Örneği)

- Nesrin Ünlü (Beykent University, Turkey)*

- Assoc. Prof. Dr. Volkan Öngel (Beykent University, Turkey)

\#1859: Türkiye’ye Yönelik Uluslararası Turizm Talebinin Sosyo-Ekonomik Belirleyicileri: Panel Veri Analiz .

- Asst. Prof. Dr. Ş. Mustafa Ersungur (Atatürk University, Turkey)

- Asst. Prof. Dr. Ömer Doru (Şırnak University, Turkey) *

- Asst. Prof. Dr. Mehmet Barış Aslan (Muş Alparslan University, Turkey)

\#1926: Türkiye'de Turizm Gelirlerinin Ekonomideki Yeri ve Önemi Üzerine Bir Değerlendirme 442

- Esra Soyu (Aksaray University, Turkey)*

- Prof. Dr. Süleyman Karaçor (Selçuk University, Turkey)

- Prof. Dr. Serdar Altınok (Gazi University, Turkey)

- Asst. Prof. Dr. Emine Frrat (Aksaray University, Turkey)

SESSION 1D: Bölgesel Çalışmalar

Session Chair: Prof. Dr. Ömer Selçuk Emsen

\#1818: Terörizm ve Makroekonomi: Avrasya Ekonomileri Üzerine Bir İnceleme 450

- Asst. Prof. Dr. Özge Korkmaz (Bayburt University, Turkey) * 
\#1848: Hollanda Hastalığı ve İran Ekonomisi: Zorunlu Otarşiye Yönelim Hastalığı Baskıladı mı? .459

- İlgar Riyazi (Atatürk University, Turkey)*

- Asst. Prof. Dr. Dilek Özdemir (Atatürk University, Turkey)

- Ph.D. Candidate Aslı Cansın Doker (Erzincan University, Turkey)

- Prof. Dr. Ömer Selçuk Emsen (Atatürk University, Turkey)

\#1844: Türkiye ve Geçiş Ekonomilerine Yönelik Yeni Bir Regülasyon Anlayışı .469

- Assoc. Prof. Dr. Yeşim Reel (Marmara University, Turkey) *

\#1940: Yolsuzluk ve Ekonomik Büyüme Arasındaki İlişki: Yeni Sanayileşmiş Ülkeler için Panel Veri Analizi .

- Ph.D. Candidate Emrah Sofuoğlu (Ahi Evran University, Turkey)

- Dr. Oktay Kızılkaya (Ahi Evran University, Turkey)

- Prof. Dr. Ahmet Ay (Selçuk University, Turkey)*

\#1907: Kırgızistan Bankacılık Sektöründe Maliyet Etkinliğini Etkileyen Faktörler 484

- Dr. Dastan Aseinov (Kyrgyzstan-Turkey Manas University, Kyrgyzstan) *

SESSION 2D: Uluslararası İlişkiler

\section{Session Chair: Prof. Dr. S. Rıdvan Karluk}

\#1874: Kırgızistan ile Kore Cumhuriyeti Arasında Siyasi ve Ekonomik İşbirliği: Perspektifler ve Engeller ...493

- Nargiza Sakmurzaeva (Kyrgyzstan-Turkey Manas University, Kyrgyzstan) *

\#1857: Suriye Savaşı Öncesi ve Sonrasında Türkiye ve Avrupa Ülkelerinin Ekonomik Analizi

- Asst. Prof. Dr. Semin Paksoy (Çukurova Üniversity, Turkey)*

\#1828: Türkiye'nin Avrupa Birliği Üyeliği ve Kıbrıs Sorunu

- Prof. Dr. S. Ridvan Karluk (Antalya AKEV University, Turkey) *

\#1903: İki Dünya Arasında Türkiye: 2071 Yılına Yönelik Projeksiyonlar

- Dr. Ahmet Salih İkiz (Muğla University, Turkey)*

SESSION 3D: Mikroekonomi I

Session Chair: Prof. Dr. Ayşe İrmiş

\#1837: Pazarlama Yönetimi Etkinliği ve Uygulamada Ölçülmesi .527

- Burak Sarıçiçek (Beykent University, Turkey)*

- Prof. Dr. Erdoğan Taşkın (Beykent University, Turkey)

\#1861: Örgütsel Adalet ve Psikolojik Güçlendirme Arasındaki İlişkinin İncelenmesi

- Esvet Mert (Pamukkale University, Turkey)*

- Prof. Dr. Sabahat Bayrak Kök (Pamukkale University, Turkey)

\#1942: Finansal Büyüme ve İnovasyon İlişkisi: OECD .546

- Prof. Dr. Harun Bal (Çukurova University, Turkey)

- Asst. Prof. Dr. Erhan İşcan (Çukurova University, Turkey) *

- Ph.D. Candidate Duygu Serin (Çukurova University, Turkey)

- Ph.D. Candidate Duygu Kara (Çukurova University, Turkey) 
\#1883: Entelektüel Sermaye ile Firma Finansal Performansı İlişkisi; BİST’te İşlem Gören Bankalar Üzerine Bir Ekonometrik Analiz .550

- Ph.D. Candidate Reşat Sakur (Şırnak University, Turkey) *

SESSION 4D: Mikroekonomi II

Session Chair: Prof. Dr. Feyzullah Eroğlu

\#1851: Kalkınma Algısında Girişimcilik Olgusu ve Genç Nesillerin Mesleki Eğilimleri: Erzincan Üniversitesi

Öğrencilerinin Girişimcilik Profilleri Üzerine Bir İnceleme .556

- Ph.D. Candidate Aslı Cansin Doker (Erzincan University, Turkey)

- Ph.D. Candidate Sevgi Elverdi (Erzincan University, Turkey)*

- Prof. Dr. Mine Gerni (Marmara University, Turkey)

- Prof. Dr. Ömer Selçuk Emsen (Atatürk University, Turkey)

\#1858: Tercih Edilen Müzik Türü ile Girişimcilik Eğilimi Arasındaki İlişki Hakkında Bir Araştırma .563

- Prof. Dr. Feyzullah Eroğlu (Pamukkale University, Turkey) *

- Esvet Mert (Pamukkale University, Turkey)

\#1855: Küresel Üretim Sürecinde Şebeke Örgütler ve İşletmeler Arası Güven

- Ph.D. Candidate Hicran Utkun Dincer Aydın (Pamukkale University, Turkey)

- Prof. Dr. Ayşe İrmiş (Pamukkale University, Turkey)*

\#1871: “İkincil” Üretim Faktörü Olarak Addedilen Kadının Kalkınmadaki Rolü: Tra2 Üzerine Araştırma 582

- Ph.D. Candidate Ülcay Ecenur Avcı (Erzincan University, Turkey) *

- Ph.D. Candidate Aslı Cansın Doker (Erzincan University, Turkey)

\#1948: Mobil E-Ticaret Türkiye'de ve Dünya'da Nereye Gidiyor? .587

- Asst. Prof. Dr. Nevin Aydın (Kyrgyzstan-Turkey Manas University, Kyrgyzstan)*

SESSION 1E: Развитие

Session Chair: Prof. Dr. Jusup Pirimbaev

\#1823: Региональная Экономическая Интеграция Стран Центральной Азии: Реалии И Перспективы

Развития

- Prof. Dr. Jusup Pirimbaev (Kyrgyzstan-Turkey Manas University, Kyrgyzstan)

- Prof. Dr. Dzhumabek Dzhailov (Ministry of Agriculture, Kyrgyzstan) *

\#1830: Распределение и Использование Финансовых Ресурсов В Здравоохранении Кыргызстана .598

- Assoc. Prof. Dr. Damira Japarova (Kyrgyzstan-Turkey Manas University, Kyrgyzstan)*

\#1850: Анализ Рынка Туристических Услуг Кыргызстана

- Prof. Dr. Anara Kamalova (Kyrgyz National University, Kyrgyzstan)*

\footnotetext{
* Presenting author
} 


\title{
Sosyo-Ekonomik Dönüşümler ve Tarihsellik Socio-Economic Transformation and Historicality
}

\author{
Prof. Dr. Muammer Tekeoğlu (Çukurova University, Turkey)
}

\begin{abstract}
Socio-economic transformations can be understood more clearly in the history of the broad period. Accordingly, we can speak of the rise and fall of civilizations. Numerous civilizations have formed in the world and many have disappeared. In this respect, the 21 st century also undergoes important civilization transformations. In this century of technological change, the computer algorithm has reached a position that exceeds human intelligence for the first time. It is a serious danger for mankind that the control of political, social sovereignty are subject to a limited elite control, as well as significant differences in development between countries that have it and those who do not. It is envisaged that many areas of human endeavor will not be needed due to artificial intelligence tools and this will create a serious unemployment problem. This means that the freedoms of the individual and the individual will become insignificant. Therefore, there is a need for global co-operation that protects freedoms and regulates ethical norms in the 21 st century. In particular, the proliferation of interdisciplinary studies is important, as social science studies tend to focus more on this field. So, in the future, either liberal freedoms will live or the dominance of computer algorithms called "dataism" will lead to a new "slavery" system. Within this context, it is hoped that Turkish Islamic civilization can create an alternative. This is because; in the past of this civilization there is an ideology that glorifies mankind. Especially with the leadership of Turkey it is possible to release this civilization from "twilight". The presentation includes titles for the breakthroughs to be made in this area.
\end{abstract}

\section{Geniş Zamanlar Tarihi}

İnsanoğlunun 70 bin yıllık geçmişinden bu yana 100 milyarı aşkın insanın geçip gittiği, yaşayan 7,2 milyar insanın bu sayının sadece 14'te 1'ini oluşturduğu düşünülürse, bugünkü hayatımız ve uygarlık düzeyleri parça parça geçmişin örüntülerini içerir. Aynı, Jeolojik katmanlarda olduğu üzere her örüntü diğerinin üzerine bina edilmiştir. Tarım toplumlarının oluşumunun 12 bin yıl öncesine dayandığını düşündüğümüzde de kaybolmuş ve yaşayan uygarlıkların birbirlerine aktardıkları bilgiler, teknikler, inançlar, bazı adet ve ritüeller toplumsal yapıların içerisine gömülmüş vaziyette devam etmektedir.

Tekerleği, evcilleştirilmiş hayvancılığı, tohum 1slahını, alet ve yapı teknolojilerini biz icat etmedik. Buna benzer konforumuza hizmet eden imkânlar geçmişten bize tevarüs etmiştir. Hukuk normları, dini inançlar, insanı değerler geçmiş dönem insanlarının oluşturduğu değer sistemleridir ve insanlığın hayatını etkilemeye devam etmektedir. Bütün bunlara tarihsellik diyoruz. O halde, tarihsellik bizim dışımızda yalıtılmış bir geçmiş değil, çeşitli dozlarda içimizde yaşattığımız gerçekliktir. Tarihsellik insanlığın kollektif bilincine yerleşmiş şablonlardır. Arzı mevud, kızıl elma, megola idea, mesih, haçlı, antisemitizm, islamfobia, antropocoğrafya vb. kadim ülküler olarak ulusları etkilemeye devam etmektedir.

Tarihsellik aynı zamanda insanlığın birikmiş tecrübesidir. Toplulukların bugünden yarına gelecek olasılıklarına 1şık tutan bir rehberdir. Bugünkü değerlendirmemize yardımcı bir kaynaktır. Özellikle sosyal bilimin tarihsellik bağını ihmal ederek aşırı uzmanlaşmaya yönelmesi insanlık için büyük bir tehlikedir. Çağdaş tarihçilerden Ferguson'a göre, insanlık ailesinin yaşayabileceği olası geleceklere ilişkin her türlü ciddi öngörü belirlemesi, örtük ve açık biçimde tarihsel prosedürlerden birine bağlıdır (Ferguson, 2012) .

İnsan neslinin başlangıcını Afrika’ya bağlayan antropologların sayısı hayli fazladır. Bir kısım bulgulardan da hareket ederek yapılan açıklamalarda Afrika'dan Avrasya'ya doğru yavaş ve emin adımlarla insanın dünya coğrafyasına yayılışı ilginçtir. Sapiens'in merkezi Afrika'nın doğu ve batısından 70 bin yıl önce başlayan yürüyüşü, Mısır ve Kızıldeniz yolundan tüm Avrasya'ya binlerce yıl boyunca devam etmiştir. Bu insanların yıllık ilerleme hizı sadece 1,6 kilometreydi (Morris, 2012).

$\mathrm{Bu}$ uzun yürüyüşe geniş zamanlar tarihi veya uygarlık tarihi diyoruz. Esas itibariyle de tarih uygarlıkların incelenmesidir. Uygarlık tarihi, Guizot'a göre en geniş tarihtir ve bütün diğerlerini kapsar. Yüzyıllar boyunca tarihçiler, siyaset bilimciler, antropologlar ve genel olarak halk uygarlıkların yükselişi ve düşüşünü döngüsel ve aşamalı bir tarih anlayışı ile değerlendirmişlerdir. Bu kapsamda sayabileceğimiz isimler şunlardır:

- Polybus (Tarihler)

- İbn-i Haldun (Mukaddime)

- Giambattista Vico (Yeni Bilim)

- Adam Smith (Ulusların Zenginliği)

- Karl Marx (Kapital)

- Oswald Spengler (Batı'nın Gerileyişi)

- Pitrim Sorokin (Sosyal ve Kültürel Dinamikler) 
- Arnold Toynbee (Tarihi İnceleme)

- Carrol Quigley (Trajedi ve Umut)

- Fernand Braudel (Uygarlık ve Kapitalizm)

- Paul Kennedy (Büyük Güçlerin Yükselişi ve Çöküşü)

- Samuel Huntington (Uygarlıklar Savaşı)

- Jared Diamond (Çöküş: Medeniyetler Nasıl Ayakta Kalır ya da Yıkılır)

- Ian Morris (Batı Dünya'ya Neden Hükmediyor: Şimdilik)

- Geoge Friedman (21. Yüzyıl İçin Öngörüler)

Farklı zamanlara yayılmış bu düşünce adamları ve diğer benzerlerinin geniş zamanlar döngüsü ve dönüşümü teorisi çerçevesindeki öngörüleri özetle şöyleydi:

"Her uygarlık bir evrim sürecinde doğar ve canlı bir yayılma dönemine girer. Çap ve güç bakımından büyümesi zamanla bir örgütlenme krizi belirinceye kadar sürer. Bu kriz aşılınca ve uygarlık yeniden düzelince, canlılığı ve morali artık zayıflamış olur. Kararlı bir çizgiye oturur ve zamanla durgunlaşır. Barış ve refah dolu bir Altın Çağ'dan sonra, iç krizler tekrar ortaya çıkar. Bu noktada ilk kez uç veren bir ahlaki ve maddi zayıflık uygarlığın kendisini dış düşmanlara karşı savunma gücü konusunda soruları gündeme getirir. Uygarlık sürekli zayıflayarak sonunda dış düşmanlarca batırılır veya gittikçe ortadan kalkar" (Ferguson, 2012)

$\mathrm{Bu}$ ifadeden anlaşılacağ üzere tarihin bir ritmi vardır. Sümer, Babil, Mısır, Roma, Bizans, Çin, Hint, Maya, Osmanlı, Büyük Britanya devletleri ve temsil ettikleri uygarlıkları benzer kaderi paylaşmışlardır.

Belirtilen çerçevede geniş zamanlar tarihi bize siyasal, ekonomik, sosyal dönüşümlerin "Güç Yasası Dağılımı" denilen bir kalıba göre şekillenebildiğini apaçık göstermektedir. Örneğin, İktisatçı Brian Arthur’a göre karmaşık bir ekonomi dağınık özneler arasındaki etkileşimle, merkezi denetimin yokluğuyla, çok sayıda örgütlenme düzeyiyle, sürekli uyum mekanizmalarılla, yeni piyasa taleplerinin aralıksız yaratılmasıyla ve genel bir dengenin olmayışıla karakterize olur. En önemlisi de böyle bir ekonomide, Ortodoks iktisat anlayışının tersine artan getirilerle devleşen şirketler oluşabilir. Örneğin, Google, Facebook, Microsoft, Apple, Tesla vb. yükselen şirketler açılarından bakıldığında, dünya gelir dağılımında üsttekilerle alttakiler arasında dramatik bir açılmanın söz konusu olduğunu, bunun yeni bir tarihsel geleceğin tohumlarını attı̆̆ı̆ı öngörebiliriz.

Tarihçi Ferguson'a göre uygarlık, tanımı gereği son derece karmaşık bir sistemdir. Görünüşte hangi merkezi otoriteye bağl1 olursa olsun, uygulamada sürekli değişen ekonomik, sosyal, siyasal ilişkilerin uyuma açık bir şebekesidir. Bu bakımdan her biçim ve çaptaki uygarlığın istikrardan istikrarsızlığa oldukça ani geçiş eğilimini de kapsamak üzere, doğal dünyadaki karmaşık sistemlerin (orman yangınları, iklimler, depremler vb.) birçok özelliğini sergiler.

Tarihsel olarak, Roma İmparatorluğu (5. yüzyıl), İnka Uygarlığı (16. yüzyıl), Ming Hanedanlığı (17. yüzyıl), Cengiz İmparatorluğu (14. Yüzyıl), Fransız Burbon Monarşisi (18. Yüzyıl), Osmanlı İmparatorluğu (20. Yüzyıl), Sovyetler Birliği (20. Yüzyıl), Japon İmparatorluğu (20. Yüzyıl) büyük bir güç olmaktan çıkıp kısa zaman aralıklarında gerilemişlerdir.

Sosyal Bilimci Matthew Melko, kadim ve yok olmuş yedi uygarlı̆̆ı Mezopotamya, Mısır, Girit, Klasik, Bizans, Orta Amerika, Andlar olarak sayar. Yaşayan uygarlıklar ise, Çin, Hint, Japon, İslam ve Batı uygarlıkları olmak üzere beş tanedir. Tabii ki bu uygarlıkların merkez ve periferisinde farklılıklar oluşturan alt unsurlar mevcuttur. Görece atılım ve gerilemeler yaşayabilmektedir. Belirtilen unsurlar arasında ver olan rekabetin neticesi geleceği belirleyecektir. Hangisi galebe çalacaktır. Yoksa bambaşka bir uygarlık düzeyi mi inşa edilecektir. Bu konuya yönelik ilgide son dönemlerde önemli bir artış gözlemlenmektedir. Ve çok sayıda yayın yapılmaktadır. Dolayısıyla kendi entelektüel dünyamızda bu alana daha fazla ilgi gösterilmek zorunluluğu bulunmaktadır. Sosyal bilimlerdeki uzmanlaşmanın artması interdisipliner çalışmaların azlığı dikkat çekici düzeydedir. Zira konu, sadece tarihçilerin, ekonomistlerin, siyaset bilimcilerin, ilahiyatçıların, hukukçuların uzmanlık bilgileriyle anlaşılabilecek basitlikte değildir. Nitekim konuyla ilgili öne çıkan isimler (Huntington, Bozemann, Morin, Zakaria, Braudel, Mc Neill, Clark, Maluf, Diamond, Kennedy, Quigley, Acemoğlu, Morris, Harari ve diğer pek çoğu) sosyal bilimlerin neredeyse hepsinde yetkinlik elde etmiş kişilerdir.

Bütün bunların ardından şimdi tarih nasıl bir şeydir. Bunu ironik bir biçimde ifade eden Bierce'ye kulak verelim. Diyor ki; "tarih lanet olası şeylerin birbirini izlediği olağanüstüyü başaran ve ahlaksızlık fiçısının dibini delen dâhilerin ve ahmakların, tiranların ve romantiklerin, şairlerin ve hırsızların karmaşı bir düzenidir (Morris, 2012)." Başka bir yaklaşımda da şu çarpıcı ifadeyi görüyoruz. "Tarihin dinamikleri insanların iyiliğini ve mutluluğunu arttırmaya yönelik değildir." "Tarihin adaleti yoktur. Bir felaket yaşandığında yoksullar her zaman zenginlerden daha çok acı çeker; felaketlerin nedeni zenginlerde olsa sonuçlarına yine yoksullar katlanacaktır" (Harari, 2016).

Tarihin altın kurallarından biri, geriye dönüp bakınca bariz olarak görünen şeyin, olay esnasında son derece belirsiz olmasıdır. Bu ifadeler bize toplum hayatına yön verenlerin tarihsellik bilincinin ne kadar hayati olduğunu göstermektedir. Tarihsellik öğretisi ve bilinci, bugünden geleceği giderken çatallaşma sonucu sonsuz sayıda seçenekle karşı karşıya kalabileceğini öngörebilme yeteneğidir. Bu yolların bazıları daha geniş daha, daha konforlu veya daha belirgindir; dolasıyla da bu yolların seçileceğini öngörebiliriz. Ancak bazen tarih ya da tarihe yön verenler beklenmedik yollara sapabilmektedirler (Harari, 2016). 
Belirtilen döngülere Stefan Zweig "Yıldızların Parladığı Anlar" diyor. Peter Drucker "Sınır Çizgisi” diyor. Edgar Morin ise "Döngüsellik" diyor. Döngüsellik ilkesi, yaratma ya da yeniden yaratma süreçlerinin her bir anının, ögesinin ya da kertesinin aynı anda başka anların, ögelerin ve kertelerin hem ürünü hem de üreticisi olduğu, kesintisiz bir üretim döngüsü gibi düşünülmesi gerektiğini ifade eder. Konuya Avrupa özelinde bakacak olursak, mesela 15.yüzyıldan itibaren kentlerin, burjuvazinin, kapitalizmin, ulusal devletlerin, tekniklerin, bilgilerin ve bilimin gelişmeleri kendi kendini çeviren bir burgaca benzeyen bir döngü oluşturmuştur. Bu döngü onu oluşturan özel gelişmelerin her biri üzerinde, onları geliştirerek ya da içine alarak retroaktif (tepkisel) etkiler yaratmıştır (Morin, 1987).

Elbette tarihsellik içerisinde coğrafi, biyolojik ve ekonomik güçlerin oluşturduğu belli sınırlar vardır. Ancak, bu sınırlar şaşırtıcı sosyo-ekonomik dönüşümler için yeterince çok alan bırakırlar. Dönüşümleri insanlara daha cazip gelen determinist tarih yasaları ile açıklayamayız (Harari, 2015).

Yakın zamanlara doğru geldiğimizde ise modern kültürün tarihte rastlanmadığı kadar güçlü bir şekilde araştırma, üretim, keşifler yaptığını ve sürekli bir büyümeyi desteklediğini görüyoruz. Adeta tarihin hızlanması söz konusu. Dolayısıyla, geniş zamanlar kavramı artık beş yüzyıllık, yüzyıllık zaman dilimleri değil, elli yıla, yirmibeş yıla dönüşen zaman dilimleri haline geliyor. 21.yüzyılın olasılıkları daha keskin dönüşümlere gebe gibi gözüküyor. Daha önce hiçbir uygarlıkta görülmediği ölçüde insanlığı büyük bir varoluş endişesi içerisine sokuyor. $\mathrm{O}$ halde şimdi 21.yüzyılın olası tehditlerine bir göz atalım.

\section{21. Yüzyıl Dönüşümleri Ve Geleceğe Hazırlanmak}

Avrasya uygarlıkların beşiğidir. Çin, Hint, İslam ve Avrupa uygarlıkları ortaçağlar ve sonrasında kâh biri önde, diğeri geride olmak kaydıyla dünyayı şekillendirmiştir. Çin ve Hint 15. yüzyıla kadar, İslam 8-12. yüzyıllarda, Avrupa ise 15. yüzylldan bu yana yüksek düzeyli bir uygarlığa önderlik etmişlerdir. Doğal olarak bu süreçler uygarlıklar arası aktarımlara da yol açmıştır. Çin ve Hint daha çok dışa kapanma, İslam Gazali etkisine bağlı durağanlıklar yaşamaya başlarken, Avrupa ileri adımlarını atmaya başlamış ve sonraki zamanlarda "Batı" adıyla Amerika'ya kadar uzanan geniş bir etki sahası yaratmıştır. Avrupa'nın neden uzun soluklu bir uygarlık oluşturduğu üzerine halen yapılan tartışmalar olsa da, bugünün dünyasını şekillendiren, sosyal ve ekonomik, siyasal ve kültürel süreçler üzerinde kalıcı damgalar oluşturan bir etkinliği söz konusudur. Sovyetler Birliği'nin dağıllması ve Çin'in piyasa sistemine evrilmesinin ardından adeta tek uygarlık söylemine konu olan Batı uygarlı̆̆ı, 20. yüzyılın sonlarında küreselleşme tezini de arkasına alarak alternatifsizlik iddialarının dozunu iyice yükseltmiş̧tir.

Ancak, 21. yüzyılın ilk çeyreği bu durumu yalanlayan pek çok gelişmeye sahne olmuş, Batı uygarlığının özgünlüğ̈̈ veya biricikliği üzerine ciddi kuşkuların doğmasına da yol açmıştır. Bu alandaki en önemli soru bilişsel teknolojilerin her alana uyarlandığı bir döneme girerken Batı liberalizminin birey ve özgürlük söyleminin ne ölçüde tüm insanlara yönelik bir duyarlılık gösterdiğidir. Zira 21. yüzyılın teknolojilerinin özgün karakteri, akıllı makineler marifetiyle üretim, dağıtım ve hizmet faaliyetlerinin yürütüleceği ve işgücüne yönelik ihtiyacı dramatik bir şekilde azaltacağıdır. Genetik bilimi, biyoteknoloji, bilgisayar algoritmaları bilimi, geçmişin sosyo-ekonomik yapılarından tam bir kopuşu haber vermektedir. Akıllı binalar, birbirleriyle iletişim kurabilen araç ve gereçler, insan gözetimine, müdahalesine olan gereksinimi çok çok azaltılacak bir noktaya hızla yaklaşmaktadır. Dolayısıyla, 21. yüzyılın ilerleme trenine yetişenler yaratmanın ve yok etmenin ilahi kudretini elde ederken, geride kalanlar yok olma tehdidi ile karşı karşıyadır (Harari, 2016).

Bu büyük meydan okumanın milyarlarca insanı tehdit etmesine pasif kalınamayacağı varsayımıyla, dünyanın yeniden acımasız çatışmalarla nereye varacağı en ürpertici sorular arasındadır.

21.yüzyılın yeni sosyo-ekonomik yapılanması Batı Liberalizminin geçmişte idealize ettiği değerleri alt üst edebilecek önemde görülmektedir. Ufukta üç seçenek görünmektedir (Harari, 2016)

1. İnsanlar ekonomik ve askeri değerlerini yitirecek, böylelikle ekonomik ve siyasi sistem insanlara bu kadar değer vermeyi bırakacak.

2. Sistem kitlesel olarak insanlara değer vermeye devam edecek, ama bireyler önemsizleşecek.

3. Sistem bazı özgün bireylere değer vermeye devam edecek, ancak bu özgün insan toplulukları, kitlelerden farklı olarak sürümleri yükseltilmiş yeni süper insan elitleri oluşturacak.

Üç öngörüye ilişkin örnekler de sunulmaktadır. Mesela, 21. yüzyılda hem erkekler hem de kadınlar askeri ve ekonomik değerlerini yitirebilirler. Zira savaşlar iyi eğitimli az sayıda asker, hatta daha az sayıda süper savaş̧̧ ve gelişmiş teknolojiler üretmeyi ve kullanmayı bilen bir avuç insanın işi haline dönüşebilir.

Siber savaşlar dönemi, kitlesel insan gücüne olan ihtiyacı bitirmektedir. Örneğin, yeterince karmaşı bir siber saldırı her ülkenin güç ağını çökertebilir. Uçuş kontrol merkezleri dağıtılabilir. Nükleer santrallerde sayısız kazaya neden olabilir. Güvenlik güçlerinin iletişim ağları bozulabilir. Mali sistem kayıtları silinerek milyarlarca kayba yol açabilir.

Zekâ ve bilinç ayrışması gerçekleşebilir. Bugüne kadar yüksek zekâ her zaman gelişmiş bir bilinçle birlikte anılırdı. Buna göre sadece yüksek bilince sahip varlıklar satranç oynamak, ileri mühendislik işlemleri yapmak, hastalıklara teşhis koymak gibi işleri başarırken, şimdi artık bilince gerek kalmaksızın sadece yapay zekâya sahip 
bilinci olmayan algoritmalar, bir sistemin oluşması ve operasyonunda insan zekasını aşan bir noktaya erişmiş bulunmaktadir.

Bazı iktisatçılar, kendilerini geliştirememiş insanların er veya geç tamamen hurdaya çıkacağını öngörmektedir. Robotlar ve üç boyutlu yazıcılar, gömlek üretimi dahil kol gücüyle yapılan işlerde dahi işçileri yerinden ederken, üstün zekâlı algoritmalar da beyaz yakalı çalışanların pozisyonunu dolduracaktır. Kısa süre öncesine kadar otomasyon tehlikesinden korunabilen banka memurluğu ve turizm temsilciliği meslek gruplarının tehdit altında olduğu görülmektedir.

2013'de Oxford'lu iki araştırmacı Frey ve Osborn, “İstihdamın Geleceği” isimli çalışmada bilgisayar algoritmalarının birçok meslek adamını işinden edeceğini belirtiyor. Buna göre, gelecek yirmi yılda ABD'deki mesleklerin yüzde 47'si yüksek risk altında olacaktır. Örneğin, 2033'de insanlar yüzde 99 ihtimalle tele-pazarlama ve sigortacılık işlemlerini algoritmalara kaptıracak. Benzer durum hakemlerin yüzde 98'inin, kasiyerlerin yüzde 97'sinin, şeflerin yüzde 96'sının, garsonların ve avukat yardımcılarının yüzde 94'ünün, tur rehberlerinin yüzde 91 'inin, fırıncıların ve otobüs şoförlerinin yüzde 89'unun, inşaat işçilerinin yüzde 88'inin, güvenlik görevlilerinin yüzde 84'ünün, denizcilerin yüzde 83'ünün, barmenlerin yüzde 77'sinin, marangozların yüzde 72'sinin, cankurtaranların yüzde 67'sinin işinden olacağı belirtilmektedir (Harari, 2016)

Eğer bu eğilimler gelecek yirmi yılın yeni gerçekleri olursa, bunun ekonomik, sosyal ve siyasi boyutları önemli sayıda kişi ve toplumların sistem dışına itilmesi kaçınılmaz olacaktır. İnsani ve etik boyutları olağanüstü sorunlu olacaktır. Algoritmalı düzen, çoğu kişiyi çalışma hayatının ve dolayısıyla sosyal hayatın dışına itecektir. Sistem varlık ve güç algoritmalarını elinde tutan bir grup elitin inisiyatifine geçerek, ciddi ekonomik, sosyal, siyasi eşitsizliğe yol açacaktır. Hatta şimdiden görüyoruz ki, dünyadaki en zengin 67 insanın varlığı en fakir 3,6 milyar insanın varlığına denktir.

Benzer gelişmelerin tıptan, özel hayata ait bilgilere varıncaya kadar yayılması, insanı sahip olduğu otoriteden mahrum bırakıp algoritmaları yetkilendirerek, liberal hümanist devrimin çarklarını geriye çevirebilir. Sosyal bilimlerin yeni görevi işlerin bu noktaya erişmesini önleyici yöntemleri önermektir. Yoksa Orwell’in ünlü polis devletindeki gibi her hareketimizin hatta bedenimizin ve aklımızın içindekilerinin bile izlenip kontrol edildiği bir dünyada kendimizi bulabiliriz. Bunu önlemek adına, özellikle biyolojinin fantezi araştırmalarına ve meydan okumalarına karşı ortak etik kodları devletlerin oluşturması hayati önemdedir. Bunun sebebi, tüm gidişatın bilgisayar bilimi yerine biyolojik öngörülerden güç aldığını bilmek durumunda olmamızdır. Zira bu bilim organizmaları birer algoritma olarak ilan etme yönünde hızla ilerlemektedir.

Konunun sağlık boyutu da ilginçtir. 20.yüzyıl tıbbının hedefi hastalığı iyileştirmek iken, 21.yüzyılda bu hedef sağlıklıyı geliştirmeye yönelmiş durumdadır. Herkesin standart bir fiziksel ve zihinsel sağlı seviyesine sahip olabileceği ve olması gerektiği varsayıldığı için hastayı iyileştirmek eşitlikçi bir projeydi. Sağlıklıyı geliştirmekse elitist bir projedir (Harari, 2016). Yani, parasını ödeyebilene daha fazla ömür vaadidir. Buna katkı sağlayacak araştırmalara öncelik vermektir. Bir diğer önemli konu dünyada artan karbon emisyonudur. Eğer, sürdürülebilirliği sağlanamaz ise, iklim etkileri ile geleceğin tarihi çok olumsuz bir düzlemde oluşacaktır ve tüm insanlığı karanlığa itecektir.

Sonuç olarak; eğer bilimsel keşifler ve teknolojik gelişmeler insanlığ işe yaramayan kitleler ve bir grup gelişmiş süperinsan eliti olarak ikiye ayırır, ya da otorite insanların elinden zeki algoritmalara geçerse, bu liberalizminde sonunu ilan edecektir. Oluşan boşlukta hangi yeni dinler ya da ideolojiler doğacaktır. Olasıdır ki, bunlar araştırma laboratuvarlarında büyüyüp, serpilecektir. Tekno-dinler de algoritmalara ve genlere dayalı bir kurtuluş vaadiyle dünyayı fethe çıkabilir. Buna “dataizm”de deniliyor. Hümanizm "Duygularınıza kulak verin diye buyuruyordu. Dataizm ise "Algoritmaları dinleyin" diye emrediyor (Harari, 2016).

\section{Türk ve İslam Dünyasının Geleceği Üzerine Özetler}

Türk ve İslam dünyası, uzun yüzyıllardır uygarlık yarışında geri kalmış gözükse bile, nüvesinde küllerinden yeniden doğma ve insanlığa örnekler oluşturma yeteneğine sahip olabilir. Bunun kaynağında yüksek bilinç düzeyini tutturma hedefi yer alıyor. Bu yüksek bilinç bazı tespitler yapmak zorunda.

Dünya yeni bir boyuta girmiştir. Eski şablonlarınızla dünyayı değerlendirmekten vazgeçmeliyiz.

Tarihlerimizle yüzleşmeliyiz. Neleri neden kaçırdığımızı objektif olarak sorgulamalıyız. Geçmişte insanlığa sunduğumuz aktarımlarla sürekli övünmekten vazgeçmeliyiz.

Aslolan insan ve insanlıktır şiarından vazgeçmemeliyiz. İnsanı ve insanlığı bütün zaaflarına rağmen yüceltme ülküsünden cayılmamalıdır.

Dini ve dindarlığı abartıp, aşkın din duygularıyla meczuplaştırmamalıyız.

Her alanda kurumsallaşmaya özel önem vermeli, bu alanda çağdaş düzenlemeleri örnek almalıyız.

İnsani değerleri pekiştiren kültür ve sanat faaliyetlerine özel teşvikler sağlamalıyız. 
Seçkin okulları kurarak, üniversite düzeyinde disiplinler arası uzman sayısını arttıran eğitime özel bir önem vermeliyiz. Bu alanda çağdaş bilime birinci sınıf katkılar sağlayabilecek yetenekleri özel olarak teşvik eden bir mekanizma kurmalıyız. Ekonomide, siyasette, teolojide taşıyıcı sütunlar olabilecek insanlar yetiştirmeliyiz.

Tarihsel mirasın ve jeopolitiğin bize yüklediği sorumluluğun farkında olarak, hep uyanık kalmanın gereğini bir devlet politikası olarak benimsemeli, buna göre stratejiler geliştirmeliyiz. Bu alanlarda gevşekliğe düşmemeliyiz.

Bilgisayar, biyoloji, biyoteknoloji ve genetik eğitimine özel önem vererek teşvikler sağlamalıyız.

19.yüzyılda Türk ve İslam dünyasının ıskaladığı sanayi devrimindeki hatayı, 21. yüzyıl teknolojileri alanında tekrarlamamak için azami bilinç ve çabayı ortaya koyacak devlet politikalarına özel önem verilmek zorunludur. $\mathrm{Bu}$ alanlardaki yurtdışı doktora eğitimleri de çoğaltılmalıdır.

Faydalı ve doğru her türlü bilimsel bilginin toplumun kılcal damarlarına yayılabilmesi demokratik ve şeffaf biçimde, kamunun, sivil toplum kuruluşlarının, akademianın ve medyanın daha efektif hale getirilmesini gerektirmektedir.

Türk İslam uygarlığını yeniden yükseltme hedefinde bugün için Türkiye'nin özel bir yeri vardır. Zira Türkiye'nin son yüzyılını dikkatle incelersek, bütün krizlerine rağmen büyük senteze doğru gittiğini söyleyebiliriz. Cumhuriyet’ten bu yana, aşağı yukarı bütün farklı görüşlerin, bir siyasi iktidar veya iktidar ortağı olarak daha realistik bir çizgiye çekildiklerini ve toplumun tümünü kucaklayacak bir demokrasi anlayışını içselleştirme noktasına yaklaştıklarını söyleyebiliriz. Artık enerjisini daha fazla ekonomiye, eğitime, dış dünyayla ekonomik ilişkilere harcayacak noktaya eriştiğini belirtebiliriz. Savunma gücünü yerli girişimlerle bir noktaya eriştirmiş, dünyayla yarışabilecek girişimcisini ve profesyonellerini artırmış bir ülkedir. Bütün bunlar Türkiye'nin platformunu yükseltirken, periferisindeki ülkeleri de cezbeden ve onların da medeniyet havuzuna katkı koymalarını teşvik edebilecek bir konumdadır.

Bunu en iyi öngörenlerden biri olan Strateji Uzmanı George Friedman, tamamen düz bir çizgide olmasa bile, Türkiye'nin yükseldiğini, coğrafi hinterlandının buna katkı sağladığını ve geleceğin büyük güçlerinden biri olmaya aday olduğunu belirtiyor (Friedman, 2015). Bize göre de Türkiye kaynayan suyun yukarı doğru burgaçlanmasını ifade eden "Benard Sarmalı" dönemindedir. Hem kendi kendini örgütleyen hem de kendi kendini ayarlayabilen bu sarmal, eski biçimlerin ve sentezlerin parçalanışı sırasında, yeni biçimler ve sentezler üretir.

Konuyu geniş zamanlar tarihi açısından örneklendirirsek, dünyanın ekonomik merkezlerinin de doğudan batıya doğru kaydığını ve sarmallar oluşturduğunu görmekteyiz (Bağdat, Kahire, Şam, İstanbul, Venedik, Anvers, Amsterdam, Londra, New York, Tokyo, Seul, Şangay). Mitolojik bir varlık olan Minerva (bilgelik) kuşu alacakaranlıkta uçarmış. Bazı bölgelerinde 500 yıldır, bazı bölgelerinde 200 yıldır geride, durağan bir konumda olan Türk İslam coğrafyalarının alacakaranlığında da artık Minerva kuşunun kanat seslerinin duyulması umulmaktadır. Bu konuda Türk İslam uygarlığının bilim ve bilinç sıçraması yapması tarihin akışıyla ilgili bir görevdir. Zira bu uygarlığın tüm insanları şerefli bir varlık olarak gören temiz bir geçmiş sicili vardır. Bu yüzden de geleceğin barış ve mutluluğu için elzem olan bu uygarlığın yeniden yükselmesi, ancak bizlerin çabasıyla mümkün olabilecektir.

\section{Kaynakça}

- Ferguson, Niall; Uygarlık; Batı ve Ötekiler (Çev. Nurettin Elhüseyni) YKY, İstanbul 2012.

- Friedman, George; Avrupa Krizi (Çev. İrem Sağlamer) Pegasus Yayınları, İstanbul 2015.

- Harari, Y. Noah; Hom Deus (Çev. P. Nur Taneli) Kolektif Kitap, İstanbul 2016.

- Harari, Y. Noah; Sapiens (Çev. Ertuğrul Genç) Kolektif Kitap, İstanbul 2015.

- Morin, Edgar; Avrupa'yı Düşünmek (Çev. Şirin Tekeli) AFA Yayınları, İstanbul 1987.

- Morris, Ian; Dünyaya Neden Batı Hükmediyor (Çev. Gül Çağalı Güven) Alfa Basım Yayın Dağıtım, İstanbul 2012. 


\title{
Economic Growth in the Eurasian Transition Economies: The Roles of Institutional and Structural Factors
}

\author{
Prof. Dr. Melike Bildirici (Yıldız Technical University, Turkey) \\ Assoc. Prof. Dr. Özgür Ömer Ersin (Beykent University, Turkey)
}

\begin{abstract}
The study aims to evaluate economic growth process and the problems faced by the selected transition economies in Eurasia during the transition period and especially after their independence. The countries analyzed are Azerbaijan, Kazakhstan, Kyrgyzstan, Tajikistan, Turkmenistan and Uzbekistan. The economic growth performances are evaluated with selected institutional and structural factors; namely, with political stability, democratization and corruption with panel regression analyses. Due to the availability of the data and to obtain a balanced panel of the analyzed countries, the sample is restricted to the 1987-2011 period. The empirical findings suggest that the role of democratization has been significant on growth for the period of transition and after the independence. Unexpectedly, the findings point at positive impacts of corruption on economic growth which suggest that high levels of corruption have significant effects on economic growth due to the enlargement of the informal economy and which translates itself on GDP growth rates. Empirical results also suggest that the success or failure in economic development in this regard is related to, in addition to measures taken in terms of economic reforms, the cooperation of the societies with these reforms, the level political stability, corruption, socialdemocratization of communist parties and failure or success in claiming the conducted reforms by the transition economies.
\end{abstract}

\section{Introduction}

If the countries which completed their transitionary process between the years of 1989-1991 are compared, the transition countries in Europe are more successful in terms of development. Furthermore, Poland, Czech Republic and Hungary reached the PPP adjusted GNI per capita levels that they had in 1989 by the year 1998. On the other hand, the PPP adjusted per capita income of Russia in the late 1990's is almost 50\% of the GNI per capita (PPP) that Russia had in year 1989. While examining the reasons behind the slowdown of growth in the transition countries, a fraction of the literature focuses on political decision-making, excessive spending, cumbersomeness and the combination of political decision-making with excessive spending and cumbersomeness and then increasing costs and expenditure and getting away from economical effectiveness.

In the study, an investigation of the development process followed after the independence by Azerbaijan, Kazakhstan, Kyrgyzstan, Tajikistan, Turkmenistan and Uzbekistan will be provided on the basis of socioeconomic, structural and political stability factors. The study also aims to analyze the relative success of the transition countries in Europe and the relative failure of former USSR countries. Accordingly, the institutional, economic and social factors are evaluated. These factors include democratization, political instability and corruption, extroversion, institutional and organizational factors.

\section{Investigation of Economic Growth, Institutional, Structural and Socioeconomic Indicators}

In the second part of the study, the concepts of institutional, structural and socioeconomic factors will be evaluated vis-à-vis the economic growth rates. In part 3, the institutional, socioeconomic and political factors will be analyzed within the economics literature framework. The econometric methods are given in part 4 . The analyses are conducted in the third section. Concluding remarks are given in the last section. The variables to be used in the study are the GDP per capita, the GDP per capita growth rates and possible impacts of institutional and political variables evaluated within the selected indices. Institutional and political variables evaluated in the study are the path followed by corruption, the political stability and democratization. These factors constitute the main focus of the study which aims at linking these factors to the economic performances.

\subsection{An Overlook of the Economic Growth in Selected Transition Countries}

A commonality that is faced while evaluating the pattern followed by the GDP per capita and GDP levels in the post-socialist countries is that sudden GDP decreases occurring following the transition. While a loss in terms of production that is reflected in the GDP series is expected phenomenon for countries experiencing transition, a striking feature of this fact is the length of the period of the low or negative GDP growth rates experienced by the evaluated transition countries. The average GDP per capita levels in 1990's, 2000's and in 2008- before the Global Economic Recession- is given in Figure 1. Since the year 2009 corresponded to the global down-turn, the post2008 period is not included to isolate the special effect of the transition. 


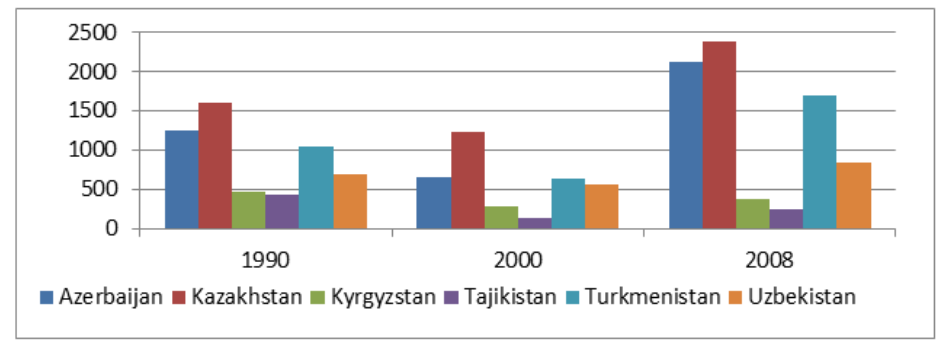

Figure 1. GDP per Capita in Selected Eurasian Economies Source: Worldbank, WDI

As observed in Figure 1, a similar pattern exists for GDP growth rates evaluated for the selected former USSR member countries. Though the WDI data is available starting from 1960's, considering the independence in early 1990's we focus on the growth performances of the transition countries for the 1990-2008 period. In 1990's, high GDP per capita levels are deserved special attention for Azerbaijan, Kazakhstan and Turkmenistan followed by Uzbekistan. Another striking feature is that the production level of these former USSR member countries in 1996, in terms of GDP per capita, is only $59 \%$ of the level they had when they were a member of USSR in 1987 . Further, in addition to the levels of production, the distribution of income and its evaluation throughout the years deserve attention as it hints possibly important social fractionalization or duality in terms of the income shares. The Gini coefficients calculated for 24 transition economies between 1986-2006, during the transition for the selected countries, are given in Figure 2.

Though the Gini coefficients represent the income distribution in these economies, they also show the income imbalances within the countries. The Gini coefficients between 1986-1990 represent substantial deterioration compared to the Gini coefficients in the post 1992 period. As there is a noticeable improvement between 20002002 compared to 1996-1998, if an overlook is to be presented, the mean Gini levels follow an increasing trend during the overall period. As a result, the factors that could result in such deterioration have a strong effect on the creation of the unfair distribution even though the GDP levels in the late 2000's are comparatively larger than those achieved during the early periods of transition. There are many macroeconomic factors that could lead to such results including the increases in the inflation rates and unemployment increases and other factors such as the privatization, dissolutions, adaptation or lack of adaptation of technologic advancements and the expected result of market economy that prioritizes productivity over equal pay. Among many factors, the study aims at focusing three of the most important factors to evaluate their effects on economic growth: democratization, political (in)stability and corruption.

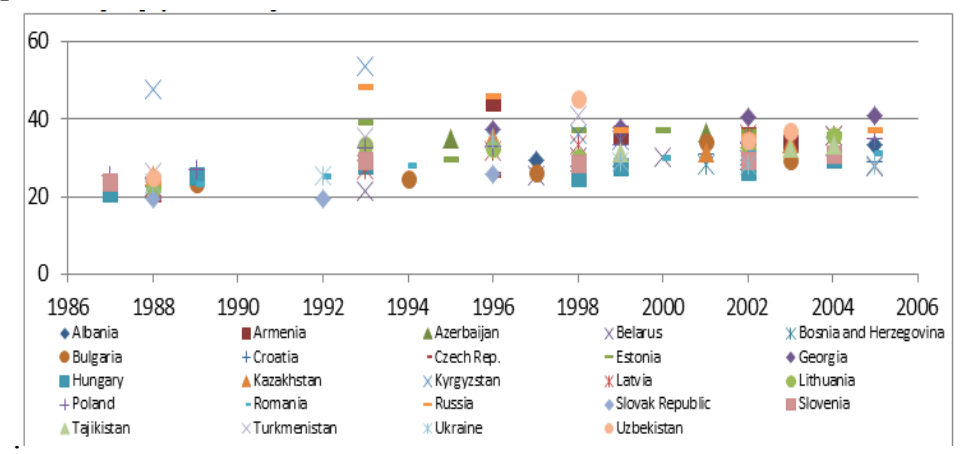

Figure 2. Gini Coefficients in the Transition Economies, 1986-2006. Source: Worldbank, WDI

\subsection{Democratization}

Democratization, political instability and corruption will be under the focus in evaluating the socioeconomic factors. Democratization is the most emphasized variable in socioeconomic factors; whereas, corruption and political instability have significant impacts on achieving economic development.

While analyzing the democratization in transition economies, one of the questions needed to be answered is "how could we define the relationship between democracy and economic growth or dictatorship and economic development?". There are many examples for both cases. We can easily say that democracy causes high speed growth if the view point is from the countries in Europe. Furthermore, Korea, Taiwan, Japan and India are the countries that showed significant successes in economic growth following their democratization policies; growth and high speed development followed by their democratic regime characteristics. Another important example on this subject is Indonesia. After the end of the dictatorship, the improvement in economic conditions deserve special attention. On the contrary, Malaysia does not have a liberal democracy although she has even better economic conditions. The studies focusing on the effects of regimes and economic growth fail to display a consensus on this relationship especially on the way of causality between these variables. We defined some of the crucial studies on these subjects below. 
Alesina and Drazen (1991), Roland (2000) and Fidrmuc (2003) pointed out that there were negative effects of democracy on economic growth whereas the main motivation on this negative effect is based on the election process and its consequences on the economy. Accordingly, the elections push the government to avoid having radical economic reforms that target to overcome loss of efficiency in the economy. In a similar fashion, Cheung (1998) attracts attention to the elections and also point to the importance of the time period of transition to democracy. Another study that discusses the positive and negative aspects of democracy is Tavares and Wacziarg (2001) study. In their analysis, Tavares and Wacziarg (2001) discuss not only the positive effects such as those that lower income inequality and augment the accumulation process of human capital but also the negative effects like lower accumulation of physical capital and greater involvement of government in the process towards democracy. Thus Tavares and Wacziarg (2001) state that the net effect was noted to be negative if the positive and negative aspects of democracy and their effects are to be evaluated in light of success in achieving economic growth.

The studies looking from the positive effect side of democracy on economic growth can be exampled as North (1990, 1993), Olson $(1993,2000)$. The main idea of these studies is that democracy ensures and guaranties better property rights. Another study that imposes the positive effects of democracy on growth is Rodrik (2000) which highlights the importance of local knowledge. Accordingly, the importance of low economic uncertainty causes high institutional outcomes and finally better response to adverse shocks.

These studies point that the debate on the subject are collected under two pillars. Krueger and Ciolko (1998) introduced an important approach by attracting attention to initial conditions versus policy choices on output decline for transition economies. In their study, they ascertain the endogenity hypothesis of the liberalization and they didn't reject it. Heybey and Murrell (1999) investigated the effects of the speed of liberalization on economic growth with an approach benefiting from simultaneous equations and found that both accumulated liberalization and the speed of liberalization had positive impacts on performance of growth. Another study analyzing the initial conditions and the growth performance in liberalization is Berg, Borensztein, Sahay and Zettelmeyer (1999) which aims to investigate the $U$ shaped per capita output over time - a common phenomenon experienced by all transition economies. They studied output level/output growth as dependent variable and utilized non-policy explanatory variables such as initial conditions and country dummies, and policy variables such as macroeconomic variables important for policies and structural reforms. They also find that the initial output decline in former Soviet Union is a result of slower structural reforms and they advise radical approaches to reforms. Havrylyshyn, Izvorski, Rooden (1998) analyzed the determinants of growth for 25 transition economies in the period 1990-1997. They found evidence for macroeconomic stabilization, structural reforms and low government expenditure on sustainable growth. Wolff (1999) suggested the J-curve effect on output growth of liberalization and shows that after a three year period, the increase in liberalization has positive effects on output and negative effects on inflation. Also Fidrmuc (2003) considered the trade-off between democracy and growth. One of the main results is economic liberalization has positive effect on growth; whereas, another important finding is the result that democracy facilitates liberalization and improves growth performance.

\subsection{Political Instability}

According to United Nations (2003), another factor that deserves to be investigated under the socio-economic factors is political instability. Political instability is investigated with its relationship to economic growth in many studies. Factors that evolve with political instability simultaneously with a parallel manner are hyperinflation, high rates of unemployment, high government expenditures and inefficiency in the structure of tax policies that results in budget deficits which lead to failure in transition of economic structure, inequality in distribution of income and sharp declines in happiness index and these factors cause also to a circular causation as the reasons and results behind underdevelopment. However, these macroeconomic variables are left out of the focus while the analysis in this paper aims at directing the analysis to investigating the political stability on growth in this section and in the empirical section.

In accordance with the political instability, the literature suggests interrelations with the structure of population, existence of minorities, the homogeneity or heterogeneity of the population, the existence of religious opposition, the parliamentary structure, polarization in the parliament and political massacres (Eren and Bildirici, 2000). In this respect, minorities, religious opposition wars, civil wars and terror attacks are evaluated among the factors that affect economic growth negatively. Ethnic heterogeneity is a very important factor that is a cause of political instability. All republics are, in varying degrees, multi-ethnic and republics have ethnic linkages to each other: Kazakhstan, Kyrgyzstan, Uzbekistan and Turkmenistan are all Turkish-speaking nations. One exception is Tajikistan, which differs by its Persian ethnic and cultural roots. The people of Tajikistan are predominantly Persian rather than Turkish origin. Ethnicity in Kyrgyzstan and ethnic minorities in the region are: Kyrgyz $52.4 \%$ Russian $18.0 \%$ Uzbek $12.9 \%$ Others $16.8 \%$ In Azerbaijan, it is Azerbaijan 82 \%, Russian 6\% and other \%12 (CIA, 2001). The figures in Uzbekistan are: Uzbek $71 \%$ and Russian $11 \%$ of population. Turkmens constitute $72 \%$ of Turkmenistan population (Eren and Bildirici, 2000).

One point that cannot be overlooked is the fact that the ethnic disputes and regional differences deserve significant attention by the economies evaluated. Starting from early 1990's ethnicity problems gained relevance and increasing problems. Political disputes such that those observed in Tajikistan were caused by on-going tensions 
regarding the Non-Central Asian minorities (Atkins, 1999). On the other hand, though the percentage of Russian were amounted to nearly 8 percent of the population, small fractions of communities such as Jews, Ukrainians Armenians, were considered collectively as the Russian-speakers, have shown their dissatisfaction before the era during which the political instability in light of the political tensions experienced gained significant attention. Russian is widely spoken in Uzbekistan, Kyrgyzstan, Tajikistan and in Kazakhstan (Eren and Bildirici, 2000).

In post-USSR countries, the shape of relationships between former USSR members have significant impacts on the development process. Cornell (2000) shows that, following the large proportion of the Russian-speaking populations; especially as is the case in Kyrgyzstan and Kazakhstan, the continued existence of these economies in its present shape could be put into question. Should these countries decide to embark on a more nationalistic, anti-Russian path is an important decision in the development process. Kyrgyzstan is a small country that shares this problem; moreover, it is vulnerable to its neighbors, China and Uzbekistan. Most members of these nationalities either supported the anti-reformists or emigrated. The emigration turned into a mass exodus by 1992 with the outbreak of civil war. Atkins (1999) shows shat another problem in Tajikistan and Uzbekistan is regarding "the problem of definition". Bukhara and Samarkand, cities that Tajiks consider as their most important cities in history, were assigned to Uzbekistan. Leaders of the new Uzbekistan tried to uzbekify the Tajik minority. "The problem of definition" of nationalization remain as significant points between Tajiks and Uzbeks to the present. During the height of the civil war, most Uzbeks in Tajikistan sided with the anti-reformist coalition and some took an active part in the fighting (Atkins, 1999).

Furthermore, the above mentioned problems in these countries co-exist with the ongoing problem regarding Afghanistan. Cornell and Sultan (2000) notes that a quarter of Afghanistan's population consists of mostly Tajiks, Uzbeks and Turkmens. In addition, Xinjiang, autonomous region in the Republic of China also has a large amount of Kazakh, Kyrgyz and Uzbek population. Though these ethnic links had considerable impact on the security of the concerned states, especially in an age of increased global ethnic awareness, the ethnic milieu of Afghanistan is affected increasingly by the cross-border ethnic linkages. These linkages are at times further strengthened by geopolitical and economic interests of stakeholders and actors in the region (Eren and Bildirici, 2000).

During the analyzed period, Azerbaijan went through certain problems in regards to its minorities: starting from 1989, the Nagorno-Karabakh autonomous region asked its autonomy in which Armenian nationalist played a crucial role in supporting the Nagorno-Karabakh region (Cornell and Sultan, 2000). Following the independence, the ongoing tension between the Armenians and Azeries led to a war during which around one-fifth of Azerbaijani territory became ruled by the Armenian authorities in October 1993 (Cornell, 2001).

In 1996, China, Russia, Kazakhstan, Kyrgyzstan, and Tajikistan inaugurated a diplomatic discourse regarding their mutual west Asian borders. On 26 April 1996, the Presidents of the five border countries signed an agreement in Shanghai on which fourteen agreements on border issues has been met in addition to the agreements in terms of economic and security issues of the mutual borders. The package is called the Shanghai Accord which established an important development in establishing a framework for border normalization. The Tajik military units controlled the Tajikistan border with Afghanistan. Further, the Afghanistan-Tajikistan border is considered as a path through which terrorist activities and illegal goods including drugs had found a route to destinations in Eurasia which was intertwined by the war between Azerbaijan and Armenia over the Nagorno-Karabakh discussed above. Thus the 1993-1996 period is considered as Azerbaijan's hard road to stability (Eren and Bildirici, 2000). After the Azerbaijani armed forces have suffered severe military setbacks in the fall of 1993, Armenian forces occupied the whole area between Karabakh and the Iranian border. In May 1994, as a military stalemate developed between Azerbaijan and Armenia, a cease-fire was signed. In 1995, a coup attempt took place, which was organized by a leader of the interior ministry forces, was deterred (Cornell, 2001). Nichol and Kim (2001) noted that this event that took place between Armenia and Azerbaijan resulted in complete displacement of ethnic Armenians from Azerbaijan and the opposite from Armenia. Another war that took place in Chechnia further increased the problems between Azerbaijan and Armenia in terms of the ongoing problems related to the Nagorno-Karabakh region. These particular set of events accelerated the ongoing instability to another level in the Caucasus region as the year 2003 was reached. One important result is the fact that the wars that had been happening in the region, following the cooperation between Armenia and Azerbaijan and between Georgia and Abkhazia, and following the Tajik civil war, another important event that extended the conflicts in the Eurasia had become the civil war in Afghanistan. Further, in late 2010's, the accelerated cultural conflicts in the region following the wars had also been affected from Russia's policies in Chechnya. Another event is the separatist movement in Xinjiang-Uigur Autonomous Republic of China that also contributed to the increased tensions in the region.

Especially Azerbaijan is very vulnerable and it has suffered several coups or attempted coups. A constitutional referendum in 1995 granted Azerbaijani President Heydar Aliyev sweeping powers. He has arrested many of his opponents. The 1995 legislative and 1998 presidential elections were marred by irregularities, according to international observers. The 1998 presidential election was very important. At first, the regime issued an electoral law that was rejected by both the OSCE and the opposition, which decided to boycott the elections. In response to the OSCE's criticism and after a dialogue with the opposition, the Aliev regime reformed the electoral law and abolished press censorship. These changes won the OSCE's approval (Cornell, 2001). In late June 2000, the 
Parliamentary Assembly of the Council of Europe (PACE) approved Azerbaijan's membership, conditioned on its compliance with commitments, including holding a free and fair legislative election. Although international observers also judged January 2001 legislative run-off elections as seriously flawed (Nichol and Kim, 2001). In elections in republics, it presented a crucial opportunity to change this state of affairs. But they produced another rubber-stamp parliament, through electoral fraud and opposition boycott (Eren and Bildirici, 2000).

The anti-government uprising in Hujand, Tajikistan, in November 1998 showed that the conflicts of the Tajikistan war had not been resolved by the Tajikistan peace accord. Uzbekistan was bombed by terrorist in Tashkent in February 1999. In this situation, in Kyrgyzstan, Security issues, reemerged with the onset of the Tajikistan war reemerged in summer 1999 with a hostage crisis. In August 2000 a new hostage crisis in Kyrgyzstan refocused attention on the country's vulnerability. In September, a military force had penetrated into Uzbekistan within 100 kilometers from the capital. Uzbekistan is the target of terrorist organizations, especially the IMU and has announced that its goal is to overthrow the Uzbekistan government. In Uzbekistan, legitimate political disagreement and political extremism, that is, political instability was increasing (Gleason, 2001).

In Uzbekistan during the first decade of independence, politics has been far from pluralistic or competitive. The political process is carefully monitored and controlled. Restrictions on the electoral registration process make it possible for the government to exercise a determining influence on the pre-selection of candidates. In theory, the judiciary is independent, but in practice, the capacity of the judiciary, being an independent branch of government is limited. The Constitution describes the legislature as the highest organ of power, in the country has a unitary. In reality, the branches are not coequal or balanced; the executive branch is dominant in virtually all matters (Gleason, 2001).

All these problems severely affected the region's political and economic development. On the other hand, the politically motivated violence, coups or attempted coups, and ordinary crime heightened the sense of insecurity in the republics. Parliaments and constitutional courts have been disbanded, elections are rigged and civil rights are systematically suppressed (Eren and Bildirici 2000). These had many important effects on instability.

All problems analyzed in the paper created increased political instability. In the empirical section, the study aims at focusing on the effects of political instability on economic growth in the selected countries.

\subsection{Corruption}

Corruption is defined as follows; "a purposeful intention not to stay away from advantageous activities of a person for himself or for an akin" (Tanzi, 1998). Johnson et. al. (1998), in their study analyzing certain Latin American, OECD and transition countries, identified significant relationships between corruption and the underground economic activities.

In the countries analyzed, a common characteristic is the fact that, the informal economy feeds on the following factors; namely, high interest rates on the government debt, the failure in the structure of tax policies, avoidance of taxes and the practice of tax evasion at high rates. Among the rising economies, the countries that have increasing volume of informal economy, are countries that have high political instability and those possessing democracy regime. In these countries, corruption and informal economy grows with an accelerating rate and also is nurtured with political instability. Even though the average economic growth rates are low in the countries that also have corruption and political instability, the rate of growth of the informal economy reaches high levels. As the informal economy in these countries in developed with increasing rates, the country shows periodically a low performance.

In 1999 in Kyrgyz Republic, the informal economy is estimated as $47.9 \%$ with the highest rate among the transition economies, whereas the rate reached $26.8 \%$ in Kazakhstan in the year 2000. Georgia's shadow economy was the largest, $64 \%$ of the GDP and Russia's was $44 \%$ of GDP (OECD, 2004). Among the transition countries that are located in central and eastern Europe in the same period, Bulgaria experienced a rate of $11.1 \%$ of their GDP in 2000 and Slovakia's and Czech Republic's were the smallest, at 7.3\% for the former and $5.6 \%$ for the latter.

Accordingly, the countries that possess corruption and informal economy at very low levels experience the stages of growth partially without problems and also are the countries that accomplish the transition process.

\section{Data and Econometric Methodology}

\subsection{Data}

The study aims to analyze Kazakhstan, Kyrgyzstan, Uzbekistan, Turkmenistan, Tajikistan and Azerbaijan. The data utilized in the study is gathered from the Gapminder Database, World Bank and IMF. The sample covers the 1987-2011 period and consists of yearly time series data for 6 countries. The variables are the corruption index, the political instability index and the democratization index. GDP data is collected from the World Bank, WDI database and represents the GNI in constant dollars. The data on democracy in collected from the Freedom House database. Political instability is taken from the Governance Indicators Database of the World Bank. All variables 
are log linearized with natural logarithms. After taking first differences, the first differenced variables represent their growth rates.

\subsection{Unit Root and Stationarity Tests with Structural Breaks}

The dataset is evaluated with Fisher Chi-square tests (Choi, 2001), Levin et. al. (2003) LLC unit root test and Carrion-i-Silvestre et al. (2005) stationarity tests that allow one or more structural breaks. The LLC panel unit root test is a panel unit root test that allows for fixed effects and unit specific time trends in addition to common time trends. The test may be evaluated as a pooled DF or ADF, potentially with differing lag lengths across the units of the panel and they use ADF tests to test for unit roots. Further, in the LLC test, the unit-specific fixed effects are an important source of heterogeneity. To save space, the structural break test results are not tabulated in the paper. However, the estimated structural break dates will be reported and evaluated in the econometric results below for the analyzed countries. The structural break test results are available upon request from the authors.

\section{Econometric Results}

\subsection{Unit Root and Stationarity Test Results}

At the first step, variables are evaluated with selected 1st generation panel unit root tests; namely, LLC, IPS, Fisher and Hadri tests. At the 2nd step, the stationarity of the variables are further investigated with the CBL stationarity tests. As noted in section 4, the selection of CBL test is based on the fact that it allows testing the stationarity by allowing multiple structural breaks both in the mean and in the slope. Further, the test is differentiated in the sense that it allows both for different number of structural breaks at unspecified dates and also by allowing for different structural break numbers and dates, the test procedure allows heterogeneity of panels investigated. At the $3 \mathrm{rd}$ step, panel regression analysis is conducted. The selected $1^{\text {st }}$ generation panel unit root tests are given in Table 1. To save space, the CBL stationary test that allow for heterogeneity in terms of multiple structural breaks are not reported. The results are available from the authors upon request. However, the calculated structural break dates will be reported within the texts below.

\begin{tabular}{|l|l|l|l|l|l|}
\hline Variables & LLC* & IPS & Fisher** & Hadri (homo)*** & Hadri (hetero) $* * *$ \\
\hline$\Delta g d p$ & -8.23 & -6.92321 & 70.37 & 8.0123 & 7.872149 \\
\hline$\Delta$ democi & -4.36 & -6.93430 & 36.68 & 7.7432 & 7.198170 \\
\hline$\Delta$ corrupi & -6.09 & -7.5349 & 41.90 & 9.6428 & 8.36507 \\
\hline Apoli & -7.14 & -9.6423 & 70.196 & 10.157 & 9.186 \\
\hline
\end{tabular}

Table 1. First Generation Unit Root Test Results

Notes. *LLC, IPS denote Levin, Lin \& Chu and Im, Pesaran and Shin panel unit root tests. ** ADF - Fisher Chi-square test. The test results are reported for the first differences to save space and $\Delta$ denotes first differences. *** Homoscedastic and heteroscedasticity-robust versions of Hadri test is reported.

The null hypothesis of LLC, IPS and Fisher tests are unit root; whereas, the null hypothesis in the Hadri test is stationarity of the variable. The results supported the hypothesis of a unit root in all variables across countries and therefore, the results for the first differenced series are reported. Accordingly, the series are accepted to be integrated I(1) of order one process and therefore, first differenced series are accepted to be taken into consideration for the panel regression analysis. If the tests are evaluated, it is concluded that the null hypotheses of stationarity are rejected for all of the series in levels. Accordingly, the null of stationary cannot be rejected at $5 \%$ significance level for all variables once the first differences of the series should be utilized in the panel regressions. This result is also confirmed with CBL tests. To include the effects of the structural breaks, dummy variables will be added in the regression analysis. It was noted in Section 1 that the countries evaluated went through some very sharp declines in in their GDP levels. As expected, the structural break dates calculated with the CBL tests coincide with the high downturns in terms of negative growth rates achieved by these countries. Azerbaijan experienced a negative growth rate of $-24.3 \%$ in 1993 and a single break is calculated for the year 1993 in Azerbaijan. The structural break dates calculated for Kazakhstan are 1992 and 1995 and the growth rate recorded as $-11 \%$ for 1991 and $-11.3 \%$ for 1994 , thus the calculated structural break dates denote two structural breaks following the years reported. Kyrgyzstan had sharp declines such as $-14.9 \%$ in $1992,-15.4 \%$ in 1994 and $-20 \%$ in 1995 and the structural break dates are calculated as the years 1991 and 1996. The GDP growth rates of Turkmenistan show highly negative values in years 1993, 1994 and 1997 with $-12.5 \%,-19.4 \%$ and $-12.6 \%$; whereas the structural break dates were calculated as 1996 and 1999. Considering the double V-shaped GDP path followed by Turkmenistan, the results were expected. The same analysis holds for Uzbekistan. The results suggested one break in the year 1994 and negative growth rates were recorded following the year $1992(-13.3 \%)$ in the country. Accordingly, sharp declines in terms of GDP growth rates are common for the evaluated transition countries following their independence after the dissolution of USSR.

Further, the break dates are calculated as 1999 and 2003 for Azerbaijan, 1995 and 1999 for Kazakhstan, 1991, 1997 and 2007 for Kyrgyzstan, 1994 and 2007 for Tajikistan, 1999 for Turkmenistan and 1993 for Uzbekistan. 


\subsection{Panel Regression Results}

The points asserted in analyses in terms of the transition economies are various and deserve special investigation. It is important to note that, in the literature, certain amount of studies use indices individually as proxies by leaving other indices out of the analyses. Following the discussion given in section 2, the following four panel regression models are estimated for 1989-2011 period,

Model 1: $\Delta g d p_{i t}=\beta_{0}+\beta_{1} \Delta$ corrupi $_{i t}+\beta_{2} D U_{i t}+u_{i t}$

Model 2: $\Delta g d p_{i t}=\beta_{0}+\beta_{1} \Delta$ democi $_{i t}+\beta_{2} D U_{i t}+u_{i t}$

Model 3: $\Delta g d p_{i t}=\beta_{0}+\beta_{1} \Delta$ poli $_{i t}+\beta_{2} D U_{i t}+u_{i t}$

Model 4: $\Delta g d p_{i t}=\beta_{0}+\beta_{4} \Delta$ corrupi $_{i t}+\beta_{5} \Delta$ democi $_{i t}+\beta_{6} D U_{i t}+u_{i t}$

Further, the following model is estimated to evaluate political instability and its effects on economic growth,

Model 5: $\Delta g d p_{i t}=\beta_{0}+\beta_{1} \Delta$ corrupi $_{i t}+\beta_{2} \Delta$ democi $_{i t}+\beta_{3} \Delta$ poli $_{i t}+\beta_{4} D U_{i t}+u_{i t}$

Where $g d p_{i t}$ represents the gross domestic product, corrupiit is the corruption index, demociit is the democratization index, poliit is the political stability index of country $i$ at year $t$. DUit is the dummy variable that equal 1 for the dated structural breaks for country i at year t. Since all variables analyzed are given in their first differences following the unit root tests, they represent their growth rates, respectively. Since all variables are in logarithms and in first differences, they are the growth rates denoted with a $\Delta$. As a typical, the economic growth

rate is denoted with $\Delta$ gdpit. Thus, $u_{i t}$ is assumed as following i.i.d. $N\left(0, \sigma^{2}\right)$ white noise process. The results for the estimated panel regressions are given in Table 2.

\begin{tabular}{|c|c|c|c|c|c|}
\hline \multirow[t]{2}{*}{ Dependent Variable: $\Delta$ gdp } & \multicolumn{5}{|l|}{ MODELS: } \\
\hline & (1) & (2) & (3) & (4) & $(5)$ \\
\hline $\mathrm{c}$ & $\begin{array}{l}-10.03 * * * \\
(-3.12)\end{array}$ & $\begin{array}{l}2.085 \\
(1.15)\end{array}$ & $\begin{array}{l}2.98 * * * \\
(2.81)\end{array}$ & $\begin{array}{l}-3.44 * * * \\
(-4.30)\end{array}$ & $\begin{array}{l}1.089 * * * \\
(2.23)\end{array}$ \\
\hline$\Delta$ corrupi & $\begin{array}{l}1.21 * * * \\
(2.77)\end{array}$ & - & - & $\begin{array}{l}5.65 * * \\
(2.41)\end{array}$ & $\begin{array}{l}1.76 * * * \\
(2.83)\end{array}$ \\
\hline$\Delta$ democi & - & $\begin{array}{l}0.987^{*} \\
(1.95)\end{array}$ & - & $\begin{array}{l}3.80 * * \\
(2.23)\end{array}$ & $\begin{array}{l}0.56^{* * *} \\
(2.77)\end{array}$ \\
\hline$\Delta$ poli & - & - & $\begin{array}{l}0.62 * * \\
(2.53)\end{array}$ & - & $\begin{array}{l}-0.28 * * \\
(-2.56) \\
\end{array}$ \\
\hline $\mathrm{DU}$ & $\begin{array}{l}0.116^{* * *} \\
(2.475)\end{array}$ & $\begin{array}{l}1.52^{*} \\
(1.88)\end{array}$ & $\begin{array}{l}1.543 * * * \\
(3.723)\end{array}$ & $\begin{array}{l}1.112 * * \\
(2.281)\end{array}$ & $\begin{array}{l}0.88 * * * \\
(3.37)\end{array}$ \\
\hline $\mathrm{R}^{2}$ & 0.761754 & 0.7841 & 0.81 & 0.416758 & 0.7673 \\
\hline Log likelihood & -456.895 & -488.51 & -477.0163 & -416.2833 & -458.47 \\
\hline Cross-section F & $\begin{array}{l}6.720914 \\
\text { Prob:(0.000) }\end{array}$ & $\begin{array}{l}7.0145 \\
\text { Prob: } \\
(0.000)\end{array}$ & $\begin{array}{l}7.90 \\
\text { Prob:(0.0000) }\end{array}$ & $\begin{array}{l}4.441811 \\
\text { Prob:(0.00016) }\end{array}$ & $\begin{array}{l}6.8216 \\
\text { Prob:(0.0000) }\end{array}$ \\
\hline Cross-section Chi-square & $\begin{array}{l}58.66913 \\
\text { Prob:(0.000) }\end{array}$ & $\begin{array}{l}55.1703 \\
\text { Prob: } \\
(0.000)\end{array}$ & $\begin{array}{l}52.1603 \\
\text { Prob:(0.000) }\end{array}$ & $\begin{array}{l}44.704077 \\
\text { Prob: }(0.0005)\end{array}$ & $\begin{array}{l}50.987 \\
\text { Prob:(0.000) }\end{array}$ \\
\hline
\end{tabular}

Table 2. Panel Regression Results

Notes: For the first 4 models, the sample is 1989-2010. For Model 5, the sample covers 1996-2010. All models are estimated under fixed effects assumption. *, **, *** denote significance at 10\%, 5\% and 1\%.t statistics are given in parenthesis.

In Model 1, we added corruption variable is the explanatory variable added to the regression. The sign of the parameter is statistically significant and is positive showing that corruption has a positive impact on economic growth. The results coincide with Tanzi (1998) findings in terms of the positive effects of corruption. Tanzi (1998) notes that the positive effect of corruption on growth is expected to be larger as the size of the underground economy increases, a factor which cannot be quantified appropriately and also cannot be included into the models since no continuous data exists. In Model 2, the democracy variable is added to the regression. While the sign of the parameter estimate is positive, its parameter is statistically significant only at $10 \%$ significance level. An overall assessment of the literature suggests that democracy has a mostly insignificant parameter estimates with either negative and positive signs (see, for example, the reviews of Przeworski and Limongi, 1993; Sirowi and Inkeles, 1990; Przeworski et al., 2000). Adelman and Morris (1967), Bhalla (1994), Chatterji et al.(1993), deLong and Schleifer (1993) and Dick(1974) points at positive; Berg-Schlosser (1984) point at positive or insignificant effects. Though our results suggest statistically significant effects of democracy on growth for Model 2 at $10 \%$ significance level only, a quick investigation of Table 1 shows that, in Model 4, level of democracy has a statistically significant 
effect on growth at $5 \%$ significance level suggesting a positive effect of democratization with a relatively large size of the parameter estimate. Therefore, in addition to the positive sign in Model 2, the statistically significant and the large and positive parameter estimate of democracy suggest that our results are in favor of the literature suggesting positive and significant effects of democratization on economic growth.

In Model 3, the relationship between political instability and economic growth is evaluated. One point to be noted is that, political instability index is an index that ranges between 0 and 100, whereas, as the index becomes closer to 100 , this denotes that political risk is decreasing. Similarly, as the index is close to 0 , political risk decreases. The coefficient of political instability is estimated with a positive sign suggest that as political instability decreases (or as political stability increases), this has a positive effect on economic growth. Further, the highest overall fit is achieved with the 5th model in terms of $\mathrm{R}^{2}$. In Model 5, both corruption and democracy has a positive and statistically significant parameter at 5\% significance level suggesting positive impacts of both corruption and democracy on growth. Further, the third explanatory variable is the political instability, which is estimated with a negative sign in contrast to its positive sign in Model 3. As known in the econometrics, omitted variables could result in biased parameter estimates as occurred in Model 3; therefore, by the inclusion of all explanatory variables representing the corruption, democracy and political instability, we expect that the results obtained in Model 5 could be considered as having more reliability. Therefore, our results in the evaluated models hint correlation between corruption, democracy and political instability though in our checks, the correlation between the variables are less than 0.80 in absolute terms suggesting no perfect multicollinearity. As a result, the results obtained in Model 5 are also in line with the suggestions of Tanzi (1998) and the literature on the democracy and growth relationship discussed above. Further, among the contrasting results in Models 3 and 5 in terms of political instability, if Model 5 is taken into the considerations, similar to corruption, the results are in favor of suggesting that increased political instability contributed in the economic growth. This result is also expected if considered in line with the Tanzi (1998) results since the periods in the economies with increased corruption that is taken as a proxy of the underground economy also coincide with the periods with increased political instability. However, our results should be read with caution: these models do not take the long run relationships between the analyzed variables. Therefore, though our econometric results suggest that in the short run, the political instability had a negative association with economic growth, in the long run, political stability instead of instability could result in increased economic growth. Availability of data also is in favor of this suggestion and we fail to consider testing the long run relations. This approach is left for the researches in the future.

Our overall results suggest that the role of democratization has significant impact on growth for the period of transition whereas, the impact of corruption has also been positive for the countries analyzed. In this regard, the results point that high levels of corruption reached in these countries have significant effects on the informal economy which also translates itself through certain channels that also affect economic growth. However, the evaluation of these channels is also left for future studies.

\section{Conclusion}

If evaluated in terms of economic success, the Middle-European countries are comparatively more successful in terms of economic growth. In the success of these countries, in addition to measures taken in terms of economic reforms, the cooperation of the societies with these reforms in these countries, political stability, socialdemocratization of communist parties and failure to claim the conducted reforms properly, and religious factors have significant roles. As stated by Erickson (1999), among the majority of former USSR member countries, the failure to achieve full transformation of the leadership and parliamentary system in the post-Soviet nations could be named as "bureaucratic capitalism" which could have resulted from certain factors. These factors are listed as inappropriate conduct of the laws, governmental looting activities, existence of mafia and informal economy and failure to receive the social support from the nations' citizens. Nevertheless, these factors encumber the achievement of success and political instability played a significant role in the lack of progress in terms development.

As discussed by Eren and Bildirici (2000), to achieve enhanced economic development levels, the transition countries should pay importance to macroeconomic stability, the establishment of competitive markets, the commitment towards "real" privatization, the ability to achieve improved property rights, the establishment of political stability. However, these goals also require a certain amount of capital stock which are accessed more successfully by the countries located closer to Europe. Compared to literature which suggests that democracy had a mostly insignificant parameter estimates with either negative and positive signs, our results showed a positive and significant effect of democratization on economic growth in the analyzed transition economies.

Similar to the findings in the literature, the parameter of corruption is statistically significant and had positive signs suggesting that corruption had a positive impact on economic growth which could result from the positive effects of the underground economy as stated by Tanzi (1998).

Further, the parameter of political stability is estimated with a positive and with a negative sign showing inconsistent results in two different models. Following this result, though the political instability seemed to 
contribute to economic growth, this result associated with the finding that increased corruption also coincide with increased political instability periods and we noted that these results lack the empirical analyses conducted to evaluate the long run relationships among the evaluated variables. As a policy perspective, among the institutional and socioeconomic factors, further achievements in terms of improving political stability and democratization is expected to have positive effects on the economic growth of the evaluated transition economies in the long run

\section{References}

- Adelman and Morris. 1967. Society, Politics and Economic Development: A Quantitative Approach. Johns Hopkins University Press, Baltimore.

- Alesina and Drazen, 1991. "Why are stabilizations delayed?” American Economic Review, 81, p. 1170.

- Atkins, 1999. “Tajikistan: A Case Study for Conflict Potential”, The Soviet and Post-Soviet Review, 24, p.175.

- Barro, 1994. "Democracy \& Growth”, NBER Working Papers, 4909, National Bureau of Economic Research.

- Barro, 1998. Determinants of Economic Growth: A Cross-Country Empirical Study. 1st Ed. MIT Press, Michigan.

- Berg, Borensztein, Sahay and Zettelmeyer, 1999. "The Evolution of Output in Transition Economies: Explaining the Differences", IMF Working Paper WP/99/73.

- Berg-Schlosser, 1984. “African Political Systems: Typology and Performance",Comparative Political Studies, 17 (4), p. 121.

- Bhalla, 1994. "Freedom and Economic Growth: A Virtuous Cycle?” In Democracy's Victory and Crisis, ed. Axel Hadenius, Cambridge University Press: Cambridge, p. 195.

- Chatterji, Gilmore, Strunk and Vanasin, 1993. "Political Economy, Growth and Convergence in LessDeveloped Countries", World Development, 21, p.2029.

- Choi, 2001. "Unit root tests for panel data", Journal of International Money and Finance, 20, p.249.

- Cornell, 2000. “Uzbekistan: A Regional Player in Eurasian Geopolitics?”, European Security, 9 (2).

- Cornell and Sultan, 2000. "The Asian Connection: The New Geopolitics of Central Eurasia”, Caspian Brief, Marco Polo Magazine 6.

- DeLong, Bradford and Shleifer, 1993. "Princes and Merchants: European City Growth Before the Industrial Revolution", Journal of Law and Economics, 36, p. 671.

- Dick, 1974. “Authoritarian versus Nonauthoritarian Approaches to Economic Development", Journal of Political Economy, 82, p. 817.

- Eren and Bildirici, 2000. "Post Sosyalist Ülkelerde Geçiş Sorunları: Başarı ve Başarısızlıklar”, In Proceedings of METU International Conference in Economics, September 13-16.

- Ericson, 2000. “The Post-Soviet Russian Economic System: An Industrial Feudalism?” Bank of Finland Institute for Economies in Transition (BOFIT) Working Paper, ISSN 1456-811X, p. 1.

- Fidrmuc, 2000. "Political Support for Reforms: Economics of Voting in Transition Countries", European Economic Review, 44, p. 1491.

- Fidrmuc, 2000. "Economics of Voting in Post-Communist Countries", Electoral Studies, 19(2/3), p. 199.

- Fidrmuc, 2003. “Economic Reform, Democracy and Growth During Post-Communist Transition”, European Journal of Political Economy, 19(3), p.583.

- Fischer, 1993. "The Role of Macroeconomic Factors in Growth”, NBER Working Papers, No. 4565.

- Havrylyshyn, Izvorski and van Rooden, 1998. "Recovery and Growth in Transition Economies 1990-97: Stylized Regression Analysis," IMF Working Paper, 98/141.

- Heybey and Murrell, 1999. "The Relationship between Economic Growth and the Speed of Liberalization during Transition", Journal of Policy Reform, 3(2), p. 121.

- IMF, 2017. International financial statistics (IFS) database, http://www.imf.org/en/Data

- Im, Pesaran and Shin. 2003. "Testing for Unit Roots in heterogeneous Panels”, Journal of Economics 115, p. 53.

- Johnson, Kaufmann, and Zoido-Lobaton, 1998. "Regulatory discretion and the unofficial economy", The American Economic Review 88(2), p. 387.

- Krueger, Gary, and Marek Ciolko, 1998. "A Note on Initial Conditions and Liberalization during Transition" Journal of Comparative Economics, 26, p. 718.

- Lee and Lee, 2009. "Energy prices, multiple structural breaks, and efficient market hypothesis", Applied Energy, 86, p. 466.

- Levin, Lin, Chu. 2002. "Unit root tests in panel data: Asymptotic and finite-sample properties", Journal of Econometrics, 108, p. 1.

- $\quad$ Liu, Wu, Zidek, 1997. “On segmented multivariate regressions”, Statistica Sinica, 7, p. 497. 
- Mankiw, Romer, and Weil, 1992. “A contribution to the empirics of economic growth”, The Quarterly Journal of Economics, 107(2), p. 407.

- Milanovic, 1998. "Income, Ineguality and Poverty during the Transition from Planned to Market Economy", World Bank regional and sectoral studies, 1, p. 1-251.

- North, 1990. “A transactions cost theory of government”, Journal of Theoretical Politics 2, p. 355.

- Olson, 1993. "Dictatorship, democracy, and development", American Political Science Review, 87,p.567.

- Olson, 2000. Power and prosperity: Outgrowing communist and capitalist dictatorships. Basic Books, New York.

- Przeworski and Limongi, 1993. "Political Regimes and Economic Growth", The Journal of Economic Perspectives, 7, p. 51.

- Rodrik, 2000. "Institutions for High-Quality Growth: What They Are and How to Acquire Them", CEPR Discussion Paper No. 2370.

- Roland, 2000. Transition and economics: Politics, markets, and firms. MIT Press, Cambridge.

- Sirowy and Inkeles, 1990. "The Effects of Democracy on Economic Growth and Inequality: A Review." Studies in Comparative International Development, 25, p. 126.

- Tanzi, 1998. "Corruption around the world Causes, consequences, scope, and cures", International Monetary Fund WP 98/63.

- World Bank, 2017. World Development Indicators, WDI, http://data.worldbank.org/data-catalog/worlddevelopment-indicators 


\title{
The Effect of Globalization on Economic Growth: Panel Data Analysis for ASEAN Countries
}

\author{
Asst. Prof. Dr. Mesut Savrul (Çanakkale Onsekiz Mart University, Turkey) \\ Prof. Dr. Ahmet İncekara (İstanbul University, Turkey)
}

\begin{abstract}
Globalization is generally expressed as the integration of countries into the external world in economic, social and political contexts. One of the most important indicators of the level of development of a country is the economic growth performance of the mentioned country. It is therefore important to examine whether the globalization process affects economic growth. Although both the developing countries and the developing ones are deeply affected by the globalization process, it's clearly visible that developing South Asian economies get use of globalization better than many other regions of the world by implementing successful policy planning and policy implementations. In this framework, this study investigates the effect of globalization on economic growth of the member countries of ASEAN. The data used in the study is obtained from globalization index of KOF Swiss Economic Institute and national accounts database of UNCTAD. GDP and three dimensions of globalization variables of the ASEAN countries are evaluated using panel data analysis within the scope of study. The results of the analysis show that globalization has a significant effect on economic growth of the member countries of the ASEAN.
\end{abstract}

\section{Introduction}

Although many definitions are made to clarify globalization term, one of the extensive one defines it as an irrevocable power affecting the world through progressive free flow of capital, services, goods, people and opinions which results in unification of societies and economies (IMF, 2002). Economic dimension of the concept refers to expanding interdependence of countries all over the world due to the rapid and wide spread of technologies, flow of international capital and increasing scale of cross-border trade of services and commodities. It also demonstrates ongoing mutual unification and extension of market boundaries, and it is an irrevocable flow for the economic development in the entire world (Shangquan, 2000: 1).

Countries have become more and more open to forces arising from outside their borders, in this era of rapid globalization which lead to a distinct experience of economic growth. The fact that they have responded so individually is proof enough that national policy decisions are the ultimate determinant of economic growth. Meantime, the countries which have leveraged the impact of globalization to their benefit are the successful ones (Rodrik, 2007: 2). The globalization process proposes that the challenges in accomplishing forthcoming prosperity and growth, especially for the developing ones, will persist to intensify regardless of the size of countries. From this point, although sometimes it is the counter of globalization concept, many countries are trying to get into regional trade agreements with neighbouring states to provide themselves some kind of strategic protection (Read, 2004: 365).

A lot of developing countries have made effort to stimulate their economic growth via following outwardoriented policies aiming to integrate into the global economy. Although many studies covering economic growth have dealt with the topic from technological knowledge, natural resources, human capital and physical capital perspectives, regarding the influence of globalization phenomenon on developing economies, the focus of this study is to examine the effect of globalization on economic growth.

In this context, whether political, social and economic dimensions of globalization have an impact on economic growth within ASEAN countries between 1970 and 2015 is dealt within the frame of the study. Firstly, globalization term and how it is related with economic growth is debated theoretically. In the second section of the study some information about ASEAN is given as it is the sample of the study. In the last section the effect of globalization on economic growth is tested empirically. Globalization data used in the analysis of the study is extracted from KOF Globalization Index and economic growth data is collected from national accounts database of UNCTAD. The results of the analysis proved a significant relationship between globalization and economic growth of the member countries of the ASEAN.

\section{Globalization and Economic Growth}

The process of globalization presented a fundamental transformation of economic life which resulted in capital, people, products and application of technical systems becomes more effective, increase in production, circulation of knowledge and the generalization of market economy (Dăianu, 2009: 211). In the global economy no countries are self-sufficient anymore and they participate in commercial relationships at various levels to sell their products to buy their needs. As mentioned by the traditional economic theory, the economies generally make production more competently in some economic sectors than trade partners of them (Rodrigue et.al., 2006: 144) an as a result 
international trade is flourished by the widening globalization after 1980s. Although some citizens of United States can't locate Beijing city of China on the map, they already consume devastating numbers of goods which were produced in that city. A report of Federal Reserve Bank of San Francisco issued in 2010 presented that nearly 35 percent of all shoes and clothing sold in the United States were indeed produced in China while the domestic ones are only 3.4 percent. Many economists admit globalization to be beneficial for individual economies all around the world by limiting military clashes, increasing competition, making markets more effective and spreading wealth around the globe more uniformly. Nevertheless, the opinion of general public is towards that in the shortterm, the risks that globalization exposed exceedingly outweigh the benefits of it (Kuepper, 2017). These benefits and risk associated with the globalization can be summarized as follows;

\begin{tabular}{|c|c|}
\hline Benefits of Globalization & Risks of Globalization \\
\hline$\sqrt{1}$ & $\sqrt{2}$ \\
\hline $\begin{array}{l}\text { Foreign direct investment tends to increase at a } \\
\text { much greater rate that the growth in world trade, } \\
\text { helping boost technology transfer, industrial } \\
\text { restructuring, and the growth of global } \\
\text { companies. }\end{array}$ & $\begin{array}{c}\text { Globalization leads to interdependence between } \\
\text { nations, which could cause regional or global } \\
\text { instabilities, if local economic fluctuations end up } \\
\text { impacting a large number of countries relying on } \\
\text { them. }\end{array}$ \\
\hline$\sqrt{2}$ & 雪 \\
\hline $\begin{array}{l}\text { Increased competition from globalization helps } \\
\text { stimulate new technology development, } \\
\text { particularly with the growth in FDI, which helps } \\
\text { improve economic output by making processes } \\
\text { more efficient. }\end{array}$ & $\begin{array}{c}\text { Some see the rise of nation states, multinational } \\
\text { or global firms and other international } \\
\text { organizations as a threat to sovereignty. } \\
\text { Ultimately, this could cause some leaders to } \\
\text { become nationalistic or xenophobic. }\end{array}$ \\
\hline$\sqrt{1}$ & 雪 \\
\hline $\begin{array}{l}\text { Globalization enables large companies to realize } \\
\text { economies of scale that reduce costs and prices, } \\
\text { which in turn supports further economic growth, } \\
\text { although this can hurt many small businesses } \\
\text { attempting to compete domestically. }\end{array}$ & $\begin{array}{l}\text { The benefits of globalization can be unfairly } \\
\text { skewed towards rich nations or individuals, } \\
\text { creating greater inequalities and leading to } \\
\text { potential conflicts both nationally and } \\
\text { internationally as a result. }\end{array}$ \\
\hline
\end{tabular}

Figure 1. Benefits and Risks of Globalization; Source: Kuepper, Justin, 2017. Globalization and its Impact on Economic Growth, http://www.thebalance.com/globalization-and-its-impact-on-economic-growth-1978843.

Although the opinions on the topic is divergent, as seen in Figure 1, risks of globalization are mostly related with social and political issues while benefits are linked with economic ones. In the context of economic effects, the relevant dimensions are reliance and interaction between countries and other economic mediums in the world economy and the rise in the degree of international integration. Accordingly, in the economic meaning, globalization constitutes many different but related aspects (Read, 2004: 366) which can be summarized as follows:

- International trade is liberalized by the help of enhancing rules of GATT, tuning into WTO by 1995.

- The liberalization of exchange rate regimes and international capital flows which lead to rising flows of international capital and international capital mobility to increase in both forms of short and long term

- The broadening basis of universal production due to the industrialization process of developing countries such as the ones in Southeast Asia.

- Developments in communications technology, such as the rapid advancements in services and goods and flows of information.

- Multinational enterprises turning into the essential operator of capital flows and international economic activities as a result of the liberalization of international trade and investment rules.

- Rise in the international competition intensity both between nations and enterprises.

- The increase in the concentration of inter-firm competition in which lesser enterprises are taking part due to the growing entry barriers. 
Given that the economic aspect of globalization is getting to the forefront, nowadays, many researchers are of the opinion that globalization's growth effects depend on the economic scheme of the economies in their globalization process (Samimi and Jenatabadi, 2014). The connection between economic growth and globalization is argued too much in the growth and development literature without being resolved. For now, theoretical growth studies are addressing a conflicting and ambiguous discussion on the relationship between growth and globalization. While some of the studies claim globalization to be harmful on economic growth of the countries which has weak political instability and institutions, others come up with positive effects through augmentation of capital, improvement in factor productivity, diffusion of technology and efficient allocation of domestic resources (Gourdon et.al, 2008). Optimistic aspect of the debate is presented in Figure 1 below.

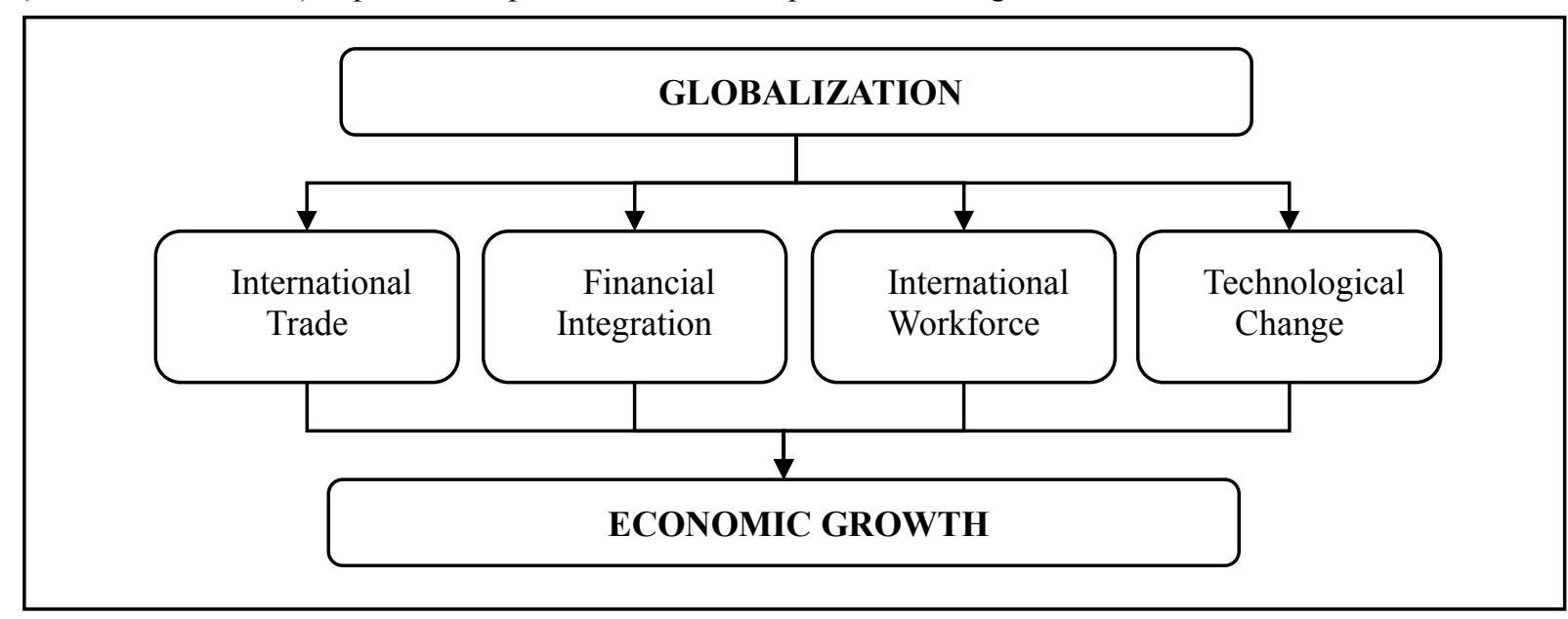

Figure 2. Globalization to Economic Growth Flow; Source: Husain, Ishrat, 2000. Making Globalization Work for the Poor Case Study of Pakistan, EMP-CIDA Globalisation Project, Lahore University of Management Sciences, $1-28, p: 2$.

As mentioned in Figure 2, although globalization flow towards economic growth includes financial integration, international workforce, international trade and technological change, it is remarkable that current movement of globalization is shaped by the increase in capital flows between developed countries and between developed and developing ones since 1980s. Although it's referred in economic literature comprehensively that these flows generally resulted with significant financial crises and collapse in growth rates in many developing countries some of these countries, such as the ones in South Asia region, achieved to obtain high growth rates thanks to this source (Prasad, 2005: 201). In this regards the scope of the following section will be the countries in that geography.

\section{ASEAN Economic Cooperation}

Southeast Asia presents one of the best examples of positive effect of globalization on economic growth of developing countries. New developing Southeast Asian countries revitalized the investments of domestic and foreign capital and input markets through positive state intervention in the market, orientation, coordination and incentives and have benefited well from international economic activities. It has been the development strategy of some of these countries to rely on domestic firms to acquire skills in workforce, technology and new products. Thus, the developing production infrastructure has attracted foreign capital and international companies to the region (Atalay and Turhan, 2002: 77-78).

Regional cooperation among ASEAN countries went through three turbulent periods since 1945.The first period, which took place between the end of the Second World War and mid-1950s was primarily on the type and nature of regional association for Southeast Asia which was governed by the ideological dominance of the Britain and U.S. Traditional colonial linkages and political realities within the region strained organization of an unified Asia. Singapore, Borneo and Malaya territories were still British colonies and Cambodia and Laos were under the control of France until 1954. During that time, while Burma was under the influence of India, Thailand and the Philippines were in favour of U.S. rather than Southeast Asia or Britain. On the other hand, Indonesia looked as if it was uninvolved in the region. The Far East (ECAFE) and Economic Commission for Asia and the Colombo Plan could be established despite to the dissociation in the region in this period however they both were dependent upon the two superpowers to a great extent (ASEAN Secretariat, 1997: 15).

In the following period, as a natural result of the globalization process and their coordination efforts resulted in establishment of some sounding organizations in the region. One of the most striking organization in the region is The Association of Southeast Asian Nations (ASEAN) which was set up in Thailand in 1967 with the ASEAN Declaration by the founders of ASEAN, namely Thailand, Singapore, Philippines, Malaysia and Indonesia in 1984 Brunei Darussalam, in 1995 Viet Nam, in 1997 Myanmar and Lao PDR and in 1999 Cambodia joined to the 
organization forming today's ASEAN which is formed of ten countries (The Association of Southeast Asian Nations, 2017). The objectives of ASEAN are to advance cultural development, further social progress promote regional stability and peace and stimulate economic growth in the region (Ying et.al., 2014: 25).

In 1992, The ASEAN Free Trade Area (AFTA) was established, which included a Common Effective Preferential Tariff (CEPT) to improve the free flow of goods within the member states. Although the newcomers couldn't fully met obligations of AFTA, they are officially regarded as a part of the Trade Area as they were needed to sign the agreement at the time of entry into ASEAN. Therefore, longer time frames were given to them so that they can meet tariff reduction obligations of AFTA (The Association of Southeast Asian Nations, 2011). The 11th ASEAN Summit held in Kuala Lumpur in 2005 constituted an important stage in the development of the Organization. During the Summit, the Kuala Lumpur Declaration for the Preparation of the ASEAN Charter was signed, providing a legal and institutional framework for achieving ASEAN goals and objectives and the establishment of the ASEAN Community based on the three pillars: the ASEAN Socio-Cultural Community, ASEAN PoliticalSecurity Community and the ASEAN Economic Community (Türkiye Cumhuriyeti Dışişleri Bakanlığı, 2011).

If ASEAN was viewed as a single economic body, it would rank among the top ten economies in the world by means of GDP. Member countries of ASEAN achieved an average economic growth between 3.8\% and 7\% during 1989-2009 period and annual GDP growth in the top five member states of ASEAN is predicted by the IMF as $6.4 \%$ in 2010 . Lately, by the end of 2015, ASEAN formed a common market by creating the AEC with the intention of establishing an economic integration in the region. As an organization accommodating a population formed of 600 million hardworking people, the growth possibility of the integration is great (Panennungi, 2011).

\section{Literature Review}

Ying et.al. (2004) examined both short and long term relationships between globalization and the growth in ASEAN countries using the data covering 1970 - 2008 period. They investigated the effect of both three categories of globalization and using panel cointegration tests, the global determinants of economic growth was taken into account within the scope of study. They analysed the data using panel fully-modified OLS to determine the elasticity of economic growth. The results of their study show that although economic globalization has a positive and significant impact on economic growth, political globalization has non-significant and negative effect and finally, social globalization has a negative impact on economic growth.

In his study, Dreher (2006) developed a globalization index incorporating economic, social and political integration as the three main dimensions of the globalization. He analysed the data of 123 countries covering the years between 1970 and 2000 using panel data. He tried to measure the effect of both overall index globalization and its dimensions on economic growth. The results of his analysis present that while over all globalization index promotes economic growth, economic flows are the most effective on economic growth in developing countries and political integration wasn't significantly effective.

Samimi and Jenatabadi (2014) carried out a study to examine the impact of economic globalization on economic growth in the countries of Organisation of Islamic Cooperation. They also questioned if the mentioned impact varies according to the income level of countries. They employed a generalized method of moments estimator as a part of approach of dynamic panel data. The results of the study present statistical evidence showing that economic globalization has a significant impact on economic growth in the countries of Organisation of Islamic Cooperation. They also prove that this impact is related with the income level of the country due to the rise in development level of financial system and workers' education.

Açıkgöz and Mert (2011) examined whether globalization had an effect on Turkey's economic growth process. In the study, they not only focused on the economic dimension of globalization, but they also took the social and political dimension into account. In the study, the globalization indices developed in Dreher (2006) were used to investigate the effects of globalization on economic growth in terms of political, social and economic dimensions in the context of causality analysis. Analyzes cover the period 1970-2008 and long-standing relationships between the series was investigated with the boundary test based on autoregressive distributed delay model (ARDL). Causality tests have not shown that there is any causal relationship from economic globalization to economic growth for the examined period in Turkey. Nevertheless, there is a causality relation from social globalization to growth.

Kılıç (2015) tested the impacts of political, social and economic dimensions of globalization on economic growth of developing countries. He analysed the mentioned effect using causality relationship using fixed effects least squares and Granger causality tests. He used the data of 74 developing countries in the study covering $1981-2011$ period. The results of the study reveal that while the economic and political globalization has a positive impact on economic growth levels of the developing countries, social globalization on the other hand produces a negative effect. Furthermore, the results causality test presents a one way causality relationship between social globalization and economic growth a two way causality relationship between social globalization, political globalization and economic growth. 
Doğan and Can (2016) investigated the relationship between globalization and economic growth using EngelGranger cointegration test. The data analysed in the study covers KOF overall globalization, social globalization and economic globalization indices of South Korea for 1970-2012 period. The research results show that economic, social and overall globalization have positive effect on growth.

\section{Model}

The aim of this study is to analyse both with cross-section and time dimensions of different countries. Because the data set covered by the study has cross-section and time dimensions together, it is eligible to use panel regression analysis for the study.

\subsection{Data Set}

In literature, many different measures are seen to be used to evaluate the effects of globalization on economic growth. Capital account openness index, foreign direct investment, openness to trade, actual trade flows can be counted as some of these popular measures (Dreher, 2006: 1091). However, The KOF Index of Globalization introduced in 2002 which covers economic, social, and political facets of the theme, provides a more comprehensive way of measuring globalization by allowing evaluating more complex relations. In the KOF Index, the dimensions of globalization are highlights as follows (Dreher et al. 2009);

\begin{tabular}{|c|c|c|}
\hline Economic Globalization & Political Globalization & Social Globalization \\
\hline $\begin{array}{c}\text { Long distance flows of services, } \\
\text { capital and goods as well as } \\
\text { perceptions and information that } \\
\text { attend market exchanges }\end{array}$ & Spread of government policies & $\begin{array}{c}\text { Expansion of information, ideas, } \\
\text { people and images }\end{array}$ \\
\hline
\end{tabular}

\section{Table 1. Dimensions of Globalization}

In this regard annual globalization indices of KOF Swiss Institute including economic, political and social dimensions are used as the globalization variables in the analysis of this study. Annual GDP per capita (constant, 2005) data collected from national accounts database of UNCTAD is used as an indicator of economic growth. The collected data encloses all 10 ASEAN countries and 1970-2015 period.

\subsection{Method}

The variables used in the study have to be stationary to prevent spurious relationships between the variables. So that in the very beginning of the analysis, variables are tested for stationarity using common unit root process developed by Levin, Lin and Chu (LLC) (2002) and assume individual unit root process developed by Im, Pesaran and Shin (IPS) (2003). The results of the tests are presented in Table 2 below;

\begin{tabular}{|c|l|c|c|c|c|}
\hline Method & Variable & GDP & EGLB & SGLB & PGLB \\
\hline \multirow{2}{*}{ Levin, Lin \& Chu } & stat & -1.78019 & -14.4816 & -14.7409 & -20.5453 \\
\cline { 2 - 6 } & p-value & 0.0375 & 0.0000 & 0.0000 & 0.0000 \\
\hline \multirow{2}{*}{$\begin{array}{c}\text { Im, Peseran \& } \\
\text { Shin }\end{array}$} & stat & -3.82840 & -14.9505 & -13.6014 & -18.4121 \\
\cline { 2 - 6 } & p-value & 0.0001 & 0.0000 & 0.0000 & 0.0000 \\
\hline
\end{tabular}

Table 2. Panel Unit Root Test

The LLC and IPS test results display that while GDP variable is stationary at 5\% significance level, EGLB, SGLB and PGLB variables are identified to be stationary at $1 \%$ significance level in their first difference and they are applicable for using in the panel data analysis. While years are the period dimension, the countries manifest the cross section dimension in the analysis. Individual effects of both years and countries have be estimated. So that these effects are outlined in equation 1 below. In the equation " $i$ " units are individuals and "t"s are the periods.

$$
G D P_{i t}=\beta_{1} E G L B_{i t}+\beta_{2} S G L B_{i t}+\beta_{3} P G L B_{i t}
$$

\begin{tabular}{|l|l|l|l|}
\hline Test & Statistic & d.f. & Prob. \\
\hline Redundant Fixed Effects & 41.236496 & $(8,349)$ & 0.0000 \\
\hline Hausman Test & 11.452609 & 3 & 0.0095 \\
\hline
\end{tabular}

Table 3. Estimation Tests

The equation is estimated with Redundant Fixed Effects and Hausman Tests, respectively for determining the suitable panel model. As the results of the tests show in Table 2. probability value of Fixed Effect test is below 0.5 value, the next estimation test is chosen as Hausman Test. As the Hausman Test also yielded $p>0.5$ value, use of fixed effects model is suitable for the current data set, so that it is analysed with Panel EGLS Fixed Effects test in the following phase. 


\begin{tabular}{|c|c|c|c|c|}
\hline Variable & Coefficient & Std. Error & t-Statistic & Prob. \\
\hline C & -2136.160 & 670.7262 & -3.184846 & 0.0016 \\
\hline EGLB & -525.9172 & 111.6459 & -4.710584 & 0.0000 \\
\hline PGLB & -11.52430 & 56.28155 & -0.204762 & 0.8379 \\
\hline SGLB & 163.7139 & 17.34437 & 9.439022 & 0.0000 \\
\hline \multicolumn{7}{|c|}{ Effects Specification } \\
\hline Cross-section fixed (dummy variables) \\
\hline R-squared & 0.487513 & Mean dependent var & 3535.615 \\
\hline Adjusted R-squared & 0.473168 & S.D. dependent var & 5408.304 \\
\hline S.E. of regression & 3925.520 & Akaike info criterion & 19.41757 \\
\hline Sum squared resid & $6.06 \mathrm{E}+09$ & Schwarz criterion & 19.53620 \\
\hline Log likelihood & -3920.057 & Hannan-Quinn criter. & 19.46452 \\
\hline F-statistic & 33.98618 & Durbin-Watson stat & 1.223123 \\
\hline Prob(F-statistic) & 0.000000 & \multicolumn{3}{l}{} \\
\hline
\end{tabular}

Table 4. Panel EGLS (Fixed Effects)

The results of Panel EGLS (Fixed Effects) test presented in Table 4 demonstrate that the overall results produced by the analysis are significant. However, when the variables are examined individually, while the relation between economic growth and economic and social dimensions of globalization are positive and significant, political globalization is found to have an insignificant relation. Finally, reliability of the results has been tested.

\begin{tabular}{|l|l|l|}
\hline \multirow{2}{*}{ Wooldridge test for autocorrelation } & $\mathrm{F}(1,8)$ & Prob $>\mathrm{F}$ \\
\cline { 2 - 3 } & 0.310 & 0.5927 \\
\hline \multirow{2}{*}{ Modified Wald Test for Heteroskedasticity } & chi2(10) & Prob > chi2 \\
\cline { 2 - 3 } & 7.6 & 0.6679 \\
\hline
\end{tabular}

Table 5. Autocorrelation and Heteroskedasticity Tests

Wooldridge Test for Autocorrelation and Modified Wald Test for Heteroskedasticity are performed respectively to check variance and autocorrelation problems. The tests rejected both heteroskedasticity and autocorrelation problems concluding that the results produced by the analyses are reliable.

\section{Conclusion}

Globalization term is explained with the developments such as deployment of nationalistic and local outlooks to a broader perspective of an interdependent and interconnected world with free transfer of services, goods and capital across national boundaries. It includes development of political, social and economic relations between the countries, better recognition of the beliefs and expectations of different societies and cultures and interrelated issues such as the intensification of international relations.

Globalization isn't a new concept however it's influence on the individual countries expanded its sphere rationally by 1980s. The economic consequences of globalization course led to rise in interdependence of the economies and proportion of cross-border trade of services and commodities increased exceptionally. Nevertheless these developments don't affect all economies of the world in the same way. While globalization process flourishes the industrialized economies with developed economic base well enough, the status of developing countries and less developed countries in this course changes from better to worse.

In this context, whether globalization is effective on economic growth in developing countries is a heated topic of interest. Regarding the fact that the countries in South Asia region achieved to obtain high growth rates because they could benefit well from globalization, the effect of political, social and economic dimensions of globalization on economic growth values of ASEAN countries for 1970-2015 period is dealt within the frame of the study. GDP and three dimensions of globalization variables of the ASEAN countries are evaluated using panel data analysis within the scope of study. The results of the analysis show that although overall globalization proved to have a positive and significant impact on economic growth of the member countries of the ASEAN when the variables are examined individually, while the relation between economic growth and economic and social dimensions of globalization are significant and positive, political globalization has an insignificant relation with economic growth.

\section{References}

- Açıkgöz, Şenay and Mert, Merter, 2011 "Küreselleşme İktisadi Büyümeyi Etkiliyor Mu? Türkiye Örneği", 12. Uluslararası Ekonometri, Yoneylem Arastırması ve Istatistik Sempozyumu, Pamukkale Üniversitesi, Denizli, pp.701-716.

- $\quad$ ASEAN Secretariat, 1997. ASEAN Economic Cooperation: Transition \& Transformation, Chong Moh Offset Printing Pte Ltd, Singapore. 
- Atalay, Mehmet, Turhan, Mustafa, 2002. “Küreselleşme, Gelişmekte Olan Ülkeler ve Türk İmalat Sanayi”, Planlama Dergisi, Sayı: Özel 42. Kuruluş Sayısı.

- Dăianu, Dana-Codruţa Dudă, 2009. “The Impact of Globalization through Iinternational Trade, Annals. Economic Science Series", International Conference, The Knowledge Society in the Space of United Europe, May 29th -30th 2009, Vol. XV/2009, pp. 211-215.

- Doğan, Buhari and Can, Muhlis, 2016. "Küreselleşmenin Büyümeye Etkisi: Güney Kore Örnekleminde Eşbütünleşme Analizi", Çankırı Karatekin University Journal of The Faculty of Economics and Administrative Sciences, Vol.6, Issue 2, pp. 197-220.

- Dreher, Axel, 2006. "Does Globalization Affect Growth? Evidence from a New Index of Globalization", Applied Economics, No:38, pp.1091-1110.

- Dreher, Axel, Gaston, Noel, Martens, Pim, 2009. Measuring Globalisation: Gauging Its Consequences, Economica, Vol.76, Issue 304, pp 779-780.

- Gourdon, Julien, Maystre, Nicolas and Melo, Jaime de, 2008. "Openness, Inequality and Poverty: Endowments Matter", World Bank Policy Research Working Paper, No.3981.

- Husain, Ishrat, 2000. "Making Globalization Work For The Poor Case Study of Pakistan", EMP-CIDA Globalisation Project, Lahore University of Management Sciences, 1-28.

- IMF, 2002. Globalization: A Framework for IMF Involvement, 02/01, https://www.imf.org/external/np/exr/ib/2002/031502.htm.

- K1lıç, Cüneyt, 2015. "Effects of Globalization on Economic Growth: Panel Data Analysis for Developing Countries", Economic Insights - Trends and Challenges, Vol.IV(LXVII), pp.1 - 11.

- $\quad$ Kuepper, Justin, 2017. "Globalization and Its Impact On Economic Growth", http://www.thebalance.com/globalization-and-its-impact-on-economic-growth-1978843.

- $\quad$ Levin, A., C.F. Lin, and C.S.J. Chu. 2002. "Unit Root Tests in Panel Data: Asymptotic and Finite-Sample Properties", Journal of Econometrics, 108: 1-24.

- Panennungi, Maddaremmeng A., 2011. "ASEAN Economies Past and Future", The jakarta Post, http://www.thejakartapost.com/news/2011/05/11/asean-economies-past-and-future.html.

- Pesaran, M.H., 2007. "A Simple Panel Unit Root Test In The Presence Of Cross Section Dependence", Journal of Applied Econometrics, 27, pp.265-312.

- $\quad$ Prasad, Eswar, Rogoff, Kenneth, Wei, Shang-Jin, Kose, M. Ayhan, 2005. Effects of Financial Globalization on Developing Countries: Some Empirical Evidence, Palgrave Macmillan, UK.

- $\quad$ Read, Robert, 2004. "The Implications of Increasing Globalization and Regionalism for the Economic Growth of Small Island States", World Development, Vol. 32, No. 2, pp. 365-378.

- $\quad$ Rodrigue, Jean-Paul, Comtois, Claude and Slack, Brian, 2006. The Geography of Transport Systems, Routledge, Newyork.

- Rodrik, Dani, 2007. One Economics, Many Recipes: Globalization, Institutions, and Economic Growth, Princeton University Press, UK.

- Samimi, Parisa and Jenatabadi, Hashem Salarzadeh, 2014. "Globalization and Economic Growth: Empirical Evidence on the Role of Complementarities", PLoS One, 9(4): e87824.

- Shangquan, Gao, 2000. "Economic Globalization: Trends, Risks and Risk Prevention”, Economic \& Social Affairs, CDP Background Paper No. 1, ST/ESA/2000/CDP/1, United Nations.

- The Association of Southeast Asian Nations, 2011. "The ASEAN Free Trade Area (AFTA)", http://www.asean.org/12021.htm.

- The Association of Southeast Asian Nations, 2017. "About ASEAN", http://asean.org/asean/about-asean.

- Türkiye Cumhuriyeti Dışişleri Bakanlığı, 2011. "Güneydoğu Asya Ülkeleri Birliği (ASEAN)", http://www.mfa.gov.tr/guneydogu-asya-ulkeleri-birligi.tr.mfa.

- $\quad$ Ying, Yung-Hsiang, Chang, Koyin, Lee, Chen-Hsun, 2014. The Impact of Globalization on Economic Growth, Romanian Journal of Economic Forecasting, No: 17/2, pp.25-34. 


\title{
The Effects of Inflation, Openness to Trade and Value Added in Production on Economic Growth in Transition Economies
}

\author{
Assoc. Prof. Dr. Özgür Ömer Ersin (Beykent University, Turkey) \\ Prof. Dr. Melike Bildirici (Yıldız Technical University, Turkey)
}

\begin{abstract}
The study aims to evaluate the economic growth process and the macroeconomic factors, namely, the inflation rates, the value added in the production taken as a proxy of productivity and openness to trade for the selected Eurasian transition economies. The paper focuses on the transition period and the economic performance achieved following the independence of the analyzed countries. By using a sample that consists of Azerbaijan, Kazakhstan, Kyrgyzstan, Tajikistan, Turkmenistan and Uzbekistan, the relationship between economic growth with inflation, trade openness and value added obtained by the national industries are evaluated within a panel setting. The dataset is investigated with traditional and structural break unit root tests followed by panel regression analyses. Considering the findings in the literature which suggest either statistically insignificant or having positive or negative effects of inflation on growth depending on the countries analyzed, the empirical findings of the paper are in favor of negative effects of inflation on growth: though the size of the effect of inflation rates on growth in rather small, negative effect of inflation cannot be rejected. Further, the positive effects of value added in the production which is taken as a proxy to productivity shows significant positive impacts on growth. Similarly, openness to international trade is shown to have positive impacts for the transition countries analyzed. The results are in favor of the findings in literature suggesting that "it is not the inflation rates, rather than the variation in inflation" which could limit economic growth. The findings for openness and value added suggest policies to enhance productivity and international trade to accelerate the economic growth in the transition economies.
\end{abstract}

\section{Introduction}

The economic growth and the problems of development are evaluated in a significant amount papers in the literature focusing on empirical investigations in light of many countries. Accordingly, the development or growth in affected from various factors. If the studies in the literature are investigated factors such as foreign capital, technology, human capital, productivity, industrialization and natural resources and their positive impacts on economic growth are evaluated in many studies. In this study, the effects of trade openness, value added in production and inflation rates on economic growth will be evaluated for selected transition economies in Eurasia.

If the countries which completed their transitionary process between the years of 1989-1991 are compared, the transition countries in Europe are more successful in terms of development. Furthermore, Poland, Czech Republic and Hungary reached the PPP adjusted GNI per capita levels that they had in 1989 by the year 1998. On the other hand, the PPP adjusted per capita income of Russia in the late 1990's is almost 50\% of the GNI per capita (PPP) that Russia had in year 1989. While examining the reasons behind the slowdown of growth in the transition countries, a fraction of the literature focuses on political decision-making, excessive spending, cumbersomeness and the combination of political decision-making with excessive spending and cumbersomeness and then increasing costs and expenditure and getting away from economical effectiveness. It is noteworthy that another fraction in the literature on the transition economies focuses on the deterioration of international trade due to poor quality products caused by the type of production process where the quantity to be produced gained priority instead of quality, which resulted from the following factors: having no bankruptcy, soft budgeting, lack of interest in cost minimization, large scale companies, decisions being made by the senior management, lack of initiative on company level, lack of the ability to keep up with the technological improvements, deficiency in creating the organizations required by the level of technology (Strecek,1996; Eren and Bildirici, 2000). Looking at other explanations, as well as the corporate crisis explanation mentioned by Kornai (1994); informational deficit explanation developed by W. Cheremza (1992), corporate devastation explanation developed by H.Schmicding (1992); J.Kornai (1997) and "Schumpeterist" creative-subversion, R. Zukowski's (Zukowski, 1996) transformational crisis explanations should be emphasized.

In the study, an investigation of the development process followed after the independence by Azerbaijan, Kazakhstan, Kyrgyzstan, Tajikistan, Turkmenistan and Uzbekistan will be provided on the basis of economic, socio-economic and corporate factors. The study also aims to analyze the relative success of the transition countries in Europe and the relative failure of former USSR countries. Accordingly, the institutional, economic and social factors are evaluated. These factors include democratization, political instability and corruption, extroversion, institutional and organizational factors and macroeconomic variables; inflation, and foreign capital on economic development are evaluated with panel regression analysis.

In the second part of the study, the macroeconomic variables in these economies are evaluated; namely, the GDP per capita levels and economic growth rates, the inflation rates, the value added as a proxy of productivity and the openness to international trade in the transition and Eurasian economies. The data and econometric methodology 
including the structural break tests are given in part 3. The econometric analyses are conducted in part 4 . Concluding remarks are given in the last section.

\section{Evaluation of the Macroeconomic Variables for the Transition Economies}

The variables to be utilized in the study are the macroeconomic variables including the GDP per capita, consumer price index, value added taken as a proxy of industrial efficiency and openness to international trade.

\subsection{The Economic Growth}

The point that should be paid attention to, while monitoring GDP developments in post-socialist countries is that the GDP decreases faced after the transitions are common. A decrease of GDP is an expected situation during a transition period; the important point is whether overcoming this in a short time and with low negative rates. Considering the growth rates as of 1989, substantial economic growth decreases were faced in all transition countries between 1990-1999. In all transition countries, the GDP followed a "letter V" like structure. This means that GDP decreased sharply following the transition and hit the bottom.

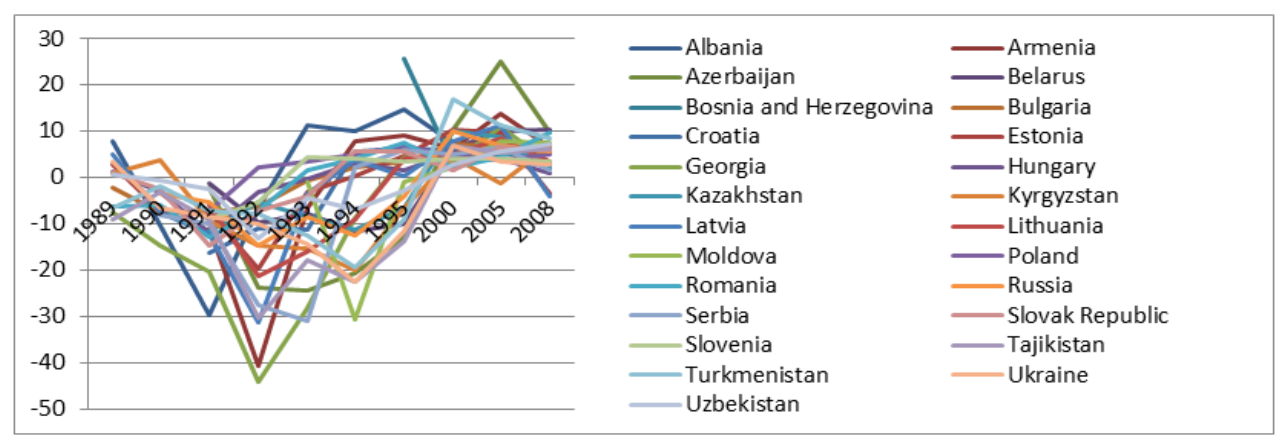

Figure 1. GDP Growth Rates Before the Global Crisis in the Transition Economies (1989-2008) Source: Worldbank, WDI Database

One striking feature of Figure 1 is that the countries evaluated went through serious minima in their GDP, respectively. Generally, central European countries began positive rates of growth within a relatively short period, and caught the GDP levels they had in 1989 by the year 1997. If the success achieved by the other transition countries in 1997 is evaluated, by comparing the former Soviet Union to Eastern Europe, serious decreases are noted in the economic growth achieved by the former Soviet Union member countries. Considering the minima points evaluated above, Azerbaijan experienced a negative growth rate as $-24.3 \%$ in 1993 . Similarly, Kazakhstan had negative growth rates between 1991-1996. As a typical, the growth rate recorded for the year 1991 is $-11 \%$ and $-11.3 \%$ for 1994 . Kyrgyzstan had sharp declines such as $-14.9 \%$ in $1992,-15.4 \%$ in 1994 and $-20 \%$ in 1995 . The GDP growth rates of Turkmenistan had similar declines in years 1993, 1994 and 1997 with $-12.5 \%,-19.4 \%$ and $-12.6 \%$. Turkmenistan made a double V-shaped GDP path. The same analysis holds for Uzbekistan. The country faced negative growth rates such as $-13.3 \%$ in the year 1992. Thus drastic decreases in the GDP growth rates are common in terms of economic growth for the countries that gained their independence after the dissolution of USSR.

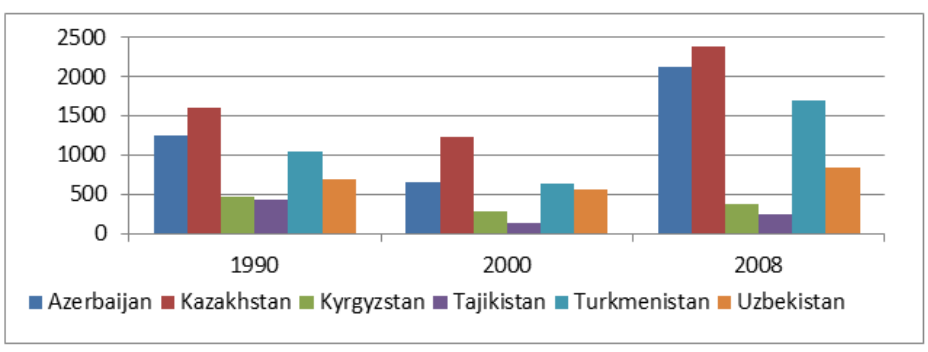

Figure 2. GDP per capita in Selected Eurasian Transition Economies Source: Worldbank, WDI

In Figure 3, the Eurasian transition economies are evaluated for the period of 1960-2008 in terms of per capita income. It is seen that a similar pattern noted for GDP growth rates in Figure 1 and 2 could be noted more clearly in Figure 3 where the dataset starts from the year 1960 though the early years of the period is not available for certain countries. If we focus on the growth performances of the transition countries for the years 1990-2008, high rates of growth are noteworthy for Azerbaijan, Armenia and Turkmenistan. One of the findings is that the production level achieved in 1996 by the former USSR, denoted in terms of GDP per capita, is only $60 \%$ of the level the USSR had in the year 1987. As of 2008, many problems still continue in these countries.

Post-transition impoverishment is examined below. Impoverishment in transition economies increased following the transition and the economic performances. Another result faced alongside impoverishment is the great increase 
in the unfair distribution of income and in the fraction of population living under the absolute poverty level. Milanovic (1998) discusses that, in 1989, 14 million people are under the poverty limit. In 1996, this number increased to 120 millions showing a sharp increase in impoverishment.

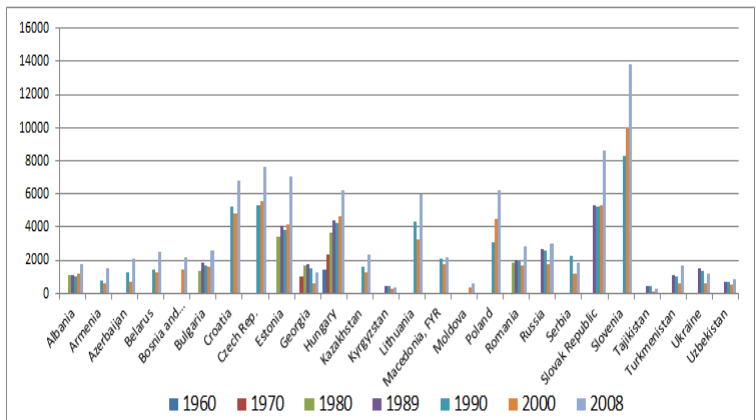

Figure 3. Income per capita in transition economies, before the Global crisis, 1960-2008

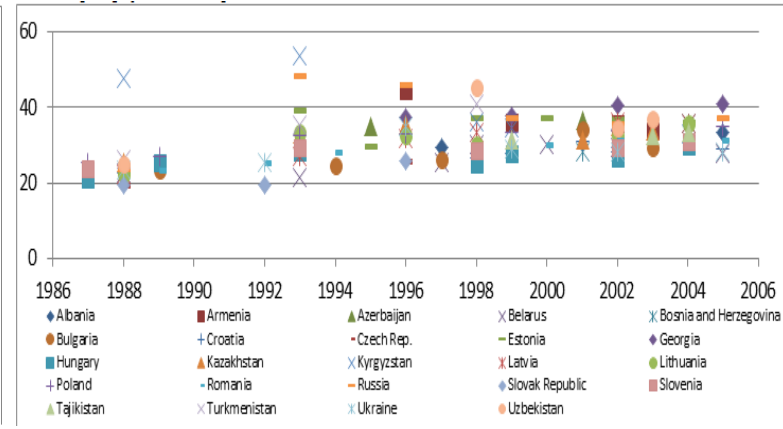

Figure 4. Gini coefficients in the transition economies, 1986-2006.

Source: Worldbank, WDI

Gini coefficients calculated for the income distribution in these economies are used to provide an evaluation in terms of income distribution imbalance. The values between 1986 and 1990 give a hint of substantial deterioration between 1992-1998, as there is relative improvement between 2004 and 2006 compared to 1996-1998. The effective factors causing to an increase in the unfair distribution have been GDP decreases, inflation increases, unemployment increases, privatization, dissolutions, adaptation to technologic advancements, and the prioritization of productivity instead of equal payment for equal work.

\subsection{The Inflation Rates}

Although high inflation rates are experienced by all of the countries evaluated following the transition process, level of inflation rates achieved provide important criteria in terms of economic success. If the literature is evaluated, the studies that link inflation and economic growth emphasize both positive and negative effects of inflation on economic growth. Until 1970's, views that consider inflation to have a positive effect on growth were abundant. In accordance with this, one of the first studies that analyzed the relation between growth and inflation, Tun Wai (1959), has found a positive relation between these two variables for 31 developing countries. Studies which test negative relation have extended the analysis for country groups, especially with the introduction of cross-sectional analysis. Cross-sectional analysis by Fischer (1983) and Kormendi and Meguire (1985), the former of which analyzes 51 countries for the period 1961-1981 and the latter being an analysis with a coverage of 47 countries for the period between 1961 and 1981, have found out that inflation effects growth negatively. Grier and Tullock (1989) support these findings by their study which analyzes 113 countries. In the study which covers 78 countries and the period 1960-1980, Motley (1993) has estimated that the growth of per capita income will increase from $1 \%$ to $3 \%$ if the inflation rate could be decreased from $5 \%$ to $0 \%$ in OECD countries and effect of inflation on growth would be negative otherwise. Haslag (1997) has analyzed the relation between real per capita GDP and inflation in 82 countries for the period 1965-1990 and found out that, there existed a negative relation between these variables when inflation is above $10 \%$ and there existed no significant relation in cases where rate of inflation is below this level. Christoffersen and Doyle (1998) have argued that, inflation effects growth negatively in 22 transition economies for the period 1990-1997, if it exceeds the threshold value of $13 \%$.

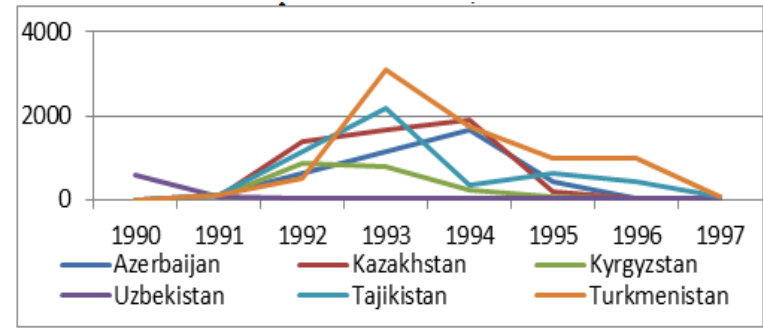

Figure 5. Inflation Rates, Turk Republics Source: Worldbank, WDI.

Although there have been serious increases in post-transition inflation rates, Hungary's special status must be mentioned. Because great amount of the pre-transition prices in Hungary had been determined in accordance with market rules, they did not face the serious inflation increases that the other transition countries experienced and a striking increase in the inflation after the transition is not experienced. Countries other than Bulgaria, Tajikistan, Ukraine, Turkmenistan, Poland, Kazakhstan, Romania and Russia succeeded to decrease their inflation rates under $30 \%$ in the period up to 1996 . Poland had 54\%, Romania had 47.7\%, Kazakhstan had 39\%, and Russia had 39\%. In 1997, with the effect of the Asian crisis, Russia and Bulgaria faced substantial inflation increases. The increase 
in the Czech Republic is very low when compared to other transition countries. Highest rate was recorded right after the transition as $56.6 \%$ in 1991 .

Inflation rate became very high in former USSR countries. Highest rate was achieved as $15606 \%$ in 1994 in Georgia. The reasons behind high inflation in these countries should be analyzed by non-economic factors as well as economic factors. Looking at the relation of economic growth and inflation between 1990-1998, sharp decreases in economic growth and drastic increases in inflation rates are recorded. However, we have to separate the transition process analysis for the first ten years and the other periods. High rates of political instability had its effects on inflation. Central European countries are observed to be more successful in terms of inflation. On the other hand, inflation became very high in the former USSR countries. Accordingly, high rates of political instability had its effects on inflation in these countries.

\subsection{The Value Added}

Azerbaijan, Tajikistan, Turkmenistan and Uzbekistan faced serious decreases in the levels of production. Undoubtedly, the most critical factor was the decrease in the value-added in the industries. The other striking point as well as the substantial decrease in added value is that the decrease in industrial production was greater than the decrease in total production (Blanchard, 1997: 4). It is thought that the sector changes were also effective in this result, as well as the transition on crisis. The striking thing is that although Central European countries' posttransition production industry productivity decrease was reversed after a while (O. Branchard, 1997:6), this could not be achieved fully in the above mentioned countries.

\subsection{The Openness to International Trade}

Rising economies liberated their foreign trade policies and opened their financial sectors to international trade and finance by removing the restrictions on capital movements and/or by implementing full convertibility. As these economies became sensitive to short-term fund flows and as the American dollar became dominant in highinflation countries, sensitivity to capital entry and exits and to financial shocks accelerated. In this context, as financial investors' risk perceptions and policy makers' reliability were becoming critical in evaluating these economies, the likelihood of financial crises and relevant expectations gained importance. We can say that the change processes observed in global scale caused a problem of adaptation to new circumstances in many developing countries and crisis in many regions of the world. Prosperity creation capacity is controversial and financial crisis creation capacity is high in countries targeted by foreign capitals. Major factors in this situation are the liberation and integration of capital markets as well as the ambiguities in the direction and amount of financial flows and countries' starting businesses without establishing sufficient institutional control mechanisms. Crisis created critical socioeconomic effects, and through integrating international finance markets, it had its effect on many other countries. In many situations, the policies applied for getting out of the crisis meant reducing the social expenditures in the budget and using low-payment employment facilities that could be created in the informal sector for fighting against poverty.

\section{Data and Econometric Methodology}

\subsection{Data}

The study aims to analyze Kazakhstan, Kyrgyzstan, Uzbekistan, Turkmenistan, Tajikistan and Azerbaijan. The data utilized in the study is gathered from the Gapminder Database, World Bank and IMF. The sample covers the 1989-2011 period and consists of yearly time series data for 6 countries Macroeconomic variables are the inflation rate, openness as a percentage of GDP and the value added. Similar to the literature, openness is calculated as $(\mathrm{EX}+\mathrm{IM}) / \mathrm{Y}$ where EX, IM and Y represent the exports, imports and GDP respectively. All variables are subject to natural logarithmic transformation. Further, by taking first differences, $\Delta g d p, \Delta c p i$, $\Delta o p e n$ and $\Delta v a$ represent the yearly GDP growth, yearly inflation rate, the yearly openness growth rate and yearly value added growth rate. GDP per capita income variable is also used in various studies, per capita variable is not utilized in the study. In the study, similar to Barro $(1994,1998)$ and Mankiw et al. (1992), yearly change of GDP is taken as a measure of economic growth.

\subsection{Unit Root and Stationarity Tests with Structural Breaks}

At the first stage, the dataset is evaluated with panel unit root and stationarity tests that allow structural breaks. Accordingly, the dataset is evaluated with Fisher type Chi-square tests (Choi, 2001), Levin et. al. (2003) LLC unit root test and Carrion-i-Silvestre et al. (2005) stationarity tests that allow one or more structural breaks. The LLC panel unit root test is a panel unit root test that allows for fixed effects and unit specific time trends in addition to common time trends. The test may be evaluated as a pooled DF or ADF, potentially with differing lag lengths across the units of the panel and they use ADF tests to test for unit roots. Further, in the LLC test, the unit-specific fixed effects are an important source of heterogeneity.

Carrion-i-Silvestre et al. (2005) CBL test is an important test to evaluate stationarity of the data within the purpose of the study since the CBL test allows testing structural breaks within a panel unit root framework. The CBL test is based on the stationarity test of Hadri Hadri (2000) and therefore, the CBL test is based on the KPSS 
stationarity test which is extended to panel setting and additionally augmented for testing multiple structural breaks through the incorporation of dummy variables in the deterministic specification of the model. In contrast to the LL panel unit root test, the CBL test methodology allows stationarity under the null hypothesis rather than the null of a unit root. Further, in contrast to the Im et al.(2003), which is a panel unit root test that incorporates maximum of two level changes, the CBL test allows unknown changes in both level and the slope and accepted to be more generalized in this context.

In the CBL test, under the null hypothesis, the data generation process is assumed to follow,

$$
y_{i, t}=\alpha_{i}+\sum_{k=1}^{m_{i}} \phi_{i, k} D U_{i, k, t}+\beta_{i} t+\sum_{k=1}^{m_{i}} \gamma_{i, k} D T_{i, k, t}^{*}+\varepsilon_{i, t}
$$

where, $y_{i, t}$ is the variable to be tested, $i$ represents the country members of the panel and $t$ represents time operator where $i=1,2, \ldots, \mathrm{N}$ and $t=1,2, \ldots, \mathrm{T}$. The $\varepsilon_{i, t}$ is a gaussian error term. The model given in Eq. (1) includes individual structural break effects defined as shifts in the mean caused by the structural breaks and temporal effects if $\beta_{i} \neq 0$; and temporal structural effects if $\gamma_{i, k} \neq 0$ so that there are shifts in the individual time trend. The dummy variables that allow testing for structural breaks are defined as $D U_{i, k, t}=1$ for $t \succ T_{b, k}^{i}$ and 0 otherwise; $D T_{i, k, t}^{*}=t-T_{b, k}^{i}$ for $t \succ T_{b, k}^{i}$ and equal to 0 otherwise. $T_{b, k}^{i}$ represents the break for the $i^{t h}$ individual at the $k^{t h}$ date where $k=\left\{1, \ldots, m_{i}\right\}$ and $m_{i} \geq 1$. The model given at Eq. (1) allows unit specific intercepts and trends and is capable of representing unit specific shifts both in the mean and in the slope. The null hypothesis implies regimewise stationarity for all countries, versus the alternative of non-stationarity for some countries. Following Carrioni-Silvestre et al. (2005), panel data stationarity test is conducted by calculating the panel KPSS test statistic as the average of univariate KPSS statistics,

$$
\operatorname{LM}(\hat{\lambda})=N^{-1} \times \sum_{i=1}^{N}\left(\hat{\psi}_{i}^{-2} T^{-2} \sum_{i=1}^{T} \hat{S}_{i, t}^{2}\right)
$$

where $\operatorname{LM}(\hat{\lambda})=\hat{\psi}_{i}^{-2} T^{-2} \sum_{t=1}^{T} \hat{S}_{i, t}^{2}$ is the univariate KPSS test statistic for individual $i$. Further, $\hat{S}_{i, t}=\sum_{j=1}^{t} \hat{\varepsilon}_{i, j}$ is the partial sum calculated by using the residuals of Eq.(1) and $\hat{\psi}_{i}^{2}$ is the consistent estimate of the long run variance of the residual. Kurozumi (2002) and Sul et al. (2003) have designed a procedure that allows to obtain consistent estimates of the long-run variance. The autocorrelation consistent estimate of the long run variance is calculated by using the Bartlett spectral window with a fixed bandwidth set according to the following specification,

$\hat{l}=\min \left\{1.1447\left(\frac{4 \hat{a} T}{(1+\hat{a})^{2}(1-\hat{a})^{2}}\right)^{1 / 3}, 1.1447\left(\frac{4 \hat{a} T}{(1+k)^{2}(1-k)^{2}}\right)^{1 / 3}\right\}$

where $\hat{a}$ is the autoregressive parameter estimated following the proposed method of Andrews (1991). Following Kurozomi's empirical results, $k$ is selected as 0.7 to aiming a successful compromise among power and size performances. Test is dependent on the breaks located within the period $\mathrm{T}$, $\lambda_{i}=\left(\lambda_{i, 1}, \ldots, \lambda_{i, m_{i}}\right)^{\prime}=\left(T_{b, 1}^{i} / T, \ldots, T_{b, m_{i}}^{i} / T\right)$. The vector of $k$ is calculated through the method provided by Bai and Perron $(1998,2006)$ by estimating the optimum break locations by focusing on global minimization of sum of squared residuals. The sequences of unit-specific $\operatorname{SSR}\left(T_{b, 1}^{i} / T, \ldots, T_{b, m_{i}, 1}^{i}\right)$ are obtained by allowing $\left(T_{b, 1}^{i}, \ldots, T_{b, m_{i}}^{i}\right)=\operatorname{argmin} S S R\left(T_{b, 1}^{i}, \ldots, T_{b, m_{i}}^{i}\right)$. Accordingly, the break points for all possible $m_{i} \leq m^{\text {max }}$ are estimated, where $m^{\max }$ is the maximum number of breaks. The number of structural breaks are determined by using the modified Schwarz Information Criterion of Liu et al. (1997)which is designed for the case of trending variables (Lee and Lee, 2009). By defining $\bar{\xi}=N^{-1} \sum_{i=1}^{N} \xi_{i}$ and $\bar{\zeta}^{2}=N^{-1} \sum_{i=1}^{N} \varsigma_{i}^{2}$ where $\bar{\xi}$ and $\bar{\zeta}$ represent the individual mean and variance of $\eta_{i}\left(\lambda_{i}\right)$, the normalized test statistic for the null hypothesis of a stationary panel with multiple shifts is calculated as, 
$Z(\hat{\lambda})=\frac{\sqrt{N}(L M(\hat{\lambda})-\bar{\xi})}{\bar{\zeta}} \rightarrow N(0,1)$

For the computation of the $Z(\hat{\lambda})$ test statistic the individual series are expected to be cross-sectionally independent with asymptotic normality. The sequential limit distribution of $Z(\hat{\lambda})$ is obtained by following the Lindberg-Feller variant of the Central Limit Theorem to the average of independent random variables of unequal means and variances. For further details, readers are referred to Carrion-i-Silvestre et. al. (2005).

\section{Econometric Results}

\subsection{Unit Root and Stationarity Test Results}

The purpose of the paper is to evaluate the effects of various macroeconomic variables on economic growth in Eurasian Turk Republics. At the first step, variables are evaluated with selected 1st generation panel unit root tests; namely, LLC, IPS, Fisher and Hadri tests. At the 2nd step, the stationarity of the variables are further investigated with the CBL stationarity tests. As noted in section 4, the selection of CBL test is based on the fact that it allows testing the stationarity by allowing multiple structural breaks both in the mean and in the slope. Further, the test is differentiated in the sense that it allows both for different number of structural breaks at unspecified dates and also by allowing for different structural break numbers and dates, the test procedure allows heterogeneity of panels investigated. At the 3 rd step, panel regression analysis is conducted. The selected $1^{\text {st }}$ generation panel unit root tests are given in Table 1; whereas, CBL stationary tests that allow for heterogeneity in terms of multiple structural breaks are given in Table 2.

\begin{tabular}{|l|l|l|l|l|l|}
\hline Variables & LLC* & IPS & Fisher** & Hadri (homo)*** & Hadri (hetero)*** \\
\hline$\Delta g d p$ & -8.23 & -6.92321 & 70.37 & 8.0123 & 7.872149 \\
\hline$\Delta c p i$ & -13.04 & -6.32331 & 104.40 & 9.9528 & 9.23348 \\
\hline$\Delta o p e n$ & -7.58 & -14.4447 & 63.89 & 7.6553 & 7.31410 \\
\hline$\Delta v a$ & -7.59 & -7.16544 & 69.56 & 9.6635 & 8.83721 \\
\hline
\end{tabular}

Table 1. First Generation Unit Root Test Results

Notes. *LLC, IPS denote Levin, Lin \& Chu and Im, Pesaran and Shin panel unit root tests. **ADF-Fisher Chi-square test. The test results are reported for the first differences to save space and $\Delta$ denotes first differences. *** Homoscedastic and heteroscedasticity-robust versions of Hadri test is reported.

\begin{tabular}{|c|c|c|c|c|c|c|c|c|c|c|}
\hline \multirow[b]{2}{*}{ Countries } & \multicolumn{5}{|l|}{$\Delta g d p$} & \multicolumn{5}{|l|}{$\Delta c p i$} \\
\hline & KPSS Test & $\mathrm{m}$ & $\mathrm{T}_{\mathrm{b}, 1}$ & $\mathrm{~T}_{\mathrm{b}, 2}$ & $\mathrm{~T}_{\mathrm{b}, 3}$ & KPSS Test & $\mathrm{m}$ & $\mathrm{T}_{\mathrm{b}, 1}$ & $\mathrm{~T}_{\mathrm{b}, 2}$ & $\mathrm{~T}_{\mathrm{b}, 3}$ \\
\hline Azerbaijan & $0.03114 * *$ & 1 & 1993 & & & $0.0599 * *$ & 2 & 1992 & 1994 & \\
\hline Kazakhstan & $0.04991 * *$ & 2 & 1992 & 1995 & & $0.04587 * *$ & 2 & 1992 & 1994 & \\
\hline Kyrgyzstan & $0.04102 * *$ & 2 & 1991 & 1996 & & $0.0396 * *$ & 1 & 1992 & & \\
\hline Tajikistan & $0.06952 * *$ & 3 & 1991 & 1994 & 1996 & $0.0416 * *$ & 2 & 1993 & 1995 & \\
\hline Turkmenistan & $0.01963 * *$ & 2 & 1996 & 1999 & & $0.0792 * *$ & 2 & 1992 & 1996 & \\
\hline \multirow[t]{2}{*}{ Uzbekistan } & $0.0805 * *$ & 1 & 1994 & & & $0.07105^{* *}$ & 1 & 1993 & & \\
\hline & \multicolumn{5}{|l|}{ Aopen } & \multicolumn{5}{|l|}{$\Delta v a$} \\
\hline Azerbaijan & $0.02925 * *$ & 2 & 1999 & 2003 & & $0.08164 * *$ & 2 & 1991 & 1994 & \\
\hline Kazakhstan & $0.03896 * *$ & 2 & 1995 & 1999 & & $0.05987 * *$ & 2 & 1997 & 2005 & \\
\hline Kyrgyzstan & $0.04125 * *$ & 3 & 1991 & 1997 & 2007 & $0.06247 * *$ & 2 & 1997 & 2007 & \\
\hline Tajikistan & $0.05111 * *$ & 2 & 1994 & 2007 & & $0.07614 *$ & 2 & 1998 & 2008 & \\
\hline Turkmenistan & $0.06132 * *$ & 1 & 1999 & & & $0.0798 * *$ & 3 & 1990 & 1993 & 2007 \\
\hline Uzbekistan & $0.07117 * *$ & 1 & 1993 & & & $0.03111 * *$ & 2 & 1995 & 2002 & \\
\hline
\end{tabular}

Table 2. CBL Stationarity and Structural Break Test Results

Notes. The test is conducted for a maximum of 3 breaks denoted with $T_{b, i}$ where $i=1,2,3$. Critical values are not reported individually to save space. At $10 \%$ significance level, the calculated critical values range between 0.085 and $0.031 . m$ is the selected lag length. At $5 \%$ significance level, the calculated critical values range between 0.097 and 0.035. At $1 \%$ significance level, the critical values range between 0.085 and 0.031. * and **epresent significance at 5 and $1 \%$ significance levels, respectively.

The null hypothesis of LLC, IPS and Fisher tests are unit root; whereas, the null hypothesis in the Hadri test is stationarity of the variable. The results supported the hypothesis of a unit root in all variables across countries and therefore, the results for the first differenced series are reported. Accordingly, the series are accepted to be integrated I(1) of order one process and therefore, first differenced series are accepted to be taken into consideration for the panel regression analysis. Furthermore, it should be noted that, by taking natural logarithms and first differences, variables will be evaluated as yearly growth rates in the rest of the analysis. Prior to the regression analysis, the variables are aimed to be evaluated with CBL stationarity tests. The CBL test procedure is conducted with applying the bootstrap procedure with 10000 replications. The maximum number of structural breaks are selected as 3. The test procedure allows two different versions of structural breaks, first in the mean and second, 
both in the mean and in the slope for each country $i$. In the analysis, the second method is followed. CBL stationary tests are conducted for the variables of gross domestic product $(g d p)$, consumer price index (cpi), openness (open) and value added $(v a)$ for the transition economies. The results are reported for the first differenced series in Table 2. Accordingly, the null of stationary cannot be rejected at 5\% significance level for all variables once the first differences of the series should be utilized in the panel regressions. The results in Table 2 suggest that both in terms of the first generation unit root tests and the CBL tests that allow for heterogeneity in terms of structural breaks, the variables are integrated of order one. Therefore, the analysis should be conducted by utilizing first differenced series in the panel regression analysis. Further, to include the effects of the structural breaks, dummy variables will be added in the regression analysis.

It was noted in Section 1 that the countries evaluated went through serious minima in their GDP and serial minima points were noted. Comparing to the structural break dates calculated in Table 2, the results coincide with the high downturns in terms of negative growth rates achieved by these countries. Azerbaijan experienced a negative growth rate of $-24.3 \%$ in 1993 and a single break is calculated for the year 1993 in Azerbaijan. The structural break dates calculated for Kazakhstan are 1992 and 1995 and the growth rate recorded as $-11 \%$ for 1991 and $-11.3 \%$ for 1994 , thus the calculated structural break dates denote two structural breaks following the years reported. Kyrgyzstan had sharp declines such as $-14.9 \%$ in $1992,-15.4 \%$ in 1994 and $-20 \%$ in 1995 and the structural break dates are calculated as the years 1991 and 1996. The GDP growth rates of Turkmenistan show highly negative values in years 1993, 1994 and 1997 with $-12.5 \%,-19.4 \%$ and $-12.6 \%$; whereas the structural break dates were calculated as 1996 and 1999. Considering the double V-shaped GDP path followed by Turkmenistan, the results were expected. The same analysis holds for Uzbekistan. The results suggested one break in the year 1994 and negative growth rates were recorded following the year $1992(-13.3 \%)$ in the country. Accordingly, sharp declines in terms of GDP growth rates are common for the evaluated transition countries following their independence after the dissolution of USSR.

Further, following transition, the evaluated countries experienced considerably high inflation rates as discussed in Section 1. A majority of the countries achieved to decrease the inflation rates around 30\% until 1996. The structural break dates are calculated as 1992 and 1994 for Azerbaijan, 1992 and 1994 for Kazakhstan, 1992 for Kyrgyzstan, 1993 and 1995 for Tajikistan, 1992 and 1996 for Turkmenistan and 1993 for Uzbekistan. It should be noted that considering the high inflation rates were highly related to the high rates of inflation in Russia following the dissolution. Central European countries are observed to be more successful in terms of inflation. On the other hand, inflation became very high in the former USSR member countries.

Azerbaijan, Tajikistan, Turkmenistan and Uzbekistan experienced serious decreases in the levels of production following the transition. The substantial decrease in value added in the industries was related with the changes in the industrial production and the changes in the total production. Further, the structural changes in terms of the production volumes in the sectors and industries were highly effective in addition to the effects of economic crises. Accordingly, the structural break dates are calculated as 1991 and 1994 for Azerbaijan, 1997 and 2005 for Kazakhstan, 1997 and 2007 for Kyrgyzstan, 1998 and 2008 for Tajikistan, 1990, 1993 and 2007 for Turkmenistan and 1995 and 2002 for Uzbekistan, respectively.

Further, the trade openness is evaluated in terms of structural breaks. The break dates are calculated as 1999 and 2003 for Azerbaijan, 1995 and 1999 for Kazakhstan, 1991, 1997 and 2007 for Kyrgyzstan, 1994 and 2007 for Tajikistan, 1999 for Turkmenistan and 1993 for Uzbekistan.

\subsection{Panel Regression Results}

The points asserted in analyses in terms of the transition economies are various and deserve special investigation. The study aims to analyze the effects macroeconomic factors, namely, value added, openness and inflation on economic growth. Following the discussion given in section 2, the following panel regression models are estimated for 1989-2011 period. The first model to be estimated is,

$\Delta g d p_{i t}=\beta_{0}+\beta_{1} \Delta c p i_{i t}+\beta_{2} \Delta v a_{i t}+\beta_{4} D U_{i t}+u_{i t}$

where $g d p_{i t}$ represents the gross domestic product, $c p i_{i t}$ is the consumer price index and $v a_{i t}$ is the value added. The economic growth rate is the dependent variable and is denoted as $\Delta g d p$. Further, by adding $o p e n_{i t}$, the openness index, the second model is achieved,

$$
\Delta g d p_{i t}=\beta_{0}+\beta_{1} \Delta c p i_{i t}+\beta_{2} \Delta v a_{i t}+\beta_{3} \Delta \operatorname{open}_{i t}+\beta_{4} D U_{i t}+u_{i t}
$$

In both models, $D U_{i t}$ represent the dummy variable that is equal to 1 and 0 , otherwise, for the reported structural breaks for country $i$ at year $t$ in Table 2. As noted in part 3.1, all variables are in logarithms and the delta signs represent the first differences. Therefore, all variables show their relevant growth rates. $u_{i t}$ is assumed to follow i.i.d. $N\left(0, \sigma^{2}\right)$ white noise process. All panel regression models are estimated by with fixed effects. Fixed 
effect assumption abolishes the heterogeneity among the variables. The panel regression results are given in Table 3 below. If Model 1 is evaluated, it should be noted that, though the size of the coefficient of inflation is rather small, the sign of inflation is negative. The results are similar to the empirical findings obtained by Kormendi and Meguire (1985), Fischer (1993), Barro (1994), Grimes (1991), Gomme (1991) Andres and Hernando (1997), Motley (1998), Jung and Peyton (1986), De Gregorio (1996), Motley (1998), Kim and Willett (2000), Gylfason and Herbertsson (2001) and Gillman and Nakov (2004) which draw attention to the negative relationship between economic growth and inflation. Grier and Perry (1998) state that it is not the inflation that affects economic growth, rather, the volatility of (or variation in) inflation of which the negative effects on economic growth cannot be rejected. Karras (2003) shows that the negative relationship between inflation and economic growth is affected by external factors such as negative supply shocks. The results are in favor of the negative effects, however, though the parameter estimates are statistically significant, they are very close to zero. If the coefficient of the value added produced by the industry is evaluated for model 1 , it has a small effect however it possesses a positive sign as expected. Additionally, the parameter of the dummy variable representing structural breaks is statistically significant at conventional levels.

\begin{tabular}{|l|l|l|}
\hline Dependent Variable: $\Delta$ gdp & \multicolumn{2}{|c|}{ MODELS } \\
\hline Explanatory Variables: & $(1)$ & $(2)$ \\
\hline $\mathrm{c}$ & $2.43^{* *}$ & $-2.50^{*}$ \\
& $(-1.76)$ \\
\hline$\Delta$ cpi & $-0.012^{* * *}$ & $-0.0007^{* * *}$ \\
& $(-4.642)$ & $(2.8646)$ \\
\hline$\Delta$ va & $0.01^{* *}$ & $2.58^{* *}$ \\
& $(2.56)$ & $(2.45)$ \\
\hline$\Delta$ open & - & $0.16^{* *}$ \\
\hline DU & & $(2.29)$ \\
\hline $\mathrm{R}^{2}$ & $0.396^{* *}$ & $2.693^{* * *}$ \\
\hline Log likelihood & $(2.356)$ & $(3.39)$ \\
\hline Cross-section F & 0.46 & 0.499166 \\
\hline Cross-section Chi-square & -445.3709 & -448.2766 \\
& 3.996864 & 6.242964 \\
& Prob: $(0.0023)$ & Prob: $(0.0001)$ \\
\hline
\end{tabular}

Table 3. Panel Regression Results

Notes: For the first 4 models, the sample is 1989-2010. For Model 5, the sample covers 1996-2010. All models are estimated under fixed effects assumption. *,**, *** denote significance at $10 \%, 5 \%$ and $1 \%$. $t$ statistics are given in parenthesis.

In Model 2, the openness variable is added to the regression as the third explanatory variable. Considering the size and the sign of the parameter estimate of the inflation rate, a similar finding is achieved for Model 2. Even though the effect of a one percentage point increase in the inflation rate is negative on the GDP growth rate, the parameter estimate is very close to zero, which suggests almost no effect of inflation on growth. In Model 2, the parameter estimate of the growth rate of value added is statistically significant and positive with a relatively large estimate suggesting positive effects of increasing value added on economic growth. The additional variable in Model 2 is the openness. The parameter estimate of openness is statistically significant and suggests that a 1 percentage point increase in openness results in a 0.16 percentage point increase in economic growth rates. Similar to this finding, if the studies focusing on openness is investigated, a large fraction of literature notes the positive effects of openness on economic growth. Among these studies, Bahmani and Niroomand (1999) shows that for 19 countries among the countries analyzed and show that trade openness and economic growth have a positive relationship in the long run. Ahmad and Anorua (2000) obtained the results suggesting two-way causality between trade openness, economic growth and GDP. Nourzad and Powell (2003) show that openness affect growth through exports and development through imports.

The overall results suggest that the negative effect of inflation cannot be rejected while the effect of inflation is very small in terms of the parameter estimate compared to the literature. Further, considering especially the Model 2 , the positive effects of value added in the production process has a large and positive effect on economic growth. The positive impact of openness to international trade also cannot be rejected statistically for the panel regressions estimated for the analyzed transition economies. As a policy recommendation following the findings of the study, policies focusing on increased international trade could accelerate economic growth while due to the limitations of the study such as the availability of data and the need to further extend the models to structural and institutional factors, future studies are encouraged to investigate further on the channels of evaluated macroeconomic variables on economic growth. 


\section{Conclusion}

The study focused on the economic performances of the transition economics. Accordingly, the economic success or failure of transition economies were investigated. Among these countries, the middle-European countries are comparatively more successful in terms of economic growth. In the success of these countries, in addition to measures taken in terms of economic reforms, the cooperation of the societies with these reforms in these countries, political stability, social-democratization of communist parties and failure to claim the conducted reforms properly, and religious factors also had significant roles as discussed in the literature. Among the countries analyzed and factors affecting economic growth, the study focused on the roles of inflation, value added and openness on economic growth in the Eurasian countries; namely, Azerbaijan, Kyrgyzstan, Kazakhstan, Tajikistan, Turkmenistan and Uzbekistan. These countries are among the former USSR member countries and also are discussed as being post-Soviet nations that experience - bureaucratic capitalism- a term that resulted from inappropriate conduct of the laws and informal economy and failure to receive the social support from the nations' citizens in Ericson (2000)'s terms. However, as noted by Eren and Bildirici (2000), to achieve high economic development levels, the transition countries should pay importance to macroeconomic stability. Further, literature focusing on the economic performances in these countries also suggest other factors, including the establishment of competitive markets, the commitment towards "real" privatization, increasing political stability, decreasing the size of the informal sector and achieving improved property rights. However, many goals of development also require a certain amount of capital stock which are accessed more successfully by the countries located closer to Europe and to achieve economic growth - restricted to be stated in terms of GDP in this paper - international trade and increasing productivity that play crucial roles in increasing GDP growth rates through export-led growth strategies. Therefore, the study is restricted to the macroeconomic factors including inflation, value added and trade openness. Further, though value added is taken as a proxy of productivity and though the study underlines the importance of trade, it should be noted that among the members of the panel evaluated in this country group, production and exports of petroleum and natural gas has a fraction on total exports. However, petrol could be considered as a natural resource that results in comparative advantage in terms of the factor endowments type trade theory, while the terms such as value added and productivity encourages further development in terms of achieving value added in other types of products.

According to the empirical results, the negative effect of inflation and positive effect of value added in the production process on growth cannot be rejected. The overall conclusion of the empirical findings in the study suggest that, among the macroeconomic variables, the value added obtained by increased production in real sector and trade openness have positive impacts on economic growth while the effect of inflation is relatively small. Following the literature, though it is important to achieve lower levels of inflation, the lowering of volatility in inflation is expected to benefit macroeconomic outcomes in the evaluated Eurasian economies.

\section{References}

- Bahmani-Oskooee and Niroomand, 1999. "Openness and economic growth an empirical investigation", Applied Economics Letters, 6(9), pp.557-561.

- Barro, 1994. "Democracy \& Growth", NBER Working Papers 4909, National Bureau of Economic Research.

- Barro, 1998. Determinants of Economic Growth: A Cross-Country Empirical Study. 1st ed. vol. 1.

- Michigan: MIT Press.

- Blanchard, O., 1997. The Economics of Post-Communist Transition. Clarendon Press, Oxford.

- Carrion-i-Silvestre, Del Barrio-Castro, Lopez-Bazo, 2005. "Breaking the panels: an application to GDP per capita", Journal of Econometrics, 8, pp.159-75.

- Choi, I. 2001. "Unit root tests for panel data”. Journal of International Money and Finance 20, pp.249-272.

- Eren and Bildirici 2000. "Post Sosyalist Ülkelerde Geçiş Sorunları: Başarı ve Başarısızlıklar”, METU International Conference in Economics, September 13-16.

- Ericson, 2000. "The Post-Soviet Russian Economic System: An Industrial Feudalism? Bank of England Institute for Economies in Transition (BOFIT), ISSN 1456-811X (Online).

- Fidrmuc, 2003. "Economic Reform, Democracy and Growth during Post-Communist Transition", European Journal of Political Economy, 19(3), pp.583-604.

- Fischer, S. (1993). "The Role of Macroeconomic Factors in Growth", NBER Working Papers, No. 4565.

- Havrylyshyn, Izvorski, and Van Rooden 1998. Recovery and growth in transition economies in 1990-97: A stylized regression analysis, No. 98-141. International Monetary Fund.

- Heybey, B. \& Murrell, P. (1999). "The Relationship between Economic Growth and the Speed of Liberalization during Transition”, Journal Of Policy Reform, 3(2), pp. 121-137. 
- IMF, International financial statics. various issues. IMF, 1997.Hungary-Statistical Appendix, 97/104. IMF, 1998. Czech Republic Statistical Annex,98/37. IMF,1998. Republic of Poland. Selected Issues and Statistical Appendix, / 51, Staff Country Report. IMF, 1999. World Economic Outlook.

- Johnson, Kaufmann, and Zoido-Lobaton 1998. "Regulatory discretion and the unofficial economy". The American Economic Review 88(2), pp. 387-392.

- Karras, 2003. “Trade Openness and Economic Growth Can We Estimate The Precise Effect?” Applied Econometrics and InternationalDevelopment, Vol. 3, No. 1, 2003.

- Kornai, 1994. "Transformational recession the main causes". Journal of Comparative Economics 19(1), 3963.

- Kornai, 1997. "The reform of the welfare state and public opinion". The American Economic Review 87(2), pp. 339-343.

- Lee and Lee, 2009. "Energy prices, multiple structural breaks, and efficient market hypothesis", Applied Energy 86, 466-479.

- Levin, Lin, Chu. 2002. "Unit root tests in panel data: Asymptotic and finite-sample properties", Journal of Econometrics 108, 1-24.

- $\quad$ Liu, Wu, Zidek, 1997. “On segmented multivariate regressions”, Statistica Sinica 7, 497-525.

- Mankiw, Romer, and Weil 1992. “A contribution to the empirics of economic growth”. The quarterly journal of economics 107(2), 407.

- Milanovic, 1998. Income, Ineguality and Poverty during the Transition from Planned to Market Economy, World Bank, Minority Rights Group.

- Nourzad, and Powell, 2003. "Openness, and Development: Evidencefrom a Panel of Developing Countries", Scientific Journal of Administrative Development, 1(1), ss. 72-93.

- $\quad$ OECD, 1998.Economic Surveys, Czech Republic. OECD, 1998.Economic Surveys, Poland. OECD,1998. Economic Surveys, Romania. OECD, 1999.Economic Surveys, Hungary. OECD, 1999. Main Economic Indicators.

- Tanzi, 1998. "Corruption around the world Causes, consequences, scope, and cures”, International Monetary Fund WP 98/63.

- World Bank, 1997. Bosnia and Herzegovina Report; World Bank, 1999. World Development Report, Knowledge for Development, 1998-1999. World Bank, 1999. World Development Indicators, 1999. World Bank, 2014. World Development Indicators. 


\title{
Effectiveness of Experimental Approaches in Economics: A Case of Ultimatum Games Experiments
}

\author{
Prof. Dr. Yusuf Akan (Atatürk University, Turkey) \\ Ph.D. Candidate Aslı Cansın Doker (Erzincan University, Turkey)
}

\begin{abstract}
In economics theory literature, it has been a crucial question whether experiments can be helpful to test theory in laboratory. Since late 1940s experimental methods has been found useful in economics however there is still some doubts about unbiasedness, ability to test. The essential of economics theory is related to mathematics resulted of this deductive reasoning to inductive one with using time series data and statistical analysis. Additionally, generally in experiments and its sessions, undergraduate or graduate students are generally chosen as participants by researchers, this brings several doubts and questions together such as reliability on their choices, power of explanation and also restrictions about rationality of players which are decision makers as individual. After the 1950s with the introduction of game theory, experimental methods have been strong placed in the research. Especially market designs, rationality and behavioral design have been subjected to experiments. However, it is still crucial question whether those experimental methods could be effective or not. This study will be discussed experimental methodology with game theoretical approach using trust and ultimatum games perspective. In addition, giving the structure of the sessions and experiments, the regulations and steps will be figure systematically. This study will be discussed rational individual decision making process and try to explain how chosen games can be lasted more effective.
\end{abstract}

\section{Introduction}

Economics and many social sciences have used game theory applications; the bargaining game is the most common game in politics and economics situations and it is still unclear in the literature of the role of mediators in the bargaining process. With either complete or incomplete information bargaining processes, bargaining has some threats which can be fixed or variable, and the expectations of players has important effects on the bargaining. In this paper, mediated bargaining will be discussed, firstly the game theoretical aspect with some empirical evidence to support the theory. Often, international negotiations may well be explained with a bargaining game with mediator, for instance, the United Nations (UN) sends a couple of diplomats as mediators to help to reach an agreement in the bargaining process between two parties representing two different countries. The common example of an international bargaining game is between Russia, formerly the United Soviet Socialist Russia (USSR), and the United States of America (USA). Another common use of bargaining game applications is in economics, such as within monopolistic and duopolistic market solutions. In the literature about bargaining games, there are two approaches discussed, which are the strategic approach and the axiomatic approach. Under the Strategic approach, the players' movements are under the assumption of rationality, as expressed by the Nash equilibria. On the other hand, the strategic method has some inherent difficulties and with the axiomatic approach these difficulties adjust the specified assumptions (Rubenstein, 1982).

The main questions about the bargaining situations are generally "what will be the agreed contract under rationality assumption for players?", and also what is the effect of the strategic mediator type? What is the effect of players' type in the bargaining game? After those questions one more critical statement appears, which is if there is mediator and also as a factor a which is symbolized as biased for mediator "is trust important for a bargaining game" and "does it affect the welfare function?". The researcher has followed Friedman's (1953) positivist perspective. According to Friedman (1953), economics and all social sciences can have the same aspect to their data and analysis as natural science does. On the other hand, Hausmann (1989) states that normative and positive philosophies of methodology can work together in economics. In addition, the researcher should be objective during the analysis part of the study because as a definition of normative perspective in social sciences this avoids bias (Hausmann,1989). Experimental designing of bargaining games can be placed in the literature as public good games or ultimatum games.

Under Harsayni and Selten's (1972) bargaining game model, the utilities, or game outcomes, for each player will depend on both players' types, which are $\mathrm{k}$ and $\mathrm{m}$. This can be shown with a bimatrix form such that;

(1.1) $\mathrm{K} \times \mathrm{M}$ is the bimatrix form of the utilities for all agreement points

$$
\mathrm{u}=\text { uikm } \quad \mathrm{i}=1,2 . \quad \mathrm{k}=(1,2, \ldots . \mathrm{K}) \quad \mathrm{m}=(1,2, \ldots . \mathrm{M})
$$

The explanation of the 1.1 equation is that player $\mathrm{i}$ and uikm shows the $\mathrm{k}$ or $\mathrm{m}$ type player i's payoff which he will get from the agreement point.

$$
\text { (1.2) } \mathrm{c}=\mathrm{cikm} \quad \mathrm{i}=1,2 . \quad \mathrm{k}=(1,2, \ldots . \mathrm{K}) ; \quad \mathrm{m}=(1,2, \ldots . \mathrm{M}) \text {; }
$$


With actual types $\mathrm{k}$ and $\mathrm{m}$ of player 1 and player 2 respectively, $\mathrm{c}$ is the conflict points set of the game. In other words, $\mathrm{c}$ is the set including payoffs of player 1 and 2 from the conflict situation of the bargaining process. Another assumption of the game is following such that players are free to bring their action to the conflict point if they desire this. After definition of those assumptions the bargaining process with incomplete information can be examined with notation $\mathrm{S}$ below;

$$
\mathrm{S}=(\mathrm{U}, \mathrm{c}, \mathrm{r}) \text {, where }
$$

$\mathrm{U}$ : all feasible agreements

c: conflict points which is also sub set of the $U$

r: probability bimatrix

Harsayni and Selten, Nash and Rubenstein bargaining games have some differences which will be discussed step by step in the next part.

In the late 1950's, Nash examined the reduced form approach in cooperative games which is now the most common and known application for game theorists. Nash's aim is to pick axioms which can characterize the agreement point for players so that they can negotiate with each other.(Nash,1950) Basically he examined a game similar to the splitting of pie game, only more complicated. In Nash modelling, there are two players and they may have different utilities; if they don't reach agreement, the utility functions can be nonlinear, regardless of sharing of the pie (Ausubel, M., et al.,1993; Nash,J.,1950). The differences between these two games will be shown in Figure 2. It is generally considered that cooperative bargaining games are fairer, more moral and more efficient than a non-cooperative bargaining process. (Donni, O. and Chiappori, P.,2006.;Nash,1950)

In Nash bargaining analysis, all bargaining situations which are show by $\mathrm{S}$ are defined by the payoffs set which is called U. Similarly in NS, players can meet at a point in a feasible agreement set or can meet at a point in a conflict set. As a result the bargaining situation in NS can be written formally as;

$$
S=(U, c)
$$

As can be seen, the difference between equation (2.3) and (3.1) in NS the bargaining situation does not have a probability set as a subset of S. The explanation is that in the NS bargaining game there is complete information related to this and there is only one possible type of player, as shown in (2.2);

(2.2) If there is complete information $K=M=1$.

Another assumption in NS is the independency of players' actions. Nash(1950) has proposed that the equilibrium points in the bargaining process are given by payoff points which are in the feasible set $U$, and he has shown the reservation values with inequalities such that;

(2.3) $u_{i} \geq c_{i}$

$$
i=1,2 \text {. }
$$

$\operatorname{Nash}(1950)$ argues that there is always a unique solution if the bargaining process can prove that these axioms exists. If we take one point which is $u=\left(u_{1}, u_{2}\right)$, then using this point the Nash product will be;

$$
\pi=\left(u_{1}-c_{1}\right) \cdot\left(u_{2}-c_{2}\right)
$$

Above, the Nash solution's first step in a bargaining game with complete information has been discussed. The next step will be analysing bargaining situations with incomplete information in NS. Harsayni and Selten (1972) discussed the bargaining game with incomplete information with using and examining the Nash Solution's axioms, but they needed a more complicated model than Nash's complete information bargaining model. This model will be discussed and a mediator position or role will be added to the equation, however before that there are some important axioms in NS which compose the NS characteristic features.

\section{Public Good Games and Experimental Applications}

Public Good Games has been evaluated for testing assumptions of homoeconomicus in economics theory which is strongly important for all applications. This can be explained how to behave consumer or firm in business cycle and also how to make economic decision in which period of time. There are some types of game applications under the public good games; dictator game, ultimatum games and gift games respectively. Before explanations in detail of those, the process of an experimental design is discussed. Previously it has been discussed above the main assumptions, additionally testing this theory will be in experimental laboratory which can be real life examples ebay costumers' consumption decision process, public share in society with extarnatlies or in game design special laboratory. For the game design analyst is the controller of the experiment and he is responsible of the clients' behaviors and unexpected situation out of the game. His first role in the experiment will be decided to inform the clients about the chosen game rules and reward or punishment of the pay offs. After these information, the game sessions will be started however the game can be full informative or incompletely informative, this is about the analyst' study question. Moreover, the experiment results will be collected and interpreted by the economist to check rationality and other strict assumptions whether those behavioral movement supported the theory with delays or not and also those experiments may well end with the conflict. Conflicts is also an explaition for the unbalancity in the economy. Figure 1 is one of the example of the process on bargaining situation. 


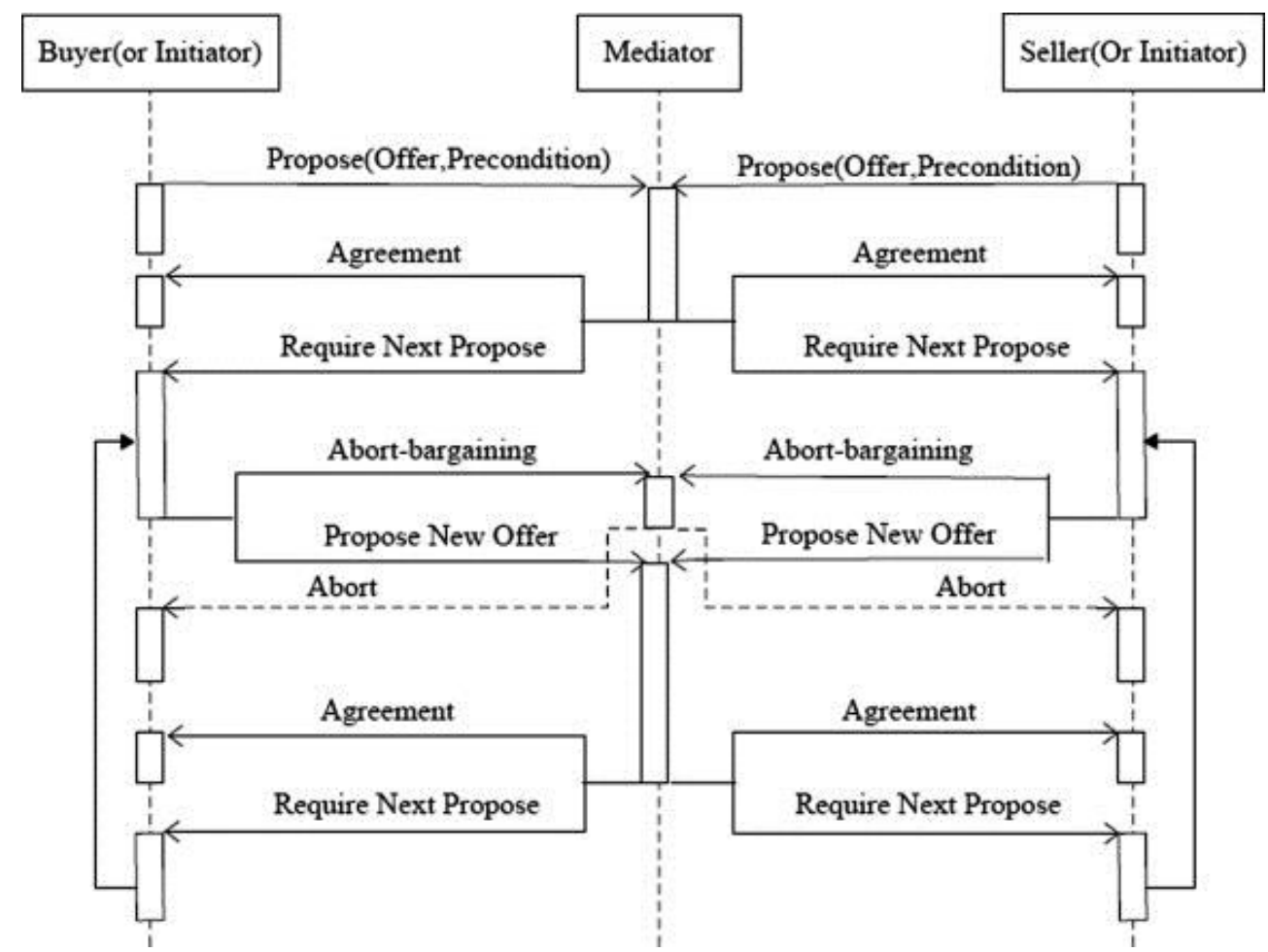

Figure 1: The Schematic of the Mediation Process: Bargaining Game with Incomplete and Complete Information

Public Good Games was improved for group behaviors on the other hand dictator games and ultimatum games is discussed individual behavior under the economic activities. For designing experiments, generally undergraduate students are chosen as players or party of the situation. The controller of the game is the researcher who is the responsive of the crying rules and information under the sessions. Bargaining game with mediation can be placed in the ultimaotom experiments with its lemma and assumption. In this paper, it was discussed under incomplete bargaining process whether end with conflict or not.

\section{Conclusion}

This paper has proposed to show how the mediation process can be helpful for an efficient bargaining game. There are several previous findings to support this paper's aims; on the other hand, in this paper the researcher designed a mediated bargaining game with incomplete information and used some assumptions from main game theoretical papers. Before having designed the game, perfect equilibrium, Nash solution, Harsayni and Selten (1972) bargaining and Rubeinstein (1982) bargaining game have been discussed. After those discussions, the researcher used the two person bargaining game and the game has been started with the splitting pie game with normalized pay size. In addition, the chosen distribution for utility function is uniform and the rules of the game were discussed and put forward. Moreover, the preliminaries, which consist of axioms and lemmas which show whether or not the solution of the game is useful and efficient. This game has the same axioms as the Rubenstein bargaining (1982) game with incomplete information, however the main difference between this game and Rubenstein game is using a third party, which is having a mediator. Furthermore, timing in the game has been chosen to be continuous, the pie is desirable, and another significant point is that there are no monetary stakes in this bargaining process. In this study, it is shown that a fixed cost of bargaining and a fixed surplus discount rate in the bargaining process helps to reach an agreement point fast and also reduces conflicts. This paper examined and showed mediation in bargaining situations using monotonicity lemma and opponent's strategic best response, which are necessary to get a general solution and interpretation of the game. Depending on this statement, the mediator still has a critical role in this game. It is still recommended using mediated bargaining game in politics and also economics to reach an agreement easily and create more efficient bargaining situations. In addition, timing preferences, as discussed briefly, can cause a delay of agreement and reduce the efficiency of bargaining (Rubenstein, 1985). In this paper, the researcher did not choose a general solution for the N-person game; the reason for that is the research time was not sufficient to reach a general solution. However, it is necessary to put a few recommendations for future studies. First, there is still one important discussion which this paper cannot address, namely the effects of the bias of a mediator who is active in the mediation process; this discussion can be linked with cheap talk, which is another important game with different credibility and reputation assumptions. In conclusion experiments which is still crucial discussion in the literature, can be helpful a for explaining person's 
role in the economics theory. Moreover, Game experiments are more acceptable with mathematical assumptions and lemma because, those can be controlled the rationality.

\section{References}

- Abreu, D. and Gul F., 2000. "Bargaining and reputation”, Econometrica, Vol.68, pp85-117.

- Ausubel, M., et al.,1993. "Efficient Sequental Bargaining”. Review of Economic Studies, Vol.60, pp.435461.

- Chatagnier, Tyson J., 2012. "Mediation and the Effects of Third Party Observation"

- Chatterjee, K. and Samuelson, W.F.,1987. "Bargaining with two-sided incomplete information," Revision Economics Studies, Vol.54, pp.175-192.

- Cross, John G.,1965. “A Theory of the Bargaining Process”, The American Economic Review, Vol. 55, pp. 67-94.

- Donni, O. and Chiappori, P.,2006. Learning from a piece of pie: The Empirical Content of Nash Bargaining. Iza Discussion Paper, No.2128,04/2006. Available at:

- Dunlop, J.T. (1984): Dispute Resolution, Auburn House, Dover MA.

- Fey, M. and Ramsay, K., 2010. "When Is Shuttle Diplomacy Worth the Commute?: Information Sharing through Mediation". World Politics, Vol.62, pp.529-560. Available at : http://muse.jhu.edu/journals/wp/summary/v062/62.4.fey.html

- Friedman, M., 1984. Essays in Positive Economics. 4th Edition. Chicago: University of Chicago Press.

- Fudenberg, D. and Tirole, J.,1986. “A theory of exit in Duopoly”, Econometrica, Vol. 54, pp.943-960.

- Goltsman, M., et al., 2009. "Mediation, arbitration and negotiation", Journal of Economic Theory, Vol.144, pp. $1397-1420$

- Harsayni, John C.,1956. "Approaches to the Bargaining Problem Before and After the Theory of Games". Econometrica, Vol.24, pp.144-157.

- Harsanyi, John C. and Selten R.,1972. "A Generalized Nash Solution for Two-Person Bargaining Games with Incomplete Information", Management Science, Vol. 18, No. 5, pp.80-106.

- Hausmann, D.,1989. "Economic Methodology in a Nutshell”, Journal of Economic Perspectives, Vol.3, No.2,pp.115-127.

- Ivanov, M.,2010. "Communication via a strategic mediator". Journal Economic Theory, Vol.145, pp.869884Avalibleat: http://www.sciencedirect.com/science/article/pii/S0022053109001100

- Jarque, X. et al.,2003. "Mediation: Incomplete information bargaining with filtered communication”, Journal of Mathematical Economics, Vol.39, pp.803-830.

- Kydd, A. 2003. "Which side are you on? Bias, credibility, and mediation”, American Journal of Political Science, pp. 597-611.

- Kydd, A. 2006. “When Can Mediators Build Trust?”, American Political Science Review, Vol.100, pp.449462.

- Lehrer, E., 1996. “Mediated Talk”, International Journal of Game Theory, Vol.25, pp.177-188.

- Myerson, R. and Satterhwaite, M.,1983. "Efficient Mechanisms for Bilateral Trading”, Journal of Economic Theory, Vol.29, pp.265-228. war of

- Nash, John F.,1950. "The Bargaining Problem”. Econometrica, Vol.18,pp.155-162.

- Ponsati, C. and Sfikovics, J.,1995. "The war of attrition with incomplete information”. Mathematica Social Sciences, Vol.29,pp.239-254.

- Ponsatí, C.,1995. "Compromise vs. Capitulation in Bargaining with Incomplete Information”, Annals of Economics and Statistics, Vol.48,pp.191-210.

- Peng, Z., "An novel ADM for finding Cournot equilibria of bargaining problem with alternating offers" Unpublished thesis, (PhD), NanJing University.

- $\quad$ Rice, A.,1979. “Turkey and Cyprus”. Foreign Affairs Vol. 58, No. 2, pp. 408-411.

- Rubenstein, A., 1982. "Perfect Equilibrium in Bargaining Model”, Econometrica, Vol. 50, No.1.

- Rubinstein, A.,1985. "A Bargaining Model with Incomplete Information About Time Preferences", Econometrica, Vol. 53, No. 5, pp. 1151-117.

- Rubenstein, A., 1983 The choice of conjectures in a bargaining game with incomplete information. In: C.V. Starr Center for Applied Economics, New York, September,1983. New York, New York University, pp.2-27. 
- Sákovics, J.,2004. “A Meaningful Two-Person Bargaining Solution Based on Ordinal Preferences”,

- Savun, B., (2006) Information, Bias, and Mediation Success: Evaluating the effectiveness of Mediation of International Conflicts. Unpublished Thesis (PhD), Rice University.

- Ståhl, I.,1973. "Bargaining Theory”. The Swedish Journal of Economics, Vol. 75, No. 4, pp. 410-413.

- Terris, Lesley G. and Maoz Z.,2005. "Rational Mediation: A Theory and a Test”, Journal of Peace Research, Vol.42, pp.563-583.

- Ugur, M.,2010. “Open-Ended Membership Prospect and Commitment Credibility: Explaining the Deadlock in EU-Turkey Accession Negotiations” JCMS: Journal of Common Market Studies. Vol.48, pp.967-991.

- Wilson, Charles A., 2001. "Mediation and the Nash bargaining solution". Review of Economic Design, Vol.6,pp.353-371.

- Wilson, C.,2001. "Mediation and the Nash bargaining solution", Revision of Economic Design, Vol.6, pp.353-370. 


\title{
The Influence of Political Economy on the "Self-Determination of Peoples"
}

\author{
Asst. Prof. Dr. Yavuz Çilliler (Istanbul Kent University, Turkey)
}

\begin{abstract}
The right of peoples to "self-determination" is influenced by varying motives in different times and geographies in its implementation, and is rarely operated according to its foundational ethic and legal bases dating back to the Kantian concept of free will and the international laws codified after the World War II. Particularly, political economy has always played an important but usually covered role in the application of this principle to national or international disputes.

This paper aims to explain the dominance of political economy in international decision making processes about the people making a claim for their own state, and to highlight the changing nature of political economy supporting sometimes the sovereign states and sometimes the sub-state level ethnic groups. In this context, the theoretical development and the application of "self-determination" principle is assessed relatively by historical comparison method. Field research for the study comprises archival research of primary and secondary resources.

This paper concludes that the political economy has usually greater influence on the application of "selfdetermination" to the national and international disputes than its ethic and legal content, and that the paradoxical content of this principle contributes to the redistribution of lands usually in compliance with the interests of great powers.
\end{abstract}

\section{Introduction}

The right of peoples to self-determination as a contested third-generation human right has the etymological meaning of self-governance, or rule by the self of peoples, that has its roots in Kantian ethic approach to individuals. Kant argues that one ought to think free of the dictates of external authority and to act according to rational moral principles. The self-determined self is one that operates without constraint, and this principle is projected later in politics as a rule of independence of peoples from outside coercion. John Stuart Mill first proposed the link between culture and ethnicity on the one hand, and statehood on the other.

This principle highlights the importance of autonomy and the dangers of intervention for social integration, wellbeing, performance, healthy development, and creativity (see Deci and Ryan, 2000; Green, 2010). Aspirations of peoples must be respected and they may be governed only by their own consent.

Unfortunately, this concept is rarely operated according to its foundational ethic bases in the application in different times and geographies. Particularly, political economy has always played an important but usually covered role in the implementation of this principle in international law. Besides, politico-economic factors have also evident impacts on the independence claim of an ethnicity from an established state (see Lineira and Cetra, 2015; Boylan, 2015) as well as on the international decision-making processes. Yet, this study focuses on the latter.

This paper aims to explain the dominance of political economy in international decision making processes about self-determination issues, and to highlight the changing nature of political economy supporting sometimes the sovereign states and sometimes the sub-state level ethnic groups. In this context, this study begins by analyzing the paradox of self-determination at entity level, and the second section studies the historical development of selfdetermination before and after the World War II, and the influence of political economy on self-determination. The final section delineates the contribution of this vague conception to great powers' interests. Consequently, it concludes that the political economy has usually greater influence on the application of "self-determination" to national and international disputes than its ethic and legal content, and that the paradoxical content of this principle contributes to the redistribution of lands usually in compliance with the interests of great powers.

The theoretical development and application of "self-determination" principle are assessed relatively by historical comparison method. Field research for the study comprises archival research of primary and secondary resources.

\section{The Paradox of Self-Determination}

The primary paradox lies at its origin. Self-determination, which has been considered for the individual level at the outset, was projected later to group level in politics. But regarding individuals and groups as similar subjects is devoid of offering a smooth analogy. Groups are the result of mixed cultural, social, political and religious formations extending over long periods of time. There is no way of identifying the precise factors that will predominate in the formation of group allegiances. 
The right of peoples to self-determination differs in this respect from an individual claim of liberty. Who can be acknowledged as "people" is not clear enough due to its involvement of complex issues of allegiance. Wilson's Secretary of State, Robert Lansing, emphasized this dilemma stating (Hasani, 2002, p. 54):

"On the surface, it seemed reasonable: let people decide. In fact, it was ridiculous because people cannot decide until someone decides who the people are."

Moreover, unlike an individual liberty claim, the right of peoples to self-determination potentially involves a territorial claim. A secessionist group necessarily asserts that it has international title to the territory concerned, a title that is superior to that of the existing state (Slattery, 1994, pp. 715-716). Briefly stated, this right gives uncertain groups the power to secede from the states they belong to.

Another paradox lies at the meaning of this notion. Does the right of peoples to self-determination in the UN Charter give the power to decide whether or not to secede from an existing state? The right of self-determination may potentially involve cultural autonomy, administrative autonomy, political autonomy, federal structure, independence (Wolff and Weller, 2005, p. 12; Macklem, 2006, p. 502) as well as expanded authority of local governance in status quo. This ambiguous nature of self-determination, to what extent peoples may have independence from the central authority causes manipulative interpretations.

The lack of clarity surrounding its nature, scope, and content has generated resistance from sovereign states, which tend to sustain their political unity, sovereignty and territorial integrity, because self-determination principle also legitimates their sovereignty. Sovereign authority is the formal phrase of this principle in international law. Sovereignty authorizes state action to protect the chosen arrangements from internal or external threat. In other words, self-determination can stand as a challenge to sovereign authority while legitimating it. This is another paradoxical feature of self-determination. It is a principle of moral legitimacy for sovereign states, while concurrently exerting secessionist pressure on them.

Together with these immanent paradoxes in self-determination, the method of application of this principle is controversial too. Can 51 per cent share of votes in a referendum be interpreted as an indicator of the will of the people? The right to self-determination potentially involves not only a claim of liberty against the existing state, but also a claim of authority with respect to the residents of the seceding territory, namely, the authority to decide their international status and ultimately to govern them to the exclusion of other states. This claim extends to all dissenting residents, and competes with the similar claim of authority advanced by the existing state.

Just as Quebec has the presumptive liberty to secede from Canada, so dissenting groups, such as Aboriginal peoples, are also equally at liberty to break away from a secessionist Quebec and attach themselves to Canada or else establish their own independent states. The Liberal Party of Quebec has also pushed for "distinct society" status for Quebec while campaigning against sovereignty referendums. The Navarrese People's Union opposes Basque secessionism in Spain and integration into a wider Basque region, but instead it supports Navarre's traditional status. The Frisian National Party defends Frisian language rights and control over local resources, but opposes any autonomy from the Dutch government that would include important regulatory and fiscal powers (Sorens, 2008, p. 327).

\section{Political Economy of Self-Determination in Historical Course}

The application of self-determination has also developed through contradictions just like the dilemmas in itself. Self-determination principle had sprouted in close relationship with the concept of sovereignty of peoples during French, American and Bolshevik revolutions. The notion has been one of the most prevalent principles shaping international structure since the middle of the nineteenth and beginning of the twentieth centuries. Ironically, some of nationalist movements of that initial era were about the breakup of empires such as secessions of Greece and Serbia from the Ottoman Empire, while the others were about the unification of "nations" such as Germany and Italy. This inconsistency was generated by sacrificing of ethic bases of self-determination principle to the interests of European powers.

According to US President Woodrow Wilson (1927, p. 182), it is not a mere phrase. It is an imperative principle of action, which statesmen will henceforth ignore at their peril. After the World War I, he did want an arrangement on self-determination to be included in the League of Nations Covenant, but his so-called idealistic proposal was overruled on that issue by the European great powers, which had deep doubts about the term (Carley, 1996, p. 3). Wilson's approach was linked to his political ambition to gain support for electoral purposes among Ukrainian, Polish, Armenian, Lithuanian, Albanian and Croatian diasporas that migrated to the USA with the outbreak of the World War I and became strongly preoccupied with the independence of their countries of origin.

Like in the nineteenth century, self-determination in 1919 had little to do with the demands of the peoples concerned, unless those demands were consistent with the geopolitical and strategic interests of the great powers. V. Epps points out the inconsistency of the use of the phrase "self-determination" during a time when victorious states such as England, France and Italy expected to, and certainly did, redistribute conquered lands after warfare 
with no regard for the wishes of the residents (Molos, 2014, p. 87). Wilson's claim for self-determination was instrumentalized by the European powers to break up the defeated empires.

Plebiscites and the mandate system after Versailles Treaty were compensating devices for inadequacies and the imperfect application of the post-WWI self-determination. They were mostly directed against former German, Austro-Hungarian and Ottoman territories. In these cases, quite apparently, economic and strategic considerations prevailed over the nationality principle. In the plebiscite in Silesia, held in March 1921, majority voted for union with Germany. Since the area was mixed and there were allegations of fraud during the plebiscite, clashes between German and Polish peasants followed. In the end, the League gave Germany the bulk of Upper Silesia but most of the rich coalmines to Poland (Hasani, 2002, p. 82). Similar economic considerations also led the decision making processes in Saar territory, Danzig and Memel (Lithuania).

Aland Islands regarded as strategically essential to Finland were the subject of a confrontation between Sweden and Finland after the World War I. In this case, the islanders (almost entirely Swedish speaking) sought to become a part of Sweden following Finland's successful independence from Russia in 1917. If Finnish people was using this right, why could not the Alanders? But, this claim was denied by Finnish authorities and, as an another aberration, the dispute had been concluded by the League of Nations against Alanders, because the secession claims was limited to those living under failed empires in war (Crawford, 2001, p. 13).

The commission of jurists appointed by the League in dealing with self-determination issues announced in 1920 that self-determination was not an absolute right but a right that is realized on a case by case basis and upon an agreement, which means that, apart from the will of the population, other factors such as economic, political and security should be taken into account (Hasani, 2002, p. 86).

This principle which was earlier based on ethical grounds was expected to solve the conflicts in national and international disputes when it became a rule in international law codified by the UN after the World War II. Selfdetermination was included in Articles 1 and 55 of the Charter of the United Nations as a principle and subsequently, in the International Covenant on Civil and Political Rights and in the International Covenant on Economic, Social and Cultural Rights as a human right in 1966. Unfortunately, neither before nor after evolving international law status, the right to self-determination did not mitigate the conflicts around the world, but triggered new disputes instead. Because, in addition to the abovementioned resolutions, which mobilize ethnic movements, the UN was also taking decisions strengthening sovereign states. For instance, the 1970-dated UN Declaration on Principles of International Law Concerning Friendly Relations and Cooperation among States mentions that the right to self-determination can never be interpreted as a right to undermine the integrity of a state with democratic governance.

The essence of self-determination after the WWII was equated with anti-colonialism. It became the basis for the demands of states against colonization of great powers and for the immunity of states' sovereignty from international interventions. During the Cold War, the case was again not that all peoples had the right of selfdetermination, but that all peoples under colonial rule, occupation and peoples exposed to systematic racism had the right to be independent (Aral, 2010, p. 28). These legal arrangements seem to be ethic-based in terms of democratic ideals at first sight, but regarding natural resources of colonized territories, decolonization per se is an economic instrument and has economic results for great powers. The desire of US to access to raw materials in third world and self-determination principle complimented each other in this era (Hoogvelt, 2001, p.33). Besides, political aim of the US was to undermine European power. An overall weaker Europe was less likely to start another world war (O'Grady, 2017, p. 6).

With the admission of ex-colonized states to the UN, the number of member countries (51 states in 1945) rose to 114, including 35 African, 15 Asian and 11 Middle Eastern countries. The borders of new states were consistent with the former colonial administrative borders which were set up in the Berlin Colonial Conference a century ago. This decision was also brought in harmony with great powers' interest to apply "trusteeship model" for territories under their and defeated states' mandate, which was also formulated to prevent Soviet territorial expansion after the WWII. In the beginning, the UN was considered as a tool of foreign policy by the Western states, but once the self-determination emerged as a threat to the interests of colonial powers, they lost their faith in the UN, and further creation of new states was not allowed during the Cold War period except for Bangladesh (East Pakistan). One of the important reasons underlying this unique resolution of the UN towards Bangladesh case was the ongoing economic exploitation of East Pakistan by the West.

Another incompatible example is the contested case of West Sahara, which was dominated by the Moroccan state after the Spanish withdrawal in 1975. However, upon the claims of independence of Polisario Front, the Saharaui nationalist movement, the International Court of Justice denied the Moroccan interpretation based on pre-colonial borders and the United Nations recognized the Polisario Front as legitimate representative of Western Sahara. Nevertheless, it is a widely known reality that the conflicting interests of Western oil companies on the existing oil reserves in the region affected the international decision-making processes more than legal and ethical aspects of the right of self-determination (see Campos, 2008). 
The detente in bipolar world system generated the struggles to build confidence and reduce tensions between parties. Both parties attended the Conference on Security and Cooperation in Europe (later became OSCE), and agreed on the final Helsinki act, which meant a challenge for the Western states, but the recognition of post-war borders in East Europe for the Soviet Union. Unsurprisingly, the article saying that the state borders can be changed by peaceful means and by agreement in accordance with international law justified the Western vision about the region. The following breakdown of Warsaw Pact Organization and the subsequent dissolution of USSR and Yugoslavia led to the emergence of five new states in Yugoslavia and fifteen new states in Soviet territory as a consequence (Roberts, 2010; pp. 729-752).

Initially, the EU made public its guidelines on Recognition of New States in Eastern Europe and the Soviet Union on December 16, 1991. Despite the European Union's limited efficacy on international relations, the adoption of the same principles by the UN in its related resolutions made EU's impact wider than expected covering the entire Soviet Union, Yugoslavia and Czechoslovakia. In this document, respect for minority and human rights, democratic institutions and the rule of law were put forward as a precondition for statehood for first time since the development of the right to self-determination. Unfortunately, the claims of Kosovo's independence were not met with a positive return from the international community, although the application based upon referendum for an international recognition was handed over by the government in exile to the European Peace Conference on Yugoslavia (December 1991), where former administrative borders of Yugoslavia were taken as a reference point for statehood except for autonomous Kosovo region. The conflicting interests of France and Germany and Austro-German pressure in the EU were argued to determine the final decision of the EU commission on Kosovo. Though the claim of independence of Kosovo people was met by the UN in 2008, the inconsistencies in the application has kept existing hitherto.

\section{Contribution of Ambiguous Nature of Self-Determination to Great Powers' Interests}

Self-determination in current world politics is still a very vague notion. It is interpreted by the established states as the sovereign equality of states and the right to be free from foreign interference, but by the intra-state entities as their right to independence from the states they belong to. Along with all paradoxes given in the first chapter, the discrepancies in the application of this right by international structure have also added to the present complexity. Relevantly, it is true that this confusion encourages a world-wide confrontational environment; however, it is also true that it has given flexibility to the policies of the great powers.

They have the freedom to make different decisions in line with their interests even in similar situations. For instance, South Sudan's claim to attain its independence from Sudan was supported and enabled by the West, but similar Western support was not sufficient for the independence of Tibet in China. Conversely, secessionist Beloch people representing a distinct group in Iran and Pakistan was not backed by the West. Catalan, Basque, Quebec, North Ireland, South Tyrol, Flanders etc. nationalisms were thereby never welcomed and Kashmir, Palestine and North Cyprus independence claims were systematically prevented by some Western great powers.

On the other hand, Russia's military intervention into and eventual annexation of Crimea has been justified with a referendum referring to the right to self-determination, which shifted the balance of power in Black Sea in favor of Russia. According to Ukrainian President Petro Poroshenko and Prime Minister Arseniy Yatsenyuk, Russia determined to leverage its pivotal role in the global oil and gas trade into a program of territorial expansion (Ozsu, 2015 , p. 443). On the contrary, Russia has always opposed the independence of the Turkish Republic of Northern Cyprus. Which of these cases can be seen as having ethic and legal ground do change up to the sides of interest groups. Since there is vague supranational law and nobody to enforce it, the cases provide flexibility for international actors and develop in line with conflicting politico-economic interests of great powers.

Nonetheless, protracted conflictual environment caused by unresolved self-determination demands are not also a disadvantage of great powers. Ongoing conflicts give great powers a chance to change the commercial status quo by deploying their armed forces in the relevant region, and to exploit natural sources of the host country through international companies, as is the case in Northern Iraq. Moreover, they may better control the economic course all over the world. O'Grady asserts that American presidents want the freedom that this uncertainty offers them. During the Iraqi invasion of Kuwait in 1990, there was great uncertainty as to whether the US would oust Iraq or consent Iraqi occupation. Therefore, oil prices got quite volatile as the rest of the world awaited its decision. A less volatile but similar situation coincided with the annexation of Crimea by Russia (O'Grady, 2017, p. 7). It means the great powers are able to hold the control of global economy by crisis. Thus, it would not be a realistic approach to expect the great powers to develop a consistent policy with regard to the right of peoples to selfdetermination instead of having the flexibility for the interventions compatible with their interests in disguise of democratic ideals.

\section{Conclusion}

The paradoxes embedded in the concept of self-determination itself render the question of who has the natural right to govern the people even harder to reply. On the one hand, the established states tend to protect their territory, 
institutions and interests, as well as global security concerns, on the other hand peoples ask for liberation from unjustified -according to themselves- authority and there is a risk of chaos due to probable states in an unmanageable number.

In the historical process accompanied by this dilemma, the practices of national and international structure did not also follow the ethical and legal traces of self-determination principle. Some of nationalist movements in the nineteenth century and the beginning of the twentieth century were about the breakup of empires such as secessions of Greece and Serbia from the Ottoman Empire, while the others were about the unification of "nations" such as Germany and Italy. Balance of power played a great role in that era. Like in the nineteenth century, selfdetermination in 1919 had little to do with the demands of the peoples concerned, unless those demands were consistent with the strategic interests of the great powers. In cases of Silesia, Saar territory, Danzig, Memel (Lithuania) and Aland Islands, quite apparently, economic and strategic considerations prevailed over the nationality principle. After self-determination principle has become a codified right in several international documents that gave peoples who were exposed to systematic racism and under colonial rule and occupation the right to be independent, the efficacy of political economy did not change even in that era. Because decolonization, which was implemented in harmony with great powers' interests, per se was an economic instrument and had economic results for all sides.

As for today, there are many peoples claiming the right of self-determination, and violent conflicts over it in different geographies around the world. With one-sided interpretations of legal arrangements, great powers support some of nationalist movements while concurrently preventing the rest incompatible with their interests. They enjoy the political flexibility provided by vagueness of self-determination principle, and by the way, it is not a zero-sum game. If the conflicting interests cannot be bargained in an acceptable way, the continuation of the disputes still contributes to their interests. Thus, it would not be a realistic approach to expect the great powers to develop a consistent policy with regard to the right of peoples to self-determination.

\section{References}

- Aral, 2010, Üçüncü Kuşak İnsan Hakkı Olarak Kolektif Haklar (Collective Rights as a Third Generation Human Rights), Ankara, Siyasal Kitabevi.

- Campos, 2008, "Oil, Sovereignty and Self-determination: Equatorial Guinea and Western Sahara”, Review of African Political Economy, no. 117, pp. 435-447.

- Carley, 1996, "Self-Determination: Sovereignty, Territorial Integrity, and the Right to Secession”, United States Institute of Peace Report (Peaceworks no. 7), Washington, pp. 1-29.

- Crawford, 2001, “The Right of Self-Determination in International Law: Its Development and Future”, ed. Philip Alston, Peoples' Rights, Oxford, Oxford University Press, pp. 7-32.

- Deci and Ryan, 2000, "The 'What' and 'Why' of Goal Pursuits: Human Needs and the Self-Determination of Behavior", Psychological Inquiry, no. 11, pp. 227-268.

- Green, 2010, "The Paradox of Self-Determination for Marginalized Individuals", Social Work and Society, vol. 8, no. 1, pp. 171-176.

- Hasani, 2002, Self-Determination, Territorial Integrity and International Stability: The Case of Yugoslavia, Vienna, Institute for Peace Support and Conflict Management.

- Hoogvelt, 2001, Globalization and the Postcolonial World, London, Palgrave Publishing

- Lineira and Cetra, 2015, "The Independence Case in Comparative Perspective", The Political Quarterly, vol. 86, no. 2, pp. 256-264; Boylan, 2015, "In Pursuit of Independence: The Political Economy of Catalonia's Secessionist Movement", Nations and Nationalism, vol. 21, no. 4, pp. 761-785. It is not uncommon that an economically disadvantaged ethnicity prefers secessionism as a way to get rid of discrimination in a host state. However, advantaged regions like Catalonia can also prefer secessionism when the arrangement of the state's taxation and spending regime is such that they must subsidize disadvantaged regions across the state rather than retain their own wealth.

- Macklem, 2006, "Militant Democracy, Legal Pluralism, and The Paradox of Self-Determination", International Journal of Constitutional Law, vol. 4, no. 3, pp. 488-516. The Canadian Court drew a distinction between the traditional formulation of the right as entitling a people to sovereign independence, which it referred to as "external self-determination," and measures that provide a people with a measure of autonomy short of independence, which it termed "internal self-determination".

- Molos, 2014, "Turning Self-Determination on its Head", Philosophy and Public Issues, vol. 4, no. 1, pp. 75115 .

- O'Grady, 2014, “The Paradox of Self-Determination”, Advisor Perspectives, March 18, pp. 1-8.

- Ozsu, 2015, "The Crisis in Ukraine: Ukraine, International Law, and Political Economy of SelfDetermination", German Law Journal, vol. 16, no. 3, pp. 434-451. 
- $\quad$ Roberts, 2010, Avrupa Tarihi (European History), tra. Fethi Aytuna, Istanbul, Inkılap Kitabevi.

- Slattery, 1994, “The Paradoxes of National Self-Determination”, Osgoode Hall Law Journal, vol. 32, no .4, pp. 703-733.

- Sorens, 2008, "Regionalists against Secession: The Political Economy of Territory in Advanced Democracies", Nationalism and Ethnic Politics, vol. 14, no. 3, pp. 325-360.

- Wilson, 1927, "War Aims of Germany and Austria (Feb 11, 1918)", Public Papers of Woodrow Wilson: War and Peace, eds. Ray Stannard Baker \& William E Dodd, New York, Harper \& Brothers, p.182.

- Wolff and Weller, 2005, "Self-Determination and Autonomy: A Conceptual Introduction", Autonomy, Selfgovernance and Conflict Resolution: Innovative Approaches to Institutional Design in Divided Societies, eds. Marc Weller and Stefan Wolff, New York, Routledge, pp. 1-22. Constitutional theorists have seen non-territorial cultural autonomy as an instrument to deal with the cultural dimension of ethnic conflict that is with matters of education, language, and religion. Administrative autonomy most commonly describes an arrangement of executive independence within the framework of central legislature and judicial system. In political autonomy, the entity is given executive and legislative power but does not have its own judicial system. The full self governance such as those in federal states, on the other hand, incorporates the right for the entity to elect its own government and legislature and grants judicial powers. 


\title{
Content Analyses on Mission Statements of the Commercial Banks in Kyrgyzstan
}

\author{
Asst. Prof. Dr. Seyil Najimudinova (Kyrgyz-Turkish Manas University, Kyrgyzstan)
}

\begin{abstract}
The concept of mission is still popular both in academic environment and business practices. Mission statements have been accepted as an important part of the strategic management process for organizations of all types; be it public sector, not-for-profit, private, for profit, a multinational or a SME. This paper aims to study the content of mission statements of Top10 commercial banks in Kyrgyzstan. The main objective of this study is to identify whether the mission statements of commercial banks contain components suggested Pierce and David (1987) and Bart and Tabone (1999). Data was based on content analysis of the mission statements and other related statements found on commercial banks' web sites. Another secondary data on general profile of commercial banks are obtained from their web-sites and other open to public resources. The results show all (11) numbers of components are not incorporated in the mission statements of commercial banks totally. According to obtained data it was done Top 3 rating of commercial banks according to their mission statements. The level of popularity of mission statement components displays the following: products or services, geographic location, statement of purpose and customers are the most of frequent occurrence components. Components like concern for public image, concern for growth and profit, and philosophy are less popular mission components. In the future this study can throw fresh light on researches on other industries and to make relationship between good mission statements and the performance of commercial banks.
\end{abstract}

\section{Introduction}

The concept of mission is still popular both in academic environment and business practices. Pearce and David (1987) stated that developing a mission statement is an important first step in the strategic planning process. Nowadays some authors attempt to find new dimensions and facets of mission statement, for instance, examine mission statements from a customer perspective, although historically mission statements have been used almost exclusively in a management context (David et al, 2014). Since 1993 until 2015, mission statement is highly popular management tool on a level with CRM, strategic planning, benchmarking, balanced scorecard (Top10), used by a large number of executives, regardless of the geography and the economic development level of the country where enterprises operates (Rigby and Bilodeau, 2015). This survey based on data of more than 13,000 respondents from more than 70 countries in North America, Europe, Asia, Africa, the Middle East and Latin America. Most of the executives in emerging markets demonstrate high satisfaction levels from the effects of mission statements on the business performance.

Hereby, in the business context, the roots of mission statements can be traced back to Selznick's leadership in Administration (1957) and Drucker's The Practice of Management (1954) (Kosmützky, 2012:60). According to some authors the strategy school of mission owes its birth to an article, 'Marketing Myopia' by Ted Levitt which appeared in the Harvard Business Review in 1960 (Campbell and Yeung, 1991:10).

Nowadays mission statements have been dominantly accepted as an indispensable part of the strategic management process for organizations of all types; be it public sector, not-for-profit, private, for profit, a multinational or a small and medium scale enterprise (Darbi, 2012:95). The companies with a mission statement expected to be more successful than those without one, and successfully completing the mission statement process demonstrates that a company can think reflectively, plan carefully, work collaboratively, and make informed decisions (Williams, 2008:98).

Much of literature studies and empirical researches on mission statement contents, often with the aim of linking these elements to company performance (Pearce \& David, 1987; Bart \& Baetz, 1998; O'Gorman \& Doran, 1999; Analoui and Karami, 2002), especially its financial performance (Williams, 2008; Jung \& Pompper, 2014). Recent years have seen increased attention to the connections between mission statements and other organizational practices like organizational citizenship (Wang, 2011); marketing positioning (Finley, et al, 2001); high-quality work-life practices (Blair-Loy, et al, 2011); corporate social responsibility (Jung and Pompper, 2014), marketing strategy (David et al. 2014); employee behavior (Darbi, 2012). In reference to the geography of researches on mission statement indicates following countries and authors: in case of USA (Pearce and David, 1987; Bolon, 2005; Williams, 2008; Blair-Loy, et al 2011; Stemler, et al, 2011; Wilson, et al, 2011; Orozco, 2012); of Canada (Bart \& Tabone, 1998; Bart \& Baetz, 1999; Finley et al, 2001); of Turkey (Acuner \& Genç, 2008; Köseoğlu, 2008; Erol \& Kanbur, 2014); of UK (Analoui and Karami, 2002; James and Huisman, 2009); of Eastern Africa (Kibuuka, 2001); of South Africa (Garg, 2014); of Germany (Kosmützky, 2012); of Croatia (Tanković, 2013); of Oman (Rajasekar, 2013); of Bangladesh (Tuhin, 2014); of Slovenia (Biloslavo, 2004; Dermol, 2012); of Ghana and West Africa (Darbi, 2012); of Macedonia (Marjanova \&Fotov, 2014); of Ireland (O'Gorman and Doran, 1999). The industrial or sectorial differentiation of researches on mission statement is pretty various: in case of education 
(Finley et al, 2001; Kibuuka, 2001; James \& Huisman, 2009; Stemler, et al, 2011; Wilson,et al, 2011; Orozco, 2012; Kosmützky, 2012); electronic industry (Analoui and Karami, 2002); health and pharmaceutics (Bart \& Tabone, 1999; Bolon, 2005; Azizi and Hosseinabadi, 2014); banks (Tuhin, 2014); mining (Garg, 2014); of confectionary industry (Marjanova \& Fotov, 2014); in case of international airlines (Kemp and Dwyer, 2003). This paper contributes to above literatures by studying the content of mission statements of commercial banks in Kyrgyzstan.

\section{Mission Statement: What It Defines and What It Gives}

Varied definitions of mission statement have been presented by the researchers. Nevertheless, the mission is predominantly accepted as the raison d'être or ikigai (in Japanese) of a company or organization (Виханский, 1998; Akgemci, 2007; Thompson and Strickland, 2006; Hill and Jones, 2010). It reflects back the reason or basis for existence of any organization. Campbell and Yeung (1991:11) called the mission as cultural 'glue' which enables an organization to function as a collective unity and it consists of strong norms and values that influence the way in which people behave, how they work together and how they pursue the goals of the organization. According to Ritson (2008) mission is a formal commitment to the vision that incorporates the company's strategy (Ritson, 2008). Mission is an enduring statement of purpose that reveals an organization's product or service, markets, customers and philosophy (Pearce and David, 1987:109). In general, mission statement should include the basic function or tasks of an organization, particularly why it exists, the nature of the businesses it is in (Ritson, 2008). Moreover, uniqueness of mission statement differentiates and distinguishes one organization from other similar institution (David and David, 2003:11; Bolon, 2005:2; Morden, 2007:177). Mission is mostly accepted as fundamental statement of purpose and direction, which defines the place of the organization within its environment (Morden, 2007:177). Tanković, (2013:333) assumed mission usually reflects the values and priorities of strategic decisions and outlines the vision and future organization's direction. As well it may reflect the values and culture of founder and decision-makers as these have evolved over the life of the organization (Morden, 2007:177). Specifically, the mission defines the long-term vision of the organization in terms of what it wants to be and whom it wants to serve (Dobson et al. 2004:10). Bart and Tabone (1998:19) defined a mission statement as a written and formalized document trying to emphasize an organization's unique and enduring purposes. In addition, mission statements can emerge from internal needs and preferences and as adjustments to environmental pressures or challenges (Bolon, 2005:23). Besides not all firms use the term 'mission statement', but may instead refer to their 'credo', 'core values', 'corporate philosophy', or 'guiding principles (Blair-Loy, et al, 2011:429). Forenamed statements often address stakeholders, including shareholders, management, employees, customers, and society. Why do organizations use a mission statement as one of the most popular management tool? To find an answer to this question many researchers approach miscellaneously. Bart and Tabone (1998:19) stated a mission statement as a central to every organization's management and hence it serves two main purposes: to provide a focused guide for decision making and to motivate and inspire employees toward common objectives. The motivational role of mission statements in directing and focusing employees, and inspiring them to perform at high levels echo back in other studies (Blair-Loy, et al, 2011:429; Rajasekar, 2013:132). Specifically, creating and using a mission statement can foster a shared value system, a focus on common objectives, teamwork, behavioral guidelines, and emotional commitment to the company (Mullane, 20002:449). Top management must be committed to the mission crafting process, and organization members must be involved to produce a mission that will evoke emotional response (David et al, 2002:449). In addition, the mission statements stand to communicate a public image of the firm to important stakeholders (Germain and Cooper, 1990). Morden (2007:177) suggests using a mission statement to define the scope of the organization in terms of location and positioning; its approach to people; and its strategies towards markets, operations management, quality, and service. Well-established mission statement can project a sense of worth, intent, and shared expectations, and should state intrinsic value of the organization's products and services (David and David, 2003:11). The mission statement facilitates decision making, planning, creating effective strategies, and formulating policies for the short and long term (Rajasekar, 2013:132). Desmidt and Heene (2003:7) stressed on not just listing an extensive list of values with the sole purpose of adorning the annual report or organizational website. In authors' opinion, mission statements must mirror those values that are embedded in the organizational culture. A mission statement allows the firm to articulate a strong vision for the organization and to communicate that to its growing number of employees and professional managers (Analoui and Karami, 2002:14). Nowadays, mission statements still serve as common corporate reporting tools (Williams, 2008). Without an effective mission statement, a firm's short-term actions may be counterproductive to long-term interests (David et al. 2014:107). Finally, mission can be the building block for a corporate strategy and healthy basis for strong corporate culture.

\section{Crafting Mission Statement}

A lot of resources have been created to assist organizations with crafting the effective mission statement. It is very important to develop the mission statement very carefully and comprehensively. For instance, Hamel and Prahalad (1994:133) used "a sense of mission", "strategic intent" and "sense of destiny" interchangeably, and 
focused on pathos and passion as main components in mission statement. They focused on making a real difference in the lives of customers. David and David (2003) stated the mission statement needs to be longer than a phrase or sentence, but not a two-page document, it should not be overly specific; it should not include dollar amounts, percentages, numbers, goals, or strategies. Too much detail can alienate managers and stifle creativity. In the narrow sense of the mission statement, it just contains texts embodying organizational tasks, organizational goals and purposes and distinct organizational images (Kosmützky (2012:69). To the wide extent, a mission statement is something comprehensive and in-depth. One of the most-cited authors Pearce and David (1987) argued that high-performance companies have exhaustive mission statements containing eight key components, as follows: specification of target customers and markets, identification of principal products and/or services, identification of geographic domain, identification of core technology, expression of commitment to growth, survival, and profitability, specification of key elements of the company philosophy, identification of the company's selfconcept, and identification of the firm's desired public image. Ackoff (1987) stressed on five must-have characteristics in mission statements: a) it should contain a formulation of the firm's objectives that enables progress toward them to be measured; b) it should differentiate it from other companies; c) it should define the business that the company wants to be in; d) it should be relevant to all the firm's stakeholders; e) it should be exciting and inspiring.

Campbell and Yeung (1991:16) underlined that a strong mission can exist when the four elements of mission reinforce each other: purpose (why the company exists), strategy (the competitive position and distinctive competence) and values (what the company believes in) and behavioral standards (the policies and behavioral patterns that underpin the distinctive competence and the value system). Afterwards Bart and Baetz (1998) identified nine key components of mission statements, a list that is modified somewhat: purpose/raison d'etre, values/beliefs/philosophy, business strategy/distinctive competence/competitive position, behavior standards and policies, corporate level aims/goals, self-concept/ identity, public image, location, technology, concern for survival. In 1999, Bart and Tabone enlarged this list to 23 components appending financial and nonfinancial objectives, specific customers served, product/services offered, concern for satisfying customers, concern for employees, concern for suppliers, concern for society, concern for shareholders, statement of vision. At the same time O'Gorman and Doran (1999) specified eleven main characteristics for a successful mission: concern for survival, product/service, concern for customer, geographic domain, company philosophy, concern for quality, self-concept, public image, customer/market, concern for suppliers, core technology. According to Analoui and Karami (2002) a typical mission statement contains long term profit, survival and growth; customer satisfaction; core technology; market; company philosophy and values; product image; geographic domain; self-concept; and concern for suppliers. In addition to readability and availability of mission statement Desmidt and Heene (2003:9) suggested following prerequisites must be fulfilled in order to have effective mission statement: a) well-conceived, it has to reflect the actual values of the organization; b) well-communicated, all members of the organization have to be aware of the existence of the mission statement; c) well-comprehended, all organization members have to understand the mission statement; d) well-supported, it has to be embedded in the systems, procedures and policies of the organization. Dobson et al. (2004:10) discussed on a good mission statement components and recommended following: the purpose of the organization - a statement of the principal activities of a business or organization; its principal business aims - its mission as regards the position it aims to achieve in its chosen business; the key beliefs and values of the company; definitions of who are the major stakeholders in the business; the guiding principles that define the code of conduct that tells employees how to behave. Managing mission is ongoing process and not many companies can articulate the behavior standards that drive their mission without working at the problem over a number of years (Campbell and Yeung,1991:20). Indisputably a good and well-established mission statement can provide the source for outlining and drafting business objectives that the organization endeavors to reach.

\section{Research Methodology}

This paper aims to study the content of mission statements of commercial banks in Kyrgyzstan. The main objective of this study is to identify whether the mission statements of commercial banks contain components suggested Pierce and David (1987) and Bart and Tabone (1999). Data was based on content analysis of the mission statements and other related statements found on commercial banks' web sites. If 20 years ago mission statements were seen often in company newsletters, speeches, annual reports, brochures, posters, and even on the backs of business cards (Fairhurst et al, 1997:244), nowadays this kind of information can be found in corporate web-sites. As it is known content analysis is a research technique for making replicable and valid inferences from texts (or other meaningful matter) to the contexts of their use (Krippendorff, 2004:18). Content analysis can be used to identify the intentions and other characteristics of the communicator; reveal the focus of individual, group, institutional, or societal attention; and reflect cultural patterns of groups, institutions, or societies (Weber, 1990:10). Azizi and Hosseinabadi (2014) argued the content analysis method can be used for surveying the quality of the mission statement, which is a well-known and trustworthy process for studying the appropriateness of the mission statement. In analyzing mission statements of organizations content analysis is one of the mostly used methods 
(Pierce and David, 1987; Kemp and Dwyer, 2003; Biloslavo, 2004; Tuhin, 2014; Azizi and Hosseinabadi, 2014; David et al., 2014; Garg, 2014).

\subsection{Research Sample}

After the independence in 1991 and because of appropriate environment for establishing banks, the banking system in Kyrgyzstan developed rapidly. In mid-1994 20 banks were functioning in Kyrgyzstan in the form of joint-stock companies or commercial banks (Kloc, 1994). As of March, 2016, 25 commercial banks (with 323 branches) have operated on the territory of the Kyrgyzstan. The total assets of the banking system are KGS 176.7 billion. The total deposit base of the banking system constituted KGS 94.2 billion. The financial sector of Kyrgyzstan is largely dominated by commercial banks. The weight of foreign contribution in the capital of banking system amounted to $45.6 \%$ of paid up assessed capital or KGS 7.8 billion (National Bank of Kyrgyz Republic Data, 2016).

This study includes Top10 commercial banks according to their amount of total assets. This index is one of the most important criteria to evaluate the stability and efficiency of the bank.

As above - mentioned corporate websites were the core instrument used for data collection in this study. Websites for each of these companies was screened to find the mission, vision, mission, values or related statements. The reason for using all of them was that many organizations use the terms mission, vision, principles, approach, values and goals interchangeably (Garg, 2014:307).

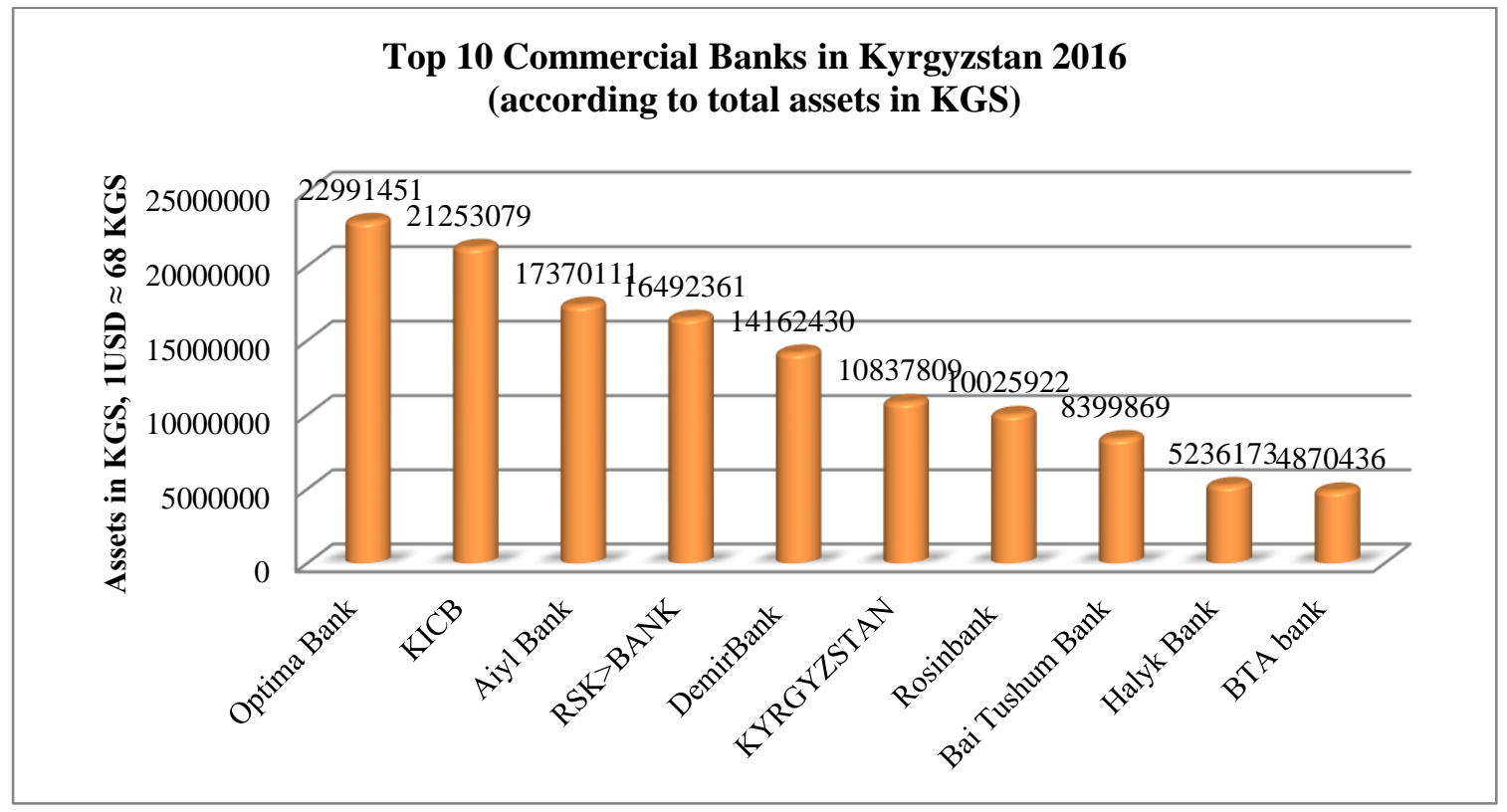

Figure 1. Top10 Commercial Banks in Kyrgyzstan According to Total Assets, 2016 Source: From Financial Statements of Commercial Banks Given in Their Web-Sites

\subsection{Research Scale}

As literature review shows content components outlined by Pearce and David in 1987 are still found in current mission statements with enough regularity and consistency. Pierce and David's scale consist of eight components. This scale was extended to 11 components adding some items offered by Bart and Tabone (1999).

\subsection{Research Findings}

Among Top10 commercial banks' web-sites 8 of them includes mission statements information in English, 6 of them in Kyrgyz, and all of them in Russian, only one bank reflects information in Japanese. Besides, three of respondents (RosinBank, Kyrgyzstan Bank and Aiyl Bank) have corporate periodical newsletters which were used as a resource. The results of this study are presented in Table 1. It shows that all (11) numbers of components are not incorporated in the mission statements of commercial banks totally. 


\begin{tabular}{|c|c|c|c|c|c|c|c|c|c|c|}
\hline Mission Statement Components & 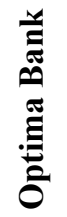 & $\underset{v}{\tilde{U}}$ & 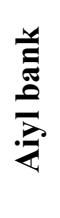 & 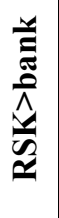 & 苛 & 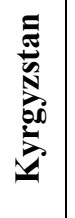 & 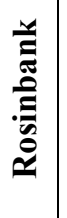 & 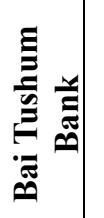 & 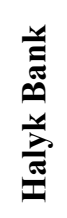 & 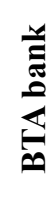 \\
\hline $\begin{array}{l}\text { Statement of purpose/raison d'etre } \\
\text { What is the reason that justifies the } \\
\text { existence of your company? }\end{array}$ & $\sqrt{ }$ & $\sqrt{ }$ & $\sqrt{ }$ & $\sqrt{ }$ & $\sqrt{ }$ & $\sqrt{ }$ & $\sqrt{ }$ & $\sqrt{ }$ & $\sqrt{ }$ & - \\
\hline $\begin{array}{l}\text { Customer: } \\
\text { Who are the target customers? }\end{array}$ & $\sqrt{ }$ & $\sqrt{ }$ & $\sqrt{ }$ & $\sqrt{ }$ & $\sqrt{ }$ & $\sqrt{ }$ & $\sqrt{ }$ & $\sqrt{ }$ & $\sqrt{ }$ & - \\
\hline $\begin{array}{l}\text { Products or Services: } \\
\text { What are the principal products or } \\
\text { services? }\end{array}$ & $\sqrt{ }$ & $\sqrt{ }$ & $\sqrt{ }$ & $\sqrt{ }$ & $\sqrt{ }$ & $\sqrt{ }$ & $\sqrt{ }$ & $\sqrt{ }$ & $\sqrt{ }$ & $\sqrt{ }$ \\
\hline $\begin{array}{l}\text { Geographic location / markets: } \\
\text { Geographically, where does the } \\
\text { company compete? }\end{array}$ & $\sqrt{ }$ & $\sqrt{ }$ & $\sqrt{ }$ & $\sqrt{ }$ & $\sqrt{ }$ & $\sqrt{ }$ & $\sqrt{ }$ & $\sqrt{ }$ & $\sqrt{ }$ & $\sqrt{ }$ \\
\hline $\begin{array}{l}\text { Core technology: } \\
\text { What technology does company use in } \\
\text { current? }\end{array}$ & $\sqrt{ }$ & - & - & $\sqrt{ }$ & $\sqrt{ }$ & $\sqrt{ }$ & $\sqrt{ }$ & $\sqrt{ }$ & - & - \\
\hline $\begin{array}{l}\text { Concern for survival, growth, and profit: } \\
\text { Is the company committed in terms of } \\
\text { financial success and future existence? }\end{array}$ & - & $\sqrt{ }$ & - & $\sqrt{ }$ & - & - & $\sqrt{ }$ & - & $\sqrt{ }$ & - \\
\hline $\begin{array}{l}\text { Philosophy/Values } \\
\text { What are the primary views, beliefs, } \\
\text { desires, and ethical priorities of the } \\
\text { company? }\end{array}$ & $\sqrt{ }$ & - & - & $\sqrt{ }$ & - & $\sqrt{ }$ & - & $\sqrt{ }$ & - & - \\
\hline $\begin{array}{l}\text { Self-concept: } \\
\text { What are the key competitive advantages } \\
\text { of the company? }\end{array}$ & - & $\sqrt{ }$ & $\sqrt{ }$ & - & $\sqrt{ }$ & - & - & $\sqrt{ }$ & $\sqrt{ }$ & $\sqrt{ }$ \\
\hline $\begin{array}{l}\text { Concern for public image: } \\
\text { Is the company sensitive to the well- } \\
\text { being of society, community and } \\
\text { environment? }\end{array}$ & $\sqrt{ }$ & $\sqrt{ }$ & - & - & - & $\sqrt{ }$ & - & $\sqrt{ }$ & - & - \\
\hline $\begin{array}{l}\text { Concern for shareholders: } \\
\text { Is the company committed to } \\
\text { shareholders and their interests? }\end{array}$ & $\sqrt{ }$ & $\sqrt{ }$ & - & $\sqrt{ }$ & $\sqrt{ }$ & - & - & $\sqrt{ }$ & - & - \\
\hline $\begin{array}{l}\text { Concern for employees: } \\
\text { Are human resources a valuable asset of } \\
\text { the company? }\end{array}$ & $\sqrt{ }$ & $\sqrt{ }$ & - & $\sqrt{ }$ & $\sqrt{ }$ & $\sqrt{ }$ & - & $\sqrt{ }$ & - & - \\
\hline $\begin{array}{l}\text { Number of components found in } \\
\text { mission statements }\end{array}$ & 9 & 9 & 5 & 9 & 7 & 8 & 6 & 1 & 6 & 3 \\
\hline
\end{tabular}

Table 1. A Comparison of Mission Statement Components of Top 10 Commercial Banks

Further it is presented detailed cases from corporate mission statements and exemplary textual statements as well.

1. Statement of purpose/raison d'etre. What is the reason that justifies the existence of your company? Almost all $(\mathrm{N}=9)$ respondents included in their mission statements this component.

to make a contribution to the development of the economy of the Kyrgyz Republic by providing the Kyrgyz private sector with medium to long-term financing (KICB).

to facilitate the development of agro-industrial sector by satisfying demand of farmers and population of the Kyrgyz Republic in available and high-quality bank services and products» (AIYL BANK).

to become the leading bank on the market for retail services and the small and medium-sized businesses segment through the provision of high quality and popular services and focus on client needs (RSK Bank).

to promotes social and economic development of the Kyrgyz Republic by providing access to a wide range of banking services and innovative financial solutions for businesses and agricultural producers to ensure their stable growth (Bai Tushum Bank). 
2. Customer: Who are the target customers? Mission statements of almost all respondents do not address to certain customer segment. Only Aiyl Bank stresses that it "is one of the biggest banks in the country and at the same time is the main finance and credit institution, providing loans for agricultural sector during 14 years". KICB stated that '... loans to the manufacturing sector comprise more than $55 \%$ of total loans and the remaining portion of the credit portfolio is spread among tourism, agriculture and trade'. Optima Bank shared that '....in more than 50 departments throughout the Kyrgyzstan serve more than 102 000customers'.

3. Products or Services: What are the principal products or services? As commercial banks are service companies, in their statements they focused on their wide-range banking services. All respondents are more definitely in specifying their services.

In addition to lending, KICB provides deposit products, current accounts, money transfers and foreign exchange operations. In 2006 the bank launched retail banking operations and offers mortgage and consumer loans, small and medium business loans.

...is a leading retail bank, which offers individual biggest range of banks services like consumer credits, money transfer in national as well as foreign currencies with and without bank accounts, money deposits, full range of payment tools - plastic cards of international systems EuroPay International, Visa International and more (BTA Bank).

4. Geographic location / markets: Geographically, where does the company compete?

..is a sound and stable financial institute, a bank with a good balance sheet structure, diversified credit and deposit portfolio and well-balanced geographical coverage throughout the Kyrgyzstan (Optima Bank).

To date, the bank has a developed infrastructure and is a multi-credit institution provides credit and settlement services to more than 20000 businesses, organizations and commercial structures located in the territory of the Kyrgyz Republic (KYRGYZSTAN).

5. Core technology: What technology does company use in current? Commercial banks are service companies however their efficiency depends on technology they use. Core technology component was specified more in details by Bai Tushum Bank “...has been introducing innovative technologies and service channels to make banking user friendly'

6. Concern for survival, growth, and profit: Is the company committed in terms of financial success and future existence? As known commercial banks are financial institutions, and financial success and future financial plans expected to be cornerstone in their mission statements. Only 4 of respondents mentioned in their statements their concern on profitability and financial success.

7. Philosophy/Values: What are the primary views, beliefs, desires, and ethical priorities of the company? Four respondents included in their statements clear expressions of their philosophy, principles and values.

...Our values are simplicity, accessibility, innovation, reliability, confidence, long-term partnership, openness and transparency, corporate social responsibility, financial inclusion (Bai Tushum Bank).

...Our values are honesty, transparency, respect, collaboration, freedom, confidence, justice (Optima Bank).

8. Self-concept: What are the key competitive advantages of the company? Five of respondents included in their statements more detailed information about their strengths and distinctive competences. This component is mostly reflected in their credos.

"A reliable bank" More than 30,000 depositors trust in us (KICB)

"Closer to you” (Aiyl Bank)

"The People's Bank" (RSK BANK)

"We value the trust. We deliver the values” (Bai Tushum Bank)

"Bank for the whole country!” (Kyrgyzstan Bank)

"Bank for your life" (DemirBank)

9. Concern for public image: Is the company sensitive to the well-being of society, community and environment? Five of respondents included in their statements more comprehensive information about their concern on wellbeing of society, community and environment. Mostly they stated on their Corporate Social Responsibility, specifying more on their charity programs, ecological sensitiveness etc. Some brief excerpts:

...to contribute into the ecological development of the Republic by developing green programs. Bank also issues easy (preferential) credits, such as: loans for education, housing heat-insulation and energy savings $(K I C B)$.

...we are committed to care about our clients' welfare growth, maximally satisfying their needs. We clearly understand our social responsibility and we are dedicated to the development of the communities in which we live (Optima Bank).

10. Concern for shareholders. Is the company committed to shareholders and their interests? 
All respondents are joint-stock companies and it means they are business entities where different stocks can be bought and owned by shareholders. In joint-stock companies, shareholders are the most critical stakeholders. Concern on shareholders and commitment to their interests are included only in 5 cases.

...to be focused on the needs and requirements of our customers and partners and to be recognized as the best commercial bank for the high quality of service, new products and services and an attractive return to shareholders of the Bank (DemirBank)

....is based on principles of respect for the interests of all stakeholders (customers, shareholders, employees, partners and society as a whole), openness and transparency, social responsibility, compliance with the business culture and business ethics, monitoring and achieving high results in business activity (RSK Bank).

Bank builds fair and transparent relationships with customers, shareholders, partners and employees, and strictly follows the laws, ethical norms and international business practices (Bai Tushum Bank).

11. Concern for employees. Are human resources a valuable asset of the company?

Six of respondents included in their mission statements this component. Some excerpts are following:

The most important value of the Bank is the friendly, solid team of the like-minded people focused on implementation of the Bank's mission and goals. Key component of success and faultless reputation of the Bank in the financial market is highly skilled and motivated personnel with relevant education degrees and work experience in financial sector... The objective of the trainings is development of practical skills with the help of which each staff member can raise the quality of services provided (Bai Tushum Bank).

Bank considers its employees the most valuable assets of the organization and tries to involve the Bank of the best professional and experienced specialists. The Bank also offers positions to graduates and students of the best universities in the country, fresh ideas and suggestions which may have a positive impact on the Bank's activities (Demir Bank)

To provide continuous training for our staff to assure high performance services and create a good atmosphere within the bank and motivate our staff to be the employer of people's dreams; management sets for individuals aiming at joining the professional team of KICB: high professional qualification, initiative, motivation and willingness to support the corporate culture and values of the Bank; (KICB)

Caring about the welfare of clients and partners, employees, society and the country as a whole; (RSK Bank)

Table 1 shows how respondents are consistent in their mission statements. According to obtained data it is possible to make some kind of Top 3 rating of commercial banks' mission statements. Bai Tushum is the most consistent in their mission statements (10 components) and good at crafting well-established mission statements. Optima Bank, KICB, RSK>Bank are in second position according to their statements (9 components), Demir Bank and Kyrgyzstan Bank are in third position (8 components). BTA bank is less unequivocal and more superficial in their mission statement. They should pay more attention to other components which were out of their sight.

\begin{tabular}{|c|c|c|c|}
\hline Mission Statement Components & Number of Respondents & Percentage & Rating \\
\hline Products or Services & 10 & $100 \%$ & \multirow{2}{*}{1} \\
\hline Geographic location / markets & 10 & $100 \%$ & \\
\hline Statement of purpose/raison d'etre & 9 & $90 \%$ & \multirow{2}{*}{2} \\
\hline Customer & 9 & $90 \%$ & \\
\hline Core technology & 6 & $60 \%$ & \multirow{3}{*}{3} \\
\hline Self-concept & 6 & $60 \%$ & \\
\hline Concern for employees & 6 & $60 \%$ & \\
\hline Concern for shareholders & 5 & $50 \%$ & 4 \\
\hline Concern for public image & 4 & $40 \%$ & \multirow{3}{*}{5} \\
\hline Concern for survival, growth, and profit & 4 & $40 \%$ & \\
\hline Philosophy/Values & 4 & $40 \%$ & \\
\hline
\end{tabular}

Table 2. Mission Statement Components Rating in the Case of Commercial Banks in Kyrgyzstan

The components suggested by Pierce and David (1987) Bart and Tabone (1999) were partly included in mission statements of commercial banks in Kyrgyzstan. Table 2 shows the level of popularity of mission statement components. Products or services, geographic location, statement of purpose and customers are the most of frequent occurrence components. Components like concern for public image, concern for growth and profit, and philosophy are less popular mission components. 


\section{Conclusion and Discussion}

Both yesterday and today the mission statement is pretty popular management tool. As literature review shows mission statement is something unique that differentiates one organization from another. It is statement of purpose and direction, which defines the place of the organization within its environment. Mission statement is raison d'être of any organization and it must be addressed toward both internal and external stakeholders. Perhaps there is no ready formula for crafting mission statement and finding best expresses the collective purpose and values of organization. The results show despite commercial banks are financial institutions, and financial success and future financial plans expected to be cornerstone in their mission statements, only 4 of respondents mentioned in their statements their concern on profitability and financial success. Despite all respondents are joint-stock companies and in joint-stock companies, shareholders are the most critical stakeholders, concern on shareholders and commitment to their interests are included only in 5 cases. Components like concern for public image and philosophy are less popular mission components.

A mission statement can be misused and thus appear outdated, inefficient, or even foolish (Mullane, 2002:454). Nevertheless, there are some theoretical helpful instruments successfully implemented in other cultures and industries (Pierce and David 1987 and Bart and Tabone, 1999). Of course, every organization will craft and design their mission statements regarding to their background, corporate culture, experience, collective mentality etc. A properly designed mission statement including all components discussed in this study pretends to become one of the most important strategic tools. All respondents mirror their mission statements in their corporate sites. In the future this study can throw fresh light on researches on other dynamically emerging industries in Kyrgyzstan and to make relationship between good mission statements and the performance of commercial banks.

\section{References}

- $\quad$ Ackoff, R. L. (1987). Mission statements, Planning Review, Vol.15, pp.30-31

- $\quad$ Acuner, T. ve Genç, K.Y. (2008) Türkiye’ nin ve Avrupa' nın Büyük İsletmelerinin Misyon ve Vizyon Açıklamalarının İçerikleri Bakımından Karşılaştırılması, 16. Ulusal Yönetim ve Organizasyon Kongresi Kongre Kitabı, İstanbul Kültür Üniversitesi, 16-18 Mayıs, Antalya, ss. 320- 324.

- $\quad$ Akgemci, T. (2007) Stratejik Yönetim, Gazi Kitabevi, Ankara

- Analoui, F.,and Karami, A. (2002) CEOs and development of a meaningful mission statement, Corporate Governance, Vol. 2, pp.13-20

- Azizi, S. and Hosseinabadi, V. (2014) A Content Analysis of the Mission Statements of Iran, Turkey, India and United States Pharmaceutical Companies, Management \& Marketing, vol.12, issue 1, pp. 52-66

- Bart, C. K., \& Baetz, M. C. (1998) The Relationship between Mission Statements and Firm Performance: An Explanatory Study, Journal of Management Studies, 16(1-3), pp.64-77.

- Bart, C. K., and J. C. Tabone. (1999) Mission statement content and hospital performance in the Canadian not-for-profit health care sector, Health Care Management Review 24 (3): 18-29.

- Biloslavo, R. (2004) Web-based mission statements in Slovenian enterprises, Journal of East European Management Studies, Vol. 9, No. 3 (2004), pp. 265-277

- $\quad$ Blair-Loy, M., Wharton, A.S. and Goodstein, J. (2011) Exploring the Relationship between Mission Statements and Work-Life Practices in Organizations, Organization Studies, Vol.32 (3), pp. 427-450

- Campbell, A., \& Yeung, S. (1991). Creating a sense of mission, Long Range Planning, 24(4), pp.10-20

- Darbi, W. P. K. (2012) Of Mission and Vision Statements and Their Potential Impact on Employee Behaviour and Attitudes: The Case of A Public But Profit-Oriented Tertiary Institution, International Journal of Business and Social Science Vol. 3 No. 14, pp. 95-109

- David M.E., David, F.R. and David F.R. (2014) Mission Statement Theory and Practices: A Content Analysis and New Direction, International Journal of Business, Marketing, and Decision Sciences, Vol.7, No1, pp.95-110

- David, F.R. and David, F.R. (2003) It's Time to Redraft Your Mission Statement, Journal of Business Strategy, 24(1), pp.11

- Dermol, V. (2012) Relationship between Mission Statement And Company Performance, International Conference on Management, Knowledge and Learning, 20-22 June 2012, Celje, Slovenia

- Desmidt, S. and Heene, A. (2003) Mission statements: in search for ameliorated performance through organisation - employee value congruence, First workshop of the EGPA Study Group on Ethics and Integrity of Governance, Oeiras, Portugal, September

- Dobson, P., Starkey K. and Richards J. (2004) Strategic management: issues and cases, $2^{\text {nd }}$ Edition, Blackwell Publishing 
- $\quad$ Drucker, P. (2008). Management, Revised edition, Harper Business

- Erol, Y. and Kanbur E. (2014) Entrepreneurial Characteristics of Turkey's Top 100 Industrial Enterprises According to Their Mission and Vision Statements, Business and Economics Research Journal, Vol.5 No 3 , pp. 149-165

- $\quad$ Fairhurst, G. T., Jordan J.M., and Neuwirth K., (1997) Why Are We Here? Managing the Meaning of an Organizational Mission Statement, Journal of Applied Communication Research, Vol.25, pp.243-263

- Finley, D.S., Rogers G. and Galloway, J. R. (2001) Beyond the Mission Statement: Alternative Futures for Today's Universities, Journal of Marketing for Higher Education, 10:4, pp.63-82

- Garg, A. K. (2014) Content analysis of mission statement of mining companies in South Africa, Problems and Perspectives in Management, Volume 12, Issue 4, pp.305-311

- Germain, R. and Cooper, M. (1990) How a Customer Mission Statement Affects Company Performance, Industrial Marketing Management, Vol. 19, pp.47-50

- Hamel, G. and Prahalad, C.K. (1994) Competing for the future, Harvard Business School Press, Boston, Massachusetts

- Hill, C.W. L. and Jones G. R. (2010) Strategic Management Theory: An Integrated Approach, $9^{\text {th }}$ Edition, South-Western Cengage Learning

- James, H. and Huisman, J. (2009) Missions statements in Wales: the impact of markets and policy on congruence between institutions, Journal of Higher Education Policy and Management, Vol. 31, No. 1, pp. 23-35

- James, H.and Huisman J. (2009) Missions statements in Wales: the impact of markets and policy on congruence between institutions, Journal of Higher Education Policy and Management, Vol:31:1, pp.23-35,

- Jung, T. and Pompper D. (2014) Assessing Instrumentality of Mission, Statements and Social-Financial Performance Links: Corporate Social Responsibility as Context, International Journal of Strategic Communication, International Journal of Strategic Communication, Vol.8: 79-99, 2014

- Kemp, S. and Dwyer, L. (2003) Mission Statements of International Airlines: A Content Analysis, Tourism Management Vol. 24, pp. 635-653

- $\quad$ Kibuuka, H.E. (2001) Vision and Mission Statement in Christian Higher Educational Management in Eastern Africa, Journal of Research on Christian Education, 10:1,pp. 87-114

- Kloc, K (1994), The Banking System in Kyrgyzstan, Center for Social \& Economic Research, Research Paper, Warsaw

- Köseoğlu, M.A. (2008) İşletmelerin Var Olma Sebeplerini Nasıl İfade Ederler? KOBİ’lerin Misyon İfadeleri Üzerine Bir Araştırma, Yönetim ve Ekonomi, Cilt: 15, Sayı:2, ss. 89-97

- Kosmützky, A. (2012) Between Mission and Market Position: Empirical findings on mission statements of German Higher Education Institutions, Tertiary Education and Management, Vol.18:1, pp.57-77

- Krippendorff, K. (2004) Content Analysis: an introduction to its methodology, $2^{\text {nd }}$ edition, Sage Publications.

- Marjanova, T. J. and Fotov, R. (2014) Corporate Mission: Much Ado about Nothing or Essential Strategic Step?, Conference Proceedings of the International Journal of Arts and Sciences, Valletta, Malta, 2-6 March 2014, pp.170-182

- Morden, T. (2007) Principles of Strategic Management, 3rd Edition, Ashgate Publishing

- Mullane, J.V. (2002) The mission statement is a strategic tool: when used properly, Management Decision, Vol.4 (5), pp.445

- O'Gorman, C., and Doran, R. (1999) Mission statements in small and medium-sized businesses, Journal of Small Business Management, Vol.37, (4), 5pp.9-66

- Orozco, R. (2012) Framing Hostilities: Analysis of Mission Statements from Segregated Chicana/o Schools, Journal of Latinos and Education, Vol.11:2, pp.80-93

- $\quad$ Pearce, J. and David, F. (1987) Corporate Mission Statements: The Bottom Line, Academy of Management Executive, Vol. 1, No. 2, pp. 109- 115

- Rajasekar, J., (2013) A Comparative Analysis of Mission Statement Content and Readability, Journal of Management Policy and Practice, Vol. 14(6), pp.131-147

- Rigby, D. K. and Bilodeau, B. (2015) Management Tools and Trends Survey 2015, Bain and Company Inc

- $\quad$ Ritson, N. (2008) Strategic Management, Bookboon, $2^{\text {nd }}$ edition, ISBN 978-87-403-0506-7 
- Stemler, S.E. Bebell D. and Sonnabend L.A. (2011) Using School Mission Statements for Reflection and Research, Educational Administration Quarterly, 47(2), pp. 383-420

- Tanković, A.Č. (2013) Defining Strategy using Vision and Mission Statements of Croatian Organizations In Times Of Crisis, Economic Research-Ekonomska Istraživanja, Vol.26,sup1, pp.331-342,

- Thompson, A.A. and Strickland A.J. (2006) Strategic Management: Concepts and Cases, $11^{\text {th }}$ edition, McGraw-Hill

- Tuhin, M.H. (2014) Content Analysis of the Banks' Mission Statements: A Study of Bangladeshi Listed Banks, Journal of Management and Science, Vol.4. No.1, pp.30-36

- Wang, Y., (2011) Mission-Driven Organizations in Japan: Management Philosophy and Individual Outcomes, Journal of Business Ethics, Vol. 101, pp.111-126

- Williams, L.S. (2008) The Mission Statement: A Corporate Reporting Tool with a Past, Present, and Future, Journal of Business Communication, Vol. 45, No 2, pp.94-119

- Weber R.P. (1990) Basic Content Analysis, $2^{\text {nd }}$ Edition, Sage Publications

- Wilson, J.L., Meyer, K.A. and McNeal, L. (2011) Mission and Diversity Statements: What They Do and Do Not Say, Innovation High Education, Vol. 37(2), pp.125-139.

- www.nbkr.kg web-site of the National Bank of the Kyrgyz Republic

- www.stat.kg web-site of the National Statistical Committee of the Kyrgyz Republic

- www.akchabar.kg financial portal

- Corporate web-sites of commercial banks in Kyrgyzstan

- https://www.optimabank.kg/en/

- http://www.ab.kg/en/

- http://www.rsk.kg/en/

- http://en.kicb.net/

- http://demirbank.kg/en

- http://www.cbk.kg/en/

- http://www.rib.kg/ru/

- http://www.baitushum.kg/

- http://www.halykbank.kg/en/

- http://www.btabank.kg/en/ 


\title{
Monetary Policy Response on Exchange Rate Dynamics: The Case of Indonesia
}

\author{
Dr. Ferry Syarifuddin (Bank Indonesia, Indonesia)
}

\begin{abstract}
Bank Indonesia has been implementing Enhanced Inflation Targeting Framework (EITF) since few years ago. The main monetary instrument is short term policy interest rate. The policy interest rate, in this regard, may also have significant role in driving the exchange rate to its desired level. Setting appropriate the interest rate to drive the exchange rate is important to drive the actual inflation to its official target. In order to see the response of policy interest rate to exchange rate dynamics as well as the impact of exchange-rate dynamics to macroeconomic indicators, Structural Co-integrating Vector Auto Regression (SC-VAR) in an open economy model, is implemented. Its finding shows that exchange rate dynamic of USD/IDR has significantly positive relationship with domestic interest rate. The increase of the USD/IDR (depreciation) will then push domestic interest rate to increase.
\end{abstract}

\section{Introduction}

As a consequence, adopting floating exchange rate, many countries face often widely fluctuation and large movements of their exchange rates as capital flows freely coming in or out the countries. This phenomenon could move market exchange rates away from their fundamental value (exchange-rate misalignment). Indeed, freely floating exchange rate system is needed by independent monetary authority to conduct independent monetary policy. However, persistent exchange-rate volatility and misalignment will exacerbate inflationary pressures and financial sector vulnerabilities. For many countries, these impacts are not welcomed and they will take some measures to mitigate those.

Indonesian foreign exchange market has been developing in conjunction with changes in the exchange rate system, which has moved gradually toward increased emphasis on market mechanisms. This development has been playing a significant role in USD/IDR movements as the exchange rate will response instantly to external shocks. Previously, the Indonesia foreign exchange system was operated in tight government control. Since adopting free-floating exchange rate when financial crises erupted in August 1997, Indonesia has been experiencing of rapid fluctuation of the rupiah. As adopting free floating exchange-rate regime and its position as a small open economy, Indonesia' exchange rate movements are strongly influenced by capital flows and net export's proceeds. Hence, existence of central bank optimal monetary policy response is needed to drive the exchange rate for the long-term equilibrium exchange rate as well as to maintain its stability. Then central bank through monetary policy can influence the exchange rate in the short or even in the long run. In the long term, monetary policy can affect exchange rate indirectly through changes in respected domestic macroeconomic variables such as inflation, productivity, and the current account (Moentjak, 2006). Meanwhile, in the short run, monetary policy is able to influence foreign-exchange markets expectations (foreign-exchange market microstructure).

Within Enhanced inflation targeting framework (EITF), inflation target is the main objective to support sustainable economic environment, and is determined by several factors. One of the significant factors is exchange rate through its power of pass through effect on domestic inflation. In addition to maintain the optimal range of the exchange rates, the exchange rate should be stable enough in order to boost the international trade and hence domestic economy. Thus, the effort to set optimal exchange rate and maintain exchange rate stability (reflected with low exchange rate fluctuations) is also main duty of the monetary authority which adopts ITF in order to achieve its objective of price stability.

As Enhanced Inflation Targeting Framework (EITF) chosen by Bank Indonesia, one of monetary operation instrument chosen is short term policy interest rate i.e. reverse repo rate or deposit facility rate. Setting appropriate policy interest rate to drive actual inflation to its target and implicitly desired economic growth is important for the central bank who adopt inflation targeting framework. Besides, while exchange rate has a significant influence to inflation and the economy, the central bank has a duty to manage it properly.

\section{The Exchange Rate and Monetary Response}

The relationship between exchange rate, inflation, and interest rate, is very closed in the economics perspective. Therefore, any monetary policy action to affect one of these three variables will affect not only the variable but will also indirectly affect the other two. Any attempt to move any two pairs of variables in opposing directions will not sustainable in the long run (Moentjak, 2014). For example, he explained when the central bank wants to hike interest rates to keep inflation down. The policy cannot at the same time keep exchange rate weak in order to stimulate exports. Raising interest rate to tame inflation while keeping the exchange rate fixed, the central bank is 
violating UIP. Such a scheme may become self-defeating for the central bank, since the higher interest rates will attract more foreign capital, increasing the demand for domestic currency, then affect domestic currency appreciation. Meanwhile, as the central bank wants to fix the exchange rate, the central bank will have to intervene in the foreign exchange market by injecting money into the domestic economy to satisfy the greater demand for domestic currency by implementing FX buying intervention policy will then increase its official foreign reserve. However, the injection of money will defeat the initial purpose of the hike in interest rates, to reduce inflation.

It is commonly agreed that foreign-exchange intervention should be consistent with the stance of monetary policy for two reasons at least i.e exchange rate stability and exchange rate alignment to support inflation target. Complemented with interest rate, the two kind monetary policies should support each other to achieve the desired monetary policy's objectives such as price stability or exchange-rate stability for countries which adopt ITF policy (Mohanty, 2013). Without this stance, he argues that any inconsistency between the monetary policy stance and the exchange rate may reduce the effectiveness in achieving these objectives. With regard to exchange-rate stability objective, exchange-rate intervention may have good result to stabilize the exchange rate but without no costs. For example, when appreciation trend exists, foreign-exchange buying intervention can create high costs as the central bank should withdraw the additional excess money supply (caused by the intervention) by selling more central banks bills, in order to halt domestic price increases. These dual actions will create more costs as negative margin commonly exists. Nevertheless, central banks purchasing intervention policy in this regards will obviously accumulate more official reserve that can be effective in improving sovereign credit ratings and reducing external shocks impact.

On the other hand, the macroeconomic effects of intervention depend on the composition of banks' portfolios (Vargas et. al, 2013). When banks hold more government bonds than their optimal portfolio from a long-term portfolio perspective, they will try to reduce the lending rate to increase loan assets until the level meets the desired loan-to-investment ratio. This is called portfolio diversification to minimize risk against 'Lazy Bank' phenomenon. This is indicated by an expansion of bank lending. There is interesting phenomenon that whenever central banks issuing large amounts of short-term securities to sterilize their foreign-exchange reserve purchases, the average maturity of their securities has shrunk to less than one year since 2000, although the EM governments have increased the average maturity of their debt as reported by Bank for International Settlements in its 2005 report (Mohanty and Berger, 2013). Generally, the interest of the central bank bills is higher than foreign assets bought by the central bank and hence negative spread exists and deteriorate central bank's balance sheet. Several studies also find similar results that central banks perform large-scale buying foreign-exchange interventions to resist domestic currency appreciation, and then respectively withdraw the additional domestic liquidity by issuing shortterm debt. This monetary operation called sterilized foreign-exchange intervention will inflate central banks monetary costs and potentionaly commercial bank balance sheets with expansionary implications for the economy. High cost of intervention could erode not only a central bank's credibility but also their financial strength which halt to deliver on the price stability objective.

In principle, interventions in the foreign exchange market should be designed to complement the stance of monetary policy. Flug and Shpitzer find Israel high interest rate cuts by the central bank combined with a buying foreign exchange intervention to resist appreciation were reasonably successful in reducing the risk of recession during the 2008 global crisis (Mohanty, 2006). Meanwhile, thightening central bank policy when economy recovering in the face of rising inflation expectations, generate strong capital inflow that appreciate domestic currency. Then the central bank performs buying foreign-exchange intervention to resist appreciation. Consequently, domestic liquidity increases which should be withdrawn by the central bank at the cost of central bank. At the same time, exchange rate depreciation (or at least not appreciate will be shifted as burden of adjustment to the external sector). Study in Peru finds that foreign exchange purchase by the central banks should be sterilized in order to keep the interbank interest rate at the policy target level (Armas, 2005). This sterilized intervention policy imply some additional costs burdened to the central bank.

In BIS paper, Korea's experience dilemna of strong capital inflows and high inflation periode push the central bank to increase interest rates to fight inflation will attract further inflows and ignite further currency appreciation pressures whereas reducing interest rates to limit capital inflows will ignite higher inflation (Ryoo and Kwon, 2013). Therefore, they suggest that foreign-exchange intervention can help to stem inflows attracted by selffulfilling expectations of currency appreciation. Some central banks prefer delivering strategic communication to avoid any market perception that foreign exchange intervention is inconsistent with monetary policy. Meanwhile, another central banks have been announcing their foreign exchange intervention with a view to send a correct signal to this effect.

Regarding to monetary response to exchange-rate dynamics, most modern central banks also implement shortterm policy interest rate policy to guide exchange rate to the level as desired. Furthermore, this short-term policy interest rate as response to misaligned exchange rates to achieve desired price (inflation) level and desired economic growth is measured by monetary policy rule i.e. Taylor rule. In BIS Paper, monetary policy rule confirms that there has been a interest rate response by the central bank to exchange rate fluctuations, over and above its effects on expected inflation, but smaller than the reaction to output (Schmidt-Hebbel and Tapia, 2002) and (Cuth, 
2003). They also explained that monetary policy responds to exchange rate shocks should depend on foreign capital regime, foreign-exchange intervention policy option, official foreign reserve, and persistence of the exchange rate volatility. The other important factor is central bank credibility. Central bank credibility will decrease the probability of persistent exchange rate shock affects on inflation, as the public will expect authorities to support price stability. In a floating exchange rate regime, a central bank only should response on exchange rate fluctuations only if they impact the rate of inflation persistently in the policy horizon. Central bank should not response temporary exchange-rate shock for example by increasing interest rate because it is costly. Conversely, the central bank should take monetary measures to prevent persistent volatility and misalignmend in the exchange rate otherwise it will lead to inflationary pressures through monetary tightening.

In monetary transmission channel mechanism, exchange rate plays a significant role in many countries especially emerging economies. This is proven by (Grenville, 1995); (Thiessen, 1995), in their paper. In the fundamental exchange rate theory called uncovered interest parity (UIP), exchange rate dynamics depend on interest rate differential between countries. Central bank's unanticipated interset rate increase of 25 basis points, is found to appreciate the exchange rate approximately 0.35 per cent, with results for the individual countries ranging from $0.25-0.50$ of a per cent (Kearns and Manners, 2005). They also find that changes in interest rate policy have substantially different effects on the exchange rate depending on how they alter expectations regarding future interest rate policy. For example, an unanticipated interest rate increase of $25 \mathrm{bps}$ appreciates approximately $0.35 \%$ of the exchange rate movement generally. Surprises that changes in future interest rate policy will appreciates $0.4 \%$, while do not change future interest policy expectations only appreciates $0.2 \%$.

\section{Research Methodology}

\subsection{Variables and Data}

This research used monthly data from 2000-2013. Data derived from CEIC, SEKI, and internal data of the Bank of Indonesia. For the quarterly data, interpolation was used in order to obtain monthly data. The variables were in the form of natural logarithm, except the rate or percentage variables. In order to embody the long-run relations (equation 1) to (equation 5) within a suitable macro-econometric model, it is important that the orders of integration of the core variables in the theoretical model are ascertained. More specifically, given the econometric methods this research employs, this research wishes to ensure that the variables used in the empirical analysis suggested to be $I(1)$ variables. The variables under consideration are $l i s p r_{-} c a p_{t}, l m r 1_{-} c a p_{t}, r e_{-} i d_{t}, l y r i d_{-} c a p_{t}, l p_{-} i d_{t}, l w r_{-} i d_{t}, l s r_{-} i d_{t}$, $\overline{\text { yrldcap }}_{t} l r_{-} u s_{t}^{*}, l p_{t}^{*}$. The results suggest that it is reasonable to treat lispr_capt $, l m r 1_{-} c a p_{t}, r e_{-} i d_{t}$, $l y r i d_{-} c a p_{t}, l p_{-} i d_{t}, l w r_{-} i d_{t}, l s r_{-} i d_{t}, l y r l d c a p_{t} l r_{-} u s_{t}^{*}, l p_{t}^{*}$ as $I(1)$ variables. It is useful to transform variables a priori to get variables that are I(1) rather than dealing with mixtures of I(1) and I(0) variables directly (Haldrup, 2012). The variables used in this research are as follows:

1) Real GDP per capita (LYRID_CAP)

The original data is in quarterly form, which was then interpolated to monthly data by using the Quadratic Math Sum. The base year used was 2005 .

2) Potential Output (LYRIDCAP_POT)

A series of potential outputs was obtained by using the Hodrick-Prescott filter.

3) Domestic Price level (LP_ID)

The real data was the Consumer Price Index (CPI) with 2005 as the base year, which was then deducted by oil price.

4) Real Money Demand per capita $\left(L M R 1_{-} C A P\right)$

This was meant to see the implication of the non-cash payment increase towards M1.

5) Real Payment System Innovation per capita (LISPR_CAP)

In this case, the variable used is the amount of payment transaction value using non-cash instruments, both account-based and card-based, such as clearing, RTGS, debit card, and credit card. The non-cash payment data (especially RTGS) used still included the clearing settlement result. However, keeping in mind that the clearing settlement amount is relatively constant and less significant, it was estimated that there is no implication for research results. Besides this, the credit card portion of the non-cash payment variable is relatively low, namely $0.1-0.3 \%$ of the total non-cash payment transaction value.

6) Real domestic Interest rate (RE_ID)

The interest rate used was the real o/n interbank money market as a proxy of CB's policy interest rate.

7) Real wages (LWR_ID)

The original data was quarterly data, with some missing values. Interpolation was then conducted in order to obtain data for the full quarterly observation period, which was then transformed into monthly data.

8) Real exchange rate (LSR_ID) 
In the form of the Rupiah exchange rate per USD multiply by relative price. According to this definition, the real exchange rate can be defined in the long run as the nominal exchange rate (e) that is adjusted by the ratio of the foreign price level $(\mathrm{Pf})$ to the domestic price level $(\mathrm{Pd})$. Mathematically, it can be shown as $\mathrm{sr}=\mathrm{s} *(\mathrm{Pf} / \mathrm{Pd})$. In terms of this definition, the decline in the SR can be interpreted as the real appreciation of the exchange rate.

9) International interest rate level ( $\left.R E_{-} U S\right)$

The international interest rate used was the interest rate of the US Federal Reserve.

10) International price level (LP_US)

The US CPI was used as the representation of the international price level then deducted by oil price.

\subsection{Methodology}

This study attempts to forecast the response of monetary policy on foreign-exchange shocks in Indonesia using a structural VAR (SVAR) approach. SVARs are defined as a multivariate time series model which shows linear representation of a vector of observable variables on its own lags (Sharifi and Renan, 2010). These models are economically interpretable simplifications of VAR models where some economic theory is referred to set the identification restrictions. SVAR model can be used to identify the shocks from respected endogenoeous variables (Lutkepohl and Kratzig, 2004).

As ITF chosen by Bank Indonesia, one of monetary operation instruments chosen to achieve ultimate objective i.e. domestic price is short-term policy interest rate. Determing optimal interest rate as response to the exchange rate is one policy tool of the central bank in driving the actual inflation closed to its target and implicitly desired economic growth. The policy interest rate, in this regard, may also significant role to drive the exchange rate to its aligned level (meet inflation target). In order to see the impact of policy interest rate to exchange rate dynamics as well as the impact of exchange-rate dynamics to macroeconomic indicators, this research implements Structural Cointegrating Vector Auto Regression (SC-VAR) in an open economy model proposed by Garrat et al. (1999) and followed by Syarifuddin et al. (2009) that may able to solve the problem. In the model, this research applies five long-run structural equations which includes payment system innovation equation, real money demand equations, aggregate demand equation, purchasing power parity, and interest rate parity equation.

This method was selected because the VAR-based estimation was appropriate to describe the simultaneous relationship among variables. Keeping in mind that some of the variables were not stationery, even though there is a long-term connection among the variables, the cointegration partnership needed to be accommodated. Some literature referred to in using this method were Harris (1995), Boswijk and Doornik (2003), Garratt, Lee et al. (1999), as well as Kapetanios et al. (2000).

The strength of Structural Cointegrating VAR over other estimation methods is its accommodation of theoretical foundation, behavioral relationship, and flexible dynamics. This is different from Structural VAR, which is unable to identify long-term relationships among variables. Unlike Vector Error Correction Model (VECM), where the long-term relationship is decided by the cointegration of data, in Structural Cointegrating VAR, the long-term relationship is built on the previous empirical studies and theories and the cointegration relationship among their variables.

Structural Cointegrating VAR begins by defining the long-term structure, then inserting the long-term relationship into an unrestricted VAR model. This is unlike the traditional approach, which begins with an unrestricted VAR, then its cointegration is sought based on data, which of course does not have a clear direction, for the Structural Cointegrating VAR cointegration set at the outset.

This cointegrating SVAR will use monthly data from 2000-2013. Data derived from CEIC, SEKI, and internal data of the Bank of Indonesia. For the quarterly data, interpolation was used in order to obtain monthly data. The variables were in the form of natural logarithm, except the rate or percentage variables. The equations, variables, and data used in this research according to Garrat, Lee et al. (1999) augmented payment system innovation equation. In this model of the monetary response on exchange dynamics, there are five long-term relationships which can be formulated as follows:

$$
\begin{aligned}
& l i s p r_{-} c a p_{t}-l p_{i d_{t}}-\text { lyrid_cap }_{t}=\alpha_{10}+\alpha_{11} t+\beta_{13} r e_{-} i d_{t}+\varepsilon_{1, t+1} \\
& \operatorname{lmr} 1_{\text {cap }_{t}}-\text { lyrid }_{\text {cap }} p_{t}-l p_{i d_{t}}=\alpha_{20}+\alpha_{21} t+\beta_{21} \text { lispr }_{\text {cap }}+\beta_{23} r e_{-} i d_{t}+\varepsilon_{2, t+1} \\
& \text { lyrid }_{\text {cap }_{t}}-\text { yridcap }_{\text {pot }} t=\alpha_{30}+\alpha_{31} t+\beta_{31} r e_{i d_{t}}+\beta_{36} l w r_{-} i d_{t}+\varepsilon_{3, t+1} \\
& l p_{-} i d_{t}-l p_{-} u s_{t}^{*}-\text { srid_g }_{t} \quad=\alpha_{40}+\alpha_{41} t+\varepsilon_{4, t+1} \\
& \text { re_id } e_{t}-r e_{-} u s_{t} \quad=\alpha_{50}+\alpha_{51} t+\text { srid }_{-} g_{t}+\varepsilon_{5, t+1}
\end{aligned}
$$

where:

- $\quad$ lispr_cap $\quad=\log$ form of real payment instrument innovation per capita

- $\quad l p_{i d_{t}}$

$=\log$ form of consumer price index

- lyrid_cap $_{t} \quad=\log$ form of real output per capita 
- $\quad l m r 1_{-} c a p_{t} \quad=\log$ form of money supply per capita

- lwrid = log form of real wage on average

- $\quad$ yridcap_pot = real output per capita potential in log form

- $l p_{-} u s_{t}^{*} \quad=\log$ form of US consumer price index

- $r_{-} i d_{t} \quad=$ real cost of domestic capital (IDR interest rate)

- $r e_{-} u s_{t} \quad=$ real cost of US capital (USD interest rate)

- $\quad$ srid $g \quad$ = growth real exchange rate

The five structural equations can be described as follows:

a) Equation 1 shows that total of the long-term real non-cash payment is determined by the amount of national income and advanced technology, which shown by the time trend. Meanwhile, the total short-term non-cash payment is also affected by the real domestic o/n interest rate (Baumol, 1952) and (Tobin,1956).

b) Equation 2 shows the representation of real money demand equation, which shows that the real M1 money demand is determined by the domestic real o/n interest rate and real GDP. In the short-term period, money demand is also affected by non-cash payment variables.

c) Equation 3 is the representation of aggregate demand equation, which shows that the long-term real GDP per capita with the current potential output is determined by the real cost of capital (interest rate), the level of real wages, and the technological change. It can be seen that in the long term, only the real variable affects the real GDP. Meanwhile price and other nominal variables have short-term effects.

d) Equation 4 shows Purchasing Power Parity (PPP).

e) Equation 5 shows Interest Rate Parity (IRP).

The five long-term partnerships (equation 6) can be written as follows:

$$
\varepsilon_{t}=\beta^{\prime} z_{t-1}-\left(\alpha_{0}-\alpha_{1}\right)-\alpha_{1} t
$$

where:

$$
\begin{aligned}
z_{t}= & \left(\text { lispr }_{\text {cap }}, l m r 1_{\text {cap }}, r e_{i d_{t}}, l y r i d_{c a p}, l p_{i d_{t}}, l w r_{i d_{t}}, \text { srid }_{g_{t}}\right. \\
& \text { lyridcap_pot,re_us } \left., l p_{t} u s_{t}\right) \\
\alpha_{0}= & \left(\alpha_{10}, \alpha_{20}, \alpha_{30}, \alpha_{40}, \alpha_{50}\right)^{\prime}, \alpha_{1}=\left(\alpha_{11}, \alpha_{21}, \alpha_{31}, \alpha_{41}, \alpha_{51}\right)^{\prime}, \text { and } \\
\varepsilon_{t}= & \left(\varepsilon_{1 t}, \varepsilon_{2 t}, \varepsilon_{3 t}, \varepsilon_{4 t}, \varepsilon_{5 t}\right)^{\prime}
\end{aligned}
$$

and also

$$
\beta^{\prime}=\left(\begin{array}{cccccccccc}
1 & 0 & -\beta_{13} & -1 & -1 & 0 & 0 & 0 & 0 & 0 \\
-\beta_{21} & 1 & -\beta_{23} & -1 & -1 & 0 & 0 & 0 & 0 & 0 \\
0 & 0 & -\beta_{33} & 1 & 0 & -\beta_{36} & 0 & -1 & 0 & 0 \\
0 & 0 & 0 & 0 & 1 & 0 & -1 & 0 & 0 & -1 \\
0 & 0 & 1 & 0 & 0 & 0 & -\beta_{57} & 0 & -1 & 0
\end{array}\right) .
$$

Matrix $z_{t}$ is divided into $z_{t}=\left(q_{t}^{\prime}, v_{t}^{\prime}\right)^{\prime}$ where $q t$ is for endogenous variables and $v t$ is a weakly exogenous variable towards that equation system. This will be decided later based on testing.

The next stage is to insert $\varepsilon_{t}$ into the equation (7) as follows:

$$
\Delta q_{t}=-\Phi \varepsilon_{t}+\sum_{i=1}^{s-1} \Gamma_{i} \Delta_{z_{t-i}}+\Psi \Delta_{v_{t}}+u_{t}
$$

where:

$\Phi=$ = error correction coefficient matrix

$\Gamma_{i} \quad=$ short-run coefficient matrix

$\Psi \quad=$ vector shows the effect of weakly exogenous variable

$u_{t} \quad=$ serially uncorrelated shocks vector

The equation shall be elaborated as follows (equation 8):

$$
\Delta q_{t}=\Phi\left(\alpha_{0}-\alpha_{1}\right)+\Phi \alpha_{1} t-\Phi \xi_{t}+\sum_{i=1}^{s-1} \Gamma_{i} \Delta_{z_{t-i}}+\Psi \Delta_{v_{t}}+u_{t}
$$

Where $\xi_{t}=\beta_{z_{t-1}}$ : error correction terms 


\section{Result and Discussion}

\subsection{Variable Description}

Before conducting various procedures in estimating and forecasting by using SC VAR, there is a description of the variables used and the relationship among those variables. The amount of lispr_cap, lkartalr_cap, lmrl_cap variables tends to rise over time. The trend of the $i s p r \_c a p$ variable increase occurs in line with the development of technology which enabled the development of non-cash payment instruments and its availability in many places. Meanwhile, the stochastic movement from the lispr_cap variable is related to the short-run factor which influences it, among other things in line with the fluctuation of real GDP per capita (lyrid_cap). The increasing trend of lmr1_cap variables is in line with the real GDP per capita increase trend. The stochastic movement of both variables is affected by the real GDP per capita and domestic real interest rate (re_id).

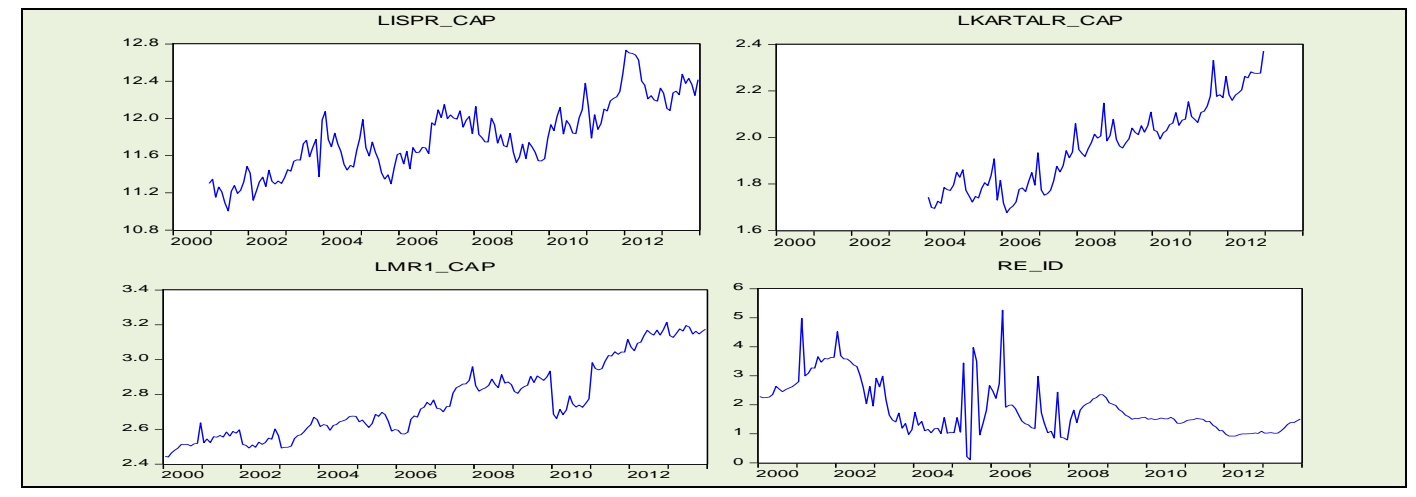

Figure 1. Variables Chart Source: Own Calculation

For the real GDP per capita variable (lyrid_cap), there is a cyclical factor, especially at the end of the year, which is shown by expansionary movement, which is then followed by a contraction in the following period. Meanwhile, there is an increasing trend for the $l p \_i d$ variable which shows that there is a continuous price hike since 2008. The behavior of the real exchange rate growth (srid_g) variable is volatile, but the real wage variable $(l w r i d)$ could be seen to tend to increase. As shown in the Figure 1, the amount of currency per capita (lkartalr_cap) and real non-cash payments per capita (lispr_cap) tended to increase during the analysis period.

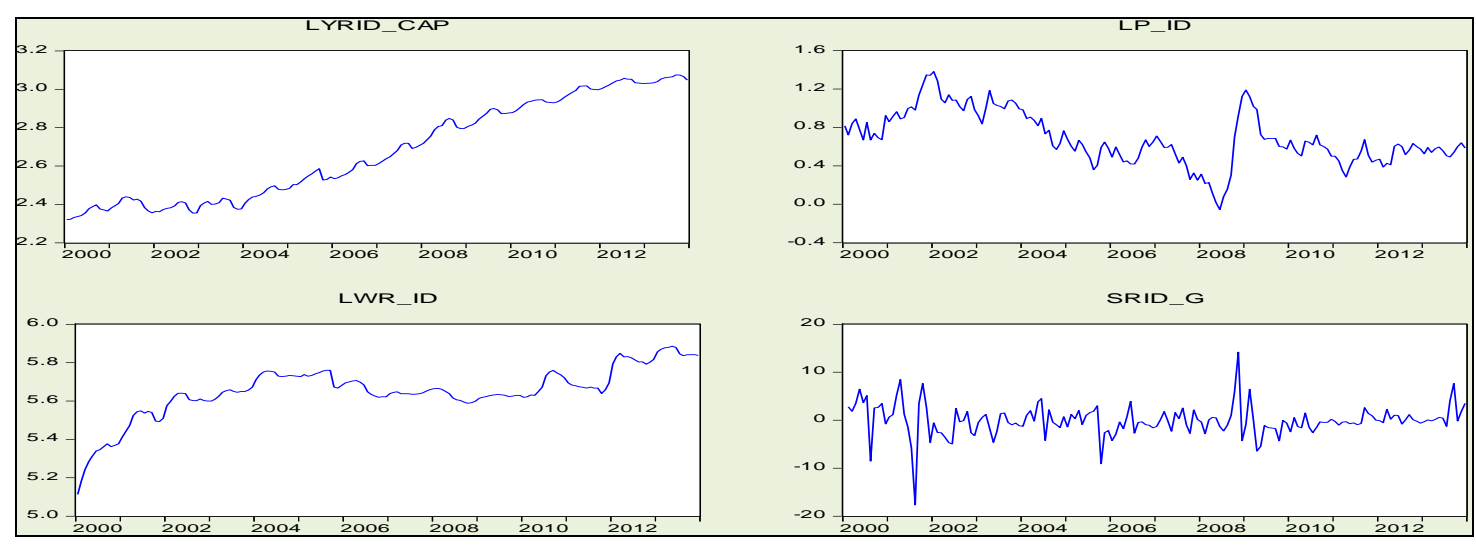

Figure 2. Development of the Variables Source: Own Calculation

Impact of non-cash payment Increase on the Economy and Its Implication for Monetary Control in Indonesia. The amount of lispr_cap, lmrl_cap variables tends to rise over time. The trend of the lispr_cap variable increase occurs in line with the development of technology which enabled the development of non-cash payment instruments and its availability in many places. Meanwhile, the stochastic movement from the lispr_cap variable is related to the short-run factor which influences it, among other things in line with the fluctuation of real GDP per capita (lyrid_cap). The increasing trend of $l m r 1 \_c a p$ variable is in line with the real GDP per capita increase trend. The stochastic movement of both variables is affected by the real GDP per capita and the domestic over nite $(\mathrm{o} / \mathrm{n})$ real interest rate $(r e$ id $)$.

For the real GDP level variable (lyrid_cap), there is a cyclical factor, especially at the end of the year, which is shown by expansionary movement, which is then followed by a contraction in the following period. Meanwhile, there is an increasing trend for the $l p \_i d$ variable which shows that there is a continuous price hike during the 
observation period. The behavior of the real exchange rate growth (srid_g) variable is fluctuated with decreasing trend (appreciation), but the real wage variable ( $\left.l w r_{-} i d\right)$ could be seen to tend to increase (see Figure 2).

\subsection{Estimation Result of Structural Cointegarting VAR}

The result of Structural Cointegrating VAR estimation is 2 lags, 5 cointegration equations with intercept and trend on its cointegrating equation, but no trend on its VAR, with restrictions on its long-term structural equation coefficient as mentioned earlier. This shows that the restriction is able to identify all cointegrating vectors and its LR statistic is 115.73 with $0.0000 \mathrm{p}$-value.

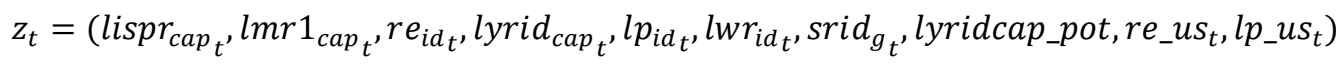

\begin{tabular}{|l|l|c|c|c|}
\hline \multicolumn{1}{|c|}{$H_{0}$} & $H_{1}$ & Test Statistics & 95\% Critical values & Prob.** \\
\hline$r=0^{*}$ & $r \geq 1$ & 595.9454 & 273.1889 & 0.0000 \\
$r \leq 1^{*}$ & $r \geq 2$ & 404.9796 & 228.2979 & 0.0001 \\
$r \leq 2^{*}$ & $r \geq 3$ & 296.9512 & 187.4701 & 0.0000 \\
$r \leq 3^{*}$ & $r \geq 4$ & 217.2547 & 150.5585 & 0.0000 \\
$r \leq 4^{*}$ & $r \geq 5$ & 159.1532 & 117.7082 & 0.0000 \\
$r \leq 5^{*}$ & $r \geq 6$ & 107.6824 & 88.80380 & 0.0011 \\
$r \leq 6^{*}$ & $r \geq 7$ & 75.80433 & 63.87610 & 0.0036 \\
$r \leq 7 *$ & $r \geq 8$ & 50.31634 & 42.91525 & 0.0077 \\
$r \leq 8^{*}$ & $r=9$ & 30.16454 & 25.87211 & 0.0137 \\
$r \leq 9$ & $r=10$ & 11.75949 & 12.51798 & 0.0667 \\
\hline
\end{tabular}

\footnotetext{
Trace test indicates 9 cointegrating eqn(s) at the 0.05 level

*Denotes rejection of the hypothesis at the 0.05 level

**MacKinnon-Haug-Michelis (1999) p-values
}

\section{Table 1. Unrestricted Cointegrating Rank Statistics for the Model (Trace Statistics)}

As mentioned earlier, (restricted cointegration test), the rejection of this restriction is much more to the possibility of an inappropriate amount of the cointegrating equation (because there is an $\mathrm{I}(0)$ variable), keeping in mind the restriction on the cointegration equation was identified and binding. The coefficient of the variables are significant, which can be seen from its t statistic, which is greater than two.

a. Maximum Eigenvalue Statistics

\begin{tabular}{|l|l|c|c|c|}
\hline \multicolumn{1}{|c|}{$H_{0}$} & \multicolumn{1}{|c|}{$H_{1}$} & Test Statistics & 95\% Critical values & Prob.** \\
\hline$r=0^{*}$ & $r \geq 1$ & 190.9657 & 68.81206 & 0.0000 \\
$r \leq 1^{*}$ & $r \geq 2$ & 108.0284 & 62.75215 & 0.0000 \\
$r \leq 2^{*}$ & $r \geq 3$ & 79.69652 & 56.70519 & 0.0001 \\
$r \leq 3^{*}$ & $r \geq 4$ & 58.10156 & 50.59985 & 0.0071 \\
$r \leq 4 *$ & $r \geq 5$ & 51.47075 & 44.49720 & 0.0075 \\
$r \leq 5$ & $r \geq 6$ & 31.87808 & 39.33101 & 0.2282 \\
$r \leq 6$ & $r \geq 7$ & 25.48799 & 32.11832 & 0.2589 \\
$r \leq 7$ & $r \geq 8$ & 20.15181 & 25.82321 & 0.2345 \\
$r \leq 8$ & $r=9$ & 18.40504 & 19.38704 & 0.0690 \\
$r \leq 9$ & $r=10$ & 11.75949 & 12.51798 & 0.0667 \\
\hline
\end{tabular}

Max-eigenvalue test indicates 5 cointegrating eqn(s) at the 0.05 level

*Denotes rejection of the hypothesis at the 0.05 level

**MacKinnon-Haug-Michelis (1999) p-values

Table 2. Unrestricted Cointegrating Rank Statistics for the Model (Maximum Eigenvalue Statistic)

The SC-VAR result of the five long-term structural equations summarized from the Eviews output, is as follows:

$$
\begin{aligned}
& \text { lispr_cap }-l p \_i d-l y r i d \_c a p \quad=6.38+\mathbf{0 . 0 1 t}+\mathbf{0 . 5 8 r e} \text { id } \\
& \text { lmrl_cap-lyrid_cap-lp_id } \quad=-6.52+\mathbf{0 . 0 1 t}+\mathbf{0 . 3 7 r e} \text { id }+\mathbf{0 . 4 2 l i s p r} \text { _cap } \\
& \text { lyrid_cap-lyridcap_pot } \quad=0.18-\mathbf{0 . 0 1 r e \_ i d - 0 . 0 2 l w r} i d \\
& l p \_i \bar{d}-l p \_u s-l s r \_i d \quad=1.40-\mathbf{0 . 0 1 t} \\
& \text { re_id - re_us } \\
& =2.37-\mathbf{0 . 0 1 t}+0.03 \text { srid } \_g
\end{aligned}
$$

Signs from some coefficients in long-term structural equations were seen to be in line with the theoretical framework. In equation 9, the trend component on structural equations was seen to be positive as these show increasing trends. Meanwhile, the re_id coefficient score was relatively high, which showed that the lispr_cap variable movement was highly influenced by the $r e \_i d$ variable positively. It means that the society prefer using non-cash instrument in payment while interest rate increasing as they deposit their money in banks as demand/saving deposit. Thus, they can earn interest from the deposit but not losing their liquidity needs. $r e \_i d$ is one of best proxy central bank's policy rate because they have closed relationship. Meanwhile, it needs to be noted that the positive trend is not trend upon the lispr_cap variable itself, but a trend in the context of the cointegration relationship between the lispr_cap variable and other variables. As mentioned earlier, based on lispr_cap series visualization, a positive time trend upon the lispr_cap variable itself was observed.

In money demand equation 10 , the long-term real money demand was also affected by the market o/n rate interest rate $\left(r e \_i d\right)$, whose amount continuously increased. The increase of the re id will increase real money demand. 
This may be caused by increasing of society's preferences in using non-cash's payment instrument as explained before. Meanwhile, in aggregate demand equation 11, the re_id increase will reduce the real GDP per capita. This is of course related to the investment decrease in line with the increasingly higher cost of capital. Negative real wages $\left(l w r_{i} i d\right)$ variable coefficient shows that the increase of real wages will actually decrease the real GDP per capita (lyrid_cap). This shows that the impact of labor demand increase through real wage increases is higher than labor productivity increase due to rising real wages, so that the net effect takes the form of decreasing real GDP. The trend component on the structural equation was seen to be positive, despite having a relatively low coefficient. The last two equations 12 and 13 respectively show the Purchasing Power Parity (PPP) and Interest Rate Parity (IRP). Within PPP rule, exchange-rate dynamic has closed relationship with inflation deviation. In this respect, exchange-rate pass trough can be explained empirically to measure how significant the relationship between exchange rate and inflation gap.

However, there may some reasons why the relationship is not significant or have a little relation. One of them is the role of central bank's monetary credibility. Akofio-Sowah (2007) find supporting evidence of this phenomenon. He reveals that developing countries that operate credible monetary regimes, and have low inflation, also experience a lower degree of exchange rate pass through. In this respect, Bank Indonesia should raise its monetary credibility to avoid exchange rate dynamics shock to domestic inflation as a consequence. The IRP equation explained that the increased real exchange return (depreciation) is followed by increasing in real domestic o/n interbank interest rate insignificantly. It means that the domestic currency depreciation will push the central bank to increase policy interest rate followed by domestic real $\mathrm{o} / \mathrm{n}$ interbank interest rate (re id) slightly in order to prevent further domestic currency depreciation though it is not significant. The small coefficient of real exchange rate is common in a country which adopts ITF. The central bank of the country generally would be more aggressive to inflation gap than exchange rate misalignment. Many countries with poor institutional quality have small coefficient of interest rate differential to response exchange-rate misalignment caused by speculative attacks (Fernandez, 2005). Even though has a small coefficient, the policy interest rate is still used and effective to drive the misaligned exchange rate to its fundamental value.

However, there are still debates to what kind of monetary defense against currency pressure (especially when facing exchange-rate crisis). Jeon (2002) find evidence to justify what kind of monetary stance central bank should pursue: tightening or accommodative in the face of currency crises. Using VAR and SVAR approach, he finds that in addition to IMF's rescue financing, the tight monetary policy (imposing high interest rate) was not necessary to stabilize exchange-rate massive depreciation. On the contrary, an expansionary monetary policy may stabilize the misaligned exchange rate as well as experiencing a milder recession.

To defense exchange rate from crises by the central bank in economic theory can be a part of a fear of free floating syndrome. Fear of Free Falling (FFF) which is reflected in decisive capital outflow would ignite domestic currency depreciation. Then central bank would respond with raising interest rates to defend the domestic currency. Thus, FFF would measure how responsive the central bank in mitigating capital outflow impact in this regard. Recently, as capital markets plays greater role in financial market, the effect of monetary policy to exchange rate is in fact showing decreasing trend. Thus it is a normal phenomenon when monetary response on exchange rate in Indonesia is insignificant recently as capital market shows greater role in financial instrument. The result is also supported by Park (2011) who investigate monetary response on exchange rate using the small open economy DSGE model in the case of Korea. He finds interesting evidence that the Bank of Korea is not responsive to exchange-rate dynamics but is more sensitive to inflation deviation. This policy is common as the Bank of Korea implement ITF as monetary framework. Another finding also supports this result. Anaraki (2001) finds interesting phenomenon such a characteristic in G-7 countries where capital markets play significant role in their own respected country. Using the cholesky forecast variance decomposition technique and impulse response functions, they show that monetary policy affects exchange rate dynamics indirectly through the pass through effect on stock market (through dividend yields, rather than through policy interest rate 'fed fund rate' in US.

Meanwhile the error correction coefficient matrix $(\Phi)$ of some variables becoming the focus of this research are lispr_cap, lmr1_cap, re_id, lyrid_cap, and lp_id, as shown in Appendix. Some of the error correction coefficients are significant, but some others are not. Cointegrating equations 1 , and 2 are significantly influenced $d\left(l i s p r \_c a p\right)$. Meanwhile, cointegrating equations 1, 2, and 3 significantly affected $d\left(l m r 1 \_c a p\right)$. Besides, cointegrating equations 2 and 3 were significantly affecting $d(r e$ id $)$. However, the significant score of $d$ (lyrid_cap) was affected by cointegrating equations 3 . Meanwhile, the $d\left(l p_{-} i d\right)$ score was merely affected by cointegrating equation 3 and 5 .

\section{Generalized Impulse Response}

In order to obtain a graphic of the influence of the real exchange rate $\left(l s r_{-} i d\right)$ towards money demand, output, inflation and its implication for the Bank of Indonesia policy as reflected by domestic o/n real interest rate (re id), the generalized impulse response is simulated. From that generalized impulse response, it was seen in Figure 28 that the shock of real exchange rate (srid_g) on the IRP equation for 1 standard deviation (0.4392) will decrease 
real non-cash instrument payment per capita (lispr_cap) before increase after 4 periods, real money demand (lmrl_cap) will decrease after two period increase, real output per capita (lyrid_cap) will be volatile after increasing in 1 period, and real wages $\left(l w r_{-} i d\right)$ will increase after one period decrease.

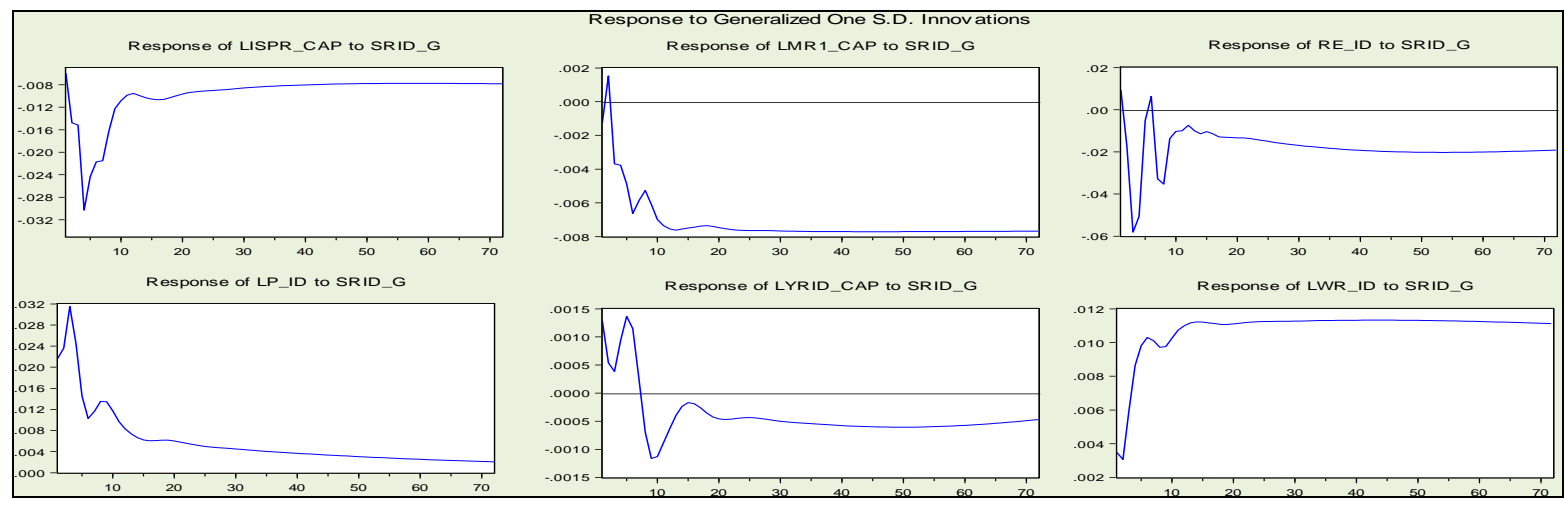

Figure 3. Generalized Impulse Response Source: Own Calculation

Meanwhile, the shock of real exchange rate will increase domestic price and after 3 periods its impact is decreasing. Meanwhile it will instantly increase domestic real o/n interbank interest rate (re_id) for a while before decreasing until two period and then increase the next period before decreasing again followed rise and down with smaller fluctuation. It can be seen that its influence on some variables are not convergent, even up to 72 months, which indicates that there is a persistent influence of the srid $g$ shock variable towards the 5 variables.

\section{Forecast Error Variance Decomposition (FEVD)}

To see the share/contribution of each endogenous variable shock to another within SCVAR model, forecast error variance decomposition (FEVD) analys is applied. Through these procedures, each shock's role on the variance of an endogenous variable in the VAR system can be known. The result showed that variance of the interest rate variable (re_id) was highly influenced by lagged itself followed by non-cash payment (lispr_cap), real money supply (lmrī_cap), real output (lyrid_cap,domestic price (lp_id) and real exchange rate (srid_g) shock variables. However, real exchange-rate shock (srid_g's influence on interest rate re id) is in increasing path. It can be viewed in Table 14 , the interest-rate shock $\left(r e \_i d\right)$ shock variable mainly affected the macroeconomic variables.

\begin{tabular}{|c|c|c|c|c|c|c|c|c|c|c|c|}
\hline Perio... & S.E. & LISPR_CAP & LMR1_CAP & RE_ID & LYRID_CAP & LP_ID & LWR_ID & SRID_G & LYRIDCAP_... & RE_US & LP_US \\
\hline 1 & 0.131417 & 0.653410 & 0.352909 & 98.99368 & 0.000000 & 0.000000 & 0.000000 & 0.000000 & 0.000000 & 0.000000 & 0.000000 \\
\hline 2 & 0.155114 & 0.968330 & 0.371222 & 96.67357 & 1.365329 & 0.346378 & 0.229331 & 0.003091 & 0.013514 & 0.000711 & 0.028520 \\
\hline 3 & 0.169168 & 4.602511 & 0.380502 & 86.42278 & 1.392862 & 0.503219 & 1.641605 & 0.819969 & 0.039581 & 0.328682 & 3.868288 \\
\hline 4 & 0.185528 & 4.366305 & 0.378099 & 84.95821 & 2.312447 & 0.519336 & 2.008518 & 1.031825 & 0.036740 & 0.395548 & 3.992971 \\
\hline 5 & 0.195433 & 4.234679 & 0.402155 & 83.39220 & 3.046647 & 1.633219 & 1.931559 & 1.082100 & 0.051548 & 0.401919 & 3.823975 \\
\hline 6 & 0.202991 & 5.800177 & 0.397045 & 80.96754 & 3.447702 & 2.111391 & 1.858787 & 1.165635 & 0.062730 & 0.516373 & 3.672627 \\
\hline 7 & 0.209953 & 6.340214 & 0.388611 & 79.75622 & 3.607736 & 2.435104 & 1.964838 & 1.181996 & 0.076762 & 0.667762 & 3.580759 \\
\hline 8 & 0.215988 & 6.316164 & 0.432208 & 78.84462 & 3.560996 & 2.962701 & 2.013991 & 1.227460 & 0.081437 & 1.031385 & 3.529039 \\
\hline 9 & 0.220947 & 6.360450 & 0.463694 & 77.74314 & 3.500369 & 3.479744 & 2.016959 & 1.207980 & 0.082571 & 1.605199 & 3.539892 \\
\hline 10 & 0.225147 & 6.343661 & 0.460746 & 76.73079 & 3.446205 & 4.061975 & 2.023802 & 1.200897 & 0.088119 & 2.161592 & 3.482217 \\
\hline 11 & 0.228740 & 6.268332 & 0.457497 & 75.64748 & 3.398179 & 4.732610 & 2.015601 & 1.200359 & 0.095745 & 2.758459 & 3.425734 \\
\hline 12 & 0.231865 & 6.195023 & 0.451745 & 74.51154 & 3.363196 & 5.361659 & 1.998622 & 1.211072 & 0.101969 & 3.435155 & 3.370015 \\
\hline
\end{tabular}

Table 2. Forecast Error Variance Decomposition Source: Own Calculation

\section{Conclusion}

From the empirical findings above, there are some conclusions. Firstly, using impulse response and structural cointegration VAR approach, a real-exchange rate shock has ambiguous effect on policy interest rate reflected by overnight inter-bank rate fluctuations in the short run. Meanwhile, in the long run, the increase (depreciation) of real exchange growth will push the central bank to raise policy interest rate slightly (reflected by small increased domestic real $\mathrm{o} / \mathrm{n}$ interbank interest rate) in order to halt further exchange-rate depreciation though it is not significant. This conclusion has in fact been done by Bank Indonesia as BI has been often raising policy interest rate whenever USD/IDR is under pressure.

Secondly, from the variance decomposition, it was seen that the shock to the domestic real o/n interbank interest rate was mainly influenced by itself and followed by non-cash payments, money supply, economic growth, inflation and exchange rate shock variables. However, exchange rate's influence on interest rate is in increasing path overtime. Thus it should be considered by the central bank. 


\section{References}

- Akofio-Sowah, 2009. Exchange rate pass-through and the monetary regime in developing countries and emerging economies: is there a link? [Dissertation]. Clark University, Massachusetts (US).

- Anaraki, 2001. How does monetary policy affect the Exchange Rate? Empirical Evidence From G-7 Countries [dissertation]. George Mason University, Virginia (US).

- Armas, 2005. "Forex Intervention in Peru: 2002-2004. Foreign Exchange Market Intervention in Emerging Markets: Motives, Techniques and Implications". BIS Papers, 24, p. 242-254.

- Bank for International Settlements, 2005. "Foreign exchange market intervention in emerging markets: motives, techniques and implications". BIS Papers, 24. p. 1-3.

- Bank for International Settlements, 2013. "Market Volatility And Foreign Exchange Intervention In Emerging Countries: What Has Changed?" BIS Papers, 73, p. 1-10.

- Boswijk and Doornik, 2003. "Identifying, Estimating and Testing Restricted Cointegrated System: an Overview." Disscussion Paper UvA Econometrics University of Amsterdam, 1. p. 1-24.

- Breitung, Bruggemann, Lutkepohl, 2004. Structural vector autoregressive modeling and impulse responses, in Applied Time Series Econometrics, Lütkepohl H, Krätzig M (eds). Cambridge University Press, Cambridge (GB).

- Fernandez, 2005. Three Essays On Current Crises And Defensive Monetary Policy [Dissertation], Texas (US), University of Houston.

- Garrat, Lee, Pesaran, and Shin, 1999. "A Long Run Structural Macroeconomic Model of the UK." Economic Journal, 113, p. 412-455.

- Garrat, et.al, 1999. "A Structural Cointegrating VAR Approach to Macroeconometric Modelling." Working Paper, p. 1-21.

- Grenville, 1995. "The Monetary Policy Transmission Process: What Do We Know? (And What Don’t We Know?)." Reserve Bank of Australia Bulletin. p.15-33.

- Harris, 1995. Using Cointegration Analysis in Econometric Modelling. Prentice Hall, New Jersey.

- Haldrup, et.al, 2012. "Unit roots, Nonlinearities and Structural Breaks".CREATES Research Paper,14, p.134.

- Jeon, 2002. Exploration on alternative monetary policy regimes in post-crisis Asia [Dissertation]. University of California, California (US).

- Kapetanios, et.al, 2000. "Cointegrating VAR Models with Endogenous I(0) Variables: Theoretical Extensions and An Application to UK Monetary Policy." NIESR Discussion Paper, 169.

- Kearns and Manners, 2005. "The Impact Of Monetary Policy On The Exchange Rate: A Study Using Intraday Data Research Discussion Paper.” Economic Research Department (Reserve Bank of Australia). 2, p. 1-24.

- Lutkepohl, Kratzig, 2004. Applied time series econometrics. Cambridge University Press, Cambridge (GB).

- Moentjak, 2014. Central Banking: Theory and Practice in Sustaining Monetary and Financial Stability. Wiley Publisher, New Jersey.

- Mohanty and Klau, 2006. "Monetary Policy Rules in Emerging Market Economies: Issues and Evidence." BIS Working Papers, 149, p. 1-17.

- Mohanty and Berger, 2013. "Central bank views on foreign exchange intervention". BIS Working Paper. 73, p. 55-74.

- Park, 2011. The Essays on Effects and Responses on Monetary Policy [dissertation]. University of California, Los Angeles (US).

- Schmidt-Hebbe and Tapia, 2002 "Monetary Policy Implementation and Results in Twenty InflationTargeting Countries." Central Bank of Chile Working Papers No 166.

- Stone, et.al, 2009. The Role of the Exchange Rate in Inflation-Targeting Emerging Economies. Washington: IMF Occasional Paper. 267, p. 3-26

- Syarifuddin, Hidayat and Tarsidin, 2009. "Impact Of Non-Cash Payment Increase on The Economy And Its Implication For Monetary Control In Indonesia." Bulletin Of Monetary Economics And Banking, 11, 369397.

- Taylor, 2001."The Role of the Exchange Rate in Monetary-Policy Rules". American Economic Review. 2, p. 91. 
- Thiessen, 1995. "Uncertainty and the Transmission of Monetary Policy in Canada." Hermes-Glendon Lecture. York University

- Vargas and Rodriguez, 2013. "Foreign exchange intervention in Colombia". Borradores de Economica, vol, p. 757

- White, 1982. "Maximum Likelihood Estimation of Misspecified Models ." Econometrica, 50, p.1-25 


\title{
Analysis of Innovation Performances of European Union Member Countries
}

\author{
Asst. Prof. Dr. Miraç Eren (Ondokuz Mayıs University, Turkey) \\ Assoc. Prof. Dr. Selahattin Kaynak (Ondokuz Mayıs University, Turkey)
}

\begin{abstract}
Together with the transition from the industrial society to the information society, Innovation at the forefront of the countries' development arguments has strategic significance for companies, industries, and countries and it is emerging as the main element of being in the market. Also, Innovation has vital importance in determining the policies of countries because of increasing social welfare and living standards of individuals. Countries having effective innovation policies and systems are rapidly advancing in the development race. Even in countries with low innovation performance, demand for innovative products and services are high. According to the Lisbon Strategy, it is important to know the innovation performances of the member countries of the European Union, which see the innovation as the basic element of economic growth, and to measure their activities. For these reasons, the purpose of this research is to analyze the innovation performances of the EU member countries. So, Data Envelopment Analysis (DEA) to measure the performance of each member country against the other member countries in the group consisting of European Union countries was considered. Therefore, the variables that are used in determining the level of innovation of the member states of the European Commission were respectively considered as Input Variables (Human Research, Research Systems, Finance, and Support) and Output Variables (Innovators, Economic effects). Tone (2001)'s Slack-Based Model and Lotfi \& Poursakhi (2012)'s dynamic DEA Model was considered together to measure the efficiency of the countries in few periods instead of a single period.
\end{abstract}

\section{Introduction}

The innovation process defined as converting scientific knowledge into products with a market value has become a necessity for countries in today's economy that global competition is experienced as intense. Countries aim to improve the citizen's living standards and quality with all kinds of innovative activities. Decision makers and policy makers also make an effort to the establishment of this culture in the common ground by moving the innovation process.

All kinds of improvements reducing production costs, increasing productivity, providing to meet changing consumer demands in optimal level, and leading a positive contribution to social life are only possible with innovation. The innovation is the main component of the economic structure of the information society and a determinant of the competitiveness of companies. So, its importance is steadily increasing.

Innovation is important and necessary not only for all size of companies and industries but also for all economic decision-making units. The countries using their resources efficiently by the effective innovation policies and providing the economic growth will gain advantages for global competition.

Innovative activities provide a new perspective on the existing markets through some changes and transformations in conjunction with uncovering new markets (Kim and Pennings, 2009). In the studies taking into account criteria such as the sales volume, export, growth, the total employment and investment return for the measurement of the success performance of countries, it is stated that those who perform the innovative activities is provided relatively better performance according to those who not perform (Kemp, et. al, 2003).

It is necessary to have a country profile that exhibits good performance with a high innovation level, achieves competitive advantage, exhibits innovative products, and dominates technology transfer, to be in the determinant position in full membership process to the EU. In the literature, various studies examining the relationship between the innovation in macro and micro level, economic growth, firm performance, and competitive advantage have been conducted. One of the first economists emphasizing the importance of innovations in economic growth in studies carried out at the macro level is Schumpeter (1943). Domar (1946), Solow (1956), Romer (1986, 1990, 1994) who pioneered the endogenous growth theory, and Lucas (1988) have made studies concerning with the impact of innovation and technology in economic growth.

Most of the work done at the micro level is related with how and at what level the performances of the firm is affected. According to the findings of some study, Innovation provides a positive contribution to the economic performance of enterprises and industries (Baregheh, et. al, 2014; Diederen, et. al, 2002; Favre, et. al, 2002; Geroski, 1989, Hassan, et. al, 2013; Mohnen and Kleinknecht, 2002; Roper, et. al, 2008; Therrien, et. al, 2011; Wong, et. al, 2005).

In the study, it was considered Data Envelopment Analysis to measure the performance of each member country against the other member countries in the group consisting of European Union countries. For this purpose, the variables that are used in determining the level of innovation of the member states of the European Commission have been considered. So that, firstly, Dynamic DEA model taking into account, an alternative Dynamic Slack- 
Based Model is developed, called DSBM was expressed in the part of the methodology. Afterward, the manner that the levels of innovation of the member states of the EU were determined using Input and output variables utilized by the European Commission for the measurement of innovative activity is shown in the application section.

\section{Methodology}

In production environments that include a broad range of income and outcome, a nonparametric method DEA is used for productivity measurement. In literature, the term DEA is first used in the study of Charnes, Cooper, and Rhodes (CCR) dated in 1978. CCR aims to assign weights to the incomes and outcomes completing the production of the analyzed units through linear programming and to estimate a limit consisting units showing the best performance in the observation cluster. When observed decision units do not make production in optimal scale, which means, in the case of profits variable according to scale, CCR models fall behind in technical effectiveness measurement because of not being able to measure scale effectiveness due to their structure. BCC model of Banker Charnes and Cooper in 1984 developed in order to measure technical effectiveness under the assumption of profit variable according to scale, by separating technical effectiveness into its components as scale efficiency and pure technical efficiency, showed that technical effectiveness is equal to the multiplication of these two components (Cooper, et. al, 2007). Since 1978 until today many DEA analysis models are developed. One of developed these models is a slack based model (SBM). This model deals directly with the input excesses and the output shortfalls of DMUs. Furthermore, it is reference-set dependent, i.e. the measure is determined only by its reference set and is not affected by statistic over the whole data set. Tone (2001) demonstrated with the numerical example that is the compatibility of SBM with other measures and its potential applicability for practical purposes (Tone, 2001). However, SBM model for a single period measures the effectiveness of DMUs. At the end of a few periods to evaluate the effectiveness of DMU's Dynamic DEA models must be developed. To measure changes, the efficiency of DMUs at the end of multiple time periods have been proposed Dynamic DEA models at different times (Sengupta, 1996; Tone and Tsutsui, 2010 and Tone, 2001). Developed Dynamic DEA models have considered in the dynamic productions the relation between the inputs and outputs. Finally by the new dynamic DEA models has been developed by Lotfi \& Poursakhi, 2012.

In this study, as Tone (2001)'s SBM model and Lotfi \& Poursakhi (2012)'s dynamic DEA model taking into account, an alternative Dynamic Slack-Based Model is developed, called DSBM.

In the literature, some of the Dynamic DEA and SBM are: Emrouznejad (2003) provides an alternative DEA model that is based on several periods. This model is useful for DMUs with capital input. As a result of studies, the dynamic efficiency results should reflect reality better than those based on static DEA models, has found that (Emrouznejad, 2003). Emrouznejad and Thanassoulis (2005), is developed a method for assessing the performance of DMUs when their input-output levels are characterized by inter-temporal dependencies. This paper is suggested that dynamic model captures the efficiency better than the static model ((Emrouznejad and Thanassoulis, 2005). Amirteimoori (2006) is developed a new DEA with dynamic revenue efficiency. He is shown that a convex combination of these period measures makes up the efficiency of the whole periods (Amirteimoori, 2006). Tone and Tsutsui (2010) developed in the slack-based measure (SBM) framework, called dynamic SBM. They classify carry-overs into four categories, i.e. desirable (good), undesirable (bad), free and fixed. Their developed dynamic SDM models that can evaluate the overall efficiency of decision-making units for the whole terms as well as the term efficiencies (Tone and Tsutsui, 2010). Hosseinzadeh Lotfi and Poursakhi (2012) developed a model proposed for evaluating the relative efficiency of units which have time-dependent input-output. Their model was presented in which the time-dependent effects of undesirable inputs and outputs were considered, and time-dependent effects were formulated via time-dependent parameters (Lotfi and Poursakhi, 2012).

\subsection{An Alternative Dynamic Slack-Based Model-DSBM}

There are two types of efficiency measures, i.e., radial and non-radial. The CCR and BCC models present the radial approach. Its shortcoming is that it neglects the non-radial input/output slacks. The non-radial approach SBM deals with slack directly, but it neglects the radial characteristics of inputs and/or outputs. Slack based measure of efficiency (SBM) is a non-radial measure of efficiency. Thus, the SBM measure reflects not only the weak efficiency values in CCR-efficiency but also the other (slack) inefficiencies as well (Cooper, et. al, 2007). SBM model deals directly with the input excesses and the output shortfalls of the DMU concerned. SBM measures the effectiveness of DMUs at a single period. The single period optimization model is not suitable for performance evaluation even if these models can take into account the time change effect. For these cases, Dynamic DEA models have been developed. In this study, as Tone (2001)'s SBM model and Lotfi \& Poursakhi (2012)'s Dynamic DEA model taking into account, an alternative Dynamic Slack-Based Model is developed, called DSBM.

SBM by Tone (2001) is given below. In model, the production possibility set $\mathrm{P}$ is defined as

$$
P=\{((x, y) \mid x \geq X \lambda, y \leq Y \lambda, \lambda \geq 0)\},
$$


Where $\lambda$ is a nonnegative vector in $R^{n}$. In SBM is considered an expression for describing a certain DMU $\left(x_{0}, y_{o}\right)$ as,

$$
\begin{gathered}
x_{o}=X \lambda+s^{-}, \\
y_{o}=Y \lambda-s^{+},
\end{gathered}
$$

The vectors $\mathrm{s}^{-} \in \mathrm{R}^{\mathrm{m}}$ and $\mathrm{s}^{+} \in \mathrm{R}^{\mathrm{s}}$ indicate the input excess and output shortfall of this expression, respectively, and are called slacks. From the conditions $X>0$ and $\lambda \geq 0$, it holds $\mathrm{x}_{\mathrm{o}} \geq \mathrm{s}^{-}$. SBM is as follows (Tone, 2001).

[SBM]

$$
\begin{aligned}
\text { minimize } \rho & =\frac{1-(1 / m) \sum_{i=1}^{m} s_{i}^{-} / x_{i o}}{1-(1 / s) \sum_{r=1}^{s} s_{r}^{+} / y_{r o}} \\
\text { subject to } x_{i o} & =\sum_{j=1}^{n} x_{i j} \lambda_{j}+s_{i}^{-} \quad i=1, \ldots, m \\
y_{r o} & =\sum_{j=1}^{n} y_{i j} \lambda_{j}-s_{r}^{+} \quad r=1, \ldots, s \\
\lambda_{j}, s_{i}^{-}, s_{r}^{+} \geq 0 &
\end{aligned}
$$

$$
\text { Here, it holds } \quad 0 \leq \rho \leq 1 \text {. }
$$

The process of dynamic production studied in 1 to $n+1$ periods and showed as an index set $\mathrm{T}=\{1, \ldots, t+1\}$. For the desired time period $t$ in the observation window (i.e. $m$-period) depicts a time-dependent model of the production process where the inputs used in the period $t$ can be used in output production in the $t, t+1, \ldots, t+m$ periods (Lotfi and Poursakhi, 2012). Accordingly, to this developed DSBM model is given below;

[DSBM]

$$
\begin{aligned}
& \text { minimize } \rho=\frac{1}{T} \sum_{t=1}^{T}\left(\frac{1-(1 / m) \sum_{i=1}^{m} \frac{s_{i}^{t-}}{x_{i o}^{t}}}{1+(1 / s) \sum_{r=1}^{S} \frac{s_{r}^{t+}}{y_{r o}^{t}}}\right) \\
& \text { Subject to } \quad x_{i o}^{t}=\sum_{j=1}^{n} x_{i j}^{t} \lambda_{j}+s_{i}^{t-}, \quad i=1, \ldots, m \\
& y_{r o}^{t}=\sum_{j=1}^{n} y_{i j}^{t} \lambda_{j}-s_{r}^{t+}, \quad r=1, \ldots, s \\
& \lambda_{j}, s_{i}^{t-}, s_{r}^{t+} \geq 0
\end{aligned}
$$

\section{Application}

In the research, the variables that are used in determining the level of innovation of the member states of the European Commission have been considered. European Innovation Scoreboard provides a comparative assessment of the research and innovation performance of the EU Member States and the relative strengths and weaknesses of their research and innovation systems. It helps Member States assess areas in which they need to concentrate their efforts in order to boost their innovation performance. Input and output variables utilized by the European Commission for the measurement of innovative activity are:

Input Variables; Human Research, Research Systems, Finance and Support

Output Variables; Innovators, Economic effects

Terms; between 2010-2014 years

A brief depiction of the content of these variables may be useful. According to this,

\section{Input Variables}

Inputs capture the main drivers of innovation performance external to the firm and differentiate between three innovation dimensions. 
The Human resources dimension includes three indicators and measures the availability of a high-skilled and educated workforce. Indicators; New doctorate graduates, Population completed tertiary education and Youth with upper secondary level education.

The Open, excellent and attractive research systems dimension includes three indicators and measures the international competitiveness of the science base. Indicators; International scientific co-publications, Scientific publications among top $10 \%$ most cited and Non-EU doctorate students.

The Finance and support dimension includes two indicators and measures the availability of finance for innovation projects and the support of governments for research and innovation activities. Indicators; Public R\&D expenditure and Venture capital.

Output Variables

Outputs capture the effects of enterprises' innovation activities and differentiate between two innovation dimensions.

The Innovators dimension includes three indicators and measures the number of enterprises that have introduced innovations onto the market or within their organisations, covering both technological and non- technological innovations and the presence of high-growth enterprises. Indicators; SMEs introducing product or process innovations, SMEs introducing marketing/organisational innovations and Employment in fast-growing enterprises.

The Economic effects dimension includes five indicators and captures the economic success of innovation in employment, exports, and sales due to innovation activities. Indicators; Employment in knowledge-intensive activities, Medium and high tech product exports, Knowledge-intensive services exports, Sales of new to market and new to firm innovations and License and patent revenues from abroad.

\begin{tabular}{lccllllr}
\hline Countries & Result & Countries & Result & Countries & Result & Countries & Result \\
\hline Belgium & 1.000 & Greece & 1.000 & Luxembourg & 0.271 & Romania & 0.623 \\
Bulgaria & 0.463 & Spain & 1.000 & Hungary & 1.000 & Slovenia & 1.000 \\
Czech Republic & 0.428 & France & 0.418 & Malta & 1.000 & Slovakia & 0.435 \\
Denmark & 1.000 & Italy & 0.429 & Netherlands & 1.000 & Finland & 1.000 \\
Germany & 1.000 & Cyprus & 1.000 & Austria & 0.385 & Sweden & 0.407 \\
Estonia & 0.485 & Latvia & 1.000 & Poland & 0.439 & United Kingdom & 0.386 \\
Ireland & 1.000 & Lithuania & 1.000 & Portugal & 0.627 & Croatia & 0.366 \\
\hline
\end{tabular}

Table 1. Dynamic Slack Based Model-DSBM Efficiency Results

According to European Innovation Scoreboard ranking results, which the innovation performances of European Union member states have been annually published, the countries is classified as Innovation Leaders, Strong Innovators, Moderate Innovators and Modest Innovators (Europe, 2008). Cyprus, Greece, Hungary, Latvia, Lithuania, and Malta are among the best-performing countries in this study while these according to the European Innovation Scoreboard ranking results are located in the class of the moderated innovators. Similarly, Sweden is located in the class of the Innovation Leaders, and Luxembourg, United Kingdom, France, and Austria are located in the class of Strong Innovators. According to the findings, they have not performed well.

\section{Conclusions}

The European Innovation Scoreboard ranking results, which the innovation performances of European Union member states have been annually published, are obtained by considering variables as Firm investments, LinkagesEntrepreneurship-Intellectual Assets, Human Research, Research Systems, Finance and Support, Innovators, Economic effects. In this study, it was considered Data Envelopment Analysis to measure the performance of each member country against the other member countries in the group consisting of European Union countries. Based on this efficiency analysis having inputs-outputs, Human Research, Research Systems, Finance and Support variables were taken as inputs, and Innovators, Economic effects variables were considered as the outputs. Firm Investments, Linkages-Entrepreneurship-Intellectual Assets variables were excluded from the study because these do not refer to any input or output. In addition, to measure the efficiency of the countries (which are called as DMU) in few periods instead of a single period, Tone (2001)'s Slack-Based Model model and Lotfi \& Poursakhi (2012)'s dynamic DEA model was considered together. The developed model was called as Dynamic Slack-Based Model-DSBM. According to DSBM results, it was observed that the overall innovation efficiencies of EU member countries between 2010-2014 were similar largely with the European Innovation Scoreboard ranking results measuring the annual innovation performance. In addition, Cyprus, Greece, Hungary, Latvia, Lithuania, and Malta that is located in the class of the moderated innovators (that is, low-level innovators) according to European Innovation Scoreboard ranking results are among the best-performing countries in this research. this situation 
shows that these countries use their innovative sources in an optimal way (that they better evaluate innovative inputs).

\section{References}

- Amirteimoori, 2006. "Data envelopment analysis in dynamic framework", Applied mathematics and computation, 181, p. 21-28.

- Baregheh, et. al, 2014. "Towards an integrative view of innovation in food sector SMEs", The International Journal of Entrepreneurship and Innovation, 15, p. 147-158.

- Diederen, et. al, 2002. "Innovation and farm performance: the case of Dutch agriculture. In Innovation and Firm Performance”, (pp. 73-85). Palgrave Macmillan UK.

- Domar, 1946. “Capital Expansion, Rate of Growth, and Employment”, Econometrica, 14, p. 137-147.

- Emrouznejad, 2003. "An alternative DEA measure: a case of OECD countries”, Applied Economics Letters, 10, p. 779-782.

- Emrouznejad and Thanassoulis, 2005. "A mathematical model for dynamic efficiency using data envelopment analysis", Applied mathematics and computation, 160, p. 363-378.

- $\quad$ Europe, 2008. European innovation scoreboard 2007: Comparative analysis of innovation performance. Office for Official Publications of the European Communities.

- Favre, et. al, 2002. "The effect of spillovers and government subsidies on R\&D, international R\&D cooperation and profits: evidence from France", In Innovation and Firm Performance, Springer, p. 201-224.

- Geroski, 1989. "Entry, innovation and productivity growth", The review of Economics and Statistics, p. 572-578.

- Hassan, et. al, 2013. "Effects of innovation types on firm performance: an empirical study on Pakistan's Manufacturing Sector”, Pakistan Journal of Commerce and Social Sciences, 7, p. 243-262.

- Kemp, et. al, 2003. Innovation and firm performance (No. H 200207). Zoetermeer, The Netherlands: EIM.

- Kim and Pennings, 2009. "Innovation and strategic renewal in mature markets: A study of the tennis racket industry", Organization Science, 20, p. 368-383.

- Kleinknecht and Mohnen, 2001. Innovation and firm performance: Econometric explorations of survey data. Springer.

- $\quad$ Lotfi and Poursakhi 2012. "A Mathematical Model for Dynamic Efficiency Using Desirable and Undesirable Input-Output”, Applied Mathematical Sciences, 6, p. 141-151.

- Lucas, 1988. "On the Mechanics of Economic Development”, Journal of Monetary Economics, 22, p. 3-42.

- Romer, 1986. “Increasing Returns and Long-Run Growth”, Journal of Political Economy, 94, p. 1002-1037.

- Romer, 1990. "Endogenous Technological Change”, Journal of Political Economy, 98, p. 71-102.

- Romer, 1994. “The Origins of Endogenous Growth”, Journal of Economic Perspectives, 8, p. 3-22.

- $\quad$ Roper, S., Du, J., \& Love, J. H. (2008). Modelling the innovation value chain. Research policy, 37(6), 961 977.

- Schumpeter, 1943. The Theory of Economic Development, Cambridge, Mass.: Harvard University Press (originally published in German in 1911; reprinted by Transaction Publishers, New Brunswick, New Jersey in 1997).

- Sengupta, 1996. "Systematic measures of dynamic Farrell efficiency", Applied Economics Letters, 3, p. 91 94.

- Solow, 1956. A Contribution to the Theory of Growth (reprinted). In: Sen, A. ed., Growth economics. Selected Readings, 161-192. Penguin, Harmondsworth.

- Therrien, et. al, 2011. "Innovation novelty and (commercial) performance in the service sector: A Canadian firm-level analysis", Technovation, 31, p. 655-665.

- Tone, 2001. “A slacks-based measure of efficiency in data envelopment analysis”, European journal of operational research, 130, p. 498-509.

- Tone and Tsutsui 2010. "Dynamic DEA: A slacks-based measure approach”, Omega, 38, p. 145-156.

- Wong, et. al, 2005. "Entrepreneurship, innovation and economic growth: Evidence from GEM data”, Small business economics, 24, p. 335-350. 


\title{
Innovativeness of SMEs in Small Non-Oil Producing Post- Communist Economies
}

\author{
Asst. Prof. Dr. Kamalbek Karymshakov (Kyrgyzstan-Turkey Manas University, Kyrgyzstan) \\ Dr. Burulcha Sulaimanova (Kyrgyzstan-Turkey Manas University, Kyrgyzstan) \\ Dr. Dastan Aseinov (Kyrgyzstan-Turkey Manas University, Kyrgyzstan)
}

\begin{abstract}
This paper aims to study the determinants of innovation propensity of small and medium-sized enterprises (SMEs) in five small non-oil exporting Former Soviet Union countries. Empirical analysis is based on the data from the fifth wave of the Business Environment and Enterprise Performance Survey (BEEPS). Innovation of SMEs is measured by five innovation practices: innovation in goods services, process, organization, marketing and R\&D spending. For each aspect of innovation bivariate regression analysis is applied. Estimation results shows that experience of managers has curvilinear effect on the innovation in SMEs. Foreign participation, export orientation and competitiveness in sectors are important for innovation.
\end{abstract}

\section{Introduction}

Small and medium-sized enterprises promote economic growth through creation of new jobs and development of innovative products (Scase, 1997; Skuras et al., 2008; Ionica, 2013). Compared to large firms SMEs may quickly adapt to new socio-economic environment and find out new ways of activity (McIntyre, 2001:11; Rogers, 2004:143, Love \& Roper, 2015:29). Recent economic transition of the former Soviet Union (FSU) countries to market economy and making of the entrepreneurship in these challenging environment have made SMEs even more important for these economies (Aidis, 2003).

The long-term sustainable economic development requires innovation activities of enterprises. SMEs and individual enterprises may demonstrate more dynamic tendency towards introduction of innovation (Love \& Roper, 2015). Innovativeness of these firms may depend on different factors ranging from the characteristics of firms' leaders to the access of financial resources.

Empirical literature determines different factors for innovation of SMEs. Among them financial constraints are found as one of the important elements of government support to increase innovation activity (Landesmann et al., 2016; Skuras et al., 2008). Some studies assert that along with this non-financial support to increase productivity of the labour force is also crucial (Szczepanska-Woszczyna, 2014). On this point study by Norek \& Arenhardt (2015) on Brazilian and Polish SMEs indicates that lack of qualified labour together with financial constraints as major difficulties related with innovation.

Other characteristics of firms which are significant for the innovation propensity of SMEs are size and technological capacity of firms. Findings by Bayarçelik et. al. (2014) on Turkish case indicate that among other factors size of firm have significant impact over the innovativeness of SMEs. Some of the studies point out importance of the external environmental conditions too. Thus, De Mel et al. (2009) investigating determinants of innovation in micro, small, and medium enterprises in Sri Lanka, demonstrate that firm size has positive impact on the process and organizational innovations, while less on product innovations. Along with this pressure coming from the competition in the industry negatively affects these innovation aspects. However, SzczepanskaWoszczyna (2014) found positive influence of the constant pressure coming from the competitors over the innovation in Polish SMEs. Manager characteristics such as gender, experience and entrepreneur skills, are also important for the innovation propensity of firms too (Romijn \& Albaladejo, 2002; Norek \& Costa, 2015; Akulava, 2015).

However, not only internal firm level characteristics, but also external cooperation is found to be important for innovation of SMEs. Turriago-Hoyos et al. (2015) in case of the Colombian SMEs argue that firm size and cooperation with other stakeholders, such as research institutions and foreign industrial groups, have more influence on production innovation. Podmetina (2011) emphasizes that innovation implementation through internationalization and cooperation with external partners can provide for Russian SMEs with opportunities to enter into new markets. Analogically, Ionica (2013) concludes that innovation in SMEs of Romania have been influenced by international strategic partnerships. In a similar vein, studies by Ehrenberger et.al. (2015) on Czech Republic, Radas \& Božić (2009) on Croatia, Pikkemaat (2008) on Austria, Keizer et al. (2002) on Netherlands confirm the positive influence of external cooperation on innovation of SMEs.

Although there are large number of studies on the innovation and SMEs, empirical evidence on the post-soviet countries is limited. Although, FSU countries have some common historical background for the enterprise development, difference in size of the economies, abundance of the natural resources and government policies have been expressed in diverging outcomes of economic performance (Iradian, 2007). Moreover, at the aftermath 
of the comprehensive economic reforms perception of government on the priority of SMEs in economic development varied (Smallbone \& Welter, 2001).

This study aims to investigate the factors that determine innovation of SMEs in small non-oil exporting FSU countries: Armenia, Georgia, Kyrgyzstan, Moldova and Tajikistan.

Under the conditions of comparatively smaller economies without large oil resources increase importance of SMEs for economic development. We use the data from the 5th wave of the Business Environment and Enterprise Performance Survey (BEEPS) and measure innovation with five innovation practices, which are indicated by the binary response variables. For each innovation activities, bivariate regression analysis is applied.

This paper is structured as follows. Next section explains methodology. Section 3 entails data description and briefly discusses descriptive statistics. Section 4 presents estimation results. Section 5 concludes.

\section{Methodology}

For the purpose of examining factors affecting innovation activity of SMEs we use binary response, probit models, for estimations. The innovation of firms is measured within five categories: innovation in goods services, process, organization, marketing and R\&D spending. Each innovation category has binary response character. Formally, model is given below (Wooldridge, 2002):

$$
\begin{gathered}
P\left(y_{i}=1 \mid x_{i}\right)=G\left(\beta_{0}+\beta_{1} x_{1}+\cdots+\beta_{k} x_{k}\right)=G\left(\beta_{0}+x \beta\right) \\
G(z)=\Phi(z) \equiv \int_{-\infty}^{z} \phi(v) d v \\
\phi(z)=(2 \pi)^{-1 / 2} \exp \left(-z^{2} / 2\right)
\end{gathered}
$$

where $\mathrm{G}$ is the standard normal cumulative distribution function (cdf) and $\phi(z)$ indicates standard normal density. $y_{i}$ is the discrete dependent variable, taking values of zero or one, showing the innovativeness of the firm; $x_{i}$ is the set of explanatory variables.

Covariates used in the analysis follow empirical literature and cover both managerial and firm characteristics, including some aspects of the external environment. For detailed variable description see Table A.1. in Appendix. Managerial features are measured by the gender and experience variables. In particular, relationship between experience and innovation may not only be linear, but also may have curvilinear path. At the earlier stages of the managerial experience SMEs may be more active in adapting new approach for production, organizational structure and other aspects of innovation. However, with longer managerial experience owners or managers of SMEs may take passive innovative position because of the several reasons: higher personal age and less desire to work on innovative approach or belonging to the "old cohort" of managers that may find difficult adaptation to new conditions through competitive and technological changes. The recent short history of emerging private sector and entrepreneurships in post-communist economies the latter argument may have higher validity in our analysis. Following this potential curvilinear effect square of experience is included too.

Firm characteristics include years since establishment, dummy variables on ownership structure and foreign participation. Industry type variable is included through four sectors: foods manufacturing, construction, retail services and other industry. Other variables indicate reported competition level in the industry, whether firm exports, has provided trainings and has current credit loan.

\section{Data and Descriptive Statistics}

This study is based on the data of the fifth wave of the Business Environment and Enterprise Performance Survey (BEEPS) for five countries: Armenia, Georgia, Kyrgyzstan, Moldova and Tajikistan. Total sample consists of 1081 micro, small and medium-sized enterprises. Following the dataset micro is defined as firms having less than 5 employees, small between 5 and 19, and medium between 20 and 99. Data includes wide range of data on firm activities such as production, expectations, regulatory burden, and different section of the questionnaire is focused on innovation activities.

Innovation activity of enterprises is measured by five aspects: introduction of new products or services innovation in goods and services; introduction of new methods of production of goods and services - innovation in process; introduction of new or significant improvement in organizational or management practices - innovation in organization; introduction of new marketing methods - marketing innovation; and whether firm did spending on research and development. These are dummy variables, indicating whether firms performed these activities or not.

Table 1. present share of firms indicated each innovation activity by countries in the sample. Among five countries the most innovative SMEs are in Kyrgyzstan and Moldova. In average and relative terms SMEs in Georgia reported lower level of innovation in all five aspects. At the total sample about 20 per cent of SMEs are 
engaged into innovation activities. However, SMEs show different performance depending on the types of innovation. The least intensive type of innovation is $R \& D$, while other types receive substantially larger consideration of firms. For instance, in Kyrgyzstan more than 30 per cent of SMEs indicated innovation in goods and services, organization and marketing, while Armenia and Georgia innovation in goods and services has comparatively larger share. These varying intensities of innovation activities may be related with their cost and priority for SMEs. Financing R\&D activities may be costly given their uncertain results and small size of firms. On the other hand, competitive environment in the industry may pressure SMEs to focus on other issues, such as better promotion of products or improvement of managerial practices of firms.

\begin{tabular}{|c|c|c|c|c|c|}
\hline & $\begin{array}{c}\text { Innovation in goods } \\
\text { and services }\end{array}$ & $\begin{array}{c}\text { Innovation in } \\
\text { process }\end{array}$ & $\begin{array}{c}\text { Innovation in } \\
\text { organization }\end{array}$ & $\begin{array}{c}\text { Innovation in } \\
\text { marketing }\end{array}$ & R\&D \\
\hline Armenia & 11.60 & 4.97 & 4.42 & 9.94 & 2.76 \\
\hline Georgia & 8.84 & 7.23 & 3.21 & 5.62 & 2.01 \\
\hline Kyrgyz Rep. & 36.87 & 22.73 & 36.36 & 39.90 & 8.59 \\
\hline Moldova & 31.29 & 30.67 & 25.77 & 25.77 & 7.98 \\
\hline Tajikistan & 13.45 & 9.66 & 19.31 & 26.90 & 5.52 \\
\hline Total & 19.06 & 13.88 & 17.21 & 21.37 & 5.18 \\
\hline
\end{tabular}

Table 1. Innovation Activity of Enterprises (in \%, by Country) Source:5th Business Environment and Enterprise Performance Survey (BEEPS)

Review of the empirical literature shows that innovation activities depends on different firm and managerial characteristics. Table 2. describes the main indicators of SMEs, which are taken into analysis. In general, SMEs are represented by male headed companies, which are more experienced than women CEO. The firm statistics show that most firms have short history since establishment and counts around 11 years, which probably could be explained by the disintegration of Soviet Union and later development of private sector in these economies.

The distribution of legal statuses of SMEs shows that almost 92 per cent of firms are shareholding companies, which do not trade their shares in the stock market, while only half percent of shareholding companies trade their shares openly. Around 7 per cent of firms have sole proprietorship. About 8 per cent of firms have foreign participation. Large share of SMEs are in sectors of service - almost 64 per cent, while activities of less than 34 per cent are in manufacturing. Services sector has low capital intensity that makes it more attractive for the establishment of SMEs without substantial financial costs. Most of the firms functioning in the service industries, and women headed firms more likely (77 per cent) to be in this sector, and only 23 per cent in the manufacturing industries. Interestingly $60 \%$ of women headed firms located in the capital city, indicating that women are more likely to manage firms in the urban areas. 28 per cent of firms conduct training activities to their employees, which can be related with some types of innovation activities of SMEs. Another interesting feature of SMEs in these countries is that more than 30 per cent of firms' report facing competition against unregistered firms. This information indicates the extent to which informal economic activities are spread and may create competition pressure for formal firms.

\begin{tabular}{|c|c|c|}
\hline & Obs. & $\%$ \\
\hline Firm amount & 1081 & 100 \\
\hline Experience of the manager (years, mean) & - & 13.56 \\
\hline Years since establishment (mean) & - & 11.25 \\
\hline \multicolumn{3}{|l|}{ Firm structure } \\
\hline -Shareholding company with shares traded in the stock market & 4 & 0.37 \\
\hline -Shareholding company with non-traded shares or shares traded privately & 990 & 91.58 \\
\hline -Sole proprietorship & 62 & 5.74 \\
\hline - Partnership and limited partnership & 10 & 0.93 \\
\hline -Other legal status & 15 & 1.39 \\
\hline Foreign participation & 89 & 8.23 \\
\hline \multicolumn{3}{|l|}{ Industry type: } \\
\hline -Manufacturing & 362 & 33.49 \\
\hline -Service & 719 & 66.51 \\
\hline Location in capital city & 494 & 45.70 \\
\hline Exporter firm & 117 & 10.82 \\
\hline Training activities & 302 & 27.94 \\
\hline Competition against unregistered firms & 356 & 32.93 \\
\hline Credit or loan from financial institutions & 315 & 29.33 \\
\hline
\end{tabular}

Table 2. Descriptive Statistics Source: 5th Business Environment and Enterprise Performance Survey (BEEPS)

\section{Estimation Results}

Table 3. reports marginal effects from estimation of probit model for each innovation component. Most of the variables have expected sign. Findings show that there is no relationship between gender of CEO and 
innovativeness of the enterprise. However, interesting results are indicated in case of the impact of experience of CEOs on innovation. In order to examine the potential curvilinear relationship between experience of managers and innovation variable measuring the experience in years and their square values is included as distinct variable. Findings show that there is statistically significant and positive relation exists between experience of manager of firm and its innovation indicators. However, squared value of the CEO experience shows statistically significant negative effect on innovation, meaning that CEOs with increase in experience after some threshold values less likely to introduce innovation in firms. Although marginal effect of the negative impact of longer experience is considerably lower.

Curvilinear effect of experience of managers has some support from the establishment history of SMEs too. As the experience of CEO, the establishment history of firm shows the same pattern, the propensity to invest in innovation increases with increase in years since establishment, then after definite years it reduces. If to consider that SMEs are mostly represented by companies with non-traded shares, then the probability of staying same managers on for the longer time is high. Therefore, curvilinear effect of both experience and establishment history is expected outcome. Shareholding companies that trade their shares in stock market more likely to introduce new goods, services, implement new production process and introduce a new marketing strategy.

Empirical findings show that foreign participation in the firm positively influences innovation in firms, thus these firms more likely to introduce new goods, marketing strategies and organizational management rather than firms that don't have foreign participation in the ownership structure. Interesting results are indicated by the sector of activity. SMEs working in the food manufacturing industries have innovation works in goods and services and process, while firm in construction have negative propensity to innovate in all types of innovation compared to other industries reference group. Retails services sector demonstrate statistically significant negative innovation in process only.

\begin{tabular}{|c|c|c|c|c|c|}
\hline & \multicolumn{5}{|c|}{ Innovation in } \\
\hline & Goods/Services & Process & Organization & Marketing & R\&D \\
\hline \multicolumn{6}{|l|}{ CEO characteristics: } \\
\hline Gender(female $=1)$ & 0.0092 & 0.0394 & 0.0317 & -0.0144 & 0.0044 \\
\hline Experience & $0.0066^{* *}$ & $0.0087 * * *$ & $0.1038 * * *$ & $0.0116^{* * *}$ & $0.0033 *$ \\
\hline Squared experience & $-0.0001 * *$ & $-0.0001 * *$ & $-0.0002 * * *$ & $-0.0003 * * *$ & $-0.00007 *$ \\
\hline \multicolumn{6}{|l|}{ Firm characteristics: } \\
\hline Years since establishment & $0.0069 * *$ & $0.0056^{* *}$ & $0.0120 * * *$ & $0.0074 *$ & 0.0015 \\
\hline Squared years since establishment & -0.00008 & $-0.00007 *$ & $-0.0002 * *$ & $-0.0001 *$ & -0.00001 \\
\hline \multicolumn{6}{|c|}{ Firm structure (reference group: Other legal status) } \\
\hline - $\quad$ Shares traded & $0.7409 * * *$ & $0.5167 * *$ & 0.3910 & $0.5267 * *$ & 0.4040 \\
\hline - $\quad$ Non-traded shares & $0.0897 * * *$ & 0.0395 & 0.0382 & $0.1219 * * *$ & $0.0275 * * *$ \\
\hline Foreign participant & $0.0877^{*}$ & 0.0063 & $0.1264 * *$ & $0.1381 * *$ & $0.0448^{*}$ \\
\hline \multicolumn{6}{|c|}{ Industry type (reference group: other industries) } \\
\hline - $\quad$ Food manufacturing & $0.1541 * * *$ & 0.1368 *** & 0.0404 & 0.0696 & 0.0165 \\
\hline Construction services & $-0.0731 * *$ & $-0.0571 * *$ & $-0.0684 * *$ & $-0.0795 * *$ & $-0.026 * * *$ \\
\hline - $\quad$ Retail services & -0.0103 & $-0.0666 * * *$ & 0.0107 & 0.0373 & -0.0082 \\
\hline Location & $0.0556^{* *}$ & -0.0264 & 0.0047 & 0.0286 & -0.0054 \\
\hline Exporter firm & $0.1112 * *$ & 0.0259 & 0.0608 & $0.1189^{* *}$ & $0.0370^{*}$ \\
\hline Training & $0.1794 * * *$ & $0.1104 * * *$ & $0.2250 * * *$ & $0.2288 * * *$ & $0.0590 * * *$ \\
\hline Competition & $0.0510 * *$ & $0.0514 * *$ & 0.0316 & 0.0428 & 0.0180 \\
\hline Credit & 0.0130 & $0.0400^{*}$ & $-0.0407^{*}$ & -0.0121 & -0.0037 \\
\hline
\end{tabular}

Table 3. Estimation Results for Probit Models (Marginal Effect Estimates)

These findings suggest that innovativeness of SMEs in particular sectors of the economy does not have actively growing tendency. Especially the negative sign of innovation in results may suggest that SMEs may grow or maintain their current position by growing demand for their products. But low level of competition in these sectors and low exporting capacity of SMEs do not create incentives to look for innovation opportunities. These arguments are supported by the exporter and competition variables in the model. Both of them have positive impact over few innovation types.

Location of firms significantly impacts only on innovation of new products. SMEs located in the capital city may have larger consumer market and lower costs for logistics that may induce them to focus on the attempt to introduce new products and services. Moreover, being located may represent another advantage of accessing current knowledge on technology and innovation opportunities. Training of permanent employees positively correlated with all types of innovation. This result points out the fact that most of the innovation activities are associated with different forms of training activities. However, their magnitude may differ by innovation types. For instance, in our result R\&D activities have lower marginal effect of training compared to other innovation elements. 
Availability of financial resources is considered as one of the important constraints for innovation of firms. Estimation results show that it has some impact at less statistically significance level over the new production process and organizational management. Nevertheless, these findings do not provide with enough evidence to conclude about significant impact of credits from financial institutions over the innovation of firms. This fact may have two explanations. First, financial system in these countries are not developed and do not supply enough financial resources for innovation activities. Second, SMEs using loans from financial institutions use them for other activities and not necessarily for innovative works.

General assessment of estimation results by types of innovation indicates that among five measured innovation activities R\&D remains as affected only by a few variables in the model, while innovation in goods and services are most intensive among SMEs. These findings suggest that R\&D activities are limited in SMEs of these economies.

\section{Conclusions}

This study using the data from the Business Environment and Enterprise Performance Survey (BEEPS) examined factors affecting innovation activities of SMEs in five small post-communist economies: Armenia, Georgia, Kyrgyzstan, Moldova and Tajikistan. The broad definition of innovation is focused on and measured by dummy variables in five aspects: introduction of new products or services; introduction of new methods of production of goods and services; introduction of new or significant improvement in organizational or management practices; introduction of new marketing methods; and whether firm did spend on research and development. Because of the binary response character innovation variables, probit model is estimated with explanatory variables on manager and firm characteristics.

In general, estimation results indicate the low intensity of R\&D in innovativeness of SMEs, while innovation in goods and services is more widespread. One of the interesting results is that curvilinear impact of experience of SMEs managers and innovative activities exist. This finding may indicate about different nature of entrepreneurship of the first and next generations. Moreover, given the recent short history of emerging private sector in post-communist economies managers with longer experience may represent the "old cohort" of entrepreneurs and may be reluctant to innovation. However, our study does not research making entrepreneurship and generational difference of managers in the in post-communist economies context. Therefore, further studies for understanding this relationship may provide with more detailed insights of this relationship.

Another interesting result is that innovation propensity of SMEs may have different pattern by sectors of the economy and depending on the foreign participation. Growing demand in some sectors may drive growth of the enterprises, but that factor may not be enough for inducing firms for the innovation. However, in perspectives growing competitive environment, foreign participation and export oriented activities of SMEs may create conditions for their higher propensity to innovate. Our results do not provide with enough evidence on the fundamental role of financial resources for innovativeness of firms. However, different study focusing on this particular topic is needed.

These findings have several policy implications. Following these results, it can be suggested that government policy towards increasing competitive environment and openness of economies are fundamental for innovation of firms. Competition forces firms to innovate in order to survive, while openness of the economy provides with exporting opportunities and participation of the foreign capital in ownership structure of firms. Especially the latter factor may significantly reduce costs of innovation through more rapid technological transformation from abroad. Concentration of the most SMEs in capital city shows that more active government support of SMEs in other regions of a country, would lead more balanced intraregional development of these economies, which in the long run is conducive to the sustainable economic development.

\section{References}

- $\quad$ Aidis, 2003. "Officially despised yet tolerated: open-air markets and entrepreneurship in post-socialist countries", Post-Communist Economies, 15(3), pp.461-473.

- Akulava, 2015. “Gender and Innovativeness of the Enterprise: the Case of Transition”, Belarusian Economic Research and Outreach Center (BEROC), No. 31

- De Mel, McKenzie, \& Woodruff, 2009. "Innovative firms or innovative owners? Determinants of innovation in micro, small, and medium enterprises. Determinants of Innovation in Micro, Small, and Medium Enterprises", World Bank Policy Research Working Paper Series

- Ehrenberger, Koudelkova, \& Strielkowski, 2015. "Factors influencing innovation in small and medium enterprises in the Czech Republic", Periodica Polytechnica, Social and Management Sciences, 23(2), p.73.

- Ionica, 2013. "The Impact of Innovation in Romanian Small and Medium-Sized Enterprises on Economic Growth Development”, Journal of Knowledge Management, Economics and Information Technology, 3(6), pp. 409-422 
- Iradian, 2007., "Rapid Growth in Transition Economies: Panel Regression Approach", IMF Working Paper, No 07/170

- Landesmann, Leitner, \& Stehrer, 2016. “Changing Patterns in M\&E-Investment-Based Innovation Strategies in CESEE and FSU Countries”, Working Paper, The Vienna Institute for International Economic Studies, No. 123

- $\quad$ Love, \& Roper, 2015. "SME innovation, exporting and growth: A review of existing evidence", International Small Business Journal, 33(1), p. 28-48.

- McIntyre, 2001. "The role of small and medium enterprises in transition: Growth and entrepreneurship", UNU World Institute for Development Economics Research (UNU/WIDER).

- Norek, \& Arenhardt, 2015. "Comparative Analysis of Innovative Activity Determinants in Selected SME's in Brazil and Poland. Results of Empirical Researches", Equilibrium. Quarterly Journal of Economics and Economic Policy, 10(2), pp.157-181.

- Norek, \& Costa, (2015). "Evaluation of the impact of the innovative potential of the companies from the SMEs sector on the efficiency of innovative actions. Suggestion of the evaluation method", International Journal of Management Science \& Technology Information, (16).

- Pikkemaat, 2008. "Innovation in small and medium-sized tourism enterprises in Tyrol, Austria", The International Journal of Entrepreneurship and Innovation, 9(3), pp.187-197.

- Podmetina, 2011. "Innovation and Internationalisation in Russian Companies: Challenges and Opportunities for Open Innovation and Cooperation", Doctoral Dissertation, Lappeenranta University of Technology.

- Radas, \& Božić, 2009. "The antecedents of SME innovativeness in an emerging transition economy”, Technovation, 29(6), pp.438-450.

- Rogers, 2004. "Networks, firm size and innovation”, Small business economics, 22(2), pp.141-153.

- Romijn, \& Albaladejo, 2002. "Determinants of innovation capability in small electronics and software firms in southeast England", Research Policy, 31(7), pp.1053-1067.

- Scase, 1997. "The role of small businesses in the economic transformation of Eastern Europe: real but relatively unimportant?”, International Small Business Journal, 16(1), pp.13-21.

- Skuras, Tsegenidi, \& Tsekouras, 2008. "Product innovation and the decision to invest in fixed capital assets: Evidence from an SME survey in six European Union member states”, Research Policy, 37(10), pp.17781789.

- Smallbone, \& Welter, 2001. "The role of government in SME development in transition economies", International Small Business Journal, 19(4), pp.63-77.

- Szczepanska-Woszczyna, K., 2014. "Determinants of Innovation Activities in Small and Medium-Sized Enterprises in Poland", Journal of Advanced Research in Management (JARM), (2 (10)), pp.65-73.

- Turriago-Hoyos, Thoene, Bernal-Torres, and Alfonso-Lizarazo, 2015. Product Innovation, Research and Development and Technology Acquisition: A Case Study of the Industrial Sector in Colombia. Institutions and Economies, 7(2).

- Wooldridge, 2002. Econometric analysis of cross section and panel data //Cambridge, MA: MIT Press. 2002. 


\section{Appendix}

\begin{tabular}{|c|c|c|}
\hline \multicolumn{3}{|r|}{ Dependent variables: } \\
\hline \multicolumn{2}{|c|}{ Innovation in goods services } & $1=$ if firm has introduced new products or services \\
\hline \multicolumn{2}{|c|}{ Innovation in process } & $1=$ if firm has introduced new methods of production of goods and services \\
\hline \multicolumn{2}{|c|}{ Innovation in organization } & 1=if firm has introduced or improved organizational practices \\
\hline \multicolumn{2}{|c|}{ Innovation in marketing } & $1=$ if firm has introduced new marketing methods \\
\hline \multirow{2}{*}{\multicolumn{2}{|c|}{ Innovation in activity }} & $1=$ if firm has has spend on research and development \\
\hline & & Explanatory variables: \\
\hline \multicolumn{3}{|c|}{ CEO characteristics: } \\
\hline \multicolumn{2}{|c|}{ Gender } & $1=\mathrm{CEO}$ is female $; 0=\mathrm{CEO}$ is male \\
\hline \multicolumn{2}{|c|}{ Experience } & The years of experience of CEO (age-education years) \\
\hline \multicolumn{2}{|c|}{ Squared experience } & Squared years of experience of CEO \\
\hline \multicolumn{3}{|c|}{ Firm characteristics: } \\
\hline \multicolumn{2}{|c|}{ Years since establishment } & Years since establishment of the firm (2013-establishment year) \\
\hline \multicolumn{2}{|c|}{ Squared years since establishment } & Squared years since establishment \\
\hline \multicolumn{3}{|c|}{ Firm structure: } \\
\hline- & Shares traded & $1=$ Shareholding company with shares traded in the stock market \\
\hline- & Non-traded shares & $1=$ Shareholding company with non-traded shares or shares traded privately \\
\hline- & Other legal status & $1=$ Sole proprietorship, partnership, limited partnership or other legal status \\
\hline \multicolumn{2}{|c|}{ Foreign participation } & $1=$ firm has private foreign individuals or companies as owner \\
\hline \multicolumn{3}{|c|}{ Industry type } \\
\hline- & Food manufacturing & $1=$ firm is in food manufacturing sector \\
\hline- & Construction services & $1=$ firm is in construction sector \\
\hline- & Retail services & $1=$ firm is in retail services sector \\
\hline- & Other industry & $1=$ firm is in other industry sectors \\
\hline \multicolumn{2}{|c|}{ Location } & $1=$ firm is located in capital city \\
\hline \multicolumn{2}{|c|}{ Exporter firm } & $1=$ firm is exporting its products \\
\hline \multicolumn{2}{|c|}{ Training } & $1=$ firm makes formal training program for permanent employees \\
\hline \multicolumn{2}{|c|}{ Competition } & $1=$ firm competes with unregistered firms \\
\hline \multicolumn{2}{|l|}{ Credit } & $1=$ firm currently has a line of credit from a financial institution \\
\hline
\end{tabular}

Table A. 1. Explanation of Variables 


\begin{tabular}{|c|c|c|c|c|c|}
\hline & \multicolumn{5}{|c|}{ Innovation in } \\
\hline & Goods/Services & Process & Organization & Marketing & Activity \\
\hline \multicolumn{6}{|l|}{ CEO characteristics: } \\
\hline Gender $($ female $=1)$ & $\begin{array}{c}0.0370 \\
(0.1176)\end{array}$ & $\begin{array}{c}0.1932 \\
(0.1250)\end{array}$ & $\begin{array}{l}0.1410 \\
(0.1207)\end{array}$ & $\begin{array}{l}-0.0557 \\
(0.1164)\end{array}$ & $\begin{array}{c}0.0633 \\
(0.1787)\end{array}$ \\
\hline Experience & $\begin{array}{l}0.0268 * * \\
(0.0132)\end{array}$ & $\begin{array}{c}0.0453 * * \\
(0.0165)\end{array}$ & $\begin{array}{c}0.0483 * * \\
(0.0164)\end{array}$ & $\begin{array}{c}0.0439 * * \\
(0.0141)\end{array}$ & $\begin{array}{l}0.0493^{*} \\
(0.0268)\end{array}$ \\
\hline Experience $^{2}$ & $\begin{array}{c}-0.0007 * * \\
(0.0003)\end{array}$ & $\begin{array}{c}-0.0010^{* *} \\
(0.0004)\end{array}$ & $\begin{array}{c}-0.0012 * * \\
(0.0004)\end{array}$ & $\begin{array}{c}-0.0011 * * \\
(0.0004)\end{array}$ & $\begin{array}{l}-0.0011 * \\
(0.0007)\end{array}$ \\
\hline \multicolumn{6}{|l|}{ Firm characteristics: } \\
\hline Years since establishment & $\begin{array}{c}0.0268 * * \\
(0.0119)\end{array}$ & $\begin{array}{c}0.0278 * * \\
(0.0126)\end{array}$ & $\begin{array}{c}0.0524 * * * \\
(0.0150)\end{array}$ & $\begin{array}{l}0.0254 * \\
(0.0141)\end{array}$ & $\begin{array}{c}0.0214 \\
(0.0189)\end{array}$ \\
\hline Years since establishment $^{2}$ & $\begin{array}{l}-0.0003 \\
(0.0002)\end{array}$ & $\begin{array}{l}-0.0004 * \\
(0.0002)\end{array}$ & $\begin{array}{c}-0.0008^{* *} \\
(0.0004)\end{array}$ & $\begin{array}{l}-0.0005^{*} \\
(0.0004)\end{array}$ & $\begin{array}{l}-0.0002 \\
(0.0004)\end{array}$ \\
\hline \multicolumn{6}{|c|}{ Firm structure (reference group: Other legal status ) } \\
\hline Shares traded & $\begin{array}{r}2.2810^{* *} \\
(0.7744)\end{array}$ & $\begin{array}{l}1.5464 * * \\
(0.6540)\end{array}$ & $\begin{array}{l}1.1745 \\
(0.7498)\end{array}$ & $\begin{array}{l}1.4588 * * \\
(0.7166)\end{array}$ & $\begin{array}{l}1.7274 * * \\
(0.8395)\end{array}$ \\
\hline - $\quad$ Non-traded shares & $\begin{array}{l}0.4455^{* *} \\
(0.2139)\end{array}$ & $\begin{array}{l}0.2340 \\
(0.2066)\end{array}$ & $\begin{array}{c}0.1958 \\
(0.2073)\end{array}$ & $\begin{array}{l}0.5944 * * \\
(0.2192)\end{array}$ & $\begin{array}{c}0.6853 \\
(0.4319)\end{array}$ \\
\hline Foreign participation & $\begin{array}{l}0.3166^{* *} \\
(0.1608)\end{array}$ & $\begin{array}{c}0.0324 \\
(0.1835)\end{array}$ & $\begin{array}{l}0.4802 * * \\
(0.1651)\end{array}$ & $\begin{array}{l}0.4503 * * \\
(0.1589)\end{array}$ & $\begin{array}{l}0.4645^{* *} \\
(0.2009)\end{array}$ \\
\hline \multicolumn{6}{|c|}{ Industry type (reference group: other industries) } \\
\hline Food manufacturing & $\begin{array}{c}0.5248 * * * \\
(0.1519)\end{array}$ & $\begin{array}{c}0.5606 * * * \\
(0.1528)\end{array}$ & $\begin{array}{c}0.1744 \\
(0.1711)\end{array}$ & $\begin{array}{c}0.2429 \\
(0.1569)\end{array}$ & $\begin{array}{c}0.2102 \\
(0.2249)\end{array}$ \\
\hline Construction services & $\begin{array}{l}-0.3437^{*} \\
(0.1855)\end{array}$ & $\begin{array}{l}-0.3572 * \\
(0.1947)\end{array}$ & $\begin{array}{l}-0.3787^{*} \\
(0.1948)\end{array}$ & $\begin{array}{l}-0.3446^{*} \\
(0.1782)\end{array}$ & $\begin{array}{l}-0.5959^{*} \\
(0.3434)\end{array}$ \\
\hline - $\quad$ Retail services & $\begin{array}{l}-0.0430 \\
(0.1099)\end{array}$ & $\begin{array}{c}-0.3786 * * \\
(0.1264)\end{array}$ & $\begin{array}{l}0.0495 \\
(0.1135)\end{array}$ & $\begin{array}{l}0.1381 \\
(0.1064)\end{array}$ & $\begin{array}{l}-0.1285 \\
(0.1687)\end{array}$ \\
\hline Location & $\begin{array}{c}0.2243 * * \\
(0.0987)\end{array}$ & $\begin{array}{l}-0.1402 \\
(0.1081)\end{array}$ & $\begin{array}{c}0.0218 \\
(0.1038)\end{array}$ & $\begin{array}{c}0.1076 \\
(0.0962)\end{array}$ & $\begin{array}{l}-0.0816 \\
(0.1499)\end{array}$ \\
\hline Exporter firm & $\begin{array}{c}0.3942 * * \\
(0.1372)\end{array}$ & $\begin{array}{c}0.1280 \\
(0.1543)\end{array}$ & $\begin{array}{l}0.2542 * \\
(0.1477)\end{array}$ & $\begin{array}{c}0.3968^{* *} \\
(0.1396)\end{array}$ & $\begin{array}{l}0.4085 * * \\
(0.1842)\end{array}$ \\
\hline Training & $\begin{array}{c}0.6447 * * * \\
(0.1008)\end{array}$ & $\begin{array}{c}0.5066 * * * \\
(0.1097)\end{array}$ & $\begin{array}{c}0.8661 * * * \\
(0.1029)\end{array}$ & $\begin{array}{c}0.7631 * * * \\
(0.0980)\end{array}$ & $\begin{array}{l}0.6541 * * * \\
(0.1465)\end{array}$ \\
\hline Competition & $\begin{array}{l}0.2011 * * \\
(0.0987)\end{array}$ & $\begin{array}{c}0.2553 * * \\
(0.1056)\end{array}$ & $\begin{array}{c}0.1433 \\
(0.1034)\end{array}$ & $\begin{array}{c}0.1583 \\
(0.0973)\end{array}$ & $\begin{array}{l}0.2472 * \\
(0.1453)\end{array}$ \\
\hline Credit & $\begin{array}{c}0.0523 \\
(0.1032)\end{array}$ & $\begin{array}{l}0.1991 * \\
(0.1089)\end{array}$ & $\begin{array}{c}-0.1986^{*} \\
(0.1118)\end{array}$ & $\begin{array}{l}-0.0466 \\
(0.1021)\end{array}$ & $\begin{array}{l}-0.0570 \\
(0.1570)\end{array}$ \\
\hline Constant & $\begin{array}{c}-2.204 * * * \\
(0.2498) \\
\end{array}$ & $\begin{array}{c}-2.135^{* * *} \\
(0.2532) \\
\end{array}$ & $\begin{array}{c}-2.2754 * * * \\
(0.2562)\end{array}$ & $\begin{array}{c}-2.283 * * * \\
(0.2564) \\
\end{array}$ & $\begin{array}{l}-3.25 * * * \\
(0.5041) \\
\end{array}$ \\
\hline Observation & 1074 & 1074 & 1074 & 1074 & 1074 \\
\hline LR chi2 & $127.99 * * *$ & $101.97 * * *$ & $158.90 * * *$ & $151.37 * * *$ & $68.13 * * *$ \\
\hline Log likelihood & -458.1209 & -383.2939 & -412.4187 & -479.5480 & -182.952 \\
\hline $\mathrm{R}^{2}$ & 0.1226 & 0.1174 & 0.1615 & 0.1363 & 0.1570 \\
\hline
\end{tabular}

Table A. 2. Estimation Results for Probit Models (Coefficient Estimates) 


\title{
The Economy-Politics Reflections of Turkey-Russian Relationship During Syria Crisis
}

\author{
Ph.D. Candidate Mehmet Nazım Uygur (Şırnak University, Turkey)
}

\begin{abstract}
The Syrian civil war began with the demonstrations that took place on 15 March 2011 and spread to over the all Middle East Countries in April 2011. This conflict in Syria affected Turkish-Russia relations negatively. On the other hand, the conflict has also caused crises among other countries. The most prominent example of this is the jet crisis between Turkey and Russia. In November 2015, the Russian jet which was in violation of the border was dropped by the Turkish Air Force. For this purpose, the study aims to reveal the source of the Syrian internal conflict, the positions of the sides involved in this process and the effects of political and economic sanctions in Russia-Turkey on economic relations between the two countries. In the study, firstly the elements that triggered the emergence of the Syrian crisis were identified and then the political actions that the sides put forward were briefly examined. The economic-political relations between Turkey and Russia, which have been developing since the 1990s, have come to an end with the antagonism created by the Syrian civil war and jet crisis. The economic embargo that Russia and Turkey have imposed on each other has caused serious reductions in foreign trade volume between the two countries and in the number of tourists from Russia to Turkey.
\end{abstract}

\section{Introduction}

In 1916, the Entente powers Britain and France secretly signed the Sykes-Picot Agreement, named after a British politician and a French diplomat, which provided for the division of the Levant region between the two powers in the event of a defeat of the Ottoman Empire. After the victorious conclusion of World War 1, the Entente powers dismantled the Ottoman Empire and the Levant became divided into a southern British and a northern French zone of influence. This division of the Bilad al-Sham produced four new territorial entities of Palestine, Jordan, Lebanon, and Syria. The former two entities of Palestine and Jordan - now separated by a British imposed borderline along the Jordan River - were handed over to Britain as League of Nations Mandates. In turn, France received two League of Nations Mandates for Lebanon and Syria (Dostal, 2014). Toward the end of the 1920s the leadership of the Syrian independence movement had coalesced into a political organization known as the National Bloc. With its headquarters in Damascus, the Bloc had active branches in Syria's other major urban centers: Aleppo, Hama and Homs (Khoury, 1987). In May 1945 demonstration began in Damascus and Aleppo and Ferench bombed Damascus with heavy weapons. However, after British Prime Minister Winston Churcill's threat of sending forces to Damascus, General De Gaulle declared a cease-fire and until April 15, 1946, all French forces abandoned Syrian lands (Okur, 2009).

Following independence in 1946, years of instability culminated in the Ba'ath Party's coup d'état of 1964. In 1970, the minister of defense General Hafez al-Assad seized power and declared himself Prime Minister, then President in 1971. In consolidating power, he reinvented the face of Syrian politics and the Ba'ath party, dividing the state apparatus between different communities and centering power about him and his family. He specifically favored his own Alawite community, initially giving them control over the state military and intelligence apparatus, and later favoring them for high-level government positions. At the same time, he gave overarching powers to the presidency; the president was given veto over all government decisions and multiparty elections for the presidency did not take place; al-Assad would conduct referenda confirming him as president. When he died in 2000, his son Bashar al-Assad took power (Mariwala, 2014). Assad ruled Syria softly until the Arab Spring erupted.

The Arab Spring actually began in the middle of winter. On 17 December 2010 a municipal inspector in the provincial Tunisian city of Sidi Bouzid confiscated vegetable seller Mohammed Bouazizi's cart because he did not have a vending license (Rosiny, 2012). So, the demonstration began in many countries of Middle East. After the authoritarian regimes in Tunisia and Egypt had already been toppled, the Syrian town of Deraa witnessed an uprising in March 2011. While protesters initially claimed reforms, demands rapidly escalated into a call for the resignation of President Bashar Al-Assad. The increasingly violent response of the Syrian Army, deployed by the president to suppress the initially peaceful protests, fueled the anger (Rozsa, 2012). The Syria civil war became a war of attorneyship that characterized by the inclusion of international forces and the presence of many associations in the field.

Assads's regime had bred discontent among the Sunni majority; although Sunnis occupied several high-level posts in the government, they were considered secondary to the elite Alawite minority. Therefore, one of the most prominent groups to oppose the Assads initially were the Muslim Brotherhood, creating a Sunni opposition from the beginning, and arguably giving scope for radical elements like Al-Qaeda and the Islamic State in Iraq and Syria (ISIS) to become prominent forces in the future. The revolutions of the Arab Spring convinced this opposition that there was scope for reform in Syria; resulting in the war we see today (Mariwala, 2014). In this conflict, there were many sides both global and local. 
In the region it can be seen four type of non-state actor which include in conflict. Dekel, Boms and Winter (2016: 24-27) clears these actors as follows:

- Radical actors espousing Salafi jihadist ideology, such as the Islamic State and the Nusra Front.

- Groups with liberal and pro-Western orientations, such as the National Coalition for Syrian Revolutionary and Opposition Forces and the Free Syrian Army.

- Local actors representing particular geographical, tribal, ethnic, religious, and sectarian interests, such as groups operating in southern Syria and the Kurdish and Druze minorities.

- Opponents of the regime that operate independently, mostly in exile, and that enjoy a variable degree of influence on Syrian public opinion in general and Syrian opposition circles in particular.
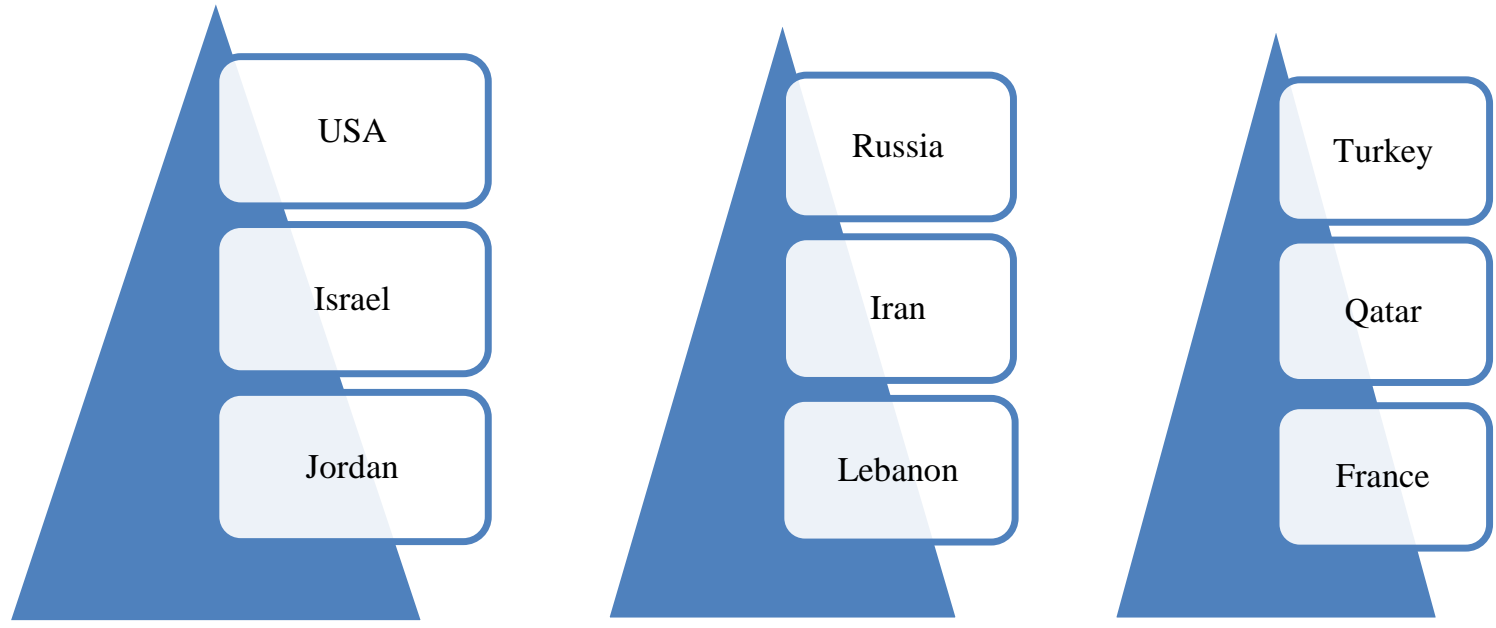

Figure 1: The Parties of the Civil War on the International Scale

In the region, Syria has few supporters: Iran and the Lebanese Hezbollah remain close to President Assad and Tehran even provided, in addition to military aid, economic support to ease the impact of sanctions (Rozsa, 2012).

Russia especially after the international intervention it had to support in Lebanon, which caused Russia was outside the equation, concentrated more on Syria. It saw Syria as a way to enter the Middle East equation again and strongly. Russia, which historically has military presence in the Syrian territory, has tried to keep this existence by arbitration and to retain Syria as a proxy for the gate to the Mediterranean. Russia has established a diplomatic shield for the Assad regime through its position in the United Nations Security Council and has prevented the UNSC from making decisions that are sanctioned against the regime. Combined with this decisive attitude of Russia, the Obama administration's highly undecided and unconvincing attitude towards Syria, Russia has positioned it as the most powerful international actor in diplomatic space. In addition to diplomatic shield, Russia continued its arms shipments to the Syrian regime (Ulutas, Kanat and Acun, 2015). By contrast, Saudi Arabia and Qatar support arming the opposition. Turkey initially reacted with caution but then grew weary of the violence in its own backyard that was leading scores of refugees to flee into the Anatolian peninsula (Rozsa, 2012). Two of these forces, Turkey and Russia's policies in Syria are important. Because of the Syrian policies of two country carried out, relations have come to the point of breaking. The aim of this study is to examine the political and economic implication of these two countries, which have strong foreign trade relations, due to Syrian politics and the consequences of reciprocal sanction.

\section{Russia's and Turkey's Policy on Syria and Jet Crisis}

When the influence of the Arab spring jumped to Syria the main aim of Russia's policy is to defend Assad regime. Saving the regime is not, however, an end in itself. Rather, it is a means of self-assertion and another step toward the goal of becoming a global superpower, this time in the Arab world (Bishara, 2015). The decisive reason for Moscow's protective role for the Assad regime is that Syria is of strategic geopolitical significance for Russia. Since the end of the Soviet Union, Moscow's position in the Middle East and North Africa has diminished greatly. Of the former allies, only Damascus remains politically close to Russia. Although Moscow's position in the Middle East was clearly weakened after the collapse of the Soviet Union, it remains a key external player in relation to Syria. On the one hand, due to decades long close ties in political, economic and military relations, it is one of few countries to have bilateral leverage on the Assad regime at its disposal (Klein, 2012).

Azmi Bishara (2015) summarized the aims of the Russian intervention as follows:

- First, in the short term the military intervention aims to prop up the regime for long enough for Moscow to achieve its desired diplomatic breakthrough. Russia's military presence, then, is meant to shore up the conflict 
and sting out media coverage meant for international consumption. For this reason, Russia's definition of terrorism has remained flexible and subservient to its other major objectives.

- Second, this intervention is a message for Turkey and the West alike. In my opinion, preparations for direct military intervention went into effect when action began to set up a safe haven in northern Syria and rebels received backing to take control of Idlib governorate. Turkey and allies of the Syrian people were very slow to achieve anything on this level, leaving space for Russian intervention.

- Third, amidst the current turmoil Russia is strengthening its diplomatic positions, making it difficult to take any decision on Syria without Moscow's express participation. In fact, ever since the intervention in Syria diplomatic contacts between the West and Russia have increased, particularly after a cooling of relations, and efforts to impose a Western embargo following the intervention in Ukraine and the annexation of the Crimean Peninsula.

After the WW -II Turkey Russia relations developments would continue in the first period of the Justice and Development Party. When the reform demands and protests started in Syria in 2011 as a part of the revolts in the whole region, first reaction of the Assad regime was to take control over the opposition. That time Turkey's response change (Boyraz). Turkey's Syria policy can be summarized at fife stage.

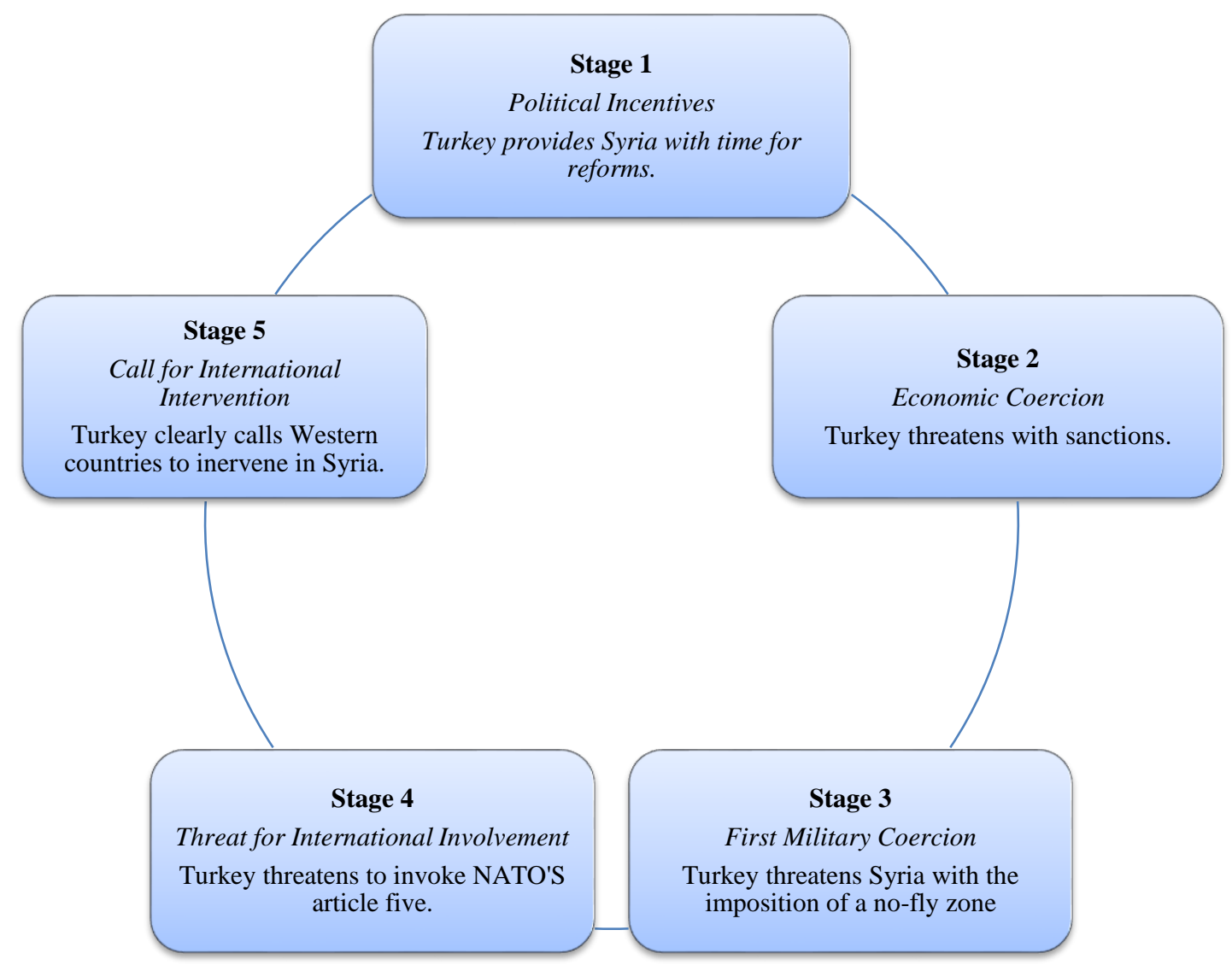

Figure 2: Stages in Turkey's Response to the Syrian Crisis Source: Tziarras, 2012.

Altunisik (2016) analyzed the involved of Turkey to Syria Crisis at four stage. The first stage ended in the autumn of 2011, when the regime opted for an open crackdown of the opposition and Turkey left its policy of dialogue with the Syrian regime. On 21 September, 2011 Turkey formally cut all its ties with the Syrian regime. In this first stage of the conflict the AKP government clearly overestimated its influence over the Assad regime. It soon became obvious that the regime would not follow Turkey's advice to reform and expand the regime to include opposition figures, but rather decided to crackdown on the opposition. On the other hand, the AKP government, eager to be part of the developments in Syria, became actively involved in organizing the opposition. The second stage was about economic coercion. By the winter of 2011, eight months after the uprisings and violence began in Syria, Prime Minister Erdoğan called upon Assad to step down for the first time and Foreign Minister Davutoğlu threatened Syria with economic sanctions (Tziarras, 2012). At the third stage Turkey's international allies began to revise their policy of supporting the opposition in Syria. For instance, in December 2013 the US and the UK suspended 'non-lethal' support for rebels in northern Syria. Thus, Turkey became increasingly alone in its insistence on supporting the opposition (Altunış1k, 2016). During the fourth and last stage, after incidents of shootings on the Turkish-Syrian border threatened camped refugees, Erdoğan referred both to the need for the UN to take action over Syria as well as the possibility of Turkey invoking article five of NATO's charter. Following 
the downing of a Turkish jet by the Syrian armed forces the situation worsened. In this light, Ahmet Davutoğlu took a decisive step to deal with the Syrian problem and openly called upon major powers such as the U.S. and the UK, "to intervene in Syria to prevent a looming humanitarian 'disaster' that...threatens the lives of millions of internally displaced people and refugees as winter approaches and could soon ignite a region-wide conflagration (Tziarras, 2012).

It is also worth to note that such approach of Turkey also brought tension in the relations between other important actors supporting Assad regime in Syria: namely Russia and Iran. That tension caused a deep crisis in TurkishRussian relations since Turkey's downing of the Russian jet. After that Russia's air campaign also helped cut oil smuggling routes to Turkey and established a de facto no-fly zone for Turkey over Syria (Stepanova, 2016). Mutual economic sanctions have begun on both sides of the result of all these political controversies.

\section{The Economic Impact of the Distinction in Syria Policy}

After a Russian warplane violated Turkish airspace near the Syrian border on 24 November 2015, Turkey downed the Russian plane in line with the military rules of engagement. This development seems to have significant implications for the two countries' bilateral economic relations. Russia has announced a package of economic sanctions against Turkey. The sanctions are listed as follows:

- Restricting imports of some Turkish agricultural products as of January 1, 2016,

- Terminating chartered flights from Russia to Turkey,

- Calling for Russian tourism companies to stop selling vacation packages that include a stay in Turkey,

- Restricting Russian companies to hire Turkish staff starting January 1, 2016 and

- $\quad$ Suspending the visa-free arrangement for Turkish nationals from January 1, 2016.

Figure 3, The number of tourists coming from Russia to Turkey in 2000-2016 are given. The number of tourists have a downward trend from 2014 to 2015. But with the effect of jet crisis and sanctions sharp decline after 2015.

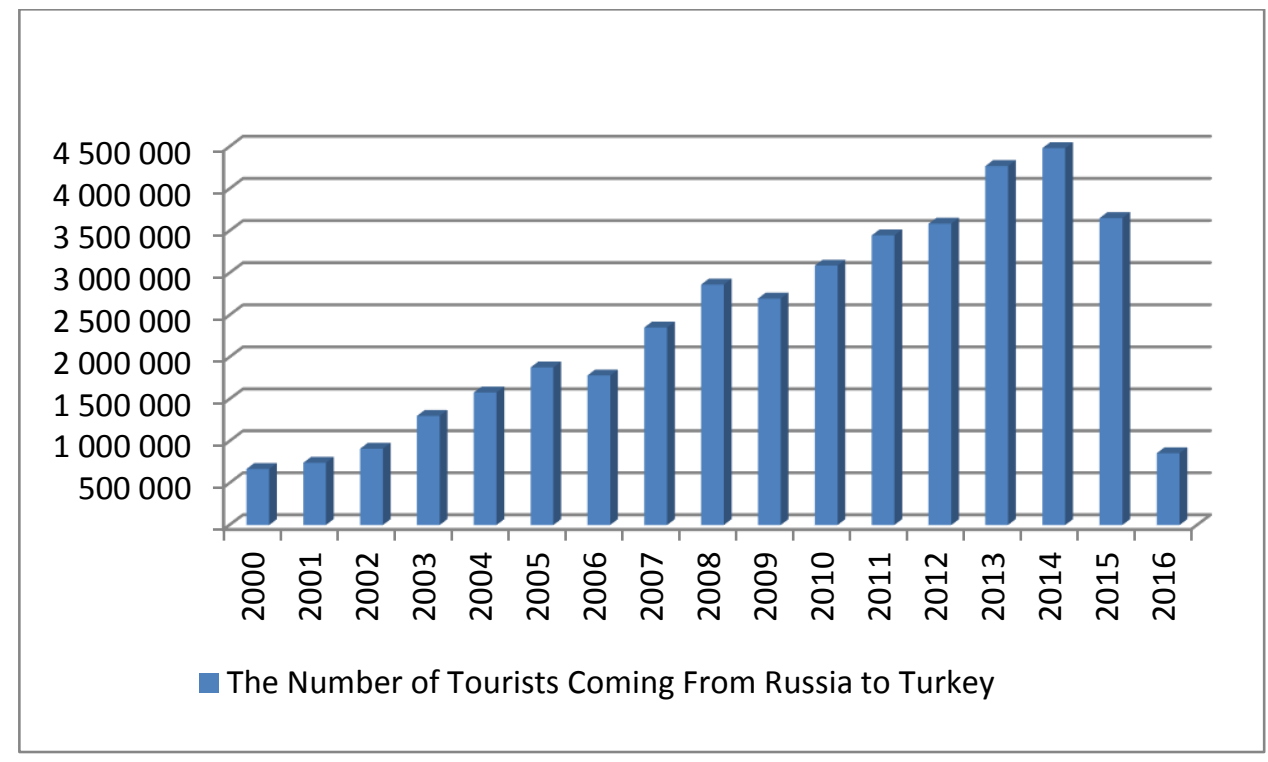

Figure 3: The Number of Tourists Coming from Russia to Turkey Source: TUIK, 2017

Turkey, which has experienced significant developments in the tourism sector in recent years, has become the 6th most attracted tourists in the world by 2014. Russian citizens who prefer Turkey have an important part in the total number of tourists. Russia ranks 2 nd in the ranking of the countries that send the most tourists to Turkey with 4.5 million in 2014 and 3.6 million in 2015 . However, with the deepening of the jet crisis, the number of tourists coming from Russia in 2016 was 8th place with 866 thousand.

In Figure 4, Turkey's imports and exports with Russia in 2005-2012 are given in dollar terms. Imports between Turkey and Russia have a downward trend from 2008 to 2014, but a sharp decline after 2014. While the highest level of export figures was in 2008, the export figures decreased to 15 million dollars at 2016. 


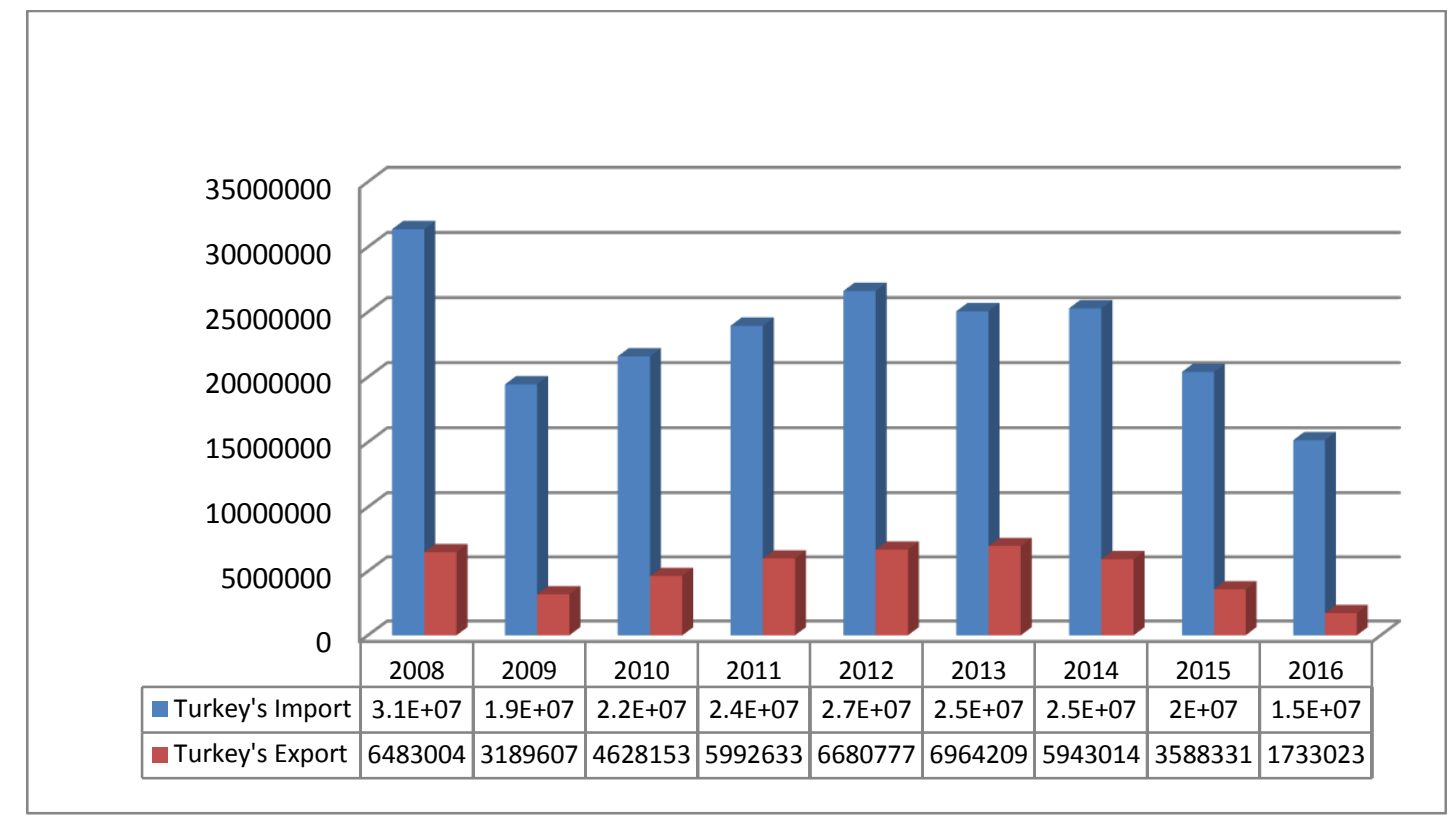

Figure 4: Foreign Trade Between Russia and Turkey Source: TUIK, 2017

When the relationship between imports and exports of Russia and Turkey is evaluated in the light of the numerical information given above, we can see how this process affects the foreign trade of Turkey. Exports to Russia in 2011 were 5,992,633 while imports were 23,952,914. When the data of 2011 and 2016 compared, it can be seen a decrease of about $50 \%$ in foreign trade. Especially after the jet crisis, the trade relations between the two countries are declining until 2016. Import figures fell to 15 million in 2016, while export figures declined by 1.7 million.

Russia is the largest foreign market for Turkish food, fruit and vegetable produce. Textile forms and automotive industry the other primary sector for Turkish exports to Russia. The decline in Turkey's exports has particularly affected these sectors. While the export figures for agriculture and livestock sector were 936 million in 2011, this figure decreased to 400 million in 2016. Similarly, there has been a sharp decline in the automotive and textile sectors. 2011 textile export figures are 1 billion 438 million while automotive figures are 843 million. By 2016, textile exports decreased by 181 million and automotive by 174 million.

\section{Evaluation and Conclusion}

Since the beginning of the Arabian spring, the Middle East has been dragged into a chaotic environment. Today, this crisis has become a global problem. This crisis, which transcends borders, has become the domain of strength of many countries in the geography where it started. Turkey did not remain unresponsive to the civil war in Syria. Turkey tried to force the Assad regime into reforms at various stages, but defended the necessity of a solution without Assad as a final. The Assad regime, one of Russia's best allies in the Middle East, has resisted it. These developments caused crises between Russia and Turkey. Russia defended the Assad regime using its role in the UN. On the other hand, Turkey defended the necessity of international intervention. With the fall of the Russian jet, the two sides were in harsh statements, and relations have come to a breaking point. So that Putin declared a series of sanction.

The Jet Crisis is a point of inflection in the history of Russia and Turkey, especially in the economic sector. The shooting down of the Russian warplane had negative consequences for Turkey and the break of a long-term effort for fruitful relations. The impact in the sectors of trade, agriculture, tourism, energy, construction and textile has reached also neighboring regions. The foreign trade of the two countries has been severely damaged and the tourism sector has reached the lowest level in recent years. Turkey and Russia, which have very strong commercial relations in various sectors like given at above, experienced serious economic troubles due to the crisis. Turkey is one of the most important tourist destinations in the world. Russian citizens have an important part in the number of serious tourists coming to Turkey. The number of tourists coming from Russia has fallen seriously in this process. In such situation, it can be said that the Syrian crisis has a great negative effect on the Turkish-Russian economy.

After that weary process a moderate policy began between the two country. By 2017, Turkey and Russia are moving towards normalization. But strategic interests and the ongoing civil war in Syria have made the situation very complicated. There are now momentary positions in the region. In order for the parties to establish a healthy trade relationship, it is necessary to get out of a crisis in terms of the parties in Syria. 


\section{References}

- Altunisik, M., (2016), The Inflexibility of Turkey’s Policy in Syria, IMed. Mediterranian Yearbook,2016.

- Ar1, T., \& Pirinççi, F. (2010). 'Turkey's New Foreign Policy Towards the Middle East and The Perceptions in Syria and Lebanon". Gazi Akademik Bakış, 4(7).

- $\quad$ BiShara, A., (2015), Russian İntervention İn Syria Geostrategy İs Paramount, Arab Center for Research and Policy Studies, Arab Center for Research and Policy Sdudies. http://english.dohainstitute.org/file/get/89ef19ad-46dc-4a19-b5d2-21a0a6360422.pdf

- Boyraz, C., (2013), Crisis Of Turkish Foreign Policy In Syrian Issue: From Regional Leadership To Overall Disappointment, Research Paper,

- Dekel, U., Boms, N., \& Winter, O. (2015). ' Syria: New Map and New Actors: Challenges and Opportunities for Israel”. INSS Memoranda.

- Dostal, J. M. (2014), "Post-independence Syria and the Great Powers (1946-1958): How Western Power Politics Pushed the Country Toward the Soviet Union”, Annual Meeting of the Academic Council on the United Nations System, Kadir Has University, Istanbul.

- http://www.eisanet.org/bebruga/eisa/files/events/warsaw2013/Boyraz_Crisis\%20Of\%20Turkish\%20Foreign \%20Policy\%20In\%20Syrian\%20Issue.pdf

- Khoury, P. S. (1988). 'The Syrian independence movement and the growth of economic nationalism in Damascus". British Society for Middle Eastern Studies. Bulletin, 14(1), 25-36.

- Klein, M., (2012), Russia's Policy on Syria: On the Way to Isolation? Senior Associate, German Institute for International and Security Affairs. https://www.scpss.org/libs/spaw/uploads/files/Policy/03302012_Russia's_Policy_on_Syria_Klein.pdf

- Mariwala, A., (2014), The Syrian Civil War Regime of Bashar Al-Assad, Stanford Model United Nations Conference.

- Okur, M. A. (2009). ' 'Emperyalizmin Ortadoğu Tecrübesinden Bir Kesit: Suriye’de Fransız Mandası". Bilig, Klş, 48.

- Rosiny, S. (2012). "The Arab spring: Triggers, dynamics and prospects". GIGA Focus International Edition English, (01).

- Stepanova, E., (2016), Russia's Policy on Syria after the Start of Military Engagement, PONARS Eurasia Policy Memo No. 421

- $\quad$ Tziarras, Z. (2012). Turkey's Syria Problem: A Talking Timeline of Events. Turkish Policy Quarterly, 11(3).

- Ulutaş, U., Kanat, B. K., and others, (2015), Sınırları Aşan Kriz Suriye, Analysıs, SETA. http://file.setav.org/Files/Pdf/20150402160617_sinirlari-asan-kriz-suriye-pdf.pdf

- TUIK (2017). http://www.tuik.gov.tr/PreTablo.do?alt_id=1046 


\title{
The 36 Strategies of the Chinese: Can It Be a Eurasian Strategic Model in a Global Context?
}

\author{
Prof. Dr. İsmail Melih Baş (Beykent University, Turkey)
}

\begin{abstract}
Although the 36 Strategies are a summary of some of the war strategies used by the ancient Chinese warriors, over the years, these have been commonly cited and used by many Chinese businessmen. These strategies are grouped under six categories. Each category contains six strategies. The six categories in turn can be used in two types of situations. While the three categories are used in a winning situation; the other three are used in a disadvantageous situation. However, the application and usage of these strategies can be mingled in various combinations. The set of these strategies is a very good alternative to the western style of management for global strategic competition for the Eurasian companies. This seems right both theoretically and practically. After the collapse of globalism of the 20th century, we are on the threshold of a new model of globalization. In that sense, while developing a Eurasian strategic management style, these 36 strategies of the Chinese provide a very good source, parallel to the market domination of Chinese economy in the global economy.
\end{abstract}

\section{Introduction}

The changing world order or the changing global economy of the twenty-first century may be titled as Eurasian Era. Perhaps the discussion in last Davos Summit the criticisms about globalisation by the western side especially USA, while Xi Jinping (president of PRC) defends a new order of globalisation. BRICS or the acronyms alike related to the Asia are the buzzwords of the economic press and literature as anyone in the street knows. According to the GDP (Gross Domestic Product) based on PPP (Purchasing Power Parity) rating of the PRC (People's Republic of China) was the first, and the USA was the second in 2016, surprisingly! Once upon a time China was the interesting market and the production center with an advantage of cheap labour for the western countries. But recently PRC companies' acquisitions even in USA is rapidly increasing. Trumponomics is characterized with a concept of new nationalism as new protectionism. These discussions are very common in the field of macroeconomics and macropolitics.

But, international business management with an Asian perspective at micro level has not been broadly discussed neither in the domains of academia nor in professional practice. Besides verbal culture, professional books and textbooks titled with these words are yet remain to be just a few, e.g. the three books written by those different authors Charles W. Hill (Hill,2012) etc.

According to George Yip and Bruce McKern, the history-making development of the Chinese economy has entered a new phase. China is moving aggressively from a strategy of imitation to one of innovation. Driven both by domestic needs and by global ambition, China is establishing itself at the forefront of technological innovation. Western businesses need to prepare for a tidal wave of innovation from China that is about to hit Western markets, and Chinese businesses need to understand the critical importance of innovation in their future (Yip and McKern,2016).

At this point, there is a question that needs to be considered: What is the strategic management culture of those Asian companies which they can use in the business? There are a few studies on this subject like Musashi's Five Rings (Japan), the 36 Strategies (China) etc.

In this proceeding, the 36 Strategies will be introduced, if this set is sufficient to be used as a Eurasian style of strategic management.

A short history first; the 36 Strategies are the war strategies used by the ancient Chinese warriors. The name of the collection comes from the Book of Qi, in its seventh biographical volume, Biography of Wang Jingze. Wang was a general who had served Southern Qi since the first Emperor Gao of the dynasty. Wang used thirty-six with a reference to the I Ching where six is the number of Yin that shared many characteristics with the dark schemes involved in military strategy. As 36 is the square of six, it therefore acted as a metaphor for numerous strategies. It is known as the original hand-copied paperback discovered and put into print by a local Publisher in 1941. The 36 Strategems only came to public's attention after its review was published in the Chinese Communist Party's Guangming Daily newspaper on September 16, 1961. It was subsequently reprinted and distributed with growing popularity.

After years, these strategies have been handled as business strategies in the light of metaphoric business wars. Although some books have been printed since 1992, a number of books published annually has not exploded (see the list at the end of this study). In that sense Prof. Harro von Senger (Senger, 1995) is a top profile. He translated the 36 Strategies into German. He also wrote a book the 36 Strategies for Business (Senger,2005). Professor Dr. Wee Chow Hou (Singapore) is also one of the names which must be remembered in 'the 36 strategies and business' topic (Hou, 1998). 
Perhaps Alibaba (by Jack Magic) as a remarkable Chinese company which is changing the face of global business must be analyzed in the light of the 36 strategies as well as say the Tencent company (Ersiman,2015; Tse 2015; Yiğ McKern 2016).

\section{The 36 Strategies: A Short View with Explanations and Examples as Titles}

These strategies are grouped under six categories. Each category contains six strategies. The six categories in turn can be used in two types of situations. While the three categories are used in a winning situation; the other three categories are used in a disadvantageous situation. However, the application and usage of these strategies can be mingled in various combinations (Senger 1995, Senger 2005, Verstappen, 1999, Hou and Luh, 1998).

\section{The Strategies Used in Winning Situation}

\section{Advantageous Strategies}

These strategies are used in situations when related resources and time are to one's advantage. Detailed planning can be carried out, because of there is no need to rush. The six strategies in this category will be handled below one by one with some illustrations:

\subsection{Deceiving the Heavens to Cross the Sea (Man tain guo tai).}

Explanation: It means to create a false impression to distract the target and so achieve one's goal without his knowledge. This strategy Works on the assumption that people take extra precautions when faced with new or difficult situations, but tend to let their guards down in familiar situations. Every one expects a secret to be hidden, so if one conducts an important plan openly, it may not be noticed. As the saying goes, 'An open situation hides a dark secret'. This strategy requires that the target is not alerted to what might happen. So even if the scheme was uncovered, it would be too late for him to take counteraction (Senger 1995, Senger, 2005, Yip and Mc Kern, 2016; De Monte; 2013; Lan,2014, Cleary, 1992, Baş, 2007).:

Examples (Taylor, 2013; Tse, 2015; Yip and Mc Kern, 2016; De Monte; 2013; Lan, 2014).:

- Managing change:

People typically resist change, more so if they have been operating within their comfort zones or in a stable environment. To lure them out of their comfort zones, their defense mechanisms must be lowered through the use of non-threatening situations, and by introducing gradual changes. A good example of this is the effort put in by Singapore Telecoms in its privatization efforts. It began preparing its whole organization at least six years before the company was listed. Changes were introduced gradually so as to minimize any negative impact on the morale of the personnel. Their efforts paid off.

- $\quad$ Adoption of products and services:

This strategy applies to marketing too. A market may be resistant to new and radical products, especially if these are high-ticket items or items that are difficult to operate. To overcome resistance, marketers may use one or a combination of the following methods:

Free trial period with Money-back guarantee / Free or low-cost lessons on usage of the products /services (For example golf clubs in Asia typically conduct low-cost lessons to lure potential participants) / Allowing the product to be bought piecemeal / Selling a basic unit with options for upgrading or add-ons / Special offers - packages (The sale of foreign properties by western companies to the more affluent Asian consumers provides a good example).

- $\quad$ Product / Service Bundling and Tying Contracts

Pricing the whole bundle lower than sum of the individual prices of each product /service, the marketer makes a product or service more attractive. As products get more sophisticated, they are sold more and more as bundles. After paying so much for the complete product bundle, many consumers do not fully use all the benefits or features offered.

Bundling is widely used by Japanese manufacturers of cars, consumer electronics, watches and appliances.

- $\quad$ Financing for expansion

Occasionally, a company may need funds for expansion. Funds can be obtained by borrowing from the bank or from shareholders. In order to entice shareholders, the company may price the rights below the market price of share so as to make them very attractive. The company may be able to meet its financial needs while making shareholders happy.

\section{- $\quad$ Management of services}

This strategy resolves round the use of distractions to lure the target from one's main concerns. These nonthreatening distractions can take many forms, and are created to appeal to the desire for creature comforts.

The way in which Singapore airlines (SIA) strives to create an enjoyable experience for its passengers is fascinating. SIA's success has led other airlines, especially those in Asia to adopt similar strategies. 


\subsection{Besieging Wei to Save Zhao.}

Explanation: Instead of attacking a cohort of strong enemies, one should try to diffuse the concentration and attack each enemy separately. Instead of a head-on attack, one should wait for the best opportunity when the enemy is at his weakest point to launch an ambush (Senger 1995, Senger, 2005, Yip and Mc Kern, 2016; De Monte; 2013; Lan,2014, Cleary, 1992, Baş, 2007).

Examples (Taylor, 2013; Tse, 2015; Yip and Mc Kern, 2016; De Monte; 2013; Lan,2014).:

- Changing the point(s) of contact

- Choosing areas ignored by competitors

- Creating one's own advantages

\subsection{Killing with a Borrowed Knife.}

Explanation: This strategy works on the premise that while the enemy has clarified its stand, the position of the alliance is still equivocal. In this situation, the best way is to entice the alliance to destroy the enemy on one's behalf. This is an adaptation of the logic in harm theory: harm the bottom to benefit the top (Senger 1995, Senger, 2005, Yip and Mc Kern, 2016; De Monte; 2013; Lan,2014, Cleary, 1992, Baş, 2007).

Examples (Taylor, 2013; Tse, 2015; Yip and Mc Kern, 2016; De Monte; 2013; Lan,2014).:

- $\quad$ Operating through surrogates

- $\quad$ Relying on foreign investments to stimulate growth

- $\quad$ Licensing, franchising and joint-ventures

\subsection{Conserving Energy While the Enemy Tires Himself Out.}

Explanation: One does not need to always make a direct attack to subdue the enemy. Sometimes, one can use the theory of 'using the mild (or weak) to control the strong to delay and exhaust the enemy and strengthen one's position (Senger 1995, Senger, 2005, Yip and Mc Kern, 2016; De Monte; 2013; Lan,2014, Cleary, 1992, Baş, 2007).

Examples (Taylor, 2013; Tse, 2015; Yip and Mc Kern, 2016; De Monte; 2013; Lan,2014).:

- $\quad$ Strike when the timing is right

- $\quad$ Capitalizing on falling prices

- $\quad$ Entering foreign markets

\subsection{Looting A House on Fire.}

Explanation: When the enemy is in a big crisis, that is the time to destroy him. This will enable the strong to conquer the weak (Senger 1995, Senger, 2005, Yip and Mc Kern, 2016; De Monte; 2013; Lan,2014, Cleary, 1992, Baş, 2007).

Examples (Taylor, 2013; Tse, 2015; Yip and Mc Kern, 2016; De Monte; 2013; Lan,2014).:

- Vulnerability created by internal squabbles

- $\quad$ Exploiting chaotic business situations

- Currency and stock market raiders

\subsection{Making A Feint to The East but Hitting Out in The West.}

Explanation: When the enemy is in a state of confusion, like grass growing wild, he will not be able to clearly assess a situation. Neither will he able to cope with sudden and unexpected changes in circumstances. A good strategist defeats the enemy by taking advantage of him when he has lost control (Senger 1995, Senger, 2005, Yip and Mc Kern, 2016; De Monte; 2013; Lan,2014, Cleary, 1992, Baş, 2007).

Examples (Taylor, 2013; Tse, 2015; Yip and Mc Kern, 2016; De Monte; 2013; Lan,2014).:

- Concealing one's true intentions

\section{Advantageous Strategies Offensive Strategies}

Like advantageous strategies, these strategies also are used in situations when time and resources are not constraining factors. However, these strategies seek to gain victory through direct attack.

\subsection{Hitting the Grass to Startle the Snake}

Explanation: An attempt should be made to clarify suspicious circumstances before making the next move. To repeatedly probe and investigate a suspicious matter is the best way to discover the enemy's plot (Senger 1995, Senger, 2005, Yip and Mc Kern, 2016; De Monte; 2013; Lan,2014, Cleary, 1992, Baş, 2007).

Examples (Taylor, 2013; Tse, 2015; Yip and Mc Kern, 2016; De Monte; 2013; Lan,2014).:

- The art of smiling in winning business 


\subsection{Hitting the Grass to Startle the Snake Borrowing a Corpse to Resurrect a Soul}

Explanation: A person that is of use may be more difficult to take advantage of our assistance. A less useful (or weaker) person may request our assistance. When I am able to use the weak one to my advantage, I am giving him my strength at his request (Senger 1995, Senger, 2005, Yip and Mc Kern, 2016; De Monte; 2013; Lan,2014, Cleary, 1992, Baş, 2007).

Examples (Taylor, 2013; Tse, 2015; Yip and Mc Kern, 2016; De Monte; 2013; Lan,2014).

- Operating under the umbrella of others

- Going overseas

- $\quad$ Extending product life cycle

- $\quad$ Sell-outs, mergers and acquisitions

\subsection{Luring A Tiger from Its Lair in The Mountain}

Explanation: Trap the enemy when the natural elements are to his disadvantage. Then create false impressions to lure him out. A direct attack may prove dangerous. It is far better to lure the enemy out of his comfort and destroy him (Senger 1995, Senger, 2005, Yip and Mc Kern, 2016; De Monte; 2013; Lan,2014, Cleary, 1992, Baş, 2007).

Examples (Taylor, 2013; Tse, 2015; Yip and Mc Kern, 2016; De Monte; 2013; Lan,2014).

- Choosing the site of negotiation

- $\quad$ Luring important foreign investments

- $\quad$ Attracting foreign talents

\subsection{Releasing the Enemy to Recapture Him Later}

Explanation: Sometimes, it is not advisable to drive the enemy into a corner as he may retaliate. The objective is not to destroy him completely as there may be good reason to keep him alive. It is better to let the enemy escape and tire himself out while pursuing closely behind. The enemy will be soon be exhausted and will lose his fighting spirit. The best time to capture him is when he has fallen apart, without bloodshed. In business war, sheer physical dominance does not ensure victory. More important is the need to win the enemy's hearts. In this way, one can secure total surrender and loyalty (Senger 1995, Senger, 2005, Yip and Mc Kern, 2016; De Monte; 2013; Lan,2014, Cleary, 1992, Baş, 2007).

Examples (Taylor, 2013; Tse, 2015; Yip and Mc Kern, 2016; De Monte; 2013; Lan,2014).:

- $\quad$ Exhaust the resources of the competitors

- Use of varied strategies

- Winning the heart takes time

\subsection{Tossing Out a Brick to Get a Jade}

Explanation: Use a decoy to entice the enemy, get him muddled and he will fall into the trap (Senger 1995, Senger, 2005, Yip and Mc Kern, 2016; De Monte; 2013; Lan,2014, Cleary, 1992, Baş, 2007).

Examples (Taylor, 2013; Tse, 2015; Yip and Mc Kern, 2016; De Monte; 2013; Lan,2014).

- Use of baits in business

- Investment incentives

- Auctions for charity

\subsection{Disband the Bandits by Arresting Their Leader}

Explanation: If the enemy's power-base is destroyed in an attack and its leader is captured, the whole organization will break down. Just like a dragon from the sea wanting to stage a war on land, it will face severe difficulties (Senger 1995, Senger, 2005, Yip and Mc Kern, 2016; De Monte; 2013; Lan,2014, Cleary, 1992, Baş, 2007).

Examples (Taylor, 2013; Tse, 2015; Yip and Mc Kern, 2016; De Monte; 2013; Lan,2014).: Corporate head hunting / Head hunting for academics and researchers / Getting to the root of the problem

\section{Deception Strategies}

Deception is commonly used in war to create advantageous for oneself, and to handicap the enemy. Such strategies are designed to mislead the enemy.

\subsection{Replace Superior Beams and Pillars with Inferior Ones}

Explanation: Find a chance to change the enemy's battle array frequently, and take away its main source of power. Wait till it is unable to cope with the situation before attacking it. Pillars and beams are important structures in a building. The quality pf the pillars and beams determine the stability of the building. The arrangement of a 
company's physical and human assets has parallel significance (Senger 1995, Senger, 2005, Yip and Mc Kern, 2016; De Monte; 2013; Lan,2014, Cleary, 1992, Baş, 2007).

Examples (Taylor, 2013; Tse, 2015; Yip and Mc Kern, 2016; De Monte; 2013; Lan,2014).: Short changing the consumer / Burden of proof on the consumers / Pirated goods / Making consumers aware of replacements

\subsection{Pointing at The Mulbery But Scolding the Locust Tree.}

Explanation: A stronger force can use warning or admonishment to control a lesser force. A proper display of power will receive support and the use of a decisive method will demand reverence. This strategy is similar to the Chinese saying, 'Kill the chicken to scare the monkeys' (Senger 1995, Senger, 2005, Yip and Mc Kern, 2016; De Monte; 2013; Lan,2014, Cleary, 1992, Baş, 2007).

Examples (Taylor, 2013; Tse, 2015; Yip and Mc Kern, 2016; De Monte; 2013; Lan,2014).:

Severe punishments on offenders / As a warning to others / Being in a position of strength

\subsection{Pretending to Be Insane but Remaining Smart.}

Explanation: It is better for one to pretend that he knows nothing and take no action rather than to pretend that he knows everything and rush into a situation hastily. One should prepare his forces in the dark and not let others know of his secret and wait for an opportunity to strike, just as lightning and thunder wait to strike in winter. To use this strategy, one has to perfect the art of deception because it takes discipline to foreign weakness when one is really strong. It requires self-imposed humility, something which few can muster. Yet when one is able to achieve such a skill, he is able even to 'pretend to be a pig to prey on the tiger' (Senger 1995, Senger, 2005, Yip and Mc Kern, 2016; De Monte; 2013; Lan,2014, Cleary, 1992, Baş, 2007).

Examples (Taylor, 2013; Tse, 2015; Yip and Mc Kern, 2016; De Monte; 2013; Lan,2014).:

Business tycoons and top executives / Self-enforced humility / Fakery and illusions

\subsection{Remove the Ladder After the Enemy Ascends to The Roof.}

Explanation: Pretend to expose one's weakness to lure the enemy into one's trap. When the enemy is within one's control, cut off its supply routes and eventually destroy him. This strategy warns against taking a small advantage when one can go for the killing as that may result in one's destruction. The key to this strategy is the 'ladder'. This ladder acts as the bait to arouse the curiosity of the enemy. Once the enemy is up on the roof, the ladder is removed, trapping the enemy (Senger 1995, Senger, 2005, Yip and Mc Kern, 2016; De Monte; 2013; Lan,2014, Cleary, 1992, Baş, 2007).

Examples (Taylor, 2013; Tse, 2015; Yip and Mc Kern, 2016; De Monte; 2013; Lan,2014).:

Creating advantages for oneself / Incremental trapping

\subsection{Deck the Tree with Flowers}

Explanation: Borrow a setting to boost one's image. Although one may be on the weak side, one's battle array can appear strong (Senger 1995, Senger, 2005, Yip and Mc Kern, 2016; De Monte; 2013; Lan,2014, Cleary, 1992, Baş, 2007).

Examples (Taylor, 2013; Tse, 2015; Yip and Mc Kern, 2016; De Monte; 2013; Lan,2014).: The art of packaging and branding / Packaging of services / Private residential properties

\subsection{The Guest Takes Over as Host.}

Explanation: Try to put a foot in when there is a crack and eventually, control the brain of the enemy (Senger 1995, Senger, 2005, Yip and Mc Kern, 2016; De Monte; 2013; Lan,2014, Cleary, 1992, Baş, 2007).

Examples (Taylor, 2013; Tse, 2015; Yip and Mc Kern, 2016; De Monte; 2013; Lan,2014).:

Foot-in-the-door approach / Involving labour in management / Profit-sharing and stock ownership schemes

\section{The Strategies Used in Disadvantageous Situations}

\section{Opportunistic Strategies}

These strategies thrive on situations where vulnerabilities can be exploited. The idea is to capitalize on all opportunities so s to gain the advantage.

\subsection{Creating Something Out of Nothing}

Explanation: The strategy advocates using a false front, not to deceive the enemy totally, but to make what is false seem real. If one can use false fronts to conceal the truth, the enemy will have a misconception about a situation. That is the time to launch an attack (Senger 1995, Senger, 2005, Yip and Mc Kern, 2016; De Monte; 2013; Lan,2014, Cleary, 1992, Baş, 2007).

Examples (Taylor, 2013; Tse, 2015; Yip and Mc Kern, 2016; De Monte; 2013; Lan,2014).: 
Bidding of favorite / popular numbers / Advertising and sales promotion / Targeting and positioning / Share buyback schemes

\subsection{Secret Escape Through Chen Cang.}

Explanation: The gist of this strategy is to hit the enemy at the point where he is least prepared, that is, his back. In battle, one should pretend to expose one's movement, then launch a surprise attack at the enemy's weakest point, when he is ill-prepared to defend himself (Senger 1995, Senger, 2005, Yip and Mc Kern, 2016; De Monte; 2013; Lan,2014, Cleary, 1992, Baş, 2007).

Examples (Taylor, 2013; Tse, 2015; Yip and Mc Kern, 2016; De Monte; 2013; Lan,2014).:

Contingency planning in business / Use of shell and project-based companies

\subsection{Observing the Fire from The Other Side of The River.}

Explanation: When there are disorder and internal struggles amongst the enemy's forces, one should wait till the enemy's situation turns bad before attacking. Arguments and unhappiness in the enemy's camp, weaken the enemy's strength. This is when one should seize the opportunity and reap the benefits with minimal effort (Senger 1995, Senger, 2005, Yip and Mc Kern, 2016; De Monte; 2013; Lan,2014, Cleary, 1992, Baş, 2007).:

Examples (Taylor, 2013; Tse, 2015; Yip and Mc Kern, 2016; De Monte; 2013; Lan,2014).:

Squabbles within family business / Exploiting conflicts in international business / Staying out of uncertain situations

\subsection{A Dagger Sheathed in a Smile.}

Explanation: One should win the trust of one's enemy so as to disarm him while preparing to launch an ambush. The enemy must not be alerted to the changes that have taken place and the ambush must only be made when one is well-prepared. This fulfils the saying, 'What appears to be weak (or soft) on the outside may actually be strong (or hard) on the inside (Senger 1995, Senger, 2005, Yip and Mc Kern, 2016; De Monte; 2013; Lan,2014, Cleary, 1992, Baş, 2007).

Examples (Taylor, 2013; Tse, 2015; Yip and Mc Kern, 2016; De Monte; 2013; Lan,2014).:

The art of smiling in winning business

\subsection{The Plum Dies in Place of the Peach.}

Explanation: Where losses are inevitable, one should be willing to make sacrifices to gain victory. In warfare, this strategy is applied when the enemy has the upper hand. To turn the tables around and achieve victory, one needs to make sacrifices. It may be necessary to sacrifice a few battles to achieve the ultimate objective of winning the war (Senger 1995, Senger, 2005, Yip and Mc Kern, 2016; De Monte; 2013; Lan,2014, Cleary, 1992, Baş, 2007).

Examples (Taylor, 2013; Tse, 2015; Yip and Mc Kern, 2016; De Monte; 2013; Lan,2014).

Prioritizing the use of limited resources / Focusing on the right markets / Sacrifices needed

\subsection{Stealing A Goat Along the Way.}

Explanation: No matter how small a hole may be; one should use it to one's advantage. No matter how small the advantage is, one should obtain it for his benefit. One should take advantage of the enemy's small weakness for one's small gain. This is similar to the analogy that by gathering crumbs of bread, one can still get a full meal. However, if one is only interested in the full loaf, there may be none at all (Senger 1995, Senger, 2005, Yip and Mc Kern, 2016; De Monte; 2013; Lan,2014, Cleary, 1992, Baş, 2007).

Examples (Taylor, 2013; Tse, 2015; Yip and Mc Kern, 2016; De Monte; 2013; Lan,2014).:

Seizing every business opportunity / Growing a business / Taking on more than one can chew / Opportunities are not limited by situations

\section{Confusion Strategies}

These strategies aim to confuse a pursuing enemy to throw him off his guard. In this way, valuable time can be gained in making one's escape.

\subsection{Pulling Out the Firewood from Beneath the Cauldron.}

Explanation: When faced with a strong opponent, direct confrontation may not be advisable. It may be better to use tactics to destroy his morale (Senger 1995, Senger, 2005, Yip and Mc Kern, 2016; De Monte; 2013; Lan,2014, Cleary, 1992, Baş, 2007).

Examples (Taylor, 2013; Tse, 2015; Yip and Mc Kern, 2016; De Monte; 2013; Lan,2014).:

Removing key corporate lieutenants / Major accounts and anchor tenants / Avoid head-on competition 


\subsection{Catching A Fish in Troubled Waters}

Explanation: The literal meaning of the strategy is to take advantage of the troubled or muddy situation in which the fish is unable to see clearly and has restricted movement. In such circumstances, catching the fish by hand may be good enough. This strategy is similar to the Chinese saying, 'Throwing a rock down a well after the enemy has fallen in'. When the enemy is in the well, his movements are restricted, thus it is easy to destroy him (Senger 1995, Senger, 2005, Yip and Mc Kern, 2016; De Monte; 2013; Lan,2014, Cleary, 1992, Baş, 2007).

Examples (Taylor, 2013; Tse, 2015; Yip and Mc Kern, 2016; De Monte; 2013; Lan,2014).:

Avoiding confusion / Exploiting chaotic situations

\subsection{Catching A Fish in Troubled Waters Making an Unnoticed Escape Like a Golden Cicada Shedding Its} Skin.

Explanation: By preserving the original formation of an army and the strength of its force, one will not arouse the suspicion of the allies. And the enemy will not be roused to action. However, in actual fact, one secretly diverting his main strength to attack the enemy from another direction (Senger 1995, Senger, 2005, Yip and Mc Kern, 2016; De Monte; 2013; Lan,2014, Cleary, 1992, Baş, 2007).

Examples (Taylor, 2013; Tse, 2015; Yip and Mc Kern, 2016; De Monte; 2013; Lan,2014).:

Contingency planning / Withdrawal of expatriate professionals / Divesting / Reducing investment \& equity / Taking a company to public listing

\subsection{Shutting the Doors to Catch the Thief.}

Explanation: The best way to destroy a weak enemy is to first have him surrounded, like shutting off all routes of escape, when catching a thief (Senger 1995, Senger, 2005, Yip and Mc Kern, 2016; De Monte; 2013; Lan,2014, Cleary, 1992, Baş, 2007).

Examples (Taylor, 2013; Tse, 2015; Yip and Mc Kern, 2016; De Monte; 2013; Lan,2014).:

Handling weaker products and brands / Exploiting the advantage of size / Zero-sum outcome

\subsection{Befriend the Far and Attack the Near.}

Explanation: Sometimes, because of geographical constraints, it is more beneficial to attack a nearby enemy than to attack another far away. If the situation permits, form a temporary alliance with a distant enemy to destroy the enemy nearby (Senger 1995, Senger, 2005, Yip and Mc Kern, 2016; De Monte; 2013; Lan,2014, Cleary, 1992 , Baş, 2007).

Examples (Taylor, 2013; Tse, 2015; Yip and Mc Kern, 2016; De Monte; 2013; Lan,2014).:

Strategic alliance with distant partners / International trade and investment / Franchising and licensing

\subsection{Borrow A Passage to Attack Guo.}

Explanation: A smaller state situated between the enemy and oneself should be given immediate support if the enemy threatens to control it. In this way, one will earn the trust of the smaller state and may eventually exert one's influence over the latter. Mere words without action will not win the trust of a small force in a precarious situation (Senger 1995, Senger, 2005, Yip and Mc Kern, 2016; De Monte; 2013; Lan,2014, Cleary, 1992, Baş, 2007).

Examples (Taylor, 2013; Tse, 2015; Yip and Mc Kern, 2016; De Monte; 2013; Lan,2014).:

Marketing under other companies' brands / Backward / Forward integration and piggybacking / Diversifying through acquisitions / Listing companies on foreign stock exchange

\section{Desperate Strategies}

In a desperate situation, one may have to resort to unconventional and unorthodox methods and means. As such, some of these strategies can be quite dramatic and tragic. However, when used appropriately, such strategies can be very effective.

\subsection{Beauty Scheme.}

Explanation: With regards to an enemy with strong troops, one should aim to control its general. Against an intelligent enemy general, one should plot to dampen his morale. Once the general's fighting spirit is quenched, the army will be weakened. Therefore, one should try to hit the enemy at its weaknesses while conserving one's energy (Senger 1995, Senger, 2005, Yip and Mc Kern, 2016; De Monte; 2013; Lan,2014, Cleary, 1992, Baş, 2007).

Examples (Taylor, 2013; Tse, 2015; Yip and Mc Kern, 2016; De Monte; 2013; Lan,2014).:

Good looks are the assets / Reality in business / Importance of training and grooming

\subsection{Empty City Scheme.}

Explanation: There is no fixed method for deploying an army. It may sometimes be better to deliberately display its weakness, to confuse the enemy and make the latter abandon the attack for fear of trickery. In a situation where 
the enemy is strong and when one is weak, proper use of this strategy can appear extraordinary (Senger 1995, Senger, 2005, Yip and Mc Kern, 2016; De Monte; 2013; Lan,2014, Cleary, 1992, Baş, 2007).

Examples (Taylor, 2013; Tse, 2015; Yip and Mc Kern, 2016; De Monte; 2013; Lan,2014).:

A high-risk strategy / Putting up a brave front / Use of bogus companies and swindling syndicates

\subsection{Double Agent Ploy.}

Explanation: When the enemy lays traps, set a trap within his traps to create internal chaos. When one secures assistance from within the enemy's ranks, one will not lose the battle. The literal meaning of the strategy is to use the enemy's spy to counter spy on the enemy (Senger 1995, Senger, 2005, Yip and Mc Kern, 2016; De Monte; 2013; Lan,2014, Cleary, 1992, Baş, 2007).

Examples (Taylor, 2013; Tse, 2015; Yip and Mc Kern, 2016; De Monte; 2013; Lan,2014).:

Industrial and commercial espionage / Consultants, research companies \& agents / Protecting the business

\subsection{Self-Injury Scheme.}

Explanation: No one would intentionally harm himself. Therefore, if someone is hurt, others would believe that he has been injured by another. Pretense will thus gain the enemy's trust and sow discord among enemy members. This is similar to playing with an innocent child (Senger 1995, Senger, 2005, Yip and Mc Kern, 2016; De Monte; 2013; Lan,2014, Cleary, 1992, Baş, 2007).

Examples (Taylor, 2013; Tse, 2015; Yip and Mc Kern, 2016; De Monte; 2013; Lan,2014).:

Price discounts and sales promotion / Overcoming short-term difficulties / Cutting losses and gaining market share

\subsection{A Series of Interconnected Ploys.}

Explanation: If the enemy has a strong and powerful army, a head-on confrontation is not advisable. Instead, one should utilize a few connected strategies to decrease the enemy's power. With a good leadership and careful planning, it will be easy to win the battle as if heaven is on one's side (Senger 1995, Senger, 2005, Yip and Mc Kern, 2016; De Monte; 2013; Lan,2014, Cleary, 1992, Baş, 2007).

Examples (Taylor, 2013; Tse, 2015; Yip and Mc Kern, 2016; De Monte; 2013; Lan,2014).:

Corporate and marketing strategies (using a combination of different strategies) / Multiple strategies in business (The case of Kia Motors) / Innovate and create advantages

\subsection{Escape - The Best Scheme.}

Explanation: In a situation where the enemy is obviously stronger, total retreat may be the best option. This strategy advocates retreating as a means to plan for the next attack (Senger 1995, Senger, 2005, Yip and Mc Kern, 2016; De Monte; 2013; Lan,2014, Cleary, 1992, Baş, 2007).

Examples (Taylor, 2013; Tse, 2015; Yip and Mc Kern, 2016; De Monte; 2013; Lan,2014).: Doing business in a corrupt environment / Operating in unfamiliar markets / Knowing when to quit

\section{The Question: Can It Be a Eurasian Strategic Model in a Global Context?}

This question seems very rational, if we consider that we are in the Eurasian Age. If it is so, a second level analysis appears: what are the factors which effect it.

\subsection{Supporting Factors}

a. Eurasian memetics (cultural genetics); b. Rising new-nationalism; c. New protectionism; d. Falling capitalism and the values related; e. Uprising of BRICS but specially China in economic competition field; $f$. Confucius Institutes affiliated with Ministry of Education of PRC; f. Others (Senger 1995, Senger, 2005, Yip and Mc Kern, 2016; De Monte; 2013; Lan,2014, Cleary, 1992, Baş, 2007).

\subsection{Inhibiting Factors}

a. Wrong habits in training in the universities (adopting only westernized strategic thinking, strategic management - westernization as globalisatorship). The 36 strategies are not included in top list Strategic Management textbooks in Turkish and in English as well. There is a Porterization (Michael Porter as a guru from Harvard University) trend; $b$. Cultural resistance (memetics?) to socialist countries including PRC (People's Republic of China) as a result of cold war mentality and 'the end of history - Fukuyama' false effect in politics; c. The golden era of capitalism (1945 + approx. three decades) and the socio-economic hallo effect of this on business strategic management style; d. Weakness of cultural relation efforts by PRC in that sense with the developing countries; e. The censorship in the management literature in the capitalist countries especially The USA (Harvard University etc.), United Kingdom (London School of Economics-LSE, London Business School-LBS etc.); d. Others (Senger 1995, Senger, 2005, Yip and Mc Kern, 2016; De Monte; 2013; Lan,2014, Cleary, 1992, Baş, 2007). 


\section{Recommendations (To Do List)}

\subsection{Academic Field}

Symposiums: International Business Strategic Management with an Asian perspective (why not?); publications, works like textbooks (not anything in Turkish yet), articles; researches works: thesis, professional researches supported by the institutions, e.g. Studies on Alibaba, Tencent etc. in the light of the 36 Strategies; consultancy works: university-industry joint projects (Senger 1995, Senger, 2005, Yip and Mc Kern, 2016; De Monte; 2013; Lan,2014, Cleary, 1992, Baş, 2007).

\subsection{Practice (Industry and Services)}

Adopting another course of action by our national companies SME's (Small and Medium Enterprises first): the 36 strategies by PRC or Five Rings by Japan instead of Portermania (as Obsessive-Compulsive Disorder); training and consultancy supports by the state especially SMBA (Small and Medium Business Administration - KOSGEB in Turkey) (Senger 1995, Senger, 2005, Yip and Mc Kern, 2016; De Monte; 2013; Lan,2014, Cleary, 1992, Baş, 2007).

\section{References}

- Baş, 2007. "Stratejik Yönetimde Asyagil Bir Araç: Çinlilerin 36 Strategemi”, Bilim ve Gelecek Dergisi, 44, p.22-30.

- Lan, 2014. The 36 Ancient Chinese Strategies for Modern Business, LAC International Press, Atlanta.

- Cleary, 1992. The Book of Leadership and Strategy: Lessons of the Chinese Masters, Shambhala.

- De Mente, 2013. The Chinese Way in Business: Secrets of Succesful Business Dealings in China, Tuttle Publishing, North Clarendon, VT.

- Ersiman, 2015. Alibaba's World, Macmillan, London.

- Hill, et. al, 2012. International Business an Asian Perspective, McGraw Hill, New York.

- Hou and Luh, 1998. The 36 Strategies of the Chinese, Singapore, Addison Wesley, Reading Massachusetts.

- Senger, 1993. The Book of Strategems, Penguin Books, (Translated into Turkish and published - titled as Savaş Hileleri - as 3 volumes by Anahtar Kitaplar Pub.Co. first in 2006, and in 2014 again).

- Senger, 2005. The 36 Stratagems for Business: Achieve Your Objectives Through Hidden and Unconventional Strategies and Tactics, Cyan Communications, (Translated into Turkish and published titled as Yöneticiler İçin 36 Strategem - by Anahtar Kitaplar Pub. Co. in 2007).

- Taylor, 2013. The Thirty-Six Stratagems: A Modern Interpretation of a Strategy Classic (Infinite Success), Infinite Ideas, Oxford.

- Tse, 2015. China Disruptors: How Alibaba, Xiaomi, Tencent, and Other Companies Changing the Rules of Business, Portfolio, London.

- Verstappen, 1999. The Thirty-six Strategies of Ancient China, China Books \& Periodicals, South San Francisco, CA.

- Yip and McKern, 2016. China's Next Strategic Advantage: From Imitation to Innovation, The MIT Press, Cambridge Massaschusetts. 


\title{
International Migration in Kyrgyzstan: Dynamics and Determinants
}

\author{
Dr. Burulcha Sulaimanova (Kyrgyz-Turkish Manas University, Kyrgyzstan) \\ Daniyar Jasoolov (Public Fund AVEP, Kyrgyzstan)
}

\begin{abstract}
After disintegration of Soviet Union, mass labor migration has been seen in newly independent states. This migration mostly caused by ethnic reasons, while after mid of 1990's the migration predominantly reasoned by economic issues, such as differences in economic growth, wage levels, social conditions and welfare in countries of destination and origin. Due to labor migration in Kyrgyzstan, which is count around the $10 \%$ percent of active population of the country, and high remittance inflow, which is more than $30 \%$ of Gross Domestic Product of Kyrgyzstan, it is important to investigate the factors causing this migration outflow. This paper aims to empirically present the determinants of international migration outflow from Kyrgyzstan, by using nationally representative "Life in Kyrgyzstan 2011" survey.
\end{abstract}

\section{Introduction}

Since 2000 the volume of economic reasoned migration has been rapidly rising in Kyrgyzstan. The number of labor migrants currently working abroad counts around 600 thousand people or about $10 \%$ of the population of Kyrgyzstan (Migration report of Kyrgyzstan, 2015). The migration directed mainly to the two countries: Russian Federation and Kazakhstan. With growing pattern of labor migration, the amount of remittances has grown as well. According to the World Bank since 2003 the money transfer to Kyrgyzstan increased by 28.7 times, from 78.16 million US \$ (4.07\% of GDP) in 2003 to 242.83 million US \$ in 2014. Kyrgyzstan with $30.3 \%$ share is the second largest country with respect to the remittance share to GDP in 2014, after Tajikistan (41.7 \%) (Migration and remittances factbook, 2016). The main remittance sending countries for 2005-2016 periods are the Russian federation (93.6\%) and Kazakhstan 1.4\%.

The large scale of migration outflow and remittances, making domestic economy of Kyrgyzstan dependent on external shocks, related with migration. The immigration law changes in Russian Federation in 2012, 2014 and 2015 have significantly influenced the migration outflow from Kyrgyzstan, consequently impacting the volume of remittance received. Particularly, the denouncement of bilateral agreement between the governments of Kyrgyzstan and Russian Federation, on obtaining the Russian citizenship on preferential terms in 2012, has reduced bymigration outflow by $71.5 \%$. While the economic crisis in Russian Federation and the rapid devaluation of Russian ruble in 2015 has significantly decreased the amount remittances received, thus havedecreased purchasing power of migrant families. These factors show the fact that Kyrgyzstan migration processes, thus demography and economy is dependent on the migrants host country's economic situation and immigration law changes. Here to make short and long term migration policies and strategies coping with migration outflow and its consequences, firstly the empirical assessment of migration determinants is required.

Given these reason this paper aims to firstly make analysis on dynamics of international migration in Kyrgyzstan and secondly empirically investigate the migration determinants and make policy recommendations. The paper is organized as follows: in the second section of the paper the dynamics of international migration and the remittances of Kyrgyzstan is analyzed; then in the third section the empirical literature on the migration determinants reviewed; in the fourth section the methodology of empirical analysis used is described; in the fifth and sixth sections the empirical estimation results and conclusions with recommendations are given.

\section{Migrational Processes in Kyrgyzstan}

Since the independence of Kyrgyzstan, the external migration of the country has faced several structural changes. While, in the literature, there is common division of these changes in to three periods (Мамырканов \& Элебаева, 2013), more detailed divisions can be found as well (Кумскова, 2015). In general, the first period of migration, starts from the the beginning of 1990 and lasts until the middle of the 1990's. In these period mostly Russian speaking population were leaving Kyrgyzstan to return to their homeland. While in the second period (1994-1998) the outflow of migration has decreased but still were mostly reasoned by political reasons, and characterized by motivation of migrants to get a permanent resettlement abroad (Мамырканов \& Элебаева, 2013; Кумскова, 2015). From 1999 a new wave of migration has started, were the movement abroad has temporary character, mostly conducted by labor migrants.

Taking into consideration that this paper aims to investigate the migration processes of Kyrgyzstan from the economics perspective, the external migration of country is divided into two main periods: the first period of migration is seen during the 1991-1998 years, while the second period starts from the 1999 and lasts to our days. The first migration period is mainly based on ethnic or political reasons. As shown in figure 1, the beginning of 
1990's accompanied by mass migration outflow, then this trend is decreasing; while the the number of those coming were declining steadily.

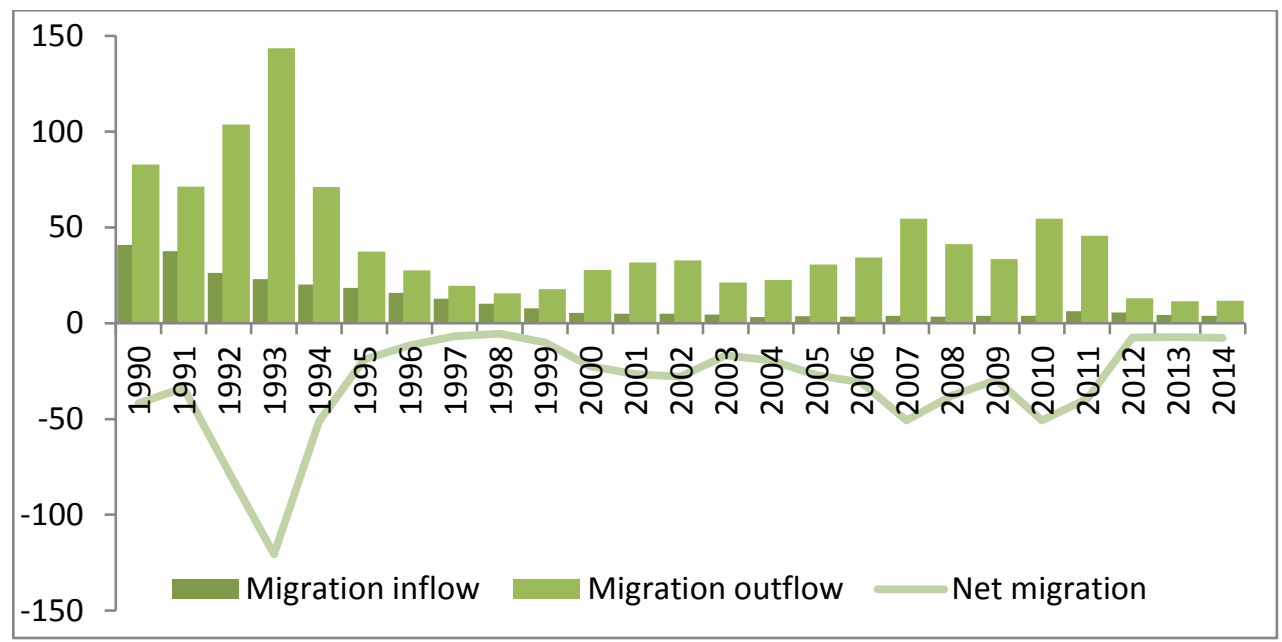

Figure 1. External Migration Dynamics of Kyrgyzstan, (Thousands, People) Source: NSCKR

This mass migration outflow of Russian-speaking population, caused not only by ethnic or historical reasons to return to their homeland, by those who were departed to Kyrgyzstan in 1940's and workers from other nationalities living in Kyrgyzstan; but also were accelerated with political reasons, such as clashes between ethnic groups in Osh in the summer of 1990 (Omarov \& Mahnovskiy, 1998), changes in laws of the state language, and establishment of ethnocentric government (Kumskov, 2015). Mass migration outflow were conducted mostly by family groups going abroad for permanent stay, thus had a negative impact on country's demographic situation.

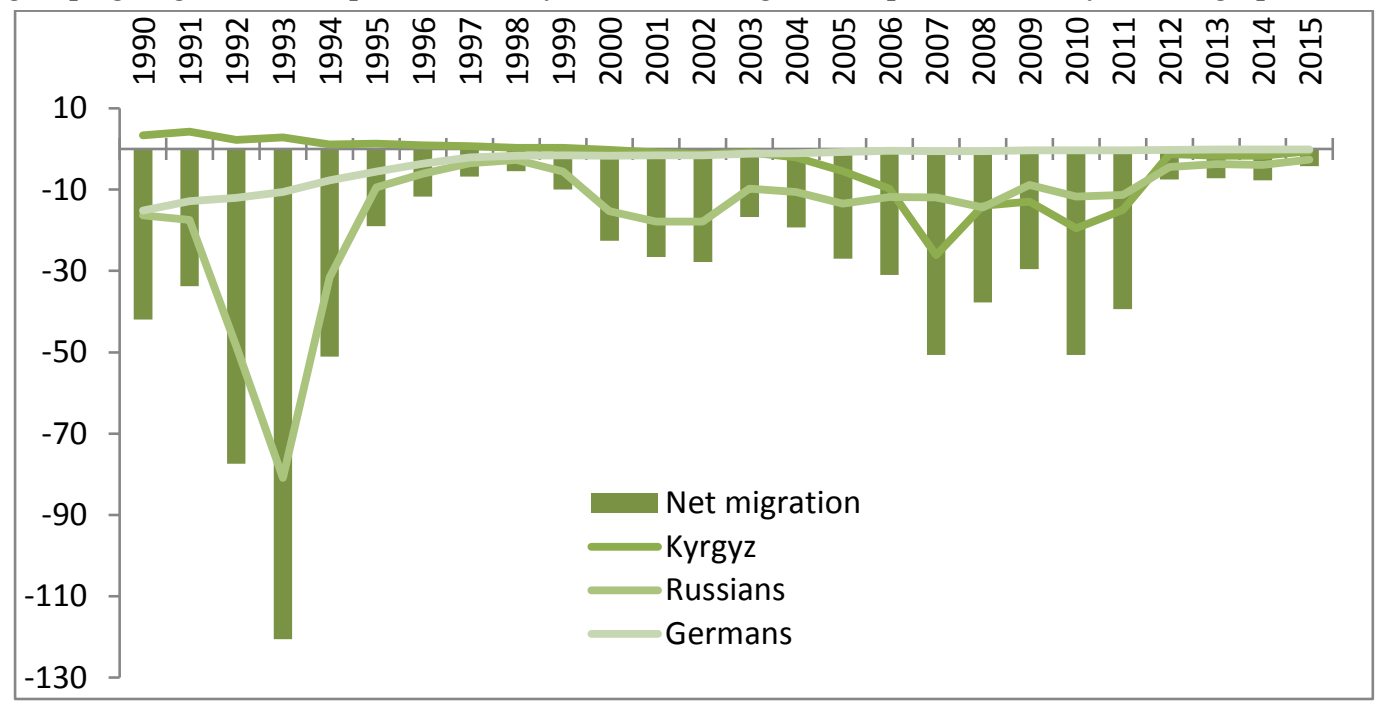

Figure 2. External Migration of the Population by Nationality, (Thousands, People) Source: NSCKR

Investigating the shares of those who have leaved Kyrgyzstan by nationalities, show that the Russian population (1991 - 44.92\%, in 1998. 50.80\%), Germans (1991 - 20.02\%. c. 1998 - 12.34\%) and Uzbeks (1991 - 10.29\%., $1998-7.12 \%$ ) have the biggest shares. During the 1991-1998 periods the destination countries of migrants can be divided into two groups: the CIS countries and the countries outside the CIS countries. Where the $81.7 \%$ of migration were directed to CIS countries, of which 59.56\% were made to Russian Federation; hose going abroad to went to the Russian Federation; the $18.3 \%$ of emigrants went to countries outside the CIS, and mostly to Germany. According to the National Statistics Committee of Kyrgyzstan (NSCKR) the average share of those who have migrated to non CIS countries count around the $22.24 \%$, of which $18.90 \%$ is directed to Germany, showing that those going outside of CIS are mostly Germans. Thus during the period of 1989-1995 the number of Germans living in Kyrgyzstan have ceased by $74.23 \%$ (Omarov \& Mahnovskiy, 1998). 


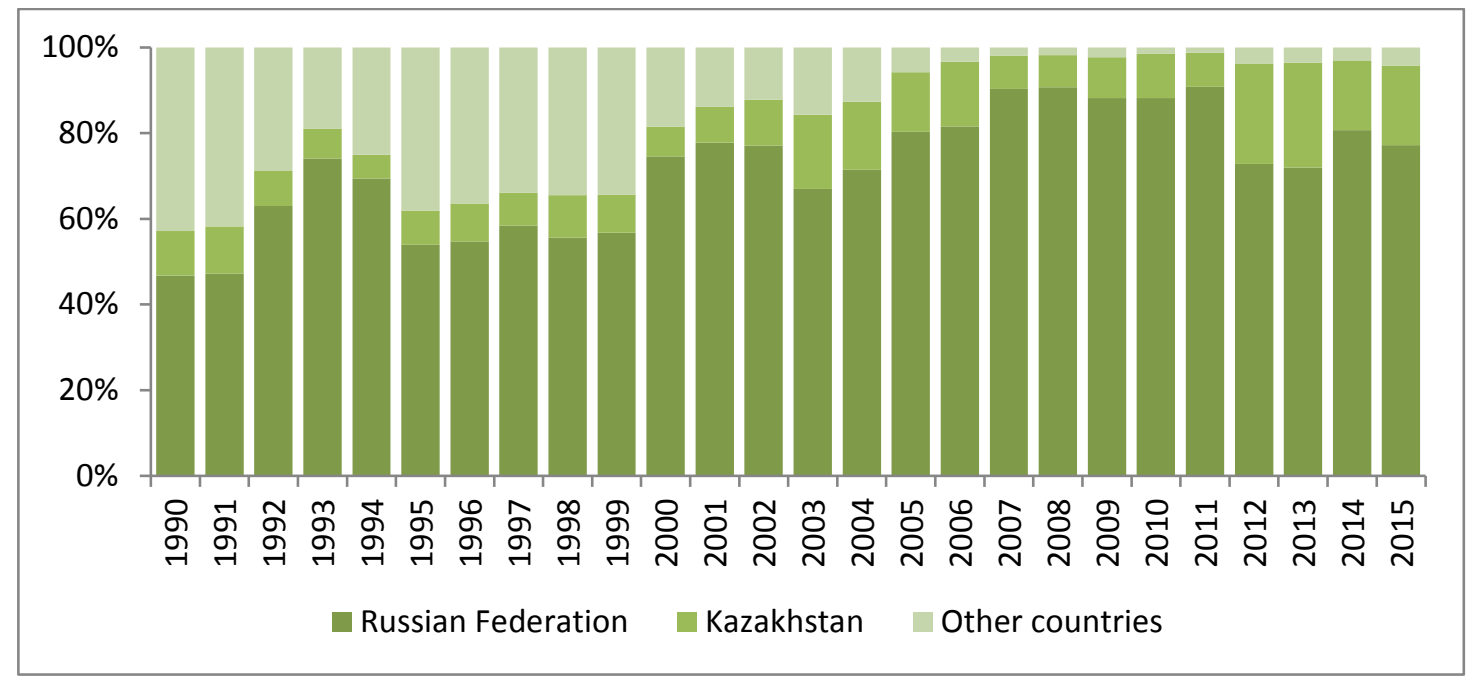

Figure 3. External Migration Shares by Countries. Source: NSCKR

After 2000 the share of those going to non CIS countries sharply decreased. This pattern is explained with the ceased level of ethnic migration stock in the country and this immigration regulations, law changes in the host countries (Mkrtchian \& Sarygulov, 2011). Hence, the immigration policy changes in Germany after 2000 have significantly decreased the number emigrants going to this country (Mkrtchian \& Sarygulov, 2011). While in 1990 's the emigration was directed both to CIS and non CIS countries, after 2000 the emigration was directed to CIS countries, particularly to Russian Federation and Kazakhstan. Furthermore, after 1999 the local population, Kyrgyz has started to actively participate in the migration processes (see Figure2). Hence this migration was economically motivated, specifically migration was conducted by labor migrants to earn more wages, and get better well being abroad. The main features of economically motivated migration are that migration conducted for short or medium term period, migrant going abroad individually leaving their families in the country of origin, sending back to relatives earned money - the remittances, and willing to come back after a while to the country of origin (Sovi, 1977). The distribution of emigrants with respect their gender and ages (see Figure 4.) shows that, in emigration process both men and women are actively participating and the majority of those going abroad are in working ages, which show that emigration after 2000's is done by mostly by active population, who are probably looking for job abroad.

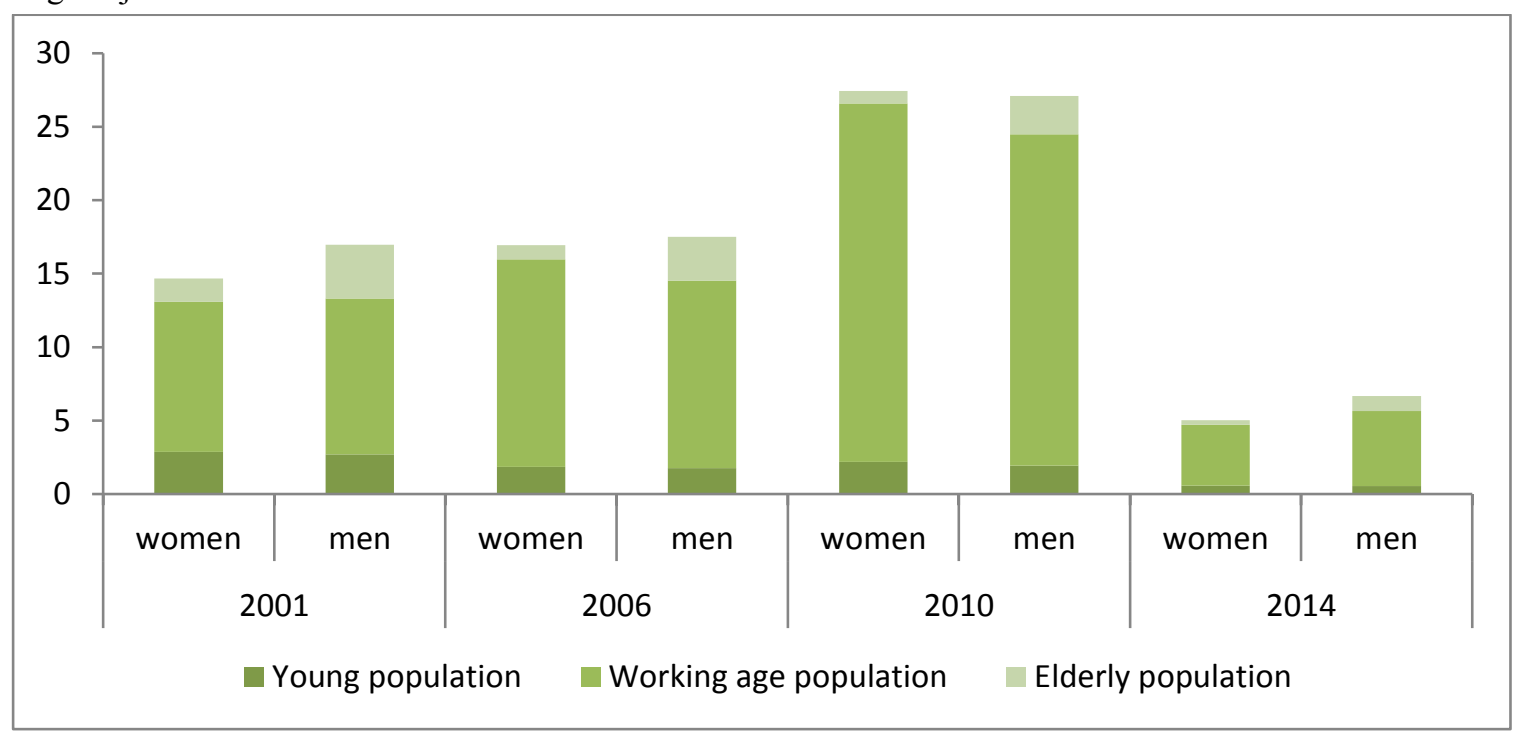

Figure 4. External Migration by Age Categories and Gender, (Thousands, People). Source: NSCKR

After 1999 in the external migration of the Kyrgyzstan the structural change is seen. Specifically, after the financial crisis in the Russian Federation in 1998, which has an economical impact on the Kyrgyzstan, and the the political situation in the south part of the country reasoned the migration outflow from Kyrgyzstan. Particularly, in 1999 the entry of armed groups from Tajikistan into the Batken region of the Kyrgyzstan resulted in internal migration of local population and aftermath emigration to abroad for job search, particularly to Russian Federation (Mkrtchian \& Sarygulov, 2011). 
Investigating the dynamics of external migration shows that there is a sharp decrease of those going abroad after 2012 (see Figure 1). As mentioned above, since 1999, the external migration is motivated by economic reasons and mostly directed to the Russian Federation, the sharp reduction in emigration could be explained with adoption of new immigration law in the Russian Federation. In particular, the denouncement of bilateral agreement between the governments of Kyrgyzstan and Russian Federation, on obtaining the Russian citizenship on preferential terms in 2012 (Demograficheskiy ejegodnik Kyrgyzstana: 2008-2012, 2013) has reduced the number of those going to Russian Federation. This in turn, shows that emigration from Kyrgyzstan is sensitive to law changes in the host countries. Thus, the number of emigrants in 2012, compared to 2011 , has reduced by $71.5 \%$.

However, the statistical data released by National Statistics Committe of Kyrgyz Republic, does not reflect the real situation on external migration of Kyrgyzstan. The methodology of gathering the migration information is based on the counting registration coupons, which are filled by migrants when they are officially changing the permanent place of live. Here we can assume that migrational data released by NSCKR shows general pattern of migration, and the number of those leaving abroad to acquire the other citizenship (in particular case, the Russian Federation citizenship), rather than the actual migration situation in Kyrgyzstan. Thus the labor migration in Kyrgyzstan has temporary and seasonal character and counts around $10 \%$ of active population.

According to experts evaluations the number of labor migrants currently staying abroad counts more than 600 thousand people (more than $10 \%$ of population of Kyrgyzstan). The State Migration Service under the Government of the Kyrgyz Republic announces the number of citizens who are working abroad, as 682 557, these numbers are estimated based on the information gathered from diplomatic missions and consular offices of Kyrgyz Repunlic abroad (Migration report of Kyrgyzstan, 2015). While according to estimations of the Tien-Shan analytical center, every fifth person of active population, or 500 thousand to 700 thousand population has been subjected to labor migration. While the National Statistical Committee of the Kyrgyz Republic, based on surveys of households and labor resources of Kyrgyzstan in 2014, announces the number of migrant workers who are currently staying abroad as 187.4 thousand people. Here, it can be said that, counting the number of labor migrants is difficult and that every organization that is making its counting on migration volume of Kyrgyzstan has different estimation results.

While the volume of external migration of Kyrgyzstan is not definite, based on the experts evaluations can be said to be at high level, and one of it is evident consequences is the remittances sent to Kyrgyzstan. According to Migration and remittances factbook (2016) Kyrgyzstan is the second largest country with respect to the share of remittances in GDP in 2014 with 30.3\% share, after Tajikistan (41.7 \%). According to the World Bank, in 2003 money transfer volume counts 78.16 million US \$ (4.07\% of GDP), while in 2014 this volume increased by 28.7 times and reached 242.83 million US \$ (30.29\% of GDP).

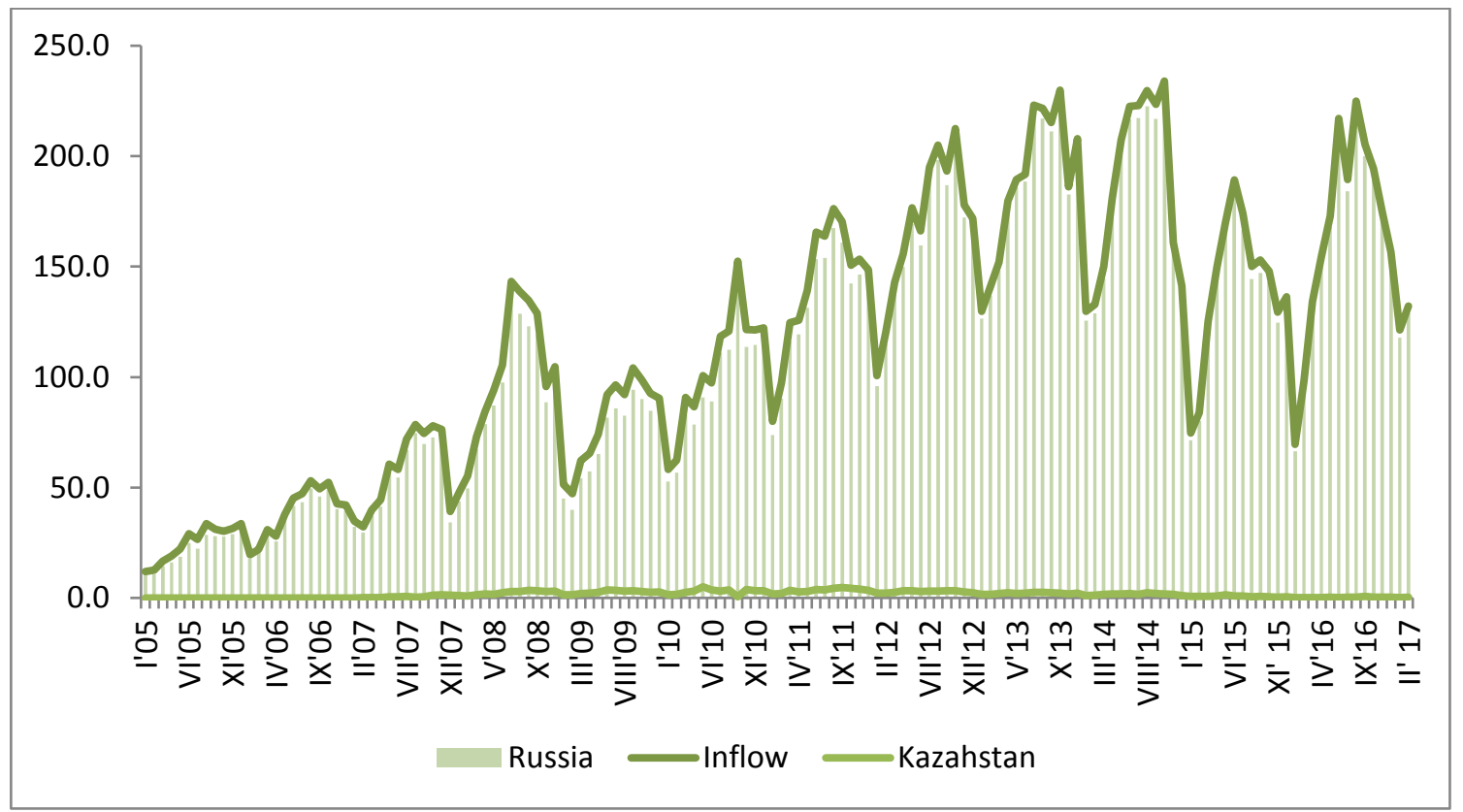

Figure 5. Remittances Made Through the Money Transfer Systems, (in millions of US dollars). Source: NBKR

In the last 15 years the remittances, money transfers have grown rapidly. As it is expected, the main countries sending remittances are Kazakhstan and Russian Federation, in average during the 2005-2016 periods the 93.6\% and $1.4 \%$ of money transfers sent to Kyrgyzstan belongs to these countries, respectively. The remittances display seasonal character, and increases during the summer time. Marat (2009) indicates that most migrants are going to 
the Russian Federation and the Republic of Kazakhstan for seasonal jobs, hence Kyrgyz migrants going abroad in the spring months and send remittance during the employment period, and coming back at winter times.

In purpose of detailed investigation of remittances dynamics, below the seasonal adjusted money transfers are given (see Figure 6). According seasonal adjusted remittances data, there is stationary amount send from Kazakstan, while money transfers send from Russian Federation has dynamic pattern.

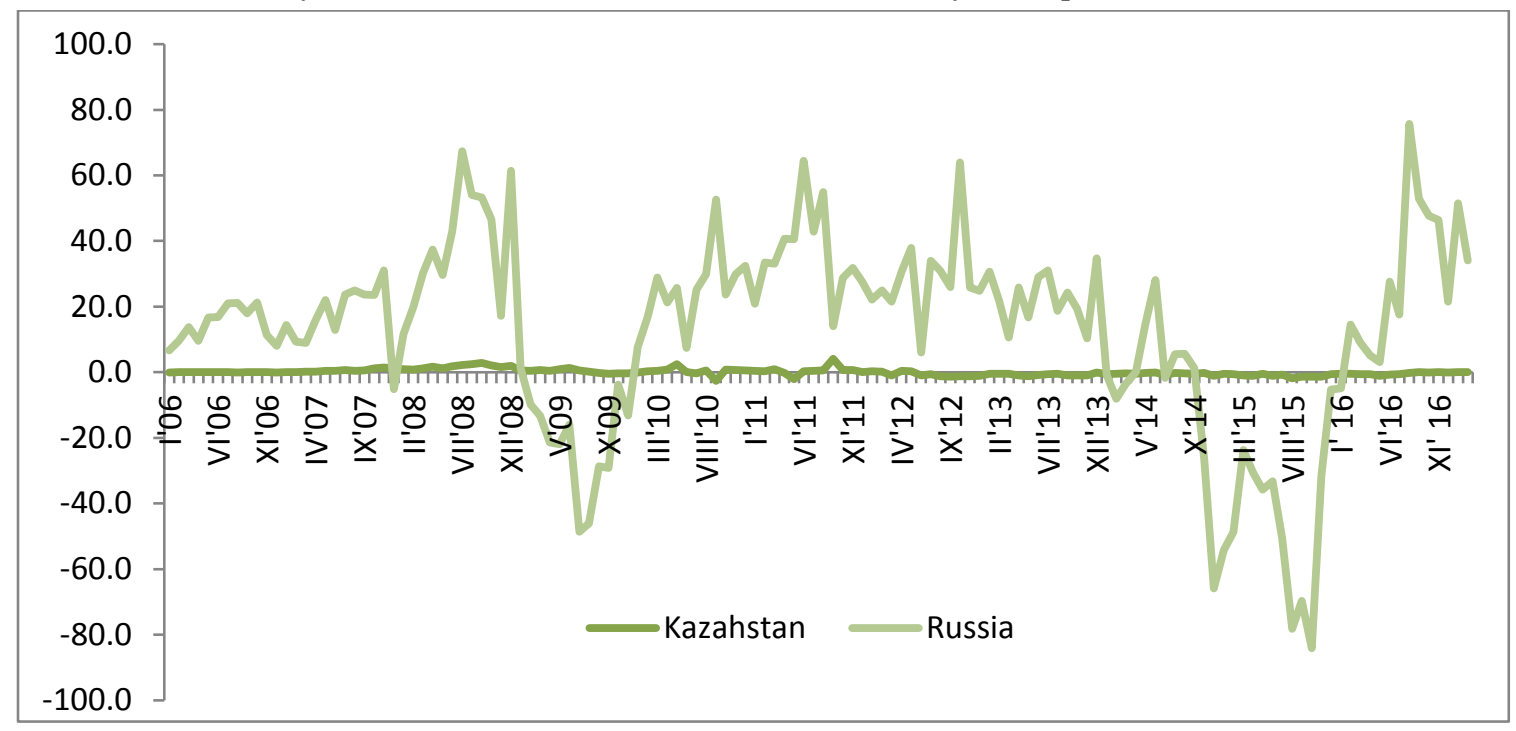

Figure 6. Seasonal Adjusted Remittances, (in millions of US dollars). Source: Calculated Based on NBKR Data

In Figure 6 it is explicitly seen the impact of the Global financial crisis in 2009. However the remittances received from Russian Federation has rapidly recovered. According to estimations of Seyitov (2012) in 2009 the share of remittances with respect to GDP of Kyrgyzstan has not reduced significantly, in 2008 this amount count around $27.1 \%$, while in crisis period, in 2009 it was $20.1 \%$, and in post crisis year, in 2010 it has rapidly recovered and reached $26 \%$ of GDP. In the OSCE and the European Commission report for 2009, despite the global financial crisis of 2009 labor migrants were sending money to their families, showing that money transfers are stable during the financial shocks (Lukashova and Makenbaeva, 2009)

However after 2012 there is reduction in money transfer from Russian Federation is seen. This steady decrease after 2012 could be explained with restrictions introduced to acquire the Russian Federation citizenship in 2012, the adoption of new immigration laws and introducing the "restriction list" ("black list") of those foreigners who are not eligible to enter the Russian Federation for definite period of time. In 2014 the illegal behavior or the number of administrative offenses given to Kyrgyz citizens have for 60\%, from 3853 in 2013 to 6189 in 2014 , resulting in increase of migrants included in restriction list. Hence, after introducing ths list, the number of Kyrgyz citizens, whose enter to Russian Federation were restricted, prohibited have increased drastically, from 7000 in 2013 to 60000 in 2014 .

The sharp decline in remittances at the end of 2014 and during the 2015 is explained with economic crisis seen in Russian Federation, mostly with the situation in foreign exchange market in Russia and the new immigration laws established in beginning of 2015. Due to the reason that official data in Kyrgyzstan on remittances received given in US dollar, it is seems that remittances have shrink very much, while taking into consider the fact that most labor migrants earning and sending transfers in Russian rubles (Muktarbek kyzy, et.al., 2015), the impact of economic crisis on amount of remittances sent is not so much and it is mostly reflecting Russian ruble devaluation. Karymshakov and Sulaimanova (2015) estimates that remittances sent to Kyrgyzstan during the economic crisis in 2015 in Russian rubles has not decreased. However the rapid devaluation of Russian ruble has significantly decreased the purchasing power of migrant families, showing that remittances very sensitive to the migrant host country's economic situation and immigration law changes.

In general in the years of independence, the migration process of Kyrgyzstan can be divided in two main periods: in the first period migration was motivated with non-economic reasons, while in the second period it was economically reasoned and unidirected to CIS countries, namely to Russian Federation and Kazakhstan. The number of those going abroad to work is reaching $10 \%$ of population, and has significant money transfers to Kyrgyzstan, which is very sensitive on the immigration law changes and economic situation in the host countries of migrants. 


\section{Literature Review}

There is large empirical literature on estimating and evaluating the macro and micro level determinants of migration. For instance, Olowa and Awoyemi (2012) have studies Nigerian migration by using multinomial logit model with 2004 survey data and have found that education level is very important factor, thus those having tertiary education are more likely to emigrate abroad, while other more likely to migrate within the country. The same result was found by Chiquiar and Hanson (2005), Uysal and Aktash (2011), .

Ambrosini and Peri (2012) have found that there is significant impact of household characteristics on migration decision of individual, here it is important to mention that the existence migration network is very strong migration causing factor.

Brogerhoff and $\mathrm{Eu}$ (1993) have showed that there is gender specific migration determinants exist, thus women are more likely to take decision on migration with respect to their education level, birth amount, ethnicity, marital status and ages. Yang and Guo have found the same results; hence they show that men more likely to decide to migrate based on the characteristics of the host country or region; while women are likely to migrate withrespect to their individual characteristics.

The main factors causing the labor migration is the wage, income and GDP differentials between regions and countries (Carlos, 2002; Cebula 2005; Guan and McElroy, 2012; Constantinou and Diamentides, 1985; Balderas and Greenwood, 2009; Mayda, 2010; Etzo, 2008; Lewer and Van der Berg, 2008). While the other important factors of deciding to the particular place is the social services given to migrants in host country (Carlos, 2002).

The other important factors at macro level are the cultural similarities between host and origin countries of migrants, demographic characteristics of these countries and geographical distances (Mayda, 2010; Lewer and Van der Berg, 2008). Thus increase of number of population in country of origin leads to migration outflow from this country (Uysal and Aktash, 2011; Carlos, 2002; Kim and Cohen, 2010). Due to the reason that most countries of giving migration are developing countries, the agricultural sector is very important, thus the unexpected agricultural shocks in these countries may cause migration outflow (del Ray Poveda, 1995; Uysal and Aktash, 2011).

One of the other important macro determinants of migration is the migrational law changes in the host countries. Migrants more likely to migrate to the regions were migration laws relaxed (Carlos, 2002; Constantinou and Diamentides, 1985). However Lottum and Marks (2012) have found that migrants are more likely to migrate to economically developed regions rather than to the regions were the immigration laws are not very strict.

The determinants of migrational process in Kyrgyzstan is investigated broadly, hence there is not much empirically investigation is made. One of the first papers examining the migration factors from Kyrgyzstan to USA is made by Sulaimanova, by using survey analysis methods. Agadjanian and et.al. (2006) has found that with increase of ages, and the individuals from other nationalities (not Kyrgyz) more likely to emigrate abroad. Here it is important to mentionthat this paper was written based on the data belonging to beginning of 2000's, where the labor migration has not spread widely, and migration were by those who were planning to go abroad for permanent stay. Thus the empirical results suggest that individual and household characteristics are not important at taking decision decision to migrate, but the presence of relative abroad is very important factor to cause migration.

Lukashova and Makenbaeva (2009) have showed that the main reason for going to Russian Federation is the wage level differentials between countries and unemployment in Kyrgyzstan. According to the macro and micro level of estimation made Eurasian Development Bank's Centre for Integrations studies in 2013, the main factors causing migration outflows are economic ones, namely the low level of Gross Domestic Product per capita in Kyrgyzstan.

Tary and Sulaimanova (2014) has empirically shown that the macro economic migration determinants are GDP, the value added per worker in the agricultural sector in Kyrgyzstan and devaluation national currency with respect to the US dollar. The same results were found by Sulaimanova and Bostan (2014) and the demographic factors were emphasized as well.

Karymshakov and et.al. (2014) have empirically shown that individuals with secondary education and having large households are likely to migrate, while individuals with households that have stable wage incomes and social insurance less likely to migrate.

In general, surveying the empirical literature, particular for Kyrgyzstan case as well, suggest that migration is mostly caused by economical reasons, wage and income level differences and the high level of unemployment rate.

\section{Methodology and Data}

In order to investigate the determinants of international migration the "Life in Kyrgyzstan in 2011" (LIK) survey is used. This survey was conducted within the research project "Economic Transformation, Household behavior and Well-being in Central Asia: The case of Kyrgyzstan" by German Institute for Economic Research DIW Berlin 
with collaboration of Center for Social and Economic Research, CASE-Kyrgyzstan. This survey is nationaly representative and includes 3000 households, 8066 individuals and 40 communities sample. The survey has detailed information on the demographics of the population, health, level of education, labor market participation, standard of living of households and other information on a wide range of topics. Moreover, LIK survey has detailed information on labor migration and remittances, in particular the number of migrants, their destinations, places of work, amount of remittances received along with their expenditure items.

The determinants of migration will be estimated in two ways. Firstly, the migration variables will be taken as a continuous variable and will be estimated with Multiple regression and Tobit models. While in the second method the migration process will be treated as binary variable, and the probability of migration will be estimated with Logit and Probit models.

The first, and simplest analysis is using the number of migrants in the household $\left(w_{i}\right)$ and regressing with the set of explanatory variables $\left(x_{k i}\right)$. Multiple regression is estimated with the least squares and formally model can be given as follows:

$$
w_{i}=\beta_{0}+\beta_{1} x_{1 i}+\beta_{2} x_{2 i}+\cdots+\beta_{k} x_{k i}+u_{i}
$$

Due to the zero inflated nature of the continuous dependent variables, in other words, due to the reason that household that does not have migrants entering to the model estimation as well, using the Tobit model, for means of comparison, will be appropriate. Formally, model is given below (Wooldridge, 2002):

$$
\begin{gathered}
w_{i}^{*}=\beta_{0}+x \beta+\varepsilon_{i} \\
x \beta=\beta_{1} x_{1}+\cdots+\beta_{k} x_{k} \\
u \mid x \sim \operatorname{Normal}\left(0, \sigma^{2}\right) \\
w=\max \left(0, w^{*}\right)
\end{gathered}
$$

where $w_{i}^{*}$ is latent dependent variable and the equation (2) is estimated with Maximum likelihood method.

In the second way of investigating factors of migration the Logit and Probit models are used, where the migration process treated as binary response outcome. These models estimated with Maximum likelihood and the formula of these models is given below (Wooldridge, 2002: 530):

$$
\begin{gathered}
P(y=1 \mid x)=\quad G\left(\beta_{0}+\beta_{1} x_{1}+\cdots+\beta_{k} x_{k}\right)=G\left(\beta_{0}+x \beta\right) \\
x \beta=\beta_{1} x_{1}+\cdots+\beta_{k} x_{k} \\
0<G(z)<1
\end{gathered}
$$

where in the Logit model the function $\mathrm{G}$ is the logistic function and is cumulative distribution function for a standard logistic random variable.

$$
G(z)=\exp (z) /[1+\exp (z)]=\Lambda(z)
$$

In the probit models the function $\mathrm{G}$ is given as standard normal cumulative distribution function (cdf), and expressed as follows:

$$
\begin{aligned}
& G(z)=\Phi(z) \equiv \int_{-\infty}^{z} \phi(v) d v \\
& \phi(z)=(2 \pi)^{-1 / 2} \exp \left(-z^{2} / 2\right)
\end{aligned}
$$

The effect of explanatory variables on migration probability, due to the nonlinear nature of $\mathrm{G}$ function, is calculated as partial effects.

$$
\begin{gathered}
\frac{\partial p(x)}{\partial x_{i}}=g\left(\beta_{0}+x \boldsymbol{\beta}\right) \beta_{i} \\
g(z) \equiv \frac{\mathrm{d} G}{\mathrm{~d} z}(z)
\end{gathered}
$$

The dependent variable $y_{i}$ is the binary response variable, where it takes value 1 if the household has any migrant, and value 0 if the household do not have migrant. The $x_{i}$ refers to a set of independent variables on individual, household and community level. The set of individual variables includes demographic and educational characteristics of individual, in the household level variables the the composition of household and location is given, while in community level variables the settlement features of the region is given. 


\section{Estimation Results}

\begin{tabular}{|c|c|c|c|c|}
\hline & \multicolumn{2}{|c|}{ Migration amount } & \multicolumn{2}{|c|}{ Migration status } \\
\hline & \multicolumn{2}{|c|}{ Coefficient estimates } & \multicolumn{2}{|c|}{ Margin estimates } \\
\hline & OLS & Tobit & Probit & Logit \\
\hline \multicolumn{5}{|l|}{ Individual characteristics: } \\
\hline Age & $\begin{array}{c}-0.0038 \\
(0.0038)\end{array}$ & $\begin{array}{l}-0.0223 \\
(0.0268)\end{array}$ & -0.0014 & -0.0008 \\
\hline Age squared & $\begin{array}{r}0.00009 * * \\
(0.00004)\end{array}$ & $\begin{array}{l}0.0005^{*} \\
(0.0003)\end{array}$ & 0.00003 & 0.00002 \\
\hline Gender $($ male $=1)$ & $\begin{array}{c}-0.0273 * * \\
(0.0127)\end{array}$ & $\begin{array}{l}-0.2664 * * \\
(0.0926)\end{array}$ & $-0.0184 * * *$ & $-0.0161 * * *$ \\
\hline Marital status (married=1) & $\begin{array}{c}0.0079 \\
(0.0211)\end{array}$ & $\begin{array}{l}-0.0177 \\
(0.1559)\end{array}$ & 0.0007 & 0.0024 \\
\hline Nationaility (kyrgyz=1) & $\begin{array}{c}0.0767 * * * \\
(0.0140)\end{array}$ & $\begin{array}{c}0.5479 * * * \\
(0.1048)\end{array}$ & $0.0281 * * *$ & $0.0220 * * *$ \\
\hline \multicolumn{5}{|c|}{ Education level (reference: basic and secondary education): } \\
\hline - $\quad$ Technical education & $\begin{array}{c}0.0454 * * \\
(0.0175)\end{array}$ & $\begin{array}{c}0.3276^{* *} \\
(0.1265)\end{array}$ & $0.0213 * *$ & $0.0209 * *$ \\
\hline - Tertiary education & $\begin{array}{l}-0.0135 \\
(0.0180)\end{array}$ & $\begin{array}{l}-0.1368 \\
(0.1374)\end{array}$ & -0.0066 & -0.0056 \\
\hline \multicolumn{5}{|l|}{ Household characteristics: } \\
\hline Household head gender (women=1) & $\begin{array}{c}0.0568 * * * \\
(0.0156)\end{array}$ & $\begin{array}{c}0.3631 * * \\
(0.1189)\end{array}$ & $0.0229 * * *$ & $0.0170^{* *}$ \\
\hline Household size & $\begin{array}{c}0.0545 * * * \\
(0.0061)\end{array}$ & $\begin{array}{c}0.3239 * * * \\
(0.0412)\end{array}$ & $0.0171 * * *$ & $0.0145^{* * *}$ \\
\hline Children (0-5 ages) & $\begin{array}{c}-0.0853 * * * \\
(0.0105)\end{array}$ & $\begin{array}{c}-0.5968 * * * \\
(0.0762)\end{array}$ & $-0.0355 * * *$ & $-0.0307 * * *$ \\
\hline Children (6-17 ages) & $\begin{array}{c}-0.0477 * * * \\
(0.0079)\end{array}$ & $\begin{array}{c}-0.2712 * * * \\
(0.0547)\end{array}$ & $-0.0149 * * *$ & $-0.0124 * * *$ \\
\hline Males (15-65 ages) & $\begin{array}{c}0.0698 * * * \\
(0.0095)\end{array}$ & $\begin{array}{c}0.4184 * * * \\
(0.0611)\end{array}$ & $0.0292 * * *$ & $0.0239 * * *$ \\
\hline Non-wage income & $\begin{array}{c}-0.0252 * * * \\
(0.0040)\end{array}$ & $\begin{array}{c}-0.1836 * * * \\
(0.0296)\end{array}$ & $-0.0120 * * *$ & $-0.0096 * * *$ \\
\hline Residence (rural=1) & $\begin{array}{c}-0.1004 * * * \\
(0.0172)\end{array}$ & $\begin{array}{c}-0.5777 * * * \\
(0.1233)\end{array}$ & $-0.0330 * * *$ & $-0.0277 * * *$ \\
\hline \multicolumn{5}{|l|}{ Regions (reference: Central region) } \\
\hline - North & $\begin{array}{c}0.0034 \\
(0.0231)\end{array}$ & $\begin{array}{c}0.2740 \\
(0.2151)\end{array}$ & 0.0130 & 0.0133 \\
\hline - $\quad$ South & $\begin{array}{c}0.0127 \\
(0.0197)\end{array}$ & $\begin{array}{l}0.8948 * * * \\
(0.1602)\end{array}$ & $0.0474 * * *$ & $0.0517 * * *$ \\
\hline \multicolumn{5}{|l|}{ Community characteristics: } \\
\hline Presence of major factory, employer & $\begin{array}{c}-0.0636 * * * \\
(0.0172)\end{array}$ & $\begin{array}{c}-0.4111^{* *} \\
(0.1289)\end{array}$ & $-0.0300 * * *$ & $-0.0254 * * *$ \\
\hline Migration network & $\begin{array}{l}0.0360 * * * \\
(0.0021)\end{array}$ & $\begin{array}{l}0.1704 * * * \\
(0.0125)\end{array}$ & $0.0120 * * *$ & $0.0092 * * *$ \\
\hline Distance to the country border & $\begin{array}{l}-0.0080 \\
(0.0054)\end{array}$ & $\begin{array}{l}-0.1261 * * * \\
(0.0373)\end{array}$ & $-0.0071 * * *$ & $-0.0060 * * *$ \\
\hline Constant & $\begin{array}{c}0.0716 \\
(0.0805) \\
\end{array}$ & $\begin{array}{c}-3.4716^{* * *} \\
(0.5897) \\
\end{array}$ & & \\
\hline Number of observation & 7341 & 7341 & 7341 & 7341 \\
\hline $\mathrm{F}-$ stat. & $83.41 * * *$ & - & - & - \\
\hline $\mathrm{R} 2$ & 0.1780 & 0.1759 & 0.2462 & 0.2485 \\
\hline LR $\chi^{2}$ & - & $1395.5^{* * *}$ & $1344.9 * * *$ & $1357.5 * * *$ \\
\hline Log likelihood & - & -3268.93 & -2058.8 & -2052.6 \\
\hline
\end{tabular}

Table 1. Estimation Results (Coefficient and Marginal Effect Estimates)

Table 1 reports the determinants of international migration in Kyrgyzstan with four models; multiple regression, Tobit, Logit and Probit models. According to empirical estimation results the model estimated with ordinary least 
squares has different results on significance of migration determinants, showing that disregarding the nature of censored data of dependent variable will lead to biased estimation, given this reason the Tobit model will be evaluated. Hence the results for probability for being migrating, estimated by Logit and Probit models, justify the significance of variables impacting the migration.

Examining the significant individual level migration determinants show that in Kyrgyzstan in migration processes the women and Kyrgyz are more actively participating, and the educational level of individuals has statistical significant impact. However the tertiary education is not significant at impacting the migration decision of the individual. The individuals, who have technical education more likely to migrate than those having basic or secondary education, this could be explained with the demand for unskilled migrant labor in Russian Federation. Hence we can say that more skilled or educated people are going abroad for Kyrgyzstan case.

The age of migrants is not significant at impacting the migration decision of individual. Interestingly this result is not in line with the literature, where migrants prone to migrate until the definite ages then the migration propensity fall (Ambrosini \& Peri, 2012). This feature of the migration in Kyrgyzstan could be explained with fact that in total decision to make migration the age factor is not significant in general. Hence the same could be said for the marital status of migrants as well.

There are statistically significant household level factors impacting the migration decision of individual. Thus the compositional and residential characteristics of the household are very important determinants of migration. The factors causing migration are the gender of household head, where individuals from female headed households more likely to migrate, with the increase of the size of the household the number of migrants going abroad is increasing as well; particularly with the increase of number of males in the working ages in the household increases the probability of migration from these households; and most migrants come from South region of Kyrgyzstan. While the increase of number of children in the household and the increases of non-wage income are decreasing the migration probability of the individual. Here the household income and welfare impact has expected impact. Thus individuals with stable income in the country of origin are less likely to migrate to work abroad (Ambrosini \& Peri, 2012).

The migration factor that has unexpected sign is the residence of individual in the rural areas. However in case of Kyrgyzstan, where the large scale of internal migration exists, this results could be explained with fact that migrants before going abroad more prone to migrate to bigger cities in Kyrgyzstan and then go abroad.

In addition to the individual and household factors, this study has examined the impact of community features on the migration processes. In line with the literature we have found that community's settled in the areas close to the country border more likely to have migrants (Yang \& Guo, 1999; Ambrosini \& Peri, 2012). However this is not explaining the mass migration to Russian Federation, thus Kyrgyzstan do not have border with this country. The impact of this variable more likely to explain the fact that communities settled near the country border are in remote areas and less developed, which causes the migration outflow from this areas.

The presence of major factor or the employer in the community is significantly reducing the probability of individual to migrate. In particular this result shows the fact that individuals facing problems finding the work in their communities and for this reason have to leave it. While the presence of migration network in this community increases the probability of migration.

\section{Conclusion}

Kyrgyzstan is demographically young country, with large share of labor migration outflow. During the 19912017 periods the two main structural changes in the migration processes are seen. The first period belongs to the 1991-1998 period, and migration has been caused mostly by non-economical reasons, such as ethnic migration, migration for political reasons etc. While after 1999 the active labor migration has started and continues to nowadays. The main countries of attraction of labor migrants are Russian Federation and Kazakhstan. Hence the major part of labor migrants from Kyrgyzstan is going to Russian Federation. However exact number of labor migrants currently working abroad is not known, and evaluated by experts and migrations institutions around 600 thousand people or about $10 \%$ of the population of Kyrgyzstan. With growing pattern of labor migration since 2000, the amount of remittances has grown as well. According to the World Bank since 2003 the money transfer to Kyrgyzstan increased by 28.7 times, from 78.16 million US \$ (4.07\% of GDP) in 2003 to 242.83 million US \$ in 2014 . Kyrgyzstan with $30.3 \%$ share is the second largest country with respect to the remittance share to GDP in 2014, after Tajikistan (41.7\%) (Migration and remittances factbook, 2016).

Since large scale of migration outflow from Kyrgyzstan and remittances received makes domestic economy dependent on external shocks related with migration, it is aimed in this paper to empirically investigate the labor migration determinants, which are could be used for migration policy strategies. In order to investigate the determinants of international migration the "Life in Kyrgyzstan in 2011" (LIK) survey is used. This survey was conducted within the research project "Economic Transformation, Household behavior and Well-being in Central Asia: The case of Kyrgyzstan" by German Institute for Economic Research DIW Berlin with collaboration of Center for Social and Economic Research, CASE-Kyrgyzstan. This survey is nationally representative and 
includes 3000 households, 8066 individuals and 40 communities sample. According to empirical estimation results the factors affecting the individual decision to migrate abroad the mostly related with household and community level characteristics rather than individual characteristics. Thus the age, marital status and education level of individual are not significant factors affecting the migration, while the gender and ethnicity are seen as significant factors. Precisely, women more actively migrating, hence the the difference is not so big, this is showing that external migration of Kyrgyzstan is gender balanced, and most migrating are Kyrgyz.

Consequently, the large scale of external migration in Kyrgyzstan has regional characteristics, and comes from communities and households with definite characteristics. These migration factors should be evaluated in the policy making in Kyrgyzstan. Thus migration is seen in the communities located near the country border, and where the lack of employment is exists. These are the main issues that should be dealed first. In these regions the employment and development program should be maintained in the short period. While the other important factors affecting the household characteristics. Here the composition of household is important. Hence migrants come from large household with labor force excess. These households should be taken into the special policy programs that could reduce migration outflow by subsidizing the potential migrants for actively taking labor participation in Kyrgyzstan. The other interesting result is that migrants mostly coming from urban areas, which is explained with internal migration from rural to urban areas before going abroad. This process should be regulated by settling informational offices in the remote areas, which could assist in acquiring the necessary information on save external migration, thus most migrants are engaged to migration with information taken from relatives or from those who have been abroad in their communities, by migration network.

\section{References}

- Ambrosini, J. W., \& Peri, G. (2012). The determinants and the selection of Mexico-US migrants. The World Economy, 35(2), 111-151.

- $\quad$ Balderas, J.U., Greenwood, M.J., (2010) "From Europe to the Americas: a comparative panel-data analysis of migration to Argentina, Brazil, and the United States, 1870-1910", Journal of population economics, 23:1301-1318

- Carlos, R. D. (2002). On the Determinants of International Migration in the Philippines: An Empirical Analysis1. International Migration Review, 36(1), 81-102.

- Constantinou, S. T., \& Diamantides, N. D. (1985). Modeling international migration: Determinants of emigration from Greece to the United States, 1820-1980. Annals of the Association of American Geographers, 75(3), 352-369.

- del Rey Poveda, A. (2007). Determinants and consequences of internal and international migration: The case of rural populations in the south of Veracruz, Mexico. Demographic Research, 16(10), 287-314.

- $\quad$ EDB Centre for Integration studies (2013) "Effects of accession of Kyrgyzstan into the CU and SES for labor market and human capital”, EDB: St. Petersburg

- Etzo, I., (2008) "Determinants of interregional migration in Italy: a panel data analysis", MPRA paper no.8637, http://mpra.ub.uni-muenchen.de/8637/

- GUAN, J., \& McElroy, J. L. (2012). The determinants of migration in small islands. Shima: The International Journal of Research into Island Cultures, 7(1), 80-95.)

- Karymshakov, K., Abdieva, R. \& Sulaimanova, B. (2014) "Determinants of international migration: The case of Kyrgyz Republic”, Вестник Кыргызского Национального Университета им.Ж.Баласагына

- Kim, K., \& Cohen, J. E. (2010). Determinants of International Migration Flows to and from Industrialized Countries: A Panel Data Approach Beyond Gravity1. International Migration Review, 44(4), 899-932.

- Lewer, J.J., Van den Berg, H., (2008) “A gravity model of immigration”, Economics letters, 99:1

- Mayda, M.A., (2010) "International migration: a panel data analysis of the determinants of bilateral flows", Journal of population economics, 23:1249-1274

- Olowa, O.W., Awoyemi, T.T., (2012) "Determinants of migration and remittances in rural Nigeria", Journal of development and agricultural economics, vol.4(7), pp.191-198

- Sulaimanova, B., \& Bostan, A. (2014). International Migration: A Panel Data Analysis of the Determinants of Emigration from Tajikistan and Kyrgyzstan. Eurasian Journal of Business and Economics, 7(13), 1-9.

- Sulaimanova, S. (2005). Labor Migration from the Kyrgyz Republic. Washington, DC: World Bank, unpublished report.

- World Bank Group (2016). Migration and Remittances Factbook 2016, Third Edition. Washington, DC: World Bank.

- $\quad$ Yang, X., \& Guo, F. (1999). Gender differences in determinants of temporary labor migration in China: A multilevel analysis. International Migration Review, 929-953. 
- Агаджанян, В., Кумсков, Г., Недолужко, Л. (2006). Демографические процессы в Кыргызстане. Журнал Демоскоп Weekly, №493-494. Январь 2012. http://demoscope.ru/weekly/2012/0493/analit02.php

- Демографический ежегодник Кыргызской Республики: 2010-2014.-Б: Нацстатком Кырг. Респ., 2015:$320 \mathrm{c}$

- Единый доклад по миграции в Кыргызской Республике, Государственная служба миграции при Правительстве Кыргызской Республики, Бишкек 2015

- Карымшаков К., Сулайманова, Б. (2015) “Экономическая ситуация в Российской Федерации и влияние на миграцию Кыргызстана”, отчет НИСИ

- Кумскова, Н.Х. (2015) «Внешняя миграция населения Кыргызской Республики», Вестник КРСУ. 2015. Том 15. № 8, стр 110

- Лукашова, И., Макенбаева, И., (2009) «Воздейтсвие мирового экономического кризиса на трудовую миграцию из Кыргызстана в Россию: качественный обзор и количественное исследование», Бишкек, $110 \mathrm{c}$

- Мамырканов, М., Элебаева, А., (2013) «Разработка Концепции миграционной политики Кыргызской Республики», Отчет НИСИ

- Мкртчян, Н., Сарыгулов, Б., (2011) «Международная миграция все больше ориентируется на Россию», Демоскоп Weekly, №481-482

- Муктарбек кызы, А., Сейитов, Ч., и Жениш, Н. (2015). Влияние денежных переводов на структуру расходов домохозяйств в Кыргызской Республике. Центр экономических исследований, НБКР, №2

- Омаров, Н., Махновский, В., «Миграционные процессы в Кыргызстане: современные тенденции и перспективы», Журнал «Центральная Азия и Кавказ», 1998 (13), http://www.cac.org/journal/131998/st_05_omarov.shtml - дата обращения 15/12/2015

- Отчет и рекомендации по Международной конференции «Передовой опыт в области защиты прав трудовых мигрантов и перспективы его применения в Кыргызстане», Тянь-Шаньский аналитический центр АУЦА, Бишкек, Кыргызстан, 3-4 июня 2013 года

- Сейитов, Ч.С., (2012) «Теоретические Аспекты Денежных Переводов», Сборник Научных Работ НБКР, ст. 45-56

- Сулайманова, Б. (2012) «Анализ влияния денежных переводов на рост ВВП с использованием систем одновременных эконометрических уравнений на примере Кыргызской Республики», журнал «Реформа», 3 (55), стр. 61-66

- Сулайманова, Б. (2011) «Влияние денежных переводов на ВВП Кыргызской Республики», журнал «Реформа»,1(53), стр.65-69, 2012

- $\quad$ Тары, Р. \& Сулайманова, Б. (2014) «Факторы, влияющие на эмиграционные процессы в Кыргызстане», Международный, научный, экономический журнал «Реформа» 


\title{
The Relationships Between the Female Labor Force Participation Rate and Economic Development: A Correlation Analysis for Turkey
}

\author{
Asst. Prof. Dr. Ayfer Ustabaş (Beykent University, Turkey) \\ Assoc. Prof. Dr. Tanses Yasemin Gülsoy (Beykent University, Turkey)
}

\begin{abstract}
Integration of women into the labor market has been a crucial indicator of economic development and social welfare. Although Turkey has taken important steps in terms of integrating with the world economy by shifting from an import-substituting industrialization model to an export-oriented growth strategy from the 1980s onward, female labor force participation rates and the significant regional variations in these rates indicate that women's integration into the labor force has still some ways to go to reach the level of EU and OECD countries. The influence of economic growth on female employment participation has been discussed in many studies. But, studies analyzing the interdependent relationship of female labor force participation and economic growth as well as the interplay of female labor force participation and sectoral GDP growth have been limited. The purpose of this study is to fill this gap by evaluating the relationships between female labor force participation rate and economic growth expressed by GDP per capita levels in Turkey for the 1990-2015 period, using data from the World Development Indicators (WDI) 2017 database of the World Bank. The empirical findings point to a strong correlation between the rate of female labor force participation in industry and services sectors and economic development.
\end{abstract}

\section{Introduction}

Gender equality and women's empowerment are "fundamental" dimensions of human development (United Nations Development Programme, 2016: 165). UNDP underlines the importance of gender equality to sustainable development by formulating its sustainable development goal number 5 to address "... achiev[ing] gender equality and empowering all women and girls" (United Nations Development Programme, 2016: 94). UNDP reports on studies that have found gender equality's positive influence on economic growth, poverty reduction, and human development (ibid., p. 42), but the reverse, as noted in the same report, is not necessarily true. In other words, economic growth does not necessarily lead to gender equality. Consequently, it befalls governments to ensure gender equality (ibid., p. 42).

Women's full integration into the economy is desirable for several reasons. First, as noted by Tansel (2002: 3), the equity perspective leads to the implication that women's increasing labor market participation will improve their relative economic position. Secondly, the efficiency perspective indicates that this participation will also affect positively the overall economic efficiency and improve development potentials of the country (Tansel, 2002: $3)$. Economic empowerment of women will also allow efficient use of government investments in education since working women are generally more involved in making decisions in relation to their children's education and health, creating positive externalities in terms of future generations' welfare (International Bank for Reconstruction and Development and State Planning Organization, 2009).

Women's economic contribution is not limited to the time when they are officially employed. Human Development Report 2016 indicates that women are globally less represented in paid employment than men. In 2015, globally 36 percent of women and 44 percent of men worked in paid employment (Hunt and Sunman, 2016, as cited in United Nations Development Programme, 2016: 42). On the other hand, women's economic contribution in unpaid and especially in domestic work is significant. A 2011 survey conducted in 46 countries indicated that to 28 percent of women who spent three to five hours a day on household work, men's percentage was only 6 (Hunt and Sunman, 2016, as cited in United Nations Development Programme, 2016: 42). As a result, the total time spent by women on paid work as well as unpaid work is higher than for men. Women work on average fifty minutes more a day than men during the course of both paid and unpaid work (World Economic Forum, 2016: 31).

The global labor force participation rate is 49.6 percent among women and 76.2 percent among men (Human Development Report, 2016: 58). Accounting for 1.16 percent of the world economy with a GDP of 856.8 billion US dollars in 2016 (Turkish Statistical Institute,2017), Turkey is represented by only a 30.4 percent in female labor force participation rate in 2016 (World Bank, 2017).

According to Global Gender Gap Report 2016 (examining the gap between men and women in four fundamental categories: Economic Participation and Opportunity, Educational Attainment, Health and Survival and Political Empowerment) published by the World Economic Forum, Turkey ranks as $130^{\text {th }}$ in global index (in 2006, the country was at the $105^{\text {th }}$ rank), $129^{\text {th }}$ in economic participation and opportunity $(33 / 770.44), 109^{\text {th }}$ in educational attainment and $113^{\text {th }}$ in political empowerment among 144 countries. Although she records progress on closing the 
gender gap in estimated earned income and for professional and technical workers, Turkey shows a widening gender gap for wage equality, number of legislators, senior officials, and managers and as well as female members of parliament (World Economic Forum, 2016: 20-21, 346-347; World Economic Forum, 2015: 346-347).

This study investigates the relationships between female labor force participation rate (FLFPR) and economic growth in Turkey during the period 1990-2015. The study begins with the theoretical framework in Section 2 . The evolution of female employment in Turkey is presented in Section 3. The econometrics literature review is given in Section 4. The method is discussed in Section 5, and the econometric evaluation and results are presented in Section 6. Finally, the conclusion is given in Section 7.

\section{Theoretical Framework}

Regarding the relationship of female labor force participation and economic development, several theoretical analyses can be found in the economic literature. Many studies indicate that there can be significant macroeconomic gains when women develop their full integration into labor market potential (Loko \& Diouf, 2009; Dollar \& Gatti, 1999, as cited in Elborgh-Woytek et al., 2013: 4). Increasing female labor force participation rate is estimated to raise GDP, for example, in the United States by 5 percent, in Japan by 9 percent, in the United Arab Emirates by 12 percent, and in Egypt by 34 percent (Aguirre et al., 2012: 9).

Classic modernization theory relates a country's female labor force participation rate to the country's modernization process during the course of which agrarian societies are shifted to industrialized and modernized ones. During this industrialization process, women's social status is expected to be improved as a result of modernization changes like urbanization, decreasing fertility rates, increasing educational and work opportunities and improving working conditions (Inglehart \& Norris, 2003). Alternatively, many of the studies analyzing the modernization effects on women's labor force participation indicate a non-linear relationship: Women's labor force participation decreases in the earlier phases of modernization and then increases in the later phases (Goldin, 1994; Gündüz-Hoşgör \& Smits, 2001; Pampel and Tanaka, 1986).

Goldin (1994) emphasized that labor force participation rate of women first decreases and then rises as countries develop. The downward portion of the $U$ is due to the movement of production from the household to the factory, and to a combination of an initially strong income effect and a weak substitution effect. But, the income effect weakens and the substitution effect strengthens at some point where women's educational resources increase and therefore the ability to obtain jobs in more prestigious occupations rises. These two factors increase the substitution effect and decrease the income effect, and the upward portion of the $U$ is observed and women's labor force participation enters the modern era (Goldin, 1994: 28). Accordingly, cross-country data indicates that high-income and low-income countries have the highest female labor force participation rates while middle-income countries have the lowest (Pampel and Tanaka, 1986; Psacharopoulos and Tzannatos, 1989).Some researchers did not agree on a U-shaped pattern for female labor force participation over the course of economic development and argued that female labor force participation depended on too many variables and thus could not be generalized by the Ushaped hypothesis (Durand, 1975; Standing, 1978).

Another group of researchers explained the U-shaped relationship by pointing to the changes on female labor force participation rate depending on per capita income. When per capita income is at lower levels, female labor force participation rate is at higher levels, indicating the necessity to work in the face of lack of social protection programs. With higher per capita income and increasing social protection, women may withdraw from employment to work at home. Finally, at advanced industrialized income levels, labor force participation becomes higher as a result of a number of factors and processes such as better education, lower fertility rates, and the availability of market-based household services (Duflo, 2012; Tsani et al., 2012).

According to the development perspective, in pre-industrial societies, women's participation in production activities was higher since most production took place at home. On the other hand, in the early industrialization phase, the opportunities for women to be economically active were reduced as a result of the mechanization of farming. Moreover, new jobs that required physical prowess emerged which negatively affected women's labor force participation as those jobs were considered to be incompatible with women's roles at home (Pampel \& Tanaka, 1986; Rau \& Wazienski, 1999; Scott \& Tilly, 1975).

The U-shaped curve hypothesis has been advanced as a good explanation for the low female labor force participation rate in Turkey, which may be in the intermediate phase of modernization (Gündüz-Hoşgör and Smits, 2008: 105). In other words, Turkey may be at the dip of the U-shaped curve where female employment rates are lowest. But, since the country's female labor force participation rate is lower than in other countries at similar levels of development in South-East Asia or Latin America, this difference requires some additional explanations that take into account cultural and economic factors specific to Turkey, as Gündüz-Hoşgör and Smits have noted (2008: 105).

Several cross-country analyses indicated that export promotion and trade liberalization policies might be one of the factors of feminization of the labor force in developing countries (Wood, 1991; Cagatay and Ozler, 1995). Increased globalization and openness to the world economy are expected to generate an increase in female labor 
force especially due to lower unit labor costs of women relative to men. As a result, it is mostly argued that women typically hold low-skill and low-paying jobs, and they tend to be concentrated in export-oriented sectors such as textile, garments and food processing which are more compatible with their traditional roles (Başlevent and Onaran, 2004; Ross, 2006).

\section{Evolution of Female Employment in Turkey}

Turkey has experienced some structural and social changes that would be expected to facilitate Turkish women's labor force participation. In the 1980s, Turkey adopted a market-oriented and liberalized economic model instead of the import-substitution development model implemented in the 1960s and 1970s. Subcontracting and outsourcing practices in the labor market as well as rapid urbanization were other important outcomes of this strategic reorientation (Buğra and Yakut-Çakar, 2010, 521-522). Despite these factors, Turkey represents a rare exception to the worldwide increase in female employment: This rate has declined in the country as a whole, from 34.1 per cent in 1990 to 30.4 per cent in 2016, as Figure 1 indicates. In European Union and OECD member countries, on the other hand, female labor force participation rate has increased within the same period from 45.8 percent to 51 percent and from 47.8 percent to 51 percent, respectively. In the Middle East and North Africa region, this rate has again shown an increase - from 18.3 percent to 21.6 percent (World Bank Indicators, 2017).

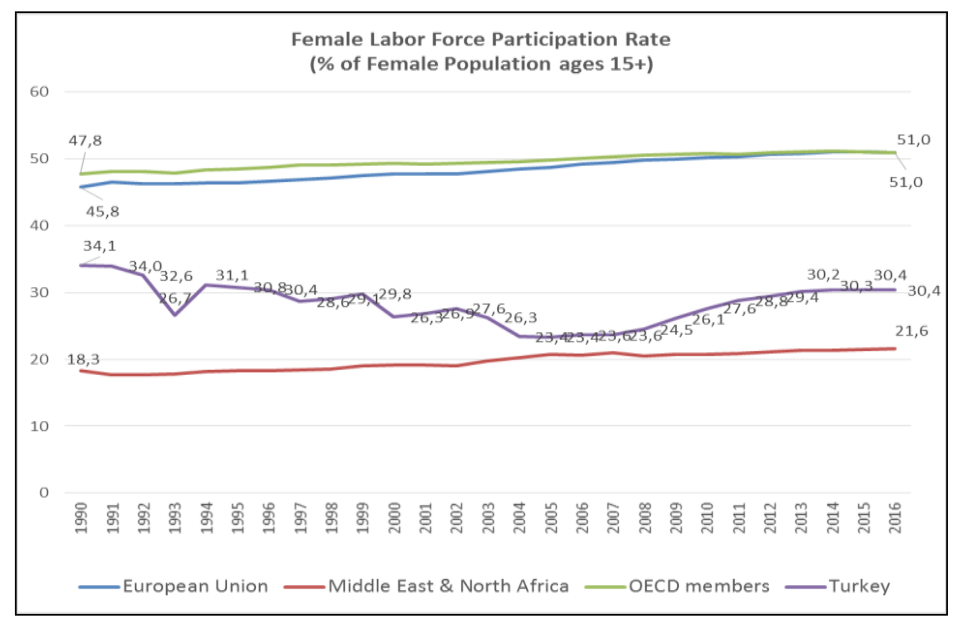

Figure 1. Female Labor Force Participation Rate in Turkey and Some Selected Regions Between 1990 and 2016 Source: World Bank, World Development Indicators 2017.

As a result of international trade liberalization policies, export competitiveness was encouraged and state-run enterprises were privatized. Thus, in Turkey female employment in light manufacturing increased, as had been the case in other export promoting countries (Ross, 2006; Tansel, 2002). The increase of women workers was even more prominent in services such as banking and social and personal services. The percentage of employed females working in the social and personal services doubled between 1985 and 2005, and the percentage working in commercial services quadrupled (Gündüz-Hoşgör and Smits, 2001: 107).

In Turkey, as Figure 2 indicates, the percentage of female labor force in agriculture was 77.4 per cent in 1991, but this ratio declined to 31.1 per cent in 2015. On the other hand, female labor force percentage in industry rose from 8.3 in 1991 to 16.2 in 2015 . Moreover, female employment has shown a spectacular increase in the services sector by rising from 14.4 per cent in 1991 to 52.7 per cent in 2015 .

In European Union and OECD member countries, the percentage of female labor force in services is always higher than the other sectors and this ratio rises from 71.6 percent in 1991 to 83.9 percent in 2015 for the European Union and from 73.7 percent in 1991 to 85 percent in 2015 for OECD member countries. In European Union, the female labor force participation rate in industry declined from 20.8 percent in 1991 to 12.1 percent in 2015 similar as that in agriculture decreased from 7.4 per cent in 1991 to 3.4 per cent in 2015. Finally, in OECD members, the female labor force participation rate in industry declined from 18.6 percent in 1991 to 11.4 percent in 2015, and that in agriculture decreased from 7.6 per cent in 1991 to 3.2 per cent in 2015 (Figure3). 


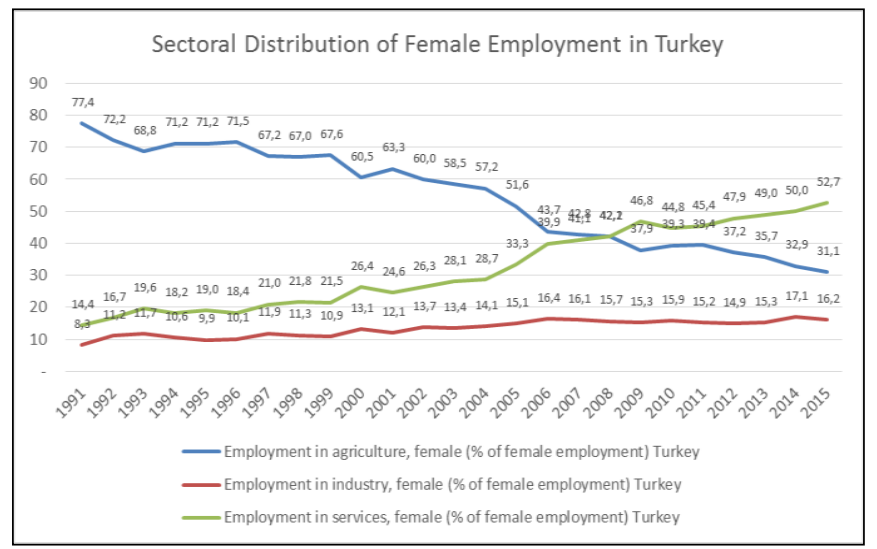

Figure 2. Sectoral Distribution of Female Labor force in Turkey (1991-2015). Source: World Bank, World Development Indicators 2017.

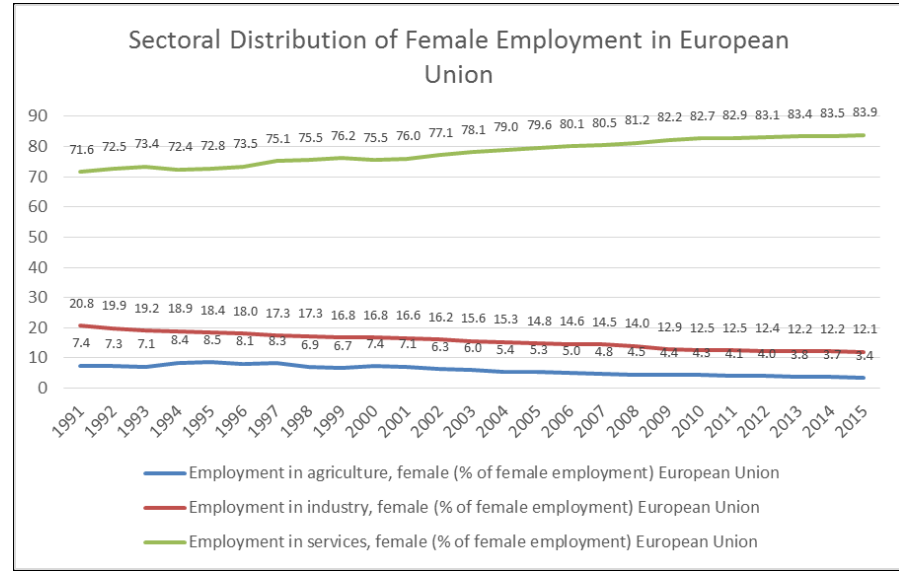

Figure 3. Sectoral Distribution of Female Labor Force in the European Union (1991-2015). Source: World Bank, World Development Indicators 2017.

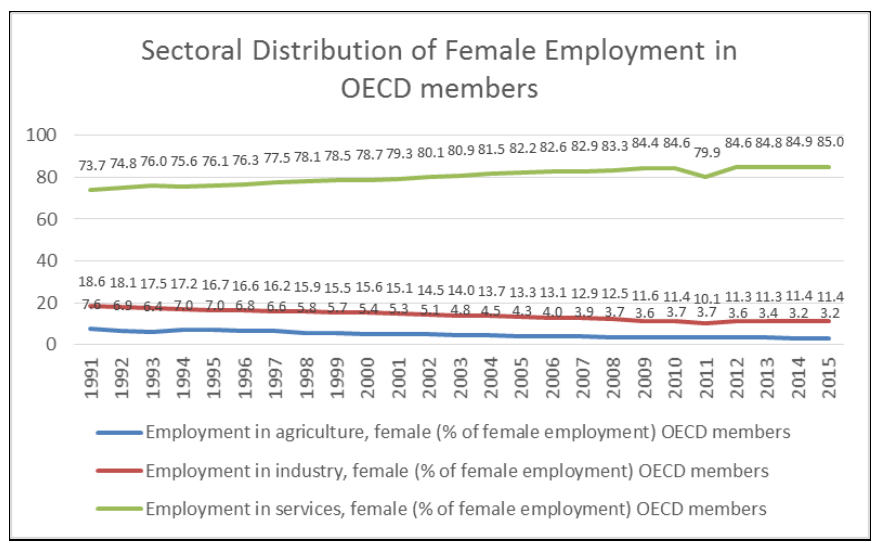

Figure 4. Sectoral Distribution of Female Labor Force in OECD Member Countries (1991-2015). Source: World Bank, World Development Indicators 2017.

In terms of female educational empowerment, adult female literacy rate rose from 68.5 per cent in 1990 to 98.9 percent in 2015 in Turkey (World Bank Indicators, 2017). As it is mostly argued, a more educated female population is likely to have a positive effect on female labor force participation. Furthermore, women are postponing marriage to a later age compared to their female ancestors, which is another factor allowing them to study and participate in the labor force. Despite these favorable indicators, female labor force participation in Turkey appears to be low by international standards (International Bank for Reconstruction and Development and SPO report, 2009: ix).

The reason for the relatively low levels of female labor force participation in Turkey may be a multidimensional issue that must be analyzed from both an economic and a socio-cultural perspective. From the economic perspective, low labor force participation of women is partly explained by the fact that for some women, the market wage level is below their reservation wage, corresponding to the sum of the value of housework and childcare. 
Labor shedding in agriculture is another important factor to be explained in terms of the changing composition of Turkey's female labor force participation. The decline in agricultural production and the concomitant rise in manufacturing and services production have resulted in migration from rural to urban areas, which in turn facilitated the transformation of rural unpaid household women workers into discouraged workers voluntarily withdrawing from the labor market. Another perspective explains the main determinant of insufficient female labor force participation through women's social role of housework and childcare/eldercare responsibilities (International Bank for Reconstruction and Development and SPO report, 2009: 11).

\section{Literature Review and Hypothesis Development}

The relationship between female labor force participation rate and economic development is widely discussed in recent research. Economists performed a variety of statistical tests to prove or disprove the existence of a relationship between the rate of female labor force participation and economic development.

Several researchers hypothesized by using different empirical models that female labor force participation rate exhibits a U-shape during the process of economic development. Goldin (1994) used the data for more than one hundred countries and for the United States and demonstrated that labor force participation of women is generally U-shaped during the course of economic development (Goldin, 1994: 25).

Tansel (2002) explained the U-shaped impact of economic development on female labor force participation rates in Turkey using data for 67 provinces for three time points: 1980, 1985 and 1990. According to the study, after a period of sharp decline (downward portion of $U$ ), the female labor force participation rates have exhibited a decrease in the rate of decline. It is also argued that an upturn in this rate may be expected during the coming decades. The study also indicated that unemployment had an important discouraging effect on female labor force participation while the education impact was strongly positive (Tansel, 2002: 1). Özer and Biçerli (2004) examined the determinants of women's labor force participation rates in Turkey by using panel data regression analyses and did not find a direct influence of macroeconomic variables, such as inflation rate, unemployment rate and growth rate on women's labor participation rates. Moreover, they argued that their finding may indicate a lack of integration of women workers into labor markets due to their traditional roles and therefore these implications have not only economic, but also sociological dimensions (Özer and Biçerli, 2004: 55).

Özler investigated the relationship between export orientation and female share of employment in the Turkish manufacturing sector during 1983-85 using plant-level data and found that an increase in the export share of output at the sectoral level led to an increase in female share of employment at the plant level (Özler, 2000: 1239).

Başlevent and Onaran analyzed the impact of export-oriented growth strategy on female labor force participation and employment in urban Turkey. They found that while the long-term economic growth at the province level was found to have a significant positive effect on both the employment and participation of women, the impact of export-orientation was not as strong in the case of non-married women (Başlevent and Onaran, 2004: 1375).

Recent studies demonstrated that when women can develop their labor market potential fully, macroeconomic gains of an economy increases significantly. Aguirre and others (2012) estimated that GDP of several countries could be increased (in United States by 5 percent, in Japan by 9 percent, in the United Arab Emirates by 12 percent, and in Egypt by 34 percent) by raising the female labor force participation rate to each of these countries' male labor force participation levels. In Japan, the annual potential growth rate could rise by about $1 / 4$ percentage point if female labor force participation rate were to reach the average for the $\mathrm{G} 7$ countries, resulting in a permanent rise of 4 percent in per capita GDP (IMF 2012c, as cited in Elborgh-Woytek et al., 2013).

Higher female labor force participation means greater availability of jobs and also higher level of household income resulting in an increase in consumption and therefore in aggregate income of a country. Therefore, we expect a positive correlation between female labor force participation and per capita GDP.

Hence, our first hypothesis is the following:

Hypothesis 1: There is a positive relationship between female labor force participation rate and economic growth as measured by GDP per capita.

Sectoral distribution of female labor force in Turkey has shown that Turkish female labor force has shifted from agriculture to industry and particularly to the services sector. In the composition of Turkey's GDP in terms of value added, the share of agriculture has decreased from 55.9 in 1960 per cent to 18 per cent in 1990 and to 8.5 per cent in 2015. Industry's value added share has increased to 26.5 per cent in 1960 to 32.1 in 1990 but decreased to 26.5 in 2015. Finally, services value added that was 26.4 per cent in 1960, has shifted from 49.7 in 1990 to 64.5 per cent in 2015. Since the total female labor force includes the female employment in agriculture, it would also be appropriate to analyze separately the correlation between the female labor force in industry and GDP growth and the correlation between female labor force in services and GDP growth (Figure 2) because these two female employment groups are likely to exhibit the same pattern with the economic growth in Turkey where the composition of GDP has been shifted from an agrarian structure to an economy highly dominated by industry and services. 
Based on the above, we also have formulated the following hypotheses:

Hypothesis 2: There is an inverse relationship between female labor force participation rate in agriculture and economic growth as measured by GDP per capita.

Hypothesis 3: There is a positive relationship between female labor force participation rate in manufacture and economic growth as measured by GDP per capita.

Hypothesis 4: There is a positive relationship between female labor force participation rate in services and economic growth as measured by GDP per capita.

The following section delineates the method used for this analysis.

\section{Method}

We have used the World Development Indicators 2017 database of the World Bank for our analyses. We have conducted correlation analyses between two indicators: Turkey's GDP level per capita and female labor force participation rate in the aggregate as well as at the sectoral levels for agriculture, industry, and services. In the study, GDP per capita in constant 2010 US dollars and female labor force participation rate (\% of female population ages $15+=$ Labor Force (Unemployed+Employed) / WAP (Working-age Population aged 15+) (modeled ILO estimate) are taken from the World Development Indicators (WDI) 2017 database of the World Bank. The dataset for GDP per capita and female labor force participation rates (total, agriculture, industry and services sectors) corresponds to the time period 1990-2015. We used the natural logarithms of both variables in the correlation analyses. The data was analyzed using SPSS software.

\section{Findings}

The correlation analysis we have performed to test our hypothesis that the higher the female labor force participation rate, the higher is economic growth as measured by GDP per capita did not turn out to be significant, and the hypothesized relationship was in the opposite direction. Thus, Hypothesis 1 was not supported. As Figure 5 indicates, time series of the female labor force participation rate and the GDP per capita do not show a linear relationship. Moreover, Spearman's rho Correlation coefficient (-0.394) shows that there is a negative correlation between female labor force participation rate and GDP per capita (Tables 1 and 2).

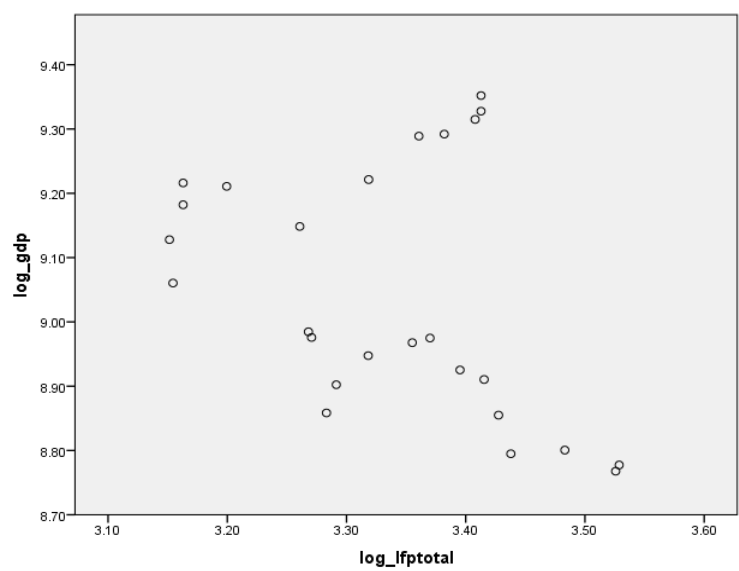

Figure 5. Scatterplot Showing the Series of GDP Per Capita and Labor Force Participation Rate. Source: World Bank, 2017.

In our subsequent analyses we examined the relationship between GDP per capita and the sectoral female labor force participation rate, i.e. FLFPR in agriculture, industry and services.

As it can be seen from the scatter plots presented in Figures 6, 7 and 8, GDP per capita is negatively correlated with FLFPR in agriculture and is positively correlated with FLFPR in industry and FLFPR in services. Accordingly, for the correlation between the GDP per capita and FLFPR in agriculture, the Pearson and Spearman's rho correlation coefficients are respectively $(-0.970)$ and $(-0.967)$ with $(\rho=0.000)$ significance value. As a result, our second hypothesis is supported (Tables 1 and 2).

For female labor force participation rate in industry, the Pearson and Spearman's rho correlation coefficients are (0.905) and (0.912), respectively, both significant at the 0.01 level $(\rho=0.000)$. Similarly, for the correlation between the GDP per capita and FLFPR in services, the Pearson and Spearman's rho correlation coefficients are $(0.974)$ and (0.973), respectively, again both significant at the 0.01 level $(\rho=0.000)$. It can be thus concluded that the correlation between FLFPR in industry and the GDP per capita as well as the correlation between FLFPR in 
services and the GDP per capita are statistically significant. As a result, our third and fourth hypotheses are also supported (Tables 1 and 2).

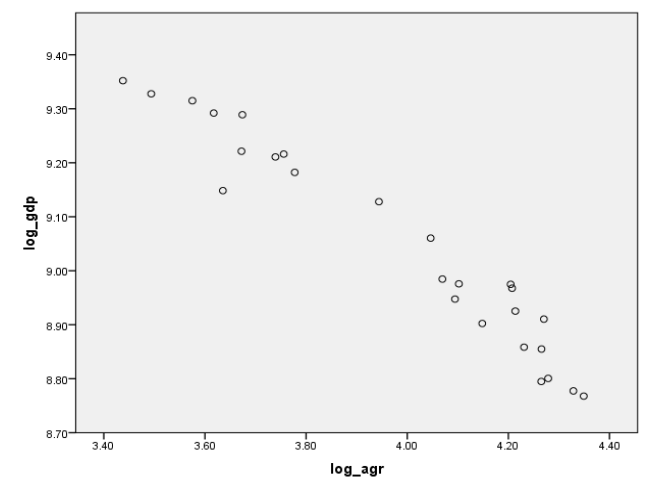

Figure 6. Scatterplot Showing the Series of GDP Per Capita and Labor Force Participation Rate in Agriculture. Source: World Bank, 2017.

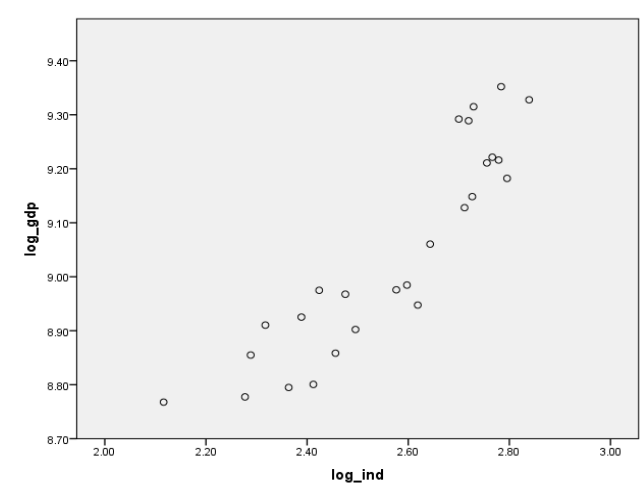

Figure 7. Scatterplot Showing the Series of GDP Per Capita and Labor Force Participation Rate in Industry. Source: World Bank, 2017.

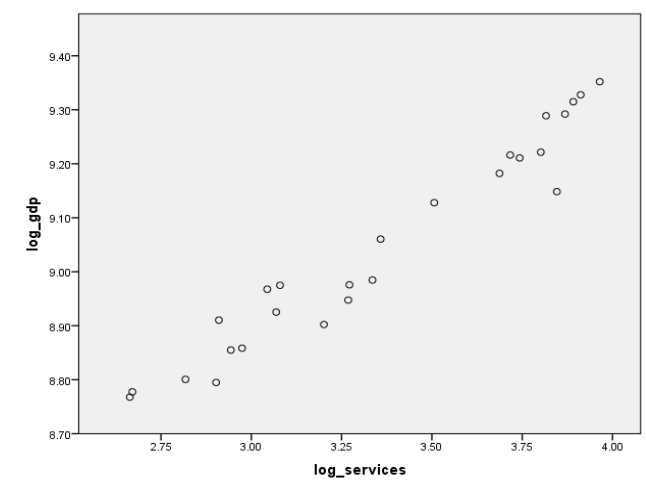

Figure 8. Scatterplot Showing the Series of GDP Per Capita and Labor Force Participation Rate in Services. Source: World Bank, 2017. 


\begin{tabular}{|c|c|c|c|c|c|c|}
\hline & & log_gdp & $\log$ agr & log_ind & log_services & log_lfptotal \\
\hline \multirow{4}{*}{ log_gdp } & Pearson Correlation & 1 & $-.970^{* *}$ & $.905^{* *}$ & $.974^{* * *}$ & -.377 \\
\hline & Sig. (2-tailed) & & .000 & .000 & .000 & .058 \\
\hline & $\mathrm{N}$ & 26 & 26 & 26 & 26 & 26 \\
\hline & Pearson Correlation & $-.970^{* *}$ & 1 & $-.899^{* *}$ & $-.979^{* *}$ & .303 \\
\hline \multirow[t]{3}{*}{ log_agr } & Sig. (2-tailed) & .000 & & .000 & .000 & .132 \\
\hline & $\mathrm{N}$ & 26 & 26 & 26 & 26 & 26 \\
\hline & Pearson Correlation & $.905^{* *}$ & $-.899^{* *}$ & 1 & $.945^{* *}$ & $-.616^{* *}$ \\
\hline \multirow[t]{3}{*}{ log_ind } & Sig. (2-tailed) & .000 & .000 & & .000 & .001 \\
\hline & $\mathrm{N}$ & 26 & 26 & 26 & 26 & 26 \\
\hline & Pearson Correlation & $.974^{* *}$ & $-.979^{* *}$ & $.945^{* *}$ & 1 & $-.456^{*}$ \\
\hline \multirow[t]{3}{*}{ log_services } & Sig. (2-tailed) & .000 & .000 & .000 & & .019 \\
\hline & $\mathrm{N}$ & 26 & 26 & 26 & 26 & 26 \\
\hline & Pearson Correlation & -.377 & .303 & $-.616^{* *}$ & $-.456^{*}$ & 1 \\
\hline \multirow[t]{2}{*}{ log_lfptotal } & Sig. (2-tailed) & .058 & .132 & .001 & .019 & \\
\hline & $\mathrm{N}$ & 26 & 26 & 26 & 26 & 26 \\
\hline
\end{tabular}

**. Correlation is significant at the 0.01 level (2-tailed)

*. Correlation is significant at the 0.05 level (2-tailed).

Table1 - Correlations

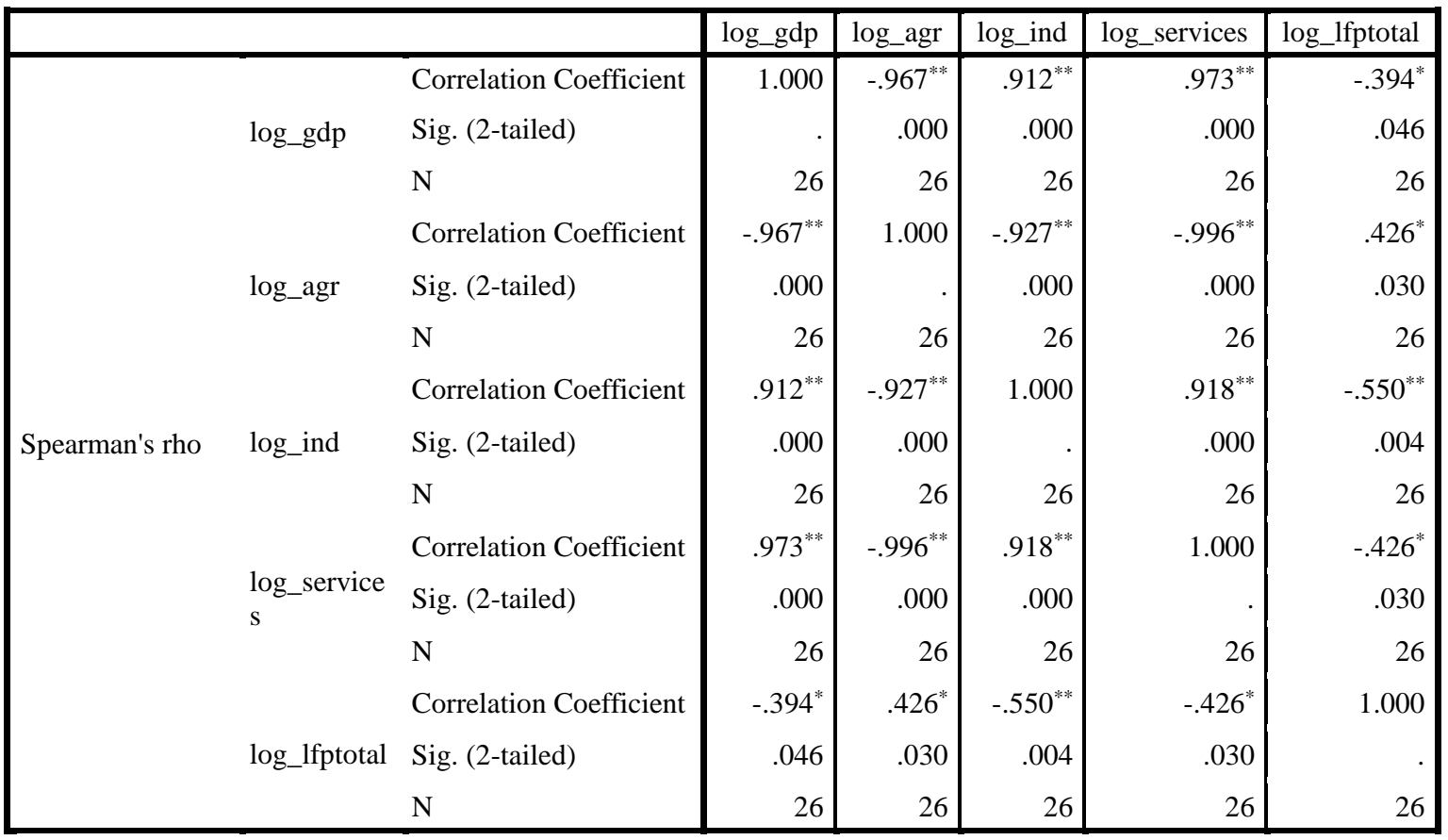

**. Correlation is significant at the 0.01 level (2-tailed).

*. Correlation is significant at the 0.05 level (2-tailed).

Table 2- Correlations

\section{Conclusion, Limitations and Implications for Further Research}

Even though women represent nearly one half of the global population, their contribution to economic activity and growth is still far below its potential. Our tentative results indicate that there may in fact exist a strong positive relationship between women's labor force participation rate in industry and in services and economic growth as measured by GDP per capita. Removing the barriers to women's labor force participation implies greater economic growth. Despite significant progress in recent years, female labor force participation in Turkey remains relatively low by international standards (International Bank for Reconstruction and Development and SPO report, 2009: ix), women account for most of the unpaid work (World Economic Forum, The Global Gender Gap Report 2016: 32 ), and when women are employed in paid work, they also face significant wage disparities compared to male workers (United Nations Development Programme, 2016). 
Increasing the labor force participation of women appears to be contingent upon women's economic empowerment. Non-paid and dangerous work, low pay, lack of social protection and job insecurity are some of the contextual factors that need to be ameliorated. Globally, relatively low wages as compared to men are a general problem of working women. On the other hand, since demographic, economic and cultural factors also contribute to these unfavorable conditions, each country's women labor force differs from others. As a result, in each country and especially in developing and underdeveloped countries, governments are required to apply tailored approaches and solutions to gender issues.

In Turkey, traditional roles of women as child/elder care providers and home makers are important determinants of labor market choice. The influences of a patriarchal society play also an important role in determining women's labor market presence. As such, female employment needs to be analyzed from both economic and socio-cultural perspectives. To increase the female labor force participation in Turkey, first these socio-cultural and economic barriers against women's employment should be recognized and then solutions should be sought to remove these barriers so that women will be encouraged to enter the workforce.

Economic barriers include generally factors such as working in the informal sector as a result of insufficient job opportunities in formal sectors, lower wages compared to male workers, long hours and poor working conditions, and shortage of childcare/eldercare services. Apart from economic barriers, sociological factors related to the traditional role of women as caregiver in the household as well as the lower level of gender diversity in workplaces worsen the effects of economic barriers and weaken women's motivation to participate in the labor force. Despite significant progress in advanced market economies, evidence of gender-based discrimination such as the glass ceiling effect persists there also. Considering the prevalence of these issues confronted by women in the labor market, leadership by international bodies such as the UN as well as national governments appears to be necessary. In fact, leadership by multinational companies as well as big business groups especially in developing economies may also go a long way towards increasing the participation of women in the labor force through implementation of women-friendly corporate policies.

Various policies for increasing the demand for female labor and improving female labor force participation can be suggested: These include government subsidies to increase the hiring of women, decreasing the percentage of informality, and rewarding of public or private enterprises within the scope of best practices.

This study has several limitations. First, it is limited to one country, Turkey, and thus its results may not be generalized to other countries. Secondly, because the data on female labor force participation is limited, the sample size of this study (1990 to 2015) is relatively small. Finally, causal analyses that treat GDP per capita as a dependent variable and female labor force participation among a host of independent variables may enrich our understanding of the interplay between economic growth and female labor force participation. Further research studies that include multiple countries and a wider time range may reveal greater insight into the relationship between female labor force participation and GDP per capita.

\section{References}

- $\quad$ Aguirre, D., Leila Hoteit, Christine Rupp, and Karim Sabbagh, 2012, "Empowering the Third Billion. Women and the World of Work in 2012," Booz and Company.

- Başlevent, C. and Onaran, Ö., 2004, "The Effect of Export-Oriented Growth on Female Labor Market Outcomes in Turkey", World Development Vol. 32, No. 8.

- Buğra, A. and Yakut-Çakar B., 2010, "Structural Change, the Social Policy Environment and Female Employment in Turkey", Development and Change 41(3), International Institute of Social Studies.

- Çağatay, N., and Özler, Ş., 1995, "Feminization of the labor force: the effects of long-term development and structural adjustment", World Development, 23.

- Dollar, D., and R. Gatti, 1999, “Gender Inequality, Income, and Growth. Are Good Times Good for Women?” World Bank Gender and Development Working Paper No. 1.

- Duflo, E., 2012, “Women Empowerment and Economic Development,” Journal of Economic Literature, Vol. 50 , No. 4.

- Durand, John D., 1975, The labor force in economic development. Princeton University Press.

- $\quad$ Elborgh-Woytek, K.; Newiak, M.; Kochhar, K.; Fabrizio, S.; Kpodar, Kangni; Wingender, P.; Clements, B.; \& Schwartz, G. 2013. Women, work, and the global economy: Macroeconomic gains from gender equity. IMF Discussion note. International Monetary Fund (Strategy, Policy, and Review Department and Fiscal Affairs Department).

- Goldin, C. 1994, "The U-Shaped Female Labor Force Function in Economic Development and Economic History" National Bureau Working Paper No. 4707.

- Gündüz-Hoşgör, A. and Smits. J., 2008, "Variation in labor market participation of married women in Turkey”, Women's Studies International Forum 31. 
- Inglehart, R., \& Norris, P., 2003, Rising tide: Gender equality and cultural change around the world. Cambridge Cambridge University Press.

- International Bank for Reconstruction and Development (World Bank) and SPO (State Planning Organization) Report, 2009, "Female Labor Force Participation in Turkey: Trends, Determinants and Policy Framework", Report No: 48508-TR.

- Loko, B., and Mame A. D., 2009 “Revisiting the Determinants of Productivity Growth: What's New?" IMF Working Paper 09/225 (Washington).

- Özer, M. and Biçerli, K. “Türkiye’de Kadın İşgücünün Panel Veri Analizi”, Sosyal Bilimler Dergisi 20032004.

- Özler, Ş. 2000, "Export Orientation and Female Share of Employment: Evidence from Turkey", World Development Vol. 28, No. 7, 2000.

- Pampel, Fred C., \& Tanaka, K., Economic development and female labor force participation: A reconsideration. Social Forces, 64.

- Psacharopoulos, G. and Z. T., 1989, Female Labor Force Participation: An International Perspective. World Bank Research Observer, 4(2).

- $\quad$ Rau, W., \& Wazienski, R., 1999, Industrialization, female labor force participation, and the modern dividion of labor by sex. Industrial Relations.

- $\quad$ Ross, Michael, 2006, Does oil hurt the status of women? Los Angeles UCLA Department of Political Science Working paper.

- Scott, Joan W., \& Tilly, L. 1975, Women's work and family in nineteenth-century Europe. Comparative Study of Society and History, 17, 36-64.

- Standing, G., 1978, Labor Force Participation and Development, Geneva: International Labor Office.

- Tansel, A. 2001, "Economic Development and Female Labor Force Participation in Turkey: Time-Series Evidence and Cross-Province Estimates", Middle East University.

- Tsani, S., Leonidas P., Costas F., Ioannis C. and Pantelis C., 2012, "Female Labor Force Participation and Economic Development in Southern Mediterranean Countries: What Scenarios for 2030?" MEDPRO Technical Report No. 19, European Commission.

- Turkish Statistical Institute, March Report No: 24566, http://www.tuik.gov.tr/HbGetirHTML.do?id=24566.

- UNDP, Human Development Report, 2016.

- Wood, A. 1991, North-South trade and female labor in manufacturing: an asymmetry. Journal of Development Studies, 27.

- World Bank, World Development Indicators, WDI Database, 2017.http://databank.worldbank.org/data/reports.aspx?source=world-development-indicators\#

- World Bank, http://data.worldbank.org/indicator/NV.SRV.TETC.ZS?locations=TR.

- World Economic Forum, (2015) The Global Gender Gap Report 2015. Geneva, Switzerland: World Economic Forum.

- World Economic Forum, (2016) The Global Gender Gap Report 2016. Geneva, Switzerland: World Economic Forum. 


\title{
Fidic Kuralları Çerçevesinde Yürütülen Tahkim Yargılamalarında Türk ve Yabancı İnşaat Firmaların Karşılaştığı Sorunlar Problems of Turkish and Foreign Construction Companies on the Fidic Arbitration Rules
}

\author{
Asst. Prof. Dr. Cahit Ağaoğlu (Beykent University, Turkey)
}

\begin{abstract}
FIDIC rules are generally accepted as standard contract for construction projects in international commercial practice. Disputes arising from standard agreements are often referred to as international arbitration rules. However, at the beginning of the difficulties encountered in the arbitration proceedings under the FIDIC Rules at the international arbitration institutions, the question is whether the engineer is impartial. On the other hand, the fact that the Dispute Adjudication Board (DAB) has been used effectively is also an important issue. It has been revealed through the case-law that the adoption of the FIDIC Rules by the domestic laws of the parties has not yet reached the desired stage. Aside from the fact that arbitral awards are confronted with public authority during the enforcement phase, there are also difficulties of parallel proceedings that national courts have resorted to legal proceedings although there is an agreement involving arbitration clauses. The protection of the investor, the equitable treatment of the investor and the protection against expropriation are all on the agenda and a direct link can be established between FIDIC and Bilateral Investment Treaties.
\end{abstract}

\section{Giriş}

İnşaat Sektörü ülkemizde günden güne gelişme göstermekte olup, küreselleşmenin etkisiyle de Türk yatırımcılar sadece ülkemiz sınırları içerisinde değil, yurtdışında da faaliyetlerine son hızla devam etmektedir. Bu çerçevede, Türk ekonomisinin lokomotif sektörü olarak kabul edilen inşaat sektörü, son 30 yılda önemli bir siçrama gerçekleştirerek, günümüzde uluslararası platformda da kendisine yer bulmaktadır.

Ülke sınırları dışında inşaat sektörü hizmetleri ilk olarak 1972 yılında Libya'da başlamış olup, günümüzde Türk müteahhitlerinin özellikle Bağımsız Devletler Topluluğunda, Orta Doğu ve Afrika'da önemli işlere imza attıkları görülmektedir. Buralarda üstlenilen faaliyetler sadece konut yapımıyla sınırlı olmayıp, karayolu/tünel/köprü, havalimanı, ticaret merkezi, fabrika ve turistik tesisleri yapımında da Türk inşaat şirketleri geniş bir kapsamda hizmet vermektedir.

Uluslararası İnşaat Sektörü Dergisi ‘Engineering News Record’ tarafından 2014 y1lında açıklanan dünyanın en büyük 250 firması arasında, ülkemiz 42 firmayla kendisine yer bularak, listede Çin'den sonra en çok firmaya sahip olan ülke sıfatıyla ikinci sırayı elde etmiştir (intes.org.tr, 2017) Bu durum yurtdışında yatırım faaliyetlerinde bulunan inşaat firmalarımızın başarılı bir şekilde ilerlediklerinin en güzel göstergesidir.

İnşaat Sektörlerinin uluslararası düzeyde yatırımlar yapması, bu konuda faaliyet gösteren uluslararası kuruluşlarca ele alınmış, hukuki ve ticari güvenliğin sağlanması, taraflar arasında adil bir dengenin kurulması ve de yeknesaklığı sağlamak amacıyla standart sözleşmeler hazırlanmaya başlanmıştır. Hazırlanan standart sözleşmelerden İnşaat Sektöründe en yaygın kullanıma sahip olan FIDIC Şartnameleri bu makalenin asıl konusunu oluşturmakta olup, Türk firmalarının FIDIC kuralları çerçevesinde yaşadığı sorunlar, yatırım uyuşmazlıklarının çözümü kapsamında ICSID ve ICC tahkimi ışığında ele alınacak ve sadece Türk Firmalarının değil, yabancı firmaların da yaşadığı problemlere ilişkin çeşitli tahkim kararları incelenecektir.

\section{Genel Olarak Fidic}

İsviçre'nin Lozan şehrinde 1913 yllında kurulmuş, federasyon statüsüne (FIDIC, 2017) sahip bu oluşum, ismini 'Fédération International Des Ingénieurs-Conseils' (Uluslararası Müşavir Mühendisler Federasyonu) kelimelerinin baş harflerinin bir araya gelmesinden almıştır.

FIDIC inşaat sektöründe hukuki standartların oluşumunda büyük katkıda bulunmuş ve halen de bu hususta çalışmalarına devam etmekte olan müşavir mühendisler odalarının oluşturduğu önemli bir uluslararası meslek kuruluşudur. Günümüz itibariyle 101 ülkenin (fidic.org/members, 2017) temsil edildiği bu kuruluşa, her ülkeden ancak bir temsilci atanabilmekte olup, 1987 yllından itibaren ülkemiz adına temsilciliğini Türkiye Müşavir/Mühendisler Mimarlar Birliği yürütmektedir.

1913 yılında Kıta Avrupası hukuk düzeninin etkisi altında kurulmuş olan FIDIC, inşaat projelerinde işverenyüklenici-müşavir (mühendis) üçlüsü arasındaki ilişkileri uluslararası çapta düzenlemek için, 1957 yılında AngloSakson hukukunun etkisi altında, özellikle İngiltere'de İnşaat Mühendisleri odası tarafından hazırlanan Institution Civil Engineers (ICE) kurallarından etkilenerek standart sözleşme şartnameleri hazırlamaya başlamıştır. 
Hazırlanan söz konusu bu şartnameler, gelişen teknolojiye ve buna bağlı olarak inşaat proje gereksinimlerinin çeşitlenmesiyle birlikte sonraki yıllarda düzenli olarak istek ve ihtiyaçlar doğrultusunda güncellenmiş, uluslararası alanda tüm iş sahipleri ve yüklenicilerin yaygın olarak kullanabileceği standart inşaat sözleşmeleri haline gelmiş ve her yeni versiyonda FIDIC standart inşaat sözleşmeleri biraz daha Anglo-Sakson özelliğinden uzaklaşmış, etkisi altında olduğu hukuk düzeni açısından daha karma nitelikli bir hal almıştır.

Her inşaat projesinin kendisine özgü özellikleri olması ve sözleşmelerde dizaynı yapan tarafin çeşitlilik göstermesi FIDIC'in bu farklılıkları dikkate alarak çeşitli kitaplar hazırlamasına neden olmuştur. Farklı Standart Sözleşmeleri barındıran bu kitaplar kapak renklerinden dolayı Kırmızı Kitap, Sarı Kitap, Yeşil Kitap, Gümüş Kitap, Turuncu Kitap, Beyaz Kitap, Mavi-Yeşil Kitap ve Altın Kitap olarak adlandırılmaktadır. Hangi durumlarda söz konusu kitaplara başvurulacağı ve kitapların içeriğine bu çalışmada yer verilmeyecek olup, uygulamada en fazla bilinen ve Türk firmaları tarafından da en fazla uygulanan kitabın 'Kırmızı Kitap' olduğunu söylemekle yetinilecektir.

Günümüzde Uluslararası İnşaat Sözleşmelerinde, sözleşme ifa edilirken tarafların hak ve yükümlülüklerini büyük bir önemle düzenleyen FIDIC şartnamesinin uygulanması çoğu kez yabancı işveren ve uluslararası kredi kuruluşları tarafından talep edilmektedir. Finansmanı sağlayan kreditörler, projelerin kendilerinin belirlediği sözleşme şartlarına göre ihale edilmesini ve uygulanmasını istemekte ve bu süreç içerisindeki her aşamada onaylarının aranmasını şart koşmaktadır. Uluslararası inşaat projelerinin yaklaşık \% 30’unda FIDIC kurallarının uygulanması, federasyonun dünya çapında ne kadar kabul gördüğünün bir göstergesidir. Milletlerarası ticaret verilerine göre de bu kuruma yapılan tahkim başvurularının yaklaşık \% 21'i FIDIC kurallarına göre yapılan sözleşmeler sonucunda olmaktadır (anahtar.sanayi.gov.tr, 2017).

Uluslararası düzeyde, yatırımcılar, iş sahipleri ve yükleniciler tarafından uygulanma oranı bu derece yüksek olan FIDIC Şartnameleri, buna rağmen sözleşmelerin taraflar seçmedikçe aralarındaki ilişkilere uygulanmaması sebebiyle bir lex mercatoria seviyesine gelmediği iddia edilmekle birlikte, inşaat sektöründe çok rağbet gören sözleşmeler oldukları kabul gören bir gerçektir. Bu kapsamda önemle belirtmek gerekir ki, FIDIC örnek sözleşme kuralları kendisinin uygulanmasını zorunlu kılacak nitelikte bir hüküm içermemektedir. Yukarıda belirtildiği üzere, sadece ilgililerin FIDIC Kurallarının uygulanması konusunda anlaşmaları halinde bu hükümler uygulama alanı bulacaktır. FIDIC Kuralları dünya genelinde kabul görmüş olsa da, dernek statüsüne sahip bir organizasyon tarafından yayımlanmış olduğu için, hukuki anlamda bunun herhangi bir dernek faaliyetinden farkı yoktur. Uluslararası alanda teamül hukuku olarak kabulünü sağlayacak güce henüz sahip değildir. Bir kısım yazarlar, burada sözleşmeye bir lex mercatoria olarak dürüstlük kurallarının uygulanmasına karşı çıkmaktadır. Buna gerekçe olarak da, dürüstlük kurallarının bir hukuki norm olarak uygulanmamasını ve bu sebeple de, hakemlerin dürüstlük anlayışı ile tarafların dürüstlük anlayışının çoğu kez örtüşmemesini göstermektedir. Doktrin'de bazı yazarlar bu görüşe katılmamaktadır. Onlara göre tarafların Kırmızı Kitap’ı esas aldıkları sözleşmelerinde hukuk seçimi yapmadıkları durumlarda, hakemler sözleşmeye lex mercatoria olarak hukukun genel ilkelerini ve hatta dürüstlük kurallarını uygulayabilmelidir. UNCITRAL Kurallarına atıfta bulunarak Birleşmiş Milletler Komisyonu'nun lex mercatoria' yı bağımsız bir hukuk sistemi olarak saymamakla birlikte, tarafların sözleşmelerine uygulanmak üzere dürüstlük (hakkaniyet veya hak ve nesafet) kurallarına yollama yaptıkları durumlarda, bunların bir lex mercatoria olarak akit statüsü ile beraber sözleşmeye uygulanabileceğini kabul etmekte ve tarafların burada sözleşmelerine uygulanmak üzere bir hukuk seçmedikleri gibi, dürüstlük kurallarına yollama dahi yapmadıkları durumlarda da, dürüstlük kuralları bir lex mercatoria olarak sözleşme şartlarıyla birlikte uygulanabileceği görüşünü savunmaktadırlar (tez.yok.gov.tr, 2017). Tarafların hukuk seçimi yapmadıkları durumlarda lex mercatoria'nın bağımsız bir hukuk sistemi olarak, sözleşmeye uygulanabileceğini bildirmektedir. Zira, lex mercatoria taraflar arasındaki sözleşmelerin mahiyet ve özelliğine, uluslararası ticaretin ihtiyaçlarına ve tarafların haklı beklentilerine uygun düşmekte veya en azından uygun düştüğü ölçüde uygulanacaktır. Bu durum yayımlanan standart kuralların ve tip sözleşmelerin uygulamada taraflarca değiştirilmesini ve dolayısıyla FIDIC Kurallarının taraflarca aksi belirtilmediği müddetçe esas alınması gerektiğini göstermektedir. Ancak yine de Dünya Bankası, Asya Kalkınma Bankası ve Afrika Bankası Projelerde şartnamelerin uygulanmasını yoğun bir şekilde tavsiye etmektedir.

1972 yılından beri yurt dışında inşaat projeleri üstlenmekte olan müteahhitlik firmalarımız, gerek katıldıkları uluslararası rekabete açık ihalelerde ve gerekse yabancı bir ülkede işveren idare ile inşaat sözleşmesi akdederlerken, karşılarına çoğu zaman FIDIC Tip Sözleşmeleri ve Şartnameleri çıkmaktadır. Ayrıca, gerek yabancı sermayedarların ülkemizde yapmakta oldukları yatırımın inşaat bölümü ile ilgili yapım sözleşmelerinin, gerekse Dünya Bankası ve benzeri uluslararası kredi kuruluşlarından veya yabancı bankaların kurduğu kredi konsorsiyumlarından sağlanan kredilerle yapılacak inşaat işleri ile ilgili inşaat sözleşmelerinin FIDIC tip sözleşmelerini esas almaları, çoğu zaman yabancı işveren ve uluslararası kredi kuruluşları tarafından talep edilmektedir. Belirtilen bu nedenlerden dolayı, Türk firmaları tarafından FIDIC Şartnamelerinin kabul edilip, uygulanma oranları hızlı bir şekilde artış göstermektedir. Bu artış sebebiyle, İnşaat sözleşmelerine uygulanan şartnamelerin anlaşmazlık çıkarma potansiyeli hususunda, Türk firmaları arasında yapılan ankette, ankete katılan 76 firmadan sadece 11'i FIDIC şartnameleriyle ilgili olarak sorun yaşadığını belirtmiştir. 


\begin{tabular}{|c|c|}
\hline Şartname Türü & Yanıt Sayısı \\
\hline Özel Şartnameler & 46 \\
\hline $\begin{array}{c}\text { Bayındırlık İşleri Genel } \\
\text { Şartnamesi (BİGŞ) }\end{array}$ & 17 \\
\hline FIDIC Şartnameleri & 11 \\
\hline Diğer & 2 \\
\hline
\end{tabular}

Tablo 1: Şartnamelerde Fidic 'in Yeri

Belirtilen anket sonucuna rağmen, yurtdışındaki yatırımcılarımızın FIDIC şartnamelerinin uygulanması sebebiyle yaşadığı sıkıntılar ve bu nedenle uğradıkları ekonomik zararlar azımsanamayacak kadar fazladır.

\section{Fidic ve Türk İnşaat Firmaları}

Türk firmalarının FIDIC kapsamında sıkıntı yaşamalarının en önemli sebeplerinden birisi, uygulamada orijinal İngilizce metni ile birlikte kullanılmakta olsa da, bazı sözleşmelerde İngilizce metin esas alınarak Türkçe tercümesinin yardımcı bir doküman olarak kabul edilmesi, başka bazı sözleşmelerde ise tam tersi durumun mümkün olabilmesidir. Bu durumun sıklıkla karışıklıklara yol açtığı görülmektedir. Buna rağmen, her ne kadar ülkemizde inşaat sözleşmeleri alanında Bayındırlık Bakanlığı'nın hazırlamış olduğu "Sözleşme Tasarısı", "Bayındırlık İşleri Genel Şartnamesi”, "Yapım İşleri için Kapalı Teklif Usulü” ile "İhale Şartnamesi”, "Teklif Formu" gibi kullanılan formlar mevcut olsa da, özellikle büyük çaplı projelerle ilgili sözleşmelerin hazırlanmasında FIDIC standart sözleşmesi esas alınmaktadır.

$\mathrm{Bu}$ çerçevede, FIDIC'in genel ve özel hükümlerden oluşan bir rehber olarak ele alındığı projelerde, her iş özelinde (resmi veya özel), işveren idarenin talepleri ve bağlı olduğu mevzuata yahut işin gereklerine uyarlanmak üzere düzenlenen özel hükümlerle genel FIDIC şartlarının sadece o konuya ilişkin maddeleri değiştirilerek yapım sözleşmesi hazırlanmaktadır. İşverenin Sayıştay denetimine bağlı bir kamu idaresi olması halinde bu düzenlemeye, sözleşmenin Sayıştay vizesi aşamasında Sayıştay uzmanları tarafından son şekli verilmekte, Sayıştay denetimine bağlı olmayan kamu veya özel işverenler tarafından hazırlanan sözleşmelerde ise ilgili mevzuatın yorumlanması ve uygulanması konusunda sorunlarla karşılaşılmaktadır. Bu şekilde düzenlenmiş bir sözleşmenin uygulanması sırasında tereddütler doğmakta, tereddüt konusu sözleşme maddesi hakkında işveren veya mühendis, sözleşmede yer almayan ve fakat çoğu kez buyurucu nitelik taşımayan mevzuata dayandırılan farklı denetim kriterleri ile yüklenicinin karşısına çıkabilmektedir. Böyle bir durumda, sözleşme uygulaması sırasında işveren ile yüklenici arasında ortaya çıkacak sorunların çözümü için FIDIC anlayışına göre arabuluculuk ile görevlendirilmiş olan mühendis, sorunları çözmek bir yana, sorun yaratan bir konuma bürünebilmektedir. Türk Borçlar Kanunu'nda eser sözleşmesinin tarafları yüklenici ve iş sahibi olarak düzenlenmekteyken, FIDIC şartnamesinde karşımıza üçüncü bir kişi olarak mühendis çıkmaktadır. Ancak burada belirtilmesi gereken önemli husus şudur ki, mühendis iş sahibi ile yüklenici arasında yapılan sözleşmeye taraf değildir. Teknik açıdan bakıldığında mühendisin tasarım alanında gözetimci; işin amaca, sanat kurallarına ve teknik belgelere göre gerçekleştirilmesinde sözleşmenin yönetiminden ve kalite kontrolünden sorumlu olduğunu söyleyebiliriz. Bu teknik görevlerin yerine getirilmesi bakımından mühendis, iş sahibinin yardımcısı (vekili) konumundadır.

Bununla birlikte FIDIC Şartnamesinde kendisine önemli ölçüde yer bulan mühendisin en önemli işlevi, yüklenici ile iş sahibi arasında çıkabilecek uyuşmazlıkların yargı yoluna gidilmeden çözülmesine katkıda bulunmaktır. Ancak iş sahibi ile mühendis arasındaki ilişkiyi, iş sahibinin belirli bir ücret ödemeyi, mühendisin ise belirli teknik hizmetleri ve/veya belgelerin teminini borçlandığı bir vekalet sözleşmesi olarak tanımlamak mümkün iken (Dayınlarlı, 1998; Karayalçın,1996), bu kapsamda mühendisin, iş sahibi ve müteahhit arasında ortaya çıkabilecek uyuşmazlıklarda ne dereceye kadar tarafsızlığını koruyabileceği konusunda, uzun süreler tartışmalar yaşanmıştır. Ancak FIDIC kurallarında 1999 yılında yapılan değişiklikle beraber, tahkim öncesinde iş sahibinden bağımsız ve tarafsız hareket etme yükümlülüğü, Uyuşmazlıkları Çözüm Kurulu’na (Dispute Adjudication Board) bırakılırken, mühendisin tarafsız olduğu ifadesinin yerine, 'mühendisin iş sahibi adına hareket ettiği' ifadesine yer verilmiştir.

FIDIC Şartnameleri teorisinde, işin başarıyla gerçekleştirilmesi ve uyuşmazlıkların en aza indirilmesi amacıyla oluşturulmuş bir kişi olarak karşımıza çıkan mühendis, iş sahibi ile müteahhit arasında bir denge unsuru oluşturmakta ve inşaat süresince ortaya çıkabilecek teknik, malî ve hukukî konularda somut olayın şartlarına göre kesin ve acil kararlar vermek ve bunlardan kaynaklanan sorumlulukları üzerine almaktadır. İnşaat sözleşmelerinde, böylesine olumlu görevi ifa etmesi üzerine yüklenen mühendis, yine de projelerin yerine getirilmesi aşamasında, özellikle yüklenici açısından çeşitli sorunlara neden olabilmektedir. Bu kapsamda yatırım tahkim içtihadının gelişmesine de son derece katkıda bulunmuş olan ICSID Bayındır İnşaat Turizm Ticaret ve Sanayi A.Ş. (bundan böyle kısaca "Bayındır A.Ş." olarak anılacaktır) kararını ve bu karar doğrultusunda Bayındır A.Ş.'nin yaşadığı problemlere aşağıda değinilecektir. 


\section{Fidic Şartnameleri Çerçevesinde Bayındır A.Ş. v. Pakistan Icsid Kararı}

\subsection{Genel Olarak}

Milletlerarası ticaretin son yıllarda hızlı gelişimini takiben, çalışmanın giriş kısmında da belirtildiği üzere, Türk yatırımcıları özellikle inşaat sektörü alanında önemli yatırımlarda bulunmakta ve büyük projelere imza atmaktadır. Yatırım dendiğinde de, 1961-1965 yılları arasında Dünya bankası nezdinde hazırlanan ve 14 Ekim 1966 tarihinde yürürlüğe giren Devletler ve diğer Devletlerin Vatandaşları Arasındaki Uyuşmazlıklarının Çözümlenmesi Hakkında Sözleşme akla gelmektedir. Bu sözleşme uygulamada kısaca Dünya Bankası Sözleşmesi olarak anılmakta olup yatırım uyuşmazlıklarının çözülmesi için merkezi Washington'da olan ve kısaca ICSID adı verilen uluslararası bir merkez oluşturulmuştur.

Yatırım uyuşmazlıklarının çözümü için tarafların bu merkeze başvurmasını çekici kılan en önemli özellikler, davacı yatırımcı ile ev sahibi devlet arasında bir tahkim anlaşması bulunmasa bile tahkime başvurmanın mümkün olması ve ICSID hakem kararlarının milli mahkemelerden ayrı bir tenfiz kararı gerektirmeden icra edilebilmeleridir (Akınc1, 2009)

Türkiye'nin taraf olduğu ICSID kararlarına bakıldığında özellikle FIDIC Kurallarının uygulandığı iki önemli karar göze çarpmaktadır. Bunlar tarih sırasına göre 27 Ağustos 2009 tarihli Bayındır İnşaat Turizm Ticaret ve Sanayi A.Ş. ile Pakistan İslam Cumhuriyeti arasında meydana gelen dava ile 7 Mart 2011 tarihli ATA İnşaat Endüstri ve Ticaret Şirketinin Ürdün Krallığı ile olan davalarıdır. Aşağıda bu davalar özetlenmeye çalışılmış ve görülmüştür ki, Türk firmalarının FIDIC Kurallarına göre ICSID nezdinde yaşadığı problemler yabancı firmaların yaşadığı problemlere ile paralellik göstermekte olup kronik bir hal almaktadır.

\subsection{Bayındır İnşaat Turizm Ticaret ve Sanayi A.Ş. - Pakistan İslam Cumhuriyeti (ICSID Kararı No. $\mathrm{ARB} / \mathbf{0 3} / \mathbf{2 9}$ )}

Türk Bayındır Firması tarafından, üstlendiği otoyol inşaatı ile ilgili olarak Pakistan aleyhine açılmış bulunan Bayındır İnşaat Davası, yatırım tahkimi içtihadının gelişmesine önemli katkıları olmuş bir ICSID davasıdır. Bu davada verilen karar genel itibariyle 'Yatırımcı ile ev sahibi devlet arasındaki sözleşme ile devletler arasında akdedilmiş Yatırım Teşvik ve Koruma Sözleşmesi arasındaki ilişki' ve 'en ziyade müsaadeyi mazhar millet kaydının' tatbiki (Ataman, 2012) hususlarıyla ilgili olsa da, yukarıda da belirtildiği üzere söz konusu bu kararın FIDIC kapsamında kalan kısımları incelenerek, müteahhidin durumu ele alınacaktır.

İncelemeye geçmeden önce belirtmek gerekir ki, inşaat projelerinin bir yatırım olarak değerlendirilmesi gerektiği hususu, Bayındır İnşaat davasında da ICSID hakem heyeti tarafından kabul edilerek, bu konudaki tartışmalara ve Pakistan tarafından ihtilafın bir yatırım ihtilafı olarak değerlendirilemeyeceği iddialarına son verilmiştir.

Bayındır İnşaat ile Pakistan Milli Karayolları Otoritesi arasında, Pakistan'da altı şeritli otoyol inşa edilmesini içeren sözleşmenin, Pakistan tarafından feshedilmesinden kaynaklanan uyuşmazlıkta, Bayındır A.Ş. tarafından sunulan dilekçelerde mühendisle ilgili olarak belirtilen problemli hususlar sırasıyla belirtilecektir.

ICSID hakem heyeti tarafından 27 Ağustos 2009 tarihinde verilen kararda (kluwerarbitration, 2017, Bayindir İnşaat Turizm Ticaret ve Sanayi AS. V Islamic Republic of Pakistan Award, ICSID Case No. ARB/03/29,27August 2009), 'madde, fikra ve sözleşme maddeleri terimleri', FIDIC Genel Şartnameleri 'nin ilgili maddeleri anlamında kullanılacaktır denilerek, verilen kararda FIDIC kurallarına atıfta bulunulduğu açıkça ifade edilmiştir (I. The Facts article 14 ve I. The Relevant Facts Regarding the Issue of Jurisdiction article 15).

Kararda yine FIDIC Şartnamesi çerçevesinde inşaat projesinin mühendis tarafından denetlendiği ve mühendisin ise işveren tarafından atandığı belirtilmiştir. İşveren tarafın kamu gücünü kullanan bir otorite olması ve işlerin düzenini sağlayıp denetlemekle yükümlü olan mühendisin de bu otorite tarafından seçilmiş bulunması, proje ifa edilirken haklarının korunması açısından Bayındır A.Ş.’yi zor bir duruma sokmuştur.

Sözleşmede belirtildiği şekliyle mühendisin, yüklenici tarafından işlerin tamamının veya bir kısmının, taraflar arasındaki sözleşmede kararlaştırılan tamamlanma süresini aşacak şekilde yavaş ilerlediğini tespit etmesi halinde, bu durumu işverene bildirme zorunluluğu bulunmaktadır. Aynı bildirim zorunluluğu mühendisin, yüklenicinin işleri makul bir sebep olmadan zamanında yerine getirmediği kanaatinde olduğu durumlarda da geçerlidir. İlaveten, Mühendisin bu görevlerini seçeceği bir temsilci aracılığıyla da yerine getirebileceği belirtilmiştir.

Uyuşmazlık bağlamında, 2 Aralık 2000 tarihinde mühendis temsilcisi tarafından, Bayındır A.Ş.'nin işlerini sözleşmede belirtilen tarihe yetişmeyecek derecede, çok yavaş ilerlettiği bildiriminde bulunulmuştur. Bu bildirim üzerine, 11 Aralık 2000 tarihinde Bayındır tarafından yapılan savunmada birçok sebep ileri sürülerek, sözleşmede kararlaştırılan süreyi aşmaya yetkili olacağı ifade edilmiştir. Yapılan birçok görüşme sonucunda mühendis temsilcisi, Bayındır'ın sözleşmesel yükümlülüklerini yerine getirmesini engelleyecek kayda değer bir sebep olmadığı kanaatine varmıştır. Söz konusu bu durum mühendis tarafından işveren Pakistan Milli Karayolları Otoritesi'ne bildirilmiştir. Esas olarak tahkime konu uyuşmazlığın ortaya çıkması yapılan bu bildirime dayanmaktadır. Şöyle ki; FIDIC kapsamında tarafsızlığı büyük tartışmalara yol açan mühendis ve yetkilisi tarafindan verilen bu karara dayanarak, Milli Karayolları Otoritesi (NHA-National Highway Authority), Bayındır'a ihtarname çekerek 14 gün içerisinde yapım sahasını boşaltması bildiriminde bulunmuştur. Akabinde 
Pakistan Ordusu İnşaat Mühendisleri birimi tarafından yapım sahası güvenlik altına alınmış ve Bayındır A.Ş. personeli tahliye edilmiştir. Bu durum hem Bayındır A.Ş. hem de çalışanlarının güvenlikleri bakımından endişe yaşamalarına sebebiyet vermiş olup, hukuki boyutuyla adil muamele ilkesinin ihlaline yol açar niteliktedir. Uyuşmazlık kapsamında meydana gelen bu olay, yurt dışında yatırım yapan firmaların, işin yapıldığı ülkelerdeki güvenlik sorunlarına, FIDIC sözleşmelerinin bile etkili çözümler sunamadığını ortaya koymuştur.

Taraflar arasındaki sözleşmenin feshedilip, işin Milli Karayolları Komitesi tarafından yerel bir firmaya verilmesi üzerine, Bayındır A.Ş. tarafından uyuşmazlık tahkime taşınmıştır. Tahkim yargılaması boyunca, Bayındır A.Ş. , sunmuş olduğu dilekçelerde bilhassa mühendis ve temsilcisi tarafından hazırlanan raporlardaki şeffaflıklarının irdelenmesi gerekliliğini ve yetkisiz işlemlerde bulunduklarını, inşaatın tamamlanmasındaki engelin arazinin uygun olmamasından kaynaklandığını, dolayısıyla süre uzatım talepleri çerçevesinde Bayındır A.Ş.'ye atfedilemeyecek sebeplerden dolayı çalışmalarda gecikme yaşandığını, bu durumu mühendise ve temsilcisine bildirmesine rağmen, bu hususun dikkate alınmayarak Bayındır A.Ş.'nin ifada temerrüde düşmesi amacıyla iş yükünün artırıldığını, mühendis raporunun objektif ve bağımsız biçimde hazırlanmadığını iddia ederek adil ve eşit davranma ilkesini, Türkiye Cumhuriyeti ile Pakistan İslam Cumhuriyeti Arasında Yatırımların Karşılıklı Teşviki ve Korunmasına İlişkin Anlaşma'nın II (1) maddesinde belirtilen en çok gözetilen ulus kaydı ilkesine, yine madde II (1) ve (2) bentlerinde belirtilen ulusal muamele standartlarına ve III(1)'de belirtilen tazminatsız kamulaştırma ve el atmalara karşı garanti maddelerine aykırılık iddiasında bulunulmuştur.

Pakistan Milli Karayolları ise karşı argüman olarak mühendis ve temsilcisinin Bayındır A.Ş.'nin süre uzatım talepleri karşısındaki tutumuna dikkat çekerek, yalnızca Sözleşme’yi ihlal etmekle kalmayıp düzenlenmiş bir komplonun parçası olduğunu ileri sürmüştür.

Tahkim heyeti tarafların tüm iddialarını değerlendirmiş, Bayındır A.Ş.'yi şirketin akdi performansıyla ilgili olmayan sebeplerden dolayı saf dışı bırakmaya yönelik bir komplonun mevcut olmadı̆̆ı sonucuna varmıştır. Ancak tahkim heyeti sözleşmenin ihlali niteliği taşıyan sebeplerden dolayı Bayındır A.Ş.'nin saf dışı bırakılması olasılığını da göz ardı etmemiştir.

Hakem heyeti Bayındır' A.Ş.'nin adil ve eşit davranma yükümlülüğüne ilişkin iddialarının, gerek münferiden gerekse de birlikte değerlendirildiğinde yerinde olmadığına, Milli Karayolları Komitesi'nin Bayındır A.Ş.'nin performansına ilişkin kaygılarının haklı temellere haiz olduğuna, sonuç itibariyle bu şartlar altında fesih hakkının doğduğuna ve Milli Karayolları Otoritesi'nin tutumunun, heyetin hakkında bir değerlendirme yapmadı $\breve{g}_{1}$ akdi sorumluluğuna yol açmasının söz konusu olabilmesine karşın bu durumun sözleşmenin ihlali niteliği taşımadığına karar vermiştir.

Hakem heyeti Pakistan'ın sözleşmede yer alan milli hukukun uygulanmasına ilişkin hükmü ihlal etmediğine, zira Bayındır A.Ş. ile Bayındır’ın proje dışına çıkarılmasının ardından Milli Karayolları Otoritesi’nin projesini tamamlama görevini alan yerel yüklenicilerin Milli Karayolları Otoritesi ile aralarındaki akdi ilişkilerin farklı olmasından dolayı farklı hukuki durumlarda bulunduklarına hükmetmiştir.

Son olarak, Hakem heyeti, Bayındır'ın “akdi haklarının Milli Karayolları Otoritesi'nin akdi hakları tarafından sınırlandırılmadığını veya Milli Karayolları Otoritesi’nin sözleşme hükümlerine dayandırıldığı iddia edilmesine karşın aslında açıkça bu hükümlerin ihlalini teşkil eden bir fiil ika ettiğini” ispatlayamadığından hareketle, Bayındır'ın akdi haklarına veya makine ve teçhizatına el konulmadığı sonucuna varmıştır. Bu yönde bir delilin yokluğundan dolayı Bayındır'ın haklarının iktisadi özünden mahrum kalması veya mallarına el konulmasının söz konusu olamayacağına hükmetmiştir.

Görüldüğü üzere, Bayındır A.Ş. kararı çerçevesinde FIDIC Şartnamelerinde mühendisin durumu eleştirel bir tavırla ele alınarak incelenmiştir. Mühendisle yapılan görüşmelerden sonuç alınamamasını sözleşmesel bir sorumluluğun doğmasına sebebiyet vereceğini kabul etmekle birlikte, bunu yatırım anlaşmasının ihlali olarak görmemektedir. Durum böyle olmakla birlikte firmaların yaşadığı sorunlar sadece mühendisin pozisyonundan kaynaklanmakta olmayıp, çeşitli nedenler gösterebilmektedir. Çalışmada yer verilecek diğer bir karar olan Ata İnşaat v. Ürdün kararı, FIDIC kuralları sonucu verilen hükmün, yatırıma ev sahibi ülke açısından ne derecede uygulanabilir olduğu hususunun bir kez daha gündeme gelmesine neden olmuştur.

\subsection{ATA İnşaat, Endüstri ve Ticaret Şirketi - Ürdün Haşimi Krallığı / ICSID Dava No: ARB/08/2}

Yine başka bir ICSID tahkim yargılaması olan, Türk yatırımcı ATA Construction, Industrial and Trading Company (ATA İnşaat) ile Ürdün Haşimi Krallığı arasında, su kanal inşaatından kaynaklanan uyuşmazlık, Ürdün Devletinin adil davranma yükümlülüğüne aykırı fiilleri iddiasıyla yargılamaya sebebiyet vermiştir.

Türk Hukuku'na göre, 21 Ekim 1983 tarihinde kurulmuş bir firma olan Ata İnşaat tarafından, 14 Ocak 2008 tarihinde, Ürdün ile Türkiye arasındaki 'Karşılıklı Teşvik ve Yatırımların Korunmasına İlişkin' anlaşmanın, yatırıma ev sahibi konumunda bulunan Ürdün Devleti tarafindan ihlal edilmesi sebebiyle ICSID tahkimine başvuruda bulunulmuştur.

ICSID kuralları uyarınca başlatılan bu tahkim, ATA İnşaat lehine FIDIC tahkim yargılaması sonucu verilmiş bir kararın Ürdün Mahkemeleri tarafından bozulması nedeniyle vuku bulmuştur. FIDIC kapsamında verilen karar ise, 
ATA İnşaat'ın, Ürdün Devletine bağlı bir şirket olan Arab Potash Company (APC) için yapmayı yüklendiği su kanallarının çökmesinden doğan uyuşmazlığa ilişkindir.

Taraflar arasında hiç tartışmasız olan nokta şudur ki; Ata İnşaat ile APC arasında 2 Mayıs 1998 tarihinde FIDIC Kurallarına göre akdedilmiş sözleşmede, yüklenicinin (ATA İnşaat) asıl edimi Ölü Deniz alanında inşa edilecek su kanallarıdır. ATA İnşaat tarafından su kanal yapımlarının tamamlanması üzerine, yapılan iş APC'ye teslim edilmiştir. Taraflar arasındaki sözleşmeye göre, kanalları suyla doldurma görevi APC'ye aittir. Ancak temel olarak uyuşmazlığın konusunu da oluşturan, dolum işlemi sırasında kanalların çökmesi, taraflar arasında bu çökmeden kimin sorumlu olması gerektiği hususunda anlaşmazlıklara sebebiyet vermiştir.

Bahsedilen anlaşmazlık dolayısıyla APC, taraflar arasındaki sözleşmenin tahkim hükmü çerçevesinde ATA İnşaat'a karşı FIDIC tahkim sürecini başlatmış ve Ürdün Hukuku'nun uygulanacağı da belirtilmiştir. Bunun üzerine ATA İnşaat ise ödenmemiş meblağlar hususunu içeren karşı bir talepte bulunmuştur.

Hakem heyeti tarafından öncelikle ele alınan husus, Ürdün Medeni Kanunu'nun ilgili maddelerinin bu uyuşmazlığa uygulanıp uygulanamayacağı noktasında toplanmıştır. Buradan yola çıkarak APC, ATA inşaatın su kanallarının amacını yerine getiremeyecek şekilde inşa ettiğini gösterdiği taktirde, yüklenicinin sorumluluğunun doğacağını iddia etmiştir. Buna karşılık ATA İnşaat, APC tarafından atanan bir mühendis gözetiminde işlere devam edildiğini, dolayısıyla kendi sorumluluğunun ancak kanalların yapımında üzerine atfedilecek bir hatası olması durumunda mümkün olabileceğini ileri sürmüştür. Bu hususa ilişkin FIDIC Hakem Heyeti de, APC'nin beyan etmiş olduğu iddialara katılmadığını belirtmiş olup, ilgili kanun maddesinin yorumlanmasıyla, bir diğer deyişle, müteselsil sorumluluğun gözetimde bulunan kişinin proje müellifi (designer) ya da mühendis olup olmamasına göre farklılık göstereceğini belirtmiştir.

Hakem heyeti tarafından üzerinde durulan bir diğer önemli husus ise, inşaat denetim görevinin kimde olduğu meselesidir. Bu konuya ilişkin olarak FIDIC Hakem Heyeti, olay kapsamında tek sorumlunun APC tarafindan görevlendirilen mühendis olduğuna karar vermiştir.

Yargılamanın gerekli tüm aşamaları tamamlandıktan sonra, FIDIC Hakem Heyeti 30 Eylül 2003 tarihinde konuya ilişkin nihai kararını vermiştir. Buna göre ATA İnşaat, çökme fiilinden sorumlu tutulmamış ve APC'nin tüm iddiaları hakem heyeti tarafından reddedilmiştir. İlaveten ATA İnşaat'a tazminat ödenmesine de karar verilmiştir. Ancak ATA İnşaat lehine verilen bu kararda, hakem heyeti üyelerinden birinin karşı görüşte olduğundan da ayrıca bahsedilmiştir.

Hakem heyeti tarafından verilen karar sonucu, dolum sırasında kanalların çökmesinden Ata İnşaat'ın sorumlu bulunmaması üzerine, APC, 29 Ekim 2003 tarihinde FIDIC Hakem Heyeti tarafından verilen bu kararın, Ürdün Tahkim Hukuku çerçevesinde iptal edilmesi için Ürdün ilk derece mahkemesine başvurmuştur. Yapılan bu başvuru neticesinde mahkeme, FIDIC hakem heyeti tarafından verilen kararı iptal etmiş ve ATA İnşaat ile APC arasındaki tahkim anlaşmasını da itfa etmiştir. Bu karar üzerine ATA inşaat tarafından bir üst mahkemeye (Court of Cassation) başvurulmuş olsa da, bu mahkeme de bozma kararını onaylamıştır.

İşte ICSID tahkim yargılamasına konu olan söz konusu bu dava, ATA İnşaat tarafından, Ürdün Mahkemelerince verilen bozma kararı üzerine, Türkiye ile Haşimi Ürdün Krallığı arasındaki Yatırımın Karşılıklı Teşviki ve Korunmasına İlişkin Anlaşma (YKTK)'nın ihlal edildiği gerekçesine dayanılarak ikame edilmiştir. Buna göre ATA İnşaat FIDIC tahkim heyeti tarafından verilen ancak Ürdün Mahkemeleri tarafindan bozulan kararda, hakem heyeti tarafından birkaç önemli nokta çerçevesinde uyuşmazlık çözülmeye çalışılmıştır.

Burada ATA İnşaat öncelikle Türkiye ile Haşimi Ürdün Krallığı arasındaki YKTK'nın II (2) maddesi (Madde II (2): Taraflardan her biri kurulmuş olan bu yatırımlara benzer durumlarda kendi yatırımcılarının yatırımlarına ya da herhangi bir üçüncü ülke yatırımcılarının yatırımlarına uyguladı̆̆ı muameleden, hangisi en elverişli ise, o muameleden daha az elverişli olmayan bir muamele uygulayacaktır) ile III. Maddelerinin ihlal edildiğini zira Ürdün Tahkim Kanunu'n un 51. Maddesinin son cümlesine atıfla Ürdün Mahkemeleri tarafindan tahkim anlaşmasının ve tahkim kararının itfa edildiğini bu durumun da Türkiye ile Ürdün arasındaki yatırım anlaşmasının yukarıda zikredilen maddelerde yer alan kamulaştırma ve el atma koşullarını ihlal ettiğini ileri sürmüştür.

ICSID Hakem Heyeti 18 Mayıs 2010 tarihinde verdiği kararda ATA İnşaat'ın talebini kabul ederek Ürdün Mahkemelerinin ATA İnşaat ile APC arasındaki tahkim anlaşmasının itfa edilmesinin Haşimi Ürdün Krallığı'nın Türkiye ile imzaladığı YKTK'daki yükümlülüklerini ihlal ettiğine karar vermiştir. Bunun üzerine Ürdün Haşimi Krallı̆̆ 7 Mart 2011 tarihinde ICSID’e ayrı bir başvuruda bulunarak Washington Konvansiyonu'nun 50. Maddesine dayanarak 18 Mayıs 2010 tarihinde verdiği kararına açıklık getirmesini talep etmiştir. Buna gerekçe olarak da Tahkim Mahkemesi'nin niyetinin taraflar arasındaki Tahkim anlaşmasının her iki taraf için de karşılıklı olarak iyileştirilmesi mi olduğunu sormuştur. Bu talebi ilginç bulan ICSID Hakem Heyeti kararda, APC'nin iyileştirilmiş tahkim anlaşmasından kaynaklanan haklarını kullanamayacağını belirtmediğini verilen hakem kararının Ürdün veya başka bir yerde ihtilafın esasına ilişkin olarak ileriye yönelik yasal işlemleri engellemiş olmasına karşın, Ürdün mahkemelerinin FIDIC tahkim işlemleri çerçevesinde yerine getirebileceği usuli işlemlerin bu durumdan etkilenmeyeceğini dolayısıyla Ürdün Mahkemelerinin yetkilerine herhangi bir kısıtlama olarak görülmemesi gerektiğini belirtmiştir. 
Burada dikkat çekici en önemli nokta, makalenin genelinde sıklıkla belirtilen FIDIC Şartnamelerinin ve bu kapsamda tahkim yolunun ne kadar efektif olduğu hususu olsa da; ATA İnşaat kararı, FIDIC tahkim yargılaması sonucunda verilen bir kararın, işverenin sahip olduğu kamu otoritesi sayesinde kendi ülkesindeki mahkemeler tarafından iptal edilebildiği gerçeğini de gözler önüne sermektedir. Bu çerçevede yabancı ülkelerde yatırım yapmayı amaçlayan firmaları teşvik edici nitelikte olması beklenen FIDIC kuralları, yatırımcıların haklarını koruyacak kadar etkili olduğu hissini uyandırmazsa, söz konusu kuralların işlevi tartışılmaya başlanacaktır. Nitekim söz konusu olayda Türk firması Ata İnşaat, FIDIC tahkimi sonucunda lehine verilen kararın, ev sahibi ülke mahkemeleri tarafından bozulması üzerine, ICSID tahkimine başvurmuş ve kendisini tekrardan hem ekonomik, hem zaman, hem de itibar olarak yıpratacak bir süreç içinde bulmuştur.

\section{Diğer Uluslararası Tahkim Merkezleri Nezdinde Fidic Kuralları ile İlgili Kararlar}

Yukarıda FIDIC kuralları kapsamında Türk firmalarının yaşadığı sorunlar ICSID tahkim yargılaması sonucu verilen kararlar ışığında incelenmiştir. Ancak mevzu bahis sorunlar sadece Türk firmalarının yaşadığı veya sadece ICSID bünyesinde yaşanan problemler olmayıp, küresel dünyada faaliyet gösteren yabancı firmaların diğer tahkim merkezlerinde yürütülen özel hukuk yargılamaları bakımından da geçerlidir. Bu bölümde söz konusu durumu örnekleyecek, FIDIC kurallarına yer veren Milletlerarası Ticaret Odası (International Chamber of Commerce (ICC)) Uluslararası Tahkim Merkezi ve aynı zamanda diğer tahkim merkezleri tarafından verilen kararlara da kısaca değinilecektir.

\subsection{Almanya (Yüklenici) v Ürdün (İşs sahibi) ICC Dava No: 10904 (kluwerarbitration.com, 2017)}

Davacı Alman yüklenici ile Davalı Ürdünlü iş sahibi arasında yapılan ve FIDIC kurallarına tâbi olan tesis inşaatına ilişkin sözleşmeden doğan ihtilafla ilgili olarak 2002 yılında verilen kararda ICC Tahkim Mahkemesi, tahkim sürecinde milli mahkemelerde açılan davaların davayı açan taraf bakımından tahkim hakkından feragat ettiği anlamına geldiğine karar vermiştir.

Karara konu olayda taraflar arasında, Davacı Alman yüklenicinin Ürdünlü iş sahibine anahtar teslim tesis inşaatı yapmasına ilişkin FIDIC kurallarının uygulanacağı ve doğacak ihtilaflarda ICC Tahkim Mahkemesi'ne gidileceğinin kararlaştırıldığı bir sözleşme yapılmıştır. İş sahibi, yapılan tesisin sözleşmeye uygun olmadığı, yapılan tesisin sözleşmede taahhüt edilen performansı göstermediği gerekçesiyle tesis teslim alma belgesi düzenlemeyi reddetmiş ve yüklenicinin banka teminat mektuplarını paraya çevirmiştir. Bunun üzerine yüklenici, teminat mektuplarının paraya çevrilmesine yönelik yasal işlemlerin ivedilikle engellenmesi ve başlamış olan işlemlerin durdurulması amacıyla Ürdün'de yerel Acil İşler Hâkimine (Judge of Urgent Matters) başvurarak bu yönde geçici karar aldırmış, akabinde bu yasal işlemlerin durdurulma süresinin sözleşmedeki tahkim şartına istinaden tahkim heyeti kararı alınana dek uzatılması amacıyla Ürdün yerel mahkemesinde dava açmıştır. Davalı iş sahibi davacının yerel hukuk yollarına başvurması sebebiyle taraflar arasındaki sözleşmeden doğan tahkim yoluna başvurma hakkından davacının feragat etmiş olduğunu ileri sürmüştür. Yerel mahkemenin davacının talebini onaylaması üzerine davalı kararı temyiz etmiş, Ürdün Yüksek Mahkemesi ise yasal işlemlerin durdurulmasına karar veren yerel mahkeme kararını onamış, davacı bu arada tahkim yoluna başvurmuştur.

İhtilafın ICC Tahkim Mahkemesi'ne intikal etmesi üzerine tahkim heyeti konuyu incelemiştir. Heyet, kararında, Ürdün Usul Hukukuna göre davacı lehine verilmiş olan kararın yerel mahkemelerin verdiği acil nitelikte geçici karar teşkil ettiğini, böyle bir kararın alınması için dava yoluna başvurmanın zaruri olmadığını, bunun yanı sıra banka teminatlarının davacının hâkime ilk başvurusundan önce banka tarafından ödenmiş olduğunu, bu sebeple davacının dava açmasının yine gerekli olmadığını belirtmiştir.

Tahkim Mahkemesi ayrıca 2001 tarihinde yürürlüğe giren Ürdün Tahkim Kanunu md. 6, 1958 New York Konvansiyonu m. 2/3 ve UNCITRAL Model Kanunu m. 8'e atıfta bulunarak, bu maddelerin işaret ettiği, dava yoluna başvurmanın tahkim hakkından feragat anlamına geldiği hususunu vurgulamıştır.

Tüm bu gerekçelerle ICC Uluslararası Tahkim Mahkemesi, davacı yüklenicinin hakkını korumak için dava yoluna başvurmasının zaruri olmadığına, ayrıca yukarıda atıfta bulunulan tahkim şartına ilişkin hükümler uyarınca davacı yüklenicinin dava yoluna başvurması sebebiyle taraflar arasındaki sözleşme kapsamındaki tahkim hakkından feragat etmiş sayıldığına hükmetmiştir.

\subsection{Yüklenici (Fransa) v. İş Sahibi (Ülke X) Nihai Karar, ICC Dava No.7722, 1999}

Fransız Yüklenici S, S.A (Société Anonyme) ve şirket Q, 1990 yılının Temmuz ayında bir inşaat projesi için aralarında sözleşme akdetmişlerdir. Q Şirketi, P Şirketine bağlı bir şirket olup, X Devleti kontrolü altındadır.

Taraflar arasındaki anlaşma diğer birçok dokümanın yanı sıra, Genel Sözleşme Şartnamelerini de içermektedir. Sözleşmenin üçüncü maddesine göre sözleşmeyi oluşturan dokümanlar birbirini tamamlayıcı şekilde yorumlanacaktır. Bununla birlikte anlam karmaşası ya da çelişkili durumlar olduğunda sonraki tarihli doküman, önceki tarihli dokümanı etkisiz kılacaktır.

Genel Sözleşme Şartnameleri açık olarak FIDIC formlarını temel almış olup, sözleşmeye uygulanacak hukuk X Ülkesinin Hukuku ve uyuşmazlık durumunda dostane çözüm yollarına ulaşılamazsa başvurulacak yol ICC Tahkim yoludur. 
Proje sırasında çeşitli zorluk ve anlaşmazlıkların çıkması üzerine yüklenici, ICC nezdinde tahkim sürecini başlatmıştır. Buna karşılık Şirket Q (davalı) hakem heyetinin yetkisinin iptal edilmesi için X ülkesi mahkemelerinde hukuki süreç başlatmıştır.

Taraflar sözleşmeye uygulanacak hukukun X ülkesi kuralları olduğunu kabul etmekle beraber, uyuşmazlığa sebebiyet veren madde süre uzatımı ve yüklenicinin neden olmadığı gecikmelerde iş sahibinin tazminat sorumluluğudur. Davacıya göre söz konusu bu hüküm açıkça uygulanmalı ve diğer tüm maddelerin anlamını etkilemelidir. Davalı ise bu hükmün, sözleşmenin diğer maddelerini etkilemeyeceğini belirtmiştir. Hakem heyeti ise, davacı tarafından iddia edilenin aksine, bu hükmün diğer hükümleri etkisiz kılmayacağına karar vermiştir. Ancak ek olarak hakem heyeti, bu hüküm için daha kapsamlı bir yorum yapılarak öncelik verilebileceğini ve davacının bu madde çerçevesinde kendisinin neden olmadığı gecikmeler için tazminat talep edebileceğini ifade etmiştir.

Genel Sözleşme Şartnameleri açıkça FIDIC formlarını temel alsa da, önemli hükümlerde dikkate değer farklılıklar vardır. Genel Şartnamelere yapılan değişiklikler ve eklemeler, farklı yorumlar yapılmasına sebebiyet vermiştir. Yapılan bu değişikler uygun bir durumu yaratmamakla birlikte, belli maddelerin yorumlanmasında taraflar arasındaki anlaşmazlıkların sona ermesine engel olamamıştır. Sonuç olarak da sözleşmenin uygulanmasında, Genel Sözleşme Şartnamelerinin bazı hükümleri ya da onun tamamlayıcı anlaşmaları taraflarca göz ardı edilmiştir. Bu konuda en bariz örnek, davalının sözleşme şartnamesi çerçevesinde gerekli olan mühendisin fonksiyonlarını engellemesi kısmıdır.

FIDIC tipi sözleşmelerde, her ne kadar mühendis iş sahibi tarafından tayin edilmekte olsa da, mühendisin kendisi bağımsız bir otorite olup, işlerin sözleşmede belirtildiği şekilde yürütülmesini garanti altına alan, yüklenicinin süre uzatımı ve tazminat taleplerinde kısmi yargılama yapacak olan kişidir. Ancak somut olayda, başından itibaren Davalı için çalışan Proje Yöneticisi, Mühendisin görevlerini ifa etmiştir. Bu nedenle FIDIC Genel Sözleşme Şartnamesinde belirtilen mühendisin tüm fonksiyonları deformasyona uğramıştır. Davalı tarafından sözleşme çerçevesinde mühendisin atanması hususunda yaratılan bu probleme rağmen, davacının bu durumu bilerek işlere devam etmesi ve sessiz kalması, hakem heyeti tarafindan mevcut durumun sözleşmeyi geçersiz kılmayacağ sonucuna ulaşmasına neden olmuştur.

\subsection{S. v X Devleti Kararı, ICC Dava No.10623, 7Aralık 2001}

İşs sahibi (Davalı) ile Yüklenici (Davacı) arasında 7 Ağustos 1996 tarihinde Emergency Dire Dam Contract ve Arıtılmamış Su İletim Hattı Projelerinin yapılması ve tamamlanması hususunda bir sözleşme akdedilmiştir.

Taraflar arasındaki sözleşmenin ilk kısmı, FIDIC Genel Sözleşme Şartnamelerini; ikinci kısmı ise FIDIC Hususi Başvurular Özel Şartlarını (Special Conditions of Particular Application) ihtiva etmektedir. Sözleşmenin kalan kısımları ise taraflar arasındaki görüşmeler sonucunda kararlaştırılmıştır.

Söz konusu tahkim yargılamasına konu uyuşmazlık taraflar arasındaki sözleşmeden kaynaklanmıştır. Davacı 12 Ağustos 1999 yılında tahkim başvurusunu ICC Tahkim Merkezi’ne ulaştırarak, davalıya karşı tahkim yargılamasını başlatmıştır.

Davacı, Davalı ile arasındaki sözleşmenin ilk kısmını oluşturan FIDIC Genel Sözleşme Şartnamesi’nin 67.maddesine dayanarak tahkim başvurusunda bulunmuştur. Buna göre sözleşmenin ilk kısım hükümlerinden 67. maddenin 3. fikrası; taraflar arasındaki uyuşmazlıklarda mühendislerin nihai ve bağlayıcı karar alamayacağı ve uyuşmazlıklarda taraflar arasında belirtilen sürelerde dostane çözüm yollarına ulaşılamaması durumlarından doğan uyuşmazlıklarda, sözleşmede aksine hüküm yoksa ICC Tahkim yoluna başvurma imkanını sağlamaktadır.

Sözleşmenin ikinci kısmı ise uyuşmazlıkların tahkim yoluyla çözümü hususunda aşağıdaki hükümleri içermektedir

-Tahkim yeri X Devleti'dir.

-Tahkim dili İngilizce'dir.

-Esasa ilişkin uygulanabilir hukuk X Devleti'nin hukukudur.

-Tahkim Kuralları X Devleti Medeni Kanunu'nun ilgili maddelerinde belirtilen kurallardır.

Davacı sözleşmenin ilk kısmı kapsamında, mühendisin ve iş sahibinin yükümlülüklerini ihlal ettikleri gerekçesiyle ICC Tahkim Merkezine başvurmuştur.

ICC tarafından Davalı iş sahibinin, yapılan tahkim başvurusundan haberdar edilmesi üzerine davalı, taraflar arasında doğabilecek uyuşmazlıkların ICC Tahkim Kuralları çerçevesinde çözülmesini öngören herhangi bir anlaşma olmadığından bahisle, tahkim merkezinin yetkisine itirazda bulunmuştur. Bununla birlikte X Devleti, taraflar arasında çıkabilecek uyuşmazlıkların, kendi Medeni Kanunu hükümleri çerçevesinde ad hoc tahkime göre çözüme kavuşturulması gerektiği konusunda davacı tarafla anlaşmış olduklarını belirterek, Sözleşmenin ilk kısmında yer alan madde 67/3'te belirtilen 'sözleşmede aksine hüküm yoksa' kısmına vurgu yaparak ICC'nin tahkim yargılamasını durdurmasını talep etmiştir. 
Davalının bu itirazlarına rağmen, 3 Ekim 1999 tarihinde ICC Tahkim Heyeti, ICC kurallarının 6.maddesinin ikinci fikrasına göre tahkimi devam ettirmeye karar vermişlerdir. Akabinde yargılamaya başlanmış, toplantılar düzenlenmiş ve taraflar dilekçelerini sunmuşlardır.

Davalı taraf sunmuş olduğu her dilekçede, taraflar arasında ICC kurallarına göre tahkim yapılacağı hususunda bir anlaşma olmadığını vurgulamıştır.

Davacı ise bu iddialara karşı, Davalı ülkenin Medeni Kanunu'nun ilgili maddelerinde belirtilen tahkim kurallarının, Genel Sözleşme Şartnamesi'nin 67/3 maddesinde belirtilen ICC Tahkim Kuralları'na yardımcı kaynak niteliğinde olduğu iddiasında bulunmuştur ve bu durumun ICC Tahkim Kuralları altında oluşturulan tahkim heyetinin yargılama yapmasını etkilemeyeceğini eklemiştir. Bunların yanı sıra Davacı, iş sahibinin kurulum için gerekli olan malzemeleri zamanında sağlamadığı ve mühendisin de sözleşme kapsamındaki yükümlülüklerini ihlal ettiğini beyan etmiştir.

Davalının cevapları her seferinde ICC'nin tahkim yargılamasına yetkisi olmaması iddiasıyla sınırlı kalmıştır. Söz konusu tahkim ışığında davalı tarafından ileri sürülen iddiaları özetleyecek olursak, ilk olarak davalı taraflar arasındaki tahkim anlaşmasının açık bir şekilde kendi Medeni Kanun hükmü altındaki ad hoc tahkimi desteklediğini, davacının karşıt yorumlamasının, taraflar arasındaki anlaşmanın anlamsız kalmasına neden olacağını ifade etmiştir. Tamamlayıcı olarak sözleşme öncesi görüşmelerin de, tahkim anlaşmasının bu şekilde yorumlanması gerektiğini destekler nitelikte olduğunu eklemiştir. Yine davalı yukarıda belirtilen Sözleşmenin ilk ve ikinci kısmının birlikte değerlendirilmesi gerektiği hususunda davacı ile anlaşmış olduklarını ve bu çerçevede anlam karmaşası olduğu durumlarda ikinci kısmın ilk kısmı hükümsüz kılacağını belirtmişlerdir. Son olarak da, taraflar arasında aksi kararlaştırıldığı için uyuşmazlığın çözümü için ICC Tahkimine gidilemeyeceği ileri sürülmüştür.

Davacı ise davalı tarafından sıralanan bu argümanların hepsini reddetmiş, tarafların ICC Tahkim Kuralları’nın uygulanacağı konusunda anlaşmış olduklarını, X Devleti Medeni Kanun'un ise sadece tamamlayıcı bir zeminde uygulanabileceğini ifade etmiştir. Sözleşmenin ikinci kısmında sadece X Devleti Medeni Kanunu’na atıf yapıldığı, ikinci kısım düzenlenirken ilk kısımdaki ICC Tahkim Kuralları'nın uygulanacağı kısmının silinmemesiyle yapılan atfın sadece yardımcı nitelikte olduğu eklenmiştir. Bunlara ilaveten Davacı, taraflar arasındaki söz konusu proje için FIDIC kurallarının esas alındığını, ikinci kısım için de bu durumun söz konusu olduğunu, dolayısıyla bu hükümlerin hiçbirinin tartışmaya açık olmadı̆̆ını belirtmiştir. Davalı tarafından 'aksi kararlaştırılmadıkça' hususu ise ICC Tahkim Kuralları'nın silinip, başka bir tahkim merkezinin seçilmesi halinde söz konusu olabilir şeklinde cevaplanmıştır.

Taraflar arasında FIDIC Şartnameleri uyarınca hazırlanan sözleşme hükümlerinin yorumlanmasından çıkan bu uyuşmazlık, ICC Hakem Heyeti'nin, sözleşmenin ikinci kısmında belirtilen X Devleti Medeni Kanunu kapsamındaki ad hoc tahkim kuralının tamamlayıcı olduğuna karar vermesi sebebiyle, uyuşmazlık hususunda yargı yetkisinin olduğu sonucuna ulaşmasıyla neticelenmiştir.

\subsection{Yüklenici (Fransa) v. İş Sahibi (Ülke X) Nihai Karar, ICC Dava No.7722, 1999}

Fransız Yüklenici S, S.A (Société Anonyme) ve şirket Q, 1990 yılının Temmuz ayında bir inşaat projesi için aralarında sözleşme akdetmişlerdir. Q Şirketi, P Şirketine bağlı bir şirket olup, X Devleti kontrolü altındadır.

Taraflar arasındaki anlaşma diğer birçok dokümanın yanı sıra, Genel Sözleşme Şartnamelerini de içermektedir. Sözleşmenin üçüncü maddesine göre sözleşmeyi oluşturan dokümanlar birbirini tamamlayıcı şekilde yorumlanacaktır. Bununla birlikte anlam karmaşası ya da çelişkili durumlar olduğunda sonraki tarihli doküman, önceki tarihli dokümanı etkisiz kılacaktır.

Genel Sözleşme Şartnameleri açık olarak FIDIC formlarını temel almış olup, sözleşmeye uygulanacak hukuk X Ülkesinin Hukuku ve uyuşmazlık durumunda dostane çözüm yollarına ulaşılamazsa başvurulacak yol ICC Tahkim yoludur.

Proje sırasında çeşitli zorluk ve anlaşmazlıkların çıkması üzerine yüklenici, ICC nezdinde tahkim sürecini başlatmıştır. Buna karşılık Şirket Q (davalı) hakem heyetinin yetkisinin iptal edilmesi için X ülkesi mahkemelerinde hukuki süreç başlatmıştır.

Taraflar sözleşmeye uygulanacak hukukun X ülkesi kuralları olduğunu kabul etmekle beraber, uyuşmazlığa sebebiyet veren madde süre uzatımı ve yüklenicinin neden olmadığı gecikmelerde iş sahibinin tazminat sorumluluğudur. Davacıya göre söz konusu bu hüküm açıkça uygulanmalı ve diğer tüm maddelerin anlamını etkilemelidir. Davalı ise bu hükmün, sözleşmenin diğer maddelerini etkilemeyeceğini belirtmiştir. Hakem heyeti ise, davacı tarafından iddia edilenin aksine, bu hükmün diğer hükümleri etkisiz kılmayacağına karar vermiştir. Ancak ek olarak hakem heyeti, bu hüküm için daha kapsamlı bir yorum yapılarak öncelik verilebileceğini ve davacının bu madde çerçevesinde kendisinin neden olmadığı gecikmeler için tazminat talep edebileceğini ifade etmiştir. 
Genel Sözleşme Şartnameleri açıkça FIDIC formlarını temel alsa da, önemli hükümlerde dikkate değer farklılıklar vardır. Genel Şartnamelere yapılan değişiklikler ve eklemeler, farklı yorumlar yapılmasına sebebiyet vermiştir. Yapılan bu değişikler uygun bir durumu yaratmamakla birlikte, belli maddelerin yorumlanmasında taraflar arasındaki anlaşmazlıkların sona ermesine engel olamamıştır. Sonuç olarak da sözleşmenin uygulanmasında, Genel Sözleşme Şartnamelerinin bazı hükümleri ya da onun tamamlayıcı anlaşmaları taraflarca göz ardı edilmiştir. Bu konuda en bariz örnek, davalının sözleşme şartnamesi çerçevesinde gerekli olan mühendisin fonksiyonlarını engellemesi kısmıdır.

FIDIC tipi sözleşmelerde, her ne kadar mühendis iş sahibi tarafından tayin edilmekte olsa da, mühendisin kendisi bağımsız bir otorite olup, işlerin sözleşmede belirtildiği şekilde yürütülmesini garanti altına alan, yüklenicinin süre uzatımı ve tazminat taleplerinde kısmi yargılama yapacak olan kişidir. Ancak somut olayda, başından itibaren Davalı için çalışan Proje Yöneticisi, Mühendisin görevlerini ifa etmiştir. Bu nedenle FIDIC Genel Sözleşme Şartnamesinde belirtilen mühendisin tüm fonksiyonları deformasyona uğramıştır. Davalı tarafından sözleşme çerçevesinde mühendisin atanması hususunda yaratılan bu probleme rağmen, davacının bu durumu bilerek işlere devam etmesi ve sessiz kalması, hakem heyeti tarafindan mevcut durumun sözleşmeyi geçersiz kılmayacağ sonucuna ulaşmasına neden olmuştur.

\subsection{ABD ve AB Drenaj Şirketleri (Joint Venture) v. Red Sea Public Authority (Kızıl Deniz Kamu Otoritesi) Nihai Kararı, CRCICA (Kaire Uluslararası Ticari Tahkim Bölgesel Merkezi), Dava No: 281/2002, 28 Haziran 2004}

Yukarıda incelenen kararlardan farklı olarak bu karar, Kahire Uluslararası Ticari Tahkim Bölgesel Merkezi tarafından verilmiştir. Mevcut dava US-EU iş ortaklığı tarafından deniz limanı konusunda ikame edilmiştir. Taraflar arasında sözleşmenin FIDIC Kırmızı Kitabının 1999 baskısı ile çok benzer olduğunu bu durumu tarafların da kabul ettiğini belirtmiştir. Ancak sözleşme akdedilir edilmez farklılıklar ortaya çıkmaya başlamıştır. Bunun en önemli nedenlerinden birisi, iş sahibinin inşaat işini iki yüklenici arasında paylaştırması, rıhtım duvarı hariç tüm proje için iş ortaklığını, rıhtım duvarı içinse başka bir yükleniciyi görevlendirmiş olmasından kaynaklanmaktadır. Bunun üzerine ortaklık, yapım alanında kendi işlerini diğer yüklenicilerle birlikte koordine edeceklerini ancak diğer yükleniciler tarafından sebep olunan gecikmelerden sorumlu tutulamayacakları çekincesini koymuştur.

Rıhtım duvarı inşaatı sebebiyle, aşırı gecikmeler yüzünden mağdur edilen iş ortaklığı, süre uzatım ve tazminat talebinde bulunmuş ancak hem FIDIC Kurallarının bir gereği olan hem de sözleşmede belirtilen, mühendisi ve işvereni durumdan haberdar etmek için gerekli olan söz konusu 28 günü göz ardı ettiği için bu hakkı düşmüştür. Bu durum aynı sebepten dolayı birçok farklı zararın meydana gelmesine yol açmıştır.

Hakem heyeti, yüklenicinin ek ödemeye ilişkin talebinin işveren ve mühendis tarafından biliniyor olması halinde, bu bildirim prosedürünün yerine getirilmesi zorunluluğunu aramamış olup, sözleşmenin 20.maddesinin ilk fikrasının gayet açık bir anlama sahip olmasına rağmen bu durumlarda gereken esnekliğin sağlanabileceğini hüküm altına almışlardır. Heyete göre söz konusu durum değerlendirilirken, tarafların davranışlarının ve iyiniyet kuralarının da göz ardı edilmemesi gerekmektedir.

Hakem Heyeti tarafindan yargılama sırasında yapılan araştırmalar sonucunda, ek ödeme talep etmeye hak veren bir durumun varlığı halinde, yüklenici tarafından sözleşmenin 20. maddesinin ilk fikrasında belirtilen prosedüre uygun olarak mühendise bildirim yapılması gerektiği ve süresi içerisinde yapılacak bu bildirim sayesinde de mühendis veya işveren tarafından aksaklığın azaltılmasının mümkün olacağı sonucuna ulaşılmıştır.

En nihayetinde Hakem Heyeti, yüklenicinin sözleşmenin ifası sırasında, hiçbir şekilde rıhtım duvarı inşaatındaki gecikme sebebiyle zarara uğradığından bahisle ek ödeme talebinde bulunmadığg, hatta ilgili yüklenicilerin birlikte çalışabilmeleri için yapılan toplantılarda bile bu durumun ne mühendise ne de işverene bildirilmediği, dolayısıyla açık bir şekilde yüklenicinin sözleşmenin 20/1 maddesine uymadığına karar vermiş olup, yüklenicinin rıhtım inşaatındaki gecikme sebebiyle herhangi ek bir ödeme talep etmeye yetkili olamayacağını hüküm altına almıştır. Diğer bir ifadeyle, mühendis ve işveren, yüklenici tarafindan talep edilecek bu durumdan haberdar olmadıkları için, söz konusu gecikmeyi azaltacak pozisyona sahip bulunmamaları nedeniyle Hakem Heyeti, yüklenicinin rıhtım duvarı inşaatının gecikmesinden doğan ek ödeme taleplerini reddetmiştir.

\section{Sonuç}

FIDIC Kuralları inşaat sektöründe hukuki standartların oluşumunda büyük katkıda bulunmuştur. Bu sektörde uluslararası düzeyde, yatırımcılar, iş sahipleri ve yükleniciler tarafindan yaygın olarak FIDIC Şartnamelerinden faydalanılmaktadır. Öte yandan, bu makalede incelenen Bayındır v. Pakistan kararında da ortaya konulduğu üzere, taraflar arasındaki sözleşmenin usulüne uygun olarak ifa edilmesinde üçüncü kişi gözetmen konumunda bulunan mühendislerin tarafsızlığı ile ilgili tartışmalar gündeme gelmekte, hatta yine bu kararda karşımıza çıktığı gibi, gözetmen mühendislerin komploya dahil oldukları gibi iddialar dahi söz konusu olabilmektedir.

İncelenen ATA İnşaat kararında ise, FIDIC tahkim kararlarının taraf ülkeler iç hukuku tarafından benimsenmesinin, henüz istenilen aşamaya gelmediği gözler önüne serilmiştir. Burada tahkim kararlarının tenfiz 
aşamasında kamu otoritesi ile karşılaşması bir yana aynı zamanda tahkim klozu içeren bir anlaşma olmasına rağmen yerel mahkemelerde de yargılamalara başvurulup paralel yargılamaların çıkarmış olduğu zorluklar da göze çarpmaktadır. Yatırımcının korunması, yatırımcıya adil davranıp eşit muamelede bulunma, kamulaştırmalara karşı koruma gibi unsurlar gündeme gelmekte ve FIDIC ile YKTK Anlaşmaları arasında doğrudan bir bağ kurulabilmektedir.

Bunların yanı sıra çalışmada yer alan diğer kararlar, sadece Türk firmalarının değil, yabancı inşaat firmalarının da yatırımlarını yerine getirirken yaşadığı zorluklara işaret etmektedir. Burada en başta sözleşmenin yorumu ve mühendisin tarafsız olup olmadığı sorularının göze çarptığını söyleyebiliriz. Aynı zamanda Uyuşmazlık Çözüm Kurulunun (DAB) ne kadar efektif kullanılıp kullanılmadığı da eklenebilir.

Tüm bunlar 1şığında, ileriki dönemlerde gerek FIDIC Şartnamelerinde yapılacak daha ayrıntılı düzenlemeler, gerekse zaman içinde ICSID ve ICC içtihadının zenginleşmesiyle özellikle mühendisin durumunun daha net bir şekilde ortaya konması ve paralel yargılamalar için FIDIC Kuralları nezdinde de ayrıntılı düzenlemeler yapılması ile bu sorunların ortadan kalkacağı düşünülmektedir.

\section{Kaynakça}

- $\quad$ Akıncı, Ziya, Milletlerarası Özel Hukukta İnşaat Sözleşmeleri, İzmir, 1996.

- Akıncı, Ziya, "Yurtdışındaki Yatırımcılarımızın Korunması Açısından ICSID Tahkimi”, II. Uluslararası Özel Hukuk Sempozyumu "Tahkim", İstanbul 2009.

- Arnaldez/Derains/Hascher, Collection of ICC Arbitral Awards I, 1991-1995, The Hague 1997, s. 477-544.

- Ataman-Figanmeşe, İnci, “Son On Y1l İçinde Türkiye'nin Muhatap Olduğu ICSID Davaları”, http://www.turkiyehukuk.org/son-on-yil-icinde-turkiyenin-muhatap-oldugu-icsid-davalari/

- $\quad$ Atik, Ebru Tüzemen, "FIDIC Kırmızı Kitap (New Red Book) Kuralları Uyarınca İnşaat Sözleşmelerinde Müteahhidin Sorumluluğu”, Gazi Üniversitesi Hukuk Fakültesi Dergisi, C. XVIII, Y. 2014, Sayı 2, s.53-84

- Aydın, Yakup, "FIDIC Sözleşmeleri”, Dış Denetim Dergisi, Sayı:2, Ekim-Kasım-Aralık 2010, s. 230.

- Birgönül, Talat Göksu Günay, Türkiye İnşaat Mühendisliği Teknik Kongre ve Sergisi bildiriler Kitabı, Ankara, Kasım 2001.

- Cem, Aktemur, "Sanayi ve Teknoloji Uzman Yardımcısı; FIDIC Sözleşme Esasları ve Türkiye Uygulamaları"; http://anahtar.sanayi.gov.tr/tr/news/fidic-sozlesme-esaslari-ve-turkiye-uygulamalari/311

- CCuhadar, Ogeday, FIDIC Standart İnşaat Sözleşmelerinde İş Sahibinin Esaslı Borçları, Bahçeşehir Üniversitesi Özel Hukuk Yüksek Lisans Programı

- Ersoy, Yüksel, "Eser Sözleşmelerinin Hazırlanmasında ve Uygulanmasında Mühendis-Hukukçu İlişkileri” (İnşaat Sözleşmeleri, Yönetici-İşletmeci, Mühendis ve Hukukçular için Ortak Seminer, Ankara 1996, s. 1344.

- $\quad$ FIDIC, Statutesand By-Laws, International Federation of Consulting Engineers (English), October 2005.

- Helvacı, İbrahim, “Türkiye'de FIDIC Uygulamaları”, Türkiye Mühendislik Haberleri, Sayı 411, 2001/1, s. 28.

- http://www.imo.org.tr/resimler/dosya_ekler/651feb4934251ff_ek.pdf?dergi=182, 2017)

- Intes, 2017, http://www.intes.org.tr/ti/953/0/Dunyanin-en-buyuk-250-firmasi-Arasinda-42-Turk-Firmasi-YerAldi- (2017)

- Karayalçın, Yaşar, “FIDIC Sözleşmesi Genel Şartlarında Mühendisin Hukukî Durumu”, İnşaat Sözleşmeleri: Yönetici - İşletmeci, Mühendis ve Hukukçular İçin Ortak Seminer, Ankara 1996.

- Kodakoğlu, Mehmet, FIDIC Standart Kuralları'na Göre hazırlanan Milletlerarası İnşaat Sözleşmelerinden Doğan Uyuşmazlıklarda Tahkim, Başkent Üniversitesi Yüksek Lisans Tezi.

- Köksal, Tunay, “Uluslararası İnşaat Sözleşmesi Modeli Olarak FIDIC İnşaat İşleri Sözleşme Şartları”, Abant İzzet Baysal Üniversitesi Sosyal Bilimler Enstitüsü Dergisi, Cilt 2010-1, Sayı 20, s. 85-109.

- $\quad$ M. Beth, The Role of the Consulting Engineer in Developing Country Construction Under the FIDIC Contract (Law and Policy in International Business), 1994, s. 276.

- Türegün, Necip, "FIDIC Açısından İnşaat Sözleşmeleri, Banka ve Ticaret Hukuku Araştırma Enstitüsü”, Sertifika Programları, Ankara, 2009, s. 254 vd.

- $\quad$ www.kluwerarbitration.com, 2017 


\title{
Ticari Sırların Ceza Hukuku Tarafından Korunması The Protection of Confidential Business Information by Criminal Law
}

\author{
Prof. Dr. Çetin Arslan (Hacettepe University, Turkey) \\ Ph.D. Candidate Didar Özdemir (Hacettepe University, Turkey)
}

\begin{abstract}
The Turkish Penal Code (TPC) no.5237 embodies "the reveal of confidential business information and documents" as a crime. However, neither article 6 of the TPC titled "definitions" nor the legal justification of the article contains the definition of the confidential business information or commercial secret. The abrogated Turkish Commercial Code no.6762 disposes the reveal of this kind of information as an act of unfair competition. In a similar vein, the current Turkish Commercial Code no.6102 assumes the illegal acquisition and the reveal of business secrets as acts of unfair competition and subjects them to criminal sanction. Also the article 562 of the TCC no.6102 disposes that if the auditors reveal the confidential business information of the auditee company, they are punished according to the article 239 of the TPC. The Proposal of Code on Business, Bank and Client Secrets refers to the article 239 of the TPC in case of the violation of the confidentiality obligation. Finally, the Act of the Protection of Competition no.4054 brings a confidentiality obligation for the Council and staff members. In this study, we will try to explain first the notion of confidential business information or commercial secret, then the penal norms about the confidential business information and the confidentiality obligation and last, the elements of the crime disposed in the article 239 of the TPC which is referred by most of the other penal norms in this respect.
\end{abstract}

\section{Giriş}

5237 sayll Türk Ceza Kanunu (TCK)'nun 239. maddesinde ticari sır niteliğindeki bilgi veya belgelerin açıklanması suç olarak düzenlenmiştir. Fakat ne TCK'nın "tanımlar" başlıklı 6. maddesinde ne de madde gerekçesinde ticari sırrın tanımı yer verilmiştir. 29.06.1956 tarihli ve 6762 sayılı mülga Türk Ticaret Kanunu (6762 s. TTK)'nun 57. maddesinde "iyiniyet kurallarına aykırı olarak elde edilen veya öğrenilen ticari sırdan haksız olarak faydalanmak veya bu sırları başkalarına yaymak” haksız rekabet teşkil eden hareket olarak sayılmış ve 64. maddede bu fiil için ceza yaptırımı öngörülmüştür. Ayrıca, anonim ve limited şirket ortakları için sır saklama yükümlülüğü getirilmiş ve ihlali cezai yaptırıma bağlanmıştır (md. 363, 556). Benzer şekilde yürürlükteki 13.01.2011 tarihli ve 6102 say1lı Türk Ticaret Kanunu (6102 s. TTK)'nun ise 55. maddesinde "işçileri, vekilleri veya diğer yardımcı kişileri, işverenlerinin veya müvekkillerinin üretim ve iş sırlarını ifşa etmeye veya ele geçirmeye yöneltmek (md. 55/1-b-3)" ve "üretim ve iş sırlarını hukuka aykırı olarak ifşa etmek (md. 55/1-d) dürüstlük kuralına aykırı, haksız rekabet teşkil eden davranış olarak sayılmış ve 62. maddede ceza yaptırımına bağlanmıştır. Ayrıca, 562/7. maddesinde, denetçilerin ticari sırları ifşa etmesi halinde TCK'nın 239. maddesi hükümlerine göre cezalandırılacakları düzenlenmiştir. Ticari Sır, Banka Sırrı ve Müşteri Sırrı Hakkında Kanun Tasarısı (Tasarı)'nın 8. maddesi de sır saklama yükümlülügüne aykırı davranılması durumunda TCK'nın 239. maddesinin uygulanacağını ifade etmektedir. Son olarak, 07.12.1994 tarihli ve 4054 sayılı Rekabetin Korunması Hakkında Kanun (RKHK)'un 25. maddesinin son fikrasında, kurul üyeleri ve personeline, kurumla ya da teşebbüslerle ilgili öğrendikleri ticari sırları ifşa etmeme yükümlülüğü getirilmiştir. Fakat bu düzenlemede yaptırım öngörülmediği gibi, TCK'ya atıf da yapılmamıştır. Çalışmamızda, öncelikle ticari sır kavramı üzerinde durulacak, ardından ticari sır konusunu cezai yaptırıma bağlayan hükümler ortaya konacak ve nihayet bu maddelerin atıf yaptığı ve genel norm niteliği taşıyan TCK'nın 239. maddesinde düzenlenen suçun unsurları incelenecektir.

\section{Ticari Sır Kavramı}

“Sır”, TDK Büyük Sözlük’te "Varlığı veya bazı yönleri açığa vurulmak istenmeyen, gizli kalan, gizli tutulan şey" olarak tanımlanmaktadır. Doktrinde ise, kişinin özel yaşamına dâhil, gizli olan, sahibinin açıklanmamasında yarar gördüğü ve başkaları tarafından bilinmeyen veya bilinmesi belirli bir kişi çevresiyle sınırlı kalmış, aleni olmayan kişinin maddi veya manevi değerleriyle ilgili hususlar olarak tanımlanmıştır (Erem et all, 1975; Erman, 1984; Sungurtekin Özkan, 2000; Kaplan, 1990; Alıc1, 2007; Bilge, 2005).

Doktrinde Donay (1978) tarafından bir hususun sır olarak kabul edilebilmesi için iki unsuru bünyesinde taşıması gerektiği ileri sürülmektedir. Bunlardan ilki olan objektif unsur, söz konusu hususun başkaları tarafindan bilinmemesi veya sınırlı bir çevre tarafından bilinmesini; ikinci unsur olan sübjektif unsur ise, sırrın sahibi olan kişinin bu hususun saklanması konusunda bir iradesinin bulunmasıdır. 
Ticari sır kavramı TCK’nın “tanımlar” başlıklı 6. maddesinde tanımlanmadı̆̆ı gibi madde gerekçesinde de bu konuda bir açıklama bulunmamaktadır. Tasarı'nın "tanımlar” başlıklı ikinci maddesinde ticari sır, "Bir ticarî işletme veya şirketin faaliyet alanı ile ilgili yalnızca belirli sayıdaki mensupları ve diğer görevlileri tarafindan bilinen, elde edilebilen, özellikle rakipleri tarafindan ögrenilmesi halinde zarar görme ihtimali bulunan ve üçüncü kişilere ve kamuya açıklanmaması gereken, işletme ve şirketin ekonomik hayattaki başarı ve verimliliği için büyük önemi bulunan; iç kuruluş yapısı ve organizasyonu, malî, iktisadî, kredi ve nakit durumu, araştırma ve geliştirme çalışmaları, faaliyet stratejisi, hammadde kaynaklarl, imalatının teknik özellikleri, fiyatlandırma politikaları, pazarlama taktikleri ve masraflarl, pazar payları, toptancı ve perakendeci müşteri potansiyeli ve ăgları, izne tâbi veya tâbi olmayan sözleşme bağlantılarına ilişkin veya bu gibi bilgi ve belgeler" olarak tanımlanmaktadır.

Doktrinde ise ticari sırrın kapsamına nelerin girdiği tartışmalıdır. Karayalçın (1968), bir ticari işletmenin teşkilatı, çalışma şekli, mal temin yöntemleri veya kaynaklarının ticari sır olarak kabul edilebileceğini belirtmektedir. Poroy ve Yasaman (2010) ticari sırrı, "tacir tarafından oluşturulan ve tacirin üçüncü kişilerden gizlemekte haklı olduğu bilgilerin tümü” olarak açıklamaktadır. Arkan (2011) ise, ticari sırrın sadece hiç bilinmeyen bilgileri değil, bunun yanında uzun veya masraflı, çaba gerektiren bir çalışma sonucunda elde edilebilen bilgileri de kapsayacağını ifade etmektedir. Yazara göre, ticari sırrın mutlaka orjinal bir bilgi içermesine gerek yoktur; isim, adres, telefon numarası, mail adresi gibi bilgiler içeren müşteri listesi de bu anlamda sır sayılabilir. Ayrıca ticari sır kapsamına şirketin üretim, dağıtım, yönetim konusunda oluşturduğu teknik bilgiler ve tecrübeler de dâhildir.

\section{Ticari Sırları Koruyan Cezai Düzenlemeler}

Öncelikle belirtmek gerekir ki, Türk Hukukunda sırların korunmasının temelini Anayasa'nın 17. maddesinin ilk fikrasında yer alan “Herkes, yaşama, maddi ve manevi varlı̆̆ını koruma ve geliştirme hakkına sahiptir.” ile 20. maddesinin ilk fikrasında yer alan "Herkes, özel hayatına ve aile hayatına saygl gösterilmesini isteme hakkına sahiptir. Özel hayatın ve aile hayatının gizliliğine dokunulamaz.” hükmü oluşturmaktadır (Alıc1, 2007; Öztürk, 2009). Diğer taraftan, TCK'nın 239. maddesinde ticari sır, banka sırrı veya müşteri sırrı niteliğindeki bilgi veya belgelerin açıklanması suç olarak düzenlenmiştir. Bu hükme göre, sıfat veya görevi, meslek veya sanatı gereği vakıf olduğu ticari sır, bankacılık sırrı veya müşteri sırrı niteliğindeki bilgi veya belgeleri yetkisiz kişilere veren veya ifşa eden kişi, şikâyet üzerine, bir yıldan üç yıla kadar hapis ve beşbin güne kadar adlî para cezası ile cezalandırılır. Ayrıca, bu bilgi veya belgelerin, hukuka aykırı yolla elde eden kişiler tarafından yetkisiz kişilere verilmesi veya ifşa edilmesi halinde de bu fikraya göre cezaya hükmolunur.

Ticari sırları koruyan bu düzenleme, fenni keşif ve buluşlar veya sınai uygulamaya ilişkin bilgiler hakkında da uygulanacaktır. Söz konusu sırların Türkiye'de oturmayan bir yabancıya veya onun memurlarına açıklanması durumunda faile verilecek ceza üçte biri oranında artırılacak ve şikâyet koşulu aranmadan soruşturma ve kovuşturma işlemleri yapılacaktır. Ayrıca, cebir veya tehdit kullanımı da cezayı ağırlaştıran nitelikli hal olarak öngörülmüş ve son fikrada, cebir veya tehdit kullanarak bir kimseyi bu madde kapsamına giren bilgi veya belgeleri açıklamaya mecbur kılmanın üç yıldan yedi yıla kadar hapis cezasıyla cezalandırılacağı düzenlenmiştir.

6762 s. TTK'nın 57. maddesinde "hüsnüniyet kaidelerine aykırı hareketler" sayılmış ve maddenin 8 numaralı bendinde "hüsnüniyet kaidelerine aykırı bir şekilde elde ettiği veya ögrendiği imalat veya ticaret sırlarından haksız yere faydalanmak veya onları başkalarına yaymak", diğer bir ifadeyle iyiniyet kurallarına aykırı olarak elde edilen veya öğrenilen ticari sırdan haksız olarak faydalanmak veya bu sırları başkalarına yaymak haksız rekabet teşkil eden bir hareket olarak gösterilmiştir. Bu madde normun kural kısmını ortaya koymuş, yaptırımı ise $6762 \mathrm{~s}$. TTK'nın “cezayı mültezim fiiller” başlıklı 64. maddesinde "Elli yedinci maddenin 1, 2, 4, 5, 6, 8 ve 9 uncu bentlerinde yazll haksız rekabet fiillerinden birini kasten işleyenler... 58. madde gereğince hukuk davasını açma hakkını haiz bulunanlardan birinin şikâyeti üzerine ceza mahkemesince bir aydan bir yıla kadar hapis veya beş yüz liradan on bin liraya kadar adli para cezasiyle veya her ikisiyle birlikte cezalandırllırlar." ş̧eklinde düzenlenmiştir (Dursun, 2009). Ayrıca 65. maddede "Hükmi şahısların işleri görülürken bir haksız rekabet fiili işlenirse 64 'üncü madde hükmü, hükmi şahıs namına hareket etmiş veya etmesi gerekmiş olan organın azaları veya ortaklar hakkında tatbik olunur. Şu kadar ki; para cezası ve masraflardan hükmi şahıs bu hakiki şahıslarla birlikte müteselsilen mesul olur." düzenlemesiyle bu konuda tüzel kişilerin sorumluluğu da kabul edilmiştir.

6762 s. TTK'nın ticari sırların korunması ile ilgili bir başka düzenlemesi 363. maddede yer almaktadır. Bu madde ikinci fikrasında "Incelenmesine müsaade edilen defter ve vesikalardan öğrenilecek sirlar hariç olmak üzere, hiçbir ortak şirketin iş sırlarını öğrenmeye salahiyetli değildir. Her ortak, her ne suretle olursa olsun öğrenmiş olduğu, şirkete ait iş sırlarını, sonradan ortaklık hakkını zayi etmiş olsa dahi, daima gizli tutmaya mecburdur. Bu mecburiyeti yerine getirmeyen ortak, meydana gelecek zararlardan şirkete karşı mesul olduğu gibi şirketin şikâyeti üzerine, her hangi bir zarar umulmasa dahi, bir ylla kadar hapis veya beş yüz liradan on bin liraya kadar adli para cezasiyle veya her ikisiyle birlikte cezalandırllır." düzenlemesini içermekte ve anonim şirket ortakları için sır saklama yükümlülüğü getirmektedir. 6762 s. TTK'nın 556. maddesinde “Incelenmesine müsaade edilen defter ve vesikalardan öğrenilecek sırlar hariç olmak üzere, hiçbir ortak şirketin iş sırlarını ögrenmeye salahiyetli değildir. Her ortak, her ne suretle olursa olsun öğrenmiş olduğu, şirkete ait iş sırlarını, sonradan ortaklık hakkını zayi etmiş 
olsa dahi, daima gizli tutmaya mecburdur. Bu mecburiyeti yerine getirmeyen ortak, meydana gelecek zararlardan şirkete karşı mesul olduğu gibi şirketin şikâyeti üzerine, her hangi bir zarar umulmasa dahi, bir yıla kadar hapis veya beş yüz liradan on bin liraya kadar adli para cezasiyle veya her ikisiyle birlikte cezalandırllır.” şeklinde yer alan atıf nedeniyle bu sır saklama yükümlülüğü limited şirket ortakları bakımından da geçerlidir. Kollektif ve komandit şirketler bakımından böyle bir düzenlemeye yer verilmediği için, bu şirket türlerini ilgilendiren ticari sırlar söz konusu olduğunda TCK uygulanacaktır (Erman, 1993).

6102 s. TTK'nın ise, “dürüstlük kuralına aykırı davranışlar, ticari uygulamalar” başlıklı 55. maddesinde “işçileri, vekilleri veya diğer yardımcı kişileri, işverenlerinin veya müvekkillerinin üretim ve iş sırlarını ifşa etmeye veya ele geçirmeye yöneltmek (md. 55/1-b-3)" ve "üretim ve iş sırlarını hukuka aykırı olarak ifşa etmek (md. 55/1-d) dürüstlük kuralına aykırı, haksız rekabet teşkil eden davranış olarak sayılmıştır. Bu dürüstlük kuralına aykırı olan ve haksız rekabet teşkil eden davranışların yaptırımı ise "cezayı gerektiren fiiller" başlıklı 62. maddede "55 inci maddede yazılı haksız rekabet fiillerinden birini kasten işleyenler... fiil daha ă̆ır cezayı gerektiren başka bir suç oluşturmadığı takdirde, 56 ncı madde gereğince hukuk davasını açma hakkını haiz bulunanlardan birinin şikâyeti üzerine, her bir bent kapsamına giren fiiller dolayısıyla iki yıla kadar hapis veya adli para cezasiyla cezalandırllırlar." şeklinde gösterilmiştir. 63. maddede ise, "Tüzel kişilerin işlerini görmeleri sırasında bir haksız rekabet fiili işlenirse 62 'nci madde hükmü, tüzel kişi adına hareket eden veya etmesi gerekmiş olan organın üyeleri veya ortakları hakkında uygulanır. Haksız rekabet fiilinin bir tüzel kişinin faaliyeti çerçevesinde işlenmesi hâlinde, tüzel kişi hakkında bunlara özgü güvenlik tedbirlerine de karar verilebilir." düzenlemesiyle tüzel kişilerin cezai sorumluluğu kabul edilmiştir.

6102 s. TTK'nın “suçlar ve cezalar” başlıklı 562. maddesinin yedinci fikrasında "527'nci maddeye aykırı hareket edenler, Türk Ceza Kanunu’nun 239 uncu maddesi hükümlerine göre cezalandırllır.” düzenlemesi mevcuttur. 527. maddede ise "404'üncü madde hükmü saklı kalmak üzere, görevi dolayısıla incelemesine sunulan defter ve belgeleri inceleyenlerin, elde ettikleri veya verilen bilgilerden ögrendikleri iş ve işletme sırlarını açıklamaları yasaktır. Aksi hâlde şirketin maddi ve manevi zararını tazmin ederler. (2) Ceza mevzuatının, suç ihbarına ilişkin hükümleri saklıdır." ifadeleriyle denetçilere sır saklama yükümlülüğü getirilmiştir. Saklı tutulan 404. maddede ise, denetçilerin sir saklamadan doğan sorumluluğu detaylı bir biçimde düzenlenmektedir. Görüldüğü üzere, 6102 s. TTK denetçilerin sır saklama yükümlülüğüne aykırı davranışları sebebiyle cezai sorumluluklarının gündeme gelmesi durumunda TCK'nın 239. maddesinin uygulama alanı bulacağını belirtmektedir.

Tasarı'nın "sır saklama yükümlülüğ̈̈" başlıklı 6. maddesinde “Bu Kanunun 5 inci maddesi uyarınca verilen sırları doğrudan veya dolayısıyla ögrenen kamu görevlileri ve diğer kişiler, bu sirları kanunen yetkili mercilerden başkasına açıklayamaz, veremez ve kendisi veya başkalarına menfaat sağlamak veya zarar vermek amacıyla kullanamazlar. Bu yükümlülük, bilgi ve belgelerin sır niteliği devam ettiği sürece görevlerinden ayrlmalarından sonra da devam eder." düzenlemesi yer almaktadır. 8. maddesinde ise bu maddeye atıfla ceza hükümleri öngörülmekte ve "6'ncı maddede belirtilen sır saklama yükümlülüğüne aykırı davrananlar 5237 sayılı Türk Ceza Kanunun 239 uncu maddesine göre cezalandırılır." şeklindeki ikinci fikrasılla TCK'nın 239. maddesine atıf yapilmaktadir (Dursun, 2009).

Son olarak, RKHK'nın 25. maddesinin son fikrasında “Kurul üyeleri ve personeli Kurumla ilgili gizlilik taşıyan bilgileri ve bu Kanunun uygulanması sırasında ögrendikleri teşebbüs ve teşebbüs birliklerinin ticarî sırlarını görevlerinden ayrılmış olsalar bile ifşa edemezler, kendilerinin veya başkalarının menfaatine kullanamazlar." düzenlemesi ile kurul üyeleri ve personeline, kurumla ya da teşebbüslerle ilgili öğrendikleri ticari sırları ifşa etmeme yükümlülüğü getirilmiştir. Fakat bu düzenlemede yaptırım öngörülmediği gibi, TCK'ya atıf da yapılmamıştır.

Haksız rekabet suçu oluşturan ticari sırrın ifşasını içeren düzenlemeler bakımından Uluslararası Avrasya Ekonomileri Konferansı 2016'da sunmuş olduğumuz “Türk Ticaret Kanunu'nda Haksız Rekabet Suçu” başlıklı bildirimize atıf yapmakla yetineceğiz. Fakat burada dikkat edilmelidir ki, 6102 s. TTK md. 62 söz konusu fiiller "daha ağır cezayı gerektiren başka bir suç oluşturmadığı takdirde" uygulanabilen bir hükümdür. Diğer bir ifadeyle, TTK md. 62 hükmü tali normdur (İtişgen, 2016). Sayılan davranışlar başka bir suçun unsurlarını oluşturduğu ve bu suç TTK md. 62'ye göre daha ağır bir cezayı gerektirdiği takdirde o suçtan hüküm kurulur. Söz konusu davranış başka bir suçu meydana getirmekle birlikte, o suçun yaptırımı TTK md. 62'ye göre daha hafif bir yaptırım getiriyorsa bu durumda yine haksız rekabet suçundan dolayı ceza uygulanır. Ticari sırrın açıklanması niteliğindeki fiiller TCK md. 239'da suç olarak düzenlendiğinden ve öngörülen yaptırım (bir yıldan üç yıla kadar hapis cezası), TTK md. 62'de öngörülenden (iki yıla kadar hapis cezası) daha ağır olduğundan, asli norm olarak TCK md. 239 uygulanacaktır. 


\section{Ticari Sır Niteliğindeki Bilgi veya Belgelerin Açıklanması Suçu}

\subsection{Suçla Korunan Hukuki Değer}

Ticari sır niteliğindeki bilgi ve belgelerin açıklanması suçuyla, dar anlamda ticari sırların gizliliğinin, geniş anlamda ise dürüst rekabet ortamının ve dürüstlüğe aykırı davranış ve uygulamalar ile zarara uğrayan rakiplerin ticari itibar ve saygınlığının, dolayısıyla ülkenin ekonomik yapısının ve kamu düzeninin korunduğu, bu sebeple çok hukuki konulu bir suç tipi olduğu söylenebilir (Tepe, 2010; Kangal, 2014).

\subsection{Suçun Unsurları}

\subsubsection{Kanuni Unsur}

TCK md. 239’a göre, “(1) Slfat veya görevi, meslek veya sanatı gereği vakıf olduğu ticari sır, bankacılık sırr veya müşteri sırrı niteliğindeki bilgi veya belgeleri yetkisiz kişilere veren veya ifşa eden kişi, şikâyet üzerine, bir yıldan üç yıla kadar hapis ve beşbin güne kadar adlî para cezası ile cezalandırılır. Bu bilgi veya belgelerin, hukuka aykırl yolla elde eden kişiler tarafindan yetkisiz kişilere verilmesi veya ifşa edilmesi halinde de bu fikraya göre cezaya hükmolunur.

(2) Birinci fikra hükümleri, fenni keşif ve buluşları veya sınai uygulamaya ilişkin bilgiler hakkında da uygulanır.

(3) Bu sırlar, Türkiye'de oturmayan bir yabancıya veya onun memurlarına açıklandı̆̆ takdirde, faile verilecek ceza üçte biri oranında artırılır. Bu halde şikâyet koşulu aranmaz.

(4) Cebir veya tehdit kullanarak bir kimseyi bu madde kapsamına giren bilgi veya belgeleri açıklamaya mecbur kılan kişi, üç yıldan yedi yıla kadar hapis cezasıyla cezalandırılır.”

\subsubsection{Maddi Unsurlar}

\section{i. Konu}

Ticari sır niteliğindeki bilgi veya belgelerin açıklanması suçunun konusunu bir kimsenin sıfat veya görevi, meslek veya sanatı gereği vakıf olduğu ticari sır oluşturmaktadır. Çalışmamızın ilk bölümünde sır ve ticari sır kavramlarına detaylı bir biçimde yer verdiğimizden dolayı, burada tekrara düşmemek adına konuya işaret etmekle yetineceğiz.

\section{ii. Fail}

TCK md.239/1'in ilk cümlesine göre, failin ticari sırra sıfat veya görevi, meslek veya sanatı gereği vakıf olması ve bu sırrı yetkisiz kişilere vermesi veya ifşa etmesi gerekmektedir. Bu sebeple, ilk cümle bakımından fail yalnızca bu niteliği haiz kişiler olabilir ve düzenleme özgü suç özelliği taşır. Doktrindeki (İçel, 2010; Kangal, 2014) suçun failinin herkes olabileceği, özgü suç niteliği taşımadığı yönündeki görüşe katılmamaktayız. İlk fikranın ikinci cümlesinde ise "bu bilgi veya belgelerin, hukuka aykırı yolla elde eden kişiler tarafından yetkisiz kişilere verilmesi veya ifşa edilmesi” cezalandırılmakta olup, bu cümlede yer alan suç bakımından herkes fail olabilir. Benzer şekilde, maddenin dördüncü fikrasında "cebir veya tehdit kullanarak bir kimseyi bu madde kapsamına giren bilgi veya belgeleri açıklamaya mecbur kılan kişi” cezalandırılmaktadır ve bu fikrada düzenlenen suç bakımından da failin herhangi bir kişi olması mümkündür.

$\mathrm{Bu}$ konuda madde gerekçesinde detaylı bilgi yer almamakla birlikte, failin bu bilgilere hukuka uygun şekilde vakıf olduğunu kabul etmek gerekmektedir. Ticari sır ile bu sırrı bilen kişinin sıfatı, görevi, mesleği veya sanatı arasında bağ bulunması zorunludur. Ayrıca failin söz konusu bağ nedeniyle bu sırrı saklama, koruma yükümlülüğ̈̈ altında olması gerekir (Tepe, 2010).

Tüzel kişilerin iradi hareket etme yeteneği bulunmadığından fail olmaları söz konusu değildir. Diğer bir ifadeyle ancak gerçek kişiler bir suçun faili olabilirler (Özgenç, 2015; Koca ve Üzülmez, 2013). Zira Türk ceza hukukunda tüzel kişilerin suç faili olamayacağı, ceza sorumluluklarının kabul edilmesinin ceza sorumluluğunun şahsiliği ilkesine aykırı olacağı ifade edilmektedir (Erman, 1976; Özgenç, 2002; Dursun, 2006; Mahmutoğlu, 2003).

Ticaret şirketleri adına ve faaliyetleri esnasında suç işlenmesi durumunda ise, tüzel kişinin yetkili organ veya temsilcisinin cezai sorumluluğu gündeme gelir (Kangal, 2003). Organ kurul halinde karar almışsa, karara olumlu oy kullanmış üyeler sorumlu olacak; toplantıya katılmamış ya da katılmakla birlikte olumsuz oy kullanmış üyelerin sorumluluğuna gidilemeyecektir. Fakat bu üyelerin kararın alınmasını önleme yükümlülükleri kanunda ya da esas sözleşmede öngörülmüş ise, bu durumda kararın alınmasını önlemeyen üyelerin ihmali suretle suça katıldıklarını söylemek mümkündür (Dursun, 2006).

Bununla birlikte, esas sözleşmede temsil organının üyeleri arasında görev dağılımı yapılması da mümkündür. Görev dağılımının bulunduğu bu gibi durumlarda, her bir üye kendisine verilen temsil yetkisi oranında sorumlu olacaktır ve eylem ya da işlemin ayrıntılarını bilen ve oluşumunda rolü bulunan temsilcilerin cezai sorumluluğuna gidilecektir. TCK'nın suça iştirake ilişkin hükümleri (TCK md. 37-40) bir tarafa bırakıldığında, suç oluşturan eylem ya da işlem hangi temsilcinin görev tanımında yer alıyorsa o temsilcinin cezai sorumluluğu tartışılacaktır (Erman, 1976). 


\section{iii. Mağdur}

Ticari suçların geniş anlamda mağduru toplumu oluşturan herkestir. Dar anlamda ise, ticari sır niteliğindeki bilgi veya belgelerinin açıklanması suretiyle zarar gören tacirler mağdur, tüzel kişiler ise suçtan zarar gören olarak kabul edilmelidir (Tepe, 2010; Kangal, 2014).

\section{iv. Hareket, Netice ve Nedensellik Bağı}

TCK md. 239'daki suçun meydana gelmesi için gerçekleştirilmesi gereken hareketler "yetkisiz kişilere verme" veya "ifşa etme"dir. Bu hareketler maddede açıkça belirlendiğinden bağlı hareketli bir suç tipi söz konusudur ve ayrıca "veya" bağlacı ile bağlandıkları için seçimlik hareketler şeklinde düzenlenmiştir (İçel, 2010; Tepe, 2010). Seçimlik hareketlerden birinin gerçekleştirilmesiyle suç tamamlanacağı gibi, birden fazlasının veya tamamının gerçekleştirilmesi halinde de tek bir suç oluşacaktır.

"Vermek" hareketi bakımından failin söz konusu bilgileri üçüncü kişiye ulaştırmak için göndermesi yeterli olup, bu bilgilerin üçüncü kişi tarafından öğrenilmiş olmasına gerek yoktur. Örneğin, belgeleri içeren zarfın postaya verilmesi ya da ticari sır niteliğindeki bilgilerin mail atılması fakat henüz üçüncü kişinin bunları okumamış be öğrenmemiş olması durumunda da suç tamamlanır. Verme işleminin hangi şekilde gerçekleştiğinin bir önemi yoktur (Tepe, 2010; Kangal, 2014).

"İf̧sa etmek" ise açıklamak olarak anlaşılmalıdır. Zira bu kavram mutlaka bilgiyi anonim hale getirmek, kamuyla paylaşmak olarak anlaşılmamalı, yetkisiz herhangi bir kişiye bu bilginin açıklanması durumunda hareket gerçekleşmiş kabul edilmelidir (Tepe, 2010; Kangal, 2014).

Ticari sır niteliğindeki bilgi veya belgelerin açıklanması suçu neticesi harekete bitişik, diğer bir ifadeyle neticesiz bir suçtur. TCK md. 239'da sayılan hareketlerin gerçekleştirilmesiyle birlikte neticenin de gerçekleştiği kabul edilmektedir. Neticesiz suç olduğundan nedensellik bağlantısının ayrıca incelenmesine gerek bulunmamaktadır.

\section{v. Nitelikli Haller}

TCK md. 239'un 3. fikrasında ticari sırların Türkiye'de oturmayan bir yabanciya veya onun memurlarına açıklanması ve 4 . fikrasında cebir veya tehdit kullanarak bir kimsenin bu madde kapsamına giren bilgi veya belgeleri açıklamaya mecbur kılınması nitelikli hal olarak gösterilmiştir. İlk durumda suçun yaptırımı üçte bir oranında artırılırken, ikinci ihtimalde üç yıldan yedi yıla kadar hapis cezası öngörülmüştür.

\subsubsection{Manevi Unsur}

Ticari sır niteliğindeki bilgi veya belgelerin açıklanması suçu kasten işlenebilen bir suç tipidir. Kanımızca suçun olası kasta işlenmesi de mümkündür. TCK md. 22/1'in “Taksirle işlenen fiiller, kanunun açıkça belirttiği hallerde cezalandırllır." düzenlemesi gereğince, ticari sırrın ifşası suçu ancak kasten işlenmesi halinde cezalandırılabilir. Zira suçun taksirli hali düzenlenmemiştir (Tepe, 2010).

\subsubsection{Hukuka Aykırılık Unsuru}

Bir fiilin suç teşkil edebilmesi için tipe uygun, kusurlu bir davranış olmasının yanında aynı zamanda hukuka aykırı olması gerekir. Suç teşkil eden fiiller kural olarak hukuka aykırıdırlar. TCK'da düzenlenen hukuka uygunluk nedenleri kanunun hükmü, meşru savunma, hakkın kullanılması ve ilgilinin rızasıdır. Genel hukuka uygunluk nedenleri niteliği uygun düştüğ̈̈ ölçüde ticari sır niteliğindeki bilgi veya belgelerin açıklanması suçu bakımından da uygulama alanı bulacaktır.

İlgilinin rızasının bulunması bu suç bakımından hukuka uygunluk nedeni olarak kabul edilebilir (İçel, 2010; Kangal, 2014). Ayrıca kanımızca, ortakların, denetçilerin veya Rekabet Kurulu üyelerinin denetimleri sırasında öğrendikleri suç oluşturabilecek nitelikteki ticari sırları suçu bildirme yükümlülüğü kapsamında açıklamaları durumunda, bu davranışları hakkında hukuka uygunluk nedeni uygulanmalıdır (Erman, 1993).

\subsection{Suçun Özel Görünüş Şekilleri}

\subsubsection{Teşebbüs}

Ticari sır niteliğindeki bilgi veya belgelerin açıklaması suçu, neticesiz suç olması sebebiyle kural olarak teşebbüse elverişli değildir; ancak belgenin posta ile gönderilmesi örneğinde olduğu gibi icra hareketlerinin bölünebilmesi mümkünse bu durumda suç teşebbüs aşamasında kalabilecektir (İçel, 2010; Tepe, 2010).

Ayrıca, birinci fikranın ikinci cümlesinde yer alan "Bu bilgi veya belgelerin, hukuka aykırı yolla elde eden kişiler tarafindan yetkisiz kişilere verilmesi veya ifşa edilmesi halinde de bu fikraya göre cezaya hükmolunur." düzenlemesinde, bir görüşe göre bilgi hukuka aykırı yoldan elde edildikten sonra kişinin bu bilgiyi açıklayamadan yakalanması durumunda suç, teşebbüs aşamasında kalmış olacaktır (Kangal, 2014). Fakat kanımızca bu cümlede gerçekleştirilmesi gereken icra hareketleri vermek veya ifşa etmek olup, örnek olayda icra hareketlerine başlanmamış olduğundan teşebbüs söz konusu değildir. Söz konusu bilgilerin hukuka aykırı yoldan elde edilmesi koşulları mevcutsa başka bir suç kapsamında cezalandırılabilecektir. Bunun yanında, kişi hukuka aykırı olarak 
elde ettiği bilgileri vermek veya ifşa etmek için icra hareketlerine başlayıp elinde olmayan nedenlerle tamamlayamazsa suç teşebbüs aşamasında kalmış olacaktır.

\subsection{2 İş̧irak}

Suç, iştirak bakımından özellik göstermez; iştirake ilişkin genel hükümler bu suç bakımından da geçerlidir.

\subsection{3 İçtima}

TCK md. 239'da düzenlenen bu suçun zincirleme suç şeklinde işlenmesi mümkündür. Ayrıca, bu bilginin vergi mahremiyetiyle de ilgili olması durumunda Vergi Usul Kanunu'nun 362. maddesi, özel hayata ilişkin olması ihtimalinde TCK md. 134 ya da göreve ilişkin sırrın açıklanması suçu (TCK md. 258) ile içtima ilişkisi gündeme gelebilir (Arslan, 2013; Kangal, 2014).

\subsection{Yaptırım}

\subsubsection{Cezai Yaptırım}

Ticari sır niteliğindeki bilgi veya belgelerin açıklanması suçunun yaptırımı bir yıldan üç yıla kadar hapis ve beş bin güne kadar adli para cezasıdır. Dikkat edilmelidir ki, hapis cezası ile adli para cezası alternatif yaptırımlar değildir; her ikisine de aynı anda hükmedilmektedir.

TCK md. 52/1'e göre, adlî para cezası, beş günden az ve kanunda aksine hüküm bulunmayan hallerde yedi yüz otuz günden fazla olmamak üzere belirlenen tam gün sayısının, bir gün karşıllğıı olarak takdir edilen miktar ile çarpılması suretiyle hesaplanan meblağa tekabül etmektedir. TCK md. 239 hükmünde adli para cezasının alt sınırı gösterilmediğinden esasında bu beş günden beş bin güne kadar adli para cezası olarak anlaşılmalıdır.

\subsubsection{Tüzel Kişilere Özgü Güvenlik Tedbirleri}

TCK md. 242 "Bu bölümde yer alan suçların işlenmesi suretiyle yararına haksız menfaat sağlanan tüzel kişiler hakkında bunlara özgü güvenlik tedbirlerine hükmolunur. " düzenlemesini içermektedir. Bu hükme göre, tüzel kişi faaliyeti esnasında, tüzel kişi yararına olarak tüzel kişinin organının üyeleri ya da temsilcilerinin ticari sırrı niteliğindeki bilgi veya belgelerin açıklanması suçunun işlemesi halinde tüzel kişi hakkında tüzel kişilere özgü güvenlik tedbirleri uygulanacaktır (Kangal, 2014). Tüzel kişiler hakkında uygulanabilecek güvenlik tedbirleri TCK md. 60'a göre, iznin iptali ve müsaderedir. Fakat bu tedbirlerin uygulanmasının işlenen fiile nazaran daha ağır sonuçlar ortaya çıkarabileceği durumlarda, TCK md. 60/3'e dayanarak hâkim bu tedbirlere hükmetmeyebilir (Öztürk ve Erdem, 2014).

\subsection{Soruşturma ve Kovuşturma}

TCK md. 239/1'e göre, "Sifat veya görevi, meslek veya sanatı gereği vakıf olduğu ticari sır, bankacıllk sirrı veya müşteri sırrı niteliğindeki bilgi veya belgeleri yetkisiz kişilere veren veya ifşa eden kişi, şikâyet üzerine, bir yıldan üç yıla kadar hapis ve beşbin güne kadar adlî para cezası ile cezalandırıllır.” Diğer bir ifadeyle, bu suç soruşturulması ve kovuşturulması şikâyete bağlı bir suç tipidir. Fakat maddenin üçüncü fikrasında düzenen, sırrın Türkiye'de oturmayan bir yabancıya veya onun memurlarına açıklanması halinde şikâyet koşulu aranmamakta; suç re'sen soruşturulup kovuşturulmaktadır.

TCK md. 73/1'e göre, "Soruşturulması ve kovuşturulması şikâyete bağlı olan suç hakkında yetkili kimse altı ay içinde şikâyette bulunmadlğı takdirde soruşturma ve kovuşturma yapılamaz." TCK md. 239'da düzenlenen suç da ticari sır niteliğindeki bilgi veya belgelerin açıklanması fiilinin ve failin kim olduğunun bilindiği veya öğrenildiği günden itibaren (TCK md. 73/2) altı ay içinde şikâyette bulunulması ile soruşturulup kovuşturulur.

\subsection{Zamanaşımı}

TCK md. 66/1-e hükmü beş yıldan fazla olmamak üzere hapis veya adlî para cezasını gerektiren suçlarda sekiz yıl dava zamanaşımı süresi öngörmektedir. Ticari sır niteliğindeki bilgi veya belgelerin açıklanması suçunun yaptırımı bir yıldan üç yıla kadar hapis ve beş bin güne kadar adli para cezasıdır. Dolayısıyla dava zamanaşımı süresi TCK md. 66/1-e'ye göre sekiz yıl olmaktadır (Öztürk ve Erdem, 2014).

\section{Sonuç}

Ticari sır niteliğindeki bilgi veya belgelerin açıklanması suçu TCK'nın “Ekonomi, Sanayi ve Ticarete İlişkin suçlar" bölümünde düzenlenen bir ekonomik suç normudur. Ticari sırrın ifşası konusunda diğer kanunlarda da düzenleme bulunduğundan ve bu düzenlemelerin bir kısmı tali norm niteliği taşıdığından, TCK md. 239 bu konuda asli ve genel normdur.

Ticari sırların korunması konusundaki en büyük eksiklik, kanunda tanımının yapılmamış olmasıdır. Tanım eksikliği sebebiyle, hangi bilgilerin ticari sır sayılacağı konusundaki uygulamalar değişebilmekte, bu da kanunilik ilkesine, eşitlik ilkesine ve öngörülebilirlik ilkesine aykırılık teşkil etmektedir.

Bununla birlikte, Tasarı'nın kanunlaşması ihtimalinde bu konudaki tanım eksikliği giderilmiş olacaktır. Fakat bu ihtimalde de kural, yürürlüğe girecek Kanun ile konmuş olacak; maddede TCK md. 239'a atıf bulunduğundan 
yaptırım konusunda TCK uygulanacaktır. Ticari sırrın korunması ile ilgili özel kanun niteliği taşıyan bu kanunda yaptırımın da yer alması kanunun bütünlüğü açısından daha faydalı olacaktır.

\section{Kaynakça}

- Alıcı, 2007. Bankacılık Kanunu Şerhi, Yetkin, İstanbul.

- Arkan, 2011. Ticari İşletme Hukuku, 15. Baskı, Banka ve Ticaret Hukuku Araştırma Enstitüsü, Ankara.

- Arslan, 2013. "Vergi Mahremiyetini İhlal Suçu (VUK md. 362)", Hacettepe Üniversitesi Hukuk Fakültesi Dergisi, 3(2).

- Bilge, 2005. Ticari Surların Korunması, Asil, Ankara.

- Donay, 1978. Meslek Sırrının Açıklanması Suçu, İstanbul Üniversitesi Yayınları, İstanbul.

- Dursun, 2006. Ekonomik Suçlar ve Bankacılık Suçları Bağlamında Bankacılık Düzenine Karşı İşsenen Suçlar, Seçkin, Ankara.

- Dursun, 2009. “Ticari Sır, Banka Sırrı ile Müşteri Sırrının Açıklanması Suçlarına Genel Bir Bakış”, Kamu$\dot{I}_{S}, 11(1)$.

- Erem, Altık ve Tandoğan, 1975. Bankalar Kanunu Şerhi, BTHA, Ankara.

- Erman, 1976. Ticari Ceza Hukuku- Genel Kısım, Matematik Araştırma Enstitüsü Matbaası, İstanbul.

- Erman, 1984. Bankacılık Suçları, Matematik Araştırma Enstitüsü Matbaası, İstanbul.

- Erman, 1993. Şirketler Ceza Hukuku, İ.Ü.Basımevi, İstanbul.

- İçel, 2010. "Ticari Sır, Bankacılık Sırrı veya Müşteri Sırrı Niteliğindeki Bilgi veya Belgelerin Açıklanması Suçları- Bu Tür Sırlarla İlgili Bilgi İstanmesinin Sınırları", İstanbul Ticaret Üniversitesi Sosyal Bilimler Dergisi, 9(18).

- İ̇işgen, 2016. "Türk Ticaret Kanununda Düzenlenen Gerçek Dışı veya Yanıltııı Açıklamada Bulunma Suçu”, Türkiye Barolar Birliği Dergisi, 122.

- Kangal, 2003. Tüzel Kişilerin Ceza Sorumluluğu, Seçkin, Ankara.

- Kangal, 2014. "Ticari Sır, Bankacılık Sırrı veya Müşteri Sırrı Niteliğindeki Bilgi veya Belgelerin Açıklanması Suçu", Ceza Hukuku Dergisi, 9(24).

- Kaplan, 1990. "Banka Gizliliği- Bankanın Sir Saklama Borcu”, BATIDER, XV(4).

- Karayalçın, 1968. Ticaret Hukuku I, 3. Baskı, Güzel İstanbul Matbaası, Ankara.

- Koca ve Üzülmez, 2013. Türk Ceza Hukuku Genel Hükümler, 6. Baskı, Seçkin, Ankara.

- Mahmutoğlu, 2003. Ekonomik Suçlar Bağlamında Kredi Hukukundan Kaynaklanan Suç ve İdari Suçlar, Seçkin, Ankara.

- Özgenç, 2002. Ekonomik Çıkar Amacıyla İşlenen Suçlar, Seçkin, Ankara.

- Özgenç, 2015. Türk Ceza Hukuku Genel Hükümler, 11. Bası, Seçkin, Ankara.

- Öztürk ve Erdem, 2014. Uygulamalı Ceza Hukuku ve Güvenlik Tedbirleri Hukuku, 14. Bası, Seçkin, Ankara.

- Öztürk, 2009. Ticari Sır, Bankacılık Sırrı veya Müșteri Sırrı Niteliğindeki Bilgi veya Belgelerin Açıklanması Suçu, DEÜ SBE yayımlanmamış yüksek lisans tezi, İzmir.

- Poroy ve Yasaman, 2010. Ticari İşletme Hukuku, 13. Bası, Vedat, İstanbul.

- Sungurtekin Özkan, 2000. “Avukatlık Meslek Sırrının Anlam ve Önemi”, Ankara Barosu Hukuk Kurultayl $2000,4$.

- Tepe, 2010. "Ticari Sır, Bankacılık Sırrı veya Müşteri Sırrı Niteliğindeki Bilgi veya Belgelerin Açıklanması Suçu (TCK m. 239/1-3)”, Ceza Hukuku Dergisi, 5(14). 


\title{
Öjenik Bağlamında Batı Ülkeleri'nde ve Türkiye'de Politika Yapımı Üzerine Karşılaştırmalı Analiz
}

\section{A Comparative Analysis on Policy Making in Western Countries and Turkey in the Context of Eugenics}

\author{
Ph.D. Candidate Ertuğrul Eryücel (Gaziosmanpaşa University, Turkey)
}

\begin{abstract}
The word eugenics was coined in 1883 by the English scientist Francis Galton, who took the word from a Greek root meaning "good in birth" or "noble in heredity". Eugenics aimed to assist states in implementing negative or positive policies which would improve the quality of the national breed. The intensive applications of eugenic policies coincide between two World Wars. İn the decades between 1905 and 1945, eugenics politics implemented in more than thirty countries.

The method of this study is based on a literature survey on the sources of the eugenic subject. The sources of the data are documents such as books, articles, journals, theses, projects, research reports about the politics and legal regulations of the countries on the family, population, sport, health and body. This study comparatively examines eugenic policy-making in Turkey and in Western countries: Britain, United States, France, Germany (1905-1945).

This study aims to discuss the relation of eugenic politics in countries with nation building process, ethnic nationalism, and racism. This is a basic claim that the eugenic practices in Turkey contain more positive measures and that there is no racial-ethnic content of eugenics in Turkey.
\end{abstract}

\section{Giriş}

Öjenik siyaset, nüfusun beden ve dimağ açısından sağlıklı unsurlarının çoğaltılması, sağlıksız unsurlarının ise azaltılması yoluyla insan soyunun geliştirilmesini amaçlayan politikalar toplamıdır. Öjenik düşüncenin geçmişi Eski Yunan düşünürlerine dek gitse de; kavram 1883 yılında Francis Galton tarafından ortaya atılmıştır. Öjenik düşüncenin kurucusu olan Francis Galton (1822-1911), eugenics kavramını Yunanca eu (iyi, normal) ve genic (doğurmak, mahsül, döl), kelimelerinden türetmiştir. Sözcük anlamıyla eugenics-öjenik "doğuştan iyi”, "soydan asil", anlamlarına gelmektedir.

Uygulama açısından öjenik siyasetin iki boyutu vardır. Öjeniğin birinci boyutunu oluşturan pozitif öjenik, çoğalması arzu edilen seçkin bir neslin üremesine yardım etmeyi amaçlamaktadır. Öjeniğin ikinci boyutunu oluşturan negatif öjenik ise; irsen hasta-sakat olanlarla; dejenere, asosyal ve millet için tehlike teşkil edenlerin çoğalmasına engel olmayı amaçlamaktadır. Buna göre, nasıl nüfusun beden ve dimağ açısından kıymetli unsurlarının çoğalması teşvik ediliyorsa, nüfusun beden ve dimağ açısından kıymetsiz unsurlarının çoğalması engellenmeye çalışılır.

Öjenik politikalar 20. yüzyılın başından itibaren, özellikle de iki dünya savaşı arası dönemde, Avrupa ve Amerika kıtası ülkeleri başta olmak üzere, pek çok dünya ülkesinin aileye, nüfûsa, sağlığa, spora ve bedene ilişkin politikalarında uygulama alanı bulmuştur. Öjenik dönemin otoriter-totaliter devletlerinde olduğu kadar, dönemin demokrat sayılan devletlerinde de etkili olmuştur. 1900'lerin başında ilk olarak Amerika Birleşik Devletleri'nde uygulanan öjenik politikalar, iki dünya savaşı arası dönemde hemen hemen tüm Batı ülkelerinde uygulama alanı bulmuştur.

İnsan neslinin geliştirilmesi konusunun çok boyutlu olması ve bunun ekonomik, sosyal ve siyasal reformlar gerektirmesi; öjeniği başta biyoloji, antropoloji, genetik, tıp, sosyoloji ve siyaset olmak üzere, birçok bilime konu yapmıştır. Her bilim dalı öjeniğe kendi perspektifinden yaklaşmakla birlikte; tüm bu çabaların arkasında daha büyük bir sorunsal vardır. Öjenik her şeyden önce modernite ve onun uzantısı olan ulus devlet anlayışının bir ürünüdür. 19. ve 20. yüzylllar modern ulus devletler için kendi ulusunu inşa etme süreci olarak geçmiştir. İki dünya savaşı arası dönemde bu süreç doruk noktasına ulaşmıştır. Ulus devletler bu süreçte kendi ulusunu yaratabilmek için bütün araçları farklı formlarda kullanmışlardır. Öjenik politikalar iki dünya savaşı arası dönemde, ulus inşa sürecinin önemli bir aracı olarak ortaya çıkmıştır. Modern ulus devletler; bu amaca ulaşmak için evlilik kanunlarından, mali mevzuata, koruyucu sağlık hizmetlerinden kısırlaştırmaya, püerikültürden beden terbiyesine, kitle iletişim araçlarına ilişkin düzenlemelerden göç politikalarına kadar uzanan bir dizi araçtan faydalanmıştır. Öjenik, modern ulus devletin oluşum sürecinde, devletin toplumu kontrol ettiği ve yeniden biçimlendirdiği politikalar bileşeni olarak ortaya çıkmıştır.

Bu çalışma, iki dünya savaşı arası dönemde Batı ülkelerinde ve Türkiye'de uygulanan öjenik politikaları incelemektedir. İncelemeye konu ülkeler Amerika Birleşik Devletleri, İngiltere, Fransa, Almanya ve Türkiye'dir. Çalışma, dünya ülkeleri ve Türkiye'deki öjenik uygulamaları benzerlikler ve farklılıklar üzerinden karşılaştırmalı olarak tartışmayı amaçlamaktadır. Buna göre; ülkelerdeki öjenik pratiğin negatif ya da pozitif yönü, modernite, 
ulus inşa süreci, etnik milliyetçilik, ırkçılık olgularıyla ilgisi tartışılmaktadır. Bu çalışma, çok az sayıda çalışmanın bulunduğu öjenik siyaset anlayışına yeni bir kapı aralama gayretidir. Türkiye'deki öjenik uygulamaların daha çok pozitif tedbirler içerdiği, Türkiye'de öjeniğin ırkçı-etnik bir içeriğinin olmadığı bu tezin temel iddiasıdır. Bu teze göre; genç Cumhuriyetin modernleşme ve ulus inşa etme sürecinin/projesinin nüfus ve insan bedeni üzerindeki boyutunu oluşturan öjenik konusunda, Cumhuriyet yönetimi aşırılıklara kaçmamıştır. Türkiye'de o dönemde kısırlaştırma, hadımlaştırma, izalâsyon, seçilmiş kişiler arası cinsel birliktelik, yabancılarla evliliği yasaklamaengelleme, ayrımcı göç politikaları gibi ırkı saflaştırmaya yönelik girişimler olmamıştır.

Bir ülkenin öjenik pratiğinin mâhiyetini belirleyen o ülkenin öjenik mevzuatı ve uyguladığı öjenik politikalarının içeriğidir. Bu açıdan bu tezin esas inceleme alanı (kapsamı); ülkelerin nüfus, beden, sağlık, spor, aile, evliliğe ilişkin yasal düzenlemeleri ile bunların politika düzeyinde uygulanmasıdır. Çalışmamızda konumuz gereği sıklıkla kullanacağımız temel kavramlar, “öjenik", "Darwinizm”, "Lamarkizm”, "Sosyal Darwinizm”, "kalıtım”,

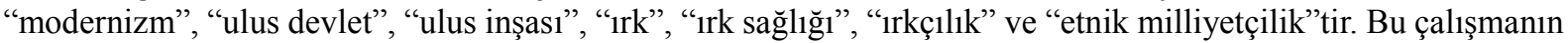
yöntemi, 1918-1945 arası dönemde dünya ülkelerindeki öjenik politikaları konu alan kaynaklar üzerine yapılan bir literatür taramasına dayanmaktadır. Dolayısıyla çalışmaya temel oluşturan verilerin toplandığı kaynaklar; ülkelerin aile, nüfus, spor, sağlık ve beden üzerine politikaları ve yasal düzenlemeleri ile konu ile ilgili yerli ve yabancı dilde yazılmış kitap, makale, dergi, gazete, tez, proje, araştırma raporu gibi belgelerdir.

\section{Amerika Birleşik Devletleri}

Amerika Birleşik Devletleri’nde öjenik siyaset yasal bir program çerçevesinde yürütülmüştür. Amerika Birleşik Devletleri, öjenik yasalar açısından dünyanın en zengin örneklerinden biridir. Amerika Birleşik Devletleri'nde öjenik düzenlemeler ulusal hükümetin değil, eyaletlerin düzenlemesine konu olmuştur. ABD’de öjenik bağlamda ulusal düzeyde ele alınan tek konu göçtür. Diğer kıtalardan gelen göç dalgası federal bir mesele olarak kabul edilmiş ve ulusal düzeyde öjenik düzenlemeler sadece göç alanında çıkarılmıştır. Bunun dışında evlenme, boşanma, cinsel eğitim, sterilizasyon eyaletler düzeyinde ele alınmıştır (Kevles, 1986).

Amerika Birleşik Devletleri’nde öjenik siyaset daha çok istenmeyenlere yönelik negatif tedbirler çerçevesinde gelişmiştir. Amerika Birleşik Devletleri öjenik siyasetinin temel vurgusu irkçılık üzerine olmuştur. Zorunlu kısırlaştırma ve göç yasaları büyük ölçüde ırkçı öğeler içermiştir. Göç kanunları ülkeye alınacak göçmenleri 1rki niteliklerine göre bir tasnife tutmuş, otuzdan fazla eyalette kabul edilen zorunlu kısırlaştırma uygulaması ise, 1rksal açıdan aşağı görülen gruplara yönelmiştir. Amerika Birleşik Devletleri'nde Kuzey Avrupa'nın beyazları (Nordik 1rk) üstün ırk olarak kabul edilmiş, Orta ve Güneydoğu Avrupa'dan gelenlerle birlikte; Asyalılar, Afrikalılar ırki açıdan düşün niteliklerle eşleştirilmiş̧tir. Mendel çizgisinde gelişen Birleşik Devletler öjenik siyaseti asil kan olarak nitelenen Kuzeyin beyazlarının çoğalmasını teşvik için her yola başvururken; diğer irkların ülkede çoğalmasını evlilik yasaları, göçmen yasaları ve sterilizasyon yasaları gibi sert negatif tedbirlerle sınırlamıştır (Kühl, 2002).

ABD’de öjenik bağlamında ilk düşünülen konu evlilik olmuştur. 19. yüzyılın son çeyreğinde Amerikan eyaletlerinde alkolik, frengili, epileptik, zihinsel engelli kişilerin evliliklerine sınırlama getiren evlilik yasalarının kabul edildiği görülmüştür. Evlilik kısıtlaması getiren yasaların ilki; 1896 yılında Connecticut eyaletinde kabul edilmiştir. Yasa öjenik olarak unfit kabul edilenlerin evliliğini yasaklamış ve bu kişilerin evlilik dışı ilişkilerinin ise; asgari 3 yıl hapis ile cezalandırılmasına hükmetmiştir. Connecticut örneği diğer eyaletler için de model teşkil etmiş, bu yasaya benzer yasalar diğer eyaletlerde de kabul edilmiştir (Kevles, 1986).

ABD eyaletlerinde kabul edilen evlilik yasaları içinde 1rklar arası karışımı-melezleşmeyi (anti-miscegenation laws) önlemeyi amaçlayan yasalar da vardı. Bu yasalar üstün Nordik ırk stoğunu korumak üzere kurgulanmıştır. Irklar arası ayrılığı en belirgin şekilde vurgulayan yasa, 1924 tarihinde Virginia parlamentosu tarafından onaylanan "Virginia Racial Integrity Act”tır. Bu yasa 1967 yılına kadar yürürlükte kalmıştır. "Amerikan Yüksek Mahkemesi" (US Supreme Court) 1967 yılında yasayı Birleşik Devletler Anayasası'na aykırı bulmuştur. Bu tarihten itibaren ırklar arası evliliği yasaklayan yasalar diğer eyaletlerde de anayasa aykırılığı gerekçesiyle yürürlükten kaldırılmıştır (Lombardo, 1988)

Amerika Birleşik Devletleri'nde istenmeyenlere karşı düşünülmüş bir diğer öjenik tedbir göçmen kısıtlama yasalarıdır. Amerika Birleşik Devletleri kurulduğu tarihten itibaren yoğun göç alan bir ülkeydi. Bu yüzden ülke göç konusunda diğer ülkelere nazaran çok daha hassas davranmıştır. ABD'de öncelikle göç eden kişilerin niteliklerine çok büyük önem verilmiştir. Burada göç eden kişilerin yalnız muayyen bir sermayeye malik olmaları değil; bir takım bedeni, ruhi ve irsi niteliklere de haiz olmaları istenmiştir.

ABD'de kabul edilen Göçmen kısıtlama yasaları göçmenleri geldikleri yere göre hiyerarşik bir derecelendirmeye tabi tutmuştur. ABD göçmen yasaları beyaz Nordik ırkı iyi-gerçek vatandaş olarak kabul etmiş, bu ırkın korunmasını ve ulus içinde çoğalmasını hedeflemiştir. Bu hedef doğrultusunda Asyalılar ve Afrikalılarla birlikte; beyaz ırkın Alpin ve Akdenizli kolu da istenmeyen ve çoğalması engellenmesi gereken ırk grupları olarak tasnif edilmiştir (Spiro,2009). Bu doğrultuda, süreç ilk olarak 1882 yılında çıkarılan "Chinese Exclusion Act" (Çinlileri Dışlama Yasası) ile başlamıştır. Chinese Exclusion Act ile Çinlilerin ABD’ye göçü yasaklanmıştır. 1907 yılında Japonya ile yapılan "Gentleman's Agreement" (Centilmenlik Antlaşması) ile Japonya vatandaşlarına sınırlar kapatılmıştır. 1917 yılında çıkarılan bir kanunla da Hintlilerin göçü yasaklanmıştır. Göçmen kısıtlama 
yasalarının en kapsamlısı 1917 yılında çıkarılan yasadır. Bu yasa ile Slavların, İtalyanların, Yahudilerin, Polonyalıların, Çinlilerin ve Meksikalıların ülkeye göç etmesi kısıtlanmıştır. Bu yasa 1910'larda Doğu ve Güneydoğu Avrupa'dan Amerika'ya gelen yoğun göç dalgası karşısında Nordik 1rkı koruma düşüncesini yansıtmaktadır (Ordover,2003). 1924 tarihli "Immigration Act”" (Göçmen Yasası) ise; yalnız beyazların Birleşik Devletler'e göçüne izin verilmiş; bu da 1920 nüfus sayımının verileri esas alınarak, ülke içindeki ataların toplam nüfus içindeki oranına göre sınırlandırılmıştır.

ABD öjenik amaçlarla zorunlu kısırlaştırma yasalarını çıkaran ve uygulayan ilk ülkedir. Amerikan sterilizasyon programının temel hedefi zihinsel engellilerdi ancak; birçok eyalette sağırlık, körlük, epilepsi, alkolizm, madde bağımlılı̆̆ı da sterilizasyon programının kapsamına dâhil edilmiştir. Bununla birlikte ceza infaz kurumlarındaki tecavüz gibi bazı özel suçlardan mahkûm olmuş kişilerle, suç işlemeyi alışkanlık haline getirmiş kişiler de programa dâhil edilerek kısırlaştırılmıştır (Reilly, 1991).

Indiana, sterilizasyon yasalarının ilk kabul edildiği eyalettir. Aynı yıl Connecticut ve California eyaletleri de benzer yasaları kabul etmiştir. 1911 yılında Nevada, Iowa ve New Jersey eyaletleri de kısırlaştırma yasalarını kabul etmiştir. 1912 yılında ise, Kansas, Michigan, North Dakota ve Oregon eyaletleri kısırlaştırma yasalarını çıkarmıştır (Ordover,2003). 1907 ile 1917 yılları arasında sterilizasyonu yasalaştıran eyalet sayısı on beşe çıkmıştır. 1930'lara gelindiğinde ise; sayı otuzları bulmuştur. Kevles (1986), 1935 yılına gelindiğinde Amerika Birleşik Devletleri'nde 20.000 insanın sterilizasyon yasaları çerçevesinde kısırlaştırıldığını ve bu sayının 10.000 yakınının sadece California'da gerçekleştiğini belirtmektedir. Kısırlaştırma Birleşik Devletler'de eyaletler düzeyinde ele alınmış ve uygulanmıştır. California en çok kısırlaştırmanın gerçekleştirildiği eyalettir. California'da sterilizasyon uygulaması 1963 yılına kadar devam etmiştir. Oregon'da ise kısırlaştırma kanunları 1980'e kadar yürürlükte kalmıştır.

\section{3 İngiltere}

İngiltere öjenik düşüncenin doğduğu ülkedir. İngiltere'de öjenik; içinde doktorların, antropologların, politikacıların, istatistikçilerin, biyologların ve akademisyenlerin bulunduğu eğitimli -profesyonel orta sınıf üyeleri tarafından savunulmuştur. İngiliz öjenik düşüncesi 20 yüzyılın başlarında ortaya çıktığı zaman büyük ölçüde profesyonel orta sınıfın istek ve endişelerini yansıtıyordu. Bu sınıf kentlerdeki yoksul insan sayısının hızla artmakta oluşundan büyük bir endişe duyuyordu. Öjenik düşünceyi savunanlar, ahlaki, toplumsal, ekonomik ve demografik sorunların altında biyolojik faktörlerin olduğuna inanıyordu. Dejenere olarak tanımlanan bu gruplar, diğer bireyler için iktisadi bir yük olarak nitelendiriliyordu. Yoksullar hem genel iktisadi sorunların hem de kendi yoksulluklarının sorumlusu olarak görülüyordu (Mazumdar, 1980:206-209). Eğer bu sınıfların yüksek doğum oranları kontrol altına alınmazsa, yoksulluk, alkolizm, suçlar, cinsel hastalıklar gibi sosyal bozuklukların artacağı ve insanlığın evriminin tersine döneceği savunuluyordu (Alemdaraoğlu, 2006) İngiltere'de öjenik düşünce sanayi devriminin ya da daha geniş bir ifadeyle modernitenin yol açtı̆ğ krizlere ülke entelektüellerin çözüm bulma kaygilarını yansitiyordu.

İngiltere ve Amerika Birleşik Devletleri Anglo-Saxon dünyada iki farklı öjenik siyaset anlayışını yansıtmaktadır. Amerika Birleşik Devletleri’nde öjenik devlet tarafından desteklenmiş ve yasal bir program çerçevesinde uygulanmıştır. Amerika Birleşik Devletleri’nde unfitlerin evliliğini kısıtlama, sterlizasyon ve göç bir devlet meselesi olarak kabul edilip yasalaşırken, İngiltere'de öjeniğe parlamento ve hükümet desteği sınırlı düzeyde kalmıştır. Amerika Birleşik Devletleri'nde 1930'lara değin otuzdan fazla eyalet sterilizasyonu kabul edip, evlenmek isteyen herkesten zihinsel engeli olmadığına, madde bağımlısı olmadığına ve cinsel yolla bulaşan bir hastalık taşımadığına dair sağlık raporu isterken; İngiltere'de evlik kısıtlaması ve sterilizasyon hiçbir zaman yasalaşmamıştır. Amerika Birleşik Devletleri'nin aksine, İngiltere'de öjenik mevzuat oluşmamıştır. Bu konudaki tek ve en önemli düzenleme, 1913 yılında yasalaşan "Mentally Deficient Act”tır. Bu yasa zihinsel engellilerin toplumdan ayrılarak çeşitli devlet kurumlarına kapatılmasına hükmediyordu. Yasa zihinsel hastalıkları açıkça belirtmiş ve bu hastalıkları taşıyanların toplumdan ayrılması konusunda devlet kurumlarına yetki vermiştir (Kevles, 1986).

İngiliz ve Amerika Birleşik Devletleri öjenik siyaseti arasındaki temel fark ırk ve sınıfa yapılan vurgu ile ilgilidir. Amerika Birleşik Devletleri’nin öjenik siyaset anlayışının temelinde “ırk” vardır. Amerika Birleşik Devletleri, kuzey Avrupa'nın beyazları ile çoğalmak istemiştir. Birçok eyalette kabul edilen göçmen kısıtlama yasaları bu amaca hizmet etmiştir. Diğer taraftan, sterilizasyon yasaları da büyük ölçüde unfit olarak nitelenen istenmeyen ırklara yönelmiştir. Öte yandan İngiliz öjenik siyasetinin temel vurgusu “sınıf” üzerine olmuştur. İngiltere'de ırkçı bir göç yasası hiçbir zaman kabul edilmemiştir. İngiliz öjenik uzmanları tüm güçlerini sosyal problem grubu olarak tanımlanan alt sosyal sınıfların kontrolü üzerine harcamıştır (Kevles, 1986) İngiltere'de melezleşmeyi önlemeye yönelik olarak ırkların karışmasını önleyici yasalar kabul edilmemiştir. İngiliz öjenik siyasetinin odak noktası ülke içindeki yabancı ırklar ya da ülkeye göç edecek göçmenler değil; ülke içindeki yerli alt sınıflar olmuştur. İngiltere'de öjenik modern, sanayileşmiş ve kentleşmiş bir ülkede işsizlik, fakirlik, alkolizm, madde bağımlılı̆̆ı, hastalıklar ve suça müptelalıkla anılan alt sınıfların çoğalmasını kontrol altına almak üzerine planlanmıştır (MacKenzie, 1976). 
İngiltere'de gerek sol gerek sağ entelektüellerin öjenik konusuna yoğun ilgisine rağmen, devlet düzeyinde öjenik politikalar dönemin Amerika Birleşik Devletleri, Almanya, İtalya gibi büyük devletleriyle karşılaştırıldığında çok sönük kalmıştır. İngiltere'de evlilik kısıtlaması, doğum kontrol, gönüllü sterilizasyon gibi öjenik uygulamalar yasalaşmamıştır.

İngiltere'de öjeniğin siyaset düzeyinde etkili olamamasının sebebi, negatif öjenik tedbirlere karşı (unfitler için doğum kontrolü, evlilik kısıtlaması, sterlizasyon gibi) büyük kamuoyu desteğinin olmamasıdır. Büyük kamuoyu desteğinin olmaması siyasi karar mercileri üzerinde bu düzenlemelerin hayata geçirilmesi ya da politik karar olarak uygulanması noktasında caydırıcı olmuştur (Macnicol, 1989). İngiltere'deki öjenik siyasetin sınırlı düzeyde kalmasının sebebi Katoliklerin ve işçi sınıfının öjenik aleyhine muhalefetinden kaynaklanmıştır. İki savaş arası dönemde işçi sınıfı ülkede çoğunluktaydı ve bu sınıf öjenik karşıtıydı. İngiliz Öjenik Topluluğu (Eugenics Society) yüksek öjenik mirasla ilişkilendirilen orta ve üst sınıfların çoğalmasını arzuluyordu. Öjenik olarak fit görülen sınıflar üst ve orta sınıflardı. Bu sıralamada işçi sınıfı düşük genetik özelliklerle ilişkilendiriliyordu. İşçi sınıfı öjenikte hedefti. Bu yüzden iş̧̧i sınıfı öjeniğe karşı cephe almış ve öjenik düzenlemelere karşı olmuştur. Bu durum öjeniğin toplumun geniş kesimleri tarafından desteklenmesini imkânsız kılmıştır. Bu durum İngiltere'de doğum kontrol ve sterilizasyon konusunda siyasetçiler üzerinde caydırıcı bir etki meydana getirmiştir. Devlet öjenik düzenlemelere soğuk yaklaşmış ve öjenik siyaset İngiltere'de sınırlı düzeyde kalmıştır (Alemdaroğlu, 2006).

İngiltere'de sterilizasyon tekliflerinin yasalaşmamasında Almanya'da yaşanan olayların da etkisi büyük olmuştur. 1930'larda İngiltere Almanya'daki Nazi rejiminin öjenik siyasetini yakından takip etmiştir. Öte yandan Almanya'da 1933 yılında kabul edilen sterilizasyon yasaları sonucu, sterilizasyon ve ötenazi alanındaki gayri insani ve tüyler ürpertici uygulamalar İngiliz basınında geniş yer bulmuştur. Almanya'da yürütülen sterilizasyon programının içeriği, İngiliz kamuoyunda büyük bir tepkiye neden olmuştur. Özellikle sol muhalefet, dini grupları da yanına alarak gönüllü sterilizasyon kampanyasına karşı bir propaganda faaliyetine başlamıştır. Onlara göre sterilizasyon, evlilik kısıtlaması Nazi uygulamalarıydı. İngiltere bu dönemde Nazi Almanyası'nın uyguladığı politikalar ile anılmak istemedi. Bu da İngiltere'de öjeniğin ivme kaybetmesi anlamına geliyordu.

Sonuç olarak iyi örgütlü işçi sınıfının ve Katolik dini grupların sert muhalefeti ve Nazi Almanyası'ndaki uygulamaların kötü şöhreti İngiltere'de sterilizasyon, doğum kontrolü ve evlilik kısıtlaması alanında yürütülen kampanyaların yasalaşmasını engellemiştir. İngiltere'de düşünce alanındaki zenginlik yasal-politik alana yansımamıştır. Devlet öjenik düzenlemelere mesafeli durmuştur. İngiltere'de 1913 tarihli “Mental Deficiency Act" dışında öjenik mevzuat oluşmamıştır.

\section{Almanya}

İki dünya savaşı arası dönemde öjenik konusunda en dikkat çekici ülke Nazi Almanyası olmuştur. En radikal öjenik politikalar ve pratikler Nazi Almanyası'nda ortaya çıkmıştır. Weimar döneminde devlet nüfus meselesi ile ciddi şekilde ilgilenmiş ve birtakım önlemler almıştır fakat Almanya'da nüfus meselesi ile topyekün olarak ilgilenmek Nasyonel Sosyalizm iktidarı ile başlamıştır. Almanya'nın istikbalini nüfusun nicel ve nitel olarak inkişafında gören III. Reich Hükümeti, total/kapsamlı bir nüfus siyaseti yürütmüştür (Ete, 1941).

Almanya'da Nazi iktidarının konsolidasyonu ile birlikte, resmi söyleme egemen özgün bir 1rksal ütopya öne çıkarılmıştır. Naziler milleti ilkel "volksgeist" ve "kan birliği”ne dayanan bir topluluk olarak görme eğilimindeydi. Nazilerin uzun vadeli hedefi ırksal hâkimiyetti. Aryan efsanesine dayanan Nazi iktidarının amacı, hem Büyük Alman İmparatorluğu'nu yeniden kurmak hem de Slavları üstün bir ırka tabi kılmak ve fiziksel-zihinsel engellilerin ve Çingenelerin ve her şeyden önce de Yahudilerin kökünü kazımaktı. Savaş ve çatışmayı yücelten Nazizm'in düşmanlara ihtiyacı vardı. Bu düşmanların en önemlisi Yabancı milletlerdi. Yabancı milletlerin yeterince yakın ve somut olmadığı durumlarda ise; iç düşmanlar önem kazanıyordu. Irkçılık; Yahudiler ve Çingeneler gibi somut düşmanlara odaklanmıştı. Fakat daha genel bir kategori olarak toplumsal bilinçten yoksun oldukları iddia edilen asosyaller kategorisini de kullanmışlardır. Bu asosyal kategori dilenciler, evsizler, serseriler, zihinsel ve fiziksel engelliler, fahişeler ve cinsel sapıklardı. Bunlar genellikle aşağı bir ırka mensup kişiler değil; ancak yozlaşmaya yol açacak şekilde millet ya da ırkın temellerini zayıflattıkları düşünülen Almanlar'dı (Mosse, 2015).

Nazi ırkçılığı inşa edilirken doğaya/Tanrı iradesine atıf yapılıyordu. Buna göre doğanın yaşama iradesinin tüm biçimleri aynı yasaya tabi idi. Hiçbir hayvan kendi ırkından olmayan bir hayvanla çoğalmazdı. Kurt kurtla, balık balıkla, kartal kartalla çoğalırdı. Doğa yasası üstün bir ırkın aşağı bir ırkla birleşmesine karşı idi. Irkın karışımı Tanrı'nın/doğanın iradesine karşı işlenen bir günahtı. İnsan iradesinin doğayı-Tanrıyı yenebileceği düşüncesi gülünç bir iddiaydı ve Yahudilere özgüydü. Melez ırklar dağa yasası gereği yenilmeye ve tarih sahnesinden çekilmeye mahkûmdu. Nazi ideolojisine göre; Aryanlar Tanrı-doğa yasası uyarınca üstün 1rktı. Dünya üzerinde medeniyet namına ne varsa, Aryanlar tarafından yaratılmıştı. Medeniyet yaratan ve medeniyet yaratma potansiyeline sahip tek ırk Kuzeyin beyaz tenli, sarı saçlı, mavi gözlü Ayranlarıydı. Bu özellikleri doğuştan geliyordu. Bir başka deyişe Tanrı-doğa iradesinin bir sonucu idi. Aryan ırkın saflığını bozan, onun fiziki ve ahlaki çöküşünün tohumlarını atan her ideoloji ve inanç yok edilmeliydi. Bunun başında da Yahudiler ve bir Yahudi doktrini olan Marksizm geliyordu (Fontette, 1991). 
Nazi Almanyası'nda öjenik üstün ırk, saf ırk yetiştirmek amacına yönelmiştir. Bu ülkede öjeniğin ırk içindeki yabancı unsurların soyunu kurutma, yabancılarla evliliği yasaklama, kitle halinde sürgünler, toplama kampları ve seçici cinsel ilişki gibi değişik versiyonları ortaya çıkmıştır. Nazi liderleri, ırklarının üstünlüğünü perçinlemek için hiçbir ahlaki ve insani kuralı tanımadan her çeşit uygulamaya girişmişlerdir. Öjenik Nazi liderleri tarafından Yahudi düşmanlığı ve saf ırk yetiştirme siyasetini haklı çıkarmaya yarayan bir araç olarak kullanılmıştır. Nazi öjenik politikası kitle halinde sürgünler, toplama kampları, seçici cinsel ilişki geniş bir sterelizasyon programı, kapsamlı bir ötenazi programı ile yürütülmüştür. Nazi öjenik politikası soykırımla sonuçlanmıştır. Naziler katliamlarını ırkçılık idealizmini ileri sürülerek haklı göstermeye çalışmışlardır. Nazi liderleri, Alman halkının kafasına Alman ırkının biyolojik olarak üstün olduğu fikrini yerleştirmek için her yola başvurmuşlardır. Sürekli bir propaganda, bedenlerini ve kanlarını her türlü pislikten uzak tutma, erkekçe bir iradenin ve doğurgan bir analığın aracı olarak bedenleri spor yaparak güçlendirmek gerektiği, okul çağından itibaren bütün Almanlara ögütlenmiştir (Erdem, 1976).

Almanya'da 14 Temmuz 1933 yılında kabul edilen “Genetik Yolla Geçen Hastalıkların Önlenmesi” başlıklı yasa ırsi (genetik) hastalık taşıyan kişilerin zorunlu olarak kısırlaştırılmalarını öngörüyordu. Yasaya göre; 1rsi hastalık taşıyan kişiler ayrıntılı bir tıbbi muayeneden sonra kısırlaştırılabiliyordu. Kanunun işaret ettiği irsi hastalıklar şunlard1: akıl hastalığı, şizofreni, cinnet, ırsi sar'a, ileri derece alkol bağımlılığı, anadan doğma körlük ve sağırlık, önemli ve ırsi şekil bozuklukları (Akalın, 1939). Yasa Alman kadınların öjenik nedenler dışında kürtaj olmalarını da yasaklıyordu. Bu yasa kapsamında Nazi iktidarı boyunca yaklaşık üç yüz altmış bin kişinin kısırlaştırıldığ tahmin edilmektedir. Nazi yönetimi sadece ırsi hastalıkları olanların kısırlaştırılmasıyla değil; Almanların ancak Ari biriyle evlenmelerini zorunlu kılmışlardır. Reichtag'ın 1935 Eylül'ünde Nüremberg şehrinde toplanıp kabul ettiği "Alman Kanı ve Onurunun Korunması Yasası", Ari ırktan olan Alman vatandaşlarının Ari olmayan biriyle evliliğini ve evlilik dışı ilişsisini yasaklıyordu. Yasa Alman vatandaşı olmayı Alman kanından olmaya bağlıyor; dinsel inançları önemli bulmuyordu. Yasaya göre; Almanlar yalnız ve yalnız Almanlarla üreme faaliyetinde bulunabileceklerdi (Mazower, 2003).

$\mathrm{Bu}$ yasanın uygulanmasına ilişkin verilen emirler Nazi liderlerinin genetik isteklerini ortaya koyuyordu. Nasyonel Sosyalist Parti evlilik konusu ile ilgili on maddelik bir emirname yayınlamıştır: 1-Alman olduğunu düşün, 2-Sıhhatin yerinde olduğu takdirde evlen, 3-Vücudunu iyi muhafaza et, 4-Fikrini ve ruhunu sağlam tut, 5Alman olduğun için ancak bir Alman veya Aryan irka mensup biriyle evlen, 6-Evleneceğin zaman müstakbel eşinin soyunu-ecdadını araştır, 7-Sağlık aynı zamanda dış güzelliğin de şartıdır, 8- Evleneceğin kişide evlilik ortaklığı ara, 9-Sağlam nesil sağlam temellere dayanan evliliklerle hayat bulur 10-Milletin sürüp gitmesi üç veya dördüncü çocuktan itibaren gerçekleşir (Hakimiyeti Milliye, 26.08.1934).

Nazi rejimi ırk ayrımıyla ilgili Nüremberg yasalarının çıkmasının ardından, tüm evlenmelerde kamu sağlığı bürolarından, çocuklarının genetik olarak sağlıklı doğacağına ilişkin sertifika alınması zorunluluğunu getirdi. Böylelikle "1rkın sağlığına zarar verecek" evlilikler yasaklandı (Weindling, 1989)

Nazi öjenik politikası, 1 Eylül 1939'da tedavisi mümkün olmayan hastalara ötenazi uygulanması için verilen gizli bir emir ile ölüm-imha siyasetine dönüşmüştür. Bu gizli emir doğrultusunda zihinsel ya da bedensel engeli olan kişiler ötenazi programına tabi tutulmuşlardır. Nazi iktidarı, bu programı kamuoyundan gizleyebilmek için, İçişleri Bakanlığı'nda görevli küçük bir birim oluşturmuştur. Bu birim; tedavisi mümkün olmayan şizofreni, epilepsi, cinsel ve her türlü ruhsal rahatsızlı̆̆ı olan hastaların isimlerini hastanelerden ve tedavi merkezlerinden gizlice alarak listeler oluşturmuş; daha sonra da bu hastaları ötenazi merkezlerine götürerek öldürmüştür. Bu işi organize eden birim, Berlin'deki "Tiergarten Caddesi” 4 numaralı adreste konuşlandığı için; bu programa "T-4" adı verilmiştir. 1940 yılı başında bu programa daha da ağırlık verilmiş, program kapsamında seksen bine yakın engelli ve hastanın öldürüldüğ̈̈ tahmin edilmektedir (Proctor, 1988).

Nazi Almanyası'nda 1940’a kadar aşağı ırklara (özellikle Yahudilere) karşı alınan yaptırımlarla toplumsal yaşamın her alanı ayrıntılı şekilde düzenlenmiştir. II. Dünya Savaşı patlak verdiğinde artık toplama kampları aşağı kabul edilen ırkların onurunu kırmaya, onları mümkün olduğu kadar aşağılamaya ve nihayet onları gaz odalarına ya da krematoryumlara (insanların yakıldığı firınlara) göndermeye hizmet etmiştir. Nazi öjenik pratiği dünyanın gördüğü en vahşi ırkçılık metotlarını içermiştir. Aşağı kabul edilen 1rkların önceden tasarlanarak sistemli şekilde imha edilmesi yoluna gidilmiştir (Fontette, 1991).

\section{Fransa}

Fransa'da iki dünya savaşı arası dönemde ekonomik büyüme ve nüfûs artış hızı yavaştı. III. Cumhuriyet yönetiminin en önemli politikası ise nüfûs üzerineydi. Fransa hızla büyüyen Almanya’nın gerisinde kalmıştı. İki dünya savaşı arası dönemde Almanya'nın nüfusu muntazam artarken, Fransa'da nüfusun artış hızının çok düşük oluşu tereddi, uluslararası yarışta bir gerilik olarak gösteriliyordu. 1935 yılında Fritz Neumark, Fransa'nın nüfûs tenakusunun yaklaşık olarak bir asırdan beri devam ettiğini yazıyordu. Neumark'ın verdiği istatistiklere göre; 1800 yılında Fransa'nın 27 milyon, Almanya'nın 25 Milyon, İngiltere'nin 16 milyon nüfûsu vardı. 1870 yılında Fransa 36 milyon, Almanya 41 milyon, İngiltere 32 milyon nüfûsa ulaşmıştı. 1925'de ise, Fransa 42 milyon, Almanya 65 milyon İngiltere 49 milyondu. Fransa, Avrupa'nın bu üç büyük gücü arasında 130 yıl önce en fazla nüfûsu olan 
devlet iken; 1935'de an az nüfûslu devlet haline gelmişti. 1935 y1lında İtalya'nın nüfusu ise 42 milyondu (Neumark, 1941).

1800'lü yılların başından itibaren Fransa'daki doğum oranlarının sürekli olarak düşmesi, ülkenin nüfûs artış hızının Almanya, İtalya, İngiltere gibi dönemin güçlü Avrupa ülkeleriyle kıyaslandığında çok gerilerde kalması, nüfûsun beden ve sağlık yapısına ilişkin verilerin -özellikle askeri muayenelerden elde edilen verilerin- ulusun biyolojik kalitesinin bozulduğuna işaret etmesi Fransa'nın öjenik tartışmalara ve öjenik bir siyaset anlayışına doğrul yol almasının temel sebepleridir. Fransız öjenik siyaseti nüfusun nicelik ve nitelik olarak gerilemesi sorununa çözüm bulmak yönünde gelişmiştir. Ulusun biyolojik ve askeri olarak çökmesi tehlikesine karşı devlet öjenik tedbirlere yönelmiştir (Schneider, 1990).

Doğurganlık oranlarının Avrupa'nın büyük devletlerinden düşük olması Fransa'da pro-natalist politikaları zorunlu kılıyordu. Fransız öjenik siyaseti bu amaçla "doğurganlık" ve "püerikültür" üzerine kurulmuştur. Doğumları artırmak ve doğan bebekleri yaşatmak Fransız öjenik siyasetinin temel hedefini oluşturmuştur. Fransız öjenik siyaseti bir taraftan doğumları artırmaya çalışırken; diğer taraftan doğan ve doğacak çocukların yaşaması için anne ve çocuk sağlı̆̆ için tıbbi yardımda bulunulmasını içermekteydi (Turda-Weindling, 2007).

Fransız öjenik siyaseti Almanya, İngiltere ve Amerika Birleşik Devletleri gibi çağdaşlarından oldukça farklı bir çizgide gelişmiştir (Schneider, 1982). Fransız öjenik siyaseti kısırlaştırma, ayırma, imha gibi negatif tedbirleri benimsemediği gibi, ırkçı bir içeriğe de sahip olmamıştır. Fransa'da öjenik millet sağlığını korumanın bir aracı olarak uygulanmıştır. Bu ülkede öjenik milleti hastalıklara karşı korumak, çocuk ölümlerini engellemek, çocuk bakım bilgisini geliştirmek, ortalama yaşam süresini ve yaşam kalitesini artırmak gibi amaçlara hizmet etmiştir (Turda-Weindling, 2007).

Fransız öjenik siyaseti hastalıkların ve yeteneklerin kan yoluyla geçtiğini savunan "Mendel” çizgisi yerine, kalıtımı geçmişteki ve gelecekteki çevresel koşulları da dikkate alarak açıklayan "Lamarck" çizgisini takip etmiştir. Bu çizgiye uygun olarak Fransa'da öjenik millet sağlığı anlamında kullanılmış ve daha çok pozitif öjenik tedbirler çerçevesinde gelişmiştir. Bu çerçevede kısırlaştırma, ayırma ve ötenazi gibi negatif tedbirler yerine, ulusun bakım, beslenme, barınma şartlarının iyileştirilmesi; salgın hastalıklarla mücadele, alkol ve uyuşturucu madde kalanımı ile mücadele, doğum kontrol yöntemleri ve kürtajla mücadele, çocuk bakım bilgisinin geliştirilmesi, başta alt gelir grupları olmak üzere tüm toplumsal grupların yaşam koşullarının iyileştirilmesi ve özellikle doğum oranlarını artırmak üzerine bir sosyal güvenlik sisteminin kurulması gibi pozitif öjenik önlemlere başvurulmuştur (Schneider, 1990).

\section{Türkiye}

Genç cumhuriyetin modernleşme ve ulus inşa etme sürecinin/projesinin nüfus ve insan bedeni üzerindeki boyutunu oluşturan öjenik konusunda, Cumhuriyet yönetimi aşırılıklara kaçmamıştır. Cumhuriyetin ilk yıllarındaki öjenik uygulamalar etnik bir tabana dayanmamıştır. Türkiye'de o dönemde yaygın olan frengi hastalığı için evlenecek kişilerden istenen sağlık raporu (evlilik muayenesi) dışında; kısırlaştırma, hadımlaştırma, izalasyon, seçilmiş kişiler arası cinsel birliktelik, yabancılarla evliliği yasaklama-engelleme, göç politikaları gibi 1rk1 saflaştırmaya yönelik girişimler olmamıştır (Durgun, 2014).

Yeni kurulan Türkiye Cumhuriyeti’nin en önemli politikası, nüfus politikası olmuştur. Bunun nedeni ülke nüfusunun durumuydu. Ülke nüfûsu on yılı aşkın savaşlar sonucu kırılmıştı. Görkemli bir devir başarısız savaşlar, kaybedilmiş topraklar ve imparatorluğun çöküşüyle kapanmıştı. Türkiye nüfûsu Osmanlı Devleti'nin son zamanlarından itibaren vatanın müdafaası uğrunda yapılan savaşlarla eriyip gitmişti Türkiye tarihinin yakın dönemi bu durumu özetlemektedir. Arapların, Arnavutların, Bulgarların, Yunanların, Ermenilerin isyanı, Balkan Savaşları, Trablusgarp Savaşı, I. Dünya Savaşı ve İstiklal Savaşı neticesinde koca imparatorluktan geriye yaklaşık 11-12 milyonluk bir nüfus kalmıştı. Ülke bedenen ve dimağen en güçlü unsurlarını bu savaşlarda kaybetmiştir (Akalın, 1939:11). Savaş ülkenin en güzide evlatlarını aldığı gibi, geride kalanlar da açlık, sefalet ve salgın hastalıkların pençesindeydi. Bu açıdan pro-natalist politikalar kaçınılmazdı. Bu amaçla cumhuriyetin ilk yıllarında evlenme ve doğum teşvik edilmiştir (Toprak, 2012).

Cumhuriyetin ilk yıllarında Türkiye nüfûsu çoğu batı ülkesinin nüfusu ile karşılaştırıldığında, ülkenin hemen hemen boş olduğunu görülüyordu. 1925 Nüfûs Sayımı'na göre; Türkiye'de kilometreye 18 kişi düşüyordu. Bu dönemde Türkiye yüzölçümünün 1/6 sı kadar olan Bulgaristan'da kilometre başına 58 kişi, yine Türkiye yüzölçümünün 1/6's1 kadar olan Yunanistan'da kilometreye 49 kişi, Türkiye yüzölçümünün 1/4'ü kadar olan Romanya'da kilometreye 62 kişi, Türkiye yüz ölümünün 1/3'ü kadar yüzölçümü olan Polonya' da kilometre başına 86 kişi isabet ediyordu (Nuri, 1941).

1935 y1lında Fransa 42 milyon, Almanya 65 milyon, İngiltere 49 milyon, İtalya 42 milyon nüfusa sahipti. 1935 sayımına göre Türkiye'nin nüfusu 16 milyondu (Neumark, 1941). Bunun için cumhuriyetin en önemli politikalarından biri sağlık politikası olmuş ve halk sağlı̆̆ına büyük önem verilmiştir. Nitekim bu politikalarla salgın hastalıkların önü büyük ölçüde kesilmiştir. Anadolu'da bebek ve çocuk ölümlerinin oranı görece düşürülmüş ve yaşam umudu yükselmiştir. Cumhuriyet idaresi bir taraftan doğumları teşvik ve doğumları kolaylaştırmak için birçok teşkilat ve organizasyon yaparken, diğer taraftan insanlarımızın uzun ve sağlıklı yaşamaları için de gereken 
tedbirleri almıştır. Cumhuriyet idaresi altında öncelikli olarak ülkenin her köşesinde kol gezen sıtma, frengi verem gibi hastalıklarla ciddi surette mücadele edilmiş, çocuk ölümlerinin önüne geçmek için büyük gayretler gösterilmiştir. Bu meyanda bulaşıcı hastalıklara karşı mücadele, aşılama, korunma tedbirleri sayesinde ortalama ömür uzatılmaya ve vatandaşların genel sağlık durumlarının iyileştirilmesine çalışılmıştır. Halkın genel sağlık durumunu düzeltici önlemler alınmış; beslenme, barınma ve hijyen konularında halk bilimin ve fennin 1şı̆̆ında bilgilendirilmiştir (Toprak, 2012).

Ulusun istikbali gelecek nesillerde görüldüğü için devlet "püerikültür” konusuna çok büyük önem vermiştir. Cumhuriyet yönetimi çocuk bakım bilgisini geliştirmek ve çocuk ölümlerinin önüne geçmek için büyük gayret göstermiştir. Bu meyanda kızıl, kızamık, boğmaca suçiçeği gibi bulaşıcı hastalıklara karşı aşı, serum ve diğer koruma usulleri yaygınlaştırılmıştır. Çocuğun gelişiminin sadece aileler tarafindan değil; devlet tarafindan da takip edilmesi için ülke genelinde iyi örgütlenmiş bir sağlık teşkilatının olmasına; çocuklara yönelik çocuk hastanelerinin, sağlık ocaklarının, çocuk dispanserlerinin, doğum ve çocuk bakım evlerinin, süt ve mektep çocukları bakım evlerinin, çocuk senatoryumlarının, çocuk kurtarma ve koruma yurtlarının, kreşlerin, görme, işitme ve konuşma yetisini kaybetmiş çocuklar için bakım ve eğitim kurumları gibi birçok kurumun ülke genelinde yayılmasına gayret edilmiştir. Bu kurumların ilk görevi çocukları hastalıklara karşı korumaktı. Dönemin sağlık politikası anlayışına göre; korumak tedavi etmekten önemliydi. Çocuğu hasta etmemek öncelikliydi, tedavi sonra geliyordu.

"Umumi Hıfzıssıhha Kanunu”nun 152. maddesi ile gebeliğe engel olacak ya da çocuk düşürmeye yarayacak her türlü araç ve gerecin ithali, dağıtımı ve satışı yasaklanmıştır. Buna paralel olarak, 1926 tarihli "Türk Ceza Kanunu"nda kürtaj ve çocuk yapmaya engel olacak diğer uygulamalar ağır ceza kapsamına alınmıştır. Türk Ceza Kanunu'nda kürtaja ilişkin maddeleri içeren kısmın başlığı eski yasada "Kasten Çocuk Düşürmek ve Düşürtmek Cürümleri” iken, 1936’da bu kısmın başlığı “Irkın Tümlüğü ve Sağlığ1 Aleyhine Cürümler” olarak değiştirilmiştir.

Türkiye Cumhuriyeti'nde öjenik bağlamında düşünülmüş bir diğer tedbir ise beden terbiyesi ve spordur. Cumhuriyetin ilk yıllarından itibaren devlet, beden eğitimi ve sporu bir program çerçevesinde ele almış ve beden eğitimi ve spor sadece okullarla sınırlı kalmayıp, gündelik yaşam pratiklerinin arasına da girmeye başlamıştır. Beden eğitimi ve spor alanında 1920'li yıllarda eğitimcilerin yetiştirilmesi için gerekli adımlar atılırken, 1930'lu yıllarda ise yapılan yasal düzenlemelerle her bir birey spor yükümlülüğü altına alınmaya çalışılmıştır. "Beden eğitimi mükellefiyeti”, genç Cumhuriyetin beden terbiyesi ve spor politikasının örgün öğretim kurumlarının ötesinde; geniş halk kitlelerini de hedeflediğinin an açık göstergesidir.

1930'ların ortasında ise tüm vatandaşlar için beden terbiyesi mükellefiyetinin getirilmiştir. Cumhuriyet Halk Partisi'nin 9 Mayıs 1935'te yapılan dördüncü kurultayınca onaylanan programının 50. maddesi okullarda, devlet kurumlarında, özel kurum ve fabrikalarda bulunanların, yaşlarına göre, beden eğitimi ile uğraşmak yükümü altına alınacağını belirtir. Böylelikle okullarda, devlet kurumlarında ve özel kurum ve fabrikalarda bulunanlar, yaşlarına göre, beden eğitimi ile uğraşmak yükümlülüğü altına alınmıştır.

Beden terbiyesi ve sporun zorunlu bir devlet politikası haline gelmesi, TBMM'nin 1938 yılında kabul ettiği “3530 sayılı Beden Terbiyesi Kanunu” ile gerçekleşmiştir. Kanun, ihtiyaç duyulan herkesin milli savunma ve sağlık için "beden terbiyesi mükellefiyeti”ni zorunlu kılmaktaydı (Akın, 2004).

Devlet beden terbiyesi ve spor politikası ile yavuz ve gürbüz bir nesil yetiştirmeyi, uysal, sağlıklı ve üretken bedenler üretmeyi, ulusu savaşa ve milli müdafaaya hazırlamayı, ulusun genel sağlık durumunu iyileştirmeyi, zararlı alışkanlıklar ile mücadele yoluyla iktisadi verimliliği sağlamayı amaçlıyordu. Bedenin terbiye edilmesi, zihnin disipline sokulması ve gençliğin karakterinin milli müdafaa ve iktisadi kalkınma hedefleri doğrultusunda yeniden şekillendirilmesi devletin taşıdığı temel kaygılardı.

Bu gayretlerin olumlu sonuçları 1927 ve 1935 yıllarında yapılan nüfus sayımları ile ortaya çıkmış nüfus kısa zamanda hızla çoğalmaya başlamış ve bundan sonra da hızla çoğalacağının sinyallerini vermiştir.

\section{Sonuç}

19. ve 20. yüzyıllar modern ulus devletler için kendi ulusunu inşa etme süreci olarak geçmiştir. İki dünya savaş1 arası dönemde bu süreç doruk noktasına ulaşmıştır. Ulus devletler bu süreçte kendi ulusunu yaratabilmek için bütün araçları farklı formlarda kullanmışlardır. Öjenik politikalar iki dünya savaşı arası dönemde, ulus inşa sürecinin önemli bir aracı olarak ortaya çıkmıştır. Modern ulus devletler; bu amaca ulaşmak için evlilik kanunlarından, mali mevzuata, koruyucu sağlık hizmetlerinden kısırlaştırmaya, püerikültürden beden terbiyesine, kitle iletişim araçlarına ilişkin düzenlemelerden göç politikalarına kadar uzanan bir dizi araçtan faydalanmıştır.

$\mathrm{Bu}$ süreçte her ülkenin öjenik pratiği kendi yerel ve bölgesel koşulları başta olmak üzere; ülkenin amaçları, kaygıları, nüfûsunun durumu, kaynakları, jeopolitik konumu gibi pek çok faktörün etkisiyle şekillenmiştir. Türkiye'nin söz konusu dönemdeki öjenik pratiğini, başta nüfûsun durumu olmak üzere; cumhuriyetin hedefleri, kaygıları sosyal, siyasal, ekonomik ve askeri önceliklerine göre şekillenmiştir. Türkiye Cumhuriyeti belli bir ülkeyi taklit etmekten çok, kendi iç ve dış dinamiklerine göre bir öjenik siyasası takip etmiştir. Türkiye'deki öjenik uygulamalar daha çok pozitif tedbirler biçiminde gelişmiş ve Türkiye'de öjeniğin ırkçı-etnik bir içeriği olmamıştır. 
Türkiye'nin iki dünya savaşı arası öjenik pratiğini büyük ölçüde askeri ve ekonomik kaygılar şekillendirmiştir. Yeni kurulan Cumhuriyetin büyük ve dağınık sınırlarını korumak, vatanı müdafaa etmek, ülke içindeki kaynakları layıkıyla işlemek için sayı ve kalite olarak yeterli bir nüfusa ihtiyacı olmuştur.

İki dünya savaşı arası dönemde, Cumhuriyet'in öjenik politikaları ile dışarıya dönük verilmek istenen mesaj, o dönem Batı bilim dünyasında Türk Milleti ile ilgili önyargılardan kaynaklanıyordu. Bu dönem Batı bilim dünyasında Türkler uygarlık-kültür dünyasına katkısı olmayan barbar bir millet olarak değerlendiriliyordu. Siyasiaskeri davasını İstiklal Savaşı ile kazanıp bunu Lozan ile taçlandıran Türkiye, kültür-uygarlık davasında hak ettiği yeri ise; temelini "antropoloji” ve "arkeoloji” çalışmalarının oluşturduğu "Türk Tarih Tezi” ve "Türk Dil Tezi" (Güneş-Dil Teorisi) ile elde etmeye çalışacaktı. Öjenik politikalar ise söz konusu dönemde bu tezlerle uyumlu ve bu çalışmaların tamamlayıcısı olarak gündeme gelecekti. Cumhuriyetin öjenik siyasası, Türk milletinin beden ve dimağ açısından mütekâmil bir millet olduğunu Batı dünyasına göstermeyi amaçlıyordu. Cumhuriyet'in "yavuz ve gürbüz bir nesil yetiştirme projesi” bu hedefe yönelikti. Cumhuriyetle birlikte kurumsallaşan, çocuk bayramı, gençlik ve spor bayramı, güzellik yarışmaları ve spor müsabakaları bu kâmil neslin tüm dünyaya sergilendiği törenler olarak işlev görüyordu.

\section{Kaynakça}

- Akalın, 1938. Türk Çocuğunu Nasıl Yaşatmalı: Nüfus Siyasetinde Çocuk, İstanbul, Ahmet İhsan Basımevi.

- Akın, 2004. Gürbüz ve Yavuz Evlatlar: Erken Cumhuriyet’te Beden Terbiyesi ve Spor, İstanbul, İletişim Yayınevi.

- Alemdaroğlu, 2006. "Eugenics, Modernity and Nationalism”, Social Histories of Disability and Deformity, Ed. DavidTurner and Kevin Stagg, London,-New York, Routledge.

- Durgun, 2014. Ulus İnşâsı ve Milliyetçilik, Ankara, Binyıl Yayınevi.

- $\quad$ Erdem, 1976. Suçlamalar 2, Ankara: Töre-Devlet Yayınevi.

- Ete, 1941, “Devletlerin Yeni Nüfus Siyasetleri”, Nüfus Meselesi ve Nüfus Sayımı Hakkında Fikirler, Ankara, Başvekalet İstatistik Umum Müdürlüğü, s.102-113.

- Fontette, 1991. Irkçılık, Çev. Haldun Karyol, İstanbul, İletişim Yayınevi.

- Hakimiyeti Milliye, 26.08.1934

- Kevles, 1986. In The Name of Eugenics: Genetics and the Uses of Human Herdeity, Berkeley and Los Angeles, University of California Press.

- Kühl, 2002. The Nazi Connection: Eugenics, American Racism, and German National Socialism, Oxford University Press.

- Lombardo, 1988. "Miscegenation, Eugenics, and Racism: Historical Footnotes to Loving v. Virginia”, Davis Law Review, 21:2, p.421-452.

- MacKenzie, 1976. “Eugenics in Britain”, Social Studies of Science, 3/4, p.499-532.

- Macnicol, 1989. "Eugenics and the Campaign for Voluntary Sterilization in Britain Between the Wars". Soc Hist Med, 2 (2), p.147-169.

- Mazower, 2003. Karanlık Kıta, Çev. Mehmet Moralı, İstanbul Bilgi Üniversitesi Yayınları.

- Mazumdar, 1980. "The Eugenists and the Residuum: The Problem of the Urban Poor", Bulletin of the History of Medicine, 54, p.204-215.

- Mosse, 2015, "Genel Bir Faşizm Teorisine Doğru”, Karşılaştırmalı Faşizm Çalışmaları, Der. Constantin Iordachı, Çev: İsmail Ilgar, İstanbul, İletişim Yayınevi, p.105-160.

- Neumark, 1941. "Zamanımızın Nüfus Meselesi”, Nüfus Meselesi ve Nüfus Sayımı Hakkında Fikirler, Ankara, Başvekalet İstatistik Umum Müdürlüğü, s.174-190.

- Nuri, 1941. “Türkiye’de Nüfus Meselesi Ulusal Bir Davadır”, Nüfus Meselesi ve Nüfus Sayımı Hakkında Fikirler, Ankara, Başvekalet İstatistik Umum Müdürlüğü, s.191-194.

- Ordover, 2003. American Eugenics: Race, Queer Anatomy, And The Science Of Nationalism. University Of Minnesota Press.

- Proctor, 1988. Racial Hygiene: Medicine Under the Nazis. Harvard University Press.

- Reilly, 1991. The Surgical Solution: A History Of İnvoluntary Sterilization in The United States. Johns Hopkins University Press.

- Schineider, 1990, "The Eugenics Movement in France 1890-1914”, The Wellborn Science Eugenics in Germany, France, Brazil and Russia, Ed. Mark B. Adams, New York, Oxford University Press.

- Spiro, 2009. Defending the Master Race: Conservation, Eugenics, and the Legacy of Madison Grant, University of Vermont Press. 
- Toprak, 2012. Darwin'den Dersim'e Cumhuriyet ve Antropoloji, İstanbul, Doğan Kitap.

- Weindling, 1989. Health, Race, and German Politics between National Unification and Nazism 1870-1945, Cambridge University Press.

- 3530 Sayılı Beden Terbiyesi Kanunu, 1938, https://www.tbmm.gov.tr/tutanaklar/KANUNLAR_KARARLAR/kanuntbmmc018/kanuntbmmc018/kanunt bmmc01803530.pdf

- 1593 Sayılı Umumi Hifzıssihha Kanunu, 1930, http://www.mevzuat.gov.tr/MevzuatMetin/1.3.1593.pdf

- 765 Sayılı Türk Ceza Kanunu, 1926, http://www.ceza-bb.adalet.gov.tr/mevzuat/765.htm 


\title{
Bakü-Tiflis-Kars Demiryolunun Türkiye ile Türk Cumhuriyetleri Arasındaki Uluslararası Ticarete Katkısı \\ The Contribution of Baku-Tbilisi-Kars Railway to International Trade between Turkey and Turkish Republics
}

\author{
Asst. Prof. Dr. Hakan Emanet (Beykent University, Turkey)
}

\begin{abstract}
This study examines the potential contribution of the Baku-Tbilisi-Kars (BTK) railway, which is planned to be in service in 2017, to the commercial relationship between Turkey and five Turkish republics (Azerbaijan, Kazakhstan, Uzbekistan, Kyrgyzstan and Turkmenistan). First, the general structure of the last five years of foreign trade between Turkey and these states will be revealed. In the second stage, transport routes which are used extensively in the physical transport of goods in the current trade, and the benefits and drawbacks of these routes will be mentioned. In the third stage, the characteristics of the BTK railway will be specified as a new route option. In the last part, the future contribution of the BTK railway to the trade between Turkey and these states will be evaluated.
\end{abstract}

\section{Giriş}

Sovyetler Birliği’nin 1991 yılında dağılmasından hemen sonra bağımsızlıklarını ilan eden Türk Devletleri ile Türkiye Cumhuriyeti arasındaki ekonomik ilişkiler aradan geçen çeyrek asırda arzu edilen seviyeye ulaşamamıştır. Ticari ilişkilerin istenilen seviyeye ulaşılamamış olmasının birçok nedeni vardır. Bunlardan bir tanesi de, Türkiye ile bu devletler arasındaki coğrafi uzaklık ile taşımacılık güzergah seçeneklerinin kısıtlı ve sorunlu olmasıdır.

Öncelikle belirtmek gerekir ki; taşıma maliyeti açısından en uygun olan taşımacılık türü (boru hattı taşımacıllığı kısıtları nedeniyle bir kenara bırakılacak olursa) deniz taşımacılığıdır. Orta Asya Türk Cumhuriyetleri’nin açık denizlere kıyısı yoktur. Dolayısı ile bu ülkeler deniz taşımacılığının maliyet avantajından faydalanamamaktadır. Bu ülkeler için geriye demiryolu, karayolu ve havayolu taşımacılık seçenekleri kalmaktadır. Havayolu taşımacılığı maliyet açısından en pahalı taşımacılık türü olduğundan doğal olarak fazla tercih edilmemektedir. Bu ülkelerin diğer devletler ile aralarında demiryolu bağlantısı olmakla birlikte Türkiye ile doğrudan bir demiryolu bağlantısı yoktur ve Türkiye ile ticaret ağılıklı olarak karayolu taşımacılığına dayanmaktadır. Karayolu taşımacılığ maliyeti yüksek hem de kısıtları fazla bir taşımacılık türüdür. Bu bağlamda, Bakü-Tiflis-Kars (BTK) demiryolu faaliyete geçtiğinde karayolu taşımacılığının bir seçeneği olacaktır.

\section{Türkiye ile Orta Asya Türk Cumhuriyetleri Arasındaki Ticaretin Yapısı}

Orta Asya Türk Cumhuriyetlerinin 2016 yılında yaptıkları toplam ihracat 54 milyar doların biraz üzerinde gerçekleşmiştir. Bu ülkelerin Türkiye'ye yaptıkları ihracat ise 2,6 milyar \$ olarak toplam ihracatlarının içerisinde sadece yüzde 4,8 seviyesinde gerçekleşmiş̧ir. 54 milyar dolarlık toplam ihracatın yarısı Kazakistan tarafından yapılmış kalan yarısı ise diğer dört ülke tarafından gerçekleştirilmiştir (Tablo 1). Bu beş ülke aynı zamanda geçiş ekonomilerindendir (Pashalieva ve Kahriman, 2016). Diğer yandan, doğal kaynaklar açısından bakıldığında bu ülkelerden Azerbaycan, Türkmenistan ve Kazakistan zengin, Özbekistan orta, Kırgızistan ise fakir ülke sınıfina girmektedir (Bal, 2011). Ülkelerin ihracatları da buna paralellik göstermektedir ki; Kırgızistan'ın ihracatı 1 milyar doların da altındadır (Tablo 1).

\begin{tabular}{|c|c|c|c|c|c|c|}
\hline Ülkeler & $\begin{array}{l}\text { Ülke } \\
\text { Toplam } \\
\text { İhracat } \\
\text { (milyon \$) }\end{array}$ & $\begin{array}{l}\text { Türkiye'ye } \\
\text { Yapilan } \\
\text { İhracat } \\
\text { (milyon \$) }\end{array}$ & $\begin{array}{l}\text { Türkiye'ye } \\
\text { Yapılan İhracatın } \\
\text { Toplamdaki Payı } \\
(\%)\end{array}$ & $\begin{array}{l}\text { Ülke Toplam } \\
\text { İthalat } \\
\text { (milyon \$) }\end{array}$ & $\begin{array}{l}\text { Türkiye'den } \\
\text { Yapilan Itthalat } \\
\text { (milyon \$) }\end{array}$ & $\begin{array}{l}\text { Türkiye'den } \\
\text { Yapılan } \\
\text { İthalatın } \\
\text { Toplamdaki } \\
\text { Payı (\%) }\end{array}$ \\
\hline Azerbaycan & 11.952 & 278 & 2,3 & 6.632 & 1.286 & 19,4 \\
\hline Türkmenistan & 7.353 & 422 & 5,7 & 4.571 & 1.242 & 27,2 \\
\hline Kazakistan & 27.205 & 1.094 & 4,0 & 27.031 & 624 & 2,3 \\
\hline Özbekistan & 6.923 & 709 & 10.2 & 9.094 & 533 & 5,9 \\
\hline Kırgızistan & 706 & 101 & 14,3 & 7.839 & 309 & 3,9 \\
\hline Toplam & 54.139 & 2.604 & 4,8 & 55.167 & 3.994 & 7,2 \\
\hline
\end{tabular}

Tablo 1: Türkiye ile Orta Asya Türk Cumhuriyetleri Arasındaki Dış Ticaret (2016) Kaynak: International Trade Centre, 2017. 
Orta Asya Türk Cumhuriyetlerinin 2016 yılında toplam ithalatı 55 milyar doların biraz üzerinde ve Türkiye'den toplam ithalatları ise 4 milyar dolar seviyesine yakın gerçekleşmiştir. Bu tutar, oransal olarak yüzde 7,2'ye denk gelmektedir (Tablo 1). Ülke bazında incelendiğinde şöyle bir sonuç çıkmaktadır: Kazakistan'ın ihracat ve ithalatı dengededir, Azerbaycan ve Türkmenistan'ın ihracatı fazla verirken Özbekistan'ın ithalatı fazla vermektedir. Kırgızistan'ın ise ithalatı ihracatının on bir katı seviyesinde gerçekleşerek diğerlerinden ayrışmaktadır (Tablo 1).

Türkiye tarafından bakıldığında; 2016 yılında bu ülkelerden yapılan 2,6 milyar \$'lık ithalat, Türkiye'nin toplam ithalatının ancak yüzde 1,3'üne denk gelmektedir ve oransal olarak son beş yıl hemen hemen aynı seviyededir. Türkiye'den bu ülkelere 2016 yılında yapılan 4 milyar dolarlık ihracatın, Türkiye'nin toplam ihracatı içindeki payı ise yüzde 2,8'dir. Bu tutar ve oran son beş y1l içindeki en düşük tutar ve orandır (Tablo 2).

\begin{tabular}{|c|c|c|c|c|c|c|c|c|c|}
\hline \multirow{2}{*}{\multicolumn{2}{|c|}{ Yillar }} & \multicolumn{2}{|c|}{2012} & \multicolumn{2}{|c|}{2013} & \multicolumn{2}{|c|}{2014} & \multicolumn{2}{|c|}{2015} \\
\hline & & Bin \$ & tp(\%) & Bin \$ & tp(\%) & Bin $\$$ & tp(\%) & Bin \$ & $\operatorname{tp}(\%)$ \\
\hline \multicolumn{2}{|c|}{$\begin{array}{l}\text { Türkiye'nin Toplam } \\
\text { İhracatı }\end{array}$} & 152.536 & 100 & 151.802 & 100 & 157.715 & 100 & 143.935 & 100 \\
\hline \multicolumn{2}{|c|}{$\begin{array}{l}\text { Türkiye'nin Toplam } \\
\text { Ithalat1 }\end{array}$} & 236.544 & 100 & 251.661 & 100 & 242.224 & 100 & 207.203 & 100 \\
\hline \multicolumn{2}{|c|}{$\begin{array}{l}\text { Türkiye Toplam Dış } \\
\text { Ticaret Hacmi }\end{array}$} & 389.080 & 100 & 403.463 & 100 & 399.939 & 100 & 351.138 & 100 \\
\hline \multirow[t]{4}{*}{ Azerbaycan } & $\mathrm{a}$ & 2.587 & 1,7 & 2.960 & 1,9 & 2.876 & 1,8 & 1.900 & 1,3 \\
\hline & $\mathrm{b}$ & 340 & 0,1 & 334 & 0,1 & 291 & 0,1 & 232 & 0,1 \\
\hline & $\mathrm{c}$ & 2.247 & & 2.626 & & 2.585 & & 1.668 & \\
\hline & $\mathrm{d}$ & 2.927 & 0,8 & 3.294 & 0,8 & 3.167 & 0,8 & 2.132 & 0,6 \\
\hline \multirow[t]{4}{*}{ Türkmenistan } & $\mathrm{a}$ & 1.480 & 1,0 & 1.957 & 1,3 & 2.232 & 1,4 & 1.859 & 1,3 \\
\hline & $\mathrm{b}$ & 303 & 0,1 & 654 & 0,3 & 624 & 0,3 & 557 & 0,3 \\
\hline & $\mathrm{c}$ & 1.177 & & 1.303 & & 1.608 & & 1.302 & \\
\hline & $\mathrm{d}$ & 1.783 & 0,5 & 2.611 & 0,6 & 2.856 & 0,7 & 2.416 & 0,7 \\
\hline \multirow[t]{4}{*}{ Kazakistan } & $\mathrm{a}$ & 1.069 & 0,7 & 1.039 & 0,7 & 978 & 0,6 & 750 & 0,5 \\
\hline & $\mathrm{b}$ & 2.056 & 0,9 & 1.760 & 0,7 & 1.236 & 0,5 & 1.110 & 0,5 \\
\hline & $\mathrm{c}$ & -987 & & -721 & & -258 & & -360 & \\
\hline & $\mathrm{d}$ & 3.125 & 0,8 & 2.799 & 0,7 & 2.214 & 0,6 & 1.860 & 0,5 \\
\hline \multirow[t]{4}{*}{ Özbekistan } & $\mathrm{a}$ & 450 & 0,3 & 562 & 0,4 & 603 & 0,4 & 489 & 0,3 \\
\hline & $\mathrm{b}$ & 813 & 0,3 & 815 & 0,3 & 781 & 0,3 & 711 & 0,3 \\
\hline & $\mathrm{c}$ & -363 & & -253 & & -178 & & -222 & \\
\hline & $\mathrm{d}$ & 1.263 & 0,3 & 1.377 & 0,3 & 1.384 & 0,3 & 1.200 & 0,3 \\
\hline \multirow[t]{4}{*}{ Kırgizistan } & $\mathrm{a}$ & 257 & 0,2 & 388 & 0,3 & 422 & 0,3 & 295 & 0,2 \\
\hline & $\mathrm{b}$ & 45 & 0,0 & 37 & 0,0 & 66 & 0,0 & 77 & 0,0 \\
\hline & $\mathrm{c}$ & 212 & & 351 & & 356 & & 218 & \\
\hline & $\mathrm{d}$ & 302 & 0,1 & 425 & 0,1 & 488 & 0,1 & 372 & 0,1 \\
\hline \multirow{4}{*}{$\begin{array}{l}\text { Türk } \\
\text { Cumhuriyetleri } \\
\text { Toplamı }\end{array}$} & $\mathrm{a}$ & 5.843 & 3,8 & 6.906 & 4,5 & 7.111 & 4,5 & 5.293 & 3,7 \\
\hline & $\mathrm{b}$ & 3.557 & 1,5 & 3.600 & 1,4 & 2.998 & 1,2 & 2.687 & 1,3 \\
\hline & $\mathrm{c}$ & 2.286 & & 3.306 & & 4.113 & & 2.606 & \\
\hline & $\mathrm{d}$ & 9.400 & 2,4 & 10.506 & 2,6 & 10.109 & 2,5 & 7.980 & 2,3 \\
\hline \multicolumn{10}{|c|}{ a: Türkiye'nin İhracatı } \\
\hline \multicolumn{10}{|c|}{ b: Türkiye'nin İthalatı } \\
\hline \multicolumn{10}{|c|}{ c: Türkiye açısından dış ticaret dengesi } \\
\hline \multicolumn{10}{|c|}{ d: Türkiye ile toplam dış ticaret hacmi } \\
\hline tp: Türkiye'ni & & hracat/ithal & . & leki pay1 & & & & & \\
\hline
\end{tabular}

Tablo 2: Türkiye ile Orta Asya Türk Cumhuriyetleri Arasındaki Dış Ticaret (2016) Kaynak: Türkiye İstatistik Kurumu, 2017.

Türkiye'nin ihracatı içinde en fazla paya sahip 10 fasıl ürün Tablo 3 'te verilmiştir. Tablo 3'de 3. ve 5. sırada yer alan ürün grupları haricindeki ürün gruplarının tamamına yakını yükte ağır pahada hafif olan ürünler olduğundan karayolu ve demiryolu taşımacılığına uygun ürünlerdir. Halihazırda Türkiye ile Orta Asya Türk Cumhuriyetleri arasında demiryolu bağlantısı olmadığından, bu ürünler Orta Asya'ya karayolu ile taşınmaktadır. Oysa bu ürünlerin demiryolu ile taşınması durumunda önemli ölçüde maliyet avantajı sağlanacaktır ve bunun sonucu olarak Türkiye'den Orta Asya Türk Cumhuriyetleri'ne ihraç edilen ürünlerin oranı artacaktır. 


\begin{tabular}{|c|c|c|c|c|c|c|c|c|c|}
\hline 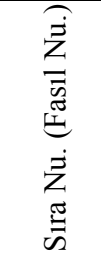 & Fasil & 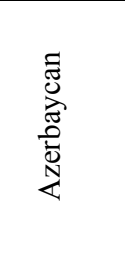 & 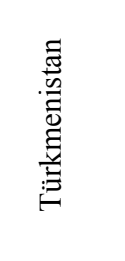 & 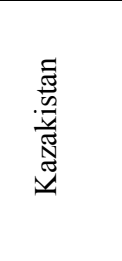 & 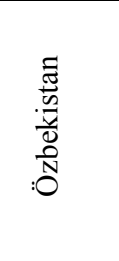 & 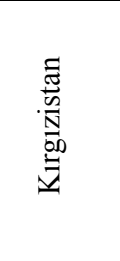 & 离营 & 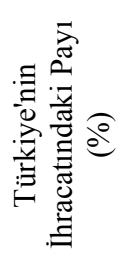 & 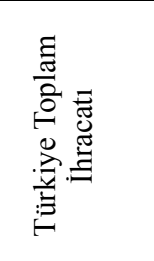 \\
\hline 1.(87) & $\begin{array}{l}\text { Motorlu kara taşıtları, } \\
\text { traktörler, bisikletler, } \\
\text { motosikletler ve diğer } \\
\text { kara taşıtları, bunların } \\
\text { aksam, parça, aksesuarı }\end{array}$ & 29.310 & 32.207 & 24.659 & 19.202 & 6.502 & 111.880 & 0,56 & 19.803 .630 \\
\hline 2. (84) & $\begin{array}{l}\text { Kazanlar, makinalar, } \\
\text { mekanik cihazlar ve } \\
\text { aletler, nükleer } \\
\text { reaktörler, bunların } \\
\text { aksam ve parçaları }\end{array}$ & 140.277 & 130.652 & 93.182 & 132.159 & 18.437 & 514.707 & 4,17 & 12.341 .436 \\
\hline 3. (71) & $\begin{array}{l}\text { Kıymetli veya yarı } \\
\text { kıymetli taşlar, kıymetli } \\
\text { metaller, inciler, taklit } \\
\text { mücevherci eşyası, metal } \\
\text { paralar }\end{array}$ & 4.288 & 2.951 & 28.019 & 20 & 32.482 & 67.760 & 0,56 & 12.176 .572 \\
\hline 4. $(61)$ & $\begin{array}{l}\text { Örme giyim eşyası ve } \\
\text { aksesuarı }\end{array}$ & 44.453 & 14.847 & 47.638 & 3.764 & 76.045 & 186,747 & 2,11 & 8.851 .607 \\
\hline 5. $(85)$ & $\begin{array}{l}\text { Elektrikli makina ve } \\
\text { cihazlar, ses kaydetme- } \\
\text { verme, televizyon } \\
\text { görüntü-ses kaydetme- } \\
\text { verme cihazları, aksam- } \\
\text { parça-aksesuarı }\end{array}$ & 101.585 & 205.245 & 61.575 & 32.834 & 10.653 & 411.892 & 5,26 & 7.831 .881 \\
\hline 6. (72) & Demir ve çelik & 22.897 & 45.411 & 1.967 & 1.804 & 63 & 72.142 & 1,17 & 6.181 .905 \\
\hline 7. (62) & $\begin{array}{l}\text { Örülmemiş giyim eşyası } \\
\text { ve aksesuarı }\end{array}$ & 31.217 & 13.115 & 42.907 & 1.591 & 29.407 & 118.237 & 2,00 & 5.926 .609 \\
\hline 8. (39) & Plastikler ve mamulleri & 109.273 & 75.849 & 29.088 & 57.022 & 11.667 & 282.899 & 5,63 & 5.026 .936 \\
\hline 9. (73) & $\begin{array}{l}\text { Demir veya çelikten } \\
\text { eşya }\end{array}$ & 74.604 & 245.691 & 37.049 & 21.705 & 2.224 & 381.273 & 7,68 & 4.966 .021 \\
\hline 10. (8) & $\begin{array}{l}\text { Yenilen meyveler ve sert } \\
\text { kabuklu meyveler }\end{array}$ & 13.426 & 7.943 & 12.075 & 1.719 & 728 & 35.891 & 0,93 & 3.873 .122 \\
\hline & Toplam & 571.328 & 773.910 & 378.163 & 271.820 & 188.208 & 2.183 .428 & 2,51 & 86.979 .719 \\
\hline
\end{tabular}

Tablo 3: Türkiye'nin 2016 Yılında Toplam İhracatı ve En Fazla İhracat Yaptı̆̆ 10 Fasıl (Bin \$) Kaynak: Türkiye Istatistik Kurumu, 2017.

Türkiye'nin ithalatında en fazla paya sahip 10 fasıl ürün ise Tablo 4'te verilmiştir. Tablo 4'te 7. ve 8. sırada yer alan ürün grupları haricindeki ürün gruplarının da tamamı yükte ağır pahada hafif olan ürünlerdir. Dolayısıyla bunlar da karayolu ve demiryolu taşımacılığına uygun ürünlerdir. Her biri geçiş ekonomisi niteliğinde olan Orta Asya Türk Cumhuriyetlerinden Türkiye'ye özellikle 2. sırada yer alan ürünlerin demiryolu ile taşınması durumunda bu ülkeler, Türkiye’ye mal satan rakiplerine karşı maliyet avantajı sağlayabileceklerdir.

Özellikle 2. sıradaki ürünler dikkate alındığında, Türkiye'nin bu ülkelerden ithal ettiği ürün tutarı toplam tutarın içinde yüzde 1 seviyesinin bile altında kalmaktır. Oysa, Azerbaycan ve Türkmenistan'ın ihracatının yüzde sekseninden fazlasını, Kazakistan'ın ihracatının yüzde altmışından fazlasını, Özbekistan'ın ihracatının ise yaklaşık yüzde yirmisini bu fasıldaki ürünler (mineral yakıtlar, mineral yağlar ve bunların damıtılmasından elde edilen ürünler, bitümenli maddeler, mineral mumlar) oluşturmaktadır (International Trade Centre, 2017). 


\begin{tabular}{|c|c|c|c|c|c|c|c|c|c|}
\hline 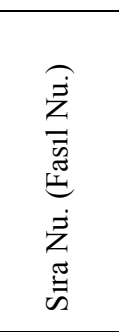 & Fasil & 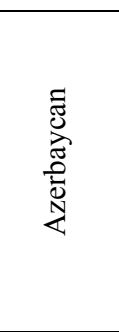 & 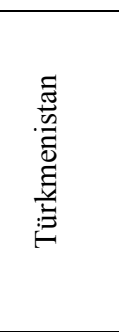 & 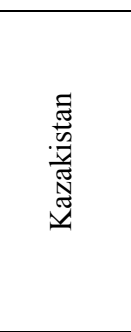 & 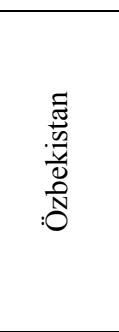 & 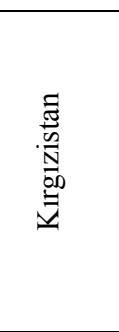 & 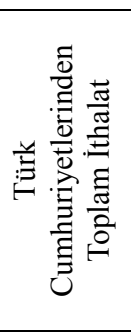 & 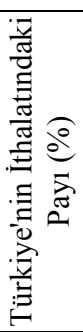 & 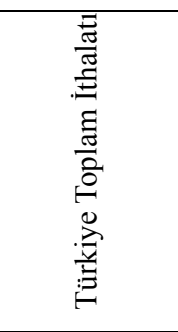 \\
\hline 1. (84) & $\begin{array}{l}\text { Kazanlar, makinalar, } \\
\text { mekanik cihazlar ve aletler, } \\
\text { nükleer reaktörler, bunların } \\
\text { aksam ve parçaları }\end{array}$ & 189 & 4.284 & 190 & 101 & 31 & 4.794 & $\mathbf{0 , 0 2}$ & 27.296 .285 \\
\hline 2. (27) & $\begin{array}{l}\text { Mineral yakıtlar, mineral } \\
\text { yağlar ve bunların } \\
\text { damıtılmasından elde } \\
\text { edilen ürünler, bitümenli } \\
\text { maddeler, mineral mumlar }\end{array}$ & 47.095 & 18.694 & 201.878 & 923 & 0 & 268.591 & 0,99 & 27.162 .759 \\
\hline 3. $(85)$ & $\begin{array}{l}\text { Elektrikli makina ve } \\
\text { cihazlar, ses kaydetme- } \\
\text { verme, televizyon görüntü- } \\
\text { ses kaydetme-verme } \\
\text { cihazları, aksam-parça- } \\
\text { aksesuar1 }\end{array}$ & 141 & 21 & 37 & 13.909 & 2 & 14.110 & $\mathbf{0 , 0 7}$ & 20.135 .022 \\
\hline 4. (87) & $\begin{array}{l}\text { Motorlu kara taşıtları, } \\
\text { traktörler, bisikletler, } \\
\text { motosikletler ve diğer kara } \\
\text { taşıtları, bunların aksam, } \\
\text { parça, aksesuarı }\end{array}$ & 15 & 129 & 73 & 430 & 577 & 1.224 & $\mathbf{0 , 0 1}$ & 17.840 .543 \\
\hline 5. (72) & Demir ve çelik & 7.681 & 1 & 15.642 & 0 & 0 & 23.323 & 0,19 & 12.575 .459 \\
\hline 6. (39) & Plastikler ve mamulleri & 80.267 & 14.280 & 292 & 112.573 & 4 & 207.415 & 1,78 & 11.627 .831 \\
\hline 7. (71) & $\begin{array}{l}\text { Kıymetli veya yarı } \\
\text { kıymetli taşlar, kıymetli } \\
\text { metaller, inciler, taklit } \\
\text { mücevherci eşyası, metal } \\
\text { paralar }\end{array}$ & 6.384 & 0 & 12.014 & 0 & 69.004 & 87.402 & 1,21 & 7.204 .353 \\
\hline 8. (90) & $\begin{array}{l}\text { Optik, fotoğraf, sinema, } \\
\text { ölçü, kontrol, ayar, tıbbi, } \\
\text { cerrahi alet ve cihazlar, } \\
\text { bunların aksam, parça ve } \\
\text { aksesuarı }\end{array}$ & 26 & 38 & 3 & 0 & 27 & 94 & $\mathbf{0 , 0 0}$ & 4.632 .460 \\
\hline 9. (29) & Organik kimyasal ürünler & 16.527 & 0 & 29 & 0 & 0 & 16.556 & 0,38 & 4.359 .497 \\
\hline 10. (88) & $\begin{array}{l}\text { Hava taşıtları, uzay taşıtları } \\
\text { ve bunların aksam ve } \\
\text { parçalar }\end{array}$ & 0 & 0 & 0 & 0 & 3 & 3 & $\mathbf{0 , 0 0}$ & 4.310 .417 \\
\hline & Toplam & 158.325 & 37,447 & 230.158 & 127,936 & 69,648 & 623.512 & 0,45 & 137.144 .626 \\
\hline
\end{tabular}

Tablo 4: Türkiye'nin 2016 Yılında Toplam Ithalatı ve En Fazla Ithalat Yaptığ 10 Fasıl (Bin \$) Kaynak: Türkiye Istatistik Kurumu, 2017.

\section{Türk Cumhuriyetleri Arasındaki Taşımacılık Güzergahları}

Türkiye'den Orta Asya’ya yapılan karayolu taşımacılığında kullanılan sınır kapıları (doğu sınır kapıları) kuzeyden güneye olmak üzere şöyledir;

- Sarp Sinır Kapısı (Artvin), Gürcistan sınırında,

- Türkgözü Sınır Kapısı (Ardahan), Gürcistan sınırında,

- Aktaş Sınır Kapısı (Ardahan), Gürcistan sınırında,

- Dilucu Sınır Kapısı (Iğdır), Azerbaycan (Nahcivan) sınırında,

- Gürbulak Sınır Kapısı (Ağrı), İran sınırında. 
Türkiye'den Orta Asya'ya yapılan çoklu taşımacılıkta izlenecek güzergahlar ise Tablo 5'de verilmiştir. Çıkış kapısı Marmara denizi ve Karadeniz limanı olan güzergahlar çoklu taşıma olarak gerçekleştirilmektedir ve güzergahın küçük bir kısmı denizyolundan, büyük kısmı karayolundan oluşmaktadır.

\begin{tabular}{|c|c|c|c|}
\hline Varış Ülkesi & Hat Numarası & Çıkış Kapısı ve Dağıtım Bürosu & İzlenecek Güzergah \\
\hline \multirow{3}{*}{ Azerbaycan } & $\mathrm{AZ1}$ & Gürbulak & İran-Azerbaycan \\
\hline & AZ2 & Sarp / Türkgözü & Gürcistan - Azerbaycan \\
\hline & AZ3 & Rize / Trabzon & Gürcistan - Azerbaycan \\
\hline \multirow{3}{*}{ Türkmenistan } & TUR1 & Gürbulak & İran - Türkmenistan \\
\hline & TUR2 & Sarp / Türkgözü & Gürcistan - Azerbaycan - Türkmenistan \\
\hline & TUR3 & Rize / Trabzon & Gürcistan - Azerbaycan - Türkmenistan \\
\hline \multirow{10}{*}{ Kazakistan } & KZ1 & Gürbulak & $\begin{array}{l}\text { İran - Türkmenistan - Özbekistan } \\
\text { Kazakistan }\end{array}$ \\
\hline & KZ2 & Kapıkule / Hamzabeyli & $\begin{array}{l}\text { Bulgaristan - Romanya - Ukrayna - Rusya - } \\
\text { Kazakistan }\end{array}$ \\
\hline & KZ3 & Sarp / Türkgözü & Gürcistan - Azerbaycan - Kazakistan \\
\hline & KZ4 & Sarp / Türkgözü & $\begin{array}{l}\text { Gürcistan-Azerbaycan-Türkmenistan- } \\
\text { Özbekistan-Kazakistan }\end{array}$ \\
\hline & KZ5 & Sarp / Türkgözü & Gürcistan - Rusya - Kazakistan \\
\hline & KZ6 & Rize / Trabzon & Gürcistan - Rusya - Kazakistan \\
\hline & KZ7 & Samsun/Trabzon/Zonguldak & Rusya - Kazakistan \\
\hline & KZ8 & Rize / Trabzon & Gürcistan - Azerbaycan - Kazakistan \\
\hline & KZ9 & Rize / Trabzon & $\begin{array}{l}\text { Gürcistan-Azerbaycan-Türkmenistan- } \\
\text { Özbekistan-Kazakistan }\end{array}$ \\
\hline & KZ10 & $\begin{array}{l}\text { Samsun/Trabzon/Zonguldak } \\
\text { Haydarpaşa/Tekirdağ }\end{array}$ & Ukrayna- Rusya - Kazakistan \\
\hline \multirow{8}{*}{ Özbekistan } & UZ1 & Gürbulak & İran - Türkmenistan - Özbekistan \\
\hline & UZ2 & Sarp / Türkgözü & $\begin{array}{l}\text { Gürcistan - Azerbaycan - Kazakistan - } \\
\text { Özbekistan }\end{array}$ \\
\hline & UZ3 & Sarp / Türkgözü & $\begin{array}{l}\text { Gürcistan - Azerbaycan - Türkmenistan - } \\
\text { Özbekistan }\end{array}$ \\
\hline & $\mathrm{UZ4}$ & Sarp / Türkgözü & Gürcistan-Rusya-Kazakistan-Özbekistan \\
\hline & UZ4 & Rize / Trabzon & $\begin{array}{l}\text { Gürcistan - Azerbaycan - Kazakistan - } \\
\text { Özbekistan }\end{array}$ \\
\hline & UZ5 & Rize / Trabzon & $\begin{array}{l}\text { Gürcistan - Azerbaycan - Türkmenistan - } \\
\text { Özbekistan }\end{array}$ \\
\hline & UZ6 & $\begin{array}{l}\text { Zonguldak / Samsun / Haydarpaşa / } \\
\text { Tekirdağ }\end{array}$ & Ukrayna-Rusya-Kazakistan-Özbekistan \\
\hline & UZ7 & Samsun/Trabzon/Zonguldak & Rusya-Kazakistan-Özbekistan \\
\hline \multirow{10}{*}{ Kirgizistan } & KS1 & Gürbulak & $\begin{array}{l}\text { İran - Türkmenistan - Özbekistan } \\
\text { Kırgizistan }\end{array}$ \\
\hline & KS2 & Gürbulak & $\begin{array}{l}\text { İran-Türkmenistan-Özbekistan-Kazakistan- } \\
\text { Kırgızistan }\end{array}$ \\
\hline & KS3 & Sarp / Türkgözü & $\begin{array}{l}\text { Gürcistan-Azerbaycan-Türkmenistan- } \\
\text { Özbekistan-Kırgızistan }\end{array}$ \\
\hline & KS4 & Sarp / Türkgözü & Gürcistan - Rusya -Kazakistan- Kırgızistan \\
\hline & KS5 & Sarp / Türkgözü & $\begin{array}{l}\text { Gürcistan - Azerbaycan - Kazakistan - } \\
\text { Kirgizistan }\end{array}$ \\
\hline & KS6 & Sarp / Türkgözü & Gürcistan - Rusya- Kazakistan - Kırgızistan \\
\hline & KS7 & Sarp / Türkgözü & $\begin{array}{l}\text { Gürcistan - Azerbaycan- Kazakistan - } \\
\text { Kırgızistan }\end{array}$ \\
\hline & KS8 & Rize / Trabzon & $\begin{array}{l}\text { Gürcistan-Azerbaycan-Türkmenistan- } \\
\text { Özbekistan-Kırgızistan }\end{array}$ \\
\hline & KS9 & Samsun/Trabzon/Zonguldak & Rusya-Kazakistan-Kırgızistan \\
\hline & KS10 & Haydarpaşa / Zonguldak & Ukrayna-Rusya-Kazakistan-Kırgızistan \\
\hline
\end{tabular}

Tablo 5: Türkiye Çıkışlı Taşımalarda İzlenecek Güzergahlar Kaynak: Uluslararası Nakliyeciler Derneği, $2017 a$. 
Doğu sınır kapılarından yapılan taşımacılık istatistikleri Tablo 6'da verilmiştir. Tablo 6 incelendiğinde ortaya çıkan sonuçlar şunlardır:

- Türkiye ile Azerbaycan arasında yapılan taşımacılığın çoğunluğu Sarp sınır kapısından Gürcistan üzerinden ve Dilucu sınır kapısından doğrudan Nahcivan'a (Azerbaycan) yapılmaktadır.

- Türkiye ile Türkmenistan arasında yapılan taşımacılığın büyük çoğunluğu Gürbulak sınır kapısından İran üzerinden yapılmaktadır.

- Türkiye ile Kazakistan arasında yapılan taşımacılığın büyük çoğunluğu Sarp sınır kapısından GürcistanAzerbaycan veya Gürcistan-Rusya üzerinden yapılmaktadır.

- Türkiye ile Özbekistan arasında yapılan taşımacılığın büyük çoğunluğu Gürbulak sınır kapısından İranTürkmenistan üzerinden yapılmaktadır.

- Türkiye ile Kırgızistan arasında yapılan taşımacılık ise büyük çoğunlukla Sarp sınır kapısından ya da Gürbulak sinır kapısından yapılmaktadır.

\begin{tabular}{|c|c|c|c|c|c|c|}
\hline & \multicolumn{6}{|c|}{ Doğu Sınır Kapılarından Gerçekleștirilen Taşımalar (2016) } \\
\hline & Sarp & Türkgözü & Aktaş & Dilucu & Gürbulak & Toplam \\
\hline $\begin{array}{l}\text { Türkiye'den İhraç Taşımaları } \\
\text { (Orta Asya Türk C. Toplamı) }\end{array}$ & 42.051 & 418 & 666 & 58.951 & 38.231 & 140.317 \\
\hline Azerbaycan'a & 29.777 & 231 & 599 & 57.950 & 367 & 88.924 \\
\hline Türkmenistan'a & 4.239 & 144 & 19 & 984 & 27.267 & 32.653 \\
\hline Kazakistan'a & 6.482 & 36 & 34 & 1 & 847 & 7.400 \\
\hline Özbekistan'a & 482 & 1 & 5 & 15 & 8.462 & 8.965 \\
\hline Kırgızistan'a & 1.071 & 6 & 9 & 1 & 1.288 & 2.375 \\
\hline $\begin{array}{l}\text { Türkiye'ye İthal Taşımaları } \\
\text { (Orta Asya Türk C. Toplamı) }\end{array}$ & 9.292 & 266 & 152 & 1.239 & 23.928 & 34.877 \\
\hline Azerbaycan'dan & 5.674 & 120 & 140 & 933 & 22 & 6.889 \\
\hline Türkmenistan'dan & 434 & 135 & 0 & 258 & 14.007 & 14.834 \\
\hline Kazakistan'dan & 1.371 & 4 & 9 & 0 & 96 & 1.480 \\
\hline Özbekistan'dan & 115 & 6 & 1 & 48 & 8.839 & 9.009 \\
\hline Kırgızistan'dan & 1.698 & 1 & 2 & 0 & 964 & 2.665 \\
\hline
\end{tabular}

Tablo 6: Doğu Sınır Kapılarından Orta Asya’ya Yapılan Taşımalar (2016) Kaynak: Uluslararası Nakliyeciler Derneği, $2017 b$.

\section{Türk Cumhuriyetleri Arasında Yeni Bir Taşımacılık Güzergâhı Seçeneği; Bakü- Tiflis-Kars Demiryolu}

Bakü-Tiflis-Kars (BTK) demiryolu olarak anılan ve 2017 yılında faaliyete geçecek olan demiryolu, Türkiye ile Gürcistan ve Azerbaycan'ı demiryolu ile doğrudan bağlayan yeni bir hattır. Aslında BTK demiryolu, sadece bu üç ülkeyi değil, doğusunda Hazar Denizi geçişiyle Orta Asya'yı, batısında Marmaray projesi tamamlandığında Türkiye üzerinden Avrupa'yı demiryolu ile birbirine bağlayacaktır (Harita 1). BTK demiryolu için "Yeni Demir İpek Yolu” ifadesi de kullanılmaktadır (Üzümcü ve Akdeniz, 2014) (Haciahmetoğlu, 2016).

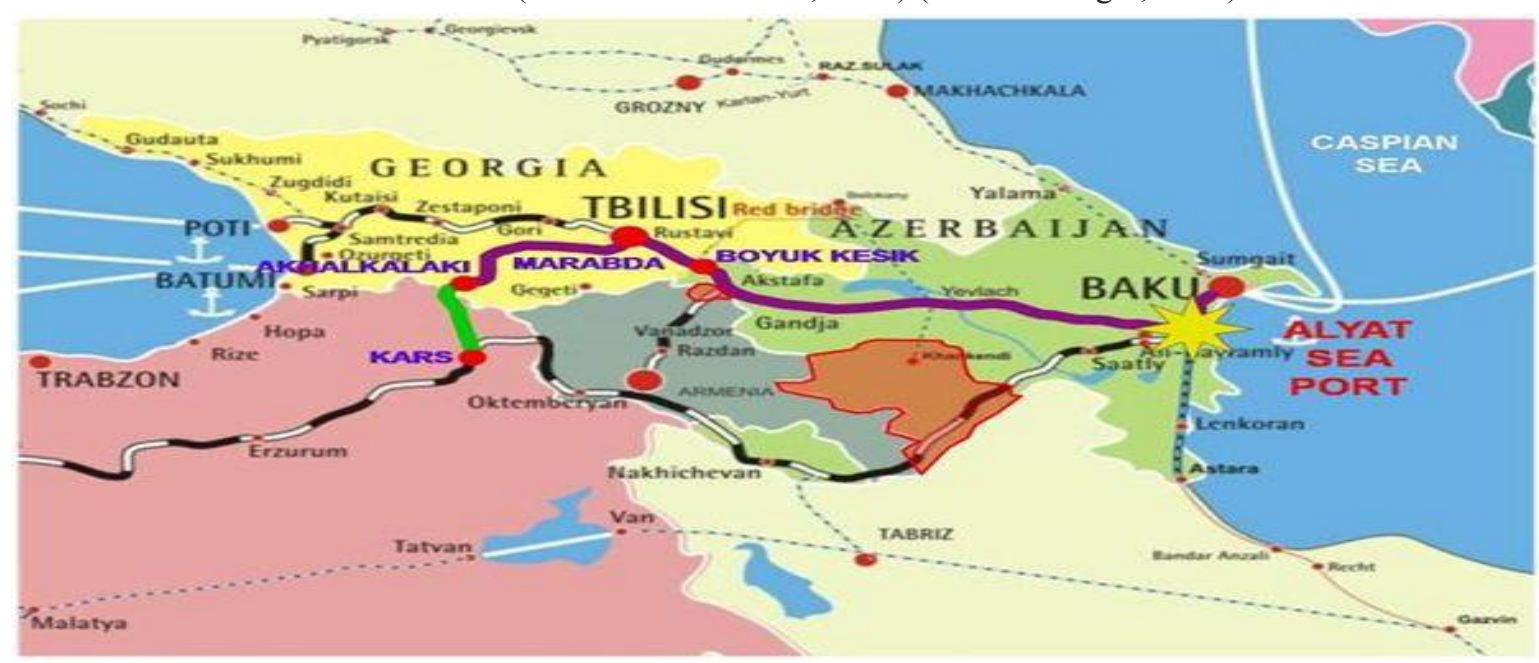

Harita 1: Bakü-Tiflis-Kars Demiryolu Kaynak: TRACECA, Azerbaycan, 2017. 
BTK demiryolu hattının toplam uzunluğu 838,6 km'dir. Hattın Bakü’den Gürcistan sınırına kadar olan kesimi $530 \mathrm{~km}$ (geniş hat $1520 \mathrm{~mm}$ ), Azerbaycan-Gürcistan sınırından Ahılkelek'e kadar olan kesimi $230 \mathrm{~km}$ (geniş hat $1520 \mathrm{~mm}$ ), Ahılkelek’ten Türkiye sınırına kadar olan kesimi 29 km (standart hat $1435 \mathrm{~mm}$ ) ve Gürcistan sınırından Kars'a kadar olan bölümü ise 76,6 km'dir (standart hat $1435 \mathrm{~mm}$ ). Bakü-Ahılkelek bölümü eski hat olup iyileştirilmiş, Ahılkelek-Kars bölümü ise yeni inşa edilmiştir (Uysal, 2016). Hat, işletmeye alındığında; 1 milyon yolcu ve 6,5 milyon ton yük taşıma kapasitesine sahip olacaktır. 2034 yılı sonunda ise; 3 milyon yolcu ve 17 milyon ton yük taşıma kapasitesine ulaşılacaktır (UBAK, 2014).

BTK demiryolu hattında iki farklı ray aralığı kullanılmakta; geniş ray aralığı $(1520 \mathrm{~mm})$ ve standart ray aralığı (1435mm). İki farklı ray aralığı Ahılkelek’te buluşarak burada bir boji değişim istasyonu vasıtasıyla Bağımsız Devletler Topluluğu (BDT) ülkelerine ait vagonların aksı değiştirilerek Türkiye’ye ilerlemesi mümkün olacak. Böylece, BDT ülkeleri ve Türkiye arasında, konvansiyonel vagonlarla taşınan yüklerin, elleçlenmeden taşınması mümkün olacak (Uysal, 2016). Ayrıca, BTK demiryolu hattı, mevcut en kısa bağlantı olan İran üzerinden yapılan ulaşımdan $375 \mathrm{~km}$ daha kısadır (Barutça, 2006).

\section{Bakü-Tiflis-Kars Demiryolunun Türk Cumhuriyetleri Arasındaki Ticarete Katkısı}

Demiryolu ulaştırmasının diğer ulaştırma seçeneklerine göre şu olumlu özellikleri genel olarak bilinmektedir:

- Orta ve uzun mesafelerde (özellikle, denize kıyısı olmayan ülkelerde) yük taşımacılığında yük trafiği miktarı ile oldukça güvenlidir.

- Yük ve yolcu taşımacılığı yılın mevsim şartlarına, hava durumuna göre değişmez.

- Diğer ulaşım olanakları ile karşılaştırıldığında çevreye daha az zarar verir.

- Fazla kapasitesi ile ulaştırma işlemlerinde küçük güç yoğunluğuna sahiptir (hava taşımacılığından 6 kez, karayolu taşımacılı̆̆ından $3 \mathrm{kez}$ daha az güç tüketimi vardır).

- İşlenmemiş maddeler ve yarı işlenmiş ürünlerin taşımacılığı için çok ucuzdur (Üzümcü ve Akdeniz, 2014).

Diğer yandan, taşımacılık türünün seçiminde hizmet alıcılarının tercihlerini etkileyen altı faktör vardır; maliyet, hız, güvenilirlik, yetenek, kapasite ve esneklik (Murphy ve Knemeyer, 2015). Demiryolu taşımacılığı, karayolu taşımacılığına oranla maliyet, güvenilirlik, yetenek ve kapasite açılarından daha üstündür. Esneklik açısından, karayolu taşımacılığının çoğu zaman bütün taşıma türlerine oranla üstün olduğu bilinmektedir. Hız faktörü açısından değerlendirildiğinde ise karayolu taşımacılığının demiryolu taşımacılığından daha üstün olduğu söylenebilir. Ancak, Türkiye ile Orta Asya ülkeleri arasında karayoluyla yapılan taşımalarda güzergahtaki üçüncü taraf ülkeler çok sık olarak taşımayı engelleyen veya aksatan tedbirlere başvurmaktadırlar. Dolayısıyla bu tür tedbirler karayolu taşımacılığının hız avantajını ortadan kaldırmaktadır. Öyle ise, tercih faktörleri açısından, BTK demiryolunun mevcut karayolu güzergahlarına oranla daha fazla tercih edilebilir olduğu söylenebilir.

Burada belirtmek gerekir ki; çekim modeli olarak adlandırılan modele göre farklı coğrafyalardaki ekonomilerin ticaret hacimlerini etkileyen çeşitli değişkenler vardır. Bunlardan bir tanesi de ticari ilişki içindeki uzaklıktır. Uzaklıkla ticaret hacmi ters orantılıdır, uzaklık azaldıkça ticaret hacmi artar, uzaklık arttıkça ticaret hacmi daralır (Doğan ve Tunç, 2016) (Tatlıcı ve Kızıltan, 2011). Çünkü uzaklık arttıkça taşıma maliyetleri artar (Dinçer, 2013). Dolayısıyla, BTK demiryolu taşıma maliyetlerini azaltacağından ticaret hacmini arttırıcı bir etki yapacaktır.

Türkiye ile Orta Asya arasında yapılan taşımacılık, 2016 yılı verilerine göre; 140.317 adet çıkış, 34.877 adet giriş olmak üzere toplam 175.194 adet ile çok büyük oranda Doğu sınır kapılarında yapılmaktadır. Diğer sınır kapıları da eklendiğinde 2016 yılında toplam giriş-çıkış yapan araç sayısı 177.785 araç olarak gerçekleşmiştir (Uluslararası Nakliyeciler Derneği, 2017b). Giriş-çıkış yapan araçların tamamının dolu olması kaydıyla, toplam taşınan yük tonajı 2016 yılı için en fazla 3,5 milyon ton olarak gerçekleşmiş olabilir. Başlangıçtaki kapasitesinin 6,5 milyon ton olduğu dikkate alındığında, BTK demiryolunun ilk yıllarında bile mevcut ticareti çok hızlı bir şekilde arttırma potansiyeli yadsınamaz bir gerçektir.

BTK demiryolu yolcu taşımacılığı açısından da fayda sağlayacaktır. BTK demiryolu, havayolu yolcu taşımacılığına kıyasla maliyet avantajı, karayolu yolcu taşımacılığına kıyasla maliyet, hız ve özellikle konfor avantajı nedeni ile tercih edilebilirliği artacağından karşılıklı olarak turizmi geliştirici etki de yapacaktır. Böylece, hizmet sektörleri açısından da olumlu gelişmelere vesile olacaktır.

\section{Sonuç ve Değerlendirme}

İnsanlık tarihi boyunca ulaşım ağları ticareti geliştirmiştir. Günümüzde de ulaşım ağlarının çeşitliliği ve gelişmişliği toplumların uygarlık seviyelerinin göstergelerinden birisi olarak görülmektedir. Ulaşım ağları çeşitlendirildikçe taşımacılık işletmelerinin ve dolayısıyla bir bütün olarak ulusal ekonomilerin seçenekleri artacağından, taşımacılıkta sıkça karşılaşılan transit geçişi engelleyici uygulamalara karşı direnci artacaktır. Böylece, kesintisiz ve öngörülebilir taşımacılık sağlanarak ekonominin tüm paydaşlarına katkı sunulacaktır. Unutulmamalıdır ki; iletişim hatları ne kadar gelişirse gelişsin ticaretin gerçekleşebilmesi malların fiziksel olarak taşınmasına bağlıdır. 
Türkiye ile Türk Cumhuriyetleri arasındaki ulaştırma hatlarının çeşitlendirilmesi, sadece bu ülkeler arasındaki ticareti geliştirmekle kalmayacak, aynı zamanda ürünlerin çeşitlenmesine de dolaylı etki yaparak Orta Asya ekonomilerinin gelişmesine de destekleyecektir. Bu kapsamda, BTK demiryolunun daha ilk yıllarından itibaren Türkiye ile Türk Cumhuriyetleri arasındaki ticarete ciddi katkılar yapacağı muhakkaktır. Ancak, BTK demiryolunun ulusal ulaşım ağları ile desteklenmesi ve entegre edilmesi daha olumlu sonuçları ortaya çıkaracaktır.

\section{Kaynakça}

- Bal, 2011. "İktisadi Gelişme ve Doğal Kaynaklar: Geçiş Ekonomileri Çerçevesinde Bir İnceleme” Ç.Ü. Sosyal Bilimler Enstitüsü Dergisi, Cilt 20, Say1 1, 87-104, p. 89.

- Barutça, 2006. “Orta Asya’ya Ulaşımda Demiryolu Alternatifi, Bölgesel Güçler ve Türkiye”, Akademik Bakuş (Uluslararası Hakemli Sosyal Bilimler E-Dergisi), Cilt: 8, 1-12, p. 9.

- Dinçer, 2013. "Dış Ticaret Kuramında Çekim Modeli", Ekonomik Yaklaşım, Cilt: 24, Sayı: 88, 1-34, p.13.

- Doğan ve Tunç, 2016. "Türkiye’nin Orta Asya Ülkeleri İle Ticaretinin Panel Çekim Modeli İle Analizi”, Dicle Üniversitesi İktisadi Ve İdari Bilimler Fakültesi Dergisi, Cilt: 6, Sayı 11, 139-156, p. 144.

- Haciahmetoğlu, 2016. "Demir İpek Yolu Projesi ve Türkiye’ye Yönelik Bir Swot Analizi” TURAN-SAM Uluslararası Bilimsel Hakemli Dergisi; Cilt: 8, Sayı: 30, 226-232, p. 227.

- International Trade Centre, 2017. Trade Competitiveness Map, http://www.trademap.org/countrymap /Country_SelProductCountry_TS.aspx? nvpm=1|795||||TOTAL ||$|2| 1|2| 3|2| 1|2| 1 \mid 1$

- Murphy ve Knemeyer, 2015. Contemporary Logistics (11th Edition). Pearson Education Limited.

- Pashalieva ve Kahriman, 2016. "Bir Geçiş Ekonomisi Olarak Kırgızistan'da Doğrudan Yabancı Yatırımlar ve Orta Asya Ülkeleri İle Kıyaslanması”, Celal Bayar Üniversitesi İ.I.B.F. Yönetim ve Ekonomi, Cilt:23 Say1:1, 163-188, p.163.

- Tatlıcı ve Kızıltan, 2011. "Çekim Modeli: Türkiye’nin İhracatı Üzerine Bir Uygulama”, Atatürk Üniversitesi İ̈BF Dergisi, 10. Ekonometri ve İstatistik Seтроzyuти Özel Saylsı, 287-299, p. 289.

- TRACECA, Azerbaycan, 2017. TRACECA - Restoration of the Historic Silk Road, http://www.tracecaorg.org/en/countries/azerbaijan/azerbaijan-in-traceca/

- Türkiye İstatistik Kurumu, 2017. Diş Ticaret İstatistikleri, http://www.tuik.gov.tr/PreTablo.do?alt_id=1046

- UBAK, Ulaşan Erişen Türkiye 2014, http://www.ubak.gov.tr/BLSM_WIYS/UBAK/tr/dokuman ust_menu/projeler_faaliyetler/20130319_101534_204_1_64.pdf.

- Uluslararası Nakliyeciler Derneği, 2017a. İzlenecek Güzergahlar, http://und.web.tr/tr/15423/izlenecekguzergahlar

- Uluslararası Nakliyeciler Derneği, 2017b. İstatistikler, http://und.web.tr/tr/19744/istatistikler

- Uysal, 2014. "Bakü-Tiflis-Kars Demiryolu Projesi Hakkında Bilmeniz Gereken 10 Şey", tr.railturkey.org/2014/10/20/baku-tiflis-kars-demiryolu/

- Üzümcü ve Akdeniz, 2014. "Yeni İpek Yolu: TRACECA ve Bakü-Tiflis-Kars Demiryolu Projesi”, Avrasya Etüdleri, 45/2014-1, 171-199, p. 185. 


\title{
Havayolu Taşımacılığı Talep Esnekliği Üzerine Ampirik Bir Analiz: Türkiye Örneği
}

\section{An Empirical Analysis on the Elasticity of Air Transportation Demand: Sample of Turkey}

\author{
Prof. Dr. Harun Bal (Çukurova University, Turkey) \\ Pınar Gümüş Akar (Gaziantep University, Turkey) \\ Ph.D. Candidate Müge Manga (Çukurova University, Turkey)
}

\begin{abstract}
Air Transportation, which is a sector ever-increasing its volume and importance because of requiring infrastructural investments, providing fast and reliable transportation facilities, offering employment and its the positive effects on the other sector activities. The demand, for air transportation which is appeared in development goals of many countries and the development indicators of the World bank, is constituted one of the most important components. The aim of this study is estimated of the sensitivity to income and price, air transportation demand in Turkey. In this direction, it is estimated the price and income elasticities in the short and long term by the FMOLS and VEC method for the air passenger demand using the data of GSYH, flight ticket price index and the number of passengers in Turkey in the period of 2007Q1-2016Q1. The results obtained, consistent with expectations, are indicated that the price inelasticity of the air passenger demand in Turkey is high and according to the income elesticity parameter is luxury good.
\end{abstract}

\section{Giris}

Havayolu taşımacılığı, yolculara ya da kargo kullanıcılarına sağladığı faydaların yanı sıra, ekonominin geneli açısından oldukça geniş faydalar sağlamaktadır. Çağımızın en belirgin özelliklerinden birinin kişilerin, sermayenin ve malların serbest dolaşımı olduğu göz önüne alındığında, havayolu taşımacılığı küresel ekonomi açısından en önemli unsurlarından biri olarak ortaya çıkmaktadır. Havacılık sektörünün doğrudan, dolaylı, uyarılmış ve katalitik etkileri (ATAG, 2005; Vasigh vd, 2008; Grancay, 2010) bir arada değerlendirildiğinde, ekonomiye kendi katkısının yanı sıra diğer sektör faaliyetleri açısından önemli etkilere sahip olduğu görülmektedir. Gerektirdiği altyapı yatırımları, sunduğu hızlı ve güvenilir ulaşım imkanları, sağladığı istihdam ve diğer sektörler açısından sağladığ geniş pazarlara ulaşım, tedarik hızı gibi pozitif etkileri ve gerektirdiği kurumsal yapı ile havayolu taşımacılığ ülkelerin ekonomi politikaları ve kalkınma hedefleri açısından büyük önem arz etmektedir. Havacılık sektörünün en önemli bileşenlerinden biri ise doğal olarak "talep"tir.

Havayolu firmaları ya da havaalanları yönetiminde ekonomik karar alma süreçlerinde en önemli unsurlardan biri olan talebi etkileyen faktörler, sosyo-ekonomik değişkenler (nüfus, GSYİH, kişi başına düşen gelir, sosyal yapı, eğitim, cazibe merkezi olma, politik olaylar, hükümet düzenlemeleri) ve havayolu taşımacılığı değişkenleri (bilet fiyat1, uçuş süresi, konfor, güven) olarak tasnif edilebilir (Taneja, 1971). Doganis (2002), Havayolu yolcu talebini etkileyen genel faktörler içerisinde en önemli faktörlerin havayolu taşımacılığı fiyatı ve hizmet sunulan pazarlardaki kişisel gelir düzeyi ve dağılımı olabileceğini ve son kırk yıldaki havayolu taşımacılığındaki büyümenin büyük kısmının hava taşımacılığında düşen fiyatlar ile dünya ekonomilerinde büyüme ve artan kişisel gelir ile açıklanabileceğini belirtmiştir. Havayolu taşımacılığı açısından talebi etkileyen faktörler diğer bir açıdan endojen ve egzojen değişkenler olarak temel iki gruba ayrıldığında, havacılık sektöründe fiyat ve hizmet endojen değişkenler; tüketici geliri, rakiplerin fiyatı ve tamamlayıcı unsurların fiyatı ise egzojen değişkenler olarak kabul edilebilir. Talebi etkileyen değişkenlerin talep üzerindeki etkilerini bilmek, havacılık sektöründe daha etkin bir kapasite ve talep yönetimi sağlamak açısından faydalıdır (Vasigh vd., 2008) Havayolu yolcu talebi, havayolu fiyatları ve gelirdeki değişimlere karşı hassastır. Talep esneklikleri ile ifade edilen bu hassaslığın derecesi, farklı durumlara göre değişiklik göstermektedir. Havayolu taşımacılığı ile ilgili liberalizasyon, altyapı yatırımları, vergilendirme, havalimanı harçları gibi politikaların etkili olabilmesi için, talep esneklikleri ile ilgili güvenilir tahminler ayrıca önem arz etmektedir (IATA, 2008).

Talebin fiyat esnekliği, fiyattaki yüzde değişime bölünen miktar değişim yüzdesi olarak tanımlanmaktadır. Talep eğrisinin negatif eğimi nedeniyle talep esneklik katsayısı negatiftir ancak, mutlak değer ile yorumlanır. Esneklik değeri 1'den küçük ise talebin esnek olmadığı (inelastik), 1'e eşit ise birim esnek olduğu, 1'den büyük ise talebin esnek olduğu kabul edilir (Varian, 2010). Çeşitli esneklik türleri içerisinde planlamalar açısından en faydalı olanlarından biri de fiyat esnekliğidir. Esnekliğin en genel tanımı ile fiyat esnekliği fiyattaki \%1'lik bir değişim sonucunda talep edilen miktarda meydana gelen yüzdelik değişimdir ve bu nedenle fiyat esnekliği, fiyat değişiklikleri sonucunda talep edilecek miktarda meydana gelecek değişimleri öngörebilme ve bu doğrultuda planlama yapabilme olanağı sağlamaktadır (Vasigh vd., 2008) 
Tüm piyasalar için geçerli evrensel bir havayolu yolculuğu talep esnekliği değeri yoktur. Aksine zaman faktörüne, uçuş süresine ve seyahat amacına dayalı bir çok esneklik değeri gözlemlenebilmektedir. Talebin fiyat esnekliği, uzun ve kısa dönem, uzun ve kısa uçuş mesafeleri, iç hat ve dış hat uçuşları ve seyahat amacı kapsamında değerlendirilebilir. Bu bağlamda genelde uzun dönem talep esnekliği, kısa dönem talep esnekliğinden daha yüksektir. Fiyatlarda beklenmeyen bir değişim, seyahat planlarının yapılmış olduğu kısa dönemde, uzun dönemden daha küçük bir etkiye sahip olacaktır. Çünkü uzun dönemde yolcular davranışlarını piyasadaki yeni duruma göre ayarlayabileceklerdir. Uçuş mesafeleri açısından, kısa yerel uçuşlar başka taşıma türleri ile kolaylıkla ikame dilebildiğinden, uzun uçuş mesafeleri genelde kısa mesafeli yolculuklara göre daha düşük fiyat esnekliğine sahiptir. Seyahat amacı açısından değerlendirildiğinde ise, iş amaçlı seyahatlerde kısa dönem fiyat esneklikleri, iş gezisinin iptali göze alınamadığından düşüktür. Dinlence amaçlı seyahatlerde ise yüksek tarifelere tepki olarak gezi erteleme ya da uygun fiyatlı yerlere yönelme söz konusu olabileceğinden fiyata karşı iş amaçlı seyahatlerden daha yüksek bir duyarlılığın söz konusu olması beklenmektedir (Gillen v.d., 2003,Vasigh v.d., 2009).

InterVISTAS (2007), uçak bileti fiyatlarında meydana gelen değişim nedeniyle talepte meydana gelen değişimleri karşılaştırmak amacıyla esneklikler için ücret sınıfı düzeyi, taşıyıcı düzeyi, rota/pazar düzeyi, ulusal düzey ve pan-ulusal düzey olmak üzere beş kümelenme düzeyi belirlemiştir. Daha yüksek kümelenme düzeyi talepte daha düşük fiyat esnekliğine yol açmaktadır. Ücret sınıfı düzeyi en ayrıştırılmış düzeydir, yolcular business class, ekonomi sınıfı gibi farklı ücret sınıflarında yolculuk seçenekleri arasında tercih yapmaktadırlar ve fiyat esnekliğinin en yüksek olduğu düzeydir. Taşıyıcı düzeyi aynı rotaya uçuşları olan havayolu firmalarını ifade etmektedir ve firmaların fiyat artırımları sonucunda karşılaşacakları fiyat esneklikleri yüksektir. Bu ilk iki düzey, ilgili çalışmanın ekonomik ve politik odağı nedeniyle araştırma dışı bırakılmıştır. Rota/Pazar düzeyi belirli bir güzergahtaki uçuşları kapsamaktadır ve bu düzey açısından yolcuların fìyat değişimlerinden korunmak için seçenekleri alternatif rotaları tercih etmektir ve dolayısıyla esneklik düzeyi daha düşüktür.. Ulusal düzey, havacılıkla ilgili hükümet politikalarının (vergi, destek vb) sonucunda gerçekleşen fiyat değişimlerini içermektedir ve bu düzeyde yolcuların alternatifi başka bir ulaşım türünü ya da başka ülkelerdeki havaalanlarını tercih etmek olduğundan esneklik daha da düşüktür. Esnekliğin en düşük olduğu pan-ulusal düzey ise en geniş düzeydir ve uçak bileti fiyatlarının bir grup ülkedeki (örn. Avrupa Birliği) değişimini sonucu talepte meydan gelecek değişimleri kapsamaktadır. Tablo 1 'de coğrafi konum ve kümelenme düzeylerine göre tahmin edilen fiyat esnekliği katsayıları yer almaktadir.

\begin{tabular}{|l|c|c|c|c|c|c|}
\hline & \multicolumn{2}{|c|}{ Güzergah/Pazar Düzeyi } & \multicolumn{2}{c|}{ Ulusal Düzey } & \multicolumn{2}{c|}{ Pan-Ulusal Düzey } \\
\cline { 2 - 6 } & $\begin{array}{c}\text { Kisa } \\
\text { Mesafe }\end{array}$ & $\begin{array}{c}\text { Uzun } \\
\text { Mesafe }\end{array}$ & $\begin{array}{c}\text { Kisa } \\
\text { Mesafe }\end{array}$ & $\begin{array}{c}\text { Uzun } \\
\text { Mesafe }\end{array}$ & $\begin{array}{c}\text { Kisa } \\
\text { Mesafe }\end{array}$ & $\begin{array}{c}\text { Uzun } \\
\text { Mesafe }\end{array}$ \\
\hline Kuzey Amerika & $-1,5$ & $-1,4$ & $-0,9$ & $-0,8$ & $-0,7$ & $-0,6$ \\
\hline Avrupa & $-2,0$ & $-2,0$ & $-1,2$ & $-1,1$ & $-0,9$ & $-0,8$ \\
\hline Asya & $-1,5$ & $-1,3$ & $-0,8$ & $-0,8$ & $-0,6$ & $-0,6$ \\
\hline Sahra Alt1 Afrika & $-0,9$ & $-0,8$ & $-0,5$ & $-0,5$ & $-0,4$ & $-0,4$ \\
\hline Güney Amerika & $-1,9$ & $-1,8$ & $-1,1$ & $-1,0$ & $-0,8$ & $-0,8$ \\
\hline Trans-Atlantik & $-1,9$ & $-1,7$ & $-1,1$ & $-1,0$ & $-0,8$ & $-0,7$ \\
\hline Trans Pasifik & $-0,9$ & $-0,8$ & $-0,5$ & $-0,5$ & $-0,4$ & $-0,4$ \\
\hline Avrupa-Asya & $-1,4$ & $-1,3$ & $-0,8$ & $-0,7$ & $-0,6$ & $-0,5$ \\
\hline
\end{tabular}

Tablo 1: Tahmin Edilen Havayolu Yolcu Talebi Fiyat Esneklikleri Kaynak: IATA (2008)

Talebin gelir esnekliği, talebin gelirdeki değişime nasıl tepki verdiğini açıklamak için kullanılmaktadır. Gelir arttıkça talebi azalan malların ya da hizmetlerin gelir esneklik değeri negatiftir ve "düşük mal" olarak kabul edilmektedir. Gelir attıkça tüketimi artan malların ya da hizmetlerin gelir esnekliği değeri pozitiftir ve "normal mal" olarak nitelendirilmektedir. Gelir esnekliği değerinin 1'den büyük olması ise söz konusu malın ya da hizmetin "lüks mal" olması ile yorumlanmaktadır (Varian 2010). InterVISTAS (2007), havayolu yolcu talebinin gelir esnekliğine dair üç ölçüt sunmaktadır: Taşıma mesafesi, kümelenme düzeyi ve ülke türü. Araştırma sonuçlarına göre talebin gelir esnekliği taşıma mesafesi ile birlikte artmaktadır, genelde GOÜ'de gelişmiş ülkelerden daha yüksektir ve kümelenme düzeyi ile birlikte düşmektedir. IATA (2008) raporunda ekonometrik araştırma ve tahminlerin gözden geçirilmesi sonucunda hava taşımacılığı talebinde gelir esnekliğinin sürekli pozitif ve birden büyük olduğu ve bunun hane halkı ya da bireylerin refahındaki artışın, gelirin artan payının havayolu seyahatine tahsis edilmesine yol açtığı belirtilmiştir. Tablo 2'de söz konusu raporda geçmiş çalışmalardan ve yapılan çalışmadan elde edilen sonuçlar doğrultusunda derlenen ulusal düzeyde ülke grupları bazında mesafe açısından havayolu yolcu talebi gelir esnekliği katsayı tahminleri yer almaktadır:

\begin{tabular}{|c|c|c|c|c|}
\hline Ulusal Düzey & Kisa Mesafe & Orta Mesafe & Uzun Mesafe & Çok Uzun Mesafe \\
\hline ABD & 1,6 & 1,7 & 1,8 & 2,0 \\
\hline Gelișmiș Ülkeler & 1,3 & 1,4 & 1,5 & 2,2 \\
\hline Gelişmekte Olan Ülkeler & 1,8 & 1,8 & 2,0 & 2,5 \\
\hline
\end{tabular}

Tablo 2: Tahmin Edilen Havayolu Yolcu Talebi Gelir Esneklikleri Kaynak: IATA (2008) 
Havacılık sektörünün nihai ürünü olan havayolu yolcu taşımacılığı hacmi hızla artmaktadır. Şekil 1'de yer alan verilerin de gösterdiği üzere, 1970'li yılların başında ortalama 400 milyon düzeylerinde olan yolcu hacminin yaklaşık 9 katlık bir artışla 2015 yılında 3,5 milyara yaklaştığı görülmektedir. Havayolu taşımacılığı, uluslararası pazarlara ulaşımı kolaylaştırmakta ve hem üretimin, hem tüketimin globalleşmesini sağlamaktadır (ATAG 2016).

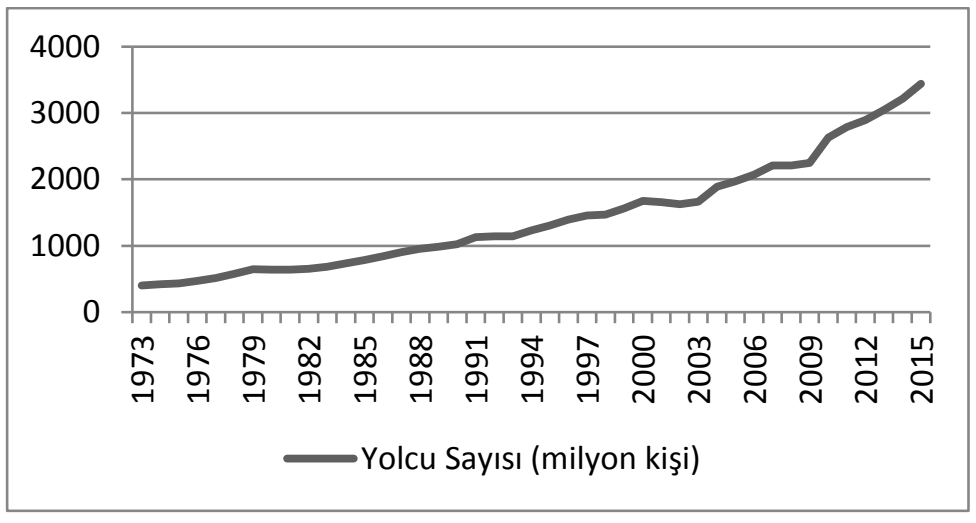

Şekil 1: Dünya Havayolu Taşımacılı̆̆ı Yolcu Sayısı Kaynak: World Bank, World Development Indicators

Türkiye, kıtalararasında bir kavşak konumunda olması itibariyle, uluslararası hava taşımacılığı bağlamında stratejik bir yere ve öneme sahiptir. Türkiye'nin artan ihracatı, turizm potansiyeli ve turizm gelirlerinin ülke ekonomisi açısından önemi, coğrafi konumunun gerektirdiği uluslararası ilişkiler bir arada değerlendirildiğinde, havacılık sektörünün büyük önem arz ettiği görülmektedir. 1983 yılına kadar sivil havacılıkta devlet kontrolünde monopol bir yapının gözlemlendiği Türkiye'de 1983'te çıkarılan kanunla özel sektörün faaliyetine izin verilmiş, 1986 ortalarından sonra belirgin bir gelişim içerisine girmiştir (Korul ve Küçükönal, 2003). 2003 y1lında uygulanmaya başlanan “serbest havacılık politikası” sonrasında ise Türkiye'de havacılık sektörü büyük gelişimler kaydetmiştir.

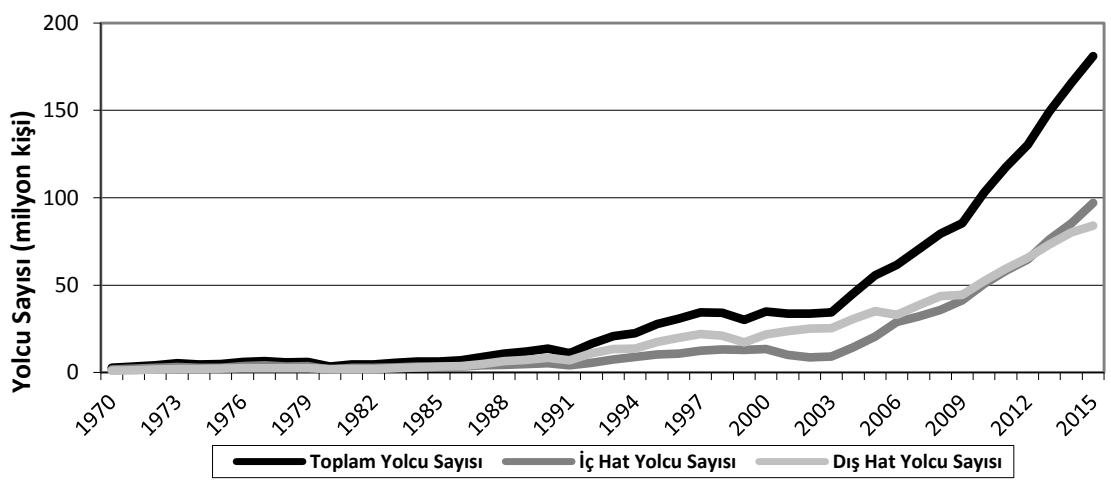

Şekil 2. Türkiye Havayolu Taşımacılı̆̆ı Yolcu Sayısı Kaynak: Türkiye İstatistik Kurumu

Çalışmamızda Türkiye açısından havayolu yolcu talebi fiyat ve gelir esnekliklerinin ulusal düzeyde araştırılması amaçlanmıştır. Bu bağlamda çalışmanın birinci bölümünde havayolu yolcu talebini etkileyen faktörler ve esneklik türleri ile ilgili genel bilgilere, ikinci bölümde konuyla ilgili genel literatür bilgisine, üçüncü bölümde ise ulusal düzeyde fiyat ve gelir esnekliklerinin araştırılması amacıyla GSYİH, ortalama uçak bileti fiyatları ve havayolu yolcu sayılarının değişken olarak kullanıldığı analize ilişkin açıklamalara, dördüncü bölümde ise çalışmanın bulgularına yönelik sonuçlara yer verilmiştir.

\section{Literatür Taraması}

Havacılık sektöründe doğrudan yolcu talebinin fiyat ve gelir esnekliği üzerine ülkelere ve ülke guruplarına, coğrafi özelliklere, güzergahlara ya da havayolu yolculuğu türlerine göre yapılan çalışmaların yanı sıra, havayolu yolcu talebini inceleyen ve bu bağlamda talep esnekliklerini de değerlendiren çalışmalar mevcuttur. Bu çalışmalar doğrultusunda ortaya çıkmış tek ya da belirli esneklik değerleri yoktur. Her ülkenin sahip olduğu ekonomik, politik, sosyal, kültürel, demografik ve coğrafi koşullar doğrultusunda farklılık gösteren birçok husus gibi, talep esneklikleri de doğal olarak farklılık göstermektedir. Söz konusu farklıkların yanı sıra hesaplamalarda kullanılan modeller, değişkenler ya da kümelenme düzeyleri de sonuçlar arasında farklılıklara neden olabilmektedir. Taneja (1971), havayolu seyahati talebi için model tahminleri ile ilgili olarak yaptığı erken çalışmada, gelir ve fiyat esnekliklerinin sayısal değerlerinde çalışmalar arasında görülen farklılığı ve dalgalanmayı esneklik tahminlerinin talep modeline ve model dahilindeki değişkenlere göre belirlenmesi ile ilişsilendirmiş ve bu durumu farklılaştırılmış modeller üzerinde göstermiştir. 
Alperovich ve Machnes (1994), havayolu seyahati talebini tahmin eden modellerde, tüketicilerin servetini temsil eden değişkenlerin yer almayışını bir eksiklik olarak nitelendirmiş ve çalışmalarındaki modele dahil etmiştirler. Çalışmalarının amacı İsrail'de havayolu yolcu talebi açısından tüketici varlıklarının oynadığı rolü araştırmak ve İsrail uluslararası havayolu seyahati talebi fiyat ve gelir esnekliği tahminlerini tespit ederek diğer ülkelerle karşılaştırmaktır. Tüketici geliri, tüketici fiyatları endeksi, tüketicilerin seyahat harcamaları ve finansal varlık değişkenlerinin kullanıldığı çalışmada 1970-1989 dönemine ait veriler kullanılmıştır. Çalışma sonuçlarına göre İsrail havayolu seyahati talebi fiyat esnekliğinin -0.26 ve -0.34 değerleri arasında, gelir esnekliğinin ise 1,55 ve 2,06 değerleri arasında olduğu belirtilmiştir.

Doganis (2002), 1975-2000 dönemi Dünya GSYİH ve ücretli yolcu kilometre (revenue passenger kilometresRPK) verileri incelendiğinde, dünya GSYİH'sı ve RPK ile ölçülen havayolu seyahati artışı arasında güçlü bir korelasyon görüldüğünü, havayolu seyahati talebindeki artışın GSYİH'daki herhangi bir artıştan iki kat daha hızlı gerçekleştiğini, dolayısıyla gelir esnekliği katsayısının bu çok genel düzey için yaklaşık 2 olduğunu belirtmiştir.

Brons v.d. (2002), havacıllk sektöründe fiyat esneklikleri tahminlerini ve fiyat esnekliklerini etkileyen faktörleri meta-analiz yöntemiyle incelemişlerdir. 37 çalışma ve 204 gözlem incelenmiş ve çalışmaların esneklik tahminleri ve kullandıkları değişkenler değerlendirilmiştir. Bu bağlamda havayolu yolcu talebi fiyat esnekliklerinin uzun dönemde daha yüksek olduğunu ve yolcuların zamanla fiyata karşı daha duyarlı hale geldiklerini, iş amaçlı seyahatlerde esnekliğin daha düşük olduğunu, Avrupa'da daha fazla ikame seçeneği olmasına karşın Avrupalı yolcuların ABD ve Avustralyalı yolculardan fiyata karşı daha duyarlı olmadıklarını belirtmişlerdir.

Njegovan (2006), İngiltere'de dinlence seyahati talebi esnekliklerini incelediği çalışmasında, yerel dinlence pazarı gelir esnekliğinin 0.6 olduğunu, uçak bileti fiyatları ile ilgili olarak esneklik değerlerinin inelastik olduğunu, havayolu seyahati talebi için çapraz fiyat esnekliklerinin, fiyat esnekliğinden nispeten büyük olduğunu ve düşük maliyetti (Low Cost) havayollarının, düşük tarifeler sunarak daha yüksek trafiği çekmede başarılı olduklarını belirtmiştir.

Gillen v.d.(2009), havayolu seyahati için talep fonksiyonu tahmini ile ilgili literatürünü inceleyerek havayolu seyahati için esneklik ölçüleri aralığı belirlemek amacıyla yaptıkları çalışmada, toplam 21 çalışmadan derlenen 254 fiyat esnekliği tahmini ile bir histogram üretmiş ve minimum esneklik değerinin -3,20 olduğunu, 0 ile 2,5 arasındaki tahminlerin yoğun olduğunu ve tüm tahminler için medyan ya da orta değerin -1,122 olduğunu belirtmişlerdir. Gelir esnekliği için toplam 14 çalışmadan 132 gelir esnekliği tahmini kullanılmış ve minimum tahmini gelir esnekliği değerinin -1,21, maximum değerin ise 11,58 olduğu, medyan gelir esnekliği tahmini 1,39 iken, 0,5-2,5 arasındaki değerlerde yoğunluk olduğunu tespit etmiştirler.

Tsekeris (2009) dinamik talep modeli ile Ege Adaları havayolu yolcu talebini açıklamak amacıyla yaptığı çalışmada, havayolu yolcu talebi fiyat esneklik değerinin negatif olduğunu ancak 1'den önemli derecede düşük olduğunu yani talebin Ege Adalarında esnek olmadığını belirtmiştir. Analiz sonuçlarına göre fiyat esnekliği değerinin ağustos ayında şubat ayına kıyasla daha yüksek olduğunu, yaz dönemi yolcularının kış dönemi yolcularına göre fiyata karşı daha duyarlı olduklarını ve gelir esnekliği değerinin pozitif fakat 1'den küçük, yani inelastik olduğunu ortaya koymuştur. Çalışma sonuçlarının, konuya dair diğer çalışmalardan farklı olarak, Ege Adalarında yaşayanlar için havayolu taşımacılığının “zorunlu mal” olduğunu gösterdiğini ifade etmiştir.

Çetin (2016), çalışmasında havayolu sektöründe deregülasyonun tüketici tercihleri ve rekabetçilik üzerindeki etkilerini daha iyi anlayabilmek için talep esnekliklerini kullanmıştır. Bu bağlamda rekabetçi bir piyasa yapısının varlığını anlayabilmek için talebin fiyat esnekliği, diğer taşıma modları ile ikame ilişkisini ortaya koymak için çapraz esneklik ve zaman içerisinde gelir ve talep arasındaki ilişkiyi anlayabilmek için gelir esnekliği değerleri tahmin etmiştir. 2003/06-2015/08 dönemi için fiyatı temsilen aylık bilet fiyatı endeksi, geliri temsilen toplam sanayi ürünü endeksi ve yolcu sayıları verilerinin kullanıldığı çalışmada, talebin fiyat esnekliği değerinin $-0,72$ olduğu, çapraz esneklik değerinin pozitif olduğu ve gelir esnekliği değerinin 3.09 olduğu belirtilmiştir.

\section{Veri ve Yöntem}

Bu çalışmada, Türkiye'de ulusal düzeyde 2007Q1-2016Q1 dönemleri arasındaki havayolu yolcu talebinin gelir ve fiyat esnekliğinin hesaplanması amacıyla üçer aylık yolcu sayıları, uçak bileti fiyat endeksi ve GSYİH verilerinden faydalanılmıştır. Çalışmada kullanılan verilerden havayolu yolcu talebi ve bilet fiyatları TUIK'ten, GSYİH değişkeni ise IMF'den elde dilmiştir. Havayolu yolcu talebinin uzun dönemli gelir ve fiyat esnekliğinin hesaplanması amacıyla Tamamen Değiştirilmiş En Küçük Kareler (FMOLS) yöntemi ve kısa dönemli esnekliğinin hesaplanması amaciyla ise Vektör Hata Düzeltme Modeli (VECM) kullanılmaktadır. Havayolu yolcu talep esnekliğinin uzun ve kısa dönem katsayılarının tahmin edilmesi öncesinde serilerin tamamı için birim kök testi yapılmaktadır. Çalışmada serilerin durağanlık sınaması, ADF (Augmented Dickey Fuller) ve PP (Phillips-Perron) testleri kullanılmaktadır. Tablo 3’te yapılan birim kök testi sonuçları verilmektedir. 


\begin{tabular}{|l|l|l|l|}
\hline \hline Değişkenler & Trendli & \multicolumn{1}{c|}{$\begin{array}{l}\text { Düzev } \\
\text { Trendsiz }\end{array}$} & $\begin{array}{l}\text { Fark } \\
\text { Trendsiz }\end{array}$ \\
\hline \multicolumn{5}{|c|}{ ADF } \\
\hline LnHYT & -2.412 & -0.382 & $-9.493^{* * *}$ \\
\hline LnHP & -1.251 & -2.828 & $-6.675^{* * *}$ \\
\hline LnGDP & -0.650 & -1.672 & $-6.520^{* * *}$ \\
\hline \multicolumn{5}{|c|}{ PP } \\
\hline LnHYT & $-3.281^{* *}$ & $-6.061^{* * *}$ & $-9.978^{* * *}$ \\
\hline LnHP & -1.214 & $-3.321^{*}$ & $-6.812^{* * *}$ \\
\hline LnGDP & -2.390 & $-4.154^{* *}$ & $-9.952^{* * *}$ \\
\hline \hline
\end{tabular}

Tablo 3: Birim Kök Testi Sonuçları

***, ** ve * strasıyla \%1, \%5 ve \%10 anlamlılı düzeylerini ifade etmektedir. Kurulan modelde otokorelasyon ve değişen varyans sorununa yol açmayan maksimum gecikme uzunluğunun belirlenmesinde Schwarz Bilgi Kriteri kullanılmıştır.

Yapılan birim kök testi sonuçlarına göre, serilerin tamamı birinci düzeyde durağan I(1), diğer bir ifade ile birinci farkları alındıktan sonra durağan hale gelmektedir. Serilerin aynı düzeyde durağan olması, değişkenler arasında eşbütünleşme ilişkisinin olup olmadığının test edilmesine imkân sağlamaktadır. Değişkenler arasındaki eşbütünleşme ilişkisinin tespiti amaciyla uygulanan Johansen Eşbütünleşme analizi sonuçları Tablo 4'te verilmektedir.

\begin{tabular}{|l|c|c|c|c|c|}
\hline $\begin{array}{c}\text { SIfır } \\
\text { hipotez }\end{array}$ & $\begin{array}{c}\text { Öz } \\
\text { Değerler }\end{array}$ & $\begin{array}{c}\text { İz } \\
\text { Değerler }\end{array}$ & $\begin{array}{c}\text { 0.05 Kritik } \\
\text { Değerler }\end{array}$ & $\begin{array}{c}\text { Maksimum Öz } \\
\text { Değerler }\end{array}$ & $\begin{array}{c}\text { 0.05 Kritik } \\
\text { Değerler }\end{array}$ \\
\hline $\mathbf{r = 0}$ & 0.644059 & 54.78087 & 29.79707 & 37.18764 & 21.13162 \\
\hline $\mathbf{r}^{\leq} \mathbf{1}$ & 0.283209 & 17.59323 & 15.49471 & 11.98695 & 14.26460 \\
\hline $\mathbf{r} \leq \mathbf{2}$ & 0.144210 & 5.606281 & 3.841466 & 5.606281 & 3.841466 \\
\hline
\end{tabular}

Tablo 4: Eşbütünleşme Testi Sonuçları

Uygulanan eşbütünleşme testi sonuçlarına göre, " $\mathrm{H}_{0}$ : Eşbütünleşme yoktur." boş hipotezi red edilir ve değişkenler arasında eşbütünleşme vektörünün varlığı tespit edilmiştir. Johansen eşbütünleşme testi sonuçlarına göre iz değere göre 3 ve maksimum öz değere göre 1 adet eşbütünleşme vektörünün varlığ tespit edilmiştir. Uygulanan eşbütünleşme testi sonrasında havayolu yolcu talebinin uzun dönemli esneklik katsayı tahminin yapılması amacıyla FMOLS yöntemi kullanılmaktadır. Tablo 5'te uygulanan FMOLS yöntemlerinin sonuçlarına yer verilmektedir.

\begin{tabular}{|l|l|l|l|l|}
\hline Değişkenler & Katsayı & Standart Hata & t- istatistiğ & Olasılık \\
\hline $\operatorname{lnGDP}$ & 3.298 & 0.284695 & 11.58441 & 0.0000 \\
\hline LnHP & -0.262 & 0.165030 & -1.591689 & 0.1202 \\
\hline
\end{tabular}

Tablo 5: Uzun Dönemli Esneklik Katsaylları

Elde edilen sonuçlar, uzun dönemde GSYİH 'da oluşan \%1'lik artış, havayolu yolcu talebini \%3.29 oranında arttırdığını göstermektedir. Bu durum uzun dönemli esneklik katsayılarına göre havayolu yolcu talebinin lüks bir mal olduğu sonucunu göstermektedir. FMOLS yönteminin havayolu yolcu talebinin uzun dönemli fiyat esnekliğini gösteren sonuçlarına göre ise, havayolu yolcu talebi ile fiyat arasında beklentilere uygun olarak negatif yönlü bir ilişki söz konusudur. Uygulanan yöntemin istatiksel olarak anlamlı olmayan sonuçları, havayolu bilet fiyatlarında oluşan \%1'lik bir artışın, havayolu yolcu talebini \%0.26 oranında azaltacağını tahmin etmektedir. Bu doğrultuda, fiyattaki artışa göre havayolu yolcu talebindeki düşüşün daha az olacağ kısa dönemli fiyat ve gelir esnekliğinin katsayıları VECM ile tahmin edilmektedir. Uygulanan VECM için kurulan model (1) nolu denklemdeki gibidir.

$$
d(\ln H Y T)=\beta_{0}+\sum_{\mathrm{i}=1}^{n} \beta_{1 \mathrm{i}} d(\ln H Y T)_{\mathrm{t}-\mathrm{i}}+\sum_{\mathrm{i}=1}^{\mathrm{n}} \beta_{2 \mathrm{i}} d(\ln H P)_{\mathrm{t}-\mathrm{i}}+\sum_{\mathrm{i}=1}^{n} \beta_{a \mathrm{i}} d(\ln G D P)_{\mathrm{t}-\mathrm{i}}+\gamma E C_{\mathrm{t}-1}+\varepsilon_{\mathrm{i}}
$$

(1) nolu modelde yer alan $E C_{t-1}$ hata düzeltme terimini ve n katsayısı gecikme sayısını ${ }^{\gamma}$ hata düzeltme katsayısını, "d" fark terimini, t model için geçerli zaman periyodunu, ${ }^{\varepsilon_{i}}$ ise otokorelasyonlu olmayan hata terimini temsil etmektedir. $d(\operatorname{lnHYT}), d(\operatorname{lnHP})$ ve $d(\operatorname{lnGDP})$ ise değişkenler arasındaki kısa dönemli ilişkileri göstermektedir. Tablo 6'da kısa dönemli havayolu yolcu talebinin fiyat ve gelir esnekliğinin katsayılarını gösteren VECM sonuçları gösterilmektedir.

\begin{tabular}{|l|l|l|}
\hline $\ln H Y \boldsymbol{T}$ & $\boldsymbol{L n G D P}$ & $\boldsymbol{L n H P}$ \\
\hline 1000000 & 1.705014 & -0.544400 \\
\hline & $(0.45530)$ & $(0.26437)$ \\
\hline & {$[-3.74481]$} & {$[-2.05921]$} \\
\hline
\end{tabular}

Tablo 6: Klsa Dönemli Esneklik Katsayıları 
VECM modeli sonuçlarına göre, GSYİH'da oluşan \%1'lik değişim havayolu yolcu talebini \%1.70 oranında arttırmaktadır. Havayolu yolcu talebinin kısa dönem gelir esnekliğine göre lüks mal olduğu ifade edilebilir. Havayolu yolcu talebinin kısa dönem fiyat esnekliğine göre ise istatiksel ve iktisadi olarak anlamlı olduğu söylenilebilir. Elde edilen sonuca göre, havayolu yolcu bilet fiyatlarındaki \%1'lik bir artış kısa dönemde havayolu yolcu talebini \%0.54 oranında azaltmaktadır. Ayrıca, -0.601 olarak hesaplanan hata düzetme terimi katsayısının negatif ve istatiksel olarak anlamlı olması, bağımsız değişkenler olan GSYİH ve havayolu bilet satış fiyatında oluşacak bir şok durumunda yaklaşık olarak 2 yıl içerisinde havayolu yolcu talebinin dengeye geleceğini göstermektedir.

\section{Sonuç}

Dünya ekonomisinin önemi ve hacmi her geçen gün artan bir bileşeni olan havacılık sektöründe hem firmalar hem de hükümetlerin planlamaları açısından talep, önemli bir belirleyici unsurdur. Bu noktadan hareketle çalışmamızda Türkiye'de havayolu yolcu talebinin ulusal düzeyde fiyat ve gelir esnekliklerinin tahmini amaçlanmıştır. Analizler sonucunda havayolu yolcu talebinin uzun dönemde gelir esnekliği katsayısı 3.29 ve fiyat esnekliği katsayısı ise -0.26 olarak; kısa dönemde ise gelir esnekliği katsayısı 1.70 ve fiyat esnekliği katsayısı ise -0.54 olarak tahmin edilmiştir. Havayolu taşımacılığı talep esneklikleri ile ilgili olarak genel ve belirli bir değer bulunmamakla beraber, çalışmamızda ulusal düzey için elde edilen esneklik tahminlerinin literatür ile uyumlu olduğu görülmektedir. Türkiye'de havayolu yolcu talebi fiyat esnekliğinin düşük olması, havacılık sektöründe rekabetçi yapının ancak 2003 yılından itibaren uygulamaya konulan "serbest havacılık politikası" sonrasında oluşmaya başlaması ve hala gelişim içerisinde olması ve ulusal düzeyin yüksek bir kümelenme düzeyi oluşu ile ilişkilendirilebilir. Elde edilen gelir esnekliği değerleri ise havayolu seyahatinin Türkiye'de "lüks mal" sınıfı içerisinde olduğuna işaret etmektedir.

\section{Kaynakça}

- Alperovich, \& Machnes, 1994. "The role of wealth in the demand for international air travel." Journal of Transport Economics and Policy, 163-173.

- $\quad$ ATAG. 2005. The Economic and Social Benefits of Air Transport

- . .http://www.icao.int/Meetings/wrdss2011/Documents/JointWorkshop2005/AT GSoc ialBenefits AirTransport.pdf

- $\quad$ ATAG,. 2016. Aviation Benefits Beyond Borders,

- http://aviationbenefits.org/media/149668/abbb2016_full_a4_web.pdf

- Brons, Pels, Nijkamp, Rietveld, 2002. "Price elasticities of demand for passenger air travel: a metaanalysis". Journal of Air Transport Management, 8(3), 165-175.

- Çetin, 2016.Airline Deregulation in Turkey.

- https://www.researchgate.net/publication/298370439_Airline_Deregulation_in_Turkey

- Doganis, 2002. Flying off course: The economics of international airlines. Routledge.

- Gillen, Morrison,,Stewart,, 2003. “Air travel demand elasticities: Concepts, issues and measurement". Department of Finance, Government of Canada.

- Grančay, 2010. "The economic impacts of air transport liberalization" Zagreb International Review of Economics and Business, 13(2), 73-88.

- IATA, 2008. Air Travel Demand.

- http://www.iata.org/publications/economic-briefings/air_travel_demand.pdf

- InterVISTAS. 2007. Estimating Air Travel Demand Elasticities.

- https://www.iata.org/whatwedo/Documents/economics/Intervistas_Elasticity_Study_2007.pdf

- Korul ve Küçükönal, 2003., “Türk sivil havacılık sisteminin yapısal analizi” Ege Akademik Baklş. 3 (1), 24 38.

- Njegovan, 2006. Elasticities of demand for leisure air travel: A system modelling approach. Journal of Air Transport Management, 12(1), 33-39.

- Taneja, 1971." A model for forecasting future air travel demand on the North Atlantic" Cambridge, Mass. Massachusetts Institute of Technology, Flight Transportation Laboratory

- Tsekeris, 2009. "Dynamic analysis of air travel demand in competitive island markets" Journal of Air Transport Management, 15(6), 267-273.

- Varian, 2010. Intermediate Microeconomics: a Modern Approach. WW Norton, New York.

- Vasigh,,Ken, Thomas, 2008. Introduction to Air Transport Economics: FromTheory to Applications. Ashgate Publishing, Ltd, Hampshire. 


\title{
Seçilmiş İmalat Sanayi Alt Sektörlerinde Sektöründe Türkiye ve Dünya Arasındaki Dikey ve Yatay Endüstri İçi Ticaret \\ Vertical and Horizontal Intra-Industry Trade between Turkey and the World in the Selected Manufacturing Industry Sub-Sectors
}

\author{
Prof. Dr. Cevat Gerni (Doğuş University, Turkey) \\ Assoc. Prof. Dr. Sabri Azgün (Atatürk University, Turkey) \\ Asst. Prof. Dr. Ziya Çağlar Yurttançıkmaz (Atatürk University, Turkey) \\ Prof. Dr. Ömer Selçuk Emsen (Atatürk University, Turkey)
}

\begin{abstract}
Intra industry trade is goods and services with the same or similar factor intensity in production or, two-way trade of goods and services that are close substitutes for each other as the demand side. There are two main categories of intra-industry trade: horizontal and vertical intra-industry trade. Intra-industry trade in similar products with differentiated varieties is horizontal intra-industry trade, the intra-industry trade of differentiated goods, which differ in terms of quality and price, is vertical intra trade. The main objectives of this paper are to explain the extent of vertical and horizontal intra-industry trade in the Turkey's foreign trade with the world in the selected manufacturing industry sectors. İn this study, using Abd-el-Rahman (1991) and Hine, Greenaway and Milner(1995) approach of Intra-industry trade decomposition methods has been analyzed the extent and development of vertical and horizontal intra-industry trade In the selected manufacturing industry sub-sectors between Turkey and The World for the period 2010:01-2016:11 by unit value indices.
\end{abstract}

\section{Giriş}

Endüstri-içi ticaret, kullanılan girdiler ve tüketim açısından birbirine yakın ikamesi olan malların eşanlı ithalat ve ihracatı olarak tanımlanabilir. Dolayısıyla, üretim, tüketim veya her ikisinde de yakın ikamesi bulunan aynı endüstriye ait malların hem ihraç hem de ithal edilmesi endüstri-içi ticaret adlandırılmaktadır. Bu tanımdan hareketle endüstri-içi ticaret, benzer faktör yoğunluklarına sahip mallar arasında gerçekleşen ticaret biçimidir. Endüstri-içi ticaret, belli bir mal kategorisinde, bütünüyle aynı endüstrinin ithalatıyla aynı düzey bir endüstrinin ihracat değeri olarak tanımlanabilir (Grubel ve Lloyd, 1971: 249).

Yatay ve dikey endüstri içi ticaret, endüstri içi ticaretteki önemli bir gelişme alanıdır. Benzer malların mübadelesi yatay endüstri-içi ticaret; kalite ve fiyat açısından farklılık içeren malların dış ticareti ise dikey endüstri içi ticaret olarak ifade edilebilir. Yatay endüstri içi ticarette uzmanlaşmave ölçek ekonomilerinden faydalanılarak benzer faktör donanımlarına sahip ekonomilerde uluslararası dış ticareti sağlarken, dikey endüstri içi ticaret işgücü niteliği veya Ar-Ge harcamaları gibi nedenlerle farkle faktör donanıma sahip ekonomilerdeki uluslararası dış ticaret yapisin yansitır.

Dikey endüstri içi ticaretin ölçümüne dönük çalışmalar endüstri içi ticaret literatürünün en güncel uygulama alanlarından biridir. Çünkü yatay ve dikey endüstri içi uzmanlaşma sektörel düzeyde ekonomik gelişme ve rekabet gücündeki değişimin de temel göstergesidir (bkz. Falvey, 1981; Helpman, 1981; Flam ve Helpman, 1987; Abd- El Rahman,1991; Aturupanevd., 1999; Greenway vd., 1995; Durkin ve Krygier, 2000; Fukau vd., 2003; Şimsek, 2005; Han ve Lee, 2012). Yatay ve dikey endüstri içi ticaret ayrımını modellerken benzer mal veya mal grupları arasındaki farklılıkları dikkate alarak yatay ve dikey endüstri iç ticareti incelemektedirler.

$\mathrm{Bu}$ çalışma dört kısımdan oluşturulmuştur. Birinci kısım çalışmanın girişidir. İkinci kısımda kavramsal çerçeve verilmektedir. Üçüncü kısımda yatay ve dikey endüstri içi ticaretin ölçüm metodolojisi ve analizi verilmekte ve dördüncü kısım ise analizlerden elde edilen değerlerin değerlendirildiği sonuç bölümdür.

\section{Kavramsal Çerçeve}

Endüstri-içi ticaret, yatay ve dikey endüstri-içi ticaret olmak üzere iki temel kategoriye ayrılır. Benzer malların mübadelesi yatay endüstri-içi ticaret; daha yüksek derecede proses edilmiş çıktılar için girdi mübadelesini dikey endüstri-içi ticaret olarak ifade edilmektedir. Tüketicileri fazla çeşitlilikte mal tüketmeyi arzuladıkları ve her bir malın birden fazla üreticinin ürettiği varsayılmaktadır. Mallar tüketicilerin malın özelliklerini algılayışlarına bağlı olarak yatay olarak farklılaşmaktadır. Her bir mal grubunu üreten üretici azalan maliyetlerle karşı karşıyadır. Ölçek ekonomileri ile yatay ürün farklılaşması arasındaki etkileşim yatay endüstri içi ticarete yol açmaktadır. Diğer bir ifadeyle farklılaştırılmış çeşitlere sahip benzer ürünlerin endüstri-içi dış ticareti yatay endüstri-içi ticaret, kalite ve fiyat açısından farklılığı bulunan farklılaştırılmış malların endüstri-içi dış ticareti ise dikey endüstri içi ticaret olarak tanımlanmaktadır. Yatay endüstri içi ticarette tam rekabet koşullarında olmayan piyasa yapısı baskın unsur olurken, dikey endüstri içi ticarette kalite yönüyle olduğu gibi, karşılaştırmalı üstünlüklere dayalı olarak ürün farklılaştırması dinamikleri etken olmaktadır. 
Rekabet eden veya ikame malların ithalat ve ihracatı yatay endüstri-içi ticaret, nihai ürünün imalatında kullanılan farklı aşamalardaki malların ithalat ve ihracatı dikey endüstri-içi ticaret olarak ayrıştırılmaktadır. (Grubel ve Lloyd, 2003: xiii). Diğer taraftan, yatay ürün farklılaştırması ve dikey ürün farklılaştırması ayrımı yapılmaktadır. Yatay ürün farklılaştırması, farklı tarzlarda karakterize edilen bir ürünün farklı çeşitlerinden oluşurken, dikey ürün farklılaştırması ise farklı seviyede hizmet sunan farklı çeşitlerden oluştuğu belirtilmektedir (Greenaway vd., 1994). Dikey ürün farklılaşması kalite farklılıklarından meydana gelirken, endüstri-içi uzmanlaşma ölçeğe göre artan getiri ile birlikte düşünülmektedir. Yatay farklılaşma, monopolistik rekabet kapsamında, her üreticinin malını farklılaştırmaya çalışarak pazar payını arttırmaya çalışmasından kaynaklanmaktadır. Mallar özünde aynıdır, ama farklı bileşimlerle üretilmiştir. Bu bakımdan, malların kalitelerindeki çeşitlenme ve fiyat farklılıkları dikey endüstri-içi ticarete, fiyatlarda sistematik değişim yaratmayan ürünün teknolojik özellikleri veya karakteristiklerindeki farklılaşma ise yatay endüstri-içi ticarete yol açmaktadır. Bir başka deyişle, dikey endüstriiçi ticaret, farklı kalitelerdeki malların, yatay endüstri-içi ticaret ise aynı kalitedeki malların endüstri-içi dış ticaretidir.

Yatay endüstri-içi ticaret, daha çok benzer faktör donanımlarına sahip ülkeler arasında gerçekleşen iki yönlü ticaret şeklidir. Benzer faktör donanımına sahip ülkelerin gelir düzeyleri de birbirine benzer olacağından aynı malın farklılaşmış çeşitlerine olan talep, farklı faktör donanımlarına sahip ülkelere göre daha yüksek olacaktır. Ülkelerin gelir seviyeleri bir birine ne kadar yakınsa, yatay endüstri-içi ticarette o kadar yüksek olacaktır. Ayrıca yatay endüstri-içi ticaretin mal farklılaştırması ve ölçek ekonomileri ile pozitif yönlü bir ilişkisinin olduğu kabul edilmektedir. Endüstride faaliyet gösteren firma sayısı ve firmaların üretim ölçeği artıkça yatay endüstri-için ticarette artacaktır.

Dikey endüstri-içi ticaret, farklı kalitelerdeki malların eşanlı dış ticaretidir. Dikey endüstri-içi ticarette malların kalitelerinin üretimde kullanılan emek/sermaye oranına bağlı olarak belirlenmekte ve aynı emek/ sermaye oranına sahip malların kalitelerinin aynı olduğu ifade edilmektedir. Dikey endüstri-içi ticaret, geleneksel faktör donatım modellerinden hareketle, sermaye yoğun ülkelerin daha kaliteli ve emek yoğun ülkelerin ise daha düşük kaliteli mallar üreteceği görüşüne dayanmaktadır (Falvey, 1981: 498). Ancak, ülke grupları içerisinde gelir eşit dağılmadığından, yüksek gelir seviyesine sahip ülkeler arasındaki düşük gelir grupları düşük kaliteli malları talep edebilmektedirler. Benzer şekilde düşük gelir seviyesine sahip ülkelerdeki yüksek gelirliler daha kaliteli mal tüketmek isteyeceklerdir. Bunun sonucunda iki ülke grubu arasında endüstri-içi ticaret doğacaktır. Dolayısıyla dikey endüstri-içi ticarette ölçek ekonomilerinin ve eksik rekabet piyasalarının etkisi olduğu söylenemez (Narin, 2002).

Ülkelerarası ekonomik gelişme farklılıkları, endüstriler arası ticarete yol açması yanında, farklılaştırılmış mallarda endüstri-içi uzmanlaşma ve dolayısıyla dikey endüstri-içi ticaret ortaya çıkmaktadır. Ülkeler arasında gelişmişlik düzeyleri bakımından farklılık varsa, endüstri-içi ticaret dikey endüstri-içi ticaret şeklinde ortaya çıkmaktadır. Dikey endüstri-içi ticaret çoğunlukla ülkeler arasındaki faktör donatım ile açıklanmaktadır. Dolayısıyla teorik olarak gelişmekte olan ülkeler ile gelişmiş ülkeler arasındaki ticaretin çoğunlukla dikey endüstri-içi ticaret biçiminde gerçekleşmesi beklenmektedir.

$\mathrm{Bu}$ bağlamda uluslararası ticaretin yapıldığı ülkelerin gelişmişlik düzeyi (talep yapısı, endüstrinin yapısı), ortalama piyasa hacmi, ülkeler arası uzaklık ve dış ticaret üzerindeki engeller endüstri içi ticareti belirleyici konumdadır. Ekonomiye has nitelikler ise mal farklılaştırması, ölçek ekonomileri, doğrudan yabancı sermaye yatırımları, değişim maliyetleri ve mal grupları toplulaştırma derecesi olarak sıralanabilir (Loertcscher ve Wolter, 1980).

İki ülke arasındaki düşük ve yüksek kaliteli benzer mallar ticareti endüstri-içi ticarete yol açmaktadır. Azalan maliyetlerle çalışan endüstriler ticarete açıldığında, talep benzerliği nedeniyle endüstri-içi ticaret ortaya çıkmaktadır. Benzer faktör donatımına sahip ülkeler arasındaki ticaret, yatay endüstri-içi ticaret şeklinde gerçekleşmekte ve klasik ticaret teorileri ile açıklanamamaktadır. Dikey farklılaşmada ise farklı ürün kaliteleri ve farklı fiyatlar söz konusu olup, tüketiciler bu mal çeşitlerini kalitelerine göre derecelendirmektedir. Fiyat farklılıkları üretim fonksiyonlarından gelmektedir. Aynı ürün grubuna ait ancak farklılaştırılmış nitelikteki mallarda, kalite farklılıkları fiyat farklılıklarına neden olmakta, bu nedenle farklı fiyatlar ortaya çıkmaktadır. Ürün farklılaşması, kalitedeki farklılıklarla açıklanmaktadır (Emirhan, 2005). Faktör donatımı boyutuyla nispeten sermaye zengin ülkelerin, daha kaliteli mallar üretip ihraç edecekleri düşünülmektedir. Dolayısıyla yatay ve dikey endüstri-içi ticaretin belirleyicileri farklık arz eder. Bu noktada yatay endüstri-içi ticaretinin belirleyicileri; ölçek ekonomileri ve ürün farklılaştırması vb. endüstri-tabanlı değişkenlerden oluşur. Dikey endüstri-içi ticaretin belirleyicileri ise; kişi basına gelir farklılıkları vb. ülkeye-has faktörlerdir. Yatay endüstri-içi ticaretin ürün farklılaşması, ölçek ekonomileri, piyasa büyüklüğü ve dolaysız yabancı yatırımlarla pozitif, beşerî sermaye donatımı ve coğrafi mesafe ile negatif ilişkili olduğu ifade edilmektedir. Nispi faktör donatımları tarafından belirlenen dikey endüstri-içi ticaret, dolaysız yabancı yatırımlarla pozitif, ölçek ekonomileri ile negatif ilişkilidir. Bu durumda, yüksek kaliteli malların üretiminde işgücü basına daha yüksek sermaye kullanılması gerekmektedir. Ülkelerarası teknoloji farklılıklarının mevcudiyeti, dikey farklılaştırılmış mallarla ilişkilendirilmiştir. Ülkeler benzer faktör donatımlarına sahip ise, sermaye yoğun ülkeler arasındaki ticarete tamamıyla endüstri-içi ticaret, emek yoğun ülkeler arasındaki ticaret ise endüstriler arası ticaret niteliğindedir. 


\section{Yöntem ve Analiz}

Çalışmada ihracat ve ithalat birim değerleri hesaplanmasında TCMB istatistiklerinden faydalanılmış ve veri setinde imalat sanayi altında yer alan mal gruplarının ihracat ve ithalat değerleri aylık olarak toplanmıştır. Mal grupları bazında dış ticaret verileri ise UNCTAD'dan toplanmış ve endüstri-içi ticaret analizleri buradan alınan yıllık veriler ile yapılmıştır. Ancak, TCMB sınıflaması ile UNCTAD'dan alınan veri seti ile birebir uyum göstermediğinden veriler eşleştirilmiş ve benzer sektörler birbiri ile analiz konusu yapılmıştır. Burada 13: Tekstil ürünlerinin imalatı; 16: Ağaç, ağaç ürünleri ve mantar ürünleri imalatı (mobilya hariç) saz, saman ve benzeri malzemelerden örülerek eşyaların imalatı; 17: Kâğıt ve kâğıt ürünlerinin imalatı; 22: Kauçuk ve plastik ürünlerin imalatı; 24: Ana metal sanayi ürünleri imalatı; 25: Makine ve teçhizat hariç, fabrikasyon metal ürünleri imalatı; 27: Elektrikli teçhizat imalatı; 29: Motorlu kara taşıtı, treyler (römork) ve yarı treyler (yarı römork) imalatı kapsamındaki ürünleri içerir. Endüstri-içi ticaretin ölçümünde 2010-2015 dönemi yıllık veriler kullanılmış ve EİT düzeyi 0.7 'nin üzerinde olduğu mal grupları yatay-dikey EİT analizine konu edilmiştir. Çalışmada yatay ve dikey endüstri-içi ticaret değerlerini hesaplamadan önce, seçilmiş imalat sanayi alt sektörlerinde Türkiye'nin Dünya ile olan ticaretinde endüstri-içi ticaret düzeyi ölçümü yapılmıştır. Bu kapsamda yapılan analizde endüstri-içi ticaret düzeyi yüksek olan sektörlerde yatay ve dikey endüstri-içi ticaret analizlerine geçilmiştir. İktisat literatüründe endüstri-içi ticaretin ölçümünde genel kabul görmüş olan Grubel-Lloyd (GL) indeksi yönteminde, EİT, bir ülkenin toplam ticaretinin bir yüzdesi olarak ifade edilmektedir. Endüstri “i” için EITT oranı;

$$
\mathrm{GLi}=1-[|\mathrm{Xi}-\mathrm{Mi}| /(\mathrm{Xi}+\mathrm{Mi})]
$$

şeklindedir. Burada Xi ve Mi, ihracat ve ithalatı ifade etmektedir. GLi değeri, 0 ile 1 arasında olacaktır. "i" sektöründe ticaretin tek yönlü olması halinde, GLi sıfıra eşit olacaktır. GLi'nin 1'e eşit olması ise, “i” sektöründe ihracat ve ithalat miktarının eşit olması anlamındadır ve endüstri-içi ticaretin geliştiğini gösterir. Toplam EİT, dikey ve yatay olarak ikiye ayrılabilmektedir. Dikey EIT, aynı sektörde farklı kalitelerde malların iki yönlü ticaretini kapsamaktadır ve gelişmiş ülkeler ile gelişmekte olan ülkeler arasında görülmektedir. Dikey EİT, ülkelere özgü farklılıklara göre belirlenmekte ve farklı gelişmişlik düzeyindeki ülkeler arası ticareti açıklamaktadır (Erün, 2010).

\begin{tabular}{|c|c|c|c|c|c|c|c|}
\hline UNCTAD seti & TCMB seti & 2010 & 2011 & 2012 & 2013 & 2014 & 2015 \\
\hline [65] Textile yarn & 13 Tekstil ür. & 0.844 & 0.825 & 0.736 & 0.717 & 0.725 & 0.725 \\
\hline $\begin{array}{l}{[63] \text { Cork and }} \\
\text { wood man. }\end{array}$ & 16 Agac, ür. & 0.906 & 0.852 & 0.812 & 0.835 & 0.991 & 0.927 \\
\hline $\begin{array}{l}\text { [64] Paper and } \\
\text { paper } \mathrm{m} \text {. }\end{array}$ & $\begin{array}{l}17 \text { Kagit ve kagit } \\
\text { ürün. }\end{array}$ & 0.596 & 0.620 & 0.718 & 0.758 & 0.774 & 0.824 \\
\hline [62] Rubber man & $\begin{array}{l}22 \text { Kauçuk ve } \\
\text { plastik. }\end{array}$ & 0.796 & 0.777 & 0.829 & 0.867 & 0.823 & 0.862 \\
\hline $\begin{array}{l}{[67] \text { Iron and }} \\
\text { steel }\end{array}$ & 24 Ana metal ü. & 0.975 & 0.947 & 0.917 & 0.973 & 0.976 & 0.864 \\
\hline $\begin{array}{l}\quad[69] \\
\text { Manufactures } \\
\text { metal, n.e.s. }\end{array}$ & $\begin{array}{l}25 \text { Makine ve } \\
\text { techizat haric, ür. }\end{array}$ & 0.772 & 0.783 & 0.733 & 0.759 & 0.738 & 0.797 \\
\hline $\begin{array}{l}{[77] \quad \text { Electrical }} \\
\text { machinery, app. }\end{array}$ & $\begin{array}{l}27 \text { Elektrikli } \\
\text { techizat i. }\end{array}$ & 0.931 & 0.926 & 0.983 & 0.957 & 0.948 & 0.997 \\
\hline $\begin{array}{cc}78] & \text { Road } \\
\text { vehicles } & \end{array}$ & $\begin{array}{l}29 \text { Motorlu kara } \\
\text { taş. }\end{array}$ & 0.987 & 0.958 & 0.983 & 0.999 & 0.938 & 0.994 \\
\hline
\end{tabular}

Tablo 1: Grubel-Lloyd Indeksine Göre Endüstri-içi Ticaret Ölçümleri

Yatay ve dikey endüstri-içi ticaret düzeylerinin belirlenmesinde kullanılan yöntem, malların kalitelerine göre sınıflandırılması, yani aynı kalitedekiler ve farklı kalitedekiler şeklinde ayrılmasıdır. Uygulamalı çalışmalarda kalite farklılıklarını temsil etmek üzere ihracat ve ithalât birim değerleri farklılıkları esas alınmaktadır. Birim değer endeksleri, aynı mal sepetinde yer alan malların ortalama fiyatlarını vermektedir. Birim değer endeksleri kullanılmasının nedeni, malların birim fiyatları kalitenin bir göstergesi olarak değerlendirildiğinden, birim değer endeksleri kullanılmaktadır. Bir başka ifadeyle, birim fiyatı daha yüksek malların diğer düşük birim fiyatlı mallara göre daha kaliteli olduğu düşünülmektedir. İthalat ve ihracat birim değerleri, ton başına, kilogram başına, metrekare başına vb. şekillerde hesaplanmaktadır.

İhracat birim değerinin, ithalât birim değerine oranı, örneğin $\pm \% 15$ aralığında ise yatay endüstri-içi ticaret ve bu aralığın dışında kalan oranlarda ise dikey endüstri-içi ticaret söz konusu olmaktadır. Kısaca birim değerler oranı $\pm \% 15$ aralığında kalan malların fiyatları benzer olduğundan, aynı kalitede (yatay) oldukları varsayılır. Bu \%30’luk 
bant dışında kalan mallar ise farklı kalitelerde (dikey) oldukları varsayılır. Yatay ve dikey endüstri-içi ticaret aşağıdaki gibi hesaplanır:

$$
B_{j k}=H B_{j k}+V B_{j k}
$$

(2) nolu eşitlikte $B_{j k}$ toplam endüstri-içi ticareti, $H B_{j k}$ yatay endüstri-içi ticareti, $V B_{j k}$ ise dikey endüstri-içi ticareti temsil etmektedir. Buna göre $H B_{j k}$ ve $V B_{j k}$ değerleri ise aşağıdaki formlara göre hesaplanır:

$$
\begin{aligned}
& H B_{j k}=1-\alpha \leq \frac{U V_{i j k}^{X}}{U V_{i j k}^{M}} \leq 1+\alpha \\
& V B_{j k}=\frac{U V_{i j k}^{X}}{U V_{i j k}^{M}}\left\langle 1-\alpha \text { ya da } V B_{j k}=\frac{U V_{i j k}^{X}}{U V_{i j k}^{M}}\right\rangle 1+\alpha
\end{aligned}
$$

(3) ve (4) nolu eşitliklerdeki $U V^{X}$ : ihracat birim değeri; $U V^{M}$ : ithalat birim değeri; $\alpha$ kabul edilen aralık değeridir. Buna göre $\alpha=0.15$ ise, $\pm \% 15$ aralı̆ğına göre yatay ve dikey endüstri-içi ticaret değeri hesaplanır. \pm $\% 15$ aralığının seçilme nedeni, ulaştırma ve navlun maliyetlerinin, malın fiyatının \%15'ini geçmeyeceğinin düşünülmesidir. Alfa $(\alpha) ; \%+/-15$, taşımacıllk ve sigorta giderlerini göstermektedir (Greenaway, 1999). Eğer aralık daha küçük seçilirse, yatay endüstri-içi ticaret daha küçük; dikey endüstri-içi ticaret daha büyük çıkacaktır. Dolayısıyla $\alpha=0,15$ kabul edilirse, endüstri-içi ticaretin tespitinde kullanılan aralık 0.85 ve 1.15 değerleri arasındadır. Ticarete konu olan malların, ihracat ve ithalat birim değerleri arasındaki fark $\% 15$ 'ten küçükse, "yatay farklılaşma"; \%15’ten büyükse, "dikey farklılaşma" söz konusudur.

Yatay ve dikey EİT ölçümünde TCMB'den alınan ihracat ve ithalat birim endeks değerleri aylık veri şeklindedir. Ancak, uygulamada söz konusu veri seti aylık ortalama şeklinde yeniden düzenlenmiş ve on iki aylık ortalamalar alınarak ihracat ve ithalat birim endeks değerleri yıllık olacak şekilde yeniden düzenlenmiştir. Burada 13: Tekstil ürünlerinin imalatı; 16: Ağaç, ağaç ürünleri ve mantar ürünleri imalatı (mobilya hariç) saz, saman ve benzeri malzemelerden örülerek eşyaların imalatı; 17: Kâğıt ve kâğıt ürünlerinin imalatı; 22: Kauçuk ve plastik ürünlerin imalat1; 24: Ana metal sanayi ürünleri imalat1; 25: Makine ve teçhizat hariç, fabrikasyon metal ürünleri imalatı; 27: Elektrikli teçhizat imalatı; 29: Motorlu kara taşıtı, treyler (römork) ve yarı treyler (yarı römork) imalatı kapsamındaki ürünleri içerir.

\begin{tabular}{|l|c|c|c|c|c|c|c|c|}
\hline Y1llar & $\begin{array}{c}\mathrm{Uvx} / \mathrm{U} \\
\mathrm{vm}\end{array}$ & $\begin{array}{c}\mathrm{Uvx} / \mathrm{U} \\
\mathrm{vm}\end{array}$ & $\begin{array}{c}\mathrm{Uvx} / \mathrm{U} \\
\mathrm{vm}\end{array}$ & $\begin{array}{c}\mathrm{Uvx} / \mathrm{U} \\
\mathrm{vm}\end{array}$ & $\begin{array}{c}\mathrm{Uvx} / \mathrm{U} \\
\mathrm{vm}\end{array}$ & $\begin{array}{c}\mathrm{Uvx} / \mathrm{U} \\
\mathrm{vm}\end{array}$ & $\begin{array}{c}\mathrm{Uvx} / \mathrm{U} \\
\mathrm{vm}\end{array}$ & $\begin{array}{c}\mathrm{Uvx} / \mathrm{U} \\
\mathrm{vm}\end{array}$ \\
\hline $\begin{array}{c}2010 \\
\text { Ort. }\end{array}$ & 1.000 & 1.005 & 1.002 & 1.001 & 1.000 & 1.000 & 1.000 & 1.000 \\
\hline $\begin{array}{c}2011 \\
\text { Ort. }\end{array}$ & 1.001 & 0.970 & 0.993 & 1.004 & 1.031 & 1.011 & 1.065 & 0.997 \\
\hline $\begin{array}{c}2012 \\
\text { Ort. }\end{array}$ & 1.020 & 1.004 & 1.074 & 0.999 & 1.094 & 0.950 & 1.074 & 0.995 \\
\hline $\begin{array}{c}2013 \\
\text { Ort. }\end{array}$ & 1.070 & 1.001 & 1.096 & 1.025 & 1.080 & 0.913 & 1.022 & 0.986 \\
\hline $\begin{array}{c}2014 \\
\text { Ort. }\end{array}$ & 1.071 & 0.931 & 1.138 & 1.037 & 1.104 & 0.915 & 1.018 & 0.983 \\
\hline $\begin{array}{c}2015 \\
\text { Ort. }\end{array}$ & 1.036 & 0.915 & 1.131 & 1.026 & 1.103 & 0.881 & 0.955 & 0.948 \\
\hline $\begin{array}{c}2016 \\
\text { Ort. }\end{array}$ & 1.033 & 0.940 & 1.120 & 1.015 & 1.184 & 0.850 & 0.941 & 0.936 \\
\hline
\end{tabular}

Tablo 2: Yatay ve Dikey Endüstri-içi Ticaret Ölçümleri

Greenaway (1999)'in çalışması yatay ve dikey EİT düzeyinin belirlenmesinde referans alınan bir çalışmadır. Bu kapsamda taşımacılık ve sigorta giderlerini gösteren katsayı $(\alpha=0,15)$ kabul edildiğinde, yatay ve dikey EITT 
aralığı 0.85 ve 1.15 değerleri arasında kalır. Bu kapsamda ticarete konu olan malların, ihracat ve ithalat birim değerleri 0.85 ve 1.15 arasında ise yatay EİT, 0.85 'den küçük, 1.15'den büyük olduğunda ise dikey EİT söz konusu olur. Yapılan analizlerde EİT düzeyi yüksek olan seçili mal gruplarında tüm mal grupları için yatay EİT'nin olduğu görülmüştür. Bu durum Türkiye'de seçili imalat sanayi ürünleri dış ticaretinde EİT düzeyi yüksek olan ürünlerde benzer kalite düzeyine sahip malların ticaretinin gerçekleştiği görülmektedir.

\section{Sonuc}

Dış ticarette rekabet gücü üstünlüğü elde etme, gelişmekte olan ülkelerin önemli sorunları arasında yer alır. Rekabet gücü üstünlügü elde etmenin yolu yeni teknik bilginin yaygın olarak kullanıldığg katma değeri yüksek ürünlerden geçmektedir. İmalat sanayi sektöründe üretilen hasılanın yaklaşık üçte ikisini üretmekte ve yeni mal icadı şeklinde tanımlanan üretim buluşu ve yeni bir üretim yöntemi olarak ifade edilen üretim süreci buluşlarının yaygın olarak kullanıldığı sektördür. Çalışmada imalat sanayi alt sektörlerinde önce endüstri-içi ticaretin varlığı ve düzeyi araştırılmış, daha sonra ise yatay ve dikey endüstri içi ticaret değerleri incelenmiştir.

Türkiye için yapılan analizlerde ihracat ve ithalat birim değerleri TCMB'den ve ülkeler arasındaki dış ticaret verileri ise UNCTAD'dan alındığından, verilerin uyumlaştırılması çeşitli zorlukları da beraberinde getirmiş ve analizlerde belirli imalat sanayi sektörleri için yapılabilmiştir. Ayrıca dikey ve yatay endüstri-içi ticaretin ölçümünde endüstri-içi ticaretin belirli bir düzeyin üstünde olması gerekmektedir. Dolayısıyla 0.7'nin üstündeki sektörler seçilmiş ve analizler bu sektörlere uygulanmıştır.

Türkiye ekonomisinde uygun değişkenlerden hareketle yapılan hesaplamalar sonucunda; elektrikli teçhizat, motorlu kara taşıtları ile kâğıt ve kâğı ürünleri gibi bazı sektörlerde endüstri-içi ticaret oranının yükseldiği görülmektedir. Çalışmada hemen hemen bütün sektörlerde endüstri-içi dış ticaretin yatay endüstri-içi ticaret şeklinde gerçekleştiği görülmektedir. Ancak, kâğıt ve kâğı ürünlerinin imalatı ile ana metal sanayi sektörlerinde yatay endüstri-içi ticaretten dikey endüstri-içi ticarete doğru bir evrilmenin varlığı tespit edilmiştir. Ayrıca Türkiye ekonomisinde 2010 sonrası dönemde genel olarak analize konu olan sektörlerde yaşanan değişimin daha çok benzer kalite ve fiyat özelliği taşıyan ürünlerin dış ticaretini arttığını göstermektedir. Sonuç olarak Türkiye'nin analize konu olan sektörlerde dış ticaretinin hemen hemen tamamı yatay endüstri içi ticaret şeklinde gerçekleştiği görülmektedir. Türkiye'de yatay endüstri içi ticaretin yüksek çıkmasında özellikle belli sektörlerdeki yabancı sermaye yatırımlarının payının yüksekliğinden kaynaklandığı düşünülmektedir. Bu bağlamda Türkiye'nin yüksek katma değer oluşturan sektörlerde yerli kaynaklara dayalı olarak mal farklılaştırmasına gitmesi ve yüksek katma değerli ve kaliteli mallar üreterek dış ticarette dikey endüstri içi ticaretin artırılması büyük önem taşımaktadır.

\section{Kaynakça}

Abd El Rahman, K. (1991), "Firms' Competition and National Comparative Advantages as Joints Determinants of Trade Composition", Weltwirtschaftliches Archiv, 127 (1): 83-97.

Aturupane, C., Djankow, S. and Hokeman, B. (1997), "Determinants Of Intra Industry Trade Between East And Weast Europe", World Bank, Development Research Group, Policy Research Working Paper: 1850

Aturupane, C., Djankov, S. and Hoekman, B. (1999), "Horizontal and Vertical Intra-industry Trade between Eastern Europe and the European Union", Weltwirtschaftliches Archiv, 135 (1): 62-81.

Aydın, A. (2008), "Endüstri İçi Ticaret ve Türkiye: Ülkeye Özgü Belirleyicilerin Tespitine Yönelik Bir Araştırma”, Marmara Üniversitesi İktisadi ve İdari Bilimler Fakültesi Dergisi, 25 (2): 881-916.

Azgün, S., Yurttançıkmaz, Z. Ç., Gerni, M. ve Sarı, S. (2016), "Türkiye ve Orta Asya Türk Ülkeleri Arasında Endüstri İçi Ticaretin Düzeyi ve Sektörel Rekabet Gücünün Belirlenmesi”, International Conference on Eurasian Economies, 29-31 August 2016 - Kaposvar, HUNGARY.

Balassa, B., (1966), "Tariff Reductions and Trade in Manufactures among the Industrial Countries", New Haven, Conn.: Yale University, Economic Growth Center, 56 (3): 466-473.

Balassa, B.,Bauwens, L. (1987), "Intra Industry Specialization İn A Multi-Country And Multi Industry Framework", The Economic Journal, 97 (338): 923-939.

Bergstand, J. H. (1990), "The Heckssher-Ohlin Model, The Linder Hypothesis and The Determinants of Bilateral of Intra Industry Trade”, Economic Journal, 100 (403): 1216-1229.

Durkin, J. T. and Krygier, M. (2000), "Differences in GDP Per Capita and The Share of Intra-industry Trade: The Role of Vertically Differentiated Trade", Review of International Economics, 8 (4): 760-774.

Emirhan, P. N. (2005), Determinants of Vertical Intra-industry Trade of Turkey: Panel Data Approach", Dokuz Eylül University Faculty of Business Department of Economics Discussion Paper, 5 (05): 468-506.

Emsen, Ö. S. ve Çağatay, K. (2009), "Merkezi Asya ve Kafkas Ekonomilerinde Entegrasyonun Olabilirliği: AB'deki Kömür-Çelik Topluluğu Benzeri Su ve Enerjide İşbirliği Arayışı”, Ç.Ü. Sosyal Bilimler Enstitüsü Dergisi, 18 (1): 181-202.

Erün, G. (2010), “Türkiye ile AB, Gıda ve Canlı Hayvan Sektörü Dış Ticaretinde Endüstri İçi Ticaret Analizi”, Ekonomi Bilimleri Dergisi, 2 (1): 71-78. 
Falvey, R .(1981), “Commercial Trade Policy And Intra Industry Trade”, Journal of International Economics, 11: 495-511.

Flam H. and Helpman, E. (1987), "Vertical Product Differentiation and North-South Trade", American Economic Review, 77 (5): 810-822.

Fukao, K., Ishito, H. and Ito, K. (2003), "Vertical Intra-İndustry Trade and Foreign Direct Investment in East Asia", Journal of the Japanese and International Economies, 17 (4): 468-506.

Greenaway, D. (1985), International Trade Policy, ELBS Macmillan Publisher Ltd., London.

Greenaway, D., Hine, R. C. and Milner, C., (1995), "Vertical And Horizantal Intra Industry Trade: Across Industry Analysis For United Kingdom", The Economic Journal, 105 (433): 1505-1518.

Greenaway, D., Hine, R. C., Milner, C., and Elliott, R. (1994), “Adjustment and The Measurement of Marginal Intra-Industry Trade”, Weltwirtschaftliches Archiv, 13 0(2): 418-427.

Grubel, H. G. and Lloyd, P. J. (1971), “The Empirical Measurement of Intra-Industry Trade”, Economic Record, (47), 494-517; (Intra-Industry Trade içinde. Herbert G. Grubel and P.J. Lloyd (Eds.) (2003), Cheltenham: Edward Elgar Publishing, 247-270)

Grubel, H. G. and Lloyd, P. J. (Eds.) (2003), Intra-Industry Trade, (The International Library of Critical Writings in Economics Series), Cheltenham: Edward Elgar Publishing.

Hamilton, C. and Kniest, P. (1991), “Trade Liberalisation, Structural Adjustment And Intra-Industry Trade: A Note", Weltwirtschaftliches Archiv, 127 (2): 356-367.

Han, K. and Lee, J. (2012), "FDI and Vertical Intra-Industry Trade between Korea and China", Korea and the World Economy, 13 (1): 115-139.

Helpman, E. (1981), "International Trade in the Presence of Product Differentiation, Economies of Scale and Monopolistic Competition", Journal of International Economics, 11 (3): 305-340.

Martin-Montaner, J. A. and Rios, V.O. (2002), "Vertical Specialization and Intra-industry Trade: The Role of Factor Endowments", Weltwirtschaftliches Archiv, 138 (2): 340-365.

Lancaster, K.(1980), “Intra-Industry Trade Under Perfect Monopolisitic Competition”, Journal of International Economics, 10 (2): 151-175.

Li, Y., Dai, Q. L. and Huang, Q.B. (2015), “Analysis of the Influential Factors of Manufactured Products IntraIndustry Trade Between China-South Korea and China' Policy”, Theoretical Economics Letters, 5 (1): 114-124.

Loertscher, R. and Wolter, F. (1980), "Determinants of Intra-industry Trade: Among Countries and Across Industries", Weltwirtschaftliches Archiv, 116 (2): 280-293.

Martin-Montaner, J. A. and Rios, V. O. (2002), "Vertical Specialization and Intra-industry Trade: The Role of Factor Endowments", Weltwirtschaftliches Archiv, 138 (2): 340-365.

Şimşek, N. (2005), “Türkiye’nin Yatay ve Dikey Endüstri-İçi Dış Ticareti”, Dokuz Eylül Üniversitesi, İktisadi ve İdari Bilimler Fakültesi Dergisi, 20 (1): 43-62. 


\title{
Uluslararası Ekonomik İşbirliği ve Kalkınma Teşkilatı Üye Ülkeleri için Linder Teorisinin Ampirik Bir Analizi
} An Empirical Analysis of the Linder Theory for Organisation for
Economic Co-Operation and Development Member Countries

\author{
Prof. Dr. Ebru Çağlayan Akay (Marmara University, Turkey) \\ Asst. Prof. Dr. Zamira Oskonbaeva (Kyrgyzstan-Turkey Manas University, Kyrgyzstan)
}

\begin{abstract}
Linder theory is one of the main theories of the international trade based on the demand side. It implies that the countries with similar demand structures trade more intensely with one another. This study presents empirical evidence in support of the Linder theory of international trade for selected OECD Countries. In order to analyze the validity of Linder hypothesis for these countries, Panel Tobit approach has been employed using the annual data for the period 2001-2005. The empirical results provide evidence supporting the panel tobit model in terms of applicability and robustness. The results of the study also show some insights in support of the Linder hypothesis for OECD Countries.
\end{abstract}

\section{Giriş}

Staffan Burenstam Linder (1961) tarafından ortaya atılan Linder teorisi, dış ticaretin talep yönüne ilk defa önem verilmesini sağlayan teori olarak bilinmektedir. Bu teori özellikle benzer gelir düzeyine sahip ülkeler arasında dış ticaretin yoğunlaştığını ileri sürmektedir. Kişi başına milli geliri yüksek ülkeler kaliteli sanayi ürünlerini talep ederlerken kişi başına milli geliri düşük ülkeler düşük kaliteli mallara yöneleceklerdir. Buna göre yüksek gelirli ülkelerin daha çok yüksek gelirli ülkelerle düşük gelirli ülkelerin ise daha çok düşük gelirli ülkelerle ticaret yapması beklenmektedir (Kennedy, 2014).

Linder'e göre bir malın potansiyel ihraç malı sayılabilmesi için yurt içi talebinin olması gereklidir. Bu talebe temsili talep adı verilir. İç pazar doyuma ulaştı̆̆ında yerli üreticiler söz konusu mallar için dış pazara yönelmeye başlarlar. Böylece talep yapısı birbirine benzeyen ülkelerin daha yoğun ticari ilişkide bulunacağı öne sürülmektedir (Choi, 2002; Hirsch ve Lev, 1973; Grančay vd., 2016). Diğer bir deyişle söz konusu teoriye göre ihracat yerli üretimin bir uzantısı olarak ele alınabilir.

Linder teorisine göre dış ticarete konu olan mallar ilkel mallar (tarım malları) ve sanayi malları olmak üzere iki kategoride ele alınmaktadır (Shenkar vd., 2015). Sanayi ürünlerinin daha çok gelişmiş ülkeler tarafından üretilmiş olması nedeniyle teorinin ancak zengin ülkeler için geçerli olabileceğini varsaymaktadır. Teoriye göre ticareti yapılan sanayi mallarının benzer fakat farklılaştırılmış mallar olması gerekmektedir. Bu yönüyle Linder teorisi gelişmiş ülkeler arasında yüksek boyutlara ulaşan endüstri içi ticaret olgusuna açıklama getirmektedir (Carbaugh, 2009). Bu olgu ülkeler aynı tip ürünlerin hem ihracatını hem de ithalatını yaptıklarında ortaya çıkmaktadır. Bununla birlikte Linder teorisinin genel olarak hem endüstri içi hem de endüstriler arası ticareti açıklamada teorik bir temel sağladığı söylenebilir (Chow, vd.,1999). Linder’in ortaya attığı teoriye göre ülkeler arasındaki gelir farklılığı azaldıkça ticaret hacmi de artmaktadır.

Bu çalışmada seçilmiş OECD ülkelerinde (ABD, Kanada, İspanya, Danimarka, İtalya, Yeni Zelanda, Meksika, Almanya, Japonya, İsveç, Macaristan, Şili, İzlanda, Avusturya, Polonya, Lüksemburg, Türkiye, Çek Cumhuriyeti, Yunanistan ve Letonya) Linder teorisinin geçerli olup olmadığı incelenmektedir. Ele alınan ülkeler için 2001-2005 dönemine ait yıllık veriler kullanılmış ve rassal etkili panel Tobit modeli uygulanmıştır.

Çalışmada, giriş bölümünün ardından bu konuda yapılan ampirik çalışmalara değinilmiştir. Üçüncü bölümde veri seti ve değişkenler tanımlanmıştır. Daha sonra uygulamada kullanılan metodoloji açıklanmıştır. Çalışmamız elde edilen bulgular ve sonuç bölümü ile sona ermektedir.

\section{Literatür}

Linder ortaya attığı teorinin ancak gelişmiş ülkeler için geçerli olabileceğini vurgulamıştır (Linder, 1961). Bu sonuç diğer araştırmacıların çalışmalarında da destek bulmuştur (Hufbauer, 1970; Thursby ve Thursby, 1987; Linnemann ve Van Beers, 1988; Hanink, 1990). Ancak günümüzde gelişmekte olan ülkeler için de Linder etkisinin doğrulandığı çalışmalara rastlanılmaktadır (Arnon ve Weinblatt, 1998; McPherson vd., 2001; Bukhari vd., 2006; Aliyu ve Bawa 2015; Kahram, 2014).

$\mathrm{Bu}$ teori ortaya atıldıktan sonra teoriyi test etmek amacıyla yapılan ampirik çalışmaların sayısı artmaya başlamıştır. Linder hipotezini farklı ülkeler için farklı ekonometrik yöntemleri kullanarak inceleyen pek çok çalışma bulunmaktadır. Bunların bazılarında Linder hipotezini destekleyici sonuçlar elde edilirken diğerlerinde Linder etkisi bulunamamıştır. İlk çalışmalar sadece korelasyon analizi kullandıkları için eleştirilmişlerdir 
(McPherson vd., 2001). Son dönemlerde yapılan çalışmalarda daha ileri teknikler kullanılmaya başlamıştır. Tablo 1 'de bunlardan bazıları özetlenmiştir.

\begin{tabular}{|c|c|c|c|c|}
\hline Yazar & Ülke & Değişkenler & Yöntem & Sonuç \\
\hline Niem (2016) & Çin & $\begin{array}{l}\text { Ticaret endeksleri, kişi } \\
\text { başına gelir, nüfus }\end{array}$ & $\begin{array}{l}\text { Regresyon, } \\
\text { sabit etkili } \\
\text { model }\end{array}$ & $\begin{array}{l}\text { Linder hipotezi } \\
\text { desteklendi }\end{array}$ \\
\hline $\begin{array}{l}\text { Aliyu ve Bawa } \\
\text { (2015) }\end{array}$ & Nijerya & $\begin{array}{l}\text { İhracat, reel GSYİH, Linder } \\
\text { katsayısı, nüfus, uzaklık, } \\
\text { kukla değişkenler }\end{array}$ & $\begin{array}{l}\text { Panel } \\
\text { regresyon, } \\
\text { havuzlanmış } \\
\text { regresyon }\end{array}$ & $\begin{array}{l}\text { Linder hipotezi } \\
\text { desteklendi }\end{array}$ \\
\hline Atabay (2015) & $\begin{array}{l}\text { Brezilya, Rusya, } \\
\text { Hindistan ve Çin }\end{array}$ & $\begin{array}{l}\text { İhracat, GSYİH, Linder } \\
\text { katsayısı, uzaklık, nüfus, } \\
\text { kukla değişken: kriz }\end{array}$ & $\begin{array}{l}\text { Panel } \\
\text { regresyon, } \\
\text { Çekim modeli }\end{array}$ & $\begin{array}{l}\text { Linder hipotezi } \\
\text { desteklendi }\end{array}$ \\
\hline Kahram (2014) & İran & $\begin{array}{l}\text { Toplam ticaret, Linder } \\
\text { katsayıs1, döviz kuru, ortak } \\
\text { ülkenin GSYİHsı }\end{array}$ & $\begin{array}{l}\text { Sabit -Rassal } \\
\text { etkiler Modeli, } \\
\text { Çekim modeli } \\
\end{array}$ & $\begin{array}{l}\text { Linder hipotezi } \\
\text { desteklendi }\end{array}$ \\
\hline $\begin{array}{l}\text { Saygili ve } \\
\text { Manavgat (2014) }\end{array}$ & Türkiye & $\begin{array}{l}\text { İhracat, ithalat, Linder } \\
\text { katsayısı, GSYİH, uzaklık, } \\
\text { kukla değişken: ortak sınır }\end{array}$ & $\begin{array}{l}\text { Panel } \\
\text { regresyon, } \\
\text { Çekim modeli }\end{array}$ & $\begin{array}{l}\text { İthalat yönüyle hipotez } \\
\text { desteklenirken, ihracat } \\
\text { yönüyle hipotez } \\
\text { desteklenmemektedir. }\end{array}$ \\
\hline Hallak (2010) & 64 ülke & $\begin{array}{l}\text { İthalat, uzaklık, Linder } \\
\text { katsayısı, GSYİH, kukla } \\
\text { değişkenler: ortak dil, ortak } \\
\text { sınır vs. }\end{array}$ & $\begin{array}{l}\text { Regresyon ve } \\
\text { maksimum } \\
\text { olabilirlik } \\
\text { tahmin yöntemi }\end{array}$ & $\begin{array}{l}\text { Linder hipotezi } \\
\text { desteklendi }\end{array}$ \\
\hline Rauh (2010) & Almanya & $\begin{array}{l}\text { İthalat, döviz kuru, GSYİH, } \\
\text { Linder katsayıs1 }\end{array}$ & $\begin{array}{l}\text { Sabit etkili } \\
\text { regresyon }\end{array}$ & $\begin{array}{l}\text { Linder hipotezi } \\
\text { desteklendi }\end{array}$ \\
\hline Atik (2006) & Türkiye & $\begin{array}{l}\text { İthalat, döviz kuru, GSYİH, } \\
\text { Linder katsayıs1 }\end{array}$ & $\begin{array}{l}\text { Panel Tobit } \\
\text { modeli }\end{array}$ & $\begin{array}{l}\text { Linder hipotezi } \\
\text { desteklendi }\end{array}$ \\
\hline Kang (2006) & $\begin{array}{l}\text { Hong Kong, Singapur, } \\
\text { Güney Kore ve Tayvan }\end{array}$ & $\begin{array}{l}\text { İhracat, Linder katsayısı, } \\
\text { GSYİH, uzaklık, nominal } \\
\text { döviz kuru, kukla } \\
\text { değişkenler }\end{array}$ & Çekim modeli & $\begin{array}{l}\text { Linder hipotezi } \\
\text { desteklendi }\end{array}$ \\
\hline Bukhari vd. (2006) & $\begin{array}{l}\text { Bangladeş, Hindistan, } \\
\text { Pakistan }\end{array}$ & $\begin{array}{l}\text { İthalat, Linder katsayıs1, } \\
\text { GSYIH, döviz kuru }\end{array}$ & $\begin{array}{l}\text { Panel Tobit } \\
\text { modeli }\end{array}$ & $\begin{array}{l}\text { Linder hipotezi } \\
\text { desteklendi }\end{array}$ \\
\hline Tang (2003) & 14 APEC ülkeleri & $\begin{array}{l}\text { İhracat, Linder katsayısı, } \\
\text { GSYİ, uzaklık }\end{array}$ & $\begin{array}{l}\text { Regresyon, } \\
\text { Çekim modeli }\end{array}$ & $\begin{array}{l}\text { Linder hipotezi } \\
\text { desteklendi }\end{array}$ \\
\hline Choi (2002) & 63 ülke & $\begin{array}{l}\text { İhracat, Linder katsayıs1, } \\
\text { uzaklık ve kukla } \\
\text { değişkenler: ortak sınır, } \\
\text { ortak dil }\end{array}$ & $\begin{array}{l}\text { Benchmark } \\
\text { regresyon, } \\
\text { çekim modeli }\end{array}$ & $\begin{array}{l}\text { Linder hipotezi } \\
\text { desteklendi }\end{array}$ \\
\hline $\begin{array}{l}\text { McPherson vd. } \\
(2000)\end{array}$ & 19 OECD ülkeleri & $\begin{array}{l}\text { İhracat, Linder katsayısı, } \\
\text { döviz kuru, GSYİH }\end{array}$ & $\begin{array}{l}\text { Panel Tobit } \\
\text { modeli }\end{array}$ & $\begin{array}{l}\text { Linder hipotezi } \\
\text { desteklendi } \\
\text { (Danimarka hariç) } \\
\end{array}$ \\
\hline $\begin{array}{l}\text { McPherson vd. } \\
(2001)\end{array}$ & $\begin{array}{l}6 \text { Doğu Afrika ülkesi } \\
\text { (Kenya, Ruanda, } \\
\text { Etiyopya Uganda, } \\
\text { Sudan ve Tanzanya) } \\
\end{array}$ & $\begin{array}{l}\text { İthalat, döviz kuru, GSYİH, } \\
\text { Linder katsayıs1 }\end{array}$ & $\begin{array}{l}\text { Sabit etkiler } \\
\text { Tobit modeli }\end{array}$ & $\begin{array}{l}\text { Linder hipotezi } \\
\text { desteklendi (Tanzanya } \\
\text { hariç) }\end{array}$ \\
\hline Chow vd. (1999) & $\begin{array}{l}\text { Hong Kong, Singapur, } \\
\text { Güney Kore ve Tayvan }\end{array}$ & $\begin{array}{l}\text { Tamamlayıcılık endeksi, } \\
\text { Kişi başına GSYİH, döviz } \\
\text { kuru/TEFE, }\end{array}$ & Regresyon & $\begin{array}{l}\text { Linder hipotezi } \\
\text { desteklendi }\end{array}$ \\
\hline $\begin{array}{l}\text { Thursby ve } \\
\text { Thursby } \\
\text { (1987) }\end{array}$ & 17 ülke & $\begin{array}{l}\text { İhracat, TÜFE, döviz kuru, } \\
\text { GSYİH, }\end{array}$ & Regresyon & $\begin{array}{l}\text { Linder hipotezi } \\
\text { desteklendi (Kanada } \\
\text { ve Güney Afrika hariç) }\end{array}$ \\
\hline Ellis (1983) & $\begin{array}{l}\text { Kanada, ABD, İsrail, } \\
\text { Japonya, Güney Afrika, } \\
\text { Avustralya, Yeni } \\
\text { Zelanda ve Batı Avrupa }\end{array}$ & $\begin{array}{l}\text { Ticaret yoğunluğu } \\
\text { göstergeleri }\end{array}$ & Korelasyon & $\begin{array}{l}\text { Linder hipotezi } \\
\text { desteklendi }\end{array}$ \\
\hline $\begin{array}{l}\text { Kennedy ve } \\
\text { McHugh (1980) }\end{array}$ & 14 ülke & $\begin{array}{l}\text { İthalat yoğunluğu, kişi } \\
\text { başına gelir farkl11ığ1 }\end{array}$ & Korelasyon & $\begin{array}{l}\text { Linder hipotezi } \\
\text { desteklenmedi }\end{array}$ \\
\hline Qureshi vd. (1980) & ABD 10 bölgesi & $\begin{array}{l}\text { İthalat eğilimleri, uzaklık, } \\
\text { kişi bașına gelir farklılığ }\end{array}$ & Korelasyon & $\begin{array}{l}\text { Linder hipotezi } \\
\text { desteklenmedi }\end{array}$ \\
\hline
\end{tabular}

Tablo 1. Literatür 


\section{Veri ve Değişkenler}

Bu çalışmada 20 OECD ülkelerinin 2001-2005 dönemine ait y1llık verilerini kullanarak Linder hipotezinin geçerliliği sınamaya tabi tutulmuştur. Söz konusu ülkeler; ABD, Kanada, İspanya, Danimarka, İtalya, Yeni Zelanda, Meksika, Almanya, Japonya, İsveç, Macaristan, Şili, İzlanda, Avusturya, Polonya, Lüksemburg, Türkiye, Çek Cumhuriyeti, Yunanistan ve Letonya'dır. Bu ülkelerin ticaret ortakları ile yaptıkları dış ticaretlerinin Linder modeliyle açıklanıp açıklanmayacağı incelenmiştir. Tüm veriler Dünya Bankası veri tabanından temin edilmiştir (World Bank, 2017). Uygulamada kullanılan verilere ilişkin bilgiler Tablo 2'de özetlenmiştir. Çalışmada tüm değişkenler logaritmik formları ile incelenmiştir.

\begin{tabular}{lll}
\hline Değişken & Kısaltma & Tanımlama \\
\hline İhracat & İHR & İhracat ABD \$ \\
Çıktı & GSYİH & Sabit 2005 ABD\$ \\
Enflasyon oranı & ENF & GSYİH deflatörü \\
Linder katsayısı & LINDER & Kişi başına gelir farklılıkları \\
\hline
\end{tabular}

Tablo 2. Değişken Tanımı

Çalışmada tobit yapılı ihracat değişkeni bağımlı değişken olarak ele alınmıştır.

$$
I H R^{*}{ }_{i t j}=\alpha_{1}+\alpha_{2} G S Y I H_{i t j}+\alpha_{3} E N F_{i t j}+\alpha_{4} L I N D E R_{i t j}+u_{i t j}
$$

$\mathrm{j}$ indisi analize dahil edilen OECD ülke sayısını göstermektedir. 20 ülke analize dahil edildiği için yukarıdaki model her bir ülke için ayrı ayrı 20 kere tahmin edilmiştir. $\mathrm{i}$ indisi j ülkesinin potansiyel ticaret ortağını gösterir. $t$ indisi zamanı ifade etmektedir.

Burada $I H R^{*}{ }_{i t j}$, t zamanında OECD j ülkesinin ticaret ortağı i ülkesine yaptığı ihracatın dolar cinsinden değerini göstermektedir. Bağımlı değişken sıfır ya da pozitif değerler alabilen sansürlenmiş bir değişkendir. Burada OECD j ülkesinin i ülkesine yaptığı ticaret hacmi sıfıra eşitse de modelde yer almaktadır. Böylece soldan sansürlenmiş gözlenebilen bağımlı değişken $I H R_{i t j}$,

$$
I H R^{*}{ }_{i t j}=\left\{\begin{array}{c}
I H R_{i t j}^{*}>0 \text { ise } I H R_{i t j}=I H R_{i t j}^{*}, \\
I H R_{i t j}^{*} \leq 0 \text { ise } 0
\end{array}\right.
$$

olarak tanımlanabilmektedir.

Ticaret yapan ülkelerin ekonomik büyüklüklerindeki farkları kontrol etmek amacıyla modele ticaret ortağı i ülkesinin gerçek gayri safi yurt içi hasıla değeri eklenmiştir. GSYIH $H_{i t j}$ OECD j ülkesinin ticaret ortağı olan i ülkesinin GSYİH değerini ifade etmektedir.

Ticaret yapan ülkelerin göreli fiyatlarındaki dalgalanmaları kontrol etmek için modelimize bağımsız bir değişken olarak enflasyon oranı eklenmiştir. $E N F_{i t j}$ potansiyel ticaret ortağı i ülkesinin GSYİH deflatörünü göstermektedir.

$L I N D E R_{i t j}$ LINDER katsayısı olarak gösterdiğimiz bu değişken, analize dahil ettiğimiz her bir OECD j ülkesi ve bu ülkenin potansiyel ticaret ortağı i ülkesi arasındaki kişi başına düşen gelir farkının mutlak değeri şeklinde ifade edilmektedir. Linder hipotezi iki ülke arasındaki gelir farkının daha az olması durumunda bu ülkelerin daha yoğun ticaret yaptıklarını savunmaktadır.

\section{Rassal Etkili Panel Tobit Modelleri}

Tobit modelleri, bağımlı değişkenin sürekli ancak sınırlı aralıkta değerler alabildiği modellerdir (Guris vd., 2015). Panel veriye sahip bağımlı değişkenin önemli bir kısmının sıfıra eşit, diğer kısımlarının pozitif olduğu durumlar incelenecekse panel Tobit modeli kullanılmaktadır. Tobit modeli rassal etkili ya da sabit etkili olmak üzere iki türlü uygulanabilmektedir. Panel veriler için Tobit modelinin sabit etkili tahmincinin tutarsız olması nedeniyle, uygulamada rassal etkili panel tobit modeli yaygın olarak kullanılmaktadır.

Rassal etkili modellerde tutarlılığının sağlanması için, etkilerin modeldeki değişkenlerle ilişkisiz olması gerekmektedir. Heckman ve Macurdy (1980) $\boldsymbol{\alpha}_{\boldsymbol{i}}$ 'nin açıklayıcı değişkenlerle ilişkili olabileceğini ifade etmişlerdir. Rassal etkili model,

$$
\begin{aligned}
& y_{i t}^{*}=\alpha_{i} \beta^{\prime} x_{i t}+u_{i t}, \mathrm{i}: 1.2 \ldots . ., \mathrm{N}, \quad \mathrm{t}: 1,2, \ldots ., \mathrm{T} \\
& u_{i t}=v_{i}+\epsilon_{i t}\left(v_{i} \sim N\left(0, \sigma_{v}^{2}\right)\right)\left(\epsilon_{i t \sim} N\left(0, \sigma_{\epsilon}^{2}\right)\right)
\end{aligned}
$$

olarak gösterilmektedir. Burada bağımlı değişken $\boldsymbol{y}_{i t}^{*}$ sıfır ya da pozitif değerler alabilen görünmeyen bir değişkendir. $\boldsymbol{x}_{\boldsymbol{i}}$ ise bağımsız değişkenleri ifade etmektedir. Soldan sansürlenmiş gözlenebilen bağımlı değişken $y_{i t}$, 
olarak belirlenmektedir.

$$
y_{i t}=\left\{\begin{array}{c}
y_{i t}^{*}>0 \text { ise } y_{i t}=y_{i t}^{*} \\
y_{i t}^{*} \leq 0 \text { ise } 0
\end{array}\right.
$$

Hata terimi $u_{i t}$ zamandan bağımsız olmalıdır. $\alpha_{i}$ 'nin tesadüfi olduğu varsayımı altında Tobit modelleri için benzerlik fonksiyonunun genel hali $\mathrm{g}(\alpha)$ ( veya $(\alpha \mid x)$ ),

$\prod_{i=1}^{N} \int\left[\prod_{t=1}^{T}\left[1-F\left(-\beta^{\prime} x_{i t}-\alpha_{i}\right)\right]^{-1} f\left(y_{i t}-\beta^{\prime} x_{i t}-\alpha_{i)}\right] g\left(\alpha_{i}\right) d \alpha_{i}\right.$ olarak ifade edilir. $\mathrm{f}(\cdot), \boldsymbol{u}_{i t}{ }^{\prime}$ nın olasılık fonksiyonunu göstermekte ve $F(\alpha)=\int_{-\infty}^{\alpha} f(u) d u$ olarak hesaplanmaktadır. Sansürlü veri benzerlik fonksiyonu,

$$
\prod_{i=1}^{N} \int\left[\prod_{t \in c_{i}} F\left(-\beta^{\prime} x_{i t}-\alpha_{i}\right) \prod_{t \in \bar{c}_{l}} f\left(y_{i t}-\alpha_{i}-\beta^{\prime} x_{i t}\right)\right] g\left(\alpha_{i}\right) d \alpha_{i}
$$

olacaktır (Hsiao, 2004). Burada $c_{i}=\left\{t \mid y_{i t}=0\right\}$ olarak tanımlanır ve $\overline{c_{i}}$ de bileşenlerini göstermektedir. Yukarıdaki ifadelerin bilinmeyen parametrelere göre maksimizasyonu tutarlı ve asimptotik olarak normal dağılan parametre tahmincilerinin elde edilmesini sağlamaktadır.

\section{Tahmin Sonuçları}

Linder teoriyi test etmek için herhangi bir model önermemiştir. Dolayısıyla ampirik uygulamada McPherson vd. (2000)'in çalışmasından yararlanarak, ele alınan OECD ülkeleri için Linder hipotezinin geçerliliği soldan sansürlenen panel Tobit modeli aracılığıyla incelenmiştir. Analizimizde tahmin edilecek model aşağıdaki gibi gösterilebilir.

$$
I H R_{i t j}=\alpha_{1}+\alpha_{2} G S Y I H_{i t j}+\alpha_{3} E N F_{i t j}+\alpha_{4} L I N D E R_{i t j}+u_{i t j}
$$

$\alpha_{2}$ GSYİH katsayısının pozitif değer alacağı beklenmektedir. Bunun nedeni, ticaret ortağı i ülkesinin gelirinde meydana gelen bir artışı $\mathrm{j}$ ülkesinden yapılacak ihracat miktarını artıracağı anlamına gelmektedir. Enflasyon oranında meydana gelen bir artış, ihracatı artıracağı için $\alpha_{3}$ enflasyon katsayısının da pozitif değer alacağı beklenmektedir. Linder katsayısının negatif ve istatistiksel olarak anlamlı olması, Linder teorisinin geçerli olduğuna dair bir gösterge olacaktır. Bu nedenle $\alpha_{4}$ katsayısının negatif değer alacă̆ı öngörülmektedir. 


\begin{tabular}{|c|c|c|c|c|}
\hline Ülke & Sabit & Çıktı & Enflasyon & Linder katsayısı \\
\hline ABD & $\begin{array}{l}-85.3017 * * * \\
(8.8445)\end{array}$ & $\begin{array}{l}3.5896 * * * \\
(0.3260)\end{array}$ & $\begin{array}{l}1.6919 * * * \\
(0.6378)\end{array}$ & $\begin{array}{l}-2.0322 * * * \\
(0.4594)\end{array}$ \\
\hline Kanada & $\begin{array}{l}-73.3575 * * * \\
(6.5458)\end{array}$ & $\begin{array}{c}2.9743 * * * \\
(0.2278)\end{array}$ & $\begin{array}{l}2.0009 * * * \\
(0.5341)\end{array}$ & $\begin{array}{l}-1.0105 * * * \\
(0.3070)\end{array}$ \\
\hline İspanya & $\begin{array}{l}-61.5924 * * * \\
(7.4576)\end{array}$ & $\begin{array}{l}2.6265 * * * \\
(0.2766)\end{array}$ & $\begin{array}{l}1.2914 * * \\
(0.5606)\end{array}$ & $\begin{array}{l}-1.1257 * * * \\
(0.4061)\end{array}$ \\
\hline Danimarka & $\begin{array}{l}-61.3211 * * * \\
(6.4901)\end{array}$ & $\begin{array}{l}3.1189 * * * \\
(0.2379)\end{array}$ & $\begin{array}{l}1.8891 * * * \\
(0.4551)\end{array}$ & $\begin{array}{c}-0.7385 * * \\
(0.3284)\end{array}$ \\
\hline İtalya & $\begin{array}{l}-83.0505^{* * * *} \\
(6.9855)\end{array}$ & $\begin{array}{l}3.5775 * * * \\
(0.2582)\end{array}$ & $\begin{array}{l}1.0184 * * \\
(0.4877)\end{array}$ & $\begin{array}{l}-1.0920 * * * \\
(0.3668)\end{array}$ \\
\hline Yeni Zelanda & $\begin{array}{l}-65.2086^{* * * *} \\
(7.9337)\end{array}$ & $\begin{array}{l}2.5530 * * * \\
(0.2906)\end{array}$ & $\begin{array}{c}1.5913 * * \\
(0.6293)\end{array}$ & $\begin{array}{c}-1.2015^{* * *} \\
(0.4264)\end{array}$ \\
\hline Meksika & $\begin{array}{l}-79.5664 * * * \\
(7.9223)\end{array}$ & $\begin{array}{c}3.0591 * * * \\
(0.2979)\end{array}$ & $\begin{array}{c}1.6865^{* * *} \\
(0.6180)\end{array}$ & $\begin{array}{l}-1.5528 * * * \\
(0.4102)\end{array}$ \\
\hline Almanya & $\begin{array}{l}-79.6334^{* * * *} \\
(6.9267)\end{array}$ & $\begin{array}{l}3.5060 * * * \\
(0.2543)\end{array}$ & $\begin{array}{l}0.8576731 * \\
(0.4964)\end{array}$ & $\begin{array}{l}-1.0302 * * * \\
(0.3657)\end{array}$ \\
\hline Japonya & $\begin{array}{l}-104.2014 * * * \\
(9.7729)\end{array}$ & $\begin{array}{c}4.2398 * * * \\
(0.3516)\end{array}$ & $\begin{array}{l}1.6444 * * \\
(0.6990)\end{array}$ & $\begin{array}{l}-1.0681 * * \\
(0.4497)\end{array}$ \\
\hline İsveç & $\begin{array}{l}-69.1857 * * * \\
(5.9658)\end{array}$ & $\begin{array}{l}2.9661 * * * \\
(0.2088)\end{array}$ & $\begin{array}{l}1.0578 * * \\
(0.4846)\end{array}$ & $\begin{array}{l}-0.5195 * * \\
(0.2888)\end{array}$ \\
\hline Macaristan & $\begin{array}{l}-91.4086^{* * * *} \\
(8.2164)\end{array}$ & $\begin{array}{c}3.4378 * * * \\
(0.3055)\end{array}$ & $\begin{array}{c}2.4301 * * * \\
(0.6135)\end{array}$ & $\begin{array}{c}-0.9858 * * \\
(0.3953)\end{array}$ \\
\hline Şili & $\begin{array}{l}-103.9445^{* * *} \\
(9.3954)\end{array}$ & $\begin{array}{l}3.9701 * * * \\
(0.3580)\end{array}$ & $\begin{array}{c}1.5890^{* * * *} \\
(0.6089)\end{array}$ & $\begin{array}{l}-0.8938 * * \\
(0.4190)\end{array}$ \\
\hline İzlanda & $\begin{array}{l}-25.1498 * * * \\
(3.2843)\end{array}$ & $\begin{array}{l}1.1595 * * * \\
(0.1183)\end{array}$ & $\begin{array}{c}0.6224 * * \\
(0.2674)\end{array}$ & $\begin{array}{l}-0.7473 * * * \\
(0.1628)\end{array}$ \\
\hline Avusturya & $\begin{array}{l}-78.1737 * * * \\
(6.9545)\end{array}$ & $\begin{array}{l}3.3434 * * * \\
(0.2578)\end{array}$ & $\begin{array}{l}0.8471 * \\
(0.4731)\end{array}$ & $\begin{array}{l}-1.3531 * * * \\
(0.3437)\end{array}$ \\
\hline Polonya & $\begin{array}{l}-96.7338 * * * \\
(9.1094)\end{array}$ & $\begin{array}{l}3.3900 * * * \\
(0.3352)\end{array}$ & $\begin{array}{l}3.8012 * * * \\
(0.7292)\end{array}$ & $\begin{array}{l}-1.4497 * * * \\
(0.4541)\end{array}$ \\
\hline Lüksemburg & $\begin{array}{l}-71.3162 * * * \\
(6.6148)\end{array}$ & $\begin{array}{l}2.8525 * * * \\
(0.2268)\end{array}$ & $\begin{array}{l}1.5126^{* * *} \\
(0.4866)\end{array}$ & $\begin{array}{l}-0.7683 * * * \\
(0.2933)\end{array}$ \\
\hline Letonya & $\begin{array}{l}-71.9678 * * * \\
(7.6976)\end{array}$ & $\begin{array}{l}2.5349 * * * \\
(0.2777)\end{array}$ & $\begin{array}{l}2.4278^{* * *} \\
(0.6681)\end{array}$ & $\begin{array}{l}-0.5723 \\
(0.3745)\end{array}$ \\
\hline Türkiye & $\begin{array}{c}3.2338 * * * \\
(0.2663)\end{array}$ & $\begin{array}{l}3.2338 * * * \\
(0.2663)\end{array}$ & $\begin{array}{c}1.4283 * * * \\
(0.5223)\end{array}$ & $\begin{array}{l}0.2425 \\
(0.3906)\end{array}$ \\
\hline Çek Cumhuriyeti & $\begin{array}{l}-82.9909 * * * \\
(6.7932)\end{array}$ & $\begin{array}{l}3.2634 * * * \\
(0.2512)\end{array}$ & $\begin{array}{l}1.8279 * * * \\
(0.5104)\end{array}$ & $\begin{array}{l}-0.4032 \\
(0.3388)\end{array}$ \\
\hline Yunanistan & $\begin{array}{l}-72.0789 * * * \\
(7.2983)\end{array}$ & $\begin{array}{c}2.8986 * * * \\
(0.2704)\end{array}$ & $\begin{array}{c}1.1390 * * \\
(0.5945)\end{array}$ & $\begin{array}{l}-0.2996 \\
(0.3869)\end{array}$ \\
\hline
\end{tabular}

*** ve ** sırasıyla \% 1 ve \% 5 kritik değerlerine göre anlamlılığı göstermektedir.

Parantezin içindeki değerler standart hatalardır.

Tablo 3. Rassal Etkili Tobit Tahminleri

Soldan sansürlenen rassal etkili panel Tobit tahminlerine bakıldığında bütün değişkenlerin bağımlı değişkeni açıklamakta anlamlı olduğu görülmektedir. Tablo 3'teki sonuçlar ele aldığımız ülkelerde Linder teorisinin geçerli olduğunu ortaya koymaktadır. Analize dahil ettiğimiz 20 ülkenin 16'sında Linder katsayısı negatif ve istatistiksel olarak anlamlı bulunmuştur. Linder teorisi destek bulmayan ülkeler Türkiye, Letonya, Çek Cumhuriyeti ve Yunanistan’dır. Dolayısıyla, ele aldığımız 16 ülkenin Linder teorisine uygun olarak kişi başına gelir seviyeleri 
birbirine benzeyen ülkelerle ticaret yaptıkları düşünülebilir. Diğer açıklayıcı değişkenlerin de beklentilere uygun sonuçlar verdiği görülmektedir. Açıklayıcı değişkenlerden GSYİH değeri tüm ülkeler için istatistiki olarak \%1 düzeyinde anlamlıdır. OECD ülkelerinin ihracatına ortak ülkelerin ekonomik büyüklükleri de pozitif yönde etki yapmakta olduğu gözlemlenmektedir. Teoriye göre ülkelerin geliri arttıkça ithalat miktarı da artış gösterecektir. Ortak ülkelerin göreli fiyatlarındaki artışın da OECD ülkelerinin ihracatı üzerindeki etkisi pozitiftir. Çünkü ortak ülkelerin yurtiçi fiyatlar genel seviyesindeki artış, ucuz ithal mal talebini artıracaktır. Ortak ülkelerin ithalatının artması OECD ülkelerinin ihracatının artması anlamına gelmektedir.

\section{Sonuç}

Bu çalışmada seçilmiş OECD ülkelerinde Linder teorisinin geçerli olup olmadığ incelenmiştir. Söz konusu ülkelerin 2001-2005 dönemine ait yıllık verilerine rassal etkili Panel Tobit modeli uygulanmıştır. 20 OECD ülkelerinin ihracat değerlerinin bağımlı değişken olarak ele alındığı modelde; ticaret ortağı ülkelerin gayrisafi yurt içi hasıla değerleri, enflasyon oranları ve Linder değişkeni açıklayıcı değişkenler olarak yer almıştır.

Elde edilen tahmin sonuçlarına göre incelenen dönemde 16 OECD ülkesinin ticaret ortakları ile yaptıkları dış ticaretlerinin Linder modeliyle açıklanabileceği ortaya çıkmıştır. Diğger bir deyişle söz konusu ülkelerin ticaret ortakları ile gelir farklılıkları azaldıkça daha yoğun ticaret yaptıkları görülmüştür. 4 ülke için (Türkiye, Letonya, Çek Cumhuriyeti ve Yunanistan) Linder etkisi bulunamamıştır. Türkiye için Linder etkisinin bulunamaması Saygılı ve Manavgat (2014)'ın çalışmalarıyla örtüşmektedir. Diğer açıklayıcı değişkenlerin de teorik beklentilere uygun sonuçlar verdiği gözlemlenmiştir. Elde edilen bulgulara göre, OECD ülkelerinin diş ticaret ortaklarının gelirlerindeki artışın ihracat üzerindeki etkisi arttırıcı yönde olduğu söylenebilir. Ticaret ortaklarının göreli fiyatlarında meydana gelen artışın da ihracat üzerindeki etkisi pozitif yöndedir. Diğer bir deyişle ortak ülkelerin fiyatlar genel seviyesindeki artışın OECD ülkelerinin bu ülkelere yapacağı ihracat miktarında artışa neden olacağ kanısına varılabilir.

Çalışmanın yöntemi ve bulguları, dış ticaretin geliştirilmesi ve incelenmesine odaklanan araştırmacılar ve politikacılar için farklı bir bakış sağlayacaktır.

\section{Kaynakça}

- Arnon, A. ve Weinblatt, J., 1998. "Linder's hypothesis revisited: income similarity effects for low income countries", Applied Economics Letters, 5(10), 607-611, DOI: 10.1080/135048598354267.

- Aliyu, S.U.R. ve Bawa, S., 2015. "Gravity model by panel data approach: empirical evidence from Nigeria", International. Journal of Trade and Global Markets, 8(1), 42-57.

- $\quad$ Atik, H., 2006. “Tercihlerde Benzerlik Teorisi: Türkiye ve Bazı Komşu Ülkelerin Dış Ticareti Üzerine Bir Analiz", Ankara Üniversitesi SBF Dergisi 61(2), 33-43.

- Atabay, R., 2015. "Validity of Linder Hypothesis in BRIC Countries", Journal of International Trade, Logistics and Law, 1(2), 85-92.

- $\quad$ Bukhari, H. A. S., Ahmad, M. H., Alam, S., Bukhari, H.A.S., Butt, M.S., 2005. "An Empirical Analysis of the Linder Theory of International Trade for South Asian Countries”, The Pakistan Development Review, 44(3), 307-320.

- Carbaugh, R.J., 2009. International Economics, 12th edition, South $\square$ Western Cengage Learning: Mason.

- Choi, C., 2002. "Linder hypothesis revisited”, Applied Economics Letters, 9, 601-605.

- Chow, P., Kellman, M. ve Shachmurove, Y., 1999. "A test of the Linder hypothesis in Pacific NIC trade 19651990”, Applied Economics, 31(2), 175-182.

- $\quad$ Ellis, M., 1983. “An alternative interpretation and empirical test of the Linder hypothesis”, Quarterly Journal of Business and Economics, 22(4), 53-62.

- Grančay, M., Grančay, N., Vveinhardt, J., 2016. "Intra-industry trade in the Visegrad countries: Does the Linder hypothesis hold?"Acta Oeconomica, 66(2).

- Guris, S., Sacakli Sacildi, I. ve Guneren Genc, E., 2015. "Determining the Effects of Factors on FDI in Global Crisis Period" International Journal of Economics and Financial Issues, 5(1), 1-10.

- Hallak, J. C., 2010. "A Product-Quality View of the Linder Hypothesis", The Review of Economics and Statistics, 92(3), 453-466.

- Hanink, D., 1990. “Linder, again”, Weltwirtschaftliches Archiv, 126(2), 257-67.

- Heckman, J.J. ve MaCurdy, T.E., 1980. “A life cycle model of female labour supply”, The Review of Economic Studies, 47(1), 47-74.

- Hirsch, Z. ve Lev, B.,1973. "Trade and per capita income differentials: a test of the Burenstam-Linder hypothesis", World Development, 1(9), 11-17. 
- Hsiao, C., 2004. Analysis of Panel Data, 2. Basım, Cambridge University Press.

- Hufbauer, G.C. 1970. The impact of national characteristics and technology on the commodity composition of trade in manufactured goods, in The Technology Factor in International Trade (Ed.) R. Vernon, pp. 145231, FIBERS, New York.

- Kang, M., 2006. "International NICs Trade and the Linder Hypothesis”, Atlantic Economic Journal, 34,507508 DOI: $10.1007 / \mathrm{s} 11293-006-9043-9$.

- Kahram, A., 2014. "The Comparative Analysis of the Linder Hypothesis:The Bilateral Trade Model between Iran and its Trade Partners", Advances in Economics and Business Management (AEBM), 1(1), 1-8.

- Kennedy M.M. J., 2014. International economics, PHİ learning Private Limited. Delhi

- Kennedy, T. E. ve McHugh, R., 1980. “An intertemporal test and rejection of the Linder hypothesis”, Southern Economic Journal , 46(3) 898-903.

- Linnemann, M. ve Van Beers, C., 1988. "Measures of export-import similarity and the Linder hypothesis once again”, Weltwirtschaftliches Archive, 124, 443-57.

- Linder, S. B., 1961. An Essay in Trade and Transformation, New York: Wiley.

- McPherson, M. A., Redfearn, M. R. ve Teslau, M. A. 2000. "A Re-Examination of The Linder Hypothesis: A Random-Effects Tobit Approach”, International Economic Journal , 14(3), 123-136.

- McPherson, M., Redfearn, M. R. ve Tieslau, M. A., 2001. "International trade and developing countries: an empirical investigation of the Linder hypothesis", Applied Economics, 33(5), 649-657.

- Niem, L.D., 2016. "Linder Hypothesis and Trade of Quality Differentiated Good: A Case of Cosmetic Industry of China", Modern Economy, 7, 307-313.

- Qureshi, U. A., French, G. L. ve Sailors, J. W., 1980. “Linder's trade thesis: A Further Examination”, Southern Economic Journal, 46(3), 933-936.

- Rauh, A., "Empirical Analysis of the Linder Hypothesis: The Case of Germany's Trade Within Europe", The American Economist, 55(2), 136-141.

- Saygıl1, F. ve Manavgat, G., 2014. “Linder Hipotezi:Türkiye'nin Dış Ticareti için Ampirik Bir Analiz”, Ege Akademik Bakiş, 14(2), 261-270.

- Shenkar, O., Luo, Y. ve Chi, T., 2014. International Business, Routledge.

- Tang, D., 2003. "Economic Integration Among the Asia-Pasific Economic Cooperation Countries: Linder Effect on Developed and Developing Countries (1985-1999)", The International Trade Journal, 17(1), 19-49.

- Thursby, J. G. ve Thursby, M. C., 1987. "Bilateral trade flows: the Linder hypothesis and exchange risk", The Review of Economics and Statistics, 69(3), 488-495.

- World Bank, 2017 http://data.worldbank.org/country/ erişim tarihi 12.01.2017 


\title{
Dış Ticaret Açıklarında Gelir ve Fiyat Etkisinin Sektörel Bazda Ekonometrik Analizi: Türkiye Örneği
}

\section{The Econometric Analysis in the Sectorial Basis of Income and Price Effects on the Foreign Trade Deficits: The Case of Turkey}

\author{
Asst. Prof. Dr. Ş. Mustafa Ersungur (Atatürk University, Turkey) \\ Asst. Prof. Dr. Mehmet Barış Aslan (Muş Alparslan University, Turkey) \\ Asst. Prof. Dr. Ömer Doru (Şırnak University, Turkey)
}

\begin{abstract}
In Turkey which is one of the countries whose current account deficit has been chronic from the 1980s until today, the most important reason for the current account deficit is foreign trade deficit. The aim of our study in this context is to shed light on policies oriented foreign trade deficits by examining foreign trade of intermediate and capital goods which are one of the most important causes of foreign trade deficits in Turkey, in terms of income and exchange rate indicators. In the study in which the Marshall-Lerner condition and the foreign and domestic income elasticities were tested separately for each model, the Econometric method and quartile data between 1998 to 2014 were used. The results of the study showed that Marshall-Lerner condition is not valid in foreign trade of any goods group, and domestic and foreign income variable coefficients are strong effect on both imports and exports. In the direction of these results, we think that the economic policies to be developed for domestic and foreign revenues will be more effective than the real exchange rate policies for being decreased the foreign trade deficits of both intermediate and capital goods in Turkey.
\end{abstract}

\section{Giriș}

Türkiye İstatistik Kurumu tarafından, ülkeler arasındaki mal ve hizmet alışverişi olarak tanımlanan dış ticaret, Çelik (2008) tarafından, ülkeler arasındaki ekonomik ve ticari ilişkiler sonucu ortaya çıkan bağımlılık ve bu bağımlılık nedeniyle yaşanan problemlerin çözüme kavuşturulması olarak ifade edilmektedir. Bu bağlamda, ithalat, ülke içerisinde üretimi kıt olan kaynaklara dayalı ve göreceli olarak yüksek maliyelerle üretilebilecek ürünlerin yurt dışından daha ucuza satın alınarak, tüketicilerin bu ürünleri daha ucuza elde edebilmelerine imkan tanırken, ihracat ise maliyet avantajından yararlanarak yüksek uluslararası fiyatlardan dış ticarete sunulabilecek malların üretimlerinin gerçekleştirilerek etkinlik ve verimlilik artışına sebep olabilmektedir (Koban v.d, 2012).

Bir ülkenin ihracatı ile ithalatı arasındaki ilişkiyi gösteren dış ticaret dengesi ise söz konusu ülkenin makroekonomik performansını gözler önüne seren en önemli göstergelerinden biridir. İthalat rakamlarının ihracat rakamlarını aşması olarak tanımlanan dış ticaret açığı ise Türkiye gibi gelişmekte olan ülkelerde özellikle yabancı sermaye yatırımlarını olumsuz yönde etkilemekte ve dolayısıyla ekonomi yönetimlerinin çözmekle yükümlü oldukları öncelikli makroekonomik problemler arasında yer almaktadır.

1960 ve 1970'li yıllarda ağırlıklı olarak ithal ikameci sanayi politikaları uygulayan Türkiye, 1980'den sonraki dönemlerde serbest dış ticaret politikası temelinde, ihracata dayalı bir sanayileşme politikası uygulamasına gitmiştir. Elastikiyeti düşük ara ve sermaye malları ithalatçısı konumunda olan Türkiye'nin gerekli altyapı ve önlemler alınmadan esnekliği yüksek malların ihracatına dayalı bir sanayileşme politikasına girişmesi ise söz konusu tarihlerden günümüze kadar ciddi miktarlarda dış ticaret açıklarıyla karşı karşıya kalmasına neden olmuştur.

2017 yılında yayımlanan “Türkiye'nin Dış Ticaretinin Gelir ve Fiyat Esnekliğine Mal Grupları Bazlı Yaklaşım” adlı doktora tezinden türetilen bu çalışmanın amacı ise Türkiye'de yıllar itibari ile dış ticaret açıklarına sebep olan ara ve yatırım malları dış ticaretini, gelir ve fiyat göstergeleri çerçevesinde incelemektir. Elde edilen sonuçlarla, dış ticaret açıklarını azaltmaya yönelik öneriler sunarak ampirik literatüre katkı sağlamak ve ekonomi politikalarına 1şı tutmaktır.

Bu bağlamda çalışmanın ilk kısmında dış ticaret ve Marshall-Lerner kuralı ile ilgili tanımsal bilgilere yer verilerek, benzer çalışma örneklerini içeren literatür özetine yer verilmiştir. Çalışmanın ikinci bölümünde ise Türkiye ile en fazla ticaret hacmine sahip 10 adet OECD ülkesi arasındaki ara ve sermaye malları dış ticareti, gelir ve fiyat göstergeleri çerçevesinde, ARDL ekonometrik yöntemi ile analiz edilerek, elde edilen bulgular doğrultusunda gelir ve fiyat etkisinin dış ticaret açıkları üzerindeki etkisi araştırılmıştır. Son olarak, elde edilen sonuçlar yorumlanmış ve çözüm önerileri sunularak çalışma sonlandırılmıştır.

\section{Literatür Özeti}

Gerek Marshall-Lerner koşulu gerekse gelir elastikiyetleri konusunda, farklı ülke ve yöntemlerin kullanıldığ çalışmaların yer aldığı Literatürde, elde edilen sonuçlar doğrultusunda, bir fikir birliğinden söz etmenin pek de 
mümkün olmadığı görülmektedir. Türkiye ve Türkiye dışındaki ülkeler nezdinde yapmış olduğumuz yazın araştırması neticesinde, ülkemizde ve çoğunluk ülkelerde, uzun dönemde Marshall-Lerner koşulunun sağlandığı, ayrıca yurt içi ve yurt dışı gelirlerinde dış ticaret dengesi üzerinde etkili olduğu görülmüştür. Bununla beraber sayı itibari ile az olmalarına karşın, Marshall-Lerner koşulu ve gelir elastikiyetlerine ilişkin olumlu sonuçların elde edilmediği de ayrıca tespit edilmiştir. Söz konusu çalışmaların yer aldığı özet tablo aşağıda yer almaktadır.

\begin{tabular}{|c|c|c|c|c|}
\hline Yazar(lar) & Yöntem & Dönem & Ülke(ler) & Sonuç \\
\hline Khan (1974) & $\begin{array}{l}\text { En Küçük Kareler } \\
\text { Yöntemi }\end{array}$ & $1951-1+969$ & $\begin{array}{l}15 \text { Gelişmekte Olan } \\
\text { Ülke }\end{array}$ & $\begin{array}{l}\text { Gelişmekte olan ülkelerin ihracat ve ithalatının } \\
\text { belirlenmesinde fiyatların önemli rolü olduğunu ve } \\
\text { Marshall-Lerner koşulunun sağlandığı ifade edilmiştir. }\end{array}$ \\
\hline $\begin{array}{l}\text { Shirvani ve } \\
\text { Wilbratte } \\
(1997) \\
\end{array}$ & $\begin{array}{l}\text { Çok değiş̧kenli } \\
\text { Eş-bütünleşme } \\
\text { Yöntemi } \\
\end{array}$ & $1973: 5-1990: 8$ & ABD ve $G 7$ ülkeleri & $\begin{array}{l}\text { Marshall Lerner koşulunun ampirik geçerliliğini } \\
\text { destekleyen devalüasyonların uzun vadede ticaret } \\
\text { dengesini iyileştirici etkide bulunduğu tespit edilmiştir }\end{array}$ \\
\hline $\begin{array}{l}\text { Bahmani } \\
\text { Oskooee ve } \\
\text { Niroomand } \\
(1998)\end{array}$ & $\begin{array}{l}\text { Johansen ve } \\
\text { Juselius } \\
\text { Eşbütünleşme ve } \\
\text { En Küçük Kareler } \\
\text { Yöntemi }\end{array}$ & 1960-1992 & 30 Ülke & $\begin{array}{l}\text { Çoğu ülkede gelir esnekliklerinin yüksek olma } \\
\text { eğiliminde oldukları ve neredeyse tüm ülkelerde } \\
\text { mutlak değer olarak ithalat ve ihracat talebi fiyat } \\
\text { esneklikleri toplamının birden büyük çıkarak uzun } \\
\text { dönem Marshall-Lemer koşulunun sağlandığı } \\
\text { görülmüştür. }\end{array}$ \\
\hline $\begin{array}{l}\text { Bahman1- } \\
\text { Oskooee ve } \\
\text { J. Brooks } \\
(1999) \\
\end{array}$ & $\begin{array}{l}\text { Johansen- } \\
\text { Juselius } \\
\text { Eşbütünleşme } \\
\text { yöntemini } \\
\end{array}$ & 1973-1996 & $\begin{array}{l}\text { Amerika ve altı (6) } \\
\text { ticaret ortağı }\end{array}$ & $\begin{array}{l}\text { Japonya, İngiltere, Fransa ve İtalya için Marshall- } \\
\text { Lerner koşulunun gerçekleştiği, kalan iki ülke olan } \\
\text { Kanada ve Almanya için ise bu koşulun } \\
\text { gerçekleşmediği tespit edilmiştir }\end{array}$ \\
\hline $\begin{array}{l}\text { Şimşek ve } \\
\text { Kadilar } \\
(2005)\end{array}$ & $\begin{array}{l}\text { ARDL Sınır Testi } \\
\text { Yaklaşımı } \\
\text { Yöntemi }\end{array}$ & 1970 - 2002 & Türkiye & $\begin{array}{l}\text { İthalat ve ihracat fiyat esneklikleri toplamının } \\
\text { Marshall-Lerner kuralını karşılaması, yani birden } \\
\text { büyük olması (-1.01), parasal, mali ve döviz kuru } \\
\text { politikalarının dış ticaret dengesi üzerinde olumlu } \\
\text { katkı sağlayabileceği şeklinde yorumlanmasına neden } \\
\text { olmuştur }\end{array}$ \\
\hline $\begin{array}{l}\text { Hatemi ve } \\
\text { Irandoust } \\
(2005)\end{array}$ & $\begin{array}{l}\text { Panel Veri } \\
\text { Yöntemi }\end{array}$ & 1960-1999 & $\begin{array}{l}\text { İsveç ve } 6 \text { ticaret } \\
\text { ortağ } 1\end{array}$ & $\begin{array}{l}\text { Her ülke için hesaplanan ihracat ve ithalat ikili fiyat } \\
\text { esneklikleri toplamı, Almanya hariç mutlak anlamda } \\
\text { 1'den küçük olduğundan, Almanya hariç Marshal- } \\
\text { Lerner koşulunun gerçekleşmediğini göstermiştir }\end{array}$ \\
\hline $\begin{array}{l}\text { Hepaktan } \\
(2009)\end{array}$ & $\begin{array}{l}\text { Parçalı } \\
\text { Eşbütünleşme } \\
\text { AnaliziYöntemi }\end{array}$ & $\begin{array}{l}\text { 1983-2008 } \\
\text { (Quarter Data) }\end{array}$ & Türkiye & $\begin{array}{l}\text { Türkiye için Marshall Lerner koşulunun uzun } \\
\text { dönemde tam olarak sağlanmadığı dikkate alınarak, } \\
\text { devalüasyon kararı alınmadan önce üzerinde titizlikle } \\
\text { düşünülmesi gerektiği ifade edilmektedir }\end{array}$ \\
\hline $\begin{array}{l}\text { Murad } \\
(2012)\end{array}$ & $\begin{array}{l}\text { Johansen-- } \\
\text { Juselius Eş- } \\
\text { bütünleşme } \\
\text { yöntemi }\end{array}$ & $1973-2009$ & $\begin{array}{l}\text { Bangladeş ve } 6 \\
\text { Ticaret Ortağı }\end{array}$ & $\begin{array}{l}\text { Altı ticaret ortağ } \text { arasında, Marshall-Lerner koşulunun } \\
\text { yalnızca Amerika Birleşik Devletleri ile Bangladeş } \\
\text { arasında yapılan karşılıklı ticarette yerine geldiği ifade } \\
\text { edilmiştir. }\end{array}$ \\
\hline $\begin{array}{l}\text { Göçer ve } \\
\text { Elmas } \\
(2013)\end{array}$ & $\begin{array}{l}\text { Çoklu yapısal } \\
\text { kırılmalı } \\
\text { Eşbütünleşme } \\
\text { Yöntemi }\end{array}$ & 1989Q1-2012Q2 & Türkiye & $\begin{array}{l}\text { Elde edilen sonuçlar, ihracat ve ithalat talep ve gelir } \\
\text { esneklikleri toplamının birden büyük olduğunu ve } \\
\text { dolayısıyla bütün mal gruplarında, Genişletilmiş } \\
\text { Marshall-Lerner koşulunun geçerli olduğunu } \\
\text { göstermiştir }\end{array}$ \\
\hline $\begin{array}{l}\text { Ogutu } \\
(2014)\end{array}$ & $\begin{array}{l}\text { Vektör } \\
\text { Otoregresif ve } \\
\text { Vektör Hata } \\
\text { Düzeltme } \\
\text { Yöntemi } \\
\end{array}$ & $1963-2013$ & Kenya & $\begin{array}{l}\text { Reel döviz kurundaki bir artışın ticaret dengesini } \\
\text { iyileştirici yönde bir etkiye neden olacağı, yurtdış1 } \\
\text { gelir esneklik katsayısının ise yine teoriyle uyumlu } \\
\text { olarak pozitif ve } \% 5 \text { düzeyinde anlamlı olduğu tespit } \\
\text { edilmiştir }\end{array}$ \\
\hline $\begin{array}{l}\text { Edoun vd. } \\
(2015)\end{array}$ & $\begin{array}{l}\text { Johansen-Juselius } \\
\text { Eşbütünleşme, } \\
\text { Vektör Hata } \\
\text { Düzeltme Modeli } \\
\text { Yöntemi } \\
\end{array}$ & $\begin{array}{l}\text { 1990-2005 } \\
\text { (Çeyreklik } \\
\text { veriler) }\end{array}$ & Zimbabve & $\begin{array}{l}\text { Zimbabve için Marshall-Lerner } \\
\text { sağlandığını ve reel döviz kurunun diş ticaret } \\
\text { dengesinin önemli bir değişkeni olduğunu kanıtlamış, } \\
\text { söz konusu devalüasyon politikalarının uzun vadede } \\
\text { ticaret dengesini artırabileceği ifade edilmiştir. }\end{array}$ \\
\hline
\end{tabular}

Tablo 1. Yapılan Çalışmalar İçin Literatür Özet Tablosu

\section{Veri, Yöntem ve Ekonometrik Uygulama}

Çalışmamızda dış ticareti, reel döviz kuruyla beraber yurtiçi ve yurtdışı gelirin bir fonksiyonu olarak modelleyen Bahmani-Oskooee ve Brooks (1999) tarafından kullanılan ekonometrik model baz alınmıştır. Söz konusu modelden yola çıkılarak Türkiye'de ihracat ve ithalatı yapılan sermaye ve ara malları dış ticaretinde MarshallLerner koşulunun geçerliliği ve gelir esneklikleri aşağıdaki denklemler yardımıyla tahmin edilmiştir.

Model 1; İhracat talep modeli

$X_{t}=\beta_{0}+\beta_{1} R E D K_{t}+\beta_{2} G S H_{t}^{O E C D}+\varepsilon_{t}$

Model 2; İthalat talep modeli

$$
M_{t}=\alpha_{0}+\alpha_{1} R E D K_{t}+\alpha_{2} G S H_{t}^{T U R}+\varepsilon_{t}
$$


Burada $X_{t}$; her bir mal grubu için ihracat rakamlarını, $M_{t}$; her bir mal grubu için ithalat rakamlarını, $R E D K_{t}$; reel efektif döviz kurunu, $G S H_{t}^{T U R}$; yurt içinde yerleşiklerin gelirini, $G S H_{t}^{O E C D}$ ise yurt dışında yerleşiklerin (OECD) gelirlerini ifade etmektedir. $\beta_{1}$; ihracatın, $\alpha_{1}$ de ithalatın reel efektif döviz kuru esneklik katsayısını, $\beta_{2}$; ihracatın, $\alpha_{2}$ ise ithalatın gelir esneklik katsayısını göstermektedir. $\varepsilon_{t}$ ise hata terimini temsil etmektedir.

Bu bağlamda, ithalat modelinde yer alan $\alpha_{1}$ reel efektif döviz kuru katsayısının pozitif $\left(\alpha_{1}>0\right)$ olması, ihracat modelinde yer alan $\beta_{1}$ reel efektif döviz kuru katsayısının ise negatif $\left(\beta_{1}<0\right)$ olması beklenmektedir. Yurt dışı ve yurt içi gelirlerini temsil eden $\beta_{2}$ ve $\alpha_{2}$ katsayılarının ise iktisadi bekletiler ile de uyumlu olarak pozitif $\left(\beta_{2}>0\right.$ ve $\alpha_{2}>0$ ) olması beklenmektedir.

Yukarıda görülen iki denklem yardımı ile ithalat talep fonksiyonunun $\alpha_{1}$ parametresi ile ihracat talep fonksiyonunun $\beta_{1}$ parametresinin mutlak değerleri toplamına bakılarak esneklik şartının sağlanıp sağlanmadı̆̆ tespit edilir. İki parametrenin mutlak değerleri toplamı birden büyük $\left(\alpha_{1}+\beta_{1}>1\right)$ ise esneklikler şartının veya diğer bir ifade ile Marshall-Lerner koşulunun sağlandığı kabul edilir (Seyidoğlu, 2015).

\subsection{Birim Kök Analizi}

Değişkenlerin durağanlık sınamaları ile ilgili güvenilir sonuçlar elde edebilmek amacıyla çalışmada kullanılan tüm değişkenlere ADF birim kök testi ile beraber Philips-Perron (PP) birim kök sınaması da gerçekleştirilmiştir. Bu kapsamda, ARDL sınır testi yaklaşımının uygulanabilirliği, hem ithalat hem de ihracat modellerine ait tüm değişkenlere uygulanmış ve elde edilen sonuçlar tablo 2'de gösterilmiştir.

\begin{tabular}{|c|c|c|c|c|c|c|}
\hline \multirow[b]{2}{*}{ Değiş̧kenler } & \multicolumn{3}{|c|}{ ADF(Düzey ) } & \multicolumn{3}{|c|}{ PHILLIPS-PERRON (Düzey) } \\
\hline & Sabitli & $\begin{array}{l}\text { Sabitli ve } \\
\text { Trendli } \\
\end{array}$ & $\begin{array}{l}\text { Sabitsiz ve } \\
\text { Trendsiz }\end{array}$ & Sabitli & $\begin{array}{l}\text { Sabitli ve } \\
\text { Trendli } \\
\end{array}$ & $\begin{array}{l}\text { Sabitsiz ve } \\
\text { Trendsiz } \\
\end{array}$ \\
\hline SER_ITH & $-1,22$ & $-3,59 * *$ & 0,50 & $-1,40$ & $-2,63$ & 0,45 \\
\hline SER_IHR & $-2,51$ & $-2,15$ & 1,58 & $-2,81 *$ & $-2,00$ & 1,80 \\
\hline ARA_ITH & $-1,69$ & $-3,81 * *$ & 0,98 & $-1,61$ & $-3,81 * *$ & 1,42 \\
\hline ARA_IHR & $-1,66$ & $-2,34$ & 2,78 & $-1,74$ & $-5,13 * * *$ & 3,31 \\
\hline$G S H^{t}$ & $-0,12$ & $-3,06$ & 2,29 & $-0,04$ & $-2,61$ & 2,82 \\
\hline GSH ${ }^{\text {oecd }}$ & $-2,17$ & $-2,56$ & 2,20 & $-2,21$ & $-1,75$ & 2,96 \\
\hline$R E D K$ & $-2,46$ & $-3,45^{*}$ & 0,66 & $-2,26$ & $-2,82$ & 0,91 \\
\hline \multirow[b]{2}{*}{ Değişkenler } & \multicolumn{2}{|c|}{ ADF(1.Fark ) } & \multicolumn{4}{|c|}{ PHILLIPS-PERRON(1.Fark) } \\
\hline & Sabitli & $\begin{array}{c}\text { Sabitli ve } \\
\text { Trendli } \\
\end{array}$ & $\begin{array}{c}\text { Sabitsiz ve } \\
\text { Trendsiz } \\
\end{array}$ & Sabitli & $\begin{array}{c}\text { Sabitli ve } \\
\text { Trendli } \\
\end{array}$ & $\begin{array}{c}\text { Sabitsiz ve } \\
\text { Trendsiz } \\
\end{array}$ \\
\hline SER_ITH & $-6,89 * * *$ & - & $-6,92 * * *$ & $-6,82 * * *$ & $-6,76^{* * *}$ & $-6,86^{* * *}$ \\
\hline SER_IHR & $-8,71 * * *$ & $-8,98 * * *$ & $-8,41 * * *$ & $-8,76 * * *$ & $-9,50 * * *$ & $-8,41 * * *$ \\
\hline ARA_ITH & $-6,47 * * *$ & - & $-4,43 * * *$ & $-12,32 * * *$ & - & $-11,43 * * *$ \\
\hline$A R A_{-} I H R$ & $-6,30 * * *$ & $-6,36 * * *$ & $-6,76^{* * *}$ & $-31,33 * * *$ & - & $14,25 * * *$ \\
\hline$G S H^{t}$ & $-6,14 * *$ & $-6,13 * * *$ & $-5,52 * * *$ & $-6,15 * * *$ & $-6,14 * * *$ & $-5,59 * * *$ \\
\hline$G S H^{\text {oecd }}$ & $-3,86 * * *$ & $-4.18 * * *$ & $-2,74 * * *$ & $-3,44 * *$ & $-3,60 * * *$ & $-2,86 * * *$ \\
\hline$R E D K$ & $-6,22 * * *$ & $-6,28 * * *$ & $-6,20 * * *$ & $-8,44 * * *$ & $-9,37 * * *$ & $-8,23 * * *$ \\
\hline Kritik Değerler & Sabitli & $\begin{array}{c}\text { Sabitli ve } \\
\text { Trendli } \\
\end{array}$ & $\begin{array}{c}\text { Sabitsiz ve } \\
\text { Trendsiz } \\
\end{array}$ & Sabitli & $\begin{array}{c}\text { Sabitli ve } \\
\text { Trendli } \\
\end{array}$ & $\begin{array}{c}\text { Sabitsiz ve } \\
\text { Trendsiz } \\
\end{array}$ \\
\hline$\% 1$ & $-3,53$ & $-4,10$ & $-2,60$ & $-3,53$ & $-4,10$ & $-2,60$ \\
\hline$\% 5$ & $-2,90$ & $-3,48$ & $-1,95$ & $-2,90$ & $-3,48$ & $-1,95$ \\
\hline$\% 10$ & $-2,59$ & $-3,17$ & $-1,61$ & $-2,59$ & $-3,17$ & $-1,61$ \\
\hline
\end{tabular}

Tablo 2. Birim Kök Testi Sonuçlarl

Not: ***, \%1,**, \%5, *ise \%10 anlamlılık düzeylerini göstermektedir.

Sabitli, sabitli ve trendli ve sabitsiz ve trendsiz modeller için uygulanan ve tablo 2'de gösterilen ADF ve PhilipsPerron (PP) birim kök testi sonuçları, bazı değişkenlerin düzey değerlerinde $(\mathrm{I}(\mathrm{O})) \% 1, \% 5$ ve \%10, bazılarının ise birinci farklarında (I(I)) \%1 ve \%5 anlamlılık düzeylerinde MacKinnon kritik değerlerinden mutlak değer olarak büyük olduğunu göstermiştir. Dolayısıyla elde edilen bu sonuçlara göre sıfır hipotezi reddedilmekte ve serilerin durağan olduğu görülmektedir. Bu sonuçlar aynı zamanda değişkenlerin durağanlık seviyelerinde mixed (karma) bir yapının ve dolayısıyla ARDL Sınır Testi yaklaşımının uygulanabilir olduğunu göstermektedir.

\subsection{ARDL Eşbütünleşme Testi}

Pesaran, Shin ve Smith (2001), seriler arasındaki eş bütünleşme ilişkisinin belirlenebilmesini oldukça kolaylaştıran ve I(2) olması dışında, değişkenlerin durağanlık seviyelerinin farklı derecelerden bütünleşik olması veya bütünleşme düzeylerinin tamamen I(0), tamamen I(1) veya mixed (karma) bir yapıda olması durumunda 
uygulanabilen ARDL Sınır Testi yaklaşımını geliştirmişlerdir. Son zamanlarda eş bütünleşme analizlerinde sık bir şekilde uygulanan söz konusu yaklaşımın en önemli özelliği değişkenlerin bütünleşme dereceleri göz önüne alınmadan eş-bütünleşme ilişkisinin araştırılabilmesidir (Erdoğan, v.d., 2015). Ayrıca söz konusu yaklaşımın diğer önemli bir özelliği de küçük örneklemler için daha daha uygun ve daha iyi sonuç vermesiyle beraber kısa ve uzun dönemli parametreleri aynı anda tahmin edebilmesidir (Alimi, 2015).

ARDL Sınır Testi model tahminleri gerçekleştirildikten sonra seriler arasında eş bütünleşmenin olmadığını gösteren sıfır hipotezinin, eş bütünleşme ilişkisinin olduğu alternatif hipotez karşısında sınandığı tüm ihracat ve ithalat modelleri için uygun gecikme uzunlukları ile eş bütünleşme testleri uygulanır. Test sonuçları elde edilen F istatistik değeri, Pesaran vd. (2001)'deki tabloda yer alan üst kritik değerin üzerinde ise seriler arasında eşbütünleşme ilişkisinin olmadığını gösteren sıfır hipotezi reddedilir (Narayan ve Smyth, 2004). Bu kapsamda, tüm modellere uygulanan eş bütünleşme testleri ve hesaplanan F istatistikleri tablo 3 'de gösterilmektedir.

\begin{tabular}{|c|c|c|c|c|}
\hline $\begin{array}{c}\text { TÜM } \\
\text { MODELLER }\end{array}$ & $\begin{array}{l}\text { Değişken } \\
\text { Sayısı(k) }\end{array}$ & $F$ istatistiğ $i$ & $\begin{array}{c}\text { Kritik } \\
\text { Değer }(\% 1)\end{array}$ & $\begin{array}{c}\text { Kritik } \\
\text { Değer(\%5) }\end{array}$ \\
\hline $\begin{array}{l}\text { Sermaye Mallar1 } \\
\text { İhracatı Modeli }\end{array}$ & 2 & $7,58 * * *$ & $\begin{array}{l}\mathrm{I}(0)-\mathrm{I}(1) \\
3,88-5,3\end{array}$ & $\begin{array}{c}\mathrm{I}(0)-\mathrm{I}(1) \\
2,72-3,83\end{array}$ \\
\hline $\begin{array}{c}\text { Ara Mallar1 } \\
\text { İhracatı Model }\end{array}$ & 2 & $20,85 * * *$ & $\begin{array}{c}\mathrm{I}(0)-\mathrm{I}(1) \\
4,99-5,85\end{array}$ & $\begin{array}{c}\mathrm{I}(0)-\mathrm{I}(1) \\
3,88-4,61\end{array}$ \\
\hline $\begin{array}{l}\text { Sermaye Mallar1 } \\
\text { İthalat1 Modeli }\end{array}$ & 2 & $11,65 * * *$ & $\begin{array}{l}\mathrm{I}(0)-\mathrm{I}(1) \\
3,88-5,3\end{array}$ & $\begin{array}{c}\mathrm{I}(0)-\mathrm{I}(1) \\
2,72-3,83\end{array}$ \\
\hline $\begin{array}{c}\text { Ara Malları } \\
\text { İthalat Modeli }\end{array}$ & 2 & $5,25 * * *$ & $\begin{array}{c}\mathrm{I}(0)-\mathrm{I}(1) \\
4,13-5\end{array}$ & $\begin{array}{l}\mathrm{I}(0)-\mathrm{I}(1) \\
3,1-3,87\end{array}$ \\
\hline
\end{tabular}

Tablo 3. Sınır Testi (F Testi ve Kritik Sinır Değerleri)

Not: $* * * \% 1$, anlamlılık düzeyini göstermektedir.

Yukarıda gerçekleştirilen ARDL sınır testi sonuçları incelendiğinde, tüm ithalat ve ihracat modelleri için hesaplanan F-istatistik değerleri yüzde 1 anlamlılık düzeyinde Pesaran vd. (2001)'in üst kritik sinır değerinden daha büyüktür. Dolayısıyla tüm modeller için seriler arasında eş-bütünleşme ilişkisinin olmadığını gösteren $\boldsymbol{H}_{\mathbf{0}}$ hipotezi reddedilmiş ve değişkenler arasında eş bütünleşme ilişkisinin var olduğuna karar verilmiştir.

\subsection{ARDL Model Tahminleri}

Seriler arasındaki kointegrasyon ilişkisinin varlığ $\mathrm{F}$ testi ile saptandıktan sonra uzun ve kısa dönem ilişkilerin tespiti amacıyla ARDL modelleri kurulur (Altıntaş, 2009). AIC veya SIC bilgi kriterlerinden yararlanılarak maksimum gecikme uzunluklarının belirlendiği modeller uygun gecikme uzunlukları ile tahmin edildikten sonra uzun dönem katsayılar elde edilir. Elde edilen katsayıların istatistiki olarak anlamlı olup olmadığ $\mathrm{F}$ testi ile belirlendikten sonra söz konusu katsayıların yorumlamaları yapılır.

\section{- Ithalat Modelleri Tahmin Sonuçları}

Serilerin üçer aylık veriler olması nedeniyle, maximum gecikme uzunluğunun 8 olarak belirlendiği ve uygun gecikme uzunlukları ile tahmin edilen söz konusu modellere ait tahmin ve tanımlayıcı test sonuçları aşağıda verilen tablo 4'de gösterilmiştir. 


\begin{tabular}{|c|c|c|c|c|}
\hline İTHALAT MODELLERİ & $\begin{array}{r}\text { Sermaye } M \\
(1,\end{array}$ & $\begin{array}{l}\text { latı ARDL } \\
\text { li }\end{array}$ & \multicolumn{2}{|c|}{$\begin{array}{l}\text { Ara Malları İthalatı ARDL }(2,1,1) \\
\text { Modeli }\end{array}$} \\
\hline Değișkenler & Katsayı & t-İst. & Katsayı & t-İst. \\
\hline SER_ITH (-1) & $0,64 * * *$ & 9,14 & - & - \\
\hline ARA_ITH(-1) & - & - & $0,40 * * *$ & 4,08 \\
\hline ARA_ITH(-2) & - & - & $0,25 * *$ & 2,46 \\
\hline$G S H^{t}$ & $1,58 * * *$ & 3,22 & $2,70 * * *$ & 6,47 \\
\hline $\boldsymbol{G S H}^{\boldsymbol{t}}(-1)$ & 0,30 & 0,38 & $-2,39 * * *$ & $-5,71$ \\
\hline $\boldsymbol{G S H}^{\boldsymbol{t}}(-2)$ & $-1,67 * * *$ & $-3,43$ & - & - \\
\hline REDK & $0,80 * * *$ & 4,17 & 0,25 & 1,57 \\
\hline$R E D K(-1)$ & $-0,71 * * *$ & $-2,91$ & $-0,38 * *$ & $-2,49$ \\
\hline$R E D K(-2)$ & $0,66^{* * *}$ & 3,63 & - & - \\
\hline $\boldsymbol{K}$ & $-0,02 *$ & $-1,91$ & - & - \\
\hline$C$ & - & - & $1,18^{* * *}$ & 3,06 \\
\hline Tanısal Testler & \multicolumn{2}{|c|}{ Katsayılar } & \multicolumn{2}{|c|}{ Katsayılar } \\
\hline$R^{2}$ & \multicolumn{2}{|c|}{0,962} & \multicolumn{2}{|c|}{$0,90 \mathrm{e}$} \\
\hline Düzeltilmiş $\boldsymbol{R}^{2}$ & \multicolumn{2}{|c|}{0,957} & \multicolumn{2}{|c|}{$0,89 \mathrm{e}$} \\
\hline Oto korelasyon & \multicolumn{2}{|c|}{$0,27(0,87)$} & \multicolumn{2}{|c|}{$4,07(0,13)$} \\
\hline Fonksiyonel F. & \multicolumn{2}{|c|}{$0,19(0,66)$} & \multicolumn{2}{|c|}{$0,36(0,55)$} \\
\hline Normallik & \multicolumn{2}{|c|}{$2,76(0,25)$} & \multicolumn{2}{|c|}{$0,53(0,77)$} \\
\hline Değişen Vary. & \multicolumn{2}{|c|}{$7,40(0,49)$} & \multicolumn{2}{|c|}{$12,43(0,052)$} \\
\hline Olasılık & \multicolumn{2}{|c|}{0,000} & \multicolumn{2}{|c|}{0,000} \\
\hline
\end{tabular}

Tablo 4. Uzun Dönem ARDL İthalat Modelleri Tahmin Sonuçları

Not: ***\%1,**\%5,***,\% 10 anlamlllık düzeyleri. Parantez içerisindeki değerler ise p(olasılık) değerleridir

ARDL $(1,2,2)$ ve ARDL $(2,1,1)$ modelleri olarak tahmin edilen sırasiyla sermaye malları ve ara malları ithalat modellerindeki yurtiçi gelir değişkenine ait cari değer katsayı işaretleri iktisadi beklentiler ve teoriye uygun olarak gerçekleşmiş ve katsayılar istatistiki olarak \%1 düzeyinde anlamlı çıkmıştır. Reel efektif döviz kuru değişkenine ait katsayı işaretleri ise ara malları ithalat modelinde iktisadi beklenti ve teoriyle uyumlu ancak katsayının kendisi istatistiki olarak anlamsız çıkmıştır. Sermaye malları ithalat modeline ait reel efektif döviz kuru katsayı işareti ise iktisadi beklentiler ve teoriye uygun olarak gerçekleşmiş ve katsayı istatistiki olarak \% 1 düzeyinde anlamlı çıkmıştır. Bununla beraber sermaye malı ithalat modelinde tespit edilen yapısal değişimi temsilen söz konusu modele dişsal olarak dahil edilen kukla değişken de istatistiki olarak anlamlı çıkmıştır.

Modellerin güvenilir tahmin sonuçları vermesi açısından büyük önem arz eden tanısal test sonuçlarına bakıldığında ise tüm ithalat modellerinde Breusch-Godfrey testine göre ardışık bağımlılık, Breusch-PaganGodfrey testine göre değişen varyans problemi olmadığı, Jarque-Bera testine göre ise hata terimlerinin normal dağılıma sahip olduğu ve ayrıca Ramsey Reset testine göre model kurma (fonksiyonel form) hatalarının olmadığ anlaşılmaktadır.

Sermaye Malları İthalat modeline ait parametrelerin kararlılığını test etmek amacıyla ardışık artıkların kareleri ile hesaplanan CUSUM of square testi modelde yapısal bir değişimin olduğunu göstermiştir. Aşağıdaki grafikten de görülebilen yapısal kırılmayı temsilen modele bir kukla değişken eklenmesine karar verilmiştir. Söz konusu kukla değişken, 2006Q4-2009Q4 arası dönem için değişkenler üzerindeki pozitif veya negatif etkilerini (yapısal kırılmaları) yansıtmak üzere, aşağıda verilen CUSUM of Squares Testi grafiğinin sınır dışında kalan frekans aralıkları da baz alınarak modele dışsal olarak eklenmiştir. Modele dahil edilen kukla değişken sonrası ise modelin artıklarının sınırlar içerisinde kalmasıyla birlikte modele ait parametrelerin kararlı bir yapı sergilemiş olduğu görülmüştür. Söz konusu dönem için modele dahil edilen kukla değişken öncesi ve sonrası, parametre kararlılık testleri olarak bilinen CUSUM ve CUSUM of Squares grafikleri aşağıda verilmiştir.

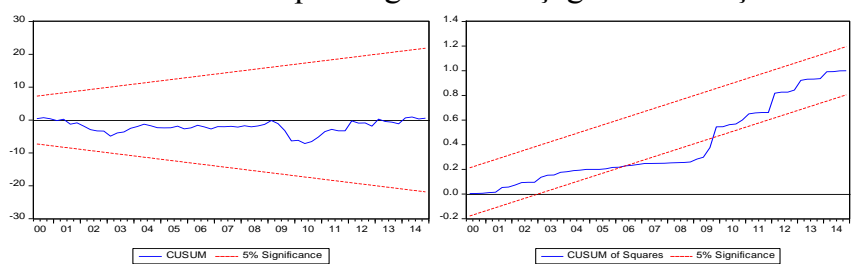

Şekil 1. Sermaye Malları Ithalat Modeli CUSUM ve CUSUM-SQ Test Sonuçları

Not: Kukla Değişken Öncesi Durum 

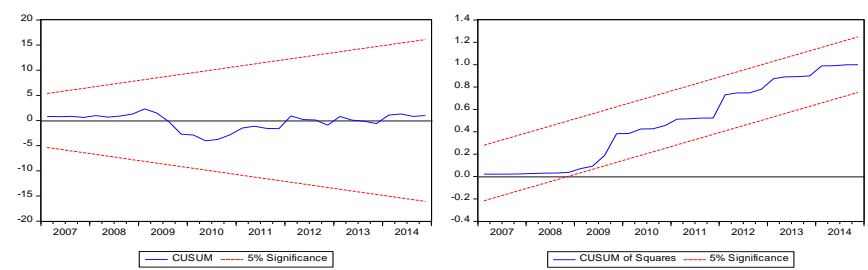

Şekil 2. Sermaye Malları Itthalat Modeli CUSUM ve CUSUM-SQ Test Sonuçları

Not: Kukla Değişken Sonrası Durum

Ara malları ithalat modeline ait parametrelerin kararlılığını test etmeye yönelik gerçekleştirilen CUSUM ve CUSUM of square test istatistikleri \%5 anlam düzeyinde kritik sınırlar içinde kaldığından yapısal bir kırılmanın olmadığı görülmüştür. Dolayısıyla ARDL yöntemi ile hesaplanan uzun dönem parametrelerin ve modelin kalıntı varyansının kararlı olduğu ve bu nedenle kukla değişken kullanılmadan modelin tahmin edilebileceği anlaşılmış ve elde edilen sonuçlar aşağıdaki grafiklerde gösterilmiştir.

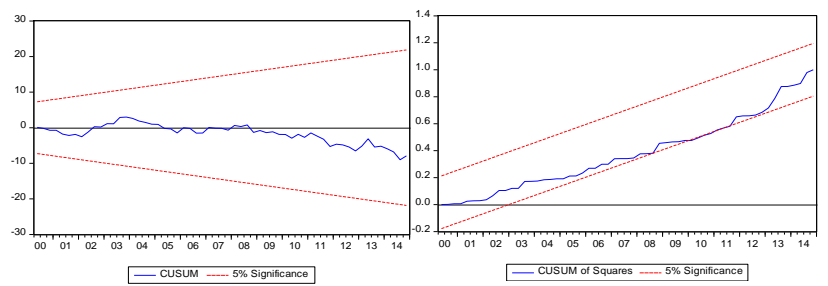

Şekil 3. Ara Malları Ithalat Modeli CUSUM ve CUSUM-SQ Test Sonuçları

\section{- Ihracat Modelleri Tahmin Sonuçları}

Serilerin üçer aylık veriler olması nedeniyle, maksimum gecikme uzunluğunun 8 olarak belirlendiği ve uygun gecikme uzunlukları ile tahmin edilen söz konusu modellere ait tahmin ve tanımlayıcı test sonuçları aşağıda verilen tablo 5'de gösterilmiştir.

\begin{tabular}{|c|c|c|c|c|}
\hline \multirow{2}{*}{$\begin{array}{c}\text { İHRACAT MODELLERİ } \\
\text { Değişkenler } \\
\end{array}$} & \multicolumn{2}{|c|}{$\begin{array}{c}\text { Sermaye Malları İhracatı } \\
\text { ARDL } \\
(\mathbf{1 , 0 , 0 )} \text { Modeli } \\
\end{array}$} & \multicolumn{2}{|c|}{$\begin{array}{c}\text { Ara Mallariİhracatı } \\
\text { ARDL } \\
(1,00) \text { Model } \\
\end{array}$} \\
\hline & Katsayı & $t$-íst. & Katsayı & $t$-İst. \\
\hline SER_IHR (-1) & $0,59 * * *$ & 7,12 & - & - \\
\hline$A R A \_I H R(-1)$ & - & - & $-0,13 * * *$ & $-1,08$ \\
\hline$G S H^{O E C D}$ & $3,00 * * *$ & 3,91 & $1,72 * *$ & 2,21 \\
\hline$G S H^{O E C D}(-1)$ & - & - & - & - \\
\hline$R E D K$ & $-0,05$ & $-0,27$ & $-0,36^{* *}$ & $-2,57$ \\
\hline$K$ & $0,07 * * *$ & 3,40 & $0,07 * * *$ & 4,45 \\
\hline$C$ & - & - & $7,31 * * *$ & 7,97 \\
\hline TREND & - & - & $0,01 * * *$ & 4,83 \\
\hline Tanisal Testler & \multicolumn{2}{|c|}{ Katsayılar } & \multicolumn{2}{|c|}{ Katsayular } \\
\hline$R^{2}$ & \multicolumn{2}{|c|}{0,96} & \multicolumn{2}{|c|}{0,932} \\
\hline Düzeltilmiş $\boldsymbol{R}^{\mathbf{2}}$ & \multicolumn{2}{|c|}{0,95} & \multicolumn{2}{|c|}{0,927} \\
\hline Oto korelasyon & \multicolumn{2}{|c|}{$0,09(0,96)$} & \multicolumn{2}{|c|}{$3,73(0,16)$} \\
\hline Fonksiyonel Form & \multicolumn{2}{|c|}{$0,64(0,43)$} & \multicolumn{2}{|c|}{$0,19(0,67)$} \\
\hline Normallik & \multicolumn{2}{|c|}{$0,40(0,25)$} & \multicolumn{2}{|c|}{$5,43(0,07)$} \\
\hline DeğişenVaryans & \multicolumn{2}{|c|}{$4,00(0,41)$} & \multicolumn{2}{|c|}{$8,75(0,12)$} \\
\hline Olasıl1k & \multicolumn{2}{|c|}{0,000} & \multicolumn{2}{|c|}{0,000} \\
\hline
\end{tabular}

Tablo 5. Uzun Dönem ARDL İhracat Modelleri Tahmin Sonuçlarl

Not: ***, \%1, **\%5, ***, \%10 anlamlılı düzeyleri, Parantez içerisindeki değerler ise p(olasılık) değerleridir

Uygun gecikme uzunlukları ile, ARDL $(1,0,0)$ ve ARDL $(1,0,0)$ modelleri olarak tahmin edilen sirasıyla sermaye ve ara malları ihracat modellerindeki yurt dişı gelir değişkenine ait cari değer katsayı işaretleri iktisadi beklentiler ve teoriye uygun olarak gerçekleşmiş ve katsayılar istatistiki olarak \%1 ve \% 5 düzeylerinde anlamlı çıkmıştır. Reel efektif döviz kuru değişkenine ait katsayı işareti ise sermaye malları ihracat modelinde iktisadi beklenti ve teoriyle uyumlu ancak katsayının kendisi istatistiki olarak anlamsız çıkmıştır. Ara malları ihracat modelinde ise reel efektif döviz kuru katsayı işareti iktisadi beklentiler ve teoriye uygun olarak gerçekleşmiş ve katsayı istatistiki olarak \% 5 düzeyinde anlamlı çıkmıştır. Bununla beraber sermaye malları ve ara mallar ihracat modellerinde tespit edilen yapısal değişimleri temsilen söz konusu modellere dışsal olarak dahil edilen kukla değişkenler de istatistiki olarak \% 1 düzeyinde anlamlı çıkmıştır. Ayrıca sabitli ve trendli model olarak tahmin edilen ara malları ihracatı 
modelinde trend değişkeni katsayısı pozitif ve istatistiki olarak \%1 düzeyinde anlamlı çıkarak ara malları ihracatında çok düşük düzeyde de olsa \% 0,01 oranında trend etkisinin de olduğu görülmüştür.

Modellerin güvenilir tahmin sonuçları vermesi açısından büyük önem arz eden tanısal test sonuçlarına bakıldığında ise tüm ihracat modellerinde Breusch-Godfrey testine göre ardışık bağımlılık, Breusch-PaganGodfrey testine göre değişen varyans problemi olmadığı, Jarque-Bera testine göre ise hata terimlerinin normal dağılıma sahip olduğu ve ayrıca Ramsey Reset testine göre model kurma (fonksiyonel form) hatalarının olmadı̆̆ anlaşılmaktadır.

Sermaye Malları İhracat modeline ait parametrelerin kararlılığını test etmek amacıyla ardışık artıkların kareleri ile hesaplanan CUSUM of square testi modelde yapısal bir değişimin olduğunu göstermiştir. Aşağıdaki grafikten de görülebilen yapısal kırılmayı temsilen modele bir kukla değişken eklenmesine karar verilmiştir. Söz konusu kukla değişken, 2004Q1-2007Q2 arası dönem için değişkenler üzerindeki pozitif veya negatif etkilerini (yapısal kırılmaları) yansıtmak üzere, aşağıda verilen CUSUM of Square Testi grafiğinin sınır dışında kalan frekans aralıkları da baz alınarak modele dışsal olarak eklenmiştir. Modele dahil edilen 2004Q1-2007Q2 dönemleri arası kukla değişken, tablo 5 'de de gösterildiği gibi $(\% 0,07)$, sermaye malları ihracatı üzerinde pozitif yönde ve istatiki olarak \%1 düzeyinde anlamlı bir etki oluşturmuştur. Modele dahil edilen söz konusu kukla değişken sonrası ise modelin artıklarının sınırlar içerisinde kalmasıyla birlikte modele ait parametrelerin kararlı bir yapı sergilemiş olduğu görülmüştür. Söz konusu dönem için modele dahil edilen kukla değişken öncesi ve sonrası, parametre kararlılık testleri olarak bilinen CUSUM ve CUSUM of Squares grafikleri aşağıda verilmiştir.

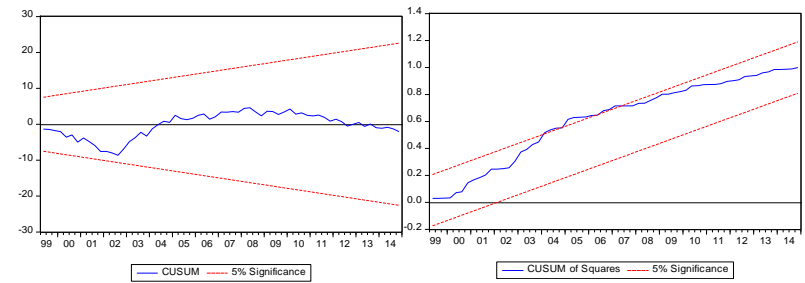

Şekil 4. Sermaye Malları İhracat Modeli CUSUM ve CUSUM-SQ Test Sonuçları

Not: Kukla Değişken Öncesi Durum

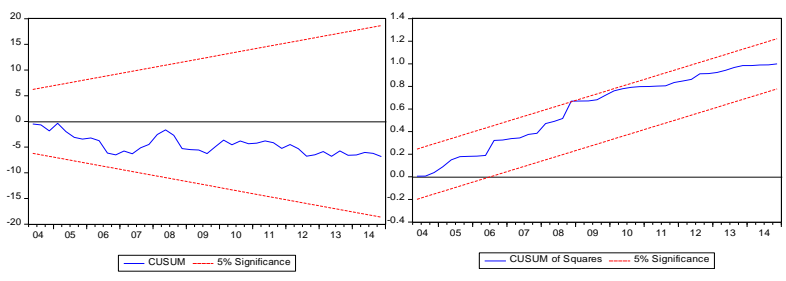

Şekil 5. Sermaye Malları İhracat Modeli CUSUM ve CUSUM-SQ Test Sonuçları

Not: Kukla Değişken Sonrası Durum

\section{- Ara Mallart Íhracat Modeli}

Ara malları ihracat modeline ait parametrelerin kararlılı̆̆ını test etmek amacıyla ardışık artıkların kareleri ile hesaplanan CUSUM of square testi modelde yapısal bir değişimin olduğunu göstermiştir. Aşağıdaki grafikten de görülebilen yapısal kırılmayı temsilen modele bir kukla değişken eklenmesine karar verilmiştir. Söz konusu kukla değişken, 2004Q2-2009Q1 arası dönem için değişkenler üzerindeki pozitif veya negatif etkilerini (yapısal kırılmaları) yansıtmak üzere, aşağıda verilen CUSUM of Squares Testi grafiğinin sınır dışında kalan frekans aralıkları da baz alınarak modele dışsal olarak eklenmiştir. Modele dahil edilen 2004Q2-2009Q1 dönemleri arası kukla değişken, tablo 5 'de de gösterildiği gibi $(\% 0,07)$, ara malları ihracatı üzerinde pozitif yönde ve istatiki olarak \%1 düzeyinde anlamlı bir etki oluşturmuştur. Modele dahil edilen söz konusu kukla değişken sonrası ise modelin artıklarının sınırlar içerisinde kalmasıyla birlikte modele ait parametrelerin kararlı bir yapı sergilemiş olduğu görülmüştür. Söz konusu dönem için modele dahil edilen kukla değişken öncesi ve sonrası, parametre kararlılık testleri olarak bilinen CUSUM ve CUSUM of Squares grafikleri aşağıda verilmişstir.

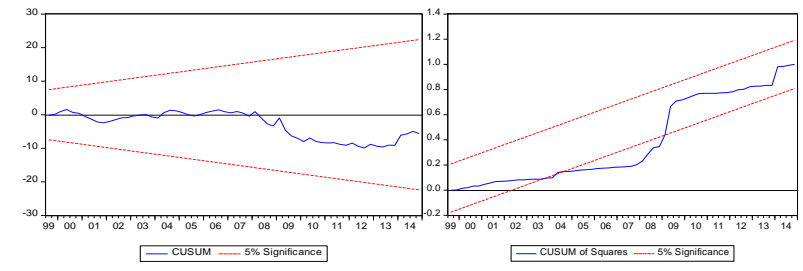

Şekil 6. Ara Malları İhracat Modeli CUSUM ve CUSUM-SQ Test Sonuçları

Not: Kukla Değişken Öncesi Durum 


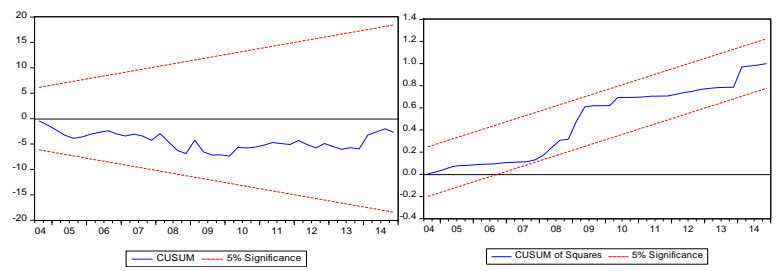

Şekil 7. Ara Malları İhracat Modeli CUSUM ve CUSUM-SQ Test Sonuçları

\section{Not: Kukla Değişken Sonrası Durum}

\subsection{Uzun Dönem Katsayılar ve Kısa Dönem Hata Düzeltme Modelleri}

Uzun dönem model tahminlerinden farklı olarak, hata düzeltme modellerinde modele Hata Düzeltme Terimi (ECM) ilave edilmekte ve söz konusu hata terimi uzun dönem modellerinden sağlanan kalıntılardan elde edilmektedir (Görüş ve Türköz, 2016).

\section{- Ithalat Modelleri Uzun Dönem Katsayılart ve Kısa Dönem Hata Düzeltme Modeli}

ARDL $(1,2,2)$ ve ARDL $(2,1,1)$ hata düzeltme modelleri olarak tahmin edilen sirasiyla sermaye ve ara malları ithalat modellerindeki yurt içi gelir değişkenine ait cari değer katsayı işaretleri istatistiki olarak \%1 düzeyinde anlamlı çıkmıştır. Reel efektif döviz kuru değişkenine ait katsayı işaretleri ise sermaye malları ithalat modelinde $\% 1$, ara malları ithalat modelinde ise \% 10 düzeyinde istatistiki olarak anlamlı çıkmıştır. Cari yurt içi gelir değişkenindeki \%1'lik bir artış, kısa dönemde sermaye malları ithalatında \%1,59, ara malları ithalatında ise \% 2,70'lik bir artışa neden olmaktadır. Cari reel efektif döviz kurundaki \%1'lik bir artış ise kısa dönemde sermaye malları ithalatında \% 0,79, ara malları ithalatında ise \% 0,25'lik bir artışa neden olmaktadır. Ayrıca modele dahil edilen kukla değişken, sermaye malları ithalat modeli için kısa dönemde istatistiki olarak anlamlı çıkmamıştır.

Hata düzeltme katsayıları (ECM-1) ise tüm modellerde beklendiği gibi negatif ve \%1 düzeyinde istatistiki olarak anlamlı çıkmıştır. Söz konusu bu sonuçlar kısa dönemde meydana gelen dengesizliklerin uzun dönemde dengeye yaklaştığı anlamına gelmektedir. Elde edilen katsayılara ait değerler, sermaye ve ara malları için -0,35 olarak gerçekleşmiştir. Hesaplanan hata düzeltme katsayıları, kısa dönem dengesizliklerin, sermaye ve ara malları ithalat modellerinde yaklaşık olarak \% 35'inin bir sonraki dönemde dengeye geldiğini göstermektedir.

\begin{tabular}{|c|c|c|c|c|}
\hline ITHALAT MODELLERİ & \multicolumn{2}{|c|}{\begin{tabular}{|c|} 
Sermaye Malları ItthalatıARDL \\
$(1,2,2)$ Modeli
\end{tabular}} & \multicolumn{2}{|c|}{$\begin{array}{c}\text { Ara Malları İthalat ARDL } \\
(2,1,1) \text { Model } \\
\end{array}$} \\
\hline Değişkenler & Katsayl & $t-\dot{I} s t$ & Katsayl & $t$-ist. \\
\hline REDK & $2,12 * * *$ & 4,36 & $-0,38$ & $-1,12$ \\
\hline$G S H^{t}$ & $0,57 * * *$ & 3,68 & $0,89 * * *$ & 5,03 \\
\hline$K$ & $-0,07 *$ & $-1,80$ & - & - \\
\hline$C$ & - & - & $3,35 * * *$ & 4,76 \\
\hline \multicolumn{5}{|c|}{ thalat Modelleri Kısa Dönem ARDL Hata Düzeltme Tahmin Sonuçları } \\
\hline$D\left(A R A \_I T H(-1)\right)$ & - & - & $-0,25 * *$ & $-2,63$ \\
\hline$D\left(G S H^{t}\right)$ & $1,59 * * *$ & 3,51 & $2,70 * * *$ & 6,99 \\
\hline$D\left(G S H^{t}(-1)\right)$ & $1,66 * * *$ & 3,60 & - & - \\
\hline$D(R E D K)$ & $0,79 * * *$ & $-4,61$ & $0,25^{*}$ & 1,74 \\
\hline$D(R E D K(-1))$ & $0,66 * * *$ & $-3,74$ & - & - \\
\hline$D(K)$ & $-0,03$ & $-1,22$ & - & - \\
\hline $\operatorname{ECM}(-1)$ & $-0,35 * * *$ & $-5,71$ & $-0,35 * * *$ & $-4,70$ \\
\hline
\end{tabular}

Tablo 6. Ithalat Modelleri ARDL Uzun Dönem Katsayıları Tahmin Sonuçları

Not: ***, \%1, **, \%5, ise \%10 anlamlllık düzeylerini göstermektedir

ARDL $(1,2,2)$ ve ARDL $(2,1,1)$ modellerinden yararlanılarak hesaplanan ithalat modelleri uzun dönem katsayılarındaki tahmin sonuçlarına göre yurtiçi gelirdeki \%1'lik bir artış, sermaye malları ithalatında \% 0.57 , ara malları ithalatında ise \% 0,89'luk bir artışa neden olmaktadır. Katsayıların tümü istatistiki olarak \%1 düzeyinde anlamlı ve katsayıların işaretleri iktisadi beklenti ile de uyumludur. Reel efektif döviz kurundaki (ulusal paranın değerlenmesi) \%1'lik bir artış ise sermaye malları ithalatında \% 2,12'lik bir artışa yol açarken, katsayı istatistiki olarak \%1 düzeyinde anlamlı ve katsayı işareti iktisadi beklenti ile de uyumludur. Ara malları ithalat modelindeki reel efektif döviz kuru katsayısı ise istatistiki olarak anlamsız çıkmıştır. Ayrıca sermaye malı ithalat modeline dahil edilen kukla değişkene ait katsayı incelendiğinde, uzun dönemde \% 10 düzeyinde istatistiki olarak anlamlı bulunmuştur. 


\section{- İhracat Modelleri Uzun Dönem Katsayılart ve Kısa Dönem Hata Düzeltme Modeli}

ARDL $(1,0,0)$, ve ARDL $(1,0,0)$ hata düzeltme modelleri olarak tahmin edilen sirasiyla sermaye malları ve ara malları ihracat modellerindeki yurt dışı gelir değişkenine ait cari değer katsayı işaretleri pozitif çıkmıştır. Sermaye malları ihracat modelinde istatistiki olarak \%5 düzeyinde anlamlı çıkan yurt dış1 gelir değişkenine ait söz konusu katsayı ara malları ihracat modelinde anlamlı çıkmamıştır. Reel efektif döviz kuru değişkenine ait katsayı işaretleri ise tüm modellerde negatif çıkmıştır. Sermaye malları ihracat modelinde anlamsız çıkan bu katsayı ara malları ihracat modelinde \%5 düzeyinde anlamlı çıkmıştır. Cari yurt dışı gelir değişkenindeki \%1’lik bir artış kısa dönemde sermaye malları ihracatında \% 5,50'lik bir artışa neden olurken, cari reel efektif döviz kurundaki \%1'lik bir artış ise kısa dönemde ara malları ihracatında \% 0,42'lik bir artışa neden olmaktadır. Ayrıca kısa dönemde istatistiki olarak \%1 düzeyinde anlamlı çıkan ara malları ihracat modeline ait kukla değişken, sermaye malları ihracat modeli için kısa dönemde istatistiki olarak anlamlı çıkmamıştır.

Hata düzeltme katsayıları (ECM) ise tüm modellerde beklendiği gibi negatif ve \%1 düzeyinde istatistiki olarak anlamlı çıkmıştır. Söz konusu bu sonuçlar kısa dönemde meydana gelen dengesizliklerin uzun dönemde dengeye yaklaştığı anlamına gelmektedir. Elde edilen katsayılara ait değerler, sermaye malları için -0,36, ara malları için 1,01 olarak gerçekleşmiştir. Hesaplanan hata düzeltme katsayıları, kısa dönem dengesizliklerinin, sermaye malları ihracat modelinde yaklaşık olarak \%35'inin bir sonraki dönemde dengeye geldiğini göstermektedir. Ara malları ihracat modelinde ise katsayısının 1'den büyük çıkması, sistemin dalgalanarak dengeye geldiğini ve söz konusu dalgalanmanın her seferinde azalış göstererek uzun dönemde dengeyi sağladığını ifade etmektedir (Karagöl, v.d., 2007; Narayan ve Smyth, 2006; Karaçor, v.d, 2011).

\begin{tabular}{|c|c|c|c|c|}
\hline İHRACAT MODELLERİ & \multicolumn{2}{|c|}{$\begin{array}{c}\text { Sermaye Malları İhracatı } \\
\text { ARDL(1,0,0) Modeli } \\
\end{array}$} & \multicolumn{2}{|c|}{$\begin{array}{l}\text { Ara Malları İhracatı } \\
\text { ARDL(1,00) Modeli } \\
\end{array}$} \\
\hline Değişkenler & Katsayl & $t-\dot{I} s t$ & Katsayl & $t-\dot{I} s t$ \\
\hline$R E D K$ & $-0,12$ & $-0,27$ & $-0,32 * *$ & $-2,63$ \\
\hline$G S H^{O E C D}$ & $7,33 * * *$ & 8,21 & $1,53 * *$ & 2,34 \\
\hline$K$ & $0,17 * * *$ & 3,91 & $0,06 * * *$ & 4,52 \\
\hline$C$ & - & - & - & - \\
\hline @TREND & - & - & $0,004 * * *$ & 5,15 \\
\hline \multicolumn{5}{|c|}{ İhracat Modelleri Kısa Dönem ARDL Hata Düzeltme Tahmin Sonuçları } \\
\hline$D\left(S E R \_I H R(-1)\right)$ & - & - & - & - \\
\hline$D\left(A R A \_I H R(-1)\right)$ & - & - & - & - \\
\hline$D\left(G S H^{O E C D}\right)$ & $5,50 * *$ & 2,16 & 2,61 & 1,39 \\
\hline$D\left(G S H^{O E C D}(-1)\right)$ & - & - & - & - \\
\hline$D\left(G S H^{O E C D}(-2)\right)$ & - & - & - & - \\
\hline$D\left(G S H^{O E C D}(-3)\right)$ & - & - & - & - \\
\hline$D\left(G S H^{O E C D}(-4)\right)$ & - & - & - & - \\
\hline$D(R E D K)$ & $-0,08$ & $-0,29$ & $-0,42 * *$ & $-2,49$ \\
\hline$D(K)$ & 0,07 & 1,63 & $0,11 * * *$ & 4,21 \\
\hline$C$ & - & - & 6,59 & 7,67 \\
\hline $\operatorname{ECM}(-1)$ & $-0,36 * * *$ & $-4,02$ & $-1,01 * * *$ & $-7,66$ \\
\hline
\end{tabular}

Tablo 7. Ihracat Modelleri ARDL Uzun Dönem Katsayıları Tahmin Sonuçları

$$
\text { Not: ***, \%1, **, \% 5, *ise \%10 anlamlıllk düzeylerini göstermektedir. }
$$

ARDL $(1,0,0)$ ve ARDL $(1,0,0)$ modellerinden yararlanılarak hesaplanan ihracat modelleri uzun dönem katsayılarındaki tahmin sonuçlarına göre yurtdışı gelirdeki \%1'lik bir artış, sermaye malları ihracatında \% 7,33, ara malları ihracatında \% 1,53'lük bir artışa neden olmaktadır. Katsayılar istatistiki olarak sırasıyla \%1 ve $\% 5$ düzeyinde anlamlı ve katsayıların işaretleri iktisadi beklenti ile de uyumludur. Reel efektif döviz kurundaki \%1'lik bir artış (ulusal paranın değerlenmesi) ise yalnızca ara malları ihracatında \% 0,32'lik bir artışa yol açarken, katsayı istatistiki olarak \%5 düzeyinde anlamlı ve katsayının işareti iktisadi beklenti ile de uyumludur. Sermaye malları ihracat modelindeki reel efektif döviz kuru katsayıları ise istatistiki olarak anlamsız çıkmıştır. Sermaye ve ara mal ihracat modellerine dahil edilen kukla değişkenlere ait katsayılar incelendiğinde ise her iki katsayı da uzun dönemde \% 1 düzeyinde istatistiki olarak anlamlı bulunmuştur. Ayrıca ara malları ihracat modelinde yer alan trend değişkeni de cüz-i de olsa anlamlı çıkarak modelde trend etkisinin olduğunu göstermiştir.

\subsection{Sonuç ve Öneriler}

Elde ettiğimiz sonuçlar reel efektif döviz kuru katsayıları veya diğer bir ifadeyle fiyat esneklikleri bakımından incelendiğinde, sermaye malları ithalat fiyat esnekliği istatistiki olarak \% 1 düzeyinde anlamlı ve pozitif, katsayı değeri olarak 1'in üzerinde esnek bir yapı arz etmiştir. Ara mallar ithalat fiyat esnekliği ise istatistiki olarak 
anlamsız ve katsayı değeri olarak 1'in altında esnek olmayan bir görünüm sergilemiştir. İhracat fiyat esnekliklerini incelediğimizde ise yalnızca ara malları ihracat fiyat esnekliğinin istatistiki olarak \% 5 anlamlı ve negatif, katsayı olarak 1'in altında esnek olmayan bir görünüm sergilediği görülmüştür.

Tüm sonuçlar iktisadi beklenti ve teoriyle uyumlu olmakla beraber, bu sonuçlara göre herhangi bir mal grubunda Marshall-Lerner kuralının geçerli olduğunu söyleyemeyiz. Bunun en önemli nedeni ise yalnızca döviz kazandırıcı veya yalnızca döviz tasarrufunu destekleyici sonuçtan ziyade her ikisinin de aynı anda gerçekleşmesini sağlayacak sonucun gerçekleşmemesinden veya diğer bir ifadeyle hem ihracat hem de ithalat fiyat esneklik katsayılarının aynı anda istatistiki olarak anlamlı çıkmamasından kaynaklanmaktadır.

Sonuçlar yurtiçi ve yurtdışı gelir etkileri bakımından incelendiğinde ise sermaye ve ara malları dış ticaretinin gerek yurtiçi gerek se yurtdışı gelir değişimlerinden istatistiki olarak $\% 1$ ve $\% 5$ anlamlılık düzeylerinde dikkat çekici oranlarda etkilendiğini göstermektedir. Bu ise Türkiye için mal gruplarına dayalı dış ticaret açıkları üzerinde kurlardaki değişimden ziyade, gelir değişimlerinin daha ciddi etkiler gösterdiğinin bir kanıtı olarak değerlendirilmektedir.

Bundan yola çıkarak, Türkiye dış ticaretine yönelik politika yapıcıların, reel döviz kurunu artırarak ihracatı teşvik etmeye ve dolayısıyla dış ticaret açıklarını düşürmeye dönük iktisadi politikalar üretmelerinin çok da faydalı sonuçlar doğuracağı yönünde şüpheler taşımaktayız. Ancak yurt içi ve özellikle yurt dişı gelir değişkenleri katsayılarından elde ettiğimiz sonuçlar gerek ithalat gerekse ihracat üzerinde gelir etkisinin güçlü olduğunu göstermiştir. Bu kapsamda Türkiye'de dış ticaret açıklarının azaltılmasına yönelik yurt içi ve yurt dışı gelirlere yönelik geliştirilecek tedbirlerin reel döviz kuru politikalarına oranla daha etkili olacağını düşünmekteyiz. Bu kapsamda, talep esnekliği düşük, yüksek / orta teknolojili ve montaja dayılı ürünlerin yurt içindeki üretimini artırmaya, ihracat yaptığımız ülkelerde yaşanacak konjonktürel dalgalanma risklerinden minimum düzeyde etkilenmek amacıyla ülke yelpazesinin genişletilmesine ve dış ülkelere olan enerji bağımlılığımızı azaltmak amacıyla ithal maliyeti yüksek başta petrol ve doğalgaz ve bunlara dayalı ürünlerin artırılması için söz konusu ürünlerin araştırma geliştirme faaliyetlerine yönelik bütçe desteklerinin artırılmasına yönelik tedbirlerin dış ticaret açıklarının azaltılmasında olumlu katkı sunabileceği kanaatini taşımaktayız.

\section{Kaynakça}

- Alimi, 2014. "ARDL Bounds Testing Approach to Cointegration: a Reexamination of Augmented Fisher Hypothesis in an Open Economy", Asian Journal of Economic Modelling, 2(2), p.103-114.

- Altıntaş, 2009. “Türkiye'de Döviz Kurunun Enflasyon Üzerine Geçiş Etkisinin Ekonometrik Analizi: 19892007", Anadolu Uluslararası İktisat Kongresi, s.1-35.

- Erdoğan, v.d, 2015. “Çevresel Kuznets Eğrisi Hipotezinin Türkiye Ekonomisi İçin Geçerliliği” Dumlupınar Üniversitesi, Sosyal Bilimler Dergisi, 44, s.113-123.

- Görüss ve Türköz, 2016. “Türkiye’de Petrol Talebinin Fiyat ve Gelir Esneklikleri: ARDL Sınır Testi ve Nedensellik Analizi”. Dokuz Eylül Üniversitesi, Sosyal Bilimler Enstitüsü Dergisi, 18(1), s.31-54.

- Hepaktan, 2008. “Türkiye’nin Dönüşüm Sürecinde Dış Ticaret Politikaları” İzmir İktisat Kongresi Anısına Düzenlenen “Türkiye'nin İktisadi Dönüşüm Süreci”, 2. Ulusal İktisat Kongresi, s.1-27.

- Karaçor, v.d., 2011. “Enflasyon ve Ekonomik Büyüme İlişkisi: Türkiye Ekonomisi Üzerine Ekonometrik Bir Uygulama (1988-2007)”. Niğde Üniversitesi İI. B.F Dergisi, 4(2), s.29-44.

- Karagöl, v.d., 2007. “Türkiye'de Ekonomik Büyüme ile Elektrik Tüketimi İlişkisi: Sınır Testi Yaklaşımı”. Doğuş Üniversitesi Dergisi, 8(1), s.72-80.

- Koban, 2012. “Dış Ticaret”. İbrahim Halil Ekşsi (Ed.). A'dan Z'ye Dış Ticaret Uygulamaları. Nobel yayın evi, Ankara.

- Narayan ve Smyth, 2004. "Temporal Causality and the Dynamics of Exports, Human Capital and Real Income in China". International Journal of Applied Economics, 1(1), p.24-45.

- Narayan ve Smyth, 2006. "What determines migration flows from low-income to high-income countries? An empirical investigation of FijiUS Migration 1972-2001." Contemporary Economic Policy, 24(2), p.332342.

- Pesaran, v.d., 2001, "Bounds Testing Approaches to the Analysis of Level Relationships", Journal of Applied Econometrics, 16(3), p.289-326.

- Seyidoğlu, 2015. Uluslararası İktisat Teori Politika ve Uygulama. Güzem Can Yayınları, İstanbul.

- T.C. Kalkınma Bakanlığı, 2004. Türkiye Cumhuriyeti 2004 Yılı Katılım Öncesi Ekonomik Programı, http://www.kalkinma.gov.tr/Pages/KatilimOncesiEkonomikProgramlar.aspx.

- TÜİK, 2008. Diş Ticaret İstatistikleri ve Endeksleri Sorularla Resmi İstatistikler Dizisi-2, http://www.tuik.gov.tr/Kitap.do?metod=KitapDetay\&KT_ID=4\&KITAP_ID=135. 


\title{
Kırgızistan'da Cari İşlemler Açığının Sürdürülebilirliği Sustainability of the Current Account Deficit in Kyrgyzstan
}

\author{
Asst. Prof. Dr. Damira Baigonushova (Kyrgyzstan-Turkey Manas University, Kyrgyzstan) \\ Asst. Prof. Dr. Junus Ganiev (Kyrgyzstan-Turkey Manas University, Kyrgyzstan) \\ Asst. Prof. Dr. Nevin Aydın (Kyrgyzstan-Turkey Manas University, Kyrgyzstan) \\ Ph.D. Candidate Mairam Baigonusheva (Marmara University, Turkey)
}

\begin{abstract}
Like most developing countries, current account deficit in Kyrgyzstan is one of the ongoing problems. The external dependency on both consumption and production goods and the lack of diversification of export goods, in other words, the formation of export from the unprocessed goods such as gold and some agricultural products further increase the risks in this area. So, in this study, it is aimed to investigate the sustainability of current account deficit in Kyrgyzstan and also its causes for 2000:1-2016:4 time periods. Time series causality, VAR-analysis approach and the Johansen cointegration methods have been used. When the relations between the current account deficits and the important sub-items of this account are examined, it is found out that the current account deficits are mostly affected by net exports and foreign debt interest payments. From a wider perspective, it has been found that the changes in current account deficit are mostly influenced by foreign direct investments. According to the Johansen cointegration test, there is no cointegration between export and import series, which is why Kyrgyzstan's foreign trade deficit is not sustainable. In the short term, the current account deficits, which are being carried out without any very important problems with the help of foreign workers' income, foreign debts and foreign direct investments, may become an important problem in the long run. To prevent this, there is a need for more active and more effective policies in the country to support real sectors that can compete with the rest of the world.
\end{abstract}

\section{Giriş}

Cari işlemler dengesi bir ekonominin dış ticaret (mal ve hizmet), dış transferler, dış yatırımlardan elde edilen gelirler, dış borçların faiz ödemelerinin toplamından oluşan, ödemeler bilançosunun bir kalemidir. En önemli bir büyüklük olan dış ticaret dengesini içerdiğinden geçiş ekonomilerınde performansın göstergesi olarak kabul edilebilmektedir. SSCB dağılımı sonrası meydana gelen hemen hemen tüm geçiş ülkelerinde ekonomik büyüme yer almıştır, fakat cari açık da artmıştır. Bir taraftan, sermaye ve yatırım girişlerini sağlayan yapısal değişimlerin başarısı hızlı ekonomik büyüme ihtimalini meydana getirirken, öte yandan, iç tasarrufların yetersizliği, hatta eksi tasarruf ülkeleri dışarıdan borçlanmaya maruz bırakmıştır. Özellikle, 1990 sonraları cari açıkların kriz sinyalleri olabilecekleri konusunda görüşler ortaya çıkmaya başlamıştır. Dornbusch ve Fischer (1990)'e göre, cari acık/GSYİH oranının \%4'ün, Freund (2000)'a göre de \%5'in üzerine çıkması kriz sinyali olarak kabul edilebilecektir. Ancak, sadece bu oranlara bakılarak krizden söz etmenin yanıltıcı olabileceği, ülkenin dış borç ve döviz kuru politikalarına da bakılması gerektiği (Edwards, 2001; Uygur, 2004), açıkların özel sektör yatırımlarından kaynaklandığı durumlarda da krizden söz etmenin yanlış olacağı (Sachs, 1981; Corden, 1994) görüşündeki iktisatçılar da vardır. Çünkü pratikte yüksek cari açıklarını sürdürebilmekte olan İrlanda, Avustralya, İsrail, Güney Kore ve Malezya gibi ülkeler varken, Şili ve Meksika gibi şiddetli dış krizi geçirmekte olan ülkeler de vardır.

1980’lerden sonra küreselleşmenin hızlanması sonucu AR-GE’ye büyük ölçüde önem veren yenilikçi ekonomilerin dış ticaretten olumlu etkilenmeleri dışında, başka ekonomilerin, iç üretimleri ithalata dayalı olanlar dahil, bu süreçten negatif etkilenmekte oldukları belirtilebilir. Özellikle, üretimde temel girdiler olan enerji ve hammaddede ithalata bağımlılık sonucu ülke ekonomisi bu faktörlerin fiyatlarındaki dalgalanmalardan negatif etkilenmektedir.

Kırgızistan bağımsızlık sonrası ekonomi politikası olarak “dışa açık büyüme” stratejisini benimsemiştir. 1998'de Orta Asya devletleri arasından ilk olarak DTÖ’ye üye olması bunun delillerindendir. Buna bağlı olarak ülkenin ithalatı ihracatına göre hızlı bir artmış göstererek ithalata bağımlılık gittikçe artmaya başlamıştır. Dolayısıyla dengeli makroekonomik politika ve istikrarlı ekonomik büyümenin sağlanabilmesi için, cari açıkların nedenlerinin, finansman kalitesinin ve sürdürülebilir olup olmadığının analiz edilmesi önem arz etmektedir.

Ödemeler bilançosunun sermaye hesabı, cari işlemler acığının finansmanını sağlamaktadır. Bu hesap yetersiz olduğunda da rezervler kullanılmaktadır. Sermaye hesabının kalemleri, borç yaratan ve borç yaratmayan kalemler olmak üzere ikiye ayrılabilir. Doğrudan yabancı yatırımlar ve portföy yatırımları borç yaratmayan, borc senetleri ve dış krediler de borç yaratan kalemleri oluşturmaktadır. Acık borç yaratmayan kalemlerle finanse edildiğinde sürdürülebilir; borç yaratan, özellikle, kısa vadeli dış borclar ve resmi rezervlerle finanse edildiğinde de sürdürülemez olduğu kabul edilmektedir (Göçer, 2013:214). Bugüne kadar bu konuda pek çok ülke üzerine yapılan çeşitli empirik çalışmalara rastlamak mümkündür, fakat Kırgızistan üzerine yapılmış bir çalışmaya 
rastlanmamıştır. Bundan dolayı bu çalışmada Kırgızistan’da cari açıkların sürdürülebilirliğinin empirik olarak araştırılması amaçlanmıştır.

\section{Kırgızistan'da Cari İşlemler Açıkları ve Nedenleri}

Kırgızistan'da cari açığın GSYİH'ya oranını bazı komşu ülkelerle karşılaştırdığımızda Kazakistan, Rusya gibi petrol ihracatçısı ülkelerin göstergelerinden çok uzakta olduğunu, ancak Beyaz Rusya, Tacikistan gibi petrol kaynakları olmayan ülkelerle karşılaştırıldığında bile bu oranın ülkede çok yüksek olduğu görülmektedir (Şekil 1).

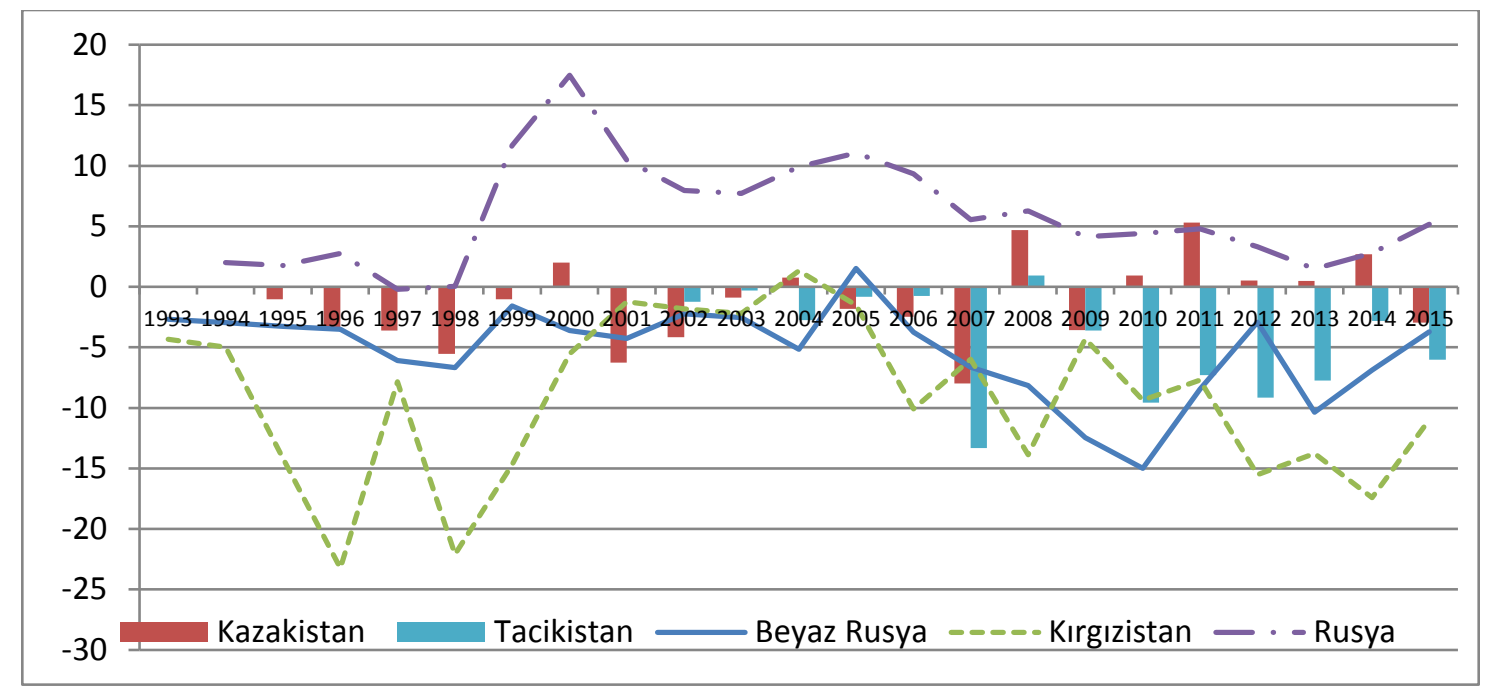

Şekil 1. Cari Işslemler Açı̆̆ının GSYİH’ya Oranı, yüzde olarak Kaynak: Şekil Dünya Bankası'nın Verilerinden Yararlanılarak Oluşturulmuştur, www.worldbank.org.

Cari işlemlerin alt kalemlerine bakıldığında dış ticaret dengesindeki açıkların çok büyük olduğu görülmektedir. Diğer yandan, cari transferlerin hacmi da oldukça büyüktür. Kırgızistan üzerinde yapılan çalışmalarda ithalatla cari transferler arasında güçlü bir ilişkinin olduğu söylenmektedir (Akmoldoev ve Budaichieva (2012), Atababaev vd. (2014), Baygonuşova ve Pirimbayev (2016)). Dış ticaret dengesindeki açıkların önemli payı cari transferlerle, kalanı da sermaye hesabındaki fazlalarla, finanse edilmektedir.

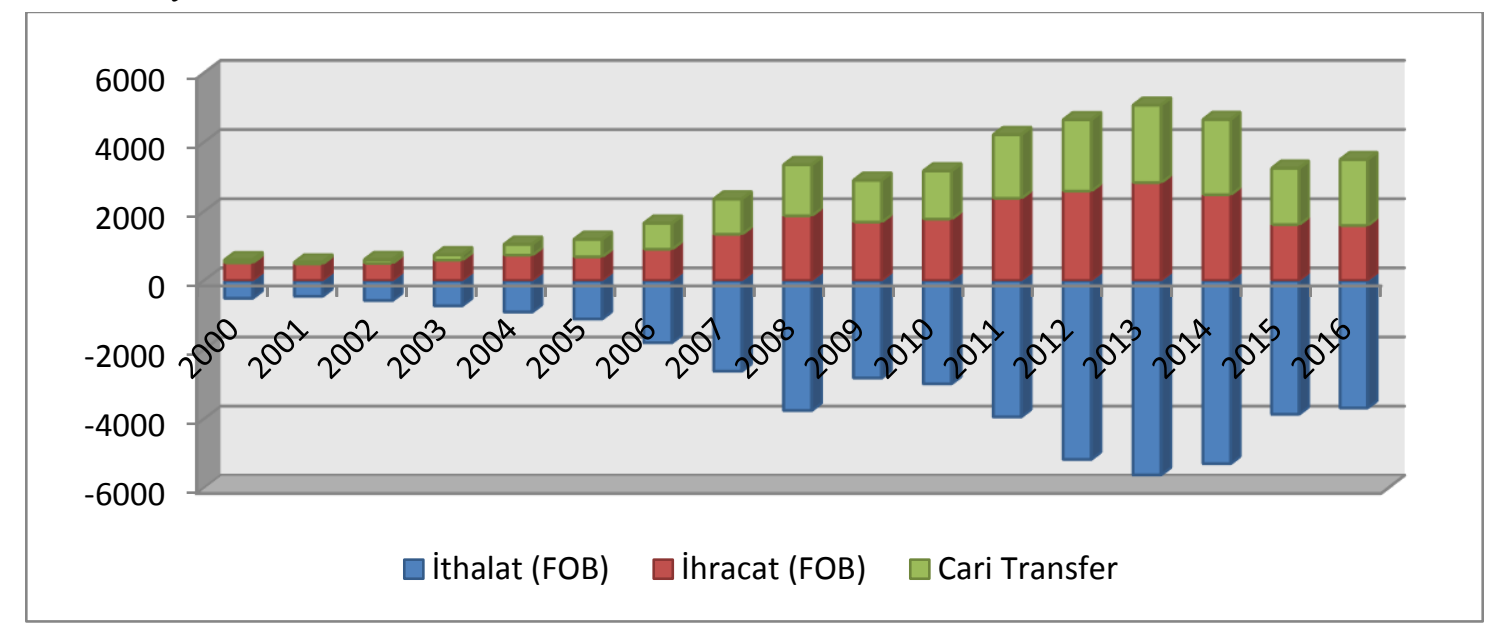

Şekil 2. Cari Işslemler Hesabının Başlıca Kalemleri, 2000-2016 (milyon ABD doları) Kaynak: Şekil Kırgız Cumhuriyeti Merkez Bankası Verilerinden Yararlanılarak Oluşturulmuştur, www.nbkr.kg.

Not: Ithalat serileri döviz giderleri anlaminda "-” olarak verilmişstir.

Bazı dönemlerde ise net hata ve noksan kaleminin çok yüksek düzeylere ulaştığı görülmektedir (Şekil 2). Bu durum kayıtdışı ekonomi ve yolsuzluğun bir sonucu olabilir. Ödemeler bilançosunun başlıca kalemleri de Şekil 3'te sunulmuştur. 


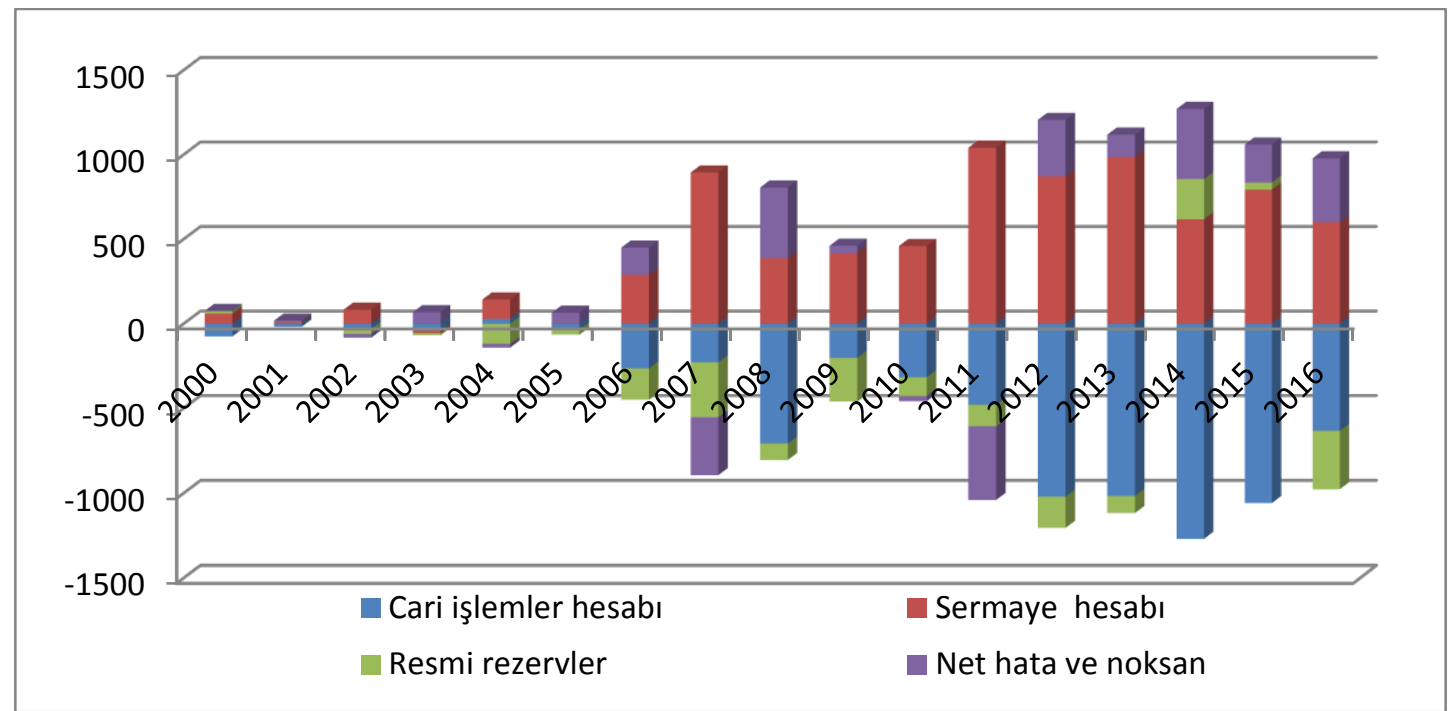

Şekil 3. Kırgızistan'da Cari Işlemler Dengesi ve Finansman Kaynakları, 2000-2016 Dönemi, Milyon ABD Doları. Kaynak: Şekil Kırgız Cumhuriyeti Merkez Bankası Verilerinden Yararlanılarak Oluşturulmuştur, www.nbkr.kg

Özetle, dünyanın çoğu gelişmekte olan ülkelerinde olduğu gibi ve yukarıda ülkeye ait istatisiklerden de görüldüğü gibi Kırgızistan’da cari açıkların temel olarak dış ticaret açığından kaynaklandığı söylenebilir.

\section{Literatür Taraması}

Konuyla ilgili literatüre bakıldığında bu konudaki ilk araştırmaları Steven Husted (1992), Gian Maria Milesi Ferretti ve Assaf Razin (1996, 1996a), Razin ve diğerleri (1997), Nouriel Roubini (1997) gibi batılı araştırmacıların başlattığı ortaya çıkmaktadır. Bu araştırmacılar konuya daha çok teorik ve istatistiki analiz yöntemleriyle yaklaşmış ve konunun teorik altyapısının oluşmasında önemli katkılarda bulunmuşlardır. Sonraları ise teorik ve istatistiki analizlerle beraber, çeşitli ekonometrik yöntemler de kullanılarak dünyanın farklı ekonomileri üzerinde araştırmalar artmaya başlamıştır. Onlardan bazıları, kullanılmış yöntem ve sonuçlarıyla beraber Tablo 1'de özetlenmiştir.

\begin{tabular}{|c|c|c|c|c|}
\hline $\begin{array}{l}\text { Yazar(lar) ve } \\
\text { yayın yılı }\end{array}$ & $\begin{array}{c}\text { Araştırma } \\
\text { dönemi ve } \\
\text { ülke(ler) }\end{array}$ & Kullanılmış veri seti & Araştırma yöntemi & Sonuç \\
\hline İsmet Göçer (2013) & $\begin{array}{l}\text { 1996M01- } \\
\text { 2012M01 } \\
\text { Türkiye }\end{array}$ & $\begin{array}{lr}\text { Enerji Hariç Diş Ticaret } \\
\text { Dengesi, Enerji Giderleri, } \\
\text { D1ş Borç Faiz Odemeleri, } \\
\text { Doğrudan Yatırımların Kar } \\
\text { Transferleri, r Portföy } \\
\text { Yatırımları Kar Transferleri, } \\
\text { Yurt İcinder Doğrudan } \\
\text { Yabancı Yatırımlar, Portföy } \\
\text { Yatırımları, } & \text { Diğer } \\
\text { Yatırımlar, Net } & \text { Hata ve } \\
\text { Noksan, rara } & \text { Rezerv } \\
\text { Varlıklardaki } & \text { Değişim, } \\
\text { İhracat, İthalat } & \\
\end{array}$ & $\begin{array}{l}\text { VAR, Johansen ve VEC } \\
\text { Yöntemleri }\end{array}$ & $\begin{array}{l}\text { Turkiye'de cari açı̆̆ın en onemli } \\
\text { nedeni, enerji giderleri ve dış ticaret } \\
\text { açığıdır. Cari açık en çok portföy } \\
\text { yatırımları, rezerv varlıklar, net hata } \\
\text { ve noksan tarafından finanse } \\
\text { edilmiştir, finansman kalitesi oldukca } \\
\text { kötüdür. Cari işlemler acığı zayıf } \\
\text { formda sürdürülebilir. }\end{array}$ \\
\hline $\begin{array}{l}\text { Jyh-Lin Wu, Show- } \\
\text { Lin Chen, Hsiu- } \\
\text { Yun Lee }(2001)\end{array}$ & $\begin{array}{l}\text { 1973Q2- } \\
1998 Q 4 \\
\text { G7 }\end{array}$ & İhracat, İthalat & $\begin{array}{l}\text { OLS, FM ve DOLS, } \\
\text { Panel Veri Analizi }\end{array}$ & $\begin{array}{l}\text { Dış borçlar sürdürülebilir, cari } \\
\text { açıklar durağandır. }\end{array}$ \\
\hline $\begin{array}{lr}\text { Ahmet } & \text { Mançellari, } \\
\text { Selami } & \text { Xhepa } \\
(2003) & \\
\end{array}$ & $\begin{array}{l}\text { 1993Q1- } \\
\text { 2001Q4 } \\
\text { Arnavutluk }\end{array}$ & $\begin{array}{l}\text { Reel Efektif Döviz Kuru, } \\
\text { Özel Sektöre Krediler, } \\
\text { GSYİH, İhracat, İthalat }\end{array}$ & OLS ve ECM & $\begin{array}{l}\text { Cari açıklar çok zayıf formda } \\
\text { sürdürülebilir, orta ve uzun vadede } \\
\text { sürdürülemez olması beklenmekte. }\end{array}$ \\
\hline $\begin{array}{l}\text { Suzette } \text { Hudson ve } \\
\text { Robert Stennett } \\
(2003)\end{array}$ & $\begin{array}{l}\text { 1962-2002 } \\
\text { Jamaika }\end{array}$ & $\begin{array}{l}\text { GSYİH, Net Faiz Gelirleri, } \\
\text { Net Transfer }\end{array}$ & $\begin{array}{l}\text { Zamanlararasi } \\
\text { Inter-Temporal } \\
\text { Solvency }\end{array}$ & $\begin{array}{l}\text { Ülke cari ödeme gücü durumunu } \\
\text { ihlal etmemiştir, ama dengesizlikte } \\
\text { şiddetli açıça tanımlanmış süreler } \\
\text { vardır ve bu durum devam ettiği } \\
\text { takdirde açı sürdürülemez hale } \\
\text { gelebilecektir. }\end{array}$ \\
\hline $\begin{array}{l}\text { Mohammed } \\
\text { Ansari (2004) }\end{array}$ & $\begin{array}{l}\text { 1973Q1- } \\
\text { 1999Q4 } \\
\text { ABD }\end{array}$ & $\begin{array}{l}\text { Reel İç Tasarruflar, Reel } \\
\text { GSYİH, Reel Sermaye Akışı }\end{array}$ & $\begin{array}{l}\text { Johansen and Juselius } \\
\text { Cointegration Tests, } \\
\text { VECM }\end{array}$ & $\begin{array}{l}\text { Sermaye girişinin ekonomik } \\
\text { büyümeye pozitif etkisinin olduğu } \\
\text { görülmesine rağmen, yabancı } \\
\text { sermayenin verimlilik etkisi anlamlı } \\
\text { bulunamamıștır. }\end{array}$ \\
\hline
\end{tabular}




\begin{tabular}{|c|c|c|c|c|}
\hline $\begin{array}{l}\text { Yazar(lar) ve } \\
\text { yayın yılı }\end{array}$ & $\begin{array}{c}\text { Araştırma } \\
\text { dönemi ve } \\
\text { ülke(ler) }\end{array}$ & Kullanılmış veri seti & Araştırma yöntemi & Sonuç \\
\hline $\begin{array}{l}\text { Ahmad Zubaidi } \\
\text { Baharumshah, } \\
\text { Evan Lau, Stilianos } \\
\text { Fountas (2004) }\end{array}$ & $\begin{array}{l}\text { 1970-2000 } \\
\text { Tayland, } \\
\text { Endonezya, } \\
\text { Malezya, } \\
\text { Filipinler, } \\
\text { Singapur, } \\
\text { Tayvan, Güney } \\
\text { Kore ve } \\
\text { Japonya }\end{array}$ & İhracat, İthalat & $\begin{array}{lr}\text { Pedroni ve } & \text { DOLS } \\
\text { Zamanlararası } & \text { Panel } \\
\text { Veri Analizi } & \end{array}$ & $\begin{array}{l}\text { Ülkelerinin cari dengesizlikleri kriz } \\
\text { sonrası dönemde sürdürülebilir hale } \\
\text { gelmiştir. }\end{array}$ \\
\hline $\begin{array}{l}\text { Rahmi Yamak, } \\
\text { Abdurrahman } \\
\text { Korkmaz (2007) } \\
\end{array}$ & $\begin{array}{l}\text { 2001M04- } \\
\text { 2005M09 } \\
\text { Türkiye } \\
\end{array}$ & $\begin{array}{l}\text { İhracat (girdiler) ile } \\
\text { İthalat (ç1ktılar) }\end{array}$ & ARDL & $\begin{array}{l}\text { Cari işlemler açığının zayıf formda } \\
\text { sürdürülebilir olduğu sonucuna } \\
\text { ulaşılmıştır. }\end{array}$ \\
\hline $\begin{array}{l}\text { Maxwell Opoku- } \\
\text { Afari (2005) }\end{array}$ & $\begin{array}{l}\text { 1960-2002 } \\
\text { Gana }\end{array}$ & $\begin{array}{l}\text { Özel Tüketim, } \\
\text { Kamu Tüketimi, Milli } \\
\text { Yatırım, GSYİH ve GSMG } \\
\text { (GNI). }\end{array}$ & Granger Causality, VAR & $\begin{array}{l}\text { Gana'da cari sürdürülebilirlik ticaret } \\
\text { akımlarından ziyade sermaye } \\
\text { akışındaki dinamiklere daha çok } \\
\text { duyarlıdır. }\end{array}$ \\
\hline Bektaş & $\begin{array}{l}\text { 1987Q1 } \\
\text { 2007Q1 } \\
\text { Türkiye }\end{array}$ & $\begin{array}{l}\text { GSMH, Özel } \\
\text { Nihai Tüketim Harcamaları, } \\
\text { Kamu Harcamaları, Gayri } \\
\text { Safi Sabit Sermaye } \\
\text { Yatırımları (Kamu ve Özel) } \\
\text { ve Net Dış Faktör Gelirleri }\end{array}$ & $\begin{array}{l}\text { Gregory-Hansen } \\
\text { Eşbütünleşme }\end{array}$ & $\begin{array}{l}\text { Türkiye'nin dönemlerarası bütçe } \\
\text { kısıtı yabancı sermaye akımlarının } \\
\text { devamlılığı koşuluyla yerine } \\
\text { getirilebilmektedir. Uygulanan } \\
\text { politikaların değişmemesi koşuluyla, } \\
\text { Türkiye ekonomisinin dönemlerarası } \\
\text { bütçe kısıtı sermaye akımlarının } \\
\text { devamı yoluyla sağlanabilir. }\end{array}$ \\
\hline Güner Polat (2008) & $\begin{array}{l}\text { 1992Q1- } \\
\text { 2006Q4 } \\
\text { Türkiye }\end{array}$ & İhracat, İthalat & $\begin{array}{l}\text { Engle-Granger } \\
\text { Eşbütünleşme }\end{array}$ & $\begin{array}{l}\text { Sözkonusu dönem için Türkiye'de } \\
\text { cari işlemler açığının sürdürülemez } \\
\text { olduğu sonucuna varılmıştır. }\end{array}$ \\
\hline Burcu Berke (2009) & $\begin{array}{l}\text { 1989Q1- } \\
\text { 2006Q2 } \\
\text { Türkiye }\end{array}$ & $\begin{array}{l}\text { Mal ve Hizmetlerin İhracatı, } \\
\text { Mal ve Hizmetlerin İthalatı, } \\
\text { Net Transfer Ödemeleri ve } \\
\text { Net Faiz Ödemeleri }\end{array}$ & $\begin{array}{l}\text { Engle-Granger, GPH ve } \\
\text { MGPH } \quad \text { Parçalı } \\
\text { Eşbütünleşme }\end{array}$ & $\begin{array}{l}\text { Reel ihracat ve reel "birleşik" ithalat } \\
\text { serileri arasında uzun dönemli parçalı } \\
\text { eşbütünleşme ilişkisi bulunmuştur, } \\
\text { cari işlemler hesabındaki } \\
\text { dengesizlikler geçicidir, cari açı } \\
\text { uzun dönemde sürdürülebilir. }\end{array}$ \\
\hline $\begin{array}{l}\text { Osman } \quad \text { Peker } \\
(2009)\end{array}$ & $\begin{array}{l}\text { 1992M01- } \\
\text { 2007M12 } \\
\text { Türkiye }\end{array}$ & İhracat, ithalat & Johansen Eşbütünleşme & $\begin{array}{l}\text { Türkiye'de cari işlemler açığı ancak } \\
\text { düşük düzeyde sürdürülebilir. }\end{array}$ \\
\hline $\begin{array}{l}\text { Shyh-Wei Chen } \\
(2010)\end{array}$ & $\begin{array}{l}\text { 1960Q1- } \\
\text { 2008Q1 } \\
\text { ABD, } \\
\text { Birleşmiş } \\
\text { Kralliklar, } \\
\text { Fransa ve } \\
\text { Kanada } \\
\end{array}$ & $\begin{array}{l}\text { Cari Açığın GSYİH'ya } \\
\text { Oranı }\end{array}$ & $\begin{array}{l}\text { Augmented Dickey- } \\
\text { Fuller (ADF), Bierens, } \\
\text { (1997) Non-Linear Unit } \\
\text { Root Tests }\end{array}$ & Cari açık sürdürülebilir niteliktedir. \\
\hline $\begin{array}{l}\text { Mehmet Mercan, } \\
\text { İsmet Göçer (2012) }\end{array}$ & $\begin{array}{l}\text { 1992M1- } \\
\text { 2012M1 } \\
\text { Türkiye }\end{array}$ & $\begin{array}{l}\text { Dış Alem Gelirleri (İhracat, } \\
\text { Hizmet Gelirleri, Transfer } \\
\text { Ödemeleri ve Dış Borç Faiz } \\
\text { Geliri) ve Diş Âlem } \\
\text { Giderleri (İthalat, Hizmet } \\
\text { Giderleri ve Diş Borç Faiz } \\
\text { Ödemeleri) }\end{array}$ & Johansen Eşbütünleşme & $\begin{array}{l}\text { İlgili dönemde cari işlemler açı̆̆ı } \\
\text { zayıf formda sürdürülebilir. }\end{array}$ \\
\hline $\begin{array}{l}\text { Reşat Ceylan, } \\
\text { İsmail Çeviş (2012) }\end{array}$ & $\begin{array}{l}\text { 1987Q1- } \\
\text { 2012Q1 } \\
\text { Türkiye }\end{array}$ & $\begin{array}{l}\text { Cari İşlemler Dengesinin } \\
\text { GSYİH'ya Oranı }\end{array}$ & $\begin{array}{ll}\text { Doğrusal Olmayan } & \text { Olman Serisi Tekniğine } \\
\text { Zaman } \\
\text { Dayanan Alternatif } \\
\text { Birim Kök Testleri }\end{array}$ & $\begin{array}{l}\text { Enflasyon hedeflemesi rejiminden } \\
\text { önceki dönemde Türkiye'de cari } \\
\text { işlemler dengesi açılkları } \\
\text { sürdürülebilir nitelikte iken, } \\
\text { enflasyon hedeflemesi rejimi sonras1 } \\
\text { dönemde ise sürdürülemez } \\
\text { niteliktedir. }\end{array}$ \\
\hline Şahbaz & $\begin{array}{l}\text { 2001M3- } \\
\text { 2011M4 } \\
\text { Türkiye }\end{array}$ & İhracat, İthalat & Johansen Eşbütünleşme & $\begin{array}{l}\text { Türkiye'de cari işlemler açığı uzun } \\
\text { dönemde sürdürülebilir. }\end{array}$ \\
\hline $\begin{array}{l}\text { Aviral Kumar } \\
\text { Tiwari (2012) }\end{array}$ & $\begin{array}{l}1970-2007 \\
\text { Hindistan }\end{array}$ & $\begin{array}{l}\text { Petrol Hariç ve Dahil } \\
\text { İhracat, Petrol Hariç ve } \\
\text { Dahil İthalat }\end{array}$ & Johansen Eşbütünleşme & $\begin{array}{l}\text { Petrol hariç ürünlerde dış ticaret açı̆̆1 } \\
\text { sürdürülebilir iken, petrol ürünleri } \\
\text { dahil edildiğinde sürdürülemez } \\
\text { konumdadır. }\end{array}$ \\
\hline
\end{tabular}




\begin{tabular}{|c|c|c|c|c|}
\hline $\begin{array}{l}\text { Yazar(lar) ve } \\
\text { yayın yılı }\end{array}$ & $\begin{array}{l}\text { Araştırma } \\
\text { dönemi ve } \\
\text { ülke(ler) }\end{array}$ & Kullanılmış veri seti & Araştırma yöntemi & Sonuç \\
\hline $\begin{array}{lr}\text { Hassan Heidari, } \\
\text { Salih Turan } \\
\text { Katircioglu, } \\
\text { Narmin Davoudi } \\
(2012)\end{array}$ & $\begin{array}{l}1960-2007 \\
\text { İran }\end{array}$ & İhracat, İthalat & ARDL & $\begin{array}{l}\text { Cari açılar uzun dönemde } \\
\text { sürdürülebilir. }\end{array}$ \\
\hline $\begin{array}{l}\text { İsmet Göçer, } \\
\text { Mehmet Mercan, } \\
\text { Hakan Hotunluoğlu } \\
(2012)\end{array}$ & $\begin{array}{l}\text { 1976-2011 } \\
\text { OECD ülkeleri }\end{array}$ & İhracat, İthalat & 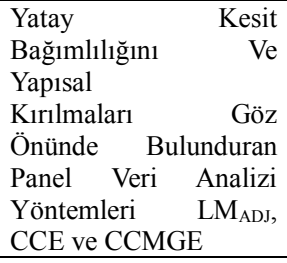 & $\begin{array}{l}\text { Cari açı Avustralya, Kanada ve } \\
\text { Meksika'da güçlü formda; } \\
\text { Finlandiya, Fransa, } \\
\text { Yunanistan, Yeni Zelanda, Polonya, } \\
\text { Türkiye ve panelin genelinde zayıf } \\
\text { formda } \\
\text { Sürdürülebilir. }\end{array}$ \\
\hline $\begin{array}{lr}\text { Mahir } & \text { Fisunoğlu, } \\
\text { Gürçem } & \text { Oransay } \\
(2014) & \\
\end{array}$ & $\begin{array}{l}\text { 2001Q4- } \\
\text { 2012Q2 } \\
\text { Türkiye }\end{array}$ & $\begin{array}{l}\text { Cari Açık, Gayri Safi Yurtiçi } \\
\text { Hasıla, Net Dış Varlıklar }\end{array}$ & Johansen Eşbütünleşme & $\begin{array}{l}\text { Günümüzde cari açık sürdürülebilir } \\
\text { niteliktedir. }\end{array}$ \\
\hline $\begin{array}{l}\text { Tuncay Çelik, Salih } \\
\text { Çağrı İlkay (2016) }\end{array}$ & $\begin{array}{l}\text { 1989-2015 } \\
\text { Türkiye }\end{array}$ & İhracat, İthalat & $\begin{array}{l}\text { Johansen } \\
\text { Eşbütünleşme, Granger } \\
\text { Nedensellik }\end{array}$ & $\begin{array}{l}\text { İhracat ile ithalat arasında pozitif ve } \\
\text { istatistiki olarak anlamlı bir ilişki } \\
\text { vardır, ithalat artışı ihracat artışının } \\
\text { tek yönlü Granger nedenidir. }\end{array}$ \\
\hline $\begin{array}{l}\text { Süleyman } \\
\text { İbrahim } \\
(2016)\end{array}$ & $\begin{array}{l}\text { 1992Q1- } \\
\text { 2015Q3 } \\
\text { Türkiye }\end{array}$ & İthalat, İhracat & $\begin{array}{l}\text { Engle ve } \begin{array}{r}\text { Granger } \\
(1987),\end{array} \text { Johansen } \\
(1991), \text { Pesaran ve Shin } \\
(1999) \text { ve Pesaran vd. } \\
(2001)\end{array}$ & $\begin{array}{l}\text { İthalat ve ihracat serileri arasında bir } \\
\text { eşbütünleşme ilişkisi vardır, ancak } \\
\text { cari açık zayıf formda sürdürülebilir. }\end{array}$ \\
\hline 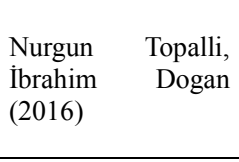 & $\begin{array}{l}\text { 1990Q1- } \\
\text { 2014Q2 } \\
\text { Türkiye }\end{array}$ & $\begin{array}{l}\text { Enerji Tüketimi, Dışa } \\
\text { Açıklı Oranı, GSYİH, } \\
\text { Döviz Kurları ve Yatırımlar, } \\
\text { Cari Hesap, Finansal } \\
\text { Derinlik }\end{array}$ & Markov-Switching Test & Cari açık zayıf formda sürdürülebilir. \\
\hline $\begin{array}{l}\text { Mehmet } \quad \text { Kaya } \\
(2016)\end{array}$ & $\begin{array}{l}\text { 1994Q4- } \\
\text { 2013Q4 } \\
\text { Türkiye }\end{array}$ & $\begin{array}{l}\text { Cari İşlemler Hesaplarının } \\
\text { Gelir ve Gider Hesapları } \\
\text { Toplamları }\end{array}$ & Johansen Eşbütünleşme & $\begin{array}{l}\text { Cari açık problemi zayıf bir şekilde } \\
\text { sürdürülebilmektedir. }\end{array}$ \\
\hline $\begin{array}{l}\text { Rüştü Yayar, Yusuf } \\
\text { Demir (2014) }\end{array}$ & $\begin{array}{l}\text { 1998-2011 } \\
\text { Türkiye }\end{array}$ & $\begin{array}{l}\text { İhracat (Mal ve Hizmet } \\
\text { İhracı) ve İthalat (Mal ve } \\
\text { Hizmet İthali }+ \text { Net Faiz } \\
\text { Ödemeleri + Net Tek Taraflı } \\
\text { Transferler + Sermaye } \\
\text { Hesabı) }\end{array}$ & $\begin{array}{l}\text { Johansen } \\
\text { Eşbütünleşme, VECM }\end{array}$ & $\begin{array}{l}\text { İncelenen dönemde cari açıkların } \\
\text { sürdürülebilir olduğu sonucuna } \\
\text { ulaşılmıştır. }\end{array}$ \\
\hline
\end{tabular}

Tablo 1. Cari Açı̆̆ın Sürdürülebilirliği ile İlgili Yayınlanmış Empirik Çalışmalar

Tablodan da görüldüğü kadarıyla, konunun araştırılmasında her ekonomi için farklı veri seti ve farklı yöntemler kullanıldığı gibi aynı ekonomi üzerinde de faklı yöntem ve veri seti kullanılarak, bazen farklı sonuçlar elde edilebilmektedir. Çalışmaların çoğunda Johansen eşbütünleşme yöntemi ve veri seti olarak da ithalat ile ihracatın kullanıldığını söylemek mümkündür. Sonuçlar itibariyle genel olarak bakıldığında gelişmiş ülkelerde ve İran gibi petrol ihracatçısı ülkelerde cari açıklar sürdürülebilirdir. Enerjide dışa bağımlı ve az gelişmiş ülkelerde ise cari açıklar zayıf sürdürülebilir ya da sürdürülemez konumdadır. Örneğin, literatürde Türkiye üzerinde birçok çalışmanın olduğu görülmektedir. Sonuçlarına bakıldığında sürdürülemez, sürdürülebilir ve zayıf formda sürdürülebilir gibi üç farklı sonuca ulaşılmıştır. Ancak daha detaylı incelendiğinde ise şöyle bir tablo görülmektedir: ülkenin enerji giderleri ayrı değerlendirildiğinde sürdürülebilir ve zayıf bir formda sürdürülebilir sonucuna ulaşılmışken, zamanlararası analizler de son dönemlerde açı̆̆ın sürdürülemez olduğunu söylemektedir. Bu sonuçlar doğrultusunda, son dönemlerde Türkiye'nin enerji giderlerinin hızla arttığı ve bundan dolayı cari açıkların zayıf sürdürülebilir olduğu ve iç enerji kaynakları geliştirilmedikçe önümüzdeki dönemlerde cari açığın sürdürülemez hale gelebileceği ifade edilmektedir. Ancak ödemeler bilançosunun tüm gider ve gelir kalemleri bazında yapılan çalışmalar açığın sürdürülebilir olduğunu kanıtlamaktadır. Demek ki, Türkiye dış ticaret açığını kapatabilecek başka dış kaynaklara sahiptir. Bu bağlamda Göçer (2013), Türkiye'de cari açıkların sırasıyla en çok (\%33 oranında) portföy yatırımları, (\%30 oranında) rezerv varlıklar ve (\%24 oranında) net hata ve noksan hesapları tarafından finanse edildiğini ve bu kaynakların güvenilirliğinin düşük olması nedeniyle uzun vadede açıkların finansmanında sıkıntıların ortaya çıkabileceğini belirtmektedir.

\section{Yöntem ve Analiz Sonuçları}

Çalışmanın amacı; Kırgızistan ekonomisindeki cari işlemler hesabı açığının nedenlerini ve açığın finansman kalitesini belirlemek ve sürdürülebilirliğini analiz etmektir. Bu amaca uygun olarak açığın nedenlerinin ve finansman kalitesinin belirlenmesinde Göçer (2013)'in çalışmasından yola çıkılarak Vektör Otoregresif Modeller 
(VAR) analizi yöntemi ve cari açığın sürdürülebilirliği de Johansen eşbütünleşme testi yardımıyla ortaya konulmaya çalışılmıştır.

\subsection{VAR Modeli}

Analizlerde kullanılan makroekonomik değişkenler birbiriyle çok taraflı ilişkide olduğu durumlarda tutarlı tahminciler elde etmek için ilişkilerin eşanlı denklemlerle araştırılması gerekmektedir. Ancak, bu tür modellerin uygulanmasında değişkenlerdeki içsel-dışsallığın araştırılması ve modellerin belirlenmesi gibi sorunlarla karşılaşılmaktadır. Ancak, Sims (1980)'in geliştirmiş olduğu VAR yöntemi, bu sorunların üstesinden gelmekte ve değişkenler arasındaki dinamik ilişkileri ortaya koyabilmektedir (Keating, 1990: 453-454). Bunun haricinde, yöntemin uygulanması iktisadi teorilere dayanmak zorunda değildir ve teorinin tam olarak oturtulmadığı durumlarda da kullanılabilmektedir. Uygulamada standart VAR modeli kullanılmıştır, çünkü bu modellere en küçük kareler yöntemi uygulanabilmekte ve tahminler tutarlı ve etkin olmaktadır.

$\mathrm{X}$ ve Y gibi iki değişkenli VAR modeli aşağıdaki model (1) ve (2) şeklinde tanımlanmaktadır:

$$
\begin{aligned}
& \Delta \mathrm{Yt}=\beta 0+\sum_{\mathrm{i}=1}^{\mathrm{n}} \beta_{5 \mathrm{i}} \Delta \mathrm{Yt}-\mathrm{i}+\sum_{\mathrm{i}=0}^{\mathrm{n}} \beta_{2 \mathrm{i}} \Delta \mathrm{Xt}-\mathrm{i}+\mathrm{ut} 1 \\
& \Delta \mathrm{Xt}=\beta 4+\sum_{\mathrm{i}=1}^{\mathrm{n}} \beta_{5 \mathrm{i}} \Delta \mathrm{Xt}-\mathrm{i}+\sum_{\mathrm{i}=0}^{\mathrm{n}} \beta_{6 \mathrm{i}} \Delta \mathrm{Yt}-\mathrm{i}+\mathrm{ut} 2
\end{aligned}
$$

Yöntemin kullanılmasında amaç kesinlikle parametre tahmini değildir. Değişkenler arasındaki ilişkiler nedensellik, etki-tepki ve varyans ayrıştırma analizleri yardımıyla açıklanır. Modelde yer alacak değişkenlerin dışsaldan içsele doğru sıralanması önemlidir ve bunun için Granger nedensellik analizinden yararlanılabilir.

\subsection{Johansen Eşbütünleşme Yöntemi}

Araştırmada kullanılan değişkenlerin aynı mertebeden durağan olmaları koşulunda değişkenler arasında uzun dönemde denge ilişkilerinin olup-olmadığı Johansen eşbutunleşme yaklaşımı ile test edilebilmektedir. Bu yaklaşım da VAR modeline dayalı olduğundan, p. dereceden bir vektor otoregresif süreci araştırmaktadır:

$$
\Delta \mathrm{Yt}=\pi \mathrm{Yt}-1+\sum_{\mathrm{i}=1}^{\mathrm{p}-1} \tau_{\mathrm{i}} \Delta \mathrm{Yt}-\mathrm{i}+\mathrm{BXt}+v \mathrm{t}
$$

\subsection{Veri ve Analiz Sonuçları}

Çalışmada Kırgızistan ekonomisinin 2000-2016 dönemine ait çeyrek verileri kullanılmıştır. Tüm veriler Kırgız Cumhuriyeti Merkez Bankası'nın yayınlarından alınmıştır. Serilerde eksi değerler olması nedeniyle bazılarının logaritmaları alınamamış ve dolayısıyla VAR analizinde serilerin yüzde değişmeleri kullanılmıştır. Serilerin durağanlığı Genişletilmiş Dickey-Fuller (ADF) birim kök test yöntemiyle test edilmiş ve sonuçlar Tablo 2'de özetlenmiştir.

\begin{tabular}{|l|l|l|}
\hline Değișkenin Adı & Kısaltma & ADF \\
\hline Cari Açı & CA SA & I (0) \\
\hline Dıș Ticaret Dengesi & NX & I (0) \\
\hline Dıș Borc Faiz Ödemeleri & BFO SA & I (0) \\
\hline Doğrudan Yatırımların Kar Transferleri & DYYKT & I (0) \\
\hline Doğrudan Yabancı Yatırımlar & DYY & I (0) \\
\hline Portföy Yatırımları & PY & I (0) \\
\hline Diğer Yatırımlar & DY & I (0) \\
\hline İstatistiki Hata ve Noksan & İHN & I (0) \\
\hline Rezerv Varlıklardaki Değișim & RD & I (0) \\
\hline Cari Transferler & CT SA & I (0) \\
\hline İhracat & LX SA & I (1) \\
\hline İthalat & LM SA & I (1) \\
\hline
\end{tabular}

Tablo 2. Veri Seti ve ADF Birim Kök Testi Sonuçları

Not: *ihracat ve ithalat serileri birim kök testine tabi tutulmadan önce logaritmaları alınmış ve Dış Borc Faiz Ödemeleri dahil, TRAMO/SEATS yöntemiyle mevsimsellikten arındırllmıştır. *ADF maksimum gecikme uzunluğu 5 olarak verilmiş ve uygun gecikme uzunluğunun belirlenmesinde Schwarz Info Criterion kullanılmıştır.

\subsection{VAR Analizi Sonuçları}

Cari işlemler açığı nedenlerinin belirlenmesi amacıyla tahmin edilecek fonksiyon aşağıdaki gibidir:

$$
\mathrm{CA}=\mathrm{f}\left(\mathrm{NX}, \mathrm{BFO} \_\mathrm{SA}, \mathrm{DYYKT}\right)
$$

Cari açı̆̆ın finansman kalitesinin belirlenmesi için de CA $=\mathrm{f}(\mathrm{DYY}, \mathrm{PY}, \mathrm{DY}, \mathrm{IHN}, \mathrm{RD})$ fonksiyonu tahmin edilecektir. Sonra da cari açığın sürdürülebilirliğini belirlemek için $X=f(M)$ fonksiyonu eşbütünleşme yöntemiyle test edilecektir.

Cari işlemlerdeki açığın nedenlerinin belirlenmesinde tahmin edilen fonksiyonun varyans ayrıştırma analizi kullanılacaktır. Varyans ayrıştırması değişkenlerin her birinin varyansında meydana gelen değişmenin yüzde kaçının kendi gecikmelerinden, yüzde kaçının diğer değişkenlerden kaynaklandığını gösterir. Bu analiz yardımıyla, bir makroekonomik büyüklüğün üzerinde en etkili değiş̧kenin hangisi olduğunu belirlemek mümkündür. 
Modellerdeki değişkenlerin içsel-dışsallıklarının belirlenmesinde Toda-Yamamoto (1995) nedensellik testi kullanılmıştır. Gecikme uzunluğu tüm bilgi kriterlerine göre 1 olarak belirlenmiştir. Tahmin edilen VAR (ll 1 ) modelinin varyans ayrıştırması yapılmış ve CA serisi için Tablo 2'de sunulmuştur. Modelin artıklarının otokorelasyonu, LM (Lagrange Multiplier) otokorelasyon testi ile kontrol edilmiş ve sonuçların olasılık değerinin 0.05 'ten büyük olması modelde otokorelasyon sorununun olmadığını göstermektedir. Otokorelasyon testi yanında, VAR modelinin köklerinin birim çember içerisinde olması da modelin bütünlüğünün durağanlığını göstermektedir (adı geçen tanımlayıcı istatistikler Tablo 3'ün alt kısmında yer almaktadır).

\begin{tabular}{|c|c|c|c|c|}
\hline \multicolumn{1}{|l|}{ Dönem } & NX & BFO_SA & DYYKT & CA_SA \\
\hline 1 & 0.509818 & 0.626629 & 0.043196 & 98.82036 \\
\hline 2 & 2.562276 & 1.913584 & 0.049016 & 95.47512 \\
\hline 3 & 2.637499 & 2.021465 & 0.068598 & 95.27244 \\
\hline 4 & 2.636666 & 2.058404 & 0.068805 & 95.23613 \\
\hline $\mathbf{5}^{*}$ & $\mathbf{2 . 6 3 7 0 5 4}$ & $\mathbf{2 . 0 6 5 5 4 2}$ & $\mathbf{0 . 0 6 8 8 0 2}$ & $\mathbf{9 5 . 2 2 8 6 0}$ \\
\hline
\end{tabular}

\begin{tabular}{|c|c|c|}
\hline Gecikme & LM-Stat & Prob \\
\hline 1 & 8.066732 & 0.9469 \\
\hline 2 & 10.19107 & 0.8565 \\
\hline 3 & 13.06173 & 0.6682 \\
\hline 4 & 10.82182 & 0.8203 \\
\hline
\end{tabular}

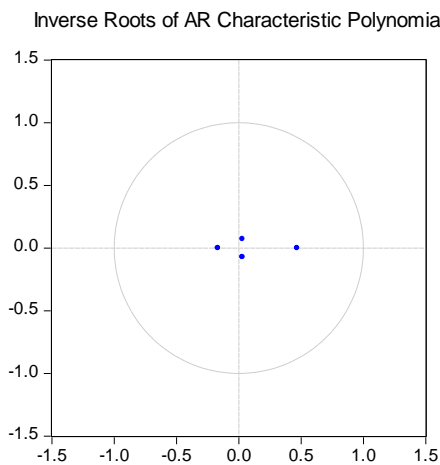

Tablo 3. Cari Işslemlerdeki Açı̆̆ı̆n Nedenlerini Gösteren CA Serisinin Varyans Ayrıştırması

Tarı (2008)'nın belirttiğine göre, varyans ayrıştırmasında değerlerin dengeye gelmeye başladıkları dönemdeki değerler yorumlanır. Tablo 2'de 5. dönemden sonra değerler dengeye yaklaştıkları için, bu dönemdeki değerler yorumlanmıştır. Tabloya göre; CA'daki değişmelerin yaklaşık \%2,63'ü NX, \%2,06'sı BFO_SA ve \%0,07'si DYYKT tarafından açıklanmakta olduğu söylenebilir. Buna göre de cari açıkların en çok net ihracattan, sonra dış borç faiz ödemelerinden ve çok düşük oranda doğrudan yabancı yatırımları kar transferlerinden etkilendiği ifade edilebilir. Göçer (2013) çalışmasında enerji giderlerinin ve portföy yatırımlarının kar transferlerini de modele eklemiştir. Ancak bu çalışmada Kırgızistan'da portföy yatırımlarının kar transferlerinin çok düşük olması nedeniyle modelden çıkartılmış ve enerji giderleri verisi tüm dönem için bulunamaması nedeniyle dış ticaret dengesi içerisinde değerlendirilmiştir.

Cari açı̆̆ın finansman kalitesinin incelenmesinde modelin uygun gecikme uzunluğu LR (Likelihood Ratio) ve FPE (Final prediction error) bilgi kriterlerine göre 4 olarak seçilmiştir. Tahmin edilen VAR (1 4) modelinden CA serisinin varyans ayrıştırması Tablo 4'te sunulmaktadır.

\begin{tabular}{|c|c|c|c|c|c|c|c|}
\hline Dönem & RD & DYY & CA_SA & CT_SA & IHN & DY & PY \\
\hline 1 & 0.009651 & 2.844738 & 97.14561 & 0.000000 & 0.000000 & 0.000000 & 0.000000 \\
\hline 2 & 0.011704 & 2.877404 & 96.72149 & 0.049140 & $1.19 \mathrm{E}-05$ & 0.334070 & 0.006184 \\
\hline 3 & 0.509592 & 8.946619 & 86.92041 & 1.726087 & 0.179823 & 1.711873 & 0.005595 \\
\hline 4 & 0.789204 & 9.447818 & 85.91613 & 1.875771 & 0.270599 & 1.688307 & 0.012174 \\
\hline $\mathbf{5}^{*}$ & $\mathbf{0 . 7 7 9 9 7 9}$ & $\mathbf{9 . 9 0 2 4 0 1}$ & $\mathbf{8 3 . 1 1 0 4 5}$ & $\mathbf{1 . 7 9 3 5 0 7}$ & $\mathbf{2 . 2 4 9 4 1 4}$ & $\mathbf{2 . 1 4 9 5 6 5}$ & $\mathbf{0 . 0 1 4 6 8 6}$ \\
\hline
\end{tabular}

\begin{tabular}{|c|c|c|}
\hline Gecikme & LM-Stat & Prob \\
\hline 1 & 53.31175 & 0.3120 \\
\hline 2 & 49.57496 & 0.4502 \\
\hline 3 & 66.01515 & 0.0528 \\
\hline 4 & 55.58263 & 0.2407 \\
\hline
\end{tabular}

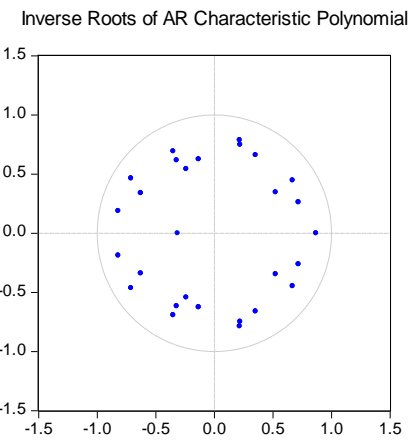

Tablo 4. Cari İ̧lemlerdeki Finansman Kalitesini Belirleyen CA Serisinin Varyans Ayrıştırması 
Bu modelde de otokorelasyon sorununun olmadığı ve modelin bütünlüğünün durağanlığı tespit edilmiştir (Tablo 3'ün alt kısmında yer almaktadır).

Ayrıca White Heteroscedasticity testine göre, modellerde değişen varyans sorununun da olmadığı tespit edilmiştir.

Tablo 3'de 5. dönemden sonra değerler dengeye yaklaştıkları için, bu dönemdeki değerler yorumlanmıştır. Buna göre, CA'daki değişmelerin yaklaşık \%9,9'u doğrudan yabancı yatırımlardan, \%2,25'i istatistiki hata ve noksanlardan, \%2,15'i diğer yatırımlardan, \%1,79'u cari transferlerden ve çok düşük oranlarda resmi rezervlerdeki değişmeler ile portföy yatırımlarından olumlu yada olumsuz yönde etkilenmektedir. Bu sonuçlara göre, doğrudan yabancı yatırımlar gibi daha istikrarlı döviz kaynağının cari işlemlerdeki değişmelerin önemli kısmını kapatabilmesi cari açıkların sürdürülebilirliği açısından olumlu bir durum olarak yorumlanabilir.

\subsection{Cari İşlemler Açığının Sürdürülebilirliğinin Eşbütünleşme Testi Sonuçları}

Sürdürülebilirliğin belirlenmesi için ihracat $(\mathrm{X})$ ve ithalat $(\mathrm{M})$ serileri arasındaki ilişki daha önce belirtilen Johansen eşbütünleşme sistemi ile kontrol edilmiştir (Tablo 5). Bunun sonucunda hem Trace hem de MaxEigenvalue değerlerine göre, ihracat ile ithalat serileri arasında eşbütünleşmenin olmadığı, dolayısıyla Kırgızistan'da dış ticaret açığının sürdürülemez olduğu sonucuna ulaşılmıştır.

\begin{tabular}{|c|c|c|c|c|c|}
\hline Data Trend: & None & None & Linear & Linear & Quadratic \\
\hline Test Type & No Intercept & Intercept & Intercept & Intercept & Intercept \\
\hline & No Trend & No Trend & No Trend & Trend & Trend \\
\hline Trace & 0 & 0 & 0 & 0 & 0 \\
\hline Max-Eig & 0 & 0 & 0 & 0 & 0 \\
\hline *Critical values based on MacKinnon-Haug-Michelis (1999) \\
\hline \multicolumn{7}{|c|}{ Information Criteria by Rank and Model } \\
\hline \multicolumn{7}{|c|}{ None } & None & Linear & Linear & Quadratic \\
\hline Data Trend: & No Intercept & Intercept & Intercept & Intercept & Intercept \\
\hline Rank or & No Trend & No Trend & No Trend & Trend & Trend \\
\hline No. of CEs & Log Likelihood by Rank (rows) and Model (columns) \\
\hline \multicolumn{7}{|c|}{142.4993} & 142.4993 & 143.8778 & 143.8778 & 144.8627 \\
\hline 0 & 145.0709 & 145.2190 & 145.6374 & 146.6216 & 147.6064 \\
\hline 1 & 145.1747 & 146.9737 & 146.9737 & 148.0679 & 148.0679 \\
\hline 2 & Akaike Information Criteria by Rank (rows) and Model (columns) \\
\hline 0 & $-4.138441^{*}$ & $-4.138441^{*}$ & -4.119317 & -4.119317 & -4.088084 \\
\hline 1 & -4.094490 & -4.068276 & -4.050382 & -4.049897 & -4.049428 \\
\hline 2 & -3.974607 & -3.968422 & -3.968422 & -3.940550 & -3.940550 \\
\hline \multicolumn{7}{|c|}{ Schwarz Criteria by Rank (rows) and Model (columns) } \\
\hline 0 & $-3.870824 *$ & $-3.870824 *$ & -3.784796 & -3.784796 & -3.686659 \\
\hline 1 & -3.693064 & -3.633399 & -3.582052 & -3.548115 & -3.514194 \\
\hline 2 & -3.439373 & -3.366284 & -3.366284 & -3.271508 & -3.271508 \\
\hline
\end{tabular}

Tablo 5. Ithalat ile İhracat Arasında Johansen Eşbütünleşme Testi Sonuçları

"Dordoy” ve "Karasuu” gibi çok büyük reexport pazarlarının yer aldığı Kırgızistan'da ihracatla ithalatın arasında bir ilişkinin bulunmaması şaşırtıcı karşılanabilir. Bu nedenle, burada belirtilmesi gereken nokta da, resmi istatistiklerde bavul ticaretin tam olarak istatistiklere yansıtılamaması ve özellikle ihracat verilerinin gerçeklerden uzak kalmasıdır.

Diğer taraftan, son on yılda önemli artışlar gösteren ve büyük kısmı yurtdışında, özellikle Rusya'da çalışan işçi gelirlerinden oluşan cari transferler ithalatın finansmanına önemli katkı sağlamaktadır. Bu durumun tespit edilmesi amacıyla ithalatla cari transferler arasında eşbütünleşme testi yapılmış ve sonuçlar Tablo 6'da sunulmuştur. 


\begin{tabular}{|c|c|c|c|c|c|}
\hline Data Trend: & None & None & Linear & Linear & Quadratic \\
\hline Test Type & No Intercept & Intercept & Intercept & Intercept & Intercept \\
\hline & No Trend & No Trend & No Trend & Trend & Trend \\
\hline Trace & 0 & 1 & 2 & 0 & 0 \\
\hline Max-Eig & 0 & 1 & 0 & 0 & 0 \\
\hline *Critical values based on MacKinnon-Haug-Michelis (1999) \\
\hline \multicolumn{7}{|c|}{ Information Criteria by Rank and Model } \\
\hline Data Trend: & None & None & Linear & Linear & Quadratic \\
\hline Rank or & No Intercept & Intercept & Intercept & Intercept & Intercept \\
\hline No. of CEs & No Trend & No Trend & No Trend & Trend & Trend \\
\hline \multicolumn{7}{|c|}{ Log Likelihood by Rank (rows) and Model (columns) } \\
\hline 0 & 96.32853 & 96.32853 & 99.06802 & 99.06802 & 101.5422 \\
\hline 1 & 100.7397 & 104.8667 & 105.6202 & 105.6381 & 106.8069 \\
\hline 2 & 101.0517 & 107.8148 & 107.8148 & 108.8579 & 108.8579 \\
\hline \multicolumn{7}{|c|}{ Akaike Information Criteria by Rank (rows) and Model (columns) } \\
\hline 0 & -2.717801 & -2.717801 & -2.740554 & -2.740554 & -2.755145 \\
\hline 1 & -2.730453 & $-2.826668 *$ & -2.819083 & -2.788866 & -2.794058 \\
\hline 2 & -2.616975 & -2.763531 & -2.763531 & -2.734090 & -2.734090 \\
\hline \multicolumn{7}{|c|}{ Schwarz Criteria by Rank (rows) and Model (columns) } \\
\hline 0 & $-2.450184 *$ & $-2.450184 *$ & -2.406033 & -2.406033 & -2.353720 \\
\hline 1 & -2.329027 & -2.391790 & -2.350753 & -2.287084 & -2.258824 \\
\hline 2 & -2.081742 & -2.161393 & -2.161393 & -2.065048 & -2.065048 \\
\hline
\end{tabular}

Tablo 6. Ithalat ile Cari Transferler Arasında Johansen Eşbütünleşme Testi Sonuçları

Tablodaki sonuçlar gösterdiği gibi, Kırgızistan'da ithalat ile cari transferler arasında eşbütünleşme ilişkisi vardır ve bu sonuç daha önceki çalışmalarla (Akmoldoev ve Budaichieva, 2012) örtüşmektedir. Bununla beraber, ilerideki çalışmalarda sözkonusu iki değişkenin arasındaki ilişkinin daha detaylı incelenmesinde yarar vardır. Çünkü işçi transferlerinin milli gelire oranı \%30'lara ulaşırken, ithalata oranı ise \%45-50'lere kadar ulaşarak dış ticaret açı̆̆ının finansmanında önemli rol oynamaktadır.

\section{Sonuç}

Bu çalışmada Kırgızistan ekonomisindeki cari işlemler hesabı açığının nedenlerini ve açığın finansman kalitesini belirlemek ve sürdürülebilirliğini analiz etmek amaçlanmıştır. Bu amaca uygun olarak açığın nedenlerinin ve finansman kalitesinin belirlenmesinde VAR analizi yöntemi ve cari açığın sürdürülebilirliği de Johansen eşbütünleşme testi yardımıyla ortaya konulmaya çalışılmıştır. Çalışmada Kırgızistan ekonomisinin 2000-2016 dönemine ait çeyrek verileri kullanılmıştır.

VAR analizi sonuçlarına göre, cari açıklar ile bu hesabın önemli alt kalemleri arasındaki ilişkiler incelendiğinde, cari açıkların en çok net ihracattan, sonra dış borç faiz ödemelerinden ve çok düşük oranda doğrudan yabancı yatırımları kar transferlerinden etkilendiği ortaya çıkmıştır.

Diğer taraftan, ödemeler bilançosunun önemli alt kalemleri ile cari işlemler açığının arasındaki ilişkiler araştırıldığında ise, cari işlemler açığındaki değişmelerin yaklaşık \%9,9'u doğrudan yabancı yatırımlardan, $\% 2,25$ 'i istatistiki hata ve noksanlardan, $\% 2,15$ 'i diğer yatırımlardan ve $\% 1,79$ 'u cari transferlerden olumlu yada olumsuz yönde etkilendiği tespit edilmiştir. Bu sonuçlara göre, doğrudan yabancı yatırımlar gibi daha istikrarlı döviz kaynağının cari işlemlerdeki değişmelerin önemli kısmını kapatabilmesi cari açıkların sürdürülebilirliği açısından olumlu bir durum olarak yorumlanabilir.

Sürdürülebilirliğin belirlenmesi için ihracat $(\mathrm{X})$ ve ithalat $(\mathrm{M})$ serileri arasındaki ilişki Johansen eşbütünleşme sistemi ile kontrol edilmiştir. Bunun sonucunda, ihracat ile ithalat serileri arasında eşbütünleşmenin olmadığg, dolayısıyla Kırgızistan'da dış ticaret açığının sürdürülemez olduğu sonucuna ulaşılmıştır. Ayrıca, son on yılda önemli artışlar gösteren ve büyük kısmı yurtdışında, özellikle Rusya'da çalışan işçi gelirlerinden oluşan cari transferler ile ithalat arasında eşbütünleşme testi yapılmış ve Kırgızistan'da ithalat ile cari transferler arasında eşbütünleşme ilişkisi bulunmuştur. Bununla beraber, ilerideki çalışmalarda sözkonusu iki değişkenin arasındaki ilişkinin daha detaylı incelenmesinde yarar vardır.

İhracatın ithalatı karşılama oranı \%40'lar civarında olan Kırgızistan ekonomisi için cari işlemler açığının sürdürülemez olarak bulunması aslında beklenen bir sonuçtu denilebilir. Kısa dönemde yurtdışındaki işçi gelirleri, dış borçlar ve doğrudan yabancı yatırımlarla belki çok önemli sorunlarla karşılaşılmadan sürdürülmekte olan cari açıklar uzun dönemde önemli bir sorun haline gelebilecektir. Bunun önlenmesi için de ülkede ihracata yönelik reel sektörlerin desteklenmesi konusunda daha aktif ve daha etkin politikalara ihtiyaç vardır. 


\section{Kaynakça}

- Akmoldoev K. ve Budaichieva A. (2012). "The Impact of Remittances in Kyrgyzstan Economy”. Proceedings of International Conference on Eurasian Economies, Almaty-Kazakhstan, s. 6-13.

- Ansari M. I., ve Ojemakinde A. (2003). "Explaining Asymmetry in the US Merchandise and Service Account Balance: Does the Service Sector Hold the Key to the US Current Account Woes?". The International Trade Journal 17, p. 51-80.

- Atabaev N., Atabaeva G. ve Baigonushova D. (2014). "Economic growth and remittances inflow: Empirical evidence from Kyrgyz Republic", Eurasian Journal of Business and Economics 7(14), p. 61-70.

- Baharumshah A.Z., Lau E. ve Fountas S. (2003). "On The Sustainability Of Current Account Deficits: Evidence From Four ASEAN Countires", Journal Of Asian Economics 14, p. 465-487.

- Baygonuşova D. ve Pirimbayev C. (2016). "Kırgızistan'da Bütçe Açığı İle Dış Ticaret Açıı̆ı İlişskisi”, Kırgızistan-Türkiye Manas Üniversitesi Sosyal Araştırmalar Dergisi 5(1), s. 64-85.

- Bektaş V. (2007). "Cari İşlemler Dengesi ve Cari Açiklarin Sürdürülebilirliği: Türkiye Uygulaması". Yayınlanmamış yüksek lisans tezi, Çukurova Üniversitesi Sosyal Bilimler Enstitüsü İktisat Anabilim Dalı, Adana-Türkiye.

- Berke B. (2009). “Türkiye'de Cari Açı̆̆ın Sürdürülebilirliği: Parçalı Eşbütünleşme Analizi”. Akdeniz İ.İ.B.F. Dergisi 18, s. 117-145.

- Ceylan R. ve Çeviş İ. (2012). "Enflasyon Hedeflemesi Rejimi Öncesi ve Sonrasında Türkiye'de Cari Açıkların Sürdürülebilirliği”. e-Journal of New World Sciences Academy NWSA-Social Sciences, 3C0101, 7(4), s. 259-276.

- Corden, W. M. (1994). Economic Policy, Exchange Rates, and the International System, Oxford: Oxford University Press, and Chicago: The University of Chicago Press.

- Çelik T. ve İlkay S.Ç. (2016). “Türkiye'de İhracat ve İthalat Arasındaki İlişkinin 1989-2015 Dönemi için Test Edilmesi”. Süleyman Demirel Üniversitesi İktisadi ve İdari Bilimler Fakültesi Dergisi 21(3), s. 961969.

- Dornbusch, R. ve Fischer F. (1990). Macroeconomics, McGraw-Hill, International Editions.

- Edwards S. (2001). “Does The Current Account Matter?", NBER Working Paper w8275 38.

- Fisunoğlu M. ve Oransay G. (2014). "Cari Açığın Sürdürülebilirliğinde Varlık Talebi Yaklaşımı”. Proceedings of the International Conference on Eurasian Economies, Skopje - Macedonia 1-3 July, s. 900908.

- Freund C. L. (2000). "Current Account Adjustment in Industrialized Countries", Board of Governers of the FED International Finance, Discussion Papers, 692.

- Göçer İ. (2013). "Türkiye'de Cari Açığın Nedenleri, Finansman Kalitesi ve Sürdürülebilirliği: Ekonometrik Bir Analiz". Eskişehir Osmangazi Üniversitesi IİBF Dergisi 8(1), s. 213-242.

- Göçer İ., Mercan M., Hotunluoğlu H. (2012). "Seçilmiş OECD Ülkelerinde Cari İşlemler Açı ğının Sürdürülebilirliği: Yatay Kesit Bağımlılı̆̆ı Altında Çoklu Yapısal Kırılmalı Panel Veri Analizi”. Maliye Dergisi 163, s. 449-467.

- Heidari H., Katircioglu S.T., Davoudi N. (2012). "Are Current Account Deficits Sustainable? New Evidence from Iran Using Bounds Test Approach to Level Relationship”. Discussion Paper No. 2012-24 | May 2 | http://www.economics-ejournal.org/economics/discussionpapers/2012-24 (10/03/2017).

- Husted S. (1992). "The Emerging U.S. Current Account Deficit in the 1980s: A Cointegration Analysis". The Review of Economics and Statistics 74(1), p. 159-166.

- Kaya M. (2016). “Türkiye'de Cari Açık Sorunu ve Nedenleri”. Dicle Üniversitesi İktisadi ve İdari Bilimler Fakültesi Dergisi 6(10), s. 51-75.

- Keating J.W. (1990). "Identifying VAR Models Under Rational Expectations". Journal Of Monetary Economics 25, p. 453-454.

- Kırgız Cumhuriyeti Merkez Bankası veri tabanı, (Erişim tarihi: 22.04.2017).

- Koç S. ve Bakırtaş İ. (2016). “Türkiye'de Cari Açığın Sürdürülebilirliği: Kointegrasyon Testlerinden Bulgular”. Sosyal Bilimler Dergisi 49, s. 252-277.

- Mançelları A. ve Xhepa S. (2003). "Sustainability Of Current Account Balance", www.bankofalbania.org./web/pub/Macellari_Xhepa_822_1.pdf, 1-23 (E.T. 08.06.2012).

- Mançellari A. ve Xhepa S. (2003). "Sustainability of current account balance". Paper presented at the Conferrence organized by the Bank of Albania and Faculty of Economics, TU, Sarande, September 11-13.

- Mercan M., Göçer İ. (2012). "Zamanlararası Dış Denge ve Optimizasyon Yaklaşımları Çerçevesinde Türkiye'de Cari Açığın Sürdürülebilirliği”. Akdeniz I.I.I.B.F. Dergisi 24, s. 73-101.

- Milesi-Ferretti G. M. ve Razin A. (1997). "Sharp Reductions in Current Account Deficits: An Empirical Analysis”. European Economic Review 42, p. 897-908. 
- Milesi-Ferretti M. ve Razin A. (1996). "Current Account Sustainability: Selected East Asian and Latin American Experiences”. NBER Working Paper Series, No:5791, p. 1-61.

- Milesi-Ferretti M. ve Razin A. (1996a). "Sustainability of Persistent Current Account Deficits". NBER Working Paper, No: 5467.

- Milessi-Ferrett G.M. ve Razin A. (1996). "Sustainability of Persistent Current Account Deficits". National Bureau of Economic Research Working Paper, No:5647.

- Milessi-Ferrett G.M. ve Razin A. "Current Account Sustainability: Selected East Asian and Latin American Experiences”, http://www.nber.org/papers/w5791, (10.03.2017).

- Opoku-Afari M. (2005). "Capital Flows and Current Account Sustainability: The Ghanaian Experience". Research Papers at www.nottingham.ac.uk/economics/credit/ (Erişim Tarihi: 10/03/2017)

- Peker O. (2009). “Türkiye'deki Cari Açık Sürdürülebilir mi? Ekonometrik Bir Analiz”. Kocaeli Üniversitesi Sosyal Bilimler Enstitüsü Dergisi 17(1), s. 164-174.

- Polat G. (2008). “Cari İşlemler Açığının Sürdürülebilirliği ve Türkiye Üzerine Bir Uygulama”. Yayınlanmamış yüksek lisans tezi, Dokuz Eylül Üniversitesi Sosyal Bilimler Enstitüsü İktisat Anabilim Dalı, Genel İktisat programı.

- Roubini R. ve Watchel P. (1998). "Current Account Sustainability in Transition Economies”. NBER Working Paper Series, p. 1-72.

- Sachs J. (1981). "The Current Account and Macroeconomic Adjustment in the 1970s", Brookings Papers on Economic Activity 1, p. 201-268.

- Shyh-Wei Chen, (2010). "Testing for the Sustainability of the Current Account Deficit in Four Industrial Countries: A Revisitation". Economics Bulletin 30(2), p. 1474-1495.

- Suzette H. (2003). "Trade Liberalization and the Jamaican Economy: Prospects and Effects of Tariff Adjustments", Research Papers Series, Bank of Jamaica.

- S Şahbaz A. (2011). “Cari İşlem Açıklarının Sürdürülebilirliği: 2001-2011 Türkiye Örneği””. Ç.Ü. Sosyal Bilimler Enstitüsü Dergisi 20(3), s. 417-432.

- Tarı R. (2005). Ekonometri, Kocaeli Üniversitesi Yayınları, Yayın No: 172, Kocaeli.

- Tiwari A.K. (2012). "Reassessment of Sustainability of Current Account Deficit In India". South-Eastern Europe Journal of Economics 1, p. 67-79.

- Topalli N. ve Dogan İ. (2016). "The structure and sustainability of current account deficit: Turkish evidence from regime switching". The Journal of International Trade \& Economic Development 25(4), p. 570-589. DOI: $10.1080 / 09638199.2015 .1090472$

- Uygur E. (2004). “Cari Acık Tartışmaları”. İktisat, Işsletme ve Finans 19(222), s. 5-20.

- Wu L. (2000). "Mean Reversion of the Current Account: Evidence from the Panel Data Unit-Rout Test", Economics Letters 66, p. 213-222.

- $\quad$ www.worldbank.org, (Erişim tarihi: 27.03.2017).

- Yayar R. ve Demir Y. (2014). "Türkiye'de Sürdürülebilir Cari Açık”. Sosyal Bilimler Dergisi VII(1), s. 118148. 


\title{
Giderek Gelişen Hizmet Ticareti ve Rekabet Gücü: Türkiye Ekonomisinde Gelişmeler (1980-2015)
}

\section{Dramatically Rising Service Trade and Competitiveness Power: Developments in Turkish Economy (1980-2015)}

\author{
Asst. Prof. Dr. Ziya Çağlar Yurttançıkmaz (Atatürk University, Turkey) \\ Assoc. Prof. Dr. Sabri Azgün (Atatürk University, Turkey) \\ Assoc. Prof. Dr. Ayşen Hiç Gencer (Istanbul Aydın University, Turkey) \\ Prof. Dr. Ömer Selçuk Emsen (Atatürk University, Turkey)
}

\begin{abstract}
It has been revealed both in the theoretical and the applied studies that the trade of goods in the traditional foreign trade theories reflects the prosperity indicators of the countries such as economic growth and employment positively. In the 1970s, especially with the developments on financial globalization, the foreign trade structure has started to evolve, and the service trade has started to become more and more important or weighted. While the literature on competitiveness is related to the commodity trade, it is noteworthy that there are more limited studies on the results and suggestions of the competition power in service trade. In this study Balassa's (1965) RCA (Revealed Comparative Advantages) approach was used to determine Turkey's competitive power on service trade. In this context, Turkey has tried to measure competition power against the world in each service sub sector related to the classification of traditional service sector such as tourism and transportation and other service sectors (telecommunication, financial services, insurance etc.) which are defined as modern services sector. It is analyzed with using annual data between 1980 and 2015 obtained from the UNCTAD. According to findings the competitive power in the tourism sector with traditional services is stronger in Turkey. This can be seen generally disadvantageous in the transportation sector, but there has been some increase in competition power since 2009 . On the other hand, in the field of other service sectors expressed as modern services, it is concluded that there is no competitive power and it is highly disadvantaged.
\end{abstract}

\section{Giris}

Ekonomik büyümenin istikrarlı ve sürekliliğini sağlama koşulları arasında yer alan unsurların başında siyasal ve iktisadi liberalizasyon uygulamaları gelmektedir. İktisadi liberalizasyon uygulaması kavramı da ekonomide korumacılık duvarlarının kaldırıldığı bir yapının benimsenmesinden hareketle, ülkenin dışa açık ekonomi politikaları ağırlıkla hayatiyete geçirmesidir (Emsen vd., 2006: 2). Dışa açık ülkelerin ekonomik ilişkilerinde dış satımda bulunabilme, yani ihracat yapabilmenin en temel koşulu maliyet avantajına sahip olabilmektir. Maliyet avantajı sahipliği en basit şekliyle ucuza üretebilme yeteneği olarak tanımlanır. Ucuz üretim genel olarak o mal veya hizmete uygun faktör yapısına sahip olmanın bir yansıması konumundadır. Bu durumda o mal veya hizmetin yurtiçi tüketiminden arta kalan kısım üretim fazlalığı olarak ortaya çıkar ve üretim fazlalığı da dünyaya arz edilir. Tersine maliyet dezavantajlığı durumundaki mal veya hizmette ise ülke ithalatçı konuma geçer. Dolayısyla ülkelerin ihracatçı ya da ithalatçı konumunu belirleyen unsur sahip olduğu faktör donanımı ve bunun üretime yansıması olan karşılaştırmalı üstünlüklerdir.

Karşılaştırmalı üstünlükler yapısı analizleri literatürde ilk kez Liesner (1958) tarafından uygulanmıș ancak Bela Balassa (1965)'nın geliştirmiş olduğu form daha faza uygulama alanı bulmuştur. Balassa tarafindan karşılaştırmalı üstünlüğün hesaplanması için ortaya konulan “Açıklanmış Karşılaştırmalı Üstünlükler” (AKÜ) yöntemi, bir ülkenin güçlü ve zayıf sektörlerini belirlemek için pratikte genişçe kullanılmaktadır. Balassa sonrasında AKÜ yönteminin çeşitli versiyonları türetilmiştir. Buna göre rekabet gücü indeksi, iki göreceli piyasa payı arasındaki oranı ifade eden "Ihracat Uzmanlık Indeksi" kullanılarak bulunabilir. Bu sayede verili bir sınaî ürünün, belirli bir ülkenin görünen kalemleri veya imalat sanayii ihracatı içindeki payı, bir başka ülkenin benzer alandaki payı ile kıyaslanabilir (Kösekahyaoğlu ve Özdamar, 2009: 21).

Balassa tarafından geliştirilen rekabet gücü indeksinin daha çok mal gurupları itibarıyla ticarette ülkelerin karşılaştırmalı üstünlükler yapısının belirlendiği dikkat çekmektedir. Buna karşılık dünya ekonomisinde mal akımları yerine giderek ağırlığı artan hizmet ticaretinde rekabet gücünün ölçümüne gidilmesinde yarar vardır. Burada gelişmişlik göstergesi olarak alınan sektörel yapıdaki değişimler de bu mesajı vermektedir. Şöyle ki, gelişmişliğin sektörel dönüşümü C. Clark’ın “üç sektör kanunu”nda tanımlanmıştır. Buna göre gelişmişliğin merhalelerine bağlı olarak tarımdan sanayiye, sanayiden de hizmetler sektörüne evrilme söz konusudur. Dış ticaret yapısı da benzeri bir evrim geçirmekte ve böylece geleneksel hizmet ticaretinin görece daha fazla emek-yoğun olması ve modern hizmet ticaretinin ise daha sermaye/teknoloji-yoğun olduğu açıktır. Burada H. Chenery'nin hasılanın sektörel paylarındaki değişmeleri tahlil eden çalışmasında fert başına katma değere etki eden sektörleri şu şekilde tahmin etmiştir (Kaynak, 2005: 132): 
$\log V=a \log +b \log Y$

Yukarıdaki eşitlikte V, fert başına katma değeri ve Y, fert başına geliri ifade etmektedir. Bu eşitlik yardımıyla farklı mallar için talebin gelir esneklikleri, yani b katsayıları tahmin edilmiştir. Buna göre bir malın talebinin gelir esnekliğinin 1'den küçük (büyük) olması, gelir artarken toplam hasıla içerisinde ele alınan malın nispi payının azalması (artması) anlamına gelmektedir. Chenery’nin 51 ülkeyi kapsayan araştırmasında tarım sektöründe büyüme esnekliğini 0.5 'den küçük, sanayininkini 1.3 'ün üzerinde ve hizmetlerinkini de 1 olarak bulmuştur. Ekonomide sektörel bazda büyümeye katkılar esneklikler açısından "sanayi > hizmetler > tarım" şeklinde bir sıralamanın olduğu ileri sürülmektedir. Buradaki açıklamalardan hizmetlerdeki esnekliğin sanayiden küçük olmasının hizmetlere evrilen bir gelişmişliğe kaçınılmaz yönelimin durağan büyümeye işaret edeceği açıktır. Ancak, hizmetler sektöründe modern hizmetlere yönelik talebin Veblensit etkiler içermesi nedeniyle zamana bağlı olarak talebin gelir esnekliği katsayısının sanayiden de büyük olması kuvvetle muhtemel olacağı söylenebilir. Dolayısıyla modern hizmetlerin yaratacağı katma değer ve dolayısıyla ekonomik büyüme üzerine daha güçlü etkiler doğuracağı düşünülebilir. Bu çalışmada dünyada ve Türkiye'de hizmet ticaretinki gelişmeler incelenerek özellikle Türkiye'nin hizmet ticaretinde rekabet gücü hesaplanarak rekabet gücündeki gelişmelerin zamana bağlı seyri ortaya konulacaktır. Bu çerçevede çalışmanın ikinci kısmında dünya ekonomisinde mal ve hizmet ticaretinin trende bağlı değişimi ele alınmıştır. Üçüncü kısımda Türkiye ekonomisinde mal ve hizmet ticaretindeki gelişmeler resmedilmiştir. Dördüncü kısmında Türkiye ekonomisinde hizmet ticareti alt kalemleri itibarıla rekabet gücü ve bunun zamana bağlı gelişimi 1980-2014 arası dönem için ortaya konulacaktır. Son kısımda ise gelinen nokta ve buna bağlı olarak politika çıkarımına gidilecektir.

\section{Dünya Ekonomisinde Dış Ticaret Yapısında Gelișmeler}

Küresel gelişmelerin temel dayanağı, liberal politika uygulamalarının yarattığ 1 refah etkilerinin belirli kişi ya da gruplara özgü olmaktan çıktığı, daha çok tüm toplumu kuşattığı ileri sürülmektedir. Burada küresel düzene eklemlenmede başarının refahı besleyeceği önsell olarak kabul görürken, bunun da daha çok dışa açık politika uygulamalarıyla sağlanacağı açıktır. Birinci küreselleşmenin ortaya çıkışı başta İngiltere olmak üzere 1870'li yıllarda yurtiçi üretim fazlasını eritmek için pazar arayışlarının bir yansıması olduğu ileri sürülmektedir. 1970'lerde ortaya çıkan ikinci küreselleşme dalgası da tıpkı ilk dalga gibi gelişmiş ülkelerde bu kez giderek artan sermayenin bulunduğu ülkede kazanç (kâr, faiz, vb.) marjlarının düşmesine paralel olarak daha yüksek kazanç marjı olan ülkelere kayma eğiliminin bir yansıması olmuştur. Ancak, ilk küreselleşme dalgasının mallar için pazar arayışlarının ve ikinci küreselleşme dalgasının da finans kapital için yatırım arayışlarının yansıması olduğu görülmüştür. Dolayısıyla her iki küreselleşme dalgasının netice itibarıyla mal ya da finans kapital kıtlığı çeken ülkelere daha ucuza mal ya da kapital temin etme imkanları sunduğu ileri sürülebilir. Diğer taraftan küreselleşme ve dışa açıklığın eşanlamlı kullanıldığı gibi yaygın bir algının varlığında, dışa açık politika uygulamalarının özellikle dış ekonomik ilişkilerde partner ülke veya ülkelerden kaynaklanan olumlu şokların ülke ekonomisine katkılarının da olumlu olacağı ve buna karşılık olumsuz şokların da partner ülkelerde tahribatlar yaratacağına dair yaygın bir literatürün varlığı dikkat çekmektedir. Ekonomi literatüründe dış yansıma olarak da ifade edilen bu durum, olumsuz şokların götürülerinden daha çok olumlu şokların getirilerinin varlğının daha baskın olduğuna vurgu yapmaktadir (Emsen, 2003).

Kısaca 1870'li yıllarda başlayan ve I. Dünya Savaşının başlaması ile sonlanan birinci küreselleşme dalgasında dünya ticareti daha çok Gelişmiş Ülke (GÜ)-Gelişmekte Olan Ülke (GOÜ) arasında cereyan etmiştir ki, ortaya çıkan yapı sömürgecilik olarak da nitelendirilmiştir. Dolayısıyla GOÜ'lerden GÜ'lere doğru yapılan ticarette GOÜ'ler açısından ihracat boyutu ilksel mallar olarak nitelendirilen tarımsal mallar ile hammaddelerden ibaret olduğu ve buna karşılık GOÜ’lerin GÜ’lerden yaptıkları ithalatın ise ikincil mallar olarak nitelendirilen sanayi mallarından oluştuğu söylenir ve bu durum da “endüstriler-arası ticaret” ile açıklanır. Buradaki ticarette GOÜ’lerin GÜ’lerin bir tür tamamlayıcısı olduğu dikkat çekmektedir. Diğer taraftan diş ticaretteki gelişmelerin zamana bağlı olarak GÜ-GÜ arasında da gözlenmeye başlamış/yaygınlaşmış ve bu durum uluslararası iktisat literatüründe “endüstri-içi ticaret” kavramı ile ifade edilmiştir. 1870'lerde gözlenen yapının ikinci küreselleşme dalgasının başladığı 1970'li yıllarda da aynen devam ettiği ileri sürülebilir. Tablo 1'de ikinci küreselleşme dalgasında dünya ticaretinin ülkelerin gelişmişlik düzeyleri açısından dağılımı verilmiştir.

\begin{tabular}{|c|c|c|c|}
\hline Yıllar & $\begin{array}{c}\text { GÜ-GÜ Ekonomileri } \\
\text { Arasında }\end{array}$ & $\begin{array}{c}\text { GÜ-GOÜ Ekonomileri } \\
\text { Arasında }\end{array}$ & $\begin{array}{c}\text { GOÜ-GOÜ Ekonomileri } \\
\text { Arasında }\end{array}$ \\
\hline $\mathbf{1 9 6 5}$ & 59.0 & 32.5 & 3.8 \\
\hline $\mathbf{1 9 7 0}$ & 62.1 & 30.6 & 3.3 \\
\hline $\mathbf{1 9 7 5}$ & 46.6 & 38.4 & 7.2 \\
\hline $\mathbf{1 9 8 0}$ & 44.8 & 39.0 & 9.0 \\
\hline $\mathbf{1 9 8 5}$ & 50.8 & 35.3 & 9.0 \\
\hline $\mathbf{1 9 9 0}$ & 55.3 & 33.4 & 9.6 \\
\hline
\end{tabular}




\begin{tabular}{|l|l|l|l|}
\hline $\mathbf{1 9 9 5}$ & 51.1 & 35.1 & 12.1 \\
\hline $\mathbf{2 0 0 0}$ & 49.8 & 36.8 & 13.4 \\
\hline $\mathbf{2 0 0 5}$ & 45.3 & 37.4 & 17.3 \\
\hline $\mathbf{2 0 1 0}$ & 37.0 & 39.3 & 23.7 \\
\hline $\mathbf{2 0 1 5}$ & 35.1 & 38.5 & 26.3 \\
\hline
\end{tabular}

Tablo 1: 1965-2015 Yılları Arası Dünya Ticaretinin Yönü (\%)

Kaynak: IMF (Various Years), Direction of Trade Statistics Yearbook'dan nakleden Held vd., 1999: 172; UNCTAD, UNCTADstat, 2017.

1965 'den 2015 y1lına kadarki süreçte dünya ticaretinin yönü izlendiğinde, GÜ-GÜ arasında ticaret \%60'lardan \%35'lere gerilediği gözlenirken, GÜ-GOÜ arası ticaretin hemen hemen istikrarlanmış (\%32.5'den \%37.5'e) olduğu dikkat çekmekte, GOÜ-GOÜ arası ticaretin ise \%3'lerden \%26'lara çıktığı görülmektedir. Buradan hareketle küreselleşmenin son zamanlarda daha çok GOÜ'lerin kendi aralarındaki ticaretten daha güçlü bir şekilde beslendiği söylenebilir.

Dünya ekonomisinde ikinci küreselleşme dalgasının başladığı 1970'li yıllarla birlikte, küresel ticaretin odağı mamül mallardan hizmetlere doğru kaymaya başlamıştır. Özellikle iletişim ve ulaştırma sektörlerinde devasa gelişmeler ile birlikte finans kapitalde ortaya çıkan artışlar ve varlık piyasaları araçlarında ortaya çıkan gelişmeler hizmet ticaretindeki genişlemeyi besleyen unsurlar olmuştur. Burada genel olarak yapılan değerlendirmeyi dünya ekonomisinde gelişmişlik düzeyine göre yapıldığında, dünyada ülkeler; (i) yüksek gelirli ülkeler, (ii) orta gelirli ülkeler ve (iii) düşük gelirli ülkeler olmak üzere üç gruba ayırarak yapmak mümkündür. Aşağıda Tablo 2'de dünya ekonomisi ile yüksek, orta ve düşük gelirli ülke grupları itibarıyla ABD doları cinsinden GSYİH, mal ihracatı ve hizmet ihracatı rakamları zaman bağlı olarak sunulmuştur.

\begin{tabular}{|c|c|c|c|c|c|c|c|c|}
\hline & & 1960 & 1970 & 1982 & 1990 & 2000 & 2010 & 2015 \\
\hline \multirow{3}{*}{ Yüksek } & Mal X & - & - & $2.56 \mathrm{E}+11$ & $3.73 \mathrm{E}+11$ & $8.91 \mathrm{E}+11$ & $3.80 \mathrm{E}+12$ & $4.48 \mathrm{E}+12$ \\
\hline & $\begin{array}{l}\text { Hizmet } \\
\text { X }\end{array}$ & - & - & $3.74 \mathrm{E}+10$ & $7.03 \mathrm{E}+10$ & $2.15 \mathrm{E}+11$ & $4.74 \mathrm{E}+11$ & $7.40 \mathrm{E}+11$ \\
\hline & GSYİH & $1.06 \mathrm{E}+12$ & $2.38 \mathrm{E}+12$ & $8.95 \mathrm{E}+12$ & $1.89 \mathrm{E}+13$ & $2.76 \mathrm{E}+13$ & $4.52 \mathrm{E}+13$ & $4.74 E+13$ \\
\hline \multirow{3}{*}{ Orta } & Mal X & - & - & $3.43 \mathrm{E}+11$ & $5.01 \mathrm{E}+11$ & $1.15 \mathrm{E}+12$ & $4.66 \mathrm{E}+12$ & $5.46 \mathrm{E}+12$ \\
\hline & $\begin{array}{l}\text { Hizmet } \\
\text { X }\end{array}$ & - & - & $5.21 \mathrm{E}+10$ & $1.03 \mathrm{E}+11$ & $2.85 \mathrm{E}+11$ & $7.53 \mathrm{E}+11$ & $1.09 \mathrm{E}+12$ \\
\hline & GSYİH & $2.99 \mathrm{E}+11$ & $5.49 \mathrm{E}+11$ & $2.30 \mathrm{E}+12$ & $3.55 \mathrm{E}+12$ & $5.84 \mathrm{E}+12$ & $2.03 \mathrm{E}+13$ & $2.64 \mathrm{E}+13$ \\
\hline \multirow{3}{*}{ Düşük } & Mal X & - & - & - & - & $2.65 \mathrm{E}+10^{(*)}$ & $5.69 \mathrm{E}+10$ & $8.22 \mathrm{E}+10$ \\
\hline & $\begin{array}{l}\text { Hizmet } \\
\text { X }\end{array}$ & - & - & $2.49 \mathrm{E}+09$ & 4.07E+09 & $1.10 \mathrm{E} 10$ & $2.07 \mathrm{E}+10$ & $2.80 \mathrm{E}+10$ \\
\hline & GSYİH & - & - & $8.95 \mathrm{E}+10$ & $9.41 \mathrm{E}+10$ & $1.13 \mathrm{E}+11$ & $2.89 \mathrm{E}+11$ & $3.94 \mathrm{E}+11$ \\
\hline \multirow{3}{*}{ Dünya } & Mal X & - & - & $1.83 \mathrm{E}+12$ & $3.45+\mathrm{E} 12$ & $6.20 \mathrm{E}+12$ & $1.50 \mathrm{E}+13$ & $1.64 \mathrm{E}+13$ \\
\hline & $\begin{array}{c}\text { Hizmet } \\
\text { X }\end{array}$ & - & - & $4.25 \mathrm{E}+11$ & $8.94+\mathrm{E} 11$ & $1.68 \mathrm{E}+12$ & $3.92 \mathrm{E}+12$ & $4.95 \mathrm{E}+12$ \\
\hline & GSYİH & $1.35 \mathrm{E}+12$ & $2.94 \mathrm{E}+12$ & $1.12 \mathrm{E}+13$ & $2.25 \mathrm{E}+13$ & $3.35 \mathrm{E}+13$ & $6.59 \mathrm{E}+13$ & $7.42 \mathrm{E}+13$ \\
\hline
\end{tabular}

Tablo 2: Dünya Ekonomisinde GSYİH ile Mal ve Hizmet İhracatı Rakamlarında Gelişmeler (Dolar)

Kaynak: World Bank, World Development Indicators, 2017. Not: ${ }^{(*)} 2005$ yllı değeri

1982-2015 arasındaki gelişmeler değerlendirildiğinde, dünya ekonomisinde GSYİH değerinin 11,2 trilyon dolardan 74,2 trilyon dolarak yükseldiği; mal ihracatının 1,83 trilyon dolardan 16,4 trilyon dolara; hizmet ticaretinin ise 425 milyar dolardan 4,95 trilyon dolara çıktığı görülmektedir. Bu veriler 1şığında dünya ekonomisinde GSYİH 6.63 kat artarken, mal ihracat1 8.96 ve hizmet ihracatı ise 11.65 katı artış sergilemiştir. Diğer bir ifadeyle 1982-2015 arasında GSYİH ortalama yıllık büyüme hız1 \%5.72, mal ihracatı ortalama yıllık büyüme hızı \%6.67 ve hizmet ihracatı ortalama yıllık büyüme hızı da \%7.49 olarak gerçekleşmiştir. Dolayısıyla 34 yıllık bir zaman diliminde dünyada ekonomik büyümeye nazaran mal ihracatı \%35 ve hizmet ihracatı da \%76 daha fazla artış göstermiştir. Dünya ekonomisinde ülkelerin gelir düzeyleri açısından yapılan sınıflandırmasına göre yüksek gelirli ülkelerde GSYİH, mal ihracatı ve hizmet ihracatı artış hızı sırasıyla 5.30, 17.5 ve 19.8 kat; orta gelirli ülkelerde de sirasıyla 11.5, 15.9 ve 20.9 kat; düşük gelirli ülkelerde ise GSYİH ve hizmet ihracatı sirasıyla 6.6 ve 11.2 kat olmuştur. Bu veriler dikkate alındığında, gelişmişlik düzeyi ne seviyede olursa olsun dünyadaki ülkelerin büyük bir çoğunluğunun görece daha fazla dış ticarete açıldığı ve bu dışa açıklık içerisinde de hizmet ticaretinin gelişme hızı ve buna paralel olarak potansiyelinin daha yüksek performans sergilediği söylenebilir. 


\section{3. Türkiye Ekonomisinde Hizmet Ticaretinde Gelişmeler}

Türkiye ekonomisinin cumhuriyetin kuruluşundan günümüze kronolojik gelişimine bakıldığında, ana hatları itibarıyla; (i) 1923-1929 liberal dönem, (ii) 1930-1945 dışa kapanma ve sanayi planı uygulamaları, (iii) 1946-1960 karşılaştırmalı üstünlükler yapısına göre dış ticaret politikaları, (iv) 1961-1979 ithal ikameci sanayileşme politikaları, (v) 1980'den günümüze kadarki süreçte ihracata yönelik sanayileşme politikaları uygulamaları şeklinde sınıflandırılabilir (Pamuk, 2014). Türkiye ekonomisinde özellikle 24 Ocak Kararları ile birlikte dış ticaret ve sanayileşme politikalarında önemli paradigma değişimine gidildiği bilinmektedir. Tablo 3 'de Türkiye ekonomisinde ABD doları cinsinden GSYİH ile mal ve hizmet ihracat ve ithalat verileri resmedilmiştir.

\begin{tabular}{|c|c|c|c|c|c|}
\hline Ylllar & Hizmet M & Hizmet X & Mal M & Mal X & GSYİH \\
\hline $\mathbf{1 9 6 0}$ & - & - & - & - & $1.4 \mathrm{E}+10$ \\
\hline $\mathbf{1 9 7 0}$ & - & - & - & - & $1.95 \mathrm{E}+10$ \\
\hline $\mathbf{1 9 7 4}$ & $3.66 \mathrm{E}+08$ & $5.49 \mathrm{E}+08$ & $3.59 \mathrm{E}+09$ & $1.53 \mathrm{E}+09$ & $3.56 \mathrm{E}+10$ \\
\hline $\mathbf{1 9 8 0}$ & $5.69 \mathrm{E}+08$ & $7.11 \mathrm{E}+08$ & $7.51 \mathrm{E}+09$ & $2.91 \mathrm{E}+09$ & $6.88 \mathrm{E}+10$ \\
\hline $\mathbf{1 9 8 2}$ & $1.03 \mathrm{E}+09$ & $1.92 \mathrm{E}+09$ & $8.52 \mathrm{E}+09$ & $5.89 \mathrm{E}+09$ & $6.45 \mathrm{E}+10$ \\
\hline $\mathbf{1 9 9 0}$ & $3.07 \mathrm{E}+09$ & $8.02 \mathrm{E}+09$ & $2.25 \mathrm{E}+10$ & $1.30 \mathrm{E}+10$ & $1.51 \mathrm{E}+11$ \\
\hline $\mathbf{2 0 0 0}$ & $8.15 \mathrm{E}+09$ & $1.94 \mathrm{E}+10$ & $5.29 \mathrm{E}+10$ & $3.09 \mathrm{E}+10$ & $2.67 \mathrm{E}+11$ \\
\hline $\mathbf{2 0 1 0}$ & $1.97 \mathrm{E}+10$ & $3.65 \mathrm{E}+10$ & $1.77 \mathrm{E}+11$ & $1.21 \mathrm{E}+11$ & $7.31 \mathrm{E}+11$ \\
\hline $\mathbf{2 0 1 1}$ & $2.10 \mathrm{E}+10$ & $4.13 \mathrm{E}+10$ & $2.32 \mathrm{E}+11$ & $1.42 \mathrm{E}+11$ & $7.75 \mathrm{E}+11$ \\
\hline $\mathbf{2 0 1 2}$ & $2.10 \mathrm{E}+10$ & $4.36 \mathrm{E}+10$ & $2.27 \mathrm{E}+11$ & $1.62 \mathrm{E}+11$ & $7.89 \mathrm{E}+11$ \\
\hline $\mathbf{2 0 1 3}$ & $2.45 \mathrm{E}+10$ & $4.82 \mathrm{E}+10$ & $2.42 \mathrm{E}+11$ & $1.62 \mathrm{E}+11$ & $8.23 \mathrm{E}+11$ \\
\hline $\mathbf{2 0 1 4}$ & $2.51 \mathrm{E}+10$ & $5.19 \mathrm{E}+10$ & $2.33 \mathrm{E}+11$ & $1.69 \mathrm{E}+11$ & $7.99 \mathrm{E}+11$ \\
\hline $\mathbf{2 0 1 5}$ & $2.26 \mathrm{E}+10$ & $4.67 \mathrm{E}+10$ & $2.00 \mathrm{E}+11$ & $1.52 \mathrm{E}+11$ & $7.18 \mathrm{E}+11$ \\
\hline
\end{tabular}

Tablo 3: Türkiye Ekonomisinde GSYIH ile Mal ve Hizmet Ticareti Rakamlarında Gelişmeler (Dolar)

Kaynak: World Bank, World Development Indicators, 2017.

Türkiye ekonomisinde ilişkin genel bir değerlendirme yapılacak olduğunda, Tablo 1'dekine benzer bir seyrin yaşandığı söylenebilir. Şöyle ki, 1982-2015 arasında GSYİH 64.5 milyar dolardan 718 milyar dolara, mal ihracatı 5.89 milyar dolardan 152 milyar dolara ve hizmet ihracatı da 1.92 milyar dolardan 46.7 milyar dolara yükselmiştir. Bu veriler 1şı̆̆ında Türkiye ekonomisinde GSYİH 11.13 kat artarken, mal ihracatı 25.81 ve hizmet ihracatı ise 24.32 katı artış sergilemiştir. Burada GSYİH ortalama yıllık büyüme hızı \%7.34, mal ihracatı ortalama yıllık büyüme hızı \%10.03 ve hizmet ihracatı ortalama yıllık büyüme hızı da \%9.84 olarak gerçekleşmiştir. Her üç kalemdeki büyüme hızının hem dünya hem de yüksek ve orta gelilri ülkeler büyüme hızının üzerinde olduğu dikkat çekmektedir. Bu veriler bir bütün olarak değerlendirildiğinde, Türkiye ekonomisinin görece çok iyi bir performans sergilediği söylenebilir. Ancak, hizmetler sektöründe dünya genelinde gözlenen görece daha yüksek ilerlemeye karşılık, Türkiye ekonomisinde görece daha düşük kalındığı söylenebilir. Diğer bir ifadeyle dünya ekonomisinde hizmetler ihracatı mal ihracatından ve mal ihracatı da ekonomik büyümeden daha yüksek büyüme skorları sergilerken; Türkiye ekonomisinde mal ihracatı himet ihracatından ve hizmet ihracatı da ekonomik büyümeden daha yüksek büyüme skorlarına sahip olmuştur.

Burada mal ticareti için ileri sürülen karşılaştırmalı üstünlükler yapısı ilksel mallardan kompleks mallar lehine değiştirildikçe, üretimde katma değer payı ve dolayısıyla büyümenin de artacağına dair savın hizmetler için de geçerlilik arz edeceği ileri sürülebilir. Gerni vd. (2013) tarafından yapılan çalışmada, Türkiye ekonomisinin rekabetçi yapısının daha çok fiyat-maliyet boyutuyla kısa vadeli rekabet avantajı sağladığı; buna karşılık teknoloji ve verimlilik boyutunun ise uzun vadede rekabet avantajını tesis ettiği gözlenmektedir (Gerni vd., 2013: 1).

Türkiye ekonomisi özelinde bir değerlendirme yapılacak olduğunda, dış ticaret açığının en önemli kapatıcı kalemi konumundaki hizmet ihracatının cari dünya trendine göre geride kaldığı gözlenirken; bunun da temel etkeninin daha rekabetçi ve daha yenilikçi olmaktan uzak kalmasıdır. Diğer bir ifadeyle Türkiye ekonomisi hizmetlerde dünyadaki akıma uygun performans sergileyememiştir ki, bu da hizmetlerde rekabet gücünün nispeten zayıf kaldığına ve dolayısıyla yeterli teşvikten uzak kaldığına/ilginin gösterilmediğine işaret etmektedir. Dolayısıyla hizmetlerde emek gücüne ve böylece fiyat-maliyet dayalı rekabet unsurunun daha çok geleneksel hizmet kalemlerinde geçerlilik arz ettiği; bunun teknoloji ve verimlilik boyutunu kuşatacak şekilde modern hizmetlere kaydırılması gerektiği dikkat çekmektedir.

\section{4. Veri, Yöntem ve Uygulama}

Türkiye ekonomisinde 1980 öncesi ithal ikameci politika uygulamalarının her şeyden önce giderek derinleşen döviz darboğazları yaratması ve uygulama mantığını oluşturan bebek endüstriler argümanından sapılması, yani iç piyasada oluşan tatlı kâr marjlarından vazgeçilemezlik, adeta ülkeyi içinden çıkılamaz bir noktaya sevk etmiştir. Bu çerçevede Türkiye 24 Ocak 1980'de önemli yapısal dönüşüm yaşamıştır. Böylece ekonomisinde nispeten liberalizasyon uygulamalarına yönelimle birlikte, ihracata yönelik sanayileşme politikası uygulamalarına gidilmiş 
ve bununla paralel olarak ithalatta serbestleşeme ve böylece korumacılık duvarlarında indirimler söz konusu olmuştur. Bu çalışmada liberalizasyon uygulamalarına bağlı olarak 1980-2015 arası dönem için geleneksel ve modern hizmetler sektöründe gelişmeler ile zamana bağlı olarak bu sektördeki rekabet gücündeki değişmeler inceleme konusu yapılmıştır.

Bir ülkenin belli bir mal grubunda ihracatının ithalatından fazla olması o alanda rekabet gücü olduğunu ifade etmektedir. Tersi durum ise yani ülkenin bir mal grubunda ithalatının ihracatından fazla olması o malı düşük maliyetle üretemediği ve bu nedenle o malın dışarından alındığı, yani ilgili malda rekabet gücünün zayıf olduğu söylenebilir. Dış ticaret mekanizmasının işlerliğinin daha çok rekabet gücü çerçevesinde ele alan ve dolayısıyla karşılaştırmalı üstünlük analizlerini ampirik literatürde ilk uygulayan Liesner (1958)'dir. Liesner, AKÜ yönteminde oluşturduğu denklem şu şekildedir:

$A K \ddot{U}=\mathrm{X}_{\mathrm{ij}} / \mathrm{X}_{\mathrm{nj}}$

(2) nolu eşitlikte $X$, ihracat sektörünü; i, analize konu olan ülkeyi; n, geri kalan ülkeler bütününü; j, analize konu olan malı temsil etmektedir. AKÜ yaklaşımı daha sonra Balassa $(1965 ; 1977)$ tarafindan geliştirilmiş ve rekabet gücünün ölçümünde genel kabul gören ve sıklıkla kullanılan bir ölçüt hakline gelmiştir. Balassa, dış ticaret verilerini kullanarak karşılaştırmalı üstünlüklerin açıklanabileceğini ifade etmiş ve AKÜ yaklaşımını geliştirmişrtir. AKÜ yaklaşımı, ülkelerin zayıf veya güçlü ihracatçı sektörlerini belirlemede büyük katkı sağlamıştır. Balassa tarafından geliştirilen temel denklem ise şu şekildedir (Utkulu ve İmer; 2009):

$\mathrm{AKÜ2}=\left(\mathrm{X}_{\mathrm{ij}} / \mathrm{X}_{\mathrm{it}}\right) /\left(\mathrm{X}_{\mathrm{nj}} / \mathrm{X}_{\mathrm{nt}}\right)=\left(\mathrm{X}_{\mathrm{ij}} / \mathrm{X}_{\mathrm{nj}}\right) /\left(\mathrm{X}_{\mathrm{it}} / \mathrm{X}_{\mathrm{nt}}\right)$

(3) nolu denklemde X, ihracatı; i, ülkeyi; j, mal (veya sektörï); t, mallar (veya sektörler) grubunu; $n$ ise ülkeler grubunu temsil etmektedir. Yukarıdaki denkleme göre $\mathrm{X}_{i j}=\mathrm{i}$ ülkesinin $\mathrm{j}$ malı ihracatı, $\mathrm{X}_{n j}=\mathrm{n}$ ülkesinin/ülkeler grubunun $\mathrm{j}$ malı ihracatı, $\mathrm{X}_{i t}=\mathrm{i}$ ülkesinin toplam ihracatı, $\mathrm{X}_{n t}=\mathrm{n}$ ülkesinin/ülkeler grubunun toplam ihracatıdır. AKÜ2, bir ülkenin bir mal ya da sektördeki ihracatının toplam ihracatı içindeki payını diğer ülkelerinkiyle (ülke grubununkiyle) karşılaştırmaktadır. AKÜ2 < 1 ise, ülkenin ilgili mal/sektörde karşılaştırmalı dezavantaja; AKÜ2 $>1$ olduğu durumda ise, karşılaştırmalı avantaja sahip olduğu söylenir. AKÜ2 endeksi diğer ülkeleri de analize katmakta ve rekabet gücünün ölçümünde karşılaştırmalı bir analize imkân tanımaktadır.

Çalışmada literatürde yaygın biçimde yapılan analizlerden farklı olarak mal ticareti yerine hizmet ticareti analize konu edilmiştir. Analizlerde hizmet ticareti üç ana guruba ayrılarak inceleme konusu yapılmış ve bu çerçevede geleneksel hizmetler olarak taşımacılık ve turizm hizmetleri alınırken, bankacılık ve sigortacılık, finansal hizmetler, inşaatçılık vb. hizmetleri içeren modern hizmetler de diğer hizmet ticareti gurubunda ele alınmıştır. Gerek betimleyici istatistikler, gerekse analizlerde kullanılan veriler UNCTAD'ın web sayfasından derlenmiştir. Tablo 4'te üç ana gurup olarak Türkiye'nin hizmetler kalemlerinde rekabet gücündeki gelişmeler resmedilmiştir.

AKÜ2 endeksi oluşturulması kapsamda elde edilen sonuçlarda rekabet gücünün varlığ1 endeks değerinin 1'den büyük olmasıyla; endeks değerinin 1'den küçük olması ise rekabet gücünün olmadığına işaret etmektedir. Bu çerçevede AKÜ2 endeks değerlerini şu şekilde yorumlamak mümkündür: Türkiye 1980-2015 döneminde genel olarak taşımacılık sektöründe diğer rakipleri karşısında rekabet gücünün düşük olduğu görülmektedir. Ancak, 2009 ve sonrası süreçte taşımacılık sektöründe rekabet gücünde bir artış ve iyileşme olduğu da analiz sonuçlarında gözlemlenmiştir. Turizm sektöründe Türkiye'nin rekabet gücünün genel olarak iyi olduğu ancak ülkede yaşanan kriz ve siyasi çalkantıların olduğu dönemlerde rekabet gücünün zayıfladığı gözlenmiştir. Özellikle 1980 askeri darbesi sonrası takip eden üç-dört yıllık süreçte turizm sektöründe rekabet gücü oldukça düşük kalmıştır. Benzer şekilde 1998-2001 döneminde de yaşanan ekonomik ve siyasi çalkantılar ülkenin turizm alanındaki rekabet gücünü olumsuz etkilediği dikkat çekmektedir.

\begin{tabular}{|c|c|c|c|c|c|c|c|}
\hline Yıllar & Taşımacılık & Turizm & $\begin{array}{c}\text { Diğer Hizmet } \\
\text { Ticareti }\end{array}$ & Yıllar & Taşımacılık & Turizm & $\begin{array}{c}\text { Diğer Hizmet } \\
\text { Ticareti }\end{array}$ \\
\hline $\mathbf{1 9 8 0}$ & 1,105 & 1,752 & 0,419 & $\mathbf{1 9 9 8}$ & 0,584 & 0,966 & 1,235 \\
\hline $\mathbf{1 9 8 1}$ & 0,945 & 1,177 & 0,934 & $\mathbf{1 9 9 9}$ & 0,759 & 0,963 & 1,146 \\
\hline $\mathbf{1 9 8 2}$ & 1,127 & 0,768 & 1,043 & $\mathbf{2 0 0 0}$ & 0,635 & 1,193 & 1,049 \\
\hline $\mathbf{1 9 8 3}$ & 0,893 & 0,838 & 1,173 & $\mathbf{2 0 0 1}$ & 0,799 & 1,644 & 0,676 \\
\hline $\mathbf{1 9 8 4}$ & 0,993 & 0,893 & 1,076 & $\mathbf{2 0 0 2}$ & 0,917 & 2,025 & 0,406 \\
\hline $\mathbf{1 9 8 5}$ & 0,773 & 1,354 & 0,925 & $\mathbf{2 0 0 3}$ & 0,571 & 2,557 & 0,289 \\
\hline $\mathbf{1 9 8 6}$ & 0,675 & 1,079 & 1,154 & $\mathbf{2 0 0 4}$ & 0,640 & 2,468 & 0,326 \\
\hline $\mathbf{1 9 8 7}$ & 0,699 & 1,273 & 0,995 & $\mathbf{2 0 0 5}$ & 0,820 & 2,510 & 0,262 \\
\hline $\mathbf{1 9 8 8}$ & 0,533 & 1,328 & 1,066 & $\mathbf{2 0 0 6}$ & 0,873 & 2,538 & 0,277 \\
\hline $\mathbf{1 9 8 9}$ & 0,548 & 1,271 & 1,096 & $\mathbf{2 0 0 7}$ & 0,970 & 2,590 & 0,256 \\
\hline $\mathbf{1 9 9 0}$ & 0,428 & 1,271 & 1,162 & $\mathbf{2 0 0 8}$ & 0,962 & 2,555 & 0,280 \\
\hline
\end{tabular}




\begin{tabular}{|l|l|l|l|l|l|l|l|}
\hline $\mathbf{1 9 9 1}$ & 0,505 & 1,012 & 1,293 & $\mathbf{2 0 0 9}$ & 1,134 & 2,549 & 0,232 \\
\hline $\mathbf{1 9 9 2}$ & 0,485 & 1,191 & 1,155 & $\mathbf{2 0 1 0}$ & 1,180 & 2,439 & 0,232 \\
\hline $\mathbf{1 9 9 3}$ & 0,476 & 1,150 & 1,184 & $\mathbf{2 0 1 1}$ & 1,269 & 2,423 & 0,228 \\
\hline $\mathbf{1 9 9 4}$ & 0,462 & 1,241 & 1,125 & $\mathbf{2 0 1 2}$ & 1,395 & 2,303 & 0,233 \\
\hline $\mathbf{1 9 9 5}$ & 0,459 & 1,036 & 1,303 & $\mathbf{2 0 1 3}$ & 1,466 & 2,272 & 0,223 \\
\hline $\mathbf{1 9 9 6}$ & 0,559 & 1,311 & 1,008 & $\mathbf{2 0 1 4}$ & 1,542 & 2,197 & 0,232 \\
\hline $\mathbf{1 9 9 7}$ & 0,475 & 1,131 & 1,188 & $\mathbf{2 0 1 5}$ & 1,632 & 2,170 & 0,223 \\
\hline
\end{tabular}

Tablo 4: Türkiye Ekonomisinde AKÜ2 Endeksine Göre Hizmetler Sektöründe Rekabet Gücünde Gelişmeler

Özellikle 2002 sonrası ise turizm sektörünün rekabet gücünün rakipleri karşısında oldukça yüksek düzeyli seyrettiği görülmektedir. Ayrıca turizmin teröre duyarlılığının yüksek olduğu dikkate alınırsa, terör vakalarının turistik bölgelerde yaygınlaştığı yıllarda turizmde düşüşlerin yaşandığı gözlenmektedir. Bu çerçevede 2014-2015 döneminde yaşanan gelişmelerin turizm rekabet gücünü azaltıcı etkiler yarattığı görülmüştür. Taşımacılık sektöründe ise özellikle son dönemde hızla artan bir gelişim olduğu görülmektedir. Bu durum özellikle son dönemde artan ulaştırma yatırımlarının ve duble yol projelerinin etkili olduğu söylenebilir. Taşımacılık ve turizm dışındaki diğer hizmet ticareti alanında ise Türkiye'nin rekabet gücünün oldukça düşük olduğu ve bunun da 2001 krizi ile birlikte dramatik bir şekilde ülke aleyhine teşekkül ettiği görülmektedir. Modern hizmetler açısından özellikle inşaat sektörü dışındaki alanlardan olan sigortacılık, finansal hizmetler ve telekomünikasyon alanlarında ihracat rekabet gücünü artırmaya yönelik politika değişikliklerine gidilmesi gerekliliğinin varlığından söz edilebilir. AKÜ2 endeksine bağlı olarak hizmetler sektöründeki gelişmeler grafik-1 de görsel olarak açıkça görülmektedir.

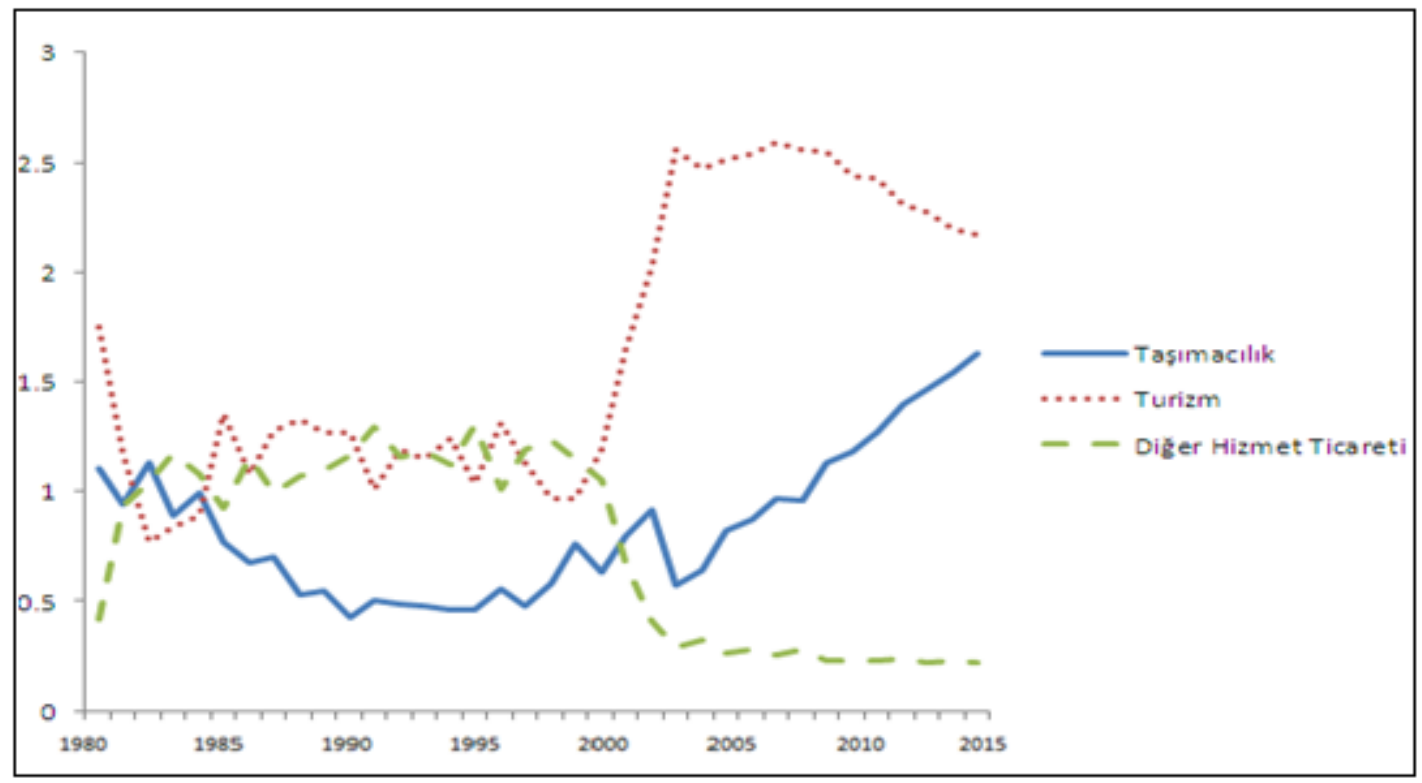

Şekil 1: AKÜ2 Endeksine Göre Hizmetler Sektöründe 1980-2015 Dönemi Değişim

Yukarıdaki şekil-1'de bize açıkça göstermektedir ki ülkemiz genel olarak turizm ve taşımacılık hizmetlerinde rekabet gücü yüksek, diğer hizmetler sektöründe ise oldukça düşüktür.

Yapılan analizlerde Balassa'nın temel formülü baz alınarak ülkenin ihracatıyla birlikte ithalatının da ele alındığı AKÜ4 endeksi de türetilmiştir. Bu analiz yönteminde ülkelerarası bir karşılaştırma değil, ülkenin ihracat ve ithalat değerlerine bağlı bir rekabet gücü ölçümü yapılmaktadır. AKÜ endeksinin bir diğer versiyonu, AKÜ4 şeklinde denklemde olduğu gibi türetilmiştir. AKÜ4 denklemi şu şekilde formüle edilir:

$\mathrm{AKÜ4}=\left(\mathrm{X}_{\mathrm{ij}} / \mathrm{X}_{\mathrm{it}}\right) /\left(\mathrm{M}_{\mathrm{ij}} / \mathrm{M}_{\mathrm{it}}\right)=\left(\mathrm{X}_{\mathrm{ij}} / \mathrm{M}_{\mathrm{ij}}\right) /\left(\mathrm{X}_{\mathrm{it}} / \mathrm{M}_{\mathrm{it}}\right)$

(4) nolu denklemde $X$, ihracatı; $M$, ithalatı; i, bir ülkeyi; $j$, bir ürün veya sektörü; t ise bir ürünler seti veya sektörler setini temsil etmektedir. Balassa (1965) AKÜ4 denkleminde elde edilen sonuç birden ne kadar büyük olursa, rekbaet gücünün o kadar yükseldiği sonucuna ulaş1lır. Göreli ihracat-ithalat ölçümü olarak da ifade edilen AKÜ4, AKÜ2'den farklı olarak ithalat bilgisini içermekte; yalnız ülkerler arası karşılaştırmaya olanak tanımamakta, sadece ülkenin ihracat ve ithalat yapısına bağlı olarak rekabet gücü analizi yapmaktadır. AKÜ4 analiz sonuçları Tablo 5 'te verilmiştir. 


\begin{tabular}{|c|c|c|c|c|c|c|c|}
\hline Yıllar & Taşımacılık & Turizm & $\begin{array}{c}\text { Diğer Hizmet } \\
\text { Ticareti }\end{array}$ & Yıllar & Taşımacılık & Turizm & $\begin{array}{c}\text { Diğer Hizmet } \\
\text { Ticareti }\end{array}$ \\
\hline $\mathbf{1 9 8 0}$ & 0,741 & 2,509 & 0,536 & $\mathbf{1 9 9 8}$ & 0,507 & 1,730 & 1,000 \\
\hline $\mathbf{1 9 8 1}$ & 0,567 & 1,366 & 1,739 & $\mathbf{1 9 9 9}$ & 0,768 & 1,968 & 0,839 \\
\hline $\mathbf{1 9 8 2}$ & 1,195 & 1,346 & 0,804 & $\mathbf{2 0 0 0}$ & 0,532 & 1,977 & 0,893 \\
\hline $\mathbf{1 9 8 3}$ & 1,012 & 1,973 & 0,822 & $\mathbf{2 0 0 1}$ & 0,609 & 2,008 & 0,696 \\
\hline $\mathbf{1 9 8 4}$ & 0,864 & 1,155 & 1,034 & $\mathbf{2 0 0 2}$ & 0,634 & 1,979 & 0,517 \\
\hline $\mathbf{1 9 8 5}$ & 0,631 & 1,572 & 0,994 & $\mathbf{2 0 0 3}$ & 0,340 & 2,496 & 0,413 \\
\hline $\mathbf{1 9 8 6}$ & 0,487 & 1,446 & 1,246 & $\mathbf{2 0 0 4}$ & 0,334 & 2,661 & 0,509 \\
\hline $\mathbf{1 9 8 7}$ & 0,515 & 1,465 & 1,146 & $\mathbf{2 0 0 5}$ & 0,425 & 2,642 & 0,422 \\
\hline $\mathbf{1 9 8 8}$ & 0,498 & 2,240 & 0,843 & $\mathbf{2 0 0 6}$ & 0,502 & 2,729 & 0,383 \\
\hline $\mathbf{1 9 8 9}$ & 0,556 & 1,739 & 0,902 & $\mathbf{2 0 0 7}$ & 0,498 & 2,824 & 0,404 \\
\hline $\mathbf{1 9 9 0}$ & 0,392 & 2,376 & 0,898 & $\mathbf{2 0 0 8}$ & 0,505 & 2,997 & 0,422 \\
\hline $\mathbf{1 9 9 1}$ & 0,489 & 1,723 & 1,007 & $\mathbf{2 0 0 9}$ & 0,612 & 2,396 & 0,357 \\
\hline $\mathbf{1 9 9 2}$ & 0,449 & 1,807 & 0,952 & $\mathbf{2 0 1 0}$ & 0,630 & 2,350 & 0,374 \\
\hline $\mathbf{1 9 9 3}$ & 0,385 & 1,571 & 1,110 & $\mathbf{2 0 1 1}$ & 0,647 & 2,597 & 0,350 \\
\hline $\mathbf{1 9 9 4}$ & 0,449 & 1,747 & 0,938 & $\mathbf{2 0 1 2}$ & 0,676 & 2,959 & 0,336 \\
\hline $\mathbf{1 9 9 5}$ & 0,417 & 1,872 & 1,011 & $\mathbf{2 0 1 3}$ & 0,699 & 2,934 & 0,319 \\
\hline $\mathbf{1 9 9 6}$ & 0,495 & 2,199 & 0,814 & $\mathbf{2 0 1 4}$ & 0,735 & 2,788 & 0,329 \\
\hline $\mathbf{1 9 9 7}$ & 0,512 & 1,792 & 0,910 & $\mathbf{2 0 1 5}$ & 0,824 & 2,376 & 0,316 \\
\hline
\end{tabular}

Tablo 5: Türkiye Ekonomisinde AKÜ4 Endeksine Göre Hizmetler Sektöründe Rekabet Gücünde Gelişmeler

AKÜ4 analiz sonuçları AKÜ2 analiz sonuçları ile benzer bulgular vermektedir. AKÜ4 analizi sonuçlarına göre 1980-2015 döneminde taşımacılık sektöründe rekabet gücünün genel olarak çok düşük olduğu görülmüştür. Turizm sektöründe aynı dönemde rekabet gücünün korunduğu ve hatta 2010 sonrasında rekabet gücünün arttı̆̆1 görülmektedir. Taşımacaılık ve turizm dışındaki hizmet ticaretinde rekabet gücünün analiz döneminde genel olarak düşük olduğu ve bu durumun son dönemlerde ise iyice azaldığı görülmüştür.

AKÜ2 ve AKÜ4 değerleri dikkate alındığında, Türkiye'nin geleneksel hizmet kalemlerinden sadece turizm sektöründe karşılaştırmalı üstünlük yapısının olduğu; buna karşılık geleneksel kalemlerden taşımacılık ile modern hizmet ticaretinde karşılaştırmalı üstünlükler yapısının olmadığı gözlenmektedir. Küreselleşmenin 2008/2009 krizi ile birlikte adeta sorgulanmaya başladığ 1 ve bu çerçevede raftaki Keynesyen reçetelere dönüş yapıldığı ve korumcaılık rüzgarlarının estiği bir yapıda, popüler iktisat kuramı liberal düşünce çerçevesinde kalınmasının ve dolayısıyla karşılaştırmalı üstünlükler mantığı ile hareket edilmesinin şüpheyle karşılandığı açıktır. Oysa Batı Avrupa ile ABD'nin gelişiminde 19. yüzyılda başta Almanya'dan F. List'in ve ABD'den A. Hamilton'un dönemin liberal bakış açısını "merdiveni itme" kavramı ile sorguladıkları ve günümüzde de "stratejik diş ticaret politikası" mantığı ile gelişmiş ülkelerin zaman zaman korumacılığa yönelmeleri dikkate alınırsa, Türkiye'nin uzun vadede karşılaştırmalı üstünlükler elde edeceği taşımacılık ve modern hizmetlere yöneliminin gerektiği düşünülmektedir. Dezavantajlı gözüken bu sektörlere yönelimin “yaparak öğrenme” mekanizmalarını işleterek gelişmişlik liğinde çıta atlamayı sağlayacağı ve böylece daha yüksek katma değer ve istihdam olanaklarının ortaya çıkarılabileceği söylenebilir. AKÜ4 endeksine göre hesaplanan hizmetler sektöründe meydana gelen 1980-2015 dönemi gelişmeler grafik-2 de gösterilmiştir. 


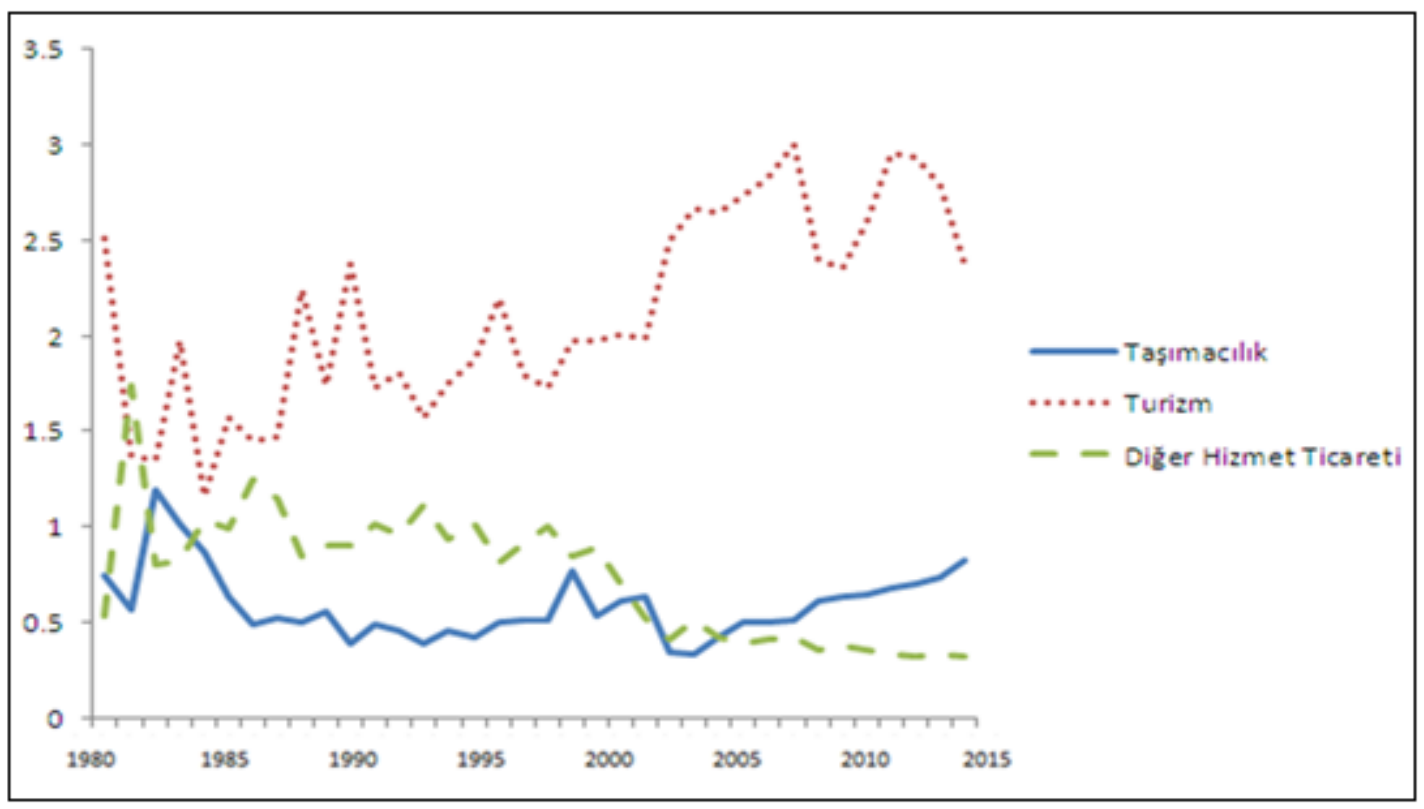

Şekil 2: AKÜ4 Endeksine Göre Hizmetler Sektöründe 1980-2015 Dönemi Değişim

Yukarıdaki şekil-2'de AKÜ4 endeksi sonuçlarına göre ülkemizin turizm alanında rekabet gücü yüksek, taşımacılık sektöründe artış trendinde ancak yine de düşük, diğer hizmetler sektöründe ise oldukça düşüktür. Bu nedenle özellikle sigortacılık, finansal hizmetler ve telekomünükasyon alanlarında hızlı bir değişim ve gelişmi gereklidir.

\section{5. Sonuç}

Uluslararası rekabet gücünün önemi, giderek küreselleşen dünyada her geçen gün artmaktadır. Bu kapsamda ülkelerin dış ticaretlerinde avantajlı ve dezavantajlı sektörleri belirlemeye yönelik pekçok uygulama geliştirilmiş ve halihazırda geliştirilmektedir. Literatürde rekabet gücü ölçümünde en sık kullanılan yöntemlerden birisi Balassa tarafından geliştirilen AKÜ yöntemidir. Bu yöntemin temeli Liesner tarafından geliştirilmiş olsa da Balassa'nın yönteme yaptığı katkılar nedeniyle daha çok Badassa endeksi olarak tanınmıştır. Diğer taraftan uygulamalı literatür daha çok mal ticareti üzerine yapılan araştırmalara yoğunlaşmış olsa da, bu çalışmada yaygın literatürden farklı olarak Türkiye'nin hizmet ticareti analize konu edilmiştir. Bu çerçevede analizlerde hizmet ticaretinde geleneksel hizmetler olarak taşımacılık ve turizm sektörü alınırken, modern hizmetler kalemi altında diğer hizmetler (bankacılık ve sigortacılık, telekomünikasyon, inşaatçılık vb.) ayrımına gidilmiş ve her üç hizmet sektörü için rekabet gücü analizleri yapılması yoluna gidilmiştir. Çalışmada AKÜ2 ve AKÜ4 yöntemleri kullanılmıştır. AKÜ2 Balassa'nın geliştirdiği en temel rekabet gücü analiz yöntemlerinden biridir. AKÜ4 ise ülkeler arası bir karşılaştırmadan ziyade ülkenin ihracat ve ithalat değerlerini kullanarak rekabet gücü analizi yapılmasına olanak tanımaktadır.

UNCTAD veri setinden elde edilen 1980-2015 dönemi için yıllık verileri ile yapılan ve AKÜ2 yönetiminin kullanıldığı çalışmada elde edilen analiz sonuçlarına göre turizm dışındaki alanlarda Türkiye'nin hizmet ticaretinde rekabet gücünün bulunmadığı tespit edilmiştir. Diğer taraftan yapılan AKÜ4 analizleri de benzer şekilde Türkiye'nin sadece turizm alanında rekabet gücüne sahip bulunduğunu göstermiştir. Gerek AKÜ2, gerekse AKÜ4 analiz sonuçları Türkiye'nin turizm dışındaki diğer hizmet sektörü alanlarında (sigortacılık, finansal hizmetler ve telekomünikasyon) rekabet gücünü artırıcı önlemler alınmasının gerekli olduğunu gözler önüne sermiştir. Türkiye'de bilişim sektörünün gelişiminin hem mal hem de hizmet sektörüne büyük katkı sağlayacağ1 düşünülmekte ve bu kapsamda üretimi artırıcı ve maliyetleri azaltıcı uygulamaların desteklenmesinin faydalı olacağ 1 düşünülmektedir. Yine sigortacılık ve finans sektörlerinde bireysel ve ticari katılım artırılarak sistemin geliştirilmesi, denetimi ve dışa açılmasını sağlayacak oluşumların desteklenmesi gerektiği söylenebilir.

Özellikle modern hizmetler olarak ifade edilen alanlarda yüksek katma değerin varlığ 1 ve dünya ekonomisinin hizmetler sektörüne doğru evrildiği gerçeği dikkate alınırsa, Türkiye ekonomisinin yüksek büyüme ve kalifiye istihdam yaratıcı bu alanlara kaymasını sağlayıcı politikaların ülke ekonomisinin gelişmişliğini besleyeceği gibi bu sektörlerdeki ilerlemeler de gelişmişliğin göstergesi olarak karşılanır. Modern hizmet kalemlerinden sigortacılık ve finansal boyutta gelişmelerin ülke ekonomisinde tasarruf ve döviz yetersizliğini elimine ederek yatırımlara ucuz maliyetli kaynak sağlayacağı ileri sürülebilir. Ayrıca üretilen malların pazara ulaştırılması sorunu olarak ifade edilen taşımacılıkta rekabet gücü yetersizliği, üretimiz pazara ulaştıramama sorununun yaşanmasına yol açma ya da yabancı nakliye şirketlerine bağımlı kılma sorunu yaratmasının yanı sıra bu sektörün sağlayacağı 
istihdam ve gelir etkilerinden mahrum kalma anlamı taşıdığı açıktır. Özetle geleceğin dünyasının katma değeri yüksek modern hizmetler ile kadimden gelen geleneksel hizmetlerden taşımacılık olduğu dikkate alınırsa, geleceğin dünyasında yer edinmek zorunluluğunda olan Türkiye ekonomisinde stratejik öneme sahip bu sektörleri geliştirici politika uygulamalarının gelişmeyi sağlama ve sürdürme adına elzem olduğu ileri sürülebilir.

\section{Kaynakça}

Balassa, B. (1965), “Trade Liberalization and 'Revealed Comparative' Advantage”, The Manchester School, 33 : 99-123.

Balassa, B. (1977), "Revealed Comparative Advantage Revisited: An Analysis of Relative Export Shares of the Industrial Countries (1953-1971)", The Manchester School of Economics and Social Studies, 45: 327-344.

Balassa, B. (1989), Comparative Advantage, Trade Policy and Economic Development, Harvester Wheatsheaf, New York, 42-44.

Emsen, Ö. S., M. K. Değer ve Ç. Karaköy (2006), "Liberalizasyon ve Ekonomik Büyüme İlişkileri: Göreceli Gelişmiş ve Az Gelişmiş Geçiş Ekonomileri Deneyimleri”, Manas Üniversitesi Sosyal Bilimler Dergisi, 16: 1-19. Emsen, Ö. S., Ekonomik Krizler ve Türkiye Deneyimi, Beta Yayınları, İstanbul, 2003.

Gerni, C., B. Kabadayı, Z. Ç. Yurttançıkmaz and Ö. S. Emsen (2013), "The Analysis of Competitiveness and Economic Growth: A Case Study of Transition Countries", International Business Research, 6 (5): 1-6.

Held, D., A. McGrew, D. Goldblatt and J. Perraton, Global Transformations: Politics, Economics and Culture, Cambridge: Polity Press, 1999.

Kaynak, M., Kalkınma İktisadı, Gazi Kitabevi, Ankara, 2005.

Kösekahyaoğlu, L. ve G. Özdamar (2009), “Avrupa Birliği’ne Üyelik Sürecinde Türk İmalat Sanayinin Rekabet Gücündeki Değişimler”, Süleyman Demirel Üniversitesi İktisadi ve İdari Bilimler Fakültesi Dergisi, 14 (1): 17 30.

Liesner, H. H. (1958), “The European Common Market and British Industry”, Economic Journal, 68: 302-316.

Pamuk, Ş., Türkiye’nin 200 Yıllık İktisadi Tarihi, Türkiye İş Bankası Kültür Yayınları, İstanbul, 2014.

Utkulu, U. ve H. İmer (2009), “Türk Tekstil ve Konfeksiyon Sektörünün Avrupa Birliği Tekstil ve Konfeksiyon Sektörü Karşısındaki Rekabet Gücünün Alt Sektörler Düzeyinde Ölçülmesi”, Rekabet Dergisi, 36: 3-43.

UNCTAD, UNCTADstat, 2017.

World Bank, World Development Indicators, 2017 


\title{
Dış Ticaretin Ölüm-Kalım Meselesi The Matter of Trade Survival
}

\author{
Ph.D. Candidate Erhan Pişkin (Akdeniz University, Turkey)
}

\begin{abstract}
Besedes and Prusa (2006a-b) reveal that international trade relationships are often very short-lived contrary to previously thoughts. In line with this unexpected result, this study provides a statistical description and empirical analysis of the duration of Turkish exports. Specifically, Kaplan-Meier survival function is used to estimate the survival of trade flows over time and also a regression analysis using discrete-time duration models which allow us to properly control for unobserved heterogeneity and the presence of many tied duration times is used to explore the impact of key variables on hazard rates of export flows. The detailed trade data reported by BACI-CEPII are employed to analyze Turkey's export to European Union countries from 1998 to 2013 according to the 6-digit Harmonized system. Results obtained from the analysis of descriptive statistics suggest that the duration of Turkey's export to European Union countries is short-lived. The median and mean duration of Turkey's exports are merely two years and 4.26, respectively. The Kaplan-Meier estimates of survival functions show that all survival curves are downward sloping with decreasing rate and about $40 \%$ of export relationships fails in the first year. The results of the discrete-time duration models indicate that product-market diversification, common language, total exports, initial value, importer GDP and lagged duration have a strong negative impact on the hazard rates of export flows. Whereas distance, common border and difference in GDP per capita have a positive effect on the hazard rates of export flows.
\end{abstract}

\section{Giriș}

Türkiye ekonomisinde ihracat teşvik politikalarına ve döviz kuru politikalarına dayanan ihracata dayalı büyüme stratejisinin benimsenmesiyle birlikte dış ticaretteki gelişmeler son derece önemli bir hal almıştır. Öyle ki, dış ticaretteki gelişmeler ekonominin birçok iç dinamiğini doğrudan ya da dolaylı olarak etkilemekte ve yön vermektedir. Bu nedenle de dış ticarette artışın devamlılığı için dinamik politikalar üretilebilmesi öncelikli bir hal almıştır. Söz konusu dış ticaret politikalarının en temel çıkış noktası dış ticarette başarılı olmak ve başarının kalıcılığını sağlamak üzerinedir. Besedes ve Prusa (2006a) çalışmasında gelişmekte olan ülkelerin dış ticarette başarısı için ticaret ilişkisinde sürekliliğin arttırılmasının son derece gerekli bir durum olduğu belirtilmektedir. Bu bağlamda, bu çalışma, Türkiye'nin Avrupa Birliği (AB) ülkelerine olan ihracatının sürekliliğini tespit etmek ve sürekliliğe etki eden unsurları belirlemeyi amaçlamaktadır. Böylelikle literatürdeki bu alanda mevcut olan açığa katkı sağlanacağı ve politika yapıcılara da önemli bulgular sunulacağı düşünülmektedir.

Besedes ve Prusa (2011) çalışmasında ihracat sürekliliğinin artmasının daha yüksek düzeyde ihracat büyümesiyle sonuçlanacağını ve aynı zamanda dış ticaretin derinleşmesi, istikrarı için de gerekli bir koşul olduğu belirtilmektedir. İhracat artışı her ne kadar dış ticaret sürekliliğiyle yakın ilişkili olmasına karşın literatürde Besedes ve Prusa (2006a) ve Besedes ve Prusa (2006b) çalışmalarına kadar ihmal edilen bir konu olarak karşımıza çıkmaktadır. Dış ticaret literatüründe yeni bir konu olmasına rağmen çalışmalardan elde edilen bulguların dış ticaret sürekliliğinin kısa olduğuna işaret etmesi, akademik çevrelerin dış ticaret sürekliliğinin altında yatan unsurlara yönelik hızla yoğunlaşmasını sağlamıştır. Ayrıca, dış ticaret sürekliliğinin araştırma konusu olması, aynı zamanda, istikrarlı bir dış ticaret patikası için yapısal bir analizi beraberinde getireceğini söylemek yanlış olmayacaktır.

Türkiye ekonomisi, 24 Ocak 1980 kararlarıyla dışa açık ekonomi olma yolunda hızlı adımlar atmış ve dış ticaretin yapısı süreç içinde hızla değişim göstermiştir. 1995 yılında Türkiye'nin de üyesi olduğu Dünya Ticaret Örgütü (DTÖ) kurulmuştur. 1 Ocak 1996 yılında yürürlüğe giren Gümrük Birliği (GB) anlaşması da yapısal dönüşüm süreci ile uyumlu olarak diş ticareti etkileyen önemli unsurlardan biri olmuştur. AB ile Türkiye arasında GB'nin yürürlüğe girmesiyle birlikte Ortak Gümrük Tarifesi'ne geçilmiş ve böylelikle anlaşma tarafları arasında serbest ticaret alanı sağlanırken, ithalatta miktar sınırlandırmaları ve tarifeler karşılıklı kaldırılmıştır. Buna ilaveten, Türkiye'nin ihracat yapısını önemli ölçüde etkileyen bir diğer unsur da GB anlaşması ile birlikte Türkiye'nin, AB'nin ticaret politikasına ve buna bağlı olarak üçüncü ülkeler ile yapılan ticaret anlaşmalarına dahil olmasıdır. Türkiye'nin yanı sıra birçok ülkenin de dış ticaret serbestisini uygulamaya geçmesi ve uluslararası ticaret anlaşmalarındaki hızlı artış, ülkelerin dış ticaret hacimlerinin kısa sürede ciddi boyutlara ulaşmasını sağlamıştır. 1996 yılında yaklaşık 23 milyar dolar düzeyinde gerçekleşen Türkiye'nin ihracat düzeyi 2016 yılında yaklaşık 145 milyar dolar düzeyine ulaşmıştır. 145 milyar dolar ihracatın da yaklaşık 70 milyar doları AB üyesi ülkelere yapılmıştır.

Bu çalışmanın amacı, Türkiye'nin AB üyesi 27 ülkeye olan ihracatının sürekliliğine ilişkin tanımlayıcı bir analiz ortaya koymak ve sürekliliğe etki eden unsurları tespit etmektir. Bu çerçevede, ilk olarak, tanımlayıcı istatistiklerle Türkiye ihracatının sürekliliği ortaya konulacak ve sağkalım (survival) fonksiyonu Kaplan Meier tahmin edicisi 
ile tespit edilecektir. Sonrasında, sürekliliğe etki eden unsurlar ekonometrik analizler çerçevesinde ortaya konulacaktır. Logit, Probit ve Cloglog tehlike modelleriyle ekonometrik analizler yapılacaktır.

\section{Literatür}

Literatürde birçok çalışma ihracata başlayan yeni firmalar ve ticareti yapılan yeni ürünler ile ilgilenmekte ve bu çerçevede dış ticaret yapısını ve artışını değerlendirmektedir. Oysaki bir ülkenin dış ticaret yapısının değerlendirilmesinde yeni başlayan ticaretin yanı sıra ticaretin bitmesi ya da ara vermesi, bir başka deyişle, diş ticaretin sürekliliği de oldukça önemli bir noktadır. Besedes ve Prusa (2006a) ve Besedes ve Prusa (2006b) çalışmalarıyla başlayan ilgili literatür hızla büyüyerek devam etmektedir. Bununla birlikte, literatürdeki yapılan çalışmalardaki ortak nokta, ampirik çalışmalardan elde edilen sonuçların oldukça kısa dış ticaret sürekliliğine işaret etmesi ve bu sonucun da mevcut ticaret teorileri tarafindan açıklamada yetersiz kalmasıdır (Hess ve Persson, 2012; Hess ve Persson, 2011; Shao ve Xu, 2011, Nitsch, 2009).

Besedes ve Prusa (2006a-b) çalışmalarından elde edilen sonuçların ilgili teoriden beklenenin aksine işaret etmesi ve elde edilen bulguların çok yönlülüğü akademik çevrelerin bu konu üzerinde hızla yoğunlaşmasını sağlamıştır. Besedes ve Prusa (2006a) çalışmasında 1972-2001 dönemine ilişkin olarak Kaplan-Meier sağkalım fonksiyonu ile yaptığı analizde ABD'nin dış ticaret sürekliliğinin 2-4 yıl medyana sahip olduğu ve ayrıca dış ticaretin \%67'sinin de sadece 1 yıl sürekliliğe sahip olduğu tespit edilmiştir. Besedes ve Prusa (2006b) çalışmasında da aynı veri seti ile Cox orantılı tehlike modeliyle (Cox Proportional Hazard Model) hem teorik hem de ampirik olarak beklenmeyen bu sonuca neden olan unsurlar değerlendirilmiştir. Bu çalışmada, Rauch (1999) çalışmasında önerilen, ürün gruplarının (Homojen mallar, heterojen mallar, fiyat bazlı mallar) sınıflandırılması bakımından değerlendirilme yapılmıştır. Cox orantılı tehlike modeli ile yapılan analizler sonucunda homojen mallara nazaran ayrıştırılmış mallarda daha düşük tehlike oranının (hazard rate) olduğu ve ayrıca her ürün grubunda da daha büyük miktarda sağlanan başlangıç ticaret değerleri ile dış ticaret sürekliliği arasında pozitif bir ilişki olduğu ortaya konulmuştur.

Nitsch (2009) çalışmasında Almanya'nın dış ticaretinin sürekliliği analiz edilmiş ve literatür ile uyumlu olarak dış ticaret sürekliliğinin oldukça kısa olduğu tespit edilmiştir. 1995-2005 döneminde ithalatı yapılan 8 fasıllı ürün kategorilerinin oluşturulduğu veri setiyle, Besedes ve Prusa (2006b) çalışmasıyla benzer şekilde, Cox orantılı tehlike modeli ile uygulamalar yapılmıştır. Analiz sonuçları, ithalatın sürekliliğinin kısa olmasının yanı sıra ihracat yapılan ülkenin kültürel ve ekonomik özellikleri, ithal edilen ürünün özellikleri ve piyasa yapısının dış ticaret sürekliliği üzerinde anlamlı derecede belirleyici olduğuna işaret etmektedir. Brenton vd. (2009) çalışmasında diğer çalışmalardan farklı olarak kesik zamanlı (discrete time) tamamlayıcı log-log modeli ile değişkenlerin tehlike oranı üzerindeki etkisi araştırılmıştır. 1985-2005 dönemine ilişkin 5 fasıllı ürün kategorilerinin oluşturduğu veri seti ile 82 ihracatçı ülkenin 53 ithalatçı ülkeye olan ticareti, ülkelerin gelir durumları (yüksek gelir, orta gelir, düşük gelir) bakımından gruplandırılarak, değerlendirilmiştir. Çalışmada yapılan analizler çerçevesinde ihracatçının hem piyasa hem de ürün anlamında yaparak öğrenme etkisinin (learning-by-doing) tehlike oranını azaltıcı etkiye sahip olduğu sonucu elde edilmiştir.

Hess ve Persson (2011) AB-15 ülkelerinin ithalatının sürekliliğinin değerlendirildiği çalışmasında yöntem tartışmasına da katkı sunmaktadır. Cox modelinin dış ticaret sürekliliğinin araştırılmasında uygun olmayan özellikleri olduğunu belirtmekte ve kesikli zamanlı probit, logit ve Clog-log modellerini önermektedir. 1962-2006 dönemine ait AB-15 ülkelerinin 140 ülkeden yaptığı ithalatın 1 yıl medyan ile oldukça kısa süreli olduğu ve ayrıca söz konusu ticaret ilişkisinin \%60'nın sadece 1 yıl devam ettiği tespit edilmiştir.

Shao ve Xu (2011) çalışması da Çin ihracatının sürekliliğini ve sürekliliğine etki eden unsurları araştırmaktadır. Bu anlamda, dünyanın en önemli ticaret hacmine sahip Çin'in dış ticaret sürekliliğini değerlendiren ilk çalışma olarak karşımıza çıkmaktadır. 1995-2007 dönemine ilişkin 6 fasıllı ürün kategorilerinin oluşturduğu veri setinin kullanıldığ farklı özelliklere sahip modeller (Cox orantılı tehlike modeli, Weibull ve Exponential üstsel modelleri) ile analizler yapılarak dış ticaret sürekliliğine etki eden unsurlar ortaya konulmuştur. Sağkalım fonksiyonunun Kaplan-Meier kestirimi sonuçları Çin ihracatının kısa süreli olduğuna işaret etmektedir (Medyan 2.84, ortalama da 2 yıl). Bununla birlikte, ihracat yapılan ülkenin milli gelirinin ve kişi başına milli gelirin ihracatın sürekliliği üzerinde pozitif bir etkiye sahip olduğu, ihracat yapılan uzak ülkeler ile denize kıyısı olmayan ülkelerin ise dış ticaret sürekliliğine olan etkisinin negatif olduğu tespit edilmiştir.

Ampirik çalışmalardan elde edilen ortak sonuçlar, ülke ekonomilerine ilişkin dış ticaret sürekliliğinin genel olarak kısa olduğuna işaret etmektedir. Bu durum ticaret teorileri tarafından direkt olarak açıklanamamaktadır. Üretim fonksiyonunun ve ticarete konu olan ürünlerin homojen olduğu geleneksel ticaret teorisi, diş ticarete konu olan ürünlerde sağlanacak miktar artışı ile ihracat artışını ilişkilendirmektedir. Ticareti yapılan ürünlerin miktarındaki artış üretim faktörlerinin artışı ile sağlanmakta ve üretim faktörlerinin artışı da dış ticaret artışını beraberinde getirmektedir. Bu durum geleneksel ticaret teorisi açısından üretim faktörlerinin yeterli olması dış ticarette sonsuz sürekliliği beraberinde getireceği sonucunu ortaya koymaktadır (Türkcan ve Pişkin, 2014, s.87). Ticaret teorilerinin, dinamik uluslararası ticaret yapısıyla birlikte, farklılaşmasına neden olmuş ve uluslararası 
ticaretin değerlendirilmesinde yeni ticaret teorileri ortaya atılmıştır. Ancak bu teoriler de tam olarak dış ticaret sürekliliğinin bu denli kısa olmasını bir temele oturtamamaktadır. Bu durum literatürdeki bazı çalışmalarda eksik bilginin olması nedeniyle firma kararlarının etkilenmesine ve ayrıca belirsizliklerin etkili olmasına bağlanmaktadır (Shao ve Xu., 2011, s.4).

\section{Tanımlayıcı Analiz}

\subsection{Veri Seti ve Açıklayııı Değişkenler}

Bu çalışmada, Türkiye'nin 1998-2013 döneminde ihracat yaptığı AB üyesi 27 ülkeye ait 5.113 ürün çeşidinin oluşturduğu kapsamlı bir veri seti kullanılmaktadır. CEPII'ye (Centre d'Etudes Prospectives et d'Informations Internationales) ait bu $B A C I$ veri seti toplam 2.208.816 gözlemden oluşmaktadır. CEPII tarafindan düzenlenen BACI veri seti, Birleşmiş Milletler COMTRADE veri tabanından alınan dış ticaret veri setinin düzenlenmesiyle elde edilmektedir. Bu nedenle de özellikle bu veri seti seçilerek veri seti kaynaklı sorunlar en aza indirgenmeye çalışılmıştır. COMTRADE veri tabanında ticarete konu olan ürünler birkaç şekilde sınıflandırılmaktadır. Bu çalışmada altı fasıllı uyumlaştırılmış mal tanım ve kod sistemi ile oluşturulan veri seti kullanılmaktadır.

Bir ülkenin dış ticaretine ilişkin süreklilik analizinin gerçekleşebilmesi için öncelikle o ülkeye ilişkin ticaret değerlerinin tanımlayıcı istatistiklerle ifade edilmesi gerekmektedir. Böylelikle hem ekonometrik analize geçmeden önce ticaret veri setinin düzenlenmesi ve ekonometrik analizlere dahil olacak değişkenlerin oluşturulması sağlanacak hem de ülkenin dış ticaret sürekliliğine ilişkin istatistiklerin sayısal hesaplamaları yapılarak detaylandırılacaktır. Yöntemin ilk aşamasında Türkiye'nin ürün bazlı ihracat değerleri ayrıştırılarak ürün, ülke ve yıl bazında ticaret dönemleri (trade spell) hesaplanmaktadır. Ticaret dönemlerine ilişkin hesaplanan bu değerler bu çalışmanın temel noktası olmaktadır. Öyle ki, bütün sayısal hesaplamalar ve ekonometrik analizler bu temel üzerinden yola çıkılarak yapılmaktadır. Öncelikle ticaret dönemi ve ticaret ilişkisi (trade relationships) kavramlarının sayısal hesaplamalarının nasıl yapıldığı belirlenmelidir. Buna göre, bu çalışmada, ticaret ilişkisi Türkiye'nin ürün bazında ihracat yaptığı ülkeye olan ticaretini göstermektedir. Her bir ülke-ürün ihracatı bir tane ticaret ilişkisi oluşturmaktadır. Ticaret dönemi ise bu ticaret ilişkisinin yıl bazında bitmesi ve aynı ürün ve ülke bazında tekrar başlamasıyla oluşan ticaret ilişkisini yeni bir ticaret ilişkisi olarak hesaplanması neticesinde elde edilmektedir. Buna da çoklu hizmet dönemi (multiple spells of service) olmaktadır ve ticaret dönemlerinin ticaret ilişkisinden farkını ortaya koymaktadır.

Hesaplanan ticaret dönemlerine göre bağımlı değişken oluşturulmaktadır. Bu bağımlı değişken de ticaret bitiyorsa 1, devam ediyorsa 0 değerini almaktadır. Türkiye'nin AB üyesi ülkelere olan ihracatının sürekliliğine etki eden unsurların tespiti için, bu çalışmada, literatürde kullanılan açıklayıcı değişkenlere yer verilmiştir. Buna göre, CEPII'nin veri tabanından elde edilen çekim değişkenleri (uzaklık, ortak dil ve ortak sınır) analizlere dahil edilmiştir. Dünya Bankası'nın veri tabanından alınan ithalatçı ülkeye ilişkin Gayri Safi Yurtiçi Hasıla (GSYİH) ve kişi başına GSYİH farkı da ekonometrik analize dahil edilmiştir. BACI'dan alınan dış ticaret veri setinden hesaplamalar yapılarak elde edilen ihracat başlangıç değeri, toplam ihracat değeri, ihraç edilen ürün sayısı, ihracat yapılan ülke sayısı ve gecikmeli süreklilik de ekonometrik analizlere dahil edilerek, Türkiye ihracatının sürekliliğine etkisi araştırılmıştır.

\subsection{Tanımlayıcı İstatistikler ve Kaplan-Meier Sağkalım Analizi}

Tablo 1'de Türkiye'nin AB üyesi ülkelere olan ihracatının sürekliliğine ilişkin sayısal hesaplamalara dayanan temel istatistiksel analiz sonuçları bulunmaktadır. Buna göre, Türkiye'nin AB üyesi 27 ülkeye 16 yıl boyunca toplam 704.083 ihracat akımı bulunmaktadır. Bu ihracat akımını 4.964 ürün çeşidi ve 86.106 ticaret ilişkisi oluşturmaktadır. Tablodan görüldügü üzere toplam 165.254 ticaret dönemi gerçekleşmiştir. Ticaret ilişkisi ile ticaret dönemi arasındaki fark çoklu hizmet dönemi nedeniyle oluşmuştur. Ancak ticaret dönemi medyanının 2, ortalamasının da 4,26 olduğu görülmektedir. Tanımlayıcı istatistiklerden elde edilen sonuçlar, literatür ile paralel olarak, Türkiye'nin AB üyesi ülkelere yaptığı ihracatın sürekliliğinin kısa olduğuna işaret etmektedir. Buna ilaveten, medyanın 2 olması, ticaret ilişkisinin neredeyse yarısının iki yıl içinde bittiğini göstermektedir.

Tanımlayıcı analiz sonuçlarının bulunduğu Tablo l'de beş farklı veri seti tanımlaması yapılmıştır. Birinci veri seti, ticaret akımlarının olduğu ve olmadığı, ürün çeşidi ve ülke kombinasyonunu içeren genel veri seti olmaktadır. $\mathrm{Bu}$ veri seti ürün çeşidi, ülke ve yıl çarpımına eşittir. İkinci veri seti ise sadece gerçekleşen ticaret akımlarının gözlemlerinin dahil olduğu temel (benchmark) veri setidir. Ticaret dönemleri başta olmak üzere tanımlayıcı istatistiklere ilişkin sayısal hesaplamalar bu veri seti ile yapılmıştır. Üçüncü veri seti ise üç farklı tanımlama ile oluşturulmuştur. İlk veri seti (veri seti ${ }^{3 a}$ ) sol sansürlü gözlemler çıkarılarak oluşturulmuştur. Bu çalışmada 19982013 dönemi kullanılmıştır. Bu nedenle de ticaret ilişkisinin 1998 yılında başladığı öngörülmektedir. Ancak 1998 yılından önce başlayan ticaretin 1998 yılında başlamış gibi almak ticaret dönemlerinin yanlış hesaplanmasına ve dolayısıyla da birçok değişkenin yanlış hesaplanmasına, sonuçların yanlış olmasına neden olacaktır. Benzer şekilde, sağ sansürlü gözlemler de ticaret akımlarının 2013 yılında bitmemesine rağmen çalışmanın dönem sınırı nedeniyle ticaret akımlarının 2013 yılında bittiğini varsayarak oluşan gözlemlerdir. Veri seti ${ }^{3 b}$ de sağ sansürlü gözlemlerin çıkarıldığı veri seti olmaktadır. Son veri seti ise hem sol sansürlü hem de sağ sansürlü gözlemlerin çıkarıldığı veri seti olmaktadır. Nitsch (2009) çalışmasında sansürlü gözlemlerin modellemelere dahil edilmesinin, 
model kestiriminde fazla tahmine neden olacağını bildirmekte ve sansürlü veri setinin ekonometrik modellemelerde kullanılması gerektiğini vurgulamaktadır. Hess ve Persson (2012) çalışmasında da, benzer şekilde, sol sansürlü veri setinin kullanılması gerektiği, sağ sansürlü gözlemlerin ise çıkarılmasına gerek olmadığını, analiz sonuçlarına herhangi bir etki yapmayacağ seti $^{3 a}$ ) ile ekonometrik modeller yapılmış ve sansürlü gözlemler nedeniyle oluşabilecek problemlerden kaçınılmıştır.

\begin{tabular}{|c|c|c|c|c|c|c|c|c|}
\hline HS6 & $\begin{array}{c}\text { Gözlem } \\
\text { sayısı }\end{array}$ & $\begin{array}{l}\text { Ülke } \\
\text { Say1s1 }\end{array}$ & $\begin{array}{l}\text { Ürün } \\
\text { Çeşidi }\end{array}$ & Dönem & $\begin{array}{l}\text { Ticaret } \\
\text { İlişkisi }\end{array}$ & $\begin{array}{l}\text { Ticaret } \\
\text { Dönemi }\end{array}$ & $\begin{array}{c}\text { Ticaret } \\
\text { Dönemi } \\
\text { Ortalama }\end{array}$ & $\begin{array}{c}\text { Ticaret } \\
\text { Dönemi } \\
\text { Medyan }\end{array}$ \\
\hline Veri Seti ${ }^{1}$ & 2.208 .816 & 27 & 5.113 & 1998-2013 & 86.106 & 165.254 & 3,1788 & 0 \\
\hline Veri Seti ${ }^{2}$ & 704.083 & 27 & 4.964 & 1998-2013 & 86.106 & 165.254 & 4,2606 & 2 \\
\hline Veri Seti $^{3 a}$ & 406.059 & 27 & 4.936 & 1999-2013 & 69.001 & 133.287 & 3,0465 & 1 \\
\hline Veri Seti ${ }^{3 b}$ & 246.581 & 27 & 4.934 & 1998-2012 & 62.910 & 114.486 & 2,1538 & 1 \\
\hline Veri Seti ${ }^{3 c}$ & 192.749 & 27 & 4.897 & 1999-2012 & 56.358 & 97.781 & 1,9712 & 1 \\
\hline İlk dönem & 455.059 & 27 & 4.964 & $1998-2013$ & 86.106 & 86.106 & 5,2848 & 2 \\
\hline Tek dönem & 352.336 & 27 & 4.925 & $1998-2013$ & 40.303 & 40.303 & 8,7421 & 10 \\
\hline $\begin{array}{c}\text { Başlangıç } \\
\text { değeri } \leq \\
10.000 \$\end{array}$ & 285.833 & 27 & 4.858 & $1998-2013$ & 54.738 & 89.125 & 3,2071 & 1 \\
\hline $\begin{array}{c}\text { Başlangıç } \\
\text { değeri }> \\
10.000 \$\end{array}$ & 418.250 & 27 & 4.756 & $1998-2013$ & 55.024 & 76.129 & 5,4939 & 2 \\
\hline $\begin{array}{c}\text { Başlangıç } \\
\text { değeri }> \\
100.000 \$\end{array}$ & 151.593 & 27 & 3.640 & $1998-2013$ & 17.065 & 19.310 & 7,8504 & 5 \\
\hline $\begin{array}{c}\text { Başlangıç } \\
\text { değeri }> \\
1.000 .000 \$\end{array}$ & 35.271 & 27 & 1.241 & $1998-2013$ & 3.329 & 3.635 & 9,7031 & 14 \\
\hline $\begin{array}{c}1 \text { y1l } \\
\text { düzeltme }\end{array}$ & 759.368 & 27 & 4.964 & $1998-2013$ & 86.106 & 126.403 & 6,0075 & 3 \\
\hline $\begin{array}{c}2 \text { y1l } \\
\text { düzeltme }\end{array}$ & 814.770 & 27 & 4.964 & $1998-2013$ & 86.106 & 109.880 & 7,4150 & 5 \\
\hline $\begin{array}{c}3 \text { yıl } \\
\text { düzeltme }\end{array}$ & 867.045 & 27 & 4.964 & $1998-2013$ & 86.106 & 100.937 & 8,5899 & 8 \\
\hline \multicolumn{9}{|c|}{$\begin{array}{l}\text { Notlar: } \\
\text { 1-Veri setine sıfır (zero) ticaret değerleri dahil } \\
\text { 2-Veri setine sıfır ticaret değerleri dahil değil } \\
\text { 3a-Başlangıç ticaret dönemi (trade spell) değerlerinin veri setinden çıkarıldı̆̆ düzenlenmiş veri seti (left-censored) } \\
\text { 3b- Son ticaret dönemi (trade spell) değerlerinin veri setinden çıkarıldı̆̆ düzenlenmiş veri seti (right-censored) } \\
\text { 3c-Başlangı̨ ve son dönem ticaret değerlerinin veri setinden çıkarıldığı düzenlenmiş veri seti (left-right cencored) }\end{array}$} \\
\hline
\end{tabular}

Tablo 1. Tanımlayıcı Analiz Sonuçları Kaynak: Yazarın Kendi Hesaplamalarına Dayanmaktadır.

Temel veri setimizden elde edilen sonuçların kontrolü bağlamında bu veri setinden elde edilen kontrol veri setleriyle de sayısal hesaplamalar yapılmış ve temel istatistikler sunulmuştur. Hess ve Persson (2011) çalışmasında ticaret dönemi hesaplamalarının sınanmasının önemi vurgulanmaktadır. Buna göre, ticaret dönemlerinin birkaç yıl boşluklu olanları hesaplama hatası olabileceği gibi ticaret akımlarının yanlış raporlanması neticesinde de ortaya çıkabilmektedir. Bu nedenle 1 yıl, 2 yıl ve 3 yıl aralıklı ticaret dönemleri tamamlanarak tanımlayıcı istatistikler tekrar hesaplanmıştır. Ayrıca, sadece tek dönemli ticaret dönemlerini ve ilk dönemli ticaret dönemlerini alarak yeni bir veri seti ile tekrar hesaplamalar yapılmış ve ana sonuçların doğruluğu sınanmıştır. Ticaret dönemlerine ilişkin yeniden hesaplamalar neticesinde temel veri seti sonuçlarıyla benzer eğilimler gösteren analiz sonuçları elde edilmiştir. Öyle ki, sadece ilk ticaret dönemlerinin dahil olduğu veri setinin gözlem sayısı önemli derecede düşmesine rağmen ticaret dönemi ortalaması yaklaşık olarak 5 yıl ve medyanı 2 olarak elde edilmiş ve bu değerlerin de temel veri setinden elde edilen sonuçlara yakın değerler olduğu görülmektedir.

İhracat başlangıç değeri, ihracatın sürekliliği için önemli bir gösterge olarak karşımıza çıkmaktadır (Gullstrand ve Persson, 2015, s.33). Nitsch (2009), Hess ve Persson (2011) çalışmalarına paralel olarak bu çalışmada da ihracat başlangıç değerlerine göre ürünler ayrıştırılıp, her bir kategori için ihracatın sürekliliği tespit edilmiştir. Buna göre, literatür ile benzer şekilde, başlangıç değeri yüksek olan ürünlerin ihracatının daha yüksek sürekliliğe sahip olduğu görülmektedir. Öyle ki, 1.000.000\$ üstünde başlangıç değerine sahip ticaret dönemlerinin ortalama sürekliliği neredeyse 10 yıl düzeyinde olduğu tespit edilmiştir.

Kaplan-Meier sağkalım fonksiyonuna ilişskin sonuçlar Şekil 1 ve Şekil 2'de sunulmaktadır. Elde edilen sonuçlar çerçevesinde, bütün grafiklerin aşağı yönlü bir eğilim gösterdiği görülmektedir. Bu durum ticaret dönemi arttıkça 
ihracat sürekliliğinin devam etme olasılığının azaldığı anlamına gelmektedir. Şekil 1'deki sol grafikte üç farklı ticaret döneminin olduğu sonuçlar raporlanmaktadır. Bütün ticaret dönemlerine ilişkin sonuçlar ile sadece ilk dönemli ticaretin olduğu sonuçlar benzer süreklilik eğilimi gösterdiği tespit edilmiştir. İlk yıl ticaretin yaklaşık \%40'ı bitmekte, bir başka deyişle, ihracat sürekliliğinin 1 yıldan fazla olma olasılığının \%60 civarında olduğudur. Ayrıca başlayan ticaretin pek azı dönem sonuna kadar devam etmektedir. Şekil 1'deki sağ grafikte de ihracat başlangıç değerlerinin ihracat sürekliliğine etkisi görülmektedir. Rauch ve Watson (2003) çalışmasında belirtildiği üzere, ihracat başlangıç değeri ile ihracat sürekliliği arasında pozitif bir ilişki olması gerekmektedir. Buna göre, açıkça görülmektedir ki, ihracat başlangıç değeri arttıkça ihracatın sürekliliğinin artma olasılığını da ciddi şekilde arttırmaktadır.

Sonuç olarak, Türkiye'nin AB üyesi 27 ülkeye yaptığı ihracatın sürekliliğinin, literatürdeki ampirik çalışmaların sonuçlarına paralel olarak, oldukça kısa olduğu tespit edilmiştir. Alternatif veri setleriyle de sayısal analizler yapılarak detaylı temel istatistikler elde edilmiş ve sonuçların benzer olduğu görülmüştür.
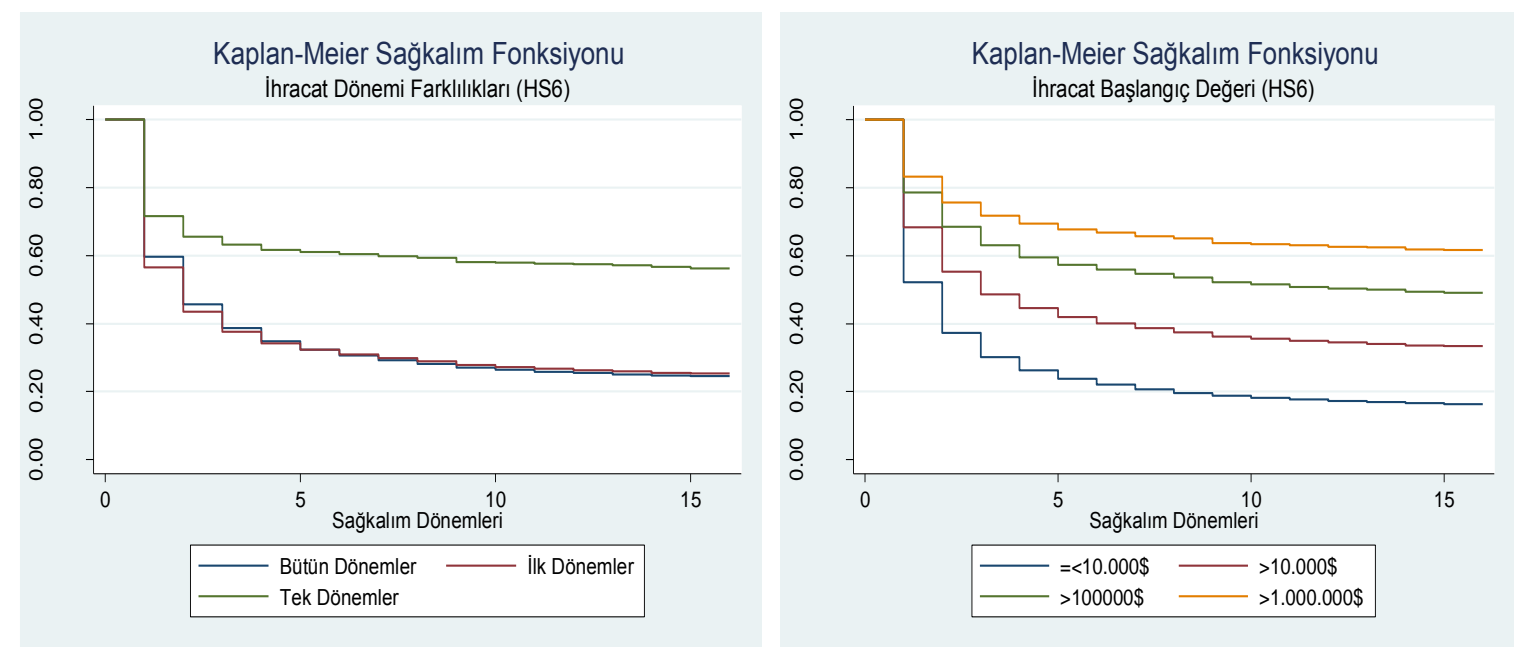

Şekil 1. Kaplan-Meier Sağkalım Analizi Sonuçları 1 Kaynak: Yazarın Kendi Hesaplamalarına Dayanmaktadır.

\section{Ekonometrik Analiz}

Bu çalışmada kesikli zamanlı Logit, Probit ve Cloglog modelleriyle kestirim yapılmaktadır. Literatürde dış ticaret sürekliliği üzerine yöntem tartışmasının olduğu görülmektedir. Hess ve Persson (2012) çalışmasında bu yöntem tartışmasına büyük ölçüde açıklık getirilmekte ve literatürde sıkça kullanılan sürekli zamanlı Cox orantılı tehlike modelinin varsayımları nedeniyle uygun olmadığ 1 ve yanlı sonuçlar verebileceği belirtilmektedir. Ticaret akımları her ne kadar günlük gerçekleşse de gözlemlerin yıllık olarak raporlanması sürekli zamanlı Cox modelinin uygun olmamasına neden olmaktadır. Ayrıca, dış ticaret sürekliliğine ilişkin olarak analizlere konu olan veri setinin boyutu oldukça büyük olmaktadır. Bu nedenle de Cox modeli, literatürde de sıkça bahsedilen gözlemlenemeyen heterojenlik problemiyle mücadele etmekte başarısız olmaktadır. Bu da parametrelerde ya da kestirilmiş süreklilik fonksiyonunda yanlılığa neden olmaktadır (Hess ve Persson, 2012, s.1086).

Bu çalışmada Hess ve Persson (2012) çalışmasında bahsedilen ve tavsiye edilen kesikli zamanlı tehlike modelleriyle Türkiye'nin AB üyesi 27 ülkeye olan ihracatının sürekliliğine etki eden unsurlar ortaya konulmaktadır. Hess ve Persson (2012) çalışmasına benzer şekilde bu çalışmada da aynı notasyonlar ile yöntem detaylı bir şekilde açıklanmaktadır.

Kesikli zamanlı modeller, belirlenmiş bir zaman aralığında belirli bir ticaret ilişkisinin son bulabilme koşullu olasılığı açısından belirlenmektedir. $T_{i}$ sürekli olsun ve belirli bir ticaret ilişkisinin sağkalım zamanıyla ölçülen negatif olmayan rassal bir değişken olarak tanımlansın. Süreklilik analizinin temel noktası, belirlenmiş bir zaman aralığında belirli bir ticaret ilişkisinin son bulma olasılığının oluşturulmasıdır. O halde; $\left[t_{k}, t_{k+1}\right), k=$ $1,2,3, \ldots, k^{\max }$ ve $t_{1}=0$; ticaret ilişkisinin sağkalım koşulu, belirli bir zaman aralığının başlamasına ve regresyon modeline dahil olan açıklayıcı değişkenlere bağlı olmaktadır. Bu koşullu olasılık kesikli zamanlı tehlike oranı (discrete-time hazard rate) olarak adlandırılmakta ve Denklem (1)'de formüle edilmektedir:

$$
h_{i k}=P\left(T_{i}<t_{k+1} \mid T_{i} \geq t_{k}, x_{i k}\right)=F\left(x_{i k} \beta+\gamma_{k}\right)
$$

$x_{i k}$, muhtemel değişken zamanlı kovaryantları göstermekte, $\beta$ da kestirilmiş katsayılara ilişkin bir vektörüdür. $\gamma_{k}$ belirlenmiş zaman aralığının bir fonksiyonudur ve bu zaman aralığı boyunca tehlike oranı değişebilmektedir. $F\left(\right.$. ) de bütün $i$ ve $k$ için $0 \leq h_{i k} \leq 1$ koşulunu garanti eden uygun dağılımlı bir fonksiyonu temsil etmektedir. Bu çalışmada, $i$, ürün ülke bazında ayrıştırılmış ticaret dönemlerini temsil etmektedir. Uygulamada tehlikenin (hazard) 
altında yatan temel dayanak bilinemediğinden, $\gamma_{k}$ regresyon modeline dahil edilmiş her bir ticaret dönemi sürekliliğine ilişkin zaman aralığını belirleyen kukla değişken grubunu göstermektedir.

Kesikli zamanlı orantılı tehlike modeli Denklem (2)'deki Log-Likelihood fonksiyonunun maksimum yaparak kestirilebilmektedir.

$$
\operatorname{Ln} L=\sum_{i=1}^{n} \sum_{k=1}^{k_{i}}\left[\gamma_{i k} \ln \left(h_{i k}\right)+\left(1-\gamma_{i k}\right) \ln \left(1-h_{i k}\right)\right]
$$

$k_{i}$ bağlantı zamanı dönemlerine işaret etmekte ve $i$ alt indisi, bu değerin ticaret dönemlerine göre değişebileceğini göstermektedir. $\gamma_{i k}$ ikili değişken olup, eğer $k$ zaman aralığı boyunca $i$ ticaret dönemi bitiyorsa 1 değerini, devam ediyorsa 0 değerini almaktadır. Bu nedenle de kesikli zamanlı tehlike modelleri, bir dizi ikili bağımlı değişken modeli olarak görülebilmektedir. Bu nedenle de ikili bağımlı değişkenler için Logit, Probit, Cloglog modelleri gibi standart modeller ile uygulamalar yapılarak kesikli zamanlı tehlike modellerinin kestirimi uygun ve mümkün olabilmektedir (Hess ve Persson, 2012, s. 1089-1090; Türkcan, 2016, s.27-28).

Tablo 2'de ekonometrik modellerin kestirimlerine ilişkin sonuçlar bulunmaktadır. Üç farklı modelin uygulanması hem değişkenlerden elde edilen değerlerin kıyaslanmasına hem de tehlike modelleri arasındaki kestirim farklarının elde edilmesini sağlamaktadır. Bununla birlikte, farklı standart modellerin uygulanması, bu çalışmanın sonuçlarını daha da güvenilir yapmaktadır. Ekonometrik analizler, sol sansürlü gözlemler çıkarılarak yapılmıştır. Ayrıca literatürde önemle bahsedildiği üzere, gözlemlenemeyen heterojenlik probleminin üstesinden gelebilmek için bütün tehlike modelleri rassal etkiler ile modellenmiştir. Bunun için de tehlike modellerine ithalatçı ülke-ürün kategorisinde rassal etkiler dahil edilmiştir. Ekonometrik uygulamalar veri seti $3^{\text {a }}$ ile yapılmıştır. Ekonometrik modellemelere ilişkin uygulamalar STATA 14.2 ekonometri programıyla gerçekleştirilmiştir.

Tehlike modellerinin sonuçlarına göre, daha önce de bahsedildiği üzere, Log Likelihood değerinin maksimum olduğu model en uygun tehlike modeli seçimi olacaktır (Hess ve Persson, 2011, s.678). Buna göre, Logit modeli Türkiye'nin AB üyesi ülkelere olan ihracatının sürekliliğine etki eden unsurları ortaya koyan en doğru model olmaktadır. Bu nedenle de Logit modelinin sonuçları doğruya en fazla yakınsayan kestirimlerdir.

Tehlike modellerine ilişkin sonuçlar literatürdeki ampirik çalışmalardan elde edilen sonuçlar ile büyük ölçüde benzer eğilim göstermektedir (Türkcan, 2016; Hess ve Persson, 2012; Shao ve Xu, 2011). Çekim değişkenleri diş ticaret nedeniyle oluşan maliyetlerin ilişkisini göstermesi bakımından önemlidir. Uzaklık değişkeninin pozitif ilişkili, ortak dil ve ortak sınırın da maliyetleri düşürmesi nedeniyle negatif olması beklenmektedir. Elde edilen sonuçlar ortak sınır dışında bu beklentiyi doğrulamaktadır. Ortak sınırın da veri setine dahil edilen ülkelerin kısıtlı olması nedeniyle böyle bir sonuca neden olduğu düşünülmektedir. Bu çerçevede uzaklık arttıkça maliyetlerin yükselmesi nedeniyle tehlike oranının da artması, bir başka deyişle, ihracatın sürekliliğinin tehlikeye girmesi, sonlanabileceği sonucunu ortaya çıkmaktadır. İthalatçı ülkeye ilişkin GSYİH, ihracata olan talep ile ilişkili olmaktadır (Hess ve Persson, 2011, s.680). GSYİH ile tehlike oranı arasında negatif bir ilişki beklenmektedir. Buna göre, ithalatçı ülkenin GSYİH'si anlamlı ve negatif bir katsayı olmakta ve tehlike oranını azaltacağına işaret etmektedir. Kişi başına GSYİH farkına ilişkin katsayı da Türkiye'nin ihracat yaptığı ülke ile arasındaki ekonomik kalkınma farkına işaret etmekte ve bu durumun ticaretin sürekliliğine olan etkisini göstermektedir. Bu açıklayıcı değişken, Türkcan (2016) ve Hess ve Persson (2012) çalışmalarının ekonometrik analizlerine de dahil edilmiştir. Kişi başına GSYİH farkının düşük olmasının sonucu olarak iki ülke arasında benzer talep yapılarının öngörüleceğini ve benzer nitelikli ürünlerin ticaretinin de daha yoğun yapılacağı bildirilmektedir (Türkcan, 2016, s.31). Bu çerçevede kişi başına GSYİH farkına ilişkin katsayının pozitif olması, tehlike oranını arttırması beklenmektedir. Elde edilen sonuçlar, açıklayıcı değişkenin tehlike oranını pozitif ve anlamlı bir şekilde etkilediğini göstermektedir.

İhracat başlangıç değerine ilişkin katsayının negatif ve anlamlı olduğu tespit edilmiştir. İhracat başlangıç değerinin yüksek olması, Rauch ve Watson (2003) çalışmasında ticaret ilişkisinde daha fazla güvene ve daha az belirsizliğe işaret ettiği belirtilmektedir. Bu çerçevede, ihracat başlangıç değerinin yüksek olması ihracatın sürekliliğine pozitif katkı sağlayacağı, tehlike oranını da azaltıcı etkide olacağı anlamına gelmektedir. Elde edilen bulgular ihracat başlangıç değeri ile tehlike oranı arasında istatistiksel olarak anlamlı negatif bir ilişki olduğunu göstermektedir. Gecikmeli süreklilik ve toplam ihracat değeri geçmiş ticaret ilişkisi nedeniyle oluşan tecrübeye ve yaparak öğrenme (learning by doing) olgusunu temsil etmektedir. Bu anlamda her iki açıklayıcı değişkenin de istatistiksel olarak anlamlı ve negatif olması geçmiş ticaret ilişkisinden elde edilen bilginin ihracat sürekliliğinin artmasına neden olduğu açıkça görülmektedir. Bu anlamda Brenton vd. (2009) çalışmasıyla benzer bir sonuç olmaktadir. 


\begin{tabular}{|c|c|c|c|}
\hline & Probit & Logit & Cloglog \\
\hline \multirow[t]{2}{*}{ Log uzaklık } & 0.0817 & 0.1520 & 0.1280 \\
\hline & $(0.000)$ & $(0.000)$ & $(0.000)$ \\
\hline \multirow[t]{2}{*}{ Ortak dil } & -0.1576 & -0.2843 & -0.2381 \\
\hline & $(0.000)$ & $(0.000)$ & $(0.000)$ \\
\hline \multirow[t]{2}{*}{ Ortak sınır } & 0.0854 & 0.1431 & 0.1035 \\
\hline & $(0.000)$ & $(0.000)$ & $(0.000)$ \\
\hline \multirow[t]{2}{*}{ Log GSYİH (ithalatçı) } & -0.0250 & -0.0498 & -0.0466 \\
\hline & $(0.000)$ & $(0.000)$ & $(0.000)$ \\
\hline \multirow[t]{2}{*}{ Log fark GSYİH-kişi başına } & 0.0323 & 0.0561 & 0.0427 \\
\hline & $(0.000)$ & $(0.000)$ & $(0.000)$ \\
\hline \multirow[t]{2}{*}{ Log ihracat başlangıç değeri } & -0.0686 & -0.1201 & -0.0950 \\
\hline & $(0.000)$ & $(0.000)$ & $(0.000)$ \\
\hline \multirow[t]{2}{*}{ Gecikmeli Süreklilik } & -0.0263 & -0.0478 & -0.0543 \\
\hline & $(0.000)$ & $(0.000)$ & $(0.000)$ \\
\hline \multirow[t]{2}{*}{ Log toplam ihracat değeri } & -0.0640 & -0.1004 & -0.0613 \\
\hline & $(0.000)$ & $(0.000)$ & $(0.000)$ \\
\hline \multirow[t]{2}{*}{ Log ihraç edilen ürün sayısı } & -0.4668 & -0.7261 & -0.4474 \\
\hline & $(0.000)$ & $(0.000)$ & $(0.000)$ \\
\hline \multirow[t]{2}{*}{ İhracat yapılan ülke sayısı } & -0.0573 & -0.0990 & -0.0758 \\
\hline & $(0.000)$ & $(0.000)$ & $(0.000)$ \\
\hline Süreklilik kukla değişkeni & Var & Var & Var \\
\hline Y1l kukla değişkeni & Var & Var & Var \\
\hline Dönem sayısı kukla değişkeni & Var & Var & Var \\
\hline Gözlem sayıs1 & 406059 & 406059 & 406059 \\
\hline İthalatçı ülke & 27 & 27 & 27 \\
\hline Ürün çeşidi & 4936 & 4936 & 4936 \\
\hline Dönem Sayısı (spells) & 133287 & 133287 & 133287 \\
\hline İhracat İlişkisi & 69001 & 69001 & 69001 \\
\hline Ortalama & 3.0465 & 3.0465 & 3.0465 \\
\hline Medyan & 1 & 1 & 1 \\
\hline \multirow[t]{2}{*}{ Rho } & 0.2448 & 0.1984 & 0.1634 \\
\hline & $(0.000)$ & $(0.000)$ & $(0.000)$ \\
\hline Log Likelihood & -182104 & -182064 & -182182 \\
\hline \\
\hline \multicolumn{4}{|c|}{ Parantez içinde P değerleri bulunmaktadır. } \\
\hline \multicolumn{4}{|c|}{ Ekonometrik analizler ithalatç-ürün için rassal etkiler modelini içermektedir. } \\
\hline \multicolumn{4}{|c|}{ Rho değeri gözlenemeyen faktörler sebebiyle oluşan hata varyansını göstermektedir. } \\
\hline \multirow{2}{*}{\multicolumn{4}{|c|}{$\begin{array}{l}\text { Gözlem sayısı ekonometrik modellemeye dahil olan veri seti büyüklügüunü göstermektedir. } \\
\text { İthalatçı ülke ekonometrik modellemeye dahil olan ihracat yapılan ülke sayısını göstermektedir. }\end{array}$}} \\
\hline & & & \\
\hline \multirow{2}{*}{\multicolumn{4}{|c|}{$\begin{array}{l}\text { Ürün çeşidi ekonometrik modellemeye dahil olan ihracata konu olan ürün sayısını göstermektedir. } \\
\text { Dönem sayısı ithalatçı-ürün için ihracat sürekliliğini göstermektedir. }\end{array}$}} \\
\hline \multirow{2}{*}{\multicolumn{3}{|c|}{$\begin{array}{l}\text { Dönem sayısı ithalatçı-ürün için ihracat sürekliliğini göstermektedir. } \\
\text { İhracat ilişkisi ithalaçı-ürün bazında ticaret ilişkisi sayısını göstermektedir. }\end{array}$}} & \\
\hline & & $\begin{array}{l}\text { dir. } \\
\text { almistır. }\end{array}$ & \\
\hline
\end{tabular}

\section{Tablo2. Ekonometrik Analiz Sonuçları}

İhracat yapılan ürün sayısına ve ülke sayısına ilişkin açıklayıcı değişkenler de anlamlı ve negatif olarak tehlike modellerinin kestirimi neticesinde elde edilen bulgular olarak karşımıza çıkmaktadır. Türkcan ve Pişkin (2014) çalışmasında ihracatta ülke ve ürün bazında çeşitliliğin artmasının, yeni ticaret ilişkisinin ve ticarete konu yeni ürünlerin ihracata başlanmasının, bir başka deyişle, hem ürün çeşitliliğinin artmasının hem de ihracat yapılan ülke sayısının artmasının ihracatın istikrarı anlamında pozitif bir gelişme olacağı vurgulanmaktadır. Bu durum ticaret ilişkisinin de daha istikrarlı ve sürekliliğinin daha uzun olacağı anlamına gelecektir. Elde edilen sonuçlar, Hess ve Persson (2011) çalışmasıyla da paralel bir şekilde, hem ihraç edilen ürün sayısındaki artışın hem de ihracat yapılan ülke sayısındaki artışın tehlike oranını azaltıcı bir etkiye sahip olduğuna işaret etmektedir.

Ekonometrik analizlerin duyarlılığının test edilmesi için alternatif veri setleriyle de modellemeler yapılmıştır. Alternatif analiz sonuçları Tablo 3'de sunulmaktadır. Ekonometrik modellemeler ilk dönemli ticaret, tek dönemli ticaret, ticaret dönemlerinde bir yıl düzeltme ve sabit etkiler için tekrarlanmış ve raporlanmıştır. Her bir modelde de daha önce en uygun kestirim modeli olarak tespit edilen Logit modeli kullanılmıştır.

Tablo 3'den elde edilen sonuçlar, ana veri seti için elde edilen sonuçları destekler niteliktedir. Açıklayıcı değişkenler büyük ölçüde aynı eğilimi ve ilişki yönünü vermektedir. Rassal etkiler modelinin neden tercih edildiği de açıkça Tablo 3'de görülmektedir. Çekim değişkenlerine ilişkin açıklayıcı değişkenler sabit etkiler modelinde atılmakta ve değişkenlerin kestirimleri yapılamamaktadır. Sonuç olarak, farklı veri seti tanımlamalarına göre 
yapılan tehlike modellerine ilişkin duyarlılık analizleri (robustness check), ana veri setine ilişkin sonuçlar ile benzer bir çerçeve sunmakta ve sonuçların sağlamlığına işaret etmektedir.

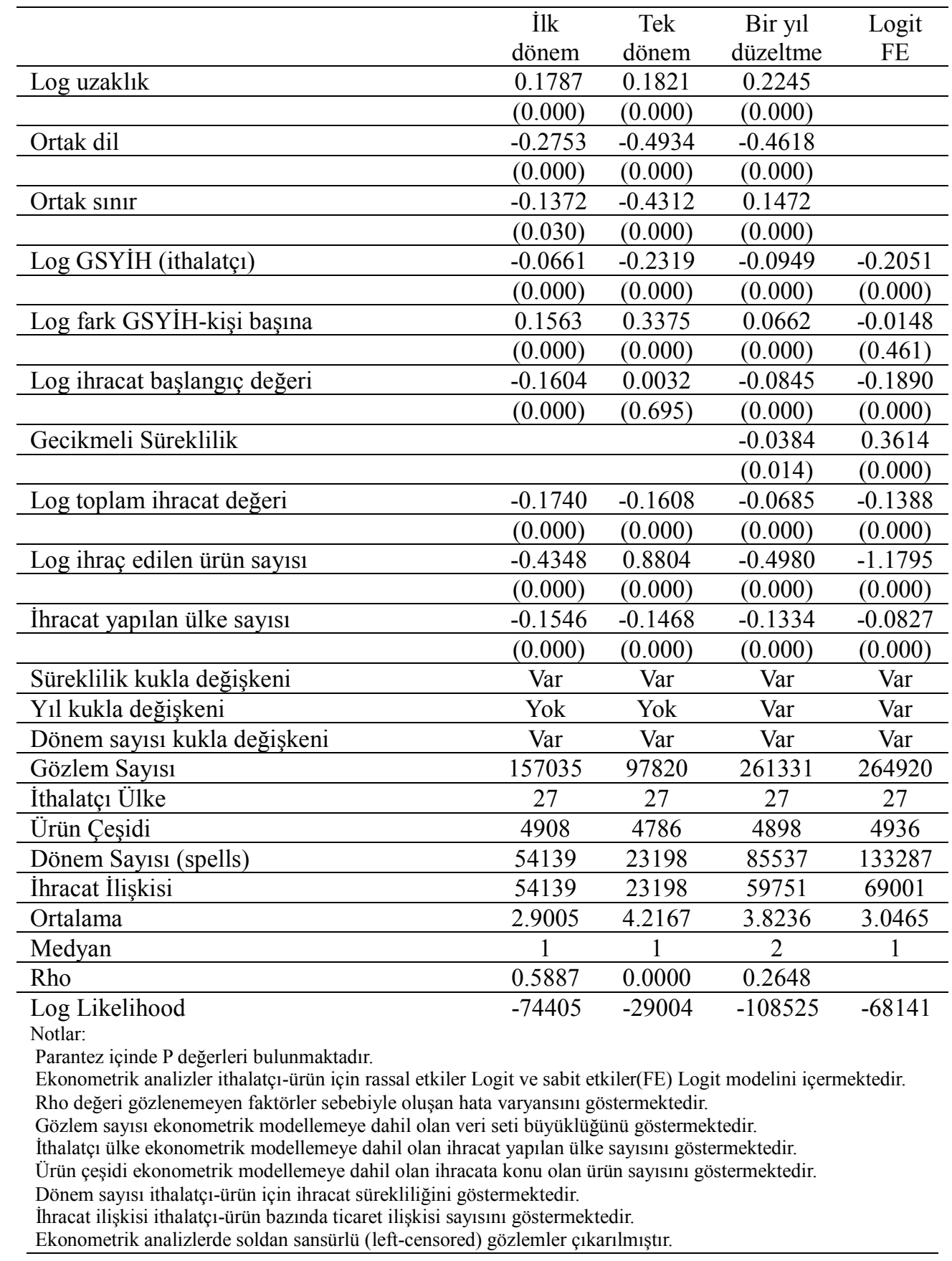

Tablo 3. Alternatif Analiz Sonuçları (Robustness Check)

\section{Sonuç}

Bu çalışmada, Türkiye'nin 1998-2013 döneminde AB üyesi 27 ülkeye gerçekleşen ihracatının sürekliliği tespit edilmiş ve sürekliliğe etki eden unsurlar ortaya konulmuştur. Türkiye ihracatının neredeyse yarısının AB üyesi ülkelere gerçekleştiği gözönüne alındığında, bu çalışmadan elde edilen bulguların, Türkiye'nin ihracat patikası için de önemli bilgiler sunacağını söylemek yanlış olmayacaktır.

Tanımlayıcı istatistiklere ve Kaplan-Meier sağkalım fonksiyonuna ilişkin analizler, Türkiye'nin AB üyesi ülkelere olan ihracatının sürekliliğinin kısa olduğuna işaret etmektedir. Bu sonuç her ne kadar teorik çerçevede beklenmeyen bir sonuç olsa da, literatürde yapılan ampirik çalışmalar ile paralel bir sonuç olarak karşımıza çıkmaktadır. $\mathrm{Bu}$ anlamda politika yapıcıların ihracatın sürekliliğini arttırıcı önlemler alması ve bu çerçevede destekleyici politikalar üretmesi, ihracatın istikrarı ve dolayısıyla da ihracatın artışına önemli bir katkı sunacağı düşünülmektedir. 
Ekonometrik analizler tehlike modelleriyle yapılmıştır. Logit, Probit ve Clog-log tehlike modelleri olmak üzere üç farklı model ile kestirimlerin yapılması yöntem tartışmasına da başlangıç niteliğinde bir giriş olmaktadır. Tehlike modellerinin kestiriminden elde edilen Log Likelihood değerleri en uygun modelin Logit modelin olduğuna işaret etmektedir. Logit model sonuçları, ürün-ülke farklılaştırılmasının, dil çekim değişkeninin, toplam ihracat ve gecikmeli sürekliliğin ve ayrıca ithalatçı ülke GSYİH ile başlangıç ihracat değerlerinin tehlike oranını azaltıcı, uzaklık ve ortak sınır çekim değişkenlerinin, kişi başına GSYİH farkının tehlike oranını arttırıcı bir etkide bulunduğu, bu çalışmanın sonuçlarından elde edilen diğer bulgular olarak karşımıza çıkmaktadır.

Bu çalışma Akdeniz Üniversitesi Bilimsel Araştırma Projeleri Koordinasyon Birimi tarafindan desteklenmiştir. Proje Numarasi: SDK-2015-312. (This work was supported by the Scientific Research Projects Coordination Unit of Akdeniz University. Project Number: SDK-2015-312).

\section{Kaynakça}

- $\quad$ Besedes, T., Prusa, T.J., 2006a. "Ins, Outs, and the Duration of Trade", Canadian Journal of Economics, 39(1), s.266-295.

- $\quad$ Besedes, T., Prusa, T.J., 2006b. "Product Differentiation and Duration of U.S. Import Trade", Journal of International Economics, 70(2), s.339-358.

- $\quad$ Brenton, P., Saborowski, C., Uexküll, E., 2009. "What Explains the Low Survival Rate of Developing Country Export Flows", World Bank Policy Research Working Paper, 4951, World Bank, Washington, DC.

- Gullstrand, j., Persson, M., 2015. "How to combine high sunk costs of exporting and low export survival", Review of World Economics, 151(1), s.23-51.

- Hess, W., Persson, M., 2011. "Exploring the Duration of EU Imports", Review of World Economics, 147(4), s.665-692.

- Hess, W., Persson, M., 2012. "The duration of trade revisited", Empirical Economics, 43(3), s.1083-1107.

- Nitsch, V., 2009. "Die Another Day: Duration in German Import Trade", Review of World Economics, 145(1), s.133-154

- $\quad$ Rauch, J.E., 1999. "Networks versus Markets in International Trade", Journal of International Economics, 48(1), s. 7-35.

- $\quad$ Rauch, J., E., Watson, J., 2003. "Starting Small in an Unfamiliar Environment", International Journal of Industrial Organization, 21(7), 1021-1042.

- Shao, J., Xu, K., 2011. "Exploring Chinese Export Duration", Asia Pasific Trade Seminers, University of Hawaii, s.1-14.

- $\quad$ Türkcan, K., Pişkin, E., 2014. "Türkiye'nin İhracat Artışında Yaygın ve Yoğun Ticaretin Rolü", İktisat Isletme ve Finans, 336(29), 83-116.

- $\quad$ Türkcan, K., 2016. "On the Role of Vertical Differentiation in Enhancing Survival of Export Flows: Evidence from a Developing Country", Munich Personal Repec Archive, 71023. 


\title{
Avrasya ve Türkiye'nin Seçilmiş Ekonomik Göstergeler İtibariyle Özet Bir Değerlendirilmesi
}

\section{A Summary of Eurasia and Turkey as Selected Economic Indicators}

\author{
Asst. Prof. Dr. Hakkı Çiftçi (Çukurova University, Turkey)
}

\begin{abstract}
Turkey aiming to be the production base of Eurasia for medium and high technology products; Abbreviated terms of SME support, sectoral policies, infrastructure studies, incentive schemes, or other harmonization of various areas such as regional differences. It plays an important role in the sales and marketing of medium and high-tech sectors, such as the number of SMEs, population structure, geographical and strategic location as well as innovation, technology and value economy. Increasing their share in production and exports, pushing molds come out of the branded industry concept and within the framework of a new industrial structural transformation; The global economy has quickly pushed forward the swift, flexible and practical industry in terms of improving the structure and texture of the Eurasian countries and Turkey; The need to increase the competitiveness of the new investment should increase the efficiency of the company, facilitate the financing of the financial statements, deepen financial markets and increase the financing instruments should gain importance and priority by targeting selective policies for our economy.
\end{abstract}

\section{Giriş}

Orta ve yüksek teknolojili ürünler için Avrasya'nın üretim üssü olmayı hedefleyen Türkiye; teknoloji, Ar-Ge, yenilikçilik, tasarım, markalaşma, kümelenme, bölgesel farklılıklar ve işletme ölçeği gibi alanlardaki eylemleriyle; Avrasya ülkelerinin ekonomilerinin öncelikle rekabet gücünü ve verimliliği artırmayı karşılıklı bağ ve bağımlılıkla KOBİ destekleri, sektörel politikalar, altyapı çalışmaları, teşvik programları veya bölgesel farklılıklar gibi çeşitli alanların uyumla, çevreye duyarlı ve sosyal sorumluluk sahibi bir sanayiye dönüşümü gelişmiş sanayi altyapısı, sanayi üretimindeki çeşitliliği, KOBİ sayısı, nüfus yapısı, coğrafi ve stratejik konum gibi hem karşılıklı bağ ve bağımlılığın olduğu hem de yenilikçiliğin, teknolojinin ve değer ekonomisinin ağırlık kazandığı orta ve yüksek teknolojili sektörlerin üretim ve ihracat içindeki paylarını artırılarak basma kalıp ezbere dayalı sanayi anlayışından çıkıp yeni bir sanayi yapısal dönüşüm anlayışı çerçevesinde; küresel ekonomiye hızla entegre olabilen sanayi de hız, esnek ve pratikliğin öne çıktığı, Avrasya ülkeleri ve Türkiye'nin sanayi yapısının ve dokusunun iyileştirilmesi açısından; rekabet gücünün artırılmasında gerek yeni yatırım gerekse işletmelerin verimliliğini artıracak dönüşümün sağlanması için yatırım finansmanına erişimin kolaylaştırılması, finansal piyasaların derinleşmesi ve finansman araçlarının çeşitlendirilmesi ekonomimiz için seçici politikalar la atılım hedeflenerek önem ve öncellik kazanmalıdır. Bununla birlikte sanayileşme içindeki ülkeler, kentleşme, sanayi yeri seçimi ve çevre sorunları bakımından büyük avantajlara sahip bulunmaktadırlar. Zira geçen yüzyılda sanayileşen ülkelerin tecrübelerinden yararlanmak ve onların düştüğü hataları tekrarlamamak gibi bir avantajları vardır. Bu ülkelerde 'doğayı bozmadan' gerçekleştirilecek bir sanayileşme hareketi insanları daha mutlu yarınlara kavuşturabilecektir (İlkin 1983).

Sanayin üçüncü girdisini oluşturan işgücü alanındaki gelişmeler ve değişmeler de makroekonomik yapı ile yakından ilgilidir. Yüksek enflasyon, işçi ücretleri konusunda ciddi pazarlıkları da beraberinde getirmiştir. Bütün bu gelişmeler sonucunda ekonomi bugün düşük enflasyon, genişleyen bir dünya ticareti ve artan yatırım karlılıkları gibi olumlu göstergelere sahip olsa da, maliyet ve verimlilik konularında hala aşılması gereken sorunlarla karşılaşmaktadır. Makroekonomik istikrar, para politikası, vergi politikalarında kararlı ve kesin önlemler alınmalı, dış ticarette, serbest bölgelerde, yabancı sermaye yatırımlarında, KİT'lerde özelleştirmede, AR-GE'de, Devlet yardımlarında, Üniversitelerde, Teknolojide, KOBİ'ler de sanayi ön planda tutulmalıdır. Hızla değişen tasarım teknolojileri ve metotları 1şı̆̆ında yeniden yapılandırılmalıdır (Ishac, 1997). Emek üzerindeki vergi yükünün azaltılması, bütün kesimleri içeren hakkaniyetli bir vergi politikası, kaynakların üretime yönlendirilmesi, imalat sanayide yoğunlaşmanın yüksekliğinin giderilmesi, sonucu, kayıt dışı ekonomi azalacak, belgeli alışveriş yaygınlaşacak, vergi gelirleri artacak, yatırımlar başlayacak, yabancı sermaye girişi artacak, güven ortamı sağlanacak ve böylece ekonomi canlanacaktır (Kızılot 2001). Ülke içinde karşılaştırılabilir maliyetle edinilmesi mümkün olmayan yatırım ve ara mallarının ithali, daha gelişmiş ülkelerden fikir ve teknoloji transferi (Uluslararası Teknoloji Transfer Süreci; yayma/oluşturma, iyileştirme/geliştirme, özümseme/uyarlama, edinme/benimseme aşamalardan geçmektedir (Demir 1986).

Yatırım ve iş ortamının iyileştirilmesi, Uluslararası Ticaret ve Yatırımlarla Türk ve bazı Avrasya ekonomileri arasındaki KOBİ'lerin pazarlama ve ihracat kapasitesini artırmaya yönelik destekler, yenilikçi fikirler ve Ar-Ge'ye dayalı, katma değeri yüksek, markalı ürün ve hizmetlerin üretim ve pazarlama süreçleri, beceri ve insan Kaynağı, KOBİ'lerin finansmana erişimi, nanoteknoloji, biyoteknoloji alanlarında kapasite oluşturma çalışmalarına ağırlık 
teknolojik gelişimi, altyapı, çevre, bölgesel Kalkınma konuları göz önünde tutularak politika alanlarıyla, sanayide teknolojik dönüşüm gerçekleştirilmesi, sanayi altyapısı güçlendirilmesi, KOBİ’lerin finansmana erişim imkanları artırılması, sanayide yeşil üretim özendirilmesi, yatırım ve iş ortamının iyileştirilmesi, Türkiye'nin uluslararası ticaret ve yatırım kapasitesini artırmaya yönelik çalışmalar yürütülmesi, sanayide ihtiyaç duyulan nitelikli insan gücünün istihdam edilmesine yönelik faaliyetler yürütülmesi, Bölgesel gelişmeye katkı sağlamak üzere sanayi politikaları geliştirilmesi açısından Avrasya Birliği'nin Türkiye'ye Yansımalarıyla, Orta Asya piyasası Türkiye'nin yeni güç kaynağı kazanması için büyük ekonomik ve ticari imkanlar vaat etmektedir. Bu çalışmada bazı Avrasya ekonomilerindeki ekonomik özgürlükler ekonomik yapısı değerlendirilerek Avrasya Ar-Ge ve yenilik projeleri yapan Türkiye'de yerleşik kuruluşlara sağlanacak destekle, ülkemizdeki teknik yeterliliğin ve bilgi birikiminin artırılması, firma düzeyinde katma değer yaratan kuruluşların Araştırma-Geliştirme (Ar-Ge) çalışmalarını teşvik etmek ve bu yolla Türk sanayisinin Ar-Ge yeteneğinin yükseltilmesine katkıda bulunmak üzere Avrasya ekonomi kuruluşların uluslararası teknoloji birikimine erişiminin ve teknoloji transferinin sağlanması, edinilen teknolojik bilgi ve deneyimin kuruluş bünyesinde içselleştirilerek, özgün teknolojilerin geliştirilmesinde ivme kazandırıcı ve yönlendirici bir etken olması ve kuruluşların Avrasya ve Türk pazarlarda yer almasına katkı sağlamasıdır (TUBITAK,2017).

\section{Avrasya Ülkeleri}

Azerbaycan; Dünya Ekonomik Forumu 2015-2016 verilerine göre Dünya geliri içerisinde \%0,15'lik katk1 sağlayan Azerbaycan 9,4 milyon nüfusuyla; 54 milyar dolarlık GSYİH ile 5739 dolar kişi başına düşen geliriyle, global rekabet edilebilirlik endeksinde 1-7 arasında ölçeklendirilen skalada 4,5 ile 40.sırada yer almaktadır. Bunun yanı sıra, teknolojiyi hazır olma durumunda, 4,3 ile 57.sırada; pazar payında 67.sırada 3,9 ile, sanayinin temelini oluşturan yenilikçilik de ise 3,3 ile 61.sırada yer almaktadır (WEF, 2017). 2017 Ekonomik Özgürlükler Endeksinde Azerbaycan Dünya sıralamasında 68.sırada 63,6 puanla bulunmaktadır.

\begin{tabular}{|c|c|c|c|}
\hline Hukuka Uygunluk & Kamu Büyüklüğü & Etkinlik Düzenlemeleri & Açık Piyasa \\
\hline Mülkiyet Hakları & Hükümet harcamaları & İş Özgürlükleri & Ticari Özgürlük \\
50,5 & 57,5 & 71,5 & 74,4 \\
\hline Etkin Hükümet & Vergi Yükü & İstihdam Özgürlüğü & Yatırım Özgürlüğü \\
37,6 & 87,7 & 75,0 & 55,0 \\
\hline Adalet etkinlikleri & Mali Yapı & Parasal Özgürlük & Finansal Özgürlük \\
33,0 & 97,4 & 73,6 & 50,0 \\
\hline
\end{tabular}

Tablo 1. Azerbaycan Ülkesi Kaynak: Economic Freedom 2017

Azerbaycan sosyo-ekonomik yapı ve dokudaki gelişme de Azerbaycan yıllık enflasyonu \% 12; Bu oran 2016 yılı Ocak ayına kıyasla \%11,9, aynı zamanda gıda ürünlerinin fiyatları \%14,5, gıda dışı ürünlerin fiyatları \%12,3, hizmet sektöründeki fiyatlar ise $\% 8$ oranında artmıştır. Türkiye-Azerbaycan ticaret hacmimiz 2016 y1lı sonu itibariyle 1,6 milyar dolar; DEIK 2023'e kadar 15 milyar dolarlık ticaret hacmi hedefi koymuştur". Türkiye ve Azerbaycan'ın birlikte üçüncü pazarlara da açılabileceğini beyan etmiş; Türkiye'nin Avrupa ve Ortadoğu, Azerbaycan'ın ise Rusya ve Orta Asya pazarlarına erişimi dikkate alındığında dışa açılmayı iki ülke açısından yararlı hale getirip bölgemizin ötesine taşıma potansiyelimiz oldukça yüksektir. İkili ilişkilerimizde TürkiyeAzerbaycan arasında mevcut tarımsal ticaretimizde yaş sebze ve meyve, işlenmiş gıda ile hayvansal ürünler öne çıkıyor. Bununla beraber; gübre, ilaç, sulama, seracılık, organik üretim, fuarcılık ve tarım makine ekipmanları gibi diğer alanlarda da iş birliği potansiyelimiz mevcut (DEIK,2017).

Gürcistan; Dünya Ekonomik Forumu 2015-2016 verilerine göre Dünya geliri içerisinde \%0,03'lik katk1 sağlayan Gürcistan 3,7 milyon nüfusuyla; 14 milyar dolarlık GSYİH ile 9629 dolar kişi başına düşen geliriyle, global rekabet edilebilirlik endeksinde 1-7 arasında ölçeklendirilen skalada 4,2 ile 66.sırada yer almaktadır. Bunun yanı sıra, teknolojiyi hazır olma durumunda, 3,8 ile 72.sırada; pazar payında 99.sırada 3 ile, sanayinin temelini oluşturan yenilikçilik de ise 2,7 ile 123.sırada yer almaktadır (WEF, 2017a). 2017 Ekonomik Özgürlükler Endeksinde Gürcistan, Dünya sıralamasında 13.sırada 76 puanla bulunmaktadır.

\begin{tabular}{|c|c|c|c|}
\hline Hukuka Uygunluk & Kamu Büyüklüğü & Etkinlik Düzenlemeleri & Açık Piyasa \\
\hline Mülkiyet Hakları & Hükümet Harcamaları & İş Özgürlükleri & Ticari Özgürlük \\
55,1 & 74,4 & 87,2 & 88,6 \\
\hline Etkin Hükümet & Vergi Yükü & İstihdam Özgürlüğü & Yatırım Özgürlüğü \\
65,0 & 87,3 & 75,9 & 80,0 \\
\hline Adalet Etkinlikleri & Mali Yapı & Parasal Özgürlük & Finansal Özgürlük \\
66,5 & 93,5 & 78,2 & 60,0 \\
\hline
\end{tabular}

Tablo 2. Gürcistan Ülkesi Kaynak: Economic Freedom 2017 
Ocak 2017 yılında 2016 yılının ayini dönemine göre ihracat \% 45 ithalat ise \% 15 arttı. 2017 Ocak ay ihracatı 177 milyon Dolar ithalatı ise 474 milyon Dolardır. Ocak 2017 toplam Dış Ticaret hacmi geçen senenin aynı dönemine nazaran \%22 artışla 651 milyon Dolar oldu. Türkiye, Azerbaycan ve Gürcistan’ın, Güney Kafkasya'nın jeostratejik konumu ile doğunun batıya, batının da doğuya açılan kapısı olduğu ekonomik ve ticari ilişkilerin güçlenmesi için her adımın atılmaya hazır olduğu Türkiye'nin Azerbaycan ve Gürcistan ile ilişkilerinin diğer ülkelerden daha hızlı geliştiğini, ancak ticaret hacminin daha da ileri taşınması gerektiğini de sözlerine ekledi. Dünya Bankası 2017 İş Yapma Kolaylığı sıralamasında Gürcistan’ın 23’üncü sırada yeralmaktadır. Türkiye, Azerbaycan ve Gürcistan'dan, Üç ülke arasındaki ticaret hacminin 20 milyar ABD Dolarına çıkarılmasının istendiğini ve bu hedefin gelecek dönemde yakalanacağını Ar-Ge ve inovasyon altyapımız, Gürcistan'ın zengin doğal kaynakları ve Azerbaycan'ın güçlü enerji altyapısını bir araya getirilmelidir(DEİK,2017). Gürcistan'ın 2016'da toplam diş ticareti: 9,852 milyar Dolar ithalat, 2,114 Milyar Dolar İhracat olmak üzere toplam 11,966 milyar Dolardır. Türkiye-Gürcistan Dış Ticareti: (Ekonomi Bakanlığı-2016) Türkiye’nin Gürcistan'a ihracatı: 2015 yılına göre \%9,8 artarak 1.352 milyar ABD Doları, Türkiye'nin Gürcistan'dan ithalatı ise 2015 yılına göre \%9,3 azalarak 174 milyon ABD Doları olarak gerçekleşmiştir. Türkiye ile Gürcistan'ın Toplam dış ticaret hacmi 2016 yılında toplam 1,526 milyar Dolardır. Türkiye ile Gürcistan'ın arasındaki dış ticaret dengesi Türkiye lehine 1,178 milyar Dolardır. Türkiye'nin Gürcistan'a İhraç ettiği başlıca ürünler: Plastik hortum, boru ve bağlantı elemanları, demir ve çelik, hijyenik havlu, yıkama, temizleme müstahzarları, Türkiye'nin Gürcistan'dan ithal ettiği başlıca ürünler: Et, sakatat, deniz ürünleri, tekstil, demir, balık ve deniz memelilerinin katı ve sıvı yağlarıdır.

Kazakistan; Dünya Ekonomik Forumu 2015-2016 verilerine göre Dünya geliri içerisinde \%0,38'lik katk1 sağlayan Kazakistan 17,7 milyon nüfusuyla; 173,2 milyon dolarlık GSYİH ile 9795 dolar kişi başına düşen geliriyle, global rekabet edilebilirlik endeksinde 1-7 arasında ölçeklendirilen skalada 4,5 ile 42.sırada yer almaktadır. Bunun yanı sıra, teknolojiyi hazır olma durumunda, 4,2 ile 61.sırada; pazar payında 46.sırada 4,5 ile, sanayinin temelini oluşturan yenilikçilik de ise 3,3 ile 72.sırada yer almaktadır. 2017 Ekonomik Özgürlükler Endeksinde Kazakistan, dünya sıralamasında; 69 puanla, 42.sırada bulunmaktadır.

\begin{tabular}{|c|c|c|c|}
\hline Hukuka Uygunluk & Kamu Büyüklüğü & Etkinlik Düzenlemeleri & Açık Piyasa \\
\hline Mülkiyet Hakları & Hükümet Harcamaları & İş Özgürlükleri & Ticari Özgürlük \\
56,1 & 85,7 & 74,5 & 78,5 \\
\hline Etkin Hükümet & Vergi Yükü & İstihdam Özgürlüğü & Yatırım Özgürlüğü \\
38,0 & 93,3 & 82,5 & 40,0 \\
\hline Adalet Etkinlikleri & Mali Yap1 & Parasal Özgürlük & Finansal Özgürlük \\
56,5 & 98,9 & 73,9 & 50,0 \\
\hline
\end{tabular}

Tablo 3. Kazakistan Ülkesi Kaynak: Economic Freedom 2017 b

Kazakistan Merkez Bankası verilerinde 2016 yılı ihracatı 37,2 milyar dolar ithalatı da 27,8 milyar Dolara gerilemiştir., 2017 yılında \%2,5 büyümesinin tahmin edildiği IMF tarafından yapılan açıklamada, ülkenin 2017 yılında \%0,6 büyümesinin tahmin edildiği petrol fiyatlarında yaşanabilecek düşüş ve Kazakistan'ın iki büyük komşusu olan Rusya ve Çin'den kaynaklı talep daralmasının ülke ekonomisi için en büyük iki dezavantaj olduğu ifade edilmiştir (Kazinform, 2017).

Kırgızistan; 2017 Ekonomik Özgürlükler Endeksinde Kırgızistan Dünya sıralamasında; 61,1 puanla, 89.sırada bulunmaktadır. Kırgızistan Ekonomisi 2016 Yılında \%3,8 Oranında Büyümesi, 2016 yılında Kırgızistan'ın Gayrisafi Yurtiçi Hasılası \%3,8 oranında artarak 6,5 milyar dolar şeklinde gerçekleşmiş olmasının yanısıra, Nominal GSYH'nin yapısının \%39,2sini oranla imalat, \%17,5ini sanayi üretimi, \%8,5ini inşaat, \%13,2sini tarım sektörünün üretimi oluşturmuştur.

\begin{tabular}{|c|c|c|c|}
\hline Hukuka Uygunluk & Kamu Büyüklüğü & Etkinlik Düzenlemeleri & Açık Piyasa \\
\hline Mülkiyet Hakları & Hükümet Harcamaları & İş Özgürlükleri & Ticari Özgürlük \\
50,9 & 55,2 & 73,7 & 75,3 \\
\hline Etkin Hükümet & Vergi Yükü & İstihdam Özgürlüğü & Yatırım Özgürlüğü \\
30,3 & 93,7 & 79,8 & 60,0 \\
\hline Adalet Etkinlikleri & Mali Yapı & Parasal Özgürlük & Finansal Özgürlük \\
17,2 & 78,9 & 68,5 & 50,0 \\
\hline
\end{tabular}

Tablo 4. Kırgızistan Ülkesi Kaynak: Economic Freedom 2017

Cumhuriyeti Milli İstatistik Komitesi verilerine göre 2016 y1lında sanayi sektörünün üretimi 2,9 milyar dolar Cari sıralamada, 180 dünya ülkesi arasında 89ncu sırada yer almakta ve Çin, Rusya, Beyaz Rusya, Slovenya, Hırvatistan gibi ülkelerin önünde gelmektedir. Kırgızistan, en yüksek puanları Vergi Yükü göstergesinde 93,7 puan, İş Özgürlüğü 79,8 puan, Mali Özgürlük 78,9 puan almıştır (Kabar,2017).

Özbekistan; 2017 Ekonomik Özgürlükler Endeksinde Özbekistan, dünya sıralamasında 148.sirada 52.3 puanla bulunmaktadır. 


\begin{tabular}{|c|c|c|c|}
\hline Hukuka Uygunluk & Kamu Büyüklüğü & Etkinlik Düzenlemeleri & Açık Piyasa \\
\hline Mülkiyet Hakları & Hükümet Harcamaları & İş Özgürlükleri & Ticari Özgürlük \\
48,0 & 66,2 & 64,8 & 66,8 \\
\hline Hükümet Entegresi & Vergi Yükü & İstihdam Özgürlüğü & Yatırım Özgürlüğü \\
27,5 & 90,7 & 50,4 & 0,0 \\
\hline Adalet Etkinlikleri & Mali Yapı & Parasal Özgürlük & Finansal Özgürlük \\
41,9 & 99,8 & 61,1 & 10,0 \\
\hline
\end{tabular}

Tablo 5. Özbekistan Ülkesi Kaynak: Economic Freedom 2017

2017-2021 Özbekistan’1 Geliştirme Eylemler Stratejisi'nin 5 öncelikli doğrultusu: Devlet ve toplum kuruluşunun pekiştirilmesi, Hukuk üstünlüğünün temin edilmesi ve yarg1-hukuk sisteminde reformlar yapılması, Ekonominin daha da geliştirilmesi ve liberalleştirilmesi, Sosyal alanların geliştirilmesi, Güvenlik, etnik uyum ve dini hoşgörünün temin edilmesi, karşılıklı çıkarlara dayalı ve yapıcı dış politikanın yürütülmesi. Türkiye Özbekistan İş Forumu'nda, ekonomik alanda işbirliğinin geliştirilmesine yönelik bir takım anlaşmalar imzalanırken, tarımdan tekstile, konfeksiyondan elektrik-elektronik ve kimyaya, turizmden makine sanayi ve lojistiğe kadar 10 ayrı sektör belirlenmiştir, iki ülke arasındaki ticaret hacminin 2016 yılında 1,2 milyar dolar tutarında olduğu belirtilmektedir.

Tacikistan; Dünya Ekonomik Forumu 2015-2016 verilerine göre Dünya geliri içerisinde \%0,02'lik katk1 sağlayan Tacikistan 8,5 milyon nüfusuyla; 7,8 milyar dolarlık GSYİH ile 922 dolar kişi başına düşen geliriyle, global rekabet edilebilirlik endeksinde 1-7 arasında ölçeklendirilen skalada 4,0 ile 80.sırada, makroekonomik çevre olarak 4,6 ile 78. yer almaktadır.

\begin{tabular}{|c|c|c|c|}
\hline Hukuka Uygunluk & Kamu Büyüklüğü & Etkinlik Düzenlemeleri & Açık Piyasa \\
\hline Mülkiyet Hakları & Hükümet Harcamaları & İş Özgürlükleri & Ticari Özgürlük \\
45,5 & 74,1 & 65,6 & 73,9 \\
\hline Hükümet Entegresi & Vergi Yükü & İstihdam Özgürlüğü & Yatırım Özgürlüğü \\
32,7 & 90,9 & 49,2 & 25,0 \\
\hline Adalet Etkinlikleri & Mali Yapı & Parasal Özgürlük & Finansal Özgürlük \\
45,6 & 95,8 & 69,8 & 30,0 \\
\hline
\end{tabular}

Tablo 6. Tacikistan Ülkesi Kaynak: Economic Freedom 2017

Bunun yanı sıra, teknolojiyi hazır olma durumunda, 2,8 ile 115.sırada; pazar payında 120.sırada 2,7 ile, sanayinin temelini oluşturan yenilikçilik de ise 3,3 ile 63.sırada yer almaktadır. 2017 Ekonomik Özgürlükler Endeksinde Tacikistan Dünya sıralamasında 109.sırada 58.2 puanla bulunmaktadır.

\section{Türkiye}

Dünya Ekonomik Forumu 2015-2016 verilerine göre Dünya geliri içerisinde \%1,4'lük katkı sağlayan Türkiye 77 milyon 700 bin nüfusuyla; 733 milyar 6 milyon dolarlık GSYİH ile 9437 dolar kişi başına düşen geliriyle, global rekabet edilebilirlik endeksinde 1-7 arasında ölçeklendirilen skalada 4,4 ile 51.sırada yer almaktadır. Bunun yanı sıra, teknolojiyi hazır olma durumunda, 4,1 ile 64.sırada; pazar payında 16.sırada 5,4 ile, sanayinin temelini oluşturan yenilikçilik de ise 3,4 ile 60.sırada yer almaktadır. 2017 Ekonomik Özgürlükler Endeksinde Türkiye; dünya sıralamasında 60 .sırada 65.2 puanla bulunmaktadır.

\begin{tabular}{|c|c|c|c|}
\hline Hukuka Uygunluk & Kamu Büyüklüğü & Etkinlik Düzenlemeleri & Açık Piyasa \\
\hline Mülkiyet Hakları & Hükümet Harcamaları & İş Özgürlükleri & Ticari Özgürlük \\
61,3 & 57,7 & 64,3 & 79,4 \\
\hline Hükümet Entegresi & Vergi Yükü & İstihdam Özgürlüğü & Yatırım Özgürlüğü \\
40,7 & 75,5 & 48,5 & 75,0 \\
\hline Adalet Etkinlikleri & Mali Yapı & Parasal Özgürlük & Finansal Özgürlük \\
52,5 & 95,7 & 72,2 & 60,0 \\
\hline
\end{tabular}

Tablo 7. Türkiye Ülkesi Kaynak: Economic Freedom 2017

Türkiye Sanayi Stratejisi’nin vizyonu, “Orta-yüksek ve yüksek teknolojili ürünlerde Afro-Avrasya'nın tasarım ve üretim üssü olmak" şeklinde belirlenmiştir. Bu vizyon doğrultusunda, 2015-2018 dönemini kapsayan Türkiye Sanayi Stratejisi'nin genel amacı ise "Türk sanayisinin rekabet edebilirliğinin ve verimliliğinin yükseltilerek, dünya ihracatından daha fazla pay alan, ağırlıklı olarak yüksek katma değerli ve ileri teknolojili ürünlerin üretildiği, nitelikli işgücüne sahip ve aynı zamanda çevreye ve topluma duyarlı bir sanayi yapısına dönüşümünü hızlandırmak" olarak belirlenmiştir. 


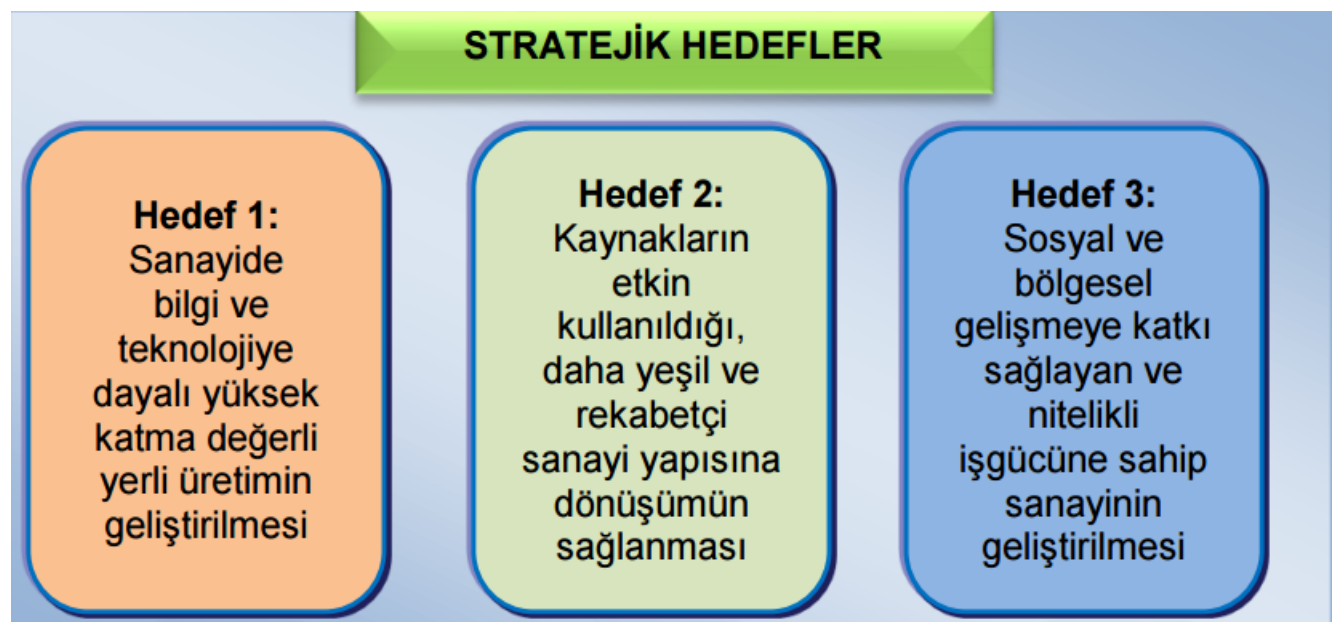

Şekil 1. Türkiye Sanayi Stratejisi’nin vizyonu Kaynak: T.C. Bilim Sanayi ve Teknoloji Bakanlı̆̆l, 2015

Uygulanacak sanayi stratejisinin odağında, bu üç temel stratejik hedef doğrultusunda yapısal dönüşümü desteklemek yer almaktadır: Hedef 1: Sanayide bilgi ve teknolojiye dayalı yüksek katma değerli yerli üretimin geliştirilmesi Hedef 2: Kaynakların etkin kullanıldı̆̆ı, daha yeşil ve rekabetçi sanayi yapısına dönüşümün sağlanması Hedef 3: Sosyal ve bölgesel gelişmeye katkı sağlayan ve nitelikli işgücüne sahip sanayinin geliştirilmesi

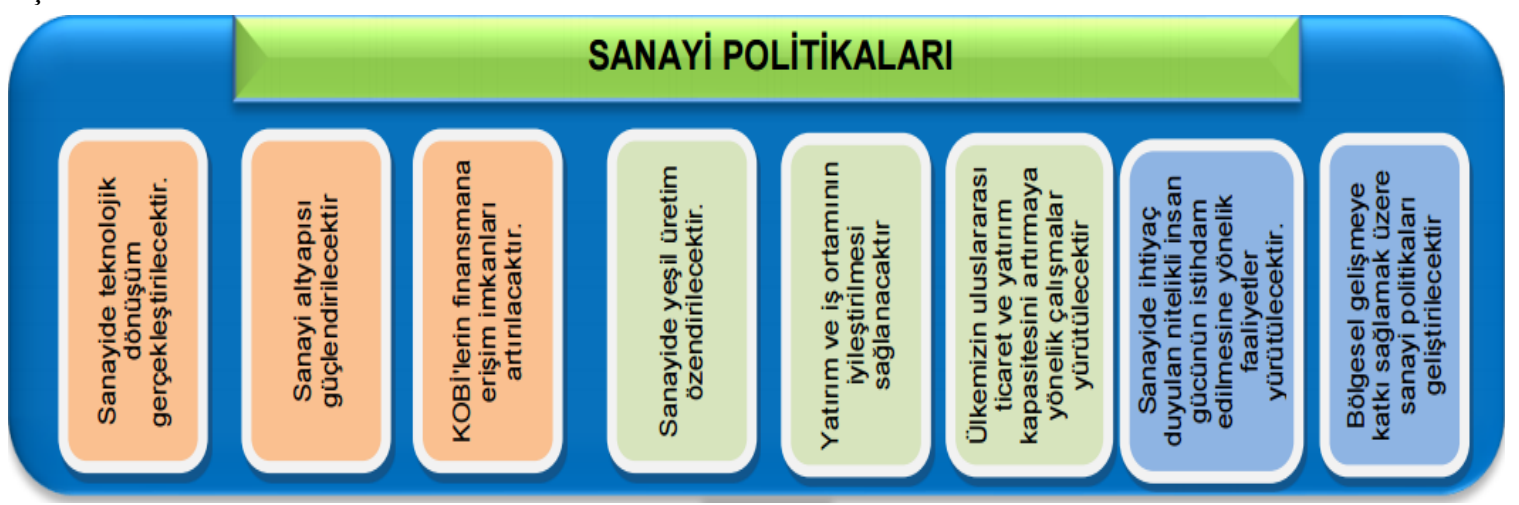

Şekil 2. Türkiye Sanayi Politikaları Kaynak: T.C. Bilim Sanayi ve Teknoloji Bakanlığı, 2015

Politika 1: Bilim, teknoloji, Ar-Ge, yenilikçilik, verimlilik, sınai mülkiyet kültürüne yönelik

Politika 2: Sanayi altyapısı güçlendirilmesi

Politika 3: KOBİ'lerin finansmana erişim imkanları artırılması

Politika 4: Çevre Politikaları ve yeşil üretim

Politika 5: Yatırım ve iş ortamının iyileştirilmesi

Politika 6: Uluslararası ticaret ve yatırım kapasitesini artırmaya yönelik çalışmalar

Politika 7: Sanayide ihtiyaç duyulan nitelikli insan gücünün istihdam edilmesi

Politika 8: Bölgesel gelişmeye katkı sağlamak üzere sanayi politikaları geliştirmek uygun sanayi iklimleri oluşturabilmek maksadıyla öncellikli politik uygulamalar arasında sıralanmaktadır.

\section{Sonuç ve Değerlendirme}

Türkiye'nin tarıma dayalı ithal ikameli sanayi anlayışından 1980 sonrası dönem boyunca, diş ticarete açık olan sektörlerin piyasa yapılarında bir değişiklik ortaya çıkmamış ve imalat sanayinin oligopol tekelci niteliği korunurken ulusal ekonomi bütün resmi söylemin ve beklentilerin aksine ihracata yönelik olarak sanayileşmemiştir (Yeldan, Köse 1998). Bunu sağlamak için Avrasya ekonomilerinin de Türkiye ekonomisinde olduğu gibi yerel bir yatırım stratejisi, yerel çatışma yönetimi kurumlarını güçlendirme stratejisi üzerinde durulmalıdır (Rodrik, 2000). Her iki ekonomide de, önce verimlilik artışı sağlayıp daha etkin bir duruma getirmek için kaynakların verimsiz alanlardan daha verimli alanlara yönlendirilmelidir. Etkinliği artırmak için üretimi artırmalı dışsal rekabete açık olan firmalar rekabet edilebilir düzeye ulaşıncaya kadar desteklenmelidir (Ehani 1995). Avrasya ve Türkiye ekonomisinin hem ekonomik özgürlükler endekslerinde hem de dünya ekonomisinin içinde paylarını arttırabilmek için değer ekonomisi tabanlı sanayide istikrarlı kalite düzeyi, güvenilirliği yüksek mamüller, tasarım değişsikliği, yeni ürün sunma hızı, düşük fiyat, satış sonrası hizmet gibi rekabetçi önceliklere önem verilmelidir (TUSİAD 2001). Seçilmiş Avrasya Ekonomiyi ve sanayiyi döviz kurunda istikrar iç talebi canlandıracak tedbirler, işletmelere finansal destek, yerli malların teşviki, tasarrufun Euroya transferi, ekonomik kararlarda reel sektör ile diyalog, 
basının rolü ve sorumluluğu canlandıracaktır (Kenanoğlu 2001). Bununla beraber seçilmiş Avrasya ülkeleri ve Türkiye'de kayıtlı ekonomi ve kayıtlı istihdam teşvik edilmeli kayıtdışı kayda alınmalı (Arıkan, 2001), belirsizlik durumu altında, teknolojik ve ekonomik tercihlerle piyasada rekabet sağlanmalıdır (Borrus 1997). Avrasya Ekonomisi belirli alanlarda güçlü olsa da, sahip olduğu potansiyelin tamamını kullanamamakta; verimlilik, yaşam standardının yükseltilmesi ve istihdam yaratma konularında rakiplerinin gösterdiği performansı gösterememektedir. Seçilmiş Avrasya ülkelerindeki bu düşük performans sanayide düşük katma değeri ve düşük karlılığı, ayrıca gelişmiş ülkelere yönelik ihracatta azalışı da beraberinde getirmektedir. Tespit edilen bu düşük performansın sebepleri şu şekilde siralanabilir; Ekonomik Özgürlükler endeksinde ve WEF ve IMF'nin göstergelerinde görüldüğü üzere; rekabet gücünün değişkenleri ekonominin dış ticarete ve yabancı yatırıma açılması, piyasalara düzenleyici standartların yerleşmesi, Bilgi teknolojisi altyapısının gelişmesi, Rekabet hukukunun etkin bir biçimde uygulanması, İletişim ile hava taşımacılığının geliştirilmesi gereklidir (DPT ÖİK, 2000, DPT ÖİK, 1988). Bununla beraber, vergi oranlarının yeniden düzenlenmesi: Türk Lirası yabancı paralar arası kurların doğru yönetimi. Meslek örgütlerinin ve sanayi kuruluşlarının yeniden yapılanması, her kuruluşun aynı zamanda bir Öğrenme Merkezi haline getirilmesi. Türkiye ve Avrasya Ekonomileri açısından DEIKK raporlarında da belirtildiği gibi sık iş forumları düzenlemeleriyle yeniden operasyonel etkinlik ve benchmarking gibi en iyi mukayeseli karşılaştırmalar doğrultusunda güçlü bir strateji bağlamında vizyon,. öz-değerler ve özniyet(misyon) belirlenmesi, özgün stratejiler tasarımlanması, iş sahipleri ve yöneticilerin ufuklarının genişıletilmesi. İnsan kaynağına yeni yaklaşım: Potansiyellerini ortaya çıkarmak, İşe ortak etmek, Beceri dokusunu geliştirmek), İşbirliği içinde rekabet için; Etik taahhütlerde bulunulması, Rekabet öncesi konularda işbirliği çağrıları yapılması, Dış rekabete karşı dayanışma, Danışmanlık kurumundan daha etkili olarak yararlanılması (İSO 2001).Türkiye bir yandan insangücü kaynaklarını artırırken bir yandan da ileri teknoloji alanlarına yatırımla uç ürünler üretimini desteklemeli ve böylece katma değeri yüksek ürünler üretimine doğru sanayi tabanını değiştirmelidir. Bunu da yabancı sermaye kanalı ile gerçekleştirebilir. Sanayide bölgesel yoğunlaşmaları önlemek için sanayinin yeniden yapılanması ve yatırımların coğrafi dağılımının yeniden değerlendirilmesi, sanayi planlarının yapılması ve iç göçlerin önlenmesi için yeni oluşumlara fırsat verilerek geri kalmış bölgelerde alt yapıların kamu tarafından karşılanması yararlı olacaktır. Yeni piyasa koşullarının rekabetçi olmasına özen gösterilmeli, yeni bin yılda önemi daha da artacak olan bilgi iletişim teknolojilerinden internet özümsenmelidir. Bir yandan sınai üretimin verimliliği ve rekabet gücünü artıran teknolojik gelişme ve yenilikler izlenirken, öte yandan gelir dağılımını düzeltici politikalar uygulanmalı verimlilik artışından geniş toplum birimleri yararlanmalıdır. Öğretim kurum müfredatlarında her sektörde, her kademede özellikle ara insan gücü kademesinde eğitimi, ülke genelinde çeşitli bakanlık kurum ve kuruluşlar ile kişiler tarafından yürütülen verimlilik çalışmaları arasında koordinasyon sağlanmalı, verimlilik düzeyinin artırılmasına yönelik nitelik ve nicelikte teknik personel yetiştirilerek istihdam edilecek yasal ve kurumsal düzenlemeler yapılmalıdır. $\mathrm{Bu}$ birim ve kurumlar desteklenmelidir. Ölçek ekonomileri ve artan rekabet verimlilik ve uzmanlaşma açısından önemlidir. İstikrarlı bir tempo ile arttırılan sınai üretiminin verimliliği rekabet etme olanağını artıracaktır. İşgücü piyasasına yönelik sendikal hak ihlallerini önlemek için caydırıcı yaptırımlar getirilmeli, işçi sağlı̆̆ ve güvenliği iyileştirilmeli, haftalık çalışma süresi AB ortalamasına indirilmeli, işgücü gelirleri üzerindeki vergi ve fon baskısı azaltılmalı, işsizliği minimize edici yatırım politikaları benimsenmelidir. Ulusal kalite altyapısı geliştirilmeli, ISO 9000 dışındaki sertifikasyon hizmeti özendirilmeli, Tip onayı sistemi günün şartlarına uyarlanmalı, kapsamlı bir metroloji mevzuatı hazırlanmalıdır. Çevre dostu teknolojilere çevre koruma kaynaklı üretimler teşvik edilmelidir. Ulusal bir tasarım politikasıyla ülkenin uzun dönemli ekonomik ve endüstriyel gelişme stratejileri belirlenmeli ve yeni markalar geliştirilmelidir. Hukuki altyapı kurumsal altyapı, finans yapısı, temiz üretim uygulamaları gibi hukuki ve kurumsal düzenlemeler yapılmalıdır. Sanayicimize yatırım heyecanını yeniden kazandıran önlemler alınmalıdır. Vergi, sosyal sigorta yüklerinin hafifletilmesi, enerji ve diğer girdilerde indirim yapılması, diğer ülkeler karşısında firsat eşitliği ve rekabet gücü yakalamaya yönelik ekonomik ve sosyal standartlar yükseltilmelidir (Küçük 2002). Sanayici ithalatında gümrük müşavirlerine ödenen bedellerin indirilmelidir (Bilgi, 2001). Ticari reform olarak da daha rekabetçi piyasalar, yerli firmaların korunması firmaların davranış ve performanslarındaki değişiklik. Seçici nitelikteki bir sanayileşme politikası, ihracata yönelecek sanayilerin esnek, sermaye, teknoloji, kapasite ve kuruluş yeri gibi temel ekonomik özellikleri yönünden planlı olmalıdır. Bunlardan ülkenin ekonomik koşullarına en uygun olanlar seçilmeli ve belirli bir olgunluk düzeyine ulaşılıncaya kadar da diş piyasanın rekabetinden korunmalıdır (Boratav,1993). Bölgesel yardımlar; sorunların yapısına göre yardımlarda tavan sınırlaması, şeffaflık, bölgesel özellik, karşılıklı sektörel etkileşim, yardımların işlenmesi gözönünde tutulmalıdır. Yardım programlarının coğrafi sınır belli bir noktaya birikmesi, nitelik ve yoğunluk açısından hazırlanmalıdır (Hendriksen, 1989).Türk ürünlerinin yurtdışında markalaşması, tanıtım ve tutundurması ile Türk malı imajının yerleştirilmesine yönelik faaliyetlerin desteklenmesi, dahilinde işleme rejimi, Eximbank kredileri, Gümrük vergisi ve toplu konut fonu istisnası, yatırım indirimi, ithal ve yerli makine ve teçhizatta KDV istisnası, vergi resim ve harç istisnası, bina inşaat harcı istisnası, fon kaynaklı kredi, enerji desteği, arsa tahsisi, çevresel sorunların çözümüne yönelik altyapı hizmetlerinin geliştirilmesi sanayi için kullanma ve içme su sistemlerinin geliştirilmesi, iletişim olanaklarının geliştirilmesi, bürokrasinin azaltılması, ölçeksel ve mekansal boyut, yerel yönetimlerin sanayi işletmelerine bakış açısının geliştirilmesi özetle; mali teşvik, yatırım teşviki ve dolaylı teşviklerde ihracata dayalı sanayi alanındaki devlet yardımları rekabet gücünü artıracaktır (DPT, 2000). 
Teknoloji yeteneğinin yükseltilmesi, ARGE'nin ve inovasyon kültürünün sanayiye yaygınlaştırılması ve bu amaçla kamunun uluslararası ölçekte kaynak ayırarak özendirmesi de rekabet gücünü artırıcı politikalar arasındadır. İhracatın sürükleyici rol oynadığı Endüstriyel kalkınma stratejisi. Dünya piyasa fiyatlarıyla serbest ithalat, ihracata dayalı endüstrileri teşvik edici mali piyasalar, pazarlama ve teknolojiye dayalı enformasyon sistemi, stratejik koordinasyon kalkınma stratejilerinin önemli aşamaları olmalıdır (Islatince 1998).

\section{Kaynakça}

- $\quad$ Arıkan, N. 2001. "Türk Ekonomisi ve Sanayi: Nasıl Canlanır? ISO Ekim, Sayı 427, İstanbul

- Bilgin, Ö.İ. 2002.“Türk Ekonomisi ve Sanayi: Nasıl Canlanır? ISO Ekim, Sayı 427, İstanbul

- Boratav K. 1984. “Türkiye'de Sanayileşmenin Yeni Boyutları ve KİT’ler” Tarih Vakfı Yurt Yayınları, İstanbul

- Borrus M., François B. 1997.“Why Competition is Necessary” US İnformation Technology Office (USITO), Beijing, China September 24-25

- Demir İ.1986, “Teknolojik Gelişme ve Türkiye’nin Teknolojik Meseleleri”, DPT,Ankara

- DPT, 2000. "Sanayi Politikaları” ÖİK Raporu, Rekabet Gücünün Arttırılması, Alt Komisyonu Raporu, DPT Yayını: No: 2529, Ankara

- DPT, 2000. "Sanayi Politikaları" ÖİK Raporu, Rekabet Gücünün Arttırılması, Alt Komisyonu Raporu, Sanayinin Gelişme Perspektifi Alt Komisyonu Raporu

- $\quad$ DPT, 1988. “Türk Sanayinin AT Sanayii Karşısında Rekabet İmkanları ÖİK Raporu, DPT Yayını No: 2141, Ankara

- Ehani E. \& Jayarah C. 1995. "Trade Reform Efficiency and Growth", The World Bank. Eastern Africa Department Country Operations Division, March 1995, Policy Research Working Paper 1438

- Henriksen S. 1992. "Sanayide Devlet Yardımları ve Teşvikler” ISO Yayını, Yenilik Basımevi, İstanbul

- Ishac D. \& Michael W. 1997. "How International Exchange, Technology, and Institutions Affect Workers The World Bank Economic Review Volume 11, January Number 1

- İlkin A.1983, 'Kalkınma ve Sanayi Ekonomisi, İstanbul Üniversitesi Yayını No:3175, İstanbul

- İslatince H. 1998. “Güney Kore'de Uygulanan Sanayileşme Stratejisinin Analizi” A. Ü. İ̈BF. Dergisi14(1-2)

- Kızılot Ş.2001. “2002 Yılı Bütçesi, Yapısı ve Öneriler” İşveren Dergisi, TiSK Yayını,11(2), Kasım Ankara

- Küçük, 2002. "Türk Sanayi ve Ekonomisinin 2002 Yılı Beklentileri" İSO Yayın No: 430, Ocak İstanbul, http://www.sp.gov.tr/upload/xSPTemelBelge/files/7kwq0+Turkiye_Sanayi_Strateji_Belgesi_.pdf

- $\quad$ Rodrik D. 2000. "Yeni Küresel Ekonomi ve Gelişmekte olan Ülkeler" Sabah Kitapları107, İstanbul

- TEPAV, 2007. Türkiye'nin Rekabet Gücü için Sanayi Politikası, Ankara. Türel, Oktar (2008), "Türkiye'de Sanayi Politikalarının Dünü ve Bugünü", http//www.bagimsizsosyalbilimciler.org/Yazilar_Uye/TurelJan08.pdf

- $\quad$ TUBİTAK, 2017. https://www.tubitak.gov.tr/tr/destekler/sanayi/ulusal-destek-programlari/icerik-1501tubitak-sanayi-ar-ge-projeleri-destekleme-programi

- $\quad$ TUSİAD, 2001. "Rekabet Stratejileri ve En İyi Uygulamalar" Bölüm 1, s. 44.

- Economic Freedom, 2017, http://www.heritage.org/index/country/azerbaijan

- Economic Freedom, 2017a, http://www.heritage.org/index/country/georgia

- World Economic Forum,2017.http://reports.weforum.org/global-competitiveness-report20152016/economies/\#economy=AZE

- World Economic Forum, 2017a,http://reports.weforum.org/global-competitiveness-report 20152016/economies/\#economy=GEO

- $\quad$ Yeldan E, \& Köse H. A. 1998 "Dışa Açılım Sürecinin Dinamikleri" Toplam Bilim Dergisi,İstanbul

- T.C. Bakü Ticaret Müşavirliği, http://businesscontract.gehttp://www.inform.kz/en/imf-ups-forecast-forkazakhstan-gdpgrowth_a2997749

- Kazianform, 2017, http://www.kazinform.kz/en/kazakhstan-s-export-down-in-2016_a2996804

- Economic Freedom, 2017b, http://www.heritage.org/index/country/kazakhstan

- Economic Freedom, 2017c, http://www.heritage.org/index/country/kyrgyzrepublic

- Economic Freedom, 2017d, http://www.heritage.org/index/country/uzbekistan

- Economic Freedom, 2017e, http://reports.weforum.org/global-competitiveness-report-20152016/economies/\#economy=TJK

- Economic Freedom, 2017f, http://reports.weforum.org/global-competitiveness-report-20152016/economies/\#economy=TUR

- T.C. Bilim Sanayi ve Teknoloji Bakanlı̆̆ı, 2015, http://www.sp.gov.tr/upload/xSPTemelBelge/files/7kwq0+Turkiye_Sanayi_Strateji_Belgesi_.pdf 


\title{
Türkiye'nin Ekonomik ve Ticari Ortakları İçinde Rusya'nın Yeri The Place of Russia in the Economic and Trade Partners of Turkey
}

\author{
Ph.D. Candidate Hamdi Aydın (İstanbul Gelişim University, Turkey)
}

\begin{abstract}
In this study, it is mentioned that export and import figures of turkey and the amount of economic and trade relationship between the countries of Turkey and Russian. The trade between two countries have been analyzed by historical perspective and made comments about the future. As looking from regional, it is the fact that the trade between two greatest power countries in the region is also important in terms of the world's trade. Cooperation between the two countries not only affects the two countries trade, but also affect the whole region countries. It can be seen that up to this time, time to time the two countries closer to each other, time to time moved away the area due to certain events in the region. When relationship of politics between countries is good, trade volume is high. Politics directly affects economics and trade relationship of countries. In this study, historically, which products is used in trade and how much is the export and import figures between two countries over years.
\end{abstract}

\section{Giriş}

Türkiye'nin ekonomik ve ticari ortakları içinde Rusya önemli bir yer tutmaktadır. Bölgenin iki önemli ve güçlü ülkesi olan Türkiye ile Rusya arasındaki ilişkiler günümüze kadar dönemsel olarak değişmiştir. Bu değişimin olmasında gerek dünyada ki gelişmeler gerekse bölgedeki gelişmelerin yanında lider değişiklikleri de etkili olmuştur. Yeryüzünde liderler her zaman iki ülke arasındaki ilişkilerin oluşmasında son derece etkili bir unsurdur. Liderlerin izlediği politikaya bağlı olarak ülkelerin dış politikaları da değişmekte ve buna bağlı olarak ülkeler arasındaki ekonomik ve ticari durumlarda da değişiklikler görülmektedir. Türkiye ile Rusya arasındaki ticaretinde bu anlamda dönemsel olarak değiştiği gözlenmektedir. Liderlerin izlediği politikaya göre iki ülke arasında oluşan ticaret hacminin bazen çok iyi bazen de çok de çok kötü olduğu görülmektedir.

Türkiye ile Rusya arasındaki ticari ilişkilere bakıldığında aslında iki ülkenin de birbirine farklı konularda ihtiyaç duyduğu görülmektedir. Türkiye'nin enerji ihtiyacının karşılanması için Rusya'ya ihtiyaç duyması buna karşın, Rusya'nın da müteahhitlik hizmetleri, tarıma dayalı ürünler, tekstil hizmetleri, turistik gezi gibi konularda Türkiye'yi tercih etmesi ve ihtiyaç duyması iki ülke arasındaki ticari ilişkilerin gelişmesinde önemli rol oynamaktadır. Bu çalışmada Türkiye ve Rusya arasındaki tarihi süreç, Türkiye'nin ticaret ortakları içerisinde Rusya ile yaptığı ticaretin ekonomik boyutu, ticari mallardan, ithalat ve ihracat oranlarından bahsedilmiştir.

\section{Türkiye ve Rusya Arasındaki Tarihi Süreç}

Türkiye ile Rusya arasında ticari ilişkilere çok geçmişe dayanmaktadır. Bu bölümde tarihi süreç anlatılırken Osmanlı döneminden çok, cumhuriyet döneminden itibaren iki ülke arasında geçmişten günümüze kadar yaşanan önemli bazı gelişmelerden özetle bahsedilmiştir.

Cumhuriyetin ilanından itibaren, petrol, seker ve dokumalar, Rusların Türkiye'ye ihraç ettikleri başlıca mallardı. Bu dönemde, 1923 yılında Türkiye'nin Rusya'dan yapmış olduğu ithalat toplam ithalatının \%2'si iken ertesi y1l bu rakam \%3.29'u bulmuştur. Tütün, maden ve hayvan ihracatına karşılık Rusya'dan petrol, yiyecek malzemesi, aydınlatma malzemesi alınıyordu. Türkiye Cumhuriyeti Dışişleri Bakanı Tevfik Rüştü ve Sovyet Dış işleri Bakanı Çiçerin arasında görüşmeler yapıllmış ve bu görüşmeler sonucunda 11Mart 1927 tarihinde "Ticaret ve Seyrisefain Anlaşması” imzalanmıştır. I. Dünya Savaşı'nda Osmanlı İmparatorluğu'nun rakibi olan ancak savaş sırasında yaşadığı ihtilâl sebebiyle savaştan çekilerek emperyalist bloğa karsı Türk Millî Mücadelesi’ni destekleyen Sovyet Rusya ve Türkiye arasında II. Dünya Savaşı'na kadar olan süreçte genelde yakın işbirliği ve iyi ilişkilerin yaşandığı bir dönem olduğu görülmektedir (Korhan, 2012). Bu sürece kadar ilişkiler sorunsuz bir şekilde devam etti.

18 Eylül 1984 tarihinde dünyanın en zengin doğal gaz rezervlerine sahip SSCB ile Türkiye'ye doğal gaz sevkiyatına dair imzalanan anlaşma büyük bir önem taşımaktadır. 1984 tarihli anlaşma kapsamında 26 Ekim 1986 tarihinde inşasına başlanan "Rusya Federasyonu-Türkiye Doğal Gaz Boru Hattı" Ağustos 1988'de Ankara'ya kadar ulaşmıştır. Sanayi kuruluşlarının doğal gaz kullanabilmelerini sağlamak amacıyla, "Rusya Federasyonu-Türkiye Boru Hattı" güzergâhındaki çeşitli sanayi bölgelerine dağıtım hatları yapılmış ve talepler doğrultusunda yeni hatların yapımı da gerçekleştirilmiştir. Ayrıca, 1984 yılında imzalanan 25 yıllık doğal gaz anlaşması kapsamında Rusya Federasyonu'ndan alınan yıllık 6 milyar $\mathrm{m}^{3}$ lü̈k doğal gaz miktarına ilaveten, 8 milyar $\mathrm{m}^{3} / \mathrm{y}$ ıllık doğal gaz alımını öngören 10 Aralık 1996 tarihli anlaşmada da ofset hükmüne yer verilmemiştir. Bu anlaşma kapsamında ilave doğal gaz alımı ise Mart 1998 tarihinde başlamıştır. Mavi Marmara projesi ile Rusya'dan Türkiye'ye olan doğalgaz akışının 16 milyar m³/yıllık olması planlandı (Şen, 2003). 
SSCB'nin dağılmasıyla birlikte İki ülke ticari ilişkileri hızla gelişmeye davam etmiştir. 2000 yılında ihracatımızda 9'uncu sırada yer alan Rusya Federasyonu 2003 ve 2004 yıllarında 8'inci sıraya yükselmiş, 2005 yılında tekrar 9'uncu sıraya yerleşmiştir. İthalatımızda ise 2000 yılında 4'üncü sırada iken 2004 ve 2005 yılında 2'nci sıraya yükselmiştir (Morfikirler, 2013). SSCB'nin dağılmasıyla ikili ticari ilişkiler ivme kazanmıştır ancak daha sonra zaman zaman dalgalanmalar olsa da belirli bir düzeye gelmiştir. 2008 yılında dünya da yaşanan ekonomik kriz Türkiye Rusya ilişkilerini de kısa süreliğine olumsuz yönde etkilemiştir.

İki Ülke Arasında Ticaretin Altyapısını Düzenleyen Anlaşma ve Protokoller: (Ekonomi, 2016 )

- 8.10.1937 tarihli “Ticaret ve Seyrisefain Anlaşması” ile 25.2.1991 tarihli “Ticari ve Ekonomik İşbirliğine Dair Anlaşma"

- 15.12.1997 tarihinde imzalanan ve 17 Mayıs 2000 tarihinde onay süreci tamamlanan "Yatırımların Karş1lıklı Teşviki ve Korunmasına ilişkin Anlaşma"

- 15.12.1997 tarihinde imzalanan ve 1 Ocak 2000 tarihinde yürürlüğe giren "Çifte Vergilendirmeyi Önleme Anlaşması"”

- 15.12.1997 tarihinde imzalanan “Ticari, Ekonomik, Sınai, Bilimsel-Teknik İşbirliğinin Geliştirilmesi Hakkında Uzun Vadeli Program"

- Türkiye-Rusya Federasyonu Hükümetlerarası Karma Ekonomik Komisyon Protokolleri (13. Dönem KEK Toplantısı Protokolü/01.12.2014)

- Türkiye-Rusya Federasyonu Hükümetler Arası Karma Ekonomik Komisyon 14. Dönem Toplantısı Protokolü (12.10.2016)

Sosyal ve kültürel ilişkilerin geliştirilmesi kapsamında iki ülke arasında karşılıklı jestler yapıldı. Kültürel ilişkilerin önemine dikkat çeken Türk ve Rus liderler, 2007'de Türkiye'de "Rusya yılı", 2008'de ise Rusya'da "Türkiye yılı" etkinlikleri düzenlenmesini kararlaştırdıklarını açıkladı. Bu açıklama ile iki ülke arasında ilişkilerin geliştirilmesinin önemsendiği belirtildi. 2011 yılında yapılan anlaşma ile iki ülke arasında vizelerin kalkması Türkiye ve Rusya arasında ilişkilerin geliştirilmesi açısından atılmış en önemli adımlardan biridir. Yapılan bu anlaşma, gerek turizm açısından gerekse ticaret açısından büyük bir ticaret hacminin doğmasına neden oldu.

Türkiye ile Rusya arasında, birçok bakanın ve iş adamlarının katıldığı ticari ilişkileri üst düzeye çıkaracak anlaşmaların imzalanması ile garanti altına alınacağı mekanizma olan Üst Düzeyli İşbirliği Konseyi (ÜDİK) 2010 yılında kuruldu. 2011 yılında Suriye'de başlayan iç savaş, 2014 yılında Ukrayna da başlayan savaş Rusya'nın Kırım’ı ilhak ettiğini duyurması gibi olaylar iki ülke arasında bazı problemler yaşanmasına neden olsa da ekonomik olarak çok da büyük bir olumsuzluk yaşatmadı. 2015 yılına normal seyirde başlayan iki ülke arasındaki ekonomik ilişkiler, kasım ayında Türkiye'de yapılan G-20 zirvesi ile daha üst düzeye çıkarmak için çalışmalar başlatılmıştır. Ancak 24 Kasım 2015 günü Türkiye hava sahasını ihlal eden Rusya'ya ait su-24 uçağının düşürülmesi ile iyimser bir hava içinde olan iki ülke ilişkilerinin aniden kötümser bir havaya bürünmesine neden oldu. 2015 yılı sonu itibari ile 24 milyar dolar ticaret hacmini yakalayan iki ülke ilişkileri 2016 yılına kötü başlamış haziran ayına kadar ilişkilerin tamamen kesilmesi noktasına yaklaşmıştır. Ancak 27 Haziran 2016 yılında iki ülke liderin karşılıklı girişimleri sonucu iyi ilişkiler kurulması için yeni bir başlangıç yapıldı. En son iki ülke yetkilileri arasında yapılan görüşmeler sonucu ticaret hacminin hedef olarak 100 milyar dolar olarak belirlenmesi, gelecekte bu iki ülkenin daha birçok yeni anlaşmaya imza atacağının ipuçlarını vermektedir.

\section{Türkiye ve Rusya Federasyonu Arasındaki Başlıca Ekonomik İşbirliği Alanları}

Türkiye ile Rusya arasındaki ticari ilişkiler bakmadan önce iki ülke ile ilgili belli başlı bazı bilgilere bakmakta fayda vardır. Türkiye'nin son 17 yılına bakıldığında yıllara göre ithalat, ihracat ve ticaret hacmi rakamları şöyledir: 


\begin{tabular}{|c|c|c|c|c|c|}
\hline & & & \multicolumn{3}{|c|}{ (Değer: Bin ABD \$ / Value: Thousand US \$) } \\
\hline & & & & & Diş ticaret hacmi \\
\hline & \multirow{2}{*}{\multicolumn{2}{|c|}{$\begin{array}{l}\text { İhracat } \\
\text { Exports }\end{array}$}} & \multirow{2}{*}{\multicolumn{2}{|c|}{$\begin{array}{l}\text { Ithalat } \\
\text { Imports }\end{array}$}} & \multirow{3}{*}{$\begin{array}{l}\text { Volume of } \\
\text { foreign trade }\end{array}$} \\
\hline & & & & & \\
\hline & & & & & \\
\hline & Değer & Değişim & Değer & Değişim & Değer \\
\hline Yillar & Value & Change & Value & Change & Value \\
\hline Years & & $(\%)$ & & $(\%)$ & \\
\hline 2000 & 27.774 .906 & 4,5 & 54.502 .821 & 34,0 & 82.277 .727 \\
\hline 2001 & 31.334 .216 & 12,8 & 41.399 .083 & $-24,0$ & 72.733 .299 \\
\hline 2002 & 36.059 .089 & 15,1 & 51.553 .797 & 24,5 & 87.612 .886 \\
\hline 2003 & 47.252 .836 & 31,0 & 69.339 .692 & 34,5 & 116.592 .528 \\
\hline 2004 & 63.167 .153 & 33,7 & 97.539 .766 & 40,7 & 160.706 .919 \\
\hline 2005 & 73.476 .408 & 16,3 & 116.774 .151 & 19,7 & 190.250 .559 \\
\hline 2006 & 85.534 .676 & 16,4 & 139.576 .174 & 19,5 & 225.110 .850 \\
\hline 2007 & 107.271 .750 & 25,4 & 170.062 .715 & 21,8 & 277.334 .464 \\
\hline 2008 & 132.027 .196 & 23,1 & 201.963 .574 & 18,8 & 333.990 .770 \\
\hline 2009 & 102.142 .613 & $-22,6$ & 140.928 .421 & $-30,2$ & 243.071 .034 \\
\hline 2010 & 11.883 .219 & 11,5 & 185.544 .332 & 31,7 & 299.427 .551 \\
\hline 2011 & 134.906 .869 & 18,5 & 240.841 .676 & 29,8 & 375.748 .545 \\
\hline 2012 & 152.461 .737 & 13,0 & 236.545 .141 & $-1,8$ & 389.006 .877 \\
\hline 2013 & 151.802 .637 & $-0,4$ & 251.661 .250 & 6,4 & 403.463 .887 \\
\hline 2014 & 157.610 .158 & 3,8 & 242.177 .117 & $-3,8$ & 399.787 .275 \\
\hline 2015 & 143.838 .871 & $-8,7$ & 207.234 .359 & $-14,4$ & 351.073 .230 \\
\hline 2016 & 142.557 .355 & $-0,9$ & 198.610 .256 & $-4,2$ & 341.167 .611 \\
\hline
\end{tabular}

Tablo 1: Türkiye'de Ithalat ve İhracat Rakamlarl Kaynak: TÜIK, 2017

Yukarıdaki tablo incelendiğinde, Türkiye'nin 2000 yılından beri ihracatının her yıl bir önceki yıla göre arttığ görülmektedir. 2008 yilında dünya da yaşanan küresel ekonomik krizin Türkiye ekonomisini de olumsuz şekilde etkilediği ve bu etkinin 2009 ve 2010 yıllarına yansıdığı görülmektedir. Daha sonraki yıllarda Türkiye ekonomisinin tekrar toparlandığı ihracat ve ithalat rakamlarının arttığı görülmektedir. 2014 yılında ihracat rakamlarının zirve yapması ve ithalat rakamlarının düşmesi ile birlikte cari açı̆̆ında düştüğü görülmektedir. 2014 yılında Türkiye tarihinin ihracat rekoru kırılmıştır. 2015 ve 2016 yıllarında Türkiye'de yaşanan iç gelişmeler, genel seçimler ve Rusya ile yaşanan uçak krizi ile birlikte ihracat ve ithalat rakamlarında düşüş yaşandı. 2017 yılına hızlı bir giriş yapan Türkiye'nin ihracat rakamlarının yeniden yükseleceği, ekonominin yeniden olumlu bir seyir izleyeceği beklenmektedir. 
Türkiye'nin yıllara ve ülkelere yapmış olduğu ihracat ve ithalat rakamları aşağıdaki tabloda incelenmiştir.

Ülkelere göre yıllık ihracat (en çok ihracat yapılan ülkeler)

Değer: Bin ABD \$ / Value: Thousand US \$)

\begin{tabular}{|c|c|c|c|c|c|c|c|c|c|c|}
\hline \multicolumn{11}{|c|}{ Ülke } \\
\hline & Yillar & 2016 & 2015 & 2014 & 2013 & 2012 & 2011 & 2010 & 2009 & 2008 \\
\hline & Toplam & 142.557 .355 & 143.838 .871 & 157.610 .158 & 151.802 .637 & 152.461 .737 & 134.906 .869 & 113.883 .219 & 102.142 .613 & 132.027 .196 \\
\hline 1 & Almanya & 14.001 .075 & 13.417 .033 & 15.147 .423 & 13.702 .577 & 13.124 .375 & 13.950 .825 & 11.479 .066 & 9.793 .006 & 12.951 .755 \\
\hline 2 & İngiltere & 11.687 .384 & 10.556 .393 & 9.903 .172 & 8.785 .124 & 8.693 .599 & 8.151 .430 & 7.235 .861 & 5.937 .997 & 8.158 .669 \\
\hline 3 & Irak & 7.638 .750 & 8.549 .967 & 10.887 .826 & 11.948 .905 & 10.822 .144 & 8.310 .130 & 6.036 .362 & 5.123 .406 & 3.916 .685 \\
\hline 4 & İtalya & 7.581 .570 & 6.887 .399 & 7.141 .071 & 6.718 .355 & 6.373 .080 & 7.851 .480 & 6.505 .277 & 5.888 .958 & 7.818 .988 \\
\hline 5 & $\mathrm{ABD}$ & 6.623 .911 & 6.395 .842 & 6.341 .841 & 5.640.247 & 5.604 .230 & 4.584 .029 & 3.762.919 & 3.240 .597 & 4.299.941 \\
\hline 6 & Fransa & 6.023 .501 & 5.845 .032 & 6.464 .243 & 6.376 .704 & 6.198 .536 & 6.805 .821 & 6.054 .499 & 6.211 .415 & 6.617 .511 \\
\hline 7 & BAE & 5.407 .548 & 4.681 .255 & .655 .710 & 4.965 .630 & 8.174 .607 & 3.706 .654 & 3.332 .885 & 2.896 .572 & 7.975 .400 \\
\hline 8 & İspanya & 4.991 .204 & 4.742 .270 & 4.749.584 & & 3.717 .345 & 3.917 .559 & 3.536 .205 & 2.818 .470 & 4.047 .267 \\
\hline 9 & İran & 4.967 .406 & 3.663 .760 & 3.886 .190 & 4.192 .511 & 9.921 .602 & 3.589 .635 & 3.044 .177 & 2.024.546 & 2.029 .760 \\
\hline 10 & ollanda & 3.589 .882 & & & & 3.244 .429 & & 2.461 .371 & & 3.143 .835 \\
\hline 11 & $\begin{array}{c}\text { Suudi } \\
\text { Arabistan } \\
\end{array}$ & 3.174 .370 & 3.472 .514 & 3.047 .134 & 3.191 .482 & 3.676 .612 & 2.763 .476 & 2.217 .646 & 1.768 .216 & 2.201 .875 \\
\hline 12 & İsrail & 2.955 .889 & 2.698.139 & 2.950 .902 & 2.649 .663 & 2.329 .531 & 2.391 .148 & 2.080 .148 & 1.522 .436 & 1.935 .235 \\
\hline 13 & Misir & 2.733 .709 & 3.124 .876 & 3.297 .538 & 3.200 .362 & 3.679 .195 & 2.759 .311 & 2.250 .577 & 2.599 .030 & 1.426 .450 \\
\hline 14 & İsviçre & 2.676 .349 & 5.675 .424 & 3.207 .526 & 1.014 .523 & 2.124 .525 & 1.484 .320 & 2.056 .860 & 3.935 .122 & 2.856 .787 \\
\hline 15 & Romanya & 2.671 .493 & 2.815 .506 & 3.008 .011 & 2.616.313 & 2.495 .427 & 2.878 .760 & 2.599.380 & 2.201 .936 & 3.987 .476 \\
\hline 16 & Polonya & 2.651 .244 & 2.329 .176 & 2.401 .689 & 2.058 .857 & 1.853 .700 & 1.758 .252 & 1.504 .280 & 1.322 .218 & 1.586 .772 \\
\hline 17 & Belçika & 2.548 .345 & 2.557 .805 & 2.939 .108 & 2.573 .804 & 2.359 .575 & 2.451 .030 & 1.960 .441 & 1.795 .682 & 2.122 .434 \\
\hline 18 & Bulgaristan & 2.383 .865 & 1.675 .928 & 2.040 .157 & 1.971 .247 & 1.684 .989 & 1.622 .777 & 1.497 .384 & 1.385 .544 & 2.151 .534 \\
\hline 19 & Çin & 2.328 .774 & 2.414 .790 & 2.861 .052 & 3.600 .865 & 2.833 .255 & 2.466 .316 & 2.269 .175 & 1.600 .296 & 1.437 .204 \\
\hline 20 & Cezayir & 1.736 .489 & 1.825 .875 & 2.078.889 & 2.002.689 & 1.813 .037 & 1.470 .547 & 1.504 .590 & 1.777.198 & 1.613 .644 \\
\hline \multirow[t]{2}{*}{21} & $\begin{array}{c}\text { Rusya } \\
\text { Federasyo } \\
\text { nu }\end{array}$ & 1.733 .218 & 3.588 .331 & 5.943 .014 & 6.964 .209 & 6.680 .777 & 5.992 .633 & 4.628 .153 & 3.189 .607 & 6.483 .004 \\
\hline & Diğerleri & 44.184 .596 & 47.355 .020 & 57.142 .401 & 56.720 .541 & 51.737 .946 & 48.750 .288 & 40.494 .114 & 36.172 .669 & 49.747 .972 \\
\hline
\end{tabular}

Ülke sıralaması; 2016 yılına göre yapılmıştır.

Tablo 2: Türkiye'nin Yıllara ve Ülkelere Göre İhracat Rakamları Kaynak: TÜIK, 2017

Yukarıdaki tabloya bakıldığında 2016 yılı baz alınarak Türkiye'nin yıllara göre en çok ihracat yaptı̆̆ ülkeler sıralanmıştır. Tabloya bakıldığında Türkiye'nin ihracat rakamlarının en yüksek olduğu ülkelerin başında Almanya, İngiltere gibi Avrupa kıtası ülkelerin olduğu görülmektedir. Rusya ise 2016 yılı baz alındığında 21. sirada yer almaktadır. Yıllara göre bakıldığında 2008 yılından itibaren Türkiye'nin Rusya'ya yapmış olduğu ihracatın 2014 yılına kadar düzenli bir şekilde arttığı 2015 ve 2016 yıllarında ise iki ülke arasında ortaya çıkan krizden dolayı düştüğü görülmektedir. 
Ülkelere göre yıllık ithalat (en çok ithalat yapılan 20 ülke)

(Değer: Bin ABD \$ / Value: Thousand US \$)

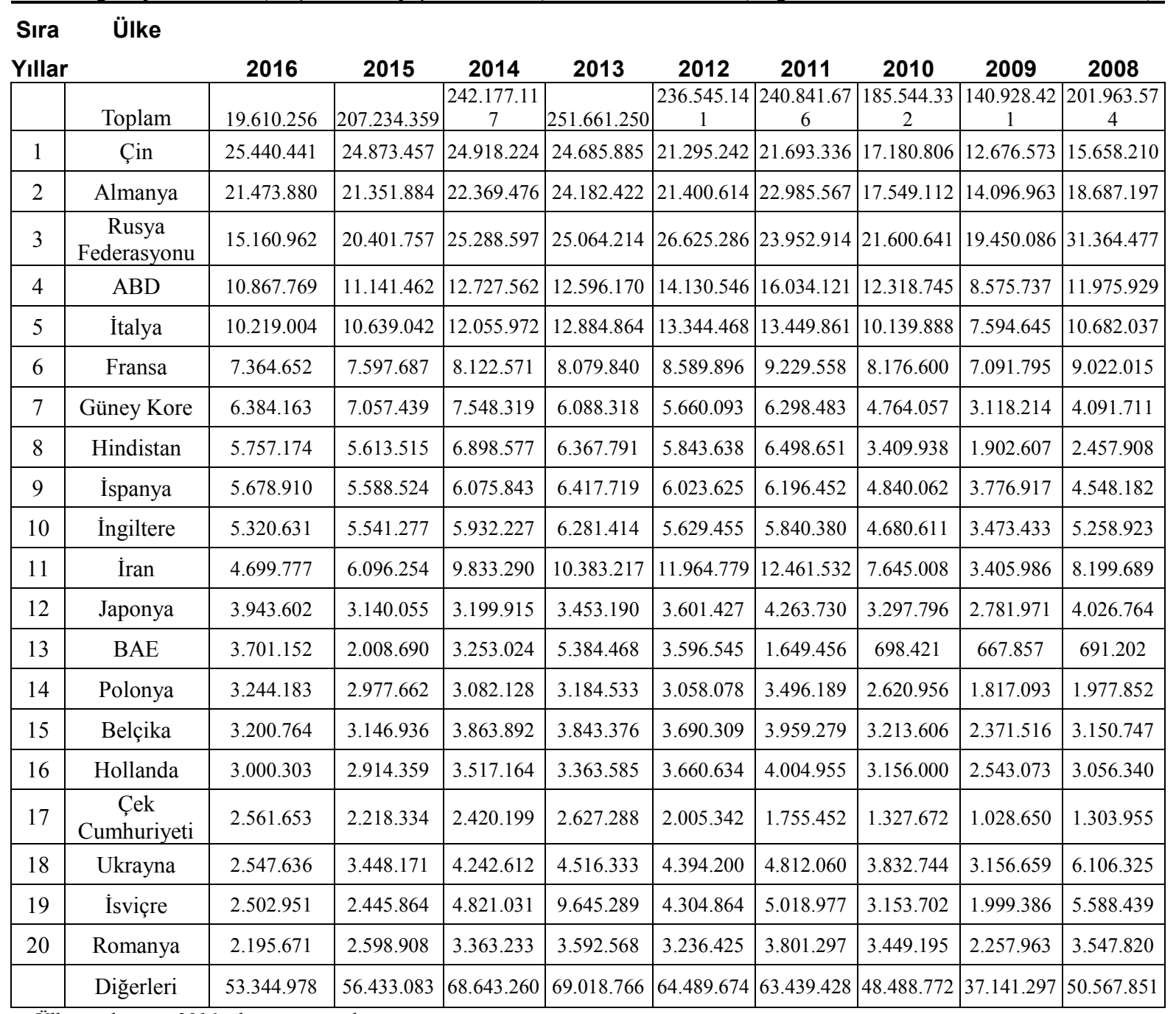

Ülke siralamasl; 2016 yılına göre yapılmıştır.

Tablo 3: Türkiye'nin Yıllara ve Ülkelere Göre Ithalat Rakamları Kaynak: TÜIK,2017

Yukarıdaki tablo incelendiğinde 2016 yılı baz alınarak Türkiye'nin yıllara göre en çok ithalat yaptığı ülkeler sıralanmıştır. Türkiye'nin en çok ithalat yaptığı ülkeler sıralamasında ilk üçte Çin, Almanya ve Rusya'nın bulunduğu görülmektedir. 2008 ile 2014 yılları arasında Türkiye'nin ençok ithalat yaptığı ülkeler arasında Rusya birinci sırada yer almaktadır. 2015 ve 2016 yıllarında ise Türkiye'nin ithalat yaptığı ülkeler arasında Rusya'nın üçüncü sıraya gerilediği görülmektedir.

\begin{tabular}{|c|c|c|c|}
\hline \multicolumn{4}{|c|}{ (Değer: Bin ABD \$ / Value: Thousand US \$) } \\
\hline Yillar & İthalat & İhracat & Diş Ticaret Hacmi \\
\hline 2006 & 137.811 .060 & 301.550 .666 & 439.361 .726 \\
\hline 2007 & 199.725 .960 & 352.266 .400 & 551.992 .350 \\
\hline 2008 & 267.051 .240 & 467.993 .960 & 735.045 .200 \\
\hline 2009 & 170.826 .590 & 301.796 .060 & 472.622 .650 \\
\hline 2010 & 228.911 .660 & 397.067 .520 & 625.979 .180 \\
\hline 2011 & 306.091 .490 & 516.992 .620 & 823.084 .110 \\
\hline 2012 & 316.192 .920 & 524.766 .420 & 840.959 .340 \\
\hline 2013 & 314.945 .100 & 527.265 .920 & 842.211 .010 \\
\hline 2014 & 286.648 .780 & 497.833 .530 & 784.482 .310 \\
\hline 2015 & 182.781 .970 & 343.907 .650 & 526.689 .620 \\
\hline 2016 & 182.261 .660 & 285.491 .050 & 467.752 .710 \\
\hline
\end{tabular}

Tablo 4: Rusya'nın Yıllara Göre Ithalat ve Ihracat Rakamlarl Kaynak: Trademap, 2017 
Yukarıdaki tablo incelendiğinde Rusya'nın dış ticaret hacminin çok büyük olduğu görülmektedir. Rusya ekonomisinin 2008 yılında ortaya çıkan küresel ekonomik krizin sonucunda ihracatının yaklaşık olarak \% 34 azaldığı, ithalatının ise \% 36 oranında azaldığı görülmektedir. Daha sonra 2009 yılından itibaren hızla yeniden artmaya başlayan ithalat ve ihracat rakamlarının, 2014'ten sonra AB ülkelerinin uyguladığı ambargo ve bölgede meydana gelen olaylar nedeniyle tekrar düşüşe geçtiği görülmektedir.

Genel olarak Rusya'nın yapmış olduğu ihracat ve ithalat rakamları şu şekilde değerlendirilebilir.2016 verilerine göre Rusya'nın en çok ihracatı Hollanda, Çin ve Almanya’ya yaptı̆̆ı görülmektedir. 2016 verilerine göre Rusya'nın en çok ihracat yaptığı ülkeler arasında Türkiye'nin beşinci sırada olduğu görülmektedir. Rusya'nın Türkiye'ye yaptığı ihracat 2008 yılında yaşanan küresel ekonomik kriz ile diğer ülkelerle olduğu gibi sert bir düşüş yaşamıştır. Türkiye'ye yapılan ihracatın 2009 yılından itibaren tekrar yükselişe geçtiğgi ve bu yükselişin 2014 yılına kadar sürdüğü, 2014 yılından itibaren tekrar düşüşe geçtiği görülmektedir. Rusya’nın 2013 yılında kadar genel olarak artan ihracatının 2014 yılından itibaren hızla düştüğü görülmektedir.

Ülkelere ve yıllara göre Rusya'nın yapmış olduğu ithalat rakamlarına bakıldığında Rusya'nın 2016 yılında en çok ithalatı Çin, Almanya ve ABD'den yapmış olduğu görülmektedir. Bu sıralamada Türkiye yaşanan krizden dolayı alt siralarda yer almaktadır (Trademap, 2017).

\begin{tabular}{|c|c|c|c|c|}
\hline \multicolumn{5}{|c|}{} \\
\hline Y1llar & İhracat & Yillık Değișim & İthalat & Y1llik \\
\hline 2007 & 1.733 .218 & $\ldots$ & 23.508 .494 & $\ldots$ \\
\hline 2008 & 3.588 .331 & $107,0 \%$ & 31.364 .477 & $33,42 \%$ \\
\hline 2009 & 5.943 .014 & $65,6 \%$ & 19.450 .086 & $-37,99 \%$ \\
\hline 2010 & 6.964 .209 & $17,2 \%$ & 21.600 .641 & $11,06 \%$ \\
\hline 2011 & 6.680 .777 & $-4,1 \%$ & 23.952 .914 & $10,89 \%$ \\
\hline 2012 & 5.992 .633 & $-10,3 \%$ & 26.625 .286 & $11,16 \%$ \\
\hline 2013 & 4.628 .153 & $-22,8 \%$ & 25.064 .214 & $-5,86 \%$ \\
\hline 2014 & 3.189 .607 & $-31,1 \%$ & 25.288 .597 & $0,90 \%$ \\
\hline 2015 & 6.483 .004 & $103,3 \%$ & 20.401 .757 & $-19,32 \%$ \\
\hline 2016 & 4.726 .853 & $-27,1 \%$ & 15.160 .962 & $-25,69 \%$ \\
\hline
\end{tabular}

Tablo 5: Türkiye'nin Rusya'ya Yapmış Olduğu Genel İhracat Ve İthalat Rakamları

Yukarıdaki tabloda Türkiye'nin Rusya’ya yapmış olduğu genel ihracat ve ithalat rakamlarının özeti verilmiştir. Bu rakamlara göre iki ülke arasındaki ticaretin dönemsel olarak değiştiği ara sıra yükselişe geçtiği ve ara sıra düşüşe geçtiği gözlemlenmektedir. İki ülke arasındaki ticaret hacmi 2008 yılında 35 milyar \$ dolar seviyesine kadar çıkmış, 2015 yılına kadar 30 milyar dolar seviyesinde seyretmiş ancak 2015 ve 2016 da düşüşe geçerek 2016 yılı sonu itibariyle 20 milyar \$ seviyesinde gerçekleşmiştir.

Türkiye ile Rusya arasında geçmişten günümüze kadar birçok alanda işbirliğine gidilmiş ve birçok alanda ortaklık sözleşmeleri imzalanmıştır. Bu günü kadar iki ülke arasındaki ticaret hacmi zaman zaman artmış zaman zaman da azalmıştır. İki ülke arasında birçok alanda ticaret yapılmaktadır.

\begin{tabular}{|l|c|c|c|}
\hline \multicolumn{1}{|c|}{ Ihracat Ürünleri } & 2016 & 2015 & 2014 \\
\hline Yenilen meyveler ve sert kabuklu meyveler & 344.008 .290 & 599.918 .272 & 622.404 .132 \\
\hline $\begin{array}{l}\text { Kazanlar, makinalar, mekanik cihazlar ve aletler, nükleer reaktörler, } \\
\text { bunların aksam ve parçaları }\end{array}$ & 185.653 .524 & 317.958 .100 & 577.387 .391 \\
\hline $\begin{array}{l}\text { Motorlu taşıtlar, traktörler, bisikletler, motosikletler ve diğer kara } \\
\text { taşıtları, bunların aksam parça, aksesuarları }\end{array}$ & 170.226 .425 & 213.328 .879 & 646.688 .858 \\
\hline $\begin{array}{l}\text { Elektrikli makina ve cihazlar, ses kaydetme- } \\
\text { verme, televizyon görüntü-ses kaydetme-verme cihazları, aksam- } \\
\text { parça- aksesuar }\end{array}$ & 93.745 .788 & 137.888 .739 & 329.594 .495 \\
\hline Plastikler ve mamulleri & 86.242 .578 & 186.083 .858 & 307.274 .945 \\
\hline Örülmemiş giyim eşyası ve aksesuarı & 57.602 .512 & 82.465 .148 & 113.027 .635 \\
\hline Demir veya Çelikten Eşya & 55.201 .296 & 93.342 .039 & 136.649 .696 \\
\hline Örme giyim eşyası ve aksesuarı & 45.592 .856 & 168.761 .022 & 147.542 .354 \\
\hline Adi metallerden çeşitli eşya (kilit, kasa, mobilya tertibatı, vb.) & 41.329 .772 & 56.809 .182 & 73.715 .214 \\
\hline $\begin{array}{l}\text { Balıklar, kabuklu hayvanlar, yumuşakçalar } \\
\text { ve suda yaşayan diğer omurgası hayvanlar }\end{array}$ & 40.049 .816 & 41.698 .691 & 56.382 .975 \\
\hline
\end{tabular}

2016 yılı rakamları baz alınarak sıralanmıştır (\$ para birimi kullanılmıştır).

Tablo 6: Türkiye'nin Rusya'ya Yapmış Olduğu Genel İhracat Ürünleri ve Rakamları Kaynak: www.tuik.gov.tr, 2017 


\begin{tabular}{|c|c|c|c|}
\hline İthalat Ürünleri & 2016 & 2015 & 2014 \\
\hline $\begin{array}{l}\text { Mineral yakıtlar, mineral yağlar ve bunların damitılmasından elde edil } \\
\text { en ürünler, bitümenli maddeler, mineral mumlar }\end{array}$ & 8.450 .321 .021 & 12.940 .487 .002 & 16.493 .399 .535 \\
\hline Demir ve çelik & 2.235 .425 .518 & 2.743 .811 .173 & 2.689 .168 .658 \\
\hline $\begin{array}{l}\text { Hayvansal ve bitkisel katı ve sıvı yağlar, } \\
\text { yemeklik katı yağlar, hayvansal ve bitkisel mumlar }\end{array}$ & 728.732 .183 & 797.549 .761 & 875.510 .440 \\
\hline Alüminyum ve alüminyumdan eşya & 626.850 .442 & 868.411 .713 & 1.10 .816 .394 \\
\hline Hububat & 598.326 .741 & 883.134 .456 & 1.451 .392 .056 \\
\hline Bakır ve bakırdan eşya & 511.094 .882 & 178.559 .380 & 178.559 .380 \\
\hline Gübreler & 271.984 .691 & 216.983 .068 & 363.275 .927 \\
\hline $\begin{array}{l}\text { Gıda sanayiinin kalıntı ve döküntüleri, } \\
\text { hayvanlar için hazırlanmış kaba yemler }\end{array}$ & 270.598 .565 & 264.429 .713 & 288.149 .280 \\
\hline Ağaç ve ahşap eşya, odun kömürü & 220.514 .248 & 212.973 .442 & 179.223 .242 \\
\hline Kağıt ve karton, kağıt hamurundan, kağıttan veya kartondan eşya & 159.358 .865 & 151.585 .852 & 201.115 .216 \\
\hline
\end{tabular}

Tablo 7: Türkiye'nin Rusya'dan Yapmış Olduğu Genel İthalat Ürünleri ve Rakamları Kaynak: www.tuik.gov.tr, 2017

Türkiye'nin son üç yılda Rusya'ya yapmış olduğu ihracat ve ithalat ürünlerinin en yüksek rakamlara sahip on tanesinin adı ve miktarı tablo 6 ve tablo 7'da görülmektedir. Tablolarda rakamlar sıralanırken 2016 yılı rakamları baz alınmıştır. Tablo 6'ya bakıldığında Türkiye'nin Rusya'ya yapmış olduğu ihracat ürünleri arasında ilk sırayı yenilen meyveler ve sert kabuklu meyveler aldığı ondan sonra da sirasıyla mekanik cihazlar ve aletlerin, motorlu taşıtlar ve aksesuarların, elektrikli makina ve cihazların olduğu görülmektedir. Türkiye'nin Rusya'dan ithal ettiği ürünlere bakıldığında tablo 7 da yer aldığı üzere; ilk sırayı açık ara farkla mineral yakıtlar ve mineral yağların aldığı ve bu ürünleri demir ve çelik, hayvansal ve bitkisel katı ve sıvı yağlar, alüminyum ve alüminyumdan eşyadan yapılmış ürünlerin izlediği görülmektedir. Türkiye'nin mineral yakıtlar konusunda zengin olmadığı ve ihtiyacının büyük bir kısmını Rusya'dan ithal ettiği görülmektedir.

\section{Türkiye ile Rusya Arasında Ticaret Hacmi Bulunan Hizmet ve Mallar}

Türkiye ile Rusya arasında ticaret hacmi bulunan birçok mal, hizmet ve ürün bulunmaktadır. Bunlar arasında ticari değeri Türkiye açısından yüksek olan hizmet ve ürünlerden; müteahhitlik hizmetleri, ençok ihracatı ve ithalatı yapılan tarım ürünleri ve turizm hakkında ayrıntılı bilgi aşağıda verilmiştir.

\subsection{Müteahittlik Hizmetleri}

Türk müteahhitlik sektörünün şimdiye kadar Rusya'da üstlendiği projelerin bedeli yaklaşı 64 milyar ABD Dolarıdır. Türk müteahhitlik sektörünün yurtdışında üstlendiği projelerin \% 20'si Rusya'dadır. Böylece Rusya Türkiye müteahhitlik firmalarının en fazla proje üstlendiği ülke konumundadır. Türk müteahhitlik sektörü 2015 yılında Rusya'da 4.3 milyar ABD Doları değerinde proje üstlenmiştir. Uçak krizi sonrasında Türkiye'ye karşı uygulanan ekonomik engellemeler kapsamında Türk firmalarının müteahhitlik ve müşavirlik sektöründe faaliyette bulunmasının yasaklanması, keza Türk vatandaşlarına yönelik olağandışı idari tedbirlerin uygulanması önümüzdeki dönemde Türk müteahhitlik sektörü açısından olumsuz gelişmeler olarak öne çıkmaktadır. (Moskova 2017) Rus hükümeti kendi ülkesine ait firmaları her ne kadar desteklese de batılı bazı firmaların bu konuda ki tecrübesine ve teknolojisine ihtiyaç duymaktadır. Çünkü Rus firmaları bu konuda henüz istenilen düzeye gelmemiştir.

\subsection{Tarım}

Tarımsal dış ticarette Türkiye'nin en önemli partnerlerinden birisi Rusya Federasyonu. Türkiye, yaptığı tarım ürünleri ihracatının ortalama yüzde 7'sini Rusya'ya gerçekleştiriyor. En fazla ihraç edilen ürün grubu ise yaş meyve ve sebze. Yaş meyve ve sebze ihracatında Rusya'nın payı yüzde 40 seviyelerinde seyrederken bazı ürünlerde yüzde 60 düzeyinde. Türkiye, Rusya Federasyonu'ndan tarım ürünü olarak en çok buğday ve ayçiçeği ithal ediyor.(Dünya,2017)Türkiye'nin Rusya'ya yaptı̆̆ı ihracat ürünlerinin başlıcaları şöyledir: Domates, Üzüm, Mandalin, Limon, Portakal, Çilek, Nar, Vişne. 2016 yılı verilerine bakıldı̆̆ında Türkiye'nin Rusya'ya yapmış olduğu yaş meyve ve sebze ihracatının 344 milyon $\$$ olduğu görülmektedir.

Türkiye'den Rusya'ya yaş meyve ve sebze ihracatı olduğu gibi Rusya'dan da Türkiye'ye ayçiçeği ve ayçiçek yağı gibi ürünler ihraç etmektedir. Türkiye ile Rusya arasında tarım ticareti hacmi yaklaşık olarak 3,5 milyar dolar olduğu bilinmektedir. Her geçen gün iki ülke arasındaki işbirliğinin artması ile birlikte tarım ticaretinin de artması beklenmektedir.

\subsection{Turizm}

Türkiye ve Rusya arasındaki bir başka önemli ticari araç ise turizmdir. Özellikle iki ülke arasında yapılan işbirliği anlaşması, turizm sektörünü çok olumlu bir şekilde etkilemiş gibi görünmektedir. 


\begin{tabular}{|c|c|c|c|c|}
\hline Y1lar & $\begin{array}{c}\text { Toplam Gelen } \\
\text { Turist }\end{array}$ & $\begin{array}{c}\text { Rusya'dan Gelen } \\
\text { Turist }\end{array}$ & $\begin{array}{c}\text { Toplam gelir } \\
\text { (bin\$) }\end{array}$ & $\begin{array}{c}\text { Rus Turistlerden Gelen } \\
\text { Gelir (bin\$) }\end{array}$ \\
\hline 2012 & 36.463 .921 & 2.647 .090 & 29.007 .003 & 2.105 .757 \\
\hline 2013 & 39.226 .226 & 3.049 .036 & 32.308 .991 & 2.511 .363 \\
\hline 2014 & 41.415 .070 & 3.451 .749 & 34.305 .904 & 2.859 .234 \\
\hline 2015 & 41.617 .531 & 2.842 .972 & 31.464 .777 & 2.149 .418 \\
\hline 2016 & 31.365 .330 & 683.335 & 22.107 .440 & 481.640 \\
\hline
\end{tabular}

Tablo 8: Türkiye'ye Gelen Turist Sayısının Yıllara Göre Dă̆llımı Kaynak: www.tuik.gov.tr, 2017

TÜİK verilerine bakıldığında 2012 yılında 2647090 Rus turistin Türkiye’ye geldiği ve bu turistlerin yaklaşık olarak ülke ekonomisine 2.105.757 bin\$ katkı sağladığı görülmektedir. 2014 yılına kadar hem gelen turist sayısının arttığı ve hem de Türkiye ekonomisine yaptığı katkının arttığ1 görülmektedir. 2014 yılında Rus ekonomisindeki daralmanın etkisiyle 2015 yılında Türkiye'yi ziyaret eden Rus vatandaşlarının sayısı 2 milyon 842 bine gerilemiştir. 2015 yılının sonunda yaşanan uçak krizi ile Türkiye’ye yönelik charter seferlerin ve paket turların yasaklanması, tarifeli seferlerle bireysel ziyaretler mümkün olsa dahi, ülkemize yönelik Rus turist sayısında kayda değer miktarda azalmaya yol açmıştır. 2016 yılında ise Türkiye’ye gelen Rus Turist sayısının 680 bine kadar düştüğü görülmektedir. Yaşanan krizin çözülmesi ile birlikte önümüzdeki yıllarda Türkiye’ye gelen turist sayısının tekrar eski düzeye çıkması beklenmektedir.

\subsection{Enerji}

Günümüzde tükettiği enerji kaynaklarından yarısını ithal etmekte olan Türkiye'de uygulanan enerji politikaları, dünya enerji sektörünün genel yapısından büyük ölçüde etkilenmektedir. Türkiye'de tüketilen birincil enerjinin \%39'u petrol, \%27'si doğalgaz, \%27'si kömür ve \% 13'ü yenilenebilir enerji kaynaklarından sağlanmaktadır. Enerji tüketiminde ithalatın payı \%70 düzeyindedir. Enerji açısından yüksek orandaki dışa bağımlılığın yanı sıra, doğal gaz ithalatının \%65'i Rusya Federasyonundan yapılmaktadır.(Bayraç,2009) Bu nedenle Türkiye açısından enerji ihtiyacının karşılanması için Rusya önemli bir yer tutmaktadır. Türkiye'nin Rusya'dan yapmış olduğu ithalatta en önemli payı petrol gazları ve doğalgaz almaktadır.

\section{Sonuç ve Tartışma}

Türkiye ve Rusya bölgenin en güçlü devletleri arasında görülen iki ülkedir. Bu iki ülkenin ilişkileri bölgede bulunan tüm devletlere yansımaktadır. Bölgede istikrarın olması, barış ve güven ortamının oluşmasında direk etki edebilen bu iki ülkenin işbirliği, ticari dengelerin kurulmasında da en önemli unsurlardan biridir. Rusya'nın sahip olduğu enerji kaynakları ve Türkiye'nin bulunduğu jeopolitik konum iki ülkenin değerini her zaman arttırmaktadır.

İki ülke arasında yeteri kadar görülmese de bir işbirliğinin olduğu görülmektedir. İki ülke birbirine ihtiyacı olan ülkelerdir. Peki, neden bu iki ülke birbirine ihtiyaç duymaktadır? Türkiye'nin kendi kendine yetecek kadar petrol ve doğalgaz rezervlerinin olmayışı ülkeyi dışa bağımlı halde tutmaktadır. Bölgede en güçlü devletlerden biri konumunda bulunan Rusya'yı yanında görmek istemesi Türkiye'yi Rusya ile işbirliğine iten en önemli nedenlerden bir kaç tanesidir. Öte yandan Rusya ise bölgedeki diğer güçlü bir devlet olan ve bulunduğu jeopolitik konumu nedeniyle önemli bir yer tutan Türkiye'yi yanında tutmak istemesi gayet doğaldır. Bu nedenlerden ötürü Türkiye ile Rusya arasında bir işbirliğinin bulunması beklenen bir gelişme olarak değerlendirilmektedir.

Türkiye'nin ekonomik ve ticari ortakları içerisinde Rusya önemli bir yere sahiptir. İki ülke arasındaki ticaret hacmine bakıldığında, bu ticaret hacminin hiç de önemsenmeyecek bir boyutta olmadığı görülmektedir. Zaman zaman dalgalanmalar yaşansa da son zamanlarda iki ülke arasındaki işbirliğinin ve ticaret hacminin giderek arttı̆̆ görülmektedir. 2008 yılında tarihin en yüksek seviyesine ulaşan yaklaşık olarak 35 milyar dolar olan iki ülke arasındaki ticaret hacmi, daha sonra zaman zaman dalgalanmalar yaşamış olsa da 2015 yılına kadar 30 milyar seviyesinde gerçekleşmiştir. 2015 yılında hedef olarak yakın gelecekte 100 milyar dolar seviyesine ulaşılması konulmuştu. Ancak 2015 yılı sonunda yaşanan uçak krizi ile birlikte iki ülke ilişkileri son derece olumsuz bir şekilde etkilenmiş ilişkiler durma seviyesine gelmiştir. 2016 yılı haziran ayına kadar iki ülke arasındaki ekonomik ilişkiler karşılıklı yaptırımlarla minimum seviyeye gelmiştir. 2016 Haziran ayında iki ülke liderinin artık bu durumu düzeltme zamanının geldiğini belirterek, Türkiye Cumhurbaşkanının ilk adımı atması ile birlikte iki ülke ilişkilerinde yumuşama dönemi başlamış ardından da hızla ilişkileri tamir etme sürecine girilmiştir. 2016 y1lı sonunda iki ülke arasındaki ticaret hacmi 20 milyar düzeyinde kaldı. 2016 yılı verilerine bakıldığında Türkiye'nin ithalat yaptığı ülkeler arasında Rusya'nın üçüncü sırada olduğu görülmektedir. Türkiye enerji konusunda dışa bağımlı olan ve ihtiyacının büyük bir bölümünü Rusya'dan satın alan bir ülkedir. Türkiye'nin özellikle petrol ürünleri ve doğalgaz ihtiyacının büyük bölümünü Rusya'dan karşılaması Türkiye'nin ithalat yaptığı ülkeler arasında Rusya'yı üçüncü sıraya çıkarmıştır. Türkiye'nin ihracat yaptığı ülkeler arasında da Rusya'nın 2014 yılında beşinciliğe kadar çıktığı ancak daha sonra yaşanan krizler nedeniyle alt basamaklara düştüğü görülmektedir.

Başka bir bakış açısıyla bakıldığında Türkiye ve Rusya ilişkilerinin aynı zamanda dünyadaki diğer olaylardan da etkilendiği gözlenmektedir. 2008 yılındaki küresel ekonomik kriz tüm Dünya’yı etkilediği gibi Türkiye ve 
Rusya ekonomisini de olumsuz yönde etkilemiştir. Aynı şekilde, 2011 yılında Suriye ortaya çıkan karışıklık ve savaş ortamı iki ülkenin hem siyasi hem de ticari ilişkilerine yansımıştır. Rusya'nın Suriye'ye sahip çıkması, Türkiye'nin ise Suriye'deki muhalefete ve halka sahip çıkması iki ülke arasında gerilim yaratmıştır. Bu ilişkiler doğrudan iki ülke arasındaki ticareti de olumsuz etkilemiş ve 2011 yılından sonra iki ülke arasında gerçekleşen ithalat ve ihracat miktarlarına da olumsuz yönde yansımıştır. İki ülke ilişkilerinin daha da gelişmesi ve ticaret hacminin artmasına Suriye krizi engel olmuştur.

Genel olarak iki ülke arasındaki ilişkiler incelendiğinde, iki ülkenin dünyanın hızlı gelişen, büyüyen ekonomilerine sahip oldukları ve bölgede etkin söz sahibi oldukları görülmektedir. Önümüzdeki y1llarda bu iki ülkenin ekonomik alanda yapacağ işbirliği sayesinde küresel ekonomide önemli rol alacağı konuşulmaktadır. İki ülke arasında hedeflenen yüksek ticari işbirliğinin gelecekte ekonomilerinin çok daha büyüyeceğine ve bölgede çok farklı ticari ortaklıkların kurulmasına işaret etmektedir.

\section{Kaynakça}

- Bayraç H.Naci, 2009,” Küresel Enerji Politikaları ve Türkiye: Petrol ve Doğal Gaz Kaynakları Açısından Bir Karşılaştırma”, Eskişehir Osmangazi Üniversitesi Sosyal Bilimler Dergisi, 10(1)

- Dünya, 2017, http://www.dunya.com/kose-yazisi/rusya-ile-tarimda-yeni-donem/28987

- Ekonomi,2016,http://www.ekonomi.gov.tr/portal/faces/oracle/webcenter/portalapp/pages/content/htmlViewe rUlkeler.jspx;jsessioni

- Korhan Tuğba, 2012 “Türkiye Cumhuriyeti’nin İlk Yıllarında Türk-Rus Ticari Ve Ekonomik İliskileri Üzerine”, Sosyal Bilimler Enstitüsü Dergisi, Cilt / Volume 1.Sayı / p: 24

- Morfikirler, 2013, http://morfikirler.com/yazi/rusyanin-turkiye-ile-ticareti

- Moskova,2017, http://moskova.be.mfa.gov.tr/ShowInfoNotes.aspx?ID=219659

- Şen Cihangir Gürkan, 2003 “Türk - Rus Ekonomik İlişkileri: Mevcut Durum, Sorunlar ve Perspektıfler”, Stradigma.com (Aylık Stateji ve Analiz e-Dergisi), Say1 7, ISSN 1303: 9804, s.3.

- Trademap, 2017, http://www.trademap.org/Country_SelProductCountry_TS.aspx?nvpm

- TÜIK, 2017, http://www.tuik.gov.tr/PreTablo.do?alt_id

- $\quad$ TÜİK, 2017, http://www.tuik.gov.tr/UstMenu.do?metod=temelist

- TÜİK, 2017, https://biruni.tuik.gov.tr/disticaretapp/menu.zul

- TÜİK, 2017, https://biruni.tuik.gov.tr/medas/?locale=tr 


\title{
Ağırlıklı Ortalama Fonlama Maliyetinin BIST100, BISTXBANK ve Döviz Kuru Üzerine Etkisinin Analiz Edilmesi Analysis of the Effect of Weighted Average Cost of the CBRT
Funding on BIST100 Index, BISTXBANK Index and Exchange
Rate
}

\author{
Asst. Prof. Dr. Serdar Kuzu (Istanbul University, Turkey) \\ Ph.D. Candidate H. Muhammet Kekeç (Istanbul University, Turkey)
}

\begin{abstract}
This study is found to find out how Weighted Average Funding Cost, which is new policy tool implemented by The Central Bank of Turkey (CBRT) in 2011, weighted average funding cost -aiming at removing the ambiguities seen in the financial variables and minimizing the effect of capital movements on these variables is reviewed.

In this study, the effects of the interest rate policy of the Central Bank of the Republic of Turkey (CBRT) on BIST100 index, BISTXBANK index and exchange rate are tested by Augmented Dickey Fuller Test (ADF), MLGARCH and DCC GARCH models based on ENGLE, R.F. and SHEPPARD, K. (2001).

According to the findings obtained, it is concluded that the decisions of the Weighted Average Funding Cost related to Central Bank of the Republic of Turkey (CBTR) lending and borrowing interest rates are direct effective on BIST100 index, BISTXBANK index but indirect with Exchange rate.
\end{abstract}

\section{Giris}

Para politikalarıyla ekonomiye yön verme hususunda merkez bankasının belirlediği kısa vadeli faiz oranları ile piyasa parametreleri ilişkisi büyük önem arz etmektedir. Geçmişten Günümüze kadar dönemlerde yaşanan finansal krizler sonrasında gelişmekte olan ülkelerin piyasaları global para politikalarına karşı daha kırılgan hale gelmiş̧ir. Sermaye akımlarında ve risk iştahında yaşanan değişimlerin etkin bir şekilde piyasalara yansıdığı için, belirsizliği arttırarak ülkelerin makroekonomik istikrarı sekteye uğratabilmektedir. Yaşanan bu süreç içerisinde beklenmedik durumlarda sağlkklı bir tepki verilmesini sağlayacak bir aracın gereksinimini ortaya koymuştur. Merkez bankalarının uyguladıkları ya da sözlü yönlendirmeler ile yapmaya çalıştıkları önlemler finansal göstergeler üzerinde etkisini gösterebilmektedir. İşte bu noktada Ağılıklı ortalama fonlama maliyeti (AOFM) Merkez Bankası'nın piyasada oluşan faizlere yön vermek ve bu yolla enflasyonu denetlemek için kullandığı araçtır. Özellikle Türkiye gibi piyasanın lokomotifi görevinin bankalar tarafından sağlandığı ülkelerde bu durum önemli rol oynayabilmektedir.

TCMB'nin Ağırlıklı Ortalama Fonlama Faizi, Merkez Bankasının farklı vadelerdeki faiz enstrümanlarını bir arada kullanması dolaysıyla efektif fonlama faizi TCMB'nin piyasayı fonladığı farklı faizlerin ağırlıklı bir ortalaması olarak hesaplanan faizdir. Bu faiz piyasaya sağlanan fonlamanın ortalama maliyetine ilişkin önemli bir gösterge niteliği taşımaktadır. Merkez Bankası bankalara ya Haftalık repo ihalesi yaparak ya da Gecelik fonlama yapmak üzere iki şekilde borç vermektedir. Bir Haftalık vadeli repo ihalesinde Merkez Bankası, borç almak isteyen bankaların ellerindeki menkul değerleri(tahvilleri) bir haftalığına ödünç almakta ve karşılığında onlara ihalede elde etkileri miktar karşılı̆̆ında belirli bir yüzdede borç para verilmektedir. Bir hafta vadeli repo ihalesi miktar ihalesi yöntemi ile piyasanın likidite ihtiyacına göre yapılmakta ve Likidite ihtiyacının bir bölümünü karşılayan bir hafta vadeli repo ihaleleri aracılığıyla gecelik faizin, faiz koridoru içinde ve Para Politikası Kurulu tarafindan belirlenen düzeylerde gerçekleşmesi sağlanmaktadır. Bir haftalık vadeli repo ihalesi sonunda bankalar Merkez Bankasından ödünç aldıkları parayı faiziyle birlikte iade edip menkul değerlerini geri alıyorlar.

Gecelik fonlamada bir başka değişle Gecelik işlemlerde uygulanan faizde bankalar Merkez Bankasından belirli bir yüzde faizle bir geceliğine ödünç para alıp bunu ertesi gün faiziyle birlikte iade etmektedirler. Gecelik fonlama faizi TCMB'nin, gecelik olarak borç almak ya da gecelik olarak borç vermek isteyen bankalara uyguladığı faiz türüdür. Merkez Bankasının ilan ettiği borç alma faiz oranı 'taban' ișlevi görürken, borç verme faiz oranı ise 'tavan' işlevi görmektedir. Bu ikisi arasında oluşan aralığa da 'faiz koridoru' adı verilmektedir. Gecelik faiz oranları söz konusu tavan ve taban oranlar arasında yani bir diğer ifadeyle faiz koridoru içinde gerçekleşmektedir. Burada yapılmak istenen durum bankaların her gün açık vermeden hesaplarını kapatması gereğidir. Burada borçlanma sadece tek taraflı olmayıp, bankaların ellerinde likidite fazlalığı oluşması halinde limitsiz olarak TCMB borçlanma faiz oranından Merkez Bankasına TL borç verebilmektedirler.

Merkez Bankasının birde görünmez ama asıl faizi olarak nitelendirilen Merkez Bankası Ağırlıklı Ortalama Fonlama Maliyeti vardır. Bu faizin görünmez ya da asıl faiz olarak görülmesinin nedeni AOFM nin bankaları fonlamada uygulanan bir çeşit ortalama faiz görevi görmesidir. Buradan hareketle bu çalışmada TCMB'nin piyasaya vermiş̧ olduğu likidite çerçevesinde oluşan faiz oranının yani ağırlıklı ortalama fonlama maliyetinin 
BİST100, BİSTXBANK, TL/USD üzerinde merkez bankasının likidite yönetiminin etkisinin analizi amaçlanmaktadır. Ağırlıkıı Ortalama Fonlama Maliyeti, Merkez Bankasının, gecelik borç verme faizi ile haftalık repo faizinin (politika faizi) ağırlıklı ortalaması alınarak hesaplanmaktadır.

\section{Literatür Taraması}

Campbell ve Ammer (1991), 1952-1987 dönemini kapsayan ve log-doğrusal varlık fiyatlama ve VAR modelini uyguladıkları çalışmalarında; hisse senetlerinin sermaye kazançlarının, enflasyonun, faiz oranlarının gelecekte beklenen değerlerin hisse senedi piyasasında ilişki derecesi ortaya konmaya çalışılmışıtır. Çalışmaya sonucunda; uzun vadeli finansal varlıkların enflasyonun gelecekteki beklenen değerinden etkilendiği ancak reel faiz oranlarının uzun vadeli finansal varlıklar üzerinde etkileri sınırlı kaldığı sonucunu gözlemlemişlerdir..

Ehrmann vd (2005), 1989-2004 yılları arasında yaptıkları çalışmada ABD'de tahvil getirileri ve hisse senedi piyasalarının kısa vadeli faiz oranlarından daha fazla etkilendiğini gözlemlemişlerdir.

Kholodilin vd (2009), yaptıkları çalışmada, Faiz oranlarında yaşanan beklenmedik bir artışın hisse senedi getirileri üzerinde olumsuz etki yarattığı sonucuna ulaşmışlardır.

Gilmore vd (2009) Amrekida altın fiyatları, altın şirketlerinin borsa fiyatları ve fiyat endeksi arasında ilişkiyi ortaya koydukları çalışma yapmışlardır. Çalışma sonucunda ilgili parametrelerin birbirleriyle yüksek bir ilişki olduğu sonucuna varmışlardır.

Mishra vd (2009) Hindistan'da altın fiyatları ve borsa fiyatları arasında ilişkiyi ortaya koydukları çalışma yapmışlardır. Çalışma sonucunda ilgili parametrelerin birbirleriyle herhangi ilişki olmadığı olduğu sonucuna varmışlardır

Kasman, Vardar ve Tunç (2011) yaptıkları çalışmada EKK ve GARCH tahmin yöntemlerini kullanarak faiz oranı ve döviz kurunun Türkiye'deki bankaların hisse getirileri üzerine etkilerini incelemeye çalışmışlardır. Çalışma sonucunda faiz oranı ve döviz kurundaki değişimlerin hisse senetleri üzerinde olumsuz etki yarattı̆̆ı gözlemlenmiştir.

Martínez vd (2015), 1993-2010 dönemlerini kapsayan ve dalgacıklar yöntemi kullanarak İspanya'da faiz oranları ve hisse senedi piyasası arasındaki ilişkiyi incelmek için ortaya koydukları çalışmalarında İspanya hisse senedi piyasalarının faiz oranlarına duyarsız olmadı̆̆ı, bu duyarlılık seviyesinin sektörden sektöre farklılık gösterdiğini ortaya koymuşlardır.

\section{Veri Seti ve Ampirik Bulgular}

Çalışmada 03/01/2011- 10/04/2017 dönemine ait Borsa İstanbul 100 Endeksi, BISTXBANK Endeksi, TL/Dolar Kuru ve Merkez Bankası Ağırlıklı Ortalama Fonlama Maliyetine ait günlük veriler (4580 gözlem) kullanılmıştır. Çalışmada düşünülen enflasyon oranı ve Tahvil faizleri günlük olarak elde olanağı yer olmadığından kapsam dışında bırakılmıştır. Ağırlıklı ortalama fonlama maliyeti (AOFM) Merkez Bankası'nın piyasada oluşan faizlere yön vermek ve bu yolla enflasyonu denetlemek için kullandığı araçtır. Özellikle Türkiye gibi piyasanın lokomotifi görevinin bankalar tarafindan sağlandığı ülkelerde bu durum önemli rol oynayabilmektedir. Bundan yola çıkarak BISTXBANK endeksi de modele dahil edilmiştir.

Söz konusu veriler TCMB-EVDS'den ve Borsa İstanbul veri tabanından elde edilmiştir. Model hesaplama öncesinde öncelikle MGARCH model durağan zaman serilerine ihtiyaç duyduğu için dataların logaritmik ilk farkları hesaplanmıştır. İkinci aşamada Parametrelerin durağanlık gösterip göstermediğini Augmented Dickey Fuller Testi(ADF) kullanılmış olup, ayrıca bazı parametreler durağanlaştırılmıştır. Öncelikle ham dataların durağan olup olmadıklarına bakıldıktan sonra parametrelerin LN leri alınarak durağanlık sağlanmıştır. Dickey Fuller Testi sonucunda dataların durağanlığı sağlanmış olduğunu ortaya çıkarmıştır. Üçüncü aşamada DCC GARCH yani dinamik şartlı korelasyon olup olmadığı konusuna bakılmıştır. Bizim kullandığımız modelde beklentimiz dinamik olması yönünde olduğu için Varyansın günlük olarak değiştiği bir modelde sabit varyans yani consant conditional correlation (CCC) kullanamayız. Burada varyans değişimin zaman nasıl yayıldığı hakkında bizlere onu takip etme firsatı sunmaktadır. MGARCH model durağan zaman serilerine ihtiyaç duyduğu için dataların logaritmik ilk farkları aşağıdaki formülden yola çıkarak hesaplanmıştır

$$
r_{t}=\log y_{t}-\log y_{t-1}
$$

Çalışmada 03/01/2011- 10/04/2017 dönemine ait Borsa İstanbul 100 Endeksi, BISTXBANK Endeksi, TL/Dolar Kuru ve Merkez Bankası Ağırlıklı Ortalama Fonlama Maliyetine ait günlük verilerin yıllar itibariyle gösterdikleri eğilim Grafik 1'de Gösterilmiştir. 


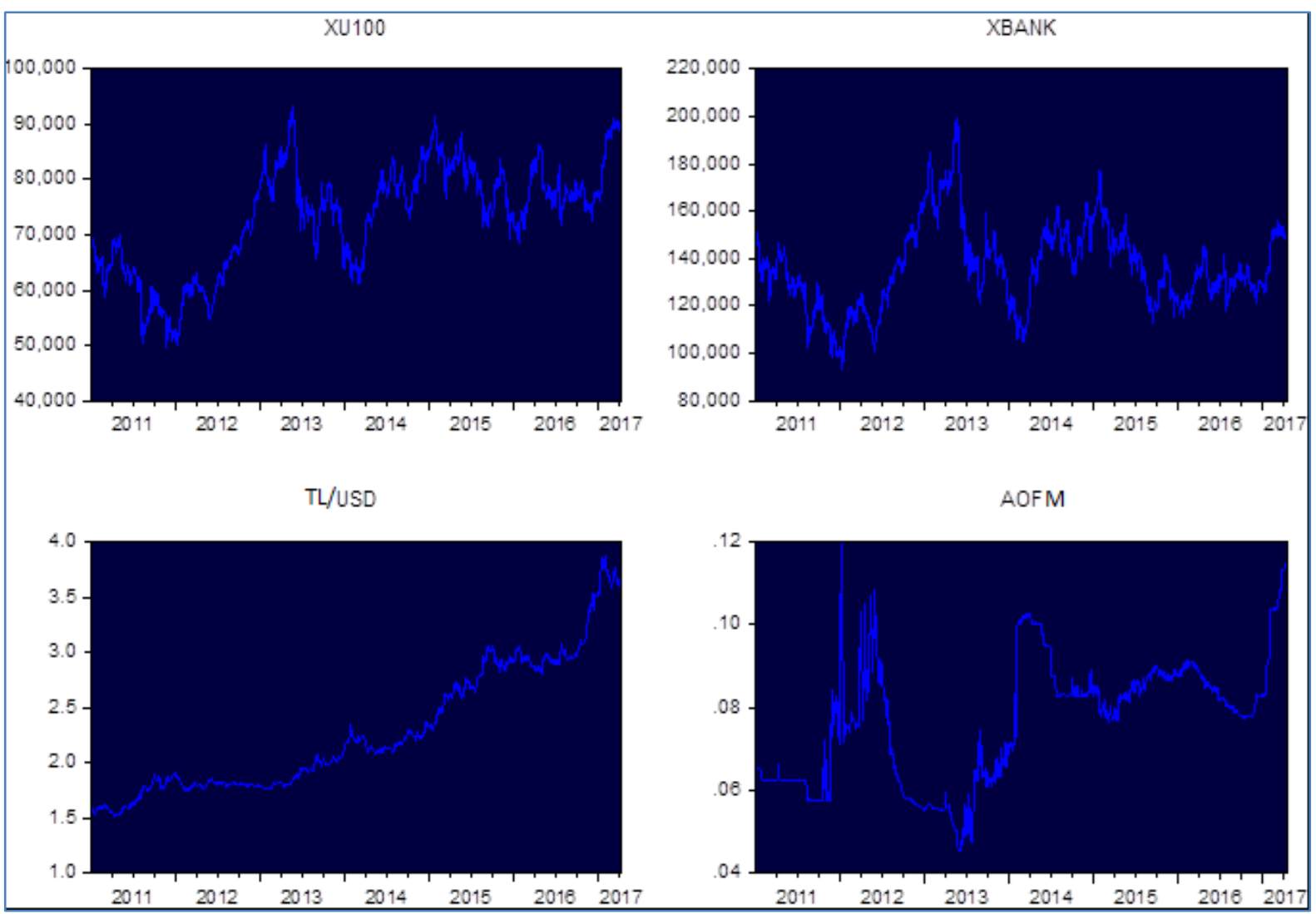

Grafik 1: BIST100, BISTXBANK Endeksi, TL/Dolar Kuru ve Merkez Bankası Ağırlıklı Ortalama Fonlama Maliyetine Ait Günlük Verilerin Ylllar İtibariyle Gösterdikleri Eğilim Kaynak: TCMB, EVDS

Grafikler incelendiğinde değişkenleri yıllar itibariyle gösterdikleri eğilim gösterilmiştir. Grafikler incelendiğinde, düzenli olmayan iniş-çıkışlar görülmektedir. Bu nedenle, serinin durağan olmayan bir yapı içerdiği söylenebilir. Çeşitli parametrelerde oynaklıklar birbirini izlerken bazı dönemlerde AOFM bu doğrusal oynaklıktan farklı bir durum ortaya koyduğu görülmektedir. Bilindiği üzere Volatilite yoğunlaşması finansal zaman serilerinin en önemli özelliklerinden birisidir. Bu durumun en kayda değer sonucu ise varyansın zamana göre değişkenlik göstermesidir.

Günümüzde Dinamik koşullu korelasyon(DCC) yönteminin oldukça güncel ampirik çalışmalarda başarıyla kullanılmaya devam edildiği görülmektedir. Dinamik koşullu korelasyon yönteminin büyük kovaryans matrisleri üzerindeki performans analizi ilk olarak Engle ve Sheppard (2001) tarafından yapılmıştır.

Zaman serilerinin durağan olması olarak ifade edilen şey, zaman içinde varyansın ve ortalamanın sabit olması ve gecikmeli iki zaman periyodundaki değişkenlerin kovaryansının değişkenler arasındaki gecikmeye bağlı olup zamana bağlı olmamasıdır.( Gujarati,1995)

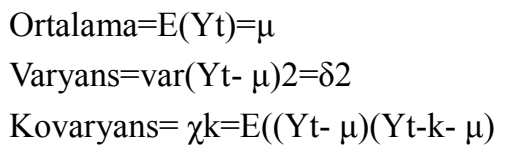

Dickey-Fuller testi, gözlenen serilerde birim kökün varlığının (serinin durağan olmadığı) olup olmadığının belirlenmesinde kullanılan bir testtir. Uygulamalarda serinin birim kök taşıyıp taşımadığının saptanması için mutlak suretle DF (Dickey-Fuller) testinin yapılması şart niteliğinde bulunmaktadır. Dickey-Fuller'in ortaya koyduğu üç denklem türü bulunmaktadır ; (Şimşek ve Halaç, 2003;6).

Sabitsiz trendsiz Dickey-Fuller denklemi $: \Delta \mathrm{Yt}=\gamma \mathrm{Y}(\mathrm{t}-1)+\mathrm{ut}$

Sabitli trendsiz Dickey-Fuller denklemi $: \Delta \mathrm{Yt}=\mathrm{a}+\gamma \mathrm{Y}(\mathrm{t}-1)+\mathrm{ut}$

Sabitli trendli Dickey-Fuller denklemi: $\Delta \mathrm{Yt}=\mathrm{a}+\mathrm{bt}+\gamma \mathrm{Y}(\mathrm{t}-1)+\mathrm{ut}$

Burada ut $=$ stokastic hata terimini ifade etmektedir. Ho $: p=1, H 1: p<1(p-1)=0$ veya $\gamma=0$ durumunda yt serisi bir birim kök içermektedir. Ancak IpI $<1$ durumunda seri durağan olur. Burada Dickey Fuller'da “ T" (tau) istatistiği kullanılmaktadır. Hesaplanan “ $T$ ” değerinin mutlak değeri Dickey-Fuller veya McKinnon DickeyFuller kritik değerlerinin mutlak değerini aşıyorsa, zaman serisinin durağan olduğu hipotezini reddedemeyiz. 'Ho: $\mathrm{p}=1$ ' reddedilirse zaman serisi durağandır 
Parametrelerin durağanlık gösterip göstermediğini Dickey Fuller Testi kullanılmış olup, ayrıca bazı parametreler durağanlaştırılmıştır. Öncelikle ham dataların durağan olup olmadıklarına bakıldıktan sonra parametrelerin LN leri alınarak durağanlık sağlanmıştır. Dikey Fuller Testi sonucunda dataların durağanlığı sağlanmış olduğunu ortaya çıkarmıştır. Dickey fuller testi AOFM ile BIST100 ve USD/TL parametreleri ilgili hipotezler ve işlemin birim kökü olup olmadığını ortaya koymak için Yapılan istatistiki sonuçlar ışı̆̆ında;

Birim kökün varlığının sınanması için kullanılan iki hipotez kullanılmaktadır. Bunlar;

H1: $\gamma<0(\mathrm{p}<1)$ (seride birim kök yoktur.) (seri durağandır.)

$\mathrm{H} 0: \gamma=0(\mathrm{p}=1)$ (seride birim kök vardır.) (seri durağan değildir.)

Dickey-Fuller testinde ' $\Delta \mathrm{yt}=\gamma \mathrm{yt}-1+\mathrm{ut}$ ' regresyonunda yer alan $\gamma$ parametresinin sahip olduğu ' $\mathrm{t}$ ' değerinin, Dickey Fuller Teste hazırlanan " $\mathrm{T}$ ” istatistik tablo değeri ile karşılaştırılarak, önceden hazırlanan Ho ve H1 hipotezlerine göre birim kökün varlığı tespit edilmektedir.

\section{LNAOFM}

H0: İşlemin birim kökü var

H1: İşlemin birim kökü yok

AOFM test istatistiki -18,5965 olup aşağıda yer alan kritik değerler ile değerlendirildiğinde;

$\% 1:-3,4335$

$\% 2:-2,8628$

$\% 3:-2,5675$

\section{LNBIST 100}

H0: İşlemin birim kökü var

H1: İşlemin birim kökü yok

LNBİST100 test istatistiki -49,9004 olup aşağıda yer alan kritik değerler ile değerlendirildiğinde;

$\% 1:-3,4330$

$\% 2:-2,8626$

$\% 3:-2,5673$

LNUSD/TR test istatistiki -45,50715 olup aşağıda yer alan kritik değerler ile değerlendirildiğinde

\section{LN USD/TR}

H0: İşlemin birim kökü var

H1: İşlemin birim kökü yok

LNXBANK test istatistiki -50,4498 olup aşağıda yer alan kritik değerler ile değerlendirildiğinde

\section{LN XBANK}

H0: İşlemin birim kökü var

H1: İşlemin birim kökü yok

Elde edilen ADF birim kök testi sonuçlarına göre LNBİST100, LNOFM, LNXBANK ve LNUSD değişkenlerinin sabitli trendli modele ait test istatistikleri \%1 önem düzeyde kritik değerlerden küçük olduğu için söz konusu değişkenlerin zayıf durağan oldukları görülmüştür. 


\begin{tabular}{|c|c|c|c|c|c|c|c|}
\hline & TR/USD & LNTR/USD & LNAOFM & XBANK & LNXBANK & BIST100 & LNBIST100 \\
\hline R2 & 0,461 & 0,475 & 0,468 & 0,5265 & 0,5268 & 0,5213 & 0,522 \\
\hline Düzeltilmiş R2 & 0,461443 & 0,4753 & 0,470916 & 0,52632 & 0,5266 & 0,5211 & 0,5213 \\
\hline Prob.mean & 0,0001 & 0,0001 & 0,0000 & 0,0001 & 0,0001 & 0,0001 & 0,0001 \\
\hline $\begin{array}{l}\text { Augmented } \\
\text { dickey fuller } \\
\text { test (the test } \\
\text { statistic-ADF) }\end{array}$ & $-44,2569$ & $-45,50715$ & $-18,5965$ & $-50,4198$ & $-50,4498$ & $-49,9004$ & $-49,9004$ \\
\hline $\begin{array}{l}\text { Kritk } \\
\text { Değerler }\end{array}$ & $\begin{array}{l}\% 1:-3,4330 \\
\% 2:-2,8626 \\
\% 3:-2,5674\end{array}$ & $\begin{array}{l}\% 1:-3,4330 \\
\% 2:-2,8626 \\
\% 3:-2,5673\end{array}$ & $\begin{array}{l}\% 1:-3,4335 \\
\% 2:-2,8628 \\
\% 3:-2,5675\end{array}$ & $\begin{array}{l}\% 1:-3,4330 \\
\% 2:-2,8626 \\
\% 3:-2,5673\end{array}$ & $\begin{array}{l}\% 1:-3,4330 \\
\% 2:-2,8626 \\
\% 3:-2,5674\end{array}$ & $\begin{array}{l}\% 1:-3,4330 \\
\% 2:-2,8626 \\
\% 3:-2,5673\end{array}$ & $\begin{array}{l}\% 1:-3,4330 \\
\% 2:-2,8626 \\
\% 3:-2,5673 \\
\end{array}$ \\
\hline $\begin{array}{l}\text { Regresyon } \\
\text { Standart } \\
\text { Hatası }\end{array}$ & 0,014 & 0,0055 & 0,0015 & 2233,739 & 0,0163 & 871 & 0,012 \\
\hline $\begin{array}{l}\text { Hata Kareler } \\
\text { Top }\end{array}$ & 0,4503 & 0,0701 & 0,0043 & $1,14 \mathrm{E}$ & 0,6141 & $1,73 \mathrm{E}$ & 0,3319 \\
\hline Log likelihood & 6515,335 & 8642,17 & 9732,56 & $-20889,29$ & 6160,59 & $-18734,49$ & $-1873,49$ \\
\hline F-İstatistiği & 1958,673 & 2070,901 & 212,056 & 2542,152 & 0,0000 & 2490,054 & 2508,03 \\
\hline Prob(F-İst) & 0,0000 & 0,0000 & 0,0000 & 0,0000 & 0,0000 & 0,0000 & 0,0000 \\
\hline $\begin{array}{l}\text { Ortalama } \\
\text { Bağımlı VAR }\end{array}$ & $1,14 \mathrm{E}$ & $1,36 \mathrm{E}$ & $-4,96$ & 2,935 & $1,88 \mathrm{e}$ & 0,9305 & $9,39 \mathrm{E}$ \\
\hline $\begin{array}{l}\text { S.D.Bağımlı } \\
\text { VAR }\end{array}$ & 0,0191 & 0,0076 & 0,002 & 3245,56 & 0,0238 & 1258,7 & 0,0174 \\
\hline $\begin{array}{ll}\text { Aveike } & \text { Bilgi } \\
\text { Ölçüitü } & \\
\end{array}$ & $-5,6934$ & $-7,552$ & $-10,155$ & 18,261 & $-5,368$ & 16,378 & $-5,998$ \\
\hline $\begin{array}{l}\text { Schwarz } \\
\text { Ölçütü }\end{array}$ & $-5,6884$ & $-7,547$ & $-10,129$ & 18,266 & $-5,378$ & 16,383 & $-5,993$ \\
\hline $\begin{array}{l}\text { Hannan- } \\
\text { Quinn Ölçütü }\end{array}$ & $-5,6916$ & $-7,550$ & $-10,145$ & 18,263 & $-5,381$ & 16,379 & $-5,996$ \\
\hline $\begin{array}{l}\text { Durbin- } \\
\text { Watson Stat }\end{array}$ & 1,9954 & 1,997 & 2,053 & 1,991 & 1,991 & 1,992 & 1,993 \\
\hline
\end{tabular}

Tablo 1: Birim Kök Test Sonuçları ve Tanımlayıcı İstatistikler

Dinamik koşullu korelasyon (DCC) ise Engle (2002) tarafından geliştirilen zaman değişkenliği içeren bir yöntemdir. Bu yöntemde ilk yapılması gereken portföydeki tüm finansal varlıklar için tek tek oynaklık tahmin edildikten sonra standartlaştırılmış hata terimlerinin oluşturulmasıdır. Bunun için, parametreyi şartlı standart sapmaya bölmek yeterli olacaktır. Bu işlem yapıldıktan sonra standartlaştırılmış hata terimleri arasındaki korelasyon az sayıdaki parametre örnekleri kullanılarak tahmin edilir. Engle ve Sheppard (2001) dinamik koşullu korelasyonu, DCC (p,q), 1 No'lu denklemdeki şekilde ifade etmiştir.

$$
Q_{t}=\bar{R}+\sum_{j=1}^{p} \alpha_{j}\left(\varepsilon_{t-j} \varepsilon_{t-j}^{\prime}-\bar{R}\right)+\sum_{j=1}^{p} \beta_{j}\left(Q_{t-j}-\bar{R}\right)
$$

DCC $(1,1)$ modeli bir çok veri seti için yeterli olmaktadır. Bu noktadan yola çıkarak koşullu dinamik korelasyon yöntemi için log olabilirlik fonksiyonu 2 No’lu denklemle gösterilmektedir.

$$
\begin{aligned}
& L=- \frac{1}{2} \sum_{t}\left(\log (2 \pi)+\log \left|H_{t}\right|+r_{t}^{\prime} H_{t}^{-1} r_{t}\right) \\
&=- \frac{1}{2} \sum_{t}\left(\log (2 \pi)+2 \log \left|D_{t}\right|+r_{t}^{\prime} D_{t}^{2} r_{t}-r_{t}^{\prime} D_{t}^{2} r_{t}+\log \left|R_{t}\right|+\varepsilon_{t}^{\prime} R_{t}^{-1} \varepsilon_{t}\right) \\
& H_{t}=D_{t} R_{t} D_{t}
\end{aligned}
$$

Denklemde, Rt zamana göre değişen korelasyon matrisini, Dt ise tek değişkenli GARCH modellerinde i'inci diyagonal için kxk diyagonal matrisin zamana göre değişen standart sapmasını ifade etmektedir. Parametre artıklarının otokorelasyon içerip içermedikleri dinamik koşullu korelasyon ile incelenmiş ve artıkların otokorelasyon içermediğini ifade eden boş hipotez bütün parametreler için red edilmiştir. 
Çalışmanın bu aşamasında, parametrelerin değişen varyans sorunu içerip içermediği DCC testi aracılığıyla sınanmıştır. Test sonuçları Tablo 2'de sunulmuştur. Parametrelerin tamamı için artıkların sabit varyanslı olduğunu savunan boş hipotez her iki test tarafından da red edilmiştir. Bu bağlamda, ilgilenilen zaman serisi modellerinin tamamında güçlü bir otokorelasyon ve değişen varyans yapısının bulunması, döviz kuru getiri serilerinin GARCH tipi modellemeye elverişli olduklarına işaret etmektedir.

\begin{tabular}{|l|l|l|l|l|}
\hline & LNUSD & LNAOFM & LNBIST100 & LNXBANK \\
\hline F-İstatistiği & 2070,9 & 212,056 & 2508,9 & 2545,185 \\
\hline Gözlem-R2 & 0,4753 & 0,4709 & 0,5213 & 0,5263 \\
\hline Olasıllk & 0,0001 & 0,0000 & 0,0001 & 0,0001 \\
\hline
\end{tabular}

Tablo 2: Değişen Varyans Test Sonuçları

Model istatistiki tahmin sonuçlarının AOFM,XBANK ile BİST100 ve TR/USD için ortalama etkisinin geçerli olduğunu göstermiştir. Bilindiği üzere, finansal çerçevede AOFM ile BIST 100 ve TR/USD parametrelerinin ilişki olduğu temeline dayanmaktadır. GARCH-ML modellerinde koşullu standart sapma ya da varyans ortalama denklemine açıklayıcı bir değişken olarak dahil edilmektedir.

Serilerin daha sağlıklı bir şekilde ifade edilebilmesi için serilerin doğal logaritması alınmaktadır. Pt herhangi bir $\mathrm{t}$ dönemindeki parametre değeri olsun. Rt diğer parametre serisi, $\mathrm{Rt}=\ln (\mathrm{Pt} / \mathrm{Pt}-1)$ olarak ifade edilebilir. Grafik 2'de incelendiğinde volatilite hareketlerinin genellikle uyumlu olduğu görülmektedir. Seriler oluşturulduktan sonra yapılması gereken durum uygun ARMA süreci ile koşulsuz varyans değerlerinin belirlenmesidir.

LNBİST100
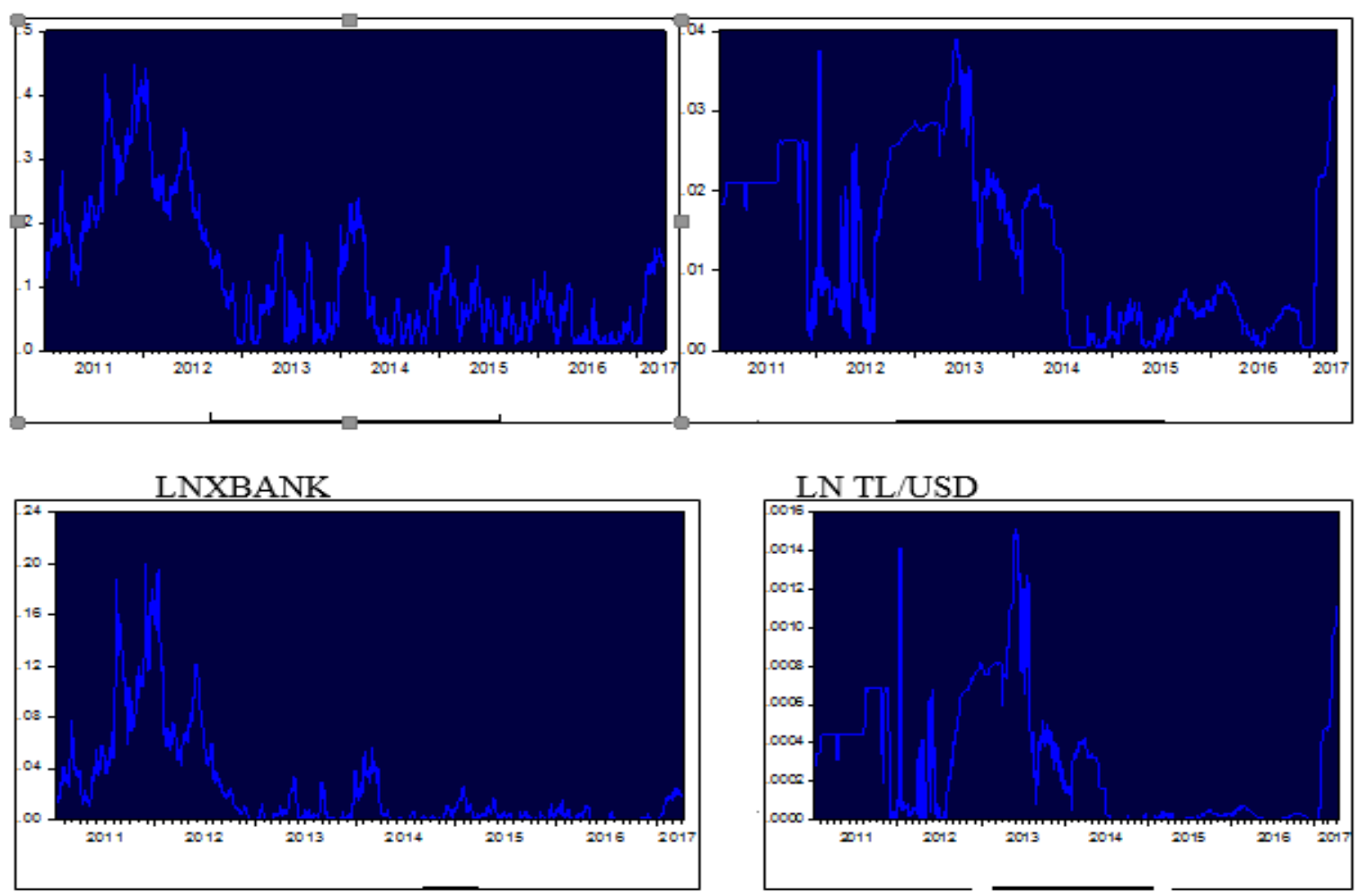

LNAOFM

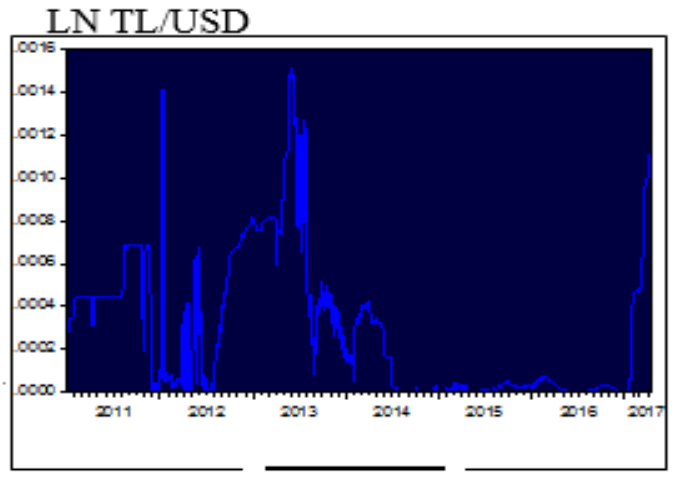

Grafik 2: LNBISST100, LNXBANK, LNTR/USD ve LNDAOFM Grafikleri 


\begin{tabular}{|c|c|c|c|c|}
\hline & $\begin{array}{c}: \\
\text { BIST100 }\end{array}$ & & & \\
\hline Metot & : EKK & & & \\
\hline \multicolumn{4}{|c|}{ Ortalama Denklemi; $\mathrm{R}=\mathrm{c}+\beta 1 R t-1+\beta 2 R t-2+\beta 3 \varepsilon t-1+\beta 4 \varepsilon t-2$} & \\
\hline Değişken & Katsayı & Standart Hata & Zİstatistiği & Prob \\
\hline $\mathbf{C}$ & 11,2594 & 0,000342 & 32937,69 & 0,0001 \\
\hline \multicolumn{5}{|c|}{ Varyans Denklemi; $\sigma t 2=c+\alpha 1 \varepsilon t-12+a 2 \sigma t-1$} \\
\hline C & $8,77 \mathrm{e}$ & $1,73 \mathrm{e}$ & 5,065 & 0,0000 \\
\hline$\alpha 1$ & 0,9714 & 0,032 & 29,479 & 0,0000 \\
\hline$\alpha 2$ & 0,0031 & 0,032 & 0,966 & 0,0339 \\
\hline R2 & $-0,2402$ & & & \\
\hline Düzeltilmiş R2 & $-0,2402$ & & & \\
\hline $\begin{array}{ll}\text { Regresyon } & \text { Standart } \\
\text { Hatası } & \end{array}$ & 0,154 & Ortalama Bağımlı VAR & & 11191 \\
\hline Hata Kareler Top & 54,296 & S.D.Bağımlı VAR & & 0,1382 \\
\hline Log likelihood & 2767,445 & Aveike Bilgi Ölçütü & & $-2,4134$ \\
\hline F-İstatistiği & 2508,03 & Schwarz Ölçütü & & $-2,4034$ \\
\hline Prob(F-İst) & 0,00000 & Hannan-Quinn Ölcütü & & -24098 \\
\hline
\end{tabular}

Tablo 3: BIST 100 Endeksi GARCH M Modeli Tahmin Sonuçlart

\begin{tabular}{|c|c|c|c|c|}
\hline Bağımlı Değişken & AOFM & & & \\
\hline Metot & : EKK & & & \\
\hline \multicolumn{5}{|c|}{ Ortalama Denklemi; $\mathrm{R}=\mathrm{C}+\delta \sigma t 2+\beta 1 R t-1+\beta 2 R t-2+\beta 3 \varepsilon t-1+\beta 4 \varepsilon t-2$} \\
\hline Değişken & Katsayı & Standart Hata & $\begin{array}{c}\text { Z- } \\
\text { İstatistiği }\end{array}$ & Prob \\
\hline C & 0,0827 & $3,46 \mathrm{E}$ & $-18,596$ & 0 \\
\hline \multicolumn{5}{|c|}{ Varyans Denklemi; ; $\sigma t 2=\mathrm{c}+\alpha 1 \varepsilon t-12+a 2 \sigma t-1$} \\
\hline C & $8,76 \mathrm{e}$ & $4,18 \mathrm{e}$ & 2,095 & 0,0362 \\
\hline$\alpha 1$ & 0,6445 & 0,0612 & 10,527 & 0,0000 \\
\hline$\alpha 2$ & 0,4017 & 0,0589 & 6,813 & 0,0000 \\
\hline R2 & $-0,1511$ & & & \\
\hline Düzeltilmiş R2 & $-0,1511$ & & & \\
\hline Regresyon Standart Hatası & 0,0162 & Ortalama Bağımlı VAR & & 0,0768 \\
\hline Hata Kareler Top & 0,0606 & S.D.Bağımlı VAR & & 0,0151 \\
\hline Log likelihood & 7869,003 & Aveike Bilgi Ölçütü & & $-6,868$ \\
\hline F-İstatistiği & 212,05 & Schwarz Ölçütü & & $-6,858$ \\
\hline Prob(F-İst) & 0,00000 & Hannan-Quinn Ölçütü & & $-6,8653$ \\
\hline
\end{tabular}

Tablo 4: AOFM GARCH M Modeli Tahmin Sonuçları

Tahmin sonuçları incelendiğinde tahminci regresyon katsayılarının $\% 1$ anlamlılık seviyesinde anlamlı oldukları gözlemlenmiştir. Ayrıca F değerinin yeterince yüksek olduğu görülmektedir. Yapılan tahminde herhangi bir tutarsızlık görülmediği ortaya çıkmıştır. Tahmin sonuçları incelendiğinde GARCH M modelinin ortalama denkleminde yer alan $\delta$ parametresinin pozitif ve istatistiki bakımdan anlamlı olması AOFM pozitif yönde değişmenin koşullu varyans değerinde bir artışa yol açarak BIST 100 üzerinde de aynı yönde etki göstereceği göstermektedir. Tahmin sonuçları incelendiğinde ortalama denkleminde yer alan koşullu varyans parametre tahmincisinin $(\delta)$ pozitif ve anlamlı olduğu görülmektedir. Bu durumda AOFM ile doğrudan doğruya ortalama denkleminde dolayısıyla BIST100 üzerinde bir etki yarattığı ifade edilebilir.

\begin{tabular}{|c|c|c|c|c|}
\hline \multicolumn{6}{|c|}{ Hata Terimlerinin Q İstatistiği } & \multicolumn{3}{l|}{} \\
\hline Oto korelasyon & AC & PAC & Q-Statistic & Prob \\
\hline $\mathbf{1}$ & 0,995 & 0,995 & 2272,4 & 0,0000 \\
\hline $\mathbf{5}$ & 0,943 & 0,013 & 108,32 & 0,0001 \\
\hline $\mathbf{1 0}$ & 0,856 & 0,000 & 19968 & 0,0000 \\
\hline $\mathbf{1 5}$ & 0,788 & 0,009 & 260,72 & 0,0000 \\
\hline
\end{tabular}

Tablo 5: GARCH Modeli Q İstatistiği Tahmin Sonuçlart

Hata terimlerinin kareleri arasında daha güçlü bir korelasyon ilişkisi olduğu görülmekle birlikte AC değerleri azalma göstermektedir. Q istatistiği 0.000 düzeyinde yeterlidir, hata terimlerinin kareleri arasında güçlü bir korelasyon ilişkisi vardır Elde edilen tahmin sonuçlarının tutarlılığına yönelik tanı istatistiklere göz atıldığında otokorelasyonun olup olmadığını gösteren $\mathrm{Q}$ istatistikleri ile değişen varyansın olup olmadığını gösteren $\mathrm{F}$ 
istatistiğine ait olasılık değerleri \%5 önem düzeyinde anlamsız çıkmıştır. Bu sonuç modellerin otokorelasyon ve değişen varyans taşıması dolayısıyla model sonuçlarının yorumlanabilmesi için gereklilik koşullarını yerine getirdikleri anlamına gelmektedir.

Çalışma sonucunda yapılan istatistiki değerlendirmede AOFM ile BIST100 ve BISTXBANK endeksleri ile anlamlı pozitif ilişkinin varlığı sonucu ortaya çıkmıştır. TL/USD kuru modelde exogenous (dışsal) veri olarak ele alınmış olup BIST 100 etkilemeyen ama indirect etkisi olduğu gözlemlenmiştir.

\section{Sonuç}

AOFM, BIST100, BISTXBANK ile TL/USD arasındaki ilişkini açıklanabilmesi için bu değişkenlerin eşbütünleşik olması yani uzun dönemde birlikte hareket ediyor olmaları gerekmektedir. Son dönemde ülkemizde ve dünyada yaşanan gelişmeler ışığında TCMB dışı fon kaynaklarının maliyetlerinin göreli olarak yüksek seyretmesi, bankaların para piyasalarındaki efektif finansman maliyetleri ile TCMB'nin ağırlıklı ortalama fonlama maliyetinin BIST100 ve TL/USD arasındaki ilişki derecesini daha da önemli hale getirmektedir. Bu çalışmanın ağırlıklı ortalama fonlama maliyeti ile BIST100, BISTXBANK ve TL/USD ilişki derecesinin ortaya konmasıyla yeni maliyet serileri oluşumunun para ve likidite politikalarının piyasa faizlerine aktarımının daha iyi anlaşılması açısından faydalı olacağı düşünülmektedir.

Bu çalışmada DKK, DCC GARCH ve ML GARCH yöntemleri kullanılmış olup yukarıda belirtilen ilişkilerle ilgili sonuçlar ortaya konmuştur. Bu amaçla Merkez Bankası'nın ağırlıklı ortalama fonlama maliyetlerinden BİST100, BISTXBANK endekslerine ve TR/USD doğru nasıl bir ilişkinin olduğu ya da olup olmadığı test edilmiştir.

Elde edilen bulgulara göre TCMB'nin ağırlıklı ortalama fonlama maliyetinin değişkenliğinin Borsa İstanbul ve BISTXBANK endeksleriyle direkt olarak, TR/USD ile indirect etkisi çalışmada kullanılan istatistiki modellerin yaklaşımlarına göre bir nedensellik ilişkisi bulunmuştur.

Buna göre ağırlıklı ortalama fonlama maliyetinin değişkenliğinin hisse senetleri piyasası ve Tl/Usd üzerinde bir oynaklık yayılımının olduğu gözlemleri 1şığında, TCMB'nin piyasayı fonlaması sonucunda oluşan faiz oranlarındaki değişiklikler sonucunda hesaplanan ağırlıklı ortalama fonlama maliyetinin, hisse senetleri piyasasında ve TL/USD da aynı yönde bir ilişki dağılımı ortaya çıkmıştır.

$\mathrm{Bu}$ sonuç bizlere ağırlıklı ortalama fonlama maliyetinin ile hisse senedi piyasası arasında bir ayrışmanın olmadığı yönünde bir bulgu sağlamaktadır. Bu noktadan yola çıkarak hisse senedi piyasasına yatırım yapmayı düşünen bireysel yada kurumsal yatırımcıların TCMB'nin AOFM göstergesine dayalı yatırım kararları üzerinde etkisinin olduğunu söyleyebiliriz.

\section{Kaynakça}

- $\quad$ Ehrmann, M., M. Fratzscher ve R. Rigobon. 2005. "Stocks, bonds, money markets and exchange rates: Measuring international financial transmission.” NBER working paper no.11166.

- $\quad$ ENGLE, R.F. ve SHEPPARD, K. (2001) "Theoretical and Empirical Properties of Dynamic Conditional Correlation Multivariate GARCH”, University of California at San Diego, Economics Working Paper Series, 2001-15, Department of Economics, UC San Diego.

- $\quad$ Gilmore, C.G., McManus M.G., Sharma, R. and Tezel, A.(2009) The dynamics of gold prices, gold mining stock prices and stock market prices comovements, Research in Applied Economics, 1(1), 1-19

- $\quad$ GUJARATİ,Damodar N.,Basic Econometrics,third edit,MC-Graw-Hill,İnc.,USA,1995.ss.712-713.

- Kasman, S., Vardar, G., \& Tunç, G. 2011. "The impact of interest rate and exchange rate volatility on banks' stock returns and volatility: Evidence from Turkey.” Economic Modelling, 28, 1328-1334.

- Kholodilin, K., A. Montagnoli, O. Napolitano ve B. Siliverstovs. 2009. “Assessing the impact of the ECB's monetary policy on the stock markets: A sectoral view.” Economics Letters 105, 211-213.

- $\quad$ Martínez,M.P., Lapena,F.R., ve Sotos, E.F. 2015. "Interest rate changes and stock returns in Spain: A wavelet analysis.” BRQ Business Research Quarterly (2015) 18, 95-110

- Mishra, P.K., Das, J.R. and Mishra, S.K. (2010) Gold price volatility and stock market returns in India, American Journal of Scientific Research, Issue 9, 49-55 


\title{
Kurgızistan'da Döviz Kuru, Resmi Rezervler ve Para Arzı Arasındaki İlişki
}

\section{The Relationship between Exchange Rate, Official Reserves and Money Supply in Kyrgyzstan}

\author{
Asst. Prof. Dr. Junus Ganiev (Kyrgyzstan-Turkey Manas University, Kyrgyzstan) \\ Asst. Prof. Dr. Damira Baigonushova (Kyrgyzstan-Turkey Manas University, Kyrgyzstan) \\ Asst. Prof. Dr. Nevin Aydın (Kyrgyzstan-Turkey Manas University, Kyrgyzstan)
}

\begin{abstract}
In recent years, there has been considerable instability in the exchange rates of many countries. This can directly affect macroeconomic stability on one side and monetary policy or rather money supply on the other. Because central banks are making interventions to the foreign exchange market by buying and selling foreign exchange in order to provide stability of exchange rate. As a result, both the official reserves and the money supply are constantly changing. Since Kyrgyzstan is a country dependent on imports in most commodities, the Central Bank of the Kyrgyz Republic sees the exchange rates' stability as an important instrument of price stabilizing. However, such a policy may deteriorate the stability of the total money supply and adversely affect the economy. Therefore, in this study, it is aimed to examine the relations between exchange rate, money supply and official reserves by using 2002-2016 monthly data and cointegration method. Empirical results have shown that a change in the exchange rate causes opposite changes in both the reserves and the money supply as a result of the central bank's interventions. However, more concrete recommendations on the effectiveness of monetary policy in Kyrgyzstan are required to make more detailed analysis.
\end{abstract}

\section{Giriş}

Döviz kurundaki istikrarsızlıklar başta dış ticaret ve dış yatırımlar olmak üzere enflasyon, dış rezervler, dış borçlar, ekonomik büyüme gibi pek çok değişkenleri olumsuz etkileyebilmektedir. Bundan dolayı tüm ülkelerin merkez bankaları mutlaka döviz piyasasını gözlemleyerek gerekli durumlarda müdahalelerde bulunurlar. Bu amaçla ve başka amaçları da gözönünde bulundurarak tüm ülkeler dış rezervler tutarlar. Uluslararası Para Fonu'nun (IMF, 2014) verilerine göre, 2014'de dünyadaki tüm ülkelerin toplam rezervleri 5,4 trilyon dolara ulaşmıştır ve bu da dünyanın o dönemdeki 77,8 trilyonluk toplam üretimine oranlandığında yaklaşık \%7'sine denk gelmektedir. Bunun 5,2 trilyonu yabancı dövizlerden, 180 milyarı da altından oluşmuştur. Böyle büyük miktardaki uluslararası rezervlerin hem faydaları hem de belirli maliyetleri vardır. Dış rezervlerin en önemli faydası döviz piyasasının ve tüm mali sistemin istikrarının sağlanması ise, en önemli maliyeti de bu kaynakların ülke ekonomisine katkı sağlamadan atıl kalmasıdır.

Bunun haricinde, yüksek miktarda dış rezervler ulusal para krizi olasılığının azaltılması veya yeni dış borçlanma zorluklarının önlenmesi amacıyla da tercih edilebilir (Calvo ve Reinhart, 1999). Pakistan eski başkanı Ishrat Hussain (2002)'e göre, Pakistan'da rezervler; döviz kuru istikrarının sağlanması, dış borçların ödenmesi, beklenmeyen dış şoklara karşı yastık görevi görmesi ve dış yatırımcıların ülkenin siyasi ve ekonomik gücüne inandirılması amaciyla tutulmaktadir.

Kırgızistan'da ise “2013-2017 Kırgız Cumhuriyeti’nin İstikrarlı Gelişme Stratejisi”ne göre, uluslararası rezervlerin en az dört aylık ithalatı karşılayabilecek kadar düzeyde tutulması temel hedeflerden biri olarak belirlenmiş ve Merkez Bankası yıllık raporlarında bu hedef doğrultusunda uluslararası rezervlerin ithalatı karşılama oranını önemli bir gösterge olarak raporlamaktadır.

Aynı zamanda, en başından itibaren piyasa tarafından belirlenen esnek kur sistemini benimseyen Kırgız Cumhuriyeti Merkez Bankası'nın döviz kurunun istikrarına da çok önem verdiği görülmektedir. SSCB'nin dağılmasından sonra Orta Asya ülkelerinden ilk olarak Kırgızistan kendi ulusal parası olan som'u 10 Mayıs 1993 'te yürürlüğe çıkarmış ve yine Orta Asya ülkeleri ile mukayese edildiğinde yaklaşık çeyrek asırlık dönemde döviz kurunu nominal olarak en değerli tutabilen ülke olabilmiştir. 1994'te 1 ABD doları 10,8 som iken Mart 2017'de 69,0 som olmuştur, yani dolar karşısında yaklaşık 6,3 kat değer kaybetmiştir. Aynı dönemde diğer ülke paralarının dolar kurlarının durumu ise şu şekilde olmuştur: Kazakistan tengesi dolar karşısında 35,5'ten 316,5'e çıkarak 8,9 kat; Tacikistan somoni'si 0,02'den 8,0'a çıkarak 400 kat; Özbekistan sum'u 29,7'den 3548,0'a yükselerek 119,4 kat ve Türkmenistan manat'ı 19'dan 17500'e (şu anda 1 dolar = 3,5 manat'tır, fakat 1 Ocak 2009'da 1 yeni manat = 5000 eski manat kuruyla daha önceki para yeni manat'a değiştirilmiştir, dolayısıyla 3,5x5000 = 17500'dür) çıkarak 921 kat değer kaybına uğramıştır. Bu durum Kırgızistan için bir taraftan çok istikrarlı ve başarılı bir para politikası gibi gözükmekle beraber, çeşitli alternatif maliyetleri de olabilen bir politikadır. Çünkü istatistiki verilerden görüldüğü gibi, Kırgız Cumhuriyeti Merkez Bankası (KCMB), döviz piyasasında istikrarsızlıklar yaşandığı dönemlerde para arzındaki istikrarsızlıklar pahasına döviz kuru istikrarını sağlamaya çalışmaktadır. Yani 
döviz piyasasına yapılan resmi müdahaleler nedeniyle, yabancı döviz bolluğu yaşanan dönemlerde ulusal para arzı hızla artarken, döviz kitlığı dönemlerinde de tam tersine hızla azalabilmektedir. Örneğin, döviz piyasasında son istikrarsızlıkların yaşandığı 2014-2016 döneminde som'un değer kayıpları sırasıyla \%10,7; \%20,1 ve \%8,4 olarak gerçekleşmiştir. Buna karşı1ık, 2014'de dolaşımdaki para miktarı \%14,7 azalmış, 2015 ve 2016 'da ise sırasıyla $\% 2,3$ ve $\% 28,1$ oranında artış göstermiştir. Para arzındaki böyle istikrarsız dalgalanmaların ekonomiyi olumsuz etkileyebileceği açıktır.

Diğer taraftan KCMB'nın izlediği böyle bir politikanın da çeşitli nedenlerinin olduğu söylenebilir. Örneğin, tüm ülke ekonomilerinin dünyayla çok sıkı ekonomik ve mali ilişkiler içinde bulunduğu günümüz koşullarında döviz kurundaki istikrarsızlıkların ülkenin sadece dış ticaret, dış yatırımlar veya dış borçlar gibi dış ilişkilerini değil, aynı zamanda tüm makroekonomik durumunu da etkilediği açıkça görülmektedir. Özellikle dolarizasyon oranı çok yüksek olan Kırgızistan gibi ülkelerde -ki Kırgızistan'da 2016 yılında toplam mevduatlardaki döviz mevduatlarının payı ortalama olarak \%56,2'yi, toplam kredilerdeki yabancı dövizle verilen kredilerin payı ise ortalama \%45,6'yı oluşturmuş̧ur ve ev, araba gibi malların alışverişlerinin yaklaşık tümü dolar üzerinden yapılmaktadır- döviz kurundaki değişmeler risk ve belirsizlikleri artırarak ve fiyat istikrarını bozarak tüm hanehalkı ve firmaları doğrudan etkileyebilmektedir. Bunun gibi nedenlerden dolayı da ülke hükümetleri ve merkez bankalar döviz kuru istikrarının sağlanmasını önemli bir hedef olarak görmektedirler.

\section{Literatür Taraması}

1970'lerde dünyadaki çoğu ülkelerin esnek kur sistemini benimsemeye başlamasından sonra döviz kuru oynaklığının uluslararası ticarete ve dış yatırımlara olan etkisi pek çok araştırmaya konu olmuştur. Döviz kuru oynaklığının dış ticareti olumsuz etkileyeceği yönünde genel bir kanı olmasına rağmen, empirik çalışmaların her zaman bunu teyit etmediği, yani bazı çalışmaların döviz kuru oynaklığı ile dış ticaret arasında pozitif iliş̧i bulduğu ortaya çıkmıştır (bu konuda Cote (1994) ve Ozturk (2006) tarafından geniş bir literatür taraması yapılmıştır).

Birkaç örnek vermek gerekirse, Rogoff ve Reinhart (2002) siyasi istikrarsız Afrika ülkelerini inceleyerek, bunun sonucunda savaşsız, barış döneminde bile fiyat ve ulusal paranın istikrarsızlı̆ğ ile ilgili beklentilerin doğrudan yabancı yatırımları olumsuz etkileyeceğini ortaya koymuşlardır.

Cote (1994) döviz kuru ve dış ticaret ilişkisi ile ilgili teorik ve empirik çalışmaları inceleyerek döviz kuru oynaklığının dış ticaret ve dış yatırımlar üzerindeki etkisinin net olmadığı sonucuna ulaşmıştır.

Döviz kuru ile dış ticaret ilişkisi konusunda çeşitli ülkeler örneğinde çok fazla empirik çalışma yapılmışken, döviz kuru ile dış rezervler ve para arzı ilişkisi, yani merkez bankaların döviz kuru politikasının para politikasına etkileri konusunda yapılan empirik çalışmalar nadir bulunmaktadır.

Hviding ve diğerleri (2004) dış rezervlerin reel döviz kuru oynaklığının azaltıp azaltmadığını araştırmış ve yükselen pazar ülkelerinde rezervlerin, reel efektif döviz kurunun kısa vadeli oynaklığı üzerinde negatif, doğrusal olmayan etkisinin olduğuna ilişkin güçlü kanıtlar bulmuşlardır.

Gerni vd. (2013), dış denge, reel faiz oranı, döviz kuru ve rezerv oynaklığı arasındaki ilişkiyi 11 geçiş ekonomisi üzerine 1996-2011 dönemi için empirik olarak incelemiş ve dış denge üzerinde reel döviz kuru oynaklığı ile rezervlerdeki oynaklığının etkili olduğu, reel faiz oranlarının etkisinin ise bulunmadığı sonucuna ulaşmışlardır.

Bu konuda yapılan son çalışmalardan biri Afzal (2010) tarafından yapılan bir çalışmadır. Sözkonusu çalışmada Bangladeş, Hindistan, Pakistan, Filipinler, Sri Lanka ve Tayland'dan oluşan altı Asya ülkesinde döviz kuru ile dış rezervlerin ilişkisi nedensellik testi ile araştırılmıştır. Araştırma sonuçlarına göre, Pakistan, Sri Lanka ve Tayland'da rezervlerden döviz kuruna doğru; Filipinlerde ise tersine döviz kurundan rezervlere doğru tek taraflı nedensellik ilişkisi tespit edilmiş̧ir. Bangladeş’te hiçbir nedensellik bulunmamışken, Hindistan'da sözkonusu iki değişken arasında çift yönlü bir ilişki ortaya konmuştur.

Kırgızistan'da ise henüz döviz kuru, rezervler ve parasal büyüklükler arasındaki ilişki empirik olarak incelenmemiştir. Bundan dolayı bu çalışmada sözkonusu değişkenler arasındaki ilişkilerin empirik olarak araştırılması amaçlanmıştır.

\section{Veri ve Yöntem}

Çalışmada Kırgız Cumhuriyeti Merkez Bankası (KCMB)'ndan temin edilen 2002:01-2016:12 dönemine ait aylık veriler kullanılmıştır. Ulusal paranın dolar kuru (ER), resmi rezervler (RES) ve parasal büyüklükler (M0, M1, M2 ve M2X) arasındaki ilişkiler koentegrasyon yöntemiyle araştırılmıştır. Değişkenlerin varyansta durağan olmama durumunu önlemek amacıyla tüm değişkenlerin logaritmik halleri analize katılmıştır. Değişken isimlerinin başındaki "In" işareti bu durumu ifade etmektedir. Diğer bir belirtilmesi gereken nokta da şudur: döviz kuru doğrudan fiyatlama yöntemine göre gösterildiği için, bu değişkendeki artış ulusal paranın dolara karşı değer kaybetmesini ve düşüş de değer kazanmasını ifade eder.

Merkez bankaların döviz piyasasına müdahale istatistiklerini kamuoyuna pek yansıtmaması nedeniyle, pek çok empirik çalışmalarda (örneğin, Taylor, 1982; Obstfeld, 1983; Gartner, 1991) bunun bir temsilcisi olarak dış 
rezervler kullanılmaktadır. Fakat bazı çalışmalar (Mastropasqua, Micossi ve Rinaldi, 1988; Neely, 2000) bazı ülkeler üzerinden analizler yaparak, rezervlerin resmi müdahaleler için mükemmel bir temsilci olmadığını, sözkonusu iki serinin arasında güçlü korelasyon ilişkisinin bulunmadığını ortaya koymuşlardır. Buna rağmen, bu çalışmada da resmi müdahale istatistiklerinin tam olarak elde edilememesi nedeniyle temsilci olarak diş rezervler serisi alınmıştır.

Değişkenler arasındaki hem uzun hem kısa dönemli ilişkileri belirlemek amacıyla, yöntem olarak Pesaran ve Shin (1995, 1999), Pesaran, Shin ve Smith (2001) tarafindan geliştirilen ARDL eşbütünleşme yaklaşımı uygun bulunmuştur. Uygun gecikme uzunluklarının belirlenmesinde Akaike kriteri (AIC) temel alınmış ve verilerin aylık olduğunu da dikkate alarak maksimum uzunluk düzeyi olarak 12 dönem seçilmiştir. Tüm tahmin ve hesaplamalar Eviews 9 paket programında gerçekleştirilmiştir.

\section{Analiz Sonuçları}

Tablo 1'de değişkenlerin birim kök testi sonuçları sunulmuştur. Genişletilmiş Dickey-Fuller ve Phillips-Perron testleri sonuçlarına göre, genel olarak değişkenlerin düzeyde durağan olmadığı ve tümünün birinci farkta durağan olduğu tespit edilmiştir.

\begin{tabular}{|c|c|c|c|c|}
\hline \multirow[b]{2}{*}{ Değişkenler } & \multicolumn{2}{|c|}{ Genişletilmiş Dickey-Fuller (ADF) } & \multicolumn{2}{|c|}{ Phillips-Perron (PP) } \\
\hline & Intercept & $\begin{array}{l}\text { Trend and } \\
\text { intercept }\end{array}$ & Intercept & $\begin{array}{l}\text { Trend and } \\
\text { intercept }\end{array}$ \\
\hline \multicolumn{5}{|c|}{$D \ddot{U Z E Y}$} \\
\hline $\operatorname{lnRES}$ & $-2,049$ & $-0,442$ & $-2,013$ & $-0,498$ \\
\hline $\operatorname{lnER}$ & $-1,334$ & $-1,051$ & 0,935 & $-1,088$ \\
\hline $\ln \mathrm{M} 0$ & $-1,971$ & $-1,725$ & $-3,272 * *$ & $-1,525$ \\
\hline $\ln \mathrm{M} 1$ & $-2,355$ & $-1,588$ & $-2,899 * *$ & $-1,727$ \\
\hline $\operatorname{lnM} 2$ & $-1,894$ & -1.552 & $-2,379$ & $-1,626$ \\
\hline $\ln \mathrm{M} 2 \mathrm{X}$ & $-3.275 * *$ & $-1,467$ & $-3,226 * *$ & $-1,539$ \\
\hline \multicolumn{5}{|c|}{ BIRINCCI FARK } \\
\hline$\Delta \ln R E S$ & $-8,539 *$ & $-12,819^{*}$ & $-12,542 *$ & $-12,819 *$ \\
\hline$\Delta \ln E R$ & $-11,497 *$ & $-12,082 *$ & $-11,622 *$ & $-12,078 *$ \\
\hline$\Delta \operatorname{lnM} 0$ & $-3,889 *$ & $-4,171 *$ & $-10,642 *$ & $-11,312 *$ \\
\hline$\Delta \operatorname{lnM} 1$ & $-6,552 *$ & $-6,905^{*}$ & $-12,739^{*}$ & $-13,014^{*}$ \\
\hline$\Delta \ln M 2$ & $-6,317^{*}$ & $-6,532 *$ & $-11,335^{*}$ & $-11,461 *$ \\
\hline$\Delta \ln M 2 X$ & $-7,499 *$ & $-12,813^{*}$ & $-12,411^{*}$ & $-12.813 *$ \\
\hline
\end{tabular}

Tablo 1. Birim Kök Testi Sonuçları

Not: *, ** straslyla \%1 ve \%5 anlamlılık düzeylerini ifade etmektedir.

ARDL eşbütünleşme yöntemine göre, eğer elde edilen F-istatistiği; Pesaran, Shin ve Smith (2001) tarafindan oluşturulan üst sınır I(1) değerinden daha yüksek ise, bu serilerin eşbütünleşik olduğu sonucu ortaya çıkar. Fakat bu kritik değerler gözlem sayısı büyük olan seriler için oluşturulduğundan dolayı Narayan (2005) tarafindan gözlem sayısı 30 ile 80 arası olan durumlar için kritik değerler yeniden hesaplanmıştır. Bu çalışmada da gözlem sayısı mukayeseli düşük olduğu için Narayan (2005) tarafından oluşturulan kritik değerler temel alınmıştır.

\begin{tabular}{|l|l|c|c|c|}
\hline Bağımlı Değişken & Bağımsız Değişkenler & F-istatistiği & Alt Sınır, I(0) & Üst Sınır, I(1) \\
\hline $\operatorname{lnRES}$ & $\operatorname{lnM} 0, \operatorname{lnER}$ & $5,999^{*}$ & 3,940 & 5,043 \\
\hline $\ln \mathrm{R}$ & $\operatorname{lnM} 2 \mathrm{X}, \ln R E S$ & 3,249 & 3,940 & 5,043 \\
\hline $\ln \mathrm{M} 0$ & $\operatorname{lnER}, \operatorname{lnRES}$ & 3,731 & 3,940 & 5,043 \\
\hline $\ln \mathrm{M} 1$ & $\operatorname{lnER}, \operatorname{lnRES}$ & $6,725^{*}$ & 3,940 & 5,043 \\
\hline $\ln \mathrm{M} 2$ & $\operatorname{lnER}, \operatorname{lnRES}$ & 4,752 & 3,940 & 5,043 \\
\hline $\ln \mathrm{M} 2 \mathrm{X}$ & $\operatorname{lnER}, \operatorname{lnRES}$ & $6,005^{*}$ & 3,940 & 5,043 \\
\hline
\end{tabular}

Tablo 2. Eşbütünleşme İlişkisinin F-istatistiğ $i$

Not: Kritik değerler Narayan (2005)'den alınmıştır, $k=2 . * \% 5$ önem düzeyinde anlamlıll̆̆ gösterir.

Serilerin arasındaki tüm olası eşbütünleşme ilişkilerini görebilmek amacıyla bütün kombinasyonlar denenmiş ve eşbütünleşme ilişkisini test eden F-istatistiği değerleri Tablo 2'de sunulmuştur. Parasal büyüklükler arasında doğal olarak güçlü bir korelasyon ilişkisi bulunduğu için, rezervlerin ve döviz kurunun bağımlı değişken olduğu 
durumlarda parasal büyüklüklerin sadece birisi modele katılmış ve F-değeri en yüksek olanı tabloya alınmıştır. Parasal büyüklüklerin bağımlı olduğu modellerde ise, bağımsız değişken olarak sadece döviz kuru ve rezervler alınmıştır. Bunun sonucunda tablodan görüldüğü üzere, \%5 önem düzeyinde; rezervlerin bağımlı değişken olduğu durumda rezervlerle M0 ve döviz kuru arasında, M1'in bağımlı değişken olduğu durumda M1 ile döviz kuru ve rezervler arasında ve M2X'in bağımlı değişken olduğu durumda da M2X ile döviz kuru ve rezervler arasında eşbütünleşme ilişkisinin olduğu ortaya çıkmıştır.

Bunun üzerine aralarında eşbütünleşme ilişkisinin olduğu tespit edilen değişkenler için hata düzeltme modelleri tahmin edilmiştir (Tablo 3). Buna göre, rezervlere kısa dönemde dolaşımdaki para miktarının (M0) pozitif, anlamlı etkisinin olduğu, döviz kurunun da genel olarak negatif, anlamlı etkisinin olduğu görülmektedir. M1 para arzına ise kendi gecikmelerinin ve rezervlerin pozitif, anlamlı etkisinin olduğu, döviz kurunun ise negatif, anlamlı etkisinin bulunduğu ortaya çıkmıştır. M2X parasal büyüklüğüne de hem döviz kurunun hem de rezervlerin pozitif, anlamlı etkisinin bulunduğu tespit edilmiştir.

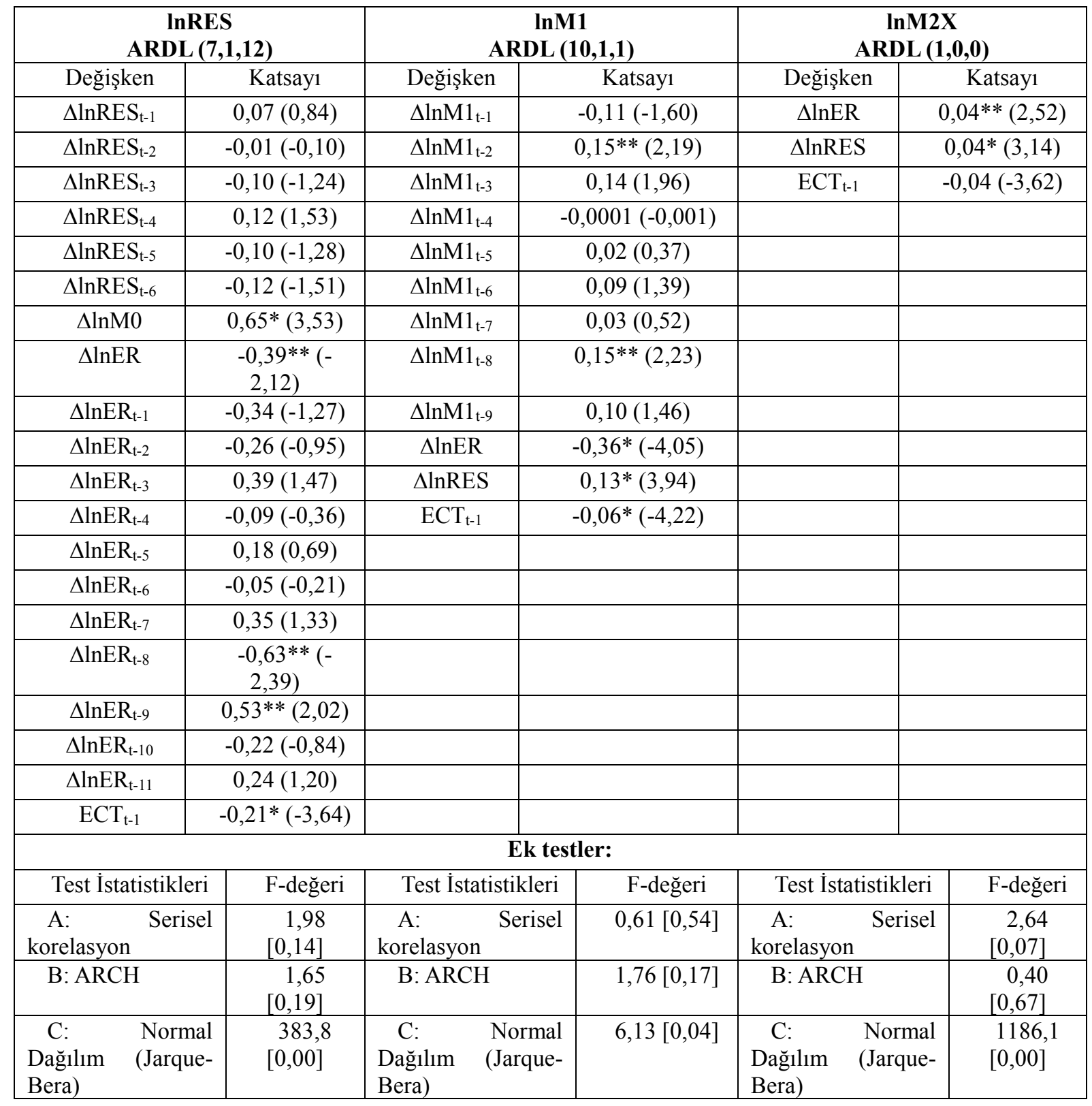

Tablo 3. Hata Düzeltme Modelleri

Not: Parantez içerisinde t-istatistikleri verilmiştir. *\%1 ve **\%5 önem düzeyinde anlamlılı̆̆ı gösterir. Köşseli parantezin içinde olasıllı değerleri verilmiştir.

Tüm modellerin hata düzeltme katsayıları (ECT) beklendiği gibi eksi işaretli ve anlamlı bulunmuştur. Katsayının büyüklüğüne göre, herhangi bir nedenle dengeden uzaklaşma olduğunda, rezervlerin dengeye dönme hızının baya yüksek olacağı, parasal büyüklüklerin dengeye dönme hızının ise çok daha düşük olacağı söylenebilir. 
Ek testler tüm modellerin hata terimlerinde serisel korelasyon, değişen varyans sorunlarının olmadığını, fakat normal dağılımda bazı sorunların olabileceğini göstermektedir.

Uzun dönem ilişkilerinin de hemen hemen kısa dönem ilişkileriyle aynı olduğu ortaya çıkmıştır (Tablo 4). Buna göre, som'un dolara göre \%1'lik bir değer kaybı rezervlerde uzun dönemde \%0,88'lik bir azalmaya neden olmaktadır. Banka dışı para miktarındaki (M0) \%1'lik bir artış ise rezervlerdeki \%0,89'luk bir artışla eşlik etmektedir. Diğer taraftan, M1 ve M2X parasal büyüklüklerinin döviz kuru ve rezervlere olan esneklik katsayılarının hepsi pozitif ve 1'e yakın bulunmuştur.

\begin{tabular}{|c|c|c|c|c|c|}
\hline \multicolumn{2}{|c|}{ InRES } & \multicolumn{2}{c|}{ InM1 } & \multicolumn{2}{c|}{ InM2X } \\
\hline Değişken & Katsay1 & Değişken & Katsay1 & Değişken & Katsay1 \\
\hline $\operatorname{lnM0}$ & $0,89^{*}(26,56)$ & $\operatorname{lnER}$ & $0,96^{*}(6,17)$ & $\operatorname{lnER}$ & $0,99^{*}(4,20)$ \\
\hline $\operatorname{lnER}$ & $-0,88^{*}(-5,70)$ & $\operatorname{lnRES}$ & $1,07^{*}(25,23)$ & $\operatorname{lnRES}$ & $0,98^{*}(14,42)$ \\
\hline SABİT & $1,25(1,81)^{* * *}$ & SABİT & $-0,78(-1,36)$ & SABİT & $0,45(0,46)$ \\
\hline
\end{tabular}

Tablo 4. Uzun Dönem Katsayılarl

\section{Not: Parantez içerisinde t-istatistikleri verilmiştir. *\%1, **\%5 ve ***\%10 önem düzeyinde anlamlılı̆̆ gösterir.}

Kısa dönem ile uzun dönem katsayıları mukayese edildiğinde, tüm anlamlı katsayıların işaretlerinin aynı olduğu, tek bir istisna olarak, kısa dönemde döviz kurunun M1'i negatif etkilediği görülmüşken, uzun dönemde ise pozitif etkilediği sonucuna ulaşılmıştır.

\section{Sonuç}

Genel olarak bakıldığında, ulaşılan empirik sonuçlar beklentilere uygun çıkmıştır. Döviz kurunda bir artış olduğunda merkez bankası müdahalede bulunduğu için rezervlerde bir azalma, döviz kurunda bir düşüş olduğunda da tam tersine bir artma ortaya çıkmaktadır.

Aynı zamanda, rezervlerle parasal büyüklükler arasında hem merkez bankası bilançosunun bir gereği olarak, hem de onun yürüttüğü politikalar sonucunda pozitif bir ilişkinin bulunduğu görülmektedir. Örneğin, ulusal para değer kaybettiği dönemlerde merkez bankasının döviz piyasasına müdahalesi, yani piyasaya dolar satması sonucunda bir taraftan rezervler azalırken, diğer taraftan piyasadaki som miktarı, yani parasal büyüklüklerde bir azalma meydana gelir.

Diğer bir tespite göre, dolar kurunun yükseldiği dönemlerde kısa dönemde som mevduatları azalırken, döviz mevduatları artmakta; uzun dönemde ise karar birimleri vadesiz som mevduatları ile vadeli ve vadesiz döviz mevduatlarına yönelmektedirler.

Nitekim son senelerdeki som'un dolar karşısındaki değer kaybı dönemlerinde bunu belirli oranda gözlemlemek mümkündür. Son üç yılda, yani 2014-2016 döneminde som'un değer kayıpları sırasıyla \%10,7; \%20,1 ve \%8,4 olarak gerçekleşmiştir. Aynı dönemde, yani 2014 ve 2015 senelerinde rezervler \% 12,5 ve \%9, 1'e azalmış, 2016' da $\% 10,7$ artış göstermiştir. 2014'de M0, M1, M2 sirasıly \%16,1; \%13,1 ve \%9,4 azalmış; fakat 2015 'te M0 ile M1'de \%2,3 ve \%1,7 gibi küçük oranlı artışlar gözlemlenirken, M2 azalmaya devam etmiş, yani \%0,1'e azalmıştır. 2016'da ise üçünde de hızlı bir artış ortaya çıkmıştır, yani sırasıyla \%30,5; \%38,6 ve \%40,3 oranında artmışlardır. M2X ise sözkonusu üç yıl boyunca \%3,0; \%14,9 ve \%14,5 oranlarında artış göstermiştir.

$\mathrm{Bu}$ istatistiki verilerden de görüldüğü gibi, Kırgız Cumhuriyeti Merkez Bankası'nın “döviz kuru tabanlı” politikası parasal büyüklüklerde istikrarsızlıklara neden olarak ekonomiyi olumsuz etkileyebilmektedir. Tabi ki, kesin olarak böyle bir sonuca ulaşabilmek için parasal büyüklüklerdeki istikrarsızlıkların diğer makro büyüklüklere ve özellikle toplam üretime olan etkilerinin empirik olarak araştırılması lazım. Diğer taraftan, döviz piyasasına daha az müdahalede bulunulması durumunda döviz kurundaki olası daha büyük istikrarsızlıkların ekonomiye olan etkilerinin de incelenmesi gerekir. Yani KCMB'nın günümüzde sürdürdüğü para ve döviz kuru politikası her iki tarafı dikkate alan bir nevi fayda-maliyet analizine göre detaylı bir şekilde incelenebildiğinde, Kırgızistan'ın etkin para politikasına ilişkin daha somut öneriler getirme imkanı doğacaktır.

\section{Kaynakça}

- Afzal M. (2010). "Exchange Rate and Reserves in Asian Countries: Causality Test". Global Economic Review 39:2, p. 215-223. DOI: 10.1080/1226508X.2010.483839

- Calvo G. ve Reinhart C. M. (1999). "When capital inflows come to a sudden stop: consequences and policy options", in: P. Kenen and A. Swoboda (Eds.) Key Issues in Reform of the International Monetary and Financial System (Washington, DC: International Monetary Fund).

- Cote A. (1994). "Exchange Rate Volatility and Trade”, Working Paper No. 95-5 (Ottawa, Ontario: Bank of Canada).

- Gartner M. (1987). "Intervention Policy under Floating Exchange Rates: An Analysis of the Swiss Case". Economica, p. 439-53. 
- $\quad$ Gerni C., Sarı S., Özdemir D., Emsen Ö.S. (2013). "Döviz Kuru Oynaklı̆̆ı, Rezerv Oynaklığı ve Reel Faiz Oranlarının Dış Ticaret Üzerindeki Etkileri: Geçiş Ekonomileri Üzerine Uygulamalar”. Proceedings book of International Conference on Eurasian Economies, s. 412-419.

- Hussain I. (2002). "Why reserves", The Daily Dawn, August.

- Hviding K., Nowak M. ve Ricci L. A. (2004). "Can Higher Reserves Help Reduce Exchange Rate Volatility? An Empirical Investigation”, Luiss Lab of European Economics Working Document No. 13 (Rome: Luiss Lab of European Economics).

- $\quad$ IMF, Annual Report 2014.

- Mastropasqua C., Micossi S. ve Rinaldi R. (1988). "Interventions, Sterilization and Monetary Policy in European Monetary System Countries, 1979-1987," in The European Monetary System: Proceedings of a Conference Organised by the Banca d' Italia, STEP, and CEPR, Francesco Giavazzi, Stefano Micossi, and Marcus Miller, eds., Cambridge University Press, p. 252-87.

- Narayan P.K. (2005). "The Saving and Investment Nexus for China: Evidence from Cointegration Tests". Applied Economics 37(17), p. 1979-1990.

- Neely C.J. (2000). “Are Changes in Foreign Exchange Reserves Well Correlated with Official Intervention?” Federal Reserve Bank Of St. Louis. 82(5), p. 17-31.

- Obstfeld M. (1983). "Exchange Rates, Inflation, and the Sterilization Problem: Germany, 1975-1981" European Economic Review March/April, p. 161-189.

- Ozturk I. (2006). "Exchange Rate Volatility and Trade: A Literature Survey”. International Journal of Applied Econometrics and Quantitative Studies 3-1, p. 85-102.

- $\quad$ Pesaran H.M. ve Shin Y. (1995). “Autoregressive Distributed Lag Modelling Approach to Cointegration Analysis”. DAE Working Paper Series No. 9514. Cambridge: Department of Applied Economics, University of Cambridge.

- Pesaran H.M. ve Shin Y. (1999). “Autoregressive Distributed Lag Modelling Approach to Cointegration Analysis". Econometrics and Economic Theory in the 20th Century: The Ragnar Frisch Centennial Symposium. Cambridge: Cambridge University Press.

- $\quad$ Pesaran H.M., Shin Y., Smith R.J. (2001). "Bounds Testing Approaches to the Analysis of Level Relationships". Journal of Applied Econometrics 16, p. 289-326.

- Rogoff K. ve Reinhart C. (2002). "FDI to Africa: The Role of Price Stability and Currency Instability", $I M F$ Working Paper (Washington, DC: IMF).

- Taylor D. (1982). “Official Intervention in the Foreign Exchange Market, or, Bet Against the Central Bank”. Journal of Political Economy April, p. 356-68. 


\title{
Uluslararası Para Sistemi ve Renminbi'nin Yükselişi International Monetary System and the Emergence of Renminbi
}

\author{
Prof. Dr. Müslüme Narin (Gazi University, Turkey) \\ Ph.D. Candidate Alpay Öznazik (Gazi University, Turkey)
}

\begin{abstract}
After the 2008 crisis International Monetary System (IMS) entered a period of change. The system under hegemony of dollar criticized in financial markets with regards to instability and lack of confidence. Whereas IMF argued that the IMS should be restructured in emerging markets, in the report of World Bank it was estimated that in the future of IMS a multipolar multiple currency system which includes Dollar, Euro and Renminbi (RMB) will improve (World Bank, 2011: xii). BRICS countries wanted diversify, especially, the Chinese reserves, but the Executive Board of IMF rejected SDR basket to be expanded until 30 November 2015. With the decision taken on this date, it took Chinese national currency RMB into SDR basket since the date of 1 October 2016. After this decision, the value of SDR has been composed of the sum of the currencies of US dollar, Euro, Chinese RMB (yuan), Japanese yen and pound sterling. Thereby, in SDR basket Chinese national currency ranked thirdly by weight.

The purpose this paper is to discuss the ever-increasing importance of Chinese national currency RMB in IMS. In this direction, at first, the formation and development of SDR will be informed, then the direction of RMB towards the SDR basket will be discussed, after that, the appearance of the idea of RMB's internationalization and the period of internationalization of RMB will be addressed. Finally, an assessment will be made about RMB's being a means of payment and international financial asset in foreign trade.
\end{abstract}

\section{Giriş}

Küresel finansal krizden sonra uluslararası para sisteminin yükselen piyasaları da içerecek biçimde yeniden şekillendirilmesi gerektiği görüşü yaygınlaşmaya başlamıştır. Bu doğrultuda IMF Yönetim Kurulu, 30 Kasım 2015 tarihinde almış olduğu kararla Çin'in ulusal para birimi Renminbi (RMB)'yi 1 Ekim 2016 tarihinden itibaren SDR sepetine dahil edeceğini açıklamıştır. Alınan bu kararın ardından SDR'nin değeri ABD doları, avro, Çin RMB'si (yuan), Japon yeni, İngiliz sterlini'ninden oluşan beş para birimince belirlenmeye başlamıştır. Böylece Çin'in ulusal parası RMB, SDR sepeti içinde ağırlık olarak üçüncü sırada yer almıştır.

Çin'in ulusal para birimi RMB'nin uluslararası para sistemi içerisindeki giderek artan önemini tartışmayı amaçlayan bu çalışmada, öncelikle SDR'nin oluşumu ve gelişimi hakkında bilgi verilmiştir. Ardından RMB'nin SDR sepetine doğru gidişi ele alınmış, daha sonra RMB'nin uluslararasılaşması düşüncesinin ortaya çıkışı ve RMB'nin uluslararasılaşması üzerinde durulmuştur. Son olarak da RMB'nin dış ticarette ödeme aracı ve uluslararası finansal varlık olması tartışılmıştır.

\section{2 Özel Cekme Hakları}

Özel çekme hakları (SDR), 1969 yılında IMF tarafından Bretton Woods sabit kur rejimini desteklemek amacıyla oluşturulan uluslararası bir rezerv para birimidir. IMF'e üye ülkelerin mevcut resmi rezervlerine katkıda bulunmak amacıyla oluşturulmuş ve aynı adı taşıyan ayrı bir kısım tarafından çıkartılmaktadır. SDR üye ülkelere IMF kotalarıyla orantılı olarak tahsis edilmektedir. Aynı zamanda SDR, IMF'nin ve diğer bazı uluslararası kuruluşların hesap birimi olarak kullanılmakta ve değeri başlıca uluslararası para birimlerinden oluşan bir sepet esas alınarak belirlenmektedir (IMF, 2016a).

SDR'nin değeri başlangıçta 0.888671 gram saf altının eşdeğeri (aynı zamanda 1 ABD dolarına eşit) olarak belirlenmiştir. Bretton Woods sisteminin 1973 yılında sona ermesi ve dalgalı kur uygulamasına geçilmesiyle SDR'nin bileşimi, dünya ticaretinde büyük paya sahip ülkelerin paralarını içerecek biçimde değiştirilmiştir. 1974 yılından itibaren SDR'nin değeri 16 ülke para birimine endekslenmiştir. Ancak 1981 yılında SDR değerinin belirlenmesine konu olan ulusal para sayısı ABD doları, Alman mark1, Fransız frang1, Japon yeni ve İngiliz sterlini olmak üzere beşe indirilerek dünya ticaretinde en büyük paya sahip olan ülkelerin ekonomik gücünü yansıtacak şekilde düzenlenmiştir. 1999 yılında Avrupa Birliği (AB) ülkelerinin avroya geçmesiyle SDR, ABD doları, avro, Japon yeni ve İngiliz sterlininden oluşan dört para birimine indirilmiştir (Zöllner, 2016: 1).

1 Ekim 2016 tarihi itibariyle SDR sepeti ABD doları, avro, Çin RMB'si (yuan), Japon yeni ve İngiliz sterlininden oluşan beş para birimini içerecek şekilde genişletilmiştir. SDR'nin ABD doları cinsinden değeri IMF'in web sitesinde günlük olarak yayınlanmaktadır. Bu değer, söz konusu beş para biriminin ilgili miktarlarının ABD doları cinsinden değerlerinin toplamına eşittir. SDR sepetinin bileşimi, sepette para birimlerinin dünya ticaret ve finans sistemlerindeki nispî ağırlığını yansıtacak şekilde beş yılda bir gözden geçirilmektedir. Bu incelemeler sonucu, 
sepetteki her para biriminin nispî ağırlığı ve SDR faiz oranını hesaplamak için hangi finansal araçların kullanılması gerektiği belirlenmektedir (IMF, 2016a).

RMB'nin SDR sepetine katılımıyla ilgili tartışmalar, 2010 yılından önce başlamış olmasına karşın, 2015 tarihine kadar devam etmiştir. Ancak IMF Yönetim Kurulu 30 Kasım 2015 tarihinde Çin'in ulusal para birimi RMB'nin 1 Ekim 2016 tarihinden itibaren SDR sepetine alınmasına karar vermiştir.

IMF'in bu kararı vermesinde iki temel kriterin yerine getirilmesi etkili olmuştur. Çünkü bir ülke parasının SDR sepetine dahil edilebilmesi için aşağıda açıklanan kriterlerin sağlanması gerekmektedir (IMF, 2016b; Eğilmez, 2015):

Birincisi, ihracat kriteridir (gateway). Bu kritere göre söz konusu üye ülkenin ticaret hacminin son beş y1lda en yüksek değerine ulaşmış olması ve sahip olduğu para biriminin üye ülkeler arasındaki dış ticaret işlemlerinde kullanılıyor olması gerekmektedir. Bu kriter 1970'lerden bu yana SDR metodolojisinin bir parçası olmuştur.

İkincisi ise serbest kullanılabilir (freely usable) olmasıdır. Söz konusu üye ülke parasının uluslararası ödemelerde kullanılabiliyor olması, uluslararası alanda sermaye akımlarına açık olması ve serbest dalgalanmaya bırakılmış olması gerekmektedir.

IMF Yönetim Kurulu, 1 Ekim 2016 tarihi itibariyle Çin'in ulusal para birimi RMB'nin bu iki koşulu sağladığına ve SDR sepetine alınmasına karar vermiştir. Böylece RMB de SDR sepetine dahil edilen beşinci rezerv para konumuna gelmiştir. SDR sepetindeki rezerv paraların ağırlıkları Tablo 1'de görülmektedir.

\begin{tabular}{|l|l|l|l|}
\hline Para Birimi & 1 Ekim 2010 (\%) & 1 Ekim 2016 (\%) & Değişiklik \\
\hline ABD doları & 41,90 & 41,73 & $-0,17$ \\
\hline Avro & 37,40 & 30,93 & $-6,47$ \\
\hline Çin RMB'si & - & 10,92 & $+10,92$ \\
\hline Japon yeni & 9,40 & 8,33 & $-1,07$ \\
\hline İngiliz sterlini & 11,30 & 8,09 & $-3,21$ \\
\hline Toplam & 100,00 & 100,00 & - \\
\hline
\end{tabular}

Tablo 1. SDR Sepetindeki Paraların Ağırlıkları, Kaynak: IMF, 2016b; Eğilmez, 2015.

Tablo 1'deki değişiklikten de görüldüğü gibi, ABD dolarının uluslararası ağırlığında önemli bir değişiklik olmazken, Japon yeni ve İngiliz sterlini değer kaybetmiş ve avro ise oldukça gerilemiştir.

IMF'in üye ülkeler için oluşturduğu toplam SDR'nin değeri, Mart 2016 tarihi itibariyle 204 milyar SDR (286 milyar ABD doları) olmuştur (IMF, 2016a; IMF, 2016c).

\section{RMB'nin SDR Sepetine Gidişi}

RMB'nin SDR sepetine alınmasındaki birinci durum, Çin ekonomisinin son 30 yıllık dönemde çok büyük ölçüde büyümesidir. Modern tarihte hiçbir ülke, bu kadar uzun dönemde böyle bir büyüme hızına ulaşamamıştır. 19802000 arasında Çin ekonomisi, her yıl ortalama \%10 büyüme göstermiştir. Bu büyüme hızıyla Çin, günümüzde dünyanın ikinci en büyük ekonomisine sahip olmuş ve satın alma gücü paritesiyle ölçüldüğünde 2015 yılında ABD ekonomisini geçerek birinci sıraya yükselmiştir. 2015 yılında yaklaşık 115.166 milyar uluslararası dolar olan satınalma gücü paritesine göre dünya GSYİH'sının Çin \%17,2'lik payına sahipken, ABD \%15,7'lik payla ikinci sırada kalmıştır. 2015 yılında Çin'in satınalma gücü paretesine göre GSYİH'sı 19.815 milyar dolar olurken, ABD'nin aynı yıl GSYİH'sı 18.037 milyar dolar olmuştur (World Bank, 2017). Çin ekonomisindeki son yedi yıllık büyüme oranı Tablo 2'de görülmektedir.

\begin{tabular}{|c|c|}
\hline Y1llar & Büyüme Oranı (\%) \\
\hline 2009 & 9,40 \\
\hline 2010 & 10,64 \\
\hline 2011 & 9,54 \\
\hline 2012 & 7,86 \\
\hline 2013 & 7,76 \\
\hline 2014 & 7,29 \\
\hline 2015 & 6,92 \\
\hline
\end{tabular}

Tablo 2. Çin'in Büyüme Oranı, Kaynak: National Bureau of Statistics of China, 2016.

Çin ekonomisindeki bu hızlı büyüme, ekonomisini dünyaya açan piyasa odaklı reformlar sayesinde olmuştur. Bu büyümenin arkasındaki temel faktörler, ihracat ve yatırımlardır.

Çin malları dünyanın her yerinde bulunmakta ve herkes tarafından kullanılmaktadır. 2015 yılında Çin küresel ihracatın (16.482 milyar dolar) yaklaşık \%13,8'ini (2.275 milyar dolar) yaparak birinci sırada yer almıştır. Küresel ihracattaki payı ile Çin, \%9,1 paya sahip ABD (1.505 milyar dolar) ve \%8,1 paya sahip Almanya'yı (1.329 milyar dolar) geçmiştir (WTO, 2016: 13). Çin'in 2009-2015 dönemine ilişkin diş ticareti Tablo 3 'te görülmektedir. 


\begin{tabular}{|l|r|r|r|r|r|r|r|r|}
\hline & \multicolumn{4}{|l}{$\mathbf{1 0 0}$ Milyon Yuan } & \multicolumn{1}{l|}{ 100 Milyon Dolar } \\
\hline Yıllar & İhr. + İth. & İhracat & İthalat & İhr. - İth. & İhr. + İth. & İhracat & İthalat & İhr. - İth. \\
\hline 2009 & 150648,1 & 82029,7 & 68618,4 & 13411,3 & 22075,3 & 12016,1 & 10059,2 & 1956,9 \\
\hline 2010 & 201722,1 & 107022,8 & 94699,3 & 12323,5 & 29739,9 & 15777,5 & 13962,4 & 1815,1 \\
\hline 2011 & 236402,0 & 123240,6 & 113161,4 & 10079,2 & 36418,6 & 18983,8 & 17434,8 & 1549,0 \\
\hline 2012 & 244160,3 & 129359,3 & 114801,0 & 14558,3 & 38671,2 & 20487,1 & 18184,1 & 2303,0 \\
\hline 2013 & 258168,9 & 137131,4 & 121037,5 & 16093,9 & 41589,9 & 22090,0 & 19499,9 & 2590,1 \\
\hline 2014 & 264241,7 & 143883,7 & 120358,0 & 23525,7 & 43015,2 & 23422,9 & 19592,3 & 3830,6 \\
\hline 2015 & 245502,9 & 141166,8 & 104336,1 & 36830,7 & 39530,3 & 22734,7 & 16795,6 & 5939,1 \\
\hline
\end{tabular}

Tablo 3. Çin'in Dış Ticareti, Kaynak: National Bureau of Statistics of China, 2016.

Çin ekonomisinin 2000'li yıllardaki önemli büyümesinin arkasındaki itici güç, yatırımlarda ve altyapıdaki çok önemli gelişmelerdir. Bu yıllardaki sermaye birikiminin, ortalama reel büyümesinin yarısından fazlasını oluşturduğu ileri sürülmektedir (Zöllner, 2016: 3).

Çin ekonomisindeki büyüme son yıllarda yavaşlamış olmasına rağmen (2015 yılında \%6,9) (World Bank, 2017), hala dünya genelinde yüksek bir büyüme oranıdır. Dolayısıyla bu durum RMB'nin uluslararası rezerv para birimi olması için IMF'in koymuş olduğu kriteri sağlamasına yetmektedir.

RMB'nin SDR sepetine alınmasındaki ikinci durum ise Çin Hükümeti ve Merkez Bankasının para birimlerinin uluslararasılaşmasını teşvik etmek için oynadığı aktif roldür. Tarihsel süreç içerisinde bakıldığında, hiçbir para birimi küresel değişim aracı olarak yetkilileri tarafından bu kadar teşvik edilmemiştir (Frankel, 2011). Çin'in yerli finansal sistemdeki finansal baskıyı sona erdirme isteği, sınır ötesi sermaye kontrollerini kaldırması ve RMB'nin değerlenmesine izin vermeyi kapsayan para birimini uluslararasılaştırmaya yönelik olarak oldukça istekli olduğu görülmektedir.

\section{RMB'nin Uluslararasılaşması Düşüncesinin Ortaya Çıkışı}

Bir para biriminin uluslararasılaşması üzerine çeşitli çalışmalar yapılmıştır. Bu çalışmalarda kavrama ilişkin yapılan tanımlamalar da çeşitlilik göstermektedir. Cohen (1971), Tavlas (1991), Hartman (1998) vb. çalışmalara göre, bir yerel paranın uluslararası ticarette ve yatırımlarda kullanılabilecek uluslararası para birimi olabilmesi için ülke içerisinde sahip olduğu mübadele aracı olma, değer saklama aracı olma ve hesap birimi olma özelliklerine uluslararası alanda da sahip olması gerekir. Dong ve Yao (1997) ve Yang (2003)'te RMB'nin uluslararasılaşması özelinde yapılan tanıma göre, RMB'nin ülke dışına çıkması ve bütün dünyada genel olarak fiyatlama, ödeme, rezerv ve müdahale aracı olarak kullanılması süreci, bu kavrama karşılık gelmektedir. Zhou ve Wen (2001)'de ise bir para biriminin uluslararasılaşması, bu para birimi cinsinden cari hesabın ve sermaye hesabının zaman içerisinde daha fazla dışa açılması süreci demektir (aktaran Lin, Xiao, Liang ve Zhang, 2017: 14). Bu tanımlamalarda ifade edilen süreçler son yıllarda Çin'in para birimi olan RMB için de gözlemlenmektedir.

1990'ların ikinci yarısından sonra, özellikle de 1997 yılında Asya'da yaşanan finansal kriz sonrasında, Çin'e komşu olan ülkeler aralarındaki ödemelerde mübadele aracı olarak RMB'yi kabul eder duruma gelmişlerdir. Böylece bu dönemde ilk defa Çin'den dışarıya doğru yüklü miktarda RMB sirkülasyonu başlamıştır. Her ne kadar bu gelişme RMB'nin uluslararası bir para birimi olması yönünde atılmış ilk adım olarak görülse de, Çin ve komşuları arasında gerçekleşen bir uluslararasılaşmadır. Bundan dolayı RMB'nin yalnızca uzak doğu Asya ülkelerinde konvertibilite kazanması bakımından söz konusu gelişmeyi uluslararasılaşmadan ziyade bir bölgeselleşme olarak görmek de mümkündür (Li, 2004: 86).

RMB'nin uluslararasılaşmasına ilişkin “ilk kıvılcım” ise 2008 yılındaki küresel finansal krizle birlikte 2009 yılında ortaya çıkmıştır. Uluslararası para sisteminin aksaklıklarından meydana gelmiş olan bu küresel krizin devamında, 23 Mart 2009 tarihinde merkez bankası işlevini gören Çin Halk Bankası (People's Bank of China, PBoC)'nın yöneticisi Xiaochuan Zhou tarafından üç sayfalık bir metin yayımlanmıştır (Wang, 2017: 28). Bu metinde IMF'nin küresel finansal istikrarın sağlanması ve dünyada ekonomik büyümenin hızlandırılması amacına paralel olarak, hiçbir ülkeyle iyelik bağlantısı olmayan ve uzun dönemde istikrarsızlık göstermeyecek uluslararası bir rezerv para birimi yaratılması önerilmiştir (Zhou, 2009). Yu (2014)'e göre, Zhou (2009)' un asıl amac1, ABD dolarını sahip olduğu aşırı ayrıcalıktan yoksun bırakacak SDR temelli uluslarüstü bir para biriminin yaratılmasını önermektir. Ancak Zhou (2009)'un bu önerisi ABD başkanı Barack Obama'nın, ABD dolarının halen çok güçlü bir para birimi olduğu gerekçesiyle, karşı çıkması sonucu rafa kalkmıştır (Yu, 2014: 5).

Bununla birlikte, yabancı rezervlerin yönetiminde daha fazla güvenlik ve likidite hedefleyen Çin'in, yılda yaklaşık 400 milyar dolarlık yabancı rezerv birikimi nedeniyle, ABD hazine bonosu piyasasından başka bir alternatifi kalmamış ve Çin'de ABD dolarına karşı aşırı bir bağımlılık oluşmuştur. Böylece yabancı rezerv cinsinden varlık kalemleri de son derece kısıtlı bir hale gelmiştir. Bu durumda RMB kurunu sabit tutmak giderek zorlaşmış, kuru sabit tutmanın tek çözümü ise yabancı rezerv birikimi içindeki ABD hazine bonosunun payını 
yüksek tutmak ve bu payı korumak olmuştur (Wang, 2017: 30). Tüm bunların yanında, Çin'in dış ticaretinde ciddi bir para birimi uyumsuzluğu sorunu ortaya çıkmıştır. Çin'deki ihracatçıların üretim maliyetlerini RMB cinsinden ödeme yaparak karşılayıp, sattıkları mallar karşılığında ABD doları almaları ve ithalatçıların da mallarını dolar karşıllığında alıp RMB karşılığında satmaları bu sorunun temel nedenidir. Para birimi uyumsuzluğu Çin'deki hem ihracatçılar hem de ithalatçılar için kur riskleri yaratmıştır. Dolayısıyla az gelişmiş olan sermaye piyasaları için bu riskler daha maliyetli ve bunlarla başa çıkılması da oldukça güç olmuştur (Lo, 2013: 38). Çin'in ABD doları karşısında yaşadığı güçlükler, uluslararası bir para birimi oluşturulmasını zorunlu kılmış̧ır. Zhou (2009)'da sunulan öneri ABD tarafından geri çevrildiği için geriye kalan tek yol, RMB'nin uluslararasılaştırılmasıdır.

\section{RMB'nin Uluslararasılașması}

2009 yılı Nisan ayında Çin Halk Cumhuriyeti Devlet Konseyi sınır ötesi ticarette ödeme aracı olarak RMB'nin kullanılması amacıyla bir pilot program yürütmeye karar vermiştir. Bu doğrultuda aynı yılın Temmuz ayında program resmen yürürlüğe konulmuş, böylece RMB'nin uluslarasılaşması doğrultusunda gerçekleştirilecek sistematik çalışmalar başlatılmıştır (12. Beş Yıllık Plan, Sütun 3, 2011: 32).

Yu (2012)'ya göre, RMB'nin uluslararasılaşmasının Çin ekonomisi için dört olası faydası bulunmaktadır. İlk olarak, Çin firmalarının karşı karşıya kaldıkları kur riskleri azalacaktır. Çünkü RMB'nin uluslararasılaşması, faturalandırmaları ve ödemeleri RMB cinsinden yapılan daha fazla dış ticaret ve finansal işlem demektir. İkinci olarak, dış ticarette ödemelerin RMB cinsinden yapılması Çin devletinin yaptığ 1 ticari işlemlerden doğan maliyetleri düşürecektir. Bu da dış ticaretin hızla artmasını sağlayacaktır. Üçüncü olarak, Çin'deki finansal kuruluşların faaliyetleri için fon bulması daha kolay hale gelecek, böylece Çin'in uluslararası alanda rekabet gücü artacaktır. $\mathrm{Bu}$ da, Çin'in finansal hizmetler sektörünü genişletecektir. Dördüncü olarak ise RMB'nin uluslararasılaşması bir mübadele ve değer saklama aracı olarak Çin'in ABD doları tutma ihtiyacını azaltacak, ABD'ye yapılan senyoraj ödemesi düşürülebilecek ve böylece büyük dolar rezervinin yol açtı̆̆ı sermaye kayıpları da azalacaktır (Yu, 2012: 6-7).

Bunların yanında, RMB'nin uluslararası bir para birimi haline getirilmesi basit bir süreç olarak görülmemelidir. Zhang (2009)'a göre, 2009 yılında RMB'nin bir uluslararası para birimi olması karşısında dört tane engel bulunmaktadır. Bunlardan birincisi, Çin'in sermaye hesabını dışa tam olarak açmamış olması ve RMB'nin konvertibl olmamasıdır. Dolayısıyla, sermaye hesabı yoluyla RMB denizaşırı ülkelerde yaygınlaştırılamamaktadır. İkincisi, RMB kurunun serbest dalgalanmaya bırakılmamış olması ve büyük ölçüde devlet müdahalesine tâbi olmasıdır. Bu, RMB'ye yönelik forward işlemlerini hem yurtdışı hem de yurtiçi piyasalarda kısıtlamaktadır. Çünkü kur risklerine karşı yapılabilecekler daha sınırlı olduğu için yurtdışındaki bireylerin ve işletmelerin ellerinde RMB tutma isteği azalmaktadır. Üçüncüsü, yabancı yatırımcının yurtiçi sermaye piyasasında doğrudan yatırım yapamıyor olması ve denizaşırı piyasalarda RMB cinsinden finansal varlıkların olmamasıdır. Dördüncüsü ise Çin devletinin RMB'yi uluslararasılaştırmak konusunda, o güne dek, pek istekli olmamasıdır. Bütün bunlar RMB'nin bir uluslararası rezerv para olması karşısında engel teşkil etmiştir. Bununla birlikte, ABD kaynaklı 2008 küresel krizi, Çin devletinin RMB'nin uluslararasılaşması konusunda fikrinin değişmesini ve daha istekli hale gelmesini sağlamıştır (Zhang, 2009: 24). 12. Beş Yıllık Plan'da bu fikir değişimine gerekçe olarak, Çin'deki işletmelerin ve bölge ülkelerinin dış ticaretlerini 2008 krizinde çok ciddi dalgalanmaların yaşandığı dolar ve avro cinsinden gerçekleştirmeleri ve bu durumun barındırdığı kur riskleri gösterilmiştir (12. Beş Yıllık Plan, Sütun 3, 2011: 32).

RMB'den önce yen ve avronun uluslararasılaşması bir yol haritası olmaksızın piyasaların "rüzgarına kapılmak" biçiminde gerçekleşmiştir. Örneğin Japonya, ulusal parasını (yen) ABD baskısı altında uluslararasılaştırmak durumunda kalmıştır. Yenin uluslararasılaşması için bir yol haritasından söz edilecekse, bu ABD'nin istekleri doğrultusunda Japonya'nın sermaye hesabını liberalleştirmesi biçiminde ortaya konmaktadır. Avro bölgesinde ise en önemli aktör olarak görülen Almanya, Alman markının yok olması pahasına uluslararası bir para birimi olarak avroyu desteklemiştir. Ancak burada da avro bölgesi menşeli borç krizinin ardından Almanya'nın düşük standartlara sahip olan bir parasal birlik içerisine sıkıştırıldığı görülmektedir. Bunlardan farklı olarak Çin, 2009 yılında para birimini uluslararası alanda dolarla eşit ölçülerde bir rezerv para haline getirmek amacıyla harekete geçmiştir (Yu, 2012: 7). Ayrıca Çin, para birimini uluslararası rezerv para yapmak için çalışan ilk gelişmekte olan ülkedir. Bu bakımdan, Çin'in RMB'yi uluslararasılaştırma deneyimi dünyada daha önce eşine rastlanmamış bir deneyimdir. Üstelik daha önce bu deneyimi yaşamış olan Almanya ve Japonya gelişmiş ülkeler olmalarına rağmen, para birimlerinin uluslararasılaşması sürecini tamamlayamamışlardır (Subacchi, 2010: 2).

Çin'de RMB'nin uluslararasılaşma sürecini daha yoğun olarak üç kurum yönetmiştir. Bunlar; PBoC (merkez bankası), Maliye Bakanlığı ve Ticaret Bakanlığı'dır. 2009 yılında yönetici koltuğunda Xiaochuan Zhou'nun oturduğu PBoC bu konuda öncü konumundadır (Campanella, 2014: 4). Çin RMB'yi uluslararası bir para birimi haline getirmek amacıyla bir dizi politika yürürlüğe koymuştur. İlk olarak, 2008 küresel krizinden de önce, 2007 yılında ve sonrasında ise 2010 yılında RMB cinsinden, dim sum tahvilleri (Çin'in dışında, ancak Çin RMB'si (yuan) cinsinden ihraç edilen tahviller) adıyla anılan tahvillerin yurtiçi bankalar ve Hong Kong bankaları tarafından yurtdışına ihraç edilmesinin önündeki engeller kaldırılmıştır (Chen, 2016: 4). Tabi ki böyle bir uluslararasılaştırma sürecinde Çin'in Hong Kong gibi çok önemli bir ticaret merkezine sahip olması büyük avantaj 
sağlamıştır. Dolayısıyla RMB'nin uluslararasılaşması, Hong Kong'dan yapılan ithalat için RMB cinsinden ödeme yapılması desteklenerek başlamıştır (Yu, 2012: 8). 2011 yılında yayımlanan 12. Beş Yıllık Plan'da, uygulanacak olan bu politikalar düzenlenmiştir. Buna göre, uluslararası finans merkezi olarak Şangay’ın yükselişine hız verilmesi ve Hong Kong ile Şangay arasındaki finansal işbirliğinin geliştirilmesi planlanmıştır. Ayrıca Hong Kong'un, kıyı ötesi RMB işlem merkezi ve uluslararası varlık idaresi merkezi olarak desteklenmesine karar verilmiştir (12. Beş Yıllık Plan, 6. Bölüm, Kısım 3, 2011: 31). Yine bu plan içerisinde Çin'in, Finansal İstikrar Kurulu (Financial Stability Board) ve Basel Bankacılık Denetim Komitesi (Basel Comitee on Banking Supervision) gibi uluslararası finansal kuruluşların belirlediği standartlara tam olarak uyum sağlaması ve denizaşırı merkez bankaları ve düzenleyici otoritelerle bilgi paylaşımının ilerletilmesi hedeflenmiştir (12. Beş Yıllık Plan, 6. Bölüm, Kısım 4, 2011: 31). Böylece sermaye hesabının dışa açılması ve RMB'nin uluslararasılaşması resmen kabul görmüş ve bir devlet politikası haline gelmiştir.

\section{Dış Ticarette Ödeme Aracı ve Uluslararası Finansal Varlık Olarak RMB}

Günümüzde RMB'nin uluslararasılaşması konusunda uygulamaya konulan politikaların yanı sıra uygulamada da somut adımlar atılmıştır. Temel amacı RMB'nin uluslararası alanda faturalandırma ve ödeme aracı olarak kullanılması olan bu politikaların önemli sonuçlar vermiş olduğunu dış ticaret ve doğrudan yatırım verilerinden gözlemlemek mümkündür. Öncelikle Çin'in cari işlemler hesabına bakılırsa, 2009-2015 döneminde RMB cinsinden dış ticareti, özellikle de mal ticaretinde çok büyük artışın ortaya çıktığı görülmektedir (Şekil 1).

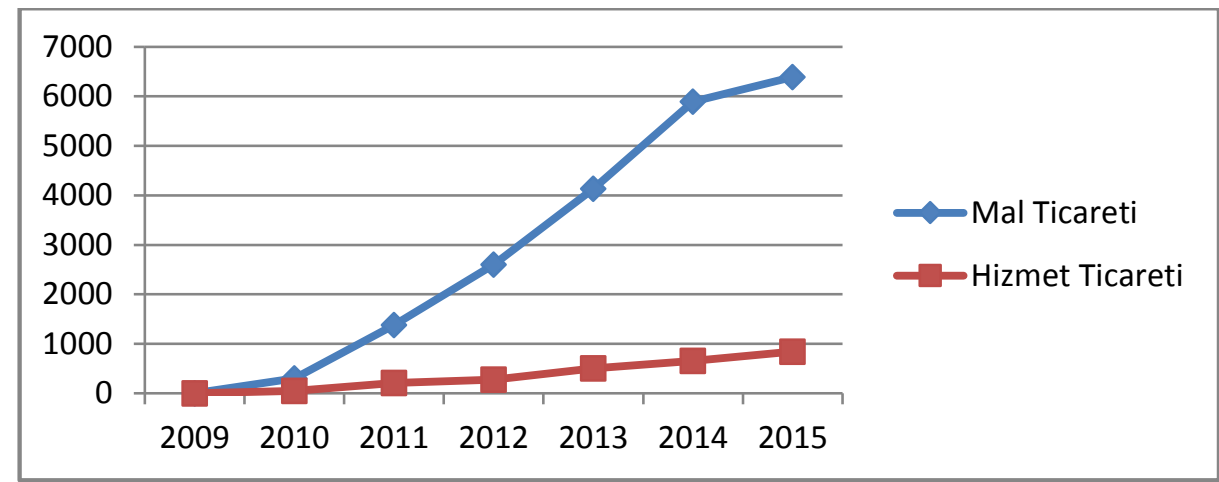

Şekil 1. Cari İşlemler Hesabında RMB Cinsinden Ödemeler 2009-2015 (Milyar Yuan), Kaynak: PBoC, $2016 a$.

Buna göre, 2009 yılında toplam 2,56 milyar yuan düzeyinde olan Çin’in RMB cinsinden dış ticaret toplamı 2015 yılında 7,23 trilyon yuan düzeyine ulaşmıştır. Bunun içinde mal ticareti toplamı 6,39 trilyon yuan ve hizmet ticareti toplamı da 843,22 milyar yuandır. 2009'dan 2015 yılı sonuna kadar ödemeleri RMB cinsinden yapılan dış ticaretin genel toplamı ise 23,2 trilyon yuandır. Bu genel toplamın içerisinde mal ticaretinin genel toplamı 20,7 trilyon yuan, hizmet ticaretinin genel toplamı da 2,5 trilyon yuandır (PBoC, 2016a: 47). Ancak, toplamda etkileyici bir artış gösteren bu iki tip ticaretin ne kadarı Çin'in geliri, ne kadarı da gideri olduğu, RMB'nin dünya piyasalarında yaygınlaşması bakımından önemlidir.

Tablo 4'te 2011-2015 döneminde ödemeleri RMB cinsinden yapılan dış ticaretin gelir ve gider kalemleri gösterilmiştir. Tabloda yer alan veriler PBoC'nin RMB Uluslararasılaşma Raporları (RMB Internationalization Reports)'dan derlenmiştir.

\begin{tabular}{|l|l|l|l|l|}
\hline & Gelir & Gider & Net Gelir & Gelir/Gider (\%) \\
\hline 2011 & 0,73 & 0,86 & $-0,13$ & 84,88 \\
\hline 2012 & 1,30 & 1,57 & $-0,27$ & 82,80 \\
\hline 2013 & 1,88 & 2,75 & $-0,87$ & 68,36 \\
\hline 2014 & 2,73 & 3,82 & $-1,09$ & 71,47 \\
\hline 2015 & 3,91 & 3,32 & 0,59 & 117,77 \\
\hline
\end{tabular}

Tablo 4. Ödemeleri RMB Cinsinden Yapılan Dış Ticaret Gelir ve Giderleri 2011-2015 (Trilyon Yuan), Kaynak: PBoC.

Bu tabloda da görüldüğü gibi, bu biçimde yapılan dış ticaret gelirleri giderlerini ilk defa 2015 yılında aşmıştır. 2014 yılına kadar yaklaşık \%70 düzeylerine ulaşan gelirlerin giderleri karşılama oranı, 2015 y1lında \%100’ün üzerine çıkmıştır. Gelirlerin giderleri karşılama oranındaki bu artışın arkasında, RMB cinsinden gelirlerdeki \% 43,2 oranında artış ve giderlerdeki \% 13,1 oranında azalış yatmaktadır. Ancak bu türden yapılan dış ticaret giderlerinin Çin için sadece para basma maliyetinden ibaret olduğu unutulmamalıdır. Bu bağlamda, gelirlerin giderleri aşmış olması, dünya piyasalarına ihraç edilmiş olan RMB'nin tekrar ülke içerisine geri dönmesi anlamına gelmektedir. $\mathrm{Bu}$ da RMB'nin uluslararası bir para birimi olarak dünya piyasalarında yaygınlaşmasını olumsuz etkilemiştir. 
Ancak, dış ticaret için Çin tarafından RMB cinsinden yapılan ödemeler ithalatın bu ödemeler kadar olan kısmının sadece para basma maliyetiyle karşılanmasını sağlamaktadır. Diğer bir ifadeyle bu türden yapılan ithalat ödemeleri Çin için neredeyse sıfır maliyetli olmaktadır. Daha önce Çin'in toplam dış ticaret verilerinin gösterilmiş olduğu Tablo 3'teki ithalat verilerinin RMB cinsinden ifade edilmiş değerleri Tablo 4'teki giderlerle karşılaştırıldığında, 2011 yılında \%7,6 düzeyinde olan RMB cinsinden yapılan ödemelerin ithalatı karşılama oranı 2015 yılına gelindiğinde \%31,82 düzeyine kadar yükselmiştir. Bu da Çin'in 2015 yılında toplam ithalatının \%31,82'sini neredeyse sıfır maliyetle karşıladığını göstermektedir.

Sınır ötesi doğrudan yatırımlar için RMB cinsinden yapılan ödemeler de RMB'nin uluslararasılaşmasına ilişkin bir gösterge olarak önemlidir. Tablo 5'te 2010-2015 dönemi için bu verilere yer verilmiştir. Tablodaki ODI Çin'in diğer ülkelerde gerçekleştirdiği doğrudan dışa dönük yatırımlar için yaptığı RMB cinsinden ödemeleri, FDI ise diğer ülkelerin Çin'de gerçekleştirdiği doğrudan yabancı yatırımlar için yaptığı RMB cinsinden ödemeleri ifade etmektedir. Tablodan da görüldüğü gibi, diğer ülkelerin Çin'de gerçekleştirdiği doğrudan yatırımlar söz konusu dönem boyunca 22,36 milyar yuan düzeyinden yaklaşık 1,6 trilyon yuan düzeyine ulaşırken, Çin'in diğer ülkelerde gerçekleştirdiği doğrudan yatırımlar aynı dönem içerisinde 5,68 milyar yuan düzeyinden 736,17 milyar yuan düzeyine ulaşmıştır. Her iki türden doğrudan yatırımların genel toplamı ise bu dönem sonunda yaklaşık 4,5 trilyon yuan düzeyinde gerçekleşmiştir (PBoC, 2016a: 50). Çin'in dişa dönük doğrudan yatırımları (ODI) ülke içerisindeki doğrudan yabancı yatırımlar (FDI) karşısında süreç boyunca hep çok düşük kalmış, yıllar geçtikçe aradaki fark sürekli artmıştır. Bu da 2015 yılı dış ticaretinde olduğu gibi, yurtdışına ihraç edilen RMB'nin ülke içerisine geri dönmesi ve doğrudan yatırım harcamalarının da RMB'nin uluslararasılaşmasını engellemesi demektir. Çin'in asıl hedefi ise RMB'nin ülke dışında ödeme aracı olarak kullanımının yaygınlaşmasıdır.

\begin{tabular}{|l|c|c|c|}
\hline & ODI & FDI & Toplam \\
\hline 2010 & 5,68 & 22,36 & 28,04 \\
\hline 2011 & 26,59 & 100,68 & 127,27 \\
\hline 2012 & 31,19 & 259,20 & 290,39 \\
\hline 2013 & 86,68 & 457,09 & 543,77 \\
\hline 2014 & 224,41 & 960,55 & 1184,96 \\
\hline 2015 & 736,17 & 1587,1 & 2323,27 \\
\hline Toplam & 1110,72 & 3386,98 & 4497,70 \\
\hline
\end{tabular}

Tablo 5. Sınır Ötesi Doğrudan Yatırımlar Iç̧in RMB Cinsinden Ödemeler 2010-2015 (Milyar Yuan), Kaynak: PBoC, $2016 a$.

Yurtiçinde yerleşik olmayanların sahip olduğu RMB cinsinden finansal varlıklar da RMB'nin uluslararasılaşması bakımından dikkate değer verilerdir. Tablo 6'da Çin'de yerleşik olmayanların ellerinde tuttuğu RMB cinsinden hisse senetleri, tahviller, krediler ve mevduat verilerinin 2013 yılı Mart ayı ile 2015 yılı Aralık ayı arasında izlediği seyir gösterilmiştir.

\begin{tabular}{|l|r|r|r|r|r|r|r|r|r|}
\hline & Mar.13 & Ara.13 & Haz.14 & Eyl.14 & Ara.14 & Mar.15 & Haz.15 & Eyl.15 & Ara.15 \\
\hline Hisse Senetleri & 344,84 & 319,29 & 364,20 & 462,48 & 642,06 & 738,41 & 784,40 & 528,52 & 598,67 \\
\hline Tahviller & 398,98 & 512,35 & 559,31 & 634,14 & 671,58 & 712,80 & 764,08 & 764,58 & 751,71 \\
\hline Krediler & 530,98 & 746,84 & 893,82 & 860,47 & 819,05 & 876,92 & 924,21 & 935,71 & 851,56 \\
\hline Mevduat & 1604,91 & 1983,98 & 2045,13 & 2237,15 & 2372,18 & 2024,80 & 2120,35 & 1664,18 & 1538,07 \\
\hline Toplam & 2879,71 & 3562,46 & 3862,46 & 4194,24 & 4504,87 & 4352,93 & 4593,04 & 3892,99 & 3740,01 \\
\hline
\end{tabular}

Tablo 6. Yerleşik Olmayanların Elinde Tuttuğu RMB Cinsinden Varlıklar (Milyar Yuan), Kaynak: PBoC, $2016 a$.

Tabloya göre 2015 yılı sonu itibariyle hisse senetleri dışındaki bütün kalemlerde azalış görülmektedir. Bu azalışların da RMB'nin yurtdışında yaygınlaşmasını olumsuz yönde etkilediği söylenebilir. Çünkü bu yurtdışında yerleşik olanların RMB cinsinden finansal varlıklara karşı ilgilerinin azaldığı anlamına gelmektedir. Tabloda 2015 yılı sonunda yerleşik olmayanların ellerinde bulundurdukları RMB cinsinden finansal varlık toplamının 3,74 trilyon yuan düzeyinde olduğu görülmektedir. Bunun yanında, başlıca kıyı ötesi (offshore) piyasalarda RMB cinsinden mevduat 2015 yılı sonu itibariyle 1,45 trilyon yuan düzeyindedir. Bunun yanında, ödenmemiş uluslararası RMB tahvilleri toplamı ise 590,07 milyar yuandır. Ayrıca denizaşırı (overseas) merkez bankaları ya da para otoritelerinde tutulan RMB tahviller, hisse senetleri ve mevduat varlıkları toplamı da 864.7 milyar yuandır (PBoC, 2016a: 41).

Çin ile 192 ülke arasında, ödemeleri RMB kullanılarak yapılan ticari ve finansal işlemler gerçekleştirilmektedir. Şekil 2'de bu ülkeler, 2015 yılı için söz konusu işlemler içerisindeki paylarıyla birlikte gösterilmiştir. Şekildeki yüzdelik dilimler ülkelerin Çin ile yaptıkları ve ödeme aracı olarak RMB'nin kullanıldığı tüm ticari ve finansal işlemler içerisinde her bir ülkenin payını ifade etmektedir. Payları \%1'in altında kalmış olan ülkeler en son dilimde toplu olarak görülmektedir. Buna göre, \%52,9'la en büyük paya sahip olan ülke Hong Kong'dur. 192 ülke arasında 
bir ülkenin tek başına bu işlemlerin yarısından fazlasının içerisinde yer alması olumsuz bir durum olmasına rağmen, Hong Kong'un hem çok büyük bir ticaret, endüstri ve turizm merkezi oluşu, hem de Çin'e bağlı bir özel yönetim bölgesi oluşu bu olumsuzluğun avantaja dönüştürülebilmesi adına önemlidir. Bunun yanında Almanya, Japonya, Birleşik Krallık ve ABD gibi dünyanın en büyük ülkeleriyle Çin arasındaki yıllık işlem hacmi \%2 - \%3 aralığında, yani oldukça düşük düzeylerde kalmıştır (PBoC, 2016a: 52).

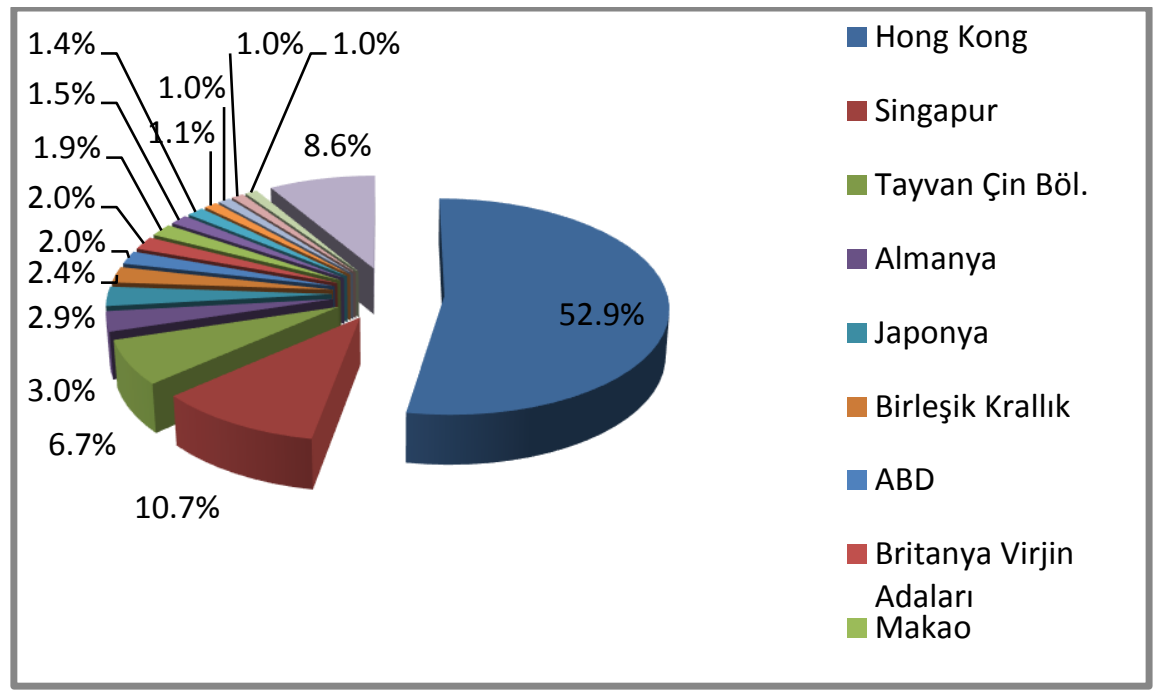

Şekil 2. Sınır Ötesi Tüm RMB Ödeme Işslemlerinin Yapıldığı Ülkeler 2015 (\%), Kaynak: PBoC, $2016 a$.

192 ülkeyle Çin arasında RMB cinsinden gerçekleşen tüm bu ticari ve finansal işlemlerin toplam hacmi 2015 yılında 12,1 trilyon yuan olarak gerçekleşmiştir. Bu toplamın 6,19 trilyon yuanlık kısmı gelirleri, 5,91 trilyon yuanlık kısmı da giderleri oluşturmaktadır (PBoC, 2016b: 15). RMB cinsinden yapılmış olan toplam dış ticaret ödemelerinde olduğu gibi, ticari ve finansal tüm işlemlerde de gelirler giderleri aşmış, yani net değerlere bakıldığında, yurtdışına ihraç edilen RMB 2015 yılında Çin’e geri dönmüştür.

PBoC'nin 17 Şubat 2017 tarihinde 2016 yılının 4. Çeyreğine ilişkin olarak yayımladığı para politikası raporunda 2016 yılı sonu itibariyle, yabancı ülkelerle Çin arasında RMB cinsinden gerçekleşen bütün ticari ve finansal işlemlerin toplam hacminin 9,85 trilyon yuan düzeyine düştüğü ifade edilmiştir. Ancak 2016 yılında RMB cinsinden giderler 6,06 trilyon yuan, gelirler de 3,79 trilyon yuan olarak gerçekleşmiş ve giderler yeniden gelirlerin önüne geçmiştir (PBoC, 2017: 15). Bu da, net değerlere bakıldığında, Çin'den dünyaya 2016 yılında RMB ihracı olduğu, yani 2016 yılında RMB'nin dünya piyasalarında yaygınlaşmasına katkı sağlanabildiği anlamına gelmektedir.

Böylece Çin'in ulusal para birimi olan RMB'nin bir uluslararası para birimi olması yolunda atılan adımlar mümkün olduğunca açık bir biçimde ortaya konmaya çalışılmıştır. 2009 yılında başlayan bu serüven 2015 yılının sonuna gelindiğinde önemli bir mesafe kat etmiştir. Çin'de Renmin Üniversitesi bünyesinde faaliyet göstermekte olan Uluslararası Para Enstitüsü (International Monetary Institute, IMI) tarafından hesaplanan ve 0-100 arasında bir değer alan uluslararasılaşma endeksi bu süreçte RMB için ancak 3,6 düzeyine kadar yükselebilmiştir. Fakat bu değer beş yıl önceki değerin on katıdır. Bu konuda en iyi durumdaki para birimi olan ABD doları yine 2015 yılı sonunda 54,97 endeks değerine sahip olmuştur. ABD dolarını takip eden para birimlerinden avronun endeks değeri 23,71, İngiliz sterlininin endeks değeri ise 4,53 ve Japon yeninin endeks değeri de 4,29'dur (IMI, 2016: 7-8). Dünyada ABD dolarının yerini RMB'nin almasını hedefleyen Çin bu konuda henüz çok geride görünmesine rağmen, söz konusu endeks değerindeki hızlı yükseliş önemli bir gelişmedir.

\section{Sonuç}

Bir ülkenin uluslararası piyasalarda, hem mal ve hizmet ticaretinde hem de finansal varlık piyasalarında, geçerliliği olan bir para birimine sahip olması o ülke için önemli bir avantaj sağlamaktadır. Bu avantaj ülkenin diğer para birimlerine olan bağımlılı̆̆ının ortadan kalkmasından, yaptığı ithalatı yalnızca para basma maliyetiyle karşılayabilmesinden ve senyoraj geliri elde etmesinden ileri gelmektedir. 2008 küresel kriziyle birlikte para birimlerine ilişkin kurlarda ciddi dalgalanmalar meydana gelen ABD ve Avrupa Birliği'nin yanında, Çin de 2009 yılında ulusal para birimi olan RMB'nin dolar ve avro gibi uluslararası rezerv para olması yönünde bir politika izlemeye başlamıştır. $\mathrm{Bu}$, gelişmekte olan bir ülkenin para birimini uluslararasılaştırması bakımından, dünya ekonomisinde daha önce benzerine rastlanmamış bir deneyimdir. Çünkü Çin'den önce ulusal para birimlerini bir uluslararası para birimi haline getiren ülkeler hep gelişmiş ülkeler olmuşlardır.

RMB'yi uluslararasılaştırmak konusunda Çin 2009 yılından bu yana önemli bir mesafe kat etmiş olsa da, bu anlamda birtakım sorunlar halen devam etmektedir. Bunlar arasında, Çin’in imkansız üçleme hipotezine aykırı 
davranıyor oluşu önemli sorunlardan bir tanesidir. Bilindiği gibi, imkansız üçleme hipotezine göre bir ülkede sabit kur rejimi, sermaye hareketlerinin serbest bırakılması ve bağımsız para politikasının aynı anda uygulanabilmesi mümkün değildir. Kur rejimine yönelik gerçekleştirilen reformlara rağmen, henüz tam olarak serbest kur rejimine geçmemiş olan Çin'de sermaye hareketleri serbest bırakılmıştır. Uygulamada sorunlara yol açabilecek olan bu durum karşısında RMB'nin tümüyle serbest dalgalanmaya bırakılması gerekmektedir. Böylece finansal işlemlerde ortaya çıkabilecek kur riskleri de en aza indirgenmiş olacaktır.

Çin'in diğer ülkelerle arasındaki, hem ticari hem de finansal olmak üzere, RMB cinsinden yapılan toplam işlem hacminin yarısından fazlasının Hong Kong'la, yani Çin'e bağlı bir ülkeyle arasında gerçekleşmesi RMB'nin bir uluslararası rezerv para olarak yaygınlaşması önünde ciddi bir engel teşkil etmektedir. Hong Kong Çin’e bağlı bir özel yönetim bölgesi olmasaydı bile bir tek ülkenin toplam işlem hacminde bu kadar yüksek bir paya sahip olması önemli bir sorundur. Buna karşılık, gelişmiş ülkelerin bu işlem hacminde payı oldukça düşüktür. 192 ülkeyle arasında RMB cinsinden ticari ve finansal ilişkiler olan Çin'in RMB'nin uluslararasılaşmasına katkıda bulunmak adına bu oranları daha dengeli bir duruma getirmesi gerekmektedir.

Diğer bir sorun ise Çin'in diğer ülkelerde faturalandırmaları ve ödemeleri RMB cinsinden yapılan dışa dönük doğrudan yatırımlarının, diğer ülkelerin aynı koşullarda Çin'de yaptığı doğrudan yabancı yatırımlara göre oldukça düşük olmasından kaynaklanmaktadır. Buna göre, doğrudan yatırımlar bakımından, yabancı ülkelerden Çin'e doğru bir net RMB akışı gerçekleşmektedir. Bu da RMB'nin dünya piyasalarında yaygınlaşması karşısında önemli bir engel olarak durmaktadır. Çin'in bu sorunun üstesinden gelebilmesi için diğer ülkelerde yaptığı RMB cinsinden faturalandırılan doğrudan yatırımlarını artırması gerekmektedir.

Son olarak, ödemeleri RMB cinsinden yapılan dış ticarette 2015 yılında gelirlerin giderleri aşmış olması yine Çin'e bir net RMB akışı olmasına neden olmuştur. Yani RMB'nin ülke dışına daha fazla ihraç edilebilmesi için Çin'in ithalatı içerisinde RMB cinsinden yapılan ödemelerin daha yüksek oranlara çıkarılması gerekmektedir. Böylece RMB dünya piyasalarında daha yaygın bir para birimi haline gelirken, ithalatın da daha büyük bir kısmı RMB cinsinden karşılanmış olacak ve ithalat maliyetleri önemli ölçüde azalacaktır. Çünkü ödemeleri RMB cinsinden yapılan ithalatın Çin için tek maliyeti, para basma maliyetidir.

$\mathrm{Bu}$ çalışmada RMB'nin dünya piyasalarındaki yükselişi Çin'in bu konuda ulaştığı noktanın saptanması çerçevesinde ele alınmıştır. Çin RMB'nin uluslararasılaşması bakımından 2009 yılından bu yana önemli bir gelişme kaydetmiş olmasına rağmen, henüz yolun başında sayılmaktadır. $\mathrm{Bu}$ nedenle, ulusal para birimini uluslararası rezerv para haline getirmek için çalışma yürüten ilk gelişmekte olan ülke konumundaki Çin'in yukarıda sıralanan sorunları çözmek adına faaliyetlerine daha da hız vermesi amaçlarına ulaşabilmesi açısından önemlidir.

\section{Kaynakça}

- Campanella, 2014. "The Internationalization of the RMB and The Rise of a Multipolar Currency System", ECIPE Working Paper, no. 01/2014, (http://www.ecipe.org/app/uploads/2014/12/WP201201_1.pdf, 18.04.2017).

- Eğilmez, 2015. "Yuan Rezerv Para Oluyor", 1 Aralık 2015, (http://www.mahfiegilmez.com/2015/12/yuanrezerv-para-oluyor.html, 12.04.2017).

- Chen, 2016. "Size Matters? RMB Internationalization and the Beijing Consensus", NUS Working Paper, no. 2016/002, (https://papers.ssrn.com/sol3/papers.cfm?abstract_id=2712203, 18.04.2017).

- Eğilmez, 2015. "Yuan Rezerv Para Oluyor", 1 Aralık 2015, (http://www.mahfiegilmez.com/2015/12/yuanrezerv-para-oluyor.html, 12.04.2017).

- $\quad$ Frankel, 2011. "The rise of the RMB as international currency: Historical precedents", Vox CEPR's Policy Portal, 10 October 2011, (http://voxeu.org/article/rise-RMB-international-currency-historical-precedents, 12.04.2017).

- $\quad$ IMF, 2016a. "Special Drawing Right (SDR)", (http://www.imf.org/About/Factsheets/Sheets/2016/08/01/14/51/Special-Drawing-Right-SDR?pdf=1, http://www.imf.org/external/np/exr/facts/sdr.htm, 12.04.2017).

- IMF, 2016b. "Review of the Special Drawing Right (SDR) Currency Basket", (http://www.imf.org/en/About/Factsheets/Sheets/2016/08/02/19/35/Review-of-the-Special-Drawing-RightSDR-Currency-Basket, 12.04.2017).

- IMF, 2016c. "The IMF at a Glance", (http://www.imf.org/en/About/Factsheets/IMF-at-a-Glance, 12.04.2017).

- IMI, 2016. "RMB Internationalization Report 2016”, (http://www.imi.org.cn/en/wpcontent/uploads/2016/10/\%E3\%80\%90IMI-Research-Report-No.-1602-EN\%E3\%80\%91RMBInternationalization-Report-2016-Press-Release.pdf, 18.04.2017). 
- Li, 2004. "Regionalization of the RMB and China's Capital Account Liberalization", China and World Economy, vol. 12, no.2, 86- 100.

- $\quad$ Lin, Xiao., Liang, and Zhang, 2017. “A Research on the Belt and Road Initiatives and Strategies of RMB Internationalization”, Business and Management Research, vol. 6, no.7, 13- 27.

- Lo, 2013. The RMB Rises: Myths, Hypes and Realities of RMB Internationalisation and Reforms in the Post-Crisis World, Palgrave Macmillan, 1. Bask1, Hampshire.

- National Bureau of Statistics of China, 2016. China Statistical Yearbook, (http://www.stats.gov.cn/tjsj/ndsj/2016/indexeh.htm, 18.04.2017).

- PBoC, 2011. "The $12^{\text {th }}$ Five Year Plan for the Development and Reform of the Financial Industry", (http://www.csrc.gov.cn/pub/csrc_en/newsfacts/release/201210/W020121010631355001488.pdf, 18.04.207).

- $\quad$ PBoC, 2016a. "RMB Internationalization Report 2016", http://www.pbc.gov.cn/huobizhengceersi/214481/214511/214695/3223865/2016123011063632789.pdf, 18.04.2017).

- $\quad$ PBoC, 2016b. "China Monetary Policy Report Quarter Four 2015”, (http://www.pbc.gov.cn/english/130727/130879/index.html, 18.04.2017).

- PBoC, 2017. "China Monetary Policy Report Quarter Four 2016”, (http://www.pbc.gov.cn/english/130727/130879/index.html, 18.04.2017).

- Subacchi, 2010. “One Currency, Two Systems: China’s RMB Strategy”, Chatnam House, Briefing Paper, (https://www.chathamhouse.org/sites/files/chathamhouse/public/Research/International\%20Economics/bp10 10RMB.pdf, 18.04.2017).

- Wang, 2017. "RMB Internationalization and Its Implications for Asian Monetary Cooperation", (https://papers.ssrn.com/sol3/papers.cfm?abstract_id=2925034, 18.04.2017).

- World Bank, 2017. World Bank Open Data, (http://data.worldbank.org/, 12.04.2017).

- WTO, 2016. "Trade growth to remain subdued in 2016 as uncertainties weigh on global demand", WTO: 2016 Press Release, Press/768, 7 April 2016, (https://www.wto.org/english/news_e/pres16_e/pr768_e.pdf, 10.04.2017).

- Yu, 2012. "Revisiting the Internationalization of the Yuan", ADBI Working Paper Series, no. 366, (https://www.adb.org/sites/default/files/publication/156221/adbi-wp366.pdf, 18.04.2017).

- Yu, 2014. "How Far Can RMB Internationalization Go?”, ADBI Working Paper Series, no. 461, (https://www.adb.org/sites/default/files/publication/156316/adbi-wp461.pdf, 18.04.2017).

- Zhou, 2009., "Reform the International Monetary System”, (http://www.bis.org/review/r090402c.pdf, 18.04.2017).

- Zöllner, 2016. "The RMB in the SDR basket and its future role in the international financial system", Bank for International Settlements (BIS), (http://www.bis.org/speeche, 12.04.2017). 


\title{
Döviz Kurunun Yurtiçi Fiyatlara Yansıması: OECD Ülkelerinden Bulgular
}

\section{Exchange Rate Pass-Through to Domestic Prices: Evidence from OECD Countries}

\author{
Prof. Dr. Harun Bal (Çukurova University, Turkey) \\ Asst. Prof. Dr. Mehmet Demiral (Ömer Halisdemir University, Turkey) \\ Asst. Prof. Dr. Filiz Yetiz (Ömer Halisdemir University, Turkey)
}

\begin{abstract}
There is an immense literature on the effects of exchange rate changes on macroeconomic indicators, specifically on the trade balance, growth, inflation, and overall productivity in open economies. One of the main attempts in the related literature is about ascertaining whether the exchange rate fluctuations alter domestic prices. This possible mechanism is called as the pass-through effect which is getting more important since the argument that exchange rate adjustment is a part of the solution for global rebalancing is empirically well-supported. Starting from this claim, this study purposes to explore whether there is an exchange rate pass-through effect in 19 highincome OECD countries over the period 1990-2015. To this end, using a panel data set of consumer price index, producer price index proxied by wholesale price index, the nominal effective exchange rates, and industrial production presented by the value-added share of industry sectors in gross domestic product, structural vector autoregressive (VAR) and autoregressive distributed lag (ARDL) models are estimated in an unbalanced panel data analysis procedure. Results reveal that exchange rate pass-through effects on the domestic prices are significant but not that strong in both the short-run and the long-run. Expectedly, the pass-through effects tend to diminish over time. The study concludes that policy-makers need to consider policy actions accompanying the exchange rate changes to ensure domestic price stability which consequently interacts with many macroeconomic indicators.
\end{abstract}

\section{Giriș}

Döviz kurlarında meydana gelen değiş̧imlerin ihracat ve ithalat fiyatlarını değiştirerek yurtiçi fiyatları etkilemesi yansıma etkisi olarak bilinmektedir. Bir başka ifade ile yansıma etkisi, döviz kurlarında meydana gelen artış veya azalış yönündeki dalgalanmaların fiyatları etkileme sürecidir.

Döviz kurunda meydana gelen bir değişimin enflasyon gibi birçok makroekonomik değişken üzerinde etkili olduğu bilinmektedir. Kurlardaki dalgalanmaların yurtiçi fiyatlara ne ölçüde yansıdığının belirlenmesi hem enflasyonun izlenmesi hem de enflasyonu kontrol altına alacak optimal para politikasının belirlenmesi açısından önem taşımaktadır. Bu nedenle döviz kurlarındaki dalgalanmaların fiyatlara ne derece yansıdığı hem gelişmiş hem de gelişmekte olan ülkeler açısından önem arz etmektedir.

Bu çalışmada seçilmiş 19 OECD ülkesindeki döviz kurunun yansıma etkisini yapısal vektör otoregresif (VAR) model ve gecikmesi dağıtılmış otoregresif modeller (ARDL) dengesiz panel veri analizi yöntemi ile incelenmiştir. Çalışmanın ilk kısmında yansıma etkisinin teorik ve kavramsal çerçevesi incelenerek literatür üzerinde durulmuştur. Sonraki kısmında ise çalışmada kullanılan değişkenler, çalışmanın kapsadığı dönem, ekonometrik model ve analiz sonucunda elde edilen bulgulara yer verilmiştir. Çalışma sonuç ve değerlendirme kısmıyla sonuçlandirılmaktadır.

\section{Teorik ve Kavramsal Çerçeve}

Nominal döviz kurunda meydana gelen değişmelerin ithalat ve ihracat fiyatlarında meydana getirdiği etki, "yansıma veya geçiş etkisi” olarak tanımlanmaktadır (Menon, 1996). Döviz kurlarında meydana gelen dalgalanmaların yurtiçi fiyatlar düzeyine etkisi üç ana kanaldan meydana gelmektedir. Bu kanallar; ithal tüketim malları, ithal ara malları ve yurtiçinde üretilen malların yabancı para cinsinden fiyatıdır (Kiptui vd. 2005).

Döviz kurundaki değişmelerin yurt içi fiyatlar (ithalat, üretici ve tüketici fiyatları) üzerindeki etkisi olarak tanımlanan yansıma etkisi doğrudan ve dolaylı etki olmak üzere iki şekilde ortaya çıkmaktadır.

Doğrudan etki; Ulusal paranın değerinin düşmesi durumunda ithalat fiyatları yani ithal edilen nihai mallar ve ara malların maliyetleri artmaktadır. Buna bağlı olarak da yurtiçi fiyatlar yükselmektedir (Kenen ve Pack, 1994). İthal edilen girdi maliyetleri artığı için, ithal mallardaki fiyat değişimi tüketici fiyatlarını etkilemektedir (Kiptui vd. 2005).

Dolaylı etki; Döviz kurlarının fiyatlara yansıma etkisini sağlayan dolaylı etki ise "Toplam Talep” kanalıdır. Kurlarda ortaya çıkan bir artış yurt içindeki malların yabancı tüketiciler açısından daha ucuz hale gelmesine neden olacaktır. Böylece ihracat ile toplam talep artacak ve fiyatlar genel seviyesi yükselecektir (Damar, 2010). 
Kurlardaki değişim ithalat, ihracat ve yurtiçi fiyatları tam olarak etkiyebileceği gibi kısmi bir şekilde de etkileyebilir. Döviz kurunda meydana gelen dalgalanmaların ithal mallar aracılığıyla yurt içi fiyatları etkilemesinin, ihracatçı firmaların fiyatlama davranışlarına bağlı olduğu söylenebilir.

Firmalar söz konusu değişmeleri satış fiyatlarına tamamen yansıtarak tam yansıma etkisini veya bir kısmını yansıtarak kısmi yansıma etkisini tercih edebilir. Firmalar, döviz kurunda yaşanan değişmeler sonucunda satış fiyatlarını değiştirmezlerse geçiş etkisi sıfır olmaktadır (Flamini, 2003). Yansıma etkisinin derecesi (tam, kısmi ve sıfır) ülkelerin rekabet yapısına, enflasyon koşullarına, döviz kuru dinamiklerine, beklentilere ve dış ticarete konu olan malların piyasa payına bağlı olarak değişebilmektedir (Hyder ve Shah, 2004).

Döviz kurlarındaki dalgalanmaların büyüklüğ̈̈ ve hızı döviz kurlarının fiyatlara yansıma etkisini etkilemektedir. Kurlardaki değişim küçük olduğunda firmalar genellikle bu değişimi fiyatlara yansıtmayabilirler (Ghosh ve Rajan, 2006).

Döviz kuru sistemleri de yansıma etkisini etkileyen etmenlerden biridir. Sabit döviz kuru sistemi ile kıyaslandığında dalgalı kur sisteminde döviz kuru ile fiyatlar arasındaki ilişki zayıflamaktadır (Coricelli vd., 2006).

Döviz kurunun fiyatlara yansıma etkisini etkileyen bir başka faktör ise ülkelerin dışa açıklık derecesidir. Dışa açıklığı yüksek ülkelerin ekonomilerinde döviz kuru hareketlerinin ara ve nihai mal fiyatlarında daha büyük dalgalanmaya yol açtı̆̆ı görülmektedir.

\section{3 İlgili Literatür Gelişimi}

Yansıma etkisini araştıran literatür incelendiğinde genel olarak tek ülke ya da çok ülke grupları üzerine yapılan çalışmaların ağırlıklı olduğu görülmektedir. Son zamanlarda bu çalışmaların daha çok gelişmiş ülkeler üzerine yoğunlaştı̆ı söylenebilir. Yansıma etkisini ölçmek için en çok kullanılan yöntemler; VAR, Yapısal Vektör Özgecikmeli Modeli (SVAR), Bayesian Vektör Özgecikmeli Modeli (BVAR) ve VECM olarak sıralanmaktadır. Tek ülke grubu için döviz kurlarının yurtiçi fiyatlara yansıma etkisini analiz eden çalışmaların bazıları; Manning ve Andrianacos (1993), Bhundia (2002), Leigh ve Rossi'nin (2002), Arat (2003), Kara ve Öğünç (2012), Shu ve $\mathrm{Su}$ (2009), Ponomarev, vd. (2014) olarak özetlenebilir.

Leigh ve Rossi (2002), Arat (2003), 2001 öncesi verileri kullanarak Türkiye'de döviz kurunun yansıma etkisini analiz etmişlerdir. Arat (2003)'in tahmin sonuçlarında Türkiye'deki geçiş etkisinin gelişmiş ekonomilere oranla daha yüksek olduğu görülmektedir. Arat (2003)'in analiz sonuçları ile Leigh ve Rossi (2002)'nin bulguları karşılaştırıldığında, Leigh ve Rossi (2002)'nin sonuçları döviz kurunun fiyatlar üzerindeki etkisinin 1 yıl sürdüğünü ve ilk 4 aylık dönemde toplam etkinin önemli bir bölümünün gerçekleştiğini göstermektedir.

Shu ve Su (2009), 1997-2007 yılları arasında Çin ekonomisinde döviz kurunun fiyatlar üzerindeki etkilerini VAR analizi ile test etmişlerdir. Çalı̧̧mada, döviz kuru değişimlerinin kısa dönemde \%7, uzun dönemde ise \%20 yansıma etkisine sebep olduğu sonucu bulunmuştur.

Kara ve Öğünç (2012), çalışmalarında Türkiye'deki yansıma etkisini VAR analizi yöntemiyle incelemişlerdir. 2002-2011 dönemi için farklı modellerle yapılan tahminler, geçişkenliğin bir yıllık zaman diliminde her iki değişken için de ortalama yüzde 15 civarında olduğuna göstermiş̧ir.

Ponomarev vd. (2014), Rusya ekonomisi için döviz kurlarının yansıma etkisini VAR analizi kullanılarak tahmin etmişlerdir. Elde edilen bulgulara göre yansıma etkisinin \%5-15 arasında gerçekleştiği ve yıllar içinde düşüş gösterdiği bulunmuştur.

Çok ülke grupları baz alınarak yapılan çalışmalar incelendiğinde ise; McCarthy (2000) çalışması ile daha sonraki yıllarda yapılacak çalışmalara öncü olmuştur. McCarthy (2000), sanayileşmiş ülkeler (ABD, Japonya, Almanya, Fransa, Birleşik Krallık, Belçika, Hollanda, İsveç ve İsviçre) için döviz kurları ve ithalat fiyatlarının yurtiçi fiyatlar üzerine etkilerini VAR modeli yaklaşımı ile incelemiştir. Çalışma sonucunda döviz kuru dalgalanmalarının yurtiçi fiyatları orta derecede etkilediği, ithalatın dış ticaretteki payının yüksek olduğu ülkelerde ise ithalat fiyatlarını önemli derecede etkilediği sonucuna ulaşılmıştır.

Campa ve Goldberg (2002), 25 OECD ülkesinde döviz kurlarının yansıma etkisini 1975 -1999 yıllarına ait verileri kullanarak araştırmıştır. Tahmin sonuçları, ithalattaki yapısal dönüşüm neticesinde yansıma etkisinin azaldığını göstermiştir.

Ca'Zorni, Hahn ve Sanchez (2007) çalışmalarında VAR metodunu kullanarak on iki gelişmekte olan ülkenin \{Asya (Çin, Güney Kore, Singapur, Tayvan ve Hong Kong), Orta ve Doğu Avrupa (Çek Cumhuriyeti, Macaristan, Polonya), Türkiye ve Latin Amerika (Arjantin, Şili ve Meksika)\} 1975-2004 yılları verileri ile yansıma etkisini ölçmüş ve üretim zinciri boyunca yansıma etkisinin zayıfladığı sonucuna ulaşmışlardır.

Ito ve Sato (2008) çalışmalarında VAR metodunu kullanarak Endonezya, Güney Kore, Tayland, Malezya, Arjantin, Brezilya, Meksika ve Türkiye üzerinde döviz kuru ile yurtiçi fiyatlar arasındaki yansıma etkisini araştırmışlardır. Yansıma etkisinin derecesi Latin Amerika ülkeleri ve Türkiye'de Güney Doğu Asya ülkeleri ile kıyaslandığında daha yüksek olduğu bulunmuştur. 
An ve Wang (2011) çalışmalarında VAR metodunu kullanarak özellikle Kanada, Finlandiya, İtalya, Japonya, Güney Kore, İspanya, İsveç, İngiltere ve ABD olmak üzere seçilmiş 9 OECD ülkesi üzerinde döviz kurunun yansıma etkisi incelemişlerdir. Bulgulara göre, yansıma etkisinin olduğu ancak yansımanın derecesinin zamanla azaldığı sonucuna ulaşılmıştır.

Comunale ve Kunovac (2017) çalışmalarında döviz kurunun geçiş etkisi Bayesian VAR metodu kullanılarak Almanya, Fransa, İtalya ve İspanya ülkeleri incelemişlerdir. 1992-2016 y1lları verileri ile incelenen bulgulara göre, döviz kurlarındaki değişimin ithalat fiyatlarına yansıma etkisinin fazla olduğu ancak bu etkinin geçici olduğu tespit edilmiştir.

Döviz kurlarındaki dalgalanmaların yurtiçi fiyatları nasıl etkilediğini araştıran çok sayıda çalışma olmasına rağmen, bunlar arasında bir görüş birliğine varılamadığı görülmektedir. Literatürde yansıma etkisini inceleyen tek veya çok ülkeli ampirik ekonometrik çalışmaların bazı örnekleri Tablo 1'de özetlenmiştir.

\begin{tabular}{|c|c|c|c|}
\hline Yazarlar ve Yill & Dönem ve Ülke & $\begin{array}{c}\text { Metodoloji ve Kullanılan } \\
\text { Değişkenler }\end{array}$ & Sonuç(lar) \\
\hline $\begin{array}{l}\text { McCarty } \\
(2000)\end{array}$ & $\begin{array}{l}\text { Gelişmiş Ülke } \\
\text { (Seçilmiş } 9 \text { ülke) } \\
\text { 1976-1998 }\end{array}$ & $\begin{array}{l}\text { VAR Analizi, } \\
\text { Petrol Fiyatları, Üretim Açı̆̆ı, } \\
\text { Döviz Kuru, İthalat Fiyatı, } \\
\text { Üretici Fiyat Endeksi (ÜFE), } \\
\text { Tüketici fiyat endeksi (TÜFE) }\end{array}$ & $\begin{array}{l}\text { Döviz kurlarındaki bir değişim ilk } \\
\text { önce ithal malların fiyatlarını, } \\
\text { ardından üretici fiyatlarını ve son } \\
\text { olarak da tüketici fiyatlarını } \\
\text { etkilemektedir. }\end{array}$ \\
\hline $\begin{array}{l}\text { Campa ve } \\
\text { Goldberg } \\
(2002)\end{array}$ & $\begin{array}{l}\text { OECD ülkeleri } \\
\text { (Seçilmiş } 25 \text { ülke) } \\
1975-1999\end{array}$ & $\begin{array}{l}\text { VAR Analizi, } \\
\text { Döviz Kurları, İthalat fiyatları, } \\
\text { İhracat fiyatları, reel gayrisafi } \\
\text { yurtiçi hasıla }\end{array}$ & $\begin{array}{l}\text { Hemen hemen bütün ülkelerde } \\
\text { kısa dönemde kısmi yansıma } \\
\text { yaşanmakta ancak yansıma etkisi } \\
\text { uzun döneme göre çok daha düşük } \\
\text { seviyede olmaktadır. }\end{array}$ \\
\hline $\begin{array}{l}\text { Ca'Zorzi vd. } \\
(2007)\end{array}$ & $\begin{array}{l}\text { Gelişmekte olan } \\
\text { Ülkeler } \\
\text { (Seçilmiş } 12 \text { ülke) } \\
1975-2004\end{array}$ & $\begin{array}{l}\text { VAR Analizi, } \\
\text { Döviz kurları, ithalat fiyat } \\
\text { endeksi, tüketici fiyat endeksi, } \\
\text { kısa vadeli faiz oranları }\end{array}$ & $\begin{array}{l}\text { Yansıma etkisinin zamanla azaldığ } \\
\text { ve tüketici fiyatlarından çok ithalat } \\
\text { fiyatlarına yansıdığı sonucuna } \\
\text { ulaşılmıştır. }\end{array}$ \\
\hline $\begin{array}{l}\text { Ito ve Sato } \\
(2008)\end{array}$ & $\begin{array}{l}\text { Gelişmekte olan } \\
\text { Ülkeler } \\
\text { (Seçilmiş } 8 \text { ülke) } \\
1993-2005\end{array}$ & $\begin{array}{l}\text { VAR Analizi } \\
\text { Petrol Fiyatları, Üretim Açı̆̆ı, } \\
\text { Para Arzı, Döviz Kuru ve } \\
\text { Tüketici Fiyat Endeksi }\end{array}$ & $\begin{array}{l}\text { Döviz kurunun yansıma derecesi } \\
\text { Latin Amerika ülkeleri ve } \\
\text { Türkiye'de Güney Doğu Asya } \\
\text { ülkelerinden daha yüksek } \\
\text { bulunmuştur. }\end{array}$ \\
\hline $\begin{array}{l}\text { Shambaugh } \\
(2008)\end{array}$ & $\begin{array}{l}\text { Gelişmiş Ülkeler } \\
\text { (Seçilmiş ülkeler) } \\
\text { 1973-1999 }\end{array}$ & $\begin{array}{l}\text { VAR Analizi } \\
\text { Döviz Kuru, İthalat fiyatları, } \\
\text { Tüketici fiyat endeksi }\end{array}$ & $\begin{array}{l}\text { İthalat fiyatlarının üretici fiyatları } \\
\text { tarafından belirlendiği özellikle } \\
\text { ABD gibi bazı ülkelerde ithalat } \\
\text { fiyatlarının reel döviz kurundaki } \\
\text { değişime tepki vermediği } \\
\text { bulgusuna ulaşmışlardır. }\end{array}$ \\
\hline $\begin{array}{l}\text { Shu ve Su } \\
(2009)\end{array}$ & $\begin{array}{l}\text { Çin } \\
1997-2007\end{array}$ & $\begin{array}{l}\text { VAR Analizi, } \\
\text { Döviz Kuru, İthalat Fiyatı, } \\
\text { Tüketici Fiyat Endeksi, }\end{array}$ & $\begin{array}{l}\text { Döviz kurunun hem kısa ve hem } \\
\text { de uzun dönemde yansıma etkisine } \\
\text { sahip olduğu bulunmuştur. Kısa } \\
\text { dönemde yansıma etkisi daha } \\
\text { düşüktür. }\end{array}$ \\
\hline $\begin{array}{l}\text { An ve Wang } \\
(2011)\end{array}$ & $\begin{array}{l}\text { OECD Ülkeleri } \\
\text { (Seçilmiş } 9 \text { ülke) } \\
\text { 1980-2007 }\end{array}$ & $\begin{array}{l}\text { VAR Analizi } \\
\text { Döviz kuru, Petrol fiyatı, Kısa } \\
\text { vadeli faiz oranı, İhracat ve } \\
\text { İthalat fiyat endeksi, Tüketici } \\
\text { fiyatı ve Üretici fiyat endeksi }\end{array}$ & $\begin{array}{l}\text { Döviz kurunun fiyatlara yansıma } \\
\text { etkisi söz konusu olup yansıma } \\
\text { etkisi zamanla azalmaktadır. }\end{array}$ \\
\hline $\begin{array}{l}\text { Ponomarev vd. } \\
\text { (2014) }\end{array}$ & $\begin{array}{l}\text { Rusya } \\
2000-2012\end{array}$ & $\begin{array}{l}\text { VAR Analizi, } \\
\text { Döviz Kurları, Tüketici Fiyat } \\
\text { Endeksi, Üretici Fiyat Endeksi }\end{array}$ & $\begin{array}{l}\text { Döviz kurlarının yansıma } \\
\text { derecesinin \% } \% \text {-15 arasında } \\
\text { gerçekleştiği ve yıllar içinde düşüş } \\
\text { gösterdiği bulunmuştur }\end{array}$ \\
\hline $\begin{array}{l}\text { Comunale ve } \\
\text { Kunovac } \\
(2017)\end{array}$ & $\begin{array}{l}\text { Gelişmiş Ülkeler } \\
\text { (Seçilmiş } 4 \text { ülke) } \\
\text { 1992-2016 }\end{array}$ & $\begin{array}{l}\text { Bayesian VAR } \\
\text { Döviz kurları, Petrol Fiyatları, } \\
\text { Üretim Açığı, Üretici ve } \\
\text { Tüketici Fiyat Endeksi, İthalat } \\
\text { fiyatları, İhracat fiyatları }\end{array}$ & $\begin{array}{l}\text { Döviz kurlarının İthalat fiyatlarına } \\
\text { yansıma etkisi yüksek ama bu } \\
\text { etkinin geçici olduğu tespit } \\
\text { edilmiştir. Tüketici fiyatlarında ise } \\
\text { çok küçük yansıma etkisi vardır. }\end{array}$ \\
\hline
\end{tabular}

Tablo 1. Döviz Kurunun Yurt İ̧̧i Fiyatlara Yansıması Etkisi Üzerine Literatür Gelişimi 


\section{Veri Seti, Model ve Analizler}

Döviz kurunun yurtiçi fiyatlara yansıma etkisi üzerine yapılan çalışmalarda genellikle döviz kurları ile birlikte petrol fiyatları, faiz oranları, sanayi üretim göstergeleri, ithalat ve ithalat fiyat endeksleri, üretici ve tüketici fiyat endeksleri gibi değişkenler kullanılmaktadır. Bu çalışmada, Beirne ve Bijsterbosch'ın (2009) ve Takhtamanova'nın (2008) çalışmalarındaki bireysel olarak her bir ülke için kurulan VAR modelleri, Pedroni (2013)'nin çalışmasından yola çıkarak,19 ülkeli panel yapısal VAR modeli ile ele alınmıştır. Bu kapsamda 19 ülkenin (Avustralya, Avusturya, Belçika, Kanada, Danimarka, Finlandiya, Fransa, Almanya, Italya, Japonya, Hollanda, Yeni Zelanda, Norveç, Portekiz, İspanya, İsveç, İsviçre, Birleşik Krallık, Amerika Birleşik Devletleri) 1990-2015 dönemini kapsayan dengesiz panel verileri formunda oluşturulan teorik model şu şekildedir:

$$
X_{i t}=\left(C P I_{i t}, P P I_{i t}, O I L P_{i t}, N E E R_{i t}, I P I_{i t}\right)
$$

Burada $X_{i t}$ ilgili değişkenler arasındaki kısıtsız etkileşimi gösteren VAR matrisleri iken, $C P I$ yurtiçi tüketici fiyat endekslerini, $P P I$ üretici fiyat endekslerini, $O I L P$ küresel petrol fiyatlarını, NEER nominal efektif döviz kurunu ve IPI sanayi üretim endeksini göstermektedir. Panel veri setleri kapsamında $i$ ve $t$ sirasıyla yatay kesit (ülke) ve zaman boyutlarını göstermektedir. Çalışmada, söz konusu değişkenleri temsilen kullanılan değişkenler ve açıklamaları Tablo 2'de özetlenmiştir. Bu değişkenlerden nominal efektif döviz kuru verileri Bank of International Settlement (BIS, 2017) ve petrol fiyatları verileri Energy Information Administration (EIA, 2017) veri tabanlarından, diğer tüm serilere ait veriler ise Dünya Bankası'nın Dünya Gelişme Göstergelerinden (WDI, 2017) alınmıştır. Bazı ülkeler için kayıp veriler nedeniyle dengesiz bir panel veri seti üzerinden analizler yürütülmüştür.

\begin{tabular}{|l|l|}
\hline Değişkenler & Değişken açıklamaları \\
\hline CPI & Tüketici fiyat endeksi. Dönem ortalaması. Endeks olarak (2005=100) alınmıştır. \\
\hline$P P I \_W P I$ & $\begin{array}{l}\text { Üretici fiyat endeksini temsilen toptan eşya fiyat endeksi. Bu endeks tarımsal ve sanayi } \\
\text { üretimlerinin belirli aşamalardaki (üretim, dağıtım ve ithalat görevleri dâhil) üretimine göre } \\
\text { ve genellikle Laspeyres formülüne göre endekslenmektedir. Endeks olarak (2005=100) } \\
\text { alınmıştır (bkz. WDI, 2017). }\end{array}$ \\
\hline OILP & $\begin{array}{l}\text { Küresel ham petrol fiyatları. Varil başına Amerika Birleşik Devletleri (ABD) doları üzerinden } \\
\text { 2005=100 olarak endekslenmiştir. }\end{array}$ \\
\hline NEER & $\begin{array}{l}\text { Nominal efektif döviz kuru. Bir ülke ulusal parasının, ticari paylarına göre ağırlıklandırılmış } \\
\text { ticaret ortaklarının ulusal paralarının ağırlıklı ortalamasına göre karş1lı̆̆ıdır. Efektif döviz } \\
\text { sepeti karşılığı ulusal para miktarı olarak dönüştürülmüş ve 2005=100 olarak endekslenmiştir. }\end{array}$ \\
\hline IPI_IVA & $\begin{array}{l}\text { Sanayi üretim endeksini temsilen sanayi sektörünün gayrisafi yurtiçi hâsıla (GSYH) içinde \% } \\
\text { katma değer payı. Sanayi sektörleri Tüm Ekonomik Faaliyetlerin Uluslararası Standart } \\
\text { Sanayi Sınıflandırması (ISIC) 10-45 sektör aralığını kapsarken çalışmada sadece imalat } \\
\text { sanayileri (ISIC, 15-37) sektör aralığı dikkate alınmıştır. Katma değer, sektörlerin üretimleri } \\
\text { ile kullandıkları girdi arasındaki fark olarak ölçülen net çıktıdır. }\end{array}$ \\
\hline
\end{tabular}

Tablo 2. Çalışmada Kullanılan Değişkenler ve Açıklamaları

Değişkenlerin tanımlayıcı istatistikleri ve korelasyon katsayıları Tablo 3'te sunulmuştur. Beklenildiği üzere tüketici fiyat endeksi $(C P I)$ ve üretici fiyat endeksini temsil eden toptan eşya fiyat endeksi $\left(P P I \_W P I\right)$ değişkenleri arasındaki yüksek korelasyon dikkat çekmektedir. Bu yüksek korelasyon nedeniyle ortaya çıkacak çoklu doğrusal bağlantı sorununu ortadan kaldırmak için regresyon modellerinde, bu iki değişkenin bağımlı değişken olarak aynı anda modele eklenmemesi gerekmektedir. Yine petrol fiyatları (OILP) ile sanayi üretim endeksini temsilen kullanılan sanayi katma değeri (IPI_IVA) arasındaki negatif ve nispeten yüksek korelasyon, gelişmiş ülkeler için bile sanayi üretimi ile petrol fiyatlarının ters yönde hareket etmesini göstermesi bakımından önemli olmaktadır.

\begin{tabular}{|c|c|c|c|c|c|}
\hline & CPI & $P P I \_W P I$ & OILP & NEER & $I P I I I V A$ \\
\hline Ortalama & 87,854 & 87,047 & 65,2 & 99,092 & 27,656 \\
\hline Medyan & 88,802 & 87,491 & 73,316 & 99,557 & 27,155 \\
\hline Maksimum & 112,045 & 120,265 & 180,527 & 143,008 & 44,803 \\
\hline Minimum & 48,905 & 40,326 & 38,375 & 66,824 & 19,407 \\
\hline Standart sapma & 13,687 & 16,244 & 11,500 & 10,430 & 4,463 \\
\hline Gözlem sayısı (bireysel) & 494 & 478 & 494 & 494 & 447 \\
\hline$C P I$ & 1 & & & & \\
\hline$P P I \quad W P I$ & 0,874 & 1 & & & \\
\hline OILP & 0,035 & 0,282 & 1 & & \\
\hline NEER & 0,131 & 0,084 & $-0,130$ & 1 & \\
\hline$I P I I V A$ & $-0,284$ & $-0,338$ & $-0,533$ & 0,012 & 1 \\
\hline Gözlem sayısı (ortak) & & & 436 & & \\
\hline
\end{tabular}

Tablo 3. Değişkenler İçin Tanımlayıcı İstatistikler ve Korelasyon Katsayıları 
Verilerin özelliklerine göre incelenecek uygun ekonometrik yöntemin belirlenmesi ve tahmin edilecek katsayıların sahte regresyona karşı kontrol edilmesi amacıyla öncelikle panel birim kök testleri uygulanmıştır. Levin, Lin, Chu (2002) ve Im, Pesaran ve Shin (2003) testleri ile CPI, PPI_WPI ve NEER değişkenlerinin seviyede birim kök içerdikleri yani $I(1)$ oldukları belirlenmiştir. Bununla birlikte diğer değişkenlerin (OILP ve IPI_IVA) seviyede durağan oldukları yani $I(0)$ oldukları belirlenmiştir. Serilerin bu özelliklerine uygun olarak önce yapısal VAR analizi ve sonrasında panel ARDL analizi birlikte uygulanmıştır.

\subsection{Yapısal Vektör Otoregresif Model Tahmini: Yapısal VAR Analizi}

Yapısal VAR modellemesine dayalı analizlerde önemli bir konu, değişkenlerin modelde sıralanmasıdır. İdeal olarak sıralamada ilk sıradaki değişkenin diğer değişkenleri etkilemesi ancak onlardan etkilenmemesi gerekmektedir. Bunun için teorik beklentiler önemli olmakla birlikte bu sıralama teknik olarak kısıtsız VAR analizi ile de yapılabilmektedir. Teorik olarak, petrol fiyatlarının bütün değişkenleri etkilemesi ve onu döviz kurunun izlemesi beklenmektedir. Sanayi üretimi göstergelerinin ise diğer değişkenlere etkisinin kısıtlı olması beklenmekle birlikte makroekonomik değișkenler arasındaki ilișkilerin tek yönlü olmadığı ve zamandan zamana ve/veya ülkeden ülkeye değişebildiğinin de göz ardı edilmemesi gerekmektedir. Çok ülkeli çalışmalarda diğer bir sorun ise ülke heterojenleridir. Bu çalışmada ülkeler yüksek gelirli sanayileşmiş OECD ülkelerinden seçilerek homojenleştirilmeye çalışılmıştır. Farklı yapısal göstergeler bakımından benzer olan bu gelişmiş ülkelerin çoğu aynı zamanda Euro bölgesinde bulunmakta ve döviz kuru değişmelerinden benzer biçimde etkilenmektedir. Yine Euro bölgesi dışında kalan diğer ülkelerin de tek ya da çok taraflı ticaret anlaşmaları ile iş birliği içinde oldukları görülmektedir. Bu nedenle ülke heterojenliğinin çalışma için bir sorun olması beklenmemektedir.

Analiz sürecinde VAR modeli kapsamında öncelikle kısıtsız olarak optimal gecikme uzunluğu Schwarz bilgi kriterine göre 2 olarak belirlenmiştir. Sims'in $(1972 ; 1980)$ öncülük ettiği VAR modelleri sistemdeki her bir değişkenin hem kendi hem de diğer değişkenlerin gecikmeli değerlerinin yer alabildiği çok boyutlu doğrusal bir modeldir.

VAR analizinde değişkenler arasındaki etkileşimlerin gerçek tepkilerden uzaklaşmasını engellemek için seviyede durağan olmayan CPI, PPI_WPI ve NEER değişkenleri birinci farkları (D) alınarak durağan bir biçimde VAR modeline dâhil edilmişlerdir. Bu kapsamda, kısıtsız VAR modellemesi ile değişkenlerin diğer değişkenleri etkilemesi yönleri ve tepkilerin önem büyüklüğüne içsellik-dışsallık sıralaması ise şu şekilde belirlenmiştir.

$$
X_{V A R}=(1) O I L P \leftrightarrow(2) D\left(P P I \_W P I\right) \leftrightarrow(3) D(N E E R) \leftrightarrow(4) D(C P I) \leftrightarrow(5) I P I \_I V A \Leftrightarrow O I L P
$$

Burada, her bir değiş̧ken kendinden sonraki değiş̧keni kendisinde önceki değişkenden daha fazla etkilemektedir. Bu yapısal kısıtlarla elde edilen yapısal VAR sonuçları Tablo 4'te sunulmuştur. Ayarlanmış 1992-2015 dönemi için yine ayarlanmış gözlem sayısı 398'dir. Tabloda sadece nominal efektif döviz kuru ile diğer değişkenler arasındaki etkileşimlere yer verilmiştir.

\begin{tabular}{|c|c|c|c|c|c|}
\hline & OILP & $D\left(P P I \_W P I\right)$ & $D(N E E R)$ & $D(C P I)$ & IPI_IVA \\
\hline$D(C P I)$ & & & $0.993(3.318)^{*}$ & & \\
\hline$\overline{D(C P I)_{t-1}}$ & & & $0,880(3,271)^{*}$ & & \\
\hline$\overline{D(C P I)_{t-2}}$ & & & $0,790(3,068)^{*}$ & & \\
\hline$(O I L P)_{t-1}$ & & & $1,175(2,269)^{*}$ & & \\
\hline$(O I L P)_{t-2}$ & & & $0,901(1,733)^{*}$ & & \\
\hline$D\left(P P I \_W P I\right)_{t-1}$ & & & $0,073(0,763)$ & & \\
\hline$\overline{D\left(P P I \_W P I\right)_{t-2}}$ & & & $0,041(0,425)$ & & \\
\hline$\overline{D(N E E R)_{t-1}}$ & $0,001(0,115)$ & $-0,009(-0,255)$ & $1,085(21,846)^{*}$ & $-0,016(-1,523)^{*}$ & $-0,023(-2,217)^{*}$ \\
\hline$\overline{D(N E E R)_{t-2}}$ & $-0,007(-1,243)^{*}$ & $0,007(0,198)$ & $-0,277(-5,867)^{*}$ & $0,010(1,027)$ & $0,010(0,999)$ \\
\hline$(I P I I V A)_{t-1}$ & & & $0,678(2,060)^{*}$ & & \\
\hline$(I P I I V A)_{t-2}$ & & & $0,605(1,846)^{*}$ & & \\
\hline
\end{tabular}

Tablo 4. Döviz Kurunun Yurtiçi Fiyatlara Yansıma Etkisi: Yapısal VAR Tahmini.

Not: * Katsayıların en fazla \%10 düzeyinde anlamlı olduğunu göstermektedir. t-istatistikleri parantez içinde gösterilmiştir.

Tablodaki sonuçlar, nominal efektif döviz kurunun (NEER) cari, bir ve iki dönem önceki tüketici fiyat endeksleri $(C P I)$ ile pozitif ilişkili olduğunu ortaya koymaktadır. Buna göre söz konusu ülkeler için ticari rekabetçiliği artırıcı yönde gelişen bir kur yükselişi bu ülkelerdeki ortalama fiyat seviyesini de yükseltme eğilimindedir. Bu gelişme, bir yandan döviz kurunun ortaya çıkardığı fiyat avantajı etkisinin azalması anlamına gelirken diğer yandan yurtiçi fiyat dengesinde bozulmaların meydana gelebileceğine işaret etmektedir. Döviz kurumun toptan eşya fiyat endeksi ile temsil edilen üretici fiyat endeksi $\left(P P I \_W P I\right)$ ile etkileşimi zayıf ve anlamsızdır. Bununla birlikte, döviz kurunun küresel petrol fiyatları $(O I L P)$ ile anlamlı bir biçimde pozitif etkileşimde olduğu ancak geçmiş dönemlerde bu iliş̧kilerin azaldığı görülmektedir. Benzer bir durum sanayi sektörünün GSYH içindeki payı ile temsil edilen sanayi üretim endeksi (IPI_IVA) değişkeni için de geçerlidir. 


\subsection{Panel ARDL: Havuzlanmış Ortalama Grup Tahmincisi}

Yapısal VAR analizi, değişkenleri bağımlı-bağımsız değişken olarak ayırmadan değişkenler arası etki-tepki temelli etkileşimleri göstermektedir. Döviz kurunun yurtiçi fiyatlara etkilerini belirleyebilmek için regresyontemelli modellerin tahmin edilmesi daha kesin sonuçlar ortaya koyabilecektir.

Çalışmanın bu kısmında serilerin özelliklerine göre ve gözlem sayısının yeterli düzeyde olması nedeniyle Pesaran, Shin ve Smith (1999) tarafından geliştirilen gecikmesi dağıtılmış otoregresif modeller (ARDL) dengesiz panel veri analizi prosedüründe tahmin edilmiştir. Serilerin $I(0)$ ve $I(1)$ karışımı olması ve serilerde $I(2)$ olmadığ durumda uygulanabilen ARDL yaklaşımı kısa ve uzun dönemde regresyon ilişkilerini ortaya koymaktadır.

Burada, $C P I$ ve $P P I-W P I$ değişkenleri arasındaki yükssek korelasyonun neden olabileceği çoklu doğrusal bağlantı sorununu engelleyebilmek için bu değişkenler modele ayrı ayrı eklenmiş be böylece iki farklı panel ARDL modeli şu şekilde belirlenmiştir.

$$
\begin{array}{ll}
C P I_{i t} & =\beta_{0}+\beta_{1} O_{L I L P}+\beta_{2} N E E R_{i t}+\beta_{3} I P I \_I V A_{i t}+e_{i t} \\
P P I \_W P I_{i t} & =\theta_{0}+\theta_{1} \text { OILP }_{i t}+\theta_{2} N E E R_{i t}+\theta_{3} I P I \_I V A_{i t}+u_{i t}
\end{array}
$$

Denklemlerdeki değişenler daha önce Tablo 2'de tanımlandığı gibidir. Bundan başka, denklemlerde $i$ panel yapıda yatay-kesit boyutunu yani ülkeleri $(i=1,2,3, \ldots, 19), t$ ise zaman boyutunu yani yılları $(t=1990,1991$, $1992, \ldots 2015)$ göstermektedir. Denklemlerde $\beta_{0}$ ve $\theta_{0}$ ülkelere özgü regresyon sabitleri iken diğer $\beta$ ve $\theta$ parametreleri ARDL modelinde tahmin edilecek katsayılardır. Bu model tahminlerine ilişkin hata terimleri ise $e$ ve $u$ ile gösterilmiştir. ARDL $(p, q, \ldots, q)$ yapısında $p$ ve $q$ sırasıyla bağımlı ve bağımsız değişkenlerin gecikme sayıları olmak üzere, dinamik panel regresyon modeli örneğin ARDL ((1),1,1,1) durumunda Denklem 3 aşağıdaki Denklem 5 biçiminde ifade edilebilmektedir:

$$
\begin{aligned}
C P I_{i t}= & \alpha_{i}+\lambda_{i} C P I_{i t-1}+\partial_{10 i} O I L P_{i t}+\partial_{11 i} O I L P_{i t-1}+\partial_{20 i} N E E R_{i t} \\
& +\partial_{21 i} N E E R_{i t-1}+\partial_{30 i} I P I_{-} I V A_{i t}+\partial_{31 i} I P I_{-} I V A_{i t-1}+\varepsilon_{i t}
\end{aligned}
$$

Denklem 5'e ilişkin panel ARDL vektör hata düzeltme modeli ise aşağıda Denklem 6'daki gibi gösterilebilecektir:

$$
\begin{aligned}
D C P I_{i t} & =\omega_{i}\left(C P I_{i t-1}-\delta_{0 i}-\delta_{1 i}(O I L P)_{i t}-\delta_{2 i}(N E E R)_{i t}-\delta_{3 i}\left(I P I_{-} I V A\right)_{i t}\right. \\
& -\theta_{11 i} D(C P I)_{i t}-\theta_{21 i} D(O I L P)_{i t}-\theta_{31 i} D(N E E R)_{i t}-\theta_{41 i} D\left(I P I_{-} I V A\right)_{i t}+\varepsilon_{i t}
\end{aligned}
$$

Burada $D$ birinci sıra farlarını gösterirken $\omega_{i}$ hata düzeltme terimidir. Bağımsız değişkenlerdeki bir şoktan sonra bağımlı değişkenin uzun dönemde yeniden dengeye gelebilmesi için hata düzeltme teriminin negatif olması beklenmektedir. Panel ARDL yapısında ortalama grup (mean group-MG), havuzlanmış ortalama grup (pooled mean group-PMG) ve dinamik sabit etkiler (dynamic fixed effect-DFE) olmak üzere üç farklı tahminci bulunmaktadır. PMG tahmincisinin bir avantajı kısa dönem dinamik ayarlamaların yatay kesit (ülkeler) birimleri arasında farklılaşmasına izin vermesidir. Yani PMG tahmincisi panel yapısında katsayıların hem kısa dönem heterojenliğini hem de uzun dönem homojenliğini test etmektedir (Pesaran vd. 1999).

Bu kapsamda çalışmanın amacına uygun olarak nominal efektif döviz kuru değişkeni ile diğer değişkenler arasındaki ilişkiler PMG tahmincisi ile ve ikili regresyon ilişkisinde tahmin edilmiştir. Model tahminlerinde maksimum gecikme uzunluğu 4 olarak belirlenmiş ve böylece en uygun modelin seçimi her bir model için 16 farklı model değerlendirilerek yapılmıştır. Havuzlanmış ortalama grup $(P M G)$ tahmincisinden elde edilen sonuçlar Tablo 5'te birlikte gösterilmiştir. Tablodaki sonuçlar, nominal efektif döviz kurunun (NEER) uzun dönemde tüketici fiyatları (CPI) üzerindeki etkisinin anlamlı olmadığını ancak kısa dönemde tüketici fiyatlarını arttırdığını göstermektedir. Döviz kurundaki değişimlerin, üretici fiyatlarını temsilen kullanılan toptan eşya fiyat endeksi $\left(P P I \_W P I\right)$ üzerine etkilerinin ise anlamlı bir biçimde hem uzun hem de kısa dönemde pozitif olarak etkilediği görülmektedir. Hata düzletme katsayıları şokların uzun dönemde dengeye gelebileceğini ancak tüketici fiyatlarında ise dengeye gelme sürecinin daha uzun zaman alabileceği görülmektedir. 


\begin{tabular}{|c|c|c|c|c|}
\hline \multicolumn{5}{|l|}{ Uzun Dönem } \\
\hline $\begin{array}{l}\text { Seçilen } \\
\text { Model } \\
\end{array}$ & $\begin{array}{l}\text { Bağımlı } \\
\text { Değişken }\end{array}$ & $\begin{array}{l}\text { Bağımsız } \\
\text { Değişken }\end{array}$ & Katsayı & $\begin{array}{l}\text { Tahmin } \\
\text { Dönemi }\end{array}$ \\
\hline $\operatorname{ARDL}(1,1)$ & $D(C P I)$ & NEER & $0,055(1,434)$ & $1991-2015$ \\
\hline $\operatorname{ARDL}(1,3)$ & $D\left(P P I \_W P I\right)$ & NEER & $0,650(6,560) * * *$ & $1993-2015$ \\
\hline \multicolumn{5}{|l|}{ K1sa dönem } \\
\hline \multirow{3}{*}{$\operatorname{ARDL}(1,1)$} & \multirow[t]{2}{*}{$D(C P I)$} & $D(N E E R)$ & $0,038(2,422) * *$ & \multirow{3}{*}{$1991-2015$} \\
\hline & & $\mathrm{C}$ & $5,952(2,984)^{* * *}$ & \\
\hline & \multicolumn{2}{|c|}{ Hata düzeltme katsayısı } & $-0,043(-2,158)^{* *}$ & \\
\hline \multirow{5}{*}{$\operatorname{ARDL}(1,3)$} & \multirow[t]{4}{*}{$D\left(P P I \_W P I\right)$} & $D(N E E R)$ & $0,109(1,824)^{*}$ & \multirow{5}{*}{$1993-2015$} \\
\hline & & $D(N E E R) t-1$ & $0,219(3,186)^{* * *}$ & \\
\hline & & $D(N E E R) t-2$ & $0,167(3,238)^{* * *}$ & \\
\hline & & $\mathrm{C}$ & $0,219(0,242)$ & \\
\hline & \multicolumn{2}{|c|}{ Hata düzeltme katsayısı } & $-0,367(-5,264) * * *$ & \\
\hline
\end{tabular}

Tablo 5. Döviz Kurunun Yurtiçi Fiyatlara Yansıma Etkisi: Havuzlanmış Ortalama Grup Tahmini

Not: $t$-istatistikleri parantez içinde gösterilmiştir. *, **ve *** sırasıyla \%10, \%5 ve\%1 düzeyinde anlamlılığı göstermektedir. Model seçimi, çalışmanın tümünde baz alınan Schwarz kriterine göre yapılmıştır.

\section{Sonuç}

Küresel düzeyde ekonomik dengesizliklerin giderilmesi sürecinde döviz kuru ayarlamalarının bir çözüm olarak görülmesi ampirik olarak da desteklenen önemli bir önermedir. Buna paralel olarak açık ekonomilerde döviz kuru dalgalanmalarının yurtiçi makroekonomik dengeleri nasıl etkilediğini belirlemeye yönelik çalışmaların sayısı da gittikçe artmaktadır. Bu kapsamda akademik çalışmalarda döviz kurlarının yurtiçi fiyatlara yansıması ayrı bir inceleme konusu olmuştur.

Bu çalışmada yüksek gelirli 19 OECD ülkesinin 1990-2015 dönemini kapsayan y1llık verileri analiz edilerek döviz kurlarının yansıma etkisinin olup olmadığı ampirik olarak incelenmiştir. Bu kapsamda, tüketici fiyat endeksi, toptan eşya fiyat endeksi ile temsil edilen üretici fiyat endeksi, nominal efektif döviz kuru ve sanayi sektöründe yaratılan katma değerin gayrisafi yurtiçi hasıla içindeki payı ile temsil edilen sanayi üretimi verileri kullanılmıştır. Çalışma, hem yapısal vektör otoregresif (VAR) model hem de gecikmesi dağıtılmış otoregresif (ARDL) modeller, dengesiz panel veri analiz prosedürü izlenerek tahmin edilmiştir. Yapısal VAR ve dinamik panel ARDL modellerinde havuzlanmış ortalama grup tahmincisinden elde edilen sonuçlar kısa ve uzun dönemde döviz kurlarının yurtiçi fiyatlara yansıma etkisinin anlamlı, ancak etkinin çok güçlü olmadığını ortaya koymaktadır. Ayrıca beklendiği üzere, yansıma etkisi zamanla azalmakladır.

Yapısal VAR analizi sonuçları nominal efektif döviz kurunun cari, bir ve iki dönem önceki tüketici fiyat endeksleri ile pozitif ilişkili olduğunu ortaya koymuştur. Böylece söz konusu ülkeler için ticari rekabetçiliği artırıcı yönde gelişen bir kur yükselişinin bu ülkelerdeki ortalama fiyat seviyesini de yükseltebileceğini göstermektedir. $\mathrm{Bu}$ gelişme, bir yandan döviz kurunun ortaya çıkardığı fiyat avantajı etkisinin azalması anlamına gelirken diğer yandan yurtiçi fiyat dengesinde bozulmaların da meydana gelebileceğine işaret etmektedir.

Havuzlanmış ortalama grup tahmincisinden elde edilen bulgular, nominal efektif döviz kurunun uzun dönemde tüketici fiyatları üzerine anlamlı bir etkisinin olmadığını ancak kısa dönemde tüketici fiyatlarını arttırdığını göstermiştir. Döviz kurundaki dalgalanmalarının toptan eşya fiyat endeksi üzerine etkileri ise anlamlı bir biçimde uzun ve kısa dönemde pozitif bulunmuştur. Ayrıca hata düzletme katsayıları şokların uzun dönemde dengeye geleceğini ancak tüketici fiyatlarında bu dengeye gelme sürecinin üretici fiyatlarına kıyasla daha uzun süreceğini göstermiştir. Çalışma, sonuç olarak, birçok makroekonomik değişken ile etkileşim halinde olan yurtiçi fiyat istikrarını sağlamak için, politika yapıcıların döviz kurlarındaki değişmeleri izleyen ek politika uygulamalarına başvurmaları gerektiğine işaret etmektedir.

\section{Kaynakça}

- An \& Wang, 2011. "Exchange Rate Pass-Through: Evidence Based on Vector Autoregression with Sign Restrictions", Federal Reserve Bank of Dallas Globalization and Monetary Policy Institute Working Papers, No. 70

- Arat, 2003.“Türkiye'de Optimum Döviz Kuru Rejimi Seçimi ve Döviz Kurlarından Fiyatlara Geçiș Etkisinin İncelenmesi”. Türkiye Cumhuriyeti Merkez Bankası, Uzmanlık Tezi

- Beirne and Bijsterbosch, 2009. "Exchange Rate Pass-Through in Central and Eastern European Member States", European Central Bank Working Papers, 1120

- BIS-Bank of International Settlement, 2017. Effective Exchange Rate Indices. http://www.bis.org/statistics/ $\underline{\text { eer.htm }}$ 
- Bhundia, 2002. “An Empirical Investigation of Exchange Rate Pass-Through in South Africa”, International Monetary Fund Working Papers, No: 02/165.

- Campa \& Goldberg, 2002."Exchange Rate Pass-Through into Import Prices: A Micro or Macro Phenomenon?”, NBER Working Paper, No: 8934.

- Ca'zorzi, Hahn \& Sanchez, 2007. Exchange Rate Pass-Through in Emerging Markets, Europan Central Bank Working Paper Series, No:739.

- Comunale \& Kunovac, 2017. "Exchange Rate Pass-Through in the Euro Area" European Central Bank Working Paper Series 2003.

- Coricelli, Egert \& MacDonald, 2006. "Monetary Transmission Mechanism in Central and Eastern Europe: Gliding on a Wind of Change". Bank of Finland BOFIT Discussion Papers, No:8/2006.

- Damar, 2010. “Türkiye'de Döviz Kurundan Fiyatlara Geçiş Etkisinin İncelenmesi”. Uzmanlık Yeterlilik Tezi”, Ankara: Türkiye Cumhuriyet Merkez Bankası Piyasalar Genel Müdürlüğü.

- EIA-Energy Information Administration, 2017. Spot Oil Prices,https://www.eia.gov/

- Flamini, 2003. "CPI Inflation Targeting and Exchange Rate Pass-Through". Enteperglistudi monetary bancarie finanziari Luigi Einaudi.

- Ghosh \& Rajan, 2007. “A Comparative Analysis of Export Price Pass-Through in Three Open Asian Economies: Korea, Singapore and Thailand”, Global Economic Review, 36(3), pp. 287-299.

- Hyder \& Shah, 2004. "Exchange Rate Pass-Through to Domestic Prices in Pakistan", State Bank of Pakistan Working Paper, No:5

- Im, Pesaran and Shin, 2003. "Testing for Unit Roots in Heterogeneous Panels”, Journal of Econometrics, 115 (1), pp. 53-74.

- Ito \& Sato, 2008. "Exchange Rate Pass-Through and Domestic Inflation: A Comparison between East Asia and Latin American Countries”. RIETI Discussion Paper Series, E-040.

- Kara \& Öğünç, 2012. “Döviz Kuru ve İthalat Fiyatlarının Yurtiçi Fiyatlara Etkisi”, İktisat İşletme ve Finans, 27 (317).

- Kenen \& Pack, 1994. Exchange Rates, Domestic Prices, and the Adjustment Process, Peter B. Kenen (ed), Group of Thirty, New York, N.Y.

- Kiptui, Ndolo \& Kaminchia, 2005. "Exchange Rate Pass-Through: to What Extent Do Exchange Rate Fluctuations Affect Import Prices and Inflation in Kenya?", Central Bank of Kenya Working Paper No.1.

- Leigh \& Rossi, 2002. "Exchange Rate Pass-Through in Turkey", IMF Working Paper, WP/02/204.

- Levin, Lin and Chu, 2002. "Unit Root Tests in Panel Data: Asymptotic and Finite Sample Properties”, Journal of Econometrics, 108(1), pp. 1-24.

- Manning \&Andrianacos, 1993. "Dollar Movements and Inflation: A Cointegration Analysis", Applied Economics, 12, pp. 1483-1488.

- Menon, 1996. "The Degreeand Determinants of Exchange Rate Pass-Through: Market Structure, Non-Tariff Barriers and Multinational Corporations", The Economic Journal, 106, No. 435.

- McCarthy, 2000. "Pass -Through of Exchange Rates and Import Prices to Domestic Inflation in Some Industrialized Economies”, Bank for International Settlements Working Paper, No:79

- Pedroni, 2013. "Structural Panel VAR”, Econometrics, 1(2), pp. 180-206.

- Pesaran, Shin and Smith, 1999. "Pooled Mean Group Estimation of Dynamic Heterogeneous Panels", Journal of the American Statistical Association, 94(446), pp. 621-634.

- Ponomarev, Trunin \& Uluykaev, 2014. "Exchange Rate Pass-Through in Russia", SSRN Working Paper

- Shambaugh, 2008. "A New Look at Pass-Through”, Journal of International Money and Finance, 27, p.591.

- Shu \& Su, 2009. "Exchange Rate Pass-Through in China. China”, World Economy, 17, 1, pp.33-46.

- Sims, 1972."Money, Income, and Causality", The American Economic Review, 62(4), pp. 540-552.

- Sims,1980. "Macroeconomics and Reality", Econometrica, 48(1), pp.1-48

- WDI-World Development Indicators, 2017. http://databank.worldbank.org/data/reports.aspx?source=worlddevelopment-indicators 


\title{
Sahiplik Yapısı ile Sermaye Yapısı ve Kar Payı Dağıtım Kararları Arasındaki İlişkinin Borsa İstanbul 30 Endeksinde Test Edilmesi Effects of Ownership Structure on Capital Structure and Divident Decisions: Case of Borsa Istanbul 30 Index
}

\author{
Assoc. Prof. Dr. İlhan Ege (Mersin University, Turkey) \\ Tuğba Nur Topaloğlu (Mersin University, Turkey)
}

\begin{abstract}
Ownership structure is one of the main dimensions of corporate governance and is widely seen to be determined by other country-level corporate governance characteristics such as the development of the stock market and the nature of state intervention and regulation. Most ownership structure research focuses on relationship between ownership structure and firm performance. This paper investigates the effects of ownership structure on capital structure and divident decisions. In this study observed that ownership structure of firms in Borsa Istanbul 30 Index. Data of this firms collected from Borsa Istanbul web page. Period of data is between 2007 and 2015. Panel regression method is used for analyzing the effects of ownership structure on capital structure and divident decisions. As a result of this study we find statistically significant nonrelationship between ownership structure and both capital structure and divident decision.
\end{abstract}

\section{Giriş}

Firmaların sahiplik yapısı, hissedarların sayısı ve yapısı esas alınarak belirlenmektedir. Sahiplik yapısı her firma için farklı özelliklerde olabilmektedir. Firmalarda hissedarların sayısının fazla olması sahiplik yapısının tabana yayıldığı anlamına gelmektedir. Diğer bir ifadeyle sahiplik yapısı hissedarların yönetimle ilişkisi ve yönetimin hissedarın elinde olup olmaması olarak algılanabilir. Bu durumda sahiplik ve kontrol tek bir kişinin elinde de olabilirken sahiplik ve kontrolün farklı kişilerde olduğu firmalarda vardır. Sahiplik ve kontrolün ayrı olduğu firmalarda temsilci ile temsil edilen arasındaki ilişki farklı iken, tek bir kişinin elinde olan firmalarda daha karmaşık ilişkiler söz konusu olabilmektedir.

Firma yöneticilerinin ve sahiplerinin beklentileri farklı olduğu için firma içerisinde alınan kararlarda da farklılık gözlemlenmektedir. Bu beklentilerin farklı olması firmalarda temsil maliyetlerinin oluşmasına sebep olmaktadır. $\mathrm{Bu}$ durumda firmalar temsilci maliyetlerine katlanmak durumunda kalabilmektedir. Ayrica firmalarda alınan sermaye yapısı ve kar dağıtım politikası kararlarında da farklılık görülmesine sebep olmaktadır. Sermaye yapısı kararları şirket varlıklarının finansmanında hangi kaynakların kullanılacağına ilişkin verilen kararları ifade ederken, kar dağıtım politikası şirketin finansal kararlarının içinde yer almaktadır.

Çalışmada, Borsa İstanbul 30 Endeksi'nde faaliyet gösteren şirketlerin sahiplik yapılarının, sermaye yapısı kararlarına ve kar payı dağıtım politikalarına olan etkisini ortaya çıkarmak amaçlanmıştır. Bu doğrultuda çalışmada öncelikle konuya ilişkin literatürdeki çalışmalara yer verilmiştir. Sonrasında ise konu kapsamında gerçekleştirilen ampirik uygulamaya değinilmiştir. Son olarak ise analiz sonucunda elde edilen bulgular değerlendirilip yorumlanmıştır.

\section{Literatür Taraması}

Sahiplik yapısı ile sermaye yapısı ve kar payı dağıtım politikası arasındaki ilişki üzerine yapılan birçok çalışma söz konusudur. Bu çalışmalar kronolojik sıralama esas alınarak aşağıda açıklanmaktadır.

Kim ve Sorenson (1986), ABD’deki endüstri işletmelerini kapsayan çalışmalarında, yönetici sahipliği türünün fazla olduğu işletmelerin diğer işletmelere göre daha yüksek borçlanma oranlarına sahip olduğunu söylemişlerdir. Ortaya çıkan bu sonucu iki sebebe bağlamışlar ve bu nedenlerden ilkini işletmenin kontrol edilmesi olarak göstermişler ve yönetici sahipliğinin bulunduğu işletmelerde yapısının sulanmasının önüne geçebilmek amacıyla, yeni ortak edinilmesine sıcak bakılamayacağı, bunun da borçla finansmanı artıracağını öne sürmüşlerdir. İkinci neden olarak ise yöneticiler kendileri de zarar görmemek için işletmenin yaptığı sözleşmelere tam olarak uyacağı ve durumda işletmenin daha kolay borçlanma ihtimaline sahip olacağını belirtmişlerdir.

Agrawal ve Nagarajan (1990), ABD'deki işletmeler üzerinde yaptıkları çalışmada, aile şirketlerinde aile ilişkilerinden dolayı aileden kişiler üst yönetimde yer almaktadır. Bu durum ise yönetici sahiplik yapısının işletmelerde daha fazla görülmesine sebep olmaktadır. Çalışmanın sonucuna göre oy haklarının kontrolü ile yöneticiler arasındaki ailesel ilişki, kaldıraç oranını azaltıcı etki yapmaktadır.

Bathala, Moon ve Rao (1994), çalışmaların da kurumsal sahipliğin, borç kullanımı ve yönetici sahiplik üzerine etkisini araştırmışlardır. Çalışma kapsamında iki model kurulmuştur. Birinci modelde bağımlı değişken olarak kaldıraç oranı alınmış olup bağımsız değişkenler olarak ise kazanç volatilitesi, varlık büyümesi, kurumsal sahiplik 
ve yönetimsel sahiplik büyümesi, maddi olmayan varlıklara yönelik masraflar ve vergi kalkanı alınmıştır. İkinci modelde ise bağımlı değişken olarak yönetimsel sahiplik büyümesi alınmış olup bağımsız değişkenler olarak hisse senedi getiri volatilitesi, varlık büyümesi, maddi olmayan varlıklara yönelik masraflar, işletme büyüklüğü, kurumsal sahiplik ve borçlanma oranı modele dahi edilmiştir. Bunun sonucunda, kurumsal sahiplik ile borç kullanımı ve yönetsel sahiplik arasında negatif yönde bir ilişki olduğu tespit edilmiş ve kurumsal yatırımcıların yöneticilerin izlenmesinde etkileri olduğunu bunun da temsil maliyetlerini düşürdüğünü belirtmişlerdir

Brailsford, Oliver ve Pua (2002), 1989-1995 dönemi için Avustralya borsasında işlem gören işletmelerin sermaye yapısı ile sermaye sahipliği arasında ilişkiyi incelemişlerdir. Yapılan araştırmanın sonucunda yönetici sahipliğinin az olduğu işletmelerdeki hâkim hissedarlar daha fazla borçlanma ile işletme üzerindeki kontrolü kaybetmemektedir. Yönetici sahipliğinin yüksek olduğu işletmelerde ise sahipler riskten kaçınan tercihlerde bulunarak kaldıraç oranı ile negatif ilişki seyretmektedir

Kumar (2003) çalışmasında, sahiplik yapısı, kurumsal yönetim ve işletmelerin kâr dağıtım politikaları arasındaki ilişkiyi incelemiştir. Çalışmada, Hindistan'da faaliyet gösteren 2575 işletmeye ait veriler, 1994-2000 döneminde ampirik olarak incelenmiştir. Sahiplik yapısı bağımsız değişkeni olarak, yönetici sahipliği, kurumsal yatırımcı sahipliği, kurumsal sahiplik ve yabancı sahiplik alınırken, bağımlı değişken olarak temettü ödeme oranları, kontrol değişkeni olarak da kâr büyümeleri, borç/özsermaye ve satışlar/toplam aktifleri analize dâhil edilmiştir. Çalışma neticesinde sahiplik yapısının kâr payı dağıtım politikaları üzerinde etkisinin olduğu sonucuna ulaşılmış olup yabancı sahiplik ile kâr payı dağıtımı arasında herhangi bir ilişki bulunamamıştır.

Stouraitis ve $\mathrm{Wu}$ (2004) çalışmalarında, serbest nakit akımları hipotezine bağlı olarak Japon firmaların serbest nakit akışı ile sahiplik yapısının kâr dağıtım politikaları üzerine etkisini araştırmışlardır. Çalışmada, 2000 firmanın 1992-2000 dönemindeki verileri kullanılmıştır. Çalışmada sahiplik yapısı bağımsız değişkenini olarak, kurumsal sahiplik ve yönetimsel sahiplik, bağımlı değişken olarak, temettü verimini, kontrol değişkenleri olarak da kaldıraç oranları, yatırımlar, kârlılık, dış finansman maliyeti, risk, şirket büyüklüğü ve piyasa değeri/defter değeri oranı analize dâhil edilmiştir. Çalışmanın sonucunda ise yönetici ve kurumsal sahipliğin kâr payı dağıtım kararları üzerine düşük büyüme hızı olan işletmeler için olumlu etkisinin olduğu sonucuna ulaşılmıştır.

Chen, Cheung ve Stouraitis (2005) Hong Kong'da yaptıkları çalışmada, 1995-1998 yıllarını kapsayan dönemde aile sahipliği yoğunlaşması, firma performansı ve temettü politikası arasındaki ilişkiyi incelemişlerdir. Çalışma sonucunda aile sahipliği yoğunlaşması ile kâr payı politikası arasında zayıf bir ilişki bulunmuştur. Sadece küçük piyasa değerine sahip işletmeler örnekleminde, kâr payı verimi ile aile sahipliği yoğunlaşması arasında pozitif ilişkiye rastlanmıştır.

Harada ve Nguyen (2006), 1995-2002 yıllarını kapsayan dönemde Japon işletmelerinde sahiplik yoğunlaşması ile temettü politikası arasındaki ilişkiyi, işletmedeki hâkim hissedarın işletmelerin kaynaklarını kendi çıkarları doğrultusunda kullanmak isteyecekleri için daha az kâr payı ödemesi yapacaklardır hipotezi çerçevesinde incelemişlerdir. Çalışma sonucunda, söz konusu hipotezle de uyumlu olarak, kâr payı politikasının sahiplik yoğunlaşması ile negatif yönde ilişkili olduğu, sahiplik yoğunlaşmasının yüksek olduğu firmaların daha az kâr payı ödedikleri tespit edilmiştir.

King ve Santor (2008), aile işletmelerinin sermaye yapısı ve işletme performansı üzerindeki etkisini Kanada'da faaliyet gösteren firmalar üzerine uygulama yaparak araştırmıştır. Çalışmada bağımsız değişken olarak, toplam yabancı kaynakların toplam varlıklara oranı kullanılmıştır. Bununla birlikte kontrol değişkenleri olarak; büyüme, işletme yaşı, aktif büyüklüğü, karlılık gibi oranlar kullanılmıştır. Çalışmada aile işletmelerinin diğer işletmelere göre daha fazla yabancı kaynakla finansmanı tercih ettikleri sonucuna ulaşılmıştır.

Toraman ve Okuyan (2009) İMKB'de işlem gören ve finansal olmayan 194 işletme üzerine 2005-2007 dönemini kapsayan çalışmada, işletmelerin ortaklık yapısındaki yoğunlaşmanın işletmelerin finansal kararlarına olan etkisi incelenmiştir. Çalışmada kullanılan bağımlı değişkenler; toplam borç/pasif toplamı, UVB/Pasif Toplamı, KVB/Pasif Toplamı olup bağımsız değişkenler; en büyük ortağın sahiplik oranı, en büyük üç ortağın sahiplik oranı, en büyük beş ortağın sahiplik oranıdır. Kontrol değişkeni olarak ise duran varlık/toplam varlık, varlık büyüklüğü, (FVÖK+Amortisman)/toplam varlık, net çalışma sermayesi/dönen varlıklar kullanılmıştır. Çalışmanın sonucunda ortaklık yapısındaki yoğunlaşmanın finansal kararların belirleyicisi olduğu ortaya çıkmış ve ortaklık yapısında yoğunlaşma ile borçlanma arasında pozitif ilişki olduğu saptanmıştır.

Mehrani, Moradi ve Eskandar (2011) çalışmalarında, sahiplik yapısı ile kâr payı dağıtım politikası arasındaki ilişkiyi incelemişlerdir. Araştırma İran Tahran Borsasında işlem gören işletmeler üzerinde yapılmış olup, 20002007 yılları arası veriler analize dâhil edilmiştir. Çalışmada bağımsız değişken olarak kurumsal sahiplik ile kurumsal sahiplik yoğunluğu ve yönetimsel sahiplik, bağımlı değişken olarak da kâr dağıtım oranları kullanılmıştır. Kontrol değişkeni olarak ise kaldıraç, nakit akışı, şirketin büyüklüğü, piyasa değeri/defter değeri kullanılmıştır. Çalışma sonucunda kurumsal sahiplik ile kâr payı ödeme arasında negatif ilişki, kurumsal sahiplik yoğunluğu ve kâr payı ödemeleri arasında pozitif ilişki tespit edilmiştir.

Shah, Ullah ve Hasnain (2011), Pakistan Karachi Borsasında işlem gören işletmelerin sahiplik yapısının kâr dağıtım politikası üzerine etkisini araştırmak için 2002 ve 2006 dönemine ait panel verilerini incelemişlerdir. Çalışmada bağımsız değişken olarak sahiplik yapısı, bağımlı değişken olarak ise kâr dağıtım oranları alınırken, 
kontrol değişkeni olarak ise firmaların büyüklüğü, özsermaye kârlılı̆̆ı ve kaldıraç oranları alınmıştır. Çalışma neticesinde yönetici sahipliğin ve nakit kâr dağıtım seviyesinin yüksek olduğu belirlenmiştir. Bu bağlamda sahiplik yapısı ve kâr dağıtım politikası arasında pozitif bir ilişki olduğu tespit edilmiştir.

Büyükmert (2015), sahiplik yapısı ile işletme kararları arasındaki ilişkinin araştırıldığı çalışmasında, Borsa İstanbul'da (BİST) faaliyet gösteren 133 işletmenin sahiplik yapıları ve 2010 ile 2013 yılları arasındaki finansal verileri kullanılmıştır. Çalışmada sahiplik yapısı değişkenleri olarak, işletmedeki en büyük hissedarın payı, en büyük üç hissedarın payı, aile sahipliği bulunan işletmeler, yabancı ortağı bulunan işletmeler, yabancı sahipliği bulunan işletmeler, devlet sahipliği bulunan işletmeler, çalışan sahipliği bulunan işletmeler, holdinge veya bir gruba bağlı olan işletmeler ve bağımsız işletmeler kullanılmıştır. Çalışmanın sonucunda, işletmelerin sermaye yapısının, sahiplik yapıları tarafından etkilendiği uygulama kapsamında tespit edilmiştir.

Ersoy ve Çetenak (2015) çalışmalarında, sahiplik yoğunlaşması ile kâr payı dağıtım politikası arasındaki ilişkiyi incelemişler ve Borsa İstanbul'da işlem gören 116 sanayi şirketinin 2004-2009 dönemi verileri esas alınmıştır. Çalışmada bağımlı değiş̧ken olarak temettü verimi kullanılırken, bağımsız değişken olarak sahiplik yoğunlaşması alınmıştır. Ayrıca aktif karlılığı, kaldıraç oranı, $\mathrm{PD} / \mathrm{DD}$ oranı ve yatırım harcamaları da kontrol değişkeni olarak kullanılmıştır. Çalışma neticesinde sahiplik yoğunlaşmasının kâr payı verimini pozitif yönde etkilediği, aynı zamanda firmaların karlılık oranı, borçlanma düzeyi, yatırım harcamaları ve Piyasa Değeri/Defter Değeri oranının kâr payı dağıtım kararları üzerinde önemli bir etkiye sahip olduğu tespit edilmiştir.

\section{Ampirik Uygulama}

Çalışmanın bu bölümünde, 2009-2015 yılları arasında devamlı olarak Borsa İstanbul 30 Endeksi'nde faaliyet gösteren şirketlerin sahiplik yapılarının sermaye yapısı kararları ve kar payı dağıtım politikalarına olan etkisini belirleyebilmek için panel regresyon analizi gerçekleştirilmiştir. Analiz kapsamında ilk olarak çalışmanın amacı, kapsamı ve veri seti açıklanmıştır. Sonrasında araştırmada kullanılan değişkenler ve modele yer verilmiştir. Son olarak ise yapılan analiz neticesinde elde edilen bulgular ve bu bulgulara ilişkin değerlendirmeler yapılmıştır.

\subsection{Amaç, Kapsam ve Veri Seti}

Araştırmada, Borsa İstanbul 30 Endeksi'nde faaliyet gösteren şirketlerin sahiplik yapılarının, sermaye yapısı ve kar payı dağıtım kararlarına olan etkisini ortaya çıkarmak amaçlanmıştır. Araştırma, Borsa İstanbul 30 Endeksi'nde 2009-2015 yılları arasında sürekli olarak faaliyet gösteren şirketleri kapsamaktadır. Analize dâhil edilen şirketler aşağıda Tablo 1 'de gösterilmektedir.

\begin{tabular}{|c|c|}
\hline$\underline{\text { KOD }}$ & Sirket Adı \\
\hline 1. $\mathrm{AKBNK}$ & Akbank T.A.Ş. \\
\hline 2. $\quad$ ARCLK & Arçelik A.Ş. \\
\hline 3. $\mathrm{DOHOL}$ & Doğan Şirketler Grubu Holding A.Ş. \\
\hline 4. $\quad$ EREGL & Ereğli Demir ve Çelik Fabrikaları T.A.Ş. \\
\hline 5. GARAN & Türkiye Garanti Bankası A.Ş. \\
\hline 6. HALKB & Türkiye Halk Bankası A.Ş. \\
\hline 7. ISATR & Türkiye İş Bankası A.Ş. \\
\hline 8. $\mathrm{KCHOL}$ & Koç Holding A.Ş. \\
\hline 9. $\mathrm{KRDMD}$ & Kardemir Karabük Demir Çelik Sanayi ve Ticaret A.Ş. \\
\hline 10. PETKM & Petkim Petrokimya Holding A.Ş. \\
\hline 11. SAHOL & Hacı Ömer Sabanc1 Holding A.Ş. \\
\hline 12. SISE & Türkiye Şişe ve Cam Fabrikaları A.Ş. \\
\hline 13. TCELL & Turkcell İletişim Hizmetleri A.Ş. \\
\hline 14. THYAO & Türk Hava Yolları A.O. \\
\hline 15. TTKOM & Türk Telekomünikasyon A.Ş. \\
\hline 16. TUPRS & Tüpraş-Türkiye Petrol Rafineleri A.Ş. \\
\hline 17. VAKBN & Türkiye Vakıflar Bankası T.A.O. \\
\hline 18. YKBNK & Yap1 ve Kredi Bankası A.Ş. \\
\hline
\end{tabular}

Tablo 1. Analiz Kapsaminda İncelenen Bankalar ve Kodlarl Kaynak: www.kap.org.tr

Araşıırmada şirketlerin sahiplik yapılarının sermaye yapısı ve kar payı dağıtım kararlarına olan etkisini ortaya çıkarmak amacıyla, iki bağımlı değişken kullanılmıştı. Sermaye yapısı kararını temsil eden bağımlı değişken, toplam borç / toplam aktif şeklinde hesaplanan finansal kaldıraç oranıdır. Kar payı dağıtım kararını temsil eden bağımlı değişken ise kar payı dağıtım oranıdır. Araştırmada kullanılan bağımsız değişkenler ise; en büyük ortağın sermaye payı, en büyük ikinci ortağın sermaye payı, en büyük üçüncü ortağın sermaye payı, yabancı yatırımcıların sermaye payları, kurumsal yatırımcıların sermaye payları ve halka açıklık oranlarıdır.

Araştırmada bağımlı ve bağımsız değişkenlerin yanı sıra, bağımlı değişkenleri etkilediği düşünülen kontrol değişkenleri de analize dâhil edilmiştir. Bu kontrol değişkenleri, sermaye yapısı için toplam varlıkların doğal 
logaritması ve aktif karlılık oranı (ROA)'dır. Diğer bağımlı değişken olan kar payı dağıtım oranını etkilediği düşünülen ve analize dâhil edilen kontrol değişkenleri ise aktif karlılık (ROA) ve finansal kaldıraç oranıdır. Araştırmada kullanılan bağımlı ve bağımsız değişkenler aşağıdaki Tablo 2'de gösterilmektedir.

\begin{tabular}{|c|c|c|c|}
\hline Değişkenler & \multirow[b]{2}{*}{ Hesaplama Şekli } & \multirow[b]{2}{*}{ Sembol } & \multirow[b]{2}{*}{ Literatür } \\
\hline $\begin{array}{l}\text { Bağımlı } \\
\text { Değiskenler }\end{array}$ & & & \\
\hline $\begin{array}{l}\text { Finansal Kaldıraç } \\
\text { Oranı }\end{array}$ & Toplam Borç / Toplam Aktif & FK & $\begin{array}{l}\text { Pushner (1995), Driffield, vd. (2007), King ve Santor (2008), Margaritis } \\
\text { ve Psillaki (2010), Li, vd. (2009), Cespedes, vd. (2010), Bathala, Moon } \\
\text { ve Rao (1994), Toraman ve Okuyan (2009), Oruç (2012), Büyükmert } \\
(2015)\end{array}$ \\
\hline $\begin{array}{l}\text { Nakit } \quad \text { Temettü } \\
\text { Oranı }\end{array}$ & $\begin{array}{l}\text { Y1l İçerisinde Paydaşlara Ödenen Toplam } \\
\text { Nakit Temettü / Yılllık Net Kar }\end{array}$ & KPDO & $\begin{array}{l}\text { Mirzaei (2012), Kumar (2003), Wei, Zhang ve Xiao (2003), Shah, Ullah } \\
\text { ve Hasnain (2010), Ullah, Fida ve Khan (2012), Mehrani, Moradi, } \\
\text { Eskandar (2011), Ramli (2010), Wei, Zhang ve Xiao (2003), Güngör } \\
\text { (2012), Kouki ve Guizani (2009) }\end{array}$ \\
\hline \multicolumn{4}{|l|}{$\frac{\text { Bağımsız }}{\text { Değiskenler }}$} \\
\hline $\begin{array}{l}\text { En Büyük Ortağın } \\
\text { Sermaye Payı }\end{array}$ & $\begin{array}{l}\text { En Büyük Ortağıın Sermaye Payı / Toplam } \\
\text { Öz Sermaye }\end{array}$ & EBO & $\begin{array}{l}\text { Margaritis ve Psillaki (2010), Okuyan (2009), Ramli (2010), Güngör } \\
\text { (2012), Driffield, vd. (2007), Brailsford et al (2002), Sayman (2012), } \\
\text { Toraman ve Okuyan (2009), Oruç (2012), Büyükmert (2015) }\end{array}$ \\
\hline $\begin{array}{l}\text { En Büyük } 2 \text { Ortağın } \\
\text { Sermaye Payı }\end{array}$ & $\begin{array}{l}\text { En Büyük } 2 \text { Ortağın Sermaye Payı / Toplam } \\
\text { Öz Sermaye }\end{array}$ & $\mathrm{EB} 2 \mathrm{O}$ & $\begin{array}{l}\text { Margaritis ve Psillaki (2010), Ramli (2010), Güngör (2012), Driffield, vd. } \\
\text { (2007), Brailsford et al (2002), Sayman (2012), Oruç (2012) }\end{array}$ \\
\hline $\begin{array}{l}\text { En Büyük } 3 \text { Ortağın } \\
\text { Sermaye Payı }\end{array}$ & $\begin{array}{c}\text { En Büyük } 3 \text { Ortağın Sermaye Payı / Toplam } \\
\text { Öz Sermaye }\end{array}$ & EB3O & $\begin{array}{l}\text { Margaritis ve Psillaki (2010), Okuyan (2009), Özvar (2015), Güngör } \\
\text { (2012), Driffield, vd. (2007), Brailsford et al (2002), Toraman ve Okuyan } \\
\text { (2009), Büyükmert (2015) }\end{array}$ \\
\hline $\begin{array}{l}\text { Halka Açıklık } \\
\text { Oranı }\end{array}$ & $\begin{array}{l}\text { Halka Açık Hisselerin Nominal Değerleri } \\
\text { Toplamı / Toplam Öz Sermaye }\end{array}$ & $\mathrm{HAO}$ & $\begin{array}{l}\text { Wei, Zhang ve Xiao (2003), Özvar (2015), Güngör (2012), Sayman } \\
\text { (2012) }\end{array}$ \\
\hline $\begin{array}{l}\text { Yabanc1 Ortak } \\
\text { Sermaye Payı }\end{array}$ & $\begin{array}{l}\text { Yabancı Ortağın Sermaye Payı / Toplam Öz } \\
\text { Sermaye }\end{array}$ & YO & $\begin{array}{l}\text { Li et al (2009), Okuyan (2009), Kumar (2003), Ullah, Fida ve Khan } \\
\text { (2012), Özvar (2015), Güngör (2012), Oruç (2012), Büyükmert (2015) }\end{array}$ \\
\hline $\begin{array}{l}\text { Kurumsal Ortak } \\
\text { Sermaye Payı }\end{array}$ & $\begin{array}{l}\text { Kurumsal Ortağın Sermaye Payı / Toplam } \\
\text { Öz Sermaye }\end{array}$ & $\mathrm{KO}$ & $\begin{array}{l}\text { King ve Santor (2008), Pushner (1995), Mirzaei (2012), Kumar (2003), } \\
\text { Ullah, Fida ve Khan (2012), Mehrani, Moradi, Eskandar (2011), Sayman } \\
\text { (2012), Demsetz ve Lehn (1985), Bathala, Moon ve Rao (1994), Marchica } \\
\text { (2008), Oruç (2012), Büyükmert (2015), Kouki ve Guizani (2009) }\end{array}$ \\
\hline
\end{tabular}

Tablo 2. Araştırmada Kullanılan Değişkenler

Araştırmada kullanılan kontrol değişkenleri aşağıdaki Tablo 3'de gösterilmektedir.

\begin{tabular}{|c|c|c|c|}
\hline $\begin{array}{l}\text { Kontrol } \\
\text { Değișkenleri }\end{array}$ & & & \\
\hline Finansal Kaldıraç & $\frac{\text { Toplam Borçlar }}{\text { Toplam Varlıklar }}$ & FK & $\begin{array}{l}\text { Okuyan (2009), Shah, Ullah ve Hasnain (2010), Ullah, Fida } \\
\text { ve Khan (2012), Mehrani, Moradi, Eskandar (2011), } \\
\text { Stouraitis ve Wu (2004), Bradford, Ehsan, vd. (2013), Chen } \\
\text { ve Zhu (2013), Özvar (2015), Ersoy ve Çetenak (2015), } \\
\text { Mossadak, Fontaine ve Khemakhem (2016) }\end{array}$ \\
\hline Şirket Büyüklüğü & Log (Toplam Varlıklar) & TV & $\begin{array}{l}\text { Brailsford et al (2002), King ve Santor (2008), Mehran, } \\
\text { Taggart ve Yermack (1999), Claessens, vd. (2002), Harvey, } \\
\text { Lins ve Roper (2002), Wei, Zhang ve Xiao (2003), Shah, } \\
\text { Ullah ve Hasnain (2010), Ullah, Fida ve Khan (2012), } \\
\text { Mehrani, Moradi, Eskandar (2011), Stouraitis ve Wu } \\
\text { (2004), Toraman ve Okuyan (2009), Ramli (2010), Sayman } \\
\text { (2012), Oruç (2012), Bradford, Chen ve Zhu (2013), Ehsan, } \\
\text { vd. (2013), Taşkın ve Coşkun (2015), Mossadak, Fontaine } \\
\text { ve Khemakhem (2016) }\end{array}$ \\
\hline Aktif Karlılık & Net Kar / Toplam Varlıklar & ROA & $\begin{array}{l}\text { King ve Santor (2008), Ramli (2010), Güngör (2012), } \\
\text { Sayman (2012), Agustin (2014), Özvar (2015), Ersoy ve } \\
\text { Çetenak (2015) }\end{array}$ \\
\hline Tobin's Q & $\frac{\text { Piyasa Değeri + Toplam Borç }}{\text { Toplam Varlıklar }}$ & TQ & Kouki ve Guizani (2009), Ullah, Fida ve Khan (2012) \\
\hline $\begin{array}{l}\text { Özsermaye } \\
\text { Karlılığ } 1\end{array}$ & Net Kar / Özsermaye & ROE & $\begin{array}{l}\text { Shah, Ullah ve Hasnain (2010), Agustin (2014), Huda ve } \\
\text { Abdullah (2013), Ehsan, vd. (2013), Mossadak, Fontaine ve } \\
\text { Khemakhem (2016) }\end{array}$ \\
\hline $\begin{array}{l}\text { Borç / Özsermaye } \\
\text { Oranı }\end{array}$ & $\begin{array}{c}\text { Toplam Yabanc1 Kaynak / } \\
\text { Özsermaye }\end{array}$ & $\mathrm{BO}$ & Shah, Ullah ve Hasnain (2010), Huda ve Abdullah (2013) \\
\hline
\end{tabular}

Tablo 3. Araştırmada Kullanılan Değişkenler 


\subsection{Yöntem ve Modeler- Bulgular ve Değerlendirilmesi}

Araştırmada, sahiplik yapısının sermaye yapısı ve kar payı dağıtım kararlarına olan etkisini belirleyebilmek için panel regresyon analiz yöntemi kullanılmıştır. Panel veri analizi, ekonomik ilişkilerin tahmin edilmesinde kullanılmakta ve zaman serisi ile yatay kesit verilerini birleştirmektedir.

Panel regresyon analizi kapsamında öncelikle analize dâhil edilen verilerin doğrusal hareket etmesi için veriler, logaritmik forma dönüştürülmüştür. Sonrasında ise değişkenler arasında durağan olmayan zaman serileri, Levin, Lin ve Chu (LLC) (2002) testine tabi tutularak durağan hale getirilmiştir. Ardından panel veri analizi doğrultusunda kullanılan tahmin modelleri, havuzlanmış en küçük kareler (EKK) modeli ve rassal etkiler modeli kullanılarak gerçekleştirilmiştir. Çalışmada tahmin modellerinin belirlenebilmesi için bu yöntemlerden hangisinin kullanılacağı, literatürde sıklıkla kullanılan F testi, Breusch-Pagan LM testi ve Hausman testi yardımıyla tespit edilmiştir. Son olarak da tahmin edilen modelde otokorelasyon, değişen varyans ve birimler arası bağımlılık sorunlarının varlığına ilişkin temel varsayım testleri gerçekleştirilmiştir.

Çalışmada, oluşturulan regresyon modelleri kapsamında otokorelasyon ve değişen varyans hipotezlerini test etmek için literatürde sıklıkla kullanılan testler tercih edilmiştir. Bu bağlamda değişen varyans problemi için, Breusch-Pagan / Cook-Weisberg Testi kullanılmıştır. Otokorelasyon için ise Wooldridge otokorelasyon testinden yararlanılmıştır.

Çalışmada, şirketlerin sahiplik yapılarının sermaye yapısı ve kar payı dağıtım kararlarına olan etkisini ortaya çıkarabilmek için iki regresyon modeli oluşturulmuştur. Bu modeller aşağıdaki gibi kurgulanmıştır.

\section{Model 1 (FK)}

$$
\begin{gathered}
\mathbf{Y}_{\mathrm{it}}=\boldsymbol{\alpha}_{\mathrm{i}}+\boldsymbol{\beta}_{1} \mathrm{EBO}_{\mathrm{it}}+\boldsymbol{\beta}_{2} \mathrm{~EB}_{2} \mathrm{O}_{\mathrm{it}}+\boldsymbol{\beta}_{3} \mathrm{~EB}_{3} \mathrm{O}_{\mathrm{it}}+\boldsymbol{\beta}_{4} \mathrm{HAO}_{\mathrm{it}}+\boldsymbol{\beta}_{5} \mathrm{YO}_{\mathrm{it}}+\boldsymbol{\beta}_{6} \mathrm{KO}_{\mathrm{it}}+\boldsymbol{\beta}_{7} \mathrm{TV}_{\mathrm{it}}+\boldsymbol{\beta}_{8} \mathrm{ROA}_{\mathrm{it}}+\boldsymbol{\varepsilon}_{\mathrm{i}} \\
\text { Model } 2(\mathbf{K P D O}) \\
\mathbf{Y}_{\mathrm{it}}=\boldsymbol{\alpha}_{\mathrm{i}}+\boldsymbol{\beta}_{1} \mathrm{EBO}_{\mathrm{it}}+\boldsymbol{\beta}_{2} \mathrm{~EB}_{2} \mathrm{O}_{\mathrm{it}}+\boldsymbol{\beta}_{3} \mathrm{~EB}_{3} \mathrm{O}_{\mathrm{it}}+\boldsymbol{\beta}_{4} \mathrm{HAO}_{\mathrm{it}}+\boldsymbol{\beta}_{5} \mathrm{YO}_{\mathrm{it}}+\boldsymbol{\beta}_{6} \mathrm{KO}_{\mathrm{it}}+\boldsymbol{\beta}_{7} \mathrm{FK}_{\mathrm{it}}+\boldsymbol{\beta}_{8} \mathrm{ROA}_{\mathrm{it}}+\boldsymbol{\beta}_{9} \mathrm{TQ}_{\mathrm{it}}+\boldsymbol{\beta}_{10} \mathrm{ROE}_{\mathrm{it}} \\
+\boldsymbol{\beta}_{11} \mathrm{BO}_{\mathrm{it}}+\boldsymbol{\varepsilon}_{\mathrm{i}}
\end{gathered}
$$

Sahiplik yapısının kar payı dağıtım kararlarına ve sermaye yapısı kararlarına olan etkisini ortaya çıkarabilmek için gerçekleştirilen panel veri analiz sonuçları, Tablo 4 ve Tablo 5 'te gösterilmektedir.

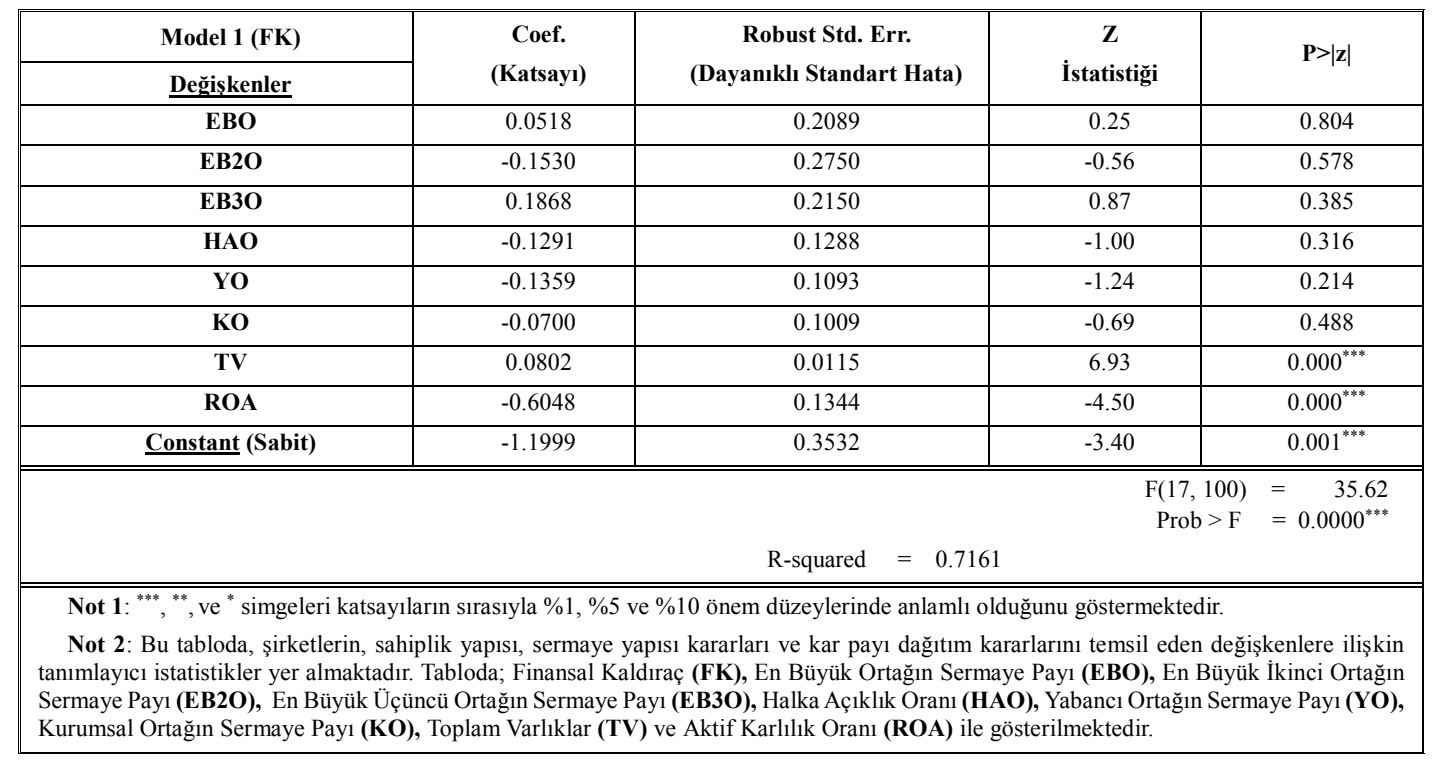

Tablo 4. Sahiplik Yapısı İle Sermaye Yapısı Kararları Arasındaki İlişkiye Yönelik Tahmin Sonuçları

Tablo 4'deki analiz sonuçları değerlendirildiğinde, finansal kaldıraç (FK) esas alınarak oluşturulmuş Model 1'e ilişkin panel veri regresyon analiz sonuçlarına göre, modelin \%90 güven düzeyinde anlamlı olduğu belirlenmiştir (f değeri $=0.0000^{* * *}$ ). Bunun yanı sıra modelde yer alan bağımsız değişkenler, FK bağımlı değişkeninin $\% 71.61$ 'ini açıklamaktadır.

Model 1 kapsamında BIST 30 şirketlerinin sahiplik yapılarını ifade eden 6 bağımsız değişken ile FK arasında istatistiksel olarak anlamlı bir ilişki tespit edilememiştir. Açıkça ifade etmek gerekirse, sahiplik yapısını ifade eden en büyük ortağın sermaye payı, en büyük 2. ortağın sermaye payı, en büyük 3. ortağın sermaye payı, halka açıklık oranı, yabancı ortağın sermaye payı ve kurumsal ortağın sermaye payı ile sermaye yapısını ifade eden finansal kaldıraç arasında herhangi bir ilişki tespit edilememiştir. Çalışmada elde edilen bu bulgu, Kumar (2004), Margaritis ve Psillaki (2010) ve Oruç (2012) tarafindan yapılan çalışmalarda elde edilen bulgular ile paralellik göstermektedir. Çalışmada bağımsız değişkenlerin yanı sıra bağımlı değişkenleri etkilediği düşünülen kontrol değişkenleri ile finansal kaldıraç arasındaki ilişki incelendiğinde ise toplam varlıklar ile finansal kaldıraç arasında istatistiksel olarak anlamlı $\left(\mathrm{p}=0.000^{* * *}\right)$ ve pozitif yönlü bir ilişki tespit edilmiştir. Diğer bir deyişle toplam varlıklarda yaşanan 
bir birim artış, finansal kaldıraçta $0.08^{\prime}$ 'lik bir artışa neden olmaktadır. Çalışma sonucunda elde edilen bu bulgu, Brailsford et al (2002), King ve Santor (2008), Sayman (2012) ve Taşkın ve Coşkun (2015) tarafından yapılan çalışmalarda sağlanan bulgular ile paralellik göstermektedir.

Bunun yanı sıra bir diğer kontrol değişkeni olan ROA ile finansal kaldıraç arasında istatistiksel olarak anlamlı $\left(p=0.000^{* * *}\right)$ ve negatif yönlü bir ilişki tespit edilmiştir. Diğer bir deyişle ROA'da yaşanacak bir birim artış, finansal kaldıraçta 0.6048'lik bir düşüşe neden olmaktadır. Çalışmada elde edilen bu bulgu, Sayman (2012) tarafindan yapılan çalışmada elde edilen bulgular ile paralellik göstermektedir.

Çalışmada şirketlerin sahiplik yapıları ile sermaye yapısı arasında herhangi bir ilişkinin bulunamaması çeşitli sebeplerden dolayı ortaya çıkmış olabileceği düşünülmektedir. Bu sebepler, işletmelerin sermaye yapıları (yabancı kaynak/toplam varlık) ile ilgili kararları genel olarak hissedarlar tarafından görevlendirilen yönetici vermektedir. $\mathrm{Bu}$ doğrultuda işletmelerin sermaye yapılarına etki eden esas faktörün, hissedarlardan oluşan sahiplik yapısından ziyade üst düzey yönetim olduğu söylenebilir. Diğer bir deyişle işletmenin sermaye yapısı kararlarının alınmasından işletme yönetim kurulu ve üst düzey yöneticiler sorumlu olmaktadır. Bu bağlamda şirket hissedarları, şirket üzerindeki sahip oldukları kontrol gücünü yönetim kuruluna devrederek, sahiplik ve kontrol ayrımına gitmektedirler.

\begin{tabular}{|c|c|c|c|c|}
\hline Model 2 (KPDO) & \multirow{2}{*}{$\begin{array}{c}\text { Coef. } \\
\text { (Katsayı) }\end{array}$} & \multirow{2}{*}{$\begin{array}{c}\text { Robust Std. Err. } \\
\text { (Dayanıklı Standart Hata) }\end{array}$} & \multirow{2}{*}{$\begin{array}{c}T \\
\text { İstatistiği }\end{array}$} & \multirow{2}{*}{$\mathbf{P}>|\mathbf{t}|$} \\
\hline Değiskenler & & & & \\
\hline EBO & -13.795 & 16.9473 & -0.81 & 0.427 \\
\hline EB2O & -38.2491 & 51.7843 & -0.74 & 0.470 \\
\hline EB3O & 72.2992 & 60.8133 & 1.19 & 0.251 \\
\hline HAO & -7.4116 & 8.7919 & -0.84 & 0.411 \\
\hline YO & -36.9204 & 62.0389 & -0.60 & 0.560 \\
\hline KO & -22.7425 & 39.6737 & -0.57 & 0.574 \\
\hline TV & 6.2559 & 3.5609 & 1.76 & $0.097^{*}$ \\
\hline FK & -84.7090 & 64.0647 & -1.32 & 0.204 \\
\hline ROA & -285.9859 & 313.645 & -0.91 & 0.375 \\
\hline TQ & -4.3550 & 4.0896 & -1.06 & 0.302 \\
\hline ROE & 62.2560 & 88.9293 & 0.70 & 0.493 \\
\hline BO & -1.0477 & 3.9699 & -0.26 & 0.795 \\
\hline \multirow[t]{2}{*}{ Constant (Sabit) } & -109.8053 & 55.8609 & -1.97 & $0.066^{*}$ \\
\hline & & \multicolumn{2}{|c|}{ R-squared $=0.0950$} & Prob $>$ F \\
\hline \multicolumn{5}{|c|}{$\begin{array}{l}\text { Not 1: }{ }^{* * *},{ }^{* *}, \text { ve }^{*} \text { simgeleri katsayıların sırasıyla \%1, \%5 ve \%10 önem düzeylerinde anlamlı olduğunu göstermektedir. } \\
\text { Not 2: Bu tabloda, şirketlerin, sahiplik yapısı, sermaye yapısı kararları ve kar payı dağıtım kararlarını temsil eden değişkenlere ilişkin } \\
\text { tanımlayıcı istatistikler yer almaktadır. Tabloda; Finansal Kaldıraç (FK), Kar Payı Dağıtım Oranı (KPDO), En Büyük Ortağın Sermaye Payı } \\
\text { (EBO), En Büyük İkinci Ortağın Sermaye Payı (EB2O), En Büyük Üçüncü Ortağın Sermaye Payı (EB3O), Halka Açıklık Oranı (HAO), } \\
\text { Yabancı Ortağın Sermaye Payı (YO), Kurumsal Ortağın Sermaye Payı (KO), Toplam Varlıklar (TV), Aktif Karlılık Oranı (ROA), Tobin’s Q } \\
\text { (TQ), Özsermaye Karlılığı (ROE) ve Borç / Özsermaye (BO) ile gösterilmektedir. }\end{array}$} \\
\hline
\end{tabular}

Tablo 5. Sahiplik Yapısı İle Kar Payı Dağıtım Oranı Arasındaki İlişkiye Yönelik Tahmin Sonuçları

Tablo 5'deki analiz sonuçları değerlendirildiğinde, kar payı dağıtım oranı (KPDO) esas alınarak oluşturulmuş Model 2'ye ilişkin panel veri regresyon analiz sonuçları incelenecek olursa, modelin \%90 güven düzeyinde anlamlı olduğu belirlenmiştir ( $\mathrm{f}$ değeri $=0.0640^{*}$ ). Bunun yanı sıra modelde yer alan bağımsız değişkenler, KPDO bağımlı değişkeninin yaklaşık \%10'unu açıklamaktadır.

Model 2 kapsamında BIST 30 şirketlerinin sahiplik yapılarını ifade eden 6 bağımsız değişken ile KPDO arasında istatistiksel olarak anlamlı bir ilişki tespit edilememiştir. Daha açık ifade etmek gerekirse, sahiplik yapısını ifade eden en büyük ortağın sermaye payı, en büyük 2. ortağın sermaye payı, en büyük 3. ortağın sermaye payı, halka açıklık oranı, yabancı ortağın sermaye payı ve kurumsal ortağın sermaye payı ile kar payı dağıtım kararlarını ifade eden kar payı dağıtım oranı arasında anlamlı herhangi bir ilişki tespit edilememiştir. Model 2'de elde edilen bu bulgular, Kumar (2003), Chen, Cheung ve Stouraitis (2005) ve Warrad, vd., (2012) tarafından yapılan çalışmalarda elde edilen bulgular ile paralellik göstermektedir.

Çalışmada bağımsız değişkenlerin yanı sıra bağımlı değişkenleri etkilediği düşünülen kontrol değişkenleri (Finansal Kaldıraç (FK), Toplam Varlıklar (TV), Aktif Karlılık Oranı (ROA), Tobin's Q (TQ), Özsermaye Karlılı̆̆ı (ROE) ve Borç / Özsermaye (BO)) ile kar payı dağıtım oranı arasındaki ilişki incelendiğinde ise sadece toplam varlıklar ile kar payı dağıtım oranı arasında istatistiksel olarak anlamlı $\left(\mathrm{p}=0.097^{*}\right)$ ve pozitif yönlü bir ilişki tespit edilmiştir. Bu bağlamda toplam varlıklardaki bir birim artış, kar payı dağıtım kararlarında yaklaşık \%10’luk bir artışa yol açmaktadır. Bu bulgu, Ramli (2010) ve Wei, Zhang ve Xiao (2003) tarafından yapılan çalışmalarda elde edilen bulgular ile paralellik göstermektedir. Ancak diğer kontrol değişkenleri ile KPDO arasında istatistiksel olarak anlamlı herhangi bir ilişki tespit edilememiştir. Çalışmada elde edilen bu bulgular, Shah, Ullah ve Hasnain 
(2010), Mehrani, Moradi, Eskandar (2011), Ullah, Fida ve Khan (2012), Bradford, Chen ve Zhu (2013) ve Mossadak, Fontaine ve Khemakhem (2016) tarafından yapılan çalışmalar ile paralel sonuçlar içermektedir.

Çalışmada şirketlerin sahiplik yapıları ile kar payı dağıtım kararları arasında herhangi bir ilişkinin bulunamaması çeşitli sebeplerden dolayı ortaya çıkmış olabileceği düşünülmektedir. Bu sebepler, İşletmelerin sermaye yapısı kararlarında olduğu gibi kar payı dağıtımlarına ilişkin kararları da genel olarak hissedarlar tarafından görevlendirilen yönetim kurulları vermektedir. Bu doğrultuda işletmelerin kar payı dağıtım kararlarına etki eden esas faktörün, hissedarlardan oluşan sahiplik yapısından ziyade üst düzey yönetim olduğu söylenebilir. Diğer bir deyişle, işletmenin sermaye yapısı kararlarının alınmasından işletme yönetim kurulu ve üst düzey yöneticiler sorumlu olmaktadır. Bu bağlamda şirket hissedarları, şirket üzerindeki sahip oldukları kontrol gücünü yönetim kuruluna devrederek, sahiplik ve kontrol ayrımına gitmektedirler. Böylelikle şirketin sahiplik yapısı ile şirket politikalarını belirleyen ve gerçekleştiren yönetim kademesi ayrışmaktadır. Dolayısıyla hissedarlar, şirketin sermaye yapısı ve kar payı dağıtım politikalarının oluşturulmasına etki etmemektedir.

\section{Sonuç}

Çalışmada Borsa İstanbul 30 endeksinde işlem gören şirketlerin sahiplik yapısı ile sermaye yapısı ve kar payı dağıtım kararları arasında ilişki olup olmadığ incelenmeye çalışılmıştır. Yapılan analiz sonucunda 2009-2015 yılları arasında şirketlerin sahiplik yapısı ile sermaye yapısı ve kar payı dağıtım kararlarını arasında ilişki bulunamamıştır.

Konuyla ilgili olarak literatürde yapılan çalışmalar incelenmiş olup değişkenler belirlenerek iki model kurulmuştur. Birinci modelde sahiplik yapısı ile sermaye yapısı arasındaki ilişkiye bakılmış olup ikinci modelde sahiplik yapısı ile kar payı dağıtım kararları arasındaki ilişki incelenmiştir. Birinci modelde sermaye yapısı kararlarını temsil eden bağımlı değişkenimiz finansal kaldıraç oranı iken ikinci modelde kar payı dağıtım kararlarını temsil eden bağımlı değişkenimiz kar payı dağıtım oranı olarak alınmıştır. Modellerde bağımsız değişken olarak, birinci en büyük ortağın sermaye payı, ikinci en büyük ortağın sermaye payı, üçüncü en büyük ortağın sermaye payı, yabancı ortağın sermaye payı, kurumsal ortağın sermaye payı ve halka açıklık oranı alınmıştır.

Sahiplik yapısı ile sermaye yapısı ve kar payı dağıtım kararları arasında ilişkinin olmaması veya çok düşük düzeyde olması, yapmış olduğumuz analizin imalat sektörüne ek olarak mali sektör ve ulaştırma, haberleşme ve depolama sektörü gibi farklı sektörlerin de analiz kapsamına alınması, değişkenler arasındaki ilişkinin ortaya çıkmasını engelleyen bir faktör olduğu düşünülmektedir. Ayrıca analiz döneminin, küresel mali kriz dönemini kapsaması ve dolayısıyla şirketlerin sermaye yapısı ve kar payı dağıtım kararlarını etkilemesi de ilişkinin tespit edilememesine etki eden bir diğer faktör olarak karşımıza çıkmaktadır.

Bunun yanı sıra, analiz kapsamında incelenen BIST 30 endeksinde faaliyet gösteren şirketlerin büyük ölçekli şirketler olması ve hisse senetlerinin halka açık olan kısmının diğer şirketlere göre daha fazla olması nedeniyle şirket yöneticileri ile hissedarlar arasında oluşabilecek temsil maliyetlerinin en aza indirilebilmesi için hissedarlar sermaye yapısı ve kar payı dağıtım kararlarını üst düzey yöneticilere devretmektedir. Bu durum da şirketin sahiplik yapısı ile sermaye yapısı ve kar payı dağıtım kararları arasındaki ilişkinin, sermaye yoğunlaşmasına ve sermaye sahipliği türüne bağlı olmadan gerçekleştiğinin göstergesidir.

\section{Kaynakça}

- Agrawal ve Nagarajan 1999. "Corporate Capital Structure, Agency Costs and Ownership Control: The Case Of All-Equity Firms". The Journal of Finance, 45(4). p.1325-1335.

- Bathala, Moon ve Ra 1994. "Managerial Ownership, Debt Policy and The Impact of Institutional Holdings: An Agency Perspective”. Financial Management, 23(4).

- Bradford, Chen ve Zhu 2013. "Cash Dividend Policy, Corporate Pyramids and Ownership Structure: Evidence from China", International Review of Economics and Finance, 27, p.445-464.

- Brailsford, Oliver ve Pua, 2002. "On The Relation Between Ownership Structure and Capital Structure" Journal Of Accounting and Finance", 42, p. 1-26.

- Büyükmert 2015. "İşletmelerde Sahiplik Yapısının Kârlılık ve Sermaye Yapısı Üzerine Etkileri: Borsa İstanbul'da Ampirik Bir Uygulama”, (Yüksek Lisans Tezi). Balıkesir Üniversitesi Sosyal Bilimler Enstütisi, Balıkesir.

- Chen, Cheung, Stouraitis, ve Wong, 2005. “Ownership Concentration, Firm Performance and Dividend Policy in Hong Kong”. Pacific-Basin Finance Journal, 13.p.431-449.

- Ersoy ve Çetenak 2015. "Sahiplik Yoğunlaşmasinin Temettü Dağitim Kararlarina Etkisi: Borsa İstanbul'da Bir Uygulama”. Ege Akademik Bakış Dergisi, 15(4).p.509-521.

- Harada,ve Nguyen 2006. Ownership Concentration, Agency Conflicts, And Dividend Policy In Japan.Kaynak:http://pbfea2005.rutgers.edu/2007/papers/055pascal\%20nguyen\%20-harada_nguyen.pdf. 
- Kimve Sorenson, 1986. "Evidence on The Impact of The Agency Costs of Debt on Corporate Debt Policy". Journal of Financial and Quantitive Analysis, 21.

- $\quad$ King, ve Santorn 2008. "Family Values: Ownership Structure, Performance and Capital Structure Of Canadian Firm“ Journal of Banking and Finance,32.p.2423-2432

- Kumar, 2003. "Ownership Structure and Dividend Policy in India. Indira Gandhi Institute Of Development Research",1, p.15-58

- Mossadak, Fontaine, ve Khemakhem 2016. “The Relationship between Ownership Structure and Dividend Policy in an Emerging Market: A Moroccan Study”, Universal Journal of Accounting and Finance, 4(2), p.89-95.

- Ramli, 2010. “Ownership Structure and Dividend Policy: Evidence From Malaysian Companies“", International Review of Business Research Papers 6(1).

- Sayman, 2012. "Sahiplik Yapisinin Firma Performansi Ve Sermaye Yapisi Üzerine Etkileri: İMKB'de Işlem Gören Üretim Firmalarinda Bir Uygulama”, (Doktora Tezi). Ankara Üniversitesi Sosyal Bilimler Enstitüsü, Ankara.

- Shah, Ullah, ve Hasnain 2011. "Impact of Ownership Structure on Dividend Policy of Firm (Evidence From Pakistan)". International Conference on Ebusiness, Management and Economics

- Stouraitis, ve Wu 2004. “The Impact of Ownership Structure on The Dividend Policy of Japanese Firms With Free Cash Flow Problem" September 16, 2004 http://www.affi.asso.fr/uploads/Externe/d0/CTR_FICHIER_114_1226315600.pdf.

- Taşkın ve Coşkun 2015. “Ortaklik Yapilarinin Finansman Kararlari Üzerine Etkisi: Bist Enerji Firmalari Incelemesi”, Sosyal Bilimler Enstitüsü Dergisi, 17(1), p.105-118.

- Toraman, ve Okuyan 2009. "Işletmelerde Ortaklik Yapisinda Yoğunlaşmanin Kaynak Yapisi Üzerindeki Etkisi: Imkb Şirketleri Üzerine Bir Uygulama“. MUFAD Muhasebe ve Finansman Dergisi,41, p.72-81

- Ullah, Fida, ve Khan, 2012. "The Impact of Ownership Structure on Dividend Policy Evidence from Emerging Markets KSE-100 Index Pakistan”, International Journal of Business and Social Science 3(9).

- Warrad, Abed, Khriasat ve Al-Sheikh 2012. "The Effect of Ownership Structure on Dividend Payout Policy: Evidence from Jordanian Context" International Journal of Economics and Finance, 4(2).

- Wei, Weiguo ve Jason 2003. "Dividend Policy and Ownership Structure in China” EFMA 2004 Basel Meetings Paper. 
Kırgızistan’da Devlet Borçları ve Borç Yönetimi

\title{
Public Debt and Public Debt Administration in Kyrgyzstan
}

\author{
Tolkun Zhumakunova (Kyrgyzstan-Turkey Manas University, Kyrgyzstan) \\ Asst. Prof. Dr. Raziiakhan Abdieva (Kyrgyzstan-Turkey Manas University, Kyrgyzstan)
}

\begin{abstract}
Public debt and public debt administration in recent years became significant economic problem of most countries. After the collapse of the Soviet Union, Kyrgyzstan has faced with public debt problem. Sharp decline of production, high level of unemployment and the need for economic and structural reforms during transition to market economy caused a large budget deficit.

Budget deficit and public debt problems still remain as one of important macroeconomic issues in Kyrgyzstan. The purpose of our paper is to overview public debt politics and analyze public debt administration in Kyrgyzstan. Also to investigate legal framework of public debt, transparency, risks and effectiveness of public debt administration in Kyrgyzstan.
\end{abstract}

\section{Giriş}

Kamu borçları günümüzde çoğu ülkelerin güncel sorunlarındandır. Özellikle az gelişmiş ülkelerde ekonomik büyümeyi hızlandırmak amacıyla kamu borçları sürekli artmaktadır. Bu tür ülkelerde ülke içindeki sermaye yetersizliğinden dolayı daha çok dış borçlanmaya dayanılmaktadır.

Kırgızistan bağımsızlığını kazandığ 1991 yılından sonra çok ciddi şoklarla karşı karşıya kalmıştır. Üretimin yarı yarıya düşmesi, Sovyetler Birliğinin genel bütçesinden gelen transferlerin durdurulması ve eski SSCB ülkeleri ile ticari bağların kopması kamu gelirlerinin azalmasına neden olmuştur. Diğer yandan ise ülkede yapısal ve ekonomik reformlar ve sosyal harcamalar kamu harcamalarını arttırarak bütçe açığının oluşmasına ve devlet borçlarının yükselmesini ortaya çıkarmıştır.

Borçlar gelecekteki mükellefler üzerindeki yük olduğundan dolayı borçların sürdürülebilir düzeyde olması önemlidir. Bunun için borçların yapısı ve özellikleri (imtiyazlı veya imtiyazlı olmaması, kısa ve uzun vadeli olması v.s.) etkin kullanıma ve zamanında borçları geri ödemeye dikkat edilmelidir. Diğer bir değişle borçların yönetimi ülkenin geleceği ve borçların ekonomi üzerindeki etkisi açısından da önemli hale gelmektedir.

Çalışmamızın amacı Kırgızistan'da kamu borçlarının ve borç yönetiminin analizini yapmaktır. Ülkede borçların yapısı, kullanım alanları, borçlarla ilgili bilgilerin saydamlığı ve borç yükünün durumu incelenecektir. Sonuç olarak da borç yönetim ile ilgili bazı önerilerde bulunulacaktır. Girişi izleyen 2. Bölümde genel olarak borç kavramı ve borç yönetiminin teorik analizi, 3. Bölümde Kırgızistan'daki genel ekonomik durum, 4. Bölümde Kırgızistan'da devlet borçlarının analizi, 5. Bölümde dış borçlar incelenerek 6. Bölümde de sonuç ve öneriler sunulmuştur.

\section{Genel Olarak Borç Kavramı ve Borç Yönetimi}

Borç ödünç alınmış herhangi bir şey karşılığında yerine getirilmesi gereken yükümlülüğü anlatan bir ilişkidir, borçlanma ise, belli bir süre sonra ödenmek üzere para veya benzeri şeylerin ödünç alınmasıdır (Eker ve Meriç, 2000; Adıyaman, 2006). Kamu borçları ise ekonomik açıdan istikrasızlıklarla mücadele edilmesi, büyüme ve kalkınmanın finansmanın sağlanması gibi nedenlerle başvurulan finansman kaynağıdır (Çaşkurlu, 2003). Diğer bir tanıma göre de devlet borçlanması, devletin bir özel hukuk tüzel kişisi olarak isteğe bağlı ve bedel karşılığında, alacaklıya ödenme vaadi ile iç ve dış kaynaklardan elde ettiği gelirdir (Orhaner, 1997).

Borçlar sağladıkları kaynak bakımından iç borçlar ve dış borçlar olmak üzere ikiye ayrılmaktadır. Devlet ülke içindeki tüzel ve özel kişilerden veya ülke dışındaki tüzel ve özel kişilerden borçlanabilmektedir. İç borçlar ülke içindeki tasarrufları ve sermayeyi azaltırken dış borçlar milli geliri arttırıcı ve ekonomik büyümeyi hızlandırıcı etkide bulunabilir. Fakat diş borçların çok yüksek seviyelere gelmesi borç servisine olan harcamaların yükselmesini ve sermayenin ülkeden çıkışına neden olabilmektedir. Dolayısıyla borçların ekonomi üzerinde olumsuz etkilerinin önlemek ve ekonomik gelişmeyi engellememesi için etkin bir borç yönetimine gerek duyulmaktadir.

Borç yönetimi düşük maliyet ve asgari risk ile piyasalardan fon sağlanmasıdır (Ateş, 2002). Borç yönetimi devletin finansman ihtiyacını riskleri ve maliyeti en düşük seviyede tutarak karşılama sürecidir. Borç yönetimi sürecini üç aşamaya ayırabiliriz. Bunlar: karar alma, kullanma ve geri ödeme aşamalarıdır. İlk aşamada borçlanmanın türü, vadesi ve riskleri ele alınarak herhangi bir borçlanmaya karar verilecektir. İkinci aşamada elde edilen borçların kullanım alanları belirlenecektir. Burada şeffaflık ve etkinlik ilkelerine uygun olarak kullanmak önemlidir. Diğer bir değişle alınan borçların ekonomik gelişmeyi hızlandırarak geri ödenmesini kolaylaştıracak ve gelir getiren alanlara harcanması ve borçların nasıl kullanıldığı ile ilgili raporların sunulması gerekmektedir. Borç 
yönetimi alınan borçların zamanında geri ödenmesi ile sonuçlanmaktadır. Böylece, borç yönetimi riskleri göz önüne alarak düşük maliyetle sağlamak ve borçları etkin kullanarak geri ödenmesi ile sonuçlayan bir süreçtir. Borç yönetiminde devlet borçlarının ekonomi üzerindeki negatif etkileri de önlenilmeye çalışılmalıdır.

Borç yönetimi ekonominin genel özellikleri ve yapısına uygun biçimde, alınacak borcun miktarının, ödeme şartlarının, ekonomiye getireceği yükün, borç servis yükünün ağırlaşması durumunda alınabilecek önlemlerin hesaplanmasinı kapsar.

Genel olarak devlet belli bir iktisadi hedeflere ulaşmak için piyasadan sağlanan fonların diğer bir deyişle borçların miktarında ve bünyesinde değişiklikler yapmasıdır diyebiliriz. Borç miktarındaki değişmeler ise belirlenen hedefler gözetilmeden gerçekleşmişse bazı aksi tesirleri olabilecektir. Bu yüzden borç yönetimi ekonomi için önemli rol oynamaktadır.

Canbay (2005) Kırgızistan'da dış borç ve borç yönetimi sorununu incelemiştir. Araştırma sonucunda Kırgızistan'da borç yönetiminin gelişmesi için borçlanma amacının, şartlarının ve borçlanma yoluyla sağlanan kaynakların nasıl kullanıldığının kamuoyu tarafından açıkça bilinebilmesi veya şeffaflığın arttırılması gerektiğini bildirmiştir.

Egeli de (2008) Kırgızistan’da dış borçların sürdürülebilirliğini 1993-2006 yıllarına ait verileri kullanarak incelemiştir. Birim kök ve eşbütünleşme testlerinin sonucu Kırgızistan'da dış borçların sürdürülebilirliği uluslararası finansal piyasalara bağlı olduğunu, uluslararası faiz oranlarındaki bir düşme dış borcun değerini arttırdığını, ilgili faiz oranlarının yükselmesi ise Kırgızistan’da likidite kısıtını yaratacağını göstermişstir. Dolayısıyla Kırgızistan'da etkin dış borç yönetimi gerekli olduğu sonucunu bulmuşlardır.

\section{Kırgizistan'da Temel Ekonomik Göstergeler}

SSCB'nın dağılmasından sonra Kırgızistan ekonomisi 1991-1995 yıllarında ciddi krizle karşı karşıya kalmıştır. Eski SSCB ülkeleri ile ticari bağların kopması, genel bütçeden gelen transferlerin durdurulması ve planlı ekonomiden piyasa ekonomisine geçiş dönemindeki karşılaşan sorunlardan dolayı üretimde \% 50 oranında düşüş yaşanmıştır. Enflasyon, işsizlik ve yoksulluk düzeyi keskin bir şekilde artmıştır. 1991-1995 dönemi krizle mücadele ve reform uygulamaları dönemi olmuştur.

Kırgızistan ekonomisi 1996 yılından itibaren tarım üretimindeki artış ve Kumtör Altın madeninin hizmete sokulması nedeni ile büyümeye başlamıştır (DEİK, 2012). Fakat 1998 yılında Rusya'daki mali krizin etkisi ile 1998-1999 yıllarında Gayri Safi Yurtiçi Hasılada (GSYH) düşüş yaşanmıştır. 2000-2001 yıllarında Kumtör maden işletmesinin ve tarımın gelişmesi nedeni ile ekonomi \% 5 oranında büyümüştür. 2002'de ise Kumtör firmasında ortaya çıkan kaza nedeniyle büyüme - \% 0.01'e azalmıştır. 2005 yılında ülkede yaşanan siyasi darbenin negatif etkilerinden dolayı GSYİH -0.1'e küçülmüştür. 2007 ve 2008 yıllarında ise ihracat, özellikle Çin'den Rusya'ya yeniden ihracatın artmasından ve göçmenlerinin transferlerinin artmasından dolayı büyüme \% 8 oranında gerçekleştirmiştir. 2010 yılında tekrar siyasi darbe ve etnik çatışmaların sonucunda üretimde $\%-0.5$ oranında düşüş olmuştur. 2012'de Kumtör altın madencilik firmasının üretimindeki düşüş nedeni ile GSYİH \% -0.08 oranında düşüş yaşamış iken 2013'te bu firmanın üretiminin artması ile ekonomide \% 11 oranında büyüme gerçekleşmiştir.

Dünya piyasalarında petrol fiyatlarında yaşanan azalışlar, petrol ithalatçısı bir ülke olan Kırgızistan'da tüketimi arttırmış, büyümeye de katkıda bulunmuştur. Özellikle altın ihracatındaki ciddi artışlara bağlı olarak ekonomik büyüme hız kazanmıştır. Kırgız mallarına olan talebin azalmasına yol açan ve dolayısıyla 2015 yılında ülkenin altın ihracatı dışındaki ihracatında bir azalış yaşanmasına neden olan Rusya'daki ekonomik durgunluğa rağmen, Kırgızistan ekonomisinde 2014 yılında \%3.6 olan ekonomik büyüme oranı, büyük ölçüde altın üretimindeki yüksek performansa bağlı olarak, 2015 yılında \%7.3'e yükselmiştir.

1993 yılında Kırgızistan'da fiyatların serbest bırakılmasıyla enflasyon oranı yüzde 1363'e yükselmiştir. Sıkı para politikaları uygulamalarının sonucunda 1998 yılında yüzde 10’a kadar düşürülmüştür. Ancak, Rusya krizi nedeni ile 1999 yılında enflasyon yüzde 37'ye ulaşmıştır. S1kı para politikası altında enflasyon 2002-2006 yıllarında \% 2 ile 5 arasında sergilemiştir. Fakat 2007-2008 yıllarında global finansal krizin etkisi ile \% 10,1 ve \% 24,5 'e yükselmiştir. Son yıllarda enflasyon oranı \% 6 ve $\% 7$ civarında tutulmaktadır.

Geçiş döneminin başında üretimin yarı yarıya düşmesi işsizliği hızla arttırmıştır. 1992 yılında işsizlerin resmi sayısı 1,792 iken 1995 'te 50,409'a yükselmiştir. İşsizlik oranı resmi istatistiklere göre 1992 ve 2015 döneminde \% 8 ile 9 civarlarında sergilemiştir. Fakat Economic Intelligence Unit'in verilerine göre 2010 yılında toplam 78.150 işsiz kaydedilmiştir. Kırgızistan'da 2010 yılı işsizlik oranı \%20 olmuştur. Çalışabilir nüfus 2.344 milyon iken, kayıtlı nüfustaki işsizlerin \%14'ü erkekler iken \%16'sını ise kadınlar oluşturmaktadır (DEİK, 2012: 10). Böylece, işsizlik hala ülkenin önemli sorunlarındandır. 


\begin{tabular}{|r|r|r|r|r|r|r|}
\hline Yıllar & $\begin{array}{c}\text { GSYIH'nın } \\
\text { büyüme oranı } \\
\mathbf{( \% )}\end{array}$ & $\begin{array}{c}\text { Enflasyon } \\
\text { oranı (\%) }\end{array}$ & $\begin{array}{c}\text { İşsizlik } \\
\text { oranı (\%) }\end{array}$ & $\begin{array}{c}\text { Ihracat } \\
\text { (milyon \$ ) }\end{array}$ & $\begin{array}{c}\text { Ithalat } \\
\text { (milyon \$ ) }\end{array}$ & $\begin{array}{c}\text { Toplam Diş } \\
\text { Borç } \\
\text { (milyon \$) }\end{array}$ \\
\hline $\mathbf{1 9 9 2}$ & $-13,8$ & 1259 & 8,6 & 317.0 & 420.7 & 5,52 \\
\hline $\mathbf{1 9 9 3}$ & $-15,4$ & 1363 & 8,7 & 360.2 & 447.8 & 231,83 \\
\hline $\mathbf{1 9 9 4}$ & -20 & 95,7 & 8,4 & 340.1 & 317.0 & 368.91 \\
\hline $\mathbf{1 9 9 5}$ & $-5,4$ & 31,9 & 8,7 & 408.9 & 531.0 & 485.14 \\
\hline $\mathbf{1 9 9 6}$ & 7 & 31,9 & 8,7 & 505.4 & 782.9 & 997.36 \\
\hline $\mathbf{1 9 9 7}$ & 9,9 & 23,4 & 8,3 & 603.8 & 646.1 & 1176.06 \\
\hline $\mathbf{1 9 9 8}$ & 2,1 & 10,4 & 9,7 & 513.8 & 755.9 & 1329.86 \\
\hline $\mathbf{1 9 9 9}$ & 3,6 & 37 & 8,2 & 462.6 & 551.1 & 1545.55 \\
\hline $\mathbf{2 0 0 0}$ & 5,4 & 18,7 & 7,5 & 510.9 & 506.9 & 1639.38 \\
\hline $\mathbf{2 0 0 1}$ & 5,3 & 6,9 & 7,8 & 480.3 & 440.4 & 1538.03 \\
\hline $\mathbf{2 0 0 2}$ & $-0,01$ & 2,1 & 12,5 & 498.1 & 552.1 & 1657.06 \\
\hline $\mathbf{2 0 0 3}$ & 7 & 2,9 & 9,9 & 590.3 & 673.0 & 1820.54 \\
\hline $\mathbf{2 0 0 4}$ & 7 & 4,1 & 8,5 & 718,8 & 941,0 & 2224.22 \\
\hline $\mathbf{2 0 0 5}$ & $-0,1$ & 4,3 & 8,1 & 672,0 & 1101,3 & 1957.58 \\
\hline $\mathbf{2 0 0 6}$ & 3,1 & 5,6 & 8,3 & 794,1 & 1718,2 & 2307.71 \\
\hline $\mathbf{2 0 0 7}$ & 8,5 & 10,1 & 8,2 & 1134,2 & 2417,0 & 2597.22 \\
\hline $\mathbf{2 0 0 8}$ & 8,4 & 24,5 & 8,2 & 1617,6 & 4072,4 & 3333.19 \\
\hline $\mathbf{2 0 0 9}$ & 2,9 & 6,8 & 8,4 & 1443,5 & 3040,2 & 3818.96 \\
\hline $\mathbf{2 0 1 0}$ & $-0,5$ & 7,9 & 8,6 & 1468,4 & 3385,8 & 3807.33 \\
\hline $\mathbf{2 0 1 1}$ & 6 & 16,4 & 8,5 & 2380,7 & 4261,2 & 5174.02 \\
\hline $\mathbf{2 0 1 2}$ & $-0,08$ & 2,7 & 8,4 & 2588,3 & 5576,3 & 5705.08 \\
\hline $\mathbf{2 0 1 3}$ & 11 & 6,6 & 8,3 & 2833,2 & 6069,8 & 6470.51 \\
\hline $\mathbf{2 0 1 4}$ & 4 & 7,5 & 8,1 & 2482,7 & 5732,5 & 6949.14 \\
\hline $\mathbf{2 0 1 5}$ & 3,4 & 6,5 & 8 & 1606,2 & 4069,5 & 7198.85 \\
\hline
\end{tabular}

Tablo-1: Kırgızistan'ın Temel Ekonomik Göstergeleri Kaynak: Dünya Bankası 2017, KC Merkez Bankası Bülteni, Bişkek, 6/2005 ve KC Merkez Bankası Bülteni, Bişkek, 12(251)/2016 verilerine göre hazırlanmıştır

Dünya piyasalarında petrol fiyatlarında yaşanan azalışlar, petrol ithalatçısı bir ülke olan Kırgızistan'da tüketimi arttırmış, büyümeye de katkıda bulunmuştur. Özellikle altın ihracatındaki ciddi artışlara bağlı olarak ekonomik büyüme hız kazanmıştır. Kırgız mallarına olan talebin azalmasına yol açan ve dolayısıyla 2015 yılında ülkenin altın ihracatı dışındaki ihracatında bir azalış yaşanmasına neden olan Rusya'daki ekonomik durgunluk dolayısı ile Kırgızistan ekonomisinde 2014 yılında \%3.6 ve 2015 yılında \%3.4 oranında büyüme gerçekleşmiştir.

İhracat bağımsızlığı kazandıktan sonra 5 kat artmışsa ithalat 9,6 kat artmıştır. Dolayısı ile dış ticaret açığı günümüzde yüksek olmaktadır. İhracatın GSYİH'ya oranı \% 55 civarında iken ithalatın GSYİH'ya oranı \% 80'den fazladır. İhracatın düşük olması ülkenin borçların geri ödemesini daha da zorlaştırabilmektedir.

Yukarıdaki Kırgızistan'ın genel ekonomik durumu dikkate alınarak ülkemizin borçlanma nedenlerini aşağıdaki gibi sıralayabiliriz:

- Sovyetler dönemindeki genel bütçeden ayrılan kaynak transferlerinin durdurulmasi;

- Sovyetler dönemi dağılması nedeniyle yapısal reformların finansmanı;

- Sovyetlerin dağılmasıyla ülkeler arası ödeme sisteminin yıkılması, bu sisteminin yıkılmasından dolayı ülkeler arası şirketlerin birbirlerine olan ödemelerindeki gecikmeler;

- Devletin iç borçlanma kaynağının kısıtlılı̆̆ı;

- Bütçe açıklarının finansmanı;

- Döviz ihtiyac1;

- $\quad$ Sosyal ve altyapı hizmetlerinin üretimi.

\section{Kırgızistan'da Devlet Borçları}

Kırgızistan'ın bağımsızlığını kazandığı ilk yıllarda kaynak sıkıntısı ile karşılaşmıştır. Bu durum bütçe açığının büyümesine neden olmuştur. Bütçe açığı 1993-1994 yıllarında GSYİH'ya oranla \% 7 iken, 1995 yılında \% 12'ye çıkmıştır. Fakat 2001 yılında bütçe açı̆̆ı \% 0.4'e kadar azalmıştır (Koyçuyev, 2003: 454). 2008'de ekonomideki canlanma ve göçmen transferlerinin yardımı ile bütçe fazla vermiştir. 


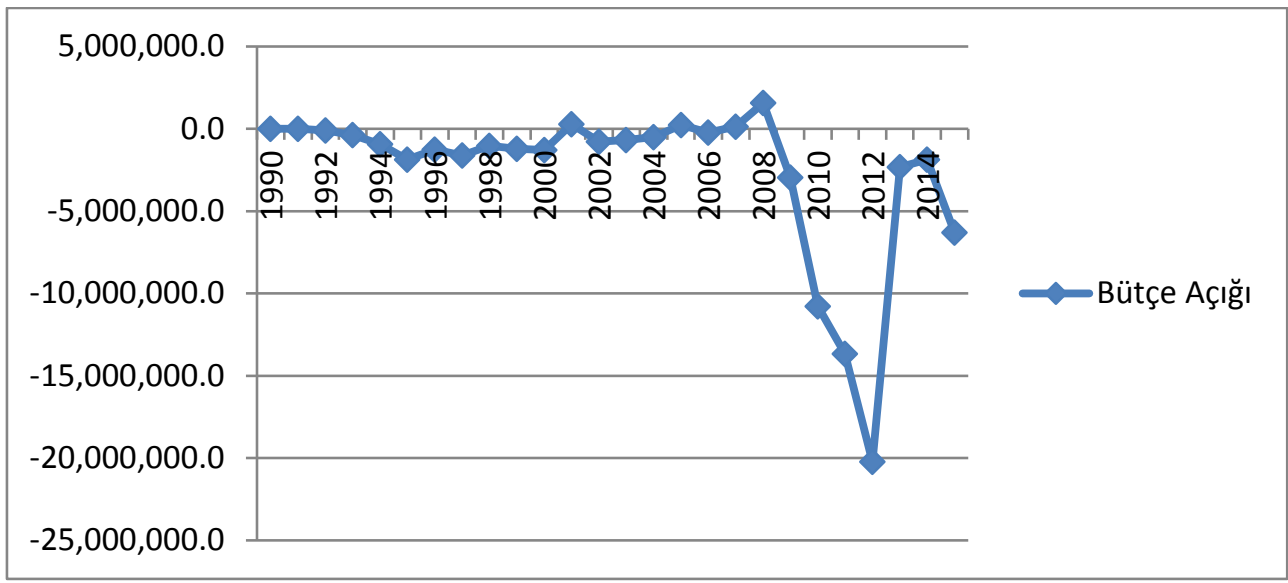

Şekil-1: Kırgızistan'da Bütçe Açı̆̆ı (bin som) Kaynak: Kırgız Cumhuriyeti İstatistik Komitesi (05.10.2016)

2009'dan itibaren bütçe açığı hızla artmaya başlamıştır ve 2012'de bütçe açığı GSYİH'ya oranla \% 6.6'ya çıkmıştır. 2015'te ise bütçe açığı GSYH'ya oranla 1.5'i oluşturmuştur. Bütçe açığı Kırgızistan'da daha çok diş borçlanma ile kapatılmaktadır. Kırgızistan'ın toplam dış borç stoğu 31 Aralık 2016 tarihi itibariyle 4105,44 milyon dolardır. Bunun \% 92.1'i dış borçlar ve \% 7.9'u iç borçlardan oluşmuştur.

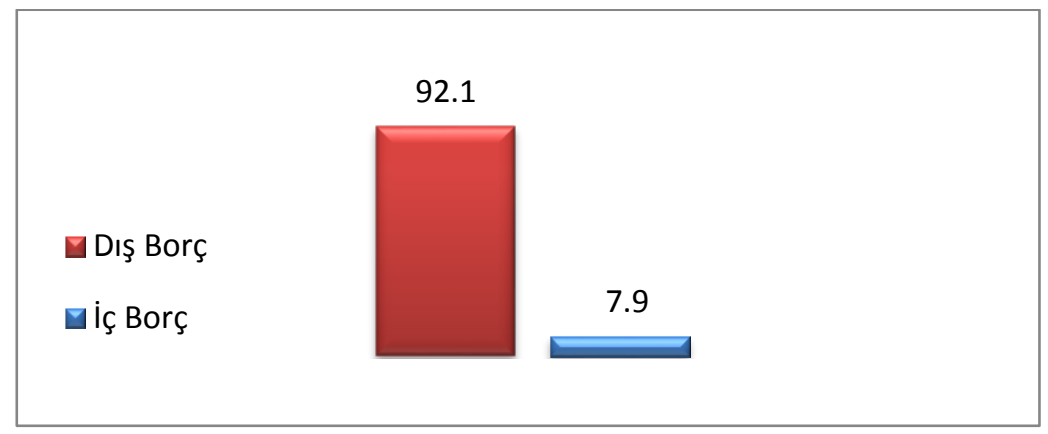

Şekil-2: Kırgızistan'da Devlet Borçlarının Dă̆ılımı Kaynak: Kırgızistan Cumhuriyeti Maliye Bakanlığı (20/02/2017)

1993 yılında dış borçların GSYİH'ya oranı \% 7.2 iken 1999 yılında \% 105'e çıkmıştır. Sonraki yıllarda azalarak 2005 yılında \%76.5 ve 2014'te 46.4'ü oluşturmuştur. Kırgızistan, yüksek dış borcu sebebiyle Dünya Bankası ve IMF tarafından ortak yürütülen Aşırı Borçlu Fakir Ülkeler ("HIPC”) Programına 2006 yılında başvurarak 1 milyar dolara yakın borcun silinmesi gibi imkanlardan faydalanmayı gözden geçirmiştir. Ancak, bu programa dahil olunmasının prestij kaybına sebep olacağı nedeniyle, ayrıca IMF ve Dünya Bankası'nın ülke ekonomisi üzerinde bulunacağı çeşitli taleplerin yükümlülügüne girilmek istenmemesinden 2007 yılı Şubat ayında hükümet bu programa dahil olmaktan vazgeçmiştir (DEİK, 2012: 7).

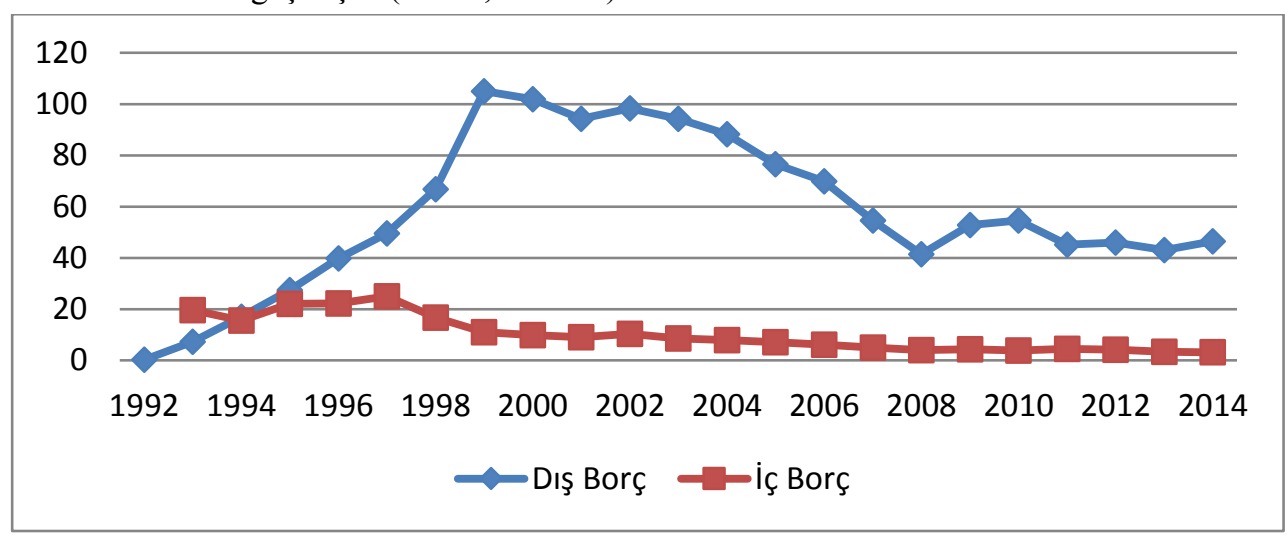

Şekil-3: Kırgızistan'da İç Borç ve Dış Borçların Gelişimi, (GSYİH'ya oranla) Kaynak: Kırgızistan Cumhuriyeti Istatistik Komitesi (10/04/2017)

İç borçlar 1998 yılına kadar Merkez Bankadan kredi alarak borçlanırken 1998 yılından sonra bu borç türü durdurulmuştur. Günümüzde iç borç hazine bonoları ve devlet tahvilleri aracılığı ile alınmaktadır. 
2014 yılında dış borçlar GSYİH'nın \% 49.5'sini iç borçlar 3.1'ini oluşturmuştur. Ancak 2015 y1lında devlet borçlarının GSYİH'ya oranı \% 64,6'ya yükselmiştir. Bunun nedeni nominal GSYİH'nın seviyesinin beklenildiğinden düşük olduğu ve ulusal paranın değer kaybetmesidir (IMF, 2016: 8).

Kırgız Cumhuriyeti Hükümetinin 6 Ekim 2016 tarihindeki 532 No'lu Kararname ile 2016-2018 y1llarında Kırgız Cumhuriyet'inde Devlet Borçları Yönetimi Stratejisi kabul edilmiştir. Bu stratejide devlet borçlarının yönetiminin temel amaçları Hükümetin finansal ihtiyacını en düşük maliyet ve asgari risk ile karşılama, ülkenin menkul kıymetler piyasasını geliştirmek ve devlet borçlarının sürdürülebilirliğini desteklemektir.

Stratejide dış borçlar ekonomik büyüme ve fakirliği azaltacak olan proje ve programlara öncelik verileceği belirtilmiştir. Bir taraftan alınan dış borç dış borçların \% 50'sinden aşmamalıdır.

İç borçlarla ilgili Kırgız Cumhuriyeti Hükümeti devlet iç borç senetlerinin süresini arttırmaya çalışmaktadır. Bunun için hazine bonolarının payını arttırma ve 2 seneden daha fazla vadeli hazine bonolarının çıkartmaya yönelik faaliyetler yapılacaktır. Devletin iç borçlanmasının temel amaçlarından biri menkul kıymetler borsasının gelişmesine katkıda bulunmaktır.

\begin{tabular}{|l|c|c|c|c|c|}
\hline & $\mathbf{2 0 1 2}$ & $\mathbf{2 0 1 3}$ & $\mathbf{2 0 1 4}$ & $\mathbf{2 0 1 5}$ & $\mathbf{2 0 1 6}$ \\
\hline Hazine Bonoları & & & & & \\
\hline Hacmi (milyon som) & 109,1 & 48,1 & 83,1 & 249,7 & 130,8 \\
\hline İslemler sayısı & 11 & 4 & 2 & 10 & 5 \\
\hline $\begin{array}{l}\text { Ortalama ağırlıklı faiz oranı } \\
\text { (bir dönem içinde, \%) }\end{array}$ & 8,53 & 8,48 & 8,45 & 13,38 & 8,14 \\
\hline Ortalama süre (günler) & 174 & 247 & 298 & 185 & 171 \\
\hline Devlet Tahvilleri & & & & & 77,0 \\
\hline Hacmi (milyon som) & - & 98,8 & - & 411,9 & 2 \\
\hline İşlemler sayısı & - & 1 & - & 7 & 15,88 \\
\hline $\begin{array}{l}\text { Ortalama ağırlıklı faiz oranı } \\
\text { (bir dönem içinde, \%) }\end{array}$ & - & 14,59 & - & 14,93 & 342 \\
\hline Ortalama süre (günler) & - & 643 & - & 1018 & 2 \\
\hline
\end{tabular}

Tablo-2: Kırgızistan'da İç Borçların Dağılımı Kaynak: Kırgız Cumhuriyeti Merkez Bankası, (02.03.17).

Kırgızistan'da iç borçlar hazine bonoları ve devlet tahvillerinden oluşmaktadır. Hazine bonolarının hacmi giderek arttığı görülmektedir. Özellikle 2015 yılında önceki y1la göre 3 kat artmıştır. Bunun en önemli nedenlerinden biri de bu sene hazine bonolorunun faiz oranın yüksek olduğu sayılabilir. Ortalama sürelerine bakıldığında daha çok 6 aya kadar kısa süreliler tercih edildiği görülmektedir.

Devlet tahvillerinde de 2015 yılında daha çok satışların gerçekleştirildiği ve ortalama faiz oranları \% 14-15 arasında olmuştur. 2016 yılında daha çok 1 yıl satın alınan devlet tahvillerinin süresinin azaldığı farkedilmiştir.

\section{Kırgızistan’ın Dış Borçların Yapısı}

Geçiş ekonomili olan Kırgızistan gibi ülkelerde ülke içindeki kaynak yetersizliğinden dolayı ekonomik gelişme amacıyla dış borçlanma daha uygun olmaktadır. Özellikle orta ve uzun vadeli ve imtiyazlı veya düşük faizli dış borçların toplum içinde ağırlık taşıması önemlidir. Borç servis kapasitesini gösteren Kısa Vadeli Dış Borçlar/TDB Oranının \%15-20 arasında seyretmesi makul karşılanırken \%20'yi aşmaması tercih edilmektedir (Tandırcıŏlu, 2000). Kırgızistan'da kısa vadeli dış borçların payı \% 3-4 arasında ve \% 91.3'ü ise uzun vadeli olduğu görülmüşsür. 


\begin{tabular}{|r|r|r|r|r|r|r|}
\hline Yıllar & $\begin{array}{c}\text { Toplam } \\
\text { Diş Borç } \\
\text { (milyon \$) }\end{array}$ & \multicolumn{1}{c|}{$\begin{array}{c}\text { Artış Trendi } \\
\text { \% }\end{array}$} & $\begin{array}{c}\text { Uzun Vadeli } \\
\text { Borçlar }\end{array}$ & $\begin{array}{c}\text { Kisa Vadeli } \\
\text { Borçlar }\end{array}$ & $\begin{array}{c}\text { Uzun Vadeli } \\
\text { Borç/TDB }\end{array}$ & $\begin{array}{c}\text { Kisa Vadeli } \\
\text { Borç/TDB }\end{array}$ \\
\hline $\mathbf{1 9 9 4}$ & 368.91 & - & 356.0 & 12.83 & 79.7 & 2.9 \\
\hline $\mathbf{1 9 9 5}$ & 485.14 & 31,5 & 472.18 & 12.97 & 77.5 & 2.1 \\
\hline $\mathbf{1 9 9 6}$ & 997.36 & 105,6 & 988.70 & 8.66 & 87.0 & 0.8 \\
\hline $\mathbf{1 9 9 7}$ & 1176.06 & 17,9 & 1143.04 & 33.02 & 85.2 & 2.5 \\
\hline $\mathbf{1 9 9 8}$ & 1329.86 & 13,0 & 1301.67 & 28.19 & 86.5 & 1.9 \\
\hline $\mathbf{1 9 9 9}$ & 1545.55 & 16,2 & 1484.88 & 60.68 & 80.1 & 3.3 \\
\hline $\mathbf{2 0 0 0}$ & 1639.38 & 6,0 & 1510.37 & 129.02 & 78.0 & 6.7 \\
\hline $\mathbf{2 0 0 1}$ & 1538.03 & $-6,2$ & 1490.29 & 47.74 & 81.7 & 2.6 \\
\hline $\mathbf{2 0 0 2}$ & 1657.06 & 7,7 & 1646.81 & 10.25 & 84.1 & 0.52 \\
\hline $\mathbf{2 0 0 3}$ & 1820.54 & 9,9 & 1783.06 & 37.49 & 83.0 & 1.7 \\
\hline $\mathbf{2 0 0 4}$ & 2224.22 & 22,1 & 1896.70 & 327.52 & 74.0 & 12.8 \\
\hline $\mathbf{2 0 0 5}$ & 1957.58 & $-12,0$ & 1825.30 & 132.28 & 80.9 & 5.9 \\
\hline $\mathbf{2 0 0 6}$ & 2307.71 & 17,9 & 2101.22 & 206.50 & 80.9 & 7.9 \\
\hline $\mathbf{2 0 0 7}$ & 2597.22 & 12,5 & 2277.97 & 319.25 & 79.0 & 11.1 \\
\hline $\mathbf{2 0 0 8}$ & 3333.19 & 28,3 & 2943.34 & 390.85 & 81.1 & 10.8 \\
\hline $\mathbf{2 0 0 9}$ & 3818.96 & 14,6 & 3395.17 & 423.80 & 82.4 & 10.3 \\
\hline $\mathbf{2 0 1 0}$ & 3807.33 & $-0,3$ & 3612.39 & 194.94 & 87.8 & 4.7 \\
\hline $\mathbf{2 0 1 1}$ & 5174.02 & 35,9 & 4985.95 & 188.07 & 91.0 & 3.4 \\
\hline $\mathbf{2 0 1 2}$ & 5705.08 & 10,3 & 5491.54 & 213.54 & 91.1 & 3.5 \\
\hline $\mathbf{2 0 1 3}$ & 6470.51 & 13,4 & 6162.75 & 307.77 & 90.6 & 4.5 \\
\hline $\mathbf{2 0 1 4}$ & 6949.14 & 7,4 & 6636.31 & 312.83 & 91.4 & 4.3 \\
\hline $\mathbf{2 0 1 5}$ & 7198.85 & 3,6 & 6853.94 & 344.91 & 91.3 & 4.6 \\
\hline
\end{tabular}

Tablo-3: Dış Borçların Vade Yapısı Kaynak: Fact Fish Verileri (20/02/2017)

Çünkü alındığı borcun verimli bir alana yatırılarak sonradan gelir getirmesi lazım ki daha ülkeye faydalı olsun, gelir getirsin. Bu yüzden borcun ödeme süresi daha uzun olması önemli rol oynar. Ülkemizde uzun vadeli borçlar kısa vadeli borçlara nadiren daha ağırlıklıdır başka bir deyişle uzun vadeli borçlar toplam borcun \%090-\%96'lük kısmına sahip olmaktadır. Fakat uzun vadeli borçların süresi geldiğinde faizleriyle birlikte ödemek gerekir. Bu yüzden uzun vadeli borçların nereye kullanıldığı daha çok önemli olmaktadır. Eğer verimli alanlarda kullanılmazsa ülkenin normal gelirlerinden ödenir ki bütçe açığının yükselme problemi ortaya çıkar ya da borçlar gelecek nesillere kalarak ülkeye dezavantajlı olur. Böylece dış borçlar çok yükselerek kontrol altına alınamaması borçların yönetimi hususunda tehlikeli olacaktır.

\subsection{Kreditörlere Göre Dıș Borçlar}

Kırgızistan'ın en önemli kreditörleri olarak Çin, Rusya, Japonya, Almanya, Türkiye, Kore, Kuveyt, Danimarka, Fransa ve Uluslararası Kalkınma Birliği ile Asya Kalkınma Bankası sayılabilir. Bunların uluslararası kuruluşlardan alınan kredileri genelde indirimli ve hafif koşullara sahiptir. Faiz oranları \%6'dan az olarak sayılır ve belli bir bölümü de silinmiştir. Bazı kreditörlerden alınan borçların vadesi uzatılmıştır. 


\begin{tabular}{|c|c|c|c|c|c|c|c|c|c|c|c|c|}
\hline & 2011 & $\%$ & 2012 & $\%$ & 2013 & $\%$ & 2014 & $\%$ & 2015 & $\%$ & 2016 & $\%$ \\
\hline İMF & 181,80 & 6,48 & 190,53 & 6,28 & 202,73 & 6,41 & 185,20 & 5,38 & 188,20 & 5,22 & 188,04 & 5,0 \\
\hline OPEC & 2,03 & 0,07 & 1,31 & 0,04 & 3,94 & 0,12 & 4,00 & 0,12 & 4,51 & 0,13 & 4,84 & 0,1 \\
\hline $\begin{array}{l}\text { Asya Kalkınma } \\
\text { Bankası }\end{array}$ & 583,36 & 20,8 & 594,65 & 19,6 & 607,07 & 19,2 & 583,57 & 17 & 575,44 & 15,9 & 567,88 & 15,0 \\
\hline $\begin{array}{l}\text { Avrasya Kalkınma } \\
\text { Bankası }\end{array}$ & - & 0 & - & 0 & - & 0 & 0,38 & 0,01 & 3,53 & 0,09 & 5,48 & 0,1 \\
\hline Avrupa Birliği & - & 0 & - & 0 & - & 0 & - & 0 & 5,44 & 0,15 & 15,81 & 0,4 \\
\hline $\begin{array}{l}\text { Uluslararası } \\
\text { Kalkınma Birliği }\end{array}$ & 660,49 & 23,6 & 674,84 & 22,3 & 697,09 & 22,0 & 671,50 & 19,5 & 639,29 & 17,7 & 618,21 & 16,3 \\
\hline $\begin{array}{l}\text { İslam Kalkınma } \\
\text { Bankası }\end{array}$ & 61,05 & 2,17 & 61,72 & 2,03 & 63,95 & 2,02 & 59,02 & 1,72 & 59,48 & 1,65 & 64,59 & 1,7 \\
\hline $\begin{array}{l}\text { Uluslararası Tarımsal } \\
\text { Kalkınma Fonu }\end{array}$ & 9,23 & 0,33 & 8,87 & 0,29 & 8,96 & 0,28 & 9,36 & 0,27 & 9,94 & 0,27 & 12,17 & 0,3 \\
\hline $\begin{array}{l}\text { Kuzey Kalkınma } \\
\text { Fonu }\end{array}$ & 5,95 & 0,21 & 5,93 & 0,19 & 6,06 & 0,19 & 5,21 & 0,15 & 4,57 & 0,12 & 4,31 & 0,1 \\
\hline $\begin{array}{l}\text { Avrupa İmar ve } \\
\text { Kalkınma Bankası }\end{array}$ & 15,41 & 0,55 & 29,63 & 0,97 & 39,99 & 1,27 & 40,61 & 1,18 & 40,95 & 1,14 & 42,45 & 1,1 \\
\hline Çin & 272,62 & 9,72 & 527,47 & 17,4 & 758,43 & 24,0 & 1115,89 & 32,5 & 1296,40 & 36 & 1522,83 & 40,3 \\
\hline Fransa & 5,77 & 0,2 & 5,88 & 0,19 & 6,14 & 0,19 & 5,41 & 0,16 & 4,85 & 0,13 & 4,69 & 0,1 \\
\hline Japonya & 357,38 & 12,8 & 320,56 & 10,6 & 263,21 & 8,33 & 229,39 & 6,67 & 229,02 & 6,35 & 235,99 & 6,2 \\
\hline Almanya & 75,77 & 2,7 & 81,3 & 2,68 & 98,35 & 3,11 & 102,4 & 2,98 & 100,07 & 2,78 & 81,72 & 2,2 \\
\hline Kore & 14,82 & 0,53 & 15,94 & 0,52 & 17,37 & 0,55 & 16,66 & 0,48 & 15,61 & 0,43 & 15,12 & 0,4 \\
\hline Kuveyt & 13,31 & 0,47 & 10,66 & 0,35 & 9,26 & 0,29 & 8,64 & 0,25 & 9,73 & 0,27 & 8,55 & 0,2 \\
\hline Rusya & 300,00 & 10,7 & 300,00 & 9,89 & 300,00 & 9,49 & 300,0 & 8,73 & 300,00 & 8,33 & 270,00 & 7,1 \\
\hline Suudi Fonu & - & 0 & 0,18 & 0,01 & 1,27 & 0,04 & 3,87 & 0,11 & 7,43 & 0,20 & 11,17 & 0,30 \\
\hline Türkiye & - & 0 & 10,00 & 0,33 & 70,54 & 2,23 & 90,00 & 2,62 & 97,00 & 2,69 & 97,00 & 2,6 \\
\hline Abu-Dabi & & & & & 1,06 & 0,03 & 2,64 & 0,08 & 6,42 & 0,18 & 8,76 & 0,23 \\
\hline Danimarka & 3,35 & 0,12 & 3,34 & 0,11 & 3,31 & 0,1 & 3,27 & 0,09 & 3,20 & 0,08 & 3,13 & 0,1 \\
\hline
\end{tabular}

Tablo-4: Kreditörlere Göre Dış Borçlar (milyon dolar) Kaynak: Kırgızistan Cumhuriyeti Maliye Bakanlığı (20/02/2017)

Dış borçların \% 40’ı Çin (Çin Cumhuriyeti İhracat-İthalat Bankası), \% 16’sı Uluslararası Kalkınma Birliği ve \% 15'i Asya Kalkınma Bankasına aittir. Dış borçların 2250 milyon ABD doları iki taraflı imtiyazlı borçlar, 1481 milyon ABD doları çok taraflı imtiyazlı borçlardır. İki taraflı imtiyazsız borç kreditörlerinin ilk sırasında 5,73 milyon dolar veren Germes Kreditverziherungs-Aktingezeliaft (Almanya) olmaktadır ve toplam iki taraflı imtiyazsız dış borç stoğu 8,86 milyon dolardır. Çok taraflı imtiyazsız borcu ise sadece Avrupa İmar ve Kalkınma Bankası (42,45 milyon dolar) vermiştir.

Çok taraflı borçların nominal değeri 2016 yılı Aralık ayı itibariyle 1523,78 milyon dolardır. Bunun 1481,33 milyon doları imtiyazlı iken 42,45 milyon doları imtiyazsız borçlardır (Kırgız Cumhuriyeti Maliye Bakanlığı, www.minfin.kg, 31.12.2016. Başka bir değişle toplam dış borcun \% 98,6 imtiyazlı iken \%1,4'ü imtiyazsız dış borç olmaktadır. Geri ödeme süresi de 15-40 senedir ve bunun 5-10 senesi ise imtiyazlı iken faizleri genel olarak \%0,752,5 olmaktadır. İki taraflı borçların da çoğunluğu imtiyazlıdır. Geri ödeme süresi 10-30 sene, bunun imtiyazlı süresi 5-10 senedir. Faiz oranları ise \%0,1-5 olmaktadır (Soy, 02/11/2016)

Geçiş döneminde kaynak yetersizliğinden dolayı önemli altyapı hizmet ve malların üretimi (yol yapmak, elektrik üretimi v.d. hizmetler) dış borçlar aracılığı ile gerçekleştirilmiştir (IMF, 2016: 8). Dış borçlar ülkenin tarım sektörüne, sosyal yardımlara, altyapı ve iletişimi geliştirmek ve başka alanlar için harcanmıştır (Koyçumanov ve Osmonaliyev, 2003). Daha ayrıntılı olarak \%24'ü enerji alanına, \%24-28'i yol altyapısına, \%20'si tarım sektörüne ve kalan kısmı ise bütçe açı̆̆ın kapatmak için harcanmıştır (Kocobayeva, 05/03/2017).

Dış borçların önemli kısmının yol gibi altyapı hizmetleri için harcandığına rağmen Dünya Bankasının verilerine göre Kırgızistan 2013-2014 yıllarında altyapı hizmetlerinin kalitesine göre 148 ülke arasından 108. sıradadır. Ayrıca yolların kalitesine göre 133. sırada, elektrik enerjisi ile ilgili 122. sırada olduğu açıklanmıştır (World Bank, 2014: 30).

Dış borçlar alınırken uygulanacak projelerin seçim prosedürü, yapılan fayda maliyet analizleri hakkında hükümet halka bilgi vermemektedir. Bununla birlikte dış borçların kullanım alanları ve alınan faydaları hakkında da bilgi bulmak zordur. Bununla birlikte dış borçların risklerinin de hesaplanıp hesaplanmadığı kesin belli değildir. Dış borçların saydamlığının düşük olması halkın devlete olan güvenini azaltabilecektir. Dolayısıyla dış borçlar ve genel olarak borçları seçiminde, kullanılacak alan veya projelere karar vermede ve riskleri hesaplayıp en düşük maliyetle en yüksek faydaları sağlayacak borçları ve projeleri belirleyecek ve borçlar hakkında geniş ve detaylı rapor hazırlayan borç ofisinin kurulması gerekmektedir.

İç borçlar ise ülkedeki zaten az olan tasarrufları azaltarak sermaye kıtlığını daha da yükselttiği tahmin edilebilir. Çünkü ticari bankalar iç borç enstrumanlarının faizleri yükselirken mevduatlarını kredilere değil bu menkul kıymetlere yönlendirebilmektedirler. İç borçların faizleri de dış borçlara kıyasla daha yüksektir. Dolayısı ile iç borçların minimize edilmesi ekonomi için daha iyi etkide bulunabilir.

Borçların sürdürülebilirliğinin arttırılması için uzun vadeli dış borçları daha etkin ve gelir getirebilen alanlara, daha ayrıntılı söylersek, ülkenin üretim kapasitesini arttıran ve işsizliği azaltabilen büyük fabrikaların kurulmasına kullanılması daha uygun olabilir. 
Borç servisini kolaylaştırmanın yolu döviz gelirleri artışından geçmektedir. Bu amaçla ülkenin uluslararası ticaretteki payını arttırıcı ve alınan kredilerin üretken yatırımlarda kullanılmasını sağlayıcı politikalar uygulaması gerekir. turizmi geliştirici önlemler alınmalıdır. dar olan vergi tabanının genişletilmesi, kayıt dışı ekonominin kayıt altına alınması, yatırımları ve üretimi teşvik edici bir vergi politikasının uygulanması gerekmektedir (Canbay, 2005).

\subsection{Borç Rasyolarıyla Kırgızistan}

Dünya Bankası ülkenin çok borçlu olup olmadığını dört kritere göre belirlemektedir. Bunlar TDB/GSYİH, TDB/İhracat, TDB Servisi/İhracat ve TDB Faiz Servisi/İhracat oranlarıdır. Bu kriterlerden her biri ayrı ayrı olarak değerlendirilir ve üçü çok borçlu rasyosuna ulaşmışsa o ülke çok borçlu ülke olarak sayılır (Sarı, 2004). Bu rasyolar açısından Kırgızistan'ı değerlendirdiğimizde aşağıdaki sonuçlara ulaşabiliriz.

\begin{tabular}{|l|r|r|r|r|r|r|r|r|}
\hline & $\mathbf{2 0 1 1}$ & $\mathbf{2 0 1 2}$ & $\mathbf{2 0 1 3}$ & $\mathbf{2 0 1 4}$ & $\mathbf{2 0 1 5}$ & $\mathbf{2 0 1 6}$ & \multicolumn{1}{c|}{$\begin{array}{c}\text { Orta } \\
\text { Derecede } \\
\text { Borçluluk } \\
\text { Aralığı }\end{array}$} & $\begin{array}{c}\text { Cok } \\
\text { Borçluluk } \\
\text { Sımır Oranı }\end{array}$ \\
\hline $\begin{array}{l}\text { Toplam D1ş } \\
\text { Borç (TDB) } \\
\text { milyon dolar }\end{array}$ & 5174.02 & 5705.08 & 6470.51 & 6949.14 & 7198.85 & 3782,74 & & - \\
\hline TDB/GSYİH & 47,7 & 47,2 & 44,4 & 54,1 & 64,5 & 56,6 & $30-50$ & 50 'nin üzeri \\
\hline TDB/İhracat & 230.76 & 295.96 & 322.42 & 368.9 & 489.65 & 244.9 & $165-275$ & 275 'in üzeri \\
\hline $\begin{array}{l}\text { TDB } \\
\text { Servisi/İhracat }\end{array}$ & 37.2 & 37.8 & 38.7 & 50.6 & 67.0 & 85.8 & $18-30$ & 30 'un üzeri \\
\hline $\begin{array}{l}\text { TDB Faiz } \\
\text { Servisi/İhracat }\end{array}$ & 18.1 & 16.7 & 16.9 & 21.9 & 25.3 & 31.3 & $12-20$ & 20 'nın üzeri \\
\hline
\end{tabular}

Tablo-5: Dış Borç Göstergeleri Kaynak: Kırgızistan Cumhuriyeti Maliye Bakanlığı, Kırgızistan Cumhuriyeti Istatistik Komitesi (10/04/2017)

Tabloda da görüldüğü gibi Kırgızistan TDB’un GSYİH’ya oranı açısından belirlenmiş olan \%50'lik sınırı 2014 yılında aşmıştır. TDB'un ihracata olan oranı 2016 yılında iki katına azalmışken TDB servisinin ihracata oranının sürekli arttığını görmekteyiz. Bu ise ülkenin borç sevisinde ciddi sorunlar olabileceği tehlikesinin sinyali olabilir. Dolayısı ile ülkede üretim kapasitesinin arttırılması gerekmektedir.

\section{Sonuç}

Kırgızistan bağımsızlığını kazandıktan sonra piyasa ekonomisine geçiş sürecinde ciddi krizleri yaşamıştır. İlk dönüşüm dönemi en ağır yıllardan olmuştur. 1996 yılından itibaren gelişmeye başlamıştır. Ülke reformları gerçekleştirmek ve ekonomik büyümeyi hızlandırmak amacıyla borçlanmak zorunda kalmıştır.

Ülkede sermaye yetersizliğinden dolayı alınan borçların \% 90’u dış borçlardır. Toplam dış borçların GSYİH'ya oranı 2016 yılında \% 56.6 iken iç borçlar \% 0.07'dir. Borç rasyolarına göre son yıllarda çok borçlu ülkeye girmişizdir. Bu durum borç yönetiminin etkinleştirilmesi gerektiğini ortaya koymaktadır.

Borç yönetiminin geliştirilmesi için borçların seçimi, risklerinin analizi ve borçlarla finanse edilecek projelerin titiz analizini yapacak ve sonuçta borçlarla ilgili detaylı rapor hazırlayacak borç ofisinin kurulması gerekmektedir.

Dış borçların kullanım alanları ve elde edilen faydalar hakkında halkı bilgilendirerek borçların saydamlığı sağlanmalıdır. Dış borçların yol yapmak gibi altyapı hizmetlerine harcanmasından daha çok ülkenin üretim ve ihracat kapasitesini arttıracak alanlara kullanılması gelecekte borç servisi açısından faydalı olabilir.

\section{Kaynakça}

- Adıyaman, A.T. 2006. "Dış Borçlarımız ve Ekonomik Etkileri” Sayıştay Dergisi, Sayı:62, s.21-45

- $\quad$ Ateş, G. 2002. "Borç Yönetimi Ofisi ve Türkiye Uygulaması Üzerine Bir Çalışma", T.C Başbakanlık Hazine Müsteşarlı̆̆, S.1-4

- Canbay, T. 2005. “Kırgızistan'da Dış Borç ve Borç Yönetimi Sorunu”, Uluslararası Hakemli Sosyal Bilimler E-Dergisi, Say1: 6, s.1-11

- Çaşkurlu, E. 2003, “1980 Sonrası Dönemde Merkez Bankasından Kaynak Kullanımının Makro Ekonomik Etkilerinin Analizi”, Gazi Üniversitesi İktisadi ve İdari Bilimler Fakültesi Dergisi, Cilt:5, Sayı:1, s.189-208

- Çataloluk, C. 2009. "Kamu Borçlanması, Gerçekleşme Biçimi ve Makro Ekonomik Etkileri (Teorik Bir Yaklaşım, Türkiye Örneği)” Balıkesir Üniversitesi, SBE Dergisi, Cilt:12, Sayı:21, s.240-258

- DEİK (Dış Ekonomiler İlişkiler Kurulu) 2012 Kırgızistan ülke bülteni,

- $\quad$ Eker, A ve Meriç, M. 2000. Devlet Borçları. Anadolu Matbaası. İzmir.

- $\quad$ Fact Fish verileri: 
- http://ftp.factfish.com/statistic-country/kyrgyzstan/external\%20debt $\% 20$ stocks $\% 2 \mathrm{C} \% 20$ short-term 20/02/2017

- http://ftp.factfish.com/statistic-country/kyrgyzstan/external $\% 20 \mathrm{debt} \% 20$ stocks $\% 2 \mathrm{C} \% 20$ long-term 20/02/2017

- $\quad \mathrm{http}: / / \mathrm{stat} . \mathrm{kg} / \mathrm{kg} / \mathrm{statistics/finansy/,(05.10.2016)}$

- http://www.minfin.kg/novosti/novosti/na-31-dekabrya-2016-goda-razmer-gosdolga-kr-sostav.html (31/03/2017),

- $\quad$ http://www.minfin.kg/ru/novosti/mamlekettik-karyz/gosudarstvennyy-dolg/struktura-gosdolga-posostoyaniyu-na-31-dekabrya-2.html (10/04/2017),

- http://www.minfin.kg/ru/novosti/mamlekettik-karyz/gosudarstvennyy-dolg/struktura-gosudarstvennogodolga-za-yanvar-dekabr-.html_(10/04/2017),

- http://www.minfin.kg/ru/novosti/mamlekettik-karyz/obsluzhivanie-gosudarstvennogo-dolga/za-dvamesyatsa-2017-goda-na-obsluzhivanie-gosdolg.html_(10/04/2017)

- http://www.stat.kg/kg/statistics/download/dynamic/516/_(10/04/2017)

- IMF, 2016. IMF Staff Country Report No. 16/186, International Monetary Fund, Publication Services, 700 19th Street, N.W. Washington, D.C. 20431.

- Kirgiz Cumhuriyeti İstatistik Komitesi verileri

- Kırgız Cumhuriyeti Maliye Bakanlığı verileri

- Kırgız Cumhuriyeti Merkez Bankası verileri, http://www.nbkr.kg/index1.jsp?item=137\&lang=KGZ (02.03.17)

- $\quad$ Kocobayeva, Z. 2016. Azattık Radyosu Kaynakları, http://www.azattyk.org/a/kyrgyzstan_economy_debt/28157315.html 05/03/2017

- Obşestvo Obediyennıh Natsiy(OON) Yıllık Yayınları: Kırgızskaya Respublika: Obşaya Otsenka Stranı Sistema OON v Kırgızskoy Respublike, Bişkek, 2003

- Orhaner, E. 1997. Kamu Maliyesi. Gazi Kitabevi. Ankara.

• Özdemir, P. 2009. "İç Borç Yönetimi ve Türkiye”, T.C. Çukurova Üniversitesi, SBE, İktisat Anabilim Dalı, Yüksek Lisans Tezi, Adana

- Sarı, M. 2004. "Dış Borç Yönetimi ve Türkiye Uygulamaları”, Türkiye Cumhuriyeti Merkez Bankası Dış İlişkiler Genel Müdürlüğü, Uzmanlık Yeterlilik Tezi, Ankara

- $\quad$ Soy, M. 2013. Veçerniy Bişkek Gazetesi Kaynakları http://www.vb.kg/doc/226539_vneshniy_dolg_kyrgyzstana_sostavliaet_pochti_poloviny_vvp.html_ $02 / 11 / 2016$

- Syzdykova, A. ve Abubakirova, A. 2016. "Kazakistan'da Dış Borç ve Borç Yönetimi Sorunu” Вестник Карагандинского университета, EOS 336.14(574), s.68-74

- Tandırcıoğlu, H. 2000, “Türkiye'de Dış Borç Sorunu, Dış Borçların Sürdürebilirliği ve Dış Borçların Sınırlandırılması”, Dokuz Eylül Üniversitesi SBE dergisi, Cilt:2, Sayı:2, s.260-284

- World Bank. 2014. Kyrgyz Republic - Public expenditure review policy notes : strategic setting. Public Expenditure Review (PER). Washington, D.C. : World Bank Group. http://documents.worldbank.org/curated/en/2015/06/24607685/kyrgyz-republic-public-expenditure-reviewpolicy-notes-strategic-setting 


\title{
Dışa Açık Büyüme Modeli ve Türkiye'de Dış Borçlar Export-Led Growth Model and External Debt in Turkey
}

\author{
Asst. Prof. Dr. İlkay Noyan Yalman (Cumhuriyet University, Turkey) \\ Asst. Prof. Dr. Özcan Iş̧1k (Cumhuriyet University, Turkey) \\ Ph.D. Candidate Şerife Merve Koşaroğlu (Cumhuriyet University, Turkey)
}

\begin{abstract}
After the $1980 \mathrm{~s}$, as the globalization movement accelerated, countries increased their foreign trade transactions. In with this process, import-based growth model was abandoned in the Turkish economy and an export-based growth model is adopted. The export-led growth model increased export revenues started to, growth has gained speed, however, due to fact that the industry is dependent on imported inputs, started to increase external balance and current account deficit problems. In addition, there have economic growth that is not create employment due to insufficient savings and investments. For this reason, the increase in external debt tended to increase further. Such causes have led to an increase in external debt. In this study, the effect of export-led growth on foreign debts will be analyzed. For this purpose, foreign debts and growth relation in Turkey will be analyzed with time series model and will be done causality analysis.
\end{abstract}

\section{Giriş}

Küreselleşmenin ve uluslararası ticaretin yaygınlaşması özellikle 1980'den sonra artmıştır. Bu dönemlerde diş ticarette aktif olan ülkelerin ekonomik büyümeleri dikkatleri çekmiş ve gelişmekte olan ülkeler için önemli bir model olmuştur. $\mathrm{Bu}$ kapsamda dış ticareti geliştirecek önlemlerin alınması ve sınırlamaların kaldırılmasıyla uluslararası ticaretin hacmi büyümüştür. Bu dönemlerden itibaren ülke ekonomileri dışa açılmıştır. Bir ülke ekonomisinin dışa açılmasındaki temel unsurlar; ihracatın büyümeye olan katkısının artırılması ve dış ticaretin daha serbestleştirilmesi, yabancı sermaye yatırımlarının teşvik edilmesi ve ulusal paranın konvertibilitesinin sağlanmasıdır. Ekonominin dışa açılması ve onu tamamlayan hedeflerin gerçekleşmesinde, ekonominin ihracat gelirini arttırmada göstereceği başarı ve bunun için sahip olduğu imkânlar önemlidir. İhracat, talebi canlandıracak kaynak sağlar. Kısa dönemde büyüme, tüketim harcamaları, yatırım harcamaları ya da devlet harcamalarıyla sağlanabilir. Ancak uzun vadede bu harcamalara kaynak sağlamak ve gerekli ithalatı yapmak için ihracat şarttır (Thirwall, 2002:53). İhracatı büyümenin kaynağı olarak gören ve sanayi ürünler ihracatında uzmanlaşmayı amaçlayan bu kalkınma stratejisi, literatürde ihracata yönelik kalkınma stratejisi olarak adlandırılır. İhracata yönelik sanayileşme stratejisi temelde serbest ticaret görüşüne dönülmesini simgeleyen bir yaklaşımdır. Türkiye'de 1980'den sonra ihracata dayalı büyüme stratejisi benimsenmiştir. Bu strateji doğrultusunda sanayi politikası yeniden yapılandırılarak, sanayinin gelişmesi ve yurtiçi üretimin artırılması hedeflenmiştir. Sermaye hareketlerinin serbestleştirilmesiyle daha çok yabancı sermaye çekerek yatırımlara finans sağlama benzeri sanayileşmeyi artıracak finansal gelişmeler söz konusudur. Ancak bu dönemlerde Türkiye ekonomisinde oluşan olumsuzluklar nedeniyle istenilen hedeflere ulaşılamamıştır. Özellikle ihracatın ithalata bağlılığı, ekonomideki yapısal sorunlar, dış konjonktürden kaynaklanan olumsuz etkiler bu durumun başlıca sebepleridir. 2000 krizinden sonra alınan istikrar tedbirleriyle enflasyon hızı düşmüş, büyümenin hız kazanmasıyla ekonomide canlanma sağlamıştır. Ancak yurtiçi tasarruf yetersizliği başta olmak üzere yatırımların dolayısıyla ihracatın istenilen kapasiteye ulaştırılamaması, Türkiye ekonomisi için istihdam yaratmayan büyüme olgusuna neden olmuştur. Ekonomik büyüme sağlanırken diğer taraftan işsizliğin düşmemesi dikkatleri çekmektedir. Bu durumun ekonomide borçluluk seviyesinin yüksek olmasına neden olduğu görüşü hakimdir.

Çalışmada öncelikli olarak büyüme teorilerinde dışa açık büyüme modeli yani ihracata yönelik büyüme modeli açıklanacaktır. İkinci olarak Türkiye ekonomisinde benimsenen büyüme teorileri ve oluşan ekonomik yap1 değerlendirilecektir. Üçüncü olarak ise Türkiye ekonomisinde dışa açık büyüme modeli olarak da adlandırılan ihracata dayalı büyüme modeli test edilecektir.

\section{Büyüme Teorilerinde Dışa Açık Büyüme Modeli}

Ülkeler arası ticaret konusunda farklı ekonomik yaklaşımlar benimsenmiştir. Merkantilizm döneminde ihracatı artırıcı fakat ithalatı sınırlandırıcı eğilimler söz konusu olmuştur. İlerleyen dönemlerde oluşan Klasik iktisadi görüş dış ticaretin serbestleşmesini savunmuştur. 1930'lu yıllardan sonra klasik görüşler terk edilerek, toplumsal çıkarın bireysel çıkara üstünlüğünü savunan, eksik piyasa şartları, devlet müdahalesi konularını içeren anti-liberal ve müdahaleci yaklaşımlar tercih edilmiştir. Bu dönemde gelişmekte olan ülkelerin sanayileşmesi konusunda ise ithal ikameci politikalar uygulanmaya başlanmıştır. 1929 Ekonomik bunalımının sonucu olarak genellikle tarım ve doğal kaynaklı ürünleri ihraç edemeyen azgelişmiş ülkeler, ihtiyaçları olan ürünleri de ithal edememiş, yerli üretime yönelmek durumunda kalmışlardır. Yani, o dönemde gelişmekte olan birçok ülkede uygulanan ithal ikameci stratejiler büyük bunalımın da etkisiyle zorunluluktan uygulanmıştır. Uygulanan ithal ikameci politikalar, 
ihracatı olumsuz yönde etkilemiş, ülkelerin döviz eksiği nedeniyle ödemeler bilançoları açık vermeye başlamıştır. 1975'lerden sonra ulusal kalkınmacılık yaklaşımının krize girmesiyle Neoklasik görüş kalkınma alanında yeniden ön plana çıkmıştır. 1970 ve 80 'lerde Neoklasik kuramcılar Dünya Bankası öncülüğünde ithal ikamesi stratejisini yoğun biçimde eleştirmişlerdir. Eleştirilerin odak noktası etkin olmayan planlama ve devlet müdahalesi ile iç pazara yönelik sanayileşme unsurlarına dayanan ithal ikamesi politikasının etkinlik ve kaynak dağılımı açısından yol açtığı maliyetler olmuştur. 1980'li yıllarda ithal ikamesi stratejisine alternatif olarak önerilen sanayileşme stratejisi "dışa dönük sanayileşme stratejisi" olmuştur (Han ve Kaya, 2006:245). İhracata dayalı sanayileşme stratejisi, büyüme ve sermaye birikimi sürecinde piyasa ilişkilerinin yarattığı kapasite kullanımı, teknolojik yenilik, karşılaştırmalı üstünlükler gibi olumlu dinamik etkileri öne çıkaran ve dolayısıyla gerek iç ekonomide, gerekse ticaret ve ödemeler bilançosunda liberalleşmeyi öngören bir yaklaşımdır. Güney Kore, Tayvan, Hong Kong ve Singapur dışa dönük kalkınmanın örnekleri arasındadır. Bu ülkelerin sahip olduğu yüksek gelişme potansiyeli diğer gelişmekte olan ülkeler için örnek olmuştur. Yani 1980'lerde ticarette liberalizasyon ve sanayileşme birçok azgelişmiş ülkede ekonomik büyüme ve kalkınmayı artırmada temel strateji olmuştur. $\mathrm{Bu}$ bağlamda ihracata dayalı sanayileşme stratejisinin temel amaçları şu şekilde sıralanabilir (Han ve Kaya, 2006:246):

- Ülkedeki sanayi yapısını, karşılaştırmalı üstünlüklere göre, dış piyasalara ihracat yapan girişimlerden oluşan bir yapıya dönüştürmek.

- Serbest piyasa ve özel girişime dayalı bir ekonomik yapı kurmak.

- Dış ticaretin liberalleşmesini ve böylece dış piyasalara açılmayı sağlamak.

- Dış ticaret politikasını aynı zamanda ihracatı özendiren bir yapıya dönüştürmek.

Ticari rejimler ve ekonomik performans ile ilgili olarak, ithal ikameci ya da içe dönük büyümeye Latin Amerika; ihracata dayalı ya da dışa dönük büyümeye Doğu Asya ülkeleri referans gösterilmektedir. Doğu Asya ülkeleri yüksek gelirli ülkelere tüketim ve sermaye malı ihraç ederek, ihracata dayalı sanayileşme stratejisiyle bir kalkınma ve büyüme modeli izlerken, Latin Amerika ülkeleri yerli piyasa için tahsis edilen mamul malları artırmak olan ithal ikameci sanayileşme yolunu izlemiştir. Latin Amerika ülkelerinin istikrarsız bir dönemi geride bırakarak olumlu bir trend yakalamış oldukları görülse de, bu durum sadece oldukça düşük büyüme oranları ile gerçekleşmiş̧ir (Noyan Yalman, 2013: 150).

Birçok çalışmada uluslararası ticaret ve ekonomik büyüme arasındaki ilişki teorik olarak ispatlansa da etkilerin büyüklüğü ve yönetimiyle ilgili anlaşmazlıklar devam etmektedir. Awokuse'ye göre, büyüme üzerinde ticarette dışa açıklı̆̆ın etkisi üzerine çalışmalarda ihracatın rolü üzerinde durulmuş, ithalatın katkısı göz ardı edilmiştir. İthalatın dikkate alınmaması sonuçları hatalı yapar. İthalat ekonomik büyümede çok önemlidir. Çünkü ihracat artışı genellikle ithalattaki hızlı büyümeyle sağlanır. İthalatlar yoluyla gelişmiş ülkelerden gelişmekte olan ülkelere teknoloji transferi, ekonomik büyüme için çok önemli bir kaynaktır. Çünkü yerli firmalar için yabancı teknolojiye ve bilgiye geçişi sağladığı için, ithalat uzun dönem ekonomik büyüme için bir yol olabilir (Awokuse, 2008:161162). Bununla birlikte literatürde ihracatın ekonomik büyümeye olan katkısıyla ilgili pek çok örnek bulunmaktadır. Farklı ülke ya da ülke grupları için yapılan analizlerde ihracat ve büyüme arasında anlamlı ve pozitif ilişkiler olduğu sonucuna ulaşılmıştır. Koçyiğit vd. (2015), 1997-2013 döneminde BRICS-T ülkeleri için ihracata dayalı büyüme hipotezinin kısa ve uzun dönemde geçerliliğini test etmişlerdir. Elde edilen frekans etki nedensellik sonuçlarına göre Türkiye, Çin, Brezilya ve Rusya için farklı zaman frekanslarında ihracata dayalı büyüme hipotezinin geçerli olduğunu belirlemişlerdir. Öte yandan Hindistan ve Güney Afrika'da ithalata dayalı büyüme hipotezinin geçerli olduğu sonucuna ulaşmışlardır. Al-Assaf ve Al-Abdulrazag (2015), 1980-2012 döneminde Ürdün için ARDL yöntemi kullanarak ihracata dayalı büyüme hipotezinin geçerliliği araştırılmıştır. Uygulanan ihracat stratejilerinin ihracat ve ekonomik büyümeyi canlandıracağı sonucu ortaya konmuştur. Muhoro ve Otieno (2014), 1976-2011 döneminde Kenya'da Var analizi kullanarak ihracata dayalı büyüme hipotezini test etmişlerdir. Sonuçlar ihracattan ekonomik büyümeye tek yönlü nedenselliğin olduğunu göstermektedir. Bu ihracata dayalı büyüme hipotezinin kısa vadede Kenya ekonomisinde desteklenebileceğini işaret etmektedir. Thaker vd. (2013), 1991:Q1-2012:Q4 döneminde Malezya ekonomisi için ARDL yöntemi ve Toda Yamamoto analizi kullanılarak ihracata dayalı büyümenin varlığı araştırılmıştır. Reel ihracat ve sermaye stoku uzun vadede ekonomik büyümeyi teşvik ederken, reel döviz kurunun ekonomik büyümeyi olumsuz etkilediği görülmüştür. Buna dayanarak ihracata dayalı büyüme hipotezinin uzun vadede geçerli olduğu sonucuna ulaşılmıştı. Kılavuz ve Altay Topçu (2012), 1998-2006 döneminde 22 gelişmekte olan ülke için ihracat ve ithalatın ekonomik büyümede etkisini sınıflandırmak için iki model kurmuştur. İleri teknoloji imalat sanayi ihracat ve yatırımı büyüme üzerinde pozitif ve önemli etki, ikinci modelde düşük teknoloji sanayi üretimi ithalatı büyüme üzerinde pozitif ve önemli etki yaptığı sonuçlarını elde etmiştir. Ogbokor (2005), 1991-2003 döneminde Zimbabwe için OLS yöntemi kullanarak ihracata dayalı büyüme hipotezini test etmiştir. Elde ettiği sonuçlara göre Zimbabwe'de ihracata dayalı büyüme modelinin varlı̆̆ını kabul etmiştir.

Küçükaksoy vd. (2015), 2003:Q1-2015:Q1 döneminde Türkiye'de Johansen koentegrasyon testi, GregoryHansen koentegrasyon testi, Toda-Yamamoto nedensellik testi, FMOLS, CCR ve DOLS yöntemleri kullanılarak ihracata dayalı büyüme hipotezi araştırılmıştır. Test sonuçlarına göre uzun dönemli ilişki Johansen koentegrasyon testi reddedilirken, Gregory-Hansen koentegrasyon testinde kabul edilmiştir. Toda-Yamamoto testine göre reel ihracat ve reel GSYH arasında çift yönlü nedensellik olduğu sonucuna ulaşılmıştır. Buradan elde edilen sonuç 
Türkiye için ihracata dayalı büyüme hipotezinin geçerli olduğunu göstermektedir. FMOLS, CCR ve DOLS yöntemlerinde de uzun dönemde reel ihracatta \%1'lik artışın reel GSYH'yi değişik oranlarda artırdığı sonucuna ulaşılmıştır. Özcan ve Özçelebi (2013), 2005(1)-2011(11) döneminde Türkiye'de ihracata dayalı büyüme hipotezinin geçerliliğini Johansen eşbütünleşme metoduyla test etmişlerdir. Elde ettikleri test sonucuna göre Türkiye'de ihracata dayalı büyüme hipotezinin geçeli olduğudur. Taban ve Aktar (2008), 1980:1-2007:2 döneminde Türkiye için ihracata dayalı büyüme hipotezi Johansen eşbütünleşme metodu ve Granger nedensellik testiyle araştırılmıştır. İhracat büyümesi ve reel GSYH büyümesi arasında kısa ve uzun dönemde çift yönlü nedensellik ilişkisi bulunarak, ihracata dayalı büyüme hipotezi kabul edilmiştir. Şimşek (2003), 1960-2002 döneminde Türkiye'de Johansen eşbütünleşme testi, ECM ve Granger nedensellik testi, etki-tepki analizi yapılmıştır. Elde edilen sonuçlara göre Türkiye'de ihracata dayalı büyüme hipotezi kabul edilmiştir.

\section{Türkiye Ekonomisinde Dışa Açık Büyüme}

Türkiye ekonomisi dünya ekonomisindeki gelişmelere paralel olarak şekillenmiştir. 1980 öncesi ithal ikamesine dayalı büyüme modeli uygulanırken, 1980 sonrası neoliberal ekonomik görüş doğrultusunda ihracata bağlı büyüme modeli benimsenmiştir. Hedef ithalat sınırlamalarını azaltmak ve ülke içi üretimi artırarak ihracat kapasitesini artırmaktır. İhracat gelirlerinin ithalat harcamalarını geçmesi böylece dış ticaret açığının kapatılması, üretimdeki artışla birlikte de yatırımlarda artış, işsizliğin azaltılması, milli gelir artışı ve tasarruf artışı gibi ekonomik etkiler beklenmiştir. Bu dönemde Türkiye'de dış ticaret politikaları serbestleştirilerek sanayi politikaları yeniden yapılandırılmıştır. TL'nin değeri düşük tutulmuş ve mali teşviklerle imalat sanayi ihracatı artırılmıştır. Sermaye hareketlerinin serbestleştirilmesi, Gümrük Birliği ve WTO üyeliğiyle birlikte Türkiye'de mal ve sermaye akımları artmıştır. Dış dünya ile ticari bağlantılarını güçlendiren Türkiye'nin ekonomisinde iyileşme beklentisi artmıştır. Ancak dönemde oluşan iç ve dış konjonktürün etkisiyle bu beklenti istenilen düzeyde olmamıştır.

2000 sonrası alınan istikrar önlemleri ve siyasi istikrarın sağlanması Türkiye için ekonomik büyüme oranını artırmıştır. Düşen enflasyon ve faiz oranları yatırımcılar için daha olumlu bir ekonomik ortam hazırlamıştır. Bu olumlu gelişmelere rağmen işsizlik oranının düşmediği ve dış borçluluğun arttığı görülmüş̧ür. Yurtiçi tasarrufların yetersizliği ve kısa vadeli yabancı sermaye yatırımlarının çokluğu, iktisadi yatırımlar için yetersiz kalmaktadır. Ayrıca ihracatın ithalata bağlılı̆̆ının devam etmesi cari açı̆̆ın sürekliliğine neden olmaktadır. Türkiye ekonomisinin yapısal sorunları haline gelen işsizlik ve cari açık sorunuyla birlikte büyümeye devam etmektedir. Bu büyümenin ise istihdam yaratmayan ve dış borçluluğu artıran bir büyüme olduğu görüşü hakimdir. 2000 sonrası alınan tedbirlerle güçlenen finans piyasalarının, reel ekonomiyi ayakta tutuğu yönünde de görüşler mevcut bulunmaktadir.

\section{Uygulama}

İhracata dayalı büyüme modelinin Türkiye için geçerliliğini inceleyen bu çalışmada, 2005:01-2016:12 dönemi ihracat, sanayi üretim endeksi ve dış borç stoku verilerine ait zaman serisi kullanılmıştır. Değişkenler arasındaki ilişkiyi belirlemek üzere Toda-Yamamoto nedensellik testi uygulanmıştır. Analizde kullanılan aylık veriler TÜİK ve EVDS'den alınmıştır. Zaman serilerinde mevsimlik davranışlar gözlenmektedir (Gujarati ve Porter, 2012:784). Aylık seriler kullanıldığı için mevsim etkisini ortadan kaldırmak için Census X12 testi yapılmıştır.

ihr_sa= Toplam ihracat (bin \$)

$$
i h r_{-} s a_{t}=f\left(s u e_{-} s a_{t}, d_{\_} b o r \_s a_{t}\right)
$$

sue_sa= Sanayi üretim endeksi $(2010=\%)$

$\mathrm{d}$ bor $\mathrm{sa}=$ Kisa vadeli toplam diș borç stoku (milyon $\$$ )

\begin{tabular}{|c|c|c||}
\hline \multicolumn{2}{|c|}{ Phillips Peron Birim Kök Test İstatistikleri: } & Olasılık \\
\hline \hline Değişkenler & t- Değeri & 0.0003 \\
\hline \hline IHR_SA* & -5.008396 & 0.0000 \\
\hline \hline SUE_SA* & -8.209468 & 0.0000 \\
\hline D_BOR_SA* & -9.109322 & \\
\hline
\end{tabular}

Tablo 1. Birim Kök Testi (*\%1 düzeyinde anlamlıdır)

Ekonometrik analizlerde kullanılan değişkenlerin durağan olmaması durumunda sahte regresyon sorunu ortaya çıkacağından, analize başlamadan önce verilerin durağanlığını incelemek gereklidir. Durağanlığı incelemek için çeşitli birim kök testleri kullanılmaktadır. Analizde Phillips-Perron birim kök testi kullanılmıştır. Test sonucunda (Tablo 1) ihracat ve sanayi üretim endeksi düzey değerinde durağanken, diş borç stokunun birinci dereceden bütünleşik olduğu belirlenmiştir. 


\begin{tabular}{|c|c|c|c|c|c|c|}
\hline \multicolumn{2}{|c|}{ İçsel Değişkenler: IHR_SA SUE_SA D__BOR_SA } & \multicolumn{1}{l}{ HQ } \\
\hline Lag & LogL & LR & FPE & AIC & SC & 61.15667 \\
\hline 0 & -4123.304 & NA & $7.10 \mathrm{e}+22$ & 61.13044 & 61.19500 & 54.39314 \\
\hline 1 & -3652.453 & 913.7998 & $7.58 \mathrm{e}+19$ & 54.28820 & 54.54645 & $53.79931^{*}$ \\
\hline 2 & -3598.057 & 103.1523 & $3.87 \mathrm{e}+19$ & 53.61565 & $54.06759^{*}$ & 53.84251 \\
\hline 3 & -3586.660 & 21.10495 & $3.74 \mathrm{e}+19$ & 53.58015 & 54.22577 & 53.89575 \\
\hline 4 & -3575.941 & $19.37359^{*}$ & $3.65 \mathrm{e}+19^{*}$ & $53.55468^{*}$ & 54.39398 & 54.03531 \\
\hline 5 & -3571.049 & 8.624961 & $3.88 \mathrm{e}+19$ & 53.61554 & 54.64852 & 54.16181 \\
\hline 6 & -3565.274 & 9.923189 & $4.08 \mathrm{e}+19$ & 53.66333 & 54.89000 & 54.24134 \\
\hline 7 & -3556.330 & 14.97434 & $4.10 \mathrm{e}+19$ & 53.66414 & 55.08450 & 54.31338 \\
\hline 8 & -3546.880 & 15.39930 & $4.09 \mathrm{e}+19$ & 53.65748 & 55.27152 & \\
\hline
\end{tabular}

Tablo 2. Gecikme Sayılart

Seriler arasında nedensellik ilişkisini belirlemek üzere yapılan Granger nedensellik testi, serilerin tamamının düzeyde durağan olduğu koşulda kullanılabilir. Analizimizdeki serilerin hepsi düzeyde durağan olmadığı için Toda-Yamamoto nedensellik testi kullanılmıştır. Toda-Yamamoto nedensellik testi, Granger nedensellik testinin genişletilmiş halidir ve farklı dereceden durağan seriler arasındaki nedensellik ilişkisini test eder.

Değişkenler arası ilişki ve geleceğe yönelik tahminlerin güvenilir bir şeklide yapılabilmesi için analizde uygun gecikme değerlerinin kullanılması gerekir. Analizde (Tablo2) LR, FPE AIC bilgi kriterlerine göre dört gecikme kullanılmıştır.

\begin{tabular}{|c|c|c|c|}
\hline \multicolumn{4}{|l|}{ Bağımlı Değiş̧ken: IHR_SA } \\
\hline \multirow{4}{*}{$\begin{array}{c}\text { SUE_SA } \\
\text { D__ BOR_SA } \\
\text { Bağımlı Değişken: SUE_SA }\end{array}$} & $\chi^{2}$ & Serbestlik & Olasilık \\
\hline & 16.90115 & 3 & 0.0007 \\
\hline & 13.95871 & 3 & 0.0030 \\
\hline & \multicolumn{3}{|c|}{ Bağımlı Değişken: SUE_SA } \\
\hline \multirow{3}{*}{$\begin{array}{c}\text { IHR_SA } \\
\text { D_BOR_SA }\end{array}$} & \multicolumn{3}{|c|}{ Serbestlik } \\
\hline & 10.62067 & 3 & 0.0140 \\
\hline & 10.29295 & 3 & 0.0162 \\
\hline \multicolumn{4}{|c|}{ Bağımlı Değişken: D__BOR_SA } \\
\hline & \multicolumn{3}{|c|}{ Serbestlik } \\
\hline & $\chi^{2}$ & Derecesi & Olasilık \\
\hline IHR_SA & 3.694811 & 3 & 0.2964 \\
\hline SUE_SA & 0.448723 & 3 & 0.9300 \\
\hline
\end{tabular}

Tablo 3. Nedensellik Testi

Toda Yamamoto nedensellik testi sonucuna göre (Tablo 3) sanayi üretim endeksi ve diş borç stoku arasında çift yönlü nedensellik ilişkisi vardır. Benzer şekilde çift yönlü nedensellik ilişkisinin ihracat ve dış borç stoku arasında da olduğu görülmektedir. İhracat ve sanayi üretim endeksi arasında ise nedensellik ilişkisi bulunmamaktadır. Elde edilen bu sonuçlar dış borç yoğun üretim ve ihracat faaliyeti olduğu yönelik yorumlanabilir. Tasarrufların artırılması yoluyla dış borçlanma azaltılarak ekonomik büyüme devam ettirilebilir. Bunun yanı sıra işsizlik gibi önemli bir makroekonomik problem de çözüme kavuşacağı ön görülmektedir. Bu model için Türkiye'de dışa açık büyüme modeli geçerli değildir.

Bu sonuçların yanı sıra ikinci bir model daha oluşturulmuş ve bu modelde yalnızca ihracat ve sanayi üretim endeksi arasındaki ilişki Granger nedensellik yaklaşımıyla test edilmiştir. Bu modelin sonucunda ihracat ve sanayi üretim endeksi arasında nedensellik ilişkisi olduğu görülmüştür. Yani ikinci modelde ihracata dayalı büyüme hipotezi geçerlidir.

\section{Değerlendirme ve Sonuç}

Bilimsel bilgi ve teknolojilerin ilerlemesi, üretim ve dağıtımda verimliliği önemli boyutlarda artırmıştır. Bu gelişmeleri takip eden ve daha üst seviyelere taşıyan ülkeler uluslararası piyasalarda önemli rekabet avantajı kazanmıştır. Bunun yanı sıra küreselleşmeyle ticaret engelleri ve kısıtlamaları zamanla aşılmış, ticaretin gelişimiyle küresel bir pazar oluşmuştur. Üretim kapasitesini artırıp ihracat hacmini geliştiren ülkeler yüksek büyüme oranları elde etmişler ve gelişmekte olan ülkeler için büyüme ve kalkınma örneği olmuşlardır. Ekonomik büyümelerini artırmak isteyen ülkeler katma değeri yüksek ürünleri daha az emek ve teknolojiyle üretme 
çabasındadır. Gelişen bu ekonomik ortama göre büyüme teorileri de şekillenmiştir. Özellikle 1980'den sonra gelişen bu akım, ihracata yönelik büyüme modeliyle açıklanmıştır.

Çalışmada Türkiye için ihracata yönelik büyüme modelinin geçerliliği araştırılmıştır. Modele ihracat ve sanayi endeksinin yanı sıra dış borç stoku da eklenmiştir. Elde edilen sonuçlara göre Türkiye'nin borçlanarak büyüyen ve ihracat yapan bir ülke olduğunu söylemek mümkündür. Türkiye'de istihdam yaratmayan büyüme olgusu yurtiçi tasarruf birikiminin, uzun vadeli yabancı sermaye yatırımlarının artırılması ve üretimde ithalat bağımlılığının azaltılarak sağlanacak döviz tasarrufu ile aşılabilecektir.

\section{Kaynakça}

- Al-Assaf, Ghaz, and Bashier Al-Abdulrazag, 2015. "The Validity of Export-Led Growth Hypothesis for Jordan: A Bounds Testing Approach", International Journal of Economics and Financial Issues, 5, 199-211.

- Awokuse, Titus O., 2008. “Trade Openness And Economic Growth: Is Growth Export-Led Or Import-Led?”, Applied Economics, 40,

- Gujarati, Damodar N. ve Dawn C. Porter (2012), Temel Ekonometri, Literatür Yayınları, İstanbul.

- Han, Ergül. ve Ayten Ayşe Kaya, 2006. Kalkınma Ekonomisi Teori ve Politik, Nobel Yayın Dağıtım, Ankara.

- K1lavuz Emine ve Betül Altay Topçu, 2012. "Export and Economic Growth in The Case of The Manufacturing Industry: Panel Data Analysis of Developing Counties", International Journal of Economics and Financial Issues, 2, 201-215.

- Koçyiğit, Ali, Tayfur Bayat, Selim Kayhan ve Mehmet Şentürk, 2015. "Short and Long Term Validity of Export-Led Growth Hypothesis in BRICS-T Countries: A Frequency Domain Causality Approach" Journal of Asian Development Studies, 4, 117-129.

- Küçükaksoy, İsmail, İsmail Çiftçi ve Rabia İnci Öztürk, 2015. “İhracata Dayalı Büyüme Hipotezi: Türkiye Uygulaması", Çankırı Karatekin Üniversitesi İktisadi ve İdari Bilimler Fakültesi Dergisi, 5, 691-720.

- Muhoro, Grace and Manaseh Otieno, 2014. "Export Led Growth Hypothesis: Evidence From Kenya", Journal of World Economic Research, 3, 37-46.

- Noyan Yalman, İlkay, 2013. "Bir Kısım Latin Amerika Ve Güney Doğu Asya Tipi, Ülkelerinde Liberalizasyon Ve Ekonomik Büyüme”, İlişkileri Trakya Üniversitesi Sosyal Bilimler Dergisi, 15, 149-168.

- Ogbokor. Cyril A., 2005. "Time-Series Evidence for Export-led Growth Paradigm: A Case Study of Zimbabwe", Journal of Social Sciences, 1, 77-80.

- Özcan, Burcu ve Oğuzhan Özçelebi, 2013. “İhracata Dayalı Büyüme Hipotezi Türkiye İçin Geçerli Mi?” Yönetim ve Ekonomi, 20, 1-14

- Taban, Sami and İsmail Aktar, 2008. "An Empirical Examination Of The Export-Led Growth Hypothesis in Turkey”, Journal of Yaşar University, 3, 1535-1551.

- Thaker, Hassanudin Mohd Thas, Tan Siew Ee and Sushant Vaidik, 2013. "Export-Led Growth Hypothesis: Econometric Evidence From Malaysia", Journal of International Business and Economy, 14, 95-112.

- Thirwall, A. P., 2002. "The Nature of Economic Growth An Alternative Framework for Understanding The Performance of Nations", Edward Elgar Publishing Limited.

- Şimşek, Muammer, 2003. "İhracata Dayalı Büyüme Hipotezinin Türkiye Ekonomisi Verileri İle Analizi, 1960-2002”, D.E.Ü.İ.İ.B.F. Dergisi, 18, 43-63.

- www.ekonomikyaklasim.org/eykongre2011/?download=07.pdf 


\title{
Elektronik Vergi Uygulamalarının Vergi Denetimi Üzerindeki Etkisi: Türkiye Örneği
}

\section{The Impact of Electronic Taxation on Tax Auditing: The Case of Turkey}

\author{
Asst. Prof. Dr. Tuğçe Uzun Kocamış (İstanbul University, Turkey) \\ Ph.D. Candidate H. Muhammet Kekeç (Istanbul University, Turkey)
}

\begin{abstract}
The advances in information and information technology provide companies with both speed and optimal benefit by using the internet intensively for every stage of their commercial activities and for all kinds of transactions. In order to reduce tax losses, it is necessary to utilize information technologies to develop new audit methods and techniques and to follow new practices in the world. It has become compulsory for public institutions to keep pace with the evolving information technology and to form the necessary information infrastructure.

E-applications prevent tax evasion and ensure tax incomes of countries not only to increase the quality of public service but also increase the taxpayer's transaction speed. With the transfer of taxpayers to electronic book and electronic document in order to conduct an effective tax audit and to obtain tax revenue studies on the establishment of a structure that is effective, fast working and using computer technologies well in the struggle with the informal economy are carried out by the tax administration.

In our work, electronic tax applications and tax audit in Turkey are explained under general headings and the process of transition to electronic tax audit is taken as basis on the basis of applications in the world. As a result, the contribution of computer and internet technology to the effectiveness of tax audit is an unquestionable reality.
\end{abstract}

\section{Giriş}

Küreselleşme olgusu toplumun her kesimini etkisi altına almıştır. Bilişim ve teknoloji alanındaki ilerlemelere paralel ülkelerin mali idarelerinin de yeniden yapılanması gündeme gelmiştir. Bu çerçevede ülkeler e-devlet yapılanmasına geçmişlerdir. Teknolojinin gücünün yadsınamadığı gerçeğinden hareketle devletlerin güçlü olmaları bilişim teknolojilerinin varlığı ile birlikte bu teknolojilerin etkin kullanımına da bağlıdır.

Türkiye'nin bu gelişmelerin gerisinde kalması beklenemez. Türkiye'de de vergi uygulamasındaki maliyetleri düşürmek ve teknolojik gelişmelerden faydalanmak amacıyla elektronik vergi uygulamalarına geçilmektedir. Maliye Bakanlığı tarafından gerçekleştirilen uygulamalar ile mükelleflerin vergi işlemleri nedeniyle üstlendiği maliyetler azalırken hizmet hızı ve kalitesi artmaktadır.

Günümüzde, devletlerin kamu harcamalarını finanse etmek için ihtiyaç duyduğu en önemli kaynak vergi olup devlet bütçelerinin en önemli kalemi vergi kalemidir. Kamu harcamalarının finansmanında vergi gelirinin bu kadar önemli olması vergi denetimini de ortaya çıkarmıştır. Çünkü vergi, bir ülke için gelirin yanında adaleti de temsil etmektedir. Devletin gücünü her alanda gösterebilmesi ve gelir dağılımına göre adaletli vergi toplaması, verginin denetimiyle doğrudan ilişkilidir.

Bilgi teknolojisindeki gelişmeler devlet faaliyetleri gibi vergi denetimi açısından da birçok gelişmeye öncü olmaktadır. Artık devletler geleneksel yapıdan kurtulup, elektronik anlayışı kurumlarına benimsetmek zorundadırlar. Türkiye'de e-devlet projesi kapsamında sınırlı sayıda işletme ile Elektronik Fatura Kayıt Sistemi (EFKS) uygulamaya başlanılmıştır. Daha sonra belirli kriterlere sahip olan işletmelere e-fatura kullanma zorunluluğu getirilerek sisteme dâhil edilmiştir. E-fatura uygulamasının kullanan işletmeler bir sonraki aşama olan e-defter uygulamasını kullanmaya başlamışlardır. Vergi sistemi, kısaca bir ülkede belli bir zamanda mevcut olan tüm vergilerden oluşan bir bütünü ifade eder. Devlet açısından e-defter ve e-fatura uygulaması denetimin kolaylığg, vergi kayıp ve kaçaklarının önlenmesi en önemli avantajlardandır (Gökçen ve Özdemir 2016)

Çalışmamızda Dünya'da ve Türkiye'de elektronik vergi uygulamalarına değinilerek, vergi denetim kavramı ve e-denetime geçiş süreci ele alınmıştır. Vergi denetiminin etkinliğinde bilgisayar ve internet teknolojisinin katkısı yadsınamaz bir gerçek olarak karşımıza çıkmaktadır.

\section{Dünyada ve Türkiye'de Elektronik Vergi Uygulamaları}

Aşağıda kısaca Dünyada ve Türkiye'de elektronik vergi uygulamaları anlatılmıştır.

\subsection{Elektronik Vergi Uygulamaları}

Elektronik vergi yönetimi; vergi beyannamelerinin mükellefler veya vergi sorumluları tarafından elektronik ortamda doldurulup vergi idaresine ulaştırılmasıdır. Vergiler, internete bağlı bilgisayarlar ve çevrimiçi haberleşme araçları vasıtasıyla vergi dairesine gitmeden ödenebilmektedir. E-devlet uygulamasıyla çoğu gelişmiş ve 
gelişmekte olan ülkede e-vergilendirme kullanılmaktadır. E-vergilendirme, verginin tahakkuku ve tahsilini sağlayan bir e- devlet uygulamasıdır. Teknolojik geliş̧meyle birlikte uygulanan bazı elektronik vergi uygulamaları şu şekilde sayılabilir:

- Elektronik Defter: Şekil hükümlerinden bağımsız olarak Vergi Usul Kanununa ve/veya Türk Ticaret Kanununa göre tutulması zorunlu olan defterlerde yer alması gereken bilgileri kapsayan elektronik kayıtlar bütününü, E-defter uygulaması ile bilanço usulüne göre defter tutan Gelir ve Kurumlar Vergisi mükelleflerinin daha önce kağıt ortamda tuttukları yevmiye defteri ile defter-i kebirin elektronik ortamda tutulmasına, muhafaza ve ibraz edilmesine olanak sağlanmıştır.

- Elektronik Beyanname (E-Beyanname): Mükelleflerin vergisel işlemlerini yerine getirmede, gelişen BİT 'ten yararlanmak, beyannameler ile bildirim ve eklerin kolay, hızlı, ekonomik ve güvenilir olarak hazırlanıp idareye gönderilmesini sağlamak, beyannamelerin doldurulması sırasında yapılan hataları en az indirerek mükelleflerin mağduriyetini önlemek, vergi dairesinin beyanname kabul, tarh, tahakkuk ve tahsilat işlemlerini azaltarak iş yükünü hafifletme ve diğer alanlarda mükelleflere daha iyi hizmet vermek amaciyla e beyanname uygulaması oluşturulmuştur (GİB 2016).

- E -Arşiv Fatura Uygulaması: Bu proje çok sayıda fatura düzenleyen ve bu faturaların ikinci nüshalarını kağıt ortamında saklamaları kendileri için ağır yük oluşturan mükelleflerin, elektronik ortamda fatura oluşturmalarına, iletmelerine, muhafaza ve ibraz etmelerine olanak sağlamak amacıyla geliştirilmiştir (GİB 2016).

- E-Bilet Uygulaması: Bu proje, çok sayıda bilet düzenleyen ve düzenledikleri bu biletlerin ikinci nüshalarını kağıt ortamında saklamaları kendileri için ağır yük oluşturan mükelleflerin, elektronik ortamda bilet düzenlemelerine, iletmelerine, muhafaza ve ibraz etmelerine olanak sağlamak amacıyla geliştirilmiş̧tir (GïB 2016).

- E-Yoklama Sistemi: Mükellef davranışları yönetimini çağın gerekleri doğrultusunda modern, dinamik ve organize bir yapı haline getirmek üzere internet, web ve kablosuz teknolojiler ile her yerde her zaman etkileşen sistemlerin yaygın kullanılmaya başlandığı günümüzde, e-devlet uygulamaları çerçevesinde yoklama ve denetim faaliyetlerinin mobil teknolojilerden yararlanarak iş amacıyla "Elektronik Yoklama" projesi hayata geçirilmiştir (GIB 2016).

- Elektronik Fatura (E Fatura): 397 Sira No'lu Vergi Usul Kanunu Genel Tebliğin yayımı ile birlikte Elektronik Fatura Uygulamasına (e-Fatura Uygulaması) GIB tarafindan başlanmıştır. Elektronik Fatura Uygulaması, standartlara uygun e-Faturaların, taraflar arasında güvenli ve sağlıklı bir biçimde dolaşımını sağlamak amacı ile oluşturulan uygulama olarak ifade edilmektedir. GỉB'nın internet sitesinde E fatura uygulamasının 21.04.2017 tarihi itibariyle kayıtlı kullanıcı sayısı 62.750 kişi olarak ifade edilmiştir.

20/06/2015 Tarih ve 29392 Sayılı Resmi Gazete 'de e-Fatura ve e-Defter uygulamalarının kapsamının genişletilmesi ve ihracat işlemlerinde e-Fatura uygulamasına ilişkin 454 Sıra Nolu Vergi Usul Kanunu Genel Tebliği yayımlanmıştır.

\subsection{Dünyada ve Türkiye'de Elektronik Vergi Uygulamaları}

Teknoloji alanındaki yaşanan değişim ve dönüşümler vergi idarelerinin otomasyon sistemlerini etkin kullanmalarına büyük imkan sağladığı ifade edilmektedir. Söz konusu teknolojik gelişmelerin sunmuş olduğu imkanlarla beraber mükellefler açısından birçok kolaylık sağlanmaktadır. Bu kolaylıklar vergi mükelleflerinin beyannamelerini elektronik ortamda verebilmeleri, beyannamelere yönelik tahsil ve tahakkuk işlemlerini bilgisayar yardımı ile yapabilmeleri, vergi mükelleflerinin gelir ve servet harcamaları ile ilgili bilgileri elektronik ortamda toplanabilmesi ve en nihayetinde vergi denetiminin bilgisayar destekli olması olarak ifade dilebilir (Çetin 2010).

Avrupa açısından elektronik fatura uygulamasının kanuni dayanağı 2001/115/EC Avrupa Birliği KDV direktifidir. Mükelleflerin gerek maliyet baskısı gerekse de evrak yüklerinin azaltılması mükellefleri elektronik faturaya uyum noktasında daha hızlı ilgi duymalarını sağlamışıtı. Hatta elektronik faturaya olan ilgi yalnızca özel sektörle sınırlı olmayıp, kamu harcama süreçlerinde etkinliğin ve kontrol düzeyinin artırılması noktasında elektronik fatura kamu kesiminin de dikkatini çekmektedir. Elektronik fatura uygulaması kamunun da desteğinin almasıyla önemli ölçüde gelişim imkanı bulmuştur. Elektronik fatura uygulamasının yaygınlaştııılması amacıyla bazı AB üyesi ülkeler yapılan kamu ile ilgili fatura işlemlerinin elektronik ortamda zorunlu kılan adımlar atmışlardır. Bu konuda verilebilecek örneklerin başında yer alan Danimarka, 2005 Şubat ayından bu yana kamu kurumlarına ait faturaları sadece elektronik ortamda kabul edilmektedir (Bayar, Ülkar ve Doğan 2013).

AB Ülkelerinde E-Fatura Uygulamasının Ana Hatları Elektronik fatura ile ilgili olarak en temel düzenleme niteliğinde olan 2001/115/EC sayılı Katma Değer Vergisi direktifi (28/11/2006 tarih ve 2006/112/EC sayllı KDV Ortak Sistemi hakkındaki Direktife entegre edilmiştir) faturalaşma işlemlerinin basitleştirilmesi ve harmonizasyonu amacına yönelik olarak hazırlanmış ve bünyesinde elektronik fatura alternatifine de yer verilmiştir. 2001/115 Avrupa Birliği direktifi ile e-faturanın oluşturulmasında, değiştirilmesinde kullanılacak üç temel yöntem belirlenmiştir. E-Faturada kullanılacak yöntemler (Bayar, Ülkar ve Doğan 2013):

- EDI (Elektronik Veri Değişimi) 
- Elektronik İmza

- Diğer yöntemler

ABD'de vergi denetim faaliyetine konu olan vergi beyannameleri elektronik seçim sistemi belirlenmektedir. Vergi müfettişleri herhangi bir şekilde mükellefin defter kayıtları ve belgelerinden faydalanamıyorsa beyan edilmeyen gelirin tespitine ilişkin olarak "Dolaylı Metot" olarak ifade edilen sistemi kullanmaktadır. Vergi müfettişi bu sistemi kullanırken istatistiksel verilerden faydalanmak suretiyle de mükellefin bildirmediği gelirlerini de tespit edebilmektedir (Yetkiner 2002). ABD de elektronik vergi uygulaması daha çok verginin hesaplanmasında belgelendirme güçlüğü yaşanan mükellefler açısından uygulanan bir yöntem olduğu ifade edilebilir.

İngiltere'de ise denetime konu olayların çoğu yerel dairelerce yerine getirilmekte olup incelemelerde farklı kurum kaynaklardan yararlanılmaktadır. Bunun yanı sıra bilgisayar sistemi, veri eşleştirmesi ve denetimde olası hedeflerin belirlenmesi amacıyla elektronik denetimden daha yoğun faydalanılması hedeflenmektedir (Can ve Kapusuzoğlu 2005). İngiltere'de e-devlet faaliyetleri göz önünde tutulduğunda, 1999'un Eylül ayında Performans ve İnovasyon Birimi'nin raporunda değinilen tavsiyeler hükümet bünyesinde yer alan Elektronik Temsilcilik Dairesi'nin kurulmasıyla hızlı bir yükselişe geçmiştir (Alptürk 2008).

Brezilya da elektronik vergi sistemlerinde devam eden iyileştirmeler ve özellikle de reformların kabul edilmesi son yıllara kıyasla daha da artmıştır. Brezilya'da son beş yılda Kamu Dijital Defter Kontrol Sistemi ya da SPED tarafindan sunulan federal ve eyalet vergilerinin her ikisi için de eklenen elektronik vergi raporlama sistemlerinin zamanla daha da olgunlaştı̆̆ tespit edilmiştir. Bu anlamda elektronik vergi uygulamalarının gelişimi gerek mükellef gerekse de vergi müfettişleri açısından büyük kolaylık sağlamakta ve zaman açısından da Brezilya örneğinde olduğu gibi elektronik vergi sistemi sayesinde vergilendirmede idari süreç kısalmaktadır (Oğuztürk ve Ünal 2015) (Packman ve Lopez-Claros 2017).

Yine Güney Amerika da elektronik vergi sistemlerinde ve bilgi teknolojisinde yapılan iyileştirmeler mükelleflerin vergilendirme ve vergi ödemeleri için gereken sürenin azalmasında önemli bir rol oynamaktadır. Elektronik dosyalama ve ödemenin gerçekleştirildiği ekonomilerde, hazırlık süresini azaltmak için sistemdeki hataları düzeltmek veya vergi sistemlerini muhasebe sistemleriyle bütünleştirmek gibi çabalar elektronik vergi sistemleri daha da geliştirmektedir. Buna ek olarak, Kenya ve Fiji gibi bazı ekonomiler, vergi prosedürlerinin sadeleştirmek veya azaltmak, vergi süreci ile ilgili dosyaların azaltılması ve vergi mükelleflerinden daha az bilgi sunmalarının istenmesi mükelleflerin desteğini ve memnuniyetini ortaya çıkarmıştır (Packman ve Lopez-Claros 2017).

Jamaika, vergi türüne göre küresel ortalama ödeme sayısı açısından büyük bir düzelme göstererek 2015 yılında küresel ortalama ödeme sayısını 26 dan 11 düşürmüştür. Jamaika'da elektronik vergi beyannamesi birkaç yıl önce tanıtılmasına rağmen vergi mükelleflerinin vergi beyannamelerini elektronik olarak sunmaları 2015 yilından itibaren başlamış ve hızla yaygınlaşmıştır. Jamaika'nın bu durumu, Moğolistan ve Kosova'nın pozisyonuna benzemektedir (Packman ve Lopez-Claros 2017).

Endonezya açısından ise elektronik vergi beyanının zorunlu olması gibi diğer elektronik vergi uygulamaları mükelleflerin vergi yükümlülüklerini yerine getirmenin idari yükünü daha da kolaylaştırmaktadır (Packman ve Lopez-Claros 2017).

Türkiye'de vergi harcaması noktasında karşılaşılan maliyetlerin azaltılması bütçe açısından büyük önem taşımaktadır. $\mathrm{Bu}$ amaçla yürütülen çalışmalardan biriside elektronik vergi uygulaması olarak karşımıza çıkmaktadır (TÜBITAK-Bilgem-YTE 2017). Aynı zamanda vergi idaresi vergi teftiş elemanlarının sayısını ve denetim imkanlarını artırırken, elektronik denetim alanına da ağırlık vererek daha fazla mükellef ve konu hakkında inceleme yapılmasını hedeflemektedir (Oğuztürk ve Ünal 2015).

Vergi idareleri, performansı artırmak için teknolojinin gücünden yararlanmaktadır (EY 2017). Dünya Ekonomik Forumu tarafından hazırlanan Küresel Rekabet Raporu'nda ülkelerin en son teknolojileri uygulayabilme durumları incelenerek bir sıralama yapılmıştır. Bu sıralamanın yapılmasında çeşitli kriterler (ülkelerin hizmet sunum şekilleri, teknoloji üretme yetenekleri, insan sermayesi, hukuki alt yapıları gibi) önemli rol oynamaktadır. Aşağıdaki tabloda ülkelerin teknolojiye uygun olma durumlarındaki sıralaması yer almaktadır: 


\begin{tabular}{|c|l|c|}
\hline & En Son Teknolojiyi Uygulayabilme Sıralamas 1 & \\
\hline Sura & Ülke & Puan \\
\hline 1 & Switzerland & 6.4 \\
\hline $\mathbf{2}$ & Luxembourg & 6.4 \\
\hline $\mathbf{3}$ & United Kingdom & 6.3 \\
\hline $\mathbf{4}$ & Sweden & 6.3 \\
\hline $\mathbf{5}$ & Hong Kong SAR & 6.2 \\
\hline$\ldots$ & $\ldots$ & $\ldots$ \\
\hline $\mathbf{6 3}$ & Thailand & 4.3 \\
\hline $\mathbf{6 4}$ & Colombia & 4.3 \\
\hline $\mathbf{6 5}$ & Georgia & 4.2 \\
\hline $\mathbf{6 6}$ & Mauritius & 4.2 \\
\hline $\mathbf{6 7}$ & Turkey & 4.2 \\
\hline $\mathbf{6 8}$ & Mongolia & 4.1 \\
\hline $\mathbf{6 9}$ & Argentina & 4.1 \\
\hline$\ldots$ & $\ldots$ & $\ldots$ \\
\hline $\mathbf{1 3 5}$ & Malawi & 2.3 \\
\hline $\mathbf{1 3 6}$ & Yemen & 2.2 \\
\hline $\mathbf{1 3 7}$ & Burundi & 2.0 \\
\hline $\mathbf{1 3 8}$ & Chad & 1.9 \\
\hline
\end{tabular}

Tablo 1: Ülkelerin En Son Teknolojiyi Uygun Olma Durumu (Technological Readiness) Kaynak: The Global Competitiveness Report 2016-2017

Türkiye 2016 yılında 4,2 puan ile 67'inci sırada yer almaktadır. Bu durum, Türkiye' nin henüz e-dönüşüm sürecinde yapması gereken işlerin olduğunun göstergesidir. Maliye Bakanlığı'nın konuya ilişkin çalışmaları devam etmektedir.

Türkiye'de 2002 yılında kurulan hükümet tarafından oluşturulan acil eylem planında E-dönüşüm Türkiye Projesi’ne değinilmiş olup ilgili projenin yönetimi, takibi, incelenmesi ve yönlendirilmesi amaciyla Devlet Planlama Teşkilatı Müsteşarlığı yetkilendirilmiştir. Bu yetki kapsamında DPT kuruluşu altında Bilgi Toplum Dairesi Başkanlığı kurulmuştur. Bununla birlikte 27 Şubat 2003 tarihinde yayımlanan 2003/12 sayılı başbakanlık genelgesi ile E-dönüşüm Türkiye Projesinin amaçları, kurumsal yapısı ve uygulama esasları ortaya konulmuştur (Öz ve Bozdoğan 2012).

Türkiye'de gelir idaresi başkanlığı iş yükünün, vergi maliyetinin ve bürokrasinin azalmasına yönelik teknolojik imkanlardan faydalanmaktadır. Teknolojik imkanlar vergi uygulamalarının daha hızlı ve daha etkin işlemesine imkan vermektedir. Söz konusu uygulama ile idare iş yükünü ve maliyeti azaltırken mükellef açısından ise bürokrasi ve evrak yoğunluğu problemi azalmaktadır. Gelir İdaresi Başkanlığı tarafından yayımlanan 2015 yılı faaliyet raporunda ifade edildiği üzere 2015 yılında Başkanlığa 225.203 adet evrak gelmiş ve 128.653 adet evrak ise gönderilmiştir. E-Devlet uygulamasına geçilmesiyle evrak sayısında ve dolayısıyla iş yükü ve ekonomik maliyetlerde azalış yaşanması hedeflenmektedir (GïB 2016). İllerin otomasyon durumu aşağıdaki tabloda özetlenmektedir.

\begin{tabular}{|c|c|c|c|c|c|}
\hline \multicolumn{6}{|c|}{ İLLERIN OTOMASYON DURUMU } \\
\hline \multicolumn{6}{|c|}{ (31.03.2017 Tarihi İtibariyle) } \\
\hline İl Kodu & Ill Adı & $\begin{array}{c}\text { EVDO'lu } \\
\text { Vergi Dairesi } \\
\text { Sayısı } \\
\end{array}$ & $\begin{array}{c}\text { EVDO } \\
\text { MOTOP' lu } \\
\text { Vergi Dairesi } \\
\text { Sayısı } \\
\end{array}$ & $\begin{array}{c}\text { EVDO'lu } \\
\text { Malmüdürlüğ̈u } \\
\text { Sayısı }\end{array}$ & TOPLAM \\
\hline \multicolumn{2}{|c|}{81 İl } & 415 & 17 & 582 & 1024 \\
\hline
\end{tabular}

Tablo 2: Illerin Otomasyon Durumu Kaynak:

http://www.gib.gov.tr/sites/default/files/fileadmin/user_upload/VI/IOD.htm

Gelir İdaresi Başkanlığı'nın internet sitesindeki veriler ışı̆̆ında e-fatura, e-defter, e-arşiv uygulamalarının kullanımıyla 115 bin adet ağacın kesilmesi engellenmiş olup 750 milyon TL'lik bir tasarruf sağlanmıştır. Ayrıca Gelir İdaresi Başkanlığı e-bilet, e-arşiv, e-fatura, e-defter, e-ticaret, e-yoklama, yeni nesil ödeme kaydedici cihazlar gibi uygulamalar, kayıt dışı ekonomiyle mücadelede de önemli bir katkı sağlamıştır (TÜBİTAK-Bilgem-YTE 2017). 
Elektronik vergi uygulamalarının denetim açsından önemi yürütme organı olan vergi idaresinin yayınlamış olduğu tebliğlerinden anlaşılmaktadır. Söz konusu elektronik vergi uygulamaları denetim personelinin işini kolaylaştırırken mükellefe de sürekli denetim algısını sağlayacağından kayıt dışı faaliyetleri de engelleyecektir.

\section{Vergi Denetimi Kavramı ve E-Denetim}

Vergi, kamu hizmetlerinin karşılanması amacıyla devletin bireylerden cebren aldığı parasal değerleri ifade etmektedir. Devlet bu görevini yerine getirirken anayasal bir güce dayanmaktadır. Denetim ise genel olarak, iktisadi faaliyet ve olaylarla ilgili iddiaların, önceden saptanmış ölçütlere uygunluk derecesini araştırmak ve sonuçları ilgi duyanlara bildirmek amacıyla, tarafsızca kanıt toplayan ve bu kanıtları değerleyen sistematik bir süreçtir.

Vergi denetimi, vergi kanunları ile vergiye tabi tutulan mükellef ve işlemlerin tam olarak kavranabilmesine ve vergi idaresi ile mükelleflerin mevcut vergi sisteminde yer alan ilke ve kurallara uygun davranıp davranmadıklarını belirlemeye yönelik olan ve vergi idaresi tarafından yapılan işlemlerin tümüdür (Oğuztürk ve Ünal 2015). Ülkemizde, vergi denetim görevinin genel çerçevesi yoklama, vergi incelemesi, arama, bilgi toplama ve istihbarat arşivi oluşturmak şeklindedir (Rakıc1 2011).

Vergi idaresinin ve özellikle mükellefin yasalara uygun bir şekilde hareket edip etmediğinin kontrol edilmesi anlamına gelen vergi denetimi, kayıt dışı ekonominin önlenmesi ile vergilemede sosyal adalet ve eşitlik ilkesini açısından son derece önemli bir fonksiyon üstlenmektedir. Vergi denetiminin amaçları mali, ekonomik, sosyal ve hukuki olmak üzere dört gruba ayrılabilir (Somuncu 2014).

1. Mali Amaç: Vergi denetiminim malî amacı bütçeye ek kaynak sağlamak olarak açıklanabilir.

2. Ekonomik Amaç: Verginin malî amacının dışında kayıt dışı ekonomi ile mücadele etmek, enflasyonist etkileri ortadan kaldırmak gibi ekonomik bir kısım amaçları daha bulunmaktadır

3. Hukuki Amaç: Vergi denetiminin bir diğer amacı da vergi kanunlarının uygulanmasını sağlaması; özellikle devletin saygınlığını ve gücünü göstermesidir.

4. Sosyal Amaç: Anayasada çerçevesi çizilmiş olan herkesin malî gücüne göre vergi ödemesini ve gelir dağılımında adaleti sağlamak, verginin sosyal amacıdır.

E-vergileme uygulaması mükelleflerin yasal zorunluluklarını yerine getirirken kolaylık sağlamasıyla birlikte, elde edilen bilgilerin diğer kurumlardan elde edilen bilgilerle değerlendirilmesi vergi toplama fonksiyonlarını etkin hale getirmiştir.

Elektronik defter, kayıt ve belgelerin oluşturulması, kaydedilmesi, iletilmesi, muhafazası ve ibrazı ile defter ve belgelerin elektronik ortamda tutulması ve düzenlenmesi uygulamasına ilişkin usul ve esasları belirlenmesine, elektronik ortamda tutulmasına ve düzenlenmesine izin verilen defter ve belgelerde yer alması gereken bilgileri internet de dâhil olmak üzere her türlü elektronik bilgi iletişim araç ve ortamında Maliye Bakanlığına veya Maliye Bakanlığının gözetim ve denetimine tâbi olduğu ifade edilmiştir. Gelir İdaresi Başkanlığı'nın vergi yönetimi kapsamında yaptığı çalışmalar son yıllarda büyük bir ilerleme kaydetmiştir. Kayıt dışılığın önlenmesinde etkin vergi denetimi önemle üzerinde durulması gereken bir konudur. Bilişim teknolojilerinden faydalanılması denetim uygulamalarına da etkinlik kazandırmıştır.

Elektronik ortamda denetime imkan veren, Maliye Teftiş Kurulu Denetim Bilgi Sistemi Projesi (MTK DEBİS) ve Maliye Bakanlığı'nın yapmış olduğu tüm mali ve mali olmayan işlemleri elektronik ortama taşımak amacıyla Maliye SGB.net Projesi gibi projeler yürütülmektedir (Çetin 2010). İş ve işlemlerin bilişsim teknolojileri kullanılarak otomasyona dayalı bir şekilde gerçekleştirilmeye başlanmasıyla birlikte iş ve işlemlerin elektronik olarak denetimi zorunluluğu ortaya çıkmıştır.

\section{Sonuç ve Değerlendirme}

Günümüzde küreselleşme ve çok uluslu şirketlerin artmasıyla birlikte vergi denetimi güçleşmektedir. Denetimin etkinliği bilişim teknolojilerindeki gelişmeler sayesinde artmaktadır. Vergi kayıplarını azaltmak için bilişim teknolojilerinden faydalanılarak yeni denetim yöntem ve teknikleri geliştirmek ve dünyada ki yeni uygulamaları takip etmek gerekmektedir. E-defter ve e-faturanın evrensel standart bir veriye göre oluşturulması hem Türkiye'de hem de uluslararası alanda her türlü raporlama ve denetim faaliyetleri için şeffaf, esnek ve kolay analiz edilebilir bir çerçeve sunmaktadır. Böylece oluşan standart veriyle başta veri madenciliği olmak üzere her türlü iş zekâsı çalışmaları için çok uygun bir altyapı oluşturarak, akıllı teknolojilerin kullanımı mümkün hale getirmektedir.

Geleneksel denetim yaklaşımları daha çok geçmişe odaklanmaktadır. Denetimlerin günümüzde artık elektronik araçlar üzerinden ve elektronik ortamda yapılıyor olması Kamu Otoritesini de klasik/geleneksel denetimlerden farklı bir denetim faaliyetine başlamaya itmiştir. Öncelikle, denetlenecek elektronik belgenin sıhhatli bir şekilde oluşturulması sağlanmalıdır. Bu aşamadan sonra elektronik belge (e-defter, e-fatura v.s.) üzerinde ilgili mevzuatın ön gördüğü denetimlerin yapılarak zaman ve maliyet tasarrufu kaçınılmaz olacaktır. 
Mükelleflerin yürütmüş oldukları ulusal ve uluslararası faaliyetleri elektronik ortamda yürütmeleri vergi denetimi alanında da büyük kolaylıklar sağlayacaktır. Böylece vergi yükünün adil dağılımı ve etkin denetimden söz etmek mümkün olacaktır.

\section{Kaynakça}

- Alptürk, 2008. Elektronik Denetim Rehberi. Gelirler Kontrolörleri Derneği, İstanbul.

- Bayar, Ülkar, ve Doğan. 2013. Türkiye'de ve Avrupa'da E-Fatura Uygulaması. https://biltek.sanayi.gov.tr (Nisan 16, 2017 tarihinde erişilmiştir).

- Can, ve Kapusuzoğlu. 2005. "Çeşitli Ülkelerde Vergi Denetiminin Organizasyonu ve Çıkarılabilecek Bazı Dersler”, Vergi Dünyası Dergisi, no. 283, s. 22-31.

- C Çetin, Güneş. 2010. "Bilişim Teknolojilerindeki Gelişmelerin Vergilemede Kayıt Düzeni Ve Denetim Uygulamalarına Etkisi”, Ekonomi Bilimleri Dergisi, II, no. 1, s. 79-86.

- EY. 2017. Indirect tax audits in the digital age. http:/www.ey.com/gl/en/services/tax/vat--gst-and-othersales-taxes/ey-ch1-indirect-tax-audits-in-the-digital-age (Nisan 22, 2017 tarihinde erişilmiştir).

- GİB. 2016. Gelir Dairesi Başkanlığ Faaliyet Raporu. http://www.gib.gov.tr (Nisan 20, 2017 tarihinde erişilmiştir).

- Gökçen, ve Özdemir, 2016. “TÜRKIYE’DE MUHASEBE UYGULAMALARINDAN E-Defter ve E-Fatura Uygulaması”, Marmara Üniversitesi Öneri Dergisi, XII, no. 46, s. 137-154.

- Oğuztürk, ve Ünal, 2015. "Türkiye'de Vergi Denetiminde Yeni Dönem”, Akademik Araştırmalar ve Çalışmalar Dergisi, VII, no. 13, s. 207-237.

- Öz, ve Bozdoğan, 2012. "Türk Vergi Sisteminde E-Maliye Uygulamaları”, Süleyman Demirel Üniversitesi Íktisadi ve Ídari Bilimler Fakülte Dergisi, XVII, no. 2, s. 67-92.

- $\quad$ Packman, ve Lopez-Claros, 2017. World Bank Group paying taxes report. http://www.doingbusiness.org/ /media/WBG/DoingBusiness/Documents/Special-Reports/Paying-Taxes2017.pdf (Nisan 16, 2017 tarihinde erişilmiştir).

- Rakıcı, 2011. "Vergi Denetiminin Yeni Yapısı Ve Denetimin Kayıtdışılığı Önleme Fonksiyonu”, ZKÜ Sosyal Bilimler Dergisi, VII, no. 14, s. 343-362.

- Schwab, Klaus, ve Xavier Sala-i-Martín, 2016. The Global Competitiveness Report 2016-2017. http://www3.weforum.org (Mart 20, 2017 tarihinde erişilmiştir).

- Somuncu, 2014. "Yaygın ve Yoğun Vergi Denetimi: Hukukî Yapı ve Uygulamanın Değerlendirilmesi”, Erciyes Üniversitesi İktisadi ve İdari Bilimler Fakültesi Dergisi, no. 43, s. 133-173.

- $\quad$ TÜBİTAK-Bilgem-YTE, 2017. Türkiye'de E-Devlet Genel Görünümü. https://www.dijitaldonusum.gov.tr/wp-content/uploads/2016/12/TUBITAK-BILGEM-YTETurkiyedeEDevletGenelGorunumRaporu2017.pdf (Mart 20, 2017 tarihinde erişilmiştir).

- Yetkiner, 2002, “A.B.D Vergi İdaresince Kullanılan Beyanname Seçim ve Vergi İnceleme Yöntemleri”, Vergi Dünyası Dergisi, no. 250, s. 84-88. 


\title{
Finansal Oranlar Kullanılarak Risk Yönetimi ve Havayolu Sektörü - Bir Uygulama
}

\section{Risk Management and Airline Sector by Using Financial Ratios - An Application}

\author{
Ph.D. Candidate Burcu Sakız (Istanbul Aydın University, Turkey)
}

\begin{abstract}
The growing airline transportation in the world and Turkey in recent years has increased the importance of airline passenger and cargo transportation operations and has brought intense competition in the domestic and international airlines market. Under intense competition, it is of utmost importance to capture the sustainable success of an ever-evolving and growing market by accurately assessing the financial performance and risks of businesses. In addition to the financial ratios generally used in all sectors, a number of indicators specific to the airline industry are used to assess the financial status of companies operating in the airline industry. These ratios and indicators will be calculated to compare for past periods and years, to assess risks for the future, to make forecasts, to report, to be able to see the financial status of the business concerned and to plan and make decisions in a more healthy and accurately. In this paper, after literature review, one of the most important financial risk evaluation model Altman Z" score is examined and an application with Turkish Airlines' quarterly last 3 years financial data is evaluated.
\end{abstract}

\section{Giriş}

Havayolu taşımacılığı hızla globalleşen dünyada ekonomik ve sosyo-kültürel gelişim açısından çok kritik bir faktör haline gelmiştir. Ülke içinde ve dişında sosyal, ekonomik ve politik kararlardan etkilenen bir hizmet sektörü olması özelliğini taşıyan, dünyada yolcu ve/veya yük iletimini sağlayan, küresel, bölgesel ve ulusal ekonomik gelişimde önemli bir rol oynayan havayolu taşımacılığı ulusal ve uluslararası kurallar ile düzenlenerek icra edilmektedir. Özellikle II. Dünya Savaşı'ndan sonra askeri havacılıktan ayrılan sivil havacılık taşımacılığı sektörü son derece hızlı büyüyen sektörlerden bir haline gelmiştir. 1944 yılında kurulan Uluslararası Sivil Havacılık Teşkilatı (International Civil Aviation Organization-ICAO), havayolu taşımacılığı yapan işletmeleri, hava aracı ile bir bedel ya da kira karşılığında taşıma hizmeti sağlayan işletmeler olarak tanımlamaktadır. Taşımacılık sektörünün bir bölümünü oluşturan hava taşımacılığı ise, icra edilme sebebi her ne olursa olsun insan, yük ya da postanın bir hava aracı vasıtası ile yer değiştirmesini sağlayan hizmet olarak tanımlanabilir (Gerede, 2002:9).

Havacılıkta işletmeler Network, Düşük maliyetli, Charter ve Bölgesel havayolları olarak olmak üzere 4 sınıfa ayrılmıştır. Havacılıkta büyümeyi sürdürürken finans fonksiyonu açısından gelir yönetimi yaklaşımı, birim koltuk kilometre üzerinden satış ve maliyet analizleri, maliyetlerdeki çeşitlilik ve artışlar, makro ekonomik düzeydeki parametrelerin faaliyetlere ve finansal yapıya yansıması çalışmaları yapılmaktadır. Zamanla en büyük maliyet kalemi olan personel giderlerinin yanına yakıt maliyetleri de eklenmiştir. Makro-ekonomik gelişmeler başta yakıt maliyetleri olmak üzere, kur, faiz, likidite vb. riskler üzerinde etkili olmaya başlamıştır. Karlılık ve mali yapıdaki bozulmalar, birçok havayolu işletmesinde risk yönetiminin önemini ortaya çıkartmıştır(Karaer,2015).

Havacılık sektörüne özel yapılan çeşitli çalışmalarda analistler, işletmeler için ana olarak üç temel faktör üzerinde odaklanılan modeller geliştirmeye çalışmışlardır. Söz konusu üç temel faktör kaynaklar (işgücü, sermaye, yakıt), üretilen çıktı (araç/saat, araç/km) ve hizmetin tüketimidir (yolcu sayısı, yolcu/km, faaliyet gelirleri v.b). Bu faktörler yardımıyla kaynakların verimli kullanımı yani kullanılan girdi ve çıktı arasındaki ilişsi ve üretilen hizmetin verimliliği (üretilen hizmet miktarı ile tüketilen hizmet miktarı arasındaki ilişki) ölçülmeye çalışılmaktadır. Ancak belirtilen bu modelden yararlanarak işletmelerin finansal performansı ve ulaştırma hizmeti arasında bir ilişsinin kurulması oldukça zorlaşmaktadır. İşgücü, uçak sayısı (filo), yer hizmetleri için kullanılan varlıklar ve sermaye gibi girdiler karşısında yapılan uçuş ve yolcu sayısı elde edilen çıktılar arasındaki ilişkinin doğru anlaşılması performansın doğru değerlendirilmesine katkı sağlayacaktır. Doğrudan havayolu endüstrisine ilişkin oranların eksikliği bu endüstride faaliyet gösteren işletmelerin doğru bir biçimde değerlendirilmesi imkanını sinırlandırmaktadır (Akkaya,2004).

\section{Literatür Araştırması}

İşletmelerin finansal performanslarının değerlendirilmesinde genellikle kullanılan yöntemler yüzde yöntemi ile analiz, finansal tabloların karşılaştırmalı analizi, trend analizi ve oran analizi gibi yöntemlerdir. Finansal risk yönetimi, finansal göstergelerin işletmelerin özel durumlarıyla ilişkilendirilmesi ile alınan kararların devamlı gözden geçirilmesi, gerekiyorsa yeni önlemlerin alınması şeklinde dinamik bir süreci içermektedir (Sayılgan, 1995: 324). Finansal risklerin ve başarısızlığın önceden tahminine ilişkin yapılan çalışmalar işletmelerin, 
devletlerin, ilgililerin, yöneticilerin, yatırımcıların ve kredi kuruluşlarının yararına olmaktadır (Brealey, Myers, Marcus, 2007).

Finansal başarısızlık ve iflaslara yönelik çalışmalarda Beaver (1966) ve Altman (1968) isimleri öne çıkmaktadır. Beaver çeşitli muhasebe rasyolarının işletmelerin iflasını tahmin etmedeki başarısı araştırmış; iflastan beş yıl öncesine kadar, iflas eden işletmelerin finansal oranlarının, etmeyen işletmelere göre daha iyi olmadıklarını belirlemiştir. Temel olarak Beaver tek boyutlu (finansal başarısızlık tek bir değişkene bağlı), Altman ise çok boyutlu tahmin modellerini kullanan çalışmalar yapmıştır. Yazarlar çalışmalarında muhasebe verilerini kullanmışlar ve oran analizlerinden yararlanmışlardır (Atan \& Güneş, 2004:3). Usatoday'da yayınlanan bir makaleye göre, Oklahoma Eyalet Üniversitesi ile Portland Eyalet Üniversiteleri'nin ortaklaşa yürüttüğü bir çalışmada, riskten korunma işlemi yapan havayolu işletmelerinin, hiç yapmayanlara göre 5\% - 10\% oranında daha iyi finansal performansa sahip oldukları gözlemlenmiştir (Usatoday, 2016).

Literatürdeki çalışmalara bakıldığında çalışmaların birçoğunda araştırmacıların finansal başarısızlığı, iflasa başvurmuş olma biçiminde tanımladıkları görülmektedir. Ancak iflas durumunun yanı sıra yükümlülüklerin karşılanamaması, borç ve veya faizlerinin ödenememesi gibi durumlar da işletmenin finansal başarısızlık içinde olduğunu gösteren haller olarak kabul edilmektedir (Özdemir, Choi, Bayazıtl1, 2012). Gritta v.d (2008)'e göre finansal risk değerlendirme ve iflas durumunu tahmin etme modelleri olarak havayollarının kullanabileceği 6 tane ana model bulunmaktadir:

- Altman Model (Z-score)

- Altman Zeta Model

- Airscore Model

- $\quad$ Pilarski Model (P-score)

- Gudmunsson Model

- Yapay Zeka Modelleri

$\mathrm{Bu}$ modellerden Altman tarafindan geliştirilen ilk iki model her sektöre uygulanabilen modeller olurken, diğerleri havayolu endüstri için geliştirilmiş havayolu verileri ile kullanılan modellerdir. Modellerde kullanılan finansal, karma ve finansal olmayan parametreler ve oranlar aşağıdaki tabloda özetlenmiştir (Gritta vd., 2008:194).

\begin{tabular}{|c|c|c|c|c|}
\hline Altman Modeli & $\begin{array}{l}\text { Altman Zeta } \\
\text { Modeli }\end{array}$ & $\begin{array}{l}\text { Airscore } \\
\text { Model }\end{array}$ & Pilarski Model & $\begin{array}{l}\text { Gudmunsson } \\
\text { Model }\end{array}$ \\
\hline $\begin{array}{l}\text { Çalışma sermayesi / } \\
\text { Toplam Varlıklar }\end{array}$ & $\begin{array}{l}\text { Faiz ve vergi } \\
\text { öncesi kar / } \\
\text { Toplam } \\
\text { Varlıklar }\end{array}$ & $\begin{array}{l}\text { Faiz / Toplam } \\
\text { yükümlülükler }\end{array}$ & $\begin{array}{l}\text { Faaliyet Geliri / } \\
\text { Toplam Varlıklar }\end{array}$ & Doluluk Oranı \\
\hline $\begin{array}{l}\text { Alıkonmuş karlar / } \\
\text { Toplam Varlıklar }\end{array}$ & $\begin{array}{l}\text { Çalışma } \\
\text { sermayesi / } \\
\text { Toplam } \\
\text { Varlıklar } \\
\end{array}$ & $\begin{array}{l}\text { Mil başına } \\
\text { faaliyet geliri }\end{array}$ & $\begin{array}{l}\text { Alıkonmuş karlar / } \\
\text { Toplam Varlıklar }\end{array}$ & $\begin{array}{l}\text { Kalkış başına } \\
\text { yolcu sayısı }\end{array}$ \\
\hline $\begin{array}{l}\text { Faiz ve vergi öncesi } \\
\text { kar / Toplam Varlıklar }\end{array}$ & Borçlar & $\begin{array}{l}\text { Özkaynaklar / } \\
\text { Toplam } \\
\text { yükümlülükler }\end{array}$ & $\begin{array}{l}\text { Özkaynak / Toplam } \\
\text { yükümlülükler }\end{array}$ & $\begin{array}{l}\text { Pilot başına } \\
\text { uçulan saat }\end{array}$ \\
\hline $\begin{array}{l}\text { Toplam Piyasa } \\
\text { Değeri / Toplam } \\
\text { Yükümlülükler }\end{array}$ & $\begin{array}{l}\text { Alıkonmuş } \\
\text { karlar / Toplam } \\
\text { Varlıklar }\end{array}$ & & $\begin{array}{l}\text { Dönen Varlıklar / } \\
\text { uzun vadeli borçlar }\end{array}$ & $\begin{array}{l}\text { Uçak başına } \\
\text { düşen kalkış } \\
\text { sayısı }\end{array}$ \\
\hline \multirow[t]{6}{*}{$\begin{array}{l}\text { Toplam Satışlar / } \\
\text { Toplam Varlıklar }\end{array}$} & Cari oran & & $\begin{array}{l}\text { Faiz ve Vergi } \\
\text { Öncesi Kar / } \\
\text { Faaliyet geliri }\end{array}$ & $\begin{array}{l}\text { Uçak başına } \\
\text { düşen pilot } \\
\text { sayısı }\end{array}$ \\
\hline & $\begin{array}{l}\text { Özkaynak / } \\
\text { Borçlar }\end{array}$ & & & $\begin{array}{l}\text { Uçak başına } \\
\text { düşen personel }\end{array}$ \\
\hline & $\begin{array}{l}\text { Şirket } \\
\text { büyüklüğü }\end{array}$ & & & $\begin{array}{l}\text { Filonun } \\
\text { ortalama yaşı }\end{array}$ \\
\hline & & & & Enflasyon Oranı \\
\hline & & & & Uçak tipleri \\
\hline & & & & Politik Etki \\
\hline
\end{tabular}

Tablo 1. Gritta v.d(2008)'e göre Altman Modeli, Altman Zeta Modeli, Airscore Model, Pilarski Model, Gudmunsson Model Parameter ve Oranları. Kaynak : Gritta v.d (2008)

Finansal risk değerlendirme ile ilgili kullanılan göstergelerle ilgilenen taraflara göre çeşitli sınıflandırmalar da yapılmaktadır. Finansal performans açısından takip edilmesi gereken finansal göstergeler ve oranlar araştırmacı Erich Helfert (2001) tarafından yöneticiler, sahipler ve borç verenler açısından üçe ayrılmaktadır. Helfert'e göre sınıflandırmaya konu olan parametreler aşağıdaki tabloda verilmiştir. 


\begin{tabular}{|c|c|c|}
\hline Yönetim & Sahipler & Borç Verenler \\
\hline Operasyonel Analizler & Yatırımın Getirisi & Likidite \\
\hline Brüt Kar Marjı & Özsermaye Getirisi & Cari Oran \\
\hline Kar Marji & Özsermaye verimliliği & Asit-Test Oranı \\
\hline $\begin{array}{l}\text { Faiz ve vergi öncesi kar(FVÖK), Faiz, vergi, } \\
\text { amortisman öncesi kar (FAVÖK) }\end{array}$ & Hisse Başı Kazanç & Çabuk Satış Değeri \\
\hline Vergi Sonrası net işletme Karı & Hisse Başı Nakit Akışı & \\
\hline Faaliyet gider analizi & Hisse bedeli fiyat Artışı & \\
\hline Katk1 analizi & Toplam Özkaynak Getirisi & \\
\hline \multicolumn{3}{|l|}{ Faaliyet Kaldıracı } \\
\hline \multicolumn{3}{|l|}{ Karşılaştırmalı Analiz } \\
\hline Kaynak Yönetimi & Kazançların Kullanımı & Finansal Kaldıraç \\
\hline Varlık devir hızı & Hisse Başına Kar Payı & Borç/Varlık Oranı \\
\hline Çalışma Sermayesi Yönetimi & Temettü Getirisi & Borç/kapitalizasyon Oranı \\
\hline Envanter devir hizı & Kazançların Ödenmesi & Borç/Özsermaye Oranı \\
\hline Alacaklılar Hesaplarını takibi & Temettü Teminatı & \\
\hline Borç Hesaplarının takibi & Temettülerin varlıklara oranı & \\
\hline \multicolumn{3}{|l|}{ İnsan Kaynaklarının etkinliği } \\
\hline Karlilik & Pazar Performans1 & Borç Durumu \\
\hline Aktif Karlılığ1 (vergi sonrası) & Fiyat/Kazanç Oranı & Faiz Karşılama Oranı \\
\hline Vergi ve Faiz öncesi Karlılık & Nakit Akış Çarpanları & Genel Gider Yükü \\
\hline Cari Değer Getirisi & Piyasa değeri defter değeri oranı & Sabit-Değişken yükler \\
\hline Firma Katma Değeri ve Ekonomik Kar & Göreceli Fiyat Hareketleri & Nakit Akım analizi \\
\hline Nakit Akış Yatırım getirisi & Değer Yaratan Etkenler & \\
\hline Serbest nakit akımı & Firma Değeri & \\
\hline
\end{tabular}

Tablo 2. Yönetim, Sahipler ve Borç Verenler Açısından Finansal Performans Parametreleri. Kaynak: Helfert (2001)

Morrell (2013) in yaptığı araştırmaya ve hesaplamalara göre ise havayolu işletmelerinde finansal göstergeler dört kategoride sınıflandırılmaktadır. Bunlar performans/kazanç oranı, ödeme gücü oranları, likidite oranları, yatırım oranlarıdır. Detaylar aşağıdaki tabloda verilmiştir.

\begin{tabular}{|l|l|}
\hline Finansal Gösterge Sınıfı & Açılama \\
\hline Performans/kazanç oranı & $\begin{array}{l}\text { Operasyonel gelir, net kâr marjı, yatırım sermayesi getirisi, özsermaye } \\
\text { kârlılık oranı finansal performans göstergelerini içerir }\end{array}$ \\
\hline Ödeme gücü oranları & $\begin{array}{l}\text { Gelirin faizi karşılama oranı ve borç/özsermaye oranı finansal } \\
\text { performans göstergelerini içerir. }\end{array}$ \\
\hline Likidite oranları & Cari oran ve asit test oranı finansal performans göstergelerini içerir. \\
\hline Yatırım (pazar değerleme) oranları & $\begin{array}{l}\text { Temettü karşılığı, piyasa kapitalizasyonu, hisse başına kazanç oranı, } \\
\text { fiyat/kazanç oranı, hisse başına net varlık değeri finansal performans } \\
\text { göstergelerini içerir. }\end{array}$ \\
\hline
\end{tabular}

Tablo 3. Havayolu Işsletmeleri için Finansal Oranlar Kaynak: Morrell (2013)

Literatür araştırmasından görüleceği üzere finansal performans ve risk belirleme için kullanılması gereken parametre ve anahtar başarı göstergelerini belirlemede varılmış bir görüş birliği yoktur. Araştırmacıların bazıları sadece finansal veriler ile değerlendirme yaparken bazıları performans değerlendirme ve geleceğe yönelik tahmin yapabilmek için finansal olmayan verilerden yararlanmaktadır. Bir kısım araştırmalara göre ise bu veriler hep birlikte kullanıldıklarında daha sağlıklı sonuçlar alınmaktadır.

Altman modeli, finansal başarısızlık tahmini konusunda yapılan ilk ve en önemli çalışmalardan biri olarak kabul edildiğinden bu çalışma kapsamında ayrıntı ile ele alınmış, uygulama kısmında, Türk Hava Yolları Anonim Ortaklığına ait son 3 seneyi içeren Altman Z" değerleri hesaplanmıştır. 


\section{Altman Modeli}

Finansal başarısızlık tahmin çalışmalarında dönüm noktası olan çalışma 1968 yılında Altman'ın yaptığı çalışma olmuştur. Finansal başarısızlık tahmini çalışmalarında çoklu diskriminant analizini ilk kullanan 1968 yılında Edward Altman olmuştur. 1968 yılında Z skor modelini geliştiren Altman’ın bu çalışması yıllar boyunca pek çok çalışmada kullanılmıştır. Diskriminant modelinin amacı hatalı sınıflandırma olasılığını en aza indirmek ve değişkenlerin ait oldukları gruplara ayrılmasını sağlamaktır. Diskriminant fonksiyonu ile bağımsız değişkenlerin yani finansal oranların doğrusal bileşimi oluşturularak bireylere ya da birimlere ait tüm değişkenler tek bir diskriminant değerine dönüştürülmektedir. Bu değer ya da skora dayanılarak işletme faaliyetleri ile ilgili tahmin ve yorumlarda bulunma imkânı doğmaktadır. İşletmeler için bulunan diskriminant değeri, kritik değerin solunda yer alıyorsa işletme başarısız olan işletmeler grubuna, sağında yer alıyorsa başarılı işletmeler grubuna dâhil edilmektedir. Altman, finansal başarısızlığı(iflası) öngörmede, tek değişkenli modellerin finansal oranları tek tek dikkate almalarını eleştirmiştir yani ona göre bir işletmenin finansal oranlarından bazılarının gösterdiği istikrara veya performansa bakılarak, işletmenin finansal başarısızlık potansiyeli taşıdığını söylemek her zaman mümkün olmamaktadır. Çünkü işletmenin bazı finansal oranları kötü bir performans sergilerken, diğer finansal oranları oldukça iyi durumda olabilir ve işletme gerçekten finansal başarısızlık potansiyeli taşımadığı halde, finansal başarısızlık riski bulunduğu sonucu çıkartılabilir. Altman, bu eksikliğin modelin tek boyutlu olmasından kaynaklandığını ileri sürerek çok boyutlu bir model geliştirmeye çalışmıştır (Çelik,2009).

New York Üniversitesinde görevli olan akademisyen Edward Altman tarafından 1968 yılında ortaya atılan teori, işletmelerin içerisinde bulunduğu mali sıkıntıyı ölçümleyip iflasa yakınlığını ortaya koymaktadır. Altman finansal oranlara yöneltilen eleştirilerin oranların yetersizliğindense ayrı ayrı değerlendirilmesinden ötürü çelişkili sonuçlar ortaya çıkmasından kaynaklandığını belirtmiştir. Çözüm olarak bunların birbirleri ile etkileşimlerinin dikkate alınarak birleştirilmesi gerektiğini öne sürmüş, 22 finansal oranı likidite, karlılık, kaldıraç, ödeyememe ve faaliyet oranları olmak üzere toplam beş kısma ayırmıştır ve model oluşturmuştur (Altman,1968). Altman çalışmasında iki grubu incelemiştir. Birinci grupta, 1946-1965 döneminde ulusal iflas kanununa göre iflas talebinde bulunmuş olan imalatçı firmaları ele almıştır ve çalışmasında çok değişkenli istatistik analiz yöntemi olan "çoklu diskriminant analizini” kullanmıştır. Bu yöntemle yaptığı finansal başarısızlık tahminine yönelik çalışmasında, finansal başarısızlık kavramı yerine "iflas" kavramını kullanmıştır. Çalışmasında yer verdiği işletmelerin aktifleri 0,7 milyon dolar - 25,9 milyon dolar arasında değişmektedir ve ortalaması yaklaşık 6,4 milyon dolardır. Bu grup, endüstri ve büyüklükleri açısından tamamen homojen değildir. İkinci grup, rasgele seçilmiş imalatçı işletmelerin eşlemeli bir örneklemesini içerir. Aktifleri 1-25 milyon \$ ile sınırlı olan işletmeler endüstri gruplarına ve büyüklüklerine göre sınıflandırılmıştır (Altman, 1968).

Çalışmasında çok değişkenli diskriminant analizini kullanmıştır. 33 iflas etmiş, 33 iflas etmemiş imalat sektöründe faaliyet gösteren toplam 66 işletmeyi baz alınmıştır. 5 tane oranı içeren tahmin modeli ile başarısızlığ ölçmüştür. Çalışma sırasında istatistik teknikler kullanarak, her bağımsız değişkenin açıklama gücü, değişkenler arasındaki karşılıklı ilişkiler, bağımsız değişkenlerin modelin doğruluğuna olan katkıları ve kendi yargılarıyla bu değişken sayısı 5 'e indirilmiştir. Altman'ın analiz için belirlediği oranlar ve diskriminant fonksiyonu şu şekildedir:

$\mathrm{Z}=1.2 \mathrm{~T}_{1}+1.4 \mathrm{~T}_{2}+3.3 \mathrm{~T}_{3}+0.6 \mathrm{~T}_{4}+0.999 \mathrm{~T}_{5}$

- $\quad \mathrm{T}_{1}=$ Çalışma sermayesi / Toplam Varlıklar: İşletmenin büyüklüğü ile likit varlıkları arasındaki ilişkiyi gösterir, yani toplam varlıklara göre dönen varlıklardaki azalmayı yansıtır. Likiditeyi ve büyüklük özelliğini dikkate alır. Dönen varlıklardan kısa vadeli borçlar çıkarıldıktan sonra elde edilen sayının toplam varlıklara bölünmesi ile bulunur.

- $\quad \mathrm{T}_{2}=$ Alıkonmuş karlar / Toplam Varlıklar: İşletmenin köklülüğü ve gelir yaratma becerisini gösterir. Firmanın faaliyette bulunduğu süre içindeki kazanma gücünü yansıtan karlılığı ölçmektedir. Bu nedenle faaliyette bulunan döneme karşı duyarlıdır.

- $\quad \mathrm{T}_{3}=$ Faiz ve vergi öncesi kar / Toplam Varlıklar: İşletmenin operasyonel karlılı̆̆ını gösterir. Vergi ve kaldıraç etkisi olmadan faaliyet etkinliğini ölçmektedir. Uzun dönemli ayakta olma durumunun göstergesi olan faaliyet kazançlarını gösterdiğinden özellikle finansal başarısızlıkla karşılaşan işletmeler için önemlidir.

- $\quad \mathrm{T}_{4}=$ Toplam Piyasa Değeri / Toplam Yükümlülükler: Piyasanın bakış açısını da dikkate alarak işletmenin değerine olan algıyı ölçer. Bu firma varlıklarının ne kadar düşebileceğinin ölçüsüdür ve tehlike sinyali olduğunda güvenli fiyat dalgalarını yansıtan piyasa boyutunu göstermektedir.

- $\quad \mathrm{T}_{5}=$ Toplam Satışlar / Toplam Varlıklar: Varlık devir hızını ortaya koymaktadır. Firma varlıklarının satışlara dönüştürme gücünü ölçen standart toplam varlık devir hızıdır. Endüstriden endüstriye büyük farklılıklar göstermekle birlikte rekabetçi şartlarla mücadelede yönetimin kabiliyetini göstermektedir.

Formülden görüldüğü üzere Altman rasyoları katsayılandırarak bir değer elde etmiştir. Eğer Z-score değeri,

- $\quad>2.99$ ise işletme güvenli alanda,

- $1.81<\mathrm{Z}<2.99$ ise işletme gri alanda,

- $\quad<1.81$ ise işletme sıkıntı alanındadır (iflas olasılıklı) sonucuna varılmaktadır. 
Altman işletmelerin iflasından bir yıl öncesi için \%95, ikinci yıl için ise \% 83 oranında doğru sınıflama yapmıştır. İflastan 3,4 ve 5 yıl öncesi için bu oran sırasıyla \%48, \%29, \%36 olarak bulunmuştur. Bu veriler modelin tahmin etme gücünün 3 yıl öncesinden itibaren önemli ölçüde azaldığını ortaya koymaktadır (Altman, 1968).

1977 yılında Altman, Haldeman ve Narayanan, Altman'ın Z Skor modeline yeni bir yaklaşım getirerek Zeta Modelini geliştirmiştir. Yeni bir model geliştirilmesinin en büyük sebeplerinden biri olarak geçmiş yıllardan farklı olarak firmaları iflasa sürükleyen sebeplerin farklılaşmış olabileceği gösterilmiştir. Yapılan çalışmada; ABD'de faaliyet gösteren, 53 başarısız firma ve 58 başarılı firmanın 1969-1975 yılları arasındaki finansal oranları kullanılmıştır. Zeta modeli kurulurken analiz yöntemi olarak ise Z Skor modelinde olduğu gibi çoklu diskriminant analizi yöntemi kullanılmıştır. Zeta modeli, başlangıçta 27 değişkenle oluşturulmuş ve diskriminant analizi 7 değişkenle tamamlanmıştır. Zeta modelinde yer alan finansal oranlar Net Kar / Toplam Varlıklar, Faiz ve Vergi Öncesi Kar / Toplam Varlıklar, Faiz ve Vergi Öncesi Kar / Faiz Ödemeleri, Dağıtılmamış Karlar / Toplam Varlıklar, Cari Oran, Özsermaye / Uzun Vadeli Yabancı Kaynaklar, Toplam Varlıklar'dır (Altman vd., 1977).

Altman'ın çalışmasını takiben, 1980'li yıllara kadar diskriminant analizi finansal başarısızlık tahmin alanına hakim olmuştur. Farklı veriler ve farklı değişkenler üzerinde diskriminant analizini kullanan pek çok çalışma yapılmıştır. Burada dikkat edilmesi gereken nokta, Altman'ın çalışmasında kullanılan oranlar imalat sektöründe faaliyet gösteren şirketler için hazırlandığından ulaştırma gibi hizmet sektöründe faaliyet gösteren işletmeler için uygulanabilirliğe sahip olmamasıdır. Altman çalışmasında modelini tüm işletmelere uygulanamama gibi aldığı eleştirilerden sonra modelini geliştirmiştir. Z' modelini özel endüstri firmaları için, Z" modelini de imalatçı olmayan ve hizmet işletmeleri için geliştirmiştir (Altman, 2000:14). Z' skor ve Z" skor formülleri aşağıda gösterildiği şekilde ifade edilmektedir:

$$
\text { Z' Skor }=0.717 \mathrm{~T}_{1}+0.847 \mathrm{~T}_{2}+3.107 \mathrm{~T}_{3}+0.42 \mathrm{~T}_{4}+0.998 \mathrm{~T}_{5} \text { (özel endüstri işletmeleri) }
$$

$Z "$ Skor $=6.56 \mathrm{~T}_{1}+3.26 \mathrm{~T}_{2}+6.72 \mathrm{~T}_{3}+1.05 \mathrm{~T}_{4}$ (özel imalat işletmesi olmayan işletmeler)

Z" skor modelinde, T5 değişkeni çıkartılarak potansiyel endüstrinin etkisinin minimize edilmesi sağlanıp işletme türünün etkisi olmadan kredi risk değişiminin ölçülmesi amaçlanmıştır. Değişkenlerin diskriminant analizine uygun olup olmadığını ölçmek için Altman " $F$ " testi ve daha sonra kuadratik diskriminant analizi uygulamıştır. Hesaplanan değerleri işletmenin güvenli alanda mı, gri alanda mı yoksa sıkıntılı alanda mı olduğunu anlamak için aşağıda verilen kriterlere göre değerlendirme yapılmaktadır.

Eğer hesaplanan Z'-score değeri,

- $\quad>2.9$ ise işletme güvenli alanda,

- $1.23<\mathrm{Z}<2.9$ ise işletme gri alanda,

- $\quad<1.23$ ise işletme sıkıntı alanındadır sonucuna varılmaktadır.

Eğer hesaplanan Z"'-score değeri,

- $>2.6$ ise işletme güvenli alanda,

- $1.1<\mathrm{Z}<2.6$ ise işletme gri alanda,

- $<1.1$ ise işletme sıkıntı alanındadır sonucuna varılmaktadır.

1980'li yıllarda araştırmacılar finansal başarısızlık tahmin çalışmalarında lojistik ve probit regresyon analizi gibi koşullu olasılık modellerini kullanmaya başlamışlarıdır. 1980 yılında Ohlson'un ve 1982 yılında Zavgren'in yaptığ çalışmalar finansal başarısızlığın tahmininde lojistik regresyon modelini kullanan ilk çalışmalardır. Bu dönemde zaman serileri ve piyasa değişkenleri ile yapılan finansal başarısızlık tahmini çalışmaları da olmasına rağmen uzunca bir süre yapılan çalışmalarda çoklu diskriminant analizi ve lojistik regresyon çalışmaları kullanılmıştır. 1990'lı yıllarda yapay zeka çalışmalarının gelişmesi paralelinde, finansal başarısızlık tahmin çalışmalarında kullanılan modellere, yapay sinir ağları modelleri de eklenmiştir. Yapay sinir ağları ile finansal başarısızlık tahmini yapan ilk çalışma Odom ve Sharda tarafından 1990 yılında yapılmıştır. Son yıllarda hem yapay sinir ağları modelleri ile yapılan finansal başarısızlık tahmin çalışmaları hem de yapay sinir ağları ve diskriminant analizi ve regresyon analizi modellerini karşılaştıran çok sayıda çalışma ortaya çıkmıştır. Günümüzde finansal başarısızlık tahmininin öneminin giderek artması sonucu başarısızlığı doğru tahmin eden en iyi modele ulaşma çabaları hızlanmış ve denetimli ögrenme içeren yapay zeka modelleri ile tahmin yapan çalışmalar ortaya çıkmıştır (Akgün, 2013).

Altman Z skor modeli işletmelerin olası iflas durumlarını tahmin etmeye, öngörmeye yönelik geliştirilmiş bir model olması ile birlikte, şirketlerin finansal güçlerini değerlendirmede ve kredi sağlayıcılar ile borç verenlerin yatırım kararlarını vermelerine yardımcı olabilecek bir yaklaşım olarak da kabul edilmektedir (Hauschild, 2013).

\section{Havayolu Taşımacılığı ve Türkiye}

Havayolu taşımacılığının gelişimi sanayi devriminden sonra 20. yüzyılın başına denk gelmektedir. Uluslararası ilk havayolu taşımacılığı zeplinler ile başlamıştır ancak zamanla yerlerini uçaklar almıştır. İlk tarifeli havayolu 
taşımacılığ 5 dolar ücret ile tek yön olarak Tampa - St. Petersburg arasında Amerika Birleşik Devletlerinde 1914 yılında icra edilmiştir John. G. Wensveen (2007), hava ulaştırma sektörünün gelişimini 4 dönemde ele almıştır:

- Gelişme (1918-1938)

- Büyüme (1938-1958)

- Olgunluk (1958-1978)

- Liberalleşme (1978-...) sonrası dönemler.

Gelişme döneminde daha çok askeri alanda sanayileşen bir sektör olan havacılıkta yıllar içerisinde sivil hava taşımacılığı yolcu taşımacılığına yönelik uçakların üretimiyle ilk yolcu taşımacılığına başlanmıştır. Büyüme döneminde uzun menzilli ve her hava şartına uçabilen tarifeli hava taşımacılığına başlanmıştır. Olgunluk döneminde havaalanları ve uçaklardaki teknolojik ilerlemeler sayesinde yolcu sayısı çok büyük oranda artış göstermiş, havayolu taşımacılığı en hızlı ve güvenli ulaşım yolu haline gelmiştir. Liberalleşme (serbestleşme) döneminde Amerikan hükümeti tam rekabete izin vermiştir. Ülkeler artan rekabet ortamında etkin ve verimli çalışabilmeleri için havayolu işletmelerinin özelleşmesini desteklemektedir. Amerika'daki gelişmeleri izleyen Avrupa'da 1980'lerin sonunda başlayan liberalleşme süreci 1993'te tamamlanmıştır (Wensveen, 2007).

Taşımacılık alanında havayolu taşımacılığı incelenirken gelişime bakılmak istendiğinde başvurulan ilk göstergelerden biri taşınan yolcu sayılarıdır. Dünyadaki havayolu şirketlerince taşınan yolcu sayılarının çeşitli kaynaklarda farklı rakamlarla ifade edildiği görülmektedir. ICAO (Uluslararası Sivil Havacılık Teşkilatı)'nun web sitesindeki verilerine göre 1950'lerde yıllık 100 milyon olan tarifeli yolcu hareketi, 1976 yılında 1 milyara, 2010 yılında da 5,126 milyara ulaşmıştır. Fakat bu sayı çift yönlü trafiği göstermekte olduğundan gerçek tarifeli yolcu sayısı yaklaşık 2,5 milyar olarak düşünülmelidir. Dünya yolcu trafiğinin \%84'ünü sağlayan 126 ülkeden 230 havayolu şirketinin üye bulunduğu IATA (Uluslararası Hava Taşıyıcılar Birliği) 2010 yılı tarifeli yolcu sayısını 1,78 milyar olarak vermiştir. 179 ülkeden 1.650 havaalanının üye olduğu ACI (Uluslararası Havaalanları Konseyi) ise 2010 yılı toplam yolcu sayısını 2,5 milyar olarak ifade etmektedir. Yolcu sayısındaki bu farklılıklar, ICAO, IATA ve ACI'ın esas aldığı bilgi kaynaklarından oluşmaktadır.

Havayolu sektöründe 2010-2015 yılları arasındaki finansal ve operasyonel veriler ve tahminler IATA ve ACI tarafından aşağıdaki gibi yapılmıştır.

\begin{tabular}{|l|r|r|r|r|r|r|}
\hline \multicolumn{7}{|c|}{ Havayolu Sektöründe Son 5 yıl } \\
\hline Küresel Endüstri & $\mathbf{2 0 1 0}$ & $\mathbf{2 0 1 1}$ & $\mathbf{2 0 1 2}$ & $\mathbf{2 0 1 3}$ & $\mathbf{2 0 1 4}$ & $\mathbf{2 0 1 5 f}$ \\
\hline Net Kar & 17,3 & 8,3 & 6,1 & 10,6 & 19,9 & 25 \\
\hline Kar Marjı & 3,1 & 1,3 & 0,9 & 1,5 & 2,7 & 3,2 \\
\hline Faaliyet Karı & 27,6 & 19,8 & 18,4 & 25,3 & 38,3 & 46,8 \\
\hline Faaliyet Kar Marjı & 4,9 & 3,1 & 2,6 & 3,5 & 5,1 & 6 \\
\hline Uçuş Sayısı (milyon) & 27,8 & 30,1 & 31,2 & 32 & 33,4 & 35,4 \\
\hline Yolcu Başına Net Kar & 6,45 & 2,92 & 2,05 & 3,38 & 6,02 & 7,08 \\
\hline Yolcu Sayısı(milyon) & 2,681 & 2,845 & 2,977 & 3,314 & 3,306 & 3,53 \\
\hline Yolcu Sayısında Artı̧ & 7,9 & 6,3 & 5,1 & 5,4 & 5,7 & 7 \\
\hline Yolcu Doluluk Oranı & 78,5 & 78,4 & 79,4 & 79,7 & 79,9 & 79,6 \\
\hline Yatırım Sermayesi Getirisi & 6,3 & 4,7 & 4,3 & 4,9 & 6,1 & 7 \\
\hline
\end{tabular}

Tablo 4. Havayolu Sektöründe Son 5 Yll Kaynak: ACI, IATA

Türkiye'de ilk uçak ile yapılan uçuşlarının 1911 yılında gerçekleştiği görülse de sivil havacılık faaliyetlerinin başlangıcı olarak 1925 yılında Türk Tayyare Cemiyeti’nin (bugün ki ismi ile Türk Hava Kurumu) kuruluşu gösterilebilir. Milli Savunma Bakanlığı’na bağlı Hava Yolları Devlet İşletmesi'nin 1933 yılında kurulmasıyla, havaalanı ve havayolu işletmeciliği faaliyetleri başlamıştır. Hava Yolları Devlet İşletmesi, bugünkü Devlet Hava Meydanları İşletmesi (DHMİ) Genel Müdürlüğü ve Türk Hava Yolları (THY) A.O.'nun bünyesini oluşturmuştur. 1933 yılında kurulan Türk Hava Yolları A.O.'nun (“THY” veya “(Ana) Ortaklık”) ana faaliyet konusu yurtiçi ve yurt dişında yolcu ve kargo hava taşımacılığı yapmaktır (Thy,2016).

Sivil havacılık genel müdürlüğ̈̈ne(SHGM) ait "http://web.shgm.gov.tr/tr/kurumsal/1--tarihce" adresli internet sitesindeki bilgilere göre, SHGM, ülkemizde sivil havacılık faaliyetinde bulunacak Türk ve yabancı gerçek veya tüzel kişilere verilecek izin, belge ve lisanslar ile denetimler ve önlemler konusunda da yetkilidir. Ayrıca Türk hava sahasını kullanan sivil hava araçlarının uyması gereken hava trafik yönetim hizmetleriyle ilgili düzenlemeler yapmak da SHGM yetkisi kapsamında olup ülkemiz hava trafik yönetim hizmetleri DHMİ Genel Müdürlüğü tarafından sağlanmaktadır. DHMİ tarafından Türkiye hükümran hava sahası ve toprakları üzerinde $1.206 .000 \mathrm{~km}^{2}$ hava sahası dâhilinde sivil havacılık faaliyetlerinin gereği olan hava seyrüsefer hizmetleri [hava trafik yönetimi 
(ATM); hava trafik kontrol (ATC), hava sahası yönetimi (ASM), hava trafik akış yönetimi (ATFM)] sağlanmaktadır (Türkiye Sivil Havacılık Meclis Raporu,2011).

1983 y1lında yürürlüğe giren "2920 sayılı Türk Sivil Havacılık Kanunu" ile özel sektöre de havaalanı ve havayolu işletmeciliği haklarının verilmesiyle, sivil havacılık sektöründe gelişim belirgin bir şekilde artmıştır. Tarifelerdeki kısıtlamalar 2001 yılında kaldırılmış, havayolu işletmeleri kendi tariflerini belirleyebilir hale gelmiştir. 2003 yılından itibaren Ulaştırma, Denizcilik ve Haberleşme Bakanlığı tarafindan özellikle iç hat uçuşlarını artırmak amacıyla geliştirilen politikalar sonucu, iç hatlarda çok merkezli çapraz uçuşların başlatılmasıyla birlikte uçuş ve yolcu sayılarında önemli düzeyde artış sağlanmıştır. 2003-2013 yılları arasında yolcu uçağı sayısında \%137, koltuk kapasitesinde \%139 ve kargo taşıma kapasitesinde $\% 456$ artış olmuş, uçuş ağı 3 kat büyümüştür (Türkiye Sivil Havac1lık Meclisi Sektör Raporu, 2013).

Havacılıkta ülkemize ilişkin büyüme verileri, en sağlıklı olarak Avrupa Hava Seyrüseferi Emniyeti Teşkilatı (EUROCONTROL) tahminlerinde yer almaktadır. 2014-2020 tahminlerinde Türkiye'nin dinamik bir büyüme eğilimi içinde olacağı öngörülmüştür (Eurocontrol, 2015). Son yıllarda Türk havacıllk sektöründeki ivmelenme, Türk şirketlerin dış hat payları toplamına da yansımıştır. Yurt dışı ticari uçuş/yolcu taşımacılığında 2007 yılında $\% 50 / \% 50$ olan yerli-yabancı hava yolları payı, 2011 yılında yerli havayolu taşıyıcılarımız lehine $\% 56 / \% 44$ olarak gerçekleşmiş̧ir. Sektörde istihdamda büyüme sağlanarak 2003'te 65.000 civarında olan çalışan sayısı, 2013 yılı sonu itibariyle 180.000 'i aşmıştır. Bu gelişmelerin bir sonucu olarak geçtiğimiz 10 yılda sektörün cirosu 2,2 milyar Dolardan 23,8 milyar Dolara varmıştır. Son 12 yılda havacılık dünyada yılda ortalama $\% 5$ büyürken, Türkiye'de ise bunun yaklaşık 3 katı yani \%14,5 seviyesinde büyümüş, uçak sayısı 422'yi aşmış, toplam yolcu trafiği 150 milyonu aşmış, koltuk kapasitesi 75.000 'i geçmiştir. Türkiye taşınan ton*km ölçeğinde 2003 yllında dünya sıralamasında 30 uncu sırada iken 2013 yılında 15 inci sıraya, Avrupa'da ise 5 inci sıraya yükselmiştir (Ulaşan ve Erişen Türkiye,2016).

\section{Uygulama}

Bu çalışmanın uygulama kısmında, Türkiye'nin ilk ve tek full servis sağlayıcısı havayolu olan Trk Hava Yolları Anonim Ortaklığı'na ait son 3 seneyi içeren Altman Z" score değerleri hesaplanmıştır. Türk Hava Yolları A.O finansal verileri kullanılarak hesaplanan Z" score modeline ait çeyrek dönemlik sonuçlar aşağıdaki gibi hesaplanarak tablo ve grafik olarak verilmiştir.

\begin{tabular}{|l|r|r|r|r|r|r|r|r|r|r|r|}
\hline & Ç3 & Ç2 & Ç1 & Ç4 & Ç3 & Ç2 & Ç1 & Ç4 & Ç3 & Ç2 & Ç1 \\
& 2016 & 2016 & 2016 & 2015 & 2015 & 2015 & 2015 & 2014 & 2014 & 2014 & 2014 \\
\hline T1 & $-0,03$ & $-0,05$ & $-0,05$ & $-0,04$ & $-0,02$ & $-0,03$ & $-0,05$ & $-0,06$ & $-0,01$ & $-0,06$ & $-0,09$ \\
\hline T2 & 0,11 & 0,11 & 0,13 & 0,16 & 0,14 & 0,13 & 0,13 & 0,14 & 0,14 & 0,10 & 0,09 \\
\hline T3 & 0,01 & $-0,01$ & $-0,03$ & 0,08 & 0,03 & 0,02 & 0,01 & 0,07 & 0,05 & 0,01 & $-0,01$ \\
\hline T4 & 0,17 & 0,20 & 0,30 & 0,30 & 0,31 & 0,40 & 0,45 & 0,58 & 0,40 & 0,41 & 0,44 \\
\hline Z” Skor & 0,37 & 0,12 & 0,19 & 1,10 & 0,88 & 0,78 & 0,65 & 1,17 & 1,12 & 0,46 & 0,12 \\
\hline
\end{tabular}

Tablo 5. Altman Z" modeli- Türk Hava Yolları(THY) Anonim Ortakllğ 2014-2016 Çeyrek Dönem Hesaplamaları - Yazar Tarafindan Yapılmıştır Kaynak: THY A.O Finansal Tabloları

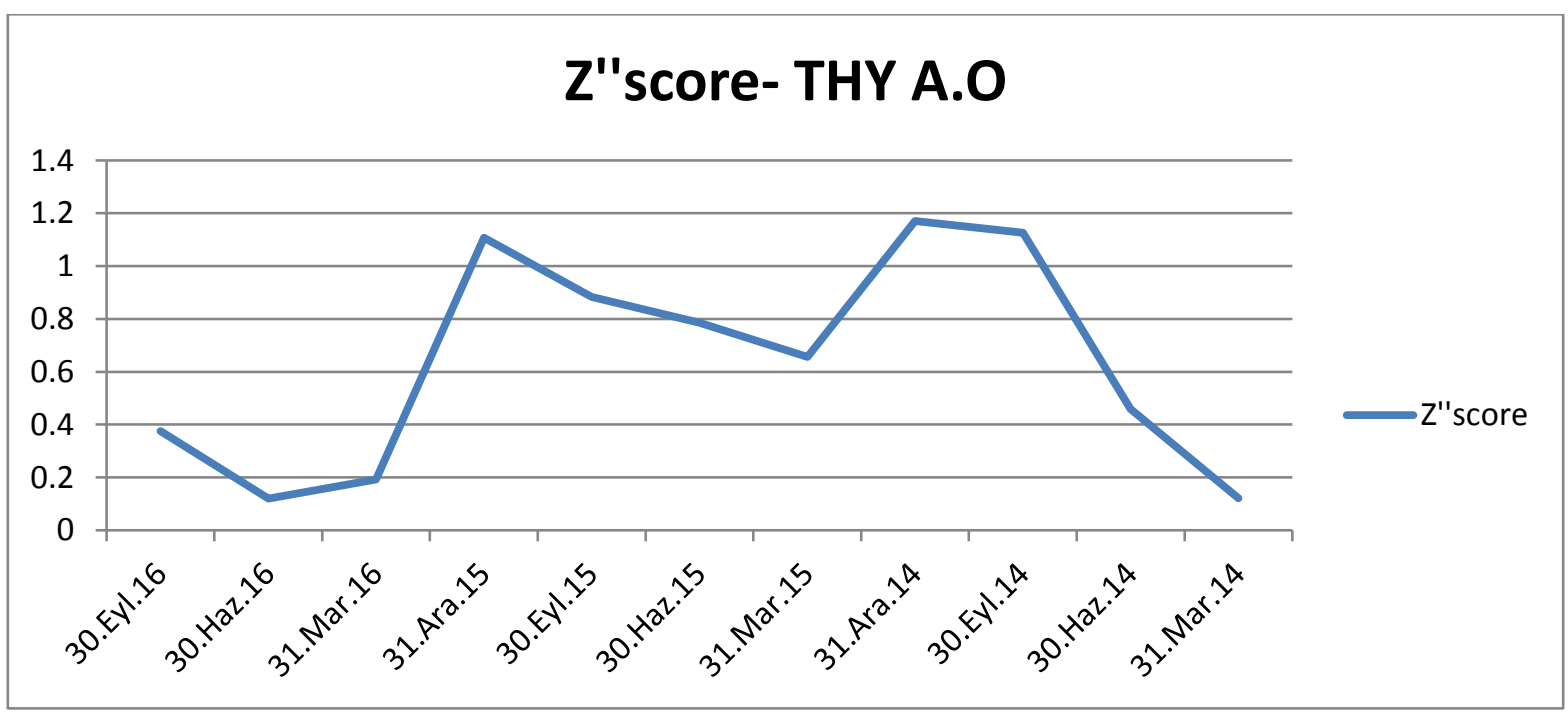

Şekil 1. Altman Z" modeli- Türk Hava Yolları(THY) Anonim Ortaklı̆̆ 2014-2016 Çeyrek Dönem Hesaplamaları Grafiği Kaynak: THY A.O Finansal Tabloları Kullanılarak Yazar Tarafindan Hesaplanmışıtı 


\section{Sonuç}

Havacılık endüstrisi işletmelerinin farklı ülkelerde ve dağıtım ağının farklı düzeylerinde varlıklarını sürdürebilmesi, global ve artan rekabetçi ortamda finansal açıdan başarılı olabilmesi için karşı karşıya kaldı̆̆ risklerin farkında olması ve bunların etkin olarak yönetilmesi zorunlu hale gelmiştir. Yaşadığımız bilgi toplumunda artan verimler kanunu geçerlidir. Bunun için katma değeri yüksek mal üretiminde uzmanlaşılması, bilgi sayesinde üretimin daha verimli bir hale getirilmesi gerekmektedir (Acar, 2000). Finansal risk konusunda da bilgi teknolojilerinden ve sektöre özel geliştirilen modellerden yararlanarak tahminleme yapılması daha sağlıklı sonuçlar alınmasına neden olmaktadır.

$\mathrm{Bu}$ çalışma kapsamında yapılan literatür araştırmasında finansal performans ve risk belirleme için kullanılması gereken parametre ve anahtar başarı göstergeleri üzerinde varılmış bir görüş birliği olmadığı görülmüştür. Altman modeli, finansal başarısızlık tahmini konusunda yapılan önemli çalışmalardan biri olarak kabul edildiğinden çalışma kapsamında ayrıntılı olarak ele alınmıştır. Uygulama bölümünde, Türk Hava Yolları Anonim Ortaklığına ait son 3 seneyi içeren Altman Z" değerlerine yer verilmiştir ve son üç yılı içeren veriler kullanılarak yapılan hesaplamalarda özellikle son dönemlerde ortaklığın gri alanda(riskli) olduğu görülmektedir.

Türkiye'nin güneydoğusunda oluşan istikrarsız jeopolitik ortam, özellikle 2015 yılından itibaren başlayarak 2016 yılında da devam eden terör olayları ve paralelinde artan güvenlik kaygısı ve benzeri sebepler ile Türkiye'de turizm sektörü ve havayolu yolcu trafiği olumsuz etkilenmektedir. Söz konusu olumsuz gelişmelerin de etkisiyle zayıf seyreden trafik, Türk Hava Yolları A.O'nun doluluk oranlarının gerilemesine ve birim gelirlerin baskılanmasına neden olmaktadır. Altman modeline göre hesaplanan son 3 yılın çeyreklik verilerine göre gri alanda yer alan THY A.O'nun finansal performansa dikkat etmesi elzemdir. Yapılanan analizlere göre THY Anonim Ortaklığının karlı olan parkurları uzun menzildeki uçuşlardır ve transit yolculardan sağlanan gelirler çok önemlidir. O yüzden önerimiz geniş gövde filo yatırımları ile uzun menzildeki operasyonu başta olmak üzere kapasite artışları yapılması, yeni hat açılışlarından ile sağlanacak transfer yolcu artışı, hizmet ve servis kalitesinin geliştirilmesi ile "Business Class" yolcu gelirlerinin artırılması ve kargo operasyonunun büyütülmesi ile ortaklık birim gelirlerinin yukarıya çekilmesidir. Bu sayede Z" score değeri de yükselişe geçebilir, skorlar güvenli alana taşınabilir.

\section{Referanslar}

- $\quad$ Acar, 2000. "Bilgi Çağı ekonomisine Teorik Bir Yaklaşım", Dokuz Eylül Üniversitesi İ.̇̇.B.F Dergisi, 15, s 87-101.

- $\quad$ ACI, 2016. http://www.aci.aero

- $\quad$ Akgün, 2013. “Firmalarda Finansal Başarısızlığın Tahmini ve İstanbul Menkul Kıymetler Borsası'nda bir Uygulama”, T.C Selçuk Üniversitesi Sosyal Bilimler Enstitüsü İşletme Bilim Dalı, Konya

- Akkaya, 2004. "Finansal Rasyolar Yardımıyla Havayolları İşletmelerinin Performansının Değerlendirilmesi”, Dokuz Eylül Üniversitesi İ.İ.B.F. Dergisi, Cilt 19, Sayı 1

- Altman, 1968. "Financial Ratios, Discriminant Analysis and the Prediction of Corporate Bankruptcy", The Journal of Finance, 23, 4: 589-609

- Altman, E., R. Haldeman, and P. Narayanan 1977. ZETA Analysis: A New Model to Identify Bankruptcy Risk of Corporations. Journal of Banking and Finance.

- Altman, E., ve Hotchkiss E., 2006. Corporate Financial Distress and Bankruptcy (3rd edition). New Jersey: Wiley Finance.

- Atan, Güneş, 2004. “IMKB’ye kote şirketlerde bilançoya dayalı risk analizi ve erken uyarı göstergelerinin araştırılması”, Dokuz Eylül Üniversitesi 4. İstatistik Günleri Sempozyumu, İzmir-Kuşadası

- Beaver, 1966. "Financial Ratios as Predictors of Failure", in Empirical Research in Accounting, selected studies, in supplement to the Journal of Accounting Research, 71-111

- Brealey, Myers, Marcus, 2007. İşletme Finansının Temelleri, Literatür Yayıncılık, 5. Basım, İstanbul

- Çelik, 2009. "Finansal Başarısızlık Tahmin modellerin İmkb’deki Firmalar İçin karsılastırmalı Analizi”, Karadeniz Teknik Üniversitesi Sosyal Bilimler Enstitüsü İşletme Bilim Dalı, Trabzon

- Eurocontrol, 2014. https://www.eurocontrol.int/sites/default/files/content/documents/officialdocuments/forecasts/seven-year-flights-service-units-forecast-2014-2020-feb2014.pdf

- Gerede, 2002. "Havayolu taşımacılığında küreselleşme ve havayolu işbirlikleri-THY AO.'da bir uygulama” (Yayımlanmamış Doktora Tezi). Anadolu Üniversitesi Sosyal Bilimler Enstitüsü, Eskişehir.

- Gritta, Adrangi, Davalos, Bright, 2015. "A Review of the History of Air Carrier Bankruptcy Forecasting and the Application of Various Models to the US Airline Industry: 1980-2005", http://www.divaportal.org/smash/get/diva2:213027/FULLTEXT01.pdf 
- Hauschild, 2013. Altman Z-Score: Not Just for Bankruptcy: From Z-Score to "Green Zone" Survivability, Amros Corporation

- Helfert, 2001. Financial Analysis: Tools and Techniques, United States: The McGraw-Hill Companies, Inc. p.95-98

- IATA, 2016. http://www.iata.org

- Karaer, 2015. "Havayolu işletmeciliğinde yakıt maliyetleri ve yönetimi”, Gazi Üniversitesi / Sosyal Bilimler Enstitüsü / İşletme Anabilim Dalı / İşletme Bilim Dalı, Doktora Tezi, Ankara.

- Morrell, 2013. Airline Finance, Fourth Edition, Ashgate Publishing, Ltd.

- Özdemir, Choi., Beyazıtlı, 2012. "Finansal Başarısızlık Tahminleri Yönüyle Ufrs Ve Bilginin İhtiyaca Uygunluğu”, İsmmmo Mali Çözüm Dergisi, Temmuz-Ağustos 2012

- Sayılgan, 1995. “Finansal Risk Yönetimi”. Ankara Üniversitesi SBF Dergisi, 50(01)

- Sistematik risk, 2016. http://www.sistematikrisk.com/2013/11/25/altmanin-z-skoru/

- Türk Hava Yolları (THY) A.O, 2016. http://investor.turkishairlines.com/en

- Türkiye Sivil Havcılık Meclisi Sektör Raporu, 2011. http://www.tobb.org.tr/Documents/yayinlar/TOBB_havacilik_meclis_sektor_2012.pdf

- Ulaşan ve Erişen Türkiye, 2016. http://www.udhb.gov.tr/images/faaliyet/a5ec26a31a72281.pdf

- Usatoday 2016, http://usatoday30.usatoday.com/money/industries/travel/2008-07-23-southwest-jetfuel_N.htm

- Wensveen, 2007. Air transportation: A management perspective. Aldershot: Ashgate. 


\title{
Enerji Fiyatlarındaki Volatilitenin Makroekonomik Performans Üzerine Etkisi
}

\section{Impact of Energy Price Volatility on Macroeconomic Performance}

\author{
Assoc. Prof. Dr. Neşe Algan (Çukurova University, Turkey) \\ Asst. Prof. Dr. Erhan İşcan (Çukurova University, Turkey) \\ Ph.D. Candidate Duygu Serin (Çukurova University, Turkey) \\ Ph.D. Candidate Duygu Kara (Çukurova University, Turkey)
}

\begin{abstract}
Last two decades witnessed increasingly volatile international markets with the many financial crises. Concurrently, volatility in energy prices and energy markets cause various adverse impacts on both national and world economies. Especially this volatility affected emerging markets and increased the fragility of the emerging economies. Because of the adverse impacts of this volatility, understanding the price behavior and impact of volatility of energy prices on economy became crucial for every economic agent in the economy including policy makers in the governments, consumers, and producers. The relationship between energy prices and macroeconomic performance has been studied widely as a consequence its long term macroeconomic impacts to world economies. Differently, the aim of this study is analyzing the effect of energy price volatility on macroeconomic indicators of Turkey. For that purpose, we employed a GARCH model to investigate effect of energy price volatility on macroeconomic performance for Turkey from 2002 to 2016 . We use various energy prices and macroeconomic indicators data for the period from January 2002 to December 2016, obtained from the IFS and CBRT-EDDS. By applying GARCH methodology to various energy prices and macroeconomic indicators, we contribute to the understanding of price volatility in energy markets, and suggest policies that would be of use to policy makers in the governments, consumers, and producers.
\end{abstract}

\section{Giriş}

Günümüzde enerji insan yaşamı için en önemli faktör konumuna gelmiştir. Hemen hemen bütün üretim ve tüketim faaliyetlerinde enerji temel girdi olarak kullanılmaktadır. Şekil 1'de dünya enerji tüketim miktarları yer almaktadır. 2014 yılında 9.425 milyar ton petrol eşdeğeri enerji tüketiminin yaklaşık \%39.9'u petrolden, \%18.1'i elektrikten, \%15.1'i doğal gazdan, \%12.2'si biyoyakıtlardan, \%11.1'i kömürden oluşmaktadır (Key World Energy Statistics, 2016). Dünya enerji tüketim oranlarına baktığımızda petrol en yüksek orana sahip enerji kaynağıdır.

Enerji sektörü ülkelerin ekonomik kalkınması için önemli rol oynamaktadır. İstikrarlı enerji fiyatları ekonomik büyümeyi artırırken, yükselen enerji fiyatları ekonomik büyümeyi olumsuz yönde etkilemektedir. Özellikle Türkiye gibi enerji ithalatı yapan ülkelerde, enerji fiyatlarındaki artışlar yurt içi enflasyonu yükseltmekte ve yerli döviz rezervlerini azaltmaktadır. Paranın değer kaybetmesi yerel paranın satın alma gücünü düşürmekte ve enerji ithalatını daha pahalı hale getirmektedir (Lescaroux ve Mignon, 2008). Bu durum ülkelerin verimliliğini olumsuz yönde etkilerken, üretim maliyetlerini artırmaktadır. Enerji fiyatlarındaki bu artış üretimde kullanılan temel girdilere erişilebilirliği azaltmakta ve potansiyel çıktıyı düşürmektedir. Verimliliğin azalması reel ücret düzeyini azaltarak, işsizliği artırmaktadır. Reel ücret oranında azalma ve işsizliğin artması enflasyonu hızlandırmaktadır. Bu durum halkın ve hatta hükümetin satın alma gücünü olumsuz yönde etkilemektedir. Buna bağlı olarak özel ve kamu harcamalarının azaltılması ülke ekonomisi üzerine olumsuz etki yaratmaktadır. Ayrıca enerji fiyatlarındaki artış enflasyon ile nominal faiz oranlarını artırmakta ve yatırımları, hisse senedi fiyatları, cari işlemler dengesini, dış borçlar ile mali dengeleri bozmaktadır. Dahası, enerji fiyatlarındaki artış kaynakların yeniden tahsis edilmesine ve böylece çıktı artışına olumsuz bir baskı oluşturmasına yol açmaktadır (Arshad, vd, 2015).

Küreselleşen dünyada gün geçtikçe enerji alanında petrol ve doğal gaza olan talep artış göstermektedir. Dolayısıyla enerji kaynaklarına sahip olan ülkeler ticari açıdan fayda sağlarken, diğer taraftan ekonomisinin büyük çoğunluğu enerji girdisi olarak petrol kullanan gelişmekte olan ülkeleri olumsuz etkilemektedir (Çınar, 2010). Ülke ekonomilerini bu yönlerle etkileyen enerji aynı zamanda ülkelerin ekonomik büyümesinde rol alan önemli etkenlerinden biri olarak kabul edilmektedir. Bu nedenle enerji fiyatlarında herhangi bir artış hem sektörel büyümeyi hem de artan taşımacılık ve üretim maliyetleri açısından kamu harcanabilir gelirini, sanayi üretimini ve aynı zamanda ekonominin genel olarak kalkınmasını ve büyümesini etkilemektedir (Maurya ve Thenmozhi, 2013). $\mathrm{Bu}$ nedenle enerji fiyatlarındaki volatilite ülkelerin makroekonomik performansları üzerinde önemli ölçüde etkilidir. Çalışmada yukarıda söz edilen nedenlere bağlı olarak özgün bir yaklaşımla 2002-2016 dönemi için aylık veriler kullanılarak Türkiye'de enerji fiyatları volatilitesi ile makroekonomik performans arasındaki ilişkisi GARCH yöntemi kullanılarak araştırılmıştır. Bu açıdan literatüre katkı sağlayacağı değerlendirilmiştir. Çalışmanın ikinci bölümünde dünyanın en önemli enerji ve hammadde girdisi olarak kabul edilen petrol fiyatlarının 
makroekonomik değişkenleri etkileme kanalları ifade edilmiştir. Üçüncü bölümde ilgili literatür özetine yer verilmiştir. Daha sonra kullanılan yöntem ve veriler hakkında bilgi verilerek uygulama sonuçları ifade edilmiştir.

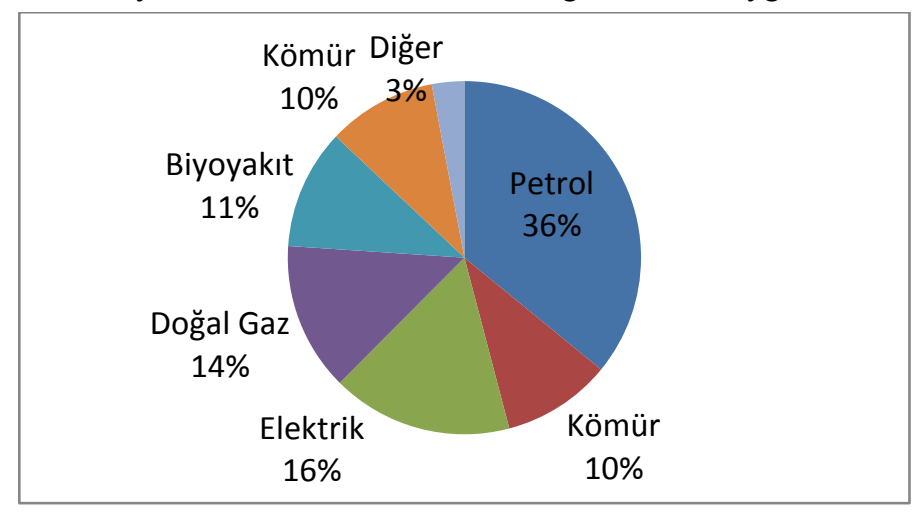

Şekil 1: Enerji Kaynaklarınin Dünya Enerji Tüketimi Payları(Mtoe)

\section{Enerji Kaynağı Olarak Petrolün Önemi}

Enerji fiyatlarındaki değişimlerin giderek önem kazanması ve dünya ekonomileri üzerinde önemli etkileri olduğu düşüncesi genel olarak kabul edilmektedir ve son zamanlarda ilgili değişkenler arasındaki ilişkiyi araştıran çalışmalar büyük ilgi görmektedir. Dünya enerji tüketimi içerisinde petrolün en yüksek paya sahip enerji kaynağı olması nedeniyle petrol fiyatlarında gerçekleşen dalgalanmalar ülkelerin çoğu açısından önem arz etmektedir. Çünkü petrol fiyatları ülkelerin makro ekonomik göstergeleri üzerinde etkili olmaktadır.

Petrol fiyatları volatilitesi belirli bir dönemde petrol fiyatlarının standart sapması olarak tanımlanmaktadır. Tarihsel olarak petrol fiyatları diğer emtia ve varlık fiyatlarına göre daha fazla volatilitesi yüksektir (Lipsky, 2009). Petrol fiyatlarındaki aşırı oynaklığın yarattığı ekonomik belirsizlik, petrol fiyat şoklarının etkilerinden belirgin şekilde farklılaşan küresel ekonomi için önemli sonuçlar doğurmaktadır. Şekil 2'de petrol fiyat şoklarının dolaylı ve doğrudan etkileri şematik olarak gösterilmektedir.

Mevcut literatürde petrol fiyatı volatilitesi ve makro ekonomik göstergeler arasındaki ters yönlü ilişki klasik arz yanlı etki, transfer etkisi, para politikası, reel denge etkisi, düzenleme maliyetleri, belirsizlik gibi yollarla etkilediği ifade edilmektedir. Bu kanallar arasında ilgili değişkenler arasında ilişkiyi en iyi açıklayan mekanizma klasik arz yanlı etki'dir. Klasik arz yanlı etki'de petrol fiyatında gerçekleşen yükseliş, verimliliği azaltmakta ve üretimin azalmasına neden olmaktadır. Tüketiciler, bu yükselişin kısa vadeli olduğunu varsaymaları halinde daha az tasarruf yapmakta ve daha fazla borçlanma yoluna yönelerek tüketimlerini sabit tutmaktadır. Borçlanma düzeyindeki artış, reel denge faiz oranını artırmaktadır. Hem üretim miktarında azalma hem de reel faiz oranındaki yükseliş reel nakit denge talebinde azaltma yaratarak, enflasyonun yükselen bir seyir göstermesine neden olmaktadır. Kısaca, petrol fiyatında artış GSYIH'da büyüme oranını azaltmakta, enflasyon ve reel faiz oranlarını yükseltmektedir. Transfer etkisi, petrol fiyatlarının artmasına bağlı olarak petrol ithalatı yapan ülkeden, petrol ihracatı yapan ülkeye satın alma gücünün aktarılması mekanizmasıdır. Petrol fiyatlarında gerçekleşen yükseliş petrol ithal eden ve ithal eden ülkelerin makroekonomik performansları üzerinde farklı etkilere neden olmaktadır. Şöyle ki, petrol fiyatlarındaki artış, petrol ithal eden ülkelerin reel milli gelirlerinin azalmasına yol açarken; petrol ihraç eden ülkelerin milli gelirlerinin artmasına neden olmaktadır. Petrol fiyatlarındaki artışın makroekonomiyi nasıl yönlendireceğini açıklayan bir diğer mekanizma aracı para politikasıdır. Petrol fiyatlarında artışın gerçekleşmesi döneminde ekonomi otoriteleri aracılığı ile faiz oranları ile yönlendirilen politika milli gelir üzerinde farklı etkilere neden olmaktadır. Diğer bir söylemle, eğer petrol fiyatında yükseliş karşısında ekonomi otoriteleri faiz artırma yolunu tercih etmesi durumunda milli gelirin azalmasına yol açmaktadır. Ancak faiz oranlarını sabit tutmayı tercih etmesi durumunda ise, milli gelirin artmasına neden olmaktadır (Bernanke,vd, 1997). Reel denge etkisi ise, petrol fiyatlarındaki artış para talebini artırmakta ve ekonomi otoriteleri bu artışa karşılık olarak, para arzını artırarak faiz oranlarının yükselmesine neden olmaktadır. Faiz oranlarının artı̧ göstermesi ülkenin üretim ve tüketim faaliyetleri üzerinde ve buna bağlı olarak ekonomik büyüme üzerinde olumsuz etki yaratmaktadır. Enerji fiyatlarının artmasıyla ortaya çıkan düzenleme maliyetlerine göre, petrol fiyatlarının yükselmesi ekonomiyi olumsuz açıdan etkilerken, petrol fiyatlarının düşmesi ekonomiyi olumlu açıdan etkilemektedir. Petrol fiyatlarının değişmesi düzenleme yapma maliyeti doğurması nedeniyle ekonomiyi daha zor duruma sokmaktadır. Petrol fiyatlarında yükselme, enerji yoğun kullanılan alanlarda küçülmeye neden olmakta, işsizliği artırmakta ve kaynakların atıl olarak kullanılmasına neden olmaktadır. Son olarak belirsizlik mekanizması, enerji fiyatları volatilitesi enerji fiyatlarına yönelik belirsizliği artırmakta ve yatırımların azalmasına yol açmaktadır. Enerji fiyatlarında görülen oynaklık, firmaların yatırım kararlarını erteletmekte ve yatııım yapılmasına yönelik teşvikleri azaltmaktadır. $\mathrm{Bu}$ durum ekonominin zayıflamasına neden olmaktadır (Brown ve Yücel, 2002). 


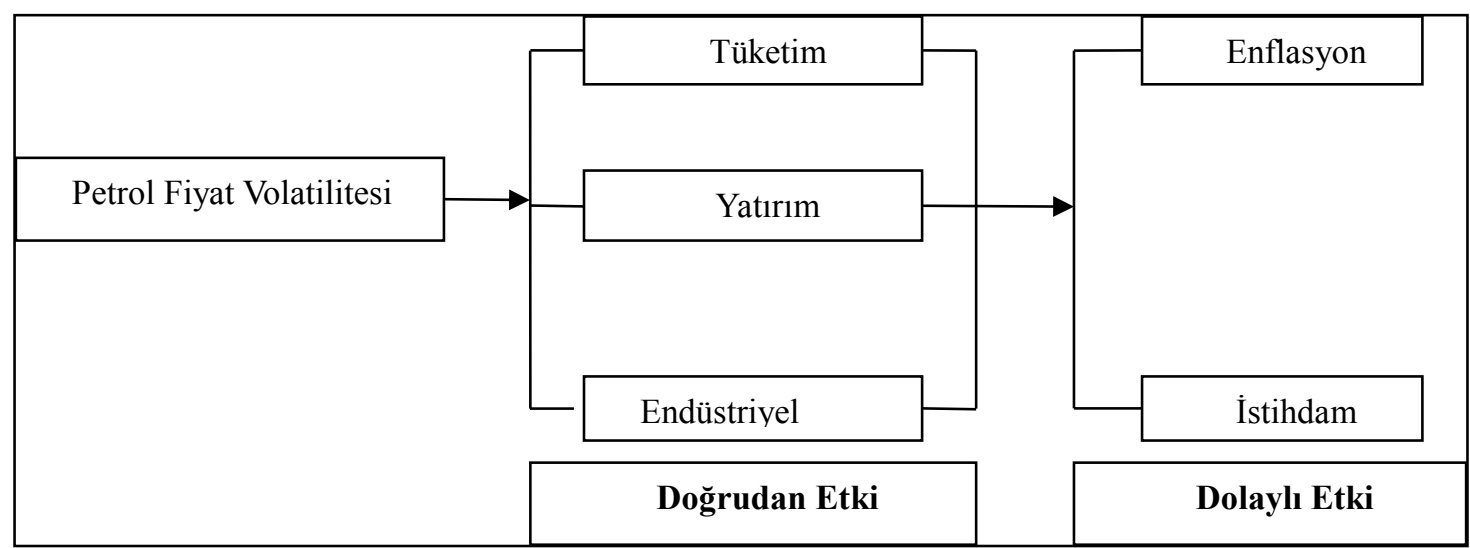

Şekil 2: Enerj Fiyatlarındaki Volatilitenin Etkisi

\begin{tabular}{|c|c|c|}
\hline & Artış \& Azalış & Nedenleri \\
\hline Tüketim & Azalır & $\begin{array}{l}\text { Petrol fiyatındaki oynaklığın yarattığı } \\
\text { ekonomik belirsizliğe bağlı olarak her } \\
\text { zaman düşüş gösterir. }\end{array}$ \\
\hline Reel Yatırım & Azalır & $\begin{array}{l}\text { Yatırımın karlılığına ilişkin belirsizlikler } \\
\text { ve tüketici talebinde azalmalara bağlı } \\
\text { olarak kısa ve orta vadede azalma } \\
\text { gösterir. }\end{array}$ \\
\hline Finansal Yatırım & Hem artar hem azalır & $\begin{array}{l}\text { Herhangi bir zamanda finansal } \\
\text { piyasalarda hakim olan risk tercihinin } \\
\text { derecesine bağlı olarak artabilir veya } \\
\text { azalabilir. }\end{array}$ \\
\hline Üretim & Azalır & $\begin{array}{l}\text { Firmaların mallarının nihai fiyatlarını } \\
\text { yükselterek üretim seviyelerini } \\
\text { korumayı seçip seçmediklerine bağlı } \\
\text { olarak ya da tüketim talebindeki düşüşe } \\
\text { karşılık olarak firmaların üretim } \\
\text { seviyelerini düşürmesine bağlı olarak } \\
\text { sabit kalabilir veya azalabilir. }\end{array}$ \\
\hline Enflasyon & Hem artar hem azalır & $\begin{array}{l}\text { Azalan tüketici talebi ile oluşan } \\
\text { deflasyonist baskıların, artan mal } \\
\text { fiyatlarında yarattığı enflasyonist } \\
\text { baskıların üstesinden gelip gelmediğine } \\
\text { bağlı olarak artmaya devam edebilir. }\end{array}$ \\
\hline İstihdam & Hem artar hem azalır & $\begin{array}{l}\text { Kısa ve orta vadede işsizlik seviyesi iki } \\
\text { denkleştirici baskıya tabidir: -İşsizlik } \\
\text { düzeyi, tüketim ve sanayi üretim } \\
\text { seviyelerinin düşmesine bağlı olarak } \\
\text { doğrudan artmaktadır. - Phillips } \\
\text { eğrisinde ifade edildiği üzere, işsizlik } \\
\text { seviyesi enflasyon arttıkça düşme } \\
\text { eğilimi göstermektedir. }\end{array}$ \\
\hline
\end{tabular}

Şekil 3: Petrol Fiyatları Volatilitesinin Dolaylı ve Doğrudan Etkileri Kaynak: Inderwıldı, 2014

Petrol fiyatlarında dalgalanmaların makro ekonomik performans üzerine etkisinin incelenmesinde önemli olan diğer konu ele alınan ülkenin petrol ihracatı ya da ithalatı yapmasına bağlı olarak değişmesidir. Petrol, ihraç yapan ülkeler açısından temel bir gelir kaynağı olurken; ithal eden ülkeler açısından ihraç eden ülkeye gelir aktarımına yol açmaktadır (Özkaya, 2001). Dolayısıyla petrol ihracı yapan ülkeleri olumlu etkilerken, petrol ithali yapan ülkeleri olumsuz yönde etkilemektedir. Petrol fiyatlarında dalgalanmaların ekonomik performans üzerine olumsuz etkisi enerji ithalatçısı olan Türkiye'de de görülmektedir. Çünkü ülkemiz enerji konusunda dışa bağımlı olmakla birlikte petrol ve doğalgaz rezervleri çok azdır. Türkiye'nin dış ticaret dengesi üzerinde olumsuz etki yaratan enerji ithalatı, ülkenin ithalat bağımlılığında en yüksek sektörüdür. Enerji ithalatında en önemli pay üretim için temel girdi olarak kullanılan petroldür. Türkiye petrol ihtiyacının yaklaşı \%90'ını ithal etmektedir. Sanayileşme ile birlikte birincil enerji kaynakları arasında petrolün gün geçtikçe artan önemi, ülkenin petrol tüketiminin toplam enerji kaynakları tüketiminde artan payı, petrol tüketiminde ithalata bağımlı bir ülke olması nedeniyle enerji 
fiyatlarındaki değişimlerin makro ekonomik performans üzerinde etkisi üzerinde durulması gereken bir konudur (Öksüzler ve İpek, 2011).

\section{Ampirik Literatür}

Günümüzde mevcut literatürde çoğunlukla petrol fiyat şokları, petrol fiyat değişimlerinin ekonomi üzerine etkisini inceleyen pek çok çalışma yer almaktadır. Bu çalışmalar farklı yöntemler ve modeller kullanılarak en önemli enerji kaynağı olan petrol fiyat değişimlerinin etkilerini farklı açılardan ele almaktadır. Bu çalışmaların özeti ve çalışmalardan elde edilen sonuçlar aşağıda yer almaktadır.

Sadorsky (1999) çalışmasında petrol fiyat şokları ve borsa arasındaki ilişkiyi analiz etmiştir. ABD için 1947 1996 yılları arası çalışmaya dahil edilerek VAR ve GARCH yöntemi kullanılmıştır. Analiz sonucunda petrol fiyatlarında gerçekleşen oynaklığın hisse senedi getirilerini etkilediği ve petrol fiyat şoklarının ekonomi üzerinde asimetrik etkiye sahip olduğu tespit edilmiştir.

Brown ve Yücel (1999) çalışmasında ABD ekonomisi için petrol fiyatları değişimleri etkisini makro ekonomik performans açısından incelemiştir. Çalışmada 1965-1997 dönemi ele alınarak VAR, Choleski varyans ayrıştırması ve etki tepki fonksiyonu yöntemi kullanılarak araştırılmıştır. Çalışma sonucunda petrol fiyatlarında ani değişimlerin reel GSYİH'yı düşürdüğü ve enflasyona neden olduğu tespit edilmiştir.

Papapetrou (2001) çalışmasında petrol fiyat şoklarının faiz oranı ve iş gücü üzerine etkisini Yunanistan için analiz etmiştir. 1989-1999 yıllarını kapsayan analizde VAR yöntemi kullanılmıştır. Analiz sonucunda petrol fiyatları değişiminin ekonomik göstergeleri etkilediği sonucunda ulaşılmıştır.

Huang vd., (2005) çalışmasında petrol fiyatlarında gerçekleşen değişimlerin ve volatilitenin ekonomik performans üzerine etkisini incelemiştir. Çalışma ABD, Kanada ve Japonya için ele alınmıştır. Analiz sonucunda, petrol fiyatı değişimlerin ve volatilitenin sanayi üretim endeksi ve hisse senedi getirileri üzerinde anlamlı etkiye sahip olduğu sonucuna ulaşılmıştır.

Lardic ve Mignon (2006) analizinde petrol fiyatları ile ekonomik büyüme arasındaki uzun dönemli ilişkiyi incelemiştir. Analizde 12 Avrupa ülkesi için 1979-2003 dönemi ele alınarak eşbütünleşme yöntemi kullanılmıştır. Analiz sonucunda ilgili Avrupa ülkelerinin çoğunda eşbütünleşme ilişkisi tespit edilememiştir.

Kumar (2007) çalışmasında petrol fiyatları ve makroekonomi arasında ilişkiyi Hindistan açısından ele almıştır. Analizde 1975-2004 dönemine ait üçer aylık veriler VAR yöntemi kullanılmıştır. Analiz sonuçlarına göre, petrol fiyatlarında gerçekleşen artışlar reel ekonomik aktivite üzerinde önemli bir etkiye sahipken, petrol fiyatlarında düşüşün reel ekonomik aktivite üzerinde herhangi bir etkisi olmadığı tespit edilmiştir.

Khademvatani (2007) çalışmasında petrol fiyatlarında değişimlerin etkisini Kanada açısından ele almıştır. Analizde 1984-2002 yılları için üçer aylık veriler eşbütünleşme analizi ve hata düzeltme modeli kullanılarak incelenmiştir. Analiz sonucunda nominal milli gelir ve ham petrol fiyatları arasında eşbütünleşme ilişkisi olduğu tespit edilmiştir. Ayrıca hata düzeltme modeline göre, petrol fiyatları, nominal milli gelir, faiz oranları ve fiyat deflatörü arasında uzun dönemli ilişkinin olduğu sonucuna ulaşılmıştır.

Lardic ve Mignon (2008) çalışmasında G-7 ülkeleri için petrol fiyatlarının gayri safi yurt içi hasıla üzerine etkisini analiz etmiştir. 1970-2004 yıllarını kapsayan çalışmada eşbütünleşme yöntemi kullanılmıştır. Analiz sonucunda ele alınan değişkenler arasında eşbütünleşme ilişkisi bulunmamıştır.

Zhang (2008) çalışmasında petrol fiyat şokları ve ekonomik büyüme arasında ilişkiyi incelemiştir. Japonya için 1957-2006 dönemi Granger nedensellik analizi ile test edilmiştir. Analiz sonucunda petrol fiyatlarında gerçekleşen artışın paralel olarak genel fiyat düzeyine yansıdığı ve buna bağlı olarak reel ücretlerde ve emek arzında düşüşe neden olduğu tespit edilmiştir.

Park ve Ratti (2008) ABD ve 13 Avrupa ülkesini ele aldığı çalışmasında petrol fiyat değişimleri ve borsa getirileri arasındaki ilişkiyi incelemiştir. Analizde 1986-2005 yılları VAR modeli ile test edilmiştir. Analiz sonucunda petrol fiyat şokları ve borsa getirisi arasında ilişki olduğu ve petrol fiyatlarının artmasının borsa getirileri üzerinde artışa neden olduğu tespit edilmiştir.

Hanabusa (2009) analizinde petrol fiyatlarının gayri safi yurt içi hasıla üzerine etkisini Japonya için 2000-2008 kapsamında araştırmıştır. Analizde EGARCH yöntemi kullanılarak gayri safi yurt içi hasıla ve petrol fiyatlarında gerçekleşen değişimler arasında çift yönlü nedensellik ilişkisi tespit edilmiştir.

Milani (2009) analizinde petrol fiyatları değişimlerinin makro ekonomik göstergeler üzerine etkisini ABD için araştırmıştır. VAR analizi kullanılan modelde 1960-2008 dönemi için petrol fiyatlarının faiz oranı ve enflasyon üzerinde önemli bir etkisi olduğu sonucuna ulaşılmıştır.

Filis (2010) çalışmasında petrol fiyatları, tüketici fiyat endeksi, sanayi üretim endeksi arasında ilişkiyi hata düzeltme modeli kullanarak Yunanistan için analiz etmiştir. Analizde 1996-2008 dönemi için aylık veriler hata düzeltme modeli çerçevesinde ele alınmıştır. Analiz sonucunda, petrol fiyatları ve hisse senedi piyasasının tüketici fiyat endeksi üzerinde uzun dönemde olumlu etkisi olduğu tespit edilmiştir. 


\section{Model ve Veri Seti}

Çalışmadaki amacımız enerji fiyatlarındaki volatilitenin makroekonomik etkilerini incelemektir. Bu amaçla bağımsız değişken olarak enerji fiyatlarını temsil etmek üzere üç spot piyasanın basit ortalamasından oluşan ham petrol fiyat endeksinin volatilitesi (OIL) ve bağımlı değişken olarak makroekonomik performans için ise sanayi üretim endeksi (IP) kullanılacaktır. Çalışmada Ocak 2005-Şubat 2017 yılı arası aylık veriler kullanılmaktadır. Sanayi üretim endeksi verisi TCMB EVDS'den ve ham petrol fiyat endeksi verisi ise IMF'den elde edilmiştir. Ham petrol fiyat endeksinin volatilitesi IMF'den elde edilen üç piyasadaki petrol fiyatının basit ortalamasından oluşturulmuş olan 2005 yılının baz alındığı fiyat endeksi kullanılmıştır. Fiyat endeksi değişkenin kullanılarak kurulan GARCH modelinden elde edilen koşullu varyans değerleri (Bollerslev, 1986) volatilite değişkeni olarak kullanılmıştır. Petrol fiyatı volatilitesini hesaplanması için fiyat endeksi değişkeni serisinin çeşitli farklı gecikme uzunlukları içeren ARIMA modeli tahmin edilmiştir. ARCH-LM testi ile volatilitenin varlığı araştırıldıktan sonra GARCH modeli tahmin edilerek koşullu varyans değerleri hesaplanmıştır. Ardından ARDL sınır testi yaklaşımı kullanılarak petrol fiyatlarındaki volatilitenin sanayi üretim endeksi üzerindeki etkisi araştırılmıştır.

\section{Uygulama Sonuçları}

\subsection{Petrol Fiyatı Volatilitesinin Hesaplanması}

Volatilitenin modellenebilmesi için öncelikle fiyat serisi endeksinin logaritması alınarak mevsimsellikten arındırılmıştır. KPSS birim kök testi uygulanan serinin seviyede durağan olduğu sonuca varılmıştır. Otokorelasyon ve kısmi otokorelasyon verileri değerlendirilerek ARIMA modeli tahmin edilmiştir.

\begin{tabular}{|c|c|c|c|c|c|c|c|c|}
\hline \multicolumn{2}{|c|}{ Autocorrelation } & \multicolumn{3}{|c|}{ Partial Correlation } & $A C$ & PAC & Q-Stat & Prob \\
\hline 1 & & 1 & & 1 & 0.964 & 0.964 & 138.36 & 0.000 \\
\hline 1 & & $\square$ & 1 & 2 & 0.912 & -0.236 & 263.04 & 0.000 \\
\hline 1 & & 담 & 1 & 3 & 0.849 & -0.134 & 371.99 & 0.000 \\
\hline 1 & & 미 & 1 & 4 & 0.778 & -0.109 & 464.17 & 0.000 \\
\hline 1 & & 1 & 1 & 5 & 0.704 & -0.052 & 540.04 & 0.000 \\
\hline 1 & & 11 & 1 & 6 & 0.631 & 0.017 & 601.47 & 0.000 \\
\hline 1 & $\square$ & 1 & 1 & 7 & 0.565 & 0.052 & 651.02 & 0.000 \\
\hline 1 & $\square$ & 10 & 1 & 8 & 0.501 & -0.039 & 690.31 & 0.000 \\
\hline 1 & $\square$ & 1 & 1 & 9 & 0.445 & 0.035 & 721.48 & 0.000 \\
\hline 1 & $\square$ & 1 & 1 & 10 & 0.394 & -0.005 & 746.16 & 0.000 \\
\hline 1 & $\square$ & 1밈 & 1 & 11 & 0.343 & -0.100 & 764.98 & 0.000 \\
\hline 1 & $\square$ & & & 12 & 0.298 & 0.058 & 779.35 & 0.000 \\
\hline
\end{tabular}

Tablo 1: AC ve PAC tablosu

Model seçim ölçütlerine göre tahmin edilen AR $(2,0)$ modelinin polinomlarının ters kökleri birim çemberin içinde olması nedeniyle durağanlık ve istikrarlılık şartlarını da sağlamaktadır. Aşağıdaki tablolarda model seçimin de kullanılan SIC'ye göre model seçimi ve ARMA polinomlarının ters kök değerlerini görmekteyiz.

\begin{tabular}{|l|l|l|l|l|}
\hline Model & LogL & AIC & SIC* & HQ \\
\hline$(2,0)(0,0)$ & 391.092185 & -5.302633 & $\mathbf{- 5 . 2 2 0 8 9 0}$ & -5.269419 \\
\hline$(2,1)(0,0)$ & 393.123243 & -5.316757 & -5.214578 & -5.275239 \\
\hline$(1,2)(0,0)$ & 392.627142 & -5.309961 & -5.207783 & -5.268443 \\
\hline$(1,1)(0,0)$ & 389.573263 & -5.281826 & -5.200083 & -5.248612 \\
\hline$(1,0)(0,0)$ & 385.840393 & -5.244389 & -5.183082 & -5.219479 \\
\hline$(2,2)(0,0)$ & 393.268134 & -5.305043 & -5.182429 & -5.255222 \\
\hline$(0,2)(0,0)$ & 317.716998 & -4.297493 & -4.215750 & -4.264279 \\
\hline$(0,1)(0,0)$ & 261.971496 & -3.547555 & -3.486248 & -3.522644 \\
\hline$(0,0)(0,0)$ & 182.974332 & -2.479100 & -2.438229 & -2.462493 \\
\hline
\end{tabular}

Tablo 2: Model Seçim Ölçütü Tablosu

\begin{tabular}{|l|l|}
\hline AR Root(s) & Modulus \\
\hline 0.945338 & 0.945338 \\
\hline 0.295840 & 0.295840 \\
\hline
\end{tabular}

Tablo 3: AR/MA Polinomlarının Ters Kökleri 
Tablo 4'te ise ARMA maksimum olabilirlik (BFGS) yöntemi ile en iyi tahmin edilen ARMA(2,0) modelinde ARCH etkisinin varlığını araştırmak üzere ARCH-LM testi yapılmaktadır.

\begin{tabular}{|c|c|c|c|c|}
\hline Variable & Coefficient & Std. Error & t-Statistic & Prob. \\
\hline $\mathrm{C}$ & 4.862540 & 0.152877 & 31.80697 & 0.0000 \\
\hline $\operatorname{AR}(1)$ & 1.241178 & 0.078909 & 15.72921 & 0.0000 \\
\hline $\mathrm{AR}(2)$ & -0.279669 & 0.079322 & -3.525727 & 0.0006 \\
\hline SIGMASQ & 0.006105 & 0.000715 & 8.540704 & 0.0000 \\
\hline R-squared & 0.945833 & \multicolumn{2}{|c|}{ Mean dependent var } & 4.922177 \\
\hline Adjusted R-squared & 0.944689 & \multicolumn{2}{|c|}{ S.D. dependent var } & 0.336870 \\
\hline S.E. of regression & 0.079226 & \multicolumn{2}{|c|}{ Akaike info criterion } & -2.185528 \\
\hline Sum squared resid & 0.891309 & \multicolumn{2}{|c|}{ Schwarz criterion } & -2.103785 \\
\hline Log likelihood & 163.5436 & \multicolumn{2}{|c|}{ Hannan-Quinn criter. } & -2.152314 \\
\hline F-statistic & 826.5069 & \multicolumn{2}{|c|}{ Durbin-Watson stat } & 2.095100 \\
\hline Prob(F-statistic) & 0.000000 & & & \\
\hline
\end{tabular}

Tablo 4: ARMA(2,0) Model Tahmini

Tablo 5'te görüldüğü üzere ARCH-LM testi sonucu 1,4,8 ve 12 gecikmede oynaklığın varlığ1 görülmektedir. Her gecikmede oynaklığın görülmüş olması GARCH yöntemi ile oynaklığın giderilmesini sağlayan bir model tahmin edilmesi gerekmektedir. Ayrıca tahmin edilecek olan GARCH modelinden elde edilecek koşullu varyans değerleri bize volatilite değişkenini verecektir.

\begin{tabular}{|l|l|l|l|}
\hline F-statistic & 14.61657 & Prob. F(1,143) & 0.0002 \\
\hline Obs*R-squared & 13.44657 & Prob. Chi-Square(1) & 0.0002 \\
\hline F-statistic & 5.333086 & Prob. F(4,143) & 0.0005 \\
\hline Obs*R-squared & 19.13186 & Prob. Chi-Square(4) & 0.0007 \\
\hline F-statistic & 2.921957 & Prob. F $(8,143)$ & 0.0050 \\
\hline Obs*R-squared & 21.17031 & Prob. Chi-Square(8) & 0.0067 \\
\hline F-statistic & 2.695694 & Prob. F(12,143) & 0.0030 \\
\hline Obs*R-squared & 28.26686 & Prob. Chi-Square(12) & 0.0051 \\
\hline
\end{tabular}

Tablo 5: ARCH Değişen Varyans Testi

\begin{tabular}{|c|c|c|c|c|c|c|}
\hline Autocorrelation & Partial Correlation & & $\mathrm{AC}$ & PAC & Q-Stat & Prob \\
\hline 101 & 101 & 1 & -0.054 & -0.054 & 0.4313 & \\
\hline 口 & $1 曰$ & 2 & 0.159 & 0.157 & 4.2279 & \\
\hline$1 \longdiv { 1 }$ & $\sqrt{1}$ & 3 & 0.014 & 0.031 & 4.2588 & 0.039 \\
\hline , & 1 & 4 & 0.066 & 0.044 & 4.9213 & 0.085 \\
\hline 11 & 1 & 5 & 0.009 & 0.008 & 4.9346 & 0.177 \\
\hline 响 & 响 1 & 6 & -0.089 & -0.109 & 6.1462 & 0.188 \\
\hline ו & 1 & 7 & 0.050 & 0.036 & 6.5376 & 0.257 \\
\hline 11 & 11 & 8 & -0.044 & -0.014 & 6.8408 & 0.336 \\
\hline 1 1 & 1 1 & 9 & -0.080 & -0.096 & 7.8437 & 0.347 \\
\hline 1 & $1 \mathrm{~B}_{1}$ & 10 & 0.077 & 0.092 & 8.7745 & 0.362 \\
\hline 叫 1 & 14 & 11 & -0.099 & -0.072 & 10.332 & 0.324 \\
\hline 111 & 11 & 12 & 0.018 & -0.019 & 10.382 & 0.408 \\
\hline
\end{tabular}

Tablo 6: AC ve PAC tablosu

Tablo 7'de BFGS/ Marquardt steps yöntemi ile tahmin edilen ve katsayı kovaryansı gözlenen Hessian kullanılarak hesaplanan GARCH(1,1) modelinin sonuçlarını görmekteyiz. Model tahmini ile birlikte varyans eşitliği de tabloda yer almaktadır. 


\begin{tabular}{|c|c|c|c|c|}
\hline \multicolumn{5}{|c|}{$\mathrm{GARCH}=\mathrm{C}(4)+\mathrm{C}(5)^{*} \mathrm{RESID}(-1)^{\wedge} 2+\mathrm{C}(6) * \mathrm{GARCH}(-1)$} \\
\hline Variable & Coefficient & Std. Error & z-Statistic & Prob. \\
\hline C & 5.173685 & 0.211898 & 24.41592 & 0.0000 \\
\hline $\mathrm{AR}(1)$ & 1.191422 & 0.117251 & 10.16129 & 0.0000 \\
\hline $\mathrm{AR}(2)$ & -0.228511 & 0.116862 & -1.955381 & 0.0505 \\
\hline \multicolumn{5}{|l|}{ Variance Equation } \\
\hline $\mathrm{C}$ & 0.002361 & 0.000892 & 2.646142 & 0.0081 \\
\hline $\operatorname{RESID}(-1)^{\wedge} 2$ & 0.399222 & 0.159447 & 2.503795 & 0.0123 \\
\hline GARCH(-1) & 0.249170 & 0.150776 & 1.652586 & 0.0984 \\
\hline R-squared & 0.944462 & \multicolumn{2}{|c|}{ Mean dependent var } & 4.928114 \\
\hline Adjusted R-squared & 0.943674 & \multicolumn{2}{|c|}{ S.D. dependent var } & 0.335376 \\
\hline S.E. of regression & 0.079595 & \multicolumn{2}{|c|}{ Akaike info criterion } & -2.301385 \\
\hline Sum squared resid & 0.893288 & \multicolumn{2}{|c|}{ Schwarz criterion } & -2.177643 \\
\hline Log likelihood & 171.6997 & \multicolumn{2}{|c|}{ Hannan-Quinn criter. } & -2.251103 \\
\hline Durbin-Watson stat & 1.960375 & & & \\
\hline Inverted AR Roots & .95 & \multicolumn{2}{|l|}{.24} & \\
\hline
\end{tabular}

Tablo 7: GARCH(1,1) Modeli Tahmini

Her gecikme değeri için yapılan ARCH-LM testine göre ARCH etkisinin kalmadığı görülmektedir.

\begin{tabular}{|l|l|l|l|}
\hline F-statistic & 0.026196 & Prob. F(1,143) & 0.8717 \\
\hline Obs*R-squared & 0.026562 & Prob. Chi-Square(1) & 0.8705 \\
\hline F-statistic & 1.206589. & Prob. F(4,143) & 0.3110 \\
\hline Obs*R-squared & 4.832349 & Prob. Chi-Square(4) & 0.3049 \\
\hline F-statistic & 0.750143 & Prob. F(8,143) & 0.6471 \\
\hline Obs*R-squared & 6.136452 & Prob. Chi-Square(8) & 0.6320 \\
\hline F-statistic & 0.951663 & Prob. F(12,143) & 0.4988 \\
\hline Obs*R-squared & 11.55831 & Prob. Chi-Square(12) & 0.4818 \\
\hline
\end{tabular}

Tablo 8: ARCH Değişen Varyans Testi

GARCH(1,1) modelinden elde edilen koşullu varyans değerleri petrol fiyatlarının volatilitesi olarak değerlendirilecektir.

\subsection{Petrol Fiyatları Volatilitesi ile Sanayi Üretim Endeksi Arasındaki Etkileşim}

Bu çalışmada petrol fiyatı volatilitesi ile makroekonomik performansın önemli bir göstergesi olan Sanayi Üretim Endeksi arasındaki kısa ve uzun dönem dinamik ilişkiyi birim kök testlerinden çıkan sonuçlardan bağımsız olarak tahmin edebilmek için geleneksel yöntemlerden farklı olan ARDL Sınır Testi Yaklaşımı kullanılacaktır. ARDL yöntemini birçok avantajı bulunmaktadır. Kullanılan birçok eşbütünleşme tekniklerinin dışında ARDL yöntemi farklı derecede bütünleşik olan yada kesirli bütünleşik olan serilerin analizinde kullanılabilmektedir. Aynı zamanda ARDL yöntemi az sayıda örneklem ile güçlü sonuçlar verebilmektedir. Tablo 9'da birim kök testi sonuçları yer almaktadır. Elde edilen sonuçlara göre petrol fiyatı volatilite serisi seviyede durağanken sanayi üretim endeksi birinci farkta durağan olmaktadır. Farklı derecede bütünleşik serilerin olması ARDL yöntemini kullanmamızı gerektirmektedir.

\begin{tabular}{|l|l|l|l|l|l|}
\hline Değişken & $\begin{array}{l}\text { Düzey Test } \\
\text { İstatistiği }\end{array}$ & $\begin{array}{l}\text { Mac Kinnon } \\
\text { Kritik Değer } \\
(\% 5)(\text { Düzey) }\end{array}$ & $\begin{array}{l}\text { 1. Farklar Test } \\
\text { İstatistiği }\end{array}$ & $\begin{array}{l}\text { Mac Kinnon } \\
\text { Kritik Değer } \\
(\% 5) \text { (1.Fark) }\end{array}$ & Sonuç \\
\hline OIL_VOL & $-6.114892(0)$ & $-3.476472^{*}$ & & & $\mathrm{I}(0)$ \\
\hline IP_SA & $-1.479980(0)$ & -3.476143 & $-27.97165(0)^{*}$ & -3.476143 & $\mathrm{I}(1)$ \\
\hline
\end{tabular}

Tablo 9: ADF Birim Kök Testi Sonuçları

Not: *, Regresyon trend içermiyor. Parantez içerisindeki rakamlar SIC’ye göre seçilen uygun gecikme uzunluğunu göstermektedir.

Tablo 10'de ise ARDL modeli Akaike Bilgi kriterine göre gecikmesini belirlenerek tahmin edilmiştir. Tablo 11 'de ise sınır testi sonuçları gösterilmektedir. Sınır testi sonuçlarına göre \%5 düzeyinde F istatistiğinin üst sınırın üzerinde olması değişkenler arasında ilişkinin varlığına işaret etmektedir. 


\begin{tabular}{|l|l|l|l|l|}
\hline Variable & Coefficient & Std. Error & t-Statistic & Prob. \\
\hline LNIP_D11(-1) & 0.149873 & 0.084571 & 1.772159 & 0.0786 \\
\hline LNIP_D11(-2) & 0.645799 & 0.064505 & 10.01165 & 0.0000 \\
\hline LNIP_D11(-3) & 0.187399 & 0.083134 & 2.254194 & 0.0258 \\
\hline LOG(GARCH01) & -0.016319 & 0.006706 & -2.433555 & 0.0162 \\
\hline R-squared & 0.903354 & \multicolumn{2}{|l|}{ Mean dependent var } & 4.662256 \\
\hline Adjusted R-squared & 0.901253 & \multicolumn{2}{|l|}{ S.D. dependent var } & 0.133904 \\
\hline S.E. of regression & 0.042078 & Akaike info criterion & -3.470812 \\
\hline Sum squared resid & 0.244339 & Schwarz criterion & -3.387549 \\
\hline Log likelihood & 250.4276 & Hannan-Quinn criter. & -3.436977 \\
\hline Durbin-Watson stat & 1.975732 & \multicolumn{3}{|l}{} \\
\hline
\end{tabular}

Tablo 10: ARDL(3,0) Modelinin Tahmini

\begin{tabular}{|l|l|l|l|}
\hline \multirow{2}{*}{$\mathrm{k}$} & & \multicolumn{2}{|l|}{ Kritik Değerler (\%5) } \\
\cline { 3 - 4 } & & Alt Sınır & Üst Sınır \\
\hline 1 & F-ist & & 4.11 \\
\hline
\end{tabular}

Tablo 11: Sinır Testi Sonuçları

Not: $k$, denklemdeki bă̆ımsız değişken sayısıdır. Gecikme uzunluğunun belirlenmesinde AIC kullanılmıştır. Kritik değer sinırları Pesaran vd (2001, s.300) TabloC1(iii) 'ten alınmıştır.

Tablo 12'de ise hata düzeltme modeli sonuçları verilmektedir. Tablo 13'te ise tanısal test sonuçları verilmiștir. Elde edilen sonuçlara göre petrol fiyatları volatilitesi ile sanayi üretim endeksi arasında ilişki bulunmaktadır. Hata düzeltme modeli sonuçlarına göre, hata düzeltme katsayısı beklenildiği gibi negatif işaretli ve istatistiki açıdan anlamlıdır. Bu durum hata düzeltme mekanizmasının çalıştığını ifade etmekte ve uzun dönemli ilişki olduğu bir kez daha kanitlanmaktadır.

\begin{tabular}{|l|l|l|l|l|}
\hline Variable & Coefficient & Std. Error & t-Statistic & Prob. \\
\hline D(LNIP_D11(-1)) & -0.812213 & 0.083475 & -9.729996 & 0.0000 \\
\hline D(LNIP_D11(-2)) & -0.179700 & 0.084455 & -2.127750 & 0.0351 \\
\hline CointEq(-1)* & -0.012770 & 0.005833 & -2.189213 & 0.0303 \\
\hline R-squared & 0.499668 & Mean dependent var & 0.003231 \\
\hline Adjusted R-squared & 0.492469 & \multicolumn{2}{|l|}{ S.D. dependent var } & 0.059710 \\
\hline S.E. of regression & 0.042538 & \multicolumn{2}{|l|}{ Akaike info criterion } & -3.455934 \\
\hline Sum squared resid & 0.251519 & \multicolumn{2}{|l|}{ Schwarz criterion } & -3.393487 \\
\hline Log likelihood & 248.3713 & Hannan-Quinn criter. & -3.430558 \\
\hline Durbin-Watson stat & 1.984289 & \multicolumn{3}{|l}{} \\
\hline
\end{tabular}

Tablo 12: ARDL Hata Düzeltme Modeli

\begin{tabular}{|l|l|}
\hline Tanısal Test Sonuçları & 0.903354 \\
\hline$R^{2}$ & 0.901253 \\
\hline Düzeltilmiş- $R^{2}$ & $0.322757(0.5709)$ \\
\hline Breusch-Godfrey LM & $0.269205(0.6047)$ \\
\hline ARCH LM & $53.25075(0.0000)$ \\
\hline Jarque-Bera Normallik Testi & $1.929730(0.1089)$ \\
\hline Breusch-Pagan Değişen Varyans Testi & $0.795064(0.4280)$ \\
\hline Ramset Reset &
\end{tabular}

Tablo 13: ARDL Sınır Testine Ait Tanısal Test Sonuçları

CUSUM ve CUSUM ${ }^{2}$ istatistikleri \%5 anlamlılık düzeyinde kritik sınırlar içerisinde yani iki çizgi arasında yer aldığını, ARDL modelindeki katsayıların kararlı olduğu, herhangi bir kırılmanın olmadığı görülmektedir. ARDL modeli uzun dönem katsayılarının istikrarlı olduğu ve herhangi bir yapay değişken kullanılmadan modelin hesaplanabileceği tespit edilmiştir. 

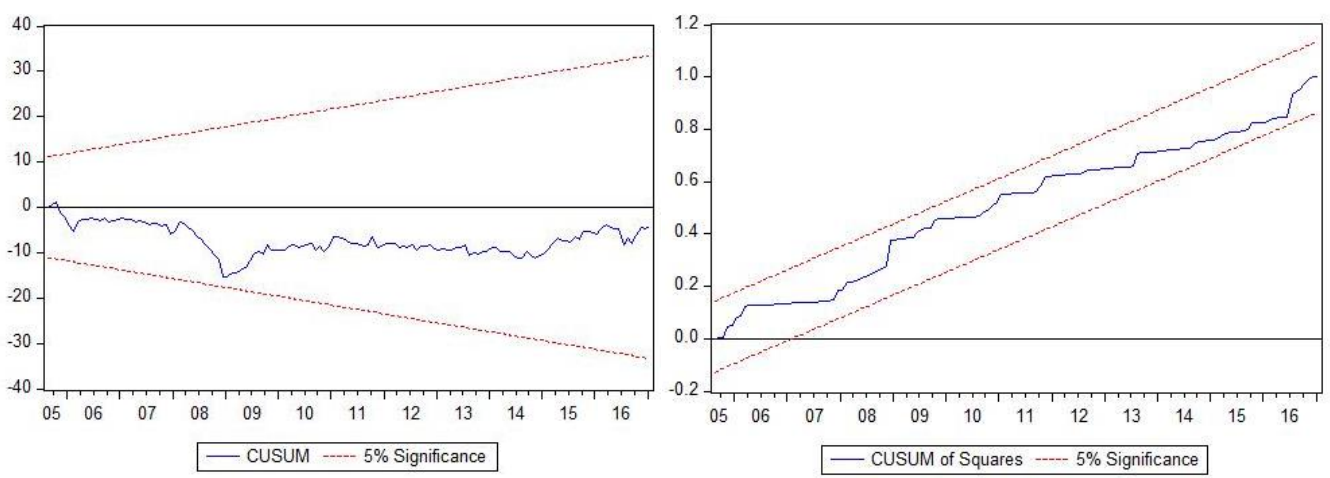

Şekil 4: CUSUM ve CUSUM² Grafikleri

\section{Sonuç}

Özellikle son 20 yıl içerisinde emtia fiyatlarında ve özel olarak enerji fiyatlarında yaşanan olağan dışı dalgalanma enerji fiyatlarının ekonomik değişkenler üzerine olan etkilerinin incelenmesi gerekliliğini göstermiştir. $\mathrm{Bu}$ nedenle bu çalışmada GARCH ve ARDL yöntemlerini kullanarak enerji fiyatlarındaki dalgalanmanın makroekonomik etkileri analiz edilmiş̧ir. Enerjinin en önemli maliyet unsuru olarak sanayini girdisi olması nedeniyle enerji fiyatındaki volatilitenin makro ekonomik etkileri özel önem taşımaktadır. Çalışmada elde edilen sonuçlara göre enerji fiyatlarındaki değiş̧im özellikle sanayi üretimini etkilemektedir. Volatilitedeki artışın sanayi üretimini azaltıcı etkisi ve şokun kalıcı olması bu çalışmanın sonucu olarak ortay çıkmıştır.

\section{Kaynakça}

- Arshad, A., Zakaria, M., \& Junyang, X. (2016). Energy prices and economic growth in Pakistan: A macroeconometric analysis. Renewable and Sustainable Energy Reviews, 55, 25-33.

- Bernanke, S.Ben; Getrler, Mark; Watson, Mark "Systematic Monetary Policy and the Effects of Oil Price Shocks" Economic Research Reports 97-25 (Haziran 1997)

- Brown, S.P.A. ve Yücel, M.K. , "OilPricesand U.S. AggregateEconomic Activity: A Question of Neutrality", EconomicandFinancal Review,1999,16-23

- Brown, Stephen P.A. ve Yucel, Mine K. (2002). Energy Prices and Aggregate Economic Activity: An Interpretative Survey. Quarterly Review of Economics and Finance, 42, 1-28.

- Çınar, E. (2010). Petrol Fiyatlarının Türkiye Ekonomisine Etkileri. Kahramanmaraş Sütçü İmam Üniversitesi, Sosyal Bilimler Enstitüsü, Yayınlanmamış Yüksek Lisans Tezi, Kahramanmaraş

- Filis, G., "Macro Economy, Stock Market and Oil Prices: Do Meaningful Relationships Exist Among Their Cyclical Fluctuations?", Energy Economics, 32(4), 2010, pp.877-886.

- Hanabusa, K. (2009). Causality Relationship betweeen the Price of Oil and Economic Growth in Japan. Energy Policy, 37, 1953-1957.

- Huang, R.D., Masulis, R.W., 1996. Energy shocks and financial markets, Journal of Futures Markets 16, 1 27.

- IEA (2016). International Energy Agency Key World Energy Statistics. Paris: IEA Publications.

- Inderwildi, O. R., Ebrahim, Z., \& King, D. A. (2014). Macroeconomic impacts of oil price volatility: mitigation and resilience. Frontiers in Energy, 8(1), 9-24.

- Khademvatani, Asgar; "Crude Oil Price and Aggregate Economic Activity: Asymmetric or Symmetric Relationship: Evidence from Canada"s Economy" (2007)

- Kumar, S.; "The Macroeconomic Effects of Oil Price Shocks: Empirical Evidence for India", SSR (Social Science Research etwork) Working Paper Series, (09.11.2007).

- Lardic, S. \& Mignon, V. (2006). The Impact of Oil Prices on GDP in European Countries: An Empirical Investigation Based on Asymmetric Cointegration. Energy Policy, 34, 3910-3915.

- Lardic, S. \& Mignon, V. (2008). Oil Prices and Economic Activity: An Asymmetric Cointegration Approach. Energy Economics, 30, 847-855.

- Lescaroux F,MignonV.On the influence of oil prices on economic activity and other macroeconomic and financial variables.OPECEnergyRev2008;32 (4):343-80.

- Lipsky J. Economic shifts and oil price volatility. 2009-03-18

- Malik A. How Pakistan is coping with the challenge of high oil prices.PakDev Rev 2007;46(4):551-75 
- $\quad$ Maurya, S., \& Thenmozhi, M. (2013). "Contagion Effect Among Crude Oil and Food Prices in India". Available at SSRN 2371018.

- Milani, F. (2009). Expectations, Learning and the Changing Relationship between Oil Prices and the Macroeconomy. Energy Economics, 31, 827-837.

- $\quad$ Öksüzler, O. \& İpek, E., (2011), Dünya Petrol Fiyatlarındaki Değişimin Büyüme ve Enflasyon Üzerindeki Etkisi, Türkiye Örneği, ZKÜ Sosyal Bilimler Dergisi, Cilt 7, Sayı 14, s. 7-31.

- Özkaya, Şule (2001), "Petrol Fiyatlarının Ekonomilere Etkisi”, Uluslararası Ekonomik Sorunlar Dergisi, Sayı. 1.

- $\quad$ Papapetrou, E. (2001). Oil Price Shocks, Stock Market, Economic Activity and Employment in Greece. Energy Economics, 23, 511-532.

- Park, J. \& Ratt1, R. A. (2008). Oil Price Shocks and Stock Markets in the U.S. and 13 European Countries. Energy Economics, 30, 2587-2608.

- $\quad$ Sadorsky, P. (1999). Oil Price Shocks and Stock Market Activity. Energy Economics, 21, 449-469.

- Zhang, D. (2008). Oil Shock and Economic Growth in Japan: A Nonlinear Approach. Energy Economics, $30,2374-2390$ 


\title{
Petrol Fiyatları ve BIST Sektör Endeksleri İlişkisi The Relationship of Petroleum Price and BIST Sector Indexes
}

\author{
Prof. Dr. Reşat Karcıoğlu (Atatürk University, Turkey) \\ Ph.D. Candidate Muhammet Özcan (Atatürk University, Turkey) \\ Asst. Prof. Dr. Ensar Ağırman (Atatürk University, Turkey)
}

\begin{abstract}
Energy is not only indispensable element of everyday life, but also underlies industrialization and manufacturing. Energy and manufacturing have become integral parts with the importance of mechanization since the Industrial Revolution. As a result of this emerging situation, businesses, have become sensitive energy and energy prices. For this reason, changes in energy prices directly affect businesses and are thought to have effects on fluctuations in stock prices. Changes in the prices of primary energy sources directly or indirectly affect capital markets. In energy importer countries including Turkey, high energy prices cause an increase in current account deficit and decrease in real national income by increasing the amount of energy imports. In addition, high energy prices lead to cost-based inflation increases as they directly affect raw material prices used in production. All these factors indirectly affect capital markets. Direct effect of energy price changes on the capital market is explained by the fact that energy is an indispensable input in industrial production. In cases where the energy price increase is not reflected to the consumer, the profitability of the enterprise is decreasing. A decrease in profitability affects firm's stock price as well. The aim of this study is to reveal the relationship between sector indices in the Stock Exchange Istanbul (BIST) and oil price changes. Weekly data set for the period for 2006:1 - 2016:4 is used. Johannes cointegration method is used to measure long term relationship in the study.
\end{abstract}

\section{Giriş}

Petrol, mevcut dünya ekonomisinde büyük önem taşımaktadır. Petrolün yaygın kullanımı, petrolün kullanıma olan bağımlılığı arttırmış ve bu durum neticesinde petrol dünyadaki diğer enerji kaynaklarından ayrı olarak stratejik bir konum kazanmıştır. Petrol üreten, ihraç eden ve tüketen ülkelerin petrol ve ekonomik kalkınma arasındaki stratejik dengeyi hızlı bir şekilde fark etmeleri sonucunda dünyadaki büyüme süreci petrole bağımlı hale gelmiştir.

Enerji kaynakları, endüstriyel üretim için en önemli girdileri oluşturmaktadır. Modern toplumlar tarafindan kullanılan enerji miktarı her geçen gün artmaktadır. Uluslararası Enerji Birliğine göre modern ekonomilerin yaşam kaynağı olarak nitelendirilen enerji kaynakları özellikle de petrol tüketimi ve talebi hızlı büyüme gösteren ülkelerde endüstriyel üretimdeki artışla ilişkilendirilmektedir.

Bilgi ve yatırımların küreselleştiği günümüz dünyasında, ekonomilerin ve finansal piyasaların birbiriyle ilişkisi ve entegrasyonu, dünya ekonomisini birbirini etkileyen ve birbirlerinden etkilenen tek bir ekonomi haline getirmiştir. Petrol fiyatındaki değişimler ve dünya ekonomisine etkisi, ekonomik küreselleşmenin çok açık bir örneğidir. Küresel seviyede, petroldeki fiyat değişimleri, petrolün ekonominin önemli bir bileşeni olması nedeniyle küresel ekonomik faaliyetleri etkilemektedir. Ayrıca, petrol fiyatları petrolün ihraçcı ülkelerden petrol ithal eden ülkelere aktarılması nedeniyle önemli bir rol oynamaktadır (Balcılar ve Özdemir, 2013). Aynı zamanda, petrol fiyatlarındaki değişmeler, küresel ekonominin yanı sıra herhangi bir ülkenin makro ve mikro ekonomik düzeyi üzerinde de bir etkiye sahiptir. Bu etkinin olumlu ya da olumsuz olması petrol-ekonomi ilişkisinin doğasına bağlıdır. Yani, petrolihracatçı ekonomi, petrol üretici ekonomi ve petrol ithalatçı ekonomi gibi (Ha Le ve diğerleri, 2015; Kilian and Park, 2009).

Hisse senetleri ve petrol fiyatlarının birlikte hareket etme eğiliminin dahası her ikisinin de ortak bir faktöre tepki veriyor olmasının makul bir açıklaması, küresel toplam talebin yumuşatılması yani hem şirket kârlarını hem de petrol talebini tahrip ediyor olmasıdır (Bernanke, 2017)

Geçtiğimiz on yıl petrol fiyatları, piyasa içerisinde var olan katılımcıların kullanmaktan hiçte hoşnut olmadıkları bir roller coaster halini almıştır. Bu dönem aşırı oynaklık ve iki keskin düşüşü içerisinde barındırmaktadır. 2008 yılında yaşanan ilk düşüş dünya finans krizi ve büyük durgunluk ile bağlantılı iken 2014'ün ortalarında 100\$ olan petrol fiyatlarının son zamanlarda $30 \$$ seviyelerine kadar inmesi nedeniyle ikinci düşüşün halen daha devam ettiği kolaylıkla söylenebilmektedir (Bernanke, 2017).

Temel emtialar dışında petrol ile kıyaslandığında petrolün sahip olduğu yaygın ve belirgin etkiye hiçbir emtia sahip değildir. Petrol, çeşitli endüstriler için hammadde olarak ya da bu endüstrilerin temel ürünleriyle birlikte tüketilen temel bir hammaddedir. Nakit akışını ve kârlılığını etkileyebilecekleri için sanayi için kritik olan enerji ve ulaşım fiyatlarının tamamı petrol fiyatıyla bağlantılıdır. Petrol fiyatları, endüstrilerin doğasına bağlı olarak firmaların nakit akışlarını da etkileyebilir. Ayrıca, enflasyon ve reel faiz oranlarını etkilediğinden, iskonto oranı tahminlerini de etkileyen petrol fiyatları varlık fiyatlamasında da rol oynamaktadır. Bütün bu nedenlerden ötürü, 
petrol ve onun küresel ekonomiyle ve makro ekonomik göstergeler ile olan ilişkisi artan sayılarda araştırmanın odağ haline gelmesine neden olmuştur.

Bu çalışmanın amacı, 2008 finansal krizi ve şu an devam etmekte olan petrol fiyatlarındaki değişimleri kapsayarak 2006 ile 2016 yılları arasındaki haftalık verileri analiz ederek, petrol fiyatları ile Borsa İstanbul'daki BIST 100, BIST KIMYA, BIST ULAŞIM ve BIST SANAYİ endeksler arasındaki ilişkiyi incelemektir. Çalışmanın sonuçları, politika yapıcılar tarafından, petrol fiyatlarının Borsa İstanbul'daki endeksler üzerindeki olumsuz etkilerinin azaltılması için kullanılabilir. Bu bağlamda çalışma şu şekilde yapılandırılmıştır. İkinci kısımda çalışma ile ilgili yerli ve yabancı literatürde yer alan çalışmalar yer almakta olup, üçün kısım veri ve yöntem ile ilgili bilgileri ihtiva etmektedir. Çalışma, elde edilen sonuçların ilgili literatür bağlamında değerlendirildiği sonuç kısmı ile nihayete ermektedir.

\section{Literatür Taraması}

Petrol fiyatları ile borsa endeksleri arasındaki ilişkiyi inceleyen çalışmaların sonuçları farklılıklar göstermekle birlikte literatürde yer alan çalışmalar genel anlamda petrol fiyatlarının borsa endeksleri üzerinde olumlu etkiye sahip olduklarıı ortaya koymaktadır. Bu çalışmaların sonuçları genellikle borsa ile ilgili her seviyede faydalı bilgi sağlamak için kullanılmaktadır. Literatürde yer alan çalışmalar yayın yılı esas alınarak yazar, dönem, çalışılan ülkeler ve sonuç başlıkları altında aşağıdaki tabloda sıralanmıştır. 


\begin{tabular}{|c|c|c|c|c|}
\hline Yazar(lar) & Yöntem & Dönem & $\begin{array}{l}\text { Çalışma } \\
\text { Alanı(Ülke) }\end{array}$ & Sonuç \\
\hline $\begin{array}{l}\text { Sadorsky } \\
(2001)\end{array}$ & $\begin{array}{l}\text { Çok } \\
\text { faktörlü } \\
\text { piyasa } \\
\text { modeli }\end{array}$ & 1983- 1999 & Kanada & $\begin{array}{l}\text { Petrol ve gaz sermaye endeksi ile ham petrol fiyatı } \\
\text { arasında önemli bir pozitif ilişki bulunmaktadır. } \\
\text { Petrol fiyatlarındaki \%1'lik bir değişiklik endeksin } \\
\text { değerinde } \% 0.305 \text { 'lik bir değişime neden } \\
\text { olmaktadır. }\end{array}$ \\
\hline $\begin{array}{lll}\text { El } & \text { Sharif } & \text { ve } \\
\text { diğ. } & (2005) & \end{array}$ & $\begin{array}{l}\text { Çok } \\
\text { değişkenli } \\
\text { VAR }\end{array}$ & 1989-2001 & $\begin{array}{l}\text { İngiltere ve } \\
\text { Çin }\end{array}$ & $\begin{array}{l}\text { Petrol ve gaz şirketlerinin hisse senedi getirileri, } \\
\text { ham petrol fiyatlarındaki değişiklikler, bir } \\
\text { bütün olarak borsa ve döviz kurları gibi çeşitli } \\
\text { risk faktörlerinden etkilenmektedir. Petrol } \\
\text { fiyatlarında ve hisse senedi piyasasında bir } \\
\text { yükselme, İngiltere petrol ve gaz sermaye } \\
\text { endeksinde artan getiri olarak görülürken, ABD } \\
\text { doları kurundaki bir artış, getiriyi düşüren } \\
\text { faktör olarak görülmektedir. }\end{array}$ \\
\hline $\begin{array}{l}\text { Basher } \quad \text { ve } \\
\text { Sadorsky } \\
(2006)\end{array}$ & $\begin{array}{l}\text { Çok } \\
\text { faktörlü } \\
\text { piyasa } \\
\text { modeli }\end{array}$ & $1992-2005$ & $\begin{array}{l}\text { Türkiye'yi de } \\
\text { içine alan } 21 \\
\text { gelişmekte olan } \\
\text { ülke ve Morgan } \\
\text { Stanley Capital } \\
\text { International } \\
\text { (MSCI) World } \\
\text { Index }\end{array}$ & $\begin{array}{l}\text { Petrol fiyat riski gelişen piyasalardaki hisse senedi } \\
\text { getirilerini etkilemektedir. Günlük ve aylık veriler } \\
\text { için, petrol fiyatlarındaki artışlar, gelişmekte olan } \\
\text { piyasalardaki borsa getirileri üzerinde olumlu bir } \\
\text { etkiye sahiptir. Haftalık ve aylık veriler için, petrol } \\
\text { fiyatlarında meydana gelen düşüşlerin, gelişmekte } \\
\text { olan piyasalardaki getiriler üzerinde olumlu ve } \\
\text { belirgin etkileri bulunmaktadır. }\end{array}$ \\
\hline $\begin{array}{l}\text { Bjornland } \\
(2008)\end{array}$ & $\begin{array}{l}\text { Yapisal } \\
\text { Vektör } \\
\text { Otoregresi } \\
\text { f Model }\end{array}$ & 1993- 2005 & Norveç & $\begin{array}{l}\text { Petrol fiyatlarının, petrol ihraç eden ülkeler } \\
\text { arasında yer alan Norveç ekonomisi üzerinde } \\
\text { uyarıcı bir etkisi var. Dahası, petrol fiyatında\% } \\
10 \text { 'luk bir artışın hisse senedi getirilerini \% } 2-3 \\
\text { oranında artığını göstermektedir. }\end{array}$ \\
\hline $\begin{array}{l}\text { Cong ve diğ. } \\
(2008)\end{array}$ & $\begin{array}{l}\text { Çok } \\
\text { değgişkenli } \\
\text { VAR }\end{array}$ & 1999- 2007 & Çin Borsası & $\begin{array}{l}\text { Petrol fiyat şokları, Çin borsa endekslerinin } \\
\text { birçoğunda hisse senedi getirileri üzerinde } \\
\text { istatistiksel olarak önemli bir etkiye sahip değilken, } \\
\text { üretim endeksi ve bazı petrol şirketleri bu duruma } \\
\text { istisna olarak kabul edilmektedir. Bazı petrol fiyat } \\
\text { şokları, petrol şirketlerinin hisse senedi fiyatlarında } \\
\text { sıkıntı oluşturmaktadır. }\end{array}$ \\
\hline $\begin{array}{l}\text { Arouri, } \\
\text { Lahiani ve } \\
\text { Bellalah } \\
\text { (2010) }\end{array}$ & $\begin{array}{l}\text { Linear ve } \\
\text { linear } \\
\text { olmayan } \\
\text { modeller }\end{array}$ & $2005-2008$ & $\begin{array}{l}\text { Petrol ihraç } \\
\text { eden ülkeler }\end{array}$ & $\begin{array}{l}\text { Katar, Umman, Suudi Arabistan ve Birleşik } \\
\text { Arap Emirlikleri'ndeki hisse senedi getirilerinin } \\
\text { petrol fiyatlarındaki değişikliklere tepki } \\
\text { gösterdiği ancak Bahreyn'de ve Kuveyt'teki } \\
\text { petrol fiyatlarında meydana gelen değişimin } \\
\text { hisse senedi getirisini etkilemediği ortaya } \\
\text { konulmaktadır. Ayrıca, uzun vadeli petrol } \\
\text { fiyatlarının ve borsa endeksinin müşteri fiyat } \\
\text { endeksi üzerinde olumlu etkisi olduğu, petrol } \\
\text { fiyatlarının borsa üzerinde olumsuz etkisi } \\
\text { olduğu ve petrol fiyatlarının sanayi üretimi } \\
\text { üzerinde herhangi bir etkisinin olmadığı tespit } \\
\text { edilmektedir. Aynı şekilde, borsa ile sanayi } \\
\text { üretimi arasında bir ilişki bulunmamaktadır. }\end{array}$ \\
\hline $\begin{array}{l}\text { Özmerdivanlı } \\
(2014)\end{array}$ & $\begin{array}{l}\text { Granger } \\
\text { nedensellik } \\
\text { testi }\end{array}$ & $2003-2014$ & $\begin{array}{l}\text { Borsa İstanbul, } \\
\text { BIST } 100\end{array}$ & $\begin{array}{l}\text { BIST-100 endeksi ile petrol fiyatları arasında uzun } \\
\text { dönemli bir ilişki olduğunu ortaya konulmaktadır. } \\
\text { BIST-100 endeksi kapanış fiyatlarından, petrol } \\
\text { fiyatlarına doğru tek yönlü bir nedensellik ilişkisi } \\
\text { olduğunu belirlenmiştir. }\end{array}$ \\
\hline $\begin{array}{l}\text { Çağlı ve diğ. } \\
\text { (2014) }\end{array}$ & & & & $\begin{array}{l}\text { Çağlı et al (2014) have investigated the effects of } \\
\text { US crude oil prices on some selected subsector } \\
\text { indices of Borsa Istanbul. In this study where } \\
\text { authors have employed VARFIMA model, daily } \\
\text { data is used for the period 1997-2012. Results of } \\
\text { the study indicate that oil prices and selected sub } \\
\text { sector indices are significantly interconnected. }\end{array}$ \\
\hline $\begin{array}{l}\text { Gönüllü ve diğ. } \\
\text { (2015) }\end{array}$ & $\begin{array}{l}\text { Çok } \\
\text { faktörlü } \\
\text { model }\end{array}$ & $2003-2012$ & Borsa İstanbul & $\begin{array}{l}\text { Petrol fiyatlarının Borsa İstanbul Petrol, Kimya ve } \\
\text { Plastik Endeksleri üzerinde etkisi olduğu ortaya } \\
\text { konulmaktadır. }\end{array}$ \\
\hline
\end{tabular}

Tablo 1. Literatür Taramasl 


\section{Yöntem ve Veriler}

Çalışmada Johansen Eşbütünleşme testinden yararlanılarak Brent petrol fiyatları ile BIST 100, BIST KİMYA, BIST ULAŞIM ve BIST SANAYİ endeksleri arasındaki ilişki araştırılmaktadır. 01.01.2006 ve 25.12.2016 yılları arası haftalık veriler kullanılarak analizler gerçekleştirilmiştir.

\subsection{Amprik sonuçlar}

\subsubsection{Birim Kök testi}

Eşbütünleşme testi yapabilmek için serilerin aynı seviyede durağan olması gerekmektedir. Durağanlık çizim incelemesi, ardışık ilişki fonksiyonu ve birim kök testleri yardımıyla ölçülebilir (Gujarati, Şenesen ve Şenesen, 2012:755). Çalışmada kullanılan serilerin durağan olup olmadıklarının test edilmesinde Augmented Dickey Fuller (ADF) ve Philips-Perron (PP) birim kök testleri kullanılmıştır. Elde edilen birim kök testi sonuçları Tablo 1ve 2 de görülmektedir.

\begin{tabular}{|l|l|l|}
\hline Düzey & Sabit & Sabit ve Trend \\
\hline Brent & $-1.626161(1)$ & $-1.676994(1)$ \\
\hline XU100 & $-1.514845(0)$ & $-2.873607(0)$ \\
\hline XUKIMYA & $-0.187925(1)$ & $-2.427805(1)$ \\
\hline XULAS & $-1.155824(0)$ & $-1.605827(0)$ \\
\hline XUSIN & $-0.629082(0)$ & $-2.848185(0)$ \\
\hline BİRİNCí FARK & & \\
\hline Brent & $-18.65169(0)^{*}$ & $-18.67065(0)^{*}$ \\
\hline XU100 & $-25.26967(0)^{*}$ & $-25.24727(0)^{*}$ \\
\hline XUKIMYA & $-27.82640(0)$ & $-27.83420(0)^{*}$ \\
\hline XULAS & $-23.09433(0)^{*}$ & $-23.08104(0)^{*}$ \\
\hline XUSIN & $-26.25532(0)^{*}$ & $-26.24374(0)^{*}$ \\
\hline
\end{tabular}

Tablo 2. ADF Birim Kök Testi Sonuçları

Not: Parantez içindeki rakamlar gecikme uzunluklarıdır. *\%1 değerinde anlamlı olan test değerleridir.

\begin{tabular}{|l|l|l|}
\hline Düzey & Sabit & Sabit ve Trend \\
\hline Brent & $-1.881144(11)$ & $-1.914014(11)$ \\
\hline XU100 & $-1.514845(0)$ & $-2.888116(3)$ \\
\hline XUKIMYA & $-0.281601(3)$ & $-2.571762(2)$ \\
\hline XULAS & $-1.155824(0)$ & $-1.687694(2)$ \\
\hline XUSIN & $-0.595908(5)$ & $-2.875726(6)$ \\
\hline BíRINCİ FARK & & \\
\hline Brent & $-19.29184(9)^{*}$ & $-19.28663(9)^{*}$ \\
\hline XU100 & $-25.26841(1)^{*}$ & $-25.24602(1)^{*}$ \\
\hline XUKIMYA & $-27.77434(2)^{*}$ & $-27.82425(1)^{*}$ \\
\hline XULAS & $-23.09413(1)^{*}$ & $-23.08084(1)^{*}$ \\
\hline XUSIN & $-26.16350(5)^{*}$ & $-26.15315(5)^{*}$ \\
\hline
\end{tabular}

Tabl .3. PP Birim Kök Testi Sonuçlarl

Not: Parantez içindeki rakamlar gecikme uzunluklarldır. *\%1 değerinde anlamlı olan test değerleridir.

Birim kök testi sonuçlarına göre tüm seriler birinci derecede durağan hale gelmektedir.

\subsubsection{Johansen Eşbütünleşme Testi}

Eşbütünleşme iki değişken arasındaki uzun dönem ilişkisini araştırmaktadır (Tarı, 2010:425). Eşbütünleşme analizi, zaman serileri alanına 1980'lerin başında girmiş ve birçok araştırmada kullanılmıştır (Kocabıyık, 2016:41)

\begin{tabular}{|c|c|c|}
\hline & $\lambda_{\text {trace }}$ & $\% 5$ kritik değer \\
\hline None & 402.4556 & 12.32090 \\
\hline At most 1 & 172.0025 & 4.129906 \\
\hline & $\begin{array}{c}\lambda_{\max } \\
\text { Max-Eigen İstatistiği }\end{array}$ & $\% 5$ kritik değer \\
\hline None & 230.4532 & 11.22480 \\
\hline At most 1 & 172.0025 & 4.129906 \\
\hline
\end{tabular}

Tablo 4. Johansen Eşbütünleşme Testi Sonuçları (Brent XU100) 
BIST 100 endeksi ile brent petrol fiyatı arasındaki eşbütünleşme ilişkisi analizi sonuçları Tablo 4'de gösterilmektedir. $\lambda \mathrm{iz}=402.455>12.320$ ve $\lambda$ maks $=230.4532>11.224 \mathrm{r}=0$ hipotezi iki test değeri içinde reddedilmektedir. Bu sonuca göre BIST100 endeksi ile brent petrol fiyatlarının eşbütünleşik oldukları görülmektedir. Bir başka ifade ile BIST 100 ile brent petrol fiyatları arasında uzun dönemde denge ilişkisinin bulunduğu söylenebilir.

\begin{tabular}{|c|l|c|}
\hline & $\lambda_{\text {trace }}$ & $\% 5$ kritik değer \\
\hline None & 432.4576 & 12.32090 \\
\hline At most 1 & 166.0857 & 4.129906 \\
\hline & \multicolumn{2}{|c|}{$\lambda_{\max }$} \\
\hline Max-Eigen İstatistiği & $\% 5$ kritik değer \\
\hline At most 1 & 266.3719 & 11.22480 \\
\hline
\end{tabular}

Tablo 5. Johansen Eşbütünleşme Testi Sonuçları (Brent XUKIMYA)

BIST KİMYA endeksi ile brent petrol fiyatı arasındaki eşbütünleşme ilişkisi analizi sonuçları Tablo 5'de gösterilmektedir. $\lambda \mathrm{iz}=432.457>12.320$ ve $\lambda$ maks $=266.371>11.224 \mathrm{r}=0$ hipotezi iki test değeri içinde reddedilmektedir. Bu sonuca göre BIST KIMMYA endeksi ile brent petrol fiyatlarının eşbütünleşik oldukları görülmektedir. Bir başka ifade ile BIST KIMYA ile brent petrol fiyatları arasında uzun dönemde denge ilişkisinin bulunduğu söylenebilir.

\begin{tabular}{|c|c|c|}
\hline & $\lambda_{\text {trace }}$ & $\% 5$ kritik değer \\
\hline None & 394.8805 & 12.32090 \\
\hline At most 1 & 176.7377 & 4.129906 \\
\hline & $\begin{array}{c}\lambda_{\max } \\
\text { Max-Eigen İstatistiği }\end{array}$ & $\% 5$ kritik değer \\
\hline None & 218.1428 & 11.22480 \\
\hline At most 1 & 176.7377 & 4.129906 \\
\hline
\end{tabular}

Tablo 6. Johansen Eşbütünleşme Testi Sonuçları (Brent XULAS)

BIST ULAŞIM endeksi ile brent petrol fiyatı arasındaki eşbütünleşme ilişkisi analizi sonuçları Tablo 6'da gösterilmektedir. $\lambda \mathrm{iz}=394.880>12.320$ ve $\lambda$ maks $=218.142>11.224 \mathrm{r}=0$ hipotezi iki test değeri içinde reddedilmektedir. Bu sonuca göre BIST ULAŞIM endeksi ile brent petrol fiyatlarının eşbütünleşik oldukları görülmektedir. Bir başka ifade ile BIST ULAŞIM ile brent petrol fiyatları arasında uzun dönemde denge ilişkisinin bulunduğu söylenebilir.

\begin{tabular}{|c|c|c|}
\hline & \multicolumn{1}{|c|}{$\lambda_{\text {trace }}$} & $\% 5$ kritik değer \\
\hline None & 290.3541 & 12.32090 \\
\hline At most 1 & 120.1491 & 4.129906 \\
\hline & $\begin{array}{c}\lambda_{\max } \\
\text { Max-Eigen İstatistiği }\end{array}$ & $\% 5$ kritik değer \\
\hline None & 170.2050 & 11.22480 \\
\hline At most 1 & 120.1491 & 4.129906 \\
\hline
\end{tabular}

Tablo 7. Johansen Eşbütünleşme Testi Sonuçları (Brent XUSIN)

BIST SANAYİ endeksi ile brent petrol fiyatı arasındaki eşbütünleşme ilişkisi analizi sonuçları Tablo 7'de gösterilmektedir. $\lambda \mathrm{iz}=290.354>12.320$ ve $\lambda$ maks $=170.205>11.224 \mathrm{r}=0$ hipotezi iki test değeri içinde reddedilmektedir. Bu sonuca göre BIST SANAYİ endeksi ile brent petrol fiyatlarının eşbütünleşik oldukları görülmektedir. Bir başka ifade ile BIST SANAYİ ile brent petrol fiyatları arasında uzun dönemde denge ilişkisinin bulunduğu söylenebilir.

\section{Sonuç}

Bu çalışma, Borsa İstanbul'daki Hisse Senedi Piyasası Endeksi ile Petrol Fiyatı arasındaki dinamik ilişkiyi ele almaya çalışmaktadır. Çalışmada Johansen Eşbütünleşme testinden yararlanılarak Brent petrol fiyatları ile BIST 100, BIST KİMYA, BIST ULAŞIM ve BIST SANAYİ endeksleri arasındaki iliş̧ki araştırılmaktadır. 01.01.2006 ve 25.12.2016 yılları arası haftalık veriler kullanılarak analizler gerçekleştirilmiştir. Haftalık veriler kullanmadaki amaç daha dinamik bir sonucun ortaya konulmak istenmesidir. Sonuçlar, petrol fiyatları ile Borsa İstanbul endeksleri arasında ele alınan dönem için pozitif ve anlamlı bir ilişki olduğunu göstermektedir. Yapılan analizler sonucunda, inceleme dönemindeki tüm borsa endeksi ile uluslararası petrol fiyatı arasındaki uzun vadeli bir ilişki, diğer bir deyişle, her bir borsa endeksinin uluslararası petrol fiyatı ile eşgüdümlü olduğu gözlemlenmiştir. Granger nedensellik analizinden elde edilen sonuçlar göz önüne alındığında, her bir hisse senedi endeksinin uluslararası petrol fiyatına yönelik tek yönlü nedensellik ilişkisi olduğu ve uluslararası petrol fiyatının herhangi bir endeks 
nedenselliğine sahip olmadığı ortaya çıkmaktadır. Elde edilen sonuçlar göz önüne alındığında, Türkiye'de borsa getirilerinin ham petrol fiyatlarındaki değişimleri işaret ettiği söylenebilir.

\section{Kaynakça}

- Arouri, M. H. E., Lahiani, A., \& Bellalah, M. (2010). Oil price shocks and stock market returns in oilexporting countries: The case of GCC countries. International Journal of Economics and Finance, 2(5), pp. 132-139.

- Basher, S.A. ve Sadorsky, P. (2006). Oil Price Risk and Emerging Stock Markets, Global Finance Journal, 17, 224-251.

- Bernanke, Ben S., https://www.brookings.edu/blog/ben-bernanke/2016/02/19/the-relationship-betweenstocks-and-oil-prices/ Erişim tarihi: 14.03.2017

- Bjørnland, H. C.(2008). Oil Price Shocks and Stock Market Booms in an Oil-Exporting Country, Working Paper 16/2008, Norges Bank.

- Cong, R., Wei, Y., Jiao, J. ve Fan, Y. (2008). Relationships between oil price shocks and stock market: An empirical analysis from China, Energy Policy,36, 3544-3553.

- Çağli, E.Ç., Taşkin, F.D., Mandacı, P.E.(2014). The Interactions between oil prices and Borsa İstanbul indices, International Journal of Economic Policy in Emerging Economies, Vol.7, No.1,pp.55- 65

- Gönüllü, Çağlar Ozan, Otluoğlu, Emir ve Şengöz, Mehmet Hakan (2015). "Ham Petrol Fiyat1 Değişimlerinin Petrokimya Sektörü Getirileri Üzerindeki Etkisi”, Uluslararası İktisadi İncelemeler Dergisi, $14,223-234$.

- Gujarati, D N, Şenesen, Ü, Şenesen, G G. (2012). Temel Ekonometri: Literatür

- Hayky A., A., ve Ahlia N.,N., "The Relationship between Oil Price and Stock Market Index: An Empirical Study from Kuwait" https://www.dohainstitute.edu.qa/MEEA2016/Downloads/Nizar\%20Naim_Final.pdf

- Kapusuzoglu, A., 2011, Relationships between Oil Price and Stock Market: An Empirical Analysis from Istanbul Stock Exchange (ISE), International Journal of Economics and Finance, Vol. 3, No. 6; November 2011

- Kocabıyık, T. (2016). Johansen Eşbütünleşme Testinde Karar Aşamalarının Analizi. Sosyal Bilimler Enstitüsü Dergisi. CIEP Özel Sayısı.

- Özmerdivanlı, Arzu. 2014. "Petrol Fiyatları ile BIST 100 Endeksi Kapanış Fiyatları Arasındaki İlişki", Akademik Bakış, 43, 1-12.

- Sadorsky, P., 2001. Risk factors in stock returns of Canadian oil and gas companies. Energy Economics 23, $17-28$.

- Tarı, R. (2010). Ekonometri (6. bs). Kocaeli: Umuttepe Yayınları.

- http://busecon.eurasianacademy.org/dergi//S2/36-Business\&Economics.pdf. Erişim tarihi: 11.04.2017 
Doğrudan Yabancı Yatırımlar ile Aramalı ve Sermaye Malı İthalatı Arası İlişkiler: Türkiye Ekonomisi Üzerine TodaYamamoto Nedensellik Analizleri (2005 M1-2016 M12)

\title{
Relations between Foreign Direct Investments and Intermediate and Capital Goods: Toda-Yamamoto Causality Analyses on Turkish Economy (2005 M1-2016 M12)
}

\author{
Prof. Dr. Mustafa Kemal Değer (Karadeniz Technical University, Turkey) \\ Muharrem Akın Doğanay (Karadeniz Technical University, Turkey)
}

\begin{abstract}
The aim of this study is to empirically test the relations between the FDI in Turkey's manufacturing industry and the imports of intermediate and capital goods. Monthly data for the period 2005-2016 belonging to the variables used in the study were obtained from the "Electronic Data Distribution System" of the Central Bank of the Republic of Turkey. In the determination of the period of the study, the presence of monthly data and the increase trend of the FDI coming to Turkey after 2005 have been influential. Relations between variables in the study were tried to be determined by Toda-Yamamoto causality analysis.

According to the empirical findings obtained in the study, one-way and statistically significant causal relations from FDI made in manufacturing industry to both capital goods imports and intermediate imports have been determined. However, from these relations, towards to intermediate imports is much more robust in terms of statistics.
\end{abstract}

Therefore, these findings obtained from the study shows that FDI on Turkey's manufacturing industry are an important determinant of capital goods, and especially intermediate goods imports.

\section{Giriș}

II. Dünya Savaşı sonrasında imzalanan Gümrük Tarifeleri ve Ticaret Genel Anlaşması (GATT), anlaşmaya taraf olan ülkeler arasında ticaretin serbestleşmesine hizmet ederek ticari anlamda küreselleşmenin ortaya çıkmasına yol açmıştır. Ticari küreselleşmeye 1973 yılında Bretton Woods Sistemi'nin yıkılmasıyla beraber finansal küreselleşme eşlik etmeye başlamıştır. Son yıllarda ise ekonomik anlamda küreselleşmenin bir diğer boyutu olan üretimin küreselleşmesi, Çok Uluslu Şirket (ÇUŞ)'lerin yatırım kararları ile belirgin hale gelmeye başlamıştır. Doğrudan Yabancı Yatırım (DYY)'lar olarak isimlendirilen bu tür yatırımların ortaya çıkmasında etkili olan birçok ekonomik faktör söz konusudur. Bunlar arasında yatırım yapılan ülkelerdeki işgücü ve hammadde gibi üretim faktörlerinin varlığı, vergilendirme politikalarındaki farklılıklar, ülkenin pazar büyüklüğü ve potansiyel pazarlara yakınlığ 1 gibi faktörler sayılabilir.

Öte yandan DYY'lar, yatırımın yapıldığı ülkede olumlu ve olumsuz bir takım etkilere de neden olabilmektedir. Örneğin yatırım yapılan ülkenin ekonomik büyümesini artırması, istihdam yaratması, teknoloji transferine yol açması, ihracatı teşvik etmesi ve döviz açığını kapatması gibi olumlu etkileri söz konusudur. Öte yandan ekonominin yabancıların kontrolüne girmesi, yurtiçi yatırımları caydırması, teknolojik bağımlılık yaratması, ithalat artışına yol açarak döviz ihtiyacını şiddetlendirmesi ve ekonomide ikili (dual) bir yapının oluşmasına neden olması gibi olumsuz etkileri de ortaya çıkabilmektedir. Dolayısıyla DYY'ların yatırımın yapıldığı ülke ekonomisi üzerindeki etkileri, son dönem ampirik literatürde sıklıkla ele alınan konuların başında yer almaktadır.

Bu çalışmanın amacı, Türkiye ekonomisi özelinde DYY'ların ülkenin ithalatı üzerindeki etkilerini ampirik olarak test etmektir. Bu amaç doğrultusunda çalışma 5 ana başlık altında oluşturulmuştur. Çalışmanın Giriş kısmını takiben DYY'ların diş ticaret ve özellikle de ithalat üzerindeki etkilerini ampirik olarak ele alan çalışma bulgularına yer verilmiştir. Çalışmanın üçüncü bölümünde ise veri seti ve değişkenler tanıtıldıktan sonra değişkenler arası nedensel ilişkileri belirlemeye yönelik kullanılacak yöntem verilmiştir. Çalışmanın dördüncü bölümünde elde edilen ampirik sonuçlar verildikten sonra çalışmanın son kısmında bu sonuçlar değerlendirilmeye çalışılmıştır.

\section{DYY'lar ve İthalat Üzerine Ampirik Literatür Özeti}

DYY'ların, yatırım yapıldığı ülke ekonomisi üzerindeki etkileri, günümüzde dahi hala en çok tartışılan ve ekonometrik testlerle yoğun bir şekilde ele alınan konular arasındadır. Bu kapsamda çalışmaların büyük bir kısmı, DYY'ların ekonomik büyüme üzerindeki etkileri üzerine yoğunlaşırken, bir kısım çalışmalar ise DYY'ların işsizlik ve ücretler üzerindeki etkilerini ele almışlardır. Son dönem çalışmaların bazıları ise DYY'ları dış ticaret ve ödemeler dengesi üzerindeki etkilerini inceleme konusu yapmıştır. 
Konu ile ilgili literatürde DYY'ların ticaret üzerindeki etkileri iki farklı boyutta ele alınmaktadır. Bunlardan ilki, DYY'ların ticaretin tamamlayıcısı veya ikamesi olup olmadığı konusunu ele alırken, diğer görüş ise DYY'lar ile ticaret arasındaki nedenselliğin yönü üzerine yoğunlaşmaktadır.

Ticaret teorisine göre, DYY'ların ticareti ikame edip etmediği veya tamamladığı DYY'ların motivasyonuna bağlıdır. DYY çok uluslu şirketlerin coğrafi olarak üretim aşamalarına sahip olduğu yerlerde dikeydir ve bu durumun ticareti teşvik etmesi muhtemeldir. Çokuluslu şirketlerin birden fazla yerde nihai mal ürettiği durumda ise DYY yataydır ve ticaretin yerini alması muhtemeldir. Eğer DYY, ticaretin yerini alıyorsa, yerel üretimden uzaklaşan bir dışa dönüklüğü temsil eder ve yabancıların ürettiği ürünler satılır ve ihraç edilir. Tersine, eğer DYY ticareti tamamlarsa, yerel üretim yurtdışındaki yatırımlardan faydalanır (Kıran, 2011: 150). Dolayısıyla çalışmanın bu kısmında DYY'lar ile ticaret (ihracat ve ithalat) arasındaki ilişkileri ampirik olarak ele alan çalışmaların bulgularına yer verilecektir.

\begin{tabular}{|c|c|c|c|}
\hline Yazarlar & Ülke ve Dönemi & Yöntem & Bulgular \\
\hline $\begin{array}{l}\text { Camarero \& } \\
\text { Tamarit } \\
(2003)\end{array}$ & $\begin{array}{c}\text { AB Ülkeleri, } \\
\text { ABD ve Japonya } \\
\text { (Q1.1981- Q3.1998) }\end{array}$ & $\begin{array}{r}\text { Panel Birim Kök \& } \\
\text { Eşbütünleşme Analizi }\end{array}$ & $\begin{array}{l}\text { İthalat ve ihracat ile DYY arasında } \\
\text { tamamlayıcılık ilişkisi vardır. }\end{array}$ \\
\hline $\begin{array}{l}\text { Dritsaki vd. } \\
(2004)\end{array}$ & $\begin{array}{l}\text { Yunanistan } \\
(1960-2002)\end{array}$ & $\begin{array}{c}\text { Eşbütünleşme \& } \\
\text { Granger Nedensellik } \\
\text { Analizi } \\
\end{array}$ & $\begin{array}{l}\text { Ekonomik büyüme, ithalat-ihracat ve } \\
\text { DYY, açık kapı politikası altında karşılıklı } \\
\text { olarak güçlenmektedir. }\end{array}$ \\
\hline $\begin{array}{l}\text { Kueh vd. } \\
(2007)\end{array}$ & $\begin{array}{l}\text { ASEAN-5 Ülkeleri } \\
\quad(1990-2005)\end{array}$ & ARDL Yöntemi & $\begin{array}{c}\text { DYY ve ithalat uzun vadede birbirlerini } \\
\text { tamamlayıcı nitelikte olmakla birlikte, } \\
\text { ithalat kısa vadede DYY'yi değiştirme } \\
\text { eğilimindedir. }\end{array}$ \\
\hline $\begin{array}{l}\text { Pourshahabi } \\
\text { vd. } \\
(2011)\end{array}$ & $\begin{array}{l}16 \text { Gelişmiş } \\
\text { Avrupa Ülkesi } \\
(1976-2008)\end{array}$ & $\begin{array}{c}\text { Eşbütünleşme \& } \\
\text { Granger Nedensellik } \\
\text { Analizleri }\end{array}$ & $\begin{array}{l}\text { Kisa dönemde DYY-İhracat ve DYY- } \\
\text { Itthalat arasında çift yönlü nedensellik, } \\
\text { uzun dönemde ise ithalat ve ihracattan } \\
\text { DYY'e doğru nedensellik mevcuttur. }\end{array}$ \\
\hline $\begin{array}{l}\text { Anwar \& } \\
\text { Nguyen } \\
(2011) \\
\end{array}$ & $\begin{array}{c}\text { Vietnam } \\
(1990-2007)\end{array}$ & $\begin{array}{l}\text { GLS Yöntemi } \\
\text { (Çekim Modeli } \\
\text { Yaklaşımı) }\end{array}$ & $\begin{array}{l}\text { DYY ile ihracat ve ithalat arasında } \\
\text { tamamlayıcı bir ilişki var olmaktadır. }\end{array}$ \\
\hline $\begin{array}{l}\text { Filippaios \& } \\
\text { Kottaridi } \\
(2013) \\
\end{array}$ & $\begin{array}{l}\text { Merkezi ve Doğu } \\
\text { Avrupa Ülkeleri } \\
(1992-2008)\end{array}$ & $\begin{array}{l}\text { 3SLS (Three-stage } \\
\text { Least Squares) } \\
\text { Yöntemi } \\
\end{array}$ & $\begin{array}{l}\text { DYY ithalatta olumlu bir rol } \\
\text { oynamaktadır. }\end{array}$ \\
\hline $\begin{array}{l}\text { Chani, Azam } \\
\& \text { Younas } \\
(2014) \\
\end{array}$ & $\begin{array}{c}\text { Pakistan } \\
(1972-2009)\end{array}$ & $\begin{array}{c}\text { Eşbütünleşme \& } \\
\text { Granger Nedensellik } \\
\text { Analizleri } \\
\end{array}$ & $\begin{array}{l}\text { DYY, ithalat ve ihracat arasında uzun } \\
\text { dönemde anlamlı bir ilişki vardır. }\end{array}$ \\
\hline $\begin{array}{l}\text { Tran \& Dinh } \\
\quad(2014)\end{array}$ & $\begin{array}{l}\text { Gelişmekte Olan } \\
\text { Asya Ülkeleri } \\
(1991-2011)\end{array}$ & $\begin{array}{l}\text { Panel Veri \& Zaman } \\
\text { Serisi Analizleri }\end{array}$ & $\begin{array}{l}\text { Mevcut DYY girdileri dış ticaret açığını } \\
\text { artırmakta ve ev sahibi ülke için olumsuz } \\
\text { sonuçlar doğurmaktadır. }\end{array}$ \\
\hline $\begin{array}{l}\text { Berasaluce \& } \\
\text { Romero } \\
(2015)\end{array}$ & $\begin{array}{l}\text { Güney Kore } \\
(1989-2014)\end{array}$ & $\begin{array}{c}\text { VAR, Granger } \\
\text { Nedensellik Analizleri } \\
\text { \& Block Exogeneity } \\
\text { Test }\end{array}$ & $\begin{array}{l}\text { Büyümeye dayalı ihracat hipotezinin yanı } \\
\text { sira DYY'nin ekonomik büyüme ya da } \\
\text { ihracat üzerinde herhangi bir etkisi } \\
\text { bulunmamaktadır. }\end{array}$ \\
\hline $\begin{array}{l}\text { Keho } \\
(2015)\end{array}$ & $\begin{array}{c}12 \text { Seçilmiş } \\
\text { Sahraaltı Ülkesi } \\
(1970-2013) \\
\end{array}$ & $\begin{array}{c}\text { Eşbütünleşme \& } \\
\text { Granger Nedensellik } \\
\text { Analizleri } \\
\end{array}$ & $\begin{array}{c}\text { Sonuçlar, DYY ve ihracat teşvik } \\
\text { politikaları için ampirik bir temel } \\
\text { oluşturmaktadır. }\end{array}$ \\
\hline $\begin{array}{l}\text { Napshin \& } \\
\text { Brouthers } \\
(2015)\end{array}$ & $\begin{array}{l}\text { Gelişmiş Ülkeler } \\
(2003-2006)\end{array}$ & $\begin{array}{l}\text { Siradan En Küçük } \\
\text { Kareler Regresyon } \\
\text { Yöntemi }\end{array}$ & $\begin{array}{c}\text { Gelişmiş ülkelerde DYY ve ithalat / } \\
\text { ihracat arasında daha güçlü ilişkiler vardır. } \\
\text { Ancak DYY ve ulusal ticaret dengeleri } \\
\text { arasında daha zayıf bağlantılar mevcuttur. }\end{array}$ \\
\hline $\begin{array}{l}\text { Albulescu \& } \\
\text { Goyeau } \\
(2016)\end{array}$ & $\begin{array}{l}\text { Merkezi ve Doğu } \\
\text { Avrupa Ülkeleri } \\
(2000-2013)\end{array}$ & $\begin{array}{l}\text { Rassal ve Sabit } \\
\text { Etkili Panel Veri } \\
\text { Analizleri }\end{array}$ & $\begin{array}{c}\text { Dışarıya çıkan DYY, CEE ülkelerinin } \\
\text { ticari entegrasyonunu arttırırken, } \\
\text { dışarıdan yapılan DYY'nin önemli bir etkisi } \\
\text { yoktur. }\end{array}$ \\
\hline
\end{tabular}

Tablo 1. Ampirik Literatür Özeti

Tablo 1'de verilen çalışmaların bulgularından hareketle, DYY'lar ile dış ticaret arasında evrensel bir geçerliliğe sahip bir sonuçtan bahsetmemiz mümkün değildir. Böyle bir sonucun ortaya çıkmasında çalışmalarda ele alınan ülke ve/veya ülke grubundaki farklılıklar, kullanılan yöntem ve dönemdeki farklılıklar etkilidir. Ayrıca DYY'lar ile dış ticaret arasındaki anlamlı ilişkilerin ortaya çıkmasında DYY'ların türü de (yatay veya dikey DYY) önemlidir 


\section{Veri ve Metodoloji}

$\mathrm{Bu}$ çalışmanın amacı, DYY'lar ile ticaretin ithalat boyutu arasında nedensel bir ilişsinin varlığını Türkiye ekonomisi özelinde ortaya koymaktır. Çalışmada Türkiye'ye yönelik DYY'ların çok büyük artışlar gösterdiği 2005 sonrası dönem dikkate alınmıştır. Türkiye Cumhuriyet Merkez Bankası'nın “Elektronik Veri Dağıtım Sistemi”den elde edilen aylık dolar bazlı DYY'lar ile ithalat değişkenleri, öncelikle ortalama aylık döviz kuru ile çarpılarak Türk Lirasına çevrilmiş ve daha sonra bu seriler 2003 yılı bazlı tüketici fiyat indeksi kullanılarak reelleştirilmiştir. Değişkenlere ait reel seriler, "Hareketli Ortalamalar Yöntemi” kullanılarak mevsimsellikten arındırılmıştır.

Çalışmada kullanılan değişkenler, Tablo 2'de tanımlanmıştır.

\begin{tabular}{|l|l|}
\hline Değişken & \multicolumn{1}{|c|}{ Tanım } \\
\hline RIMLDYY & Reel İmalat Sanayindeki Doğrudan Yabancı Yatırımlar \\
RTOPDYY & Reel Toplam Doğrudan Yabancı Yatırımlar \\
RSERITH & Reel Sermaye Malı İthalatı \\
RARAITH & Reel Ara Malı İthalatı \\
RTOPITH & Reel Toplam Mal İthalatı \\
\hline
\end{tabular}

Tablo 2. Çalışmada Kullanılan Değişkenlerin Kısaltma ve Açılımları

Çalışmada 2005 M1-2016 M12 dönemi verileri kullanılarak değişkenler arası nedensel ilişkiler Toda ve Yamamoto nedensellik analizi ile belirlenmeye çalışılmıştır. Toda ve Yamamoto nedensellik analizleri aşağıdaki gibi tanımlanan eşitlik kullanılarak gerçekleştirilmiştir.

Toda ve Yamamoto (1995) nedensellik sınaması yaklaşımı, değişkenlerin seviye değerlerinin yer aldığ Vektör Otoregressif (VAR) modeli üzerinden gerçekleştirilir. VAR modelinin optimal gecikme uzunluğu (k) ve değişkenlerin en büyük durağanlık seviyesi olan maksimum bütünleşme derecesi $\left(\mathrm{d}_{\max }\right)$ belirlenerek, VAR sistemi aşağıdaki gibi tanımlanan eşitliklerle tahmin edilir (Tandoğan ve Genç, 2016: 66).

$$
\begin{aligned}
& X_{t}=\emptyset_{0}+\sum_{i=1}^{k} \gamma_{1 i} X_{t-i}+\sum_{i=k+1}^{k+d_{\max }} \gamma_{2 i} X_{t-i}+\sum_{i=1}^{k} \beta_{1 i} Y_{t-i}+\sum_{i=k+1}^{k+d_{\max }} \beta_{2 i} Y_{t-i}+E_{1 t} \\
& Y_{t}=\tau_{0}+\sum_{i=1}^{k} \sigma_{1 i} Y_{t-i}+\sum_{i=k+1}^{k+d_{\max }} \sigma_{2 i} Y_{t-i}+\sum_{i=1}^{k} \delta_{1 i} X_{t-i}+\sum_{i=k+1}^{k+d_{\max }} \delta_{2 i} X_{t-i}+E_{2 t}
\end{aligned}
$$

\section{Ampirik Bulgular}

Çalışmada nedensellik sınamaları yapılmadan önce değişkenlere ait tanımlayıcı istatistikler ile korelasyon matrisi, Tablo 3 ve Tablo 4'te sunulmuştur.

\subsection{Tanımlayıcı İstatistikler ve Korelasyon Matrisi}

\begin{tabular}{|l|c|c|c|c|c|}
\hline Değişkenler & RIMLDYY & RTOPDYY & RSERITH & RARAITH & RTOPITH \\
\hline Ortalama & 207.425 & 894.840 & 2372.749 & 10831.090 & 15115.250 \\
\hline Ortanca & 119.148 & 573.474 & 2296.726 & 11106.580 & 15371.310 \\
\hline Maksimum & 1782.191 & 7264.261 & 4225.708 & 14826.810 & 20810.930 \\
\hline Minimum & 12.666 & 51.727 & 1190.758 & 6388.344 & 8533.777 \\
\hline Standart Sapma & 279.886 & 1031.147 & 566.773 & 2206.615 & 3066.746 \\
\hline Gözlem Sayıs1 & 143 & 143 & 143 & 143 & 143 \\
\hline
\end{tabular}

Tablo 3. Tanımlayıcı İstatistikler ve Korelasyon Matrisi

Tablo 3'de yer alan bilgilere göre Türkiye'de 2005M1-2016M12 döneminde yapılan RIMLDYY, ortalama olarak 207 Milyon TL kadar iken, ortalama RTOPDYY yaklaşık 895 Milyon TL olarak gerçekleşmiştir. En yüksek olduğu dönemde ise 7.264 Milyon TL seviyesine ulaşmıştır. Belirtilen dönemde ortalama RSERITH 2.372 Milyon TL olurken, RARAITH ortalama olarak aylık 10.831 Milyon TL olmuştur. Ayrıca RTOPITH 15.115 Milyon TL ortalamaya sahiptir.

Çalışmada kullanılan veriler ile ilgili bu genel görünümün yanında değişkenler arası ikili ilişsileri veren korelasyon katsayıları, Tablo 4'te sunulmuştur. 


\begin{tabular}{|c|c|c|c|c|c|}
\hline Olasılık & LRIMLDYY & LRTOPDYY & LRSERITH & LRARAITH & LRTOPITH \\
\hline \multirow{2}{*}{ LRIMLDYY } & 1.000 & & & & \\
\hline & ----- & & & & \\
\hline \multirow{2}{*}{ LRTOPDYY } & 0.496 & 1.000 & & & \\
\hline & $(0.000)$ & ----- & & & \\
\hline \multirow{2}{*}{ LRSERITH } & 0.213 & 0.160 & 1.000 & & \\
\hline & $(0.011)$ & $(0.056)$ & ----- & & \\
\hline \multirow{2}{*}{ LRARAITH } & 0.336 & 0.237 & 0.818 & 1.000 & \\
\hline & $(0.000)$ & $(0.004)$ & $(0.000)$ & ----- & \\
\hline \multirow{2}{*}{ LRTOPITH } & 0.310 & 0.212 & 0.893 & 0.987 & 1.000 \\
\hline & $(0.000)$ & $(0.011)$ & $(0.000)$ & $(0.000)$ & ----- \\
\hline
\end{tabular}

Tablo 4. Tanımlayıc İstatistikler ve Korelasyon Matrisi

Not: Korelasyon analizi için reel serilere uyarlanan mevsimsel düzeltmeden sonra logaritmaları (L) alınmıştır.

Tablo 5'de verilen korelasyon katsayıları ise değişkenler arasında pozitif ve anlamlı ilişkinin varlığına işaret etmektedir.

\subsection{Toda ve Yamamoto Nedensellik Analizi Sonuçları}

Çalışmada nedensellik analizlerine geçmeden önce değişkenlerin durağanlık sınamaları ADF yöntemi ile gerçekleştirilmiş ve sonuçlar Tablo 5'de verilmiştir.

\begin{tabular}{|c|c|c|c|c|c|}
\hline \multirow[b]{2}{*}{ Değişkenler } & LRIMLFDI & LRTOPFDI & LRSERITH & LRARAITH & LRTOPITH \\
\hline & $\mathrm{t}$ istatistiği & $\mathrm{t}$ istatistiği & $\mathrm{t}$ istatistiği & $\mathrm{t}$ istatistiği & $\mathrm{t}$ istatistiği \\
\hline Seviye & $-4.353 *$ & $-3.547 * *$ & -2.265 & -2.825 & -2.492 \\
\hline \multirow[b]{2}{*}{ Değişkenler } & DLRIMLFDI & $\Delta$ LRTOPFDI & DLRSERITH & DLRARAITH & $\triangle$ LRTOPITH \\
\hline & $\mathrm{t}$ istatistiğ $\mathrm{i}$ & $\mathrm{t}$ istatistiği & $\mathrm{t}$ istatistiği & $\mathrm{t}$ istatistiği & $\mathrm{t}$ istatistiğ $\mathrm{i}$ \\
\hline Birinci Fark & $-15.947 *$ & $-11.467 *$ & $-13.064 *$ & $-17.572 *$ & $-19.359 *$ \\
\hline
\end{tabular}

Tablo 5. ADF Birim Kök Sinama Sonuçlarl (Sabitli ve Trendli)

Not: *, **ve *** sırasıyla \%1, \%5 ve \%10'da istatistiki açıdan anlamlılığı ve $\Delta$ ise serilerin birinci farkını ifade etmektedir.

Tablo 5'deki ADF Birim Kök sınamaları sonuçlarına göre TOPDYY ile IMLDYY değişkenleri seviyesinde durağan iken, ARAITH, SERITH ve TOPITH değişkenleri ise seviyesinde durağan değildir. Değişkenlerin birinci farkları alındığında ise tüm serilerin I(1)'de durağan hale geldiği görülmektedir. Dolayısıyla çalışmada farklı seviyelerde durağan hale gelen değişkenleri kullanarak nedensellik analizlerini gerçekleştirmeye imkân veren Toda ve Yamamoto nedensellik analizleri, aşağıdaki eşitlikleri kullanarak yapılmıştır.

Tablo 6, Toda ve Yamamoto nedensellik analizi sonuçlarını göstermektedir. 


\begin{tabular}{|c|c|c|c|c|c|c|c|}
\hline \multicolumn{8}{|c|}{$\operatorname{VAR}(4) \mathrm{k}=3, \mathrm{dmax}=1$} \\
\hline \multicolumn{4}{|c|}{ Bağımlı Değişken: LRIMLDYYSA } & \multicolumn{4}{|c|}{ Bağımlı Değişken: LRSERITHSA } \\
\hline Bağımsız Değişken & Ki-kare & df & Olasilik & Bağımsız Değişken & Ki-kare & $\mathrm{df}$ & Olasıl1k \\
\hline LRSERITHSA & 4.599 .352 & 3 & 0.2036 & LRIMLDYYSA & 6.429 .202 & 3 & 0.0925 \\
\hline \multicolumn{8}{|c|}{$\operatorname{VAR}(3) \mathrm{k}=2, \mathrm{dmax}=1$} \\
\hline \multicolumn{4}{|c|}{ Bağımlı Değișken: LRIMLDYYSA } & \multicolumn{4}{|c|}{ Bağımlı Değişken: LRARAITHSA } \\
\hline Bağımsız Değişken & Ki-kare & df & Olasılık & Bağımsız Değişken & Ki-kare & $\mathrm{df}$ & Olasıl1k \\
\hline LRARAITHSA & 0.753302 & 2 & 0.6862 & LRIMLDYYSA & 712.886 & 2 & 0.0283 \\
\hline \multicolumn{8}{|c|}{$\operatorname{VAR}(3) \mathrm{k}=2, \mathrm{dmax}=1$} \\
\hline \multicolumn{4}{|c|}{ Bağımlı Değișken: LRIMLDYYSA } & \multicolumn{4}{|c|}{ Bağımlı Değişken: LRTOPITHSA } \\
\hline Bağımsız Değişken & Ki-kare & df & Olasılık & Bağımsız Değişken & Ki-kare & $\mathrm{df}$ & Olasılık \\
\hline LRTOPITHSA & 0.452004 & 2 & 0.7977 & LRIMLDYYSA & 9.842 .969 & 2 & 0.0073 \\
\hline \multicolumn{8}{|c|}{$\operatorname{VAR}(6) \mathrm{k}=5, \mathrm{dmax}=1$} \\
\hline \multicolumn{4}{|c|}{ Bağımlı Değișken: LRTOPDYYSA } & \multicolumn{4}{|c|}{ Bağımlı Değişken: LRSERITHSA } \\
\hline Bağımsız Değişken & Ki-kare & $\mathrm{df}$ & Olasılık & Bağımsız Değişken & Ki-kare & $\mathrm{df}$ & Olasılık \\
\hline LRSERITHSA & 9.692 .734 & 5 & 0.0844 & LRTOPDYYSA & 1.241 .797 & 5 & 0.0295 \\
\hline \multicolumn{8}{|c|}{$\operatorname{VAR}(3) \mathrm{k}=2, \mathrm{dmax}=1$} \\
\hline \multicolumn{4}{|c|}{ Bağımlı Değişken: LRTOPDYYSA } & \multicolumn{4}{|c|}{ Bağımlı Değişken: LRARAITHSA } \\
\hline Bağımsız Değişken & Ki-kare & df & Olasılık & Bağımsız Değişken & Ki-kare & $\mathrm{df}$ & Olasılık \\
\hline LRARAITHSA & 388.353 & 2 & 0.1435 & LRTOPDYYSA & 4.714 .841 & 2 & 0.0947 \\
\hline \multicolumn{8}{|c|}{$\operatorname{VAR}(3) \mathrm{k}=2, \mathrm{dmax}=1$} \\
\hline \multicolumn{4}{|c|}{ Bağımlı Değișken: LRTOPDYYSA } & \multicolumn{4}{|c|}{ Bağımlı Değișken: LRTOPITHSA } \\
\hline Bağımsız Değişken & Ki-kare & df & Olasilık & Bağımsız Değişken & Ki-kare & $\mathrm{df}$ & Olasılık \\
\hline LRTOPITHSA & 3.481 .395 & 2 & 0.1754 & LRTOPDYYSA & 5.358 .214 & 2 & 0.0686 \\
\hline
\end{tabular}

Tablo 6. Nedensellik Analizi Sonuçları

Tablo 6'da verilen ampirik bulgulara göre imalat sanayi DYY'larından toplam, aramalı ve sermaye malı ithalatına doğru tek yönlü nedensel ilişkiler mevcut iken, bu ilişkiler içerisinde istatistiki olarak en güçlü olanı, toplam ithalata doğru olanıdır. Diğer taraftan toplam DYY'lar ile sermaye malı ithalatı arasında iki yönlü ve toplam DYY'lardan toplam ve aramalı ithalatına doğru ise tek yönlü nedensel ilişkiler söz konusudur.

\section{Sonuç ve Değerlendirme}

DYY'ların nedenleri ve sonuçları hakkında tartışmalar, son yıllarda giderek artmaya ve çeşitlenmeye başlanmıştır. Bu kapsamda DYY'ların nedenlerini araştıran “Tekel Üstünlüğü Teorisi”, "Oligopolcü Tepki Teorisi”, "İçselleştirme Teorisi” ve "OLI Teorisi” gibi son zamanlarda ortaya çıkmaya başlamıştır. Aynı şekilde DYY'ların yatırımın yapıldığı ülke ekonomisi üzerinde etkilerini ele alan bir kısım çalışmalar DYY'ların olumlu etkilerine dikkatleri çekerken, diğer bir kısım çalışmalar ise DYY'ların olumsuz etkilerini dile getirmektedir. DYY'ların olumlu etkileri arasında sermaye malı ithalatına yol açarak ülkeye yeni teknoloji ve yönetim bilgisinin transferine imkan vermesi yer alırken, olumsuz etkileri arasında ise aramalı ve sermaye malı ithalatını uyararak döviz giderlerini artırma ve teknolojik bağımlılık yaratma gibi etkilerinden bahsedilebilir. Dış ticaret ve özelde de ithalat üzerinde DYY'ların etkilerine yönelik bu tezat açıklamaların her ikisi de kendi içlerinde haklılık payına sahiptir. Dolayısıyla DYY'ları ticaret üzerindeki net etkisi, birbirine ters etkilerin hangisinin büyük olacağına bağlıdır. DYY'ların dış ticaret üzerinde özellikle de aramalı ve sermaye malı ithalatı üzerindeki etkileri her şeyden önce DYY'ların türüne ve niteliğine bağlı olacaktır.

Bu çalışmanın amacı, 2005 yılı sonrası büyük miktarda DYY çekebilen fakat son yıllarda ise bu özelliğini kaybeden Türkiye'de DYY'lar ile aramalı ve sermaye malı ithalatı arasındaki ilişkileri ampirik olarak belirlemektir. Bu kapsamda 2005-2016 dönemi aylık verileri dikkate alınarak, hem imalat sanayine yönelen DYY'lar, hem de toplam DYY'lar ile ithalat arası ilişkiler, Toda ve Yamamoto nedensellik analizleri yardımıyla inceleme konusu yapılmıştır. Çalışmada yapılan analizlerden elde edilen bulgulara göre imalat sanayi DYY'larından toplam, aramalı ve sermaye malı ithalatına doğru tek yönlü nedensel ilişkiler mevcut iken, toplam DYY'lar ile sermaye malı ithalatı arasında iki yönlü, aramalı ve toplam mal ithalatı ile ise tek yönlü nedensellikler söz konudur. Çalışmada elde edilen bu bulgular, Türkiye'deki DYY'ların ülkenin döviz ihtiyaçlarını artırarak ithalat üzerinde uyarıcı etkilere neden olduğuna işaret etmektedir. Ayrıca DYY'lardan sermaye malı ithalatına doğru nedensel ilişkilere dair bulgular ise DYY'ların ülkeye yeni teknoloji transferine imkan verdiği şeklinde yorumlanabilir. 
Sonuç olarak DYY'ların Türkiye'de sermaye malı ithalatına yol açarak, yeni teknolojilerin ülke ekonomisine kazandırması önemli bir etki iken, bu yatırımların ihtiyaç duyduğu aramalı niteliğindeki girdilerin ithal edilen alternatiflerinin yurtiçi pazarlardan temin edilmesi DYY'ların olumlu etkilerinin daha da artmasına yol açacaktır. Dolayısıyla küreselleşme süreci ile birlikte dünya ekonomisine entegre olan Türkiye'de DYY'ların miktarını artıracak ve bu yatırımların özellikle imalat sanayi sektörlerine yönelmesini sağlayacak sanayi ve teşvik politikalarına ihtiyaç duyulmaktadır. Bununla birlikte son yıllarda Türkiye ekonomisine yönelen yatırımların ağırlıkla "Bankacılık ve Finans” sektörleri ile "Gayri Menkul” sektörlerinde yoğunlaştığı gerçeği, DYY'ların ülke ekonomisine olumlu katkıları konusunda endişelere de yol açmaktadır. Bu nedenle DYY'ların imalat sanayini hedef alan yatırımlar olarak gerçekleşmesinin ülke ekonomisine katkılara çok daha fazla olacaktır.

\section{Kaynakça}

- $\quad$ Albulescu, C. T., \& Goyeau, D. (2016). The Interaction between Trade and FDI: the CEE Countries Experience (No. hal-01361954).

- Anwar, S., \& Nguyen, L. P. (2011). "Foreign Direct Investment and Trade: The Case of Vietnam", Research in International Business and Finance, 25(1), 39-52.

- $\quad$ Berasaluce, J., \& Romero, J. (2015). "Exports, Imports, FDI and GDP in the Republic of Korea: 19802014”, (No. 2015-06), El Colegio de México, Centro de Estudios Económicos.

- Camarero, M., \& Tamarit, C. (2004). "Estimating the Export and Import Demand for Manufactured Goods: The Role of FDI", Review of World Economics/Weltwirtschaftliches Archiv, 347-375.

- Chani, M. I., Azam, M., \& Younas, A. (2014). "The Causal Relationship between Foreign Direct Investment, Imports and Exports in Pakistan”, Bulletin of Business and Economics (BBE), 3(3), 142-149.

- $\quad$ Dritsaki, M., Dritsaki, C., \& Adamopoulos, A. (2004). “A Causal Relationship between Trade, Foreign Direct Investment and Economic Growth for Greece”, American Journal of Applied Sciences, 1(3), 230-235.

- Filippaios, F., \& Kottaridi, C. (2013). “Complements or Substitutes? New Theoretical Considerations and Empirical Evidence on the Imports and inward FDI Relationship in Central and Eastern European Countries", International Review of Applied Economics, 27(6), 766-797.

- Hsiao, F. S., \& Hsiao, M. C. W. (2006). "FDI, Exports, and GDP in East and Southeast Asia-Panel Data versus Time-Series Causality Analyses", Journal of Asian Economics, 17(6), 1082-1106.

- Keho, Y. (2015). "Foreign Direct Investment, Exports and Economic Growth: Some African Evidence”, Journal of Applied Economics \& Business Research, 5(4), 209-220.

- Kiran, B. (2011). “Causal Links between Foreign Direct Investment and Trade in Turkey”, International Journal of Economics and Finance, 3(2), 150-158.

- $\quad$ Kueh, J., Puah, C. H., Lau, E., \& Abu Mansor, S. (2007). "FDI-Trade Nexus: Empirical Analysis on ASEAN-5", University Library of Munich, Germany.

- Napshin, S., \& Brouthers, L. E. (2015). "Intermediary Products: FDI Strategies, Imports, Exports, and Trade Balances in Developed Economies”, Thunderbird International Business Review, 57(4), 311-322.

- Pourshahabi, F., Salimi Soderjani, E., \& Mahmoudinia, D. (2011). "Panel Causality Relationship among FDI and Trade (Evidence from 16 Advanced Europe Countries)", Iranian Economic Review, 17(1), 115-133.

- Tandoğan, D., \& Genç, M. C. (2016). “Türkiye'de Turizm ve Ticari Açıklık Arasındaki İlişki: Toda ve Yamamoto Nedensellik Yaklaşımı”, AİB̈̈-IIIBF Ekonomik ve Sosyal Araştırmalar Dergisi, 12(1), 59-70.

- $\quad$ Toda, H. Y., \& Yamamoto, T. (1995). "Statistical Inference in Vector Autoregressions with Possibly Integrated Processes", Journal of Econometrics, 66(1), 225-250.

- $\quad$ Tran, T. A. D., \& Dinh, T. T. B. (2014). "FDI Inflows and Trade Imbalances: Evidence from Developing Asia", The European Journal of Comparative Economics, 11(1), 147. 


\title{
Bilgi Ekonomisinin Dönüşümü Üzerine Bir İnceleme An Investigation on the Transformation of Information Economy
}

\author{
Asst. Prof. Dr. Emine Frrat (Aksaray University, Turkey) \\ Prof. Dr. Zeynep Karaçor (Selçuk University, Turkey) \\ İnci Mine Özkan (Aksaray University, Turkey)
}

\begin{abstract}
The economy, which is one of the basic building institutions of society, has been the most affected institution in this situation. Since the Industrial Revolution, new disciplines have emerged in the changing and developing world economic and social order. One of the most popular branches of knowledge economy in recent years has been the effects of Information technology on the economy. Since the Industrial Revolution, new disciplines have emerged in the changing and developing world economic and social order. Changing production and consumption preferences, the development of technology has set the stage for the formation of a knowledge-based economy. The information economy, which examines how information affects economic and economic decisions, has been one of the favorites of the economy in recent years. The change and development process that started with the Industrial Revolution changed the production and consumption preferences gradually and radically. These radical changes brought about certain transformations in every institution of society. The social and economic field has also begun a wholesale rise process. The development of technology has brought divisions in the bottom of the economy in particular, accelerating the transformation process of the world economy by revealing concepts like knowledge economy and innovation economy. In this study, the stages of transformation from the industrial society to the information economy and the structure of the emerging information society have been evaluated. The historical process of the information economy as a result of the work is evidence of how the information economy evolved.
\end{abstract}

\section{Giriș}

Değişen ve gelişen dünya düzeninde toplumun tüm kurumlarında dönüşümler yaşanmaktadır. Özellikle ekonomi kurumunda, buhar makinasının icadıyla başlayan köklü değişim toplumun diğer tüm kurumlarına yansımış ve yeni organizasyonlar, yeni üretim ve tüketim modelleri ortaya çıkarmaya başlamıştır. Dünya ekonomisinde yaşanan birçok gelişme; toplumun tüm kurumlarında domino etkisiyle ortaya çıkan bir süreci beraberinde getirmiştir. Üretimin makinalaşması ve teknolojinin gelişmesi ülkelerin rekabet edebilirliklerini artıran önemli bir unsur haline gelmiştir. Teknolojinin değişmesi ve gelişmesi yeni iş alanları ve yeni ekonomi kurumlarının doğmasına neden olmuştur. Bu bağlamda bilgi ekonomisi bunun en güzel ve en gözde örneklerindendir. Teknolojinin gelişmesi üretim ve tüketimdeki gelenekleri değiştirmiş, ekonomi kurumunda yapısal ve kavramsal olarak bir çok yeniliğe neden olmuş ve yeni alt disiplin dallarının doğmasına da zemin hazırlamıştır. Bilgi ekonomisi her ne kadar son yıllarda ortaya çıkmış bir kavram gibi görünse de Endüstriyel Devrim ile başlayan köklü sürece bağlı en önemli sonuçlardandır. Bilgi ekonomisi bilgi eksenli bir ekonomidir. Bilginin üretilmesi, bilginin kullanılması, bilgiye dayalı üretimin gerçekleştirilmesi bilgi ekonomisinin yapı taşlarındandır. Bilgiye dayalı üretim sürecinde beyin gücünün ve eğitimin önemi büyüktür. Niteliksel olarak emek faktörünün evirilmesi, hızla değişen ve gelişen teknolojiye uyum sağlaması; hem uluslararası hem de ulusal ekonomide bir rekabet avantajına dönüşmüş durumdadır. Küreselleşen dünya düzeninde; ulusal ve uluslararası platformda rekabet edebilmek için mevcut teknolojik seviyeyi ileri taşımak ve teknolojik hıza yetişmek gerekmektedir. Bunun en önemli yolu da bilgiyi üreten ve yöneten bir toplum olmaktan geçmektedir. Bu bağlamda bilgi eksenli bir küresel düzende var olabilmenin temel şartı toplumu bilgiye adapte etmekten geçmektedir. 1771 Endüstriyel Devrimi dünya ekonomisinde birçok yeniliğin kilit noktası olmuştur. Üretimde faktör yoğunluklarının değişmesi, sosyal ve siyasal anlamda birçok olgu ve olayın yaşanması, tüketim tercihlerinin, rekabet koşullarının ve pazar politikasının değişmesi ekonomi kurumunun baştan başa yenilenmesine zemin oluşturmuştur. 17. Yüzyıl Aydınlanma Dönemi, aklın önemini ortaya çıkarmış ve bilimsel bilginin akıl yoluyla inşa edilme sürecinin başlangıcı olmuştur. Bilimsel bilgi ve rasyonel düşünme ilkeleri ortaya çıkmış ve teknolojik gelişmeleri etkilemiş, Fransız İhtilali aracılığıyla sanayi toplumuna uygun siyasal bir yapılanmanın temelleri atılmış, bireysel özgürlükler egemen olmuş, toplumsal ve bireysel tercihlerin değişmesini beraberinde getirmiştir. Emek yoğun üretim süreci hakimken buhar makinasının icadıyla sermaye yoğun bir üretim sürecine geçilmiş ve bununla birlikte üretim, tüketim, yönetim anlayışında birçok kavramsal ve yapısal anlamda değişme ve gelişmeler yaşanmıştır.

Toplumsal ve sosyal olay ve olguların yaşanması bilgi ve teknolojinin önemini tırmandırmış bireysel ve toplumsal yaşam tarzlarında değişikliklere neden olmuştur. Bu bağlamda bilgi ekonomisinin nasıl oluştuğunu anlatmak için bahsetmek gerekmektedir. Çalışmada bilgi toplumunun ve ekonomisinin oluşumu ayrıntılı şekilde anlatılmaktadır. 


\section{Geçmişten Bugüne Bilgi Toplumu}

Tüketim ve üretim hareketliliğine dayalı yenilik arayışlarının sonucu olarak ortaya çıkan birinci sanayi devrimine 16. Yüzyılda Avrupa'da başlayan reform hareketleri neden olmuştur. Avrupa'da yaşanan bu gelişmelerin başlangıcı; James Watt'ın icat ettiği buhar makinesi, John Kayl ve Crompton'un dokuma tezgahları gibi önemli teknolojik yeniliklere dayanmaktadır, bu yenilikler ile İngiltere'nin zengin kömür yatakları, İskoçya ve Galler'de bulunan demir cevheri gibi hammaddeler değer kazanmış ve birinci sanayi devrimi gerçekleştikten sonra bu devrim tek bir bölgeyle sınırlı kalmayıp diğer batı ülkelerini de etkileyip 1840'lı yıllardan itibaren diğer ülkeler de endüstrileşmeye başlayarak bu dönemin değişim ve gelişimini sağlayan başlıca teknolojiler; telefon, telgraf, uçak, transistor ve nükleer teknoloji olmuştur (Ünal, 2009). Yeni çıkan teknolojiler yeni toplum düzenini ortaya çıkarmıştır. Toplumun tüm kurumlarındaki kavramlar değişmiş, yeni kavramları doğurmuş ve zekâ ekonomisi, bilgisayar teknolojisi, aktif bilgi üretimi önem kazanmış ve gelişmiş endüstrileri arka planda bırakmıştır. Bilgi, ekonominin başlıca hammaddesi ve en önemli ürünü haline gelmiştir. Zenginlik yaratmak için gerek duyulan sermaye varlıkları arazi, bedensel emek, imalat aletleri ve fabrikalar yerini bilgiye bırakmıştır (Yenilmez, 1993: 17). Toplumsal anlamda gerçekleşen tüm faaliyetlerde, aktif sayısal iletişim ağları yoğun olarak kullanılmaya başlanmıştır. Teknolojinin ve uygulamanın üretilmesi olan ve 1950'li yıllarda başladığı kabul edilen bu çağa bilgi toplumu çağı denir (Tübitak, 2002). Bilgi toplumu; örgütsel ve toplumsal alanda öğrenmenin, yaşam merkezi olarak algılandığı, bilginin stratejik kaynak olarak değerlendirildiği, teknoloji kaynaklı değişim ve gelişimin hız kazandığı, küresel rekabetin yoğunlaştığı bir dönemi temsil etmektedir (Ünal, 2009). Bilgi toplumu, bilgisayar ve bilgisayara dayalı olarak çalışan araçlara, elektronik ticaret gibi teknolojik gelişmelere hızlı adapte olan, bireysel ve kitle iletişiminin küreselleştiği, sinerjik ekonomik faaliyetlerin kullanıldığ , maldan çok bilginin üretildiği bir toplumdur (Kocacık, 2003; Rukancı ve Anameriç, 2004; Ünal, 2009). Bireysel, örgütsel ve toplumsal düzeyde öğrenmenin yaşam biçimi olarak algılandığ değişim ve gelişimin hız kazandığ toplumu, tarım ve sanayi toplumlarına göre birçok açıdan farklılık göstermektedir. Bu toplumun içinde bulunduğu bilgi çağının en tipik özelliği mevcut toplumları hızla değiştirmesidir. Toplumlardaki değişmeyi hızlandıran en belirgin etmenler, bilgi, teknoloji, iletişim ve ekonomi alanlarında görülmektedir. Bu çağa bilgi çağı adı verilerek bilgi toplumu kavramı ortaya çıkarılmış ve yapısal ve kavramsal anlamda yeniliklerin doğmasının önü açılmıştır (Burke, 2004; Ünal, 2009). Anlaşılacağı üzere bilgi toplumu ve bilgi çağının en belirgin özelliği toplumların hızla değişmesidir. Toplumlardaki değişmeyi hızlandıran en belirgin etkenler, bilgi, teknoloji, iletişim ve ekonomi alanlarında görülmektedir. Bu çağa bilgi çağı adı verilerek bilgi toplumu kavramı ortaya çıkarılmıştır. Bilgi toplumu kavramı, bu değişim sürecinin çerçevesini açıklamaktadır (Ünal, 2009). Toplumsal gelişim ve değişim sürecinde başta insan faktörü ve bilgi olmak üzere tüm alanlarda yapısal değişimi kaçınılmaz kılan, sanayi toplumunun uzantısı olarak ortaya çıkan bilgi toplumu, bilgi ekonomisi, sanayi sonrası toplum, bilişim toplumu, bilgi çağı ve benzeri şekillerde ifade edilmektedir. Ayrıca, toplumsal gelişme sürecinde tarım devrimi birinci dalga, sanayi devrimi ikinci dalga, bilgi toplumundaki gelişmeler ise üçüncü dalga olarak nitelendirilmektedir. Üçüncü dalga, ekonomik, sosyal, kültürel ve siyasal alanda yeni bir yaşam biçimi ortaya çıkarmaktadır (Ekin, 1976) Matbaanın bulunmasıyla okur-yazarlık artmış, Rönesans tüm Avrupa'ya yayılmıştır. Aydınlanma çağında bilim alanındaki gelişmeler sanayi sektörüne de yansımış, yeni enerji kaynakları, makineler ve yöntemler kullanılması, sanayi devriminin gerçekleşmesine neden olmuştur. İletişim araçlarının ortaya çıkması ile yeni bir düzen ve hayata geçilmiş, son aşamada bilgisayar ve iletişim teknolojisinin geliştirilmesi ile yeni bir çağa ulaşılmıştır (Aydın, 1997). 1950'li yıllardan itibaren bazı sosyal bilimciler ve akademisyenler, ileri düzeyde sanayileşmiş ülkelerin toplumsal yapısında, özellikle ekonomik açıdan köklü bir değişim eğilimi gözlemlemişlerdir. Bu toplum biçimi sanayi toplumuna göre birçok açıdan farklılık göstermektedir (Koroğlu, 2004). Bunun temel nedeni olarak, günümüzde bilginin ekonomik kalkınma ve toplumların gelişmesi açısından taşıdığı önemin giderek artması ve insanların yaşantılarını özellikle çalışma hayatını ve üretim süreçlerini etkilemeye başlaması ve rekabet elde etme avantajına dönüşmesi olarak gösterilebilir. Bilindiği üzere 18. yüzyıl, insanlık tarihinde en çok değişen ve en çok şeyi değiştiren yüzyıl olarak adını tarihe yazmıştır. Rönesans'la birlikte başlayan, Fransız Devrimi ve Sanayi Devrimi ile değişen ve gelişen bir domino etkisi oluşmuş ve tüm insanlık tarihinin ezberi bozulmuştur. Toplumsal ve ekonomik olayların birbirinden etkilendiği gerçeği göz önünde bulundurulduğunda Fransız İhtilali'nin olması bir anlamda tüm dünya düzeninin toplumsal siyasal ve ekonomik anlamda radikal değişimlerin kapısını açmıştır.

Sanayi toplumu, teknolojik bakımdan, büyük aşamalar kat etmiş 1769 yılında James Watt tarafından icat edilen buhar makinesinin kullanılmasıyla başlayan yeni bir dönem olmuştur. James Watt'ın buhar makinesini 1776 yılına kadar yeniden tasarımlaması, bu makineyi enerji elde etmenin etkin bir aracı haline getirmiştir. Ancak Watt'ın ortağı, Matthew Boulton derhal buhar makinesini her türlü sanayi sürecine enerji kaynağı olarak sunmuş, özellikle de o zamanın en büyük imalat sanayisi olan tekstilcilere götürmüştür (Gültan, 2003). Otuz beş yıl sonra, Robert Fulton adlı bir Amerikalı, ilk buharlı gemiyi New York'un Hudson Nehri'nde dolaştırmıştır. Yirmi yıl daha geçtiğinde, buhar makinesi tekerlekler üzerine yerleştirilmiş ve böylece lokomotif doğmuştur. 1840 ya da 1850 yılında, buhar makinesi her imalat sürecini değiştirmiş, cam sanayinden, matbaaya kadar her yere sokulmuştur. Karada ve denizdeki uzun yolculukları değiştirmiş ayrıca çiftçiliğe yeni teknikler kazandırmıştır (Ünal, 2009).

Bilgi toplumunun dönüşüm sürecini anlatan altı dalgayı Akyos şematik olarak şu şekilde göstermiştir: 


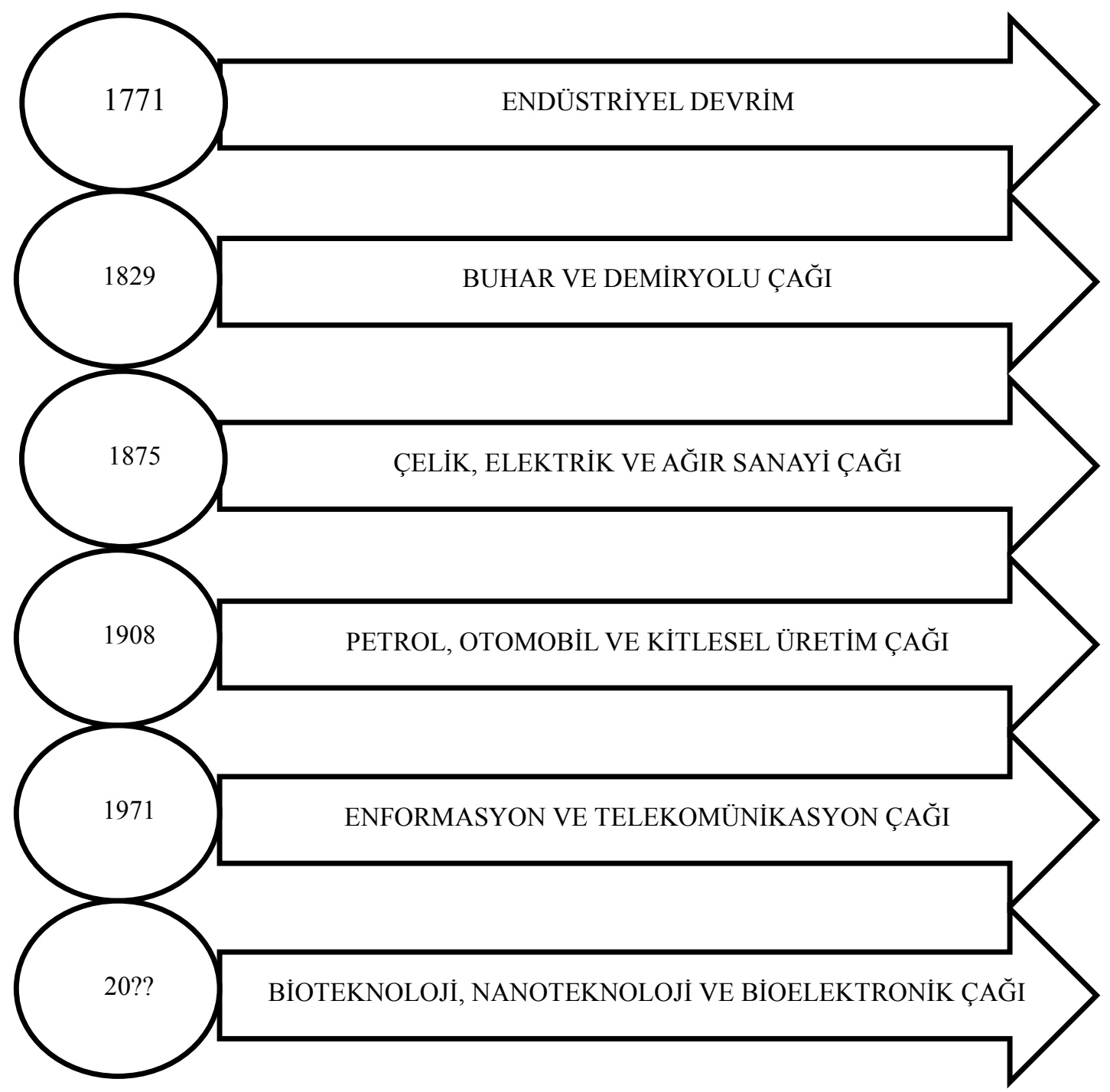

Şekil 1: Toplumun Süreci, Kaynak: (Akyos, 2005: 4).

Freyer, tüm dünyadaki teknik, teknolojik ve yenilik içeren gelişmeleri, merkezi İngiltere olarak; altı aşama halinde anlatmıştır. Bu altı aşamayı şu şekilde özetleyebiliriz (Canlığlu, 2008; Ünal, 2009):

1. Dokuma sanayii aşaması: Endüstrileşme bu dalga ile başlamıştır. 1700'lü yılların ortalarında, dokuma endüstrisinde teknik anlamda büyük adımlar atılmış önemli icatlar ortaya çıkmıştır. Dönemin en önemli ve göze çarpan özelliği ise, bu icatların bilim insanları tarafindan değil, aynı meslekte olmayan, belli zanaatlara sahip, kendi alanında tecrübeli teknisyenler tarafından yapılmıştır. 1769 yılında James Watt'ın buhar makinasını icadı bu döneme damga vuran aşaması olmuştur.

2. Demir-çelik aşaması: Bu aşama 1800 yılında başlamıştır. Gelişmiş ve kapsamlı sanayilerde işlenen ve makine imalatı dâhil her alanda kullanılan demir, dönemin en gözde maddesi olmuştur.

3. Ulaştırma aşaması: Bu aşama 1825 yılında başlamıştır. Lokomotifin icadı ve geliştirilmesi üzerine yapılan teknik çalışmaların sonucunda ilk trenler ortaya çıkmıștır. Daha sonra ilerleyen yıllarda ilk buharlı gemilerin icadı ile deniz yolculukları başlamıştır. Ulaştırma aşaması, hammadde, ara malların ve endüstriyel ürünlerin uzak mesafelere ulaşımını kolaylaştırmışıtır.

4. Kimya aşaması: 1800 'lü yılların ortalarından sonra kimya biliminin önemi artmış ve var olan bilgiler bir araya toplanmaya başlamıştır. Toplanan bilgiler yeni kurulan ve ortaya çıkan endüstrilerin teknik ve teorik zeminini oluşturmuştur. Yeni bulunan suni gübreleme yöntemi, tarım sektörünün reform geçirmesine neden olmuştur. $\mathrm{Bu}$ yıllarda modern teknik ve teknolojiler, bilim insanlarının çalışma yaptı̆̆ı bir araştırma koluna dönüşmüştür.

5. Elektrik endüstrisi aşaması: Telefon, telgraf, 1830 ile 1840 yılları arasında icat edilmiştir. Bu yenilikler kendisinden önceki bütün teknik yenilikleri tamamen değişime uğratmıştır. Elektrik ile birlikte ulaştırma farklı bir boyut kazanmıştır. 
6. Benzin motoru aşaması: 1800’lü yılların sonlarına doğru Paris’te ilk kez otomobil sergisi açılmış, ilk kez uluslararası otomobil yarışı yapılmış ve Henry Ford Motor Fabrikası kurulmuştur.

Yaşanan tüm bu teknolojik, birikimsel olarak artan ve yenilenen dalgalar insanlık tarihinde yeni dönemlerin, yeniçağların açılmasına neden olmuştur. İçinde bulunulan çağda gelişmiş ülkeler, sanayi toplumu çizgilerinden çıkmış bilgi toplumu olma konusunda ivme kazanmışlardır.

İletişim teknolojisinde gerçekleşen gelişmeler, bilgi toplumuna geçmekte en büyük etken olmuştur. Bilgi toplumunda, bilgi en önemli ve temel kaynaktır. Bilgiyi üretme, yayma, değişim ve gelişmeler toplumda birlikte yaşamanın bir gereğidir. Toplumsal ve dini değerlerde bir çöküşün yaşanmayacağı, aksine dinsel inançların güçleneceği beklenmektedir (Altay, 2001). Bilgi toplumunda, en önemli veri teknolojik altyapının varoluşudur. Bilgi toplumunda sermaye, maddi değerlerle değil, bilgiyle ölçülmektedir. Bilginin kaynağı da beşeri sermaye olan insandır. Ekonomi, demografi ve teknoloji değişirken giderek artan oranlarda organizasyonlar yetenekli insanları ve bilginin niteliğini rekabet avantajı olarak değerlendirmektedir. Üretim, dağıtım ve tüketim süreçlerinde bilginin organizasyonu etkili olmaktadır. Bu yeni gelişmeler yeni davranış şekillerini ortaya çıkarmakta ve toplumu standartlaşma ve merkezileşmenin ötesine taşımaktadır. Bu yeni toplum, farklı bir dünya görünümünü de beraberinde taşımakta; zamanı, mekânı, mantık ve sebep sonuç ilişkisini değerlendirmede kendine özgü ölçütleri geliştirmekte ve geleceğin politikasının ilklerinin de kendine göre oluşmasını sağlamaktadır (Aktan ve Tunç, 1998).

\section{Sonuç}

18. Yüzyılda İngiltere'de başlayıp tüm dünyaya yayılan Endüstri Devrimi toplumun birçok kurumunda değişimlere ve gelişmelere neden olmuştur. Üretim sürecinin değişmesiyle başlayan bu köklü süreç ekonominin tüm mekanizmalarına hızla ve kalıcı olarak yayılmıştır. Değişen ve gelişen dünya ekonomik düzeni, teknoloji geliştikçe var olan sistemlerin evrileceği, dönüşeceği ve belki de yok olup yeni sistemlerin oluşmasına ortam sağlayacağının habercisidir. Sanayi toplumundan bilgi toplumuna nasıl geçildiğini kısa bir şekilde analiz yaparak özetlemek gerekirse (Alpaslan ve Özen Kutanis, 2007; Kocacık, 2003; Ünal, 2009);

1. Sanayi toplumunda madde ve meta gibi fiziksel sermayeler yerini bilgi toplumunda bilgi ve eğitim gibi beşeri sermayelere bırakmıştır.

2. Sanayi toplumunda mal ve hizmet üretiminde sürecin başlangıcında buhar makinesi yer alırken bilgi toplumunda bilgisayarlar yer almaktadır.

3. Sanayi toplumunda insanın fiili emeğinin yerini, bilgi toplumunda beyin gücü almaktadır.

4. Sanayi toplumunda kişisel mülkiyet, kar marjı ve rekabet ön plandayken bilgi toplumunda sosyal yararı ve faydayı gözeten ortaklaşa katılım ön plana çıkmıştır.

5. Sanayi toplumunda üretilen mal ve hizmet standardizasyonu yerini bilgi toplumunda esnek üretim yapısına birakmaktadir.

6. Sanayi toplumundaki fabrikalar yerini bilgi toplumunda bilgi kullanımını içeren bilgi ağlarına bağlı üretime ve veri bankalarına bırakmaktadır.

7. Sanayi toplumunda; imalat sanayinin ön planda olduğu tarım, sanayi ve hizmetler endüstrisi, bilgi toplumunda yerini bilgi endüstrisine bırakmıştır.

8. Sanayi toplumunda yeni pazar oluşturmak için kolonilere yönelme fikri yerini bilgi toplumunda küreselleşmeye bırakmıştır.

9. Sanayi toplumunda var olan meta ekonomisinin yerini bilgi toplumunda sinerjik ekonomi almıştır.

10. Sanayi toplumunda olan merkeziyetçilik görüşü yerini bilgi toplumunda çok merkezli fonksiyonel toplum görüşüne bırakmıştır.

Yukarıda yazılan maddeler sonucunda küreselleşen dünya düzeninde ülkeler ve firmaların teknolojik gelişmeye kayıtsız kalamadıklarını, teknolojik gelişmeyi ve bilgiyi bir rekabet avantajına dönüştürdüklerini söylemek yerinde olacaktır. Öte yandan küresel rekabet ortamında kalabilmek için dönüştürülen ekonomik sistemler, üretim süreçleri aynı zamanda toplumların sosyal ve siyasal yapılarının da değiştiğini gözler önüne sermektedir

\section{Kaynakça}

- $\quad$ Akyos, M. (2005). Ulusal Inovasyon (Yenilikçilik) Sistemi, Uluslararası Silahlı Kuvvetler Muhabere ve Elektronik Derneği Türkiye Şubesi, Ankara, 1-46.

- Aktan, C. ve M. Tunç. (2008). “Bilgi Toplumu ve Özellikleri”, Yeni Türkiye Derneği, Ocak-Şubat 1998, s. $118-134$. 
- Alpaslan, S. ve Kutanis, Özen, R. (2007). "Sanayi ve Bilgi Toplumu ve Yönetim Metaforlarının Karşılaştırılması", Akademik Incelemeler, 2(2), 50-71.

- Altay, L. (2001). Bilgi Toplumu Örgütlerinde Yaratıcı Yönetim Anlayışı-Bir Alan, Araştırması, Ankara, 2001, Gazi Üniversitesi, s.13.

- Aydın, T. (1997). Bilgi Toplumu ve Demokrasi, Trabzon, 1997, Efor Masaüstü Yayıncılık, s.27

- Burke, P. (2004). Gutenberg'ten Diderot'ya Bilginin Toplumsal Tarihi. çev. Mete Tunçay, İstanbul: Tarih Vakfi Yurt Yayınları, 2004.

- Canlıoğlu, G. (2008). Değişen Toplum Yapılarında Bilginin Değişen Konumu. Yüksek Lisans Tezi, Marmara Üniversitesi, İstanbul

- Ekin, N. (1976). Endüstri İlişkileri, İstanbul: İstanbul Üniversitesi İktisat Fakültesi, 1976. s.1

- Gültan, S. (2003). Bilgi Toplumu Sürecinde Avrupa Birliği ve Türkiye, Ankara, 2003, Ankara Üniversitesi Avrupa Toplulukları Araştırma ve Uygulama Merkezi, s.15.

- $\quad$ Kocacık, F. (2003). "Bilgi Toplumu ve Türkiye”, C. Ü. Sosyal Bilimleri Dergisi, 27(1), 1-10.

- Koroğlu, F., E. (2004). Bilgi Toplumu ve E-Devlet (TBMM'de Türkiye Bilişim Stratejileri ve e-Türkiye Genel Görüşmesinin Çözümlenmesi), Ankara, Ankara Üniversitesi, 2004, s. 4.

- Rukancı, F. ve H. Anameriç, (2004). "Bilgi Toplumu ve Toplumun Bilgilenmesinde Kütüphanelerin Rolü”, Kütüphaneciliğin Destanı Uluslararası Sempozyumu (21-24 Ekim 2004), Ankara, (http://acikarsiv.ankara.edu.tr/fulltext/165.htm), Erişim Tarihi (20.04.2017).

- Türkiye Bilimsel ve Teknik Araştırma Kurumu (2002) Bilgi Toplumu Politikaları Üzerine Bir Değerlendirme (Dünya ve Türkiye), Ankara: Türkiye Bilimsel ve Teknik Araştırma Kurumu, s.4

- Ünal, Y. (2009). Bilgi Toplumunun Tarihçesi, Tarih Okulu, 5, 123-144

- Yenilmez, E., H. (1993). Bilgi Toplumu Olgusu ve Türkiye Hedef 2000 Yılı, İstanbul, İstanbul Üniversitesi, 1993. 


\title{
Sürdürülebilir Kalkınma Perspektifinde Uygulanan Yenilenebilir Enerji Kaynakları
}

\section{Renewable Energy Sources in Perspective of Sustainable Development}

\author{
Prof. Dr. Bedriye Tunçsiper (Balıkesir University, Turkey) \\ Asst. Prof. Dr. Emine Firat (Aksaray University, Turkey)
}

\begin{abstract}
It is one of the most important issues of our time that meeting the energy needs for developing countries. Especially in recent years, the developed and developing countries emphasize the importance of resorting to current and renewable energy sources in order to be able both to feed them and to show sensitivity to the environment.

It is an important tool in reducing external dependency that increased use of those resources in countries which is a country in an advantageous position in terms of renewable energy sources. From past to present with increased production and consumption and the point where the environmental problems reach, renewable energy sources is shown as a solution to this problem. Sustainable development makes an important contribution not only in quantity but also in quality to the economy. It is provided that enhancing human capital by performing technological development and sustainability of the environment by raising awareness of the environmental community and reducing of energy imports by applying renewable energy in energy production.

It can be reduced its dependence on foreign energy with sustainable energy policies and R\&D activities for the use of renewable energy sources where countries have the potential to be an ample supply. In light of this, it has been demonstrated that introduction of renewable energy sources should not be delayed in achieving sustainable development in economic, social and environmental dimensions. In this study, the strengths and weaknesses are evaluated in terms of sustainable development of renewable energy sources.
\end{abstract}

\section{Giriş}

Günümüzde küreselleşme ve değişen teknoloji ile birlikte dünya hızlı bir değişim sürecine girmiştir. Bu değişim sürdürülebilirlik gibi dünyayı olumlu yönde etkileyen kavramların önem kazanmasına neden olmuştur. Dünyanın büyük bir yer olması önceleri kafaları karıştırmazken, nüfusun hızla artması dünya ekonomistlerinin ilgi odağı olmuştur. Kıt olan kaynakların dünya nüfusunu karşılayamayacağı paniğine kapılan ekonomistler sürdürülebilir kalkınma perspektifinde bu konuyu ele almış ve çözüm bulmaya çalışmışlardır. Hızla sanayileşen dünyada yenilenemez kaynakların yeri büyüktür. Sanayileşen ekonomiler tarımdan, mekaniğe, binalardan elektroniğe pek çok alanda yenilenemez kaynaklar tarafından üretilmiş ve geliştirilmiştir. Yenilenemez kaynaklar, hızlı ve modern hayatın vazgeçilmezleri haline gelmiştir. Nüfus artışının devam etmesi, su sorunlarının yaygınlaşması, küresel ısınmanın ve kirlenmenin artması gündemden düşmemektedir. Özellikle yenilenemez kaynakların giderek kıtlaştığı ve bu olumsuz durumun daha da kötüleşeceği senaryoları yazılmaktadır. Bu duruma insanoğlu da hizmet etmekte, bitmek tükenmek bilmeyen tüketim kapasitesiyle dünyanın kirlenmesine ve kaynakların yok olmasına sebep olmaktadır. Özellikle insanların vazgeçemedikleri tüketim ve üretim alışkanlıkları çevrenin bozulmasına ve kıt olan kaynakların yenilenebilmesine izin vermeyen bir hızla tükenmesine yol açmaktadır. Dünyada kıt olarak bulunan kaynaklardan biri de enerjidir. Enerji üretiminin tüketimi karşılayamadığı açıkça görülmektedir. Dünyada ihtiyaç duyulan enerji kaynaklarının birçoğu genellikle fosil yakıtları olarak adlandırılan kömür, petrol, doğal gaz gibi yakıtlardan oluşmaktadır. Dünya'daki enerji kaynaklarının ihtiyaçları karşılayamaması çağımızın en önemli sorunlarından birisidir. Özellikle son yıllarda, gelişmiş ve gelişmekte olan ülkeler, hem kendi ihtiyaçlarını karşılayabilme hem de çevreye olan sorumluluklarını yerine getirebilme amacıyla yenilenebilir enerji kaynaklarına yönelmişlerdir. Yenilenebilir enerji; çevrede değişik şekillerde bulunmakla beraber, güneş, rüzgâr, su, jeotermal gibi kaynaklar daha ön plana çıkmaktadır. Bu kaynaklardan elde edilen enerji hem sonsuz hem de sürekli olarak kendini yenilemesi bakımından özellikle sürdürülebilir kalkınma perspektifinden yaklaşıldığında büyük bir öneme sahip olmaktadır. Sürdürülebilir kalkınma, ekonomiye tek yönden değil her yönden önemli bir katkı sağlamaktadır. Özellikle küreselleşen yeni dünyada teknolojik gelişmeler ve beşeri sermayenin hızlanmasıyla toplumun çevre ve enerji konusundaki duyarlılığının artmasına ve enerji üretiminde yenilenebilir kaynakların kullanılıp, sürdürülebilir kalkınmanın yakalanmasına imkan sağlayacaktır.

\section{Sanayileșme ve Enerji}

Değişen, gelişen ve dönüşen dünyanın gücü enerjidir. Enerji, insanlarının barınma, korunma, sağlık, eğitim, beslenme vb. gibi bütün temel unsurlarını karşılayan gelişmiş ve gelişmekte olan ülkelerin teknolojik gelişmeleri hızlandıran bir güçtür (Karataşlı vd, 2016). İnsanoğlu, tarihin ilk çağlarından beri doğa karşısında devamlı bir 
değişim içerisinde bulunmuştur. Özellikle 16. yüzyılda Avrupa'da Rönesans hareketleri ile tarım toplumundan sanayi toplumuna doğru bir geçiş süreci yaşanmıştır (Ünal, 2009). 18. yüzyılda buhar gücünün keşfi ve sermayenin birikimi konusuyla tanışan toplumlar, üretim ve tüketim sistemlerinde değişimler yaparak, sanayi toplumu kavramının temelleri atılmıştır (Küçükkalay, 1997). Sanayi toplumunu ele alan ilk kişi Henry Ford'dur. Taylorizm'den yararlanarak sistematik bir üretim şekli oluşturmuştur (Y1lmaz, 2012). O tarihlerde enerji kaynaklarının hem ucuz olması hem de üretim teknolojisindeki gelişmeler nedeniyle kullanım sahası genişlemiştir. Sanayileşme devriminin ardından kömür kullanımı yaygınlaşmış daha sonraki dönemlerde petrol ve doğal gazın da kullanımına geçilmiştir. 1920'lerden 1973 Petrol Krizi'ne kadar geçen süreçte genel olarak kabul gören Fordist üretim sistemi, bilim ve teknolojinin ilerlemesi ve beşeri sermaye kavramının yaygınlaşmasıyla yerini Toyotizm'e bırakmıştır. Toplumların üretim sürecinde verimliliğin artması amaç edinilmiştir (Sakl1, 2016). Enerji endüstriyel anlamda insanlığın huzuru ve refahı için hizmet veren her enerji türünü kapsamaktadır. Günümüzde, endüstrinin en temel enerji tüketimi elektrik enerjisi olup, onu 1sınma veya 1sıtma amaçlı fosil yakıtlar (petrol, kömür, doğal gaz...) takip etmektedir. Geçmişten günümüze elektrik ekseriyetle hidrolik santraller vasıtasılla üretilmektedir. Arazi yapısı ve nehir potansiyeli uygun olmayan ülkeler ise termik santraller vasıtasıyla elektrik ihtiyacını karşılamışlardır. Tüm ülkeler yine ısınma ihtiyacını kömür veya petrol ile karşılamaktadırlar. Özellikle kömür ve petrol rezervlerinin sınırlı olmasının yanında enerji ve yakıt talebinin sürekli olarak artması hidrolik santraller veya termik santrallerle, kömür veya petrol vasıtasıyla yakıt talebi karşılanamaz hale gelecektir (Worldwatch Enstitüsü, 129). Günümüzde gelişen teknoloji ve nüfus artışı, enerjiye olan talebi arttırmıştır. Gelecekte ise bu artışı devam edeceği öngörülmektedir. Artan enerji talebini karşılamak için enerji piyasasına yeni etmenler (yenilenebilir enerji kaynakları) eklenmektedir. Ülkeler rekabet gücünü artırmak üzere ekonomiyi büyütecek ve yaşam standartlarını yükseltecek yeterli, sürekli ve temiz enerjiye ihtiyaç duymaktadır (Mutlu, 2013). 1973 Petrol Krizi'nin ardından dünya bir kaynak arayışına girmiş, kullanılan enerji kaynaklarının yerine yeni enerji kaynakları bulma düşüncesine yoğunlaşmışlardır. Bu arayış fosil yakıtların çevre kirliliğine neden olması ve Neoliberal politikaların savunduğu sürdürülebilir kalkınma perspektifi açısından değerlendirildiğinde daha da hızlandırmıştır (Yılmaz, 2012). Neo liberal politikaların yaygınlaşmaya başladığı 1980'li yıllara gelindiğinde baş döndürücü değişmelerin yaşandığı, sürdürülebilirlik kavramlarının belirlendiği ve kalkınmanın yeni bir anlam kazandığı görülmüştür. Üretimde verimlilik artışının yaşanmaya başladığı, her geçen gün toplumsal refah düzeyinde artışların gerçekleştiği ve bilgiiletişim sektöründeki yeniliklerin küresel sorumluluk anlayışıyla gerçekleştiği yeni bir sürece girilmiştir (Yalçınkaya, 2001). Kömür, petrol ve doğalgaz kaynaklarının kuruldukları bölgede yerel olarak verdikleri zararların yanında tüm dünyayı tehdit eden etkileri de bulunmaktadır. Fosil yakıtlar yakıldığında atmosfere yayılan karbon dioksit, kükürt dioksit, azot oksit, toz ve kurum yakın çevreyi kirletip ölümlere yol açarken, karbon dioksit ve benzeri sera gazları küresel iklim değişikliğine yol açmakta ve tüm dünya ülkelerinde yaşamı tehdit etmektedir (Mutlu, 2013) Bu bakımdan enerjide yeterli, kaliteli, sürekli, düşük maliyetli ve çevreye uyumlu bir şekilde tüketicilerin kullanımına sunulması hedeflenmektedir. Ekonomilerin enerji bağımlılı̆̆ nedeniyle enerji kaynaklarının ve alternatif enerjiye yönelik teknolojilerin stratejik önemi günden güne daha fazla hissedilmektedir. Enerjide dışa bağımlılığımızı azaltacak alternatif politikalar cari açık ve ekonomik büyüme üzerinde de olumlu etki yapacaktır. Bu kapsamda ülkelerin yenilenebilir enerji üretimindeki payının artırılması yönündeki amaçları ayrı bir önem taşımaktadır (Gürson vd, 2014).

Buradan hareketle, tüm dünyada enerji kaynaklarının verimli kullanılması ve küresel çevre sorunlarının önlenmesi gibi konular gündeme yerleşmiş, alternatif enerji kaynakları arayışlarına gidilmiştir. Tüm dünyada kıtlaşan fosil yakıtların kullanımını azaltma ve yenilenebilir enerji kaynaklarına yönelme hızlanmıştır. Sürekli artan nüfus ve değişen teknolojiler karşısında enerji ihtiyacını karşılayabilmek için yenilenebilir enerji kaynaklarının kullanımını artırabilmek amaçlanmıştır. Rüzgar ve güneş enerjisi, su, biyokütle enerjisi, dalgalar ve jeotermal enerji gibi yenilenebilir enerji kaynakları ile ilgili çalışmalar arttırılmıştır. Yenilenebilir kaynaklar sonsuz olduğundan üretim ve yatırım maliyetlerinin kısa bir süre içinde kendini yenilemesi söz konusudur. Fosil yakıtlar çevreye zarar verip, zararın maliyeti ise küresel sorunlara yol açtığından yenilenebilir enerji kaynakları bir çözüm yolu olarak görünmektedir. Bununla birlikte yenilenebilir enerji kaynaklarının kullanımı, ülkelerin ekonomileri açısından maliyetlerin azaltılması açısından günümüzde oldukça büyük bir kesim yenilebilir kaynaklar ve uygulama alanlarını araştırmaktadır. Dünya devleri ve güçleri bu konudaki çalışmalarını arttırarak ve yenilebilir enerji kaynaklarıyla ilgili ilkleri gerçekleştirmiştir. Yenilenebilir enerji kaynakları bakımından avantajlı konumda olan ülkelerde bu kaynakların kullanımının artması, dışa bağımlılığın azaltılmasında önemli bir araç olmaktadır. Ülkeler yenilenebilir enerji kaynaklarının kullanımına yönelik ar-ge çalışmaları ve sürdürülebilir enerji politikaları ile enerjide dışa bağımlılıklarını azaltabilir. Geçmişten günümüze artan üretim ve tüketim ile birlikte çevresel sorunların geldiği son nokta ve bu soruna bir çözüm olarak gösterilen yenilenebilir enerji kaynakları üzerinde durulmaktadır. Sürdürülebilir kalkınma, ekonomiye tek yönden değil her yönden önemli bir katkı sağlamaktadır. Teknolojik gelişmelerle birlikte enerji üretiminde yenilenebilir enerjiye geçilip enerji ithalatının azaltılması ekonomik olarak da kalkınmayı olumlu yönden etkilemektedir. 


\section{Yenilenebilir Enerji Teorisi}

Yenilenebilir enerji kaynaklarının kullanımı çok eskiye dayanmaktadır. İlk çağdan günümüze kadar odun ve bitki artıkları enerji kaynağı olarak kullanılmaktadır. Yine aynı şekilde yel değirmenleri yardımıyla enerji elde etme çalışmaları da çok eskilere dayanmaktadır. Yenilenebilir enerji kaynaklarının mevcut teknik ve ekonomik sorunlarının çözümlenmesi hâlinde 21. yüzyılın en önemli enerji kaynağı olacağı kabul edilmektedir (Milli Eğitim Bakanlığı, 2011). Doğal süreç içerisinde kendini yenileyebilen, sonsuz bir şekilde kullanıma açık olarak doğada bulunan ve kendini göreceli olarak hızlı bir şekilde yeniden üreten, yenileyen doğal kaynaklardan elde edilen enerjiye "yenilenebilir enerji" denir (Erişim, 2017). Yenilenebilir enerji kaynağı; enerji kaynağından alınan enerjiye eşit oranda veya kaynağın tükenme hızından daha çabuk bir şekilde kendini yenileyebilmesi ile tanımlanır. $\mathrm{Bu}$ enerji kaynaklarının maliyetleri oldukça azdır, yenilenebilir olduklarından dolayı tükenmezler ve konvansiyonel yakıtların aksine çevre ve insan sağlığı için önemli bir tehdit oluşturmazlar. Enerji üretimi ve kullanımı sırasında yaşanan çevre sorunları, eski teknolojilerin terk edilmesinin temel nedenlerinden biridir (Mutlu, 2013). Bu enerji kaynakları şunlardır (Ataman, 2007). Hidrojen enerjisi (su, akarsular, dalgalar), rüzgar enerjisi, güneş enerjisi, jeotermik enerji (gayzerler, sıcak sular vs. gibi yeryüzü 1sı kaynakları), biyo-kütle (odun, bitkisel yă̆, bitkisel mazot, biyogaz vs.)

Günümüzün geleneksel enerji üretim ve tüketim teknolojilerinin insan, çevre ve doğal kaynaklar üzerinde yerel, bölgesel ve küresel seviyede olumsuz etkilere neden olduğu bilinmektedir. Bu nedenle, enerjinin çevreye zarar verilmeden üretilmesi ve tüketilmesi amacı ön plana çıkmıştır. Ülkeler özellikle yenilenebilir enerji kaynaklarını güvenilir, ekonomik, kaliteli ve serbest piyasa mekanizması ile şartlarını zorlamadan ekonomiye kazandırılmasına, enerji üretim teknolojilerini bu yönde geliştirmeye, üretimi ile tüketimini teşvik edici çeşitli politikaların oluşturulmasına ve strateji belgelerinin hazırlanmasına hız vermişlerdir. Yenilenebilir enerji kaynakları, coğrafi olarak çok geniş alanlarda bulunabilmekte, yerel ve modüler olarak istenilen miktarda enerji talebini karşılayacak şekilde kullanılabilmekte ve daha çok kırsal, dağınık yerleşim birimlerinin enerji talep yapısıyla uyum göstermektedir (Çalışkan, 2014). Dünya nüfusu sürekli artmakla beraber ekonomik gelişmelerde aynı hızla devam etmektedir. Bu ekonomik gelişmeler ve artan nüfus, enerji talebini arttırırken, yeni teknolojileri de beraberinde getirmektedir. Bu yüzden ülkeler, enerjiyi güvenilir, çevreye uyumlu, temiz, işletim-üretim maliyetleri ucuz enerji kaynaklarını mutlaka çeşitlendirmek durumunda kalmaktadır. Petrol, doğal gaz ve kömürün yakın gelecekte tükenecek olmasının tahmin edilmesi, yenilenemeyen enerji kaynaklarının artan enerji ihtiyacını karşılamaması ülkeleri farklı enerji kaynağı arayışlarına sürüklemektedir. Bu nedenle ülkeler enerjiyi kullanma ve bulma açısından değişik politikalar sürdürmektedir. Doğal kaynaklar bakımından zengin olmayan ülkeler, enerji çıkmazını ortadan kaldırmak için yenilenebilir enerji kaynakları biyoenerji, rüzgâr enerjisi, güneş enerjisi gibi alternatif çözümler olarak düşünmesine rağmen, nükleer enerjiye yönelmiş, doğal kaynaklar yönünden zengin olan ülkeler hem yenilenebilir kaynakları değerlendirme ve hem de bununla birlikte meydana gelebilecek enerji dar boğazına karşı nükleer santral yapma eğilimi içindedirler (Karataşlı vd, 2016).

\begin{tabular}{|c|c|c|c|c|c|c|}
\hline Yıllar & Toplam & Kömür & S. Yakıtlar & Doğalgaz & Hidrolik & $\begin{array}{c}\text { Yenilebilir } \\
\text { Enerji/Yakıtlar }\end{array}$ \\
\hline $\mathbf{2 0 0 8}$ & 198.418 & 29,1 & 3,8 & 49,7 & 16,8 & 0,6 \\
\hline $\mathbf{2 0 0 9}$ & 194.813 & 28,6 & 2,5 & 49,3 & 18,5 & 1,2 \\
\hline $\mathbf{2 0 1 0}$ & 211.208 & 26,1 & 1,0 & 46,5 & 24,5 & 1,9 \\
\hline $\mathbf{2 0 1 1}$ & 229.395 & 28,8 & 0,4 & 45,4 & 22,8 & 2,6 \\
\hline $\mathbf{2 0 1 2}$ & 239.497 & 28,4 & 0,7 & 43,6 & 24,2 & 3,1 \\
\hline $\mathbf{2 0 1 3}$ & 240.154 & 26,6 & 0,7 & 43,8 & 24,7 & 4,2 \\
\hline $\mathbf{2 0 1 4}$ & 251.963 & 30,2 & 0,9 & 47,9 & 16,1 & 4,9 \\
\hline $\mathbf{2 0 1 5}$ & 261.783 & 29,1 & 0,9 & 37,9 & 25,6 & 6,5 \\
\hline
\end{tabular}

Tablo 1: Enerji Kaynaklarına Göre Elektrik Enerjisi Üretimi ve Payları Kaynak: TUIKK.

Tablo 1'de görüldüğü gibi enerji kaynaklarına göre elektrik enerjisi üretimi ve payları incelendiğinde 2008 yılından bu yana yüzdelik payın 0,6'dan 6,5'e yükseldiğini ancak dünyadaki enerji kaynaklarının dengesiz bir şekilde dağılması sonucu yeterli olmadığı sonucu ortaya çıkartılmıştır.

\begin{tabular}{|c|c|c|c|c|}
\hline & 2006 & 2012 & 2013 & 2018 \\
\hline Birincil Enerji Talebi (BTEP) & 99.642 & 119.302 & 123.600 & 154.000 \\
\hline Elektrik Enerjisi Talebi (GWh) & 174.637 & 241.949 & 255.000 & 341.000 \\
\hline Kişi Bașı Birincil Enerji Tüketimi (TEP/kiși) & 1,44 & 1,59 & 1,62 & 1,92 \\
\hline Kiși Bașı Elektrik Enerjisi Tüketimi (kWh/kiși) & 2.517 & 3.231 & 3.351 & 4.241 \\
\hline Doğal Gazın Elektrik Üretimindeki Payı (\%) & 46 & 43 & 43 & 41 \\
\hline Yenilenebilir Kaynakların Elektrik Üretimindeki Payı & 25 & 41 & 28 & 27 \\
\hline Elektrik Kurulu Gücü (MW) & 40.565 & 57.058 & 58.500 & 78.000 \\
\hline Enerji Yoğunluğu (TEP/1000 Dolar) & 0,288 & 0,276 & 0,272 & 0,243 \\
\hline
\end{tabular}

Tablo 2: Yenilenebilir Enerji Kaynaklarının Elektrik Üretimi Payı Kaynak: Gürson vd, 2014. 
Tablo 2'den görüldüğü gibi, dünyada elektrik enerjisi talebi yıldan yıla artış göstermekte, enerji tüketimi giderek artmaktadır. Dünyadaki enerji yoğunluğunun karşılanması için gereken geleneksel kaynakların yanında yenilenebilir kaynakların enerji üretimindeki payın 2006 yılında \%25 olmasına rağmen sürekli bir artış göstermekle birlikte dengesiz bir dağılım görülmektedir. Ülkelerin enerji yatırımlarına önem verdikleri ve sahip oldukları doğal kaynaklarını (su, güneş, rüzgâr, termik vb.) etkin ve verimli kullanarak enerji ihtiyacını karşılamaya yönelik faaliyetlerini arttırdıkları da görülmektedir. Artan enerji talebine, yenilenebilir enerji kaynaklarının kullanımını artırarak cevap vermeye çalışmaktadır. 2015 yılında dünyanın en büyük ikinci enerji üretim kaynağı olacak olan yenilenebilir enerji kaynaklarının, 2035 yılında kömür ile birlikte dünyanın en temel elektrik kaynağı haline geleceği öngörülmektedir (İzmir Kalkınma Ajansı, 2013). Bununla birlikte, yenilenebilir enerji kaynaklarının elektrik üretimindeki payının \%20'lerden 2035 yılında \% 29'a çıkması beklenmektedir (Onuncu Kalkınma Planı, 2013).

\begin{tabular}{|c|c|c|c|c|c|}
\hline ÜLKE & 2013 & 2014 & 2015 & $\begin{array}{c}\text { Dünya Toplamındaki } \\
\text { Payı }(\%)\end{array}$ & Sira \\
\hline Cin & $2.903,90$ & $2.970,3$ & 3014 & $22,9 \%$ & 1 \\
\hline ABD & $2.271,70$ & $2.300,5$ & $2.280,6$ & $17,3 \%$ & 2 \\
\hline Hindistan & 626 & 666,2 & 700,5 & $5,3 \%$ & 3 \\
\hline Rusya & 688 & 689,8 & 666,8 & $5,1 \%$ & 4 \\
\hline Japonya & 465,8 & 453,9 & 448,5 & $3,4 \%$ & 5 \\
\hline Kanada & 335 & 335,5 & 329,9 & $2,5 \%$ & 6 \\
\hline Almanya & 325,8 & 311,9 & 320,6 & $2,4 \%$ & 7 \\
\hline Brezilya & 290 & 297,6 & 292,8 & $2,2 \%$ & 8 \\
\hline Güney Kore & 270,9 & 273,1 & 276,9 & $2,1 \%$ & 9 \\
\hline İran & 247,6 & 260,8 & 267,2 & $2,0 \%$ & 10 \\
\hline Suudi Arabistan & 237,4 & 252,4 & 264 & $2,0 \%$ & 11 \\
\hline Fransa & 247,4 & 237,5 & 239 & $1,8 \%$ & 12 \\
\hline Endonezya & 175 & 188,3 & 195,6 & $1,5 \%$ & 13 \\
\hline Birleșik Krallık & 201,4 & 188,9 & 191,2 & $1,5 \%$ & 14 \\
\hline Meksika & 188,9 & 190 & 185 & $1,4 \%$ & 15 \\
\hline İtalya & 155,7 & 146,8 & 151,7 & $1,2 \%$ & 16 \\
\hline İspanya & 134,2 & 132,1 & 134,4 & $1,0 \%$ & 17 \\
\hline Avustralya & 130,7 & 129,9 & 131,4 & $1,0 \%$ & 18 \\
\hline Türkiye & 120,3 & 123,9 & 129,3 & $1,0 \%$ & 19 \\
\hline Tayland & 120,3 & 123,4 & 124,9 & $0,9 \%$ & 20 \\
\hline Güney Afrika & 124,6 & 128 & 124,2 & $0,9 \%$ & 21 \\
\hline Tayvan & 109,9 & 111,4 & 110,7 & $0,8 \%$ & 22 \\
\hline BAE & 97,2 & 99 & 103,9 & $0,8 \%$ & 23 \\
\hline Polonya & 96 & 92,4 & 95 & $0,7 \%$ & 24 \\
\hline Ukrayna & 114,7 & 101 & 85,1 & $0,6 \%$ & 25 \\
\hline TOPLAM & $12.873,1$ & $13.020,6$ & $13.147,3$ & $100,0 \%$ & \\
\hline
\end{tabular}

Tablo 3: Dünya Birincil Enerji Tüketimi (Milyon TEP) Kaynak: Enerji ve Tabi Kaynaklar Bakanlı̆̆l.

Tablo 3'de yer alan verilere göre Çin ve Amerika dünyada birincil enerji tüketiminde ilk sıralarda yer almaktadır. Bu iki ülke yaklaşık \% 42 oranında birincil enerji kaynağı tüketimini gerçekleştirmiştir. Rusya, Hindistan, Japonya gibi ülkeler birincil enerji tüketimi açısından Çin ve ABD ülkelerini takip etmektedir. Türkiye'de ise 2013 yılında 120,3 iken 2015 yılında 129,3 artış olmuştur. Türkiye'nin birincil enerji tüketimi 1,0\% ile 19. Sırada yer almaktadır. Yıllar itibariyle ülkelerde birincil enerji tüketiminde inişli-çıkışlı dalgalanma görülmektedir. Dünya birincil enerji tüketiminde \%1'ini kullanan Türkiye'de 2015 yılında doğalgaz ve kömür tüketimi azalırken, petrol ve yenilenebilir enerji tüketimi artış göstermiştir. Amerika Birleşik Devletleri, Çin, Hindistan ve Almanya'da kömür, Rusya'da doğal gaz, Fransa'da nükleer enerji ve Kanada'da yenilenebilir enerji 10 elektrik enerjisi üretiminde en fazla paya sahip olan kaynaklardır.

\section{Sürdürülebilir Kalkınma Perspektifi}

Sürdürülebilir Kalkınma kavramının "Günümüzde ve gelecekteki kuşaklar da dâhil olmak üzere herkes için çok daha yüksek bir yaşam kalitesine erişmek felsefesi” fikriyle yola çıkmış, ilk kez 1987 Brundtland Raporu'nda "bugünün ihtiyaçlarının, gelecek kuşakların kendi ihtiyaçlarını karşılama kabiliyetlerinden ödün vermeden karşılanması" olarak tanımlanmış, 1997 yılında Amsterdam Antlaşmasıyla Avrupa Birliği’nin (AB) temel hedefi haline gelmiştir. Bir yandan sanayileşme, nüfusta meydana gelen artış ve aşırı tüketim eğilimi diğer yandan doğal kaynakların, enerjinin gelecek nesillerin ihtiyacını karşılayabilecek şekilde dengeli kullanılması ihtiyacı 'çevre' ve 'kalkınma' kavramlarını birbirlerine yaklaştırmıştır (European Commission, 2013). 2007 yılında ortaya konulan Sürdürülebilir Kalkınma Stratejisi ile ilgili raporda, enerjinin de içinde bulunduğu öncelikli alanlarda, bu konuda 
uygulama alanında gecikmeler yaşandığı ifade edilmiştir (AB-Türkiye Görünüm, 2000). Doğal kaynakları eşit bir şekilde kullanılması ve çevre dostu teknolojilerin üretilmesi, geliştirilmesi sürdürülebilir kalkınma ile doğrudan ilişkilidir. Günümüzde küresel kaynakların birçoğu yok olmakta bir k1smı ise istenilen etkinlikte kullanılamamaktadır. Bu durum ekonomik verimliliği engellemektedir. Sürdürülebilir kalkınma bir değişim sürecidir (Keleş, Hamamcı, 1998). Son 20 yılda dünyada yaşanan gelişmeler ve değişimler bu sürecin daha da güçlendirilmesi ve desteklenmesine olan ihtiyacı artırmıştır (Kalkınma Bakanlığı, 2012). Dünyada bir yandan hızlı ekonomik büyümeden kaynaklanan diğer bir yandan ise nüfus artışından kaynaklanan sorunlar giderek artmaktadır. $\mathrm{Bu}$ sürdürülebilir kalkınma yaklaşımıyla çözülebilmesi için yenilenebilir kaynaklarla ilgili uygulamaların arttırılması gerekmektedir.

Küresel kaynak kıtlığı sorununa geleneksel klasik sürdürülebilir kalkınma yaklaşımı ile çözüm bulunabileceği yönündeki yaklaşımlar terkedilmektedir. Yeni sürdürülebilir kalkınma yaklaşımı; çevreyle iç içe bir ekonomik sistem için gereken yapılandırma üzerinde durmaktadır. Sanayileşmiş ülkelerin küresel kaynakların tüketilmesindeki rolünün fazla olmasından dolayı bu süreçte en fazla sorumluluğu alması gerektiği temel alınmıştır (Dobson, 2003). Kaynakların aşırı kullanılmasında büyük paya sahip olan sanayileşmiş Kuzey ülkelerinin gelişmekte olan Güney ülkelerine çevresel anlamda bir sorumluluk içerisinde bulunmaları gerektiği belirtilmektedir (Roberts ve Parks, 2007). Sürdürülebilir kalkınma sürecinde zengin ülkelerin gelişmemiş ülkelere geçmişten gelen borçlarının ödenmesi, sanayileşmiş ülkelerin kaynakların aşırı kullanımlarına bir sınır getirilmesi amaçlanmıştır (Benlisoy, 2009). Yenilebilir kaynakların Avrupa Birliği ve UNESCO tarafından çevre dostu oluşu nedeniyle desteklenen projelerle özellikle kırsal kesimde istihdam yaratması ve o bölgenin kalkınması üzerine olumlu etkileri örnek teşkil etmiştir. Küresel iklim sorunlarına çözüm alternatifi olarak yenilenebilir enerji ekonomisi için gerekli teknolojilere sahiptir (Brown, 2008). Sürdürülebilirliğin hem ekolojik sistemin tamamında uygulanabilmesi hem de ekonominin bir dalı haline getirilmesi gerekmektedir (Algore, 2009).

\section{Yenilenebilir Enerji Kaynakları Uygulamaları}

\begin{tabular}{ccc}
\hline & Yenilenebilir Enerji Kaynakları & Kaynak veya Yakitı \\
\hline $\mathbf{1}$ & Güneş Enerjisi & Güneş \\
\hline $\mathbf{3}$ & Rüzgâr Enerjisi & Rüzgâr \\
\hline $\mathbf{4}$ & Dalga Enerjisi & Okyanus ve Denizler \\
\hline $\mathbf{5}$ & Biyokütle Enerjisi & Biyolojik Atıklar \\
\hline $\mathbf{6}$ & Jeotermal Enerji & Yeraltı Suları \\
\hline $\mathbf{7}$ & Hidrolik Enerji & Nehirler \\
\hline
\end{tabular}

Tablo 4: Bazı Yenilenebilir Enerji Kaynakları Kaynak: Çevre ve Şehircilik Bakanlı̆̆

Yenilenebilir enerji kaynakları Tablo 4'den de görüldüğü gibi güneş, rüzgâr, jeotermal, dalga, biyokütle, hidrolik ve hidrojen enerji kaynakları gibi birçok yenilenebilir enerji şeklindedir.

Güneş enerjisi yenilenebilir kaynaklar arasında en önemlisidir. Dünyanın enerji kaynağıdır. Güneş enerjisi rüzgâr, deniz dalgası, biyokütle gibi enerjilere dönüşebilir. Güneş enerjisi sonsuz olması, kısa süre içerisinde kurulup uzun yıllar kullanılması açısından günümüzde en yaygın kullanım alanına sahiptir (Varınca ve Gönüllü, 2006). Hidrolik enerji genellikle akarsular üzerinde barajlar kurarak suyun biriktirilmesi ve biriken suyun potansiyel enerjisinden faydalanılması aşamalarıyla elektik üretmektir (Koç ve Şenel, 2013). Rüzgar enerjisi, güneş 1şınlarının dünyayı farklı ısıtmasından dolayı ortaya çıkar. Yerküredeki hava sıcaklığı, nem ve basınç farkları havayı etkileyerek rüzgarı oluşturur (Önal ve Yarbay, 2010). Rüzgâr enerjisi, türbinin şaft gücünden yararlanılarak su pompalama, çeşitli ürünleri kesme, biçme, öğütme, sıkıştırma, yağ çıkarma gibi mekanik enerjiye veya elektriksel uygulamalara (şebeke bağlantılı ve şebeke bağlantısız-stand alone sistemler) gerek duyulan yerlerde kullanılmaktadır (Erişim Tarihi, 2017). Jeotermal enerji, önemli bir yenilenebilir enerji kaynağı olarak kabul edilmektedir. Bu enerji kaynağı dünyanın su ihtiyacının karşılanmasında ve isınmasında kullanılırken aynı zamanda sağlık ekonomisinde de tedavilerde yoğun olarak görülmektedir. Bitkisel ve hayvansal olan doğal maddelerden elde edilen enerji ise biyokütle enerjisidir (Yılmaz, 2012). Çoğunlukla biyokütle; odun ve odun atıklarından (\% 64), kentsel katı atıklardan (\% 24), tarımsal atıklardan (\% 5) ve atık gazlardan (\% 5) üretilir (Önal ve Yarbay 2010). Hidrojen birincil geleceğin alternatif enerji kaynağı olarak görülmektedir. Herhangi bir fosil yakıt içermediğinden çevreye zararı bulunmamaktadır. Çeşitli alanlarda kullanma amaçlı gerekli çalışmalar başlatılmıştır (Kumbur vd., 2005). Dalga enerjisi kullanarak denizlerden de enerjiyi, deniz dalga enerjisi, deniz sıcaklık gradyant enerjisi, deniz akıntıları enerjisi (boğazlarda) ve gel-git (medcezir) enerjisi şeklinde dört kısıma ayırmak mümkündür (Önal ve Yarbay, 2010).

Her enerji ve kalkınma projesinde olduğu gibi yenilenebilir enerjinin kullanılması da çevresel ve ekonomik sınırları dikkate alarak sürdürülebilir olmalıdır. Bu kaynaklardan bazıları doğadan kolay bir şekilde elde edilebilirken bazılarının kullanımı ise çok zordur. Bir bölgeye enerji sağlanması istendiğinde ön hazırlığının çok iyi yapılması, bölgenin enerji kaynaklarının iyi araştırılması ve de varolan enerjilerin iyi değerlendirilmesi 
gereklidir. Bunun için sürdürülebilir bir küresel enerji sistemine geçilmesi gerekmektedir (Wordwatch Enstitüsü, 2013).

\section{Sonuç}

Sanayileşme ve küreselleşme süreci birleşince dünyanın taşıma kapasitesi tehlikeye girerek çevresel bozulmalar hızlanmıştır. Sürdürebilir bir kalkınma perspektifinde incelendiğinde bu sorun yenilenebilir enerji kaynakları ile çözüme kavuşacaktır. Gelecek nesillerin de refahının sağlanmaya çalışıldığı sürdürülebilir kalkınma anlayışında şu andan itibaren acil olarak önlemlerin alınması gerekmektedir. Sanayileşmenin ve küreselleşmenin tehlikeye attığı dünya refahı için hatalardan ders alınması ve sürdürülebilirlik kavramının uygulamaya döndürülmesi gerekmektedir. Dünyanın karşı karşıya olduğu kaynak kıtlığı sorununun çözülmesi için sürdürülebilir bir ekonomik kalkınma perspektifinin oluşturulması gerekmektedir. Sürdürülebilir kalkınma için mevcut olan yaklaşımların yanında küresel olarak ortak kararın alındığı geniş kapsamlı stratejiler izlenmelidir. Bireysel çabaların yetersiz kaldığı özel girişimlerin, devlet politikaları ile desteklenmesi gerekmektedir. Sürdürülebilir bir ekonomik kalkınmanın evrensel bir hale getirebilmek için yeni bir çevre ekonomisi oluşturmak gerekmektedir. Yeni bir çevre ekonomisi etkin bir piyasa çerçevesinde makro önlemlerle uygulama alanı bulmalıdır. Dünyada kömür ve petrolün çevreye verdiği tahribatı önleyecek sınırlamalar getirecek yasalar ve vergi politikaları içeren bir piyasa oluşturulmalıdır.

Buradan hareketle ekonomik hedefler kaynakların duruma göre sürdürülebilir olan "kalkınma politikası" ile günümüz ve gelecekteki nesillere yüksek bir yaşam kalitesi sağlayabilir hale getirilmelidir. Artan dünya nüfusuyla birlikte azalan kaynakların alternatifleri sayesinde sürdürülebilir bir kalkınma hedeflenmelidir. Bilim ve teknolojilerin hızla değiştiği çağımızda bu sorumluluğun yerine getirilebilmesi mümkündür ancak uygulama süreci uzun dönemlere yayılabilecek hatta alınması güç kararlara bağlı olabilecektir. Sürdürülebilir kalkınma anlayışının yol göstericiliğinde uygulanan yenilebilir enerji kaynakları; hem günümüz hem de gelecek nesiller için önemli bir rol oynayacaktır.

\section{Kaynakça}

- Ataman, A.R., 2007. Türkiye’de Yenilenebilir Enerji Kaynakları, Ankara Üniversitesi Sosyal Bilimler Enstitüsü Yayınlanmamış Yüksek Lisans Tezi, s.1-325.

- Algore, 2009. “Tercih Sizin İklim Krizinin Çözümü İçin Bir Plan”, Optimistik Yayınları, Hazırlayan: Mutlu Dinçer, s.304-316.

- AB-Türkiye Görünüm, 2000. Avrupa Komisyonu Türkiye Delegasyonu, AB Türkiye Görünüm, Sürdürülebilir Kalkınma, (12), s.2-3.

- Brown, Lester R. 2008. "Plan Bb.3.0 Uygarlığını Kurtarmak İçin Harekete Geçmek” Çeviri: Ayşe Başcı, Tema Vakfi Yayını.

- Benlisoy, S., 2009. Çözüm İklim Adaleti Hareketi, www.ekolojistler.org (Erişim Tarihi: 19.12.2009).

- Çalışkan, M., 2011.“Türkiye Rüzgar Enerjisi Potansiyeli ve Mevcut Yatırımlar”, Rüzgar Enerjisi ve Santralleri Semineri, s.1-33.

- Çevre ve Şehircilik Bakanlığı, 2015 Verileri Slaytı.

- Dobson, A., 2003. Introduction, Fairness and Futurity/Essays on Environmental Sustainability and Social Justice, (Ed.Andrew Dobson), Oxford Press, s.3-4.

- Gürson, P., Topçu, M.K., Ülker, H.İ. ve Erkan, T.E., 2014. Yenilenebilir Enerji Politikaları ve Enerji Arz Güvenliği, s.1-6.

- Keleş, R., Hamamc1, C., 1998. “Çevrebilim”, İmge Kitabevi, Ankara, 1998, s.158.

- Karataşlı, M., Özer, T. ve Varinlioğlu, A., 2016. "Enerji ve Çevre”, İstanbul Aydın Üniversitesi Dergisi, (30), s.103-124.

- Koç, E., Şenel, M.C., 2013. “Dünyada ve Türkiye'de Enerji Durumu- Genel Değerlendirme”, Mühendis ve Makina, 54(639), s.32-44.

- Küçükkalay, A. Mesut 1997. “Endüstri Devrimi ve Ekonomik Sonuçlarının Analizi”, Süleyman Demirel Üniversitesi Sosyal Bilimler Enstitüsü Dergisi, Sonbahar 1997, s.51-68.

- Kumbur, H., Özer, Z., Özsoy, H.D., Avc1, E.D., 2005. Türkiye’nin Geleneksel ve Yenilenebilir Enerji Kaynaklarının Potansiyeli ve Çevresel Etkilerinin Karşılaştırılması, Mersin Üniversitesi.

- Mutlu, E. 2013, Türkiye'de Yenilenebilir Enerji Ekonomisi ve Ankara İline Ait SWOT Analizi, İstanbul Kültür Üniversitesi Sosyal Bilimler Enstitüsü Yayınlanmamış Yüksek Lisans Tezi, s.1-97.

- Milli Eğitim Bakanlığı, 2011. Yenilenebilir Enerji Kaynakları I, s.1-49. 
- Önal, E., Yarbay, R.Z., 2010. “Türkiye’nin Yenilenebilir Enerji Kaynakları Potansiyeli ve Geleceği”, November/2016 Kasım/2016 Sosyal Bilimler Dergisi ICEBSS Özel Sayısı, İstanbul Ticaret Üniversitesi Fen Bilimleri Dergisi, 9 (18), s.77-96.

- $\quad$ Roberts, T., Parks, B. 2007. A Climate of Injustice: Global Inequality/North-South Politics and Climate Policy, The MIT Press, s.21.

- Saklı, Ali Rıza (2016). “Fordizm’den Esnek Üretim Sistemine Dönüşümün Kamu Yönetimi Üzerindeki Etkileri”, Elektronik Sosyal Bilimler Dergisi, Cilt 12, Sayı: 44, Kış 2013 ss. 109-110. http://www.esosder.org/dergi/44107-131.pdf(10.01.2016).

- $\quad$ Ürün E., Soyu E. 2016. “Türkiye’nin Enerji Üretiminde Yenilenebilir Enerji Kaynakları Üzerine Bir Değerlendirme”, Sosyal Bilimler Dergisi, ICEBSS Özel Sayı, s. 31-45.

- Varınca, K.B., Gönüllü, M.T. 2006. “Türkiye'de Güneş Enerjisi Potansiyeli ve Bu Potansiyelin Kullanım Derecesi, Yöntemi ve Yaygınlığı Üzerine Bir Araştırma”, UGHEK, 1. Ulusal Güneş ve Hidrojen Enerji Kongresi, Eskişehir.

- Yalçınkaya, T., 2001. "Sanayi ve Bilgi Toplumlarında Rekabet Ekonomisi” Rekabet Bülteni Dergisi, ESC Consulting Yayını, (5), .s.10.

- Y1lmaz, M., 2012. “Türkiye’nin Enerji Potansiyeli ve Yenilenebilir Enerji Kaynaklarının Elektrik Enerjisi Üretimi Açısından Önemi “, Ankara Üniversitesi Çevrebilimleri Dergisi, 4(2), 33-54.

- $\quad$ European Commission, 2013. European Commission, 2013. http://www.oxfordscholarship.com/view/10.1093/0198294891.001.0001/acprof-9780198294894- chapter-2, Erşim Tarihi: 22.07.2013

- Worldwatch Enstitüsü, 2013. Dünyanın Durumu 2013 Sürdürülebilirlik Hala Mümkün mü? Editör: Linda Starke Türkiye İş Bankası Kültür Yayınları e Çev. Cana Ulutaş Ekiz- Çağrı Ekiz, s. 9-183.

- Yılmaz, M., 2012. “Türkiye’nin Enerji Potansiyeli ve Yenilenebilir Enerji Kaynaklarının Elektrik Enerjisi Üretimi Açısından Önemi”, Ankara Üniversitesi Çevrebilimleri Dergisi, 4(2), s.33-54.

- http://www.oxfordscholarship.com/view/10.1093/0198294891.001.0001/acprof-9780198294894- chapter-2, (Erişim Tarihi: 22.07.2013).

- $\quad$ Enerji ve Tabi Kaynaklar Bakanlığı, http://www.enerji.gov.tr/File/?path=ROOT\%2f1\%2fDocuments\%2fEnerji\%20ve\%20Tabii\%20Kaynaklar\% 20G\%C3\%B6r\%C3\%BCn\%C3\%BCm\%C3\%BC\%2fSayi_14.pdf (Erişim Tarihi: 21.04.2017).

- İzmir Kalkınma Ajansı, 2013.

- http://www.normenerji.com.tr/menu_detay.asp?id=10374 (Erişim Tarihi: 12.04 2017).

- http://www.tuik.gov.tr/UstMenu.do?metod=temelist (Erişim Tarihi: 14.04.2017).

- Onuncu Kalkınma Planı, 2013. http://www.tcma.org.tr/images/file/10_\%20kalkinma\%20plani\%20ozeti.pdf (Erişim Tarihi: 12.04.2017)

- http://www.enerji.gov.tr/tr-TR/Anasayfa, (Erişim Tarihi: 14 Nisan 2017) 


\title{
Ülke Kredi Notlarının Sermaye Piyasalarına Etkisi Impact of Sovereign Credit Ratings on Capital Markets
}

\author{
Ph.D. Candidate Mustafa Batuhan Tufaner (Beykent University, Turkey) \\ Asst. Prof. Dr. S1tkı Sönmezer (Beykent University, Turkey) \\ Assoc. Prof. Dr. Ahmet Alkan Çelik (Beykent University, Turkey)
}

\begin{abstract}
Sovereign credit ratings are of great importance in terms of country's economy in recent years. Sovereign credit ratings can greatly affect both financial markets and macroeconomic balances. On the other hand, these credit ratings are closely related to the political situation of the countries. Therefore, all factors behind the credit rating announcements operating in global markets needs to be put forward. The content of this paper is to identify policy interest reaction towards sovereign credit ratings and examine of countries that experienced severe rating changes. In this bulletin, big three credit rating agencies are compared and critically assessed various credit rating of Turkey. The analyzed dataset covers sovereign rating announcements released by reputable rating agencies, stock price, Dollar / TL exchange rate, Dollar / Euro exchange rate and benchmark bond.
\end{abstract}

\section{Giriș}

Kredi derecelendirme kuruluşları bilhassa son yıllarda verdikleri notlarla dikkatleri üzerine toplamışlardır. Bu kuruluşların verdikleri notlara yapılan itirazlar, hakkettiğinden düşük not aldığına inanan devlet ya da kuruluşların, daha yüksek faiz ödeme zorunluluğuyla karşı karşıya bırakılmalarıyla açıklanabilir. Bu çalışmanın amacı bu notların doğruluğunu tespit etmekten ziyade, bu notların seçilmiş bazı finansal enstrümanların getirilerine kısa vadeli etkilerini ortaya koymaktır. Çalışmanın bir diğer amacı da, piyasanın olası not değişikliğini öngörüp, fiyatlara yansıtıp, yansıtmadığını tespit etmeye çalışmaktır.

$\mathrm{Bu}$ çalışmada kredi derecelendirme kavramı ve tarihçesine, derecelendirme kuruluşlarının yapısına ve derecelendirme kuruluşlarının kullandığı ölçütler yorumlandıktan sonra notların yönünün kukla değişken olarak kullanıldığı bir regresyon analizi uygulanmıştır. Burada beklenildiği üzere, not değişikliklerinin piyasa tarafından fiyatlandığ 1 ve beklenmedik, belirgin bir etkinin tespit edilemediği ortaya konmaya çalışılmıştır. Benzer şekilde notlar açıklandıktan sonra, beklentiler gerçekleştikten sonra da açıklanma etkisi ölçülmeye çalışılmıştır.

$\mathrm{Bu}$ çalışmamızda sadece Türkiye piyasalarına etkisi incelenmiş olup, bir başka çalışmada, diğer piyasaların getirilerine etkileri de incelenecektir. Çalışmanın kısıtları arasında, 2008 öncesinde verilerin bir kısmına ulaşılamaması yer almaktadır.

\section{Kredi Derecelendirme Kavramı ve Tarihçesi}

Sermaye, özellikle gelişmekte olan ekonomilerin makroekonomik büyümesi açısından oldukça önem taşımaktadır. Gelişmekte olan ülkelerde yaşanan iç sermaye yetersizliği, bu ülkeleri dış dünyadan borç almaya yöneltmektedir. Ancak, küresel ölçekte yaşanan risk ve güven sorunu dış finansman ihtiyacının teminini zorlaştırabilmektedir. $\mathrm{Bu}$ açıdan, ülke kredi notları ülkelerin yatırım ortamının risk düzeyini ölçmekte ve dolayısıyla hem finansal hem de makroekonomik değişkenleri etkileyebilmektedir. Kredi derecelendirmesi, genellikle mutlak olmasa da göreceli olarak yükümlülükleri yerine getirememe ihtimaline odaklanmaktadır.

\subsection{Derecelendirme Kavramı ve Özellikleri}

Derecelendirme (rating) ile ilgili literatürde pek çok farklı tanım bulunmaktadır. Kredi derecelendirme kavramı en genel haliyle, verilecek kredilerin zamanında ve eksiksiz bir şekilde geri ödenmesiyle ilgili olarak, borçlunun ihraç ettiği menkul kıymetlere yatırım yapılması halinde, yatırımcının bu işlemden dolayı üstlendiği riski ifade etmektedir (Karagöl ve Mihçıokur, 2012, 8). Söz konusu derecelendirme işlemleri, böylelikle uluslararası sermaye piyasalarındaki ölçütlere uyumlu ve objektif bir değerlendirme ortaya koyabilmektedir. Ülke kredi derecelendirmesi ise, bir ülkenin finansal yükümlülüklerini zamanında yerine getirip getiremeyeceği hakkında yapılan bağımsız değerlendirme olarak tanımlanabilmektedir. Bu değerlendirme sürecine etki eden iki önemli faktör bulunmaktadır. Bunlar; ekonomik risk ve politik risktir. Ekonomik risk; ekonomik yapı, demografik yapı ve makroekonomik gösterge potansiyellerindeki riskleri ifade ederken, politik risk ise; ülke hükümetlerinin geri ödeme konusundaki istekliliğini ifade etmektedir (Karg1, 2014, 358).

Derecelendirme işlemi, içsel ve dişsal derecelendirme olarak iki farklı kategoride ele alınabilmektedir. İçsel derecelendirme; bankaların borç talep edenlere karşı uyguladıkları banka içi ölçütleri kapsarken, dışsal derecelendirme ise; uluslararası kredi derecelendirme kuruluşları tarafından ülke bazında güven düzeyi ve borçlanma kabiliyeti ölçütlerini kapsamaktadır (Hasbi, 2012, 5). İçsel derecelendirmede banka, müşterilerini değerlendirmeye tabi tutmak amacıyla bazı belgeler istemekte ve böylelikle belirlediği kriterlere uygunluklarını tespit edebilmektedir. Dışsal derecelendirme ise, uluslararası bir nitelik taşıdığından ülkelerin uluslararası alandaki 
durumunu ortaya koyabilmektedir. Diğer yandan, derecelendirme işlemleri yükümlülüklerin yerine getirilmesi süresi açısından kısa ve uzun vadeli derecelendirme olarak iki kategoride değerlendirilmektedir. Kısa vadeli derecelendirme vadesi bir yıla kadar olan yükümlülükleri tanımlarken, uzun vadeli derecelendirme ise bir yıldan uzun vadeli yükümlülükleri tanımlamaktadır.

Kredi derecelendirme işlemlerine ilişkin yapılan araştırmalarda, özellikle ülke derecelendirmesine ilişkin talebin 2000'li yıllardan itibaren arttığı görülmektedir. Zamanla kredi derecelendirme kuruluşlarının ve derecelendirilmeye tabi tutulan ülke sayısının artması, özellikle gelişmekte olan ülkeler bağlamında birtakım sorunların ortaya çıkmasına yol açmıştır. Uluslararası derecelendirme kuruluşları gelişmekte olan ülkelerdeki yerel derecelendirme kuruluşları ile birleşerek veya onları satın alarak bu sorunu aşmaya çalışmışlardır.

\subsection{Derecelendirmenin Tarihsel Gelişimi}

Kredi derecelendirme kuruluşlarının geçmişi bir asırdan öteye dayanmaktadır. İlk ortaya çıktıkları yıllarda üst düzey bir kurumsal niteliğe sahip olmasalar da, insanlar tarafindan kabul edilir bir organizasyon olarak yer almışlardır. Kredi derecelendirme kavramı ilk olarak, 1837 yılında ABD'de yaşanan finansal krizin ardından tüccarların yükümlülüklerini yerine getirememeleri sonucunda ortaya çıkmıştır. Krizden etkilenen yatırımcılardan biri olan Lewis Tappan, yatırımcılar adına şirketleri izlemek ve değerlendirmek amacıyla Mercantile Agency isimli şirketi kurmuş̧tur (Gülmez ve Gündoğan, 2014, 67). Şirket, derecelendirme işlemi yapmadan belirli aralıklarla müşterilerini bilgilendirme faaliyeti yürütmüştür.

Derecelendirme kavramsal olarak, 1900'lü yılların başında ABD'de ortaya çıkmıştır. Şirketlerle ilgili bilgilerin yer aldığı bir el kitabı ile başlayan kavramsal süreç, 1905 yılında ilk derecelendirme kuruluşu olan Moody's Investors Service'in kurulmasıyla somut bir hal almıştır. Özel şirket ve kamu kurumlarının derecelendirilmesine 1922 yllında başlayan Moody's, derecelendirme faaliyetlerine en fazla yoğunlaşan derecelendirme kuruluşu konumundadır.

Zamanla piyasadaki şirket sayısının artması, mobil şirketlerin ortaya çıkması ve çok sayıda iflasın yaşanması, tek bir derecelendirme kuruluşunun yetersiz olduğunu göstermiştir. Dolayısıyla, şirketlerin risk durumlarını değerlendirmek üzere diğer bir derecelendirme kuruluşu olan Standard and Poor's kurulmuştur. 1913 yilına gelindiğinde ise, üçüncü büyük kredi derecelendirme kuruluşu olan Fitch Publishing Company of Newyork kurulmuş ve 1924 yılında faaliyet alanını genişletmiş̦tir. Günümüzde kredi derecelendirme kuruluşlarının işlemleri, ülkeleri de kapsayan geniş bir alana yayılmıştır. Çok sayıda kredi derecelendirme kuruluşu var olmasına karşın, uluslararası alanda itibar gören en önemli üç kuruluşun S\&P, Standard and Poor's ve Fitch olduğu ifade edilebilmektedir.

\section{3 Ülke Kredi Notu Derecelendirmesinde Kullanılan Ölçütler}

İlk kurulduklarında faaliyetlerine şirket kredi derecelendirmesi ile başlayan kredi derecelendirme kuruluşları, liberalizasyon ve uluslararası sermaye hareketleri kavramlarını önem kazanmasıyla birlikte ülke risklerini de değerlendirmeye almışlardır. Bu değerlendirmede de temel amaç aynı olduğundan ülke riski; ekonomik, politik ve sosyal şartların ülke durumunu nasıl etkilediğini ortaya koymaktadır. Ülke kredi notu, borçlanma maliyetlerinin düşürülmesi ve yabancı yatıımcıların ülkeye çekilmesi açısından belirleyici olmaktadır. Diğer taraftan, özellikle gelişmekte olan ülkeler küresel finansal sisteme entegre olabilmek için kredi derecelendirmesine başvurabilmektedir. Dolayısıyla, ülke kredi notlarının ülke ekonomileri açısından büyük bir öneme sahip olduğu ifade edilebilmektedir.

Kredi derecelendirmesini etkileyen iki temel ölçüt bulunmaktadır. Bunlar; ülkenin taşıdığı ekonomik ve politik risktir. Politik risk; ülkelerin borçlarını ödeyebilmesinde etkili olan sosyal ve politik unsurların değerlendirilmesidir. Hükümet politikaları, sosyal düzenlemeler ve hukuki yapı ülkelerin politik risk göstergelerine örnek olarak gösterilebilmektedir. Ekonomik risk ise, daha ziyade ülkelerin ekonomik koşullarının ve makroekonomik dengelerinin değerlendirilmesini kapsamaktadır. Ekonomik riskin en belirleyici ölçütü, ülkelerin gelir yaratma potansiyeli yani GSMH'sıdır (Haan ve Amtenbrink, 2011, 11). Ekonomik risk ölçütlerinden bir diğeri, dış borç servis oranıdır. Dış borç servis oranının yüksek olması, ülkenin borçlarını geri ödeyebilme kabiliyetinin zayıf olduğu şeklinde değerlendirilmektedir. Ekonomik riskin belirlenmesindeki bir diğer ölçüt ise, ülkelerin doğal kaynak miktarları ve bu kaynakların etkin tahsisi ve kullanımıdır. Ülke kredi derecelendirmesinde esas alınan genel ölçütler aşağıdaki tabloda gösterilmektedir; 


\begin{tabular}{|c|c|}
\hline Politik yapıya ilişkin ölçüitler & $\begin{array}{l}\text { Politik kurumların istikrarı, siyasal hayata katılım oranı, karar } \\
\text { alıcıların şeffaflığı, devletin güvenliği ve jeopolitik risk. }\end{array}$ \\
\hline Gelir ve ekonomik yapıya ilişkin ölçütler & $\begin{array}{l}\text { Gelir ve servet dağılımında adaletsizlik, finansal piyasaların } \\
\text { etkinliği, finans dışındaki sektörlerdeki karlılık oranı ve } \\
\text { rekabetçi yapı, kamu kesiminin etkinliği, işgücü esnekliği ve } \\
\text { korumacı politikalar. }\end{array}$ \\
\hline Ekonomik büyümeye ilişkin ölçütler & $\begin{array}{l}\text { Tasarruf ve yatırım hacminin büyüklüğü ve yapısı, ekonomik } \\
\text { büyüme modeli ve oranı. }\end{array}$ \\
\hline Finansal esnekliğe ilişkin ölçütler & $\begin{array}{l}\text { Kamu bütçesi dengesi, gelir artış esnekliği ve etkinliği, harcama } \\
\text { etkinliği ve kamu harcamaları üzerindeki baskılar, sosyal } \\
\text { güvenlik sisteminin karakteri. }\end{array}$ \\
\hline Kamusal sorumluluklara ilişkin ölçütler & $\begin{array}{l}\text { Kamunun borcunun GSMH'ya oranı, faiz ödemelerine ayrılan } \\
\text { kamu gelir düzeyi, uluslar paranın döviz karşısındaki değeri, } \\
\text { sermaye piyasasının derinliği ve hacmi. }\end{array}$ \\
\hline $\begin{array}{l}\text { Offshore ve şartlı sorumluluklara ilişkin } \\
\text { ölçütler }\end{array}$ & $\begin{array}{l}\text { Reel sektörün derinliği ve büyüklüğü, finansal sektörün } \\
\text { dayanıklılığı. }\end{array}$ \\
\hline Parasal esnekliğe ilişkin ölçütler & $\begin{array}{l}\text { Konjonktürel dalgalanmalarda fiyat hareketliliği, para ve kredi } \\
\text { genişliği, döviz kuru rejimi ile parasal hedeflerin uyumu, merkez } \\
\text { bankası bağımsızlığı, parasal hedeflerin niteliği ve etkinliği. }\end{array}$ \\
\hline Yabancı sermayeye ilişkin ölçütler & $\begin{array}{l}\text { Parasal ve finansal politikaların dış ülkelerdeki hesaplar } \\
\text { üzerindeki etkileri, cari hesapların yapısı, sermaye akımlarının } \\
\text { karakteri, rezerv miktarı. }\end{array}$ \\
\hline Dış borç yüküne ilişkin ölçütler & $\begin{array}{l}\text { Brüt ve net dış borç stoğu ve yapısı, toplam döviz } \\
\text { yükümlülüklerinin niteliği ve dövizin faize duyarlılığı, borç } \\
\text { servis yükü. }\end{array}$ \\
\hline
\end{tabular}

Tablo 1. Ülke Kredi Notu Derecelendirmesinde Esas Alınan Ölçütler Kaynak: (Demir ve Eminer, 2014, s.102).

\section{Küresel Ölçekte Faaliyet Gösteren Kredi Derecelendirme Kuruluşları}

Dünya genelinde, farklı ülke ekonomilerini değerlendirmeye tabi tutan birçok kredi derecelendirme kuruluşu bulunmaktadır. Bu kuruluşlar arasında üç kredi derecelendirme kuruluşu ön plana çıkmaktadır. Bunlar; Standard \& Poor's, Moody's ve Fitch'dir. Derecelendirme faaliyetlerinin yaklaş1k olarak \%97'si bu üç büyük kredi derecelendirme kuruluşu tarafindan gerçekleştirilmektedir (Haspolat, 2015, 16).

\subsection{Uluslararası Kredi Derecelendirme Kuruluşlarının Yapısı}

Kredi derecelendirme kuruluşlarına duyulan gereksinimin birçok nedeni bulunmaktadır. Ülkelere ilişkin mevcut verileri değerlendirmenin yanı sıra, mevcut bilgilerin geçmiş dönemlerle birlikte ele alınarak geleceğe yönelik sinyallerin okunabilmesi büyük önem taşımaktadır. Tarafsızlık, bağımsızlık, güvenilirlik ve saydamlık uluslararası kredi derecelendirme kuruluşlarının kabul ettikleri temel ilkeler arasında gösterilmektedir.

Küresel ölçekte kabul görmüş üç büyük uluslararası derecelendirme kuruluşu Standard\&Poor's, Moody’s ve Fitch kredilere ilişkin risk seviyelerini kategorize etmişlerdir. Kategorize edilmiş kredi risk göstergeleri, piyasa aktörleri tarafından benimsenmiştir. Kredi derecelendirmesinde kullanılan semboller ve anlamları aşağıdaki tabloda gösterilmiştir; 


\begin{tabular}{|c|c|c|c|c|}
\hline Standard\&Poor's & Fitch & Moody's & \multicolumn{2}{|c|}{ Not Açıklaması } \\
\hline AAA & AAA & Aaa & En yüksek derece & \multirow{10}{*}{$\begin{array}{c}\text { Yatırım } \\
\text { yapılabilir seviye }\end{array}$} \\
\hline $\mathrm{AA}+$ & $\mathrm{AA}+$ & Aal & & \\
\hline AA & AA & $\mathrm{Aa} 2$ & Yüksek derece & \\
\hline AA- & AA- & Aa3 & & \\
\hline $\mathrm{A}+$ & $\mathrm{A}+$ & A1 & & \\
\hline $\mathrm{A}$ & $\mathrm{A}$ & A2 & İyi derece & \\
\hline A- & A- & A3 & & \\
\hline $\mathrm{BBB}+$ & $\mathrm{BBB}+$ & Baal & & \\
\hline $\mathrm{BBB}$ & BBB & Baa2 & $\begin{array}{l}\text { Ortanın altı } \\
\text { derece }\end{array}$ & \\
\hline BBB- & BBB- & Baa3 & & \\
\hline $\mathrm{BB}+$ & $\mathrm{BB}+$ & Ba1 & & \multirow{9}{*}{ Spekülatif seviye } \\
\hline $\mathrm{BB}$ & $\mathrm{BB}$ & $\mathrm{Ba} 2$ & $\begin{array}{r}\text { Yatırım } \\
\text { yapılamaz }\end{array}$ & \\
\hline BB- & BB- & $\mathrm{Ba} 3$ & & \\
\hline $\mathrm{B}+$ & $\mathrm{B}+$ & B1 & Spekülatif & \\
\hline $\mathrm{B}$ & $\mathrm{B}$ & B2 & $\begin{array}{l}\text { Önemli derecede } \\
\text { spekülatif }\end{array}$ & \\
\hline B- & B- & B3 & & \\
\hline $\mathrm{CCC}+$ & $\mathrm{CCC}+$ & $\mathrm{Caa}$ & & \\
\hline $\mathrm{CCC}$ & $\mathrm{CCC}$ & Caa3 & Şiddetli riskli & \\
\hline $\mathrm{CC}$ & $\mathrm{CC}$ & $\mathrm{Ca}$ & Aşırı spekülatif & \\
\hline $\mathrm{D}$ & $\begin{array}{c}\text { DDD } \\
\text { DD } \\
\text { D }\end{array}$ & $\mathrm{D}$ & $\begin{array}{l}\text { Yükümlülüğünü } \\
\text { yerine getiremez }\end{array}$ & Default \\
\hline
\end{tabular}

Tablo 2. Uluslararası Kredi Derecelendirme Kuruluşlarının Not Sistemi Kaynak: (Karagöl ve Mıhçıokur, 2012, 16)

\subsection{Uluslararası Kredi Derecelendirme Kuruluşlarının İşlevleri}

Kredi derecelendirme kuruluşları borçlunun kredibilitesini, borcunu zamanında ve tam olarak ödeyebilme kapasitesini ve ödeme istekliliğini ölçmektedir. Uluslararası kredi derecelendirme kuruluşları, finansal piyasaların etkin, güvenilir ve istikrarlı bir şekilde işlemesini sağlamaya yardımcı olmaktadır. Bununla birlikte, piyasalarda ortaya çıkabilecek asimetrik enformasyon problemini önleyerek tasarruf sahiplerinin tam olarak bilgilendirilmesi ve kamunun aydınlatılması bu kuruluşların temel işlevleri arasındadır.

Kredi derecelendirme kuruluşlarının ülkeler için belirledikleri notlar, yatırımcıların mevduatlarını yönlendirmeleri için yol gösterici olmaktadır. Dolayısıyla, kredi notu aracılığıyla yatırım yapılabilirlik seviyesini ölçen uluslararası kredi derecelendirme kuruluşları, ülkelerin yatırım ve dolayısıyla büyüme düzeylerine önemli ölçüde etki edebilmektedir. Bu süreçte, borçlanmak isteyen ülkeler faiz oranlarını belirleyerek borçlanma maliyetini oluşturmaktadır. Tasarruf sahipleri faiz oranlarının yüksek olduğu ülkelere yatırım yapma eğiliminde iken, ülkeler ise faiz oranlarını düşürebileceği en alt düzeye indirerek borçlanma maliyetlerini azaltma eğilimindedirler. Bu bağlamda, ülkelere verilen kredi notu derecesi ile faiz oranları arasında bir ilişki olduğu ifade edilebilmektedir.

Uluslararası kredi derecelendirme kuruluşlarının birçok işlevi yerine getirdiği söylenebilmektedir. Bu işlevler finansal piyasalar aracılığıyla yayılıp ekonominin tamamına tesir edebilmektedir. Uluslararası kredi derecelendirme kuruluşlarının işlevleri şu başlıklar altında toplanabilmektedir (Yardımcıoğlu ve Bora, 2013, 116117);

- Ülke yönetimlerinin ve merkez bankalarının kredi değerliliklerini ölçer,

- Borçluların, borçların, menkul kıymetlerin ve ihraççı kuruluşların geri ödeme güçlerini ve yatırım yapılabilirlik derecelerini belirler,

- Finansal piyasaların gücünü ve borç ödeyebilme kapasitelerini analiz eder,

- Periyodik olarak değerlendirme ve notlandırma yapar,

- Verdiği notları uluslararası kamuoyuna ilan eder. 


\subsection{Uluslararası Kredi Derecelendirme Kuruluşlarının Sermaye Piyasaları Üzerindeki Etkileri ve Önemi}

Ülke kredi derecelendirmeleri, faiz oranı kanalıyla özellikle gelişmekte olan piyasalardaki yatırım akışlarını hem teşvik edici hem de istikrarı bozucu şekilde etkileyebilmektedir. Borçluların yükümlülüklerini yerine getirebilme kapasitesini ve isteğini ölçen derecelendirme işlemi, ekonomik performans, borç tahsili geçmişi ve siyasi faktörleri de içeren geniş bir kriter yelpazesine dayanmaktadır (Christopher ve diğerleri, 2012, 1071). Kredi riski değerlendirmeleri, asimetrik enformasyon probleminin şiddetli olabileceği gelişmekte olan ülkelerdeki yatırım firsatlarını değerlendirmek için çok önemli bir araç olarak kabul edilmektedir.

Uluslararası kredi derecelendirme kuruluşları sermaye piyasalarında iki temel rol oynamaktadır. İlk olarak, kredi kalitesini değerlendirmek için gerekli bilgileri analiz ederek piyasa katılımcılarına bilgi aktarmaktadır. Derecelendirmenin zamanlaması ve aktarılan bilginin kullanışlılığı kredi notlarının etkinliğiyle yakından ilişkilidir (Frost, 2007, 474). İkinci olarak, finansal regülasyonları da kapsayacak şekilde yapılacak sözleşmeleri kolaylaştırmaktadır. Özel sözleşmelerde derecelendirmeye dayalı kısıtlamalar ortaya çıkabileceğinden, kurumsal yatırımcıların şirket içi yatırımlarında da derecelendirme kullanılabilmektedir.

Ülke kredi risk seviyesinin düşürülmesi, uluslararası sermaye girişlerini ve finansal entegrasyonu arttırmakta, finansal piyasaların gelişimine ise katkıda bulunmaktadır. Finansal gelişme, sermayenin küresel ekonomilerde optimum biçimde tahsis edilmesi açısından önem taşımaktadır. Diğer taraftan, yaşanan borç krizleri, yükümlülükleri yerine getirememe ve yeniden yapılan müzakereler ülke riskinin önemini ortaya koymaktadır (Pukthuanthong-Le, 2007, 48). Kredi riski yüksek olan ülkelerden sermaye çıkışı yaşanırken, kredi riski düşük ülkelere ise yoğun sermaye girişleri yaşanmaktadır. Dolayısıyla, kredi riskinin sermaye piyasaları aracılığıyla ülkelerin hem finansal piyasaları hem de makroekonomik dengeleri üzerinde etkili olduğu ifade edilebilmektedir.

\subsection{Literatür Taraması}

Ülke kredi notu açıklamalarının finansal piyasalar üzerindeki etkileri konusunda literatürde geniş bir araştırma alanı bulunmaktadır. Bu konuyla ilgili ilk sistematik çalışma Cantor ve Packer (1996) tarafından yapılmıştır. OLS tahmin yöntemini kullanarak 49 gelişmiş ve gelişmekte olan ülke üzerine yaptıkları çalışmada; ülke kredi notlarının ülke tahvillerinin getiri oranları üzerinde \%90'lık bir açıklama gücü olduğunu ortaya koymuşlardır. Erb, Harvey ve Viskanta (1999) yaptığı çalışma sonucunda, ülke kredi notları ile gelişmekte olan piyasaların tahvil getiri spreadleri arasında güçlü bir ilişki olduğunu bulmuşlardır. Kaminsky ve Schmukler'in (2002) yaptığ çalışmada, 16 gelişmekte olan piyasa üzerinde panel veri analizi uygulanmış ve ülke kredi notlarının tahvil ve hisse senedi piyasaları üzerindeki etkilerini araştırmışlardır. Çalışma sonucunda, kredi notlarındaki değişmelerin tahvil ve hisse senedi getirileri üzerinde etkisi olduğunu bulmuşlardır. Reinhart ve Rogoff (2004) ile Kim ve Wu'nun (2008) yaptığı araştırmalar da, kredi notlarının sermaye piyasalarını önemli derecede etkilediği fikrini desteklemektedir.

Kräussl'in (2005) Türkiye'nin de içinde yer aldığı 28 gelişmekte olan ve geçiş ekonomileri üzerinde yaptığ çalışmada negatif kredi notlarının; spekülatif piyasa baskısı endeksini, günlük kısa vadeli faiz oranı değişikliklerini ve günlük borsa fiyatındaki değişiklikleri önemli ölçüde arttırdığını bulmuştur. Buna karşılık, derece yükseltilmesinin zayıf veya önemsiz bir etki gösterdiğini ortaya koymuştur. Afonso ve diğerlerinin (2014) panel sabit-etki analizi kullanarak 21 Avrupa ülkesi üzerinde yaptığ çalışmada, ülke notundaki değişmelerin hem hisse senedi hem de tahvil getirisi oynaklıkları üzerinde asimetrik etkileri olduğunu bulmuş ve not arttırımının oynaklık üzerinde herhangi bir belirgin etkisi olmadığını ortaya koymuşlardır. Kang ve Min'in (2016) panel VAR yöntemini kullanarak yedi Doğu Asya ülkesi üzerinde yaptığı çalışmada, ülke kredi notu yükseltilmesinin kredi riski swap genişliği ve hisse senedi endeksleri üzerinde derece düşürülmesinden daha güçlü bir etkiye sahip olduğu ortaya konulmuştur.

\section{Veri ve Yöntem}

Bu çalışmada, Moodys, Fitch ve S\&P 500 adlı kredi derecelendirme kuruluşlarının 2008-2016 yılları arasında ülkemiz için verdiği not değişikliği açıklamalarının çeşitli finansman enstrümanları üzerindeki etkiler incelenmiştir. Bu enstrümanların getirilerinde 1 ay, 1 hafta ve 1 gün önceden açıklama tarihine kadar getirilerinde bir anormallik olup olmadığı araştırılmıştır. Var olan anormallikler, piyasaların kredi derecelendirme kuruluşlarının kararlarını, piyasaların ekseri doğru fiyatladığını ortaya koymuştur.

Bu çalışmada kullanılan bağımlı değişkenler arasında BIST 100 getirileri, USD/TL paritesi getirileri (satış fiyatları kullanılarak), 2034 vadeli Türkiye Euro tahvillerinin getirisi, oynaklık ölçütü olarak da VIX endeksi kullanılmıştır. Derecelendirme kuruluşları, notlarını pozitif, durağan veya negatif olarak revize ettiklerinde değişimin yönü esas alınmıştır.

\subsection{Hipotezler}

Çalışmada, not değişimlerinin BIST 100, 2034 Euro tahvili ve oynaklık üzerindeki etkilerini ölçümlemek için aşağıdaki hipotezler oluşturulmuştur.

H1: Not artışlarının BIST100 getirileri üzerinde etkisi yoktur.

H2: Not artışlarının VIX endeksi üzerinde etkisi yoktur. 
H3: Not artışlarının 2034 Euro tahvilinin getirisi üzerinde etkisi yoktur.

H4: Not düşüşlerinin BIST100 getirileri üzerinde etkisi yoktur.

H5: Not düşüşlerinin VIX endeksi üzerinde etkisi yoktur.

H6: Not düşüşlerinin 2034 Euro tahvilinin getirisi üzerinde etkisi yoktur.

H7: Notun değiştirilmemesinin BIST100 getirileri üzerinde etkisi yoktur.

H8: Notun değiştirilmemesinin VIX endeksi üzerinde etkisi yoktur.

H9: Notun değiştirilmemesinin 2034 Euro tahvilinin getirisi üzerinde etkisi yoktur.

Öncelikle kredi notlarındaki değişikliklerin BIST 100, oynaklık ve tahvil getirileri üzerindeki etkilerini görebilmek için anormal getirilerini hesaplamak gerekmektedir:

Anormal getiri $=$ gerçekleşen getiri - beklenen getiri

Toplam anormal getiriyi bağımlı değişken, Amerikan dolarının getirisini bağımsız değişken ve kredi notlarını kukla değişken olarak kullanıldığı model aşağıdaki gibidir;

$$
\begin{aligned}
& \text { CAR BIST } 100=\mathrm{B} 0+\mathrm{B} 1 \text { (USDgetirisi) }+\mathrm{B} 2(\text { Artış })+\mathrm{B} 3 \text { (Azalış) }+\mathrm{B} 4(\text { Sabit })+\mathrm{e} \\
& \text { CAR } 2034=\mathrm{Bo}+\mathrm{B} 1(\text { USDgetirisi) })+\mathrm{B} 2(\text { Artış })+\mathrm{B} 3(\text { Azalış })+\mathrm{B} 4(\text { Sabit })+\mathrm{e} \\
& \mathrm{CAR} 2 \mathrm{yr}=\mathrm{Bo}+\mathrm{B} 1(\mathrm{USD} \text { getirisi })+\mathrm{B} 2(\text { Artış })+\mathrm{B} 3(\text { Azalış })+\mathrm{B} 4(\text { Sabit })+\mathrm{e} \\
& \mathrm{CAR} \text { VIX }=\mathrm{Bo}+\mathrm{B} 1(\mathrm{USDg} \text { etirisi })+\mathrm{B} 2(\text { Artış })+\mathrm{B} 3(\text { Azalış })+\mathrm{B} 4(\text { Sabit })+\mathrm{e}
\end{aligned}
$$

\subsection{Bulgular}

Aşağıdaki tabloda görüldüğü gibi Not artış ve azalışlarının, 2034 vadeli Euro tahvil getirileri üzerinde anlamlı bir etkisi olduğu görülmüştür; not artışı $t$ değeri -2.5 (anlamlı \% 95 )ve not azaltımı $t$ değeri -2.3 , olmak üzere (anlamlı \% 95). Sabit ve diğer bağımsız değişkenlerde anlamlı bir etki görülmemiştir. Not değişimleri doğrudan bu tahvillerin risk seviyelerini belirlediğinden fiyatlamalara olan etkisi beklenildiği gibidir.

Model Summary

\begin{tabular}{|c|r|r|r|c|}
\hline Model & R & R Square & $\begin{array}{c}\text { Adjusted R } \\
\text { Square }\end{array}$ & $\begin{array}{c}\text { Std. Error of the } \\
\text { Estimate }\end{array}$ \\
\hline 1 &, $508^{2}$ &, 258 &, 117 &, 021515 \\
\hline
\end{tabular}

a. Predictors: (Constant),@1HaftaÖncesiDolarSatışFiyatı, @1HaftaÖncesiVIXEndeksi, Not Artışı, Not Azaltımı

\begin{tabular}{|rl|r|r|r|r|r|}
\hline \multicolumn{2}{|c|}{ Model } & \multicolumn{1}{c|}{$\begin{array}{c}\text { Sum of } \\
\text { Squares }\end{array}$} & df & Mean Square & F & Sig. \\
\hline \multirow{2}{*}{1} & Regression &, 003 & 4 &, 001 & 1,829 &, $161^{\text {b }}$ \\
& Residual &, 010 & 21 &, 000 & & \\
& Total &, 013 & 25 & & \\
\hline
\end{tabular}

a. Dependent Variable: @1HaftaSonrasıTürkiye802142034GovtGetiri

\begin{tabular}{|c|c|c|c|c|c|c|}
\hline \multirow{2}{*}{\multicolumn{2}{|c|}{ Model }} & \multicolumn{2}{|c|}{ Unstandardized Coefficients } & \multirow{2}{*}{$\begin{array}{c}\begin{array}{c}\text { Standardized } \\
\text { Coefficients }\end{array} \\
\text { Beta }\end{array}$} & \multirow[t]{2}{*}{$\mathrm{t}$} & \multirow[t]{2}{*}{ Sig. } \\
\hline & & $\mathrm{B}$ & Std. Error & & & \\
\hline \multirow{6}{*}{1} & (Constant) &, 061 &, 022 & & 2,806 &, 011 \\
\hline & Not Artış1 &,- 056 &, 022 & $-1,205$ & $-2,502$ & 021 \\
\hline & Not Azaltımı &,- 053 & 023 & $-1,125$ & $-2,309$ &, 031 \\
\hline & @1HaftaÖncesiVIXEnde & ,022 &, 031 &, 131 & ,688 & ,499 \\
\hline & & & & & & \\
\hline & $\begin{array}{l}\text { @1HaftaÖncesiDolarSatış } \\
\text { Fiyatı }\end{array}$ &,- 079 & ,097 &,- 166 &,- 812 & ,426 \\
\hline
\end{tabular}

b. Predictors: (Constant),@1HaftaÖncesiDolarSatışFiyatı,@1HaftaÖncesiVIXEndeksi, Not Artışı, Not Azaltımı

Coefficients $^{\mathrm{a}}$

a. Dependent Variable: @1HaftaSonrasiTürkiye802142034GovtGetiri

1 ay önce, 1 hafta önce, açıklanma tarihi, 1 hafta sonra ve 1 ay sonra olmak üzere toplam 5 dönem için analizler gerçekleştirilmişse de bu modellerde kredi derecelendirme kuruluşlarının gerçekleştirdiği not değişimlerinin, USD 
getirileri, oynaklık ve BIST getirileri üzerinde anlamlı bir etki bulunamamıştır. Bu durum piyasanın not değişimlerini doğru bir şekilde evvelden fiyatlara yansıtma kabiliyetine yorulmuştur.

\section{Sonuç}

Çalışmada kredi derecelendirme kuruluşlarının açıkladığı not değişimlerinin birkaç piyasa enstrümanının getirilerine etkisi incelenmiştir. Açıklamadan bir ay ve bir hafta evvel alınan örneklemler kullanılarak kurulan modellerden bu açıklamaların anlamlı etkileri bulunamamıştır. Bu durum, muhtemel bir içerden öğrenenlerin ticareti hususunun var olmadığı olarak açıklanabilir.

Yine not değişikliklerinden sonra takip eden dönemde incelenen getirilerin anlamlı bir şekilde etkilenmedikleri görülmüsşür. Piyasaların üzerinde etkili diğer etmenlerin daha baskın olduğu veya zaman içinde bu etkilerin fiyatlara nüfuz ettiği söylenebilir. Çalışmada gerek not artırımlarının, gerekse not azaltışlarının, bir hafta sonraki 2034 vadeli Euro tahvil getirisi üzerinde anlamlı etkisi bulunmuş̧ur. Bu kredi notundaki değişimi fark eden yabancı yatırımcının pozisyon değiştirmesinin yaklaşık bir hafta aldığı olarak yorumlanabilir. Bu çalışma, not değişimlerinin, diğer yabancı piyasalarında getirilerine etkilerinin inceleneceği bir çalışmanın ön çalışması olarak yapılmıştır.

\section{Kaynakça}

- Afonso ve diğerleri, 2014. "Sovereign Credit Ratings, Market Volatility and Financial Gains", ECB Working Paper, 1654.

- Cantor ve Packer, 1996. "Determinants and Impact of Sovereign Credit Ratings", FRBNY Economic Policy Review, 9608, ss. 37-53.

- Christopher ve diğerleri, 2012. "Do Sovereign Credit Ratings Influence Regional Stock and Bond Market Interdependencies in Emerging Countries?", Journal of International Financial Markets, Institutions \& Money, 22, ss. 1070-1089.

- Demir ve Eminer, 2014. "Kredi Derecelendirme Kuruluşları Üzerine Düşünceler”, LAÜ Sosyal Bilimler Dergisi, 5;2, ss. 96-113.

- Erb, Harvey ve Viskanta, 1999. "New Perspectives on Emerging Market Bonds: Looking Beyond the Current Crisis", Journal of Portfolio Management, 25, ss. 83-92.

- Frost, 2007. "Credit Rating Agencies in Capital Markets: A Review of Research Evidence on Selected Criticisms of the Agencies", Journal of Accounting, Auditing and Finance, 22;3, ss. 469-492.

- Gülmez ve Gündoğan, 2014. "Uluslararası Politik İktisat Çerçevesinde Kredi Derecelendirme Kuruluşlarının Türkiye Uygulaması", Siyaset, Ekonomi ve Yönetim Araşstırmaları Dergisi, 2;4, ss. 65-90.

- Haan ve Amtenbrink, 2011. "Credit Rating Agencies", DNB Working Paper, 278.

- Hasbi, 2012. "Kredi Derecelendirme Kuruluşları Tarafından Yapılan Not Değerlendirmelerinin Ülke Ekonomileri Üzerine Etkileri: Türkiye Örneği”, Adnan Menderes Üniversitesi (Yüksek Lisans Tezi).

- Haspolat, 2015. "Ülke Kredi Notlarının Belirleyicileri: Türkiye'nin Kredi Notunun Ülke Karşılaştırmalı Analizi”, Kalkinma Bakanlığ Uzmanlık Tezi.

- Kaminsky ve Schmukler, 2002. "What Triggers Market Jitters? A Chronicle of the Asian Crisis", Journal of International Money and Finance, 18, ss. 537-560.

- Kang ve Min, 2016. "Effect of the Sovereign Credit Ratings in East Asia Countries: Evidence from Panel Vector Autoregression”, Emerging Markets Finance and Trade, 52;5, ss. 1121-1144.

- Karagöl ve Mıhçıokur, 2012. "Kredi Derecelendirme Kuruluşları: Alternatif Arayışlar", SETA Raporu, 7.

- Karg1, 2014. "A Study on International Credit Rating Agencies and Turkey's Credit Rate (1998-2013)", International Journal of Social Science, 24, ss. 351-370.

- Kim ve Wu, 2008. "Sovereign Credit Ratings, Capital Flows and Financial Sector Development in Emerging Markets", Emerging Markets Review, 9, ss. 17-39.

- Kräussl, 2005. "Do Credit Rating Agencies Add to the Dynamics of Emerging Market Crises?", Journal of Financial Stability, 1, ss. 355-385.

- Pukthuanthong-Le ve diğerleri, 2007. "Equity and Debt Responses to Sovereign Credit Ratings Announcement”, Global Finance Journal, 18, ss. 47-83.

- Reinhart ve Rogoff, 2004. "Serial Default and the 'Paradox' of Rich-to-Poor Capital Flows", American Economic Review, 94, ss. 53-58.

- Yardımcıŏglu ve Bora, 2013. "Uluslararası Kredi Derecelendirme Kuruluşlarının Çalışma Prensipleri, İşleyişleri, Küresel Dünyadaki Rol ve İşlevleri”, KSÜ IIIBF Dergisi, 3;1, ss. 111-118. 


\title{
Teknolojik Gelişme Göstergeleri ile Ekonomik Büyüme Arasındaki Nedensellik İlişkisi: Türkiye Örneği
}

\section{The Causality Relationship between Technological Development Indicators and Economic Growth: The Case of Turkey}

\author{
Assoc. Prof. Dr. Neşe Algan (Çukurova University, Turkey) \\ Ph.D. Candidate Müge Manga (Çukurova University, Turkey) \\ Prof. Dr. Muammer Tekeoğlu (Çukurova University, Turkey)
}

\begin{abstract}
The improvements in technological development indicators play a driving role in the process of economic growth and industrialization. Especially, technological developments are vital for developing countries. This study investigates the relationship between the share of R \& D expenditure in GDP, the number of patent applications and GDP per capita utilizing Granger causality test for the period of 1996 - 2015. According to Granger Causality test analysis results, it is concluded that short-term one-way causality from high-tech product exports and R \& D spending to GDP per capita, and one-way causality relationship from GDP per capita to patent application numbers. In addition, long-term R \& D expenditures and patent applications have resulted in a positive GDP per capita, while high-tech exports, contrary to anticipation, negatively affected.
\end{abstract}

\section{Giriş}

Sanayi devrimi ile birlikte iktisadi ve soysal alanda birçok değişim yaşanmıştır. Yaşanan değişimlerin en önemlilerinden biri, üretimin yöntem ve miktarında ortaya çıkmıştır. Sanayi devrimi ile birlikte sanayi sektöründe yaşanan hızlı ve kesintisiz üretim artışları II. Dünya savaşı sonrasında ekonomik büyüme ve üretim zincirinin birlikte anılmasına yol açmıştır. Özellikle gelişmekte olan ülkeler, gelişmiş ülkelerin seviyesine ulaşma güdüsüyle hareket ederek, ekonomik büyüme ve kalkınmalarını sağlamak ve refah seviyelerini arttırmak amacıyla üreterek sanayileşmeyi önemli bir hedef olarak kullanmışlardır. Sanayi sektöründe oluşturulacak üretim artışının etkin ve verimli bir şekilde gerçekleştirilmesi için atılacak adımların neler olması gerektiği beraberinde, teknolojik gelişmelerin ve uygulanan bilim ve sanayi politikalarının önemini ortaya koymuştur. Bu gelişme ekonomik büyüme ile teknolojik gelişmelerin birbiriyle yakından ilişki halinde olduğu sonucuna ulaşılmıştır.

Günümüzde büyüme olgusunun, ülkelerin sahip oldukları teknoloji düzeyi ile ilişkili olduğu vurgulanmaktadır. Teknoloji; iktisatçıya göre, milletlerin refahını ve yaşam standardını yükselten bir araç ve kaynak girdileri ile üretim çıktıları arasında sıkışmış bir ölçme tekniği, mühendise göre bir malın üretilmesi için kullanılan yöntemler dizisidir. Diğer bir tanımla teknoloji, var olan malların ve hizmetlerin üretimini, pazarlama etkinliğini iyileştirmek, yeni mal ve hizmet üretmek için faydalanılan bilgi kaynağıdır (Kılınçarslan ve Dinç, 2007). Dinamik bir yapıya sahip olan teknoloji, ülkelerin sınıflandırılmasında kullanılan bir ölçüt niteliği taşımaktadır. Gelişmiş ülkelerde belirlenen sanayileşme ve ekonomi politikaları, teknolojiye göre belirlenmektedir. Dünya arenasında genel kabul görmüş görüş, ülkelerin ileri teknoloji ile üretim yapması ile ekonomik büyüme ve kalkınmaları arasında önemli bir pozitif ilişki olduğu yönündedir. $\mathrm{Bu}$ görüşe dayalı olarak teknolojik gelişmelerden bağımsız olarak değerlendirilen bir ekonomik büyüme politikalarının noksan kalacağı açıkça ifade edilebilir.

Bu çalışmanın amacı, Türkiye'deki teknoloji politikalarının tarihsel gelişimini analiz etmek ve uygulanan bilim ve teknoloji politikalarının Türkiye'deki ekonomik büyümeye olan katkısını ölçebilmektir. Bu amaçla, çalışmanın amaç ve kapsamını belirten giriş bölümü, ikinci bölümünde Türkiye'deki teknoloji gelişimi ve uygulanan politikalardan bahsedilmektedir. Çalışmanın üçüncü bölümünde teknolojik gelişme göstergeleri ile ekonomik büyüme arasındaki ilişki ve bu iki olgu arasındaki ilişki konusunda yapılan bazı çalışmalara yer verilmektedir. Çalışmanın dördüncü bölümünde, Türkiye'deki 1996-2015 yılları arasındaki teknolojik gelişme göstergelerinden seçilmiş göstergeler ile ekonomik büyüme arasındaki ilişkinin analiz edilmesi amacıyla uygulanan Granger nedensellik testi sonuçlarına yer verilmektedir. Çalışmanın sonuç bölümünde ise, analiz sonucunda elde edilen bulgulara yer verilerek, bu bulgulara bağlı olarak politik önerilerde bulunulmaktadır.

\section{Türkiye'de Teknolojinin Gelişimi}

Neoklasik büyüme modellerine göre dışsal ve tüm dünya ülkelerinin bir kamu malı niteliği taşıdığ görüşünün aksine "İçsel Büyüme Modellerin”e göre gelişimi ekonomi açısından içsel bir faktör olarak değerlendirilen teknoloji, ekonomide yer alan piyasa güçleri tarafından belirlenmektedir. Türkiye, Cumhuriyetin ilk yıllarından başlayarak II. Dünya Savaşı'na kadar devam eden süreçte sanayileşme amacı doğrultusunda teknolojinin gelişimi için çaba sarf etmişse de, içinde bulunduğu koşullar nedeniyle sanayi sektöründe ve buna bağlı olarak teknoloji üretiminde yeterli gelişmeyi gösterememiştir. Ulusal teknolojik bilgi üretimi ve birikimini teknik bilgi, teknoloji, 
iş tecrübesinin noksanlığı ve özel kesimin yeterli sermaye birikimine sahip olmayışı nedeniyle sağlayamamıştır. Bununla birlikte 1950'li yıllarla yabancı sermaye ve teknoloji girişi ile ithal-ikameci politika adı altında teknoloji transferi, know- how, patent hakkı gibi yollarla Türkiye'nin diğer ülkelere teknolojik açıdan bağımlılığına neden olmuştur. 1960-1980 Türkiye'sinde ise planlı kalkınma süreci ve bu süreci yönetmek için Devlet Planlama Teşkilatı'nın kurulduğu görülmektedir. 1980 sonrası dönem ihracata yönelik ekonomik politikalarının uygulandı ğ ancak yaşanan gelişmeler ile Türkiye'de hedeflenenler doğrultusunda ihracatın yapılamadığ 1 ve dışarıda gelişen teknolojilerin de takip edilerek ülkeye aktarımının sağlanamadığı bir dönemdir (Yücel, 2003).

Teknoloji politikalarından bahsedilmeye başlanan 1970’lerin sonunda, 7. Beş Yıllık Kalkınma Planı ile "bilim teknoloji politikası" öncelikli ele alınmaya başlanmıştır. 1980'de ihracat gelirlerini artırmak için teşvik tedbirlerine öncelik verilmesi, ancak buradan sağlanacak gelirin AR-GE yatırımlarına yönelmemesi teknolojik gelişmeyi olumsuz etkilemiştir (Oğuztürk, 2004). 2001 yılında Teknokent yasası olarak da anılan "Teknoloji Geliştirme Bölgeleri Kanunu" çıkarılmış bu yasa ile teknoloji geliştirme bölgelerinde akademisyenlerin de çalışmaları ve teknoloji üretimine katkı sağlayabilmeleri kolaylaştırılmıştır (Yıldız, vd. 2010). KOSGEB'in girişimi ile ODTÜ ve İTÜ'de birer tane "Yenilik Merkezi" türünde, Teknoloji Geliştirme Merkezi açılmıştır. 26 Haziran 2001 tarihinde çıkartılan 4691 sayılı "Teknoloji Geliştirme Bölgeleri Kanunu" ile bu konu yasal zemine oturtulmuştur. Ancak 2008 yılında bu merkezlerin 30 civarında olmasına rağmen sadece birkaç tanesinin konumları gereği başarılı olduğu görülmüştür (Çomak ve Sancaktar, 2011). Türkiye'nin yakın tarihine bakılacak olursa bilim ve teknoloji alanında ulusal ya da uluslararası düzeyde faaliyet gösteren oluşumlar içerisinde en büyüğü olan TÜBİTAK, bünyesinde halen çalışmalarını sürdüren, Bilim, Teknoloji ve Yenilik Politikaları Daire Başkanlığı (BTYPD) ve Bilim ve Teknoloji Yüksek Kurulu (BTYK) birimler oluşturulmuştur. BTYK'nin görevlendirmesiyle TÜBİTAK tarafından 2002 yılında, "Vizyon 2023: Bilim ve Teknoloji Stratejileri" başlığı altında yapılan çalışmada bilim ve teknolojiye hakim, teknolojiyi bilinçli kullanan, yeni teknolojiler üretebilen, teknolojik gelişmeleri toplumsal ve ekonomik faydaya dönüştürme yeteneği kazandırma çabası yer almaktadır (TÜBİTAK, 2004).

TÜBİTAK tarafından 1991yılında düzenlenen I. Bilim ve Teknoloji Şurası'nda "Yaşanılan ekonomik, politik ve sosyal tıkanıklıklar yüzünden Türkiye, çağa teknolojik ve bilimsel düzeyi çok düşük bir ülke olarak girmektedir" açıklaması yapılmış ve Türkiye'nin rekabet avantajı yakalayabileceği şartları zamanında sağlayamamış olması ve yanlış teknoloji politikaları uygulamış olmasına işaret edilmiştir. bu durumun önemli bir nedeni, AR-GE harcamalarının GSYİH içindeki payının oldukça düşük olmasıdır (DPT, 2006). Gelişmiş ülkelerin teknoloji alanında üstün olmalarının önemli bir sebebi, AR-GE harcamalarına ayırdıkları payların yüksek olmasıdır. Seçilmiş gelişmiş ülkeler ile Türkiye'nin, 2013 yılı Ar-Ge harcamalarının GSYİH'deki payları Şekil 1'de gösterilmektedir.

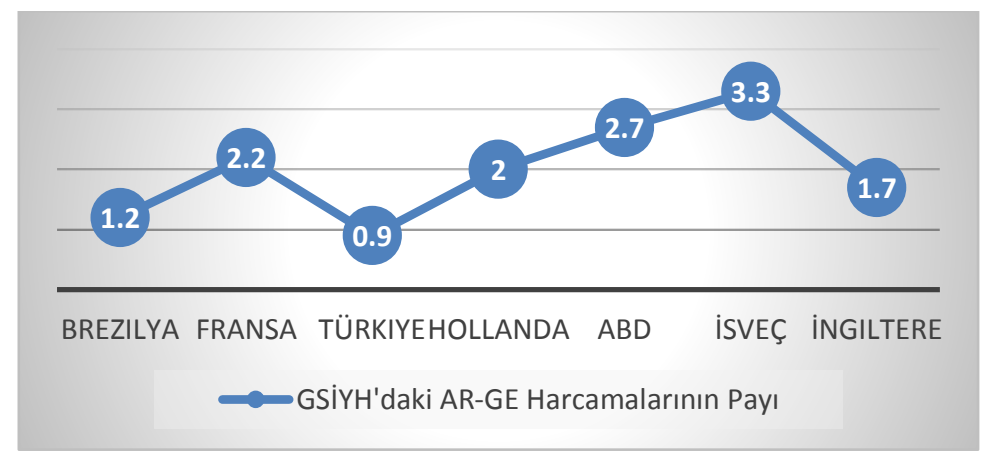

Şekil 1. Seçişmiş Gelişmiş Ülkelerin AR-GE Harcamalarının GSYIH'deki Payı Kaynak: World Bank

Şekil 2'de görüleceği üzere 2002 yılı itibariyle yüzde 0,53 olan AR-GE harcamalarının GSYİH içindeki payının, teknoloji alanında gelişmiş ülkelerle karşılaştırıldığında oldukça düşük düzeyde kaldığı görülmektedir.

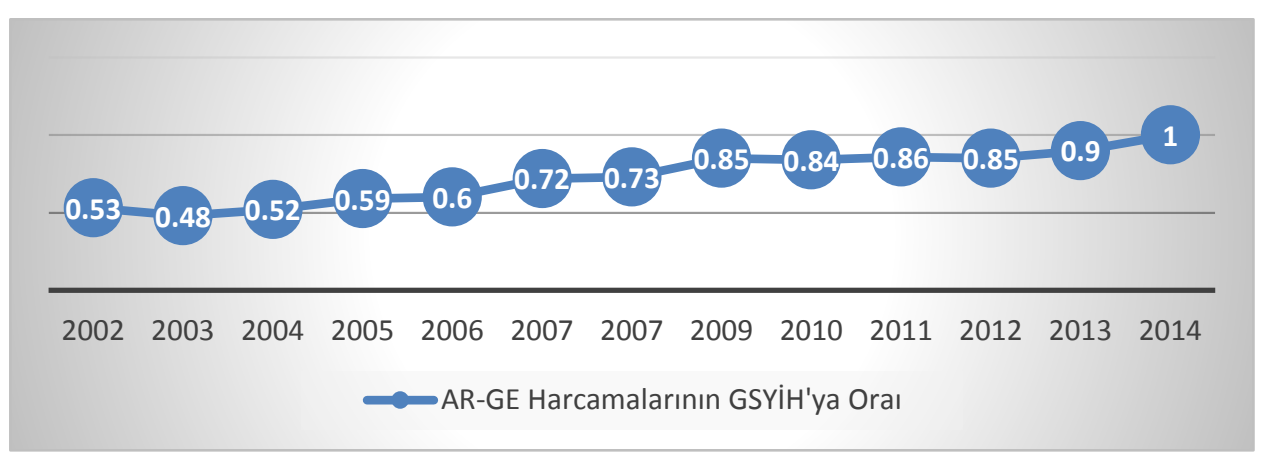

Şekil 2: Türkiye'deki AR-GE Harcamalarının GSYİH'ye Oranı Kaynak: TUIKK 
2002 yılından itibaren bilim ve teknolojiye ayrılan kamu kaynakları önemli ölçüde arttırılsa da AR-GE harcamalarının 2002-2014 yılları arasında GSYİH içindeki payının ortalaması halen eşik değer olarak kabul edilen \%1'in altındadır. Düşük düzeyde gerçekleşen AR-GE harcamaları incelendiğinde, bu rakamların Türkiye'deki teknolojinin geliştirilmesi ve bunun üretime dönüştürülmesi için yetersiz kaldığını göstermektedir. Bunun sonucu olarak da Türkiye'de sanayinin hala teknoloji transferine dayalı olarak sürdürüldüğü söylenebilir. 1996-2015 yılları arasında Türkiye'de teknolojinin gelişimi ve ülkenin inovasyona dayalı gelişim trendini gösteren önemli faktörlerden olan patent başvuru sayısı, yüksek teknolojiye dayalı ürün ihracatı değişkenlerinde yaşanan değişimler ise Tablo 1'de gösterilmektedir.

\begin{tabular}{|l|c|r|}
\hline \multicolumn{1}{|c|}{ Yıllar } & $\begin{array}{c}\text { Patent Başvuru } \\
\text { Sayıs }\end{array}$ & $\begin{array}{c}\text { Yüksek Teknolojili } \\
\text { Ürün ihracatı (\$) }\end{array}$ \\
\hline 1996 & 189 & 275.112 .382 \\
\hline 1997 & 203 & 423.832 .071 \\
\hline 1998 & 207 & 454.047 .637 \\
\hline 1999 & 276 & 870.979 .600 \\
\hline 2000 & 277 & 1.077 .574 .539 \\
\hline 2001 & 337 & 990.847 .814 \\
\hline 2002 & 414 & 536.439 .348 \\
\hline 2003 & 489 & 763.179 .631 \\
\hline 2004 & 682 & 1.010 .840 .536 \\
\hline 2005 & 928 & 881.846 .891 \\
\hline 2006 & 1072 & 1.281 .261 .668 \\
\hline 2007 & 1810 & 1.643 .907 .482 \\
\hline 2008 & 2221 & 1.680 .777 .551 \\
\hline 2009 & 2555 & 1.359 .548 .592 \\
\hline 2010 & 3180 & 1.712 .937 .113 \\
\hline 2011 & 3885 & 1.922 .123 .172 \\
\hline 2012 & 4434 & 1.978 .537 .781 \\
\hline 2013 & 4392 & 2.176 .908 .249 \\
\hline 2014 & 4766 & 2.346 .682 .136 \\
\hline 2015 & 4766 & 2.323 .079 .468 \\
\hline
\end{tabular}

* Türkiye'de yerleşik olarak yaşayan kişi ve kurumlarca yapılan patent başvuru sayısıdır.

\section{Tablo 1: Türkiye için Teknolojik Gelişme Göstergeleri}

Tablo 1'de görüldüğü üzere Türkiye'deki patent başvuru sayısı ile yüksek teknolojiye dayalı ihracat payı genel olarak artma eğilimi göstermiştir. Ancak teknolojik göstergelerde oluşan artışın kişi başına GSYİH'yi harekete geçirecek büyüklükte olup olmadığı asıl önem arz eden noktadır. Bu doğrultuda, çalışmada teknolojik gelişmeyi gösteren değişkenler ile kişi başına GSYİH arasındaki nedensellik ilişkisi üzerine analiz yapılarak teknolojik gelişmelerin ekonomik büyüme üzerinde etkisinin ölçülmesi amaçlanmıştır.

\section{Literatür Taraması}

Sürdürülebilir kalkınma ve ekonomik büyümenin sağlanmasında teknolojik gelişme göstergelerindeki gelişmelerin artan önemi dolayısıyla iki olgu arasındaki ilişkiyi analiz eden çalışmaların arttığı ve genel olarak yapılan çalışmalarda, Ar-Ge harcamalarının GSYİH içerisindeki payı ile ekonomik büyümenin ilişkilendirildiği görülmektedir. Lichtenberger (1993) çalışmasında, 1964-1989 yılları arasında 74 ülke üzerine yapılan çalışmada özel sektör tarafından finanse edilen Ar-Ge harcamalarının ekonomik büyüme ve verimlilik düzeyini pozitif yönde etkilediği, kamu sektörü tarafından finanse edilen Ar-Ge harcamaları için ise aynı ilişkinin söz konusu olmadığı sonucuna ulaşılmıştır. Sylwester (2001), OECD ülkelerinde kamu ve özel sektör tarafından yapılan Ar-Ge harcamalarının ekonomik büyüme ve verimlilik düzeyine etkisini araştırdı̆̆ ekonomik büyüme ile Ar-Ge harcamaları arasında pozitif yönlü ilişkinin söz konusu olduğu diğer 20 OECD ülkesinde mevcut olmadığı sonucuna ulaşmıştır. Ar-Ge harcamaları ile ekonomik büyüme arasındaki ilişkiyi test eden Freire-Serén (1999), Wang (2007), Zachariadis (2004), Saraç (2009), Korkmaz (2010), Kırankabeş ve Erçakar (2012)'ın çalışmalarında iki kavram arasındaki pozitif yönlü ilişki desteklenmiştir.

Weng vd. (2012) çalışmasında, VAR analizi yardımıyla 1991-2009 yılları Şanghay için doğrudan yabancı yatırımlar, patent başvurusu, teknolojiye dayalı ticaret payı ve ekonomik büyüme arasındaki ilişki analiz edilmeye çalışılmıştır. Uygulanan yöntem sonucunda, ekonomik büyüme ile diğer teknolojik göstergeler arasında pozitif yönlü ilişki olduğu sonucu elde edilmiştir. Song ve Nan (2014) çalışmasında 1993-2012 yılları arasında Çin ekonomisindeki teknolojik inovasyon endeksi ve patent başvuru endeksi ile ekonomik büyüme arasındaki ilişkinin test edilmesi amacıyla VAR modelinin kullanıldığı çalışmada, uzun dönemde değişkenler arasında karşılıklı ilişkinin söz konusu olduğu, kısa dönemde ekonomik büyüme tarafindan teknolojik inovasyon ve patent 
başvurusunun etkilendiği ancak tersi yönde bir ilişkinin söz konusu olmadığı sonucuna ulaşılmıştır. Bir başka çalışmada, Ülkü (2004) 1981-199 dönemi için 20 OECD ülkesi 10 OECD olmayan ülkedeki Ar-Ge harcamaları inovasyon ve ekonomik büyüme arasındaki ilişkiyi panel veri yöntemi ile analiz ederek seçilmiş tüm ülkelerde inovasyon ile ekonomik büyüme arasında pozitif yönlü ilişkinin var olduğu sonucuna ulaşılmıştır.

Çin üzerine yapılan bir başka çalışmada Wu ve Zhou (2007), Ar-Ge harcamaları ile ekonomik büyüme arasındaki ilişki eşbütünleşme ve nedensellik yaklaşımları ile test edilerek Ar-Ge harcamaları ile ekonomik büyüme arasında çift yönlü nedensellik ilişkisinin var olduğu tespit edilmiştir. Işık (2014) çalışmasında, 1990:1-2010:4 yılları arasında Türkiye'deki patent harcamaları ile ekonomik büyüme arasındaki nedensellik ilişkinin analiz edilmesi amaciyla uygulanan Granger testi sonucunda, patent harcamalarından ekonomik büyümeye doğru tek yönlü nedensellik ilişkisinin söz konusu olduğu sonucuna ulaşılmıştır. Sungur vd. (2016), Türkiye'deki 1990-2013 yılları arasındaki Ar-Ge harcamaları, Ar- Ge araştırmacı sayısı, patent ve inovasyon faaliyetlerinin ihracat ve ekonomik büyüme arasındaki nedensellik ilişkisi iki farklı model kurularak test edilmesinin amaçlandığı çalışmalarında, patent sayısından büyümeye; ihracattan AR-GE harcamalarının milli gelir içindeki payına, patent sayısından ihracata ve Ar-Ge faaliyetlerinde çalışan sayısından ihracata doğru tek yönlü nedensellik ilişkisinin olduğu tahmin edilmiştir.

Göçer (2013a) çalışmasında, 1996-2012 yılları arasındaki 11 farklı Asya ülkesi için AR-GE harcamaları, yüksek teknolojili ürün ihracatı, bilgi-iletişim teknolojileri ihracatı, toplam ihracat ve ekonomik büyüme arasındaki ilişki ele alınmıştır. Yapılan çalışmada, Ar-Ge harcamalarındaki artışın, ekonomik büyüme, yüksek teknolojili ürün ihracatı, bilgi iletişim teknolojileri ihracatını pozitif yönde etkilediği sonucuna ulaşılmıştır. Göçer (2013b) çalışmasında ise, Yeni sanayileşen ülkelerdeki 1996-2012 dönemleri baz alınarak teknolojik ilerleme göstergeleri ile Ar-Ge harcamaları arasında çift yönlü nedensellik olduğu görülmüştür. Önder ve Hatırlı (2014), 1994-2009 dönemi Türkiye'si yapılan analiz sonucunda, patent değişkeni ile ekonomik büyüme arasında pozitif ancak istatiksel olarak anlamsız bir ilişki olduğu sonucuna ulaşılmıştır.

Ustabaş ve Ersin (2016) çalışmasında, 1989-2014 yılları arasında Güney Kore ve Türkiye 'deki yüksek teknolojili ürün ihracatı ile ekonomik büyüme arasındaki ilişki nedensellik ve koentegrasyon testleri ile analiz edilmiştir. Yapılan çalışmada, Güney Kore'de uzun ve kısa dönemde Türkiye'de ise, kısa dönemde ekonomik büyümenin yüksek teknolojili ürün ihracatından pozitif yönde etkilendiği sonucuna ulaşılmıştır. Kılıç vd. (2014) çalışmasında, 1996-2011 yılları arasında G-8 ülkelerinde Ar-Ge harcamaları ile yüksek teknolojili ürün ihracatı arasındaki ilişki analiz edilmiştir. Elde edilen sonuçlara göre, Ar-Ge harcamaları ile reel döviz kurunun yüksek teknolojili ürün ihracatı üzerinde pozitif yönlü ilişkisi söz konusudur. Ayrıca yüksek teknolojili ürün ihracatı ile Ar-Ge harcamaları ve Ar-Ge harcamaları ile reel döviz kuru arasında çift yönlü nedensellik, yüksek teknolojili ürün ihracatından reel döviz kuruna doğru ise, tek yönlü nedensellik ilişkisi mevcuttur.

Yapılan ampirik çalışmalar ve raporlar incelendiğinde, genel olarak teknolojik göstergelerdeki iyileşmelerin ekonomik büyümeye pozitif yönde katkı sağladığı sonucuna ulaşılmaktadır. Bu çalışmada diğer çalışmalardan farklı olarak, teknolojik gelişmeyi temsilen sadece Ar-Ge harcamalarındaki değişimin kullanılmasından ziyade, farklı teknolojik göstergelerin aynı model içerisinde analiz edilerek bu göstergelerin Türkiye ekonomisinin büyümesindeki rolü üzerine fikir elde edilmesi amaçlanmıştır.

\section{Ampirik Analiz ve Bulgular}

Türkiye ekonomisinde 1996-2015 yılları arası için yapılan çalışmada, teknolojik gelişme göstergeleri ile ekonomik büyüme arasındaki ilişkinin analizinde Granger nedensellik testi uygulanmaktadır. Yapılan çalışmada, Teknolojik gelişme göstergeleri olarak; Ar-Ge harcamalarının GSYİH'deki payı, patent başvuru sayısı ve yüksek teknolojili ürün ihracatı (\$) değişkenleri kullanılmaktadır. Ekonomik büyüme göstergesi olarak kişi başına GSYİH'deki değişimin (sabit, 2010\$) kullanıldığı çalışmada veriler Dünya Bankasından veri tabanından elde edilmiştir. Modelde yer alan değişkenlerin seçiminde Weng vd. (2012) çalışması takip edilmiştir. Değişkenler arasındaki nedensellik ilişkisinin analiz edilmesinde Granger testi kullanılmıştır. Granger nedensellik testi öncesinde modelde yer alan seriler için ADF (Augmented Dickey Fuller) ve PP (Phillips-Perron) birim kök testleri ile durağanlık sınaması yapılmıştır. Tablo 2'de seriler için uygulanan birim kök testleri sonuçlarına yer verilmektedir. 


\begin{tabular}{|c|c|c|c|}
\hline Değişkenler & Trendli & $\begin{array}{c}\text { Düzey } \\
\text { Trendsiz }\end{array}$ & $\begin{array}{c}\text { Fark } \\
\text { Trendsiz }\end{array}$ \\
\hline \multicolumn{4}{|c|}{ ADF } \\
\hline $\operatorname{LnGDP}$ & -0.384496 & $-3.313982 *$ & $-4.229365 * * *$ \\
\hline$L n A r-G e$ & -0.476915 & $-3.588767 * *$ & $-6.826433 * * *$ \\
\hline LnPAT & -0.603938 & -1.657715 & -3.439190 \\
\hline LnHigh & -2.159755 & $-4.450563 * *$ & $-4.648732 * * *$ \\
\hline \multicolumn{4}{|c|}{ PP } \\
\hline$L n G D P$ & -0.384496 & -2.176825 & $-4.229365 * * *$ \\
\hline LnAr-Ge & -0.165203 & $-3.568556^{* *}$ & $-6.828579 * * *$ \\
\hline LnPAT & -0.593851 & -1.372086 & $-3.436570 * *$ \\
\hline LnHigh & -2.389037 & $-4.685884 * *$ & $-7.638136 * * *$ \\
\hline
\end{tabular}

Tablo 2: Birim Kök Testi Sonuçları

***, ** ve * sırasıyla \%1, \%5 ve \%10 anlamlılık düzeylerini ifade etmektedir. Kurulan modelde otokorelasyon ve değişen varyans sorununa yol açmayan maksimum gecikme uzunluğunun belirlenmesinde Schwarz Bilgi Kriteri kullanılmıştır.

Yapılan birim kök testi sonuçlarına göre, serilerin tamamı birinci düzeyde durağan I(1), diğer bir ifade ile birinci farkları alındıktan sonra durağan hale gelmektedir. Serilerin aynı düzeyde durağan olması, değişkenler arasında eşbütünleşme ilişkisinin olup olmadığının test edilmesine imkân sağlamaktadır. Serilerin birinci düzeyde durağan olması nedeniyle, seriler arasındaki eşbütünleşme ilişkisinin Vektör Hata Düzeltme (VEC) modeline uzantılı olarak uygulanan Johansen Eşbütünleşme analizi sonuçlarına ise Tablo 3'te yer verilmektedir.

\begin{tabular}{|c|c|c|c|c|c|}
\hline $\begin{array}{c}\text { Sıfır } \\
\text { hipotez }\end{array}$ & Öz Değerler & İz Değerler & $\begin{array}{c}\mathbf{0 . 0 5} \text { Kritik } \\
\text { Değerler }\end{array}$ & $\begin{array}{c}\text { Maksimum } \\
\text { Öz Değerler }\end{array}$ & $\begin{array}{c}\mathbf{0 . 0 5} \\
\text { Kritik } \\
\text { Değerler }\end{array}$ \\
\hline $\mathbf{r}=\mathbf{0}$ & 0.965322 & 93.51024 & 47.85613 & 60.50981 & 27.58434 \\
\hline $\mathbf{r} \leq \mathbf{1}$ & 0.620524 & 33.00043 & 29.79707 & 17.44134 & 21.13162 \\
\hline $\mathbf{r} \leq \mathbf{2}$ & 0.503263 & 15.55909 & 15.49471 & 12.59450 & 14.26460 \\
\hline $\mathbf{r} \leq \mathbf{3}$ & 0.151851 & 2.964591 & 3.841466 & 2.964591 & 3.841466 \\
\hline
\end{tabular}

Tablo 3: Eşbütünleşme Testi Sonuçlart

Uygulanan eşbütünleşme testi sonuçlarına göre, "H${ }_{0}$ : Eşbütünleşme yoktur" boş hipotezi red edilerek değişkenler arasında eşbütünleşme vektörünün varlığı tespit edilmiştir. Johansen eşbütünleşme testi sonuçlarına göre iz değerine göre 3 ve maksimum öz değere göre ise 1 adet eşbütünleşme vektörünün varlığı tespit edilmiştir. Elde edilen bu sonuç modelde yer alan değişkenlerin uzun dönemde birlikte hareket ettiğini göstermektedir. Değişkenler arasında eşbütünleşme ilişkisinin tespiti sonucunda değişkenler arasındaki nedensellik ilişkisinin tespit edilmesi amacıyla VECM uzantılı Granger nedensellik testi yapılmıştır. Ho hipotezi: “Granger nedeni değildir" şeklinde olan Granger nedensellik testi sonuçları Tablo 4'te gösterilmektedir.

\begin{tabular}{|l|l|l|l|}
\hline Nedensellik & F-istatistiği & Olasılık & Sonuç \\
\hline GSYİH $\rightarrow$ HIGH & 0.02295 & 0.9774 & Ho: Kabul \\
\hline HIGH $\rightarrow$ GSYİH & 4.19075 & 0.0394 & Ho:Red \\
\hline GSYİH $\rightarrow$ PAT & 4.27698 & 0.0374 & Ho:Red \\
\hline PAT $\rightarrow$ GSYİH & 0.40992 & 0.6720 & Ho: Kabul \\
\hline GSYİH $\rightarrow$ Ar-Ge & 1.77812 & 0.2077 & Ho: Kabul \\
\hline Ar-Ge $\rightarrow$ GSYİH & 5.29853 & 0.0208 & Ho:Red \\
\hline HIGH $\rightarrow$ PAT & 3.76849 & 0.0512 & Ho:Red \\
\hline PAT $\rightarrow$ HIGH & 0.00153 & 0.9985 & Ho: Kabul \\
\hline HIGH $\rightarrow$ Ar-Ge & 1.71930 & 0.2175 & Ho: Kabul \\
\hline Ar-Ge $\rightarrow$ HIGH & 22.8098 & $6 . E-05$ & Ho: Kabul \\
\hline PAT $\rightarrow$ Ar-Ge & 4.42528 & 0.0342 & Ho:Red \\
\hline Ar-Ge $\rightarrow$ PAT & 12.7695 & 0.0009 & Ho:Red \\
\hline
\end{tabular}

Tablo 4: Granger Nedensellik Testi Sonuçlart

Yapılan Granger nedensellik testi sonuçlarına göre kısa dönemde, teknoloji gelişimi göstergelerinden Ar-Ge harcamalarından kişi başına GSYİH'ye, yüksek teknolojili ürün ihracatından kişi başına GSYİH değişkenine 
doğru tek yönlü ve kişi başına GSYİH'den patent başvuru sayısına doğru tek yönlü nedensellik ilişkisinin söz konusu olduğu görülmektedir. Ayrıca yapılan analiz sonucunda, yüksek teknolojili ürün ihracatından patent başvuru sayısına doğru tek yönlü nedensellik, patent başvuru sayısı ile Ar-Ge harcamaları arasında ise çift yönlü nedensellik ilişkisinin olduğu sonucuna ulaşılmıştır. VECM Granger Nedensellik testleri sonuçlarına göre ise, uzun dönemde teknoloji gelişme göstergelerindeki değişimler ile ekonomik büyüme arasındaki nedensellik ilişkisi sonuçları Tablo 5'te gösterilmektedir.

\begin{tabular}{|l|l|l|l|}
\hline Bağımlı değişken & LnAr-Ge & LnPAT & LnHigh \\
\hline$\Delta$ GSYİH & $0.059^{* * *}$ & $0.023^{* *}$ & $-0.028^{* *}$ \\
\hline
\end{tabular}

Tablo 5: Uzun Dönemli Nedensellik İlişkisi

Elde edilen sonuçlara göre, uzun dönemde Ar-Ge harcamaları ile patent başvuru sayısından kişi başına GSYİH'ye doğru pozitif yönlü bir nedensellik ilişkisi söz konusudur. Uzun dönemde yüksek teknolojili ürün ihracatından kişi başına GSYİH'ye doğru ise iktisadi beklentilerle uyumsuz olarak negatif yönlü bir ilişki olduğu ve kısa dönemde iki gösterge arasındaki anlamlı ilişkinin uzun dönemde ortadan kalktığı görülmektedir.

\section{Sonuç}

Bu çalışmada, Türkiye üzerine 1996-2015 yılları arasındaki teknolojik gelişme göstergeleri ile ekonomik büyüme arasındaki nedensellik ilişkisinin analiz edilmesi amaçlanmıştır. Granger nedensellik testinin kullanıldığı çalışmada, teknolojik gelişme göstergelerini temsilen, yüksek teknolojili ürün ihracatı, patent başvuru sayısı ile Ar-Ge harcamalarının GSYIH'deki payı kullanılırken, ekonomik büyüme için ise kişi başına GSYIH değişkeni kullanılmıştır. Granger Nedensellik analizi öncesinde kurulan modelde yer alan seriler için ADF ve PP testleri ile birim kök sınaması yapılmıştır. Birim kök testleri sonucunda, serilerin birim köke sahip olmadığı ve I(1) düzeyinde durağan olduğu sonucuna ulaşılmıştır. Birim kök testi sonrasında uygulanan Johansen eşbütünleşme testi ile de değişkenlerin uzun dönemde birlikte hareket ettiklerini ve aynı model içerisinde yer alabileceği sonucuna ulaşılmıştır. Eşbütünleşik olan serilere uygulanan Granger nedensellik testi sonuçlarına göre, kısa dönemde, ArGe harcamaları ve yüksek teknolojili ürün ihracatından kişi başına GSYİH'ye doğru tek yönlü nedensellik ilişkisi söz konusu olduğu görülmektedir. Benzer şekilde kişi başına GSYIH'deki değişimden patent başvuru sayısına doğru tek yönlü nedensellik ilişkisi de söz konusudur. Teknolojik gelişme göstergeleri arasındaki nedensellik ilişkisi sonuçlarına bakıldığında ise yüksek teknolojili ürün ihracatından patent başvuru sayısına doğru tek yönlü ve patent başvuru sayısı ile Ar-Ge harcamaları arasında ise çift yönlü nedensellik ilişkisi söz konusudur. Uzun dönemde ise kişi başına GSYIH, Ar-Ge harcamaları ile patent başvuru sayısından pozitif yönde, yüksek teknolojili ürün ihracatından negatif yönlü etkilendiği sonucuna ulaşılmıştır.

1980 sonrası ihracata yönelik sanayileşme stratejisini tercih eden ve anlamlı bir sanayileşme politikası yakalayamayan Türkiye'de olarak, yapılan ampirik analizi ile elde edilen sonuçlara bağlı olarak teknolojik gelişmelere yapılan yatırımın, sürdürebilir ekonomik büyüme için uzun vadeli önemli bir strateji olduğunun bilinmesi gerekmektedir. Özellikle Ar-Ge harcamaları ve yüksek teknolojili ürün ihracatı üzerine alınacak politik kararlarının ekonomik büyüme için itici bir güç olacağı açıktır. Bu açıdan, Türkiye'de büyüme trendinin kısa ve uzun süreli etkili olan sanayileşme teşvik politikalarıyla ve AR-GE faaliyetlerinin artışını sağlayacak bilim ve teknoloji politikaları ile desteklenmesi gerekmektedir. Ayrıca teknolojiyi kullanabilecek kalifiye bireylerin yetişmesi ve bunun için gerekli olan yatırımların yapılabilmesi de atılması gereken adımlardandır. Türkiye için alınabilecek uzun vadeli en köklü değişim, teknoloji ile birlikte sanayileşmenin artacağı ve dolayısıyla ülke refahının ciddi bir sıçrama göstereceği gerçeğinin toplumun tüm tabanına yayılması şeklinde ifade edilebilir. $\mathrm{Bu}$ sebeple, özellikle katma değeri yüksek olan sanayi sektörünün gelişimi için alınacak önlemlerde, toplum desteği sağlanması ve ülkenin dünyada yakalanan teknoloji gelişim seviyesinin yakından takip edilmesi gerekmektedir. Bunun için teknoloji transferi yoluyla ülkeye getirilen teknolojinin AR-GE destekli geliştirilmesi ve gerekli teşvik sisteminin oluşturulması da gerekmektedir. Ayrıca özellikle uzun dönemde yüksek teknolojili ürün ihracatının potansiyelini arttırabilecek faaliyetlerde de bulunulması oldukça önemlidir.

\section{Kaynakça}

- Çomak, H. \& Sancaktar, C. 2011. "21. Yüzyılda Uluslararası Örgütlerin Güvenlik Yaklaşımları ve Balkanlar'ın Güvenliği”, Uluslararası Balkan Kongresi, 28-29 Nisan

- Devlet Planlama Teşkilatı (DPT), 2006, “2006 Yılı Programı”, http://ekutup.dpt.gov.tr/program/2006.pdf

- Freire-Serén, M. J. 1999. “Aggregate R\&D Expenditure and Endogenous Economic Growth”. UFAE and IAE Working Papers, No.WP 436.99

- GÖÇER, İ. 2013a. "Ar-Ge Harcamalarının Yüksek Teknolojili Ürün İhracatı, Dış Ticaret Dengesi ve Ekonomik Büyüme Üzerindeki Etkileri”. Maliye Dergisi, 165, 215-240.

- GÖÇER, İ. 2013b. "Teknolojik İlerlemenin Belirleyicileri: NIC Ülkeleri için Panel Eşbütünleşme ve Panel Nedensellik Analizleri”. Maliye Finans Yazllarl, 27(100), 116-141 
• Isik, C. 2014. "Patent Harcamalari ve Iktisadi Büyüme Arasindaki Iliski: Türkiye Örnegi”, Sosyoekonomi 1, 69.

- Kilıçarslan, O. \& Dinç, O. 2007. “Türkiye Ekonomisinde Teknoloji ve Transferi”, GAU J. Soc. \& Appl. Sci., 3(5), ss. 73-75

- Kırankabeş, M.C. \& Erçakar, M.E. 2012. "Importance of Relationship Between R\&D Personnel and Patent Applications on Economics Growth: A Panel Data Analysis”. International Research Journal of Finance and Economics, ISSN 1450-2887, Issue 92, 72-81.

- Kılıç, C., Bayar, Y. \& Özekicioğlu, H., 2014. "Effect of Research and Development Expenditures on High Technology Exports: A Panel Data Analysis for G-8 Countries” Erciyes Üniversitesi İIBF Fakültesi Dergisi,44,p.115-131.

- $\quad$ Korkmaz, S. 2010. “Türkiye'de Ar-Ge Yatırımları ve Ekonomik Büyüme Arasındaki İlişkinin VAR Modeli İle Analizi”, Journal of Yaşar University, 20(5), 3320 $\square 3330$.

- $\quad$ Lichtenberg, F. R. 1993. "R\&D Investment and International Productivity Differences”. NBER Working Paper Series, Vol.W4161

- Oğuztürk, B, S. 2004. “Türkiye'de Uygulanan Teknoloji Politikaları”, Doğu Anadolu Bölgesi Araştırmaları, ss:100-105

- Ö̈nder, K. \& Hatırlı, S.A. 2014. “Türkiye’de İmalat Sanayi İhracatı ve Büyüme İlişkisinin İktisadi Analizi”. Yaşar Üniversitesi Dergisi, 9(34), 5851-5869.

- Saraç, B. T. 2009. “Araştırma-Geliştirme Harcamalarının Ekonomik Büyüme Üzerindeki Etkisi: Panel Veri Analizi”, EconAnadolu 2009, 17-19 Haziran, Eskişehir,

- $\quad$ Song, Z. S., \& Nan, G. J. 2014. "Empirical studies of the relationship between technological innovation and economic growth-Shanghai-based panel data analysis". BioTechnology: An Indian Journal, 10(9).

- $\quad$ Sungur, O., Aydın, H. İ., \& Eren, M. V. 2016. “Türkiye'de AR-GE, inovasyon, ihracat ve ekonomik büyüme arasındaki ilişki: Asimetrik nedensellik analizi”. Süleyman Demirel Üniversitesi İktisadi ve İdari Bilimler Fakültesi Dergisi, 21(1).

- Sylwester, K. 2001. "R\&D and Economic Growth. Knowledge”, Technology, \& Policy, 13(4), 71-84

- TÜBİTAK. 2004. "Bilim ve Teknoloji Stratejileri-Vizyon 2023”, www.vizyon2023.tubitak.gov.tr/genelbilgi/, (Erişim tarihi: 26.10.2016).

- Türkiye İstatistik Kurumu (TUİK), http://www.tuik.gov.tr/UstMenu.do?metod=temelist

- Ulku, H. 2004. "R\&D, Innovation, and Economic Growth: An Empirical Analysis". IMF Working Paper, No.04/185.

- Ustabaş, A. \& Ersin, Ö., 2016, "The Effects of R\&D and High Technology Exports on Economic Growth: A Comparative Cointegration Analysis for Turkey and South Korea", International Conference On Eurasian Economies, Kaposvar, p. 44-55

- Wang, D., Tiffany, H. \& Liu, H. 2013. "Heterogeneous Effect of High-Tech Industrial R\&D Spending on Economic Growth”. Journal of Business Research, 66 (10), 1990-1993.

- Weng, L., Song, W., \& Sheng, S. 2012. "Empirical Research on Scientific and Technical Innovation and Economic Growth in Shanghai”, American Journal of Operations Research, 2, pp. 82-90

- World Bank (2014), http://www.worldbank.org/tr (25.10.2016)

- Wu, Y., \& ZHOU, L., 2007. "Cointegration and causality between R\&D expenditure and economic growth in China: 1953-2004”. In International Conference on Public Administration (Vol. 76).

- Yıldız, B, Ilgaz, H. \& Seferoğlu, S.S. 2010. "Türkiye'de Bilim ve Teknoloji Politikaları: 1963'den 2013'e Kalkınma Planlarına Genel Bir Bakış", Akademik Bilişim 10-12 Şubat, Muğla

- Yücel, İ. H. 2003. "Bilim Teknoloji Politikaları ve 21. Yüzyılın Toplumu" http://ekutup.dpt.gov.tr/bilim/yucelih/biltek04.pdf (15.10.2016)

- Zachariadis, M. 2004. “R\&D-induced Growth in the OECD?”. Review of Development Economics, 8 (3), $423-$ 439 . 


\title{
Lewis'in İki Sektörlü Büyüme Modeline Çin Özelinde Bakış: Büyümenin Sınırlarına Gelindi mi?
}

\section{A Glance of China with Lewis' Two Sector Growth Modelling: Has Been Reached to Growth Limit?}

\author{
Prof. Dr. Murat Nişanc1 (Erzincan University, Turkey) \\ Prof. Dr. Selahattin Sarı (Beykent University, Turkey) \\ Ph.D. Candidate Aslı Cansin Doker (Erzincan University, Turkey) \\ Assoc. Prof. Dr. Ahmet Alkan Çelik (Beykent University, Turkey) \\ Prof. Dr. Ömer Selçuk Emsen (Atatürk University, Turkey)
}

\begin{abstract}
The growth model developed by Lewis depends on availability of cheap and sustainable labor and this can be explained by a country on the path of industrialization, rural / urban population in the agricultural sector / industry is the labor store. In this approach, which is based on in particular the labor-intensive growth model, the labor demand that the investments will need, will be met by the rural labor store. In Lewis's model, it is important to prevent uncontrolled migration to the urban area in order for the mechanism to function. This, however, is only possible with a very authoritarian government aspect. In this framework, China's industrialization process is worthy of examination in the Lewis model's perspective. In the study, urbanization and its dynamics were analyzed in China between 1960 and 2015 by RStduio programming. Thus, research has been conducted on how long the industrialization of China, which constitutes the dynamics of economic development, can be sustained by the function of rural workforce storage. According to the analysis by the HoltWinters method, it can be said that the Chinese economy's growth form based on the labor store will continue for the next 20 years. However, according to findings, it can be argued that when China reaches the limits of this growth form, socio-economic inertia will become inevitable if it does not push the capital-intensive and transition to technology-containing growth phase.
\end{abstract}

\section{Giriş}

Arthur Lewis'in iki sektörlü büyüme modeli sınırsız emek arzı ile ekonomik büyümenin sürdürülebilirliği üzerine inşa edilmiş bir modeldir. Modelde sınırsız emek arzı ile ifade edilen olgu kırsal alanda ve dolayısıyla tarım sektöründe bulunan gizli işsizlik üzerine inşa edilmiştir. Buna göre kırsal alandaki gizli işsizlik, kentsel alanda bulunan sanayi sektörünün gereksinim duyduğu işgücünü temin etme deposu konumundadır. Mekanizma bu şekilde işlemediğinde, çok önemli denilebilecek bir olumsuz yansımanın ortaya çıkması kuvvetle muhtemeldir. Buna göre kırsalın itmesi ve böylece kentin cazibesi neticesinde kırdan kente göçün kentsel alanda işsizliğin artmasını tetikleyerek Lewis'in ücret mekanizmasının işlerliğinin bozulmasına yol açmasıdır. Zira kademeli göç ya da kentsel alanda ihtiyaca binaen ortaya çıkacak göç olgusu sanayi kesiminde ücret mekanizmasını bozucu bir işleve yol açmayacağı gibi kentsel alanda negatif dışsallıkların doğmasını da önleyici bir fonksiyon işlevi göreceği açıktır.

Lewis'in kontrollü nüfus akıș mekanizmasının, yani kentte yatırımlar artıp işgücüne talep artmasına bağlı bir şekilde işlerliğinin ortaya çıkabilmesi ya çok bilinçli bir toplumda veyahut da oldukça otoriter sistemlerde ancak mümkün kılınabilir. İlk koşulun ortaya çıkması oldukça güçtür. Zira bilinç düzeyinin yükselebilirliği iktisadi gelişmişlik düzeyi ile doğru orantılıdır ve burada az gelişmiş ülkelerin kalkınmasına yönelik reçete olarak öne sürülen modelde böyle bir bilinç düzeyinden yoksunluk belirgin bir şekilde gözlenmektedir. Dolayısıyla ikinci koşul, yani otoriter bir devlet anlayışına dayalı kentleşme sürecinin varlığında Lewis modelinin işleyeceği söylenebilir. Bu türden bir devlet anlayışına ise günümüzde Çin örnek olarak verilebilir. Bilindiği gibi Çin Halk Cumhuriyeti Mao ile başlayan komünist yapısını 1979'da özellikle dış ekonomik ilişkilerde kontrollü biçimde liberalize etmesine rağmen, hâlihazırda oldukça otokratik bir devlettir. Öyle ki, çocuk edinmeden eğitim planlamasına, turistik seyahatten ikamet edilen yeri değiştirmeye kadar oldukça kontrollü devlet uygulamaları; ancak Çin'de söz konusudur. Dolayısıyla Lewis modelinin mantığı gereği, kırdan kente göç olgusunun frenlenebilirliği, mekanizmanın işlemesi açısından önem arz eder ve bu da Çin'deki otokratik uygulamalarla mümkündür.

Çin'in 1960'lardaki ekonomik yapısı değerlendirildiğinde, kırsal nüfusun toplam nüfus içerisindeki payının \%80'in üzerinde, tarım sektörünün GSYİH içindeki payının \%40'larda ve kişi başı gelirin ise 80 dolar olduğu görülmektedir. Liberalizmi özellikle dış ekonomik ilişkilerde deneyim etmeye başladığı 1980'lerde bu profilin hemen hemen benzerlik gösterdiği dikkat çekmektedir. $2015^{\prime}$ 'e gelindiğinde ise, kırsal nüfusun payı \%45'lere gerilemiş, tarımın ulusal gelirdeki payı ise \%9'lara çekilmiş ve kişi başı gelir ise 8 bin dolara merdiven dayamıştır. Çin muazzam denebilecek bu büyüme performansını frenlenmiş tüketim ve dolayısıyla yüksek tasarruf ve yabancı sermaye çekme yeteneği ile sağlarken; adeta dünyanın fabrikası unvanını almıştır. Çin'de iç tasarruflar ve dışarıdan 
gelen sermaye, yatırımlara kanalize edilmekte ve yatırımlar için gereksinim duyulan emek gücü de kırsaldan kontrollü göçlerle sağlanmaya devam edilmektedir. Burada, kontrollü tüketim ve göç mekanizması da ücretlerde baskı yaratmamış ve düşük üretim maliyetleri çoğu gelişmiş ülkelere ait çok uluslu şirketler için de fason üretim kaynağı olmuştur. Çin'de yaşanan bu sürecin, kırda tutulan işgücünün massedileceği noktaya kadar sürdürülebilir olduğu açıktır. Dolayısıyla bu nokta, emek-yoğun büyüme kaynağı olan kırsal işgücü deposu tamamen tükendiğinde sonlanacaktır ve Çin, emek-yoğun büyümeyi sermaye-yoğun ve/veya teknolojik açıdan emek ikamesini sağlayacak konuma gelebilirse, sürekli büyüme mekanizmasını bünyesine kazandırmış olacaktır.

Çalışmada, Lewis'in emeğe dayalı büyüme formunun en iyi işleyebileceği düşünülen Çin'deki gelişmelerin durması kuvvetle muhtemel olan noktanın belirlenmesi amaçlanmaktadır. Zira sınırsız emek arzına dayalı emekyoğun sanayileşme/kalkınma çabalarının sınırlarına gelinebileceğine dair temel örnek Sovyet sanayileşmesidir. Emek deposunun sonlanmaya başlamasıyla birlikte kalkınma modelinin sermaye/teknoloji-yoğun boyuta evrilememesi halinde durağanlığın kaçınılmaz hale geleceği ileri sürülmektedir. Bu çerçevede çalışmanın hemen ikinci kısmında Lewis’in iki sektörlü büyüme modeli teorik olarak anlatılacaktır. Üçüncü kısımda Çin ekonomisindeki sosyo-ekonomik gelişmeler tablolarla sunulacaktır. Dördüncü kısımda ise Çin'de sanayileşme ile eş olarak kullanılan kentleşme oranı hedef değişken olarak alınıp bu hedef değişkene etkide bulunacağı düşünülen girdiler, yani sanayinin GSYİH içindeki payı, ihracat, kişi başı gelir ve hizmetler sektörünün toplam gelirdeki payları alınmıştır. Böylece Holt-Winters üstel düzeltme yöntemi ile emek-yoğun büyümenin yaklaşık kaç yıl daha sürdürülebileceği belirlenmeye çalışılacaktır. Sonuç kısmında ise analizlerden elde edilen bulgulardan hareketle politika çıkarımlarında bulunulacaktır.

\section{Lewis'in İki Sektörlü Büyüme Modeli ve Kapitalist Kentleşme Mekanizması}

Başta F. List ve A. Hamilton gibi korumacılıkla kalkınılabileceğine dair görüşlere karşı neo-liberal perspektifte kalınarak ekonomik kalkınmanın sağlanabileceğine dair görüşleri savunanlar arasında yer alan A. Lewis'in görüşleri 1954 yılında yapısal formasyon konusunda geliştirilmiş ilk teorik modellerdendir. Lewis'in “iki sektörlü büyüme" olarak tanımladığı modeli 19. yüzyılın ikinci yarısından sonra emek arzı fazlası olan üçüncü dünya ülkeleri için bir kalkınma modeli niteliği taşımıştır (Todaro, 1994: 74; Kulkarni ve Huang, 2007: 208). Modelde, adından da anlaşılacağı üzere iki sektör bulunmaktadır. Bunlardan birincisi, geleneksel sektör olarak tanımlanan tarım sektörü ve ikincisi de sanayi sektörüdür. Tarım sektöründe "kırsal geçimlik ücret" düzeyi söz konusu olup aşırı nüfus fazlalığı bir tür sınırsız emek arzının varlığı ile resmedilir. Sınırsız emek arzı fazlalığında, tarım sektöründe emeğin marjinal verimliliği sıfır ve hatta negatif olarak addedilir ve dolayısıyla gizli işsizliğin varlığına vurgu yapılır. Kapitalist-modern olarak nitelendirilen sanayi sektöründe ise yüksek marjinal emek verimliliği söz konusudur. Sanayi sektöründe sermayedarın yüksek tasarruf eğilimi söz konusudur ve yüksek kârların temelinde de yıllık büyüme hızının altındaki ortalama kişi başı ücret artışları yer almaktadır (Fan vd., 2016: 2). Girişimciler ise kârlarını tüketim değil, tasarruf yoluyla yatırıma yönlendirirler. Yeni yatırımlar sermaye birikimine katkıda bulunmakta ve iş imkânları sunmaktadır. Bu yatırımların gereksinim duyduğu işgücü ise geleneksel sektörden çekilmektedir (Karabulut ve Emsen, 1997: 32-33).

İki sektörlü büyüme modelinde kırsal ücretler kentsel ücretlerin altında yer almaktadır. Zira kırsalda yaşam maliyeti kente göre daha düşüktür. Kentteki yaşam maliyetinin görece yüksekliği kentten kaynaklanan maliyetlerin bir yansıması konumundadır. Diğer taraftan kıra göre kentteki ücretlerin bir nebze yüksek olması, kentte işgücü çekebilmenin de koşulu konumundadır (Morgan, 1975: 75-76). Kentte girişimcinin elde ettiği kâr şüphesiz emek maliyeti ücretlerin üzerindedir. Ancak, girişimci hemen hemen ücretli yaşam maliyetine yaklaşık bir yaşam tarzı sürmekte ve dolayısıyla kârdan düşülen yaşam maliyeti arasındaki fark ise bir kez daha yatırımlara yönlendirilmektedir.

Yukarıda anlatılanlar kısaca özetlenecek olursa, ucuz emek deposu konumundaki tarım ağırlıklı kırsal kesim ile bu depodan beslenen sanayi ağırlıklı kentsel kesim arasındaki ilişkiler, özellikle her iki kesimin yalıtılmış olması koşuluyla Lewis'in sınırsız emek arzı ile sanayileşme analiziyle açıklanabilir. Aşağıdaki şekilde Lewis modelinin işleyişi grafik yardımıyla resmedilmiştir. 


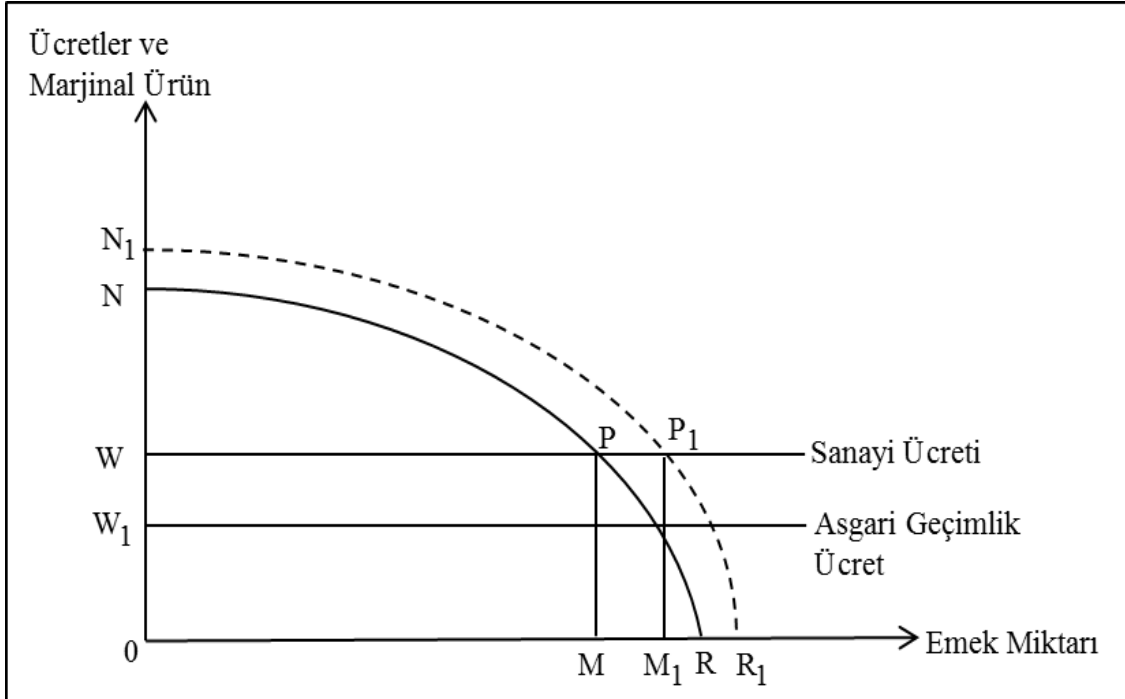

Şekil 1: Lewis'in İki Sektörlü Büyüme Modeli Kaynak: Kaynak, 2005: 168.

Lewis modelinde, geleneksel geçimlik sektör olan tarımdaki ücretler (W1) sanayideki ücret (W) düzeyinden daha düşüktür. Zira yukarıda da belirtildiği üzere, önsel olarak ifade edilen varsayım gereği kırsalda yaşam maliyeti kentsel yaşama göre kısmen de olsa daha düşüktür. Bu nedenle kentsel sanayi alanında yaşam sürdürebilmek için görece daha yüksek ücretlerin sunulması gerekmektedir. Ancak, bu ücretler de yukarı ya da aşağı doğru eğilimli olmamalıdır. Çünkü yukarı doğru bir ücret eğiliminin ortaya çıkması, kırdan kente nüfus hareketini tetikleyecek ve ücretlerin aşağı doğru kaymasına neden olacaktır. Aşağı doğru bir ücret eğilimi ise tersine bir göç mekanizmasını tetikleyecektir. Yukarıdaki şekilde kapitalist sektörde elde edilen emeğin toplam ürünü (ONPM), emeğe ücret olarak yapılan ödemeler (OWPM) ile kapitalist artığı (WNP) arasında paylaşılmıştır. Modelde kapitalist sektörde ve geçimlik sektörden artık emeğin emilme oranı, kapitalist artığın kullanımına bağlanmaktadır. Kapitalist artık yeniden yaratıldığında, emeğin toplam ürünü yükselmiş olacaktır. Yeni yatırımlar da emeğin verimliliğini arttığından, marjinal ürün eğrisi NR de sağa doğru kayarak N1R1 şeklini alır. Yeni durumda istihdam düzeyi de OM'den OM1'e geçer. Nihai olarak toplam çıktı ON1P1M1 düzeyine ulaşırken, bu hasıla da emeğe ücret olarak yapılan ödemeler (OWP1M1) ile kapitalist artığı (WN1P1) arasında yeniden paylaşılır olmuştur. Elde edilen bu kapitalist artık yeniden yatırımlara kanalize edildiğinde, aynı süreç bir kez daha yaşanır ve en nihayetinde bu artık emek, yani kırsaldaki sıfır marjinal verimliliğe sahip emek tüketilmiş olunur. Dolayısıyla bir tür emekyoğun büyüme stratejisine dayalı Lewis'in modelinin sınır noktası da kırsalda artık emeğin kalmaması; yani geçimlik sektörde artık emeğin kalmaması olarak ortaya çıkar ve bu da geçimlik sektörde ücretlerin yükselmeye başlamasıyla kendini gösterir.

Lewis'in iki sektörlü modelinin işleyişi aşağıdaki şekilde emek piyasası denge mekanizmasının işleyiş̧i üzerinden anlatılmıştır. Burada kırdan kente göçü besleyen ilave yatırımlar ve bunun sonucunda ortaya çıkan kentleşme mekanizması kendini gösterir. Dolayısıyla sanayileşme ile kentleşme eş anlamda kullanılabilmektedir.

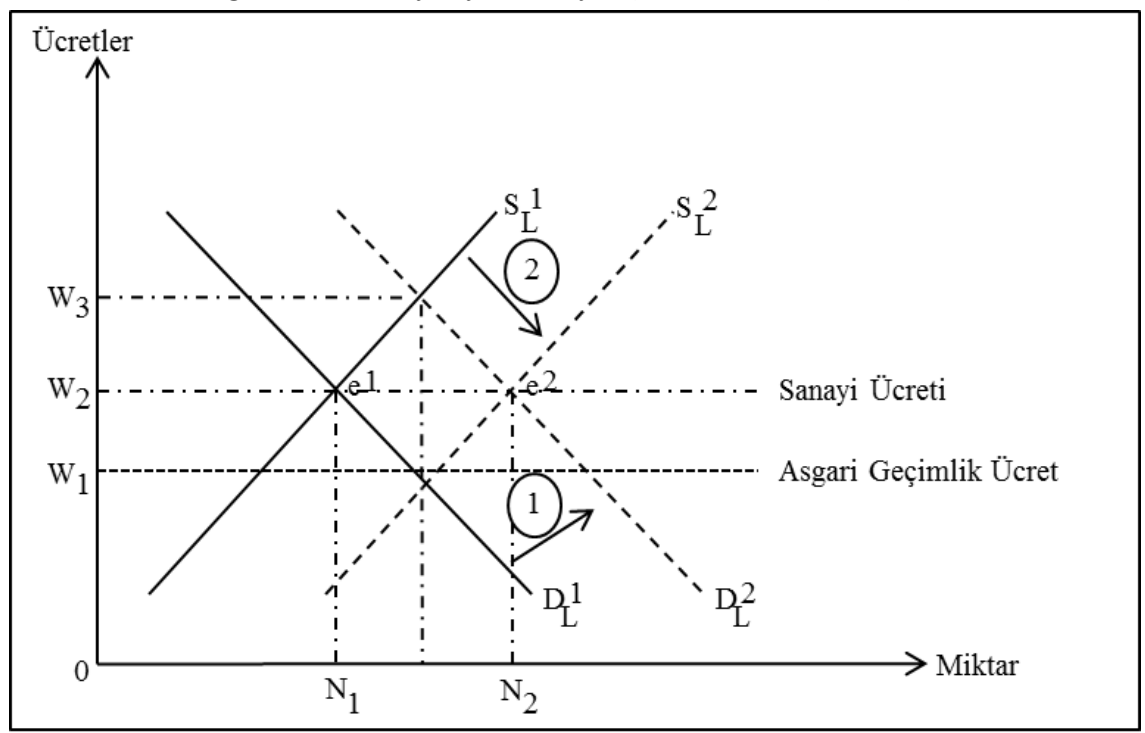

Şekil 2: Emek Arz ve Talep Ĕ̈rileri ile Kırdan Kente Emek Aktarımı ve Kentleşme 
Yukarıdaki şekilde W1 kırsal kesim asgari geçimlik ücretlerini ve W2 de kentsel kesim sanayi ücretlerini göstermektedir. Başlangıçta kentsel kesimde emek arzı SL1 ile emek talebi DL1'in kesiştiği e1 noktasında emek piyasası dengesi, N1 istihdam düzeyinde sağlanmıştır. Kentsel kesimde sermaye birikimi sonucu yapılan yeni yatırımlar ile birlikte emek talebi artarak DL2 şeklinde sağa kayacaktır. Bu durumda ücretler W2'den W3 düzeyine yükselecektir. Kentsel alanda ücretlerin ve dolayısıyla refahın arttığını gözleyen kırsaldaki işçiler kentsel alana göç ederek emek arzının SL1'den SL2'düzeyine kaymasına yol açacaktır. Emek arzındaki artışlar sonucu ücretler düşmeye başlar; bu durum ücret düzeyinin W2 olduğu noktaya kadar kırdan kente emek göçü ile devam edecektir. Kırdan başlayan emek göçü, yeni denge noktasını tesis edecektir; burada emek talebi DL2 ile emek arzı SL2'nin kesiştiği e2 denge noktasında ve N2 istihdam düzeyinde dengenin oluşmasını mümkün kılacaktır. Başlangıçta ON1 olan kentsel istihdam düzeyi şimdi ON2 düzeyine çıkacaktır ve N1-N2 arasındaki işgücü artışı ise kentleşme oranındaki artı̧̧ ifade edecektir. Dolayısıyla başlangıçta kentteki emek miktarı 0N1 iken, yeni durumda kentteki emek miktarı 0N2'ye çıkacaktır. Ortaya çıkan bu olgu, sanayileşme ve dolayısıyla kapitalist kentleşme mekanizması olarak tanımlanabilir (Emsen, 1999: 166).

Lewis'in büyüme modeli ve buna bağlı olarak ortaya çıkan sanayileşme-kentleşme süreci; dayandığı varsayımlar gereği oldukça ütopik kabul edilir. Ancak, Çin'in hem tasarrufçu yapısı hem de kırdan kente göçü frenleyen mekanizmalarının ya da iki bölge emek piyasalarının işleyişindeki farklılıkların varlığı (Kulkarni ve Huang, 2007: 211), Lewis modelinin uygulanabilirliğine adeta bir laboratuvar teşkil etmiştir. Ayrıca 1970'lerde başlayan sermaye hareketlerindeki hızlı gelişme ve serbestleşme gelişmiş ülkeler ile başta Çin olmak üzere çevre ülkeler arasında olması muhtemel emek hareketliliğini sınırlandırmakta; doğrudan yabancı yatırımların ve ulus ötesi işletmelerin artması, emeğin ulusal ekonomilerin sınırları içerisinde kalmasına sebep olmaktadır. Diğer taraftan yabancı yatırımları kendine çekmek ve ulus ötesi şirketleri kendi bünyesinde artırmak gayesi içerisinde bulunan çevre ülkeler, emek maliyetlerini olabildiğince düşük tutarak, cazip hale gelmeye çalışmaktadırlar.

\section{3 Çin'de Halk Cumhuriyetinden "Sosyalist Piyasa Ekonomisi”"ne Geçiş}

Çin'in başarı öyküsünün temellerinde Deng Şioping'in 1977'de göreve atanması ve Deng'in ileri sürdüğü reformların uygulanabilirliği yatmaktadır. Temmuz 1978 'de ise Deng destekçilerinin Beijing'teki bir duvara astıkları ilan ile birlikte Çin'de Demokrasi Duvarı hareketi ortaya çıkmıştır. Bu çerçevede Deng'in destekçilerinden biri olan Hu Qiaomu, ekonomik reformlar için dört temel prensip sunmuştur (Acemoğlu ve Robinson, 2014: 401-404):

(i) şirketlere daha fazla inisiyatif,

(ii) üretimle ilgili olarak şirketlerin kendi kararlarını almalarının gerekliliği,

(iii) fiyatların safi hükümet tarafından ayarlanması yerine arz ve talebi buluşturmaya imkân tanınması,

(iv) ekonomi üzerinde devlet denetiminin azaltılması.

Daha sonrasında Aralık 1978'de On Birinci Merkez Parti Komitesinin Üçüncü Genel Kurulunda, 1980'de ve 1982'deki On İkinci Ulusal Kongresi ile Eylül 1985'deki Ulusal Halk Kongresinde sırasıyla aşağıdaki kararlar alındı:

(a) partinin o tarihten itibaren sınıf mücadelesine değil, ekonomik modernizasyona odaklanmasına,

(b) Hua yerine Zhou Ziyang başbakanlığa getirilmesine,

(c) partinin gençleştirilmesine,

(d) ekonomik kurumlarda ilave bir dizi değişikliğe gidilmesine,

(e) çiftçilere ekonomik teşvik sağlayacak aile sorumluluk sisteminin tüm ülkede hayatiyete geçirilmesine,

(f) tarımda zorunlu devlet alımı terk edilerek gönüllülük esasına dayalı sözleşme sistemi yürürlüğe konulmasına ve tarım fiyatlarındaki idari kontrolün gevşetilmesine,

(g) şehir ekonomisinde devlet girişimlerine daha fazla özerklik sağlanmasına ve on dört "açık şehir" belirlenerek bunlara yabancı yatırım çekme olanağının tanınmasına karar verilmiştir.

Çin'in 1970'lerin sonunda başlayan serüveninde kat ettiği mesafe ile üstlendiği fonksiyon tartışmalı kabul edilmektedir. Çin'in başta ABD olmak üzere Batının taşeronu ya da kirli üretim merkezi olup olmadığı tartı̧̧alarının yanı sıra dış ekonomik ilişkiler boyutunda kapitalist uygulamalarının içeride refaha olumlu yansımalarına şüphe ile bakılmaktadır. Aşağıdaki tabloda burada belirtilen paradoksların Çin'de sosyo-ekonomik göstergeler boyutuyla değişimleri özet olarak verilmiştir. 


\begin{tabular}{|c|c|c|c|c|c|c|c|c|c|}
\hline Yıllar & $\begin{array}{c}\text { Kirsal } \\
\text { Nüfus } \\
(\%)\end{array}$ & $\begin{array}{c}\text { Yaşam } \\
\text { Beklentisi }\end{array}$ & $\begin{array}{c}\text { GSYIH'da } \\
\text { Tarımın } \\
\text { Payı } \\
\end{array}$ & $\begin{array}{c}\text { Mal ve } \\
\text { Hizmet } \\
\text { İhracatının } \\
\text { GSYİH } \\
\text { İçindeki } \\
\text { Payı }\end{array}$ & $\begin{array}{c}\text { DYSY'nın } \\
\text { GSYIH } \\
\text { İçindeki } \\
\text { Payı } \\
\end{array}$ & $\begin{array}{c}\text { GSYİH'nın } \\
\text { Yüzdesi } \\
\text { Olarak } \\
\text { Tasarruflar }\end{array}$ & $\begin{array}{c}\text { GSYIH } \\
\text { (cari } \\
\text { milyar } \\
\text { ABD } \\
\text { doları) }\end{array}$ & $\begin{array}{c}\text { Fert Başına } \\
\text { GSYIH } \\
\text { (cari ABD } \\
\text { doları) } \\
\end{array}$ & $\begin{array}{c}\text { Fert } \\
\text { Başına } \\
\text { GSYİH } \\
\text { Büyüme } \\
\text { Hızı } \\
\end{array}$ \\
\hline 1960 & 83,8 & 44,8 & 23,38 & 4,34 & .. & .. & 59,2 & 88,7 & .. \\
\hline 1970 & 82,6 & 60,5 & 35,21 & 2,52 & .. & .. & 91,5 & 111,8 & 16,1 \\
\hline 1980 & 80,6 & 68,0 & 29,86 & 5,96 &.. & .. & 189,7 & 193,3 & 6,4 \\
\hline 1990 & 73,6 & 70,7 & 26,72 & 15,90 & 0,97 & 38,47 & 358,9 & 316,2 & 2,4 \\
\hline 2000 & 64,1 & 73,5 & 14,74 & 20,68 & 3,49 & 36,22 & $1.205,3$ & 954,5 & 7,6 \\
\hline 2005 & 57,5 & 73,8 & 11,72 & 33,70 & 4,59 & 46,72 & $2.268,6$ & 1740,1 & 10,7 \\
\hline 2010 & 50,8 & 73,8 & 9,62 & 26,53 & 4,04 & 51,27 & $6.039,7$ & 4514,9 & 10,1 \\
\hline 2011 & 49,4 & 73,8 & 9,53 & 26,78 & 3,74 & 48,96 & $7.492,4$ & 5574,2 & 8,9 \\
\hline 2012 & 48,1 & 73,8 & 9,52 & 25,71 & 2,85 & 49,87 & $8.461,6$ & 6264,6 & 7,2 \\
\hline 2013 & 46,8 & 73,8 & 9,40 & 24,81 & 3,06 & 49,24 & $9.490,6$ & 6991,8 & 7,2 \\
\hline 2014 & 45,6 & 73,8 & 9,17 & 23,92 & 2,59 & 48,66 & $10.351,1$ & 7587,2 & 6,7 \\
\hline 2015 & 44,4 & .. & 8,99 & 22,37 & 2,29 & .. & $10.866,6$ & 7924,6 & 6,4 \\
\hline
\end{tabular}

Tablo 1: Çin'de Sosyo-Ekonomik Boyutta Gelişmeler Kaynak: World Bank, WDI, 2016.

Çin ekonomisinde özellikle 1980'li yıllardan itibaren muazzam bir dönüşümün yaşandığı gözlenmektedir. Bu dönüşümde sanayileşme ve bunun yansıması olan kentleşme nispetlerinde ortaya çıkan gelişmeleri de görmek mümkündür. 1960'larda köylü bir toplum olan ve nüfusunun \%83,8'i kırsalda yaşayan Çin'de 2015'e gelindiğinde, kırsalda yaşayanların oranı \%44,4'e gerilemiş; kentte yaşayanların oranı ise \%55,6'ya yükselmiştir. Buradan hareketle GSYİH'de tarımın payı 1960'da \%23,4'den 1970'lerde \%35,2'ye ve 1980'de de \%29,9'a ulaşan yüksekliğin özellikle devrimci uygulamaların tarımda başlatılmasının bir yansıması olarak algılanırken; sanayileşme hamlelerinin de devreye girmesiyle birlikte tarımın payı azalmaya başlamıştır. Bu durum istihdamın sektörel dağılımında da kendini hissettirmiştir. Burada Lewis'in sınırsız emek arzı ile kalkınmaya dayalı yaklaşımında kırsaldaki nüfusun kentsel işgücü deposu olduğu gerçeği dikkate alındığında, Çin'in emeğe dayalı kalkınma formunda marjının halen daha geniş olduğu ve dolayısıyla potansiyelinin yüksel olduğu söylenebilir. Yaşam standartlarında iyileşme belirtisi olarak ortalama yaşam göstergesi açısından da 1960'da 44,8 yaştan 2014 'te 73,8 yaşa çıkılması, önemli bir gelişmenin sağlandığına işaret etmektedir.

Diğer taraftan Çin ekonomisinde özellikle 1980'lerde başlayan ve ihracat yapma hedefini içeren stratejiye bağlı olarak ekonomik göstergelerde de olumlulaşmanın ortaya çıktığı görülmektedir. Bu bağlamda Çin'de mal ve hizmet ihracatının GSYİH'ye oranının 1960'da \%4,34 ve 1970'de \%2,72 gibi oldukça düşük seviyelerde seyrettiği ve bunun da sosyalist sistemin bir yansıması ve ilaveten az gelişmişliğin ürünü olduğu söylenebilir. 1980'lerde dışa yönelik politika uygulamaları ile birlikte ihracatta sürekli artış trendinin 2006 yılına kadar devam ettiği gözlenmekte; 2008-2009 küresel krizin yansıması olarak dışa açıklıkta düşüşler yaşandığı dikkat çekmektedir. Dış ekonomik ilişkilerde liberal politikalar Çin'in net DYSY çeken ülke olmasını sağlamış; çok uluslu şirketler vasıtasıyla akan bu yabancı sermaye, Çin'i dünya üretim üssü haline getirmiştir. Yabancı sermaye çekebilme yeteneğinin yanı sıra yüksek tasarruflar ve cari fazla başarıları ile yüksek işgücü deposunun varlığı (Kulkarni ve Huang, 2007: 207) bir bütün olarak Çin'de muazzam denebilecek düzeyde gelir artışlarını beraberinde getirmiştir. Buna göre 1960'da 89,2 milyar dolarlık GSYİH ve 88,7 dolarlık fert başına GSYİH değerlerine sahip olan Çin, 2015 yılı itibarıyla 10,9 trilyon dolarlık GSYİH değeri ile ABD ekonomisinden sonraki en büyük güç olmayı başarmıştır. Fert başına GSYİH değerini de 7924,6 dolara ulaştırmış; 1960-2015 arası dönemde ortalama fert başı büyüme hızı \%6.9 iken, 1960-1979 arası dönemde bu oran \%3.4 ve devrimci uygulamalar ile birlikte, yani 19802015 yılları arasında fert başına ortalama büyümesi \%8.7 olarak gerçekleşmişstir. Çin'in devasa denebilecek ve uzun süre devam ettirdiği (55 yıldır) büyüme mucizesini geçmişte 1928-1984 döneminde (56 yıl) ortalama \%4.3\%4.8 arasında skorlar yakalamış olan Sovyetler ile 1874-1984 arası dönem (110 yıl) için ancak \%4.5'lik bir ortalamayı tutturan Japonya yaklaşabilmiştir (Emsen vd., 2011: 47).

\section{Veri Seti, Yöntem ve Ampirik Bulgular}

Çalışma Çin ekonomisinin hâlihazırda büyüme dinamiğinin temelini oluşturan işgücünün kırsaldan çekilebilirliği sürecinin ne kadar süre ile devam ettirilebileceği şeklinde kurgulanmıştır. Diğer bir ifadeyle Lewis'in iki sektörlü büyüme modelinin Çin özelinde işleyebilmesi ve dolayısıyla bu büyüme formunun ne kadar süre ile devam ettirileceği biçiminde kurgulanmıştır. Dolayısıyla çalışmada kullanılan veri setleri Çin'e ait 1960 ile 2015 yılları arası dönemi kapsamış olup veriler Dünya Bankasının WDI göstergelerinden derlenmiştir.

Çalışmada Çin için emek-yoğun büyüme sürecinin işlerliğinin belirlenmesi amaciyla Holt-Winters Yöntemi (HWY) kullanılmıştır. Holt-Winters metodunun çıkış sebebi ARIMA modellerle tahminlerde mevsimselliğin ve trendin kestirimlere etki etmesi ve ARIMA modellerin 2 parametreli tahmin gücüyle kısıtlı olmasından kaynaklanmaktadır. Bunun yanı sıra Box-Jenkins metodunun ise Holt-Winters'ın tahmin sürecine yakın olmasına 
karşın, analiz yapan araştırmacının hesaplanma süreçlerinde daha yoğun olarak karar vermesinin gerekli olduğu karmaşık bir metot olmasıdır. HWY bu iki yönteme alternatif olarak ortaya çıkmıştır. Tahmin süreci daha kolay olan ve çoklu parametrik kestirim yapabilen HWY, gerek mevsimselliği gerekse trendi dikkate almasıyla oldukça kullanışlı bir yöntem olarak ortaya çıkmıştır (Chatfield, 1978). HWY üstel düzeltme yöntemi ile tahminlerin temel alındığı noktalar, serilerin trend ve mevsimsellik içermesi yönüyle avantajlar sağlar. Seçilen serilerin bu iki koşulu içermesi durumunda uygulanan yöntem ile ele alınan zaman serisi aşağıda (1) nolu eşitlikte ifade edilmiştir.

$y_{t}=\left(\beta_{1}+\beta_{2} t\right) S_{t}+\epsilon_{t}$

Burada;

$Y t$ : Gözlem değeri,

$\beta_{1}$ : Sürekli bileşen olarak tanımlanan temel sinyal

$\beta_{2}$ : Trend düzeltme sabiti

St: Mevsimsel bileşen,

$\epsilon_{\mathrm{t}}$ : rassal hata bileşeni,

t: zaman serisidir.

(1) nolu eşitlik temel alınarak, seri mevsimsellikten arındırılmaktadır. Mevsimsel arındırma süreci de aşağıdaki (2) nolu eşitlikte yapılmaktadır.

$\overline{\mathrm{R}}_{\mathrm{t}}=\alpha \frac{\mathrm{y}_{\mathrm{t}}}{\overline{\mathrm{S}}_{\mathrm{t}-\mathrm{L}}}+(1-\alpha) *\left(\overline{\mathrm{R}}_{\mathrm{t}-1}+\overline{\mathrm{G}}_{\mathrm{t}-1}\right)$

Burada $0<\alpha<1$ arasında değer alan bir sabittir. Yöntemin ikinci aşaması olan trendden arındırma ise (3) nolu eşitlikteki sürecin takibi ile mümkün olmaktadır:

$$
\overline{\mathrm{G}}_{\mathrm{t}}=\beta *\left(\overline{\mathrm{S}}_{\mathrm{t}}-\overline{\mathrm{S}}_{\mathrm{t}-1}\right)+(1-\beta) * \overline{\mathrm{G}}_{\mathrm{t}-1}
$$

Üçüncü aşamada hesaplanan gözlem değerleri dikkate alınarak seri yalnızca mevsimsellikten arındırılmaktadır. (4) nolu eşitlikte genel olarak tüm bu iki bileşenden arındırılma süreci birlikte ortaya konulmuştur.

$$
\overline{\mathrm{S}}_{\mathrm{t}}=\gamma *\left(\mathrm{y}_{\mathrm{t}} / \overline{\mathrm{S}}_{\mathrm{t}}\right)+(1-\gamma) * \overline{\mathrm{S}}_{\mathrm{t}-\mathrm{L}}
$$

Yukarıdaki mekanizmalardan hareketle HWY'nin ekonometrik analizlerde kullanılabilirliğini arttıran temel nokta trend ve mevsimselliğe sahip serileri indirgeyerek gecikmeleri ile tahmin etmesidir (Kalekar, 2004). (1) nolu eşitlikte yer alan indirgemelerin (2) ve (3) nolu eşitlikler dikkate alınarak hesaplandığ görülmektedir.

İleriye dönük zaman serileri tahmini ise (5) nolu eşitlik yardımıyla yapılmaktadır:

$$
\mathrm{y}_{\mathrm{t}+\mathrm{T}}=\left(\overline{\mathrm{R}}_{\mathrm{t}-1}+\mathrm{T} * \overline{\mathrm{G}}_{\mathrm{t}-1}\right) * \overline{\mathrm{S}}_{\mathrm{t}+\mathrm{T}-\mathrm{L}}
$$

Çalışmada serilerin hem mevsimsellik hem de trend içermesi nedeni ile tercih edilen HWY ile tahmin yapılmıştır. HWY veri setine ait ortalamanın ve büyüme oranlarının değişkenlik gösterdiği durumda kullanılması gereken bir yöntemdir. (5) nolu modelde yer alan tahminde kullanılan temel düzey genellikle başlangıç yılı olarak belirlenirken; tıpkı baz yılı belirlenmesindeki gibi bir denklemle de belirlenmektedir (Özüdoğru ve Görener, 2015).

$$
\begin{aligned}
& \mathrm{L}_{\mathrm{t}}=\propto \mathrm{Y}_{\mathrm{t}}+(1-\propto)\left(\mathrm{L}_{\mathrm{t}-1}+\mathrm{T}_{\mathrm{t}-1}\right) \\
& \mathrm{F}_{\mathrm{t}+\mathrm{n}}=\mathrm{L}_{\mathrm{t}}-\mathrm{nT}_{\mathrm{t}} \\
& \mathrm{T}_{\mathrm{t}}=\beta\left(\mathrm{L}_{\mathrm{t}}-\mathrm{L}_{\mathrm{t}-1}\right)+(1-\beta) \mathrm{T}_{\mathrm{t}-1}
\end{aligned}
$$

(6), (7) ve (8) nolu eşitliklerde temel düzeyin R programında belirlenme süreci ele alınmıştır. Çalışmada Çin için Lewis'e ait çift sektörlü büyüme modelindeki değişkenler dikkate alınmıştır. Bu değişkenlerin fonksiyonel gösterimi aşağıdaki gibidir.

$$
\mathrm{UR}=\mathrm{f}(\mathrm{PCY}, \mathrm{S}, \mathrm{EX})
$$

(9) nolu eşitlikte UR, kentleşme oranını; PCY, fert başına geliri; S, hizmetler sektörünün GSYİH içindeki oranını ve EX, ihracatıın GSYİH içindeki payını temsil etmektedir. Seçilmiş değişkenlere ait yapılan analizlerde Lewis'in dönüm ya da büküm noktasının yirmi yıllık bir projeksiyonda yakalanıp yakalanmayacağı araştırılmıştır. Bu çerçevede Lewis modelinde kırsal işgücü deposu özelliğinin sanayileşmeyi beslemeye devam edip etmeyeceği önem arz etmektedir. Dolayısıyla hem sanayinin hem de sanayideki evrilmenin yansıması olan hizmetler sektörünün kentsel alanda yoğunlaştığı dikkate alındığında, kırsal verimliliğin ve kenti besleyebilme özelliğinin devamının gelişmiş ülkelerdeki oranlar açısından kentleşmenin \%90-95'lerde ulaşması ile ifade edilebilir. Aşağıdaki tabloda HWY'ne göre seçili değişkenlere ilişkin tahminlerin beş y1llık değerleri gösterilmiştir. 


\begin{tabular}{|c|c|c|c|c|}
\hline & $\begin{array}{c}\text { Hizmet Sektörünün } \\
\text { GSYIH Payı }\end{array}$ & $\begin{array}{c}\text { Fert Başına } \\
\text { Gelir }\end{array}$ & $\begin{array}{c}\text { İhracatın } \\
\text { GSYIH Payı }\end{array}$ & $\begin{array}{c}\text { Kentleşme } \\
\text { Oranı }\end{array}$ \\
\hline $\mathbf{2 0 1 5}$ & 50.47 & 7924.65 & 22.37 & 55.61 \\
\hline $\mathbf{2 0 2 0}$ & 55.66 & 12632.58 & 19.43 & 60.19 \\
\hline $\mathbf{2 0 2 5}$ & 63.62 & 16746.22 & 21.07 & 64.34 \\
\hline $\mathbf{2 0 3 0}$ & 71.59 & 20859.86 & 28.03 & 67.79 \\
\hline $\mathbf{2 0 3 5}$ & 79.55 & 24973.50 & 38.80 & 70.73 \\
\hline
\end{tabular}

Tablo 2: HWY’ye Göre Değişkenlerin Beş Yıllık Projeksiyonları

Aşağıdaki şekilde Çin'de 1960'dan bu yana kentleşme oranları ile ileriye dönük projeksiyonları verilmiştir.

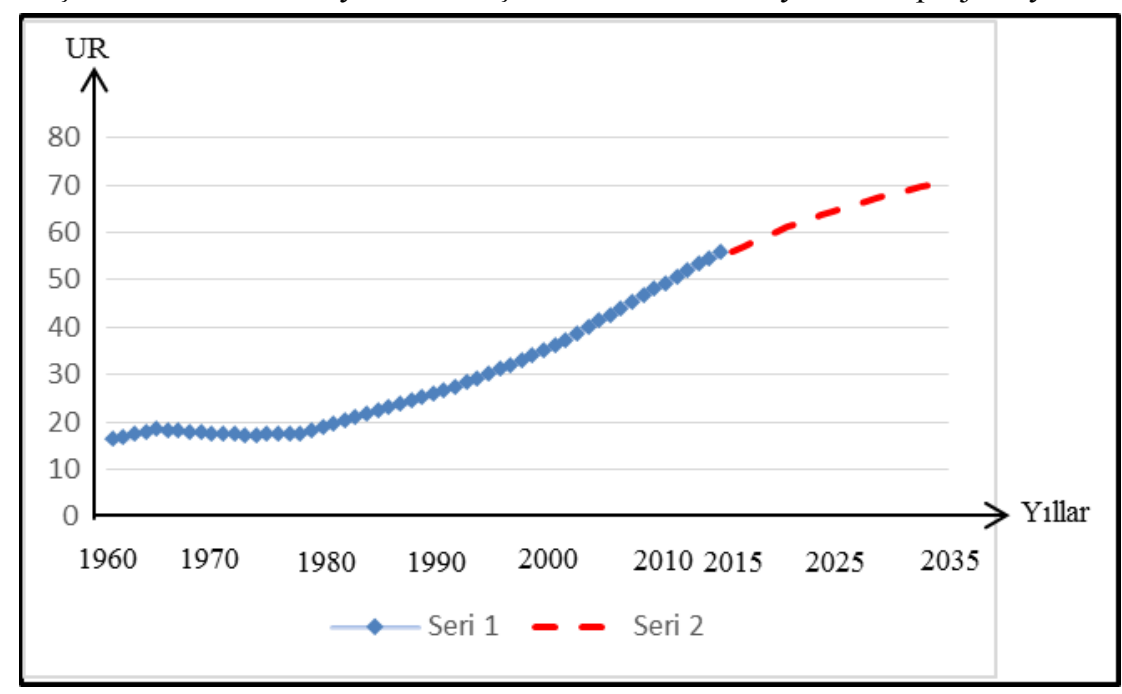

Şekil 3: Kentleşme Oranının Trendi ve Tahminleri

Kentleşme oranlarına ait analiz sonuçlarına göre oluşturulan grafikte tahmin edilen dönem içerisinde bir büküm noktasına ulaşmayacağı; artış trendinin devam edeceği gözlemlenmiştir. Hâlihazırda \%60'lara henüz varmış olan kentleşme oranının 2035'e kadarki tahminlemesinde \%80'lere dahi varmayacağı ve dolayısıyla Çin'in Lewis modeline göre kentleşme-sanayileşme olgusunu devam ettirebileceği söylenebilir.

Lewis Modelinde yer alan kır-kent ilişkisinin en önemli unsurları arasında hizmetler sektörü, ihracat ve fert başına gelir gelmektedir. Bu çerçevede Hizmet Sektörünün GSYİH içerisindeki payı, İhracatın GSYİH içerisindeki payı ve FBY değişkenlerine ait veri setleri de yine 20 yıllık bir projeksiyona tabi tutularak yorumlanmıştır. Diğer bir ifadeyle bu üç değişkene ilişkin 1960-2015 arası trend değeri ve devamında 2015-2035 arası dönemde HWY ile tahmin edilmiştir. İlk olarak ihracatın GSYİH içindeki payındaki gelişmeler aşağıdaki grafikteki gibi bir yol izlediği gösterilmiştir.

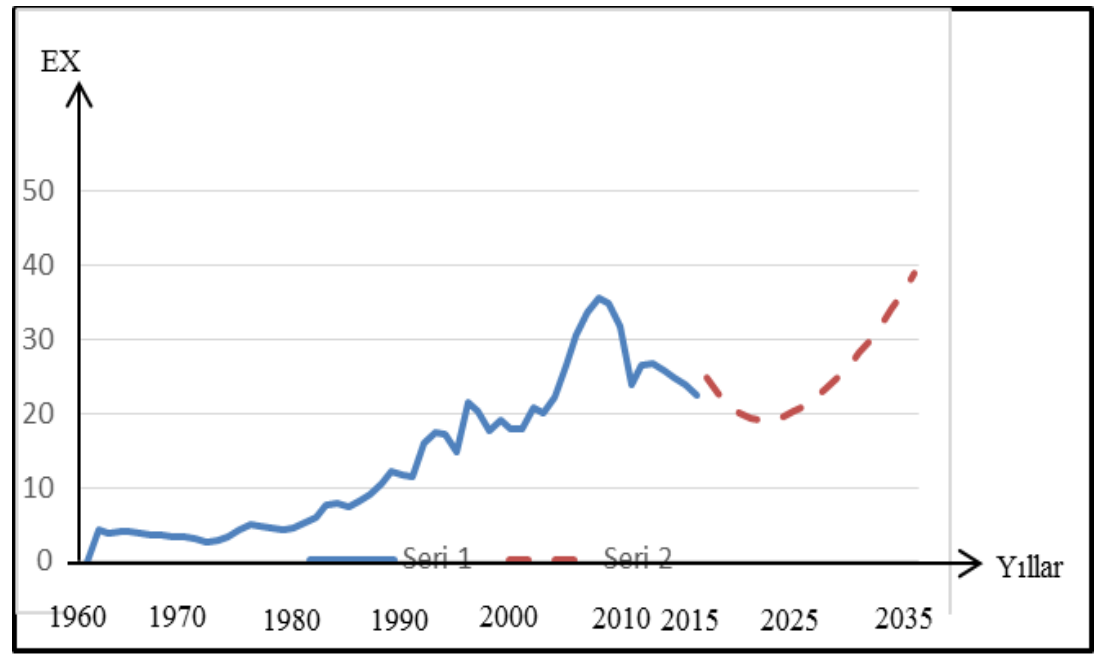

Şekil 4: İhracatın GSYİH'ya Oranının Trendi ve Tahminleri

Yapılan analizler sonucunda; ihracata ait serinin ters parabolik bir seyir izlediği ve ardından artış trendine geçiş yaptığı gözlenmektedir. İlk beş yılda azalma seyri izlerken 19,17'lik bir oranda dip noktayı görmüş ardından artış trendine devam etmiştir. İhracatın hem büyümenin hem de kentleşmenin motoru olduğu dikkate alındığında, Çin'in 
ihracatının dışsal şoklara oldukça duyarlı olduğu ve dolayısıyla Lewis modelinin sürdürülebilirliğinde yardımcı faktör olan ihracattaki olumsuz şokların modelin eşik değeri olarak ifade edilen kentleşmede belirli bir olgunluk düzeyine ulaşmayı geciktirici etki yapacağı söylenebilir.

Diğer taraftan kentleşmenin hem sonucu hem de nedeni olarak ifade edilen kişi başına düşen milli gelire ait serinin zamana bağlı değişimi aşağıdaki grafikte resmedilmiştir.

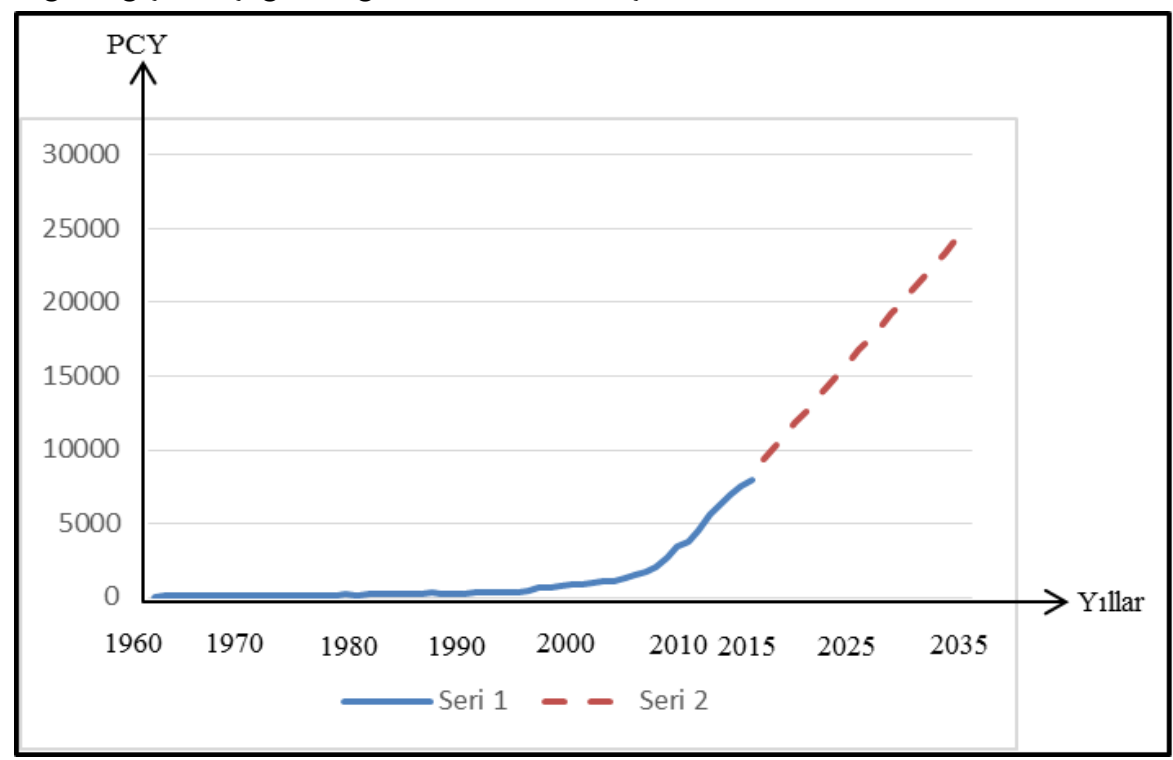

Şekil 5: Kişi Başına Düşen Milli Gelirin Trendi ve Tahminleri

Çin ekonomisinde ABD doları cinsinden fert başına GSYİH değerlerinin alt, üst ve ortalama değerleri dikkate alındığında, tüm değerlerde artış trendinin sürdüğü gözlenmektedir. Dolayısıyla 2015 yılı itibarıyla 8.000 dolara ulaşmış olan Çin'deki fert başı gelir rakamının önümüzdeki 20 yıllık süreçte 25.000 dolar düzeyine ulaşması kuvvetle muhtemeldir ki, bu yönüyle Çin'in gelir değerleri açısından yüksek gelirli ülkeler kategorisi içerisinde yer alması beklenmektedir.

Son olarak kalkınmanın dinamikleri içerisinde yer alan hizmetler sektöründeki zaman bağlı olarak gelişmeleri gösteren grafik aşağıda verilmiştir.

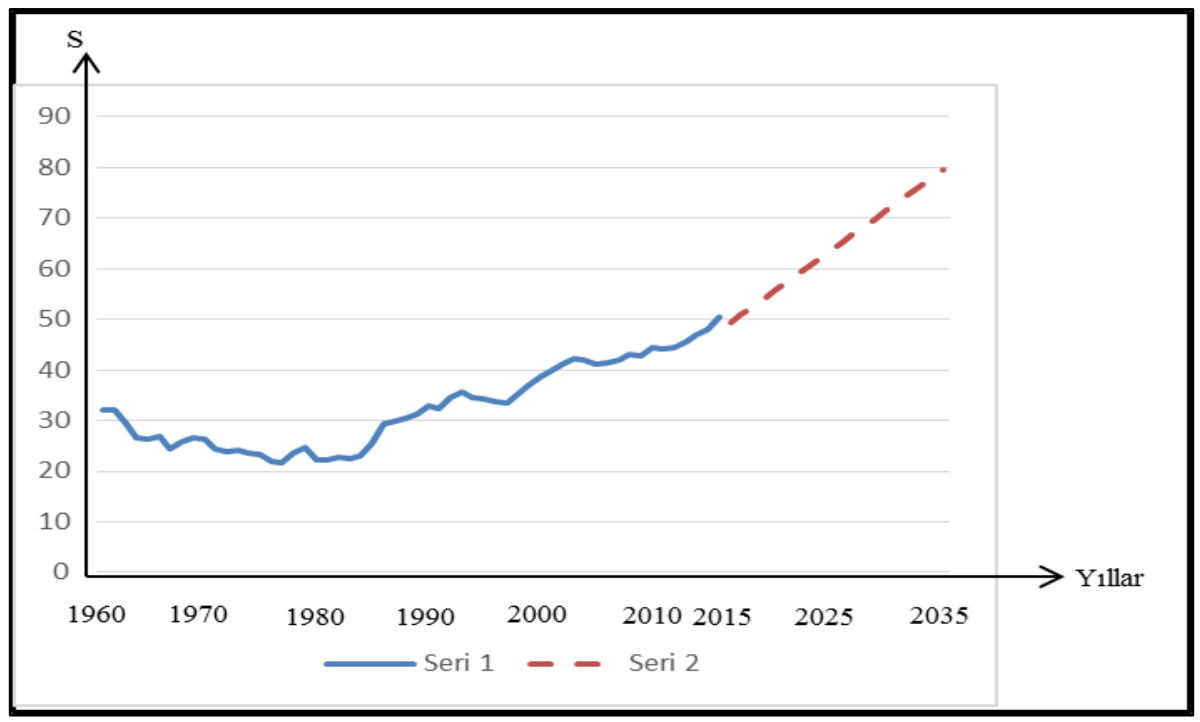

Şekil 6: Hizmetler Sektörünün GSYİH’ya Oranının Trendi ve Tahminleri

PCY değerleri açısından ortaya çıkan durum, tıpkı hizmet sektörünün GSYİH içerisindeki oranı için yapılan ileriye yönelik tahmin sonuçları ile örtüşen ve dolayısıyla sürekli artan bir seyir izlediği dikkat çekmektedir. Fakat hizmet sektörünün 1980 sonrasında genel eğilimi artış yönündeyken, PCY serisi 1990'ların sonlarında patlayan bir seriye sahip olduğu ve dolayısıyla PCY'nin 10 yıllık gecikme ile S değişkenindeki değişmeyi takip ettiği gözlenmiştir 


\section{Sonuç}

Çok kısa zamanda çok önemli denebilecek başarılara imza atan Çin'in, ekonomik gelişimi ve hâlihazırda geldiği nokta ile dünyanın ikinci büyük ekonomisi olması, şimdilerde bir mucize olarak adlandırılmaktadır. Ancak, bu devasa gelişimin varlığına rağmen, halen katı denebilecek sosyalist uygulamalarıyla ve tüketimin frenlenen yapısıyla Çin'in bir refah toplumu olup olmadığı tartışmalıdır. Diğer bir ifadeyle milyonlarca insanın asgari yaşam koşullarında kaldığı ve demokratik hak ve özgürlüklerden eser bulunmadığı bir toplumda, gelirdeki artışların refaha yansımalarının olmaması boyutuyla Çin, bu devasa üretim merkezi olmasının nimetlerinden toplumun çoğu kesimi yeterli ölçüde faydalanamamakta, bundan kimlerin faydalandığı ise sorgulanmaya değerdir. Diğer taraftan dünyanın çoğu yerinde Çin üretimi/menşeili mallar adeta istila etmişken, Çin'in kendi markasının olmaması, artı değerin nerelerde kümelendiği ve bu refahtan kimlerin nemalandığı bilinmezler arasında yer almaktadır.

Ancak, bu eleştirel bakış açıları şüphesiz Çin'deki büyümenin topluma mâl olmayan bir büyüme olduğunu belirtmesine karşılık, ortaya çıkan gelişmenin sürdürülebilirliği de bir diğer tartışma konusudur. Bu çalışmada yapılan analizler çerçevesinde, Çin'in teorik düzeyde Lewis benzeri büyüme formunu, mevcut koşulları koruması dâhilinde uygulamada sürdüreceğine dair güçlü sinyaller elde edilmiştir. Burada Lewis benzeri büyüme sürecini sekteye uğratması muhtemel olgu, yani dünya ekonomisinin fabrikası olarak Çin'de kırılganlığı yükseltecek unsur, Çin ekonomisinin dünya ihracatındaki dalgalanmalara duyarlılığın fazla olmasıdır. Bu türden bir dezavantajı da içeride aşamalı bir liberalizm uygulaması ile ortadan kaldırılabileceği, yani giderek artan gelirin iç piyasada hissettirtilmesinin yaratacağı iç talebin dış satıma dayalı büyümeye alternatif olarak sürdürülebilir bir büyüme sağlayacağı ileri sürülebilir. Dolayısıyla yapılan analizlerde Çin ekonomisinin dünyanın birinci ekonomisi olması kaçınılmaz iken; bunun sürdürülebilirliği için iç talebi uyaracak aşamalı liberalizasyon uygulamalarına yönelmesinin yararlı olacağı düşünülebilir. Ayrıca, Çin'in mevcut emek-yoğun büyüme formunu da sermayeyoğun büyüme formuna çevirmek suretiyle hem kendi markasını yaratma hem de buna paralel olarak yüksek katma değer oluşturma çabalarının kalıcı büyüme ve ekonomik liderliğini destekleyeceği söylenebilir. Bütün bu değerlendirmeler ışı̆̆ında, Lewis modelini 1960-1970’lere kadar başarı ile uygulayıp da, yukarıda ifade edilen anlamlarda dönüşümü sağlayamamış Sovyetler deneyiminden Çin'in yeterli deneyimler edinerek yarışmacılığını sürdüreceği olasılık dâhilindedir.

\section{Kaynakça}

- Acemoğlu, D. ve J. A. Robinson, Ulusların Düşüşü: Güç, Zenginlik ve Yoksulluğun Kökenleri, (Çev. F. R. Velioğlu), Doğan Kitap, İstanbul, 2014.

- Chatfield, C. (1978), “The Holt-Winters Forecasting Procedure”, Journal of Royal Statistical Society. Series C(Applied Statictics), 27 (3): 264-279.

- $\quad$ Emsen, Ö. S. (1999), "Kapitalist Kentleşme Marksist ve Yedek Sanayi Ordusu: Analitik Bir Bakış”, Atatürk Üniversitesi İktisadi ve İdari Bilimler Fakültesi Dergisi, 13 (1): 161-172.

- $\quad$ Emsen, Ö. S., Ş. M. Ersungur ve D. Özdemir, Ekonomik Sistemler ve Geçiş Ekonomileri: Orta Asya ve Kafkasya Geçiş Ekonomilerine Bir Bakış, Siyasal Kitabevi, Ankara, 2011.

- Fan, Y. Q. Fan and L. Zeng (2016), Transformation Strategy of the Three Industries in China at the Lewis Turning Point, 2016 International Conference on Industrial Economics System and Industrial Security Engineering (IEIS), 24-27 July 2016: 1-5.

- $\quad$ Herbrich, R., M. Keilbach, T. Graepel, P. Bollmann-Sdorra and K. Obermayer (1998), “Applications and New Developments", Neural Networks in Economics Background: 169-193 (Erşimi: Ocak 2017; https://www.semanticscholar.org/paper/Neural-Networks-in-Economics-Background-HerbrichKeilbach/2d8e00bd4e2ef022b5eb5637376a5c9e757c9398\#paperDetail)

- Kalekar, P. S. (2004), “Time Series Forecasting Using Holt-Winters Exponential Smoothing”, Kanwal Rekhi School of Information Technology, 4329008, 1-13.

- $\quad$ Karabulut, K. ve Ö. S. Emsen (1997), Kalkınma Teorileri ve Geliştirilen Son Büyüme Modeli: Yeni Büyüme Teorisi”, Atatürk Üniversitesi İktisadi ve İdari Bilimler Fakültesi Dergisi, 11 (3-4): 27-50.

- Kulkarni, K. G. and W. Huang (2007), Dualistic Eceonomic Structure and Unemployment in China, AsianAfrican Journal of Economics and Econometrics, 7 (1-2): 207-219.

- Morgan, T., Economic Development: Concept and Strategy, Harper and Row, New York, 1975.

- Özüdoğru, A. G. ve A. Görener (2015), "Sağlık Sektöründe Talep Tahmini Üzerine Bir Uygulama”, İstanbul Ticaret Üniversitesi Sosyal Bilimler Dergisi, 14 (27): 37-53.

- Todaro, M. P., Economic Development, Longman Group Ltd., New York, 1994. 


\title{
Sürdürülebilir Ekonomik Büyüme Kavramına Teorik Bakış Theoretical Perspective on the Concept of Sustainable Economic Growth
}

\author{
Assoc. Prof. Dr. Oğuz Bal (Kocaeli University, Turkey)
}

\begin{abstract}
Economic growth, real GDP is a concept that is related to the growth rate of the country. The history of this concept dates back to the mercantilist era. Mercantilist period the active actor is the state, while state intervention in fizyokrat, in contrast to the natural order, rationalism, and "laissez-fairy, laissez passer" was highlighted. The main idea in the classics of liberalism. Opinions that are based on the pressure of its population. Neoklasik the successor of the classics, according to the exogenous growth of labor supply and the concept of "labor growth and technological process" is one of the main determinants of the growth rate along the balanced. Classical and neoclassical growth models, the supply factor describes. Supply-side and demand is internal to the economic system is limited by assumptions. Keynesian and post-Keynesian growth models demand-oriented is referred to as. Vascular growth is tied to investment. The production capacity of the economy and new investments to increase production. Harrod, actual, guaranteed, and has made the difference between the natural growth rate. HarrodDomar; are bound by the terms of the balance of the sustainability of growth. Stabilizing role of the state have been given. These models had been undertaken by N. Kaldor, Thirlwall was developed by. This article is intended that the components of the theoretical framework of the challenges of sustainable growth and developments is to examine and discuss. The method applied the inductive method.
\end{abstract}

\section{Giriş}

Milli gelirin ve buna bağlı olarak kişi başına düşen yıllık ortalama milli gelirin satın alma gücü paritesi ile artışının gerçekleşmesine ekonomik büyüme denir. Sürdürülebilir ekonomik büyüme de; bu tanıma, sağlıklı bir büyüme dinamiğine dayanarak gerçekleştirilmesi ile sağlanabilen bir olgu olduğu eklenerek tanımlanır. Sürdürülebilir büyüme, uzun vadeli bir büyümeyi içerir. Uzun vadeli büyüme de iki temele dayanır. Birincisi; üretim kaynaklarının nicelik(miktar)bakımından artmasıdır. İkincisi ise; kaynakların nitelik (verimlilik ve kalite) bakımından artıştır. Artan yıllık büyüme hızı ile ortalama yaşam standartları katlanarak artar. Milli gelirin dağılımında asıl kuvvetin ekonomik büyüme olduğu gözden uzak tutulmamalıdır. Büyüme sürdüğü müddetçe, milli gelir de artacaktır. Ekonomik büyüme rakamlarının gelişmesi, bunun reel hayata etkisiyle önem kazanır.

Ülkelerin hayatta kalması ekonomik büyümeye bağlıdır. Ekonominin büyümesi tüketim için talebinin artması anlamına gelir. Talep, arzı canlandırır. Tarım, sanayi ve hizmet sektörlerinin dönmesini sağlayan şey ise enerjidir. Sürdürülebilir Ekonomik Büyüme için; tüketimin sürekli olarak artış göstermesi gerekir. Firmaların talebin yıllık düzeyini bilmeleri; kendi geleceklerini planlamalarına olanak sağlar.

Bu makale beş bölümden oluşmaktadır. Birinci bölüm, giriş bölümüdür. İkinci bölümde "Ekonomik Büyüme Kavramı, Konusu ve Kapsamı" başlığı altında çeşitli ekonomik ekollerin teorik yapısına dair görüşlerine değinilmektedir. Dışsallığın iktisat teorisindeki arkaplan ele alınmaktadır. Üçüncü bölümde, içsel ekonomik büyüme modeli hakkında açıklamalar yapılmakta, Türkiye ekonomisinin OECD ülkelerinin verileriyle karşılaştırılması grafiksel metotla açıklanmaktadır. Dördüncü bölümde, sürdürülebilir büyümenin kapsamı hakkında açıklamalar yapıldı. Beşinci bölümde sonuç ve öneriler yer almaktadır.

\section{Ekonomik Büyüme Kavramı, Konusu ve Kapsamı}

Ekonomik büyüme, üretim faktörlerinin kişi başına reel milli geliri yükseltecek şekilde sürekli artmasıdır (Ünay, 1983). Ekonomik büyüme teorisi uzun süreli bir teoridir. Ekonomik büyüme konusuyla ilgilenme tarihsel arkaplanı olan bir konudur. Bu arkaplana aşağıdaki bölümlerde değinilecektir.

\subsection{Klasik Yaklașım}

Klasik ekonomistler büyümeyi, sadece sermaye birikimi anlamında ve basit bir şekilde ele almışlardı. Onlarda temel görüş« laisses-faire » ya da eylemci olmayan politikalardı. Onlara göre bireyler, rasyonel beklentilere yani; gelecek hakkındaki bilgilerin şu anki eniyi bilgilere bağlı olacağını, dolayısıyla hükümetin reaksiyonunun buna göre tahmin edebileceğini, hükümetin kontrolünün girişimleri zayıflatabileceğini düşünmekteydiler.

Klasik ekonomistlerin emek arzının içsel ve ekonomik büyümeyi açıklamada ana özellik olarak kabul etmiş olmakla diğerlerinden ayrılmışlardır. Bu Thomas Malthus (1766-1834)'un çalışmalarında belirgindir. Klasik büyüme modelinde kişi başına gelir düzeyi ve nüfus büyüme oranının arasında nedensel bir ilişkinin varlığ 1 belirleyicidir. Malthus'un meşhur görüşü, geçimlik düzeydeki kişi başına gelirin nereye kadar genişleyeceği, her zaman nüfusun belirleyeceği şeklindedir. Eğer gelir, geçimlikten daha yüksek ise ölüm oranları düşecektir. Çünkü beslenme standartları yüksektir, doğum oranı artar, insanlar daha fazla çocuk sahibi olmayı tercih ederler. Daha 
yüksek düzeyde popülasyon iş gücünün genişlemesi sonucunu doğurur ve azalan verimler yasası yürürlükte olması nedeniyle kişi başına verim düşer. $\mathrm{Bu}$ süreç kişi başına verim düzeyinin önceki düzeyi neredeyse oraya kadar devam eder. Doğum ve ölüm oranları ekonomi için istikrarlı nüfus ile tutarlı olmak zorundadır. Örneğin; bir defalık bazı teknolojik innovasyon ile emek verimliliği artmış olsun. Derhal kişi başına gelir artırıcı bir etkide bulunur. Yaşam standardı da artar. Ancak, bir dizi Maltusyan dinamikler harekete geçer. Popülasyon artmaya başlar, ardından gelir, yeni durumun denge düzeyine kadar düşer. Giderek kişi başına geçimlik gelir düzeyi, öncekinden daha yüksek olarak eski haline döner. Klasik büyüme modeline dair dikkate değer şey, büyümenin kalıcı olarak görülen bir olgu olmadığı, ya da dengeli ekonomik büyüme özelliğinin olmadığıdır. Ekonomik büyüme dengeli nüfus düzeyinden bir başka denge düzeyine geçişle devam eder. Ekonomi biliminde küçük bir başarı olarak klasik ekonomistlerce ekonomi bilimine "karamsar bilim" adı takılmıştı. Çünkü bu model uzun dönemde yaşam standartlarının iyileştirilmesinin imkansız olduğunu kabul eder.

\subsection{Neo-Klasik Yaklașım}

Büyüme sürecini modellemede Klasikler ve ardılı olan Neo-Klasikler arasında farklılıklar vardır. Neoklasik yaklaşımda büyüme süreci için bir takım ayırt edici özellikler şu şekilde sıralanabilir:

a) Uzun vadeli büyümenin motoru işgücü artı̧sı ve teknik gelişmedir.

b) Neoklasik teoride "teknik bilgi" bir kamu malıdır,

c) Farklı ülkelerin farklı büyüme hızlarına sahip olmalarının nedeni iş gücünün farklı oranda büyümeleridir.

d) İşgücü ve teknik gelişme faktörlerinin ikisi de exojen (dışsal) varsayılır.

e) Kişi başına gelirdeki büyüme ve sermayedeki artış teknik ilerlemeye yol açar.

Neo-Klasikler emek arzını büyüme modeline dıșsal olarak sunar dolayısıyla emek büyümesi teknolojik süreçle birlikte dengeli büyüme oranının temel determinantlarından biri kabul edilir. Bu açıklamalar için ekonomi yazınında dışsallık olgusunun tanımına açıklık getirilmelidir.

Dışsallık, mal ve hizmetlerin üretim veya tüketiminin, diğer kişilere maliyet (negatif dışsallık) veya yarar (pozitif dışsallık) getirdiği durumları ifade eden bir olgudur. Piyasa fiyatlarını etkilememekle birlikte toplum refahının artmasına ya da azalmasına yol açan her türlü etkidir. Bu tanıma göre; ahlak, estetik ve toplumsal değerler, ekonomik eylemlerin dışında tutulmuştur. Marshall'ın ortaya koyduğu dışsallık kavramını Pigou yeniden ele almıştır. Marshall'a, göre dışsallık; geniş ölçekte yapılan üretimin oluşturduğu dışsal etkiler olarak nitelendirilmiş olup, bu etkileri endüstriye giren her yeni firmanın, önceki firmaların ortalama üretim maliyetlerini azaltmalarıdır (Marshall, 1962: 227). Pigou, refah ekonomisi ile dişsal ekonomi arasındaki bağı kurmuş̧tur. Pigou'nun en önemli vurgusu, eksik rekabet piyasasında refah artışı için devlet müdahalesinin gerekliliğidir. Pigou'nun dışsallıklar teorisine katkıları ilk defa 1912 de yayınlamış olan "Wealth and Welfare" adlı eserde yer almıştır. Ancak bu eser dışsallıkla özet bilgiler içermekteydi ve Marshall'ın analizine dayanmaktaydı. Dışsallıkla ilgili detaylı bilgiler 1920 de yayınlanan "The Economics of Welfare" adlı eserinde ele alınmıştır ( Pigou,1912).

\subsection{Dıșsal Büyüme Modeli}

Standart büyüme hesaplaması toplam milli gelirin paydaşlarında emek ve sermaye ağırlıktadır. David Cass (1965) ve Tjalling Koopmans (1965) tarafından izlenen Frank P. Ramsey (1928), dışsal emek-teknolojik ilerlemeyi artıran bir ekonomi için sürekli zaman içinde en uygun büyümenin kanonik modelini oluşturdu. Toplam büyüme modeli veya Ramsey büyüme olarak bilinen model, bir neoklasik modeldir. Model, sadece iş çevrimindeki dalgalanmalardan çok, uzun süredir devam eden ekonomik büyümeyi açıklamayı amaçlıyor. Ancak, Neo-klasik büyüme modeli uzun dönemli büyümeyi açıklayamamaktadır. Uzun vadede büyümeyi açıklamada en önemli unsurun teknoloji olduğunu ifade eden Solow-Swan modelinden faklı olarak tüketimin seçiminde ayrılılar. Mikro düzeyde belirli bir zaman diliminde tasarruf oranı içseldir. Başlangıçta Ramsey, modeli, ardışık nesiller boyunca tüketim seviyelerini en üst düzeye çıkarmak için merkezi planlamacının bir sorunu olarak belirledi. Daha sonra Cass ve Koopmans tarafindan merkezi olmayan dinamik ekonominin tanımı olarak benimsenen bir model ortaya koymuşlard1.

Piyasa kusurları, hane halkları arasındaki heterojenlik veya dışsal şoklar gibi herhangi bir sorun kaynağı olarak düşünülmüyor. Bu nedenle araştırmacılar modeli genişleterek hükümet alım şokları, istihdamdaki değişiklikler ve gerçek "iş çevrimi teorisi" olarak bilinen diğer rahatsızlık kaynaklarına izin verdiler.

Neo-Klasik büyüme teorilerine dayanan "Dışsal Büyüme Teorisi"nin kurucularından biri de Solow' dur. Solow tarafından gerçekleştirilen çalışma bir neoklasik büyüme modeliydi. Solow'a göre geliri artıran şey, dışsal olan teknolojidir. Solow modelinde sermaye stoğu ve hasıla, nüfus artışı, teknik ilerleme hızlarının toplamına eşit olan dengeli bir büyüme oranında artmaktadır. Teknik ilerleme hem nüfusu ve hem de emeği çoğaltacak ancak, sabit bir hızda artmayan teknolojik ilerleme «sermayenin marjinal etkisi»nin azalması nedeniyle büyüme duracaktır. Sonuç olarak Lucas'a göre, Solow doğrudan bir büyüme teorisi geliştirmeye yönelik davranmamış, yalnızca ABD ekonomisinin büyüme dinamiklerini incelerken bir sonuç çıartmıştır (Lucas,1988). Keynesçi "knife-edge" teorisinin tersine, tam istihdamla istikrarlı ve uzun vadeli büyüme sorunuyla ilgilidir. Ekonomik süreçte uzun 
dönemde kişi başına milli gelir artmaktadır. Teknolojinin dışsal olmasına karşın, ekonominin kendi yapısal özelliklerinden kaynaklanan büyüme hızına herhangi bir etkide bulunmaz ve bu sabittir. Bu nedenledir ki teknoloji dışsaldır.

Schumpeter, teknolojik gelişmeleri ekonomik konjonktür içerisinde ele almıştır (Schumpeter, 1966). Ona göre; teknolojik gelişme, rekabetin bir aracı olduğu kadar "yaratıcı yıkım" aşamasını da tetikler. Yaratıcı yıkım; yeni teknolojilerin ve endüstrilerin ortaya çıkmasını sağlayan evrimsel bir süreçtir. Ekonomik büyüme de bu sürecin bir sonucudur (Justman ve Teubal, 1991). Schumpeterci görüş ile neo-klasik yaklaşım, teknolojinin dişsal bir kavram olduğunda ortaktır. Teknolojik yenilik ayrı ve daha geniş kapsamlı bir kavram olmak üzere üretimden, üretim yöntemi, pazarlama, yeni hammadde bulunması gibi aşamaları da kapsar. İçsel büyüme modellerini ortaya koyan evrimci yaklaşımın da temelini, Schumpeteryen kuram oluşturmaktadır

\subsection{Keynesyen Yaklaşım}

Hem Keynes hem de ardılı olan Keynesyenler genelde eylemci hükümet politikalarını esas almaktadırlar. Çă̆daş teoriler ise biri diğerinden daha önemli olmayan pek çok faktörlerin büyümeyi etkilediğini belirtmektedir. Bunların bazılarını şöyle sıralamak mümkündür: Çalışan başına düşen sermaye miktarı, sermayenin kalitesi, emeğin kalitesi, emek miktarı, yapısal değişimler, kurumsal çabalardır. Görüldüğü gibi bunlardan hiç biri diğerinden önemsiz değildir. Bu sayılanlara ek olarak, hızlı ekonomik büyüme için, istikrarlı bir şekilde sermaye stokunun varlığından, kalitedeki iyileşmeden, sağlıklı ve iyi eğitilmiş iş gücünden, nüfus artış oranından, kişi başına düşen sermaye oranından, teknolojik inovasyondan, enerji fiyatlarından, hizmetler sektörünün gelişmişliğinden de bahsedilmelidir.

Keynes'in ardılı olarak Kaldor'un büyüme modeline göre ekonominin dengeli gelişmesi, sermaye stokunun, toplam üretiminin ve emek prodüktivitesinin eşit oranlarda artışına bağlıdır. Kaldor; ekonomik büyümede öncü sektör olarak imalat sanayisini belirlemişti. Ona göre; herhangi bir ülkenin GSMH nın büyümesi yeni tekniklerin kullanıldığı imalat sanayisinin verimliliğine bağlıdır. Verimlilik artışı da çıktı artışına neden olmaktadır. Çıktı büyümesi, ölçeğe göre statik ve dinamik getirisi üzerine odaklanmaktadır.

Kaldor'a göre; imalat sanayisinde istihdam artışı tarım sektöründeki işsizliğe negatif bir etkide bulunacaktır. Kaldor'un büyüme yaklaşımı, ihracata dayalı büyüme olarak sanayileşmiş ülkelerde tüketim harcamalarının yanı sıra gelir tarafından desteklenen imalat sanayi yatırımları da talebin içsel bileşenlerindendir. Talep ise imalat sanayi dışından fakat yerel sektörlerden olan tarım kesimi, kamu harcamaları ve ihracat talebi gibi dişsal talepten kaynaklanabilmektedir. Bu durum Thirlwall tarafından da ele alınmış, açıklanması ise Harrod'un dış ticaret çarpanıyla yapılmıştır. Buna göre; uzun dönemli büyüme, sanayileşmiş ülkelerin ithalat talebinin gelir esnekliği ile ihracatın büyüme oranı tarafindan belirlenmektedir.

Neoklasik teoriden farklı olarak Kaldor'un yaklaşımı uluslararası ticaretin, faktör fiyatlarını eşitlemeyeceği ve mutlaka tüm ülkelerin gelirlerinin artmasını sağlamayacağı üzerine kuruludur. Kaldor'un birinci, ikinci ve dördüncü yasaları bazı ülkeler için kısır döngüye, bazı ülkeler içinse kendini besleyen büyüme sürecine işaret etmektedir. Böylece bölgesel ve ülkelerarası gelişmişlik farklılıkları açıklanmaya çalışılmakta, sürdürülebilir bir büyüme için dış talebin (bölge dışı veya diğer ülkelerden) önemi üzerinde durulmaktadır (Blecker, 2009: 22).

Domar; yatırımların gelir ve kapasite artırıcı etkisi görerek büyümeyi yatırıma bağlamıştır (Domar, 1970). Dengeli büyümenin olabilmesi için bu iki etkinin birbirine eşit olması gerekir. Yeni yatırımlar ekonominin üretim kapasitesini ve üretimini artırır. Harrod' da, fiili büyüme oranı, garantili büyüme oranı ve doğal büyüme oranı ayırımı yapmıştır (Harrod, 1970). Harrod-Domar modelinde büyümenin sürdürülmesi denge şartlarına bağlanmıştır. Dengesizliklerin önlenmesinde devlete dengeleyici rol verilmiştir. Bu modeller temelde N. Kaldor tarafından ele alınmıştır, A.P. Thirlwall tarafından ödemeler bilançosunu dikkate alan modellerle geliştirilmişstir. $\mathrm{Bu}$ modellerin uzun dönemli büyüme oranının yine bu ülkeye ait ihracatın ve ithalat talep esnekliğinin bir sonucu olarak belirleneceğini sunmaktadır (Thirlwall, 1979).

Neoklasik büyüme kuramı arz yanlıyken, Post-Keynesyen büyüme kuramı talep yönelimli büyüme kuramını benimsemektedir. 1930-1950 arası bir dönemde yoğun olarak tartışılan kapitalist bir ekonomideki büyüme, bölüşüm, ekonomideki ve gerçek dünyadaki kurumsal yapılar (örneğin endüstriyel yapı, piyasa yapısı) günümüzde de Post-Keynesyen büyüme kuramında önemli yer tutmaya devam etmektedir. Post-Keynesyen büyüme kuramı, Kaldor'un, Harrod'un istikrarsız büyüme modelini genişlettiği ve teknik gelişmeleri sistemin içine yerleştirdiği ihracata dayalı büyüme modelidir. Modele göre, ülkeler göreceli olarak hızlı teknolojik gelişmeyi gerçekleştirerek rekabet ortamında, ihracatını ve büyümesini artırabilir. Böylece kendini besleyen büyüme olgusu gerçekleşmiş olur.

1950 lerden 1980 lerin sonuna kadar iktisadi kalkınma teorilerinde hakim olan neoklasik yaklaşıma göre; kişi başına düşen sermaye miktarının artması sermaye faizinin düşmesine yol açar. Sermaye faizi sadece sermaye birikim hızının, işgücü artışındaki ve teknik gelişmedeki hıza eşit olması durumunda sabit kalır. İşgücünün sayısal artışı ve nitelikli teknik gelişme sermaye faizini geri çeker. 


\section{3 İçsel Büyüme Modeli ve Ar-Ge İlişskisi}

Dünyanın yoksul alanları için bile son elli yıldaki büyüme oldukça dikkat çekicidir. Kuzey Amerika, Batı Avrupa ve Japonya gibi gelişmiş ülkelerinin hariç tutulduğunda, kişi başına düşen ekonomik büyümenin, ömrün uzatılması, hastalık ve beslenme yetersizliğinden kaynaklanan ölüm oranlarındaki düşüşleri göz önünde bulundurulmalıdır. Nitekim Çin, Güney Kore ve Tayvan'ın ekonomik büyümesi, 1960'lardan bu yana, otuz ya da kırk yılda, İngilizler, Fransızlar ve Almanların yüzyıl veya daha fazla başarısını elde etmek için maddi gelişmeleri hızlı olmuştur.

Robert Lucas ve Paul Romer'in önderliğinde araştırmacılar fiziksel ve beşeri birimin birlikteliğinin ekonomik büyümeyi sürdürmek için yeterli olabileceğini açıklamışlardır. Bu araştırmacıların açıklamış olduğu modeller endojen (içsel) büyüme modelleri olarak adlandırılır (Romer, 1986; Lucas, 1988). Solow'a ait neoklasik modelinin azalan getiriye dayanan üretim fonksiyonunu değiştirerek bunun yerine sabit getiri fonksiyonunu benimsemişlerdir. Aslında bu "yeni büyüme teorisi" olarak 80 li yılların sonlarından itibaren, Kuzey Amerika kökenli bazı ekonomistler tarafından geliştirilen "Endojen Büyüme Teorileri” Neo-klasik iktisatçıların büyüme teorileri geliştirdikleri teorilerin bir parçasıdır hatta devamıdır.(Romer,1986;Verspagen,1992.b). Bu teori üretim fonksiyonunun değişkenlerini sorgulamaktadır. Ekonomik büyüme, insanların tasarruflarına ve tükettikleri gelirlerinden daha fazlasını yatırımlara ayırmasına bağlıdır. Şu andaki yatırım, gelecekteki üretim için kullanılabilecek, daha fazla çıktı ve daha az çaba gerektiren makine yaratmaya yardım edecektir. Bugün kullanılan ham maddeler son çeyrek yüzyıldır değişmedi ancak deneme yanılma, bilimsel araştırmanın sonucunda hammaddeleri birleştirmede izlenilen yöntemler- talimatlar çok daha karmaşık hale geldi. Hammaddeleri kullanmak suretiyle teknolojiyi elde etmek daha heyecan verici sonuçlar ortaya çıkarmıştı. Ancak bugün onların sıradan bir sonuç olduğu izlenmektedir. Bu model Romer'e göre üç önermeye dayanmaktadır. Bunlardan birincisi; Ekonominin kalbindeki hammaddeler için yeni talimatlar, makine ve teknolojik değişim ekonomik büyümenin merkezindedir. Teknolojik değişim, devam eden sermaye birikimine teşvik sağlar ve birlikte, sermaye birikimi ve teknolojik değişim, çalışılan saat başına çıktıdaki artışın sayısal olarak daha fazla artırır. Sonuç olarak burada sunulan model Solow'un sunduğu teknolojik model ile benzeşmektedir (Solow,1956). İkincisi, teknolojik değişimin, büyük oranda piyasa teşviklerine cevap veren kişilerce, bilinçli eylemler nedeniyle ortaya çıkmasıdır. Dolayısıyla model ekzojen olmayan teknolojik değişimden ziyade içsel faktörlerden biridir.

Uzun döneme dair sezgici ekonomistlerin çoğu bu temel formu devam ettirdiler. Yatırımlardaki getiri oranlar ve kişi başına çıktının kişi başına sermaye stoğu düzeyinin azalan bir fonksiyonu olduğundan bahsetmektedirler. Fazla mesai ücret oranları ve sermaye-emek oranları farklı ülkelerde değişik ve yakınsaması beklenmektedir. Sonuç olarak başlangıç koşulları veya güncel bozukluklar dikkate alındığında, tüketim düzeyi üzerinde uzun dönemde etkisiz olduğu ifade edilmiştir. Örneğin: veri bir ülkede sermaye büyüme stoğundaki eksojen bir düşüş, yatırımdaki artışı dengeler. Teknolojik değişimin yokluğunda, kişi başına çıktı denge değeri ile kişi başına büyüme ile yakınsamış olmalıdır. Tüm bu varsayımlar kişi başına çıktı üretiminde kişi başına sermayenin azalan verimler varsayımı ile direkt ilgilidir. Romer'in sunmuş olduğu model uzun dönem büyüme için alternatif bir görüştür.

Piyasa teşviklerinin, yeni bilgilerin pratik değere sahip mallara dönüştürülmesi sürecinde önemli bir rol oynamasıdır. Örneğin, herhangi bir teknik alet hakkındaki ilk anlayış, yapılan araştırmalardan ortaya çıkmaktadır. Daha sonra da o aletten şekil, düzenek ve çeşitli estetik özellikleri özel firmaların kazanç elde etme girişimlerinden kaynaklanır. Üçüncüsü; hammaddelerle çalışma kurallarının diğer ekonomik ürünlerden doğası gereği farklı olmasıdır. Bilginin yeni bir seti oluşturulduktan sonra bilgi ek bir ücret ödemeden tekrar tekrar kullanılabilir. Daha iyi bilgiyi geliştirmek, sabit bir maliyet ödemeye eşdeğerdir. Bu özellik, teknolojinin belirleyici özelliği olarak anılmaktadır. Ekonomik büyüme sadece gündelik yaşam bakımından kaynakları aynı kullanma türünden daha fazla şey yaparak gerçekleştirirse, sonunda hammadde tükenecek ve kabul edilemez kirlenme seviyeleri ve krizler yaşanacaktır.

Büyüme hesaplamasında standart yöntem, sermaye ve emek girdilerinin değerlerinden toplam gelirdeki payları, toplam çıktıdan toplam faktör girdilerinin büyüme oranları çıkarılarak elde edilir. Bu dışsal verimliliğin büyüme göstergesidir. Son yıllarda çok sayıda ekonomist bu prosedürün yetersiz olduğunu iddia etmeye başlamıştır. Romer'in çalışmaları buna değişik bir yöntem getirmiştir (Romer, 1986). Lucas modelinde ise, tek sektörlü bir ekonomide fiziksel sermaye ile birikim ilişkilerinde yoğunlaşmaktadır (Lucas, 1988). Nüfus, dışsal olarak alınmaktadır. Lucas; teknoloji ve bilgi stoku kavramlarının farklı olduklarını ifade eder. Beşeri sermayenin dışsal etkilerini modele katmaktadır.

İçsel büyümenin arkasındaki temel fikir, ölçülen faktör girdilerinin büyümesiyle yakından ilişkili olan ve dışsal bir teşvik olarak görülmemelidir. Bu iki yolla açıklanabilir. Birincisi; bilginin yayılmasıdır. Bu konu şu sorunun cevaplandırılmasını gerektirir. Sermaye stoğuna pozitif bir etkisi olan bilgi düzeyi gerekli midir? Buna birinci gerekçe; sermaye büyümesi genellikle en son teknolojik gelişmelerin meyvesi olan yeni makinelerin kurulumunun bir sonucudur. Bir kere sermaye kurulduktan sonra bu araştırma etkin bir şeklide kamu malı haline gelir. Herkes ona uyar ve innovasyonu taklit eder. Bu dönüşüm herhangi bir yerdeki firmanın sermaye stoğunu artırmasını ifade eder. İşte bu durum bilginin dağılımını açıklamaktadır. Bilgi dağılımı sermaye stoğu ile pozitif ilişkilidir. Modelin bu tipinde Pareto yetersizliği ile sonuçlanacak olan enteresan bir refah mülkiyeti ortaya çıkar. Dolayısıyla firmalar 
tüm yatırımlarını yeni teknolojiye tahsis etmezler, hem sermaye hem de temel araştırmayı azaltma eğilimine giderler.

İkincisi; uzmanlaşmış sermayedir. İçsel büyüme yaklaşımı genelde Klasiklere, özelde ise, Adam Smith’e kadar uzanan bir fikir olarak mevcuttur. Üretime katkıda bulunan sermaye miktarının bir fonksiyonu değildir, fakat uzmanlaşmış birimler kendi içinde bölünmüştür. Örneğin; makine araçlarından oluşan sermaye stoğu varsayılsın, sermaye stoğunun verimliliği tüm görevleri yerine getiren genel amaçlı araçlara veya kendi içinde alt gruplara bölünen belirli üretim gereksinimlerince tolere edilen çok sayıda alt gruplarca karşılanabilir. Böylece sermaye stoğu artar ve daha yüksek düzeyde uzmanlaşmış sermaye mallarının stokları artmış olur. Bu nedenlerle emeğin verimliliği daha yüksek düzeyde artmış olur (Turner,1993).

Potansiyel gelir hesaplamalarında aktüel milli gelirin kısa vadeli dalgalanmaları göz ardı edilir, potansiyel geliri artırmak için yatırımın etkileri üzerine yoğunlaşır. Uzun dönemde tasarruf paradoksu söz konusu değildir; toplumlar yüksek tasarruf oranları sayesinde yüksek yatırımlar yaparlar ve diğer şeyler sabitken, reel gelir yüksek düzeydedir. Buradaki diğer şeylerden kastedilen; yönetimlerin iş alemine olan politik baskılar, artan vergi oranları, politik liderlerin destekleri, politik stratejiler, gıda maddelerindeki fiyat artışları gibi şeylerdir.

Ekonomik büyümenin göstergesi GSMH daki artıştır. Bu artışla üretim artışı ifade edilir. Aksi halde ekonomik durgunluk ve gerileme söz konusu olacaktır. Kısaca ekonomik büyüme, üretim kapasitesindeki artışlar olarak tanımlanabilir. GSMH daki artış, sonuç itibariyle kişisel gelirini ve bireylerin yaşam standardını artıracak harcamaları için daha fazla bir kaynak elde etme başarısıdır. Günümüzde gelişmiş ekonomilerin çoğunda fiilen çalışma zamanlarını kısaltmak için bir çaba içerinde oldukları görülmektedir. Bunu ortaya çıkarabilecek şey ise; teknolojidir. Diğer taraftan teknolojinin meydana getirdiği kirlenme dolaylı olarak GSYİH da azaltıcı bir etki oluşturmaktadır. Örneğin kullanılan fosil yakıt türleri 1sınma başta olmak üzere birçok farklı alanda kullanılmaktadır. Fakat kalitesiz yakıtlardan yüksek karbon salınımı nedeni ile hava kirliliği meydana gelmekte ve bu durum dolaylı yoldan insanların da sağlığını etkilemekte ve bu da doğal olarak GSYİH yı olumsuz etkilemektedir.

GSYIMH daki, değişiklikler insanların günlük yaşamlarının büyük ölçüde değiştiğini göstermektedir. Bu dönüşümün nedeni, teknolojik gelişmeye ve toplumun büyük miktarda ekonomik özgürlüğüne sahip olmas1 nedeniyle sermayenin birikimidir. Bu dönüşüm sadece kişi başına düşen GSMH ile değil, aynı zamanda ölüm oranlarının düşmesine de bağlıdır (Fogel,2004). Bahsi geçen husus eskisinden daha temiz su, gıda maddelerinin miktar ve kalitesinden ve temiz hava sayesinde gerçekleşmektedir (Baumol, 1995).

Ekonomik büyümede ölçütün GSYİH nın uzun dönemde ortalama vatandaşın yıllık gelirinin, kaç fazla artmış olduğunu göstermektedir. Örneğin Türkiye'nin 2000-2015 dönemi büyümesine dair gelişme Grafik 1 de belirtilmiştir.

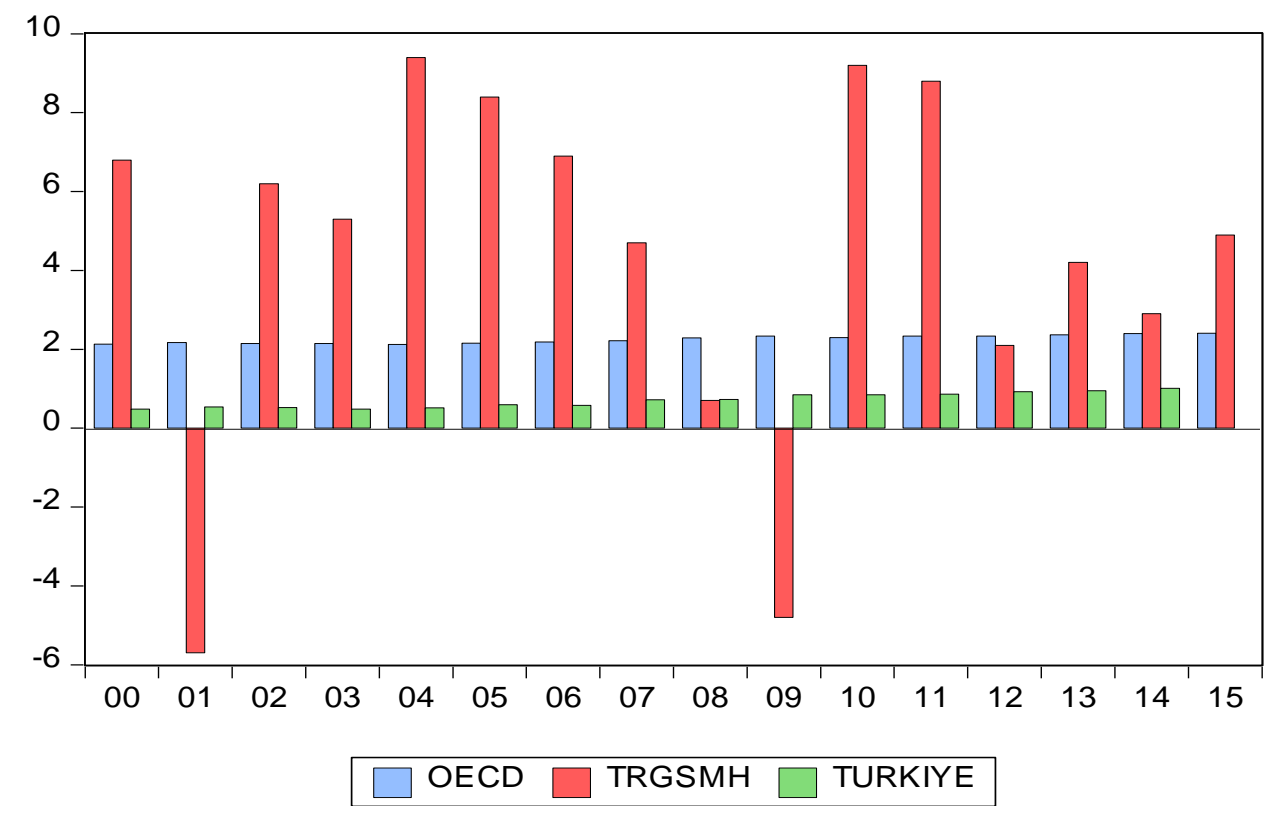

Grafik 1. 2000-2015 arası OECD Ülkelerinin AR-GE/GSMH Paylart ile Türkiye'nin AR-GE/GSMH Payları Karşılaştırmast. Kaynak:TÜIK;www.hazine,org.tr; OECD

Grafik 1 de mavi butonla 2000-20015 yıllarını kapsamak üzere OECD verilerine göre üzere AR-GE/ GSMH, yeşil butonla Türkiye'nin yine anılan yıllar içerisinde OECD verilerine göre AR-GE/GSMH oranları, kırmızı buton ile Türkiye'nin 2000-2015 dönemindeki GSMH yüzde büyüme oranları gösterilmektedir. 


\begin{tabular}{|l|l|l|}
\hline TRGSMH & 1.000000 & -0.174559 \\
\hline TÜRKIYYE & -0.1745591 & 1.000000 \\
\hline
\end{tabular}

Tablo 1 Türkiye Ekonomisinde 2000-2015 Dönemine Ait \%GSMH ile AR-GE/GSMH Korelasyonu

Tablo1 deki korelasyon katsayılarının yorumu: Korelasyon analizini yaparken katsayı (r) ile gösterilir. ( r ) nin değerleri $-1 \leq r \leq+1$ ölçütüne uyar. Korelasyon katsayısı (0) ise değişkenler arası ilişki yoktur. İlişkinin şiddeti ise şu şekilde ifade edilmektedir:

0 - 0,49 arası korelasyon katsayısı zayıf; 0,5-0.74 arası korelasyon katsayı orta; 0,75-1 arası korelasyon katsayısı kuvvetlidir. Bu ölçütlere göre mutlak değerlerle bakıldığında Türkiye açısından AR-GE ayrılan pay bir hayli düşük değerleri göstermektedir.

\section{Sürdürebilir Büyümenin Sağlanması}

\subsection{Sürdürülebilir Büyümede Literatür}

Ramirez (1997)'e göre, sürdürülebilir büyüme doğal çevresel sermaye stokunun korunarak ekonomik büyümenin gerçekleştirilmesi ve her zaman çevre kalitesinin devam ettirilmesini ifade etmektedir. Dinler (2002) büyümeyi, çevreyi tahrip etmeden sağlamanın yollarının araştırılması gerektiğini ileri sürer. Walde (1999: 207)'ye göre, "Kirlilik/üretim" oranını azaltan yeni teknolojilerle büyüme sürdürülebilir hale gelecektir. Bu nedenle sürdürülebilir bir büyüme için bilgi birikimi ve bunan bağlı olarak yeni teknolojiler kritik hale gelmiştir. Sürekli yeni bilgi olmazsa dünya nüfusunun şimdiki ihtiyaçlarını ve arzularını karşılayabilmek hiçbir yerde mümkün olamaz (Lipsey, 1990: 358). Bartelmus (1995)'a göre sürdürülebilir büyüme için reel değişkenlerin aynı sabit hızda büyümesi gerekmediği, eğer gelecek nesillerin büyümesi için yeterince doğal kaynak ayrılıyorsa, ekonomideki reel değişkenler aynı sabit hızda büyümeseler de büyümenin sürdürülebileceğini ifade eder. Faucheux (1997)'a göre sürdürülebilir büyüme kısa dönemdeki büyüme hızının uzun dönemde devam etmesidir. IMF ve T.C.M.B. yayınlarına göre; çevresel bağlantı olmaksızın oluşan büyümenin kalıcı hale gelerek uzun dönemde devam etmeyeceği iddia edilmektedir. (Saçkan (2006). Basu (2001) sürdürülebilir büyümenin kriz yaratmayan bir büyüme şekli olduğuna işaret etmektedir. Camdessus (1995)'a göre sürdürülebilir büyümenin kamuda denetim, tasarruflar, artan kurumsallaşma, dışa bağımlılığın minimize edilmesi gibi bileşenlere bağlı olduğunu ifade etmiştir. O'na göre kamu sektörünün sıkı denetiminin en önemli göstergesi ise kamu tasarruflarındaki artıştır. Uysal (2013) tarafından yapılan çalışmada sürdürülebilir büyümenin ekoloji bilimiyle yakın ilintili olduğu, ekonomideki reel değişkenler sabit hızda büyümemesine karşın ekonomik büyüme kalıcı olduğu sonucuna ulaşılmıştır. Türkiye'nin sürdürülebilir büyüme performansını yakalayabilmesi için "teknoloji geliştirme", "işgücünün eğitimi” ve “sermaye yatırımları” konularına öncelik vermesi gerektiğini söylüyor. Ona göre, bu 3 alanda iyileşme sağlanırsa, yüzde 7'lik büyüme temposunu yakalamak mümkündür (Acemoğlu, 2005). Örneğin Türkiye'nin sürdürülebilir bir büyüme yakalayabilmesi için bu üç unsurun da kesintisiz olarak devam etmesi gerekiyor. Kendi içinde bir krize yol açacak dinamikleri olmayan bir büyümeden bahsetmektedir.

Sürdürülebilir büyüme, fiyat istikrarının bozulmadığı, ekonomik göstergeler ile makroekonomik dengelerin uyumlu olduğu, potansiyel büyüme seviyesine yakın büyüme oranlarının kalıcı olarak sağlandığı ekonomik büyümeyi ifade eder. Büyümenin sürdürülebilir olması neden gereklidir? Birinci neden; sermayenin marjinal etkisinin azalma yerine artmasıdır. Yani sermayenin getirileri uzun dönemde artmalıdır ki bu sayede yeni yatırımlar teşvik edilmiş olsun. İkinci neden; Sürdürülebilir büyüme ancak teknik ilerlemeye bağlı bir dışsal trend mevcutsa görülebilir. Üçüncü neden; Sürekli bir büyümeye ulaşmak için girdilerin verimliliğini artıran ve dışsal bir faktör olan teknik ilerleme üretim fonksiyonuna dahil edilmelidir. Sürdürülebilir ve yüksek bir büyümeyi sağlayabilmek için gerekli üç ana başlık sıralanabilir; 1. Makroekonomik istikrar: 2. Yapısal reformlar 3. İyi yönetim

Ekonominin hedefleri GSYİH yı ve dolayısıyla kişi başına düşen milli geliri artırmak ise, bunun önündeki engeller ve sorun nüfus ve işsizlik olarak saptanmaktadır. Belirtilen engeller ve sorunların çözümünde gelişmiş olan ekonomilerde uygulanan yöntemlere, örneğin Amerika, Kanada, Avustralya gibi İngilizce konuşan ülkelerin ayırt edici özelliklerine bakıldığında; azami bireysel girişimi, asgari devlet müdahalesini, serbest ticareti, serbest piyasayı ve bireysel girişimci için yüksek kazanç olduğu kadar yüksek riski de içerdiği görülmektedir. Ulusal ekonomik planlamayı veya sanayi stratejilerini rekabete aykırı, bireysel ve piyasa özgürlüklerine karşı girişimler olarak değerlendirilir.

Endojen Büyüne Teorisine göre, gelişmiş ülkelerden, gelişmekte olan ülkelere sermaye akışı olmamıştır. Bu nedenle sermaye faiz oranının küresel yakınsaması ve uzun vadede dengeye ulaşması da söz konusu olamaz (Ghatak,1995). Açıklamaya çalışılan endojen büyüme Teorisi’ Romer'in ifadelerine göre; teori, pratik ve teorik olarak tatmin edici olmaktan uzaktır (Romer, 1994). Romer'e göre içsel büyüme modelinde teknolojik gelişmenin maliyetini azaltmak için bilgiyi üreten bir konumda olmanın yönteminin teoriden çok pratik yönüne ağırlık verilmesidir. 


\section{Sonuç}

Teknolojinin yaygınlaşması için liberal dış ticaret politikaların uygulanması gereklidir çünkü üretimin maliyetinin düşmesi açısından yararlıdır.

Özellikle Türkiye açısında Ar-Ge Harcamaları/GSYİH oranının artırılması gereklidir.

Beşeri sermaye büyüme oranı, beşeri sermaye yatırımındaki etkinlik ile artırılabilir.

Ekonomik büyümenin dengeli ve sürekli olması için yalnız yeni yatırımlarla kapital stokunun arttırılması yeterli değildir. Sermaye stokundaki artış oranına denk bir prodüktivite yükselişine ve istihsal çoğalışına da ihtiyaç vardır.

Türkiye ekonomisine yönelik teknolojik gelişme ve inovasyon teşvikleri artırılmalıdır.

Sürdürülebilir büyüme için azami bireysel girişimci, asgari devlet müdahalesini, serbest ticareti, serbest piyasayı kollayan iktisadi politikalar için ortam sağlanmalıdır. Bu ortamın bireysel girişimci için yüksek kazanç olduğu kadar yüksek riski de içerdiği görülmektedir.

Ulusal ekonomik ve sanayi stratejilerinin rekabete aykırı, bireysel ve piyasa özgürlüklerine karşı girişimler olarak değerlendirilmektedir.

\section{Kaynakça}

- Acemoğlu,D.2015.Capital.http:// www.capital.com.tr(15.07.2015).

- Bartelmus, S.P. 1995. “ Environment, Growth and Development”, London, Routledge.

- Basu, A. 2003. The Role of The IMF in Africa, http://www.unitar.org/dfm/Resource_Center/Document_Series/Document16/DocSeries16.pdf/, (15.04.2012).

- Baumol, W.J., and Wallace E. O.(1995) “Long Run Trends in Environmental Quality”, Oxford.

- Camdessus, M. 1995. Income Distribution and Sustainable Growth, International Monetary Fund (www.imf.org/,2011).

- Dinler, Z. 2002. “İktisada Giriş”, Ekin Kitabevi, Bursa.

- Domar, E. 1970. "The causes of slavery or serfdom: a hypothesis”, Journal of Economic History. Cambridge, 30: 18-32.

- $\quad$ Fogel, R. W., 2004. “The Escape from Hunger and Premature Death”, Cambridge,70. p..950.

- Ghatak, Subrata, 1995. “.Introduction to Development Economics.” London.

- Harrod, R.F., 1970 "Harrod after twenty-one years: A comment", Economic Journal

- $\quad 80$, pp. 737-41.

- Justman, M., ve Teubal M.,1991 “A Structuralist Perspective on the Role of Technology in Economic Growth and Development”, World Development, . 19,p.9.

- $\quad$ Lipsey, R., Steiner, P.O., Purvis, D.D. ve Courant, P.N., 1990. "Economics” McGraw Hill Companies Inc., New York. P: 358.

- $\quad$ Lucas, R.E.,(1988) “On the Mechanics of Economic Development”, Journal of Monetary Economics , 22 (1),pf. $3-42$.

- $\quad$ Lucas, Robert E., 1988. “ Journal of Monetary Economics”, 22,(1),Jully(3-4).

- Marshall, A., 1962."Principles of Economics”, London.

- OECD,2015..http://www.oecd.org/Turkey.

- Pigou, A. C. 1912. “Wealth and Welfare”, London.

- Robert A. B. \& Arslan R. 2009. "Export-led Growth, Real Exchange-rates and The Fallacy of Composition", American University, Department of Economics. 22.

- $\quad$ Ramirez, D., Khanna, M. ve Zilberman, D. 1997. "Conservation Capital and Sustainable Economic Growth, Environmental and Resource Economics" Working Papers, No. 25: 1-34.

- $\quad$ Romer, P., 1986. "Increasing returns and long-run growth", 94:1002-37.

- Romer, P.M.,1994. “The Origins of Endogenous Growth” Journal of Economic Perspectives, 8: 3-22.

- Saçkan, O. 2006. “Genel Fiyat Düzeyinin Belirlenmesinde Para Ve Maliye Politikası Dominant Rejimler: Türkiye Örneği” 1988 - 2005, Uzmanlık Yeterlilik Tezi, Türkiye Cumhuriyet Merkez Bankası Emisyon Genel Müdürlüğü, Ankara.

- Turner, P., 1993. "Modern Macroeconomics Analysis." London.

- $\quad$ TÜİK, (http://www.tuik.gov.tr/,2015) 
- TC.Hazine Müsteşarlığ1,(.http://www.hazine.org.tr/makaleler, 2016).

- Unay, C.,1983. "Makro Ekonomi”, Bursa.

- Uysal,Ö.,2013. “Uluslararası Alanya İşletme Fakültesi Dergisi International Journal of Alanya Faculty of Business" 5(2): 111-118.

- Vespagen, B. 1992. “Endogenous Innovations in Neo-clasical Growth Models: a survey”, Journey of MacroEconomics, $14: 631-62$.

- Walde, K. 1999. " Recent Research in Endogenous Growth: A Review of Aghion and Howitt's Textbook " The World Bank, AFTM4, Washington DC, 20433, U. S. A. 


\title{
Yeşil Üretim Uygulamaları \\ Green Production Practices
}

\author{
Asst. Prof. Dr. Nevin Aydın (Kyrgyzstan-Turkey Manas University, Kyrgyzstan)
}

\begin{abstract}
Green production is a method developed for manufacturing, which leads to the greatest reduction in waste and pollution through process design. Creating sustainable products that become an increasingly popular trend for the conservation of natural resources that will remain in future generations, such as making the product reusable, making it appealing for producers, increasing sales, lowering operating costs, and providing collective benefit. The legal requirements of green production are supported by consumers in many countries around the world. While these changes encourage companies in different sectors to offer products and services with an environmentally sensitive approach, green applications are emerging, focusing on creating economic and ecological values in every process of the product. In this study, we discuss the benefits and examples provided by the firm and gathering of green production.
\end{abstract}

\section{Giriş}

1970'lerin sonlarından itibaren sanayileşme devrimiyle hızlı gelişimi ve nüfus artışı, çevre kirliliğini artarak hem canlılar hem de doğal kaynaklar üzerinde geri dönülemez olumsuz etkiler yaratmıştır. Bunun sonuçunda, çevreyi koruma için yasal düzenlemeler yapılmış, uluslararası sözleşmeler imzalanmıştır. Son zamanlarda su, enerji ve malzeme gibi kaynakların en az kullanımını ve atıkların en aza indirimini amaçlayan yeşil üretim uygulamaları başlamıştır. Uluslararası düzeyde ortaya çıkan sürdürülebilirlik kavramı sosyal ve ekonomik hayatı etkilemiş. İşletmeler, çevreye duyarlı üretim süreçlerinde, çevreye olumsuz etkileri en aza indirerek maliyetlerde azalma yaratmışlardır.

Weismann, et.al, çevreye duyarlı üretimin, çevre yasalarına uyumun ilerisine giderek, kirliliğin önlenmesi felsefesini desteklediğini açıklamışlardır.

Yeşil üretimle temiz çevre oluşturmak ve ekonomik kalkınmayı destekleyerek toplum gereksinimlerini en az malzeme ile sağlamdır.

Yeşil üretim planını ve mümkün olan en az çevresel kirliliği, daha az kaynak ve enerji tüketimi üretim teknolojisi programını ve proses rotalarına ekleyerek uygulamalarıdır. Yeşil imalata ulaşmak için güvenlik problemleri, ürün kullanıcıları için çevre sağlık tehditleri ve mümkün olduğunca üretim sürecinde sıfır çevresel kirlilik, atık geri dönüşümü ve atık bertarafını içermektedir (Gao, 2009).

Son yıllarda Yeşil ve Sürdürülebilirlik arasında farklar çıkmasına ragmen, "Yeşil" ve "Sürdürülebilirlik" kavramları genellikle birbirlerinin yerine kullanılır. Sürdürülebilir ürünler ya tamamen yenilenebilir ya da sürdürülebilir hasat edilen, sorumlu kaynaklı ürünler kullanarak çevre üzerindeki etkilerini azaltırlar. Sürdürülebilir hasat ile elde edilen ürün, çevreyi, havayı kirletmeyecek ve kaynağı kalıcı bir şekilde azaltmayacak şekilde toplanmaktadır (Yeşil1).

\section{Yeșil Üretim}

Yeşil imalat, 1990'lı yılların bir ürünü olarak görülebilecek yeni bir kavramdır. Yeşil üretim, ekonomik olarak yönlendirilen, sistem çapında ve entegre bir yaklaşım olarak tanımlanmıştır. Tasarım, üretim, kullanma ve / veya kullanma ile ilgili tüm atıkların azaltılması ve ortadan kaldırılması, Ürünlerin ve malzemelerin elden çıkarılması (Handfield, 1997).

Yeşil" terimi, günlük yaşamda belirsizlik diye tanımlanır (Elsayed, 2006). Yeşil üretim, üretim süreçlerinin yenilenmesi ve üretim alanında çevre dostu süreçlerin oluşturulmasıdır. İş gücünün daha az doğal kaynak kullanması, kirliliği ve atıkları azaltılması, materyalleri geri dönüşümü yeniden kullanımı ve bertaraf edilmesi şeklindedir.

Yenilenebilir kaynaklardan gelen enerji. Çalışanlar, kuruluşları dahilindeki enerji verimliliğini artırmak için belirli teknolojileri ve uygulamaları kullanırlar; yenilenebilir kaynaklardan elektrik, 1sı veya yakıt üretebilir. Bu kaynaklar rüzgar, biyokütle, jeotermal, güneş, okyanus, hidroelektrik, depolama gazı ve katı atıklarını içerebilir.

Firmalar çevresel duyarlılıgı gözönüne alırken, üretim süreci boyunca oluşacak artıkların geri dönüşümünü maksimize etmektir.

Yeşil üretim farklı yöntemlerle ürünlerin tekrar kullanımını sağlayarak hammadde kullanımını azalmak ve canlıların sağlılığına olan zararlı etkileri minimum seviyeye düşürmektir.

Yeşil üretim süreçlerinin özellikleri şu şekilde belirtilebilir (KTO)

- Daha az doğal kaynak tüketir 
- Üretim için daha az enerjiye gereksinim duyar

- Küresel iklim değişikliğine yol açan zararlı gazlardan daha az ortaya çıkarır

- Daha az toksik materyal kullanır ve ortaya çıkarır

- Daha az atık meydana getirir

\section{Yeşil Üretim Yaklaşımı}

Yeşil üretim, çevre etkileri düşük girdiler kullanan, yüksek verimliliğe sahip olan ve çok az veya sıfir atık içeren ve kirlilik oluşturmayan üretim süreçlerini kapsar (Atlas, 1999). Bu tanımıyla yeşil üretim atık ve kirliliğin engellenmesi veya azaltılmasını, geri dönüşümü ve yeşil ürün tasarımını içeren faaliyetler çerçevesinde ele alınabilir. Tasarımıyla, bileşimiyle ve kullanımıyla çevreye olan etkileri yaşam döngüsü süresince en aza indirilmiş ürünlerin yaratılması süreci yeşil ürün tasarımını ifade etmektedir. Mark Atlas ve Richard Florida yeșil üretim alternatiflerini beş başlık altında incelemişlerdir (Atlas, 1999): Ürün değişikliği, üretim süreçlerinde değişiklik, üretim girdilerinde değişiklik, atıkların dahili kullanımı ve daha iyi yönetim. Çevreye etkileri minimum veya az olan ürünlerin üretilmesi yeşil üretim için en basit yaklaşımdır. Fakat mevcut üretim süreçlerinde değişiklik yapmak; en başta insana dayalı süreçlerden kurtulmayı, grup üretim süreçleri yerine sürekli süreçlerin kullanılmasını, üretim sürecinde izlenen adımların sırasını değiştirmeyi ve sayısını azaltmayı, son olarak da temizleme işlemlerinde değişiklik yapmayı gerektirmektedir. Öte yandan, üretim girdilerinde değişiklik yapmak, yeşil üretim için önemli kazançlar sunmaktadır. Bunun için, üretime katkı sağlayan fakat sonuçta üretilen ürünün içinde yer almayan büyük küçük her türlü malzeme ve girdinin değiştirilmesi iyi bir strateji olacaktır (Yavuz, 2010).

\section{Yeşil Ergonomi}

Ergonomi bilimi tüm bu işlevleri yerine getirirken hedeflediği verimlilik, yeterlilik, sağllk, güvenlik ve kullanılabilirlik gibi unsurlar çevresel sürdürülebilirliğin hedefleriyle örtüşmektedir (Thatcher, 2013).

Ekolojik çevreye duyarlı olmak, işletmelerin kendi iç çevrelerindeki ergonomik ve sosyal koşulları da, yeşil anlayış çerçevesinde geliştirmeyi gerekli kılmaktadır. Toplam ekoloji, çalışma ortamlarının ve çalışma alışkanlıklarının, ekolojik anlamda iyileştirilmesini de kapsamaktadır. Çalışılan mekanlarında kullanılan araçgereç ve büro malzemelerinin çevreye duyarlı, tekrar kullanılabilen ve geri kazanıma müsait, bilgisayar ve benzeri donanımın çevreyi ve insan sağlığını tehdit etmeyecek kalitede ve düzenlemesi, yeşil ergonominin başlıca dayanaklarıdır (Hawkins, 2001).

Martin, et.al ergonomi ve sürdürülebilirliğin tasarımcıların çalışmalarında teşvik edilmesi gerektiğini vurgulamış ve ergonomi ve insan faktörleri uygulayıcılarının kalite ve verimliliğin geliştirilebilmesi için bu çalışmalara dâhil edilmesi gerektĭgini belirtmişlerdir.

Sürdürülebilir ürün tasarımı ve ergonominin buluştuğu noktada yeşil ürünler "green products" olarak adlandırılır. Çevresel koruma amacıyla yapılan çalışmalarda ergonomi ve tasarım alanında bütünleştirilmiş yeşil ürünler tasarlama olanaşı doğmuştur.

\subsection{Yeşil Üretimin Avantajları}

1. Havaya zararlı hiçbir atık yayılamaz

2. Bazı durumlarda ekonomik yararlar sağlayabilir.

3. Az kaynakla üretim bunun sonuçunda maliyetlerlerde azalma saglanabilir

4. Yenilenebilir alternatifler, bitmeyen kaynak demektir.

5. CO2 sara gazını azaltarak küresel ısınmanın etkilerini yavaşlatabilir.

6. Verimli enerji kullanımı sağlanabilir

7. Maliyetlerin azalmas1

\subsection{Yeşil Üretim Uygulamaları}

Unilever, 190'dan fazla ülkede satılan ürünleri ile her gün 2.5 milyar tüketiciye ulaşan, Gıda, Ev Bakım, Kişisel Bakım ve İçecek Ürünleri konusunda dünyanın önde gelen tedarikçilerinden biridir. Dünya genelinde 169.000 çalışanı olan Unilever, 2016 yılında 52.7 milyar Avroluk yıllık satış hacmine ulaşmıştır. Unilever, 2025 yılına kadar ürünlerinde kullandığı plastik ambalajların yüzde 100'ünün yeniden kullanılabilir, geri dönüştürülebilir olacağını açıkladı. Bu kapsamda Unilever, hızlı tüketim ürünleri endüstrisini, "al-kullan-çöpe" at şeklinde olan tüketim modelinden ürünlerin ve üretim süreçlerinin ürünlerin yaşam döngüleri sonunda kolaylıkla yeniden kullanımlarının ve geri kazanımlarının gerçekleştirmektedir.

Depolama atıklarının yaklaşık \% 30'u ambalajlardan oluştuğu için, ambalajlama sürdürülebilir ürün imalatının önemli bir bileşenidir. Birç̧ok şirket ambalajlarını küçültmekte veya geri dönüştürülebilir malzemelerle yapmaktadır. Ambalajın azaltılması, ürünün kullanım sonundaki atık kalıntılarını ortadan kaldırmakla kalmaz aynı 
zamanda imalat, kaynak maliyetleri, Atıklardan enerjiye üretimdeki artış eğilimi. Üreticiler, atıklarını, temiz, yenilenebilir enerji kaynağı olan buhar haline getirmek için yanmayı kullanan bir bitkiye atıklarını gönderebilirler. Yerel ham maddelerin tedarik edilmesi ve ürünlerin mümkün olduğunca yerel olarak satılması bir imalat tesisinin çevresel etkisini azaltmasına yardımcı olabilir. Nakliye masrafları çok daha düşük olacak ve yerel ekonomiyi artırmaya yardımcı olabilir. Depoların veya ana müşteri tabanının yakınında bir üretim tesisi bulunması, maliyet ve enerji kullanımını azaltan ulaşım mesafelerini önemli ölçüde azaltabilir (Unilever).

Coca Cola, Sürdürülebilirlik İşinin uzun vadede sürdürülebilirliğini sağlamak için çevrenin korunmasında proaktif ve yenilikçi davranarak, tüm paydaşlarımızın gözünde en sorumlu kurumsal vatandaşlardan biri olarak kabul görmek.

2013'te yürüttüğ̈̈ OE projeleri ile Türkiye, Kazakistan, Ürdün, Azerbaycan ve Pakistan'daki fabrikalarımızda toplam yaklaşık 56 milyon MJ enerji tasarrufu sağlayarak. Sadece Türkiye'de yaklaşık 47 milyon MJ enerji tasarrufu sağlarken yürüttügümüz çeşitli projeler sayesinde sera gazı emisyonumuzu da 170 bin ton azaltmiştır.

Çevre dostu soğutucularımız sayesinde 2013 'te 13,8 milyon ağacın bir yıl içinde emdiği CO2 tutarında emisyonu önlerken, 2013 itibariyle Lightweight Projeleri sayesinde Türkiye'de 2 bin 500 tondan fazla PET malzeme tasarrufu yapmayı başarmıştır. CCI 2013 yılından beri UNGC 100 Sürdürülebilirlik Endeksinde Türkiye'den katılan ilk ve tek şirket olarak yer alıyor. Pakistan'da WWF ile ortak yürüttüğümüz Paani Temiz Su projemizi büyütmeye devam ettik. Proje kapsamında kurduğumuz sekiz su filtreleme tesisi ile 160.000 kişiye temiz içme suyu sağlıyoruz. Soğutucularımıza \% 42 enerji tasarrufu sağlayan EYC (enerji yönetim cihazı) kurulumu yapmaya devam ettik ve bu sayede bir yıl içinde yaklaşık 184.000 ton $\mathrm{CO}_{2}$ emisyon azalımı sağladık. Türkiye, Pakistan, Azerbaycan, Ürdün ve Kazakistan fabrikalarımızda yıllık su tüketimimizi \%5,1 azalttık. Yerel su programları sayesinde Türkiye'de üretimde kullandığımız her litre su için, 1,5 litre suyu yerine koyuyoruz. Bu miktar, yaklaşık 363.000 evin günlük tüketimine eşdeğer. CCI, Borsa Istanbul'un (BIST 50) yeni kurulan Sürdürülebilirlik Endeksine kabul edilen 29 şirketten biri oldu ve bu yıl ilk defa olarak Euronext Vigeo Emerging 70 Endeksinde yer aldı (CCI).

Apple, Düşük Karbonlu Üretim ve Yeşil Büyümeyi Desteklemek için Çin'de Yeni Temiz Enerji Programları Başlatıyor. Apple Şimdi Çin'deki Operasyonlarının yüzde 100'ü için Temiz Enerji Üretiyor. Çin'deki üretim ortaklarının karbon ayak izini azaltmayı amaçlayan iki yeni program geliştirerek. Bu programlar ülkede bugünden 2020'ye kadar 20 milyon metrik ton sera gazı kirliliğin önüne geçmeyi planlıyor. Bu bir yılda neredeyse 4 milyon yolcu taşıma aracını trafikten çekmeyle eşdeğer bir azalma. Apple Çin'deki temiz enerji yatırımlarını önemli oranda genişletiyor. Apple Çin'in kuzey, doğu ve güney bölgelerinde toplam kapasitesi 200 megavatın üzerine çıkacak güneş enerjisi tesisleri kurmayı planlıyor. Bu tesisler 265.000'den fazla Çinli ailenin bir yılda kullandığ enerjiye eşdeğer bir üretim yapacak ve Apple'ın tedarik zincirinde kullanılan enerjiyi karşılamaya başlayacak. Apple, fosil yakıtlardan temiz enerjiye geçerek çevreyi koruma yolunda önemli adımlar attı. Şirket bugün Çin'deki ve ABD'deki operasyonlarının \%100'ünü ve tüm dünyadaki operasyonlarının yüzde 87'den fazlasını yenilenebilir enerjiyle besliyor (Apple).

Eczacıbaşı Topluluğu, sürdürülebilir kalkınma alanında gerçekleştirdiği çalışmalarıyla, daha yeşil ve sürdürülebilir iş ve yaşam pratiklerini özendiriyor, uyguluyor ve yaygınlaştırıyor. Eczacıbaşılılar'ın, sürdürülebilir bir gelecek için doğal kaynakların aşırı tüketimine yol açmayan, doğa dostu, etik kaygılarla üretilen ürün ve hizmetleri tercih etmelerini, geri dönüşüm, ekolojik ve güvenli gıdaların seçimi gibi "yeşil” alışkanlıklar edinmelerini özendiriyor. Eczacıbaşı Topluluğu, sürdürülebilir kalkınma alanında gerçekleştirdiği çalışmalarıyla, daha yeşil ve sürdürülebilir iş ve yaşam pratiklerini özendiriyor, uyguluyor ve yaygınlaştırıyor (Eczacibaşı).

BMW, Şirketi İmalat başladığı andan bitmiş taşıtın sahibine gönderilmesine kadar üretim kalitesinin asla çevremizin bütünlüğünü bozmamasını sağlıyor. Düzenli depolama ihtiyacını azaltacak katı bir atık geri dönüşüm programı ve her yıl 9.5 milyon galon su tasarrufu yapmaya yardımcı olan bir su tasarrufu girişimi gibi birçok formda. Aynı zamanda, yeşil çabalarımızın birçoğu daha küçük, ancak daha az önemli olmayan bir ölçekte yer almaktadır (BMW-green).

Ford Motor Company, İmalâtçılar, kuru işleme, süreç veya atık su geri kazanım ve yeniden kullanma gibi stratejileri kullanabilir, mümkün olduğunda içilebilir olmayan suyu kullanarak ve su tasarrufu için boyayı veya durulama oranını düşürebilir. Ford Motor Company, bu stratejilerin bir kısmını kullandı ve yılda 883 milyon galon azalttı ve Green Manufacturer'a göre şirketin yılda 22 milyon avro tasarruf sağladığını belirtti (Poplar).

Starbucks En çok dikkat çeken kampanyalardan biri de Starbucks'un karton bardaklarını plastik bardağa dönüştürme projesidir. 1.2 milyon Starbucks müşterisinden 47.127 müşteri plastik kahve kabı kullanmak istemişstir. Hakkında ulusal TV'lerde 20, yerelde ise 265 haber gerçekleşti. 12 ulusal basılı medyada kampanyanın hikayesi yer aldı. Sadece bu kampanya ile yılda 16000 ağacın kurtulduğu tespit edildi (Gülçin, 2015).

Garanti Bankası Çevreye duyarlılık yalnızca imalat sanayi şirketleri için değil perakende, finans gibi hizmet sektörlerinde faaliyet gösteren çok sayıda firma için de önemli bir değer. WWF Türkiye'nin (Doğal Hayatı Koruma Vakfi) ana sponsoru Garanti Bankası ve Türkiye'nin doğasının korunması ve sürdürülebilir kalkınmaya yönelik çalışmalarını destekliyor. Banka, kendi bünyesinde bu amaç doğrultusunda ürünler de geliştiriyor. Garanti Bankası'nın "Çevreye duyarlı Bonus Card" projesi buna örnek verilebilecek bir ürün. Bu kartın yapımında 
mümkün olan en az seviyede PVC kullanılıyor. Böylece kartın kısa zamanda doğada yok olması sağlanıyor (Gülçin, 2015).

Temsa, Türkiye'nin ilk hibrid otobüsü Hybrid Avenue ile hayat buldu. TEMSA, Avenue'nin hibrid versiyonunda Siemens'in tüm dünyada beğeniyle karşılanan ELFA Hibrid Sistemleri'ni kullanılıyor. Çevreci oto, düşük karbondioksit salınımı, sıfır emisyon gibi kavramlardan biri de hibrid sistemler. Hibrid teknolojisi, tamamen elektrik enerjisiyle çalışan sıfır emisyonlu araçlara geçiş öncesinde yaşanan bir ara dönemi temsil ediyor. Hem geleneksel motor teknolojilerini hem de elektrik enerjisi kullanımını kapsayan bir teknoloji olan hibrid, mevcut akü teknolojilerinin uzun mesafeli yolculuklarda ihtiyacı tam karşılayamaması nedeniyle tercih sıralamasında yerini koruyor. TEMSA tarafindan üretilen şehir içi toplu ulaşım aracı Avenue, Siemens'in ELFA Hibrid Sistemleri aracılığıyla Hibrid Avenue olarak da hazırlandı. TEMSA Hybrid Avenue'de frenleme esnasında oluşan enerji, elektrik motorlarının yardımıyla depolanıyor ve aracın tekrar hareketi esnasında kullanılıyor. Elektriğin depolandığı ultra kapasitörlerde yeterli enerji olduğu müddetçe araç bunu kullanarak dizel motora gelen ek yüklenmeleri karşılıyor, dolayısıyla dizel otobüslere kıyasla yakıt tüketiminde ve karbondioksit emisyonunda yüzde 25'e varan tasarruf sağlıyor (Yeşil).

Türk Telekom, Ofislerdeki sürdürülebilirlik çalışmaları kapsamında bina/salon optimizasyon projeleri ile alan tasarrufu ve buna bağlı olarak soğutmada harcanan enerji tüketiminde ciddi azalma sağlanmaktadır. Bunların yanı sıra tasarruflu ampul kullanımı, koridor ve tuvaletlerde sensörlü aydınlatma kullanımı, 1sı yalıtımı ve mantolama, çalışanlara servis hizmeti sağlanması, musluklarda su tasarruf aparatı kullanımı, sensörlü musluk kullanımı, bina otomasyonları, çevre dostu araç filosu, atıkların ayrıştırılması, atık geri dönüşümü, elektronik belge ve dokümantasyon sistemi (EDİTT), merkezi baskı sistemleri, e-öğrenme, telepresence ve video konferans kullanımı ile geri dönüşüm, enerji ve su tasarrufunda artış, karbon salınımında azalma sağlanmaktadır. Çevreci ürünler kapsamında e-fatura uygulaması da müşterilerin karbon ayak izini azaltmaya yönelik fayda sunmaktadır (Türk Telekom).

Arçelik A.Ş'de üretim süreçleri, doğal kaynakları az tüketen yüksek verimliliğe sahiptir. Temiz ve sağlıklı bir çevrenin gelecek nesillere aktarılması için ARÇELIKK A.Ş, çevre etkilerini kontrol altına almaya ve kaynak kullanımını azaltmaya yönelik çevre amaç ve hedeflerini belirleyerek, çevresel performansını düzenli olarak takip etmektedir. Temiz ve sağlıklı bir çevrenin gelecek nesillere aktarılması, Enerji ve doğal kaynakların verimli kullanılması, Tasarımdan ömür çevrimi sonuna kadar tüm süreçlerde olumsuz çevresel etkilerin azaltılması, Kirliliğin kaynağında önlenmesi, Çalışanlarımızın ve toplumun çevre bilincinin artırılmasıdır (Arçelik).

\begin{tabular}{|c|c|c|c|}
\hline Firma Adı & Üretim Alanı & $\begin{array}{l}\text { Nerede Faaliyet } \\
\text { Gösteriyor }\end{array}$ & Yeşil Üretim Uygulaması \\
\hline Apple & Bilgisayar & Dünya da & Enerji Tasarrufu \\
\hline Temsa & Hibrit Otomobil & Türkiye de & CO2 Karbon yayılımı \\
\hline BMW & Otomobil üretimi & Almanya & $\mathrm{Su}, \mathrm{CO} 2$ Karbon yayılımı \\
\hline $\begin{array}{l}\text { Ford Otosan Otomotiv } \\
\text { Sanayi Anonim } \\
\text { Şirketi/ Gölcük }\end{array}$ & Otomobil Üretimi & Gölcük & $\begin{array}{l}\text { Çok Katmanlı Üretim İle Hurda ve Boya } \\
\text { Maddesi Tasarrufu }\end{array}$ \\
\hline $\begin{array}{l}\text { Asaş Alüminyum } \\
\text { Sanayi ve Ticaret A. Ş. }\end{array}$ & $\begin{array}{l}\text { Alüminyum } \\
\text { profil sistemleri }\end{array}$ & Sakarya & Tüketilen enerjiden $\% 90$ tasarruf \\
\hline Coca-Cola & İçecek Üretimi & Çeşitli Ülkelerde & $\begin{array}{l}\text { Ambalaj, su ve enerji kullanımımızı } \\
\text { azaltma yoluyla karbon ve sudaki ayak } \\
\text { izimizi asgari düzeye indirmek }\end{array}$ \\
\hline $\begin{array}{l}\text { Nuh Çimento Sanayi } \\
\text { A.Ş }\end{array}$ & Çimento & İzmit & Sera gazı azaltımı \\
\hline Starbucks & Hizmet Üretimi & Dünya da & $\begin{array}{l}\text { Karton bardaklarını plastik bardağa } \\
\text { dönüștürme }\end{array}$ \\
\hline Türk Telekom & Hizmet Üretimi & Türkiye & Enerji Tasarrufu \\
\hline Garanti Bankası & Hizmet Üretimi & Türkiye & Bonus Kartta en az PVC kullanımı \\
\hline
\end{tabular}

Tablo 1. Sürdürülebilir Bazı Firmalar

\section{Sonuç}

Yeşil imalata stratejilerinde yer veren firmalar gelecek nesiller için doğal kaynakları korumalıdır.

Yeşil üretim, belirli bir makine ile değil, süreçlerle geliştirilir. Hammadde kullanımını en üst düzeye çıkarır ve atıkları en aza indirir. Günümüzde yeşil imalatı firmalar programlarında uygulamaya koymaya çalışmaktadırlar.

Yeşil yaklaşım ile uzun vadede, işletmenin imajının geliştirilmesi, maliyetlerin azaltılması, kalıcı müşteri kitlesine oluşturulması, müşteri sadakatinin sağlanması, verimliliğin arttırılması, çalışanların motivasyonun yükseltilmesi ve firmaya olan bağlılıklarının arttırılması ile rekabet üstünlüğü ön plana çıkarılabilir. 
Depolama atıklarının yaklaşık \%30'u ambalajlardan oluştuğu için, ambalajlama sürdürülebilir ürün imalatının önemli bir bileşenidir. Birçok firma ambalajlarını küçültmekte veya geri dönüştürülebilir malzemeler kullanmaktadır.

İşletmeler, daha çok üreterek, ekonomik kalkınmayı sağlarken, üretim sonucu ortaya çıkan atıkları azaltmak için yeni süreçler geliştirmelidirler. Dünya'da Yeşil Üretim konusunda çalışmalar devam etmesine rağmen, henüz yeterli düzeye ulaşamamıştır. Bu nedenle konu ile ilgili kuruluşların ve halkın yeterli şekilde bilgilendirilmemesi ve bu konuya önem verilmesi gerekmektedir. Toplumun çevre dostu ürünlere yönelmesi üretim felsefelerini değiştirmelerini sağlayacaktır. Aynı zamanda firmalar ve tüketiciler bu konuda bilgilendirilerek yeşil pazarlama stratejileriyle desteklenmelidir. Bu nedenle yeşil pazarlama uygulamaları maliyetlerin düşmesini, az malzeme kullanımına, daha az atık oluşturmaya sebebiyet verir. Hızla gelişen teknoloji ve değişen dünya koşullarında çevrenin atıklardan korunması, kirletilmemesi için çevreye dost yeşil ürünlerin üretilmesinde firmalara önemli işler düşmektedir. Bu işleri başarı ile gerçekleştiren işletmeler gelecekte ayakta kalabilen ve devamlılıklarını sağlayan işletmeler olacaktır.

Hızla gelişen teknoloji ve değişen dünya koşulları işletmeleri yeşil ürün üretmeye zorlamaktadır.

\section{Kaynakça}

- Apple. Apple Inc., apple.com

- Arçelik. Arçelik A.Ş., Koç Holding, www.arcelik.com

- Atlas, 1999. Atlas, M. ve Florida, R. (1999). “Green Manufacturing”. (Ed: Richard C. Dorf), The Technology Management Handbook, CRC Press, s. 13/85-88.

- BMW-green. BMW Group, Plant Spartanburg,

- CCI. Coca-Cola Turkiye, http://www.cci.com.tr/tr/surdurulebilirlik/surdurulebilirlik-raporumuz/

- Eczacibaşı. Eczacibaşı Holding A.Ş., http://www.eczacibasi.com.tr/tr/surdurulebilirlik/yesiliz

- $\quad$ Elsayed, 2006. Elsayed, K. (2006). "Reexamining the expected effect of available resources and firm size on firm environmental orientation: an empirical study of UK firms", Journal of Business Ethics, 65(3), 297 308. http://dx.doi.org/10.1007/s10551-006-6402-z

- Gao, 2009. Gao, Y., Li, J, and Song, Y. (2009). "Performance Evaluation of Green Supply Chain Management Based on Membership Conversion Algorithm”, 2009 ISECS International Colloquum on Computing, Communication, Control, and Management, 237-240.

- Gülçin, 2015. Gülçin, "Yeşil Pazarlama”, 14 Mayıs 2015,

- http://www.kto.org.tr/d/file/yesil-tedarik-zinciri-yaklasimi-ve-ornekleri.pdf

- https://www.bmwusfactory.com/sustainability/corporate-sustainability/green-manufacturing/

- https://www.poplarnetwork.com/topics/green-manufacturing

- https://www.slideshare.net/gulcinun3/yeil-pazarlama-48142646

- Ince, 2013. Ince, M.E. "Yeşil Tedarik Zinciri Yaklaşimi ve Ornekleri”, Konya Ticaret Odasi, Mart 2013.

- $\quad$ KTO. Konya Ticaret Odasi, www.kto.org.tr

- Martin, 2012. Martin, K., S. Legg, and C. Brown, 2012. "Designing for Sustainability: ErgonomicsCarpe Diem", Ergonomics.

- Poplar. Green Buildings Online Inc. - Poplar Netowrk,

- Thatcher, 2013. Thatcher, A.,2013. "Green ergonomics, definition and scope”, Ergonomics, 56:3, 389-398.

- Türk Telekom. Türk Telekomünikasyon A.Ş., https://www.turktelekom.com.tr

- Unilever. Unilever Türkiye, https://www.unilever.com.tr/sustainable-living/

- Weisman, 1994. Weisman, S.H., Sekutowski, J.C., (1994), Environmentally Conscious Manufacturing: A Technology for the Nineties, Enviromental TQM, (W1llig J.T. Editor), McGraw Hill Inc.,USA

- Yavuz, 2010. V. Alpagut Yavuz. 2010. "Sürdürülebilirlik Kavramı ve İşletmeler Açısından Sürdürülebilir Üretim Stratejileri', Mustafa Kemal Üniversitesi Sosyal Bilimler Enstitüsü Dergisi s. 63 - 86.

- Yeşil. Yaman, A., Yeşil Pazarlama, http://yesilpazarlama.blogspot.com/

- Yeşil1. Yeşil Odak, http://www.yesilodak.com/icerik/58/Yesil-ve-Surdurulebilirlik-Kavramlari-ArasindakiFark-Nedir? 


\title{
Doğrudan Yabancı Sermaye Yatırımları ve Ekonomik Büyüme Arasındaki İlişki: Azerbaycan Örneği \\ Relationship Between Foreign Direct Investments and Economic Growth: The Azerbaijan Sample
}

\author{
Asst. Prof. Dr. Serap Ürüt Kelleci (Aksaray University, Turkey) \\ Asst. Prof. Dr. Emine Frrat (Aksaray University, Turkey)
}

\begin{abstract}
Today, foreign direct investment is very important for both developed and developing countries. It is seen as an opportunity to overcome the inadequacy of capital, especially in developing countries. It is expected that these investments will make a serious contribution in solving the problems related to the balance of payments, in the realization of the investments that will enable the growth of the economies, in increasing the employment.

The study will examine the size, development and effects of foreign capital in Azerbaijan economy. Azerbaijan, which is also known as transition economies, has gone from the Soviet Union in 1991 to regulating its economic structure from the beginning. At this point, they have undertaken various reforms to improve their inadequate investment capabilities and to attract foreign direct investment into the country. In this respect, they tried to have a share of this great pasty shared by the developed countries in the world.

In this study, firstly foreign direct investments and economic effects will be examined. Then, general information about Azerbaijani economy will be given and the dimensions and effects of foreign direct investments in Azerbaijan will be revealed. After the literature review on the subject has been made, the relationship between economic growth and foreign direct investment in Azerbaijan will be empirically analyzed. The figures for Azerbaijan during the period 1995-2015 were obtained from the World Bank.
\end{abstract}

\section{Giriş}

Günümüzde küreselleşmeyle birlikte para ve sermaye piyasalarının hızla gelişmesi finans piyasalarını hareketlendirmiş, işlem sayılarını arttırmıştır. Finansal hareketliliğin hızlanmasıyla ülkeler arasında engeller kalkmış, serbestleşme ülkeleri birbirine yakınlaştırmıştır. Birçok uluslararası yatırımcı hem kendinin hem de ülkesinin gelirlerini arttıracak yollar aramış, çeşitli yöntemler denemiştir. $\mathrm{Bu}$ yöntemlerin başında portföy yatırımları ve doğrudan yabancı sermaye yatırımları gelmektedir. Portföy yatırımları özellikle birbiriyle rekabet edebilen finans piyasaları tarafından tercih edilmiş, gelişmekte olan piyasalar geride kalmıştır. Sermaye piyasası yetersiz olan ülkeler ise borçlanmayla küresel rekabetin içerisine dahil olma yoluna gitmişlerdir. Doğrudan yabancı sermaye yatırımları ülkelere sermaye ve teknoloji transfer etmekle birlikte, ekonomik büyümelerine de olumlu katkılar yapmıştır.

Küreselleşme sonucu, iktisatçıların çalışma konuları farklı alanlara kaymış, ekonomik büyümenin anlamı değişmiştir. Geçmişten günümüze kadar gelen klasik ekonomik büyüme yaklaşımı terkedilmiş, özellikle 1980 sonrasında büyümenin belirleyicileri değişmiş, ülkelerin ekonomik büyüme ile doğrudan yabancı yatırımları arasındaki ilişki artmıştır. Ekonomik büyüme, ülkelerin gelişmesi ve kalkınması için en başta gelen makro ekonomik göstergelerden biridir. Ülkelerin makro anlamda istikrarlı olması ekonomik büyümeyi arttıran unsurların başında gelmektedir. Bir ülkenin büyümesi için gerekli olan en önemli faktör ise sermayedir. Üretim faktörlerinin temelini oluşturan sermayenin yetersizliği bir ülkenin en büyük ekonomik sorunlarındandır. Büyümenin gerçekleşmesi için sermayenin yeterli olması sermayenin olması için de tasarrufun yeterliliği şartı vardır. Tasarrufların yetersiz olması gelişmişliğin önüne büyük bir ket vurmakta ve sıkıntılar artmaktadır. Bu yüzden ekonomik büyümenin gerçekleşmesi için ülkenin öz kaynaklarının yetersiz olduğu durumda dış sermaye kaynaklarına yönelmesi zorunluluğu doğmaktadır. Dış sermaye kaynakları, doğrudan yabancı yatırımlar sayesinde ülkeye girip, sermayenin yeterliliğini sağlayarak, ekonomik büyüme sürecini hızlandırmaktadır. Özellikle ithal ikameci sanayileşme stratejilerinin terkedilip, ihracata yönelik sanayileşme stratejilerini benimseyen ülkelerin doğrudan yabancı sermaye yatırımları ile ekonomik büyüme hızlarını arttırdıkları görülmektedir.

Yeni dünya düzeninde doğrudan yabancı sermaye transferlerinin giderek artan bir düzeye çıkması ve Neoliberalizmin bir gereği olarak kabul edilmesi konuları gündemi epey meşgul etmiştir. Gelişmekte olan ülkelerde sermaye birikiminin yetersizliği ekonomik büyümeyi olumsuz etkilemektedir. Gelişmekte olan ülkelerden biri olan Azerbaycan ekonomik büyüme için doğrudan yabancı sermayenin önemini fark etmiş bu yatırımların artırılması için faaliyetlere başlamıştır. Ancak uzun yıllar boyunca Sovyetler Birliği’nin yönetiminde bulunan Azerbaycan'ın 1991 yılında bağımsızlığını aldıktan sonra bu konuda uygulamaya başlaması mümkün olabilmiştir. 
$\mathrm{Bu}$ çalışmada, doğrudan yabancı yatırımlar ile ekonomik büyüme arasındaki ilişki nedensellik analizi çerçevesinde incelenmiştir. Bu bağlamda, doğrudan yabancı yatırımlar ile ekonomik büyüme arasındaki ilişki Azerbaycan örneği üzerinden ele alınmıştır. Azerbeycan'ın bir geçiş ekonomisi olmasından dolayı makro verilere ancak 1995 yılında itibaren düzenli bir şekilde ulaşılabilmektedir. Bu nedenle çalışmada 1995-2015 dönemi incelenmiştir.

\section{Azerbeycan'ın Temel Özellikleri}

Bağımsız Devletler Topluluğu ve Eski Sovyetler Birliği Cumhuriyetlerinin oluşturduğu devletlerin arasında petrol bakımından en zengini Azerbaycan'dır. Azerbaycan'ın ekonomisi petrole dayanmaktadır. Dünyanın belli başlı petrol üreticisi ülkeleri arasında yer alır. Petrol kuyularının büyük kısmı Apşeron Yarımadasında toplanmıştır. Çıkarılan petrol, borularla işlenmek üzere Bakü yakınlarındaki Çernagorod'a nakledilir. Ayrıca Bakü 890 kilometrelik bir boru hattı ile Batum'a bağlanır. Petrolden sonra en önemli gelir kaynağı doğal gazdır. Büyük bir çeşitlilik gösteren Azerbaycan sanayisinin temelini enerji, imalat ve kimya sanayi meydana getirir. Gübre, tarım ilaçları, yakıt, sanayi yağları, sun'i kauçuk ve plastik sanayii gelişmiştir. Dışarıya ihraç ettiği en önemli ürünlerden biri de petrol arama ve çıkartma makinalarıdır. Termik santrallerden elde ettiği elektriğin bir kısmını satmaktadır. Azerbaycan, verimli tarım arazileri ve doğal gaz, petrol ve demir bakımından zengin kaynaklara sahip bulunmaktadır. Azerbaycan Geçişin başlangıcında GSYİH'larının yaklaşık yarısını kaybetmiş, ancak 2000 yılından sonra istikrarlı büyümeye gerçekleştirebilmişlerdir. 2006 yılında \% 34,5'lik oran ile Azerbaycan büyüme rekoru gerçekleştirmiştir (Özdemir, Yalman; 2012).

\begin{tabular}{|l|r|r|r|r|r|r|}
\hline & \multicolumn{1}{|c|}{$\mathbf{1 9 9 5}$} & \multicolumn{1}{c|}{$\mathbf{2 0 0 0}$} & \multicolumn{1}{c|}{$\mathbf{2 0 0 5}$} & \multicolumn{1}{c|}{$\mathbf{2 0 0 6}$} & \multicolumn{1}{c|}{$\mathbf{2 0 0 7}$} & \multicolumn{1}{c|}{$\mathbf{2 0 0 8}$} \\
\hline Dünya & 341.537 & 1.363 .215 & 927.402 & 1.393 .034 & 1.871 .702 & 1.489 .732 \\
\hline Gelișmekte Olan Ülkeler & 117.767 & 232.216 & 330.178 & 403.881 & 528.536 & 585.647 \\
\hline Gelișmiș Ülkeler & 219.772 & 1.125 .227 & 565.423 & 930.175 & 1.254 .988 & 787.761 \\
\hline Geçiș Ekonomileri & 3.999 & 5.772 & 31.801 & 58.978 & 88.178 & 116.324 \\
\hline & & & & & & \\
\hline Dünya & $\mathbf{2 0 0 9}$ & $\mathbf{2 0 1 0}$ & $\mathbf{2 0 1 1}$ & $\mathbf{2 0 1 2}$ & $\mathbf{2 0 1 3}$ & $\mathbf{2 0 1 4}$ \\
\hline Gelișmekte Olan Ülkeler & 1.186 .513 & 1.328 .215 & 1.564 .935 & 1.403 .115 & 1.467 .149 & 1.228 .283 \\
\hline Gelișmiș Ülkeler & 463.637 & 579.891 & 639.135 & 639.022 & 670.790 & 681.387 \\
\hline Geçiș Ekonomileri & 652.306 & 673.223 & 828.447 & 678.960 & 696.770 & 498.784 \\
\hline
\end{tabular}

Tablo 1: Doğrudan Yabancı Sermaye Yatırımları (milyon \$) Kaynak: Dünya Bankası, Erişim Tarihi: (20.02.2017)

Tablo 1'de görüldüğü gibi, yabancı sermaye yatırımlarının, gelişmekte olan ülkeler üzerindeki olumlu etkisi 1995 yılından itibaren ön plana çıkmış, bu ülkelere yönelik sermaye girişindeki artış Tablo 2'de görüldüğü üzere, sermaye girişi olan ülkelerde ekonomik büyümeyi de beraberinde getirmiştir. Tabloya göre 1995 yılında doğrudan yabancı sermaye yatırımlarının geçiş ekonomilerine yapılan miktarı 3.999 milyon dolarken 2008 yılında bu miktarın artarak 116.324 milyon dolara çıktığı görülmüştür. Gelişmekte olan ekonomilerin ise 1995 yılındaki doğrudan yabancı sermaye yatırımları 219.772 milyon dolarken 2014 yılına gelindiğinde 681.387 milyon dolara çıktığ1 görülmüştür. 1995 yılından beri gelişmekte olan ülkeler ve geçiş ekonomilerine yönelen yabancı sermaye miktarı önemli bir artış gösterirken, gelişmiş ülkelerde sermaye girişindeki gelişmenin durduğu hatta 2014 y1lında gelişmiş ülkenin çekmekte olduğu sermaye yabancı sermaye miktarının gelişmekte olan ülkelerden daha düşük düzeylerde seyrettiği gözlenmiştir.

\begin{tabular}{|l|l|l|l|l|l|l|l|l|l|l|l|}
\hline y1l & 1995 & 1996 & 1997 & 1998 & 1999 & 2000 & 2001 & 2002 & 2003 & 2004 & 2005 \\
\hline FDI & 330 & 627 & 1.114 & 102 & 510 & 129 & 819 & 2.024 & 4.007 & 4.719 & 4.476 \\
\hline GDP & 3.052 & 3.176 & 3.962 & 4.446 & 4.581 & 5.272 & 5.707 & 6.236 & 7.275 & 8.680 & 13.245 \\
\hline GDP $(\%)$ & $-11,80$ & 1,30 & 5,80 & 10,00 & 7,40 & 11,10 & 9,90 & 10,60 & 11,20 & 10,20 & 26,40 \\
\hline \multicolumn{10}{|l|}{} \\
\hline y1 & 2006 & 2007 & 2008 & 2009 & 2010 & 2011 & 2012 & 2013 & 2014 & 2015 \\
\hline FDI & 4.485 & 4.594 & 3.986 & 2.900 & 3.352 & 4.485 & 5.293 & 2.619 & 4.430 & 4.047 \\
\hline GDP & 20.983 & 33.050 & 48.852 & 44.291 & 52.902 & 65.951 & 68.730 & 73.560 & 75.198 & 53.047 \\
\hline GDP $(\%)$ & 34,50 & 25,05 & 10,77 & 9,41 & 4,85 & 0,07 & 2,20 & 5,80 & 2,00 & 1,10 \\
\hline
\end{tabular}

Tablo 2: Azerbeycan'daki Doğrudan Yabancı Sermaye Yatırımları ve Milli Gelir Verileri (milyon \$) Kaynak: Dünya Bankası, Erişim Tarihi: (20.02.2017)

Tablo 2'de görüldüğü gibi, Azerbeycan'a yapılan doğrudan yabancı sermaye yatırımları ile milli gelir arasındaki ilişki genellikle pozitif bir biçimde artarak seyretmiştir. $\mathrm{Bu}$ da doğrudan yabancı sermaye yatırımlarının Azerbaycan ekonomisinin büyümesinde önemli bir faktör olarak düşünülebilir. 1995 yılında doğrudan yabancı sermaye yatırım miktarı 330 milyon \$ iken bu rakam 2003-2008 yılları arasında yıllık 4 milyar \$'ın üzerinde 
çıkmıştır. 2008 yılından sonra ise küresel krizin etkisiyle durgunlaşan dünya ekonomisi Azerbeycan'a yapılan doğrudan yabancı sermaye yatırımlarının da azalmasına neden olmuş, oran giderek azalmıştır. 2008 yılından sonra büyüme oranlarında da ciddi azalışlar dikkat çekicidir.

\section{Literatür}

Doğrudan yabancı sermaye yatırımları ve ekonomik büyüme arasındaki ilişkinin incelendiği birçok çalışma söz konusudur. $\mathrm{Bu}$ çalışmalarda incelenen ülkeler, izlenen yöntemler ve sonuçlar açısından birçok farklılıklar mevcuttur. Bazı çalışmalarda ülke grupları incelenirken bazılarında tek ülke incelemeleri yapılmıştır. Aşağıda konu ile ilgili literatürdeki çalışmalardan bazıları değerlendirilmiştir.

Borensztein, De Gregorio ve Lee (1998) çalışmalarında, 1970-1989 dönemi arası 69 GOÜ için Panel SUR analizi yapmışlardır. Analiz sonuçlarına göre, beşeri sermayenin çok düşük olduğu ülkelerde doğrudan yabancı sermaye yatırımları büyümeyi negatif yönde, diğer ülkelerde ise pozitif yönde etkilediği sonucuna ulaşmışlardır.

De Mello (1999), çalışmasında 32 OECD üyesi olan ve olmayan ülkelerde doğrudan yabancı sermaye yatırımlarının sermaye birikimi, ekonomik büyüme ve toplam faktör verimliliği artışı üzerindeki etkisi zaman serisi ve panel veri yöntemleri çerçevesinde araştırılmıştır. Çalışma sonuçlarına göre doğrudan yabancı sermaye yatırımlarının büyümeye etkisi bu yatırımların iç yatırımlarla tamamlayıcılık ve ikame derecesine bağlıdır.

UNCTAD (2000), 1970-1995 arası dönem için 100 ülke üzerine analiz yapmıştır. Granger nedensellik ve EKK yöntemleri uygulanan çalışmada, DYY'ın ekonomik büyümeyi olumlu etkilediği sonucuna ulaşılmıştır.

Carkovic ve Levine (2002) çalışması, 72 ülke için yapılmıştır. Panel GMM yönteminin kullanıldı̆̆ı çalışmaya göre, gelişmiş ve gelişmekte olan ülkelerde doğrudan yabancı sermaye yatırımları ekonomik büyüme üzerinde herhangi bir etkisinin bulunmadığı sonucuna varılmıştır.

Nath (2005) çalışmasında geçiş ekonomilerini incelemiştir. Panel sabit etkiler yönteminin kullanıldığı ve 13 geçiş ekonomisini kapsayan çalışma sonuçlarına göre dış ticaret ekonomik büyümeyi önemli ölçüde ve pozitif yönde etkilemektedir. Aynı zamanda yurt içi yatırımlar da büyümeyi etkilemektedir. Dış ticaret değişkeninin panellere dahil edildiği durumlarda doğrudan yabancı sermaye yatırımları değişkenine ait katsayılar istatistiksel olarak anlamsız bulunurken dış ticaret değişkeni dahil edilmeden tahmin edilen büyüme modelinde ise yabancı sermaye yatırımlarına ait katsayılar anlamlı bulunmuştur.

Afşar (2007) çalışmasında, Türkiye için Granger nedensellik analizi çerçevesinde doğrudan yabancı sermaye ve büyüme ilişkisini ortaya koymaya çalışmıştır. 1992-2006 dönemi için yapılan çalışma sonuçlarına göre Türkiye ekonomisi için doğrudan yabancı sermaye yatırımlarından büyümeye doğru tek yönlü nedensellik ilişkisi bulunmuştur.

Aleksynska, Gaisford ve Kerr (2008) çalışmalarında 1991-2000 dönemi için 17 geçiş ekonomisini incelemişlerdir. Çalışmada EKK ve Granger nedensellik analizleri kullanılmıştır. Çalışma sonuçlarına göre doğrudan yabancı sermaye yatırımları ile ülke içi yatırımlar arasında daha çok tamamlayıcılık ilişkisi görülmüştür. Ekonomi büyüdükçe gelecek yabancı sermayenin artacağını ileri süren yazarlar analiz sonucunda aynı sonuca ulaşamamışlardır. Çalışma sonucunda doğrudan yabancı sermaye yatırımları ile büyüme arasında zayıf bir ilişkinin var olduğu tespit etmişlerdir.

Ağayev (2010), 25 geçiş ekonomisinde, doğrudan yabancı sermaye yatırımı ile ekonomik büyüme arasındaki ilişkiyi incelemiştir. 1994-2008 dönemi için yapılan çalışmada panel nedensellik analizi, doğrudan yabancı sermaye yatırımlarından ekonomik büyümeye doğru güçlü, tersi yönde ise daha zayıf bir nedensellik ilişkisinin olduğunu göstermiştir.

Turan Koyuncu (2011), 1990-2010 dönemi için Türkiye’de doğrudan yabancı sermaye yatırımları ile büyüme arasındaki ilişkiyi Granger nedensellik analizini kullanarak incelemiştir. Analiz sonucunda doğrudan yabancı sermaye yatırımlarının ekonomik büyümeyi pozitif yönde etkilediği sonucuna ulaşmıştır.

Chowdhary ve Kushwaha (2013) ise 1992-2011 dönemi için Hindistan üzerine inceleme yapmışlardır. Turan Koyuncu (2011) ile aynı sonuçlara ulaşılan çalışmada da Granger nedensellik analizi kullanılmıştır.

Gürsoy ve Kalyoncu (2012), Gürcistan'da 1977-2010 dönemleri arasında doğrudan yabancı sermaye yatırımlarının ekonomik büyüme üzerindeki etkisini analiz etmişlerdir. Çalışmada Engle-Granger eşbütünleşme testi ve Granger nedensellik analizi yöntemi kullanılmıştır. Analiz sonucunda, değişkenler arasında eşbütünleşme ilişkisi bulunmuştur. Ayrıca nedensellik analizi de doğrudan yabancı sermaye yatırımlarının ekonomik büyümenin nedeni olduğunu ortaya koymuştur.

\section{Ekonometrik Yöntem, Veri Seti ve Analiz Sonuçları}

Bu çalışmada Azerbaycan ekonomisi için doğrudan yabancı sermaye yatırımları ve ekonomik büyüme arasındaki ilişki nedensellik analizi çerçevesinde incelenecektir. Azerbaycan’a ait 1995-2015 dönemini kapsayan yıllık veriler kullanılmıştır. Söz konusu veriler Dünya Bankasının internet sitesinden 10.02.2017 erişim tarihinde 
elde edilmiştir. Çalışmada kullanılan değişkenler doğrudan yabancı sermaye yatırım girişleri (FDI) ve Gayrı safi yurt içi hasıladaki artış oranlarıdır (GDP).

Çalışmada, doğrudan yabancı sermaye yatırımları ile ekonomik büyüme arasındaki ilişkinin tahmininde, her değişkenin zaman serisi özelliklerini incelemek için öncelikle serilerin durağan olup olmadıkları saptanmıştır. Zaman serisi analizlerinde, verilerin durağan olması gerekmektedir. Durağan olmayan zaman serileriyle çalışılması halinde sahte regresyon problemiyle karşılaşılabilmektedir. Bu durumda regresyon analiziyle elde edilen sonuç gerçek ilişkiyi yansıtmamaktadır (Gujarati, 1999: 713, 726).

Çalışmada, kullanılan değişkenlerin durağan olup olmadıkları ve durağan iseler hangi seviyede durağan oldukları Augmented Dickey Fuller (ADF) ve Phillips-Perron (PP) birim kök testi ile analiz edilmiştir.

\begin{tabular}{|c|c|c|c|c|c|}
\hline \multirow[b]{2}{*}{ Test } & \multirow[b]{2}{*}{ Değişken } & \multicolumn{2}{|c|}{$\begin{array}{c}\text { Düzey } \\
\text { (prob ve t-ist değerleri) }\end{array}$} & \multicolumn{2}{|c|}{$\begin{array}{c}\text { Birinci Fark } \\
\text { (prob ve t-ist değerleri) }\end{array}$} \\
\hline & & Sabit & Sabit+Trend & Sabit & Sabit+Trend \\
\hline \multirow{2}{*}{ ADF } & FDI & $\begin{array}{c}0.4354 \\
(-1.659400)\end{array}$ & $\begin{array}{c}0.5793 \\
(-1.974387)\end{array}$ & $\begin{array}{c}0.0020^{*} \\
(-4.595361)\end{array}$ & $\begin{array}{c}0.0102 * \\
(-4.522248)\end{array}$ \\
\hline & GDP & $\begin{array}{c}0.2566 \\
(-2.072604)\end{array}$ & $\begin{array}{c}0.5457 \\
(-2.036381)\end{array}$ & $\begin{array}{c}0.0311 \\
(-3.288050)\end{array}$ & $\begin{array}{c}0.0747 * * \\
(-3.460134)\end{array}$ \\
\hline \multirow{2}{*}{ PP } & FDI & $\begin{array}{c}0.4424 \\
(-1.644919) \\
\end{array}$ & $\begin{array}{c}0.5565 \\
(-2.018898) \\
\end{array}$ & $\begin{array}{c}0.0020^{*} \\
(-4.609282) \\
\end{array}$ & $\begin{array}{c}0.0099 * \\
(-4.540070) \\
\end{array}$ \\
\hline & GDP & $\begin{array}{c}0.1373 \\
(-2.468906)\end{array}$ & $\begin{array}{c}0.4000 \\
(-2.331540) \\
\end{array}$ & $\begin{array}{c}0.0170^{*} \\
(-3.573033)\end{array}$ & $\begin{array}{c}0.0629 * * \\
(-3.544960)\end{array}$ \\
\hline
\end{tabular}

Tablo 3: Birim Kök Test Sonuçları

Not: *\%5 ve **\%10 olasılık düzeyinde anlamlılı̆̆ı göstermektedir. Parantez içi değerler t istatistik değerleridir.

Tablo 3'den de görüldüğ̈̈ gibi, birim kök test sonuçları yabancı sermaye yatırımı (FDI) ve milli gelir (GDP) değişkeninin düzeyde durağan olmadığını gösterir (p-değerleri $\geq \alpha=0,05$; Boş hipotez ret edilemez). Buna karşın birçok durumda her iki değişken için değişkenlerin birinci farklarında_durağan olduğuna işaret etmektedir (pdeğerleri $<\alpha=0,05$; Boş hipotez ret edilir). Dolayısıyla serilerin düzeyde birim köke sahip olduğu fakat birinci derece farklarının $\% 5$ ve \% 10 anlamlılık düzeyinde durağan olduğu görülmektedir. Yani, serilerin entegre seviyesinin I(1) olduğu tespit edilmiştir.

Birim kök testleri sonucunda değişkenlerin bütünleşme derecelerinin 1. Derecede aynı olduğunun belirlenmesiyle birlikte eş-bütünleşme analizi yapılmış ve böylelikle değişkenler arasında uzun dönemli bir ilişkinin var olup olmadığı incelenmiş̧tir. Değişkenler arasında eş-bütünleşme olup olmadığı Johansen eşbütünleşme testiyle araştırılmıştır (Johansen ve Juselius, 1990: 169-210). Eş- bütünleşme, durağan olmayan değişkenlerin doğrusal kombinasyonlarının uzun dönemde durağan olmasına, dolayısıyla değiş̧kenlerin birbirleriyle eş-bütünleşmesine, zaman serileri arasındaki uzun dönem ilişkisinin modellenmesine ve tahmin edilmesine yöneliktir. Johansen eşbütünleşme yönteminde, seriler arasında eşbütünleşme analizi yapılabilmesi için, bütün serilerin aynı düzeyde durağan I(1) olması gerekmektedir. Değişkenler arasında eş- bütünleşmenin bulunması gerçek bir uzun dönemli ilişki anlamına gelmektedir.

Eşbütünleşmenin varlığı ve vektörlerinin sayısını belirlemek amacıyla gerekli iz (trace) ve maksimum öz (max) değerleri test sonuçları Tablo 4'de verilmiştir.

\begin{tabular}{|c|c|c|c|c|c|c|}
\hline & İz (Trace) & $\begin{array}{c}0.05 \text { Kritik } \\
\text { Değer }\end{array}$ & $\begin{array}{l}\text { Olasılık } \\
\text { (Prob).** }\end{array}$ & $\begin{array}{c}\text { Maksimum } \\
\text { Özdeğer (Max) }\end{array}$ & $\begin{array}{c}0.05 \text { Kritik } \\
\text { Değer }\end{array}$ & $\begin{array}{l}\text { Olasılık } \\
\text { (Prob).** }\end{array}$ \\
\hline None $*$ & 25.40900 & 15.49471 & 0.0012 & 17.41502 & 14.26460 & 0.0154 \\
\hline At most $1 *$ & 7.993978 & 3.841466 & 0.0047 & 7.993978 & 3.841466 & 0.0047 \\
\hline
\end{tabular}

Tablo 4: Johansen Eşbütünleşme Analizi Sonuçları

İz(trace) ve maksimum özdeğer istatistiklerine göre, değişkenler arasında hiçbir eşbütünleşme ilişkisinin olmadığı boş hipotez $(r=0)$, değişkenler arası eşbütünleşme ilişkisinin olduğuna ilişkin alternatif hipoteze $(r>0)$ karş1 reddedilmektedir. Tablo 2'den de görüldüğü gibi, iz (trace) ve maksimum öz (max) değeri \% 5 kritik değerden daha büyüktür. Dolayısıyla en az bir eşbütünleşme ilişkisinin varlığı kabul edilmiştir. Yani; FDI ve GDP serileri arasında eşbütünleşmenin olması FDI'nin GDP'yi etkilediğine ilişkin bir kanıt olarak görülebilir.

Uzun dönem ilişkisi Johansen eşbütünleşme testi ile belirlendikten sonra değişkenler arasındaki nedensellik ilişkisi ve ilişkinin yönü, "Granger Nedensellik Testi” yardımıyla araştırılmıştır. Nedensellik testi iki değişken arasında bir sebep-sonuç ilişkisinin olup olmadığını, eğer varsa ilişkinin yönünü test etmek amaciyla kullanılmaktadır. Uygulamada zaman serileri arasındaki nedensellik ilişkisinin tespit edilmesinde en sık kullanılan 
yöntem Granger (1969) tarafından geliştirilen Granger nedensellik analizidir (Granger, 1969: 426-435). Granger nedensellik testi, bağımsız değişkenin gecikmeli değerlerin katsayılarının, belirli bir anlamlılık düzeyinde, grup halinde sıfıra eşit olup olmadığı test edilerek yapılır.

\begin{tabular}{|l|l|l|}
\hline Nedenselliğin Yönü & ki-kare Değeri & Olasılık Değeri \\
\hline FDI $\longrightarrow$ GDP & 4.908452 & 0.0859 \\
\hline GDP $\longrightarrow$ FDI & 0.278226 & 0.8701 \\
\hline
\end{tabular}

Tablo 5: Granger Nedensellik Test Sonuçları

Granger nedensellik testi sonuçlarına göre “doğrudan yabancı yatırımlar ekonomik büyümenin Granger nedeni değildir” hipotezi, olasılık değerinin \% 10’ten küçük olması nedeniyle reddedilmektedir. Granger nedensellik testi sonucunda, \%10 anlamlılık düzeyinde FDI, GDP'nin Granger nedenidir. Yani FDI'den GDP'ye doğru tek yönlü bir nedensellik ilişkisi mevcuttur.

\section{Sonuç}

Finansal piyasalardaki hareketlerin 1990'l1 yıllardan beri gözle görünür bir şekilde artması sonucu doğrudan yabancı yatırımlar, ekonomik büyümenin en önemli belirleyicileri haline gelmiştir. Doğrudan yabancı yatırımlarının gelen ülkeye sermaye ve teknoloji getirmesiyle beraber verimliliği arttırması da ekonomik büyümenin üzerinde önemli rol oynamıştır. Yapılan çoğu araştırmalarda doğrudan yabancı sermaye yatırımlarının ekonomik büyümeyi artıracağı yönündeki bulguları bu konunun daha çok tartışılmasına zemin hazırlamıştır.

Küreselleşmenin yoğun bir şekilde kendisini hissettirdiği günümüz dünyasında doğrudan yabancı sermaye yatırımları hızla artmaktadır. Doğrudan yabancı sermaye yatırımları gittikleri ülkelerin birçok makro verisini de etkilemektedir. Bu makro göstergelerin başında da ekonomik büyüme gelmektedir. Literatürde, yabancı sermaye yatırımları ile büyüme ilişkisi üzerine pek çok çalışma yapılmıştır. Bu yapılan çalışmaların bazıları doğrudan yabancı sermaye yatırımlarının ekonomik büyüme üzerinde pozitif etkileri olduğunu destekler iken; diğer bir grup çalışmada ise bu pozitif etkinin mutlak olmayacağ 1 ve hatta anlamsız bir ilişkinin bulunduğu ortaya konulmuştur. Azerbeycan'ın 1995-2015 yılları arasındaki doğrudan yabancı sermaye verileri ve büyüme oranları kullanılarak, doğrudan yabancı sermaye ile büyüme arasında ilişki Granger nedensellik testine tabi tutulmuştur. İncelenen dönem içerisinde doğrudan yabancı sermayeden büyümeye doğru bir nedensellik ilişkisi bulunurken, büyümeden doğrudan yabancı sermayeye doğru bir nedensellik ilişkisi bulunamamıştır. Bu çalışmada, günümüz dünya ekonomisinin bir gerçeği olan doğrudan yabancı sermayeye yatırımları incelenmiş, bu konuda rekabet yarışına giren ülkelerin arasında Azerbaycan 'da yerini alma çabası içindedir.

\section{Kaynakça}

- Afşar, M. (2008). "The Causality Relationship Between Economic Growth and Foreign Direct Investment in Turkey”. Selçuk Üniversitesi Sosyal Bilimler Enstitüsü Dergisi, 20, 1-9.

- Ağayev S. (2010), "Doğrudan Yabancı Sermaye Yatırımları ve Ekonomik Büyüme İlişkisi: Geçiş Ekonomileri Örneğinde Panel Eştümleşme ve Panel Nedensellik Analizleri”, Gazi Üniversitesi İ̉ktisadi ve İdari Bilimler Fakültesi Dergisi 12/1, 159-184.

- Aleksynska, M., Gaisford, J. and Kerr, W. (2008), "Foreign Direct Investment and Growth in Transition Economies", University Library of Munich MPRA Paper, No. 7668.

- Borenzstedn, Eduardo, D Gregorı Jose, Lee, Jong, Wha (1998), "How Does Foreign Direct Investment Affect Economic Growth", Journal of International Economics, Vol. 45 S 1, 115-135.

- Carcovic M. and Levine R (2002), "Does Foreign Direct Investment Accelerate Economic Growth? Financial Globalization: A Blessing or Curse", World Bank Conference Washinghton.

- Chowdhury, A. and Mavrotas, G. (2005), "FDI and Growth: A Causal Relationship. Research Paper. United Nations University (UNU)", World Institute for Development Economic Research (WIDER). N. 25, 2-10.

- De Mello, L. (1999), "Foreign Direct Investment Led Growth: Evidence From Time Series and Panel Data", Oxford Economic Papers 51, 133-151.

- Dünya Bankası, http://data.worldbank.org/indicator/bx..klt.dinv.cd.wd (Erişim tarihi: 20.02.2017)

- Granger, Clive. W. J. (1969). "Investigating Causal Relations by Econometric Models and Cross-Spectral Methods", Econometrica, 37 (3), 424-438.

- Gujarati, Damodar N., (1999), Basic Econometrics, McGraw Hill, Intriligator, M.D., Econometric Models, Techniques and Applications, Prentice Hall, 1995.

- Gürsoy, F. ve Kalyoncu, H. (2012). "Foreign Direct Investment and Growth Relationship in Georgia", International Journal of Economics and Financial Issues, C. 2, S. 3, 267-271. 
- Johansen, S. ve Juselius K. (1990), "Maximum Likelihood Estimation And Inference on Cointegration with Application to the Deman for Money", Oxford Bulletin of Economic and Statistics, 52, 169-210.

- $\quad$ Nath, H. K. (2005). “Trade, Foreign Direct Investment and Growth: Evidence from Transition Economies”. Sam Houston State University Department of Economics and International Business Working Paper Series, (05-04).

- Özdemir, Z. ve Yalman (2012), A. P. D. İ. N. "Kadın İstihdamı ve Ekonomik Kalkınma: Geçiş Ekonomileri Örneği”, http://avekon.org/papers/476.pdf (Erişim Tarihi: 12.04.2017).

- Turan F. (2011), "Doğrudan Yabancı Yatırımların İktisadi Büyümeye Etkisi: Türkiye için Bir Ekonometrik Analiz”. Paper presented at Econ Anadolu. Anadolu International Conference in Economics, 15-17.

- $\quad$ UNCTAD (2000), World Investment Report, Cross- Border Mergers and Acquisitions and Development (Chapter XI), United Nations, NewYork and Geneva.

- World Bank, http://data.worldbank.org/data-catalog/world-development-indicators (Erişim tarihi: 10.02.2017). 


\title{
Türkiye’de Sürdürülebilir Kırsal Kalkınma İçin Köyden Kente Göçün Önlenmesinde Etkili Unsurların Saptanması ve Bir Araştırma
}

\section{A Research and Determination of the Effective Elements in the Prevention of Migration from the Village to the City for Sustainable Rural Development in Turkey}

\author{
Prof. Dr. Lutfiye Özdemir (İnönü University, Turkey) \\ Ph.D. Candidate Orhan Polat (İnönü University, Turkey) \\ Gamze Seyitoğlu (Gazi University, Turkey) \\ Sevde Çiçekli (Mehmet Akif Ersoy University, Turkey)
}

\begin{abstract}
In today's Turkey, rapid technological changes and developments at global level has increased to migration from village to urban areas. Sustainable rural development (SRD) means that future generations can meet their needs in a settlement that is less than a population of 20,000, so that past generations can't complain about them. For sustainable rural development, it is important to prevent rural migration and to present labour, production, marketing and living opportunities in rural areas. In this context, the study was conducted in order to investigate the causes of migration from the village to the city, to take the necessary precautions and to make suggestions for the SRD. For this purpose, the research has been applied to farmers in selected villages in Central Anatolia, Black Sea, Aegean, Marmara, Mediterranean and Eastern Anatolia Regions in Turkey with face to face discussions and 141 questionnaires have already been collected.

It was found that Cronbach Alpha was found to be quite reliable as the result of the analysis with a scale value of 0.785 . Reasons for migration as a result of factor analysis can be classified as: 1) Migration due to education, 2) Migrations based on physical infrastructure. Numerous independent variables considered to be effective on these problems were analyzed by multiple linear regression analysis. As a result, it has been determined that many factors, mainly demographic qualities, are effective on migrations based on both education and physical infrastructure.
\end{abstract}

\section{Giris}

Günümüz Türkiye'sinde, küresel düzeyde meydana gelen hızlı teknolojik değişme ve gelişmelerle birlikte kırsal alanlardan kentlere olan göçler de artmaktadır. Sürdürülebilir kırsal kalkınma (SKK), nüfusu 20 binden az olan yerleşim yerlerinde gelecek nesillerin ihtiyaçlarını geçmiş nesilden şikâyet etmeyecek şekilde karşılayabilmesi anlamına gelmektedir. Sürdürülebilir kırsal kalkınma için köyden kente göçün önlenmesi ve kırsal alanlarda çalışma, üretim, pazarlama ve yaşam şansının sunulması önem arz etmektedir. Bu bağlamda çalışma, köyden kente göçün nedenlerinin araştırılması, gerekli önlemlerin alınabilmesi ve SKK için önerilerde bulunabilmek amacıyla gerçekleştirilmiştir. Bu amaçla araştırma Türkiye'de İç Anadolu, Karadeniz, Ege, Marmara, Akdeniz ve Doğu Anadolu Bölgeleri'nden seçilmiş köylerde çiftçilerle yüzyüze anketlerle uygulanmış ve hâlihazırda 141 anket toplanmıştır.

Analiz sonucunda 0,785 değer aldığı saptanan ölçeğin Cronbach Alpha'sının oldukça güvenilir olduğu bulunmuştur. Faktör analizi sonucunda göçlerin nedenleri: 1) Eğitim kaynaklı göçler ve 2) Fiziksel altyapıya dayalı göçler olarak sınıflandırılmıştır. Bu sorunlar üzerinde etkili olabileceği düşünülen çok sayıda bağımsız değişken analize dâhil edilerek çoklu doğrusal regresyon analizi yapılmıştır. Sonuç olarak hem eğitim kaynaklı göçler hem de fiziksel altyapıya dayalı göçler üzerinde başta demografik nitelikler olmak üzere pekçok unsurun etkili olduğu saptanmıştır.

\section{Literatür Taraması}

Sürdürülebilirlik; ekonomik gelişmenin ve kalkınmanın sürdürülebilir olmasını sağlayabilmek için doğal kaynakları tüketmeksizin ve tabiatın dengesini bozmaksızın gelecek nesillerin gereksinimlerini karşılayarak kalkınmalarına imkân sağlamak amacıyla bugün ve yarın için kalkınmanın planlanması ve uygulanmasıdır (Koçel, 2015). Sürdürülebilirlik; sosyal, ekonomik, çevresel ve tarımsal sürdürülebilirlik olarak dört ana bölüme ayrılabilir (Altınok vd., 2015; The EU Explained, 2014; Kırımhan, 2005). Sosyal sürdürülebilirlik, toplumun manevi yapıs1; ekonomik sürdürülebilirlik, maddi yapısı (yapı, hammadde, enerji, doğal kaynaklar vb.); çevresel sürdürülebilirlik, tabiatın korunması ve tarımsal sürdürülebilirlik, tarımsal faaliyetlerin devamlılı̆̆ı ile ilgilidir. Sürdürülebilir kalkınma; bugün yaşayanların ve gelecekte yaşayacakların gereksinimlerini karşılamaları ve gelişmeleridir 
(WCED, 1987; OECD, 2004; Strange ve Bayley, 2008). Sosyal, ekonomik ve çevresel sürdürülebilirliğin sağlanabilmesi için kırsal alanlardaki insan kaynaklarının eğitilmesi stratejik bir önem taşımaktadır (EC, 2016; EUR-Lex, 2016; UNCED, 1992; IISD, 2010). Kırsal alanlardaki temel ekonomik faaliyetler tarıma dayalıdır (UKKS, 2014-2020; İrmiş ve Eroğlu, 2015). Tarım; bitkisel ve hayvansal ürünlerin üretilmesi, kalite ve verimlerinin yükseltilmesi, uygun koşullarda korunması, işlenip değerlendirilmesi ve pazarlanmasıdır (Büyük Türkçe Sözlük, 2016). Bitkisel ve hayvansal ürünlerin üretimi, büyük oranda kırsal alanlarda yapılabildiğinden tarım ve kırsal alan birbiri ile doğrudan ilişkilidir. Bu nedenle tarımın kalkınması kırsal alanların kalkınması anlamına gelmektir. Dünya Bankası'nın 2008 yılı Dünya Kalkınma Raporu'nda kırsal kalkınmanın önündeki en büyük engelin göç olduğu (T.C. Kalkınma Bakanlığı, 2016) ve göçü önlemek için eğitimlerle kırsal alanlardaki potansiyelin geliştirilmesi gerektiği vurgulanmakta ve örneklerle gösterilmektedir. Uygulanan eğitim modelleri; resmi eğitimde kalitenin artırılması, resmi olmayan eğitimde Sivil Toplum Kuruluşları'nın (STK) ikinci şans eğitimleri, mesleki ve yüksek eğitimin yeniden düzenlenmesi şeklinde olmuştur. Tüm eğitimlerin ana mantığını, günümüz koşullarına uygun sorgulayıcı, yenilikçi tarımsal eğitimlerin yanında işletmecilik ve girişimcilik eğitimleri oluşturmaktadır (World Development Report 2008, 2007).

Kırsal alanların kalkınmasındaki en büyük engel insan kaynaklarının göç yoluyla kırsaldan ayrılmasıdır. Göç ile ilgili olarak geçmişten günümüze teorileri beş başlıkta toplayabiliriz. Bunlar kısaca şöyledir (Tavas, 2015);

1. Ravensttein Kuramı: Ravenstein Birleşik Krallık’ta 1885 ve 1889 yıllarında gerçekleştirdiği araştırmada; göçün temel sebebinin ekonomik olduğunu vurgulamaktadır. Bu araştırmaların sonuçlarını ayrıntılı olarak "Göç Kanunları" isimli makalelerinde göçün kurallarını anlatmaktadır (Ravenstein, 1885; Ravenstein, 1889; Lee, 1966).

2. Kesişen Fırsatlar (Intervening Opportunities) Kuramı: Stouffer'in 1940 yılında yaptığı bir çalışma olan "Kesişen Fırsatlar" ile elde ettiği bulgular sonucunda geliştirilen bir kuramdır. Bu kuramın oluşturulmasına katkı sağlayan çalışmada, göç edilecek mesafe, firsatlar ve firsatların çeşitliliği ile göçün sebepleri araştırılmıştır. Çalışmanın sonucunda göç için tercih edilen yerin/mesafenin, firsat ve fursatların çokluğu ile doğru orantılı olduğunu bulunmuştur (Tavas, 2015).

3. İtme-Çekme (Push-Pull) Kuramı: Everett Lee, 1966 yılında yayınladığı “Göç Teorisi” (A Theory of Migration) adlı makalesinde göç davranışının faktörlerini; yaşanan yer, göç edilecek yer, araya giren engeller ve kişisel faktörler olarak dört başlıkta toplamıştır. Bu faktörlerin ilk üçü ile grafik oluşturarak "itme-çekme model’'ini oluşturmuştur. Bunlar grafikte itici (-, eksi), çekici (+, artı) ve etkisiz (0, nötr) olarak ifade edilmiştir. İtici faktörler bireylerin bulunduğu yerlerden ayrılmasına neden olan ekonomik, sosyal ve siyasi vb. sorunları içermektedir. Çekici faktörler ise; göç sonucu gidilen yerin çekici-cezbedici özelliklerini içermektedir (Lee, 1966; IOM, 2017).

4. Petersen Göç Kuramı: Petersen 1958 yılında yaptığı "Göçün Genel Tipolojisi” isimli çalışmasında genel olarak göçün oluşmasında en büyük etkinin ekonomik faktörler olduğunu belirtmekte ve ekonomideki yükseliş ve düşüşlerin toplumdaki sınıfları etkilediğini ve bireylerin ve toplumdaki sınıfların ekonomideki değişikliklere tepkilerinin farklı olduğunu ifade etmektedir (Petersen, 1958).

5. Göç Sistemleri ve Göç İlişkileri Kuramı: Bu kuramda göç, devletlerarası, kültürlerarası, bireysel-ailesel ve göç ajansları arasındaki ilişkilere göre incelenmektedir (Tavas, 2015). Fawcett, göç sistemini genel olarak bağlantılar ve ilişkiler üzerine kurmuştur. Bu bağlantıların tiplerini, somut, düzenleyici ve ilişkisel bağlantılar olarak ifade etmektedir. Bağlantı kategorilerini ise; devletten devlete, kitlesel kültürler arası, ailesel ve kişisel, göç ajansları olmak üzere dört kategoride incelemektedir. Çalışmanın sonucunda ise göçün sadece ekonomik boyutunun değil kültürel boyutunun da incelenmesi gerektiğine vurgu yaparken, uluslararası göç çalışmalarının yapılmasının önemine dikkat çekmektedir (Fawceet, 1989). Uluslararası göç incelenirken iç göçten farklı olarak ekonomik, sosyal, politik ve çevresel konular gibi pekçok alanların da uluslararası göç teoremlerine göre uygulamalı incelenmesi gerekmektedir (Massey, 1993).

Literatürde göç hareketlerini açıklayacak tek ve kapsamlı bir kuram henüz mevcut bulunmamaktadır. Göç araştırmalarında; bazen birey, bazen hane halkı, bazen ulusal bazen de uluslararası alanlar araştırma evreni olarak kabul edilmişlerdir. Göçün ve ekonominin kuralları fizik kuralları gibi katı ve değişmez değildir. Topluma, zamana, mekâna, duruma ve pekçok değişkene göre göçün kuralları değişebilir. Bu durum göç konusunda sürekli çalışma ve araştırmaların yapılmasını zorunlu kılmaktadır. Göç, kırsal alanlardaki emek ve sermaye gibi üretimin ana kaynaklarının kaybedilmesine neden olabilmektedir. Genç ve nitelikli iş gücünün kırsal alanlardan göçü ise hem üretim faktörlerinin kaybına hem de kırsal alanlarda yaşlı nüfusun oluşmasına yol açmaktadır. BM'de yapılan çalışmalarda demografik değişikliklere veya göçlere; çevresel faktörler, yoksulluğun azaltılması, güvenlik ihtiyacı, sağlık, kaliteli yaşam, gelir seviyesini artırma isteği, okula erişim/gitme, mesleki eğitim, kişisel istekler ve kendini güçlendirme/gerçekleştirme gibi ihtiyaçların neden olduğu sonucuna ulaşılmıştır (UNCED, 1992).

\section{Araştırmanın Amacı ve Araștırma Soruları}

Araştırmanın amaçları sürdürülebilir kırsal kalkınmanın sağlanabilmesi için kırsal alanlardan kentlere olan göçlerin sınıflandırılması ve bu göçlerin önlenmesinde etkili olan unsurların saptanmasıdır. Bu amaçlara yönelik 
olarak oluşturulan araştırma soruları şunlardır: 1) Köyden kente göçün nedenleri nelerdir? 2) Çiftçilerin demografik nitelikleri köyden kente göçte etkili midir? 3) Demografik niteliklerin dışında köyden kente göçte etkili olan unsurlar nelerdir?

\section{Araştırmanın Yöntemi}

Araştırma verileri anket yöntemi ile bizzat araştırmacılar tarafından yüzyüze yapılan görüşmelerle toplanmıştır. Toplanan veriler Microsoft Excel ve SPSS 22.0 programlarına yüklenerek analiz edilmiş olup; analiz işlemlerinde öncelikle ölçeğin güvenilirliğini ölçebilmek için Cronbach Alpha testi yapılmış ardından demografik niteliklerle ilgili frekans dağılımları, göç nedenlerini sınıflandırmak üzere faktör analizi uygulanmış ve son olarak demografik nitelikler ile diğer etkili unsurların köyden kente göçü ne derece etkilediklerini saptayabilmek için çoklu regresyon analizi istatistiki tekniklerinden yararlanılmıştır.

\section{Araştırmanın Anakütle ve Örneklemi}

Araştırma Türkiye'de seçilmiş bazı bölgelerde yapılmıştır: Bu bağlamda anket İç Anadolu Bölgesi'nden Eskişehir-Çifteler-Yıldızören Köyü'nde, Doğu Anadolu Bölgesi'nden Malatya-Yeşilyurt-Kırlangıç Köyü'nde, Karadeniz Bölgesi'nden Amasya-Taşova-Andıran Köyü'nde ve Artvin-Şavşat-Düzenli Köyü'nde, Akdeniz Bölgesi'nden Mersin-Silifke-Ovacık Köyü'nde, Ege Bölgesi'nden Manisa-Selendi-Terziler Köyü'nde ve son olarak Marmara Bölgesi’nden Çanakkale-Ayvacık-Tuzla Köyü’nde uygulanmıştır. Adı geçen bölgelere 200 adet anket gönderilmiş; ancak 153 anket geri dönmüştür. Geri dönen anketlerin 141 adedinin değerlendirilebilir nitelikte olduğu kabul edilmiştir. Analiz sonucunda 0,785 değer aldığı saptanan ölçeğin Cronbach's Alpha'sının oldukça güvenilir olduğu bulunmuştur. Araştırmada veri ve bilgi toplamada anketörler vasıtasıyla yüzyüze anket yöntemi kullanılmıştır. Anket formu araştırmacıların kendileri tarafından kapsamlı literatür taraması sonucunda edindikleri bilgiler bağlamında hazırlanmış olup, toplam 93 sorudan oluşmaktadır.

\section{Araştırmanın Hipotezleri}

1. Demografik nitelikler köyden kente göçler üzerinde anlamlı bir etkiye sahiptir.

2. Binek araçlarının varlığı, il ve ilçe merkezlerine uzaklık, toplu taşıma araçlarının köye gelme sıklığı ve kış nedeniyle yolların kapanması birlikte köyden kente göç üzerinde anlamlı bir etkiye sahiptir.

3. Tarım görevlilerinin bilgi vermesi, kuyu ve depoların kontrolü ve toprak analizlerinin yapılması birlikte köyden kente göç üzerinde anlamlı bir etkiye sahiptir.

4. Su, doğalgaz/kalorifer 1sıtma sistemi, PTT ve İnternet hattı, ekmek satışı, market, kargo imkanı, yem/un değirmeni, gazete, cep telefonu ile haberleşebilme, hızlı İnternet bağlantısı, gezici benzin/akaryakıt istasyonu ve süt toplama, depolama ve işleme istasyonlarının varlığı birlikte köyden kente göç üzerinde anlamlı bir etkiye sahiptir.

5. Elektrik ustası, inşaat ustası, motor/kaynak vb. ustası, tesisat ustası, veteriner vb., meslek erbaplarına ödenen ücretler, tarım işçilerine ödenen ücretler, sürekli tarım işçisinin varlığı birlikte köyden kente göç üzerinde anlamlı bir etkiye sahiptir.

6. Tarımsal faaliyetlerin kazancı, kullanılan yapay gübre miktarı, kullanılan hayvansal gübre miktarı, tarladan sağlanan yıllık yem miktarı, satın alınan yem miktarı ve üretilen aylık yem miktarı birlikte köyden kente göç üzerinde anlamlı bir etkiye sahiptir.

7. Tarımsal/hayvansal danışmanlık, danışmanlık ücretleri, danışmanlara olan güven ve tarımsal hibelerle ilgili anlık bilgi verilmesi birlikte köyden kente göç üzerinde anlamlı bir etkiye sahiptir.

\section{Araştırma Bulguları}

\subsection{Demografik Niteliklerle İlgili Bulgular}

Bu bölümde araştırmaya katılan köylüler cinsiyetleri, medeni durumları, eğitim durumları, yaşları, kaç yıldır köyde yaşadıkları ve çiftçilik deneyimleri açısından değerlendirilmişlerdir. Bu değişkenleri ilişsin frekans dağılımları Tablo 1'de görülebilir. 


\begin{tabular}{|c|c|c|c|c|c|}
\hline Cinsiyet & Frekans & Yüzde & Medeni Durum & Frekans & Yüzde \\
\hline Erkek & 130 & 92.2 & Evli & 119 & 84.4 \\
\hline Kadın & 11 & 7.8 & Bekar & 22 & 15.6 \\
\hline Toplam & 141 & 100.0 & Toplam & 141 & 100.0 \\
\hline Eğitim Durumu & Frekans & Yüzde & Yaş & Frekans & Yüzde \\
\hline İlkokul & 65 & 46.1 & 40 yaş ve altı & 39 & 27.7 \\
\hline Ortaokul & 16 & 11.3 & $41-55$ & 57 & 40.4 \\
\hline Lise & 53 & 37.6 & 56 yaş ve üstü & 45 & 31.9 \\
\hline Lisans ve önlisans & 7 & 5.0 & Toplam & 141 & 100.0 \\
\hline Toplam & 141 & 100.0 & & & \\
\hline $\begin{array}{l}\text { Kaç Yıldır Köyde } \\
\text { Yaşandığı }\end{array}$ & Frekans & Yüzde & \begin{tabular}{|l} 
Çiftçilik \\
Deneyimleri
\end{tabular} & Frekans & Yüzde \\
\hline $1-20$ y1l aras1 & 22 & 15.6 & $1-15$ y1l aras1 & 70 & 49.6 \\
\hline $21-40$ y1l aras1 & 43 & 30.5 & $16-30$ y1l arası & 47 & 33.3 \\
\hline 41-60 y1l arası & 58 & 41.1 & 31 yıl ve üzeri & 21 & 14.9 \\
\hline 61 yıl veya üstü & 18 & 12.8 & Cevapsiz & 3 & 2.1 \\
\hline Toplam & 141 & 100.0 & Toplam & 141 & 100.0 \\
\hline
\end{tabular}

Tablo 1. Demografik Nitelikler ile İlgili Dă̆llımlar

Araştırmada yüzde 92'si erkek olan katılımcıların yüzde 84'ünün evli oldukları ve en yüksek oranla yüzde 46'sının ilkokul mezunu oldukları saptanmıştır. Yüzde 40'ının 41-55 yaş aralığında bulunduğu katılımcıların yüzde 49'unun 1-15 yıl arası çiftçilik deneyimlerinin bulunduğu ve yine en yüksek oranla yüzde 41'inin 41-60 yıl arası köyde yaşadıkları tespit edilmiştir.

\subsection{Köyden Kente Göçün Boyutlarının Saptanması: Açıklayıcı Faktör Analizi}

Kırsal alanlardan kentlere olan göçlerin nedenlerini belirleyebilmek ve sınıflandırabilmek amacıyla yapı geçerliği kullanılmıştır. Yapı geçerliği kapsamında, ölçeğin faktör yapısını belirleyebilmek için açıklayıcı faktör analizi yapılmıştır. Açıklayıcı faktör analizi, 2017 yılında İç Anadolu, Karadeniz, Ege, Marmara, Akdeniz ve Doğu Anadolu Bölgeleri’nden seçilmiş köylerdeki 141 çiftçiden elde edilen veriler üzerinde gerçekleştirilmiştir. Veriler üzerinde faktör analizi yapılmadan önce verilerin dağılım özellikleri Kolmogorov-Smirnov testi ile incelenmiş ve dağılımın normale yakın olduğu saptanmıştır (Kalaycı, 2009: 54). Çünkü tanımlayıcı istatistiki analiz sonucunda değişkenlerin ortalaması, medyanı ve modunun yakın değerler aldığı görülmüştür. Bu aşamadan sonra yapılan Kaiser-Mayer-Olkin ve Bartlett Testleri sonucunda (Kaiser Meyer Olkin= .708, Bartlett's Test of Sphericity= $387.284, \mathrm{df}=55, \mathrm{p}=.000$ ) verilerin faktör analizine uygun olduğu belirlenmiştir. Açıklayıcı faktör analizinde şu ölçütler esas alınmıştır: Her bir faktörün özdeğerinin en az 1 olması, her bir faktördeki maddelerin faktör yüklerinin en az .50 değerine sahip olması, her bir faktöre yüklenen maddelerin anlam ve içerik olarak tutarlı olması, bulundukları faktördeki yük değerleri ile diğer faktördeki yük değerleri arasındaki farkın en az .10 ve daha yukarı olması (binişik olmaması)dır. Ölçeği geliştirmek üzere anketteki değişkenler arasından toplam 11 madde belirlenmiştir. Ölçeğin boyutlarını belirleyebilmek amacıyla temel bileşenler analizi (principal component analysis), Kaiser kriteri (özdeğeri 1'den büyük olan faktörler) ve her faktöre düşen yüksek ağırlıklı değişkenleri minimize etmek için de Varimax dik döndürme tekniği uygulanmıştır. Belirlenen ölçütlere uymayan maddelerin $(89,86,91,73)$ elenmesi ve yinelenen analizler sonucunda ölçeğin iki boyutlu, yedi maddeden oluşan bir yapıya sahip olduğu belirlenmiştir. Analizler sonucunda elde edilen aritmetik ortalama, standart sapma, faktör yükleri, özdeğerler, açıklanan toplam varyans yüzdesi ve iç tutarlık katsayıları, Tablo 2'de verilmiştir.

\begin{tabular}{|c|c|c|c|c|c|c|}
\hline Maddeler & $\begin{array}{l}\text { Aritmetik } \\
\text { Ortalama }\end{array}$ & $\begin{array}{c}\text { Standart } \\
\text { Sapma }\end{array}$ & $\begin{aligned} \text { Faktör } \\
\text { Yükleri }\end{aligned}$ & Özdeğerler & Varyanslar & $\begin{array}{l}\text { Cronbach's } \\
\text { Alpha }\end{array}$ \\
\hline 1. Eğitim Kaynakłı Göçler & & & & 2.948 & 38.109 & .785 \\
\hline $\begin{array}{l}\text { 75) Verimli tarım yapılamadığından insanlar yoksulluktan/işsizlikten } \\
\text { göç ediyor }\end{array}$ & 4.1277 & 1.21215 & .823 & & & \\
\hline $\begin{array}{l}\text { 74) Tarımsal mesleki eğitim verilmediğinden verimli/kazançlı bir tarım } \\
\text { yapıllamıyor }\end{array}$ & 3.9929 & 1.16800 & .730 & & & \\
\hline $\begin{array}{l}\text { 77) Gençler küçük yaşlardan itibaren ilçe merkezlerinde okuduğu için } \\
\text { kursalda yaşamak istemiyorlar }\end{array}$ & 3.8298 & 1.28706 & .717 & & & \\
\hline $\begin{array}{l}\text { 76) Bilinçsiz tarım ile gelecek nesillerin yaşayabilmesi için gerekli olan } \\
\text { doğal kaynaklar (toprak, yeraltı suları, orman ve çevre) yok ediliyor }\end{array}$ & 4.1560 & 1.05752 & .711 & & & \\
\hline $\begin{array}{l}\text { 87) Okullarda tarım ile ilgili mesleki eğitim alan öğrencilerin } \\
\text { uygulamalı eğitimlerinin köylerde verilmesi faydalı olur }\end{array}$ & 3.9645 & 1.14898 & .640 & & & \\
\hline 2. Fiziksel Altyapıya Dayalı Göçler & & & & 1.378 & 23.698 & .758 \\
\hline 78) İnsanlar hastalıklarının tedavisi için göç ediyorlar & 2.9078 & 1.41371 & .891 & & & \\
\hline $\begin{array}{l}\text { 79) Şehirde yaşamanın kolaylıkları (su, elektrik, doğalgaz, ulaşım, } \\
\text { telefon, market, firın, İnternet vb.) insanları göç ettiriyor }\end{array}$ & 3.0638 & 1.45510 & .884 & & & \\
\hline Açıklanan Toplam Varyans: & & & & & 61.807 & \\
\hline
\end{tabular}

Tablo 2. Köyden Kente Göçün Nedenlerinin Sınıflandırılması

Tablo 2'de görüldüğü gibi, analiz sonucunda, ölçekte öz değeri (eigen value) 1'den büyük iki faktör saptanmıştır. Bu iki faktörün açıkladıkları toplam varyans, \%61.807'dir. Kline (1994) toplam varyansı açıklama düzeyinin \%40’ın üzerinde olmasını, yapı geçerliği için önemli göstergelerden biri olarak kabul etmektedir. Birinci faktörde yük değerlerinin .823 ile .640 arasında, ikinci faktörde ise yük değerlerinin .891 ile .884 arasında değiștiği 
görülmüştür. Ayrıca maddenin ölçekten çıkarılıp/çıkarılmayacağını saptamak amacıyla, madde silindiğinde, alpha katsayılarındaki değişmelere ve ortalamalardaki değişime bakılmıştır. Her bir madde ölçekten çıkarıldığında, alpha katsayısının yükselmediği görülmüştür. Bu maddelerin güvenirliliği değiştirmeyen, ölçeği destekleyen maddeler olduğuna ve ölçekten çıkarılmamaları gerektiğine karar verilmiştir. Varimax eksen döndürme tekniği sonucunda birinci faktörün beş maddeden $(75,74,77,76$ ve 87 ) ve ikinci faktörün ise iki maddeden (78 ve 79) oluştuğu bulunmuştur. Maddelerin içerikleri incelendiğinde, birinci faktöre "Eğitim Kaynaklı Göçler (EKAG)" ve ikinci faktöre "Fiziksel Altyapıya Dayalı Göçler (FAYDAG)" isimleri verilmiştir. Köyden kente göçün boyutlarını belirlemede güvenirlilik çalışması için iç tutarlılık katsayıları (Cronbach alpha) da hesaplanmıştır. Köyden kente göçlerin nedenlerinden biri olan eğitim kaynaklı göç boyutunun iç tutarlılık katsayısı alpha: .785 ve fiziksel altyapıya dayalı göç boyutunun alpha katsayısı 758 bulunmuştur. Kalaycı'ya (2009: 405; Can, 2013: 343) göre, alpha katsayısına bağlı olarak ölçeğin güvenilirliği şu şekilde yorumlanır; " $0 \leq \alpha<.40$ ise ölçek güvenilir değildir", “. $40 \leq \alpha<.60$ ise ölçeğin güvenilirliği düşük”, “. $60 \leq \alpha<.80$ ise ölçek oldukça güvenilir” ve ".80 $\leq \alpha<1.00$ ise ölçek yüksek derecede güvenilir”. Bu bağlamda ölçeğin oldukça güvenilir olduğu söylenebilir.

\subsection{Araştırma Hipotezlerinin Testine İlişkin Bulgular}

Belirtilen yedi araştırma hipotezi yapılan çoklu regresyon analizleri ile elde edilen bulgular doğrultusunda değerlendirilmiştir. Geliştirilen hipotezlerin herbiri eğitim kaynaklı ve fiziksel altyapıya dayalı göçlerin yordanması açısından ele alınmıştır. Bu bağlamda EKAG'ın yordanmasında demografik niteliklerin etkisine ilişkin bulgular Tablo 3 'te sunulmuştur.

\begin{tabular}{|l|c|c|c|c|c|c|c|}
\hline \multicolumn{1}{|c|}{ Değişken } & $\mathbf{B}$ & Standart Hata & $\mathbf{\beta}$ & $\mathbf{T}$ & $\mathbf{P}$ & İkili “r” & $\begin{array}{c}\text { Kismi } \\
\text { "r" }\end{array}$ \\
\hline Sabit & 4.369 & .481 & & 9.079 & .000 & & \\
\hline Yaş (Y) & .003 & .105 & .003 & .031 & .975 & .059 & .003 \\
\hline Cinsiyet (C) & .486 & .270 & .151 & 1.802 & .074 & .100 & .153 \\
\hline Eğitim Durumu (ED) & -.063 & .075 & -.074 & -.840 & .402 & -.122 & -.072 \\
\hline Medeni Durum (MD) & $\mathbf{. 6 6 5}$ & $\mathbf{. 2 0 2}$ & $\mathbf{. 2 8 1}$ & $\mathbf{- 3 . 2 9 4}$ & $\mathbf{. 0 0 1}$ & -.271 & -.273 \\
\hline Çiftçilik Deneyimi (ÇD) &, 006 & .106 &, 006 & .059 & .953 & .041 & .005 \\
\hline $\mathrm{R}=.317$ & $\mathrm{R}^{2}=.101$ & $\mathrm{~F}(5,135)=3.019$ & $\mathrm{P}=.013$ & \\
\hline
\end{tabular}

Tablo 3. EKAG'ın Yordanmasinda Demografik Niteliklerin Etkisi

EKAG'ın yordanmasında etkili olduğu düşünülen değişkenlerin EKAG'1 ne şekilde yordadıklarını ortaya koyabilmek amacıyla yapılan çoklu doğrusal regresyon analizi sonucunda demografik niteliklerle EKAG arasında anlamlı bir ilişki $\left(R=.317, R^{2}=.101\right)$ sergiledikleri $(F(5,135)=3.019$, $p<.05)$ saptanmıştır. Regresyon katsayılarının anlamlılık testleri göz önüne alındığında, yordayıcı değişkenlerden sadece medeni durumun $(\mathrm{p}<.01, \beta=-.281)$ EKAG üzerinde ters yönlü anlamlı bir yordayıcı olduğu görülmektedir. Yordayıc1 değişkenle EKAG arasındaki ilişkilere bakıldığında, medeni durum ile olan ikili ilişkide (İi) $r=-.271$, Diğer Yordayıcı Değişkenlerdeki Kısmi İlişki (DYDKİ) $\mathrm{r}=-.273$ düzeyindedir. Regresyon analizi sonuçlarına göre, EKAG yordayan regresyon denklemi şu şekildedir: $\mathrm{EKAG}=(4.369)+(.003 \times \mathrm{Y})+(.486 \times \mathrm{C})-(.063 \times \mathrm{ED})-$ $(.665 \times \mathrm{MD})+(.006 \times$ ÇD) .

FAYDAG'ın yordanmasında demografik niteliklerin etkisine ilişkin bulgular Tablo 4'te görülebilir.

\begin{tabular}{|c|c|c|c|c|c|c|c|}
\hline Değişken & B & $\begin{array}{c}\text { Standart } \\
\text { Hata }\end{array}$ & $\beta$ & $\mathbf{T}$ & $\mathbf{P}$ & İkili"r" & Kısmi "r" \\
\hline Sabit & 3.002 & .717 & & 4.186 & .000 & & \\
\hline Yaş (Y) & .488 & .157 & .293 & 3.106 & .002 & .259 & .258 \\
\hline Cinsiyet (C) & -.064 & .402 & -.013 & -.160 & .873 & -.048 & -.014 \\
\hline Eğitim Durumu (ED) & .018 & .111 & .014 & .159 & .874 & -.027 & .014 \\
\hline Medeni Durum (MD) & -.536 & .301 & -.152 & -1.782 & . 077 & -.193 & -.152 \\
\hline Çiftçilik Deneyimi (ÇD) & -.211 & .159 & -.132 & -1.333 & .185 & .027 & -.114 \\
\hline \multicolumn{2}{|l|}{$\mathrm{R}=.319$} & \multicolumn{2}{|l|}{$\begin{array}{l}\mathrm{R}^{2}=.102 \\
\end{array}$} & \multicolumn{2}{|c|}{$\mathrm{F}(5,135)=3.064$} & \multicolumn{2}{|c|}{$\mathrm{P}=.012$} \\
\hline
\end{tabular}

Tablo 4. FAYDAG'ın Yordanmasinda Demografik Niteliklerin Etkisi

Yapılan çoklu doğrusal regresyon analizi sonucunda demografik niteliklerle FAYDAG arasında anlamlı bir ilişki $\left(R=.319, R^{2}=.102\right)$ sergiledikleri $(F(5,135)=3.064, p<.05)$ saptanmıştır. Regresyon katsayılarının anlamlılık testleri göz önüne alındığında, yordayıcı değişkenlerden sadece yaş $(p<.01, \beta=.293)$ değişkeninin FAYDAG üzerinde anlamlı bir yordayı olduğu görülmektedir. Yordayıcı değişkenle FAYDAG arasındaki ilişkilere bakıldığında, yaş ile olan İ̇, $\mathrm{r}=.259$ iken DYDKİ, $\mathrm{r}=.258$ düzeyindedir. Regresyon analizi sonuçlarına göre, FAYDAG'1 yordayan regresyon denklemi şu şekildedir: FAYDAG $=(3.002)+(.488 \times \mathrm{Y})-(.064 \times \mathrm{C})+(.018 \times$ ED) $-(.536 \times \mathrm{MD})-(.211 \times \mathrm{C} D)$.

EKAG'ın yordanmasında binek araçların varlığının, il ve ilçe merkezlerine uzaklığın, toplu taşıma aracının gelme sıklığının ve kışın yolların kapanma süresinin etkisine ilişkin bulgular Tablo 5'te verilmiştir. 


\begin{tabular}{|c|c|c|c|c|c|c|c|}
\hline Değişken & B & Standart Hata & $\beta$ & $T$ & $\mathbf{P}$ & İkili "r" & Kısmi "r" \\
\hline Sabit & 4.246 & .351 & & 12.109 & .000 & & \\
\hline Binek Aracın Varlığı (BAV) & -.219 & .150 & -.127 & -1.453 & .148 & $\begin{array}{l}.094 \\
-.094 \quad r\end{array}$ & -.124 \\
\hline İl Merkezine Uzaklık (İLMU) & .018 & .127 & .013 & .138 & .890 & -.089 & .012 \\
\hline İlçe Merkezine Uzaklık (İLÇEMU) & .139 & .079 & .167 & 1.752 & .082 & .179 & .149 \\
\hline Toplu Taşıma Aracının Gelme Sıklığı (TTAGS) & -.099 & .114 & -.080 & -.874 & .384 & -.152 & -.075 \\
\hline Kışın Yolların Kapalı Olması (KYKO) & -.133 & .138 & -.091 & -.966 & .336 & -.113 & -.083 \\
\hline $\mathrm{R}=.251$ & & \multicolumn{2}{|l|}{$\mathrm{R}^{2}=.063$} & \multicolumn{2}{|c|}{$\mathrm{F}(5,135)=1.821$} & \multicolumn{2}{|l|}{$\mathrm{P}=.113$} \\
\hline
\end{tabular}

Tablo 5. EKAG'ın Yordanmasında Aracın, Uzaklı̆̆ın ve Klşın Etkisi

Yapılan çoklu doğrusal regresyon analizi sonucunda değişkenler ile EKAG arasında anlamlı bir ilişki $(\mathbf{R}=\mathbf{. 2 5 1}$, $\left.\mathbf{R}^{2}=.063\right)$ sergilemedikleri $(\mathrm{F}(5,135)=1.821, \mathrm{p}>.05)$ bulunmuştur.

FAYDAG'ın yordanmasında aynı değişkenlerin etkisine ilişkin bulgular Tablo 6' da verilmiştir.

\begin{tabular}{|c|c|c|c|c|c|c|c|}
\hline Değişken & B & Standart Hata & $\beta$ & $\mathbf{T}$ & $\mathbf{P}$ & İkili "r" & KIsmi "r" \\
\hline Sabit & .594 & .473 & & 1.256 & .211 & & \\
\hline Binek Aracın Varlığı (BAV) & .513 & .203 & .199 & 2.530 & .013 & .306 & .213 \\
\hline İl Merkezine Uzaklık (İLMU) & .000 & .172 & .000 & .003 & .998 & .033 & .000 \\
\hline İlçe Merkezine Uzaklık (İLÇEMU) & .479 & .107 & .388 & 4.494 & .000 & .308 & .361 \\
\hline Toplu Taşıma Aracının Gelme Sıklığı (TTAGS) & .520 & .153 & .282 & 3.396 & .001 & .152 & .281 \\
\hline Kıșın Yolların Kapalı Olması (KYKO) & .283 & .186 & .130 & 1.524 & .130 & .088 & .130 \\
\hline $\mathrm{R}=.485$ & & \multicolumn{2}{|l|}{$\mathrm{R}^{2}=.235$} & \multicolumn{2}{|c|}{$F(5,135)=8.285$} & \multicolumn{2}{|l|}{$\mathrm{P}=.000$} \\
\hline
\end{tabular}

Tablo 6. FAYDAG'ın Yordanmasında Aracın, Uzaklı̆̆ın ve Klşın Etkisi

Yapılan çoklu doğrusal regresyon analizi sonucunda değişkenler ile FAYDAG arasında anlamlı bir ilişki $(\mathbf{R}=$ $\left..485, R^{2}=.235\right)$ sergiledikleri $(F(5,135)=8.285, p<.001)$ bulunmuştur. Regresyon katsayılarının anlamlılık testleri göz önüne alındığında, yordayıcı değişkenlerden ilçe merkezine uzaklık $(\mathrm{p}<.001, \beta=.388)$, belediyenin toplu taşıma araçlarının köye gelme sıklığı $(p<.01, \beta=.282)$ ve binek aracın varlığı $(p<.05, \beta=.199)$ değişkenlerinin FAYDAG üzerinde anlamlı yordayıcılar oldukları görülmektedir. Ayrıca bu sıralama standartlaştırılmış regresyon katsayılarına göre, yordayıcı değişkenlerin FAYDAG üzerindeki göreli önem sırasını göstermektedir. Yordayıcı değişkenlerle FAYDAG arasındaki ilişkilere bakıldığında, ilçe merkezine uzaklık ile olan İ̇, $\mathrm{r}=.308$, DYDKİ, $\mathrm{r}=.361$; belediyenin toplu taşıma araçlarının köye varma sıklığı ile olan İI, $\mathrm{r}=.152$ iken DYDKİ, $r=.281$; son olarak binek aracın varlığ analizi sonuçlarına göre, FAYDAG'1 yordayan regresyon denklemi şu şekildedir: FAYDAG $=(.594)+(.513 \mathrm{x}$ $\mathrm{BAV})+(.000 \times \mathrm{I} L M U)+(.479 \times$ İLÇEMU $)+(.520 \times \mathrm{TTAGS})+(.283 \times \mathrm{KYKO})$.

EKAG'ın yordanmasında “İlçe Tarım Müdürlüğü, Tarım Kredi Kooperatifi veya Ziraat Odası'ndan görevlilerin tarım ile ilgili bilgi vermek üzere düzenli olarak köye gelme durumu”, "köyde içme sularının sağlandığı kuyu ve depoların kontrolünün düzenli olarak yapılma durumu" ve "tarlaların toprak analizinin yıllık olarak yapılma durumu" gibi değişkenlerin etkisine ilişkin bulgular Tablo 7'de sunulmuştur.

\begin{tabular}{|l|c|c|c|c|c|c|c|}
\hline Değişken & $\mathbf{B}$ & Standart Hata & $\mathbf{\beta}$ & $\mathbf{T}$ & $\mathbf{P}$ & İkili “r” & Kısmi “r” \\
\hline Sabit & 4.081 & .545 & & 7.482 & .000 & & \\
\hline Tarım Görevlilerinin Bilgi Vermesi (TGBV) & -.240 & .160 & -.125 & -1.500 & .136 & -.115 & -.127 \\
\hline Kuyu ve Depoları Kontrolü (KDK) & -.338 & .142 & -.196 & -2.374 & .019 & -.191 & -.199 \\
\hline Toprak Analizinin Yapılması (TAY) & .448 & .248 & .151 & 1.807 & .073 & .119 & .153 \\
\hline $\mathrm{R}=.264$ & \multicolumn{2}{|l|}{$\mathrm{R}^{2}=.070$} & $\mathrm{~F}(3,137)=3.434$ & $\mathrm{P}=.019$ \\
\hline
\end{tabular}

Tablo 7. EKAG'ın Yordanmasında Görevlilerin Bilgilendirmesinin, Kuyu/Depo Kontrolünün ve Toprak Analizinin Etkisi

Yapılan çoklu doğrusal regresyon analizi sonucunda değişkenler ile EKAG arasında anlamlı bir ilişki (R= $\left..264, R^{2}=.070\right)$ sergiledikleri $(F(3,137)=3.434, p<.05)$ bulunmuştur. Regresyon katsayılarının anlamlılık testleri göz önüne alındığında, yordayıcı değişkenlerden sadece köyde içme sularının sağlandığı kuyu ve depoların kontrolünün düzenli olarak yapılması $(\mathrm{p}<.05, \beta=-.196)$ değişkeninin EKAG üzerinde anlamlı bir yordayıcı olduğu görülmektedir. Yordayıcı değişkenle EKAG arasındaki ilişkilere bakıldığında, köyde içme sularının sağlandığı kuyu ve depoların kontrolünün düzenli olarak yapılması ile olan İ̇, r= -.191 iken DYDKİ, r= -.199 düzeyindedir. Regresyon analizi sonuçlarına göre, eğitsel kaynaklı göçleri yordayan regresyon denklemi şu şekildedir: $\mathrm{EKAG}=(4.081)-(.240 \times \mathrm{TGBV})-(.338 \times \mathrm{KDK})+(.448 \times \mathrm{TAY})$.

FAYDAG'ın yordanmasında aynı değişkenlerin etkisine ilişkin bulgular Tablo 8'de sunulmuştur. 


\begin{tabular}{|l|c|c|c|c|c|c|c|}
\hline Değişken & $\mathbf{B}$ & Standart Hata & $\boldsymbol{\beta}$ & $\mathbf{T}$ & P & Íkili “r" & Kismi “r" \\
\hline Sabit & 2.668 & .839 & & 3.179 & .002 & & \\
\hline Tarım Görevlilerinin Bilgi Vermesi (TGBV) & -.169 & .246 & -.059 & -.687 & .493 & -.050 & -.059 \\
\hline Kuyu ve Depoların Kontrolü (KDK) & .200 & .219 & .078 & .912 & .364 & .077 & .078 \\
\hline Toprak Analizinin Yapılmas (TAY) & .162 & .381 & .037 & .426 & .671 & .035 & .036 \\
\hline $\mathrm{R}=.101$ & \multicolumn{2}{|l}{$\mathrm{R}^{2}=.010$} & $\mathrm{~F}(3,137)=.473$ & $\mathrm{P}=.702$ \\
\hline
\end{tabular}

Tablo 8. FAYDAG'ın Yordanmasında Görevlilerin Bilgilendirmesinin, Kuyu Depo Kontrolünün ve Toprak Analizinin Etkisi

Yapılan çoklu doğrusal regresyon analizi sonucunda değişkenler ile FAYDAG arasında anlamlı bir ilişki (R= $\left..101, R^{2}=.010\right)$ sergilemedikleri $(F(3,137)=.473, p>.05)$ bulunmuştur.

EKAG'ın yordanmasında; "yaşanan evde suyun varlığı”, "yaşanan evde doğalgaz veya merkezi/kaloriferli 1sıtma sisteminin varlığı", "yaşanan yerde PTT telefon hattı ve İnternet hattının varlığı", "yaşanan yerde günlük ekmek satışının varlığı”, "yaşanan yerde marketin varlığı”, "yaşanan yerden kargo gönderilip alınma durumu”, "yaşanan yerde yem/un değirmeninin varlığı", "yaşanan yere günlük gazetelerin gelme durumu”, "evde cep telefonları ile kaliteli iletişim kurabilme", "evde cep telefonları ile hızlı İnternet bağlantısı sağlayabilme", "gezici benzin/akaryakıt istasyonunun köye gelme durumu" ve "köyde süt depolama, toplama veya işleme tesisinin varlığı” gibi temel değişkenlerin etkisine ilişkin bulgular Tablo 9'da sunulmuştur.

\begin{tabular}{|c|c|c|c|c|c|c|c|}
\hline Değişken & $\mathbf{B}$ & Standart Hata & $\boldsymbol{\beta}$ & $\mathbf{T}$ & $\mathbf{P}$ & İkili “r” & Kısmi "r" \\
\hline Sabit & 4.741 & 1.465 & & 3.235 & .002 & & \\
\hline Su & -.333 & .355 & -.084 & -.939 & .349 & -.110 & -.083 \\
\hline Doğalgaz/kaloriferli isitma sistemi (DKIS) & .142 & .306 & .042 & .463 & .644 & .050 & .041 \\
\hline PTT ve İnternet Hatt1 (PIH) & .048 & .213 & .028 & .224 & .823 & -.071 & .020 \\
\hline Ekmek Satışı (ES) & -.062 & .235 & -.036 & -.265 & .791 & -.064 & -.023 \\
\hline Market (M) & .091 & .250 & .050 & .364 & .716 & -.138 & .032 \\
\hline Kargo İmkanı (Kİ) & -.130 & .246 & -.053 & -.527 & .599 & -.069 & -.047 \\
\hline Yem/Un Değirmeni (YUD) & -.341 & .293 & -.154 & -1.165 & .246 & -.175 & -.102 \\
\hline Gazete (G) & .306 & .414 & .066 & .737 & .462 & .030 & .065 \\
\hline Cep Telefonu ile Haberleşebilme (CTH) & -.212 & .176 & -.112 & -1.199 & .233 & -.098 & -.105 \\
\hline Hızlı İnternet Bağlantısı (HİB) & .395 & .221 & .160 & 1.789 & .076 & .182 & .156 \\
\hline Gezici Benzin/Akaryaktt İstasyonu (GBAI) & -.178 & .233 & -.097 & -.764 & .446 & -.062 & -.067 \\
\hline Süt Toplama, Depolama, İşleme İstasyonu (STDïi) & -.348 & .265 & -.128 & -1.311 & .192 & -.160 & -.115 \\
\hline $\mathrm{R}=.322$ & & \multicolumn{2}{|l|}{$\mathrm{R}^{2}=.104$} & \multicolumn{2}{|c|}{$F(12,128)=1.238$} & \multicolumn{2}{|l|}{$\mathrm{P}=.264$} \\
\hline
\end{tabular}

Tablo 9. EKAG'ın Yordanmasında Yaşamsal Temel Değişkenlerin Etkisi

Yapılan çoklu doğrusal regresyon analizi sonucunda değişkenler ile EKAG arasında anlamlı bir ilişki $(\mathbf{R}=\mathbf{. 3 2 2}$, $\left.R^{2}=.104\right)$ sergilemedikleri $(F(12,128)=1.238, p>.05)$ bulunmuştur.

FAYDAG'ın göçlerin yordanmasında aynı değişkenlerin etkisine ilişkin bulgular Tablo 10'da sunulmuştur.

\begin{tabular}{|c|c|c|c|c|c|c|c|}
\hline Değişken & B & Standart Hata & $\beta$ & $\mathbf{T}$ & $\mathbf{P}$ & İkili "r" & Kısmi "r" \\
\hline Sabit & 2.731 & 1.840 & & 1.485 & .140 & & \\
\hline $\mathrm{Su}$ & -.258 & .446 & $\begin{array}{l}.044 \\
\end{array}$ & -.579 & .564 & .092 & $\begin{array}{l}.051 \\
\end{array}$ \\
\hline Doğalgaz/kaloriferli ıstma sistemi (DKIS) & .551 & .384 & .110 & 1.434 & .154 & .148 & .126 \\
\hline PTT ve İnternet Hatt1 (PİH) & -.079 & .268 & -.031 & $\begin{array}{l}.294 \\
\end{array}$ & .769 & .132 & -.026 \\
\hline Ekmek Satışı (ES) & .755 & .295 & .288 & 2.558 & .012 & .393 & .220 \\
\hline Market (M) & 1.583 & .314 & .579 & 5.046 & .000 & .415 & .407 \\
\hline Kargo İmkanı (Kİ) & .158 & .309 & .043 & .510 & .611 & .186 & .045 \\
\hline Yem/Un Değirmeni (YUD) & -1.181 & .367 & -.357 & -3.215 & .002 & .009 & -.273 \\
\hline Gazete (G) & -.074 & .520 & -.011 & -.142 & .887 & -.017 & -.013 \\
\hline Cep Telefonu ile Haberleşebilme (CTH) & -.238 & .222 & -.084 & -1.076 & .284 & -.036 & -.095 \\
\hline Hızlı İnternet Bağlantısı (HİB) & .229 & .277 & .062 & .827 & .410 & .091 & .073 \\
\hline Gezici Benzin/Akaryakıt İstasyonu (GBAİ) & -1.230 & .293 & -.450 & -4.202 & .000 & .022 & -.348 \\
\hline Süt Toplama, Depolama, İșleme İstasyonu (STDİ̇̇) & .191 & .333 & .047 & .574 & .567 & -.004 & .051 \\
\hline $\mathrm{R}=.604$ & & \multicolumn{2}{|l|}{$\mathrm{R}^{2}=.365$} & \multicolumn{2}{|c|}{$\mathrm{F}(12,128)=6.131$} & \multicolumn{2}{|l|}{$\mathrm{P}=.000$} \\
\hline
\end{tabular}

Tablo 10. FAYDAG'ın Yordanmasında Yaşamsal Temel Değişkenlerin Etkisi

Yapılan çoklu doğrusal regresyon analizi sonucunda değişkenler ile FAYDAG arasında anlamlı bir ilişski $(\mathbf{R}=$ $\left.\mathbf{. 6 0 4}, \mathbf{R}^{2}=\mathbf{. 3 6 5}\right)$ sergiledikleri $(\mathbf{F}(12,128)=6.131, p<.001)$ bulunmuştur. Regresyon katsayılarının anlamlılık testleri göz önüne alındığında, yordayıcı değişkenlerden yaşanan yerde marketin varlığı $(p<.001, \beta=.579)$, gezici benzin/akaryakıt istasyonunun köye gelme durumu $(\mathrm{p}<.001, \beta=-.450)$, yaşanan yerde yem/un değirmeninin varlığı $(p<.01, \beta=-.357)$ ve yaşanan yerde günlük ekmek satışının yapılması $(p<.05, \beta=.288)$ değişkenlerinin FAYDAG üzerinde anlamlı yordayıcılar oldukları görülmektedir. Ayrıca bu sıralama standartlaştırılmış regresyon katsayılarına göre, yordayıcı değişkenlerin FAYDAG üzerindeki göreli önem sırasını göstermektedir. Yordayıcı değişkenlerle FAYDAG arasındaki ilişkilere bakıldığında, yaşanan yerde marketin varlığı ile olan İ̇, $\mathrm{r}=.415$, DYDKİ, $\mathrm{r}=.407$; gezici benzin/akaryakit istasyonunun köye gelme durumu ile olan İI, 
$\mathrm{r}=.022$ iken DYDKİ, $\mathrm{r}=-.348$; yaşanan yerde yem/un değirmeninin varlığı ile olan Iİ, $\mathrm{r}=.009 \mathrm{iken}$ DYDKİ, $\mathrm{r}=-$ .273; son olarak yaşanan yerde günlük ekmek satışının yapılması ile olan İ̈, $r=.393$ iken DYDKİ, $r=.220$ düzeyindedir. Regresyon analizi sonuçlarına göre, FAYDAG'1 yordayan regresyon denklemi şu şekildedir: FAYDAG $=(2.731)-(.258 \times \mathrm{su})+(.551 \times \mathrm{IS})-(.079 \times \mathrm{PI} H)+(.755 \times \mathrm{ES})+(1.583 \times \mathrm{M})+(.158 \times \mathrm{KI})-(1.181$ x YUD $)-(.074 \times$ G) $-(.238 \times$ CTH $)+(.229 \times$ HIB $)-(1.230 \times$ GBAI $)+(.191 \times$ STDIII $)$.

EKAG'ın yordanmasında; "yaşanan yerde elektrik ustası bulmanın kolaylı̆̆ı", "yaşanan yerde inşaat ustası bulmanın kolaylığı", "yaşanan yerde motor/kaynak ustası bulmanın kolaylı̆̆ı", "yaşanan yerde tesisat ustası bulmanın kolaylığı", "yaşanan yerde veteriner bulmanın kolaylığı", "yaşanan yerde meslek erbaplarına ödenen ücretler" ve "yaşanan yerde tarım iş̧̧ilerine ödenen günlük ücretler" gibi değişkenlerin etkisine ilişsin bulgular Tablo 11'de sunulmuştur.

\begin{tabular}{|c|c|c|c|c|c|c|c|}
\hline Değişken & B & $\begin{array}{c}\text { Standart } \\
\text { Hata }\end{array}$ & $\beta$ & $\mathbf{T}$ & $\mathbf{P}$ & İkili "r" & Kısmi "r" \\
\hline Sabit & 5.281 & .678 & & 7.794 & .000 & & \\
\hline Elektrik Ustası (EU) & -.286 & .269 & -.125 & -1.064 & .289 & -.172 & -.092 \\
\hline İnşaat Ustası (İU) & -.268 & .243 & -.151 & -1.099 & .274 & -.192 & -.095 \\
\hline Motor/kaynak vb. Ustası (MKU) & -.086 & .247 & -.042 & -.348 & .728 & -.123 & -.030 \\
\hline Tesisat Ustası (TU) & -.169 & .256 & -.091 & -.662 & .509 & -.197 & -.058 \\
\hline Veteriner vb. (V) & .305 & .192 & .156 & 1.593 & .113 & .077 & .137 \\
\hline Meslek Erbaplarına Ödenen Ücret (MEÖÜ) & -.205 & .125 & -.164 & -1.635 & .104 & -.114 & -.141 \\
\hline Tarım İşçilerine Ödenen Ücret (TİÖÜ) & -.063 & .081 & -.074 & -.769 & .443 & .022 & -.067 \\
\hline Sürekli Tarım İşçisi (STİ) & .142 & .210 & .065 & .677 & .500 & .012 & .059 \\
\hline $\mathrm{R}=.322$ & & \multicolumn{2}{|l|}{$\mathrm{R}^{2}=.103$} & \multicolumn{2}{|c|}{$F(8,132)=6.131$} & \multicolumn{2}{|l|}{$\mathrm{P}=.065$} \\
\hline
\end{tabular}

Tablo 11. EKAG'ın Yordanmasinda Ustalık ve Onlara Ödenen Ücretin Etkisi

Yapılan çoklu doğrusal regresyon analizi sonucunda değişkenler ile EKAG arasında anlamlı bir ilişki $(\mathbf{R}=\mathbf{. 3 2 2}$, $\left.\mathrm{R}^{2}=.103\right)$ sergilemedikleri $(\mathrm{F}(8,132)=6.131, \mathrm{p}>.05)$ bulunmuştur.

FAYDAG'ın yordanmasında aynı değişkenlerin etkisine ilişkin bulgular Tablo 12'de sunulmuştur.

\begin{tabular}{|c|c|c|c|c|c|c|c|}
\hline Değişken & B & $\begin{array}{c}\text { Standart } \\
\text { Hata }\end{array}$ & $\beta$ & $\mathbf{T}$ & $\mathbf{P}$ & İkili "r" & Kısmi "r" \\
\hline Sabit & 1.220 & .972 & & 1.255 & .212 & & \\
\hline Elektrik Ustas1 (EU) & .271 & .385 & .079 & .704 & .483 & .120 & .061 \\
\hline İnşaat Ustası (IUU) & .153 & .349 & .058 & .438 & .662 & .180 & .038 \\
\hline Motor/kaynak vb. Ustası (MKU) & .381 & .355 & .126 & 1.075 & .284 & .144 & .093 \\
\hline Tesisat Ustası (TU) & .006 & .367 & .002 & .016 & .987 & .161 & .001 \\
\hline Veteriner vb. (V) & .116 & .275 & .040 & .423 & .673 & .119 & .037 \\
\hline Meslek Erbaplarına Ödenen Ücret (MEÖÜ) & -.280 & .179 & -.150 & -1.558 & .122 & -.277 & -.134 \\
\hline Tarım İşçilerine Ödenen Ücret (TíÖÜ) & .353 & .117 & .281 & 3.026 & .003 & .306 & .255 \\
\hline Sürekli Tarım İşçisi (STI) & -.022 & .301 & -.007 & -.073 & .942 & .107 & -.006 \\
\hline $\mathrm{R}=.412$ & & \multicolumn{2}{|l|}{$\mathrm{R}^{2}=.170$} & \multicolumn{2}{|c|}{$\mathrm{F}(8,132)=3.380$} & \multicolumn{2}{|l|}{$\mathrm{P}=.001$} \\
\hline
\end{tabular}

Tablo 12. FAYDAG'ın Yordanmasında Usta Bulma Kolaylı̆̆ı ve İşçilik Ücretlerinin Etkisi

Yapılan çoklu doğrusal regresyon analizi sonucunda değişkenler ile FAYDAG arasında anlamlı bir ilişki (R= $\left..412, R^{2}=.170\right)$ sergiledikleri $(F(8,132)=3.380, p<.01)$ bulunmuştur. Regresyon katsayılarının anlamlılık testleri göz önüne alındığında, yordayıcı değişkenlerden sadece yaşanan yerde tarım iş̧̧ilerine ödenen günlük ücretler $(\mathrm{p}<.01, \beta=.281)$ değişkeninin FAYDAG üzerinde anlamlı bir yordayı olduğu görülmektedir. Yordayıcı değişkenle FAYDAG arasındaki ilişkilere bakıldığında, yaşanan yerde tarım işçilerine ödenen günlük ücretler ile olan İ̈, $\mathrm{r}=.306$ iken DYDKİ, $\mathrm{r}=.255$ düzeyindedir. Regresyon analizi sonuçlarına göre, FAYDAG'ı yordayan regresyon denklemi şu şekildedir: $F A Y D A G=(1.220)+(.271 \times \mathrm{EU})+(.153 \times \mathrm{IIU})+(.381 \mathrm{x} \mathrm{MKU})+(.006 \mathrm{x}$ TU $)$ $+(.116$ x V.) $-(.280 \times$ MEÖÜ $)+(.353 \times$ Tİ̈̈̈ $)-(.022 \times$ STİ $)$

EKAG'ın yordanmasında "Tarımsal faaliyetlerden (hayvancılık dâhil) sağlanan yıllık kazanç", "yıllık kullanılan yapay gübre miktarı", "yıllık kullanılan hayvansal gübre miktarı", "tarlalardan sağlanan yıllık yem miktarı", "satın alınan yıllık yem miktarı" ve "üretilen aylık süt miktarı" gibi değişkenlerin etkisine ilişkin bulgular Tablo 13'de verilmiştir.

\begin{tabular}{|c|c|c|c|c|c|c|c|}
\hline Değişken & B & Standart Hata & $\beta$ & $T$ & $\mathbf{P}$ & İkili “r” & Kısmi "r" \\
\hline Sabit & 3.728 & .449 & & 8.309 & .000 & & \\
\hline Tarımsal Faaliyetlerin Kazancı (TFK) & .009 & .051 & .017 & .181 & .856 & -.001 & .016 \\
\hline Kullanılan Yapay Gübre Miktarı (KYGM) & -.130 & .056 & -.219 & -2.327 & .021 & -.158 & -.197 \\
\hline Kullanılan Hayvansal Gübre Miktarı (KGHM) & .183 & .208 & .082 & .880 & .381 & .016 & .076 \\
\hline Tarladan Sağlanan Yıllık Yem Miktarı (TSYYM) & .084 & .091 & .097 & .928 & .355 & .066 & .080 \\
\hline Satın Alınan Yem Miktarı (SAYM) & .054 & .093 & .066 & .583 & .561 & .060 & .050 \\
\hline Üretilen Aylık Süt Miktarı (ÜASM) & -.030 & .091 & -.037 & -.327 & .744 & .053 & -.028 \\
\hline $\mathrm{R}=.211$ & & \multicolumn{2}{|l|}{$\mathrm{R}^{2}=.044$} & \multicolumn{2}{|c|}{$F(6,134)=1.038$} & \multicolumn{2}{|l|}{$\mathrm{P}=.404$} \\
\hline
\end{tabular}

Tablo 13. EKAG'ın Yordanmasında Gelir/Giderin Etkisi 
Yapılan çoklu doğrusal regresyon analizi sonucunda değişkenler ile EKAG arasında anlamlı bir ilişki $(\mathbf{R}=\mathbf{. 2 1 1}$, $\left.\mathbf{R}^{2}=.044\right)$ sergilemedikleri $(\mathrm{F}(6,134)=1.038, \mathrm{p}>.05)$ bulunmuştur.

FAYDAG'ın yordanmasında aynı değişkenlerin etkisine ilişkin bulgular Tablo 14'te verilmiştir.

\begin{tabular}{|c|c|c|c|c|c|c|c|}
\hline Değişken & B & Standart Hata & $\beta$ & $\mathbf{T}$ & $\mathbf{P}$ & İkili "r" & Kısmi "r" \\
\hline Sabit & 4.405 & .644 & & 6.840 & .000 & & \\
\hline Tarımsal Faaliyetlerin Kazancı (TFK) & -.182 & .073 & -.224 & -2.498 & .014 & -.264 & -.211 \\
\hline Kullanılan Yapay Gübre Miktarı (KYGM) & -.105 & .080 & -.119 & -1.306 & .194 & -.185 & -.112 \\
\hline Kullanılan Hayvansal Gübre Miktarı (KGHM) & -.443 & .298 & -.134 & -1.486 & .140 & -.226 & -.127 \\
\hline Tarladan Sağlanan Yıllık Yem Miktarı (TSYYM) & .051 & .130 & .039 & .390 & .697 & .054 & .034 \\
\hline Satın Alınan Yem Miktarı (SAYM) & .008 & .134 & .007 & .061 & .952 & .025 & .005 \\
\hline Üretilen Aylık Süt Miktarı (ÜASM) & .098 & .131 & .080 & .746 & .457 & .014 & .064 \\
\hline $\mathrm{R}=.339$ & & \multicolumn{2}{|l|}{$\mathrm{R}^{2}=.115$} & \multicolumn{2}{|c|}{$\mathrm{F}(6,134)=2.898$} & \multicolumn{2}{|l|}{$\mathrm{P}=.011$} \\
\hline
\end{tabular}

Tablo 14. FAYDAG'ın Yordanmasında Gelir/Giderin Etkisi

Yapılan çoklu doğrusal regresyon analizi sonucunda değişkenler ile FAYDAG arasında anlamlı bir ilişki (R= $\left..339, R^{2}=.115\right)$ sergiledikleri $(F(6,134)=2.898, p<.05)$ bulunmuştur. Regresyon katsayılarının anlamlılık testleri göz önüne alındığında, yordayıcı değişkenlerden sadece tarımsal faaliyetlerden (hayvancılık dâhil) sağlanan yıllık kazançlar $(\mathrm{p}<.05, \beta=-.224)$ değişkeninin FAYDAG üzerinde anlamlı bir yordayı olduğu görülmektedir. Yordayıcı değişkenle FAYDAG arasındaki ilişkilere bakıldığında, tarımsal faaliyetlerden (hayvancılık dâhil) sağlanan yıllık kazançlar ile olan İ̇, $r=-.264$ iken DYDKİ, $r=-.211$ düzeyindedir. Regresyon analizi sonuçlarına göre, FAYDAG'1 yordayan regresyon denklemi şu şekildedir: FAYDAG= $(4.405)-(.182 \mathrm{x}$ TFK $)-(.105 \times$ KYGM $)-(.443 \times$ KHGM $)+(.051 \times$ TSYYM $)+(.008 \times$ SAYM $)+(.098 \times$ ÜASM $)$.

EKAG'ın yordanmasında "Yaşanan yerde tarımsal danışmanların varlığı”, "danışmanlık ücretleri”, "danışmanların sağladıkları güven" ve "tarımsal destek ve hibelerle ilgili anlık bilgi” gibi değişkenlerin etkisine ilișkin bulgular Tablo 15 ’te verilmiştir.

\begin{tabular}{|l|c|c|c|c|c|c|c|}
\hline Değişken & $\mathbf{B}$ & $\begin{array}{c}\text { Standart } \\
\text { Hata }\end{array}$ & $\boldsymbol{\beta}$ & $\mathbf{T}$ & $\mathbf{P}$ & Íkili “r” & Kısmi “r” \\
\hline Sabit & 4.161 & .408 & & 10.188 & .000 & & \\
\hline Tarımsal/Hayvansal Danışmanlık (THD) & .059 & .150 & .034 & .395 & .693 & .008 & .034 \\
\hline Danışmanlık Ücretleri (DÜ) & -.288 & .173 & -.148 & -1.666 & .098 & -.130 & -.141 \\
\hline Danışmanlara Olan Güven (DOG) & .166 & .153 & .096 & 1.081 & .282 & .082 & .092 \\
\hline Tarımsal Hibelerle İlgili Anlık Bilgi (THİAB) & -.082 & .156 & -.048 & -.525 & .601 & .010 & -.045 \\
\hline $\mathrm{R}=.164$ & & $\mathrm{R}^{2}=.027$ & $\mathrm{~F}(4,136)=.941$ & $\mathrm{P}=.442$ \\
\hline
\end{tabular}

Tablo 15. EKAG'ın Yordanmasında Danışmanlığın Etkisi

Yapılan çoklu doğrusal regresyon analizi sonucunda değişkenleri ile EKAG arasında anlamlı bir ilişki (R= .164, $\left.R^{2}=.027\right)$ sergilemedikleri $(F(4,136)=.941, p>.05)$ bulunmuştur.

FAYDAG'ın yordanmasında aynı değişkenlerin etkisine iliş̧in bulgular Tablo 16'da verilmiştir.

\begin{tabular}{|l|c|c|c|c|c|c|c|}
\hline Değişken & $\mathbf{B}$ & Standart Hata & $\boldsymbol{\beta}$ & $\mathbf{T}$ & $\mathbf{P}$ & Ikili “r” & Kısmi “r” \\
\hline Sabit & .609 & .552 & & 1.103 & .272 & & \\
\hline Tarımsal/Hayvansal Danışmanlık (THD) & 1.051 & .203 & .408 & 5.178 & .000 & .429 & .406 \\
\hline Danışmanlık Ücretleri (DÜ) & .192 & .234 & .066 & .819 & .414 & .151 & .070 \\
\hline Danışmanlara Olan Güven (DOG) & .263 & .207 & .103 & 1.270 & .206 & .138 & .108 \\
\hline Tarımsal Hibelerle İlgili Anlık Bilgi (THİAB) & .075 & .211 & .029 & .357 & .722 & .044 & .031 \\
\hline $\mathrm{R}=.448$ & & $\mathrm{R}^{2}=.200$ & $\mathrm{~F}(4,136)=8.514$ & $\mathrm{P}=.000$ \\
\hline
\end{tabular}

Tablo 16. FAYDAG'ın Yordanmasında Danışmanlı̆̆ı̆n Etkisi

Yapılan çoklu doğrusal regresyon analizi sonucunda değişkenler ile FAYDAG arasında anlamlı bir ilişki $(\mathbf{R}=$ $\left..448, R^{2}=.200\right)$ sergiledikleri $(F(4,136)=8.514, p<.001)$ bulunmuştur. Regresyon katsayılarının anlamlılık testleri göz önüne alındığında, yordayıcı değişkenlerden sadece yaşanan yerde tarımsal/hayvansal danışmanların varlığı $(\mathrm{p}<.001, \beta=.408)$ değişkeninin FAYDAG üzerinde anlamlı bir yordayı olduğu görülmektedir. Yordayıcı değişkenle FAYDAG arasındaki ilişkilere bakıldığında, tarımsal/hayvansal danışmanların varlığı ile olan İ̇, $\mathrm{r}=.429$ iken DYDKİ, r=.406 düzeyindedir. Regresyon analizi sonuçlarına göre, FAYDAG'1 yordayan regresyon denklemi şu şekildedir: FAYDAG $=(.609)+(1.051 \times$ THD $)+(.192 \times$ DÜ $)+(.263$ $\mathrm{x}$ DOG $)+(.075 \mathrm{x}$ THİAB $)$.

\section{Sonuç}

Türkiye'de köyden kente göçün giderek önlenemez bir hal alması, bilim adamlarının dikkatlerini kırsal alanlarda yaşanan sorunların çözümüne yöneltmiştir. Çünkü kırsal alanlarda yaşanan sorunların çözümü hem sürdürülebilir kırsal kalkınma için hem de ülkenin gelişimi açısından yadsınamaz bir öneme sahiptir. Kırsal alanlarda yaşanan sorunların saptanması ve çözümlerin üretilebilmesi köyden kente göçün önlenmesinde etkili unsurlar olarak 
değerlendirilebilir. Bu bağlamda İç Anadolu, Doğu Anadolu, Karadeniz, Akdeniz, Eğe ve Marmara Bölgelerinde uygulanan ve araştırma soruları bağlamında ulaşılan bulgular şunlardır:

1. Faktör analizi sonucunda adı geçen bölgelerde köyden kente göçün nedenleri iki grup altında sınıflandırılmıştır:

1) Eğitim kaynaklı göçler (EKAG) ve 2) Fiziksel alt yapıya dayalı göçler (FAYDAG).

2. Demografik niteliklerin köyden kente göç üzerinde anlamlı bir etkiye sahip oldukları saptanmış olup: demografik nitelikler olarak yaş, cinsiyet, eğitim durumu, medeni durum ve çiftçilik deneyiminin hem EKAG hem de FAYDAG üzerinde \%10'luk bir etkiye sahip olduğu bulunmuştur. Bir başka ifadeyle köyden kente göçlerde meydana gelen değişimlerin \%10’u demografik niteliklerden kaynaklanmaktadır.

3. Binek araçların varlığı, il ve ilçe merkezlerine uzaklık, toplu taşıma araçlarının köye gelme sıklığı ve kış nedeniyle yolların kapanmasının EKAG üzerinde anlamlı bir etkiye sahip olmadığı buna karşılık bu değişkenlerin FAYDAG üzerinde anlamlı bir etkiye sahip oldukları saptanmıştır. FAYDAG'ın takribi \%24'ü; binek araçların bulunmaması, il ve ilçe merkeze uzak olunması, toplu taşıma araçlarının sık sık köye gelmemesi ve kış nedeniyle yolların kapanması gibi ulaşım sorunlarından kaynaklanmaktadır.

4. “İlçe Tarım Müdürlüğ̈̈, Tarım Kredi Kooperatifi veya Ziraat Odası'ndan görevlilerin tarım ile ilgili bilgi vermek üzere düzenli olarak köye gelme durumu", "köyde içme sularının sağlandığı kuyu ve depoların kontrolünün düzenli olarak yapılma durumu" ve "tarlaların toprak analizinin yıllık olarak yapılma durumu" değişkenleri EKAG üzerinde anlamlı bir etkiye sahip iken FAYDAG üzerinde bir etkisinin olmadığı görülmüştür. EKAG'da meydana gelen değişimin \%7'si tarım görevlilerinin çiftçilere bilgi vermek üzere düzenli olarak köye gelmemeleri, içme suyunun sağlandığı depo/ve kuyuların düzenli kontrolünün yapılmaması ve yıllık olarak toprak analizinin yapılmamasindan kaynaklanmaktadır.

5. "Yaşanan evde suyun varlı̆̆ı", "yaşanan evde doğalgaz veya merkezi/kaloriferli ısıtma sisteminin varlığı", "yaşanan yerde PTT telefon hattı ve İnternet hattının varlığı", "yaşanan yerde günlük ekmek satışının varlığı", "yaşanan yerde marketin varlı̆̆ı", "yaşanan yerden kargo gönderilip alınma durumu", "yaşanan yerde yem/un değirmeninin varlığı", "yaşanan yere günlük gazetelerin gelme durumu", "evde cep telefonları ile kaliteli iletişim kurabilme", "evde cep telefonları ile hızlı İnternet bağlantısı sağlayabilme", "gezici benzin/akaryakıt istasyonunun köye gelme durumu" ve "köyde süt depolama, toplama veya işleme tesisinin varlığı" değişkenleri birlikte EKAG üzerinde anlamlı bir etkiye sahip değilken, FAYDAG üzerinde önemli bir etkiye sahip olduğu görülmüştür. FAYDAG'da meydana gelen değişimlerin takriben \%37'si bu değişkenlerden kaynaklanmaktadır. Bu değişkenler değerlendirildiğinde, köylerde yaşayan insanların en temel yaşamsal gereksinimleriyle ilgili olduğu söylenebilir. Bu durumda eğer insanlar, en temel yaşamsal nitelikte olan ve Maslow'un İhtiyaçlar Hiyerarşisi'nde fizyolojik ihtiyaçlar katmanında yer alan bu gereksinimlerini karşılayamazlarsa kentlere olan göçler kaçınılamaz bir hal alabilir.

6. Yaşanan yerde elektrik ustası, inşaat ustası, motor/kaynak ustası, tesisat ustası ve veteriner bulmanın kolaylığı, meslek erbaplarına ödenen ücretler ve tarım işçilerine ödenen günlük ücretlerin EKAG üzerinde bir etkisinin olmadığı ancak FAYDAG üzerinde anlamlı bir etkisinin bulunduğu saptanmıştır. FAYDAG'ın \%17'si meslek erbabı bulmanın zorluğundan (inşaat, elektrik, tesisat, motor/kaynak, veteriner gibi) ve tarım işçilerine ödenen ücretlerin yüksekliğinden kaynaklanmaktadır. Köylerde tarımsal ve hayvansal faaliyetlerin yapılabilmesi için kuşkusuz ki, bu alanlarda uzmanlaşmış kişilere gereksinim bulunmaktadır.

7. "Tarımsal faaliyetlerden (hayvancılık dâhil) sağlanan yıllık kazanç", "yıllık kullanılan yapay gübre miktarı", "yıllık kullanılan hayvansal gübre miktarı", "tarlalardan sağlanan yıllık yem miktarı", "satın alınan yıllık yem miktarı" ve "üretilen aylık süt miktarı" değiş̧enlerinin eğitsel kaynaklı göçleri yordamadıkları buna karşılık FAYDAG'ın yordanmasında anlamlı bir etkiye sahip oldukları bulunmuştur. FAYDAG'ın takriben \%12'si bu değişkenlerden kaynaklanmaktadır. Bu bağlamda tarımsal ve hayvansal faaliyetlerden elde edilen kazanç giderlere göre çok değildir; çünkü çiftçilerin ürettikleri ürünlerden daha yüksek kazancı aracı kişilerin sağladıkları söylenebilir.

Ulaşılan bu bulgular doğrultusunda kırsal kesimlerde yaşanan sorunların çözümü ve köyden kente göçün önlenmesi yönünde dikkate alınması gerekli öneriler iki grup altında toplanmıştır:

a. Eğitim kaynaklı köyden kente göçün önlenmesi için öneriler

1. Köylerde ilkokulların açılması (bunun için ilkokul düzeyinde 10 öğrenci olmalı ve muhtarların kaymakamlığa dilekçe ile okul açılma talebinde bulunması gereklidir),

2. Tarım ile ilgili mesleki eğitimlerin lise seviyesinde verilmesi (bunun için meslek, teknik veya çok programlı liselerde bölüm açılabilmesi için 9. sınıf öğrencilerinden en az 10 kişinin, 'tarla bitkileri' veya 'hayvan sağlığı ve yetiştiriciliği' bölümlerini seçmesi gerekmektedir)

3. Danışmanlık hizmetlerinin düzenli olarak sunulması, danışmanlar çiftçilerin güveninin kazanabilmeli ve danışmanlık ücretleri düşürülmeli ya da ücretsiz olarak sunulmalı,

4. Teknoloji, köy ve kent arasındaki farkı azaltıcı veya ortadan kaldırıcı bir etkiye sahiptir. Ancak bu etkinin oluşabilmesi teknolojinin iyi bir şekilde kullanımına bağlıdır. Bu nedenle günümüz teknolojik imkânlarından faydalanarak çiftçilere kırsal alanlarda yapılan işin niteliğine uygun e-tarım eğitimi verilmesi (İnternet kursları, webinar 'İnternet üzeri yayınlar ile', POSCASTS 'ses, görüntü ve yazı içeren yayınların yayın tarihinden sonra yayınlanması', grup aktiviteleri ve durum çalışmaları, anlık 'online' sınıf dersleri, e-eğitim, bilgisayar, tablet, akıllı telefon temelli eğitimler şeklinde). 
b. Fiziksel altyapı kaynaklı köyden kente göçün önlenmesi için öneriler;

1. Belediyeler, tüm köyleri kapsayacak şekilde günlük toplu taşıma araçları planlamalı ve uygulamalıdır.

2. Halk Sağlığı Müdürlüklerince köyde içme sularının sağlandığı depoların ve içme sularının kontrolü, İnternet ve bilgisayar teknolojisi kullanılarak online su analiz ve takip yöntemi veya düzenli olarak mevzuatta belirtilen yöntemlerle ve aralıklarla kontrolleri yapılarak (ITTASHY, 2005) analiz sonuçları köy halkına duyurulmalıdır.

3. Köylerde sosyal amaçlı tesislerin yapılması (kültür merkezi, okuma salonu, çocuk bakım evi, anne eğitim merkezi, bayanlar toplantı salonu vb.) ve etkinliklerin (festival, kurtuluş günü, anma etkinlikleri vb.) düzenlenmesi için hazırlanan projeler ilgili bakanlıklar (Kültür ve Turizm Bakanlığı, Aile ve Sosyal Politikalar Bakanlığı, Milli Eğitim Bakanlığı vb. veya yeni oluşturulacak Kırsal Kalkınma Bakanlığı) tarafından desteklenmelidir.

4. Ziraat Odaları, Esnaf ve Sanatkârlar Odaları, Hayvancılık (Koyun-Keçi; Damızlık Sı̆̆ır vb.) Birlikleri, Sulama Birlikleri, Kalkınma Kooperatifleri, Tarım Kredi Kooperatifleri, Esnaf Kefalet ve Kredi Kooperatifleri, Arıcılık Birlikleri gibi sivil toplum kuruluşlarının bölgedeki ekonomik ve sosyal faaliyetlerde, kamu kurum ve kuruluşları ile; köylerin ihtiyaç duydukları sabit veya gezici bakkal/market, gezici benzin istasyonu, seyyar toprak analiz laboratuvarları, küçük ölçekli yem ve un üretim yerleri, küçük ölçekli ürünleri işleme tesislerinin kurulmasıişletilmesi ve kırsalda yaşayanlara tarımsal, hayvansal ve pazarlama faaliyetlerinde danışmanlık hizmetinin verilmesi konularında işbirliğini geliştirmelidir.

Amasya ili, Göynücek ilçesi Esnaf ve Sanatkârlar Odası Başkanlı̆̆ı tarafindan yurt içi bilimsel etkinliklere katılım desteği programı kapsamında desteklenmiştir.

\section{Kaynakça}

- $\quad$ Altınok, Fırat, Soyu, 2015. "Küresel İklim Değişikliği Sorununun Çözümü İçin Yeni Bir Sürdürülebilir Kalkınma Anlayışı”, International Conference on Eurasian Economies, s.623.

- Büyük Türkçe Sözlük, 2016. Tarım, http://www.tdk.gov.tr/index.php?option=com_bts\&arama=kelime\&guid $=$ TDK.GTS.56f835cc8acfa7.61756333

- Can, 2013. SPSS ile Bilimsel Araştırma Sürecinde Nicel Veri Analizi. Pegem Akademi, Ankara.

- $\quad$ EUR-Lex (Access to European Union Law), 2016. 2009 Review of the European Union Strategy for Sustainable Development, http://eur-lex.europa.eu/legal-content/EN/TXT/?uri=CELEX:52009DC0400.

- European Commission (EC), 2016. Sustainable Development, http://ec.europa.eu/environment/eussd/

- Fawcett, 1989. "Networks, Linkages and Migration Systems", International Migration Review, Vol. 23, No. 3, s.671-680, Special Silver Anniversary Issue: International Migration an Assessment for the 90'sAutumn, 1989, http://www.jstor.org/stable/2546434.

- International Institute for Sustainable Development (IISD),2010. Sustainable Development: From Brundtland to Rio 2012. United Nations Headquarters, New York, 2010.

- International Organization for Migration (IOM), 2017. Key Migration Term, http://www.iom.int/keymigration-terms.

- İnsani Tüketim Amaçli Sular Hakkinda Yönetmelik. (ITTASHY), 2005. (Ek ibare:RG-7/3/2013-28580 madde 10.), http://www.mevzuat.gov.tr/ Metin.Aspx?MevzuatKod=

7.5.7510\&MevzuatIliski=0\&sourceXmlSearch= İnsani Tüketim Amaçlı Sular Hakkında Yönetmelik.

- İ̀miş, Eroğlu, 2015. "Bir Kırsal Kalkınma Modeli Olarak Geleneksel Üretimi Yeniden Canlandırma Örneği: Yeşilyuva Ayakkabı Üretimi”, International Conference on Eurasian Economies, s.690.

- Kalaycı, 2009. SPSS Uygulamalı Çok Değişkenli İstatistik Teknikleri. Asil Yayın Dağıtım Ltd. Şti., Ankara.

- Kırımhan, 2005. Organik Tarım Sistemleri ve Çevre. Turhan Kitabevi Ofset Matbaacılık Tesisleri, Ankara.

- Kline, 1994. An Easy Guide to Factor Analysis. Routledge, New York.

- Koçel, 2015. İşletme Yöneticiliği. Beta, İstanbul.

- Lee, 1966. “A Theory of Migration”, Demography, Vol:3, p. 47-57. http://links.jstor.org/sici?sici=0070$3370 \% 281966 \% 293 \% 3 \mathrm{~A} 1 \% 3 \mathrm{C} 47 \% 3 \mathrm{AATOM} \% 3 \mathrm{E} 2.0 . \mathrm{CO} \% 3 \mathrm{~B} 2-\mathrm{B}$.

- Massey, Arango, Hugo, Kouaouci, Pellegrino, Taylor, 1993. “Theories of International Migration: A Review and Appraisal", Population and Development Review, 19(3), September, p. 431-466, http://www.academia.edu/4394106/Theories_of_international_migration,

- OECD, 2004. Measuring Sustainable Development: Integrated Economic, Environmental and Social Frameworks, OECD Publications Paris, France.

- Petersen, 1958. “A General Typology of Migration”, American Sociological Review. (23), p.256-266. http://www.cserpe.org/wp-content/uploads/2015/09/Petersen-EN.pdf. 
- Ravenstein, 1885. "The Laws of Migration.” Journal of the Statistical Society of London, vol. 48, no. 2, pp. 167-235. https://cla.umn.edu/sites/cla.umn.edu/files/the_laws_of_migration.pdf.

- Ravenstein, 1889. “The laws of migration," Journal of the Royal Statistical Society, Parts 2, Vol. 52, pp. 241-301. https://www.jstor.org/ stable/2979333?seq=48\#page_scan_tab_contents.

- Strange, Bayley, 2008. Sustainable Development Linking Economy, Society, Environment, OECD.

- $\quad$ T.C. Kalkınma Bakanlığı, Kurumsal ve Stratejik Yönetim Dairesi Başkanlığı, 2016. "Ulusal Kalkınma Stratejisi (2005-2009)”, http://www.sp.gov.tr/upload/xSPTemelBelge/files/3chYO+KirsalKalkinmaStrateji. pdf.

- Tavas, 2015. "Türkiye'nin Avrupa Birliği'ne tam üyelik sürecinde uluslararası göç yönetimi stratejisi (Bir model önerisi)”. s.11. Gazi Üniversitesi, Sosyal Bilimler Enstitüsü, Yayınlanmamış Doktora Tezi.

- $\quad$ The EU Explained, 2014. European Commission Directorate, General for Communication Citizens Information, "Agriculture”, 1049 Brussels Belgium, Manuscript updated in November 2014, Luxembourg: Publications Office of the European Union.

- Ulusal Kırsal Kalkınma Stratejisi (UKKS, 2014-2020), 2015. Yüksek planlama kurulunun 31.12.2014 tarihli 2014/45 sayılı kararı, 21.02.2015 tarihli Resmi Gazete, Say1: 29274.

- United Nations Conference on Environment \& Development (UNCED), 2016. "Sustainable Development Agenda 21, 1992”, Rio de Janerio, Brazil, https://sustainabledevelopment.un.org/content/documents/ Agenda21.pdf.

- World Commission on Environment and Development (WCED), 1987, Our Common Future, From One Earth to One World, Oslo, http://www.un-documents.net/our-common-future.pdf.

- World Development Report 2008, 2007. Agriculture for Development. The World Bank, Washington DC. 


\title{
Tarıma Dayalı Sanayi İşletmelerinin Ar-Ge Potansiyelinin İncelenmesi: Çanakkale İli Örneği
}

\section{Investigation of R\&D Potential of the Agricultural Industry Firms: Çanakkale Province Case}

\author{
Assoc. Prof. Dr. Sibel Tan (Çanakkale Onsekiz Mart University, Turkey) \\ Cansu Tepeli (Çanakkale Onsekiz Mart University, Turkey) \\ Dr. Bengü Everest (Çanakkale Onsekiz Mart University, Turkey)
}

\begin{abstract}
Recently, national economy has an important role in level of development and in steadily increase of the level of production. Research and Development is the use of background information and an intensive effort with a systematic base in new technologies in order to increase fund of knowledge. For the sake of this purpose, the importance given to R\&D studies has been increased both in all over the world. When these countries examined, sources are used efficiently thanks to these activities. In addition to this, R\&D has been an indispensable factor in the competition environment. Çanakkale belonging to the second group out of five in the socio-economic development framework is one of the prominent provinces in terms of development level. Thanks to being the building stone, Çanakkale is expected to give the needed importance R\&D studies to increase its own agricultural competition capacity to gain economical added value. In this study, it is aimed to examine the overall position of the provincial $R \& D$ activities, the number of the enterprises running $R \& D$ activities, the capacity of the enterprises, their business segment, their position in agricultural industry, the importance given to the R\&D activities in agricultural industry thanks to the questionnaires done with 153 enterprises taken from the industrial scaling of Çanakkale Provincial Directorate of Science Industry and Technology.
\end{abstract}

\section{Giriş}

Dünyada gittikçe yaygınlaşan küresel rekabet çerçevesinde bilimsel ve teknolojik gelişmeler ekonomik gelişmeyi hızlandırmada temel araç olarak karşımıza çıkmaktadır. Toplumların ekonomik, sosyal ve kültürel gelişmişlikleri bilimsel ve teknolojik gelişmeleri ile doğrudan ilişkilidir. Bu kapsamda tüm dünyada ve ülkemizde bilgi ekonomisi kavramı giderek önem kazanmıştır. Bilgi ekonomisi; toplumun ve organizasyonların bilginin üretimi, dağılımı ve tüketiminde kaynakları nasıl tahsis ettiğini inceleyen bir disiplindir. Bilgi ekonomisi çalışmaları, bilgi yoğun yeni ürün ve hizmetlerin üretimindeki fonksiyonuna odaklanır (Kavak, 2009).

İnsanlık için Ar-Ge faaliyetleri yani yenilik veya buluşun anlamı sadece firma bazında ekonomik amaçlı ürün geliştirilmesi ve buna bağlı refah artırıcı işlemlerin çok ötesinde, hastalıklara yeni tedavi yöntemleri geliştirilmesi, enerji, su, gıda, çevre vb. küresel sorunlar için yeni çözüm yolları bulunması, yeni iletişim yolları veya güvenlik araçları keşfedilmesi gibi daha geniş kitleleri ilgilendiren açılımlara sahiptir. Bu nedenle insanlık Ar-Ge faaliyetlerine aralıksız ve artan ölçüde devam etmekte olup, bu alanda söz sahibi olmayı başaran ülkeler, küresel anlamda ekonomik ve siyasal olarak da üstünlük sağlayabilmektedir (Akbulak ve Akbulak, 2015).

Tüm gelişmiş ülkelerde bilgi ekonomisinin hüküm sürdüğü günümüzde ekonomik sektörlerin tamamında Ar-Ge ve inovasyon kavramları giderek yaygınlaşmıştır. Bu kapsamda ortaya çıkan Ar-Ge çalışmaları sanayi işletmelerinde, büyümenin, üretim artışı sağlamanın ve piyasa koşulları içerisinde ayakta kalabilmenin unsuru olma konumundadır. Ar-Ge; bilimsel ve teknik bilgi düzeyinin arttırılması amacı ile belli bir sisteme dayalı ve düzenli gerçekleştirilen çalışmalar bütünü olarak nitelendirilmektedir (Erkek, 2011).

Ülkeler ürettiği bilgi, geliştirdiği teknoloji ve yenilikler ölçüsünde dünyada söz sahibi olmaktadır. Bu yüzden Türkiye; Dünya ülkeleri ile rekabet edebilmek, ithal etmek yerine kendi teknolojisini geliştirmek ve kullanmak, gelişmiş ülkelere bağımlı kalmamak, gıda güvenliğini sağlamak için Ar-Ge çalışmaları yapmak zorundadır. Gelişmiş ülkeler Ar-Ge harcamaları için bütçelerinden Gayri Safi Yurtiçi Hasılasının (GSYH) yaklaşık \%2'si oranında pay ayırmaktadırlar. Türkiye'de bu oran \%0,95 olup, 2023 yılında \%3'e ulaşması hedeflenmektedir (Anonim, 2015a).

Türkiye'de 2023 hedeflerine ulaşmak amacıyla bir çok politik düzenleme yapılmıştır. Özellikle ihracatın \%20'sinin orta ve yüksek teknoloji ürünlerinden oluşması hedefi doğrultusunda yeni, yenilikçi, rekabet üstünlüğü olan, katma değeri yüksek ve teknoloji tabanlı ürünler ile üretim yöntemleri geliştirmenin yanında, geleneksel imalat sanayimizin de bu yönde değişim ve dönüşümünün sağlanması bakımından ihtiyacımız olan bilgi ve teknolojinin ülkemizde üretilmesi hedeflenmiştir (Anonim, 2013). Dolayısıyla ihracatımızda geleneksel tarım ürünlerinin ve işlenmiş tarım ürünlerinin aldığı pay düşünüldüğünde konunun önemi anlaşılmaktadır.

Bilgi ekonomisinin ön plana çıktığı ve teknoloji odaklı üretim politikalarının uygulandığı günümüzde diğer tüm sektörlerde olduğu gibi tarım sektöründe de Ar-Ge çalışmaları sektörün geleceği ve rekabet şansı açısından son 
derece önemlidir. Ar-Ge faaliyetleri ile ülkelerin yapı taşlarından biri olan tarım ve bunun bir sonucu olan tarıma dayalı sanayi alanında gerekli çalışmaların gerçekleştirilip Türkiye gibi tarım ülkesi olarak geçimini sürdüren ülkelerin rekabet güçlerini arttırmaları açısından son derece önemlidir. Tarıma dayalı sanayide gerekli $\mathrm{Ar}-\mathrm{Ge}$ çalışmalarının üretim modellerine uygulanması ile istihdamın sürekliliği sağlanacak, üretici ve sanayici ile devlet arasında kazancın çift taraflı arttııılı̆ğı, toplumsal refahın sağlandığı bir ekonomi modeli gerçekleşecektir.

Türkiye'de tarım ve gıda sektörünün ülkenin genel ekonomik kalkınmasına kayda değer biçimde katkı sağlama potansiyeli mevcuttur. Ancak ülkenin bunu gerçekleştirme kabiliyeti çoğunlukla verimlilik artışına dayanmaktadır. Tarımda ulusal ve uluslararası düzeyde rekabet şansının artırıması için, temel zorunluluklarından biri tarımın geleneksel olarak oynadığı tampon rolünün üstesinden gelinmesi olacaktır (Anonim, 2016a).

Gelişmekte olan bir çok ülke gibi, Türkiye de sanayileşme yolunda doğal kaynaklardan en üst düzeyde yararlanmak durumundadır. Bu bakımdan tarım sektörü, Türkiye ekonomisine önemli katkılar sağlamaktadır (Demirbaş, 2004). Fakat Türkiye'de tarıma dayalı sanayi sektöründe Ar-Ge faaliyetinde bulunan işletme sayısının oldukça düşük olduğu görülmektedir.

Verimli toprak özelliği, bitkisel üretime uygun arazi mevcudu ve elverişli iklimi sayesinde Türkiye'de tarım sektörü çok çeşitli bir üretim desenine sahiptir. Buna ek olarak tarım ve tarımsal sanayi kuruluşları içerisinde süt ve süt ürünleri, unlu mamüller, tütün, deri, kağıtt, tekstil gibi sektörler tarımsal ekonomide önemli paya sahiptirler. Türkiye ekonomisinin tarihsel sürecinde sanayi ve hizmet sektörlerinin GSYIH'den (Gayrisafi Yurtiçi Hasıla) aldığı pay artmış, tarım sektörünün aldığı pay ise gerilemiştir. Genel bir değerlendirme yapıldığında tarımın Türkiye ekonomisindeki öneminin nispi olarak azalma gösterdiğini söylemek mümkündür. Cumhuriyetin kurulduğu yıllarda tarımın GSYIH'deki payı \%42,8 iken 1970'li yıllarda \%36,0, 1985 yılında \%25,0, 1990 yılında $\% 16,0,2000$ yılında \%13,5 oranında gerçekleşmiştir. Günümüzde ise tarımın GSYİH'deki payı \%9,0'dur (Anonim, 2016b).

Çanakkale ilinde tarımsal faaliyetlerin yoğun olarak yapılmasına bağlı olarak tarıma dayalı sanayi ilerlemiş ve sanayinin ekonomideki payı artmıştır. İl merkezi ve ilçelerinde bulunan işletmeler en fazla süt ve süt ürünleri, zeytinyağı, meyve-sebze işleme, unlu mamuller gibi alanlarda yoğunlaşmış̧ır. Ekonominin yapı taşlarından olan bu faaliyetlerin Ar-Ge çalışmaları ile desteklenmesinin, ilin ekonomik gelişiminde ve teknolojik alt yapısının ilerlemesinde etkili olacağ 1 şüphesizdir.

Çanakkale'de sürdürülen başlıca ekonomik etkinlikler ve yürütülmekte olan sanayi sektörü faaliyetleri tarıma dayalıdır. İl halkının \%70'i ekonomik varlığını tarımsal üretim yaparak sağlamaktadır. İlin önde gelen tarımsal ürünleri; domates, elma, buğday, bakla ve ayçiçeğidir. Çanakkale tarıma elverişli arazileri ve iklimi ile meyve ve sebze üretimine oldukça elverişli durumdadır. Tarımsal üretim verilerine göre 2016 yılında Çanakkale'de üretim yapılan tarım arazisi 284.324 hektardır. İlin bitkisel ürün değeri 1.871 .511 bin TL, hayvansal ürün değeri 418.390 bin TL'dir. İlin tarıma dayalı sanayisi ve üretim verilerine göre pazarlanan ürünler toplamının \%40,17'sini meyveler, \%34,76'sını sebzeler, \%25,07'sini ise tarla ürünleri oluşturmaktadır (Anonim, 2016c).

Çanakkale'de piyasa değeri yüksek ürünlerin sanayi işletmelerinde katma değeri arttırılarak pazarda etkin rol oynaması sağlanmaktadır. Tarıma dayalı sanayide sayıca en fazla olan işletme 442 adet ile süt ve süt ürünleri işletmesidir. Hayvancılık faaliyetlerinin yoğun olarak yapılmasına bağlı olarak bu sektör ön plana çıkmıştır. Bu sektörü izleyen diğer işletmeler 267 adet olan unlu mamüller işletmeleri ve 227 adet olan ekmek ve ekmek çeşitleri üreten işletmelerdir. $\mathrm{Bu}$ işletmeler üretim-tüketim zincirine katkıda bulunarak ilin ekonomisine katkı sağlamaktadır (Anonim, 2015b).

Türkiye'de tarımın ekonomiye katkısında önemli rol oynayan Çanakkale'nin, tarım sektörü rekabet gücünün arttırılmasında Ar-Ge çalışmaları önemli rol oynamaktadır.

Çanakkale'de tarıma dayalı sanayinin Ar-Ge potansiyelinin belirlenmesi ve bu potansiyelin geliştirilmesine yönelik öneriler sunmak amacıyla hazırlanan bu çalışmanın ikinci bölümünde materyal ve yöntem verilmiş, üçüncü bölümünde araştırma bulguları irdelenmiş ve dördüncü bölümde bu bulgulardan varılan sonuçlar ve öneriler sunulmuştur.

\section{Materyal ve Yöntem}

\subsection{Materyal}

Araştırmanın ana materyalini Çanakkale ilindeki tarıma dayalı sanayi işletmelerinden anket yoluyla elde edilen veriler oluşturmaktadır. İşletmelere ilişkin veriler Çanakkale ilinin tüm ilçelerinden elde edilmiştir. Araştırmada birincil ve ikincil verilerden yararlanılmış olup, anket sonucu elde edilen veriler birincil verileri oluşturmaktadır. Araştırmanın ikincil verilerini, konuyla ilgili çeşitli kurum ve kuruluşların yapmış oldukları yayınlar ile diğer araştırmacılar tarafindan yapılmış ve sonuçlanmış olan araştırma sonuçları, resmi istatistikler, derleme, inceleme ve tezlerden elde edilen veriler oluşturmuştur.

\subsection{Yöntem}

Çalışmada Güney Marmara Kalkınma Ajansı tarafından desteklenen "Çanakkale İlinde Sanayi Envanterinin Oluşturulması, İl Sanayisinin Ar-Ge, Yenilikçilik ve Kümelenme Potansiyelinin Araştırılması Projesi” kapsamında 
oluşturulan sanayi veri tabanından tarımsal faaliyet yapılan işletmeler seçilmiş ve örnekleme bu populasyon üzerinden yapılmıştır. $\mathrm{Bu}$ envanterde yer alan 352 tarıma dayalı sanayi işletmesi araştırmanın populasyonunu oluşturmaktadır. Örnek hacmi oransal örnekleme yöntemine dayalı olarak 153 olarak belirlenmiştir.

Anket yapılacak işletme seçiminde \%90 güven aralığında, 0,05 hata payı ile yapılan örneklemede oransal örnekleme formülünden yararlanılmıştır (Miran, 2002).

$$
n=\frac{N p(1-p)}{(N-1) \sigma_{\hat{p}_{X}}^{2}+p(1-p)}
$$

Yapılan örnekleme ile yapılacak anket sayısı 153 olarak belirlenmiştir. Örneğe çıkan işletmelerin bulunduğu ilçe ve köylere gidilerek, daha önceden araştırmanın amacına uygun olarak hazırlanmış bulunan anket formları işletme yöneticileriyle karşılıklı görüşmek yoluyla bizzat araştırıcı tarafından doldurulmuştur.

Araştırma alanında örneğe giren her işletme yetkilisi için doldurulan anketler ayrı ayrı gözden geçirilerek gerekli kontrol ve hesaplamalar yapılmış ve veriler SPSS paket programlarına aktarılarak ortalamalar, yüzdeler, Ki-kare analizi gibi istatistiksel yöntemler kullanılarak analiz edilmiştir. Ki-kare, bir ana kitlenin iki sınıflandırma kriterine göre farklılık gösterme veya birbirinden bağımsız olma hipotezini test etmede kullanılır. Bağımsızlık testlerinde tek bir ana kitle vardır. Bu ana kitle iki kritere göre sınıflandırılır. Bir kritere göre dağılım, diğer bir kritere göre dağılıma hiçbir şekilde bağlı değilse, iki sınıflandırma kriterinin birbirinden bağımsız olduğu düşünülür (Miran, 2002).

\section{Araştırma Bulguları}

\section{1 İnsan Kaynakları ile İlgili Bulgular}

Çanakkale ilinde tarıma dayalı sanayinde Ar-Ge potansiyelinin belirlenmesi amacıyla yapılan bu çalışmada örnek olarak seçilen 153 işletmede tüm çalışanların ve Ar-Ge personelinin eğitim durumları Tablo 1.'de gösterilmiştir. Tabloya göre seçilen işletmelerde 189 kadın, 352 erkek olmak üzere toplam 541 kişi çalışmaktadır. Diğer taraftan bu işletmelerde 11 kadın, 59 erkek olmak üzere toplam 70 Ar-Ge personeli görev yapmaktadır. Bu değerler toplam çalışanlar içerinde Ar-Ge personelinin oranın \%13 civarında olduğunu göstermektedir. Çalışanların eğitim durumları incelendiğinde sırasıyla ortaokul $(\% 39,74)$, ilkokul $(\% 27,91)$ ve lise $(\% 20,89)$ şeklinde yoğunlaşmaktadır. Diğer taraftan Ar-Ge personelinin eğitim durumu incelendiğinde sirasıyla lisans $(\% 45,71)$, yüksek lisans $(\% 34,29)$ ve lise şeklinde sıralanmıştır. Doktora düzeyinde sadece bir personel istihdam edilmiştir.

Ar-Ge personelinin kadın ve erkek olarak dağılımı incelendiğinde lisans düzeyinde erkek sayısı kadın sayısından fazla olurken, yüksek lisans düzeyinde kadın Ar-Ge personeli sayısının erkek Ar-Ge personeli sayısından yüksek olduğu görülmektedir. Bu işletmelerde doktoralı tek Ar-Ge personelinin ise kadın olduğu görülmektedir.

\begin{tabular}{|c|c|c|c|c|c|c|}
\hline \multicolumn{7}{|c|}{ İşletmelerde Tüm Çalışanların Eğitim Durumu } \\
\hline \multirow[b]{2}{*}{ Eğitim Düzeyi } & \multicolumn{2}{|c|}{ Kadın } & \multicolumn{2}{|c|}{ Erkek } & \multicolumn{2}{|c|}{ Toplam } \\
\hline & Kişi & Yüzde (\%) & Kişi & Yüzde (\%) & Kişi & Yüzde (\%) \\
\hline İlkokul & 57 & 30,16 & 94 & 26,7 & 151 & 27,91 \\
\hline Orta öğretim & 80 & 42,32 & 135 & 38,35 & 215 & 39,74 \\
\hline Lise & 34 & 17,99 & 79 & 22,44 & 113 & 20,89 \\
\hline Ön Lisans & 4 & 2,11 & 5 & 1,42 & 9 & 1,66 \\
\hline Lisans & 8 & 4,24 & 30 & 8,52 & 38 & 7,02 \\
\hline Yüksek Lisans & 5 & 2,65 & 9 & 2,56 & 14 & 2,59 \\
\hline Doktora & 1 & 0,53 & 0 & 0 & 1 & 0,18 \\
\hline Toplam & 189 & 100 & 352 & 100 & 541 & 100,00 \\
\hline \multicolumn{7}{|c|}{ İşletmelerde Çalışan Ar-Ge Personellerinin Eğitim Durumu } \\
\hline \multirow[b]{2}{*}{ Eğitim Düzeyi } & \multicolumn{2}{|c|}{ Kadın } & \multicolumn{2}{|c|}{ Erkek } & \multicolumn{2}{|c|}{ Toplam } \\
\hline & Kiși & Yüzde (\%) & Kisi & Yüzde (\%) & Kiși & Yüzde (\%) \\
\hline İlkokul & 0 & 0 & 2 & 3,4 & 2 & 2,86 \\
\hline Orta öğretim & 1 & 9,1 & 2 & 3,4 & 3 & 4,29 \\
\hline Lise & 0 & 0 & 7 & 11,8 & 7 & 10,00 \\
\hline Ön Lisans & 0 & 0 & 1 & 1,7 & 1 & 1,43 \\
\hline Lisans & 4 & 36,4 & 28 & 47,5 & 32 & 45,71 \\
\hline Yüksek Lisans & 5 & 45,4 & 19 & 32,2 & 24 & 34,29 \\
\hline Doktora & 1 & 9,1 & 0 & 0 & 1 & 1,43 \\
\hline Toplam & 11 & 100 & 59 & 100 & 70 & 100 \\
\hline
\end{tabular}

Tablo 1. Işsletmelerde Toplam Çalışanların ve Ar-Ge Personelinin Eğitim Durumuna Göre Dağllımı

Seçilen işletmelerde Ar-Ge çalışanların herhangi bir Ar-Ge eğitimi alıp almadığg sorulmuştur ve \%13,73'ünün Ar-Ge eğitimi aldığı, \%86,27'sinin ise almadığı görülmüştür (Tablo 2). 


\begin{tabular}{|l|l|l|}
\hline Ar-Ge Eğitimi Alma Durumu & Kiși & Yüzde (\%) \\
\hline Eğitim Alındı & 21 & 13,73 \\
\hline Eğitim Alınmadı & 132 & 86,27 \\
\hline Toplam & 153 & 100 \\
\hline
\end{tabular}

Tablo 2. Ar-Ge Ĕ̆itimi Alma Durumu

Seçilen işletmelere devlet tarafından verilen Ar-Ge destekleri hakkında işletme çalışanlarının bilgi sahibi olup olmadığı sorulduğunda \%19'u bilgi sahibi olduğunu \%81'i ise bilgi sahibi olmadığını ifade etmiştir. İşletme çalışanlarının verilen Ar-Ge destekleri hakkında bilgi sahibi olması ile durumu Ar-Ge çalışmalarında bulunma durumu birlikte incelendiğinde, değişkenler arasında farklılıkların istatistiksel bakımdan önemli olduğu sonucuna varılmıştır $(\mathrm{P}<0,05)$. Tablo 3. incelendiğinde Ar-Ge çalışmalarına verilen destekler hakkında bilgi sahibi olan işletmelerin Ar-Ge çalışması yapma oranı \%82,7'iken, bilgi sahibi olmayan işletmelerde bu oranın \%11,3'e düştüğü görülmüştür.

\begin{tabular}{|l|l|l|l|l|}
\hline $\begin{array}{l}\text { Ar-Ge Çalıșmalarına Verilen Destekler Hakkında } \\
\text { Bilgi Sahibi Olma }\end{array}$ & \multicolumn{2}{|l|}{ Bilgi Sahibi Olan } & \multicolumn{2}{l|}{ Bilgi Sahibi Olmayan } \\
\hline Ar-Ge Çalıșması Yapma & Kiși & Yüzde (\%) & Kiși & Yüzde (\%) \\
\hline Yapan & 24 & 82,7 & 14 & 11,3 \\
\hline Yapmayan & 5 & 17,3 & 110 & 88,7 \\
\hline Toplam & 29 & 100 & 124 & 100 \\
\hline$\chi^{2}=64,307 ;$ P Değeri= 0,00 & \multicolumn{4}{l}{} \\
\hline
\end{tabular}

Tablo 3. Ar-Ge Destekleri Hakkında Bilgi Sahibi Olma ve Ar-Ge Yapma Durumu Arasındaki İlişki

\section{2 İşletmelerin Yapısal Durumları ve Nitelikleri İle İlgili Bulgular}

Bu bölümde işletmelerin kuruluş yılı, çalışan sayısı, marka ve tescil durumu gibi kriterler ile Ar-Ge potansiyeli arasındaki ilişkiler tespit edilmeye çalışılmıştır. Araştırma yapılan işletmeler kuruluş yılları itibarıyla incelendiğinde \%35,29'u 1965-2004 yılları arasında, \%64,71'i 2004 yılı sonrasında kurulmuştur. İşletmelerin genelde 2004 yılı sonrası kurulmuş olması işletmelerin henüz genç işletmeler olduğunu göstermektedir.

\begin{tabular}{|l|l|l|}
\hline Yıllar & Sayı & $\mathbf{( \% )}$ \\
\hline $1965-2004$ & 54 & 35,29 \\
\hline$>2004$ & 99 & 64,71 \\
\hline Toplam & 153 & 100 \\
\hline Min=1965, Mak=2015, Ort=2004, S. Sapma=9,6 \\
\hline
\end{tabular}

Tablo 4. İşletmelerin Kuruluş Yılları

Seçilen işletmelerin çalışan sayısına göre dağılımları ise Tablo 5 'de verilmiştir. Tabloya göre işletmelerin büyük çoğunluğunda $(\% 93,46)$ çalışan sayısının 2 kişiden fazla 23 kişiden az, \%6,54'ünde ise 23 kişiden fazla 75 kişiden az olduğu tespit edilmiştir. Anket yapılmak üzere seçilen işletmelerde çalışan sayısının az olması bu işletmelerin küçük ve orta ölçekli işletmeler olduğunu ifade eden göstergelerdendir.

\begin{tabular}{|l|l|l|}
\hline Çalıșan Sayısı Aralığı & Sayı & \multicolumn{1}{c|}{$(\mathbf{)})$} \\
\hline $2-23$ & 143 & 93,46 \\
\hline $23-75$ & 10 & 6,54 \\
\hline Toplam & 153 & 100 \\
\hline Min=2, Max=75, Ort=23,6, S.Sapma=21,1 \\
\hline
\end{tabular}

Tablo 5. İşletmelerin Çalışan Sayısına Göre Dă̆ılımı

İşletmede çalışan personel sayısı ile işletmede Ar-Ge çalışması yapılma durumu beraber incelendiğinde, üzerinde durulan özellik bakımından değişkenler arasındaki farkların istatistiksel olarak önemli olduğu görülmüştür $(\mathrm{P}<0,05)$. Tablo 6. incelendiğinde personel sayısı 8 kişiden az olan işletmelerin \% \%,6'sı Ar-Ge çalışmlarında bulunmakta iken çalışan sayısı 8 kişiden fazla olan işletmelerin Ar-Ge yapma oranı \% 85,2 dir. Bu durum çalışan sayısı ile Ar-Ge yapma durumu arasında pozitif bir ilişki olduğunu göstermektedir.

\begin{tabular}{|l|l|l|l|l|}
\hline İșletmede Ar-Ge Personel Sayısı & $\mathbf{1 - 8}($ Kiși) & \multicolumn{2}{l|}{ (Kiși) } \\
\hline Ar-Ge Yapma Durumu & Kişi & $(\%)$ & Kiși & $(\%)$ \\
\hline Yapan & 9 & 7,6 & 29 & 85,2 \\
\hline Yapmayan & 110 & 92,4 & 5 & 14,8 \\
\hline Toplam & 119 & 100 & 34 & 100 \\
\hline$\chi^{2}=85,590 ;$ P Değeri= 0,000 & \multicolumn{4}{|l}{} \\
\hline
\end{tabular}

Tablo 6. İşletmelerde Çalışan Sayısı İle Ar-Ge Yapma Durumu Arasındaki İlişki

Anket yapılan işletmelerde işletmeye ait web sayfalarının bulunup bulunmadığı sorusuna verilen cevaplar incelendiğinde işletmelerin \%19,61'inin web sayfasının bulunduğu, \%80,9'unun web sayfasının bulunmadığı 
sonucuna ulaşılmıştır (Tablo 7). Bu durum işletmelerin çoğunluğunun günümüz teknoloji koşullarına uyum sağlayamadığını ifade etmektedir.

\begin{tabular}{|l|l|l|}
\hline Web Sayfası Bulunma Durumu & Sayı & Yüzde (\%) \\
\hline Bulunanlar & 30 & 19,61 \\
\hline Bulunmayanlar & 123 & 80,39 \\
\hline Toplam & 153 & 100 \\
\hline
\end{tabular}

Tablo 7. Işletmelerin Web Sayfaları Bulunma Durumu

Çalışmada incelenen işletmelerdeki işletme kuruluş yılının Ar-Ge niteliğinde proje gerçekleştirme üzerine etkisi incelendiğinde, üzerinde durulan özellik bakımından değişkenler arasındaki ilişki istatistiksel olarak önemli olduğu görülmüştür $(\mathrm{P}<0,05)$. Tablo 8'den de görüldüğü gibi 1965-2004 yılları arasında kurulan işletmelerden, $\% 20,4$ 'ü Ar-Ge niteliğinde proje gerçekleştirmiş, \%79,6'sı proje gerçekleştirmemiştir. 2004 yılı sonrasında kurulan işletmelerin ise \%9,1'i proje gerçekleştirmiş, \%90,9'u proje gerçekleştirmemiştir. Bu sonuçlar işletme tecrübesi olan yani daha uzun yıllardır faaliyet gösteren işletmelerin Ar-Ge proje ve uygulamalarında daha başarılı olduğunu ifade etmektedir. Diğger bir deyişle 2004'ten önce kurulan işletmeler, 2004'ten sonra kurulanlara göre daha fazla Ar-Ge çalışması yapmaktadır.

\begin{tabular}{|l|l|l|l|l|}
\hline İșletmenin Kuruluș Yılı & $\mathbf{1 9 6 5 - 2 0 0 4}$ & $\mathbf{> 2 0 0 4}$ \\
\hline Ar-Ge Niteliğinde Proje Yapma & Say1 & $(\%)$ & Say1 & $(\%)$ \\
\hline Proje Yapan & 11 & 20,4 & 9 & 9,1 \\
\hline Proje Yapmayan & 43 & 79,6 & 90 & 90,9 \\
\hline Toplam & 54 & 100 & 99 & 100 \\
\hline$\chi^{2}=3,912 ;$ P Değeri $=0,048$ & \multicolumn{5}{|l|}{} \\
\hline
\end{tabular}

Tablo 8. İşletmelerin Kuruluş Yılı İle Ar-Ge Projesi Yapma Durumu Arasındaki İlişki

İşletme kuruluş yılının işletme bünyesinde ayrı bir Ar-Ge departmanın bulunması üzerine etkisi araştırıldığında üzerinde durulan özellik bakımından değişkenler arasındaki farklılıkların istatistiksel bakımdan önemli olduğu sonucuna varılmıştır $(\mathrm{P}<0,05)$. Yapılan inceleme kapsamında 1965-2004 aralığındaki yıllarda kurulan işletmelerin \%20,4'ünde işletme bünyesinde ayrı bir Ar-Ge departmanı bulunmakta, 2004 y1lı ve sonrasında kurulan işletmelerin ise sadece \%8, '’inde Ar-Ge departmanı bulunmaktadır.

\begin{tabular}{|l|l|l|l|l|}
\hline İșletme Kuruluș Yılı & $\mathbf{1 9 6 5 - 2 0 0 4}$ & $\mathbf{2 0 0 4}$ \\
\hline Ar-Ge Departmanı Bulunma Durumu & Say1 & $(\%)$ & Say1 & $(\%)$ \\
\hline Birim Bulunan & 11 & 20,4 & 8 & 8,1 \\
\hline Birim Bulunmayan & 43 & 79,6 & 91 & 91,9 \\
\hline Toplam & 54 & 100 & 99 & 100 \\
\hline$\chi^{2}=4,852 ;$ P Değeri $=0,028$ & \multicolumn{4}{|l}{} \\
\hline
\end{tabular}

Tablo 9. İşletmelerin Kuruluş Yılı İle Ar-Ge Departmanı Bulunma Durumu Arasındaki İlişki

Anket yapılan işletmelere marka ve tescil durumları sorulduğunda 39 işletme marka ve tescilinin mevcut olduğunu 114 işletme ise mevcut olmadığını ifade etmiştir. Çalışmada incelenen işletmelerde Marka Tescilinin ArGe çalışmalarında bulunma ile ilişkisi araştırıldığında üzerinde durulan nitelik bakımından değişkenler arasındaki farklılıkların istatistiksel bakımdan önemli olduğu sonucuna varılmıştır $(\mathrm{P}<0,05)$. Marka tescilinin varlığı ile ArGe çalışması yapma arasında pozitif bir ilişki olduğu görülmektedir. Nitekim marka tescili olan firmalarda Ar-Ge yapma oranı \%84,6 iken, marka tescili olmayanların Ar-Ge yapma oranı \%4,4 olarak tespit edilmiştir (Tablo 10). Bu sonuçtan hareketle marka tescili bulunan işletmelerin Ar-Ge çalışmalarında bulunmaya daha eğilimli olduğu görülmektedir.

\begin{tabular}{|l|l|l|l|l|}
\hline Tescilli Marka Durumu & Marka Tescili Mevcut & \multicolumn{2}{l|}{ Marka Tescili Mevcut } \\
\hline Ar-Ge Çalıșmalarında Bulunma & Sayı & $(\%)$ & Sayı & $(\%)$ \\
\hline Çalışmada Bulunan & 33 & 84,6 & 5 & 4,4 \\
\hline Çalışmada Bulunmayan & 6 & 15,4 & 109 & 95,6 \\
\hline Toplam & 39 & 100 & 114 & 100 \\
\hline$\chi^{2}=100,195 ;$ P Değeri= $=0,000$ & \multicolumn{4}{|l}{} \\
\hline
\end{tabular}

Tablo 10. Marka ve Tescilin Varlı̆̆ı İle Ar-Ge Çalışmasında Bulunma Durumu Arasındaki İlişki

\section{Sonuç ve Öneriler}

Tarımsal ürün çeşitliliği bakımından zengin ve verimli topraklara sahip Çanakkale ekonomisinde tarımın yeri önemlidir. İlde tarıma dayalı sanayinin gelişme potansiyeli olmasına rağmen bu konuda istenilen düzeye gelinememiştir. Mevcut tarıma dayalı sanayi işletmeleri küçük ve orta ölçekli, kuruluş zamanı bakımından yeni ve Ar-Ge çalışmalarının yeterince yapılmadığı işletmeler konumundadır. Bu durum öncelikle bölgesel üretim potansiyelinin yeterince değerlendirilememesi, bölgesel istihdama katkı sağlayamama ve üretimden sağlanan 
katma değerin il dışına kaymasına neden olmaktadır. Bu şartlar ilde bulunan tarıma dayalı sanayi işletmelerinin iç ve dış pazardaki rekabet şansını azaltmaktadır.

Çalışmada Güney Marmara Kalkınma Ajansı tarafından desteklenen "Çanakkale İlinde Sanayi Envanterinin Oluşturulması, İl Sanayisinin Ar-Ge, Yenilikçilik ve Kümelenme Potansiyelinin Araştırılması Projesi” kapsamında oluşturulan sanayi veri tabanından tarımla ilgili olanlar arasında bir örnekleme yapılmış olup 153 işletme ile anket yapılmıştır. Anketlerden elde edilen sonuçlara göre bu işletmelerde çalışan personelin sadece \%13'ü Ar-Ge personelidir. Ar-Ge personelinin büyük çoğunluğu lisans düzeyinde eğitim almış olup $(\% 45,71)$ bunu yüksek lisans takip etmektedir $(\% 34,29)$. Ar-Ge personeli içerisinde doktora yapma oranı ise sadece $\% 1,43$ 'dür.

Tarıma dayalı sanayi işletmelerin \%86'sı işletmeleri bünyesinde herhangi bir Ar-Ge eğitimi yapılmadığını ifade etmiştir. İşletmelerin sadece \%20'si kurumsal web sayfasına sahiptir.

İşletmelerin \%65'i 2004 yılından sonra kurulmuş olup, bu işletmelerin \%93'ünde çalışan sayısı 23 kişiden daha azdır. Bu değerlerin işletmelerin yeni kurulmuş, küçük ve orta ölçekli işletmeler olduğunu göstermektedir.

Araştırma bulgularına göre kuruluş yılı ile Ar-Ge projesi yürütme arasındaki ilişki, yine kuruluş yılı ile Ar-Ge departmanı bulunma arasındaki ilişkiler incelendiğinde istatistiki olarak anlamlı bir ilişki tespit edilmiştir. Yine Ar-Ge destekleri hakkında bilgi sahibi olmayla Ar-Ge faaliyeti yapma arasında istatistiki olarak anlamlı ilişki tespit edilmiştir. Çalışmadan elde edilen bir başka bulgu ise marka ve tescili olan durumu ile Ar-Ge faaliyeti yapma arasında istatistiki olarak anlamlı ilişki olduğudur.

Dolayısıyla gıda üretim-tüketim zincirinin başlangıç noktasını oluşturan tarım alanında, kişi başına düşen tarım arazisi miktarları son yıllarda özellikle artan nüfusa bağlı olarak ciddi oranda düşmeye başlamıştır. Bu nedenle önümüzdeki dönemde var olan tarım topraklarının verimliliğini arttıracak çalışmaların yapılması oldukça önem arz etmektedir. Bir taraftan birim alandan ve birim hayvandan elde edilecek verimliliği artırmak, diğer taraftan tarıma dayalı sanayinin geliştirilmesi açısından tarım Ar-Ge ilişkisi geliştirilmesi ve incelenmesi gereken bir konudur.

Tarımsal üretimdeki büyüme, belirli ölçüde bilimsel ve teknolojik gelişmelerden faydalanabilme olanaklarına bağlıdır. Diğer taraftan, tarım ve tarıma dayalı sanayi işletmelerinin rekabet avantajı sağlamada fiyat, kalite ve maliyet kadar, yeni ürün geliştirmeye de önem vermeleri gerekmektedir. Yapılacak Ar-Ge çalışmalarıyla tarım ve tarıma dayalı sanayi sektörlerinde üretim, verim ve katma değer daha da arttırılabilecektir.

$\mathrm{Bu}$ bağlamda tarıma dayalı sanayi işletmelerinde Ar-Ge bilincinin artırılması, Ar-Ge teşvik ve destekleri konusunda farkındalığın artırılması, işletmelerin markalaşma konusunda teşvik edilmesi, mevcut personelin ArGe konusunda eğitilmesi ve Ar-Ge tecrübesi olan kişilerin istihdamının artırılması bu çalışma kapsamında sunulabilecek önerilerdir. Bu önerilerin gerçekleşmesinde üniversitelerle ve Gıda, Tarım ve Hayvancılık Bakanlığının Araştırma Enstitüleri ile işbirliği son derece önemlidir.

\section{Kaynakça}

- Akbulak, Y., Akbulak, S., 2015. “Türkiye'nin Rekabet Gücü Bağlamında Araştırma ve Geliştirme (Ar-Ge) Faaliyetlerinin özendirilmesi. Gündem Dergisi.

- Anonim, 2013. "3. Sanayi Şurası Komisyon Raporları” Bilim Sanayi ve Teknoloji Bakanlığı. Ankara.

- Anonim, 2015a. "Bakanlık Ar-Ge Çalışmaları" Gıda, Tarım ve Hayvanclık Bakanlığı, Tarımsal Araştırmalar ve Politikalar Genel Müdürlüğ̈̈, Ankara. Erkek, D. (2011), “Ar-Ge, İnovasyon ve Türkiye”, http://geka.org.tr (Erişim Tarihi: 25.06.2016).

- Anonim, 2015b. "Çanakkale İlinde Sanayi Envanterinin Oluşturulması, İl Sanayisinin Ar-Ge, Yenilikçilik ve Kümelenme Potansiyelinin Araştırılması Projesi” Güney Marmara Kalkınma Ajansı, Çanakkale.

- Anonim, 2016a. "Innovation, Agricultural Productivity and Sustainability in Turkey" OECD Food and Agricultural Reviews.

- Anonim, 2016b. "Temel İstatistikler" http://www.tuik.gov.tr/UstMenu.do?metod=temelist. (Erişim Tarihi: 24.03.2017).

- Anonim, 2016c. "2016 Brifing Raporu” Gıda, Tarım ve Hayvancılık Bakanlığı :anakkale İl Müdürlüğü.

- avak, Ç., 2009. “Bilgi Ekonomisinde İnovasyon Kavramı ve Temel Göztergeleri”, Akademik Bilişim’09 XI. Akademik Bilişim Konferansı Bildirileri, s: 617-628, Harran Üniversitesi, Şanlıurfa.

- Demirbaş, N., (2004). Ege Bölgesi'nde Tarıma Dayalı Sanayinin Yeri ve Önemi, Ege Üniversitesi Ziraat Fakültesi Dergisi, 41(3), 29-48. İzmir.

- Erkek D., 2011. Ar-Ge, İnovasyon ve Türkiye, (Erişim tarihi: 25.03.2017).

- Miran, B., 2002. “Temel İstatistik”, Ege Üniversitesi Basımevi, İzmir. 


\title{
Organik Tarım Yapan Üreticilerin Mevcut Tarım Politikalarından Faydalanma Düzeyini Etkileyen Faktörlerin Analizi: İzmir İli Seferhisar İlçesi Örneği
}

\section{Analysis of Factors Affecting the Available Agricultural Policy Utilization Levels of Organic Farming Producers: The Case of Izmir Seferhisar Town}

\author{
Assoc. Prof. Dr. Sibel Tan (Çanakkale Onsekiz Mart University, Turkey) \\ Uğur Şimdi (Çanakkale Onsekiz Mart University, Turkey) \\ Dr. Bengü Everest (Çanakkale Onsekiz Mart University, Turkey)
}

\begin{abstract}
Within the agricultural policies of the country, supports are provided to producers for the implementation of certain activities. Sufficiency of such supports feedbacks received from the target groups using these supports. There are 141 agricultural facilities in Seferihisar dealing with organic farming and these facilities constituted the research universe. Full-count method was used to determine the research sample. A face-to-face questionnaire was performed with 100 farmers dealing with organic farming. Basic descriptive statistics were used to put forth the socio-economic status of the farmers, facility characteristics and their current status with regard to use of available agricultural supports. The factors influencing the use of available agricultural supports were analyzed by "Logistic Regression" method. Logistic regression analysis was performed to find out the utilization levels of available policies by the farmers dealing with organic farming. Farmer age was identified as the most significant factor influencing the utilization level of consultancy services provided by the state. On the other hand, credit utilization was identified as the most significant factor for the deficiency payments and fuel-fertilizer supports. Education levels was the most significant factor in using supports provided for organic farming and age was the most significant factor in using soil analysis supports. Results revealed age, educational level, credit use capability and land size as the most significant factors in utilization of agricultural policies and state supports. Development of such characteristics of the producers will increase the chance of success of available policies and proper allocation of agricultural supports.
\end{abstract}

\section{Giriş}

Dünyada nüfus artışıyla beraber artan insan refahı ve hızlı endüstrileşme doğal kaynakların aşırı kullanımını gerektirmektedir. Dolayısıyla gelecekte daha az endüstrileşmiş ülkelerin doğal kaynak ve çevre konusundaki sorunlarını çözmesi endüstrileşmiş ülkelere göre daha olasıdır (Tietenberg, 2002).

Diğer taraftan Yeşil Devrim sonrası kullanılan kimyasal ilaç ve gübreler insan sağlığını ve doğanın kendi içerisindeki düzenini tehdit eder hale gelmiştir. Yoğun tarım sisteminin uzun yıllar kullanılması nedeniyle; taban suyu yükselmesi, tuzluluk, kimyasal ilaç kalıntılarının sulama suyuyla derine inmesi ve yeraltı sularına karışması, toprak erozyonu ve bu sulardan yararlanan canlıların üzerinde hastalık ve zararlar başlıca çevre sorunları olarak sayılabilir. Temeli insan kaynaklı olan yanlış uygulamalar çevre üzerinde büyük tahribatlara neden olmuştur. Bunun önlenebilmesi için Organik Tarım ve İyi Tarım Uygulamaları (İTU) gibi çevre dostu alternatif tarım yöntemleri dünya gündeminde yerini almıştır.

Organik tarım; kullanımında sakınca bulunmayan girdi ve tarım teknikleri ile bitkisel ve hayvansal ürünlerin elde edilmesi, işlenmesi, etiketlenmesi, kontrolü, sertifikalandırılması ve pazarlanmasına ilişkin sürdürülebilir bir tarım şeklidir. Kısaca, organik tarım kimyasal girdi kullanmadan, doğadan sofraya kadar her aşaması kontrol altında olan sertifikalı tarımsal üretim biçimidir (Demiryürek, 2000).

Avrupa Ülkeleri ve ABD’nin canlı yaşam ve çevreye duyarlı üretim sistemi anlayışı organik tarım olgusunu meydana getirmiştir. Organik Tarım, Ekolojik Tarım, Biyolojik Tarım olarak adlandırılan bu sistem ilk defa 1972'de Stockholm Konferansı'nda görüşülmüştür. Bu görüşme Organik Tarımı uluslararası alanda kontrol edebilecek Uluslararası Organik Tarım Hareketleri Federasyonu'nun (IFOAM) kurulmasını sağlamıştır (Aksoy ve Altındişli, 2010).

Tarımın diğer sektörlerden farklı olarak doğal şartlara olan bağlılığı ve kıt kaynakların kullanımı, uzun vadeli sürekli bir plan çalışmasının zorunluluğunu ortaya koymaktadır. Üretimi yağmur, dolu gibi iklimsel etkenlerin yanında, hastalık ve zararlılar da etkilemektedir. Arazinin etkin kullanımı, müdahale ve yöntemler ne kadar etkin olsa da gıda ihtiyacını karşılama misyonu, risk ve belirsizliklerle karşı karşıyadır. Buna bağlı nedenlerle tarımda diğer sektörlerden ayrı politikalar geliştirilmesi gerekmektedir. Sektörde uzun vadeli politikalara ve stratejik hedeflere bağlılık gereklidir. 
Devletin tarım sektörüne yaptığı harcamaların tamamı destekleme politikası kapsamında yer alır. Destekleme; tarımın korunması, özendirilmesi ve sürdürülebilirliğinin sağlanması için alınan önlemlerin tamamıdır. Fiyat ve alım desteği, tarım ürünleri dış ticaretine yönelik düzenlemeler, girdi desteği, fark ödeme sistemi, üretim teşvik ödemeleri veya üretimi azaltmaya yönelik ödemeler, tarıma yönelik altyapı yatırımları, araştırma, yayım, eğitim, kontrol hizmetleri, pazarlama ve tanıtım çalışmaları gibi alanlara yönelik devlet harcamaları tümüyle tarımsal desteklemenin içindedir (Gaytancığlu, 2009).

Tarımda; gıda ihtiyacının karşılanması, birim alandan en yüksek verimliliğin elde edilmesi, istihdam sağlanması ve ürünlerin dış pazara ihraç edilmesi genel hedefler arasında yer almaktadır. Bu hedeflere ulaşmak için tarım politikaları oluşturulmaktadır. Tarım politikalarının içeriğinde tarımsal destekleme araçları da yer almaktadır. Bu kapsamda; ekonomik, sosyal ve altyapı yatırımlarına yönelik olarak destekleme faaliyetleri sürdürülmektedir (Civan, 2010).

Günümüzde üretimde birçok alanda farklı destekler verilmektedir. Politikalar içerisinde yer alan düzenlemelerle üretici desteklenerek, üretimin cazibesi arttırılmaya çalışılmaktadır. Hiç şüphesiz ki Organik tarımın gelişmesi için de politikalar oluşturulmaktadır. Bir sisteminin toplum tarafından kabullenip, uygulanabilmesi için şüphesiz ki karar vericilerin konu ile ilgili yasal mevzuat ve politikalar üretmesi gerekmektedir. Ülkemizde 18.12.1994 tarih ve 22145 sayılı Resmi Gazete'de yayınlanan "Bitkisel ve Hayvansal Ürünlerin Ekolojik Metotlarla Üretilmesine İlişkin Yönetmelik”, daha sonra AB mevzuatında 1991 yılından sonra yapılan değişiklikleri içerecek şekilde güncellenmiş ve "Organik Tarımın Esasları ve Uygulanmasına İlişkin Yönetmelik” 11.07.2002 tarih ve 24812 sayılı Resmi Gazete'de yayınlanarak yürürlüğe girmiştir.

Organik tarımla ilgili yasal mevzuat son olarak; 03.12.2004 tarih ve 25659 sayılı Resmi Gazete'de yayımlanan 5262 sayılı "Organik Tarım Kanunu” ve 10.06.2005 tarih ve 25841 sayılı Resmi Gazete'de yayımlanan "Organik Tarımın Esasları ve Uygulamasına İlişkin Yönetmelik” olarak yürürlüktedir (Anonim, 2005).

Tarımdaki girdilerin bilinçsiz kullanımının, uzun süre devam etmesi sonucunda çevreye verdiği zararlı etkiler, konvansiyonel tarıma alternatif üretim modelleri arayışına sebep olmuştur. Organik tarım; doğal dengenin korunabilmesi için çözüm yollarından biri haline gelmiştir. Özellikle stresli şehir yaşamından fazlasıyla etkilenen bireyler sağlıklı ürün tüketmek istemektedir. Organik tarım, kimyasal gübre ve ilaç kullanımını kesinlikle kabul etmeyen bir üretim şekli olduğu için cazibesi son yıllarda gittikçe artmaktadır. Organik tarım özellikle ABD ve AB ülkelerinde yaygınlaşmış olup, gıda ihtiyacının karşılanmasının yanında hayatın her alanında yer almaya başlamıştır. İnsanlar organik gıda tüketip, organik giyeceklerden giyip, organik eşyalar kullanmak istemektedirler.

Dünyada organik ürünlerin tüketim miktarındaki artış eğilimleri özellikle gelişmekte olan ülkelerde organik tarımı alternatif bir gelir kaynağı olarak gündeme getirmiştir. Tüm ülkelerde olduğu gibi Türkiye'de de üreticinin refah seviyesinin yükseltilmesi olduğu kadar, tüketicinin yaşam kalitesi ve çevre sağlı̆̆ının korunması tarım politikalarının temel amaçları arasında yer almaktadır. Dolayısıyla hem alternatif gelir kaynağı olması, hem tüketici sağlığının korunması ve hem de çevre sağlığı açısından organik tarım alternatif bir üretim yöntemi olarak önemi giderek artmaktadır.

Mevcut tarım politikalarının etkinlik derecesi, üreticilerin bakış açısı göz önüne alınarak değerlendirildiği zaman tam anlamıyla başarıya ulaşabilir. Bu politikalara olan katılım düzeyinin yüksekliği yapılan işin ne kadar doğru olduğuyla orantılıdır. Yüksek katılımla beraber memnuniyet derecesinin de ölçülmesi önemlidir.

Türkiye'de yıllardan beri organik tarımın geliştirilebilmesi için yürürlüğe konulan politikalar kapsamında üreticiler desteklenmektedir. Organik üretimin arttırılması için hazırlanan destekleme politikalarının fayda düzeyinin belirlenmesi; bu politikaların doğruluğunu kanıtlayacaktır. Yapılan bu araştırmada temel amaç, organik tarım üreticilerinin mevcut politikalardan faydalanma düzeyinin belirlenmesidir.

Araştırma, İzmir İli Seferihisar İlçesi’nde organik tarım yapan üreticileri kapsamaktadır. Çalışmanın ikinci bölümde araştırmanın materyal ve yöntemi verilmiş, üçüncü bölümde araştırma bulguları, genel bulgular, organik tarım ile ilgili bulgular ve uygulanan politikalarla ilgili bulgular olmak üzere üç başlık altında tartış1lmış, dördüncü ve son bölümde ise çalışma ile ilgili sonuç ve öneriler sunulmuştur.

\section{Materyal ve Yöntem}

\subsection{Materyal}

Araştırmada birincil ve ikincil verilerden yararlanılmıştır. İzmir İli Seferihisar İlçesinde organik tarım yapan çiftçilerden, anket yoluyla elde edilen bilgiler birincil nitelikli veriler oluşturmaktadır. Araştırmanın ikincil verilerini İzmir İl Gıda, Tarım ve Hayvancılık Müdürlüğü verileri, TUİK verileri, konuyla ilgili çeşitli kurum ve kuruluşların yapmış oldukları yayınlar ile diğer araştırmacılar tarafından yapılmış ve sonuçlanmış olan araştırma sonuçları, resmi istatistikler, derleme, inceleme ve tezlerden elde edilen veriler oluşturmaktadır.

\subsection{Yöntem}

Seferihisar ilçesinde organik tarım yapan 141 adet tarım işletmesi mevcut olup, bu işletmeler araştırmanın popülasyonunu oluşturmaktadır. Çalışmanın örneklemesi tam sayım yöntemine göre belirlenmiş ve görüşmeyi kabul eden 100 adet organik tarım yapan çiftçi ile yüz yüze anket çalışması yapılmıştır. 
Çalışmada çiftçilerin sosyo-ekonomik durumlarını, işletme özelliklerini, tarımsal desteklerden faydalanma durumlarını ortaya koymak amacıyla temel tanımlayıcı istatistikler kullanılmıştır.

Çiftçilerin mevcut tarım desteklerinden faydalanma durumlarını etkileyen faktörler Logistik Regresyon yöntemi ile analiz edilmiştir. Logit modeller, genelleştirilmiş doğrusal modelin belirli koşullar altında oluşturulmuş özel durumlarıdır. Bu durumda yapılacak olan çalışmada, eğer bağımsız değişkenlerin bazısı sürekli veya uygun (ilgili) sınıflar içine ayrıştırılamazsa, o zaman log-linear analiz yerine Lojistik regresyon kullanılmalıdır. Aynı zamanda eğer değişkenlerin bazısı bağımlı olarak ele alınırsa, o zaman logit model uygundur. Böyle bir durumda 0'la 1 arasında kalma koşulunu sağlayabilmek için logit modelin uygulanması önerilmektedir (Gujarati, 1995).

\section{Araştırma bulguları}

\subsection{Genel Bulgular}

Bu bölümde İzmir İli Seferihisar İlçesinde organik tarım yapan üreticilerin yaş, eğitim, iş tecrübesi, gelir ve kredi kullanım durumu gibi bilgiler verilmiştir. İzmir İli Seferihisar İlçesinde anket yapılan organik tarım üreticilerinin yaşlarına göre dağılımı incelendiğinde araştırma alanı içinde anket yapılan üreticilerin yaş aralığına bakıldığında \%38'inin 41-50 yaş aralığında, \%37'sinin 50 yaşın üzerinde, \%24'ünün 31-40 yaş aralığında ve \% 1 'inin 20-30 yaş aralığında olduğu belirtilmiştir. Bu değerler Seferihisar'da organik tarım yapan üreticilerin \%63'ünün 20 ile 50 yaş aralığında olduğunu, bununda organik tarım yapan üreticilerin genç bir yaş diliminde yer aldığını göstermektedir (Tablo 1).

\begin{tabular}{|l|l|l|l|}
\hline Yaș & Sayı & \% & Kümülatif \% \\
\hline $20-30$ & 1 & 1.0 & 1.0 \\
\hline $31-40$ & 24 & 24.0 & 25.0 \\
\hline $41-50$ & 38 & 38.0 & 63.0 \\
\hline$>50$ & 37 & 37.0 & 100.0 \\
\hline TOPLAM & $\mathbf{1 0 0}$ & $\mathbf{1 0 0 . 0}$ & \\
\hline
\end{tabular}

Tablo 1. Üreticilerin Yaşlarına Göre Dă̆ılım

Organik tarım yapan üreticilerin eğitim durumu incelendiğinde araştırma alanı içinde anket yapılan üreticilerin \%72'sinin ilkokul, \%15'inin lise, \%9'unun ortaokul, \%2'sinin yükseköğretim mezunu olduğu ve \%2'sinin ise okuryazar olmadığı belirtilmiştir. Bu değerler İzmir İli Seferihisar İlçesi’nde organik tarım yapan üreticilerin eğitim seviyesinin ilköğretimde yoğunlaştığını göstermektedir (Tablo 2).

\begin{tabular}{|l|l|l|l|}
\hline Ĕ̆itim & Sayı & \% & Kümülatif \% \\
\hline Okuryazar & 2 & 2.0 & 2.0 \\
\hline İlkokul & 72 & 72.0 & 74.0 \\
\hline Ortaokul & 9 & 9.0 & 83.0 \\
\hline Lise & 15 & 15.0 & 98.0 \\
\hline Yükseköğretim & 2 & 2.0 & 100.0 \\
\hline TOPLAM & $\mathbf{1 0 0}$ & $\mathbf{1 0 0 . 0}$ & \\
\hline
\end{tabular}

Tablo 2. Üreticilerin Ĕ̆itim Durumlarına Göre Dă̆ılımı

Anket yapılan üreticilerin tarımda çalışma sürelerine bakıldığında \%60'ının 30 yıldan fazla, \%32'sinin 20-30 yıl aralığında ve \%8'inin ise 20 yıldan az olduğu belirtilmiştir. Bu değerlere göre üreticilerin \%60 gibi bir büyük çoğunluğu 30 y1l üzerinde tecrübeye sahiptir ki bu durumun bölgede tarımın atadan dededen gelen bir meslek olarak sürdürüldüğü sonucunu ortaya çıkarmaktadır. Diğer taraftan bu sürenin uzun olması üreticilerin bu konudaki tecrübelerini de ortaya koymaktadır (Tablo 3).

\begin{tabular}{|l|l|l|l|}
\hline Tarımda & Sayı & \% & Kümülatif \% \\
\hline$<20$ & 8 & 8.0 & 8.0 \\
\hline $20-30$ & 32 & 32.0 & 40.0 \\
\hline $30>$ & 60 & 60.0 & 100.0 \\
\hline TOPLAM & $\mathbf{1 0 0}$ & $\mathbf{1 0 0 . 0}$ & \\
\hline
\end{tabular}

Tablo 3. Üreticilerin Tarımsal Faaliyette Çalışma Süresine Göre Dă̆̆lımı

Üreticilerin bağlı oldukları sosyal güvenlik kuruluşuna göre dağılımı incelendiğinde araştırma alanı içinde anket yapılan üreticilerin \%58.1'inin Bağkur, \%16,1'inin Emekli Sandığ1, \%24,7'sinin SSK ve \%1,1'inin ise başka bir sosyal güvenceye sahip olduğu ifade edilmiştir. Sosyal güvencesi olduğunu ifade eden üreticilerin büyük çoğunluğunun çiftçi bağkuru yaptırdığı görülmektedir (Tablo 4). 


\begin{tabular}{|l|l|l|l|}
\hline Sosyal & Sayı & \% & Kümülatif \% \\
\hline SSK & 23 & 24.7 & 24.7 \\
\hline Emekli & 15 & 16.1 & 40.8 \\
\hline Bağkur & 54 & 58.1 & 98.9 \\
\hline Diğer & 1 & 1.1 & 100.0 \\
\hline TOPLAM & $\mathbf{9 3}$ & $\mathbf{1 0 0 . 0}$ & \\
\hline
\end{tabular}

Tablo 4. Üreticilerin Sahip Olduğu Sosyal Güvence Türüne Göre Dă̆ılımı

Mülk arazi, kiralanan arazi ve ortağa tutulan arazilerin toplam işlenen arazilerin büyüklüğüne göre dağılımı incelendiğinde üreticilerin \%37'sinin 100 dekardan daha büyük araziye, \%28'inin 50-80 dekar arasında, \%26'sının 20-50 dekar arasında, \%7'sinin 80-100 dekar arasında, \%2'sinin ise 20 dekardan daha küçük araziye sahip olduğu görülmektedir (Tablo 5).

\begin{tabular}{|l|l|l|l|}
\hline Toplam ișlenen arazi varlığı (da) & Sayı & \% & Kümülatif \% \\
\hline$<20$ & 2 & 2.0 & 2.0 \\
\hline $20-50$ & 26 & 26.0 & 28.0 \\
\hline $50-80$ & 28 & 28.0 & 56.0 \\
\hline $80-100$ & 7 & 7.0 & 63.0 \\
\hline $100>$ & 37 & 37.0 & 100.0 \\
\hline TOPLAM & $\mathbf{1 0 0}$ & $\mathbf{1 0 0}$ & \\
\hline
\end{tabular}

Tablo 5. Üretici Sayısının Toplam İşlenen Arazi Varlı̆̆ının Büyüklüklerine Göre Dă̆ılımı

Üreticilerin gelir aralıklarına göre dağılımları incelendiğinde araştırma alanı içinde anket yapılan üreticilerin \%36'sinın yıllık 20-30 bin TL arasında, \%35'inin 10-20 bin TL arasinda, \%17'sinin 30-40 bin TL arasinda ve \%6'sının 40-50 bin TL arasında ve \%6'sının 50 bin TL den fazla gelir elde edildiği belirtilmiştir (Tablo 6).

\begin{tabular}{|l|l|l|l|}
\hline Toplam gelir (Bin TL/Yıl) & Sayı & \% & Kümülatif \% \\
\hline $10-20$ & 35 & 35.0 & 35.0 \\
\hline $20-30$ & 36 & 36.0 & 71.0 \\
\hline $30-40$ & 17 & 17.0 & 88.0 \\
\hline $40-50$ & 6 & 6.0 & 94.0 \\
\hline $50>$ & 6 & 6.0 & 100.0 \\
\hline TOPLAM & $\mathbf{1 0 0}$ & $\mathbf{1 0 0 . 0}$ & \\
\hline
\end{tabular}

Tablo 6. Üretici Sayısının Gelir Aralıklarına Göre Dă̆glımı

\subsection{Organik Tarım Faaliyeti ile İlgili Bulgular}

Küçük ve yoksul aile işletmelerinin hayatta kalması doğal kaynakların sürekliliğine bağlıdır. Bu üreticiler klasik ekonomik yaklaşımların aksine temel amaçları maksimum kar değildir. Fakat bu üreticiler de doğal kaynakların kullanımı üzerinde etki sahibidir. $\mathrm{Bu}$ üreticilerin doğal kaynaklar üzerindeki etkisini azaltmak için klasik yaklaşımlardan farklı çözümler gereklidir (Sterner, 2003). Bu çözümlerin başında üreticiye alternatif gelir kaynakları yaratmaktır ki organik tarım da bunun için çok uygun bir çözümdür.

Çalışmanın bu bölümünde üreticilerin organik tarım yapma kararını etkileyen faktörler, organik tarım yapmanın sebepleri, organik tarım yapmaktan elde ettikleri faydalar, karşılaştıkları zorluklar incelenmiştir. Bölgede organik tarıma geçiş genellikle alternatif gelir kaynaklarının yaratılması amacını taşımaktadır. Üreticilerin \%32'sinin geçiş2, \%38'inin organik ürün, \%15'inin başlangıç, \%10'unun geçiş3 ve \%5' inin geçiş1 aşamasında olduğu belirtilmiştir. Dolayısıyla İzmir İli Seferihisar ilçesinde organik üreticilerinin büyük bölümü organik ve geçiş2 aşamasındadır.

İzmir İli Seferihisar ilçesinde üreticilerin organik tarım yapma kararını etkileyen kurum ve kuruluşlar incelendiğinde araştırma alanı içinde anket yapılan üreticilerin \%46'sının tarım danışmanı, \%13'ünün yerel yönetim, \%12'sinin üretici örgütü, \%11'inin sözleşmeli firma ve \%6'sının Gıda Tarım ve Hayvancılık İl Müdürlüğü etkisiyle olduğu ifade edilmiştir. Üreticilerin \%12'si ise bu kararın kendi kişisel kararı olduğunu belirtmiştir (Tablo 7).

\begin{tabular}{|l|l|l|}
\hline Organik üretime bașlama kararı & Sayı & $\mathbf{\%}$ \\
\hline Kendi kișisel kararı & 12 & 12.0 \\
\hline Sözleșmeli firma & 11 & 11.0 \\
\hline Yerel yönetim & 13 & 13.0 \\
\hline Gıda Tarım ve Hayvancılık İl Müdürlüğü & 6 & 6.0 \\
\hline Üretici örgütü & 12 & 12.0 \\
\hline Tarım Danıșmanı & 46 & 46.0 \\
\hline TOPLAM & $\mathbf{1 0 0}$ & $\mathbf{1 0 0 . 0}$ \\
\hline
\end{tabular}

Tablo 7. Üreticilerin Organic Tarım Yapma Kararını Etkileyen Kurum ve Kuruluşlar 
İzmir İli Seferhisar İlçesinde organik tarım yapan üreticilerine organik tarım yapma nedenleri çok önemli, orta önemli ve az önemli şeklinde ölçeklendirilerek sorulmuştur. Üreticiler çok önemli gördükleri sebepleri doğa dostu üretim (\%69), bakanlık destekleri (\%10), organik ürün fiyatlarının yüksekliği (\%10), ortak bir projede yer alma $(\% 6)$, bakanlık eğitim faaliyetlerine katılma (\%4), organik pazara yakınlık (\%1) şeklinde sıralamıştır. Organik ürün talebindeki artış çok önemli nedenler arasında yer almazken orta önemli nedenler arasında \%3, az önemli nedenler arasında ise \%8'lik pay almıştır (Tablo 8).

\begin{tabular}{|l|l|l|l|l|l|l|}
\hline \multirow{2}{*}{ Organik tarım yapma nedeni } & \multicolumn{2}{l|}{ Cok önemli } & \multicolumn{2}{l|}{ Orta derece önemli } & \multicolumn{2}{l|}{ Az derece önemli } \\
\cline { 2 - 7 } & Sayı & $\%$ & Sayı & \% & Sayı & $\%$ \\
\hline Bakanlığın eğitim faaliyeti ile & 4 & 4.0 & 12 & 12.0 & 21 & 21.0 \\
\hline Doğa dostu üretim & 69 & 69.0 & 12 & 23.0 & 9 & 9.0 \\
\hline Bakanlık destekleri & 10 & 10.0 & 23 & 22.0 & 8 & 8.0 \\
\hline Organik ürün fiyatının yüksekliği & 10 & 10.0 & 30 & 30.0 & 23 & 23.0 \\
\hline Ortak bir projede yer alındığı için & 6 & 6.0 & 18 & 18.0 & 12 & 12.0 \\
\hline Organik ürün pazarına yakınlık & 1 & 1.0 & 2 & 2.0 & 19 & 19.0 \\
\hline Organik ürün talebindeki artıș & 0 & 0 & 3 & 3.0 & 8 & 8.0 \\
\hline TOPLAM & $\mathbf{1 0 0}$ & $\mathbf{1 0 0 . 0}$ & $\mathbf{1 0 0}$ & $\mathbf{1 0 0 . 0}$ & $\mathbf{1 0 0}$ & $\mathbf{1 0 0 . 0}$ \\
\hline
\end{tabular}

Tablo 8. Önem Derecelerine Göre Üreticilerin Organik Tarım Yapma Nedenleri

Araştırma alanı içinde anket yapılan üreticilerin organik tarım yapmanın faydalarından çok önemli olanlar incelendiğinde, \%71'i çevremizi korumak, \%16'sı desteklemelerden yararlanmak, \%'10 u yüksek fiyatla ürün satmak ve \%3'ü de yüksek fiyatta ürün satmak olduğu belirtilmiştir. Orta derece önemli nedenlerde yüksek fiyatlarla ürün satmak en önemli seçenek olurken (\%35), desteklerden faydalanma seçeneği az önemli nedenler arasında ön plana çıkmıştır (\%34) (Tablo 9).

\begin{tabular}{|l|l|l|l|l|l|l|}
\hline \multirow{2}{*}{ Organik tarım yapmanın faydaları } & \multicolumn{2}{l|}{ Cok önemli } & \multicolumn{2}{l|}{ Orta derece önemli } & \multicolumn{2}{l|}{ Az derece önemli } \\
\cline { 2 - 7 } & Sayı & $\mathbf{\%}$ & Sayı & \% & Sayı & \% \\
\hline Yüksek fiyatla ürün satmak & 10 & 10.0 & 35 & 35.0 & 24 & 24.0 \\
\hline Desteklemelerden yararlanmak & 16 & 16.0 & 34 & 34.0 & 34 & 34.0 \\
\hline Girdi maliyetini azaltmak & 3 & 3.0 & 24 & 24.0 & 23 & 23.0 \\
\hline Çevremizi korumak & 71 & 71.0 & 7 & 7.0 & 19 & 19.0 \\
\hline TOPLAM & $\mathbf{1 0 0}$ & $\mathbf{1 0 0 . 0}$ & $\mathbf{1 0 0}$ & $\mathbf{1 0 0 . 0}$ & $\mathbf{1 0 0}$ & $\mathbf{1 0 0 . 0}$ \\
\hline
\end{tabular}

Tablo 9. Önem Derecelerine Göre Organik Tarım Yapmanın Faydaları

Üreticilere önem derecesine organik tarım yapmanın zorluklarından çok önemli olanlara bakıldığında;\%36'sı ürünlerin pazar sıkıntısı olması, \%22'si maliyetlerinden yüksek olması, \%21'i ürün fiyat garantisinin olmaması, \%14'ü organik ruhsatlı ilaç ve gübre sıkıntısı ve \%7'si de kalite ve verim düşüklüğü olduğu belirtilmiştir (Tablo $10)$.

\begin{tabular}{|l|l|l|l|l|l|l|}
\hline \multirow{2}{*}{ Organik tarım yapmanın zorlukları } & \multicolumn{2}{l|}{ Çok önemli } & \multicolumn{2}{l|}{ Orta derece önemli } & \multicolumn{2}{l|}{ Az derece önemli } \\
\cline { 2 - 7 } & Sayı & $\mathbf{\%}$ & Sayı & \% & Sayı & $\%$ \\
\hline Ürünlerin pazar sıkıntısı & 36 & 36.0 & 16 & 16.0 & 24 & 24.0 \\
\hline Ürünün fiyat garantisinin olmaması & 21 & 21.0 & 37 & 37.0 & 21 & 21.0 \\
\hline Maliyetlerin yüksek olması & 22 & 22.0 & 23 & 23.0 & 22 & 22.0 \\
\hline Organik ruhsatlı ilaç ve gübre sıkıntısı & 14 & 14.0 & 19 & 19.0 & 21 & 21.0 \\
\hline Kalite ve verim düșüklügü & 7 & 7.0 & 5 & 5.0 & 12 & 12.0 \\
\hline TOPLAM & $\mathbf{1 0 0}$ & $\mathbf{1 0 0 . 0}$ & $\mathbf{1 0 0}$ & $\mathbf{1 0 0 . 0}$ & $\mathbf{1 0 0}$ & $\mathbf{1 0 0 . 0}$ \\
\hline
\end{tabular}

Tablo 10. Önem Derecelerine Göre Organik Tarım Yapmanın Zorlukları

\subsection{Tarımsal Desteklerle ile İlgili Bulgular}

Araştırma alanı içinde anket yapılan üreticilerin mevcut desteklere bakış açıları incelendiğinde; hayvancılık desteğinden yararlananların \%50 si yeterli, \%50si ise yetersiz olduğu, mazot gübre desteğinden yararlananların \%60'1 yetersiz, \%40'ının yeterli olduğu, toprak analizi desteğinden yararlananların \%56,7 si yetersiz, \%43,3 ünün yeterli olduğu, sertifikalı fidan desteğinden yararlananların \%75'ii yetersiz, \%25'i ise yeterli olduğunu ifade etmiştir. Diğger taraftan fark ödemeleri desteğinden yararlananların \%56,25'i yetersiz olduğu, \%43,8'i yeterli olduğu, organik tarım desteğinden yararlananların \%52,94' yetersiz olduğu, \%47,06 sı ise yeterli olduğu, iyi tarım uygulamaları desteğinden yararlananların \%75.0'i yetersiz olduğu ve \%25.0'i ise yeterli olduğunu belirtilmiştir. Bu sonuçlardan üreticilerin en memnun olduğu desteklerin hayvancılık destekleri en yetersiz bulduğu desteklerin ise sertifikalı fidan ve iyi tarım uygulamaları desteği olduğunu söylemek mümkündür (Tablo 11). 


\begin{tabular}{|l|l|l|l|l|l|l|}
\hline \multirow{2}{*}{ Destekler } & \multicolumn{2}{|l|}{ Yeterli } & \multicolumn{2}{l|}{ Yetersiz } & \multicolumn{2}{l|}{ Toplam } \\
\cline { 2 - 7 } & Sayı & \% & Sayı & \% & Sayı & \% \\
\hline Hayvancıllk desteklemeleri & 3 & 50.0 & 3 & 50.0 & 6 & 100.0 \\
\hline Mazot gübreleme desteği & 34 & 40.0 & 51 & 60.0 & 85 & 100.0 \\
\hline Toprak analizi desteği & 13 & 43.3 & 17 & 56.7 & 30 & 100.0 \\
\hline Sertifikalı fidan kullanım desteği & 1 & 25.0 & 3 & 75.0 & 4 & 100.0 \\
\hline Fark ödemeleri desteği & 28 & 43.8 & 36 & 56.3 & 64 & 100.0 \\
\hline Organik tarım desteği & 16 & 47.1 & 18 & 52.9 & 34 & 100.0 \\
\hline İyi tarım uygulamaları desteği & 3 & 25.0 & 9 & 75.0 & 12 & 100.0 \\
\hline
\end{tabular}

Tablo 11. Üreticilerin Mevcut Politikalara Genel Bakış Açısı

Çalışmada çiftçilerin devlet tarafından verilen organik tarım desteğinden faydalanma durumlarını etkileyen faktörler Logistik Regresyon Modeli ile analiz edilmiştir. Modelin bağımlı değişkeni çiftçilerin organik tarım desteğinden faydalanma durumlarıdır (0:faydalanmayanlar, 1:faydalananlar). Bağımlı değişkenin açıklanmasında kullanılan bağımsız değişkenler ise eğitim, çiftçilik deneyimi (yıl), arazi miktarı (da), tarımsal kredi kullanma durumu, tarım dışı gelir varlığı, tarım programlarını izleme, internet kullanma durumu, örgütlenme durumu, pazarlama sorunu varlı̆̆ı, desteklerin yeterliliğidir.

\begin{tabular}{|l|l|l|l|l|}
\hline & Sabit & Std. Hata & p-değeri & Ĕgim \\
\hline Sabit & -2.40664 & 3.0382 & 0.42829 & \\
\hline Ĕgitim & 0.600418 & 0.34658 & $0.08320^{*}$ & 0.129725 \\
\hline Deneyim & 0.0265714 & 0.0260184 & 0.30713 & 0.00574097 \\
\hline Arazi & 0.01141 & 0.00559117 & $0.04128^{* *}$ & 0.00246523 \\
\hline Kredi kullanma & -0.325748 & 0.516611 & 0.52834 & -0.0703806 \\
\hline Ek gelir & -0.500341 & 0.514689 & 0.33099 & -0.108103 \\
\hline Tarım prog. İzleme & 0.671218 & 1.0097 & 0.50620 & 0.145022 \\
\hline İnternet kullanımı & 0.411127 & 0.53435 & 0.44166 & 0.0888276 \\
\hline Örgütlenme durumu & -0.701727 & 0.510461 & 0.16923 & -0.151614 \\
\hline Pazarlama durumu & 0.0780871 & 0.551574 & 0.88742 & 0.0168714 \\
\hline Desteklerin yeterliliği & -0.222482 & 0.512341 & 0.66411 & -0.0480692 \\
\hline
\end{tabular}

Chi-square $(10)=17.8489[0.0576]$

\section{Tablo 12. Üreticilerin Organik Tarım Desteğinden Faydalanma Durumlarını Etkileyen Faktörlerin Analizi}

Yapılan regrasyon analizi sonuçlarına göre üreticilerin organik tarım desteğinden faydalanma durumunu etkileyen faktörlerden eğitim durumu ve arazi büyüklüğü anlamlı çıkmıştır. Tablo 12'den görüldüğü gibi eğitim seviyesi arttıkça organik tarım desteğinden faydalanma eğilimi \%12 artmakta, diğer taraftan arazi miktarının 10 dekar artması ise organik tarım desteğinden faydalanma eğilimini \%2.4 artırmaktadır.

\section{Sonuç ve Öneriler}

Çalışmada İzmir İli Seferihisar İlçesinde organik tarım yapan üreticilerin mevcut tarım politikalarından faydalanma düzeylerini etkileyen faktörlerin analiz edilmesi amaçlanmıştır. Araştırmanın örneklemesi tam sayım yöntemiyle belirlenmiş İlçede organik tarım yapan 141 üreticiden ulaşılabilen 100 tanesi ile yüz yüze anketler yapılmıştır. Anketlerde öncelikle üreticilerin kişisel potansiyelleri ve işletme yapılarını ortaya koymak amacıyla yaş, eğitim, tecrübe, arazi yapısı, gelir ve gibi göstergeler ortaya koyulmak amacıyla sorular sorulmuştur. Daha sonra işletmenin organik tarım yapma kararı ve organik tarım yaparken karşılaştıkları güçlükler tespit edilmiştir. Ayrıca üreticilerin mevcut tarım politikaları hakkındaki bakış açıları bu politikalardan faydalanma düzeyleri ve bu düzeyleri etkileyen faktörlerin analiz etmek amacıyla regresyon analizleri yapılmıştır.

Anket sonuçlarına göre elde edilen bulgular incelendiğinde; üreticilerin büyük çoğunluğu 30 ile 50 yaş arasında olup (\%62), eğitim olarak çoğunluğu ilk okul mezunudur (\%72). Yine üreticilerin büyük çoğunluğu 30 yıl üzerinde üretici tecrübesine sahiptir. Toplam işlenen arazi miktarı bakımından üreticilerin \%35'i 50-100 dekar arasında işletmeye sahiptir. Üreticilerin gelir düzeyleri incelendiğinde \%71'i gelir sevilerinin 10.000 ile $30.000 \mathrm{TL}$ arasında olduğunu belirtmiş \%45'i ise tarım dışı gelire sahip olduğunu ifade etmiştir.

Üreticilerin organik tarıma geçme kararı \%46'sı bu kararı tarım danışmanın etkisiyle verdiğini açıklamıştır. Üretim şeklini değiştirmede etkili faktörden en önemlisi doğaya yararlı bir üretim şekli olması saptanmıştır. Üretici pazarına yakın olmak ve ürün satış fiyatlarının daha yüksek olması da diğer önemli faktörlerdendir. Üreticilerin \%38'i organik tarım desteğinden faydalandığını ifade etmiş, verilen desteklerin onları organik tarım yapma konusunda cesaretlendirdiğini belirtmişlerdir.

Üreticilerin genel tarım politikalarından faydalanma durumları incelendiğinde toplam tarımsal desteklerde en fazla payın organik tarım destekleri olduğu ikinci sırada ise mazot ve gübre desteğinin aldığı ifade edilmiştir. 
Üreticilerin, destekleme politikalarından yararlanma düzeyinin ölçülmesi için yapılan anket çalışması sonucunda, desteklemelerden yararlananların yarısından fazlası destekleme miktarlarının düşük olduğunu belirtmişlerdir. Üreticilerin desteklemelerden yararlanmada karşılaşmış olduğu en büyük sorunun bürokratik işlemler olduğu saptanmıştır. Uygulanan destekleme politikalarından üretim kararını en olumlu etkileyen politika organik tarım desteklemesi olup, fark ödeme sistemi, mazot ve gübre desteği bunu takip etmektedir.

Yukarıda elde edilen sonuçlardan yola çıkılarak; organik tarımla ilgili bilinç düzeyi, arazi büyüklüğü ve gelir seviyesindeki avantajlar dikkate alındığında bölgede organik tarım yapılması üreticiye çeşitli avantajlar sağlayacak niteliktedir. Dolayısıyla öncelikle bu bölgedeki üreticilere organik tarımın karlı olduğu çeşitli eğitim ve yayım programlarıyla benimsetilmeli, genç üreticilerin dikkati bu konuya çekilmelidir. Şu anda alan bazlı destek şeklinde dekara 70 Lira olarak verilen organik tarım destekleri ile birlikte sertifikasyon aşaması içinde çeşitli destekleme sistemleri geliştirilmelidir. Organik tarım üreticilerinin örgütlenerek hazırladıkları projeler kapsamında grup sertifikasyon sistemine geçmesi sağlanmalıdır.

Diğer taraftan organik tarımda üretim kadar tüketim açısından yetersizlikleri de dikkate alarak bir taraftan yurt içi talebi geliştirecek, diğer taraftan ihracatı geliştirecek politikalar uygulanmalıdır. Bu konuda tüketicinin organik ürün pahalıdır algısını kıracak ve daha kolay ulaşabileceği pazarlama teknikleri ve pazar yerleri geliştirilmelidir.

Genel tarım politikalarının başarısı açısından bakıldığında ise destekleme sistemindeki bürokratik yoğunluğun azaltılması ve üreticinin desteklere daha kolay ulaşması sağlanmalıdır.

\section{Kaynakça}

- Aksoy U., Altındişli A., 2010, “Organik Tarımın Dünya'da ve Türkiye’deki Durumu”. VII. Türkiye Ziraat Mühendisliği Teknik Kongresi, s.213-215, Ankara.

- Anonim, 2005, Organik Tarımın Esasları ve Uygulamasına İlişkin Yönetmelik, 10.06.2005 Tarih, 25841 Sayll Resmi Gazete.

- Civan A., 2010, “Türkiye'de Tarımsal Destek Politikaları”. DEÜ İkt. ve İdr. Bil. Fak. Derg., 1: (127-146), İzmir.

- Demiryürek K., 2000, “The Analysis of Information Systems for Organic and Conventional Hazelnut Producers in Three Villages of the Black Sea Region”, PhD Thesis. Reading: The University of Reading, UK.

- Gaytancıoğlu O., 2009, "Türkiye'de ve Dünyada Tarımsal Destekleme Politikası", İstanbul Ticaret Odası Yaylnlarl, s.14, İstanbul.

- Gujarati D. N., 1995, Basic Econometrics. McGraw-Hill Inc., Int. Eds. 3. ed., Istanbul.

- Sterner, T., 2003, Policy Instruments for Environmental and Natural Resource Management” p:390.Stockholm.

- Tietenberg T., 2002, “Environmental and Natural Resource Economics”. p:590, USA. 


\title{
Etkin Enerji Kullanımı Bakımından Türkiye Ekonomisinin MINT Ülkelerindeki Yeri: Karşılaştırmalı Bir Ayrıştırma Analizi The Place of Turkey among MINT Countries from Efficient
Energy Use Perspective: A Comparative Decomposition Analysis
}

\author{
Prof. Dr. Harun Bal (Çukurova University, Turkey) \\ Asst. Prof. Dr. Banu Tanrı̈̈ver (Osmaniye Korkut Ata University, Turkey) \\ Ph.D. Candidate Müge Manga (Çukurova University, Turkey)
}

\begin{abstract}
The security of energy supply has become an important issue for energy-dependent countries due to increasing energy demand and energy input prices in recent years. Therefore, energy-dependent countries have developed energy safety strategies to reduce dependence. However, the environmental problems that occur because of the increase in energy consumption, countries had to adopt an economic development process, sustainable development strategies taking account of environmental factors together with economic growth. Thus, an energy input and optimal energy policies have become increasingly important. This paper investigates the real energy efficiency by decomposing the structural and production activities and energy consumption changes of MINT countries, namely, Mexico, Indonesia, Nigeria and Turkey for the period of 1990-2014 utilizing Logarithmic Average Division Index Method. The results show that Mexico uses energy more efficiently among the countries. Mexico is followed by Indonesia, Turkey and Nigeria, respectively.
\end{abstract}

\section{Giriş}

Enerji, dünya ekonomisi açısından sosyal, ekonomik ve çevresel alanlarda önemli değişimler yaratabilecek potansiyele sahip bir unsurdur. Bu nedenle günümüzde sürdürülebilir kalkınmanın şekillenmesinde enerji ve enerji etkinliğine karşı duyarlılığın arttığı görülmektedir. Enerji etkinliğinin artan önemi, enerji kaynaklarının arzı ile talebi arasındaki farkın giderek arttığı kömür, petrol ve doğal gaz gibi birincil enerji kaynaklarının mevcut rezerv durumu ile de ilgilidir. Son dönemlerde her ne kadar birincil enerji kaynaklarının yerini yenilenebilir enerji kaynaklarının alması gerektiği vurgulansa da, hala dünya genelinde yenilenebilir enerji kaynaklarının kullanımının çok fazla yaygınlaşmadığı ve enerji taleplerinin büyük bir kısmının birincil enerji kaynaklarından sağlandığı görülmektedir (Vikhorev vd. 2013). Enerjinin etkin kullanımı, enerjinin arz güvenliğinin sağlanmasında, ithalat bağımlılığının azaltılmasında, uluslararası rekabet gücünün arttırılmasında, iklim değişiklikleriyle mücadele amaçlı koruma alanlarının verimliliğinin arttırılmasında ve enerji maliyetlerinin sürdürülebilir kılınmasında büyük bir rol oynamaktadır. Ekonomik büyüme göstergeleri ile enerji etkinliği arasında pozitif bir ilişki olduğunu ifade eden (Allan, vd. 2007; Hanley vd. 2006; Tanrı̈̈ver ve Biçer, 2016a, 2016b; Semboja (1994), Barker, vd. 2007,2009; Glomsrød ve Taoyuan, 2005; Vikström, 2008) çalışmalara paralel olarak, son dönemlerde hemen hemen tüm dünya ülkeleri, enerji verimliliğinin ülke ekonomisindeki mali dengesizliği azaltacağı ve enerji arz güvenliğinin artacağı görüşüyle enerji etkinliği konusunda çeşitli politikalar uygulamaktadırlar. Asıl amacı teknolojik gelişme gibi çeşitli iyileşmeler ile enerji etkinliği önündeki temel sorunların giderilmesine yönelik olarak (Thollander ve Dotzauer, 2010) hazırlanan enerji program ve politikaları, ulusal koşullara uygun bir şekilde çoklu politik hedeflere yönelik olarak belirlenmektedir. Özellikle son dönemlerde ülkeler, Kyoto Protokolü çerçevesinde enerji politikalarının şekillendirilmesine, enerji yatırımları ve enerji erişimini arttırarak, mevcut enerji kaynaklarının kullanımında etkinliğinin sağlanmasına odaklanmaktadırlar. Enerjinin etkin kullanımı hususunda artan farkındalık, enerji etkinliğinin ölçümündeki yöntemlerin belirlenmesine yönelik olarak yapılan çalışmalarda artışı da beraberinde getirmiştir. Enerji etkinliğinin ölçümü ve bu kapsamda uygulanacak enerji politikalarının doğru tespit edilmesi de önem kazanmıştır. Son dönemlerde enerji etkinliğinin ölçümünde enerji tüketimini, fiziksel ölçütlere dayalı olarak alt sektörlerdeki tüketimleri de içerek şekilde ele alan ve gerçek enerji etkinliğinin hesaplanmasını sağlayan ayrıştırma yöntemleri kullanılmaktadır.

Özellikle ülkelerin ekonomik büyüklüklerindeki, iklim yapılarındaki, nüfus büyüklüklerindeki ve sanayi yoğunluklarındaki farklılıklar nedeniyle ortaya çıkan enerji tüketimindeki farklılıklar, enerji etkinliğinin ölçülmesinde dikkate alınması gereken bir unsur olarak düşünülmektedir. Reel üretim düzeyi, sanayi yoğunluğu ve nüfusu yüksek olan soğuk iklime sahip ülkelerin enerji tüketimleri, üretim düzeyi, sanayi yoğunluğu ve nüfusu düşük olan ülkelere göre daha yüksek olacağı kesindir. Ancak enerji tüketimi yüksek olan bu ülke guruplarının enerjiyi kısmen daha fazla tüketmesi, enerjiyi etkin kullanmadıkları anlamına gelmemektedir. Bu nedenle ülkelerin enerji etkinliklerinin ölçülmesinde, ekonomik büyüklüklerinin, sanayi yoğunluklarının, nüfus ve iklim yapılarının dikkate alınması ve buna göre gerçek enerji etkinliklerinin ortaya konulması gerekmektedir. Bu kapsamda çalışmada iklim ve nüfus yapıları birbirine benzer özellik sergileyen etkinliğinin MINT ülke grubunda yer alan Meksika, Endonezya ve Nijerya ülkeleri ile Türkiye'nin enerji etkinliklerinin 1990-2010 dönemi için 
karşılaştırılması amaçlanmıştır. Bu amaçla, söz konusu ülkelerin gerçek enerji etkinliklerinin elde edilmesinde, ülkelerin üretim büyüklükleri ve sanayi yoğunluklarının ayrıştırılmasına imkân sağlayan ve bir ayrıştırma tekniğine dayanan Logaritmik Ortalama Divisia Endeksi kullanılmıştır. Elde edilen analiz bulgularına bağlı olarak, Türkiye ve diğer MINT üyesi ülkeler ile politik olarak karşılaştırma yapılması amaçlanmıştır. Çalışmanın birinci bölümünde, enerjinin etkin kullanımının artan önemi ile ilgili genel bilgilere; ikinci bölümünde, MINT ülkelerinin ortak özellikleri ve enerji sektörleri ile ilgili çeşitli bilgilere yer verilmiştir. Çalışmanın veri ve yönteminin tanıtıldığı üçüncü bölüm sonrasında, dördüncü bölümde uygulanan Logaritmik Ortalama Divisia Endeks yönteminin bulguları özetlenmiş ve değerlendirilmiştir. Çalışmanın sonuç bölümünde ise, uygulanan yöntem ile elde edilen bulgulara bağlı olarak Türkiye'nin de içinde bulunduğu MINT ülkeleri için çeşitli değerlendirmeler ve enerji politikalarına yönelik öneriler yapılmıştır.

\section{Literatür Taraması}

MINT ekonomileri, 2013 yılında O’Neill tarafından ortaya atılan, Meksika, Endonezya, Nijerya ve Türkiye’yi kapsayan ve demografik canlılık, stratejik konumlar, istikrarlı ekonomik görünüm ve emtia faktörlerinde sahip oldukları avantajlı yönleri dolaysıyla gelecekte önemli ekonomik başarılar elde etmesi beklenen bir ülke grubunu temsil etmektedir. Ancak ağırlıklı olarak bu ülkelerin birlikte anılmasına etki eden en önemli faktörler sahip oldukları demografik yapıları ve stratejik lokasyonlarıdır (Karahan, 2014). Bir ekonomide yer alan 15-64 yaş grubu, aktif, üretken, çalışan, bağımlı olmayan nüfusu temsil etmektedir. 15-64 yaş grubunda gerekli dönüşümlerin sağlanmasının, ekonomik ve sosyal kalkınmaya hız kazandırması beklenir. 2050 yılına kadar, MINT ülkelerinde sürdürebilir kalkınma için itici bir güç oluşturabileceği düşünülen genç nüfus grubunda ciddi artışların olması ve en fazla nüfus artışının ortalama 398 milyon ile Nijerya'da gerçekleşmesi beklenmektedir. Diğer üç ülkede olduğu gibi Türkiye'de de 2050 yılına kadar yaklaşık olarak 95 milyon olması beklenen nüfusun içerisinde aktif ve üretken olarak nitelendirilen 15-64 yaş grubunun 60 milyon gibi büyük bir rakama ulaşarak Türkiye ekonomisinin dinamik, genç ve üretken bir nüfus potansiyeline sahip olması beklenmektedir. MINT grubunun diğer bir ortak özelliği ise, bulundukları jeopolitik konumlarının stratejik önemidir. Meksika'nın Amerika'ya, Endonezya'nın Çin'e, Türkiye'nin Avrupa Birliği'ne yakın oluşu ve Nijerya'nın ise Afrika'nın ekonomi merkezi olma potansiyeline sahip olması nedeniyle MINT ülkeleri coğrafi konum itibariyle avantajlı bir ülke grubudur (Durotoye, 2014).

Sürdürülebilir kalkınmanın sağlanmasıyla hızlı bir şekilde büyümeyi hedefleyen MINT ülkeleri için enerji sektörü kritik bir role sahiptir. MINT ülke grubunda en fazla enerji tüketimi artışının sanayi sektöründe, petrol ve petrol ürünlerinde olduğu görülmektedir (Nnaji vd., 2016). 1990 yılında MINT ülkelerinde 56.929 Btep olan enerji kullanımı 2014 yılında yaklaşık olarak \%100'lük bir artışla 106.565 Btep düzeylerine yükselmiştir. Bu artışın ağırlıklı payının Meksika ve Endonezya'dan kaynaklı olarak gerçekleştiği söylenilebilir. MINT ekonomileri ülke özelinde incelendiğinde, Meksika ülkesi için 2013 yılının oldukça önemli olduğu ve uygulanan enerji reformuyla sektörü yöneten yapılarda önemli değişimler olduğu, devlet tekelinde olan petrol ve doğal gaz gibi kaynakların üretiminin özel sektöre de açıldığı görülmektedir. Asıl hedefi ülke ekonomisinin petrole karşı bağımlılığını azaltmak olan enerji reformunun uygulamasına 2014 yılında yine petrol fiyatındaki değişimden kaynaklı yaşanan krize rağmen devam edilmiştir. Meksika'da, üretilen mal ve hizmet başına tüketilen birincil enerji miktarını temsil eden enerji yoğunluğu 2000 yılından beri OECD ülke ortalamasının üzerindedir (IEA, 2016). Endonezya'da ise, son dönemlerde enerji üretimi ve tüketimi arasındaki farkın iyice arttığı görülmektedir. 2015 yılında yerli enerji tüketimi son 15 yıla göre iki katına yükselirken, toplam enerji üretiminde $\% 10,6$ düzeylerine düşüş yaşanmıştır. Petrol üretiminde ise son yıllarda görülen düşüş, 1969 yılı sonrasındaki en kritik noktadadır. Endonezya'nın 2015 yılında sahip olduğu enerji yoğunluğu ise, 10 yıllık ortalamasını koruyarak yaklaşık olarak \%0,9 oranında gerilemiştir (BP, 2016). Petrol ve doğal kaynak rezervi bakımından zengin olan Nijerya ekonomisi ise, GSYİH içerisinde tarım ekonomisinin payı yüksek olan bir ülkedir. Sanayi sektörü çok fazla gelişmeyen ülke, 1970'li yıllarla birlikte ham petrolün etkisi altına girerek diğer enerji kaynaklarıyla ilgili alanları ihmal etmiş ve geri kalmışlık sorunuyla karşı karşıya kalmıştır. Türkiye ise enerji yoğun bir ülke olarak enerjide yerli kaynakları sahip olmadığından ithalata bağımlı bir ülkedir. Türkiye'de kullanılan enerji kaynaklarının \%73'ü birincil enerji kaynağından oluşmaktadır. Bu durum enerji yoğunluğunun OECD ülke grubu ortalamasına göre yaklaşık olarak \%10 daha yüksek düzeylere ulaşmasına neden olmaktadır. MINT grubunda yer alan ülkelerde enerji yoğunluğunun yüksek değerlere sahip olması dolayısıyla, çalışmanın devamında MINT ülkelerindeki enerji tüketiminde oluşan artışın, milli gelirdeki ve sanayi yoğunluğundaki artıştan yaşanan değişimden arındırılarak gerçek enerji etkinliğini gösteren yoğunluk etkisinin ortaya konulması hedeflenmektedir.

\section{Veri Seti ve Yöntem}

Bu çalışmada, MINT ülkelerinin 1990-2014 yılları için sanayi sektöründeki gerçek enerji etkinliğinin ortaya koyulması amaçlanmıştır. Gerçek enerji etkinliğinin ölçülmesi amacıyla yapılan analizde, ülkelerin enerji, tüketimleri, reel GSYH ve sanayi sektörünün GSYH içerisindeki payını gösteren değişkenlerden faydalanılmıştır. Kullanılan değişkenlerden, 2010 yılı sabit fiyatlarıyla ABD doları cinsinden (\$) olan Reel GSYH ile sanayi sektörünün GSYH'deki payı değişkenleri Dünya Bankası (WB) veri tabanından, toplam enerji tüketimleri ise Btep (bin ton petrol eşdeğeri) cinsinden, Uluslararası Enerji Ajansı (IEA)'ndan elde edilmiştir. 
Çalışmada, özellikle enerji ve çevre alanlarında kullanılan, enerji tüketimi ve yoğunluğunda oluşan değişikliklere çeşitli faktörlerin göreli katkılarını değerlendirmeye imkân sağlayan (Wang, vd. 2010) "Ayrıştırma Analizi" (Decomposition Analysis) kullanılmışırı. Kullanılan ayrıştırma analizi ile ekonomik, çevresel, istihdam ve diğer sosyo-ekonomik göstergelerdeki değişikliklerin ve bu değişikliklerin altında yatan temel itici güçlerin analizi gerçekleştirerek MINT ülkelerinin sanayi sektöründeki gerçek enerji etkinliğinin ölçülmesi ve çıkan sonuçlara bağlı olarak ülkeler arasında karşılaştırma yapılması ve politika önerilerinde bulunulması amaçlanmıştır.

Ang (2004)'e göre, ayrıştırma analizi özellikle 1970'lerin sonlarında, yapısal değişimin endüstrideki enerji kullanımına etkisini incelemek amacıyla politika yapımı vb. alanlara katkı sağlaması amacıyla ortaya atılmış olan bir analizdir. Sahip olduğu esneklikler ile ayrıştırma analizi (i) enerji arz ve talebi, (ii) enerji ile ilgili emisyon değerleri (iii) doğal gaz, petrol ve kömür gibi kaynakların kullanılan enerjideki yoğunluğu, (iv) ulusal enerji verimliliğinin trendi ve diğer ülkeler ile karşılaştırılmasına imkân sağlamaktadır (Ang, 2004).

Genel olarak, ayrıştırma analizlerini; yapısal ayrıştırma analizi- SDA (Structural Decomposition Analysis) ve endeks ayrıştırma analizi -IDA (Index Decomposition Analysis) olarak iki gruba ayırabilmek mümkündür. SDA yönteminin bir avantajı, girdi-çıktı modelinin dolaylı talep etkilerini içeriyor olması sebebiyle, doğrudan ve dolaylı enerji talepleri arasında ayrım yaparak yapısal etkileri ayrıştırmasıdır. IDA modeli ise, dolaylı talepleri içermemekte ve zaman serisi formunda bulunan veriler için kullanılmaktadır (Ma ve Stern, 2006). Bu çalışmada, dolaylı yayılmaları dikkate almadan, doğrudan enerji tüketimini gösteren IDA yöntemi kullanılarak MINT grubunda yer alan ülkelerin enerji etkinliklerinin karşılaştırılması ve çeşitli politika önerilerinin geliştirilmesi hedeflenmiştir. $n$ sayıdaki endüstri sektörünün toplam enerji talebi ile toplam üretim miktarı veri kabul edildiğinde, IDA denklemi;

$$
\Delta E_{t 0 t}=\Delta E_{p d n}+\Delta E_{\text {str }}+\Delta E_{\text {int }}
$$

şeklinde gösterilmektedir. (1) nolu denklemde yer alan $\Delta E_{t 0 t}$, başlangıç dönemi olarak kabul edilen 0 ile $\mathrm{t}$ dönemleri arasındaki toplam enerji tüketimindeki değişimi $\left(\mathrm{E}_{\mathrm{t}} \mathrm{E}_{0}\right)$ göstermektedir. $\Delta E_{t 0 t}$ değişkeni, üç farklı etkiye bağlı olarak oluşmaktadır. Bunlar, toplam sektörel üretimdeki değişim (üretim etkisini- $\Delta E_{p d n}$ ), üretim yapısındaki değişim (yapısal etki- $\Delta E_{s t r}$ ) ve sektörel enerji yoğunluğundaki değişim (yoğunluk etkisi- $\Delta E_{\text {int }}$ ) toplamı şeklinde ifade edilebilir. Ancak (1) nolu denklemde tahmin edilen üç etki tam olarak $\Delta E_{t 0 t}$ 'ye eşit olmadığından, denkleme artık etkiyi (residual effect) temsilen $\Delta E_{r s d}$ parametresi eklenir ve (1) nolu denklem;

$$
\Delta E_{t 0 t}=\Delta E_{\text {pdn }}+\Delta E_{\text {str }}+\Delta E_{\text {int }}+\Delta E_{\text {rsd }}
$$

şeklinde tekrar yazılır. (2) nolu denklemde artık etkiyi gösteren $\Delta E_{r s d}$ parametresinin büyük olması; $\Delta E_{t 0 t}$ parametresinin içerdiği enerji tüketiminde üretim etkisi, yapısal etki ve yoğunluk etkisi tarafından açıklanamayan bölümü gösterdiğinden istenmeyen bir durumu temsil etmektedir (Ang, 1998).

Toplam enerji tüketimindeki değişimler üzerindeki üretim etkisi, yapısal etki ve yoğunluk etkilerinin ayrıştırılarak gerçek enerji etkinliğinin hesaplanması amacıyla Laspeyers Endeksi ve Divisia Endeksi olmak üzere iki farklı yöntem kullanılmaktadır. 1970'li yılların sonu ile 1980'li yılların başından kullanılan, kalıntı değerlerinin çok büyük hesaplandığı ve sıfir değerlerinin yer aldığı veri setinde uygulanamayan Laspeyers yöntemi, baz yıldaki ağırlıklara dayalı olarak, bir gruptaki öğelerin yüzdelik değişimini ölçmektedir. Bu çalışmada Ang, vd. (1998)'te ifade edildiği gibi, daha kolay uygulama esnekliği ile daha küçük bir artık etki hesaplayan, sıfir değerini içeren veri seti kullanılabilen aritmetik ortalama ağırlık fonksiyonuna dayalı Divisia endeks yöntemine bağlı Logaritmik Ortalama Divisia Endeks (Logarithmic Mean Divisia Index-LMDI) yöntemi kullanılmıştır (Ang, 1998). LMDI modeli, küresel ekonomik faaliyetlerde, ekonomik sektörün yapısı, enerji yoğunluğu ve verimliliğinden kaynaklı enerji tüketiminde yaşanan değişimlerin ayrıştırılmasını sağlamaktadır. LMDI yöntemi aşağıdaki gibi hesaplanmaktadır:

$$
\begin{aligned}
& \Delta E_{p d n}=\sum_{i=1}^{k} L\left(E_{i, t}, E_{i, 0}\right) \ln \left(Y_{t} / Y_{0}\right) \\
& \Delta E_{\text {str }}=\sum_{i=1}^{k} L\left(E_{i, t}, E_{i, 0}\right) \ln \left(S_{i, t} / S_{i, 0}\right) \\
& \Delta E_{\text {int }}=\sum_{i=1}^{k} L\left(E_{i, t}, E_{i, 0}\right) \ln \left(I_{i, t} / I_{i, 0}\right)
\end{aligned}
$$

Denklemlerde yer alan $E_{i, t}$ i.sektörün $\mathrm{t}$ dönemindeki enerji talebini, $E_{i, 0}$ i.sektörün başlangıç dönemindeki enerji talebini ifade etmektedir. Enerji tüketiminde üretim etkisinden kaynaklanan değişimi hesaplamak amacıyla oluşturulan (3) nolu denklemde $Y_{t}$ ve $Y$ sırasıyla t dönemindeki ve başlangıç dönemindeki üretimin toplam katma değerinin göstermektedir. (4) nolu denklemde ise; $S_{i, t}\left(=Y_{i, t} / Y_{t}\right)$ ve $S_{i, 0}\left(=Y_{i, 0} / Y_{0}\right)$ sirasiyla i. sektörün $\mathrm{t}$ ve başlangıç dönemindeki sektörel üretim payını, (5) nolu denklemde yer alan $I_{i, t}\left(=E_{i, t} / Y_{i, t}\right)$ ve $I_{i, 0}\left(=E_{i, 0} / Y_{i, 0}\right)$ sırasıyla i. sektörün t ve başlangı̨̧ dönemindeki enerji yoğunluğunu ifade etmektedir. (3), (4) ve (5) nolu denklemlerde yer alan $L\left(E_{i, t}, E_{i, 0}\right)$ katsayısı ise, logaritmik ortalamaya göre hesaplanan ağırlık fonksiyonlarını göstermekte ve aşağıdaki gibi hesaplanmaktadır.

$$
L\left(E_{i, t}, E_{i, 0}\right)=\left(E_{i, t}, E_{i, 0}\right) / \ln \left(E_{i, t}, E_{i, 0}\right)
$$


Ayrıştırma analizinden elde edilen üretim etkisi $\left(\Delta E_{p d n}\right)$, ekonomide meydana gelen üretim dönüşümleri karşısında kullanılan enerji miktarında oluşan değişimleri göstermektedir. Yapısal etki $\left(\Delta E_{s t r}\right)$, ele alınan sektörde üretim kompozisyonlarında yaşanan değişimler (emek-yoğun teknolojilerden sermaye-yoğun teknolojilere geçiş) sonucu aynı sektörde kullanılan enerji miktarında meydana gelen değişimleri temsil ederken, yoğunluk etkisi $\left(\Delta E_{\text {int }}\right)$ ise alt sektörlerde enerji etkinliğine bağlı olarak enerji kullanımındaki değişikliği göstermektedir. Gerçek enerji yoğunluğu, daha verimli üretim teknolojilerinin ve enerji yönetimi tekniklerinin benimsenmesinin, alt sektörler içindeki ürün karışımındaki ve ürün değerindeki değişikliklerin yanı sıra, malzeme ve yakıt girişlerinin kalitesinde ve karışımındaki değişiklikler sonucunda negatif veya pozitif yönlü bir seyir izleyebilir. Yoğunluk etkisi enerjinin etkin kullanımını temsil eder ve teknolojik değişiklikler içeren değişimler ile enerjinin etkin kullanımı ile azalan bir seyir izlemektedir (Zhang, 2003).

\section{Ampirik Bulgular ve Değerlendirme}

Bu çalışmada, Meksika, Endonezya, Nijerya ve Türkiye'den oluşan ve MINT grubu olarak ifade edilen ülkelerde sanayi sektörü enerji kullanımında etkinliğin hangi derecede sağlandığını tespit etmek için Logaritmik Ortalama Divisia Endeks Analiz yöntemi kullanılarak homojen bir karşılaştırma yapılması hedeflenmektedir. Bu doğrultuda, Meksika üzerine uygulanan LMDI yöntemi sonuçları Tablo 1'de gösterilmektedir.

\begin{tabular}{ccccc}
\hline Yıllar & Çıtı Etkisi & Yapısal Etki & Yoğunluk Etkisi & Toplam Etki \\
\hline $\mathbf{1 9 9 1}$ & 1065.399 & -352.214 & -689.186 & 24 \\
$\mathbf{1 9 9 2}$ & 912.1253 & 60.85628 & -1339.98 & -367 \\
$\mathbf{1 9 9 3}$ & 997.122 & 3148.075 & -4863.2 & -718 \\
$\mathbf{1 9 9 4}$ & 1151.164 & -689.764 & 6.600599 & 468 \\
$\mathbf{1 9 9 5}$ & -1496.39 & 1174.664 & 466.7312 & 145 \\
$\mathbf{1 9 9 6}$ & 1482.469 & 1716.275 & -1853.74 & 1345 \\
$\mathbf{1 9 9 7}$ & 1816.413 & -92.2355 & -1045.18 & 679 \\
$\mathbf{1 9 9 8}$ & 1273.62 & -622.679 & 140.0587 & 791 \\
$\mathbf{1 9 9 9}$ & 727.5646 & 212.1816 & -1883.75 & -944 \\
$\mathbf{2 0 0 0}$ & 1419.662 & 634.8403 & -1382.5 & 672 \\
$\mathbf{2 0 0 1}$ & -161.683 & -1437.98 & -810.339 & -2410 \\
$\mathbf{2 0 0 2}$ & 34.30684 & -117.668 & 1269.361 & 1186 \\
$\mathbf{2 0 0 3}$ & 384.676 & 683.9305 & 160.3935 & 1229 \\
$\mathbf{2 0 0 4}$ & 1206.545 & 1384.09 & -901.635 & 1689 \\
$\mathbf{2 0 0 5}$ & 901.6245 & -176.217 & 565.592 & 1291 \\
$\mathbf{2 0 0 6}$ & 1545.754 & 1124.149 & -241.903 & 2428 \\
$\mathbf{2 0 0 7}$ & 1035.338 & -298.038 & -1594.3 & -857 \\
$\mathbf{2 0 0 8}$ & 458.2077 & 413.5048 & 234.2875 & 1106 \\
$\mathbf{2 0 0 9}$ & -1500.06 & -1994.13 & -1091.82 & -4586 \\
$\mathbf{2 0 1 0}$ & 1535.125 & 707.5633 & 1598.312 & 3841 \\
$\mathbf{2 0 1 1}$ & 1352.265 & 1180.588 & 190.1467 & 2723 \\
$\mathbf{2 0 1 2}$ & 1390.745 & 27.38914 & -1783.13 & -365 \\
$\mathbf{2 0 1 3}$ & 480.7479 & -1957.68 & 2414.932 & 938 \\
$\mathbf{2 0 1 4}$ & 770.1333 & -84.7467 & -3399.39 & -2714 \\
\hline Nihai Etki & $\mathbf{1 8 7 8 2 . 8 7}$ & $\mathbf{4 6 4 4 . 7 6 1}$ & $\mathbf{- 1 5 8 3 3 . 6}$ & $\mathbf{7 5 9 4}$ \\
\hline
\end{tabular}

Tablo 1. Meksika Ekonomisinde Gerçek Enerji Etkinliğine İlişkin LMDI Sonuçlarl

Meksika için yapılan sanayi sektörü ayrıştırma analizi sonuçlarının gösterildiği Tablo 1'e göre, 1990-2014 yılları arasında kullanılan enerjide 7594 Btep'lik bir artış meydana geldiği görülmektedir. Enerji tüketiminde meydana gelen artışın 18782.87 Btep'lik kısmı çıktı etkisinden, 4644.761 Btep'lik kısmı, yapısal etkiden ve -15833.6 Btep'lik kısmı ise yoğunluk etkisinden kaynaklı olarak gerçekleşmiştir. Üzerinde çalışılan sektördeki yapısal etkinin pozitif yönlü bir değer alması, enerji kullanımına etki edecek yapısal dönüşümün enerji tasarrufu sağlamaya yönelik olarak gerçekleşmemesi ve üretim yapısının genel anlamda makine, petrokimya, otomotiv gibi ağır sanayi ürünleri üretilmesine bağlanabilir. 2013 yılı sonrası yapısal etkide oluşan negatif yönlü değişim ise, 2013 yılında uygulanan Enerji reformuna bağlı olarak, devlet tekelinde yer alan petrol arama çıkarma faaliyetlerinin özel sektöre açı hale gelmesiyle oluşan yapısal dönüşümle ilişkilendirilebilir. Meksika ekonomisinin büyüme hızına bağlı olarak kullanılan enerji miktarındaki değişimleri gösteren 18782.87 Btep'lik çıktı etkisinin 1994, 2000 ve 2008 yıllarında negatif değerler aldığı görülmüştür. 1994 yılında oluşan negatif yönlü çıktı etkisini, siyasal değişimlerden kaynaklı Aralık 1994'te Meksika'da patlak veren ve ulusal paranın değer kaybetmesi ile oluşan finansal krize bağlamak mümkündür. 2000 yılında oluşan negatif yönlü çıtı etkisi, oldukça sancılı bir şekilde gerçekleşen ve 6 yılda bir tekrarlanan başkanlık seçiminden kaynaklı olarak yaşanan ekonomik 
konjonktürel dalgalanmalara, 2008 yılında oluşan negatif yönlü çıktı etkisi ise tüm dünya ülkelerindeki iç ve dış talebin daralmasına neden olan küresel krizle ilişkilendirilebilir.

Bir ülke veya sektörde kullanılan enerjinin gerçek etkinliğini yansıtması bakımından hesaplanan yoğunluk etkisine göre, 1990-2014 dönemi arasında tüketilen enerji miktarında-15833.6 Btep'lik bir azalış meydana gelmiş̧ir. Yoğunluk etkisinin 2000-2014 yılları arasında azalması Meksika'da 25 yıldır üzerinde çalışılan enerji verimliliğ̈inin arttırılmasına yönelik, özellikle 2012 yılı sonrası yeni yönetim tarafından uygulanmaya konulan kapsamlı enerji reformlarına bağlı olarak belirlenen katı standartlar ve programlarla ilgilidir. Özellikle Meksika'nın inşaat malzemeleri, ekipman, havalandırma, yalıtım gibi bölümlerde belirlediği standartlar enerjinin etkin kullanımında oldukça etkili olmuştur. Ayrıca elde edilen bu sonuç, enerji verimliliğine yönelik olarak kurulan, FIDE ve CONUEE gibi birimlerin enerji etkinliğinde oldukça etkili olmasına, ülkenin rüzgâr ve güneş enerjisi gibi yenilenebilir enerji kaynaklarını kullanma ve jeotermal kaynaklardan elektrik üretme potansiyeline sahip olmasına bağlanabilir.

MINT grubunda yer alan diğer bir ülke Endonezya'nın enerji etkinliğine ilişkin ayrıştırma analizi sonuçları Tablo 2'de gösterilmektedir.

\begin{tabular}{ccccc}
\hline Yıllar & Çıtı Etkisi & Yapısal Etki & Yoğunluk Etkisi & Toplam Etki \\
\hline $\mathbf{1 9 9 1}$ & 1564.381 & 942.611 & -2224.99 & 282 \\
$\mathbf{1 9 9 2}$ & 1315.916 & -571.312 & 142.3961 & 887 \\
$\mathbf{1 9 9 3}$ & 1398.564 & -1640.67 & 1554.102 & 1312 \\
$\mathbf{1 9 9 4}$ & 1589.684 & 523.6197 & 403.6967 & 2517 \\
$\mathbf{1 9 9 5}$ & 1995.607 & 695.8627 & 582.5307 & 3274 \\
$\mathbf{1 9 9 6}$ & 1958.863 & 1032.615 & -2645.48 & 346 \\
$\mathbf{1 9 9 7}$ & 1271.788 & 550.9962 & 38.21582 & 1861 \\
$\mathbf{1 9 9 8}$ & -3928.11 & 560.6088 & 1944.506 & -1423 \\
$\mathbf{1 9 9 9}$ & 235.2319 & -1259.18 & 6473.951 & 5450 \\
$\mathbf{2 0 0 0}$ & 1506.944 & 1803.464 & -5842.41 & -2532 \\
$\mathbf{2 0 0 1}$ & 1098.787 & 351.9433 & -289.73 & 1161 \\
$\mathbf{2 0 0 2}$ & 1344.457 & -1338.75 & -1474.71 & -1469 \\
$\mathbf{2 0 0 3}$ & 1473.138 & -510.244 & 2559.106 & 3522 \\
$\mathbf{2 0 0 4}$ & 1690.677 & 684.4497 & -144.127 & 2231 \\
$\mathbf{2 0 0 5}$ & 1966.266 & 1490.992 & -3571.26 & -114 \\
$\mathbf{2 0 0 6}$ & 2123.995 & 341.5498 & 6266.455 & 8732 \\
$\mathbf{2 0 0 7}$ & 2646.283 & -132.538 & -4840.74 & -2327 \\
$\mathbf{2 0 0 8}$ & 2399.564 & 1093.022 & -5029.59 & -1537 \\
$\mathbf{2 0 0 9}$ & 1845.731 & -348.289 & -565.441 & 932 \\
$\mathbf{2 0 1 0}$ & 2484.54 & -4442.21 & 1740.666 & -217 \\
$\mathbf{2 0 1 1}$ & 2354.624 & 1032.238 & -6761.86 & -3375 \\
$\mathbf{2 0 1 2}$ & 2163.476 & -269.967 & -3317.51 & -1424 \\
$\mathbf{2 0 1 3}$ & 1977.616 & -812.58 & -515.036 & 650 \\
$\mathbf{2 0 1 4}$ & 1868.962 & -666.063 & 1297.101 & 2500 \\
\hline Nihai Etki & $\mathbf{3 6 3 4 6 . 9 7}$ & $\mathbf{- 8 8 7 . 8 2}$ & $\mathbf{- 1 4 2 2 0 . 1 5}$ & $\mathbf{2 1 2 3 9}$ \\
\hline
\end{tabular}

Tablo 2. Endonezya Ekonomisinde Gerçek Enerji Etkinliğine İlişkin LMDI Sonuçları

Endonezya ekonomisine ait ayrıştırma analizi sonuçlarına göre, 1990-2014 yılları arasında tüketilen enerji miktarında 21.239 Btep'lik bir artı̧ sağlanmıştır. Artan bu enerji tüketiminin 36346.97 Btep'lik bölümü çıktı etkisinden, -887.82 Btep'lik bölümü yapısal etkiden,-14220.15 Btep'lik bölümü ise yoğunluk etkisinden kaynaklı olarak gerçekleşmiştir. 1990-2014 yılları arasında üretim miktarındaki değiş̧imleri gösteren çıktı etkisinin 1998 yılında negatif bir değer alması, 1997 yllında Tayland'da başlayan Doğu Asya Mali krizinden en çok etkilenen ülkelerde birinin Endonezya olması nedeniyle oluşan daralmaya bağlanabilir. Ele alınan sektörün, ülke ekonomisine ait yapısal faktörlere bağlı olarak kullandığı enerji miktarında meydana gelen değişimleri gösteren yapısal etkinin -887.82 Btep'lik bir değer alması enerji tasarrufuna yönelik yapısal dönüşümün gerçekleştiğini göstermektedir. Bu durum özellikle 2005 yılına kadar tarım sektörünün sanayi sektörüne oranla GSYH'deki yüksek payına ve 1997 yılı sonrası imalat sanayisinde yüksek teknolojili ürünlerin ihracatının belirli ölçüde artmasına bağlanabilir. Endonezya'da gerçek enerji etkinliğini gösteren yoğunluk endeksinin -14220.15 Btep'lik bir değer alması enerji etkinliğinin arttığını enerji tasarrufuna yönelik olarak hükümet ve özel sektör tabanlı düzenlemelerin olduğunu, Endonezya'nın enerji tasarrufunun sağlanmasına yönelik bir dönüşüm sürecinden geçtiğini göstermektedir. Bu durum, ayrıca 1990 yılından itibaren birincil enerji kullanımı ve özellikle elektrik tüketiminde \%7'nin üzerinde oluşan azalmalara ve ülkenin güneş, rüzgar, hidroelektrik santralleri gibi enerji kaynaklarında potansiyele sahip olmasına bağlanabilir.

MINT üyesi ülkelerden Nijerya'nın enerji etkinliğine ilişkin ayrıştırma analizi sonuçları Tablo 3 ’te gösterilmektedir. 


\begin{tabular}{ccccc}
\hline Yllar & Çıtı Etkisi & Yapısal Etki & Yoğunluk Etkisi & Toplam Etki \\
\hline $\mathbf{1 9 9 1}$ & -13.2752 & 22.91080157 & 22.36436 & 32 \\
$\mathbf{1 9 9 2}$ & 10.0202 & 340.1030002 & -28.1232 & 322 \\
$\mathbf{1 9 9 3}$ & 51.26558 & -536.080923 & 480.8153 & -4 \\
$\mathbf{1 9 9 4}$ & 22.14195 & -639.791063 & 555.6491 & -62 \\
$\mathbf{1 9 9 5}$ & -7.43835 & 813.4721438 & -803.034 & 3 \\
$\mathbf{1 9 9 6}$ & 123.7959 & 134.4510887 & -7.24697 & 251 \\
$\mathbf{1 9 9 7}$ & 73.50066 & -251.580942 & 161.0803 & -17 \\
$\mathbf{1 9 9 8}$ & 73.02258 & -746.728457 & 823.7059 & 150 \\
$\mathbf{1 9 9 9}$ & 13.7774 & 350.9733636 & -139.751 & 225 \\
$\mathbf{2 0 0 0}$ & 162.02 & 1004.810946 & -962.831 & 204 \\
$\mathbf{2 0 0 1}$ & 141.358 & -801.491887 & 750.1339 & 90 \\
$\mathbf{2 0 0 2}$ & 128.6061 & -1011.32227 & 1170.716 & 288 \\
$\mathbf{2 0 0 3}$ & 459.3379 & 866.3523386 & 970.3098 & 2296 \\
$\mathbf{2 0 0 4}$ & 1658.491 & 774.0835101 & -2825.57 & -393 \\
$\mathbf{2 0 0 5}$ & 187.3664 & 183.2098522 & -327.576 & 43 \\
$\mathbf{2 0 0 6}$ & 452.5289 & -213.631869 & 126.103 & 365 \\
$\mathbf{2 0 0 7}$ & 413.6276 & -191.853442 & 477.2258 & 699 \\
$\mathbf{2 0 0 8}$ & 417.6138 & 138.8900214 & -52.5038 & 504 \\
$\mathbf{2 0 0 9}$ & 454.6682 & -1308.14251 & 183.4743 & -670 \\
$\mathbf{2 0 1 0}$ & 510.7797 & -2036.20574 & 2166.426 & 641 \\
$\mathbf{2 0 1 1}$ & 399.9337 & 947.3496832 & 1376.717 & 2724 \\
$\mathbf{2 0 1 2}$ & 418.2531 & -370.682126 & 283.429 & 331 \\
$\mathbf{2 0 1 3}$ & 526.9995 & -480.086702 & -280.913 & -234 \\
$\mathbf{2 0 1 4}$ & 523.7132 & -366.369338 & -2737.34 & -2580 \\
\hline Nihai Etki & $\mathbf{7 2 0 2 . 1 0 7}$ & $\mathbf{- 3 3 7 7 . 3 6 0}$ & $\mathbf{1 3 8 3 . 2 5 2}$ & $\mathbf{5 2 0 8}$ \\
\hline
\end{tabular}

Tablo 3. Nijerya Ekonomisinde Gerçek Enerji Etkinliğine İlişkin LMDI Sonuçları

Tablo 3'de Nijerya ekonomisinde talep edilen enerji miktarındaki ayrıştırma analizi sonuçları gösterilmektedir. Elde edilen sonuçlara göre, 1990-2014 yılları arasında tüketilen enerji miktarında 5208 Btep'lik artış yaşanmıştır. Enerji kullanımında oluşan bu artışın, 7202.107 Btep'lik kısmı çıktı etkisinden, -3377.360 Btep'lik kısmı yapısal etkiden ve 1383.25 Btep'lik kısmı ise yoğunluk etkisinden kaynaklanmıştır. Çıktı etkisinin 1991 ve 1995 yıllarında negatif yönlü olmasında, 1990 ve 1995 yıllarında milli gelir düzeyinde yaşanan daralmanın etkisi olduğu tahmin edilmektedir. Yapısal etki sonuçlarına göre, 1990-2014 yılları arasında Nijerya'da enerjinin tasarruflu kullanıldığ görülmektedir. Oluşan enerji tasarrufunun önemli bir kısmının, ülkede ağır sanayi sektörünün gelişememesi ve endüstrideki üretimin \%60'ının tekstil, içecek, sigara ve sabun gibi küçük çaplı işletme tesislerden oluşması kaynaklı olabileceği düşünülmektedir. Sanayi sektörü enerji kullanımında enerjinin gerçek anlamda etkinliğini gösteren yoğunluk etkisi sonuçlarına göre ise 1990-2014 yılları arasında Nijerya'da enerjinin etkin kullanılmadığını görülmektedir. Nijerya ekonomisinde enerjinin etkin kullanılmaması, sanayi sektöründeki fon yetersizliği, petrol tesislerine yönelik sabotajlar ve yönetim zayıflı̆̆ı dolayısıyla etkin faaliyetlerin gerçekleşememesine, özellikle dağıtım ağlarındaki sorunlardan kaynaklı yaşanan elektrik kayıplarına ve potansiyeli olan yenilenebilir enerji kaynaklarının aktif hale getirilmesindeki teknik yetersizliklere bağlanabilir.

Türkiye ekonomisinde tüketilen enerji miktarındaki gerçek etkinliği ortaya koymak için yapılan ayrıştırma analizi sonuçları Tablo 4'te gösterilmektedir. 


\begin{tabular}{ccccc}
\hline Yllar & Çıtı Etkisi & Yapısal Etkisi & Yoğunluk Etkisi & Toplam etki \\
\hline $\mathbf{1 9 9 1}$ & 79.723143 & 183.5874185 & 155.6894381 & 419 \\
$\mathbf{1 9 9 2}$ & 556.24404 & -107.1776279 & -443.0664103 & 6 \\
$\mathbf{1 9 9 3}$ & 849.90745 & -467.6244303 & 25.71697923 & 408 \\
$\mathbf{1 9 9 4}$ & -543.3229 & 760.3024542 & -944.9795796 & -728 \\
$\mathbf{1 9 9 5}$ & 881.16417 & -4.327092691 & 375.1629247 & 1252 \\
$\mathbf{1 9 9 6}$ & 957.38003 & -679.4219883 & 2175.041963 & 2453 \\
$\mathbf{1 9 9 7}$ & 1117.998 & 122.8185655 & -32.81656134 & 1208 \\
$\mathbf{1 9 9 8}$ & 370.52201 & 1687.896018 & -1416.418025 & 642 \\
$\mathbf{1 9 9 9}$ & -543.988 & -1017.876002 & 241.8639879 & -1320 \\
$\mathbf{2 0 0 0}$ & 1140.1214 & -981.3388419 & 4342.217457 & 4501 \\
$\mathbf{2 0 0 1}$ & -1026.928 & -671.7933232 & -2596.278828 & -4295 \\
$\mathbf{2 0 0 2}$ & 1019.218 & -886.0574089 & 3160.839391 & 3294 \\
$\mathbf{2 0 0 3}$ & 1022.0004 & -37.55773868 & 1417.557355 & 2402 \\
$\mathbf{2 0 0 4}$ & 1901.1594 & -90.35931895 & -1610.800065 & 200 \\
$\mathbf{2 0 0 5}$ & 1717.117 & 11.03070745 & -1842.147745 & -114 \\
$\mathbf{2 0 0 6}$ & 1487.3694 & -214.8026314 & 931.4332178 & 2204 \\
$\mathbf{2 0 0 7}$ & 1074.5488 & -374.7299518 & -463.8188428 & 236 \\
$\mathbf{2 0 0 8}$ & 136.08321 & -425.515278 & -5345.56793 & -5635 \\
$\mathbf{2 0 0 9}$ & -909.4202 & -1354.890227 & 2975.310446 & 711 \\
$\mathbf{2 0 1 0}$ & 1811.0509 & 913.6275828 & 1255.321521 & 3980 \\
$\mathbf{2 0 1 1}$ & 2011.7629 & 959.0833127 & -529.8462384 & 2441 \\
$\mathbf{2 0 1 2}$ & 536.05068 & -756.4431612 & 820.3924834 & 600 \\
$\mathbf{2 0 1 3}$ & 1026.6613 & -55.38234353 & -2490.278992 & -1519 \\
$\mathbf{2 0 1 4}$ & 739.84393 & 455.3138889 & 53.84218039 & 1249 \\
\hline Nihai Etki & $\mathbf{1 7 4 1 2 . 2 6 7}$ & $\mathbf{- 3 0 3 1 . 6 3 7 4}$ & $\mathbf{2 1 4 . 3 7 0 1 2 7}$ & $\mathbf{1 4 5 9 5}$ \\
\hline
\end{tabular}

Tablo 4. Türkiye Ekonomisinde Gerçek Enerji Etkinliğine İlişkin LMDI Sonuçları

Tablo 4'te verilen analiz sonuçlarına göre, 1990-2014 dönemi arasında Türkiye ekonomisindeki enerji tüketiminde 14595 Btep'lik artış olduğu görülmektedir. Enerji miktarında oluşan değişimin, 17412.267 Btep'lik kısmı çıktı etkisinden, -3031.6374 Btep'lik kısmı yapısal etkiden, 214.370127 Btep'lik kısmı ise yoğunluk etkisinden kaynaklanmıştır. Sanayi sektörünün GSYH içerisindeki payı ve sanayi alt sektörlerinde meydana gelen değişimlerin kullanılan enerji üzerindeki etkisini gösteren yapısal etki, enerji kullanımında -3031.63 Btep'lik tasarruf sağladığını göstermektedir. Bu durum özellikle sanayi sektörünün GSYH'deki payının 2002 yılı sonrasında giderek azalmasına, hizmetler sektörünün GSYH içeresindeki payındaki artışa, Ar-Ge harcamalarındaki artış dolayısıyla enerji tüketimindeki azalmaya bağlanabilir. Çıktı etkisinin 1994, 1999 ve 2009 yıllarında negatif değerler aldığı görülmektedir. 1994 yılında oluşan negatif yönlü çıktı etkisi, aynı yıl Türkiye ekonomisinde yaşanan finansal krize, 1999 yılında yaşanan negatif yönlü çıktı etkisi ise, ekonomide 2000 yılında yaşanacak olan finansal krize hazırlık evresinde olan piyasalardaki daralma ve belirsizliğe, 2008 yılındaki negatif yönlü çıktı etkisi ise Türkiye de dahil olmak üzere tüm dünya ülkelerini etkileyen küresel ekonomik krize bağlanabilir.

İncelenen sektörde enerji girdisinin etkinliğinin homojen bir göstergesi olan yoğunluk etkisi ise, 1990-2014 yılları arasında ele alınan sanayi sektörü enerji kullanımında 214.370 Btep'lik artış yaşandığını ve enerjinin etkin kullanılmadığını göstermektedir. Türkiye enerji yoğun kullanan bir ülkedir ve enerji yoğunluğunu en fazla etkileyen sektör kullanılan enerji miktarına bağlı olarak sanayi sektörüdür. Sanayi sektöründe sağlanacak enerji etkinliği, enerji yoğunluğunun ciddi oranda azaltılmasına ve gerekli yapısal dönüşümlerin gerçekleştirilmesine bağlıdır. Türkiye'deki sanayi sektöründe demir çelik, çimento, seramik ve cam gibi enerji yoğun alt sektörler hakimdir (TMMOB, 2012) ve sanayi sektörü 3.0 milyar ABD\$ civarında bir enerji tasarruf potansiyeline sahiptir. Türkiye için yapılan analiz sonucunda enerjinin etkin kullanılmadığının görülmesi, sanayi alt sektörlerinde istenilen enerji tasarrufu potansiyelinin sağlanmadığının da önemli bir göstergesidir.

\section{Sonuç}

Yapılan çalışmada, son dönemlerde politika yapıcıları tarafından özellikle vurgulanan enerji etkinliği, MINT ülkeleri açısından araştırılmıştır. Bu doğrultuda, gerçek enerji etkinliğinin tespiti amacıyla enerji kullanımında oluşan artışı yapısal etki ve üretim etkisinden arındırarak yoğunluk etkisinin hesaplanması amaçlanarak MINT ülke grubu verileri üzerine, ayrıştırma yöntemlerinden biri olan Logaritmik Ortalama Divisia Endeks yöntemi uygulanmıştır. Elde edilen sonuçlar, 1990-2014 yılları arasında MINT ülkelerinde toplam enerji tüketiminde artış yaşandığını, sanayi sektörü enerji kullanımında oluşan artışın, Meksika'da 18782.87 Btep, Endenozya'da 36346.97 Btep, Nijerya'da 7202.107 Btep ve Türkiye'de 17412.267 Btep ile çıktı etkisinin baskınlığından kaynaklı olarak ortaya çıktığını göstermektedir. Bu durum sektörel enerji tüketimindeki artışın büyüme tabanlı bir yükseliş 
olduğunu ve üretimde enerjinin belirleyici bir unsur teşkil ettiğini ifade etmektedir. Yapılan analiz yapısal etki sonuçları bakımından incelendiğinde ise, 4644.761 Btep'lik yapısal etkiye sahip Meksika haricinde diğer ülkelerin sahip oldukları negatif yönlü nihai yapısal etki enerji tasarrufu sağlanması, yapısal dönüşümün gerçekleştirilmesine yönelik uygulanan ve benzer amaçlara hizmet eden çeşitli program ve planlamaların başarılı sonuçlar elde ettiğini ifade etmektedir. Bu ülkelerde ekonominin tamamını etkileyecek yeterlilikte olmasa da yüksek teknolojili ürünlerin üretimi ile Ar-Ge harcamalarının artış göstermesi enerji tasarrufunu etkilemektedir. Ayrıca, gerçek enerji etkinliğini gösteren yoğunluk etkisi sonuçları, Meksika, Endonezya, Nijerya ve Türkiye'de sirasiyla, -15833.6, -14220.15, 1383.252, ve 214.370127 Btep olarak tahmin edilmiştir. Elde edilen sonuçlar, Meksika ve Endonezya'da enerji yoğunluğunun daha düşük olduğunu, diğer bir ifadeyle enerjinin etkin kullanıldığını, Nijerya ve Türkiye'de ise enerjinin etkin kullanılmadığını göstermektedir. Nijerya ve Türkiye arasında karşılaştırma yapıldığında ise, Türkiye'nin Nijerya'ya göre enerjiyi daha etkin kullandığı görülmektedir. Elde edilen sonuçlar, Meksika ve Endonezya'nın enerji verimliliği odaklı olarak uyguladığı enerji reformların enerji etkinliği açısından olumlu sonuçlar elde edilmesini sağladığını göstermektedir. MINT ülke grubunda yer alan diğer ülkeler ile Türkiye'nin enerji etkinliğinin karşılaştırılması üzerine yapılan bu çalışmada elde edilen sonuçlar, Türkiye'nin enerji etkinliği açısından Meksika ve Endonezya'nın gerisinde kaldığını göstermektedir. Uygulanan analiz sonucunda Türkiye üzerine elde edilen bulgular, Türkiye ekonomisindeki enerji etkinliğini Avrupa Birliğinde yer alan Almanya, İtalya ve Bulgaristan ekonomileri ile karşılaştıran Tanrı̈ver ve Biçer (2016b) çalışmasında elde edilen sonuçlar ile uyumludur. Tanrı̈ver ve Biçer (2016b) çalışmasında da, Türkiye ekonomisinin enerji etkinliği bakımından diğer üç ülkenin gerisinde kaldığı sonucuna ulaşılmıştır.

Türkiye ve Nijerya'nın enerji etkinliği üzerine elde edilen bulgular ise, enerji etkinliği üzerine uygulanacak olan politikaların standartlarının belirlenmesi ve bu standartların gelişimine politika yapıcılarının desteği ile gerçekleştirildiği reformlarla desteklenmesi gerektiği ve enerjide verimlilik adı altında uygulanacak politikaların spesifik kanun ve yönetmeliklerle tüm ülke ekonomisine yayılması gerektiğini göstermektedir. Ayrıca her iki ülke için enerji kaynaklarının etkin kullanılmasını sağlayacak gerekli örgütlenme, teşvik sistemi ve sektörel potansiyellerin gerçekleştirilmesine yönelik düzenlemelerin yapılması gerektiği açıkça ifade edilebilir. Bununla Türkiye ve Nijerya gibi ülkeler için, enerji verimliliğinin ölçülmesi ve izlenmesine yönelik kapasite kullanımının çeşitli yönetmelikler ve uygulamalar ile geliştirilmesi, enerji verimliliği uygulamalarına özel sektör desteğini sağlanması, enerji etkinliğinin temel hedeflerinin açıkça belirtilmesi ve bu amaçla özel birim ve kaynakların oluşturulmasının enerji etkinliğinin arttırılmasında kritik bir öneme sahip olduğu söylenilebilir (WB, 2011).

\section{Kaynakça}

- Allan, G., Hanley, N., McGregor, P., Swales, K., \& Turner, K. (2007). "The impact of increased efficiency in the industrial use of energy: a computable general equilibrium analysis for the United Kingdom". Energy Economics, 29(4), 779-798.

- Ang, B. W. 2004, "Decomposition analysis for policymaking in energy: which is the preferred method?" Energy Policy 32, pp. 1131-1139.

- $\quad$ Ang, B.W., Zhang, F.Q., Choi, Ki-Hong, 1998. "Factorizing Changes in Energy and Environmental Indicators Through Decomposition," Energy, 23, 489-495.

- $\quad$ Barker, T., Ekins, P., Foxon, T. 2007, "Macroeconomic effects of efficiency policies for energy intensive industries: the case of the UK Climate Change Agreements, 2000-2010". Energy Economics 29(5), 760-78

- BP, Statistical Review, 2016. “Indonesia’s Energy Market in 2015 “, bp.com/statisticalreview

- Durotoye, A. 2014. "The Crisis of Youth Unemployment in the MINT Countries: Causes, Consequences and Corrections". Crisis, 6(24).

- Glomsrød, S., Taojuan, W. 2005, “Coal cleaning: a viable strategy for reduced carbon emissions and improved environment in China?”, Energy Policy 33, 525-542.

- Hanley, N.D., McGregor, P.G., Swales, J.K., Turner, K.R., 2006, “The impact of a stimulus to energy efficiency on the economy and the environment: a regional computable general equilibrium analysis". Renewable Energy 31, 161-171

- International Energy Agency (IEA), 2016, "World Energy Outlook 2016", https://www.iea.org/media/publications/weo/WEO2016Chapter1.pdf

- Karahan, H. 2014, "Küresel ekonomi “taze” bir soluk ararken Hoşçakal "BRIC”, Merhaba "MINT “, SETA, 100, Haziran

- $\quad$ Ma C., Stern D. I. 2008, “China’s Changing Energy Intensity Trend; A Decomposition Analysis,” Energy Economics, 30, 1037-1053.

- $\quad$ Nnaji C. E., Nnaji M., Jonathan N. C. \& Monica C. M., 2016, “The Energy Intensity of Economic Sectors in Mint Countries: Implications for Sustainable Development”, IRA-International Journal of Management \& Social Sciences 4 (1), ISSN 2455-2267 
- Semboja, H.H.H. 1994, "The effects of an increase in energy efficiency on the Kenyan economy”. Energy Policy, 217-225.

- $\quad$ Tanrı̈̈ver, B. \& Biçer, B. 2016a, "Measurement of Real Energy Efficiency in Turkey: A Structural Decomposition Analysis”, 8 th International Ege Energy Syposium May 11-13, Afyonkarahisar

- $\quad$ Tanrı̈ver, B. \& Biçer, B. 2016b, "Enerji Etkinliği Bakımından Türkiye Ekonomisinin Avrupa Birliğindeki Yeri: Homojen Bir Karşılaştırma”, Türkiye Ekonomi Konferansı, 20-26 Ekim, Bodrum,

- $\quad$ Thollander, P., \& Dotzauer, E. 2010. “An energy efficiency program for Swedish industrial small-and medium-sized enterprises”. Journal of Cleaner Production, 18(13), 1339-1346.

- TMMOB, 2012.’Dünyada ve Türkiye'de Enerji Verimliliği”, Makina Mühendisleri Odası Oda Raporu, Genişletilmiş 3. Baskı, Yayın No: MMO/589

- Vikström, P. 2008. "Energy efficiency and energy demand: a historical CGE investigation on the rebound effect in the Swedish economy 1957”. Umeå Papers in Economic History Nr. 35. Department of Economic History. Umea: Umea University.

- Vikhorev, K., Greenough, R., \& Brown, N. 2013. "An advanced energy management framework to promote energy awareness". Journal of Cleaner Production, 43, 103-112.

- Wang, Y., Zhao, H., Li, L., Liu, Z., \& Liang, S. 2013. "Carbon dioxide emission drivers for a typical metropolis using input-output structural decomposition analysis”. Energy Policy, 58, 312-318.

- World Bank, 2011, “Türkiye'de Enerji Tasarrufu Potansiyelini Kullanmak”, Ocak, 52210, http://siteresources.worldbank.org/TURKEYEXTN/Resources/361711-1294661147811/TurkeyEE-tr.pdf

- Zhang, Z. X. 2003. "Why Did The Energy Intensity Fall in China's Industrial Sector in The 1990s? The Relative Importance of Structural Shange and Intensity Change,”Energy, 31 (25), 625-638. 


\title{
Rusya, Kazakistan ve Azerbaycan'ın Devlet Bütçe Giderlerinde Sosyal Harcamaların Karşılaştırmalı Analizi
}

\section{Comparative Analysis of Budget Expenditures on Social Sphere in Russia, Kazakhstan and Azerbaijan}

\author{
Assoc. Prof. Dr. Elchin Suleymanov (Baku Engineering University, Azerbaijan)
}

Prof. Dr. Farhad Rahmanov (Azerbaijan State Economy University, Azerbaijan)

Assoc. Prof. Dr. Anar Eminov (Azerbaijan Tourism and Management University, Azerbaijan)

\begin{abstract}
Azerbaijan, Russia and Kazakhstan as Post-Soviet countries are known fortheir oil-gas industry and its huge share in their economies. Considering these mentioned points, these countries are supposed to be the most relevant countries for common analysis. The role of social related expenditures in the state budgets was examined throughout the years for all three countries comparatively. By this analysis, it is targeted to define the differences and similarities in budget structure of these countries. Due to specific relevant structures and to resource-rich points, these countries have different revenue and expenditure policies than other post-soviet countries. These countries manage oil revenues to improve social-economic conditions of the country. Accordance of increasing oil revenues, education, health, and social defense expenditures as main social expenditure types in these countries increased until recent oil price shocks. Considering huge share of oil sector in these countries, it is crucial to examine the impacts of recent decline of oil prices on social expenditures in these countries. In this study, share of social related expenditures in the budget of these countries are comparatively analyzed in the period 1992 and 2015 years.
\end{abstract}

\section{Giriş}

70 yıllık bir serüvenin sonunda 1990 sonrası SSCB 15 bağımsız devlet olarak yeni bir döneme başladı. Bağımsızlık kazanan cumhuriyetler bağımsızlık sonrası kendilerine özgü liberal bir ekonomi sistemi kurmağa başladılar. Bağımsızlık sonrası Post-Sovyet kaynak zengini ülkeleri Rusya, Kazakistan ve Azerbaycan için petrol ihraç gelirleri ülkelerin bütçeleri için önemli bir gelir kaynağı oldu. Doğal kaynak zengini olan her üç ülke özellikle bağımsızlık sonrası ilk dönemlerde önemli petrol projeleri gerçekleştirmiş ve bu projelerin faaliyete geçmesi ile ciddi petrol gelirleri elde etmişlerdir. Her üç ülkenin ihracatının büyük bir oranı petrol ve petrol yan ürünleri olmasından dolayı, özellikle petrol fiyat artışları nedeniyle 2000 sonrası dönemde bütçe gelirlerinin önemli bir kısmı ihraç ettikleri petrol gelirlerinden karşılanmış ve bu durum her üç ülkeyi lüks ve rahat bir harcama politikasına alıştırmıştır. Sosyal ve ekonomik hayatta yaşanan geçiş süreci problemleri Post Komünist ülkelerin ortak problemi olmuş ve ekonomik sistem değişiminin zorluklarını aşmada petrol zengini olan ülkelerde ise petrol gelirleri ekonominin can simidi olmuş, geçiş süreci transformasyon sürecini hızlandırmıştır. Elbette doğal kaynak gelirlerinin kullanılması ile bazı temel problemlerin çözümü kolaylaşıp, sosyo-ekonomik yapıda değişim süreci hızlanırken, aynı zamanda olumsuz sonuçlar da ortaya çıkmaktadır. Özellikle 2008 yılından itibaren literatüre "Hollanda Hastalığı" olarak dahil olmuş olan bu "doğal kaynak laneti" her üç ülkede de kendini göstermiştir. Ülkeler ekonomilerinde beklenenin ötesinde yapısal değişimlere gidip önemli rahatlama seviyelerine ulaşırken, gelirlerin kolayca elde edilmesi ve bu kolaylığın devam edeceği beklentisi bu ülkelerde rasyonel veya verimli kullanım, tedbirli olma anlayışının oluşmasını engelleye bilmiştir. Başta petrol olmak üzere enerji kaynaklarında yaşanan ucuzlama ile 2015 yılından itibaren bu üç ülke ekonomisinde daha önce görülen rahatlama veya hızlı transformasyon süreci durgunluğa, daralmaya, hatta işsizlik, enflasyon, dengesiz büyüme gibi değişik ekonomik problemlere dönüşmeye başlamıştır. Gerek finansal, gerekse de reel sektörlerde yaşanan bu zorlu sürecin kısa dönemde çözüme kavuşması beklenmemektedir. Tersine, bu doğal kaynak fiyatlarında eskiden olduğu gibi yeniden bir artış olmadığı sürece ekonomik problemlerin ve bu problemlerin yansıması olan sosyal problemlerin çözümünün kolay olmayacağı, doğal kaynak dışı sektörlerdeki gelişimin zaman alması nedeniyle bu problemlerin kısa süreli olamayacağı beklenmektedir. Hazar Havzası petrol zengini devletleri, Rusya ve Kazakistan, Azerbaycan petrol fiyatlarının düşmesinin akabinde ulusal para birimleri ABD Doları ve Avro karşısında ciddi değer kaybetti. Rusya rublesi ve Kazakistan tengesinde değer kaybı hemen 2014 sonlarından başlasa da, Azerbaycan manatı eskiye dönüş umuduyla bir süre döviz rezervlerinin erinmesi pahasına sıkı para politikasıla korumağa çalışmış ve bunu ancak 2015 yılının şubat ayına kadar sürdürebildi. Daha sonra Azerbaycan Merkez Bankası bir yılda iki kere Azerbaycan parası devalüe etme zorunda kaldı.

Bu çalışmada üç ülkenin ekonomik durumu hakkında genel bilgiler verildikten sonra bağımsızlık sonrası bütçe harcamalarındaki inkişaf dinamiği ve sosyal harcamalarda nasıl bir uygulama içinde oldukları ele alınmaya çalışılmaktadır. Çalışmanın sonunda özellikle petrol fiyatlarının azalmasından dolayı son yıllarda azalan bütçe gelirlerini telafi etmek için yapılabileceklerle ilgili genel tavsiyelerde bulunulmaktadır. 


\section{Petrol Fiyatlarındaki Düşüş Nedenleri ve Ülke Ekonomilerine Etkileri}

Petrol, 19. Yüzyılın sonlarından itibaren üretim sürecinde önemli girdi olarak yer almaya başlamıştır. Esas değerini Alman mucit Rudolf Diesel tarafından "diesel motor" diye tanımlanan motorun icat edilmesi ile kazanmıştır. Dünyanın en önemli enerji kaynaklarından olan petrol, diğer enerji kaynaklarına göre daha geniş kullanım alanına sahiptir. Enerji kaynağı olmanın yanı sıra hammadde olarak da kullanılmasıyla petrolden farklı ihtiyaçları karşılamak üzere değişik ürünler elde edilebilmektedir. Ayrıca çıkarılma ve taşıma açısından diğer enerji kaynaklarına göre daha ucuz olmaktadır. Petrol ve petrol ürünlerinin maliyeti içerisinde temel yük petrolün çıkarılması, nakil masrafı ve dağıtılması için yapılan harcamalar tutmaktadır (Aras, 2007). Küresel enerji tüketiminde petrolün pay1 1938 'de $\% 20.7,1950$ 'de $\% 27.7,1960$ 'da $\% 34.7,1970$ 'de $\% 44.1,1980$ 'de $\% 44.9,1990$ 'da $\% 40.5$ olarak gerçekleşmiştir. 2010 yılında \%45 civarında gerçekleşen oranın, 2020 yılı itibariyle \%55'in üzerinde olacağı tahmin edilmektedir. BP Dünya Enerji İstatistikleri Raporuna göre, 2015 yılında küresel petrol üretimi, küresel tüketimin iki katından fazla büyüme ile yüzde 2.3'e karşılık gelen günlük 2.1 milyon varil artmıştır. Petrol İhraç Eden Ülkeler Örgütü’nün (OPEC) dışındaki üretim günlük 2.1 milyon varil artarak veri setindeki en yüksek artışı kaydetmiştir. Dünya petrol üretiminin denetimini elinde tutan ve dünya petrol üretiminin yaklaşık yarısını sağlayan OPEC ülkeleri ham petrol rezervlerinin üçte ikisine ve doğal gaz rezervlerinin de üçte birine sahip olmalarından dolayı dünya petrol piyasasında uzun dönemdir etkili olmalarına rağmen 2015 yılı itibariyle bu etkileri azalmıştır. OPEC ülkelerinin etkilerinin azalmasının bazı nedenleri bulunmaktadır. Başta Amerika'nin dünyadaki en büyük üretim artışını kaydederek bugüne kadar üretimini üç yıl ardı ardına en az 1 milyon varil artıran ilk ülke olmasıdır. Hatta dünyanın en büyük petrol üreticisi unvanını Suudi Arabistan'dan devralmıştır. ABD ile birlikte, Kanada 310 bin varil ve Brezilya 230 bin varil rekor düzeylere üretim artışına ulaşmışlardır. 2015 y1lı itibariyle OPEC üretimi yerinde sayarken grubun küresel üretimden aldığ 1 pay da yüzde 41 ile 2003 'ten bu yana en düşük seviyesine inmiştir. Küresel piyasalarda petrol fiyatları 2014 yılının sonlarından başlayarak düşmeye başlamış ve bu süreç 2016 yılının ilk aylarına kadar sürekli devam etmiştir. 2014 yılı haziran ayında bir varili yaklaşık 120 ABD \$ civarında olan petrol fiyatı 2016 yılının ilk aylarında 30 \$'a kadar gerileyerek bir yılda yaklaşık dört kat fiyat kaybetmiştir. Petrol arz ve talebine ilişkin gelişmeler ile vadeli piyasalarda oluşan fiyatlar değerlendirildiğinde, petrol fiyatlarının 2016 yılı boyunca da mevcut düşük seviyelerine yakın seyredeceğine yönelik beklentiler güçlenmektedir. Nitekim, birçok uluslararası kuruluş petrol fiyatı tahminlerini aşağı yönlü güncellemektedir. Petrol gelirlerine duyarlılı̆̆ı yüksek olan ülkeler bu süreçten farklı düzeyde negatif yönde etkilenmektedir. Öte yandan, fiyatlardaki düşüşün enerji ithalatçısı ülkelerin dış dengelerine pozitif katk1 sağlayacağı ve bu ülkelerde büyümeyi destekleyeceği öngörülmektedir. Petrol fiyatlarında keskin düşüşte en önemli faktörlerden birisi ABD’de yeni geliştirilen teknolojilere bağlı olarak maliyetlerin düşmesinin etkisiyle kaya petrolü üretiminde gözlenen hızlı artıştır. Aynı zamanda çatışmalara bağlı olarak Irak ve Libya'da petrol üretiminin azalması beklenirken, tam tersine her iki ülkede de üretimin artması, fiyatlardaki düşüşte etkili olan arz yönlü gelişmelerden bir diğeri olmuştur. Bir diğer neden OPEC' in üretim kotasını azaltmama kararı alması petrol fiyatlarındaki düşüşü hızlandırmıştır. Petrol gelirleri bütçelerinin ve ekonomik dengelerinin vazgeçilmezi olan petrol zengini Körfez ülkeleri gibi, Rusya'nın da bütçe dengesi için tahmini varil başı fiyatı yüz dolar civarı olması gerekmektedir. Aynı durum Azerbaycan ve Kazakistan için de geçerli sayılır. Dolayısıyla petroldeki hızlı düşüş her ülke ekonomisi için kabus olmuş ve bütçe dengesini sarsmıştır.

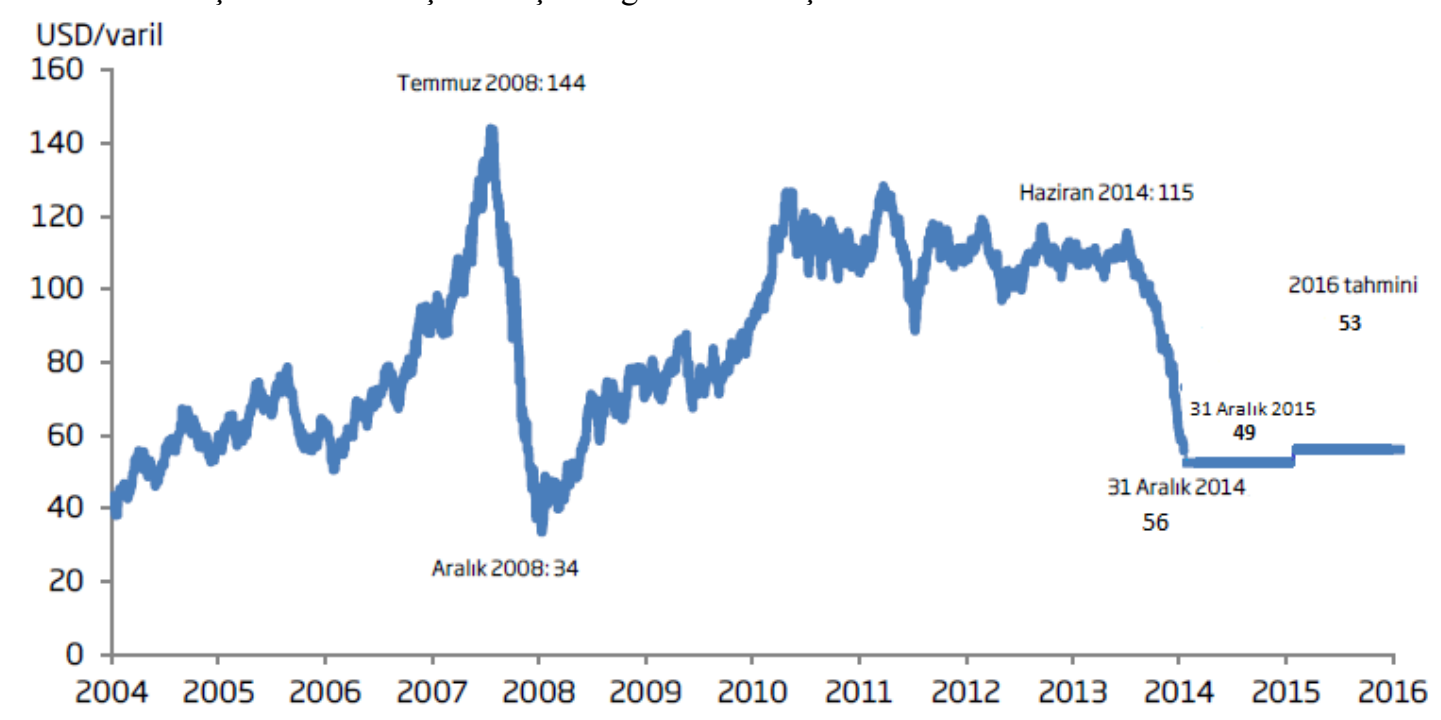

Grafik 1. Ham Petrol Fiyatları (Varil Başı ABD \$) Kaynak:Datastream 


\section{Petrol İhraç Eden Post-Sovyet Ülkelerinin Ekonomik Yapısı}

70 yıllık bir sürenin sonunda 19901 yıllarda SSCB 15 bağımsız devlet olarak yeni bir döneme başladı. Bağımsızlık kazanan ülkeler liberal temelli ekonomik sistemler kurdular. Yeni ekonomik sistemde önemli enerji kaynaklarına sahip olan Rusya, Kazakistan ve Azerbaycan kendine özgü enerji politikaları izlemeye başladılar. Bu politikalar sonucunda büyük kazançlar elde ettiler. Bu kazançların bir kısmı yeniden enerji sektörüne yatırılsa da, önemli bir kısmı nüfusun yaşam kalitesinin artırılmasına yönelik projelere yönlendirilmiştir. Nüfusun ekonomik gelişimi bu kaynaklardan elde edilen gelirlerin harcanma şekli ile doğrudan irtibatlıdır. Enerji kaynaklarının ihracı ülke GSMH artırdığından kişi başına gelir artışına neden olmakta, insanların harcama imkanlarını artırmaktadır. Ayrıca enerji kaynakları ihraç eden ülkelerin bütçe gelirlerinin önemli kısmı bu kaynakların ihraç gelirlerine dayanmaktadır (Aras, Süleymanov. 2016).Dünya toplam üretim miktarı son on yılda (2006-2016) \%16 artmış olan petrolün yaklaşık \%25'i ABD tarafından tüketilmektedir. Dünya petrol rezervlerindeki azalma, mevcut alanların daha iyi işletilmesi ve yeni rezerv alanlarının bulunması ile dengelenmeye çalışılmaktadır. Bu doğrultuda petrol piyasasındaki rekabet kısmen Hazar petrolleri üzerinden devam etmektedir.

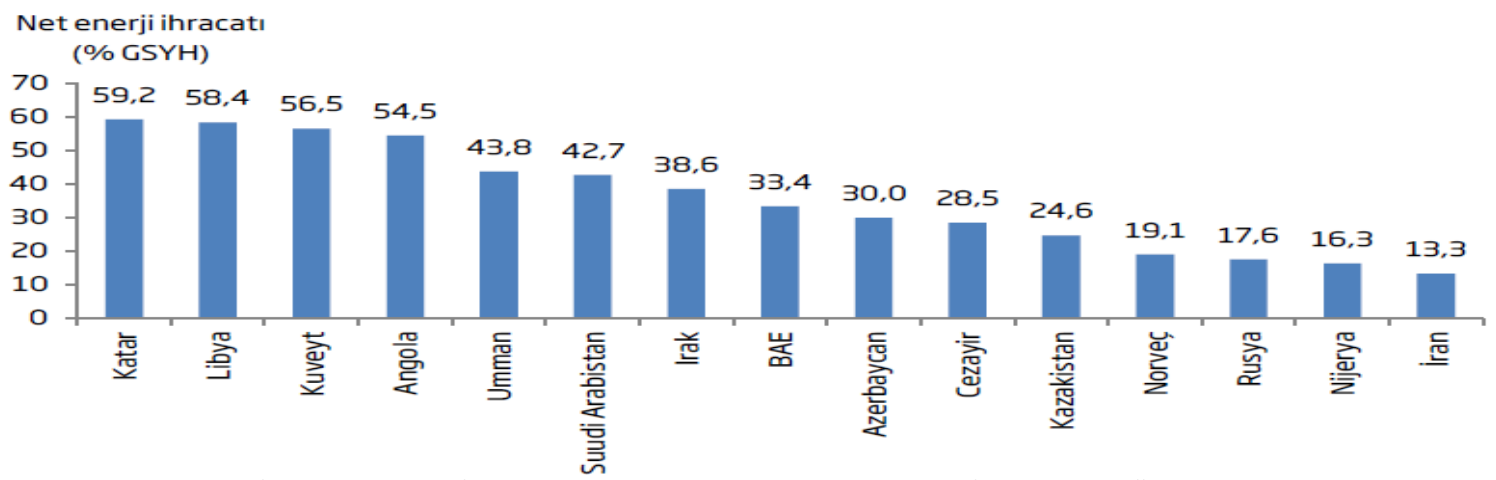

Grafik 2. 2015 Yılı İtibarıyla GSYİH'daki Payına Göre Başlıca Enerji İhracatçısı Ülkeler Kaynak: Trademap, $I M F$

\subsection{Rusya Federasyonunun Ekonomik Yapısı}

Rusya ekonomisi, GSYİH'ya göre dünyanın en büyük dokuzuncu ülkesi iken satın alma gücü paritesi göre altıncı ekonomisidir. Yine dünyanın en büyük doğal gaz ve petrol üreticisidir.

\begin{tabular}{|c|c|c|c|c|c|c|c|c|}
\hline & 2009 & 2010 & 2011 & 2012 & 2013 & 2014 & 2015 & 2016 \\
\hline \multicolumn{9}{|l|}{ Nüfus ve İstihdam } \\
\hline Nüfus (milyon) & 142,7 & 142,9 & 142,9 & 143,0 & 143,7 & 143,8 & 146,5 & 146,3 \\
\hline İşsizlik Oranı (\%) & 8,1 & 6,9 & 6,6 & 5,5 & 5,5 & 5,5 & 5,6 & 6,2 \\
\hline \multicolumn{9}{|l|}{ GSYH } \\
\hline Büyüme (\%) & $-7,8$ & 4,5 & 4,3 & 3,4 & 1,3 & 0,2 & $-3,5$ & $-1,4$ \\
\hline Özel tüketim harcamaları (\%) & $-5,1$ & 5,5 & 6,8 & 8,0 & 4,7 & 0,5 & $-6,0$ & $-1,0$ \\
\hline Toplam yatırım harcamaları (\%) & $-14,4$ & 5,9 & 9,1 & 6,4 & $-0,3$ & $-10,0$ & $-15,0$ & $-8,0$ \\
\hline Nominal GSYH (USD milyar) & 1.223 & 1.53 & 1.9 & 2.007 & 2.096 & 1.833 & 1.366 & 1.375 \\
\hline \multicolumn{9}{|l|}{ Dış Denge } \\
\hline USD/RUB (y1lsonu) & 29,9 & 30,9 & 31,6 & 30,7 & 32,9 & 58,0 & 58,2 & 61,8 \\
\hline Reel efektif Döviz Kuru (\%) & -5.8 & 10,6 & 4,9 & 1,5 & 2,2 & $-8,6$ & $-25,6$ & 1,7 \\
\hline Diş Ticaret Dengesi (milyar\$) & 113,2 & 147,0 & 196 & 192 & 180,9 & 169,9 & 153,2 & 183,8 \\
\hline Cari Denge (milyar USD) & 55,5 & 71,0 & 101 & 66,6 & 33,2 & 53,7 & 63,6 & 82,1 \\
\hline Cari Denge $(\%$ GSYH) & 4,5 & 4,7 & 5,3 & 3,3 & 1,6 & 2,9 & 4,7 & 6,0 \\
\hline Dış Borç (\% GSYH) & 38,2 & 32,1 & 28,7 & 31,8 & 34,5 & 34,9 & 41,2 & 40,7 \\
\hline \multicolumn{9}{|l|}{ Kamu Maliyesi } \\
\hline Bütçe Dengesi (\% GSYH) & $-5,4$ & $-3,9$ & 0,4 & $-0,1$ & $-0,3$ & $-1,1$ & $-1,2$ & $-1,6$ \\
\hline Kamu Borcu (\% GSYH) & 8,1 & 9,0 & 9,2 & 8,9 & 8,2 & 7,3 & 8,3 & 9,8 \\
\hline \multicolumn{9}{|l|}{ Enflasyon } \\
\hline TÜFE $(\%, y 1$ sonu $)$ & 8,8 & 8,8 & 6,1 & 6,5 & 6,5 & 9,8 & 11,2 & 8,1 \\
\hline
\end{tabular}

Tablo 1. Rusya Ekonomisinin 2009-2016 Yılları Temel Göstergeleri Kaynak: IMF, Ekonomi Raporu -2016 
Rusya'nın ihracatının \%80'inden fazlasını petrol, doğal gaz, demir ve kereste ve diğer doğal kaynaklar oluşturmaktadır. 2003 yılından bu yana, iç pazarın önemli ölçüde güçlenmesiyle doğal kaynakların ihracatının ekonomik önemi kısmen azalsa da hale ağırlığı devam etmektedir (Bulut, Hasanov, Suleymanov, 2014)

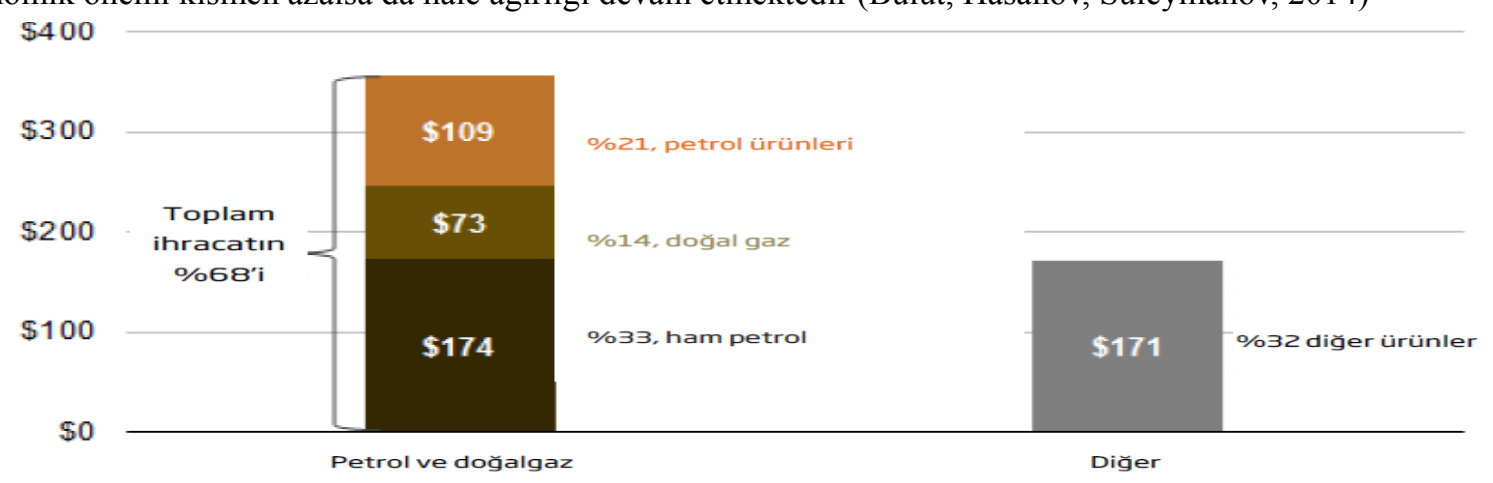

Grafik 3. 2015 Yll İtibariyle Rusya'nın İhracat Yapısı Kaynak: Energy Information Administration

Özellikle petrol ve doğal gaz gibi muazzam doğal kaynaklara sahip bir piyasa ekonomisi olan Rusya'da21. Yüzyılın başından bu yana, yüksek iç tüketim ve uzun süreli siyasi istikrar sayesinde ekonomik büyümede önemli başarılar elde edilmiştir. Kişi başına düşen reel GSYİH, 2014'te 19,970 \$ olmuştur. Büyüme öncelikle petrolmineral çıkarma ve ihracatı ile iç piyasa için mal ve hizmet ticareti ile sağlanmıştır. Petrol ihracatından elde edilen kazancı 1999'da 12 milyar \$ olan ülkede bu rakam her geçen gün artmış, yabancı rezerv miktarı 1 Aralık 2013'de 697.3 milyara çıkarak Rusya'yı dünyanın üçüncü büyük döviz rezervine sahip ülke haline getirmiştir. Fakat daha sonra dünya piyasalarında petrol fiyatlarının düşmesi bu rezervin yüzde 40 oranında değer kaybetmesine neden olmuştur (Ekonomi. İsbank,2015).

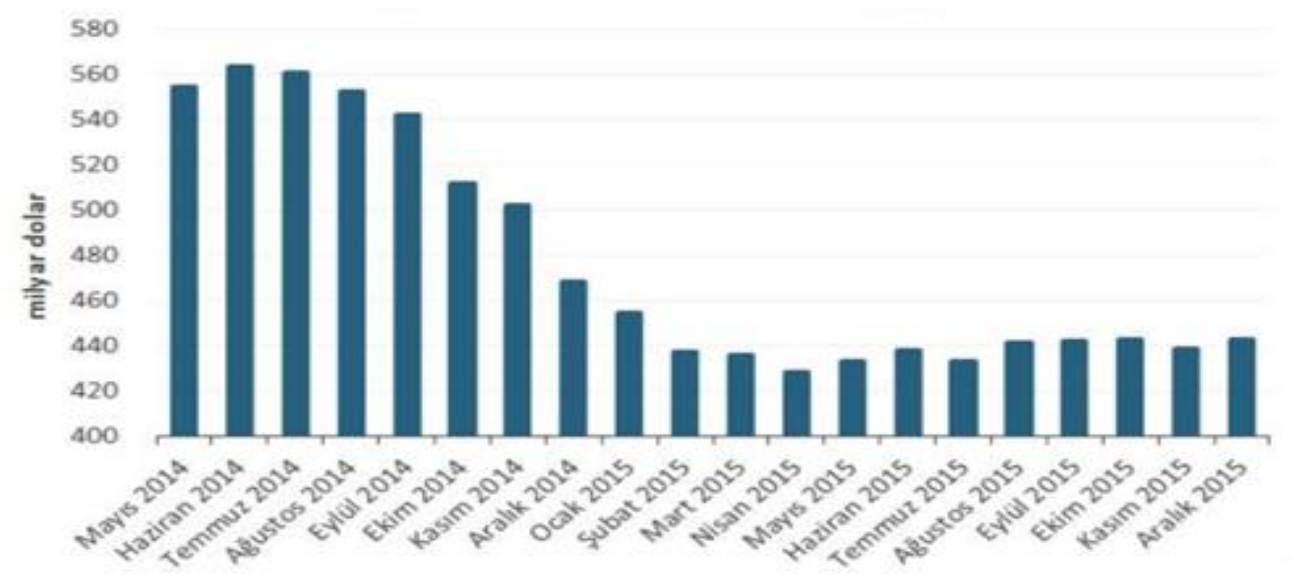

Grafik 4. Rusya Döviz Rezervi ve Varlık Fonu Toplamı Kaynak: Datastream

2013 yılında yaklaşık 400 milyar dolara yükselen Rusya'nın devlet bütçesi 2016 yılında yarıya kadar azalmasının başlıca nedeni petrol fiyatındaki düşüştür. Çünkü bütçe gelirlerinin yarıdan fazlası petrol satış gelirinden oluşmaktayd1.

\subsection{Kazakistan'ın Ekonomik Yapısı}

Kazakistan, kendi doğal kaynaklarına ve ekonomik gücüne göre Orta Asya'da önemli bir mevkide bulunmaktadır. Kendi kaynaklarına göre dünyada tercih edilen ülkelerden birisidir. Dünyadaki kromun \%26's1, altının\% 20'si, uranyumun \%17'si Kazakistan'dadır. Çinko ve volfram kaynakları açısından dünyada birinci, gümüş, uranyum, kurşun ve krom madenleri bakımından ikinci; bakır rezervleri bakımından üçüncü sırada yer almaktadır. Ülkede 1200'den fazla mineral kaynak çeşidini barındıran yaklaşık 500 maden yatağı bulunmaktadır. Kazakistan petrol ve doğal gaz rezervine göre dünyada ilk on beş ülke arasında yer almaktadır. BP' nin Haziran 2014 Dünyanın Enerji İstatistik özetlerine göre Kazakistan küresel petrol rezervlerinin \%1.8'ne, dolayısıyla 30 milyar varil petrole sahip bulunmaktadır. Petrol üretiminin 2020'e kadar 92 milyon tona ulaşması beklenen doğal kaynak zengini Kazakistan, yeni yüzyılın ilk 10 yılında bu kaynak zenginliğinin avantajlarından oldukça faydalanmıştır. Devlet gelirlerinin yarıdan fazlasının bu kaynaklardan karşılandığı ülkede ortalama 8.4'ün üzerinde yıllık büyüme oranı ile önemli bir ekonomik yapıya ulaşmıştır. Ülke ihracatının çok büyük kısmını petrol ve ana metaller oluşturmuştur. Dünya petrol fiyatlarının yüksek seyretmesinden dolayı Kazakistan diş ticaretinde fazla verme süreci yaşanmıştır. Global piyasalarda bu ürünlerin fiyatlarında yaşanan değişimlerden ülke ekonomisi önemli ölçüde etkilenmiştir. Gerçekleştirdiği üretimin büyük çoğunluğu petrol ve gaz sektörlerinde iken, sermaye ve tüketim mallarında yapılan üretim henüz iç tüketimi karşılayacak düzeyde bulunmamaktadır. Ülke ekonomi 
politikalarının temel hedefi enerji dışı sektörleri kalkındırarak petrol fiyatlarında yaşanan değişimlerden etkilenme oranını en aza indirmek olmuştur. Ülke bu amaç doğrultusunda 2003-2015 dönemini kapsayan Yenilikçi Sınai Kalkınma Stratejisi ile GSYİH'deki büyümenin yıllık bazda \%8 üzerinde tutulmasını ve ekonominin çeşitlilik kazanmasını amaçlamıştır. Bu program dahilinde turizm, petrol, doğalgaz, gıda, tekstil, taşımacılık ve lojistik sektörlerine öncelik verilerek yeni teknolojilerin kullanılması ve bu sektörlerde yatırım projelerinin geliştirilmesi hedeflenmiştir. Fakat bu hedeflerin ulaşılmasında önemli engeller olarak ülkenin iki temel dezavantajı bulunmaktadır. Bunlar uluslararası piyasalara olan uzaklık ve iç piyasaların küçük olmasıdır. Ülkenin denizlere kapalı, tamamen kara ile çevrili coğrafik konuma sahip olması ticaretin gelişimini sınırlayan en önemli faktörlerdendir. Uluslararası piyasalara uzaklık, petrol dışında üretilebilecek olan malların ulaşım maliyetlerini arttırıcı etki yapmaktadır. Diğer yandan nüfusun az olması, iç piyasaların yetersiz kalmasına bu da petrol dışı sektörlere yönelik doğrudan yatırımları engelleyen faktörler olmaktadır. Ancak son dönemlerde yaşanmaya başlayan petrol ve doğalgaz fiyatlarındaki düşüş, doğal kaynak zengini her ülkede olduğu gibi bu ülkede de önemli ekonomik zorluklara neden olmuştur. Reel büyüme oran1 2013 yılında \% 6, 2014'te 4.3, seviyelerinde olmuştur. Yapılan devalüasyon yurt içi ekonomi üzerinde çok yönlü etkilere neden olmuştur. Satın alma gücü zayıflarken yurt içi tasarruflar azalmış, büyük ölçüde dış borçlanmaya dayalı olarak faaliyet gösteren şirketler ciddi zararlar etmişlerdir. Bankacılık kesiminde geri ödenmeyen kredilerin payı da hızla yükselmiştir. Devalüasyonun finansal piyasalarda yol açtığı olumsuz etkilere rağmen dış ticaret üzerinde oluşturduğu olumlu etkiler sonucunda ihracatın artmasıyla dış ticaret dengesinde iyileşme yaşanmıştır[4].İlgili dönemde Kazakistan Merkez Bankası'nın döviz rezervleri önemli ölçüde azalmıştır. Rusya ve Çin piyasalarında yaşanan olumsuz gelişmeler, petrol fiyatlarında yaşanan düşüşle Kazakistan mali piyasalarına yansıyan tesirler nedeniyle 20 Ağustos 2015'den itibaren Kazakistan Merkez Bankası serbest dalgalı döviz kuruna yönelik yeni para politikasını uygulamaya başlamıştır. Şubat 2014 yılında \% 19 oranında para birimini devalüe eden hükümet, 2015 yılı Ağustosunda \% 22 ikinci bir devalüasyona gitmiştir. Böylece 18 aylık kuru koruma mücadelesinin bedeli yaklaşık olarak 28 milyar dolar olmuştur (Şimşek,2015). Kazak parası Tenge'nin değerini korumak için uygulanan sert para politikası ve baz faiz oranının yükseltilmesi gibi uygulamalar 2015 yılında başta sanayi üretimi olmak üzere durgunluğa neden olmuştur. Yaşanılan durgunluk ekonomik büyüme rakamlarına ve büyüme ile ilgili beklentilere yansımıştır. 2015'te \%1 seviyelerinde olan Kazakistan ekonomik büyümesi ile ilgili Dünya Bankası'nın beklentileri 2016 için \%1.1 iken 2017 için 3.3 ve 2018 için \%3.4 olmuştur. Kazakistan'ın bütçe gelirleri GSYİH-nın\% 15'ini teşkil etmektedir. Kazakistan bütçesinde 2005-2014 yıllarında gelirlerin ortalama olarak 74\% -i vergilerle finanse edilmektedir. Vergilerin son yıllarda bütçedeki payında halen devletin temel finans kaynağı olma işlevini taşımaktadır. 2005 yılında vergiler devlet bütçesinin\% 95 sini oluşturmakta iken, 2014 yılında bu pay 62\% 'e inmiş ve en düşük seviyesine ulaşmıştır. Vergi gelirlerinin azalması nedeniyle son yıllarda Milli Petrol Fonu transferleri artmış bulunmaktadır. Petrol Fonu'nun payı 2014 yılında ülke bütçesinin \% 33'ne ulaşmış durumdadır. Oysa, "Norveç Modeli" esas alınarak 2000 yılında kurulan Milli Fon'dan bütçeye yapılan ilk transfer bütçenin sadece \%7'sini teşkil etmekteydi. Bu transferlerin artışında petrol-gaz sektöründeki gelirlerin artmasının da önemli payı bulunmaktadır. Son yıllarda petrol ve gaz sektörünün GSYİH içindeki payı artarak \% 20' den fazlaya ulaşmıştır (Şimşek,2015).

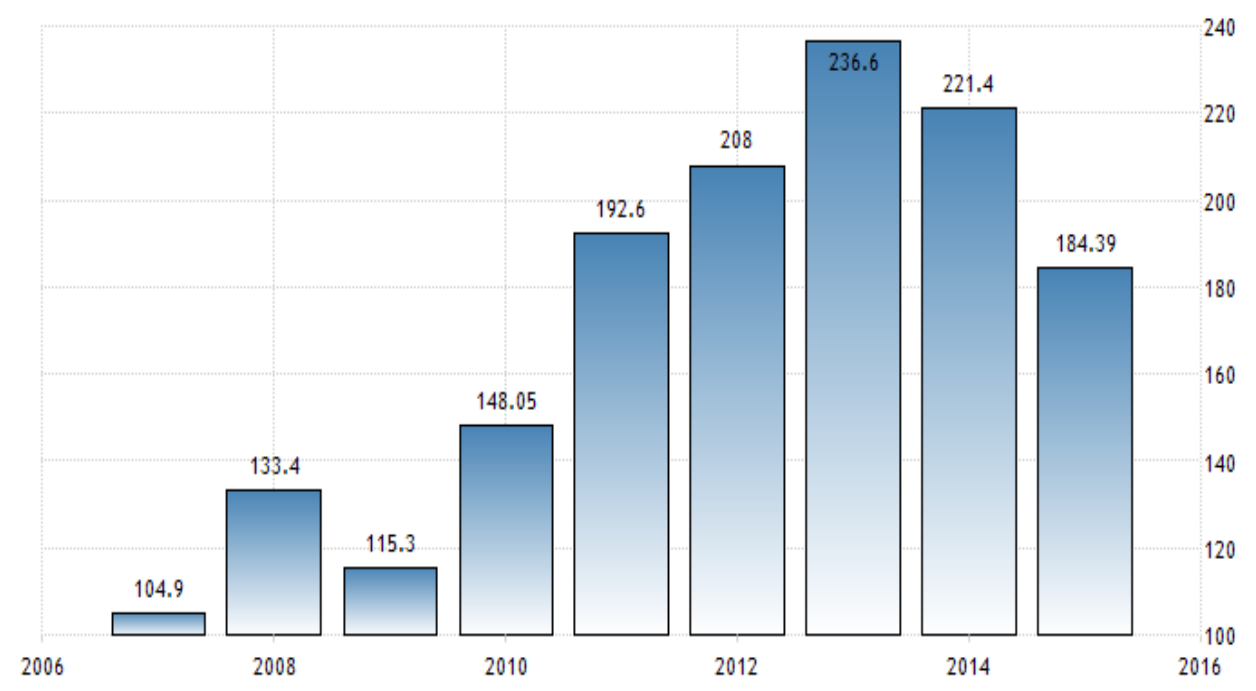

Grafik 5. Kazakistan GSYİH-si (2005-2016), mlr.\$ Kaynak: Tradingeconomics

2014-2016 için Kazakistan'ın bütçe rakamlarına göre bütçe harcamaları 2014 yılında 62 milyar tenge, 2015 yılında $69 \mathrm{mlr}$ tenge ve 2016 yılında $68 \mathrm{mlr}$ tenge tutarındadır. Bütçede petrol fiyatı 50 \$ iken varil başına, 20162017 yılında varil başına 40 \$ seviyesinde yer almaktadır. 2018-2020 yılında. beş yıllık bir dönem için, dünya 
metal fiyatlarındaki yıllık ortalama büyüme yüzde 2,4 olacağı tahmin ediliyor. Bütçede Kazak ekonominin reel büyüme 2016 yılında yüzde 2,1, 2017 yılında yüzde 3,6 oranında, 2018 y1lında yüzde 2,9, 2019 y1lında yüzde 3 ve 2020 yılında yüzde 3,2 olacağı tahmin ediliyor. Nominal GSYİH kişi başına 2020 GSYİH 2020 yılında 11.470 \$ bir başka artış ile 2016 yılında 8557 \$ olacağı tahmin ediliyor

\subsection{Azerbaycan'ın Ekonomik Yapısı}

Azerbaycan Güney Kafkasya'da ekonomik gücüne göre en gelişmiş ülkedir. Azerbaycan'ın sahip olduğu petrolgaz rezervleri bu ekonomik gücün kazanılmasında vazgeçilmez role sahip olmuştur. 2014 yılında Azerbaycan GSYİH's1 59 milyar manat oluşturmuştur ki, bunun\%39'u petrol-gaz sektöründen kaynaklanmıştır. Son 10 yılda ülke ekonomisinin büyüklüğü 7 defadan fazla artmıştır. Bu süre içinde kişi başına düşen GSYİH ise yaklaşık 6,7 kat artmıştır. BDT'nin ikinci güçlü ekonomisi olarak görülen Kazakistan'da bu gösterge 6 defaya yakın olmuştur. Görüldüğü gibi Azerbaycan ekonomisi büyüme temposuna göre diğer Kafkas ülkelerini yaklaşık iki kere üstelemiş, BDT'de ilk sırada yer almıştır. Ayrıca, söz konusu dönem boyunca ekonomik büyümenin dayandığı faktörlerde çeşitlenmeler gerçekleştirilmiştir (Aras, Suleymanov, Huseynov,2013). 2005 yılında Bakü-TiflisCeyhan petrol boru hattının açılışı petrol üretimi ve ihracatını önemli ölçüde artırmıştır ki, bu da ekonomiye büyük miktarda gelir akışı demekti. Bu olay ülke ekonomisinin yapısında köklü değişikliğe neden olmuştur. Yıllar üzere petrol gelirlerinin artması devlet bütçesinde kendisini 2008 yılında daha keskin bir şekilde göstermiştir. 2008 yılında bütçeye Azerbaycan Petrol Fonundan transferler 4 defadan fazla artmış ve bu da devlet gelirlerinde gözle görülür derecede sıçrayışa neden olmuştur. 2015 yılının sonuçlarına göre Azerbaycan'da tahmini yetmiş milyar dolar olan GSYİH'nın \%38.5'i, genel ihracatın \%93.5'i, bütçe gelirlerinin \%66'sı, toplam yatırım harcamalarının \%33.9'u petrol sektörünün payına düşmektedir. Petrol - doğal gaz üretiminin ve ihracatının artması, dünya piyasasında petrol fiyatının yükselmesi ülkeye büyük petrol paralarının dahil olmasına yol açmıştır. 2004 yılında petrol üretimi 15.6 milyon ton iken, 2010 yılında en yüksek noktasına yani 50.8 milyon tona ulaşmıştır. Petrol üretimi yükselen trendle devam etmiştir. Fakat 2008 yılında yaşanan dünya mali krizi bir çok alana etki ettiği gibi, petrol sektörüne de etkilemiştir. 2007 yılında 42.6 milyon ton petrol üretilmiş ve 2006 yılı ile karşılaştırıldığında 10.3 milyon ton artmışken 2008 yılında artım toplam 1.9 milyon ton olmuştur. 2011 yılından itibaren petrol üretimi azalmaya başlamış ve yaklaşık 2007 yılındaki seviyesine inmiştir. Bu düşüş sonraki yıllarda da kendini göstermiştir.

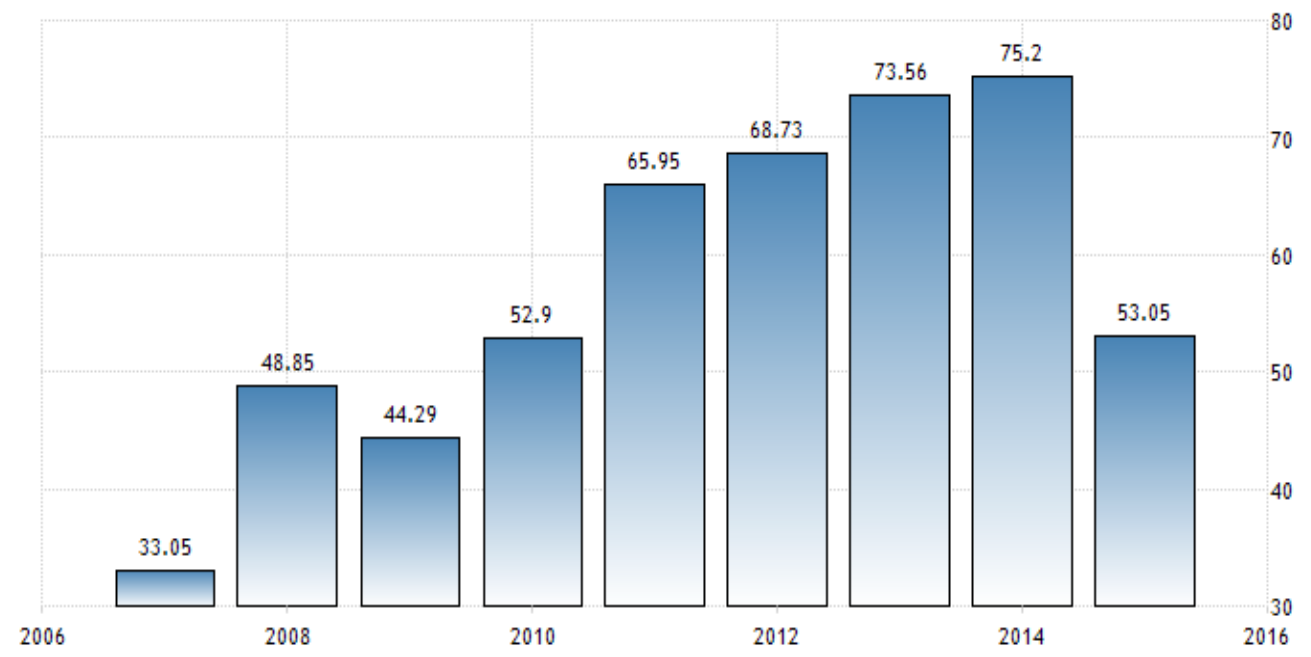

Grafik 6. Azerbaycan'ın GSYIH-si (2005-2016), mlr.\$ Kaynak: http://www.tradingeconomics.com

GSYİH'nın artışında ülkede petrol ve doğalgaz üretiminin artması ve büyük finansmanın dahil olması etkili olmuştur. Örneğin, 2004 yılında GSYİH'nın ortalama yıllık büyüme oranı \%9-10'a eşdeğerken, 2005 y1lında \%26.4, 2006 yılında \%34.5 'e, 2008 ve 2010 yılına göre \%10.8 ve\% 5.0 olmuştur. 2008 yılında GSYİH'nın büyüme oranının hızlı düşmesinde ana neden küresel mali kriz idi. Nitekim, yaşanan krizle petrol fiyatları bir süre düşük kalmıştır. 2008 yılında GSYİH'nın bünyesinde petrol sektörünün payı \%55'e eşitken artış \%10.8 olmuştur. Bu oran 2010 yılında Azerbaycan'da petrol üretiminin en yüksek sınırı olup (50.8 mln.ton), GSYİH'nın büyüme oranı \%5, GSMH içinde petrol sektörünün payı \%56 teşkil etmiştir. Petrol hasılasının azalması ve 2014 yılının sonlarından itibaren petrol fiyatlarının yaklaşık 2 kat aşağı inmesi GSYİH'nın artış temposunda da kendini göstermiştir(Aras, Suleymanov,2016). 2004 yılında petrol sektörünün GSYİH içindeki payı \%31 olmuştur. 2005 yılından itibaren petrol sektörüne büyük yatırımların ülkeye girmesiyle petrol sektörünün GSYİH'nın içerisinde payının artmasına yol açmıştır. 2006 yılında artık petrol sektörünün payı \%54' e ulaşmıştır. 2007 ve 2011 yıllarında da bu oran \%55 ve $\% 57$ hacminde olmuştur. Petrol ve doğal gaz üretiminin ve ihracatının azalması, GSYİH'nın artış temposunun düşmesi petrol sektörünün GSYİH içindeki payına da etki göstermiştir. 2012 yılında petrol sektörünün GSYİH içindeki payı \%53 e ulaşmıştır. Bu oran 2014 yılında daha da artarak \%62olmuştur. Petrol gelirlerinin artması 
bütçe harcamalarının da artmasına yol açmıştır. 2005 yılında bütçe harcamaları 2.1 milyar manat iken 2015 yılında 21 milyar manat hacminde onaylanmıştır. Yani $10 \mathrm{kez}$ artış olmuştur. 2015 yılında ise bu rakam 19 milyar manat civarında gerçekleşmiştir.

\begin{tabular}{|c|c|c|c|}
\hline Yıllar & $\begin{array}{c}\text { Devlet Petrol Fonundan } \\
\text { Bütçeye Transferler }\end{array}$ & $\begin{array}{c}\text { Devlet Petrol Fonundan } \\
\text { transferlerinin bütçedeki oranı, \% }\end{array}$ & $\begin{array}{c}\text { Devlet Petrol Fonu transferlerinin } \\
\text { GSYIH-de oran, \% }\end{array}$ \\
\hline 2009 & 4915,0 & 47,6 & 14,2 \\
\hline 2010 & 5915,0 & 51,9 & 14,2 \\
\hline 2011 & 9000,0 & 57,3 & 18,0 \\
\hline 2012 & 9905,0 & 57,3 & 18,3 \\
\hline 2013 & 11350,0 & 58,2 & 19,7 \\
\hline 2014 & 9337,0 & 50,7 & 15,8 \\
\hline 2015 & 8130,0 & 47,6 & 14,2 \\
\hline 2016 & 7615,0 & 45,3 & 12,6 \\
\hline
\end{tabular}

Tablo 2. Azerbaycan Devlet Petrol Fonundan 2009-2016 Yılları Bütçe Transferlerinin Hacmi

2011 yılından itibaren petrol üretimi azalmaya başlamış ve yaklaşık 2007 yılındaki seviyesine inmiştir. Bu düşüş sonraki yıllarda da kendini göstermiştir.

\section{Petrol Fiyatlarındaki Düşüşlerin Petrol İhraç Eden Post-Sovyet Ülkelerinin Bütçe Harcamalarına Etkisi}

Rusya, Kazakistan ve Azerbaycan'ın ülke ekonomileri hacim açısından birbirinden çok farklıdır. Rusya bütçe gelirleri, ekonomisinin ve alan boyutunun büyüklüğü nedeniyle diğer iki ülkeden oldukça farklıdır. 2014 yılında Rusya'nın bütçe gelirleri 532 milyar dolarken, Kazakistan ve Azerbaycan bütçe gelirleri sırasıyla 31 ve 17 milyar dolar civarında olmuştur. Fakat miktar farklılıklarının olması karşılaştırmalı tahlile engel olacak durum değildir. Yıllar üzere artış oranları ile bu karşılaştırmaları başka boyutta gerçekleştirmek mümkündür. Tablo 4'ten de göründüğü gibi 2009 yılına kadar bütçe gelirlerindeki en yüksek büyüme oranı Azerbaycan'a ait olmuştur. Bu büyüme oranı direkt olarak petrol gelirlerinin artmasıyla ilgilidir (Bulut, Hasanov, Suleymanov, 2014). 2008 yılında Azerbaycan bütçe gelirlerindeki artışın \% 79 olmasına karşılık, Rusya Federasyonu ve Kazakistan'da bu artış sırasıyla \% 20 ve\% 40 olmuştur. 2008 küresel mali krizinden bütçe gelirleri açısından belirtilen üç ülke arasında en az etkilenen Azerbaycan olmuştur. Buna neden Azerbaycan ekonomisinin büyük ölçüde globalleşmemesi ve aynı yıl Petrol Fonundan transferlerde 29\% 'lik bir artışın olmasıdır. Aynı yıl bu artış Kazakistan'da \% 3-e tekabül etmiştir. Global Maliye krizinden sonra her üç ülkenin bütçe gelirlerinin artış hızı düşmüş, 2013 yılında Azerbaycan bütçe gelirlerinde \% 13'lük bir artış olurken, Kazakistan bütçe gelirleri \% 11 azalmış, Rusya bütçe gelirleri ise toplamda \% 3 artmıştır. 2014 yılında ise Azerbaycan bütçe gelirlerinde \% 6 azalma olurken, Rusya Federasyonu ve Kazakistan'da artış görülmüştür. Petrol fiyatlarının düşmesinden kaynaklanarak 2015 yılından ise her üç ülkenin bütçe gelirleri kendi para birimlerinde kısmen artış gösterse de ABD \$ paritesiyle 2014 yılına nazaran neredeyse yarıya kadar azalmıştır. Her üç ülkede sosyal harcamalar son yıllarda milli para nominal değerine göre yaklaşık yüzde 10 artırılırken reel değeri eski yıllara oranla ciddi azalmıştır.

\begin{tabular}{|l|c|c|c|c|c|c|c|c|}
\hline & $\mathbf{2 0 0 9}$ & $\mathbf{2 0 1 0}$ & $\mathbf{2 0 1 1}$ & $\mathbf{2 0 1 2}$ & $\mathbf{2 0 1 3}$ & $\mathbf{2 0 1 4}$ & $\mathbf{2 0 1 5}$ & $\mathbf{2 0 1 6} *$ \\
\hline Rusya & $\mathbf{2 7 4 5 2 5}$ & $\mathbf{3 2 3 ~ 6 2 2}$ & $\mathbf{4 2 0 ~ 9 8 9}$ & $\mathbf{4 7 3 0 6 3}$ & $\mathbf{4 8 6 1 3 0}$ & $\mathbf{5 3 2 ~ 3 2 9}$ & $\mathbf{2 6 2 ~ 0 9 8}$ & $\mathbf{2 0 8 0 4 0}$ \\
\hline artış oranı & $-15 \%$ & $18 \%$ & $30 \%$ & $12 \%$ & $3 \%$ & $10 \%$ & -49 & -8 \\
\hline Kazakistan & $\mathbf{1 8 ~ 8 5 6}$ & $\mathbf{2 3 ~ 1 2 6}$ & $\mathbf{2 8 ~ 8 9 1}$ & $\mathbf{3 1 2 7 0}$ & $\mathbf{2 7 ~ 8 6 2}$ & $\mathbf{2 8 ~ 6 8 5}$ & $\mathbf{1 5 7 1 2}$ & $\mathbf{1 5 3 6 2}$ \\
\hline artı̧̧ oranı & $-13 \%$ & $23 \%$ & $25 \%$ & $8 \%$ & $-11 \%$ & $14 \%$ & $-54 \%$ & -1 \\
\hline Azerbaycan & $\mathbf{9 8 6 5}$ & $\mathbf{1 0 8 9 4}$ & $\mathbf{1 5 0 0 0}$ & $\mathbf{1 6 5 1 0}$ & $\mathbf{1 8 6 2 6}$ & $\mathbf{1 7 5 8 0}$ & $\mathbf{1 7 0 8 0}$ & $\mathbf{1 0 8 5 2}$ \\
\hline artı̧̧ oran1 & $-4 \%$ & $10 \%$ & $38 \%$ & $10 \%$ & $13 \%$ & $-6 \%$ & $-3 \%$ & $-63 \%$ \\
\hline
\end{tabular}

Tablo 3. Kazakistan, Azerbaycan ve Rusya Federasyonu'nun 2009-2016 Yıl Bütçe Gelirleri (Milyon USD) ve Yıllar Üzere Artış Oranı (\%), Kaynak: Tablo Ülkelerin Istatistik Verilerine Göre Yazarlar Tarafindan

\section{Hazırlanmıştır}

Yukarıda değinilen noktalardan da anlaşıldığı gibi bütçe gelirlerinin büyüme dinamiğinde RF ve Kazakistan daha benzer yol izlemekte, Azerbaycan ise belli bir farklılık göstermektedir. Bu, Kazakistan ve Rusya ekonomilerinin birbirleriyle daha yoğun şekilde bağlılığının durumu ile açıklanabilir. Petrol fiyat düşüşü her üç ülkenin para değerini ciddi olarak yitirmesine sebep olmuştur. Küresel ekonomide yaşanan gelişmelerle beraber Kazakistan Merkez Bankası Şubat 2014'de devalüasyon yaparak Tenge'nin değerini \%18 oranında düşürmüştür (185 Tenge/ABD Doları). Ağustos 2015'te dalgalı kura geçme kararı sonrası tenge yüzde 35 değer kaybetmişti. 
Serbest kur öncesi, 188 Tengeden satılan ABD doları, 255 tengeye yükselmiştir. 2016 yılının mayıs ayının evvellerinde ise 1 Amerikan doları 336 tengeden işlem görmektedir. Aynı süreç Azerbaycan için de geçerli olmuştur.2015 yılının Şubat ayında 1 dolar 0.78 Azn den 1.05 Azn ye, Aralık sonunda ikinci devalüasyonla 1.55 AZN olmakla Azerbaycan tarihinde Merkez Bankası bir yılda iki kez devalüasyona gitmiştir. Merkez Bankası ilk devalüasyon iki dövizli sepete geçitle ilgili ikinci devalüasyon ise 21 Aralık 2015 tarihinde yüzen kur rejimine geçilmesi için karar almıştır. Rusya'da 2013-2015 yılı itibarıyla petrol ve doğal gaz ihracatının Rusya'nın toplam ihracat gelirinin \%68'ini oluşturduğu dikkate alındığında, 2016 yılında petrol fiyatlarının mevcut düşük seviyesini koruması halinde ülkenin bütçe sosyal harcaması bu gelişmeden olumsuz etkileneceği öngörülmektedir. Rusya'nın toplam ihracat gelirlerinin petrole bağımlılığına ek olarak, bütçe gelirlerinde de petrol ve doğalgaz ile ilgili vergiler toplam gelirlerin \%50'sini oluşturmaktadır. Dolayısıyla, her ne kadar Rusya'nın mevcut kamu maliyesi verileri pozitif bir görünüm sergilese de, petrol kaynaklı gelirlerin azalması bütçe performansını olumsuz etkileyebilecektir. Rus yetkililer tarafından 2014 yılında denk bütçe için petrol fiyatlarının ortalama 114 USD/varil olması gerektiği varsayılmıştı. Ancak bütçenin fazlası vermesi neticesinde, 2014 yılı için 93 USD/varil seviyesindeki petrol fiyatının denk bütçe için yeterli olmuştur. 2015 yılı için ise, denk bütçeye ulaşabilmek amacıyla başa baş petrol fiyat1 90 USD/varil olarak hesaplanmaktadır. 2015 yılına ilişkin petrol fiyatı tahminlerinin ortalama 70-75 USD/varil civarında hesaplanmasına rağmen, yıllık $50 \mathrm{USD}$ /varil'in altındaki seviyelerin de görüldüğünden dolayı Rusya'nın bütçesi açık vermiştir. Yatırımcıların söz konusu gelişmeleri fiyatlamaya başlamaları ile Ruble'nin ABD doları karşısındaki değer kaybı hızlanmış ve USD/RUB kuru 2014-2016 yılları arasında iki kata yakın yükselmiştir. Rusya Merkez Bankası'nın Ağustos ayından itibaren döviz rezervlerinden 60 milyar USD kullanarak rublenin değerini korumaya çalışması hedeflenen etkiyi gösterememiştir. Rusya Merkez Bankası politika faiz oranını 650 baz puan artırarak \%10,5'ten \%17'ye yükseltmiş, faiz artışına ek olarak izleyen günlerde Gazprom'un da döviz satışı yapmasına rağmen USD/RUB kurundaki yükselişin önüne geçilmemiştir. 2014 yılındaki hızlı azalışa karşın, Aralık 2014 itibarıyla Rusya Merkez Bankası'nın 390 milyar USD ile yüksek miktarda döviz rezervine sahip olması dikkat çekmektedir. Bununla birlikte, söz konusu rezervlerin yaklaşık 170 milyar USD tutarındaki kısmının Merkez Bankası'nın serbest kullanımında olmayan fonlarda denk bütçe için gerekli gördüğü petrol fiyatıdır. Toplam ihracatın $\% 68$ 'i $\% 21$, petrol ürünleri $\% 14$, doğal gaz $\% 33$, ham petrol $\% 32$ diğer ürünler dolayısıyla petrol fiyatlarındaki düşüş ülke ekonomisini ciddi olarak etkilemiştir., Rusya'nın kullanılabilir durumdaki döviz rezervinin 200 milyar USD civarında olmasına rağmen, uluslararası kredi derecelendirme kuruluşu Standard \& Poor's Aralık 2014’te Rusya'nın kredi notunu negatif izlemeye aldığını açıklamıştır. S\&P karara gerekçe olarak, Rusya'da para politikasının esnekliğinde gözlenen hızlı bozulmayı ve ekonomik aktivitedeki zayıflamanın finans sistemi üzerindeki olumsuz etkisini göstermiştir. Aldığı tedbirlerle ek olarak, Rusya Merkez Bankası büyük ihracatçı şirketlere Dolar ve Euro cinsinden kredi sağlayarak bu şirketlerin dış borçlarının finansmanına yardım edeceğini açıklamıştır. Nitekim, aralarında Gazprom'un da bulunduğu beş büyük ihracatçı firmanın döviz cinsi varlıklarını Ekim 2014 seviyelerine çekecekleri ve Mart 2015'e kadar söz konusu varlıklarda artııma gitmeyecekleri açıklanmıştır(Ekonomi. İşbank, 2015).Petrol fiyatlarının seyrinin yanı sıra Ukrayna'ya ilişkin gelişmeler, 2015 ve 2016 yıllarında Rusya ekonomisinin performansına yönelik belirsizlikleri artırmaktadır. Rusya Merkez Bankası'nın faiz oranlarını artırmasına ve iç talepte beklenen daralmaya rağmen rubledeki değer kaybının ithal ürünlerin fiyatlarını artırması nedeniyle enflasyonun, 2014 sonunda \%9,2 ve 2015 sonunda \%11,2'ye yükselmiştir[10]. 2014 y1lında \%0,2 büyüme olan Rusya ekonomisinin, söz konusu varsayımlar altında 2015 yılında \%3,5, 2016 y1lında \%1,4 küçüleceği tahmin edilmektedir. Rubledeki değer kaybı ve Rusya Merkez Bankası'nın para politikasını sıkılaştırmasına bağlı olarak özel tüketim harcamalarının 2016 yılında reel bazda \%10 azalacağı tahmin edilmektedir. Finansal koşulların sıkılaşması ve reel sektörün güveninin azalması sonucunda toplam sosyal harcamalarının 2016 yılında reel bazda \%20 daralacağ tahmin edilmektedir. Öte yandan, net ihracatın ekonomideki küçülmeyi sınırlayacağ tahmin edilmektedir.2014 yılında Ukrayna krizinin yol açtığı bölgesel türbülans, Rusya'ya uygulanan yaptırımlar, rubledeki düşüş ile son çeyrekte ivme kazanan petrol fiyatlarındaki düşüşe maruz kalan Kazakistan ekonomisi, bunlara rağmen yılı yüzde 4,2 büyümeyle kapatt1. Ukrayna çevresindeki olaylarla ilgili olarak ülke ekonomisinde genel bir yavaşlamadan söz edilen bildiride, ABD Merkez Bankası'nın (Fed) parasal genişlemeye ilişkin aldığı pozisyonları ile son çeyrekte ivme kazanan dünya petrol fiyatlarındaki düşüş, bozulan dış etkenler arasında sayıldı. Kazakistan Hükümeti ve Merkez Bankası ortak bildirisinde, 2014 yılı Ocak-Ekim döneminde Kazakistan'ın dış ticaret cirosunun 2013 yılının aynı dönemine göre yüzde 8,3 azaldığı hatırlatılırken, kömür, demir, bakır, alüminyum kalemlerindeki ihracat hacminin düştüğü belirtildi. Söz konusu azalma dünya fiyatlarındaki düşüşle birlikte değerlendirildi. 2016 yılında rezervlerin erimesine önlem artırıldı ve ekonomide daralmaya gidildi. Ekonomi güvenliği ve mali sistem istikrarını tehdit eden harici şoklara karşı alınacak önemlere değinilen bildiride, 2015 yılında döviz piyasasına ilişkin kanunlarda değişiklik yapıldı. Kazakistan'ın 105 milyar dolar seviyesinde olan ulusal altın ve döviz rezervlerinin yeterli düzeyde kalmasının sağlanmaya devam edilmesi için 2016 yılı maliye politikasının bütçeyi dengelemeyi gözetlenmiş ve yatırım cazibesini azaltacak herhangi vergi politikası öngörülmemiştir. 2016 yılı ekonomi politikasının, olumsuz dış etkileri hafifletici ve ülkenin sosyo-ekonomik istikrarını güçlendirme amaçlı olmuştur. Bu karara göre manatın kuru ağırlıklı olarak döviz piyasasında talep ve teklifin oranını belirleyen temel faktörlerin etkisine göre oluşturulmuştur. Merkez Bankası döviz piyasasında katılımı ise bu rejime uygun yapmağa başlamıştır. Dünya piyasasında ham petrolün satış fiyatının 30-50 dolar seviyesine düşeceğini dikkate alarak, 
2016-2019 yılları için kamu ve icmal bütçe temel yönleri ve öncelikleri üzere iyimser (60 dolar olursa), taban (50 dolar olursa), kötümser (40 dolar olursa) senaryoları hazırlanmıştır. 2003-2016 yıllarında Petrol Fonu'ndan devlet bütçesine yapılan transferlerin toplam tutarı seksen milyar manattan fazla olmuştur. Genellikle bu transferin hacmi 2016 yılına kadar bütçenin yarıdan fazlası olmuştur. 2016 yılı bütçesinde petrol fiyatlarının azalmasından dolayı bu transferin hacmi önceki yıllardan\% 50 azalarak yedi milyar manat, yani yaklaşık 5 milyar dolar olmuştur. Azerbaycan'da finanse edilen kamu yatırım projeleri de dahil olmak üzere devlet bütçesi harcamaları azaltılmış ve Devlet Petrol Şirketi (SOCAR)-ın sermaye yoğun yatırım projeleri dondurulmuştur. Manatın devalüasyon sonrası, ülkenin dünya ekonomisindeki sıralamasında hızla düşmüştür. 2015 yılı sonu itibariyle Azerbaycan'da yıllık GSYİH kişi başına \$ 7986 seviyesinden \$ 3.490 seviyesine gerilemiş ve ülkenin milli geliri nominal bazda yüzde 60 azalmıştır. Fakat bu miktarın sadece $\$$ bazında olduğunu satın alma gücü paritesinde düşüşün daha az olduğunu vurgulamak gerekir. Özellikle hükümetin sıkı denetim politikalarıyla fiyat artışını engellemesi bu süreci biraz yavaşlatmıştır. Dikkat çeken diğer husus da şudur ki devalüasyon öncesi Azerbaycan'ın dış borcu GSYİH-nin \% 8.6 iken, 1 Ocak 2016 itibariyle dış borcun GSYİH'ye oranı \% 19.8 olmuştur. Petrol ihraç eden ülkeler içinde dış borcu en az olan ülkelerden olan Azerbaycan devalüasyon sonrası bu konuda bir hayli geriledi. Azerbaycan için, post-devalüasyon döneminde Devlet Petrol Fonu varlıklar (SOFAZ) GSYİH yaklaşık\% 50 den fazla olması onun petrole bağımlılı̆̆ının daha da fazla olduğunu göstermektedir. vardır yukarı (bu yıl GSYİH'nın\% 100'e yükselmesi bekleniyor 2014 yılında GSYİH'nın). Rusya ve Kazakistan için karşılaştırılabilir rakamlar sırasıyla\% 10 ve\% 35 iken Azerbaycan'ın GSYİH'nın neredeyse yarısı petrol sektöründen oluşur. 2004-2015 yılları arasında GSYİH büyümesi ortalama olarak Azerbaycan'da \%15, Rusya'da \%4 ve Kazakistan'da \% 7 olmasının esas etkeni Azerbaycan'da petrol ihraç hacminin artışı ve yükselen petrol fiyatı olmuştur. Rusya'nın emeklilik sistemini desteklemek amaciyla 2008 yılında oluşturulan Milli Refah Fonu'nda 1 Ocak 2016 itibariyle 80 milyar dolar (bu rakamın yüzde 97'si Ruble olarak tutuluyor), Rezerv Fonunda ise petrol ve gaz ihraç gelirlerinden oluşmuş 50 milyar \$ ve 180 milyar \$ Merkez Bankası rezerviyle ekonomik darboğazı 2-3 yıl erteleyecek kapasitededir. Kazakistan'ın Ulusal Fonu \$ 69 milyar dolar (GSYİH \% 30 ), Azerbaycan Devlet Petrol Fonu (SOFAZ) \$ 36 milyar (GSYH'nin \% 47) kaynak gelirlerinin biriktirildiği kaynakları 2016 yılından ciddi olarak düşüş eğilimindedir. Her üç ülkede enerji ihraç gelirlerin rezervleri 2016 yılının ilk çeyreğinde yüzde 10 kadar erise de halen finansal riskleri azaltır ve yakın gelecekte makroekonomik çöküşü önleyen en önemli "emniyet yastığıdır". Özellikle Azerbaycan'da 2015 yılında Merkez Bankası 9 milyar \$ harcamasına rağmen manatın değerini koruyamaması ve bir yılda iki kez devalüasyon sürecinde Merkez Bankasındaki döviz rezervlerinin yüzde 70-ni erittiğine göre 2016 yılında piyasanın döviz talebini kısmen Petrol Fonunun piyasaya sürdüğü dövizlerle karşılamaktadır. Her üç ülke 2016 bütçesinde daha evvel petrol fiyatı ayarlamasını varil başına \$ 50 olarak yasalaştırsalar da 2016 yılında yeniden bütçelerini revize etmiş Rusya ve Azerbaycan varil başına \$25, Kazakistan \$40 olarak yenilemiştir.

\begin{tabular}{|c|c|c|c|c|c|c|}
\hline \multirow{4}{*}{ 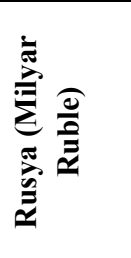 } & & 2012 & 2013 & 2014 & 2015 & 2016 \\
\hline & Eğitim & 2558 & 2888 & 3037 & 3635 & 3634 \\
\hline & Sağlık & 2283 & 2318 & 2532 & 2652 & 2662 \\
\hline & $\begin{array}{l}\text { Sosyal } \\
\text { Güvenlik }\end{array}$ & 7730 & 8397 & 8803 & 8842 & 8879 \\
\hline & \$-RUB kuru & $1 \$=31850 R$ & $\$=32512 \mathrm{RR}$ & $1 \$=38512 R R$ & $1 \$=61194 \mathrm{RR}$ & $1 \$=64194 \mathrm{RR}$ \\
\hline \multirow{3}{*}{ 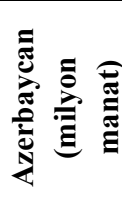 } & Eğitim & 1575.9 & 1530.4 & 1653.4 & 1711.2 & 1713.2 \\
\hline & Sağlık & 662.7 & 669.3 & 725.6 & 777.7 & 744,9 \\
\hline & $\begin{array}{l}\text { Sosyal } \\
\text { Güvenlik }\end{array}$ & 1781.6 & 1813.6 & 2072.2 & 2040.5 & 1896 \\
\hline & \$-AZN kuru & $1 \$=0.78 \mathrm{AZN}$ & $1 \$=0.78 \mathrm{AZ}$ & $1 \$=0.80 \mathrm{AZN}$ & $1 \$=1.17 \mathrm{AZN}$ & $1 \$=1.67 \mathrm{AZN}$ \\
\hline \multirow{4}{*}{ 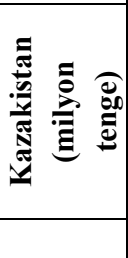 } & Eğitim & 1080600 & 1113100 & 1220100 & 1228000 & 1234000 \\
\hline & Sağlık & 631800 & 695400 & 744000 & 755200 & 764600 \\
\hline & $\begin{array}{l}\text { Sosyal } \\
\text { Güvenlik }\end{array}$ & 1146600 & 1253300 & 1429300 & 1583000 & 1587000 \\
\hline & \$-KZT kuru & $1 \$=182 \mathrm{KZT}$ & $1 \$=182 \mathrm{KZT}$ & $1 \$=185 \mathrm{KZT}$ & $1 \$=238 \mathrm{KZT}$ & $1 \$=335 \mathrm{KZT}$ \\
\hline
\end{tabular}

Tablo 4. 2011-2016 Yıllarında Ülkelerin Sosyal Bütce Harcamaları ve ABD \$ nın Ülke Paralarına Oranı (Yıl Ortalaması) Kaynak: Ülkelerin Istatistik Verilerine Göre Yazarlar Tarafindan Hazırlanmıştır

Her üç ülke en kısa zamanda devlet bütçelerinde azalan petrol fiyatlarından kaynaklanan olumsuz etkiyi azaltmak için ekonomileri çeşitlendirmesi gerekir. Ekonomilerinde sektör çeşitlendirerek alınacak vergiler ile petrol gelirlerinin azalmasını telafi etmek ve genel ekonominin petrol bağımlılığı azalta bilir. Başka bir öneri destek ve gümrük ve vergi ayrıcalıklı krediler ve reformlar yoluyla ülkedeki girişimciliği teşvik etmektir. Reformları yapmak için başlamış olsa da, gerçek sonuçlar ve reformların uygulanması üzerinde kontrol güçlendirilmelidir. 


\section{Sonuç}

Bu ülkelerde petrol sektörünün büyük oranı göz önüne alındığında, petrol fiyatlarının son yıldaki düşüşü hem ülkelerin sosyal-ekonomik harcamalarını, hem de milli paralarının yabancı paralara göre kurlarını etkilemiştir. Önemli oranda devalüasyonlar ve ya dolar karşısında değer kaybetmeler her üç ülkede 2016-yılı ekonomi politikalarını etkilemiştir. Azerbaycan ve Kazakistan petrol fonu rezervlerinin ve Merkezi Bankalarındaki döviz rezervini önemli miktarda kaybetmiştir. Aynı zamanda her üç ülkenin post-petrol dönemine yönelik bir sıra acil önlem paketinin gerçekleştirme zaruretini ortaya çıkarmıştır. Bu çalışmada 2015-2016 yılları arasında her üç ülkenin petrol fiyat düşüşlerinden dolayı ekonomik kayıpları ve bu kayıpların azaltılması yönünde ülkelerin attıkları ekonomik politikalar araştırılmıştır. Ayrıca "Hollanda sendromu" olarak adlandırılan tek bir sektöre bağlı kalmanın, fiyat düşüşleri ve ya kaynağın tükenmesi durumunda ülke ekonomisi için tehdit olmasını önleyici adımların önemi ve ihraçta farklı mal gruplarının olması için ülkelerin ihraç teşvik adımları araştırılmıştır. Her üç ülkede serbest piyasa ekonomisine geçiş, serbest piyasa ortamında yeniden yapılanma, kalkınma ve dünya ekonomisine entegrasyonu gerçekleştirmek amacıyla birçok önemli reformlara imza atmalarına, pek çok başarılı projelerle dünya ekonomisine entegrasyonda da önemli mesafeler almalarına rağmen, petrol fiyat dalgalanmaları serbest piyasa ekonomisinin daha etkin işleyişi adına ülkede atılması gereken adımlar, yapılması gereken reformlar ve çözümü gereken bazı sorunlar da acilen çözülmesi zaruretini ortaya çıkarmıştır. Herhangi önemli gelir türünde büyük dalgalanmaların görülmesi bütçeyi de eşitsiz ve riskli hale getirmektedir. Dolayısıyla bütçe gelirlerinin sektör çeşitlendirilmesine gidilmeli, ayrıca petrol ihracatçısı olan her üç ülkede bütçe gelirlerinin yapısı ve ekonominin kaynak gelirlerine bağlı olmadan yapılandırılması önemli mesele haline getirilmelidir. Buna göre ekonominin diğer verimli alanlarına yatırımları teşvik etmek ve diğer sektörlerde de sanayileşme sürecini hızlandırmak gerekir. Sektör çeşitlendirilmesine acil geçiş hâlihazırdaki durumda bütçe riskinin azaltılması ve daha stabil gelir kaynaklarının oluşturulması açısından en uygun çözüm olacağı düşünülmektedir. Her üç ekonomide maden endüstrisi ile birlikte işleme endüstrisini de geliştirmek için çok büyük olanaklar mevcuttur. Kazakistan'da yerli şirketlerin ekonomideki payını yükseltmek ve onları desteklemek amacıyla ülkeye yatırım yapan her bir yabancı şirkete herhangi yerel şirketle ortak hareket etmek ve kârı paylaşmak şartı konulmaktadır. Azerbaycan'da petrol sektörünün gelişimi ile ilgili uygulanan programlar bu yönde atılan adımlara örnektir. Bu adımların sonuç açısından etkinliğinin yükseltilmesine büyük ölçüde ihtiyaç duyulsa da gelecek için hesaplanan takdir edilecek durum olarak değerlendirilebilir. Genel olarak değerlendirildiğinde Rusya'da, 2006-2016 y1lları arasında toplam bütçedeki payı yüzde 20 olan güvenlik ve savunma harcamaları iki kat artarken, sosyal harcamalar aynı hızla artmamış ve 2016 yılında bu harcamalar artarken sağlık ve eğitim harcamalarına ayrılacak bütçe payı yüzde 8 , sosyal güvenlik harcamalarıysa yüzde 4 azalmıştır. Ham petrol fiyatları azalmaları maliye ve bütçe gelirlerinin azalmasına, dolayısıyla bütçedeki sosyal harcamaların da azalmasına ve aynı zamanda bütçe açığına neden olmuştur. Genel olarak her üç ülke hükümetleri 2016 yılında sosyal harcamaları kendi milli para birimine göre azaltmasalar da kamu yatırım harcamalarını azaltmayı planlıyorlar. Rusya Federasyonu'nda 2015-2017 dönemi yılı bütçe planlaması, son dönemde yaşanan olumsuz ekonomik gelişmelerin öncesinde yapıldı̆̆ 1 için bütçede revizyon yapılması ihtiyacı hasıl olmuştur. Bütçede yapılan revizyonda, 2015 yılı petrol fiyatları 50 dolar olarak baz alınmış (bütçenin ilk planlamasında petrol fiyatları 100 dolar olarak baz alınmıştı), ekonomideki küçülme \%3 olarak öngörülmüş ve ruble/dolar kuru ise 61,5 olarak revize edilmiştir (bütçenin ilk planlamasında baz alınan ruble/dolar kuru: 37,7). Revize edilen bütçeye göre, bütçe gelirleri yaklaşık \%17 azalarak 15, 1 trilyon rubleden 12,5 rubleye düşürülmüş, bütçe giderleri ise 15,2 trilyon ruble olarak öngörülmüştür. Bütçedeki revizyon sonrasında, bütçe açığının GSYİH'ye oranının \%3,7 (2,7 trilyon Ruble) olması öngörülmektedir. Bütçeye göre Rusya'nın 2016 yılında 13 trilyon 738 milyar ruble gelir elde etmesi, 16 trilyon 98 milyar ruble harcama yapılması ve 2 trilyon 360 milyar ruble (veya gayrisafi yurt içi hasılanın \%3’ü) bütçe açığı vermesi bekleniyor. 2016 yılı tahminlerine göre GSYİH'de \%0,7 oranında büyüme beklenmektedir. Rusya Kazakistan ve Azerbaycan'da Ocak 2015 'ten bu yana petrol ve gaz gelirleri petrol fonlarına değil de, bütçeye aktarıldığı için bu fonlar giderek küçülmektedir. Bu kriz ortamında hükümet bu fonlardaki parayı da kullanabilir. Her üç ülke 2016 yılında bütçe harcamalarını nominal olarak 2015 seviyelerinde korusalar da dolar bazında harcamalar yarıya kadar azalmıştır. Özellikle Rusya'da savunma harcamaları bilim, sağlık ve eğitim harcamalarının azalmasına karşılık yükselmeye devam etmesi ekonomi otoriteleri tarafından eleştirilmektedir. Çünkü emekli maaşlarını yüzde 20 enflasyon ortamında yüzde 4 ilk baharda ve sonbaharda daha 4 oranında artışına rağmen reel olarak önceki yılın altına gerilemiştir. Eğitim, sağlık ve sosyal harcamaların \% 7.3 artmasına rağmen savunma harcamaları 2015 yılına göre $21.4 \%$ artması Rusya'nın ekonomi politikasının olumsuz nüanslarındandır.

\section{Kaynakça}

- $\quad$ Aras, O. N."Azerbaycan'ın hazar ekonomisi ve stratejisi"Der Yayınları, 2007

- $\quad$ Aras, O. N, \&Süleymanov, E."Azerbaycan İqtisadiyyatı"Şark-Garb Matbaası, Bakü, 2016

- Aras, O.N, Suleymanov, E. Huseynov, R"The Importance of Azerbaijan's Energy Revenues in its Exports Volume and the Effects on the National Economy" International Journal of Business and Social Science 4 No 6 June 2013, 79-87 
- Şimşek, A."Devalüasyonu Sonrası Kazakistan Ekonomisi Üzerine Gözlemler -1" Ekonomi, Finans ve Enerji Araştırma GrubuŞubat 2014

- British Petroleum "Statistical Review of World Energy" 2015.

- $\quad$ Bulut,C.Suleymanov,E."Azerbaycanin Hollanda Hastaliği Problemini Önleme Stratejilerinde Türkiye Ile Yapilan Ekonomik Ilişkilerin Önemi" International Symposium on Regional Cooperation and Development on October 17-20, 2012 (Erzurum, Turkey) http://dx.doi.org/10.2139/ssrn.2172960

- $\quad$ Bulut, C. , Hasanov,F. Suleymanov,E. Post-Sovyet Petrol İhraç Eden Ülkelerde Petrol Gelirlerinin Yaşam Standartlarına Etkisi International Conference on Eurasian Economies, July 2014 Available http://dx.doi.org/10.2139/ssrn.2463409

- Petrol Fiyatlarındaki Düşüşün Nedenleri ve Etkileri İktisadi Araştırmalar Bölümü Ocak 2015 https://ekonomi.isbank.com.tr/UserFiles/pdf/ar_01_2015.pdf

- Thomson Reuters Datastream

- Trademap

- U.S. Energy Information Administration

- Uluslararası Enerji Ajansı (2015). "World Energy Outlook 2014"

- Uluslararası Para Fonu "Dünya Ekonomik Görünüm Raporu - Ekim 2015"

- http://www.tradingeconomics.com

- Rusya Federasyonu Devlet İstatistik Kurumu resmi web sitesi http://www.gks.ru/

- Kazakistan Cumhuriyeti Devlet İstatistik Kurumu resmi web sitesi http://www.stat.gov.kz/

- Azerbaycan Cumhuriyeti Devlet İstatistik Kurumu resmi web sitesi http://www.stat.gov.az/ 


\title{
Sağlık Sektöründe Kurumsal Sürdürülebilirlik Yönetimi ve İstanbul Avrupa Yakasında Faaliyette Bulunan Hastanelerde Bir Araştırma
}

\section{Institutional Sustainability Management in the Health Sector and a Research on the Hospitals in European Side of İstanbul}

\author{
Asst. Prof. Dr. Kerem Toker (Beykent University, Turkey) \\ Asst. Prof. Dr. Fadime Çınar (Beykent University, Turkey)
}

\begin{abstract}
In 1987, The World Commission on Environment and Development report on our Common Future formulated the definition of sustainable development and put forward the issue that caused the conflict between environment and development (Harris, 2000). It was proposed for the first time that the use of the concept of sustainable development, which is the most common today, (WCED, 1987), is the expression of "the ability to supply today's needs and expectations without compromising the ability of future generations to supply their needs and expectations" (Akgül, 2010). Today, sustainability means that businesses should not only create economic value but also be involved in activities that facilitate and improve living conditions (Caymaz, etc., 2014). Within the globalizing economy, the health sector is one of the most important sectors that have taken human life as a focus. The survey examined whether the governance processes of private and public-sector hospitals in European Side of Istanbul are in line with sustainable policies, and if so, what kind of policies they take. In order to be able to conduct the examination, data were collected from the hospitals through the sustainability questionnaire and statistically analyzed in the obtained computer environment. The findings show that the sustainable environmental policy implementations of hospitals are not at the desired level. Sustainable social policies are also at a high level of implementation. The research showed that; it is necessary to increase the awareness level of hospital administrations on sustainability.
\end{abstract}

\section{Giriş}

Ekonomik, sosyal ve çevresel boyutu olan sürdürülebilir kalkınma, ilk başlarda sadece ülkeleri ve politikalarını kapsayan bir kavram olarak karşımıza çıkarken daha sonraki yıllarda gerçekleştirilen konferanslarda sorumluluğun diğer paydaşlarda da olduğu konusu gündeme gelmiştir (Engin ve Akgöz, 2013). Bu bağlamda işletmeler faaliyetlerini gerçekleştirirken kar sağlamanın yanı sıra toplumsal fayda ve süreklilik sağlamak amacını taşıyarak plan ve projelerini bu amaçla gerçekleştirmektedirler. Bu nedenle işletmeler, hisse sahipleri, iş görenler, toplum, çevre, müşteriler ve ekonomi gruplarına karşı sorumludurlar (Yıldırım ve Uğuz, 2013). Buradan hareketle, kurumsal sürdürülebilirlik, bir ülke içerisinde yer alan ve ekonomik bir amaca sahip kurumların, geleneksel büyüme kuramlarına bir alternatif olarak geliştirilen maddi manevi her türlü riski minimize etmeyi sağlayarak kurumları geleceğe daha sağlıklı aktarmayı hedefleyen bir yönetim anlayışı olarak tanımlanabilir (Kuşat, 2012). $\mathrm{Bu}$ bağlamda, günümüzün hizmet sektörlerinin başında gelen sağlık sektörünün sürdürülebilirlik konusunda uygulamaları, ülke refahının arttırılması ve korunması açısından son derece önemlidir.

\section{Kurumsal Sürdürülebilirlik ve Sağlık Sektörü}

Sürdürülebilirlik anlayışını benimseyen günümüzde birçok işletme, insanı, dünyayı ve kazançlarını dikkate alarak sosyal, çevreyle ilgili ve ekonomik performansları arasında bir denge gözetme yoluna gitmektedir. İşletmeler, kritik performans ölçütlerini sürdürülebilir kalkınma paradigması ile yeniden değerlendirerek kurumsal karar verme süreçlerine işlerlik kazandırmaktadır (Toker, 2017). Sancar'a (2013) göre işletmelerin daha sorumlu davranma gerekliliği, onların her zaman müşterilerinin memnuniyetsizlikleri ve aktivistlerin protestoları ile karşılaşabilme ihtimallerinden kaynaklanmaktadır. Bu nedenle küresel dünyanın işletmeleri kapalı bir sistem değil aksine açık ve hesap verebilir konumda olmak zorundadırlar.

Sürdürülebilir Ekonomi: Kârlılık temelinde ekonomik performans bir işletmenin temel göstergelerinden biridir. İşletmelerin uzun dönemde başarılı olabilmesi, rekabet edebilmesi ve ayakta kalabilmesi kârını bulundukları sektör ortalamasının üzerinde tutmalarına bağlıdır (Şişman vd., 2016). Bununla birlikte günümüzde işletmeler sadece ekonomik sorumluluklarını yerine getirerek varlık gösterememektedir. Çevreleriyle ve toplumla olan ilişkileri onları daha 'görünebilir' ve 'gözlemlenebilir' olmaya zorlamaktadır (Engin ve Akgöz, 2013). O halde ekonomik sürdürülebilirlik, olumlu sosyal ve çevresel sonuçların elde edilmesini sağlarken, aynı zamanda kıt kaynakların tahsisi ve korunması süreci olarak daha iyi tanımlanabilir (Doane ve MacGillivray, 2001).

Sürdürülebilir Çevre: Günümüzde çevre sorunları yaşam alanlarını ve insan hayatını tehdit eden önemli bir problem olarak karşımıza çıkmaktadır. Çevre kirliliğinin insan yaşamı üzerindeki olumsuz etkileri, su ve hava 
kirliliği, ozon tabakasının incelmesi, biyolojik zenginliklerin azalması, iklimin değişmesi, denizlerin kirlenmesi gibi geri kazanılamayan kayıplara yol açmakta, insanların sağlığını olumsuz etkilemekte, kültür varlıklarını da tehdit etmektedir (Tuğun ve Karaman, 2014). Balcı ve Koçak, (2014) çevresel sürdürülebilirliği, kurum ve kuruluşların üretimlerinde ve tesis planlamalarında, atıkları ve zararlı salınımları en aza indirmek, kaynakların kullanımında verimliliği artırmak ve ülke kaynaklarından gelecek nesillerin üst düzeyde yararlanmasını sağlamak şeklinde ifade etmiştir.

Sürdürülebilir Toplum: Sosyal sürdürülebilirlik toplumsal homojenlik, adil gelir dağılımı, mal, hizmet ve istihdama adil erişim gibi bir dizi toplumsal unsurları içermektedir (Vallance vd., 2011). Şahin ve Kutlu (2014) sürdürülebilirliğin sosyal boyutunun temel olarak eşitlik kavramı çerçevesinde şekillendiğini ve insan hakları, toplumsal cinsiyet eşitliği, sağlık ve sosyal hizmetlere erişim gibi konuları içerdiğini belirtmiştir. Dempsey ve arkadaşları (2011) ise sürdürülebilir toplulukları, insanların şimdi ve gelecekte çalışmayı veya yaşamaya isteyecekleri yerler olarak tanımlamıştır.

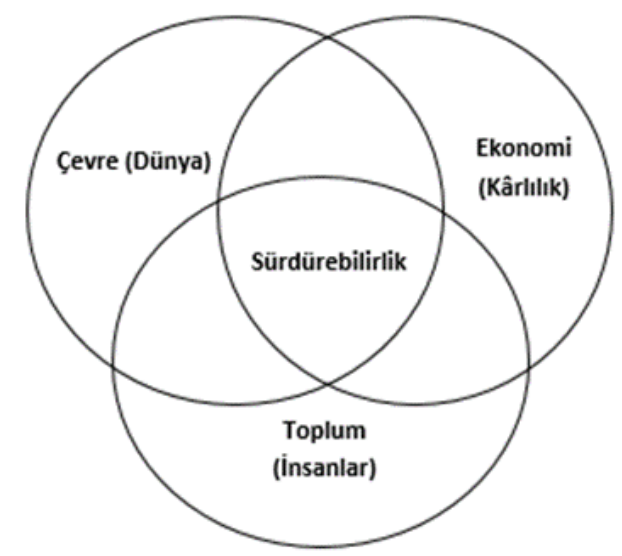

Şekil 1. Kurumsal Sürdürülebilirliğin Üç Boyutu Kaynak: Fauzi H., Svensson, G. \& Rahman, A.A. (2010). "Triple Bottom Line" as "Sustainable Corporate Performance": A Proposition for the Future. Sustainability, (2), 1345-1360.

Ülkelerin sosyo-ekonomik açıdan kalkınmışlık düzeylerinin en önemli göstergelerinden birisi de sağlık hizmetleridir (Tutar ve Kılınç, 2007). Gelişmiş ekonomilerde, sağlık sektöründe mal ve hizmet üretimi, GSYİH'nin \% 7'sine ulaşmakta ve bu sektörde istihdam oranı \% 10'dur. Toplam sağlık harcamasının GSYİH'ye oranının 2020 'de \%16'ya yükseleceği hesaplanmaktadır (Çınar ve Eren, 2015). Sürdürülebilirlik konusu sağlık sektörü açısından ele alındığında Türkiye'de sağlık sektörü; erişebilirliğin artması ve olumlu ekonomik gelişmeler neticesinde artan satın alma gücü gibi etkenler ve son yıllarda sektöre ilişkin gerçekleşen destekleyici gelişmelere paralel olarak büyümektedir. İlaç, hizmet sunumu, sigorta ve tıbbi cihazlar gibi alt sektörler bazında bakıldığında dünya genelinde önemli bir noktaya gelindiği görülmektedir (Yased, 2012). TÜİK 2015 verilerine göre Türkiye genelinde yataklı ve yataksız olmak üzere toplam 30.449 sağlık kurumu bulunmaktadır.

\begin{tabular}{|c|c|c|c|c|c|}
\hline & Yataklı & & & Yataksız & Toplam \\
\hline Sağlık Bakanlığı'na Bağlı & Üniversite & Özel & Diğer* & & \\
\hline 865 & 70 & 562 & 36 & 28.916 & 30.449 \\
\hline
\end{tabular}

Tablo 1. Türkiye'deki Yataklı ve Yataksız Sağlık Kurumları Sayısı, Kaynak: TÜIK (2015)

Tutar ve Kılınç (2007), sağlık ekonomisinin gelişiminde, sağlık sektörünün giderek daha fazla kaynak kullanılan bir sektör olmasının önemli rol oynadığını ifade etmiştir. Bu bağlamda sağlık sektöründe faaliyette bulunan kurumların ekonomik, sosyal ve çevre açıdan sürdürülebilir politikalara sahip olması ve bu politikaları uygulaması, ülke ekonomisini ve toplum refahını yükseltici etkilere neden olacaktır. Sağlık sektöründe kamu ve özel sektör olmak üzere iki farklı sahiplik biçimine sahip kuruluşların faaliyette bulunması, yönetim süreçlerinde sosyal ve kâr amaçlarının birbirine karışıp belirsizleşmesine neden olabilmektedir. Bu yüzden sağlık sektörü kuruluşlarının faaliyetlerinin sürdürülebilirlik çerçevesinde yapılandırılması ve kontrol mekanizmalarının kurularak standartların oluşturulması ülke kalkınmasında önemli rol oynamaktadır. 


\section{3 İstanbul Avrupa Yakasında Faaliyette Bulunan Hastanelerde Sürdürülebilirlik Yönetimi Ölçümü}

Sürdürülebilirlik ve sağlık sektörü ile ilgili yukarıda değinilen açıklamalardan sonra, sağlık sektöründe faaliyette bulunan kurumların sürdürülebilirlik uygulamalarının kapsam ve ölçümüne yönelik bir araştırma gerçekleştirilmiştir.

\subsection{Araştırmanın Amacı ve Önemi}

Araştırmanın amacı, günümüz ülke ekonomisi içerisinde önemli bir paya sahip olan sağlık sektöründe faaliyette bulunan kurumların sürdürülebilirlik uygulamalarını ne düzeyde gerçekleştirdiğini saptamaktır. Elde edilen sonuçlar bağlamında sağlık kurumlarının sürdürülebilirlik konusunda ne düzeyde duyarlı olduklarını tespit edilecek ve böylece yetersiz kalınan faaliyet alanları için iyileştirme çalışmaları yapılabilecektir. Sağlık kurumlarının sürdürülebilirlik konusunda gösterecekleri hassasiyet ülke ekonomisinin gelişimine ve toplumsal refaha doğrudan pozitif katkılar sağlarken aynı zamanda gelecek kuşaklara daha yaşanabilir bir ülke bırakmanın zeminini hazırlayacaktır.

\subsection{Araştırmanın Kapsamı}

Araştırma kapsamında İstanbul'da Avrupa Yakasından faaliyette bulunan kamu ve özel sektör hastaneleri incelenmiştir. İstanbul, Türkiye'nin nüfus ve ekonomi açısından en büyük ili olması nedeniyle temsil kabiliyeti yüksek illerimiz arasında yer almaktadır. Tablo 2, İstanbul'da faaliyette bulunan sağlık kuruluşlarının sayısını ve dağılımını göstermektedir.

\begin{tabular}{|c|c|c|c|c|c|}
\hline & Yataklı & & & Yataksız & Toplam \\
\hline Sağlık Bakanlığı'na Bağlı & Üniversite & Özel & Diğer* & & \\
\hline 51 & 15 & 159 & 3 & 23.345 & 23.573 \\
\hline
\end{tabular}

Tablo 2. Istanbul'daki Yataklı ve Yataksı Sağlık Kurumları Sayısı Kaynak: www.istanbulsaglik.gov.tr

\subsection{Araştırmanın Yöntemi}

Sağlık kuruluşlarının sürdürülebilirlik konusunda bilgi düzeylerini ve uygulamalarını ölçmek için Aly ve Mansour (2017) tarafından geliştirilen sürdürülebilirlik performans ölçeğinin sosyal ve çevreye yönelik olan kısımları yazarlar tarafından sağlık sektörüne uyarlanmıştır. Anket yöntemi ile elde edilen veriler, SPSS 20 istatistik programına girilmiştir. Veri giriş işleminden sonra öncelikle araştırmaya dâhil olan sağlık kurumlarındaki yöneticilerin tanımlayıcı istatistikleri ortaya konulmuştur. Tanımlayıcı istatistiksel analizin ardından kurumların sürdürülebilirlik uygulamalarının düzeyini ve uygulamalarda kamu / özel sektör ayrımının olup olmadığı test etmek için "bağımsız örneklem t testi” analiz tekniğinden yararlanılmıştır.

\subsection{Araştırmanın Sınırlılıkları}

Araştırmada kullanılan veriler, Türkiye'nin İstanbul ilinde faaliyette bulunan 3'ü kamu ve 2'si özel hastane olmak üzere toplam 5 hastanede çalışan toplam 142 yöneticiye uygulanan anket çalışması ile elde edilmiştir. Bu bağlamda araştırma sonucunda elde edilen bulgular sadece araştırmaya katılan hastaneler için yorumlanabilir. Bununla birlikte sağlık sektörü, özel poliklinikler, muayenehaneler, laboratuvarlar, görüntüleme merkezleri vb. hastane dışında birçok küçük ve orta ölçekli kuruluşların da içinde faaliyette bulunduğu bir sektördür, Bu nedenle, gelecek araştırmaların anılan kuruluşları da kapsayacak şekilde ve daha geniş bir coğrafi alanda yapılması, elde edilecek bilimsel sonuçların bütün sektöre yönelik yorumlanması açısından daha anlamlı olacaktır. Araştırmanın bir başka sınırı ise, araştırmaya dâhil olan hastanelerin sadece sürdürülebilir sosyal ve sürdürülebilir çevre faaliyetlerinin incelenmiş olmasıdır. Sürdürülebilirliğin ekonomik boyutu araştırmaya dâhil edilmemiştir. Bunun nedeni ise araştırma evreni içerisinde yer alan hastanelerin sermaye yapılarının kamu ve özel sektör olmak üzere birbirinden çok farklı dinamiklere sahip yapılar olmasıdır. Bu farklı sermaye yapılarının birbirinden farklı ekonomik motivasyonları olacağı gerekçesiyle, iki yapının ekonomik bağlamda karşılaştırılması bilimsel olarak anlamlı görülmemiştir.

\subsection{Analiz ve Bulgular}

Araştırmanın konusu olan hastanelerin sürdürülebilirlik yönetimi ile ölçek İstanbul'un Avrupa yakasında faaliyette bulunan 2 kamu ve 3 özel olmak üzere toplam beş hastanede uygulanmıştır. Araştırmaya katılan toplam 142 yönetici pozisyonundaki cevaplayıcının demografik bilgileri Tablo 3 'te gösterilmiştir. 


\begin{tabular}{|c|c|c|c|c|c|}
\hline \multirow{3}{*}{ Cinsiyet } & Kadin & 70 & \multirow{3}{*}{ Çalışılan Hastane } & Kamu & 75 \\
\hline & Erkek & 72 & & Özel & 57 \\
\hline & Toplam & 142 & & Toplam & 142 \\
\hline \multirow{5}{*}{ Yaş } & $21-30$ & 18 & \multirow{5}{*}{ Öğrenim Durumu } & Lise & 3 \\
\hline & $31-40$ & 53 & & Önlisans & 19 \\
\hline & $41-50$ & 57 & & Lisans & 61 \\
\hline & 51 ve üzeri & 14 & & Lisansüstü & 59 \\
\hline & Toplam & 142 & & Toplam & 142 \\
\hline \multirow{5}{*}{$\begin{array}{c}\text { Kurumda } \\
\text { Çalıştığı Pozisyon }\end{array}$} & Şef & 4 & \multirow{5}{*}{$\begin{array}{c}\text { Kurumda Çalışma } \\
\text { Süresi }\end{array}$} & $1-5$ y1l & 52 \\
\hline & Alt Kademe Yön. & 27 & & $6-10 \mathrm{y} 1 \mathrm{l}$ & 70 \\
\hline & Orta Kademe Yön. & 78 & & $11-15$ y1l & 14 \\
\hline & Üst Kademe Yön. & 33 & & 16 y1l ve üzeri & 6 \\
\hline & Toplam & 142 & & Toplam & 142 \\
\hline
\end{tabular}

Tablo 3. Araştırmaya Katılan Cevaplayıcıların Demografik Özellikleri

Tablo 3'te görüldüğü gibi araştırmaya 70'i kadın, 72'si erkek olmak üzere toplam 142 hastane çalışanı katılmıştır. Söz konusu cevaplayıcıların 75'i kamu hastanesinde, 57'si ise özel hastanede çalışmaktadır. Aynı zamanda cevaplayıcıların 3'ü lise mezunu, 19'u önlisans, 61'i lisans ve 59'u lisansüstü öğrenim derecesine sahiptir. Cevaplayıcıların 4'ü şef pozisyonunda, 27'si alt kademe yönetici, 78'i orta kademe yönetici ve 33'ü üst düzey yönetici pozisyonunda çalışmaktadır. Elde edilen bulgular, eğitim bilgileri ile birlikte değerlendirildiğinde çalışanların entelektüel birikimleri ve çalıştıkları pozisyonlar itibariyle sürdürülebilirlik politikalarını değerlendirmeye yeterli olduklarını göstermektedir. Bütün bunlara ek olarak cevaplayıcıların 52'si kurumda 1-5 yıl, 70'si 6-10 yıl, 14'ü 11-15 yıl ve 6'sı ise 16 yıl ve üzeri çalışmaktadır. Bu bulgu ise, cevaplayıcıların çalıştıkları kurumdaki iş süreçlerini değerlendirebilecek kıdeme sahip olduklarını göstermektedir.

Araştırmanın temel problemi olan hastanelerde sürdürülebilirliğin çevre ve sosyal boyutlarının uygulama düzeylerinin, kamu / özel sektör ayrımında farklılık gösterip göstermemesini ölçmeye yönelik yapılan analizler ise Tablo 4'te gösterilmiştir.

\begin{tabular}{llllll}
\hline Sürdürülebilirlik Boyutu & Hastane & $\mathbf{N}$ & $\overline{\boldsymbol{X}}$ & $\mathbf{t}$ & $\mathbf{p}$ \\
\hline \multirow{3}{*}{ Çevre } & Kamu & 75 & 2,9390 &,- 598 &, 551 \\
\cline { 2 - 6 } & Özel & 57 & 2,8955 & & \\
\end{tabular}

Tablo 4. Hastanelerin Sahiplik Yapısına Göre Sürdürülebilirliğin Çevre Boyutunu Ölçmeye Yönelik t Testi Sonucu

Tablo 4’te görüldüğü gibi hastanelerin sahiplik yapısı ile sürdürülebilirliğin çevre uygulamaları arasında anlamlı bir fark görülmemiştir $\left(\mathrm{t}_{-598}=, 551>0,05\right)$. Bununla birlikte kamu hastaneleri sürdürülebilirliğin çevre boyutuna yönelik uygulamalar için 2,9390 ortalama değer ve özel hastaneler ise 2,8955 ortalama değer almıştır $(1 \leq X \leq 5)$. Elde edilen bulgular, hem kamu hastanelerinin hem de özel hastanelerin sürdürebilirliğin çevre boyutu ile ilgili politikaları uygulama düzeylerinin arzu edilen seviyede olmadığını göstermektedir.

\begin{tabular}{lllllll}
\hline Sürdürülebilirlik Boyutu & Hastane & $\mathbf{N}$ & $\overline{\boldsymbol{X}}$ & $\mathbf{t}$ & $\mathbf{p}$ \\
\hline \multirow{2}{*}{ Sosyal } & Kamu & 75 & 3,8472 & 1,231 &, 221 \\
\cline { 2 - 7 } & Özel & 57 & 3,9836 & & & \\
\hline
\end{tabular}

Tablo 5. Hastanelerin Sahiplik Yapısına Göre Sürdürülebilirliğin Çevre Boyutunu Ölçmeye Yönelik t Testi Sonucu

Tablo 5 ise, hastanelerin sahiplik yapısı ile sürdürülebilirliğin sosyal uygulamaları arasında anlamlı bir fark olmadığını göstermektedir $\left(\mathrm{t}_{1,231}=, 221>0,05\right)$. Bununla birlikte kamu hastaneleri sürdürülebilirliğin sosyal boyutuna yönelik uygulamalar için 3,8472 ortalama değer ve özel hastaneler ise 3,9836 ortalama değer almıştır $(1 \leq X \leq 5)$. Elde edilen bulgular, hem kamu hastanelerinin hem de özel hastanelerin sürdürebilirliğin sosyal boyutu ile ilgili politikaları uygulama düzeylerinin, çevre boyutuna göre daha yüksek olduğunu göstermektedir. Bu durum, hastanelerin öncelikli misyonlarının toplumsal hizmet olmasından ve bu yüzden iş süreçlerinde sosyal konulara daha duyarlı yaklaşıyor olmalarından kaynaklanabilir. Araştırmada sürdürülebilirliğin ekonomik boyutu, kamu hastaneleri ile özel hastanelerin karşılaştırılması noktasında adil olmayacağı gerekçesiyle yazarlar tarafından analiz dişı tutulmuştur. 


\section{Sonuç}

Artan dünya nüfusuna paralel olarak üretim ve tüketim süreçlerinde yaşanan artış, doğal kaynakların hızla tükenmesi, işsizlik, yoksulluk, kirlilik ve hastalık gibi birçok ekonomik, sosyal ve çevreye yönelik problemi beraberinde getirmektedir. Yaşanan söz konusu problemler, kamu sektörünü ve özel sektörü şimdiki ve gelecek kuşaklara yaşanabilir bir dünya bırakması için mal ve hizmet üretim faaliyetlerinde sürdürülebilir politikalar uygulamaya zorlamaktadır. Ülkelerin içinde bulundukları ekonomik yapı içerisindeki en önemli sektörlerden biri de sağlık sektörüdür. Sağlık sektörü gerek milli gelir içinde aldığı pay, gerekse ülkenin ekonomik ve sosyal refahına yaptığı katkı nedeniyle, yaşanabilir bir dünyanın kurulması konusunda üzerinde en çok görev düşen sektörlerden biridir. Bu yüzden sağl1k sektörü yöneticilerimin yönettikleri kurumlarda sürdürülebilir politikalar uygulama sorumlulukları son derece önemlidir. Bu araştırmada Türkiye'de İstanbul ilinin Avrupa yakasında faaliyette bulunan hastanelerin yöneticilerinin kurumlarında uyguladıkları sürdürülebilirlik politikalarının düzeyinin ölçülmesi hedeflenmiştir. Bu amaçla, 2 kamu hastanesi ve 3 özel hastanenin yöneticilerine Aly ve Mansour'un (2017) çalışmasından uyarlanan sürdürebilirlik performans ölçeği uygulanmıştır. Elde edilen bulgular, sürdürülebilirlik politikalarının çevre ve sosyal boyutunun uygulanmasında kamu ve özel hastaneler arasında istatistiksel olarak anlamlı bir fark olmadığını göstermiştir. Bununla birlikte hastanelerin sürdürülebilir çevre politikalarını uygulama düzeylerinin, sürdürülebilir sosyal politika uygulama düzeylerinden daha düşük olduğu saptanmıştır. Aynı zamanda, sürdürülebilirliğin üçüncü boyutu olan ekonomik boyut bu araştırmada analiz kapsamının dışında tutulmuştur. Araştırma sonuçları, hastanelerin çevrenin korunması ve geliştirilmesine yönelik uygulamalarını arttırması gerektiğini ortaya koymuştur. Örnek kütlede yer alan hastaneler, sürdürülebilir sosyal politikaların uygulanması konusunda ise daha duyarlıdır. Sağlık sektörünün temel yetenekleri arasında toplumun sosyal refahına arttırmaya yönelik nitelikler olmasının araştırmada böyle bir sonucun ortaya çıkmasında etkili olduğunu düşündürmektedir. Araştırma sonuçları anket uygulamasının yapıldığı beş hastane ile sınırlıdır. Daha kapsamlı sonuçlar elde edilebilmesi için örneklemin Türkiye genelinde genişletilmesi ve sürdürülebilirliğin ekonomik boyutunun araştırmaya dâhil edilmesi, yazarlar tarafından gelecek araştırmacılara önerilmektedir.

\section{Kaynakça}

- Akgül, U. (2010). “Sürdürülebilir Kalkınma: Uygulamalı Antropolojinin Eylem Alanı”, Antropoloji Dergisi. 24, 133-164.

- $\quad$ Aly, A.H. \& Mansour, M.E. (2017). "Evaluating the Sustainable Performance of Corporate Boards: The Balanced Scorecard Approach”, Managerial Auditing Journal, 32(2), 167-195.

- $\quad$ Balcı, V. \& Koçak, F. (2014). "Environmental Sustaınability In The Design And Use of Sports And Recreation Areas", Journal of Sports and Performance Researches, 5(2), 46-58.

- Caymaz, E., Soran, S. \& Erenel, F. (2014). "The Relationship Between Corporate Sustainability And Corporate Social Responsibility In Business: Global Compact Turkey”, Journal of Management, Marketing and Logistics. 1(3), 208-217.

- Çankaya, S.Y. \& Sezen, B. (2015). "Moderator Effect of Environmental Uncertainty On The Relationship Between Ecologic Innovation And Sustainability Performance”, Int. Journal of Management Economics and Business, 11(24), 111-134.

- Çınar, F. \& Eren, E. (2015). “Organizational Learning Capacity Impact on Sustainable Innovation: The Case of Public Hospitals. 3rd International Conference on Leadership, Technology and Innovation Management”, Procedia - Social and Behavioral Sciences (181), 251 - 260.

- Dempsey, N., Bramley, G., Power, S. \& Brown, C. (2011). "The Social Dimension of Sustainable Development: Defining Urban Social Sustainability”, Sustainable Development, (19), 289-300.

- Doane, D. \& MacGillivray, A. (2001). "Economic Sustainability: The Business of Staying in Business", The SIGMA Project, R\&D Report.

- $\quad$ Engin, E. \& Akgöz, B.E. (2013). “An Evaluation Of Corporate Social Responsibilty Within The Framework Of Sustainable Development And Corporate Sustainability”, Selçuk İletişim, 8(1), 85-94.

- Fauzi H., Svensson, G. \& Rahman, A.A. (2010). “"Triple Bottom Line” as "Sustainable Corporate Performance": A Proposition for the Future" Sustainability, (2), 1345-1360.

- Gür, B. (2012). "Sustainable Development, Corporate Social Responsibility, And The Micro Finance Practices In Turkey”, İstanbul Ticaret Üniversitesi Sosyal Bilimler Dergisi, (11)21, 87-106.

- Harris, J.M. (2000). Basic Principles of Sustainable Development. Global Development and Environment Institute Working Paper: 00-04, [Çev: Emine Özmete] Tufts University, USA.

- İstanbul'da Sağlık 2015, http://www.istanbulsaglik.gov.tr/w/anasayfalinkler/belge/istanbulda_saglik_2015_faaliyetleri.pdf [Erişim Tarihi: 02.04.20147] 
- Kurnaz, N. \& Kestane, A. (2016). "Investigation of Corporate Sustainability In Economic Perspective And Investor Behavior Relationship: An Application of Bist Sustainability Index", Sosyal Bilimler Dergisi, (49), 278-303.

- Kuşat, N. (2012). “Organizational Sustainablity For Sustainable Corporations And Its Endogenous Determinants”, Afyon Kocatepe Üniversitesi, IIBF Dergisi, 14(2), 227-242.

- Onay, A. (2015). "Sustainable Develeopment, Corporate Sustainability and Sustainability Reporting", Electronic Journal Of Occupational Improvement And Research, Iwcea Özel Sayısl, (3), 104-118.

- $\quad$ Öztel, A., Köse, M.S. \& Aytekin, İ. (2012). "Kurumsal Sürdürülebilirlik Performansının Ölçümü İçin Çok Kriterli Bir Çerçeve: Henkel Örneği”, Journal of History Culture and Art Research, 1(4), 32-44.

- Sancar, G.A. (2013). "Kurumsal Sürdürülebilirlik Bağlamında Kurumsal Yönetişim: Kavramın Doğuşu, Gelişimi Ve Değerlendirilmesi”, Selçuk İletişim, 8(1), 71-84.

- Seydioğulları, H.S. (2013). "Renewable Energy for Sustainable Development”, Planlama, 23(1), 19-25.

- Sünnetçioğlu, S. \& Yılmaz, B.S. (2015). "Evaluation of Restaurant Managers' Approaches to the Sustainable Restaurant Management Concept: Case of Izmir”, Karabük Üniversitesi Sosyal Bilimler Enstitüsü Dergisi, 5(1), 94-114.

- $\quad$ Şahin, İ. \& Kutlu, S.Z. (2014). “Cittaslow: An Assessment From The Perspective of Sustainable Development”, Journal of Tourism and Gastronomy Studies 2(1), 55-63.

- Ş̧şman, B., Doğan, M. \& Ağca, V. (2016). "Linkıng Supply Chain Management Dimensıon of Corporate Sustainability to Financial Performance: A Research On Firms In Bist Sustainability Index", AIB Ü Sosyal Bilimler Enstitüsü Dergisi, 16(1), 75-96.

- Tuğun, Ö. \& Karaman, A. (2014). “A Sustainability Model for Bringing Core Villages into Eco-tourism”, MEGARON, 9(4), 321-337.

- Tutar, F. \& Kılınç, N. (2007). “Türkiye’nin Sağlık Sektöründeki Ekonomik Gelişmişlik Potansiyeli ve Farklı Ülke Örnekleriyle Mukayesesi”, Afyon Kocatepe Üniversitesi I.I. B.F. Dergisi, 9(1), 31-54.

- Toker, K. (2017). Tedarik Ağları, Sürdürülebilirlik ve Değer. İşletmelerde Sürdürülebilirlik Dinamikleri [ed. Iş11 Mendeş Pekdemir], Beta, İstanbul, 274-216.

- Uluslararası Yatırımcılar Derneği (Yased) (2012). Türkiye Sağlık Sektörü Raporu

- $\quad$ Vallence, S., Perkins, H.C. \& Dixon, J.E. (2011). "What is Social Sustainability? A Clarification of Concepts", Geoforum (42), 342-348.

- Yangil, F.M. (2015). "The Content Analysis of Sustainability Reports On the Context of Corporate Sustainability: Top 100 Industrial Enterprises in Turkey”, Journal of Business Research-Türk, 7(3), 356-376.

- Yıldırım, M.H. \& Uğuz, Ş. (2013). "Importance Of Corporate Social Responsibility In The Process Of Sustainable Development: A Research In Aksaray”, Sosyal ve Beşeri Bilimler Dergisi, 5(2), 202-212. 


\title{
Estetik ve Güzellik Sektöründe Verilen Tedavi ve Bakım Hizmetlerinin Talebini Etkileyen Demografik ve Sosyo-Psikolojik Özellikler
}

\section{Demographic and Socio-Psychological Characteristics Affecting the Demand for Treatment and Care Services in Aesthetic and Beauty Sector}

\author{
Ph.D. Candidate Gülay Bakar Tamer (İstanbul Gelişim University, Turkey)
}

\begin{abstract}
At the present time, number of aesthetic and health centers are rapidly increasing. In the light of this fact, in this study, the demographic and psychological profiles of the individuals who are getting service in these institutions will be discussed. The various parameters such as gender, age and marital status, which are affecting the types and processes of treatment will be examined. This study is aimed at to guide institutions to determine optimal customer profiles and encourage them to provide better service by offering them assistance for gathering information to make appropriate decisions regarding to future investments.
\end{abstract}

\section{Giriş}

Sağlık Hizmeti veren kuruluşların genel özellikleri; sağlklı bir durum oluşturulması, sağlık durumunun korunması ve devamlılığının sağlanması amacıyla sağlık kuruluşlarında hizmet üreten bütün kurum ve kuruluşların oluşturduğu yapı olarak açıklanabilir. Sağlık hizmetlerini üç boyutta açıklayabiliriz. Birincisi koruma boyutu, ikincisi tedavi boyutu ve son olarak da iyileştirme boyutudur Dünya Sağlık örgütünün (WHO) tanımına göre sağlık kavramı "'Sağlık yalnızca hastalık ya da sakatlığın olmayışı değil, bedence, ruhça ve sosyal yönden tam iyilik durumudur." (Akın, 2007).

Sağlık alanında hizmet sunan organizasyonlar içinde bulunduğu toplumun ihtiyaçları, kültür, ekonomik değerler doğrultusunda çalışma alanlarını gelişimin, sunulan hizmetlerin çeşitliliğini, gelişimi, bireylerin talepleri ve kurumsallaşma özellikler gibi pek çok etken tarafindan belirlenmektedir (Seçim, 1996). Sağlık hizmeti veren işletmelerin hizmet kalitesi başarılı tedavi ve bakım hizmetleri ve uygulama sonrası hasta mutluluğu ile ölçülmektedir (Hayran, 1997). Sağlık hizmeti ülkelerin kalkınma düzeyine bağlı olarak önemli miktarlarda ve giderek artarak kaynak tüketimi yaparak hizmet çeşitliği oluşturmaktadır. Sağlık örgütlerinin hizmet odaklı olmaları çalışanların performansı, bilgi, beceri, tecrübe ve yetenek alanlarına göre hizmet planlanması örgüt kültüründe ve işletmenin başarısında çok büyük öneme sahiptir.

\section{Estetik Ve Güzellik Amaçlı Hizmet Veren Sağlık Merkezlerinin Özellikleri}

Sağlık hizmetlerinden elde edilen bireysel fayda pazarlanabilir iken bu hizmetlerin sağladığı sosyal fayda ise pazarlanamaz. Mal ve hizmet üretmek isteyen bir üretici yalnızca pazarlayabileceği özel faydayı dikkate alarak hareket eder ancak sağlık sektöründe bu durum farklılaşmaktadır (Tokalaş, 2006). Estetik ve güzellik hizmetleri gelişmiş ve gelişmekte olan ülkelerin bireyleri açısından her geçen gün daha fazla önem arz etmeye başlamıştır. . Ülkelerin ekonomik gelişmişlik düzeyleri ile hizmet veren sağlık sektörlerinin yapısı ve dolaylı olarak alacağı sağlık hizmetine ayırdığı bütçe arasında yakın ve karşsılıklı bir nedensellik ilişkisi bulunduğunu iddia edebiliriz. Ekonomik gelişmesini belli bir seviyeye ulaştırabilmiş toplumlarda estetik sağlık sektöründe ayrılan kaynaklar arttığı gibi, bireylerin sağlık konusunda farkındalıkları da artmaktadır. Aynı şekilde denebilir ki, sağlık hizmetlerinin gelişimi de ekonomik gelişimi hızlandırmaktadır (Mazgit, 1998).

Toplumların yaşam kalitelerinin yüksek olması, sağlık hizmetlerinin toplumun geniş kesimlerine ulaşabilmesi beraberinde iş gücü katılımı sağlık kalitesinin yükselmesi ekonomik büyümeyi olumlu etkilediğine dair birçok görüş bulunmaktadır (Akın 2007); Estetik tıp sektörüne olan talep toplumdaki, eğitim düzeyi ve nüfus yapısı ile ekonomik ve sosyal kalkınma düzeyi arasında yakın bir ilişsi bulunmaktadır. Toplumun sağlık düzeyini yükselten sağlık hizmetlerine yapılan yatırımlar, daha başarılı ve eğitim için sağlıklı bir nüfus yapısını getirir, bu da verimlilik ve sektörel üretim artı̧̧ını hızlandırır. Sektörün üretim artışı gelir artışını, gelir artışı da ekonomik ve sosyal kalkınmayı yükseltir. Güzellik ve Estetik sektöründe yapılan klinik araştırmalar; Cerrahi ve medikal hizmet alan kişi açısından bazı uygulamalar risk unsuru taşıdığından, kalıcı kötü sonuçlar doğurabildiği için hizmeti sağlayan kurumların mevzuata uygunluğu, uzmanlık standartları ve fiziki koşullarının denetim konusu tedavinin güvenirliği açısından çok büyük önem taşımaktadır. Kişilerin görünümüyle ve var olan görsel bir problemin çözümüyle ilgilenen estetik ve güzellik amaçlı uygulanan sağlık hizmeti sunan bu merkezlerde; Rekrokonstürüktif cerrahi uygulamaları ve anti aging tedaviler plastik cerrah, dermatolog, medikal estetik hekimi, hemşire, beslenme uzmanı, 
estetiysen, spor koçu gibi alanlarında deneyime sahip uzman ekip tarafından sağlanmaktadır (Gürgen, 1997). Sunulan tedavilerin çeşitliliğine göre kurumların standardı değişmektedir.

\subsection{Estetik Ve Güzellik Sektöründe Hizmet Veren Kuruluşlar}

Estetik ve güzellik sektöründeki kuruluşlar; Tam teşekküllü hastaneler, Estetik Cerrahi hastaneleri, Medikal estetik poliklinikleri, Muayenehane hizmeti veren plastik cerrahlar, Dermatologlar Estetik Tip Hekimleri, Güzellik salonlarındaki uygulamalar, kozmetik bazı çalışmalar, yapan kozmotoloklar, Kuaför salonları, Natural ürün hazırlayan aktarlar, medya kanalı ile yapılan bazı kozmetik ürün satışı yapan kampanya şirketleri v.b iş kolları estetik ve güzellik hizmetlerinde alternatif teşkil etmektedirler (Tamer; 2016).

\subsection{Estetik Ve Güzellik Hizmeti Veren Sağılı Kuruluşlarında Müşteri Profili Ve Hizmet Talebini Etkileyen Özellikler}

Önceleri sadece kadınların hizmet talep ettiği alan olarak düşünülmekte; ya da medyatik ve sosyo kültürel düzeyi yüksek ve maddi alım gücü iyi olan kişilerin sahip olabileceği uygulamalar olarak düşünülmekte iken; artık günümüz de cinsiyet farkı gözetmeden bireyler bu tarz koruyucu tedavi ve bakımlara gereksinim duymaktadırlar medikal estetik kliniklerine gelen kişilerin beklentilerini kişiden kişiye değişmekle birlikte şu şekilde özetlenebilir. Dünyanın herhangi bir yerinde gerçekleştirilen bilimsel estetik faaliyetlerinden haberdar olmak, estetik ve güzellik hizmetlerine imkanları ölçüsünde sahip olmak ve fiziki görünüşlerini daha iyi hale getirmek, görünümlerini koruyarak, sosyal çevrelerine karşı daha dinç, daha bakımlı ve prezantasyonu yüksek görüntü sergilemek sağlıklı ve güzel bir görüntü ile iş hayatında ve içinde bulundukları sosyal ortamlarda kendilerini huzurlu ve rahat hissederek özenilen bir görüntü sergilemek ,her daim genç ve enerjik görünüşüyle yıllara meydan okuma arzusu ,medyada gördüğü veya beğendiği kişilere benzeme arzusu, arkadaşım, yakınlarım veya ,tanıdığım kişiler estetik tedavi ve bakımlarına gidiyor bazı uygulamalar yaptırıor, ben neden yaptırmayayım.? v.b ..nedenler siralanabilir.(Tamer,2016).

\section{Sektördeki Müssteri Profili Ve Tedavi Türlerinin Belirlenmesi Amacıyla Uygulanan Veri Toplama Yöntemi}

Anket değişik müşteri profili olan birkaç farklı estetik merkezlerinde 600 kişiye uygulandı. Anketin farklı yaş, eğitim, gelir guruplarına uygulaması için çok titizlik gösterildi. Elde edilen sayısal veriler SPSS paket programılla analiz edildi.

\subsection{Verilerin Analiz Edilmesinde Kullanılan İstatistiksel Yöntemler}

Bu çalışmada, güzellik ve estetik merkezlerine gelen müşterilerin genel profili belirlenerek, yaş, cinsiyet, medeni durum ve gelir ile tercih edilen hizmetlerin ilişsisi araştırılmıştır. Aynı zamanda gelirin güzellik ve bakım harcamaları ile ilişkisi saptanarak, harcamayı tahmin etmeye yönelik bir çoklu regresyon modeli geliştirilmiştir. Söz konusu amaçlar doğrultusunda, verilerin analiz edilmesinde kullanılan yöntemler şunlardır:

- Müsşterilerin yaş, cinsiyet, medeni durum ve eğitim düzeylerine göre dağılımı frekans tabloları ile özetlenmiş̧ir.

- Yaş, cinsiyet ve medeni durum ile tercih edilen hizmetler arasında ilişki olup olmadığını ve bu değişkenlerin tercih edilen hizmetlere göre dağılımını belirlemek amacıyla Ki-Kare bağımsızlık testi yapılmıştır.

- Müş̧erilerin gelirlerine göre tercih ettikleri hizmetleri saptamak, hizmet alan ve almayan bireylerin gelirleri arasında anlamlı fark olup olmadığını araştırmak için Independent Samples T-Testi (Bağımsız İki Örnek TTesti) kullanılmıştır.

- Müşterilerin gelirleriyle harcamaları arasında ilişki olup olmadığını araştırmak için Tek Yönlü Varyans Analizi (One-Way ANOVA) yapılmışıtır.

- Güzellik ve bakım harcamasını tahmin etmek için Çoklu Regresyon Analizi yapılmıştır. 


\subsection{Araştırmanın Bulguları}

\section{Frekans / Sıklık Dăğllımları}

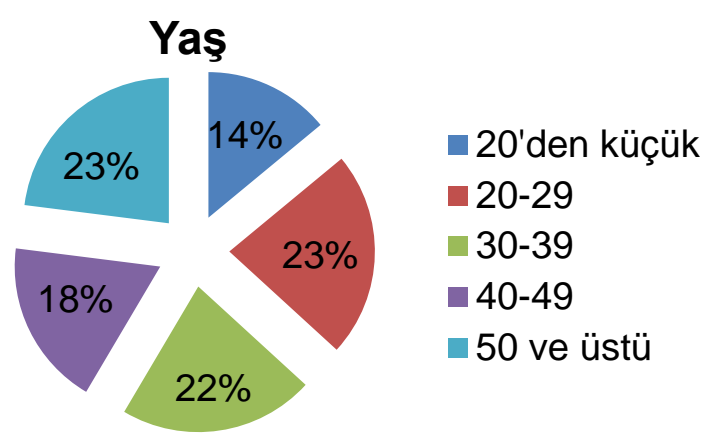

\section{Cinsiyet}
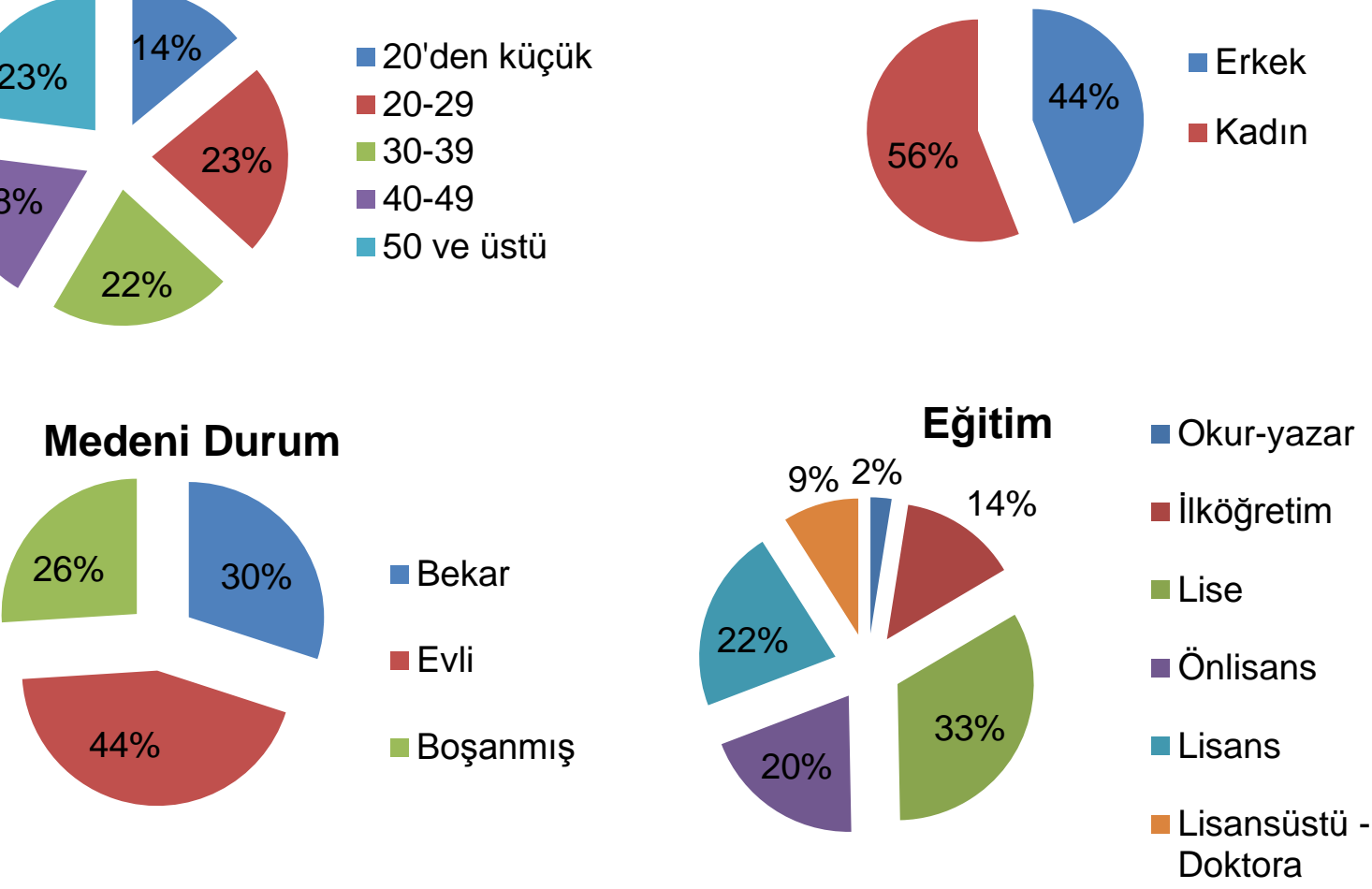

\section{Ki-Kare Bă̆ımsızlık Testi}

Müşterilerin bireysel özellikleri (cinsiyet, yaş ve medeni durum) ile hizmet aldıkları uygulamaları ikili olarak karşılaştırmak için Ki-kare Testi yapılmış ve aşağıdaki sonuçlar elde edilmiştir.

\begin{tabular}{|l|l|l|}
\hline Hizmet Türü & Cinsiyet & Sonuç \\
\hline Cilt Problemleri & Ki-kare değeri $=11,723$ ve $p=0,003$ & Anlamlı İlişki Var \\
\hline Anti-Aging & Ki-kare değeri $=49,911$ ve $p=0,000$ & Anlamlı İlişki Var \\
\hline Lazer & Ki-kare değeri $=37,918$ ve $p=0,000$ & Anlamlı İlişki Var \\
\hline Saç-Makyaj & Ki-kare değeri $=68,890$ ve $p=0,000$ & Anlamlı İlişki Var \\
\hline El-Ayak Bakımı & Ki-kare değeri $=37,144$ ve $p=0,000$ & Anlamlı İlişki Var \\
\hline
\end{tabular}

Tablo 1. Cinsiyet - Hizmet Türleri Arasındaki Ki-kare ve p (Sig.) Değgerleri

Sonuç olarak cinsiyet ile tüm hizmet türleri arasında anlamlı ilişki tespit edilmiştir.

\begin{tabular}{|l|l|l|}
\hline Hizmet Türü & Yaş & Sonuç \\
\hline Kırışıklık & Ki-kare değeri $=76,621$ ve $\mathrm{p}=0,000$ & Anlamlı İlişki Var \\
\hline Cilt Problemleri & Ki-kare değeri $=61,889$ ve $\mathrm{p}=0,000$ & Anlamlı İlişki Var \\
\hline Anti-Aging & Ki-kare değeri $=74,820$ ve $\mathrm{p}=0,000$ & Anlamlı İlişki Var \\
\hline Lazer & Ki-kare değeri $=22,580$ ve $\mathrm{p}=0,000$ & Anlamlı İlişki Var \\
\hline Estetik Ameliyatlar & Ki-kare değeri $=84,460$ ve $\mathrm{p}=0,000$ & Anlamlı İlişki Var \\
\hline Saç-Makyaj & Ki-kare değeri $=19,817$ ve $\mathrm{p}=0,001$ & Anlamlı İlişki Var \\
\hline
\end{tabular}

Tablo 2. Yaş-Hizmet Türleri Arasındaki Ki-kare ve p (Sig.) Değerleri

Sonuç olarak yaş ile tüm hizmet türleri arasında anlamlı ilişki tespit edilmiştir. 


\begin{tabular}{|l|l|l|}
\hline Hizmet Türü & Medeni Durum & Sonuç \\
\hline Kırışıklık & Ki-kare değeri $=61,051$ ve $p=0,000$ & Anlamlı İlişki Var \\
\hline Cilt Problemleri & Ki-kare değeri $=18,162$ ve $p=0,001$ & Anlamlı İlişki Var \\
\hline Anti-Aging & Ki-kare değeri $=36,081$ ve $p=0,000$ & Anlamlı İlişki Var \\
\hline Lazer & Ki-kare değeri $=17,654$ ve $p=0,001$ & Anlamlı İlişki Var \\
\hline Estetik Ameliyatlar & Ki-kare değeri $=34,659$ ve $p=0,000$ & Anlamlı İlişki Var \\
\hline Saç-Makyaj & Ki-kare değeri $=16,405$ ve $p=0,003$ & Anlamlı İlişki Var \\
\hline
\end{tabular}

Tablo 3. Medeni Durum - Hizmet Türleri Arasındaki Ki-kare ve p (Sig.) Değerleri

Sonuç olarak medeni durum ile tüm hizmet türleri arasında anlamlı ilişki tespit edilmiştir.

\section{Bă̆ımsız İki Örnek T-Testi}

Hizmet alan ve almayan müşterilerin gelirleri arasında anlamlı fark olup olmadığını araştırmak için gelir ortalamaları karşılaştırılır ve t-test uygulanır. Müşterilerin gelir düzeyleriyle tercih ettikleri hizmetler arasında anlamlı fark olup olmadığını belirlemek amacıyla uygulanan t-test sonuçları aşağıdaki tablolarda yer almaktadır.

\begin{tabular}{|l|l|l|}
\hline Hizmet Türü & Gelir & Sonuç \\
\hline Kırışıklık & $\mathrm{t}$ değeri $=-2,603$ ve $\mathrm{p}=0,009$ & $\begin{array}{l}\text { Anlamlı Fark Var; kırışılık hizmeti alanların } \\
\text { ortalama geliri almayanlardan oldukça yüksek }\end{array}$ \\
\hline $\begin{array}{l}\text { Bölgesel } \\
\text { Yağlanma }\end{array}$ & $\mathrm{t}$ değeri $=-2,890$ ve $\mathrm{p}=0,004$ & $\begin{array}{l}\text { Anlamlı Fark Var; bölgesel yağlanma hizmeti } \\
\text { alanları ortalama geliri almayanlardan oldukça } \\
\text { yüksek }\end{array}$ \\
\hline Anti-Aging & $\mathrm{t}$ değeri $=-4,438$ ve $\mathrm{p}=0,000$ & $\begin{array}{l}\text { Anlamlı Fark Var; anti-aging hizmeti alanların } \\
\text { ortalama geliri almayanlardan oldukça yüksek }\end{array}$ \\
\hline $\begin{array}{l}\text { Estetik } \\
\text { Ameliyatlar }\end{array}$ & $\mathrm{t}$ değeri $=-6,662$ ve $\mathrm{p}=0,000$ & $\begin{array}{l}\text { Anlamlı Fark Var; estetik ameliyat hizmeti alanların } \\
\text { ortalama geliri almayanlardan oldukça yüksek }\end{array}$ \\
\hline
\end{tabular}

Tablo 4. Gelir - Hizmet Türleri Arasındaki t ve p (Sig.) Dĕgerleri

Sonuç olarak, gelir düzeyinin belirleyici olduğu hizmetler; kırışıklık, bölgesel yağlanma, anti-aging ve estetik ameliyatlardır. Dolayısıyla bu hizmetler yüksek gelirli müşterilere hitap etmektedir. Diğer hizmetlerde gelirin anlamlı bir etkisi bulunmamıştır.

\section{Tek Yönlü Varyans Analizi}

Gelire göre ne kadar güzellik ve bakım harcaması yapıldığını saptamak için Tek Yönlü Varyans Analizi (Oneway ANOVA) yapılmış ve aşağıdaki sonuçlar elde edilmiştir.

\begin{tabular}{|c|c|c|c|c|c|c|c|c|}
\hline & \multirow[b]{2}{*}{$\mathrm{N}$} & \multirow[b]{2}{*}{ Mean } & \multirow[b]{2}{*}{$\begin{array}{c}\text { Std. } \\
\text { Deviation }\end{array}$} & \multirow[b]{2}{*}{ Std. Error } & \multicolumn{2}{|c|}{$\begin{array}{l}95 \% \text { Confidence } \\
\text { Interval for Mean }\end{array}$} & \multirow[b]{2}{*}{ Minimum } & \multirow[b]{2}{*}{ Maximum } \\
\hline & & & & & $\begin{array}{l}\text { Lower } \\
\text { Bound }\end{array}$ & $\begin{array}{l}\text { Upper } \\
\text { Bound }\end{array}$ & & \\
\hline $\begin{array}{l}1000- \\
2500\end{array}$ & 161 & 881,81 & 1131,558 & 89,179 & 705,69 & 1057,93 & 6 & 3500 \\
\hline $\begin{array}{l}2500- \\
4000\end{array}$ & 130 & 663,32 & 618,026 & 54,204 & 556,07 & 770,56 & 6 & 3500 \\
\hline $\begin{array}{l}4000- \\
8000\end{array}$ & 157 & 850,64 & 714,356 & 57,012 & 738,02 & 963,25 & 75 & 3500 \\
\hline $\begin{array}{l}8000- \\
20000\end{array}$ & 89 & 1217,42 & 783,607 & 83,062 & 1052,35 & 1382,48 & 300 & 3500 \\
\hline $\begin{array}{l}20000- \\
60000\end{array}$ & 49 & 1760,20 & 873,450 & 124,779 & 1509,32 & 2011,09 & 750 & 3500 \\
\hline $6000-+$ & 14 & 2714,29 & 1289,220 & 344,559 & 1969,91 & 3458,66 & 750 & 3500 \\
\hline Total & 600 & 990,59 & 949,573 & 38,766 & 914,45 & 1066,72 & 6 & 3500 \\
\hline
\end{tabular}

Tablo 5. Gelir Düzeyleri ile Güzellik- Bakım Harcamaları

Yukarıdaki tabloya göre gelir sınıfları ve "mean" sütununda yer alan ortalama güzellik ve bakım harcamaları dikkate alınarak, gelir attıkça ortalama harcamaların da arttığı görülmektedir. Gelir düzeylerine göre harcamalar arasında anlamlı fark olup olmadığını test etmek için yapılan Tek Yönlü Varyans Analizi sonucunda hesaplanan F değeri 25,065 ve $\mathrm{p}=0.000<0.05$ 'tir. Buna göre harcama ortalamaları arasındaki fark anlamlıdır. 


\section{Çoklu Regresyon Modeli}

Son olarak güzellik ve bakım harcamasını açıklayacak ve tahminlerde kullanılacak bir Çoklu Regresyon modeli oluşturulmuştur. Bağımlı değişken; estetik-bakım harcaması (Y), bağımsız değişkenler; gelir(x1), yaş(x2) ve cinsiyettir (x3).

\begin{tabular}{|c|c|c|c|c|}
\hline model & $\mathrm{R}$ & R Square & Adjusted R Square & $\begin{array}{c}\text { Std. Error of the } \\
\text { Estimate }\end{array}$ \\
\hline 1 &, $432^{\mathrm{a}}$ &, 187 &, 183 & 858,506 \\
\hline
\end{tabular}

Tablo. 6. Model Özeti

Model özetinde yer alan R Square bize bağımlı değişkenin yüzde kaçlık kısmının bağımsız değişkenler tarafından açıklandığını göstermektedir. Bizim örneğimizdeki R Square = 0,187 (\%18,7)’ dir. Bu değer açıklayıcılığın düşük olduğunu göstermektedir. Ancak bu model, eldeki verilerle denenen birçok model içinde en yüksek açıklayıcılığa sahip olanıdır.

Aşağıdaki ANOVA tablosuna göre modelin anlamlılığg incelendiğinde $F=45,607$ ve $\mathrm{p}=0.000<0.05$ 'tir ve modelin istatistiksel olarak anlamlı olduğu görülmektedir.

\begin{tabular}{|ll|c|c|c|c|c|}
\hline Model & & Sum of Squares & $\mathrm{df}$ & Mean Square & F & Sig. \\
\hline 1 & Regression & $1,008 \mathrm{E} 8$ & 3 & $3,361 \mathrm{E} 7$ & 45,607 &, $000^{\mathrm{a}}$ \\
& Residual & $4,393 \mathrm{E} 8$ & 596 & 737032,576 & & \\
& Total & $5,401 \mathrm{E} 8$ & 599 & & & \\
\hline
\end{tabular}

Tablo 7. Varyans Analizi Tablosu (ANOVA Tablosu)

Katsayıların anlamlılığına bakıldığında tüm değişkenlerin t değerlerine karşılık gelen p'ler 0.05 'ten küçüktür ve katsayılar anlamlıdır.

\begin{tabular}{|c|c|c|c|c|c|c|}
\hline \multirow[b]{2}{*}{ Model } & & \multicolumn{2}{|c|}{ Unstandardized Coefficients } & \multirow{2}{*}{$\begin{array}{l}\text { Standardized } \\
\text { Coefficients } \\
\text { Beta }\end{array}$} & \multirow[b]{2}{*}{$\mathrm{t}$} & \multirow[b]{2}{*}{ Sig. } \\
\hline & & $\mathrm{B}$ & Std. Error & & & \\
\hline \multirow[t]{4}{*}{1} & (Constant) & 540,042 & 126,772 & & 4,260 &, 000 \\
\hline & gelir &, 028 & ,003 & ,352 & 9,008 & ,000 \\
\hline & yaşlar & 11,458 & 2,807 &, 165 & 4,082 &, 000 \\
\hline & Cinsiyet & $-155,125$ & 72,465 &,- 082 & $-2,141$ & ,033 \\
\hline
\end{tabular}

Tablo 8. Katsayılar Tablosu

Elde edilen regresyon denklemi;

$$
y=540,042+0,028 x_{1}+11,458 x_{2}-155,125 x_{3}+e \quad \text { Şeklinde yazılır. }
$$

Buna göre gelirdeki 1 birimlik artış, harcamada 0,028 birimlik artış; yaştaki 1 birimlik artış, harcamada 11,458 birimlik artış yaratmaktadır. Cinsiyet ile ilişki ters yönlü olsa da bu bir kukla değişken olduğundan tahmini ya hiç etkilemeyecek ya da 155,125 azaltacaktır.

\section{Sonuç Ve Öneriler}

Estetik Tıp Merkezlerinden hizmet alan müşteri profilinin incelendiği ve analiz uygulandığı edildiği bu çalışma da; analiz sonuçları değerlendirildiğinde, sunulan hizmetler içinde cinsiyet yaş ve medeni durumdan etkilenen hizmetler kırışıklık, cilt problemleri, anti aging, lazer, estetik uygulamalar, saç-makyaj hizmetleridir. Söz konusu hizmetler özellikle kadınlar tarafından çok daha fazla tercih edilmektedir.

Yaşa göre yapılan karşılaştırmada hizmet alanların büyük kısmı 40-60 yaş arasındadır. Medeni durum açısından ise hizmet alanlar büyük oranda evli müşterilerden oluşmaktadır. Hizmetlerin tercih edilmesinde gelir çok büyük öneme sahiptir. Zira gelir arttıkça harcamalarda da büyük artış olduğu gözlemlenmiştir. Bu yaş aralığındaki müşteri profilimizi yılların izlerini göstermek istemeyen veya daima genç, sağlıklı görünüme sahip olma arzusu ya da ekonomik imkânlara, zaman imkânlarına daha geç yaşlarda sahip olan kişiler oluşturmaktadır.

Yapılan bu analiz çalışmasıyla; estetik tıp merkezlerinin müşteri profilini belirleme, yatırım yapılacak hizmet alanlarını belirleme, daha iyi hizmetler sunma konusunda büyük katkılar sağlayacağı, hem de benzer konularda araştırma yapacak diğer kişi ve sektörde yer alan kuruluşlara referans olabilmek, estetik ve güzellik merkezlerindeki kaliteli hizmet hastalara sunulan tedavi ve bakım hizmetlerde beklentilerini karşılamak hatta daha fazlasını verebilmek uygulama sonrası oluşabilecek soruları çözmek gereken durumlarda da hastaların taleplerini karşılamak amacı gözetilmektedir. 


\section{Kaynakça}

- Ak B. Akar Ç. Karaca H. (1988), "Hastane İdaresi Ve Organizasyonu”, H.Ü. SiYYO Yayınları, Ankara,

- Ak, Bilal (1990), "Sağlık Bilimlerinde Yönetim", Yeni Asya Yayınları, İstanbul Aupha (1996-1998), "Health Services Administration Education: Directory of Programs", 10th Edition,

- Ağırbaş, İ., Tatar, M. 2001 "Sağlık Hizmetlerinde Ekonomik Değerlendirme Teknikleri”, Yeni Türkiye Dergisi, Sağlık Özel Sayısı 2 Yı1 7, Sayı 40

- Arslanhan Memiş, S. 2012. 'Son Dönemdeki Harcamalarının Analizi”, Değerlendirme notu. Ankara: Türkiye Ekonomi Politikaları Araştırma Vakfı.

- Atasever, Mehmet, "Türkiye Sağılk Hizmetlerinin Finansmanı ve Sağlı Harcamalarının Analizi 20022013".

- Charles, E. Phelps (2012), "Health Economics," Addison Wesley,

- Çaışkan, Z. (2008), "Sağlık Ekonomisi: Kavramsal Bir Yaklaşımı", Hacettepe Üniversitesi İktisadi ve İdari Bilimler Fakültesi Dergisi, Cilt 26, Sayı 2, s. 29-50.

- Çilingiroğlu, Nesrin, "Ekonomik Kalkınma ve Sağlık Ekonomisi”, Yeni Türkiye, Sayı 40, 2001, s.1592 .

- Çilingiroğlu, Nesrin, "Sağlık Ekonomisi, Yayımlanmamış Halk Sağlığı Ders Notları," Hacettepe Üniversitesi, Halk Sağlığı Anabilim Dalı, Kasım 2003, s. 11

- "Sağlık Kuruluşlarında Stratejik Yönetim", (Çev. Osman Akınhay), Sistem Yayıncılık No: 184, İstanbul Driver,J(2007).The Fundamenttals.Oxford,UK:Blackwell Publishing Engiz O. (1998),

- "Sağlık İşletmeleri İçin Yeni İnsangücü Tipi, Toplam Kalite Yöneticisi. Modern Hastane Yönetimi”" Cilt: 2, Say1: 5, Haziran-Temmuz, İstanbul,

- Hayran O.Sur H. (1998), "Sağlık Hizmetlerinin Özel ve Kamusal Yönü Hastane Yöneticiliğì”, Nobel Kitabevi, İstanbul.

- Kavuncubaşı Ş. (2000), "Hastane ve Sağlık Kurumları Yönetimi”, Siyasal Kitabevi, Ankara, Kavuncubaşı Ş. Ersoy K. (1998),

- Lewis G. (1976), "How to Handle Your Own Public Relations", Nelson -

- Hall inc. Publishers, Chigaco. L. Rosenbaum, B., "Yönetici İçin Küçük Motivasyon Modelleri”, Çev: Serdar Özgerçin, 1993, Ankara

- .McGregor DT. (1960), "The Human Side of Enterprise”, McGraw Hill, New York, Tokat M. Seçim H. (1996),

- “Sağlık Ekonomisi”, Anadolu Üniversitesi, AÖF Yayını, No:403, Eskişehir, Nusret F. (1983),

- Özgen H. (1993), "Hastane Hizmetlerinin Kalite Yönetimi ve Kalite Güvencesi Standartlarına Göre Örgütlenmesi" TSE Sağlık Hizmetleri Kalite Paneli, Adana.

- Özkul A. E. (1994), "Sağlık Sistemleri Planlama ve Kontrolü”, A.Ü. Yayın No: 819: ARakich JS, (1992),

- "Sağlık Hizmetlerinde Ve İşletmelerinde Yönetim", Nobel Yayın Dağıtım, Ankara Mıntz,S. Cases in Accounting Ethics and Professionalism: Ethics and Professionalism Mc Graw- Hill,New York,s.139

- “Sağlık Hizmetlerinde Denetim”, SSYB. Sağlık Eğitimi Genel Müdürlüğü, Çağ Matbaası, Ankara, (www.sağlık.gov.tr/1.337/Yönetmelikler)

- Folland, S., Goodman, A. C., Stano, M. (1997), The Economics of Health and Health Care, New Jersey: Prentice Hall, 1997.

- Iş̧ı, Abdülkadir (1998); "Sağlık Ekonomisi, Finansmanı ve Ekonometrik Bir Analiz Çerçevesi", Yayınlanmamış Doktora Tezi, Marmara Üniversitesi SosyaBilimler Enstitüsü, İstanbul.

- Mazgit, İsmail, "Ekonomik Kalkınma Sürecinde Türkiye'de Sağlık Sektörünün Yeniden Yapılanması", Yayınlanmamış Doktora Tezi, Dokuz Eylül Üniversitesi Sosyal Bilimler Enstitüsü, İzmir, 1998.

- Tokalaş, Sevinç, (2006) 'Kamu Sağlık Hizmetlerinin Satın Alınması”, Yüksek Lisans Tezi, İstanbul.

- Tamer, Gülay(2016) "Sağlık Kurumlarında Etik Yönetim Anlayışı Ve Estetik Tıp Merkezlerindeki Stratejik Hedefler" İ.T.U UAS. İstanbul. Uluslararası Katılımlı 16. Üretim Araştırmaları Sempozyomu İstanbul Teknik Üniversitesi -İşletme Fakültesi 1074

- Sağılk Bakanlığı Sağlıkta Dönüşüm Programı, 2013. Sağlık İstatistikleri Yıllığı. Ankara. Sosyal Güvenlik Kurumu 2014 


\title{
Hemşirelerin Sosyal Sorumluluk Algılarının İncelenmesi (Sakarya İli Örneği)
}

\section{Analysis of Nurses' Social Responsibility Perception (Example of the Sakarya City)}

\author{
Nesrin Ünlü (Beykent University, Turkey) \\ Assoc. Prof. Dr. Volkan Öngel (Beykent University, Turkey)
}

\begin{abstract}
By analyzing the development of the social responsibility conception, this study illustrates corporate social responsibility perception and applies it into the medical sector with participation of some subject nurses. In the scope of this study in order to measure nurses' social responsibility perception and to analyze the interaction between the perception and demographic features three hundred nurses who work in the city of Sakarya's some public hospitals were given questionnaires that includes some demographic statistics and social responsibility indications. Consequently 250 of 300 questionnaires received back and included to the study (feedback percentage is $83.3 \%$ ). According to the data acquired from the survey the average rating of participants is 3.13 so that it is considered that the nurses are equipped with a high level of corporate social responsibility perception. However, it is also observed that the nurses' social responsibility perception is variable in accordance with their rank, gender and education.
\end{abstract}

\section{Giriș}

Modern dünyada işletmelerin kar odaklı çalışmalarının yanı sıra toplumsal konulara duyarlı davranmalarının gerekliliğinin kaçınılmaz olduğu anlaşılmıştır. Özel sektör ve kamu alanında hizmet veren kuruluşlar gerçekleştirdikleri toplumsal projelerle üstlerine düşen sosyal sorumluluk faaliyetlerini yerine getirmektedir. İşletmelerin gerçekleştirdikleri tüm bu sosyal sorumluluk çalışmaları toplumun yanı sıra kurumların kendileri için de faydalı olmaktadır. Kurumlar bu faaliyetler sayesinde kendilerine olumlu bir imaj sağlamanın yanında toplumun beklentilerine cevap vererek gelişen rekabet ortamında kendilerine üst sıralarda yer bulma firsatını yakalamaktadır. Son zamanlarda önemi işletmeler tarafından daha iyi anlaşılan sosyal sorumluluk kavramının gelişimini incelemek ve kurumsal sosyal sorumluluk (KSS) anlayışını sağlık alanında yapılan bir araştırma ile kamu sektöründe örneklendirmek amacıyla konu seçimi bu yönde yapılmıştır. Çalışmanın amacı hemşirelerin kurumsal sosyal sorumluluk konusuna olan bakış açılarını belirleyerek bu bakış açısının cinsiyet ve yaş ile nasıl bir etkileşim içinde olduğunu belirlemektir.

Ülkemizde özellikle sağlıkta dönüşüm projesi ile hasta ve çalışan hakları, kaliteli hizmet sunumu ve hasta memnuniyeti açısından oldukça yol kat eden sağlık kurumları gerçekleştirecekleri KSS faaliyetleri ile de toplumsal açıdan olumlu bakış açısı kazanma firsatını bulmaktadır. Tüm bu değerlendirmeler ışığında, sağılık kurumlarında çalışan hemşirelerin KSS uygulamalarına yaklaşımının oldukça önemli olduğu düşünülmektedir. Araştırma kapsamı 2016 yılı Mayıs-Haziran ayları arasında Sakarya ilinde kamu sektörüne bağlı olan sağlık kurumlarında tam zamanlı olarak çalışan hemşirelerden oluşmaktadır.

Araştırmada veri toplama aracı olarak katılımcıların demografik özellikleri ve sosyal sorumluluk algılarını belirlemeye yönelik ifadeler içeren anket yöntemi kullanılmıştır. Sakarya ilinde yer alan sağglık kurumlarında görev yapan 250 hemşire tarafından yanıtlanarak elde edilen bulgular SPSS 20 programı kullanılarak analiz edilmiştir.

\section{Sosyal Sorumluluk}

İşletmeler sanayileşmedeki gelişmeler sonucu yarattıkları ürün çeşitliliği ile tüketici beklentilerinin en uç noktalarda ve en iyi şekilde tatmin edilebilmesine ve dolayısı ile yaşam kalitesi ve refahının iyileştirilmesine olanak tanımaktadır. Ancak bu olumlu sayılabilecek etkilerinin yanında; aşırı tüketim, insan ve çevre sağlığının zarar görmesi, sosyal gruplar arasında derin farklılıkların oluşması gibi olumsuz sonuçlarda da işletmelerin katkısı tartışılmaz bir gerçektir. Hal böyle olunca bu olumsuzlukların giderilmesi ya da sonuçlarının hafifletilmesi işletmelerin üstlenmesi gereken bir sorumluluk olarak ortaya çıkmaktadır. İşletmelerin toplum yararına üstlendikleri bu yükümlülükler "sosyal sorumluluk" olarak tanımlanmaktadır (Ceritoğlu, 2011).

Sosyal sorumluluk, bireysel sorumluluklar dışında kişinin ya da işletmenin topluma karşı olan yükümlülüklerini tanımlar. Başka bir deyişle işletmenin yalnızca kendi çıkarlarını değil sosyal paydaşlarının çıkarlarını da düşünmesi, kar odaklı faaliyetlerinin yanında toplumsal sorunlarla da ilgilenmesi sorumlu davranışın temelini oluşturmaktadır. Burada önemli olan nokta ise sosyal sorumluluğun gönüllülük esasına dayanmasıdır.

Günümüzde sosyal sorumluluk kavramı oldukça sık kullanılmaya başlamıştır. Bu durumun nedeni olarak işletmelerin kar odaklı faaliyetlerden toplumun beklentilerine uygun faaliyetlere geçişi gösterilebilir. Özellikle 
bilgi teknolojileri ve medyanın gelişimiyle birlikte müşteriler bilinçlenmiş ve şirketlerden beklentileri artmıştır.

Tüm bu değişimler sosyal sorumluluk uygulamalarını şirketler için kaçınılmaz kılmıştır.

Sosyal sorumluluk birbirleriyle ilişki içinde olan ve öncelik sırasına göre sıralanmış 4 bileşenden oluşmaktadır. Bu bileşenlerden en alt kademede bulunan ekonomik sorumluluk şirketin kar etmesi gerektiğini, yasal sorumluluk kademesi ise yasalara uygun faaliyet göstermesi gerektiğini ifade etmektedir. Ahlaki sorumluluk toplumun etik değerlerine saygı göstermesi gerektiğini ve en üst kademe ise şirketin gönüllü faaliyetlerde bulunarak iç ve diş paydaşlara katkı sağlaması gerektiğini anlatmaktadır (Carroll, 1991).

\subsection{Kurumsal Sosyal Sorumluluk}

KSS kavramı ülkemizde 1990'lı yıllardan itibaren yer edinmiştir. Kurumsal vatandaşlık, iş etiği, paydaş yönetimi, sürdürülebilirlik gibi kavramları altında toplayarak işletme yönetimi uygulamalarına ve toplumun işletmeden beklentilerine yeni bir bakış açısı kazandırmıştır (Deren Van HetHof, 2015).

İş dünyasında zamanla oldukça önemli bir yer edinmeyi başaran KSS kavramı ekonomik, yasal, ahlaki ve gönüllülük boyutlarıyla tanımlanması gereken, iç ve dış olmak üzere tüm paydaşlara yönelik faaliyetleri kapsayan, işletmenin kar etmesinin yanında topluma yarar sağlayan yatırımları da yapacak şekilde işletme yönetiminin planlanıp uygulanmasını içeren kavramdır (Ceritoğlu, 2011). Kurumsal Sosyal Sorumluluk kavramının ABD ve Avrupa'da ortaya çıkışından itibaren zaman içinde geçirdiği değişim ele alındığında birçok ülkede yasal zorunluluk olarak ifade edilen bu kavram ülkemizde halen kurumsal iletişim adı altında gönüllü uygulamalar kapsamında yer almaktadır. KSS kavramı kısaca şirketlerin topluma karşı olan sorumluluklarını tanımlarken oldukça geniş bir yelpaze karşımıza çıkmaktadır. Birçok şirket için bu sorumluluklar eğitim, sağlık, spor, sanat gibi alanlarda yatırımlar yapmayı içerirken; bazı şirketler için ise üretim aşamasında çevreye zararlı hammadde kullanmaktan kaçınmak gibi faaliyetleri içerebilmektedir. Fakat ülkemizde kısa zaman öncesine kadar işletmelerin ana amacı kar etmek olarak görülüyor ve sosyal sorumluluk faaliyetlerine "olmazsa da olur" gözüyle bakılarak bütçe ayrılmıyordu. Bugün ise bir şirketin yönetimi için en önemli sermaye marka değeri ve kurum itibarı olarak değerlendirilmektedir.

Türkiye'de KSS kavramının ortaya çıkışı Osmanlı Devleti zamanına kadar uzanmaktadır. Osmanlı Devleti’nde ahilik ve lonca teşkilatları gibi yapılanmalar toplumsal sorumluluğu oldukça ileri bir noktaya taşımıştır. Osmanlı İmparatorluğu'nda eğitim, sağlık, sosyal güvenlik gibi temel ihtiyaçların vakıflar ve lonca teşkilatı gibi yapılanmalar tarafından yürütüldüğü bilgisine ulaşılmaktadır. Günümüzde de özellikle büyük aile şirketlerinin sahip olduğu vakıfların hayırseverlik faaliyetleriyle toplumsal dayanışmayı güçlendirerek sorumluluklarını yerine getirdiği görülmektedir (Ersöz, 2014).Türkiye' de KSS faaliyetleri ekonomide uzun vadeli planlar yapılamaması ve sürdürülebilir kalkınma için uygun olmayan şartlar nedeniyle gelişme gösterememiştir. 1980'li yıllardan sonra serbest ekonomiye geçiş ve özellikle son yıllardaki istikrarlı ekonomi Türkiye'de işletmelerin KSS konusuna eğilmelerini sağlamıştır (Ceritoğlu, 2011).Ülkemizde KSS kavramının doğuşu Avrupa ve ABD'de olduğu gibi menfaat sahiplerinden gelen baskılar sonucunda olmamıştır. Dünya genelinde KSS uygulamalarının önem kazanması ile Türk firmaların da faaliyetlerini sürdürebilmeleri ve AB'ye uyum sağlamaları için bu uygulamalara önem vermesi gerektiği anlaşılmıştır (Akansel, 2011).

\subsection{Türkiye'de Kurumsal Sosyal Sorumluluk Uygulama Örnekleri}

Ülkemizde özellikle son yıllarda artan KSS uygulamalarının çevre, eğitim, spor ve toplumsal gelişim konularında ağırlıklı olduğu görülmektedir. Fakat literatüre bakıldığında KSS faaliyetlerini çalışanlara yönelik, müşterilere yönelik, topluma yönelik, tedarikçilere yönelik olarak gruplandırmak mümkündür.

Türkiye'de çalışanlar için yürütülen sosyal sorumluluk kampanyalarından biri olan "Turkcell Akademi”, 2005 yılında GSM operatörü Turkcell tarafından uygulanmıştır. Turkcell, insan kaynağının gelişimini sürekli kılmak misyonuyla 30 Mayıs 2006 tarihinde Beyoğlu'nda Turkcell Akademi’yi açmıştır. Güvenilir ve güncel öğrenim kaynaklarının paylaşan Turkcell Akademi; çalışanları satış noktaları aboneleri ve pek çok iş ortağı olan kurum ve bireyleri geleceğe hazırlama ortamı sunmaktadır (Coşkun Değirmen, 2010). Çalışanlar için gerçekleştirilen diğer bir sosyal sorumluluk örneğini BP Türkiye'nin işleticisi ve en büyük hissedarı olan ATAŞ Rafinerisi uygulamıştır. Bu işletme faaliyetlerini 2004 yılında terminal olarak sürdürmeye karar vermesinin ardından "çalışanlarının yeni işlerine geçişlerine destek sunmak” amacıyla ROTAM projesini hayata geçirmiştir. Proje kapsamında Personel Destek Merkezi kurularak dönüşüm aşamasında personel ve ailelerinin zihinsel anlamda huzurlu olmaları için psikolojik destek sağlanmıştır (Coşkun Değirmen, 2010).

Kurumlar müşterilerini tatmin etmek ve rakipleri karşısında öne geçmek amacıyla çeşitli kampanyalar düzenlemektedir. Bu kampanyalardan biri "doğru ve sağlıklı beslenme” tartışmalarının odağında olan "Fastfood" kavramıyla özdeşleşen McDonald's firması tarafından gerçekleştirilmiştir. Firma bu tartışmaların oluşturduğu olumsuz algıdan etkilenmemek adına, uzun vadeli olarak geliştirdiği iletişim stratejisi ile McDonald's'ın dengeli ve sağlıklı yaşam içindeki önemini anlatmayı hedeflemiştir. Bu bağlamda beslenme uzmanı ile anlaşma yapılmış ve menüye "Yediğin Kadar Yak, Yaktığın Kadar Ye" sloganıyla "Hafif \& Aktif” ürün grubunda yer alan salatalar eklenmiştir. Bunun yanı sıra beslenme uzmanlarının hazırladığı ve içeriğinde tüm ürünlerin besin değerlerinin yer aldığı bilgiler; tepsi örtüleri, web sitesi gibi görülebilecek yerlerde müşterilere sunulmuştur. Bu kampanya ile 
McDonald's müşterilerine seslenerek kurumun imajını ve itibarını korurken aynı zamanda sosyal sorumluluğunu yerine getirmiştir (Coşkun Değirmen,2010).

Çevre konusunda yürütülen kampanyalar doğal kaynakları korumak ve kirliliği önlemek başlıkları altında toplanmaktadır. Soyak firmasının 2007 yılında başlattığı su tasarrufuna ilişkin toplumun bilinçlendirilmesini kapsayan kampanya ile İzmir'de belirlenen 15 devlet okulunda su tasarrufu için çalışmalar yapılmıştır. Okullardaki musluk ve pisuarlar tasarruf sağlayan sensörlü tipleriyle değiştirilmiştir. Suyun bilinçli olarak tüketilmesi ve hijyenin öneminin anlatıldığı eğitim programları düzenlenerek öğrencilerin bilinçlenmesi sağlanmıştır. Bu sayede susuzluk tehlikesine dikkat çekilmiş ve bu konuda bilinçli bir neslin yetişmesine katkı sağlanmıştır (Coşkun Değirmen, 2010).DHL Expres taşımacılık firmasının gerçekleştirdiği meyve çekirdeklerinin doğaya geri kazandırılmasına yönelik kampanya ile firma çalışanları tükettikleri meyvelerin çekirdeklerini, ofisslerde oluşturulan çekirdek toplama kutularında toplamışlardır. Bu çekirdekler TEMA Vakfı aracılığı ile Manisa Belediyesi'ne ulaştırılmış ve gönüllüler sayesinde toprakla buluşturulmuştur (Coşkun Değirmen, 2010).TEMA “El Koyun" projesi ile 9 köyde başlatılan çalışmalar ile verimli toprakların kurtarılmasını sağlamak, kamuoyunu bu konuda bilinçlendirmek ve bu amaç için kamuoyundan finansal destek sağlamak amaçlanmıştır. Bu konuda medyadan ve ünlülerden yardım alınarak proje hedeflerine ulaşmıştır (Gürel Boran, 2015).Çevre ile ilgili kampanyalardan biri de Falım markasının "Sakız Ağaçlarına Sevgi Aşılıyoruz” projesidir. Bu proje kapsamında Sakız Ağacı gibi ekonomik, sosyal ve yerel bir değeri ülkemize yeniden kazandırmak ve bu konuda kamuoyunda farkındalık yaratmak hedeflenmiştir (Gürel Boran, 2015).

Özellikle az gelişmiş ülkelerde ağırlıklı olmak üzere eğitim, toplumun sosyal açıdan gereksinim duyduğu diğer bir önemli konudur. Eğitime yapılan katkılar bir eğitim kurumu açmak ya da toplumu çeşitli konularda eğitmek şeklinde olabilmektedir. Eğitim konuları kurumların kendi faaliyet konularından belirlenebildiği gibi genel konulardan da seçilebilmektedir. Eğitim konusunda düzenlenen kampanyalardan biri Eczacıbaşı tarafından yürütülen “Genç Mucitler” örneğidir. Eczacıbaşı ve Türkiye Eğitim Gönüllüleri Vakfe (TEGV) 2005 yılında çocuklara yönelik matematik ve fen alanında eğitim kampanyası başlatmıştır. Bu kampanya ile çocukların analitik, yaratıcı düşünebilmesi bilime önem vermesi amaçlanmıştır (Coşkun Değirmen, 2010).Eczacıbaşı tarafından eğitime yönelik düzenlenen bir diğer kampanya ise Hijyen Projesi'dir. Bu kampanya ile Yatılı İlköğretim Bölge Okulları öğrencilerine çağdaş tuvalet ve banyo ortamları sunmak, verilen hijyen eğitimleri ile çocuklara doğru ve hijyenik kullanım şekilleri konusunda alışkanlık kazandırmak amaçlanmıştır. Proje kapsamında, 2010 yılı sonunda yaklaşık 5500 öğrenci çağdaş, kaliteli ve sağlıklı yaşam koşullarına kavuşmuştur (Gürel Boran, 2015).

Sosyal sorumluluk kampanyalarının uygulanma alanından bir diğeri ise sanattır. Sanat alanında 1987 yılından bu yana her yıl Türkiye genelinde ortalama 250 bin çocuğa ücretsiz olarak tiyatro izleme imkânını sunan Pınar Kido Çocuk Tiyatrosu en büyük örneklerden biridir (Coşkun Değirmen, 2010). OMO firmasının 2004 yılında 612 yaş arası çocuklara spor ve eğlenceyi konu alan "Spor OMO Çocuk Şenliği” spor alanında oluşturulan sosyal sorumluluk kampanyalarından biridir. Bu kampanya ile çocuklar aileleriyle birlikte düzenlenen şenliğe katılarak basketbol, voleybol ve atletizm gibi spor dallarında oynanan oyunlara katılmaktadırlar (Coşkun Değirmen, 2010).Kültür ve Tarih alanında düzenlenen kampanyalardan biri olan "Opet-Tarihe Sayg1 Kampanyası" faaliyetlerinde ise 2006 yılında Gelibolu Yarımadası'nda yer alan 12 köyde yenileme, peyzaj, çevre düzenleme ve eğitim başlıkları altında rehabilitasyon çalışmaları yürütülmüştür. Proje kapsamında zengin tarihi mirasa sahip Gelibolu Yarımadası'nda Kültür ve Sanat Merkezi inşa edilmiş, çocuk parkları yapılmış, köy meydanları yenilenmiş ve peyzaj düzenlemeleri yapılmıştır (Coşkun Değirmen, 2010).

Tedarikçi ve bayilere yönelik sosyal sorumluluk örneklerinden biri olan Tofaş'ın faaliyetleri sonucunda; 99 yan sanayi firmasının ISO 14001 belgesi alması desteklenmiş ve tedarikçilerle daha verimli iletişim kurmak amacıyla Tofaş TV kurulmuştur (Coşkun Değirmen, 2010).

\subsection{Türkiye'de Kurumsal Sosyal Sorumluluk Kavramına İlişkin Literatür İncelemesi}

Aydemir ve Ateş tarafından yapılan araştırmada Bilecik Küçük Sanayi Sitesi'nde faaliyet gösteren 100 işletme sahibiyle yüz yüze görüşülerek 40 sorudan oluşan anket doldurulmuştur. Araştırma sonucunda elde edilen bulgulara bakıldığında, işletme sahiplerinin çalışanları ile ilişkileri başlığı altında deneklerin \%46'sının işletme sahiplerini yeni çırak, kalfa ve usta yetiştirme konusunda “çok kötü” olarak değerlendirmiştir. Araştırmanın işletme sahiplerinin müşterileri ile ilişkileri başlığı altında ise deneklerin \%57'si işletme sahiplerini müşterilere ürün ve hizmetler hakkında doğru bilgi verme konusunda "çok iyi” olarak değerlendirmiştir. Araştırmanın işletme sahiplerinin komşu işletmelerin sahipleri ile ilişkileri başlığ 1 altında deneklerin \% 76 'sı işletme sahiplerini diğer esnaflara selam verme, onların selamını alma; hal-hatır sorma konusunda "çok iyi" olarak değerlendirmiştir. İşletme sahiplerinin mesleki gelişme ve çevre konusundaki düşünceleri, \%61 atık yağ, talaş vb. çöplerini dikkatlice yok etme ve siteyi temiz tutma konusunda "çok iyi”, buna karş1lık deneklerin \%59'u işletme sahiplerini kentin sağlık, eğitim ve kültür gibi ihtiyaçlarına maddi ve manevi destek verme konusunda "çok kötü” olarak değerlendirirken, \%52' si ise işletme sahiplerini fakirlere, öğrencilere burs vb. yardımlar yapma konusunda "çok kötü” olarak değerlendirmiştir. Araştırmanın sonucunda mesleki gelişme ve çevre konusundaki eksikliklerin işletme sahiplerinin ekonomik sıkıntılarından kaynaklandığı tahmin edilmiştir (Aydemir ve Ateş, 2011). 
Aslantaş Ateş ve Senal Süleyman Demirel Üniversitesi’nde ön lisans ve lisans düzeylerinde muhasebe eğitimi alan öğrencilerin Kurumsal Sosyal Sorumluluğa bakış açılarının belirlenmesi amacıyla saha araştırması yapılmıştır. Geleceğin yöneticileri olmaya aday olarak nitelendirilen 556 öğrenci üzerinde yapılan bu araştırma sonucunda, öğrencilerin KSS ile ilgili bilgileri olduğu görülmüş, buna karşın bu bilginin ön lisans ve lisans düzeyinde görülen eğitim açısından farklılık göstermediği anlaşılmıştır (Aslantaş Ateş ve Senal, 2012)

Bakioğlu ve Akkaya tarafından yapılan bir araştırmada okul yöneticilerinin sosyal sorumluluğa yönelik algılarının ölçülerek kadın yöneticilerin sürdürülebilir sorumluluk, demokratik sorumluluk, inovatif sorumluluk ve sosyal sorumluluğu algılama düzeylerinin cinsiyete göre farklılaşmadığı; yasal sorumluluk puan ortalamalarının ise kadın yöneticilerin erkek yöneticilerinkine göre anlamlı derecede yüksek olduğu görülmüştür. Okul yöneticilerinin sosyal sorumluluk algılamalarının kıdem değişkenine göre farklılık göstermediği, buna karşın lisansüstü eğitim almış okul yöneticilerinin ön lisans ve lisans eğitimi almış okul yöneticilerinden anlamlı derecede yüksek çıktığı görülmüştür. Bu sonuca göre eğitim düzeyi ile sosyal sorumluluk algısı arasında pozitif bir ilişki olduğu söylenebilmektedir (Bakioğlu ve Akkaya, 2013).

Kaya tarafından yapılan ve amacı demografik özelliklerin KSS algılaması üzerindeki rolünü belirlemek olan araştırmanın sonuçlarına göre, araştırmaya katılanların kadın veya erkek olmalarına, kamu veya özel sektörde çalışmalarına göre KSS algılamalarının pek farklılık göstermediği belirlenmiştir. Buna karşın KSS algılamalarının bireylerin yaşlarına göre orta düzeyde, eğitim durumlarına göre ise yüksek düzeyde farklılık gösterdiği belirlenmiştir (Kaya, 2008).

2007 yılında yapılan bir araştırmada Opet firmasında çalışan 127 kişiye anket uygulanarak çalışanların kurumsal sosyal sorumluluk algılamalarının örgütsel özdeşleşme, örgütsel bağlılık ve iş tatmini düzeyleri üzerindeki etkisinin belirlenmesi amaçlanmıştır. Araştırma sonuçlarına göre, çalışanların kurumlarının ekonomik sorumluluklarına ilişkin algılamalarının çeşitli özelliklerine göre farklılıkları incelendiğinde sadece çalışanların kurumsal sosyal sorumluluk faaliyetleri hakkında bilgi sahibi olma durumlarının söz konusu algılamaları üzerinde anlamlı düzeyde farklılık gösterdiği ortaya çıkmaktadır. Buna göre, kurumsal sosyal sorumluluk faaliyetleri hakkında bilgi sahibi olan çalışanların bilgi sahibi olmayanlara göre ekonomik boyuta ilişkin algılamalarının daha olumlu olduğu görülmektedir (Özdemir, 2007).

Köroğlu ve Ersöz tarafindan yapılan bir araştırmada muhasebe meslek mensuplarının KSS algılamalarında yaş ve eğitim düzeyi değişkenleri açısından farklılık görülmezken çalışma süreleri ve mükellef sayılarının kısmen farklılık yarattığı belirlenmiştir (Köroğlu ve Ersöz, 2015).Özgen tarafından yapılan bir araştırmada kurumların çalışanlarının motivasyonunu sağlamada sosyal sorumluluk uygulamalarının ve bu konudaki gönüllülüğün önemli bir yeri olduğu belirtilmiştir (Özgen, 2007).

\section{Sakarya İlinde Çalışan Hemşirelerin Kurumsal Sosyal Sorumluluk Algı Düzeylerinin Belirlenmesine Yönelik Bir Alan Araştırması}

Araştırma, kurum içi paydaşlardan olan çalışanların Kurumsal Sosyal Sorumluluk algılamaları ile ilgili yapılmış az sayıda çalışma olması nedeniyle önem kazanmaktadır. Araştırmanın diğer bir önemi ise Türkiye’deki Kurumsal Sosyal Sorumluluk faaliyetlerinden bahsedilirken özellikle kamu sektöründe bu faaliyetlerin istenen düzeyde gerçekleştirilemediği vurgulanmıştır. Özellikle sağlık sektörünün sosyal sorumluluk konusunda ayrı bir yer tuttuğu düşünülürse araştırmamızın ikinci bölümünde yer alan sosyal sorumluluk ölçeğine verilen yanıtların önemi kamu sektörüne bağlı olarak hizmet veren sağlık kurumlarında görev yapan hemşirelerin Kurumsal Sosyal Sorumluluk faaliyetlerine olan yaklaşımları hakkında bilgi verecek olması ve literatüre katkıda bulunmasıdır. Son olarak bu araştırma Kurumsal Sosyal Sorumluluk kavramını çalışanların bakış açısından ele alarak yöneticilere ve sağlık profesyonellerine bilgi sağlaması açısından önem kazanmaktadır.

\subsection{Araştırmanın Yöntemi}

Araştırmada veri toplama aracı olarak yazılı soru sorma (anket) yöntemi tercih edilmiştir. Anket yönteminin diğer yöntemlere göre daha ekonomik ve daha hızlı veri toplama olanağı sağlaması bunun nedenidir. Araştırmada kullanılan anket Gültekin'in (2003) yılında kullanmış olduğu ankettir. Anket formu toplam iki ana bölümden oluşmaktadır. Anket formunun ilk bölümünde anket hakkında bilgi verilerek katılımcılardan yaş, cinsiyet, eğitim düzeyi ve kaç yıldır hemşirelik mesleğini icra ettikleri gibi demografik bilgi sorularını yanıtlamaları istenmiştir.

Anketin ikinci bölümünde ise hemşirelerin KSS anlayışlarını belirlemek amacıyla Gültekin tarafindan geliştirilen sosyal sorumluluk ölçeğinden yararlanılmıştır. Bu bölümde yer alan ifadeler beşli Likert ölçeğindedir ve cümleler karşısında "tamamen katılıyorum", "katılıyorum", "çekimserim", "katılmıyorum", "kesinlikle katılmıyorum" ifadeleri ile beş katılma derecesinde sınıflandırılmıştır. Toplamda 28 ifadeden oluşan sosyal sorumluluk anketine güvenilirlik testi uygulanmış cronbach $\alpha$ değeri 0,744 olarak bulunmuştur. Bu test sonucunda güvenilir olduğu görülen anketin 14 cümlesi olumlu 14 cümlesi ise olumsuz ifadedir. Olumlu cümlelerde "tamamen katılıyorum" seçeneğine 5, "kesinlikle katılmıyorum" seçeneğine 1 puan; olumsuz cümlelerde "kesinlikle katılmıyorum" seçeneğine 5, "tamamen katılıyorum” seçeneğine 1 puan verilerek değerlendirme 
yapılmıştır. Demografik bilgileri toplamak amacıyla çift şıklı (cinsiyet) ve çoklu seçenekli (diğer tüm sorular) soru tipleri kullanılmıştır. Tüm sorular kapalı uçludur.

Tüm değişkenlerin frekans (f) ve yüzde (\%) değerleri hesaplanmıştır. Katılımcıların sosyal sorumluluk konusuna bakış açılarının ölçümlenmesi için hazırlanmış ölçeğe güvenilirlik analizi uygulanmıştır. Ölçeğin normallik varsayımlarının test edilebilmesi için Kolmogrov Smirnov Testi uygulanmıştır. Karşılaştırmalı analizlerde Kruskal Wallis-H Testi ve Mann Whitney U Testi uygulanmıştır. Kruskal Wallis-H Testi sonucunda farklılık gözlenmesi durumunda farklılı̆ıın hangi gruplardan kaynaklandığının bulunması için Mann Whitney U Testi uygulanmıştır. Elde edilen bulgular $\% 95$ güven aralığında $\% 5$ anlamllık düzeyinde değerlendirilmiştir.

\subsection{Araştırmanın Evreni ve Örneklemi}

Araştırmanın evreni Sakarya ilinde kamu sektörüne bağlı olan sağlık kurumlarında tam zamanlı çalışan hemşirelerden oluşmaktadır. Uygulamada hemşirelerin çalıştı̆ı birimler araştırmacı tarafından ziyaret edilerek çalışanlara 300 adet anket dağıtılmış ve belirli bir süre sonra birimler tekrar ziyaret edilerek anketler toplanmıştır. Geri dönen geçerli anket sayıs 250 olmuştur (geri dönüş oranı=\%83,3). Dolayısıyla araştırmaya katılarak anketi yanıtlamayı kabul eden 250 hemşire örneklemi oluşturmaktadır.

\subsection{Araştırmanın Kısıtlılıkları}

Araştırmanın kısıtlarından biri hemşirelik mesleği mensuplarının daha çok kadın cinsiyet ağırlıklı olması nedeniyle erkek katılımcıların örneklem içindeki oranının kadınlara göre az olmasıdır. Araştırmanın diğer bir kısıtı ise kıdem yılı fazla olan hemşirelerin anketleri cevaplamayı kabul etmemesi nedeniyle kıdem yılı düşük olan katılımcıların örneklem içindeki oranının yüksek olmasıdır. Araştırmanın Sakarya İlinde gerçekleştirilmiş olması nedeniyle sonuçların genellenemeyecek olması araştırmanın diğer bir kısıtı olarak karşımıza çıkmaktadır. Araştırmaya katılan tüm hemşirelerin ankette yer alan ifadelere içten ve gerçekçi yanıtlar verdiği varsayılmıştır.

\subsection{Ankete Katılanların Demografik Özellikleri}

Çalışmaya dâhil edilen 250 katılımıının \%76'sı kadın, \%24'ü ise erkektir. Katıılımcıların \%45,60'1 20 ile 27 yaş arasında, $\% 22,80$ 'i 28 ile 35 yaş arasında, $\% 22,40$ ' 136 ile 43 yaş arasında, $\% 9,20$ 'si ise 44 yaş ve daha üstündedir. Katılımcıların eğitim seviyesi incelendiğinde, \%24,40'ının lise mezunu, \%30'unun yüksekokul mezunu, \%36,40'ının lisans mezunu, \%9,20'sinin ise lisansüstü eğitim veren programlardan mezun olduğu görülmektedir. Katılımcıların meslekteki kıdemleri incelendiğinde ise, \%19,20'sinin 1 ylldan az, \%29,60'ının 1 ile 5 yıldır, \%15,60'ının 6 ile 10 yıldır, \%35,60'ının 10 yıldan fazla süredir bu mesleği icra etmekte olduğu belirlenmiştir.

\subsection{Sosyal Sorumluluk Ölçeğine Ait Bulgular}

Hemşirelerin sosyal sorumluluk anketinde yer alan "Toplumu geliştirmek ve çevreye duyarlı olmak, işletmeye daha kalıcı bir başarı sağlar" ifadesine \%36,40 $(n=91)$ oranındaki "tamamen katılıyorum" yanıtı ile en yüksek katılım düzeyini gösterdikleri belirlenmiş̧ir. Bu ifadeye yüksek düzeyde katılım göstermeleri işletmenin kalıcı olarak başarıyı sağlayabilmesi için toplumsal sorunlara duyarlı olması gerektiği ve çevre bilinci ile hareket etmesinin önemli olduğunu düşündüklerini göstermektedir.

Hemşirelerin sosyal sorumluluk anketinde yer alan "Kalıcı başarı, ekonomik başarının sosyal sorumluluk konusunda gösterilen başarıyla desteklenmesiyle mümkündür" ifadesine $\% 32,00(n=80)$ oranındaki "tamamen katılıyorum" yanıtı ile ikinci en yüksek katılım düzeyini gösterdikleri belirlenmiştir.

"Toplumun sorunlarına duyarlı olan yönetici, şirkete daha kalıcı bir başarı getirecektir" ifadesine katılımcıların vermiş oldukları "tamamen katılıyorum" yanıtı yüzdesi \%31,60 $(\mathrm{n}=79)$ olarak hesaplanmış ve katılım oranı yüksek olan üçüncü ifade olduğu görülmüştür. Katılımcıların bu ifadeyi yüksek oranda onaylamaları işletmenin başarısının sürekliliğinin sağlanması, yöneticinin toplumsal sorunları görmezden gelmeyerek çözüm üretmesine, topluma fayda sağlamasına ve toplumu geliştirmesine bağlı olduğunu göstermektedir.

"Her şirket kendi çapında sosyal sorumluluğu yerine getirebilir" ifadesine katılımcıların vermiş oldukları "tamamen katılıyorum” yanıtının katılım yüzdesi \%29,60 (n=74) olarak hesaplanmıştır. Dolayısıyla bu ifade katılım yüzdesi yüksek olan dördüncü ifade olarak görülmektedir. Bu ifadeden anlaşıldığı üzere işletmenin büyük ya da küçük ölçekli olmasının sosyal sorumluluk gerekliliklerini yerine getirmesi ile ilgili olmadığı, her işletmenin kendi olanakları kapsamında sosyal sorunlarla ilgilenebileceği katılımcılar tarafından olumlu yönde anlaşılmıştır.

Katılımcıların sosyal sorumluluk ölçeğindeki ifadelere katılım yüzdeleri incelendiğinde "Şirket çıkarı için, sonuçlarını düşünmeksizin her şey yapılabilir" ifadesine verilen "kesinlikle katılmıyorum" yanıtının \%41,20 (n=103) yüzde ile en düşük katılım oranına sahip ifade olduğu dikkat çekmektedir.

Katılımcıların sosyal sorumluluk ölçeğindeki ifadelere katılım yüzdeleri incelendiğinde "Ekonomik amacı gerçekleştirmek için takip edilen her yol mubahtır" ifadesine verilen "kesinlikle katılmıyorum" yanıtının \%32,80 $(\mathrm{n}=82)$ yüzde ile en düşük katılım oranına sahip ikinci ifade olduğu belirlenmiştir.

Katılımcıların sosyal sorumluluk ölçeğindeki ifadelere katılım yüzdeleri incelendiğinde "İşletmeler sosyal sorumluluğu sadece kendi çıkarları için yerine getirmelidirler" ifadesine verilen "kesinlikle katılmıyorum" yanıtının \%28,40 $(\mathrm{n}=71)$ yüzde ile en düşük üçüncü katılım oranına sahip ifade olduğu dikkat çekmektedir. İşletmelerin varlıklarını sürdürebilmelerinin ekonomik anlamda kar sağlamalarına bağlı olduğu bilinmekle beraber 
sosyal sorumluluk kavramının gelişimi ile birlikte karın tek amaç olmadığı düşüncesi önem kazanmıştır. Gerçekleştirdikleri sosyal sorumluluk faaliyetlerinin işletmeye olumlu imaj kazandırması ve uzun dönemde kara katkı sağlaması gibi faydaları bulunmaktadır. Fakat bu ifadede belirtildiği üzere işletmeler sosyal sorumluluk faaliyetlerini sadece kendi çıkarlarını gözeterek değil içinde bulundukları ve hizmet sundukları toplumun gelişmesine katkı sağlamak amacıyla uygulamalıdırlar.

"İşletmenin başarısı için toplumu geliştirmek ve çevreye duyarlı olmak şart değildir" ifadesine katılımcıların vermiş oldukları "kesinlikle katılmıyorum" yanıtının katılım yüzdesi \%27,20 (n=68) olarak hesaplanmıştır. Bu katılım yüzdesinin sosyal sorumluluk ölçeğindeki dördüncü en düşük orana sahip ifade olduğu görülmektedir.

\subsection{Sosyal Sorumluluk Ölçeğine Ait Güvenilirlik Analizi}

28 değişkenin Cronbach's alfa değeri 0,744 olarak hesaplanmıştır. Buna göre sosyal Sorumluluk Ölçeği’nin oldukça güvenilir olduğunu söyleyebiliriz. Bu sonuca göre katılımcıların soruları aynı oranda algılamadıkları şeklinde yorum yapılabilir.

Ölçek istatistiklerine göre 28 öğenin ortalaması 87,86 standart sapması 9,99 ve varyansı ise 99,84 olarak hesaplanmiştır.

\subsection{Hemşirelerin Sosyal Sorumluluk Algısının Cinsiyet Açısından Değerlendirilmesi}

Katılımcıların sosyal sorumluluk ölçeğindeki ifadelere verdikleri puanların cinsiyet değişkenine göre farklılaşıp farklılaşmadığının belirlenebilmesi için gerçekleştirilen Mann Whitney U Testi'ne ait sonuçlar Tablo 1'de görülmektedir.

\begin{tabular}{|c|c|c|c|c|}
\hline Cinsiyet Değişkenine Göre & Kadın & Erkek & $\begin{array}{c}\text { Mann } \\
\text { Whitney U }\end{array}$ & $\mathrm{p}$ \\
\hline $\begin{array}{l}\text { 1. Sosyal sorumluluk gereği yapılan harcamalar, işletmeye ek bir maliyetten başka bir şey } \\
\text { getirmez. }\end{array}$ & 2,95 & 3,17 & 5175,500 & 0,267 \\
\hline $\begin{array}{l}\text { 2. İşletmeye kısa vadede kar olarak geri dönmeyen hiçbir faaliyete destek verilmesinden yana } \\
\text { değilim. }\end{array}$ & 2,34 & 2,62 & 5212,000 & 0,290 \\
\hline $\begin{array}{l}\text { 3. Optimum karlılıkla beraber, toplumu geliştiren ve çevreye duyarlı bir şirket olmaktansa, } \\
\text { maksimum karlılığı sağlayan bir şirket olmayı tercih ederim. }\end{array}$ & 2,28 & 2,68 & 4586,500 & $0,017 *$ \\
\hline $\begin{array}{l}\text { 4. İşletme toplumu ilgilendiren sosyal konulara yönelirse, temel amacı olan kar sağlamada } \\
\text { başarısız olur. }\end{array}$ & 2,35 & 2,83 & 4343,000 & $0,003 *$ \\
\hline 5. Sosyal sorumluluk sadece büyük ișletmelerin yapabileceği bir görevdir. & 2,17 & 2,53 & 4764,000 & $0,040^{*}$ \\
\hline $\begin{array}{l}\text { 6. Sosyal sorumluluk gereği yapılan harcamalar uzun vadede işletmeye olumlu geri bildirim } \\
\text { sağlayacaktır. }\end{array}$ & 3,98 & 4,02 & 5557,000 & 0,730 \\
\hline 7. Toplumu geliştirmek ișletmenin değil, devletin görevidir. & 2,53 & 2,88 & 4741,000 & $0,037 *$ \\
\hline 8. İşletmeler sosyal sorumluluğu sadece kendi çıkarları için yerine getirmelidirler. & 1,96 & 2,17 & 5149,000 & 0,207 \\
\hline 9. İșletmenin başarısı için toplumu geliștirmek ve çevreye duyarlı olmak şart değildir. & 1,95 & 2,40 & 4580,000 & $0,012 *$ \\
\hline 10. İşletmenin tek amacı karını maksimize etmek olmalıdır. & 2,05 & 2,47 & 4650,500 & $0,019 *$ \\
\hline 11. Her şirket kendi çapında sosyal sorumluluğu yerine getirebilir. & 4,11 & 4,15 & 5658,000 & 0,921 \\
\hline $\begin{array}{l}\text { 12. Toplum, çevre sorunlarına karşı hassas olmayı, ekonomik büyümeden daha önemli } \\
\text { görmektedir. }\end{array}$ & 3,29 & 3,60 & 4754,000 & $0,043^{*}$ \\
\hline $\begin{array}{l}\text { 13. İsletmeler sosyal sorumluluğu, toplumsal değerlere saygının gereği olarak yerine } \\
\text { getirmelidirler. }\end{array}$ & 3,88 & 4,02 & 5085,500 & 0,150 \\
\hline 14. Toplumu geliştirmek ve çevreye duyarlı olmak, işletmeye daha kalıcı bir başarı sağlar. & 4,16 & 4,32 & 5182,500 & 0,236 \\
\hline $\begin{array}{l}\text { 15. Toplum, rahatından biraz fedakârlık etme ve yüksek fiyat ödeme pahasına da olsa, çevre } \\
\text { dostu ürünlere daha çok rağbet gösterir. }\end{array}$ & 3,29 & 3,62 & 4387,500 & $0,005^{*}$ \\
\hline 16. Toplumun sorunlarına duyarlı olan yönetici, şirkete daha kalıcı bir başarı getirecektir. & 4,09 & 4,25 & 5153,500 & 0,209 \\
\hline 17. Sirket çıkarı için, sonuçlarını düșünmeksizin her șey yapılabilir. & 2,01 & 2,30 & 5155,000 & 0,237 \\
\hline $\begin{array}{l}\text { 18. Sosyal konulara duyarlı bir şirketin toplumdaki imajı, finansal açıdan güçlü fakat sosyal } \\
\text { konulara duyarsız bir şirketin imajından daha olumludur. }\end{array}$ & 3,73 & 3,75 & 5591,000 & 0,813 \\
\hline 19. Toplum merkezli yönetim fikri, gittikçe daha çok önem kazanacaktır. & 3,88 & 3,88 & 5691,500 & 0,984 \\
\hline 20. Şirket yeterince kar ediyorsa, toplumdaki imajı fazla önemli değildir. & 2,09 & 2,50 & 4536,000 & $0,009^{*}$ \\
\hline 21. Ekonomik amacı gerçekleştirmek için takip edilen her yol mubahtır. & 2,01 & 2,45 & 4420,000 & $0,006^{*}$ \\
\hline $\begin{array}{l}\text { 22. Toplumun ahlaki değerleri, temel amacı kar etmek olan işletmeler için bir bağlayıcılık } \\
\text { ifade etmez. }\end{array}$ & 2,64 & 2,83 & 5126,000 & 0,223 \\
\hline $\begin{array}{l}\text { 23. Toplum, işletmelerin toplumsal sorunlara karşı duyarlılıklarını, giderek daha hassasiyetle } \\
\text { takip etmektedir. }\end{array}$ & 3,66 & 3,63 & 5606,000 & 0,829 \\
\hline 24. Sosyal yardım ve yatırımlar, işletmeye uzun vadede olumlu getiri sağlamaktadır. & 3,85 & 4,00 & 5194,500 & 0,234 \\
\hline $\begin{array}{l}\text { 25. Şirketin herhangi bir uygulaması, toplumun ahlaki değerlerine aykırıssa, karlı dahi olsa } \\
\text { uygulamadan vazgeçilmelidir. }\end{array}$ & 3,85 & 3,85 & 5672,500 & 0,950 \\
\hline 26. Bir işletme karını kısa vadede maksimize ediyorsa başarılıdır. & 3,24 & 3,68 & 4292,000 & $0,003 *$ \\
\hline $\begin{array}{l}\text { 27. Başarılı işletme, sosyal sorumluluğunu da yerine getirip, karlılığını uzun vadeye yayan } \\
\text { işletmedir. }\end{array}$ & 4,08 & 4,13 & 5379,000 & 0,465 \\
\hline $\begin{array}{l}\text { 28. Kalıı başarı, ekonomik başarının sosyal sorumluluk konusunda gösterilen başarıyla } \\
\text { desteklenmesiyle mümkündür. }\end{array}$ & 4,03 & 4,05 & 5641,500 & 0,896 \\
\hline
\end{tabular}

$* \mathrm{p}<0.05$

Tablo 1.Katılımcıların Sosyal Sorumluluk Ölçeğindeki İfadelere Verdikleri Puanların Cinsiyet Değişkenine Göre Anlamlılık Düzeyleri

H1: Katılımcıların sosyal sorumluluk algısı cinsiyetlerine göre farklılık göstermektedir. 
Mann Whitney U Testi sonucunda, sosyal sorumluluk bilinçlerini belirlemeye yönelik puan ile cinsiyetlerine ait sıralamalar ortalamaları arasındaki farklılık istatistiksel olarak anlamlı bulunmuştur $(p<0,001<0,05)$. Bulgulara göre erkek katılımcıların, kadın katılımcılara göre sosyal sorumluluk algılarının daha yüksek olduğu görülmektedir. Erkek katılımcılara göre, şirketlerin sosyal sorumlulukların yerine getirmesi, çevreye daha duyarlı olması, toplumun sorunlarına karşı duyarlı olması gerekmektedir. Kadınların ise bu fikirden erkeklere oranla daha uzak olduğu ortaya çıkmaktadır. Kadın katılımcılar şirket çıkarlarını, sosyal sorumluluk gerektiren davranışlardan daha önemli görmektedirler.

\begin{tabular}{lllllrl}
\hline Boyut & Değişken & Gruplar & N & $\square$ sıra & Mann Whitney-U & P \\
\hline Sosyal Sorumluluk Ölçeği Puanı & Cinsiyet & Kadın & 190 & 113.94 & 3504,5 & $<0,001$ \\
& & Erkek & 60 & 162,11 & & \\
\hline
\end{tabular}

Tablo 2. Katılımcıların Sosyal Sorumluluk Ölçeğindeki Iffadelere Verdikleri Puanların Cinsiyet Değişkenine Göre Farklılaşıp Farklılaşmadığını Belirlemek Üzere Yapılan Mann Whitney U Testi Sonuçları

\subsection{Hemşirelerin Sosyal Sorumluluk Algısının Yaş Değişkeni Açısından Değerlendirilmesi}

Katılımcıların sosyal sorumluluk ölçeğindeki ifadelere verdikleri puanların yaş değişkenine göre farklılaşıp farklılaşmadığının belirlenebilmesi için gerçekleştirilen Kruskal Wallis H Testi' ne ait sonuçlar Tablo 3'de görülmektedir.

\begin{tabular}{|c|c|c|c|c|c|c|}
\hline Yaș Değișkenine Göre & 20-27 & 28-35 & $36-43$ & $44+$ & $\chi^{2}$ & p \\
\hline $\begin{array}{l}\text { 1. Sosyal sorumluluk gereği yapılan harcamalar, işletmeye ek bir maliyetten başka } \\
\text { bir şey getirmez. }\end{array}$ & 2,79 & 2,96 & 3,50 & 2,96 & 11,298 & $0,010^{*}$ \\
\hline $\begin{array}{l}\text { 2. İşletmeye kısa vadede kar olarak geri dönmeyen hiçbir faaliyete destek } \\
\text { verilmesinden yana değilim. }\end{array}$ & 2,53 & 2,26 & 2,25 & 2,57 & 2,773 & 0,428 \\
\hline $\begin{array}{l}\text { 3. Optimum karlılıkla beraber, toplumu geliştiren ve çevreye duyarlı bir şirket } \\
\text { olmaktansa, maksimum karlılığı sağlayan bir şirket olmayı tercih ederim. }\end{array}$ & 2,57 & 2,32 & 2,13 & 2,17 & 5,525 & 0,137 \\
\hline $\begin{array}{l}\text { 4. İşletme toplumu ilgilendiren sosyal konulara yönelirse, temel amacı olan kar } \\
\text { sağlamada başarısız olur. }\end{array}$ & 2,52 & 2,30 & 2,46 & 2,61 & 1,190 & 0,756 \\
\hline 5. Sosyal sorumluluk sadece büyük işletmelerin yapabileceği bir görevdir. & 2,36 & 2,07 & 2,18 & 2,43 & 1,722 & 0,632 \\
\hline $\begin{array}{l}\text { 6. Sosyal sorumluluk gereği yapılan harcamalar uzun vadede işletmeye olumlu geri } \\
\text { bildirim sağlayacaktır. }\end{array}$ & 4,16 & 3,98 & 3,88 & 3,43 & 16,191 & $0,001 *$ \\
\hline 7. Toplumu geliştirmek işletmenin değil, devletin görevidir. & 2,68 & 2,61 & 2,54 & 2,48 & 0,845 & 0,839 \\
\hline 8. İşletmeler sosyal sorumluluğu sadece kendi çıkarları için yerine getirmelidirler. & 2,00 & 1,88 & 2,02 & 2,35 & 4,109 & 0,250 \\
\hline $\begin{array}{l}\text { 9. İşletmenin başarısı için toplumu geliştirmek ve çevreye duyarlı olmak şart } \\
\text { değildir. }\end{array}$ & 1,94 & 2,09 & 2,30 & 1,96 & 5,868 & 0,118 \\
\hline 10. İşletmenin tek amacı karını maksimize etmek olmalıdır. & 2,09 & 2,14 & 2,18 & 2,39 & 1,884 & 0,597 \\
\hline 11. Her şirket kendi çapında sosyal sorumluluğu yerine getirebilir. & 4,09 & 4,21 & 4,27 & 3,70 & 7,179 & 0,066 \\
\hline $\begin{array}{l}\text { 12. Toplum, çevre sorunlarına karşı hassas olmayı, ekonomik büyümeden daha } \\
\text { önemli görmektedir. }\end{array}$ & 3,52 & 3,07 & 3,38 & 3,35 & 6,787 & 0,079 \\
\hline $\begin{array}{l}\text { 13. İşletmeler sosyal sorumluluğu, toplumsal değerlere saygının gereği olarak } \\
\text { yerine getirmelidirler. }\end{array}$ & 3,89 & 3,89 & 3,93 & 4,04 & 1,304 & 0,728 \\
\hline $\begin{array}{l}\text { 14. Toplumu geliştirmek ve çevreye duyarlı olmak, işletmeye daha kalıcı bir başarı } \\
\text { sağlar. }\end{array}$ & 4,26 & 4,14 & 4,16 & 4,09 & 4,763 & 0,190 \\
\hline $\begin{array}{l}\text { 15. Toplum, rahatından biraz fedakârlık etme ve yüksek fiyat ödeme pahasına da } \\
\text { olsa, çevre dostu ürünlere daha çok rağbet gösterir. }\end{array}$ & 3,49 & 2,95 & 3,48 & 3,57 & 13,462 & $0,004 *$ \\
\hline $\begin{array}{l}\text { 16. Toplumun sorunlarına duyarlı olan yönetici, şirkete daha kalıcı bir başarı } \\
\text { getirecektir. }\end{array}$ & 4,21 & 3,93 & 4,20 & 4,09 & 10,544 & $0,014 *$ \\
\hline 17. Şirket çıkarı için, sonuçlarını düşünmeksizin her şey yapılabilir. & 2,05 & 1,96 & 2,20 & 2,22 & 2,083 & 0,555 \\
\hline $\begin{array}{l}\text { 18. Sosyal konulara duyarlı bir şirketin toplumdaki imajı, finansal açıdan güçlü } \\
\text { fakat sosyal konulara duyarsız bir şirketin imajından daha olumludur. }\end{array}$ & 3,76 & 3,67 & 3,93 & 3,30 & 7,185 & 0,066 \\
\hline 19. Toplum merkezli yönetim fikri, gittikçe daha çok önem kazanacaktır. & 3,85 & 3,91 & 4,00 & 3,70 & 3,106 & 0,376 \\
\hline 20. Şirket yeterince kar ediyorsa, toplumdaki imajı fazla önemli değildir. & 2,31 & 2,04 & 2,18 & 2,04 & 2,970 & 0,396 \\
\hline 21. Ekonomik amacı gerçekleştirmek için takip edilen her yol mubahtır. & 2,31 & 1,77 & 2,13 & 2,00 & 10,644 & $0,014 *$ \\
\hline $\begin{array}{l}\text { 22. Toplumun ahlaki değerleri, temel amacı kar etmek olan işletmeler için bir } \\
\text { bağlayıcılık ifade etmez. }\end{array}$ & 2,74 & 2,67 & 2,77 & 2,26 & 3,375 & 0,337 \\
\hline $\begin{array}{l}\text { 23. Toplum, işletmelerin toplumsal sorunlara karşı duyarlılıklarını, giderek daha } \\
\text { hassasiyetle takip etmektedir. }\end{array}$ & 3,64 & 3,75 & 3,70 & 3,35 & 2,864 & 0,413 \\
\hline $\begin{array}{l}\text { 24. Sosyal yardım ve yatırımlar, işletmeye uzun vadede olumlu getiri } \\
\text { sağlamaktadır. }\end{array}$ & 3,89 & 3,88 & 3,91 & 3,87 & 0,939 & 0,816 \\
\hline $\begin{array}{l}\text { 25. Şirketin herhangi bir uygulaması, toplumun ahlaki değerlerine aykırıysa, karlı } \\
\text { dahi olsa uygulamadan vazgeçilmelidir. }\end{array}$ & 3,75 & 4,00 & 3,91 & 3,83 & 1,757 & 0,624 \\
\hline 26. Bir işletme karını kısa vadede maksimize ediyorsa başarılıdır. & 3,54 & 3,23 & 3,25 & 2,96 & 9,132 & $0,028 *$ \\
\hline $\begin{array}{l}\text { 27. Başarılı işletme, sosyal sorumluluğunu da yerine getirip, karlılığını uzun } \\
\text { vadeye yayan işletmedir. }\end{array}$ & 4,16 & 4,16 & 4,00 & 3,87 & 3,061 & 0,382 \\
\hline $\begin{array}{l}\text { 28. Kalıcı başarı, ekonomik başarının sosyal sorumluluk konusunda gösterilen } \\
\text { başarıyla desteklenmesiyle mümkündür. }\end{array}$ & 4,00 & 4,14 & 4,05 & 3,87 & 2,159 & 0,540 \\
\hline
\end{tabular}


H2: Katılımcıların sosyal sorumluluk bilinci yaşlarına göre farklılık göstermektedir.

Kruskall Wallis-H Testi sonucunda, katılımcıların sosyal sorumluluk bilinçleri ile yaş değişkenine ait sıralamalar ortalamaları arasındaki farklılık istatistiksel olarak anlamlı bulunmamıştır ( $\mathrm{x} 2=7,330 ; \mathrm{p}>0,05)$. Buna göre, çalışmamızdaki 4 farklı yaş grubundaki katılımcıların, sosyal sorumluluğa olan bakış açısı birbiri ile benzerdir.

\begin{tabular}{llllllll}
\hline Puan & Değişken & Gruplar & $\mathrm{N}$ & $\overline{\mathrm{X}}$ sira & $\mathrm{x}^{2}$ & $\mathrm{sd}$ & $\mathrm{P}$ \\
\hline \multirow{3}{*}{ Sosyal Sorumluluk } & & $20-27$ & 114 & 134,54 & & & \\
Ölçeği Puanı & Yaş & $28-35$ & 57 & 104,07 & 7,330 & 3 & 0,062 \\
& & $36-43$ & 56 & 131,38 & 7,330 & \\
& & 44 ve yukarıs1 & 23 & 119,50 & & & \\
\hline
\end{tabular}

Tablo 4. Katılımcıların Sosyal Sorumluluk Ölçeğindeki İfadelere Verdikleri Puanların Yaşlarına Göre Farklılaşıp Farklılaşmadı̆̆ııı Belirlemek Üzere Yapılan Kruskal Wallis-H Testi Sonuçları

\section{Sonuç}

Karşılaştırmalı analiz sonucunda, katılımcıların cinsiyetleri sosyal sorumluluk konusuna bakış açılarını farklılaştırmaktayken, yaşın sosyal sorumluluğa yönelik bakış açısında kayda değer bir farklılığa yol açmadığı görülmüştür.

Erkek katılımcıların, kadın katılımcılara göre sosyal sorumluluk bilinçlerinin daha yüksek olduğu görülmektedir. Erkek katılımcıların sosyal sorumluk konusuna bakış açılarının daha olumlu olduğunu söyleyebiliriz. Erkeklere göre kurumun sosyal sorumluluklarını yerine getirmesi, çevreye daha duyarlı olması, toplumun sorularına karşı duyarlı olması gerekmektedir. Sosyal sorumluk faaliyetlerinin doğru yürütülmesi sonucunda, işletme uzun vadede olumlu getiri sağlayabilecektir. Kadınların ise bu fikirden erkeklere oranla daha uzak olduğu ortaya çıkmaktadır. Kadın katılımcılar kurum çıkarlarını, sosyal sorumluluk gerektiren davranışlardan daha önemli görmektedirler. Yani kadınlara göre kurum sosyal faaliyetlerden önce kendisine kar sağlayacak faaliyetlerde bulunmalıdır.

Kurumda çalışanlarının yaşlarına göre sosyal sorumluluk konusuna bakış açısının herhangi bir farklılık yaratmadığı, her yaştan çalışanın görüşlerinin birbiri ile yakın olduğunun ortaya çıktığı çalışmamızda, çalışanların meslekteki kıdemleri, cinsiyetleri ve eğitim durumları önemli farklılıklar yaratmaktadır.

* Çalışma Ünlü, 2017. "Hemşirelerin Sosyal Sorumluluk Algılarının İncelenmesi (Sakarya İli Örneği)” isimli tezi esas alınarak hazırlanmıştır.

\section{Kaynakça}

- Akansel, 2011. Türk Futbolunun Kurumsal Sosyal Sorumluluk Algısı, Bahçeşehir Üniversitesi, Sosyal Bilimler Üniversitesi, Spor Yönetimi Yüksek Lisans Programı, Yayınlanmamış Yüksek Lisans Tezi, İstanbul.

- Aslantaş Ateş ve Senal, 2012. “Kurumsal Sosyal Sorumluluk Kapsamında Muhasebenin Sosyal Sorumluluğu”, Süleyman Demirel Üniversitesi'nde Bir Araştırma, Çukuova Üniversitesi İİB Dergisi, Cilt 16, Sayı 1, Haziran 2012, 71-85

- $\quad$ Aydemir, ve Ateş, 2011. “ Küçük Sanayi Sitelerinde Sosyal Sorumluluk Olgusu: Bilecik Küçük Sanayi Sitesi Örneği”, Dumlupınar Üniversitesi Sosyal Bilimler Dergisi, Say1 30, Ağustos 2011, 169-180.

- Bakioğlu ve Akkaya, 2013. "Okul Yöneticilerinin Sosyal Sorumluluğu Algılamalarının İncelenmesi”, Marmara Üniversitesi Atatürk Eğitim Fakültesi Eğitim Bilimleri Dergisi, Sayı 37, 2013, 56-67.

- Carroll, 1991. "The Pyramid of Corporate Social Responsibility: Toward the Moral Management of Organizational Stakeholders", Business Horizons, July-August, pp. 39-48.

- Ceritoğlu, 2011. Kurumsal Sosyal Sorumluluk ve İşletmelerin Çevre Bilinci Eksenindeki Uygulamalarının Tüketici Satın Alma Davranışı ve Kurum İmajı Algısına Etkisi, İstanbul: Yalın Yayıncılık.

- Coşkun Değirmen, 2010. Kurumsal Pazarlama ve Sosyal Sorumluluk, İzmir: Nobel Yayıncılık.

- Deren Van HetHof, 2015.Kurumsal Sosyal Sorumluluk Kavramlar, Uygulama ve Örnekler, Antalya: Nobel Yayıncilık.

- Ersöz, 2014. Kurumsal Toplumsal Sorumluluk: Aydın Organize Sanayi Bölgesinde Üretim İşletmeleri Örneği, Adnan Menderes Üniversitesi, Sosyal Bilimler Enstitüsü, İşletme Anabilim Dalı, Yayınlanmamış Doktora Tezi, Aydın.

- Gültekin, 2003. İşletmelerin Sosyal Sorumluluğunun Rolü ve GAP Bölgesi Yöneticilerinin Sosyal Sorumluluk Anlayışlarını Belirlemeye Yönelik Bir Araştırma, Marmara Üniversitesi, Sosyal Bilimler Enstitüsü, Yayınlanmamış Yüksek Lisans Tezi, İstanbul.

- Gürel Boran, 2015.Türkiye'den Uygulama Örnekleriyle Kurumsal Sosyal Sorumluluk, İstanbul: Beta Yayınevi. 
- Kaya,2008."Demografik Özelliklerin Kurumsal Sosyal Sorumluluk Algılaması Üzerindeki Rolü: Bandırma Yerelinde Bir Araştırma”, Balıkesir Üniversitesi Sosyal Bilimler Enstitüsü Dergisi, Cilt 11, Sayı 20, Aralık 2008, 96-110.

- Köroğlu ve Ersöz, 2015. "Muhasebe Meslek Mensuplarının Bakış Açılarından Kurumsal Sosyal Sorumluluk Muhasebe İlişkisi”, Journal of Accounting, Finance and Auditing Studies, Cilt 1, Sayı 3, 123-153.

- Özdemir, 2007. Çalışanların Kurumsal Sosyal Sorumluluk Algılamalarının Örgütsel Özdeşleşme, Örgütsel Bağlılık ve İş Tatminine Etkisi: Opet Çalışanlarına Yönelik Bir Uygulama, Marmara Üniversitesi Sosyal Bilimler Enstitüsü, Yayınlanmamış Doktora Tezi, İstanbul.

- Ö̈zen, 2007.“Kurumsal Sosyal Sorumluluk Kavramı ve Çalışan Memnuniyetine Etkisi”, Dicle Üniversitesi Ziya Gökalp Eğitim Fakültesi Dergisi, Sayı 8, 1-6. 


\title{
Türkiye'ye Yönelik Uluslararası Turizm Talebinin Sosyo- Ekonomik Belirleyicileri: Panel Veri Analiz
}

\section{Socio-Economic Determinants of International Tourism Demand for Turkey: Panel Data Analysis}

\author{
Asst. Prof. Dr. Ş. Mustafa Ersungur (Atatürk University, Turkey) \\ Asst. Prof. Dr. Ömer Doru (Şırnak University, Turkey) \\ Asst. Prof. Dr. Mehmet Barış Aslan (Muş Alparslan University, Turkey)
}

\begin{abstract}
Tourism is one of the main sectors that is rapidly growing across the world, especially for developing countries that yields considerable foreign exchange. In this sense, tourism has become a significant factor in the development processes that have been introduced in order to bring especially developing countries which have begun to develop aftermath of World War II closer to developed countries. Tourism is an important source of development for Turkey which has a high tourism potential. The aim of this study is to investigate the determinants of international tourism demand for Turkey with panel data method. Within this aim, the factors which affect movements of tourism have been tried to determine by using socio-economic data of 22 countries which generate the largest number of tourist from 2000 to 2014. The number of tourists from each selected country which come Turkey has been used as dependent variable in the study. As the independent variables; income levels and relative price levels of tourist sending countries, exchange rate variable between the two countries, political stability variable of tourist sending country and tourism expenditures per capita have included in the study. Within using panel data method, the findings of the study show that all the variables have received the expected sign. Therefore, these findings have indicated that they are effective on the tourism demand.
\end{abstract}

\section{Giriş}

Turizm; ülke ekonomilerine yarattığı gelir, döviz girdisi ve iş olanaklarıyla işsizliği azaltan, kazandırdı ̆̆ döviz ile üretim sürecinde gerekli olan sermaye malları teminini sağlayan, girişimciliği canlandıran, yerel el sanatlarının üretimini teşvik eden ve bunların yanında kültürel değişimi sağlayan ekonomik bir faaliyettir. Bu anlamda turizm, özellikle 2. Dünya Savaşı’ndan sonra gelişmekte olan ülkelerin gelişmiş ülkelere yakınsaması amacıyla giriştikleri kalkınma süreçlerinde önemli bir faktör olarak yer almıştır.

Turizmin 2. Dünya Savaşı’ndan sonra gelişmesinin en önemli nedenlerinden biri, savaş sonrası dönemde, gelişmiş ve gelişmekte olan ülkelerin gelirlerinde meydana gelen artışların bireylerin refah düzeylerini artırmasıdır. Bunun yanında; sivil havacılıktaki gelişmeler ve jet kullanımı, çalışanların sendikal haklarından elde ettikleri düşük çalışma saatleri ve yıllık izin hakkı sonucu boş zamanlarının oluşması, ülkeler arasında oluşan birlikler ve anlaşmaların seyahat özgürlüğü üzerindeki kısıtlamaları bir nebze ortadan kaldırmış olması gibi nedenler sayılabilir. Bu gelişmeler, turizm sektörünü 20.yy’ın ikinci yarısından itibaren küresel ekonomide en fazla büyüyen sektör konumuna getirmiştir. Turizm sektörü, bu dönemde yaşanan ekonomik krizler, türbülanslar, yoksulluklar, afetler ve küresel toplumda meydana gelen çatışmalardan en az etkilenen sektör olmuştur. UNWTO'nun 2016 yılında yayınlamış olduğu çalışmaya göre; dünya genelinde 1950 yılında 25 milyon olan turist sayısı, 2000 yılında 675 milyona ve 2015 yılında 1.186 milyon turist sayısına ulaşmıştır. Uluslararası turizm gelirleri ise, 1950 yılında 2,1 milyar dolar iken 2000 yılında 495 milyar dolar ve 2015 yılında ise 1.260 milyar dolara ulaşmıştır (UNWTO, 2016).

Turizm sektöründe yaşanan bu hızlı gelişmeler akademik çevrelerinde ilgi odağı olmuştur. Bu amaçla, literatürde turizm ile ilgili oldukça fazla çalışma yapılmıştır. Ancak yapılan çalışmaların büyük kısmı, turizm sektörünün büyüme üzerindeki etkisi inceleyen çalışmalar olmuştur. Turizmde en önemli alan olan talep konusunda ve özellikle turizm talebini etkileyen faktörler üzerine yapılan çalışmalar kısıtlı olmuştur. Turizm talebinin belirleyicilerinin tespiti politika yapıcıları ve sektör yöneticilerinin yaptıkları uzun vadeli planlamalarda önem arz etmektedir. 2017 yılında kabul edilen “Türkiye'ye Yönelik Dış Turizm Talebinin Ekonometrik Modeller İle Analizi" adlı doktora tezinden türetilen bu çalışma, Türkiye'nin uluslararası turizm talebinin belirleyicilerini Türkiye'ye en çok turist gönderen 22 ülke özelinde 2000-2014 dönemi için analitik olarak incelemeyi amaçlamaktadır.

\section{Dünyada ve Türkiye'de Turizmin Gelişimi}

Avrupa'da yaşanan Rönesans hareketleri ve daha sonra gelişen Sanayi Devrimi toplumda sosyal, ekonomik ve teknik gelişmeler meydana getirmiştir. Özellikle emeğe dayalı düşük miktardaki üretimin yerini makineye dayalı yüksek üretimin alması, kırsaldan merkezlere doğru göç hareketlerini başlatmış ve aynı zamanda çalışanların 
zamanla sosyal ve ekonomik olarak çalışma şartlarını iyileştirmiştir. Bunlar daha iyi ücret, daha az çalışma ve seyahat süreleri ile maliyetlerinin azalması olarak kendini göstermiştir. Raylı sistemlerin kullanılması sonucu seyahat süreleri ve maliyetlerindeki azalış, daha iyi bir gelir ve boş zaman günümüzdeki kullanılan anlamıyla turizmi ortaya çıkarmıştır (Kozak vd. 2015: 54-55).

Sanayi Devriminden sonra turizm gelişimi için en önemli dönüm noktası, 2. Dünya Savaşı sonrası yaşanan gelişmelerdir. Savaş sonrası dönemde ABD tarafından sağlanan yardımlar ile kurulan uluslararası kuruluşlar ve birlikler sayesinde Avrupa ülkeleri savaş tahribatını ortadan kaldırarak hızlı bir kalkınma sürecine girmişlerdir. Ancak bu dönemde ülkeler kalkınma süreçlerini tamamlamak için dövize ihtiyaç duymuşlar ve bu problemi çözmek için ihracattan başka yollar aramışlardır. Bu esnada gelişmeye başlayan turizm sektörü iktisatçıların ve hükümetlerin dikkatini çekmeyi başarmış ve ihracat ile beraber önemli bir döviz kazandırıcı işlem olarak görülmeye başlanmıştır. Bu gelişmelerle beraber, savaş döneminde gelişen savaş teknolojisi ve buradan sağlanan bilgi birikiminin savaş sonrası dönemde sivil alana transfer edilmesiyle havayolu ulaşımını hızlı bir şekilde geliştirmiştir (Giritlioğlu, 2015: 45). Bu durum seyahat sürelerini kısalttığı gibi maliyetleri de azaltmıştır. Bunlara ek olarak teknolojideki imkânlardan dolayı insanların çalışma sürelerinde önemli azalmalar meydana gelmiştir. Çalışma sürelerinde meydana gelen azalma insanları gezip-görme, eğlenme, dinlenme, öğrenme gibi sosyokültürel ihtiyaçlarını karşılamak üzere sürekli yaşadıkları yerlerden geçici olarak başka bölgelere seyahat etmelerine olanak sağlamıştır. Yaşanan bütün bu gelişmeler, dünyanın farklı yerlerinde yaşanan ekonomik krizler, savaşlar, salgın hastalıklar ve doğal afetlere rağmen turizmi hızla ekonominin en büyük sektörlerinden biri haline getirmiştir.

1950-2014 yılları arasında uluslararası turist sayısı ve turizm gelirlerinin seyrini gösteren Grafik 1'e göre; 2001 yılında ABD’de meydana gelen terör saldırıları ve 2008 yılında ortaya çıkan finansal kriz dönemlerinde kısa süreli durgunluk yaşanmasına rağmen turizm sektörünün sürekli hızlı bir büyüme trendinde olduğunu söylemek mümkündür.

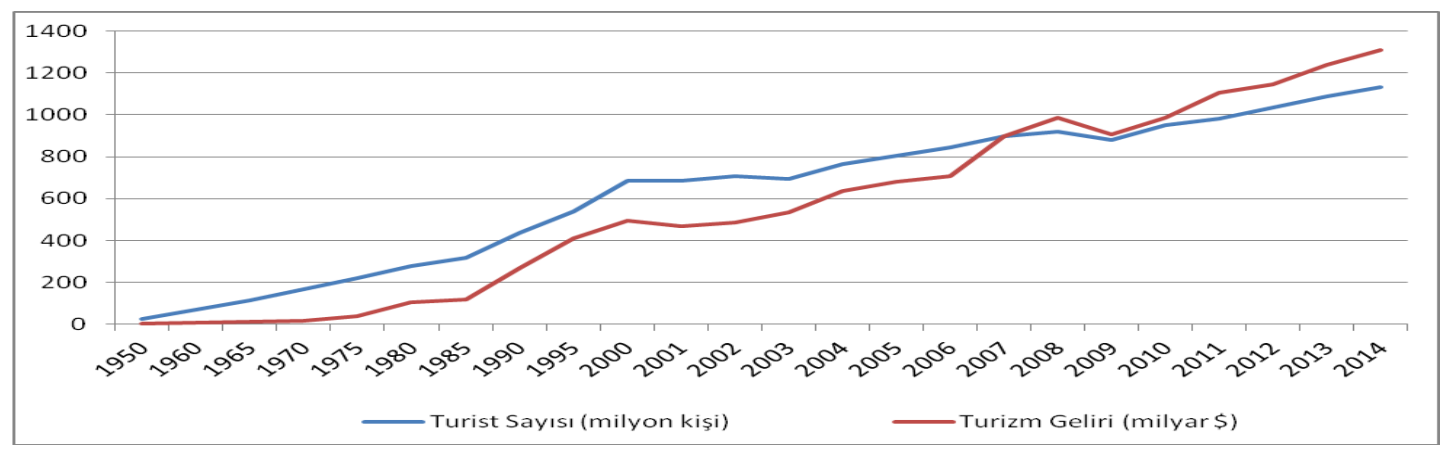

Grafik 1. Uluslararası Turist Saylsı ve Turizm Gelirleri Kaynak: UNWTO (2015)

Grafikten çıkarılacak bir diğer sonuç, turizmden elde edilen gelirdeki büyüme hızının turist sayısındaki büyüme hızından fazla olmasıdır. Turizmdeki kalitenin ve turizm çeşitliliğinin artması kişi başına düşen turizm harcamasını arttıran unsurlar olmuştur. Buna göre turist başına düşen turizm harcaması tutarı 1980'den sonra hızlı bir artış trendine girmiş ve 2008 yılından sonra 1000 \$'ın üzerine çıkmıştır.

Dünyada en çok turist çeken ve en çok turizm geliri elde eden ülkelere bakıldığında Avrupa ülkeleri, ABD ve Asya ülkelerinin diğer ülkelere göre ön sıralarda olduğu görülmektedir. Tablo 1'de 2012, 2013 ve 2014 yıllarına ait dünyada en çok turist kabul eden ve en çok turizm geliri elde eden ülkeler belirtilmiştir. Fransa 83,7 milyon turist ile dünyada en çok turist kabul eden ülke iken ABD 75,1 milyon turist sayısı ile ikinci ve İspanya ise 68,2 milyon turist ile üçüncü sırada yer almaktadır. Türkiye son yıllarda yakaladığı ivme ile 39,8 milyon turist ile altınc1 sırada yer almıştır. 


\begin{tabular}{|c|l|r|r|r|r|l|r|r|r|}
\hline \multicolumn{9}{|c|}{$\begin{array}{c}\text { En Çok Turist Çeken Ülkeler } \\
\text { (Milyon Kişi) }\end{array}$} & \multicolumn{4}{c|}{$\begin{array}{c}\text { En Çok Turizm Geliri Elde Eden Ülkeler } \\
\text { (Milyar Dolar) }\end{array}$} \\
\hline Sira & Ülkeler & 2012 & 2013 & 2014 & Sira & Ülkeler & 2012 & 2013 & 2014 \\
\hline 1 & Fransa & 81,9 & 83,6 & 83,7 & 1 & ABD & 161,7 & 177,5 & 191,3 \\
\hline 2 & ABD & 66,7 & 69,9 & 75,1 & 2 & Çin & 50,02 & 51,7 & 105,4 \\
\hline 3 & İspanya & 57,5 & 60,7 & 68,2 & 3 & İspanya & 58,16 & 62,5 & 65,1 \\
\hline 4 & Çin & 57,7 & 55,7 & 55,6 & 4 & Fransa & 53,7 & 56,7 & 58,1 \\
\hline 5 & İtalya & 46,3 & 47,8 & 48,6 & 5 & İngiltere & 36,6 & 41,02 & 46,5 \\
\hline 6 & Türkiye & 35,7 & 37,8 & 39,8 & 6 & İtalya & 41,2 & 43,9 & 45,5 \\
\hline 7 & Almanya & 30,1 & 31,5 & 33,1 & 7 & Almanya & 38,1 & 41,3 & 43,3 \\
\hline 8 & İngiltere & 29,3 & 31,1 & 32,6 & 8 & Macao & 43,9 & 51,8 & 42,6 \\
\hline 9 & Rusya & 25,7 & 28,4 & 29,8 & 9 & Tayland & 33,9 & 41,8 & 38,4 \\
\hline 10 & Meksika & 23,4 & 24,2 & 29,3 & 10 & Hong Kong & 33,1 & 38,9 & 38,4 \\
\hline 11 & Hong Kong & 23,8 & 25,7 & 27,8 & 11 & Avustralya & 31,9 & 31,3 & 31,9 \\
\hline 12 & Malezya & 25,1 & 25,8 & 27,4 & 12 & Türkiye & 25,3 & 27,9 & 29,5 \\
\hline
\end{tabular}

Tablo 1. En Çok Turist Çeken ve Turizm Geliri Elde Eden Ülkeler (2012-2014) Kaynak: UNWTO (2015)

En çok turizm geliri elde eden ülkelere bakıldığında ise; ABD, Çin ve İspanya'nın Fransa'dan daha az turist kabul etmesine rağmen daha fazla turizm geliri elde ettikleri görülmektedir. Toplam 191,3 Milyar Dolar ve yaklaşık 2500 Dolar turist başına düşen gelir ile ABD dünyada en fazla turizm geliri elde eden ülke konumundadır. ABD'yi 105,4 Milyar Dolar ile Çin ve 65,1 Milyar Dolar ile İspanya takip etmekte, en çok turist çeken ülke olan Fransa ise toplam 58,1 Milyar Dolar ve yaklaşık 700 Dolar kişi başına düşen turizm geliri ile dördüncü sırada yer almaktadır. Türkiye'de toplam 29,5 Milyar Dolar ve 740 Dolar kişi başına düşen turizm geliri ile on ikinci sırada yer alabilmiştir.

Ülkemizde turizm ile ilgili gelişmeler, 20.yüzyılın başında ulaştırma sektöründe meydana gelen bazı gelişmeler sonucu İstanbul'un bir çekim merkezi haline gelmesiyle başladığı kabul edilmektedir. Ancak günümüzde kullanılan anlam itibariyle turizm, günümüz gelişmiş ülkeleriyle aynı dönemde yani 2. Dünya Savaşı'ndan sonra ekonomik bir değer olarak önemsenmeye başlanmış ve çıkarılan yasal düzenlemeler ile hükümet politikalarında yer edinmeye başlamıştır (Kozak vd., 2015;150).

Planlı dönemde Türkiye'ye gelen yabancı turist sayısı ile turizm gelirlerinin tarihsel gelişimi Grafik 2'de verilmiştir.

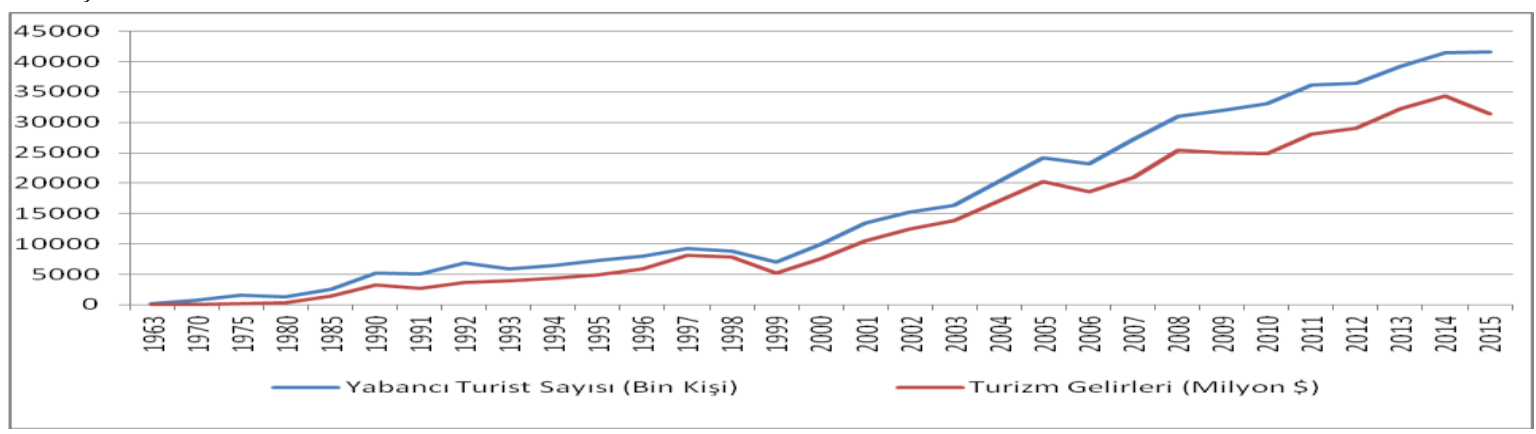

Grafik 2. Yabancı Turist Saylsl ve Turizm Gelirleri (1963-2015) Kaynak: TÜIK (2016), TÜRSAB (2016)

Grafikte görüldüğü üzere hem yabancı turist sayısında hem de buna bağlı olarak turizm gelirlerinde 1980'den sonra bir artış görüldüğü ancak asıl sıçramanın 2000'li yılların başından itibaren başladığı görülmektedir. Grafikten çıkarılacak bir diğer sonuç, turizm sektörünün 1999 yılında gerçekleşen deprem ve 2008 yılında gerçekleşen küresel krizden olumsuz yönde etkilenmiş olmasıdır.

\section{Uluslararası Turizm Talebi Üzerine Literatür Özeti}

Turizm ile ilgili yapılan literatür incelemesinde, turizm gelirlerinin ekonomik büyüme üzerinde oldukça etkili olduğu sonucuna ulaşan fazla sayıda çalışma bulunmaktadır. Ancak turizm talebini etkileyen faktörleri belirlemeyi amaçlayan ampirik çalışmaların oldukça sınırlı kaldığı görülmektedir. Turizm talebini etkileyen belirleyiciler üzerine yapılan ampirik çalışmalar, daha çok 1990’lı yılların ortasından itibaren çalışılmaya başlanmıştır. Konu ile ilgili yapılan ampirik çalışmalara ait özet bilgiler aşağıdaki tabloda verilmiştir. 


\begin{tabular}{|c|c|c|c|c|c|}
\hline Yazar & $\begin{array}{l}\text { Ülke } \\
\text { Gurubu }\end{array}$ & Veri Seti & Bağımsız Değişkenler & $\begin{array}{l}\text { Bağımlı } \\
\text { Değişken }\end{array}$ & Yöntem \\
\hline $\begin{array}{l}\text { Proenca } \\
\text { ve } \\
\text { Soukiazis, } \\
(2005)\end{array}$ & $\begin{array}{l}\text { Portekiz } \\
\text { için } 4 \text { ülke }\end{array}$ & $1977-2001$ & $\begin{array}{l}\text { Kişi başına düşen GSYH, Fiyat Düzeyi, } \\
\text { konaklama kapasitesi, hükümet yatırımları } \\
\text { oranı, kukla değişken }\end{array}$ & $\begin{array}{l}\text { Turizm } \\
\text { Harcamaları } \\
\text { oranı }\end{array}$ & $\begin{array}{lr}\text { Panel } & \text { Veri } \\
\text { OLS, LSDV, } \\
\text { GLS }\end{array}$ \\
\hline $\begin{array}{l}\text { Aslan vd. } \\
\text { (2008) }\end{array}$ & $\begin{array}{l}\text { Türkiye için } \\
9 \text { ülke }\end{array}$ & $1995-2004$ & $\begin{array}{l}\text { Kişi başına düşen GSYH, Fiyat endeksi, } \\
\text { Yatak sayısı, kamu yatırımları oranı, kukla } \\
\text { değişken( Marmara depremi, } 11 \text { Eylül) }\end{array}$ & $\begin{array}{l}\text { Turizm } \\
\text { harcamaları } \\
\text { oranı }\end{array}$ & $\begin{array}{l}\text { Panel Veri } \\
\text { GMM, DİFF }\end{array}$ \\
\hline $\begin{array}{r}\text { Ketenci } \\
(2009)\end{array}$ & $\begin{array}{l}\text { Türkiye için } \\
13 \text { ülke }\end{array}$ & $1996-2006$ & $\begin{array}{l}\text { Kişi Başına düşen GSYH, Tüketici Fiyat } \\
\text { endeksi, Rakip ülkenin tüketici fiyat endeksi }\end{array}$ & $\begin{array}{l}\text { Gelen turist } \\
\text { say1s1 }\end{array}$ & Panel ARDL \\
\hline $\begin{array}{l}\text { Walle } \\
(2010)\end{array}$ & $\begin{array}{l}\text { Etiyopya } \\
\text { için } 40 \text { ülke }\end{array}$ & $1998-2004$ & $\begin{array}{l}\text { Kişi başına düşen GSYH, reel döviz kuru, } \\
\text { uzaklık, nüfus, kentleşme, karayolu uzunluğu } \\
\text { ve internet kullanımı, kukla değişken }\end{array}$ & $\begin{array}{l}\text { Gelen turist } \\
\text { say1s1 }\end{array}$ & $\begin{array}{l}\text { Panel } \\
\text { GMM, }\end{array}$ \\
\hline $\begin{array}{l}\text { Görmüş ve } \\
\text { Göçer } \\
(2010)\end{array}$ & $\begin{array}{l}\text { Türkiye için } \\
32 \text { ülke }\end{array}$ & $2006-2007$ & $\begin{array}{l}\text { GSYH, Diş ticaret miktarı, uzaklık, } \\
\text { konaklama potansiyeli, nüfus, fiyat endeksi, } \\
\text { reel döviz kuru, reklam harcaması, rakip ülke } \\
\text { fiyatları }\end{array}$ & $\begin{array}{l}\text { Gelen turist } \\
\text { sayısı }\end{array}$ & $\begin{array}{l}\text { Panel } \\
\text { GLS }\end{array}$ \\
\hline $\begin{array}{l}\text { Jintranun } \\
\text { vd. }(2011)\end{array}$ & $\begin{array}{l}\text { Tayland için } \\
10 \text { ülke }\end{array}$ & $1997-2010$ & $\begin{array}{l}\text { Kişi başına düşen GSYH, fiyat endeksi, reel } \\
\text { döviz kuru, uzaklık }\end{array}$ & $\begin{array}{l}\text { Gelen turist } \\
\text { say1s1 }\end{array}$ & $\begin{array}{l}\text { Panel Veri } \\
\text { GMM, }\end{array}$ \\
\hline $\begin{array}{l}\text { Eita vd. } \\
(2011)\end{array}$ & $\begin{array}{l}\text { G.Afrika } \\
\text { için } 27 \text { ülke }\end{array}$ & 1999- 2007 & $\begin{array}{l}\text { GSYH, fiyat endeksi, döviz kuru, ulaştırma } \\
\text { maliyetleri, alt yapı durumu }\end{array}$ & $\begin{array}{l}\text { Gelen Turist } \\
\text { say1s1 }\end{array}$ & $\begin{array}{l}\text { Panel Veri } \\
\text { Fixed Effect } \\
\text { GLS }\end{array}$ \\
\hline $\begin{array}{r}\text { Ibrahim } \\
(2011)\end{array}$ & $\begin{array}{l}\text { Misır için } 8 \\
\text { ülke }\end{array}$ & $1990-2008$ & $\begin{array}{l}\text { Nüfus, Kişi başına düş̧en GSYH, fiyat } \\
\text { endeksi, reel döviz kuru, iki ülke arasındaki } \\
\text { dış ticaret, Tunus'un fiyat endeksi }\end{array}$ & $\begin{array}{l}\text { Gelen turist } \\
\text { say1s1 }\end{array}$ & $\begin{array}{l}\text { Panel Veri } \\
\text { Fixed Effects }\end{array}$ \\
\hline $\begin{array}{l}\text { Surugiu vd } \\
\qquad(2011)\end{array}$ & $\begin{array}{l}\text { Romanya } \\
\text { için } 23 \text { ülke }\end{array}$ & $1997-2008$ & $\begin{array}{l}\text { GSYİH, dış ticaret, nüfus, iki ülke arasında ki } \\
\text { mesafe, fiyat düzeyi }\end{array}$ & $\begin{array}{l}\text { Gelen turist } \\
\text { say1s1 }\end{array}$ & $\begin{array}{l}\text { Panel Veri } \\
\text { Fixed Effects }\end{array}$ \\
\hline $\begin{array}{l}\text { Ekanayake } \\
\text { (2012) }\end{array}$ & $\begin{array}{l}\text { Amerika } \\
\text { için } 50 \text { ülke }\end{array}$ & $1986-2011$ & $\begin{array}{l}\text { Kişi başına düşen GSYH, fiyat endeksi, reel } \\
\text { döviz kuru, seyahat maliyetleri, vize işlemleri } \\
\text { kukla değişkeni }\end{array}$ & $\begin{array}{l}\text { Gelen turist } \\
\text { say1s1 }\end{array}$ & $\begin{array}{l}\text { Panel } \\
\text { LSDV }\end{array}$ \\
\hline $\begin{array}{l}\text { Kaya ve } \\
\text { Canli } \\
(2013)\end{array}$ & $\begin{array}{l}\text { Türkiye için } \\
24 \text { ülke }\end{array}$ & $\begin{array}{l}1990-2010 \\
1990-2008\end{array}$ & $\begin{array}{l}\text { GSYH, Fiyat düzeyi, Rakip ülkelere ait fiyat } \\
\text { düzeyi }\end{array}$ & $\begin{array}{l}\text { Gelen turist } \\
\text { say1S1 }\end{array}$ & $\begin{array}{l}\text { Panel Veri } \\
\text { Fixed Effects }\end{array}$ \\
\hline $\begin{array}{l}\text { Aydin vd. } \\
\text { (2015) }\end{array}$ & $\begin{array}{l}\text { Türkiye için } \\
5 \text { ülke }\end{array}$ & $1996-2013$ & $\begin{array}{l}\text { GSYH, Fiyat endeksi, Reel döviz kuru, } \\
\text { Seyahat Maliyetleri }\end{array}$ & $\begin{array}{l}\text { Gelen turist } \\
\text { say1s1 }\end{array}$ & $\begin{array}{l}\text { DOLS } \\
\text { FMOLS, } \\
\text { Cup_FM }\end{array}$ \\
\hline $\begin{array}{l}\text { Özcan } \\
(2015)\end{array}$ & $\begin{array}{l}\text { Türkiye için } \\
20 \text { ülke }\end{array}$ & $1995-2011$ & $\begin{array}{l}\text { GSYH, Fiyat düzeyi, reel döviz kuru, politik } \\
\text { istikrar endeksi }\end{array}$ & $\begin{array}{l}\text { Gelen turist } \\
\text { say1s1 }\end{array}$ & $\begin{array}{l}\text { DOLS } \\
\text { FMOLS }\end{array}$ \\
\hline $\begin{array}{l}\text { Güneş ve } \\
\text { Kabadayı } \\
(2015)\end{array}$ & $\begin{array}{l}\text { Türkiye için } \\
89 \text { ülke }\end{array}$ & 1995- 2011 & GSYH, Nüfus, iki ülke arasındaki uzaklık & $\begin{array}{l}\text { Gelen turist } \\
\text { say1s1 }\end{array}$ & $\begin{array}{l}\text { Panel Çekim } \\
\text { Modeli }\end{array}$ \\
\hline
\end{tabular}

Tablo 2. Literatür Özeti

\section{Veriler, Yöntem ve Bulgular}

Türkiye'nin uluslararası turizm talebini etkileyen faktörleri belirlemeyi amaçlayan bu çalışmada, Türkiye'ye en çok turist gönderen 25 ülkenin verisi kullanılmıştır. Çalışılması hedeflenen ülke grubu, Türkiye'ye olan toplam turizm talebinin \%80'i gibi çok yüksek bir oranını temsil etmektedir. Ancak Irak, Azerbaycan ve Kazakistan'ın verileri ulaşılabilir olmadığından dolayı modelden dışlanmak zorunda kalınmıştır. Geriye kalan 22 ülkenin Türkiye'ye olan turizm talebi, Türkiye'nin uluslararası turizm talebinin yaklaşık \%75'ini oluşturmaktadır. Çalışmada yıllık bazda, ülke grubunda bulunan her bir ülkenin Türkiye'ye gönderdiği turist sayısı bağımlı değişken olarak kullanılmıştır. Bağımsız değişken olarak ise uluslararası turizm talebini etkileyen ekonomik ve ekonomik olmayan faktörlere modelde yer verilmiştir. Ekonomik faktörler olarak, turist gönderen ülkenin kişi başına düşen GSYH verisi, Türkiye'nin tüketici fiyat endeksinin turist gönderen ülkenin tüketici fiyat endeksine oranlanmasıyla elde edilen fiyat değişkeni ve Türkiye'nin reel efektif döviz kuru endeksinin turist gönderen ülkenin reel efektif döviz kuru endeksine bölünmesiyle bulunan reel döviz kuru değişkeni kullanılmıştır. Bunun yanında ekonomik olmayan faktörler için nüfus ve politik istikrar değişkenleri kullanılmıştır. Nüfus verisini temsil etmek üzere turist gönderen ülkenin kişi başına düşen turizm harcaması verisi kullanılırken istikrar endeksi için Dünya Bankası tarafından yıllık olarak yayınlanan Politik İstikrar Endeksi (Political Stability Index) verisi kullanılmıştır. Veri seti 2000-2014 yılları arasını temsil etmekte olup logaritmik formda ve yıllık bazda modele dâhil edilmiştir. Çalışmada 
yapılan testlerin sonuçlarını elde edebilmek için Gauss 10 paket programı kullanılmıştır. Modelde kullanılan turist sayısı değişkenine ait veriler TÜİK veri tabanından elde edilirken diğer değişkenlere ait veriler Dünya Bankası veri tabanından elde edilmiştir.

Ülkelerin ekonomik, demografik ve politik göstergelerinin Türkiye’ye yönelik turizm talepleri üzerindeki etkileri eşitlik 1 yardımı ile incelenmiştir.

$\operatorname{lnTRSTit}=\mathrm{f}(\operatorname{lnGDPit}, \operatorname{lnCPIit}, \operatorname{lnRDKit}, \operatorname{lnTRZHARit}$, lnPSIit $)$

eşitlik 1'de;

TRST $=$ i ülkesinden Türkiye'ye gelen turist sayısını

$\mathrm{GDP}=\mathrm{i}$ ülkesinin kişi başına düşen gelirini

CPI= Türkiye ile i ülkesi arasındaki fiyat endeksi oranını

RDK = Türkiye ile i ülkesi arasındaki reel döviz kuru oranını

TRZHAR = i ülkesinin kişi başına düşen turizm harcamalarını

PSI= i ülkesinin politik istikrar endeksini göstermektedir. Modelde simgelenen ln ise değişkenin logaritmik formda kullanıldığını, i Türkiye'ye turist gönderen ülkeyi, t zamanı temsil etmektedir.

Kurulacak modelde hem birim hem de zaman boyutu olduğundan dolayı değişkenler arasındaki ilişkiler panel veri analizleri ile test edilmiştir. Panel data hem zaman hem de birim boyutu içerdiğinden dolayı daha yüksek gözlem sayıları ile çalışma imkanı sunmaktadır (Verbeek, 2008). Panel veri ile yapılan çalışmalarda öncelikle yatay kesit bağımlılığının varlığı tespit edilmelidir. Değişkenlerde ve eş-bütünleşme denkleminde yatay kesit bağımlılığının varlığını test etmek, yapılacak birim kök ve eş-bütünleşme testlerinin seçiminde önemlidir. Yatay kesit bağımlılığı tespit edilmeden seçilen testler hatalı sonuçlar verebilecektir (Göçer vd., 2012). Yatay kesit bağımlılığını dikkate almayan testlere birinci nesil testler, dikkate alan testlere ise ikinci nesil testler adı verilmektedir. Turizm talebinin belirleyicilerini araştırdığımız bu çalışmada, öncelikle değişkenlerde ve modelde yatay kesit bağımlılığının varlığı tespit edilmiş ve kullanılan birim kök testi ile eş-bütünleşme testi çıkan sonuca göre seçilmiştir.

\subsection{Yatay Kesit Bağımlılığının Test Edilmesi:}

Yatay kesit bağımlılı̆̆ının varlığını tespit etmeyi amaçlayan testlerin seçiminde, serinin zaman ve yatay kesit boyutu göz önünde bulundurulması gereken faktörlerdir. Yatay kesit bağımlılığının varlığı, panelin zaman boyutunun yatay kesit boyutundan büyük olduğu durumda (T>N) Breusch-Pagan (1980) CDLM1 (Cross-section Dependence Lagrange Multiplier) testiyle; zaman boyutu kesit boyutuyla eşit veya küçük olduğu durumlarda Pesaran (2004) CDLM2 testleri ile incelenmektedir. Bununla birlikte CDLM testi, grup ortalamasının sıfır ve birim ortalamasının sıfırdan farklı olduğu durumlarda sapmalı sonuçlar vermektedir. Pesaran vd. (2008), bu sapmayı yapmış oldukları LMadj testi ile çözmüşlerdir. Yazarlar bu sapmayı çözmek için test istatistiğine varyansı ve ortalamayı eklemişlerdir. Bu nedenle testin ismi, sapması düzeltilmiş LM testi olarak ifade edilmektedir (Göçer vd., 2012, Yalçınkaya ve Hüseyni, 2016).

Bu çalışmada, serinin zaman boyutu yatay kesit boyutundan küçük olduğundan $(\mathrm{N}>\mathrm{T})$ değişkenlerde ve eşbütünleşme denkleminde yatay kesit bağımlılığının varlığı, LMadj testi ile test edilmiş ve Tablo 3 'teki sonuçlar elde edilmiştir.

\begin{tabular}{|l|l|l|}
\hline & LMAdj Test & Prob \\
\hline $\ln$ TRST & 10,008 & 0,000 \\
\hline $\operatorname{lnRDK}$ & 3,638 & 0,000 \\
\hline $\ln$ GDP & 26,350 & 0,000 \\
\hline $\ln$ TRHAR & 18,744 & 0,000 \\
\hline $\ln$ PSI & 2,972 & 0,001 \\
\hline $\ln$ CPI & 24,753 & 0,000 \\
\hline Model & 11,728 & 0,000 \\
\hline
\end{tabular}

Tablo 3. Yatay Kesit Bă̆ımlılı̆̆ Testi Sonuçları

Tablo incelendiğinde, bütün değişkenler ve model için hesaplanan istatistiklerin olasıllk değeri 0,05 'ten küçük olduğu için hem değişkenlerde hem de modelde "yatay kesit bağımlılığı yoktur” boş hipotezi ret edilmektedir. Bu sonuç hem değişkenler de hem de modelde yatay kesit bağımlılığı olduğuna işaret etmektedir. Değişkenler arasında ve modelde yatay kesit bağımlılığının varlığı, çalışmanın bundan sonraki aşamasında yapılacak birim kök ve eşbütünleşme testlerinde YKB'yi dikkate alan testlerin kullanımını zorunlu kılmıştır.

\subsection{Panel Birim Kök Testi:}

Panel veri analizlerinde zaman serisi verilerinde olduğu gibi değişkenlerin durağan olması önem arz etmektedir. Durağan olmayan seriler ile kurulacak bir modelde elde edilen parametreler, değişkenler arasındaki gerçek ilişkiyi yansıtmaktan ziyade serilerde var olan aşağı veya yukarı yönlü bir trendden kaynaklanabilir. Sahte regresyon 
olarak adlandırılan böyle bir olguya düşmemek için serilerin durağanlığı incelenerek uygun gecikmede modele dâhil edilmelidir (Gujarati, 2010, Tarı, 2011). Hem modelde hem de bütün değişkenlerde yatay kesit bağımlılığı olduğundan durağanlık testi için ikinci nesil birim kök testi olan CADF testi kullanılmış ve sonuçları Tablo 4 'te verilmiştir.

\begin{tabular}{|c|c|c|c|c|c|c|}
\hline \multirow[b]{2}{*}{ Değişkenler } & \multicolumn{3}{|l|}{ Seviye } & \multicolumn{3}{|l|}{ 1.Fark } \\
\hline & Trend & Gecikme & $\begin{array}{l}\text { İstatistik } \\
\text { Değeri }\end{array}$ & Trend & Gecikme & $\begin{array}{l}\text { İstatistik } \\
\text { Değeri }\end{array}$ \\
\hline $\operatorname{lnTRST}$ & 1 & 3 & $-2,07$ & 1 & 2 & $-3,6^{*}$ \\
\hline $\operatorname{lnRDK}$ & 1 & 2 & $-2,38$ & 1 & 2 & $-3,1^{*}$ \\
\hline InTRHAR & 1 & 3 & $-2,62$ & 1 & 2 & $-2,76 * *$ \\
\hline $\operatorname{lnGDP}$ & 0 & 3 & $-2,04$ & 0 & 2 & $-2,37 * *$ \\
\hline $\operatorname{lnCPI}$ & 1 & 1 & $-2,42$ & 1 & 1 & $-2,93 * *$ \\
\hline $\ln$ PSI & 1 & 2 & $-2,52$ & 1 & 2 & $-3,29 *$ \\
\hline \multicolumn{3}{|c|}{ Tablo Kritik Değerleri } & \multicolumn{2}{|l|}{ Sabit } & \multicolumn{2}{|c|}{ Sabit + Trend } \\
\hline \multicolumn{3}{|c|}{$1 \%$} & \multicolumn{2}{|l|}{$-2,45$} & \multicolumn{2}{|l|}{$-3,00$} \\
\hline \multicolumn{3}{|l|}{$5 \%$} & \multicolumn{2}{|l|}{$-2,22$} & \multicolumn{2}{|l|}{$-2,77$} \\
\hline \multicolumn{3}{|l|}{$10 \%$} & \multicolumn{2}{|l|}{$-2,11$} & \multicolumn{2}{|l|}{$-2,65$} \\
\hline
\end{tabular}

Tablo 4. CADF Birim Kök Testi Sonuçları

Tablo incelendiği zaman, tüm değişkenler için hesaplanan seviye istatistik değerlerinin Pesaran (2007)'de verilen CADF tablo kritik değerlerinden küçük olduğu, bu nedenle durağan olmadıkları anlaşılmaktadır. Ancak değişkenlerin birinci farkları alındıktan sonra yapılan testlerde; bütün değişkenler için hesaplanan istatistik değerlerin CADF tablo kritik değerlerinden mutlak olarak büyük olduğu belirlenmiştir. Bu durum değişkenlerin birinci farklarının durağan olduğunu göstermektedir. Çalışmanın bundan sonraki bölümünde değişkenler arasındaki eş-bütünleşme ilişkisi incelenmeye çalışılmıştır.

\subsection{Panel Eş-Bütünleşme Testi:}

Aynı düzeyde durağan olan seriler arasında uzun dönemli bir ilişkinin varlığı eş-bütünleşme testleri ile yapılabilmektedir. Panel verilerle yapılan çalışmalarda durağanlık testlerinde olduğu gibi eş-bütünleşme analizlerinde de serilerde yatay kesit bağımlılığının tespiti önemlidir. Panel eş-bütünleşme testleri yatay kesit bağımlılığını dikkate alan testler ve dikkate almayan testler olarak ayrılmaktadırlar. Serilerde yatay kesit bağımlılığının olması durumunda birinci nesil testler sapmalı sonuçlar verebileceğinden dolayı yeni nesil panel eşbütünleşme testleri (Westerlund ve Edgerton, 2007; Westerlund, 2008) kullanılmalıdır. Bu çalışmada Düzeltilmiş LM testi ile incelenen yatay kesit bağımlılı̆ı testi sonucunda, modelde yatay kesit bağımlılı̆̆ olduğu tespit edilmiştir. $\mathrm{Bu}$ durum eş-bütünleşme testi için yeni nesil testlerin kullanılmasının daha uygun olduğunu göstermektedir. Bunun için Westerlund (2008) Durbin-Hausman eş-bütünleşme testi kullanılmış ve test sonuçları Tablo 5'te verilmiştir.

\begin{tabular}{|l|l|l|l|c|}
\hline & Test İstatistiği & Olasılık Değeri & \multicolumn{2}{|c|}{ Tablo Kritik Değerleri } \\
\hline Durbin-h grup & 9.85 & 0.000 & $\% 1$ & 1.98 \\
\hline Durbin-h panel & 8.33 & 0,000 & $\% 1$ & 1.98 \\
\hline
\end{tabular}

Tablo 5. Westerlund (2008) Eş-bütünleşme Testi Sonuçları

Tablo incelendiğinde Durbin-h grup ve Durbin-h panel istatistikleri için hesaplanan olasıllk değerlerinin 0,01'den küçük olduğu görülmektedir. Bu durum \%1 önem düzeyinde "seriler arasında eş-bütünleşme ilişsisi yoktur" boş hipotezinin ret edildiğini işaret etmektedir. Boş hipotezin ret edilmesi seriler arasında eş-bütünleşme ilişkisinin olduğunu göstermektedir.

Eş-bütünleşme ilişkisi olan aynı zamanda yatay kesit bağımlılığı içeren serilerde uzun dönem eş-bütünleşme katsayılarını tahmin etmek için OLS tahmincisi sapmalı sonuçlar vermektedir. Böyle bir durumda modelde yatay kesit bağımlılığını dikkate alan tahminciler kullanılmalıdır. Bu çalışmada da uzun dönem eş-bütünleşme katsayıları, Paseran (2006) tarafından geliştirilen CCE (Common Coraleted Estimator) tahmincisi ile tahmin edilmiştir. Bunun yanında eş-bütünleşik olan seriler arasında oto-korelasyonu ve değişen varyansı düzelten ancak yatay kesit bağımlılığını dikkate almayan FMOLS ile de tahminler yapılarak elde edilen sonuçlar karşılaştırmalı olarak Tablo 6'da verilmiştir. 


\begin{tabular}{|l|r|r|}
\hline Bağımsız Değişkenler & Fixed Effects Estimates Parametre & $\begin{array}{r}\text { Pesaran(2006) } \\
\text { CCE Mean Group Parametre }\end{array}$ \\
\hline \multirow{2}{*}{$\ln$ TRHAR } & 0,18019 & 0,11206 \\
\hline \multirow{2}{*}{$\ln$ DK } & $(0,08403)$ & $(0,23093)$ \\
\hline \multirow{2}{*}{$\ln$ GDP } & $-0,22443$ & $-0,38173$ \\
& $(0,17099)$ & $(0,16554)$ \\
\hline \multirow{2}{*}{$\ln$ CPI } & 0,73732 & 1,62071 \\
& $(0,12089)$ & $(0,52639)$ \\
\hline \multirow{2}{*}{$\ln$ PSI } & 0,32875 & $-1,24185$ \\
& $(0,05132)$ & $(0,67941)$ \\
\hline
\end{tabular}

() içindeki değerler parametrenin standart hatalarını temsil etmektedir.

\section{Tablo 6. Uzun Dönem Eş-Bütünleşme Katsayılarının Tahmini}

Çalışma sonucunda elde edilen bulgular incelendiğinde, yatay kesit bağımlılığını dikkate almayan Fixed Effect Tahmincisi ile elde edilen parametreler incelendiğinde tüketici fiyat endeksi değişkeni ile politik istikrar endeksi değişkeninin beklenen işaretlere sahip olmadığı görülmektedir. Aksine yatay kesit bağımlılığını dikkate alan CCE tahmincilerinde ise bu değişkenlerin ekonomik teoriye uygun olduğu anlaşılmaktadır. Bu olgu yatay kesit bağımlılığını dikkate almanın önemini ortaya koymaktadır.

CCEMG tahmincisine göre Türkiye'ye turist gönderen ülkenin kişi başına düşen gelirinde meydana gelen \% $\%$ 'lik bir değişim Türkiye'ye gelen turist sayısında aynı yönde \%1,6’lık bir değişim meydana getirmektedir. Bireylerin gelirlerinde meydana gelen değişimlerin turizm faaliyetlerine katılma eğilimlerini aynı yönde etkilediğini söylemek teorik olarak mümkündür. Bu durumda ortaya çıkan sonucun ekonomik teoriye uygun olduğu belirtilebilir. Dolayısıyla turist gönderen ülkenin kişi başına düşen gelirlerinde meydana gelebilecek bir değişim, turist kabul eden Türkiye'nin uluslararası turizm talebinde aynı yönde bir etkiye sahip olacağını söylemek mümkündür.

Türkiye'ye turist gönderen ülkelerin kişi başına düşen turizm harcamalarında meydana gelen \%1'lik bir değişim Türkiye'ye gelen turist sayısını aynı yönde \%0,1 etkilemektedir. Kişi başına düşen turizm harcamasının artması, ülkedeki vatandaşların turizme olan eğilimlerinin arttığını göstermektedir. Bu durumda turizm için ülke vatandaşlarının tercih ettikleri ülkelerden biri olan Türkiye’ye olan turizm talebinde artış yaratacaktır.

Türkiye'nin Reel Efektif Döviz Kurunun her bir ülkenin Reel Efektif Döviz Kurlarına oranlamasıyla bulunan RDK değişkeninde meydana gelen \%1'lik bir değişim, Türkiye'ye olan turizm talebini negatif yönde \%0,38 oranında etkilemektedir. Reel döviz kurunun artması ulusal paranın değerinin artmasını belirtmektedir. Dolayısıyla Türkiye'nin ulusal parasının değerinin artması gelen yabancı turistler için turizm fiyatlarının dolaylı olarak artması anlamına gelmektedir. Bu durum değişken için bulunan negatif işaretin sunulan ekonomik teoriye uygun olduğunu göstermektedir.

Türkiye'nin tüketici fiyat endeksinin her bir ülkenin tüketici fiyat endeksine bölünmesiyle elde edilen CPI değişkeni için bulunan parametre sunulan ekonomik teoriye uygun olarak negatif işaretlidir. Buna göre fiyat değişkenindeki \%1'lik bir değişim Türkiye'nin uluslararası turizm talebini ters yönde \%1,2 oranında etkilemektedir. Bu sonuca göre, Türkiye'deki fiyatların turist gönderen ülkedeki fiyatlara göre nispi olarak artması durumunda bu ülkelerden Türkiye'ye olan turizm talebinde bir azalış meydana gelecektir.

Son olarak turist gönderen ülkedeki politik istikrar durumunun Türkiye'nin turizm talebine olan etkisine bakıldığında; bulunan parametrenin beklenen işarete sahip olduğu görülmektedir. Buna göre turist gönderen ülkelerin politik istikrar endeksinde meydana gelen \%1'lik bir değişim Türkiye'nin uluslararası turizm talebinde aynı yönde \%0,11'lik değişim gösterecektir. Ülkedeki politik istikrar durumu insanların geleceğe yönelik beklentilerini etkilediği için turizm faaliyetlerine katılma eğilimlerini de aynı yönde etkileyecektir.

\section{Sonuç}

İkinci Dünya Savaşı sonrasında, Dünya genelinde ve buna paralel olarak Türkiye'nin turizm sektöründe yaşanan hızlı gelişmeler, ulusal ve uluslararası akademik çevrede konu ile ilgili birçok çalışmanın yapılmasını beraberinde getirmiştir. Yapılan çalışmaların çoğunun, turizm gelirlerinin ekonomik büyüme üzerindeki etkisini inceleyen araştırmalar olduğu görülmektedir. Bu çalışmaların büyük bir kısmında, turizm gelirlerinin ekonomik büyüme üzerinde etkili olduğu sonucuna ulaşılmıştır. Turizm sektörünün ekonomik büyüme üzerindeki etkisi tespit edilmiş olmasına rağmen, turizm talebini etkileyen faktörler üzerine yapılan ampirik çalışmalar ise kısıtlı olmuştur. Turizm talebi belirleyicilerinin tespiti, politika yapıcıları ve sektör yöneticilerinin yaptıkları uzun vadeli planlamalarda önem arz etmektedir.

Bu amaçla yapılan bu çalışmada, son yirmi yılda turizm sektöründe kat ettiği gelişmeler ile dünya sıralamasında önemli bir yer edinen Türkiye'nin, uluslararası turizm talebinin belirleyicileri tespit edilmeye çalışılmıştır. Çalışmada, Türkiye'nin uluslararası turizm talebini etkileyen faktörler ekonometrik analizlerle tespit edilmeye 
çalışılmıştır. Yapılan analizde turist gönderen ülkenin kişi başına düşen geliri, Türkiye ile turist gönderen ülke arasındaki nispi fiyat ve reel döviz kuru değişkenleri turist gönderen ülkenin kişi başına düşen turizm harcaması ve politik faktörleri temsil etmek üzere turist gönderen ülkenin politik istikrar endeksi verisi kullanılmıştır. Yapılan eş-bütünleşme analizinde serilerin eş-bütünleşik oldukları tespit edildikten sonra değişkenlerin uzun dönem parametreleri tahmin edilmiştir.

Turist gönderen ülkelerin kişi başına düşen gelirlerinin uzun dönem katsayısının pozitif çıkması, ülke refahındaki bir artışın turizme olan taleplerini arttıracağı ve dolayısıyla Türkiye'ye gelen turist sayısında da artış göstereceği şeklinde yorumlanmalıdır. Ayrıca bulunan katsayının 1'den büyük olması $(1,62)$, turizm gelir esnekliğinin 1'den büyük olduğunu göstermektedir. Dolayısıyla Türkiye'nin turistik mal ve hizmetleri, talep edenler için lüks bir maldır. Buradan turizm için Türkiye'yi tercih edenlerin yüksek gelirli turistler olmadıkları sonucunu çıkarabiliriz. $\mathrm{Bu}$ durum, Türkiye'nin turist sayısındaki artış ivmesini turizm gelirlerinde yakalayamaması sonucunu beraberinde getirmiştir. Türkiye'nin turist başına elde ettiği gelirin dünya ortalaması olan 1150 dolardan düşük olmasının bir sonucu olarak; Türkiye 2014 yılı itibariyle en çok turist kabul eden ülke sıralamasında 6.sırada yer alırken, en çok turizm geliri elde eden ülke sıralamasında 12.sırada yer almaktadır. Türkiye'nin turizm politikası açısından üzerinde önemle durulması gereken bu husus, olması muhtemel küresel ekonomik krizlerde turizm sektörü için önemli sorunları beraberinde getirecektir.

Çalışmada, gelir ile beraber fiyat ve döviz kuru değişkenlerinin de turizm talebini etkileyen faktörler arasında ön plana çıktı̆̆g görülmektedir. Bu bulgular ışığında, ekonomik faktörlerin turizm talebini açıklamada en önemli etkenler olduğunu söylemek mümkündür. Bunun yanında döviz kurunun, talebi belirleyen önemli bir faktör olarak tespit edilmesinin temelinde fiyat değişimi gelmektedir. Turistlerin döviz kuru değişiminde algıladığı temel nokta, fiyat değişiminden kaynaklı toplam turizm maliyetinin değişimidir. Bu noktada modelde fiyat esnekliğinin yüksek çıkmasından dolayı; turizm talebi, nispi fiyat değiş̧iminin yanında döviz kuru değişimine de duyarlıdır. Bu bulgular rekabetin yüksek düzeyde olduğu turizm sektörü için turizm talebinin gelir ve fiyat esnekliğinin belirlenecek politika hedeflerinde dikkate alınması gerektiğini göstermektedir. Bunun yanında, uygulanacak para politikasıyla, döviz kuru istikrarının sürdürülebilirliğini sağlamak diğer sektörlerde olduğu gibi turizm sektörü içinde önemli bir husustur.

Gelir, fiyat ve döviz kuru değişkenleri göz önüne alındığında; turizm gelirlerini arttırmak için, turist başına düşen turizm harcamaların arttıracak politikalar belirlenmelidir. Bunun için yapılacak en önemli politika, yüksek gelirli turistlerin beklentilerine yönelik alternatif turizm politikalarının geliştirilmesidir. Sektöre yapılacak yatırımların; spor, kongre, eko turizmi, termal, sağlık, kış sporları, kültür ve golf turizmine kaydırılması, gelir ve fiyat esnekliğini düşürecek etkiler sağlayacaktır. Gelir esnekliği düşük alternatif turizm çeşitlerinin yaygınlaşması, meydana gelecek küresel ekonomik krizlerin sektöre olan olumsuz etkilerini minimize edecektir. Bunun yanında turistik faaliyetlerin belli bir mevsimden on iki aya yayılmasını sağlayarak, istihdam üzerinde de pozitif etkiler birakacaktır.

Turizm sektöründe, politika yapıcıların üzerinde yoğunlaşmaları gereken bir diğer faktör hem turist gönderen hem de turist kabul ülkelerde yaşanan siyasi istikrarsızlık durumlarıdır. Turist gönderen ülkelerde yaşanan siyasi istikrarsızlıklar, turistik mal ve hizmetler lüks bir ihtiyaç olarak kabul edildiği için turizm talebinde olumsuz etkiler doğurmaktadır. ABD'de yaşanan 11 Eylül saldırıları sonucu ABD'ye olan turizm talebi düşerken, ABD'nin yapmış olduğu turizm harcaması da önemli oranda düşmüştür. En çok turizm harcaması yapan ülkelerden biri olan ABD'de yaşanan bu terör olayının küresel turizm piyasasına da olumsuz etkileri olduğunu söylemek mümkündür. Son yıllarda bölgemizde yaşanan siyasi krizler ve terör olaylarının Türkiye turizm sektörü üzerinde ciddi etkileri olduğunu söylemek mümkündür. Özellikle komşu ülkelerde yaşanan siyasi krizler ve terör olayları, 2013-2015 dönemi için Türkiye turizminin büyüme hızını önemli derecede düşürmüştür. Bu anlamda, çalışmamızda yapılan analiz sonucunda kullanılan politik istikrar değişkeninin turizm talebini pozitif etkiliyor olması teorik anlamda beklenen bir sonuç olarak karşımıza çıkmaktadır.

\section{Kaynakça}

- Aslan, A., Kaplan, M. \& Kula, F. (2008). International Tourism Demand for Turkey. Munich Personal Repec Archive

- Aydın, A., Darıcı, B., Taşçı, H. M. (2015). "Uluslararası Turizm Talebini Etkileyen Ekonomik Faktörler: Türkiye Üzerine Bir Uygulama”. Erciyes Üniversitesi İktisadi ve İdari Bilimler Fakültesi Dergisi, (45), 143177.

- $\quad$ Breusch, T. S. ve Pagan, A. R. (1980). "The Lagrange Multiplier Test and Its Applications to Model Specification in Econometrics". The Review of Economic Studies, 47(1), 239-253.

- Eita, J. H., Jordaan, A. C., Jordaan, Y. (2011). “An Econometric Analysis of The Determinants Impacting On Businesses in The Tourism Industry". African Journal of Business Management, 5(3), 666-675.

- $\quad$ Ekanayake, E. M., Halkides, M., Ledgerwood, J. R. (2012). "Inbound International Tourism to the United States: A Panel Data Analysis". International Journal of Management and Marketing Research, 5(3), 15-27. 
- Giritlioğlu, İ. (2015). Turizmin Tarihsel ve Yapısal Gelişim. Aslan, Z. (Editör), Genel Turizm (35-51), Ankara: Grafiker Yayınları

- Göçer, İ., Mercan, M., Hotunluoğlu, H. (2012). “Seçilmiş OECD Ülkelerinde Cari İşlemler Açığının Sürdürülebilirliği: Yatay Kesit Bağımlılığı Altında Çoklu Yapısal Kırılmalı Panel Veri Analizi1”. Maliye Dergisi, 163, 449-470.

- Görmüş, Ş., Göçer, İ. (2010). “The Socio-Economic Determinant of Tourism Demand in Turkey: A Panel Data Approach”. International Research Journal of Finance and Economics, 55(1), 88-99.

- Gujarati, D. N. (2010). “Temel Ekonometri” (Çev. Ümit Şenesen ve Gülay Günlük Şenesen). Yedinci Basım, Istanbul: Literatür Yayınlarl.

- Güneş, E. ve Kabadayı, B. (2015). "Türkiye Turizm Talebini Açıklamaya Yönelik Bir Panel Çekim Modeli Analizi”. Çukurova Üniversitesi IIBBF Dergisi. 19(2), 31-46

- Ibrahim, M. A. (2011). "The Determinants of International Tourism Demand for Egypt: Panel Data Evidence". European Journal of Economics, Finance and Administrative Sciences, 30, 50-58.

- Jintranun, J., Sriboonchitta, S., Calkins, P., Chaiboonsri, C. (2011). "Thailand's International Tourism Demand: Seasonal Panel Unit Roots and The Related Cointegration Model”. Review of Economics and Finance, 1,

- Kaya, A. A. ve Canlı, B. (2013). “Türkiye’ye Yönelik Uluslararası Turizm Talebinin Belirleyenleri: Panel Veri Yaklaşımı”. Anadolu Üniversitesi Sosyal Bilimler Dergisi, 13(1), 43-54.

- Ketenci, N. (2009). "The ARDL Approach to Cointegration Analysis of Tourism Demand in Turkey with Greece as The Substitution Destination”. METU Studies in Development, 36(2), 363-382.

- Kozak, N., Kozak, M. A. ve Kozak, M. (2015). Genel Turizm Illkeler-Kavramlar. Ankara: Detay Yayıncıl1k.

- Özcan, C. C. (2015). “Türkiye'de Turizm Gelirinin Makroekonomik Belirleyicileri: Panel Veri Analizi”. Ç. Ü. Sosyal Bilimler Enstitüsü Dergisi, 24(1), 203-220

- Pesaran, M. H. (2004). "General Diagnostic Tests for Cross Section Dependence in Panels”. Cambridge Working Papers in Economics, No:435.

- $\quad$ Pesaran, M. H. (2006). "Estimation and Inference in Large Heterogeneous Panels with A Multifactor Error Structure”. Econometrica, 74(4), 967-1012.

- $\quad$ Pesaran, M. H. (2007). “A Simple Panel Unit Root Test in the Presence of Cross-Section Dependence". Journal of Applied Econometrics, 22(2), 265-312.

- $\quad$ Pesaran, M. H., Ullah, A., Yamagata, T. (2008). “A Bias-Adjusted LM Test of Error Cross-Section Independence”. The Econometrics Journal, 11(1), 105-127.

- Proenca, S. A., Soukiazis, E. (2005). "Demand for Tourism in Portugal: A Panel Data Approach". Coimbra, Portugal: Escola Superior Agrária, Instituto Politécnico de Coimbra, 2-22.

- Surugiu, C., Leitão, N. C., Surugiu, M. R. (2011). “A Panel Data Modelling of International Tourism Demand: Evidences for Romania”. Economic Research-Ekonomska Istraživanja, 24(1), 134-145.

- The World Bank (2016). http://databank.worldbank.org/data/reports.aspx?source= world- developmentindicators, Erişim Tarihi: 10.08.2016.

- $\quad$ TÜİK (2016). http://www.tuik.gov.tr/PreTablo.do?alt_id=1072.

- TÜRSAB (2016). http://www.tursab.org.tr/tr/turizm-verileri/istatistikler

- UNWTO (2015). “Tourism Highlights 2015 Edition”. http://www.eunwto.org/doi/pdf/10.18111/9789284416899.

- Walle, Y. M. (2010). "Tourist Flows and Its Determinants in Ethiopia”, Ethiopian Development Research Institute, (No. 001).

- Westerlund, J. (2008). "Panel Cointegration Tests of The Fisher Effect". Journal of Applied Econometrics, 23(2), 193-233.

- Westerlund, J. ve Edgerton, D. L. (2007). “A Panel Bootstrap Cointegration Test”. Economics Letters, 97(3), 185-190.

- $\quad$ Wooldridge, J. M.(2013). Ekonometriye Giriş Modern Yaklaşım (Çeviri Editörü: Ebru Çağlayan), Nobel Yayıncılik.

- Yalçınkaya, Ö., \& Hüseyni, İ. (2016). "Tasarruf-Yatırım İlişkisi: Feldstein-Horioka Hipotezinin OECD Ülkeleri Açısından Değerlendirilmesi (1980-2013)”. Dokuz Eylül Üniversitesi İktisadi ve İdari Bilimler Fakültesi Dergisi, 31 (1), 343-369. 


\title{
Türkiye'de Turizm Gelirlerinin Ekonomideki Yeri ve Önemi Üzerine Bir Değerlendirme
}

\section{An Evaluation on the Place and Importance of Tourism Revenues of Turkey in Economy}

\author{
Esra Soyu (Aksaray University, Turkey) \\ Prof. Dr. Süleyman Karaçor (Selçuk University, Turkey) \\ Prof. Dr. Serdar Altınok (Gazi University, Turkey) \\ Asst. Prof. Dr. Emine Frrat (Aksaray University, Turkey)
}

\begin{abstract}
Globalization has allowed a number of countries to make important progresses that would contribute to economy in areas like industry and information technologies. Developed economies have obtained a cost advantage and increased both product potential and economic progress by means of advanced technologies. Developing economies, on the other hand, are required to determine the sectors to invest in order to progress. Regarding progress, it is primarily required to evaluate the tourism supply potential of countries.

The tourism sector in Turkey has made a great progress for nearly more than 30 years and tourism has had positive effects upon economy. Foreign currency inflow of the country has increased the investment, revenue and employment and positively affected the balance of payments. Taking necessary precautions for Turkey to get more share from the international tourism revenue will also increase the social welfare.

In this study, the place and importance of the tourism sector in economy are evaluated with the help of data. These data consist of the number of foreign tourists that come to Turkey for touristic reasons, acquired tourism revenue, touristic expenditure rates, share of tourism in the Gross National Product, as well as its effects upon the national income and share in foreign trade. Interpreting the reasons and outcomes of the recent decrease in tourism revenues in our country; it has been concluded that Turkey is in a serious need of tourism revenues and it is required to urgently intervene in this matter.
\end{abstract}

\section{Giriș}

Ekonomi yazınında gelişmiş ve gelişmekte olan ülke ayrımı uzun yıllardır yapılmaktadır. Bunun nedeni ise sanayi, bilişim, teknoloji gibi alanlarda rekabet eden ve gelişme gösteren ülkelerle bu alanlarda gelişme gösteremeyen ülkeler arasındaki farkı görebilmek içindir. Özellikle küreselleşen yeni dünyada yaşanan gelişmeler ve uluslararası serbestleşmenin artmasıyla toplumların turizm konusundaki duyarlılığının artması ve ülkelerin kalkınması hız kazanmıştır. Gelişme yönünden kısır döngüye girmiş ülkeler kendilerine alternatif bir sektör arayışına girmişlerdir. Böylece turizm potansiyellerini gözden geçirerek bu alanda ilerleme kaydetmeye çalışmışlardır. Bugün dünyanın en büyük endüstrilerinden biri olarak kabul edilen turizm, gerek pazar büyüklüğü gerekse ekonomik potansiyeli bakımından önemli bir sektördür. Bu yüzden turizmi anlamanın yolu geçmişi değerlendirmek bugünü anlamak ve geleceğe ilişkin tahminler yapabilmekten geçmektedir (Akoğlan Kozan, vd, 2013).

Dünyada en hızlı gelişme gösteren sektörlerden biri olan turizm, 20. yy sonrası hem bölgesel hem de ulusal kalkınma açısından en önemli aracı sektörlerin arasında yer almıştır. Türkiye'de ise 1980'li yıllardan sonra turizm faaliyetleri gelişmeye başlamıştır. Bu süreçle birlikte turizm potansiyeli belirlenmiş ve gerekli çalışmalar hızla devam ettirilmiştir.

Kültür ve Turizm Bakanlığg 16.04.2003 tarih ve 4848 sayılı Kanun ile kurulduktan sonra amacını net bir şekilde açıklamış ve uygulama aşamasına geçmiştir. Turizm Bakanlığ kültürel değerleri korumak, yaşatmak, geliştirmek, yurdun turizme elverişli bütün imkânlarını ülke ekonomisine olumlu katkı sağlayacak şekilde değerlendirmek, destek ve teşvikle turizmi geliştirmek için gerekli önlemleri almak gibi pek çok görevi üstlenmektedir (Kültür ve Turizm Bakanlığ 1,2017$)$.

Turizm faaliyetleri ekonomik, sosyal, politik ve kültürel etkileri nedeniyle sürekli değer görmektedir. Bu durum tüm ülkelerin turizm sektörüne önem vermesini sağlamaktadır (Bozgeyik, Yoloğlu, 2015). Ayrıca turizm, ülkeler için önemli bir gelir kaynağı olarak görülmektedir. Döviz girdisi sağlayarak ödemeler dengesi üzerindeki sorunları ortadan kaldırmak için önemli rol oynamaktadır.

Türkiye hızlı nüfus artışı, düşük gelir düzeyi, işsizlik, teknoloji ve altyapı yetersizliği gibi birçok sorunla karşı karşıyadır. Bu sorunları çözmek için büyük yatırımların olması gerekmektedir. Gerek yatırım malları, gerek petrol ürünleri gerekse tüketim mallarını ithal edebilmek için dövize ihtiyaç duyulmaktadır. Mevcut üretimle dünya piyasasında rekabet edebilmek oldukça güçtür. Var olan problemler turizm sektörünün gelişmesiyle azalma eğilimi 
göstermektedir. Turizm, kısa zamanda döviz getirisi sağlayan, geliri, istihdamı ve verimliliği arttıran önemli bir sektör olarak görülmektedir (Kozak, vd, 2013).

Turizm her ne kadar sürekli gelişen bir sektör olsa da gerek ülke içinde gerekse dünya da yaşanan terör ve şiddet olaylarından çok fazla etkilenmektedir. İnsanların meydana gelen saldırılardan etkilenmeleri turistik seyahate bakış açılarını değiştirmektedir. Bu durum uzun yıllar boyunca terör sorunuyla karşı karşıya olan Türkiye için büyük bir risk oluşturmakta ve turist sayısındaki azalmaya bağlı olarak turizm gelirlerinde de bir azalma meydana getirmektedir.

Ayrıca sadece terör sorunu değil hem siyasi hem ekonomik krizler de turizm sektörünü olumsuz etkilemektedir. Uluslararası odaklı krizlerin ülke imajını olumsuz yansıtması ve bunun da medya tarafindan desteklenmesi sonucu turizm faaliyetleri sekteye uğramaktadır (Göçen, vd, 2011). Yani şekli ve algısı ne olursa olsun turizm faaliyetleri toplumları etkileyen her krizden etkilenir. $\mathrm{Bu}$ durum bazen turistlerin güzergâhlarını değiştirmelerine ve tatil hayallerini bir başka zamana ertelemelerine sebep olabilir (Sarıçay ve Ünal, 2014). Ayrıca bu olumsuz faktörlerin yanı sıra doğal afetler ve salgınlar da turizm faktörünü etkilemektedir. Geçmişe baktığımızda kuş gribi, domuz gribi hastalıkların ortaya çıkması ve yaygınlaşması turizm faaliyetlerini olumsuz etkilemiştir.

Bu çalışmada Dünya'da ve Türkiye'de turizm endüstrisinin nasıl başladığı ve buna ilişkin teorik bilgilerle en çok turist çeken ülkeler, turizm amaçlı en çok tercih edilen yerler anlatılmıştır. Daha sonra turizm ve ekonomi arasındaki ilişkiye bakılarak döviz girdisinin artması ya da azalmasının ülke ekonomisini nasıl etkilediği üzerine literatür taraması yapılmıştır.

\section{Dünya'da ve Türkiye'de Turizm}

İnsanlar var olduklarından beri çeşitli nedenlerle seyahat etmektedir. Aslında turistik faaliyetlerin geçmişinin insanlık tarihi kadar eski olduğu da söylenebilir. Mısırlıların yeni merkezlere imparatorluklarını ulaştırabilmek için yollar yapıp, konaklama yerleri inşa ettikleri bilinmektedir. Sonraki dönemlerde Eski Yunanlılar Olimpiyat oyunlarını izlemek için seyahat etmişlerdir. Konaklamaya ilişkin en eski örneklerden biri bu gibi yerlere ulaşabilmek için yol üzerine kurulmuş hanlardır. 1500-1600 yılları arasında kilise otoritesi ortadan kalkmış insanlar eğlence, sanat gibi alanlara yönelmişlerdir. Bunun için gerekli binalar ve konaklama işletmeleri yapılmış ve faaliyete geçirilmiştir. 1900'lü yıllarda keşif gezileri başlamış, ulaşım ise daha ucuz ve kolay hale gelmiştir. II. Dünya Savaşı sonrası ise turizm faaliyetleri daha fazla artmıştır. 1918-1920 yılları arası modern turizmin başlangıcı olarak kabul edilmektedir. Bu dönemde ise turizm, otel, ulaşım araçları ve yolları, plajlar, eğlence merkezleri, spor alanları, konaklama tesisleri ve bütün altyapısı ile büyük bir sektör haline gelmiştir (Albayrak, 2013).

Zamanla küreselleşmenin ortaya çıkardığı ekonomik gelişmeler, bilgi ve hizmetin ön planda olduğu sektörlerin önemini arttırmıştır. Turizm sektörü bilgi birikimi ve kullanımı açısından önemli bir yere sahiptir. Bilgi sürekli kullanılmakta ve değerlendirilmektedir. Bu bağlamda turizm sektöründe hizmet arz edenler bilgiyi üretmekte ve tüketiciye sunmaktadır. Bilgi teknolojilerinde yaşanan gelişmeler bölgenin küresel pazardaki rekabet gücünü etkilemektedir. $\mathrm{Bu}$ sistemin oluşturduğu iletişim ağları, bilgisayarlar, televizyon sistemleri, küresel pazarlar, risk faktörü mevcut ekonomik yapıyı değiştirmekte ve firmaların geleceğe yönelik stratejilerini yeniden belirlemeye yönlendirmektedir. Bu sayede hizmet sektörünün önemi artmaktadır (Karataş ve Babür, 2013).

Ülkemizde turizm hareketlerine bakıldığında ise coğrafi konum gereği oldukça büyük önem taşımasının yanında eski tarihlerden itibaren çok sayıda insanın ilgisini çekmiştir. Turizm faaliyetlerine ilişkin ilk yasal düzenlemeler 1900'lü yılların başlarında başlamıştır. 1960'da yaşanan ihtilal sonucunda turizm sektörü için yapılan yatırımların çoğu durdurulmuştur. Bu süreçte ciddi durgunluk yaşayan turizm sektörü gelişmesi açısından sekteye uğramıştır. $\mathrm{Bu}$ süreç sonrasında turizm hizmet sektörünün bir alt dalı olarak kalkınma planlarında yer alarak gelişmesi için önemli bir adım sayılmıştır (Albayrak, 2013). Ayrıca kalkınma planlarında devlet, turizmin gelişmesi için yasal düzenlemeler yapmış, destek ve teşviklerle, vergi muafiyetleri ile sektörü hedeflere ulaştırmaya çalışmaktadır. Son döneme bakıldığında ise turizmin teşviklerle desteklendiği politikaların uzun soluklu bir turizm anlayışına yöneldiği görülmektedir. Geçmişte olduğu gibi günümüzde de turizm ülkemizin kalkınmasında ve gelişmesinde bir motor görevi görmektedir. 


\begin{tabular}{|c|c|c|c|}
\hline 2016 & 2015 & Ülkeler & $\mathbf{2 0 1 6}$ \\
\hline 1 & 1 & Fransa & $\mathbf{7 9 , 4}$ \\
\hline 2 & 2 & ABD & $\mathbf{7 7 , 1}$ \\
\hline 3 & 3 & İspanya & $\mathbf{7 5 , 5}$ \\
\hline 4 & 4 & Çin & $\mathbf{5 9 , 5}$ \\
\hline $\mathbf{5}$ & $\mathbf{5}$ & İtalya & $\mathbf{5 2 , 7}$ \\
\hline 6 & 7 & Almanya & $\mathbf{3 5 , 5}$ \\
\hline 7 & $\mathbf{8}$ & İngiltere & $\mathbf{3 5 , 1}$ \\
\hline $\mathbf{8}$ & $\mathbf{9}$ & Meksika & $\mathbf{3 4 , 9}$ \\
\hline 10 & 11 & Tayland & $\mathbf{3 2 , 5}$ \\
\hline 11 & 10 & Rusya & $\mathbf{2 9 , 6}$ \\
\hline 12 & 11 & Yunanistan & $\mathbf{2 8 , 1}$ \\
\hline 13 & 14 & Avusturya & $\mathbf{2 6 , 8}$ \\
\hline 14 & 13 & Malezya & $\mathbf{2 6 , 5}$ \\
\hline
\end{tabular}

Tablo 1: Dünya Genelinde En Çok Turist Çeken Ülkeler (Milyon) Kaynak: UNWTO (Dünya Turizm Örgütü), Turizm Veri Bankası

Ülke bazında bakıldığında ise en çok turist çeken ilk üç ülke sırasıyla Fransa, ABD ve İspanya'dır. 2015 yılı verilerine göre Türkiye gelen ziyaretçi açısından dünya sıralamasında 6. sırada yer almakta olup bu konuma 1980'li yıllardan bu yana yaptığı atılımlarla kademeli olarak yükselmiştir. Ancak 2016 yılındaki rakamlar açısından bu yükseliş ciddi derecede inişe geçtiğini göstermektedir. 2016 yılında ise 15. sırada yer almaktadır.

Bu durum ekonomik büyüklük bakımından büyük öneme sahip olan turizm sektörünün çok hassas bir yapıda olduğunun göstergesidir. Turizm her türlü riskten etkilenen bir sektördür. Siyasi ve ekonomik krizlerle birlikte bulaşıcı hastalık riskinin artması, asayiş konusunda görülen bazı eksiklikler turizm sektörünün belli aşamalarda performansını olumsuz yönde etkilemektedir. Böylece rakamlardaki azalış ciddi oranda olmaktadır (Sarsın Kaya, 2016).

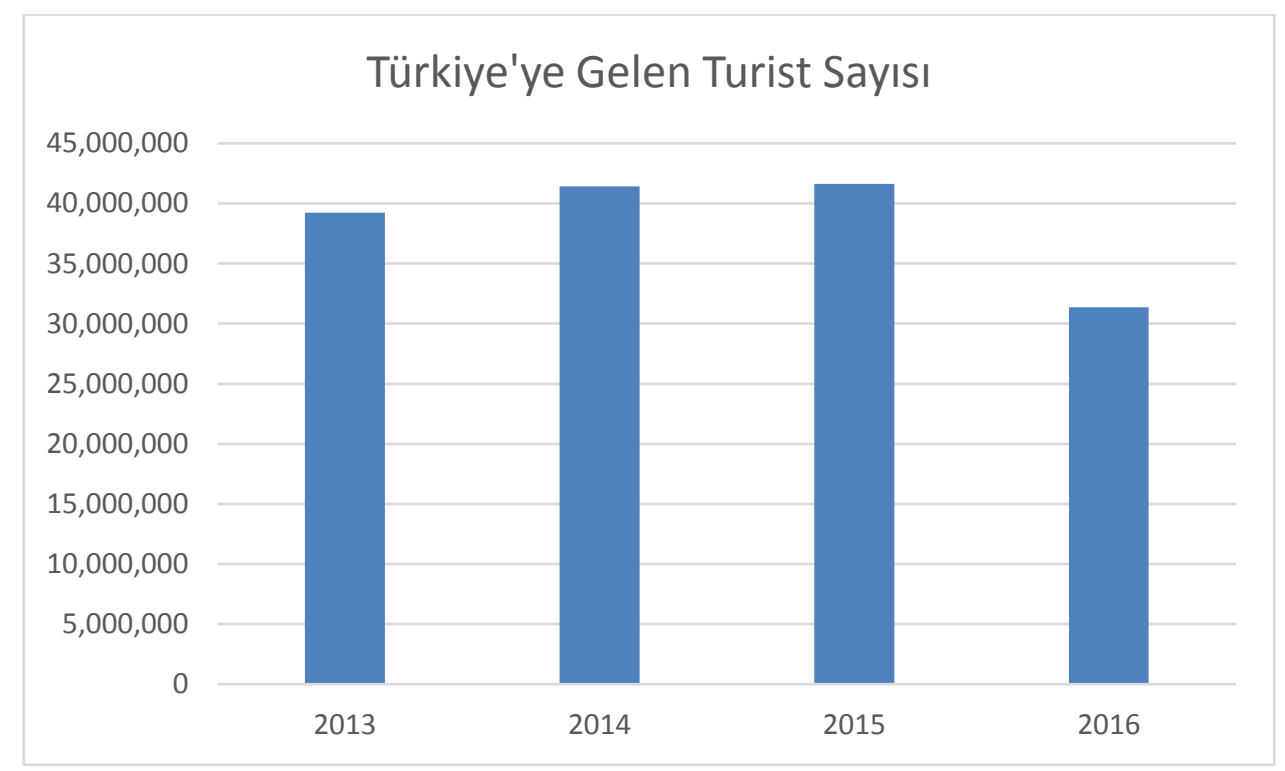

Şekil 1: Türkiye’ye Gelen Ziyaretçi Sayısı Kaynak: TÜRSAB

Türkiye'ye yaşanan son gelişmelerin de etkisiyle gelen ziyaretçi sayısı 2014-2015 yıllarında 41 milyon civarında iken 2016 yılında 31 milyona düşmüştür. Hem ülkede hem de dünya da yaşanan siyasi-ekonomik olaylar sonucunda ziyaretçi sayısında azalış olduğu gözlenmektedir.

Sadece Türkiye'nin dünya sıralamasında ziyaretçi sayısında azalma olmamıştır. Aynı zamanda Türkiye'den yurtdışına giden turist sayısında da azalma vardır. 


\begin{tabular}{|c|c|c|c|c|}
\hline \multicolumn{5}{|c|}{ Türkiye'den Yurtdışına Çıkan T.C. Vatandaş Sayısı } \\
\hline \multicolumn{3}{|c|}{ Yıllar } & \multicolumn{2}{c|}{ Değişim oranı } \\
\hline $\mathbf{2 0 1 4}$ & $\mathbf{2 0 1 5}$ & $\mathbf{2 0 1 6}$ & $\mathbf{2 0 1 5 / 2 0 1 4}$ & $\mathbf{2 0 1 6 / 2 0 1 5}$ \\
\hline 8.363 .966 & 9.256 .486 & 8.062 .065 & 10.67 & -12.90 \\
\hline
\end{tabular}

Tablo 2: Türkiye'den Yurtdışına Çıkan T.C. Vatandaş Sayısı (Ocak-Aralık) Kaynak: TÜRSAB

2016 yılında yurtdışına çıkan Türk Vatandaşlarının sayısı 2015 yılına göre \%-12.90 oranında düşerek 8 milyon 62 bin 65 seviyesine gerilemiştir. 2015 yılının aynı döneminde ise yurtdışına çıkan Türk vatandaşı sayısı ise 9 milyon 256 bin 486 kişi olarak gerçekleşmiştir.

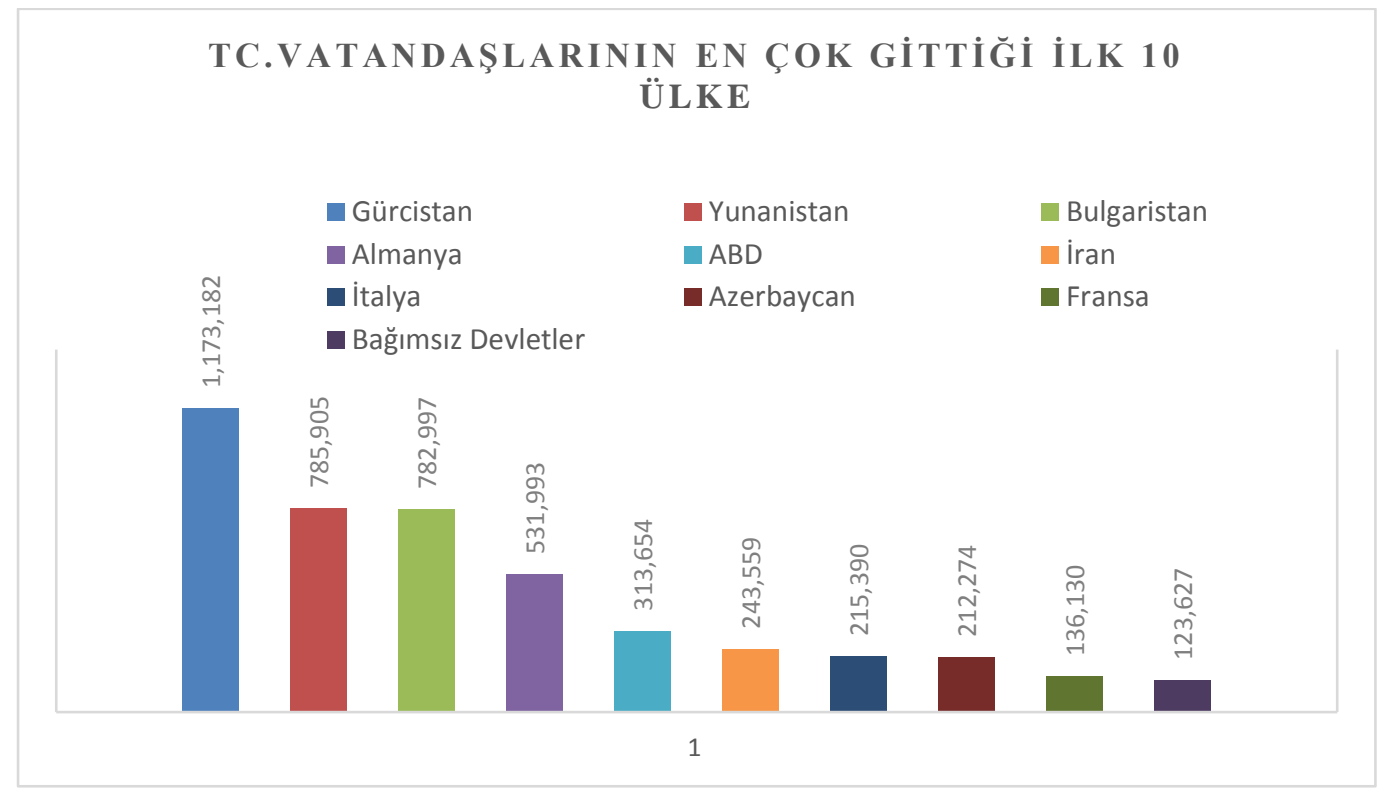

Şekil 2: T.C. Vatandaşlarının En Çok Gittiği İlk 10 Ülke (2016) Kaynak: TÜRSAB

2016 yılı verilerine göre en fazla seyahat 1 milyon 173 bin 182 kişi ile Gürcistan’a gerçekleşmiştir. Bu ülkeyi 785 bin 905 ile Yunanistan, 782 bin 997 kişi ile Bulgaristan ve 531 bin 993 kişi ile Almanya izlemiştir.

Küreselleşmeyle birlikte uzun mesafelerin ortadan kalkması ülkeler arası etkileşimi hızlandırmıştır. Bir ülkede var olan olumlu etkenler turistlerin tercihini kolaylaştırmaktadır. Ancak yaşanan ya da yaşanacak olan olumsuz gelişmeler ise turizm faaliyetlerini önemli derecede etkilemektedir.

\section{Turizm ve Ekonomi İlişsisi}

Turizmi, boş zaman değerlendirmek için kişisel bir kararla başlayan, yatırım, tüketim, istihdam gibi ekonomiyle de ilişkili yönleri bulunan sosyo-ekonomik bir faaliyettir (Kozak, vd, 2013). Turizmin sosyal bir faaliyet olmasının yanında ülkenin döviz darboğazı ve işsizlik gibi problemleriyle de yakından ilgilenen ekonomik bir politikası vardır. Turizmin ülkelerin makro sorunlarına çözüm getireceği anlayışı hâkim olmuş ve son yıllarda gösterdiği büyük gelişmeyle birlikte kalkınmanın en önemli unsurlarından biri sayılmaktadır (Çımat ve Bahar, 2003).

Planlı dönemde turizm sektörüyle ilgili alınan önlemlerin ve gelişmelerin Beş Yıllık Kalkınma Planlarında yer alması turizm sektörüne verilen değerin göstergelerinden bir tanesidir. Birinci Beş yıllık Kalkınma Planı'nda (1963-1967) Türkiye'nin ödemeler dengesi açı̆̆ını kapatmak için turizm faaliyetlerini arttırmak ilk amaç olmakla birlikte, gerek doğal gerekse tarihi turizm kaynaklardan yararlanmak, tanıtım için daha fazla faaliyetlerde bulunmak temel ilkeler olarak belirlenmiştir. Daha sonraki süreçlerde devam eden kalkınma planlarında ise turizm faaliyetleri üzerinde durulmakta ve turizm gelirlerinin arttırılması için teşvik paketleri hazırlanmaktadır. Turizmin ekonomik, sosyal ve kültürel işlevlerinden yararlanmak, turizm gelirini arttırmak, ortalama tüketim harcamalarını arttırmak, tanıtım ve organizasyon faaliyetlerini turizm esaslarına göre yürütmek, turizm yatırımlarını özendirmek, turistik yerlerin korunmasını sağlamak gibi pek çok faktör her kalkınma planında yer almış, tutturulması için uğraşılar verilmiştir. Son kalkınma planı olan Onuncu Beş Yıllık Kalkınma Planı'nda (2014-2018) ise daha spesifik konulara değinilmiştir. Sağlık turizmi başta olmak üzere kongre turizmi, kış turizmi, kültür turizmi, helal turizmi gibi alanlarda altyapı eksikliklerinin giderilmesi pazarın çeşitlendirilmesi, alternatif turizm türlerinin gelişimi gibi konularda pazar ve müşteri profili izlenerek tanıtım faaliyetlerinin geliştirilmesi hedeflenmektedir (Kozak, vd, 2013).

1960’l1 yıllarda başlayan ve günümüze kadar devam eden süreçte yer alan kalkınma planlarında turizm sektörünün önemi üzerinde durulmuş ve geliştirilmesi için her türlü destek ve teşvik politikaları arttırılmıştır. 2023 
hedefleri içinde aynı şekilde turizm planlamaları yapılmış 500 milyar dolarlık ihracat hedefinin tutturulması amaçlanmıştır.

Türkiye Turizm Stratejisi'nde 2023'ün öngördüğü hedeflerde ülkede geniş bir coğrafyaya yayılmış durumda olan sağlık, termal, yayla, kış ve dağ sporlarının, kültürel açıdan önemli yerlerin birbiriyle uyumu sayesinde daha güçlü konumlar oluşturulacak ve bölgeler içinde zayıf kalan yerleşim yerlerinin de güçlenmeleri sağlanmış olacaktır (T.C. Kültür ve Turizm Bakanlığı, 2007). Turizm gelirleri ve turizm giderleri ödemeler dengesinin en can alıcı kalemlerinden biridir.

Turizm gelirleri; yabancı ziyaretçiler için milliyet bazında, geceleme yapanlar ile günübirlikçiler ayrımlarına göre ve turla gelenlerin tura ödedikleri bedellerin Türkiye'de kalan kısımları da değerlendirilerek elde edilen ortalama harcamaların; ilgili döneme ait Emniyet Genel Müdürlüğü kayıtlarından sağlanan kişi sayılarıyla genişletilmesi ile hesaplanmaktadır. Turizm giderleri ise yurtdış ülkeleri ziyaret edip ülkemize giriş yapan yurtiçinde yerleşik kişilerin yurtdışında yaptıkları harcamaların saptanması amaçlanmaktadır (TCMB). Her alanda olduğu gibi turizm gelir ve giderlerin de ülke ekonomisi açısından önemi çok büyüktür. Çünkü ödemeler dengesi içindeki payı ülkenin ekonomik seyrini belirlemektedir. Döviz hareketlerinin bu denge içindeki payı çok önemlidir. Bu özelliği ile turizm gelirleri, döviz sıkıntısı çeken ve ödemeler dengesi açık veren ülkeler için oldukça önemli bir döviz kaynağıdır. Ĕger ki turistik döviz kazançları, turistik döviz kayıplarından fazla ise ödemeler dengesine olumlu katkısından söz etmek mümkündür (Kızılgöl ve Erbaykal, 2008).

Ayrıca turizm sektörü doğrudan ya da dolaylı olarak yaklaşık 55 sektörle etkileşim halindedir. Bu nedenle Türkiye ekonomisi üzerindeki etkisi küçümsenmeyecek oranda fazladır

Doğrudan etkiyi; konaklama, gıda ve içecek, ulaşım, eğlence ve kültür hizmetleri olarak sıralamak mümkündür. Aynı zamanda yerli iş gezisi harcamaları, yerli kişisel turizm harcamaları, yabancı ziyaretçi harcamaları, kişisel devlet harcamaları gibi faktörlerde doğrudan etki grubuna girmektedir.

Yatırım harcamaları, kamu harcamaları, tedarikçi alımla önemli bir paya sahiptir. Turizmde istihdam edilen kesimde gelir üzerinde etki yapmaktadır (Sarsın Kaya, 2016).

Turizm sektörü sadece döviz girdisi sağlayarak ödemeler bilançosu üzerinde etki yapmaz. Aynı zamanda birçok kesimi de etkilemektedir. Örneğin, turist harcamalarının artması kapasitenin artmasına neden olacaktır. Böylece iş alanları açılacak ve istihdam sağlanacaktır. Emek yoğun üretim tekniğine dayalı bir sektör olduğu için geniş istihdam olanakları yaratmak mümkündür. Ayrıca gençlere ve kadınlara yönelik iş olanakları yaratarak aileler ek gelir sağlamakta ve hayat standardını yükseltmektedir (Kızılgöl ve Erbaykal, 2008).

\begin{tabular}{|c|c|c|c|}
\hline Yllar & İhracat & Turizm Gelirleri & $\begin{array}{c}\text { Turizm Gelirlerinin İhracat } \\
\text { Gelirlerine Oranı (\%) }\end{array}$ \\
\hline $\mathbf{2 0 0 7}$ & $107.271,8$ & $20.942,5$ & 19,5 \\
\hline $\mathbf{2 0 0 8}$ & $132.027,2$ & $25.415,1$ & 19,2 \\
\hline $\mathbf{2 0 0 9}$ & $102.142,6$ & $25.064,5$ & 24,5 \\
\hline $\mathbf{2 0 1 0}$ & $113.883,2$ & $24.931,0$ & 21,9 \\
\hline $\mathbf{2 0 1 1}$ & $134.906,9$ & $28.115,7$ & 20,8 \\
\hline $\mathbf{2 0 1 2}$ & $152.478,5$ & $29.351,4$ & 19,2 \\
\hline $\mathbf{2 0 1 3}$ & $157.610,2$ & $34.305,9$ & 21,3 \\
\hline $\mathbf{2 0 1 4}$ & $151.802,6$ & $32.309,0$ & 21,8 \\
\hline $\mathbf{2 0 1 5}$ & $143.934,9$ & $31.464,8$ & 21,9 \\
\hline $\mathbf{2 0 1 6}$ & $142.606,2$ & $22.107,4$ & 15,5 \\
\hline
\end{tabular}

Tablo 3: Turizm Gelirlerinin İhracat Gelirlerine Oranı Milyar \$ (1980-2016) Kaynak: TÜRSAB

Turizm kalkınmada bir lokomotif görevi üstlenmektedir. Sektör 1980'li yıllardan beri ekonomi içindeki görevini yerine getirmeye çalışmaktadır (Çımat ve Bahar, 2013). Son yıllarda yaşanan gerek siyasi gerekse ekonomik krizler ve çalkantılar turizm sektörünü de etkilemiş ve bu durum kalkınma politikaları içinde önemli bir yer tutmuş ancak turizmde istenilen hedefler tutturulamamıştır. Yine de turizm gelirlerine bakıldığı zaman küçümsenmeyecek rakamlar ortaya çıkmaktadır. 2015 yılına kadar ortalama rakamlar küçük artışlar ya da azalışlarla devam ederken 2016 yılında elde edilen gelir ciddi oranda düştüğü gözlenmektedir. Burada ülkenin yaşamış olduğu birtakım ulusal ve uluslararası olumsuz durumların etkisi hissedilmektedir. Turizmin ekonomik göstergelerinden bir diğeri de, turizmden elde edilen döviz gelirlerinin ihracattan elde edilen gelire oranıdır. Turizm gelirlerinin ihracat gelirlerine oranı 2010-2015 arasında yaklaşık \%20 civarında iken, 2016 yılında bu oran \%15.5’e düşmüştür. 


\begin{tabular}{|c|c|c|c|}
\hline Yıllar & İthalat & Turizm Giderleri & $\begin{array}{c}\text { Turizm Giderlerinin İthalat } \\
\text { Giderlerine Oran (\%) }\end{array}$ \\
\hline $\mathbf{2 0 0 7}$ & $170.062,7$ & $4.043,3$ & 2,4 \\
\hline $\mathbf{2 0 0 8}$ & $201.963,6$ & $4.266,2$ & 2,1 \\
\hline $\mathbf{2 0 0 9}$ & $140.928,4$ & $5.090,4$ & 3,6 \\
\hline $\mathbf{2 0 1 0}$ & $185.544,3$ & $5.847,5$ & 3,2 \\
\hline $\mathbf{2 0 1 1}$ & $240.841,7$ & $5.531,5$ & 2,3 \\
\hline $\mathbf{2 0 1 2}$ & $236.545,1$ & $4.593,4$ & 1,9 \\
\hline $\mathbf{2 0 1 3}$ & $242.177,1$ & $5.253,6$ & 2,1 \\
\hline $\mathbf{2 0 1 4}$ & $251.661,3$ & $5.470,4$ & 2,2 \\
\hline $\mathbf{2 0 1 5}$ & $207.203,4$ & $5.698,3$ & 2,8 \\
\hline
\end{tabular}

Tablo 4: Turizm Giderlerinin Ithalat Giderlerine Oranı Milyar \$ (1980-2016) Kaynak: TÜRSAB

Ülkeye döviz girdisinin artmasıyla turizm sektörünün canlanması bazı sektörler için ithalat talebini arttırmaktadır (Egeli, t.y). Turizm giderlerinin ithalat içindeki payı 2010-2016 arasında istikrarlı bir şekilde aynı düzeyde devam etmektedir. Veriler sektörün düşük oranda ithalata dayalı olduğunu göstermektedir. Hizmet sektörü olduğu için herhangi bir ithal malına aşırı derecede duyarlı değildir. Ülkedeki kaynakların turizm faaliyeti gerçekleştirebilmesi için yeterli olduğunu göstermektedir.

\begin{tabular}{|c|c|c|c|c|}
\hline Yıllar & $\begin{array}{c}\text { Dış Ticaret Açı̆̆ı } \\
\text { (DTA)\$ }\end{array}$ & Turizm Geliri & $\begin{array}{c}\text { Turizm Gelirinin DTA } \\
\text { Kapama Payı (\%) }\end{array}$ & $\begin{array}{c}\text { Turizm Gelirlerinin } \\
\text { GSMH İçindeki Payı (\%) }\end{array}$ \\
\hline $\mathbf{2 0 1 0}$ & 71.661 .113 & $24.931,0$ & 46,09 & 3,4 \\
\hline $\mathbf{2 0 1 1}$ & 105.934 .807 & $28.115,7$ & 34,13 & 3,6 \\
\hline $\mathbf{2 0 1 2}$ & 84.066 .659 & $29.351,4$ & 43,75 & 3,7 \\
\hline $\mathbf{2 0 1 3}$ & 99.858 .613 & $34.305,9$ & 32,35 & 3,9 \\
\hline $\mathbf{2 0 1 4}$ & 84.508 .918 & $32.309,0$ & 40,59 & 6,3 \\
\hline $\mathbf{2 0 1 5}$ & 63.268 .398 & $31.464,8$ & 49,73 & 2,6 \\
\hline $\mathbf{2 0 1 6}$ & 55.995 .686 & $22.107,4$ & 39,48 & 6 \\
\hline
\end{tabular}

Tablo 5: Dış Ticaret Verileri ve Turizm Gelirlerinin GSMH İçindeki Payı Kaynak: TÜRSAB

Türkiye sürekli dış ticaret açığı veren ve bu açığı kapatmak için de turizm gelirlerine ihtiyaç duyan bir ülke konumundadır. Turizm gelirlerinin dış ticaret açığını kapatma oranına baktığımızda artan ve azalan bir eğilim vardır. İstikrarlı bir artış ya da azalış söz konusu değildir. En yüksek oranı 2015 yılında \%49.73 oranında gerçekleştirmiştir. Ancak 2016 yılı için aynı şeyi söylemek mümkün değildir. 2016 yılında hem ihracat azalmış, hem de turizm gelirleri azalmıştır. Buna bağlı olarak turizm gelirlerinin dış ticaret açığını kapatma payı ise \%10 oranında azalmıştır. Yine aynı şekilde 2015 yılında \%6,2 olan turizm gelirlerinin GSMH içindeki payı, 2016 yılında \%2,6’ya düşmüştür. Bu durum ise ödemeler dengesi üzerinde ağır bir yük oluşturmuştur.

\begin{tabular}{cllll}
\hline & & & \multicolumn{2}{l}{ Sermaye Girişlerinin Dağılımı (\%) } \\
\hline & Aralık 2015 & Aralık 2016 & Aralık 2015 & Aralık 2016 \\
\hline Cari İşlemler Dengesi & $\mathbf{- 3 2 . 1 1 8}$ & $\mathbf{- 3 2 . 6 0 5}$ & - & - \\
\hline $\begin{array}{l}\text { Toplam Net Yabancı } \\
\text { Sermaye Girişi }\end{array}$ & $\mathbf{2 0 . 2 8 7}$ & $\mathbf{3 3 . 4 2 3}$ & $\mathbf{1 0 0 , 0}$ & $\mathbf{1 0 0 , 0}$ \\
\hline -Doğrudan Yatırımlar & 12.455 & & & \\
\hline -Portföy Yatırımları & -15.719 & 6.998 & 61,4 & 26,9 \\
\hline -Diğer Yatırımlar & 13.374 & 6.929 & $-77,5$ & 19,2 \\
\hline -Net Hata ve Noksan & 10.198 & 11.069 & 65,9 & 20,7 \\
\hline -Diğer & -21 & 23 & 50,3 & 33,1 \\
\hline Rezervler & $\mathbf{1 1 . 8 3 1}$ & $\mathbf{- 8 1 8}$ & $-0,1$ & 0,1 \\
\hline
\end{tabular}

Tablo 6: Türkiye’ye Net Sermaye Girişlerinin Dağılımı (12 Aylık Kümülatif, Milyon \$) Kaynak: TCMB, Türkiye İs Bankası 
2016 yılında cari açığın 2015 yılına kıyasla 0,5 milyar \$ artarak 32.6 milyar \$’a yükseldiği görülmektedir. Bu durumda ihracat rakamlarındaki azalışın yanısıra turizm gelirlerindeki azalışında etkisi vardır. Yani dış ticaret açı̆̆ı ile turizm gelirlerinin azalması bu düşüşü önemli derecede etkilemiştir.

2016 yılında jeopolitik gelişmeler cari dengeyi olumsuz yönde etkilemiştir. Yurtiçinde artan güvenlik problemleri, Rusya ile ilişkilerde yaşanan önemli sıkıntılar, Ortadoğu'da yaşanan savaşlar, dünya genelinde terör endişeleri turizm gelirleri üzerindeki etkisini ciddi bir biçimde hissettirmiştir.

2016 yılında Türkiye'ye gelen turist sayısı yaklaşık 31 milyondur. Turizm gelirleri ise 2015 yılına göre yaklaşık 10 milyar \$ azalmıştır. Ayrıca Rusya'dan gelen turist sayısı 3,7 milyondan 1 milyona düşmüştür (Türkiye İş Bankası, 2017). Buradan hareketle ülkeler arasında yaşanan siyasi ve ekonomik gerginliklerin ekonomik bir gösterge olan turizme olumsuz yansıdığı ve kötü ilişkilerin turizmi bitirdiği söylenebilir.

\section{Sonuç}

Bir turizm cenneti olan Türkiye gerek konumu gerekse tarihiyle tüm dünyanın ilgisini çeken ender ülkelerden biridir. Geçmişten günümüze kadar bir turizm ülkesi olarak bilinen Türkiye'de 1980'li yıllardan sonra turizm alanında önemli gelişmeler yaşanmıştır. Hem ekonomik politikaların rahat bir şekilde uygulanabilmesi hem de ülkenin dış alemde tanıtılabilmesi açısından kalkınma planlarında turizm sektörünün önemi üzerinde ayrıca durulmuştur. Böylece günümüzde turizm sektörü en gözde alanlardan bir tanesi olmayı başarmıştır.

Turizm sektörünün gelişmesinin her alanda görüldüğü gibi, ödemeler dengesi üzerinde de olumlu etki yaptığı gayet açıktır. Ödemeler dengesi üzerinde yapılan her artış, döviz girdisinin sağlanmasına ve birçok sektörü etkileyecek oranda ekonominin canlanmasına yol açacaktır. Bu yüzden turizm gelirlerinin artması hayati öneme sahiptir. Çünkü kronik bir dış ticaret açı̆̆ına sahip ülkede bu dengeyi sağlayabilmenin en önemli ölçütü turizm gelirlerini arttırmaktır. Böylelikle sektörel yatırımların artmasıyla birlikte istihdam alanları açılacak ve milli gelir üzerinde pozitif etki yaratacaktır.

Yaşanan ekonomik krizlerden ödemeler dengesi olumsuz etkilenmektedir. Türkiye'de yaşanan 2000-2001 krizi, işsizliğin en çok arttığı ve piyasada durgunluğun en fazla hissedildiği dönemdir. Kriz döneminde dış ticaret açığı artmış, enflasyon yükselmiş, şirketler batmış ve işsizlik en yüksek seviyelerine çıkmıştı. Ayrıca dünya piyasasında büyük tedirginlik yaratan 2008 küresel ekonomik krizi, bütün ülkeleri ekonomik anlamda olumsuz etkilemiş, ülkelerin durgunluk yaşamasına neden olmuştur. Yatırım alanlarının etkilenmesiyle işsizlik de artmıştır. Bunun için yeni yatırım alanlarının açılması, istihdamın arttırılması, devlet destekli politikaların izlenmesi, yatırımcıların teşvik edilmesi gibi çözüm önerileri sunulmuştur. Turizm istihdam yaratma konusunda en önemli alanlardan bir tanesidir Türkiye ise bir çok turizm potansiyeline sahip zengin bir ülkedir. Her mevsim turizm faaliyetlerinden yararlanmak mümkündür. Eğer bu konuda isabetli yatırımlar yapılırsa işsizlik büyük oranda azalacaktır.

Turizm için olmazsa olmazlardan bir tanesi güvenliktir. Gerek ülke içindeki vatandaşlar gerekse yurtdışından gelen turistler güvenli bir ortamda turistik faaliyetlerini gerçekleştirmek isterler. Ancak son zamanlarda hemen hemen dünyanın her yerinde görmekte olduğumuz sorun güvenlik ve terörizm sorunudur. Bu durum turistlerin kararlarını olumsuz yönde etkilemektedir. Türkiye'de aynı sorunla baş etmeye çalışmaktadır. Hem ülke içindeki terör faaliyetleri, hem de özellikle Ortadoğu'da süren savaşlar neticesinde turistlerin ülkeye bakış açısı değişmektedir. Terör konusunda Türkiye önemli adımı atmıştır. Fakat savaşın daha fazla uzaması ülke ekonomisini daha fazla etkileyeceğinden dolayı bir an önce çözüm odaklı çalışmaların yapılması ve uygulanması gerekmektedir.

Ayrıca ülkelerarası siyasi krizlerinde bir an önce çc̈züme kavuşturulması gerekmektedir. Rusya ile yaşanan ikili anlaşmazlıklar sonucunda 2015 yılında 3,7 milyon olan turist sayıs1 2016 yılında 1 milyona düşmüştür. Bu önemli düşüşün nedenlerinden en önemlisi siyasi anlaşmazlıklardır. Yaklaşık 2,7 milyon turistin ülkeye kazandıracağı dövizin kaybı ekonomi üzerinde büyük baskı yaratmaktadır. Ekonomimizi düzeltmek, kalkınmayı hızlandırmak istiyorsak elimizdeki en önemli gelir kaynağımız olan turizm faaliyetlerini arttırmamız gerekmektedir. Nüfusumuzun büyük bir kısmının genç olduğu ülkemizde turizmde istihdam etme imkanları yaratılarak bu genç nüfus değerlendirilmelidir. Bunun için yapabileceğimiz şeyler toplum ve devlet olarak bizleri beklemektedir. Toplumun daha da bilinçlendirilerek turizme olan katkısının arttırılması, devlet politikalarının da yatırım ve projeleri daha çok destekleyici olması gerekmektedir.

\section{Kaynakça}

- Akoğlan Kozan, M., Evren, S., Çakır, O., 2013. “Tarihsel Süreç İçinde Turizm Paradigması”, Anatalia Turizm Araşttrmaları Dergisi, Cilt: 24, Sayı:1, ss:7-22.

- Albayrak, A. 2013. “Alternatif Turizm”, Detay Yayıncılık. Ankara.

- Bozgeyik, Y., Yoloğlu, Y., 2015. Türkiye'de Turizm Gelirleri ile GSYH Arasındaki İlişki: 2002-2014 Dönemi”, Uluslararası Sosyal Araştırmalar Dergisi, Cilt:8, Sayı:40, ss:627-632

- Çımat, A., Bahar, O., 2003. "Turizm Sektörünün Türkiye Ekonomisi İçindeki Yeri ve Önemi Üzerine Bir Değerlendirme” Akdeniz İ̈BF Dergisi, Sayı: 6, ss:1-18. 
- Egeli, H., “Türk Turizminin Dış Ticaret ve Sektörlerarası Bağlantıları Açısından Değerlendirilmesi”, http://dergiler.ankara.edu.tr/dergiler/42/480/5575.pdf. Erişim Tarihi: 201.04.2017

- Göçen, S., Yirik, Ş., Yılmaz Y., 2011. “Türkiye’de Krizler ve Krizlerin Turizm Sektörüne Etkileri”, Süleyman Demirel Üniversites, IIIBF Dergisi, Cilt: 16, Sayı: 2, ss:493-509.

- Karataş, M., Babür, S., 2013. “Gelişen Dünya'da Turizm Sektörünün Yeri”, KMÜ Sosyal ve Ekonomik Araştırmalar Dergisi, Cilt: 15, Sayı: 25, ss:15-24.

- K1zılgöl, Ö., Erbaykal, E. 2008. “Türkiye’de Turizm Gelirleri ile ekonomik büyüme İlişkisi: Bir Nedensellik Analizi” Süleyman Demirel Üniversitesi, İktisadi ve İdari Bilimler Dergisi, Cilt:13, Sayı:2, ss:351-360

- Kozak, N., Kozak, M.A., Kozak, M. 2013. Genel Turizm. Detay Yayıncılık, 14. Bask1, Ankara.

- Kültür ve Turizm Bakanlığ1, “Kuruluş Amacı ve Görevleri”, http://www.kultur.gov.tr/TR,96130/kurulusamaci-ve-gorevleri.html. Erişim Tarihi: 18.04.2017

- Sarıçay, N. S., Ünal, M., 2014. Krizlerin turizm Sektörü Üzerindeki Etkileri, Ar-Ge Bülten, 2014 OcakSektörel, http://www.izto.org.tr/Portals/0/Argebulten/KRIZTURIZM-25022014.pdf.Erişim Tarihi: 21.04.2017

- Sarsın Kaya, Dilek. 2016. “Turizm Sektörü”, İktisadi Araştırmalar Bölümü, İş Bankası, https://ekonomi.isbank.com.tr/UserFiles/pdf/sr201606_turizmsektoru.pdf. Erişim Tarihi:19.04.2017

- T.C. Kültür ve Turizm Bakanlığı, 2007. “Türkiye’de Turizm Stratejisi 2023- Eylem Planı 2007-2013”, T.C. Turizm Bakanlığı Yayınları, Ankara.

- TCMB, “Ödemeler Dengesi İstatistikleri’ne İlişkin Yöntemsel Açıklama” İstatistik Genel Müdürlüğü. http://www.tcmb.gov.tr/wps/wcm/connect/94562f9f-fa7d-471e-89f9c0e0e00cf99f/odemet.pdf?MOD=AJPERES\&CACHEID=94562f9f-fa7d-471e-89f9-c0e0e00cf99f. (Erişim Tarihi: 11.04.2017).

- Turizm Veri Bankas1, Turizm İstatistikleri 2016:2017, http://www.turizmdatabank.com/haber/turizmistatistikleri-2016-2017 Erişim Tarihi: 11.04.2017

- TÜRSAB, 2016, http://www.tursab.org.tr/tr/turizm-verileri Erişim tarihi: 11.04.2017

- TÜRSAB, 2016. Outgoing Pazarı Sonuçları, http://www.tursab.org.tr/dosya/15831/2016outgoing_15831_5118486.pdf.Erişim Tarihi: 19.04.2017

- Türkiye İş Bankası, 2017. “Ödemeler Dengesi-Aralık 2016” İktisadi Araştırmalar Bölümü, https://ekonomi.isbank.com.tr/UserFiles/pdf/od_201612.pdf.Erişim Tarihi: 22.04.207

- UNWTO (Dünya Turizm Örgütü), http://mkt.unwto.org/barometer 


\title{
Terörizm ve Makroekonomi: Avrasya Ekonomileri Üzerine Bir İnceleme
}

\section{Terrorism and Macroeconomy: A Review of The Eurasian Economies}

\author{
Asst. Prof. Dr. Özge Korkmaz (Bayburt University, Turkey)
}

\begin{abstract}
The relationship between terrorist incidents, inflation rate, unemployment rate, per capita GDP, export rate and import rate for Eurasian countries Ukraine, Moldova, Georgia, Kyrgyzstan, Kazakhstan, Tajikistan, Azerbaijan, Armenia and Belarus for the period 1994-2015. For this purpose, the Westerlund cointegration analysis and have been using the causality test introduced by Holtz-Eakin, Newey and Rosen. As a result of the analyzes, it is observed that there is a long-term relationship between the export rate and the terrorist incidents and the export rate is the reason for the terrorist incidents. At the same time, it has been found that there is no long-term interaction and causal link between all other variables and terrorist incidents considered in the study.
\end{abstract}

\section{Giriş}

Terör kavramı toplumun hemen hemen her alanında önemli etkilere neden olan bir olgu ve olağandışı bir durum olarak nitelendirilir. Terör ve terörizm kavramları ile ilgili olarak devletlerin yasalarındaki farklılık nedeniyle ilgili kavramlara ilişkin farklı tanımlamalar mevcuttur ve bu nedenle genel geçer bir tanımın literatürde var olmadığı söylenebilmektedir. İktisat literatürüne göre, terörist saldırılar zaman içerisinde sıkça gerçekleşmeyen ve ekonomideki oynaklığ arttıran olaylar olarak nitelendirilmektedir (Korkmaz vd., 2017:12). Basitçe terör olaylarının sürekli olarak ortaya çıkması durumu olarak tanımlanan terörizm kavramı, ülkelerin gelişmişlik düzeylerine göre fark etmeksizin istikrarı etkileyen önemli bir sorundur.

"Terör eylemleri toplumda sosyal, psikolojik, siyasal ve ekonomik sonuçlar doğurur. Bu sonuçların bir kısmı dolaylı bir kısm ise dolaysız etkilerdir. Terörün ekonomik sonuçları, terör eyleminin olmasından hemen sonra ortaya çıkarak etkisini çok kisa vadede gösterirken, orta ve uzun vadede ise ekonomi üzerinde olumsuz etkilerin ortaya çıktı̆̆ görülmektedir. Terörün doğrudan ekonomik maliyetlerinin (can kayıplarl, zarar gören altyapı tesislerinin onarımı ve yapımı vb.) terör eylemini takip eden süreçte ortaya çıktı̆̆l, dolaylı ekonomik maliyetlerinin (tüketici ve yatırımcılar üzerinde yarattığl güvensizlik) ise ülkelere, sektörlere ve zamana göre farklllı gösterebildiği söylenebilmektedir (Algan vd., 2017:147)."

Terör saldırıları dünyanın farklı coğrafi bölgelerinde değişik şekil ve türlerde ortaya çıkabilmektedir ve bu nedenle de terör saldırılarının tahminlenmesi oldukça zordur. Örneğin 11 Eylül 2001'de Amerika Birleşik Devletleri'nde, 2004'te İspanya'da, 2005 yılında İngiltere'de yaşanan, 2015 yılında Paris'te ve 2016'da İstanbul'da gerçekleştirilen saldırılardan sonra terörle mücadele politikalarına Dünya genelinde ağırlık verilmeye başlanmış̧ır. Dolayısı ile gelişmişlik düzeyine bakılmaksızın tüm ülkeler için terörizm sorunu, göz ardı edilemez bir niteliğe sahiptir.

$\mathrm{Bu}$ çalışmada Avrasya ülkeleri için terör olayları ile makroekonomik değişkenler arasındaki ilişki Westerlund Panel Eşbütünleşme Testi aracıllğıyla araştırılmak istenmiştir. Çalışmanın zaman boyutu 1994-2015 dönemini kapsamakta olup, Avrasya ülkelerinden olan 9 ülke örneklem olarak seçilmiştir. Çalışmada ilk olarak terör olayları ile makroekonomik değişkenler arasındaki ilişkiyi araştıran literatür özetlenmek istenmiş, ardından çalışmada kullanılan veri seti ve yöntem hakkında bilgi verilmiştir. Akabinde ise, analiz sonuçlarına geçilmiş ve genel bir değerlendirmenin yapıldığı sonuç kısmı ile çalışma sonlandırılmıştır.

\section{Literatür}

Terör olaylarının makroekonomik etkilerini inceleyen literatürde birçok çalışma mevcuttur. Bu çalışmalara ilişkin literatür özeti Tablo 1'de sunulmuştur. 


\begin{tabular}{|c|c|c|c|c|}
\hline Yazar & Ülke & Dönem & Yöntem & Bulgular \\
\hline $\begin{array}{l}\text { Bravo ve Dias } \\
(2006)\end{array}$ & $\begin{array}{l}\text { Batı Avrupa, Doğu } \\
\text { Avrupa, Orta Doğu } \\
\text { ve Güney } \\
\text { Asya'daki } 85 \text { ülke }\end{array}$ & 1997-2004 & $\begin{array}{l}\text { Panel Veri } \\
\text { Analizi }\end{array}$ & $\begin{array}{l}\text { Ülkenin kalkınma düzeyinin terörist olayları } \\
\text { azaltan önemli bir unsur olduğu sonucuna } \\
\text { varılmıştır. }\end{array}$ \\
\hline Persitz (2007) & İsrail & $1980-2003$ & VAR analizi & $\begin{array}{l}\text { Çalışmada İsrail'de terörün olduğu durum ile } \\
\text { olmadığ1 durum karşılaştırılmış ve 1994'ten } \\
\text { sonra şiddet eylemlerinin olmaması durumunda } \\
\text { ülkenin 2003:03 dönemindeki kişi başı GSYİH } \\
\text { oranın daha fazla olduğu sonucuna ulaşılmıştır. }\end{array}$ \\
\hline $\begin{array}{l}\text { Caruso ve } \\
\text { Schneider } \\
(2011)\end{array}$ & $\begin{array}{l}12 \text { Batı Avrupa } \\
\text { ülkesi }\end{array}$ & $1994-2007$ & $\begin{array}{l}\text { Panel Veri } \\
\text { Analizi }\end{array}$ & $\begin{array}{l}\text { Çalışmada ekonomik büyüme, enflasyon ve } \\
\text { işsizlik ile terör saldırıları arasında negatif ancak } \\
\text { genç işsizlik ile terör saldırıları arasında pozitif } \\
\text { bir ilişki olduğu belirlenmiştir. }\end{array}$ \\
\hline $\begin{array}{l}\text { Freytag vd. } \\
(2011)\end{array}$ & 110 ülke & $1971-2007$ & $\begin{array}{l}\text { Negatif binom } \\
\text { regresyon } \\
\text { modeli }\end{array}$ & $\begin{array}{l}\text { Çalışmada daha yüksek gelir düzeyinin, } \\
\text { terörizmin firsat maliyetini arttırdığı ve bu } \\
\text { durumun terörist saldırıların azalmasına neden } \\
\text { olduğu görülmüştür. }\end{array}$ \\
\hline $\begin{array}{l}\text { Kis-Katos vd. } \\
(2011)\end{array}$ & 159 ülke & $1970-2007$ & $\begin{array}{l}\text { Panel Veri } \\
\text { Analizi }\end{array}$ & $\begin{array}{l}\text { Çalışma sonucunda kişi başına düşen } \\
\text { GSYIH'nın artması, daha açık ve rekabetçi } \\
\text { politik sistemi ölçen politik skorun yüksek } \\
\text { olması ve yurtiçindeki çatışma, anarşi ve rejim } \\
\text { geçişkenliğinin terörü arttırdığı sonucuna } \\
\text { varılmıştır }\end{array}$ \\
\hline $\begin{array}{l}\text { Meierrieks ve } \\
\text { Gries (2012) }\end{array}$ & 160 ülke & $1970-2007$ & $\begin{array}{l}\text { Granger } \\
\text { nedensellik testi }\end{array}$ & $\begin{array}{l}\text { Çalışma sonucunda politik istikrarsızlığın } \\
\text { yaşandığı Latin Amerika ülkelerinde ekonomik } \\
\text { büyümenin terörist saldırılar üzerinde etkili } \\
\text { olduğu gözlenmiștir. }\end{array}$ \\
\hline $\begin{array}{l}\text { Shahbaz } \\
(2013)\end{array}$ & Pakistan & $1971-2010$ & $\begin{array}{l}\text { ARDL sinır } \\
\text { testi, Granger } \\
\text { Nedensellik } \\
\text { Analizi }\end{array}$ & $\begin{array}{l}\text { Enflasyon, ekonomik büyüme ve terörizm } \\
\text { arasında eşbütünleşme ilişkisinin var olduğu } \\
\text { tespit edilmiştir. }\end{array}$ \\
\hline $\begin{array}{l}\text { Altay vd. } \\
(2013)\end{array}$ & $\begin{array}{l}\text { Türkiye, Misir ve } \\
\text { Suudi Arabistan }\end{array}$ & $1996-2010$ & $\begin{array}{l}\text { Panel Veri } \\
\text { Analizi }\end{array}$ & $\begin{array}{l}\text { Çalışmada terörün ihracat, ithalat, ekonomik } \\
\text { büyüme, doğrudan yabancı yatırımlar, turizm, } \\
\text { kişi başına düşen gelir ve işsizlik üzerinde } \\
\text { negatif etkisi olduğu tespit edilmiştir. }\end{array}$ \\
\hline $\begin{array}{l}\text { Malik ve } \\
\text { Zaman (2013) }\end{array}$ & Pakistan & $1975-2011$ & $\begin{array}{l}\text { Johansen } \\
\text { eşbütünleşme } \\
\text { testi ve Granger } \\
\text { nedensellik testi }\end{array}$ & $\begin{array}{l}\text { Analizler sonucunda nüfus artışı, enflasyon, } \\
\text { yoksulluk ve politik istikrarsızlık } \\
\text { değişkenlerinin teröre neden olduğu } \\
\text { gözlenmiştir. Bununla birlikte, gelir eşitsizliği, } \\
\text { işsizlik ve ticari açıklık değişkenleri ile terör } \\
\text { arasında uzun dönemli bir ilişkinin var olmadığ1 } \\
\text { tespit edilmiştir. }\end{array}$ \\
\hline $\begin{array}{l}\text { Ak1nc1 vd. } \\
(2014)\end{array}$ & $\begin{array}{l}45 \text { gelişmiş, } 77 \text { 'si } \\
\text { gelişmekte olan ve } \\
\text { 30’u azgelişmiş } \\
\text { ülkeler }\end{array}$ & $2002-2011$ & $\begin{array}{l}\text { Pao ve Kadroni } \\
\text { eşbütünleşme } \\
\text { testleri ve } \\
\text { Granger } \\
\text { nedensellik testi }\end{array}$ & $\begin{array}{l}\text { Terörizm enflasyon düzeyini olumsuz yönde } \\
\text { etkilemektedir ve değişkenler arasında uzun } \\
\text { dönemli ve tek yönlü nedensel bir ilişki vardır. }\end{array}$ \\
\hline Choi (2015) & 127 ülke & $1970-2007$ & $\begin{array}{l}\text { Panel Veri } \\
\text { Analizi }\end{array}$ & $\begin{array}{l}\text { Çalışmada ekonomik büyümenin terörü azaltan } \\
\text { önemli bir etken olduğu, gelir eşitsizliğinin, } \\
\text { demokrasinin bozulmasının ve devlet } \\
\text { başarısızlığının terörü arttırdığı tespit edilmiştir. }\end{array}$ \\
\hline $\begin{array}{l}\text { Ak1nc1 vd. } \\
(2015)\end{array}$ & $\begin{array}{l}67 \text { gelişmekte olan } \\
\text { ve } 18 \text { az gelişmiş } \\
\text { ülke }\end{array}$ & $2005-2011$ & $\begin{array}{l}\text { Panel Pedroni } \\
\text { ile Kao } \\
\text { eşbütünleşme } \\
\text { testleri }\end{array}$ & $\begin{array}{l}\text { Terörün, doğrudan ve dolaylı yatırımları negatif } \\
\text { olarak etkilediği gözlenmiştir. Aynı zamanda } \\
\text { çalışmada değişkenler arasında uzun dönemli ve } \\
\text { tek yönlü bir ilişkinin mevcut olduğu } \\
\text { belirlenmiştir. }\end{array}$ \\
\hline $\begin{array}{l}\text { Kurt ve } \\
\text { Karagöl } \\
(2015)\end{array}$ & $\begin{array}{l}\text { Düşük ve yüksek } \\
\text { gelire sahip ülkeler }\end{array}$ & $1989-2002$ & $\begin{array}{l}\text { Panel Veri } \\
\text { Analizi }\end{array}$ & $\begin{array}{l}\text { Savunma harcamalarının ve terörün ekonomik } \\
\text { istikrarsızlığı arttırdığı sonucuna ulaşılmıştır. }\end{array}$ \\
\hline $\begin{array}{l}\text { Yardimcioglu } \\
\text { ve İlhan } \\
(2016)\end{array}$ & Türkiye & $1980-2015$ & $\begin{array}{l}\text { Engle-Granger } \\
\text { eşbütünleşme ve } \\
\text { nedensellik } \\
\text { testleri }\end{array}$ & $\begin{array}{l}\text { Politik istikrar ile GSYİH arasında uzun } \\
\text { dönemli bir ilişki olduğu ve Politik istikrarın } \\
\text { GSYİH 'nın nedeni olduğu saptanmıştır. }\end{array}$ \\
\hline
\end{tabular}


Literatürde, makroekonomik değişkenlerin terör üzerindeki etkilerini Avrasya ülkeleri için ele alan herhangi bir çalışmanın olmadığı gözlenmiştir. Bu bağlamda çalışmada örneklem olarak Avrasya ülkeleri seçilmiş ve eşbütünleşme ile nedensellik testlerinden yararlanılmıştır.

\section{Veri Seti ve Yöntem}

Çalışmada 12 Avrasya ülkesinden 1994-2015 dönemi için verilerin temin edilebildiği 9 ülke ile çalışılmış ve terör olayları ile makroekonomik değişkenler arasındaki ilişki araştırılmıştır. Çalışmanın başlangıcında okullaşma oranı ve gini katsayısı değişkenleri de dikkate alınmış ancak ilgili ülkeler için çok fazla noksan veri olması nedeniyle eşbütünleşme ve nedensellik analizleri yapılamamıştır. Dolayısı ile makro ekonomik değişkenlerin seçiminde sınırlandırmaya gidilmek zorunda kalınılmış ve Tablo 3 'te sunulan değişkenler ile çalışılabilinmiştir. $\mathrm{Bu}$ doğrultuda çalışmada ele alınan ülkeler Tablo 2'de; kullanılan değişkenlere ait bilgiler ise Tablo 3'te gösterilmiştir. Çalışmada kullanılan değişkenlere ait veriler "World Data Bank" sitesinden temin edilmiştir. Çalışmanın analizleri ise STATA13 programı aracılığıyla yapılııı̧tır.

\begin{tabular}{|l|l|l|}
\hline Ukrayna & Moldova & Gürcistan \\
\hline Kırgizistan & Kazakistan & Tacikistan \\
\hline Beyaz Rusya & Azerbaycan & Ermenistan \\
\hline
\end{tabular}

Tablo 2. Çalışmada Ele Alınan Avrasya Ülkeleri

\begin{tabular}{|l|l|}
\hline Değişkenler & Açılaması \\
\hline INF & Enflasyon oranı \\
\hline EXPORT & İhracat oranı \\
\hline IMPORT & İthalat oranı \\
\hline EVENT & Terör olay sayısı \\
\hline GDP & Kişi başına düşen GSYİH oranı \\
\hline UNEMP & İşizlik oranı \\
\hline
\end{tabular}

Tablo 3. Çalışmada Kullanılan Değişkenler

Çalışmada değişkenler arasındaki uzun dönemli ilişkinin varlığı Westerlund Panel Eşbütünleşme testi aracılığıyla araştırılmaktadır. Westerlund (2007), eşbütünleşmenin varlığını sınamak için, hata düzeltme modeli temelli 4 adet panel eşbütünleşme testi önermiştir. Testlerin temelinde, her bir birimin kendi hata düzeltmesine sahip olup olmadığına karar verilmesi yoluyla eşbütünleşmenin varlığı sınanmaktadır (Tatoğlu, 2012). Westerlund Panel Eşbütünleşme testinin hipotezleri şu şekildedir (Westerlund, 2007).

$\mathrm{H}_{\mathrm{o}}$ : Eşbütünleşme yoktur.

$\mathrm{H}_{1}$ : Eşbütünleşme vardır.

Westerlund Panel Eşbütünleşme testinin seçilmesindeki en önemli nedenleri şu şekilde belirtmek mümkündür: i) $\mathrm{Bu}$ test dengesiz panel verilerde kullanılabilmektedir. ii) Ayrıca, bu eşbütünleşme testi hem yapısal kırılmaları hem de yatay kesit bağımlılığını dikkate almaktadır. iii) Bu bağlamda çalışmada elde edilen bulguların daha güvenilir sonuçlar verebileceği söylenebilir.

Panel eşbütünleşme testi sonucunda değişkenler arasında uzun dönemli ilişki bulunmuş ise bu durumda uzun ve kısa dönem parametrelerinin tahminine geçilmektedir. Bu yöntemlerden biri olan Havuzlanmış Ortalama Grup Tahmincisi (PMGE), uzun dönem parametrelerini sabit tutmaktadır ve ayrıca kısa dönem parametrelerinin ve hata varyansının birimlere göre değerlendirilmesine izin vermektedir (Tatoğlu, 2012).

Çalışmada eşbütünleşme ilişkinin varlığının araştırılmasının ardından, değişkenler arasında nedensel bir ilişkinin olup olmadığ 1 araştırılmak istenmektedir. Bu amaçla ise, Holtz-Eakin, Newey ve Rosen tarafindan ortaya atılan nedensellik testi kullanılmaktadır. Granger nedensellik testinin geliştirilmiş bir şekli olan Holtz-Eakin, Newey ve Rosen Nedensellik Testi, en küçük kareler yöntemine dayanmaktadır.

$$
\begin{aligned}
& y_{i t}=\alpha_{0 t}+\sum_{j=1}^{m} \alpha_{j t} y_{i t-j}+\sum_{j=1}^{m} \delta_{j t} x_{i t-j}+\psi_{t} f_{i}+u_{i t} \quad(\mathrm{i}=1, \ldots, \mathrm{N} ; \mathrm{t}=1, \ldots, \mathrm{T}) \\
& y_{i t}-y_{i t-1}=\sum_{j=1}^{m} \alpha_{j}\left(y_{i t-j}-y_{i t-j-1}\right)+\sum_{j=1}^{m} \delta_{j}\left(x_{i t-j}-x_{i t-j-1}\right)+\left(u_{i t}-u_{i t-1}\right)
\end{aligned}
$$

(1) ve (2) nolu denklemlerden görüldüğü üzere bu test, sabit etkilerden arındırmak için değişkenlerin farklarını almaktadır ve testin hipotezleri X'in Y'nin nedeni olup olmadığı üzerine kuruludur (Holtz-Eakin vd, 1988: 1373).

\section{Bulgular}

Çalışmada terör olayları ile enflasyon oranı, işsizlik oranı, kişi başına düşen GSYİH oranı, ihracat oranı ve ithalat oranı arasındaki ilişki ortaya konulmak istenmektedir. Bu amaçla ilk olarak Pesaran, Ullah ve Yamagata (2008), tarafından geliştirilen sapması düzeltilmiş LM testi aracılığıyla değişkenler arasında yatay kesit bağımlılığının olup olmadığı araştırılmış ve elde edilen bulgular Tablo 4’te raporlanmıştır. 


\begin{tabular}{|l|l|l|}
\hline Değişkenler & İstatistik Değeri & Olasılık Değeri \\
\hline INF & -0.549 & 0.2911 \\
\hline EXPORT & 0.335 & 0.6311 \\
\hline IMPORT & 1.280 & 0.9000 \\
\hline EVENT & -1.611 & 0.6772 \\
\hline GDP & -0.986 & 0.1621 \\
\hline GINI & 1.192 & 0.883 \\
\hline UNEMP & -1.478 & 0.8081 \\
\hline PRIMARY & -0.866 & 0.1932 \\
\hline $\begin{array}{l}* * * \text { ve } * * * \text { sirasılya } \\
\text { etmektedir. }\end{array}$ & \multicolumn{2}{l}{0.05 ve 0.01 düzeyinde istatistiksel olarak anlamlılığ1 ifade } \\
\hline
\end{tabular}

Tablo 4. Yatay Kesit Bă̆ımlılı̆̆ı (LM) Test Sonuçları

Tablo 4 incelendiğinde yatay kesit bağımlılığının tüm değişkenler için var olmadığı söylenebilmektedir. Bu bulgudan hareketle, değişkenlerin durağan oldukları seviye/farklar 1. Nesil Birim Kök testlerinden olan Fisher Philips-Perron birim kök testi aracılığıyla araştırılabilmektedir. Çalışmada önce değişkenlerin düzey değerleri için birim kök analizi yapılmış ve elde edilen sonuçlar Tablo 5 'te verilmiştir.

\begin{tabular}{|c|c|c|c|c|}
\hline \multicolumn{5}{|c|}{ I(0) İçin Fisher Philips-Perron Birim Kök Testi } \\
\hline \multicolumn{3}{|l|}{ Sabit Terimli } & \multicolumn{2}{|c|}{ Sabit Terimli ve Trendli } \\
\hline Değişkenler & İstatistik Değeri & Olasılık Değeri & İstatistik Değeri & Olasılık Değeri \\
\hline INF & 1610.10 & $0.0000^{* * *}$ & 1619.50 & $0.0000^{* * *}$ \\
\hline EXPORT & 8.6074 & 0.9682 & 8.7838 & 0.9511 \\
\hline IMPORT & 4.2399 & 0.9996 & 16.4147 & 0.5636 \\
\hline EVENT & 227.315 & $0.0000^{* * *}$ & 206.905 & $0.0000^{* * *}$ \\
\hline GDP & 2.8780 & 0.9996 & 8.8502 & 0.9631 \\
\hline GINI & 44.0391 & $0.0006^{* * *}$ & 40.8777 & $0.0006^{* * *}$ \\
\hline UNEMP & 21.6962 & 0.2458 & 27.2388 & $0.0746^{*}$ \\
\hline PRIMARY & 59.6992 & $0.0000^{* * *}$ & 68.1476 & $0.0000^{* * *}$ \\
\hline
\end{tabular}

Tablo 5. Değişkenlerin Düzey Değerleri İçin Birim Kök Analiz Sonucu

Tablo 5'ten hareketle, ithalat oranı, ihracat oranı ve kişi başına düşen GSYİH oranı değişkenlerinin düzey değerlerinde durağan olmadığı söylenebilmektedir. İşsizlik oranı değişkeni için ise birim kök test sonuçlarından hangisinin dikkate alınacağı hususunda kararsız kalınmış ve ilgili değişkenin grafiği incelenmiştir. Buna göre işsizlik oranı değişkeni için sabit terimli ve trendli birim kök test sonucunun dikkate alınması gerektiğine karar verilmiştir. Dolayısı ile ithalat oranı, ihracat oranı ile kişi başına düşen GSYİH oranı değişkenleri hariç, diğer tüm değişkenlerin düzey değerlerinde durağan olduğu belirlenmiştir. Söz konusu üç değişken için birinci farkları dikkate alınmak suretiyle birim kök analizi tekrarlanmış ve elde edilen sonuçlar Tablo 6'da sunulmuştur.

\begin{tabular}{|c|c|c|c|c|}
\hline \multicolumn{5}{|c|}{ I(1) İçin Fisher Philips-Perron Birim Kök Testi } \\
\hline \multicolumn{3}{|l|}{ Sabit Terimli } & \multicolumn{2}{|c|}{ Sabit Terimli ve Trendli } \\
\hline Değişkenler & İstatistik Değeri & Olasılık Değeri & İstatistik Değeri & Olasılık Değeri \\
\hline EXPORT & 87.4659 & $0.0000^{* * *}$ & 55.3158 & $0.0000^{* * *}$ \\
\hline IMPORT & 74.0723 & $0.0000^{* * *}$ & 45.2898 & $0.0004^{* * *}$ \\
\hline GDP & 48.9942 & $0.0000^{* * *}$ & 84.8689 & $0.0000^{* * *}$ \\
\hline
\end{tabular}

Tablo 6. Değişkenlerin Birinci Farkları İçin Birim Kök Analiz Sonucu

Tablo 6'dan görüldüğü üzere, ithalat oranı, ihracat oranı ve kişi başına düşen GSYİH oranı değişkenlerinin birinci farklarında durağan olduğu söylenebilmektedir.

Çalışmanın bu aşamasında, değişkenler arasındaki uzun dönemli ilişki araştırılmak istenmiştir. Bu doğrultuda Westerlund eşbütünleşme testi yapılmış ve elde edilen sonuçlar Tablo 7'de gösterilmiştir. 


\begin{tabular}{|c|c|c|c|c|c|}
\hline \multicolumn{3}{|c|}{ EVENT-INF } & \multicolumn{3}{|c|}{ EVENT--EXPORT } \\
\hline & İstatistik Değeri & Olasılık Değeri & & İstatistik Değeri & Olasılık Değeri \\
\hline $\mathrm{Gt}$ & -9.571 & $0.000^{* * *}$ & $\mathrm{Gt}$ & -25.664 & $0.000^{* * *}$ \\
\hline $\mathrm{Ga}$ & -7.008 & 0.543 & $\mathrm{Ga}$ & -12.639 & $0.001^{* * *}$ \\
\hline $\mathrm{Pt}$ & -2.861 & 0.939 & $\mathrm{Pt}$ & -63.870 & $0.000^{* * *}$ \\
\hline $\mathrm{Pa}$ & -1.970 & 0.941 & $\mathrm{~Pa}$ & -33.880 & $0.000^{* * *}$ \\
\hline \multicolumn{3}{|c|}{ EVENT-IMPORT } & \multicolumn{3}{|c|}{ EVENT--GDP } \\
\hline & İstatistik Değeri & Olasılık Değeri & & İstatistik Değeri & Olasılık Değeri \\
\hline $\mathrm{Gt}$ & -12.403 & $0.000^{* * *}$ & $\mathrm{Gt}$ & -5.781 & $0.000^{* * *}$ \\
\hline $\mathrm{Ga}$ & -15.869 & $0.022^{* *}$ & $\mathrm{Ga}$ & -204.747 & 0.939 \\
\hline $\mathrm{Pt}$ & -3.305 & 0.865 & $\mathrm{Pt}$ & 0.024 & 0.996 \\
\hline $\mathrm{Pa}$ & -4.078 & 0.572 & $\mathrm{~Pa}$ & 0.643 & 0.998 \\
\hline \multicolumn{6}{|c|}{ EVENT--UNEMP } \\
\hline & \multicolumn{2}{|l|}{ İstatistik Değeri } & \multicolumn{3}{|c|}{ Olasılık Değeri } \\
\hline $\mathrm{Gt}$ & \multicolumn{2}{|l|}{-3.842} & \multicolumn{3}{|c|}{$0.000^{* * *}$} \\
\hline $\mathrm{Ga}$ & \multicolumn{2}{|l|}{266.532} & \multicolumn{3}{|c|}{0.963} \\
\hline $\mathrm{Pt}$ & \multicolumn{2}{|l|}{-1.677} & \multicolumn{3}{|c|}{0.999} \\
\hline $\mathrm{Pa}$ & \multicolumn{2}{|c|}{74.957} & \multicolumn{3}{|c|}{0.996} \\
\hline \multicolumn{6}{|c|}{$\begin{array}{l}\text { Ho: Eşbütünleşme yoktur (Westerlund, 2007:710). Uygun gecikme sayıs Akaike (AIC) bilgi kriterine göre } \\
\text { belirlenmiştir. Stata programında maksimum gecikme uzunluğu } 4 \text { ve öncül uzunluk aralığı } 0-3 \text { olarak seçilmiş; uygun } \\
\text { gecikme sayısı ile uygun öncül uzunluk dikkate alınarak eşbütünleşme sonuçları verilmiştir. }{ }^{* * *} \text { ve }^{* * *} \text { sırasıyla } 0.10 \text {, } \\
0.05 \text { ve } 0.01 \text { düzeyinde istatistiksel olarak anlamlllığı ifade etmektedir. }\end{array}$} \\
\hline
\end{tabular}

\section{Tablo 7. Westerlund Eşbütünleşme Testi Sonuçları}

Tablo 7'deki enflasyon, kişi başına düşen GSYİH oranı ve işsizlik oranı için eşbütünleşme test sonuçları, her üç değiş̧ken ile terör olayları arasında uzun dönemli bir ilişkinin olmadığını göstermektedir. Benzer şekilde Gt ve Ga istatistik değerleri baz alındığında, ithalat oranı ile terör olayları arasında uzun dönemli bir ilişkinin var olduğu söylenebilmektedir. Ancak burada Pt ve Pa istatistik değerleri dikkate alındığında ilgili değişkenler arasında uzun dönemli bir ilişkinin varlığından söz edebilmek mümkün değildir.

Tablo 7'de dikkat çeken bir diğer bulgu ise, tüm istatistiki değerlere göre sadece terör olayları ile ihracat oranı arasında istatistiki olarak anlamlı ve uzun dönemli bir ilişkinin var olmasıdır. Bir diğer ifadeyle çalışmada, Gt, Ga, $\mathrm{Pt}$ ve $\mathrm{Pa}$ istatistiki değerlerinin tümü birlikte ele alındığında, kişi başına düşen GSIYYH oranı, ithalat oranı ve işsizlik oranları ile terör olayları arasında uzun dönemde bir bağ olmadığı ancak ihracat oranı için bu durumun söz konusu olmadığı sonucuna ulaşılmıştır.

Çalışmada ihracat oranı ile terör olayları arasında uzun dönemli ilişkinin var olması nedeniyle uzun ve kısa dönem parametre değerleri tahmin edilmek istenmiştir. Bu amaçla ise Pesaran, Shin ve Smith (1999) tarafindan önerilen Havuzlanmış Ortalama Grup Tahmincisinden (PMGE) yararlanılmıştır. İhracat oranı ile terör olayları arasındaki ilişki için PMGE sonuçları Tablo 8'de sunulmuştur.

\begin{tabular}{|l|l|l|l|}
\hline Uzun Dönem & Katsay1 & Z istatistik değeri & Olas1lık değeri \\
\hline & 0.0000000016 & 2.30 & $0.021^{* *}$ \\
\hline EXPORT & Katsay1 & Z istatistik değeri & Olasılık değeri \\
\hline Kisa Dönem & -0.7874 & 7.86 & $0.000^{* * *}$ \\
\hline & -0.0000000008 & -1.25 & 0.211 \\
\hline$\emptyset$ & 1.19 & 0.234 \\
\hline EXPORT & 7.3358 & $0.10,0.05$ ve 0.01 düzeyinde \\
\hline Sabit Terim & $\begin{array}{l}\text { Ø: hata düzeltme parametresini göstermektedir. }{ }^{* *}{ }^{*} \text { ve }^{* * *} \text { sirasiyla } \\
\text { istatistiksel olarak anlamlılığ1 ifade etmektedir. }\end{array}$
\end{tabular}

Tablo 8. İhracat Oranı İle Terör Olayları Arasındaki İlişki İçin PMGE Sonuçları

Tablo 8 ele alındığında, hata düzeltme parametresinin (-0.7874) negatif ve anlamlı olduğu söylenebilmektedir. Dolayısı ile iki değişken arasında uzun dönemli bir ilişki mevcuttur. Bu sonuç Westerlund eşbütünleşme test sonuçları ile paralellik göstermektedir. Hata düzeltme parametresi, serilerin durağan olmamasından kaynaklanan kısa dönem sapmalarının bir sonraki dönemde dengeye gelme hızını göstermektedir (Tatoğlu, 2012:245). Bu bağlamda, bir dönemde oluşan dengesizliklerin yaklaşık \%79'u bir sonraki dönemde düzelecek ve uzun dönem dengesine yaklaşması sağlanabilecektir. Ayrıca ihracat oranının uzun dönem parametresi (0.0000000016) anlamlı ve işareti pozitif, kısa dönem parametresi ise $(-0.0000000008)$ istatistiksel olarak anlamsızdır. Dolayısıyla uzun dönemde ihracat oranındaki \%1'lik artış, terör olaylarını \%0.0000000016 oranında arttırmaktadır. 
Çalışmanın bu kısmında ise ithalat oranı ile terör olayları arasındaki uzun dönemli ilişki için elde edilen Westerlund eşbütünleşme test sonuçlarından hangisinin dikkate alınabileceğine karar verebilmek amacıyla Havuzlanmış Ortalama Grup Tahmincisinden (PMGE) yararlanılmıştır. Çalışmada ithalat oranı ile terör olayları arasındaki ilişki için elde edilen PMGE sonuçları Tablo 9'da verilmiştir.

\begin{tabular}{|c|c|c|c|}
\hline \multicolumn{4}{|l|}{ Uzun Dönem } \\
\hline & Katsayı & $\mathrm{Z}$ istatistik değeri & Olasılık değeri \\
\hline IMPORT & 0.0000000014 & 1.81 & $0.070^{*}$ \\
\hline \multicolumn{4}{|l|}{ Kısa Dönem } \\
\hline & Katsayı & $\mathrm{Z}$ istatistik değeri & Olasılık değeri \\
\hline$\emptyset$ & -0.7901 & -7.92 & $0.000^{* * *}$ \\
\hline IMPORT & -0.0000000008 & -1.45 & 0.147 \\
\hline Sabit Terim & 7.6268 & 1.19 & 0.235 \\
\hline
\end{tabular}

Tablo 9. Ithalat Oranı ile Terör Olayları Arasındaki İlişki Iç̧in PMGE Sonuçları

Tablo 9 incelendiğinde, hata düzeltme parametresi (-0.7901) negatif ve anlamlı olduğu için ithalat oranı ile terör olayları arasında uzun dönemli bir ilişkinin var olduğu söylenebilmektedir. Bu sonuç Westerlund Eşbütünleşme test sonuçlarından Gt ve Ga istatistik değerlerinin baz alınması gerektiğine işaret etmektedir. Çünkü hatırlanacağı üzere, ilgili test sonuçları terör olayları ile ithalat oranı arasında uzun dönemli bir ilişkinin var olduğunu göstermekteydi. PMGE hata düzeltme parametresinin anlamlı olması nedeniyle bir dönemde oluşan dengesizliklerin yaklaşık \%79'u bir sonraki dönemde düzeleceği ve uzun dönem dengesine yaklaşmasının sağlanabileceği ifade edilebilmektedir. Ayrıca ihracat oranının uzun dönem parametresinin $(0.0000000014)$ anlamlı ve işaretinin pozitif olduğu, kısa dönem parametresinin $(-0.0000000008)$ ise istatistiksel olarak anlamsız olduğu Tablo 8'den görülebilmektedir. Sonuç olarak uzun dönemde ithalat oranındaki \%1'lik artış, terör olaylarını $\% 0.0000000014$ oranında arttırmaktadır.

Çalışmada son olarak, terör olayları ile ele alınan makroekonomik değişkenler arasındaki nedensel bağın varlığı araştırılmak istenmiştir. Bu amaçla da Holtz-Eakin, Newey ve Rosen tarafından geliştirilen nedensellik testinden yararlanılmıştır. Elde edilen sonuçlar ise Tablo 10'da raporlanmıştır.

\begin{tabular}{|c|c|c|c|}
\hline \multicolumn{2}{|l|}{$\mathrm{INF} \neq>\mathrm{EVENT}$} & \multicolumn{2}{|l|}{$\mathrm{EVENT} \neq>\mathrm{INF}$} \\
\hline İstatistik Değeri & Olasılık Değeri & İstatistik Değeri & Olasılık Değeri \\
\hline 0.0080 & 0.9287 & 0.4924 & 0.4838 \\
\hline \multicolumn{2}{|c|}{ EXPORT $\neq>$ EVENT } & \multicolumn{2}{|c|}{ EVENT $\neq>$ EXPORT } \\
\hline İstatistik Değeri & Olasılık Değeri & İstatistik Değeri & Olasılık Değeri \\
\hline 9.1418 & $0.0029^{* * *}$ & 0.2297 & 0.6324 \\
\hline \multicolumn{2}{|c|}{ IMPORT $\neq>$ EVENT } & \multicolumn{2}{|c|}{ EVENT $\neq>$ IMPORT } \\
\hline İstatistik Değeri & Olasılık Değeri & İstatistik Değeri & Olasılık Değeri \\
\hline 0.4056 & 0.5252 & -0.2275 & 0.8205 \\
\hline \multicolumn{2}{|l|}{ GDP $\neq>$ EVENT } & \multicolumn{2}{|l|}{ EVENT $\neq>$ GDP } \\
\hline İstatistik Değeri & Olasılık Değeri & İstatistik Değeri & Olasılık Değeri \\
\hline 0.1566 & 0.6928 & 0.0535 & 0.8170 \\
\hline \multicolumn{2}{|c|}{ UNEMP $\neq>$ EVENT } & \multicolumn{2}{|c|}{ EVENT $\neq>$ UNEMP } \\
\hline İstatistik Değeri & Olasılık Değeri & İstatistik Değeri & Olasılık Değeri \\
\hline-0.2870 & 0.7745 & 0.2316 & 0.8168 \\
\hline
\end{tabular}

Tablo 10. Holtz-Eakin, Newey ve Rosen Nedensellik Testi Sonuçlarl

Tablo 10 incelendiğinde, çalışmada ihracat oranından terör olaylarına doğru tek yönlü nedensel bir bağın var olduğu görülebilmektedir. Ancak çalışmada ele alınan diğer değişkenler ile terör olayları arasında herhangi bir yönde nedensel bağın var olmadığı tespit edilmiştir. Bir diğer ifadeyle, ithalat oranı ile terör olayları arasında; kişi başına düşen GSYİH oranı ile terör olayları arasında; işsizlik oranı ile terör olayları arasında ve enflasyon oranı ile terör olayları arasında çift veya tek yönlü nedensel bir bağın varlığından bahsedilememektedir. 
Tablo 9 ve Tablo 10 birlikte ele alındığında; uzun dönemde ithalat oranındaki artışın, terör olaylarını oldukça az oranda etkilediği, kısa dönemde ise ithalat oranındaki artışın terör olayları üzerinde anlamlı bir etkisi olmadığı göz önünde bulundurulduğunda ithalat oranı ile terör olayları arasında herhangi bir nedensel bağın tespit edilmemiş olması beklenen bir sonuçtur.

Çalışmadan elde edilen sonuçları kısaca özetlemek gerekirse, ihracat oranı ile terör olayları arasında uzun dönemli bir ilişkinin var olduğu ve ihracat oranındaki artışın terör olaylarını oldukça az oranda etkilediği söylenebilmektedir. Çalışmada ayrıca, ele alınan diğer tüm değişkenler ile terör olayları arasında uzun dönemde bir etkileşimin olmadığı ve nedensel bir bağın tespit edilemediği gözlenmiştir. Bu sonuçların en önemli nedeni olarak ise, Avrasya ülkelerinin teröre maruz kalma sıklıklarının olduğu düşünülmektedir. Bu bağlamda çalışmada Avrasya ülkelerinin terör olaylarına maruz kalma sıklıkları verilmek istenmiştir. İlgili gösterim Şekil 1'de sunulmuştur.

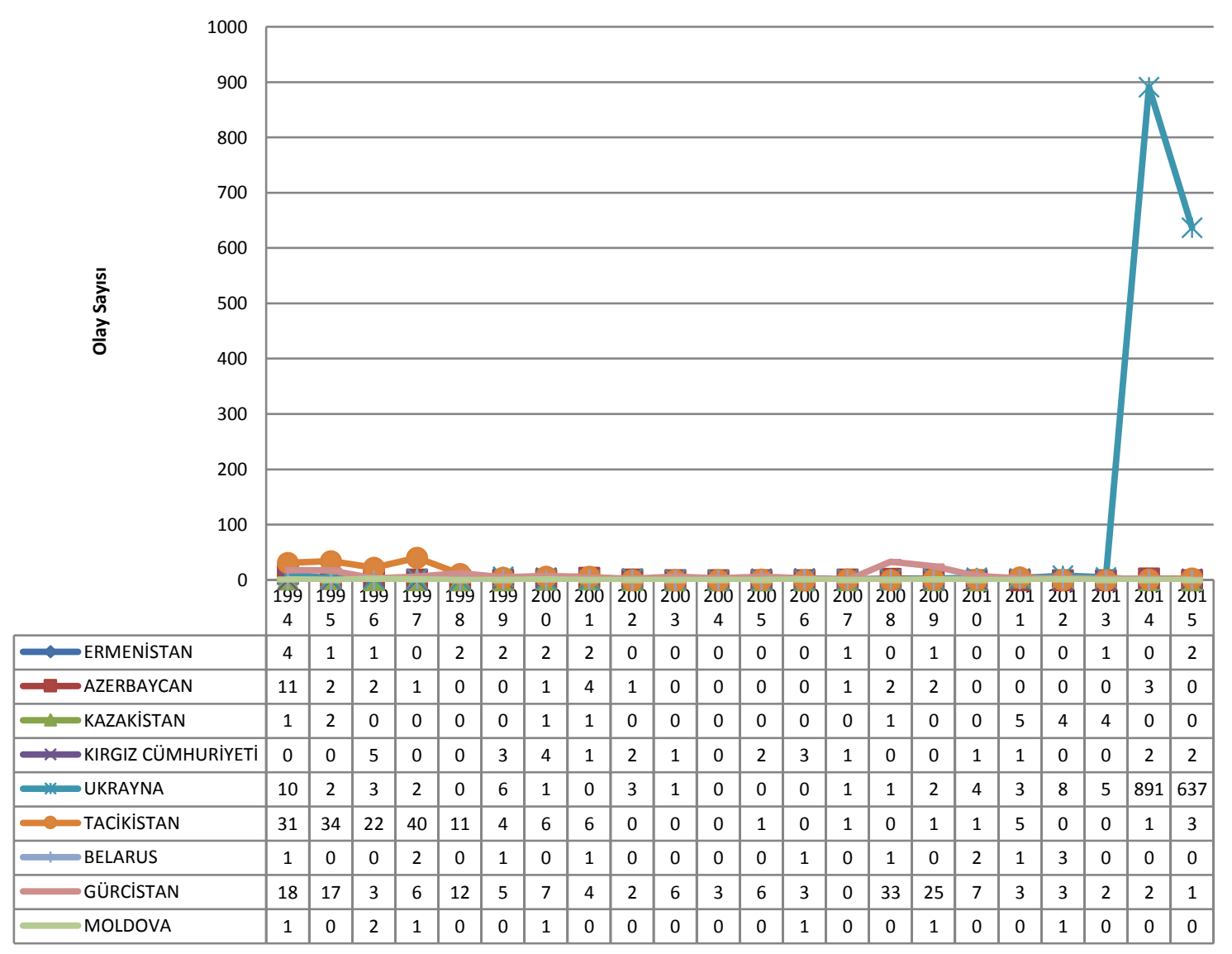

Şekil 1: Avrasya Ülkelerinin 1994-2015 Dönemi İçin Terör Olaylarına Maruz Kalma Sıklıkları

Daha önce bahsedildiği üzere, Avrasya ülkelerinin terörist saldırılara mazur kalma sıklıkları çalışmanın sonuçlarının değerlendirilmesinde önemli bir ipucu sunmaktadır. Bu doğrultuda Şekil 1'den sadece Ukrayna'da 2014 ve 2015 yılında çok yoğun sıklıkta terör olaylarının yaşandığı görülmektedir. Bu zaman dilimi hariç, Ukrayna dahil diğer tüm ülkelerde yaşanan terör olaylarının oldukça az olduğu söylenebilmektedir. Bir diğer ifadeyle, Avrasya ülkelerinin terör olaylarına çok yoğun maruz kalmadıkları ve bu nedenle de çalışmada ele alınan makroekonomik değişkenler ile terör olayları arasında uzun dönemli ve nedensel bir bağın tespit edilememesinin beklenen bir durum olduğu düşünülmektedir.

\section{Sonuç}

Terör geçmişten günümüze değin beklenmeyen ve istenmeyen bir durumdur. Çok yoğun terör olaylarına maruz kalan toplumların gelişmişlik düzeyinin düştüğü ve istikrarsız bir yapıya sahip olduğu söylenebilmektedir. Benzer şekilde ülkelerin politik istikrarı olarak ele alınan terör olayları sadece toplumsal refahı etkilemekle kalmamakta, ekonomik boyutu da olumsuz yönde etkilemektedir. Bu çalışmada Sovyetler Birliği'nin (SSCB) dağılmasından sonra aynı coğrafyada kurulan Avrasya ülkelerinden seçilen 9 ülke örneklem olarak seçilmiş ve terör olaylarına maruz kalma sıklıkları, enflasyon oranı, işsizlik oranı, kişi başına düşen GSYİH oranı, ihracat oranı ve ithalat oranı değişkenleri 1994-2015 dönemi için dikkate alınmıştır. 
Çalışmada terör olayları ile makroekonomik değişkenler arasındaki uzun dönemli ilişkinin varlığı Westerlund eşbütünleşme testi aracılığıyla, nedensel bağın varlığı ise Holtz-Eakin vd. tarafından geliştirilen nedensellik testi ile araştırılmıştır. Eşbütünleşme analizi sonucunda ihracat oranı ile terör olayları arasında ve ithalat oranı ile terör olayları arasında uzun dönemli bir ilişkinin var olduğu sonucuna ulaşılmıştır. İşsizlik oranı ile terör olayları arasında uzun dönemli bir ilişkinin var olmadığı tespit edilmiştir ve çalışmadan elde edilen bu sonuç Malik ve Zaman (2013)'ın çalışmalarındaki bulgu ile örtüşmektedir.

Çalışmada Havuzlanmış Ortalama Grup Tahmincisinden (PMGE) yararlanılmış ve bir dönemde oluşan dengesizliklerin yaklaşık \%79'unun bir sonraki dönemde düzeleceği ve uzun dönem dengesine yaklaşabileceği sonucuna ulaşılmıştır. Ayrıca çalışmada uzun dönemde ihracat oranındaki \%1'lik artışın, terör olaylarını $\% 0.0000000016$; ithalat oranındaki \%1'lik artışın ise terör olaylarını \%0.0000000014 oranında arttırdı ğ gözlenmiştir. Kısa dönemde ise istatistiki olarak ilgili değişkenlerin terör olayları üzerinde anlamlı bir etkiye sahip

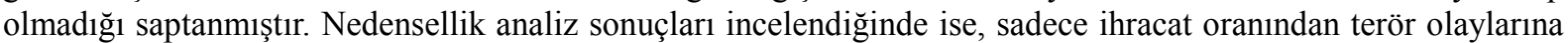
doğru nedensel bir bağın var olduğu görülmüştür. Sonuç olarak Ukrayna'nın, Moldova'nın, Gürcistan'ın, Kırgızistan'ın, Kazakistan'ın, Tacikistan'ın, Azerbaycan'ın, Ermenistan'ın ve Beyaz Rusya'nın ilgili dönem aralığı için yadsınamaz boyutta terör olaylarından etkilendiği söylenememektedir.

\section{Kaynakça}

- $\quad$ Akıncı, M., Gönül Y. A. , Yılmaz, Ö., 2007. “Terörizmin Enflasyon ve Ekonomik Büyüme Üzerindeki Etkileri: Panel İki Aşamalı En Küçük Kareler Yöntemi”, Uluslararası Güvenlik ve Terörizm Dergisi, 5(1), p.1-24

- Akıncı, M., Gönül Y. A. , Yılmaz, Ö., 2015. ”Terörizmin Doğrudan ve Dolaylı Yatırımlar Üzerindeki Etkisi: Dış Yardımlar Ne Kadar Telafi Edici?”, Ankara Üniversitesi SBF dergisi, 70(1), p.1-33.

- Algan, Neşe; Balcılar, Mehmet; Bal, Harun.; Manga, Müge (2017), "Terörizmin Türkiye Finansal Piyasaları Üzerine Etkisi: Ampirik Bir Çalışma”, Ege Akademik Bakış, Cilt:17, Sayı:1, ss. 147-160.

- $\quad$ Altay, H., Ekinci, A., Peçe, M. A. 2013., “Ortadoğu'da Terörün Ekonomik Etkileri: Türkiye, Misır ve Suudi Arabistan Üzerine Bir İnceleme ”, Dumlupınar Üniversitesi Sosyal Bilimler Dergisi, 37, p. 267-288.

- $\quad$ Bravo, A. B. S. and Dias, C. M. 2006.“An Empirical Analysis of Terrorism: Deprivation, Islamism veGeopoliticial Factors", Defence vePeace Economics, 17(4), p.329-341.

- Caruso, R. and Schneider, F., 2011. “The Socio-Economic Determinants of Terrorism and Political Violance in Western Europe", European Journal of Political Economy,27 (1), p.27-49

- Choi,S., 2015., "Economic Growth and Terrorism: Domestic, International and Suicide", Oxford Economic papers, p.157-181.

- $\quad$ Freytag, A., Krüger, J., Meierrieks, D. and Daniel, S. F. 2011. "The Origins of Terrorism: Cross-Country Estimates of Socio-Economic Determinants of Terrorism", European Journal of Political Economy, 27, p.516.

- Holtz-Eakin, D., Whitney N. and Harvey, R. S., 1988. "Estimating Vector Autoregressions With Panel Data". Econometrica, 56, p. 1371-1395.

- Kis-Katos, K., Liebert, H. and Schulze, G. 2011. "On The Origin of Domestic veInternational Terrorism”, European Journal of Political Economy, 27, p.516-536.

- Korkmaz, Özge; Deniz Erer; Elif Erer, “Terör Olaylarının Finansal Piyasalar Üzerine Etkisi”, Sosyoekonomi, 2017, 25(31), s.11-30.

- $\quad$ Kurt, S. ve Karagöl, E. T., 2015. "The Effects of Terrorism and Defence Expenditures On Economic Growth”, 6(2), p.07-17, www.ijeronline.com/Vol6issue2.php Erişim: 01/12/2015.

- Malik, Z., Zaman, K., 2013. "Macroeconomic Consequences of Terrorism in Pakistan”, Journal of Policy Modeling, 35, p.1103-1123.

- Meierrieks, D. ve Gries, T., 2012. "Causality Between Terrorism And Economic Growth”, Journal of Peace Research, 50(1), p.91-104.

- Persitz, D., 2007. "The Economic Effects of Terrorism: Counterfactual Analysis of The Case of Israel”, p. 1 55,www.aeaweb.org/annual_mtg_papers/2007/0106_1015_1802.pdf, ,Erişim: 15/12/2015.

- $\quad$ Pesaran, M. H., Shin, Y. ve Smith, R. P. 1999. "Pooled Mean Group Estimation of Dynamic Heterogeneous Panel”, Jornal of the American Statistical Assosiciation, 94, p.621-634.

- Pesaran, M. H., Ullah, A. ve Yamagata, T. 2008. “A Bias-Adjusted LM Test of Error Cross-Section Independence”, Econometrics Journal, 11 (1), p.105-127.

- Shahbaz, M. 2013.'Linkages Betwwen Inflation, Economic Growth And Terrorism in Pakistan", Economic Modelling, 32, s.496-506 
- Shahbaz, M. ve Shabbir, S. M., 2011. "Is Hike in Inflation Responsible for Rise in Terrorism in Pakistan?”, MPRA Working Paper, No:31236.

- Tatoğlu, F. Y. 2012. İleri Panel Veri Analizi. Beta Basım, İstanbul.

- Westerlund, J. 2007. "Testing for Error Correction in Panel Data", Oxford Bulletin of Economics and Statistics, 69 (6), p.709-747.

- Yardimcioglu, M. ve İlhan, A. (2016), “A Study Regarding the Advences of Political Stability and Economic Development Experienced in Turkey during the Periods of 1980-2015", International Journal of Economics and Finance, 8(10), pp. 167-175. 


\title{
Hollanda Hastalı̆̆ı ve İran Ekonomisi: Zorunlu Otarşiye Yönelim Hastalığı Baskıladı mı?
}

\section{Dutch Disease and Iranian Economy: Has Orientation to Compulsory Autarky Suppressed the Disease?}

\author{
İlgar Riyazi (Atatürk University, Turkey) \\ Asst. Prof. Dr. Dilek Özdemir (Atatürk University, Turkey) \\ Ph.D. Candidate Aslı Cansin Doker (Erzincan University, Turkey) \\ Prof. Dr. Ömer Selçuk Emsen (Atatürk University, Turkey)
}

\begin{abstract}
The discovery of natural resources and its impact on the increase in export revenues is highly likely to affect production, consumption and foreign trade relations of non-natural resources sectors. The inertia condition created by the resource exploration is defined as the curse of natural resources. Additionally, the curse of the resources reveals negative repercussions such as the Dutch Disease, rent-seeking, overconfidence and neglect education. Within this aspect, the Dutch disease can be defined as a mechanism emerging through the discovery of natural resources and its exports, which causes negativity in other export products. As the disease will be expected to come out, war and embargo practices can also be considered to be self-sufficiency in diversity in the local/national economy. In this framework, it is discussed in this study, whether Iran falls to the Dutch Disability, or it is organized by external forces the period between 1980 and 2014. According to findings obtained from the time series analyzes, the natural resource richness was determined in Iran if the presence of the Dutch disease is not strong. In recent years, however, it can be said that the weakness of the disease has led to the war and embargo that Iran experienced especially in self-sufficiency.
\end{abstract}

\section{Giriş}

İktisadi büyüme literatüründe ana hatlarıyla ihracata yönelik ve ithal ikameci strateji uygulamaları söz konusudur. İthal ikameci strateji ülkenin ithalata bağımlılık yapısını ortadan kaldırmayı amaçlar. Bu stratejide karşılaştırmalı üstünlük yapısı gereği ithal edilenin ikamesini yurtiçinde üretmek suretiyle ithalattan ve dolayısıyla döviz giderlerinden tasarruf sağlanması söz konusudur. İhracata yönelik strateji ise ülkenin karşılaştırmalı üstünlükler yapısının gerektirdiği alanlara ağırlık vererek ülkenin döviz gelirlerini ve dolayısıyla ulusal gelir ve refahını artırmayı amaçlar. Burada doğal kaynak keşfi ile birlikte bir tür ihracata yönelik stratejinin işlemesinin yansıması olarak döviz kazandırıcı mekanizmanın devam edeceği açıktır. Böylece doğal kaynak ihracatıyla birlikte ortaya çıkan döviz kazançlarının ekonominin talep yönlü dinamiklerini harekete geçirerek kısa dönemde büyümeye "olumlu" etkilerinin olması olasılık dahilindedir. Ancak, ekonomide fiyat mekanizmalarının yaratacağı baskılar ve istikrarsızlıkların uzun dönemde ekonomik büyüme üzerinde "olumsuz" yansımalarının olacağı da ileri sürülmektedir.

Olumlu yansımalar Rosenstein-Rodan (1943, 1961) ile Murphy vd. (1989) tarafindan ele alındı ̆̆ şekliyle "büyük itiş" olarak adlandırılmaktadır. Doğal kaynak keşfi ya da fiyatlarındaki artışlar toplam talep üzerinde artırıcı etkiler yaratmakta; bunun da doğal kaynak ihracatındaki artıştan kaynaklanan etkilere bağlı olacağı kabul edilmektedir. İktisat literatüründe bu etkiler, doğal kaynağa dayalı kalkınma formu şeklinde tanımlanır. Diğer taraftan doğal kaynakların olumsuz yansıması ise literatürde "kaynakların laneti” olarak tanımlanmaktadır: Doğal kaynakların ileri ve geri bağlantılarının zayıf olmasının genel ekonomi üzerinde beklenen şekliyle yüksek olumlu etkiler yaratmayacağı Hirschman (1958) tarafından ileri sürülmüştür. Ayrıca gelir artışlarının yatırımlardan ziyade tüketime kanalize olması da gelir artışlarını sürekli kılmayan en önemli unsurların başında gelmektedir (Sachs ve Warner, 1999: 43-45). Bunlara ilave olarak petrol fiyatlarındaki oynaklıklar bu malda gerek ihracatçı, gerekse ithalatçı ülke ekonomilerinde kırılganlıkları artırabilmektedir (Özdemir vd., 2016: 632). Doğal kaynakların laneti argümanının yol açtığı dört temel olumsuzluktan bahsedilmektedir. Bunlardan biri de Hollanda Hastalığıdır. En kısa tanımlamasıyla Hollanda Hastalığı doğal kaynak ihracatının yol açtığı döviz girişlerinin ulusal parayı değerlendirerek diğer sektörlerde rekabet gücünü zayıflatmasına ve ihracatçı yapılardaki bozulmaya dikkatleri çeker. İhracatçı yapılarda bozulma ise, artan iç talebin dışa satılan mallara, yani ihracatçı sektörlere kayması ve böylece geleneksel ihracatın azalmasıdır.

Çalışmanın ikinci kısmında genelde kaynakların laneti ve özelde de Hollanda Hastalığının işleyişi ve bu işleyiş üzerine ampirik literatüre ilişkin araştırmalar özetlenmiştir. Üçüncü kısımda doğal kaynak zengini İran ekonomisinde ortaya çıkması beklenen Hollanda Hastalığının var olup olmadığı, literatürdeki özetlerden hareketle modellenmeye çalışılmıştır. Çalışmanın savı, İran'da Hollanda Hastalığı olgusunun yaşanmama olasılığı üzerine kurulmuştur ve bunun kökeninde de devrimle birlikte yaşadığı uzun süreli savaş ile savaş esnasında ve sonrasında karşı karşıya kaldığı ambargo uygulamalarının yatacağı düşünülmektedir. Zira savaş ve ambargonun İran 
ekonomisinde kendi kendine yeterliliği zorlayacağı açıktır. Bu çerçevede dördüncü veya uygulama kısmında çalışmanın veri, metodolojisi ve ekonometrik analizlerden elde edilen bulgulara yer verilmiştir. Analizlerle İran ekonomisi için Hollanda Hastalığı mı, yoksa Fransızca kökenli bir kavram olan otarşi (autarcie)'nin getirdiği nimetleri mi, yani kötü komşu mal sahibi yapar prensibinin mi geçerli olduğu belirlenmeye çalışılmıştır. Burada otarşinin kendi kendine yeterlilik anlamı taşıdığı dikkate alınırsa, özellikle ambargo uygulamaları ile dış alım ve satımına tahdit konulan İran'ın rekabet üstünlüğü olmasa da, dezavantajlı mallarının iç piyasada üretimi yapılarak dışa bağımlılığının azalması söz konusu olmuş mudur? Sonuç kısmında ise İran'ın izlediği politikalarda tutarlılıklar ile olası politika çıkarımları tartışma konusu yapılmıştır.

\section{Hollanda Hastalığı ve Literatür Araştırması}

Bir ekonomide doğal kaynaklara dayalı zenginleşmede ortaya çıkan ani bir gelir artışının ekonomide paradoks, yani zenginliğin parasal boyuttan öteye geçmediğine ve dolayısıyla refahta bozulmaya teşkil ettiğine dair tartışmalar oldukça eskilere dayanmakta ve hatta Merkantilist dönem İspanyasına kadar götürülmektedir (Ebrahim-zadeh, 2015: 1). Buna göre ekonomide tam istihdam varsayımı önsel olarak kabul edildiğinde, yeni keşfedilen ve zenginliğin kaynağ konumundaki sektörde ortaya çıkan genişlemelerin diğer sektörlerden kaynakları çekmeye başlaması, adeta "dışlama etkisi" (crowding out) yaratır. Bunun paralelinde avantajlı sektörlerde üretim daralması ortaya çıkarır. Özellikle petrol şokları ile birlikte ortaya çıkan kazançların düşük kârlılığa sahip ticarete konu olan sektörlerden ticarete konu olmayan sektörlere doğru kaynak transferini tetikleyeceği açıktır (Smith, 2014: 1; Ismail, 2010: 5-6; Allcott ve Keniston, 2013: 3). Diğer taraftan dışlama etkisinin yanı sıra doğal kaynaklar ihracatının dolaylı olarak yönetişim ve hukuk sistemini kapsayan kurumlara zarar verebildiği, bürokraside rant kollayan sınıflar arasında nizayı derinleştirebildiği ve kamuyu vergi toplama konusunda zayıflığa teşvik edebildiği gibi olumsuz yansımaları söz konusu olabilmektedir (Brunnschweilera ve Bulteb, 2008: 249). Belirtilen bu olumsuz yansımaları doğal kaynakların laneti olarak tanımlanmaktadır. Özetle kaynakların laneti; (i) Hollanda Hastalığı, (ii) rant kollama, (iii) aşırı güven ve (iv) eğitimin ihmali olmak üzere dört temel sorun şeklinde ele alınmaktadır (Gylfason, 2001: 847-850):

- Hollanda Hastalığı: Doğal kaynak zenginliği ve bunun dünyaya ihraç edilmesi ulusal paranın aşırı kıymetlenmesine yol açarken, ulusal paranın kıymetlenmesi de diğer ihraç ürünlerinde rekabet gücünün azalmasına sebebiyet vermektedir (bkz. Rajan ve Subramanian, 2011: 108).

- Rant Kollama: Rant kollama, iş alemi ve hükümette yolsuzluğu tetikleyebilir ve böylece bu durum kaynak tahsisini bozduğu gibi hem ekonomik etkinliği hem de sosyal adaleti azaltır (bkz. Bardhan, 1997).

- Așırı Güven: Doğal kaynak zenginliği sahte bir güvenlik duygusunu insanlara aşılayabilir, hükümetlerin ihtiyaçlarında önceliği kaybettirebilir ve serbest ticaret, bürokratik etkinlik ile kurumsal kaliteyi içeren ekonomi yönetimini ahbap-çavuş ilişkisine çevirebilir.

- Eğitimin İhmali: Doğal kaynak sermayesi ile beşeri sermaye arasında ters yönlü ilişkilerin varlığı dikkat çekmektedir.

Yukarıda da belirtildiği gibi kökenleri Merkantilizme kadar dayanan Hollanda Hastalığı olgusu, kavramsal olarak 1960'larda Hollanda'da doğalgazın bulunması ve sonrasında Hollanda para birimi Florin'in değerinin aşırı artması sonucunda; (a) bunun tetiklediği giderek ucuzlayan ithalatın artması ve (b) buna karşılık rekabet gücünün zayıflamasıyla birlikte geleneksel ihracatın azalması süreçleri gözlenir olmuştur. 1960'larda Hollanda özelinde gözlenen olgunun 1970'lerde İngiltere'de yaşanması ve bunun kaynak zengini ülkelerde de benzeri karakteristikler sergilemesi ile birlikte "Hollanda Hastalığı" (Dutch Disease) kavramı ilk kez The Economist dergisinin 26 Kasım 1977 tarihli yayınında kullanılmış ve ilk gözlenen ülkenin adıyla anılır olmuştur. Dolayısıyla ithalatın artması ve geleneksel ihracatın azalması şeklinde kendini gösteren yapıyı ifade etmek üzere Hollanda Hastalığı kavramı kullanılmaya başlanmıştır. Diğer bir ifadeyle Hollanda'da doğal gazın keşfiyle başlayan ekonomik zenginleşme süreci bir süre sonra adeta "sanayisizleşme (de-industrialization)" ile sonlanmayı tanımlamak için kullanılır olmuştur (Boyraz, 2015: 1).

Hollanda Hastalığı kavramı aynı zamanda "Aşırı Sıcak Para Hastalığı” olarak da tanımlanmaktadır. Diğer bir ifadeyle Hollanda Hastalığı ile Aşııı Sıcak Para Hastalığı kavramları birbirlerinin yerine, eş-anlamlı olarak kullanılabilmektedir. İktisat literatüründe teorik düzeyde Hollanda Hastalığı kavramı ise ilk olarak Corden ve Neary (1982) tarafindan yapılan çalışmayla ele alınmıştır. Bu iki yazara göre bir ülkenin Hollanda Hastalığına düştügüne dair en temel bulgu, o ülkenin geleneksel mal ihracatı sektörünün diğer iki sektör tarafindan, yani yeni ihracatçı sektör ile ticarete konu olmayan sektörler tarafindan dışlanmasıdır (Corden ve Neary, 1982: 825).

Hollanda Hastalığının akademik çevrelerde tartışılmaya başlaması ile birlikte yukarıda da belirtildiği gibi ilk teorik çalışma Codren ve Neary (1982) tarafından ortaya konulurken, ilk ampirik çalışma da Bruno ve Sachs (1982) tarafından İngiltere üzerine yapılmış ve daha sonrasında konuyla ilgili çok sayıda çalışmanın ortaya çıktığı gözlenmiştir (Ismail, 2010: 6-7). Ampirik çalışmalarda [bkz. Bruno ve Sachs (1982), Sachs ve Warner (1999), Gylfason (2001), Sachs ve Warner (2001), Oomes ve Kalçeva (2007), Abrişmi vd. (2009), İsmail (2010), Nazari (2010), Rajan ve Subramanian (2011), Gurbanov (2011), Clay ve Weckenman (2014), Nişancı vd. (2016)] Hollanda Hastalığının varlığına dair bulgular ortaya konulmuştur. Diğer taraftan Hollanda Hastalığının ancak belirli koşullarda gerçekleşebildiğini ileri süren araştırmalara [bkz. Brunnschweilera ve Bulteb (2008), Bahrami 
ve Nasiri (2010), Boyce ve Emery (2011), Smith (2014)] da rastlanmıştır. İki uç bulgu veren araştırmaların yanı sıra bir kısım çalışmalarda [bkz. Hooker (1996), Allcott ve Keniston (2013)] ise bu türden ilişsiler yakalanamamıştır. Ancak, doğal kaynakların lanet teşkil etmediği, bilakis ekonomik büyümeyi teşvik ettiği de ileri sürülmektedir. Bu son duruma, belirli bir kalkınmışlık düzeyinde ya da kalkınmada eşik değerleri aşmış ülke ekonomilerinde doğal kaynakların ne atalete yol açtığı, ne de sıkıştırma etkileri yarattığ belirlemesi yapılarak ekonomik büyüme üzerinde olumsuzluktan ziyade olumlu etkiler doğurduğu tespit edilmiştir. Doğal kaynakların olumlu yansımalarda bulunduğu ülke örneği olarak ise Norveç gösterilmektedir.

\section{Ampirik Bulgular}

İktisat literatüründe Hollanda Hastalığını belirleyen faktörler arasında ihracat ve ithalatta ortaya çıkan değişimler yer almaktadır. Bu faktörlerden birincisi, doğal kaynak zengini ülkelerde, bu kaynağın fiyatındaki artışlardan dolayı adeta ataletin kaçınılmaz hale gelmesi ve/veya ihraç mallara iç talebin artmasıdır. Böylece dünya piyasasındaki rekabet gücünün azalması ve buna paralel olarak diğer mal ihracatlarının kısıtlanması söz konusu olmaktadır. İkincisi ise, petrol gelirlerindeki artışın yol açtığı satın alma gücünün başta Veblenist mallar olmak üzere ithalata kanalize olmasıdır. Dolayısıyla ülke ihracatı ve ithalatındaki bu değişimlerin ise özellikle yurtiçi sanayi üretimini zayıflatması kuvvetle muhtemeldir.

Araştırmaya konu olan İran ekonomisine ilişkin analizlere geçmeden önce betimleyici olarak Hollanda Hastalığına dair bulguların olup olmadığının araştırılması yoluna gidilmiştir. Bu çerçevede İran ekonomisinin mal ihracatının toplam ihracattaki paylarının zamana bağlı sergilediği gelişmelerin gözden geçirilmesinde fayda vardır. Böylece İran'ın özellikle ihracatta mal çeşitlemesine gidip gitmediği, yani petrole bağımlı bir ticaret yapısının olup olmadığının belirlenmesi amaçlanmıştır. Ham verilerle yapılacak bu incelemeyle bir biçimde İran'ın rekabet gücünün varlığı da ortaya konulmuş olacaktır. $\mathrm{Bu}$ amaçla mal ihracatının toplam ihracattaki payları değerlendirilmek istendiğinde, Uluslararası Standart Ticaret Sınıflandırılmasına (SITC-Rev. 3) göre oluşturulmuş mal gruplarına göre petrol ve sanayi boyutu ilişkilerine bakılmaya çalışılmıştır. Buna göre SITC-Rev. 3 de 10 ana guruptan (0'dan 9'a) müteşekkildir. Bunlardan SITC3 Mineral yakıtlar, yağlayıcılar ve ilgili malzemeler şeklinde tanımlanan yakıt ihracatı (Mineral fuels, lubricants and related materials) ile SITC5 Kimyasal maddeler ve ilgili ürünler (Chemicals and related products, n.e.s), SITC6 İşlenmiş mallar (Manufactured goods classified chiefly by material), SITC7 Makine ve taşıma ekipmanları (Machinery and transport equipment) ve SITC8 Çeşitli mamul eşyaları olarak tanımlanan mal grupları (Miscellaneous manufactured articles)'nın toplamı (SITC4+SITC5+SITCH6+SITCH7+SITCH8) olarak alınan sanayi ihracatının grafiksel seyri Şekil 1'de görülmektedir.

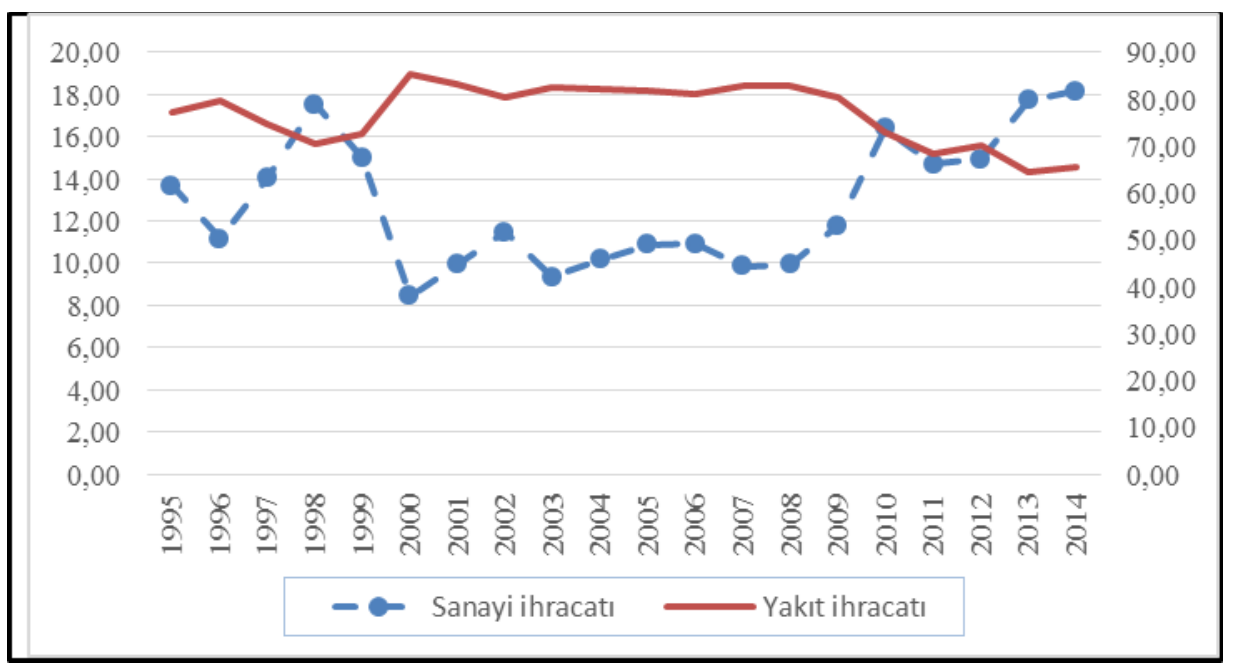

Şekil 1. Iran'ın Sanayi ile Yakıt İhracatının Toplam İhracattaki Paylarının Genel Seyri

İran'ın yakıt ihracatının (ikincil eksen) toplam ihracattaki payı değerlendirildiğinde, genel olarak bunun \%80'ler civarında olduğu ancak, 2009'da petrol fiyatlarındaki önemli artışlara karşılık, İran'ın toplam ihracatında petrolün payında tedrici düşüşlerin olduğu ve bu oranının 2014'de \%65'lere kadar gerilediği görülmektedir. Ancak, petrolün toplam ihracattaki payında gözlenen gerilemeye karşılık halen daha hatırı sayılabilir bir oranda yer tuttuğu da ihmal edilmemelidir. İran'ın sanayi ihracatı olarak tanımlanabilecek kalemlerin toplamı 2008 yılından itibaren \%10'lardan 2014 yılına gelindiğinde yaklaşık \%18'lik seviyelere çıkarak artış eğilimi sergilemiştir. Bu bilgiler ışığında, İran için ilk etapta Hollanda Hastalığının varlığına dair işaretler görünmekte, ancak zamana bağlı olarak petrol ihracatının payının görece düşüş gösterdiği dikkat çekmektedir.

Yukarıdaki değerlendirmeler ışığında, İran ekonomisinde Hollanda Hastalığının olma ihtimalinin zayıf olduğu söylenebilir. Hatta literatürde İran'ın cumhuriyetin ilanıyla birlikte Irak ile 8 yıl süren savaşa maruz kalması, o 
süreçte ve devamında Batı tarafından uygulanan ambargoların bu ülkeyi adeta otarşiye, yani kendi kendine yeterliğe sevk ettiği; özellikle son dönem ihracat yapısındaki çeşitlenme ya da diğer malların son yıllardaki ihracatındaki artışlardan hareketle söylenebilir (Yurttançıkmaz vd., 2012).

Diğer taraftan Hollanda Hastalığının varlığında ticarete konu olan sanayi sektörü yerine, görece kârlılığın yükseleceği ticarete konu olmayan diğer sektörlerin gelişmesi söz konusu olacaktır. Bu çerçevede Şekil 2'de İran ekonomisinde sanayi sektörünün toplam ulusal gelir içerisindeki payının zamana bağlı genel seyri verilmiştir.

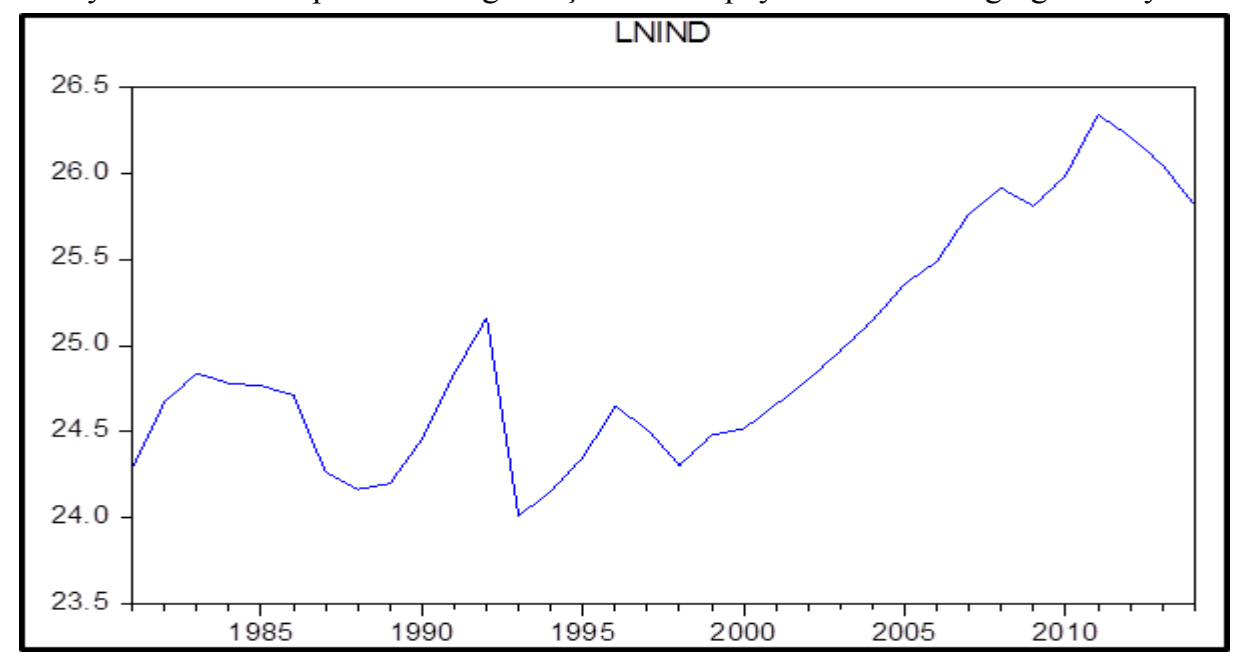

Şekil 2. Iran'ın Sanayi (INND) Sektörünün 1981-2014 Yılları Arası Genel Seyri

Şekil 2'de görüldüğü gibi İran'1n sanayi sektörü (İND), Irak ile savaş döneminde (1980-1988) önce artış ve daha sonra azalış göstermiştir. 1988-1992 yılları arasında savaştan sonra bu sektörde gelişmeler olmuştur. 1992 yılında petrol fiyatlarının artış yerine kısmen azalış göstermesine rağmen, petrol ihracatı geçen yıllara göre daha fazla olmuş; petrol sayesinde ülkede artan gelir, hükümeti ithalata doğru yönlendirerek iç sanayinin giderek gerilemesine neden olmuştur. Dolayısıyla sanayi sektörü 1992-1993 yıllarında aşırı derecede azalma yaşamıştır. 1993 yılını İran'ın sanayi tarihinde dip noktası olarak adlandırmak mümkündür. Bu tarihten sonra sanayi sektörünün, giderek artış göstermesi, İran'ın gelişmesine önemli bir katkıda bulunmaktadır.

Şekil 3'de ise İran'ın petrol gelirlerinin GSYH içindeki payı ile Brent petrol fiyatlarının genel seyri verilmiştir.

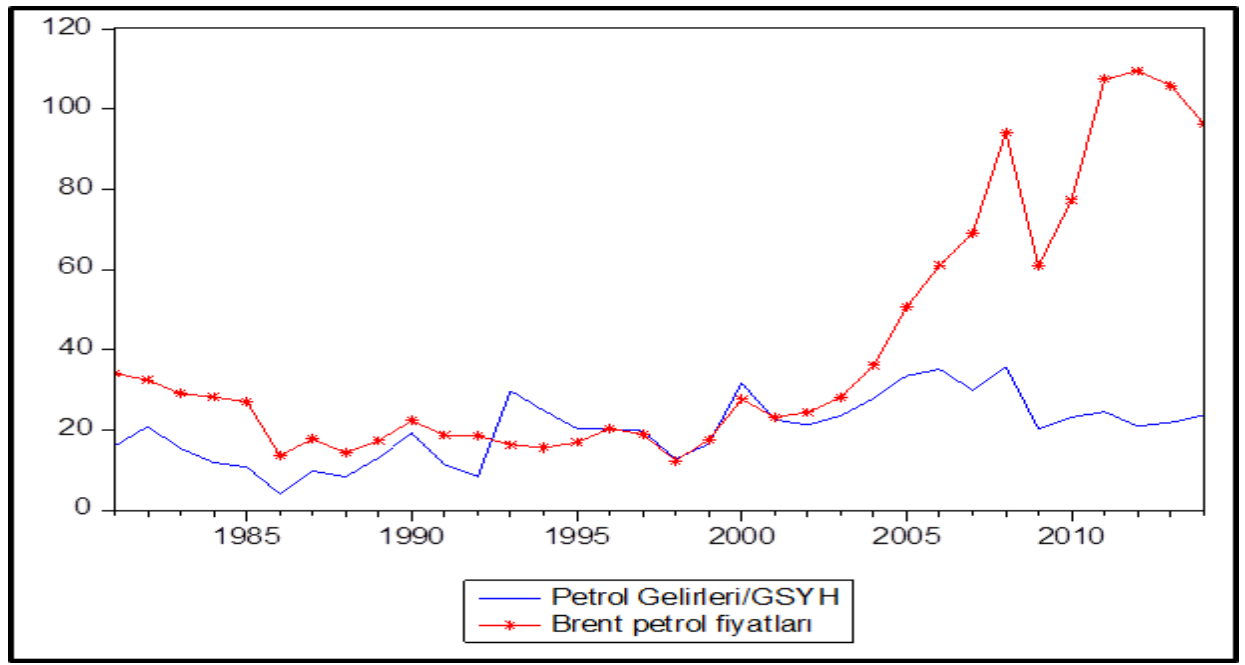

Şekil 3. Petrol Gelirlerinin GSYH İçindeki Payı ve Brent Petrol Fiyatlarının 1981-2014 Yılları Arasındaki Birlikte Seyirleri

Şekil 3'e bakıldığında, Petrol Gelirlerinin GSYH içindeki payı 2001 yılına kadar petrol fiyatlarıyla birlikte hareket etmiştir, ama 2001 yılından sonra petrol fiyatları arttığında, petrol gelirlerinin GSYH içindeki payı onunla birlikte artış göstermemiştir. Bu durum İran ekonomisi özelinde petrol fiyatlarına duyarlı bir ekonomik yapının başlangıçta çok güçlü olduğuna işaret etmektedir. 2001 öncesi için güçlü olan bu duyarlılığın ise sonraki dönemlerde bir kopuş sergilediği gözlenmektedir. Dolayısıyla 2001 öncesi dönem için Hollanda Hastalığının varlığına dair çok güçlü sinyaller bulunmasına karşılık, 2001 sonrası dönemde ise hastalığın bir tür baskılanmaya başlandığına dair izler söz konusudur. 


\subsection{Model ve Veri Seti}

Çalışmada doğal kaynak zengini İran ekonomisinde Hollanda Hastalığının işleyip işlemediği araştırma konusu yapılmıştır. Bu çerçevede İran'da ana sektörler itibarıyla, yani sanayi, hizmetler ve tarım sektörler ihracatına petrol ve gaz ihracat gelirlerinin etkileri analiz edilmeye çalışılmıştır. Veri seti 1980-2014 aralığını kapsamaktadır. Kullanılan modeller aşağıdaki gibidir.

$$
\begin{aligned}
& \text { INDic }_{t}=\beta_{0}+\beta_{1} \text { OILic }_{t}+\beta_{2} \text { GOVic }_{t}+\beta_{3} \text { RERGROWic } c_{t}+\varepsilon_{t} \\
& \text { SERic }_{t}=\beta_{0}+\beta_{1} \text { OILic }_{t}+\beta_{2} \text { GOVic }_{t}+\beta_{3} \text { RERGROWic } t+\varepsilon_{t} \\
& \text { AGRic }_{t}=\beta_{0}+\beta_{1} \text { OILic }_{t}+\beta_{2} \text { GOVic }_{t}+\beta_{3} \text { RERGROWic } c_{t}+\varepsilon_{t}
\end{aligned}
$$

Yukarıdaki modellerde IND, sanayi ihracatının GSYH içerisindeki payını, SER hizmet ihracatının GSYH içerisindeki payını, AGR tarım ihracatının GSYH içerisindeki payını, OIL petrol ihracatının GSYH içerisindeki payını, GOV kamu harcamalarının GSYH içerisindeki payını ve RERGROW ise reel efektif döviz kuru $(2010=100)$ endeksindeki büyüme oranını temsil etmektedir. Literatürden hareketle Hollanda Hastalığının varlığı durumunda, $\beta_{1}$ katsayısının sanayi (1 nolu) ve tarım (3 nolu) sektöründe negatif işaretli olması ve buna karşılık hizmetler sektöründe (2. nolu) pozitif olması beklenmektedir. RERGROW değişkeni Dünya Bankasının, GOV değişkeni İran Merkez Bankasının ve IND, SER, AGR ve OIL değişkenleri ise UNCTAD’ın internet sitelerinden elde edilmiştir.

\subsection{Yöntem ve Ampirik Sonuçlar}

Zaman serisi analizlerinde öncelikle sahte regresyon sorununun ortaya çıkmaması için serilerin durağanlık araştırması yapılır. Bu araştırma bulgularından hareketle serilerin I(1)'de durağan olması ya da serilerin bir kısmının I(0) ve bir kısmının da I(1)'de durağan olması durumunda uygulanacak eş-bütünleşme testleri farklılık göstermektedir.

\section{- $\quad$ Birim Kök Testleri}

Zaman serileri analizinde durağanlık kavramı çok önemlidir. Durağan olmayan serilerle yapılan regresyon analizleri gerçeği yansıtmayacağından öncelikle serilerin durağanlık düzeylerinin araştırılması söz konusudur. Bu çerçevede durağanlık araştırmaları öncelikle geleneksel birim kök testlerinden olan ADF, bir yapısal kırılmayı içeren Zivot Andrews (1992) ve iki yapısal kırılmayı içeren Lee ve Strazicich (2003) birim kök testleriyle yapılmıştır. Diğer taraftan serilerin gecikme uzunlukları da SC (Schwarz Criterion) kriterine göre belirlenmeye çalışılmıştır. Tablo 1'de birim kök testlerinin sonuçları yer almaktadır. 


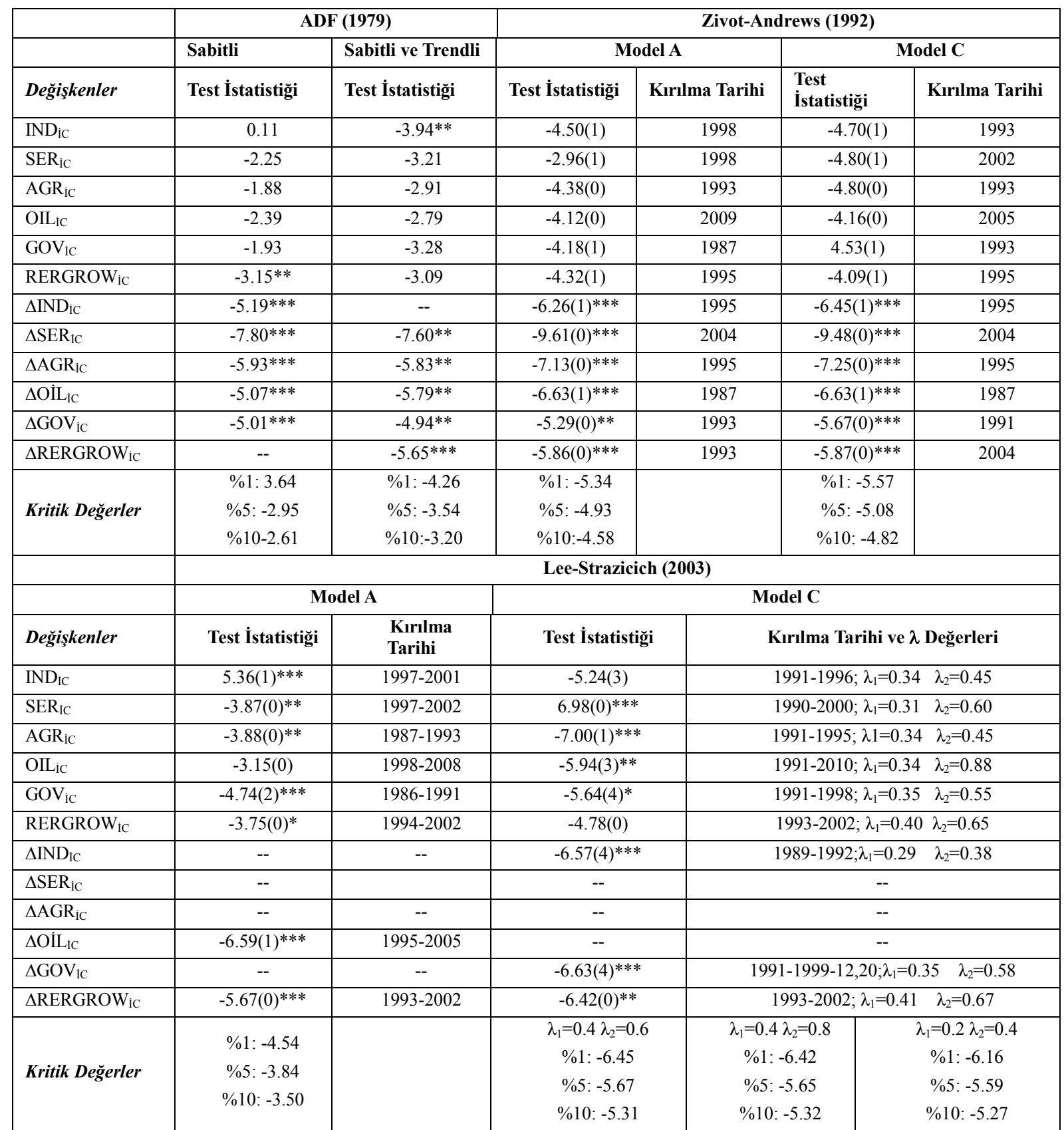

Tablo 1: Birim Kök Testleri Sonuçları

Not: (*), (**) ve (***) değerleri sirasıyla \%10, \%5 ve \%1 anlamlılı düzeyini göstermektedir. Parantez içerisindekiler gecikme uzunluklarını ifade etmektedir.

Tablo 1'e bakıldığında, her üç birim kök testinin de $\mathrm{H}_{0}$ hipotezi birim kök vardır şeklindedir. Hesaplanan test istatistikleri kritik değerlerden küçük olduğunda, $\mathrm{H}_{0}$ hipotezi reddedilmekte; diğer bir ifadeyle incelenen serinin Nürembergdurağan olduğu kabul edilmektedir. ADF birim kök testine göre IND değişkeni sabitli ve trendli modelde $\% 5$ anlamlılık düzeyinde durağan iken, diğer tüm değişkenler hem sabitli hem sabitli trendli modellerde farkı alınınca durağan hale gelmektedir. Zivot-Andrews birim kök test sonuçlarına göre tüm değişkenler farkta, yani I(1)'de durağandır. Lee-Strazicich birim kök testine göre ise sabitli modelde (A) \%5 anlamlılık düzeyinde IND, SER, AGR ve GOV değişkeni düzeyde, yani I(0)'da durağan iken, RERGROW ve OIL değişkeni farkta, yani I(1)'de durağandır. Sabitli ve trendli modelde ise \%5 anlamlılık düzeyinde SER AGR ve OIL değişkeni seviyede $[\mathrm{I}(0)]$ durağan iken, diğer kalan değişkenlerin farktan [I(1)] durağan oldukları görülmektedir.

Birim kök testleri arasındaki bu farklılıklar (çelişkiler) sonucunda serilerin düzey değerlerinde durağan olup olmadığı belirsizken, ancak birinci farkta durağan oldukları tespit edilmiştir. Bu durumda serilerin farklı düzeyde eş-bütünleşik olma ihtimallerini göz önüne alan ARDL modelinin uygulanması diğer eş-bütünleşme modellerine göre daha anlamlı sonuçlar verecektir. 


\section{- $\quad$ Eş-bütünleşme ARDL Modeli}

Pesaran vd. (2001) tarafından geliştirilen sınır testi yaklaşımı ile serilerin I(0) veya I(1) olmalarına bakılmaksızın seriler arasında eş-bütünleşme ilişkisinin varlığı araştırılabilir. Buna bağlı olarak Pesaran ve Shin (1999) ile Pesaran vd. (2001) tarafından geliştirilen gecikmesi dağıtılmış otoregresif modellere dayanan ARDL (Autoregressive Distrubuted Lag) sınır testi yaklaşımı kullanılmıştır. ARDL yöntemi üç aşamadan oluşmaktadır. İlk aşamada değişkenler arasında eş-bütünleşme ilişkisinin varlığ 1 test edilmektedir. Eş-bütünleşme ilişkisi ortaya çıkarıldığında, ikinci aşama olan değişkenlerin uzun dönem katsayılarının bulunmasına geçilir. Üçüncü aşamada ise değişkenlere ait kısa dönem katsayıları elde edilir. Bu amaçla öncelikle değişkenler arasında uzun dönemli bir ilişkinin olup olmadığı aşağıdaki kısıtsız hata düzeltme modeline uygulanan F testi ile araştırılmaktadır.

İlk aşamada önce kısıtsız hata düzeltme modeli (Unrestricted Error Correction Model UECM) en küçük kareler tahmincisi yardımıyla tahmin edilmektedir. Her sektör için bu çalışmaya uyarlanmış kısıtsız hata düzeltme modelleri aşağıdaki gibidir:

$$
\begin{aligned}
& \Delta I N D i c_{t}=\beta_{0}+\sum_{i=1}^{p} \beta_{1} \Delta I N D i c_{t-i}+\sum_{i=0}^{p} \beta_{2} \Delta \text { OILic }_{t-i}+\sum_{i=0}^{p} \beta_{3} \Delta \text { GOVic }_{t-i}+\sum_{i=0}^{p} \beta_{4} \Delta R E R G R O W i c_{t-i}+ \\
& \theta_{1} \text { INDic }_{t-1}+\theta_{2} \text { OILic }_{t-1}+\theta_{3} \text { GOVic }_{t-1}+\theta_{4} \text { RERGROWic } t-1+\varepsilon_{t} \\
& \Delta S E \text { Ric }_{t}=\beta_{0}+\sum_{i=1}^{p} \beta_{1} \Delta S E R i c_{t-i}+\sum_{i=0}^{p} \beta_{2} \Delta \text { OILic }_{t-i}+\sum_{i=0}^{p} \beta_{3} \Delta \text { GOVic }_{t-i}+\sum_{i=0}^{p} \beta_{4} \Delta R E R G R O W i c_{t-i}+ \\
& \theta_{1} \text { SERic }_{t-1}+\theta_{2} \text { OILic }_{t-1}+\theta_{3} \text { GOVic }_{t-1}+\theta_{4} \text { RERGROWic }_{t-1}+\varepsilon_{t} \\
& \Delta \text { AGRic }_{t}=\beta_{0}+\sum_{i=1}^{p} \beta_{1} \Delta \text { AGRic } \text { t }-i+\sum_{i=0}^{p} \beta_{2} \Delta \text { OILic }_{t-i}+\sum_{i=0}^{p} \beta_{3} \Delta \text { GOVic } \text { I }_{t-i}+\sum_{i=0}^{p} \beta_{4} \Delta R E R G R O W i c_{t-i}+ \\
& \theta_{1} \text { AGRic }_{t-1}+\theta_{2} \text { OILic }_{t-1}+\theta_{3} \text { GOVic }_{t-1}+\theta_{4} \text { RERGROWic } t-1+\varepsilon_{t}
\end{aligned}
$$

Modellerde yer alan $\Delta$ sembolü birinci dereceden farkları ve $\mathrm{p}$ ise gecikme uzunluklarını göstermektedir. $\mathrm{F}$ testinin gecikme uzunluklarına karşı duyarlı olmasından dolayı öncelikle Akaike, Schwarz ve Hannan-Quinn gibi bilgi kriterleri kullanılarak yukarıdaki modellerde farkı alınmış değişkenlerin uygun gecikme uzunluğunun belirlenmesi (p) gerekmektedir. En küçük kritik değeri sağlayan ve otokorelasyon problemi olmayan gecikme uzunluğu, modelin gecikme uzunluğu olarak alınır. Uygun gecikme uzunluğu ile oluşturulan modelin gecikme sayısı belirlendikten sonra, bağımlı ve bağımsız değişkenlerin seviye değerlerinin bir dönem gecikmelerine ait katsayılarının sıfıra eşit olduğunu ileri süren temel hipotez Wald testiyle sınanır. Wald kısıt testine göre sıfır hipotezi " $H_{0}=\theta_{1}=\theta_{2}=\theta_{3}=\theta_{4}=0$ ", yani "uzun dönemli bir ilişki yoktur" şeklindedir. Wald testi sonucu hesaplanan F istatistik değeri, Pesaran vd. (2001) tarafından geliştirilen kritik değerlerle karşılaştırılır. Bu kritik değerler iki kısımdan oluşmaktadır: Birincisinde bütün değişkenlerin I(1) olduğu varsayılırken, diğerinde bütün değişkenlerin I(0) olduğu varsayılmaktadır. Dolayısıyla bu değerler arasında bir bant oluşmaktadır. Eğer hesaplanan $\mathrm{F}$ istatistik değeri üretilen kritik değerin soluna düşerse (küçük kalırsa), eş-bütünleşme ilişkisinin olmadığı; iki kritik değer arasına düşerse, uzun dönem ilişkisi hakkında herhangi bir karar verilemeyeceği; üretilen kritik değerin sağına düşerse, yani üst sınırından büyükse, eş-bütünleşme ilişkisinin olduğu anlamı çıkmaktadır

\begin{tabular}{|c|c|c|c|c|c|c|c|c|c|}
\hline \multirow{2}{*}{ Sektörler } & & $\mathbf{k}$ & \multirow{2}{*}{$\begin{array}{c}F \\
\text { İstatistiği }\end{array}$} & \multicolumn{3}{|c|}{ I(0)Alt Sinır } & \multicolumn{3}{|c|}{ I(1) Üst sınır } \\
\hline & & \multirow{4}{*}{3} & & $\% 1$ & $\% 5$ & $\% 10$ & $\% 1$ & $\% 5$ & $\% 10$ \\
\hline Sanayi & $\operatorname{ARDL}(1,2,1,0)$ & & 6.35 & \multirow{3}{*}{5.17} & \multirow{3}{*}{4.01} & \multirow{3}{*}{3.47} & \multirow{3}{*}{6.36} & \multirow{3}{*}{5.07} & \multirow{3}{*}{4.45} \\
\hline Hizmetler & $\operatorname{ARDL}(1,0,1,0)$ & & 2.97 & & & & & & \\
\hline Tarım & $\operatorname{ARDL}(1,2,1,0)$ & & 4.04 & & & & & & \\
\hline
\end{tabular}
(Pesaran vd, 2001: 289-326).

Çalışmada gecikme uzunluğuna karar verebilmek amacıyla en büyük gecikme uzunluğu olarak 4 alınmış ve Schwarz bilgi kriterine göre gecikme sayısı maksimum 4 olarak belirlenmiştir. Daha sonra modelde otokorelasyon problemi olup olmadığını araştırmak için LM testi yapılmıştır. Her üç sektöre ait uygun gecikme uzunlukları ve F istatistikleri Tablo 2'de verilmiştir.

Tablo: 2: ARDL Sınır Testi Sonuçları

Not: $k$ : Bă̆ımsız değişken sayısı

Tablo 2'de ARDL Sınır Testi sonuçlarında görüldüğü gibi sanayi sektörü için hesaplanan F istatistiği \%5 anlamlılık düzeyinde üst kritik değerden daha büyük olduğundan, değişkenler arasında ilişki olmadığını gösteren temel hipotez reddedilir, yani seriler arasında eş-bütünleşme ilişkisi olduğu kabul edilir. Ancak, hizmetler sektörü için hesaplanan F istatistiği alt sınırın altındadır ve dolayısıyla eş-bütünleşme ilişkisinin olmadığı, tarım sektörü için ise hesaplanan F istatistiğinin iki kritik değerin arasına düşmesinden dolayı uzun dönem ilişki hakkında bir karar verilemeyeceği açıktır.

Değişkenler arasında bir uzun dönemli ilişki elde edildikten sonra ikinci aşamada ARDL( $\left.\mathrm{p}_{\mathrm{i}} \mathrm{q}_{\mathrm{i}}\right)$ şeklindeki uzun dönem denklemi tahmin edilmektedir. Buna göre tahmin edilecek uzun dönem denklemi aşağıdaki gibidir.

INDic $_{t}=\beta_{0}+\sum_{i=1}^{j} \beta_{1}$ INDic $_{t-i}+\sum_{i=0}^{k} \beta_{2}$ OILic $_{t-i}+\sum_{i=0}^{l} \beta_{3}$ GOVic $_{t-i}+\sum_{i=0}^{m} \beta_{4}$ RERGROWic $_{t-i}+\beta_{4} T+\varepsilon_{t}$

Sanayi sektörü için değişkenler arasında hesaplanan uzun dönem katsayıları Tablo 3 'de verilmiştir. 


\begin{tabular}{|l|c|c|c|c|}
\hline Değişkenler & Katsayı & Standart hata & t-istatistiği & Olasılık değeri \\
\hline OIL & -0.084627 & 0.043525 & -1.944320 & 0.0637 \\
\hline GOV & -0.018683 & 0.007823 & -2.388291 & 0.0251 \\
\hline RERGROW & -0.001927 & 0.005322 & -0.362041 & 0.7205 \\
\hline C & 1.135409 & 0.575992 & 1.971223 & 0.0603 \\
\hline TREND & 0.133883 & 0.022051 & 6.071613 & 0.0000 \\
\hline
\end{tabular}

Tablo 3: Sanayi Sektörü ARDL(1,2,1,1) Modelinden Elde Edilen Uzun Dönem Katsayıları

Tablo 3 incelendiğinde, İran'ın sanayi sektöründe petrol ihracatının GSYH içindeki payının (OIL) \%10 anlamlılık düzeyinde, kamu harcamalarının GSYH içindeki payının (GOV) \%5 anlamlılık düzeyinde negatif ve istatistik açıdan anlamlı olduğu görülmektedir. Buradaki değişkenlerin negatif bulgu vermesi, hem petrol ihracatının hem de petrol gelirlerinden beslenen bir kamunun sanayi ihracatını olumsuzlaştırdığı gibi bir sonuç ortaya çıkmaktadır. Diğer taraftan reel efektif döviz kurundaki büyüme oranının (RERGROW) anlamsız olduğu görülmektedir. Oysa reel kurun rekabetin güçlü olduğu sanayi ihracatında etkisizliği, İran özelinde sanayi ihracatının zayıflığının bir yansıması konumundadır. Sabit terimin \%10 anlamlılık düzeyinde ve trendin de pozitif ve anlamlı olduğu görülmektedir. Özetle çalışmanın temel dinamiğini oluşturan OIL'ın \%10 anlamlılık düzeyinde de olsa negatif ve anlamlı olması Hollanda Hastalığının varlığına dair bulgu vermektedir.

İran'ın sanayi sektörü ile ilgili değişkenler arasında kısa dönemli ilişkileri incelemek için hata düzeltme modeli aşağıdaki gibi kurulmuştur.

$$
\begin{aligned}
\Delta I N \text { Dic }_{t}= & \beta_{0}+\sum_{i=1}^{p} \beta_{1} \Delta I N D i c_{t-i}+\sum_{i=0}^{p} \beta_{2} \Delta \text { OILic }_{t-i}+\sum_{i=0}^{p} \beta_{3} \Delta \text { GOVic }_{t-i}+\sum_{i=0}^{p} \beta_{4} \Delta R E R G R O W i c_{t-i}+ \\
& \beta_{5} T+\emptyset E C M_{t-1}+\varepsilon_{t}
\end{aligned}
$$

Hata düzeltme katsayısı $\left(\mathrm{ECM}_{\mathrm{t}-1}\right)$, kısa dönemde meydana gelen sapmalardan sonra tekrar dengeye dönülüp dönülmediğini, dönülüyorsa sapmanın ne kadarının telafi edildiğini göstermektedir. Sanayi sektörü için hata

\begin{tabular}{|c|c|c|c|c|}
\hline Değişkenler & Katsayı & Standart hata & t-istatistiği & p değeri \\
\hline DOIL & 0.031715 & 0.011125 & 2.85094 & 0.0088 \\
\hline DOIL(-1) & 0.048290 & 0.012368 & 3.90434 & 0.0007 \\
\hline DGOV & -0.017975 & 0.004841 & -3.7132 & 0.0011 \\
\hline DRERGROW & -0.000882 & 0.002366 & -0.37291 & 0.7125 \\
\hline DTREND & 0.061307 & 0.013809 & 4.43959 & 0.0002 \\
\hline ECMT(-1) & -0.457917 & 0.150230 & -3.048113 & 0.0055 \\
\hline \multicolumn{5}{|c|}{ Tanısal Sınama Test İstatistikleri } \\
\hline $\mathbf{R}^{2}$ & 0.96 & \multicolumn{2}{|l|}{ Düzeltilmiş $\mathbf{R}^{2}$} & 0.94 \\
\hline $\begin{array}{c}\text { Breush-Goldfrey } \\
\text { (Otokorelasyon) }\end{array}$ & $0.19(0.90)$ & \multicolumn{2}{|c|}{ Jargue-Bera (Normallik) } & $0.03(0.98)$ \\
\hline $\begin{array}{l}\text { Breush-Pagan-Godfrey (Değişen } \\
\text { varyans) }\end{array}$ & $7.61(0.47)$ & \multicolumn{2}{|c|}{$\begin{array}{c}\text { Ramsey } \begin{array}{c}\text { Reset(1) } \\
\text { kurma hatası) }\end{array} \\
\text { (model }\end{array}$} & $1.15(0.29)$ \\
\hline
\end{tabular}
düzeltme modeli tahmin sonuçları ve tanısal sınama test istatistikleri Tablo 4'de sunulmaktadır.

Tablo 4: Sanayi Sektörü Iç̧in Hata Düzeltme Modeli Tahmin Sonuçları

Hata düzeltme değişkeninin katsayısı -0.45 olarak belirlenmiştir. Diğer bir değişle katsayının negatif ve anlamlı olması ele alınan dönemde denge değerinde meydana gelen sapmaların uzun dönemde düzelme eğiliminde olduğunu göstermektedir. Bu durum modelin uzun dönem dengesine ayarlanma hızının (1/0.45) 2.2 yıl olduğuna işaret etmektedir. Yani sanayi sektöründe gerçekleşen sapmaların her yıl yaklaşık 0.45 kadarının ortadan kalktığını söylemek mümkündür. Petrol ihracatının GSYH içindeki payının cari ve bir önceki dönemle sanayi ihracatının GSYH içindeki payı arasında kısa dönemde pozitif ve istatistiksel olarak anlamlı bir ilişki bulunmuştur. Bu sonuca göre kısa dönemde petrol ihracatının GSYH içindeki payının artmasının sanayi ihracatının GSYH içindeki payı üzerinde pozitif yönde bir etki yarattığı görülmektedir. Halbuki, uzun dönemde petrol ihracatının GSYH içindeki payının artmasının sanayi ihracatının GSYH içindeki payı üzerinde negatif etki yarattığı, dolayısıyla İran ekonomisinde Hollanda Hastalığının varlığına dair bulguların mevcut olduğunu söylemek mümkündür.

Betimleyici test sonuçlarına bakıldığında, modelin fonksiyonel formu doğru belirlenmiş olup, modelde otokorelasyon ve değişen varyans sorunu yoktur. Ayrıca modelin artık terimleri de normal dağılmaktadır.

\section{Sonuç}

İktisat literatüründe doğal kaynak keşfi ve bunun ihracat gelirlerindeki artışa olan etkisinin, doğal kaynak dışı sektörlerin üretim, tüketim ve dış ticaret ilişkilerini olumsuz etkilemesi muhtemeldir. Ortaya çıkan bu olumsuz etkiye karşı, Norveç örneğinde olduğu gibi, kaynakların ekonomide belirleyici olmasının önüne geçici politikalar uygulamak suretiyle refahın tüm ülkeye yayılması sağlanabilir. Adeta istisnai örnek olan Norveç dışında, doğal kaynak keşfinin yol açtığı etkilerin genelde uzun dönemde ekonomiler üzerinde olumsuz yansımaları olmuştur. Dolayısıyla kaynak keşfinin yarattığı atalet durumu doğal kaynakların laneti olarak tanımlanır. Kaynakların laneti 
de Hollanda Hastalığı, rant kollama, aşırı güven ve eğitimin ihmali gibi olumsuz yansımalar şeklinde ortaya çıkmaktadır. Burada Hollanda Hastalığı, doğal kaynak keşfi ve bunun ihracatıyla ortaya çıkan ve diğer ihraç ürünlerinde olumsuzluk doğuran bir mekanizma olarak tanımlanır. Hollanda Hastalığına kaynak keşfinin yanı sıra doğal kaynak fiyatlarında ani artışlar ile dış yardımlar veya doğrudan yabancı sermaye yatırımlarında ani sıçramalar sonucu devasa döviz girişleri de yol açabilmektedir.

Yaygın literatürde gözüktüğü şekliyle doğal kaynak zengini İran ekonomisinde Hollanda Hastalığının ortaya çıkması kuvvetle muhtemeldir. Ancak, İran özelinde 1980-1988 arası dönemdeki uzun süreli Irak savaşı ile İran'a yönelik ambargo uygulamalarının kendi kendine yeterliliği sağlamış olacağı da düşünülmektedir. Bu çerçevede 1980-2014 arası dönem için İran'ın Hollanda Hastalığına mı düştüğü, yoksa savaş ve ambargo gibi dışsal zorlamalardan dolayı çeşitliliğe mi yöneldiği araştırma konusu yapılmıştır.

İran'ın ihracat yapısı incelendiğinde, mineral yakıtların 1995-2014 aralığındaki gelişiminde doğal kaynak ihracatının toplam ihracattaki payının azaldığı dikkat çekmektedir. İhracatta doğal kaynak ağırlıklı yapının yerini giderek artan oranlarda kimyasal maddeler ve gıda ihracatının almaya başladığı gözlenmiştir. Ekonometrik testlerden elde edilen bulgulara göre ise doğal kaynak zengini İran'da Hollanda Hastalığının varlığı, istatistiki açıdan zayıf da olsa tespit edilmiştir. Ancak, beklenen durum, genelde doğal kaynak zengini ülkelerde olduğu gibi Hollanda Hastalığının İran ekonomisi özelinde ortaya çıkmasıydı. Oysa İran'da hastalığın varlığına karşılık, katsayıların zayıf çıkması ve verilerin zamana bağlı gelişimi incelendiğinde son yıllarda ticaret yapısı içinde petrol ve minerallerin payının \%80'lerden \%60'lara gerilemesi, İran'ın yaşadığı savaş ve ambargoların bu ülkeyi adeta kendi kendine yeterliliğe sevk ettiği söylenebilir. Buradan hareketle İran ekonomisinin kaynak zenginliğinin yol açacağı atalet durumuna dışsal faktörlerden dolayı daha az düştüğü ve halihazırda dünya ile eklemlenme sürecinin, yani ambargonun/izolasyonun kalkmasının olası ataleti tetiklemesinin önüne geçecek politikalar uygulamasının ekonomik gelişmesini sürdüreceği ileri sürülebilir.

\section{Kaynakça}

- $\quad$ Abrişmi, H., Mehrara, M. ve H. Zamanzade (2009), "Petrol Şokları ile OPEC Ülkelerinin Büyümesi Arasında Olan İlişki: Bu İlişki Simetrik Bir İlişki midir?”, Faslnameye Motaleate Eghtesade Enerji, 6.yıl, p. 93-112.

- Allcott, H. and D. Keniston (2013), "Dutch Disease or Agglomeration? The Local Economic Effects of Natural Resource Booms in Modern America", Technical Report, Working Paper, (Erişim: Kasım 2015; http://www.cbpp.illinois.edu/pdf/Allcott\%20paper.pdf).

- Bahrami, J. ve S. Nasiri (2010), "Petrol Şokları ve Hollanda Hastalığı, Faslnameye Pajuheşhaye Eghtesadi-e Iran, 16y1l, 2001, p 25-54.

- Bardhan, P. (1997), "Corruption and Development: A Review of Issues", Journal of Economic Literature, 35 (3), p. 1320-1346.

- Boyce, J. R. ve J. C. H. Emery (2011), "Is a Negative Correlation between Resource Abundance and Growth Sufficient Evidence That There is a "Resource Curse?", Resources Policy, 36 (1), p. 1-13.

- Boyraz, H. M. (2015), “Hollanda Hastalığı Nedir?”, Uluslararası Politika Akademisi, (Erişim: Kasım 2015; http://politikaakademisi.org/2014/07/18/hollanda-hastaligi-nedir/)

- Bunnschweilera, C. N. and E. H. Bulteb (2008), The Resource Curse Revisited and Revised: A Tale of Paradoxes and Red Herrings, Journal of Environmental Economics and Management, 55, p. 248-264.

- Bruno, M. and J. Sachs (1982), "Energy and Resource Allocation: A Dynamic Model of the Dutch Disease", Review of Economic Studies, XLIX, p. 845-859.

- Clay, K. and A. Weckenman (2014), "Resource Curses: Evidence from the United States 1880-2012", Carnegie Mellon University and NBER, (Erişim: Kasım 2015; https://www.aeaweb.org/conference/2015/retrieve.php?).

- Corden, W. M. and J. P. Neary (1982), "Booming Sector and De-Industrialization in a Small Open Economy", The Economic Journal, 92 (368), p. 825-848 (Erişim: Kasım 2015; http://www.jstor.org/stable/2232670?seq=1\#page_scan_tab_contents).

- Ebrahim-zadeh, C., Hollanda Hastalı̆ğ: Beceriksizce İdare Edilen Zenginlik, (2015), (Çev. Ayşe Keskiner Musullugil), (Erişim: Kasım 2015; http://iktisat.biz/2015/08/hollanda-hastaligi-beceriksizce-idare-edilenzenginlik/).

- Gylfason, T. (2001), "Natural Resources, Education, and Economic Development", European Economic Review, 45, p. 847-859.

- Gurbanov, S., Azerbaycan'da Enerji Kaynaklart ve Hollanda Hastalı̆̆ , Anadolu Üniversitesi Sosyal Bilimler Enstitüsü, Yayımlanmamış Doktora Tezi, Eskişehir, 2011.

- Hooker, M. A. (1996), "What Happend the Oil Price-Macroeconomy Relationship?", Journal of Monetary Economics, 38, p. 195-213.

- Ismail, K. (2010), "The Structural Manifestation of The Dutch Disease: The Case of Oil Exporting Countries", IMF Working Papers, p. 1-36.

- Lee, J. and M. C. Strazicich (2003), "Minimum Lagrange Multiplier Unit Root Test With Two Structural Breaks", The Review of Economics and Statistics, 85(4), p. 1082-1089. 
- Nazari, M. ve A. Mobarak (2010), "Petrol İhraç Eden Ülkelerde Doğal Kaynak Bolluğu ve Ekonomik Büyüme”, Journal of Enerjy Economics Studies, 27, p. 47-68.

- $\quad$ Nişancı, M., Z. Ç. Yurttançıkmaz, A. C. Doker ve Ö. S. Emsen, "Geçiş Ekonomilerinden Petrol Gelirlerine Bağımlılığı Yüksek Olduğu Dört Ülkede Petrol Fiyatları-İhracat-İstihdam ve Ekonomik Büyüme İlişkileri”, International Conference on Economics Finance and Banking, Kaposvar-Macaristan, 29-31 August 2016, p. 752-759.

- Oomes, N. and K. Kalcheva (2007), "Diagnosing Dutch Disease: Does Russia Have the Symptoms?", International Monetary Fund, 7, p. 1-32.

- Özdemir, D., Ö. Buzdağlı, M. Akdağ ve Ö. S. Emsen, "Rusya Borsasının Petrol Fiyatlarına Bağımlılığı”, International Conference on Economics Finance and Banking, Kaposvar-Macaristan, 29-31 August 2016, p. 632-640.

- $\quad$ Pesaran, M. H., Y., Shin and R. J. Smith (1999), "Pooled Mean Group Estimation of Dynamic Heterogeneous Panels", Journal of the American Statistical Association, 94 (446), p. 621-634.

- Pesaran, M. H., S. Yongcheol and J. S. Richard (2001), "Bounds Testing Approaches to the Analysis of Level Relationships", Journal of Applied Econometrics, 16 (3), p. 289-326.

- Rajan, R. G. and A. Subramanian (2011), “Aid, Dutch Disease, and Manufacturing Growth”, Journal of Development Economics, 94 (1), p. 106-118.

- Sachs, J D. and A. M. Warner (1999), "The Big Push, Natural Resource Booms and Growth", Journal of Development Economics, 59, p. 43-76.

- Sachs, J. D. and A. M. Warner (2001), "The Curse of Natural Resources", European Economic Review, 45 (46), p. 827-838.

- Smith, B. (2014), "Dutch Disease and the Oil and Boom and Bust", Department of Economics OxCarre Oxford Centre for the Analysis of Resource Rich Economies (Erişim: Kasım 2015; http://www.economics.ox.ac.uk/materials/papers/13824/paper133.pdf).

- Yurttançıkmaz, Z. Ç., A. Aali ve Ö. S. Emsen (2012), “Askeri Harcamalar, Ambargo ve Ekonomik Büyüme: İran Üzerine Bir Uygulama (1965-2008)", Atatürk Üniversitesi İktisadi ve İdari Bilimler Dergisi, 26 (2), p. 171-190.

- Zivot, E. and D. Andrews (1992), "Further Evidence on the Great Crash, The Oil-Price Shock, and the UnitRoot Hypothesis", Journal of Business and Economic Statistics, 10 (3), p. 251-270.

- BM Ticaret ve Kalkınma Konferans1, www.unctad.org

- Dünya Bankası, www.worldbank.org

- İran Merkez Bankası, www.cbi.ir 


\title{
Türkiye ve Geçiş Ekonomilerine Yönelik Yeni Bir Regülasyon Anlayıșı
}

\section{A New Regulatory Understanding towards Turkey and Transition Economies}

\author{
Assoc. Prof. Dr. Yeşim Reel (Marmara University, Turkey)
}

\begin{abstract}
Turkey has many important economic relations with transition countries. Furthermore, there is high potential that these relations are getting to be stronger. Meanwhile, the importance of regulation of sectors in these economies, is increasing for both side. However, adaption of regulatory institutions could play the key role in making stronger the economic relations. Besides, the problems of the world economy lead to discuss about the functioning of the regulatory institutions, the qualifications of employees, and new implementation of regulation. Turkey as a developing country, has some regulatory institutions in order to regulate some specific sectors. Yet, these regulatory institutions have poorly performed because of facing challenges. For these reasons, existing regulatory understanding and implementation problems should be evaluated, and so that, new regulatory understanding should be created. In order to make efficient evaluation, primarily, the explanation about dominant factors of establishing on regulatory institutions, are given. The main point of the evaluation could provide to have new regulatory understanding. Additionally, the evaluation of regulatory institutions and understanding in Turkey may also provide that the new understanding to transition economies. Hence, all the explanations and evaluations are suggested to support implementing efficient regulation in transition countries.
\end{abstract}

\section{Giriş}

Dünyadaki değişim dinamikleri ile beraber geleneksel devlet anlayışı değişmiştir. Yeni devlet anlayışında belirleyici olan, etkin, verimli ve küçük devlet anlayışıdır. Ekonomide serbestleştirme, özelleştirme, yerelleştirme gibi reformlar ile devletin hareket alanı daraltılırken devletin işleyişinde de piyasa mekanizmasının esasları hakim kılınmaya çalışılmıştır. Özellikle Dünya Bankası, IMF, OECD gibi uluslararası kuruluşlar, gelişmekte olan ülkelere yönelik kurumsal ve yapısal reform talepleriyle bu ülkeler üzerinde ciddi etki ve hatta kontrollere sahip olmuşlardır. Bunların sonucu olarak da devlet yapılanmaları bu uluslararası kuruluşların taleplerine cevap verebilecek ölçüde değiştirilmeye çalışılmıştır.

Belirtilen gelişmelerin Türkiye'ye yansıması ise, hem Dünya Bankası, IMF, OECD gibi kuruluşlar hem de AB ile ilişkiler çerçevesinde bir zorunluluk olarak kurumsal ve yapısal reformlar ile düzenlemelerin gerçekleştirmesi şart koşulmuştur.

Türkiye'de gerek sözü edilen dışsal zorunluluklar gerekse içsel şartlardan kaynaklanan 1980 sonrası başlayan ve günümüze kadar devam eden süreç kendinden önceki dönemlerden ayrılmaktadır. 1980 sonrasında, bakanlıkların birleştirme yoluyla azaltılması ve örgütlenmelerinde bir örnekliğin sağlanması yönündeki düzenlemelerle başlayan kurumsallaşma hareketi, ülkenin temel kalkınma ve sosyo-ekonomik politikalarının değiştirilmesine koşut olarak yeni bir eğilime, yeni bir yapılanma dönemine girmiştir (Sezen, 2003).

Sözü edilen yapılanmalar ile gerçekte nelerin uygulandığı/uygulanabildiği ve sorunlar daha netlikle ortaya konulabilirse yapılabileceklere yönelik yeni bir anlayışın geliştirilebilmesi de mümkün olabilir. Bu düşünceden hareketle, Türkiye'de "Düzenleyici Devlet" anlayışı çerçevesinde yapılmaya çalışılanları analiz edebilmek için öncelikle Türkiye'deki "Düzenleyici Devlet", düzenleyici kurumları ve düzenleme anlayışııın arka planını ortaya koyup, ikinci olarak Türkiye'de "Düzenleyici Devlet" anlayışının uygulamadaki sonuçları ve bağımsız düzenleyici kurumların değerlendirmesi yapılacaktır. En son bölümde ise, değerlendirmelerden çıkarılabilecek sonuçlar çerçevesinde hem Türkiye hem de geçiş ekonomileri için nasıl bir anlayış ve uygulamanın benimsenmesi gerekliliği tartışlacaktır.

\section{Türkiye'de Düzenleyici Devlet, Düzenleyici Kurumlar ve Düzenleme (Regülasyon) Anlayışının Arka Planı}

Dünya'da 1980'ler kamu mal ve hizmetlerinin özelleştirilmesi, devletin daha önceden yatırım yaptığı alanlardan çekilmesi, pek çok sektörde deregülasyona gidilmesi, ticaretin ve finansın liberalleşmesine tanıklık etmiştir. Ancak deregülasyon süreci (düzenleme) regülasyonun sona ermesi anlamına gelmemekte yeniden regülasyon (reregülasyon) olarak değerlendirilmektedir. Bunun anlamı: Piyasaların işlemesi ve toplumsal aktörler arasındaki ilişkilerin gerçekleşmesi için düzenlemeye her zaman ihtiyaç vardır. Ancak 1980 ve 1990'larda tartışılan düzenlemenin biçimi ve aktörleri farklı. Dolayısıyla, düzenleme yeni bir olgu olmamakla beraber düzenleyici 
devlet yeni bir modeldir. Bu yeni model de "Neoliberalizmin Düzenleyici Çerçevesi" olarak adlandırmaktadır (Sönmez, 2011).

Thatcher (2002), düzenleyici devletin dört temel özelliğinin bulunduğunu belirterek, bu özellikler arasında "kamu mülkiyeti", "liberalizasyon", "reregülasyon" ve "bağımsız düzenleyici ajanslara yetki devri" ni sıralamaktadır (Thatcher, 2002). İlk özelliğe göre, özelleştirme uygulamalarının yaygınlaşmakta olmasına rağmen, bazı sektörlerde kamu mülkiyeti de mevcuttur (Thatcher, 2002). Fransa ve Almanya'da demiryolu sektöründeki kamu mülkiyetini, düzenleyici devlette kamu mülkiyetinin devam ettiğinin örnekleri olarak göstermektedir. Diğer bir özellik olan liberalizasyon, devlet tekellerinin kaldırılması ile özelleştirme süreçlerini ifade etmektedir. Devlet tekelleri ile kısıtlayıcı lisans uygulamalarına son verilmesi ve dolayısıyla hükümetlerin piyasaların işleyişindeki doğrudan kontrollerinin kaldırılmasını ifade eden "deregülasyon" süreci ise, tekelleri düzenleyen kuralların yerine geçecek yeni kurallar aracılığıyla rekabetin düzenlenmesini gerektirmektedir. Bu nedenle, düzenleyici devletin üçüncü özelliği, rekabeti düzenleyecek kuralların oluşturulmasını ifade eden "reregülasyon" sürecidir. Düzenleyici devletin dördüncü özelliği ise, düzenleme yetkilerinin hükümetler dışında bağımsız düzenleyici kurumlara devredilmesidir (Thatcher, 2002). 1980'lerin başından itibaren, Avrupa'da, tekellerin varlığına son veren ve rekabeti düzenleyen kuralların oluşturulmasıyla, rekabet otoritelerinin yanı sıra, mali hizmetler, telekomünikasyon, enerji ve posta hizmetleri gibi sektörlerde bağımsız düzenleyici kurumlar kurulmuş ve yaygınlaşmıştır.

Azgelişmiş ya da gelişmekte olan ülkelerde ise, uygulamada deregülasyon sürecine yeniden düzenleme süreci eşlik etmedi. Tersine, kamu tekellerinin yerini özel tekeller aldı ve piyasa reformları yeni yolsuzluk biçimleri üretti. Böylece, 1990'larla beraber Dünya Bankası gibi uluslararası kuruluşlar piyasanın tek başına işlemeyeceği, bilgi asimetrisi, işlem maliyeti ve piyasa aksaklıkları gibi sorunlara karşı düzenleyici kurumların kurulması gerektiğini vurgulayarak, "Bütünlüklü Kalkınma Programı" çerçevesinde devletin rolünü yeniden tanımladılar. Ayrıca, bu kuruluşlar borç ve kredi verme koşulu olarak yapısal reformların yanı sıra kurumsal reformları da dayatırken, siyasetten "bağımsız" kurumlar aracılığıyla, gelişmekte olan ülkelerde istenen sonuçları vermeyen neoliberal reformların tamamlanmasını şart koştu (Sönmez, 2011) Bu belirtilen uygulamalara muhatap ülkeler arasında Türkiye de bulunmaktaydı. Pamuk (2014) neoliberal politikaların Türkiye ekonomisinin dünya ekonomisi ile ilişkilerini radikal bir biçimde değiştirdiğini vurgularken, uluslararası kurumların sözü edilen baskısına dair açıklamalarını da ortaya koymaktadır: Dış ticaret engelleri ve uluslararası sermayeye yönelik engellerin kaldırılmasıyla beraber uluslararası kuruluşların ve uluslararası sermayenin, daha genel olarak da sermayenin ülke içindeki kurumsal dönüşümleri etkileme gücünü çok arttırmış, bunun da ötesinde Uluslararası tahkim gibi kurumların yerleşmesinden sonra ülke hukukunun uluslararası sermaye üzerindeki denetimini azaltmış, uluslararası hukukun ülke hukuku üzerindeki konumunu da güçlendirmiştir (Pamuk, 2014).

Özellikle, neoliberal politikaların uygulanmaya çalışıldığı dönemde devletin işlevlerindeki değişmenin Türkiye'de kamu örgütlenmesine yansımalarından en önemli iki oluşum, devletin iktisadi ve toplumsal yaşama doğrudan müdahalesinin sınırlandırılarak düzenleyici rolünün ön plana çıkarılmasıyla birlikte, önemi artan bu işlevi yapacak kamu örgütleri olarak, 1981'de, sermaye piyasasını düzenlemek ve denetlemekle görevli Sermaye Piyasası Kurulu'nun (SPK) kurulmasidır.

1990'larda Radyo ve Televizyon Üst Kurulu (RTÜK), Rekabet Kurumu (RK) ve Bankacılık Düzenleme ve Denetleme Kurumu (BDDK) izlemiştir. 2000'li yıllarda bunlara Telekomünikasyon Kurumu (TK), Enerji Piyasası Düzenleme Kurumu (EPDK), Şeker Kurumu (ŞK), Tütün, Tütün Mamulleri ye Alkollü İçkiler Piyasası Düzenleme Kurumu (TAPDK) ve son olarak da Kamu İhale Kurumu (KİK) dahil edilmiştir. Böylece, piyasaya açılan her sektör için bir kurul kurulması olağan hale gelmeye başlamıştır.

Diğer önemli oluşum da, "kurumlara dayalı yönetim" anlayışının giderek "kurullara dayalı bir yönetim" anlayışına yerini bırakmasıdır (Sezen, 2003).

Türkiye'de bu değişmeler yaşanırken, 1980'ler ve 1990'larda düzenleyici yönetim ve reformlara odaklanan çoğu OECD ülkesinde ise daha ziyade regülasyon kalitesinin iyileştirilmesi ile tutarlı regülasyon politikalarının gerçekleştirilmesi hedeflenmektedir. Zhang (2010), regülasyon kalitesini iyileştirmek için hükümet düzeyindeki kapsamlı politika ve belirli sektörlere yönelik politika uygulamalarının daha geniş kapsamlı bir hükümet yönetimi ile ulusal yönetim eksikliklerine vurguda bulunmaktadır. Burada regülasyon ile ilgili devletin ve kamunun varlığının önemi ortaya çıkmaktadır. Türkiye'de bu konuda kamunun varlığını ve buradan hareketle oluşturduğu bir reform örneği olarak ancak 2000'li yılların başında gerçekleştirilmeye çalışılan "Kamu Yönetimi Reformu” kabul edilebilir. Söz konusu reformda en dikkati çeken konulardan birincisi, kamu yönetimi ve Pazar ilişkisi. Bu ilişki çerçevesinde daha çok piyasalaştırmanın ön planda tutulması, devletin iktisadi faaliyet alanından çekilmesi, ancak diğer taraftan da piyasanın iyi işlemesi için gerekli düzenlemelerin devlet tarafindan yerine getirilmesi beklenmektedir. Kamu yönetimi reformunun ikinci unsuru olan yönetişim ile birlikte, çok aktörlü bir katılımcılık sağlanacaktır. Böyle bir katılım ile hedeflenen amaç ise, merkezi idare, kamu kurumları, şirketler, odalar/birlikler ve sivil toplum kuruluşları ile iş birliği ve iletişim mekanizmalarını geliştirerek, bu kurumların da dahil olduğu hizmet üreten ve belli işlevleri yerine getiren kurumların oluşturulmasıdır. Sözü edilen kurumların ortaklığıyla oluşturulan ve yönetilen yeni yapılar ise, üst kurullardır (bağımsız düzenleyici kurumlar) (Topak, 2012). Bu 
kurullara, kural koyma, politika yapma, hem uygulama hem de denetleme gibi birçok alanda sorumluluklar ve yetkiler verilmiştir (en azından teorik olarak).

Devletin yapısındaki dönüşümün diğer bir önemli adımı, devletin şirketleştirilmesine yönelik düzenlemeler denilebilir. Özellikle 1990 sonrasında yapısal uyum programları ve OECD kriterleri çerçevesindeki dönüşümde Üst kurullar ve Düzenleyici Etki Analizi önemlidir. Diğer düzenlemeler arasında Gelir İdaresi Başkanlığı'nın Teşkilat ve Görevleri Hakkında Kanun Tasarısı' dır. Devlet gelirlerinin toplanması işlevinin özel şirket mantığıyla gerçekleştirilmesidir. Şirketleştirilme ile ilgili diğer bir düzenleme de, Sayıştay kanun taslağında yer alan mali denetimin özel mali denetleme şirketlerine dair devri, performans denetiminin şirketler veya kurullar aracılığıla gerçekleştirilmesidir (Topak, 2012).

\section{Türkiye’de Düzenleyici Devlet Anlayışının Uygulamadaki Sonuçlarının ve Bağımsız Düzenleyici Kurumların Değerlendirmesi}

Neoliberal model'e göre devletin küçüleceği, devletin eski müdahaleci rolünün ortadan kalkacağ1 savunuluyordu, fakat bu modelin benimsetilmeye çalışıldığı Türkiye'de ise devletin ve yerel yönetimlerin dağıtım ve birikim süreçlerindeki önemi azalmadığı gibi, keyfi uygulamaları ile dağıttıkları ayrıcalıklar ve pek çok başka olumsuzluğun da oluşmasında etken rol oynamışlardır (Pamuk, 2014). Müdahaleci devlet modelleri, geleneksel bürokratik aygıt ve çoğulculuk prensibine dayalı seçim sistemleri yolsuz, verimsiz ve irrasyonel olduğu gerekçesi ile eleştirilirken, diğer taraftan da ekonomi politikalarında değişikliği uygulayan dönemin Başbakanı Özal' in, eleştirdiği devlet aygıtının olanaklarını kendi hedefleri doğrultusunda sonuna kadar kullandığı not edilmelidir (Sönmez, 2011). Diğer bir ifade ile, devletin minimize edildiği uygulamalar değil, tam tersine devletin daha fazla, keyfi hem de yanlış şekilde dahil olduğu uygulama örneklerine rastlamak mümkündür.

En azından teorik olarak siyasetin ve bürokrasinin etki alanının daraltılmaya çalışılırken, bu kurumlara duyulmayan güvenin başka kurumlara özellikle bağımsız düzenleyici kurumlar ve sivil toplum kuruluşları gibi kurumlara yöneltilmesi de başka sorunlara yol açmaktadır. Bu sorunlardan birincisi ve belki de en temel olanı, söz konusu güvenin tesis edilebilmesi için gerekli kurumsal ve yasal altyapı için güven duyulmadığı iddia edilen siyaset kurumlarının işleyişine ihtiyaç duyulmasıdır. İkincisi ise, seçilmiş siyasilerin seçmenlere karşı sorumluluklarını BDK'lara atama ile iş başına getirdikleri bürokratlara yüklemeleri ki, yeri geldiğinde topluma yaptıkları açıklamalarda da bunun ispatlarına rastlanmaktadır. Üçüncüsü, seçilmişlerin seçmenlere karşı sorumluluklarını çoğunluğu temsil etmeyen bağımsız düzenleyici kurumlara devretmelerinin bu kurumların demokratik meşruiyet sorununu doğurmasıdır. Bu belirtilen sorunlardan birincisi, siyasilerin hem sorun yaratan ama aynı zamanda da yarattıkları sorunlara çözüm bulabilecekleri gibi çelişkili bir duruma işaret etmektedir. Öyle ki, sorunu yarattığı iddia edilen siyaset mekanizmasının, çözüm üretmek üzere kendi hareket alanını daraltacak yapıyı üretmesi talep edilmekte hatta dayatılmaktadır. Böyle bir talebin de uluslararası kurumlar ve Avrupa Birliği'nden geldiğini hatırlatmak gerekir. Ne uluslararası kuruluşlar ne de yurtiçinden söz konusu talep kapsamında düzenleyici kurumların idari ve hukuksal yapısı ile ilgili ciddi bir ön araştırma ya da planlamanın izini belirlemek mümkün değildir. Sadece, 1970'lerde yaşanan ekonomik problemlerin kaynağı olarak aşırı devlet müdahalesi ve geleneksel bürokrasinin verimsiz olması gösterildiğinden, kamu sektöründe reformlar gerekli görülmüş ve uygulanmıştır. Bu uygulamalarda ise, özellikle Özal döneminde, piyasa reformlarını tamamlayacak kurumsal reformlar yerine, geleneksel yapıları koruyarak, alternatif aktör, metot ve örgütlenmeler oluşturulmuştur. Dolayısıyla bu açıklamadan tam da güvenilmez kabul edilen siyasetin kendi hareket alanını daraltan uygulamalar yerine kendine çok daha fazla alan açan ve kendi lehine sonuçlar üreten uygulamalar gerçekleştirdiği sonucunu çıkarmak yanlış olmayacaktır. Tabii burada siyasetçileri bu şekilde davranmaya iten saiklerin neler olduğu da irdelenmelidir. Bunlardan en temel olanına değinmek gerekirse, hem siyasiler hem de seçmenler miyopluk içindedir. Ne siyasiler ne de seçmenler uzun vadeli pozitif getiriler için kısa vadeli sıkıntıları göze almazlar hatta almak da istemezler. Her iki kesim de kısa vadeli kayıplara uğramadan uzun vadede elde edilebilecek sonuçlara ulaşmak gibi irrasyonel bir beklenti içindedir. Bütün bunların olağan sonucu da gerçekleştirilmesi elzem olan uygulamalardan kaçınılmasıdır.

Devletin düzenleyici kapasitesini daha etkili kılmak amacıyla idari ve mali özerkliğe sahip olarak kurulan BDK' lara yönelik büyük ölçüde stratejik ve bütüncül bir yaklaşım geliştirilemediğinden/geliştirilmediğinden görevleri, yetkileri, idari yapılanmaları, karar alma süreçleri, bütçeleri ve nihayetinde bağımsızlıkları ve hesap verebilirlikleri konusunda halen yoğun tartışmalar mevcuttur (TÜSİAD, 2002). Devlet Denetleme Kurulu tarafindan bu kurumların her birini ve genelini kapsayacak ayrıntılı raporlar da bu açıklamayı destekler tarzdadır. Özellikle, Devlet Denetleme Kurulu'na ait Araştırma ve İnceleme Raporu'ndaki(2010/11) şu açıklama bütün BDK' lara ilişkin genel ve en temel sorunu özetler niteliktedir: "Anayasa mahkemesi tarafından verilen kararlarda düzenleyici ve denetleyici otoritelerin kamu kurumu olduğu Anayasal sistem açısından yerinden yönetim kuruluşları arasında yer alan hizmet yerinden yönetim kuruluşları olduğu kabul edilmekle birlikte özellikle bu kurumların merkezi idare ile ilişkileri, idarenin bütünlüğü ilkesinin nasıl gerçekleştirileceği ve vesayet yetkisi tartışılmaya devam etmektedir.” Ayrıca kurum personelinin hukuki statüsünden ücret ve mali konulara, kurul kararlarının yargısal 
denetiminden mali konularda hesap vermeye kadar çok çeşitli konularda düzenleyici ve denetleyici kurumların mevzuatlarında farklı hükümlerin yer aldığı da vurgulanmaktadır.

Düzenleyici kurumlar, görev ve yetkileri, siyasi iktidarla ilişkileri ve örgütlenmeleri ile işleyişleri açısından geleneksel örgütlenme yapısından ciddi bir farkl1lık göstermektedir. Bu kurumlar kural koyma, uygulama hem de denetleme ve yaptırım yetkilerine sahiptir. Dolayısıyla bütün yetkilerin tek bir kurumda toplanması açısından tartışmalı bir durumda bulundukları ileri sürülmektedir. Diğer taraftan bu yetkilerin icrasında ortaya çıkan sorunlar da mevcut tartışmaların boyutunu ayrıca karmaşıklaştırmaktadır. Özellikle de hesap verebilirlikleri ile ilgili tartışmalar, hem bu kurumlara yönelik güven kaybı hem de etkin olmayan yönetim ve yanlış olan kişisel davranışlara da yaptırım uygulamasına dair ciddi çalışmaların gereğine işaret etmektedir.

\section{Türkiye ve Geçiş Ekonomilerine Yönelik Yeni Bir Regülasyon Anlayışıı ve Uygulama Gerekliliği Hakkında}

Gelişmekte olan ülkelere ısrarla yapısal ve kurumsal reformları benimsetmeye çalışan ve bu konudaki çalışmaların gerek OECD ve gerek World Bank' in çeşitli raporlarıyla ortaya konulduğu bilinmektedir. Bunlardan biri olan World Development Report (2002), düzenleme sisteminin yapısına dair daha ziyade düzenleyici kurumlar ve prosedürleri hakkında açıklamalarda bulunmaktadır. Düzenleyici kurumların şeffaf, güçlü ve bağımsız bir yönetime sahip olma gerekliliğine vurgu yapmaktadır. Pratikte ise bu gerekliliklerin yerine getirilmesinin zor olduğu, buna ilave olarak da kontroller ve dengeler sağlanmadan, bürokratik etkinsizliklerin özel kesim yolsuzluklarıyla yer değiştirebileceği de ileri sürülmektedir. Ayrıca, gelişmekte olan ülkelerde beşeri sermayenin kıtlığı da hesaba katıldığında kurumsal tasarımının yenilenmesi şarttır (World Bank, 2002).

Aslında bu gereklilikler değerlendirilip analiz edildiğinde, teknik olmaktan ileri gidemedikleri göze çarpmaktadır. Zira, ülke bazında, veri ekonomik, toplumsal, siyasi ve tarihsel koşullar tamamıyla göz ardı edilerek, sadece piyasanın etkinleştirilmesine yönelik zorunluluklar ortaya konmaktadır. Ancak, devletin yapısının, bürokrasinin rolünün ve görevinin değiştirilmesini hedef alan bu değişiklikler, tarihleri boyunca devlet yönetiminde belirgin bürokratik davranış kalıplarının ve uygulamalarının hakim kılındığı ülkelerde, bunun nasıl sorunlar oluşturabileceği dikkate alınmamıştır. Diğer taraftan uluslararası kuruluşların taleplerini yerine getirmeye çalışan gelişmekte olan Türkiye'de de önerilen modellerin uygunluğu analiz edilmemiş, sadece bürokratik yapının siyasi yapıdan daha fazla güç sahibi olacağı endişesi duyulmuş ve bu endişe sergilenmiştir de.

Ne var ki, siyasilerin kamu kuramlarını analiz ederek daha sağlıklı çözümler üretebilme potansiyelleri mevcuttur. Hem geçmiş uygulamaları hem de kuramlara ilişkin çalışmaları dikkate alarak optimal bir regülasyonun tasarımı söz konusu olabilir. Dolayısıyla regülasyon ve bağımsız düzenleyici kurumlar ile ilgili sorunlara bir tasarım sorunu olarak bakıldığında optimal çözüm üretilebilir. Böylece gelişmiş ülkelerin empoze etmeye çalıştı̆̆ hazır ve çok da işlevsel olmayan bir model yerine ülke koşullarına uygun olanı inşa edilebilir.

Böyle bir çalışmada öncelikli olarak, daha önceki bazı kuramlarda ve uluslararası kuruluşların taleplerinde devletin/siyasetin iktisadi faaliyetteki rolünün küçültülmesi ve bir ülkenin bütün olası sorunlarını sadece piyasa üzerinden çözümlemeye çalışmak yerine, devletin ve siyasetin sorumluluk alarak etkin rol oynayabileceği ve piyasa dışındaki sorunları da dikkate alacağı bir yöntem geliştirilebilir. Bunların kabulünden sonra ülkedeki çeşitli sosyal ve/veya ekonomik düzenlemelerin tasarımında her bir kesimin yararının gözetildiği açıklıkla ortaya konarak yararlar sağlayabilecekleri iletişim ve harekete onları yönlendirmek için teşvikler sunmak mümkün olabilir. Özellikle bu konuda mekanizma tasarımı teorisinden yararlanmak mümkündür. Mekanizma tasarımı teorisi, kurumsal düzenlemelerin ekonomik faaliyet ve kolektif karar almaya ilişkin kurallar ile prosedürlerin tasarımını kapsar. Söz konusu teori, mübadele mekanizmalarının, regülasyon planlarının ve oylama prosedürlerinin iktisatçılar tarafından belirlenmesine yardımcı olmuştur (Reel, 2010).

Bütün gerekli çalışmalar yürütülürken, bağımsız düzenleyici kurumların bağımsızlığına ilişkin şu sorularını neden, niçin ve nasıl sorularını da ekleyerek cevap vermeye çalışmak son derece yararlı olabilir:

1) Herhangi bir bakanlık spesifik durumlarda düzenleyici birimlerin faaliyetlerine karışıp aldıkları kararları geçersiz kılabilir mi ve/veya kılmalı mıdır? Bunun sınırı nasıl belirlenebilir?

2) Herhangi bir bakanlık regülasyonu gözeten stratejik kararlar alabilir mi ve/veya almalı mıdır?

3) İlgili bakanlık düzenleyici kurumdan bağımsız olarak politika oluşturabilir mi ve/veya oluşturmalı mıdır?

4) Düzenleyici kurum bütçe aracıllğ̆ıla finanse edilir mi ve/veya edilmeli midir?

Bu soruların her birine yönelik neden, niçin ve nasıl sorularını da ekleyerek cevap aramaya çalışmak, temel problemlerin ve çözüm önerilerinin belirlenmesine önemli bir katkı sağlayabilir. Ayrıca bu cevaplanan soruların cevaplarının da netlikle toplumla paylaşılması hem iyi bir iletişim ortamını, hem güveni tesis etmesinin yanı sıra uygulama sonuçlarının başarıya ulaşmasına ciddi katkıda bulunabilecektir.

Hassasiyet barındıran bir konu da, seçilmiş hükümetlerin kendilerini seçen seçmenlere karşı sorumlulukları nedeniyle, büyük ölçüde yetki devri konusunda çekimser olabilecekleridir. Bunun ötesinde, hükümetlerin asil vekil ilişkisi ve bu konudaki potansiyel sıkıntıların da farkında olmaları önemlidir. Yetki ve sorumluluk devrine dair 
başka sorunlar arasında da, geçmişte böyle bir yönetim modeline alışılamamış olması da vardır. Bu durum, patika bağımlılığı ile ilgili olabilecek bir sorun olarak da değerlendirilebilir. Patika bağımlılığı çerçevesinde ele alınmaya değer diğer bir konuda bugünkü davranış kalıpları ve uygulamaların da geleceğe yönelik yapılabileceklerin sınırını oluşturacağıdır. Bu konu göz önünde bulundurularak değişiklikler için adım atılırsa daha verimli sonuçlara ulaşılabilir.

Devlete düzenleyici rolünün verildiği modelin temelinde çelişkinin bulunduğu, çünkü ekonomik alandan devletin çekilmesi amacıyla yürütülen özelleştirme ve liberalizasyon uygulamalarının tam tersine devletin düzenleyici görevlerini artırıcı etki yaptığı ve düzenleyici kurumları gerekli kıldığı iddia edilmektedir. Dolayısıyla, devletin ekonomiden çekilmesi ile oluşturulması hedeflenen daha serbest piyasaların, daha fazla kural ile daha fazla düzenleyici ajansı gerektirdiği ileri sürülmektedir (Gilardi ve diğerleri, 2006). Bu açıklamaların bir eleştiri niteliğinde ortaya konulması çok anlamlı değildir. Zira, piyasaların serbestliğinin gerekli düzenlemeler ve kurallar aracılığıyla mümkün olabileceği, bu konuda da devlete büyük bir rol düşeceğinin göz ardı edilmesi kabul edilebilir değildir. Piyasaların serbestleştirilmesinin adeta "kuralsızlaştırılma" olarak algılandığı da ortadadır. Ancak, dünyada gelişmiş ülkeler de dahil son 10 yıldır içinde bulunulan dönem hesaba katıldığında "kuralsızlaştırmanın" ne kadar büyük bedeller yarattığı ortadadır.

Piyasaların işleyişinin düzenlenmesi, denetlenmesi ve gözetilmesi işlevlerinin gerektiği gibi yerine getirilmesi için güçlü ve etkin bir kamu yönetimi ihtiyacı ortadadır. Diğer taraftan konunun kapsamında gelişmekte olan ülkeler söz konusu olduğunda, piyasaları yapılandıracak olan reformlar kadar bunları uygulamaya koyacak olan kamu yönetiminin de yapılandırılmasına yönelik reformların da devletin rolünü en iyi/etkin şekilde yerine getirip getiremeyeceğini ile bu konudaki sınırlarını belirleyebilir ve belirlemelidir de.

Türkiye'deki "Kamu yönetimi reformu" 'nda, başarı için hem regülasyon politikaları ve yapıları gibi resmi kurumlarda hem de gibi resmi olmayan kurumlarda değişikliklere neden olmaları gerekliliği hatırlanmalıdır. Söz konusu kamu yönetimi reformunun bu gereklilikleri ne ölçüde yerine getirdiği, nelere dikkat edildiği, nelerin gözden kaçtığ 1 ve sorunların neler olduğu etkili ve doğru bir şekilde analiz edilebilirse, genelde kamu ve özelde de regülasyon uygulaması konusunda bütünlüklü bir değişim gerçekleştirilebilir. Zira, regülasyon çerçevesi kurumsal temelde vücut bulduğu için iyileştirici bir regülasyon yönetimi, kamu yönetimi reformuna bütün olarak entegre edilmeden daha ileriye taşınamaz. Söz konusu olabilecek dezavantaj ve tehditlerden kaçınabilmek için regülasyon teorilerini de detaylı incelemek yol gösterici olabilir. Zira, Radaelli ve Francesco (2007) farklı mantığa dayanarak açıklanan regülasyon teorilerinin temelleriyle düzenleyici devlet üzerine gerçekleştirilen daha yeni tartışmalar arasında bağlantı kurmuşlardır. Buradan hareketle de birçok düzenleyici devlet modelinin sınıflandırmasına dair bir liste sunmuşlardır. Bu sınıflandırmalar aslında tek tip bir düzenleyici devlet modelinin bulunmadığını ortaya koymaktadır. Bunun sonucunda düzenleyici devlet veya düzenleyici sistemleri ile ilgili değişikliklere yönelecek/yönlendirilen ülkelerin kamu yönetimine dair teorilerin yanı sıra bu teorileri de değerlendirmeye tabi tutmaları tavsiye edilebilir.

Geçiş ekonomilerinde düzenleme konusunun ayrıntılı bir analizi ise, geçiş öncesi dönemdeki yapılarının dikkate alınmasını gerektirir. Nasıl bir temele sahip oldukları açısından bu konu önem arz etmektedir. Özellikle önceki Sovyetler Birliği ve önceki diğer planlı ekonomilere ilişkin şu temel özellikler sayılmaktadır: 1) Neredeyse bütün ekonomik kararlar üzerinde merkezi planlamanın hakimiyeti ve ekonomik birimlerin kararlarını sınırlayan düzenleme 2)Sermaye, doğal kaynaklar ve toprak gibi üretim faktörlerinin kapsamlı şekilde millileştirilmesi 3) Devlete ait tarımsal firmaların kullanımıyla tarımda kollektivizasyon 4)İşgücüne yönelik sıkı düzenleme 5) Merkezi planlama tarafından büyük oranda sınırlandırılmış yönetimsel otonomi 6) Bir çok ekonomik sorunun bürokratik yöntemler ile çözümlenmeye çalışılması (Van Brabant, 2002).

Söz konusu temel özelliklere sahip olan ülkelerin, 1989 sonrası uluslararası toplumdan gelen çok çeşitli yardımlar ile geçiş süreçlerini hızlı bir şekilde tamamlamaları beklenmiştir. Bu konudaki temel varsayım da bu ülkelerdeki, ekonomik, politik ve sosyal dönüşümlerinin bir mühendislik becerisiyle çabuk ve sorunsuz gerçekleştirebilecekleridir. Ancak bunun hatalı bir varsayım olduğu, çünkü, geçiş sürecinin ne çabuk ne de sosyal ve politik anlamda hiçbir maliyeti olmadan atlatılamayacağı vurgulanmaktadır (Van Brabant, 2002). Zira patika bağımlılığının ciddi bir sınırlama oluşturabileceği uluslararası kurumlar tarafından göz ardı edilmiştir. Patika bağımlılı̆̆ çerçevesinde her ülkenin geçmişten gelen kurumsal, sosyal ve idari yapıları oluşmuştur. Bu yapılar sorunlu bile olsa, kolaylıkla terkedilebilmeleri, dönüştürülmeleri mümkün değildir. Hatta iyi niyetle dönüşüm çabaları gösterilse bile ulaşılması beklenen yapıya ulaşılması mümkün olmayabileceği gibi gerekli de değildir.

Diğer taraftan kamu sektörünün reformuna yönelik Yeni Kamu Yönetimi Modeli veya bu modelin versiyonlarının geniş ölçüde gelişmekte olan ülkeler tarafından uluslararası kurumlar ve yardım kuruluşları aracılığıyla taklit edilmiş olması sürecini "politika transferi” olarak nitelendiren akademik çalışmada, özelleştirme ve sözleşme gibi piyasa odaklı kurumsal değişikliklerle sıkı bağlantılı olan düzenleyici reformlar Yeni Kamu Yönetimi Modeli'nin bütünleyici parçası kabul edilmektedir. Sözü edilen transfere ilişkin Phillips, Taylor'dan şunu alıntılamaktadır; Yeni Kamu Yönetimi Modeli’ni gelişmekte olan ülkelere aktarırken gelişmişten gelişmekte olan devlete ve kamu-özel arasındaki sınıra yönelik olmak üzere çift transfer gerçekleştiriliyor. Bu konuyla ilgili problem aslında azgelişmişliğin kendine özgü koşulundan ortaya çıkmaktadır. Çünkü, neo-liberal ekonomik ve 
politik reformların uygulanmasının koşulu olan ve ekonomik, sosyal ve politik koşullar gelişmekte olan ülkelerde nadiren bulunmaktadır (Phillips, 2006).

Belki buraya kadar yapılan açıklamalardan çok daha önemli bir nokta, yoksulluk, yolsuzluk ve bürokratik sorunların az gelişmenin nedenlerinden ziyade sonuçları olduklarını göz önünde bulundurma gerekliliğidir. Dolayısıyla bunları mevcut yapının sonuçları olarak değerlendirmeden atılacak her adım ve uygulama beklenen sonuçları da vermeyecektir. Yoksulluk, yolsuzluk ve bürokratik sorunları geçiş ekonomilerinde zaten mevcut olduğu ve düzenleme reformlarının yarattığı sorunlar olmadığı dikkate alınırsa, bu sorunların veri olduğu bir ortamda neler yapılabileceğini araştırmak doğru bir yöntem olabilir.

Şimdiye kadar yürütülen çalışmalarda aynı bakış açısıyla aynı unsurlar tekrar tekrar vurgulanmakta ve etkin sonuçlara ulaşılamamaktadır. Bundan dolayı, farklı bakış açıları ve farklı çözüm yöntemlerine yönelmek kaçınılmazdır. Hem geçiş ekonomileri hem de Türkiye için buraya kadar yapılan açıklamalara dair hassas noktaları şu sorular aracılığıyla incelemek farklı çözümlere yönlendirebilir: 1) Gerçekten önerilen ve dayatılmaya çalışılan modeller ülke için uygun muydu? (Bu uygun olup olmama durumunu cevaplarken, hangi perspektiften değerlendirildiğini vurgulayarak ne gibi farklılıklar bulunduğunun farkında olmak elzemdir.) 2) Gerçekte ülkedeki temel sorunlar neydi ve bunlara ilişkin neler yapıldı ve yapılamadı? Neden? 3) Ülkede yürütülen uygulamalara yönelik temel bir anlayış geliştirme kaygısı mevcut mudur? Neden? 4) Yürütülen uygulamalara özgü aksaklıklar ve eksiklerin hem geçmiş hem de günümüz koşullarında neler olduğu? 5) Dört soruya verilen cevapların sağlıklı bir analizi gerçekleştirilerek neler yapılabilir?

Hem Türkiye hem de geçiş ekonomilerinde başarılı ekonomik, sosyal hatta siyasi performansın gerçekleştirilebilmesi, işlevsel olmayan kurum, kural ve davranışların terkedilerek daha işe yarar olanların uygulamaya çalışılmasıyla mümkündür. Bunların hangilerinin kısa hangilerinin de uzun vadede gerçekleştirilebileceğini doğru belirleyerek gereken adımlar kararlılıkla atılmalıdır.

\section{Sonuç ve Değerlendirme}

Günümüzde tartışılması gereken husus, devletin iktisadi faaliyetlere müdahale etmesi veya etmemesi değil; ne zaman, hangi araçları kullanarak ve nasıl müdahale ederse etkin sonuçları alabileceğidir. Gelişmiş ekonomilerde yaşanan ve küresel çapta etkisi olan finansal kriz dahi ekonomide kuralların, düzenlemelerin bulunması gerekliliğini çok etkili bir şekilde hatırlatmıştır.

Teorik olarak hedeflenenin ne olduğu ile gerçekte uygulamanın örtüşmesi mümkün olmadığı gibi, uygulamadaki hedef ile sonuçlar arasında da ciddi farklılıklar olabilmektedir. Düzenleme anlayışı çerçevesinde sorunlara çözüm ararken söz konusu farklılıkları yaratan ve değiştirilmesi mümkün olabilecek unsurların belirlenmesi önemlidir.

Diğer önemli nokta da, devletin ve özel kesimin sınırlarının belirlenmesi gereğidir. Bu sınırların aşılması durumunda ne tür davranış, uygulama ve yaptırımların gerçekleştirileceği kararlaştıılarak netleştirilmelidir. $\mathrm{Bu}$ netlik uygulamalardan etkilenebilecek kesimlerin hiçbirinde şüpheye yer bırakmayacak şekilde olmalıdır. Bütün uygulamaların temelinde toplumsal çıkarların ön planda tutulması gereği daima göz önünde tutulursa, sözü edilen sinırları belirlemek ve uygulamak hem kolay hem de inandırıcı olacaktır. Bunlara ilave olarak, siyasiler ve bürokratlar açısından güven ve iletişim sorunları da minimize edilebilecektir.

Hem Türkiye hem de geçiş ekonomilerinde başarılı ekonomik, sosyal hatta siyasi performansın gerçekleştirilebilmesi, işlevsel olmayan kurum, kural ve davranışların terkedilerek daha işe yarar olanların uygulamaya çalışılmasıyla mümkündür. Bunların hangilerinin kısa hangilerinin de uzun vadede gerçekleştirilebileceğini doğru belirleyerek gereken adımlar kararlılıkla atılmalıdır.

\section{Kaynakça}

- Devlet Denetleme Kurulu, 2010. Devlet Denetleme Kurulu Araştırma ve İnceleme Raporu https://www.tccb.gov.tr/assets/dosya/ddk45.pdf (22/12/2016).

- Gilardi, F., Jordana, J. ve Levi-Faur, D., 2006. Regulation in the Age of Globalization: The Diffusion of Regulatory Agencies across Europe and Latin America, Institut Barcelona D'estudis Internacionals.

- Pamuk, Ş., 2014. Türkiye'nin 200 Yıllık İktisadi Tarihi, Türkiye İş Bankası Kültür Yayınları, İstanbul.

- Phillips, N., 2006. "States and modes of regulation in the global political economy", in Regulatory Governance in Developing Countries, (edts.) Minogue, M. ve Carino, L., s.18-19.

- Radaelli, C.M. \& Francesco, F.D.,2007. "Regulatory Impact Assessment in Comparartive Perspective" 4th General Conference of the European Consortium for Political Research, Pisa, ITALY, 6-8 September 2007.

- Reel, Y., 2010. "Mekanizma Tasarımı Teorisi ve Uygulamaları", Marmara Üniversitesi İktisadi ve İdari Bilimler Fakültesi Dergisi, XXVIII, 1, s.68

- Sezen, S., 2003. Türk Kamu Yönetiminde Kurullar, TODAİE, Ankara.

- Sönmez, Ü., 2011. Piyasanın İdaresi-Neoliberalizm ve Bağımsız Düzenleyici Kurumların Anatomisi, İletişim Yayınları, İstanbul. 
- Thatcher, M., 2002. "Analysing Regulatory Reform in Europe”, Journal of European Public Policy, 9, 6, p.862, 864. (http://dx.doi.org/10.1080/1350176022000046391).

- The World Bank, 2002. World Development Report 2002- Building Institutions for Markets, Oxford University Press, p.158.

- Topak, O., 2012. Refah Devleti ve Kapitalizm- 2000'li Yıllarda Türkiye'de Refah Devleti, İletişim Yayınları, İstanbul.

- $\quad$ TÜSİAD, 2002. Bağımsız Düzenleyici Kurumlar ve Türkiye Uygulaması, Yayın No. TÜSİAD-T/200212/349, İstanbul.

- Van Brabant, J. M., 2002. The Political Economy of Transition, Routledge, p.31, 428.

- Zhang, Y.F., 2010. “Towards Better Regulatory Governance?”, Public Management Review, 12:6, 873-891. (http:dx.doi.org/10.1080/14719037.2010.488865). 


\title{
Yolsuzluk ve Ekonomik Büyüme Arasındaki İlişki: Yeni Sanayileşmiş Ülkeler için Panel Veri Analizi
}

\section{The Relationship between Corruption and Economic Growth: The Case of Newly Industrialized Countries}

\author{
Ph.D. Candidate Emrah Sofuoğlu (Ahi Evran University, Turkey) \\ Dr. Oktay Kızılkaya (Ahi Evran University, Turkey) \\ Prof. Dr. Ahmet Ay (Selçuk University, Turkey)
}

\begin{abstract}
Studies on corruption have been increasing in the literature recently. The effects of corruption, especially on macroeconomic variables, are a matter of curiosity for researchers. The aim of this study is to examine the relationship between corruption and economic growth. In this sense, Newly Industrialized Countries (NIC) are investigated in the study. The study covers the period 2001-2014 and to determine the long-term relationship, Pedroni cointegration test, panel FMOLS and panel DOLS coefficient estimators are utilised. According to the results of Pedroni cointegration test, there is a long-term relationship between corruption and economic growth. In addition, both panel FMOLS and DOLS results indicate that rise in corruption index contributes to higher economic growth in related countries.
\end{abstract}

\section{Giriş}

Yolsuzluk, siyaset, sosyoloji ve iktisat gibi birçok disiplin içinde tartışılan, incelenen ve pek çok araştırmaya konu olan sosyal bir olgudur. Dünyada özellikle 1990 yıllarda serbest piyasa kavramını kendi ekonomilerinde yerleştirmeye çalışan geçiş ekonomileri ile beraber tartışılmaya başlanmıştır. Küreselleşmenin yaygınlaşması, demokrasinin getirdiği hesap verilebilirlik, iletişim teknolojilerinin gelişimi, sermaye hareketlerinin önemli boyutlara ulaşması vb. faktörler yolsuzlukları ülke ekonomileri için önemli hale getirmiştir. Böyle bir ortamda, ülke yönetimleri yolsuzlukların getirmiş olduğu olumsuzlukları çözmek ve azaltmak istemektedir.

Literatürde yolsuzluğun tanımı farklı açılardan yapılmıştır. Yolsuzluk genel olarak bilinenin aksine sadece kamu sektörüne özgü bir olay değildir. Özel sektörde de yolsuzluk örnekleri bulunmaktadır. Ayrıca kamuoyunda yanlış bilinen diğer bir konu yolsuzluk sadece rüşvet vermek ya da almak da değildir. Rüşvet yolsuzluğun sadece bir çeşididir. Nedir peki yolsuzluk? Yolsuzluk, piyasadaki karar birimlerinin oyunu kurallarına göre oynamaması, başka bir ifadeyle kuralları ihlal etmesidir. Yani hedefe ulaşmak için hile yapmak veya zor kullanmaktır. Tanzi’ye (1998) göre, yolsuzluk bürokratik veya siyasi olabilir, yani bürokratlar veya siyasetçiler tarafindan yapılabilir; maliyet azaltıcı (rüşvet veren için) veya menfaat sağlayıcı olabilir; rüşvet teklif eden veya rüşvet talep edenden kaynaklanabilir; zorunlu kalınarak veya rıza ile yapılabilir; merkezi hükümetlerde veya yerel yönetimlerde olabilir; nakit bir ödeme içerebilir ya da içermeyebilir. Dünya bankası tarafından yapılan tanıma göre; yolsuzluk, kişisel çıkar için kamu gücünün kötüye kullanılmasıdır (Castro, 2013:62). Uluslararası Şeffaflık Örgütü’ne göre (1996) yolsuzluk, siyasetçiler ve kamu çalışanları tarafından uygunsuz ve kanunsuz bir şekilde kendilerini veya kendilerine yakın olanları kamunun verdiği gücü kötüye kullanarak zenginleştiren davranışları içermektedir. Bu davranış rüşveti (kamu otoritelerinin kararlarını etkilemek amacı ile para veya başka faydalar sağlama), yakınlara iltiması, kişisel faydalar için görevi kötüye kullanmayı (kamu mal ve hizmetlerini vb. yasal olmayan şekilde kullanma) v.b. durumları içermektedir (Ay vd., 2016:74). Bu durumda, yolsuzluk toplumu sosyolojik olarak etkilemesinin yanı sıra kurumların faaliyetlerini olumsuz etkilemekte ve ekonomik büyümeyi engellemektedir. Yolsuzluk piyasa ekonomisi işleyişinde bir düzensizliğe neden olmakta, karar verme süreçlerini bozmakta ve bu yüzden de rasyonelliği ve ekonomik verimliliği etkilemektedir (Caetano ve Caleiro, 2009:46, Primorac ve Smoljic, 2011: 177).

Ülke ekonomilerinin belirli bir büyüme hızını yakalayabilmeleri için geleneksel üretim kaynakları dışında diğer faktörlere de ağırlık vermeleri gerekmektedir. Bu faktörler arasında, iktisat alanında sıkça tartışmalara konu olan ve daha çok kurumların üretim üzerindeki etkilerini dikkate alan yolsuzluk kavramı da bulunmaktadır. Yolsuzluk ekonomik, sosyal ve siyasi açıdan ülkelerde riske ve belirsizliğe neden olan önemli bir faktör olarak karşımıza çıkmaktadır. Yolsuzluk, serbest piyasa ekonomisinin işlerliği için gerekli olan ortamın, toplumsal normların, değerlerin olmadığı sosyal bir bozukluk ve ülkelerin uluslararası ekonomik ilişkilerinin gelişmesi önünde katlanılmaz bir engel olmaktadır (Primorac ve Smoljic, 2011: 178). Dünyadaki son gelişmelerle beraber yolsuzluk artık ekonomik büyümenin önemli belirleyicileri arasında kabul edilmektedir.

Bu bağlamda çalışmamızın amacı, düşük yolsuzluk düzeyinin ekonomik büyüme hedeflerini gerçekleştirmede önemli bir faktör olup olmadığını test etmektir. Bu amaçla çalışmada 2001-2014 dönem aralığı baz alınarak Yeni Sanayileşen Ülkelerde (NIC) yolsuzluk-ekonomik büyüme ilişkisi araştırılmıştır. Bu doğrultuda üç bölümden oluşan çalışmanın birinci bölümünde yolsuzluk kavramı ve ekonomik büyüme ile arasındaki ilişki hakkında bir 
kısım bilgiler verilmiştir. İkinci bölümünde yolsuzluk ve ekonomik büyüme arasındaki teorik ilişki açıklandıktan sonra bu ilişkiyi ele alan çalışmalardan oluşan bir literatür taramasına yer verilmiştir. Üçüncü bölümde ise model ve veri seti hakkında bilgi verilerek ampirik sonuçlar değerlendirilmiştir. Sonuç bölümünde de ekonometrik bulgular tartışılarak bir kısım politika önermelerine yer verilmiştir.

\section{Teorik ve Ampirik Literatür}

Ekonomi alanında yolsuzlukların tartışılması 1960’lı yıllara kadar dayanmaktadır. İktisat literatüründe yolsuzluğun ekonomik performansı olumsuz yönde etkilediği, yatırımlar ve ekonomik büyüme üzerinde negatif etkileri bulunduğu, sağlık hizmetleri ve eğitim hizmetlerinde altyapının kalitesini düşürdüğü, kamu yatırımlarında verimliliği etkilediği ve gelir dağılımında adaletsizliğe neden olduğu düşünceleri sıkça tartışılmaktadır. Fakat yolsuzlukların makroekonomik değişkenler üzerindeki etkilerini inceleyen çalışmaların bir kısmı ise yolsuzluk düzeyinin ekonomik performansı artırdığına dair görüş bildirmişlerdir.

Yolsuzluğun ekonomik performans üzerindeki etkileri üzerine literatürde olumsuz (negatif) ve olumlu (pozitif) olmak üzere iki farklı etkiden söz edilmektedir. Negatif etki, “yolsuzluk, maliyetleri ve belirsizliği arttırdı̆̆ı için ekonomik büyüme üzerinde olumsuz bir etkiye sahiptir" şeklinde açıklanmaktadır. Bu yaklaşımın savunucuları (Gould and Amaro-Reyes 1983; Murphy vd.,1993; Birleşmiş Milletler, 1990; Mauro, 1995; Mo, 2001; Monte ve Papagni, 2001) yolsuzluğun ekonomi açısından dezavantajlı bir olay olduğunu, özellikle kaynak sıkıntısı çeken girişimcilerin rüşvet vererek işlemlerini gerçekleştirmeye çalıştığını savunmaktadır. Pozitif etki ise, "ülkelerdeki gelişmemiş düzenleme ve denetlemeler bürokrasiyi azaltırken, üretim maliyetlerini de azaltmaktadır ve bu durum özellikle yatırımları arttırmakta dolayısıyla ekonomik büyümeyi artırmaktadır" şeklinde açıklanmaktadır. Bu etkiyi savunan yaklaşım literatürde "Etkin Yağlama Hipotezi” olarak bilinmektedir. Bu yaklaşımın savunucularının (Leff, 1964; Leys, 1965; Nye, 1967; Huntington, 1968; Acemoglu ve Verdier, 1998) bir ülkede yolsuzluk düzeyinin yükselmesinin ekonomik büyüme üzerinde olumlu katkı yapacağına yönelik düşünceleri bulunmaktadır (Anoruo ve Braha, 2005; 43). Örneğin; Literatürde bu ilişkiyi inceleyen ilk çalışmalar olma özelliğine sahip Leff (1964) ve Huntington (1968), yolsuzluğun iki tür mekanizma yoluyla ekonomik büyümeyi artırabileceğini öne sürmüşlerdir. Bu çalışmalarda, hızlı para olarak ifade ettikleri yolsuzluğun bürokratik gecikmeleri ortadan kaldırdığı ve rüşvet alan kamu görevlilerinin ise daha çok çalıştığı savunulmaktadır. Söz konusu çalışmalara göre, bürokrasinin fazla olduğu ülkelerde yolsuzluğun büyümeye faydalı olma ihtimali artmakta ve yolsuzluk bürokratik engelleri ortadan kaldırarak yatırım kararlarının hayata geçirilmesini hızlandırmaktadır. Buna karşılık, Shleifer ve Vishny (1993), yolsuzluğun ekonomik büyümeyi azaltma eğiliminde olacağını savunurken, Rose-Ackerman (1978) ise, çalışmasında yolsuzluğun ekonomik açıdan büyüme potansiyeli olan sektörleri sınırlandırma ihtimali konusunda uyarmaktadir.

1990'ların başında dünyada küreselleşmenin yaygınlaşması ile beraber ekonomistler yolsuzluğun ekonomi üzerindeki olumsuz etkisini açıklamayı amaçlamışlardır. Hines (1995), yolsuzluğun ekonomik büyümeyi negatif etkilediğini, Rose-Ackerman (1999), yolsuzluğun üretim maliyetlerini artırdığını, Della Porta ve Vanucci (1999), ev sahibi ülkedeki yolsuzluğun yabancı yatırımları olumsuz etkilediğini, Busse-Hefeker (2007) yolsuzluğun yatırımlar için önemli bir belirleyici olduğunu, Mathur ve Singh (2013) ise yolsuzluğun yatırımcıların yatırım kararlarını büyük oranda etkilediğini savunmuştur. Yolsuzluğun potansiyel olarak yatırımları özellikle de yabancı yatırımları azalttığı kabul edilmektedir (Mauro, 1995; Keefer ve Knack, 1995; Castro ve Nunes 2013). Bu açıdan yolsuzluk düzeyinin ekonomik büyümeyi etkilediği en önemli kanallardan bir tanesi yatırımlardır.

Yolsuzluğun yüksek olduğu ekonomilerde iş yapma maliyetleri artarken belirsizlik de artmaktadır. Al-Sadig (2009) göre; teorik olarak ele alındığında yolsuzluk rüşvet ödeyerek bürokratik engelleri aşmak şeklinde değerlendirilmektedir. Bu yaklaşıma göre; yolsuzluk, i) üretim yapan sektörler için ciddi bir maliyet tehdidi olarak görülmektedir, ii) piyasadaki yatırım projelerinin karlılığını azaltabilmekte ve piyasadaki belirsizliğin artmasına sebep olabilmektedir, iii) üretim ve hizmet sektörlerinde yüksek maliyetlere neden olması ve belirsizliği artırmasından ötürü ekonomik bir problem olarak düşünülmektedir. Primorac ve Smoljic (2011) ise, modern ve demokratik toplumlarda giderek artan yolsuzluğun sistematik aksaklığına vurgu yapmaktadırlar. Bu düşünceye göre, yolsuzluk ahlaki olarak yanlış bir davranış olmakla birlikte, aynı zamanda ülkelerin siyasi ve ekonomik sistemlerindeki bozuklukların bir parçası olarak görülmektedir.

Yolsuzluğun ekonomik performans üzerindeki etkilerini farklı açılardan inceleyen çalışmalar da literatürde mevcuttur. Dahlström ve Johnson (2007) göre, gelişmekte olan ekonomilerde yolsuzluğun meydana getirmiş olduğu yüksek maliyetler ve belirsizlik süreci gelişmiş ülkelerinkinden daha fazladır. Dahlström ve Johnson (2007), bunun gerekçesini yolsuzluğun gelişmekte olan ülkelerde yatırımların önemli bir belirleyicisi olması ile açıklamaktadır. Cuervo-Cazurra (2008), yolsuzluğun yerleşmiş piyasa kuruluşlarının olduğu ülke ekonomilerinde ekonomik büyümeyi engellediğini, piyasa kuruluşlarının düzgün işlemediği kurumsallaşmamış ülke ekonomilerinde ise ekonomik büyümeyi artırdığını savunmaktadır.

Bir ülkede yolsuzluğu etkileyen faktörler aşırı bürokrasi, politikaların oluşturulmasında ve uygulanmasındaki sıkı kurallar, hukuk sisteminin yavaşlığı, kamu sektöründeki ücret seviyeleri, mülkiyet haklarının düzenlenmemesi, vergilendirme yasaları, ceza sistemi vb. şeklinde sıralanabilmektedir. Fakat günümüzde 
yolsuzluk sadece azgelişmiş ve gelişmekte olan ülkeler için değil aynı zamanda gelişen ülkeler için de çözülmesi gereken bir ekonomik sorun olarak değerlendirilmektedir (Leon, 2010:2). Ülkeler küreselleşme süreci ile yatırım politikalarında ve iş kanunlarında yeni standartlar getirmeye çalışırken diğer taraftan da yolsuzluğun bu sürecin gelişmesinde büyük bir engel olarak ortaya çıktı̆̆ını gözden kaçırmamalıdır (Castro ve Nunes, 2013: 62).

Yolsuzluk düzeyinin ekonomik büyüme üzerindeki etkisini inceleyen ampirik literatüre bakıldığında bu iki değişkenin arasındaki ilişkinin yönüne dair bir uzlaşı bulunmamaktadır. İlgili literatür incelendiğinde yapılan uygulamalı çalışmaların büyük çoğunluğunda negatif bir ilişki gözlemlenirken, bazı çalışmalarda ise pozitif bir ilişki dikkat çekmektedir. Ehrlich ve Lui (1999), Salisu (2000), Sarkar ve Hassan (2001), Kutlar ve Doğanoğlu (2001), Mo (2001), Monte ve Papagni (2001), Mauro (2002), Toatu (2004), Drury ve diğ. (2006), Yakar ve Cebeci (2007), Aliyu ve Elijah (2008), Podobnik et.al. (2008), Göktan (2009), Halko ve Tzeremes (2010), Yüksel (2010), Johnson vd. (2011), Hodge vd. (2011), Uğur ve Dasgupta'ya (2011), Lisciandra ve Millemaci (2013), Dridi (2013), Johnson vd. (2014) gibi çalışmalar yolsuzluk düzeyinin artmasının ekonomik büyümeyi düşürdüğüne (negatif etki) dair sonuçlar elde etmiştir.

Yolsuzluk düzeyinin artmasının ekonomik büyümeyi artırdığına (pozitif etki) dair sonuçlar ise Nye (1967), Acemoğlu ve Verdier (1998), Swaleheen ve Stansel (2007), Ali vd. (2010), Powell vd. (2010), Huang (2012), Algan vd. (2014) gibi çalışmalarda gözlenmektedir. Literatürde Mauro (1995), Svensson (2005), Karagöz ve Karagöz (2010), Swaleheen (2011), Beşel ve Savaşan (2014) gibi iki değişken arasında anlamlı bir ilişki bulamayan çalışmalar da mevcuttur. Bu konuyla ilgili literatür aşağıdaki tabloda özetlenmiştir:

\begin{tabular}{|c|c|c|c|c|c|}
\hline Yazarlar & Ülke/Bölge & Dönem & Yöntem & Değişkenler & Sonuç \\
\hline $\begin{array}{l}\text { Mauro } \\
(1995)\end{array}$ & $\begin{array}{l}\text { Seçilmiş } 70 \\
\text { Ülke }\end{array}$ & $1980-1983$ & $\begin{array}{l}\text { Etnikdilsel } \\
\text { Ayrım } \\
\text { Endeksi }\end{array}$ & $\begin{array}{l}\text { Yolsuzluk } \\
\text { Büyüme }\end{array}$ & $\begin{array}{l}\text { Yolsuzluk yatırımları azaltarak ekonomik büyümeyi } \\
\text { olumsuz etkilemektedir }\end{array}$ \\
\hline $\begin{array}{l}\text { Leite ve } \\
\text { Weidman } \\
(1999)\end{array}$ & $\begin{array}{l}\text { ABD ve } \\
\text { seçilmiş } \\
\text { Afrka-Asya } \\
\text { ve Güney } \\
\text { amarikn }\end{array}$ & $1970-1990$ & $\begin{array}{l}\text { Infinite } \\
\text { Horizon } \\
\text { Büyüme } \\
\text { Modeli }\end{array}$ & $\begin{array}{lr}\text { Yolsuzluk, } & \text { Doğal } \\
\text { Kaynaklar r ve } & \text { Ekonomik } \\
\text { Eüyüme }\end{array}$ & $\begin{array}{l}\text { Az gelişmiş ülkelerde doğal kaynaklar yolsuzluğa ve } \\
\text { negatif büyümeye neden olurken kurumları güçlü } \\
\text { gelişmiş ülkelerde bu etkiler görülmemektedir. }\end{array}$ \\
\hline $\begin{array}{l}\text { Del Monte } \\
\text { ve Papagni } \\
(2000)\end{array}$ & $\begin{array}{l}\text { İtalya'da } \\
\text { Seçilmiş } 20 \\
\text { Bölge }\end{array}$ & $1963-1991$ & $\begin{array}{l}\text { Dinamik } \\
\text { Panel Veri } \\
\text { Analizi }\end{array}$ & $\begin{array}{l}\text { Kamu Harcamaları, } \\
\text { Yolsuzluk ve } \\
\text { Ekonomik Büyüme }\end{array}$ & $\begin{array}{l}\text { Yolsuzluğun ekonomik büyüme üzerinde iki farklı } \\
\text { negatif etkisi vardır. Biri özel yatırımları azaltırken, } \\
\text { diğeri kamu harcamalarının etkinliğini } \\
\text { azaltmaktadır. }\end{array}$ \\
\hline $\begin{array}{l}\text { Hung Mo } \\
(2000)\end{array}$ & $\begin{array}{l}\text { Seçilmiş } 54 \\
\text { Ülke }\end{array}$ & $1960-1985$ & $\begin{array}{l}\text { En Küçük } \\
\text { Kareler } \\
\text { Yöntemi }\end{array}$ & $\begin{array}{l}\text { Yolsuzluk ve } \\
\text { Ekonomik Büyüme }\end{array}$ & $\begin{array}{l}\text { Yolsuzluk seviyesinde } 1 \% \text { 'lik artış büyüme } \\
\text { oranlarını } 0.72 \% \text { oranında azaltmaktadır. Ayrıca } \\
\text { yolsuzluk, özel yatırımı ve beşerî sermaye seviyesini } \\
\text { azaltmaktadır }\end{array}$ \\
\hline $\begin{array}{l}\text { Abed ve } \\
\text { Davoodi } \\
(2000)\end{array}$ & $\begin{array}{l}25 \text { Geçiş } \\
\text { Ekonomisi }\end{array}$ & 1994-1998 & $\begin{array}{l}\text { Regresyon } \\
\text { ve Ayrışma } \\
\text { Analizi }\end{array}$ & $\begin{array}{l}\text { Yolsuzluk, Yapısal } \\
\text { Reformlar, } \\
\text { Ekonomik } \\
\text { Performans }\end{array}$ & $\begin{array}{l}\text { Yolsuzluk seviyelerinin azaltılmasında yapısal } \\
\text { reformların önemini ortaya koyan kanıtlar } \\
\text { sunmaktadır. } \\
\mathrm{Bu} \text { şekilde yolsuzluğun azaltılması yatırımların } \\
\text { artmasına ve ekonomik büyümeye katk } \\
\text { sağlamaktadır. }\end{array}$ \\
\hline $\begin{array}{l}\text { Mauro } \\
(2002)\end{array}$ & $\begin{array}{l}\text { OECD } \\
\text { Ülkeleri }\end{array}$ & $\begin{array}{l}1997 \\
\text { Dönemi }\end{array}$ & $\begin{array}{l}\text { Barro } \\
\text { Büyüme } \\
\text { Modeli }\end{array}$ & $\begin{array}{l}\text { Yolsuzluk ve } \\
\text { Ekonomik Büyüme }\end{array}$ & $\begin{array}{l}\text { Büyümenin düşük ve yolsuzluğun yaygın olduğu } \\
\text { ülkelerde kamu sektörünün büyük ve üretimin } \\
\text { verimsiz olması gelir dağılımı adaletsizliğini } \\
\text { artırmaktadır. }\end{array}$ \\
\hline $\begin{array}{l}\text { Gyimah ve } \\
\text { Brempong } \\
(2002)\end{array}$ & $\begin{array}{l}\text { Seçilmiş } \\
\text { Afrika } \\
\text { Ülkeleri }\end{array}$ & $\begin{array}{l}1990 \\
\text { Dönemi }\end{array}$ & $\begin{array}{l}\text { Panel Veri } \\
\text { Analizi }\end{array}$ & $\begin{array}{l}\text { Yolsuzluk, } \\
\text { Ekonomik Büyüme, } \\
\text { Gelir Eşitsizliği }\end{array}$ & $\begin{array}{l}\text { Yolsuzluk, ekonomik büyümeyi fiziksel } \\
\text { sermayedeki azalan yatırımlar vasıtasıyla doğrudan } \\
\text { veya dolaylı olarak azaltmaktadır. }\end{array}$ \\
\hline $\begin{array}{l}\text { Anoruo ve } \\
\text { Braha } \\
(2005)\end{array}$ & $\begin{array}{l}\text { Seçilmiş } 18 \\
\text { Afrika } \\
\text { Ülkesi }\end{array}$ & $1984-2000$ & $\begin{array}{l}\text { Philips } \\
\text { Hansen } \\
\text { FMOLS }\end{array}$ & $\begin{array}{l}\text { Ekonomik Büyüme } \\
\text { ve Yolsuzluk }\end{array}$ & $\begin{array}{l}\text { Yolsuzluk, üretkenliği ve yatırımları azaltarak } \\
\text { ekonomik büyümeyi negatif yönde etkilemektedir. }\end{array}$ \\
\hline $\begin{array}{l}\text { Drury, } \\
\text { Krieckhaus } \\
\text { ve Lusztig } \\
\text { (2006) }\end{array}$ & $\begin{array}{l}\text { Seçilmiş } \\
\text { 100'den } \\
\text { Fazla Ülke }\end{array}$ & $1982-1997$ & $\begin{array}{l}\text { Panel Veri } \\
\text { Analizi }\end{array}$ & $\begin{array}{l}\text { Yolsuzluk, } \\
\text { Demokrasi ve } \\
\text { Ekonomik Büyüme }\end{array}$ & $\begin{array}{l}\text { Demokrasinin yaygın olduğu ülkelerde yolsuzluk } \\
\text { ekonomik büyüme üzerinde önemli bir etkisi yok } \\
\text { iken, demokrasinin olmadığ } 1 \text { ülkelerde ekonomik } \\
\text { büyüme yolsuzluktan olumsuz etkilenmektedir. }\end{array}$ \\
\hline $\begin{array}{l}\text { Aidt } \\
(2009)\end{array}$ & $\begin{array}{l}\text { Seçilmiş } 73 \\
\text { Ülke }\end{array}$ & $1970-2000$ & $\begin{array}{l}\text { Etkin } \\
\text { Yağlama } \\
\text { Hipotezi }\end{array}$ & $\begin{array}{l}\text { Yolsuzluk, } \\
\text { Kurumlar, } \\
\text { Ekonomik Kalkınma }\end{array}$ & $\begin{array}{l}\text { Sürdürülebilir kalkınmanın doğrudan bir göstergesi } \\
\text { olan kişi başına gelir ile yolsuzluk arasında kuvvetli } \\
\text { negatif bir ilişki vardır. }\end{array}$ \\
\hline $\begin{array}{l}\text { Swaleheen } \\
(2009)\end{array}$ & $\begin{array}{l}\text { Seçilmiş } \\
117 \text { Ülke }\end{array}$ & 1984-2007 & $\begin{array}{l}\text { Dinamik } \\
\text { Panel Veri } \\
\text { Analizi }\end{array}$ & $\begin{array}{l}\text { Ekonomik Büyüme } \\
\text { ve Yolsuzluk }\end{array}$ & $\begin{array}{l}\text { Yolsuzluk ekonomik büyüme oranları üzerinde } \\
\text { negatif etkisi vardır. }\end{array}$ \\
\hline
\end{tabular}

Tablo 1: Ampirik Literatür 


\section{Model ve Veri Seti}

Yolsuzluk ve ekonomik büyüme arasındaki ilişkiyi araştıran bu çalışmada aşağıdaki gibi panel veri formatında bir doğrusal regresyon modeli kurulmuştur.

$$
\mathrm{GSYH}_{i t}=\alpha_{0 \mathrm{i}}+\alpha_{1 \mathrm{i}} \mathrm{YOL}_{\mathrm{it}}+\mathrm{u}_{\mathrm{it}} \quad \mathrm{i}=1, \ldots, \mathrm{N} ; \mathrm{t}=1, \ldots \mathrm{T}
$$

Burada; GSYH ekonomik büyümeyi ve YOL ise yolsuzluk endeksini temsil etmektedir. Analizde kullanılan veri seti 2001-2014 dönemi yıllık verilerinden oluşmakta olup, Yeni Sanayileşmiş Ülkeleri kapsamaktadır. Bu ülkeler sırasıyla Çin, Hindistan, Endonezya, Brezilya, Malezya, Tayland, Meksika, Güney Afrika ve Türkiye’dir. GSYH değişkenine ait veriler World Bank istatistiksel veri tabanından, YOL değişkenine ait veriler ise ICRG (Uluslararası Risk Göstergeleri Rehberi) raporlarından derlenmiştir.

\section{Metodoloji ve Ampirik Sonuçlar}

Bu çalışmada ekonomik büyüme ve yolsuzluk arasındaki ilişki panel eşbütünleşme analizi yöntemiyle incelenecektir. Söz konusu ilişki üç aşamada incelenecektir. Birinci aşamada değişkenlerin durağanlıkları IPS ve Maddala ve Wu (1999) panel birik kök testleri ile araştırılmıştır. İkinci aşamada Pedroni (1999) panel eşbütünleşme testi ile değişkenler arasındaki uzun dönemli ilişki test edilmektedir. Üçüncü aşamada Panel DOLS ve Panel FMOLS tahmincileri ile eşbütünleşme katsayıları tahmin edilmiştir.

\subsection{Panel Birim Kök Testleri}

Eşbütünleşme ilişkisinin tespitinden önce değişkenlerin durağanlığının kontrol edilmesi gerekmektedir. Eğer değişkenlere ait veriler durağan ise değişkenler arasındaki ilişkileri tespit etmek amacıyla regresyon analizi kullanılacak, durağan değilse sahte regresyon sorunu ortaya çıkacak, tahmin edilen regresyon sonuçları sağlıklı olmayacaktır. Değişkenlerin durağanlığının tespiti durumunda eşbütünleşme ilişkisinin varlığı test edilecektir. Bu anlamda, çalışmada Im, Pesaran ve Shin (2003, IPS) testi ve Maddala ve Wu (1999) tarafindan geliştirilen FisherADF testi panel birim kök sınamasında kullanılacaktır.

IPS panel birim kök testi için aşağıdaki modelin tahmin edilmesini gerektirmektedir:

$$
\Delta y_{i t}=\mu_{i}+\rho y_{i t-1}+\sum_{j=1}^{m} \alpha_{j} \Delta y_{i t-j}+\delta_{i t}+\theta_{t}+\varepsilon_{i t}
$$

Denklem 2'de, $\Delta$ birinci fark operatörü, m gecikme uzunluğu, $\mu$ i ve $\theta$ t sırasıyla birime özgü sabit ve zaman etkileridir. Tüm i'ler için $\rho=0$ sıfır hipotezi, tüm i'ler için $\rho<0$ hipotezine karşı test edilmektedir. Sıfır hipotezinin reddedilmesi durumunda serinin durağan olduğu ortaya çıkmaktadır.

Maddala ve Wu (1999) tarafından geliştirilen Fisher-ADF testi ise, her yatay kesit i için birim kök testlerinden elde edilen $\rho$ değerlerini birleştirmektedir. Test parametrik değildir ve 2 n serbestlik derecesiyle ki-kare dağ 1 lımına sahiptir. Testte “n”' göstergesi, paneldeki yatay kesit verisi sayısını vermektedir. İlgili test istatistiği Denklem 3'de gösterilmiştir.

$$
\lambda=-2 \sum_{\mathrm{i}=1}^{\mathrm{n}} \log _{\mathrm{e}}\left(\mathrm{p}_{\mathrm{i}}\right) \sim \chi 2 \text { n(d.f.) }
$$

Denklem 3'de pi birim i için ADF birim kök testinden elde edilen p değeri görülmektedir. ADF-Fisher testi, bireysel ADF regresyonlarındaki farklı gecikme uzunluklarına bağlı olmama avantajına sahiptir (Hossain and Saeki, 2011: 322).

Panel birim kök testinden elde edilen ampirik sonuçlar Tablo 2'de gösterilmektedir. Birim kök test sonuçlarına göre değişkenlerin genel görünümü düzey değerde durağan değilken ilk farkta durağan olduğu, yani I(1) olduklarıdır. $\mathrm{Bu}$ durumda değişkenler arasında uzun dönemli bir eşbütünleşme ilişkinin olup olmadığı test edilebilmektedir. Eğer değişkenler arasında eşbütünleşme ilişkisi varsa bu durumda elde edilen regresyon yanıltıcı olmayacaktır.

\begin{tabular}{llclc}
\hline Variables & IPS Testi & \multicolumn{2}{c}{ ADF-Fisher Testi } & \\
\cline { 2 - 5 } & İstatistik Değeri & $\begin{array}{c}\text { Prob. } \\
\text { Değeri }\end{array}$ & İstatistik Değeri & $\begin{array}{c}\text { Prob. } \\
\text { Değeri }\end{array}$ \\
\cline { 2 - 4 } GSYH & -1.18 & 0.12 & 26.06 & 0.16 \\
YOL & -0.04 & 0.49 & 19.66 & 0.48 \\
$\Delta$ GSYH & -4.18 & $0.00^{*}$ & 53.72 & $0.00^{*}$ \\
$\Delta$ YOL & -1.49 & $0.07^{* * *}$ & 30.34 & $0.04^{* *}$ \\
\hline
\end{tabular}

*, $* *, * * *$, sirasıyla $\% 1, \% 5 \mathrm{vw} \% 10$ anlamlılık düzeylerini göstermektedir.

Tablo 2: Panel Birim Kök Test Sonuçları

\subsection{Panel Eşbütünleşme Testi}

Literatürde durağan olmayan değişkenler arasında uzun dönem eşbütünleşme ilişkisinin olup olmadığını sınamak için kullanılan yöntemlerden biri de Pedroni $(1999 ; 2004)$ tarafından geliştirilen panel eşbütünleşme testidir. Pedroni, eşbütünleşme ilişkisi yoktur şeklinde tanımlanan sıfır hipotezini sınamak için 7 farklı test istatistiği geliştirmiştir. Bu istatistikleri panel eşbütünleşme regresyonundan elde edilen artılardan elde etmektedir. 
$\mathrm{Bu}$ testlerin dört tanesi grup içi (panel-v, panel- $\rho$, yarı parametrik panel-t ve parametrik panel-t) istatistiklerden, diğer üç tanesi gruplar arası (grup- $\rho$ istatistiği, yarı parametrik group-t istatistiği ve parametrik group-t) istatistiklerden oluşmaktadır.

Tablo 2, Pedroni panel eşbütünleşme test sonuçlarını göstermektedir. Sabitli model değerlendirildiğinde, yedi istatistiğin 1'i \% 10, 5'i \% 1 anlamlılık düzeyinde sıfır hipotezinin reddedildiğini göstermektedir. Sabitli ve trendli modelde ise, yedi istatistiğin 4'ü \%1 anlamlılık düzeyinde sıfır hipotezinin reddedildiğini göstermektedir. Bu sonuçlar değişkenler arasında uzun dönemde eşbütünleşme ilişkisinin olduğu şeklinde yorumlanabilmektedir.

\begin{tabular}{lll}
\hline Test & Sabitli & Sabitli ve Trendli \\
\hline Panel v-Statistic & 0.09 & -2.73 \\
Panel rho-Statistic & $-3.02^{*}$ & -0.46 \\
Panel PP-Statistic & $-6.31^{*}$ & $-6.65^{*}$ \\
Panel ADF-Statistic & $-4.35^{*}$ & $-3.98^{*}$ \\
Panel rho-Statistic & $-1.24^{* *}$ & 0.94 \\
Group PP-Statistic & $-7.12^{*}$ & $-7.60^{*}$ \\
Group ADF-Statistic & $-4.22^{*}$ & $-3.94^{*}$ \\
\hline
\end{tabular}

*, \%1 anlamlılık düzeyini göstermektedir.

***, \%10 anlamlılık düzeyini göstermektedir.

Tablo 3: Pedroni Panel Eşbütünleşme Test Sonuçları

\subsection{Panel Eşbütünleşme Katsayılarının Tahmini}

Uzun dönem eşbütünleşme ilişkisinin elde edilmesinin ardından sonra ikinci aşama olan uzun dönem eşbütünleşme katsayılarının tahmine geçilebilmektedir. Bu amaçla Pedroni (2000, 2001) tarafından geliştirilen panel fully modified ordinary least squares (FMOLS) and panel dynamic ordinary least squares (DOLS) yöntemleri tercih edilmiştir. FMOLS ve DOLS tahmincileri, aralarında uzun dönemli ilişki bulunan serilerin en küçük kareler yöntemiyle tahmin edilmesi durumunda sapmalı sonuçların ortaya çıkması üzerine geliştirilmiştir. FMOLS yöntemi, oto korelasyon ile içsellik problemini parametrik olmayan bir yaklaşım ile düzeltmekte iken; DOLS yönteminde ise değişkenler gecikmeli değerleri ile alınarak oto korelasyon giderilmekte ve tahmin yapılmaktadır. Tablo 'de panel DOLS ve FMOLS analizlerinden elde edilen sonuçlar gösterilmiştir.

\begin{tabular}{cll}
\hline Değişken & Panel FMOLS & Panel DOLS \\
\hline YOL & $2.18^{*}$ & $2.25^{*}$ \\
& $(0.00)$ & $(0.00)$ \\
\hline${ }^{*} \%$ l anlamlılık düzeyini göstermektedir & &
\end{tabular}

( ), değişkenlerin prob değerlerini göstermektedir.

\section{Tablo 4: Panel Eşbütünleşme Katsayıları (GSYH bă̆ımlı değişken)}

Analizden elde edilen sonuçlar değerlendirildiğinde hem Panel FMOLS hem de Panel DOLS sonuçlarına göre uzun dönem katsayıları YOL için \%1 önem düzeyinde anlamlı ve işaretleri pozitiftir. Bu bulgulara göre yolsuzluğu temsil eden YOL değişkeni ekonomik büyümeyi temsil eden GSYH değişkenini pozitif yönde etkilemektedir. Dolayısıyla yolsuzluk endeksinde meydana gelen pozitif gelişmeler söz konusu ülkelerde ekonomik büyümeyi pozitif yönde etkilemektedir. Dikkat edilmesi gereken bir başka husus yolsuzluk endeksi üzerinedir. Buna göre yolsuzluk endeksinin metodolojisine bakıldığında endeksin yükselmesi, yolsuzluğun azalması anlamına gelmektedir. Dolayısıyla hem FMOLS hem de DOLS analizlerinden elde edilen bulgular neticesinde yolsuzluk endeksinin katsayısının pozitif ve anlamlı çıkması; yolsuzluk endeksinde meydana gelen artışın (söz konusu artış, ülkelerde yolsuzluğun azaldığı anlamına gelmektedir) ekonomik büyümeyi arttırdığı anlamına gelmektedir. Başka bir deyişle, yolsuzluk düzeyinin azalması (artması) ekonomik büyümeyi artırmaktadır (azaltmaktadır). Ayrıca her analizden de elde edilen sonuçların aynı olması modelin tutarlılı̆̆ı konusunda önem arz etmektedir.

\section{Sonuc}

Bu çalışmada 2001-2014 dönemi yıllık verileri ile yeni sanayileşmiş ülkelerde (Çin, Hindistan, Endonezya, Brezilya, Malezya, Tayland, Meksika, Güney Afrika ve Türkiye) yolsuzluk düzeyinin ekonomik büyüme üzerindeki etkisi panel veri analizi yöntemi araştırılmıştır. Uygulama sonuçlarına göre yolsuzluk düzeyi ile ekonomik büyüme arasında anlamlı bir ilişki gözlenmiştir. Ayrıca test sonuçlarına göre, yolsuzluk düzeyinin düşmesi söz konusu ülke grubunda ekonomik büyümeyi artırmaktadır. Bu sonuç literatürdeki Ehrlich ve Lui (1999), Salisu (2000), Sarkar ve Hassan (2001), Kutlar ve Doğanoğlu (2001), Mo (2001), Monte ve Papagni (2001), Mauro (2002), Toatu (2004), Drury ve diğ. (2006), Yakar ve Cebeci (2007), Aliyu ve Elijah (2008), Podobnik et.al. (2008), Göktan (2009), Halko ve Tzeremes (2010), Yüksel (2010), Johnson vd. (2011), Hodge vd. (2011), Uğur ve Dasgupta'ya (2011), Lisciandra ve Millemaci (2013), Dridi (2013), Johnson vd. (2014) gibi çalışmalarla desteklenmektedir. 
Çalışma genel olarak değerlendirildiğinde, yolsuzluk düzeyi ülke ekonomilerinin büyümesinde önemli bir göstergedir. Yolsuzluklar ekonomik büyümeyi artırmak için hem bir engel hem de dikkate alınması gereken bir sorun olarak ortaya çıkmaktadır. Bu sorunun çözümüne ilişkin uygulanacak politikalar ülkelerin ekonomik büyümelerine uzun dönemde katkı sağlayacaktır. Ayrıca yolsuzluk düzeyinin ekonomik büyüme üzerindeki etkisini ayrıntılı olarak analiz edilmesinde yatırımlar, beşeri sermaye, yapısal reformlar gibi etkileme kanalları da önem arz etmektedir. Bu çalışmanın, yolsuzluk ve ekonomik büyüme arasındaki ilişkiyi inceleyeceğimiz bundan sonraki çalışmalara öncü olması da ayrıca önemlidir.

\section{Kaynakça}

- $\quad$ Abed, George T., ve Hamid R. Davoodi 2000. Corruption, Structural Reforms, And Economic Performance in the Transition Economies", IMF Working Papers, p.1-47.

- Acemoglu, Daron, ve Thierry Verdier, 1998. "Property Rights, Corruption and the Allocation of Talent: A General Equilibrium Approach" The economic journal, 108(450), p.1381-1403.

- $\quad$ Toke S. Aidt, 2009. "Corruption, Institutions, and Economic Development" Oxford Review of Economic Policy, 25(2) p.271-291.

- Al-Sadig, Ali, 2009. The Effects of Corruption on FDI Inflows. Cato Journal, 29(2), p.267-294.

- Neşe Algan, Başak Gül Aktakaş, İpek Tekin, 2014. “Toplumsal Bir Mesele Olarak Yolsuzluk ve Büyüme İlişkisi: Türkiye Örneği”, Internatıonal Conference On Eurasıan Economıes, http://avekon.org/papers/996.pdf

- Ali, Nasrul, Grant Cullen ve Dominic Gasbarro, 2010. "The Coexistence of Corruption and Economic Growth in East Asia: Miracle or Alarm?”, Murdoch Business School.

- Aliyu, Shehu Usman Rano ve Akanni Oludele Elijah, 2008. "Corruption and Economic Growth in Nigeria: 1986-2007.", MPRA, p.1-20.

- Anoruo, Emmanuel ve Habtu Braha, 2005. "Corruption and Economic Growth: The African Experience" Journal of Sustainable Development in Africa 7(1), p.43-55.

- Ay, Ahmet, Oktay Kizilkaya ve Tuba Akar, 2016. "Gelismekte Olan Ülkelerde Yolsuzluk ve Demokrasi'nin DYY Üzerindeki Etkisi: Ampirik Bir İnceleme" Business and Economics Research Journal 7(3), p.73.

- Bardhan, Pranab.1997. "Corruption and Development: A Review of Issues" Journal of Economic Literature, 35(3), p.1320-1346.

- $\quad$ Beşel, Furkan ve Fatih Savaşan, 2014. "Türkiye’de Yapısal Kırılmalar Altında Yolsuzluk-Ekonomik Büyüme İlişkisi.", Kocaeli Üniversitesi Sosyal Bilimler Dergisi, 27, p.73-86.

- $\quad$ Busse, Matthias ve Carsten Hefeker, 2007. "Political Risk, Institutions and Foreign Direct Investment." European Journal of Political Economy 23(2), p.397-415.

- Caetano, José ve António Caleiro, 2009. "Is There a Relationship Between Transparency in Economic and Political Systems and Foreign Direct Investment Flows?" IUP Journal of Applied Economics, 8(2), p.45-58

- Castro, Conceição ve Pedro Nunes, 2013. "Does Corruption Inhibit Foreign Direct Investment?" Política. Revista de Ciencia Política, 51(1), p-61-83.

- Cuervo-Cazurra, Alvaro, 2008. "Better the Devil You Don't Know: Types of Corruption and FDI in Transition Economies." Journal of International Management, 14(1), p.12-27.

- Dahlström, Tobias ve Andreas Johnson, 2007. "Bureaucratic Corruption, MNEs and FDI" CESISElectronic Working Paper Series, 82, p.1-39.

- Della Porta, Donatella ve Vanucci, Alberto, 1999. “Corrupt Exchanges, Actors, Resources and Mechanisms of Political Corruption”, 1st Edition, New York, NY

- Del Monte, Alfredo ve Erasmo Papagni, 2001. "Public Expenditure, Corruption, and Economic Growth: The Case of Italy" European Journal of Political Economy, 17(1), p.1-16.

- Dridi, Mohamed, 2013. "Corruption and economic growth: the transmission channels.", MPRA, p.121-152.

- Cooper Drury, Jonathan Krieckhaus ve Michael Lusztig, 2006. "Corruption, Democracy and Economic Growth”, International Political Science Review, 27(2), p.121-136.

- Ehrlich, Isaac ve Francis T. Lui, 1999."Bureaucratic Corruption and Endogenous Economic Growth." Journal of Political Economy, 107(6), p.270-S293.

- Halkos, George Emm ve Nickolaos G. Tzeremes,2010. "Corruption and Economic Efficiency: Panel Data Evidence." Global Economic Review, 39(4), p.441-454.

- $\quad$ Andrew Hodge Sriram Shankar D. S. Prasada Rao ve Alan Duhs, 2011. "Exploring the Links Between Corruption and Growth", Review of Development Economics, 15(3), p.474-490. 
- James R. Hines, Jr. 1995. "Forbidden Payment: Foreign Bribery and American Business After 1977", National Bureau Of Economic Research (NBER) Working Paper, No:5266, p.1-21.

- Huang, Chiung-Ju, 2012. “Corruption, Economic Growth, and Income Inequality: Evidence from Ten Countries in Asia”, World Academy of Science, Engineering and Technology, 66, p.354-358.

- Gyimah-Brempong, Kwabena 2002. "Corruption, Economic Growth, and İncome İnequality in Africa", Economics of Governance, 3(3), p.183-209.

- Göktan Alper, (2009), "Yolsuzluğun Büyüme Üzerindeki Etkileri ve Yolsuzluğu Önleme Stratejileri”, Çimento İşveren, p. 20-27.

- Johnson, N. D., Ruger, W., Sorens, J., \& Yamarik, S. 2014. "Corruption, Regulation, and Growth: An Empirical Study of the United States, Economics of Governance, 15(1), p.51-69.

- Karagöz, Kadir, ve Murat Karagöz, 2010. "Yolsuzluk, Ekonomik Büyüme ve Kamu Harcamaları: Türkiye için Ampirik Bir Analiz" Sayıştay Dergisi, 76(1-3), p.5-22.

- Stephan Knack ve Philip Keefer, 1995. "Institutions And Economic Performance: Cross-Country Tests Using Alternative Institutional Measures”, Economics And Politics, 7(3), p.207-227.

- Kutlar Aziz ve Doğanoğlu Fatih, 2001. Türkiye'de 1980 Sonrası Yolsuzluklar, Kamu Yatırımları ve Büyüme Üzerine Bir Ekonometrik Çalışma, 5.Ulusal Ekonometri ve İstatistik Sempozyumu,10-12 Mayıs 2001.

- Lisciandra, Maurizio ve Millemaci, Emanuele, 2013. "A Panel Investigation on Corruption and Economic Growth: The Case of the Italian Regions”, Rassegna Economica, 1, p.169-185,

- Aparna Mathur ve Kartikeya Singh, 2013. "Foreign Direct Investment, Corruption and Democracy", Applied Economics, 45(8), p.991-1002.

- Mauro, Paolo, 1995. “Corruption And Growth”, Quarterly Journal Of Economics, 110(3), p.681-712

- Mauro, Paolo. 1996. "The Effects of Corruption on Growth, Investment, and Government Expenditure", IMF Working Papers, No 96/98, p.1-28.

- Mauro, Paolo. 2002. "The persistence of corruption and slow economic growth", IMF Working Papers, No 02/213, p.1-23.

- Mo, Pak Hung, 2001. "Corruption and Economic Growth”, Journal of Comparative Economics, 29(1), p.6679.

- $\quad$ Mo, Pak Hung, 2000. "Income Inequality and Economic Growth", Kyklos, 53(3), p.293-315.

- Del Monte Alfredo ve Erasmo Papagni, 2001. "Public Expenditure, Corruption and Economic Growth: The Case of Italy", European Journal of Political Economy, 17(1), 1-16.

- $\quad$ Leff, Nathaniel H. 1964."Economic Development Through Bureaucratic Corruption" American Behavioral Scientist, 8(3), p.8-14.

- Leite, Carlos A., ve Jens Weidmann. 1999. "Does Mother Nature Corrupt? Natural Resources, Corruption, and Economic Growth", IMF Working Papers, No 99/85, p.1-32.

- $\quad$ Leon, Tony. 2010. "The State of Liberal Democracy in Africa", Development Policy Analysis, 12, p.1-29.

- Podobnik, Boris, Jia Shao, Djuro Njavro, Plamen Ch. Ivanov ve H.E. Stanley,2008). "Influence of Corruption on Economic Growth Rate and Foreign Investment", The European Physical Journal B, 63, p.547-550.

- Powell, Benjamin, G.P. Manish ve Malavika Nair, 2010. "Corruption, Crime and Economic Growth", Handbook on the Economics of Crime, p.328-339.

- $\quad$ Primorac, Dinko ve Smoljic, Mirko, 2011. "Impact of Corruption on Foreign Direct Investment. Megatrend Review, 8(2), p.169-190.

- Huntington Samuel, P. 1968. "Huntington, Political Order in Changing Societies (New Haven, 1968)", Huntington Political Order in Changing Societies.

- Salisu, M., 2000. “Corruption in Nigeria”, Lancaster University, Management School, Working Paper, 2000/006, Lancaster, UK.

- Sarkar, Hiren ve M. Aynul Hassan, 2001. "Impact of Corruption on the Efficiency of Investment: Evidence from A Cross-Country Analysis", Asia-Pacific Development Journal, 8(2), p.111-116.

- $\quad$ Mushfiq us Swaleheen ve Stansel Dean, 2007. "Economic Freedom, Corruption, and Growth." Cato J. 27, p.343.

- Swaleheen, Mushfiq 2011. "Economic Growth with Endogenous Corruption: An Empirical Study", Public Choice, 146(1), p.23-41. 
- $\quad$ Shleifer, Andrei ve Robert W. Vishny, 1993. "Corruption." The Quarterly Journal of Economics, 108(3), p.599-617.

- $\quad$ Rose-Ackerman, Susan, 1997.. "Corruption and Development." Annual World Bank Conference on Development Economics.

- Rose-Ackerman, S., (1999). Corruption And Government: Causes, Consequences, And Reform, 1st Edition Cambridge, UK.

- Tanzi Vito, 1998. "Corruption around the World: Causes, Consequences, Scope, and Cures", Staff Papers, 45(4), p.559-594.

- Tanzi, Vito ve Hamid Davoodi, 1998. "Corruption, Public Investment, and Growth", The Welfare State, Public Investment, and Growth, Springer Japan, p.41-60.

- $\quad$ Toatu, T. 2004. "Corruption, Public Investment and Economic Growth: evidence from Pacific Island Countries”, PIAS-DG Governance Program Working Paper, University of South Pacific.

- Pope Jeremy, 1996. “Transparency Internatıonal”, The TI Source Book 1996. Berlin

- Uğur Mehmet ve Nandini Dasgupta, 2011. "Evidence on the Economic Growth Impacts of Corruption in Low-income Countries and Beyond: a Systematic Review", EPPI-Centre Social Science Research Unit, Institute of Education, University of London.

- Yakar Soner ve Kemal Cebeci, 2007. "Yolsuzluğun Ekonomik Büyümeye Etkileri Üzerine Teorik Bir İnceleme", Çimento Işsveren Dergisi, p.16-29.

- Yüksel Harun, 2010. "Yolsuzluk ve Ekonomik Büyüme”, Akademik Araştırmalar Dergisi, 43, p.41-47. 


\title{
Kırgızistan Bankacılık Sektöründe Maliyet Etkinliğini Etkileyen Faktörler
}

\author{
Factors Affecting Cost Efficiency in the Banking Sector of \\ Kyrgyzstan
}

\author{
Research Assistant, Dr. Dastan Aseinov (Kyrgyz-Turkish Manas University, Kyrgyzstan)
}

\begin{abstract}
Instabilities in the banking sector have had an adverse effect on the economy as a whole, since the largest share in the financial system and financial intermediation in Kyrgyzstan have been captured by banking sector. Economic efficiency in banking can be viewed as a source of financial stability of banking system. Economic efficiency of the banking is more important challenge not only for shareholders and managers of banks, and also for regulation and supervision authorities, and public and potential investors.

The aim of this study is to examine factors affecting the banking cost efficiency for Kyrgyz banks. It is also important to choose the appropriate approach in measurement of banking cost efficiency, since there are many different methods. In this study preferred stochastic frontier approach which assumes random error term which captures sampling, measurement and specification errors. We adopted stochastic cost frontier model proposed by Battese ve Coelli (1995) which also allow to examine investigate the impact of variables on efficiency.

We used unbalanced panel data set captured 17-23 Kyrgyz commercial banks for period of 2000-2013. Obtained results suggest that capitalization, foreign ownership, credit risk, liquidity risk and currency risk have most influence on cost efficiency scores of banks calculated averagely at level of 0,766. Overall results indicate that domestic banks more cost efficient than domestic private and foreign banks. Average cost efficiency scores of domestic banks, foreign and separately public banks are 0,848; 0,649 and 0,875, respectively.
\end{abstract}

\section{Giriş}

Çoğu durumlarda bankaların finansal ve iktisadi sağlamlığının ve güvenliğinin bir göstergesi olarak da ele alınabilen karlılığı doğrudan etkileyen belirleyici maliyetlerdir. Bankacılık maliyetleri mevcut koşullar altında banka sahipleri ve yöneticileri tarafından alınan kararların etkinliğinin bir göstergesidir. İşü̈cü, sermaye ve fonlar gibi girdilerin etkin kullanımı ve maliyetleri arttıran risklerin daha başarılı yönetimi ile bankaların iktisadi ve mali durumlarının güçlendirilmesi sektördeki istikrarına katkıda bulunabilir.

Kırgızistan'ın finansal sisteminin ve finansal aracılığın en çok payını kapsayan bankacılık sektöründeki istikrarsızlıklar ülke ekonomisini olumsuz yönde etkilemiştir. Dolayısıyla, büyük bir kısmı bankalardan oluşan Kırgızistan'ın finansal sektöründeki istikrarın belirleyicilerinden bankaların iktisadi etkinliği belirtilebilir.

Dışsal faktörleri etkileyerek bankacılık sektöründe gerçekleştirilen deregülasyonun amacı maliyetleri minimize etme, kaynakların etkin kullanılma ve kalitenin arttırılmasına yöneliktir (Goddard vd., 2014). Bundan hareketle bankaların etkinliklerindeki farklılıkların analizi hem bankaların hem de uygulamanın sonuçlarından genel politika çıkarımları yapan taraflar için önemlidir (Kök ve Deliktaş, 2003:46). Bankacılık faaliyetinin etkinliğgi esas alınarak elde edilen araştırma sonuçları ve bulgular, düzenleyici ve gözetim otoriteleri tarafından bankacılık sektörüne yönelik politika geliştirilmesinde kullanılabilir bilginin üretimini destekleyebilir. Bu açıdan ele alındığında Kırgızistan bankacılık sektöründeki bankaların finansal aracılıktaki maliyet etkinliğini etkileyen etkenlerin araştırılması önem taşımaktadır.

Bu çalışmamızda Kırgızistan’daki bankaların finansal aracılık faaliyetinin iktisadi bir göstergesi olarak değerlendirilen maliyet etkinliğini etkileyen faktörlerin tesirinin araştırılması amaçlanmıştır. Bu amaç doğrultusunda, Kırgızistan bankacılık sektöründe maliyet etkinliğinin ölçülmesinde izlenebilecek yaklaşımlardan Stokastik Sınır Yaklaşımı (SSY) ve risk alma eğilimi, büyüklük, sahiplik yapısı, dışsal çevre gibi etkenlerin maliyet etkinliği üzerindeki etkisinin incelenmesine imkan sağlayan Battese ve Coelli (1995) tarafından önerilen model uygulanmıştır.

\section{Literatür}

Bu çalışmada uygulanan Stokastik Sınır Yaklaşımı (SSY), 1990'lardan sonraki dönemlerde farklı ülkelerin bankacılık sektöründe yoğun uygulanan yöntemlerden biridir. Ancak, eski Sovyetler cumhuriyeti geçiş ekonomilerinde SSY uygulanan çalışmalar yeterli sayısı sınırlıdır.

Sovyet blokundan ortaya çıkan BDT, Doğu Avrupa, Baltık ülkelerinin bankacılık sektörü üzerine SSY uygulanan çalışmalar mevcuttur (Mertens ve Urga, 2001; Grigorian ve Manole, 2002; Kasman ve Yildirim, 2006; Maslak ve Buryak, 2009; Delis vd., 2011; Kumar ve Gulati, 2014; Djalilov ve Piesse, 2014; Glass vd., 2014). Fakat geçiş ekonomilerindeki bankacılık sektörünü araştıran bu tür çalışmalarda Kırgızistan bankalarının dahil edilmemesinin 
başlıca nedeni Bankscope veri tabanında Kırgızistan bankalarına ait verilerin yetersiz olması gösterilebilir. Bu çalışmamızda ise gazete arşivlerinde ve bankaların resmi sitelerinde yayınlanmış veriler kullanılmıştır.

Kırgızistan'ın bankacılık sektörünün etkinliği üzerine son dönemleri kapsayan çalışmaların yeterli olmaması ve bu çalışmalarda (Khadjimouratov, 2004; Keleş, 2011; Abdyzhaparov, 2013; Cheng vd., 2013) uygulanan yöntemlerin farklı olması konunun ve yöntemin belirlenmesinde önemli etkenlerden biri olmuştur.

Djalilov ve Piesse (2014)'de diğer Orta Asya ve Baltık ülkelerindeki bankaların verileri ile birlikte Kırgızistan'daki sadece 3 bankanın kar etkinliği SSY ile ölçülmüştür. Bilindiği kadar Djalilov ve Piesse (2014) Kırgızistan bankalarının kar etkinliğinin ölçülmesinde SSY kullanılan tek çalışmadır.

Sadece Kırgızistan bankalarının araştırılması; hem zaman hem de banka sayısı açısından daha geniş veri setinin kullanılması ve maliyet etkinliğinin araştırılması Djalilov ve Piesse (2014)'in çalışmasından bu çalışmanın esas farkını ortaya koymaktadır.

\section{Yöntem ve Model}

\subsection{Yöntem}

Bu çalışmada bankaların maliyet etkinliğinin ölçülmesinde parametrik ve ekonometrik yaklaşım olarak bilinen ve ilk olarak Meeusen ve van den Broeck (1977)'un, ve Aigner vd. (1977)'in çalışmalarında önerilmiş olan Stokastik Sınır Yaklaşımı tercih edilmiştir. Bu çalışmalarda, tesadüfi yapı hesaba alınmadan etkinlik sınırının hesaplanması yanıltıcı olabileceği belirtilerek SSY önerilmektedir. Aigner vd., (1977) tarafından tanımlanan SSY'nın temel (baz) modeli aşağıdaki gibidir:

$$
\begin{aligned}
y_{i}=f\left(x_{i}, \beta\right)+\varepsilon_{i} & , \quad i=1,2,3, \ldots, I \\
\varepsilon_{i}=v_{i}-u_{i} & , \quad u_{i} \geq 0, \quad i=1,2,3, \ldots, I \\
y_{i}=f\left(x_{i}, \beta\right)+v_{i}-u_{i} & ,
\end{aligned}
$$

Burada $y_{i}$, i. firmanın üretilen çıktı miktarını; $x_{i}$, i. firmanın (1xK)'lık girdi vektörünü; $\beta$, tahmin edilmesi gereken ve bilinmeyen parametreler vektörünü; $\varepsilon_{i}, N\left(0, \sigma_{\varepsilon}^{2}\right)$ dağılan kompozit (birleşik) hata terimini; $\mathrm{v}_{\mathrm{i}}$, bağımsız ve simetrik $N\left(0, \sigma_{v}^{2}\right)$ dağıllım gösteren ve verilerdeki gürültüyü ve genellikle beyaz gürültü şeklinde belirtilen rassal hata terimini (Kumar ve Gulati, 2014:98) ve/veya spesifikasyon hataların (Belotti vd., 2013:722), banka yönetiminin kontrolü dışında belirlenen, beklenmeyen, verilerdeki veya ölçüm hatasından kaynaklanan rassal faktörlerin etkisi sonucunda meydana gelen bankanın çıktısındaki artış veya düşüşleri (Isik ve Hassan, 2002:262); $u_{i}$ ise negatif değer almayan ve sıfırda kesilmiş $N^{+}\left(0, \sigma_{u}^{2}\right)$ dağılımından türetilen ve asimetrik tek taraflı yarı normal dağılım gösteren (Kasman, 2003:86) etkinsizliği temsil eder. Hata terimi ve etkinsizlik ölçüleri birbirinden bağımsız dağılıma sahip rassal değişkenlerdir. Kavramların karıştırılmasından kaçınmak amacıyla, $v_{i}$ 'nin iki taraflı hata terimi veya istatistiki gürültü; $u_{i}$ etkinsizlik terimi veya etkinsizlik bileşeni; $\varepsilon_{i}$ kompozit (birleşik) hata terimi olarak belirtilmiştir.

\subsection{Model}

Panel verilere uygulanabilecek birçok alternatif modellerin olmasına rağmen, yazındaki çalışmaların çoğunda Battese ve Coelli (1995)'nin "etkinlik etkileri" modeli ve son yıllarda yaygınlaşan Greene (2005a,b)'in "gerçek" sabit etkiler ve "gerçek" rassal etkiler modelleri uygulanmıştır (Duygun vd., 2014; Spulbăr vd., 2015).

Battese ve Coelli (1995)'nin modelinde firma etkileri (heterojenlik) etkinsizlik ile karışımı ele alınmaktadır. Simetrik rassal hata, etkinlik ve firma etkisi olmak üzere üç bileşene ayrılmasına imkan sağlayan Greene (2005a,b)'in "gerçek" sabit etkiler ve "gerçek"sabit etkiler modellerinde zamanla değişmeyen heterojenliğin tümü zamanla değişmeyen etkiler olarak varsayılmaktadır. Bunun sonucunda, etkinlik ölçüleri olduğundan daha yüksek (1'e yakın) ve bankalar arasında da birbirine çok yakın (neredeyse eşit) düzeylerde hesaplanmaktadır. Bu soruna karşı çözüm olarak Shen vd. (2009)'da bankalara özgü değişkenlerin etkisi vasıtasıyla bankalar arasındaki heterojenlik hesaba alınabilen Battese ve Coelli (1995)'nin modeli önerilmiştir.

$\mathrm{Bu}$ çalışmada farklı modellerden esnekliği, yazılım programları ile uygulanabilirliği ve dengesiz panel verilere uygulanabilirliği dikkate alınarak yazındaki çalışmalarda yaygın olarak kullanılan Battese ve Coelli (1995)'nin modeli tercih edilmiştir. Kırgızistan bankaları için belirlenmiş girdi fiyatları ve çıktı miktarları değişkenlerine göre, Battese ve Coelli (1995) tarafindan önerilen stokastik maliyet sınırı modelinin transcendental logaritmik (translog) fonksiyonel formundaki fonksiyonunun açık formu bu şekilde yazılabilir: 


$$
\begin{aligned}
& \ln T C_{i t}=\alpha+\sum_{m=1}^{M} \beta_{m} \ln Q_{m i t}+\sum_{n=1}^{N} \gamma_{n} \ln W_{n i t}+1 / 2\left(\sum_{m=1}^{M} \beta_{m m}\left(\ln Q_{m i t}\right)^{2}+\sum_{n=1}^{N} \gamma_{n n}\left(\ln W_{n i t}\right)^{2}\right) \\
& +\sum_{m=1}^{M} \sum_{r=1}^{R} \sum_{m \neq r}^{M, R} \beta_{m r} \ln Q_{m i t} \ln Q_{r i t}+\sum_{n=1}^{N} \sum_{s=1}^{S} \sum_{n \neq s}^{N, S} \gamma_{n s} \ln W_{n i t} \ln W_{s i t} \\
& +\sum_{m=1}^{M} \sum_{n=1}^{N} \varphi_{m n} \ln Q_{m i t} \ln W_{n i t}+u_{i t}+v_{i t}
\end{aligned}
$$

Bu denklemdeki $\ln T C_{i t}, \ln Q_{m i t}, \ln W_{\text {nit }}$, $i$. bankanın $t$. dönemindeki (sırasıyla) toplam maliyetini (faiz, faiz dışı ve operasyonel maliyetlerin toplamı), $m$. çıktısının miktarı, $n$. girdisinin fiyatının doğal logaritmalarını; $\alpha, \beta, \gamma, \varphi$ ise tahmin edilecek parametreleri $u_{i t}$ ve $v_{i t}$ sırasıyla etkinsizlik terimini ve beyaz (istatistiki) gürültüyü ifade etmektedir.

Belirtilen denklemde, $u_{i t}$ bağımsız, ancak özdeşçe simetrik olmayan dağılan etkinsizlik terimi $v_{i t}$ ve $\omega_{i t}$ beyaz (istatistiki) gürültü veya rassal hata; $\sigma_{u}^{2}$ ve $\sigma_{v}^{2}$ ile sırasıyla $u_{i t}$ ve $v_{i t}$ 'nin varyansları $z_{i t}$ ile etkinsizlik terimini etkileyen bankaya özgü ve dişsal değişkenleri $\xi$ ile tahmin edilecek katsayıların vektörü gösterilmiştir.

\section{Değişkenler ve Veri Seti}

Çoğu çalışmalarda bankaların girdi ve çıktı değişkenlerinin belirlenmesinde neoklasik firma teorisi çerçevesinde Sealey ve Lindley (1977) tarafindan önerilen ve temel rolünün finansal aracılık olduğunu öne çıkaran finansal aracılık yaklaşımı izlenmiştir. Bu yaklaşıma göre bankaların emek ve fiziki sermaye kullanarak mobilize ettiği mevduatları ve borçlanarak ulaştığı diğer fonları gelir getiren varlıklara dönüştürdüğü ve veri olan girdi fiyatları dikkate alınarak veri olan çıktı düzeyinin üretimi için çıktıların girdi miktarlarının optimum bileşimlerini kullanmaya çaba gösterdikleri varsayılmaktadır (Berger ve De Young, 1995; Altunbas vd., 2000; Casu ve Girardone, 2005; Chen vd., 2015).

Fakat bu yaklaşımda bankaların hesap açma, banka kartları çıkarma, havale işlemleri gibi hizmetler sunduğu ihmal edilmesinden dolayı (Kumar ve Gulati, 2014:246), yazındaki bazı çalışmalar (Altunbas vd., 2000; Nigmonov, 2010; Mamonov, 2013; Dong vd., 2015) izlenerek Kırgızistan bankalarının girdi ve çıktıları emek ve fiziki sermayenin faiz dışı gelir getiren faaliyetlerin gerçekleştirilmesi için de kullanıldığını esas alan varlıklar yaklaşımının modifiye (Tente, 2010:67) veya Matthews vd. (2009)'de belirtildiği gibi, genişletilmiş (hibrid) varlıklar yaklaşımına göre belirlenmiştir. $\mathrm{Bu}$ yaklaşıma göre üçüncü bir çıktı olarak bankaların bilanço dışı işlemlerinden elde edilen gelirleri de kapsayan faiz dışı gelirleri belirlenmiştir.

\subsection{Girdiler ve Çıktılar}

Bankaların girdileri olarak emek, sermaye, mevduatlar ve satın alınan diğer fonlar şeklinde belirlenmiştir. Maliyet fonksiyonunda girdi miktarlarından ziyade girdi fiyatları kullanılmaktadır. Emeğin fiyatı $\left(W_{l}\right)$ toplam personel giderlerinin toplam varlıklara oranı, fiziki sermayenin fiyatı $\left(W_{2}\right)$ operasyonel giderlerden personel giderlerinin çıkartılmasından sonraki giderlerin duran varlıkların bilanço değerine oranı, üçüncü bir girdinin fiyatı $\left(\mathrm{W}_{3}\right)$ toplam faiz giderlerinin finansal fonlara oranı şeklinde ölçülerek kullanılmıştır.

Yazındaki bazı çalışmalar (Casu ve Girardone, 2005:1056; Koetter, 2006; Košak vd., 2009; Nigmonov, 2010:10) izlenerek çıktılar olarak bankanın müşterilere ve diğer finansal kurumlara sağlanan kredilerden KKR'lerin çıkartılması sonucundaki elde edilen net krediler $\left(Q_{1}\right)$, bankaların bilançosunda kaydedilmiş menkul kıymetler ve yatırımlar $\left(\mathrm{Q}_{2}\right)$, bankacılık faaliyetinin diğer kollarını da kapsayan diğer bir çıktı türü olarak faiz dışı gelirler $\left(\mathrm{Q}_{3}\right)$ belirlenebilmiştir.

\subsection{Dışsal Değişkenler}

Aynı ülkedeki bankalar etkinliğinin tek etkinlik sınırına göre ölçülmesi durumunda banka özelliklerini kapsayan kontrol değişkenlerin modele yerleştirilmesiyle bankalar arası heterojenlik sorununun azaltılması mümkün olabilmektedir. Bankaların maliyetleri ve karları, dolayısıyla iktisadi etkinliklerini etkilediği varsayılan değişkenleri bankalarca kontrol edilebilir (bankaya özgü) ve kontrol edilemeyen (dışsal) değişkenler olarak ayırmak mümkündür.

\subsection{Veri Seti}

Bu çalışmada 2000-2013 döneminde faaliyette bulunan 17-23 ticari bankaya ait yıllık ve dengesiz panel veri seti kullanılmıştır. Veriler ticari bankalarca gazetelerde ve resmi internet sitelerinde yayınlanmış bilanço ve gelir tablosundan temin edilmiştir. Makroiktisadi ve bankacılık sektörü değişkenleri ile ilgili verilerin temin edilmesinde KCMB ve Dünya Bankası veri tabanlarından yararlanılmıştır. Kullanılan veri setine ait bilgi ve betimsel istatistikler Tablo 1.'de sunulmuştur. Bin Som olarak gösterilmiş olan toplam maliyetlerin ve çıktı miktarlarının GSYİH deflatörüne göre reelleştirilmiş değerleri kullanılmıştır. 


\begin{tabular}{|c|c|c|c|c|c|}
\hline $\begin{array}{l}\text { Değişken } \\
\text { notasyonu }\end{array}$ & Açıklama & Ortalama & $\begin{array}{l}\text { Standart } \\
\text { sapmas1 }\end{array}$ & Min. & Maks. \\
\hline$T C$ & $\begin{array}{l}\text { Toplam maliyetler }=\text { toplam faiz giderleri }+ \text { toplam faiz } \\
\text { diş1 giderler }+ \text { toplam operasyonel giderler, (bin Som)* }\end{array}$ & 202592 & 438802 & 6105 & 4314728 \\
\hline$Q_{1}$ & $\begin{array}{l}\text { Toplan net krediler }=\text { müssterilere ve diğer finansal } \\
\text { kurumlara sağlanan krediler }-\mathrm{KKR} \text {, (bin Som)* }\end{array}$ & 459825 & 562301 & 520 & 3343711 \\
\hline$Q_{2}$ & Menkul kıymetler, (bin Som)* & 133911 & 241526 & 0.3 & 1921961 \\
\hline$Q_{3}$ & Faiz diş1 gelirler (bin Som)* & 46568 & 72651 & 150.9 & 714200 \\
\hline$W_{1}$ & $\begin{array}{l}\text { Emeğin fiyat1 }=\text { toplam personel giderleri/toplam } \\
\text { varlıklar* }\end{array}$ & 0.0422 & 0.0220 & 0.0006 & 0.1269 \\
\hline$W_{2}$ & $\begin{array}{l}\text { Fiziki sermayenin fiyat } 1=(\text { operasyonel giderler - toplam } \\
\text { personel giderleri)/duran varlıklar* }\end{array}$ & 1.0992 & 1.8931 & 0.108 & 24.6168 \\
\hline$W_{3}$ & $\begin{array}{l}\text { Satın alınan fonların fiyatı = toplam faiz giderleri/toplam } \\
\text { fonlar (vadeli mevduatlar + borçlanma)* }\end{array}$ & 0.0479 & 0.0380 & 0.001 & 0.2539 \\
\hline CAR & Ödenmiş özsermaye / toplam varlıklar* & 0.2739 & 0.1405 & 0.071 & 0.9246 \\
\hline$L I Q R$ & Likit varlıklar/toplam varlıklar* & 0.2954 & 0.1613 & 0.0008 & 0.8493 \\
\hline FOREIGN & $\begin{array}{l}\text { Sahiplik yapısı kukla değişkeni. Ödenmiş sermayesinin } \\
\% 50 \text { 'si ve üzeri payı yabancı kişilere ait ise 1, diğerleri için } \\
\text { s1fir olarak oluşturulan kukla değişken* }\end{array}$ & 0.4179 & 0.4941 & 0.000 & 1.0000 \\
\hline SPREAD & Faiz oran $1=$ kredi faiz oran $1-$ mevduat oran $1, \% * *$ & 24.0 & 5.4102 & 17.1 & 41.3 \\
\hline$G D P \_G R W$ & $\begin{array}{l}2005 \text { sabit fiyatlar ile GSYİH'nın yıllık büyüme oranı, \% } \\
* *\end{array}$ & 4.6310 & 3.6165 & -0.5 & 10.9 \\
\hline$S T D E V_{-} F X$ & $\begin{array}{l}\text { ABD dolarının değişim kur oranı varyansı, 2000-2009- } \\
\text { y1lları için haftalık veriler, 2010-2013 yıllar için günlük } \\
\text { veriler ile hesaplanmıştır*** }\end{array}$ & 0.9444 & 0.4150 & 0.2000 & 1.7000 \\
\hline LNTA & Banka büyüklüğ̈̈=Toplam varlıkların doğal logaritması* & 13.8014 & 1.3335 & 10.446 & 16.9127 \\
\hline SLLR & $\begin{array}{l}\text { Sorunlu krediler ile ilgili kayıp ve zararların karşılanması } \\
\text { için oluşturulan KKR /net krediler* }\end{array}$ & 0.0596 & 0.1458 & 0.000 & 1.5193 \\
\hline
\end{tabular}

Not: Min.: minimum dĕgeri; Maks.: maksimum değeri

Tablo 1. Kırgızistan'daki Ticari Bankalarına, Bankacllık Sektörüne Ait Betimleyici İstatistikler Kaynak: Resmi Gazeteler ve Bankaların Resmi Sitesinde Yayılanan Finansal Raporlar (*), Dünya Bankası (**), Kırgız Cumhuriyeti Merkez Bankası (***).

\section{Analiz Sonuçları}

Maksimum olabilirlik tahmincilerinin alternatif tahmincilere göre asimptotik olarak daha etkin olması (Košak vd., 2009), bankaya özgü etkinlik ölçülerinin elde edilebilmesine imkan sağlaması (Hassan, 2008:362) ve dağılımlar ile ilgili bilgilerin kullanılabilmesi SSY modelleri tahmin edilen çalışmalarda daha çok maksimum olabilirlik yönteminin tercih edilmesine neden olmuştur (Lampe ve Hilgers, 2015:2). Bu yönteme göre, gözlemlenen değerlerin gerçekleşme olasılığını mümkün olduğunca yüksek yapan etkinlik sınırı fonksiyonunun parametrelerin vektörü seçilmektedir (Bogetoft ve Otto, 2011:198). Bu çalışmada uygulanan Battese ve Coelli (1995)'nin modelinin tahmin edilmesinde maksimum olabilirlik yöntemi uygulanmıştır.

Dualite teoremi, maliyet fonksiyonunda yer alan girdi fiyatlarının doğrusal homojenliğini ve ikinci dereceden parametrelerin simetrik olmasını gerektiğinden dolayı, fonksiyon parametrelerine bu şekildeki şartların sağlanmasını gerektirmektedir: $\sum_{n=1}^{N} \gamma_{n}=1, \sum_{n=1}^{N} \sum_{s=1}^{S} \gamma_{n s}=0, \sum_{m=1}^{M} \sum_{n=1}^{N} \varphi_{m n}=0$. Maliyet fonsiyonunda girdi fiyatlarındaki doğrusal homojenlik şartı $T C_{i t}$, $W_{1 i t}$ ve $W_{2 i t}$ 'nin $W_{3 i t}$ 'e bölünmesi şeklinde dönüşüm ile sağlanmıştır. İlgili parametrelerde $\gamma_{n s}=\gamma_{s n}, \beta_{m r}=\beta_{r m}$ şeklindeki kısıtın sağlanması ile simetrik şartı yerine getirilmiştir.

Tahmin edilen modele ait parametre sonuçları Tablo 2.'de sunulmuştur. Tablonun ilk kısmında maliyet sınır fonksiyonunda yer alan değişkenler ile ilgili tahmin sonuçlarını betimleyen istatistiki bilgiler sunulmuştur.

Tahmin sonuçlarına göre, $\beta_{2}$ hariç girdi fiyatları ve çıktı miktarlarına ait katsayıların tümü pozitif işaretli ve \%1 düzeyinde istatistiksel olarak anlamlıdır. Tahmin edilen katsayıların işaretinin pozitif olması iktisadi teoriye ve beklentilerimize uyumluluk sağlamaktadır. Girdi fiyatları ve çıktıların ikinci dereceden katsayıları ve çapraz çarpımlarına ait katsayıların çoğu en az \%10 düzeyinde istatistiki olarak sıfırdan farklıdır.

Tahmin edilen katsayıların büyüklüğüne göre, bankaların maliyetlerini arttırma yönünde en büyük ölçüde etkileyen değişkenler faiz dışı gelirlerin hacmi $(\ln Q 3)$, işgücü fiyatı $(\ln W 1)$ ve fon kaynaklarının fiyatıdır $(\ln W 2)$. 


\begin{tabular}{|c|c|c|c|c|c|c|c|}
\hline Değişken & Parametre & değeri & t-değgeri & Değişken & Parametre & değgeri & t-dĕgeri \\
\hline \multicolumn{8}{|c|}{ Maliyet Sınırı Denklemi } \\
\hline $\ln Q_{1}$ & $\beta_{1}$ & $0.398 * * *$ & $(3.64)$ & $\ln Q_{1} \ln W_{2}$ & $\varphi_{12}$ & $0.0777 * * *$ & $(4.13)$ \\
\hline $\ln Q_{2}$ & $\beta_{2}$ & $0.0800 * *$ & $(2.06)$ & $\ln Q_{2} \ln W_{1}$ & $\varphi_{21}$ & 0.0000729 & $(0.01)$ \\
\hline $\ln Q_{3}$ & $\beta_{3}$ & $0.731^{* * *}$ & (12.14) & $\ln Q_{2} \ln W_{2}$ & $\varphi_{22}$ & 0.0133 & (1.19) \\
\hline $\ln W_{l}$ & $\gamma_{1}$ & $0.659 * * *$ & $(6.52)$ & $\ln Q_{3} \ln W_{1}$ & $\varphi_{31}$ & -0.0164 & $(-0.85)$ \\
\hline $\ln W_{2}$ & $\gamma_{2}$ & $0.593 * * *$ & $(7.69)$ & $\ln Q_{3} \ln W_{2}$ & $\varphi_{32}$ & $-0.0237 *$ & $(-1.71)$ \\
\hline $\ln Q_{1} \ln Q_{1} / 2$ & $\beta_{11}$ & $0.0419 *$ & $(1.87)$ & $\ln W_{2} \ln W_{1}$ & $\gamma_{21}$ & $-0.112 * * *$ & $(-5.14)$ \\
\hline $\ln Q_{2} \ln Q_{2} / 2$ & $\beta_{22}$ & $0.0128 * * *$ & $(5.54)$ & $\ln Q_{1} \ln Q_{2}$ & $\beta_{12}$ & $-0.041 * * *$ & $(-5.27)$ \\
\hline $\ln Q_{3} \ln Q_{3} / 2$ & $\beta_{33}$ & $0.151 * * *$ & $(12.75)$ & $\ln Q_{1} \ln Q_{3}$ & $\beta_{13}$ & -0.00102 & $(-0.06)$ \\
\hline $\ln W_{I} \ln W_{l} / 2$ & $\gamma_{11}$ & $0.173 * * *$ & $(6.28)$ & $\ln Q_{2} \ln Q_{3}$ & $\beta_{23}$ & -0.00499 & $(-0.98)$ \\
\hline $\ln W_{2} \ln W_{2} / 2$ & $\gamma_{22}$ & $0.164 * * *$ & $(7.21)$ & Sabit & $\alpha$ & $3.119 * * *$ & $(13.96)$ \\
\hline $\ln Q_{1} \ln W_{1}$ & $\varphi_{11}$ & -0.0271 & $\begin{array}{r}(- \\
1.57)\end{array}$ & & & & \\
\hline \multicolumn{8}{|c|}{ Etkinsizlik Etkileri Denklemi } \\
\hline CAR & $\xi_{1}$ & $-3.043 * * *$ & $(-2.99)$ & STDEV_FX & $\xi_{6}$ & $0.669 * *$ & $(2.46)$ \\
\hline$L I Q R$ & $\xi_{2}$ & $0.798^{*}$ & $(1.81)$ & $L N T A$ & $\xi_{7}$ & $-0.140 *$ & $(-1.68)$ \\
\hline FOREIGN & $\xi_{3}$ & $1.494 * * *$ & $(3.71)$ & $S L L R$ & $\xi_{8}$ & $0.863 * *$ & $(2.21)$ \\
\hline SPREADWB & $\xi_{4}$ & $0.0599 * * *$ & $(3.10)$ & Sabit & $\xi_{0}$ & -0.514 & $(-0.33)$ \\
\hline$G D P \_G R W$ & $\xi_{5}$ & $-0.0836^{* *}$ & $\begin{array}{r}(- \\
2.54)\end{array}$ & & & & \\
\hline
\end{tabular}

(1) Maliyet sınırı denkleminde bă̆ımlı değişken: InTC; etkinsizlik etkileri denkleminde: etkinsizlik ölçüsünün beklenen değeri

\section{Tablo 2. Maliyet SSY Stokastik Maliyet Etkinlik Sınırı Tahmin Sonuçları}

Faiz dışı gelirlerdeki \%1'lik artış diğer değişkenler sabit iken ortalama olarak toplam maliyetlerdeki \%0,73'lük artışa neden olmaktadır. Diğer bir ifade ile Kırgızistan'daki bankaların faiz dışı gelirlerin kaynağı olan bankacılık ürünlerinin üretimi kredi ve menkul kıymetler portfoyünü oluşturma ve bulundurmaya göre daha çok maliyetlere neden olduğuna dair sonuçlar elde edilmiştir. Son yıllarda Kırgızistan bankacılık sektöründe uygulanmaya başlayan POS terminal, ATM, internet bankacılı̆̆ı, mobil bankacılık gibi bankacılık hizmetlerinin üretimi daha çok uzun dönem yatırımlar gerektirmektedir. Bu değişkenin katsayısı, havale, ödeme işlemleri, bankamatik kartların ihracı gibi faiz dışı faaliyetler işgücü ve fiziki sermaye gerektirdiğinden daha çok maliyetlere neden olmasının sonucu olarak değerlendirilebilir.

İşgücü fiyatı ve kredilerin miktarındaki değişim, sırasıyla fon kaynaklarının fiyatı ve menkul kıymet ve diğer yatırımların miktarındaki değişime göre toplam maliyetleri daha çok oranda etkilediğine dair elde edilen sonuçlar, Kazakistan (Glass vd., 2014), Rusya (Styrin, 2004; Mamonov, 2013), ve bazı geçiş ekonomilerinin (Staikouras vd., 2008) bankacılık sektörleri araştırılan çalışmaların sonuçlar ile tutarlı bulunmuştur.

Sonuçlara göre, bankacılığın temel ve geleneksel çıktısı olan kredilerin hacmindeki değişim faiz dışı gelirlerdeki değişime göre analiz edilen bankaların maliyetlerini daha az oranda etkilemiştir. Kredi portföyünün hacminin (lnQ1) maliyetler üzerindeki göreceli daha düşük düzeyde olması, bankaların ölçek ekonomisi, uzmanlaşma ve diğer avantajlardan yararlanarak bu çıtı türünün üretimini daha düşük maliyetler ile gerçekleştirebildiklerinin bir sonucu olabilir.

Maliyetlerdeki artışı en az ölçüde (0,08-086) pozitif yönde etkileyen bankacılık çıktısı olarak menkul kıymetler portföyü hacmi (lnQ2) tahmin edilmiştir. Kırgızistan'da menkul kıymetler piyasasının az gelişmiş olması ve bankaların daha risksiz ve düşük maliyetli devlet tahvilleri ve bonoları üzerinden işlem yürüttüklerinin sonucu olabilir.

Çıktıların ve girdi fiyatlarının ikinci dereceden (çapraz çarpımları ve kareleri) değişkenlerine ait katsayıların bazıları istatistiki olarak anlamsız bulunmuştur. Tahmin edilen bu katsayıların çoğunluğunun özellikleri Eski Sovyetler ülkeleri bankacılık sektörleri için elde edilen önceki çalışmalardaki (Pilyavskyy vd., 2012; Pestova ve Mamonov, 2013; Glass vd., 2014) bulgular ile tutarlıdır. Çıktı miktarlarının çapraz çarpımlarının katsayılarının negatif bir değer alması bu çıktı türlerinin birbirini tamamlayıcı ürünler olduğunu, dolayısıyla birleşik şekilde üretimi maliyetleri azaltabileceğini göstermektedir. Örneğin, $\ln Q 1 \ln Q 2$ değişkenine ait tahmin edilen katsayının işaretine göre kredi portföyü ve menkul kıymetler birbirini tamamlayan çıktı türleridir.

Stokastik sınır modellerinin geçerliliğinin sınanmasında kullanılabilir diğer bir önemli parametre Jondrow vd. (1982) tarafindan önerilen ve $\lambda=\sigma_{u} / \sigma_{v}$ förmülüne göre hesaplanan lambda $(\lambda)$ değeridir. Tablo 2.' de raporlanan $\lambda$ değerinin istatistiki olarak anlamlı ve 1 'den büyük elde edilmesi, kompozit hata terimindeki değişimlerin büyük 
kısmının (0.76) maliyet etkisizliğinden kaynaklandığını, dolayısıyla stokastik sınır modeli tanımlamasının geçerliliği olduğunu desteklemektedir.

Tablo 2.'nin ikinci kısmında ise etkinsizlik teriminin beklenen değeri üzerinde etkilediği varsayımı ile maliyet sınır fonksiyonu ile eş anlı olarak tahmin edilen Etkinsizlik Etkileri denklemine ait sonuçlar sunulmuştur. İncelenmiştir. Raporlanmış tahmin sonuçlarına göre, modelde belirlenen değişkenlerden $C A R, F O R E I G N, S L L R$, $L I Q R$ ve STDEV_FX diğer değişkenlere göre etkinsizliğin beklenen değerini daha büyük oranda etkilemiştir.

CAR'a ait katsayının negatif işareti banka sermayeleşmesindeki artışların etkinsizlikteki azalmalar ile ilişkili olduğunun ve "ahlaki tehlike" hipotezinin (Berger ve De Young, 1995) Kırgızistan bankalarında geçerliliğinin bir göstergesi şeklinde yorumlanabilir. Daha yüksek sermayeleştirilmiş bankaların maliyetlerinin banka sahiplerinin sıkı kontrolü altında olması ve banka yönetiminin maliyetlerin ve üretim sürecinin daha etkin yönetmesi ile açıklanabilir. Bu sonuçlar yazındaki bazı çalışmaların sonuçları ile tutarlıdır (Fiordelisi vd., 2011; Radic vd., 2012). Varlıkların büyük kısmı sahiplerin sermayesi ile finanse edilmiş bankalar daha az riskli varlıklar edinme eğiliminde olduğundan dolayı bu bankaların sorunlu kredilerle ile ilgili maliyetleri göreceli daha az ve hesaplanan maliyet etkinlik ölçüleri daha yüksek olmaktadır.

Bankalarda yabancı sermayenin etkinsizlik üzerinde negatif etkisinin olduğunu destekleyen bazı çalışmalardan (Bonin vd., 2005; Fries ve Taci, 2005) farklı olarak FOREIGN'in katsayısı pozitif olduğuna dair sonuçlar elde edilmiştir. Katsayısının istatistiki olarak anlamlı ve pozitif işaretli olması, yabancı sermayeli bankaların ortalama maliyet etkinliklerinin yerel sermayeli bankalara göreceli olarak daha düşük olduğu ifade edilebilmekte. Kamu bankaları dahil yerel bankalar, kamu bankalar ayrıca ve yabancı sermayeli bankalar olmak üzere üç gruba ait maliyet etkinlikleri Tablo 3.'te sunulmuştur. Kamu bankalarına ait maliyet etkinliği ölçülerinin göreceli olarak daha yüksek olması kamu bütçesinden sübvansiyonlar şeklindeki ucuz finansal fon kaynaklardan yararlanma imkanına sahip olması ile açıklanabilir.

\begin{tabular}{lccccc}
\hline Sahiplik yapısına göre & N & Ortalama & SS & Min & Max \\
\hline Yerel bankalar & 156 & 0.848 & 0.112 & 0.268 & 0.973 \\
Yabanc1 bankalar & 110 & 0.649 & 0.214 & 0.134 & 0.949 \\
Kamu bankaları & 28 & 0.875 & 0.094 & 0.614 & 0.963 \\
\hline
\end{tabular}

N: gözlem saylsl; SS: standart sapma; Min ve Max: strasıyla minimum ve maksimum değerleri

\section{Tablo 3. Sahiplik Yapısına Göre Bankaların Maliyet Etkinliği}

Yerel bankaların daha maliyet etkin olması, biriktirdikleri tecrübe ile Kırgızistan bankacılık piyasasının özelliklerini daha yakından tanımaları ve kurdukları kişisel, kurumsal ve diğer bağlantılar ile açıklanabilir. Yerel koşullarda ilgili maliyetleri daha başarılı azaltabilen yerel bankalar bankacılık faaliyetini daha az maliyetle gerçekleştirebildiği durum söz konusu olabilir.

$S L L R$ 'in katsayı \%5 düzeyde istatistiki olarak anlamlı ve pozitif işaretli bulunmuştur. Elde edilen tahmin sonuçları kredi riski yönetiminde başarısız olan banka yönetiminin maliyetlerin yönetiminde de başarısız olduğu öne sürülen "kötü yönetim" hipotezinin (Berger ve De Young, 1995) Kırgızistan bankacılık sektöründe geçerliliğini destekleyen bulgu olarak değerlendirilebilir.

LIQR'nin \%10 önem seviyesinde istatistiki olarak anlamlı bulunan katsayısının pozitif işareti, likiditesi yüksek bankaların daha riskli kredileme faaliyetinden kaçınarak finansal fon kaynaklarını düşük riskli ve likit varlıklara yönlendirmesi sonucunda, bu kaynaklar, işgücü ve fiziki sermaye ile ilgili sabit maliyetler bankaların maliyet etkinliğinin daha düşük olmasına neden olduğu durumu yansıtabilir.

Kırgızistan ekonomisi ve bankacılık sektörünün küçük ve açık olmasından dolayı dış ülkelerdeki gelişmelere karşı, özellikle BDT ülkelerindeki iktisadi ve finansal şoklara karşı duyarlıdır (Mitra, 2010). Diğer ülkelerdeki gelişmelerin etkisini ve döviz kuru riskini belirli bir ölçüde yansıttığı varsayılarak ve Mamonov (2013) izlenerek ABD dolarının değişim kurunun standart sapması (STDEV_FX) modele etkinsizliği etkileyen değişken olarak dahil edilmiştir. Pozitif işaretli ve \%5 önem seviyesinde anlamlı olarak tahmin edilen ilgili katsayı döviz kurundaki dalgalanmalardaki artış bankaların etkinliğini azaltıcı yönde etkilediğini desteklemektedir. Dış ülkelerdeki gelişmelerden kaynaklanan döviz kurundaki dalgalanmalar bankaların kredi portfoyünün kalitesindeki bozulmalara, dolayısıyla maliyetlerindeki artışlara ve maliyet etkinliğindeki azalmalara neden olmuştur.

\%10 düzeyde anlamlı tahmin edilen LNTA'e ait katsayının işareti büyük bankaların ölçek ve kapsam ekonomisinden yararlanarak faaliyetlerini daha az maliyetle yürütebildikleri sonucunda büyük bankaların daha maliyet etkin olduğunu destekleyen bulgu olarak değerlendirilebilir.

$\% 5$ anlamlılık seviyesinde istatistiki olarak anlamlı olan GDP_GRW değişkenine ait katsayının işareti maliyet etkinsizliği ile ters yönlü ilişkili olduğuna dair beklentileri destek-klemektedir. Mamonov (2013)'daki sonuçlar ile tutarlı olan bu bulgu esas alınarak Kırgızistan'da iktisadi büyüme dönemlerinde bankaların başlıca çıktısı olan krediler ve diğer bankacılık hizmetlerine talebin artması sonucunda maliyet etkinliklerinin daha yüksek olduğu ileri sürülebilir. Diğer taraftan, iktisadi daralma dönemlerinde bankaların kredi portföyü kalitesindeki bozulmalar ve kredilendirme ile ilgili maliyetlerdeki artışlara neden olabildiğinden GDP_GRW'nin katsayısı "şanssızlık" 
hipotezini belli bir ölçüde desteklemektedir. Tahmin edilen katsayının değerine göre SPREAD'in maliyet etkinsizliği üzerindeki etkisinin diğer değişkenlere göre daha az ölçüde olduğu belirtilebilir.

\section{Sonuç}

Bu çalışmada Kırgızistan bankacılık sektöründe maliyet etkinliği üzerinde belirlenmiş faktörlerin etkisinin araştırılması amaçlanmıştır. Bu amaçla Battese ve Coelli (1995)'nin etkinsizlik etkileri modeli uygulanmıştır. Elde edilen tahmin sonuçlarına göre, Kırgızistan'daki ticari bankaların maliyet etkinliği daha çok sermayeleşme oranı, sahiplik yapısı, kredi riski, likidite oranı ve döviz kurundaki dalgalanmalardan etkilendiği sonucuna ulaşılmıştır.

Sermayeleşme oranı, reel GSYİH'daki büyüme oranı ve bankanın aktif büyüklüğündeki artışlar bankaların maliyet etkinliklerini artırıcı yönde etkilediğini destekleyen bulgular elde edilmiştir. Yabancı sahipliği, likidite oranı, ABD doları kurunun standart sapması, kredi riski, rekabetteki azalma ile maliyet etkinliği arasında ters yönlü bir ilişkinin olduğunu öne süren sonuçlara ulaşılmıştır.

Kırgızistan bankacılık sektörü için belirlenen çıktıların bir veri miktarının göreceli daha az maliyetle üretilmesi için girdilerin doğru bileşenini kullanma çabasında kamu bankalarının yabanıı sermayeli ve yerel özel bankalara göre daha başarılı olduğunu destekleyen bulgular elde edilmiştir. Ulaşılan sonuçlara göre, Kırgızistan'daki ticari bankaların maliyetlerinin ortalama olarak \%76.6'sı etkin kullanılmışıtır.

Kırgızistan bankacılık sektörü üzerine yapılmış önceki çalışmalardaki yöntemlerden farklı yöntemin kullanılmasıyla ölçülen maliyet etkinliği, hem sektörü denetleyen ve düzenleyen Merkez Bankası, hem de ticari bankaların yöneticileri için yararlı sonuçlar ortaya koyabilecektir. Bankacılıkta maliyet etkinliği iktisadi ve finansal açıdan sağlam bir bankacılık faaliyetinin, dolayısıyla iktisadi istikrarın ve sürdürülebilir gelişmenin bir kaynağı olarak değerlendirilebilir.

\section{Kaynakça}

- Abdyzhaparov, A.S. (2013). Banking system development in the Kyrgyz Republic. "Working papers series of the conference devoted to the 20-th anniversary of the Kyrgyz som intorduction", "National currency circulation system: formation and development prospects", March 6, 2013, Bishkek", pp. 46-52

- Aigner, D., Lovell, C. K., ve Schmidt, P. (1977). Formulation and estimation of stochastic frontier production function models. Journal of Econometrics, 6(1), pp. 21-37.

- Altunbaş, Y., Gardener, E. P., Molyneux, P., ve Moore, B. (2001a). Efficiency in European banking. European Economic Review, 45(10), pp. 1931-1955.

- Altunbas, Y., Carbo, S., Gardener, E.P.M. veMolyneux, P. (2007). Examining the Relationships between Capital, Risk and Efficiency in European Banking, European Financial Management, 13(1), pp. 49-70

- Battese, G. E., \& Coelli, T. J. (1995). A model for technical inefficiency effects in a stochastic frontier production function for panel data. Empirical economics, 20(2), pp. 325-332.

- Belotti, F., Daidone, S., Ilardi, G. ve Atella, V., (2013). Stochastic frontier analysis using Stata, Stata Journal, 13(4), pp. 718-758

- Berger, A. N., \& DeYoung, R. (1997). Problem loans and cost efficiency in commercial banks. Journal of Banking \& Finance, 21(6), pp. 849-870.

- Bogetoft, P. ve Otto, L. (2011). Benchmarking with DEA, SFA, and R. Springer, New York Dordrecht Heidelberg London

- Bonin, J. P., Hasan, I., ve Wachtel, P. (2005). Bank performance, efficiency and ownership in transition countries. Journal of Banking ve Finance, 29(1), pp. 31-53.

- Casu, B., ve Girardone, C. (2009). Does competition lead to efficiency? The case of EU commercial banks. The Case of EU Commercial Banks (January 15, 2009).

- Chen, M. J., Chiu, Y. H., Jan, C., Chen, Y. C., ve Liu, H. H. (2015). Efficiency and Risk in Commercial Banks-Hybrid DEA Estimation. Global Economic Review, 44(3), pp. 335-352.

- Cheng, H., Lu, Y. C., ve Mukashev, U. (2013). Productivity of the banking sector: A case study in Kyrgyz Republic. In Innovative Computing Technology (INTECH), 2013 Third International Conference on, IEEE, pp. $173-180$

- Coleman, B. E., Goffe, V., Perolli, B., Usupova, M., Castillo, L. V., Holzhacker, H., ve Kappeler, A. (2012). Banking in the Eastern neighbours and Central Asia: Challenges and opportunities. Regional Studies and Roundtables, European Investment Bank (EIB), pp. 56-61

- Delis, M. D., Molyneux, P., ve Pasiouras, F. (2011). Regulations and productivity growth in banking: Evidence from transition economies. Journal of Money, Credit and Banking, 43(4), pp. 735-764. 
- Djalilov, K., ve Piesse, J. (2014). The Determinants of Bank Efficiency in Centralb Asia. Corporate Ownership ve Control, pp. 656-670.

- Drakos, K. (2003). Assessing the success of reform in transition banking 10 years later: an interest margins analysis. Journal of Policy Modeling, 25, pp. 309-317.

- $\quad$ Duygun, M.; Sena, V. ve Shaban, M. (2014).Trademarking status and economic efficiency among commercial banks: Some evidence for the UK. Journal of Banking ve Finance, 49, pp. 506-514E

- $\quad$ Ferhi, A., ve Chkoundali, R. (2015). Credit Risk and Efficiency: Comparative Study between Islamic and Conventional Banks during the Current Crises. Journal of Behavioural Economics, Finance, Entrepreneurship, Accounting and Transport,3(1), pp. 47-56.

- $\quad$ Fiordelisi, F., Marques-Ibanez, D. ve Molyneux, P. (2011). Efficiency and risk in European banking, Journal of Banking and Finance, Volume 35, Issue 5, pp.1315-1326.

- $\quad$ Fries, S., ve Taci, A. (2005). Cost efficiency of banks in transition: Evidence from 289 banks in 15 postcommunist countries. Journal of Banking ve Finance, 29(1), pp. 55-81.

- Goddard, J., Molyneux, P., ve Williams, J. (2014). Dealing with cross-firm heterogeneity in bank efficiency estimates: Some evidence from Latin America. Journal of Banking ve Finance, 40, pp. 130-142.

- Glass, A. J., Kenjegalieva, K., ve Weyman-Jones, T. (2014). Bank performance and the financial crisis: evidence from Kazakhstan. Applied Financial Economics, 24(2), pp. 121-138.

- Greene, W.H. (2005a). Fixed and Random Effects in Stochastic Frontier Models. Journal of Productivity Analysis, 23, pp. 7-32

- Greene, W.H. (2005b). Reconsidering Heterogeneity in Panel Data Estimators of The Stochastic Frontier Model. Journal of Economics, 126, pp. 269-303

- Grigorian, D., ve Manole, V. (2002). Determinants of commercial bank performance in transition: An application of data envelopment analysis. World Bank Policy Research Working Paper, No: 2850.

- Hassan, M. S. M. (2008). Financial liberalization, privatization, and productivity in banking: The experience of two emerging economies. Published PhD Thesis, University of Leicester, Leicester.

- Huang, J., Chen, J., ve Yin, Z. (2014). A Network DEA Model with Super Efficiency and Undesirable Outputs: An Application to Bank Efficiency in China.Mathematical Problems in Engineering, 2014.

- Isik, I. ve Hassan, M.K. (2002a). Cost and Profit Efficiency of the Turkish Banking Industry: An Empirical I nvestigation, The Financial Review, 37, pp. 257-280

- Jarraya, B. (2014). Parametric Meta-Technology Frameworks to Study Technical Efficiency and MacroEconomic Effects in the European Banking System. Contemporary Economics, 8(1), pp. 73-88.

- Kasman, A. (2003).Banking Efficiency During the Financial Crisis Period. ISE Review, 7, pp. 83-97

- Kasman, A. ve Carvallo, O. (2013). Efficiency and Risk in Latin American Banking: Explaining Resilience. Emerging Markets Finance and Trade, 49(2), pp. 105-130,

- Kasman, A. ve Yildirim, C. (2006). Cost and profit efficiencies in transition banking: the case of newEU members, Applied Economics, 38:9, pp. 1079-1090

- Keleş, İ. (2011). Kırgız Bankacılık Sisteminde EtkinliğinVeri Zarflama Analiziyle Ölçülmesi, DoktoraTezi, Kırgızistan-Türkiye Manas Üniversitesi, Sosyal Bilimler Enstitüsü, İşletme Anabilim Dalı

- Kenjegalieva, K.A., Simper, R., ve Weyman-Jones, T.G. (2009). Efficiency of transition banks: intercountry banking industry trends, Applied Financial Economics, 19:19, pp.1531-1546

- Khadjimouratov, A. (2004). "Financial System of Kyrgyzstan", "Management Horizons". Issue N 2, (erişimtarihi: 08.02.2016, http://www2.umt.edu/cali/KyrgyzstanFinancialSystem.htm)

- Koetter, M., ve Porath, D. (2007). Efficient, profitable and safe banking: an oxymoron? Evidence from a panel VAR approach (No. 2007, 02). Discussion Paper, Series 2: Banking and Financial Supervision. Deutsche Bundesbank, Research Centre.

- Koetter, M. (2006). Measurement matters - alternative input price proxies for bank efficiency analyses. Journal of Financial Services Research, 30(2), pp. 199-227.

- Kök, R., \& Deliktaş, E. (2003). Endüstri İktisadında Verimlilik Ölçme ve Strateji Geliştirme Teknikleri. Dokuz Eylül Üniversitesi İIBF Yayını, İzmir.

- Košak, M., Zajc, P., ve Zorić, J. (2009). Bank efficiency differences in the new EU member states. Baltic Journal of Economics, 9(2), pp. 67-89.

- $\quad$ Kumar, S. ve Gulati, R. (2014). Deregulation and Efficiency of Indian Banks, India Studies in Business and Economics, Springer İndia, Chapter 3, pp. 49-131 
- Jondrow, J., Lovell, C. K., Materov, I. S., \& Schmidt, P. (1982). On the estimation of technical inefficiency in the stochastic frontier production function model. Journal of econometrics, 19(2-3), pp. 233-238.

- Mamonov, M. (2013). Bad management, skimping, or both? The relationship between cost efficiency and loan quality in Russian banks. (No. WP BRP 19/FE/2013), NRU, Higher School of Economics

- Maslak, N.G. ve Buryak, A.V. (Маслак, Н. Г. ve Буряк, А. В.) (2009). Методические подходы к оценке эффективности деятельности банка, Бизнес Информ, № 12(2), сc. 187-191 (erişim tarihi: 19.04.2013, http://dspace.uabs.edu.ua/bitstream/123456789/2301/1/Buriak_001.pdf)

- $\quad$ Matthews, K., Xiao, Z., ve Zhang, X. (2009). Rational cost inefficiency in Chinese banks. Cardiff University, Cardiff Business School, Economics Section Working Papers (No. E2009/13).

- Meeusen, W., \& van Den Broeck, J. (1977). Efficiency estimation from Cobb-Douglas production functions with composed error. International Economic Review, pp. 435-444.

- Mitra, P. K. (2010). The Impact of Global Financial Crisis and Policy Responses The Caucasus, Central Asia and Mongolia. Global Journal of Emerging Market Economies, 2(2), pp. 189-230.

- Nigmonov, A. (2010). Bank Performance and Efficiency in Uzbekistan. Eurasian Journal of Business and Economics, 3(5), pp. 1-25.

- Parmeter, C. F., \& Kumbhakar, S. C. (2014). Efficiency analysis: a primer on recent advances. Foundations and Trends ${ }^{\circledR}$ in Econometrics, 7(3-4), pp. 191-385.

- Mamonov, M., Pestova, A., \& Solntsev, O. (2013). Estimation of Systemic Effects from Tightening of Prudential Regulation of the Banking Sector: Results of a Stress Test. Problems of Economic Transition, 56(7), pp. 37-74.

- Pilyavskyy, A. I., Matsiv, Y. I., ve Vovchak, O.D. (2012). Cost Efficiency Of Ukrainian Banks. Does It Make Difference?. Warsaw School of Information Technology ve Systems Research Institute

- Quagliariello, M. (2007). Banks' riskiness over the business cycle: a panel analysis on Italian intermediaries. Applied Financial Economics, 17(2), pp. 119-138.

- Radic, N., F. Fiordelisis, and C. Girardone. 2012. Efficiency and Risk-Taking in Pre-Crisis Investment Banks. Journal of Financial Services Research 41, pp. 81-101

- Sealey, Jr.C.W., Lindley, J.T., (1977). Inputs, Outputs, and Theory of Production Cost at Depository Financial İnstitutions. Journal of Finance, Vol. 32, pp. 1251-1266.

- Seven, Ü., \& Yetkiner, H. (2016). Financial intermediation and economic growth: Does income matter?. Economic Systems, 40(1), pp. 39-58.

- Shen, Z., Liao, H., ve Weyman-Jones, T. (2009). Cost efficiency analysis in banking industries of ten Asian countries and regions. Journal of Chinese Economic and Business Studies, 7(2), pp. 199-218.

- Spulbăr, C., Niţoi, M., ve Anghel, 1. (2015). Efficiency in Cooperative Banks and Savings Banks: A Stochastic Frontier Approach. Romanian Journal of Economic Forecasting, 18(1), pp. 5-21.

- $\quad$ Staikouras, C., Mamatzakis, E., ve Koutsomanoli-Filippaki, A. (2008). Cost efficiency of the banking industry in the South Eastern European region. Journal of International Financial Markets, Institutions and Money, 18(5), pp. 483-497.

- Styrin, K. (2005). What Explains Differences in Efficiency Across Russian Banks? (No. 01-258e-1). EERC Research Network, Russia and CIS.

- Sufian, F., ve Habibullah, M. S. (2012). Developments in the efficiency of the Malaysian banking sector: the impacts of financial disruptions and exchange rate regimes. Progress in Development Studies, 12(1), pp. 1946.

- Tente, S.D. (2010). Bank Efficiency Estimation: Methodology and the Problem of Adequation. Faculty of Economics, University of Münster, Inaugural Dissertation for The Academic Degree Doctor of Economic Sciences

- Williams, J., (2004). Determining management behaviour in European banking. Journal of Banking and Finance, 28, pp. 2427-2460.

- Xu, H. (2016). Financial Intermediation and Economic Growth in China: New Evidence from Panel Data. Emerging Markets Finance and Trade, 52(3), pp. 724-732. 


\title{
Kırgızistan ile Kore Cumhuriyeti Arasında Siyasi ve Ekonomik İşbirliği: Perspektifler ve Engeller
}

\section{Political and Economic Cooperation between Kyrgyzstan and the Republic of Korea: Perspectives and Obstacles}

\author{
Nargiza Sakmurzaeva (Kyrgyzstan-Turkey Manas University, Kyrgyzstan)
}

\begin{abstract}
Diplomatic relations between Kyrgyzstan and The Republic of Korea were established on 31 January in 1992. Political and economic relations between Kyrgyzstan and The Republic of Korea is a new topic for the study. That's why there are no books and dissertations on this topic. The aim of this paper is to analyze bilateral relations and find out the perspectives and obstacles of the economic cooperation which can really impact the economic development of the country. In order to research the topic, the empirical and comparative methods of analysis were used. As a data sources were used papers of F. Matteo, M. Douglass, S. Chung, and C. Eshimbekov. "Saemaul Undong" or "The New Village Movement" is the South Korea's Rural Development Model for countries such as Kyrgyzstan. Kyrgyzstan has all conditions for applying the «The New Village Movement» program. First, Kyrgyzstan's an agrarian country. Second, $65 \%$ of the total population is the rural population. Third, about 1931 000 people live below the poverty line in 2015 . And, $67.7 \%$ of these people are rural settlements. So it means that by the financial support of the Korean International Cooperation Agency and the local government Korean rural development program can be implemented successfully in Kyrgyzstan. The perspective fields of economic cooperation between two countries are tourism, agriculture, textile industry, information technology and the mining. Some obstacles of the cooperation are the absence of direct flight Bishkek-Seoul, ineffective use of Korean investments and insufficient resources of information about Kyrgyzstan for Korean businessmen.
\end{abstract}

\section{Giriş}

Aralık 1992'de Kore Cumhuriyeti Kırgızistan'ı bağımsız bir ülke olarak ilk tanıyan devletlerin arasında yer almaktadır. 31 Ocak 1992'de ise Kırgızistan ile Kore Cumhuriyeti arasında diplomatik ilişkiler kurulmuştur. İki devlet arasında diplomatik ilişkiler 2000'li yıllara kadar çok sınırlı olmuştur. Sadece birkaç ziyaretler ve antlaşmalar çerçevesinde yürütülmüştür. Bundan dolayı iki ülke arasında ilişkileri canlandırmak amacıyla Kırgızistan'ın ilk Cumhurbaşkanı Askar Akayev 3-5 Temmuz 1997 tarihinde Kore Cumhuriyeti'ni resmi ziyaret etmişti. Cumhurbaşkanının bu ziyaretinde iki ülke arasında işbirlik alanlarına ilişkin antlaşmalar ve belgeler imzalanmıştır. İmzalanan belgelerin en önemlisi 'Birlik Deklarasyonu’dur. Bu antlaşmada Kırgızistan ile Kore Cumhuriyeti arasında dostluk ilişkileri ve işbirliğinin temelleri atılmıştır.

Kırgız Cumhuriyeti Ulusal İstatistik Kurumu'nun verilerine göre 2000'li yıllara kadar Kırgızistan'da 20'ye yaklaşık Güney Koreli şirket mevcuttu. Genellikle bu şirketler orta gelirli şirketler olarak ticaret ve hizmet sektörlerinde faaliyet göstermekteydi. Kore Cumhuriyeti destekli yapılan büyük proje teknolojik iletişim alanında 2000 yılında gerçekleşmiştir. Çüy bölgesinde yapılan bu projeye mali desteği 'Hanhva' şirketi sağlamıştır. 1998 yılında projeyi hayata geçirmek için 12.000 .000 dolar kredi şeklinde hükümete verilmişti. Bu projenin uygulanmasından sonra yavaş yavaş Güney Koreli girişimcilerinin Kırgızistan'ın turizm, inşaat, teknolojik iletişim araçlarını geliştirme ve madencilik alanlarına ilgisi artmaya başlamıştır.

2000'li yıllardan başlayarak iki ülke arasında yapılacak işbirlik alanları belli olmaya başlamıştı. Özellikle 2001 2002 yıllar aralığında Kırgızistan ile Kore Cumhuriyeti Afganistan'ın yeniden yapılanması konusunda insani yardım işbirliği yapmışlar. Bunun yanında Kırgızistan vatandaşlarının Kore Cumhuriyeti'nde çalışmaları için emek kotaları verilmeye başlamıştır. Mart 2001 yılında ise Kore Cumhuriyeti'nin EKSPO-2010 uluslararası kermesini organize eden kurumun delegesi Kırgızistan’1 ziyaret etmişti. Bu ziyaretin asıl amac1 EKSPO-2010 kermesine Kırgızistan'ın katılımını teşvik etmekti. Ziyaret sırasında Kore Cumhuriyeti delegasyon temsilcileri Kırgızistan Başbakanı ve Dışşşleri Bakanı ile görüşmeleri düzenlenmiştir. Kore Cumhuriyeti'nden gelen işadamlarının Kırgızistan'da özelleştirilme ve yeni şirketlerin kuruluş süreçlerine katılmaları Kırgız hükümeti tarafınca destekleneceği açıklanmıştı. Orta Asya ülkeleri arasında Kırgızistan ilk olarak Güney Kore’yle ekonomik işbirliğini başlatmıştır. Ancak önemli gelişmeler 2000-2005'lere kadar yer almamıştı.

\section{Kırgızistan ile Kore Cumhuriyeti Arasında Siyasi İlişkiler}

2007 yılında Kırgızistan Başbakan Vekili Almazbek Atambayev’in, 2008 yılında ise Başbakan Yardımcısı İskenderbek Aydaraliyev'in Kore Cumhuriyeti üst düzey ziyaretleri gerçekleşmiştir. Ziyaret sırasında iki ülke arasında siyasi işbirliğinin derinleşmesi, ekonomik ve kültürel ilişkilerinin gelişmesine ilişkin antlaşmalar imzalanmıştı. Başbakan'ın resmi ziyaretinde Kore Cumhuriyeti Başbakanı Han Dok Su ile ikili bir görüşme yapılmıştı. Kore Cumhuriyeti Başbakanı’nın konuşmasında Kore hükümeti Kırgızistan ile ilişkileri geliştirmek 
için ithalat ve ihracatı arttıracakları söylenmişti. Kırgızistan'ın ekonomisindeki turizm, hidroenerji ve inşaat sektörleri Kore yatırımcıları için çok çekici olduğu vurgulanmıştı. Kırgızistan ile Kore Cumhuriyeti hükümetleri ikili bir düzeyde ve uluslararası forumlar çerçevesinde işbirliği yapmaktadır. Bunların içinden 'Orta Asya- Kore Cumhuriyeti' uluslararası forumu önemli bir rol oynamaktadır. Bu forum çerçevesinde Orta Asya ülkeleriyle ile Kore Cumhuriyeti'nin temsilcileri enerji, sağlık, turizm ve madencilik gibi alanlarda deneyim değişimi yapmaktadır. Buna ek olarak bu alanlarda işbirliği için perspektifler konusunda görüşmekteler. 2008 yılında iki ülkenin karşılıklı olarak Büyükelçilik'lerinin açılması ilişkilerin gelişmesinde önemli adımı oluşturmuştu. Kırgızistan ile Kore Cumhuriyeti arasında diplomatik ilişkileri düzenleyen hukuki belgeler ve antlaşmalar şunlardır:

- Diplomatik İlişsilerin Kurulmasına Dair Protokol

- Dostça İlişkiler ve İşbirliğinin Esasları Hakkında Ortak Deklarasyon

- Kültürel İşbirliği Antlaşması

- Hava Bağlantıların Kurulmasına İlişkin Antlaşma

- Turizmde İşbirliği Antlaşması

- Dışişleri Bakanlıkları Arasında İşbirliği Protokolü

- Her İki Ülkenin Kültür Bakanlığı Arasındaki İşbirliği Protokolü

- E-devlet Kurulması için Memorandum

- Yatırımların Geliştirilmesi ve Korunması Antlaşması

18-20 Kasım 2013 tarihinde Kırgızistan Cumhurbaşkanı Atambayev Kore Cumhuriyeti'ni resmi ziyaret etmişti. $\mathrm{Bu}$ siyasi olay iki ülke arasındaki diplomatik ilişkilerin gelişmesini derinden etkileyeceği beklenmektedir. Atambayev Kore Cumhuriyeti'ni resmi ziyareti sırasında Kırgız-Kore Yatırımlar Forumu'na katılmıştır. Bu forum Kırgız ve Koreli işadamlarının katılımıyla gerçekleştirilmişti. Bu ziyaret sonucunda iki hükümet arasında antlaşmalar imzalanmıştır. Bunlar:

-Kırgızistan Kore Cumhuriyeti Hükümetleri Arasında Hibe Yardımına İlişkin Çerçeve Antlaşması;

-Kırgızistan ile Kore Cumhuriyeti Hükümetleri Arasında Sürücü Lisanslarının Karşılıklı Tanınması ve Değiştirilmesine İlişkin Antlaşma;

-Kırgızistan Ekonomi Bakanlığı ile Kore Cumhuriyeti Ticaret, Sanayi ve Enerji Bakanlık Arasında Enerji ve Sanayi Alanlarında İşbirliğine İlişkin Mutabakat Zaptı.

İki devletin parlamentoları arası ilişkileri de aktif bir şekilde gelişmeye başlamıştır. Şubat 2014 yılında Kırgızistan Parlamentosu (Cogorku Keneş) Başkanı Asılbek Ceenbekov'un Kore Cumhuriyeti'ni resmi ziyareti gerçekleştirilmişti. Bu ziyaretin sırasında Kırgızistan ile Kore Cumhuriyeti parlamentoları arasındaki işbirliğinin temel alanları belirlenmiştir. Ayrıca Kore Cumhuriyeti'nin teknolojik yeniliklerini kullanarak ikili ekonomik işbirliğinin geliştirilmesi konuları ele alınmıştır.

Kırgızistan ile Kore Cumhuriyeti arasında düzenlenen üst düzey ziyaretler tablosundan Kore Cumhuriyeti Başkan, Başbakan ve Parlamento Başkanı düzeyinde Kırgızistan'da resmi ziyaretlerinin gerçekleşmediği gözükmektedir. Üst ziyaretlerin karşılıklı olarak yapılması devletlerarası ilişkilerin gelişmesini etkilemektedir. İki devlet arasında yapılan ziyaretler konusunda diğer Orta Asya ülkeleriyle bir karşılaştırma yapılırsa, Kırgızistan'ın Kore Cumhuriyeti'yle ilişkilerinin daha gelişme aşamasında olduğu sonucuna ulaşılmaktadır. Çünkü Kazakistan ve Özbekistan'ın Kore Cumhuriyeti'yle karşılıklı yapılan üst düzey ziyaretlerinin sayısı oldukça yüksektir.

\begin{tabular}{|l|l|}
\hline 3-5 Temmuz 1997 & Kırgızistan Cumhurbaşkanı Askar Akayev'in Kore Cumhuriyeti Resmi Ziyareti \\
\hline 2007 yılında & Kırgızistan Başbakan Vekili Almazbek Atambayev'in Kore Cumhuriyeti Resmi Ziyareti \\
\hline 2008 yılında & $\begin{array}{l}\text { Kırgızistan Başbakan Yardımcısı İskenderbek Aydaraliyev'in Kore Cumhuriyeti Resmi } \\
\text { Ziyareti }\end{array}$ \\
\hline 30-31 Mayıs 2012 & Kırgızistan Başbakanı Ömürbek Babanov'un Kore Cumhuriyeti İ̧̧ Ziyareti \\
\hline Şubat 2014 & $\begin{array}{l}\text { Kırgızistan Parlamentosu (Cogorku Keneş) Başkanı Asılbek Ceenbekov'un Kore } \\
\text { Cumhuriyeti Ziyareti }\end{array}$ \\
\hline 18-20 Kasım 2013 & Kırgızistan Cumhurbaşkanı Almazbek Atambayev'in Kore Cumhuriyeti Resmi Ziyareti \\
\hline
\end{tabular}

Tablo 1. Kırgızistan ile Kore Cumhuriyeti Arasında Üst Düzey Ziyaretler Kronolojisi Kaynak: Kırgız Cumhuriyeti Dış İsler Bakanlı̆̆

Kırgızistan ile Kore Cumhuriyeti arasında diplomatik ilişkilerinin bir boyutunu Kırgızistan'da yaşayan Kore kökenliler topluluğu oluşturmaktadır. 17000 civarı Kore Kökenliler günümüzde Kırgızistan'da yaşamaktadır. Kırgızistan'ın bağımsızlığını izleyen yıllardan günümüze kadar Kore Cumhuriyeti yerel Kore kökenlilere destek sağlamaktadır. Kırgızistan'da yaşayan Koreli nüfus Kırgızistan ile Kore Cumhuriyeti arasında bir köprü rolünü üstlenmektedir. Kore kökenlilerin Kore Cumhuriyetine gidebilmeleri için özel vize verilmektedir. Kırgızistan’daki 
Kore topluluğu, Orta Asya ve diğer eski Sovyet topraklarında yaşayan Korelilere kıyasla ilk olarak 16 Aralık 1989 tarihinde Korelilerin 'Çinson Derneğini’ oluşturmuşlar. Ayrıca Kırgızistan Koreliler Kamu Derneği faaliyetini yürütmektedir. Kırgızistan’da Kore kökenlilerin nüfusunun giderek azaldığı görülmektedir. Kırgız Cumhuriyeti Ulusal İstatistik Kurumu'nun verilerine göre 1990'larda 20000'e yakın Koreli nüfus varken, 2016'da bu sayı 17000 olmuştur. Kore kökenli nüfusunun azalmasının çeşitli sebepleri vardır. Bunlardan bazıları Korelilerin bir kısmının Bağımsız Devletler Topluluğu (BDT) ülkelerine göç etmeleridir. Özellikle Kazakistan ve Rusya’ya göç etmektedirler. Çünkü bu ülkelerde Kırgızistan'la kıyasla sosyo-ekonomik şartlar daha iyidir. Kırgızistan vatandaşı Kore kökenlilerin diğer bir kısmı Güney Kore’ye gitmektedir. Çünkü Kırgızistan vatandaşı Kore kökenliler için Güney Kore'ye gitmeye özel vize verilmektedir. Demek ki Kırgızistan'daki Kore kökenlilerin yurtdışına göç etmeleri nüfusunun azalmasının bir sebebini oluşturmaktadır. Diğer taraftan Korelilerin yerel halk ile evlilik yapmaları Koreli nüfusun azalmasında etkileyici bir unsur olmaktadır. Koreli nüfusunun son yıllar içinde azaldığı Tablo 2'de görülmektedir.

\begin{tabular}{|l|c|c|c|c|c|c|c|c|c|}
\hline Yillar & 1999 & 2009 & 2010 & 2011 & 2012 & 2013 & 2014 & 2015 & 2016 \\
\hline Kore nüfusu & 19784 & 17299 & 17182 & 16938 & 16711 & 16753 & 16807 & 16828 & 16957 \\
\hline
\end{tabular}

Tablo 2. Kırgızistan Vatandaşı Kore Kökenliler Nüfusu Kaynak: Kırgız Cumhuriyeti Ulusal İstatistik Kurumu

Kırgızistan'lı Korelilerin büyük çoğunluğu Bişkek’te ve şehrin etrafında yaşamaktadır. Başkentte, hatta Kore nüfusunun büyük bir kısmı yaşayan 'Kore ilçeleri' vardır. Bunlar Kızıl-Asker, Kommunarov sokağı, Tuğla fabrikasının yerleştiği ilçe, Novopavlovka, Voyenno-Antonovka ve Sokuluk’tur. Ayrıca, Korelilerin küçük bir topluluğu Kırgızistan'ın güney bölgelerinde Oş ve Aravan'da yaşamaktadır.

\section{Kore Cumhuriyetindeki Kırgız Topluluğu}

İki ülke arasında ilişkilerin bir boyutunu Kore Cumhuriyeti’nde bulunan Kırgız vatandaşları oluşturmaktadır. Kırgızistan'da 'Kore Dalgası'nın etkisiyle 2008-2009 yıllardan günümüze kadar Güney Kore’ye giden Kırgız vatandaşlarının sayısı artmaktadır. Bir taraftan 'Kore Dalgası'nın etkisi diğer taraftan Kırgızistan'ın işsizlik sorunu Kırgızları Kore Cumhuriyeti gibi gelişmiş ülkelere gitmeye neden olmaktadır. Günümüzde Kore Cumhuriyeti’nde kalıcı ve geçici olarak ikamet eden Kırgız vatandaşlarını birkaç grup içinde toplamak mümkündür. Bunlar:

- Korelilerle evlenen Kırgız vatandaşları (kadınlar);

- EPS sistemi temelinde resmi olarak çalışan Kırgız vatandaşı misafír işçiler

- Özel vizeyle Kore Cumhuriyeti’nde bulunan Kore kökenliler;

- Kore üniversitelerinde lisans, yüksek lisans ve doktora öğrencileri;

- Gayriresmi olarak Kore Cumhuriyeti’nde çalışan Kırgız vatandaşlarıdır.

Kore Cumhuriyeti'nde yaşayan Kırgız vatandaşlarının \% 50’si Kırgız, \% 40 Özbek, \%10’u Kore kökenliler ve Ruslar oluşturmaktadır. Kore Cumhuriyeti yasaları çok katı olduğu için Kırgızistan'dan giden misafir işçiler Kore Cumhuriyeti'nin yasa ve çalışma kurallarına uyarak çalışmaktalar. Bu konuda Kırgız işçilerinin sorunları yoktur. Asıl sorun Güney Kore'de yasadışı olarak bulunan Kırgız vatandaşlarının durumudur. Bu vatandaşların hemen hepsi iş aramaya gelenlerdir. Bu kategorideki vatandaşlarının büyük sayıda olması farklı sorunlara neden olmaktadır. Kırgızistan'ın işsizlik sorununun çözülmesi ve halkın sosyo-ekonomik hayatının iyileşmesine kadar Kırgız vatandaşları Kore Cumhuriyeti gibi gelişmiş ülkelere hem yasa hem yasadışı olarak çalışmaya giderler. Bu ciddi bir sorundur. Şu anda Kore Cumhuriyeti’nde cinayet işleyip bir insanın ölümüne sebep olan bir Kırgız vatandaşı cezaevinde bulunmaktadır. Diğer bir Kırgız vatandaşı ise trafik kazası dolayısıyla hapiste kalmaktadır.

Kırgızistan'ın Büyükelçiliği’nin verilerine göre Kore Cumhuriyeti’nde 4673 Kırgız vatandaşı yaşamaktadır. Bunların içinden 647 kişi yasadışı olarak bulunmaktadır. Bu sayının içinden sadece 47 Kırgız vatandaşı 6 aylık süre içinde Kore Hükümeti tarafından ceza yaptırıma uygulanmadan kendi isteğiyle tekrar Kırgızistan'a dönmüştü. Son zamanlarda Kore Cumhuriyeti'ne yasal olmayan yollarla çalışmaya gidenlerin sayısı artmaktadır. Bundan dolayı Kore hükümetinin ilgili kurumları ülke içinde yasadışı olarak bulunan yabancı uyruklu vatandaşları tekrar vatanlarına zorunlu bir şekilde göndermekte ve 5 yıllık bir sürenin tamamlanmasına kadar yeniden Güney Kore'ye girmelerini yasaklamaktadır.

Mart 2016'da Kırgızistan Büyükelçiliği Güney Kore Adalet Bakanlığı, Dışişleri Bakanlığı, Çalışma ve İstihdam Bakanlığı temsilcileri ile ülkede yasadışı olarak bulunan Kırgızistan vatandaşlarının durumuna ilişkin birkaç görüşmeler düzenlemişler. Bu görüşmeler sonucunda yasadışı olarak bulunan Kırgızistan vatandaşlarına ülkeden zorunlu çıkartılmadan 6 aylık bir ek süre verilmiştir. Yani 1 Nisan'dan 30 Eylül 2016'a kadar bir süre içinde yasal süresi bitmiş bulunan vatandaşların kendi isteğiyle Kırgızistan'a gitmelerine firsat verilmiştir. Bu durumda ceza yatırımları uygulanmaz ve yeniden Güney Kore'ye yasal bir şekilde girmek mümkündür. Bunun için Bişkek’teki Güney Kore Büyükelçiliği’nden Çalışma İzin Sisteminin (EPS) temelinde vize almaları gerekmektedir.

2012'den başlayarak Güney Kore Hükümeti her devlete ayrı olarak farklı sayıda işçi kotaları verirken son yıllar içinde Employment Permit Sistem (EPS) uygulamaktadır. Bu sisteme üye olan 16 ülkeye her yıl toplam kota sayısı 
verilmektedir. 2016 y1lında tüm üye ülkelere verilen kota sayıs1 58 000'di. Böylece Kırgızistan'dan Kore Cumhuriyeti'ne giden misafir işçilerin sayısını arttırmak için şartlar kolaylaşmaktadır. Güney Kore'deki Kırgızistan'ın Büyükelçisi Beşimov'a göre Kırgız vatandaşı misafir işçi sayısı 850 civarıdır. 1 Ocak 2008'den 1 Eylül 2011'e kadar Kırgızistan Kore Cumhuriyeti'ne 1183 kişi misafir işçi olarak gitmiştir. Çalışma İzin Sistemi (EPS) çerçevesinde Kırgızistan vatandaşları Güney Kore'ye gitmek için önce Korece öğrenmekteler. Dil sınavlarını geçtiklerinde Koreli işverenleriyle bir iş anlaşması yapmaktadırlar. Kore Cumhuriyeti'nde çalışmaya izin alanlar Kore Cumhuriyeti Eğitim Merkezi’nde ücretsiz olarak hazırlık yapmaktalar.

Kırgızistan'dan gelen misafir işçilerin büyük bir kısmı ülkenin tarım-sanayi sektöründe çalışmaktadır. Kırgız iş̧i misafirlerinin sayısının düşük olması farklı etkenlerden kaynaklanmaktadır. Bunlardan biri Güney Koreli işverenlerin Kırgız misafir iş̧̧isi hakkında bilgi eksikliğidir. Bu nedenle Kırgızistan'ı farklı forum, konferans ve kermesler çerçevesinde Koreli işletmeci ve girişimcilere tanıtmak gerekmektedir. Diğer bir mesele günümüzde Kore Cumhuriyeti'nde bulunan Kırgız işçilerinin olumlu bir imaj oluşturmasıdır. Koreli işverenleri arasında Kırgız vatandaşı misafir işçisinin zamanında işe gelen, işini eksiksiz yapan, çalışkan ve sorumlu bir iş̧̧inin olarak olumlu imaj yaratması Kırgızistan için iş̧̧i kotalarının artmasını sağlayacaktır.

\section{Kurgızistan ile Kore Cumhuriyeti Arasında Ekonomik İliş̧kiler}

Kırgızistan ile Kore Cumhuriyeti arasında diplomatik ilişkilerin 2000'li yıllara kadar gelişmemiştir. İki ülke arasında siyasi ilişkilerin sınırlı olması ekonomik işbirliğini olumsuz yönde etkilemiştir. Bağımsızlığı izleyen yıllarda Kırgızistan ile Kore Cumhuriyeti arasında ticaret yapısının \%90'ı Kore'den gelen ithalata dayanmıştı. 1992 yılında ikili ticaretin hacmi 994.000 dolara eşitti. Bunun 937.000'i Kırgız ihracatını oluştururken, 57.000 doları ise Güney Kore'den gelen ithalata denk geliyordu. Kırgızistan'da Güney Kore'ye ihraç edilen mallar genelde antimon ve metal kalıntılarıydı. Güney Kore'den ithal edilen mallar ise çoğunlukla elektronik hesap makineleri ve kayıt verileri için el cihazlarıydı. Yıllar geçtikçe Kore Cumhuriyeti'nden ithal edilen malların hacmi artmıştı. Bunlar: elektrik iletkenleri, telgraf hatlarının parçaları, elektrikli ses yükselticiler, tütün ve inşaat malzemeleriydi.

Bağımsızlığın ilk döneminde Kore Cumhuriyeti’nden ithal edilen mallar genellikle televizyon, telefonlar, ilaç ve arabalardı. Ağustos 1993 yılında Kırgızistan Başbakanı'nın Kore Cumhuriyeti'ni ziyareti gerçekleşmişti. Bu ziyaretin asıl amac1 'Tedjon-EKSPO/93' konulu uluslararası kermese katılmaktı. Bunun sonucunda Kırgız delegasyonu Kore Cumhuriyeti'ndeki küçük ve orta girişimciliği destekleyen Kore Ticaret-Yatırım Teşvik Ajansı (KOTRA) ile yakından irtibata geçmişti. 2000'lere kadar Kırgızistan ile Güney Kore arasında ekonomik işbirliğinin gelişmemesinin sebepleri ekonomik işbirliğinin hukuki bir temelinin yokluğu, vergi sisteminin sabit ve çekici olmaması ve Kırgız şirketlerinin Kore'nin LG-Gold Star şirketine büyük miktardaki borcuydu (3.500.000 milyon dolar. 2001'de bu borç ödenmiştir. Diğer yandan 1997-1998 yıllarında Asya Mali Krizi Kore Cumhuriyeti ile Kırgızistan'ın diplomatik ilişkilerinin gelişmesini olumsuz yönde etkilemiş̧tir.

1998'de iki ülke arasında ticaret hacmi 29.127.000 dolarken, bir sene önce ise bu indeks 8.000.000 dolardı. Güney Kore'den tütün ürünleri, kullanılmış lastikler, pamuk, örme giysiler ve tıbbı aşılar ithal edilmişti. 1990'lardan 2004'lere kadar Kırgızistan ile Güney Kore arasında ticaret hacminde çok değişiklik gözükmemiştir. Ancak 2004'de ticaret hacmi 53.184.000 dolara yükseldi, bunun \%90'1 Kore Cumhuriyeti'nden gelen ithalatı oluşturmuştu. Bu dönemden başlayarak ikili ticaretin artması söz konusu olmuştu. 2007'de ise iki ülke arasında ticaret hacmi 136.983.000 dolarken, 2008'de 168.910.000 dolara denk gelmiş. Ancak Kore Cumhuriyeti'nin ithalatı hala \% 95 olarak kalmıştı. Kore Cumhuriyeti'nden ithal edilen mallar genellikle tütün ürünleri, elektronik cihazlar, bilgisayarlar, otomobil parçaları ve kamyonlardır. Kırgızistan ihraç eden mallar ise hububat ve buğday, bal ve kuru meyveler, çelik, kimyasal ürünler, metalik olmayan mineraller, tıbbi ürünler, plastik, endüstriyel cihazlar ve ekipmanlardır.

2008'de iki ülke arasındaki ticaret 3.000.000 dolar ile ölçülürken, 2011'de 142.000.000 dolara çıkmış olması oldukça dikkat çekicidir. 2009-2010 yıllarında Kırgızistan ile Kore Cumhuriyeti arasında ticari hacminde bir düşüş gözükmektedir. Küresel Mali Krizin etkisiyle 2009 y1lında ticaret hacmi 101.293.000 dolarken ve Ocak-Ekim 2010 yılında ise 89.191 .000 doları oluşturmuş. Bu sırada Kırgız ihracatı \% 3'ü aşmamıştır. Kırgızistan'dan Kore'ye giden mallar kireçtaşı, atık ve hurda, kömür (antrasit ve bitümlü kömür hariç), antilrigit alçıydı. 2010 yılında bunlara ham titanyum tozu, kireçtaşı, sentetik ve kimyasal liflerin, anıt veya yapı üretimi için taşlar eklenmiştir. Kore mallarını ihraç edenler genellikle Kırgız vatandaşı girişimcilerdir. Buna karşılık Güney Koreli girişimciler Kırgız mallarının Kore pazarına gönderilmesinde aktif olarak katılmamıştı. Aynı yıl içinde Kırgız ihracatını geliştirmek amacıyla Kırgızistan Ekonomi Bakanlığı'yla Kore Cumhuriyeti İthalatçılar Derneği bir işbirliği yapmıştı. Kore'nin istatistik verilerine göre Kırgızistan'a yapılan yatııımların hacmi 66.000 .000 oluşturmuş.

7 Nisan 2010 tarihinde Kırgızistan'da gerçekleşen devrim ile Haziran olayları ülke içinde siyasi istikrarsızlı̆ğ oluşturmuştu. Bu durum ülkenin hem iç hem dış politikasında olumsuz etkileri yaratmıştır. Ülke içindeki siyasi istikrarsızlık ve belirsizlik sosyo-ekonomik kalkınmayı yavaşlatmış. Bundan dolayı yabancı ülkelerden gelen yatırımların hacminde de bir düşüş gözlenmiştir. Bu durum Güney Koreli yatırımcılarının ve girişimcilerini de 
olumsuz olarak etkilemiştir. İlk önce Kırgızistan'da orta ve küçük işletmeleri bulunan Güney Koreli iş adamları tekrar yurduna dönmüştü. Böylece Kırgızistan'da siyasi istikrarın sağlanması ve yatırımlar ortamının iyileşmesine kadar ikili ekonomik ilişkilerde bir durgunluk söz konusu olmuştu. 2011 yılında Atambayev’in Kırgızistan’ın Cumhurbaşkanı olarak seçilmesi ve ülkede siyasi ve sosyal gerginliklerin giderilmesi tekrar iki ülke arasında ilişkilerin canlanmasına neden olmuştu.

2013 yılında Güney Kore'den ihraç edilen malların hacmi 180.000.000 doları oluştururken Kırgızistan'dan Güney Kore'ye ihracatın hacmi ise sadece 2.000.000 dolara ulaşmıştır. 2014 yılında Kore Cumhuriyeti Büyükelçisi Kim Chang Gyu Kırgızistan ile Kore arasındaki ticaret hacminin 2014 yılında 200.000.000 dolara ulaştığını söylemişti. Kore Büyükelçisi, ülkedeki diplomatik misyonunun tamamlanması üzerine gazetecilere verdiği konuşmasında ikili ekonomik ilişkilerin dinamik olarak geliştiğini belirtmişti. İki ülke arasında ekonomik işbirliğinin perspektifli alanlarının tıp, tarım, hafif sanayi, bilgi teknolojisi ve madencilik olduğunu vurgulamıştır. Büyükelçi, ayrıca, Kırgızistan'daki Kore Cumhuriyeti'nden yapılan toplam yatırımın 170.000.000 dolar olduğunu belirlemiştir. 2015 yılında Kore Cumhuriyeti ile Kırgızistan arasında ticaret hacmi 80.000.000. doları eşitti. Bu rakam 2014 yılına nazaran \%48'e azalmıştır. Güney Kore'den gelen yatırımların hacmi ise 3.152.000 dolara eşitti. $\mathrm{Bu}$ gösterge bir önceki yılla kıyasla artış göstermiştir. Çünkü 2014'de yatırımların hacmi 1.349.000 dolardı. Kırgızistan ile Kore Cumhuriyeti arasında ekonomik işbirliğinin bir sonucu olarak Sokuluk rayonu'nda Kırgızistan-Güney Kore Tarım-Sanayi Merkezi açılmıştır. Ayrıca Isık-Göl'de Koreli girişimciler ilaç için kullanılacak otları yetiştirip Güney Kore'ye göndermektedir. Bunun gibi ekonomik projelerin yapılması iki ülke arasında ekonomik ilişsilerin derinleşmesini sağlayacaktır. Günümüzde Koreli girişimcilerin desteğiyle 116 Koreli şirket Kırgızistan'da faaliyet göstermektedir. Bağımsızlığı izleyen yıllarda bu sayı 20’ydi. Demek ki giderek Kore Cumhuriyeti'nden gelen yatırımların arttığı, Koreli girişimcilerin Kırgızistan'ı tanımaya başladığı gözlenmektedir.

\section{Kırgizistan'da 'Saemaul Undong' (Yeni Köy) Hareketi}

«Saemaul Undong» (Yeni Köy) hareketi 1969 yılında Güney Kore Devlet Başkanı Park’ın ülke nüfusunun üçte ikisini oluşturan köylülerin sosyo-ekonomik hayatını iyileştirmeye yönelik aldığı karar temelinde ortaya çıkmıştır. Saemaul Undong, 1970'lerde Kore Cumhuriyeti'nin topluluk temelli bir kırsal kalkınma programı olarak halka sunulmuştu. Kore nüfusunun çoğunluğunu oluşturan köylülerin zihniyetine radikal bir yenilenme getirerek hayat standartlarını geliştirmeyi amaçlamıştı. Bu bağlamda dayanışma, özen ve karşılıklı yardımlaşma ilkelerinin temelinde bir hareket başlamıştı.

Temel olarak, Saemaul Undong Hareketi, toplum gelişimi ve modernleşme arayışı içinde olan bir harekettir. İlk olarak, yoksulluğu gidermek için bir harekettir. Bu hareket, sadece bireylerin yaşam standartlarıyla sınırlı değildir, ancak tüm topluluğu kapsar. Hareketin temel ilkelerinden biri her bir insanın kendi köyü için çalışmasını ön plana çıkarmasıdır. Hareketin diğer bir anlayışı sosyo-ekonomik kalkınmanın ve zenginleşmenin bir şans veya rüya olarak görmemek ya da gelişmeyi diğerlerine bağımlı olarak kabul etmemektir. Özellikle en önemlisi doğru yollarla kendi emeğiyle başkalarının yardımına bağlı kalmadan köyün gelişmesini sağlamaktır. Burada 'başkalar' kavramı hükümet ya da komşu köy, şehir ya da yabancı devlet anlamına gelmektedir. Ayrıca kırsal kesimlerde çok sıkça rastlanılan 'yoksulluk bizim kaderimiz' gibi düşüncelerle bir mücadeledir. İnsanların bu kötümser davranışlarını gidermek 'Saemaul Undong' hareketinin amaçladığı zihinsel reformun bir parçasıdır. 'Saemaul Undong' hareketinin faaliyetleri ve yabancı devletlerle etkileşim sorunları Kore Cumhuriyeti İçişleri Bakanlık ve Bakanlık altında ayrı bir Bölüm tarafından koordine edilmesi dikkati çekmektedir.

1960-1970’lerde «Saemaul Undong» basit bir kırsal kalkınma programı değildi. Daha doğrusu, 1960' lardaki Güney Kore'nin toplumsal kalkınma modelinin kırsal kesime uygulanmış bir kalkınma programıydı. Güney Kore hükümeti, köylerin her birine ücretsiz olarak belirli bir miktarda hammadde temin etmesi ve yerli halkı onlarla istediği her şeyi yapmalarına emanet etmesi nedeniyle, halkın kendi aralarında yardım ve işbirliğini teşvik etmişti. Hükümet ilk olarak 33.267 köyü seçerek ve bu kırsal kesimlere 335 çuval çimento tedarik etmişti. Daha sonra, bu hammaddeyi başarıyla kullanmış olan 16.600 köye, 500 çuval çimento ve bir ton demir çubuğu da sağlamıştı. 'Yeni Köy Hareketi', kırsal bölgelerdeki sulama sistemleri, köprüler ve yollar gibi modern tesislerin kurulması Güney Kore'deki köylerin altyapısını geliştirmesinde önemli rol oynamıştı. Kırsal kesimlerdeki başarıyla tamamlanan hareket, giderek kentsel alanlara da yayılmış ve sonuçta ülke çapında bir modernleşme hareketi haline gelmişti. 2010 yılında Kırgızistan başkenti Bişkek’te Güney Koreli «Saemaul Undong» Merkezi Kamu Vakfi olarak faaliyete başlamıştı. Bu merkezin kuruluş amacı Koreli kırsal kalkınma deneyimini yerel halka öğretmek ve uygulamaya katkıda bulunmaktır.

«Saemaul Undong» ya da «Yeni Köy Hareketi», Kırgızistan gibi az gelişmiş ülkeler için Kore Cumhuriyeti’nin Kırsal Kalkınma Modeli'dir. Kırgızistan'da, 'Yeni Köy' modelinin uygulanması için tüm şartlar bulunmaktadır. İlk önce, Kırgızistan tarım ülkesidir. Tarım sektörü, Kırgızistan ekonomisinde yüzde 40’lık bir paya sahiptir. Ülkedeki insan gücünün yüzde 60'ı tarım sektöründe çalışmaktadır. Tarım faaliyetlerinin en yoğun olduğu yerler ülkenin güney batısındaki Oş ve Celalabad illeri, Fergana vadisi, kuzeyde Talas ve Çuy vadileri, ayrıca Issık Göl çevresindeki tarım alanlarıdır. Tarım ürünleri açısından, tütün, pamuk, patates, üzüm ve sebzeler hem en çok üretilen hem ihraç edilen maddelerdir. İkinci olarak, ülkenin toplam nüfusunun \%65'i kırsal nüfusu 
oluşturmaktadır. Kırsal kesimlerde yaşayan halkın sosyo-ekonomik şartları düşüktür. Üçüncüsü, ülkede 1931000 kişi yoksulluk sınırının altında yaşamaktadır. Bu nüfusun \% 67.7'si köylerde yaşayan halkı oluşturmaktadır. Dördüncü etken olarak, halkın zihniyetinin değişmesi gerekmektedir. Çünkü halk hep devletin yardım etmesinin, devletten para ve zenginliğin gelmesinin beklemektedir. «Yeni Köy Hareketi'nin» asıl amacı doğru yollarla kendi emeğiyle başkalarının yardımına bağlı kalmadan köyün gelişmesini sağlamaktır. Burada 'başkalar' kavramı hükümet ya da komşu köy, şehir ya da yabancı devlet anlamına gelmektedir. İnsanların zihniyetinde bir reformanın yapılması beklenmektedir. Ayrıca Kırgızistan, değerli maden kaynaklarına sahip bir ülkedir. Özellikle altın, hem bolca üretilen, hem de ihraç edilen bir maden. Altın ihracatının ülke ekonomisine hayli önemli bir katkısı var. Buna karşılık, hidroelektrik üretimi zengindir. Ülkenin ekonomik kalkınmasını sağlamak için tüm şartlar mevcuttur. Asıl mesele «Yeni Köy» kalkınma modelini uygulamak ve uygulattırmaktır. Hükümet ile halk bir dayanışma ortamında işbirliği yapması gerekmektedir.

\section{Sonuç}

Kırgızistan ile Kore Cumhuriyeti arasında diplomatik ilişkiler gelişme aşamasına girmiştir. 1992'de iki ülke arasında diplomatik ilişkilerin kurulmasının arkasından üst düzey ziyaretler yapılmıştır. Ticaret miktarı az da olsa ihracat-ithalat ilişkileri düzenlenmiştir. 2008'de karşılıklı olarak Kırgızistan ile Kore Cumhuriyeti'nde Büyükelçiliklerin açılması ikili ilişkileri canlandırmıştır. Bir taraftan 17000 civarı Koreli topluluğun varlığı iki ülke arasında ilişkilerin gelişmesinin olumlu olarak etkilemektedir. Diğer taraftan Kore Cumhuriyetine giden Kırgızistan vatandaşı misafir işçi sayısının artması ikili ilişkilerin bir boyutunu oluşturmaktadır. Misafir işçilerin yasal olarak çalışmaları Kırgızistan'ın ekonomisinde küçük de olsa olumlu etki yapmaktadır. Buna karşılık yasadışı olarak bulunan Kırgızistan vatandaşları Kırgızistan-Güney Kore ilişkilerinde bir sorun oluşturmaktadır. Ancak bu sorun Kırgızistan ile Kore Cumhuriyeti arasında ciddi bir mesele olarak algilanmaktadır.

İki ülke arasındaki ekonomik işbirliğinin perspektifli alanları olarak tarım, tekstil endüstrisi, bilgi teknolojisi ve madencilik sayılmaktadır. Kırgızistan’da, «Yeni Köy» modelinin uygulanması için tüm şartları bulunmaktadır. İlk önce, Kırgızistan tarım ülkesidir. Tarım sektörü, Kırgızistan ekonomisinde yüzde 40’lık bir paya sahiptir. Ülkedeki insan gücünün yüzde 60’1 tarım sektöründe çalışmaktadır. İkinci olarak, ülkenin toplam nüfusunun \% 65'i kırsal nüfusu oluşturmaktadır. Kırsal kesimlerde yaşayan halkın sosyo-ekonomik şartları düşüktür. Üçüncüsü, ülkede 1 931000 kişi yoksulluk sınırının altında yaşamaktadır. Bu nüfusun \% 67.7'si köylerde yaşayan halkı oluşturmaktadır. Dördüncü etken olarak, halkın zihniyetinin değişmesi gerekmektedir. Bu kalkınma modelini uygulamak için Hükümet ile halk bir dayanışma ortamında işbirliği yapması gerekmektedir.

Kırgızistan ile Kore Cumhuriyeti arasında işbirliği olumsuz olarak etkileyen unsurlar ya da engeller olarak ise doğrudan Bishkek-Seul-Bişkek uçuşunun olmaması, Koreli yatırımlarının etkinsiz kullanımı, Koreli girişimciler için Kırgızistan hakkında bilgi eksikliği, iki ülke arasında üst düzey ziyaretlerin az olması, özellikle Kore Cumhuriyeti Başkan ve Başbakan düzeyindeki ziyaretlerin gerçekleşmemesi sayılmaktadır.

\section{Kaynakça}

- Boronçiyeva, 2016. "Poltiçeskiy Analiz Dvuhstoronnih Otnoşeniy Kırgızstana s Respublikoy Koreya”, Vestnik Mejdunarodnogo Universiteta Kırgızstana. 30, s.96

- Douglass, 2013. "The Saemaul Undong: South Korea’s Rural Development Miracle in Historical Perspective". Asia Research Institute, Working Paper Series, 193, s.8

- Eşimbekov, 2010. "The Current Situation of the Kyrgyz-Korea Diplomatic Relations and a Future Direction for Strategic Cooperation”, The 3rd Korea-Central Asia International Conference, p.9

- Fumagalli, 2016. "Growing İnter-Asian Connections: Links, Rivalries, and Challenges in South KoreanCentral Asian Relations”, Journal of Eurasian Studies, 7, p. 39-40.

- Fumagalli, 2016. "Identity and İnterests in Korea’s Policy Towards Central Asia”. ss.3. http://congress.aks.ac.kr/korean/files/2_1358493169.pdf

- Fumagalli, 2012. "South Korea's Engagement in Central Asia from the End of the Cold War to the "New Asia Initiative", The Journal of Northeast Asian History, 9, p.73

- Kozmina, 2012. "Comparative Analysis of Inter-Ethnic Marriages in Korea and Among the Korean Diaspora in Central Asia”, International Journal of Central Asian Studies, 16, p.53-54.

- Lee, 2011. "Study on Korea’s Policy towards Central Asian States since 1991: Evaluation and Prospect for Policy Cooperation”, Institute of Central Asian Studies, Hankuk University of Foreign Studies, p.15.

- Men, 2015. "Koreyts1 Tsentralnoy Azii v Gosudarstvennoy Politike Sovetskogo Soyuza (1937-1991)", http://group-global.org/ru/publication/21731-koreycy-centralnoy-azii-v-gosudarstvennoy-politikesovetskogo-soyuza-1937-1991-gg , (10 Aral1k 2016)

- Namatbayeva, 2016. Budut Noviye Derevni v Kırgızstane, AKİpress. http://mnenie.akipress.org/unews/un_post:7852 
- Natsionalnıy Statistiçeskiy Komitet Kırgızskoy Respubliki. 2016. Natsionalnıy sostav Kırgızskoy Respubliki na 01.01.2016. Bişkek.

- Natsionalnıy Statistiçeskiy Komitet Kırgızskoy Respubliki. 2016. Çislennost Naseleniya oblastey, rayonov, gorodov, poselkov gorodskogo tipa v 2016 goda. Bişkek.

- Ormonova, 2014. "Ekonomiçeskoe Sotrudniçestvo Kırgızskoy i Koreyskoy Respublik”. Nauka, Novıye Tehnologii i Ínovatsii, 3, s.262.

- Reed, 2010. 'Is Saemaul Undong a Model for Developing Countries Today? ”, İnternational Symposium in Commemoration of the 40th Anniversary of Saemaul Undong. //asiafoundation.org/resources/pdfs/SaemaulUndongReedSept2010FINAL.pdf

- Sooyoung, 2009. “Analysis of Saemaul Undong: A Korean Rural Development Programme in the 1970s”. Asia-Pacific Development Journal,16, p.123

- Soltoyeva, 2007. 'O Trudovoy Migratsii iz Kirgizii v Koreyu'. Veçerniy Bişkek, http://demoscope.ru/weekly/2007/0283/gazeta021.php

- The Saemaul Undong movement in the Republic of Korea: Sharing Knowledge On Community-Driven Development. 2012. Asian Development Bank.

Philippineshttps://www.adb.org/sites/default/files/publication/29881/saemaul-undong-movement-korea.pdf

- Toktomuşev, 2001. Vneşnyaya Politika Nezavisimogo Kırgızstana. Sabır, Bişkek. 


\title{
Suriye Savaşı Öncesi ve Sonrasında Türkiye ve Avrupa Ülkelerinin Ekonomik Analizi
}

\section{Economic Analysis of Turkey and European Countries Before and After the Syrian War}

\author{
Asst. Prof. Dr. Semin Paksoy (Çukurova Üniversity, Turkey)
}

\begin{abstract}
Undoubtedly, a war in a country is a great destruction for its citizens. The Syrians have had to take refuge in other countries because of their vital problems. European countries have adopted a rigid attitude towards refugees to protect themselves. How did the refugee mobility, arising from internal conflicts in Syria and embodying different qualities within its constitution, affect European countries due to global economic relations? Or did Europe continue its economic development without being negatively affected by the geographically distant war? On the other side, to what extent has Turkey been able to protect itself economically? Can Turkey continue their progress towards the EU? This work investigating answers to these questions is based on the Maastricht criteria set to ensure economic integration at an advanced level among EU countries. The data related to these criteria cover 6 annual data of pre and post of the war. In the analysis, countries are ranked and evaluated with the flows of criteria, using PROMETHEE method. The result of the analysis shows that generally there is a decrease, in comparison, in the net flows of the second period. This implies that countries are not in better situation compared to the first period which covered 2008 financial crisis. In other words, the EU may likely remain behind of its economic and fiscal targets.
\end{abstract}

\section{Giriş}

2014 yılı itibariyle, dünyada 59,5 milyon insan, zorlayıcı nedenlerle kendi ülkeleri içinde veya başka ülkelere yer değiş̧irmek zorunda kalmıştır. Bu da bir günde ortalama 42,500 insanın, bir dakikada 24 insanın yer değiştirmesine karşılık gelmektedir. Yer değiştirmek zorunda kalan bu insanların 19.5 milyonu göçmen, 38.2 milyonu kendi ülkesinde yer değiştiren ve 1.8 milyonu mülteci konumundadır (UNCHR,2014).

2015 yılında 2 milyondan fazla insan, 38 Avrupa ülkesine sığınma başvurusunda bulunmuştur. Bu rakam 2014 yılında yapılan başvuruların $(709,000)$ yaklaşık 3 katı kadardır. Sı̆̆ı̆nma başvurusunda bulunanların ülkelere göre dağılımı; Suriye (675,000), Afganistan(406,000) ve Irak $(253,000)$ şeklindedir (UNCHR,2015:35). 1,2 milyona ulaşan bu başvuruların \%50'ye yakını Almanya ve İsveç'e yapılmıştır. Ocak 2016 itibari ile başta İspanya, İtalya ve Yunanistan olmak üzere Akdeniz yoluyla $\mathrm{AB}$ ülkelerine yapılan başlıca mülteci ve göç hareketlerinin \%21,7 oranı ile Suriye kaynaklı olduğu görülmektedir Akdeniz yoluyla gerçekleşen mülteci hareketlerinin doğduğu ülkelerin dağılımı Tablo 1'de gösterilmektedir.

\begin{tabular}{lccc}
\hline Ülkeler & Nüfusu & Sığınma Tarihi & Sı ğınma Yüzdesi \\
\hline Gambiya & 14,036 & 28 Şubat 2017 & $3.6 \%$ \\
Fildişi Sahili & 15,588 & 28 Feb 2017 & $4.1 \%$ \\
Gine & 16,280 & 28 Feb 2017 & $4.2 \%$ \\
Eritre & 20,765 & 28 Feb 2017 & $5.4 \%$ \\
Irak & 28,244 & 31 Mar 2017 & $7.3 \%$ \\
Nijerya & 39,275 & 28 Feb 2017 & $10.2 \%$ \\
Afganistan & 42,009 & 31 Mar 2017 & $10.9 \%$ \\
Suriye & 83,570 & 31 Mar 2017 & $21.7 \%$ \\
Diğerleri & 15,626 & 28 Feb 2017 & $4.1 \%$ \\
\hline
\end{tabular}

Tablo 1. Ocak 2016 itibari ile Akdeniz Ülkelerine Giden Sığınmacıları Dă̆ılımı

Diğer yandan, 2015 yılı itibari ile dünyada, göç ve sığınma talep eden toplam nüfusun 13,9 milyonu gelişmekte olan ülkeler, 2,2 milyonu gelişmiş ülkeler ve 4 milyonu ise sığınma krizi doğuracak düzeyde kendi vatandaşlarının ihtiyaçlarını en az karşılayabilen, az gelişmiş ülkeler tarafından sığınma sağlanmıştır. Dolayısı ile düşük ve orta gelirli gelişmekte olan ülkeler orantısız bir şekilde göç ve sığınmacı hareketlerine ev sahipliği yapmaktadır (UNCHR, 2015:18). Türkiye (2,5 milyon) dünyada en fazla mülteci kabul eden ülke konumuna gelmiştir. Türkiye'yi Pakistan (1,6 milyon), Lübnan (1,1 milyon), İran İslam Cumhuriyeti $(979,400)$, Etiyopya $(736,100)$ ve Ürdün $(664,100)$ takip etmektedir. Lübnan ülke nüfusuna oran ile kabul ettiği mülteci sayısı (183/1000) açısından dünyada birinci sirada yer almaktadır (UNCHR, 2015:3).

Uluslararası göç örgütü, 2016 yılı için toplam 669.867.115 \$ yardım planı yapmış, ancak ülkelere sadece 359.651 .048 \$ (\%54'ünü) ödeme yapmıştır. 2016 yılına ait uluslararası yardım fonun ülkelere dağılımı aşă̆ıda Tablo 2'de gösterilmektedir. Tablo 2'de görüldüğü gibi bir yandan dünyanın en fazla mülteci misafir eden ülkesi 
olan Türkiye, vaat edilen yardımın sadece \%31'ini almıştır. Göç ve sığınma hareketlerinde, eğitim, sağlık, koruma, temel ihtiyaçlar, gıda güvenliği ve geçim gibi acil durum programlarına destek olmak üzere 132 üye ülkenin geniş katılımına sahip göç örgütünün böylesine büyük bir ihmali manidardır. Diğer yandan AB ülkeleri içinde de $A B$ göç politikalarına uygun davranan ülke sayısının yok denecek kadar az olduğu bilinmektedir. Yapılan antlaşmalar rağmen bazı ülkelerin göç ve mültecilere karşı katı tutumları, göç örgütünün amacına sekte vurduğu görülmektedir.

\begin{tabular}{|l|l|l|l|}
\hline Ülkeler & Yardım $(\$)$ & Ödenen K1smı $(\$)$ & Yüzde \\
\hline Türkiye & 73.930 .385 & 22.858 .000 & 31 \\
\hline Yunanistan & 466.836 .326 & 266.638 .719 & 57 \\
\hline Makedonya & 26.014 .080 & 17.639 .047 & 68 \\
\hline Sirbistan & 20.729 .867 & 12.463 .133 & 60 \\
\hline Hırvatistan & 7.444 .775 & 1.010 .634 & 14 \\
\hline Slovenya & 6.939 .274 & 1.861 .034 & 27 \\
\hline
\end{tabular}

Tablo 2. 2016 Yılı Avrupa Mülteci ve Göç Yardım Planı Kaynak: https://data2.unhcr.org/en/documents/download/49750

Oysa taraflara sıkıntıların yanı sıra sorumluluk da yükleyen bu sürecin planlı ve programlı bir şekilde geçirilmesinde sayısız faydalar vardır. Özellikle eğitim, toplumsal uyum için sosyal faaliyetler ve sağlık hizmetlerinin verilmesinin yanı sıra çalışma olanaklarının sunulması, ev sahibi ülkeye uzun vadede büyük fayda sağlayacaktır (World Bank, 2014).

Ülkeler böylesine büyük insani sorunla uğraşırken, kendi vatandaşlarının geleceğine yönelik sosyal ve ekonomik refahlarını sağlamak adına gerekli ekonomik gelişmeye devam etmeyi hedeflemektedir. Kaldı ki 2008 krizinden sonra gerek ülkelerin genel ekonomik performansları, gerekse bireylerin hayat standartlarında negatif yönde bir değişme olduğu bilinen bir gerçektir. $\mathrm{AB}$ düzeyinde bu durum dikkate alındığında, ülkeler arası standart farklılıkları da ortaya çıkmaktadır. İşsizlik seviyesi, genç işsizlik seviyesi ve gelir düşüklüğü dikkate alındığında Güney Avrupa ülkeleri ile Kuzey Avrupa ülkeleri arasındaki daha öncede var olan bu farklıların derecesi gittikçe yükselmektedir. Ekonominin reel yansımaları aynı zamanda AB kurumsal geleneği ile ilgili geleceğinin de sorgulanmasına yol açmaktadır. Burada borç krizleri ve Euro'nun devamlı değer kaybetmesi böyle bir riskin belirtileri olarak algılanabilir. Bu endişelerin giderilmesi Mundell ile başlayan ve diğer iktisatçılarla devam eden optimum para alanı kavramının yeniden dikkate alınarak, AB ülkeleri arasında henüz belli bir olgunluğa erişmemiş bu farklı yaklaşımların giderilmesi söz konusu edilmelidir (Pütün, 2014:179).

Ekonomik alanda bu gelişmeler yaşanırken, aslında hem AB politikacılarının hem de - genel nitelemeyle - ülke vatandaşlarının gündemdeki en önemli siyasi konulardaki algı ve yorumlarındaki farklılıklar da önemli seviyelere ulaşmaktadır. Birlik içerisinde yaşanan algı farklılıkları, özelde de göçmen ve sığınmacı konularına çarpıcı bir şekilde yansımaktadır

$\mathrm{Bu}$ durum ülkeler arasındaki uygulamalardaki farklılıkları da içine almaktadır. Hatta zaman zaman bu uygulamalar AB kurumsal politika ve gelenekleri dikkate alınmadan yürütülmektedir. Avusturya ve Macaristan'ın bu konudaki politik tutum ve davranışları yakinen bilinmektedir. İngiltere'nin, ekonomik birliğin temel öğelerinden olan birlik içi işgücü mobilitesinin ülke ekonomisini istikrarsızlığa götürdüğü konu edilerek bir referandumun en önemli bir parçası olması, AB entegrasyonun geleceği açısından oldukça önemlidir. Halbuki tartışıldığı üzere optimum para alanı yaklaşımı genel olarak faktör mobilitesini, özel olarak ta işgücü mobilitesini ekonomik ve parasal birlik içinde vazgeçilmez dengeleyici unsurlar olarak görmektedir (Pütün, 2014:183).

AB ülkeleri arasındaki politik ve güvenlik konularındaki farklılıklar nedeniyle, hükümetler arası uzun tartışmalar sonrası uzlaşıya varılan Mastricht antlaşması (1992) ekonomik entegrasyonun son halkası olarak benimsenmiştir. Belirlenen Mastricht yakınsama kriterleri, nominal ölçüler olarak parasal birliğe katılmaya elverişli olma kriterleri olup, bir ölçüde birliğin optimum para alanı ölçülerini yansıtmaktadır (Pütün, 2014).

Berlin duvarının yıkılması (1989) ve Sovyetler Birliği'nin çöküşü (1991) sonrasında Avrupa'da uzmanlar, milyonlarca sığınma ve göç hareketleri ihtimaline karşı önlem almak üzere çalışmalara zaten başlamışlardı. 90'lı yıllardan sonra bu tehdit- işsizlik, kaynak sıkıntısı, şiddet ve savaşlar nedeniyle- giderek şiddetini arttırmıştır. Avrupa ülkeleri kendilerini bu dışsal sorundan korumaya çalışarak, sığınmacılara yönelik katı tutum benimsemişlerdir. Ancak aşırı sınır önlemleri yasadışı sınır geçişlerini, denetimlerin üstesinden gelmek için örgütlü suç faaliyeti oluşturulması şeklinde etkileri doğurmuştur (Thränhardt, 2009).

Savaş ve çatışmaların yanı sıra, ülkeler arasında mevcut ekonomik eşitsizlik, ekonomik gelişme sürecinde enerji ve doğal kaynaklara büyük talebin neden olduğu çevresel bozulmalar uluslararası mülteci ve göç hareketlerinin daha da artmasına neden olmaktadır. Uluslararası düzeyde gerekli önlemler alınmadığı durumda, 2050 yılına kadar uluslararası mülteci ve göç hareketinin 320 milyona ulaşacağı beklenmektedir (UNCHR, 2015:32).

2011 yılında başlayan Suriye krizi, 2015 yılı itibariyle 4,9 milyona ulaşan insanın mülteci konumuna geçmesine neden olan, dünyanın en büyük nüfus hareketi ve mülteci krizidir (UNCHR,2015). Birleşmiş Milletler Mülteciler Yüksek Komiserliği raporuna göre (2014), Suriye (3,88 milyon) ile mülteci veren ülkeler arasında birinci ülke konumundadır ve Afganistan (2,59 milyon) ve Somali (1.11 milyon) hemen peşi sıra gelmektedir (UNCHR,2014). 
Kuşkusuz bir ülkede savaş, kendi vatandaşlarına büyük bir yıkımdır. Suriyeliler, yaşamsal sorunlar nedeniyle diğer ülkelere, öncelikle komşu ülkelere, özellikle de Türkiye'ye sığınmak zorunda kalmışlardır. 2014 yılı itibari ile Suriyelilerin 1,7 milyonu AB ülkelerine, 1,6 milyonu (yaklaşık \%51’i) sadece Türkiye'ye sı̆̆ınmışlardır (UNCHR,2014:10). Mültecilik sürecin uzaması ile mülteciler gittikleri ülkelerde ekonomik, sosyal ve güvenlik alanında çeşitli etkiler yaratmaya başlamışlardır. Kontrollü ve planlı mülteci hareketinin faydalarına rağmen, kontrolsüz göç; kalıcı yoksulluk, artan çatışma ve şiddet, sosyal huzursuzluk, ekonomik eşitsizlik, kaçakçılık ve insan ticaretine neden olmaktadır. Diğer yandan mülteci, göçmen ve sığınmacılar da gittikleri ülkede mahrumiyet, ayrımcılık, şiddet ve taciz gibi bir çok zorluklarla karşılaşmaktadır.

Suriye'deki iç çatışmalardan kaynaklanan ve farklı nitelikleri de bünyesinde taşıyan sığınmacı hareketliliği, küresel ekonomik ilişkiler nedeniyle Avrupa ülkelerini ne şekilde etkiledi? Veya Avrupa, coğrafi olarak uzağında olan savaştan etkilenmeyerek ekonomik gelişimine devam etti mi? Diğer yandan bu soruna farklı yaklaşım benimseyen ve yarım asırdan fazla bir süreden beri Avrupa Birliğine(AB) adaylık konumunu sürdüren Türkiye, Suriye'nin yakın komşusu olarak kendini ekonomik yönden ne derecede koruyabildi? Ve Türkiye AB yolunda ilerlemelerine devam edebildi mi?

Bu çalışmanın amacı, Suriyeli mültecilerin bir kısmına ev sahipliği yapan AB ülkeleri ve Türkiye'nin bir karşılaştırmasını yapmaktır. Karşılaşıırmada ülkelerin daha geniş ekonomik hedeflerine ulaşmasına katkı sağlayan fiyat istikrarı (Gendesmeier,2009:5) ve mali durumunu yansıtan ülke göstergeleri (Maastricht kriterleri) temel alınarak yapılmaktadır. Çalışmaya ait veriler, 2008-2010 ve 2013-2015 yıllarını kapsayan iki dönem halinde gruplandırılmıştır.

\section{PROMETHEE Yöntemi}

PROMETHEE yöntemi, çok kriterli karar verme problemlerinde yaygın olarak kullanılan yöntemlerden biridir. Yöntemde alternatif ve kriterler için karşılaştırma matrisleri oluşturmak yerine, tercih fonksiyonlarına yer vermektedir.

PROMETHEE yöntemi, karar vericiye tüm kriterler için ayrı tercih fonksiyonu belirleme imkânı tanımaktadır. Tercih fonksiyonlarında kullanılan parametre veya eşik değerleri, problemin tipine ve kriterin özelliklerine göre karar verici tarafindan belirlenmektedir. Bu parametreler, alternatiflerin ikili karşılaştırılmasında, alternatiflerin performanslarında ara değerlerin tercih edilip edilmemesi ve etkili derecesi konusunda önem kazanmaktadır. $\mathrm{Bu}$ nedenle, parametre (eşik değerlerini) belirlerken gerektiğinde uzman kişilerden destek alınmaktadır. Tercih fonksiyonları, bir alternatife ait üstünlük skorunun gereğinden fazla şişirilmesine imkân tanımayacak şekilde belirlenmelidir.

$a$ alternatifinin $b$ alternatifine göre ne denli tercih edilebilir olduğu veya üstünlüğü, ikili karşılaştırma ile eşitlik (1)'den yararlanarak yapilir.

$$
x=f(a)-f(b)
$$

Elde edilen bu fark, kriterin tipine göre seçilen tercih fonksiyonuna uyarlanarak j. kritere göre, alternatif $a$ 'nın diğer alternatiflere olan üstünlüğünün belirlendiği “tercih endeksi” $\pi(a, X)$ 'nin hesaplanmasında kullanılmaktadır.

Tercih fonksiyonu $\mathrm{P}(\mathrm{x})$ 'in genel matematiksel gösterimi eşitlik (2)'de verilmektedir (Brans ve Vinche,1985). Tercih fonksiyonu $\mathrm{P}(\mathrm{x})$, kriter için seçilen tercih fonksiyonu tipine adapte edilmektedir. Somut durumlarda, $\mathrm{f}(\mathrm{a})$ ile $\mathrm{f}(\mathrm{b})$ arasındaki farka bağlı olarak, $\mathrm{p}$ fonksiyonu aşağıda verilen eşitlik (3) gibi hesaplanmaktadır.

$$
\begin{aligned}
& P(x)=P_{j}(a, b)= \begin{cases}P(a, b), & x>0 \\
0 & , x \leq 0\end{cases} \\
& P_{j}(a, b)=p[f(a), f(b)]=p[f(a)-f(b)]
\end{aligned}
$$

Burada; $P_{j}(a, b)$ : j. kriter altında, $a$ alternatifinin $b$ alternatifi ile karşılaştırılması sonucundaki $a$ alternatifinin üstünlük değeridir. Daha öncede ifade edildiği gibi, $a$ alternatifi $b$ alternatifine göre üstün (ya da tercih edilebilir) değilse, bu karşılaştırmada, $a$ alternatifinin üstünlük skorunda artı̧̧ olmamaktadır (Paksoy,2017).

PROMETHEE yöntemi her bir kriter altında alternatiflerin birbiri ile tercih üstünlüklerinin (üstünlük skoru) hesaplanmasını sağlamaktadır. Alternatiflerin tüm kriterler açısından tercih üstünlüğünün skorlarının toplamının, tercih edilme skorları toplamından farkı, PROMETHEE skorudur ve alternatiflerin üstünlüğü bu skorun büyüklüğü ile belirlenmektedir (Paksoy,2017).

Yöntem, hesaplamalarında üstünlük ve zayıflık akımlarını kullanmaktadır. Ppozitif ve negatif akımlar olarak adlandırılan bu akımlar Şekil 1'de gösterilmektedir. Pozitif akım, $a$ alternatifinin diğer tüm alternatiflerle ikili karşılaştırılmasında üstün olduğu diğer alternatifleri göstermekte ve bu karşılaştırmalardan elde edilen üstünlük (tercih) endekslerinin toplamını ifade etmektedir. Negatif akım ise tam tersine, $a$ alternatifinin zayıf olduğu alternatifleri ve $a$ alternatifinin bu alternatifler karşısında negatif üstünlük skorlarının(zayıflı̆̆ının) toplamını ifade etmektedir. 


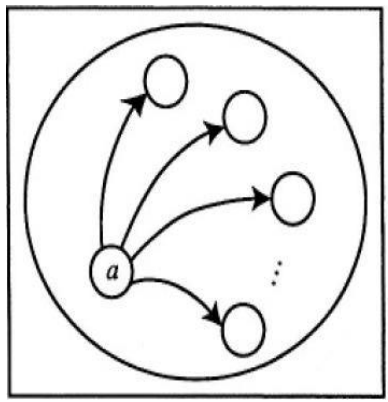

$\Phi^{+}(\mathrm{a})$ : Pozitif akım

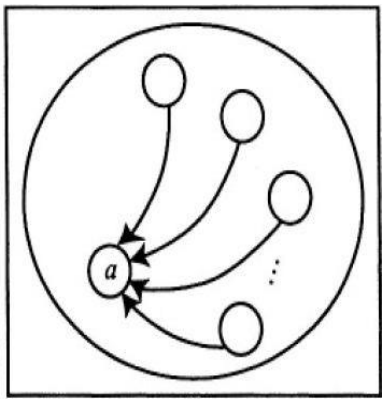

$\Phi^{-}(\mathrm{a})$ : Negatif akım

Şekil 1. Üstünlük Akımları Kaynak: Brans \& Mareschal, 2005:173

$\Phi^{+}\left(\right.$a), a alternatifinin diğer alternatifler üzerinde nasıl bir üstünlük sağladığını göstermektedir. $\Phi^{+}($a) ne kadar büyürse, alternatif o kadar üstün duruma gelir. $\Phi^{-}$(a) ise diğer alternatiflerin a alternatifine nasıl bir üstünlük sağladığını gösterir. $\Phi^{-}$(a) ne kadar küçülürse, alternatif o kadar üstün duruma gelir. Akımların belirlenmesinden sonra, ikili alternatif karşılaştırılması yapılır ve aralarındaki ilişki; üstünlük, eşitlik ve karşılaştırılamaz kategorilerine yerleştirilir (Brans ve Mareschal, 2005:173; Genç, 2013:141). Hesaplanan net akım Ф’ye göre alternatifler siralanmaktadır.

Çalışmada ülkelerin sıralama ve karşılaştırılmasında kullanılan göstergeler Maastricht kriterleri olarak seçilmiştir. Suriye savaşı öncesi (2008 - 2010) ve sonrası (2013-2015) yıllarına ait ülke göstergeleri ile analiz yapılmıştır. Visiual Promethee Academik yazılımı ile hesaplana pozitif, negatif ve net akımlar Tablo 3 ve Tablo 4'de gösterilmektedir.

Tablo3'de birinci döneme ait PROMETHEE sıralamasında, en yükseksek net skor İrlanda'ya, en düşük skor Macarista'a aittir. Yunanistan, Bulgaristan, Türkiye ve Macaristan sıralamada en aşağıda yer alan ülkelerdir.

\begin{tabular}{|c|c|c|c|c|}
\hline Sira & Ülkeler & Phi & Phi+ & Phi- \\
\hline 1 & İrlanda & 0,3266 & 0,5642 & 0,2375 \\
\hline 2 & Slovakya & 0,3147 & 0,4564 & 0,1418 \\
\hline 3 & İspanya & 0,2772 & 0,4463 & 0,1691 \\
\hline 4 & Slovenya & 0,1954 & 0,3898 & 0,1943 \\
\hline 5 & Çek Cumh & 0,1648 & 0,3839 & 0,2191 \\
\hline 6 & Birleşik Krallık & 0,1501 & 0,4117 & 0,2616 \\
\hline 7 & Lüksemburg & 0,0938 & 0,3757 & 0,2819 \\
\hline 8 & Portekiz & 0,0936 & 0,3772 & 0,2836 \\
\hline 9 & Fransa & 0,0796 & 0,3325 & 0,2528 \\
\hline 10 & Estonya & 0,0675 & 0,4206 & 0,353 \\
\hline 11 & Hollanda & 0,0579 & 0,3455 & 0,2876 \\
\hline 12 & Litvanya & 0,0566 & 0,4055 & 0,3489 \\
\hline 13 & Danimarka & 0,036 & 0,3251 & 0,2892 \\
\hline 14 & İsveç & $-0,0012$ & 0,3298 & 0,331 \\
\hline 15 & Finlandiya & $-0,0022$ & 0,3116 & 0,3138 \\
\hline 16 & Letonya & $-0,0131$ & 0,431 & 0,4441 \\
\hline 17 & Kibris & $-0,0216$ & 0,2911 & 0,3127 \\
\hline 18 & Romanya & $-0,0384$ & 0,4354 & 0,4739 \\
\hline 19 & Almanya & $-0,0516$ & 0,2947 & 0,3463 \\
\hline 20 & Avusturya & $-0,0542$ & 0,2612 & 0,3154 \\
\hline 21 & Polonya & $-0,0619$ & 0,3289 & 0,3908 \\
\hline 22 & Malta & $-0,0901$ & 0,2502 & 0,3404 \\
\hline 23 & Bulgaristan & $-0,1039$ & 0,3236 & 0,4275 \\
\hline 24 & Yunanistan & $-0,108$ & 0,3252 & 0,4332 \\
\hline 25 & Hurvatistan & $-0,1201$ & 0,299 & 0,4191 \\
\hline 26 & İtalya & $-0,1351$ & 0,2096 & 0,3446 \\
\hline 27 & Belçika & $-0,1522$ & 0,2201 & 0,3723 \\
\hline 28 & Türkiye & $-0,4446$ & 0,2158 & 0,6604 \\
\hline 29 & Macaristan & $-0,5155$ & 0,1561 & 0,6717 \\
\hline
\end{tabular}

Tablo 3. 2008 - 2010 Yllı PROMETHEE Siralaması

Aşağıda Şekil 2'de bazı ülkelerin her bir kritere göre net akımını (skorunu) gösteren ülke profilleri gösterilmektedir. Her bir kritere ait 3 yıllık veri kullanıldığından, kriterlere ait skorlar 3'lü çubuklar halinde görülmektedir. Ülke profilinde gösterilen 3'lü çubuklar, sırasıyla 2008, 2009 ve 2010 yıllarına ait devlet borcu, 
bütçe açığı, uzun dönem faiz oranı ve enflasyon oranlarını göstermektedir. Aşağı yöndeki çubuklar kriter açısından alternatifin negatif akımının pozitif akımından fazla olması halini yansıtmaktadır. Sıralamada net skorun büyük olması tercih edilmektedir. Aşağı yönlü çubuklar, temsil ettiği kriter açısından alternatifin iyi olmadığını, yukarı yönlü çubuklar ilgili kriter açısından alternatifin iyi olduğunu ifade etmektedir.

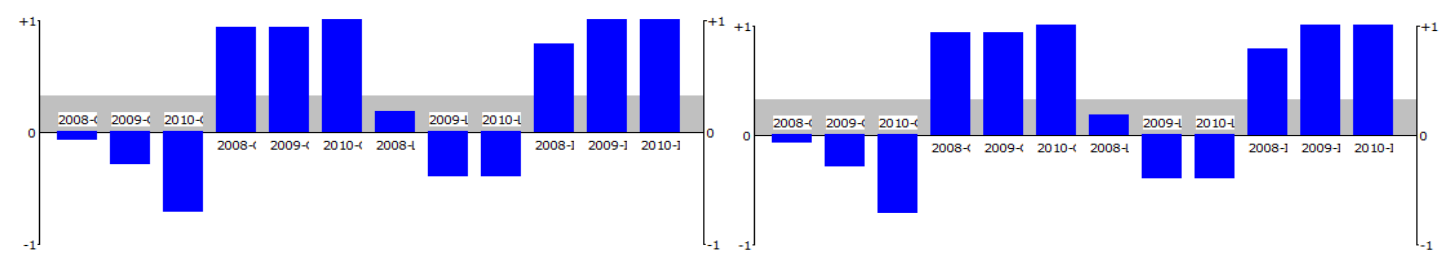

İrlanda Profili

Yunanistan Profili

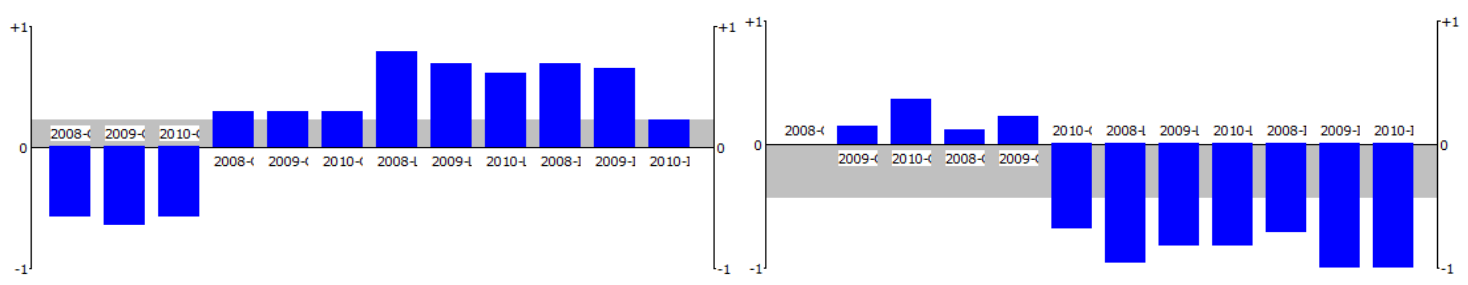

Fransa Profili

Türkiye Profili

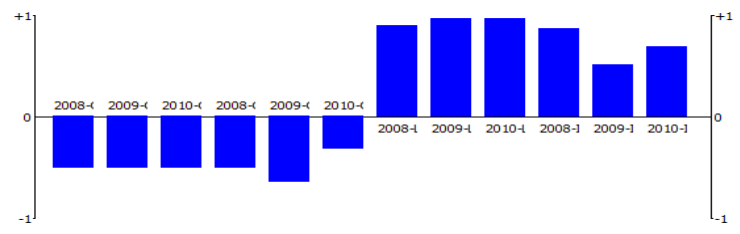

Almanya Profili

Şekil 2. 2008 - 2010 Dönemi Ülke Profilleri

Örneğin İrlanda'nın birinci dönemdeki her üç yıla ait borç açı̆̆ı ve enflasyon oranları gayet iyi olduğundan, pozitif net akımları da yüksek görünmektedir. Negatif akımlarınında fazla olmaması İrlandayı birinci sıraya taşımıştır.

Şekil 2'de, Türkiye ve Slovakya gibi birkaç ülke hariç, bir çok AB ülkesinin bu döneme ait yıllardaki devlet borçları temsil eden ilk 3 sütunda da görüldüğü gibi, devlet borçları açısından negatif net akıma sahip oldukları görülmektedir. Başka bir ifadeyle, AB ülkelerinin kamu borçları, negatif akım skorlarını borçları nispetinde artırmaktadır. PROMETHEE sıralamasında birinci sırada olan İrlanda, 2008 yılında negatif akım skoruna daha az yük bindirirken, 2009 ve 2010 yılında bu yükün şiddetini giderek artırmıştır. İrlanda, uzun dönem yıllık faiz oranı açısından 2009 ve 2010 yıllarında negatif akım skorunun yükünü artırmıştır. Buna rağmen bütçe açı̆̆ı ve enflasyon oranında bu dönemde göstermiş olduğu performans, pozitif akım skorunu bariz bir şekilde artırmasına neden olmuştur. Dolayısı ile net akım skoru pozitif yönde olup, diğer ülkelerden de büyü olması sebebiyle birinci konuma yerleşmiştir. Almanya ise bu dönemi kapsayan tüm yıllarda hem kamu borçları hem de bütçe açıkları nedeniyle negatif akım skorunu artırarak on dokuzuncu sırada yer almaktadır. AB ülkelerinin aksine, Türkiye kamu borç kriterine göre iyi konumda olan tek ülke olmasına rağmen, enflasyon ve uzun dönemli faiz oranlarının yüksek olması ve bu durumun da negatif akım toplamına çok yüksek değerle yansıması nedeniyle sıralamada sonlarda yer almıştır. Türkiye bu dönemde yer alan 3 yıla ait devlet borcu açısından pozitif net akım skorlarını artırmıştır. Ama 2010 yılı bütçe açığının yanı sıra tüm yıllar için faiz ve enflasyon oranları açısından negatif net akıma sahiptir.

Şekil 3'de Türkiye ve Macaristan'ın 2008-2010 dönemine ait göstergelerde birçok AB ülkesinin gerisinde kaldığı net bir şekilde görülmektedir. Şeklin ortasında bulunan sütun PROMETHEE net akım değerini gösteren bir ölçektir. Sütun, ortasında konumlandırılan sıfır değeri ile iki parçalı düşünülebilir. Üstteki birinci kısmın sağında yer alan ülkeler daha iyi konumdadır. Sol tarafta ise ülkelere ait toplam net akımlar görülmektedir.

Tablo 4'de 2013- 2015 dönemine ait PROMETHEE sıralaması yer almaktadır ve en çarpıcı ilerleme Bulgaristan'a ait görülmektedir. Türkiye, Yunanistan, İtalya ve Macaristan yine sıralamanın gerisinde kalan ülkeler olarak görünmektedir. Ancak ülkelere ait net skorlara bakıldığında, genel olarak önceki dönem göre bir azalmanın varlığı da göze çarpmaktadır. Bu durum, ikinci dönemde Avrupa ülkeleri genelinde ve Türkiye açısından tercih edilebilir iyileşmenin olmadığı veya birlik içinde genel bir kötüleşme olduğunu göstermektedir. 


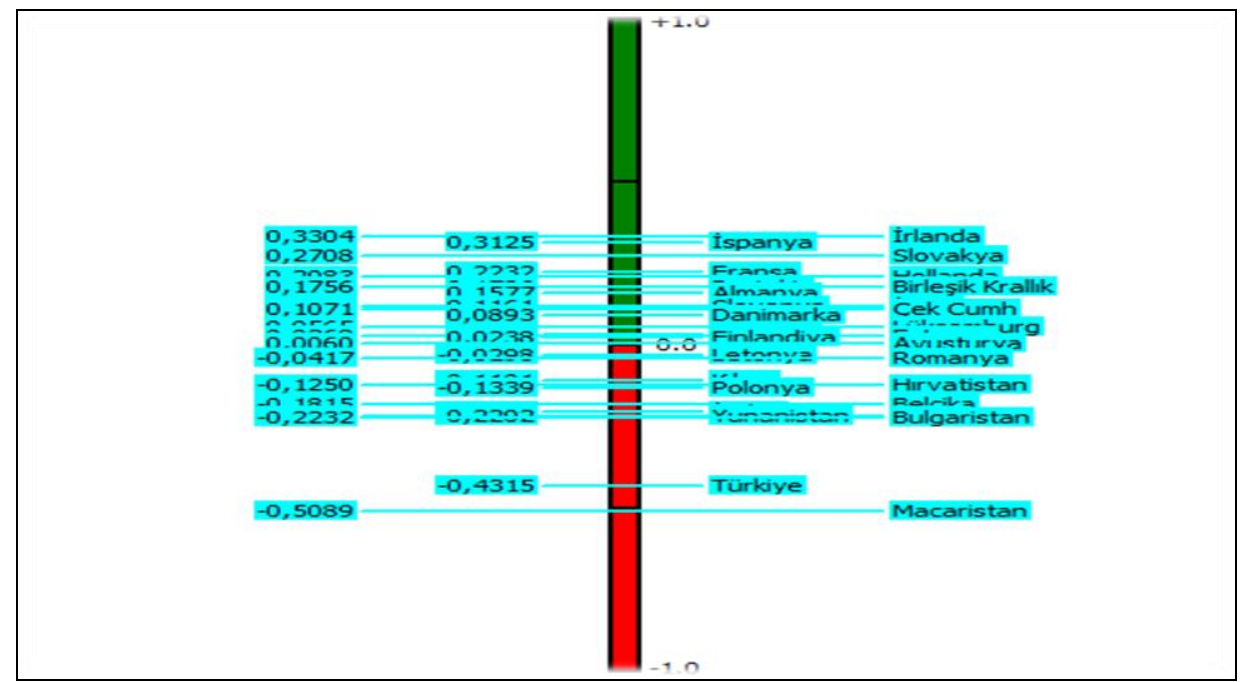

Şekil 3 . Net Skorla Göre Ülke Konumları (2008-2010 Dönemi)

\begin{tabular}{|c|c|c|c|c|}
\hline Sira & Ülke & Phi & Phi+ & Phi- \\
\hline 1 & Bulgaristan & 0,3015 & 0,497 & 0,1956 \\
\hline 2 & Slovakya & 0,1629 & 0,3456 & 0,1827 \\
\hline 3 & Estonya & 0,1608 & 0,4206 & 0,2598 \\
\hline 4 & Finlandiya & 0,1584 & 0,3629 & 0,2045 \\
\hline 5 & Letonya & 0,1457 & 0,3517 & 0,2059 \\
\hline 6 & Danimarka & 0,1208 & 0,3556 & 0,2348 \\
\hline 7 & Çek Cumh & 0,1169 & 0,3321 & 0,2152 \\
\hline 8 & Lüksemburg & 0,099 & 0,3612 & 0,2622 \\
\hline 9 & İsveç & 0,0963 & 0,3313 & 0,235 \\
\hline 10 & Polonya & 0,0898 & 0,3493 & 0,2596 \\
\hline 11 & Birleşik Krallık & 0,0873 & 0,3551 & 0,2678 \\
\hline 12 & Fransa & 0,076 & 0,3212 & 0,2452 \\
\hline 13 & Slovenya & 0,0692 & 0,3519 & 0,2827 \\
\hline 14 & İspanya & 0,0686 & 0,3386 & 0,27 \\
\hline 15 & Hollanda & 0,0681 & 0,317 & 0,2489 \\
\hline 16 & Litvanya & 0,065 & 0,3095 & 0,2445 \\
\hline 17 & Malta & $-0,0057$ & 0,2729 & 0,2787 \\
\hline 18 & İrlanda & $-0,0092$ & 0,2842 & 0,2934 \\
\hline 19 & Hirvatistan & $-0,0654$ & 0,3037 & 0,3691 \\
\hline 20 & Belçika & $-0,076$ & 0,2365 & 0,3125 \\
\hline 21 & Avusturya & $-0,1009$ & 0,2397 & 0,3405 \\
\hline 22 & Portekiz & $-0,1063$ & 0,2828 & 0,3891 \\
\hline 23 & Almanya & $-0,1115$ & 0,2433 & 0,3548 \\
\hline 24 & Romanya & $-0,1399$ & 0,2752 & 0,4151 \\
\hline 25 & Yunanistan & $-0,1607$ & 0,3509 & 0,5116 \\
\hline 26 & Kibris & $-0,1968$ & 0,2908 & 0,4876 \\
\hline 27 & İtalya & $-0,1995$ & 0,1737 & 0,3731 \\
\hline 28 & Macaristan & $-0,2216$ & 0,212 & 0,4336 \\
\hline 29 & Türkiye & $-0,493$ & 0,2301 & 0,7231 \\
\hline
\end{tabular}

Tablo 4. 2013 - 2015 Dönemi PROMETHEE Siralaması

Göç ve sığınma hareketlerinin göreli olarak daha az olduğu birinci dönem (Tablo 3) ile sığınma ihtiyacının giderek şiddetlendiği 2013-2015 dönemi (Tablo 4) pozitif net akımlar açısından kıyaslandığında, AB ülkelerinde genel bir düşüş görülmektedir. Bu durum, analizde kullanılan parasal ve mali göstergeler açısından, ikinci dönemde AB ülkelerinde genel olarak bir ilerleme kaydedilmediğini göstermektedir. Bulgaristan pozitif net akımındaki artışın yanı sıra negatif net akımındaki önemli azalış ile sıralamada birinci olmuştur. İngiltere, pozitif net akımında, birinci dönemin neredeyse yarısı kadar bir skor kaybı ve negatif akımında da artış nedeniyle 6. sıradan 11. sıraya gerilemiştir. Fransa'nın ise negatif akımındaki azalıştan daha fazla bir oranda pozitif akımındaki kayıp, sıralamada 9. sıradan 12. sıraya gerilemesine neden olmuştur. Almanya kamu borç yükünü hafifletmesi rağmen, bütçe açığından kaynaklanan negatif akım yükü ile 12. sıradan 23.sıraya gerilemesine neden olmuştur. Çalışmada inceleme amaçlı seçilen birinci dönemin 2008 finansal krizi kapsamasına rağmen, ikinci dönemde birçok $A B$ ülkesinin pozitif net akımlarında düşüş görülmesi dikkat çekicidir. 
Ülke profillerini içeren Şekil 4'de ayrıca bazı ülkelerin net skorlarının sayısal olarak değiştiği, pozitif ve negatif akımların bir önceki yıla göre yön değiştirmediği görülmektedir. Zaten pozitif ve negatif akımlara ait skorları olumlu yönde gelişen ülkelerin sıralamalarına da bu değişimler yansımaktadır. Slovakya ve İsveç gibi, bu özelliklere sahip olan ülkelerin göstergeler açısından gayet tutarlı olmasının akımlarına da yansımış olduğu gözlenmektedir.

Maalesef Türkiye'nin, Şekil 4'de görüldüğü üzere, enflasyon ve faiz oranlarındaki negatif net skorlarının yanı sıra 2014 ve 2015 yıllarına ait kamu borçlarından kaynaklanan olumsuz etkinin negatif net akım skoruna yansıması; bir önceki döneme göre gerilemesine ve AB ülkelerinden bir hayli kopuk hale gelmesine neden olmuştur. Bu durum Şekil 5'de daha net görülmekte olup, AB ülkeleri ile aramızdaki makasın daraltılmasına yönelik çalışmaların gecikmeden hayata geçirilmesi, Bulgaristan gibi atakta bulunması beklenmektedir. Paksoy ve Kılıç (2013) Maastricht kriterleri açısından AB ülkelerinin karşılaştırılması ile ilgili yaptıkları çalışmada, o dönemde Bulgaristan'ın Türkiye ve Romanya gibi birlik içerisinde en geride kalan ülkeler arasında yer aldığı sonucunu varmışlardır. Son yıllardaki sıkı mali politikalar uygulayan Bulgaristan, kamu borcu açısından AB'nin Maastricht standartlarının bir hayli altına inmiş, bütçe açığı ve faiz sorununu çözmüştür (Commission, 2015). Gösterge değerleri açısından Bulgaristan Maastricht kriterlerini karşılayan en iyi ülke konumuna gelmiştir. Bu durum PROMETHEE ile ülke karşılaştırmalarında Bulgaristan'ın pozitif ve negatif net akımlar açısından olumlu skorlarının toplamını artırmıştır. Maastricht kriterlerini karşılamaya çok odaklanan Bulgaristan'ın, bu hedefini yakalamış olduğu görülmektedir.

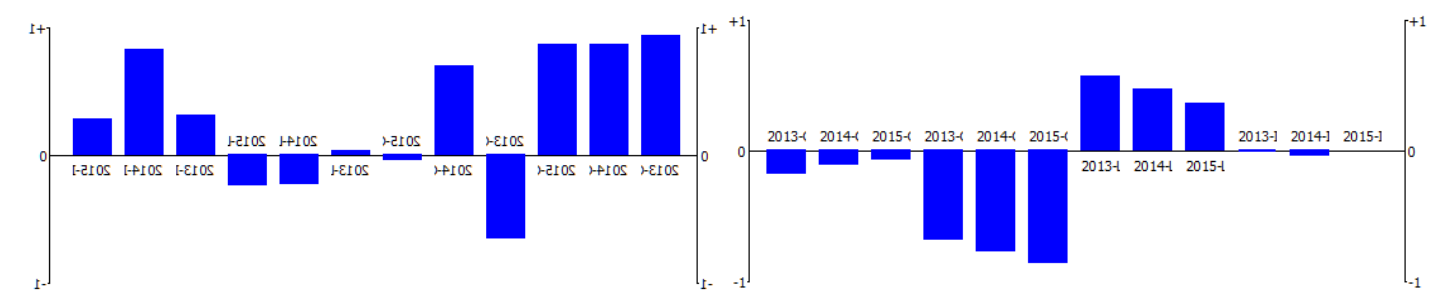

Bulgaristan Profili

Almanya Profili

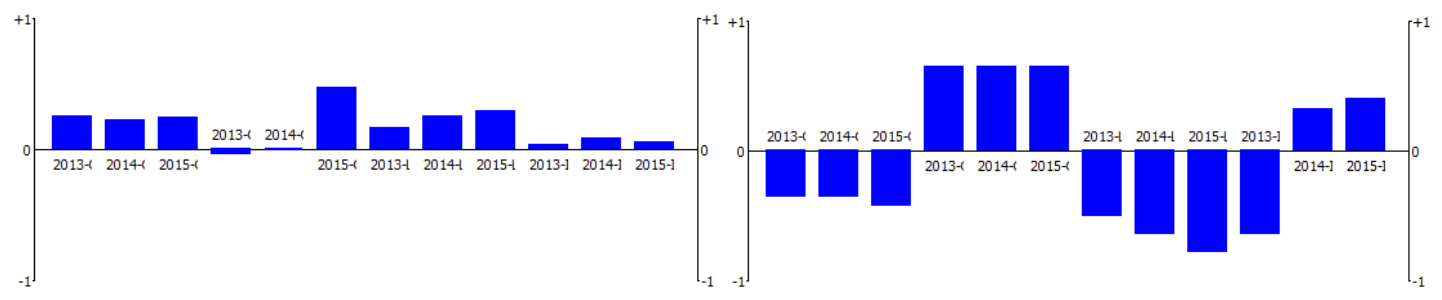

Slovakya Profili

Hurvatistan Profili

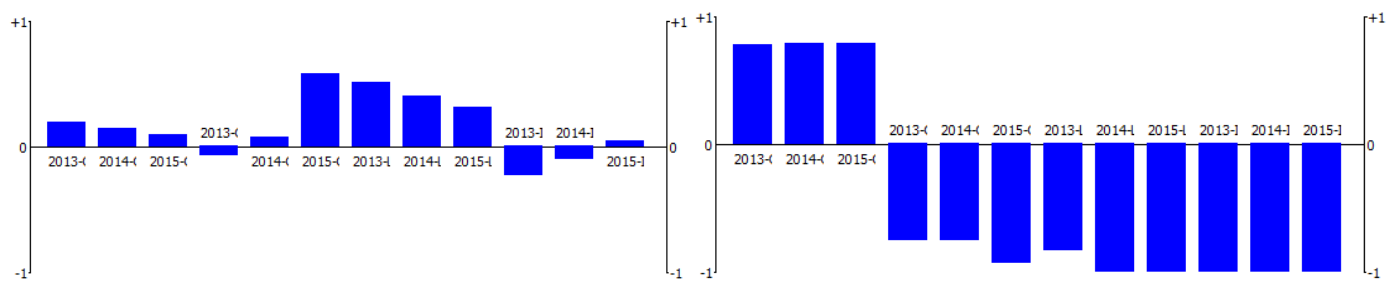

Finlandiya Profili

Türkiye Profili

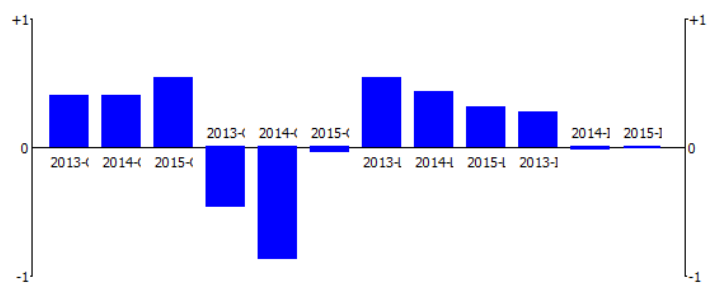

Danimarka Profili

Şekil 4. 2013 -2015 Dönemi Ülke Profilleri 


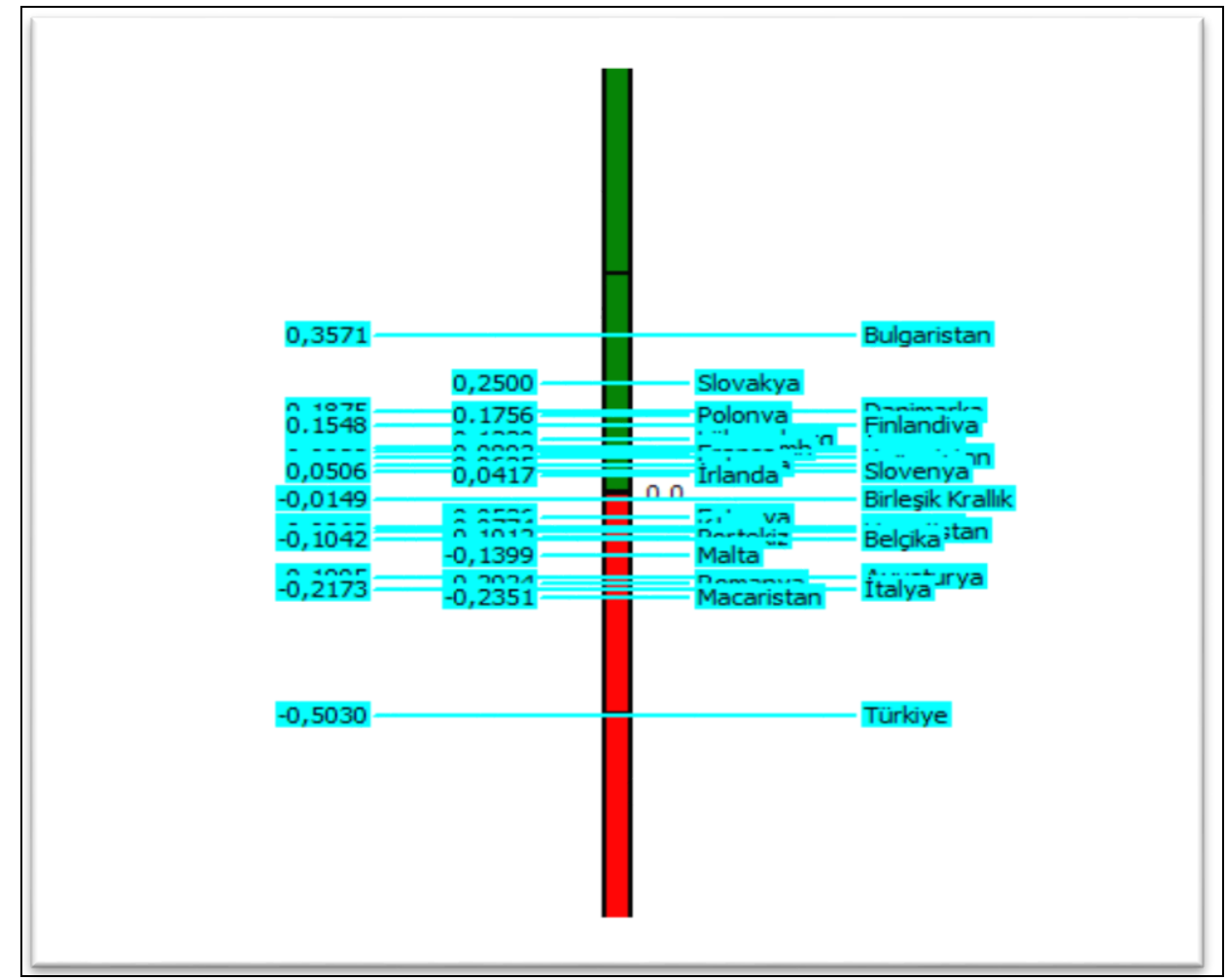

Şekil 5. Net Skorla Göre Ülke Siralamaları (2013-2015 Dönemi)

\section{Sonuç}

Altı yıldır devam ede Suriye savaşı 5 milyona yakın insanı sığınmacı konumuna düşürmüş; sürecin uzaması ile mülteciler gittikleri ülkelerde siyasi, ekonomik, sosyal ve güvenlik alanında çeşitli etkiler yaratmaya başlamışlardır. Bu çalışmada AB ülkeleri parasal ve mali açıdan incelenerek, göç ve sığınma hareketlerinin göreli olarak daha az olduğu 2008-2010 dönemi ile sığınma ihtiyacının giderek şiddetlendiği 2013-2015 dönemleri performanslarına göre kıyaslanmıştır. Çalışmada inceleme amaçlı kullanılan birinci dönem, 2008 finansal krizi kapsamasına rağmen, ikinci dönemde birçok $\mathrm{AB}$ ülkesinin pozitif net akımlarında düşüş görülmesi dikkat çekicidir.

Diğer yandan, analiz sonuçları İngiltere'nin giderek sıralamada aşağı yöne kayması, ülke ekonomisinin ekonomik istikrar kaybetme endişesi nedeniyle 2016 yılında BreExit referandumu ile paralellik taşımaktadır. Benzer şekilde Fransa'nın ve Hollanda'nın sıralamada aşağı yöne kaymaları ve bu ülkelerin de AB üyeliğinden ayrılma konusunu sorgulamaları ve referanduma gitme düşünceleri ile paralel olduğu görülmektedir. Dolayısı ile AB'nin hali hazırdaki göçmen politikası birlik üyelerini, mali ve ekonomik göstergeler açısından korumakta uzak görünmektedir.

Sonuç olarak, ülkelerin kendi sınırlarında barış ve huzur içinde olmaları, farklı bölgelerde yaşanan çatışma ve savaşlardan etkilenmemesinin mümkün olmadığı şeklinde yorumlanabilir. Bu sosyal ve bölgesel yaraların el birliği ile ve rasyonel katkılar sağlayarak tedavi edilmesine destek olmak, ülkelerin çıkarlarına ve kendi vatandaşlarının refahına yönelik daha etkin çalışma yapmaları gerektiği yönündeki beklentileri güçlendirmektedir.

\section{Kaynakça}

- Brans, J. P. \& Vincke, Ph. (1985). ” A Preference Ranking Organisation Method (The Promethee Method For Multiple Criteria Decision-Making)", Management Science, 31(6), 647-656.

- Brans, J. P. ve Mareschal, B. (2005). "PROMETHEE Methods”, içinde Figueira vd. (ed.) Multiple Criteria Decision Analysis, State of the Art Survey, New York, Springer Science.

- Genç, T. (2013), "PROMETHEE Yöntemi ve GAIA Düzlemi”, Afyon Kocatepe Üniversitesi İktisadi ve İdari Bilimler Fakültesi Dergisi, 15(1), 133-154.

- Commission.(2015). Bulgaria Report prepared in accordance with Article 126(3) of the Treaty.

- Gendesmeier, D. (2009). Price Stability: Why Is It Important For You ?, European Central Bank e-book, http://www.ecb.europa.eu/pub/pdf/other/whypricestability_en.pdf 3.3.2017.

- Paksoy, S. (2017) . Çok Kriterli Karar Vermede Güncel Yaklaşımlar, Karahan Kitabevi, Adana. 
- $\quad$ Paksoy, S. ve Kılıç, S. B. (2013) “Avrupa Birliği Müzakere Sürecinde Türkiye’nin Üyelik Olasılığının Değerlendirilmesi”, Çukurova Üniversitesi Sosyal Bilimler Enstitüsü Dergisi, Cilt 22, Sayı 2, 2013, 81-96.

- Pütün, M. (2014), “The Theories of Optimum Currency Area: A Critical Review”, Çukurova Üniversitesi Sosyal Bilimler Enstitüsü Dergisi, Cilt 23, Sayı 1, 177-192.

- Thränhardt, D. (2009). "The Future of International Migration to OECD Countries Regional Note Russia and South East Europe”, OECD Latest Documents,1-17. Erişim: www.oecd.org/futures 12.3.2017.

- Tunç, A. Ş. (2015). “Mülteci Davranışı ve Toplumsal Etkileri: Türkiye’deki Suriye'lilere İlişkin Bir Değerlendirme“, Tesam Akademi Dergisi, (2). 29 - 63.

- UNCHR-UN Refugee Agency (2014). Global Trends Forced Displacement in 2014, http://www.unhcr.org/statistics/country/556725e69/unhcr-global-trends-2014.html 10.1.2017.

- UNCHR- UN Refugee Agency (2015). Global Trends Global Trends Forced Displacement in 2015. 10.1.2017

- World Bank (2014). Syrian Refugees Living in Jordan and Lebanon: Young, Female at Risk, http://www.worldbank.org/en/news/press-release/2015/12/16/syrian-refugees-living-in-jordan-and-lebanoncaught-in-poverty-trap 10.1.2017

Bu çalışma Çukurova Üniversitesi Bilimsel Araştırma Projeleri birimi tarafindan desteklenmiştir. Proje no SED2017-8953. 


\title{
Türkiye'nin Avrupa Birliği Üyeliği ve Kıbrıs Sorunu The EU Membership of Turkey and the Issue of Cyprus
}

\author{
Prof. Dr. S. Ridvan Karluk (Antalya AKEV University, Turkey)
}

\begin{abstract}
When the Republic of Cyprus has been accepted to EU membership with the territory of whole of the Cyprus Island a serious issue aroused as how the Customs Union will be implemented with Turkey, since Turkey do not recognize The Greek Cypriot Administration of Southern Cyprus. After its EU membership, Cyprus becomes the most troublemaker EU country for Turkey. On $17^{\text {th }}$ December 2004 Turkey signed the Additional Protocol which enlarges the extent of Ankara Agreement to all countries and also published a declaration that it unrecognized Southern Cyprus. On $21^{\text {st }}$ September 2005 the EU published a declaration against Turkey's Cyprus Declaration which brought additional conditions for Turkey that provides a method to make Turkey to recognize Southern Cyprus. Since the Customs Unions of Turkey not includes the transportation sector, Turkey does not have the obligation to open its airports and seaports to the Greek Cypriot Administration of Southern Cyprus. The Customs Union with Southern Cyprus does not bring an obligation of recognition. If the issue of Cyprus resolves, it is expected that the veto of The Greek Cypriot Administration of Southern Cyprus on chapters of negotiations would be removed. Even if the vetoes of Southern Cyprus would end, there are important barriers related to the EU membership of Turkey. In our paper, the EU membership of Turkey will be examined within the scope of attempts of resolving the issue of Cyprus also the Turkey Cyprus relationship will be analyzed.
\end{abstract}

\section{Giriş}

Türkiye AB üyesi olmadığı sürece, Kıbrıs sorununun Türkiye lehine bir çözüme kavuşturması çok zordur. Kıbrıs Cumhuriyeti adı altında anayasasına ve devleti kuran anlaşmalara aykırı olarak Rumlardan oluşan Kıbrıs Cumhuriyeti, 1 Mayıs 2004 tarihinden bu yana AB üyesidir. Bu sebeple Kıbrıs sorunu, uluslararası hukuk sorunu olmakla birlikte aynı zamanda AB'nin de sorunudur. Kıbrıs Cumhuriyeti anayasal statüsü ve uluslararası kuruluş anlaşmaları gereği bağımsızlığı ve egemenliği kısıtlı ülkeler grubu arasındadır. Kıbrıs sorunun adil bir şekilde çözümlenmesi için Türkiye'nin AB ile ilişkilerinin kopmaması gerekir. Çünkü AB'de geçerli standartlar; kişi hak ve özgürlükleri, hukuk devleti, kuvvetler ayrılığı, çoğulcu demokrasi, yargının bağımsızlığı, adaletin tarafsızlığı gibi temel alanlara çağdaş düzenlemeler getirmektedir.

\section{Kıbris Sorununun Geçmişi}

Kıbrıs’ta 352 yıl Türkler, 37 yıl İngilizler ve 3 yıl 4 ay Türk- Rum ortak Kıbrıs Cumhuriyeti egemen olmuştur. 1955 yılında Ethniki Organosis Kyprion Agoniston (Kıbrıslıların Milli Mücadele Örgütü: EOKA) kurulmuştur. EOKA'nın lideri Makarios, icra başkanı Polikarpos Yorgacis ve askeri lideri Kıbrıs asıllı Yunan albayı Georgios Grivas idi (Dudley, 2005). EOKA, önce İngiliz yönetimine sonra da Enosis’i reddeden Kıbrıs Türklerine karş1 silahlı saldırılara başlayınca 1958 yılında örgüte karşı mücadele etmek amacıyla Rauf Denktaş, Burhan Nalbantoğlu ve Mustafa Kemal Tanrısevdi tarafından Türk Mukavemet Teşkilatı kurulmuş, Rauf Denktaş da TMT’nın başkanlığına getirilmiştir (Ertekün, 1983).

1960 yılında kurulan Kıbrıs Cumhuriyeti'ni Rumlar 1963 yılında kanlı bir darbeyle yıkmış, 1974'de ikinci Yunan darbesiyle Kıbrıs'ı Yunanistan'a bağlamak üzere başlatılan katliam, Türkiye'nin askeri müdahalesiyle önlenmiştir (Borowiec, 2000). 11 Şubat 1959'da Zürih’te Türkiye, Yunanistan, Birleşik Krallık (İngiltere) devletleri temsilcileri ile Kıbrıs'taki Türk (Fazıl Küçük) ve Rum (Başpiskopos Makarios) toplumları liderlerinin katılımıyla imzalanan belgeler kapsamında, Kıbrıs Türk ve Rum halklarının hakları kabul edilmiş, 19 Şubat 1959'da Londra'da Harold Macmillan, Konstantin Karamanlis ve Adnan Menderes tarafindan imzalanan anlaşma ile de Kıbrıs'ta kurulacak konfederal yapıdaki Kıbrıs Cumhuriyeti'nin temelleri atılmış ve 16 Ağustos 1960 tarihinde Kıbrıs bağımsız bir ülke olmuştur (Karpat, 1975).

Başpiskopos Makarios, 1960 yılında Bağımsız Kıbrıs Cumhuriyeti’nin kuruluş anlaşmasını imzalarken, diğer yandan "Bu anlaşma Enosis'e giden yolu engellemiyor. Tam tersi kolaylaştırıyor" diyerek 1963'te Kıbrıslı Türklere yönelik silahlı saldırılara ortam hazırlamıştır (Ker-Lindsay, 2011). 1963 yılında Akritas Planı (Dışişleri Bakanlığı,1979) yürürlüğe konulmuştur. Bu Plan gereğince Kıbrıslı Rumlar, Kıbrıslı Türkleri yönetimden zayıflatarak Kıbrıs Cumhuriyeti'ni Yunanistan ile birleştirmeyi (Enosis) amaçlamışlardır (Hasgüler, 2007). Türk Silahlı Kuvvetleri 20 Temmuz 1974 tarihinde Kıbrıs’ta başlattığı harekât sonucunda 14 Ağustos'ta Lefkoşa'ya girerek Enosis'e engel olmuştur (Necatigil, 1985). Bu harekât Londra Anlaşması'nın 4'ncü maddesine göre yapılmış (Council of Europe, 1974) olmasına rağmen Birleşmiş Milletler ve Avrupa Konseyi harekâtı işgal olarak değerlendirmiştir (Cyprus is under Turkish military occupation).

Kıbrıs Cumhuriyeti'nin temel yapısı Zürih'te belirlenmiş, 27'nci madde ile belgedeki tüm maddelerin Kıbrıs Anayasasının temel maddeleri sayılması kabul edilmiştir (Bora, 2013). Güney Kıbrıs Rum Lideri ve Kıbrıs 
Cumhuriyeti'nin dördüncü Devlet Başkanı Glafkos Klerides, Cyprus: My Deposition adlı kitabında AB'ye girildiğinde 1960 Garanti Anlaşması'nın uygulamada işlemeyeceğini açıklamıştır (Clerides, 1989). Klerides'in kitap kapağı ile Yunanistan'ın Kavala kenti giriş ve çıkışlarındaki harita benzerliği dikate alındığında, Kıbrıs'ta bir çözümün ne kadar zor olduğu kendiliğinden ortaya çıkar (Gazioğlu, 1999).

Kıbrıs'ın AB üyeliği konusunda görüşüne başvurulan İngiliz hukukçu Maurice H. Mendelson, Kıbrıs'ın AB'ye tam üyelik başvurusunun geçersiz olduğunu açıklamıştır: "Republic of Cyprus, and particularly the Treaty of Guarantee of 1960, the Greek Cypriot Administration in the South can not apply for membership of Cyprus in the European Union under the usurped title of the Republic of Cyprus and can not become a member of any international organization, economic and political union of which both Turkey and Greece are not members." (Mendelson, 1997).

Kıbrıs sorunu çözülürse, Güney Kıbrıs Rum Yönetimi'nin (sahte Kıbrıs Cumhuriyeti) müzakere başlıklarına koyduğu vetonun kalkacağı umulmaktadır. Ama müzakerelere Kıbrıs'ın koyduğu veto kalksa bile Türkiye'nin $\mathrm{AB}$ üyesi olması yönünde büyük engeller vardır. Kıbrıs, $\mathrm{AB}$ ile müzakerelerin açılması uğruna feda edilmemelidir. BM Güvenlik Konseyi'nin 11 Mayıs 1984 tarihindeki 550 sayılı kararında Türkiye'nin Kıbrıs'1 işgal ettiği unutulmamalıdır (Akgün, 2010). Kararda; 13 üye ülke tarafindan kabul, Pakistan karşı ve Amerika Birleşik Devletleri çekimser oy kullanmışlardır. Kıbrıs Cumhuriyeti'nin Türkiye tarafından işgal alıında kalan kısmında yapılan karşılıklı büyükelçi atamaları ve anayasal referandum yapılması, ayrılıkçı hareketler olarak değerlendirilmiştir. Güvenlik Konseyi, tüm ülkelere ayrılıkçı hareket ile kurulan Kuzey Kıbrıs Türk Cumhuriyeti'nin tanınmaması çağrısını tekrarlamıştır.

Kıbrıs’ta süreç devam ederken Yunanistan Dış Politika Ulusal Konseyi 23 Aralık 2016 tarihinde toplanmıştır. Yunanistan Başbakanı Aleksis Çipras ve Güney Kıbrıs Rum Yönetimi Lideri Nikos Anastasiadis, 30 Aralık 2016'da Dışişleri Bakanlarıyla birlikte Atina'da Cenevre Konferansı için ortak eylem planı hazırlayarak strateji belirlemişlerdir. Yunanistan'a müzakere sürecinde fazla güvenilmemelidir. Dönemin Yunanistan Başbakanı Yorgo Papandreou için 2011 Dünya Üniversitelerarası Kış Oyunları açılış töreninde "Erzurum seninle gurur duyuyor" sloganı atılmıştır. Fakat aynı Papandreou Erzurum'da yapılan Üçüncü Büyükelçiler Konferansı'nda Türkiye'yi işgalci olmakla suçlamış ve "Kıbrıs'ta işgal sürdükçe Avrupa Birliğine giremezsiniz" demiş̧tir. İstanbul'da 5 Ocak 2017 tarihinde düzenlenen Konferans'ta eski TBMM Başkanı Hüsamettin Cindoruk, rahmetli Adnan Menderes'e atıfla, O’nun "Kıbrıs Anadolu'nun devamından ibarettir. Bugün de ana vatandır, yavru vatan değildir" dediğini hatırlatmıştır. Toplantıda alınan kararlar, Kıbrıs'ta çözüm için mutlaka dikkate alınması gereken niteliktedir.

Bunlar; Kıbrıs Rumları uluslararası hukuka göre self determinasyon hakkını kullanan Kıbrıs Türklerini gayrimeşru sayamaz, eşit egemenliğe dayanmayan federasyon, veto yetkisi tanınmayan siyasi eşitlik olamaz, KKTC bölgesine 60-100 bin Rum yerleştirilerek iki bölgelilik yok edilemez, karışık oturumu öngören ve çatışmaya zemin hazırlayan 1963 şartlarına dönülemez, Türklerin sahip olduğu Güzelyurt, Karpaz ve Maraş gibi Türk varlığı açısından stratejik bölgeler Rumlara verilemez, mülkiyet sorunu, tüm dünyada olduğu gibi ancak global takasla çözülebilir, Kıbrıs'ta Türklerin can ve mal güvenliğinin garantisi olacağız vaadiyle Türk askerinin adadan çekilmesi sağlanarak Girit'in Yunanistan'a teslim edilmesinde olduğu gibi bir tuzağa düşülemez, garanti ve ittifak anlaşmalarından vazgeçilemez.

\section{Avrupa Birliği Üyeliği Kapsamında Almanya ve Hollanda ile Gerilen İlişkilerin Türkiye'ye Yansıması}

Adalet Bakanı Bekir Bozdağ’’n Almanya'da Türklerle yapacağı toplantının iptal edilmesiyle başlayan, Hollanda'nın bir Türk Bakan'a Hollanda'da toplantı yapmasının engellenmesiyle zirveye ulaşan gerginlik, AB Türkiye ilişkilerine olumsuz yansımıştır. Cumhurbaşkanı Erdoğan 23 Mart 2017 tarihinde CNN Türk’te katıldığı bir programda, "16 Nisan'dan sonra çok sürprizlerle karşılaşabilirsiniz, onlar da karşılaşabilirler ekonomik ilişkilerimizi devam ettirebiliriz. Ama bizim artık siyasi, idari noktalardaki şeylerde gözden geçirmeye ihtiyacımız var" demiştir. AB'nin Türkiye'ye karşı çifte standart uyguladığı bir gerçektir. Fakat bu çifte standart, AB'den tamamen kopulmasına yol açmamalıdır. Siyasi ilişkiler koparsa, bundan ekonomik ilişkilerin zarar görmemesi mümkün değildir (Füle, 2012).

Avrupa Birliği Türkiye ilişkilerinin yarım yüzyılllık geçmişi vardır. Türkiye'nin Avrupa Birliği'ne ortak üyelik için yaptığı başvurusunun (31.07.1959) üzerinden 58, 14 Nisan 1987 tarihinde o dönemki adıyla Avrupa Ekonomik Topluluğu'na üyelik başvurusu üzerinden 30, gümrük birliğinin gerçekleşmesinden (31.12.1995) 22, adaylık statüsü kazanmasından (12.12.1999) 18, müzakerelerin başlaması üzerinden de (3 Ekim 2005) 12 yıl geçmiştir. $\mathrm{Bu}$ sürede $\mathrm{AB}$ üye sayısı 6'dan 28'e çıkmıştır. Türkiye, Avrupa Birliği kapısında 1959 yılından bu yana bekletilmektedir. Bunun sebebi Türkiye'nin Avrupalılığı konusunda süregelen tartışmalardır. Tartışmalar yeni değildir. Bu olgu son 200 ylldır devam etmektedir.

Avrupa Birliği'nde aşırı sağın yükselmesi ve müzakerelerin popülist yaklaşımlara kurban edilmesi durumunda ilişkilerde bir düzelmenin olması oldukça zordur. Prof. Dr. Burhan Kuzu'nun NTV kanalında "Avrupa'dan Çıkalım" dedikten sonra 11'nci Cumhurbaşkanı Abdullah Gül'ün 25'nci Kalite Kongresi'nin açılışında "Esas hedef, AB'nin 27-28 üye ülkesinden biri olmak değildir; mesele o seviyede bir ülke olmaktır. Bunu Avrupa'y1 
tatmin etmek, Avrupa’ya taviz vermek anlamında görürseniz yanılırsınız” açıklamasını, (Gül, 2014) bu kapsamda değerlendirmek gerekir. Başbakan Ahmet Davutoğlu'nun 28 Ocak 2015, (Hürriyet, 2015). AB Bakanı Volkan Bozkır'ın 18 Mayıs 2016 tarihinde “AB bizim için stratejik bir hedeftir” (AA, 2016) ve Dişişleri Bakanı Mevlüt Çavuşoğlu'nun 9 Ocak 2017 tarihindeki “Türkiye'nin olmadığı Avrupa eksiktir” açıklamaları (Çavuşoğlu, 2017) AB ile iplerin henüz kopma noktasına gelmediğini göstermektedir

Ekonomi Bakanı Nihat Zeybekçi’nin 20 Mart 2017 tarihindeki açıklamasını da bu kapsamda değerlendirmek gerekir: "Türkiye'nin yolculuğu, Avrupalı dostları ile birlikte medeniyet yolculuğudur." Başbakan Yardımcısı Mehmet Şimşek Marmara Grubu Vakfı tarafından 5 Nisan 2017 tarihinde İstanbul'da düzenlenen 20'nci Avrasya Ekonomi Zirvesi'nin açılışında yaptığı konuşmada, Gümrük Birliğinin güncelleşmesi gerekiyor. Bunlar sayesinde Türkiye AB ticaret hacmi 150 milyardan 300 milyara çıkabilir. AB Komisyonu da oy birliği ile bu süreci oylamıştı. Tarihi de belirmeme söz konusuydu. Şimdi Türkiye'ye avaz avaz bağırma süreci kapanmalı" diyerek gerilen ilişkilerin yumuşayacağı sinyalini vermiştir (Milliyet, 2017). Mehmet Şimşek daha önce de "AB bizim için önemli bir çıpa, Batı'dan bir kopuş görmüyorum," demişti. Avrupa Birliği ile ilişkilerin kopması, Kıbrıs sorunun çözümünü de güçleştirecektir. Çünkü Kıbrıs, AB üyesidir. Türkiye'nin uzak bir ihtimal olsa da günün birinde AB üyesi olması, Kıbrıs sorunun çözümüne de katkıda bulunacaktır.

\section{Ankara Anlaşması’na Güney Kıbrıs Rum Yönetimi’ni Taraf Yapan Ek (Uyum) Protokolü ve Kuzey Kıbrıs'a Yönelik AB Tüzükleri}

Türkiye'nin AB üyelik sürecindeki önemli engellerin başında Kıbrıs sorunu gelmektedir. Türkiye'nin tanımadığı Kıbrıs Cumhuriyeti (Güney Kıbrıs Rum Yönetimi) 2004 yılında AB üyesi olduktan sonra bu ülkenin Ankara Anlaşmasına taraf olması büyük sorun yaratmıştır. 17 Aralık 2004 tarihli AB Zirve Bildirisi'nin 19'ncu maddesinde müzakerelere başlayabilmek için Türkiye'nin AB'ye yeni katılan ülkelere uyum sağlaması gerekiyordu. Çünkü 3 Ekim 2005 tarihinde müzakerelerin başlatılabilmesi için bu durum Avrupa Birliği tarafindan bir ön şart olarak öne sürülmüştür: “Avrupa Konseyi, Birliğe on yeni üye devletin katılmış olduğunu göz önünde bulundurarak, Türkiye'nin, Ankara Anlaşması'nın uyarlanmasına yönelik Protokolü imzalama kararını memnuniyetle karşıladı. AB Konseyi bu bağlamda, 'Türk Hükümeti, müzakerelerin fiilen başlamasından önce ve Avrupa Birliği'nin mevcut üyeliğine dair uyarlamalar üzerinde anlaşmaya varılarak sonuçlandırıldıktan sonra, Ankara Anlaşması'nın uyarlanmasına ilişkin Protokolü imzalamaya hazırdır' şeklinde Türkiye tarafından yapılan beyandan da memnuniyet duyar."

26 Nisan 2005 tarihinde Lüksemburg'da toplanan Türkiye-AB Ortaklık Konseyi Toplantısı'nda, (Ortak Tutum Belgesi) Ek Protokol'ün imzalanması ve Türkiye'nin tüm üye ülkelerle ilişkisinin normalleştirilmesinin gerekliliğine vurgu yapılmıştır. Bu amaçla AB Dışişleri Bakanları, Ankara Anlaşması'nı Kıbrıs’ı da kapsayacak şekilde genişleten Ek Protokol'ü (Uyum Protokolü) 13 Haziran 2005 tarihinde onaylamıştır. Türkiye, Protokol metnine olurunu bildiren mektubu 29 Mart 2005 tarihinde Brüksel'e iletmiştir. Metin, daha önce AB üyesi ülkelerin Brüksel'deki Daimi Temsilcilerinden oluşan COREPER tarafından 10 Haziran 2005'de kabul edilmişti. Ek Protokol'ün imzalanmasının GKRY'nin fiilen tanınması anlamına gelebileceği kaygısıyla imza sürecinin ne şekilde gerçekleştirileceği konusu taraflar arasında uzun süre sorun yaratmıştır.

Ankara Anlaşması'nda öngörülen Türkiye ile AB arasındaki gümrük birliğini Güney Kıbrıs Rum Yönetimi de dahil 10 yeni AB üyesini kapsayacak şekilde genişletecek Ek Protokol, 29 Temmuz 2005 tarihinde Brüksel'de AB Dönem Başkanı İngiltere Temsilcisi John Grant ile AB Komisyonu nezdinde Daimi Temsilci Büyükelçi Oğuz Demiralp tarafından mektup değişimi usulüyle imzalanmıştır. Böylece Türkiye, AB tarafından kendisinden istenen iki şartı da yerine getirmiştir. Şartlardan ilki, Türk Ceza Kanunu’nun onaylanarak yürürlüğe sokulmasıydı. Çünkü hiçbir AB üyesinde idam cezası yoktu. Türkiye bu şartı 26 Eylül 2004 tarihinde kabul edilen ve 1 Haziran 2005 tarihinde yürürlüğe giren 5237 sayılı Ceza Kanunu ile yerine getirmiştir. İdam, ilk önce 2001 yılında savaş tehdidi ve terör suçları halleri dışındaki suçlar için, 3 Ağustos 2002'de ise savaş ve çok yakın savaş tehdidi hallerinde işlenmiş suçlar dışındaki suçlar için kaldırılmış, 7 Mayıs 2004 tarihli 5170 sayılı kanun ile de anayasadan ölüm cezaları ile ilgili maddeler çıkarılmıştır.

İkinci şart ise Kıbrıs Cumhuriyeti'ni de kapsayan bir Protokol'ün imzalanmasıydı. Bu şart da yerine getirilmiştir. Aralarında Kıbrıs Cumhuriyeti'nin de bulunduğu AB'ye 2004 yılında giren 10 yeni üyenin, 12 Eylül 1963 tarihli Türkiye AB Ortaklık (Ankara) Anlaşması'na diğer AB üyeleri gibi taraf olacağı Ek Protokol'de kabul edilmiştir. Protokol'ün ilk iki sayfasındaki giriş ve anlaşmanın tarafları bölümünde GKRY, üç defa "Kıbrıs Cumhuriyeti" adıyla anılmıştır. Fakat AB Kıbrıs Cumhuriyeti’nin 1959-1960 Zürih ve Londra Anlaşmaları (TRCN, 1959) ile kurulmuş Cumhuriyet olmadığını, aksine Kıbrıslı Rumlar tarafından işgal edilmiş Cumhuriyet olduğunu kabul etmemiştir.

Türkiye'nin Ek Protokol'ü imzalamasının ardından Avusturya Başbakan Yardımcısı Hubert Gorbach, “Türkiye'nin, sınırları devletler hukukuna göre belirlenmiş olan Güney Kıbrıs'ı tanımadan AB'ye tam üye olmasının mümkün olmadığı” yönünde yazılı bir açıklama yapmıştır. Gorbach, Türkiye’nin Güney Kıbrıs’1 tanıyarak ileri doğru önemli bir adım atmış olacağını, ancak bunun son adım olmayacağını açıklamıştır. Avrupa Parlamentosu'nda Hıristiyan Demokratları temsil eden Avrupa Halkları Partisi'nin lideri Hans Gert Pottering de, 
“Tanımadığınız bir kişiyle müzakere edemezsiniz” demiştir. Avrupa Parlamentosu, 21 Eylül 2005 tarihinde Türkiye ile müzakerelerin başlamasını onaylamıştır ama Avrupa Parlamentosu'nda 28 Eylül 2005 tarihinde Ek Protokol'ün onaylanması ertelenmiş, Komisyon'dan 2006 yılında Ankara Anlaşması'nın Türkiye tarafından tam uygulanıp uygulanmadığına ilişkin rapor hazırlaması istenmiştir.

Parlamento'nun kararında, “Bu Anlaşma'nın (Ankara) Türkiye tarafından tam yerine getirilmemesi durumunda, bunun müzakere sürecini ciddi bir biçimde etkileyeceği” belirtilmiştir. Karar'da, AB Konseyi'nin KKTC'ye yönelik ekonomik izolasyonunun kaldırılmasına ilişkin aldığı karara atıfta bulunulmuş ve bu konuda verilen sözlerin yerine getirilmesi istenmiştir. Kıbrıslı Türklerin 24 Nisan 2004 tarihindeki halk oylamasında evet oyu vermelerine rağmen ambargo altında bırakılmaları, AB'nin söz verdiği halde Doğrudan Ticaret Tüzüğü'nü uygulamaya koymaması, AB'nin bir çifte standardıdır. Türkiye'nin Ek Protokol'e ilişkin yayınlamış olduğu Bildiri'nin 5'nci maddesinde “Türkiye, işbu Protokol'e taraf olmasının Kuzey Kıbrıs Türk Cumhuriyeti ile mevcut ilişkilerini değiştirmeyeceğini teyit eder” denmektedir ama Bildirinin geçerliliği ve AB üyeleri açısından bağlayıcılığı tartışmalıdır.

Avrupa Parlamentosu'na AB Dış İlişkiler Komisyonu Başkanı Elmar Brok tarafindan sunulan Birliğin diş ve savunma politikası ile ilgili Rapor'a eklenmek istenen ve AP Yeşiller Grubu'nun, “AB'nin dış politikasında saygınlığı açısından Kıbrıslı Türklerin izolasyondan kurtulması gerektiğini vurgulayan” değişiklik önergesi, 504 red, 73 evet ve 29 çekimser oyla kabul edilmemiştir. Şubat ayı başında Ankara'yı ziyaret eden Fransa Dışişleri Bakanı Phillipe Douste Blazy, Türkiye’nin Rumlara karşı Gümrük Birliği’nden doğan taahhütlerini 2006'da yerine getirmesini talep etmiştir. Ayrıca, "Kıbrıs Cumhuriyeti ile ilişkilerinizi en hızlı biçimde normalleştirmenizi istiyoruz" demiştir. Deniz ve hava limanlarının, AB mevzuatına ve Ankara Anlaşması'na aykırı bir şekilde tek taraflı olarak açılmasını Türkiye'den beklediklerini de açıklamıştır.

Kıbrıs, 2004 yılında bölünmüş bir ada olarak AB'ye tam üye olmuştur. Fakat Kıbrıs sorununun çözüm süreci devam etmesi ve Annan Planı'nın Türkler tarafından kabul edilmesi üzerine adanın tekrar birleşmesi durumunda Kıbrıslı Türklerin olabildiğince AB müktesebatına hazırlanabilmesi amacıyla bir program oluşturmuştur. Avrupa Birliği Genel İşler Konseyi bölünmüş adanın Türk tarafının kalkınmasını, Güney Kıbrıs AB üyesi olmadan bir hafta önce 26 Nisan 2004 tarihinde almış olduğu bir kararla onaylamıştır. Orjinal metin şöyledir: "The Turkish Cypriot community have expressed their clear desire for a future within the European Union. The Council is determined to put an end to the isolation of the Turkish Cypriot community and to facilitate the reunification of Cyprus by encouraging the economic development of the Turkish Cypriot community. The Council invited the Commission to bring forward comprehensive proposals to this end with particular emphasis on the economic integration of the island and on improving contact between the two communities and with the EU."

Bu kapsamda Kıbrıs’ta çözüme yönelik üç tüzük hazırlamıştır: Doğrudan Ticaret, Yeşil Hat ve Mali Yardım Tüzükleri. Bunlardan Yeşil Hat ve Mali Yardım Tüzükleri yürürlüğe girmiş, Doğrudan Ticaret Tüzüğü Kıbrıslı Rumların vetosu sebebiyle uygulamaya geçirilememiştir. AB Dışişleri Bakanları 27 Şubat 2006 tarihinde iki Tüzüğü birbirinden ayırarak, Mali Yardım Tüzüğü'nü onaylamış, KKTC’yi izolasyondan kurtaracak Doğrudan Ticaret Tüzüğü’nü rafa kaldırmış, Doğrudan Ticaret Tüzüğü ile ilgili olarak bu defa oybirliği şartı getirmiş, Nisan 2004 'de alınan karardan geri adım atmıştır. Tüzüklerin birbirinden ayrılmasının GKRY'ne sağladığı en önemli kazanım, Katılım Anlaşması'nın 10 No.lu Protokolü'ne atıfta bulunulmasıdır. Böylece GKRY, bundan sonra bypass edilemeyecektir (EUR Lex, 2006). Kıbrıslı Türklerin 24 Nisan 2004 tarihindeki halk oylamasında evet oyu vermelerine rağmen ambargo altında bırakılmaları, AB'nin söz verdiği halde Doğrudan Ticaret Tüzüğü'nü uygulamaya koymaması, Türk kamuoyunda AB'ye güveni sarsmıştır.

\section{Gümrük Birliği Kapsamında Kıbrıs Rum Yönetiminin Tanınma Sorunu}

Brüksel'de 6 Mart 1995 tarihinde toplanan AET- Türkiye Ortaklık Konseyi’nin aldığı 1/95 sayılı Kararla (Gümrük Birliği Kararı'nın Gümrük Birliği Anlaşması olarak anılması doğru değildir) Türkiye ile AB arasında gümrük birliğinin ilkeleri belirlemişlerdir. 1/95 sayılı OKK, ATRG'nin 13 Şubat 1996 tarih ve L 35 sayılı nüshasında yayımlanmıştır. Kararın kabul edilmesinden sonra AB ile Gümrük Birliğgi 1 Ocak 1996 tarihinde yürürlüğe girmiştir. Daha sonra 12-13 Aralık 2002 Kopenhag Zirvesi’nde, Türkiye ile Avrupa Birliği arasındaki Gümrük Birliği’nin geliştirilip derinleştirilmesi kararı alınmıştır (Aksu, 2004). Gümrük Birliği’nin derinleştirilmesinden kastedilen, Gümrük Birliği’nin dışında bulunan hizmetler ve kamu alımlarının serbestleştirilmesi ile karşılıklı tarım tavizlerinin daha ileri götürülmesidir.

1/95 sayılı OKK TBMM'den geçirilmemiştir. Bu durumu, DYP-SHP Koalisyon Hükümeti’nde SHP Genel Başkanı ve Dışişleri Bakanı olan Murat Karayalçın şu şekilde açıklamıştır: “AB ile 1960'lardaki adıyla Avrupa Ekonomik Topluluğu ile yapılan Ankara Anlaşması, o tarihte Meclis’ten geçmiş. Gümrük Birliği bunu devam ettiren bir anlaşmaydı. O nedenle, 1995'te biz Gümrük Birliği Anlaşmasını Meclis’in onayına sunmadık. Çünkü Gümrük Birliği, asıl anlaşmanın bir türevi. Şimdi ise, Meclis’ten geçmemiş bir anlaşmayı genişleten Ek Protokol'ün Meclis'in onayına sunulması, bence yanlış ve sakıncalı.” Karayalçın'a göre bu sakınca şöyledir: "Ek Protokol'de Kıbrıs Rum Cumhuriyeti'nin de adı geçecek. Dolayısıyla, Türkiye tanımıyor bile olsa, Kıbrıs Rum 
Cumhuriyeti'nin statüsü yükselmiş olacak. Çekincemizi açıklasak bile, biz onları tanımış olacağı." (Hürriyet, Mart 2005)

GKRY AB üyesi olduktan ve Türkiye ile AB arasında gümrük birliğinin gerçekleşmesinde sonra, Türkiye'nin kendisini tanıma girişimlerinde bulunmuştur. Türkiye hukuken GKRY'ni tanımasa bile taraflar arasında gümrük birliğinin olması fiili ve hukuki tanımaya yol açabilir. Gümrük Birliği kapsamında yükümlülüklerin yerine getirilmesi, resmi yazışmalar ve uyuşmazlıkların çözülmesi için zorunlu yöntemlerin uygulanması sonucunda tanıma olabilir. Nitekim GKRY, gümrük birliği kapsamında mal taşıyan Rum bayraklı bir geminin 22 Şubat 2006 tarihinde Mersin Limanı'na yanaşmasına Türk makamlarınca izin verilmemesine tepki göstermiştir. Rum hükümet sözcüsü Yorgo Lilikas, yaptığı yazılı açıklamada Türkiye'nin bu hareketiyle Avrupa Birliği’ne verdiği sözleri yerine getirmediğini belirterek, bu konuda $\mathrm{AB}$ nezdinde tüm gerekli girişimlerde bulunmakta olduklarını açıklamıştır. Ankara'nın son hareketiyle AB ile yürürlükte olan Ankara Anlaşması'nı ciddi olarak ihlal ettiğini ileri süren Lilikas, Türkiye'nin bu davranışıyla $\mathrm{AB}$ ile uyumu reddettiğini bir defa daha kanıtladığını, AB'ye katılım sürecinde verdiği sözleri ve sorumlulukları yerine getirme konusunda inandırıcı olmadığını savunmuştur.

GKRY'nin bilerek GKRY bandıralı gemiyi Mersin Limanı'na göndermesi, Türkiye'ye yönelik bir provakasyondur. Çünkü GKRY gümrük birliğini bir araç olarak kullanıp, fiilen (de facto) GKRY'nin Türkiye tarafından tanınmasını istemektedir. Kıbrıslı akdemisyen Prof. Dr. Ata Atun, Ankara Anlaşması uyarınca gümrük birliğinin GKRY'ne de genişletilmesinin GKRY'nin ne şekilde tanınacağını şöyle açıklamaktadır: “Türkiye-AB ortaklık belgesine bir de dipnot (footnote) eklendi. Bu dipnot bir yerde Türkiye-Kıbrıs (Rum) Cumhuriyeti ilişkilerinin normalleşmesini hızlandırıyor ve Ankara Anlaşması Gümrük Birliği Protokolü’nün 2006 yılında zoraki olarak uygulanmasını kaçınılmaz hale getiriyor. 30 Mart 2006'da deniz limanlarının, 30 Eylül 2006'da da hava limanlarının açılmasını talep ediyorlar. Limanların açılması demek ticaretin başlaması demektir. Limanların açılması demek Kıbrıs (Rum) Cumhuriyeti resmi evrakları ile mal girişi ve çıkışı başlayacak demektir. Limanların açılması demek, Kıbrıs Rum bayraklı gemi ve uçakların limana giriş ve çıkışlarında, resmi Kıbrıs (Rum) Cumhuriyeti seyir evrakları kullanılacak demektir. Limanların açılması demek, Kıbrıs (Rum) Cumhuriyeti denizci kimliğine sahip gemi personelinin, bu belgelerle Türkiye’ye girip çıkması demektir” (ABHaber, 2005).

Dönemin Ulaştırma Bakanı Binali Yıldırım Türkiye deniz taşımacılığı rejiminde Güney Kıbrıs bayraklı gemilere 1987 yılından bu yana uygulanan kısıtlamalar bulunduğunu hatırlatarak, "Dün Mersin limanına yanaşmak isteyen Rum bandıralı gemiye bu kısıtlama çerçevesinde izin verilmedi” demiştir. Yıldırım, soruna adil bir çözüm bulunarak, Güney Kıbrıs limanlarıyla Kuzey Kıbrıs limanlarının eşzamanlı olarak uluslararası trafiğe açılması gerektiğine dikkat çekmiş ve bu tip fiili durum oluşturma faaliyetlerinin yeni olmadığını ve eskiden beri yapıldığını belirtmiştir. Yıldırım, Kıbrıs Rum bandıralı bir geminin doğrudan Türk limanlarına gelip yük alması ve yük boşaltmasının yasak olduğunu, bunun yanı sıra herhangi bir geminin Güney Kıbrıs limanına uğradıktan sonra Türk limanlarına gelemediğini hatırlatmıştır. Bakan, "Bu bağlamda Mersin limanına yanaşmak isteyen gemi de Kıbrıs Rum bayraklı bir gemidir. Dolayısıyla bu kısıtlama çerçevesinde yanaşmasına Dışişleri Bakanlığı tarafından izin verilmemiştir" açıklamasını yapmıştır.

Kıbrıs AB üyesi olduktan sonra gümrük birliği kapsamına alınması, 2 Ekim 2004 tarih ve 25601 sayılı Resmi Gazete'de yayınlanan “Türkiye ile Avrupa Topluluğu Arasında Oluşturulan Gümrük Birliğinin Uygulanmasına İlişkin Esaslar Hakkında Kararda Değişiklik Yapılmasına Dair Karar” ile mümkün olmuştur. Böylece 3 Eylül 2002 tarihli ve 24865 sayılı Resmi Gazete'de yayımlanan 24 Temmuz 2002 tarihli ve 2002/4616 sayılı Kararnamenin eki "Türkiye ile Avrupa Topluluğu Arasında Oluşturulan Gümrük Birliğinin Uygulanmasına İlişkin Esaslar Hakkında Karar'ın 2. maddesinin (a) bendi değiştirilmiştir (Başbakanlık, 2004). Böylece 1 Mayıs 2004'de tam üyeliği gerçekleşen ülkelerle birlikte Kıbrıs Avrupa Birliği’ne üye ülkeler arasında kabul edilerek gümrük birliğine alınmıştır. Ancak kararda GKRY, tanıma anlamına gelmemesi için Kıbrıs Cumhuriyeti olarak değil Kıbrıs adıyla yer almıştır. Türkiye'nin Ek Protokol uyarınca Güney Kıbrıs ile gerçekleştireceği gümrük birliğine ulaştırma sektörü dahil olmadığı için Türkiye'nin deniz ve hava limanlarına Güney Kıbrıs Rum Yönetimine açma zorunluluğu yoktur. Ayrıca, Güney Kıbrıs ile gümrük birliğinin kurulması, Türkiye'nin bu ülkeyi tanımasını da gerektirmez (Karluk, 2006)

Avrupa Parlamentosu Türkiye Raportörü Hollandalı Hıristiyan Demokrat Parlamenter Camiel Eurlings o dönemde hizmetlerinin serbest dolaşımı ile malların serbest dolaşımı (gümrük birliği sadece sanayi mallarının serbest dolaşımını kapsamaktadır) konularını birbirine karıştırmıştır. Eurlings, 22 Eylül 2005 tarihinde Kıbrıs'a yaptığı ziyarette, GKRY Dışişleri Bakanı ile görüşmesi sonrasında yaptığı açıklamada, “Türkiye’nin Ankara Anlaşması'nın Ek Protokolü’nü, katılım müzakereleri sürecinde çok geç bir zamanda değil, en kısa sürede uygulaması gerektiğini" öne sürmüştür. Avrupa Parlamentosu'nun, Türkiye'nin Gümrük Birliği’ni Kıbrıs Cumhuriyeti'ne uygulaması için ikna edecek bir yönteme sahip olup olmadığının sorulması üzerine Eurlings, "Çok fazla siyasi baskı uygulayabiliriz, çünkü Türkiye'nin katılım süreci sonunda uzlaşmamız gerekiyor, aksi takdirde Türkiye girmez ve sanırım Brüksel'de herkes bunu çok iyi biliyor" demiştir.

Eurlings, Ek Protokol'ün uygulanmasının, üye devletler için başlıca önceliğe sahip olduğunu, bunun sadece Rum tarafı ile Türkiye arasında bir konu olmadığını, bir protokolün imzalandığı zaman uygulanmasının AB için önemini belirtmiştir. Güney Kıbrıs'ta bu açıklamaları yapan Eurlings'e KKTC'de yaptığı temaslarda Cumhurbaşkanı Talat, Türkiye'nin Ek Protokol uyarınca limanlarını Rumlara açması halinde, KKTC'ye uygulanan tüm ambargoların da 
kalkması gerektiğini söylediklerini ve Eurlings'le bu konuda anlaştıklarını açıklamıştır. Avrupa Birliği’nin, 26 Nisan 2004'te yaptığı bir açıklama ile Kıbrıslı Türklere uygulanan izolasyonları kaldıracağı ve doğrudan ticaretle mali yardım tüzüğünü hayata geçireceği sözü verdiğini de açıklayan Cumhurbaşkanı Talat, bu konuda verilen tüm sözlerin yerine getirilmesini beklediklerini söylemiştir.

\section{Türkiye'nin Yayınladığı Kıbrıs Bildirisi}

Türkiye, Ek Protokol'ü 29 Temmuz 2005 tarihinde imzalarken birlikte yayınladı̆̆ı Kıbrıs Bildirisi (Dışişleri Bakanlığı, 2005) ile Kıbrıs Cumhuriyeti’nin 1960 yılında kurulan ortaklık devleti olmadığını ve Kıbrıs Türklerini temsil etmediğini açıklamıştır. Ayrıca, Dışişleri Bakanlığı tarafından yapılan yazılı açıklamada, Kıbrıs Cumhuriyeti olarak tanınan Rum Yönetimi'nin adada sadece ara bölgenin güneyinde kalan topraklar üzerinde hukuksal ve idari egemenliğe sahip olan Güney Kıbrıs Rum Yönetimi olduğu, Kıbrıs Cumhuriyeti'nin 1960 yılında kurulan asıl ortaklık devleti olmadığını belirtmiştir. Böylece, Türkiye'nin devam eden görüşmelerde de gündeme gelen 1960 Garanti, İttifak ve Kuruluş Anlaşmaları ile elde ettiği hak ve sorumluluklardan vazgeçmediği vurgulamıştır (Uyum Protokolü, 2005).

Kıbrıs Bildirisi’nde özellikle GKRY'nin Türk hava ve deniz limanlarını kullanamayacağı çekincesine yer verilmiştir. Ek Protokol'ün imzalanmasının Kıbrıs Cumhuriyeti'ni tanıma anlamına gelmediği güçlü ifadelerle vurgulanmıştır: “1 Mayıs 2004 tarihinde AB’ye katılacak olan Rumlar, Kıbrıs Türklerini veya Kıbrıs'ın tamamını temsil etmeye yetkili olmadıkları gibi, eşit statüye sahip Kıbrıs Türkleri veya Kıbrıs Adası'nın tamamı üzerinde yetki veya egemenlikleri de bulunmamaktadır. Kıbrıs Cumhuriyeti Kıbrıs Türklerine zorla empoze edilemez. Kendi anayasal düzenleri altında ve kendi sınırları içerisinde örgütlenmiş bulunan Rumlar, Kıbrıs Türklerini veya Kıbrıs'ın tamamını temsil eden yasal hükümet olarak kabul edilemez.” (Dışişleri Bakanlığı, 2004). Türkiye için Protokol'ün imzalanması, onaylanması ve uygulanmasının Protokol'de atıfta bulunulan Kıbrıs Cumhuriyeti'nin tanınması anlamına gelmediği açıklanmıştır. Türkiye'nin Kıbrıs Rum makamlarının, Kıbrıs'ta sadece ara bölgenin güneyinde otorite, denetim ve yetki icra ettiği ve Kıbrıs Türk halkını temsil etmediği şeklindeki tutumunu sürdüreceği belirtilmiştir. Protokol'de atıfta bulunulan Kıbrıs Cumhuriyeti'nin, herhangi bir biçimde tanınması anlamına gelmediğine ve Türkiye'nin 1960 Garanti, İttifak ve Kuruluş Anlaşmalarından kaynaklanan hak ve mükellefiyetlerini ortadan kaldırılmadığına dikkat çekilmiştir.

Uluslararası hukuk açısından değerlendirildiğinde Türkiye'nin GKRY'ni tanıdığı anlamına gelmediği yönündeki bildirisi, AB açısından bağlayıcı değildir. Avrupa Parlamentosu Dışişleri Komisyonu Başkanı Alman Hıristiyan Demokrat Elmar Brok, Türkiye'nin Kıbrıs Bildirisini yayınlamadan önce şunları söylemiştir: "Müzakerelere başlamak için Güney Kıbrıs’ın Türkiye tarafından tanınması şart değil. Ancak tam üye olabilmek için Türkiye’nin Güney Kıbrıs’ı tanıması kaçınılmaz. Burada önemli olan, Türkiye’nin, altını çiziyorum müzakerelere başlamak için Ankara Anlaşmasını ve Gümrük Birliği Protokolü'nü Güney Kıbrıs’ı kapsayacak şekilde genişletmesi. Şu an için bu gerekli." Fransa'da o dönemde iktidardaki Halk Hareketi İçin Birlik Partisi (UMP) Başkanı Nicholas Sarkozy, Türkiye'nin GKRY'ni tanımayı reddetmesinin müzakere tarihinin ertelenmesi için bir gerekçe olduğunu söyleyerek; "Ya Ankara'ya başka bir ortaklık şekli sunulması ya da müzakere takvimi değiştirilsin" görüşünü dile getirmiştir (Hürriyet, 2005b). Aslında Sarkozy Türkiye'nin AB üyeliğine tamamen karşı bir siyasetçidir (Agence France-Presse, 2008).

Avrupa Parlamentosu Türkiye Raportörü Camiel Eurlings, Gümrük Birliği Protokolü’nü uygulamayı ve GKRY ile ilişkilerini normalleştirmeyi reddeden Ankara'ya hoşgörü gösterilmeyeceğini, Lefkoşe’ye yaptığı ziyaret sırasında şöyle açıklamıştır: "Bizim için bir protokolü imzaladığınızda, onu uygulamanız da önemlidir. Bu nedenle Kıbrıs bayrağı taşıyan araçlara limanlarını açmayan, uçaklara izin vermeyen Türkiye'nin pozisyonunu onaylamıyoruz. Avrupa Komisyonu ve Avrupa Parlamentosu da onaylamaz" (Hürriyet, 2005a). Fransa Başbakanı Domnique Villepin, 2 Ağustos 2005 tarihinde bir Fransız radyo kanalına verdiği demeçte, Avrupa Birliği üyelerinin tamamını tanımayan bir aday ülke ile müzakerelerin başlamasının düşünülemez olduğunu belirtmiş̧tir.

Türkiye GKRY'ni tanımadığını belirtmiş bile olsa, Ankara Anlaşması'nın GKRY'ne uygulanmasına ilişkin Ek Protokol'ü imzalaması, ileride sorun yaratabilir. Çünkü Ek Protokol'de GKRY'i, aynen AB'nin Kıbrıs Bildirisi'nde olduğu gibi Kıbrıs Cumhuriyeti (Republic of Cyprus) olarak tanımlanmaktadır (DPT, 2005). Türkiye'nin Ortaklık (Ankara) Anlaşması'nda ve bu Anlaşma'nın tüm yeni AB üye ülkelerini içine alacak şekilde genişleten Ek Protokol'de yer alan yükümlülükleri yerine getirmesi hükmü vardır (Md.6). Bu sebeple Türkiye, Ankara Anlaşması'nın Kıbrıs'a da uygulanacağına ilişkin bir hukuk metnine imza attığı için bir Bildiri yayınlamak zorunda kalmıştır. GKRY lideri Papadopulos liman ve havaalanlarını Kıbrıs bandıralı gemilere ve uçaklara açmaması durumunda, Türkiye'yi AB müzakerelerini engellemekle tehdit ederek, Rumların Türkiye'ye karşı veto kartını kullanabileceklerini belirtmiştir. Papadopulos'un Türkiye karşıtlığına rağmen GKRY'nin eski Başkanı George Vassiliou, Türkiye'nin kriterleri yerine getirdiğinde AB'ye katılmasına destek vermiştir (Vassiliou, 2006).

GKRY Ek Protokol ile Ankara Anlaşması'na Kıbrıs Cumhuriyeti sıfatıyla taraf olunca, Protokol'ün TBMM'de onaylanması gündeme gelmiştir. Dönemin SHP Genel Başkanı Murat Karayalçın 31 Temmuz 2005 tarihinde Ek Protokol'ün TBMM tarafından onaylanmasının gerekli olmadığını, dolayısıyla bu kararın türevi olan daha alt düzeydeki bir metin için TBMM'ye gidilmesinin hatalı olacağını öne sürmüştür. Uluslararası bir sözleşmenin 
Meclis onayına sunulmasının esasları Anayasa'nın 90'ncu maddesinde belirlenmiştir. Yürürlüğe girmeleri durumunda üst hukuk statüsü kazanmalarından dolayı uluslararası anlaşmalar Meclis onayını gerektirir. Bu sebeple Ankara Anlaşması Meclis onayından geçmiştir. Fakat 90'ncı maddeye göre uluslararası bir anlaşmaya dayanan uygulama anlaşmaları ile kanunun verdiği yetkiye dayanılarak yapılan ekonomik, ticari, teknik veya idari anlaşmaların Türkiye Büyük Millet Meclisi’nce uygun bulunması zorunluğu yoktur. 1963 Ankara Anlaşması'na dayanan Ortaklık Konseyi kararına (1/95 sayılı OKK) dayanan Gümrük Birliği, Meclis onayına tabi değildir. Ek Protokol, Türkiye'yi 10 yeni katılımcıya taraf yaptığından ve Ankara Anlaşması'nda değişiklik getirdiğinden, anayasanın aynı maddesine göre Meclis onayını gerektirir.

GKRY ile gerçekleştirilecek gümrük birliği kapsamında Türk hava ve deniz limanlarının Rum hava ve deniz araçlarına açılmaması, Ankara Anlaşması'nın 7'nci maddesinde yer alan “Anlaşma hedeflerinin gerçekleşmesini tehlikeye düşürecek her türlü girişimden uzak durma yükümlülüğü”, Türkiye’ye karşı ileri sürülebilir. Aynı Anlaşma'nın 9'ncu maddesinde anılan uyrukluğa dayalı ayırım yapmama şartı da Rum gemi ve uçaklarına Türk havaalanlarını ve limanlarını kullandırmamaya aykırı olabilir. Anlaşma'nın 25'nci maddesine göre uygulamalarda anlaşmazlığa düşülmesi durumunda Rum tarafı ihtilaf konularının Ortaklık Konseyi'ne gelmesini ve AB Adalet Divanı'na götürülmesini isteyebilir ya da kendisi doğrudan AB Adalet Divanı'na başvurma yolunu deneyebilir.

\section{Avrupa Birliği Kıbrıs Bildirisi’nin Türkiye ve Kıbrıs Açısından Önemi}

Avrupa Birliği, 21 Eylül 2005 tarihinde Türkiye’nin Kıbrıs Bildirisi’ne cevaben karşı Kıbrıs Bildirisi yayınlamıştır. 7 maddelik AB Kıbrıs Bildirisi'nde Türkiye'nin Birlik üyeleri ile ilişkilerini normalleştirilmesi talep edilmiştir. Bildiri'nin son paragrafına Kıbrıs sorunu (Cyprus problem) konulmuştur ama 4'ncü paragrafta Kıbrıs Cumhuriyeti'nin tüm Kıbrıs adına tanındığını açıklanmıştır. Bildiri ile Güney Kıbrıs Rum Yönetimi'nin tüm Ada'yı temsilen tanınması, AB'nin ortak bir pozisyonu olmuştur. Çünkü AB, Rum Yönetimi (GKRY) adanın resmi temsilcisi olarak tanıdığını açık bir şekilde dile getirmiştir. Bildiri'de, Kıbrıs’ın adı geçmeden "üye ülkelerin tanınması katılım sürecinin gerekli unsurudur" denmekte ve AB'nin Türkiye ile üye ülkeler arasındaki ilişkilerin normalleşmesine atfettiği önemin altı çizilmektedir. Bildiri'nin beş numaralı paragrafinda, tanınma "isteniyor", "bekleniyor" gibi şart koşan ifadeler yoktur ama altıncı paragraf bu sorunun 2006'da değerlendirileceğini belirtmektedir.

Brüksel'de 16-17 Aralık 2004 tarihlerinde yapılan Avrupa Birliği Devlet ve Hükümet Başkanları Zirvesi'nde, 3 Ekim 2005 'de Türkiye ile müzakerelere başlama kararı alınmıştır. Zirve Bildirisi'nin Türkiye'yi en fazla rahatsız eden tarafı, 3 Ekim 2005 tarihine kadar GKRY'nin Ankara Anlaşması kapsamında Gümrük Birliği’ne dahil edilmesi için Türkiye'nin taahhüt altına sokulmasıdır. Zirve Bildirisi'nin 19'ncu maddesine eklenen onay yazısına Devlet Bakanı Beşir Atalay imza atmıştır. Türkiye, (Karluk, 2013). Konsey toplantısında şu sözleri tutanağa geçirmiştir: "Türkiye bunun bir tanıma anlamına gelmediğini kaydeder, Kıbrıs Rumlarının Kıbrıs Türklerini temsil etmediğini de belirtir.” Türkiye'nin Ankara Anlaşması'ndan doğan yükümlülüğü gereği Ek Protokol'e imza atmasının Güney Kıbrıs Rum Yönetimi’ni tanıdığı anlamına gelmediğini, Komisyon adına sözcü Françoise Le Bail açıklamıştır (Karluk, 2004). AB'nin Kıbrıs Bildirisi’nde, Türkiye'nin Kıbrıs Bildirisi'nin Katma Protokol gereğince Türkiye ile GKRY arasında gerçekleşecek gümrük birliğine bir etkisinin olmadığı şöyle ifade edilmiştir: “... has no legal effect on Turkey's obligations under the Protocol."

AB Bildirisi ile Güney Kıbrıs Rum Yönetimi’nin adadaki muhtemel çözümden önce tüm adayı temsilen tanınması AB'nin ortak pozisyonu olmuştur. Bildiri'de Kıbrıs'ın adı geçmeden “üye ülkelerin tanınması katılım sürecinin gerekli unsurudur” denmekte ve AB'nin Türkiye ile üye ülkeler arasındaki ilişkilerin normalleşmesine atfettiği önemin altı çizilmektedir. Bildiri’de, Türkiye'nin 29 Temmuz 2005 tarihinde Ankara Anlaşması Ek Protokolü'nü imzalarken (Uyum Protokolü, 2005) Kıbrıs Cumhuriyeti ile ilgili bildiride bulunma ihtiyacı hissetmesinin üzüntüyle karşılandığı açıklanmıştır.

AB Bildirisi'nde; Türkiye'nin Kıbrıs Bildirisi'nin tek taraflı olduğu, Ek Protokol'ün bir parçasını oluşturmadığg, Türkiye'nin Protokol'den kaynaklanan yükümlülükleri üzerinde herhangi bir yasal etkisi bulunmadığı öne sürülmüştür. AB'nin; Protokol'ün Türkiye tarafından ayrım yapılmaksızın uygulanmasını ve malların serbest dolaşımı üzerindeki ulaştırma araçlarıyla ilgili olanlar dahil tüm kısıtlamaları kaldırmasını beklediği ve Protokol'ün uygulamasını 2006'da yakından izleyeceği belirtilmektedir. Türkiye'nin yükümlülüklerini yerine getirmemesi durumunda 3 Ekim'de başlaması öngörülen üyelik müzakerelerinde başlıkların açılmayacağı mesajı verilmekte, 1 Mayıs 2004'ten itibaren AB üyesi olan Kıbrıs Cumhuriyeti'nin, uluslararası hukuk çerçevesinde devlet olarak tanındığ

Bildiri'de, Türkiye'den, tüm AB üyesi ülkelerle arasındaki ilişkileri en kısa sürede normalleştirmesi beklentesine yer verilirken, tüm üye ülkelerin tanınmasının, müzakere sürecinin bir parçası olduğu açıklanmaktadır. Türkiye'nin, BM Genel Sekreteri'nin çabaları çerçevesinde Kıbrıs sorununun kapsamlı çözümü doğrultusunda çabaları destekleme taahhüdünün devam ettiğine dikkat çekilirken, adada kalıcı çözümün barış istikrar ve uyumlu ilişkilere katkıda bulunacağı konusunda görüş birliğine varıldığı belirtilmektedir. Bildiri'nin can alıcı noktası, malların serbest dolaşımı üzerindeki ulaştırma araçlarına konan kısıtlamaların Türkiye tarafından kaldırılmasının istenmesidir. 
Avrupa Birliği Türkiye’ye, GKRY bandıralı gemilere Türk limanlarını açmasını isterken, bir "çifte standart klasiği” ortaya koymuş ve Türk TIR'larına uygulanan kotaların kaldırılmasını hizmet sunumu serbestisine bağlamıştır. AB Kıbrıs Bildirisi ile "malların serbest dolaşımı" ile "hizmetlerin serbest dolaşımını" birbirine karıştırmıştır. Çünkü ulaşım (transport) üzerindeki kısıtlamaların kaldırılması (Türk deniz limanlarının GKRY bandıralı gemilere, Türk hava limanlarından Rum uçaklarına açılması) AB ile gerçekleştirilen gümrük birliği kapsamı dışındadır. Türkiye AB üyesi olmadan hizmetlerin serbest dolaşımı kapsamına giren ulaştırma sektöründe tanımadığı GKRY'ne yönelik kısıtlamaları kaldırma zorunluluğunda değildir.

Gümrük birliği, sadece malların serbest dolaşımını kapsar. Hizmetler sektörü gümrük birliği kapsamında değildir. Bu durum, AA’na 23 Eylül 2005 tarihinde vermiş olduğum demeçte şöyle açıklanmıştır: "Prof. Dr. Karluk: AB, Güney Kıbrıs’ı Tanıtma Peşinde. Anadolu Üniversitesi İktisadi ve İdari Bilimler Fakültesi Öğretim Üyesi Prof. Dr. Rıdvan Karluk, AB'nin, Türkiye'nin ulaşım alanında Güney Kıbrıs Rum Yönetimine uyguladığı kısıtlamaların kaldırılmasına ilişkin talebinin altında, Güney Kıbrıs Rum Yönetimini tanıtma düşüncesinin yattığını söyledi” (AA, 2005).

Türkiye'nin itirazlarına rağmen GKRY'i Müzakere Çerçeve Belgesi’ne limanların açılması konusunu koydurmayı başarmıştır. 6'ncı madde de Türkiye'den, Ortaklık Anlaşması ve Katma Protokol'ü tüm yeni AB üyesi ülkeleri kapsayacak şekilde genişleten Ek Protokol kapsamındaki yükümlülüklerini yerine getirmesi istenmektedir. GKRY, Türkiye'nin Ek Protokol kapsamında liman ve hava alanlarını Rum kesimi uçak ve gemilerinin kullanımına açmaması durumunda Avrupa Birliği ile müzakere sürecini veto edeceği uyarısında bulunmuştur. Rum Yönetimi Hükümet Sözcüsü Yorgo Lillikas, "Türkiye'nin Avrupa müktesebatını uygulamamaya devam etmesi halinde, Avrupa Birliği'ne giden yolu sona erecektir” demiştir. Güney Kıbrıs'ın veto hakkını kullanıp kullanmayacağına ilişkin sorulara Lillikas, "kesinlikle" cevabını vermiştir.

Türkiye'nin Kıbrıs Bildirisi, AB müktesebatına dahil değildir. Fakat AB'nin Bildirisi, AB müktesebatı içinde yer almış ve Türkiye için bir önşart haline gelmiştir. Müzakere Çerçeve Belgesi'nin 10'ncu maddesinde AB, müktesebatı (acquis) tanımlanmıştır. Müktesebat kapsamında "kurumlararası anlaşmalar, kararlar, beyanatlar (statements), tavsiyeler, kılavuzlar gibi yasal olarak bağlayıcı olan ya da olmayan Birlik çerçevesinde benimsenmiş diğer belgeler” yer almıştır (Dışişleri Bakanlığı, 2005). Bu durumda AB'nin Kıbrıs Bildirisi, müktesebatın bir parçası olmuştur. Ankara Anlaşması'nın hedefi, Türkiye'nin AB üyeliğidir. Eğer üyelik söz konusu olmayacaksa, Ankara Anlaşması'nın tüm hüküm ve sonuçlarıyla fesh edilmesi ve Türkiye'nin bu Anlaşma yerine bir serbest ticaret anlaşması akdetmesi gerekir. Aksi halde, dimyata pirince giderken evdeki bulgurdan olma durumu ortaya çıkar ve AB üyesi olma hevesiyle KKTC, GKRY dolaylı yoldan tanınarak ortadan kaldırılmış olur.

Ek Protokol'de GKRY'nin Kıbrıs Cumhuriyeti olarak geçmesi ve Türkiye'nin bu Protokol'ü imzalamış olması, yayınlamış olduğu karşı Bildiri'ye rağmen GKRY'ni tanımadığı savını kısmen zayıflatmaktadır. Eğer taraflar arasında GKRY'nin tanınması anlamına gelecek olan Türk limanlarının GKRY gemilerine açılması sorun oluşturursa, bu sorun Ortaklık Konseyi'nde çözümlenecektir. Ortaklık Konseyi, taraflar arasında çıan anlaşmazlıkların çözümü konusunda da görevlendirilmiştir. Dolayısıyla Konsey, yargı işlevi benzeri yetkilere sahiptir (Can ve Özer, 2005). Eğer Ortaklık Konseyi’nde soruna bir çözüm bulunmazsa, o zaman ABAD’a gidilebilir.

Mevcut anlaşmalar kapsamında eğer objektif bir değerlendirme yapılırsa, ABAD'dan Türkiye'nin aleyhine bir karar çıkması ve gümrük birliği kapsamında Türk limanlarının GKRY gemilerine açılması mümkün değildir. Her ne kadar 266/81, C/265/95 ve C112/00 sayılı davalarda ABAD, ulaştırma yoluyla yaratılan engelleri, malların serbest dolaşımı bağlamında yorumlamış olsa da, gümrük birliği kapsamında malların serbest dolaşımı, GKRY bandıralı gemiler Türk limanlarına girememe durumunda engellenmiş olmaz. Çünkü GKRY hariç diğer gemiler ile Türkiye'ye Rum malları rahatlıkla giriş yapabilir. C/112/00 sayılı Schmitberger Davası'nda; Avusturya'da çevreci bir toplantıya izin verilmesi sonucunda 30 saat süre ile kapalı tutulan yolla ilgili durum, malların serbest dolaşımının engellenmesi ile ilişkili olarak yorumlanmıştır. Oysa sadece GKRY gemilerinin Türk limanlarına yanaşmaması benzer bir olay değildir.

\section{Görüşmeleri Aksatan 1950 Yılında Alınan Enosis Kararı}

Kıbrıs'ta Mustafa Akıncı'nın Cumhurbaşkanı seçilmesinin ardından yeniden başlayan müzakerelerde, liderler haftada bir ya da iki defa görüşmeye başlamışlardır. İki toplum lideri uzun bir süre müzakereleri belirli bir noktaya getirdikten sonra 9 Ocak 2017 tarihinde Cenevre'de görüşmelere devam etme kararı almışlardır. Fakat GKRY Meclisinde 12 Şubat 2017 tarihinde, Yunanistan ile Kıbrıs adasının birleşmesini (Enosis) öngören halk oylamasıdan (plesibit) çıkan kararın okullarda kutlanmasının uygun bulunması, Cenevre'de devam eden görüşmelerin aksamasına yol açmıştır. Plesibitte sadece Kıbrıs Rumları oy kullanmış ve katılanların yüzde 96'sı Enosis lehinde oy vermiştir.

Enosis kararının okullarda kutlanması; aşırı sağ eğilimli ELAM Partisi’nin Başkan Yardımcısı Linos Papayiannis' in önerisi ile gündeme gelmiş ve Atina'nın desteğiyle çıkmıştır. ELAM, DİKO, EDEK, Vatandaşlar İttifakı, Dayanışma Hareketi ve Çevrecilerin 19 oyuyla kabul edilen tasarıya AKEL milletvekilleri 16 ret oyu vermiştir ama 18 oya sahip 1974 darbesini yapan Demokratik Seferberlik Partisi (DİSİ: EOKA-B teröristlerinin 
partisi) çekimser kalınca tasarı kabul edilmiştir. Kıbrıs kökenli Prof. Dr. Mehmet Hasgüler konuyu 15 Şubat 2017 tarihinde şöyle değerlendirmiştir: "Kısacası ilk hedef, müzakerelerde Akıncı karşısında sürekli çözüm istemeyen taraf durumuna düşen Anastasiadis'in bu durumdan kurtulmasıdır" (Hasgüler, 2017)

Cenevre'de 12 Ocak 2017 tarihinde Dışişleri Bakanları düzeyinde garantör ülkeler Türkiye, Yunanistan ve İngiltere'nin katılımı ile başlayan görüşmelerde Yunanistan, garantörlük sisteminin sona erdirilmesini, onun yerine Kıbrıs, Türkiye ve Yunanistan arasında bir dostluk ve işbirliği anlaşması imzalanmasını savunmuştur. Türkiye ise, garantörlük sisteminin devamından ve Türk askerinin bir bölümünün adada kalmasından yana olduğunu açıklamıştır. 16 Şubat 2017 tarihinde yapılan son görüşmede Kıbrıslı Rum Lider Anastasiadis'in kapıyı çarpıp çıkması üzerine görüşmeler kesilmiştir. 1950 Enosis Kararı, 1960’lı yıllarda Rumların Türklere saldırılarını tetiklemiş, adada iki toplum arasında çatışmaların çıkmasına yol açmıştır. Türkiye'nin 1974 yılındaki müdahalesiyle çatışmalar sona erdirilmiş ve Kıbrıs BM'nin gözetimindeki bir ara bölgeyle ikiye ayrılmıştır.

Görüşmelere, GKRY Meclisinin Enosisi kararından vazgeçmesi ve ulusal gün ilan etme yetkisinin de hükümete devredilmesi üzerine 11 Nisan'da yeniden başlanmıştır. Bu süreçte BM Genel Sekreteri Antonio Guterres Brüksel'de Mustafa Akıncı ile biraraya gelmiştir. Akıncı Guterres'le görüşmesinin ardından yaptığı açıklamada, "Görüşmemiz esnasında, Cenevre'den bu yana meydana gelen gelişmeleri kendisine Kıbrıs Türk tarafı olarak aktarma fursatı bulduk. Çeşitli yönleriyle, ayrıntılarıyla kendilerini, kendi düşüncelerimiz ve pozisyonlarımız hakkında aydınlattık" demiştir. Cenevre görüşmelerinde Rum tarafının 1974 yılındaki müdahaleye yasal zemin sağlayan garantörlüğün kalkması konusundaki ısrarı sonuç alınmasını zorlaştırmıştır. Kıbrıs sorununun müzakere tarihinde ilk defa Kıbrısı Türk ve Kıbrıslı Rum heyetler harita takası gerçekleştirerek birleşik federal bir Kıbrıs'ın iç sınırının nasıl çizileceğine ilişkin somut adımlar atmışlardır. Tarafların sunduğu haritalar uzmanların kontrollerinin ardından BM'nin kasasına kilitlenmiştir.

Görüşmelerin kesilmesinin ardından Dışişleri Bakanı Mevlut Çavuşoğlu 21 Şubat 2017'de KKTC'yi ziyaret etmiştir. Çavuşoğlu, Akıncı ile görüştükten sonra şu açıklamayı yapmıştır: "67 yıl sonra bir Enosis için vaktiyle yapılan, kilisenin öncülük ettiği bir imza toplama olayını okullarda kutlanacak, anılacak bir hadise haline getiren bir kararın Güney’deki Rum meclisinde onaylanmış olması, Kıbrıs Türk toplumunda infiale neden oldu. Bu konu düzeltilmeli, bu karar iptal edilmelidir."

\section{Annan Planı ve Sonrasındaki Gelişmelerin Işı̆̆ında Kıbrıs’ta Çözüm Süreci}

Kıbrıs'ta 24 Nisan 2004 tarihinde oylanan Annan Planı hayata geçmemiştir. Referandumdan bir hafta sonra Kıbrıs AB'ye üyesi olmuştur. Türkler ise izolasyonlar altında Kuzey'de kaderlerine terk edilmiştir. Bu durum, AB'nin bir çifte standardı, diğer bir deyişle Bobon kriteridir (Bo: Bizden olanlar, Bon: Bizden olmayanlar). 2004 yılından bu yana Kıbrıs uyuşmazlığının parametreleri değişmemiştir. Annan Planı, Garanti ve İttifak Anlaşmaları'nın Ada'da kurulan yeni düzeni dikkate alarak aynen devam etmesine dayanmaktaydı. Referandumda Kıbrıslı Türkler hem BM planına hem de AB üyeliğine evet dedikleri halde, hayır diyenler ödüllendirilip Kıbrıs Cumhuriyeti AB üyesi olurken evet diyen Kıbrıslı Türkler çözümsüzlüğe mahkum edilmiştir.

Annan Planı, Garanti ve İttifak Anlaşmaları'nın adada kurulan yeni düzeni dikkate alarak aynen devam etmesine dayanıyordu (Hoffmeister, 2006). Garantörlük kalacak, askerler 14 yılda kademeli olarak çekilecekti. Fakat buna rağmen Yunanistan Cumhurbaşkanı Prokopis Pavlopoulos 2 Aralık 2016'da Atina'da şu açıklamayı yapmıştır: “Kıbrıs'ın AB'nin tam ve eşit üyesi olması sebebiyle AB'nin ve AB bölgesinin sorunudur... Kıbrıs konusunda Yunanistan ve Kıbrıs ortak bir cephe oluşturur. Kıbrıs Cumhuriyeti'nin egemenliği ilkesinde meydana gelebilecek bir zedelenme, AB'nin üyesi olan diğer devletler için de söz konusu olabilecektir. Bu egemenlik kavramı ne işgal kuvvetlerine ne de garantilere izin verir."

Annan Planı’nın 12 Kasım 2002 tarihinde ilk açıklanan ilk versiyonunda Kıbrıs Türk Federe Devleti’ne yerleşecek Rumların siyasal haklarına yer verilmiştir. Fakat yeni süreçte Kuzey’e yerleşecek 60 bin Rum'un seçme ve seçilme hakkı olacağı için iki bölgelilik ve iki kesimlilik aşındırabilecektir. Annan Planı'ndaki rakam 100 bin iken Cenevre'de görüşülen metinde Türk tarafının Güney’e iade edeceği topraklara 80 bin kişi, Kıbrıs Türk Federe Devleti topraklarında ise 60 bin Rum yerleşecek ve bu kişiler seçme ve seçilme hakka sahip olacaktır. Bu durum, iki bölgelilik ve iki kesimlilik ilkesine aykırıdır. Annan Planı'nda Türk askerinin 14 yılda Kıbrıs'tan çekilmesi öngörülürken, Cenevre'deki süreçte çözümle birlikte hemen geri çekilme gündeme gelmiştir. Yeni süreçte Kıbrıs Türk Federe Devleti'nin kıyı uzunluğunda önemli bir azalma söz konusudur. Annan Planı'nda yüzde 49 olan kıyı uzunluğu, çözüm olursa yüzde 10-12 oranında azalacaktır.

Garantör ülke olarak Türkiye'nin AB ile ilişkileri fiilen donmuş durumdadır. İngiltere, AB'den ayrılma sürecine girmiştir. Bu iki önemli garantör ülke AB'nin dışında kalırsa, Kıbrıs sorununun çözümünde AB'nin etkinliği azalacaktır. Bunun sonucunda Türkiye ile Yunanistan baş başa kalırsa çözüm umudu artacaktır. Başbakanı Adnan Menderes ile Yunanistan Başbakanı Konstanstin Karamanlis'in anlaşması, Kıbrıs Cumhuriyeti’nin kurulmasında etkili olmuştur. Yunanistan'ın ve Kıbrıs'ın AB üyeliği çözümü güçlendirmektedir.

1960 sistemi içinde yer alan İngiltere'nin askeri üslerinin statüsünün Cenevre'de görüşülmemesi, bir çifte standarttır. Yunanistan Cumhurbaşkanı'nın egemenlik konusundaki açıklamalarında İngiltere'nin üsleriyle ilgili bir atıf olmaması dikkat çekicidir. 1963 yılındaki toplumlararası çatışmalar ve 15 Temmuz 1974'te Yunan 
Cuntasının Makarios'a darbe girişimi gerçeği karşısında Türkiye'nin garantisinden vazgeçilmesi mümkün değildir. Annan Planı'nın 2004'te iki topluma sunulmadan önceki son haline getirildiği Bürgenstock Zirvesi'nde iki kesimin liderleri vardı ama İngiltere yoktu. Bürgenstock'da Erdoğan, Gül, Karamanlis ve Papadopulos'un katılımı ile dörtlü bir görüşme yapılmıştır. Bugünse Cenevre'de İngiltere de vardır.

12 Şubat'ta alınan 1950 Plesibiti'nin okullarda okutmasına yönelik karar, Türk düşmanlığını daha da körükleyecek, iki bölgeli, iki toplumlu federasyon kurulmasını amaçlayan görüşmeleri çıkmaza sürükleyecektir. Bu gelişme, Kıbrıslı Rumların değişmediğini göstermesi bakımından önemlidir. Kıbrıs'ın bağımsız ve egemen bir ülke olması yönünde mücadele ettiğini söyleyen Rum Lideri Nikos Anastasiadis'in Onursal Başkanı olduğu DİSİ'nin oylamada çekimser kalması önemli bir göstergedir. Anastasiadis oylama öncesinde karşı çıłıp, bugün bu zihniyetin hastalıklı olduğunu açıkça söyleyemediği için Kıbrıs’ta yeşeren ümitler solmuştur.

\section{Sonuç}

Avrupa Birliği süreci, Türkiye Cumhuriyeti'nin 1923 yllında ilanından sonraki en önemli çağdaşlaşma projesidir. Başbakan Erdoğan 12 Ağustos 2010 tarihinde Ankara'daki büyükelçilere vermiş olduğu iftar yemeğinde "Türkiye'nin dış politika ekseni değişmemiştir" derken haklıdır. AB üyeliği hedefinden bir sapma söz konusu değildir. Çünkü 2001, 2003 ve 2008 ylllarında güncellenerek Bakanlar Kurulu kararıla Resmi Gazete'de yayınlanan $\mathrm{AB}$ üyeliği hedefine yönelik Türkiye Ulusal Programı'nın giriş bölümündeki hedefte bir değişiklik olmamıştır. Fakat buna rağmen Cumhurbaşkanı Erdoğan 6 Nisan 2017'de Balıkesir'deki açılış töreninde yaptığı konuşmada "Avrupa öyle bir hale geldi ki bitti, tükendi. Ama bedelini çok ağır ödeyecekler" demiştir.

Türkiye AB üyesi olmadığı sürece, Kıbrıs sorununu Türkiye lehine bir çözüme kavuşturması da çok zordur. Kıbrıs Cumhuriyeti adı altında anayasasına ve devleti kuran anlaşmalara aykırı olarak Rumlardan oluşan Kıbrıs Cumhuriyeti, 1 Mayıs 2004 tarihinden bu yana AB üyesidir. Bu sebeple Kıbrıs sorunu, uluslararası hukuk sorunu olmakla birlikte aynı zamanda AB'nin de sorunudur. Kıbrıs Cumhuriyeti anayasal statüsü ve uluslararası kuruluş anlaşmaları gereği bağımsızlığı ve egemenliği kısıtlı ülkeler grubu arasındadır. Kıbrıs sorunun adil bir şekilde çözümlenmesi için Türkiye'nin $\mathrm{AB}$ ile ilişkilerinin kopmaması gerekir. Çünkü AB'de geçerli standartlar; kişi hak ve özgürlükleri, hukuk devleti, kuvvetler ayrılığı, çoğulcu demokrasi, yargının bağımsızlı̆̆ı, adaletin tarafsızlığı gibi temel alanlara çağdaş düzenlemeler getirmektedir.

22 Şubat 2017 tarihinde AB Bakanı Ömer Çelik'in sıkıntılı bir süreçten geçen Türkiye-AB ilişkilerinde ilerlemenin ancak 2017 senesinin ilk yarısında, somut gündemli bir zirvenin toplanmasıyla mümkün olacağı tespiti, doğrudur. Türkiye Brexit sonrası AB'nin izleyeceği yöne göre $\mathrm{AB}$ stratejini yeniden değerlendirmelidir. Büyük düşünür Lucius Annaeus Seneca "Hangi kapıya yöneldiğini bilmeyen hiçbir zaman uygun esen rüzgarı bulamaz" (ignoranti quem portum petat nullus suus ventus est) görüşünden hareketle $\mathrm{AB}$ 'den kopmamalıdır. $\mathrm{AB}$ üyeliği karşı̆̆ında Kıbrıs'tan vazgeçilmemeli, Prof. Dr. İlber Ortaylı'nın “Kıbrıs'ta milletlerarası bir müdahaleye izin vermemeliyiz. Büyükannesinin çeyizini dağıtan deli kız gibi davranmamalıyız. Kıbrıs olmazsa Türkiye boğulur" görüşünü de yok saymamalıyız.

\section{Kaynakça}

- AA, 2015. Prof. Dr. Karluk: AB, Güney Kıbrıs'1 Tanıtma Peşinde. 23.09.2005.

- AA, 2016. AB Bakanı Bozkır: Avrupa Birliği Türkiye açısından stratejik bir hedeftir. 18 Mayıs 2016. http://aa.com.tr/tr/turkiye/ab-bakani-bozkir-avrupa-birligi-turkiye-acisindan-stratejik-bir-hedeftir/573891

- AB Bakanlığı, 2012. Türkiye-AB Pozitif Gündem Çerçevesinde AB ile Türkiye Arasında Güçlendirilmiş Enerji İşsirliği. http://www.ab.gov.tr/files/haberler/2012/turkiye_ab_gelistirilmis_isbirligi_turkce.pdf

- AB Haber, 2016. Başbakan Yardımcısı Mehmet Şimşek: AB bizim için önemli bir çıpa, Batı'dan bir kopuş görmüyorum. http://www.abhaber.com/55396-2.

- Agence France-Presse, 2008. Sarkozy Opposes Turkish Entry into EU," Vows Referendum, 24 Nisan 2008. http://www.hurriyetdailynews.com/sarkozy-opposes-turkish-entry-into-eu-vowsreferendum. aspx?pageID=438\&n=sarkozy-opposes-turkish-entry-into-eu-vows-referendum-2008-04-26

- Akgün, 2010. "The Case of TRNC in the Context of Recognition of States under International Law," Ankara Bar Review, Ankara, s.1-5. http://www.ankarabarosu.org.tr/siteler/AnkaraBarReview/tekmakale/20101/1.pdf

- Bora, 2013. "Cyprus in International Law," Ankara Bar Review.

- http://www.ankarabarosu.org.tr/siteler/AnkaraBarReview/tekmakale/2013-1/1.pdf

- Borowiec, 2000. Cyprus: A Troubled Island. Prager, London.

- Can ve Özer, 2005. Türkiye Avrupa Topluluğu Hukuku. Gazi Kitapevi, Ankara.

- Clerides, 1989. Cyprus: My Deposition. (3 vols.) Alithia Publishing, Nicosia. 
- Council of Europe, 1974. Resulation 573, Resulation Regretting the failure of the attempt to reach a diplomatic settlement which led the Turkish Government to exercise its right of intervention in accordance with Article 4 of the Guarantee Treaty of 1960.

- Çavuşoğlu, 2017. Türkiye'nin olmadığı Avrupa eksiktir. 9 Ocak 2017. http://www.byegm.gov.tr/turkce/haber/turkiye-olmadan-ab-eksik-kalir/104341.

- Dışişleri Bakanlığı, 2004. TC Dışişleri Bakanlı̆̆'nın GKRY'nin AB üyeliği ile ilgili Açıklaması 1 Mayıs 2004. http://www.mfa.gov.tr/tc-disisleri-bakanligi_nin-gkry_nin-ab-uyeligi-ile-ilgili-aciklamasi-_1-mayis2004_tr.mfa

- Dişişleri Bakanlığı, 2005. Akritas Plan. http://www.mfa.gov.tr/akritas-plan.en.mfa https://books.google.co.uk/books?id=mQ2822RQ5UYC\&pg=PA90\&dq=akritas+plan + hakki\&hl=en\&sa=X \&ei=25AlVYzUOcacsAHe0oLwDA\&ved=0CCAQ6AEwAA\#v=onepage\&q=akritas\%20plan\&f=false

- Dışişleri Bakanlığı, 2005. Müzakere Çerçeve Belgesi.

http://www.ab.gov.tr/files/AB_Iliskileri/AdaylikSureci/MuzakereCercevesi/Muzakere_Cercevesi_2005.pdf

- DPT, 2005. Türkiye İçin Müzakere Çerçeve Belgesi ve İlgili Diğer Belgeler. http://www.ab.gov.tr/files/AB_Iliskileri/AdaylikSureci/MuzakereCercevesi/Muzakere_Cercevesi_2005.pdf

- Dudley, 2005. Grivas Portrait of a Terrorist. Harcourt Brace and Company, New York.

- EC, 2004. Council Regulation, No 866/2004 of 29 April 2004 on a regime under Article 2 of Protocol 10 to the Act of Accession (OJ L 206, 9.6.2004, p. 51)

- EC, 2005. Green Line Regulation: Commission welcomes Council adoption of measures that further facilitate trade across the Green Line in Cyprus, Brussels, $17^{\text {th }}$ February 2005. http://europa.eu/rapid/pressrelease_IP-05-197_en.htm?locale=en.

- EC, 2016. Aid Programme for the Turkish Cypriot community. http://www.welcomeurope.com/europeanfunds/aid-programme-turkish-cypriot-community-676+576.html\#tab=onglet_details

- Ertekün, 1983. The Cyprus Dispute and the Birth of the Turkish Republic of Northern Cyprus. Oxford University Press, New York.

- EUR Lex, 2006. Council Regulation (EC) No 389/2006 of 27 February 2006 establishing an instrument of financial support for encouraging the economic development of the Turkish Cypriot community and amending Council Regulation (EC) No 2667/2000 on the European Agency for Reconstruction. http://eurlex.europa.eu/legal-content/EN/TXT/?uri=CELEX\%3A32006R0389

- Füle, 2012. Turkey and the EU: common challenges, common future," Commissioner for Enlargement and the European Neighbourhood Policy, 10 Aralık 2012. http://ec.europa.eu/archives/commission_20102014/fule/docs/articles/20121010_turkey_article.pdf.

- Gazioğlu, 1999. Two Equal and Sovereign Peoples: A Documented Background to the Cyprus Problem and the Concept of Partnership. Lefkoşa, Turkey: CYREP.

- Gül, 2014. Avrupa Birliği Türkiye İçin Stratejik Bir Hedeftir. https://www.youtube.com/watch?v=BGUL7_buWIA.

- Hasgüler, 2007. Kıbrıs'ta Enosis ve Taksim Politikalarının Sonu, Alfa Yayınları, İstanbul. s.231

- Hasgüler, 2017. Akılsız Evlat: Kıbrıs Rum Elitleri, http://www.kibrisgazetesi.com/yazarlar/prof-dr-mehmethasguler/akilsiz-evlat-kibris-rum-elitleri/1536.

- Hoffmeister, 2006. Legal Aspects of the Cyprus Problem: Annan Plan and EU Accession. Martinus Nijhoff Publishers.

- Hürriyet, 30 Mart 2005, 23 Eylül 2005, 25 Eylül 2005, 28 Ocak 2015

- IFO Institut. 2013. Dimensions and Effects of a Transatlantic Free Trade Agreement Between the EU and the USA. http://www.cesifo-

group.de/ifoHome/research/Projects/Archive/Projects_AH/2013/proj_AH_freihandel_USA-GER.html

- Karluk, 2004. “Avrupa Birliği’nde Bölünmüş Bir Delet: Kıbrıs”, İrfan Kalaycı, (der.), Kıbrıs ve Geleceği içinde Nobel Yayın Dağıtım, Ankara. s.127-148.

- Karluk, 2006. Güney Kıbrıs’ın Gümrük Birliği'ne Katılım Sürecinde Karşılaşılan Sorunlar, Ankara Avrupa Çalışmaları Dergisi, 5, s. 69-89.

- Karluk, 2013. Avrupa Birliği Türkiye İlişkileri: Bir Çıkmaz Sokak, Beta Basım Yayın, İstanbul.

- Karluk, 2014 Avrupa Birliği, Beta Basım Yayın, İstanbul.

- Karluk, 2015. “Turgut Özal ve Avrupa Birliği: Uzun ve Meşakkatli Bir Yol”, Turgut Özal: Değişim, Dönüşüm, E. Ertosun ve E. Demirbaş (edt.) Turgut Özal Üniversitesi Yayınları, Ankara. 
- Karluk, 2016. The Examination of the Accession Attempts of Turkey to the Shanghai Cooperation Organization and the Eurasian Customs Union within the scope of The EU Membership Perspective of Turkey. https://www.researchgate.net/publication/301205097_The_Examination_of_the_Accession_Attempts_of_T urkey_to_the_Shanghai_Cooperation_Organization_and_the_Eurasian_C $\bar{C}$ ustomsUnion_within_the_scope_o f_The_EU_Membership_Perspective_of_Turkey

- Karpat, 1975. Turkey's Foreign Policy in Transition: 1950-1974. E. J. Brill, Leiden.

- Ker-Lindsay, 2011. The Cyprus Problem: What Everyone Needs to Know. Oxford University Press, New York.

- Mendelson, 1997. EU and Cyprus: An Expert View Opinion of Professor M.H. Mendelson Q. C on the Application of 'the Republic of Cyprus' to Join the European Union, http://www.mfa.gov.tr/eu-and-cyprus_an-expert-view.en.mfa

- Necatigil, 1985. The Turkish Republic of Northern Cyprus in Perspective, Z. M. Nejatigil, Nicosia.

- Sarkozy, 2007. Testimony: France, Europe and the World in the Twenty-First Century, Harper Collins, New York.

- Straw, 2013. Last Man Standing: Memoirs of a Political Survivor, Macmillan, London.

- Şimşek, 2017. Ekonomide dönüşüm ve reform zamanı. http://www.hurriyet.com.tr/ekonomide-donusumvereform-zamani-40429950

- TEPAV, 2013. Turkey \& The EU: The Sick Man Bites Back. http://www.tepav.org.tr/tr/haberler/s/3466.

- $\quad$ TRCN, 1959. London-Zurich Agreements of 1959. http://www.cfr.org/cyprus/london-zurich-agreements$1959 / \mathrm{p} 24844$

- Vassiliou, 2006. "Why Turkey Should Join the EU”, Europe's World, Spring, s.144-147.

- Wimmel, 2016. "Beyond the Bosphorus? Comparing German, French and British Discourses on Turkey's Application to Join the European Union," Journal of Language and Politics. http://aei.pitt.edu/8068/1/wimmel-a-04g.pdf.

- World Bank. 2014. Evaluation of the EU-Turkey Customs Union, http://documents.worldbank.org/curated/en/298151468308967367/Evaluation-of-the-EU-Turkey-customsunion 


\title{
İki Dünya Arasında Türkiye: 2071 Yılına Yönelik Projeksiyonlar Turkey Between Two Worlds: Projections For Year 2071
}

\author{
Dr. Ahmet Salih İkiz (Muğla University, Turkey)
}

\begin{abstract}
Doğan Avcıoğlu, says in his famous book, Regime of Turkey that Turkey has oriental roots with attempts to cope to occidental cultures. Since westernization was always conceptualized as economic growtIn and development from the Ottoman times to young Turkish Republic western values and techniques were modified to our country. Although we accomplished in surface the oreintalist roots remained in the core of social structure of country. Thus Turkey attemted to organize capitalist western economic structure in eastern habits. In this study I aim to give some projections for coming decades under those arguments.
\end{abstract}

\section{Giriş}

Doğan Avcıoğlu, 1968 yılında Türkiye'nin Düzeni adlı kitabında Türkiye'nin doğuyla bağlantısı devam ederken batıya yol aldığını belirtir. 1960 darbesi sonrası süreçte sağ partilerin tekrar iktidara gelmesi bu önermeyi yapmasına neden olsa da tarihi süreç yazarı haklı çıkarmaktadır. Bu çalışmada bu yürüyüş metaforu ile Anadolu'ya gelişimizin milenyuma evrilmesine yönelik bazı öngörü ve projeksiyonlar Batı, Doğu (Occident, Orient) ekseninde kurgulanacaktır. Son yüzyıldaki siyasi ve ekonomik iklimdeki değişim çerçevesinde ülkemizin hangi Dünya ile daha fazla yakınlaşabileceği tartışılacaktır.

\section{Anadolu'ya Türklerin Akması}

Anadolu’ya gelen Türk boyları bir devlet düzeni kurarak, 18. Yüzyıla kadar bir dönemin süper gücünü oluşturacak bir Devleti Aliye kurmayı amaçlayarak, göç etmediler. Dahası daha çok tribal bir geleneğe dönük bir düzlemde aynı göçer kültürünü de bir süre muhafaza ettiler. Avcılık ve hayvancılık temelli bu nomadic düzen nadiren yerleşik tarımsal kültürü içeriyordu. Doğudan gelen bu akımların Batının kadim kültürleri ile etkileşime geçmesi kaçınılmazdı. Bu durum bir vakum etkisi yaratmış, tarihsel süreçte bu coğrafyadaki eski kültürler yenilerine yönelik bir kap fonksiyonu görmüş ve yeni gelenler bu kabın şekline uyum sağlamışlardır. Bu konuda Ekrem Akurgal, Anadolu Uygarlıkları adlı eserinde günlük hayatta ve kültürel yaşantımızın kodlarında pek çok hareket tarzı, davranış ve uygulamaların 5000 yıl öncesi Hititlerle önemli benzerlikler içerdiğini (mezar kültü, gelinlik kültü, dini ritüeller) göstermiştir. Kültürel katmanlaşma aynı zamanda toplumsal değişimlerde eski kültürün devlet yönetimi tarz ve şekillerinin geleceğe taşınmasına yol açmıştır.

Bu nedenle Türk Boyları Pax Romana dönemindeki kamu uygulamalarını ciddi anlamda yerleşik düzene geçişte kullandılar. Bu vergi sisteminden, yönetim sürecine her boyutta ortaya çıktı ve evrimsel süreçte daha etkin ve adaptif bir hal aldı. Tarihsel diyalektikte anlaşılacağı gibi bir ülkenin ayakta kalması ve yaşamını idame ettirmesi o coğrafyaya özgün bir yönetimi sağlaması ile mümkündü. Osmanlılar yerleşik Türk boyları arasında Doğu Roma imparatorluğuna en yakın sınırı olan ve en yakın ilişkilerde bulunan beylikte ve bu nedenle Bizans kamu yönetimi sistemini yakından gözlemlemişlerdi. Bu süreçte birçok yönetim tekniğini yönetimde devamlılık ilkesi kapsamında devraldılar. Fatih döneminde yer alan iktidarın tekliği için kardeş katlini vacip kılan uygulama bile yüzyıllardır Batıda uygulanan bir gelenekti.

Kuruluşundan itibaren Osmanlılar Roma İmparatorluğunun emperyal güç sınırlarına yakın bir bölgeyi (Merkez Avrupa hariç) kontrol altında tuttular. İlber Ortaylı bu dönemi bir Pax Ottomana olarak adlandırmakta bir sakınca görmez. Osmanlı millet düzeni devşirme kurumu aracılığı ile batılıların tanımı ile karışık bir salata (Bu konuda ABD’li bilim insanlarının ülkeleri için kullandığı mixed salad teriminin karşılığı olarak kullanılmıştır) şeklinde varlığını sürdürmüştür. İnsan yaşamı ve uygarlıkların ömrü arasındaki ilişkide görüleceği üzere Osmanlı için 18. Yüzyıl bir çöküş dönemidir ve artık tarih sahnesinden ayrılma süreci başlamıştır. Balkan savaşları ile yeni ulus devletler ortaya çıkmış Osmanlı imparatorluğu I. Dünya savaşından sonra kendisi ile birlikte Rusya ve Habsburgları da tarih sahnesinden alıp götürmüştür. İzleyen dönem, Dünya düzeninde ulus devletlerin dönemini pekiştirmesine rağmen büyüme ve bölüşüm temelli iktisadi düzende alternatif paradigmaları da ortaya çıkaracaktır. Devrimsel teknolojik gelişmeler, köleci toplumdan çalışan sınıfına geçiş ve yeni Dünyanın ABD'de kurulması eski Avrupa'da klasik iktisadi sistem sorgulamalarına yönelik sınıfsal tahlillere yol açmıştır.

İlk Dünya savaşının Avrupa'da Almanya merkezli güç sıkışmasını gidermemesi yeni bir siyasi patlamayla 2. Dünya savaşına neden olmuştur. Etkisi itibari ile ilkinden daha yıkıcı olan bu savaş sonucunda hem Avrupa küresel gücünü yitirmiş ve hem de yeni güç olarak ABD ve SSCB ortaya çıkmıştır. Tarihin tekerrürü bu süreçte eskinin yeniye geçişi şeklinde ortaya çıkar. Yani Yeni Dünya ABD ile Anglo Sakson temelli süreci devam ettirirken, SSCB temelli düzen Doğu kültürel geçişini korporatif bir formda materyalist inanç şeklinde devam ettirmiştir. Soğuk savaş dönemi her ne kadar ekonomik sistem farklılığı temelinde incelense de ben bunun geleneksel Doğu, 
Ortodoks, Asyatik yapı ile liberal Protestan, Yeni Dünya arasında olduğunu düşünmekteyim. Nitekim 1992 sonrası gelişmeler ve yeni Dünya paktları, güvenlik kurumları bunu pekiştirmektedir.

SSCB'nin geçici bir kırılması ve Huntington tezi çerçevesinde kenar sınır bölgelerde çatışmalar 1992 sonrasında geçici bir süre ABD temelli hegemon gücün yükselmesine yol açsa da kontrolsüz bir gücün kendine yönelik olas1 tahriplerini de gösterir. Böylelikle 1996 sonrasında Şanghay Paktı NATO’nun alternatifini de Doğu ekseninde yaratmıştır. Doğu Batı ekseninde yeni Dünya düzeni müdahaleci ve liberal ekonomik sistemlerin güvenlik ve savunma eksenli güç dengesinde oluşacaktır. Bu süreçte ekonomik güç dengesinin Asya'ya kayması da beklenmelidir.

Osmanlının temelini oluşturan Türk boylarının Anadolu'ya akması her şeyden önce binlerce yıllık tarihi kültüre sahip bu topraklarda değişim yaratmıştır. Şöyle ki zamanın ruhu ve maddenin tabiatı itibari ile bu bölgede yaşayan farklı etnik kökende, dinde ve dilde farklı milletlerden insanlar yeni gelenlerle birlikte Osmanlı imparatorluğunun harcını oluşturmuşlardır. Bu nedenle Asya ve Türk kökenli genetik havuz açısından Finlandiya ve Danimarka vatandaşları Türkiye'den daha aridir. Bu insanlar millet sistemi aracılığı ile güçlü bir devlet yapısında sorunsuz birlikte yaşarken imparatorluğun çöküş döneminde Fransız milliyetçiliği akımı ile ulus devletler kendi yaşam sahalarını ister hale gelmişlerdir. Dönemin padişahlarının yegâne çözümü Batıya yönelik kalkınma ve demokrasi temelli açılımlardı. Benzer açılımları Cumhuriyet rejiminin de 1923 yılı sonrasında yaptığını görerek ülkemizde uzun yıllardır, Avrupalılaşma, batılılaşma, kalkınma ve uygarlığın aynı eksende anlaşılması gerektiğini belirtmeliyiz.

17. Türk Devleti Türkiye Cumhuriyeti 1923 yılında Kurtuluş Savaşı sonrasında kuruldu. Destansı bir kahramanlığın ürünü olan bu devlet hâlihazırda Müslüman coğrafyasında tek demokratik rejimdir. Bugün bile ülke içinde bu abidevi başarının tam anlaşılmış olduğundan kuşkuluyum. En yalın haliyle anlatmak gerekirse topraklarının 3/2sini yitirmiş bir coğrafyada, 18 yaşından itibaren Balkanlardan Trablusgarp, Suriye ve Arap ülkelerinde savaşmış bir gurup gözü pek tarafından kazanılmış bir zaferdir bu. Bu nedenle uzunca bir süre mazlum, koloniyel milletler için Türkiye bir model olarak algılanmış Müslüman devletlerde ve Güney Amerika'da antiemperyalist bir güç olarak görülmüştür.

\section{Cumhuriyet ve Çok Partili Dönem}

Cumhuriyetin Kurucu Babalarının önemli bir kısmı, doğup büyüdükleri vatan bildikleri yerlerin ülke toprakları dışında kalmasının acısını çekmiş kuşaklardı. Bu nedenle Türklük kavramının katalizör etkisine önemli ölçüde sarıldılar ve bu terimi dar epistemolojik anlamda kullanmak zorunda kaldılar. Türklük ulus kavramını, Batılı değerlerle birleştirerek kalkınma sağlamak amacı ile yaşamın tüm alanlarında modern giyim tarzından, Latin harfleri ile alfabeye ve çağdaş ekonomik sisteme Batı kurumsal araçlarını genç Türkiye Cumhuriyetine uyguladılar. Dolayısı ile yaşamsal öneme sahip sosyokültürel ve ekonomik alan çok kısa süre önce ülkemizde işgalci konumunda olan Avrupalı ülkelerin değer sistemlerine bırakıldı. Haklı gerekçelerle Kurtuluş Savaşı sürecinde demonize edilen Batı diğer yandan ülke içinde bir uygarlık ve kurtuluş reçetesi olarak ortaya kondu. Bu tür bir çözüm gerekli olsa da pratik yaşamda kültürel kodların değişimi daha çok içsel, tabandan gelen baskılarla yerleşik hale gelir ve kabul edilir. Bu durumda, çok kısa zamanda yapılan çok iyi niyetli uygulamalar, çeşitli toplumsal kademelerde çok farklı algılandı. Sosyal yaşamda önemli bir yer tutan dini kurumlardan, cemaat ve tarikatlar bu süreçte kurucu kadroların faaliyetlerine son vermesinden oldukça rahatsız oldular ve Cumhuriyet rejimi ve kurucu kadrolarını tamamen yanlış ve ters bir anlayış ile İslam karşıtı olarak algıladılar. Bu süreçte tek parti rejiminin biraz da Batıya yönelimli politikalarını Doğuyu ve kültürünü yerleşik alandan çıkarmaya yönelik kalkınma planları dini alanın siyasal alanda pasifize edilmesine yol açtı.

Türkiye'de gerçek anlamda demokratik rejime çok partili siyasi yaşam ile geçildiği savunulabilir. Ancak Atilla İlhan'ın 1950 sonrasının kurucu Cumhuriyete bir karşıdevrim olarak tanımlanmasını da rezervde tutmak isterim. 1950 sonrası iktidara gelen DP liberal ekonomik düzen kurgusunda muhafazakâr kökenlere de hitap eden bir partiydi. Bu siyasi partiyi daha da önemli kılan ise çok partili rejimin muhalefet ruhunu iktidara taşıması ile oluşan demokratik takas başarısı idi. Bu nedenle eğer müdahale olmasaydı yüksek olasılıkla aynı sistem içinde seçim vasıtası ile iktidarını kaybedebilirdi. Tek parti rejimlerinin muhalefet yoluğunda fren denge mekanizması içermemesi nedeniyle kaçınılmaz bir şekilde baskıcı ve zorlayıcı yönleri bulunur. Bu durum belki de resmi muhalefet olmaması nedeni ile kurucu CHP kadrolarını etkilemiştir. Seçimlerde kullanılan açık oy gizli tasnif yöntemi bu durumu daha da radikalleştirmekteydi.

DP iktidarı Türkiye'yi milli güvenlik öncelikli nedenlerle Batı sistemine entegre etti. Bu durum geçmişteki kurumsal yapı ile yani Batı değerlerini uygarlaşma ve kalkınma ekseni algısı çerçevesinde kavramsallaştıran görüşle örtüşüyordu. Laik sistemin dozunda bir parça değişim yapılarak cemaatçi yapıya akışkanlık sağlayan bu durum, Türkiye'nin Düzeninde belirtildiği gibi kendini sol olarak adlandıran fakat buna rağmen toplumsal uygulamalarında dini alanda müdahalenin dozunu abartan (Bununla birlikte 1940'ların sonunda bu pozisyonda ciddi dönüşümler görülmektedir), sıkı bütçe politikası ve sınırlı kaynaklarla kalkınmaya öncelik vermesi nedeni ile de bireysel refahta istenilen düzeyde artış yapamayan, CHP'den kendini sağ olarak tanımlamakla birlikte daha 
liberal ve özgürlükçü söylemleri olan DP'ye kaymaya yol açmıştır. Bu nedenle Batı'dan Doğu'ya ilk yürüyüşün bu dönemde başladığı söylenebilir.

Türkiye'de yeni bir düzen tesis etmekte bu dönemde bence temel darboğaz Doğu ekseninde bu yürüyüşe geçen yani kalkınma dinamiklerini Müslüman coğrafyada uygulamaya çalışan ilk örnek olmasıdır. Yani hızlı bir süreçte yeni bir nizam tesis ederken ekonomik, mali, hukuki alanda kalkınma ve uygarlaşmanın kalesi kabul edilen Batı normları bu kadim medeniyetin geçmiş Türk boylarının Doğu Roma'dan yaptıkları aktarım sürecinden çok daha hızlı implement edilmek zorunda kalınmıştır. Özellikle soğuk savaş dönemi bu sürecin önemli derinliklerinden olmuştur. Çünkü kenar ülke olması nedeni ile coğrafi sınırlar itibari ile ve NATO üyeliği çerçevesinde ülkemiz iki güç bloğunun anarşi ve terör odaklı çatışmasının kaynağı olmuştur.

Ali Adnan Ertekin Menderes liderliğindeki DP, yaygın Batı ekonomik desteği, geçmiş dönem ekonomik rezervlerini rahatça kullanma ve ılımlı muhafazakârlık ile iktidarın ilk beş yılında önemli atılımlar yapmıştır. Yine de belirtilmelidir ki ekonomik büyüme hiçbir zaman çift haneli rakamlara çıkmamıştır. Bu süreçte NATO üyeliği önemli bir güvenlik argümanı olarak sunulmuştur. Ayrıca AB'nin kurucusu olan AET' ile ilişkiler başlatılmıştır. İktidarın ikinci beş yılı azalan Batı desteği sonucu zayıf ekonomik büyüme ile geçmiştir. ABD destekli sınai kalkınma hamlelerinde ciddi anlamda tüketim malları yönelimli sanayinin desteklenmesi, ağır sanayiye teşvik etmeme yolunda telkinler, dönemin hükümetinde alternatif arayışlarına yol açmıştır. Bu durumda enerji, madencilik ve diğer sanayi yatırımlarında SSCB desteği öne sürülmüş ve bu yönde ilişkiler başlamıştır. Özellikle ABD eksenli dış yardım konularında yıkıcı etkilere sahip kur ayarlaması yapılması önerileri bu süreci hızlandırmıştır. İşte bu politika sapması Türkiye'nin Batı güvenlik şemsiyesi olan NATO'nun aslında üye ülkeler içindeki gelişmeleri de etkileme gücünü görmesine neden olmuştur. Türk Silahlı Kuvvetleri tarafından böylece siyasete ilk müdahale bu yönelimin önünü kesmek amaçlı yapılmıştır. Darbe özü itibari ile laik ve sosyal demokrat yönetim tarzını getirmeyi amaçlamaktaydı. Böylece hem Batı ile ilişkilerde bir kopuş yaşanmayacak ve hem de Kemalist ideoloji (Atatürk kendi ismi ile anılan bir ideolojiyi tasvip eder miydi diye sormak isterim) çerçevesinde yönetim sol partilerle devam ettirilecekti. Belki de darbenin en olumlu çıktısı sonraki örnekleri ile karşılaştırıldığında son derece özgürlükçü ifadeler içeren yeni anayasa idi. Bu dönemde CHP yıllar sonra tekrar iktidar ile buluştu. 1965 seçimlerinde bu geçiş dönemi Adalet Partisinin seçim zaferi ile son buldu. Bu durum Cumhuriyet Halk Partisi danışmanı yazar Doğan Avcıoğlu tarafından ciddi bir araştırma süzgecinden geçirildi. Milliyetçi sol düşünceye sahip olan Avcıŏlu evrensel sol değerleri referans alan söylemlerin Türk seçmeninde çok karşılığının olmadığını ulusal söylemlerin daha etkili olduğunu ilk keşfedenlerdendi. Bu daha sonraları Bülent Ecevit tarafından ortanın solu, ulusalcı sol olarak işlenecek ve seçmen nezdinde bir karşılık bulacaktır.

AP iktidarları belirli dönemlerde CHP tarafından devralınmış 1977 yılı ise ortanın solu söylemi ile tarihteki en yüksek oy oranına ulaşmıştır. Yapısı itibari ile Türk solu içinde antiemperyalist söylemleri oldukça yüksek oranda barındırmaktadır. Uzun bir dönem AP ve MHP siyasi düzlemde küresel sistemle daha 1lımlı geçinmişlerdir. 1974 yılındaki Kıbrıs savaşının Ecevit iktidarında yapıldığını unutmamak gerekir. ABD eksenli küresel sisteme bir başkaldırı olan bu hareket askeri ve ekonomik ambargo ile Batı tarafından etkisiz hale getirilmeye çalışılmıştır. Bağlantısızlar hareketi ve dönemin Libya lideri Muammer Kaddafi'nin yaptığı stratejik yardımlar uygulanan petrol ambargosunu delmede yardımcı olmuştur. Bu dönemde Türk sağı daha fazla Batı ile angaje olurken Türk solunun bahsettiğimiz çizgide bulunması aslında solu törpülemeye yönelik yeni bir askeri darbenin de yolunu çizmekteydi. Nitekim 1977 sonrasında kaotik bir ortamda gerçekleşen terör eylemleri her nasılsa 12 Eylül 1980 askeri müdahalesi sonucu bıçakla kesilmiş gibi ortadan kalktı (Bu dönmede ABD Başkanına söylenen Our boys emrin nereden geldiğini açıkça gösterir).

1970'lerin sonlarından itibaren yakın coğrafyada yapılan darbelerde Türkiye ekseninde ortaya çıkan siyasi üstmetin bir öncekinde olduğu gibi yoğun bir Atatürkçü söylemi içeriyordu. Türk ordusunun Atatürkçü düşünce ile her zaman birlik halinde olduğu kanısı günümüze kadar gelmiş olsa da bu söylemi bir gizlenme aracı olarak kullanan kesimler her zaman mevcuttu. Nitekim 1980 sonrasında Türk İslam sentezi, yoğunluklu bir resmi ideoloji olarak gündeme geldi. Bu söylem kitlelerin dini alanda serbestisini artırarak izleyen dönemde muhafazakârlık dozu yüksek siyasi hareketleri de güçlendirdi. Türkiye yönetim sistemi bu dönemde laik Batılı yönetim yapısını korumakla birlikte bu Türk İslam sentezi ideolojisi ile kitlelere ulaştırıldı. Böylelikle Batı değerlerine yönetim sistemi bağlı kalırken, İslami kesimde bir güçlenme yarattı. İlginç olan durum liberal 24 Ocak kararlarının uygulanmasının, küresel finansal sisteme entegrasyonun başlamasının ve ithal ikameci ekonomi politikasından ihracata dayalı ekonomik sisteme geçilmesinin hep bu dönemde gerçekleşmesiydi.

Kurdukları montaj sanayisi nedeni Batı ile ilişkileri bulunan ve be belirli bir birikime sahip seçkinci İstanbul sermayesi bu dönemden itibaren Anadolu aslanları olarak adlandırılan muhafazakâr İslamcı sermayesinin ilk hamleleri ile karşılaştı. Yurtdışı entegrasyonun artması ülke içi tasarruf yetersizliğinin dış borçlanma ile sağlanmasını daha da arttırdı ve yüksek faiz düşük kur denkleminde ekonomik krizlerin de başlamasına yol açtı. Diyalektik gereği her ekonomik kriz sosyal yapıda da bir değişime yol açtı. Kurucu ideolojik önderleri, demokrasinin kesintiye uğradığı 1980 öncesinde MSP ve MHP'ye tek hanelik oy oranları getirebilirken ve Kürt milliyetçileri CHP ve diğer sol partiler içinde yer bulabilirken 1994 ekonomik krizi, bu kesimlerin oy oranını arttırdı. MSP kurucuları Refah Partisi adıyla bu seçimlerde merkez să̆ partileri eriterek oy oranlarında önemli kazanım elde ettiler. Bu dönemde Türk sağının özellikle büyük şehirlerde kitlelerin mobilizasyonunda etkisini 
yitirmesinin, Yeşil kuşak projesi kapsamında kotarılan siyasi gurupların RP yanında yer almasının ve ekonomik alanda bu partinin devlet müdahaleciliğini savunmaktan liberal söyleme geçişinin bunda etkisi vardı. Bu satırların yazarı 1990'ların başında çeşitli İslami grupların Beyazıt meydanında kendilerinden 20 yıl önce devrimci grupların giydiği kıyafetler (Bere, yeşil parka ve postal) ve benzer formda siyasi eylem yapmalarını antiemperyalist solun siyasi islamla yumuşatılarak form değiştirmesi olarak yorumlamıştır. Merkez sağ her ne kadar bir müddet daha iktidarda dirense de, bir askeri karışma ve 2001 ekonomik krizi sonrasında, siyasi alanı yeni bir siyasi oluşum olan AKP'ye bıraktı. Bu Avcıoğlu'nun yıllar önce sözünü ettiği Doğu'ya yönelmenin bir göstergesiydi. Bununla birlikte bu yönelimin ekonomik tabanı korporatist olmaması, yoğun ekonomik liberalizm içermesi ve ABD merkezli küresel finansal sistemle yakın ilişkileri nedeniyle izaha muhtaçtı. İktidarın ilk yıllarında (küresel sistemde kabul görmek gayesiyle) AB ile uzun yıllar sonra üyelik müzakerelerinin başlatılması bile Milli Görüş çizgisinden kesin bir kırılmanın göstergesiydi. Halen ülkemiz dominant İslami söylemin yoğunluğuna rağmen enerji ve finans alanında, Batı sermayesi ekseninde ABD ve İsrail ile yakın ilişkiler içinde bulunmaktadır. Bu durum özellikle ekonomik alanda Türk siyaset yapısının farklı siyasi partilere rağmen benzer bir yapıda olduğunu savunan Mete Tuncay'ı haklı çıkarmaktadır. Türk siyasetinde pozitivizmden ziyade dogmatizmin geçerli olduğunu savunan yazar bunu vahiyci anlayış ve kültürel kuraklığa bağlamaktadır. 2002 sonrasında siyasi atmosferde ulusalcı solun kalkınma dinamiklerini yansıtan yen siyasi oluşumlar ortaya çıksa da toplumsal alanda çok fazla karşılık bulmadı. Bununla birlikte Sina Akşin'in çalışmalarında belirttiği bu oluşumlar özellikle düşünsel düzlemde zenginliği nedeni bir değer olarak anılmalıdır.

Muhafazakâr demokrat olarak sınıflandırılan bu siyasi oluşum geçmişteki merkez sağ partiler ANAP, DYP ile Milli Görüşçü RP ve FP'nin oy tabanları üzerinde yükselirken ekonomik sahada liberal politikalar izlemiştir. Bu nedenle Cihan Tuğal bu siyasi partinin dinamiklerini Gramschinin Pasif Devrim teorisi ile çözümlemektedir. Yani en basit anlatımla eski düzeni yıkarak yeni bir düzen yaratma amacıyla ortaya çıkan bu siyasi oluşum eski düzenin liberal ekonomi politikası başta olmak üzere temel dayanaklarını tutarak kendi iktidarlarını meşrulaştırmıştır. İstanbul'un Sultanbeyli ilçesinde yaptığı saha araştırmasına dayanan bu çalışma 1990'ların RP dönemi ile 2002 sonrası AKP döneminin karşılaştırmasını içermektedir. Bu süreçte yüzeydeki muhafazakâr İslami söylemin koyu tonlarda olması uygulanan politikalardan olumsuz etkilenen kesim ve katmanların eleştirilerini sistem üzerinden verili diğer hedeflere kaydırmalarına yol açmıştır. Bu yaratılan suni krizler veya düşmanlar olabilir. Tuğal'ın bu önermesi bir model çöküşü ile sonlanmayı savunur. Bununla birlikte bu teorik çerçeve bazı konularda açıklanmaya muhtaçtır. Örneğin Türkiye belirli aralıklarla askeri darbelere maruz kalmıştır. Bu demokrasi kültürünün zayıf olmasına yol açmıştır. Bu nedenle kesintisiz bir sivil rejime olumlu bakılmalıdır. Din devlet ilişkileri batıda tamamı ile ayrılmış ve laiklik bunun üzerinden tanımlanmış iken Osmanlıdan beri İslam devlet aracıdır. Bu araç dün Şeyhülislam tarafından yürütülürken bugün Diyanet İşleri Başkanlığı tarafından yürütülmektedir. Tüm bunların üstünde ülkemiz sınai alanda kalkınma sürecinde ( hatta Yunanistan, Bulgaristan vb. AB ülkelerinden daha ilerde) bulunmaktadır. Dış ticaretinin yarısı AB iledir ve Dünya finans sistemine entegre olmuştur. Halen pek çok Avrupa Birliği ülkesinden daha yüksek ekonomik büyüme hızına sahiptir. Tüm bu nedenlerle çöküş temelli öngörülerin değerlendirilmesinde dikkatli yaklaşmak gerekir.

\section{Gelecek Yüzyıl}

Türkiye şüphesiz günümüz Dünya ekonomik sisteminin temeli olan liberal ekonomik düzeni kuruluş döneminden itibaren benimsemiştir. 1923 sonrasında Batı Bloğu içinde yer almasının temel gereği de bu olarak düşünülebilir. Ayrıca SSCB modelinin Dünya düzeninden ayrılması, Üçüncü Dünyanın korporatizm ve dağıtımc1 modellerini uygulayan İran ve diğer ülkelerin sistemden izole edilmiş olması ve Çin modeli gibi bir modeli geliştirememiş olmamız da bunun temel nedenleridir. Bu durum, güvenlik alanında NATO, siyasi ve ekonomi stabilite için AB'nin kurumsal olarak araçsallaştırılmasına yol açmış ve bu kurumların ülke içi çeşitli alanlarda etkili olmasına yol açarak milli politika bağımsızlığını etkilemiştir.

Doğan Avcıoğlu Batılılaşma ve Düzene Yabancılaşma adlı eserinde yıllar önce bu dilemmaya dikkat çekmiştir. Günümüzde siyasi islam muhazakarlıkla liberalizmin kaynaşmasıyla bu soruna geçici çözüm getirmiştir. Bununla birlikte Arap baharı süreci benzer kombinasyonları yapan baskıcı rejimlerin sonucunu da ortaya çıkarmıştır. Bu durum demokratik temellerin esas alınması gereğini ortaya çıkarmaktadır.

Türkiye geleceği Batı içinde ve dışında çeşitli alternatif kalkınma paradigmalarına gebedir. Bunları sırası ile değerlendirelim.

a. AB içinde bir Türkiye

Türkiye Avrupa Birliği ile uzun yolculuğunda farklı bir Avrupa, kimliği yaratılmasına yol açarak tan üye olacak ve işbirliğgini arttıracaktır. Ama eğer bir gün Türkiye Avrupa Birliği üyesi olursa bu ya farklı bir Avrupa Birliği ya da farklı bir Türkiye olacaktır. Bu durum Avcıoğlunun Batıya yürüyen adamının AB'nin çok vitesli bir konuma gelmesi nedeni ile yeni Doğu Avrupa liderliğini de Türkiye’ye yükleyebilir. Batının doğusunun en gelişmişi olan Türkiye entegrasyon içinde güvenlik ve ekonomi alanında böylece etki alanını arttırabilir. Ayrıca Batnın Doğuya açılan penceresi işlevini de yerine getirir. Önemli enerji koridorları Türkiye üzerinden Avrupa Birliği ülkelerine ulaşmaktadır bu nedenle Kıta Avrupası enerji güvenliği konusunda Türkiye'nin istikrarına muhtaçtır. Ülkemiz bir 
tampon mekanizması görerek özellikle istikrarsız Asya ülkelerinden Avrupa'ya geçişleri önleme misyonu da üstlenecektir. İki tarafın da kazanımına dayanan bu durum Nedim Gürsel'in tabiriyle Yaşlı Avrupa'ya genç damat olarak Türkiye'yi getirerek bir gençlik aşısı uygulayacaktır. Bu ayrıca NATO şemsiyesine paralel bir güvenlik sistemi kurmak isteyen Avrupa ülkelerine yeni güvenlik ve savunma sisteminin kurulmasında bir omurga yaratacaktır. Dış ticaretimizin yüksek oranda Avrupa ülkeleri ile yapılması, ülkemizde Avrupa bölgesinden yüksek oranlı Doğrudan yabancı sermaye yatırımları dikkate alındığında bu entegrasyonun Milli Gelir düzeyi, istihdam oranı üzerinde önemli pozitif etkisi olacağı aşikârdır.

b. Avrasya Paktı üyesi Türkiye

1996 yılında kurulan Şangay Ekonomik Organizasyonu zaman sürecinde ekonomik birlikten güvenlik boyutunu öne çıkartan birlik haline evirilmiştir. Bu durum üye ülkelerin Rusya Federasyonu başta olmak üzere eski coğrafi sınırlarına yönelik siyasi etkilerini attırmıştır. Böylece Türkiye'nin Azerbaycan ile yarattı̆ğ iki devlet tek millet mottosu eski Türk coğrafyasına uygulanabilir. Ayrıca askeri strateji uzmanlarının belirttiği gibi Dünya merkezi kalpak (hearthland) bu bölgede bulunmaktadır. 1000 yıl önce gelinen topraklarda yeni bir entegrasyon dil, kültür ve din birlikteliği çerçevesinde mümkün olsa da Rusya ile birlikte küresel platformda işbirliği her zaman bazı sürprizlere gebe olma sonucu da getirebilir. Batı savunma bloğu NATO üyesi Türkiye'nin bir anda bu bloktan diğerine geçmesi bir küresel fay hattı kırığından ziyade bir deprem etkisi de gösterebilir. Ayrıca bu pakta dâhil ülkeler demokratik kültür ve ekonomik refah seviyesi bakımından Batı bloğundan geri kalmış olsalar da Dünyanın ekonomik çekim merkezi Çin merkezli Asya ülkeleri olma yolundadır.

\section{c. İslam Birliği ve D8 Gurubu}

Necmettin Erbakan’ın uzun dönem öne sürdüğü ve Milli Görüş olarak teorisini çizdiği bu yaklaşım hiçbir dönem Türkiye'de çok taraftar bulmamıştır. Son 15 yılda iktidarda bulunan AKP hükümeti için bile ekonomik temelli dış ilişkilerde diğer angajmanların gerisinde kalan bu birlik, Müslüman ülkelerin de kendi içlerinde ayrılıkları sebebi ile kadük olmuştur. Bununla birlikte önemli enerji kaynakları bulunan ve sanılanın aksine uzun dönem yetecek rezervlere sahip bu ülkeler önemli ölçüde finans kapitallerini Batı ülkelerinde tutmaktadırlar. Bu nedenle ülkemiz yatırımlara ayıracak tasarruf yetersizliğini bu ülkelerden akacak sermaye yatırımları ile giderebilir. Bu projeksiyonu destekleyecek önermeleri George Friedman Gelecek Yüzyıl isimli eserinde 2050 yılına yönelik bir harita çerçevesinde sunmaktadır. Neo Osmanlı akımın da etkilendiği bu harita eski Osmanlı coğrafyasında Türk İslam etkisini göstermektedir.

$\mathrm{Bu}$ önermelerin her biri Türkiye Cumhuriyeti siyasi ve ekonomik etki alanı coğrafyasının farklı olası hegemen güçler çerçevesinde geleceğe yönelik olası genişlemesini göstermektedir. Bu olası gelişmelerde yönetimin başarısı bu olası stratejiler arasında ülke çıkarına uygun politika bileşenlerini ülke çıkarlarına uygun harmanlayarak gerçekleştirmektir. Ülkelerin dış ilişkilerde dost veya düşmanları yoktur, çıkarları vardır. Doğan Avcıoğlu, İdris Küçükömer ve Mete Tuncay gibi diyalektik birikime sahip yazarlar, özellikle 1980 öncesi kültürel açıdan verimli ortamda yaratılan düşünce ikliminde ekonomik kalkınmanın sosyal dinamiklerini tarihsel süreçte tartışmışlardır. Bu yazarlardan Avcıoğlu ve Küçükömer milliyetçi ve devrimci yaklaşımla kalkınma önerileri yapmışlardır. Mete Tuncay özellikle AKP iktidarına yönelik görüşlerinde Türkiye sağının siyasi alanda yerini araştırmıştır. Bu konuda şahsi eleştirim müesses nizamı eleştirerek iktidara gelen şu anki hükümetin halen pek çok seçimden başarılı çıkmasına rağmen zaman sürecinde kendine yönelik yeni bir nizam yaratırken aynı yanlışlara düşme riskidir. Bu durum milliyetçi muhafazakâr söylemlerin İslami temelini kof ve zayıf hale getirmekte ve dinin araçsallaştırılması ekonomik alandaki kırılganlıklardan etkilenmesine yol açmaktadır.

\section{Kaynakça}

- $\quad$ Akşin Sina, Yakın Tarihimizi Sorgulamak, Arkadaş yayınevi, Ankara,2011

- Akurgal Ekrem, Anadolu Uygarlıkları, Phoenix Yayınları, Ankara,2015

- Avcıoğlu Doğan, Türkiye’nin Düzeni, Dün Bugün Yarın, Kırmızı Kedi Yayınları, İstanbul.2016

- Bora Tanıl Can Kemal, Devlet ve Kuzgun, İletişim yayınları, 2007

- Gürsel Nedim, Türkiye Yaşıı Avrupa’ya Genç Damat, Doğan Kitap,2009

- Heywood Andrew, Siyasi İdeolojiler, (çeviren Hüsamettin İnaç), Adres Yayınları, Ankara, 2014

- İslamoğlu Huricihan, Neden Avrupa Tarihi, İletişim yayınları, İstanbul,1997

- Kahraman Hasan Bülent, Postmodernite ile modernite arasında Türkiye, Agora kitaplı̆̆

- Kaleağası Bahadır, Avrupa Galaksisinde Türkiye Yıldızı, Doğan Kitap, İstanbul,2006

- Küçükömer İdris, Halk Demokrasi İstiyor mu, Profil Yayıncılık, İstanbul,2013

- Ortaylı İlber, Türkiye'nin Yakın Tarihi, Timaş Yayınları, İstanbul,2010

- Ortaylı İlber, Osmanlıyı 'Yeniden Keşfetmek, Timaş yayınları, İstanbul, 2006

- Özbudun Ergun, Otoriter Rejimler, Seçimsel Demokrasiler ve Türkiye, İstanbul Bilgi Üniversitesi Yayınları,2011 
- $\quad$ Passig David, 2050, Koton kitap, 2010

- Sayılgan Aclan, Türkiye'de Sol Hareketler, Doğu Kütüphanesi, İstanbul, 2009

- Tuğal Cihan, Pasif Devrim İslami Muhalefetin Düzenle Bütünleşmesi, Koç Üniversitesi Yayınları, İstanbul,2011

- Tuncay Mete, Bilineceği Bilmek, Alan Yayıncılık,1983

- Yavuz Hakan (Ed.), Ak Parti, Kitap yayınevi, 2010 


\title{
Pazarlama Yönetimi Etkinliği ve Uygulamada Ölçülmesi Marketing Management Effectiveness and Measurement of Implementation
}

\author{
Burak Sarıçiçek (Beykent University, Turkey) \\ Prof. Dr. Erdoğan Taşkın (Beykent University, Turkey)
}

\begin{abstract}
Marketing audit is a tool inciting the development and the evaluation of marketing efforts of an enterprise. In addition to this, marketing audit is also an effort to evaluate the potential, the resources and the goals of an enterprise against the effectiveness and efficiency of its marketing principles and strategies. In this research, the effectiveness levels of different enterprises will be investigated and measured with the help of the scoring system used in determining the effectiveness of the marketing management, the strategic orientation, the marketing management structure, the market and the marketing knowledge, the customer value creation capacity and the efficiency in implementation of marketing policies of an enterprise, using Philip Kotler's Strategic Auditing Approach. The effectiveness of marketing management will be analyzed and commented from the point of view of practicing marketing managers in the area.
\end{abstract}

\section{Giriş}

İşletmenin pazarlama çabalarını değerlendirmek ve geliştirmek için teşvik eden bir araç, pazarlama denetimidir. Pazarlama denetimi, pazarlama ilkeleri etkinliği ve verimliliği, stratejileri, uygulama faaliyetlerine karşılık işletmenin imkânları, hedefleri ve kaynaklarını değerlendirme çabasıdır. İşletmelerin pazarlama yönetimi etkinliği uygulamada elli yıla yakın bir süredir pazarlama denetimi kapsamında incelenmekte ve ölçülmektedir (Kotler, Gregor ve Rodgers, 2015).

Pazarlama denetiminin amacı pazarlama yönetimi etkinliğinin yükseltilmesidir. Pazarlama denetiminde Philip Kotlerin stratejik denetim yaklaşımı esas alınarak pazarlama etkinliği beş kısımda incelenmiştir. Philip Kotlerin stratejik denetim yaklaşımına göre işletmelerin pazarlama yönetimi etkinliği, stratejik yönlendirme, pazarlama örgüt yapısı, pazar ve pazarlama bilgisi, müşteri değeri ile uygulama etkinliği boyutları açısından ölçülerek denetlenmelidir (Kotler ve Armstrong, 1991; Taşkın, 2005).

Bir işletmenin; stratejik iş biriminin, bir bölümünün, bir şirketinin veya bir mamulünün pazarlama etkinliği büyük ölçüde şu beş önemli sorunun cevaplandırılmasına bağlıdır. "Müşteri değeri: Yönetim, piyasanın ve müşterilerin gereksinimlerine ve isteklerine uygun işletme planlaması ve faaliyetleri yapıyor mu?" "Bütünleşmiş pazarlama örgütü: Pazarlama analizi, planlama, yürütme ve kontrol yapabilecek kaynakları örgüt yapısı içinde mevcut mudur?" "Güncel piyasa bilgisi: Yönetimin etkili bir pazarlama yapabilecek uygun piyasa bilgisi var mı?” "Stratejik uyum: Pazarlama yöneticisi, uzun dönemli büyüme ve kârlılık için yaratıcı stratejiler ve planlar meydana getiriyor mu?" "Faaliyet etkinliği: Pazarlama planı, uygulamada maliyet etkin gelişmiş bir yaklaşımla yürütülüyor mu?" (Taşkın, 2009).

\section{Pazarlama Yönetimi Etkinliği}

\subsection{Müşteri Değerinin Ölçülmesi}

İlgili sorunun "Yönetim, piyasanın ve müşterilerin gereksinimlerine ve isteklerine uygun işletme planlaması ve faaliyetleri yapıyor mu?” cevaplandırılabilmesi için müşteri değeri kavramı incelenmelidir. Müşteri değeri kavramı incelendikten sonra müşteri değerinin etkinlik düzeyleri; hedef pazarda etkinlik, farklı pazarlarda etkinlik ve pazarlama sisteminde etkinlik olmak üzere müşteri değerinin üç alt değişkeni altında ölçülmelidir.

Müşteri değeri, bir ürün ya da hizmetin satın alınması ve kullanılması sürecinin sonucunda oluşan değerlerdir. $\mathrm{Bu}$ değerler müşteriye ve işletmeye fayda sağlar. Satın alma ve kullanma sürecinin müşteriye sağladı faydalar müşterinin algıladığı değerdir. Satın alma ve kullanma sürecinin işletmeye sağladığı faydalar müşteri yaşam boyu değeridir (Yükselen, 2015).

Müşterinin algıladığı değer, toplam müşteri değeri ile toplam müşteri maliyeti arasındaki farktan oluşur. Toplam müşteri değeri; ürün değeri, hizmet değeri, personel değeri, imaj değeri unsurlarının toplamlarından oluşur. Toplam müşteri maliyeti ise; parasal maliyet, zaman maliyeti, enerji maliyeti, zihni maliyet unsurlarının toplamlarından oluşur (Kotler, 2003).

$\mathrm{Bu}$ sekiz unsurun toplamında müşterinin algıladığı değer oluşur. Bu değerler toplamı sonucuna göre de müşteriler aynı işletmeden satın alma davranışını devam ettirebilir, satın almaların bir kısmını farklı işletmelerden yapabilir ya da mevcut işletmedeki satın alma davranışını sonlandırabilir (Taşkın, 2009). 
Müşterilerin aynı işletmeden satın alma davranışları devam ettiğinde işletmeler fayda sağlar. Bu fayda bir müşteriye indirgenir ve müşterinin yaşamı boyunca sağladığı fayda hesaplanırsa müşterinin yaşam boyu değeri hesaplanmış olur. Buna göre işletmeye fayda sağlayan müşteri yaşam boyu değeri; bir müşterinin yaşamı boyunca gerçekleşen satın almalarının, toplam faydalarından beklenen kârın bugünkü değeridir (Yükselen, 2015).

Hedef pazarda etkinlik incelenirken öncelikle pazarlama yönetimi, işletmenin belirlenmiş pazarlardaki müşteri ihtiyaç ve isteklerine hizmet edecek örgüt yapısı kurmanın önemini fark etmelidir. Pazarlama yönetimi, "mevcut ürünleri ve yeni ürünleri” her kim almak isterse o müşterilere satılmasını öngörüyorsa hiç etkin değildir. Yönetim, geniş bir pazara ve ihtiyaç yelpazesine aynı yöntemler ve yetkinlikte hizmet vermeyi düşünüyorsa bir ölçüde etkindir. Özellikle yönetim, işletmenin uzun vadeli büyümesi ve kâr potansiyeli için, daha önceden belirlenmiş belirli pazarların ihtiyaç ve isteklerine hizmet vermeyi düşünüyorsa büyük ölçüde etkindir. Hedef pazarda etkinlik düzeyleri araştırılırken belirlenen hedef pazarda müşteriye rakiplerden daha fazla müşteri değeri sunmaya çalışır.

Farklı pazarlarda etkinlik incelenirken pazarlama yönetimi, pazarın farklı kesimleri için farklı pazarlama iletişimleri ve pazarlama planları geliştirmelidir. Geliştirmiyorsa hiç etkin değildir. Bir ölçüde geliştiriyorsa orta derecede etkindir. Büyük ölçüde geliştiriyorsa çok etkindir. Farklı pazarlarda etkinlik düzeyleri araştırılırken hedef pazar dışındaki pazarlarında müşteri değeri potansiyeli taşıdığı görülür ve bu nedenle farklı pazarlarda da müşteri değeri oluşturulmaya çalışılır.

Pazarlama sisteminde etkinlik incelenirken yönetim, işletmenin temel planını hazırlarken pazarlamayı (dış kaynak kullanımı, taşeronlar, tedarikçiler, pazarlama kanalları, aracılar, rakipler, müşteriler, çevre) bir bütün olarak göz önünde bulundurmalıdır. Yönetim, planlamasını, mevcut müşteriye satış yapmak ve hizmet vermek üzere odaklıyorsa hiç etkin değildir. Yönetimin yoğun çabası mevcut müşterilere satış yapmak ve hizmet vermeye yönelik olmakla birlikte, uzun vadede pazarlama kanallarını da göz önünde tutuyorsa bir ölçüde etkindir. Yönetim, pazarlama sisteminin herhangi bir kesimindeki değişikliğin işletme için yaratacağı tehlikelerin ve firsatların bilincinde davranıyorsa büyük ölçüde etkindir. Pazarlama sisteminde etkinlik düzeyleri araştırılırken pazarlama sisteminin dış kaynakların kullanımını, taşeronları, tedarikçileri, pazarlama kanallarını, aracıları, rakipleri, müşterileri ve çevreyi bir bütün olarak ifade ettiği gözlemlenir ve müşteri değeri oluşturmadaki etkisi arttırılmaya çalışılır.

\subsection{Pazarlama Örgüt Yapısının Ölçülmesi}

İlgili sorunun "Pazarlama analizi, planlama, yürütme ve kontrol yapabilecek kaynakları örgüt yapıs1 içinde mevcut mudur?" cevaplandırılabilmesi için örgüt yapısı kavramı incelenmelidir. Örgüt yapısı kavramı incelendikten sonra pazarlama örgüt yapısının etkinlik düzeyleri; pazarlama işlevlerinde etkinlik, sistem yaklaşımında etkinlik ve yaratıcı yenilik sürecinde etkinlik olmak üzere pazarlama örgüt yapısının üç alt değişkeni altında ölçülmelidir.

Örgüt yapısı, örgütün amaçlarının gerçekleşmesi için kabul edilen düzenlemeler ve uygulama sonucu oluşan ilişkiler bütünün oluşturduğu yapıdır (Jones, 1998; Ülgen, 1997; Schermerhorn vd., 2000).

Bu tanımdan yola çıkıldığında öngörülen örgütlerin amaçları, kabul ettikleri düzenlemeler ve uygulama sonucu oluşan ilişkilerin farklılık gösterdiğidir. Bu farklılıklarda tek bir örgüt yapısından söz edilemeyeceğini yani mutlak bir örgüt yapısının söz konusu olmadığını gösterir. Bu nedenle örgüt yapısı ile ilgili çok çeşitli olmak ile beraber siniflandirmalar mevcuttur.

Örgüt yapısı ile ilgili yapılan sınıflandırmalardan en bilineni ve uygulamalarda en yaygını mekanik örgüt yapısı ve organik örgüt yapısı olarak ikiye ayrılan sınıflandırmadır. Mekanik örgüt yapısı; kapalı sistem, klasik örgüt teorisi anlayışı ve formal bir yapının bütünüdür. Organik örgüt yapısı ise; açık sistem, modern örgüt teorisi anlayışı ve informal bir yapının bütünü sonucu oluşur (Burns ve Stalker, 1961; Atayeter, 2015; Martin ve Fellenz, 2010).

Pazarlama işlevlerinde etkinlik incelenirken öncelikle, temel pazarlama işlevleri arasında bütünleşmiş resmi bir pazarlama yönetimi örgüt yapısı bulunmalıdır. Satış yönetimi ve diğer pazarlama işlevleri üst yönetimde birleşmiyor ve üretken olmayan birtakım çelişkiler yaşanıyorsa, mevcut örgüt yapısı hiç etkin değildir. Fakat temel pazarlama işlevleriyle ilgili olarak usulen bir bütünleşme ve denetim varsa; fakat birimler arasında yeterli koordinasyon ve iş birliği sağlanamıyorsa, mevcut örgüt yapısı bir ölçüde etkindir. Temel pazarlama işlevleri etkin bir bütünleşme içinde yürütülüyorsa pazarlama örgüt yapısı uyumludur ve mevcut örgüt yapısı büyük ölçüde etkindir. Pazarlama işlevlerinde etkinlik düzeyleri araştırılırken temel pazarlama işlevlerinin etkin bir bütünleşme içinde yürütülerek pazarlama örgüt yapısında uyum yakalanmaya çalışılır.

Sistem yaklaşımında etkinlik incelenirken işletmenin örgüt yapısı içinde araştırma konumuz açısından pazarlama yönetimi, araştırma, üretim, satın alma, dağıtım ve finans konularında yönetimle uyum içinde çalışmalıdır. Pazarlama yönetiminin gerek taleplerinde, gerekse başka bölümlere yüklediği maliyetlerde makul olmadığı yolunda şikâyetler varsa uyumlu çalışma yoktur. Bu durumda etkinlik düzeyi hiç etkin değil olarak belirlenir. Her bölüm kendi çıkar ve amaçları doğrultusunda hareket etmekle birlikte bölümler arasında ilişsiler yine de dostça bir ortamda yürüyorsa bir ölçüde uyumlu çalışma vardır. Bu durumda etkinlik düzeyi bir ölçüde etkin olarak belirlenir. Bütün bölümler etkin bir iş birliği içinde çalışıyor ve bir bütün olarak işletmenin çıkarlarına en uygun sonuçları sağlıyorsa pazarlama örgüt yapısı uyumludur. Bu durumda etkinlik düzeyi büyük ölçüde etkin 
olarak belirlenir. Sistem yaklaşımında etkinlik düzeyleri araştırılırken sistem olarak ele alınan bütünün amacını gerçekleştirerek örgüt yapısında uyum oluşturulmaya çalışılır.

Yaratıcı yenilik sürecinde etkinlik incelenirken yönetim örgüt yapısında, yeni ürün yaratma veya hizmet süreci uyumlu olarak düzenlenmiş durumda olmalıdır. $\mathrm{Bu}$ süreç yeterince belirlenmemiş ve yetersiz biçimde yürütülmekte ise düzenleme yoktur. Bu durumda etkinlik düzeyi hiç etkin değil olarak belirlenir. Süreç, usulen var olmakla birlikte yeterince geliştirilmemiş ise bir ölçüde düzenleme vardır. Bu durumda etkinlik düzeyi bir ölçüde etkin olarak belirlenir. Süreç, gerektiği biçimde kurulmuş ve profesyonel elemanlar tarafından yürütülmekte ise pazarlama örgüt yapısı uyumlu olarak düzenlenmiş durumdadır. Bu durumda etkinlik düzeyi büyük ölçüde etkin olarak belirlenir. Yaratıcı yenilik sürecinde etkinlik düzeyleri araştırılırken örgüt yapısında yeni ürün süreci oluşturmadaki uyumun düzenlenip etkisi arttırılmaya çalışılır.

\subsection{Pazar ve Pazarlama Bilgisinin Ölçülmesi}

İlgili sorunun "Yönetimin etkili bir pazarlama yapabilecek uygun piyasa bilgisi var mı?” cevaplandırılabilmesi için pazar ve pazarlama bilgisi kavramı incelenmelidir. Pazar ve pazarlama bilgisi kavramı incelendikten sonra pazar ve pazarlama bilgisinin etkinlik düzeyleri; pazar bilgisinde etkinlik, pazarlama bilgisinde etkinlik ve pazarlama çabalarında etkinlik olmak üzere pazar ve pazarlama bilgisinin üç alt değişkeni altında ölçülmelidir.

Pazar ve pazarlama bilgisi; çeşitli pazar uygulamalarının sonucunda ve pazarlama kararlarının alınması sürecinde, belirli verilerin iç ve dış kaynaklardan sürekli olarak toplanması ve derlenmesi ile oluşan bilgilerdir (Yükselen, 2013; Aksungur, 2013; Gündoğdu, 2013).

Bu tanımdan yola çıkıldığında; pazar ve pazarlama bilgisi kavramının daha iyi anlaşılabilmesi için, temel pazar ve pazarlama çeşitleri açıklanmalıdır.

Pazarlama çeşitleri açıklanırken temel olarak pazarlama işletmeler için üçe ayrılır. Bunlar; yığın pazarlama, mamul farklılaştırmaya dayalı pazarlama ve hedef pazarlamadır. Daha önce birinci bölümün birinci kısmının ilk alt başlığında; yığın pazarlama, mamul farklılaştırmaya dayalı pazarlama ve hedef pazarlama açıklanmış olduğundan burada tekrar yer verilmeyecektir. Bununla beraber; modern pazarlama anlayışı ve toplumsal pazarlama anlayışı gibi pazarlama anlayışları ile işletmelerde uygulanan pazarlamalar, yeşil pazarlama ve gerilla pazarlama gibi çeşitlendirilebilir (Taşkın, 2009; Yükselen, 2015).

Pazar çeşitleri açıklanırken temel olarak pazarda pazarlamadaki gibi üçe ayrılır. Bunlar; tüketici, örgütsel ve uluslararası pazardır (Taşkın, 2009; Yükselen, 2015).

Pazar bilgisinde etkinlik incelenirken pazarlama yönetimi, işletmenin belirlenmiş pazar ve pazarlamadaki pazar ve pazarlama bilgisinin güncel olmasının önemini fark etmelidir. Pazarlama yönetiminin; müşteriler, satın almayı etkileyen unsurlar, dağıtım kanalları ve rakipler konuları ile ilgili düzenli zaman aralıkları içinde yaptığı pazarlama araştırmalarına bakılır. Bu zaman aralığı birkaç yılda tekrarlanıyorsa, etkinlik düzeyi hiç etkin değil olarak belirlenir. Zaman aralığı bir iki yılda tekrarlanıyorsa, etkinlik düzeyi bir ölçüde etkin olarak belirlenir. Zaman aralığı bir yıldan kısa süreler içinde tekrarlanıyorsa, etkinlik düzeyi büyük ölçüde etkin olarak belirlenir. Pazar bilgisinde etkinlik düzeyleri araştırılırken yönetim tarafından yapılan pazar araştırmalarının sık aralıklarla ve düzenli olarak yapılması sağlanmaya çalışılır.

Pazarlama bilgisinde etkinlik incelenirken yönetimin öncelikle satış imkânı ve kârlılık konularında, farklı pazar bölümleri, müşteriler, bölgeler, ürünler, pazarlama kanalları ve sipariş miktarları ile ilgili bilgisine bakılır. Hiç bilgisi yok ise, etkinlik düzeyi hiç etkin değil olarak belirlenir. Biraz bilgisi varsa, etkinlik düzeyi bir ölçüde etkin olarak belirlenir. Ayrıntılı bilgisi varsa, etkinlik düzeyi büyük ölçüde etkin olarak belirlenir. Pazarlama bilgisinde etkinlik düzeyleri araştırılırken işletme içi pazarlama bilgisi arttırılmaya çalışılır.

Pazarlama çabalarında etkinlik incelenirken pazarlama yönetimi elde ettiği pazar ve pazarlama bilgisi doğrultusunda diğer işletmeler karşısında avantaj elde etmeyi gösterebildiği kadarıyla pazarlama çabalarıyla sağlar. Bu doğrultudan yola çıkıldığında yönetimin değişik pazarlama giderlerinin maliyet etkinliğini ölçmek için gösterdiği çabanın düzeyi pazarlama çabalarında etkinlik düzeyini belirler. Yönetim tarafından hiç çaba gösterilmiyor veya çok az çaba gösteriliyorsa, etkinlik düzeyi hiç etkin değil olarak belirlenir. Yönetim tarafindan biraz çaba gösteriliyorsa, etkinlik düzeyi bir ölçüde etkin olarak belirlenir. Yönetim tarafından yeterli çaba gösteriliyorsa, etkinlik düzeyi büyük ölçüde etkin olarak belirlenir. Pazarlama çabalarında etkinlik düzeyleri araştırılırken yönetim tarafından farklı pazarlamalar çalışmaları için pazarlama çabası oluşturulmaya çalışılır.

\subsection{Stratejik Yönlendirmenin Ölçülmesi}

İlgili sorunun "Pazarlama yöneticisi, uzun dönemli büyüme ve kârlılık için yaratıcı stratejiler ve planlar meydana getiriyor mu?" cevaplandırılabilmesi için stratejik yönlendirme kavramı incelenmelidir. Stratejik yönlendirme kavramı incelendikten sonra stratejik yönlendirmenin etkinlik düzeyleri; pazarlama planlamasında etkinlik, pazarlama stratejisinde etkinlik ve pazarlama taktiklerinde etkinlik olmak üzere stratejik yönlendirmenin üç alt değişkeni altında ölçülmelidir.

Stratejik yönlendirme kavramı, pazarlama yönetimi açısından önemli bir kavramdır. Çünkü pazarlama yönetimleri; günümüz pazarlarındaki ihtiyaçların tek bir işletme tarafından karşılanamaması ile pazarlarda işletmeler arası rekabet oluşması ve oluşan bu şartlarda işletmelerin kazanç sağlayarak devamlılık elde 
edebilmeleri nedenleri ile önceden planlama yapmalıdır. Bu planlamanın işletme açısından gerçekçi ve uygulanabilir olması gerekliliği stratejik yönlendirme kavramını ortaya çıkarır (Taşkın, 2009; Yükselen, 2015).

Stratejik yönlendirme pazarlama yönetimi tarafindan sırasılya; stratejik yönün belirlenmesi, SWOT analizinin yapılması, büyüme ve rekabet stratejilerinin belirlenmesi, portföy analizinin yapılması ve son olarak pazarlama planın oluşturulması ile gerçekleştirilir (Taşkın, 2009; Yükselen, 2015).

Pazarlama planlamasında etkinlik incelenirken pazarlama yönetiminde işletmenin pazarlama planlaması yazılı olarak mevcut olmalıdır. Pazarlama yönetimi özellikle resmi ve yazılı bir pazarlama planlaması yapmıyor veya çok sınırlı yapıyorsa etkinlik düzeyi hiç etkin değil olarak belirlenir. Yönetim, pazarlama planını sadece yıllık olarak yapıyorsa etkinlik düzeyi bir ölçüde etkin olarak belirlenir. Oysa yönetim, ayrıntılı ciddi bir yıllık plan ile diğer taraftan her yıl yenilenip güncelleştirilen ileriye yönelik pazarlama planı yapıyorsa etkinlik düzeyi büyük ölçüde etkin olarak belirlenir. Pazarlama planlamasında etkinlik düzeyleri araştırılırken yönetim tarafindan pazarlama planlamasının resmi ve yazılı olarak mevcut olması sağlanmaya çalışır.

Pazarlama stratejisinde etkinlik incelenirken pazarlama yönetimi tarafindan uygulanmakta olan strateji belirgin, açık ve anlaşılır olmalıdır. Pazarlama yönetimi tarafından uygulanmakta olan strateji belirgin bir nitelikte değilse etkinlik düzeyi hiç etkin değil olarak belirlenir. Uygulanan strateji belirgin ve geleneksel stratejinin bir devamı niteliğinde ise etkinlik düzeyi bir ölçüde etkin olarak belirlenir. Uygulanan strateji belirgin, yeniliklere açık, verilere dayanan ve sağlam bir mantığa oturtulmuş nitelikte ise etkinlik düzeyi büyük ölçüde etkin olarak belirlenir. Pazarlama stratejisinde etkinlik düzeyleri araştırılırken yönetim tarafindan uygulanmakta olan pazarlama stratejisinin temel nitelikleri arttırılmaya çalışılır.

Pazarlama taktiklerinde etkinlik incelenirken pazarlama yönetimi, özellikle teknolojik yenilikler, siyasi olaylar, idari kararlar, döviz kurlarındaki değişiklikler ve petrol fiyatları gibi beklenmedik olası gelişmelerle ilgili düşüncelerini planlamaya dönüştürmelidir. Pazarlama yönetimi farklı olasılıklar üzerinde hiç durmuyor veya yeterince durmuyorsa etkinlik düzeyi hiç etkin değil olarak belirlenir. Yönetim, beklenmedik olasılıkları düşünmekle birlikte, muhtemel gelişmeler için plan geliştirmekte yetersiz kalıyorsa etkinlik düzeyi bir ölçüde etkin olarak belirlenir. Yönetim, olasılıkları belirliyor ve gerekli planlamayı yapıyorsa etkinlik düzeyi büyük ölçüde etkin olarak belirlenir. Pazarlama taktiklerinde etkinlik düzeyleri araştırılırken yönetim tarafindan beklenmedik olası gelişmelerin planlanması oluşturulmaya çalışılır.

\subsection{Uygulama Etkinliğinin Ölçülmesi}

İlgili sorunun "Pazarlama planı, uygulamada maliyet etkin gelişmiş bir yaklaşımla yürütülüyor mu?" cevaplandırılabilmesi için uygulama etkinliği kavramı incelenmelidir. Uygulama etkinliği kavramı incelendikten sonra uygulama etkinliğinin etkinlik düzeyleri; yaklaşımların iletilmesinde etkinlik, kaynakların kullanılmasında etkinlik ve anlık gelişmelerde etkinlik olmak üzere uygulama etkinliğinin üç alt değişkeni altında ölçülmelidir.

Uygulama etkinliği kavramı, pazarlama yönetimi tarafından daha önceden alınmış kararların ve yapılmış planların gerçekleşmeleri esnasındaki başarı oranıdır. Bu başarı oranının artması yani uygulama etkinliğinin yükselmesi için konuyla ilgili deneyim sahibi kişilerin bilgisine başvurma, benzer durumları inceleme ve güvenilir kaynaklardan veri sağlama yolları izlenebilir (Taşkın, 2005; Yükselen, 2013).

Yaklaşımların iletilmesinde etkinlik incelenirken pazarlama yönetimi, üst düzey yönetimden gelen pazarlama yaklaşımının alt kademelere geniş ölçüde iletilmesinin ve uygulanmasının önemini fark etmelidir. Pazarlama yönetimi, üst düzey yönetiminden gelen pazarlama yaklaşımının alt kademelere iletilmesinde ve uygulanmasında çok yetersiz ise etkinlik düzeyi hiç etkin değil olarak belirlenir. Pazarlama yönetimi, üst düzey yönetiminden gelen pazarlama yaklaşımının alt kademelere iletilmesinde ve uygulanmasında oldukça iyi ise etkinlik düzeyi bir ölçüde etkin olarak belirlenir. Pazarlama yönetimi, üst düzey yönetiminden gelen pazarlama yaklaşımının alt kademelere iletilmesinde ve uygulanmasında başarılı ise etkinlik düzeyi büyük ölçüde etkin olarak belirlenir. Yaklaşımların iletilmesinde etkinlik düzeyleri araştırılırken üst düzeydeki pazarlama yaklaşımlarının alt kademeler geniş ölçüde iletilmesi ve uygulanması sağlanmaya çalışılır.

Kaynakların kullanılmasında etkinlik incelenirken için yönetim pazarlama kaynaklarını yeterli ve verimli kullanmalıdır. Pazarlama yönetimi, pazarlama kaynaklarını kullanırken ayrılan kaynaklar yapılması gereken iş ve faaliyet için yeterli olmuyorsa etkinlik düzeyi hiç etkin değil olarak belirlenir. Yönetim pazarlama kaynaklarını kullanırken bir ölçüde ayırdığı kaynaklar yeterli oluyor ama gereken verimlilikte kullanmıyorsa etkinlik düzeyi bir ölçüde etkin olarak belirlenir. Oysa yönetim, pazarlama kaynaklarını kullanırken ayrılan kaynakları yeterli ve gereken verimlilikte kullanıyorsa etkinlik düzeyi büyük ölçüde etkin olarak belirlenir. Kaynakların kullanılmasında etkinlik düzeyleri araştııılırken pazarlama kaynaklarının etkin ve verimli kullanımı arttırılmaya çalışılır.

Anlık gelişmelerde etkinlik incelenirken yönetim, anlık gelişmelere hızla ve etkin biçimde karşılık verebilecek yetkinlikte olmalıdır. Yönetimin satış ve pazar bilgileri güncel değilse ayrıca harekete geçmekte yavaş kalıyorsa etkinlik düzeyi hiç etkin değil olarak belirlenir. Yönetim satış ve pazar konusunda oldukça güncel bilgi alıyor ancak hareket geçme hızı bazen yavaş bazen de hızlı oluyorsa etkinlik düzeyi bir ölçüde etkin olarak belirlenir. Yönetim güncel bilgi almak ve hızla harekete geçebilmek için gerekli sistemleri geliştirmişse etkinlik düzeyi 
büyük ölçüde etkin olarak belirlenir. Anlık gelişmelerde etkinlik düzeyleri araştırılırken anlık gelişmelere hızlı ve etkin biçimde karşılık verebilecek sistemler oluşturulmaya çalışılır.

\section{Etkinliğin Uygulamada Ölçülmesi}

Kotler 1977 yılında yaptığı çalışmada pazarlama denetimini tanımlamamıştır. Bunun yerine beş fonksiyonla açıklanan pazarlama denetimi üzerinde durmuştur. Bunlar stratejik yönlendirme, pazarlama örgüt yapısı, pazar ve pazarlama bilgisi, müşteri değeri ve uygulama etkinliğidir. Literatüre katkısı pazarlama fonksiyonlarına denetim ilkelerini uygulaması ile pazarlama etkinliğinin kişisel ve düzenli bir değerlendirmesi için soru ve puanlama sistemi geliştirmesidir. Ölçüm aracı olarak pazarlama etkinliği puanını veren 15 kapalı uçlu soru kullanılmıştır (Berry, Conanat ve Parasuraman, 1991; Balıkçığlu, 2000).

Soruların cevapları sayısal değerlere dönüştürülürken $0,1,2$ şeklinde puanlama sistemi kullanılmıştır. Bu tür bir puanlama sistemi ile pazarlama yöneticilerine her bir değişkenle ilgili etkinlik ölçeklerini belirleme ve çeşitli karşılaştırmalar yapma imkânı sağlanmıştır. Anketteki soruların cevapları sayısal değerlere dönüştürülürken kullanılan puanlama sistemi ile değişkenlerin etkinlik ölçeklerinin belirlenmesi ve ayrıca birinci bölümde pazarlama yönetimi etkinliği başlı̆ğ ile etkinlik düzeyleri belirlenirken kullanılan sözlü ifadeler sayısal değerlere dönüştürüldüğünde puan karşıllkları "Hiç etkin değildir.” için 0 puan, "Bir ölçüde etkindir." için 1 puan ve "Büyük ölçüde etkindir.” için 2 puandır.

İşletmelerin pazarlama etkinliği düzeyleri ise; 0-5 puan: Hiçbir etkinliği yok (I. Düzey), 6-10 puan: Çok az etkin (II. Düzey), 11-15 puan: Oldukça etkin (III. Düzey), 16-20 puan: Etkin (IV. Düzey), 21-25 puan: Çok etkin (V. Düzey), 26-30 puan: Üstün etkinlik (VI. Düzey) olarak altı farklı düzey ile belirlenmiştir.

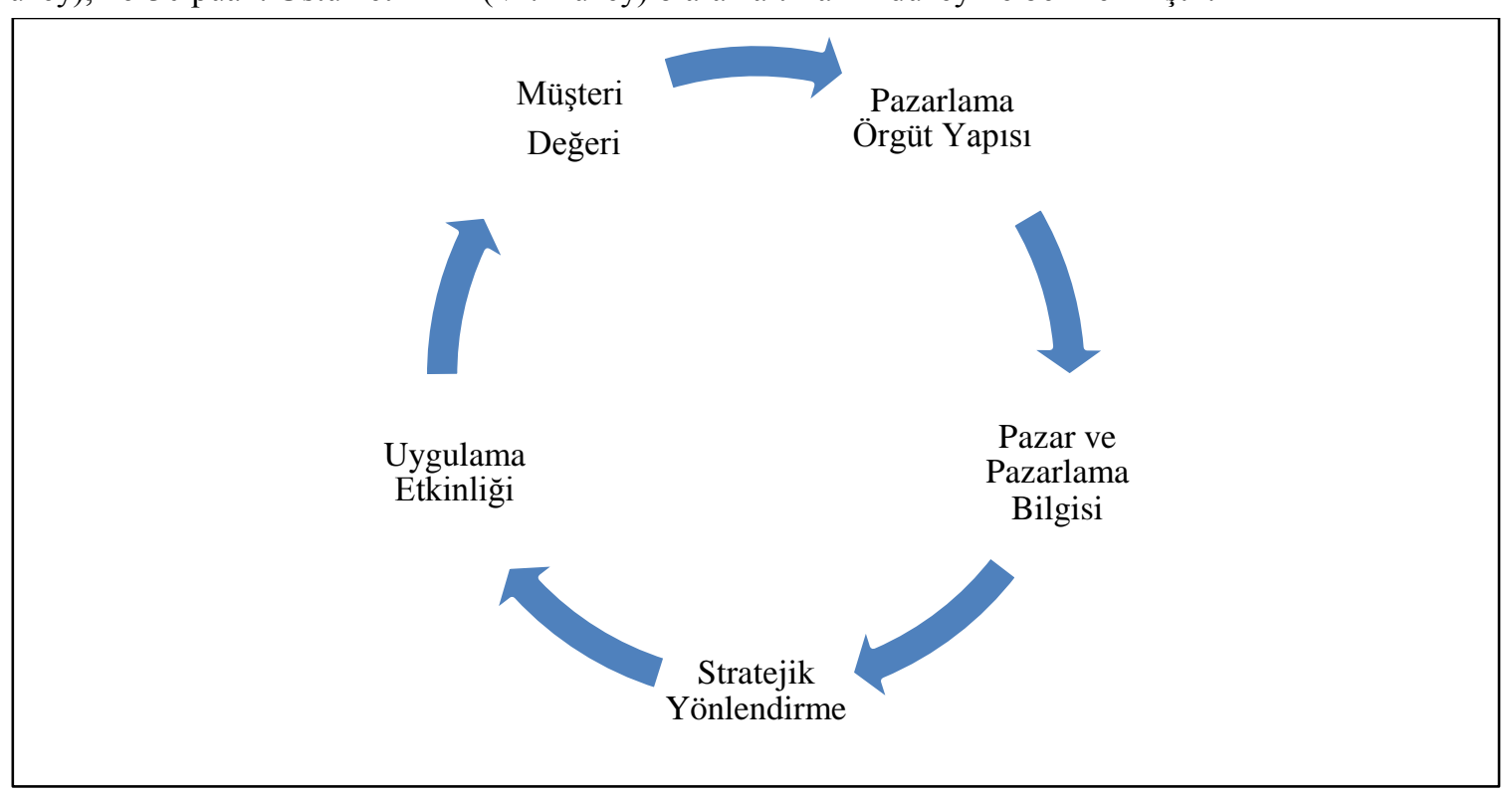

Şekil 1. Pazarlama Yönetimi Etkinliği Değişkenleri

Şekil 1'de bağımlı değişken olan pazarlama yönetimi etkinliğinin bağımsız olan değişkenleri bir döngü diyagramı ile gösterilmiştir. Bu beş bağımsız değişken şekilde gösterilen döngüdeki gibi birbirlerine eklenerek bu değişkenlere bağımlı olan pazarlama yönetimi etkinliğini belirlemektedir.

İşletmelerin pazarlama yönetimi etkinliğinin uygulamada ölçülmesine yönelik ana kütle İstanbul ilindeki işletmelerden oluşmaktadır. Ancak tüm işletmelere ulaşılması mümkün olmayacağından örnekleme yapılması zorunlu görülmüştür. Bu doğrultuda maliyet ve zaman kısıtları nedeniyle de İstanbul ilinde faaliyet gösteren tüm işletmeler örnek kapsamına alınamamıştır. Dolayısıyla araştırma kapsamı belirlenirken İstanbul ilindeki, örneklemenin ana kütleyi iyi temsil edeceği düşünülerek, Beykent Üniversitesi Yüksek Lisans öğrencilerinin çalıştıkları işletmeler arasından kolayda örnekleme yöntemi ile 106 işletme seçilmiştir. Araştırma kolayda örnekleme yöntemi ve yüz yüze görüşmeler ile İstanbul'da 2015 yılında 106 işletmenin pazarlama yönetiminden sorumlu müdürler ile yapılmıştır. Ayrıca anket formunda anketi yapan ve anketi dolduran kişilerin kartvizitleri eklenmiştir ve anketi yapan kişinin işletme hakkında yorumlarına yer verilmiştir. Araştırmada tanımlayıcı araştırma modellerinden kesit analizi modeli kullanılmıştır. 106 işletmenin hepsinin anket formu analizlerde kullanılabilir durumdadır.

Araştırmanın genel olarak sınırlılıklarına bakıldığında özellikle araştırmayı maddi olarak destekleyen bir kurum olamaması ve araştırma bütçesinin olmaması en önemli zorluk olmuştur. Ayrıca inceleme yapılan işletmelerin ve görüşülen pazarlama yöneticilerinin farklı işletmelerde çalışması karşılaştırma yapılmasını zorlaştırmaktadır. Değerlendirilen ve görüşülen işletmelerin iş yaptığı piyasaları, müşterileri, rakipleri, dağıtıcıları, tedarikçileri, 
hizmet aldığı işletmeler ile pazarlama karması unsurları farklıdır. Bu nedenle, araştırmaya katılan işletmeler tek olarak değil hepsi bir bütün olarak değerlendirilmiş ve yorumlanmıştır (Sarıçiçek, 2017).

\section{Bulgular ve Yorumlar}

Altı etkinlik düzeyinden I. Düzey (Hiçbir etkinliği yok: 0-5 puan) içinde hiçbir işletme bulunmamaktadır. Bu nedenle pazarlama yönetimi etkinliği I. Düzey olan işletme sayısı 0 , yüzdesi \%0 olarak görülmektedir. İşletmelerin pazarlama yönetimi etkinliği düzeyleri 106 işletme için beş farklı düzeyde belirlenmiştir. İşletmelerin; 2 tanesi \%1,887 ile II. Düzey (Çok az etkin: 6-10 puan), 10 tanesi \%9,434 ile III. Düzey (Oldukça etkin: 11-15 puan), 12 tanesi \%11,321 ile IV. Düzey (Etkin: 16-20 puan), 41 tanesi \%38,679 ile V. Düzey (Çok etkin: 21-25 puan), geriye kalan 41 tanesi ise \%38,679 ile VI. Düzey (Üstün etkinlik: 26-30 puan) olarak belirlenmiştir. 106 işletmenin topladığ1 toplam puan ise 2489 puandır. Şekil 2'de işletmelerin pazarlama yönetimi etkinliği altı etkinlik düzeyindeki dağılımlarına göre gösterilmiştir. Ayrıca Tablo 1'de işletmelerin pazarlama yönetimi etkinliği düzeylerinin değerleri gösterilmiştir.

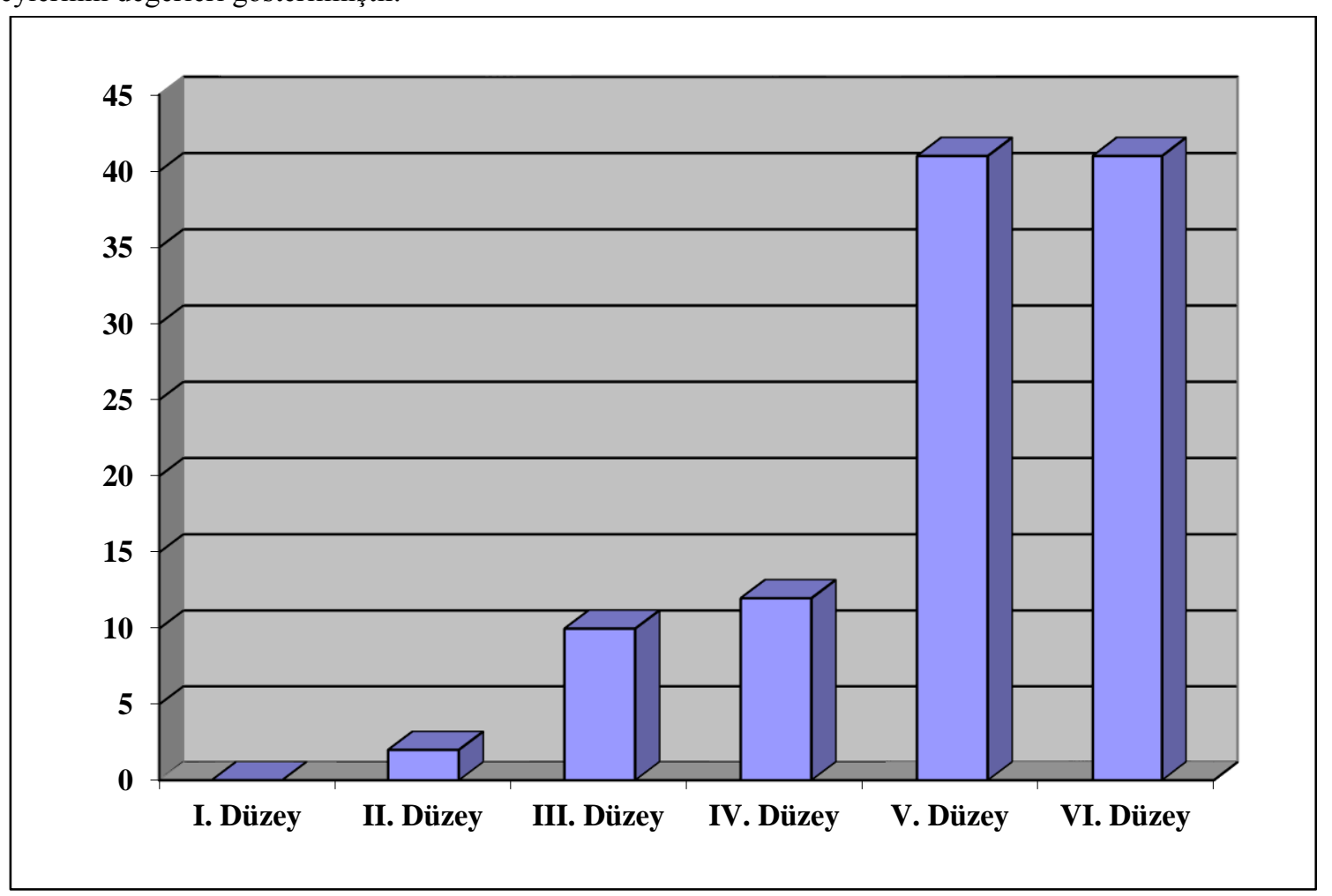

Şekil 2. İşletmelerin Pazarlama Yönetimi Etkinliği Düzeylerine Göre Dă̆ılımı

\begin{tabular}{|l|l|l|}
\hline Etkinlik Düzeyleri & Sayı & Yüzde \\
\hline $\begin{array}{l}\text { Hiçbir etkinliği yok } \\
\text { (I. Düzey: 0-5 puan) }\end{array}$ & 0 & $\% 0$ \\
\hline $\begin{array}{l}\text { Çok az etkin } \\
\text { (II. Düzey: 6-10 puan) }\end{array}$ & 2 & $\% 1,887$ \\
\hline $\begin{array}{l}\text { Oldukça etkin } \\
\text { (III. Düzey: } 11-15 \text { puan) }\end{array}$ & 10 & $\% 9,434$ \\
\hline $\begin{array}{l}\text { Etkin } \\
\text { (IV. Düzey: } 16-20 \text { puan) }\end{array}$ & 12 & $\% 11,321$ \\
\hline $\begin{array}{l}\text { Çok Etkin } \\
\text { (V. Düzey: } 21-25 \text { puan) }\end{array}$ & 41 & $\% 38,679$ \\
\hline $\begin{array}{l}\text { Üstün Etkinlik } \\
\text { (VI. Düzey: 26-30 puan) }\end{array}$ & 41 & $\% 100$ \\
\hline Toplam Veri & 106 & \\
\hline Toplam Puan & 2489 & $\% 38,679$ \\
\hline
\end{tabular}

Tablo 1. İsletmelerin Pazarlama Yönetimi Etkinliği Düzeylerine Göre Değerleri

Merkezi eğilim ölçüleri ve dağılım ölçüleri incelendiğinde; en küçük değer 8'dir yani 106 işletme arasında alınan en düşük puandır. En büyük değer 30'dur, işletmeler arasında alınan en yüksek puandır. Aralık değeri 22 'dir, buradan anlaşılan işletmelerin etkinlik puanları arasındaki en küçük ve en büyük değer arasındaki puan farkıdır. 
Bu şekilde işletmelerin 22 birimlik puan arasında etkinlik gösterdikleri anlaşılmaktadır. Ortalama 23,481'dir, 106 işletmenin topladığı toplam puanların eşit olarak bölünmesi ile bir işletmeye indirgenmiş etkinlik puanını göstermektedir. Medyan 24,5'tir, işletmelerin puanları rakamsal değerlerine göre sıralandığında ortada kalan 53 ve 54 numaralı işletmelerin puanlarının toplanıp ikiye bölünmesi ile bulunur. Mod 30'dur, bu ifade işletmeler arasında en sık rastlanan etkinlik puanını göstermektedir. Çarpıklık -0,935'tir, çarpıklığın eksi değerde olması ilgili şekilde dağılımın sola doğru kaydığını gösterirken artı değerde olması sağa doğru kaydığını gösterir. Basıklık 0,421'dir, artı değerde olması sivri bir dağılımı gösterirken eksi değerde olması basık bir dağılımı gösterir. Bu ifadeler genel olarak merkezi eğilim ölçülerini belirtmektedir. Dağılım ölçülerinin değerleri; ortalama mutlak sapma 4,066'dır, standart sapma 5,330'dur, standart hata 0,518'dir, varyans 28,404'dür ve değişkenlik katsayıs1 \%22,699'dur. Dağılım ölçülerinin değerleri; ortalama mutlak sapma, standart sapma, standart hata ve varyans ortalamadan çıkartılarak ve toplanarak merkezi eğilim ölçülerinin dağılımı incelenir. Değişkenlik katsayısında ise dağılım yüzdesine bakılır. Bu yüzde 40'dan küçük ise dağılım düzenlidir yorumu yapılabilir. 40 ile 80 arasında ise düzensiz, 80 'den büyük ise çok düzensizdir olarak yorumlanabilir. Tablo 2'de işletmelerin pazarlama yönetimi etkinliği düzeylerinin merkezi eğilim ölçüleri ve dağılım ölçüleri gösterilmiştir.

\begin{tabular}{|c|c|c|c|}
\hline \multicolumn{2}{|c|}{ Merkezi Eğilim Ölçüleri } & \multicolumn{2}{|l|}{ Dağılım Ölçüleri } \\
\hline En Küçük Değer & 8 & Ortalama Mutlak Sapma & 4,066 \\
\hline En Büyük Değer & 30 & Standart Sapma & 5,330 \\
\hline Aralık Değeri & 22 & Standart Hata & 0,518 \\
\hline Ortalama & 23,481 & Varyans & 28,404 \\
\hline Medyan & 24,5 & Değişkenlik Katsayısı & 22,699 \\
\hline Mod & 30 & & \\
\hline Çarpıklık & $-0,935$ & & \\
\hline Basıklık & 0,421 & & \\
\hline
\end{tabular}

Tablo 2. Işsletmelerin Pazarlama Yönetimi Etkinliği Düzeylerine Göre Merkezi Ĕgilim ve Dağllım Ölçüleri

$\mathrm{Bu}$ bulgular ile işletmelerin pazarlama yönetimi etkinliğinin yüksek olduğu yorumu yapılabilir. Özellikle çarpıklık ve basıklık değerleri bunu desteklemektedir. Çarpıklık eksi değerde yani dağılım sola doğrudur. Basıklık artı değerde yani dağılım sivridir. Sola doğru ve sivri olan bu dağılımda ortalamanın 23 puandan fazla olması, medyanın 24,5 olması ve mod değerinin 30 olması işletmelerin genel olarak pazarlama yönetiminde V. Düzeyde etkin olduğunu ifade etmektedir. Ayrıca dağılım ölçüleri de özellikle değişkenlik katsayısı \%22,699 ile \%40'ın altında kalarak düzenli bir dağılım göstererek merkezi eğilim ölçülerinin doğruluğunu desteklemektedir. Bu nedenle işletmelerin pazarlama yönetimi etkinliğinin yüksek olduğu yorumu yapılabilmektedir.

\section{Sonuç}

İşletmelerin pazarlama yönetimi etkinliği pazarlama denetimi ile ölçülürken stratejik denetim yaklaşımı kullanıldı. Bu yaklaşıma göre belirlenmiş beş değişken; stratejik yönlendirme, pazarlama örgüt yapısı, pazar ve pazarlama bilgisi, müşteri değeri ile uygulama etkinliği incelendi. Kullanılan yaklaşım ile yapılan incelemelerde bir işletmenin; stratejik iş biriminin, bir bölümünün, bir şirketinin veya bir mamulünün pazarlama etkinliği büyük ölçüde şu beş önemli değişkenin ölçülmesine, stratejik uyum, bütünleşmiş pazarlama örgütü, güncel piyasa bilgisi, müşteri değeri ve faaliyet etkinliğine ve bu beş önemli değişken ile ilgili sorulan soruların cevaplandırılmasına bağlı olduğu anlaşıldı.

Müşteri değeri ölçülürken müşteri değeri kavramı bir ürün ya da hizmetin satın alınması ve kullanılması sürecinin sonucunda oluşan değerler olarak tanımlandı. Bu tanımın daha iyi anlaşılabilmesi için müşteri değeri kavramına daha yakından bakılarak müşterinin algıladığı değer ve müşteri yaşam boyu değeri kavramları da incelendi. Bu kavramlar doğrultusunda müşteri değeri değişkeninin üç alt değişkeni olan hedef pazarda etkinlik, farklı pazarlarda etkinlik ve pazarlama sisteminde etkinlik düzeyleri araştırıldı. Araştırmada işletmelerin öncelikle hedef pazarda etkili olduğu sonra sırasıyla farklı pazarlarda ve pazarlama sisteminde etkili olduğu gözlemlendi. Müşteri değeri değişkenin alt değişkenleri arasında etkinlik artıkça işletmelerin etkinlik puanlarının homojenliklerinde yükselme olduğu görüldü. Ancak bu genellemede istisna olarak işletmelerin hedef pazarda etkinliği farklı pazarlara göre daha etkinken homojenliğin farklı pazarlarda daha yüksek olduğu gözlemlendi. Müşteri değeri değişkenine bağlı üç alt değişkende 166 puan ile 181 puan arasında puan elde eden işletmelerin bu alanlarda pazarlama yönetimlerinin etkin ancak geliştirilebilir oldukları anlaşıldı. Bu nedenler ile "Müşteri değeri: Yönetim, piyasanın ve müşterilerin gereksinimlerine ve isteklerine uygun işletme planlaması ve faaliyetleri yapıyor mu?" sorusuna "Yönetim, piyasanın ve müşterilerin gereksinimlerine ve isteklerine uygun işletme planlaması ve faaliyetleri yapıyor" cevabı verilerek işletmelerin müşteri değeri açısından pazarlama yönetiminde etkin olduğu sonucuna varıld1. 
Pazarlama örgüt yapısı ölçülürken örgüt yapısı kavramı örgütün amaçlarının gerçekleşmesi için kabul edilen düzenlemeler ve uygulama sonucu oluşan ilişkiler bütünün oluşturduğu yapı olarak tanımlandı. Bu tanımın daha iyi anlaşılabilmesi için örgüt yapısı kavramına daha yakından bakılarak mekanik örgüt yapısı ve organik örgüt yapısı kavramları da incelendi. Bu kavramlar doğrultusunda pazarlama örgüt yapısı değişkeninin üç alt değişkeni olan pazarlama işlevlerinde etkinlik, sistem yaklaşımında etkinlik ve yaratıcı yenilik sürecinde etkinlik düzeyleri araştırıldı. Araştırmada işletmelerin öncelikle sistem yaklaşımında etkili olduğu sonra sırasıyla pazarlama işlevlerinde ve yaratıcı yenilik sürecinde etkili olduğu gözlemlendi. Pazarlama örgüt yapısı değişkenin alt değişkenleri arasında etkinlik artıkça işletmelerin etkinlik puanlarının homojenliklerinde yükselme olduğu görüldü. Pazarlama örgüt yapısı değişkenine bağlı iki alt değişkende, pazarlama işlevlerinde ve sistem yaklaşımında, 166 puan ile 181 puan arasında puan elde eden işletmelerin bu alanlarda pazarlama yönetimlerinin etkin ancak geliştirilebilir oldukları anlaşıldı. Pazarlama örgüt yapısı değişkenin yaratıcı yenilik süreci alt değişkeninde ise 166 puanın altında kalan işletmelerin bu alanda pazarlama yönetimlerinin etkin ancak kesinlikle geliştirilmesi gerektiği anlaşıldı. Bu nedenler ile "Bütünleşmiş pazarlama örgütü: Pazarlama analizi, planlama, yürütme ve kontrol yapabilecek kaynakları örgüt yapısı içinde mevcut mudur?" sorusuna "Pazarlama analizi, planlama, yürütme ve kontrol yapabilecek kaynakları örgüt yapısı içinde mevcuttur.” cevabı verilerek işletmelerin pazarlama örgüt yapısı açısından pazarlama yönetiminde etkin olduğu sonucuna varıldı.

Pazar ve pazarlama bilgisi ölçülürken pazar ve pazarlama bilgisi kavramı çeşitli pazar uygulamalarının sonucunda ve pazarlama kararlarının alınması sürecinde, belirli verilerin iç ve dış kaynaklardan sürekli olarak toplanması ve derlenmesi ile oluşan bilgiler olarak tanımlandı. Bu tanımın daha iyi anlaşılabilmesi için pazar ve pazarlama bilgisi kavramına daha yakından bakılarak temel pazar ve pazarlama çeşitleri ve kavramları da incelendi. Bu kavramlar doğrultusunda pazar ve pazarlama bilgisi değişkeninin üç alt değişkeni olan pazar bilginde etkinlik, pazarlama bilgisinde etkinlik ve pazarlama çabalarında etkinlik düzeyleri araştırıldı. Araştırmada işletmelerin öncelikle pazarlama bilgisinde etkili olduğu sonra sırasıyla pazarlama çabalarında ve pazar bilgisinde etkili olduğu gözlemlendi. Pazar ve pazarlama bilgisi değişkenin alt değişkenleri arasında etkinlik artıkça işletmelerin etkinlik puanlarının homojenliklerinde yükselme olduğu görüldü. Pazar ve pazarlama bilgisi değişkenine bağlı üç alt değişkende; pazarlama bilgisi alt değişkeninde 181 puanın üstünde olan işletmelerin bu alanda pazarlama yönetimlerinin etkin ve gelişmiş oldukları, pazarlama çabaları alt değişkeninde 166 puan ile 181 puan arasında puan elde eden işletmelerin bu alanda pazarlama yönetimlerinin etkin ancak geliştirilebilir oldukları, pazar bilgisinde ise 166 puanın altında kalan işletmelerin bu alanda pazarlama yönetimlerinin etkin ancak kesinlikle geliştirilmesi gerektiği anlaşıldı. Bu nedenler ile "Güncel piyasa bilgisi: Yönetimin etkili bir pazarlama yapabilecek uygun piyasa bilgisi var mı?" sorusuna "Yönetimin etkili bir pazarlama yapabilecek uygun piyasa bilgisi vardır." cevabı verilerek işletmelerin pazar ve pazarlama bilgisi açısından pazarlama yönetiminde etkin olduğu sonucuna varıldı.

Stratejik yönlendirme ölçülürken stratejik yönlendirme kavramı pazarlama yönetimi açısından önemli olan planlamanın işletme açısından gerçekçi ve uygulanabilir olarak yapılmasında gerçekleştirilen adımlar bütünü olarak tanımlandı. Bu tanımın daha iyi anlaşılabilmesi için stratejik yönlendirme kavramına daha yakından bakılarak tanımlanan bu adımlar bütünü sırasıyla stratejik yönün belirlenmesi, SWOT analizinin yapılması, büyüme ve rekabet stratejilerinin belirlenmesi, portföy analizinin yapılması ve son olarak pazarlama planın oluşturulması kavramları da incelendi. Bu kavramlar doğrultusunda stratejik yönlendirme değişkeninin üç alt değişkeni olan pazarlama planlamasında etkinlik, pazarlama stratejisinde etkinlik ve pazarlama taktiklerinde etkinlik düzeyleri araştırıldı. Araştırmada işletmelerin öncelikle pazarlama taktiklerinde etkili olduğu sonra sırasıyla pazarlama stratejisinde ve pazarlama planlamasında etkili olduğu gözlemlendi. Stratejik yönlendirme değişkenin alt değişkenleri arasında etkinlik artıkça işletmelerin etkinlik puanlarının homojenliklerinde yükselme olduğu görüldü. Stratejik yönlendirme değişkenine bağlı üç alt değişkende; pazarlama taktikleri alt değişkeninde 181 puanın üstünde olan işletmelerin bu alanda pazarlama yönetimlerinin etkin ve gelişmiş oldukları, pazarlama stratejisi alt değişkeninde 166 puan ile 181 puan arasında puan elde eden işletmelerin bu alanda pazarlama yönetimlerinin etkin ancak geliştirilebilir oldukları, pazarlama planlaması alt değişkeninde ise 166 puanın altında kalan işletmelerin bu alanda pazarlama yönetimlerinin etkin ancak kesinlikle geliştirilmesi gerektiği anlaşıldı. Bu nedenler ile "Stratejik uyum: Pazarlama yöneticisi, uzun dönemli büyüme ve kârlılık için yaratıcı stratejiler ve planlar meydana getiriyor mu?" sorusuna "Pazarlama yöneticisi, uzun dönemli büyüme ve kârlılık için yaratıcı stratejiler ve planlar meydana getiriyor." cevabı verilerek işletmelerin stratejik yönlendirme açısından pazarlama yönetiminde etkin olduğu sonucuna varıldı.

Uygulama etkinliği ölçülürken uygulama etkinliği kavramı pazarlama yönetimi tarafından daha önceden alınmış kararların ve yapılmış planların gerçekleşmeleri esnasındaki başarı oranı olarak tanımlandı. Bu tanımın daha iyi anlaşılabilmesi için uygulama etkinliği kavramına daha yakından bakılarak başarı oranının artması yani uygulama etkinliğinin yükselmesi için konuyla ilgili deneyim sahibi kişilerin bilgisine başvurma, benzer durumları inceleme ve güvenilir kaynaklardan veri sağlama yolları ve kavramları da incelendi. Bu kavramlar doğrultusunda uygulama etkinliği değişkeninin üç alt değişkeni olan yaklaşımların iletilmesinde etkinlik, kaynakların kullanılmasında etkinlik ve anlık gelişmelerde etkinlik düzeyleri araştırıldı. Araştırmada işletmelerin öncelikle kaynakların kullanılmasında etkili olduğu sonra sırasıyla anlık gelişmeler ve yaklaşımların iletilmesinde etkili olduğu 
gözlemlendi. Uygulama etkinliği değişkenin alt değişkenleri arasında etkinlik artıkça işletmelerin etkinlik puanlarının homojenliklerinde yükselme olduğu görüldü. Ancak bu genellemede istisna olarak işletmelerin kaynakların kullanılmasında etkinliği anlık gelişmelere göre daha etkinken homojenliğin anlık gelişmelerde daha yüksek olduğu gözlemlendi. Uygulama etkinliği değişkenine bağlı üç alt değişkende 166 puanın altında puan elde eden işletmelerin bu alanlarda pazarlama yönetimlerinin etkin ancak kesinlikle geliştirilmesi gerektiği anlaşıldı. Bu nedenler ile "Faaliyet etkinliği: Pazarlama planı, uygulamada maliyet etkin gelişmiş bir yaklaşımla yürütülüyor mu?" sorusuna "Pazarlama planı, uygulamada maliyet etkin gelişmiş bir yaklaşımla yürütülüyor.” cevabı verilerek işletmelerin uygulama etkinliği açısından pazarlama yönetiminde etkin olduğu sonucuna varıldı.

Araştırmada işletmelerin öncelikle pazar ve pazarlama bilgisinde etkili olduğu sonra sırasıyla müşteri değeri, stratejik yönlendirme, pazarlama örgüt yapısı ve uygulama etkinliğinde etkili olduğu gözlemlendi. Bu sıralamada özellikle pazar ve pazarlama bilgisi ile müşteri değeri değişkenlerinin işletmeler tarafından ön planda tutulduğu pazarlama örgüt yapısı ve stratejik yönlendirmenin genellikle göz ardı edildiği anlaşıldı. Bunun sonucunda uygulama etkinliği değişkeninin sıralamada son yere sahip olmasıyla işletmelerin pazarlama yönetimlerinde istenilen sonuçları almada sıkıntılı oldukları gözlemlendi.

\section{Kaynakça}

- Aksungur, Aycan, Moda Perakendesinin Yapı Taşları Eğitimi, 25-30 Aralık ile 6-8 Ocak, İstanbul Moda Akademisi, İstanbul, 2013.

- Atayeter, Coşkun, Yönetim ve Organizasyon Ders Notları, Beykent Üniversitesi, İstanbul, 2015.

- Balıç̧ığlu, Betül, Pazarlama Kontrolü: Pazarlama Etkinliği ve Mükemmelliğinin Ölçülmesi Üzerine Bir Araştırma, Yüksek Lisans Tezi, Hatay: Mustafa Kemal Üniversitesi Sosyal Bilimler Enstitüsü, 2000.

- Berry, L.L., J.S. Conant ve A. Parasuraman, "A Framework for Conducting a Services Marketing Audit", Journal of the Academy of Marketing Science, Cilt 19, Say1 3, 1991, s.255-268.

- Burns, T. ve G.M. Stalker, The Management of Innovation, Oxford: Oxford University Press, 1961.

- Gündoğdu, Gökay, Marka Kavramı ve Yönetimi Eğitimi, 13-18-20-25 Kasım, İstanbul Moda Akademisi, İstanbul, 2013.

- Jones, Gareth R., Organizational Theory, Design and Change Text and Cases, New Jersey: Pearson Education, Inc., 1998.

- Kotler, Philip ve Gary Armstrong, Principles of Marketing, 5th Edition, Prentice-Hall, New Jersey, 1991.

- Kotler, Philip, Marketing Management, Analysis, Planning, Implementation, and Control, Eleventh Ed., Prentice Hall, Inc., 2003.

- Kotler, Philip, William T. Gregor ve William H. Rodgers III, “The Marketing Audit Comes of Ages”, MIT Sloan: Management Review, 1977;18(2):25-43.http://sloanreview.mit.edu/article/the-marketing-auditcomes-of-age/19.11.2015.

- Martin, John ve Martin Fellenz, Organizational Behavior \& Management, Cengage Learning EMEA, 2010.

- Sarıçiçek, Burak, Pazarlama Yönetimi Etkinliği ve Uygulamada Ölçülmesi, Yüksek Lisans Tezi, İstanbul: Beykent Üniversitesi Sosyal Bilimler Enstitüsü, 2017.

- Schermerhorn, John R.; James G. Hunt ve Richard N. Osborn, Organizational Behavior, USA: John Wiley \& Sons, Inc., 2000.

- Taşkın, Erdoğan, Pazarlama Esasları, Türkmen Kitapevi, İstanbul, 2009.

- Taşkın, Erdoğan, Yönetim Pazarlama Satış, Türkmen Kitapevi, İstanbul, 2005.

- $\quad$ Ülgen, Hayri, İşletmelerde Organizasyon İlkeleri ve Uygulaması, İstanbul Üniversitesi İşletme Fakültesi Yayınları, İstanbul, 1997.

- Yükselen, Cemal, Pazarlama Araştırmaları, Gözden geçirilmiş altıncı baskı, Detay Yayıncılık, Ankara, 2013.

- Yükselen, Cemal, Pazarlama, İlkeler, Yönetim ve Örnek Olaylar, Gözden geçirilmiş on ikinci baskı, Detay Yayıncilık, Ankara, 2015. 


\title{
Örgütsel Adalet ve Psikolojik Güçlendirme Arasındaki İlişkinin İncelenmesi
}

\section{An Examination of the Relationship between Organizational Justice and Psychological Empowerment}

\author{
Esvet Mert (Pamukkale University, Turkey) \\ Prof. Dr. Sabahat Bayrak Kök (Pamukkale University, Turkey)
}

\begin{abstract}
The perceptions of empowerment and justice that employees create in their minds affect all processes within the organization. Psychological empowerment is the perception of the organization that the organization has built to empower its employees. Organizational justice encompasses rules and social norms developed in the distribution of benefits, distribution processes and interpersonal relationships. This study aims to determine the relationship between psychological empowerment and perceptions of organizational justice. The 105 employees who work in a public institution constitute the universe of the researcher. According to Spearman correlation analysis results, the statistically significant relation was found between psychological empowerment and organizational justice perception. The main hypothesis has not been rejected. The study also examined the relationship between dimensions of psychological empowerment and dimensions of organizational justice. The results revealed a statistically significant relationship. The most striking result is that the relationship between the dimension of autonomy and the dimension of organizational justice is found to be strongest. The weakest relationship is the relationship between the meaning dimension of psychological empowerment and the dimensions of the concept of organizational justice.
\end{abstract}

\section{Giriş}

Günümüz koşulları yoğun rekabet ortamını, risk koşullarını, artan müşteri talepleri gibi sürekli değişen ve gelişen şartları (Koçel, 2015) beraberinde getirmektedir. Değişen ve gelişen bu şartlar; firsat ve tehditleri her geçen gün arttırmaktadır. Bu koşullar altında örgüt içinde yer alan bireylerin de sahip oldukları özellikler, durum ve mevzuları algılayış biçimleri; tutum ve davranışlarına doğrudan etki etmektedir (Allen, vd, 2003). Bu bağlamda bireylerin sahip oldukları özellikleri sebebiyle insan kaynaklarına verilen önem yadsınmayacak kadar önceliğe sahip olmaktadır. Çünkü örgütte gerçekleştirilen her türlü uygulamaya ait sahip olunan alg1 ve tutumlar, uygulamanın sonucunu belirlemektedir. Başka bir ifade ile örgütte gerçekleştirilmek istenen bir uygulama çalışanların uygulamayı algılamaları doğrultusunda başarı ya da başarısızlıkla sonuçlanmaktadır.

Tüm bu süreçlerde yapılan işler esnasında yaşanan ilişkilerde; çalışanlar ve örgüt arasında, girdiler ve çıktılar ekseninde karşılıklı beklentiler var olagelmektedir. Bu beklentilerin yaşanan değişimlerin olağan sonucu olduğu düşünülmektedir (Kalay, 2016). Bahsi geçen değişimler sonucu gerçekleşen beklentilerin ve uygulamaların taraflarca adil olması en fazla istenen durumdur. Diğer taraftan bu koşullar çalışanların güçlenmesi gerekliliğini de beraberinde getirmektedir. Çalışanların güçlenmesi en genel manada yetki ve sorumluluk artışı ile gerçekleşmektedir. $\mathrm{Bu}$ doğrultuda psikolojik güçlendirme çalışanların işleri hakkındaki gerekleri doğru algılamaları ve işlerine hâkim olabilmeleri için teşvik edici bir araçtır (Laschinger, vd, 2004). Çalışanların değişen ve gelişen koşullar karşısında böylesi bir yaklaşımla ancak ayakta kalabilecekleri düşünülmektedir.

Bu yaklaşımdan yola çıkarak; çalışma örgütsel adalet kavramı, psikolojik güçlendirme uygulamalarının başarısı için önemli bir unsur olarak değerlendirilmektedir. Çünkü çalışanlar, görev aldıkları işyerlerinde kendilerine yönelik adil davranıldığına inandıklarında sergiledikleri tavırlar olumlu olurken; tam tersi durumda çalışanların kendilerine adil davranılmadığına inandıklarında ise sergiledikleri tavırlar olumsuz olmaktadır. Dolayısıyla çalışanlar kendilerine yönelik tavır ve tutumları adil olarak algıladıklarında psikolojik güçlendirme algılarının da olumlu yönde etkileneceği düşünülmektedir. Bu sebeple bu çalışmada psikolojik güçlendirme ile örgütsel adalet arasındaki ilişkinin incelenmesi amaçlanmaktadır.

\section{2 Örgütsel Adalet Kavramı}

Çalışanların örgütsel adalet algıları, bireysel ve örgütsel boyutlardaki neticelere olan etkileri sebebiyle alan yazında üzerinde fazlaca durulan örgütsel davranış konularından biri olarak karşımıza çıkmaktadır (Yürür, 2008). Bahsedilen etkiler örgütsel adalet kavramının tanımı, yaklaşımları, boyutları ve sonuçları aracılığıyla kendini göstermektedir. Çünkü çalışanların iş yerlerinde adaleti nasıl algıladıkları ve algılamalarının sonuçları önemli olmaktadır. Zira çalışanların adalet algılamaları yaptıkları işin niteliğini doğrudan doğruya belirlemektedir. Bu nitelik de yapılan işin örgüte kattığı değere işaret etmektedir. 


\section{1 Örgütsel Adaletin Kavramsal Çerçevesi}

Örgütsel adalet ile ilgili ilk çalışmalar sosyal etkileşim süreciyle ilişkilendirilmeye çalıșılmıştır (Colquitt, vd, 2001). Bu bağlamda bir bireyin diğer bireye ya da bireylere nasıl davranması gerektiği ve kaynakların nasıl paylaşılacağı yasal düzenlemeler gerekliliğini doğurmuştur (Yürür, 2008). Çalışmalar daha sonra farklı yaklaşımların da etkisi ile gelişme göstermiştir. Bu yaklaşımların en önemlisi Adams'ın (1965) Eşitlik Teorisidir. Eşitlik Teorisi değişim, uyumsuzluk ve sosyal karşıllaştırma kuramlarından yola çıkarak bireylerin başkalarıyla olan ilişkilerini yönetmek üzerine kuruludur. Birey örgüt içerisinde sonuca ulaşmak için belli bir çaba harcar, daha sonra başkalarının çaba ve sonuçlarını kendisininki ile karşılaşııırı. Birey bu karşılaştırmasının neticesinde eşit olmayan bir durum algıladığında eşitlik sağlamak adına çaba sarf etmektedir (Huseman, vd, 1987). Eşitlik Teorisi ile benzerlik gösteren ve örgütsel adalet kavramının tarihsel gelişiminde etkisi olan diğer önemli yaklaşım Crosby'nin (1976) Göreli Yoksunluk Teorisidir. Göreli Yoksunluk Teorisine göre örgüt içerisinde alt kademelerde bulunan çalışanlar uğraşları sonucu elde ettikleri kazanımlarını, üst kademelerdeki çalışanların uğraşları sonucu elde ettikleri kazanımlar ile karşılaştırırlar. Karşılaştırma neticesinde görülen farklıllk yoksunluk algısına neden olur (Greenberg, 1989). İki yaklaşım türü de çalışanların örgüt içindeki dağıtım süreçlerine odaklanmaktadır. Bu sebeple örgütsel adalet yaklaşımının temellerini oluşturan bu teoriler ayrıca örgütsel adalet boyutlarından dağıtım adaletinin de alt yapısını oluşturacaktır. Ardından çalışmaların kapsamı genişletilerek örgütsel adalet kavramının diğer boyutları olan işlem adaleti ve etkileşim adaleti incelenmiştir (Kalay, 2016).

Örgütsel adalet kavramı insan kaynakları yönetimi, örgütsel davranış ve endüstri-örgüt psikolojisi gibi alanlara ilişkin teorik ve pratik çalışmalarla üzerinde fazlaca çalışılan bir konudur (Colquitt, vd, 2001). Bu sebeple kavram farklı yönleri ile ele alınmayı gerektirdiğinden, kolektif bir araştırma sahası olarak değerlendirilmektedir (İyigün, 2012). Kavram ile ilgili literatürde yer alan yaklaşımlar incelendiğinde ilk olarak kavramın öncülerinden Greenberg'in örgütsel adalet yaklaşımı yer almaktadır. Greenberg kavramı sınıflandırmaya çalışmışıtır. Genel adalet ve sosyal yapılar arasındaki ilişkiyi ön plana çıkarmak istemiştir. Örgütsel adalet kavramını, bireyin çalıştı̆ı yer ile ilgili adalet algılaması olarak tanımlamıştır (Greenberg, 1987). Örgütsel adalet başka bir tanımlamaya göre ise, örgütte gerçekleşen uygulamalardan ücretler, ödüller, cezalar ve terfilerin nasıl gerçekleştirildiği, bu uygulamalara dair kararların nasıl alındığı, bu kararların çalışanlara nasıl iletildiği ve son olarak tüm bunların çalışanlarca nasıl algılandığıdır (İçerli, 2010).

\section{2 Örgütsel Adalet Kavramının Boyutları}

Örgütsel adalet kavramını oluşturan boyutlar hakkında birbirinden farklı yaklaşımlara rastlamak mümkün olmaktadır (Özmen, vd, 2007). Ancak konu, literatürde en kabul görmüş ve sıklıkla rastlanan şekliyle ele alınmaya çalışılmıştır. Bu nedenle örgütsel adalet boyutları dağıtım adaleti, işlem adaleti ve etkileşim adaleti (Nirmala ve Akhilesh, 2006; Cropanzano, vd, 2007) olmak üzere üç boyutta incelenmiştir.

Dağıtım adaleti: Dağıtım adaleti, bazı kaynaklarda bölüşümsel adalet olarak da isimlendirilmektedir. Eşitlik Teorisi içerisinde yer almaktadır. Bu teoriye göre amaç eşit işe eşit sonuç verilebilmesidir (Cropanzano, vd, 2001). $\mathrm{Bu}$ düşünceden yola çıkarak dağıtım adaleti uygulayan yöneticilerin çalışanların çabaları doğrultusunda eşit ceza veya ödülü dağıtabilmeleridir. Dağıtım adaleti bu bağlamda görev, ürün, hizmet, ceza, ödül, rol, statü, ücret ve terfi gibi kazanım veya kayıpların çalışanlar arasında paylaşımını esas almaktadır (Cohen, 1987). 1980'li yıllardan itibaren gelişme gösteren dağım adaleti kavramı kazanımlara odaklanmaktaydı. Ancak zamanla bu kavramın örgütsel adaleti açıklamada yetersiz kaldığı öne sürülmüştür. Buna sebep olarak da çalışanların elde ettikleri kazanımların adaletli olmasının yanı sıra kazanımları belirleyen süreçlerin de adaletli olması gerektiği vurgulanmıştır. Böylelikle dağıtım adaletini gerçekleştiren süreçlerdeki yöntemleri inceleyen işlem adaleti kavramı ortaya çıkmıştır (Çakmak, 2005).

İşlem adaleti: İşlem adaleti, bazı kaynaklarda prosedür adaleti, süreç adaleti ve uygulamaya ilişkin adalet gibi kavramlarla isimlendirilmektedir. İşlem adaleti en genel tanımıyla örgüt içindeki kaynakların dağılımını belirleyen süreçlerin uygunluğunu ifade etmektedir (Stroh, vd, 2002). Çünkü kaynak dağılımını belirleyen süreçlerde takip edilen adımlar her zaman önemli olmuştur. Bu süreçte bireyler kendi elde ettikleri kazanımlarla başkalarının elde ettikleri kazanımları kıyaslayarak yargılamaktadır (Greenberg, vd, 2007). Başka bir ifade ile işlem adaleti, alınan terfi, maddî imkânlar, çalışma koşulları ve performans değerlendirmeleri gibi unsurların belirlenmesinde kullanılan metot, prosedür ve politikaların adil bir şekilde ele alınabilmesi olarak değerlendirilebilmektedir (Doğan, 2002: 72). Örgütsel adalet kavramı ile ilgili alan yazın araştırması incelendiğinde kavramı tanımlamak için dağıtım adaletinin ve işlem adaletinin de yetersiz kaldığı görülmüştür. Çünkü örgütsel adaletin sağlanabilmesi için kazanımların dağıtımının ve dağıtım süreçlerinin adil olmasının yanında bu süreçleri uygulayan yöneticilerin davranışlarının da adil olmasının gerekliliği vurgulanmıştır. Bu doğrultuda etkileşim adaleti boyutu ortaya çıkmıştır (Çakmak, 2005: 39).

Etkileşim adaleti: Etkileşim adaleti, örgütsel adalet kavramının kişilerarası yönüne vurgu yapmaktadır. Kavram en genel tanımıyla, prosedürlerin uygulanması esnasında kişilerarası davranışların niteliği ve uygunluğu olarak tanımlanabilmektedir (Cohen-Charash ve Spector, 2001). Etkileşim adaletinin öncülerinden olan Bies ve Moag'a göre etkileşim adaletini belirleyen iki önemli unsur bulunmaktadır. Bunlardan ilki kişilerarası ilişkilerin niteliğidir. Yani, yöneticilerin prosedürleri uygulamaları esnasında çalışanlarına haysiyet, saygı ve nezaket kuralları içinde yaklaşıp yaklaşmamaları ile ilgilidir. Diğer unsur ise yöneticilerin çalışanlarına süreç ile ilgili gerekli açıklamaları 
yapıp yapmadıkları ile ilgili olandır (Dai ve Xie, 2016). Çalışanlar prosedürlerin uygulanması esnasında kendileriyle bă̆ kurulması halinde alınan kararların kendilerine izah edilmesi noktasında daha duyarlı olmaktadırlar. Beraberinde daha samimi ve saygılı davranılması beklentisi oluşmaktadır. Bu bağlamda etkileşim adaleti yöneticiler, karar vericiler ve çalışanlar arasındaki etkileşimin adil olup olmaması ile alakalı bütünleyici unsur olarak önem kazanmaktadır (İyigün, 2012).

\section{Psikolojik Güçlendirme Kavramı}

Modern yönetim anlayışı içerisinde sosyal, siyasal, kültürel, ekonomik, teknolojik ve daha birçok alanda sürekli ve hızlı bir değişim yaşanmaktadır. Yaşanan bu değişimler ve gelişmelerin hızı ve önemi karşısında örgütler çeşitli uygulamalara başvurmak zorunda kalmaktadır. Bu uygulamalarda çalışanlara önem veren yaklaşımlar öncelikli gelmektedir. Psikolojik güçlendirme kavramı bu yaklaşımlardan birisi olarak karşımıza çıkmaktadır (Spreitzer, 1995).

\subsection{Psikolojik Güçlendirmenin Kavramsal Çerçevesi}

İnsan ilişkileri ve sosyal niteliklerin önem kazandığı günümüz koşullarında personel güçlendirme kavramı farklı boyutları ile ele alınmaya çalışılmıştır. Bu bağlamda, literatür incelendiğinde personel güçlendirmenin iki temel yaklaşıma dayandığını söylemek mümkündür. Bu yaklaşımlardan ilki sosyo-yapısal boyut, bir diğeri ise psikodavranışsal boyuttur (Conger ve Kanungo, 1988; Spreitzer, 1995). Bu yaklaşımlardan ilki olan sosyo-yapısal boyut örgütte yer alan çalışanların üst kademeden alt kademeye doğru sahip oldukları görev ve sorumluluklarla ilgilenen yaklaşımdır (Niehoff, vd, 2001). Diğer boyut olan psiko-davranışsal boyutta ise ilişkisel nitelikler öncelenerek algılar anlam kazanmaktadır. Yani güçlendirme uygulamalarında nasıl bir ortam hazırlandığı ve çalışanların güçlendirilmeyi nasıl algıladıklarıyla ilgilenen yaklaşımdır (Thomas ve Velthouse, 1990). Bu iki yaklaşımı birbirinden farklı ele alan araştırmacılar olduğu gibi, birlikte ele alan araştırmacılar da vardır. Güçlendirme kavramı farklı boyutları ile ele alındığı için literatürde ortak bir tanıma rastlanamamaktadır.

Kavramın yönetim literatürüne kazandırılmasının öncülerinden ve psikolojik bakış açısı ile ele alınması gerektiğini düşünen ilk araştırmacılardan Conger ve Kanungo'ya (1988) göre güçlendirme; motivasyon boyutu ile ele alınmalıdır. Böylece kişinin kendi kendine yeterliliğinin ve özerkliğinin, kişinin gücü olacağını vurgulamaktadır (Conger ve Kanungo, 1988). Ancak bu tanımın karşılığını bulmasıyla kişinin güçlendirilmiş olacağını ifade etmektedirler. Thomas ve Velthouse (1990) ise psikolojik güçlendirmeyi bütüncül bir bakış açısı ile ele alarak Conger ve Kanungo'nun (1988) yaklaşımının kapsamını genişletmişlerdir. Geliştirdikleri bilişsel model kapsamında psikolojik güçlendirme kavramını dört boyut altında ele almışlardır. Dört boyut anlam, yetkinlik, seçim ve etkidir. Güçlendirmeyi hem yönetim hem de çalışanların algılamaları bakımından ayırarak incelemişlerdir (Thomas ve Velthouse, 1990). Spreitzer (1995) ise psikolojik güçlendirme kavramını inceleyebilmek için çok bölümlü bir değerlendirme aracı geliştirmiştir. Bu yönüyle ilk araştırmacıdır. Spreitzer, Thomas ve Velthouse'un (1990) araştırmasını baz alarak psikolojik güçlendirme kavramını daha geniş ele almıştır. Çalışan bireyin işine karşı duyduğu motivasyonunu etkileyen dört boyutu içsel bir görev motivasyonu olarak ifade etmiştir (Spreitzer, 1995). En genel anlamıyla psikolojik güçlendirme, kişilerin görevlerine dair kontrollerinin olduğu psikolojik durumları ifade eder. Sadece gücün çalışanlar ile paylaşıldığı yönetim ile ilgili uygulanmalara odaklanmaktan ziyade çalışanların işlerini nasıl yaptıklarına da odaklanan psikolojik anlamlı bir bakış açısıdır (Spreitzer, vd, 1999).

\subsection{Psikolojik Güçlendirme Kavramının Boyutları}

Kavramla ilgili boyutlar daha önce de değinildiği gibi ilk olarak Thomas ve Velthouse (1990) tarafindan geliştirilmiştir. Boyutlar daha sonra Spreitzer'in (1995) katkılarıyla genişletilmiştir. Psikolojik güçlendirme boyutları birbirinin öncüsü ya da neticesinde oluşmuş gibi düşünülmemelidir. Psikolojik güçlendirmenin genel çerçevesini oluşturan unsurlar olarak düşünülerek ele alınmalıdır (Spreitzer, 1995). Bahsi geçen psikolojik güçlendirme boyutları dört tanedir: Anlam, etki, yetkinlik, otonomi.

Anlam: Anlam, örgütte yer alan bireylerin inançları, değerleri ve davranışları ile iş gereksinimleri arasındaki uyumu ifade etmeye çalışır (Laschinger, vd, 2004). Diğer bir ifade ile anlam boyutu, çalışanların yaptıkları işe yükledikleri değer ile ilgilidir. Aynı zamanda çalışanların yaptıkları işi ne kadar önemsedikleri ve işlerinin gerekliliğini düşünme seviyeleridir (Spreitzer, 1995).

Etki: Etki, çalışanın yaptığ 1 işin sonucuna anlamlı ve önemli katkı sağlayabileceğini düşünebilmesidir (O'Brien, 2010). Başka bir ifade ile çalışanların örgütte gerçekleşen işlerde kendi paylarının bulunup bulunmamasıyla ilgilidir. Gerçekleşen işler operasyonel, stratejik ve yönetsel olabilmektedir. Etki boyutu örgütteki üç işlev türünün çıktılarını da etkileme gücünü kapsamaktadır (Luthans, 2011).

Yetkinlik: Yetkinlik, çalışanın sahip olduğu bilgi, beceri ve deneyimle bağlantılı olarak yaptığ değerlendirmeler ve hükümlerdir. Bu değerlendirme ve hükümler çalışanın işi ile ilgili etkinlikleri ve sorumlulukları yerine getirip getiremeyeceği ile ilgili kişisel yetkinliği kapsamındaki unsurları içine almaktadır (Bolat, 2003). Çalışanlar kişisel yetkinlikleri imkân verdiği ölçüde etkinliklere katılarak sorumluluk üstlenebilirler (Kalat, 1993). 
Otonomi: Otonomi boyutu, özerklik veya seçim diye de isimlendirilebilmektedir. Bu boyut, çalışanların işlerini yaparken, izleyecekleri yöntem seçiminde ve işleyişte özgürce karar verebilmeleri ile ilgilidir. Başka bir ifade ile çalışanların yaptıkları işlerde kontrolü elden bırakmadan işlerini başlatıp devam ettirebilmesindeki özerkliği ifade etmektedir (Siegall ve Gardner, 2000). Özerk bir şekilde davranabilen çalışanın kendini güçlü hissetmesinin yanında esnek, yaratıcı, dayanıklı ve inisiyatifli olacağı vurgulanmaktadır (Thomas ve Velthouse, 1990).

Psikolojik güçlendirmenin dört boyutu anlaşılacağı üzere birbirinden tamamen farklı boyutlar değildir. Güçlendirme sürecinin farklı aşamalarında olması gereken özelliklere vurgu yapmaktadır (Spreitzer, vd, 1997). Psikolojik güçlendirmenin dört boyutunun bir arada bulunması sürecin daha iyi işlediğini ve güçlü bir etki yaptığını göstermektedir. Boyutlardan herhangi birinin ya da birkaçının eksikliği ise güçlendirmenin etkisinin azlığını ifade etmektedir (Spreitzer, 1995).

\section{Psikolojik Güçlendirme ve Örgütsel Adalet Arasındaki İlişki}

Örgütsel adalet, işletmeler için oldukça önemli bir güç kaynağı olarak değerlendirilebilmektedir. Örgütsel adaletin sağlanabildiği örgütlerde bilhassa güven, bağlılık, tatmin, özdeşleşme, memnuniyet ve performans artış1 gibi birçok örgütsel davranışın olumlu yönde etkilendiği çalışmalarla ortaya konmuştur (Kalay, 2016). Bu bağlamda örgütsel adalet algısı ile psikolojik güçlendirmenin arasındaki ilişki de dikkat çekmiştir.

Kamalian ve çalışma arkadaşlarının (2010) yaptıkları araştırma örgütsel adalet ile personel güçlendirme kavramları arasındaki ilişkiyi inceleyen çalışmalardan biri olarak karşımıza çıkmaktadır. Bir bakır işleme tesisindeki 290 çalışana uygulanan araştırma, güçlendirme ile örgütsel adalet boyutları arasında istatistiksel anlamlı ve güçlü bir ilişkiye işaret etmektedir (Kamalian, vd, 2010). Benzer başka bir çalışmada Tsai'in (2012) Amerika'da yaptığı araştırma yüksek öğrenim kurumlarında örgütsel adalet genelinde psikolojik güçlendirme, örgütsel bağlılık ve ayrılma niyeti konuları incelenmeye çalışılmıştır. Araştırma sonuçları göstermektedir ki sadece örgütsel adalet ve psikolojik güçlendirme arasında doğrudan bir ilişki bulunmaktadır. Diğer kavramlar arasında dolaylı bir ilişki bulunmaktadır (Tsai, 2012). Örgütsel adalet kavramı boyutları ile psikolojik güçlendirmeyi ele alan başka bir çalışmada, Kalaani ve çalışma arkadaşları (2014) gençlik ve spor kurumunda yaptıkları araştırmada örgütsel adaletin psikolojik güçlendirme üzerindeki etkisini araştırmak istemişstirler. Araştırma neticesinde dağıtım adaleti ile psikolojik güçlendirme arasında anlamlı bir ilişki bulunamamıştır. İşlem adaleti ve etkileşim adaletinin ise psikolojik güçlendirme ile arasında anlamlı bir ilişki bulunmuştur. Hatta etkileşim adaletinin ilişki gücü daha fazla çıkmıştır (Kalaani, vd, 2014). Diğer benzeri çalışmada, Azeem ve çalışma arkadaşlarının (2015) yaptıkları çalışma, örgütsel adalet ve psikolojik güçlendirmenin algılanan örgütsel performans üzerindeki etkilerini, algılanan örgütsel vatandaşlık davranışlarının aracılık rolüyle incelemeye çalışmaktadır. Çalışma 260 banka çalışanı ile gerçekleştirilmiştir. Çalışmanın sonuçlarına göre, örgütsel vatandaşlık davranışı kısmen örgütsel adalet ve algılanan örgütsel performans arasındaki ilişkiye aracılık etmektedir. Ayrıca, örgütsel vatandaşlık davranışı tamamen psikolojik güçlendirme ve algılanan örgütsel performans arasındaki ilişkiye aracılık etmektedir (Azeem, $\mathrm{vd}, 2015)$.

\section{Araştırma}

\subsection{Araştırmanın Amacı ve Kapsamı}

İş hayatının koşulları her geçen gün gelişme ve değişme göstermektedir. Yaşanan değişim ve gelişimleri yakalamak ve ötesine geçebilmek için çalışanların etkin ve verimli bir şekilde hizmet veya ürün elde edebilmeleri gerekmektedir. Bunu sağlayabilmek için de çalışanların bir takım ihtiyaçlarının karşılanması önem kazanmaktadır (Yüksekbilgili ve Hatipoğlu, 2015). Bu ihtiyaçlar fiziksel ve güvenlik gereksinimleri olabildiği gibi sosyal ve psikolojik gereksinimler de olabilmektedir. Bu kapsamda ön plana çıkan çalışanların psikolojik güçlenme algıları, örgüt içerisindeki gücün çalışanlarla paylaşıldığı ve yapılacak işlere odaklanan psikolojik bir bakış açısı sunmaktadır (Spreitzer, 2008). Çalışanların aynı zamanda örgütten beklentileri de olmaktadır. Bu beklentilerin başında örgüt içerisindeki adaletin sağlanabilmesi gelmektedir. Yapılan çalışmalar, bir örgütte çalışanların yöneticileriyle, iş yaptıkları arkadaşlarıyla ve örgütün genel işleyişiyle alakalı ekonomik ve sosyal etkileşim süreçlerinde, eşitlik ve adil olma unsurlarını algılamak istedikleri yönündedir (Aytemiz Seymen, vd, 2013). Bu sebeple örgütsel adalet ile psikolojik güçlendirme kavramları arasında ilişki olduğu düşünülmektedir. Literatürde yapılan araştırmalar da bu yöndedir (Kamalian, vd, 2010; Yürür ve Demir, 2011; Tsai, 2012; Saufi, vd, 2013; Alvandi, 2014; Kalaani, vd, 2014). Çalışmanın amacı da bu ilişkiyi tespit etmeye yöneliktir. Bu amaç doğrultusunda ana hipotez şu şekilde oluşturulmuş ve araştırmanın basit modeli Şekil 1'de gösterilmiştir.

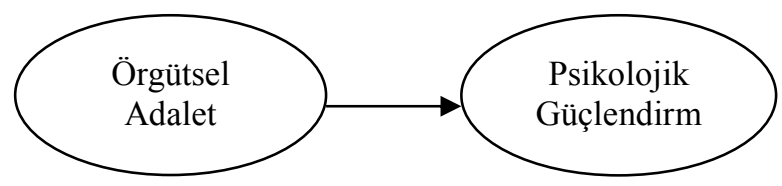

Şekil 1. Araştırmanın Basit Modeli 
Hipotez: Çalışanların algıladıkları örgütsel adalet ile psikolojik güçlendirme arasında anlamlı ve pozitif yönlü bir ilişki bulunmaktadır.

Araştırmada ayrıca örgütsel adaletin boyutları olan, dağıtım adaleti, işlem adaleti ve etkileşim adaleti ile psikolojik güçlendirmenin boyutları olan, anlam, etki, yetkinlik ve otonomi boyutları arasındaki ilişkiler de tespit edilmek istenmektedir. Bu amaçlar doğrultusunda da aşağıdaki alt hipotezler oluşturulmuş ve araştırmanın kapsamlı modeli Şekil 2'de gösterilmiştir.

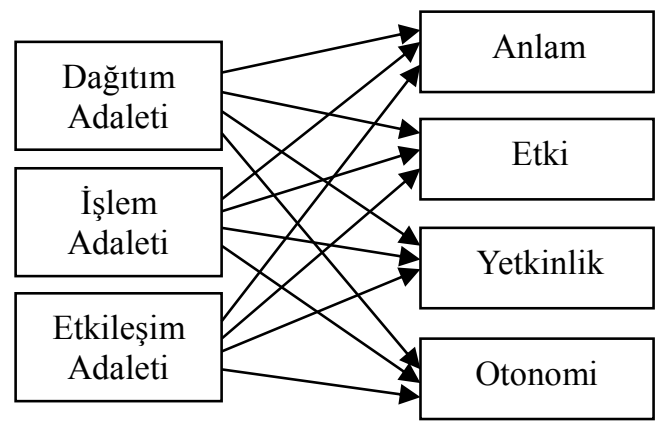

Şekil 2. Araştırmanın Kapsamlı Modeli

H1: Dağıtım adaleti ile anlam boyutu arasında anlamlı ve pozitif yönlü bir ilişki bulunmaktadır.

$\mathbf{H}_{2}$ : Dağıtım adaleti ile etki boyutu arasında anlamlı ve pozitif yönlü bir ilişki bulunmaktadır.

H3: Dağıtım adaleti ile yetkinlik boyutu arasında anlamlı ve pozitif yönlü bir ilişki bulunmaktadır.

$\mathbf{H}_{4}$ : Dağıtım adaleti ile otonomi boyutu arasında anlamlı ve pozitif yönlü bir ilişki bulunmaktadır.

H5: İşlem adaleti ile anlam boyutu arasında anlamlı ve pozitif yönlü bir ilişsi bulunmaktadır.

H6: İşlem adaleti ile etki boyutu arasında anlamlı ve pozitif yönlü bir ilişki bulunmaktadır.

H7: İşlem adaleti ile yetkinlik boyutu arasında anlamlı ve pozitif yönlü bir ilişki bulunmaktadır.

H8: İşlem adaleti ile otonomi boyutu arasında anlamlı ve pozitif yönlü bir ilişki bulunmaktadır.

H9: Etkileşim adaleti ile anlam boyutu arasında anlamlı ve pozitif yönlü bir ilişki bulunmaktadır.

$\mathbf{H}_{10}$ : Etkileşim adaleti ile etki boyutu arasında anlamlı ve pozitif yönlü bir ilişki bulunmaktadır.

H11: Etkileşim adaleti ile yetkinlik boyutu arasında anlamlı ve pozitif yönlü bir ilişki bulunmaktadır.

H12: Etkileşim adaleti ile otonomi boyutu arasında anlamlı ve pozitif yönlü bir ilişki bulunmaktadır.

\subsection{Yöntem}

Çalışmanın evrenini Denizli'de yer alan bir kamu kurumu oluşturmaktadır. Kurum içerisindeki çalışanlara psikolojik güçlendirme ile örgütsel adalet algıları oluşturulmaya çalışıldığı için tercih edilmiştir. Son yıllarda yapılan kamu sektörü araştırmaları örgütsel adalet ve psikolojik güçlendirme konusunda sorunlar olduğunu göstermektedir. $\mathrm{Bu}$ nedenle çalışma bu konuya dikkat çekmek ve özellikle psikolojik güçlendirmenin bu kurumlarda etkin değerlendirildiği takdirde örgütsel adalet algısını değiştirebileceğini dikkate alarak sektör seçimi yapılmıştır. Bu bağlamda çalışmanın amacı ile uyum göstermektedir.

Kurum Denizli merkez olmak üzere Acıpayam, Çivril ve Sarayköy'de faaliyet göstermektedir. Kurum yetkililerinden alınan bilgiye çalışan personel sayısı toplamda 150'dir. Çalışanlar arazi çalışmaları sebebiyle sürekli iş yerinde bulunamamaktadırlar. Bu sebeple tüm çalışanlara erişim ihtimali eşit olamamaktadır. Bu sebeple olasılığa dayalı olmayan kolayda örnekleme yöntemi kullanılmıştır (Gegez, 2015). Verilerin sağlıklı bir şekilde doldurulması ve geri dönüş oranının yüksek olması için geleneksel yöntemler tercih edilmiştir. Cevaplayıcının yönettiği elden bırakıp alma yöntemi ve yüzyüze anket yöntemi kullanılmıştır (Burns ve Bush, 2015). Anket uygulamak üzere 120 kişiye verilmiştir. Ancak 108 tanesi geri dönmüştür. 3 tanesi de hatalı veya eksik doldurulduğundan 105 anket çalışmanın örneklemini oluşturmuştur. Geri dönüş oranı \%87'dir. Araştırmadan elde edilen veriler araştırma evrenini \%95 $(\alpha=.05)$ güven düzeyi seviyesinde temsil edebilecek niteliktedir. Çalışmanın iki farklı veri aracı kullanılmıştır. Bunlardan ilki Spreitzer (1995) tarafından oluşturulan 12 soruluk psikolojik güçlendirme ölçeğidir. Ölçek dört boyuttan oluşmaktadır. Bu boyutlar, anlam, etki, yetkinlik ve otonomidir (Spreitzer, 1995). Diğer veri aracı ise Niehoff ve Moorman (1993) tarafından oluşturulan 20 sorudan meydana gelen örgütsel adalet ölçeğidir. Ölçek üç boyuttan oluşmaktadır. Bu boyutlar, dağıtım adaleti, işlem adaleti ve etkileşim adaletidir (Niehoff ve Moorman, 1993).

\subsection{Bulgular}

Araştırmada kullanılan ölçeklerin iç tutarlılığını ölçmek için yapılan güvenilirlik analizi sonuçları Tablo 1'de yer almaktadır. Psikolojik güçlendirme ölçeğine ait güvenilirlik katsayısı 0,983 çıkarken boyutları olan anlam, etki, yetkinlik ve otonominin güvenilirlik katsayıları sırasıyla 0,$993 ; 0,955 ; 0,980 ; 0,970$ olarak bulunmuştur. Örgütsel 
adalet ölçeğine ait güvenilirlik katsayısı 0,990 çıkarken boyutları olan dağıtım adaleti, işlem adaleti ve etkileşim adaletinin güvenilirlik katsayıları sırasıyla 0,980;0,983; 0,982 olarak bulunmuştur. Bir ölçeğin güvenilir olduğunu söyleyebilmek için güvenilirlik katsayısının 0,70'den büyük olması gerekmektedir (Akbulut, 2010). Kullanılan ölçekler ve alt boyutlarına ait güvenilirlik katsayıları bu koşulu sağlamaktadır. Bu nedenle ölçeklerin oldukça güvenilir olduğu söylenebilmektedir.

\begin{tabular}{llcc}
\hline & \multicolumn{1}{c}{ Boyutlar } & İfade Sayısı & Cronbach's Alpha( $\boldsymbol{\alpha})$ \\
\hline Psikolojik Güçlendirme & & 12 & $\mathbf{9 8 3}$ \\
& Anlam & 3 &, 993 \\
& Etki & 3 &, 955 \\
& Yetkinlik & 3 &, 980 \\
& Otonomi & 3 &, 970 \\
\hline \hline Örgütsel Adalet & & 20 &, 990 \\
& Dağıtım Adaleti & 5 &, 980 \\
& İşlem Adaleti & 8 &, 983 \\
& Etkileşim Adaleti & 7 &, 982 \\
\hline \hline
\end{tabular}

Tablo 1. Güvenilirlik Analizi Sonuçları

Araştırmada kullanılan ölçeklere ilişkin yapı geçerliliği test edilmek istenmiştir. Bunun için faktör analiz uygulanmak istenmiştir. Ancak öncesinde psikolojik güçlendirme veri setinin faktör analizine uygunluğunu kontrol etmek için Kaiser-Meyer-Olkin (KMO) Testi ve Barlett Küresellik Testi uygulanmıştır. KMO Testi değeri 0,783; Barlett Küresellik Testi'nin anlamlılık düzeyi 0,000 çıkmıştır. KMO Testi değerinin 0,5'ten büyük olması ve anlamlılık düzeyinin 0,000 çıkması verilerin faktör analizine uygunluğunu göstermektedir. Aynı zamanda faktörlerin toplam varyansı açıklama yüzdesi de \%97 bulunmuştur. Değer oldukça yüksek olduğundan sonuçlar faktör analizinin uygunluğunu göstermektedir. Aynı şekilde, örgütsel adalet veri setinin faktör analizine uygunluğunu kontrol etmek için Kaiser-Meyer-Olkin (KMO) Testi ve Barlett Küresellik Testi uygulanmıştır. KMO Testi değeri 0,654 Barlett Küresellik Testi'nin anlamlılık düzeyi 0,000 çıkmıştır. KMO Testi değerinin 0,5'ten büyük olması ve anlamlılık düzeyinin 0,000 çıkması verilerin faktör analizine uygunluğunu göstermektedir. Ancak 11. ve 17. ifadeler faktör analizine dâhil edilemediğinde çıkarılmışlardır. Aynı zamanda faktörlerin toplam varyansı açıklama yüzdesi de \%93 bulunmuştur. Değer oldukça yüksek olduğundan sonuçlar faktör analizinin uygunluğunu göstermektedir.

Bir sonraki analizde verilerin normal dağılıma uyup uymadıkları kontrol edilmek istenmiştir. Bunun için Kolmogorov-Smirnov ve Shapiro-Wilk testleri uygulanmıştır. Her iki ölçeğin de sonuçlarına göre dağılım normal dağılmamaktadır. Çünkü anlamlılık değerleri 0,05'ten küçük çıkmıştır. Basıklık ve çarpıklık değerleri de bu sonuçları desteklemektedir.

Araştırmaya katılanların genel özellikleri incelenmek istendiğinde şu sonuçlar dikkat çekmektedir: Katılımcıların cinsiyet dağılımı incelendiğinde \%79 erkek, \%21 kadın bulunmaktadır. Yaşlara göre dağılım incelendiğinde ise 26-32 yaş arası \%50,5 ile yoğunlukta iken 33-39 yaş arası \%22,9, 40-46 yaş aralığ $\% 17,1$ ve 47 yaş ve üstü \%9,5 orana sahiptir. Eğitim durumlarına göre katılımcılar \%56,2 ile ön lisans, \%25,7 ile lise ve son olarak \%18,1 ile lisans mezunudur. Medeni hâllerine göre \%62,9'u evli iken \%37,1'i bekârdır. Çalışılan yere göre katılımcılar merkez yoğunluktadır oranı ise \%62,9'dur. Bu sıralamayı Acıpayam, Çivril ve Sarayköy takip etmektedir. Çalışma süresi en fazla 2-5 yıl arası tecrübeye sahip olanlardadır, Yüzdesi \%47,6'dir. Bu oranı 0-1 yıl ile 6-10 yıl arası \%20 oran ile izlemektedir. Çalışılan birimler ise \%32,4 ile işletme ve bakım bölümü, $\% 28,6$ proje ve izleme bölümü, \%27,6 barajlar ve HES ve \%11,4 ile elektromekanik bölümü takip etmektedir.

Araştırmaya katılanların ölçekteki sorulara verdikleri cevaplara ilişkin ortalamalar ve standart sapma değerleri Tablo 2'de yer almaktadır. Analiz sonuçlarından görüldüğü üzere psikolojik güçlendirme sorularının ortalaması yüksek düzeyde çıkmış ve 3,65 bulunmuştur. Standart sapma değeri de 0,96 bulunmuştur. Örgütsel adalet sorularına verilen yanıtların ortalaması ise orta düzeyde bulunmuş ve 3,29 olarak bulunmuştur. Standart sapma 1,01 çıkmıştır.

\begin{tabular}{|c|c|c|c|c|}
\hline & & Ortalama $(\overline{\mathbf{x}})$ & Standart Sapma & Düzey* \\
\hline \multirow[t]{5}{*}{ Psikolojik Güclendirme } & & 3,65 & 0,96 & Yüksek \\
\hline & Anlam & 3,88 & 0,94 & Yüksek \\
\hline & Etki & 3,81 & 0,93 & Yüksek \\
\hline & Yetkinlik & 3,5 & 1,07 & Yüksek \\
\hline & Otonomi & 3,4 & 1,1 & Yüksek \\
\hline \multirow[t]{4}{*}{ Örgütsel Adalet } & & 3,29 & 1,01 & Orta \\
\hline & Dağıtım Adaleti & 3,12 & 1,09 & Orta \\
\hline & İşlem Adaleti & 3,35 & 0,99 & Orta \\
\hline & Etkileşim Adaleti & 3,37 & 1,06 & Orta \\
\hline
\end{tabular}

Tablo 2. Ölçeklere İlişkin Ortalama ve Standart Sapma 
En son olarak araştırmanın hipotezleri test edilmek istenmektedir. Bunun için Spearman korelasyon analizinden yararlanılmıştır. İki ölçeğe ait ilişki ve tüm boyutları arasındaki sonuçlar Tablo 3 'te gösterilmektedir. Spearman korelasyon analizi sonuçlarına göre istatistiksel anlamlılık tüm sonuçlarda 0,05'ten küçük çıkmıştır. Bu bilgi de bize belirtilen değişkenler arasında istatistiksel anlamlı bir ilişkinin varlığını göstermektedir. Tablo 3 'te koyu renk ile gösterilen değerler hipotezlerin sonuçlarını göstermektedir. Bu durumda tüm hipotezler reddedilememiştir. Psikolojik güçlendirme ve örgütsel adalet arasındaki korelasyon sonucu 0,593 olarak bulunmuş ve çalışmanın ana hipotezi reddedilememiştir. Diğer değişkenler arasındaki korelasyon düzeyleri ve yorumları da şu şekilde bulunmuştur: En kuvvetli ilişkiler otonomi boyutu ile dağıtım adaleti, işlem adaleti ve etkileşim adaleti arasında bulunmuştur. Değerleri sırasıyla 0,61, 0,596, 0,596'dır $\left(\mathrm{H}_{4}, \mathrm{H}_{8}, \mathrm{H}_{12}\right)$. Daha sonra etki boyutu ve işlem adaleti arasındaki ilişki sıralamayı takip etmektedir. Korelasyon sonucu 0,582'dir $\left(\mathrm{H}_{6}\right)$, en düşük ilişki ise anlam boyutu ile etkileşim adaleti boyutu arasındadır. Korelasyon değeri 0,466'dır $\left(\mathrm{H}_{9}\right)$. Diğer değerler ise şu şekildedir: anlam ve dağıtım adaleti ilişkisi $0,563\left(\mathrm{H}_{1}\right)$, anlam ve işlem adaleti $0,532\left(\mathrm{H}_{5}\right)$, etki ve dağıtım adaleti $0,517\left(\mathrm{H}_{2}\right)$, etki ve etkileşim adaleti $0,555\left(\mathrm{H}_{10}\right)$ ve son olarak da yetkinlik ve etkileşim adaleti arasındaki korelasyon değeri 0,512 'dir $\left(\mathrm{H}_{11}\right)$. Bulunan sonuçlar literatürde yer alan çalışmalarla benzerlik göstermektedir. Kalaani ve çalışma arkadaşlarını yaptığı çalışmada da psikolojik güçlendirme ile örgütsel adalet ve boyutları arasında anlamlı bir ilişki bulunmuştur (Kalaani, vd, 2014). Benzer sonuç Alvandi ve çalışma arkadaşlarının spor ve gençlik dairesinde yaptıkları çalışmada da bulunmuştur (Alvandi, vd, 2014). Aynı şekilde Azeem ve çalışma arkadaşlarının banka çalışanları ile yaptıkları arştırmada da örgütsel adalet ile psikolojik güçlendirme arasında anlamlı ve pozitif yönlü bir iliş̧ki bulunmuştur (Azeem, vd, 2015). Bu nedenle $\mathrm{H}, \mathrm{H}_{1}, \mathrm{H}_{2}, \mathrm{H}_{3}, \mathrm{H}_{4}, \mathrm{H}_{5}, \mathrm{H}_{6}, \mathrm{H}_{7}, \mathrm{H}_{8}, \mathrm{H}_{9}, \mathrm{H}_{10}, \mathrm{H}_{11}, \mathrm{H}_{12}$ hipotezleri reddedilememiştir.

\begin{tabular}{|c|c|c|c|c|}
\hline & $\begin{array}{l}\text { Örgütsel } \\
\text { Adalet }\end{array}$ & $\begin{array}{l}\text { Dağıtım } \\
\text { Adaleti }\end{array}$ & İşlem Adaleti & Etkileşim Adaleti \\
\hline Psikolojik Güçlendirme & $0,593^{*}$ & 0,605 & 0,6 & 0,585 \\
\hline Anlam & $\begin{array}{l}0,511 \\
0,551\end{array}$ & $\begin{array}{l}0,563^{*} \\
0,517^{*}\end{array}$ & $\begin{array}{l}0,532^{*} \\
0,582^{*}\end{array}$ & $\begin{array}{l}0,466^{*} \\
0,555^{*}\end{array}$ \\
\hline Yetkinlik & 0,517 & $0,521^{*}$ & $\mathbf{0 , 5 3 3}{ }^{*}$ & $0,512^{*}$ \\
\hline Otonomi & 0,596 & $0,610^{*}$ & $0,596^{*}$ & $0,596^{*}$ \\
\hline
\end{tabular}

Tablo 3. Spearman Korelasyon Analizi Sonuçları

\section{Sonuç ve Öneriler}

Psikolojik güçlendirme diye bahsedilen süreçler üst yönetimin çalışanlarına verdiği bir ayrıcalık değildir. Kavram motivasyon sağlama biçimi olarak düşünüldüğünde zihinsel bir yapı olarak ele alınabilmektedir. Bu kavram neticesinde psikolojik güçlendirme bu zihinsel yapının kendisi olmaktadır. Böylesi yetkilendirilmiş, kontrol imkânı tanınmış, özerklik verilmiş ve yaptığı işi değerli görebilen çalışanlar örgütsel adalet algısını da hissetmek isteyecektirler. Bu doğrultuda bu iki kavram birbirinin öncülü olmamakla birlikte ilişki içerisindedir. Yani, örgütsel süreçlerde iki kavramın da etkileşimi olumlu sonuçları beraberinde getirecektir. Çalışmada bu düşüncelerden yola çıkarak psikolojik güçlendirme ile örgütsel adalet kavramı arasındaki ilişki incelenmiştir. Sonuçlar göstermektedir ki örgütsel adalet ile psikolojik güçlendirme kavramı arasında anlamlı ve pozitif yönlü bir ilişki vardır. Bu doğrultuda çalışmanın ana hipotezi reddedilememiştir. Çalışmada ayrıca örgütsel adalet boyutları ile psikolojik güçlendirme boyutları arasındaki ilişki de incelenmiştir. Oluşturulan tüm ilişkilerde sonuç istatistiksel bakımdan anlamlı bulunmuştur ve tüm ilişkiler de pozitif yönlü bir ilişki tespit edilmiştir. İlişkilerin gücü bakımdan incelendiğinde psikolojik güçlendirmenin otonomi boyutu ile örgütsel adalet kavramının boyutları arasındaki ilişki en güçlü bulunmuştur. Otonomi boyutu çalışanların işlerini yaparken izleyecekleri yöntem seçiminde ve işleyişte özgürce karar verebilmelerini kapsamaktadır. Bu sebeple örgütsel adalet kavramının tüm boyutları ile otonomi boyutu arasında güçlü bir ilişki bulunması tesadüf değildir. Çünkü örgütsel adalet kavramı, örgütte gerçekleşen uygulamalardan ücretler, ödüller, cezalar ve terfilerin nasıl gerçekleştirildiği, bu uygulamalara dair kararların nasıl alındığı, bu kararların çalışanlara nasıl iletildiği ve son olarak tüm bunların çalışanlarca nasıl algılandığıdır. Bu sebeple, kişilerin iş yerindeki seçimlerini özgürce yapabilmeleri ile adalet algılamaları yakından ilişkili olmaktadır. Araştırmanın sonuçları da bunu desteklemektedir.

En zayıf bulunan ilişki de psikolojik güçlendirmenin anlam boyutu ile örgütsel adalet kavramının boyutları arasındaki ilişkidir. Anlam boyutu örgütte yer alan bireylerin inançları, değerleri ve davranışları ile iş gereksinimleri arasındaki uyumu ifade etmeye çalışır. Bu bağlamıyla çalışanların örgüt içerisindeki adalet algıları ile psikolojik güçlendirme algıları yakından ilişkili olmaktadır. Sonuçlar anlam boyutu ile örgütsel adalet kavramının boyutları arasındaki ilişkinin varlığını göstermektedir. Sadece yetkinlik, otonomi ve etki boyutlarına nazaran daha düşük bir değere işaret etmektedir. Ayrıca katılımcıların ölçeklerde yer alan sorulara verdikleri yanıtlara göre psikolojik güçlendirme boyutları, algıladıkları örgütsel adaletten daha yüksek bulunmuştur. Bu oran çalışanların işlerini daha anlamlı, yetkin, etkili ve özerk bir şekilde yapabilmelerine verdikleri öneme işaret etmektedir. 
Çalışmada elde edilen sonuçlar doğrultusunda birtakım önerilerde bulunulmuştur. Çalışmanın sonuçlarına göre en zayıf bulunan ilişki psikolojik güçlendirmenin anlam boyutu ile örgütsel adalet kavramının boyutları arasında tespit edilen ilişkidir. Bu bağlamda çalışanların yaptıkları işis sahiplenerek ve özveriyle yapmalarını sağlamak için işi anlamlı kılmak öncelikli olmalıdır. Çünkü çalışan anlamlı bulduğu işi daha etkin ve verimli yapmak için çaba harcayacaktır. Bunun için de görev dağılımları esnasında işin niteliği ve sonuçları çalışanlara anlatılmalıdır. Bu işlem psikolojik güçlendirmenin anlam boyutuna işaret ettiği gibi örgütsel adaletin işlem adaleti boyutuna da işaret etmektedir. Diğer yandan, çalışanlara kendilerini rahatça ifade edebildikleri özgür çalışma ortamları sunulmalıdır. Böylece psikolojik güçlendirmenin otonomi boyutu desteklenmiş olacaktır. Bunun neticesinde çalışanlar arasındaki ilişkilerde söz konusu olan adaletin etkileşim boyutu anlam kazanacaktır.

Örgüt içerisindeki adaleti sağlayabilmek için işe alım ve değerlendirme süreçlerinde liyakata göre işlem yapılmalıdır. Bu şekilde haksızlığın önüne geçilip iş bilene verilmiş olacaktır. Böylece örgütsel adalet işe alım süreçlerinde de sağlanmış olacaktır. Kişiler ister yönetici olsun ister çalışan, sahip oldukları bilgi ve becerilerden kaynaklı güçlerini işlerine faydalı olacak şekilde kullanmalıdırlar. Başkalarının hakkını yemeden adil olmalılardır. Başka bir ifadeyle kişiler sahip oldukları güçleri kötüye kullanmamalılardır. Bunu sağlayabilmek için de örgüt içerisinde etkin denetleme mekanizmaları oluşturulmalıdır. Örgütsel adaletin dağıtım adaleti boyutu kapsamında ekonomik ve sosyal kaynaklar çalışanlar arasında adil bir düzen içerisinde paylaştırılmalıdır. Özellikle terfi, maaş zammı ve teşviklerde hakkaniyet ve eşitlik unsurları göz ardı edilmemelidir.

\section{Kaynakça}

- Akbulut, 2010. Sosyal Bilimlerde SPSS Uygulamaları. İstanbul: İdeal Yayıncılık.

- Allen, Shore and Griffeth, 2003. "The Role of Perceived Organizational Support and Supportive Human Resource Practices in the Turnover Process", Journal of Management, 29 (1), p. 100.

- Alvandi, Foroghi and Suleymani, 2014. "The Relationship Between the Organizational Justice and Empowerment of the Employees of Hamadan Sport and Youth Government Offices in Iran", International Research Journal of Applied and Basic Sciences, 8 (2), p. 146.

- Aytemiz Seymen, Kılıç ve Saç, 2013. "Örgütsel Adalet Algısının Oluşmasında "Başkalarına Dönük Uygulamaların” Anlamlı Etkisi Var Mıdır?", 21. Ulusal Yönetim ve Organizasyon Kongresi Bildiriler Kitabı, s. 527.

- Azeem, Abrar, Bashir and Zubair, 2015. "Impact of Organizational Justice and PsychologicalEmpowerment on Perceived Organizational Performance: The Mediating Role of Organizational Citizenship Behaviour", American Journal of Industrial and Business Management, 5, p. 272.

- Bolat, 2003. "Personeli Güçlendirme: Davranışsal ve Bilişsel Boyutta İncelenmesi ve Benzer Yönetim Kavramları ile Karşılaştırılması", Íktisadi ve İdari Bilimler Dergisi, 17 (3-4), s. 203-204.

- Burns and Bush, 2015. Pazarlama Araştırması. Ankara: Nobel Yayınları.

- Cohen, 1987. "Distributive Justice: Theory and Research". Social Justice Research, 1 (1), p. 20.

- Cohen-Charash and Spector, 2001. "The Role of Justice in Organizations: A Meta-Analysis", Organizational Behavior and Human Decision Processes, 86 (2), p. 281.

- Colquitt, Conlon, Wesson, Porter and Ng, 2001. "Justice at the Millennium: A Meta-Analytic Review of 25 Years of Organizational Justice Research", Journal of Applied Psychology, 86 (3), p. 425.

- Conger and Kanungo, 1988. "The Empowerment Process: Integrating Theory and Practice", The Academy of Management Review, 13 (3), p. 472-473.

- Cropanzano, Bowen and Gilliland, 2007."The Management of Organizational Justice", Academy of Management Perspectives, 21 (4), p. 36.

- Cropanzano, Byrne, Bobocel and Rupp, 2001. "Moral Virtues, Fairness Heuristics, Social Entities, and Other Denizens of Organizational Justice", Journal of Vocational Behavior, 58, p. 167.

- Çakmak, 2005. Performans Değerlendirme Sistemlerinde Örgütsel Adalet Algısı ve Bir Örnek Olay Çalışması (Basılmamış Yüksek Lisans Tezi). İstanbul Üniversitesi, Sosyal Bilimler Enstitüsü, İstanbul.

- Dai and Xie, 2016. "Review and Prospect on Interactional Justice", Open Journal of Social Sciences, 4, p. 56.

- Doğan, (2002). "İşgörenlerin Adalet Algılamalarında Örgüt İçi İletişim ve Prosedürel Bilgilendirmenin Rolü", Ege Akademik Bakış, s. 72.

- Gegez, 2015. Pazarlama Araştırmaları. İstanbul: Beta Yayınları.

- Greenberg, 1987. "A Taxonomy of Organizational Justice Theories", Academy of Management Review, 12 (1), p. 19.

- Greenberg, 1989."Cognitive Reevaluation of Outcomes in Response to Underpayment Inequity", The Academy of Management Journal, 32 (1), p. 174. 
- Greenberg, Ashton-James and Ashkanasy, 2007. "Social comparison Processes in Organizations", Organizational Behavior and Human Decision Processes, 102, p. 24-25.

- Huseman, Hatfield and Miles, 1987. "A New Perspective on Equity Theory: The Equity Sensitivity Construct", Accidemy of Management Review, 12 (2), p. 222.

- İçerli, (2010). "Örgütsel Adalet: Kuramsal Bir Yaklaşım", Girişimcilik ve Kalkınma Dergisi, 5 (1), s. 69.

- İyigün, 2012. "Örgütsel Adalet: Kuramsal Bir Yaklaşım", İstanbul Ticaret Üniversitesi Sosyal Bilimler Dergisi, 11 (21), s. 59.

- Kalaani, Rad and Mozaffari, 2014. "The Influence of Organizational Justice on the Psychological Empowerment of Youth and Sports Organization Employees in Ilam", Indian Journal of Fundamental and Applied Life Sciences, 4, p. 2159.

- Kalat, 1993. Introduction to Psychology. California: Wadsworth Inc.

- Kalay, 2016. "İşletmelerde Örgütsel Adaletin İşgören Performansı Üzerindeki Etkisi: Teorik Bir İnceleme", Kastamonu Üniversitesi İktisadi ve İdari Bilimler Fakültesi Dergisi, 11, s. 147-148.

- Kamalian, Yaghoubi and Moloudi, (2010). "Survey of Relationship between Organizational Justice and Empowerment (A Case Study)", European Journal of Economics, Finance and Administrative Sciences, 26, p. 165.

- Koçel, 2015. İşletme Yöneticiliği. İstanbul: Beta Yayıncılık.

- Laschinger, Finegan, Shamian and Wilk, 2004. "A Longitudinal Analysis of the Impact of Workplace Empowerment on Work Satisfaction", Journal of Organizational Behavior, 25, p. 527-528.

- Luthans, 2011. Organizational Behavior: An Evidence-Based Approach (12. Bask1). New York: The McGraw-Hill Companies.

- Niehoff and Moorman, 1993. "Justice as a Mediator of the Relationship between Methods of Monitoring and Organizational Citizenship Behavior", The Academy of Management Journal, 36 (3), p. 541.

- Niehoff, Moorman, Blakely and Fuller, 2001. "The Influence of Empowerment and Job Enrichment on Employee Loyalty in a Downsizing Environment", Group \& Organization Management, 26 (1), p. 97.

- Nirmala and Akhilesh, 2006. "An Attempt to Redefine Organizational Justice: In the Right sizing Environment", Journal of Organizational Change Management, 19 (2), p. 138.

- O'Brien, 2010. Structural Empowerment, Psychological Empowerment and Burnout in Registered Staff Nurses Working in Outpatient Dialysis Centers. Degree of Doctor of Philosophy, New Jersey, The State University of New Jersey.

- Özmen, Arbak ve Süral Özer, 2007. "Adalete verilen Değerin Adalet Algıları Üzerindeki Etkisinin Sorgulanmasına İlişkin Bir Araştırma", Ege Akademik Bakış, 7 (1), s. 22-23.

- Saufi, Kojuri, Badi and Agheshlouei, 2013. "The Impacts of Organizational Justice and Psychological Empowerment on Organizational Citizenship Behavior: The Mediating Effect of Job Involvement", International Journal of Research in Organizational Behavior and Human Resource Management, 1 (3), p. 116.

- Siegall and Gardner, 2000. "Contextual Factors of Psychological Empowerment", Personnel Review, 29 (6), p. 706 .

- Spreitzer, 1995. "An Empirical Test of a Comprehensive Model of Intrapersonal Empowerment in the Workplace", American Journal of Community Psychology, 23 (5), p. 603-605.

- Spreitzer, 1995. "Psychological Empowerment in the Workplace: Dimensions, Measurement, and Validation", Academy of Management Journal, 38 (5), p. 1442-1444,1464-1465.

- Spreitzer, Janasz and Ouinn, 1999. "Empowered to Lead: The Role of Psychological Empowerment in Leadership", Journal of Organizational Behavior, 20, p. 512.

- Spreitzer, 2008. "Taking Stock: A Review of More Than Twenty Years of Research on Empowerment at Work", Handbook of Organizational Behavior, p. 56.

- Spreitzer, Kizilos and Nason, 1997. "A Dimensional Analysis of the Relationship between Psychological Empowerment and Effectiveness, Satisfaction and Strain", Journal of Management, 23 (5), p. 682.

- Stroh, Northcraft and Neale, 2002. Organizational Behavior (3. Bask1). New Jersey: Lawrence Erlbaum Associates, Inc., Publishers.

- Thomas and Velthouse, 1990. "Cognitive Elements of Empowerment: An "Interpretive" Model of Intrinsic Task Motivation", Academy of Management Review, 15 (4), p. 667-673. 
- Tsai, 2012. An Empirical Study of the Conceptualization of Overall Organizational Justiceand Its Relationship with Psychological Empowerment, Organizational Commitment and Turnover Intention in Higher Education. Doctor of Philosophy, University of Washington.

- Yüksekbilgili ve Hatipoğlu, 2015. "Kuşaklara Göre Örgütsel Adalet Algısı", Gaziantep University Journal of Social Sciences, 14 (2), s. 403-404.

- Yürür, 2008. "Örgütsel Adalet ile İş Tatmini ve Çalışanların Bireysel Özellikleri Arasındaki İlişkilerin Analizine Yönelik Bir Araştırma", Süleyman Demirel Üniversitesi İktisadi ve İdari Bilimler Fakültesi Dergisi, 13 (2), s. 296.

- Yürür ve Demir, 2011. "Örgütsel Adalet ve Psikolojik Güçlendirme: Karşılıklı Etkileri Üzerine Bir Araştırma", Süleyman Demirel Üniversitesi İktisadi ve İdari Bilimler Fakültesi Dergisi, 16 (3), s. 311. 


\title{
Finansal Büyüme ve İnovasyon İlişkisi: OECD The Nexus between Financial Development and Innovation: Case of OECD
}

\author{
Prof. Dr. Harun Bal (Çukurova University, Turkey) \\ Asst. Prof. Dr. Erhan İşcan (Çukurova University, Turkey) \\ Ph.D. Candidate Duygu Serin (Çukurova University, Turkey) \\ Ph.D. Candidate Duygu Kara (Çukurova University, Turkey)
}

\begin{abstract}
Finance-growth nexus is a very known topic in the finance literature and most of the studies confirmed the finance-led growth hypothesis for all developed and developing countries. On the other hand, numerous studies investigated the impact of innovation on economic growth and found a substantial effect of the innovation. Especially for the last two decades almost every study agreed on the positive impact of financial development and innovation on growth. Besides various innovation-based growth models indicated that financial development is one of the main promoter of innovation-based economy. Financial development affects the efficiency of the market or the firm and this increases the innovation capacity. Despite this, only few studies focused on the relation of financial development and innovation. The main purpose of this study is to analyze the relationship between the financial development and innovation for selected OECD countries. Especially this study highlighted the changing role of the financial markets to promote the innovative activity of OECD countries. For this purpose, ARDL model employed to analyze the nexus between the financial development and innovation. The empirical findings of this study provided more knowledge to implement more effective policies to policymakers.
\end{abstract}

\section{Giriş}

İnovasyon; küresel sorunların çözülmesine yardımcı olan, verimliliği artırıcı hizmetleri geliştiren, yeni üretim teknikleri geliştiren, yeni istihdam olanakları sağlayan, insanların yaşam kalitelerini artıran, yeni teknolojileri ve yeni ürünleri beraberinde getiren ve bu özellikleriyle ekonomik büyüme sürecine ciddi katkılar sağlayan önemli bir faktördür (Işık ve Kılınç,2016). İnovasyon, sadece ülkelerin gelişimi ve büyümesi için değil, faaliyet gösterdikleri sektörde rekabet güçlerini ve büyümelerini sürdürmeyi hedefleyen firmalar için de anahtar faktör haline gelmiştir. Bu nedenle inovasyon, hem mikro hem de makro yönden ekonomide önemli bir kavram olmaktadır. Son yıllarda artan teknolojik gelişmelere paralel olarak toplumlar hızlı tüketim kültürüne sahip olmakta, bu da pazarda faaliyet sürdürmekte olanlar için önemli inovasyonlar gerektirmektedir. Modern ekonomide inovasyon, değer yaratma, büyüme ve istihdam için önemlidir ve inovasyon süreçleri, kurumsal, bölgesel ve ulusal düzeyde gerçekleşir. İnovasyon, yeni işletmelerin yanı sıra mevcut işletmelerin rekabet gücünün artmasına da yol açacaktır (Işık ve Kılınç,2016).

20. yüzyılın başlarında inovasyonun çoğunlukla reel sektör ile ilişkili olduğu düşünülmüş ve bu düşünce Schumpeter tarafindan eserlerinde öncül hale getirilmiştir. Schumpeter, ekonomik büyüme ve teknolojik inovasyon için finansın önemli olduğunu vurgulamıştır. Bununla birlikte, yenilik sadece reel sektördeki oluşumu ile sınırlı kalmamakla birlikte, finansal piyasalarda da gerçekleşen yeniliklere atıfta bulunarak, "finansal inovasyon" olarak adlandırılan finansal sektörde de önemli bir yere sahip olmuştur (Hergüner, 2015)

Ekonomik ve teknolojik ilerlemenin teşvik edilmesi için iyi bir finansal sistemin olması gerektiği uzun zamandır tartışılan bir konu olmuştur. Finansal gelişme, bilgi ve işlem maliyetlerini düşürerek ekonomik büyümeyi arttırmaktadır. Modern finansal kalkınma teorisinde finansal gelişme, daha iyi bir finansal hizmet sunabilen ve teknik yeniliği sağlayabilen inovasyonu teşvik etmektedir.

Finansal sistemin inavasyon aktiviteleri ve ekonomik gelişmeyi nasıl etkilediğine baktığımızda; finansal aracılar (örneğin, bankalar) piyasadaki kusurların varlığı nedeniyle ortaya çıkar ve gelişir (yani mükemmel bilgi eksikliği ve kusursuz rekabet). Bu durum, bilgi edinme, mal ve hizmet alışverişi ve sözleşmelerin uygulanması gibi işlem maliyetlerini yaratmaktadır. Finansal sektör (diğer bir deyişle, mali aracılık alanında uzmanlaşmış olan tüm kurumların toplamı), bu pazarın kusurlarını azaltmaya veya aşmaya yardımcı olan belirli finansal hizmetleri sağlar ve böylece işlem maliyetlerini düşürür. Sonunda, finansal aracılığın ortaya çıkışı ve gelişimi, finansal pazarlar olmaksızın bir dünya karşısında daha verimli ekonomik sonuçlara katkıda bulunmaktadır. Yenilikçi (girişimci) faaliyet, finansal arabulucuların faaliyetleri ve belirli finansal hizmetlerin sağlanmasıyla daha yenilikçi bir faaliyete yönlendirilebilen belirli pazar kusurları ve işlem maliyetleriyle ilişkilendirilmektedir (Meierrieks, 2014).

Bu çalışmanın temel amacı, OECD ülkelerinde finansal büyüme ve inovasyon ilişkisini ve bu ilişkinin yönünü ve boyutunu ortaya çıkarmaktır. Bu amaçla öncelikle finansal büyüme ve inovasyon arasındaki ilişki, yapılmış olan çalışmalar da özetlenerek teorik olarak ortaya konulmuş, daha sonra ARDL modeli kullanılarak finansal büyüme ve inovasyon arasındaki ilişki analiz edilmiştir (Gülmez ve Yardımcıoğlu, 2012) 


\section{Finansal Büyüme-İnovasyon İlişkisi ve Literatür Taraması}

Literatürde inovasyon üzerine birçok çalışma yapılmasına rağmen finansal büyüme ve inovasyon ilişkisi üzerine daha az sayıda çalışma yapıldığı görülmüştür. Bu konu ile ilgili yapılan çalışmaları şu şekilde özetleyebiliriz:

Hanley, Liu ve Vaona (2011), Çindeki 30 şehrin (Tibet hariç) 2000-2008 dönemlerini kapsayan çalışmalarında, doğrudan yabancı sermaye yatırımları, finansal büyüme ve inovasyon ilişkisi araştırılmış, diğer çalışmaların aksine doğrudan yabancı sermaye yatırımlarının inovasyon üzerine etkisinin çok az olduğu ve bölgenin finansal derinliğinin bölgesel inovasyon performası üzerinde pozitif etkiye sahip olduğu sonucuna ulaşmışlardır.

Laeven, Levine ve Michalopoulos (2011), 1960-1995 dönemini kapsayan 63 ülke için kesitsel verileri ve resesyon yöntemini kullanarak yaptığ ç̧alışmalarında, finansal ve teknolojik inovasyon ile ekonomik büyüme ilişkisi incelenmiş, çalışmada finansörlerin inovasyona devam etmedikleri sürece teknolojik inovasyon ve ekonomik büyümenin duracağı sonucuna ulaşılmıştır. Ayrıca çalışmaya göre, finansal inovasyonu engelleyen kurumlar, yasalar, yönetmelikler ve politikalar, teknolojik değişimi ve ekonomik büyümeyi yavaşlatmaktadır.

Hsu, Tian ve Xu (2014), 1976-2006 yılları arasında 32 gelişmiş ve gelişmekte olan ülkeler için panel veri analiz yöntemini kullanarak yaptıkları çalışmada, hisse senedi ve kredi piyasası büyümesinin ekonomik mekanizmalar aracılığıyla inovasyonu olumlu etkilediği ve finansal büyümenin inovasyonu arttıracağı sonucuna ulaşmışlardır.

Meierrieks (2014), 1993-2008 dönemlerini kapsayan 51 gelişmiş ve gelişmekte olan ülke için kesitsel zaman serisi yöntemini kullanarak yaptığı çalışmada, finansal büyümenin inovasyon üzerindeki etkisini açıklamaya çalışmış ve finansal büyüme seviyesindeki artışların daha güçlü bir inovasyonu meydana getirdiği sonucuna ulaşmıştır. Ayrıca çalışma, finansal sistemin bir ulusun inovasyon altyapısının önemli bir bileşeni olduğu bu nedenle inovasyonu olumlu bir şekilde etkilediği sonucunu desteklemiştir.

Tee, Low, Kew ve Ghazali (2014), 1998-2009 yılları arasında yedi Doğu Asya ülkesi için (Endonezya, Japonya, Güney Kore, Malezya, Filipinler, Singapur, Tayland) panel verilerini kullanarak inovasyon ile ilgili faaliyetlerin desteklenmesinde finansal büyümenin rolünü incelemişlerdir. Finansal sektörün büyüklüğü, banka aktiviteleri ve borsanın genel faaliyetinin patent başvuruları üzerine olumlu etkiler yarattığı sonucuna ulaşmışlardır.

Aristizabal, Botero ve Canavire (2015) gelişmekte olan ülkelerin 2006-2013 dönemlerini kapsayan çalışmalarında, finansal büyümenin inovasyon üzerine etkisini araştırmışlar ve finansal büyümenin gelişmekte olan ülkelerde firmanın inovasyon yapma ihtimalini olumsuz yönde etkilediği sonucuna ulaşmışlardır.

Chu, Cozzi, Pan ve Zhang (2016), 105 ülkenin 1980-2009 dönemleri verileri ile resesyon analizi yöntemi kullanarak yaptığı çalışmalarında, patentle koruma, finansal gelişme ve ekonomik büyüme ilişkisi incelenmiş, çalışmanın sonucuna göre faiz kanalı ile patentin korunması, daha yüksek bir finansal büyüme seviyesinde inovasyon üzerinde olumsuz bir etkiye yol açabilecektir.

Zhao (2016), 2003-2014 dönemleri arasında Çin ülkesinin 31 şehrini kapsayan panel yöntemi kullanarak yaptığı çalışmada, finansal büyümenin bölgesel inovasyon üzerinde etkisi incelenmiş ve finansal büyümenin inovasyonu olumlu şekilde etkilediği sonucuna ulaşmıştır.

\section{Veri Seti ve Yöntem}

Çalışmada finansal gelişme ve inovasyon arasındaki ilişkisi dinamik panel veri analizi tekniği olan Sistem Genelleştirilmiş Momentler Metodu kullanılarak test edilmiştir. Çalışmada seçilmiş 28 OECD üyesi ülkenin 20032014 dönemini kapsayan yıllık veriler kullanılmıştır. Söz konusu ülkeler şu şekildedir: Almanya Amerika Avusturya, Belçika, Çek Cumhuriyeti, Danimarka, Estonya, Fransa, Finlandiya, Hollanda, İrlanda, İtalya, İspanya, İsveç, İsrail, İngiltere, Japonya, Kore, Lüksemburg, Macaristan, Meksika, Norveç, Portekiz, Polonya, Slovenya, Slovakya, Türkiye, Yunanistan'dır. Uygulamada Ekonomik Kalkınma ve İşbirliği Örgütü (OECD) ve Dünya Bankası (World Development Indicators) veri tabanlarından elde edilen veriler kullanılmıştır. Finansal gelişme ve inovasyon arasındaki ilişkinin açıklanması için oluşturulan model aşağıdaki gibidir:

$$
\operatorname{Lnp}_{i, t}=\boldsymbol{\alpha}_{0}+\beta_{1} \operatorname{Lnp}_{i, t-1}+\beta_{2} \operatorname{Ldc}_{i, t}+\varepsilon_{i, t}
$$

Modelde, i ve t sırasıyla ülke ve zaman periyodunu, $\boldsymbol{\alpha}_{\mathbf{0}}$ sabit terimi ve $\varepsilon_{\mathbf{i}, \mathbf{t}}$ hata terimini ifade etmektedir. Çalışma kapsamında kullanılan değişenler Tablo 1'de yer almaktadır. Değişkenlerin isimlerinin önünde yer alan "L" ise, değişkenlerin logaritmik dönüşümlerinin yapılmış olduğunu ifade etmektedir. 


\begin{tabular}{|l|l|}
\hline Değişkenin $A d \imath$ & Tanımlayıcı Bilgi \\
\hline Patent Sayısı (Lnp) & $\begin{array}{l}\text { İnovasyonun ara çıktı göstergesi olarak kabul edilen patent sayısı } \\
\text { ekonometrik modelin bağımlı değişkenidir. }\end{array}$ \\
\hline $\begin{array}{l}\text { Özel sektöre verilen yurtiçi krediler } \\
\text { toplamı (Ldc) }\end{array}$ & $\begin{array}{l}\text { Finansal gösterge olarak özel sektöre verilen yurtiçi krediler } \\
\text { toplamının GSYİH'ya oranı bağımsız değişken olarak ele } \\
\text { alınmıştır. }\end{array}$ \\
\hline
\end{tabular}

Tablo 1: Analizde Yer Alan Değişkenler Listesi

Çalışmada kullanılan değişkenlere ait veri setlerinin logaritmik dönüşümleri yapılmış ve reelleştirilmiştir. Daha sonra dinamik panel veri analizi yöntemi ile tahmin edilmiştir. Dinamik modeller uygulama kolaylığ ve modellerin tahmin edilmesi için gereken araç değişkenlere kıyasla basit varsayımlara dayandığından literatürde çok sık karşılaşılmaktadır. Analizde dinamik modeller arasında yaygın olarak kullanılan Arellono ve Bover (1995) ve Blundell ve Bond (1998) tarafından geliştirilen iki aşamalı GMM yöntemi kullanılmıştır. GMM yöntemleri bir aşamalı ve iki aşamalı olmak üzere ikiye ayrılmaktadır. Bir aşamalı tahminde hata terimlerinin zaman içinde ve gruplar arasında sabit varyanslı olduğu varsayılmaktadır. İki aşamalı tahmincide ise, hata terimlerinin sabit varyanslı olmadığı kabul edilmektedir. İkinci aşamada birinci aşamadan elde edilen hata artıkları da kullanılmakta bu nedenle iki aşamalı tahmin asimtotik olarak daha güçlü sonuçlar vermektedir (Khadraoui, 2012). Bu yüzden analizde diğer GMM yöntemleri ile karşılaştırıldığında daha iyi bir tahmin edici olan iki aşamalı Sistem-GMM tekniği kullanılmıştır.

\section{Ampirik Sonuçlar}

Modele ilişkin iki aşamalı Sistem-GMM analizi tahmin sonuçları Tablo 2'de yer almaktadır.

\begin{tabular}{|l|l|}
\hline Değişkenler & Katsayılar \\
\hline$L n p_{i, t-1}$ & .9677417 \\
& $(0.000)^{*}$ \\
\hline$L d c_{i t}$ & .0187201 \\
& $(0.000)^{*}$ \\
\hline Wald Testi & $\chi^{2}(2)=867822.57$ \\
& {$[0.0000]^{*}$} \\
\hline Sargan Testi & $\chi^{2}(64)=27.96376$ \\
& {$[1.0000]$} \\
\hline Spesifikasyon Testleri & \\
\hline AR(1) & -2.6269 \\
& {$[0.0086]^{*}$} \\
\hline AR(2) & 1.5265 \\
& {$[0.1269]$} \\
\hline
\end{tabular}

Tablo 2: Modelin GMM Tahmin Sonuçları

Not: *\%1 düzeyindeki anlamlılıkları ifade etmektedir. Parantez içindeki değerler standart sapmaları, köşeli parantezler ise testlerin olasılık değerlerini göstermektedir.

Finansal gelişme ve inovasyon arasındaki ilişkinin incelendiği dinamik panel veri analizi sonuçlarına göre, bağımlı değişkenin gecikmesinin pozitif ve istatistiksel açıdan anlamlı olduğu görülmektedir. Bununla birlikte özel sektöre verilen yurtiçi krediler toplamının GSYİH'ya oranını temsil eden göstergenin ( Ldc $_{\text {it }}$ ) inovasyon üzerine etkisinin pozitif ve anlamlı olduğu tespit edilmiştir. Buna bağlı olarak finansal gelişme sürecinde beklenen, özel kesime verilen kredi hacmindeki artışın inovasyonu pozitif yönde etkilemesidir. Kredi hacminde \%1'lik artış olmasının inovasyon üzerinde 0.018 oranında artış yaratacağının bir göstergesidir. Wald testi, modelde kullanılan değişkenlerin bir bütün olarak anlamlı olup olmadığını test etmektedir. Modelde hesaplanan Wald testi olasılık değerine bakıldığında model bir bütün olarak anlamlı bulunmuştur. Modelde kullanılan araç değişkenlerin uygun olup olmadığının analizi için Sargan testinin yapılması gerekmektedir. Sargan testinin olasılık değeri beklenen şekilde araç değişkenlerin içsellik sorunu taşımadığını ve araç değişkenlerin tam ve doğru olduğunun göstergesidir. Dinamik panel veri analiz tekniği olan Sistem-GMM yönteminde birinci dereceden otokorelasyon olması modelin kendi yapısı gereği sıklıkla karşılaşılan bir durum olduğundan önem arz etmemektedir. Ancak tahmin sonuçlarının tutarlı ve etkin olması için modelin ikinci dereceden otokorelasyon sorununun olmaması gerekmektedir. Tabloya bakıldığında modelde beklenildiği gibi birinci dereceden otokorelasyon bulunduğu ancak ikinci dereceden otokorelasyon olmadığı görülmektedir. Dolayısıyla Sistem-GMM tahmin sonuçları etkin ve tutarlıdır. 


\section{Genel Değerlendirme}

Günümüzde gelişmişlik derecesi ne olursa olsun bütün ülkeler için gelişme ve kalkınma sürecinin sürekliliğinin sağlanması amacıyla yatırımların artırılması gerekmektedir. Dolayısıyla çalışmada finansal gelişimin inovasyon üzerine etkisi seçilmiş OECD ülkeleri için dinamik panel veri analizi tekniği olan Sistem-GMM yöntemi ile incelenmiştir. Çalışma sonuçları teorik literatürle uyumlu olarak, finansal gelişimi destekleyen bileşenlerden birinin inovasyon olduğunu açıklamaktadır. Özel sektöre verilen kredi hacminin GSYİH içindeki oranının artması ülkelerin yenilik süreçlerinin önünün açılmasına ve gelişmişlik derecesinin yükselmesine katkı sağlamaktadır. Ayrıca finans piyasalarında kredi hacminin artması iktisadi aktörler arasında ilişkilerin hızlanmasını ve buna bağlı olarak iktisadi faaliyetlerin hız kazanmasına neden olmaktadır.

\section{Teşekkür}

Bu çalışma Çukurova Üniversitesi Bilimsel Araştırma Projeleri Birimi tarafindan desteklenmektedir.

\section{Kaynakça}

- Arellano, M., \& Bover, O. (1995). Another look at the instrumental variable estimation of error-components models. Journal of econometrics, 68(1), 29-51.

- Aristizabal, Canavire and Botero, 2015. "Does Financial Development Promotes Innovation In Developing Economies? An Empirical Analysis", Escuela de Economia y Finanzas, p. 22.

- Blundell, R., \& Bond, S. (1998). Initial conditions and moment restrictions in dynamic panel data models. Journal of econometrics, 87(1), 115-143.

- Chu, Cozzi, Pan and Zhang, 2016. "Do Stronger Patents Stimulate or Stifle Innovation? The Crucial Role of Financial Development”, Munich Personal Repec Archive, p. 30.

- Gerguri and Ramadani, 2010. “The Impact of Innovation Into The Economic Growth”, Munich Personal Repec Archive, p. 22.

- Gülmez, A., \& Yardımcıoğlu, F. (2012). OECD Ülkelerinde Ar-Ge Harcamaları ve Ekonomik Büyüme İlişkisi: Panel Eşbütünleşme ve Panel Nedensellik Analizi (1990-2010). Maliye Dergisi, 163, 335-353.

- Hanley, Liu and Vaona, 2011. "Financial Development and Innovation in China: Evidence From The Provincial Data”, Kiel Working Paper, 1673, p. 33.

- Hergüner, 2015. "Financial Innovations in Developing Countries The Case Of Turkey", Middle East Technical University, The Department of Economics, p. 115.

- Hsu, Tian and Xu, 2014. "Financial Development and Innovation: Cross-Country Evidence”, Journal of Financial Economics, p. 116-135.

- Işık, N., \& Kılınç, A. G. E. C. (2016). İnovasyon-Temelli Ekonomi: Seçilmiş Ülkeler Üzerine Bir Uygulama. Anadolu Üniversitesi Sosyal Bilimler Dergisi, 16(1).

- Khadraoui, N. (2012). Capital Movements and Economic Growth Fluctuations: The Threshold Effect of Financial Development. International Journal of Economics and Finance, 4(4), p193.

- Laeven, Levine and Michalopoulos, 2011. "Financal Innovation and Endogenous Growth", Brown University and NBER, p. 46.

- Meierrieks, 2014. "Financial Development and Innovation: Is There Evidence of a Schumpeterian FinanceInnovation Nexus?", Annals of Economics And Finance, 15-2, p. 343-363.

- $\quad$ Tee, Kew, Low and Ghazali, 2014. "Financial Development and Innovation Activity: Evidence From Selected East Asian Countries”, Progue Economic Papers, 2, p.478.

- Zhao, 2016. "Financial Development and Regional Innovation Output Growth: Based on Empirical Analysis of Provincial Panel Data in China", Modern Economy, 7, p. 19. 


\title{
Entelektüel Sermaye ile Firma Finansal Performansı İlişkisi; BİST'te İșlem Gören Bankalar Üzerine Bir Ekonometrik Analiz
}

\section{The Relationship between Intellectual Capital and Firm Financial Performance; An Econometric Analysis on the Banks which Processed to the BIST}

\author{
Ph.D. Candidate Reşat Sakur (Şırnak University, Turkey)
}

\begin{abstract}
Nowadays, the rapid development of information, communication and information technology increases the importance of information. The concept of knowledge management for businesses is becoming the biggest competitive element of the business and the prospect of intangible assets is steadily increasing. This situation gives priority to the concept of intellectual capital, which contributes the most to the value of the enterprises. In the literature, there are many studies on the relationship between intellectual capital concept and firm financial performance, and these studies generally focus on how intellectual capital is calculated. Human capital, structural capital and customer capital, which are the elements of the intellectual capital concept, are more prominent in the banking sector than the service producing sectors and are more evident than the company performance.

The aim of our work is to examine the effect of intellectual capital on banks operating in Turkey and whose stocks are traded on the Stock Exchange Istanbul. In this context, the Intellectual Value Added Coefficient (VAIC) method developed by Ante Pulic was used to calculate the intellectual capital of the banks. In our study, the data of 13 banks under independent supervision during the period of 2009-2016 were analyzed by panel data analysis method and the relationship between intellectual capital and profitability of the banks, profitability of assets, net profit margin and equity profitability ratios were tested. As a result of the analysis made, a positive relationship was found between the intellectual capital of the banks and the financial performance.
\end{abstract}

\section{Giriș}

İlkel toplumlarda sadece hayatın idame edilmesi ve belirli durumlarda ihtiyaç duyulan bilgi kavramı günümüzde yaşamın her alanında kullanılmaya başlanmış ve her geçen zaman bilginin önemi daha da artmıştır. Bilginin bu denli çabuk değişmesi ve gelişen teknoloji ile uluslar arasındaki uçurumun kalkması bilginin güncelliğini takip etmeyi zorlaştırmıştır. İşletmeler başarılı olabilmek için bilgiye yoğun bir ihtiyaç duymakta ve bilgiyi elde tutma ve doğru kullanmak adına büyük yatırımlar yapmaktadır. Eskiden aktifleri büyük olan işletmeler başarılı olabilmekteyken günümüzde bilgi yoğunluğuna sahip olabilen ve sahip olduğu bu bilgiyi doğru zamanda ve doğru bir şekilde kullanabilen işletmeler başarılı olmaya başlamışlarıdır. İşte bu bilginin ve bilgi yönetiminin önemi, işletmelerde entelektüel sermaye kavramını ortaya çıkarmıştır. Entelektüel sermaye kavramı ilk olarak J. Kenneth Galbraith tarafından 1969 yılında kullanılmış ve son yıllarda gerek akademik gerekse iş dünyası tarafından temel bir ilgi alanı olmaya başlamıştır. Leif Edvinsson ilk profesyonel entelektüel sermaye yöneticisi olup entelektüel sermayeyi ''değere dönüşen bilgi' 'olarak tanımlamıştır. Stewart ise 1997 yılındaki 'Entelektüel Sermaye, Kuruluşların Yeni Zenginliği’” adlı eseriyle entelektüel sermaye konusunda bir öncü konumuna gelmiştir.

Entelektüel sermaye kavramı günümüzde işletmelerin, en çok önemsediği ve rakiplerine rekabet üstünlüğü sağlayabilmek ve başarılı olabilmek için entelektüel sermaye unsurları olan yapısal sermaye, insan sermayesi ve müşteri sermayesi unsurlarına yoğun bir yatırım yaptığı gözlenmektedir. Entelektüel sermaye kavramı hesaplanması konusunda literatürde çok sayıda hesaplanma yöntemi bulunmakta ve kullanılmakta olup bu hesaplama yöntemlerinden en çok kabul görmüş olanı 1998 yılında Ante Pulic tarafindan geliştirilen Entelektüel Katma Değer Katsayısı (VAIC) hesaplama yöntemi çalışmamızda kullanılacaktır.

Çalışmamızda, entelektüel sermayenin temeli olan bilgi ve yönetimi kavramlarından bahsedilmiş, entelektüel sermaye kavramı ve unsurları tanımlanarak konu ile ilgili literatür çalışmalarından bahsedilmiştir. Çalışmanın analiz kısmında ise Borsa İstanbul'a kote olmuş 2009-2016 yılları verilerine tam olarak ulaşılabilen 13 bankanın entelektüel sermaye ile finansal performans arasındaki ilişkisi ekonometrik model yardımıyla incelenmiş ve entelektüel sermaye ile finansal performans ölçütlerinden olan karlılık arasında anlamlı bir ilişki tespit edilmiştir.

\section{Bilgi Kavramı ve Bilginin Yönetimi}

Günümüz dünyasında işletmelerin başarıya ulaşabilmesinin en önemli anahtarı, doğru bilgiyi doğru zamanda elde ederek, bu bilgiyi iyi yönetebilmektir. Teknolojinin hızla değiştiği günümüzde bilginin stabil olmadığı, sürekli gelişip güncellendiği ve geçmişten günümüze gerek yazılı gerek sözlü gerekse nesnelere yüklenerek geldiği bilinen bir gerçektir. Geçmişten günümüze kadar bilgi, dört devrim yaşamış olup içinde bulunduğumuz dördüncü bilgi devrimidir. Bu bilgi devrimlerinin ilki 5000-6000 yıl önce Mezopotamya'da, sonra birkaç bin yıl sonra Çin’de ve 
1500 yıl kadar sonra da Mayalar tarafından Orta Amerika'da yazının icat edilmesiyle gerçekleşmiştir. İkinci Bilgi Devrimi, Yunanistan'da ezberde olan Homeros destanının yazıya dökülmesi sonucu kitabın icadı ile olmuştur. Üçüncü Bilgi Devrimi, Alman Gutenberg'in 1450'lerde matbaayı icat etmesiyle başlamış, çağdaş oymacılığın icadıyla devam etmiştir. En son olan dördüncü Bilgi Devrimi ise günümüzü de kapsayan, bilgisayarın yoğun olarak kullanıldığı, Yönetim Bilgi Sistemlerinin geliştiği, bilgi teknolojilerinin yoğunlaştı̆̆ı, bilginin hızla yayıldı̆̆ ve çok hızlı gelişip her an her yerde ulaşılabilir olduğu dönemdir (Drucker, 2007).

\section{Entelektüel Sermaye Kavramı}

İşletmelerin sahip oldukları sermaye, genel olarak üç kavram şeklinde değerlendirilebilir. Bunlardan birincisi olan ve geçmişten günümüze işletmelerde önem ağırlığını bir nebze yitiren fiziksel sermaye, ikinci olarak da işletmelerin sahip oldukları nakit varlık, menkul değerler ve kredi ve benzer finansal varlıklarından oluşan finansal sermaye, en son olarak da günümüzde bu diğer iki sermayeye göre işletmeler için daha fazla önemli olan ve işletmeye rakiplerine karşı rekabet gücü sağlayan entelektüel sermaye olarak tanımlanabilir.

İşletmelerin, soyut ve manevi değerlerinden yararlanarak istediği sonuca ulaşması, fiziki varlıklarına yatırım yaparak sonuca ulaşabilmesinden daha önemli hale gelmiştir (Tıwana, 2003). İşletmeler istediği kadar fiziki varlıklara sahip olursa olsun, bilgiyi iyi yönetemeden başarılı olma şansına sahip değildir. Bir işletmenin başarıya ulaşabilmesi için sürekli yeni bilgi üretmesi, ürettiği bu bilgiyi harmanlayıp çabuk yaygınlaştıran ve böylece ürettikleri yeni ürün ve hizmetleri somutlaştırabilmesi gerekir. Bu bağlamda işletmeler için en önemli sermaye olan fikri sermaye olarak da bilinen entelektüel sermaye kavramı önemini her geçen gün arttırmaktadır. Stewart, entelektüel sermayeyi, zenginlik yaratmak üzere kullanıma sokulabilen entelektüel malzemedir, yani bilgi, enformasyon, entelektüel mülkiyet ve deneyimdir şeklinde ifade etmektedir (Stewart, 1997). Entelektüel sermaye bir şirkete rekabet üstünlüğü kazandıran, işletme çalışanlarının bildiği her şeydir. Geleneksel muhasebe anlayışına göre entelektüel sermayenin karşılığı şerefiye olarak bilinir, fakat entelektüel sermayeyi sadece piyasa değeri ile defter değeri arasındaki fark olarak tanımlamak, entelektüel sermayenin ağırlığını taşımaktan oldukça uzaktır (Şamiloğlu, 2002). Entelektüel sermaye, işletmeler ve diğer bütün ekonomik ve sosyal yapıların ürünlerine ve hizmetlerine katkıda bulunarak, her türlü kazanç sağlamalarına ve amaçladıkları değerleri oluşturmaya olanak sağlayan insan kaynağı, bilgi, deneyim, yetenek, fikirler gibi maddi olmayan varlıklarının, bu yapıların birbirleri ve hedef kitleleriyle olan ilişkilerinin çıktıları üzerindeki etkisini belirleyen süreçlerin bir bütünü olarak da tanımlanabilir (Akyüz, 2011). Entelektüel sermaye görünmeyen değerlerden oluşan bir kavramdır. Bu bağlamda entelektüel sermayeyi az çok tanımlayabilen bir kavram olan işletmenin sahip olduğu maddi olmayan varlıklar olarak bilinse de entelektüel sermayeyi, daha çok insan kaynakları ve çalışanların sahip olduğu bilgiden yaratılan katma değer olarak tanımlamak daha doğru olur.

Bir örgütün entelektüel sermayesinin en iyi şekilde üç ana unsurdan oluştuğu konusunda görüş birliği mevcuttur. Buna göre entelektüel sermaye kavramı;

- Yapısal (Örgütsel) Sermaye

- Insan Sermayesi

- Müş̧eri Sermayesi

Şeklinde üç unsura ayrılmaktadır. Bu üç unsurun her birinin işletmelerin sahip olduğu entelektüel sermayesine katkısı farklı yapı ve oranda olmaktadır. Bir sanayi kuruluşunda yapısal sermaye ön planda olabilse de bir pazarlama işletmesinde müşteri sermayesi veya bir finans kuruluşunda insan sermayesi ön planda olabilir.

Yapısal Sermaye; İşletme çalışanlarının verimliliğini destekleyen donanım, yazılım, veri-tabanları, organizasyonel yapı, patentler, markalar ve diğer benzeri şeylerin bütünüdür. Yapısal sermaye, işletmenin bir ürünü üretme aşamasından dağıtım aşamasına kadar sahip olduğu süreçlerin bütünüdür (Şamiloğlu, 2002). Yapısal sermaye bu süreçte ortaya çıkan ürün ve hizmetlerin yanında ortaya çıkan bilgi, patent ve yenilikleri ve işletme içinde edinilen örgüt kültürü ve iklimi, kurum yapısı, yönetim felsefesi, bilgi ve karar sistemleri gibi bilginin işletme içerisinde aktarılmasını, depolanmasını, paylaşılmasını ve çoğaltılmasını da sağlayan bütün sistemlerden oluşmaktadır (Akyüz, 2011). Yani kısacası elde edilen bilginin işletme içinde kalması ve işletme çalışanları kendi düşünce ve ürünlerini toparlamak, paketlemek, tanıtmak ve dağıtmak için bir mekanizmaya gereksinim duyulur. Bu mekanizma entelektüel sermaye açısından yapısal sermaye olarak değerlendirilmektedir (Eren, Akpınar, 2004)

Ínsan Sermayesi; bilindiği gibi örgütler insanlardan oluşan sosyal varlıklardır. İşletmeler de belli bir amacı gerçekleştirmek üzere bir araya gelmiş örgütlü insanlardan oluşmaktadır. Bu insanlar, örgütte bazen alt kademede bir çalışan, bazen de üst kademede bir karar verici konumunda bulunmaktadır. Sonuç olarak örgütlerin hammaddesi insan olup, başarıya ulaşmada insan odaklı olmak insan ilişkileri güçlü ve şirket hedefleri ile bütünleşmiş çalışanlara sahip bir örgüt oluşturmak önem arz etmektedir (Şamiloğlu, 2002). Rekabet avantaj1 sağlamada büyük önem arz eden entelektüel sermayenin insan sermayesi unsuru bu bağlamda hayati öneme sahiptir. Bir örgütün en büyük ve en önemli maddi olmayan kaynağı olarak tanımlanmaktadır. Bu insan sermayesi müşterilerin ihtiyaç duyduğu mal ve hizmetlere ve bunların ortaya çıkardığı sorunlara çözümler sunmaktadır. İnsan sermayesi örgüt içindeki kişilerin ortak bilgi, yetkinlik, deneyim, beceri ve yeteneklerini içermekte ve aynı zamanda organizasyonun yaratıcı kapasitesini ve yenilikçi olma becerilerini de içermektedir. Günümüzde insan 
sermayesine yatırım hızla artmakta ise de insan sermayesi, işletmelerin finansal tablolarında henüz yeterli bir belirginlik ve açıklayıcılıkta değildir (Ghosh, Mondal, 2009).

Müşteri Sermayesi; geçmişte işletmeler üretim odaklı ve müşteri ihtiyaçlarını önemsemeyen bir anlayışa sahipti. Küreselleşme olgusu ve küresel rekabetin hızla yayılması, tüketicileri birbirine yakınlaştırmış ve Pazar ve müşteri yönlü bir pazarlama paradigması ortaya çıkmıştır. İşletmelerin müşteri istek ve ihtiyaçlarını önemsemeden başarıya ulaşmaya çalışması neredeyse imkânsız bir hal almıştır bu sebeple müşteriyi anlama ve keşfetme üzerine yapılan harcamalar işletmelerin giderlerinde önemli bir yer tutmaktadır. Hubert Saint - Onge, müşteri sermayesini, şirketin unvan değeri, satış yaptığı kişi ve kuruluşlarla süregiden ilişkilerin değeri olarak tanımlamaktadır (Stewart, 1997). Pazarlama alanında yapılan çalışmalarda ortaya çıkan en büyük gerçeklik yeni müşteri bulmanın mevcut müşteriyi elde tutmaktan daha pahalı olduğudur. Bu nedenle müşteri ilişkileri büyük bir öneme sahiptir. Entelektüel sermaye unsurlarından en belirgin ve ön planda olan müşteri sermayesidir. Üretim, alım, satım, harcama ve tüketime müşteri konu olmaktadır. Firmanın tüm gelir kalemlerinde ve finansal tablolarında müşteri sermayesinin ayak izi bulunmaktadır. Müşteri sadakati ve güçlü müşteri ilişkileri işletmelerin gelişmesine rekabet edebilmesine ve kısacası ayakta durabilmesine olanak sağlamaktadır.

\section{Literatür Taraması}

Entelektüel Sermaye ile finansal performans arasındaki ilişkiyi ölçme konusunda literatürde çok sayıda çalışma yer almaktadır. Bankacılık üzerine yapılan çalışmalarda kimi yazarlar entelektüel sermayeyi ölçmede anket yöntemi ile veri toplayarak bir analiz yapmıştır, kimi yazarlar ise literatürde yer edinen entelektüel sermayeyi ölçmede kullanılan çeşitli ölçüm yöntemleri kullanarak istatistiki ve ekonometrik analizlerle araştırmasını anlamlandırmaya çalışmıştır.

Yalama ve Coşkun (2007), Türkiye'de İstanbul Menkul Kıymetler Borsası Piyasası'nda (İMKB) işlem gören bankaların entelektüel sermaye (IC) performansını ölçerek entelektüel sermaye performansının kârlılık üzerindeki etkisini test etmiştir. Çalışmada yazarlar, Katma Değer Fikri Katsayısı (VAICTM) olarak adlandırılan verimlilik katsayısını kullanarak İMKB'de işlem gören bankaların entelektüel sermaye performansını ölçmüş ve bu zihinsel sermaye performansının Veri Zarflama Analizi (DEA) kullanılarak kârlılık üzerindeki etkisini test etmiş ve entelektüel sermayenin bankacılık sektöründeki karlılık üzerinde etkisini \%61,3 olarak ölçmüş ve entelektüel sermayenin karlılık üzerinde pozitif bir etkiye sahip olduğu sonucuna ulaşmışlardır.

El-Bannany (2008), çalışmasında İngiltere bankalarında entelektüel sermaye kavramının belirleyicilerini araştırmıştır. Yazar 1999-2005 yılları arası verilerini kullanarak Entelektüel sermayeyi Ante Pulic tarafından geliştirilen Entelektüel katma değer katsayısı yöntemiyle ölçmüş ve entelektüel sermaye performansını bağımlı değişken ve bazı bağımsız değişkenler arasındaki ilişkiyi sınamak için çoklu regresyon analizi kullanılmıştır. Yazar, yatırımların entelektüel sermaye performansı üzerinde önemli bir etkisinin olduğu sonucuna ulaşmıştır.

Murthy ve Mouritsen'in (2008), bankalardaki entelektüel sermaye ile finansal sermaye arasındaki ilişkiyi vaka analizi yoluyla ve görüşmeler yöntemiyle inceleyen çalışmalarında, entelektüel sermayeye yatırım yaparak finansal sermayenin ne yönde etkilendiği tespit edilmeye çalışılmış ve literatürdeki istatistiki bulguların doğruluğu araştırılmıştır. Çalışmada entelektüel sermaye unsurlarının birbirleriyle etkileşimleri haricinde bazen de kendi aralarında rekabet içinde olduğu ve aslında entelektüel sermaye ve finansal sermayenin birbirleriyle bir ilişki içinde olmalarından çok bu iki öğenin birbirinin tamamlayıcısı olduğu bulgusuna ulaşmışlardır.

Yıldız, (2011) 'Entelektüel Sermayenin İşletme Performansına Etkisi: Bankacılık Üzerine bir Araştırma' adlı çalışmasında entelektüel sermayenin işletme performansına etkisinin olup olmadığını yöneticilerin algılarıyla tespit etmeye çalışmıştır. Yazar, İMKB’ye kote olmuş 8 özel sermayeli bankanın 421 yöneticisi ile anket çalışması yapmış ve entelektüel sermayenin unsurlarının bankaların hem sübjektif hem de objektif performansını olumlu yönde etkilediğini gözlemlemiştir. Ayrıca ankete katılan yöneticilerin demografik özellikleri de entelektüel sermaye unsurlarının algılanışında farklılık göstermiştir.

Topaloğlu ve Bayraktar (2012), çalışmalarında entelektüel sermaye kavramını oluşturan insan sermayesi, yapısal sermaye ve müşteri sermayesi unsurlarının bankacılık sektöründe faaliyet gösteren bankalar üzerindeki etkilerini İç Anadolu Bölgesinde yer alan bankaların 475 çalışanı üzerinde anket uygulanmış ve yapılan analiz sonucunda İç Anadolu Bölgesi bankacılık sektöründe entelektüel sermaye unsurlarının varlığının olduğu ve bu bağlamda entelektüel sermaye varlıklarına sahip olan bankaların birbirilerine yakın konumda oldukları ve yapısal sermaye varlığının diğer entelektüel sermaye unsurlarına göre zayıf kalması, bankaların bilişim altyapılarına, kurum içi eğitime, teknolojik gelişmelere ve teknik altyapı anlamında gereken önemin verilmesi ve yatırımların yapılması gerekliliği sonucuna ulaşmışlardır.

Turgut (2016), 'Borsa İstanbul'da İşlem Gören Bankaların, 1999-2000-2001 Ekonomik Krizleri Öncesi Ve Sonrası 5'er Yıllık Dönemlerde Entelektüel Sermayelerindeki Değişimin Analizi' adlı çalışmasında Borsa İstanbul'da işlem gören 17 bankanın 1999-2000-2001 krizleri öncesi ve sonrasındaki 5'er yıllık dönemdeki entelektüel sermayelerindeki değişimi incelemiştir. Çalışmada verilerine ulaşılabilen 7 bankanın 1993-2006 yılları verileri üzerinden grafiksel ve eşleştirilmiş gruplar t-testi ile değişim ortalamaları karşılaştırılarak her iki dönem 
arasında anlamlı bir fark olduğu ve kriz sonrası dönemdeki PD/DD değeri kriz öncesi döneme göre daha yüksek bir değişim sergilemekte olduğu sonucuna ulaşılmıştır.

\section{Veriler, Araştırmada Kullanılan Yöntem ve Araştırma Modeli}

Bu çalışmada Türkiye'de BísT'de işlem gören banka ve özel finans kurumları sektör grubundaki 14 bankadan 2009 ve 2016 yılları arasında verisi ulaşılabilir olan 13 bankanın verileri, bankaların yıllık bağımsız denetim raporlarından elde edilmiştir. Bu veriler ışığında entelektüel katma değer katsayısı (EKDK) hesaplamasında gerek duyulan net faaliyet karı, personel giderleri, amortisman ve itfa payı nominal verileri ile özsermaye karlılı̆̆ını(OSK) hesaplayabilmek için gerekli olan net kar ve özsermaye nominal verileri kullanılarak Eşitlik 1 yardımı ile entelektüel sermayenin firma performans üzerindeki etkisi incelenmiştir.

$$
\text { EKDKit }=\beta 0+\beta 1 \text { OSKit }+\varepsilon \text { it }
$$

Eşitlikte 'EKDK' bankaların sahip olduğu entelektüel sermaye katma değer katsayısını, 'OSK' bankaların özsermaye karlılığını temsil etmektedir. " $\varepsilon$ " hata terimini, " $t$ " zamanı " $i$ " ise birimi yani firmayı göstermektedir. Çalışmada kullanılan tüm veriler kamu aydınlatma platformunun resmî web sayfasında yayınlanan şirketlere ait bağımsız denetim raporlarından derlenmiştir (KAP, 2016).

Çalışmada Ante Pulic (1998) tarafından geliştirilen Entelektüel Katma Değer Katsayısı yani VAIC yöntemi kullanılmış olup, bu yöntemin, hem firmaların finansal tablolarındaki veriler aracılığıyla kolay hesaplanabilir olması, hem de literatürde kabul görmüş bir yöntem olmasından dolayı tercih edilmiştir. Bu yöntem değer yaratabilmek adına fiziksel ve entelektüel sermayeye ihtiyaç duyulması mantığına dayalı bir performans değerleme yöntemidir (Kayalı, Yereli ve Ada, 2007). Bu yöntem işletmenin sahip olduğu maddi olmayan varlıkların değer oluşturma etkinliğini belirlemektedir. VAIC yöntemi üç bileşenin toplamından oluşmaktadır.

Kullanılan Sermaye Etkinliği (Capital Employed Efficiency: CEE)

İnsan Sermayesi Etkinliği (Human Capital Efficiency: HCE)

Yapısal Sermaye Etkinliği (Structural Capital Efficiency: SCE)

$\mathrm{VAIC}=\mathrm{CEE}+\mathrm{HCE}+\mathrm{SCE}$

Ancak VAIC'ın hesaplanabilmesi için öncelikle Katma Değer'in (VA) hesaplanması gerekmektedir. Ante Pulic'in önerdiği hesaplama formülü aşağıdaki gibidir:

$$
\mathrm{VA}=\mathrm{OP}+\mathrm{EC}+\mathrm{D}+\mathrm{A}
$$

VA (Value Added) : Katma Değer

OP (Operating profit) : Faaliyet Karı

EC (Employee Costs) : Personel Giderleri

D (Depreciation) : Tükenme ve İtfa Payları

A (Amortisation) : Amortisman

Kullanılan Sermaye Etkinliği: Toplam Katma Değer'in (VA) Kullanılan Sermaye'ye bölünmesi yoluyla hesaplanmaktadır (CEE=VA/CE).

Insan Sermayesi Etkinliği: Toplam Katma Değer'in(VA) İnsan Sermayesine bölünmesiyle elde edilir. Burada insan sermayesinden kasit 'personel giderleri' olup işletmelerin finansal tablolarından kolaylıkla ulaşılabilmektedir $(\mathrm{HCE}=\mathrm{VA} / \mathrm{HC})$.

Yapısal Sermaye Etkinliği: Hesaplanması diğer iki değişkene nazaran farklılık göstermektedir. Pulic, değer katma sürecinde İnsan Sermayesi ile Yapısal Sermaye arasında ters orantılı bir ilişkinin olduğunu savunmaktadır. $\mathrm{Bu}$ görüşten hareketle Yapısal Sermaye etkinliği (SCE), yapısal sermayenin (SC) toplam katma değere (VA) bölünmesi yoluyla hesaplanmaktadır. Buradaki yapısal sermaye değeri ise, işletmenin oluşturduğu toplam katma değerden insan sermayesinin çıkartılması sonucu elde edilmektedir (SCE=SC/VA; SC=VA-HC) (Şen, 2014).

Özsermaye Karlılı̆̆ı: Bankacılık sektöründe bir finansal performans göstergesi olan özsermaye karlılığının hesaplaması, firmanın net karının firma özsermayesine bölünmesiyle bulunmaktadır (Net Kar / Özsermaye).

Kurulacak modelde hem birim hem de zaman boyutu olduğundan dolayı değişkenler arasındaki ilişkiler panel veri analizleri ile test edilmiştir. Panel data hem zaman hem de birim boyutu içerdiğinden dolayı daha yüksek gözlem sayıları ile çalışma imkânı sunmaktadır (Verbeek, 2008). Panel veri analizlerinde, zaman serisi verilerinde olduğu gibi değişkenlerin durağan olması önem arz etmektedir. Durağan olmayan seriler ile kurulacak bir modelde, elde edilen parametreler değişkenler arasındaki gerçek ilişkiyi yansıtmaktan ziyade, serilerde var olan aşağı veya yukarı yönlü bir trendden kaynaklanabilir. Sahte regresyon olarak adlandırılan böyle bir olgudan kaçınmak için serilerin durağanlığı incelenerek uygun gecikmede modele dâhil edilmelidir (Tarı, 2011). Bu çalışmada da serilerin durağanlığı panel veri çalışmalarında sıklıkla kullanılan IPS (Im Pesaran Shin) ve (ADF Fisher) testleri ile incelenmiş ve sonuçları tablo 1'de verilmiştir. 


\begin{tabular}{|c|c|c|c|}
\hline \multicolumn{2}{|c|}{ Değişkenler } & Seviye & 1. Fark \\
\hline \multirow[t]{2}{*}{ LnEKDK } & Im - Pesaran ve Shin testi & $\begin{array}{l}-0.3315 \\
(0.3701)\end{array}$ & $\begin{array}{l}-1.8058 \\
(0.0355)\end{array}$ \\
\hline & ADF - Fisher testi & $\begin{array}{l}33.1742 \\
(0.1571)\end{array}$ & $\begin{array}{l}45.4207 \\
(0.0106)\end{array}$ \\
\hline \multirow[t]{2}{*}{ LnOSK } & IM - Pesaran ve Shin Testi & $\begin{array}{l}1.0782 \\
(0.8595)\end{array}$ & $\begin{array}{l}-6.9261 \\
(0.0000)\end{array}$ \\
\hline & $\mathrm{ADF}$ - Fisher testi & $\begin{array}{l}22.2422 \\
(0.6754)\end{array}$ & $\begin{array}{l}71.4207 \\
(0.0000)\end{array}$ \\
\hline
\end{tabular}

Parantez içindeki veriler testlerin olasılık değerlerini temsil etmektedir. Birim kök testleri yapılırken gecikme uzunlukları Schwartz bilgi kriterine göre otomatik olarak belirlenmiştir.

Tablo.1 Panel Birim Kök Testi Sonuçları

Tablo 1'de verilen birim kök testi sonuçlarına göre, her iki değişkenin seviyede durağan olmadığı, birincil farklarda durağan oldukları gözlemlenmektedir. Farklarda durağan olan seriler arasındaki eş bütünleşme ilişkisi Pedroni eş bütünleşme testi yardımı ile incelenmiş, sonuçları Tablo 2'de verilmiştir.

\begin{tabular}{|l|l|l|}
\hline & Istatistik & Olas lik \\
\hline Group PP - Istatistik & -9.5520 & $0.0000^{*}$ \\
\hline Group ADF - İstatistik & -2.9824 & $0.0014^{*}$ \\
\hline
\end{tabular}

*, işareti test istatistiğinin \%1 önem düzeyinde anlamlı olduğu belirtir.

Tablo 2. Pedroni Eş Bütünleşme Testi

Tablo 2'de verilen Pedroni eş bütünleşme testinde olasılık değerlerinin 0.05 'ten küçük olması ' 'seriler arasında eş bütünleşme ilişkisi yoktur" boş hipotezinin reddedildiğini göstermektedir. Bu durum serilerin eş bütünleşik olduğunu göstermektedir.

Aynı seviyede durağan, aynı zamanda eş-bütünleşik olan seriler arasında vektör hata düzeltme modeli ile uzun süreli ilişkisi incelenebilir. Yani değişkenler arasında oluşacak kısa dönemli bir şokun etkisinin uzun dönemde düzelip düzelmeyeceği incelenebilir. Vektör hata düzeltme modelinde kullanılan bütün değişkenler bir defa bağımlı değişken olarak seçilir. Modelin hata serileri bir dönem gecikmeli olarak modele dâhil edilir hata serisinin t istatistiğinin anlamlı ve parametresinin negatif olması değişkenler arasında oluşacak bir dengeden sapmanın etkisinin uzun dönemde düzeleceğini işaret eder. Çalışmada uygulanan Hata düzeltme modeli test sonuçları Tablo 3'de verilmiştir.

\begin{tabular}{|l|c|c|}
\hline & Katsayı & Olasılık Değeri \\
\hline Model 1 & -0.1630 & 0.0508 \\
\hline
\end{tabular}

Tablo 3. Vektör Hata Düzeltme Modeli (VECM)

Tablo 3'de verilen VECM sonuçları incelendiğinde modele dâhil edilen hata düzelt teriminin parametresi negatif ve istatistiki olarak anlamlı çıkmıştır. Bu durum değişkenler arasında oluşacak kısa dönemli bir şokun etkisinin uzun dönemde düzeleceği şeklinde yorumlanabilir.

\begin{tabular}{|c|c|c|}
\hline & Bağımlı Değişken (lnOSK) & Bağımlı Değişken (lnEKDK) \\
\hline LnEKDK & 0.2021 & \\
\hline LnOSK & $(0.0000)$ & 3.1837 \\
& & $(0.0000)$ \\
\hline
\end{tabular}

Tablo 4. Tahmin Sonuçları FMOLS

FMOLS ile Eş bütünleşme Katsayıları Bulguları ve Değerlendirilmesi Eş bütünleşme testleri uygulandıktan sonra bu ilişkinin nihai sapmasız katsayılarını tahmin etmek üzere tahmin edicilerinin beklentilerimiz çerçevesindeki tutarlılığını test etmek amacıyla Pedroni (2000, 2001) tarafından geliştirilen FMOLS (Full Modified Ordinary Least Square) yöntemi, standart sabit etkili tahmincilerdeki (otokorelasyon, değişen varyans gibi sorunlardan kaynaklanan) sapmaları düzeltmektedir. Pedroni'nin bireysel kesitler arasında önemli ölçüde heterojenliğe izin veren bu FMOLS yöntemi, sabit terimin ve hata terimi ve bağımsız değişkenlerin farkları arasındaki olası korelasyonun varlığını hesaba katmaktadır. Panel FMOLS test sonuçları Panel bazında değerlendirildiğinde Ekonomik Katma Değer Katsayısı(EKDK) işareti beklenildiği gibi pozitif ve istatistiksel olarak \%1 düzeyinde anlamlıdır. Yani uzun dönemde Özsermaye Karlılık oranındaki artış, EKDK'yı panel genelinde pozitif bir şekilde etkilemektedir. Panel genelinde Ekonomik Katma Değer Katsayısı(EKDK) 0,2021 olarak hesaplanmıştır. Yani Ekonomik Katma Değer Katsayısındaki 1 birimlik değişme özsermaye karlılığında 
0,2021'lik bir değişim yaratmaktadır. Özsermaye karlılığının Ekonomik Katma Değer Katsayısı üzerindeki değişimi incelendiği zaman OSK' da meydana gelen \%1'lik artış EKDK'da \%3,187'lik bir artışa neden olmaktadır.

\section{Sonuç}

Bilgi kavramı her geçen gün hızla büyümekte ve çok hızlı bir şekilde güncellenmektedir. Bilgiyi elde etmek, depolamak, aktarmak ve muhafaza etmek işletmeler için önemli olduğu kadar zor bir hal almıştır. İşletmelerin, eldeki bilgiyi doğru bir şekilde harmanlayarak doğru zamanda ve doğru yerde kullanabilmesi en büyük başarı göstergesi olmaktadır. Günümüz bilgi toplumunda işletmeler ne kadar fiziki ve finansal varlığa sahip olursa olsun entelektüel sermayeye gerekli önemi göstermedikleri takdirde başarılı olmaları imkansızdır. Entelektüel sermaye kavramının unsurları olan yapısal sermaye, insan sermayesi ve müşteri sermayesi, her firma için farklı bir önem arz etmekte ve bulunduğu sektöre göre bu unsurlar birbirlerine göre farklı öneme sahip olmaktadır. Bankacılık sektöründe entelektüel sermaye diğer sektörlere göre farklılık göstermektedir. Bankacılık sektörü insan ve müşteri odaklı çalışan ve kazanç oranı diğer sektörlere oranla daha yüksek bir sektör olduğundan dolayı entelektüel sermayeye olan yatırımın boyutu daha yüksek olmaktadır.

Çalışmamızda, Bankacılık sektöründe faaliyet gösteren firmaların, entelektüel sermaye ile finansal performans arasındaki ilişkisi ekonometrik model yardımıyla test edilmiş ve entelektüel sermaye ile firma performansı arasında anlamlı bir ilişki tespit edilmiştir. Bankalar, entelektüel sermayeye olan yatırımlarını arttırdıkça karlılığı artmakta ve rakiplerine oranla rekabet edebilirlik gücü artmaktadır.

\section{Kaynakça}

- Akyüz, Ö. F., 2011. İnsan ve bilgi ekseninde entelektüel sermayenin etkin yönetimi Doctoral dissertation, Cem Ofset.

- El-Bannany, M. 2008. "A study of determinants of intellectual capital performance in banks: the UK case". Journal of intellectual capital, 9(3), 487-498.

- Eren, E., \& Akpınar, S. 2004. "Yapısal sermayenin işletme performansı üzerindeki etkilerinin araştırılması", Marmara Üniversitesi Sosyal Bilimler Enstitüsü Dergisi, 6 (22), 9-17. ss.

- Ghosh, S. K., \& Mondal, A. 2009. ' Intellectual Capital and financial performance: Evidence from the Indian Banking Industry'. In Proceedings of the 1st European Conference on Intellectual Capital: ECIC (p. 217-228)

- Kayalı, C. A., Yerel, A. N., 2007. ''Entelektüel katma değer katsayısı yöntemi kullanılarak entelektüel sermayenin firma değeri üzerindeki etkisinin belirlenmesine yönelik bir araştırma”. Yönetim ve Ekonomi, CB $\ddot{U} n, 14(1), 68$.

- Murthy, V., \& Mouritsen, J. 2011. 'The performance of intellectual capital: mobilising relationships between intellectual and financial capital in a bank". Accounting, Auditing \& Accountability Journal, 24(5), 622-646.

- Stewart, Thomas A., 1997. Entelektüel Sermaye, Çev: Nurettin Elhüseyni, Mess Yayınları, İstanbul,

- Şamiloğlu, F. 2002. Entelektüel Sermaye, Birinci Bask1, Gazi Kitabevi

- Şen, İ. K. 2014. 'Uluslararası Finansal Raporlama Standartlarına Geçişin Entelektüel Sermaye Üzerindeki Etkileri: Toprak ve Toprağa Dayalı Ürünler Sektöründe Bir Araştırma”. Journal of the Institute of Social Sciences Cankiri Karatekin University/Cankiri Karatekin Üniversitesi Sosyal Bilimler Enstitusu Dergisi, 12(1).

- $\quad$ Tarı, R. 2011. Ekonometri, 7. Baskı, Umuttepe Yayınları, Kocaeli.

- Topaloğlu, E. E., \& Bayrakdaroğlu, A. 2012. '’Entelektüel Sermayenin Türk Bankacılık Sektörü Üzerindeki Etkisini Belirlemeye Yonelik Bir Alan Araştırması”. Elektronik Sosyal Bilimler Dergisi, 41(41).

- Tiwana, A., 2003. Bilginin Yönetimi, Dışbank Yayınları (Çev. Elif Özsayar)

- Turgut, O. 2016. ' 'Borsa İstanbul'da İşlem Gören Bankaların, 1999-2000-2001 Ekonomik Krizleri Öncesi Ve Sonrası 5'er Yıllık Dönemlerde Entelektüel Sermayelerindeki Değişimin Analizi”. Elektronik Sosyal Bilimler Dergisi, Cilt:15, Say1:57(661-680)

- Verbeek, M. 2008. A Guide To Modern Econometrics, 3rd. edition, John Wiley \& Sons, England

- Yalama, A., \& Coskun, M. 2007. "Intellectual capital performance of quoted banks on the Istanbul stock exchange market'. Journal of Intellectual capital, 8(2), 256-271.

- Yıldız, S. 2011. 'Entelektüel sermayenin işletme performansına etkisi: bankacılık sektöründe bir araştırma'. Anadolu Üniversitesi Sosyal Bilimler Dergisi, Cilt/Sayı: 11/3, (11-28) 


\title{
Kalkınma Algısında Girişimcilik Olgusu ve Genç Nesillerin Mesleki Eğilimleri: Erzincan Üniversitesi Öğrencilerinin Girişimcilik Profilleri Üzerine Bir İnceleme
}

\section{Vocational Tendencies of Young Generation in the Development of Perception: A Survey Analysis on Entrepreneurship Profiles of Erzincan University Students}

\author{
Ph.D. Candidate Aslı Cansın Doker (Erzincan University, Turkey) \\ Ph.D. Candidate Sevgi Elverdi (Erzincan University, Turkey) \\ Prof. Dr. Mine Gerni (Marmara University, Turkey) \\ Prof. Dr. Ömer Selçuk Emsen (Atatürk University, Turkey)
}

\begin{abstract}
Entrepreneurship, which is one of the most important elements of the production-supply dimension of the economy, is also the main determinants of economic growth, including economic growth in the context of positive externalities emerging from the information age. It is clear that the development is linked to industrialization, which is related to spirit of innovative thinking. Therefore, undeveloped must be considered in concert with the lack of innovative thinking. According to Schumpeter, who defines entrepreneurship in such an understanding as "the replacement of the present and the future of Pareto Optimum with tomorrow's new and different things," this factor also encompasses innovation. Therefore, factors such as the characteristics of the entrepreneur, the risk perception profile and the socio-economic, socio-cultural and demographic structure of the population in which it is located can have significant effects on the development and development of entrepreneurship. In this study, it is aimed to investigate what factors are more effective on the perception of entrepreneurship by using the statistical methods on Erzincan University Students, taking into consideration that today's students will be the future production factor (labor or enterprise). Another important goal of the paper is to determine whether the entrepreneurship factor, which has a significant role in the development of the country and especially in urban development, is based on scientific or traditional elements. It can be considered that the existence and sustainability of the enterprise spirit will be tested with the awareness of the opportunities and opportunities for incentives to act rationally.
\end{abstract}

\section{Giriș}

Girişimcilik ülkelerin gelişmişlik seviyelerini artırmada önemli unsurlardan biridir. Ekonomik, sosyo-kültürel, teknolojik ve bireylerin karakteristik özelliklerinin birleşmesi sonucu ortaya çıkan "girişimcilik" olgusu; ekonomik kalkınmanın dinamiğini oluşturan önemli unsurlardan biridir. Diğer taraftan hem kendi işini kurma ile kendisi açısından işsizliğe çözüm olma hem de kurduğu işi için istihdam oluşturmada ve üretim artışında; gelişmekte olan ülkelerin pek çok sosyo-ekonomik meselelerinin çözümüne katkı sağlayan girişimci bireyler 21. yüzyıl itibariyle de önemlerini artırarak devam ettirmektedirler. Zira girişimci olarak nitelendirilen bireyler; bulunduğu ortamı gözlemleyebilen, çevresindeki muhtemel ihtiyaçları görebilen ve bu ihtiyaçlar doğrultusunda gerekli kaynakları bir araya getirebilen, risk algısı yüksek ve yeniliklere açık olan konumundadır. Girişimci bireylerde yer alan risk üstlenme ve yenilikçilik gibi vasıflar; günümüzde gelişmekte olan ekonomiler için ekonomik büyümede ve kalkınmada stratejik öneme sahip inovasyon yapmanın da bir tür ön koşulu olarak da kabul edilebilir. Dolayısıyla Schumpeter'in vurguladığı üzere; girişimcilik, ekonomik büyüme ve kalkınmanın motoru olan inovasyonun kaynağıdır ve üretken kaynakların dinamik yeniliklere dönüştüğü ortamın oluşmasında başat aktörlerdendir.

Büyümenin sürdürülebilirliği açısından tüm toplumlar dünya çapında etkili girişimciler yetiştirmek durumundadırlar. Zira toplumsal refahın artmasında gerek ülkesel, gerekse bölgesel kalkınmanın sağlanmasında ve bölgeler arası dengesizliğin elimine edilmesinde, girişimcilik önemli bir role sahiptir ve taşıdığ itibariyle girişimci bireyler çağdaş uygarlığın gelişmesinde önemli bir misyona sahiptirler. Bu noktada gerek ulusal, gerekse uluslararası platformda ülke vizyonuna önemli katkılar sağlayan girişimci bireyleri yetiştirmede önemli kurumlardan biri de üniversiteler olduğu ileri sürülebilir. Ayrıca üniversiteler, beşeri sermayenin oluşturulmasında özellikle mesleki eğitimin edinilmesinde girişimcilerin ihtiyaç duydukları kaynakları oluşturma potansiyeli taşımaktadırlar. Bu iki noktadan hareketle çalışmada Erzincan Üniversitesi öğrencilerinin girişimcilik profilleri incelenmiş ve yapılan anket çalışması ile öğrencilerin girişimcilik profilleri ve öğrencilerin demografik özelliklerinin bu unsura etkileri faktör analizi çerçevesinde araştırılmıştır. 


\section{Literatür Özeti}

Literatürde üniversite öğrencilerinin girişimci kişilik özelliklerine ve girişimcilik algısına yönelik yapılmış pek çok çalışma mevcuttur. Çalışmalar yoğunlukla iktisadi ve idari bilimler fakültesi öğrencilerine yönelik olmakla beraber, genel olarak tüm üniversite bazında ve üniversitelerin diğer birimleri (Mühendislik Fakültesi, Eğitim Fakültesi, Fen-Edebiyat Fakültesi, Meslek Yüksekokulları gibi) üzerinde yapılmış çalışmalar da mevcuttur. Literatürdeki çalışmalar aynı zamanda bu çalışmanın anket formunun hazırlanmasından yöntem bilime kadarki kısımları için temel dayanak olmuştur. Aşağıda, literatürde yapılan bu çalışmalardan bazılarına özet olarak yer verilmiştir.

Koh (1996), öğrencilerin girişimci kişilik özelliklerini etkileyen faktörlerini -başarma ihtiyac1, kontrol odağ1, risk alma eğilimi, belirsizliğe tolerans, kendine güven ve yenilikçilik- belirlemek amacıyla Hong Kong'daki 100 lisansüstü öğrencisi üzerine uygulamalarda bulunuştur. Çalışmasında; risk alma eğilimi, belirsizliğe tolerans ve yenilikçilik özelliklerinin girişimci eğilime sahip olan öğrencilerde, sahip olmayan öğrencilere göre daha fazla olduğu tespit edilmiştir.

Emsen vd. (2001), çalışmalarında Atatürk Üniversitesi İİBF öğrencilerinin girişimcilik eğilimlerine etki eden faktörler inceleme konusu yapılmıştır. Yapılan analiz sonuçlarına göre kız öğrencilere göre erkek öğrencilerde, düşük gelirli ailelere göre yüksek gelirli ailelerde, babası bağımlı olarak çalışanlara göre kendi işini ifa edenlerde girişim eğiliminin yüksek olduğu belirlenmiştir. Buna karşılık yüksek gelir ve kentsel yaşamda yaşamanın beklenene uygun sonuçlar vermediği gözlenmiştir.

Gurel vd. (2010), çalışmalarında Türkiye ve İngiltere'de 409 turizm öğrencisi üzerine; girişimcilik niyetini, risk alma sorumluluğunu, yenilikçiliklerini, belirsizliği tolere etme becerilerini, özdenetim ve sosyo-kültürel faktörleri araştırmışlardır. Çalışma sonucunda yenilikçilik, risk alma sorumluluğu ve girişimci aile faktörlerinin, girişimcilik üzerindeki etkisi anlamlı bulunurken; eğitimin, girişimci tutumlar ve niyetler üzerinde çok önemli bir etkisinin olmadığı tespit edilmiştir.

Wang ve Wong (2004), Singapur'un en büyük devlet üniversitesi olan Singapur Milli Üniversitesinde, mühendislik, bilim ve bilgisayar lisans öğrencilerinden oluşan 5326 öğrenci üzerine bir çalışma yapmışlardır. Öğrencilerin, girişimciliğe ilgilerini nelerin belirlediğini bulmak amacı ile yapılan çalışmada, girişimcilik ilgilerinin yüksek olduğu ancak yetersiz işletmecilik bilgisi ve risk algısı gibi faktörlerin caydırıcı bir nitelik taşıdığı tespit edilmiştir. Cinsiyet, ailenin işletmecilik deneyimi ve eğitim düzeyi gibi faktörler, girişimcilik eğilimini etkilerken; ailenin ekonomik statüsü, etnik köken ve vatandaşlık algısı gibi faktörlerin de bir etkisi olmadığ görülmüştür.

Patır ve Karahan (2010), çalışmalarında İnönü Üniversitesi'nde öğrenim gören öğrencilerden basit rastgele örnekleme yöntemiyle belirlenen, fakülte/yüksek okullardaki 235 öğrenci verisi kullanılmışlardır. Üniversite öğrencilerin girişimcilik profillerini belirlemek amacıyla, anketlerden elde edilen veriler SPSS 15,0 kullanarak irdelenmiştir. Veriler öncelikle mutlak ve nispi frekans olarak ele alınmış ve daha sonra bu verilerin çeşitli değişkenlere göre farklıkları ki-kare, t-testi, tek yönlü varyans analizi gibi analizlere tabi tutulmuştur. Analizler sonucunda, girişimciliğe başlamak için yeterince sermayeye sahip olma durumuyla; anne babaların yaptıkları iş, ailenin sahip olduğu işyeri türü, daha önce bir iş kurup/kurmama durumu, rekabet öncelikleri, kredi kaynak ve imkânları hakkındaki bilgi düzeyi, aileden veya arkadaşlarından sermaye bulabilme durumu ile girişimcilik yetenek puanları arasında anlamlı ilişkiler bulunmuştur.

Kaya vd. (2010), Atatürk Üniversitesi mühendislik, iktisadi ve idari bilimler fakültesi ve meslek yüksekokulu öğrencileri üzerinde yaptıkları çalışmalarında; öğrencileri, özerklik, fırsatçılık ve kişisel kontrol gibi girişimcilik özellikleri açısından analiz etmişlerdir. 191 öğrenci üzerine anket uygulandığı çalışmada, student's t testi ve varyans analizleri yapılmıştır. Çalışmanın bulgusu; mühendislik, iktisadi ve idari bilimler fakültesi ile meslek yüksekokulu öğrencileri arasında girişimcilik faktörlerinden özerklik, firsatçılık ve kişisel kontrol açısından anlamlı bir fark olmadığı yönündedir.

Bilge ve Bal (2012), Celal Bayar Üniversitesi lisans ve ön lisans öğrencilerinin girişimcilik konusunda ilgi seviyesini ve yeterliliklerini belirlemek amacı ile yaptıkları çalışmalarında; cinsiyet ve eğitim seviyesi (okullar bazında) açısından karşılaştırma yapmışlardır. Çalışmanın ana kütlesini 2011-2012 öğretim yılında Salihli Meslek Yüksek Okulu, Uygulamalı Bilimler Yüksek Okulu ve Fen Edebiyat Fakültesi öğrencileri oluşturmuştur. Araştırmada açıklayıcı faktör analizi sonucunda bireysel gücü; risk alma, firsatları değerlendirme, liderlik yönlü, gelecek odaklı, kararlılık ve dış etkenlere karşı olmak altı boyut oluşturduğu tespit edilmiştir. Araştırmada cinsiyetin, girişimciliğin alt boyutları üzerindeki etkisi anlamlı bulunmamıştır. Buna karşılık okulların, girişimciliğin alt boyutları üzerindeki etkisi sadece "gelecek odaklı" ve "liderlik yönlü" alt boyutlar açısından anlamlı bulunmuştur.

Akkaya vd. (2014), Yalova Meslek Yüksekokulu öğrencileri üzerine yaptıkları çalışmalarında, gelecekte girişimci olmayı planlayan öğrenciler ile planlamayan öğrenciler arasında fark olup olmadığını araştırmak amacıyla 280 öğrenci üzerine anket uygulamışlardır. Mann-Whitney U testi ve Kruskal-Wallis $H$ testlerinin uygulandığı çalışmada, Cronbach Alfa değeri 0,81 olarak hesaplanmıştır. Mann Whitney U testi sonucunda 
cinsiyetin başarma ihtiyacı boyutu üzerinde anlamlı bir etkisinin olduğu; kontrol odağı, risk alma eğilimi, belirsizlik toleransı, kendine güven ve yenilikçilik boyutları üzerinde ise anlamlı bir etkisinin olmadığı belirlenmiştir. Kruskal Wallis H testi sonucuna göre ailelerin ekonomik durumları ile kendine güven boyutuna bakış açıları arasında anlamlı bir fark olduğu, yerleşim yeri ile kendine güven boyutuna bakış açıları arasında yine anlamlı bir fark olduğu tespit edilmiştir.

Akpınar ve Küçükgöksel (2015), çalışmalarında Namık Kemal Üniversitesi Çorlu Meslek Yüksekokulu'nda öğrenim gören öğrenciler üzerine anket uygulamışlardır. Çalışmanın sonucunda, öğrenciler arasında ücretli olarak bir kuruluşa bağlı olarak çalışmak isteyenlerin oranı \% 72, girişimci olarak serbest çalışmak isteyenlerin oranını $\% 28$ olarak bulunmuştur. Girişimciliğin önündeki engeller açısından bakıldığında ise en yüksek oranda "başarısızlık korkusu"nun, öğrencilerin girişimci olma isteklerini körelttiği belirlenmiştir.

Soylu vd. (2015), Pamukkale Üniversitesi Honaz Meslek Yüksekokulunda girişimcilik dersi alan öğrenciler üzerinde bir saha araştırması yapmışlardır. Çalışmada girişimci kişilik özellikleri bağlamında öğrenciler arasındaki belirsizliğe; tolerans, risk alma, yenilikçilik, yaratıcılık, bağımsızlık, başarı ihtiyacı, insanlarla ilişkiler, içsel kontrol odağı boyutları incelenerek, istatistiksel analizler yapılmıştır. 594 öğrenci üzerine anketin uygulandığı çalışmada, değerlendirmeler 5'li likert ölçeğine göre yapılmış ve her bir soru grubu için Cronbach Alfa değerleri hesaplanmıştır. Non-parametrik testlerden biri olan Kruskal-Wallis testi kullanılmış ve normallik sınaması için Kolmogorov Simirnov testi uygulanmıştır. Çalışmada, girişimcilik dersi alanların, almayanlara göre; daha fazla yaratıcı ve daha fazla yenilikçi fikirlere sahip olduğu sonucuna ulaşılmıştır.

\section{Veri Seti ve Analiz}

Çalışmada Erzincan Üniversitesi öğrencilerinin girişimcilik profillerinin incelenmesi amaçlanarak örneklem belirlenirken, nitelikli ağırlıklandırılmış tabakalı örneklem yapılmıştır. Ana kütle olarak Erzincan Üniversitesinde öğrenime devam eden lisans öğrencisi sayıları üniversitenin stratejik raporundan elde edilerek orantılı dağıtım yaklaşımınca fakültelerin/yüksekokulların öğrenci mevcutlarının genel toplam içerisindeki payları dikkate alınmış olup buna ilişkin bilgilere Tablo 1'de yer verilmiştir.

\begin{tabular}{|r|l|c|c|c|}
\hline & Fakültte ve Yüksek Okullar & Klz & Erkek & Toplam \\
\hline $\mathbf{1}$ & Eğitim Fakültesi & 1976 & 1361 & 3337 \\
\hline $\mathbf{2}$ & Fen Edebiyat Fakültesi & 571 & 466 & 1037 \\
\hline $\mathbf{3}$ & İİ̈F & 947 & 903 & 1850 \\
\hline $\mathbf{4}$ & İlahiyat Fakültesi & 463 & 266 & 729 \\
\hline $\mathbf{5}$ & Mühendislik Fakültesi & 162 & 860 & 1022 \\
\hline $\mathbf{6}$ & Sivil Havac1lı Yüksek Okulu & 77 & 145 & 222 \\
\hline $\mathbf{7}$ & Sağllk Yüksek Okulu & 279 & 168 & 447 \\
\hline $\mathbf{8}$ & Hukuk & 415 & 581 & 996 \\
\hline $\mathbf{9}$ & Adalet Meslek Yüksek Okulu & 102 & 145 & 247 \\
\hline $\mathbf{1 0}$ & Turizm ve Otelcilik MYO & 93 & 172 & 265 \\
\hline $\mathbf{1 1}$ & Meslek Yüksek Okulu & 844 & 2249 & 3093 \\
\hline & Toplam & $\mathbf{5 9 2 9}$ & $\mathbf{7 3 1 6}$ & $\mathbf{1 3 2 4 5}$ \\
\hline
\end{tabular}

Tablo 1. Erzincan Üniversitesi Fakültelere Göre Öğrenci Sayıları

Çalışmada veri toplama yöntemi olarak yüz yüze yazılı anket araştırması kullanılmış ve analizde Excel ve SPSS yazılımlarından yararlanılmıştır. Çalışmada İIBF, Eğitim Fakültesi, Sağlık MYO, Meslek Yüksek Okulu, Hukuk, Fen Edebiyat, İlahiyat, Sivil Havacılık YO, Mühendislik ve Turizm Meslek Yüksek Okulu araştırmanın alanı olarak belirlenmiştir. Bu belirleme yapılırken, dikkate alınan bölgesel kısıt Erzincan ilinin merkezinde yer alan kurumlar olmuştur. Çalışmada seçilen örneklemden analize uygun olan veri seti büyüklüğü 450 olarak belirlenmiş̧ir.

Çalışmada Erzincan Üniversitesi öğrencilerinin girişimcilik profilleri likert ölçeği kullanılarak faktör analizine tabi tutulmuştur. Tanımlayıcı istatistikler yardımıyla öğrencilere ait demografik özellikler frekans tabloları ve ortalamalar yardımıyla incelenmiştir. Girişimcilik istekleri ile demografik özellikler arasında ilişki olup olmadığı ki kare analizi yardımıyla hipotetik olarak incelenmiştir.

Cinsiyet değişkeni frekans analizi tablosu Tablo 2 de yer almaktadır. Bu tabloda veri setinin yüzde 43,6'sı kız ve yüzde 56,4'ünün erkek öğrenciler olduğu belirtilmiştir. Tabakalı örnekleme kullanılarak yapılan analizde fakültelere göre dağılım ise; \%33,1 ile eğitim fakültesi, \%19,8 ile Meslek Yüksek Okulu, \%14,7 ile İktisadi ve İdari bilimler fakültesi, \%8,7 ile Hukuk Fakültesi, \%6,4 ile İlahiyat ve Mühendislik Fakültesi yer almıştır (Tablo 2).

Araştırmaya katılan lisans öğrencilerinin \%34,7'si Erzincan, \%3,6'sı Malatya, \%2,7'si Erzurum, \%2,4'ü Adana, \%2,4'ü Maraş, \%2,2'si Trabzon illerinde ikamet ettiklerini belirtmiştir. En yüksek frekansa sahip olan ilin Erzincan olması, üniversitenin bir eğitim kurumu olarak bölgeye daha fazla hitap ettiğini göstergesi konumundadır. Yaş 
grubu için uygulanan açık uçlu soruda alınan cevapların ortalaması 21,22'dir. İkamet edilen iller sorusuna ek olarak sorulan çoktan seçmeli soruda, araştırmaya katılan öğrencilerin \%46,9'u il (büyük şehir olmayan illerde), \%21,6’s1 büyükşehir, \%20,4'ü ilçe ve \%11,1'i köyde ikamet ettiğini belirtmiştir. Bir diğer demografik değişken olarak belirlenen anne-baba eğitim durumlarında ise öğrencilerin anne eğitim durumları \%47,1'i ilkokul, \%15,3 okuryazar olmayan, \%15,3 ü lise, \%13,1 ortaokul, \%5,6's1 okur-yazar ve \%3.5'i lisans ve lisansüstü şeklindedir. Araştırmaya katılan lisans öğrencilerinin baba eğitim durumları ise, \%38,4’ü ilkokul, \%18,4 ortaokul, \%17,6 lise, $\% 16$ üniversite, \%4 okur-yazar, \%4,2 okur-yazar olmayan ve \%1,3 lisansüstü seviyededir. Araştırmaya katılan öğrencilerin \%8,9’u kısmi zamanlı olarak bir işte çalıştığını ifade etmişlerdir.

\begin{tabular}{|l|c|c|c|c|}
\hline & $\begin{array}{l}\text { Mutlak } \\
\text { Frekans }\end{array}$ & $\begin{array}{l}\text { Nispi } \\
\text { Frekans }\end{array}$ & $\begin{array}{l}\text { Geçerli } \\
\text { Cevap (\%) }\end{array}$ & $\begin{array}{l}\text { Kümülatif } \\
(\%)\end{array}$ \\
\hline İïBF & 66 & 14,7 & 14,7 & 14,7 \\
\hline Eğitim Fakültesi & 149 & 33,1 & 33,1 & 47,8 \\
\hline Sağlık Yüksek Okulu & 15 & 3,3 & 3,3 & 51,1 \\
\hline Meslek Yüksek Okulu & 89 & 19,8 & 19,8 & 70,9 \\
\hline Hukuk Fakültesi & 39 & 8,7 & 8,7 & 79,6 \\
\hline Adalet Meslek Yüksek Okulu & 9 & 2,0 & 2,0 & 81,6 \\
\hline İlahiyat Fakültesi & 29 & 6,4 & 6,4 & 88,0 \\
\hline Sivil Havacilık Yüksek Okulu & 10 & 2,2 & 2,2 & 90,2 \\
\hline Mühendislik Fakültesi & 29 & 6,4 & 6,4 & 96,7 \\
\hline Turizm ve Otelcilik MYO & 15 & 3,3 & 3,3 & 100,0 \\
\hline TOPLAM & 450 & 100,0 & 100,0 & \\
\hline
\end{tabular}

Tablo 2. Erzincan Üniversitesi Fakültelere/Yüksekokullara Göre Tanımlayıcı İstatistikler

Demografik istatistiklerin yorumlanmasından sonra girişimciliği belirleyen tanımlayıcı bir takım sorular ile seçili demografik özellikler arasında ilişki olup olmadığı incelenmiştir. Araştırmaya dair hipotezler şu şekildedir:

H1: Erzincan Üniversitesi öğrencileri arasında cinsiyet bakımından girişimcilik özellikleri bakımından farklılık vardir.

H2: Erzincan Üniversitesi öğrencileri arasında yaş değişkeni bakımından girişimcilik özellikleri bakımından farklılık vardır.

H3: Erzincan Üniversitesi öğrencileri arasında ikametleri bakımından girişimcilik özellikleri bakımından farklılık vardır.

H4: Erzincan Üniversitesi öğrencileri arasında gelirleri bakımından girişimcilik özellikleri bakımından farklılık vardir.

H5: Erzincan Üniversitesi öğrencileri arasında eğitim aldıkları fakülteler/yüksekokullar bakımından girişimcilik özellikleri bakımından farklılık vardır.

Yukarıda yer alan beş hipotez çapraz tablo analizleri ile ki-kare testine tabi tutularak analiz edilmiştir. Hipotetik karşılaştırma analizinde 17. soru olarak belirtilen "Kariyer hedefi olarak eğitiminizi tamamladıktan sonra ne yapmayı düşünüyorsunuz?" sorusuna kendi işini kurmak, kamu kesiminde çalışmak, özel bir şirkette çalışmak, aile işletmesine devam etmek ve diğer şeklindeki cevaplardan ilk seçeneğin cevap olarak vermesi girişimciliği temsil edeceği düşünülmektedir. Öğrencilerin toplamda, yani herhangi bir gruplamanın yapılmadığı durumda \%65,6's1 kamu kesiminde çalışmak istediğini belirtmiş, \%19,6’s1 ise kendi işini kurmak istediğini belirtmiştir. Bunun yanı sıra özel kesimde çalışmak isteyenlerin oranı \%9,6, aile şirketinde çalışmak isteyenler \%1,1 olarak belirtilmiştir. Elde edilen bulgulara göre "az olsun, benim olsun" diye tanımlanabilecek bir algının hakim olduğu ve bu bulgunun Akpınar ve Küçükgöksel (2015) tarafından yapılan araştırma ile örtüşük olduğu görülmektedir. Hipotezlerin kurulumuna göre yapılan çapraz analizlerin sonuçları Tablo 3'te yer almaktadır.

\begin{tabular}{|c|c|l|}
\hline Hipotezler & Pearson Chi-Square test & Karar \\
\hline $\mathrm{H}_{1}$ & 28,051 & Reddedilemez \\
\hline $\mathrm{H}_{2}$ & 59,982 & Red \\
\hline $\mathrm{H}_{3}$ & 312,182 & Reddedilemez \\
\hline $\mathrm{H}_{4}$ & 270,407 & Red \\
\hline $\mathrm{H}_{5}$ & 128,025 & Reddedilemez \\
\hline
\end{tabular}

Tablo 3. Çapraz İlişki Hipotezlerinin Test Sonuçları

SPSS 21 yazılımının serbestlik derecesi olan 0,05'e göre karar verilmiş, buna göre cinsiyet değişkenine göre kariyer hedefi sorusu gruplandırıldığında, gruplar arası bir farklılık olduğu kabul edilmiştir. Buna göre erkeklerin \%25,9'u girişimciliği planlarken, kadınların \%14,6'sı girişimciliği planlamaktadır. Kadınların \%75,1'i kamu kesiminde çalışmayı hedeflerken, erkeklerin de \%53,3'ü bunu hedeflemektedir. Bu bulgular görece cinsiyet ayırımının girişimcilikte etkili olduğuna işaret ederken, bulgunun Wang ve Wong (2004) Bilge ve Bal (2012) ile Akkaya vd. (2014) tarafından yapılan araştırmalarla paralellik arz ettiği görülmüştür. Bir diğer önemli bulgu ise, 
aile şirketinde çalışmayı kadınlarda kimsenin tercih etmeyerek, erkeklerde bu oranın \%4,6 olduğu gözlemlenmiştir. İkinci hipoteze göre araştırmaya dahil edilen yaş değişkeninin gruplanması sonucunda gruplar arasında bir farklılık olmadığı sonucuna ulaşılmıştır. Bu durumun açıklayıcı bir nedeni olarak, seçilen örneklemin yaş ortalamasının 21,2 olması gösterilebilir. Üçüncü hipotezde öğrencilerin ikamet ettikleri iller ile girişimcilik test edilmiş ve hipotez anlamlı bulunmuştur. Buna göre, Afyon, Bursa, Ordu, Rize, Tekirdağ, Trabzon, Şanlıurfa illerinden ikamet eden öğrenciler arasında girişimci olmayı hedefleyenlerin oranı \%60'ın üzerinde ve en etkili iller olarak belirlenmiştir. Buna karşlık TRA1 Erzurum alt bölgesinde yer alan Erzincan'da bu bölgedeki ve yakın olan TR90 Trabzon alt bölgesinde yer alan illerin girişimcilik potansiyelleri önem taşımaktadır. Fakat analiz sonuçlarında, Erzincan \%19,2, Erzurum \%16,7, Bayburt \%37,5, Gümüşhane \%14,3 olarak gözlemlenmiştir. Bu sorunun hayır ise neden başlıklı ek sorusunda gerekçeler \%67,5 oranında Erzincan'ın küçük bir il olmasına bağlanmıştır. Dolayısıyla Bayburt'u bu bölgedeki en yüksek oranlı il haline getiren durum; bölgedeki iller arasında en küçük il olması olarak belirtilebilir. Bu bulgu ise Wang ve Wong (2004) tarafindan yapılan araştırmada etnik köken ve vatandaşlık unsurunun etkisizliğini ortaya koyan çalışmasıyla tezatlık teşkil etmiştir. Dördüncü hipotez olan ailenin geliri ile girişimcilik isteği arasında gruplama yapıldığında, anlamlı bir farklılığa ulaşılamamıştır. İktisadi birey olarak öğrencilerin ailelerine bağımlı olması dolayısıyla kendi gelir gruplarına ve girişimcilik faaliyetinin gereği olan sermaye noktasında farklılıkları algılayamamış olması gösterilebilir. Bu da Wang ve Wong (2004) ile Patır ve Karahan (2010) çalışma bulguları ile tezat sonuç vermişstir. Beşinci hipotez olan öğrencilerin eğitim aldıkları fakülteler ile girişimcilik istekleri arasındaki grup farklılığı incelendiğinde, hipotez anlamlı bulunmuştur. Buna göre yapılan gruplama analizlerinin sonucunda Mühendislik Fakültesi $(\% 37,9)$, Turizm ve Otelcilik MYO (\%33,3), Hukuk Fakültesi $(\% 28,2)$, Meslek Yüksek Okulu $(\% 25,8)$, İ̈BF $(\% 22,7)$ şeklinde \%20'nin üzerinde olan fakülteler sıralanmaktadır. İ̈BF'nin örneklem içerisinde beklenilen seviyede girişimcilik düzeyine ulaşmamasının nedenleri arasında bölümlerin eşit tabakalı olarak ele alınması sayılabilir. Bu bulgu da Kaya vd. (2010)'in çalışmasından elde edilen sonuçlarla örtüşük niteliktedir.

Araştırmada kullanılan 34 soruluk beşli likert tipi ölçek kullanılarak girişimcilik profilleri incelenmiştir. Faktör analizi ile öğrencilerin hangi faktörler üzerinde daha etkili olduklarının incelenmesi amaçlanmıştır. Araştırmada kullanılan veri seti ve 34 sorunun değişken olarak faktör analizine uygunluğu, yani veri setinin faktör analizine uygunluk testleri $\mathrm{KMO}$ ve Barlett test istatistikleriyle test edilmektedir. Bu istatistiklerden $\mathrm{KMO}$ istatistiğinin 0,7'den büyük olması uygunluğu ifade ederken Barlett istatistiğinde 0,05 'ten küçük olması şartı aranmaktadır (Tablo4).

\begin{tabular}{|c|c|c|}
\hline KMO's Test Statistics & 0,903 & $>0,7$ Oldukça güvenilir \\
\hline Barlett Test Statistics & 0,000 & $<0,5$ Oldukça güvenilir \\
\hline
\end{tabular}

Tablo 4. KMO ve Barlett Test Sonuçları

Doğrulayıcı faktör analizine uygun olan veri seti ve değişkenleri faktörlere ayırırken Shumpeter'in yaratıcı yıkım tezinin geçerliliğini de ele almak amacıyla hazırlanan sorularda sosyal yenilikçilik, teknolojik yenilikçilik, yaratıcılık, yenilikçilik ve risk algısı olarak 5 faktör bazında oluşturulmuştur. İşcan ve Kaygın (2011)'ın kullandıkları likert ölçeğini, araştırmada yenilik ve risk almayı profil faktörü tanımlamada kullanılmıştır. Sosyal, teknolojik yenilikçilik ve yaratıcılık ölçekleri ise Eren (2010)'in çalışmasından hareketle araştırmada yer almıştır. Araşıırmanın üçüncü kısımda yer alan ve 34 sorudan oluşan beşli likert ölçeğindeki soruları teknolojik yenilik, sosyal yenilikçilik, yaratıcılık ve risk alma olarak beş faktörde incelenmesi hedeflenmiş̧ir. Çalışmada anketin örneklemini oluşturan öğrencilerin girişimcilik profillerini algılamaya yönelik toplanan veriler, doğrulayıcı faktör analizine tabi tutulmuştur.

\begin{tabular}{|c|c|c|c|c|}
\hline & FAKTÖRLER & MADDE SAYISI & CRONBACH ALFA & KARAR \\
\hline F1 & TEKNOLOJIK YENİLİK & 9 & 0,839 & $>0,5$ Oldukça güvenilir. \\
\hline F2 & SOSYAL YENILIKKÇİİK & 6 & 0,807 & $>0,5$ Oldukça güvenilir. \\
\hline F3 & YARATICILIK & 5 & 0,743 & $>0,5$ Oldukça güvenilir. \\
\hline F4 & YENİL̇KÇİLİK & 4 & 0,741 & $>0,5$ Oldukça güvenilir. \\
\hline F5 & RİSK ALMA & 3 & 0,692 & $>0,5$ Oldukça güvenilir. \\
\hline
\end{tabular}

Tablo5. Faktörlerin Güvenilirlik Analizi Sonuçları

Doğrulayıcı faktör analizinde faktör yük değerleri için baz alınan eşik değer 0,50 olarak belirlenmiş ve bu değerin altında kalan sorular ölçekten arındırılarak faktörler belirlenmiş̧tir. Toplamda beş faktörden oluşan ölçekte 27 madde yer almaktadır. Faktörlere düşen madde sayıları ve Cronbach Alfa faktör güvenilirlik analiz sonuçları Tablo 5 'te yer almaktadır. Buna göre beş faktörde güvenilir düzeyde ve toplam varyansın $\% 51,652$ 'sini açıklamaktadır.

Faktör yükleri, özdeğerler ve varyans açıklama oranları ise Tablo 6'da verilmiştir. 


\begin{tabular}{|c|c|c|c|}
\hline & $\begin{array}{l}\text { FAKTÖR } \\
\text { YÜKLERİ }\end{array}$ & $\begin{array}{l}\text { EİGEN } \\
\text { VALUE (ÖZ } \\
\text { DEĞER) }\end{array}$ & $\begin{array}{l}\text { VARYANS } \\
\text { AÇIKLAMA } \\
\text { ORANI }(\%)\end{array}$ \\
\hline FAKTÖR 1: TEKNOLOJIKK YENILİKÇILIIK & - & 7,695 & 15,083 \\
\hline $\begin{array}{l}\text { Yapılabilirliğini görmek için yazılım veya donanım teknolojileri } \\
\text { kullanarak aklıma gelen çözümleri gerçekleştirmeye çalışırım. }\end{array}$ & 0,689 & & \\
\hline Teknolojik değişiklik ve yenilikleri takip eder ve kullanırım. & 0,599 & & \\
\hline $\begin{array}{l}\text { Eksikliğini hissettiğim bir konuya teknolojik bir çözüm bulmaya } \\
\text { uğraşırım. }\end{array}$ & 0,704 & & \\
\hline $\begin{array}{l}\text { "Şöyle bir sistem olsa iyi olur" diye aklımdan geçirdiğim teknolojik } \\
\text { çözümlerin var olup olmadığına internet, kütüphane vb. kaynaklardan } \\
\text { araştırırım. }\end{array}$ & 0,653 & & \\
\hline $\begin{array}{l}\text { Sorun yaşanan bir konuya çözüm bulmak için teknik alt yapımı nasıl } \\
\text { kullanacağımı düşünürüm. }\end{array}$ & 0,599 & & \\
\hline $\begin{array}{l}\begin{array}{l}\text { Düşüncelerimle ürettiğim } \\
\text { dönüştürebilirim. }\end{array} \\
\end{array}$ & 0,587 & & \\
\hline $\begin{array}{l}\text { Bu düşünceleri paylaştığım çevremdeki insanlarda olumlu yönde tepki } \\
\text { alırım. }\end{array}$ & 0,518 & & \\
\hline Tasarıma ilgi duyarım. & 0,544 & & \\
\hline $\begin{array}{l}\text { Beğendiğim bir teknolojik çözümün nasıl yapıldığıyla ilgili fikirler } \\
\text { oluşturabilirim. }\end{array}$ & 0,561 & & \\
\hline FAKTÖR 2: SOSYAL YENILİKÇİLIK & - & 2,319 & 11,183 \\
\hline Toplumda, politik ve sosyal değişimler yaratmanın yollarını ararım & 0,692 & & \\
\hline $\begin{array}{l}\text { Toplumun yenilikçi gücünü artırmak için bilimsel yeni eğitim } \\
\text { teknikleri geliştirmek isterim }\end{array}$ & 0,676 & & \\
\hline $\begin{array}{l}\text { Sosyal ihtiyaçları geliştirmek ve problemlere çözüm bulmak için yeni } \\
\text { teknolojileri kullanırım }\end{array}$ & 0,569 & & \\
\hline $\begin{array}{l}\text { Toplumda, sosyal dayanışma ve sosyal katılımı artırmanı yollarını } \\
\text { ararım }\end{array}$ & 0,591 & & \\
\hline $\begin{array}{l}\text { Sosyal değer yaratacak ve toplumu daha etkin hale getirecek yeni } \\
\text { fikirler üretirim }\end{array}$ & 0,609 & & \\
\hline $\begin{array}{l}\text { Toplumun yaşam kalitesini artırmak için sosyal içerikli yeni ürünler ve } \\
\text { hizmetler geliştirmek isterim }\end{array}$ & 0,696 & & \\
\hline FAKTÖR 3: YARATICILIK & - & 1,663 & 9,713 \\
\hline İnsanlar girişimcilerden etkilenirler & 0,751 & & \\
\hline Yeni fikirlerin doğması için katılımcılık mutlaka sağlanmalıdır & 0,648 & & \\
\hline İnsan her fikri öğrenmeli ve kendisi için bir sentez oluşturmalıdır & 0,792 & & \\
\hline Yaşamdan deneyimler kazanmalı ve yeni objeler tasarlamalıyım & 0,613 & & \\
\hline Başarı için doğru zamanda doğru işi yapmak gerekir & 0,560 & & \\
\hline FAKTÖR 4: YENILIKÇILİK & - & 1,250 & 8,902 \\
\hline $\begin{array}{l}\text { Diğer insanlar çevrede olağan dışı bir şeyler görmediği halde ben işle } \\
\text { ilgili firsatları yakalayabilirim }\end{array}$ & 0,523 & & \\
\hline $\begin{array}{l}\text { Bir konu üzerinde farklılık yaratacak düşünceler ortaya koyma } \\
\text { yeteneğine sahibim }\end{array}$ & 0,774 & & \\
\hline Yeni, ilginç, hatta çılgın fikirler üretme yeteneğine sahibim & 0,785 & & \\
\hline İşlerin yapılma şeklini değiştirmekten kaçınmam & 0,534 & & \\
\hline FAKTÖR 5: RİSK ALMA & - & 1,195 & 7,311 \\
\hline Kendimi risk alabilen biri olarak görebiliyorum & 0,674 & & \\
\hline $\begin{array}{l}\text { Hisselerinin kar getirebileceğini hesaplayabildiğim bir ortaklığa } \\
\text { paramı yatırmaktan çekinmem }\end{array}$ & 0,692 & & \\
\hline Yaptığım işte yükselmek için büyük risk almaya gönüllüyüm & 0,711 & & \\
\hline
\end{tabular}

Tablo6. Faktör Yükleri, Özdeğerler ve Varyans Açıklama Oranları

Tablo 6'da, faktörler arasında açıklayıcıları en yüksek olan faktörün teknolojik yenilikçilik ve en azının ise risk alma olduğu gözlemlenmektedir. Bu durum aynı zamanda girişimcilik hedefi sorusunda da ortaya konulmuş ve Erzincan Üniversitesi öğrencilerinin \%65,6’sının kamu kesiminde çalışmak istediğini belirtmişlerdir. 


\section{Sonuç}

İktisat teorisi literatüründe girişimcinin tanımı; "Üretimin riskini, üretilen malın satış olanaklarından kaynaklanan belirsizliği üstlenerek, her üç faktörü bir araya getirip, üretime koşan kişidir” şeklindedir (Dinler, 2013). Girişimcinin üretim faktörlerini, yani sermaye, emek, toprak ve teknolojiyi bir araya getirmesi için en önemli unsur risk algısıdır. Diğer taraftan kalkınmanın temelinde yatan sanayileşmenin lokomotifi girişimcilik ve dolayısıyla inovatif düşüncedir. Çalışmada alan olarak belirlenen Erzincan ili aynı zamanda sahip olduğu sosyoekonomik boyutuyla bölgesel kalkınmaya en yüksek oranda ihtiyaç duyan Kuzeydoğu Anadolu bölgesi içerisinde yer almaktadır. Erzincan Üniversitesi 2006 yılında kurulmuş olan üçüncü kuşak yükseköğretim kurumlarından biri olmasıyla bölgeye istihdam ve inovatif düşüncenin sağlayıcısı rolü üstlenmesi beklenmektedir.

Araştırmanın örneklemini oluşturan Erzincan Üniversitesinin öğrencilerinin girişimci olarak karakteristik özellikleri inovatif faktörler açısından incelenmiş ve demografik özellikler ile girişimci olma isteği arasındaki ilişkilerin varlığı sorgulanmıştır. Erzincan Üniversitesi öğrencilerinin risk alma özelliklerinin faktörler arasında en düşük açıklayıcılığa sahip olmasının kamu sektöründe çalışma istekleri bağlamında ele alındığında, işsiz kalma korkusu ve garanti gelir kaynağı algısından kaynaklandığı söylenilebilir. Aynı zamanda araştırmaya katılanların \%46,9'u küçük şehirden üniversiteye geldiğini ve Erzincan ilinin büyükşehir olmamasının dezavantajı olduğunu belirtmiştir. Bölgesel olarak sanayileşme potansiyeline sahip olan TRA1 bölgesinin en önemli ihtiyacı inovatif düşünceyken, üniversite öğrencilerinin algısında talep yetersizliğine sahip olan bölge, ancak sanayi-üniversite işbirliği çalışmalarının öğrencilerin dahilinde projelerle değiştirilebilir. Öğrencilerin genel girişimcilik profillerinde teknolojik yeniliğin en üstün faktör olması, gelişen teknolojik yenilikler açısından önemli bir avantajı teşkil etmektedir. Genel bir değerlendirme yapıldığında, girişimcilik ile ilgili eğitim ve simülasyonların öğrencilerin potansiyellerini ortaya çıkarak onları risk alabilme kabiliyetlerini arttıracağı ön görülmektedir.

\section{Kaynakça}

- $\quad$ Akkaya, D. T., Yıldız, E. ve Koldere, A. Y. (2014), “Üniversite Öğrencilerinin Girişimci Kişilik Özelliklerinin Değerlendirilmesi: Yalova Meslek Yüksekokulu Öğrencilerine Yönelik Bir Uygulama”, Yalova Üniversitesi Sosyal Bilimler Dergisi, 5 (8): 108-122.

- $\quad$ Akpınar, T. ve Küçükgöksel, N. Ç. (2015), "Meslek Yüksekokulu Öğrencilerinin Girişimcilik Algısı ve Girişimciliği Engelleyen Sebepler”, Balkan ve Yakın Doğu Sosyal Bilimler Dergisi, 1 (1): 13-19.

- Bilge, H. ve Bal, V. (2012), “Girişimcilik Eğilimi: Celal Bayar Üniversitesi Öğrencileri Üzerine Bir Araştırma”, Süleyman Demirel Üniversitesi Sosyal Bilimler Enstitüsü Dergisi, 2 (16): 131-148.

- Dinler, Z., Mikro Ekonomi, Ekin Basım Dağıtım, 24. Basım, Bursa, 2013.

- $\quad$ Emsen, Ö. S., Yılmaz, Ö. ve Çınar, S. (2001), “Genç Nesilde Mesleki Eğilimler ve Girişimcilik: Ampirik Bir Çalışma”, Verimlilik Dergisi, 1: 153-176.

- $\quad$ Eren, H., Üniversite Öğrencilerinin Sosyal Yenilikçilik Kapasitelerinin Teknolojik Yenilikçilik Eğilimlerine Etkisini Ölçmeye Yönelik Bir Model Önerisi, Kara Harp Okulu Savunma Bilimleri Enstitüsü Teknoloji Yönetimi Ana Bilim Dalı, Doktora Tezi, Ankara, 2010.

- Gurel, E., Altinay, L. and Daniele, R. (2010), “Tourism Students’ Entrepreneurial Intentions”, Annuals of Tourism Research, 37 (3): 646-669.

- İşcan, Ö. F. ve Kaygın, E. (2011), “Üniversite Öğrencilerinin Girişimcilik Eğilimlerini Belirlemeye Yönelik Bir Araştırma”, Atatürk Üniversitesi Sosyal Bilimler Enstitüsü Dergisi, 15 (2): $443-462$.

- Kaya, D., Güzel, D. ve Çubukçu, B. (2010), "Üniversite Öğrencilerinin Girişimcilik Eğilimlerinin Araştırılması: Atatürk Üniversitesinde Bir Araştırma”, Kafkas Üniversitesi İ̈BF Dergisi, 1 (2): 77-89.

- $\quad$ Koh, C .H. (1996), “Testing Hypotheses of Entrepreneurial Characteristics: A Study of Hong Kong MBA Students", Journal of Managerial Psychology, (11) 3: 12-25.

- $\quad$ Nakip, M., Pazarlamada Araştırma Teknikleri, Seçkin Yayıncılık, 3. Baskı, Ankara, 2013.

- $\quad$ Patır, S. ve Karahan, M. (2010), “Girişimcilik Eğitimi ve Üniversite Öğrencilerinin Girişimcilik Profillerinin Belirlenmesine Yönelik Bir Alan Araştırması”, İşletme ve Ekonomi Araştırmaları Dergisi, (1) 2: 27-44.

- Soylu, A., Şenel, D., Kalfa, V. R. ve Kocaalan, M. L. (2015), “Girişimcilik Eğilimlerinin Öğrencilerin Girişimcilik Eğilimlerine Olan Etkilerini Belirlemeye Yönelik Bir Araştırma: Pamukkale Üniversitesi Honaz Meslek Yüksekokulu Örneği”, İşletme Araştırmaları Dergisi, (7) 3: 311-335.

- Wang, K. C., and Wong, P. K. (2004), "Entrepreneurial Interest of University Students in Singapore", Technovation, 24: 163-172. 


\title{
Tercih Edilen Müzik Türü ile Girişimcilik Eğilimi Arasındaki İlişki Hakkında Bir Araştırma
}

\section{A Research on the Relationship between Preferred Music Type and Entrepreneurship Tendency}

\author{
Prof. Dr. Feyzullah Eroğlu (Pamukkale University, Turkey) \\ Esvet Mert (Pamukkale University, Turkey)
}

\begin{abstract}
Cultural systems are grouped into high culture, folk culture and popular culture. High cultural, scientific, philosophical, aesthetic information, etc. Folk culture is based on folklore information from the past day. Popular culture represents the degraded and dissolved state of traditional cultures, various subculture areas, which have failed after modernization efforts. The aim of the study is to reveal the influence of young musical genres on the entrepreneurial tendencies. The first method used in the research is the questionnaire survey for senior students studying in the university business and economics. According to the survey data, questionnaires were distributed out of a total of 350 students, only to the evaluation of the survey of 311 eligible. The most important findings of the research can be summarized as follows. While $6,1 \%$ of the "youth of higher education" who participated in the survey preferred "high culture product" music; 10,6\% were "folk culture products" music; and 83,3\% preferred "popular culture product" music. The "entrepreneurship tendencies", which are the main aim of the subjects of "education for young people" receiving basic courses in economics and business administration, were found to be 131,5 (Min 36, Max.180). According to the research findings, in the direction of the basic assumption of the study, "entrepreneurial tendencies" of students who prefer music, which is a high cultural product, are higher than others. The sort of "entrepreneurial tendencies" is followed by popular genres and popular music genres.
\end{abstract}

\section{Giriș: İnsan Kültürel Bir Varlıktır}

Bütün canlı türlerinin doğuştan getirdikleri biyolojik özellik ve genetik yapıları, onların yaşamlarını sürdürme konusundaki davranış temellerinin esasını tayin eder. İnsan türü, diğer canlı türlerinden farklı olarak, yaşadıkları hayat içerisinde sadece biyolojik ve genetik yapılarının belirlediği davranışlarla sınırlı olmayıp, aynı zamanda doğumdan sonra öğrendikleri çok çeşitli davranış seçenekleri arasında tercih yapma serbestliğine ve imkânına da sahiptir (Özakpınar, 1999).İnsan türü, akıl sahibi olmasından dolayı biyolojik ve nörofizyolojik bir alt yapının oluşumuyla donanmıştır. Bu yüzden insanlar, kendi iç ve dış evrenlerinden bir şekilde ulaşmış olan çeşitli uyarımlara karşı uygun reaksiyonları göstermek yanında, diğer canlı türlerinden farklı olarak ayrıca bu durumu bir belirsizlik olarak algılarlar. Aslında, insanların, çeşitli olaylar ve olgular karşısındaki bu belirsizlik algılamaları, onların "merak duygusunu" harekete geçirmek suretiyle yeni bilgilenme süreçlerine katılmalarına imkân ve ortam hazırlar. İnsanların, yaşadıkları hayat içerisindeki her duygu, düşünce ve davranışları, doğuştan getirdikleri "içgüdüler" ile doğumdan sonra öğrendikleri çevresel ve kültürel "bilgilerin”, farklı bileşimlerinin yarattı̆̆ müşterek yönelimlerdir (Eroğlu, 2015).

İnsanların doğuştan getirdikleri içgüdülerin kaynaklık ettiği biyolojik kökenli duygu, düşünce ve davranışların, her bir kişide farklı dışavurum ve tezahürleri olsa da, normal şartlarda bütün bunların varlığı her bir kişi için veri olduğu kabul edilir. Buna karşılık, insanların toplam duygu, düşünce ve davranışlarındaki türlerin kaynakları, çeşitliliği, yoğunluğu, geçici ya da sürekliliği, olumlu ya da olumsuzluğu, kalitesi ya da kalitesizliği gibi farklı dereceleri, büyük ölçüde insandan insana, gruptan gruba, toplumdan topluma değişiklikler gösterir. Başka bir deyişle, herhangi bir insan içinde doğduğu, büyüdüğü, yetiştiği ve etkileşim içerisinde bulunduğu kültürel sistemin kapsadığı bütün bilgi öğelerini ve kültürel özelliklerini "aynen” içselleştiremez. Her bir kişinin normal şartlarda sahip olduğu kültürleşme ve sosyalleşme düzeyi, içinde bulunduğu alt kültürler ile genel kültür sistemi içindeki farklı sosyal kurumların (aile, konu komşu, okul, dinî inanç, hukuk ve ahlak anlayışı, medya v.b.), kendisine edindirdiği bilgilenme ile ilgili kişinin kendi istek ve iradesi sonucunda bizzat öğrenebildiği bilgilenmeden ibarettir. Her bir kişinin normal şartlarda sahip olduğu öğrenme ve bilgilenme kalitesi ise yine içinde bulunduğu alt kültürler ile genel kültür sistemi içindeki farklı sosyal kurumların, nispeten hangi bilgi sistemi içerisine dâhil olması ile yine ilgili kişinin bilgilenme ve kültürleşme sürecindeki özel çabalarıyla yakından ilintilidir. Buna göre, kültürel sistemler içerisinde yaşayan ve yetişen kişilerin, içinde yer aldıkları kültürel alt sistemler ile genel kültür sisteminin bilgi türlerinin, nispeten "nitelikli bilgiler" (vahiy bilgisi, bilimsel bilgi, felsefe bilgisi, sanat bilgisi, hukuk ve ahlak bilgisi gibi) kategorisi içinde yer alıyor olması, o bireylerin yüksek derecede sosyalleşmiş ve kültürleşmiş olduklarının temel göstergelerinden biridir. Eğer, kültürel alt sistemler ile genel kültür sisteminin bilgi türlerinin, nispeten "niteliksiz bilgiler" (hayatta karşılığı olmayan gelenekler, hurafe inançlar, içi boş ve anlamsız spor yorumları, rasyonel düşünceyi temsil etmeyen siyasi polemikler, hiçbir yaratıcılığı olmayan medya ve sosyal 
medya enformasyonları ile her türlü popüler bilgiler) kategorisi içinde yer alıyor olması, o kişilerin düşük derecede sosyalleşmiş ve kültürleşmiş olduklarının temel göstergelerinden biri olacaktır.

\section{Yetkinlik Açısından Kültürel Öğeler Hiyerarşisi}

İnsanların, teker teker kişisel hayatları ile içinde yer aldıkları toplumsal grupların şekillendirdiği temel duygu, düşünce ve davranışlarının belirleyici öğelerinin önemli bir kısmını, içerisinde yaşadıkları kültür ortamı tayin etmektedir. Bu durumda, İçinde yaşanılan alt kültür sistemleri ile genel kültür sistemi, kendilerine kaynaklık yapan bilgi türlerinin bileşimlerine göre, "yüksek kültür", "halk kültürü” ve "popüler kültür" olmak üzere üç grupta kategorize edilmektedir.

"Yüksek Kültür", geçmişten günümüze, günümüzden geleceğe uzanan üç boyutlu zaman sürecinde, nitelikli bilgilere (hayatta büyük ölçüde karşıllğı olan, sorun çözme kapasitesini geliştiren, tabiata ve hayata yüksek katma değerler yaratabilen geleneksel ve çağdaş bilgi sistemlerine) dayanan yaşam biçimi örnekleridir. Söz gelimi, "bilimsel araştırma yöntem ve tekniklerinin kullanımıyla kazanılmış bilimsel bilgiler ile çeşitli "yaratıcı düşüncelerin" farklı bileşimleriyle elde edilmiş bilimsel teori ve yaklaşımlar, çeşitli felsefe-bilim açıklamaları, sorun çözme yetisi yüksek yönetim sistemleri, etkili ve verimli örgütler ve kurumlar, katma değeri yüksek teknolojik ürünler, hayata ve tabiata estetik değeri yüksek eserler yaratmak, "yüksek kültürün" önemli işlev ve sonuçları arasındadır. Bu çerçevede, yoğun rekabet ve hızlı değişimlerin yaşandığı günümüz dünyasında, geçmişin olumlu-olumsuz deneyimlerinin 1şı̆ı̆ altında, günümüzün mevcut şartları ve imkânları arasında, geleceğin son derece belirsizlikler içerisinde olduğu bir iş ortamında, özü itibarıyla "bilgi-yoğun" ve karmaşık iliş̧kiler ağı olarak "girișimcilik" gibi etkinlikler de birer "yüksek kültür" eseri sayılmaktadır. Çok sayıda yerli ve yabancı araştırmacılar tarafından ortaya konulan girişimcilik etkinlikleri için insanların, sıra dışı ve önemli niteliklere sahip olmaları gerektiği vurgulanmıştır. Bu bağlamda, nicel ve nitel araştırma bulgularına göre, girişimcilerin taşıması gereken nitelikler, başarı ihtiyacının yüksekliği, risk alma cesareti, belirsizlikler karşısında yüksek bir tolerans, karşılaşılan olaylar karşısında yüksek bir içsel odaklılık, yüksek bir öz güvenin varlığı, erişilebilir ya da makul ölçülerde yüksek bir amaçlar seti ile nispeten yüksek bir bağımsızlık duygusu, şeklinde ifade edilmektedir (İrmiş, vd, 2010). Bu insani niteliklere sahip olmak, asla bir tesadüf ya da rastgelelik içerisinde sahip olunacak davranışlar değillerdir. Bütün bunlar, ancak kişilerin yüksek kültür becerileri ile gerçekleşecek bir kazanımdır. Aynı şekilde, nitelikli bilgilerin önemli öğelerinden felsefe-bilim, yaratıcı estetik değerler ve sanat bilgisinin yarattı̆̆ı "klasik müzik", yine yüksek kültür eserleri arasında sayılır. Klasik müziğin, yüksek bir yetenek ve yüksek bir emek ile gerçekleşip, üzerinden yillar ve asırlar geçmesine rağmen, sanat gücünden ve değerinden hiçbir şey kaybetmeyen, hatta giderek anlamı ve önemi artan eserler olması gerçeği, bu etkinliğin de hem üretim ve sunum aşamasında, hem de yararlanılması aşamasında ne kadar yüksek bir kültür gereği olduğunu ortaya koymaktadır.

"Halk Külttürü", toplumların üç boyutlu zaman sürecinde, ağırlıklı olarak geçmişten günümüze geleneksel ve folklorik bilgilere dayalı olarak üretmiş oldukları, sosyal ve gündelik hayatın birçok alanında hâlâ geçerliliği ve yararı bulunan, bu anlamda toplumun çoğunluğu için yaşam kolaylı̆̆ı ve rahatllğı sağlayan kültür öğeleri ve yaşam biçimleridir. Söz gelimi, konuk ağırlama, evlilik ve nişan törenleri, bayram kutlamaları gibi geçmişten günümüze kullanılagelmiş ve hali hazırda kullanım değerlerini de korumakta olan toplumsal davranış kalıplarıdır. Aynı şekilde, toplumsal geçmişin eğlenme ve dinlenme biçimi olarak doğmuş olmakla birlikte, yer yer çeşitli insani ve toplumsal sorunlar ile insan-tabiat-evren ilişkilerine dair göndermelerde bulunan halk türküleri, yine bu kapsamda kültürel öğeler olarak görülmektedir.

"Popüler Kültür" ise üç boyutlu zaman sürecinde, yaşanmakta olan "Âna" odaklanmış olup, geçmiş ile gelecek zaman boyutlarıyla duygusal ve zihinsel bağı pek bulunmayan bir yaşam biçimini temsil eden kültür kategorisidir. "Popüler Kültür", modernleşme çabasında nispeten başarısız olan geleneksel kültürlerin, hemen her alt kültür alanlarındaki bozulmuş ve ç̧̈zülmüş halini temsil eden bir kültür çeşididir. Popüler kültürün doğuşunda en etkili faktör, modernleşmenin kendinden önceki geleneksel kültür dokularını çözmüş olması gerçekliği ve olgusudur. Böyle olunca da popüler kültür bileşenlerinde, "rasyonel düşünceye" dayalı "bireyselleşmiş" bir modernist tavır olmadığı gibi, bir kısım geleneklerin çözülmüş olması nedeniyle artık işlevlerini kaybetmiş olmasından ileri gelen geleneksel davranışların asli geçerlilikleri de yeterince görünme imkânı bulamaz. Bunların yerine, popüler kültür kapsamında, fazla bir işlevselliği, üretkenliği, yararı bulunmayan, böyle olduğu için hiçbir kalıcıllğı da olmayan ve sıradan bilinçler tarafından ortaya çıkarılmış olup geniş bir kitle tarafından kolayca beğenilen türedi kültür öğeleri ve yaşam biçimleri yer almaktadır. Söz gelimi, popüler kültür kapsamında, özensiz ve uyumsuz k1lık kıyafet, ahlaki içeriği boşaltılmış görüntü dindarlığı, gerçeği yaratılamadığı için sahtesi çıkarılmış magazin ve medya bilgileri, üretimden ve paylaşımdan koparılmış tüketim çılgınlığı, medeni ve geleneksel insan ilişkileri kurulamadığı için "yağcılık-yalakalık" ve "yıldırma-şiddet" davranışları gibi yaşam biçimleri örnekleri sayılabilir. $\mathrm{Bu}$ anlamda, popüler kültürün gerçekte en önemli ve simgesel kültür örneği ise hemen bütün kültür sistemlerinde, o toplumların "modernleşme" çabaları ile "geleneksel değerleri" arasındaki çatışma, dengesizlik ve düzensizlik ortamlarında ortaya çıkan "popüler müziklerdir".

Her toplumun egemen kültür sistemi, içinde yer aldıkları genel medeniyet çerçevesi ve modernleşme düzeyleri ile kültürel geçmiş ve geleneksel yapılarının elverdiği ölçüde, bu üç kültür çeşidinin her üçünden kültürel öğeler 
bileşiminden oluşmaktadır. Şu andaki dünya toplumları içerisinde, Batı medeniyet dairesinde yer alıp modernleşme düzeyleri de yüksek olan kültür sistemlerinde, nispeten yüksek oranda bilimsel bilgiye, felsefebilime, sanat bilgisine ve teknolojiye dayalı kültürel yaratmalardan dolayı "yüksek kültür" boyutu oldukça gelişmiştir. Bununla birlikte, genel kültür hiyerarşisinin, özellikle göçmen toplulukların gelişmiş kültür sistemine yeterince uyum sağlayamadığı ölçüde "popüler kültür” örnekleri de mevcuttur. Ayrıca, bu toplumların kendi kırsal bölgelerindeki yerli nüfus ile göçmen topluluklarının dar ve kapalı koloniler halinde yaşadıkları alt kültür alanlarında "halk kültürü” kapsamında kültürel öğeler de görülmektedir. Buna karşılık, Batı medeniyet dairesine girme ve modernleşme çabası içerisinde bulunup, beklenildiği ölçüde modernleşmeyi başaramayan, ayrıca önceki geleneksel yapısını da koruyamayarak sosyal dokusu çözülen Batı dışı toplumların hemen hepsindeki genel kültür hiyerarşisinde en yaygın kültür çeşidi, "popüler kültürdür”. Bu toplumlarda, kültür sistemlerinden geleneksel özelliklerini koruyabildikleri kadarıyla "halk kültürü”, çok ender olarak bazı kesimlerde "yüksek kültür” bileşenleri bulunmaktadır. Bu bağlamda, bu toplumlarda farklı kültürel melezleşmeden meydana gelen "popüler kültürün”, aşağıdan yukarıya doğru bütün sosyal sınıf ve grupların yaşam biçimini etkisi altına almış olması haline "kitle kültürü" denilmektedir.

\section{Müzik Kültürünün İnsan ve Toplum Davranışlarındaki Yeri}

Bütün kültür öğeleri içerisindeki sanatsal etkinlikler gibi, “müzik sanatı” da insan zihninin bir ürünüdür. İnsan zihni, biyolojik ve genetik yapısındaki potansiyel doğal güdü, duygu ve eğilimler yanında, doğduğu andan itibaren insani ve toplumsal çevresinden, kendinin edindiği ve kendine kazandırılmış olan çok sayıdaki sosyal güdü, duygu, bilgi ve düşüncelerle sürekli işleyen bir iletişim merkezidir. İnsanların, çeşitli durum ve şartlardaki uyarımlara ve sinyallere karşı geliştirdiği eylem ve davranışların esas kaynağı, bilinçaltı ve bilinç üstü oluşumlarıyla zihinde depolanmış olan bu güdü, duygu, eğilim, bilgi ve düşünce toplamıdır. İnsanlar, sahip oldukları zihinsel birikimlerin aracılığıyla dış dünyayı algılar, anlar ve tavır geliştirirler. Bu bağlamda, insan zihninin, tabiatta var olan belli sesleri, belirli ses bileşenleri şeklinde tasarlayarak, sonradan onları aktif olarak dışa vurmasına, böylece tabiatta ve hayatta daha önceden olmayıp, tabiat ve hayata yeni ses bileşenleri katmasına, kültür teorisi çerçevesinde "müzik sanatı" denilmektedir. Bu anlamda, müzik sanatını, insan zihninin, tabiatta var olan belli seslerin, sayısız denilecek kadar çok sayıda olan ses ilişkileri ve bileşenleri arasında, şunu ya da bunu bilgi-deneyim ve sezgi yoluyla yakalayıp ifade etmesidir. Bu ses ilişki ve bileşenlerinin ifadeleri, mümkün olan en güzel duygu ve düşünceleri çağrıştırıyor ise bu müziğin sanatsal gücünü temsil eden bir değerdir (Öner, 1999).

Genel kültür teorisine göre, insanların doğada hazır bulmadıkları ve doğuştan getirmedikleri, ama doğada hazır buldukları ve doğuştan getirdikleri varlık ve imkânlar ile çeşitli "hammaddeler" üzerinden doğaya ve hayata kattıkları her şeye kültür denilmektedir. Bu anlamda, doğadaki ağaç ile insan beyni ve eli kültür değildir, ama insan beyninin tasarladığı ve insan elinin ağaçtan yaptığı "masa" bir kültürel yaratmadır. Ağaçlardan gelen bir yaprak hışırtısı ve kuş cıvıltısı, derenin akışından gelen bir çağıltı, denizin dalgasının kıyıya vuruş sesi duyulduğu zaman ne kadar hoşa giderse gitsin bir kültür değildir. İnsanlar, doğadan gelen bir sürü sese karşı duyarlıdır, ancak bu doğal sesler müziği akla getirse bile, bu doğal seslerin insan tarafindan bir düzene sokulması sonrasında ortaya çıkan yeni ses bileşenlerine müzik denir. "Tonal öğeler”, ancak insani düzenlemeler sayesinde müziğe dönüşür ve böyle bir düzenleme, farklı düzeylerde olmak kaydıyla bir insan edimini varsayar. Doğadaki bütün sesler (yalın ve doğal haliyle insanın sesi de dâhil), müzik kültürünün hammaddesidir. İnsan zihninin, bu doğal sesler üzerinde tasarladığ 1 ve yaptığ düzenleme, bu seslere doğal halinin ötesinde verdiği biçim ve tarz, hayat veren ve yaratan aklın çalışmasının bir sonucu ve ürünüdür. Bu anlamda, bir kuşun şakımasından üzerimize yağan hoşnutluk ve zevk duygusu kendi başına bir sanat ve kültür olmayıp, ama insan tarafından icra edilmiş en basit bir modülasyon bile sanat ve kültürdür (Stravinsky, 2011).

Bütün kültürel öğelerin esas çıkış kaynağı insan ihtiyaçlarıdır. İnsanlar, zihinlerindeki her türlü duygu ve düşüncelerini, sözlü iletişim ve beden dili ile yanı sıra, doğal seslerine veya çeşitli müzik aletlerinin seslerine, bir takım anlam ve çağrışımlar katmak suretiyle müzik kültürü üzerinden de dışa vurma eğilimlerine sahiptirler. Belirli duygu ve düşüncelerin, iletişim kültürü kapsamında ses düzenlemesi yapılarak dışa vurumu esnasında, genel olarak sesin iki ayrı yoldan birini izlediği görülmüştür. Ses öğesi, anlam bakımından ihmale değer olduğu halde, "kulağa yağmur gibi pitır pıtır dökülerek" hoşnutluk ve zevk verebilir. Ses öğesi, bir duygu ve düşünce aracı, bir işaretler ya da simgeler sistemi haline gelerek, içindeki seda unutulup ihmal edilebilir. Başka bir deyişle, ses bir istek ya da ihtiyacı sözlü iletişim yoluyla anlatma aracı olursa "dil" olur. Müzik kültürü kapsamında, sadece ses öğesine bir dizi duygu ve anlam çağrışımları katmak suretiyle düzenleme yapmak mümkün olduğu gibi, belirli bir söz öğesine temsil ettiği anlamı duygusal anlamda güçlendirmek maksadıyla düzenleme yapmak kabildir. Bazen müzik, mantıklı bir anlamdan yoksun olmakla birlikte, duygu ve estetik bakımdan büyük bir önem taşıyan bir sanattır. İnsanlar üzerinde, duyusal olarak müziğin çekiciliği de diğer sanatların çekiciliği gibi en soyut ve zihinsel etkiler bırakacak imkânlara sahip olmasıdır (Edman, 1977).

Müzik kültürüne konu olan ses düzenlemelerinin çıkış kaynağı, insanların doğuştan getirdikleri biyolojik kökenli duygu ve eğilimleri ile doğumdan sonra kültürel çevrelerinin kazandırdığı çeşitli duygu ve düşünce birikimlerinin müşterek zihniyet dünyalarıdır. Aynı şekilde, başka insanların müzik kültürü öğelerine ilgi duyan ve dinleyen insanlar da, bu yöndeki tercih ve taleplerini, büyük ölçüde kendi biyolojik kökenli duygu ve eğilimleri ile 
doğumdan sonra kültürel çevrelerinin kazandırdığı çeşitli duygu ve düşünce birikimlerinin ortaklaşa şekillendirdiği zihniyet çerçevesinde tayin ederler. Bu durumda, bütün kültürel öğelerin üretilmesi ve yaratılması nasıl bir zihniyet sonucu ve ürünü ise müzik kültürü ile zihniyet olgusu arasında da birebir bir ilişki vardır. Müzik kültürü öğeleri üretenler, bu kültürel öğeleri, mevcut yetenek ve kapasiteleri ölçüsünde, zihniyet dünyalarını oluşturan duygu ve düşüncelerin ifadesi olarak dişa vururlar.

İnsanların, doğada hazır bulmadıkları ve doğuştan getirmedikleri, doğumdan sonra sosyalleşme ve kültürleşme süreçlerine bağlı olarak sonradan öğrendikleri her kültür öğesinin algılama ve kavrama merkezi insan zihnidir. İnsan zihnindeki, küçük yaşlardan itibaren öğretilmiş ve öğrenilmiş bilgi ve kültür bileşenleri, kişilerin hayatlarının her aşamasında üretecekleri bilgi ve kültür öğelerini idare etmektedir. Bu durumda, insanların duygu ve düşüncelerini ifade etme ile bilgi ve kültür üretme etkinlikleri ile daha önceden zihinlerinde oluşmuş kültür piramidi bileşenlerinin doğrudan ve ya dolaylı bir şekilde etkileşimi söz konusudur. Zihinlerinin "yüksek kültür" boyutu gelişmiş olanlar, büyük ölçüde “yüksek kültür” ürünü sayılan duygu ve düşünceler ile bilgi ve kültür öğeleri yaratırlar. Buna karşılık, zihinlerinde büyük ölçüde "popüler kültürün” baskın olarak içselleştirildiği "kitle toplumu" insanlarının, büyük ölçüde dışa vurdukları duygu ve düşünceleri ile ortaya koydukları bilgi ve kültür öğeleri de niteliksiz olmaktadır. Buna karşılık, insanların hayatlarını sürdürdükleri egemen kültür çevresinin etkisiyle yer yer kendi tercihlerinin sonucunda zihinlerinde yerleşmiş olan kültürel öğelerin bileşeni, onların bir taraftan yeni bilgi ve kültür öğelerine olan ihtiyaç derecelerini, bir taraftan da bunların niteliklerinin düzeyini tayin eder. Bu bağlamda, zihinlerinde "yüksek kültür" bileşenleri ağırlıklı bulunanlar, büyük bir ihtimalle "yüksek kültür” ürünü olan duygu ve düşünce ile bilgi ve kültür öğelerine duyarlılık gösterirler. Zihinlerinde "popüler kültür" bileşenleri baskın olanlar ise büyük bir ihtimalle "popüler kültür” ürünü olan duygu ve düşünceler ile bilgi ve kültür öğelerine eğilim gösterirler.

\section{Müzik Türü Tercihinin Davranışsal Yansımaları}

Bütün kültür sistemlerinin ve her kültür çeşidinin içerdiği çok sayıda kültür öğeleri bulunmaktadır. Bu kültür öğelerinin her biri, kültürel sistemlerin farklı işlev ve amaçlara sahip olan parçalarını temsil etmektedir. Genel olarak, kültür sistemleri içerisindeki "Müzik” öğesinin, hem kendisiyle ilgili işleve ve amaca hizmet ederken, aynı zamanda diğer bütün kültürel öğelerin oluşum ve işleyişi üzerinde de olumlu ya da olumsuz birçok etkilerinin olduğu varsayılmaktadır. Bu bağlamda, birçok filozof ve düşünür, müzik üzerinde düşünmüş ve bu konuda son derece özgün sözler söylemişlerdir. Karl Marks, müzik için "gerçeğin aynasıdır” derken, Friedrich Nietzsche ise müziği "hakikati söyleyen söz" olarak görmektedir. Sigmund Freud için müzik, "şifresi çözülecek bir metindir; Pierre Schaeffer için "insanın, insanı nesneler dilinde tanımlamasıdır”. Toplumsal kültürler, o toplumu meydana getiren kişilerin bütün eylem ve hareketlerinin yansıdığı bir ortak ayna gibidir; fakat müzik kültürü de insan toplumlarının kültürel değişim ve gelişimlerinin en etkili yankısıdır. Müzik, toplumsal kültürün bir aynası, kristal küresi ve kişioğlunun yaptıklarının kayıt altına alındığı bir yüzey ve ortamdır. Müzik kültürüne dair tercihler, her dinleyicinin kendi duygu ve düşüncelerini kaydettiği özel bir bellek ve bir “anamnezdir”.Bu bakımdan, müzik sadece kendi başına yalın bir etkinlik olmadığı gibi, yalnızca ekonomik alt yapının ürünü de değildir. Müzik, bir dönemin estetiğinin yankısı olmaktan da öte, günceli aşarak kişilerin, sanatçıların, grupların, halkların gelecekleri hakkında da bildirimde bulunur (Attali, 2014).

Müzik kültürünün, felsefe-bilim bakışı açısından insanların genel kültür dokularının "aynası” olma tespitine ek olarak "müzik ile kişilik özellikleri arasındaki ilişki”" hakkında da çeşitli bilimsel araştırmalar yapılmıştır. Bu araştırma sonuçlarının büyük bir kısmı, insanların tercih ettikleri müzik kültürünün veya türünün, onların sahip oldukları bütün kişilik özelliklerinin adeta psiko-sosyal bir özeti gibi bulgular ortaya koymaktadır. Sözgelimi, Adrian North tarafından 36.000 kişi üzerinde ve dünya çapında yapılan geniş katılımlı bir araştırmada, insanların müzik kültürlerinin ve bu yöndeki tercihlerinin, kişilik, siyasi kimlik ve çeşitli zihinsel becerileriyle yakından ilişkili olduğu bulunmuştur (Akt. Yağışan, 2013). Deneysel - duygusal müziksel ifade çalışmalarında kullanılan dört temel yöntem bulunmaktadır. Bunlar, Nöropsikoloji teknikleri, davranışların gözlemlenmesi, fizyolojik tepkilerin ölçümlenmesi ve test-anket çalışmalarıdır. Bunlardan nöropsikoloji çalışma olarak, Fırat Kutluk yönetiminde gerçekleştirilen araştırmada, kültürel geçmiş bağlamında beğenilen ve beğenilmeyen müziklerin beyinde yarattığı etkiler incelenmeye çalışılmıştır. Çalışmada bir grup katılımcıya, fMRI (FunctionalMagneticResonance Imaging) çekilirken dört farklı türde müzik örneği dinletilip aktif olan beyin bölgelerine odaklanılmıştır. Kültürel etkenlerin müzik beğenisine olan katkısının ve insan beyninde "müziği beğenme" bölgesinin belirlenmeye çalışıldığı tezde istatistiksel olarak anlamlı bir sonuca ulaşılamasa da, kültürel olarak etkilenmenin kişinin söylemlerini değiştirdiği varsayımı doğrulanmıştır (Akt. Erdal, 2009).

Müzik kültürü ile insanların duygu ve davranışları arasında, doğrudan ya da dolaylı bir biçimde ilişki olduğu hakkındaki araştırma bulguları ve gözlemler, her bir kişinin ağırlıklı bir şekilde tercih ettiği müzik türünün, küçük yaşlardan itibaren zihninde birikmiş olman kültür bileşiminin bir sonucu olduğu gerçeğini ortaya çıkarmaktadır. $\mathrm{Bu}$ durumda, en çok tercih edilen ve beğenilen müzik, özellikle sürekli dinleyicisi olan kişiler üzerinde, sürekli dalgalanan, çok çeşitli ve yoğun duygu ve düşüncelerin ortaya çıkmasına neden olmaktadır (Canetti, 1998).Birey, “yüksek kültür” bileşeninin ağırlıklı olduğu bir kültür birikimine sahipse, muhtemelen "yüksek kültür" odaklı bir müzik kültürüne dair duygu ve düşünceler ile nitelikli hareket tarzlarına yönelik davranışlar bağlamında uyarılmış 
olacaktır. Kişi, "halk kültürü” bileşeninin ağırlıklı olduğu bir kültür birikimine sahipse, muhtemelen "halk kültürü” odaklı bir müzik kültürüne dair duygu ve düşünceler ile ilintili davranış seçeneklerine yönelecektir. Aynı şekilde, kitle kültürü mensubu olan bir kişi, "popüler kültür” bileşeninin baskın olduğu bir kültür birikimine sahipse, muhtemelen "popüler kültür" odaklı bir müzik kültürüne dair duygu ve düşüncelerin dayattığı davranış kalıplarına doğru yönelecektir.

\section{Araştırma Yöntemi ve Bulguları}

\subsection{Araştırmanın Konu Seçimi}

Modernleşme projesinin yeterince tamamlanamadığı Türkiye'de, toplumsal hayatı şekillendiren kültürel sistemin, büyük ölçüde "popüler kültür" etkisi altında kalmış olması nedeniyle katma değeri düşük veya niteliksiz kitle davranışlarında belirgin bir artışın ortaya çıkması gibi, aynı paralelde sanat ve estetik değeri düşük müzik türleri de hızla çoğalmıştır. Bu bağlamda, modern toplumların yarattığı "yüksek kültür" odaklı medeniyetin en etkili ve önemli hareket tarzı olan "girişimcilik" kapsamındaki nitelikli insan davranışlarının, "popüler kültür" bileşeninin baskın olduğu kitle toplumlarında ortaya çıkma ihtimali oldukça düşük kalmaktadır. "Girişimcilik", genel olarak belirli bir kişi ya da grubun, yeni bir ürün ve pazar yaratmak amacıyla çeşitli üretim faktörlerini bir araya getirmek suretiyle bütün kaynakların dengeli ve düzenli bileşimlerinden daha fazla katma değer yaratılması sürecidir. Günümüz şartlarında, girişimcilik gibi yüksek kültür ürünü olan insani hareket ve davranışların, sıradan bilinç ve eylemlerle gerçekleştirilmesi artık mümkün görünmemektedir. Girişimcilerin, yapmayı düşündükleri ve tasarladıkları iş ve faaliyetlere ilişkin kullanılacak teknoloji ve üretim süreçleri ile gelecek zaman içerisindeki talep, pazar ve rekabet durumları gibi konularda, son derece duyarlı, bilgili ve bilinçli olmaları gerekmektedir. Bütün bu konularda, çağdaş girişimcilerin, karşılaştıkları son derece karmaşık olaylar karşısında, telafisi mümkün olmadığından ya da bedelinin çok ağır olma ihtimalinden dolayı, isabetli ve uygun kararlar almaları gerekmektedir. Bazen, çeşitli karmaşık ve belirsizlik durumlarında, sahip olunan nesnel bilgiler yeterli olmadığı zamanlarda, ayrıca isabet derecesi yüksek sezgilerin de kullanılması söz konusudur.

\subsection{Araştırmanın Amacı ve Yöntemi}

Çalışmanın temel varsayımı, insan zihninin duygusal ve düşünsel arka planı ile yaptıkları tercihler ve davranışlar arasında doğrusal bir ilişki olduğu yönündedir. Buna göre, duygusal ve düşünsel bütünlüğü bulunmayan ve estetik değeri düşük müziklerle özdeşleşmiş olan kişilerin, “girişimcilik davranışları” gibi katma değeri yüksek ve nitelikli hareketler içerisinde bulunma ihtimalinin daha düşük olacağıdır.

$\mathrm{Bu}$ araştırmada, nicel yöntem tekniği olarak üniversitede işletme ve ekonomi alanında eğitim gören son sınıf öğrencilerine yönelik olarak anket uygulanmak suretiyle sevdikleri müzik türleriyle ilgili tercihleri ile girişimcilik eğilimleri arasında bir ilişki olup olmadığı öğrenilmeye çalışılmıştır.

Araştırmanın amacı, genç kuşakların dinledikleri müzik türlerinin girişimcilik eğilimleri üzerindeki etkisini ortaya çıkarmaktır. Araştırmada kullanılan yöntem öğrencilere yönelik anket uygulamasıdır. Araştırmanın evrenini Pamukkale Üniversitesi İktisadi ve İdari Bilimler Fakültesinde İşletme, İngilizce İşletme, İktisat, İngilizce İktisat ve Maliye bölümlerinde öğrenim gören 3. ve 4. sınıf öğrencileri oluşturmaktadır. Seçilen bölümlerin diğer bölümlere nazaran nispeten daha fazla girişimcilik eğilimi sergileyecekleri varsayılmıştır. Belirtilen örneklemde yer alan mevcut öğrenci sayısı toplamda 2890 'dır. Toplamda 350 anket dağıtılmış, 315 anket geri dönmüş ancak çeşitli nedenlerden dolayı 311 tanesi değerlendirmeye uygun bulunmuştur. Geri dönüş oranı \%89'dur. Araştırmadan elde edilen veriler araştırma evrenini \%95 $(\alpha=.05)$ güven düzeyi seviyesinde temsil edebilecek niteliktedir.

Çalışmada kullanılan veri aracı Yılmaz ve Sünbül (2009) tarafından geliştirilen üniversite öğrencilerinin girişimcilik düzeylerini belirlemeye yönelik 36 maddelik "Üniversite Öğrencileri Girişimcilik Ölçeği”dir. Ölçekte yer alan her bir madde 5'li likert ölçek tipindedir. İfadeye verilebilecek yanıtlar, 1, "Hiçbir zaman"; 2, "Nadiren"; 3, "Bazen"; 4, "Sıı sık"; 5, "Çok sık" şeklindedir. Ölçekteki maddeler 36 ile 180 arasında değişen puan değerine sahiptir. Araştırmaya katılan kişilerden alınan yanıtların puan değeri karşılıkları ile her bir kişinin genel girişimcilik düzeyine ilişkin puanları hesaplanmaktadır (Yılmaz ve Sümbül, 2009). Bahsi geçen aralıklar şu şekilde sınıflandırılmaktadır: 36-64, "Çok düşük girişimcilik"; 65-92, "Düşük girişimcilik"; 93-123, "Orta düzeyde girişimcilik"; 124-151, "Yüksek girişimcilik"; 152-180, "Çok yüksek girişimcilik". Ölçek ayrıca tek bir faktör ile değerlendirilmektedir. Çalışmanın amacı doğrultusunda aşağıdaki hipotezler oluşturulmuştur:

$\mathbf{H}_{1}$ : Öğrencilerin bulundukları sınıf ile girişimcilik düzeyleri arasında anlamlı bir farklılık bulunmaktadır.

$\mathbf{H}_{2}$ : Öğrencilerin cinsiyetleri ile girişimcilik düzeyleri arasında anlamlı bir farklılık bulunmaktadır.

H3: Öğrencilerin bölümleri ile girişimcilik düzeyleri arasında anlamlı bir farklılık bulunmaktadır.

$\mathbf{H}_{4}$ :Öğrencilerin tercih ettikleri müzik türü ile girişimcilik düzeyleri arasında anlamlı bir farklılık bulunmaktadır.

\subsection{Araştırmaya İliş̧kin Bulgular}

Araştırmada kullanılan ölçeklerin iç tutarlılı̆̆ını ölçmek için yapılan güvenilirlik analizi sonuçları Tablo 1'de yer almaktadır. Üniversite Öğrencileri Girişimcilik Ölçeği'nin güvenilirlik analizine ait sonuçları incelendiğinde çıkan ilk katsayı 0,868'dir. Ancak analiz sonuçları tablosunda yer alan "Cronbach's Alpha If Item Deleted" sütunu 
sonuçlarına göre 21.madde ölçekten çıkarıldığında güvenilirlik katsayısının 0,893'e çıktı̆̆g görülmektedir. Bu sebeple ölçekteki 35 madde değerlendirilmeye alınarak; güvenilirlik katsayısı 0,893 olarak kabul edilmiştir. Bir ölçeğin güvenilir olduğunu söyleyebilmek için güvenilirlik katsayısının 0,70 'den büyük olması gerekmektedir (Akbulut, 2010). Kullanılan ölçekler ve alt boyutlarına ait güvenilirlik katsayıları bu koşulu sağlamaktadır. Bu nedenle ölçeklerin oldukça güvenilir olduğu söylenebilmektedir. Ölçeğin kullanıldığı benzer çalışmada da bulunan sonuca yakın sonuç tespit edilerek 0,90 bulunmuş. Sonucun literatür ile uyumlu olduğu söylenebilir (Yılmaz ve Sünbül, 2009).

\begin{tabular}{ccc}
\hline & İfade Sayısı & Cronbach's Alpha( $\boldsymbol{\alpha})$ \\
\hline Üniversite Öğrencileri Girişimcilik Ölçeği & 35 & 0,893 \\
\hline
\end{tabular}

Tablo 1. Güvenilirlik Analizi Sonuçlarl

Bir sonraki analizde verilerin normal dağılıma uyup uymadıkları kontrol edilmek istenmiş̧tir. Bunun için Kolmogorov-Smirnov ve Shapiro-Wilk testleri uygulanmıştır. Her iki ölçeğin de sonuçlarına göre dağılım normal dağılmamaktadır. Çünkü anlamlılık değerleri 0,05 'ten küçük çıkmıştır. Basıklık ve çarpıklık değerleri de bu sonuçları desteklemektedir. Sonuçlara göre veriler normal dağılım göstermemektedir. Bu sebeple kullanılacak analiz yöntemleri parametrik olmayan analiz yöntemleridir. Bu bağlamda verilen yanıtlar arasındaki farklılıkları ölçmek amacıyla iki değişkenliler için Mann-Whitney U Testi ve ikiden fazla değişkenliler için Kruskal Wallis Testi uygulanmıştır. Ayrıca araştırmada elde edilen verilerin değerlendirilmesi için tanımlayıcı istatistik yöntemlerinden sayı, yüzde, ortalama ve standart sapma kullanılmıştır.

Araştırmaya katılanlara ilişsin veriler analiz edildiğinde çıkan sonuçlar Tablo 2'de görülmektedir. Sonuçlar yorumlandığında kadınların katılım oranı \%53,7 ile dağılım gösterirken erkeklerin katılım oranı \%46,3 olarak bulunmuştur. Çalışmaya katılanlar sadece 3 . sınıf ve 4 . sınıf öğrencilerinden oluştuğundan yaş aralığı da onunla ilişkili olarak tespit edilmiştir. 3.sınıflar \%55,63 çıkarken, 4.sınıflar \%44,37 çıkmıştır. Yaş dağılımı da 20-22 aralığında $\% 57,56$ ile yoğunlaşırken, $23-25$ aralığında $\% 39,87$ ve son olarak 26 ve üzeri yaş aralığında ise $\% 2,57$ bulunmuştur. Normal öğrenim süresince mezun olamayan öğrenciler sebebi ile aralığa uygun olmayan yaşlar da tespit edilmiştir. Bölüm dağılımı incelendiğinde ise \%26,37 ile işletme ilk sırayı alırken, sırasıyla \%22,5 ile maliye, $\% 18,33$ ile iktisat, \%16,72 ile İngilizce iktisat ve son olarak \%16,08 ile İngilizce işletme yer almaktadır.

\begin{tabular}{lcc|lcc}
\hline & Sayı & Yüzde (\%) & \multicolumn{1}{c}{ Sinıf } & Sayı & Yüzde (\%) \\
\hline \multicolumn{1}{c}{ Cinsiyet } & & & \multicolumn{1}{c}{ Sın } & \\
\hline Kadın & 167 & 53,70 & 3.sınıf & 173 & 55,63 \\
Erkek & 144 & 46,30 & 4.sınıf & 138 & 44,37 \\
\hline \multicolumn{1}{c}{ Yaş } & & & \multicolumn{1}{c}{ Bölüim } & & \\
\hline $20-22$ & 179 & 57,56 & İșletme & 82 & 26,37 \\
$23-25$ & 124 & 39,87 & İng. İşletme & 50 & 16,08 \\
26 ve üzeri & 8 & 2,57 & İktisat & 57 & 18,33 \\
& & & İng. İktisat & 52 & 16,72 \\
& & & Maliye & 70 & 22,51 \\
\hline Toplam & 311 & 100 & Toplam & 311 & 100 \\
\hline
\end{tabular}

Tablo 2. Ankete Katılanlara İlişkin Demografik Veriler

Öğrencilere yöneltilen anket formunda 12 türde müzik bulunmaktaydı. Bu türler literatür ile bağlantılı olarak üç kültür düzeyi arasında dağılım göstermiştir. Ankete katılan yüksek öğrenim gençliğinin müzik tercihleri, yetkinlik ve işlevsellik ile kalite açısından kültürel öğelerin hiyerarşik sıralanması sonucunda, oluşan yüksek kültür, halk kültürü ve popüler kültür şeklindeki üç kültür hiyerarşisiyle bağlantılı olarak üç müzik hiyerarşisi tarzında gruplandırılmıştır. Yüksek kültüre ait müzik türleri: Klasik Türk Müziği ve Klasik Batı Müziği; Halk kültürüne ait müzik türleri: Türk Sanat Müziği, Tasavvuf Müziği ve Türk Halk Müziği; Popüler Kültüre ait müzik türleri ise şu şekilde sıralanmaktadır: Türk Pop Müziği, Arabesk/Fantezi, Yabancı Pop Müzik, Rock Müzik, Jazz/Blues, Rap/Hiphop ve Özgün Müzik. Araştırmaya katılanların verdikleri yanıtlara göre tercih edilen müzik türü en fazla popüler kültüre ait müzik türlerinde yoğunlaşarak $\% 83,3$ oranına sahiptir. Bu oranı $\% 10,6$ ile halk kültürüne ait müzik türleri ve son olarak \%6,1 ile yüksek kültüre ait müzik türleri izlemektedir. Araştırmaya katılanlara müzik türünü tercih etme nedenleri sorulduğunda ise en yüksek yanıtlama oran $1 \% 47,9$ ile hem müzikal faktörlerden hem de şarkı sözlerinden cevabına karşılık gelmiştir. Bu yanıtı müzikal faktörler, şarkı sözleri ve aldığım eğitim/tecrübe yanıtı izlemiştir. Tercih edilen müzik türünün işlevi sorusuna $\% 69,1$ rahatlama ve dinlenme aracı, $\% 13,5$ kendini ifade etme ve sosyalleşme, $\% 10,6$ boş zaman etkinliği ve son olarak $\% 6,8$ eğitim ve kültürlenme yanıtı verilmiştir. $\mathrm{Bu}$ verilere ilişkin bilgiler Tablo 3 'te gösterilmektedir.

\begin{tabular}{lcc}
\hline \multicolumn{1}{c}{ Tercih edilen müzik türü } & Sayı & Yüzde (\%) \\
\hline Yüksek kültüre ait türler & & \\
Halk kültürüne ait türler & 19 & 6,1 \\
& 33 & 10,6
\end{tabular}




\begin{tabular}{lcc} 
Popüler kültüre ait türler & 259 & 83,3 \\
\hline \multicolumn{1}{c}{ Müzik türünü tercih nedeni } & \\
\hline Müzikal faktörler (Ritm, ezgi, tempo vb.) & 102 & 32,8 \\
Şarkı sözleri & 44 & 14,1 \\
Hem müzikal faktörler hem şarkı sözleri & 149 & 47,9 \\
Aldığım eğitim / Geçmişten bugüne kadar elde ettiğim deneyim ve birikim & 16 & 5,1 \\
\hline \multicolumn{2}{c}{ Müziğin işlevine ilişkin görüsş } & 42 \\
\hline Kendini ifade etme ve sosyalleşme aracı & 33 & 13,5 \\
Boş zaman etkinliği & 21 & 6,8 \\
Eğitim ve kültürlenme aracı & 215 & 69,1 \\
Rahatlama ve dinlenme aracı & \multicolumn{2}{c}{} \\
\hline
\end{tabular}

Tablo 3. Tercih Edilen Müzik Türü ve İlgili Analizleri

Üniversite öğrencilerinin genel girişimcilik düzeyleri Tablo 4'te gösterilmektedir. Girişimcilik düzeyleri ortalaması 131,5 bulunduğundan sonuç yüksek girişimcilik düzeyine karşılık gelmektedir. Sonuçlar literatürde yer alan çalışmalarla benzerlik göstermektedir (Çatır, vd, 2015; Aksel ve Bağc1, 2016).

\begin{tabular}{lccc}
\hline \multirow{2}{*}{ Genel girişimcilik düzeyi } & Sayı & Ortalama* & Standart Sapma \\
\cline { 3 - 4 } & 311 & 131,5 & 32,3 \\
\hline *min. 36, maks. 180.
\end{tabular}

\section{Tablo 4. Genel Girişimcilik Düzeyi}

Üniversite öğrencilerinin girişimcilik düzeyleri ile cinsiyet, sınıf, bölüm ve tercih edilen müzik türleri arasında anlamlı bir farklılık olup olmadığını test etmek için Mann-Whitney U Testi ve Kruskal Wallis Testi uygulanmıştır. Çıkan sonuçlar Tablo 5'te gösterilmektedir. Sonuçlar anlamlılık düzeyine göre $(p<0,05)$ incelendiğinde sadece sınıf ile tercih edilen müzik türüne göre anlamlı farklılık tespit edilebilmiştir ( $\mathrm{H}_{1}$ hipotezi kabul edilmiştir). Sınıf değişkenine göre 4.sınıflar girişimcilik düzeyine göre farklılık göstererek 165,02 sıralama ortalamasına sahip olmuşlardır. 3.sınıflar ise 142,36 sıralama ortalaması ile daha düşük düzeyde girişimcilik özelliği göstermişlerdir. Aynı zamanda girişimcilik düzeyi tercih edilen müzik türü ile anlamlı farklılık göstermektedir $\left(\mathrm{H}_{4} \mathrm{kabul}\right.$ edilmiştir). En yüksek girişimcilik seviyesi 219,63 ile yüksek kültüre ait müzik türlerinde çıkarken; sıralamayı halk kültürüne ait müzik türleri ve popüler kültüre ait müzik türleri izlemektedir. Girişimcilik düzeyi ile cinsiyet ve bölüm değişkenleri arasında ise anlamlı bir farklılık tespit edilememiştir ( $p>0,05$ olduğundan) $\left(\mathrm{H}_{2}\right.$ ve $\mathrm{H}_{3}$ hipotezleri kabul edilememiştir). Alan yazında bu sonuçları destekleyen çalışmalara rastlamak mümkündür (Pan ve Akay, 2015).

\begin{tabular}{|c|c|c|c|}
\hline & Sayı & Siralama Ort. & p \\
\hline \multicolumn{4}{|l|}{ Sinıf } \\
\hline 3.sinif & 173 & 142,36 & \multirow{2}{*}{$\mathbf{0 , 0 2 5}$} \\
\hline 4.sinif & 138 & 165,02 & \\
\hline \multicolumn{4}{|l|}{ Cinsiyet } \\
\hline Kadın & 167 & 155,01 & \multirow{2}{*}{0,834} \\
\hline Erkek & 144 & 157,15 & \\
\hline \multicolumn{4}{|l|}{ Bölüm } \\
\hline İşletme & 82 & 165,60 & \multirow{5}{*}{0,153} \\
\hline İngilizce İşletme & 50 & 152,66 & \\
\hline İktisat & 57 & 157,73 & \\
\hline İngilizce İktisat & 52 & 171,53 & \\
\hline Maliye & 70 & 134,20 & \\
\hline \multicolumn{4}{|l|}{ Müzik türü } \\
\hline Yüksek kültüre ait türler & 19 & 219,63 & \multirow{3}{*}{$\mathbf{0 , 0 0 2}$} \\
\hline Halk kültürüne ait türler & 33 & 174,17 & \\
\hline Popüler kültüre ait türler & 259 & 149,02 & \\
\hline
\end{tabular}

Tablo 5. Değişkenler ve Farklılık Analizi Sonuçları

\section{Sonuç}

Toplumsal hayatı şekillendiren kültür sistemlerinin, farklı amaç ve işlevlere sahip çok sayıda öğeleri bulunmaktadır. Kültür sistemleri içerisindeki müzik öğesinin, kendisiyle ilgili işlev ve amaçlara hizmet ettiği gibi, diğer kültürel öğelerin işleyiş tarzları üzerinde de bir takım etkilerinin olduğu varsayılır. Kültür sisteminin, belirli ölçüde nitelikli bilgiler tarafından yaratıldığı yüksek kültür öğelerinin hâkim olduğu toplumlarda, bir yandan estetik ve sanat değeri yüksek kültür ürünü müzikler yaratılırken, diğer yandan da katma değeri yüksek nitelikli 
insan davranışlarının oluşma ihtimali giderek yükselmektedir. Buna karşılık, popüler kültür ve hatta "kitle kültürü" etkisi altındaki toplumlarda ise sanat ve estetik değeri düşük müzik örnekleri çoğalırken, bu duruma paralel olarak hayatın diğer alanlarında da nispeten katma değeri düşük veya niteliksiz davranışlarda artış ortaya çıkmaktadır.

İnsanların, çeşitli durum ve şartlar karşısında nasıl karar alacaklarını ve tercihte bulanacaklarını, o zamana kadar zihinlerinde birikmiş olan kültürel birikim denilen bilgi sistemleri tayin etmektedir. Bu zihniyet dünyasının veya bilgi birikimlerin bileşiminin kapsamı ve nitelik derecesi, onların her türlü davranışlarının dışa vurumunda ortaya çıkan eylem ve hareketlerinin de niteliğini temsil etmektedir. Bu durumda, bütün insanlar, doğuştan edindikleri biyolojik kökenli her türlü dürtü, duygu ve eğilimlere ek olarak doğumdan sonraki zaman içerisinde tecrübelerden başlayarak çeşitli kültürlenme süreçleriyle öğrendikleri ve kazandıkları kültürel birikimin karışımı bir düzenek içerisinde davranışlarda bulunurlar. İnsan davranışlarının kalitesini tayin eden temel dinamik, özellikle doğumdan sonraki sosyalleşme ve kültürlenme sürecine bağlı olarak zihinlerinde oluşmuş ve birikmiş olan çeşitli bilgi bileşenlerinin niteliğidir. Eğer insanlar, imkân ve potansiyeli olup da yüksek kültür birikimine sahipseler, büyük bir ihtimalle tavır ve davranışları hem daha özgür, hem de daha kaliteli hareketler olacaktır. Buna karşılık, kişilerin yaşam şartları ve imkânları ölçüsünde zihinlerinde halk kültürü birikimi söz konusu ise o zaman tavır ve davranışları da o kapsam ve çerçevedeki eylemlerden meydana gelecektir. Kişilerin içerisinde büyüdüğü ve sürekli etkileşim içerisinde bulunduğu kültür iklimi popüler ya da ağır bir kitle kültürü ortamı ise bu insanların direnme ahlakına bağlı olarak çok özel bir çabaları olmayacaksa, büyük bir ihtimalle sıradan, gündelik, zaman kavramı olarak geçmişten ve gelecekten kopuk ama "Ânı yaşamaya” odaklanmış, içi boş ve anlamsız, yaygın ve egemen kitle davranışlarına bağımlılaşmış kolektif davranışlardan meydana gelecektir.

Yüksek kültürün yaratılışında bilimsel bilgi, felsefe bilgisi, estetik bilgi, etik bilgisi gibi son derece nitelikli bilgiler etkili olmaktadır. İnsanların, bu bilgi türleriyle özel ve yalın bağlantıları olabileceği gibi, bu bilgilerin diğer nitelikli kültür öğeleriyle kurumsallaşmış bir kültür birikimi tarzında onların yaşam biçimi tarafından içselleştirilmiş de olabilir. Girişimcilik, çeşitli üretim faktörlerini bir araya getirip, yeni ürün ve pazar yaratarak bütün kaynakların değerlerinin toplamından daha fazla katma değer yaratılması sürecidir. Dolayısıyla, girişimcilik, başkalarının hazırladığı yapı ve faaliyet içerisinde yer almak yerine, insanların kendilerinin içinde yer alacakları davranış düzlemini yapılandırmaları ve kurgulamalarını ifade eden nitelikli davranış özelliği göstermektedir. Girişimcilik, her şeyden önce zihinsel planda somut düşünceden soyut düşünceye geçmeyi başarabilmiş, geleceğe dair kuvvetli tasavvurları olan, tümden gelim ve tüme varım gibi akıl yürütme yöntemlerini kullanabilme becerisini gösteren kişiler tarafından tasarlanıp gerçekleştirilebilecek bir etkinliktir.

Yüksek kültürün hareket tarzlarında, kendini oluşturan bilgi bileşenlerinin mahiyeti gereği olarak rasyonel düşünceye dayalı bireysel irade ve kararların çok belirgin bir yeri ve önemi vardır. Bu bağlamda, "girişimcilik eğilimlerine" sahip olan "bireylerin", yüksek başarı ihtiyacı, risk alma cesareti, belirsizliklere karşı toleranslı, iç kontrol odağı yüksek, bağımsız hareket edebilme ve kendine güven duyma gibi son derece kaliteli davranış nitelikleri taşıdıkları gözlenmiştir. Kültür sistemi teorisine göre, davranışsal bir patoloji ya da herhangi bir kişilik bozukluğu olmadığı sürece, yüksek kültür taşıyıcısı bireylerin çoğu tavır ve hareketlerinin holistik bir bütün içinde birbiriyle tutarlı olmaları gerekir. Bu durumda, yüksek kültür taşıyıcısı "bireyler”, müzik türleri konusunda büyük bir ihtimalle yüksek kültür ürünü müzikleri tercih ederler; başka bir yüksek kültür işlevi olduğu bilinen ve çalışmamızın konusunu oluşturan "girişimcilik eğilimleri” nispeten yüksek olur.

Araştırma bulgularımıza göre, araştırmaya katılan ekonomi ve işletmecilik eğitimi almakta olan 311 kişilik örneklemin, ancak \% 6,1'i “yüksek kültür ürünü” müzikleri tercih ederken; \% 10,6's1 "halk kültürü ürünü” müzikleri; \% 83,3'ü ise yerli ve yabancı "popüler kültür ürünü” müzikleri tercih ettiklerini beyan etmişlerdir. Temelde iktisadi ve idari bilimler alanında ekonomi ve işletmecilik dersleri alan "yüksek öğrenim gençliğinin", eğitimini aldıkları konuların temel işlev ve amaçlarından biri olan "girişimcilik eğilimleri" ise ortalama 131,5 (Min.36; Max.180 aralığında) olarak tespit edilmiştir. Araştırmada kullanılan "Üniversite Öğrencileri Girişimcilik Ölçeğine" göre, araştırmaya katılan kişilerden alınan yanıtların puan değeri karşılıkları ile her bir kişinin genel girişimcilik düzeyine ilişkin puanları, şu şekilde hesaplanmaktadır (Yılmaz ve Sümbül, 2009). 36-64: "Çok düşük girişimcilik"; 65-92, "Düşük girişimcilik"; 93-123, "Orta düzeyde girişimcilik"; 124-151, "Yüksek girişimcilik"; 152-180, "Çok yüksek girişimcilik". Bu durumda, bu araştırmada çıkan 131,5 şeklindeki bir ortalama, "yüksek düzeyde girişimcilik" kategorisinde yer almaktadır. Toplumsal yapı içerisinde "girişimcilik eğilimlerinin", özellikle günümüz şartlarında, temel ekonomi ve işletmecilik dersleri alan “yüksek öğrenim gençliğinin”, böyle bir anket çalışmasındaki yanıtlarının 152-180 aralığında yani, "çok yüksek girişimcilik" eğilimine sahip olmaları beklenirdi. Bu araştırmanın ortaya çıkardığı en önemli sonuçlardan birisi, yüksek katma değer yaratacak bir insani etkinlik olarak "girişimcilik eğiliminin" daha fazla yükselmesi ve güçlenmesi için sadece eğitim ve öğrenim faaliyetlerine ek olarak, uygun "psikolojik destek ve kültürel ortam "gibi psiko-sosyal motivasyonların gerektiği olmuştur. Bu bağlamda, girişimcilik eğilimi düzeyi, tercih edilen müzik türü ile anlamlı farklılık göstermektedir En yüksek seviye 219,63 ile yüksek kültüre ait müzik türlerinde çıkarken; sıralamayı halk kültürüne ait müzik türleri ve popüler kültüre ait müzik türleri izlemektedir. Sonuç olarak bu çalışmada, ülkemizde egemen olan "kitle kültürünün” yaygın ve egemen bir kültür öğesi olarak "popüler müzik”, özellikle yüksek öğrenim gören genç kuşakların "girişimcilik" eğilimlerinin güçlenmesine ket vurmakta ya da zayıflamasına yol açmaktadır. 
Türk toplumsal yapısındaki kaliteli bir eğitim sistemi ve firsat eşitliğine dayalı bir eğitim tarzının gerçekleştirilememesi ile modernleşme çabalarının büyük ölçüde başarısız kalması sonucunda kaçınılmaz bir durum olarak yaşanmakta olan kitle kültürü, insanlardaki yaratıcı düşünce ve öz güven duygusunu eriterek, toplumsal düzlemde her türlü "nitelikli hareketin” doğuşunu engellemektedir. Toplumsal kalkınma ve gelişmenin, daha yüksek bir orana çekilebilmesi için yüksek öğrenim gençliğine yönelik "girişimcilik” eksenli "yüksek öğrenim” programlarına ek olarak, ayrıca “yüksek kültürün” önemli diğer öğesi "müzik türlerinin” tanıtım ve sevdirilmesi şeklinde tamamlayıcı programlar uygulanmalıdır.

\section{Kaynakça}

- $\quad$ Akbulut, 2010. Sosyal Bilimlerde SPSS Uygulamaları. İdeal Yayıncılık, İstanbul.

- $\quad$ Aksel ve Bağcı, 2016. "Girişimcilik Eğilimi; Bir Kamu Üniversitesinin İIBF’sinde Öğrenim Gören Son Sınıf Öğrencilerinde Bir Araştırma", İnsan ve Toplum Bilimleri Araştırmaları Dergisi, 5(7), s. 2128.

- $\quad$ Attali, 2014.Gürültüden Müziğe, Müziğin Ekonomi-Politiği Üzerine. İkinci Basım,(Çev. Gülüş Gülcügil Türkmen), Ayrıntı Yayınları:450, İstanbul.

- Batmaz, 1981. "Popüler Kültür Üzerine Değişik Kuramsal Yaklaşımlar”, AİTİ Gazetecilik ve Halkla Illişkiler Yüksek Okulu İletişim Dergisi, 1981/1, s.163-192.

- Bozkurt,2014. Endüstriyel ve Post-Endüstriyel Dönüşüm, Bilgi, Ekonomi, Kültür. 3. Baskı, Ekin Basım Yayın Dağıtım, Bursa.

- Canetti, 1998. Kitle ve İktidar. (Çev. Gülşat Aygen), Ayrıntı Yayınları: 200, İstanbul.

- Çatır, Şimşek ve Ölekli, 2015. "Meslek Yüksekokulu Öğrencilerinin Girişimcilik Eğilimlerinin Belirlenmesine Yönelik Ampirik Bir Çalışma", Electronic Journal of Vocational Colleges, 4, s. 111.

- Edman, 1977.Sanat ve İnsan, Estetiğe Giriş. (Çev. Turhan Oğuzkan), İnkilap ve Aka, İstanbul.

- $\quad$ Erdal, 2009. "Müzik Türlerinin Tercih Edilmesinde Kişilik Özellikleri ve Beğeni İlişkisi",T.C Dokuz Eylül Üniversitesi Güzel Sanatlar Enstitüsü, Müzik Bilimleri Anabilim Dalı Doktora Tezi, İzmir.

- Eroğlu, 2015. Davranış Bilimleri. 14. Basım, Beta Yayınları, İstanbul.

- İ̀miş, Durak ve Özdemir, 2010.Girişimcilik Kültürü, Anadolu Girişimciliğinden Örnekler. Ekin Basım Yayın Dağıtım, Bursa.

- Özakpınar, 1999. İnsan İnanan Bir Varlık. Ötüken Yayınları: 426, İstanbul.

- Öner, 1999. Felsefe Yolunda Düşünceler. Akçağ Yayınları: 298, Ankara.

- Pan ve Akay, 2015. "Eğitim Fakültesi Öğrencilerinin Girişimcilik Düzeylerinin Çeşitli Değişkenler Açısından İncelenmesi", Education Sciences, 9(6), s. 131-132.

- Stravinsky, 2011. Altı Derste Müziğin Politikası. (Çev. Cem Taylan), Üçüncü Basım, Pan Yayıncılık:73, İstanbul.

- Yağışan, 2013. "Üniversite Öğrencilerinin Müzik Tercihleri Ve Saldırganlıkla İlişkisi", Sanat Ĕ̆itimi Dergisi, 1(2), s. 98.

- Y Yllmaz ve Sünbül, 2009. "Üniversite Öğrencilerine Yönelik Girişimcilik Ölçeğinin Geliştirilmesi", Selçuk Üniversitesi Sosyal Bilimler Enstitüsü Dergisi, 21(2), s. 198. 


\title{
Küresel Üretim Sürecinde Şebeke Örgütler ve İşletmeler Arası Güven
}

\section{Network Organizations in the Global Production Process and Trust between Businesses}

\author{
Ph.D. Candidate Hicran Utkun Dincer Aydın (Pamukkale University, Turkey) \\ Prof. Dr. Ayşe İrmiş (Pamukkale University, Turkey)
}

\begin{abstract}
Network organizations are organizational structures consisting of coordinating basic capabilities and resources in line with their own responsibilities and roles, even though geographically distant businesses are experts in a particular field or function. Businesses are involved in to the networks for reducing uncertainty in global competition, gaining flexibility, acting quickly, and providing capacity, benefiting from resources and talents they cannot have alone, and providing information. However, it is also possible for enterprises to maintain their assets in the network and to benefit from the competitive advantage of the network through providing trust between businesses and ensuring trust.

The purpose of the study is to reveal how trust is defined among the enterprises within the network organizations and what constitutes the trusting elements. The universe of the research constitutes businesses operating in Uşak and located in national or international networks with contract manufacturing. The study was conducted using qualitative research method and interview technique. According to research findings; it has been seen that business owners are positively anticipating other businesses within their business networks and they have been working for a long time with the companies which they trust and watching the businesses they have not been trusting for a while and ending their cooperation. According to business owners participating in the interview, trust is equivalent with the fulfilment of given promises, goodwill, quality and intra-family relationships. At the same time, it was stated that trust depends on the businesses; and so, religion, language and race differences are not important.
\end{abstract}

\section{Giris}

Yönetim teorilerine göre işletmelerde yapılan işlerin daha etkin ve verimli olabilmesi, işbölümü ve uzmanlaşmayla sağlanmaktadır. Yapılan çalışmalarda örgüt içerisinde işlerin küçük birimlere ayrılmasının ve bu iş birimlerinin teknik bilgi ve beceriye sahip uzmanlaşmış çalışanlar tarafından yapılmasının işletmelerde kârlılığı ve verimliliği artırdığı görülmüştür. İşbölümünün genişliği üretim ölçeğiyle ilgilidir. Daha önceden sadece örgütlerin kendi bünyelerinde gerçekleşen işbölümü, artan üretim kapasitesi ve daralan pazardan dolayı özellikle 1970'li yıllardan itibaren ekonomilerin uluslararasılaşmasıyla beraber, işletmelerin kendi çekirdeklerinin ötesine taşarak, ulus ötesi zemine yayılmaya başlamıştır. Avrupa ve Amerika'da çok daha önce başlayan sanayileşme ve buna uygun örgütlenme faaliyetleri neticesinde verilen üretim fazlası ve kendi bölgelerinde doyan pazardan dolayı işletmeler, dünyanın başka üretim ve pazar alanlarına farklı firsatları değerlendirmek, daha fazla kâr elde edebilmek için yönelmişlerdir.

İşletmeler için üretimdeki işbölümüne yönelme çoğu zaman iki şekilde gerçekleşmektedir. Bunlardan ilki daha yatay düzlemde birbirine daha yakın güce ve üretim standardına sahip işletmeler arasındaki yatay işbölümüdür. $\mathrm{Bu}$ işbölümü, üretim konuları birbirinden farklı olan işletmelerin ürünlerini ve ürünlerinin özelliklerini tekbir üründe toplayarak inovasyonla gerçekleştirdikleri işbirliğine dayalıdır. İkincisi ise, işletmelerin kendi temel yeteneklerine odaklanarak, bu temel yetenekleri dişındaki faaliyet ve fonksiyonları, bu faaliyet ve fonksiyonlarda uzmanlaşmış başka işletmelere kaydırmalarıyla gerçekleşmektedir. Böyle bir işbölümü nispeten daha dikey bir yapılanmayla gerçekleşmektedir. Her iki türde de işletmeler arasında işbölümü, uzmanlaşma ve işbirliğine dayalı bir ağ (şebeke) oluşmaktadır.

Küreselleşmeyle beraber, ulus ötesi işletmelerin arasında yatay ya da dikey işbölümleri ve işbirlikleri hızla artmaya başlamıştır. Ancak gelişmiş ülke işletmeleri arasında işletmelerin tecrübelerinin, sermayelerinin ve üretimlerinin nitelik ve nicelik düzeylerinin birbirine yakın olması sebebiyle yatay işbölümüne gidilmektedir. Buna karşılık gelişmiş ülke işletmeleriyle az gelişmiş veya gelişmekte olan ülke işletmeleri arasında nispeten daha dikey işbölümü söz konusu olmaktadır. Dikey işbölümünde gelişmiş ülke işletmeleri, daha önceden kendi işletmelerinin içerisinde gerçekleştirdikleri pek çok fonksiyonu (tedarik, üretim, pazarlama, finansman vb.), işbirliği sağladığı diğer işletmeler arasında bölüştürmektedir. Bu işletmeler de çoğu zaman kendi işletmelerine göre daha az gelişmiş olan ülke işletmeleridir. Çünkü az gelişmiş ve gelişmekte olan ülke işletmeleri sanayileşmede yaşadıkları geri kalmışlığın ve deneyimsizliğin ortaya çıkardığı, bir an önce gelişme ve diğer ülkelere yetişme ve tecrübelenme isteklerini uluslararası işbölümü ağına katılarak telafi etme telaşını yaşamaktadırlar.

Gelişmiş ülke işletmeleri az gelişmiş veya gelişmekte olan ülke işletmeleriyle işbölümünü daha ziyade üretim fonksiyonlarını kaydırarak yapmışlardır. Bunun sebebi, az gelişmiş veya gelişmekte olan ülkelerde doğal 
kaynakların, enerji güçlerinin, işgücü ve çevre maliyetinin kendi ülkelerine göre çok daha düşük düzeyde olmasıdır. Gelişme çabası gösteren işletmelerin fason üretim bağlamında uluslararası üretim ağına (şebekesine) katılmaları aynı zamanda uluslararası pazar alanına dâhil olmalarını hızlandırmış ve gelişmiş ülke işletmelerinin markalı ürünlerinin pazar kapsamını genişletmiştir. Çünkü gelişmiş ülke işletmelerinin markalarına üretim yapan gelişme çabası içerisindeki ülke işletmeleri ürettikleri yabancı markalı ürünlerin aynı zamanda alıcısı olmuşlardır. Hatta bu ürünleri bizzat üretim yapan ülkelerde ve dünyanın pek çok pazarında satışını gerçekleştiren pazarlama şirketleri de küresel işbölümü ağına dâhil olmuştur. Dünyanın farklı bölgelerinde yer alan işletmelerin yukarıda ifade edildiği gibi öz yeteneklerini birleştirerek oluşturdukları ve fonksiyonları bağlamında işbölümü yaptıkları bu ağ yapılanması küreselleşmenin örgütlenme şekli olarak, şebeke örgütler adıyla yazında yerini almıştır.

\section{2 Şebeke Örgütler}

Küreselleşme sürecinin bir unsuru olan ekonomik entegrasyon işletme fonksiyonlarının işletmeler arasında uzmanlığa (temel yeteneğe) dayalı olarak bölümlenmesi noktasında şekillenmiştir. Sürecin en önemli özelliği; işletmelerin birbiriyle ilişki düzeyindeki artışla birlikte küresel alan içerisinde kendilerine rekabet alanı oluşturmak gayesiyle bir ă̆ yapısı kurarak, işbirliğgine gitmeleridir. İşbirliğine dayalı ă̆ yapılarıyla şebeke örgütler şekillenmiştir (Yeşil, 2010).

Davranışsal görüşe göre şebeke kişiler, gruplar veya örgütler arası sosyal ilişkilerin bir modelidir (Alstyne, 1997). Kişiler ve gruplar arası bu ilişki modeli örgütler arası ilişkilerin açıklanmasında da kullanılmaktadır. Örgütler arası karşılıklı ilişkiler şebekeler açısından iki farklı bakış açısı ile ele alınmaktadır. Birinci yaklaşım ilişkileri sosyolojik ve örgüt teorileri açısından ele alırken, ikinci yaklaşım bu ilişkilere organize etme, düzen oluşturma mantığı ile bakmaktadır (Koçel, 2011). İkinci yaklaşıma göre şebeke oluşturma örgüt faaliyetlerinin düzene girmesi amacıyla bilinçli yapılan bir örgütleme olarak ortaya çıkmakta ve şebeke yapılarının oluşmasına imkân vermektedir. Bu bağlamda şebeke örgütler oluşan ilişkiler modeline göre iki veya daha fazla sayıdaki bağımsız işletmenin rekabet üstünlüğü sağlamak, bu üstünlüğü sürdürmek vb. amaçlarla bir araya gelerek oluşturdukları örgütlenme biçimi olarak tanımlanmaktadır (Tutar, 2000).

Örgütler arası ağlar (şebekeler) veya ağ (şebeke) örgütleri olarak adlandırılan şebeke örgüt kavramı 1980'lerin sonundan beri çeşitli bilimsel disiplinlerin analiz konusu olmuştur. Şebeke örgüt tanımlarında şebeke içerisindeki katılımcıların çeşitli ilişki ve davranışlarının yanı sıra, pek çok yazar tarafından ağ içerisindeki işletmelerin bağımsızlık düzeylerine de vurgu yapılmıştır (Lacka, 2015). Powel'ın 1990 yılında yayınlanan eserinde şebeke örgütler bağımsız kaynak akışlarının ve karşılıklı iletişim kanallarının olduğu yatay veya dikey modeller olarak tanımlanmıştır. Miles ve Snow’un $(1986,1992)$ yaptıkları tanımda şebeke örgütlerin pazar mekanizması ile koordine edilen örgütler kümesi veya uzmanlaşmış birimler olduğu ifade edilmiştir. Larson (1992) ise şebeke örgütleri anlatırken işletmelerin birbirine olan karşılıklı yükümlülükleri, beklentileri, itibarları ve çıkarlarına dayalı olan bağımlılıklarının uzun vadeli değişimi üzerinde durmuştur (Jones, vd, 1997). Yapılan tanımların çıkış noktası şebeke örgütlerin küresel alandaki belirsizlikle baş edebilme gücünü kazanabilmek gayesiyle şekillenmeleridir. Şebeke örgütler belirsizliği azaltmak, esneklik kazanmak, hızlı hareket etmek, kapasite sağlamak, işletmenin tek başına sahip olamadığı kaynak ve yeteneklere geçiş olanağı ve bilgi sağlamak gayesiyle oluşturulmaktadırlar (Durak, 2005). Belirsizliğin fazla olması işbirliklerinin oluşumunda önemli bir etken olarak görülmektedir. İşbirliği içinde yer alan bir işletme uluslararası pazarda tek başına sahip olduğu güç ile değil dâhil olduğu şebekenin pazardaki gücü ile rekabet edebilme ve ihtiyaç duyduğu bilgiyi daha kolay elde etme şansına ulaşabilmektedir. Aynı zamanda şebekeler girişimcilere kaynak edinimi, rekabet, büyüme ve uluslararası pazara giriş konusunda önemli firsatlar sağlamaktadır (Malewicki, 2005).

Bütün bu tanımlardan hareketle şebeke örgütlerin, belirli bir alanda ya da fonksiyonda uzman işletmelerin bir araya gelerek kendi sorumluluk ve rolleri doğrultusunda şekillenen ağlardan oluşan bir yapıyı ifade ettiği söylenebilir. İşletme bilimi açısından ise şebeke örgüt, planlama, koordinasyon, stratejik karar verme ve süreçlerin bütünlüğünü içeren, karşılıklı fayda sağlamak ve amaçlara ulaşmak için örgütler arasında bilgi değişimi ile sorumluluk, kaynak ve risk paylaşımının yanı sıra "fonksiyon-iş birimleri-coğrafya- küresel müşteriler" arasındaki dört boyutlu değiş tokuşun gerçekleştirildiği büyük şirket içerisindeki küçük şirketi tanımlamaktadır (İrmiş, 2003; İplik, 2010). Şebeke örgütlerin temelde üç önemli özelliği bulunmaktadır. Birincisi, bir şebeke modeli ve iş ilişkisi oluşturmalarıdır. İkincisi, belirli bir derecede otonomi taşımasıdır. Üçüncüsü ise değişimin piyasa mekanizması ve dikey bütünleşmeden farklı bir şekilde gerçekleşmesidir. Şebeke içerisinde her bir işletme kendi çıkarları doğrultusunda hareket ederken aynı zamanda diğer işletmelerin de performanslarını arttırmaya çalışmaktadır (Sydow ve Windeler, 1998). Bu üç önemli özelliğin yanı sıra şebeke örgütler; iletişim ve güven odaklı yapılardır. İşbirliğinin sorunsuz ve etkin bir şekilde devam ettirilebilmesi doğru ve zamanında bilgi paylaşımını, iletişimin güçlü olmasını ve tüm ilişki ağı içerisinde tarafların birbirlerine güvenmelerini gerektirmektedir. Durak'ın (2006) yaptığı araştırmada şebeke içerisindeki işletmeler arasında iyi bir iletişsimin karşılıklı bilgi akışının açık olmasının güveni etkileyen unsurlar olduğu belirlenmiştir. Bu bağlamda şebekeleri başarıya ulaştıran ana unsurun güven temelli bir ilişki ve etkili iletişim olduğu açıkça görülmektedir. 


\section{3 Şebeke Örgütlerde Güven}

Güven kavramı, başkalarının davranış ve niyetlerinin olumlu yönde olduğu beklentilerine dayalı ancak bir güvenlik açığının da olabileceğini kabul etmeye hazır olmayı içeren, psikolojik bir durum olarak tanımlanmaktadır (Evily ve Tortoriello, 2011). Brockner ve arkadaşlarının (1997) yapmış olduğu çalışmada güvenin ön koşulları risk, belirsizlik, beklenti ve zarar görme ihtimali olarak belirtilmiştir. Kişi, belirsizlikler içerisinde olumlu bir beklentiye sahipse belirli bir riski göze alarak güven duymaktadır. Riski göze alıyor olması zarar görme ihtimalini de kabulleniyor olması anlamına gelmektedir. Bu bağlamıyla güven bir seçimdir ve belirsizlik her zaman risk içermektedir. Zarar görme ihtimali gönüllü olarak bu riski üstlenmek, beklenti ise zarar görme ihtimalini gönüllü olarak kabul etmektir (Derin, 2011).

Güven kavramının, şebeke örgüt yapısının teorik gelişiminde büyük bir rol oynadığı belirtilmektedir. Miersch (2016) yapmış olduğu çalışmada, günümüzde çok sayıda akademisyenin kendine özgü bir örgüt biçimi olarak şebeke örgütlerini kendi mantık sistemi içerisinde onu oluşturan sistemin parçaları arasında gerçekleşen etkileşimin türü olarak özerk bir örgüt biçimi şeklinde tanımladıklarını ifade etmektedir. Bu tür etkileşimler karşılıklı, tercihli ve destekleyici oldukları için merkezi koordinasyon sistemi olarak kabul edilen şebeke örgütlerde güven ile sonuçlanmaktadırlar.

Şebekeler farklı temel yeteneklere sahip işletmelerin bir araya gelerek oluşturdukları yapılardır. Her işletme varlığını sürdürebilmek ve rekabet üstünlüğü sağlayabilmek amacıyla çeşitli stratejiler geliştirmekte ve kendi amaçları doğrultusunda hareket etmektedir. Tek başına hareket eden işletmelere nazaran amaçlara ulaşmak için birlikte hareket etmek işletmeler için daha zor olabilmektedir. Şebeke örgüt yapılarında şebekeyi oluşturan her işletmenin başarısı şebekenin başarısına bağımlı olmaktadır. Şebekede yer alan herhangi bir işletmenin zayıflığı tüm şebekenin başarısızlığı ile sonuçlanabilmektedir. Bu noktada şebekenin başarısı birlikte çalışabilme becerisine, sorumluluk sahibi olmaya ve birbirine güvenmelerine bağlıdır (Özgen, vd, 2003). Birbirinden bağımsız örgütlerin ortak bazı hedeflere ulaşmak için birlikte çalışmaya başlamalarındaki birçok zorluk göz önüne alındığında, şebeke üyeleri arasındaki güven, işbirlikçi dinamiklerin kolaylaştırılmasında ve olumlu sonuçlara daha kolay ulaşılmasında oldukça önemli bir rol oynamaktadır. Ayrıca güvenin, şebekenin oluşmasındaki etkisi kadar diğer önemli bir işlevi de uyumu korumaya yardımcı olması ve potansiyel çatışmaları önlemesidir (Lee, vd, 2012).

Şebeke örgütler içindeki ortak zihniyet, işbirliğini ve ortaklığı, koordinasyonu, gücün dağıtımını ve bilgi yaratmayı ve paylaşmayı desteklemektedir. Güven, şebeke içerisinde bu ortak zihniyetin kurulması için önemli bir davranış olarak görülmektedir. Şebeke üyeleri taraflar arasında bu güveni tesis etmek zorundadırlar. Özellikle değişimi korumak ve şebeke içindeki tarafların beklentilerindeki değişimi en aza indirgemek için güven, bir şebekenin kurulmasında ve sürdürülmesinde önemli bir unsurdur (Morisse, vd, 2014). Keza, Seppanen ve arkadaşlarının yaptığı çalışmada (2007) çift taraflı bir kavram olarak güvenin, iletişim, işbirliği ve performans gibi unsurların hem öncüsü hem de sonucu olduğunu ifade edilmektedirler. Örgütler arası ilişkilerde güven, firsatçı davranışları azaltmak, işlem maliyetlerini düşürmek, belirsizliği azaltmak, kontrol ve koordinasyon ihtiyacını azaltmak, taahhüt ve motivasyonu arttırmak, bilgi paylaşımı, öğrenme, yenilikçilik gibi birçok fayda da sağlamaktadır (Willem ve Lucidarme, 2014).

Güven etkileşimden doğan çok boyutlu, kültür temelli, iletişime dayalı, dinamik bir olgudur (Demircan ve Ceylan, 2003). Farklı kültürlere ve iletişim biçimlerine sahip şebeke üyeleri arasında güvenin oluşması daha farklı bir çabayı gerektirmektedir. Rousseau ve arkadaşları (1998) yaptıkları çalışmada güven gelişiminin üç farklı mekanizmasını tespit etmişlerdir. İlk mekanizma hesaba dayalı güvendir. Bu mekanizmada, ilgili taraflar, eylemlerinin risklerini ve yararlarını rasyonel bir temel üzerinde tartmaktadırlar. İkinci mekanizma kurumsal güvendir. Sözleşmeler, garantiler ve kanunlar ilişkileri düzenlemek için kullanılmaktadır. Bir şebeke üyesi beklendiği gibi davranmazsa, diğer üyeler herhangi bir tazminat talebinde bulunabilmektedir. Bu tür mekanizmalarda etkileşimler diğerleri kadar riskli değildir. Üçüncü mekanizma ilişkiye dayalı güvendir. Güvenen ve güvenilen arasında zamanla tekrarlanan etkileşimlerden kaynaklanmaktadır. Duygusal temelli bir güven olduğu için olumlu deneyimlerle artacak bir yapıya sahiptir (Morisse, vd, 2014).

Güveni, şebeke örgütlerin oluşma aşamasından ilişkilerin sona erdirilmesine kadar, örgütler arasındaki ilişkilerin kritik bir bileşeni olarak değerlendirmek mümkündür. Olumlu bir beklentiyi ifade eden güven şebekede yer alacak örgütlerin seçim aşamasında önemli bir etken olarak görülmektedir. Şebeke üyeleri ortak amaçlar etrafında faaliyet gösterdikleri için şebekeyi başarıya ulaştıracak, güven duydukları örgütler ile çalışmak isteyeceklerdir. Bu noktada taraflar birbirilerini tanımadıkları, iş yapma biçimlerini bilmedikleri, farklı bir örgütsel kültür ve yapıya sahip örgütlerle ilişkilerinde uyumu sağlayıp sağlamayacaklarını bilmedikleri için tüm belirsizlikler içinde risk alarak işbirliğini başlatmaktadırlar. Bu kapsamda şebekenin oluşturulmasında risk ve belirsizliklerin en aza indirilmesi için ilişkilerin rasyonel bir temel üzerine oturtulması gerekmektedir. Taraflar arasındaki güvenin bu aşamada hesaba dayalı ve kurumsal nitelik göstermesi şebekenin zarar görme ihtimalini azaltacak bir unsur olarak değerlendirilebilir. İlişkilerin sürdürülmesi aşamasında da fiyat, ödeme dengesi, beklenilen zamanda ve kalitede ürün/hizmetlerin üretilmesi, bilgi paylaşımı gibi unsurların tarafların beklentilerini karşılıyor olması güveni pekiştirirken, olumsuz davranışlar güvenin kaybedilmesine neden olmaktadır. Şebeke üyeleri arasındaki güvenin 
güvensizliğe dönüşmesi şebekenin faaliyetlerini olumsuz etkilemekte ve tarafların birbirinden zarar görme ihtimali beklentilerinin artmasına neden olmaktadır. Örgütler için önemli bir risk arz eden bu durumda örgütler şebeke içerisindeki faaliyetlerine son verebilmekte ya da güven sorunu yaşadıkları örgütleri şebeke dışına atabilmektedirler.

\section{4 Şebeke Örgütler ve İşletmeler arası Güven Üzerine Alan Araştırması}

\subsection{Araştırmanın Amacı}

Yapılan literatür incelemelerinde şebekelerin oluşum sürecinde, şebeke ilişkilerinin sürdürülmesinde veya sona erdirilmesinde güven kavramının önemli bir unsur olduğu görülmektedir. Bu çalışmada şebeke örgüt yapıları ile güven olgusu yönetici bakış açısıyla ele alınıp değerlendirilmiştir. Çalışmanın birinci amacı, işletmelerin şebeke örgütleri nasıl oluşturduklarını, bu ağlara nasıl dâhil olduklarını ve ağ içerisinde devamlılıklarını nasıl sağladıklarını araştırmaktır. Çalışmanın diğer amacı şebeke örgütler içerisinde yer alan işletmeler arasında güven olgusunun nasıl tanımlandığını ve güven sağlayan unsurların neler olduğunu ortaya koymaktır.

\subsection{Araştırmanın Yöntemi, Kapsamı ve Temel Varsayımlar}

Araştırma kapsamında ihtiyaç duyulan verilere nitel araştırma kapsamında yer alan biçimsel mülakat tekniği kullanılarak ulaşılmaya çalışılmıştır. Mülakat formunun oluşturulmasında ikincil kaynaklardan ve uzman görüşlerinden faydalanılmıştır. Formda araştırma varsayımları doğrultusunda çalışmaya katılanlara 25 soru sorulmuştur.

Araştırmanın ana kütlesini Uşak ilinde tekstil alanında faaliyet gösteren şebeke örgütlere, fason üretim bağlamında katılan örgütler oluşturmaktadır. Araştırma örneklemini Uşak ilinde faaliyet gösteren 15 işletmenin hem sahibi hem de yönetici pozisyonunda bulunan kişiler oluşturmaktadır. Örneklem içine dâhil edilen işletmeler tekstil alanında 50 yıllık iş tecrübesi olan kişinin görüşleri doğrultusunda yargısal örnekleme yöntemi ile belirlenmiştir.

\subsection{Araştırma Soruları}

Araştırma amaçları doğrultusunda oluşturulan araştırma soruları şu şekildedir:

1. Şebeke içerisine girilmesinde temel amaç nedir?

2. Şebeke ilişkilerinin oluşmasında ve sürdürülmesinde önemli olan unsurlar nelerdir?

3. Yöneticilerin bakış açısına göre şebekelerin işletmelere sağladığ faydalar nelerdir?

4. Yöneticilerin bakış açısına göre şebeke ilişkilerinde karşılaşılan güçlükler ve yaşadıkları sorunlar nelerdir?

5. Yöneticiler şebeke ilişkisinde güveni nasıl tanımlamaktadırlar ve ağın oluşum sürecinde güven bir etken midir?

6. Yöneticiler yurtiçi mi yurtdışı işletmelere mi daha fazla güvenmektedirler?

\subsection{Araştırma Bulguları ve Değerlendirilmesi}

Yöneticilere ilk olarak iş ağlarının nasıl oluştuğu sorulmuştur. İşletme yöneticilerinden 1 tanesi distribütör aracılığıyla, 2 tanesi internet aracılığıyla, 2 tanesi referanslar yoluyla, 5 tanesi eski müşteri portföyü sayesinde, 1 tanesi müşterileri davet ederek, 1 tanesi numuneler göndererek bağlantının kurulduğunu belirtmiştir. Yöneticilerden 2 tanesi iki tarafın da ortak çıkarlar etrafında buluştuğunu ve bağlantının bir şekilde kurulduğunu ifade etmişlerdir. Yöneticilerden 3 tanesi müşterilerin onları bulduğunu, 2 tanesi ise ürüne talep olabilecek yerleri ve işletmeleri ziyaret ederek bağlantı kurduklarını belirtmişlerdir.

İşletme yöneticilerine ikinci soru olarak bu ağların oluşmasında önemli gördükleri unsurların neler olduğu sorulmuştur. İşletme yöneticilerinin işbirliğinin oluşmasında önemli gördükleri unsurlar; insan ilişkileri, ikna, güven, süreklilik, taleplere cevap verebilmeleri, fiyat avantajı, kalite, temiz üretim, samimiyet, dürüstlük, çok iyi piyasa analizi, işini iyi yapmak, karşı tarafı anlamak, sağlamlık, kazancın iyi olması, karşı tarafın karakteri, iyi niyet, ödeme şartları ve termin olarak belirtilmiştir. İşletme K yöneticisi, iş ağları noktasında din, dil, 1rk gözetmediğini en kötü zamanlarda bile karşı tarafın karakteri sağlam ise sonsuz kredi açabileceğini ifade etmiştir. İşletmelerin çoğunluğu bu süreçte karşı tarafla olan ilişkilerin önemli olduğunu özellikle ilk etapta dürüstlük, güven ve niyete bakıldığını söylemişlerdir. Ayrıca İşletme M yöneticisi, iş ağları oluşurken henüz kazanılmamış para için her iki tarafın da ortak amaçlar etrafında birleştiğini, niyetler iyiyse iş sürekliliği açısından olumlu olabileceğini, niyetler kötü ise en fazla üç iş yapılarak ağın dışına çıkarılacağını belirtmiştir.

Yöneticilere üçüncü soru olarak işbirliği yapmalarındaki amaç sorulmuştur. Bu soruyu 15 işletme yöneticisinden 7 tanesi para kazanmak olarak cevaplandırmıştır. Yöneticilerden 2 tanesi satış yapma, 2 tanesi üretim kapasitesinin arttırılabilmesi amacıyla işbirliğini tercih ettiklerini belirtmiştir. Kapasitesinin \%99'luk bölümünü ihracatın oluşturduğu işletme yöneticisi, amaçlarını çok taraflı kazanç ve ülke ekonomisine katkı sağlamak olarak belirtmiştir. Ayrıca yönetici çöpe giden bir nesnenin hammaddeye dönüştürülerek üretim yapılmasının hammadde tedarikçisi için de bir gelir kaynağı yarattığını ifade etmiştir. İşletme E yöneticisi işçi kaynaklı sorunların azaltılması ve iş alanındaki firsatlardan faydalanabilmek amacıyla işbirliği yaptığını belirtmiştir.

Şebeke örgütlerin en önemli avantajlarından biri öz yeteneklere dönüş yapmak olarak belirtilmektedir. İşletme F yöneticisi bu soruyu literatürde yer alan bilgiye uygun olarak "herkesin iyi olduğu alanda iş yapması ve kendi 
alanlarına yönelmeleri”" şeklinde cevaplandırmıştır. İşletme O fason üretim yaptırmaktadır. İşletme yöneticisi ürün kalitesinde sorun yaşamamak ve marka imajının zarar görmemesi için sürekli aynı firmalarla çalıştığını belirtmiştir. Daha önce farklı işletmeleri de ağ içerisine dâhil etmeye çalıştıklarını ancak üründe sorun yaşadıkları için ağdan çıkarttıklarını, bu nedenle tekrar riske girmemek adına aynı işletmelerle işbirliği yaptıklarını ifade etmiştir. İşletme $H$ yöneticisi bu şekilde bir ağ içerisinde olmanın önünü görmelerini sağladığını ve sipariş usulüne dayalı çalıştıkları için satış kaygısı yaşamadıklarını belirtmiştir. İşletme G yöneticisi ise ürettikleri ürünün yurt içinde fazla talep görmediğini, üretimin arttırılabilmesi için bu tür ağlar içerisinde bulunmak gerektiğini ifade etmiştir.

Mülakatın gerçekleştirildiği işletme yöneticilerine fason üretim yaptıkları ya da yaptırdıkları işletmelerle herhangi bir yazılı sözleşmeleri olup olmadığı sorulmuştur. Yöneticilerden sadece bir tanesi tüm işletmelerle yazılı sözleşmelerinin bulunduğunu, 2 tanesi sadece yurtdışı işletmelerle yazılı sözleşme yaptıklarını, 4 tanesi işletmelerin bir kısmı ile yaptıklarını, 8 tanesi ise yazılı bir sözleşme olmadığını söze ve güvene dayalı bir anlayış olduğunu ifade etmişlerdir. Sözleşme yapan işletme yöneticilerinden 2 tanesi talebin karşı taraftan geldiğini belirtmiştir. 30 yıldır aynı işletmelerle çalışan İşletme L yöneticisi karşı taraf isterse sözleşme yaptığını ve işbirliklerinin \% 80'nin söze dayalı olduğunu belirtmiştir. İşletme P yöneticisi de 30 yıldır aynı işletme ile sadece söze dayalı bir işbirliği sürdürmektedir. Ayrıca işletme yöneticilerinden bir tanesinden alınan bilgiye göre ihracat yapılan ülkelerin yasal yapısının önemli bir etken olduğu görülmektedir. Örneğin; Suudi Arabistan'da yasal sözleşmeler için bir zemin olmadığı belirtilmiştir.

İşletme yöneticilerine şebeke ilişkisinin olumlu yönlerinin neler olduğu sorulmuştur. Bu soruya alınan cevaplar şunlardır: satış kaygısının olmaması, para kazandırması, süreklilik, gelişmeye yardımcı olması, değerinde satış yapabilmek, herkesin kendi işine odaklanabilmesi, zaman, sermaye ve emek kazancı sağlaması, güvenilen işletmelerle çalışılabilmesi, paylaşmak, üretim hacminin artması, hedefleri yakalamakta sağladığı kolaylık, müşteri aramayı gerektirmemesi, insan beceri ve görüşlerindeki farklılıklardan yararlanılarak ortak faydanın oluşturulabilmesi, iki tarafın da kazanması, riskin azaltılması, karşılıklı güven, sıkıntıların telafi edilebilmesi, fikir alışverişi, referans oluşturmaları, ar-ge desteği.

İşletme yöneticilerinden alınan bilgiler doğrultusunda şebeke yapılarının özellikle işletmelerin sürekliliği için oldukça önemli olduğu görülmektedir. Ayrıca şebekelerin, işletmelerin satış, kâr, zaman, emek, sermaye, üretim hacmi, pazar gibi ticari kaygılarını hafiflettiği de alınan cevaplardan çıkartılabilecek bir diğer sonuçtur. Ticari ilişkilerin oluşmasında ve sürdürülmesinde önemli bir husus olarak görülen güven şebeke örgütlerin olumlu yönlerinden bir diğeridir. Şebeke içerisinde yer alan işletmelerin güvenilir işletmelerle çalışmaya devam etmeleri, güvenilir bulmadıklarını dışarıya atmaları şebekede kalan işletmelerin ticari faaliyetlerini güvenle oluşturulan bu yapıda daha rahat sürdürmelerini sağlamaktadır. Aynı zamanda şebekede yer alan her işletmenin farklı bilgi ve tecrübeye sahip olması işletmeler açısından olumlu olarak değerlendirilmektedir. Bilginin paylaşılması ve birbirlerinin tecrübelerinden faydalanabilmeleri yapılan işin niteliğini iyileştirmekte ve sıkıntıların daha kolay atlatılmasını sağlamaktadır.

Şebekelerin işletmelerin gelişmesine katkı sağlayıp sağlamadığını tespit etmek amacıyla sorulan 6. soruya 14 işletme yöneticisi olumlu cevap vermiştir. Ürün yönünden gelişime katkı sağladığını düşünen yönetici sayısı 6'dır. Kalite açısından sürekli geliştiklerini ifade eden 3 yönetici bulunmaktadır. Yöneticilerden 4 tanesi moda, talep, teknoloji, işin sürekliliği ve sonraki aşamalarda yaşanabilecek hataların önlenmesi gibi nedenlerle sürekli geliştiklerini ifade etmektedirler. İşletme İ yöneticisi şebekedeki ilişkilerinin devamı için sürekli gelişmek zorunda olduklarını belirtmektedir. İşletme C yöneticisi ise yaptıkları işlemi sürekli geliştirmek zorunda olduklarını çünkü bir sonraki işlemde yaşanabilecek sorunların önlemini alamazlarsa ürünün kendilerine geri iade edildiğini ifade etmektedir. Bu nedenle şebeke içinde olmanın zorunlu olarak kalite standartlarına dâhil olmalarını sağladığını ve işletmeye çekidüzen verdiklerini belirmektedir.

İşletme yöneticilerinin bakış açısına göre şebeke yapılarının işletmelere rekabet avantajı sağlayıp sağlamadığının tespiti için sorulan 7. soruya 11 işletme yöneticisi avantaj sağladığı yönünde cevap vermiştir. İşletme D yöneticisi güçlü işletmelerin güçlerini arttırdıklarını, İşletme L yöneticisi diğer işletmeler büyüdükçe kendilerinin de büyüdüğünü, İşletme Ö yöneticisi diğer işletmelerin imajının ve ürünlerinin kalitesinin ürününü satmasında kolaylık sağladığını ve rakiplerinden sıyrılmasına katkı sağladığını ifade etmektedir.

Soru 8'de şebeke örgüt yapılarının önemli avantajlarından biri olarak görülen bilgi, tecrübe ve kaynak paylaşımı yönetici bakış açısına göre değerlendirilmeye çalışılmıştır. Alınan bilgiler ışığında 14 işletme yöneticisi şebekelerin işletmelerine bilgi, tecrübe ve kaynak açısından fayda sağladığını düşünmektedir. Özellikle bu paylaşımların ürünün geliştirilmesi ve ürün çeşitliliği açısından faydalı olduğu ifade edilmektedir.

“Şebeke yapısının işletmenizi daha dinamik kıldığını düşünüyor musunuz?” sorusuna tüm işletme yöneticileri olumlu cevap vermektedir. Ürünlerini ve kalitelerini sürekli geliştirmek zorunda olduklarını aynı zamanda moda ve talepler nedeniyle teknolojiyi takip etmeleri gerektiğini, yeni iş ağları nedeniyle üretim kapasitelerini geliştirdiklerini ifade etmektedirler. 
Şebekelerin ekonomik faydalarının olup olmadığına yönelik sorulan 10. soruda işletme yöneticilerinin hepsi şebekelerin ekonomik kazanç sağladığını ifade etmektedir. Ayrıca sürekliliğin ekonomik açıdan önemli olduğunu belirtmektedirler.

Soru 11'de işletme yöneticilerine şebekelerin sağladığı faydalar sorulmuştur. Şebeke örgüt yapılarının işletmelere sağladığı faydalar şebekelerin olumlu görülen yönleri ile benzeşmektedir. İşletme yöneticilerine göre şebekeler, sürekliliği, daha düzenli çalışılmasını, satış garantisini, kazancın olmasını, güçlü firmalarla çalışmanın sağladığı rahatlığı, yalnızlığın yarattığı sorunların hafiflemesini, emek, sermaye, bilgi paylaşımını, ürün çeşitliliğinin ve kalitesinin arttırılmasını, üretim hacminin belirli olmasını ya da arttırılmasını, hedeflere daha kolay ulaşılmasını, öngörüyü, ticari çevrenin geliştirilmesini, ayakta kalmayı ve tanıtıma katkıyı sağlamaktadır.

Soru 12 işbirliği yapmanın zorluklarının tespitine yönelik hazırlanmıştır. 4 işletme yöneticisi işbirliğinin herhangi bir zorluğunun olmadığını belirtmektedir. Yapılan görüşmelerde ödeme, reklam, takip, fiyatın sürekli düşürülmesi talebi, kalitenin standartlaştırılması isteği, termin karşılaşılan zorluklar olarak gösterilmektedir. İhracat yapan firmalar dolardaki dalgalanmaları zorluk olarak görmektedirler. İşletme İ yöneticisi şebeke içerisindeki ilişkilerin sürekliliği nedeniyle daha kazançlı olabilecek iş bağlantıları kuramadıklarını belirtmektedir. Yurtdışına ihracat yapan bir işletme yöneticisi ihracat yaptıkları ülkenin yasal yapısı nedeniyle kefalet sistemiyle çalışmaları gerektiğini belirtmektedir.

Soru 13'de işletme yöneticilerine şebekede yer alan diğer işletmelerle sorun yaşayıp yaşamadıkları sorulmuştur. İşletme yöneticilerinden alınan bilgiye göre ödeme, termin, kalite ve kârlılık açısından sorunlar yaşamaktadırlar. İşletme F yöneticisi şebekeden kopmamak adına fiyat düşürme taleplerini yerine getirdiklerini ifade etmektedir. Ayrıca İşletme G ve H yöneticileri ürünün hammaddesinin özelliği nedeniyle standart bir kaliteyi (ürünün renk, tuşe gibi özellikleri açısından) sağlayamadıklarını ancak fason üretim yaptıkları firmaların bunu sorun haline getirdiklerini belirtmektedir.

"Şebekede yer alan diğer işletmelerin karar verme sürecinizi (işletmeyle ilgili kararlar verilirken) olumsuz etkilediğini düşünüyor musunuz?" sorusuna 7 işletme yöneticisi olumlu ya da olumsuz hiçbir şekilde işletmelerine etki etmediklerini ifade etmektedirler. Geriye kalan 8 işletme yöneticisi ise karar verme süreçlerine etki ettiklerini ancak bunun olumsuz değil olumlu yönde olduğunu belirtmektedir. İşletme F yöneticisi bu soruyu "karışmazlarsa yardımlaşmanın bir anlamı kalmaz" şeklinde cevaplandırmaktadır.

Soru 15 'de var olan işbirlikleri devam ettiği sürece yeni işbirlikleri yapmayı düşünüp düşünmedikleri, soru 16'da işbirliği yaptıkları işletmeler dışında gelen işbirliği tekliflerini nasıl değerlendirdikleri sorulmuştur. Yöneticilerden 13 tanesi yeni işbirliklerine açık olduklarını, 2 tanesi yeni işbirlikleri yapmayı düşünmediklerine ifade etmektedirler. İşletme N yöneticisi yeni bir işbirliğinin yeni makine, fazla vardiya anlamına geleceğini belirterek olumlu değerlendirmediğini ifade etmektedir. İşletme Ö yöneticisi daha önce olumsuz bir deneyim yaşamıştır ve ürün kalitesi açısından risk ifade ettiği için yeni işbirliklerine olumlu bakmadığını belirtmektedir. Olumlu bakan işletme yöneticileri kapasitelerini arttırma yoluna gidebileceklerini ya da daha çok kazanç sağlayacak işbirliklerini tercih edebileceklerini ifade etmektedirler. İşletme H yöneticisi şebekede kendisi için fason üretim yaptırdığı işletmeler arasında eksilen bir işletme olduğunda kendini güvende tutabilmek için gelen tekliflerde açık kapı bıraktığını belirtmektedir. İşletme İ yöneticisi ise yeni işbirliklerine bakış açısını "yaşlananı çıkarıp yenisini koymak lazım" ifadeleri ile açıklamaktadır.

İşletme yöneticilerine 17. soru olarak bir şekilde şebekede yer alan işletmelerle işbirlikleri sona ererse işletmelerinin ne gibi zorluklarla karşılaşabileceklerini düşündükleri sorulmuştur. İşletme yöneticileri böyle bir durumda işletmenin kapanabileceğini, üretimin durdurulacağını, işçi çıkarılacağını, yeni bağlantılar kurulması için zaman gerektiğini, katma değeri düşük işlerle ayakta kalmaya çalışılacağını, farklı sektörlere yönleneceğini belirtmektedirler. İşletme B yöneticisi yeni bağlantılar kurmak için araştırma yapmak gerektiğini, şu andaki işletmelerin kalite, prensip ve çalışma şekillerini biliyor ve güveniyor olduklarını, yeni birlikteliklerde en az 1 yıl "1sınma turu” atılması gerektiğini ifade etmektedir. İşletme L yöneticisi iş ortaklığının büyüklüğüne bağlı olarak sorunların değişeceğini, yeni bağlantı kurana kadar kapasitenin düşeceğini, kendisinin ürettirdiği fason üretimi keseceklerini belirtmektedir. Kendi işletmesi dışında fason üretim yaptırdığı işletmeleri bu gibi durumlarda güvenlik zırhı olarak tanımlamaktadır.

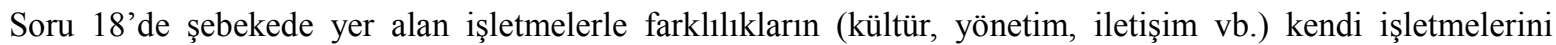
olumsuz etkileyip etkilemediği sorulmuştur. Yöneticilerden 10 tanesi sorun olmadığını, 1 tanesi bazı farklılıkların onları geliştirdiğini bazı farklılıkların gerilettiğini, 1 tanesi başlangıçta farklılıkların sorun yarattığını ancak sonradan bu sorunların ortadan kalktığını, 3 tanesi ise farklılıkların işletmelerini olumsuz etkilediğini ifade etmiştir. Olumsuz etkilemediğini düşünen çoğu yönetici ticaretin ortak dilinin olduğunu ve bu dilin tüm farklılıkları aştığını söylemektedirler.

Şebeke örgütlerde ağın oluşturulması kadar bu ağ içerisinde işbirliklerinin de sürdürülmesi önemli olmaktadır. İşletme yöneticilerine şebekedeki ilişkilerin devamlılığı için gerekli gördükleri unsurlar sorulmuştur. Soru 19'a yöneticilerin verdiği cevaplar ışığında ilişkilerin sürdürülmesinde iki farklı boyutun öne çıktığı görülmektedir. Birincisi insan ilişkileri boyutudur. Bu boyutta yöneticilerin beklentileri dürüstlük, güvenirlik, verilen sözleri yerine getirmek, karşılıklı iyi niyet, zor koşullarda destek olmak, önemli günlerde aramak, hediyeler göndermek, 
paylaşmayı bilmek, gündelik düşünmemek ve yalansız ticaret yapmaktır. İkinci boyut ise iş süreçleri ile ilgilidir. Kaliteden taviz vermemek, ödeme dengesi, ucuza mal etmek, yaptığı işlerde titiz davranılması, termin, talebe cevap verebilmek, teknolojiyi takip etmek ve iki tarafin da kazanması bu boyutta yer alan beklentilerdir. Ayrıca İşletme A ve D yöneticisi ilişkilerin sürdürülmesinde devlet desteğinin de önemli olduğunu belirtmiştir. İlişkilerin oluşmasında ve sürdürülmesinde devlet politikalarının önemli olduğunu belirten İşletme A yöneticisi daha önce iki farklı ülkeye ihracat yaptığını ancak ülkeler arasındaki sorunlar nedeniyle ihracatının tamamiyle sona erdiğini ifade etmiştir.

İşletme yöneticilerine 20. soru olarak şebeke içerisinde güveni nasıl tanımladıkları sorulmuştur. İşletme A yöneticisi güvenin tamamen gözleme dayalı olduğunu belirtmektedir. Davranış ve iletişimini değerlendirerek güven duyup duyulmayacağına karar verdiklerini ve eğer bir işletme güven vermezse uzun süre o işletmeyi izlediklerini ifade etmektedir. İşletme B, K ve N yöneticileri ticaretin güven olduğunu, güven olmazsa ticaret yapılamayacağını belirtmektedirler. İşletme $\mathrm{C}$ yöneticisi farklı bir bakış açısıyla bir işletmeye güvenip güvenmeyeceklerine ağ içerisindeki işletmelerin müşterilerine bakarak ve müşterilerinin müşterilerini takip ederek karar verdiklerini belirtmektedir. Müşterilerinin müşterileri iyi olduğu, satış yapabildikleri sürece kendi işlerinin de sorunsuz devam edeceğini öngördüklerini ifade etmektedirler. İşletme D yöneticisi güven olmazsa ticaretin de olamayacağını, kendilerini güvene almak için peşinat aldıklarını, güven sorunu varsa tamamen peşin çalıştıklarını söylemektedir. Ayrıca yönetici, firmaların kaç yıllık olduğuna bakarak, insan ilişkileri ve davranışlarını gözlemleyerek güvenin oluştuğunu belirtmektedir. İşletme E yöneticisi güven kavramını açıklarken iş hayatını aileye benzetmekte ve aile ortamındaki güvenin iş hayatında da olması gerektiğini vurgulamaktadır. İşletme F yöneticisi güvenin tecrübeyle oluştuğunu, düşünce yapılarının birbirine uyması gerektiğini ve ticari ahlakın güven için önemli olduğunu belirtmektedir. İşletme G yöneticisi iş hayatının sığ olduğunu ve güven ilişkilerinin iş ağ içinde öğrenildiğini ifade etmektedir. İşletme H ve P yöneticisine göre güven sözdür. İşletme İ yöneticisi için güven firmanın piyasadaki ismi ve ilişkileriyle ilgilidir. İşletme L yöneticisi güvenin işletmenin büyüklüğüne, işbirliği süresine ya da aralarında yazılı sözleşme olup olmamasına bağlı olmadığını belirtmektedir. Yalansız ticaretin güveni doğuracağını belirterek "ürünümü çeke değil insana satıyorum” demiştir. İşletme M yöneticisine göre güven zamanla oluşmaktadır. Güveni niyet olarak tanımlamaktadır. Şüpheci ve art niyetli kişilerden uzak durulduğunu belirterek güven için işletme büyüklüğünün önemli olmadığını ifade etmektedir. Fason üretim yaptıran ve markası bulunan İşletme Ö yöneticisi için güven kalitedir. Vadedilen şeylerin yerine getirilmesi işletme yöneticisi için güven verici bir sözden daha kıymetli olmaktadır.

Yöneticilerden alınan cevaplar doğrultusunda iş ağları içerisinde güveni söz, niyet, dürüstlük vb. olarak tanımladıkları görülmektedir. Güvenle ilgili Whitener ve arkadaşları (1998) yaptıkları çalışmada güvenle ilgili özellikle üç unsurun dikkat çektiğini belirtmişlerdir. Birincisi bir tarafın diğer tarafın iyi niyetli hareket edeceğiyle ilgili beklentisi ve inancıdır. İkincisi, kimsenin bu beklentiyi yerine getirmek için diğer tarafi zorlamamasıdır. Üçüncüsü güvenin taraflar arasındaki bağımlılığı içermesidir Yapılan çalışma ile yöneticilerin iş ağları içerisinde güvene bakış açılarının örtüş̧ügü görülmektedir. 2. soruda ilişkilerin oluşması için gerekli görülen unsurlardan biri olarak iyi niyet gösterilmiştir. Aynı şekilde yöneticilerin çoğunluğu yazılı herhangi bir sözleşme olmadan şebeke içerisindeki diğer işletmelerle söze dayalı işbirliği sürdürdüklerini de ifade etmişlerdir. Ayrıca iş bağlantılarının kurulmasında, iş ağlarının oluşmasında gerekli görülen unsurlar arasında, işbirliği yapmanın olumlu yönlerinde ve işbirliğinin sürdürülmesiyle ilgili sorularda verilen cevaplar arasında güvenin olduğu görülmektedir.

İşletme yöneticilerine 21. soru olarak çalıştıkları işletmelerle hukuki bir sorun yaşayıp yaşamadıkları sorulmuştur. Yöneticilerin 8 tanesi hukuki bir sorun yaşarken 7 tanesi herhangi bir hukuki sorun yaşamadıklarını ifade etmişlerdir. Yaşanan hukuki sorunların ödemelerle ilgili olduğu belirtilmiştir. Yöneticilerden elde edilen bilgiler 1şığında iş ağları içerisinde güven ve söz hukuktan daha geçerli ve güvenilir bulunmaktadır.

Kısmen yurt dışı kısmen yurt içi işletmelerle çalışan toplam 8 işletme yöneticisine yurtdışı mı yurt içi işletmelere mi daha fazla güvendikleri sorulmuştur. İşletme yöneticilerinden 6 tanesi yurtdışı işletmelere, 1 tanesi yurtiçi işletmelere güvendiğini, 1 yönetici durumun ülkelere, milliyet ve dinlerine göre değiştiğini, 1 yönetici aynı zamanda durumun işletmeye bağlı olduğunu belirtmektedir. Yurtdışı işletmelere güvenen yöneticilerin belirttiği nedenler, yurtdışındaki işletmelerin çalışmalarında titiz olmaları, büyük ve prensipli işletmeler olmaları, yurtiçi işletmelerin alım güçlerinin daha düşük olması, yurtiçi işletmelerin günlük kârları daha çok hesaplamaları, daha önce hiç yurt dışı işletmelerle ödeme sorunu yaşamamaları, devlet tarafından garanti altına alınması ve banka teminatlı çalışılmasıdır. Yurtiçi işletmelere güvenen işletmenin belirttiği neden ise çözümün daha hızlı gerçekleşmesidir.

İşletme yöneticilerine ihalelere katılıp katılmadıkları ve ihale açıp açmadıkları bilgisi de sorulmuştur. İhalelere katılan işletme sayısı 3, katılmayanların sayısı ise 12'dir. İşletmelerden hiçbiri ihale açmamaktadır.

İşletme yöneticilerine son olarak fuarlara katılıp katılmadıkları sorulmuştur. Fuar standı açan işletme sayısı 2'dir. İşletme İ yöneticisi fuarları etkili bulduklarını, yeni bakış açısı kazandırdığını ve üretim şekillerindeki farklılıkları gördüklerini belirtmiştir. Yöneticilerden 7 tanesi fuarlara ziyaretçi olarak katıldıklarını ifade etmişlerdir. Yöneticilerden 6 tanesi ise hiçbir şekilde katılmadıklarını belirtmişlerdir. 


\section{Sonuç ve Öneriler}

Yapılan mülakatlarda işletme sahibi yöneticilerin verdikleri bilgilere göre şebeke örgüt yapılarının işletmelerin ihtiyaçları doğrultusunda kişisel ilişkiler sonucu oluştuğu görülmüştür. Yapılan mülakatlardan elde edilen bilgiler aracı kuruluşların ya da internetin de bu ağların oluşmasında kullanıldığını göstermektedir. Uşak ilinde mülakatın gerçekleştirildiği işletmeler dikkate alındığında genel olarak şebeke yapısının dinamik olduğu söylenebilir. Yazılı bir sözleşmenin olmaması yapının daha kolay değişebilir olduğunun bir göstergesi olarak kabul edilebilir. Çok sayıda yurtiçi ve yurtdışı işletmelerle işbirliği yapan bu işletmeler birbirinden tamamen bağımsızdırlar ve sadece üretim sürecine etki eden bilgi ve tecrübeyi paylaşmaktadırlar.

Araştırma sorularından bir diğeri şebeke ilişkilerinin oluşmasında ve sürdürülmesinde önemli olan unsurların tespitine yöneliktir. Konuyla ilgili olarak yöneticilere 2 farklı soru yönetilmiştir. Soru 2 ve soru 19'dan elde edilen bilgiler ışığında işbirliğinin oluşmasında ve sürdürülmesinde iki farklı boyutun oluştuğu görülmektedir. Bu boyutlar insan ilişkileri ve iş süreçleriyle ilgilidir. İnsan ilişkileri boyutunda iş ağlarında ikna, güven, samimiyet, dürüstlük, karşı tarafı anlamak, karşı tarafın karakteri, iyi niyet, zor koşullarda destek olmak, önemli günlerde aramak, hediyeler göndermek, paylaşmayı bilmek, verilen sözleri yerine getirmek, gündelik düşünmemek ve yalansız ticaret yapmak önem kazanmaktadır. İkinci boyutta kalite, ödeme şartları, yaptığ işlerde titiz davranılması, termin, talebe cevap verebilmek, teknolojiyi takip etmek, iki tarafın da kazanması, süreklilik, fiyat avantajı, çok iyi piyasa analizi ve sağlamlık yöneticilerin iş ağlarındaki iş süreçleri ile ilgili beklentilerini oluşturmaktadır. Bu noktada şebeke örgüt yapılarının hem insan ilişkilerine hem de yapılan işin niteliğine bağlı oluştuğu ve devam ettiği söylenebilmektedir. Bu bağlamda sadece ürünün varlığı ve kalitesinin işletmenin şebekede kalması için yeterli olmadığı sonucuna da ulaşılmıştır.

İşletmeler çok farklı amaçlarla şebekelere dâhil olabilmektelerdir. Temel yetenekleri ölçüsünde yaptıkları en iyi işi yapmaları onlara maliyet, yönetim vb. konularda avantaj sağlamaktadır. Ayrıca şebeke içerisinde diğer işletmelerle yaratılan sinerji rekabet anlamında güç sağlamaktadır. Mülakat yapılan yöneticiler de benzer şekilde şebekeye dâhil olma amaçlarını (Soru 3) kâr elde etmek, satış yapabilmek ve üretim kapasitelerini arttırmak olarak açıklamışlardır.

Araştırma sorularından bir diğeri şebeke ilişkilerinin formal ya da informal nitelik taşıyıp taşımadığıyla ilgilidir. Yapılan araştırma sonucunda şebekede yer alan işletmelerin çoğunlukla informal niteliğe sahip olduğu görülmektedir. 15 işletmeden sadece bir tanesinin tüm işletmelerle sözleşme yapması 8 tanesinin ise hiçbir işletme ile sözleşme yapmaması elde edilen bulgular arasındadır. Bu açıdan şebeke ilişkilerinin ağırlıklı olarak informal şekilde oluştuğu görülmektedir. İşletme D yöneticisi ihracat yaptığı ülkede sözleşmelerin geçerliliğinin olmadığııı söylemesi yapılan işbirliklerinde sözleşmelerin sadece işletme kararlarına bağlı olmadığını göstermektedir. Sözleşme yapan işletme yöneticilerinin sözleşme taleplerinin karşı taraftan geldiğini ifade etmeleri işbirliğinde işletmelerin sözleşmeyi çok tercih etmediklerini bunun yerine söz ve güvenin işbirliğinde daha geçerli görülen iki unsur olduğu sonucunu doğurmaktadır. Mülakatın gerçekleştiği işletmelerin 8 tanesinin işbirliği yaptıkları işletmelerle hukuki bir sorun yaşamış olmalarına rağmen sözleşmeyi sadece karşı taraf istediğinde yapmaları araştırılması gereken farklı sorun olarak ortaya çıkmaktadır. Sadece karşı taraf talep ettiği takdirde yurtdışı işletmelerle sözleşme yapan İşletme K yöneticisi hukuki sorunlar yaşadığı işletmelerle sorunlarının çözüme kavuşmadığını belirtmesi ancak bu sorunun hukuki süreçlerden kaynakladığını ifade etmesi dikkat çekmektedir.

Şebeke örgüt yapılarının işletmelere sağladığı faydaların yöneticilerin bakış açısıyla değerlendirilebilmesi amacıyla 7 farklı soru sorulmuştur (Soru 5, 6, 7, 8, 9, 10 ve 11). Elde edilen sonuçlara göre şebeke örgüt yapılarının işletmelere üretim sürecinden kurum imajına kadar her noktada fayda sağladığı görülmektedir. İşletmelerin rekabet ortamında varlıklarını sürdürebilmeleri ürün ve kalite açısından sürekli gelişmelerini gerektirmektedir. Bu ise bilgiye duyulan ihtiyaca dikkat çekmektedir. İşletmeler ihtiyaç duydukları bilgi ve tecrübeleri şebekede yer alan diğer işletmelerden sağlayabilmektedirler. Çünkü şebekede yer alan işletmeler birlikte hareket ettikleri için bilgi paylaşımı yüksek olduğu ölçüde başarıya ulaşmaktadırlar. Aynı zamanda iş ağları işletmelerin kendi işine odaklanabilmelerini ve bu alanda sürekli gelişmelerini de teşvik etmektedir. Şebekede yer almak belirli düzeyde süreklilik ifade ettiği için satış, kâr, zaman, emek, sermaye, üretim hacmi, pazar gibi ticari kaygıların hafiflemesini sağlamaktadır. Bu durum ise işletmeler için risklerin azalması anlamına gelmektedir. Ayrıca şebeke içerisinde güçlü bir işletme varsa bu işletmeler diğer işletmeler için bir referans niteliği taşımakta ve tanıtımlarına katkı sağlamaktadır. Araştırmadan elde edilen bilgiler sonucunda şebekelerin genel olarak işletmelere rekabet avantaj1 sunduğu, dinamik bir yapı, sürekli gelişim imkânı ve çok sayıda ekonomik faydalar sağladığı görülmektedir.

Şebeke örgütlerin işletmelere sağladığı faydaların yanı sıra bir takım zorlukları da beraberinde getirdiği bilinmektedir. Yöneticiler açısından şebekelerin ne gibi zorluklar yüklediği ve ne gibi sorunlarla karşılaşıldığ hakkındaki araştırma sorusu çerçevesinde bilgi toplanabilmesi için yöneticilere 6 soru sorulmuştur (Soru 12, 13, $14,17,18$ ve 21). Şebekenin kendi yapısından kaynaklanan bir takım zorlukların mevcut olduğu görülmektedir. Örneğin şebeke ağına dâhil olan işletmelerin farklı ülkelerde bulunması iş yapma süreçlerini, termini vb. hususları olumsuz etkileyebilmektedir. Özellikle fason üretim yapan işletmeler için maliyetlerin sürekli düşürülmesinin istenmesi yaşanan bir diğer önemli sorun olarak görülmektedir. Şebekedeki devamlılıklarını sağlayabilmek için işletmeler daha ucuza üretmek zorunda kalmakta ancak kaliteden taviz veremedikleri için de çoğunlukla kendi 
içyapılarında kâr marjını düşürmek ya da işletme giderlerini kısmak (işçi ücretleri, yemek, servis hizmetlerini kısıtlamak vb.) gibi farklı uygulamalara gitmektedirler. Bir diğer sorun kapasitelerini arttırma imkânı olmayan işletmelerin gelen kazançlı iş tekliflerini olumlu değerlendirememeleridir. Özellikle kazancın düşük olduğu durumlarda bile şebekenin işletme yöneticileri tarafindan daha güvenli bir yapı olarak görülmesi risk almak istemeyen işletmelerin yeni iş ağları oluşturmalarına engel olmaktadır. Yöneticilerin en çok karşılaştıkları sorun ödeme ile ilgilidir. Şebekede yer alan bir işletmenin ödeme şartlarını aksatması tüm iş süreçlerini olumsuz etkileyebilmektedir. Ayrıca yaşanan hukuki sorunların hepsinin ödemeyle ilgili olduğu belirtilmiştir. Şebeke örgütlerin işletmeler için oluşturduğu en önemli zorluklardan biri şebeke için üretirken herhangi bir nedenle şebeke dışına atılması sonrasında meydana gelebilecek sorunlardır. Böyle bir durumda işletmeler açısından yeni bir pazarın bulunmasının oldukça zor olması yanında işletmelerin kapanması dahi söz konusudur.

Şebekelerin oluşmasında ve sürdürülmesinde oldukça önemli görülen güven, yöneticiler tarafindan işbirliği için olmazsa olmaz olarak tanımlanmaktadır. Araştırma bulguları doğrultusunda yöneticilerin iş ağları içindeki diğer işletmelere karşı olumlu bir beklenti içinde oldukları görülmektedir. Güven duydukları işletmelerle çalışmaya devam ettikleri güven vermeyen işletmeleri uzun süre izlediklerini ve belli bir zaman sonra karar verdiklerini belirtmektedirler. Yöneticiler için güven verilen sözün yerine getirilmesi, iyi niyet, kalite ve aile içi ilişkilere eşdeğer olarak görülmektedir.

Şebekeler çok farklı bölgelerde faaliyet gösteren işletmelerden oluşabilmektedir. Yurtdışındaki işletmelerle çalışan 8 işletmeden 6 tanesinin yurtiçindeki işletmelere nazaran yurtdışı işletmelere daha fazla güven duymaları önemli bir noktadır. Yurtdışındaki işletmelerle yapılan işbirliklerinde İşletme M yöneticisi banka teminatlı çalıştıkları için, İşletme A yöneticisi devlet garantisi olduğu için, İşletme L yurtdışında hiç ödeme sorunu yaşamadığ 1 için, İşletme B yöneticisi prensipli işletmelerle çalıştıkları için, İşletme D ve G yöneticileri ise yurtiçi işletmelerin yurtdışı işletmelere göre alım güçlerinin daha düşük olması nedeniyle yurtdışı işletmelere daha fazla güvendiklerini belirtmişlerdir. Güven konusunun işletmelere bağlı olduğunu belirten işletme yöneticileri ise din, dil, rk farklılıklarının önemli olmadığını ifade etmişlerdir.

İşletmelerin işbirlikleri devam ettiği sürece yeni işbirlikleri yapmayı düşünüp düşünmedikleri, işbirliği yaptıkları işletmeler dişında gelen işbirliği tekliflerini nasıl değerlendirdiklerine yönelik araştırma sorusu için işletme yöneticilerine 2 farklı soru (Soru 15 ve 16) sorulmuştur. Yöneticilerin büyük çoğunluğu (13 yönetici) yeni işbirliklerine açık olduklarını ifade etmişlerdir. Bu teklifleri ya var olan işbirliklerine ilaveten kapasite artırılarak yeni ağların oluşturulması şeklinde ya da şebekedeki bazı işletmelerin yerine daha kazançlı olanlarının konulması şeklinde olumlu değerlendirebileceklerini belirtmişlerdir. Olumsuz değerlendirilmesinin sebebi olarak ise işletme kapasitesinin uygun olmaması gösterilmiştir. Şebeke yapılarının işletmeler açısından önemli bir avantajı olarak görülen sürekliliğin işletmelerin yeni tekliflere bakış açısını etkilemektedir. Süreklilik bir takım ticari kaygıların hafifletilmesini sağlarken aynı zamanda işletmelerin daha kazançlı alanlara girmelerine engel de olabilmektedir. Ancak yapılan mülakatların gerçekleştirildiği işletmelerin bu anlamda şebeke yapılarından olumsuz etkilenmedikleri özellikle dinamik yapı arz etmeleri nedeniyle hâlâ yeni ağlar oluşturulması noktasında pozitif bir bakış açısına sahip oldukları görülmektedir.

Sonuç olarak şebeke örgüt yapıları işletmelere önemli faydalar sağlarken aynı zamanda işletmelerin bir takım sorunlarla karşılaşmalarına da neden olmaktadır. Şebekelerin oluşum sürecinden ilişkilerin sürdürülmesine ve hatta sona erdirilmesine kadar olan süreçte iş yapma süreçlerinin birbiri ile bağlantıll ilerlemesi sinerjinin yaratılması kadar ortaya çıkan sorunlardan her işletmenin de belirli düzeylerde etkilenmesine neden olmaktadır. Şebeke yapısının işletmelere sağladığı firsatlardan en üst düzeyde faydalanabilmeleri ve olası sorunlardan kaçınabilmeleri şebekede yer alan işletmelere bağlı olmaktadır. Bu doğrultuda işbirliği sürecinde ilk doğru adım güven duyulan işletmelerle etkin bir ağ içine dâhil olmaktır. Şebekede yer alan diğer işletmelerin güvenilir ve başarılı olması işletmeler açısından fayda sağlarken, güvenilir olmayan her işletme diğer işletmeler için bir tehdit unsuru oluşturmaktadır. Özellikle rekabetin yoğun olarak hissedildiği dinamik şebeke yapılarında her işletme maksimum verimlilikle çalışmak zorunda kalmaktadır. Bu durumda ağ içerisinde yaratılan firsat işbirliğinden her işletme için ortak paydanın yaratılması önemli olmaktadır.

Yapılan araştırma sonucunda işletmelere şebeke yapılarında daha fazla faydalanabilmeleri ve karşılaşılan güçlüklerin en aza indirilebilmesi için bir takım önerilerde bulunulabilir. Karşılıklı olumlu beklenti ve çıkarlara dayalı olarak kurulan işbirliklerinde güven kavramının duygusal değil bilişsel bir nitelik taşıması, sağlam bir temel üzerine kurulan kurumsal bir güvenin yaratılması ve işbirliği devam ettiği sürece güveni besleyecek bilgi paylaşımı ve davranışlarda bulunulması şebekelerin başarısı için kritik bir öneme sahiptir. Bu noktada güveni destekleyecek bir unsur olarak işletmelerin ağ içerisindeki diğer işletmelerle yazılı sözleşme yapmaları bir çözüm önerisi olarak görülmektedir. İşletmelerin şebeke içerisinde karşılaşııkları hukuki sorunlar, ödeme, kalitenin standartlaştırılması, termin gibi zorluklarla başa çıkabilmeleri için sözleşme güven unsurunun hukuki bir zemine oturtulmasını sağlamaktadır. Böylece şebekede yer alan işletmelerin yazılı sözleşmeler yapmaları tarafların karşılıklı olarak birbirlerine vadettiklerini (yapılacak işin niteliği, süresi, kalite standartları, ödeme vb.) yasal olarak teminat altına almaları anlamına gelmektedir.

Şebekelerin çoğunlukla dikey ilişkilerden oluştukları görülmektedir. Kendi içlerinde yatay bir yapılanmaya gidilmemesi her işletmenin kendi sahip olduğu kaynakları, üretim kapasitesi, kalitesi vb. noktalarda rekabete dâhil 
olmalarına neden olmaktadır. Yatay yapılanma işletmelere güçlü firmalar karşısında önemli bir rekabet avantajı sağlamaktadır. Bu bağlamda işletmelere kendi kapasiteleri ölçüsünde yatay yapılar oluşturarak kendi içlerinde bir sinerji yaratmaları önerilebilir.

\section{Kaynakça}

- Alstyne, 1997. “The State of Network Organization: A Survey in Three Farmeworks”. Journal of Organizational Computing, 7/3, p.2.

- $\quad$ Brockner, Siegel, Daly, Tyler, Martin, 1997. "When Trust Matters: The Moderating Effect of Outcome Favorability". Administrative Science Quarterly, 42/3, p.558.

- Demircan, Ceylan, 2003. "Örgütsel Güven Kavram: Nedenleri ve Sonuçlar1”. Celal Bayar Üniversitesi, Iktisadi ve İdari Bilimler Fakültesi, Yönetim ve Ekonomi Dergisi, 10/2, s.142.

- Derin, 2011. İşletmelerde Geri Kalan Sendromu ve Örgütsel Güven. Nobel Yayınları, Ankara, s.89-90.

- Durak, 2005. Küreselleşme Sürecinde Şebeke Organizasyonlar ve Denizli Tekstil İşletmeleri Uygulaması. Doktora Tezi, Ankara Üniversitesi, Sosyal Bilimler Enstitüsü İşletme Anabilim Dalı, Ankara, s.39-44.

- Durak, 2006. "Denizli Tekstil İşletmeleri Neden Fason Üretim Yapıyor? Bir Şebeke Organizasyon Çeşidi Olarak Fason Üretim ve Denizli Tekstil İşletmeleri Uygulaması”. Erciyes Üniversitesi İktisadi ve İdari Bilimler Fakültesi Dergisi, 27, s.110-111.

- İplik, 2010. Şebeke Organizasyonlar. Nobel Kitabevi, Adana, s.23.

- İ̀miş, 2003. Yeni Bir Örgütlenme Şekli Olarak Şebeke Organizasyonlar. Beta Yayıncılık, İstanbul, s.58

- Jones, Hesterly, Borgatti, (1997). “A General Theory of Network Governance: Exchange Conditions and Social Mechanisms". Academy of Management Review, 22/ 4, p.915.

- Koçel, 2011. İşletme Yöneticiliği. Beta Yayınları, İstanbul, s.388.

- Lacka, 2015. Evaluation of the Effectiveness of Relations in Network Organizations. Edit. Sroka, Wlodzimierz, Hittmar, Stefan. Switzerland. Management of Network Organizations. Spinger International Publishing, p.137-138.

- Lee, Robertson, Lewis, Sloane, Galloway-Gilliam, Nomachi, 2012. ' 'Trust in a CrossSectoral Interorganizational Network: An Empirical Investigation of Antecedents' , , Nonprofit and Voluntary Sector Quarter/y, 41/4, p. 610.

- Malewicki, 2005. "Member Involvement in Entrepreneur Network Organizations: The Role of Commitment and Trust". Journal of Developmental Entrepreneurship, 10/2, p.143.

- McEvily, Tortoriello, 2011. "Measuring Trust in Organizational Research: Review and Recommendations". Journal of Trust Research, 1/1, p.24.

- Miersch, 2016. "Beyond Trust: Towards A Practice-Based Understanding of Governing 'Network Organizations”. Journal of Management and Governance, DOI: 10.1007/s10997-016-9351-7.

- Morisse, Horlach, Kappenberg, Petrikina, Robel, Steffens, 2014. “'Trust in Network Organizations A Literature Review on Emergent and Evolving Behavior in Network Organizations' '. 47th Hawai i International Conference on System Science, p. 4578-4580.

- Ö̈zgen, Kılıç, Karademir, 2003. "Birlikten Kuvvet Doğar : Küçük ve Orta Ölçekli İşletmeler için Bir Örgütlenme Modeli Olarak Ăg Organizasyonları Önerisi”. Çukurova Üniversitesi Sosyal Bilimler Enstitüsü Dergisi, 12/12, s.90.

- Sydow, Windeler, 1998. "Organizing and Evaluating Interfirm Networks: A Structurationist Perspective on Network Processes and Effectiveness”. Organization Science, 9/3, p.266-267.

- Tutar, 2000. Küreselleşme Sürecinde İşletme Yönetimi. Hayat Yayınları, İstanbul, s.120.

- Whitener, Brodt, Korsgaard, Werner, 1998. “Managers As Initiators of Trust: An Exchange Relationship Framework for Understanding Managerial Trustworthy Behaviour". Academy of Management Review, 23/3, 513.

- Willem, Luciderma, 2014. "Pitfalls And Challenges for Trust And Effectiveness In Collaborative Networks". Public Management Review, 16/5, p.737.

- Yeşil, 2010. "Küreselleşme ve İşletmelerin Küreselleşme Süreçleri: Karşılaşılan Fırsatlar ve Tehditler." Ekonomik ve Sosyal Araştırmalar Dergisi; 6/1, ss. 22-72, s.28. 


\title{
“İkincil” Üretim Faktörü Olarak Addedilen Kadının Kalkınmadaki Rolü: Tra2 Üzerine Araștırma
} The Role of Women on the Economic Development as the
"Secondary" Production Factor: An Analysis on Nuts-2

\author{
Ph.D. Candidate Ülcay Ecenur Avcı (Erzincan University, Turkey)
}

Ph.D. Candidate Aslı Cansın Doker (Erzincan University, Turkey)

\begin{abstract}
In underdeveloped societies, in both the reflection of the limitations on the position of women in social life, as a result of business life is also restricted. However, optimum use of production factors is essential at the forefront of the elements of sustainable development. The reflections of economic exclusion of women are the increase of dependency and the deepening of poverty. According to data, it is observed that labor force participation rates of women in Turkey are relatively inadequate and unbalanced. Women are not able to participate in employment because of low education, professional skills and qualifications, etc. and therefore are more exposed to poverty and social exclusion risk. Moreover, global economic crises in Turkey and similar countries are accompanied by a high unemployment rate resulting from the shrinkage of the markets. On the other hand, new emerging microentrepreneurship, which began in Turkey, which counts more than 8 million poor women for "a contribution to the family income," but in fact it is seen as a way to stay alive. Through this initiative developing self-esteem of women, family and community is growing in reputation. Additionally, quality of the human capital, which is the most important source of the countries, passes through the family institution. In the study, social policy will be made by subjecting micro-credits to comparative analysis of regional development, poverty, nature of women's employment and role of women in social life in the light of face-to-face interviews on five families using microcredit and data on poverty in NUTS-2.
\end{abstract}

\section{Giriş}

Mikro kredi, düşük gelirli insanların yaşamlarını idame ettirebilmeleri, kendi işletmelerini kurmaları veya kurulu işlerini geliştirmeleri için verilen küçük miktarlı bir kredi programıdır (Erdoğan, 2002). Günümüzde, ülkemizde ve tüm dünyada mühim bir sorun teşkil eden yoksulluk ve yoksullukla mücadele salt sosyal politikalarla baş edilemeyecek duruma varmış, yeni çözüm arayışlarıyla birlikte mikro kredi programları gündeme gelmiştir. Güven odaklı, teminat göstermeksizin ve kefilsiz küçük sermaye şeklindeki mikro kredi, bireyin kendi kaderini tayin hakkı (self determinasyon ilkesi) çerçevesinde kendi isteği ve çabasıyla kişinin içinde bulunduğu durumdan kurtulabilmesi için etkin bir yoldur. Uygulama şartları uyarınca önce 5 ile 8 kişilik gruplar oluşturulur, gruptaki kişiler birbirlerinin kefili olmaktadır. Kredi geri ödemesi haftalık taksitlerle yapılmakta olup, fazladan ödenen para kumbara sistemi ile kenarda birikmekte, ihtiyaç halinde kişinin kredi taksiti oradan ödenmektedir. Bununla birlikte mikro kredinin en önemli farkı krediyi alan kişinin başladığı ekonomik faaliyetin sürekliliğinin sağlanması amacıyla kredi geri ödemeleri konusunda ısrarcı ve kararlı olunmasıdır.

Mikro kredi uygulaması hem kadın hem erkek emeğini destekleme, yeni girişimciler yaratma amaçlı görülse de, Dünya'da ve ülkemizde mikro kredi sağlayan organizasyonların amaçlarına bakıldığında çoğunlukla "kadınları güçlendirme" söylemi dikkat çekmektedir (Balkız, 2013). Bu söylemin alt metninde yatan pek çok sosyal ve kültürel unsur vardır. Patriyarkanın hakim olduğu geleneksel aile yapılarında kadın sadece yemek, temizlik, çocuk bakımı gibi günlük rutin işleri yapan ve evine bakan bir birey olarak addedilmektedir. Hane içerisinde gelir getiren üretici unsur baba yani erkektir. Dolayısıyla babanın haneye gelir getirememe durumundan da ilk etkilenecek olan kişi anne yani kadındır. Kadın erkeğe bağımlı hale gelmiş, erkek eve gelir getiremediğinde ya da kadına bu gelirden vermediğinde hane içindeki pek çok sorumluluğu yüklenen kadın yoksulluğu mikro bazda en çok hisseden birey haline gelmiştir.

Aile ve Sosyal Politikalar Bakanlığı ve valilikler aracılığıyla verilen sosyal yardımlar yoksulluğu ortadan kaldırmaya yönelik kalıcı çözüm geliştirmekten oldukça uzak olup bireyi devlete bağımlı hale getirmektedir. Bununla birlikte, verilen yardımlar kişiye girişimcilik anlamında herhangi bir katkı sunmamakta, bireyin "gününü kurtarmasına" yardımcı olmaktadır. Mikro kredi sistemi kadın emeğinin değerlendirilmesi ve kadın yoksulluğunun azaltılması açısından etkin bir hizmet modeli olarak karşımızda durmaktadır.

"Kadınları ekonomik hayatın içine sokarak bağımsız kazanç elde etme kapasitelerini arttırmayı hedefleyen program, bu yolla kadınların aile içi konumlarında da değişim olacağını varsaymaktadır. Kredi ve borçluluk ilişkisi çerçevesinde gruplar halinde organize olan kadınların, kolektif bilinçlerinin ve kolektif eylem kapasitelerinin artacağı, nihai olarak da toplum içinde sosyo-ekonomik ve politik açıdan güçlenecekleri ileri sürülmektedir." (Balkı, 2013). 
Mikro kredi uygulamaları yoksullukla mücadelede bireysel bazda mühim bir silah olup toplumsal anlamda da olumlu etkiler yaratabilmektedir. Mikro kredi ile birlikte kendi işletmesini kuran, var olan işletmesini büyüten ve geliştiren pek çok kadın bulunmaktadır. Kendi emeğinin karşılığını alan kadının toplumdaki statüsü olumlu yönde değişmekte, bu gelişme hem bireysel bazda kadını güçlendirmekte hem de toplumsal kalkınmaya katkı sağlamaktadır. Ayrıca yeni işletmelerin açılması yeni iş olanakları yaratmakta, işsizliğin azaltılmasına katkı sağlamaktadır. Kadın girişimciliğin tanımını araştııırken birçok tanımla karşılaşılmaktadır. Her yazarın kendi tanımı bulunmaktadır. Yeni gelişen bir kavram olduğu için tanımlar birbirinden kopuktur. Genellikle, Batı'da kadın girişimci kavramı üst yönetimde çalışan kadınlar veya bağımlı çalışmaktan hoşlanmayıp kendi işini kuranlar için kullanılırken Doğu ülkelerinde geçim yükü yüzünden çalışmak zorunda kalan kadınlar için kullanılmaktadır. Geleneksel düşünce sistemine göre kadının yeri evidir ve alışılmış görev kocasının eşi, çocuklarının annesi olmaktır. Ancak bu role sanayileşme ve kentleşme ile birlikte yeni sosyal roller eklenmiştir. Bu gelişmelerin sonucu olarak, kendi işinin sahibi olmayı isteyen kadın girişismciler ortaya çıkmıştır (Şahin, 2010).

"Piyasa ekonomisi içinde, kendi işinin sahibi olan, tek başına çalışan ya da yanında işçi çalıştıran, mal ve hizmet üretip satan, kredi kaynaklarını araştıran, işle ilgili acil problemlerin üstesinden gelebilen, yeni koşullara adapte olabilen ve alanında deneyim sahibi olmaya çalışan kadın; kadın girişimci olarak tanımlanmaktadır” (Çelebi, 1993:18).

Girişimcilik, üretim faktörlerini cesaretle bir araya getirme, risk alma anlamına gelmektedir. Kendi mesleğini yapan kadınlar ise eğitimini aldıkları alanlarda çalışmadıklarından girişimci olarak sayılmamaktadırlar (Özdevecioğlu ve Çelik, 2000). Tanımsal olarak kadının girişimci olabilmesi için 6 temel kriterden söz edilmektedir (Tablo 1).

\begin{tabular}{|c|c|}
\hline 1 & Ev dış1 bir mekanda, kendi adına kurduğu bir veya birkaç işyeri olan \\
\hline 2 & $\mathrm{Bu}$ iş yerinde tek başına veya istihdam ettiği diğer kişilerle birlikte çalışan veya ortaklık kuran, \\
\hline 3 & $\begin{array}{l}\text { Herhangi bir mal veya hizmetin üretilmesiyle ilgili faaliyetleri yürüten, bu mal veya hizmetin } \\
\text { dağıtım, pazarlama ve satışını yapan/yaptıran, }\end{array}$ \\
\hline 4 & İşle ilgili olarak iletişime geçmesi gereken kişi, örgüt, kurum ve kuruluşlarla kendi adına ilişki kuran, \\
\hline 5 & $\begin{array}{l}\text { İş sürecinin örgütlenmesi, mal ve hizmet üretiminin planlaması, işyerinin işletilmesi, kapatılması } \\
\text { veya işin geliştirilmesi konusunda kendisi karar veren, }\end{array}$ \\
\hline 6 & İşinden elde ettiği kazancı yatırım ve kullanım alanları üzerinde söz sahibi olan girișimci kadındır \\
\hline
\end{tabular}

Tablo 1. Kadın Girişimci Kriterleri (Ecevit, 1993; Arat, 1993).

Batı kültüründe kadın girişimci, eğitim alarak iş hayatına girmiş, yaptığı işten tatmin olmayarak kendi işini kurup yöneten kişiye denirken; az gelişmiş ülkelerde bir şey alıp satmakla sınırlı kalmış, gelişmekte olan ülkelerde ise bir şey alıp satan, birkaç kişi çalıştıran kişilere denmektedir (Coughlin, 2002).

\section{Kadın Girişimciliğini Engelleyen Sorunlar ve Çözümleri}

Kadın girişimcilerin sorunları üç başlıkta incelenirken çözümleri yedi başlıkta incelenmektedir. Girişimciliğe başlamadan başlayan sorunlar girişimciliğin gelişmesini önemli derecede etkilemektedir.

\subsection{Sorunlar}

Kadın karakterinin daha duygusal, merhametli ve çalışkan olması onların işlerini bir hayli zorlaştırmaktadır. Bir yandan geçim yükü sırtlarına yüklenirken diğer yandan da geçinmenin yolları engellenmektedir.

Kadın girişimcilerin sorunlarını başlıca üç grupta inceleyebiliriz. Bunlar; kadın kimliği ve kişiliğine ait sorunlar, kadın girişimcilerin girişimciliğe başlamadan önce karşılaştıkları sorunlar ve kadın girişimcilerin girişimciliğe başladıktan sonra karşılaştıkları sorunlardır. Kadın kimliği ve kişiliğine bağlı bireysel sorunlar; eğitim düzeyinin yetersiz olması, karakter, huy ve mizaç özelliklerinden kaynaklanan sorunlar, alt kültür çatışmasından kaynaklanan sorunlar ve aile ve toplum desteğinin yetersizliğinden kaynaklanan sorunlar şeklinde sıralanmaktadır. Bunun yanısıra kadın girişimcilerin girişimciliğe başlamadan önce karşılaştıkları sorunlar; girişimcilik bilgi ve deneyiminin yetersizliği, girişimcilik koşullarının uygun olmaması, girişimcilik eğiliminin yetersizliği, sermaye bulma zorluğu, toplumun bazı kesimlerinin girişimci kadına karşı olumsuz tutum ve davranışları, girişimci kadınların yeterince desteklenmemesi ve mevzuat ve bürokratik işlemlerin fazlalığıdır. Kadın girişimcilerinin işe başladıktan sonra karşılaştıkları sorunlar ise sermaye yetersizliği, piyasanın dengesiz olması, kalifiye personel bulma zorluğu, girişimcilik ve iş konusundaki bilgi ve deneyim eksikliği, ödemelerde karşılaşılan sorunlar, rekabette karşılaşılan sorunlar, pazarda müşterilerin az olması ve ekonomik kriz nedeniyle fiyat maliyet ve üretimde karşılaşılan sorunlardır (Şahin, 2006; Kutanis, 2006).

Toplumumuzda pek çok kadın geleneksel aile rollerini benimsemiş, kadının asli işinin ev düzenini sağlamak, çocuk bakımını ve aile sorumluklarını yerine getirmek olduğunu içselleştirmiştir. İşin bir diğer boyutuysa erkek bireylerin de bu içselleştirmeye sahip olması ve kadın üzerinde bir çeşit baskı yaratmasıdır. Bu da kadının 
kabuklarını kırıp kendi parasını kazanmasının, varolan düzeni bozmasının ne kadar zor olduğunu gözler önüne sermektedir. Kadın kendi parasını kazanmakla birlikte sadece aile bütçesine katkı sağlamayacak aynı zamanda çocukları ve çevresi için de rol model olarak örnek bir birey haline gelecektir.

Gerek kız çocuklarının okutulmaması gerekse toplum baskısı kadının kişilik oluşumuna ciddi zarar vermekte, özgüven oluşumunu zedeleyerek kendi potansiyelini keşfetmesine engel olmaktadır. Potansiyelinin farkında olmayan kadın sınırlarını zorlamaktan kaçınarak yeni deneyimlere kapalı olmaktadır. Kadın girişimci profilleri incelendiğinde özgüveni yüksek ve sosyal destek unsurlarına sahip bireyler oldukları görülmektedir (Balkız, 2013; Buğra,2007).

\section{2 Çözümleri}

Ülke olarak, kadın girişimcilerle ve kadın yöneticilerle ilgili sorunlar çözülerek, girişimcilik özendirildiği takdirde, ekonomik gelişmenin de bu sosyal gelişmenin paralelinde geleceği söylenebilir.

$\mathrm{Bu}$ sorunların ortadan kalkması ve kadının iş kurabilmesini kolaylaştırmak için kredi koşullarının kolaylaştırılması gerekmektedir. Kredi miktarları sembolik rakamlar olmaktan çıkarılmalı, faizler düşük tutulmalıdır. Teminat koşulları hafifletilmeli, kredi verilecek alanların sınırlandırılmaması, koşullandırılmaması ve daraltılmaması sağlanmalıdır (Kınay, 1994). Uygulanan mikro kredi programları ile kadının girişimci olmasındaki en büyük engellerden olan sermaye temini yolu bir nebze olsun açılmış bulunmaktadır. Bu programların desteklenmesi ve genişletilmesi gereklidir. Hükümetin söz konusu kadın girişimcilere pazarlama ve kredilendirme kuruluşlarıyla işbirliği yapmasını ve düşük faizli kredi almasını sağlaması gerekmektedir.

Gerekli eğitimden yoksunluk kadın girişimcilerin en çok karşılaştıkları sorunlar arasındadır (TESK, 1992). Türkiye'nin mevcut eğitim sistemi genç kadınlar arasındaki girişimcilik fikrini ve becerilerini geliştirecek ve güçlendirecek nitelikte değildir. Diğer taraftan "toplumdaki geleneksel rol dağılımından dolayı iş piyasasında yeterli deneyime sahip olmamaları, çıraklık ve mesleki eğitimden mahrum kalmaları" kadınları sınırlamaktadır (Kutanis, 2006:68). İş kurmaya ve meslek öğrenmeye yönelik girişimcilik için altyapı oluşturacak tarzda eğitim programları verilmelidir. Bu kurslarda kadın girişimciler mesleki açıdan eksikliklerini tamamlayarak, mesleklerinde gerekli olan araç ve malzemelerin kullanımını öğretilebilir. Eğitimdeki gelişmeyle birlikte kadınların kendilerine güveni artar ve aynı zamanda toplumdaki hak ettikleri yere gelmiş olurlar. İyi planlanmış bir eğitimle kalifiye eleman eksiklikleri giderilebilir. Değişik kamu kuruluşları ve dernekler bu yönde çalışmalarını yapmaktadırlar ancak yeterli değildir. Bu eğitim ve öğretimleri topluma yayarak yapmak gerekir. Yasal ve kurumsal bilgiyi alma eksikliğini gidermek için işletmecilik ve yöneticilik eğitimi, personel temini, kalifiye eleman bulma, kendini kabul ettirme gibi başka adlar altında girişimci kadınlar için düzenlenecek eğitim programları, hem halen çalışmakta olanlara kolaylık sağlayacak, hem de bu alana yeni girecekler içi teşvik edici bir etken olacaktır. Bu eğitimlerin yanı sıra kadınlara özgüven veren, girişimciliğin gerektirdiği nitelikleri ortaya çıkaran, girişimcilik yeteneklerini ve yaratıcılıklarını geliştirici programlar yapılıp uygulanması gerekmektedir.

Devlet dairelerine girmeye korkan kadınların iş yapması, girişimci olması çok zordur. Devlet daireleri daha şeffaf bir yapıya kavuşturulup korkulmaz hale getirilmeli ve girişimci kadın için rehber görevi yapacak bir ofis oluşturulmalıdır. Kadının statüsü ve sorunlarıyla bağlantılı olarak kadınların bilinçlendirilmesi ve kamuoyu oluşturulması için ilgili kuruluşlar tanıtıcı ve eğitici faaliyetlerde bulunmalıdır.

$\mathrm{Bu}$ sorunların giderilmesi için kadın girişimciler çeşitli aracı şirketlerden yardım alabilir, bağlı bulunduğu odalardan kaliteli ve ucuz araç - gereç temini için destek isteyebilir. Bu yönde destek sağlayacak derneklerin kurulması faydalı olacaktır.

Girişimci kadınların işlerini yürütürken birçoğunun sıkıntı çektikleri bir başka konu ise; örgütlenme ve işletme dışı ilişkileri kurmadır (Kümbetoğlu, 1994). Kadınların örgütlenmesine yardım edilmeli ve örgütlü şekilde çalışması için gerekli adımlar atılmalıdır. Örgütlü şekilde çalışmak birçok işi kolaylaştıracaktır. İleri gelen sendika ve dernekler bu konuda yardımcı olmaktadırlar.

Vergilerin fazlalığı ve adaletsiz olması küçük girişimciyi ezmektedir. Rekabet edemez duruma getirmektedir. Vergilerin yüksek oluşu kadın girişimcilerin ödemelerinde zorluklar oluşturmakta ve hatta işyerlerinin kapatılmasına sebep olmaktadır. Vergi teşvik mevzuatının kadınları ve zayıf halkayı destekleyecek biçimde düzenlenmesi sosyo-ekonomik açıdan faydalı olacaktır.

Kadın girişimcilerin ulusal ve uluslararası pazara girebilmeleri için destek verilmeli ve bu yönde yönlendirmeler yapılmalıdır. Devletin ortak bir pazar stratejisi geliştirmesi gerekir. Her kuruluş kendi başının çaresine baksın denilemez. Çünkü iyi organize olan çok uluslu şirketlerin yüzünden küçük girişimci pazarlarda kendine yer bulamaz. Diğer yandan pazara girmeyi kolaylaştıran bilgiler (pazarlama, satış, muhasebe, finansman, standardizasyon ve işletme teknolojisi) kadın girişimcilere sağlanmalıdır.

\section{Veri Seti ve Analizler}

Erzincan İl Özel İdaresi’nin “Kadın Girişimciler” isimli projesi kapsamında dar gelirli kadınlara mikro düzeyde ekonomik destek sağlanarak küçük sermayelerle kendi ayakları üzerinde durmalarının sağlanması, kendilerine, ailelerine ve makro düzeyde topluma gelir getirici faaliyetlerde bulunmaları amaçlanmış; kadınların 
özgüvenlerinin artırılarak, kimseye muhtaç olmayan bireyler olabilmeleri hedeflenmiş, bu kapsamda 2010 yılından itibaren çoğunluğunu ev hanımlarının oluşturduğu giderek artan sayıda pek çok kadına mikro kredi desteği sağlanarak kadınların başkalarına bağımlılığı azaltılmaya çalışılmıştır.

Küçük sermayelerle bir kadın girişiminin desteklenmesi, mikro düzeyde kadının yaşam kalitesini ve hayata bakışını etkilerken, mezzo düzeyde desteklenen bireyin ailesi ve sosyal çevresi içinde görünürlüğünü artıracak, toplumdaki statüsünü değiştirecek bu sayede küçük dokunuşlarla hem bir bireyin hem de toplumun çehresi değişecektir.

Bu çalışmada Erzincan örnekleminde mikro krediyle desteklenmiş 5 kadın girişimciyle yüz yüze mülakat tekniğiyle görüşmeler yapılmıştır. Girişimcilerin 4 tanesi ev hanımı olup, 2 tanesi boncuk işlemesi ile yaptıkları örtülere sermaye olması amacıyla, 1 tanesi çamaşır satmak amacıyla, 1 tanesi ise seracılık yapmak amacıyla bu krediye başvurmuştur. 5. Katılımcı kuaför dükkanını büyütüp işlerini geliştirmek amacıyla krediye başvurduğunu ifade etmiştir.

Katılımcıların 3'ü evli olup, 1'i eşinden boşanmış, diğeri ise eşini kaybetmiştir. Evli olan katılımcıların eşleri kredi almalarında herhangi bir engel yaratmamış ancak kredinin ne konuda harcanacağı konusunda eşlerini yönlendirmek istemişlerdir. Aynı katılımcıların eşlerinin eve herhangi bir şey alınırken ya da evle ilgili bir karar alırken ortak karardan ziyade eşlerinin görüşlerinin baskın olduğunu belirttikleri görülmüştür. Buradan görülebilir ki kadının aile bütçesine mikro katkısı onun aile kararları konusunda da mikro etki yaratabildiğini göstermektedir. Diğer yönden mikro krediyle verilen destekler küçük sermayeler olduğundan katılımcıların hayatlarında büyük etkiler yaratamamaktadır.

Katılımcıların tamamı mikro kredi ile birlikte ürün çeşitliliklerinin ve kalitelerinin arttığını, kredi kullanmadan öncesine göre daha fazla gelir elde ettiklerini ifade etmişlerdir. Bununla birlikte kredi kullanmadan önce ve kullandıktan sonraki varlıklarına bakıldığında katılımcıların hayatlarında herhangi bir değişiklik olmadığı görülmektedir. Birikimleri incelendiğinde katılımcıların krediyle birlikte herhangi bir birikim yapamadıkları kazandıkları küçük çaplı paralarla kendilerine ve ailelerine yönelik harcamalar yaptıkları görülmüştür.

Mikro krediye başvuran kadın girişimcilerin eğitim durumları incelendiğinde katılımcıların 3 'ünün lise terk olduğu, l'inin ortaokul terk olduğu, l'inin ise ilkokul mezunu olduğu görülmektedir.

Katılımcıların devlette herhangi bir makama adaylık koymalarına ilişkin soruda hiçbirinin adaylığ düşünmedikleri görülmüştür. Belirtilen sebeplerde kendilerine güvenmediklerini, hali hazırda krediyi kullandıkları işlerde kendilerini geliştirmek istediklerini belirtmişlerdir. Mikro kredinin kadın girişimcilerin kendi ayakları üzerinde durup ekonomik bağımsızlıklarını kazanmaları konusunda destek sağladığı ancak yeterli düzeyde özgüven sağlayamadığ görülmektedir.

Çalışmada görüşülen görüşmecilerin 4'ü kadınların da erkeklerin yaptıkları tüm işleri yapabileceklerini, iş dünyasında onlar kadar aktif olabileceklerini belirtirken; 1 katılımcı çocuk sahibi olmanın ve fiziki durumların kadınları erkeklerin yaptığı her işi yapmak konusunda ve onlar kadar çalışma konusunda engellediğini ifade etmiştir. Bununla birlikte katılımcıların tamamı eşit çalışma şartlarında cinsiyet fark etmeksizin aynı işi yapanların aynı ücreti almaları gerektiğini savunurken; 3 katılımcı eşlerinin bu konuda onlarla aynı fikirde olmadıklarını, eşit çalışma koşullarında erkeklerin daha fazla ücret almaları gerektiğini düşündüklerini ifade etmişlerdir. Aynı katılımcılar eşlerinin mikro kredi alırken kendilerini desteklediklerini ancak kıskanç olduklarını ve dışarıda çalışmalarına izin vermediklerini, kendilerini geliştirmelerini istemediklerini belirtmişlerdir. Mikro kredinin kadının toplumsal statüsünü ve çalışma hayatındaki yerini belirgin kılma yönündeki iddiası pratikte yetersiz kalmaktadır çünkü krediyi kullanan kadınların büyük çoğunluğu hali hazırda yaptıkları el emeği ürünlerine sermaye oluşturmak amacıyla bu krediye başvurmaktadırlar. Bu da katılımcıların hayatlarında büyük çaplı bir fark yaratmamakta olup eşlerin görüşlerini değiştirme yönünde bir etkisi olmamaktadır.

\section{Sonuç ve Politik Önermeler}

Mikrokredi yoksulluk, kadın istihdamının kalkınmadaki rolü ve beşeri sermayeden bağımsız düşünülemez. Bu nedenle çalışmada yapılan mülakatlarda özellikle kadın girişimcilerin aile birliği eğitim ve iktisadi karar aşamalarındaki rol üstlenimleri tartışılmıştır. İktisadi kalkınma boyutuyla çalışma, beşeri sermayenin KUDAKA bölgesinde şekillenişi hakkında önsel bir çerçeve çizilmesinde yardımcı olmaktadır. Katılımcıların mikrokredi kullanım düzeyleri ve amaçları Türkiye'deki neoliberal politikaların gelişmesi sürecinde oldukça önemli rol oynarken, asıl çıkış noktası olan Bangaladeş’teki kadar etkin olmamaktadır. Bunun temel nedenini, ülkeler arasındaki gelişmişlik düzey farklılığı ve kadın hakları bağlamındaki farklılıklar olarak ortaya koymak mümkündür. Ülkemizde sosyal politikaların giderek maddi ve aile politikası çerçevesinde genişlemesinden dolayı mikrokrediler kadın girişimcileri gelişmiş bölgelerde daha etkili bir biçimde desteklerken; KUDAKA bölgesi gibi gelişmişlik düzeyi daha sınırlı kalan sanayileşme noktasında noksan olan bölgelerde daha çok kadınları kendi "harçlıklarını çıkarma" olarak tabir edilebilecek bir noktaya sürüklemiştir. Bangladeş’teki uygulama kadın emeğini İslami hukuk kurallarında yer bulması için çalışmalar başlatılmıştır. Türkiye'de kadın emeğinin istihdama katılım oranı 2015 y1lında yüzde 27,5 seviyelerinde seyrederken, gelişmiş ülkelerde bu oranın ortalama olarak yüzde 51 düzeyinde olduğu görülmektedir. Kadın istihdamının iktisadi gelişmişlikteki önemi yalnızca sanayileşme ve 
işsizlik bağlamında değil, aynı zamanda beşeri sermayenin aile içi eğitimden ve oluşan geleneklerden etkilenmesi bağlamında da dikkate alınması gereklidir. Kuzeydoğu Anadolu Bölgesi içerisinde yer alan Erzincan İli örneğinde mülakatlarla yapılan analiz sonuçlarında kadınların mikrokredi kullanarak küçük işlerle uğraştıklarını, ev içerisinde tüketim ile ilgili kararlarda mikro kredi kullanımın değişim yaratmadığını fakat kendi özel ihtiyaçlarını aile reisine sormadan elde edebildiklerini belirtmişlerdir. Mikro kredinin İslami koşullara uygunluğu sorusuna ise genel olarak evet cevabı verilmiştir. Bangladeş’teki uygulamalarla kıyaslandığında Türkiye'deki uygulamada karşı karşıya olunan kadın profilinin daha eğitimli ve girişken olduğu görülmektedir. Bölgesel geri kalmışlığa rağmen, kadınlar açısından mikro kredi kullanımından çekinilen bir unsur olmamaktadır. Türkiye'de sosyal yardımların sayısının ve hacminin artması ve aynı zamanda mikro kredi ile "balık tutmayı öğretme" vizyonu Türkiye'de kadın yoksulluğunun çehresini bir nebze değiştirebilme umudunu taşımaktadır. Kadının ikincil bir üretim faktörü olarak görülmesinin önünde, sosyo psikolojik bir engelleyici olarak mikrokredi uygulamaları kısmen de olsa başarılı görülmektedir. Kadın yoksulluğunun ve istihdamdaki payının düşük olmasının en temel nedeninin sosyolojik bağlamda gelenekler ve geleneklerden kaynaklanan bastırılmışlı̆̆ın yarattığı öz güven eksikliği olduğu göz önüne alındığında halen çok da yaygın olamayan mikro kredi uygulamalarının önemi artmaktadır. Gremeen Bank'ın Erzincan ili ofisiyle yapılan görüşmeler sonucunda mikrokredinin halen bölgede yaşayan kadınlar tarafindan yeterince anlaşılamadığı ve KUDAKA bölgesinin gelişmeye açık olduğu bilgilerine ulaşılmıştır. Ekonomi ve sosyal politikalar birbirlerinden bağımsız olamayacağı gibi bu iki unsurun harmanlanmasıyla oluşturulacak bölgesel eğitimler ve teşviklerle kadın yoksulluğuna ve özellikle istihdama katılımda kadınların öz güven problemine çözüm bulunabileceği söylenebilir.

\section{Kaynakça}

- Balkız \& Öztürk, 2005. Neo-Liberal Gelişme Anlayışı ve Kadın: Mikro Finans Uygulamaları Kadınları Güçlendiriyor mu?, Mediterranean Journal of Humanities, III/2, 2013, 1-21.

- Buğra, A. 2007. "Yoksullukla Mücadele Yöntemi Olarak Mikrokredi: Acıklı Bir Hikâye”. B.Ü Sosyal Politika Forumu Bülteni, 2, 1-4.

- Coughlin, 2002. "The Rise of Women Entrepreneurs: People, Processes, and Global Trends" http://www.flipkart.com/rise-women-entrepreneurs-jeanne-halladay/1567204627- , 25.02.2010

- CCelebi, 1993. “Kadın Girişimciliğini Özendirme Ve Destekleme Konusunda Politikalar”, Kadını Girişimciliğe Özendirme ve Destekleme Paneli Bildiriler ve Tartışmalar, Devlet Bakanlığı Kadın Ve Sosyal Hizmetler Müsteşarlığı Kadının Statüsü ve Sorunları Genel Müdürlüğü, Eğitim Serisi, Yayın No:74

- Ecevit, 2007. Türkiye' de Kadın Girişimciliğine Eleştirel Bir Yaklaşım, Uluslararası Çalışma Ofisi, Ankara

- Erdoğan, 2004. Yoksullukla Mücadelede Etkili Bir Enstrüman Mikro Kredi, Finansal Forum Özel Eki

- Kınay, 1994. "Küçük Yatırımlara Başlama Rehberi”, Halk Bankası Yayınları, Ankara

- Kutanis, 2006. Girişimci Kadınlar, Değişim Yayınları, Sakarya

- Kümbetoğlu, 1994. Kadın, Çalışma ve Evde Üretim, Dünya"da ve Türkiye"de Güncel Sosyolojik Gelişmeler, Sosyoloji Derneği, Ankara

- Özdevecioğlu ile Çelik, 2000. "Kadın Girişimcilerin Demografik Özellikleri Ve Karşılaştıkları Sorunlara İliş̧in Nevşehir İlinde Bir Araştırma", 8. Ulusal Yön.Org. Kong.Bildirileri, Nevşehir

- Şahin, 2006. Kadın Girişimcilik ve Konya İlinde Kadın Girişimcilik Profili Üzerine Bir Uygulama, Konya

- TESK, 1992. Esnaf ve Sanatkarlar ve Küçük İşletmeler Açısından Kadın Girişimciler, Türkiye 'de Kadın Ĕgitimi Birinci Uluslararası Konseyi İ̧̧in Hazırlanan Çalışma, Ankara 


\title{
Mobil E-Ticaret Türkiye'de ve Dünya'da Nereye Gidiyor? Where is Mobil E-Commerce Going in Turkey and in the World?
}

\author{
Asst. Prof. Dr. Nevin Aydın (Kyrgyzstan-Turkey Manas University, Kyrgyzstan)
}

\begin{abstract}
The number of mobile e-commerce users in our country and in the world is increasing day by day. This shows that sales made through mobile e-commerce increase customer satisfaction. Increased payment security in mobile e-commerce and well-designed sites are among the factors that increase sales. Approximately 17 percent of ecommerce in Turkey and about 30 percent of e-commerce in the world is carried out over the mobile. The increase in the number of mobile users in the world is also driving mobile sales. Many brands in the world have started to increase the value of their brand by driving their strategies towards mobile commerce after seeing the advantages of mobile commerce. Every day, E-commerce is transformed into a market place for e-mobile users, where they enjoy shopping.
\end{abstract}

\section{Giriș}

Dünyadaki e-ticaretin yüzde 30'u mobil üzerinden yapılıyor. Buna karşılık gelen satış hacmı 300 milyar dolar civarında. Türkiye'de e-ticaretin yüzde 17'si mobil üzerinden gerçekleştiriliyor. Akıllı telefonların, daha sonra tablet ve alternatif mobil cihaz teknolojilerinin gelişmesi, uygulama mağazalarında kullanıcıların daha fazla vakit geçirmesi, mobili satış ve pazarlama için en ideal konuma getirdi. Buna karşılık, "mobil” ifadesi markaların bu alana daha çok akıllı telefon ağırlıklı olarak yaklaştığını da gösteriyor. Alternatif mobil cihazlar göz ardı edilebiliyor. Bu nedenle, tablet gibi görsel içeriğin çok daha ikna edici olabileceği mobil cihazları da kapsama almakta fayda var. Tabletlerin akıllı telefonlardan çok daha yaygın olduğu pazarlara (Çin'de tablet ve akıllı telefon üzerinden mobil alışveriş her ikisi de yüzde 33, Rusya'da tablet üzerinden yüzde 12, akıllı telefon üzerinden ise yüzde 8) yönelmesi bekleniyor (Mapplico, 2016).

Experian Pazarlama Hizmetlerinin raporuna göre, M-Ticaretin bazı ürün kategorilerinde E-ticareti geride bırakmaya başlamıştır (Montgallo, 2014). M-Ticaret"elektronik işlemler ve iletişim". Dizüstü bilgisayarlar, PDA'lar ve cep telefonları gibi mobil cihazları kullanarak gerçekleştirilen ve genellikle bir kablosuz bağlantı ile gerçekleştirilen ticaret şeklidir" (Chaffey, 2007).

Türkiye İstatistik Kurumu, Adrese Dayalı Nüfus Kayıt Sistemi sonuçlarına göre Türkiye nüfusunu 78 milyon 741 bin 53 kişi olarak açıklandı. We Are Social'daki Türkiye rakamlarına göre Türkiye'deki aktif internet kullanıcı sayısı ise 46.28 milyon kişi. Yani nüfusumuzun yüzde 58'i, internete bağlı. Türkiye'deki aktif sosyal medya kullanıcı sayısı 42 milyon. Türkiye nüfusunun tam yüzde 90'ının mobil aboneliği bulunuyor, 71 milyon kişi mobil bağlantıya sahip. Türkiye'de aktif mobil sosyal medya kullanıcı sayısı ise 36 milyon. Yani nüfusumuzun yüzde 45'i mobil üzerinden (akıllı telefon ya da tabletler aracılığıyla) sosyal medya kullanıyor. Türkiye'de mobil cihazlar üzerinden aktif olarak sosyal medya kullanan kişilerin sayısı geçtiğimiz yıla nazaran yüzde 13'lük bir artış gösterdi. Türkiye'de telefona sahip olan yetişkinlerin yüzde 56'sı akıllı telefona sahip (Bkmexpress, 2016).

Barcelona'da düzenlenen Mobil Dünya Kongresi'nde (Mobile World Congress-MWC) Mobil Ekonomi 2017 başlıklı rapora göre, 2016 sonu itibariyle dünyada mobil abone sayısı 4,8 milyar oldu. 2020 sonundaki beklentisi ise 5,7 milyar aboneye ulaşılacağı yönünde. Bu veriye göreyse 2020'de dünyanın üçte ikisinin mobil kullanıcı olması bekleniyor. Bağlantı türüne göre ele alındığıysa 3G ve 4G'nin yüzde 55'e ulaştığı görülüyor. 2020'deki tahmin yüzde 75. 4G özelindeki ise 2016 sonunda 188 ülkede $5804 \mathrm{G}$ ağı kuruldu ve kullanım oranı yüzde 60 oldu (Digitalage, 2016).

\section{M-Ticaret}

M-ticaret, "mobil telefon veya benzeri araçlar yardımıyla yapılan, mal ve hizmetlerin satın alınması ve ücretlerinin ödenmesi işlemlerine verilen genel bir tanımdır. M-ticaret, e-ticaretin biraz daha gelişmiş bir durumudur. Mobil ticaret iki şekilde gerçekleşir; biri mobil aplikasyon üzerinde başlar ve ödeme yine mobil aplikasyon üzerinden tamamlanır. Diğer sistemde ise alışveriş bilgisayarda başlar, sadece ödeme kanalı olarak cep telefonuna yönlendirme yapılır, sonrasında alışveriş yine bilgisayarda tamamlanır (mobile-checkout) (Euro, 2015).

M-ticaret, ürünleri satın almak veya satmak için mobil cihazların kullanımını, servisleri veya bilgileri herhangi bir zamanda, herhangi bir yerden bir kablosuz ăg üzerinden kullanımı. Mobil ürünler, Mobil alışveriş, mobil biletleme ve mobil cüzdandır. Mobil cihazlar, akıllı telefonlar gibi farklı elektronik ürünlerden oluşur. Mobil uygulamalar, m-ticaretin önemli bir parçası. Dünyaca ünlü e-ticaret siteleri, fiziksel mağazalar, yerel işletmeler, hatta şahıslar, artık dijital dünyanın en çok kazandıran alanlarından biri olan mobil e-ticarete yönelmektedir. Mobil stratejiler, e-ticaret uygulamalarına yönlendiren sosyal medya stratejileri ve daha pek çok yöntemle, hedef kitlelerini de mobile çekerek, satışlarını artırmayı hedefliyor (Mapplico, 2016a). M-ticaret (mobil ticaret) sanal 
ortamda alışveriş, pazarlamadır. M-ticaret, akıllı telefon kullanıcısının artması ile, kablosuz teknolojiler ve cihazlar üzerinden mal ve hizmetin satışının yapılmasıdır.

Dünya genelinde 1.2 milyar insanın mobil uygulamaları kullandığını tahmin etmekteydi (Whitfield, 2013). 2017 yılı sonunda 4.4 milyar kullanıcı olacağı tahmin ediliyor. Mobil uygulamalar büyük potansiyel yaratmaktadır (Portio Research, 2013). 2017 yılı sonuna kadar yılda 200 milyardan fazla uygulama indirme yapılacağını ve gelirin 63,5 milyara dolara ulaşacağ tahmin etmektedir (ComScore, 2012). Tüketicilerin M-Ticaret uygulamaları için akıllı telefon kullanmaya istekli olduklarını görülüyor (Nielsen, 2012). Mobil uygulamalar bir Mobil ticareti mobil sitelerden daha kabul edilebilir bir şekilde yapılmasını sağlamaktadır (Compuware, 2013).

\subsection{M-Ticaret Uygulamaları Alanları (Euro, 2015)}

- SMS/MMS: Katıl Kazan Kampanyaları, TV İçerik Oylama, Banka Hatırlatmaları

- Mobil Kuponlar: Cebinize gelen kupon ile fiziksel mağazalarda indirim kazanma

- Mobil Siteler: Mobil tarayıcılara göre optimize edilmiş, mobil internet kullanıcı deneyimini arttıran siteler

- Mobil Oyunlar: Kullanıcı etkileşimini arttıran, sosyal paylaşımlı oyunlar

- Mobil Reklam: Markaların oyunlarda, mobil sitelerde, uygulamalarda görüntülenen ücretli reklamları

- Mobil Uygulamalar: Hepimizin bildiği mobil cihazlarımıza indirdiğimiz ücretli/ücretsiz uygulamalar. Apple App Store, Android Market

- Konum Bazlı Servisler (LBS): Foursquare, Facebook Places gibi uygulamalar yardımıyla, operatörlerin LBS sistemlerinin yardımıyla ya da GPS ile kullanıcının konumuna bağlı yapılan iletişim çalışmaları

- Mobil Ticaret: Mobil ödeme sistemleri, Mobil bankacılık, Near Field Communications (NFC), Fiyat Karşılaştırma

- Mobil Search: Google Mobile Ads, Mobil Arama Optimizasyonu

- QR Kod: Taratıldığında belli bir siteye/video’ya yönlenen barkodlar, mobil bilet uygulamaları

- IVR (Interactive Voice Response): Ses bazlı mobil reklam

\subsection{Mobil Ticaret Dünyasında Fark Yaratacak 3 Trend (Mobiroller, 2016)}

Mobil e-ticaret, geleceğin ticaret hayatının yeni tacı olacak görünüyor. Bu alanda fark yaratacak 3 trend:

1- Hedef kitleye yönelik bildirimler: Mobil e-ticaret ile, hedef kitlesine yönelik kampanyalar, yeni ürün ve kategorilerin bildirimleri, internet bağlantısı olan her yerde kullanılabiliyor. Kullanıcıların bu bildirimlere karşılık vermesi, bu karşılığın satışa dönüşebilmesi için, mobil uygulamanızı indirmiş olması, söz konusu kampanyalarla ilgilenebilecek kitleye en uygun şekilde içerik oluşturarak, bildirimleri de bu içeriğe uygun bir dille hazırlamak, karlılığınızı artırmaktır.

2- Omnichannel optimizasyonlar: Sosyal medya uygulamaları ve mobil uyumlu web sitelerinde, mobil cihaz kullanıcıları oldukça fazla zaman geçiriyor. Bu kanallar üzerinde ziyaret ettikleri sayfaların önemli bir kısmını da e-ticaret siteleri ya da e-ticaret markalarının sosyal medya kanalları oluşturuyor. Dolayısıyla, kullanıcılar ilgilendikleri ürünlerle ilgili hem ürün sayfalarını inceliyor, hem de yine benzer ürünlerle ilgili anahtar kelime aramaları yapıyorlar. Mobil e-ticaret uygulamalarının omnichannel optimizasyonlara sahip olması, kullanıcıların bu ziyaretleri ve anahtar kelime aramaları ile ilgi alanlarının belirlenmesi ve mobil uygulaması üzerinde de yine ilgi duyabileceği kategorilerdeki ürünlerle karşılaşmalarını sağlıyor. Böylece, kullanıcının karşılaştığı ürünü satın alma olasılığı artarken, sepet ortalamaları da aynı oranda artış gösteriyor. Dolayısıyla, omnichannel optimizasyona sahip mobil e-ticaret uygulamaları, rakipleri karşısında oldukça büyük avantaj sağlıyor.

3- Satış odaklı tasarımlar: Mobil e-ticarette rekabet gittikçe artarken, güçlü ve etkili içerik oluşturmak rakipler arasında oldukça önemli bir hale geldi. Bu nedenle, pek çok marka profesyonel içerik ajanslarıyla çalışmayı tercih etmeye başladı. Doğru tasarımlarla ürün ve hizmetleri sunmak, son dönemde mobil ticarette öne çıkan trend'lerden biri olmuştur.

\subsection{Mobil Ticaret Trendleri (Iyzico, 2017)}

- Dünya genelinde internet kullanıcılarının yaklaşık \%80’i akıllı telefon kullanıyor.

- Son 3 yılda mobil cihazlarda e-posta açma oranı \%180 yükselmiş durumda.

- Mobil cihaz kullanıcılarının \%70’i, mobil uyumlu olmayan e-postaları okumadan siliyor.

- E-ticaret firmalarının \%70’e yakını, dijital pazarlama stratejilerinde mobil pazarlamaya yer veriyor.

- Mobil cihazlarda zamanın \%85'ten fazlası uygulamalarda, kalan kısmı ise web sitelerinde geçiriliyor.

- 1980-2000 yılları arasında doğanları kapsayan Y kuşağının \%50’ye yakını, sadece mobil cihazlar üzerinden video izliyor.

- Mobil aramaların \%40’1, yerel ihtiyaçlara yönelik.

- Kullanıcıların \%50'si, araştırmalarına mobil cihazlarındaki arama motorlarıyla başlıyor.

Mobil ticaretin 2017 trend beklentileri aşağıdaki gibidir. 
- Akıllı Telefonlar Mobil Ticarete Hakim Olacak: 2016'da ABD'de mobil ticarette akıllı telefonların payı \%58'e ulaşt1. 2017 tahminlerine göre ise bu oran \%65 olacak.

- Canlı Yayınlar Etkinliğini Arttıracak: 2016 yılında popülerliğini arttıran canlı video içerikleri, 2017'de daha da değerli bir duruma gelecek. Youtube, Facebook, Instagram gibi araçlarda canlı video özelliklerinin bulunması, tekil kullanıcılar kadar markalar ve e-ticaret sitelerinin de yatırım yaptı̆̆ bir alan konumunda.

- Mobil Uygulamalar Daha da Yaygınlaşacak: Mobil uyumlu web siteleri daha fazla ziyaret edilmelerine rağmen mobil uygulamalar, başarılı alışveriş oranında öne çıkıyor. Mobil uygulamalara yönelik indirim, promosyon ve kodların sunulması da tüketicilerin bu alana daha fazla yönelmesini sağlıyor.

- ChatBotlar ve Sosyal Medyada Alışveriş Gelişecek: Son yıllarda ortaya çıkan ve 2016'da asıl kimliği oluşan ChatBot'lar, 2017'de gelişimini sürdürecek ve e-ticarette daha geniş bir alanı kaplayacak. Yapay zeka uygulamalarının yalnızca standart cevaplar vermek yerine günlük bilgileri, haberleri ve online alışverişi yönlendirmesi, 2017'de e-ticarette ve mobil ticarette yeni bir boyut kazandıracak.

- Kişisel Verilerin Analizi Daha Değerli Olacak: Akıllı telefonlar ve tabletlerin günlük hayatta daha geniş bir alanı kaplaması, markalar ve e-ticaret siteleri için bir avantajı da beraberinde getiriyor.

- Video İçerikler ve Görsellerin Etkisi Sürecek: Video içerikleri, kullanıcıların online alışverişteki kararlarını \%65 oranında daha olumlu etkiliyor. 2017'de de video içerikler ve kaliteli görseller, çekici olmayı sürdürecek.

\subsection{Mobil Ticaret Uygulayan Firmalardan Bazları (Linkedin, 2015)}

Mobil cihazların artan kullanımı, mobil ticaretin yükselmesine neden oldu. M-ticaret uygulamaları yalnızca satış gelirini artırmakla kalmaz, aynı zamanda müşterinin ilgi çekici özelliklerinden dolayı müşteri tutma oranını da artırir.

eBay Uygulaması: Mobil cihazların gittikçe artan kullanımını fark eden online pazardaki dev devi eBay, kendi e-ticaret mobil uygulaması oluşturmaya karar verdi. Açık artırmalar oluşturdu ve kullanıcıları uygulamanın her yerinde bu uygulamayı kullanarak dünyanın herhangi bir yerinden 24 saat boyunca teklif vermelerini sağladılar. Kullanıcıların en sevdikleri ürünleri hızlı bir şekilde erişmelerini sağlamak için arama seçenekleri kolaylaştırıldı. $\mathrm{Bu}$ mobil ticaret uygulaması sayesinde alışveriş yapan müşteriler eBay hesabını PayPal hesabıyla bağlayarak işlemleri daha hızlı yapabiliyorlardı.

Amazon Uygulaması: Daima yeşil pazarda dev Amazon, eTicaret alanındaki adımlarını attı. Benzersizlikleri ile tanınan kullanıcılar, mobil alışveriş sepeti uygulamalarını da etkiledi. Bu m-ticaret uygulaması, civardaki yerel işletmelerdeki ürünlerle ilgili teklifleri belirlemek için kullanıcının konumunu kullanır. Ayrıca, kullanıcıların ilgisini çekmek için bağlılık programlarını da içeriyorlar

Walmart Uygulaması: Perakende devi Walmart tarafından piyasaya sürülen mükemmel bir mobil ticaret uygulaması. 'Scan \& Go' kişisel check-out programını yükseltmek için yakın zamanda mobil kuponları eklediler. Alışverişçiler, öğelerini taramak ve bir sanal alışveriş sepetine eklemek için bu uygulamayı kullanabilirler. Alış veriş bittiğinde, parayı bir self-checkout sayacında ödeyebilirler. Böylece, uzun kuyruklarda harcanan zaman kazanılabilir.

Starbucks Uygulaması: Starbucks, Amerika'da en çok kullanılan mobil ödeme uygulaması olarak listelenmiştir. Müşterilerin kayıtlı Starbuck'taki Ödül Kartının bilgilerini mobil uygulamalarına yazmaları gerekecek. Müşteriler, en sevdikleri içecekleri izleyebilir, sipariş durumunu denetleyebilirler vb. Müşteri deneyimi artırmak için, müşteriler belirli sayıda yıldız biriktikten sonra bu uygulama da indirimler sunulmaktadır.

CVS Caremark: Bu e-Ticaret uygulaması en iyi 5 mobil uygulama arasında yer aldı. Bu mobil uygulama, kullanıcıların hızlı doldurma işlemleri gerçekleştirmesine, ürünlerde en yeni fırsatları bulmalarına, sipariş vermelerine ve yerel mağazalarından alışveriş yapmalarını sağlıyor.

Q uygulaması: Bu mobil alışveriş sepeti tasarım uygulaması, kullanıcıların barlarda, stadyumlarda, konserlerde veya tiyatrolarda yer ayırmaları için ön sipariş vermelerine olanak tanıyor. Müşteriler menü kartına göz atabilir, sipariş verebilir ve Q app'ini kullanarak sipariş için ödeme yapabilir. Sipariş hazır olduğunda, müşteriler telefonlarında uyarı bildirimleri alacaklar ve Q app alanına gidebilir ve benzersiz kodu göstererek personelden toplayabilirler.

Neiman Marcus uygulaması: Bu mobil uygulama mağaza sahipleri ve müşteriler arasında iletişimi sağlamak için lüks özel mağaza zinciri Neiman Marcus'ı geliştirdi. Bu mobil e-ticaret uygulaması, biri müşteri için, diğeri mağaza sahipleri için olmak üzere iki arayüz ile oluşturuldu. Müşteriler mevcut ürünleri taramak için bu uygulamayı kullanabilir ve ayrıca mağaza sahibinden deneme için giyecekleri hazır tutmalarını isteyebilir. Ayrıca satış ekipleriyle posta, telefon vb. Yollarla bağlantı kurmak için çeşitli departmanları arayabilirler.

Spring Uygulaması: Bu e-Ticaret uygulaması, alışveriş yapanların 700'den fazla marka ile rahatça alışveriş etmelerini sağlar. Ödeme işlemi basit ve daha az zaman harcıyor. Alışverişte parmaklarınızın ucunda çeşitli koleksiyon listesi bulabilirsiniz. Ücretsiz kargo hizmeti vermektedir. 


\section{M-Ticaretin Geleceği}

Bugün, mobil ticaret (m-ticaret), herhangi bir ticaret stratejisi için değerli bir taktik olmaya başliyor. En iyi 500 perakende ticaret şirketi m-ticaret çözümlerine yatırım yapmazlarsa müşterileri daha çevik, mobil odaklı rakipler için kaybetmek zorunda kalacaklar. 2011 mobil ticaret geliri 13.63 milyar dolardan 2012 de 24.81 milyar dolara yükselerek 11 milyar dolarla artış gösterdi. 2017 yılına gelindiğinde, eMarketer bu büyümenin devam edeceğini tahmin ediyor.

Aşağıdaki analizde baktığımızda mobil üzerinden gerçekleşen ve 2017 projeksiyonlarını görmekteyiz. Burada en önemlisi sağdaki analizdeki cihaz ayrımı, USA'da en çok Tablet ile satınalmanın gerçekleştiğini görüyoruz. Bu demek oluyor ki akıllı telefonlara nazaran tablet den yapılan ziyaretlerin daha çok conversion getireceğini diyebiliriz (USA'nın 2013 e ticaret cirosu 384 Milyar \$, aşağıda gördügüünuz gibi bunun sadece 41 Milyar \$'1 mobilden gerçekleşmiş, yaklaşı \% $11-12$ lik bir oran)

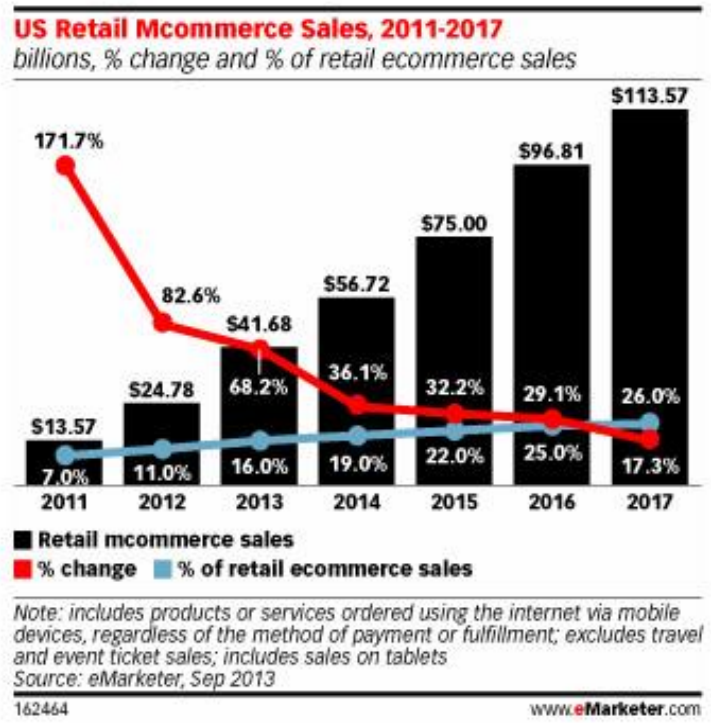

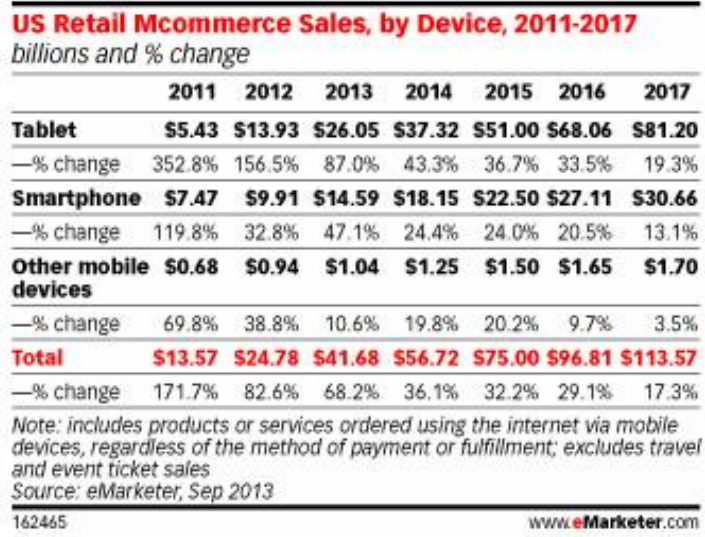

Tablo 1. M-Ticaret Analizi (Emarketer, 2013)

Şimdi, bunu 2012 'de 3.09 trilyon dolarlık toplam perakende satışlarla karşılaştırdığınızda, 24.81 milyar doların fazla önemli olmadığının farkındayız. Ancak, büyüme oranının şaşırtıcı bir şekilde büyüyor. Mobil ticaret toplam e-ticaret, ticaretinin \% 10'unu oluşturuyor (mobil için 24,8 milyar dolar, e-ticaret için ise 225 milyar dolar)

Şirketler, müşterilerini daha iyi anlamak için web analitiği, araştırma araçları ve diğer verileri kullanarak eticaret stratejilerini geliştirmektedir. E-ticaretle karşılaştırıldığında, mobil ticaret hâlâ mevcut durumda, fakat mobil müşteriyi anlamak için daha fazla teknoloji gereklidir (Appentive, 2016).

The Goldman Sachs Group Rapora göre, 2018'de m-ticaret satışları 626 milyar dolara ulaşacak ve e-ticaret satışlarını üçe katlayacak. Bu öngörüye göre 2018'de internetten sadece akıllı telefonlar ve tabletlerden yapılan satışlar neredeyse 5 yıl önce bütün cihazlar kullanılarak yapılmış internet satışlarıyla eşit hale gelecek. 2017'de yüzde 16'lık artışla bu sayının 961 milyon, 2018'de ise yüzde 13'lük artışla 1,09 milyar olacağı öngörülüyor (BpnRapor, 2016).

Gartner'ın verilerine göre, ABD'deki müşterilerin mobil etkileşim davranışlarına bakıldığında, 2017 yılına kadar ABD'deki dijital ticaret gelirlerinin yüzde 50'sini m-ticaretin oluşturacağı belirtiliyor. Mobil cihazların eticaretteki satışlara ve satışlardaki büyümeye katkısı iki şekilde oluşuyor. Bunlardan biri, müşterilerin satın alımları için akıllı telefon ve tabletlerini kullanmaları, bir diğeri ise giderek artan bir şekilde müşterilerin mobil cihazları bir alışveriş araştırma aracı olarak görmeleri ki bu da kullanıcıları eninde sonunda mağaza içi veya online olarak satın alıma yönlendiriyor. Global araştırmalardan çıkan sonuçlara göz atmak gerekirse, markaların yüzde 54'ü pazarlama bütçelerinin yüzde 5 veya daha azını mobil pazarlamaya harcarken markaların dörtte birine yakını pazarlama bütçelerinden mobil pazarlamaya sadece yüzde 1 ile yetiniyor. Mobil uygulama ve mobil siteler, müşteri satın alım yolculuğunda önemli bir yer tuttuğu gözlemleniyor. Türkiye'de mobil kullanıcıların yüzde 53'ü mağaza içerisinde mobilden fiyat karşılaştırması yapıyor. Türkiye'de alışveriş için ürün araştırması yapılırken yüzde 49 oranında mobil kullanılıyor (Digitalage, 2016a).

\section{Çin'in E-ticaret Satışı Mobil Sayesinde 1 Trilyon Dolar}

Forrester'ın yeni araştırma raporuna göre, 2019 yılında Çin'de yapılan online e-ticaret harcaması 1 trilyon dolara çıkacak. Bu büyümenin iki önemli ayağı mobil uygulamaların gelişimi ve yaygınlaşması ile, gelişen lojistik ağları ile en küçük şehirlere bile ulaşılabilmesi. 
Mobile yatırım yapmak çok önemli çünkü Çin'de çoğu kişi internete bağlanmak için mobil cihazlarını kullanıyor. Çin'in e-ticaret pazarı Alibaba ‘nın Tmall'u ve JD.com tarafından ele geçirilmiş durumda. Alibaba'nın B2C pazar payı \%57 iken, JD.com'un \%21. Toplamda \%78'lik pazar payını kapmış durumdalar. Ancak mobil tarafa baktığımızda Alibaba'nın Tmall ve Taobao mobil uygulamaları toplamda \%85'lik pazar payına sahipler. JD.com'un pazar payı mobilde \%7,1 iken, VIP.com'un payı \%1,6. Çin'in mobil e-ticareti tamamen Alibaba tarafindan gerçekleştiriliyor (Eticaret-Analiz, 2016).

\section{Amerika'da Mobil Ticaret 2020 Yılında 252 Milyar Dolar'ı Aşacak}

Forrester'ın hazırladı̆̆ Mobil Sahtecilik Yönetimi Çözümleri Raporu'na göre, ABD'de akıllı telefon ve tabletler üzerinden gerçekleştirilen mobil ticaretin 2020 yılına kadar yaklaşık 252 milyar Dolar'1, mobil ödemelerin ise 2019 yılına kadar yaklaşık 141 milyar Dolar’’ aşması bekleniyor (Experian, 2016)

\section{M-Ticaret ve Yaygın Olduğu Sektörler}

Yapılan araştırmalara göre dünya çapında 2014 yılında 285 milyar doları bulan mobil ödeme hacminin, 2017 yılı sonunda 800 milyar doları geçmesi bekleniyor. Türkiye'de online alışveriş yapan her 3 kişiden 1'i mobil alışverişi tercih ediyor. Mobil alışveriş yapanların \%52'si ürün araştırması veya karşılaştırması ve ödemesi yapıyor. En çok 25-34 yaş arasındaki üniversite ve üstü eğitim seviyesindeki kişiler mobil araçlar ile alışveriş yapıyor. Mobil ticaret yolu ile en fazla satış yapan sektörlerin aynı zamanda müşterilerine perakende hizmet verenler oldukları görülüyor. Ülkemizde en fazla alışveriş yapılan sektörlerin başında \%53'lük oran ile giyim sektörü geliyor. Bu sektörü \%34'lük pay ile elektronik, \%27 ile seyahat sektörleri takip ediyor. Dünyada ise eğlence, seyahat ve elektronik sektörleri ilk üçü oluşturuyor (Inveon, 2016).

\section{Sonuç}

Son yıllarda mobil teknolojilerin ortaya çıkmasıyla birçok işletme m-ticareti en iyi şekilde uygulamaya başladı. Mobil kullanımı yeni pazarları ortaya çıkararak cazibesini artırdı. Amerika, İngiltere ve Çin m-ticaretin en çok kullanıldığı ülkeler arasındadır. Türkiye'de online alışveriş işlem hacmi \%19'u mobil cihazlar üzerinden gerçekleştirilerek Dünyada genç tüketicilerin pazarda önemli yere sahip olduğu görülmektedir.

Mobil ticaretin önemli bir yere sahip olduğu firmaların e-ticareti artık mobil cihazlara uygun programları üzerinden gerçekleştirmektedirler. Akıllı cihaz satışlarının artmaya devam ettiği son yıllarda mobil ticaret araçları tüketiciler tarafından çok kullanılıyor. Tüketicilerin mobil alışverişi tercih etmesinin sebebi; hız, ürün araştırması yapabilme promosyon firsatları, uygun kullanım gibi firsatlar başta gelmektedir

Mobil, Türkiye ve dünyada gerçekleşmekte olan dijital pazarda önemli bir yere sahip, her geçen yılda da payını artırmaktadır. Statista'nın verilerine göre 2017'de 76,5 milyar dolarlık bir büyüme bekleniyor . Üstelik birkaç y1l içinde, mobil cihazların, internet aracılığg ile yapılan satın alımların yüzde 87'sini oluşturulacağı belirtiliyor. Tüm bu veriler, mobilin kişilerin gündelik hayatına nasıl girdiyse markalarında günlük hayatlarında yer almaya başlayacağına işaret ediyor (Digitalage, 2016a).

Dünya da ve Türkiye'de e-ticaret çok hızlı bir şekilde büyüme göstermektedir. Dünyada Amerikalı tüketiciler alışverişlerinin \%70'e yakınını, Avrupa tüketicilerin \%35'e yakını alışverişlerini internet üzerinden gerçekleştiriyor. İnternetin ortaya çıkısı ile e-ticaret, her geçen gün dünya piyasalarında yerini artırmaya devam ederken, Türkiye de bu alanda Avrupa'nın en büyük pazarlarından biri olmaya devam etmektedir.

Dünya e-ticaret hacmi, net olarak hesaplanamasa da, istatistikler göre 10 trilyon doları aştı̆̆ını tahmin ediliyor. Türkiye 30 milyon internet kullanıcısıyla, dünyanın en büyük 12'nci internet pazarı konumunda, ortalama her y1l yaklaşık yüzde 50 büyüme göstermektedir.

\section{Kaynakça}

- Appentive, 2016. https://www.apptentive.com/blog/2013/07/02/mobile-commerce

- Bkmexpress, 2016. https://bkmexpress.com.tr/dijital-dunyada-2016-yilinin-ilk-turkiye-istatistikleri/

- BpnRapor, 2016. raporm.bpnistanbul.com/raporlama/1454054166

- Chaffey, 2007. E-Business and E-Commerce Management, 3rd Edition, Harlow:Pearson Education Limited, pp. 132

- Compuware, 2013. Mobile Apps: What Consumer Really Need and Want, http://offers2.compuware.com/rs/compuware/images/Mobile_App_Survey_Report.pdf

- ComScore, 2012. Apps Account for 4 in every 5 US Mobile Media Minutes, http://www.qrcodepress.com/mobile-commerce-market-to-grow-ineurope/8510722/

- Digitalage, 2016a. http://digitalage.com.tr/2016-mobil-ticaret-trendleri/

- Digitialage, 2016. http://digitalage.com.tr/2016-sonunda-mobil-abone-sayisi-bes-milyara-yaklasti/

- $\quad$ eMarketer, 2013. http://www.eMarker.com 
- Eticaret-Analiz, 2016. http://eticaretmag.com/ozel/analiz-ozel/ulke

- Euro, 2015. http://www.euro-dmc.com/m-ticaret

- Experian, 2016. http://www.experian.com.tr/blogs/experian-hakkinda/2016/09/amerikada-mobil-ticaret2020-yilinda-252-milyar-dolari-asacak/

- Inveon, 2016. https://www.inveon.com.tr/mobil-ticaretin-dunyadaki-ve-turkiyedeli-yeri/

- Iyzico, 2017, https://www.iyzico.com/blog/2017-mobil-ticaret-trendleri

- LinkedIn, 2015. https://www.linkedin.com/pulse/best-10-mobile-commerce-apps-2015-vignesh-waran

- Mapplico, 2016. http://www.mapplico.com/turkiye-ve-dunyada-mobil-e-ticaret-nereye-gidiyor/?lang=tr

- Mapplico, 2016a. http://www.mapplico.com/tag/mobil-ticaret/?lang=tr

- Mobiroller, 2016. http://www.mobiroller.net/tr/blog/mobil-ticaret-dunyasinda-fark-yaratacak-3-trend

- Montgallo, 2014. Mobile commerce is beginning to outpace e-commerce, http://www.qrcodepress.com/mobile-commerce-beginning-outpace-ecommerce/8526022/

- Nielsen, 2012. Which Smartphone Apps Do Savvy Shoppers Use Most, http://www.nielsen.com/us/en/newswire/2012/top-mobile-shopping-apps.html

- Portio Research, 2013. Mobile Application Futures 2013-2017, http://www.portioresearch.com/en/majorreports/current-portfolio/mobileapplications-futures-2013-2017.aspx

- Whitfield, 2013. Fast growth of apps user base in booming Asia Pacific market, http://www.portioresearch.com/en/blog/2013/fast-growth-of-appsuser-base-in-booming-asia-pacificmarket.aspx 


\title{
Региональная Экономическая Интеграция Стран Центральной Азии: Реалии И Перспективы Развития Regional Economic Integration in Central Asia: Realities and Prospects
}

\author{
Prof. Dr. Jusup Pirimbaev (Kyrgyzstan-Turkey Manas University, Kyrgyzstan) \\ Prof. Dr. Dzhumabek Dzhailov (Ministry of Agriculture, Kyrgyzstan)
}

\begin{abstract}
The analysis of the socio-economic development and the state of trade and economic relations in Central Asia. The features of economic development in Central Asian countries, conditional on the development of disintegration processes in the region. Substantiates the role, importance and the need to strengthen economic integration in the region. Determine the vector of development of trade-economic and investment cooperation between the Central Asian countries. Grounded perspective directions of economic integration and cooperation mechanisms. Perspective forms of cooperative development, integration links sharing the natural and economic potential of the region. Identified economic factors and conditions for balanced development of the economy of the region in the context of increasing globalization processes.
\end{abstract}

В настоящее время страны Центральной Азии (ЦА-Узбекская Республика, Республика Казахстан, Кыргызская Республика, Республика Таджикистан и Туркменистан) превращаются в центр геополитики, где фокусируются и пересекаются интересы крупнейших стран мира. Основными странами, которые стремятся активизировать свое присутствие на этом континенте в последнее время становятся Россия, КНР и Турция, имеющих не только свои особые стратегические интересы, но и общие приграничные территории с отдельными странами ЦА. Внутри самой ЦА наиболее устойчивые экономические связи со всеми ее странами имеет только Казахстан.

Основным игроком на центрально-азиатском экономическом пространстве по прежнему остается Россия. Россия занимает 1 места во внешнеторговом обороте Казахстана (30,1\%), Узбекистана (24,5\%), Кыргызстана (24,8\%), Таджикистана (24,0\%). Сравнительно низок уровень внешнеторговых связей России только с Туркменистаном (3 место после КНР и Турции). Несмотря на то, что в начальные периоды суверенного развития стран ЦА Россия несколько ослабила свое влияние вследствие разрыва прежних союзнических экономических отношений, она предпринимает целенаправленные и весьма успешные усилия по усилению своего экономического влияния на страны ЦА посредством расширения Евразийского экономического союза (ЕАЭС), где она играет ключевую роль Несмотря на , что западные экономические санкции против России косвенно повлияли на ослабление ее экономического влияния на страны Центральной Азии Россия остается важным торговым и инвестиционным партнером в Центральной Азии и основной площадкой трудоустройства растущего количества трудовых мигрантов из региона.

В создании евразийского экономического союза на постсоветском пространстве активно включаются страны ЦА, две страны которого (Республика Казахстан и Кыргызская Республика) стали уже полнокровными ее членами. Факторами, благоприятствующими расширению евразийской интеграции в центрально-азиатском регионе, выступает два особых обстоятельства. Во -первых, это то, что бывшие республики Средней Азии в рамках СССР достигли высокого уровня индустриального и интеграционного развития и в рамках союза республики Средней Азии наделялись статусом особого среднеазиатского экономического района. Во-вторых, в настоящее время из большинства стран ЦА( Узбекистана, Кыргызстана, Таджикистана) в России, Казахстане находятся миллионы трудовых мигрантов, которые представляют основу усиления евразийской экономической интеграции.

В то же время в последние периоды суверенного развития практически все страны ЦА становятся зоной активного внешнеэкономического взаимоотношения с КНР. КНР занимает 1 место во внешнеторговом обороте с Туркменистаном и 2 места с Казахстаном (13,0\%), Узбекистаном (12.0\%), Кыргызстаном (18,5\%) и Таджикистаном (14,0\%).

Страны ЦА, интегрируясь в ЕАЭС , параллельно включаются в зону реализации Экономического Пояса Щелкового Пути (ЭПШП), которое последовательно проводит с 2013г. КНР. Как известно в рамках стратегии ЭПШП КНР в перспективе планируется создание семи «поясов», охватывающих и ЦА: транспортно-логистического; энергетического; торгового; информационного; научно-технического; аграрного и туристического.

В контексте перспективного участия стран ЦА в стратегии ЭПШП надо подчеркнуть, что по всем указанным поясам экономическое сотрудничество стран ЦА и КНР активно развивается и углубляется. В 
основном это связано с тем, что страны ЦА, не имея прямого выхода на морские пути, с неразвитостью железнодорожных путей сообщения, связывающих ее с внешним миром, однако удобно расположены на историческом пути Шелкового пути, модернизация которого в современных условиях провозглашена в КНР как стратегическая задача мирового развития XX1 века.

Следует указать также на то обстоятельство, что и Турция, с самого начала распада СССР и формирования в центрально-азиатском пространстве суверенных государств, последовательно проводит курс на сближении почти со всеми странами ЦА. Турция активно развивает торговлю, экономические и гуманитарные связи, направляет инвестиционные ресурсы в различные проекты в страны ЦА. Турция занимает 2 место во внешнеторговом обороте с Туркменистаном, 3 место-Узбекистаном $(4,8 \%)$ и 4 места -с Кыргызстаном (4,8\%) и Таджикистаном (4, 3\%), 9 место -с Казахстаном (2,8 \%). В отличии от России и КНР, однако экономическая активность Турции в ЦА не носит широкомасштабного характера. Ее присутствие достаточна высока лишь в отдельных секторах экономики и в отдельных странах ЦА. Но тем не менее, в отличии от указанных конкурентов( России и КНР), Турция обладает ввиду турко язычной общности со странами ЦА, существенным потенциалом для усиления своего экономического присутствия.

Несмотря на то, что с распадом СССР и формированием суверенных государств произошел существенный разрыв экономических связей между странами уже Центральной Азии (ЦА) в настоящее время понимание процессов усиления глобальных игроков на социально-экономическое развитие обьективно обусловливают необходимость усиления экономической интеграции стран ЦА. Однако следует подчеркнуть, что предпринимаемые за последние годы попытки интеграции стран ЦА наталкивались на политические амбиции отдельных руководителей суверенных стран. В результате интеграция стран ЦА в основном ограничена сферой взаимной торговли, обьемы которой , к сожалению, резко снизились. В то же время интеграция и кооперация в сфере совместного использования производственно-экономического и природного потенциала региона, практически не происходит.

Несмотря на разрыв прежних экономических и культурно-гуманитарных связей братских республик в условиях суверенитета каждая республика начала проводить самостоятельную внутреннюю и внешнюю экономическую политику с учетом интересов своего государства и народа. Центрально-азиатский экономический район выделяется развитым сельским хозяйством, особенно развитым животноводством, производством и переработкой технических культур, большим потенциалом гидроэнергетических ресурсов, запасов газа, цветных и драгоценных металлов, угля. В результате существенным образом изменились структуры национальных экономики и направленность их внешнеэкономических связей, обусловливающих диспропорции в экономическом развитии стран ЦА (табл.1).

\begin{tabular}{|c|c|c|c|c|c|c|c|c|c|c|}
\hline \multirow{2}{*}{ Показатели } & \multicolumn{2}{|c|}{ Казахстан } & \multicolumn{2}{|c|}{ Узбекистан } & \multicolumn{2}{|c|}{ Таджикистан } & \multicolumn{2}{|c|}{ Туркменистан } & \multicolumn{2}{|c|}{ Кыргызстан } \\
\hline & 2010 & 2015 & 2010 & 2015 & 2010 & 2015 & 2010 & 2015 & 2010 & 2015 \\
\hline $\begin{array}{l}\text { Числ.нас, } \\
\text { млн.чел }\end{array}$ & 16.7 & 17,7 & 29,1 & 31,6 & 7,6 & 8,5 & 5,0 & 5,3 & 5,4 & 6,0 \\
\hline ВВП, млр.долл & 192,0 & 184,3 & 86,1 & 68,0 & 5,65 & 7,81 & 22,1 & 37,3 & 4,8 & 6,65 \\
\hline $\begin{array}{l}\text { ВВП на душу } \\
\text { нас., тыс долл. }\end{array}$ & 11,6 & 10,5 & 3,0 & 2,1 & 0,74 & 0.93 & 4,4 & 7,0 & 0,88 & 1,1 \\
\hline $\begin{array}{l}\text { Экспорт, } \\
\text { млр.долл }\end{array}$ & 60,3 & 49,9 & 11,3 & 13.5 & 1,19 & 0,89 & 9.6 & 12,1 & 1,75 & 1,67 \\
\hline $\begin{array}{l}\text { Импорт, } \\
\text { млн.долл. }\end{array}$ & 31,1 & 30,6 & 8,3 & 13,5 & 2,65 & 3,4 & 8,2 & 14,0 & 3,22 & 4,0 \\
\hline $\begin{array}{l}\text { Ин.инв, } \\
\text { млр.долл }\end{array}$ & 19.8 & 14,8 & 2,9 & 3,3 & 0,46 & 0,85 & 4,5 & - & 3,5 & 4,3 \\
\hline $\begin{array}{l}\text { Гос.внешн. долг } \\
\text { в \% к ВВП }\end{array}$ & 13,0 & 22,1 & - & 21,3 & 39.6 & 4,1 & 4,1 & 18,7 & 59,7 & 68,3 \\
\hline $\begin{array}{l}\text { Деф. (-), } \\
\text { проф.(+) } \\
\text { бюджета в \% к } \\
\text { ВВП }\end{array}$ & $-1,9$ & $-2,6$ & - & $+0,1$ & +1.3 & $+1,8$ & - & - & $-4,9$ & $-1,5$ \\
\hline
\end{tabular}

Таблица 1. Экономическое развитие стран Центральной Азии Источник: Даннье межгосударственного статистического комитета СНГ

Как наглядно видно из табл. 1 за анализируемый период отмечаются существенные различия в динамике и уровне экономического развития стран ЦА, что в основном связана со структурой национальных экономик, их встроенностью в мировые и региональные рынки. По основным социально-экономическим показателям - численности населения, ВВП, производству ВВП на душу населения, обьемам экспорта и импорта заметны лидирующие позиции Казахстана и Узбекистана. К ним вплотную приближается и Туркмения. 
Казахстан по уровню экономического развития остается одним из высокоразвитых стран в регионе и в целом на постсоветском пространстве, о чем свидетельствует высокий уровень производства ВВП на душу населения (более 10,0 долл.США). В структуре национальной экономики преобладают экспорториентированные отрасли (производство нефти, газа, зерна), что в целом обуславливает, несмотря на сокращение разрыва между обьемами экспорта и импорта, положительную динамику внешнеторгового баланса страны.

Со странами ЦА, несмотря на рост товарооборота, удельный вес внешнеторгового оборота остается низким (в среднем 4,0 \% внешнеторгового оборота Казахстана). Основным внешнеторговым партнером Казахстана в ЦА является Узбекистан, доля которого в экспорте-2,1\%, в импорте- 2,4\%, соответственно с Кыргызстаном- 1,1 и 0,6 \%, Таджикистаном- 0,9 и 0,5 \% и Туркменистаном- 0,2 и 0,3\%. По сравнению с 2010г. в 2015 г. удельный вес стран ЦА в общем внешнеторговом обороте Казахстан увеличилась с 2,6 до 4,0 \%, что свидетельствует об активизации внешнеэкономических связей Казахстана со странами ЦА и наличии потенциала расширения внешнеэкономических связей Казахстана со странами ЦА .

В Узбекистане сальдо внешнеторгового оборота страны, несмотря на значительный рост импорта( на 43,6\%), является сбалансированным. Такое положение обьясняется тем, что в отличии от Казахстана, структура экономики Узбекистана более диверсифицирована и сбалансирована ( рациональное сочетание промышленности, сельского хозяйства, сферы услуг), что обуславливает ее определенную устойчивость к изменившейся коньюктуре на энергоносители. Наиболее развитыми отраслями промышленности являются машиностроение, золотодобывающая, нефтегазовая, химическая. Основные статьи экспорта - хлопок, газ, золото, удобрения, металлы. Потери от экспорта энергоносителей компенсируются ростом валютных поступлений от продовольствия и хлопка, что положительно сказывается на низком уровне внешнего долга $(21,3 \%)$ и роста профицитности госбюджета страны. Главными внешнеторговым партнером Узбекистана из стран ЦА является Казахстан, доля которого во внешнеторговом обороте составляет 6,1 \% и Туркмения $-1,5 \%$.

Экономика Туркменистана в силу преобладания в ней добывающих отраслей и в целом промышленности (50.0\% ВВП страны) является в ЦА наиболее экспортоориентированной. В частности, если во всех странах ЦА производство экспортной продукции на душу населения снижается , в Туркменистане это показатель увеличился на 21,0\% и составил 2,3 тыс .долл. В основном это обусловлено высоким уровнем развития промышленности и растущим экспортным потенциалом экономики Туркменистана, обьемы которого также выросли на 26,0 \%.

Основной экспортной продукцией страны является газ, доля которого в обьеме экспорта составляет более 79,3\%. Также нельзя не отметить, что в республике сравнительно высокий уровень развития текстильной отрасли, доля которого в обьеме экспорта занимает более 4,2 \%. Из стран ЦА Туркменистан более менее тесные экономические связи имеет с Узбекистаном и Казахстаном .

Таджикистан и Кыргызстан являются наименее развитыми в экономическом отношении странами ЦА с примерно идентичными низкими макроэкономическими показателями и сырьевой структурами национальных экономик, в которых сравнительно низок уровень промышленности и высок уровень сельского хозяйства.

Наиболее слабым в экономическом отношении государством в ЦА остается Таджикистан, где несмотря на рост валовых показателей производство ВВП на душу населения является самым низким в ЦА: по сравнению с Казахстаном и Туркменистаном ее уровень ниже в 10,0 и 7,0раза. В структуре национальной экономики Таджикистана ведущую роль играет сельское хозяйство, удельный вес которого увеличился с 21,0 до 25,0\% за анализируемый период. В то же время доля промышленности сократилась на 1,9 пункта. Во внешнеэкономической деятельности Таджикистана обьемы экспорта продукции снижаются, а импорта, наоборот, растут, что в целом обусловливают тенденцию роста отрицательного сальдо внешнеторгового оборота страны.

Кыргызстан по уровню экономического развития в ЦА стоит на предпоследнем месте. В структуре национальной экономики растет удельный вес сферы услуг и торговли, остается высоким удельный вес сельского хозяйства, слабо развивается промышленность. Внешнеторговый баланс страны отрицательный и она продолжает усугубляться.

Тем не менее экономику Кыргызстана в ЦА во внешнеэкономической деятельности отличает то обстоятельство , что она имеет в отличии от других стран региона, экономика которых ориентирована на страны дальнего зарубежья, более тесные торгово-экономические связи со странами ЦА. (Со странами ЦА взаимный товарооборот Кыргызстана начиная с 2010г начинает динамично развиваться, о чем в определенной степени может свидетельствовать рост обьемов внешней торговли и развития инвестиционного сотрудничества Кыргызской Республики со странам ЦА Несмотря на то, что общий товарооборот Кыргызстана за указанные годы имеет тенденцию к снижению со странами ЦА, наоборот , обьемы внешней торговли имеют тенденцию к существенному росту. Если в 2010 г. на страны ЦА приходилось только 14,5 \% обьема внешнего товарооборота республики, то к 2015 он почти удвоился и 
достиг уровня 23,2 \%.Основными торговыми партнерами Кыргызстана в ЦА являются Республика Казахстан (78,2\% от общего обьема товарооборота со странами ЦА) и Республика Узбекистан(15,0\%) (табл.2.).

\begin{tabular}{|c|c|c|c|c|c|c|}
\hline Показатели & 2010г. & $2011 г$. & 2012 г. & $2013 \Gamma$. & 2014 г. & $2015 \Gamma$. \\
\hline $\begin{array}{l}\text { Экспорт- всего в страны ЦА } \\
\text { В т.ч., в: }\end{array}$ & 241,8 & 437,8 & 629,5 & 591,4 & 520,9 & 587,5 \\
\hline Республику Казахстан & 181,6 & 289,7 & 394,7 & 377,1 & 367,7 & 368,0 \\
\hline Республику Узбекистан & 40,1 & 124,4 & 190,1 & 159,0 & 116,7 & 142,0 \\
\hline Республику Таджикистан & 15,4 & 36,2 & 39,6 & 50,3 & 28,7 & 71,2 \\
\hline Туркменистан & 4,7 & 7,5 & 5,1 & 5,0 & 7,8 & 6,3 \\
\hline Импорт, всего из стран ЦА & 483,1 & 498,9 & 772,5 & 661,6 & 890.3 & 749,2 \\
\hline В т.ч.из: & 385,6 & 411,1 & 698,6 & 558,6 & 776,7 & 678,0 \\
\hline Республики Казахстан & 93,8 & 84,3 & 67,4 & 97,9 & 102,2 & 59,2 \\
\hline Республики Узбекистан & 2.6 & 1.0 & 4.1 & 3,4 & 7.9 & 8,1 \\
\hline $\begin{array}{l}\text { Республики Таджикистан } \\
\text { Туркменистана }\end{array}$ & 1,1 & 2,5 & 2,4 & 1,6 & 3,5 & 3,9 \\
\hline $\begin{array}{l}\text { Обьем внешнеторгового оборота со } \\
\text { странами ЦА-всего }\end{array}$ & 724,9 & 936,7 & 1402,0 & 1253,0 & 1411,2 & 1336,7 \\
\hline 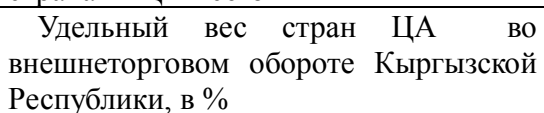 & 14,5 & 14,3 & 18.6 & 15,6 & 18,5 & 23,2 \\
\hline
\end{tabular}

Таблица 2. Внешняя торговля Кыргызской Республики со странами ЦА, млн.долл. США Источник: НСК $K P$

В целом внешнеторговый оборот Кыргызской Республики со странами ЦА более менее сбалансирован. За исключением Республики Казахстан, основного внешнеторгового партнера республики в ЦА, баланс внешнеторгового оборота республики с остальными странами положительный. Данное обстоятельство подчеркивает особую значимость глубокой интеграции экономики Кыргызстана и стран ЦА для конкурентоспособного развития экономики Кыргызстана.

Однако в отличии от динамично развивающейся сферы внешней торговли инвестиционное сотрудничество Кыргызстана со странами ЦА нестабильна и остается на самом низком уровне , характер инвестиционного сотрудничества Кыргызстана со странами ЦА носит неустойчивый и ограниченный по сферам привлечения инвестиций характер. К тому же основным инвестором Кыргызстана из стран ЦА является Казахстан, на долю которого приходится более 80,0 \% инвестиционных ресурсов ЦА. Инвестиции из Казахстана в основном направляются в сектор финансовых и страховых услуг, торговлю, обрабатывающую промышленность.

В целом общий обьем инвестиций за указанные годы стабильно рос до 2014 г. , но в 2015 г. резко упал и опустился даже ниже уровня 2010 г. В основном это обусловлено кризисной ситуацией, сложившейся в экономике Казахстана. Также следует подчеркнуть, что в общем обьеме иностранных инвестиций из стран ЦА преобладают кредитные ресурсы, доля которой составляет порядка 90,0 \%. Причем, за исключением Казахстана, остальные три республики не вкладывают в экономику Кыргызстана прямые инвестиции. Сложившаяся структура и практика инвестиций из стран ЦА привела к значительному снижению инвестиций в экономику Кыргызстана из стран ЦА, доля которой в общем обьеме иностранных инвестиций опустилась с 8,4 \% в 2010 г. до 5,2 \% в 2015 г.

В целом проведенный анализ внешнеэкономического сотрудничества в странах ЦА свидетельствует о том, что почти во всех странах ЦА во внешнеэкономической деятельности растет доля стран дальнего зарубежья- Европы, Азии и Ближнего Востока. Также значительна во внешнеторговом обороте стран ЦА доля России, КНР и Турции .Следует подчеркнуть динамику роста торгово-экономического сотрудничества между странами ЦА, которые базируются двухсторонними межправительственными соглашениями между странами, что создают благоприятные предпосылки для более глубокой и тесной экономической интеграции стран ЦА.

Также учитывая, что в последние годы в странах ЦА наметились тенденция роста обьемов торговли, инвестиций, меняется политический климат представляется возможным сдвинуть с мертвой точки развитие интеграционных процессов внутри центрально-азиатских стран (ЦА) - между Республикой Казахстан, Республикой Узбекистан, Кыргызской Республикой, Республикой Таджикистан и Туркменистаном и придать им более устойчивый и целенаправленный характер. Естественно следует принимать во внимание изменившиеся со времени получения этими республиками суверенитета социально-экономическую и политическую ситуацию, сложившийся определенный их статус в мировом пространстве.

Экономическая интеграция стран ЦА должна преследовать цели более эффективного использования природно-экономического и трудового потенциала региона. Приоритетными направлениями 
взаимовыгодного экономического сотрудничества должны стать освоение природных ресурсов, рациональное использование гидроэнергетического потенциала, создание разветвленной транспортной и энергетической системы, создание крупных региональных финансово-промышленных групп, развитие потенциала сельских, горных и пустынных территорий и т.д.

\section{Литература}

- Содружество Независимых Государств 1991-2015: статсборник / межгосстатком СНГ. -M.,2016.-500с.

- Казахстан в 2015г.: статсбрник. www.stat,gov.kz.

- Таджикисттан в цифрах в 2015г.: статсборник http://www.stat.tj/ru/img/695c206e2b1ce86f333f33fdc268a469_1439617140.pdf

- Кыргызстан в цифрах, 2015: статсборник.-Бишкек, Нацстатком КР, 2016.-351с.

- Инвестиции в Кыргызской Республике: 2011-2015гг.: статсборник: http:/www.stat.kg 


\title{
Распределение и Использование Финансовых Ресурсов В Здравоохранении Кыргызстана
}

\author{
Allocation and Use of Financial Resources in Health Care in \\ Kyrgyzstan
}

\author{
Assoc. Prof. Dr. Damira Japarova (Kyrgyzstan-Turkey Manas University, Kyrgyzstan)
}

\begin{abstract}
The distribution of the limited financial resources in the state hospitals in Kyrgyzstan is uneven. The problems associated with the current method of distribution of resources: the poor quality of services at the level of polyclinics and high hospitalization rates that require an evaluation of the budget allocation of healthcare organizations operating in the Single Payer system. In order to improve the efficiency of resource use it is suggested to review the principles of allocation of resources to the primary level of patient care.
\end{abstract}

\section{1 Введение}

Несмотря на сокращение количества больничных учреждений и увеличение государственных расходов на здравоохранения, количество пациентов стационарного лечения растет. Увеличивается число больных по основным видам заболевания. В связи с этим есть необходимость рационального распределения и эффективного использования ограниченных ресурсов здравоохранения.

Финансирование здравоохранения осуществляется из: республиканского бюджета, средств Фонда обязательного медицинского страхования и местного бюджета города Бишкек, а также расходов частного сектора на здравоохранение. Средства из Республиканского бюджета, предназначенные для здравоохранения, финансируют большинство расходов, в том числе:

Министерство Здравоохранения финансирует общественное здравоохранение, медицинское образование, финансирует фонд высокотехнологичной помощи, по статье индивидуальные услугигемодиализ, централизованные закупки лекарств как инсулин и др.

ФОМС, распределяет бюджетные средства по лечебным учреждениям третичного,(11 специализированных учреждений третичного уровня с 2016 года перешли на ведение ФОМС), первичного и вторичного уровней по областям в рамках финансирования Программы государственных гарантий и Дополнительной программы ОМС по лекарственному обеспечению. (Д. Джапарова Экономика здравоохранения, 2016)

Государственные источники финансирования и расходы частного сектора на здравоохранение составляют поток их внутренних расходов. Частные средства финансирования здравоохранения представляют собой выплаты на оздоровление за счет средств доходов домохозяйств. Домашние хозяйства осуществляют официальные - сооплата, платные услуги и неформальные расходы за предоставляемые медицинские услуги, а также покупают лекарства за свой счет. Государственные расходы на здравоохранение в 2016 году составили 15835,5 млн. сом, или 3,2 \% к ВВП. В расчете на душу населения составили 2747 сом. (отчет ФОМС 2016)

\section{2 Основная Часть}

Аккумулирование средств на республиканском уровне позволило с 2007 года установить единые нормативы финансирования по всем регионам республики для службы скорой помощи и стоматологии. В 2008 году установлена единая базовая ставка из средств государственного бюджета за пролеченный случай в стационарах.

Медицинская помощь по Программе государственных гарантий на стационарном уровне предоставляется центрами общеврачебной практики, территориальными, областными и республиканскими больницами общего профиля и отдельными специализированными стационарами. Стационарную помощь населению республики оказывают 67 организацй, в которых имеются 25833 койки. За 2016г. в стационары республики было госпитализировано 924000 пациентов (2015г. 933600;) (отчет ФОМС 2016).

Нормативы финансирования рассчитываются в соответствии с Методикой расчета базовых нормативов финансирования медико-санитарной помощи, оказываемой гражданам Кыргызской Республики по Программе государственных гарантий, утвержденные постановлением Правительства Кыргызской Республики «Об оптимизации методов финансирования медико-санитарной помощи в системе Единого плательщика» от 13 июня 2008 года № 300.(Постановление Правительства КР.) 
Нормативы финансирования состоят из базовых нормативов финансирования по средствам государственного бюджета и обязательного медицинского страхования с корректировкой на поправочные коэффициенты. Базовая ставка - средний расчетный показатель финансирования стационарной помощи, за каждый пролеченный случай, исходя из объема финансирования стационарной помощи.

По средствам обязательного медицинского страхования установлены единые нормативы финансирования по всей стране. По учреждениям первичной медико-санитарной помощи нормативы финансирования по регионам с 2010 года единые. Норматив подушевого финансирования это средний расчетный показатель финансирования первичной медико-санитарной помощи на одного обслуживаемого или прикрепленного жителя с корректировкой на поправочные коэффициенты.

В 2016 годах для ГСВ подушевой норматив на одного застрахованного гражданина в год был утвержден в размере 115 сомов, за пролеченный случай в стационаре - 2050сом. Единые нормативы финансирования корректируются с помощью коэффициентов с учетом географических и демографических особенностей каждого региона.

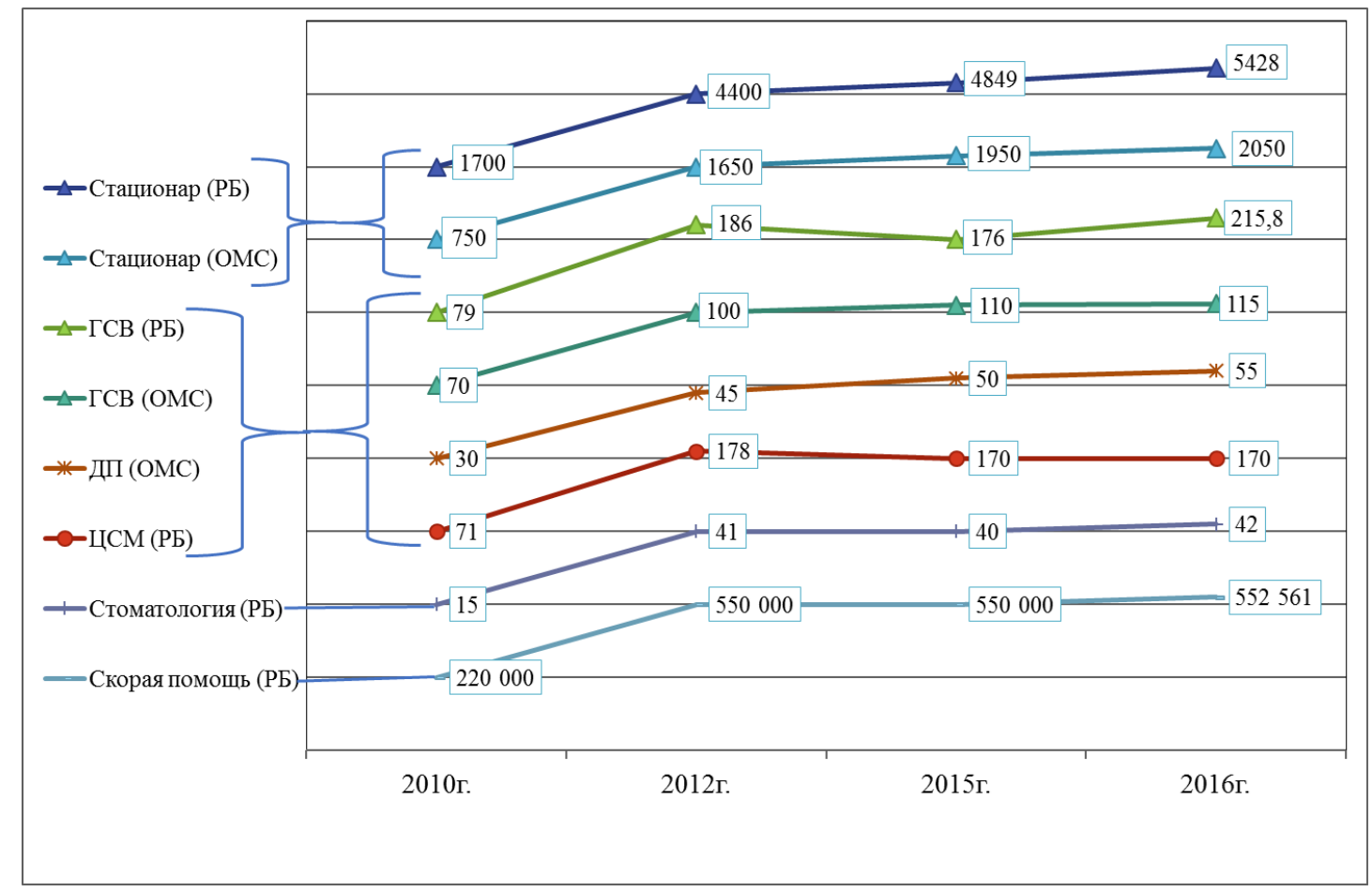

График1. Нормативы Финансирования По Средствам Республиканского Бюджета И ОМС 3 а 2010 2016г., В Сомах. Источник: Данные ФОМС КР За 2016.

По диаграмме видно, за последние два года особых изменений в нормативах не произошли. Нормативы финансирования стационаров значительно превышают показатели нормативов ЦСМ и ГСВ. Одновременно с выравниванием прослеживается и ежегодное увеличение утверждаемых нормативов финансирования. Однако с ежегодным увеличением нормативов финансирования за пролеченный случай, наблюдается рост госпитализаций по всем регионам республики.

Как видно из таблицы 1, в целом по республике количество пролеченных случаев по республике увеличилось. Это связано с увеличением госпитализации не приписанных и незастрахованных больных в областных центрах и в Бишкеке. Если проанализировать по регионам, самое большое число пролеченных случаев отмечается в г. Бишкек, где его число увеличилось на 7,8 \%, или на 16312.

Сократилось число пролеченных случаев во всех регионах, кроме Чуйской, Ошской и Джалал-Абадской областей. Особенно большое число сокращений произошло в Таласской (на 8,4\%), в Иссык-Кульской, Нарынской областях, соответственно, на 3,6 и 7,4\%. Это можно объяснить тем, что пациенты с более сложным диагнозом для получения более качественной медицинской помощи, приезжают в столицу. 


\begin{tabular}{|c|c|c|c|c|c|c|c|c|c|}
\hline $\begin{array}{lr}\text { Кол-во } & \text { пролеч. } \\
\text { случаев } & \text { по } \\
\text { регионам } & \\
\end{array}$ & 2009 & 2010 & 2011 & 2012 & 2013 & 2014 & 2015 & 2016 & $\begin{array}{l}2016 \text { г. в \% } \\
\text { к } 2009 \text { г. }\end{array}$ \\
\hline Бишкек: & 207814 & 216852 & 224702 & 224610 & 227992 & 232691 & 236089 & 288564 & 138,8 \\
\hline Чуйская обл. & 114186 & 115964 & 114441 & 117940 & 116971 & 111362 & 108276 & 105058 & 92,0 \\
\hline Ошская обл. & 219937 & 215671 & 224928 & 209687 & 224050 & 234503 & 233765 & 235991 & 107,3 \\
\hline Баткенская обл. & 80519 & 85341 & 83380 & 81770 & 80745 & 80679 & 82021 & 82108 & 101,9 \\
\hline $\begin{array}{l}\text { Жалалабадская } \\
\text { обл. }\end{array}$ & 155062 & 165119 & 164411 & 165465 & 162245 & 162302 & 163532 & 159173 & 102,6 \\
\hline $\begin{array}{l}\text { Иссык-Кульск. } \\
\text { обл. }\end{array}$ & 62147 & 64898 & 62867 & 62633 & 59131 & 61187 & 61187 & 62334 & 100,3 \\
\hline Нарынская обл. & 36585 & 36092 & 36653 & 35886 & 34129 & 35292 & 35343 & 35254 & 96,4 \\
\hline Таласская обл. & 33157 & 34090 & 33338 & 32675 & 31101 & 30235 & 30964 & 30699 & 92,6 \\
\hline Итого & 909407 & 934027 & 944720 & 930666 & 936367 & 945010 & 951177 & 940181 & 103,4 \\
\hline
\end{tabular}

Таблица 1. Количество Пролеченных Случаев По Регионам За 2009-2016 г2. Источник: Данные ФОМС КР за 2009-20162)

В поликлиниках подушевое финансирование составляет в 2016 году 555,8 сома на приписанного человека, тогда как в стационары за пролеченный случай предусмотрена выплата 7478сомов. Отсюда, кажется, что изначально настрой на то, чтобы пациенты получили осложнение и были направлены на стационарное лечение.

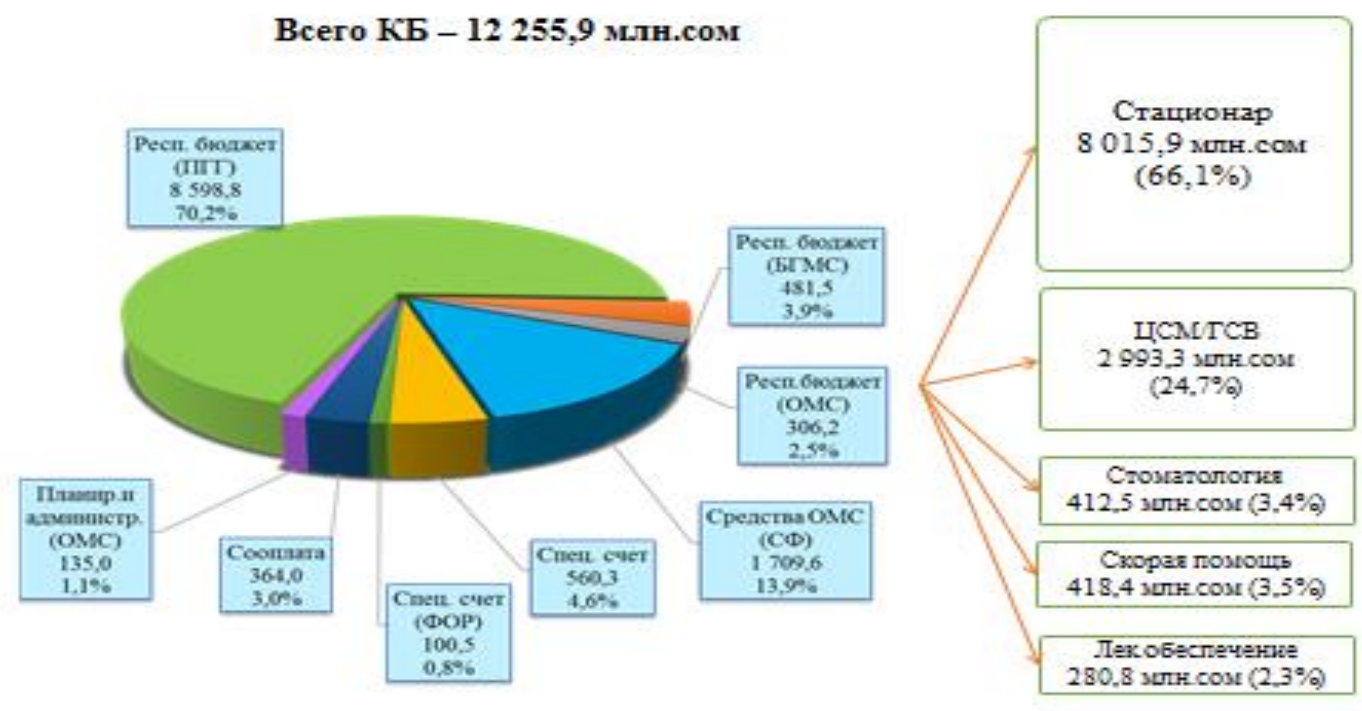

Диаграмма 1.Консолидированный Бюджет Системы Единого Плательщика За 2016 год (в млн. сомах).

Источник: Данные ФОМС КР за 2016 год.

По данным распределения консолидированного бюджета в 2016 году мы видим, что на финансирование стационаров было направлено 66,1\% финансовых средств, тогда как на финансирование центров семейной медицины и группы семейных врачей всего 24,7\%

Результатом такого распределения ресурсов является увеличение госпитализации по всем регионам. Это показатель неэффективной работы на первичном уровне, т. е. недолеченные в поликлиниках больные становятся пациентами стационаров. Рассмотрим изменение расходов медицинских учреждений и количества пролеченных случаев. 


\begin{tabular}{|c|c|c|c|c|c|c|c|c|c|}
\hline Показатели & 2009 & 2010 & 2011 & 2012 & 2013 & 2014 & 2015 & 2016 & $\begin{array}{c}2016 \text { г. в \% } \\
\text { к } 2009 \text { г. }\end{array}$ \\
\hline $\begin{array}{l}\text { Расходы на } \\
\text { лечение в } \\
\text { стационарах, } \\
\text { млн.сом }\end{array}$ & 3097,6 & 3193,7 & 4546,8 & 5911,6 & 6117.3 & 6302.8 & 6347.0 & 6538.0 & 211.1 \\
\hline $\begin{array}{l}\text { Количество } \\
\text { пролеченных } \\
\text { случаев }\end{array}$ & 901469 & 934027 & 944720 & 923853 & 916367 & 945010 & 951177 & 940181 & 104,3 \\
\hline $\begin{array}{l}\text { Темпы роста } \\
\text { пролеченных } \\
\text { случаев,в \% }\end{array}$ & 100,0 & 103,6 & 101,1 & 97,8 & 98,9 & 103.1 & 100.7 & 99,4 & -0.6 \\
\hline $\begin{array}{l}\text { Количество } \\
\text { приписанного } \\
\text { населения } \\
\end{array}$ & 52645 & 52462 & 53344 & 542288 & 540161 & 54878 & 54558 & 54727 & 103.9 \\
\hline $\begin{array}{l}\text { Темпы роста } \\
\text { приписанного } \\
\text { населения, в \% }\end{array}$ & 100,0 & 99,7 & 101,7 & 101,7 & 99,6 & 101.3 & 99,4 & 100.3 & +0.3 \\
\hline $\begin{array}{l}\text { Расходы, в сомах: } \\
\text { на } 1 \text { пролеченный } \\
\text { случай }\end{array}$ & 3436,11 & 3419,25 & 4812,83 & 6398,86 & 66533 & 6570 & 6673 & 6954 & 202.4 \\
\hline Темпы роста, в \% & 100,0 & 99,5 & 140,8 & 133,0 & 113,1 & 98.5 & 101.6 & 104.2 & $+4,2$ \\
\hline $\begin{array}{l}\text { На } 1 \\
\text { приписанного } \\
\text { человека } \\
\end{array}$ & 381,81 & 408,77 & 563,61 & 692,75 & 679 & 675 & 694 & 714 & 187 \\
\hline Темпы роста, в \% & 100,0 & 107,0 & 137,9 & 122,9 & 104,7 & 99.4 & 102.8 & 102.9 & $+2,9 \%$ \\
\hline
\end{tabular}

Таблица 2. Динамика И Структура Расходов Государства На Пролеченный Случай И 1 Приписанного Больного За 2009-2016 Годы. Источник: Данные ФОМС КР За 2009-2016г)

Как видно из анализа, расходы на 1 пролеченный случай в стационарах увеличились с 3097, 6 сома до 6538.0 сома, или в 2,1 раза. Рост пролеченных случаев за 8 лет произошел на 4,3\%. Расходы на 1 приписанного человека также выросли с 381,8 до 714 сомов, или в 1,9 раза, при увеличении приписанного населения на 3,4 \% . Рост расходов по сравнению с результатами лечения, характеризует неэффективное использование ресурсов в здравоохранении республики.

Итак, количество пациентов, вынужденных обращаться в стационар, растет. Если учесть, что стационары - наиболее дорогостоящий вид оказания медицинской помощи, по сравнению с амбулаторно поликлиническим лечением, такое распределение финансов, при их остром дефиците, является неэффективным. При этом наблюдается большая нагрузка врачей на уровне поликлиники. Например, лор врач в поликлинике в районном центре должен принять в месяц 420-460 человек, что нереально. Одна машина скорой помощи на поликлинику. Очень узкий перечень больных можно лечить в стационарах. Растет число хронических больных, особенно среди детей. Дети болеют каждые 2-3 месяца.. У многих детей 6-7 лет гайморит, говорят врачи. Заслуживает внимания опыт Белоруссии, где значительная часть финансовых ресурсов направляется на содержание и развитие первичного звена. В поликлиниках медицинские услуги оказываются бесплатно. В связи с тем, что пациенты вылечиваются на начальной стадии болезни, 70\% процентов больных не нуждаются в стационарном лечении. Поэтому Белоруссия относится к странам с низкими показателями младенческой смертности и высокой продолжительностью жизни. (Рейтинг стран мира) По данным ООН за 2015 год, в Беларуси средняя продолжительность жизни женщин составляет 78, а у мужчин - 66 лет (ООН: в Беларусии)

Методы оплаты стационарных услуг за «пролеченный случай» приводят к искусственному увеличению количества госпитализаций и необоснованному назначению диагностических и лечебных процедур. В этой связи значительную часть средств Единого плательщика необходимо направлять на финансирование поликлинического уровня по сравнению с дорогостоящим стационарным лечением. А также необходимо осуществлять финансирование на профилактику болезней. Для мотивации медицинских работников поликлиник, качество работы на наш взгляд, необходимо оценивать не по количеству приписанных больных, а по выбору самого больного, где больной голосует своими средствами, которые имеются на его персонифицированном счете. И со временем, из числа приписанных больных контингент здоровых приписанных людей будет определять качество оказания медицинских услуг.

Ограниченные ресурсы в здравоохранении используются неэффективно. По отчетам Минздрава КР, на лечение льготных пациентов используется 94 процента выделяемых государством средств. Соответственно, на остальных граждан приходится не более 6 процентов бюджетных денег. На практике это означает, что на лекарственное обеспечение одного пациента государство в среднем тратит 171,6 сомов в сутки и на питание 73,9 сом. Для больных с запущенной формой заболеваний, поступивших в 
стационары, этих денег на лекарство недостаточно. Итак, программа государственных гарантий по обеспечению граждан медико-санитарной помощью в Кыргызстане не работает. Льготы и бесплатные лекарства декларируются властями, а на деле каждый платит сам за свое лечение.

Ясно, что без всеобщего оздоровления экономики республики существенных изменений в системе здравоохранения не произойдет. Но экономический рост - это вопрос будущего, а люди нуждаются в медицинской помощи сейчас. Чтобы выйти из сложившейся ситуации, предлагается перевести некоторые категории лиц, имеющих право на бесплатное лечение, на платные условия.

Имеющиеся в системе здравоохранения ресурсы используются неэффективно. Существующая система оказания медицинской помощи характеризуется избыточной сетью медицинских учреждений с низким материально-техническим оснащением; доминированием стационарной помощи, низкой приоритетностью первичной медико-санитарной помощи.

Динамика роста госпитализаций характеризует тот факт, что лечение в стационарах не сокращается, а напротив, увеличивается, что противоречит целям реформы в здравоохранении. Это показывает, что ограниченные ресурсы в здравоохранении используются неэффективно. Вывод: сложившаяся сеть медицинских учреждений и порядок взаимодействия между ними таковы, что этапы лечебнодиагностического процесса осуществляется неэффективно: с перегрузкой стационаров, недооценкой возможностей амбулаторно - поликлинических учреждений и при почти полном отсутствии специализированных учреждений для долечивания и ухода, а также профилактики болезней.

\section{3 Вывод}

- Значительную часть средств Единого плательщика необходимо направлять на финансирование поликлинического уровня по сравнению с дорогостоящим стационарным лечением.

- В структуре средств ФОМС следует предусмотреть фиксированную долю средств на развитие материально-технической базы поликлиник с целью своевременного диагностирования болезней и качественного лечения на уровне поликлиник.

- Качество работы поликлиники необходимо оценивать не по количеству приписанных больных, а по выбору самого больного, где больной голосует своими средствами, которые имеются на его персонифицированном счете.

- Со временем контингент здоровых людей из числа приписанных больных, будет определять качество оказания медицинских услуг.

\section{Литература:}

- Данные ФОМС КР за 2016 год

- Данные ФОМС КР. за 2009-2016г.г.

- Д. Джапарова Экономика здравоохранения Кыргызстана в период трансформации. Экономический анализ здравоохранения Кыргызстана. LAP LAMBERT Academic published. Германия 2016г., стр.13

- Отчет ФОМС за 2016 год

- $\mathrm{OOH:} \mathrm{в} \mathrm{Беларуси} \mathrm{средняя} \mathrm{продолжительность} \mathrm{жизни} \mathrm{женщин} \mathrm{составляет} \mathrm{78,} \mathrm{а} \mathrm{у} \mathrm{мужчин} \mathrm{-} 66$ лет: news.tut.by/society/497147.html

- Постановление Правительства Кыргызской Республики «Об оптимизации методов финансирования медико-санитарной помощи в системе Единого плательщика» от 13 июня 2008 года № 300

- Рейтинг стран мира по уровню младенческой смертности. gtmarket.ru/ratings/child-mortality-rate/info 


\title{
Анализ Рынка Туристических Услуг Кыргызстана Analysis of the Modern Condition of Tourism in the Kyrgyz Republic
}

\author{
Prof. Dr. Anara Kamalova (Kyrgyz National University, Kyrgyzstan)
}

\begin{abstract}
The theoretical issues of tourism marketing, modern methods of tourism promotion on the market, as well as the main questions of success marketing research of tourism services in general, and for consumers in particular are covering in this article. Materials of marketing research of tourism in Kyrgyzstan by using data from tourists' survey, who rest in Issyk-Kul during the summer season in 2016 also are analyzing. The results of marketing research of tourist behavior as the consumers are summarizing by identifying positive and negative reviews, as well as investigating the activities of the main competitors, operating in the tourism sphere in Kyrgyzstan, preparing SWOT-analysis. The main reasons for the low level of the tourism sector in the country's GDP is also identifying, as well as the low level of development of tourism logistics and customer service. Based on the above mentioned materials at the end in the article the problems and ways to improve are emphasizing. The ways to further improve the service and leisure for the travelers and the main directions of further development of tourism as a business in the Kyrgyz Republic are identifying.
\end{abstract}

В настоящее время, когда Кыргызстан определился приоритетными направлениями развития отраслей экономики, наиболее важным вопросом является комплексное изучение рынка этих отраслей. Так как туристическая отрасль наряду с другими является приоритетным направлением, актуальность изучения рынка туристических услуг становится наиболее важным.

Как мы уже отметили, сфера туризма является одной из перспективных отраслей экономики, обеспечивающей экономический рост Кыргызстана, а также она влияет на важные макроэкономические показатели республики. На следующей таблице можно это рассмотреть:

\begin{tabular}{|l|c|c|c|c|c|c|}
\hline & $\mathbf{2 0 1 0} \boldsymbol{\Gamma}$ & $\mathbf{2 0 1 1} \boldsymbol{\Gamma}$ & $\mathbf{2 0 1 2} \boldsymbol{\Gamma}$ & $\mathbf{2 0 1 3} \boldsymbol{\Gamma}$ & $\mathbf{2 0 1 4} \boldsymbol{\Gamma}$ & $\mathbf{2 0 1 5} \boldsymbol{\Gamma}$ \\
\hline Вклад туризма в ВВП & 3,7 & 4,5 & 4,6 & 4,6 & 4,8 & 4,5 \\
\hline Вклад туризма в экспорт & 8,4 & 15,5 & 21,3 & 25,6 & 21,7 & 24,5 \\
\hline $\begin{array}{l}\text { Доля инвестиций(1) в туризм в } \\
\text { общем объеме инвестиций }\end{array}$ & 3,2 & 5,1 & 1,8 & 1,4 & 2,7 & 1,02 \\
\hline Вклад туризма в доходы бюджета & 0,13 & 0,25 & 0,11 & 0,10 & 0,08 & 0,08 \\
\hline
\end{tabular}

Таблица 1. Вклад туризма в макроэкономические показатели Кыргызской Республики (в \% Источник: Ист. - Статистический сборник КР за 2015 г.

Несмотря на положительные моменты, удельный вес сферы туризма в ВВП на протяжении последних лет остается незначительным (4.5\%). Одной из причин такого положения является то, что в республике комплексно не изучается рынок туристических услуг, поэтому в данной статье мы попытаемся остановится и рассмотреть эти вопросы.

При изучении и анализа туристических услуг необходимо в первую очередь знать факторы, которые влияют на объем спроса. Как всем известно, объем спроса на туристические услуги зависит от многих факторов, и их можно разделить на общие и специфические.

I. Общие факторы спроса. Размер туристического рынка на данной территории (страны, региона, города и т.д.) определяется следующими факторами:

1. Покупательская способность. Высокая степень зависимости между уровнем жизни и интенсивностью путешествий является одним из фундаментальных фактов туризма.

Положительная эластичность спроса на туристические услуги по отношению к доходу объясняет быстрый рост спроса на туризм. Увеличение личных доходов приводит к перераспределению общих расходов, расходы на услуги в целом, и туризм в частности.

2. Демографическая структура и тенденции. Численность населения и ее рост незначительно влияют на туристический спрос. Страны с большим населением, но низким средним уровнем доходов имеют ограниченные возможности для туризма, как внутреннего, так и международного. Наиболее важным является 
изменение возрастной структуры, так как увеличение среднего возраста приводит к тому, что больше людей имеют уровень дохода, позволяющей им путешествовать.

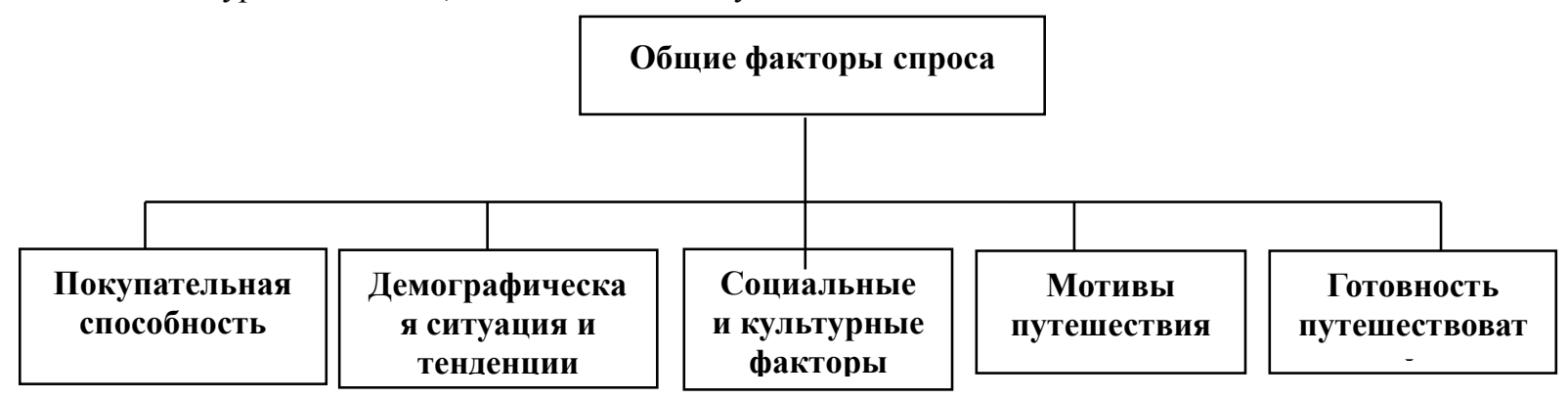

Pис 1. Общчие факторы спроса

3. Социальные и культурныле факторы. Индустриализация экономики не только производит доходные структуры и перераспределение доходов, благоприятные для туризма, но также способствуетт росту спроса на туризм в части развлечений, отдыха и укрепления здоровья. Увеличение свободного времени и оплачиваемые отпуска как социальные нужды увеличивают спрос на туризм.

4. Мотивация и отношение к путешествиям. Тесно связанные социальные и культурные факторы являются основными мотивами, желаниями и ожиданиями, связанными с путешествиями. Критерий, по которому потенциальные туристы могут судить о туристических услугах и товарах, является менее однородным и специфическим, чем в случае большинства других товаров.

5. Возможности для путешествий и интенсивность маркетинга в туризме. Спрос на туризм тем выше, чем больше мест назначений, различий в ценах, типов мест расположений. Все это позволяет туристам произвести выбор из широкого ряда возможностей мест отдыха.

Все эти факторы определяют объем спроса на туризм в данном рынке и, следовательно, их необходимо учитывать при определении рыночных условии и при попытке предсказать будущий рыночный потенциал. Большинство из них могут быть количественно измерены и относительно легко определены. По этой причине прогнозы общего спроса обычно более достоверны и точны, чем прогнозы специфического спроса.

II. Факторы, определяющие специфический спрос. Специфические факторы спроса включают себе следующие:

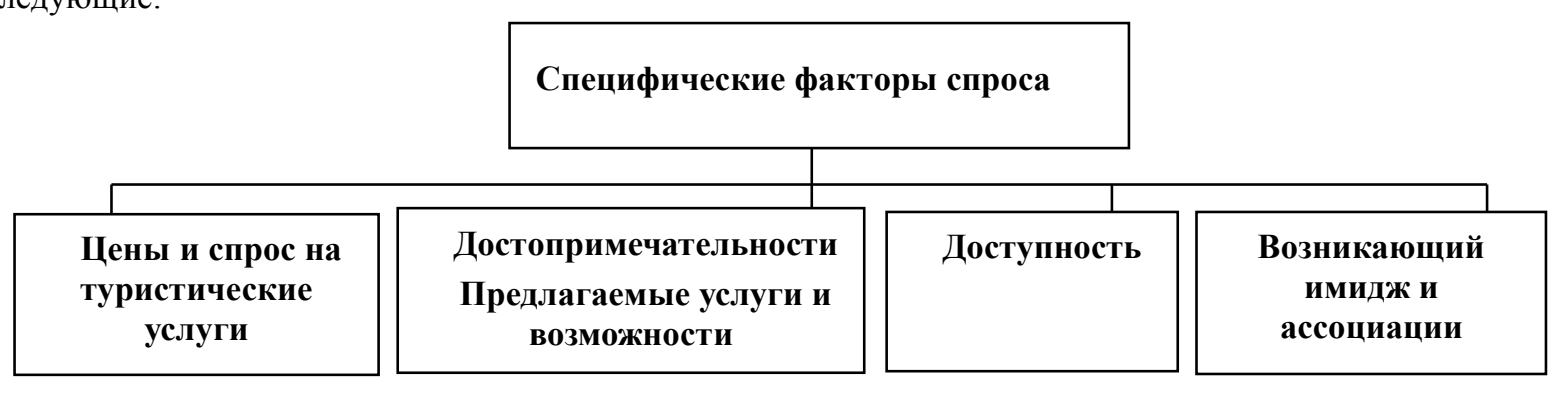

Pис. 2. Факторы, определяющие специчфический спрос

1. Цена и спрос на туристические услуги. В туризме цена - это главный фактор, определяющий спрос. В значительной степени определяются ценовыми решениями решения о местах назначений, способах путешествий, видах мероприятий вовремя путешествий, об условиях проживания и деятельности, о продолжительности путешествий. Ценовая эластичность спроса на туристические услуги является высокой, так как спрос на путешествия является дискретным, и он может быть удовлетворен различными путями, каждый из которых оценивается потенциальными потребностями, и предлагается для равного или, по крайней мере, сравнимого удовлетворения потребностей туристов.

Цена является также важным фактором в конкуренции между туроператорами. Очень часто программы различных туроператоров включают одни и те же места назначения, способы перемещения, отели, экскурсионные туры и т. д. Поскольку услуги не особо отличаются друг от друга, ценовые различия в значительной мере определяют выбор потребителя (того или иного туроператора).

2. Способы привлечения к месту назначения, возможности и услуги. Решения относительно путешествий концентрируются вокруг выбора места назначения. Самое важное решение потенциальный путешественник принимает тогда, когда решает, куда ему ехать. Этот выбор определяется его оценкой разнообразным способам привлечения, которыми обладают различные места назначения. 
Путешественника привлекает возможность удовлетворения его нужд, желаний и ожиданий. Привлекать может место расположения, события или наличие возможностей для определенной деятельности.

3.Доступность. Это относится в первую очередь к тем способам передвижения, которые выберет турист, их стоимости, времени необходимого для путешествия и комбинации комфорта, скорости и надежности. Кроме того, принимаются во внимание такие факторы, как визовая медицинская проверка, контроль валюты, таможня.

4. Информирование $u$ другие подготовительные услуги. Потенциальным туристам необходимо предоставить широкий набор подготовительных услуг. Поскольку польза и качество этих услуг важны для туриста, они включаются в качестве элементов турпродукта.

5. Имидж. Восприятия туристов субъективны по своей природе. Очевидно, что идеи и представления, с которыми ассоциируется данное место назначения, являются важными факторами, влияющими на величину спроса.

На успешное развитие туристической сферы влияют и внешние факторы, которые мало изучены и не всегда им уделяется должное внимание. Анализ внешней среды позволяет создать перечень опасностей и возможностей, с которыми она сталкивается в этой среде. Для успешного планирования руководство должно иметь полное представление не только о существенных внешних проблемах, но и о внутренних потенциальных возможностях и недостатках отрасли. Оценка влияния факторов внешней макросреды представлена в таблице 2.

\begin{tabular}{|c|c|c|c|}
\hline \multicolumn{2}{|r|}{ Факторы внешней среды } & \multirow{2}{*}{$\frac{\text { Влияние }}{+}$} & \multirow{2}{*}{$\begin{array}{c}\text { Степень } \\
\text { влияния } \\
\text { Сильное } \\
\end{array}$} \\
\hline \multirow{3}{*}{ Экономические } & Развитие экономики & & \\
\hline & Уровень инфляции & - & Сильное \\
\hline & Развитие МЭО & + & Умеренное \\
\hline \multirow{3}{*}{ Политико-правовые } & $\begin{array}{l}\text { Принятие благоприятного закона в } \\
\text { отрасли туризма }\end{array}$ & + & Умеренное \\
\hline & Повышение ставок налогообложения & - & Сильное \\
\hline & $\begin{array}{l}\text { Подписание договоров с зарубежными } \\
\text { странами }\end{array}$ & + & Умеренное \\
\hline \multirow{3}{*}{ Научно-технические } & Развитие новых технологий & + & Слабое \\
\hline & $\begin{array}{l}\text { Усовершенствование производственных } \\
\text { процессов }\end{array}$ & + & Слабое \\
\hline & Развитие научных технологий & + & Слабое \\
\hline \multirow{3}{*}{ Демографические } & Повышение уровня рождаемости & + & Слабое \\
\hline & Рост уровня образования населения & + & Слабое \\
\hline & Высокий уровень безработицы & - & Сильное \\
\hline Социально-культурные & Развитие культуры, культ. центров & + & Сильное \\
\hline \multirow{2}{*}{ Международные } & $\begin{array}{l}\text { Проведение фестивалей, тренингов } \\
\text { конкурсов, конференций }\end{array}$ & + & Сильное \\
\hline & $\begin{array}{l}\text { Государственная поддержка социальных } \\
\text { программ }\end{array}$ & + & Умеренное \\
\hline Природные & Загрязнение окружающей среды & - & Сильное \\
\hline
\end{tabular}

Таблица 2. Оиченка влияния факторов внешней средьл на деятельность туристических фирм Кыргызстана

Как видно из данной таблицы, наиболее слабую степень влияния оказывают следующие факторы: научно-технические и демографические, а наиболее сильную - экономические и природные. Довольно существенное влияние проявляют социально-культурные и политико-правовые факторы.

Немаловажным фактором, влияющим на объем спроса на туристические услуги - это уровень доходов населения и стоимость путевки. Известно, что с ростом доходов населения спрос на товары первой необходимости растет медленнее, чем спрос на различные услуги, то есть с удовлетворением потребности населения на товары первой необходимости появляется возможность отдыхать и путешествовать. Для более весомого доказательства выше сказанного, рассмотрим данные об использовании совокупного дохода в семьях с различным достатком (табл. 3 ). 


\begin{tabular}{|c|c|c|c|c|c|c|}
\hline \multirow{2}{*}{ Статья расходов } & \multicolumn{6}{|c|}{$\begin{array}{c}\text { Структура \% расходов при среднедушевом совокупном } \\
\text { доходе, тыс.сом в месяц }\end{array}$} \\
\hline & До 10,0 & $10,1-20,0$ & $20,1-30,0$ & $30,1-40,0$ & 1 & $\begin{array}{c}\text { Более } \\
40,1\end{array}$ \\
\hline Питание & 53,5 & 47,7 & 39,8 & 36,7 & & 28,4 \\
\hline Непродовольственные товары & 17,4 & 19,2 & 20,3 & 22,0 & & 26,6 \\
\hline Услуги & 28,4 & 31,0 & 35,6 & 36,2 & & 38 \\
\hline Накопления & 0,7 & 2,1 & 4,3 & 5,1 & & 7 \\
\hline итого & 100 & 100 & 100 & 100 & & 100 \\
\hline
\end{tabular}

Таблица 3. Структура расходов семейного бюджета Кыргызской республики на приобретение товаров и услуг. Источник: Статистический сборник КР за 20152

Как показывают анализы семейного бюджета, в семьях с наименьшими доходами больше половины расходов составляет питание (53.5\%), а в семьях с наибольшими доходами - расходы на услуги (38\%). Причем в таких семьях увеличиваются расходы на непродовольственные товары (26.6\% против 17.4\%). Если структуру расходов семейного бюджета сравнить с данными прошлых лет (2005г.), то можно проследить, что за последние годы резко увеличилась доля расходов на питание и прочие услуги. Это объясняется кризисной ситуацией в республике, ростом цен на продукты питания и тарифов на услуги, а также увеличением суммы налогов.

Однако, несмотря на это республика может успешно найти свою нишу на мировом рынке туристических услуг. Так, с образованием суверенитета в Кыргызской Республике получил значительное развитие деловой и особенно коммерческий туризм. За последние годы Кыргызская Республика возглавила ряд мировых рейтингов в сфере туризма, что свидетельствует о возросшей туристической привлекательности. Растет количество въездных туристов. Так, с 2011 по 2015 годы доля прибывших в Кыргызстан туристов из стран Содружества увеличилась с 75,4\% до 86,1\%. В основном туристы приезжают в Кыргызскую Республику из государств-участников СНГ: Казахстана $(70,1 \%)$, России $(15,7 \%)$ и Узбекистана $(4,4 \%)$, из стран вне СНГ - это прежде всего Турция (1,2\%), Китай $(1 \%)$, Германия $(0,5 \%)$ и США (0,5\%).

Иностранцев, работающих в городе Бишкек, и приезжающих бизнесменов могут заинтересовать такие туры, как однодневный выезд в Ала-Арчинское ущелье, катание на лыжах, конные прогулки, 2-3-х дневные туры с ночевками в палатках, юртах, посещение пансионатов на Иссык-Куле. В этом направлении у туристических фирм есть хорошие шансы, и успешное развитие этих туров зависит от хорошей рекламы.

Кроме этого в условиях развития экономики республики выгодно продать туристическую продукцию, организуя «шоптуры» или путевки на месте (где расположены крупные компании или через госорганы) в другие государства. Здесь основное внимание необходимо уделить на гарантию, своевременной доставки груза, облегчению визовых вопросов туристов, так как в эти поездки уезжают в основном для коммерческих целей.

Для детального изучения туристического рынка, проведено маркетинговое исследование поведения иностранных туристов в Кыргызстане методом опроса. Результаты этих исследований показали, что, большая доля опрошенных иностранных туристов приехала в Кыргызстан с целью отдыха (66.7\%), визит к друзьям или родственникам составляет $21,4 \%$ из всего количества опрошенных. Деловой туризм и посещение страны с целью развития бизнеса не сильно развиты (всего лишь 6,6\%). Подавляющее большинство (75\%) опрошенных приезжих туристов использовало воздушные пути сообщения, 5\% использовали железнодорожный вид транспорта, остальные $20 \%$ - автомобильный вид транспорта. Так как большинство опрошенных приезжих туристов использовало воздушные пути сообщения, встает вопрос о необходимости акцентирования внимания на инфраструктуре международных аэропортов страны, качестве и объеме предоставляемого в них сервиса.

На вопрос «Какой раз вы приезжаете в Кыргызстан», респонденты ответили следующим образом: менее половины опрошенных респондентов (48\%) в первый раз приехали в Кыргызстан, остальные (52\%) уже посещали до этого страну, большинство из которых посетило Кыргызстан более 2-х раз. Это говорит о том, что у республики, как у туристического рынка, имеются постоянные потребители туристических услуг. Среди так называемых «постоянных клиентов» туристических услуг Кыргызстана - большая доля туристов из стран СНГ.

По данным опроса, основными источниками информации о Кыргызстане для туриста из дальнего зарубежья являются интернет и рекомендации друзей и родственников. В отличие от туриста из СНГ, турист из дальнего зарубежья больше пользуется услугами туристических агентств. Однако большинство туристов из СНГ полагаются на собственный опыт знакомства с Кыргызстаном. 
Меньше всего иностранным туристам понравились уровень обслуживания, пренебрежительное отношение людей к природе и ограниченность видов развлечений.

Необходимым этапом в маркетинговом исследовании рынка туристических услуг является изучение конкурентов. Целью исследований деятельности конкурентов является выявление сильных и слабых сторон, определение собственных позиций на рынке и, в конечном счете, улучшение конкурентоспособности туристических фирм на рынке Кыргызстана.

\begin{tabular}{|c|c|}
\hline $\begin{array}{l}\text { Сильные стороны: } \\
\text { • Уникальность природного богатства } \\
\text { • Наличие туристических объектов } \\
\text { • Развитый гостиничный бизнес } \\
\text { • Экологически чистые продукты } \\
\text { питания } \\
\text { • Наличие санаторно-курортных } \\
\text { лечений; } \\
\text { • Расширенный спектр предоставляемых } \\
\text { услуг } \\
\text { • Повсеместный доступность Интернет } \\
\text { системы } \\
\text { • Растущая сеть постоянных клиентов } \\
\text { • Удобное месторасположение } \\
\text { • Многоканальная сеть партнеров - } \\
\text { туроператоров } \\
\text { • Отзывчивость и гостеприимность } \\
\text { местных жителей } \\
\text { • Доброжелательность местных жителей } \\
\text { к туризму }\end{array}$ & 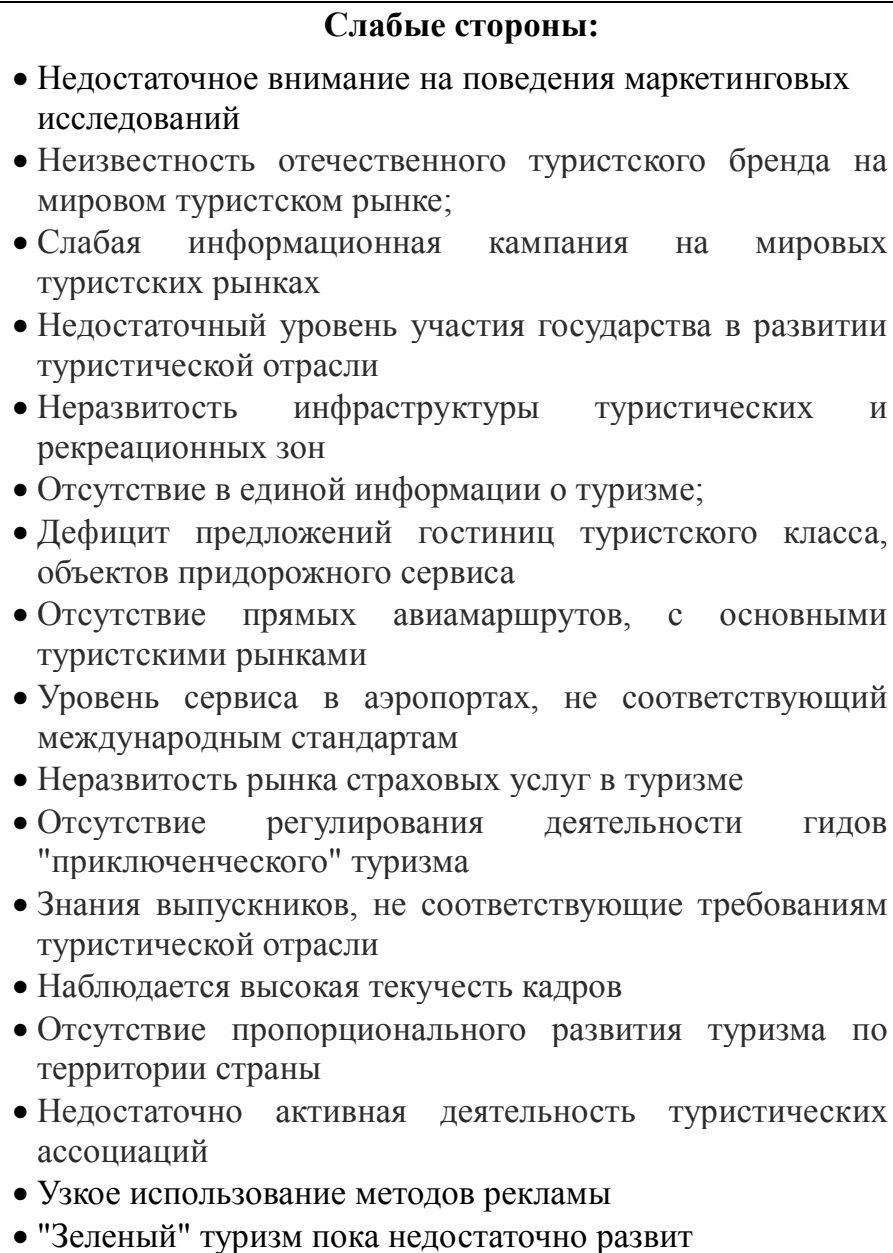 \\
\hline $\begin{array}{l}\text { Возможности: } \\
\text { • Растуший спрос на туристические } \\
\text { услуги } \\
\text { • Усиление интереса на маршрут } \\
\text { «Великий шелковый путь» } \\
\text { • Выступление Кыргызстана в ЕвразЭС } \\
\text { • Расширение сети интернет } \\
\text { • Высокая степень сотрудничества с } \\
\text { мировыми туристическими } \\
\text { компаниями } \\
\text { • Повышение спроса на } \\
\text { приключенческий туризм } \\
\text { • Развитие в мировом масштабе } \\
\text { "зеленого" туризма }\end{array}$ & $\begin{array}{l}\text { Угрозы: } \\
\text { • Вероятность экологических, техногенных катастроф и } \\
\text { стихийных бедствий; } \\
\text { • экономический спад } \\
\text { • Снижение глобального спроса на туристические услуги } \\
\text { за счет военной террористической и иной деятельности; } \\
\text { • Высокая безработица } \\
\text { • Запаздывание в выходе на мировой рынок. } \\
\text { • Отсутствие нормативной базы в области обеспечения } \\
\text { безопасного функционирования горнолыжных курортов } \\
\text { и баз. } \\
\text { • Загрязнение окружающей среды, в частности бытовыми } \\
\text { отходами; } \\
\text { • Отсутствие санитарно-эпидемиологических требований } \\
\text { к временным туристским лагерям; } \\
\text { • Несоблюдение правил охраны окружающей среды }\end{array}$ \\
\hline
\end{tabular}

Таблица 4. SWОТ анализ туристической отрасли КР

В Кыргызской Республике прием и обслуживание туристов в 2015 году осуществлялись 418 учреждениями отдыха и организациями туризма. Из них 172 - специализированные средства размещения (86 пансионатов, 29 детских оздоровительных комплексов, 18 санаторий, из них 5 - детских, 9 домов отдыха, 10 санаториев-профилакториев, 8 турбаз, 4 базы отдыха, 5 спортивно-оздоровительных лагерей и 
3 пансионата с лечением), а также 139 гостиниц, 76 турфирм и туроператоров. Наблюдается увеличение количества хозяйствующих субъектов в сфере туризма. Так, с 2011 года по 2015 год их число увеличилось с 6955 единиц до 9524 единиц. Это означает, что на рынке туристических услуг республики существует жесткая конкуренция.

В результате исследования рынка мы сможем составить SWOT анализ туристической отрасли Кыргызстана, отмечая сильны и слабые стороны, а также выявляя угрозы и возможности.

SWOT-анализ является первым шагом на пути к разработке маркетингового плана, потому, возможно, что это относительно простой процесс. Это полезная ревизия, помогающая активизировать мыслительный процесс, но эффективна она только в том случае, если за анализом последует рассмотрение вопросов, поднятых им, и составление фактических планов по использованию полученных в его ходе данных.

Выполнив SWOT-анализ, можно продумать, как воспользоваться сильными сторонами и возможностями и что желательно сделать, чтобы свести к минимуму слабые стороны и риски. Результаты этого анализа можно учесть в маркетинговом плане. Использование командного подхода и "мозгового штурма" полезный путь проведения SWOT-анализа.

Результаты SWOT-анализа туристической отрасли Кыргызской Республики приведены в таблице 4. Можно достичь определенных успехов в перспективе, если развивать свои сильные стороны, воспользоваться своей возможностью, которые показаны в этой таблице и решить проблемы, устраняя свои слабые стороны, уменьшая угрозы.

В результате рыночных исследований делается сегментация туристических рынков. Как нам известно, спрос на туризм формируется неоднородными группами людей, стремящихся путешествовать и побуждаемых одинаковыми мотивами. Это комплекс различных, иногда конфликтных желаний, нужд, вкусов, склонностей и антипатии. Расслоение этой структуры не может происходить по национальности или социальному положению, а также это не зависит от возраста или пола, в то же самое время, не все производители туристических услуг могут удовлетворить нужды путешественников одинаково хорошо.

По отношению к потенциалу общего туристического рынка, объем услуг отдельного туристического предприятия более ограничен количественно и качественно. Следовательно, было бы неразумно направить усилия на удовлетворение общего рыночного спроса.

Маркетинг и продвижение туристических услуг должны быть дифференцированными в том смысле, что усилия должны быть сконцентрированы и направлены на потенциальные туристические группы, т. е. на сегменты общего туристического рынка. Сегментация общего туристического рынка на однородные группы туристов является абсолютно необходимым шагом процесса планирования маркетинга и продвижения услуг. Ее целью является определить сегменты рынка, к которым усилия в области маркетинга и продвижения услуг должны быть направлены исключительно или в большей степени.

Чаще всего для сегментации рынка используются социально-экономические критерии, такие как: возраст, пол, уровень дохода, образование, профессия, размер семьи и другие.

Вторая группа критериев сегментации связана с отношением к продукту. Группы потребителей определяются в соответствии с использованием турпродукта, частотой и величиной покупок, "верности" продукту или месту покупок.

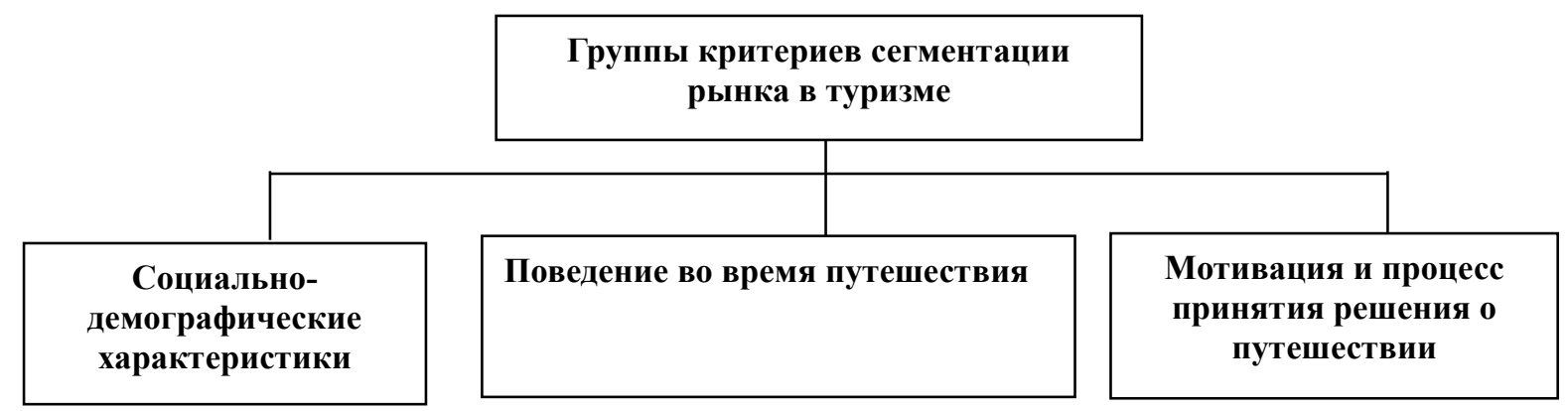

Рис. 3. Группы критериев сегментации туристских рынков

Необходимо пояснить, что все упомянутые выше характеристики покупателей не достаточны для сегментации рынка. Сегменты, определенные только по социально-экономическим критериям, становятся постепенно все больше похожими друг на друга, в результате теряется эффект от сегментации, следовательно, необходимы дополнительные критерии. Можно предложить следующие три группы критериев сегментации для туризма:

1. Социально-демографические характеристики: возраст, пол, семейное положение, размер семьи, социальное положение, образование, профессия, чистый доход семьи, постоянное местожительство, религия. 
2. Поведение: цели и причины путешествия, места назначений, используемый транспорт, расстояние путешествия, длительность стоянки, типы расселения и питания, использование посредников, количество людей, расходы во время путешествия, оплата.

3. Мотивация и процесс принятия решения о путешествии: мотивация и ожидание, подготовительные этапы к путешествию, факторы, влияющие на принятие решения, источники информации о путешествии, удовлетворение потребностей, связанных с туром.

Таким образом, для Кыргызстана туризм является одним из важных путей интеграции в мировом туристическом рынке, и он сможет найти свою «нищу» в этом рынке. Более детальное изучение рынка туристических услуг, продвижение турпродукта на рынок и проведение комплексных маркетинговых исследований, на наш взгляд, дает большой толчок успешного развития этой отрасли.

\section{Литература:}

- Бейшембаева Ж.Т., Абдукадырова А.К. Туризм Кыргызстана. Б., 2000 г.

- Жыргалбеков Т. Туризм Кыргызстана: современность и перспективы. Бишкек, 1998 г.

- Камалова А. Маркетинг. Бишкек, 2008 г.

- Максудинов А. Камалова А. Маркетинг услуг. Бишкек, 2016 г.

- Чудновский А.Д., Жукова М.А., Сенин В.С. Управление индустрией туризма. М., 2005 г.

- З Закон КР «О туризме» от 25 марта 1999 г.

- Национальный статистический сборник «Туризм Кыргызстана».

- Кониепция развития туристической отрасли в КР до 2020 г.

- Шубаева, В. Г. «Проблемы рынка туризма и специфика применения маркетинга». Труды академии туризма: сб. науч. тр. СПб.: Невский Фонд. 4. с. 73-76. 2002 г. 


\section{Author Index}

Abdieva, Raziiakhan (Kyrgyzstan-Turkey Manas University, Kyrgyzstan) …...........................................262

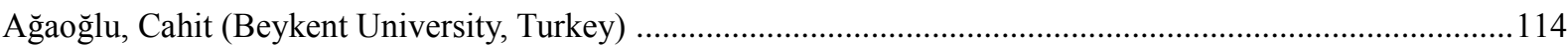

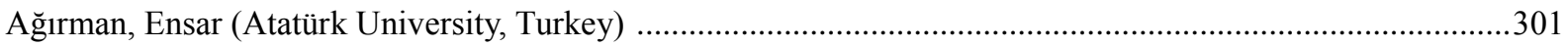

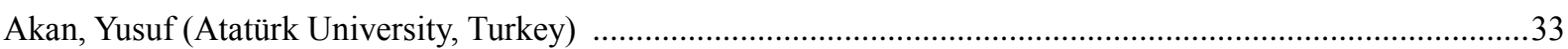

Algan, Neşe (Çukurova University, Turkey) ...................................................................................291, 332

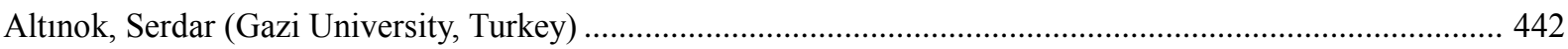

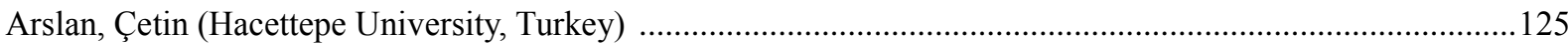

Aseinov, Dastan (Kyrgyzstan-Turkey Manas University, Kyrgyzstan) ................................................ 70,484

Aslan, Mehmet Barış (Muş Alparslan University, Turkey) .................................................................. 168, 433

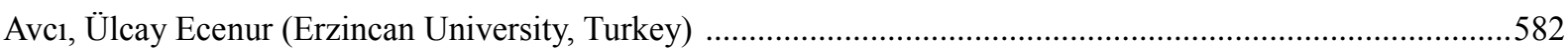

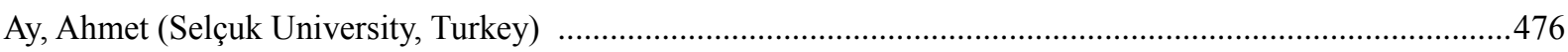

Aydın, Hamdi (İstanbul Gelişim University, Turkey) ..........................................................................214

Aydın, Nevin (Kyrgyzstan-Turkey Manas University, Kyrgyzstan) .................................. 178, 231, 356, 587

Azgün, Sabri (Atatürk University, Turkey) ............................................................................. 155, 189

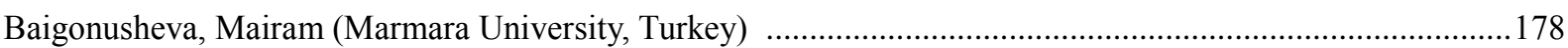

Baigonushova, Damira (Kyrgyzstan-Turkey Manas University, Kyrgyzstan) ..................................... 178, 231

Bakar Tamer, Gülay (İstanbul Gelişim University, Turkey) ....................................................................418

Bal, Harun (Çukurova University, Turkey) ................................................................. 149, 246, 392,546

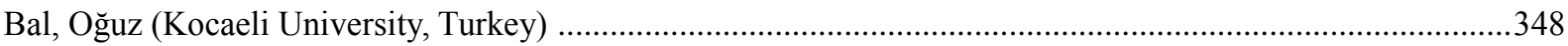

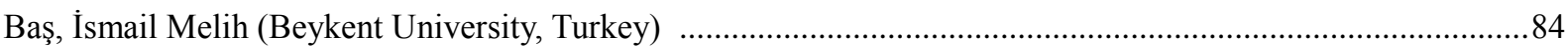

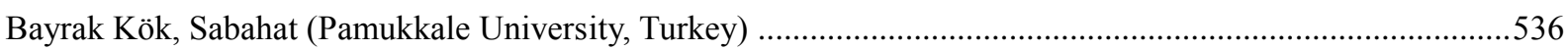

Bildirici , Melike (Yıldız Technical University, Turkey) ...................................................................6, 23

Çağlayan Akay, Ebru (Marmara University, Turkey) ............................................................................. 161

Çelik, Ahmet Alkan (Beykent University, Turkey) ..........................................................................325, 339

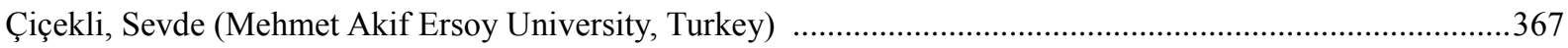

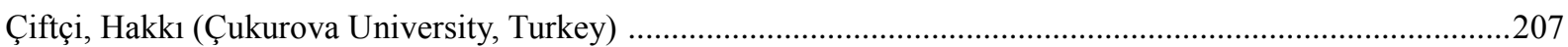

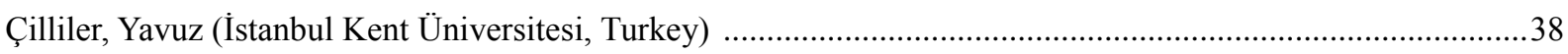

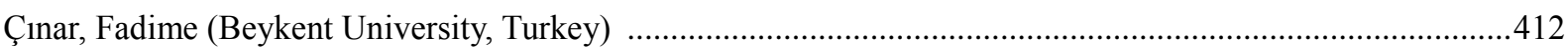

Değer, Mustafa Kemal (Karadeniz Technical University, Turkey) ............................................................307

Demiral, Mehmet (Ömer Halisdemir University, Turkey) .......................................................................246

Dincer Aydın, Hicran Utkun (Pamukkale University, Turkey) ......................................................................572

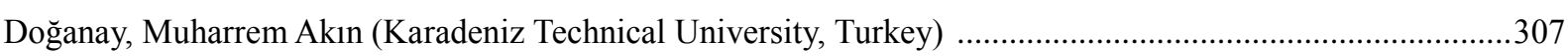

Doker, Asl Cansin (Erzincan University, Turkey) .................................................. 33, 339, 459, 556, 582

Doru, Ömer (Şırnak University, Turkey) ................................................................................ 168, 433

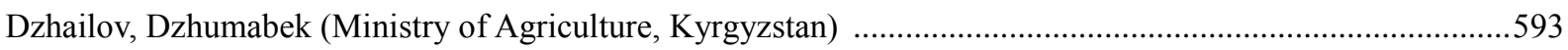

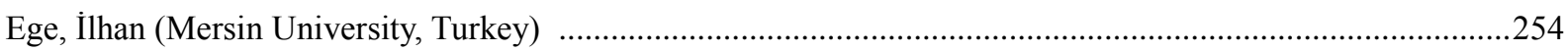

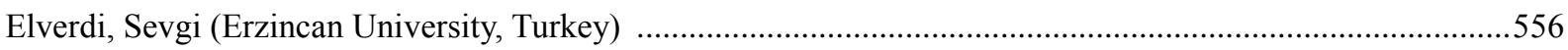

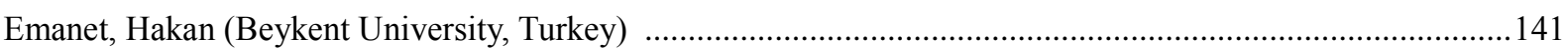

Eminov, Anar (Azerbaijan Tourism and Management University, Azerbaijan) ...........................................401

Emsen, Ömer Selçuk (Atatürk University, Turkey) ........................................................ 155, 189, 459, 556

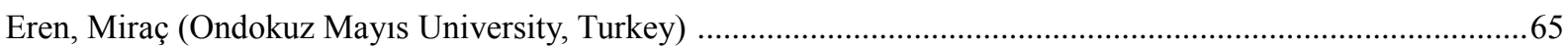

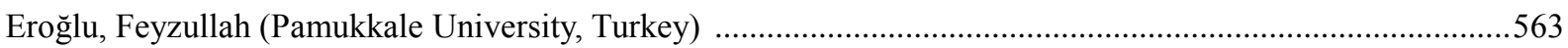

Ersin, Özgür Ömer (Beykent University, Turkey) ..........................................................................6, 23

Ersungur, Ş. Mustafa (Atatürk University, Turkey) ......................................................................... 168, 433

Eryücel, Ertuğrul (Gaziosmanpaşa University, Turkey) ............................................................................ 132

Everest, Bengü (Çanakkale Onsekiz Mart University, Turkey) .......................................................379, 385

Firat, Emine (Aksaray University, Turkey) ................................................................ 313, 318, 361, 442

Ganiev, Junus (Kyrgyzstan-Turkey Manas University, Kyrgyzstan) ...................................................178, 231 


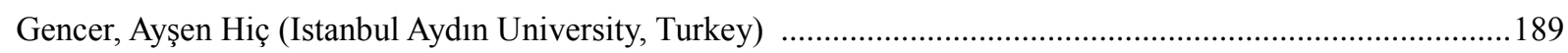

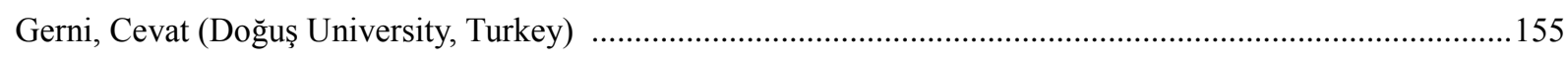

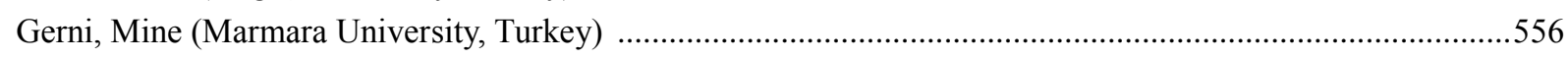

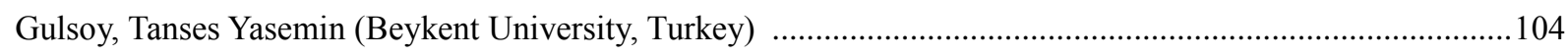

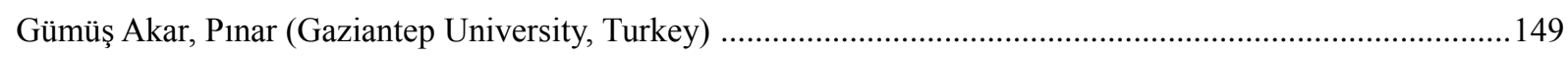

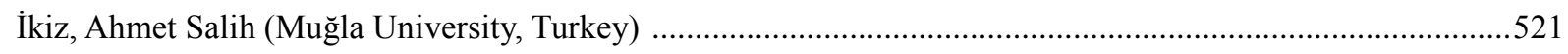

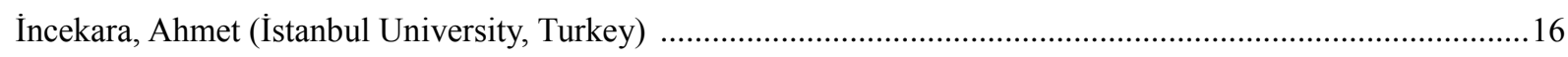

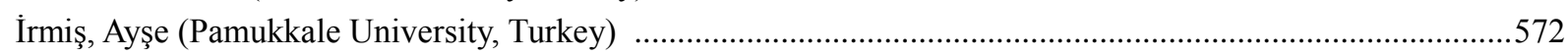

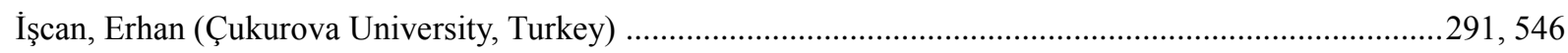

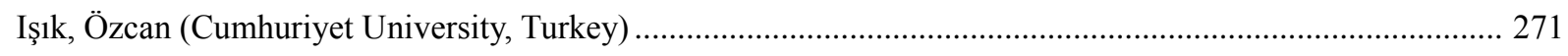

Japarova, Damira (Kyrgyzstan-Turkey Manas University, Kyrgyzstan) …………………………………......59

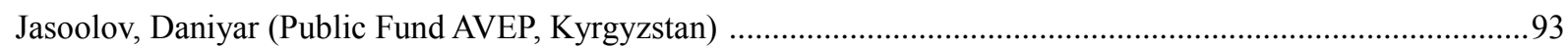

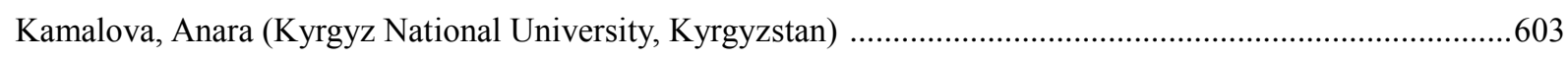

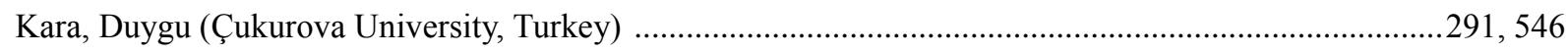

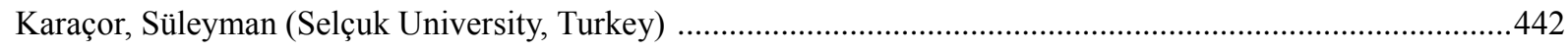

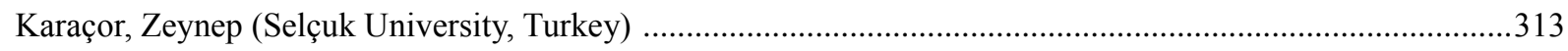

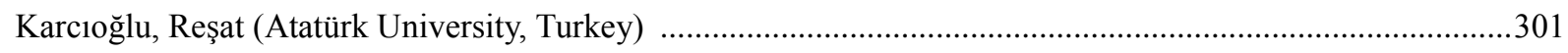

Karluk, S. Ridvan (Antalya AKEV University, Turkey) .............................................................................509

Karymshakov, Kamalbek (Kyrgyzstan-Turkey Manas University, Kyrgyzstan) .................................................70

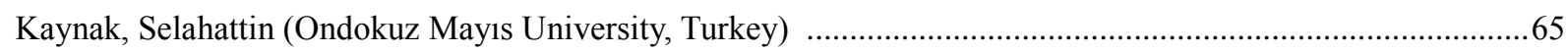

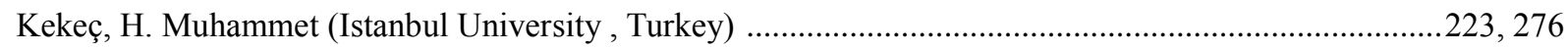

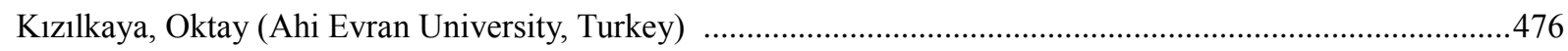

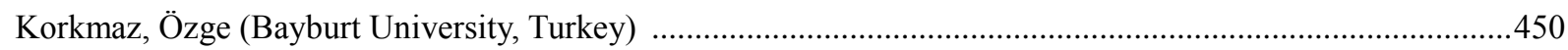

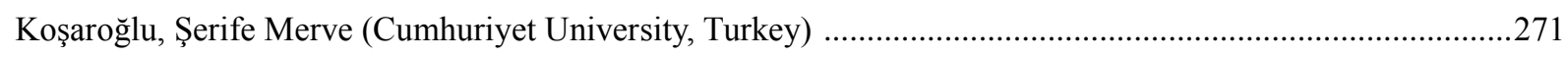

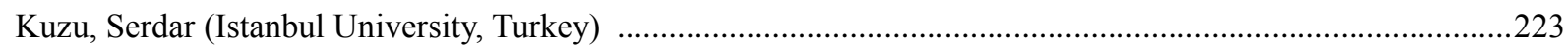

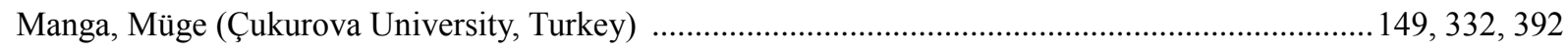

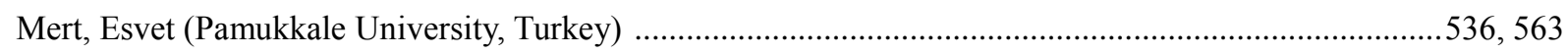

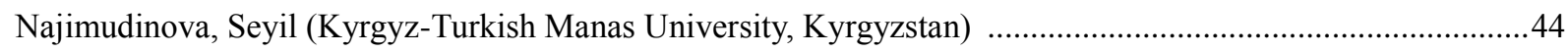

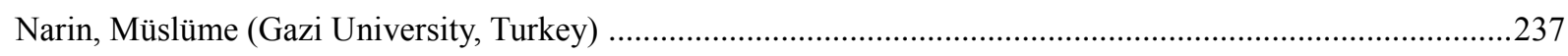

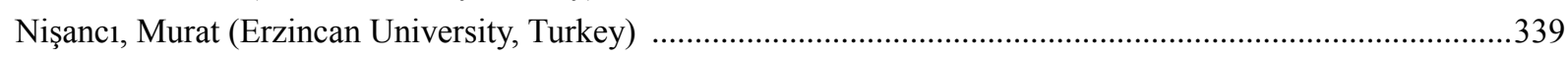

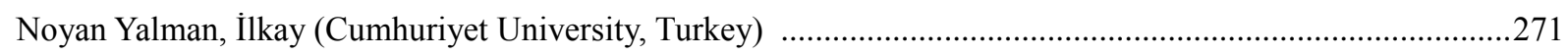

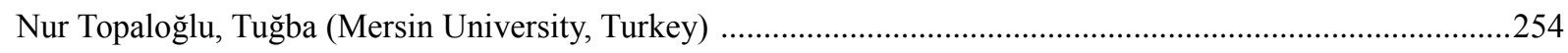

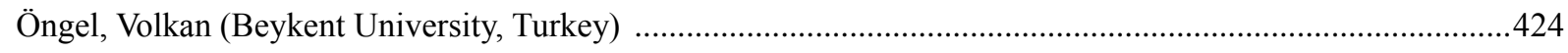

Oskonbaeva, Zamira (Kyrgyzstan-Turkey Manas University, Kyrgyzstan) ..................................................161

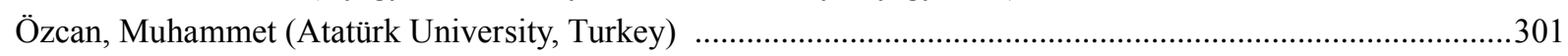

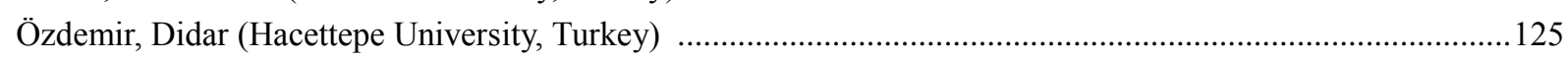

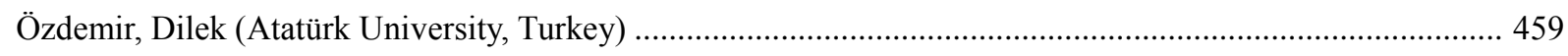

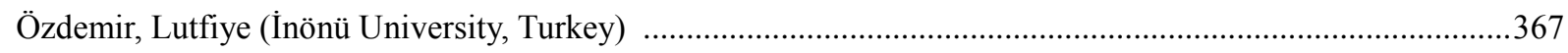

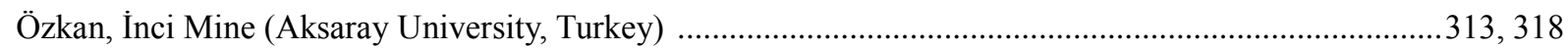

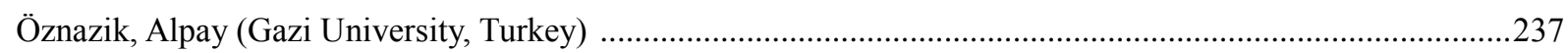

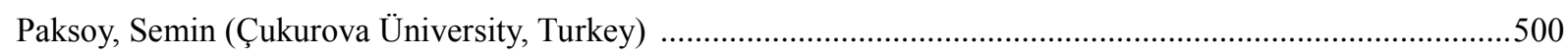

Pirimbaev, Jusup (Kyrgyzstan-Turkey Manas University, Kyrgyzstan) ...............................................................593

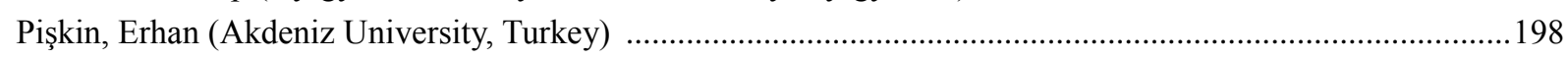

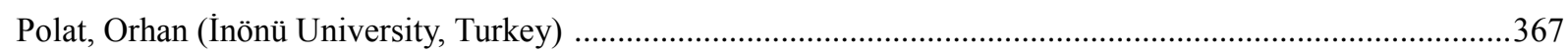

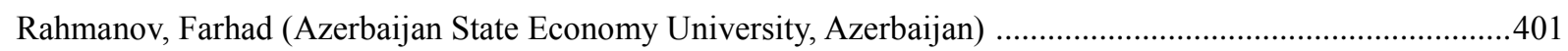

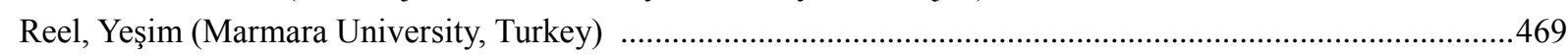

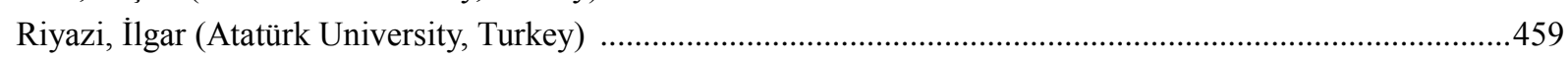

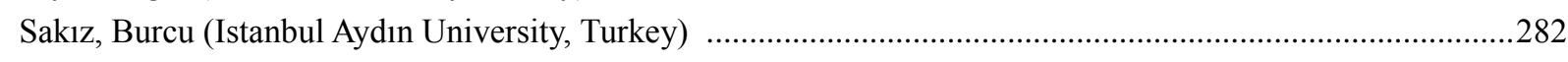

Sakmurzaeva, Nargiza (Kyrgyzstan-Turkey Manas University, Kyrgyzstan) …………………………….........493 


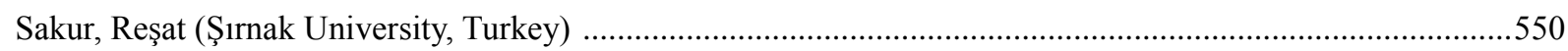

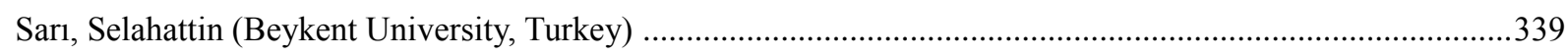

Sarıçiçek, Burak (Beykent University, Turkey) ....................................................................................527

Savrul, Mesut (Çanakkale Onsekiz Mart University, Turkey) ...................................................................16

Serin, Duygu (Çukurova University, Turkey) ..............................................................................291, 546

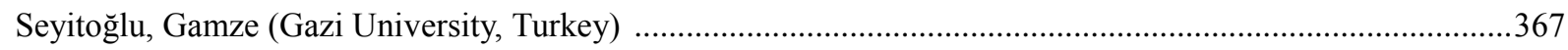

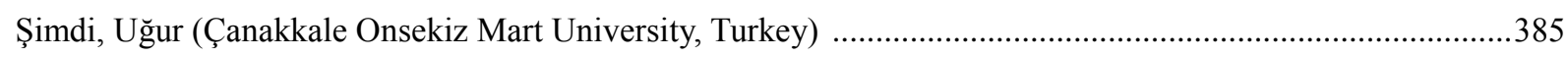

Sofuoğlu, Emrah (Ahi Evran University, Turkey) …...........................................................................476

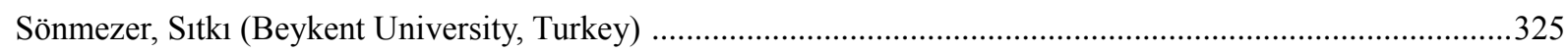

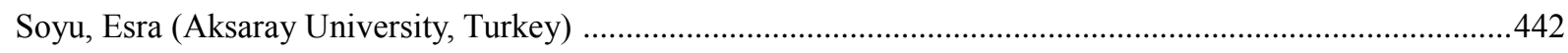

Sulaimanova, Burulcha (Kyrgyz-Turkish Manas University, Kyrgyzstan) ….........................................70, 93

Suleymanov, Elchin (Baku Engineering University, Azerbaijan) ...............................................................401

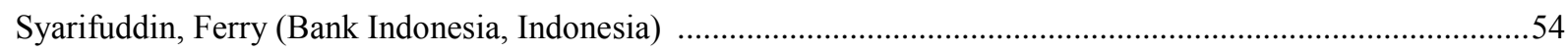

Tan, Sibel (Çanakkale Onsekiz Mart University, Turkey) ...............................................................379, 385

Tanrı̈ver, Banu (Osmaniye Korkut Ata University, Turkey) .....................................................................392

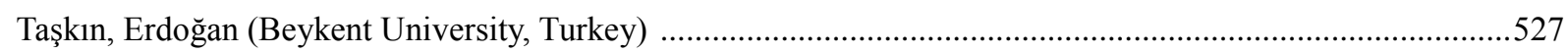

Tekeoğlu, Muammer (Çukurova University, Turkey) ................................................................... 1, 332

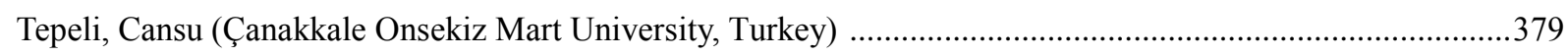

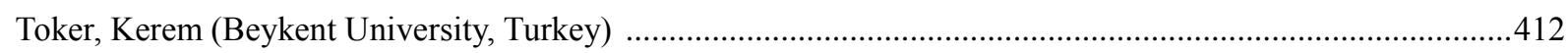

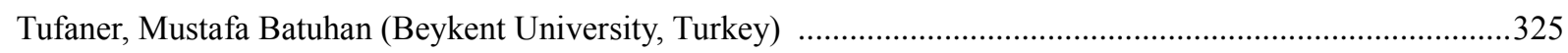

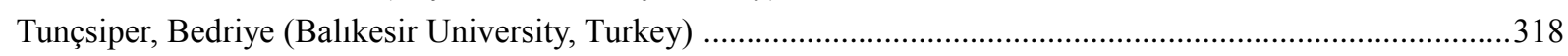

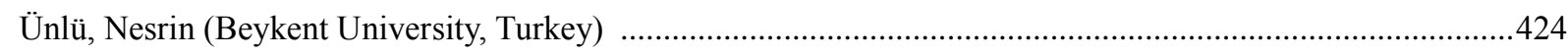

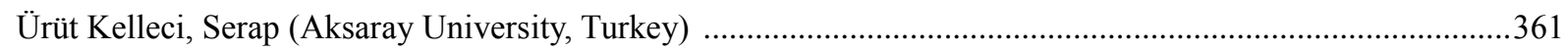

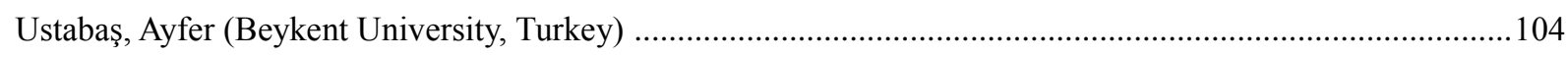

Uygur, Mehmet Nazım (Şırnak University, Turkey) ................................................................................78

Uzun Kocamış, Tuğçe (İstanbul University, Turkey) .............................................................................2276

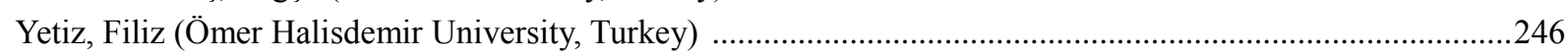

Yurttançıkmaz, Ziya Çağlar (Atatürk University, Turkey) .............................................................155, 189

Zhumakunova, Tolkun (Kyrgyzstan-Turkey Manas University, Kyrgyzstan) ..................................................262 
